\title{
Chiral Phosphoric Acid Catalysis: The Terada Model Revisited
}

\author{
Matthew N. Grayson* \\ Department of Chemistry, University of Bath, Claverton Down, Bath BA2 7AY, UK \\ *Corresponding Author: M.N.Grayson@bath.ac.uk \\ Supporting Information
}

\section{List of contents:}

1. Full list of authors in the Gaussian 16 reference. Page S2.

2. Computational methods. Page S3.

3. Ethyl ester results. Page S4.

4. Distortion energy analysis. Page S5.

5. Diastereoselectivity. Page S6.

6. Energies, frequencies and molecular geometries of computed structures. Pages S7-1156.
a) Conformations of Catalyst (R)-1. Pages S7-15
b) Conformations of Catalyst (R)-1 TS. Pages S15-1006
c) Conformations of Catalyst (R)-1 TS with ethyl group. Pages S1007-1108
d) Conformations of Catalyst (R)-2 TS. Pages S1108-1140.
e) Reoptimization of TS-1Si and TS-2Si with M06-2X. Pages S1140-1145.
f) Distortion energy calculations for TS-1Si and TS-1Re. Pages S1145-S1150.
g) Diastereoselectivity calculations. Pages S1150-S1156.

7. References. Page S1157. 


\section{Full list of authors in the Gaussian $\mathbf{1 6}$ reference}

Gaussian 16, Revision A.03,

M. J. Frisch, G. W. Trucks, H. B. Schlegel, G. E. Scuseria, M. A. Robb, J. R. Cheeseman, G. Scalmani, V. Barone, G. A. Petersson, H. Nakatsuji, X. Li, M. Caricato, A. V. Marenich, J. Bloino, B. G. Janesko, R. Gomperts, B. Mennucci, H. P. Hratchian, J. V. Ortiz, A. F. Izmaylov, J. L. Sonnenberg, D. Williams-Young, F. Ding, F. Lipparini, F. Egidi, J. Goings, B. Peng, A. Petrone, T. Henderson, D. Ranasinghe, V. G. Zakrzewski, J. Gao, N. Rega, G. Zheng, W. Liang, M. Hada, M. Ehara, K. Toyota, R. Fukuda, J. Hasegawa, M. Ishida, T. Nakajima, Y. Honda, O. Kitao, H. Nakai, T. Vreven, K. Throssell, J. A. Montgomery, Jr., J. E. Peralta, F. Ogliaro, M. J. Bearpark, J. J. Heyd, E. N. Brothers, K. N. Kudin, V. N. Staroverov, T. A. Keith, R. Kobayashi, J. Normand, K. Raghavachari, A. P. Rendell, J. C. Burant, S. S. Iyengar, J. Tomasi, M. Cossi, J. M. Millam, M. Klene, C. Adamo, R. Cammi, J. W. Ochterski, R. L. Martin, K. Morokuma, O. Farkas, J. B. Foresman, and D. J. Fox, Gaussian, Inc., Wallingford CT, 2016. 


\section{Computational Methods}

Conformational searches were carried out using the conformational search tool within Schrödinger's MacroModel (version 11.3) ${ }^{1}$ with the OPLS3 force field. Conformations provided by these searches were subsequently optimized by DFT calculations carried out using Gaussian 16 (Revision A.03) ${ }^{2}$ with the B3LYP density functional and the split-valence polarized 6-31G(d) basis set. A total of 400 unique transition state structures (TSs) were located. Single point energy (SPE) calculations were used to correct the Gibbs free energy derived from the original B3LYP calculations. ${ }^{3}$ These were performed using B3LYP, dispersion-corrected with the D3 version of Grimme's dispersion with Becke-Johnson damping (B3LYP-D3(BJ)), and the larger, polarized, triple- $\zeta$ valence quality def2-TZVPP basis set within the IEFPCM (DCM) model. The free energy corrections were calculated using Truhlar's quasiharmonic approximation ${ }^{4}$ at $298.15 \mathrm{~K}$ and 1 atmosphere of pressure. Similar methods have previously been used in the successful modeling of organocatalysis. ${ }^{5}$ The ethyl ester of the electrophile was replaced by a methyl ester to simplify the calculations. 40 TSs with the ethyl ester present instead of the methyl ester were located to assess the impact of this truncation. The lowest energy TSs leading to the major and minor products are TS-5Si and TS-5Re respectively (Figure S1). The free energy difference between TS$\mathbf{5 S i}$ and TS-5Re is the same as the difference between TS-1Si and TS-1Re which shows that truncation of the ester group has minimal effect on the calculated TSs. 11 TSs were located for the reaction catalyzed by (R)-2, of which TS-4Si and TS-4Re were calculated to be the lowest energy diastereomeric TSs. TS-1Si and TS-2Si were re-optimized with M06-2X/6-31G(d)IEFPCM(DCM) followed by a single point energy with M06-2X/def2tzvpp-IEFPCM(DCM). TS-2Si is disfavoured relative to TS-1Si by 3.6 and $3.5 \mathrm{kcal} / \mathrm{mol}$ with B3LYP and M06-2X respectively. This agreement supports the use of B3LYP in the original calculations. TS-S1(anti) and TS-S2(syn) were optimized from the lowest energy TSs located for the reaction outlined in Scheme 1 from which the correct anti or syn approach could be constructed. Computed structures are illustrated with CYLView. ${ }^{6}$ 


\section{Ethyl ester results}

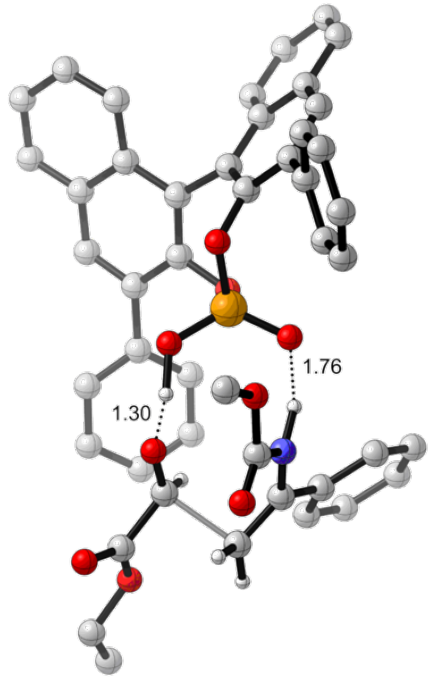

TS-5Si

$\Delta \Delta G^{\ddagger}=0$

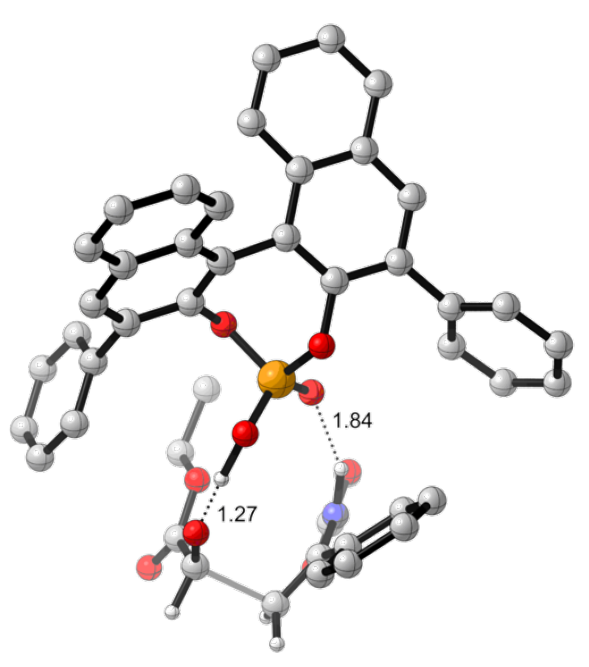

TS-5Re $\Delta \Delta G^{\ddagger}=2.3$

Figure S1. Comparison of C-C bond forming TSs in the (R)-1-catalyzed asymmetric aza-ene-type reaction with an ethyl ester. Non-critical hydrogen atoms omitted for clarity. All energies in $\mathrm{kcal} \mathrm{mol}^{-1}$. 


\section{Distortion energy analysis}

Table S1. Distortion energy analysis of TS-1Si and TS-1Re. Energies calculated at the B3LYP-D3(BJ)/def2TZVPP-IEF-PCM(DCM) level of theory.

\begin{tabular}{lc}
\hline & Energy $\left(\mathrm{kcal} \mathrm{mol}^{-1}\right)$ \\
\hline Isolated catalyst from TS-1Si & 0 \\
Isolated catalyst from TS-1Re & 4.6 \\
& \\
Isolated substrate pair from TS-1Si & 0 \\
Isolated substrate pair from TS-1Re & 4.3 \\
\hline
\end{tabular}




\section{Diastereoselectivity}

Scheme S1. Diastereoselective aza-ene-type reaction.

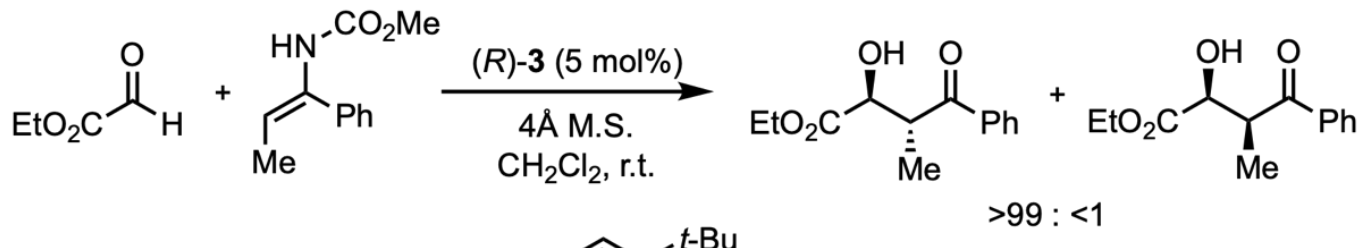<smiles>CC(C)(C)c1ccc(-c2cc3ccccc3cc2OP(=O)(O)Oc2c(-c3ccc(C(C)(C)C)cc3)cc3ccccc3c2-c2c(OP(=O)(O)O)c(-c3ccc(C(C)(C)C)cc3)cc3ccccc23)cc1</smiles>

$(R)-3$

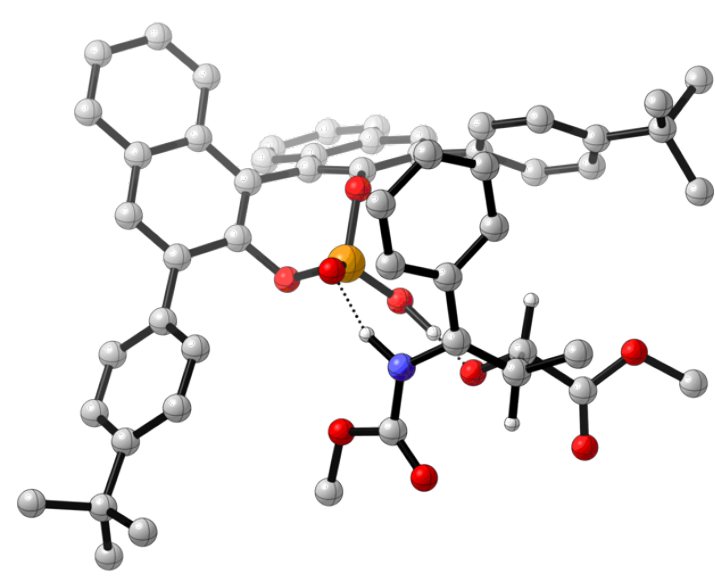

TS-S1(anti) $\Delta \Delta G^{\ddagger}=0$

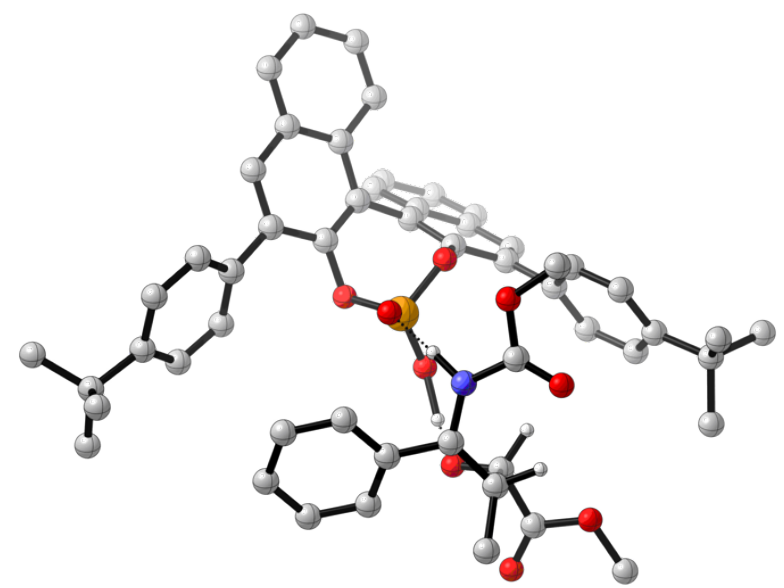

TS-S2(syn) $\Delta \Delta G^{\ddagger}=1.9$

Figure S2. Comparison of C-C bond forming TSs in the diastereoselective aza-ene-type reaction. Noncritical hydrogen atoms omitted for clarity. The ethyl ester of the electrophile was replaced by a methyl ester to reduce conformational flexibility. All energies in $\mathrm{kcal} \mathrm{mol}^{-1}$.

Figure S2 shows that TS-S1(anti), which leads to the major diastereomer observed experimentally, is lower in free energy than TS-S2(syn) by $1.9 \mathrm{kcal} \mathrm{mol}^{-1}$ thus adding further weight to the new mechanistic model presented in this paper. The aldehyde carbonyl and Me group of the nucleophile approach syn, and therefore clash, in TS-S2(syn) but approach anti in TS-S1(anti) which explains the calculated energy difference between the two TSs. 


\section{Energies, frequencies and molecular geometries of computed structures}

All energies in Hartrees, coordinates in $\AA$. Cartesian coordinates generated by ESIgen software ${ }^{7}$.

\section{a) Conformations of Catalyst (R)-1}

Catalyst (R)-1 Conformation 1

B3LYP/6-31G(d) Energy = -1874.416847

B3LYP-D3(BJ)/def2-TZVPP-IEF-PCM(DCM) Energy = -1875.235006

B3LYP-D3(BJ)/def2-TZVPP-IEF-PCM(DCM)//B3LYP/6-31G(d) Free Energy (Quasiharmonic) = 1874.842537

Frequencies (Top 3 out of 168)

1. $\quad 25.1812 \mathrm{~cm}-1$

2. $\quad 26.1085 \mathrm{~cm}-1$

3. $37.0925 \mathrm{~cm}-1$

B3LYP/6-31G(d) Molecular Geometry in Cartesian Coordinates

$\begin{array}{llll}\text { C } & -0.702436 & 1.093636 & 0.145759 \\ \text { C } & -1.516830 & 0.046140 & -0.251394 \\ \text { C } & -2.922234 & 0.002463 & -0.022558 \\ \text { C } & -3.478740 & 1.065543 & 0.662187 \\ \text { H } & -4.551993 & 1.081540 & 0.832060 \\ \text { C } & 3.533365 & 0.951644 & -0.664101 \\ \text { C } & 0.752779 & 1.065308 & -0.188651 \\ \text { C } & 1.523491 & -0.022688 & 0.189400 \\ \text { C } & 2.931937 & -0.104448 & -0.006519 \\ \text { H } & 4.609912 & 0.936627 & -0.811124 \\ \text { O } & -0.937888 & -1.029818 & -0.927812 \\ \text { P } & -0.016196 & -2.080873 & -0.097146 \\ \text { O } & 0.892359 & -1.100717 & 0.821632 \\ \text { C } & -5.458887 & -3.232241 & -1.297872 \\ \text { C } & -4.515316 & -2.699281 & -2.178689 \\ \text { C } & -3.676568 & -1.662556 & -1.772021 \\ \text { C } & -3.768826 & -1.134945 & -0.472614 \\ \text { C } & -4.720296 & -1.682126 & 0.404598 \\ \text { C } & -5.557784 & -2.719959 & -0.003414 \\ \text { H } & -4.431840 & -3.089537 & -3.189466 \\ \text { H } & -6.282708 & -3.132097 & 0.693704 \\ \text { C } & 5.376771 & -3.373247 & 1.348418 \\ \text { C } & 4.424216 & -2.815099 & 2.203336\end{array}$




\begin{tabular}{llll}
$\mathrm{C}$ & 3.611514 & -1.770510 & 1.766723 \\
$\mathrm{C}$ & 3.741428 & -1.259925 & 0.464434 \\
$\mathrm{C}$ & 4.700989 & -1.831426 & -0.386553 \\
$\mathrm{C}$ & 5.510972 & -2.878642 & 0.050648 \\
$\mathrm{H}$ & 4.313693 & -3.192420 & 3.216565 \\
$\mathrm{H}$ & 6.240578 & -3.313477 & -0.627323 \\
$\mathrm{C}$ & 1.383333 & 2.119309 & -0.935562 \\
$\mathrm{C}$ & 2.796959 & 2.055089 & -1.159607 \\
$\mathrm{C}$ & 3.435400 & 3.095364 & -1.888289 \\
$\mathrm{C}$ & 2.711371 & 4.143296 & -2.406601 \\
$\mathrm{C}$ & 1.309564 & 4.188837 & -2.220632 \\
$\mathrm{C}$ & 0.663227 & 3.205876 & -1.504081 \\
$\mathrm{H}$ & 4.510707 & 3.037620 & -2.038855 \\
$\mathrm{H}$ & 3.209177 & 4.928825 & -2.968295 \\
$\mathrm{H}$ & 0.735757 & 5.004618 & -2.651751 \\
$\mathrm{H}$ & -0.412438 & 3.250780 & -1.379789 \\
$\mathrm{C}$ & -1.285432 & 2.154043 & 0.922198 \\
$\mathrm{C}$ & -2.698228 & 2.136837 & 1.161190 \\
$\mathrm{C}$ & -3.291214 & 3.186003 & 1.915061 \\
$\mathrm{C}$ & -2.524533 & 4.197227 & 2.444812 \\
$\mathrm{C}$ & -1.123876 & 4.194463 & 2.245707 \\
$\mathrm{C}$ & -0.520806 & 3.202226 & 1.504528 \\
$\mathrm{H}$ & -4.366420 & 3.164501 & 2.075861 \\
$\mathrm{H}$ & -2.987851 & 4.990059 & 3.025423 \\
$\mathrm{H}$ & -0.516303 & 4.980467 & 2.685780 \\
$\mathrm{H}$ & 0.554375 & 3.210922 & 1.369805 \\
$\mathrm{O}$ & 0.623109 & -3.061521 & -0.988676 \\
$\mathrm{O}$ & -0.934646 & -2.679351 & 1.082070 \\
$\mathrm{H}$ & -1.228087 & -3.575083 & 0.845866 \\
$\mathrm{H}$ & -4.786589 & -1.301904 & 1.420222 \\
$\mathrm{H}$ & -6.109264 & -4.042146 & -1.617252 \\
$\mathrm{H}$ & -2.950653 & -1.254604 & -2.466814 \\
& 4.793341 & -1.465736 & -1.405361 \\
\hline & 2.005868 & -4.190900 & 1.689986 \\
$\mathrm{H}$ & & -1.340970 & 2.441188
\end{tabular}

Catalyst (R)-1 Conformation 2

B3LYP/6-31G(d) Energy $=-1874.417772$

B3LYP-D3(BJ)/def2-TZVPP-IEF-PCM(DCM) Energy $=-1875.234828$

B3LYP-D3(BJ)/def2-TZVPP-IEF-PCM(DCM)//B3LYP/6-31G(d) Free Energy (Quasiharmonic) = 1874.842134 
Frequencies (Top 3 out of 168)

1. $24.8230 \mathrm{~cm}-1$

2. $\quad 28.6187 \mathrm{~cm}-1$

3. $40.0743 \mathrm{~cm}-1$

B3LYP/6-31G(d) Molecular Geometry in Cartesian Coordinates

\begin{tabular}{|c|c|c|c|}
\hline C & 0.651089 & 1.086421 & -0.119377 \\
\hline C & 1.543591 & 0.090315 & 0.235804 \\
\hline C & 2.938185 & 0.128829 & -0.050525 \\
\hline C & 3.401564 & 1.225213 & -0.751383 \\
\hline $\mathrm{H}$ & 4.463930 & 1.306196 & -0.965234 \\
\hline C & -3.559599 & 0.805199 & 0.748243 \\
\hline C & -0.784338 & 0.977326 & 0.277302 \\
\hline C & -1.521499 & -0.145288 & -0.069875 \\
\hline C & -2.931170 & -0.249203 & 0.113612 \\
\hline $\mathrm{H}$ & -4.633031 & 0.755223 & 0.909379 \\
\hline 0 & 1.054742 & -1.023481 & 0.925393 \\
\hline$P$ & 0.173052 & -2.113428 & 0.108958 \\
\hline 0 & -0.873854 & -1.201195 & -0.722836 \\
\hline C & 5.708797 & -2.957306 & 1.099399 \\
\hline C & 4.773261 & -2.483545 & 2.021690 \\
\hline C & 3.859819 & -1.495738 & 1.656411 \\
\hline C & 3.867501 & -0.958590 & 0.357614 \\
\hline C & 4.811766 & -1.446234 & -0.561567 \\
\hline C & 5.724225 & -2.435170 & -0.194782 \\
\hline $\mathrm{H}$ & 4.754622 & -2.881939 & 3.032540 \\
\hline $\mathrm{H}$ & 6.442404 & -2.801640 & -0.923627 \\
\hline C & -5.384965 & -3.475647 & -1.330820 \\
\hline C & -4.278185 & -3.755107 & -0.527162 \\
\hline C & -3.458960 & -2.725847 & -0.063309 \\
\hline C & -3.740349 & -1.391709 & -0.397890 \\
\hline C & -4.857622 & -1.120822 & -1.205401 \\
\hline C & -5.672563 & -2.152861 & -1.669452 \\
\hline $\mathrm{H}$ & -4.049094 & -4.781508 & -0.252939 \\
\hline $\mathrm{H}$ & -6.527831 & -1.922178 & -2.299321 \\
\hline C & -1.438594 & 2.017923 & 1.023634 \\
\hline C & -2.849874 & 1.924929 & 1.245762 \\
\hline C & -3.510468 & 2.948845 & 1.977650 \\
\hline C & -2.809031 & 4.012420 & 2.495341 \\
\hline C & -1.409002 & 4.089770 & 2.306316 \\
\hline C & -0.741906 & 3.121296 & 1.589015 \\
\hline $\mathrm{H}$ & -4.583746 & 2.866170 & 2.130821 \\
\hline
\end{tabular}




$\begin{array}{lrrr}\mathrm{H} & -3.323045 & 4.785965 & 3.059057 \\ \mathrm{H} & -0.852891 & 4.917985 & 2.736913 \\ \mathrm{H} & 0.332463 & 3.189836 & 1.463266 \\ \mathrm{C} & 1.137436 & 2.180977 & -0.917190 \\ \mathrm{C} & 2.537872 & 2.248483 & -1.213258 \\ \mathrm{C} & 3.036838 & 3.331620 & -1.986853 \\ \mathrm{C} & 2.190626 & 4.295260 & -2.483086 \\ \mathrm{C} & 0.801831 & 4.207478 & -2.229471 \\ \mathrm{C} & 0.289131 & 3.180924 & -1.467125 \\ \mathrm{H} & 4.104115 & 3.374286 & -2.190349 \\ \mathrm{H} & 2.582129 & 5.114674 & -3.079413 \\ \mathrm{H} & 0.130847 & 4.954644 & -2.644294 \\ \mathrm{H} & -0.778496 & 3.124974 & -1.291908 \\ \mathrm{O} & -0.334890 & -3.168810 & 1.004645 \\ \mathrm{O} & 1.063477 & -2.611379 & -1.134994 \\ \mathrm{H} & 1.443943 & -3.484125 & -0.939843 \\ \mathrm{H} & 4.813939 & -1.058638 & -1.576558 \\ \mathrm{H} & 6.417644 & -3.729215 & 1.386770 \\ \mathrm{H} & 3.141247 & -1.132957 & 2.383226 \\ \mathrm{H} & -5.075142 & -0.093134 & -1.484125 \\ \mathrm{H} & -6.017786 & -4.282476 & -1.691177 \\ \mathrm{H} & -2.610232 & -2.962756 & 0.569176\end{array}$

Catalyst (R)-1 Conformation 3

B3LYP/6-31G(d) Energy = -1874.414161

B3LYP-D3(BJ)/def2-TZVPP-IEF-PCM(DCM) Energy = -1875.232262

B3LYP-D3(BJ)/def2-TZVPP-IEF-PCM(DCM)//B3LYP/6-31G(d) Free Energy (Quasiharmonic) = 1874.839854

Frequencies (Top 3 out of 168)

1. $23.8553 \mathrm{~cm}-1$

2. $\quad 23.9767 \mathrm{~cm}-1$

3. $\quad 37.8479 \mathrm{~cm}-1$

B3LYP/6-31G(d) Molecular Geometry in Cartesian Coordinates

$\begin{array}{llll}\text { C } & -0.757986 & 0.954783 & 0.279703 \\ \text { C } & -1.527961 & -0.149560 & -0.055968 \\ \text { C } & -2.938866 & -0.207134 & 0.145333 \\ \text { C } & -3.529658 & 0.857435 & 0.796881 \\ \text { H } & -4.603190 & 0.839815 & 0.964829\end{array}$




\begin{tabular}{|c|c|c|c|}
\hline C & 3.414049 & 1.183205 & -0.801518 \\
\hline C & 0.668857 & 1.048647 & -0.150212 \\
\hline C & 1.559214 & 0.042692 & 0.179817 \\
\hline C & 2.953971 & 0.083714 & -0.103217 \\
\hline $\mathrm{H}$ & 4.476015 & 1.265395 & -1.016646 \\
\hline 0 & -0.938833 & -1.221706 & -0.728484 \\
\hline$P$ & 0.230459 & -2.134798 & -0.075547 \\
\hline $\mathrm{O}$ & 1.057317 & -1.085007 & 0.842386 \\
\hline C & -5.507034 & -3.325328 & -1.341427 \\
\hline C & -4.446450 & -3.648365 & -0.492851 \\
\hline C & -3.593746 & -2.653004 & -0.016786 \\
\hline C & -3.790866 & -1.312323 & -0.379924 \\
\hline C & -4.863531 & -0.997956 & -1.229748 \\
\hline C & -5.713343 & -1.995177 & -1.708292 \\
\hline $\mathrm{H}$ & -4.284336 & -4.681308 & -0.195480 \\
\hline $\mathrm{H}$ & -6.533055 & -1.731570 & -2.371461 \\
\hline C & 5.754814 & -2.942531 & 1.118294 \\
\hline C & 4.811218 & -2.459015 & 2.027077 \\
\hline C & 3.885097 & -1.494309 & 1.634541 \\
\hline C & 3.889875 & -0.990289 & 0.323183 \\
\hline C & 4.841469 & -1.486589 & -0.582001 \\
\hline C & 5.765338 & -2.453948 & -0.188657 \\
\hline $\mathrm{H}$ & 4.797312 & -2.831421 & 3.048071 \\
\hline $\mathrm{H}$ & 6.487365 & -2.831822 & -0.907610 \\
\hline C & 1.151764 & 2.148227 & -0.943372 \\
\hline C & 2.548992 & 2.209137 & -1.255425 \\
\hline C & 3.044437 & 3.293603 & -2.029343 \\
\hline C & 2.197813 & 4.265183 & -2.509238 \\
\hline C & 0.811989 & 4.185279 & -2.237575 \\
\hline C & 0.302783 & 3.157475 & -1.474560 \\
\hline $\mathrm{H}$ & 4.109229 & 3.330989 & -2.246250 \\
\hline $\mathrm{H}$ & 2.586726 & 5.085228 & -3.106409 \\
\hline $\mathrm{H}$ & 0.140557 & 4.939251 & -2.639169 \\
\hline $\mathrm{H}$ & -0.762894 & 3.106922 & -1.285864 \\
\hline C & -1.371359 & 2.004203 & 1.049940 \\
\hline C & -2.780150 & 1.949462 & 1.297722 \\
\hline C & -3.398826 & 2.983321 & 2.051489 \\
\hline C & -2.658715 & 4.021430 & 2.567169 \\
\hline C & -1.260925 & 4.061314 & 2.352759 \\
\hline C & -0.634465 & 3.082533 & 1.613008 \\
\hline $\mathrm{H}$ & -4.471222 & 2.929069 & 2.222762 \\
\hline $\mathrm{H}$ & -3.140446 & 4.803133 & 3.147880 \\
\hline $\mathrm{H}$ & -0.673748 & 4.869016 & 2.781085 \\
\hline $\mathrm{H}$ & 0.438797 & 3.123266 & 1.467963 \\
\hline
\end{tabular}




$\begin{array}{lrrr}\mathrm{O} & 0.940379 & -2.935844 & -1.085757 \\ \mathrm{O} & -0.455229 & -2.986682 & 1.113083 \\ \mathrm{H} & -0.322488 & -3.932920 & 0.935290 \\ \mathrm{H} & -5.018598 & 0.035290 & -1.528390 \\ \mathrm{H} & -6.166997 & -4.104413 & -1.713451 \\ \mathrm{H} & -2.783529 & -2.909112 & 0.656225 \\ \mathrm{H} & 4.838125 & -1.127144 & -1.607114 \\ \mathrm{H} & 6.473273 & -3.697662 & 1.425851 \\ \mathrm{H} & 3.160372 & -1.120820 & 2.350473\end{array}$

Catalyst (R)-1 Conformation 4

B3LYP/6-31G(d) Energy $=-1874.414723$

B3LYP-D3(BJ)/def2-TZVPP-IEF-PCM(DCM) Energy $=-1875.231881$

B3LYP-D3(BJ)/def2-TZVPP-IEF-PCM(DCM)//B3LYP/6-31G(d) Free Energy (Quasiharmonic) = 1874.83929

Frequencies (Top 3 out of 168)

1. $\quad 22.0188 \mathrm{~cm}-1$

2. $25.4114 \mathrm{~cm}-1$

3. $\quad 35.9879 \mathrm{~cm}-1$

B3LYP/6-31G(d) Molecular Geometry in Cartesian Coordinates

$\begin{array}{lrrr}\text { C } & -0.706699 & 0.950489 & 0.251533 \\ \text { C } & -1.555013 & -0.105433 & -0.043063 \\ \text { C } & -2.958066 & -0.078127 & 0.207448 \\ \text { C } & -3.460622 & 1.025534 & 0.867161 \\ \text { H } & -4.527017 & 1.075702 & 1.070337 \\ \text { C } & 3.452024 & 1.042667 & -0.872004 \\ \text { C } & 0.704402 & 0.961324 & -0.236190 \\ \text { C } & 1.561245 & -0.085706 & 0.059644 \\ \text { C } & 2.960742 & -0.063309 & -0.206008 \\ \text { H } & 4.514692 & 1.092311 & -1.093486 \\ \text { O } & -1.050525 & -1.217921 & -0.722105 \\ \text { P } & 0.061041 & -2.192790 & -0.066307 \\ \text { O } & 1.042662 & -1.192883 & 0.742952 \\ \text { C } & -5.750363 & -3.052549 & -1.165031 \\ \text { C } & -4.705250 & -3.423681 & -0.316902 \\ \text { C } & -3.781915 & -2.475538 & 0.122361 \\ \text { C } & -3.890861 & -1.135630 & -0.278143 \\ \text { C } & -4.949044 & -0.772060 & -1.126037\end{array}$




\begin{tabular}{|c|c|c|c|}
\hline C & -5.869959 & -1.722168 & -1.567817 \\
\hline $\mathrm{H}$ & -4.611153 & -4.456405 & 0.009075 \\
\hline $\mathrm{H}$ & -6.677631 & -1.421919 & -2.230145 \\
\hline C & 5.772620 & -3.050672 & 1.091344 \\
\hline C & 4.672147 & -3.425883 & 0.318517 \\
\hline C & 3.738983 & -2.475858 & -0.096991 \\
\hline C & 3.897914 & -1.126557 & 0.256167 \\
\hline C & 5.010262 & -0.758273 & 1.030787 \\
\hline C & 5.939247 & -1.711617 & 1.446817 \\
\hline $\mathrm{H}$ & 4.538498 & -4.465132 & 0.029618 \\
\hline $\mathrm{H}$ & 6.789385 & -1.407353 & 2.051877 \\
\hline C & 1.214365 & 2.053984 & -1.022746 \\
\hline C & 2.613224 & 2.089439 & -1.326789 \\
\hline C & 3.134179 & 3.165188 & -2.095939 \\
\hline C & 2.309674 & 4.156547 & -2.573919 \\
\hline C & 0.921685 & 4.105181 & -2.305834 \\
\hline C & 0.388535 & 3.084693 & -1.549481 \\
\hline $\mathrm{H}$ & 4.199975 & 3.179920 & -2.310544 \\
\hline $\mathrm{H}$ & 2.717326 & 4.970362 & -3.167100 \\
\hline $\mathrm{H}$ & 0.267547 & 4.874899 & -2.706107 \\
\hline $\mathrm{H}$ & -0.678675 & 3.055467 & -1.364232 \\
\hline C & -1.227550 & 2.039315 & 1.037222 \\
\hline C & -2.627927 & 2.072129 & 1.333207 \\
\hline C & -3.156559 & 3.145601 & 2.099952 \\
\hline C & -2.337324 & 4.138248 & 2.584424 \\
\hline C & -0.947712 & 4.090144 & 2.324526 \\
\hline C & -0.407671 & 3.072008 & 1.569857 \\
\hline $\mathrm{H}$ & -4.223878 & 3.157918 & 2.307185 \\
\hline $\mathrm{H}$ & -2.750433 & 4.950580 & 3.175849 \\
\hline $\mathrm{H}$ & -0.297637 & 4.860847 & 2.729486 \\
\hline $\mathrm{H}$ & 0.660634 & 3.045759 & 1.390673 \\
\hline $\mathrm{O}$ & 0.635383 & -3.114886 & -1.063678 \\
\hline $\mathrm{O}$ & -0.629924 & -2.914966 & 1.201103 \\
\hline $\mathrm{H}$ & -0.609431 & -3.876971 & 1.064164 \\
\hline $\mathrm{H}$ & -5.037322 & 0.260979 & -1.451404 \\
\hline $\mathrm{H}$ & -6.465962 & -3.794748 & -1.508444 \\
\hline $\mathrm{H}$ & -2.984483 & -2.765346 & 0.797188 \\
\hline $\mathrm{H}$ & 5.134949 & 0.281689 & 1.320811 \\
\hline $\mathrm{H}$ & 6.494981 & -3.795978 & 1.413836 \\
\hline $\mathrm{H}$ & 2.896967 & -2.782066 & -0.708647 \\
\hline
\end{tabular}

Catalyst (R)-1 Conformation 5 
B3LYP/6-31G(d) Energy $=-1874.415037$

B3LYP-D3(BJ)/def2-TZVPP-IEF-PCM(DCM) Energy $=-1875.233254$

B3LYP-D3(BJ)/def2-TZVPP-IEF-PCM(DCM)//B3LYP/6-31G(d) Free Energy (Quasiharmonic) = 1874.840974

Frequencies (Top 3 out of 168)

1. $\quad 23.4767 \mathrm{~cm}-1$

2. $28.6314 \mathrm{~cm}-1$

3. $41.5998 \mathrm{~cm}-1$

B3LYP/6-31G(d) Molecular Geometry in Cartesian Coordinates

$\begin{array}{llll}\text { C } & 0.655587 & 1.061566 & -0.131868 \\ \text { C } & 1.544313 & 0.057080 & 0.217090 \\ \text { C } & 2.941592 & 0.095530 & -0.068463 \\ \text { C } & 3.403071 & 1.191138 & -0.774304 \\ \text { H } & 4.466011 & 1.274203 & -0.983780 \\ \text { C } & -3.547137 & 0.824239 & 0.779823 \\ \text { C } & -0.776760 & 0.968939 & 0.280461 \\ \text { C } & -1.529978 & -0.142323 & -0.066938 \\ \text { C } & -2.938598 & -0.232842 & 0.129944 \\ \text { H } & -4.619121 & 0.785308 & 0.953095 \\ \text { O } & 1.052533 & -1.054377 & 0.905457 \\ \text { P } & 0.149752 & -2.140650 & 0.100200 \\ \text { O } & -0.892792 & -1.197712 & -0.730962 \\ \text { C } & 5.744939 & -2.938822 & 1.135284 \\ \text { C } & 4.772568 & -2.494447 & 2.033297 \\ \text { C } & 3.846721 & -1.526103 & 1.649432 \\ \text { C } & 3.879387 & -0.978894 & 0.355461 \\ \text { C } & 4.861946 & -1.436098 & -0.538870 \\ \text { C } & 5.785958 & -2.406336 & -0.153767 \\ \text { H } & 4.732811 & -2.902727 & 3.039441 \\ \text { H } & 6.531996 & -2.751416 & -0.864667 \\ \text { C } & -5.440121 & -3.414742 & -1.330497 \\ \text { C } & -4.324526 & -3.716784 & -0.547519 \\ \text { C } & -3.490543 & -2.702258 & -0.077349 \\ \text { C } & -3.765736 & -1.360409 & -0.385556 \\ \text { C } & -4.892244 & -1.066671 & -1.172395 \\ \text { C } & -5.722088 & -2.084042 & -1.642175 \\ \text { H } & -4.099124 & -4.749330 & -0.294576 \\ \text { H } & -6.584500 & -1.835831 & -2.255444 \\ \text { C } & -1.410006 & 2.013660 & 1.038503 \\ \text { C } & -2.819650 & 1.933213 & 1.276232\end{array}$




$\begin{array}{lrrr}\text { C } & -3.461185 & 2.959804 & 2.021216 \\ \text { C } & -2.743105 & 4.013896 & 2.535523 \\ \text { C } & -1.344819 & 4.078904 & 2.329853 \\ \text { C } & -0.695673 & 3.107429 & 1.600194 \\ \text { H } & -4.533249 & 2.886899 & 2.187077 \\ \text { H } & -3.242684 & 4.789426 & 3.109342 \\ \text { H } & -0.775678 & 4.899636 & 2.757686 \\ \text { H } & 0.377895 & 3.166085 & 1.462604 \\ \mathrm{C} & 1.141891 & 2.153244 & -0.933505 \\ \mathrm{C} & 2.540690 & 2.214048 & -1.238476 \\ \mathrm{C} & 3.039312 & 3.293446 & -2.017986 \\ \mathrm{C} & 2.193733 & 4.259658 & -2.510119 \\ \mathrm{C} & 0.806214 & 4.179368 & -2.246006 \\ \mathrm{C} & 0.294033 & 3.156780 & -1.478112 \\ \mathrm{H} & 4.105486 & 3.331816 & -2.227811 \\ \mathrm{H} & 2.584742 & 5.076444 & -3.110300 \\ \mathrm{H} & 0.136204 & 4.929789 & -2.656390 \\ \mathrm{H} & -0.772290 & 3.107004 & -1.293145 \\ \mathrm{O} & -0.382446 & -3.171116 & 1.001351 \\ \mathrm{O} & 1.022574 & -2.710723 & -1.119948 \\ \mathrm{H} & 1.124508 & -2.067056 & -1.841036 \\ \mathrm{H} & 4.888000 & -1.040130 & -1.550633 \\ \mathrm{H} & 6.461501 & -3.698022 & 1.436666 \\ \mathrm{H} & 3.099085 & -1.187540 & 2.357950 \\ \mathrm{H} & -5.105488 & -0.032674 & -1.430599 \\ \mathrm{H} & -6.084306 & -4.210280 & -1.695745 \\ \mathrm{H} & -2.635739 & -2.957442 & 0.539637\end{array}$

\section{b) Conformations of Catalyst (R)-1 TS}

Catalyst (R)-1 TS Conformation 1 (TS-1Si)

B3LYP/6-31G(d) Energy $=-2809.699587$

B3LYP-D3(BJ)/def2-TZVPP-IEF-PCM(DCM) Energy = -2810.993883

B3LYP-D3(BJ)/def2-TZVPP-IEF-PCM(DCM)//B3LYP/6-31G(d) Free Energy (Quasiharmonic) = 2810.351854

Frequencies (Top 3 out of 270)

1. $-447.1618 \mathrm{~cm}-1$

2. $\quad 12.4103 \mathrm{~cm}-1$

3. $\quad 16.4176 \mathrm{~cm}-1$ 
B3LYP/6-31G(d) Molecular Geometry in Cartesian Coordinates

\begin{tabular}{|c|c|c|c|}
\hline C & 3.316880 & -0.293254 & 0.225595 \\
\hline C & 2.735409 & 0.912185 & -0.145343 \\
\hline C & 3.369892 & 2.174115 & 0.063605 \\
\hline C & 4.568927 & 2.175196 & 0.750635 \\
\hline $\mathrm{H}$ & 5.068990 & 3.122849 & 0.932019 \\
\hline C & 1.457128 & -4.022977 & -0.891455 \\
\hline C & 2.700778 & -1.584511 & -0.200354 \\
\hline C & 1.377634 & -1.848802 & 0.109204 \\
\hline C & 0.722499 & -3.073820 & -0.208296 \\
\hline $\mathrm{H}$ & 0.998191 & -4.979589 & -1.127045 \\
\hline $\mathrm{O}$ & 1.533169 & 0.895572 & -0.845156 \\
\hline$P$ & 0.152462 & 0.422188 & -0.108820 \\
\hline $\mathrm{O}$ & 0.647052 & -0.865021 & 0.771233 \\
\hline C & 1.952904 & 5.963548 & -1.407693 \\
\hline C & 1.095465 & 5.139362 & -0.675653 \\
\hline C & 1.526803 & 3.895638 & -0.213024 \\
\hline C & 2.835609 & 3.459046 & -0.469543 \\
\hline C & 3.689664 & 4.294976 & -1.209131 \\
\hline C & 3.253580 & 5.534503 & -1.675923 \\
\hline $\mathrm{H}$ & 0.081645 & 5.463633 & -0.455901 \\
\hline $\mathrm{H}$ & 3.929434 & 6.161768 & -2.251489 \\
\hline C & -3.352335 & -3.976639 & 0.841288 \\
\hline C & -2.495803 & -3.414102 & 1.790780 \\
\hline C & -1.180369 & -3.095201 & 1.454829 \\
\hline C & -0.692489 & -3.342314 & 0.160951 \\
\hline C & -1.565040 & -3.903768 & -0.786331 \\
\hline C & -2.881730 & -4.217649 & -0.450796 \\
\hline $\mathrm{H}$ & -2.849377 & -3.223068 & 2.800374 \\
\hline $\mathrm{H}$ & -3.540933 & -4.644899 & -1.201861 \\
\hline C & 3.428748 & -2.551724 & -0.977836 \\
\hline C & 2.791292 & -3.791945 & -1.306847 \\
\hline C & 3.501069 & -4.764064 & -2.062785 \\
\hline C & 4.777640 & -4.517990 & -2.511045 \\
\hline C & 5.394299 & -3.277655 & -2.224423 \\
\hline C & 4.740006 & -2.322123 & -1.478230 \\
\hline $\mathrm{H}$ & 3.005655 & -5.704553 & -2.292140 \\
\hline $\mathrm{H}$ & 5.307902 & -5.265373 & -3.094786 \\
\hline $\mathrm{H}$ & 6.392859 & -3.073433 & -2.601190 \\
\hline $\mathrm{H}$ & 5.224435 & -1.373958 & -1.277951 \\
\hline C & 4.512999 & -0.264794 & 1.022581 \\
\hline C & 5.146003 & 0.993797 & 1.274956 \\
\hline C & 6.331297 & 1.036224 & 2.058238 \\
\hline
\end{tabular}




\begin{tabular}{|c|c|c|c|}
\hline C & 6.864773 & -0.111715 & 2.595952 \\
\hline C & 6.223962 & -1.353776 & 2.375295 \\
\hline C & 5.081752 & -1.429302 & 1.608923 \\
\hline$H$ & 6.802490 & 2.000567 & 2.233239 \\
\hline $\mathrm{H}$ & 7.768084 & -0.067231 & 3.198153 \\
\hline $\mathrm{H}$ & 6.633335 & -2.256903 & 2.819878 \\
\hline $\mathrm{H}$ & 4.597242 & -2.387194 & 1.458798 \\
\hline 0 & -0.422504 & 1.426869 & 0.837526 \\
\hline $\mathrm{O}$ & -0.693161 & -0.080557 & -1.295243 \\
\hline $\mathrm{H}$ & -1.801464 & 0.061052 & -1.403240 \\
\hline $\mathrm{H}$ & 4.698819 & 3.958891 & -1.431880 \\
\hline $\mathrm{H}$ & 1.611159 & 6.931489 & -1.765497 \\
\hline $\mathrm{H}$ & 0.851379 & 3.269641 & 0.358907 \\
\hline $\mathrm{H}$ & -1.210418 & -4.072676 & -1.799012 \\
\hline $\mathrm{H}$ & -4.378415 & -4.219813 & 1.103540 \\
\hline $\mathrm{H}$ & -0.524527 & -2.659114 & 2.200502 \\
\hline C & -3.932441 & -0.399840 & -0.965371 \\
\hline $\mathrm{O}$ & -3.064531 & 0.158520 & -1.718902 \\
\hline $\mathrm{H}$ & -3.603667 & -1.006342 & -0.111676 \\
\hline C & -5.180828 & -0.956740 & -1.645739 \\
\hline $\mathrm{O}$ & -5.538724 & -0.705105 & -2.769371 \\
\hline $\mathrm{O}$ & -5.834351 & -1.792344 & -0.800648 \\
\hline C & -7.031499 & -2.381663 & -1.336720 \\
\hline $\mathrm{H}$ & -7.750684 & -1.605824 & -1.613067 \\
\hline $\mathrm{H}$ & -6.799540 & -2.980168 & -2.221504 \\
\hline C & -3.890180 & 1.533253 & 0.754360 \\
\hline C & -4.971394 & 1.026879 & 0.021160 \\
\hline $\mathrm{H}$ & -1.967123 & 2.192143 & 0.489990 \\
\hline$N$ & -2.944699 & 2.304223 & 0.159036 \\
\hline C & -3.094080 & 3.011536 & -1.050477 \\
\hline $\mathrm{O}$ & -4.137865 & 3.294317 & -1.591830 \\
\hline $\mathrm{O}$ & -1.872744 & 3.381213 & -1.464453 \\
\hline C & -1.835853 & 4.058764 & -2.734606 \\
\hline $\mathrm{H}$ & -2.200196 & 3.393170 & -3.520646 \\
\hline $\mathrm{H}$ & -0.787297 & 4.308420 & -2.889916 \\
\hline $\mathrm{H}$ & -2.453234 & 4.959813 & -2.703870 \\
\hline $\mathrm{H}$ & -5.764578 & 0.538884 & 0.575318 \\
\hline $\mathrm{H}$ & -5.276783 & 1.568457 & -0.864375 \\
\hline C & -3.622492 & 1.123147 & 2.147908 \\
\hline C & -2.815649 & 1.918588 & 2.982156 \\
\hline C & -4.201428 & -0.043530 & 2.683484 \\
\hline C & -2.600180 & 1.562129 & 4.310319 \\
\hline $\mathrm{H}$ & -2.371921 & 2.829483 & 2.596601 \\
\hline C & -3.979471 & -0.397762 & 4.010453 \\
\hline
\end{tabular}




$\begin{array}{llll}\mathrm{H} & -4.804973 & -0.690404 & 2.055729 \\ \mathrm{C} & -3.180507 & 0.404206 & 4.829452 \\ \mathrm{H} & -1.978078 & 2.191647 & 4.939489 \\ \mathrm{H} & -4.429847 & -1.303638 & 4.406448 \\ \mathrm{H} & -3.011373 & 0.126779 & 5.866157 \\ \mathrm{H} & -7.431413 & -3.011186 & -0.541305\end{array}$

Catalyst (R)-1 TS Conformation 2

B3LYP/6-31G(d) Energy $=-2809.700866$

B3LYP-D3(BJ)/def2-TZVPP-IEF-PCM(DCM) Energy = -2810.993744

B3LYP-D3(BJ)/def2-TZVPP-IEF-PCM(DCM)//B3LYP/6-31G(d) Free Energy (Quasiharmonic) = 2810.351804

Frequencies (Top 3 out of 270)

1. $-439.7576 \mathrm{~cm}-1$

2. $\quad 10.6860 \mathrm{~cm}-1$

3. $16.3945 \mathrm{~cm}-1$

B3LYP/6-31G(d) Molecular Geometry in Cartesian Coordinates

$\begin{array}{llll}\text { C } & 2.807238 & -1.461444 & -0.273588 \\ \text { C } & 1.500903 & -1.809466 & 0.030437 \\ \text { C } & 0.940976 & -3.087139 & -0.262375 \\ \text { C } & 1.750277 & -3.999040 & -0.911114 \\ \text { H } & 1.361336 & -4.990409 & -1.128558 \\ \text { C } & 4.262612 & 2.495746 & 0.628672 \\ \text { C } & 3.313857 & -0.109153 & 0.105124 \\ \text { C } & 2.635949 & 1.019556 & -0.331106 \\ \text { C } & 3.110850 & 2.347420 & -0.119932 \\ \text { H } & 4.665736 & 3.492570 & 0.786835 \\ \text { O } & 0.696604 & -0.871634 & 0.668414 \\ \text { P } & 0.118595 & 0.392272 & -0.200504 \\ \text { O } & 1.448059 & 0.854777 & -1.037323 \\ \text { C } & -3.087196 & -4.225776 & 0.740238 \\ \text { C } & -2.588656 & -4.435798 & -0.546593 \\ \text { C } & -1.286512 & -4.051530 & -0.865468 \\ \text { C } & -0.458347 & -3.443874 & 0.092523 \\ \text { C } & -0.971680 & -3.231770 & 1.382444 \\ \text { C } & -2.270706 & -3.626085 & 1.702399 \\ \text { H } & -3.218216 & -4.890695 & -1.306632 \\ \text { H } & -2.644807 & -3.461562 & 2.709277\end{array}$




\begin{tabular}{|c|c|c|c|}
\hline C & 1.343819 & 5.886605 & -1.810739 \\
\hline C & 1.522647 & 4.747888 & -2.600512 \\
\hline C & 2.057080 & 3.583735 & -2.049835 \\
\hline C & 2.438492 & 3.541298 & -0.698542 \\
\hline C & 2.246489 & 4.689819 & 0.086254 \\
\hline C & 1.702459 & 5.850544 & -0.462492 \\
\hline $\mathrm{H}$ & 1.257276 & 4.768046 & -3.654771 \\
\hline $\mathrm{H}$ & 1.558169 & 6.726380 & 0.164787 \\
\hline C & 4.470468 & 0.064738 & 0.939796 \\
\hline C & 4.945551 & 1.391755 & 1.194759 \\
\hline C & 6.092364 & 1.577030 & 2.013785 \\
\hline C & 6.732774 & 0.503738 & 2.587909 \\
\hline C & 6.244188 & -0.805673 & 2.367541 \\
\hline C & 5.145407 & -1.019994 & 1.564758 \\
\hline $\mathrm{H}$ & 6.447293 & 2.590316 & 2.186796 \\
\hline $\mathrm{H}$ & 7.604584 & 0.658074 & 3.217776 \\
\hline $\mathrm{H}$ & 6.737773 & -1.650767 & 2.839810 \\
\hline $\mathrm{H}$ & 4.777566 & -2.028265 & 1.413380 \\
\hline C & 3.615191 & -2.396165 & -1.008566 \\
\hline C & 3.072465 & -3.687035 & -1.311732 \\
\hline C & 3.863040 & -4.626731 & -2.027449 \\
\hline C & 5.128079 & -4.304006 & -2.459787 \\
\hline C & 5.651723 & -3.016299 & -2.197306 \\
\hline C & 4.917313 & -2.088775 & -1.491469 \\
\hline $\mathrm{H}$ & 3.439348 & -5.605900 & -2.238011 \\
\hline $\mathrm{H}$ & 5.720641 & -5.028204 & -3.012034 \\
\hline $\mathrm{H}$ & 6.641648 & -2.753626 & -2.560525 \\
\hline $\mathrm{H}$ & 5.330568 & -1.103858 & -1.308591 \\
\hline $\mathrm{O}$ & -0.402464 & 1.405698 & 0.761738 \\
\hline $\mathrm{O}$ & -0.789097 & -0.148019 & -1.324522 \\
\hline $\mathrm{H}$ & -1.906404 & -0.064046 & -1.328351 \\
\hline $\mathrm{H}$ & -0.348836 & -2.762181 & 2.136396 \\
\hline $\mathrm{H}$ & -4.106504 & -4.510354 & 0.983374 \\
\hline $\mathrm{H}$ & -0.910510 & -4.197597 & -1.874179 \\
\hline $\mathrm{H}$ & 2.512878 & 4.663056 & 1.139201 \\
\hline $\mathrm{H}$ & 0.930047 & 6.794032 & -2.243066 \\
\hline $\mathrm{H}$ & 2.195250 & 2.706813 & -2.673094 \\
\hline C & -3.934306 & -0.654531 & -0.649301 \\
\hline $\mathrm{O}$ & -3.206533 & -0.040992 & -1.505350 \\
\hline $\mathrm{H}$ & -3.460345 & -1.230325 & 0.155825 \\
\hline C & -5.206915 & -1.359106 & -1.108952 \\
\hline $\mathrm{O}$ & -5.744345 & -2.230118 & -0.453402 \\
\hline $\mathrm{O}$ & -5.645780 & -0.908238 & -2.289620 \\
\hline C & -6.843290 & -1.534255 & -2.780579 \\
\hline
\end{tabular}




$\begin{array}{llll}\mathrm{H} & -7.668599 & -1.387709 & -2.078439 \\ \mathrm{H} & -7.055923 & -1.047187 & -3.732081 \\ \mathrm{C} & -3.839251 & 1.254988 & 1.080335 \\ \mathrm{C} & -4.952273 & 0.681260 & 0.449734 \\ \mathrm{H} & -2.009456 & 2.068794 & 0.623277 \\ \mathrm{~N} & -3.025980 & 2.109933 & 0.409724 \\ \mathrm{C} & -3.368089 & 2.852116 & -0.736267 \\ \mathrm{O} & -4.485737 & 3.062605 & -1.151076 \\ \mathrm{O} & -2.237231 & 3.352040 & -1.252912 \\ \mathrm{C} & -2.404490 & 4.145175 & -2.439809 \\ \mathrm{H} & -2.824796 & 3.535020 & -3.243245 \\ \mathrm{H} & -1.401424 & 4.485805 & -2.692437 \\ \mathrm{H} & -3.066870 & 4.991973 & -2.242733 \\ \mathrm{H} & -5.647997 & 0.126736 & 1.068823 \\ \mathrm{H} & -5.386157 & 1.216885 & -0.384042 \\ \mathrm{C} & -3.392715 & 0.833282 & 2.422918 \\ \mathrm{C} & -2.539399 & 1.655566 & 3.181934 \\ \mathrm{C} & -3.845057 & -0.374584 & 2.989508 \\ \mathrm{C} & -2.156352 & 1.284856 & 4.467676 \\ \mathrm{H} & -2.189166 & 2.596270 & 2.772754 \\ \mathrm{C} & -3.456192 & -0.741731 & 4.273785 \\ \mathrm{H} & -4.480330 & -1.042391 & 2.417359 \\ \mathrm{C} & -2.612702 & 0.086717 & 5.018463 \\ \mathrm{H} & -1.500303 & 1.934731 & 5.039061 \\ \mathrm{H} & -3.811078 & -1.678474 & 4.694219 \\ \mathrm{H} & -2.312731 & -0.201606 & 6.022105 \\ \mathrm{H} & -6.683032 & -2.606152 & -2.923219\end{array}$

Catalyst (R)-1 TS Conformation 3

B3LYP/6-31G(d) Energy $=-2809.698659$

B3LYP-D3(BJ)/def2-TZVPP-IEF-PCM(DCM) Energy $=-2810.993424$

B3LYP-D3(BJ)/def2-TZVPP-IEF-PCM(DCM)//B3LYP/6-31G(d) Free Energy (Quasiharmonic) = 2810.351533

Frequencies (Top 3 out of 270 )

1. $-424.0801 \mathrm{~cm}-1$

2. $\quad 10.5276 \mathrm{~cm}-1$

3. $\quad 15.7240 \mathrm{~cm}-1$

B3LYP/6-31G(d) Molecular Geometry in Cartesian Coordinates 


\begin{tabular}{|c|c|c|c|}
\hline C & 3.311500 & -0.183452 & 0.154414 \\
\hline C & 2.675586 & 0.967795 & -0.286003 \\
\hline C & 3.180522 & 2.279879 & -0.047891 \\
\hline C & 4.315803 & 2.388522 & 0.732103 \\
\hline $\mathrm{H}$ & 4.741474 & 3.372223 & 0.911789 \\
\hline C & 1.673414 & -4.017075 & -0.951957 \\
\hline C & 2.779339 & -1.516994 & -0.254200 \\
\hline C & 1.456692 & -1.833306 & 0.011456 \\
\hline C & 0.871154 & -3.091714 & -0.313232 \\
\hline $\mathrm{H}$ & 1.265265 & -4.995526 & -1.191422 \\
\hline $\mathrm{O}$ & 1.501879 & 0.842125 & -1.023675 \\
\hline$P$ & 0.140329 & 0.408253 & -0.224349 \\
\hline $\mathrm{O}$ & 0.661735 & -0.882536 & 0.641634 \\
\hline C & 1.559811 & 5.884289 & -1.746600 \\
\hline C & 1.880347 & 5.824476 & -0.389634 \\
\hline C & 2.376345 & 4.643299 & 0.160940 \\
\hline C & 2.557032 & 3.497815 & -0.630926 \\
\hline C & 2.213713 & 3.564540 & -1.991399 \\
\hline C & 1.727711 & 4.748985 & -2.543613 \\
\hline $\mathrm{H}$ & 1.743746 & 6.697716 & 0.242955 \\
\hline $\mathrm{H}$ & 1.491472 & 4.787228 & -3.604244 \\
\hline C & -3.197452 & -4.171663 & 0.581099 \\
\hline C & -2.668645 & -4.388675 & -0.692333 \\
\hline C & -1.354982 & -4.017471 & -0.977326 \\
\hline C & -0.544596 & -3.419668 & 0.001936 \\
\hline C & -1.090842 & -3.196257 & 1.276513 \\
\hline C & -2.402222 & -3.574871 & 1.562592 \\
\hline $\mathrm{H}$ & -3.279690 & -4.842176 & -1.468342 \\
\hline $\mathrm{H}$ & -2.800661 & -3.404143 & 2.558980 \\
\hline C & 3.581470 & -2.463611 & -0.980175 \\
\hline C & 3.013343 & -3.735775 & -1.313874 \\
\hline C & 3.797463 & -4.687626 & -2.020590 \\
\hline C & 5.081455 & -4.393372 & -2.415635 \\
\hline C & 5.631552 & -3.123243 & -2.123203 \\
\hline C & 4.903469 & -2.185045 & -1.424994 \\
\hline $\mathrm{H}$ & 3.353876 & -5.652506 & -2.254770 \\
\hline $\mathrm{H}$ & 5.669154 & -5.126219 & -2.961594 \\
\hline $\mathrm{H}$ & 6.637186 & -2.882581 & -2.457298 \\
\hline $\mathrm{H}$ & 5.337363 & -1.213689 & -1.219019 \\
\hline C & 4.450124 & -0.050398 & 1.020615 \\
\hline C & 4.953620 & 1.260409 & 1.303253 \\
\hline C & 6.083065 & 1.405596 & 2.153889 \\
\hline C & 6.679318 & 0.309120 & 2.731764 \\
\hline C & 6.161977 & -0.984134 & 2.483381 \\
\hline
\end{tabular}




\begin{tabular}{|c|c|c|c|}
\hline C & 5.079276 & -1.159837 & 1.649943 \\
\hline $\mathrm{H}$ & 6.460318 & 2.406938 & 2.347871 \\
\hline $\mathrm{H}$ & 7.538145 & 0.432899 & 3.385742 \\
\hline $\mathrm{H}$ & 6.620395 & -1.847408 & 2.958210 \\
\hline $\mathrm{H}$ & 4.688850 & -2.156128 & 1.477172 \\
\hline $\mathrm{O}$ & -0.375047 & 1.425034 & 0.737025 \\
\hline $\mathrm{O}$ & -0.756894 & -0.097947 & -1.372645 \\
\hline $\mathrm{H}$ & -1.862911 & 0.057269 & -1.415705 \\
\hline $\mathrm{H}$ & 2.343880 & 2.690384 & -2.620263 \\
\hline $\mathrm{H}$ & 1.183590 & 6.807373 & -2.180037 \\
\hline $\mathrm{H}$ & 2.613337 & 4.598398 & 1.220291 \\
\hline $\mathrm{H}$ & -0.483471 & -2.732296 & 2.046127 \\
\hline $\mathrm{H}$ & -4.221288 & -4.458543 & 0.804678 \\
\hline $\mathrm{H}$ & -0.954926 & -4.169494 & -1.975681 \\
\hline C & -3.955833 & -0.455496 & -0.859836 \\
\hline 0 & -3.155232 & 0.165887 & -1.638393 \\
\hline $\mathrm{H}$ & -3.553934 & -1.104862 & -0.070958 \\
\hline C & -5.238431 & -1.002927 & -1.482119 \\
\hline $\mathrm{O}$ & -5.679713 & -0.699530 & -2.562617 \\
\hline 0 & -5.815705 & -1.898071 & -0.641866 \\
\hline C & -7.034803 & -2.485369 & -1.127361 \\
\hline $\mathrm{H}$ & -7.785964 & -1.712809 & -1.313061 \\
\hline $\mathrm{H}$ & -6.852376 & -3.031623 & -2.056494 \\
\hline C & -3.823536 & 1.388545 & 0.953382 \\
\hline C & -4.945920 & 0.877680 & 0.286909 \\
\hline $\mathrm{H}$ & -1.955866 & 2.144616 & 0.557544 \\
\hline$N$ & -2.964611 & 2.227278 & 0.321968 \\
\hline C & -3.255085 & 3.008025 & -0.814077 \\
\hline $\mathrm{O}$ & -4.356358 & 3.280984 & -1.234721 \\
\hline $\mathrm{O}$ & -2.095318 & 3.461135 & -1.308103 \\
\hline C & -2.211195 & 4.278647 & -2.485313 \\
\hline $\mathrm{H}$ & -2.649702 & 3.699694 & -3.301869 \\
\hline $\mathrm{H}$ & -1.190484 & 4.576129 & -2.720956 \\
\hline $\mathrm{H}$ & -2.836124 & 5.152164 & -2.282913 \\
\hline $\mathrm{H}$ & -5.672470 & 0.332007 & 0.877386 \\
\hline $\mathrm{H}$ & -5.345504 & 1.456117 & -0.535634 \\
\hline C & -3.421115 & 0.918080 & 2.294644 \\
\hline C & -2.557786 & 1.691625 & 3.092332 \\
\hline C & -3.926751 & -0.285893 & 2.822043 \\
\hline C & -2.216491 & 1.277260 & 4.376635 \\
\hline $\mathrm{H}$ & -2.166122 & 2.628840 & 2.714037 \\
\hline C & -3.579990 & -0.697330 & 4.105044 \\
\hline $\mathrm{H}$ & -4.572630 & -0.916022 & 2.220020 \\
\hline C & -2.725561 & 0.083060 & 4.888115 \\
\hline
\end{tabular}




$\begin{array}{rrrr}\text { H } & -1.551567 & 1.890300 & 4.977685 \\ \mathrm{H} & -3.976565 & -1.630628 & 4.495026 \\ \mathrm{H} & -2.458569 & -0.239155 & 5.890751 \\ \mathrm{H} & -7.367847 & -3.164541 & -0.341948\end{array}$

Catalyst (R)-1 TS Conformation 4

B3LYP/6-31G(d) Energy $=-2809.697745$

B3LYP-D3(BJ)/def2-TZVPP-IEF-PCM(DCM) Energy = -2810.992337

B3LYP-D3(BJ)/def2-TZVPP-IEF-PCM(DCM)//B3LYP/6-31G(d) Free Energy (Quasiharmonic) = 2810.351256

Frequencies (Top 3 out of 270)

1. $-676.9367 \mathrm{~cm}-1$

2. $\quad 10.0729 \mathrm{~cm}-1$

3. $\quad 18.6749 \mathrm{~cm}-1$

B3LYP/6-31G(d) Molecular Geometry in Cartesian Coordinates

$\begin{array}{llll}\text { C } & 2.821607 & -1.417311 & -0.342432 \\ \text { C } & 1.524587 & -1.783028 & -0.013605 \\ \text { C } & 0.981285 & -3.073959 & -0.287140 \\ \text { C } & 1.802505 & -3.982274 & -0.927673 \\ \text { H } & 1.433399 & -4.985717 & -1.122573 \\ \text { C } & 4.223676 & 2.557878 & 0.573042 \\ \text { C } & 3.317733 & -0.058285 & 0.029383 \\ \text { C } & 2.610256 & 1.063094 & -0.379859 \\ \text { C } & 3.052561 & 2.398803 & -0.143073 \\ \text { H } & 4.606516 & 3.560253 & 0.745521 \\ \text { O } & 0.721957 & -0.857351 & 0.635373 \\ \text { P } & 0.105206 & 0.404971 & -0.224882 \\ \text { O } & 1.422600 & 0.880135 & -1.077255 \\ \text { C } & -3.039819 & -4.265660 & 0.700007 \\ \text { C } & -2.485605 & -4.581817 & -0.541113 \\ \text { C } & -1.188942 & -4.174974 & -0.853389 \\ \text { C } & -0.414011 & -3.448695 & 0.067109 \\ \text { C } & -0.985787 & -3.133778 & 1.312556 \\ \text { C } & -2.284395 & -3.538806 & 1.623896 \\ \text { H } & -3.066028 & -5.136210 & -1.274016 \\ \text { H } & -2.715695 & -3.277838 & 2.586642 \\ \text { C } & 1.041909 & 5.927614 & -1.567954 \\ \text { C } & 1.523556 & 5.864358 & -0.259362\end{array}$




\begin{tabular}{|c|c|c|c|}
\hline C & 2.150046 & 4.706394 & 0.200322 \\
\hline C & 2.311622 & 3.590259 & -0.637146 \\
\hline C & 1.813432 & 3.663722 & -1.949008 \\
\hline C & 1.187447 & 4.821374 & -2.407838 \\
\hline $\mathrm{H}$ & 1.411239 & 6.716058 & 0.407060 \\
\hline $\mathrm{H}$ & 0.816556 & 4.859629 & -3.428741 \\
\hline C & 4.489981 & 0.126943 & 0.840016 \\
\hline C & 4.947745 & 1.459677 & 1.097096 \\
\hline C & 6.113621 & 1.657632 & 1.885926 \\
\hline C & 6.788527 & 0.591032 & 2.432180 \\
\hline C & 6.315704 & -0.724455 & 2.213935 \\
\hline C & 5.199443 & -0.950656 & 1.438910 \\
\hline $\mathrm{H}$ & 6.454554 & 2.675638 & 2.059625 \\
\hline $\mathrm{H}$ & 7.674653 & 0.755112 & 3.039251 \\
\hline $\mathrm{H}$ & 6.835610 & -1.565108 & 2.665571 \\
\hline $\mathrm{H}$ & 4.845387 & -1.964003 & 1.289320 \\
\hline C & 3.632229 & -2.345052 & -1.082592 \\
\hline C & 3.111756 & -3.651947 & -1.353414 \\
\hline C & 3.908989 & -4.587899 & -2.066979 \\
\hline C & 5.157882 & -4.245915 & -2.530138 \\
\hline C & 5.657678 & -2.942179 & -2.301763 \\
\hline C & 4.917342 & -2.018338 & -1.597351 \\
\hline $\mathrm{H}$ & 3.502536 & -5.579464 & -2.252301 \\
\hline $\mathrm{H}$ & 5.755306 & -4.966993 & -3.081252 \\
\hline $\mathrm{H}$ & 6.633750 & -2.664407 & -2.690371 \\
\hline $\mathrm{H}$ & 5.311774 & -1.021329 & -1.440161 \\
\hline $\mathrm{O}$ & -0.364891 & 1.424612 & 0.760063 \\
\hline $\mathrm{O}$ & -0.827861 & -0.146001 & -1.303847 \\
\hline $\mathrm{H}$ & -2.031393 & -0.080921 & -1.417047 \\
\hline $\mathrm{H}$ & -0.408141 & -2.570069 & 2.036636 \\
\hline $\mathrm{H}$ & -4.053999 & -4.569676 & 0.942191 \\
\hline $\mathrm{H}$ & -0.776488 & -4.398482 & -1.832961 \\
\hline $\mathrm{H}$ & 1.923851 & 2.813264 & -2.612401 \\
\hline $\mathrm{H}$ & 0.558289 & 6.831074 & -1.930900 \\
\hline $\mathrm{H}$ & 2.503645 & 4.655576 & 1.226272 \\
\hline C & -3.898318 & -0.795847 & -0.819426 \\
\hline $\mathrm{O}$ & -3.201013 & -0.133297 & -1.659127 \\
\hline $\mathrm{H}$ & -3.407514 & -1.431919 & -0.077812 \\
\hline C & -5.255978 & -1.254750 & -1.316913 \\
\hline $\mathrm{O}$ & -5.865864 & -0.737404 & -2.224760 \\
\hline $\mathrm{O}$ & -5.688379 & -2.311740 & -0.602061 \\
\hline C & -6.981496 & -2.818602 & -0.979138 \\
\hline $\mathrm{H}$ & -6.969188 & -3.158214 & -2.017884 \\
\hline $\mathrm{H}$ & -7.177279 & -3.650919 & -0.303300 \\
\hline
\end{tabular}




$\begin{array}{llll}\mathrm{C} & -3.771586 & 1.243347 & 0.958609 \\ \mathrm{C} & -4.840222 & 0.383903 & 0.701757 \\ \mathrm{H} & -1.835714 & 1.288366 & 1.658735 \\ \mathrm{~N} & -2.796289 & 0.954566 & 1.876847 \\ \mathrm{C} & -2.886690 & 0.056803 & 2.940587 \\ \mathrm{O} & -3.845734 & -0.621350 & 3.249795 \\ \mathrm{O} & -1.716688 & 0.082294 & 3.604685 \\ \mathrm{C} & -1.642642 & -0.768285 & 4.758648 \\ \mathrm{H} & -0.662647 & -0.573443 & 5.193655 \\ \mathrm{H} & -1.728503 & -1.819137 & 4.469614 \\ \mathrm{H} & -2.437393 & -0.523958 & 5.467851 \\ \mathrm{H} & -5.688465 & 0.797959 & 0.170336 \\ \mathrm{H} & -5.049779 & -0.410124 & 1.404877 \\ \mathrm{C} & -3.556021 & 2.456984 & 0.157174 \\ \mathrm{C} & -4.177756 & 2.608109 & -1.100908 \\ \mathrm{C} & -2.730214 & 3.497565 & 0.632086 \\ \mathrm{C} & -3.974860 & 3.762760 & -1.851143 \\ \mathrm{H} & -4.787357 & 1.814953 & -1.514945 \\ \mathrm{C} & -2.536187 & 4.648222 & -0.121269 \\ \mathrm{H} & -2.250256 & 3.411216 & 1.599710 \\ \mathrm{C} & -3.156079 & 4.783408 & -1.366242 \\ \mathrm{H} & -4.449402 & 3.856798 & -2.823405 \\ \mathrm{H} & -1.888296 & 5.433332 & 0.255468 \\ \mathrm{H} & -2.996760 & 5.681068 & -1.957449 \\ \mathrm{H} & -7.742923 & -2.042287 & -0.866656\end{array}$

Catalyst (R)-1 TS Conformation 5

B3LYP/6-31G(d) Energy $=-2809.698722$

B3LYP-D3(BJ)/def2-TZVPP-IEF-PCM(DCM) Energy = -2810.991531

B3LYP-D3(BJ)/def2-TZVPP-IEF-PCM(DCM)//B3LYP/6-31G(d) Free Energy (Quasiharmonic) = 2810.350181

Frequencies (Top 3 out of 270)

1. $-690.8895 \mathrm{~cm}-1$

2. $\quad 11.6367 \mathrm{~cm}-1$

3. $21.0167 \mathrm{~cm}-1$

B3LYP/6-31G(d) Molecular Geometry in Cartesian Coordinates
C $\quad 2.777961 \quad-1.379020 \quad-0.334210$
$\begin{array}{llll}\text { C } & 1.477712 & -1.765962 & -0.052005\end{array}$ 


\begin{tabular}{|c|c|c|c|}
\hline C & 0.951329 & -3.049620 & -0.383975 \\
\hline C & 1.792607 & -3.925760 & -1.042479 \\
\hline $\mathrm{H}$ & 1.434581 & -4.923241 & -1.283196 \\
\hline C & 4.279000 & 2.549227 & 0.579829 \\
\hline C & 3.262336 & -0.032056 & 0.090933 \\
\hline C & 2.581189 & 1.108352 & -0.313592 \\
\hline C & 3.101160 & 2.426043 & -0.132578 \\
\hline $\mathrm{H}$ & 4.692958 & 3.540735 & 0.743138 \\
\hline $\mathrm{O}$ & 0.654138 & -0.865957 & 0.611533 \\
\hline$P$ & 0.063324 & 0.426435 & -0.214936 \\
\hline 0 & 1.388492 & 0.963816 & -1.012339 \\
\hline C & -3.057919 & -4.350010 & 0.504522 \\
\hline C & -2.312978 & -3.679356 & 1.478054 \\
\hline C & -1.020454 & -3.233580 & 1.196565 \\
\hline C & -0.442911 & -3.457059 & -0.065255 \\
\hline C & -1.205262 & -4.130994 & -1.034683 \\
\hline C & -2.497630 & -4.573057 & -0.754076 \\
\hline $\mathrm{H}$ & -2.749426 & -3.489798 & 2.454744 \\
\hline $\mathrm{H}$ & -3.073308 & -5.079524 & -1.524131 \\
\hline C & 1.431089 & 5.990292 & -1.876979 \\
\hline C & 2.779387 & 5.673976 & -2.046884 \\
\hline C & 3.298017 & 4.508125 & -1.484806 \\
\hline C & 2.482445 & 3.637076 & -0.741936 \\
\hline C & 1.127347 & 3.964989 & -0.576626 \\
\hline C & 0.612339 & 5.131912 & -1.141067 \\
\hline $\mathrm{H}$ & 3.427548 & 6.328532 & -2.624089 \\
\hline $\mathrm{H}$ & -0.440002 & 5.366368 & -1.003648 \\
\hline C & 4.435136 & 0.119785 & 0.907664 \\
\hline C & 4.944635 & 1.435846 & 1.147270 \\
\hline C & 6.102880 & 1.600250 & 1.954507 \\
\hline C & 6.726975 & 0.515753 & 2.525752 \\
\hline C & 6.208733 & -0.783914 & 2.315111 \\
\hline C & 5.095703 & -0.977266 & 1.526638 \\
\hline $\mathrm{H}$ & 6.480511 & 2.606625 & 2.119882 \\
\hline $\mathrm{H}$ & 7.608668 & 0.653865 & 3.145650 \\
\hline $\mathrm{H}$ & 6.690091 & -1.637803 & 2.784348 \\
\hline $\mathrm{H}$ & 4.704537 & -1.978073 & 1.383177 \\
\hline C & 3.613250 & -2.272307 & -1.091665 \\
\hline C & 3.108118 & -3.570304 & -1.426178 \\
\hline C & 3.926841 & -4.473204 & -2.157643 \\
\hline C & 5.183788 & -4.106704 & -2.578063 \\
\hline C & 5.669399 & -2.810275 & -2.287268 \\
\hline C & 4.907551 & -1.918914 & -1.564096 \\
\hline $\mathrm{H}$ & 3.530551 & -5.458730 & -2.390890 \\
\hline
\end{tabular}




\begin{tabular}{|c|c|c|c|}
\hline $\mathrm{H}$ & 5.798216 & -4.802221 & -3.143183 \\
\hline $\mathrm{H}$ & 6.651950 & -2.511528 & -2.642559 \\
\hline $\mathrm{H}$ & 5.292691 & -0.927011 & -1.360567 \\
\hline $\mathrm{O}$ & -0.449605 & 1.398180 & 0.803082 \\
\hline 0 & -0.847498 & -0.069668 & -1.339452 \\
\hline $\mathrm{H}$ & -2.058710 & -0.020102 & -1.411053 \\
\hline$H$ & -0.785581 & -4.284623 & -2.024754 \\
\hline $\mathrm{H}$ & -4.072239 & -4.673020 & 0.716666 \\
\hline $\mathrm{H}$ & -0.449868 & -2.711119 & 1.956983 \\
\hline $\mathrm{H}$ & 0.481238 & 3.315645 & 0.003918 \\
\hline $\mathrm{H}$ & 1.021798 & 6.895830 & -2.317834 \\
\hline $\mathrm{H}$ & 4.343428 & 4.254209 & -1.638453 \\
\hline C & -3.855664 & -0.856668 & -0.786036 \\
\hline $\mathrm{O}$ & -3.235668 & -0.088419 & -1.603079 \\
\hline $\mathrm{H}$ & -3.289406 & -1.520735 & -0.127271 \\
\hline C & -5.173880 & -1.455866 & -1.242619 \\
\hline $\mathrm{O}$ & -5.611907 & -2.499396 & -0.808328 \\
\hline $\mathrm{O}$ & -5.778662 & -0.696633 & -2.170064 \\
\hline C & -7.024488 & -1.216308 & -2.669987 \\
\hline $\mathrm{H}$ & -7.747130 & -1.327717 & -1.857143 \\
\hline $\mathrm{H}$ & -7.371923 & -0.484992 & -3.399395 \\
\hline C & -3.787411 & 1.010419 & 1.180198 \\
\hline C & -4.793226 & 0.106196 & 0.829427 \\
\hline $\mathrm{H}$ & -1.841402 & 1.104925 & 1.826139 \\
\hline$N$ & -2.771919 & 0.695628 & 2.041237 \\
\hline C & -2.790644 & -0.289456 & 3.031618 \\
\hline 0 & -3.721406 & -1.012101 & 3.321395 \\
\hline $\mathrm{O}$ & -1.596597 & -0.278637 & 3.648847 \\
\hline C & -1.454151 & -1.205311 & 4.737529 \\
\hline $\mathrm{H}$ & -1.515802 & -2.235137 & 4.376567 \\
\hline $\mathrm{H}$ & -2.231292 & -1.038006 & 5.487242 \\
\hline $\mathrm{H}$ & -0.466295 & -1.006799 & 5.152359 \\
\hline $\mathrm{H}$ & -5.682272 & 0.523255 & 0.370517 \\
\hline $\mathrm{H}$ & -4.939818 & -0.771219 & 1.445117 \\
\hline C & -3.695280 & 2.335234 & 0.548603 \\
\hline C & -3.031067 & 3.390647 & 1.206716 \\
\hline C & -4.303204 & 2.588427 & -0.698106 \\
\hline C & -2.992724 & 4.661495 & 0.645337 \\
\hline $\mathrm{H}$ & -2.572133 & 3.219511 & 2.174098 \\
\hline C & -4.243602 & 3.859537 & -1.262854 \\
\hline $\mathrm{H}$ & -4.788998 & 1.788997 & -1.242579 \\
\hline C & -3.596601 & 4.899213 & -0.593022 \\
\hline $\mathrm{H}$ & -2.493531 & 5.467882 & 1.174478 \\
\hline $\mathrm{H}$ & -4.702001 & 4.036281 & -2.231338 \\
\hline
\end{tabular}


$\begin{array}{llll}H & -3.564292 & 5.892726 & -1.032014 \\ \mathrm{H} & -6.867035 & -2.188317 & -3.143814\end{array}$

Catalyst (R)-1 TS Conformation 6

B3LYP/6-31G(d) Energy $=-2809.700145$

B3LYP-D3(BJ)/def2-TZVPP-IEF-PCM(DCM) Energy = -2810.991895

B3LYP-D3(BJ)/def2-TZVPP-IEF-PCM(DCM)//B3LYP/6-31G(d) Free Energy (Quasiharmonic) = 2810.349993

Frequencies (Top 3 out of 270)

1. $-458.0915 \mathrm{~cm}-1$

2. $\quad 11.1568 \mathrm{~cm}-1$

3. $\quad 13.0829 \mathrm{~cm}-1$

B3LYP/6-31G(d) Molecular Geometry in Cartesian Coordinates

$\begin{array}{llll}\text { C } & 3.658445 & 0.355238 & 0.313086 \\ \text { C } & 2.809011 & 1.314819 & -0.218292 \\ \text { C } & 3.005600 & 2.717464 & -0.042976 \\ \text { C } & 4.054648 & 3.109892 & 0.766951 \\ \text { H } & 4.253705 & 4.170089 & 0.897353 \\ \text { C } & 2.999485 & -3.823446 & -0.538997 \\ \text { C } & 3.460458 & -1.085272 & -0.026857 \\ \text { C } & 2.234001 & -1.681740 & 0.213683 \\ \text { C } & 1.974933 & -3.065775 & -0.007140 \\ \text { H } & 2.843583 & -4.887082 & -0.699475 \\ \text { O } & 1.738394 & 0.901524 & -1.004753 \\ \text { P } & 0.462046 & 0.152500 & -0.310956 \\ \text { O } & 1.200739 & -0.894794 & 0.711236 \\ \text { C } & 0.749127 & 5.814541 & -2.001949 \\ \text { C } & 1.114957 & 4.665457 & -2.707114 \\ \text { C } & 1.814515 & 3.640573 & -2.072757 \\ \text { C } & 2.165545 & 3.744634 & -0.715605 \\ \text { C } & 1.775277 & 4.897074 & -0.013371 \\ \text { C } & 1.077805 & 5.923611 & -0.649156 \\ \text { H } & 0.863322 & 4.569120 & -3.759965 \\ \text { H } & 0.791900 & 6.808451 & -0.085945 \\ \text { C } & -1.780438 & -4.957270 & 0.918521 \\ \text { C } & -1.166373 & -4.124221 & 1.857677 \\ \text { C } & 0.040192 & -3.491575 & 1.559132 \\ \text { C } & 0.662801 & -3.687514 & 0.314357\end{array}$




\begin{tabular}{|c|c|c|c|}
\hline C & 0.039269 & -4.531529 & -0.618865 \\
\hline C & -1.170644 & -5.159334 & -0.320760 \\
\hline $\mathrm{H}$ & -1.628303 & -3.967082 & 2.829047 \\
\hline $\mathrm{H}$ & -1.643000 & -5.797622 & -1.062732 \\
\hline C & 4.494787 & -1.870371 & -0.644426 \\
\hline C & 4.252141 & -3.261378 & -0.888395 \\
\hline C & 5.268379 & -4.052295 & -1.489868 \\
\hline C & 6.467732 & -3.495661 & -1.868374 \\
\hline C & 6.695718 & -2.114584 & -1.664158 \\
\hline C & 5.737699 & -1.324202 & -1.067968 \\
\hline $\mathrm{H}$ & 5.071671 & -5.108729 & -1.656656 \\
\hline $\mathrm{H}$ & 7.234479 & -4.108820 & -2.333834 \\
\hline $\mathrm{H}$ & 7.634198 & -1.670824 & -1.985311 \\
\hline $\mathrm{H}$ & 5.925403 & -0.266053 & -0.928402 \\
\hline C & 4.694684 & 0.779003 & 1.214792 \\
\hline C & 4.890712 & 2.180769 & 1.431372 \\
\hline C & 5.918428 & 2.614901 & 2.312155 \\
\hline C & 6.705511 & 1.707773 & 2.982220 \\
\hline C & 6.489830 & 0.321519 & 2.799328 \\
\hline C & 5.514045 & -0.130804 & 1.938470 \\
\hline $\mathrm{H}$ & 6.061308 & 3.683439 & 2.454975 \\
\hline $\mathrm{H}$ & 7.483248 & 2.050771 & 3.658982 \\
\hline $\mathrm{H}$ & 7.096847 & -0.394324 & 3.346956 \\
\hline $\mathrm{H}$ & 5.355738 & -1.196090 & 1.817511 \\
\hline $\mathrm{O}$ & -0.442037 & 1.012946 & 0.505518 \\
\hline 0 & -0.144245 & -0.628491 & -1.498676 \\
\hline $\mathrm{H}$ & -1.273454 & -0.668008 & -1.521710 \\
\hline $\mathrm{H}$ & 2.011172 & 4.980946 & 1.043680 \\
\hline $\mathrm{H}$ & 0.215747 & 6.618272 & -2.503473 \\
\hline $\mathrm{H}$ & 2.101975 & 2.759240 & -2.634880 \\
\hline $\mathrm{H}$ & 0.497343 & -4.673607 & -1.593660 \\
\hline $\mathrm{H}$ & -2.731834 & -5.429319 & 1.144136 \\
\hline $\mathrm{H}$ & 0.508997 & -2.847327 & 2.295621 \\
\hline C & -2.977708 & -1.601221 & -0.637678 \\
\hline $\mathrm{O}$ & -2.570005 & -0.757820 & -1.505131 \\
\hline $\mathrm{H}$ & -2.274168 & -2.317333 & -0.195907 \\
\hline C & -4.358192 & -2.225707 & -0.788937 \\
\hline $\mathrm{O}$ & -4.736837 & -3.163122 & -0.115481 \\
\hline $\mathrm{O}$ & -5.076636 & -1.647692 & -1.761739 \\
\hline C & -6.377352 & -2.220972 & -1.981790 \\
\hline $\mathrm{H}$ & -6.290873 & -3.288020 & -2.201364 \\
\hline $\mathrm{H}$ & -7.008059 & -2.083153 & -1.100123 \\
\hline C & -3.924307 & 0.428656 & 0.923653 \\
\hline C & -3.213098 & -0.743760 & 1.208711 \\
\hline
\end{tabular}




$\begin{array}{llll}\mathrm{H} & -2.192610 & 1.318572 & 0.305137 \\ \mathrm{~N} & -3.214853 & 1.462688 & 0.405194 \\ \mathrm{C} & -3.628949 & 2.794602 & 0.229143 \\ \mathrm{O} & -4.701570 & 3.267903 & 0.528675 \\ \mathrm{O} & -2.604047 & 3.466839 & -0.315284 \\ \mathrm{C} & -2.833303 & 4.869731 & -0.523295 \\ \mathrm{H} & -3.659989 & 5.020275 & -1.222847 \\ \mathrm{H} & -1.899260 & 5.249680 & -0.934710 \\ \mathrm{H} & -3.070381 & 5.361616 & 0.423705 \\ \mathrm{H} & -3.734459 & -1.545713 & 1.717567 \\ \mathrm{H} & -2.151163 & -0.645867 & 1.412295 \\ \mathrm{C} & -5.401101 & 0.448511 & 1.026439 \\ \mathrm{C} & -6.009117 & -0.071368 & 2.180251 \\ \mathrm{C} & -6.211241 & 0.895519 & -0.031222 \\ \mathrm{C} & -7.398053 & -0.120844 & 2.287531 \\ \mathrm{H} & -5.389513 & -0.411867 & 3.004153 \\ \mathrm{C} & -7.596834 & 0.825088 & 0.071165 \\ \mathrm{H} & -5.752943 & 1.272654 & -0.937694 \\ \mathrm{C} & -8.194264 & 0.324953 & 1.232369 \\ \mathrm{H} & -7.855130 & -0.508980 & 3.193141 \\ \mathrm{H} & -8.213876 & 1.167813 & -0.754660 \\ \mathrm{H} & -9.277204 & 0.283303 & 1.311996 \\ \mathrm{H} & -6.789743 & -1.683992 & -2.836168\end{array}$

Catalyst (R)-1 TS Conformation 7

B3LYP/6-31G(d) Energy $=-2809.69549$

B3LYP-D3(BJ)/def2-TZVPP-IEF-PCM(DCM) Energy = -2810.990829

B3LYP-D3(BJ)/def2-TZVPP-IEF-PCM(DCM)//B3LYP/6-31G(d) Free Energy (Quasiharmonic) = 2810.349898

Frequencies (Top 3 out of 270)

1. $-710.4169 \mathrm{~cm}-1$

2. $\quad 5.5484 \mathrm{~cm}-1$

3. $\quad 13.9136 \mathrm{~cm}-1$

B3LYP/6-31G(d) Molecular Geometry in Cartesian Coordinates

$\begin{array}{llll}\text { C } & 2.613423 & -1.630052 & -0.177709 \\ \text { C } & 1.314862 & -1.862875 & 0.243906 \\ \text { C } & 0.618652 & -3.084507 & 0.006491 \\ \text { C } & 1.274015 & -4.051607 & -0.730773\end{array}$




\begin{tabular}{|c|c|c|c|}
\hline $\mathrm{H}$ & 0.786402 & -5.007003 & -0.905485 \\
\hline C & 4.662385 & 2.041026 & 0.758256 \\
\hline C & 3.303203 & -0.368505 & 0.222013 \\
\hline C & 2.731088 & 0.866320 & -0.058232 \\
\hline C & 3.410187 & 2.099607 & 0.178590 \\
\hline $\mathrm{H}$ & 5.196371 & 2.968163 & 0.949385 \\
\hline $\mathrm{O}$ & 0.656848 & -0.854334 & 0.940137 \\
\hline$P$ & 0.126565 & 0.424153 & 0.052384 \\
\hline 0 & 1.498871 & 0.919229 & -0.693953 \\
\hline C & -3.321001 & -3.960628 & 1.505964 \\
\hline C & -2.974042 & -4.279028 & 0.191715 \\
\hline C & -1.704060 & -3.967352 & -0.293479 \\
\hline C & -0.751303 & -3.337956 & 0.525463 \\
\hline C & -1.115695 & -3.016123 & 1.844781 \\
\hline C & -2.386608 & -3.326110 & 2.328002 \\
\hline $\mathrm{H}$ & -3.693645 & -4.765284 & -0.461962 \\
\hline $\mathrm{H}$ & -2.644777 & -3.077949 & 3.354335 \\
\hline C & 1.961424 & 6.047690 & -0.729243 \\
\hline C & 1.202963 & 5.194974 & 0.076356 \\
\hline C & 1.633753 & 3.894188 & 0.340774 \\
\hline C & 2.850568 & 3.433031 & -0.184543 \\
\hline C & 3.605407 & 4.296422 & -0.995218 \\
\hline C & 3.163270 & 5.590207 & -1.271401 \\
\hline $\mathrm{H}$ & 0.273395 & 5.549408 & 0.516221 \\
\hline $\mathrm{H}$ & 3.760402 & 6.240466 & -1.905556 \\
\hline C & 4.558099 & -0.405750 & 0.924510 \\
\hline C & 5.250583 & 0.822009 & 1.171735 \\
\hline C & 6.498680 & 0.799499 & 1.851303 \\
\hline C & 7.038749 & -0.383393 & 2.298782 \\
\hline C & 6.339908 & -1.595694 & 2.089888 \\
\hline C & 5.135581 & -1.607632 & 1.421245 \\
\hline $\mathrm{H}$ & 7.012579 & 1.742646 & 2.021801 \\
\hline $\mathrm{H}$ & 7.990674 & -0.389151 & 2.822650 \\
\hline $\mathrm{H}$ & 6.754025 & -2.527223 & 2.466349 \\
\hline $\mathrm{H}$ & 4.609945 & -2.544777 & 1.280873 \\
\hline C & 3.248871 & -2.611749 & -1.015053 \\
\hline C & 2.563668 & -3.842051 & -1.277050 \\
\hline C & 3.183747 & -4.827589 & -2.092243 \\
\hline C & 4.416015 & -4.602930 & -2.660070 \\
\hline C & 5.077028 & -3.372246 & -2.437272 \\
\hline C & 4.511414 & -2.404928 & -1.635816 \\
\hline $\mathrm{H}$ & 2.654398 & -5.760775 & -2.269995 \\
\hline $\mathrm{H}$ & 4.876832 & -5.360112 & -3.288489 \\
\hline $\mathrm{H}$ & 6.038855 & -3.185317 & -2.907158 \\
\hline
\end{tabular}




\begin{tabular}{|c|c|c|c|}
\hline $\mathrm{H}$ & 5.026952 & -1.463982 & -1.484104 \\
\hline $\mathrm{O}$ & -0.419985 & 1.437619 & 1.007012 \\
\hline 0 & -0.724567 & -0.081783 & -1.113166 \\
\hline $\mathrm{H}$ & -1.879900 & -0.371222 & -1.217905 \\
\hline $\mathrm{H}$ & -0.396663 & -2.529503 & 2.494328 \\
\hline $\mathrm{H}$ & -4.311585 & -4.196705 & 1.884094 \\
\hline $\mathrm{H}$ & -1.450989 & -4.193897 & -1.325060 \\
\hline $\mathrm{H}$ & 4.542692 & 3.943001 & -1.416777 \\
\hline $\mathrm{H}$ & 1.621420 & 7.060844 & -0.928686 \\
\hline $\mathrm{H}$ & 1.033322 & 3.239384 & 0.963357 \\
\hline C & -3.873986 & -0.814161 & -0.595376 \\
\hline $\mathrm{O}$ & -3.006559 & -0.693680 & -1.522376 \\
\hline $\mathrm{H}$ & -3.561181 & -0.958917 & 0.443247 \\
\hline C & -5.172466 & -1.489733 & -1.003739 \\
\hline $\mathrm{O}$ & -5.575218 & -1.567117 & -2.140990 \\
\hline $\mathrm{O}$ & -5.814156 & -1.975123 & 0.077357 \\
\hline C & -7.077114 & -2.608892 & -0.192716 \\
\hline $\mathrm{H}$ & -6.938197 & -3.471467 & -0.849573 \\
\hline $\mathrm{H}$ & -7.763051 & -1.904464 & -0.670594 \\
\hline C & -3.777366 & 1.786765 & 0.020080 \\
\hline C & -4.906466 & 0.981249 & -0.132131 \\
\hline $\mathrm{H}$ & -2.081212 & 1.977061 & 1.185070 \\
\hline$N$ & -3.115281 & 1.896738 & 1.217038 \\
\hline C & -3.641764 & 1.629991 & 2.482761 \\
\hline $\mathrm{O}$ & -4.779091 & 1.297294 & 2.746728 \\
\hline $\mathrm{O}$ & -2.669944 & 1.831706 & 3.389726 \\
\hline C & -3.046687 & 1.586044 & 4.753194 \\
\hline $\mathrm{H}$ & -3.846881 & 2.265272 & 5.058635 \\
\hline $\mathrm{H}$ & -2.143874 & 1.767690 & 5.335862 \\
\hline $\mathrm{H}$ & -3.384604 & 0.554032 & 4.877875 \\
\hline $\mathrm{H}$ & -5.511211 & 1.129337 & -1.018602 \\
\hline $\mathrm{H}$ & -5.423870 & 0.642725 & 0.754563 \\
\hline C & -3.151090 & 2.448942 & -1.132128 \\
\hline C & -2.237877 & 3.508419 & -0.949565 \\
\hline C & -3.457520 & 2.041199 & -2.448525 \\
\hline C & -1.653132 & 4.136281 & -2.042372 \\
\hline $\mathrm{H}$ & -1.999542 & 3.851536 & 0.050771 \\
\hline C & -2.863812 & 2.672117 & -3.537461 \\
\hline $\mathrm{H}$ & -4.125549 & 1.208594 & -2.625976 \\
\hline C & -1.962416 & 3.718197 & -3.339492 \\
\hline $\mathrm{H}$ & -0.944168 & 4.941809 & -1.881611 \\
\hline $\mathrm{H}$ & -3.098843 & 2.334798 & -4.542512 \\
\hline $\mathrm{H}$ & -1.497718 & 4.205971 & -4.191905 \\
\hline $\mathrm{H}$ & -7.460751 & -2.921048 & 0.778498 \\
\hline
\end{tabular}


Catalyst (R)-1 TS Conformation 8

B3LYP/6-31G(d) Energy $=-2809.699422$

B3LYP-D3(BJ)/def2-TZVPP-IEF-PCM(DCM) Energy = -2810.991337

B3LYP-D3(BJ)/def2-TZVPP-IEF-PCM(DCM)//B3LYP/6-31G(d) Free Energy (Quasiharmonic) = 2810.349703

Frequencies (Top 3 out of 270)

1. $-442.5740 \mathrm{~cm}-1$

2. $\quad 11.1960 \mathrm{~cm}-1$

3. $11.9120 \mathrm{~cm}-1$

B3LYP/6-31G(d) Molecular Geometry in Cartesian Coordinates

$\begin{array}{llll}\text { C } & 3.459608 & -1.106231 & -0.004607 \\ \text { C } & 2.222455 & -1.692196 & 0.205045 \\ \text { C } & 1.955130 & -3.072101 & -0.030847 \\ \text { C } & 2.984776 & -3.837531 & -0.541423 \\ \text { H } & 2.822782 & -4.898776 & -0.711460 \\ \text { C } & 4.067017 & 3.081646 & 0.816508 \\ \text { C } & 3.661663 & 0.331542 & 0.344419 \\ \text { C } & 2.831450 & 1.299021 & -0.203016 \\ \text { C } & 3.033270 & 2.699651 & -0.017745 \\ \text { H } & 4.270134 & 4.139955 & 0.955657 \\ \text { O } & 1.185583 & -0.898472 & 0.682904 \\ \text { P } & 0.478046 & 0.155152 & -0.355676 \\ \text { O } & 1.777127 & 0.895694 & -1.015845 \\ \text { C } & -1.831946 & -4.944509 & 0.794653 \\ \text { C } & -1.242813 & -4.109366 & 1.747748 \\ \text { C } & -0.026829 & -3.481058 & 1.480348 \\ \text { C } & 0.629393 & -3.682695 & 0.253971 \\ \text { C } & 0.026888 & -4.523833 & -0.695541 \\ \text { C } & -1.191859 & -5.148530 & -0.429021 \\ \text { H } & -1.728182 & -3.950954 & 2.707473 \\ \text { H } & -1.644170 & -5.788662 & -1.181898 \\ \text { C } & 0.829926 & 5.816732 & -2.005307 \\ \text { C } & 1.133470 & 5.918071 & -0.646094 \\ \text { C } & 1.814378 & 4.885538 & -0.002121 \\ \text { C } & 2.212880 & 3.734752 & -0.702408 \\ \text { C } & 1.887795 & 3.638910 & -2.066610 \\ \text { C } & 1.204575 & 4.669708 & -2.709088\end{array}$




\begin{tabular}{|c|c|c|c|}
\hline $\mathrm{H}$ & 0.840585 & 6.801419 & -0.084118 \\
\hline $\mathrm{H}$ & 0.972109 & 4.579282 & -3.766822 \\
\hline C & 4.680643 & 0.744684 & 1.270266 \\
\hline C & 4.881932 & 2.144340 & 1.495602 \\
\hline C & 5.893217 & 2.568193 & 2.400099 \\
\hline C & 6.658881 & 1.653312 & 3.084306 \\
\hline C & 6.437185 & 0.269229 & 2.892370 \\
\hline C & 5.477198 & -0.173287 & 2.008942 \\
\hline $\mathrm{H}$ & 6.040668 & 3.635210 & 2.549453 \\
\hline $\mathrm{H}$ & 7.424120 & 1.988574 & 3.778955 \\
\hline $\mathrm{H}$ & 7.026881 & -0.452691 & 3.450854 \\
\hline $\mathrm{H}$ & 5.313823 & -1.237039 & 1.881190 \\
\hline C & 4.500597 & -1.898444 & -0.601527 \\
\hline C & 4.250936 & -3.286106 & -0.857280 \\
\hline C & 5.273689 & -4.084147 & -1.437948 \\
\hline C & 6.486616 & -3.537143 & -1.785920 \\
\hline C & 6.722295 & -2.159002 & -1.570810 \\
\hline C & 5.757941 & -1.362104 & -0.993843 \\
\hline $\mathrm{H}$ & 5.071204 & -5.137995 & -1.613950 \\
\hline $\mathrm{H}$ & 7.258392 & -4.155473 & -2.235944 \\
\hline $\mathrm{H}$ & 7.671966 & -1.722661 & -1.868319 \\
\hline $\mathrm{H}$ & 5.951895 & -0.306280 & -0.845667 \\
\hline 0 & -0.441228 & 1.020562 & 0.437181 \\
\hline 0 & -0.102878 & -0.625867 & -1.556347 \\
\hline $\mathrm{H}$ & -1.229631 & -0.615390 & -1.623378 \\
\hline $\mathrm{H}$ & 0.509943 & -4.668450 & -1.657690 \\
\hline $\mathrm{H}$ & -2.783337 & -5.426338 & 1.001948 \\
\hline $\mathrm{H}$ & 0.423932 & -2.837391 & 2.228277 \\
\hline $\mathrm{H}$ & 2.182168 & 2.759134 & -2.627574 \\
\hline $\mathrm{H}$ & 0.308852 & 6.624720 & -2.512839 \\
\hline $\mathrm{H}$ & 2.030076 & 4.963214 & 1.059718 \\
\hline C & -3.043039 & -1.488773 & -0.875940 \\
\hline $\mathrm{O}$ & -2.529225 & -0.623179 & -1.657925 \\
\hline $\mathrm{H}$ & -2.428658 & -2.304548 & -0.474558 \\
\hline C & -4.487902 & -1.876035 & -1.151737 \\
\hline 0 & -5.220810 & -1.303266 & -1.923565 \\
\hline 0 & -4.839427 & -2.961813 & -0.426764 \\
\hline C & -6.199026 & -3.396922 & -0.601989 \\
\hline $\mathrm{H}$ & -6.388483 & -3.646781 & -1.649089 \\
\hline $\mathrm{H}$ & -6.893078 & -2.612070 & -0.289974 \\
\hline C & -3.934732 & 0.474321 & 0.809581 \\
\hline C & -3.246554 & -0.727090 & 1.026361 \\
\hline $\mathrm{H}$ & -2.196213 & 1.355540 & 0.202916 \\
\hline$N$ & -3.214114 & 1.511622 & 0.317037 \\
\hline
\end{tabular}




$\begin{array}{llll}\text { C } & -3.615550 & 2.850278 & 0.163437 \\ \text { O } & -4.685958 & 3.326791 & 0.464583 \\ \text { O } & -2.580982 & 3.522653 & -0.362021 \\ \text { C } & -2.799578 & 4.929230 & -0.555388 \\ \text { H } & -3.042502 & 5.411473 & 0.395104 \\ \text { H } & -3.618479 & 5.093018 & -1.261031 \\ \text { H } & -1.859293 & 5.307960 & -0.953589 \\ \text { H } & -3.778599 & -1.530211 & 1.522114 \\ \text { H } & -2.177886 & -0.668546 & 1.207868 \\ \text { C } & -5.406760 & 0.521083 & 0.970307 \\ \text { C } & -5.972023 & 0.008879 & 2.149728 \\ \text { C } & -6.253298 & 0.973323 & -0.055413 \\ \text { C } & -7.355801 & -0.027039 & 2.313134 \\ \text { H } & -5.321936 & -0.334373 & 2.949089 \\ \text { C } & -7.634324 & 0.913998 & 0.102840 \\ \text { H } & -5.829633 & 1.333829 & -0.984496 \\ \text { C } & -8.189249 & 0.422667 & 1.287688 \\ \text { H } & -7.780194 & -0.405240 & 3.238901 \\ \text { H } & -8.279671 & 1.252864 & -0.702256 \\ \text { H } & -9.268621 & 0.389866 & 1.409855 \\ \text { H } & -6.307610 & -4.279434 & 0.029159\end{array}$

Catalyst (R)-1 TS Conformation 9

B3LYP/6-31G(d) Energy $=-2809.700324$

B3LYP-D3(BJ)/def2-TZVPP-IEF-PCM(DCM) Energy = -2810.99145

B3LYP-D3(BJ)/def2-TZVPP-IEF-PCM(DCM)//B3LYP/6-31G(d) Free Energy (Quasiharmonic) = 2810.349575

Frequencies (Top 3 out of 270)

1. $-528.3385 \mathrm{~cm}-1$

2. $\quad 11.4544 \mathrm{~cm}-1$

3. $\quad 12.7571 \mathrm{~cm}-1$

B3LYP/6-31G(d) Molecular Geometry in Cartesian Coordinates

$\begin{array}{llll}\text { C } & 3.614906 & 0.334035 & 0.366586 \\ \text { C } & 2.789824 & 1.271045 & -0.240099 \\ \text { C } & 3.016247 & 2.678546 & -0.159495 \\ \text { C } & 4.043302 & 3.105087 & 0.660868 \\ \text { H } & 4.234469 & 4.170874 & 0.753653 \\ \text { C } & 3.031992 & -3.870899 & -0.432395\end{array}$




\begin{tabular}{|c|c|c|c|}
\hline C & 3.447200 & -1.118516 & 0.060081 \\
\hline C & 2.216402 & -1.724249 & 0.247086 \\
\hline C & 1.975947 & -3.111646 & 0.029969 \\
\hline $\mathrm{H}$ & 2.890305 & -4.937156 & -0.588968 \\
\hline 0 & 1.749147 & 0.825468 & -1.049334 \\
\hline$P$ & 0.457469 & 0.092607 & -0.373932 \\
\hline $\mathrm{O}$ & 1.153264 & -0.941563 & 0.685396 \\
\hline C & 0.943143 & 5.594269 & -2.558613 \\
\hline C & 2.336632 & 5.581128 & -2.491283 \\
\hline C & 2.988687 & 4.624441 & -1.713977 \\
\hline C & 2.264102 & 3.667581 & -0.982280 \\
\hline C & 0.861598 & 3.697079 & -1.047920 \\
\hline C & 0.213221 & 4.649065 & -1.835173 \\
\hline $\mathrm{H}$ & 2.919345 & 6.305614 & -3.054393 \\
\hline $\mathrm{H}$ & -0.872250 & 4.639405 & -1.888173 \\
\hline C & -1.845423 & -4.970920 & 0.721881 \\
\hline C & -1.276860 & -4.154784 & 1.703822 \\
\hline C & -0.046756 & -3.535867 & 1.482382 \\
\hline C & 0.645028 & -3.729233 & 0.274626 \\
\hline C & 0.067630 & -4.557311 & -0.701250 \\
\hline C & -1.166133 & -5.170986 & -0.481248 \\
\hline $\mathrm{H}$ & -1.791484 & -4.002185 & 2.649181 \\
\hline $\mathrm{H}$ & -1.601394 & -5.797721 & -1.255062 \\
\hline C & 4.518579 & -1.907419 & -0.487971 \\
\hline C & 4.299162 & -3.305035 & -0.718186 \\
\hline C & 5.351592 & -4.099623 & -1.248349 \\
\hline C & 6.565736 & -3.541367 & -1.573112 \\
\hline C & 6.772074 & -2.154667 & -1.385822 \\
\hline C & 5.778176 & -1.360258 & -0.857579 \\
\hline $\mathrm{H}$ & 5.170842 & -5.160483 & -1.404757 \\
\hline $\mathrm{H}$ & 7.360565 & -4.157462 & -1.984433 \\
\hline $\mathrm{H}$ & 7.722656 & -1.709308 & -1.666608 \\
\hline $\mathrm{H}$ & 5.951076 & -0.298158 & -0.731729 \\
\hline C & 4.620497 & 0.798184 & 1.282929 \\
\hline C & 4.830608 & 2.207601 & 1.422357 \\
\hline C & 5.819867 & 2.679759 & 2.327129 \\
\hline C & 6.561357 & 1.803669 & 3.085041 \\
\hline C & 6.335632 & 0.411584 & 2.971234 \\
\hline C & 5.393366 & -0.078119 & 2.093623 \\
\hline $\mathrm{H}$ & 5.971282 & 3.753027 & 2.415368 \\
\hline $\mathrm{H}$ & 7.310922 & 2.176298 & 3.777781 \\
\hline $\mathrm{H}$ & 6.906756 & -0.278277 & 3.586664 \\
\hline $\mathrm{H}$ & 5.224425 & -1.146752 & 2.026205 \\
\hline $\mathrm{O}$ & -0.447027 & 0.982878 & 0.415480 \\
\hline
\end{tabular}




\begin{tabular}{|c|c|c|c|}
\hline $\mathrm{O}$ & -0.147900 & -0.693763 & -1.555750 \\
\hline $\mathrm{H}$ & -1.286502 & -0.633343 & -1.639624 \\
\hline $\mathrm{H}$ & 0.274777 & 2.986026 & -0.477911 \\
\hline $\mathrm{H}$ & 0.431419 & 6.329456 & -3.174415 \\
\hline $\mathrm{H}$ & 4.074815 & 4.599214 & -1.690745 \\
\hline $\mathrm{H}$ & 0.581010 & -4.697144 & -1.648368 \\
\hline $\mathrm{H}$ & -2.812088 & -5.437218 & 0.888722 \\
\hline $\mathrm{H}$ & 0.386418 & -2.904253 & 2.251066 \\
\hline C & -3.051539 & -1.519979 & -0.908100 \\
\hline O & -2.566420 & -0.621102 & -1.673158 \\
\hline $\mathrm{H}$ & -2.410790 & -2.333370 & -0.545120 \\
\hline C & -4.475041 & -2.009926 & -1.131388 \\
\hline $\mathrm{O}$ & -4.922369 & -2.996847 & -0.582680 \\
\hline 0 & -5.144327 & -1.254454 & -2.011385 \\
\hline C & -6.482508 & -1.696943 & -2.302045 \\
\hline $\mathrm{H}$ & -7.104808 & -1.640911 & -1.405710 \\
\hline $\mathrm{H}$ & -6.851722 & -1.016551 & -3.069437 \\
\hline C & -3.927367 & 0.352234 & 0.936610 \\
\hline C & -3.241964 & -0.864450 & 1.026545 \\
\hline $\mathrm{H}$ & -2.191525 & 1.305788 & 0.417427 \\
\hline$N$ & -3.202935 & 1.453213 & 0.594339 \\
\hline C & -3.569959 & 2.795041 & 0.789052 \\
\hline $\mathrm{O}$ & -4.607462 & 3.202134 & 1.259550 \\
\hline $\mathrm{O}$ & -2.544323 & 3.568391 & 0.390232 \\
\hline C & -2.718558 & 4.976045 & 0.630890 \\
\hline $\mathrm{H}$ & -2.876674 & 5.162667 & 1.695925 \\
\hline $\mathrm{H}$ & -3.574759 & 5.356309 & 0.067805 \\
\hline $\mathrm{H}$ & -1.792882 & 5.438236 & 0.290559 \\
\hline $\mathrm{H}$ & -3.777441 & -1.720687 & 1.419053 \\
\hline $\mathrm{H}$ & -2.176188 & -0.824142 & 1.228128 \\
\hline C & -5.400844 & 0.393436 & 1.050103 \\
\hline C & -6.034511 & -0.333644 & 2.070770 \\
\hline C & -6.188796 & 1.079066 & 0.108966 \\
\hline C & -7.424903 & -0.356868 & 2.164357 \\
\hline $\mathrm{H}$ & -5.433821 & -0.856151 & 2.808634 \\
\hline C & -7.576244 & 1.037375 & 0.193936 \\
\hline $\mathrm{H}$ & -5.710599 & 1.620218 & -0.699368 \\
\hline C & -8.198166 & 0.326358 & 1.225357 \\
\hline $\mathrm{H}$ & -7.901508 & -0.908605 & 2.969324 \\
\hline $\mathrm{H}$ & -8.175584 & 1.565596 & -0.542171 \\
\hline $\mathrm{H}$ & -9.282372 & 0.306381 & 1.294887 \\
\hline $\mathrm{H}$ & -6.470468 & -2.725470 & -2.671077 \\
\hline
\end{tabular}


Catalyst (R)-1 TS Conformation 10

B3LYP/6-31G(d) Energy $=-2809.699682$

B3LYP-D3(BJ)/def2-TZVPP-IEF-PCM(DCM) Energy $=-2810.991814$

B3LYP-D3(BJ)/def2-TZVPP-IEF-PCM(DCM)//B3LYP/6-31G(d) Free Energy (Quasiharmonic) = 2810.349493

Frequencies (Top 3 out of 270)

1. $-396.3572 \mathrm{~cm}-1$

2. $\quad 11.0522 \mathrm{~cm}-1$

3. $\quad 18.3057 \mathrm{~cm}-1$

B3LYP/6-31G(d) Molecular Geometry in Cartesian Coordinates

$\begin{array}{llll}\text { C } & 2.831589 & -1.425336 & -0.329226 \\ \text { C } & 1.516908 & -1.753544 & -0.038346 \\ \text { C } & 0.925605 & -3.006765 & -0.373319 \\ \text { C } & 1.716010 & -3.916459 & -1.048296 \\ \text { H } & 1.304914 & -4.891000 & -1.298442 \\ \text { C } & 4.374329 & 2.461291 & 0.732167 \\ \text { C } & 3.370608 & -0.099800 & 0.099121 \\ \text { C } & 2.719719 & 1.061662 & -0.289887 \\ \text { C } & 3.217969 & 2.369786 & -0.018463 \\ \text { H } & 4.796564 & 3.441779 & 0.935776 \\ \text { O } & 0.734311 & -0.816893 & 0.629062 \\ \text { P } & 0.188906 & 0.488475 & -0.200152 \\ \text { O } & 1.531555 & 0.953249 & -1.007477 \\ \text { C } & -3.148952 & -4.044377 & 0.550620 \\ \text { C } & -2.332888 & -3.482826 & 1.535794 \\ \text { C } & -1.015783 & -3.128528 & 1.243085 \\ \text { C } & -0.486383 & -3.336122 & -0.041285 \\ \text { C } & -1.316616 & -3.904401 & -1.021989 \\ \text { C } & -2.634856 & -4.253531 & -0.730528 \\ \text { H } & -2.722444 & -3.312685 & 2.535953 \\ \text { H } & -3.267418 & -4.673327 & -1.507735 \\ \text { C } & 1.455455 & 6.007641 & -1.492676 \\ \text { C } & 1.846029 & 5.900571 & -0.156831 \\ \text { C } & 2.391810 & 4.709274 & 0.319352 \\ \text { C } & 2.555839 & 3.600785 & -0.527227 \\ \text { C } & 2.145626 & 3.715772 & -1.865903 \\ \text { C } & 1.606059 & 4.909418 & -2.343443 \\ \text { H } & 1.723480 & 6.744010 & 0.517625 \\ \text { H } & 1.311941 & 4.983731 & -3.387371\end{array}$




\begin{tabular}{|c|c|c|c|}
\hline C & 4.531109 & 0.014624 & 0.939173 \\
\hline C & 5.035611 & 1.319595 & 1.246891 \\
\hline C & 6.187549 & 1.446173 & 2.070015 \\
\hline C & 6.804798 & 0.336789 & 2.599017 \\
\hline C & 6.286581 & -0.951456 & 2.327668 \\
\hline C & 5.182254 & -1.108894 & 1.519316 \\
\hline $\mathrm{H}$ & 6.564821 & 2.443580 & 2.283185 \\
\hline $\mathrm{H}$ & 7.680715 & 0.446316 & 3.232532 \\
\hline $\mathrm{H}$ & 6.761666 & -1.825626 & 2.764656 \\
\hline $\mathrm{H}$ & 4.792224 & -2.101965 & 1.328488 \\
\hline C & 3.618043 & -2.354461 & -1.094051 \\
\hline C & 3.045863 & -3.622499 & -1.437209 \\
\hline C & 3.815465 & -4.557321 & -2.181705 \\
\hline C & 5.087729 & -4.250140 & -2.604005 \\
\hline C & 5.640399 & -2.983394 & -2.301993 \\
\hline C & 4.926971 & -2.061825 & -1.567437 \\
\hline $\mathrm{H}$ & 3.369731 & -5.519525 & -2.422683 \\
\hline $\mathrm{H}$ & 5.663923 & -4.970133 & -3.178597 \\
\hline $\mathrm{H}$ & 6.636093 & -2.732084 & -2.657350 \\
\hline $\mathrm{H}$ & 5.362281 & -1.092637 & -1.354140 \\
\hline $\mathrm{O}$ & -0.322320 & 1.471864 & 0.797969 \\
\hline $\mathrm{O}$ & -0.721478 & 0.003901 & -1.347721 \\
\hline $\mathrm{H}$ & -1.827247 & 0.151249 & -1.351721 \\
\hline $\mathrm{H}$ & -0.929374 & -4.044977 & -2.027245 \\
\hline $\mathrm{H}$ & -4.181290 & -4.300125 & 0.770721 \\
\hline $\mathrm{H}$ & -0.392375 & -2.690510 & 2.015026 \\
\hline $\mathrm{H}$ & 2.261841 & 2.871405 & -2.536575 \\
\hline $\mathrm{H}$ & 1.039565 & 6.939028 & -1.868518 \\
\hline $\mathrm{H}$ & 2.678403 & 4.626179 & 1.363937 \\
\hline C & -3.905052 & -0.524062 & -0.900216 \\
\hline $\mathrm{O}$ & -3.125772 & 0.263347 & -1.540633 \\
\hline $\mathrm{H}$ & -3.489799 & -1.281372 & -0.224049 \\
\hline C & -5.145612 & -1.070136 & -1.602605 \\
\hline $\mathrm{O}$ & -5.701737 & -2.091083 & -1.251159 \\
\hline $\mathrm{O}$ & -5.528442 & -0.305291 & -2.632480 \\
\hline C & -6.683902 & -0.772513 & -3.348335 \\
\hline $\mathrm{H}$ & -6.493817 & -1.759518 & -3.778206 \\
\hline $\mathrm{H}$ & -7.549256 & -0.834828 & -2.682734 \\
\hline C & -3.922601 & 0.979211 & 1.216240 \\
\hline C & -4.993921 & 0.516937 & 0.437892 \\
\hline $\mathrm{H}$ & -2.112869 & 1.972145 & 1.023356 \\
\hline$N$ & -3.102934 & 1.952989 & 0.740059 \\
\hline C & -3.414725 & 2.864132 & -0.290818 \\
\hline $\mathrm{O}$ & -4.517469 & 3.097496 & -0.731870 \\
\hline
\end{tabular}




$\begin{array}{lrrr}\mathrm{O} & -2.285581 & 3.492450 & -0.640167 \\ \mathrm{C} & -2.426337 & 4.472797 & -1.681685 \\ \mathrm{H} & -1.422540 & 4.868260 & -1.832443 \\ \mathrm{H} & -3.115824 & 5.262489 & -1.371622 \\ \mathrm{H} & -2.801464 & 4.001150 & -2.593310 \\ \mathrm{H} & -5.649502 & -0.227314 & 0.873922 \\ \mathrm{H} & -5.439956 & 1.199407 & -0.272945 \\ \mathrm{C} & -3.561137 & 0.315317 & 2.492358 \\ \mathrm{C} & -4.587997 & -0.254230 & 3.272187 \\ \mathrm{C} & -2.240868 & 0.259577 & 2.979168 \\ \mathrm{C} & -4.305868 & -0.868424 & 4.488718 \\ \mathrm{H} & -5.619143 & -0.185816 & 2.943618 \\ \mathrm{C} & -1.964980 & -0.364093 & 4.194620 \\ \mathrm{H} & -1.415867 & 0.667250 & 2.404260 \\ \mathrm{C} & -2.990470 & -0.930074 & 4.953715 \\ \mathrm{H} & -5.115883 & -1.289219 & 5.077655 \\ \mathrm{H} & -0.937819 & -0.406684 & 4.545483 \\ \mathrm{H} & -2.768703 & -1.408644 & 5.903742 \\ \mathrm{H} & -6.855057 & -0.037206 & -4.134410\end{array}$

Catalyst (R)-1 TS Conformation 11

B3LYP/6-31G(d) Energy $=-2809.70226$

B3LYP-D3(BJ)/def2-TZVPP-IEF-PCM(DCM) Energy = -2810.993191

B3LYP-D3(BJ)/def2-TZVPP-IEF-PCM(DCM)//B3LYP/6-31G(d) Free Energy (Quasiharmonic) = 2810.349038

Frequencies (Top 3 out of 270)

1. $-278.0891 \mathrm{~cm}-1$

2. $\quad 13.0684 \mathrm{~cm}-1$

3. $23.5383 \mathrm{~cm}-1$

B3LYP/6-31G(d) Molecular Geometry in Cartesian Coordinates

$\begin{array}{llll}\text { C } & -3.213965 & 0.149289 & -0.341337 \\ \text { C } & -2.330173 & 1.200895 & -0.138166 \\ \text { C } & -2.648817 & 2.552468 & -0.474010 \\ \text { C } & -3.860332 & 2.784622 & -1.095942 \\ \text { H } & -4.122980 & 3.803672 & -1.367123 \\ \text { C } & -2.325198 & -3.866555 & 0.950941 \\ \text { C } & -2.906663 & -1.214349 & 0.182965 \\ \text { C } & -1.726675 & -1.842173 & -0.178257\end{array}$




\begin{tabular}{|c|c|c|c|}
\hline C & -1.416975 & -3.193062 & 0.156605 \\
\hline $\mathrm{H}$ & -2.140894 & -4.907819 & 1.201220 \\
\hline $\mathrm{O}$ & -1.129999 & 0.959405 & 0.522113 \\
\hline$P$ & 0.047759 & 0.019256 & -0.121369 \\
\hline 0 & -0.800009 & -1.120177 & -0.927653 \\
\hline C & -0.215921 & 6.002765 & 0.368333 \\
\hline C & -1.541665 & 5.942454 & 0.803962 \\
\hline C & -2.311156 & 4.807004 & 0.548558 \\
\hline C & -1.771363 & 3.712683 & -0.148883 \\
\hline C & -0.437864 & 3.784054 & -0.577810 \\
\hline C & 0.332653 & 4.917912 & -0.319991 \\
\hline $\mathrm{H}$ & -1.978241 & 6.777993 & 1.345422 \\
\hline $\mathrm{H}$ & 1.365578 & 4.934670 & -0.653913 \\
\hline C & 2.005436 & -5.367949 & -1.289274 \\
\hline C & 1.610037 & -5.473684 & 0.045572 \\
\hline C & 0.521751 & -4.737280 & 0.514988 \\
\hline C & -0.199278 & -3.887308 & -0.339984 \\
\hline C & 0.215514 & -3.782432 & -1.679257 \\
\hline C & 1.304552 & -4.516780 & -2.147010 \\
\hline $\mathrm{H}$ & 2.146421 & -6.132067 & 0.724548 \\
\hline $\mathrm{H}$ & 1.596487 & -4.434892 & -3.190978 \\
\hline C & -3.800433 & -1.901283 & 1.076377 \\
\hline C & -3.497111 & -3.249625 & 1.452552 \\
\hline C & -4.375754 & -3.945420 & 2.326754 \\
\hline C & -5.493925 & -3.331806 & 2.841112 \\
\hline C & -5.775445 & -1.987537 & 2.502084 \\
\hline C & -4.954203 & -1.292286 & 1.641766 \\
\hline $\mathrm{H}$ & -4.137158 & -4.972793 & 2.591571 \\
\hline $\mathrm{H}$ & -6.154382 & -3.870737 & 3.514790 \\
\hline $\mathrm{H}$ & -6.646249 & -1.496400 & 2.927784 \\
\hline $\mathrm{H}$ & -5.179544 & -0.260423 & 1.399455 \\
\hline C & -4.422841 & 0.395129 & -1.081655 \\
\hline C & -4.748413 & 1.739987 & -1.446437 \\
\hline C & -5.943575 & 2.000761 & -2.170027 \\
\hline C & -6.779760 & 0.975890 & -2.546333 \\
\hline C & -6.444336 & -0.358701 & -2.217951 \\
\hline C & -5.300191 & -0.641793 & -1.504791 \\
\hline $\mathrm{H}$ & -6.176560 & 3.030244 & -2.431542 \\
\hline $\mathrm{H}$ & -7.687870 & 1.185169 & -3.104946 \\
\hline $\mathrm{H}$ & -7.092305 & -1.170470 & -2.537359 \\
\hline $\mathrm{H}$ & -5.054192 & -1.671505 & -1.273413 \\
\hline $\mathrm{O}$ & 0.893680 & -0.504469 & 0.988787 \\
\hline 0 & 0.720752 & 0.761971 & -1.305052 \\
\hline $\mathrm{H}$ & 1.628500 & 1.337568 & -1.132660 \\
\hline
\end{tabular}




\begin{tabular}{|c|c|c|c|}
\hline $\mathrm{H}$ & -0.004592 & 2.962839 & -1.133287 \\
\hline $\mathrm{H}$ & 0.385172 & 6.886501 & 0.566519 \\
\hline $\mathrm{H}$ & -3.338770 & 4.759298 & 0.899517 \\
\hline $\mathrm{H}$ & -0.327097 & -3.134422 & -2.358533 \\
\hline $\mathrm{H}$ & 2.849069 & -5.944917 & -1.658853 \\
\hline $\mathrm{H}$ & 0.231348 & -4.811159 & 1.559126 \\
\hline C & 3.850627 & 2.217397 & -1.210935 \\
\hline 0 & 2.592575 & 2.315014 & -0.934244 \\
\hline $\mathrm{H}$ & 4.361833 & 3.140521 & -1.523424 \\
\hline C & 4.373040 & 1.062070 & -2.070382 \\
\hline 0 & 5.458474 & 1.070972 & -2.613949 \\
\hline 0 & 3.496767 & 0.049887 & -2.129303 \\
\hline C & 3.905019 & -1.093530 & -2.899949 \\
\hline $\mathrm{H}$ & 3.094645 & -1.814827 & -2.797938 \\
\hline $\mathrm{H}$ & 4.047032 & -0.811651 & -3.946530 \\
\hline C & 4.276959 & 0.963084 & 0.994967 \\
\hline C & 4.916069 & 2.041824 & 0.333457 \\
\hline $\mathrm{H}$ & 2.413979 & 0.386445 & 1.679635 \\
\hline $\mathrm{N}$ & 3.084241 & 1.162984 & 1.593302 \\
\hline C & 2.564505 & 2.398757 & 2.052584 \\
\hline 0 & 3.164960 & 3.446019 & 2.128934 \\
\hline 0 & 1.318293 & 2.173907 & 2.473970 \\
\hline C & 0.634324 & 3.304897 & 3.046344 \\
\hline $\mathrm{H}$ & 0.634852 & 4.141703 & 2.347587 \\
\hline $\mathrm{H}$ & 1.118157 & 3.597377 & 3.982434 \\
\hline $\mathrm{H}$ & -0.380840 & 2.954836 & 3.226168 \\
\hline $\mathrm{H}$ & 5.914289 & 1.862829 & -0.051108 \\
\hline $\mathrm{H}$ & 4.753183 & 3.025463 & 0.754577 \\
\hline C & 4.779616 & -0.421302 & 0.879529 \\
\hline C & 6.170645 & -0.631499 & 0.797619 \\
\hline C & 3.923827 & -1.541177 & 0.872637 \\
\hline C & 6.692109 & -1.919398 & 0.715087 \\
\hline $\mathrm{H}$ & 6.849685 & 0.213157 & 0.832193 \\
\hline C & 4.453139 & -2.825441 & 0.775462 \\
\hline $\mathrm{H}$ & 2.845204 & -1.419673 & 0.896799 \\
\hline C & 5.834323 & -3.020550 & 0.700370 \\
\hline $\mathrm{H}$ & 7.767916 & -2.060582 & 0.666106 \\
\hline $\mathrm{H}$ & 3.776240 & -3.673776 & 0.746255 \\
\hline $\mathrm{H}$ & 6.240586 & -4.026118 & 0.631066 \\
\hline $\mathrm{H}$ & 4.838809 & -1.502137 & -2.506011 \\
\hline
\end{tabular}

Catalyst (R)-1 TS Conformation 12 
B3LYP/6-31G(d) Energy $=-2809.697634$

B3LYP-D3(BJ)/def2-TZVPP-IEF-PCM(DCM) Energy $=-2810.991358$

B3LYP-D3(BJ)/def2-TZVPP-IEF-PCM(DCM)//B3LYP/6-31G(d) Free Energy (Quasiharmonic) = 2810.349007

Frequencies (Top 3 out of 270)

1. $-382.2786 \mathrm{~cm}-1$

2. $\quad 11.1105 \mathrm{~cm}-1$

3. $\quad 16.8832 \mathrm{~cm}-1$

B3LYP/6-31G(d) Molecular Geometry in Cartesian Coordinates

$\begin{array}{lrrr}\text { C } & 3.372311 & -0.192572 & 0.141009 \\ \text { C } & 2.769276 & 0.987408 & -0.268846 \\ \text { C } & 3.308776 & 2.279495 & 0.000441 \\ \text { C } & 4.453056 & 2.336713 & 0.772738 \\ \text { H } & 4.906149 & 3.303452 & 0.975642 \\ \text { C } & 1.614683 & -3.960327 & -1.012694 \\ \text { C } & 2.797346 & -1.502112 & -0.289324 \\ \text { C } & 1.466996 & -1.783970 & -0.022393 \\ \text { C } & 0.841057 & -3.019338 & -0.361271 \\ \text { H } & 1.177541 & -4.923378 & -1.263066 \\ \text { O } & 1.590537 & 0.913885 & -1.006616 \\ \text { P } & 0.219091 & 0.502132 & -0.219353 \\ \text { O } & 0.704229 & -0.817722 & 0.624888 \\ \text { C } & 1.721037 & 5.966010 & -1.548289 \\ \text { C } & 2.078544 & 5.858783 & -0.203214 \\ \text { C } & 2.566186 & 4.652312 & 0.297174 \\ \text { C } & 2.703617 & 3.528699 & -0.534058 \\ \text { C } & 2.325916 & 3.644235 & -1.882210 \\ \text { C } & 1.844893 & 4.852899 & -2.383897 \\ \text { H } & 1.975621 & 6.714113 & 0.459433 \\ \text { H } & 1.575358 & 4.926718 & -3.434429 \\ \text { C } & -3.278235 & -3.934457 & 0.489974 \\ \text { C } & -2.739730 & -4.187353 & -0.773031 \\ \text { C } & -1.407999 & -3.873466 & -1.042277 \\ \text { C } & -0.587000 & -3.301466 & -0.056064 \\ \text { C } & -1.141907 & -3.048804 & 1.209525 \\ \text { C } & -2.473512 & -3.363841 & 1.479214 \\ \text { H } & -3.359169 & -4.619742 & -1.554348 \\ \text { H } & -2.881983 & -3.159444 & 2.465209 \\ \text { C } & 3.567407 & -2.462231 & -1.032170 \\ \text { C } & 2.960859 & -3.713652 & -1.376914\end{array}$




\begin{tabular}{|c|c|c|c|}
\hline C & 3.713720 & -4.679501 & -2.098581 \\
\hline C & 5.003341 & -4.417504 & -2.497931 \\
\hline C & 5.591123 & -3.166870 & -2.194966 \\
\hline C & 4.894168 & -2.216344 & -1.481835 \\
\hline $\mathrm{H}$ & 3.241445 & -5.628584 & -2.341023 \\
\hline $\mathrm{H}$ & 5.566759 & -5.160612 & -3.055475 \\
\hline $\mathrm{H}$ & 6.601163 & -2.951097 & -2.532695 \\
\hline $\mathrm{H}$ & 5.356695 & -1.260067 & -1.267649 \\
\hline C & 4.519827 & -0.111854 & 1.002523 \\
\hline C & 5.063447 & 1.177276 & 1.310079 \\
\hline C & 6.202867 & 1.270698 & 2.154760 \\
\hline C & 6.770727 & 0.145004 & 2.704239 \\
\hline C & 6.213402 & -1.126711 & 2.432450 \\
\hline C & 5.120158 & -1.252464 & 1.603728 \\
\hline $\mathrm{H}$ & 6.610457 & 2.256152 & 2.367654 \\
\hline $\mathrm{H}$ & 7.637455 & 0.229346 & 3.354025 \\
\hline $\mathrm{H}$ & 6.649239 & -2.013181 & 2.885282 \\
\hline $\mathrm{H}$ & 4.699628 & -2.233019 & 1.412894 \\
\hline $\mathrm{O}$ & -0.273794 & 1.508294 & 0.764855 \\
\hline 0 & -0.691356 & 0.038595 & -1.375921 \\
\hline $\mathrm{H}$ & -1.780608 & 0.264047 & -1.414044 \\
\hline $\mathrm{H}$ & 2.422122 & 2.788298 & -2.541310 \\
\hline $\mathrm{H}$ & 1.350822 & 6.908819 & -1.942894 \\
\hline $\mathrm{H}$ & 2.827545 & 4.569948 & 1.348423 \\
\hline $\mathrm{H}$ & -0.526846 & -2.606744 & 1.985501 \\
\hline $\mathrm{H}$ & -4.318013 & -4.171094 & 0.698415 \\
\hline $\mathrm{H}$ & -1.001897 & -4.047784 & -2.034568 \\
\hline C & -3.919762 & -0.285909 & -1.062986 \\
\hline $\mathrm{O}$ & -3.065676 & 0.468129 & -1.640063 \\
\hline $\mathrm{H}$ & -3.582421 & -1.091818 & -0.398648 \\
\hline C & -5.160861 & -0.655830 & -1.874468 \\
\hline $\mathrm{O}$ & -5.529145 & -0.103256 & -2.881325 \\
\hline $\mathrm{O}$ & -5.788503 & -1.715027 & -1.307757 \\
\hline C & -6.966645 & -2.161674 & -1.999710 \\
\hline $\mathrm{H}$ & -7.708231 & -1.359885 & -2.053114 \\
\hline $\mathrm{H}$ & -6.716239 & -2.479366 & -3.015316 \\
\hline C & -3.908295 & 1.183582 & 1.088936 \\
\hline C & -4.986613 & 0.786329 & 0.285183 \\
\hline $\mathrm{H}$ & -2.047139 & 2.085713 & 0.943848 \\
\hline$N$ & -3.030601 & 2.117809 & 0.639826 \\
\hline C & -3.276874 & 3.052170 & -0.389815 \\
\hline $\mathrm{O}$ & -4.360098 & 3.351012 & -0.838285 \\
\hline $\mathrm{O}$ & -2.110086 & 3.614759 & -0.724951 \\
\hline C & -2.185579 & 4.602864 & -1.767001 \\
\hline
\end{tabular}




$\begin{array}{lrrr}\mathrm{H} & -1.159969 & 4.942096 & -1.906873 \\ \mathrm{H} & -2.833360 & 5.429059 & -1.462377 \\ \mathrm{H} & -2.577642 & 4.152835 & -2.682304 \\ \mathrm{H} & -5.687433 & 0.072243 & 0.699902 \\ \mathrm{H} & -5.383878 & 1.499470 & -0.424807 \\ \mathrm{C} & -3.609009 & 0.491788 & 2.367187 \\ \mathrm{C} & -2.304887 & 0.367693 & 2.883569 \\ \mathrm{C} & -4.680113 & -0.029881 & 3.120333 \\ \mathrm{C} & -2.087953 & -0.275424 & 4.100980 \\ \mathrm{H} & -1.447900 & 0.738996 & 2.331284 \\ \mathrm{C} & -4.456774 & -0.664545 & 4.338714 \\ \mathrm{H} & -5.698943 & 0.093905 & 2.770108 \\ \mathrm{C} & -3.157116 & -0.794261 & 4.833029 \\ \mathrm{H} & -1.072520 & -0.369491 & 4.475256 \\ \mathrm{H} & -5.300050 & -1.046563 & 4.907147 \\ \mathrm{H} & -2.981188 & -1.287631 & 5.785088 \\ \mathrm{H} & -7.348834 & -3.001294 & -1.418304\end{array}$

Catalyst (R)-1 TS Conformation 13

B3LYP/6-31G(d) Energy $=-2809.699797$

B3LYP-D3(BJ)/def2-TZVPP-IEF-PCM(DCM) Energy = -2810.990594

B3LYP-D3(BJ)/def2-TZVPP-IEF-PCM(DCM)//B3LYP/6-31G(d) Free Energy (Quasiharmonic) = 2810.348925

Frequencies (Top 3 out of 270)

1. $-497.5758 \mathrm{~cm}-1$

2. $\quad 10.4330 \mathrm{~cm}-1$

3. $\quad 12.8328 \mathrm{~cm}-1$

B3LYP/6-31G(d) Molecular Geometry in Cartesian Coordinates

$\begin{array}{llll}\text { C } & 3.453216 & -1.137676 & 0.078449 \\ \text { C } & 2.218012 & -1.738296 & 0.251815 \\ \text { C } & 1.974424 & -3.124794 & 0.033168 \\ \text { C } & 3.032704 & -3.889235 & -0.415412 \\ \text { H } & 2.888957 & -4.955237 & -0.571878 \\ \text { C } & 4.055729 & 3.084477 & 0.681367 \\ \text { C } & 3.622467 & 0.314640 & 0.384956 \\ \text { C } & 2.806996 & 1.253446 & -0.232050 \\ \text { C } & 3.036435 & 2.660396 & -0.149899 \\ \text { H } & 4.248823 & 4.149797 & 0.775433\end{array}$




\begin{tabular}{|c|c|c|c|}
\hline $\mathrm{O}$ & 1.152639 & -0.951404 & 0.676286 \\
\hline$P$ & 0.472413 & 0.080284 & -0.395105 \\
\hline $\mathrm{O}$ & 1.775153 & 0.809735 & -1.053394 \\
\hline C & -1.852735 & -4.980882 & 0.693762 \\
\hline C & -1.160705 & -5.188346 & -0.500885 \\
\hline C & 0.073597 & -4.572750 & -0.711971 \\
\hline C & 0.638662 & -3.736888 & 0.264328 \\
\hline C & -0.068799 & -3.532484 & 1.461089 \\
\hline C & -1.299897 & -4.151976 & 1.673834 \\
\hline $\mathrm{H}$ & -1.583085 & -5.825968 & -1.273076 \\
\hline $\mathrm{H}$ & -1.824882 & -3.992920 & 2.612428 \\
\hline C & 0.994586 & 5.581843 & -2.568334 \\
\hline C & 2.387415 & 5.564278 & -2.488710 \\
\hline C & 3.029612 & 4.605747 & -1.705484 \\
\hline C & 2.295325 & 3.651304 & -0.980372 \\
\hline C & 0.893608 & 3.685145 & -1.058539 \\
\hline C & 0.255060 & 4.639154 & -1.851378 \\
\hline $\mathrm{H}$ & 2.977342 & 6.286799 & -3.046819 \\
\hline $\mathrm{H}$ & -0.829899 & 4.632786 & -1.913820 \\
\hline C & 4.619242 & 0.776511 & 1.311986 \\
\hline C & 4.832142 & 2.185426 & 1.452138 \\
\hline C & 5.812869 & 2.655565 & 2.367194 \\
\hline C & 6.543308 & 1.778105 & 3.134209 \\
\hline C & 6.314488 & 0.386601 & 3.019566 \\
\hline C & 5.380363 & -0.101198 & 2.132232 \\
\hline $\mathrm{H}$ & 5.966609 & 3.728462 & 2.455863 \\
\hline $\mathrm{H}$ & 7.286397 & 2.149248 & 3.834680 \\
\hline $\mathrm{H}$ & 6.876668 & -0.304304 & 3.642033 \\
\hline $\mathrm{H}$ & 5.208862 & -1.169403 & 2.064321 \\
\hline C & 4.527670 & -1.931731 & -0.455988 \\
\hline C & 4.305445 & -3.328835 & -0.686776 \\
\hline C & 5.360877 & -4.128407 & -1.203304 \\
\hline C & 6.580887 & -3.575366 & -1.514694 \\
\hline C & 6.790422 & -2.189175 & -1.327143 \\
\hline C & 5.793590 & -1.390052 & -0.811702 \\
\hline $\mathrm{H}$ & 5.177829 & -5.188789 & -1.360316 \\
\hline $\mathrm{H}$ & 7.378038 & -4.195157 & -1.915823 \\
\hline $\mathrm{H}$ & 7.745912 & -1.747967 & -1.597589 \\
\hline $\mathrm{H}$ & 5.969079 & -0.328440 & -0.685430 \\
\hline $\mathrm{O}$ & -0.444883 & 0.973536 & 0.374758 \\
\hline $\mathrm{O}$ & -0.116756 & -0.714962 & -1.580452 \\
\hline $\mathrm{H}$ & -1.238966 & -0.581808 & -1.719028 \\
\hline $\mathrm{H}$ & 0.353473 & -2.892879 & 2.229018 \\
\hline $\mathrm{H}$ & -2.813550 & -5.460563 & 0.860100 \\
\hline
\end{tabular}




$\begin{array}{llll}\mathrm{H} & 0.598291 & -4.719757 & -1.651681 \\ \mathrm{H} & 0.299431 & 2.975809 & -0.494089 \\ \mathrm{H} & 0.490697 & 6.318447 & -3.188852 \\ \mathrm{H} & 4.115424 & 4.577186 & -1.672432 \\ \mathrm{C} & -3.133827 & -1.360047 & -1.159280 \\ \mathrm{O} & -2.515393 & -0.456413 & -1.810785 \\ \mathrm{H} & -2.613288 & -2.281574 & -0.867444 \\ \mathrm{C} & -4.604884 & -1.551731 & -1.494218 \\ \mathrm{O} & -5.265102 & -0.792439 & -2.163445 \\ \mathrm{O} & -5.068984 & -2.697510 & -0.949428 \\ \mathrm{C} & -6.461115 & -2.969605 & -1.190643 \\ \mathrm{H} & -7.083557 & -2.188756 & -0.746019 \\ \mathrm{H} & -6.659365 & -3.019503 & -2.264256 \\ \mathrm{C} & -3.945932 & 0.390942 & 0.827788 \\ \mathrm{C} & -3.297352 & -0.850622 & 0.826610 \\ \mathrm{H} & -2.194680 & 1.325557 & 0.332895 \\ \mathrm{~N} & -3.200538 & 1.486425 & 0.524423 \\ \mathrm{C} & -3.544973 & 2.830191 & 0.748067 \\ \mathrm{O} & -4.575651 & 3.244033 & 1.226794 \\ \mathrm{O} & -2.506071 & 3.593213 & 0.365337 \\ \mathrm{C} & -2.659042 & 4.999701 & 0.626440 \\ \mathrm{H} & -3.510760 & 5.400117 & 0.070680 \\ \mathrm{H} & -1.727378 & 5.452906 & 0.290376 \\ \mathrm{H} & -2.812032 & 5.173241 & 1.694462 \\ \mathrm{H} & -3.853817 & -1.706142 & 1.190668 \\ \mathrm{H} & -2.226686 & -0.860866 & 1.004303 \\ \mathrm{C} & -5.413332 & 0.459468 & 1.005463 \\ \mathrm{C} & -6.232522 & 1.154949 & 0.099896 \\ \mathrm{C} & -6.008899 & -0.264584 & 2.051537 \\ \mathrm{C} & -7.615709 & 1.123946 & 0.243519 \\ \mathrm{H} & -5.785708 & 1.684464 & -0.732908 \\ \mathrm{H} & -7.394074 & -0.274376 & 2.204944 \\ \mathrm{H} & -5.380727 & -0.793569 & 2.761980 \\ -8.199837 & 0.417265 & 1.298629 \\ \mathrm{H} & -8.240037 & 1.652998 & -0.470428 \\ \mathrm{H} & -9.280445 & 0.406322 & 1.413088 \\ \mathrm{H} & & -3.932737 & -0.718478\end{array}$

Catalyst (R)-1 TS Conformation 14

B3LYP/6-31G(d) Energy $=-2809.698832$

B3LYP-D3(BJ)/def2-TZVPP-IEF-PCM(DCM) Energy $=-2810.990594$ 
B3LYP-D3(BJ)/def2-TZVPP-IEF-PCM(DCM)//B3LYP/6-31G(d) Free Energy (Quasiharmonic) = 2810.348725

Frequencies (Top 3 out of 270)

1. $-565.6663 \mathrm{~cm}-1$

2. $\quad 8.9072 \mathrm{~cm}-1$

3. $12.6781 \mathrm{~cm}-1$

B3LYP/6-31G(d) Molecular Geometry in Cartesian Coordinates

$\begin{array}{llll}\text { C } & 3.365705 & -1.123102 & -0.154082 \\ \text { C } & 2.153349 & -1.683003 & 0.210246 \\ \text { C } & 1.804389 & -3.041069 & -0.044667 \\ \text { C } & 2.714254 & -3.803636 & -0.750404 \\ \text { H } & 2.493503 & -4.850731 & -0.940259 \\ \text { C } & 4.368012 & 2.933999 & 0.885927 \\ \text { C } & 3.693248 & 0.267720 & 0.275227 \\ \text { C } & 2.842327 & 1.321747 & -0.030665 \\ \text { C } & 3.172788 & 2.683602 & 0.239935 \\ \text { H } & 4.638341 & 3.962841 & 1.108022 \\ \text { O } & 1.221756 & -0.874495 & 0.860574 \\ \text { P } & 0.435236 & 0.217787 & -0.076146 \\ \text { O } & 1.664601 & 1.071022 & -0.728104 \\ \text { C } & -1.839845 & -4.884715 & 1.317377 \\ \text { C } & -1.096496 & -4.080124 & 2.184777 \\ \text { C } & 0.073110 & -3.459977 & 1.745658 \\ \text { C } & 0.527327 & -3.638072 & 0.427106 \\ \text { C } & -0.229165 & -4.448852 & -0.435249 \\ \text { C } & -1.400156 & -5.066395 & 0.005100 \\ \text { H } & -1.428059 & -3.935024 & 3.209635 \\ \text { H } & -1.975094 & -5.681475 & -0.682162 \\ \text { C } & 0.826057 & 6.149758 & -0.747416 \\ \text { C } & 0.247168 & 5.097847 & -0.034042 \\ \text { C } & 0.977952 & 3.944744 & 0.253064 \\ \text { C } & 2.316192 & 3.836970 & -0.154580 \\ \text { C } & 2.888206 & 4.897564 & -0.877047 \\ \text { C } & 2.149886 & 6.041996 & -1.176233 \\ \text { H } & -0.779834 & 5.173172 & 0.312444 \\ \text { H } & 2.610479 & 6.848930 & -1.740356 \\ \text { C } & 4.881102 & 0.538979 & 1.040691 \\ \text { C } & 5.225130 & 1.898144 & 1.326619 \\ \text { C } & 6.402274 & 2.182799 & 2.070651 \\ \text { C } & 7.202331 & 1.168844 & 2.542558\end{array}$




\begin{tabular}{|c|c|c|c|}
\hline C & 6.846315 & -0.177722 & 2.294265 \\
\hline C & 5.719580 & -0.484720 & 1.563616 \\
\hline $\mathrm{H}$ & 6.649996 & 3.222665 & 2.270333 \\
\hline $\mathrm{H}$ & 8.096897 & 1.396631 & 3.115633 \\
\hline $\mathrm{H}$ & 7.464364 & -0.979325 & 2.689615 \\
\hline $\mathrm{H}$ & 5.457543 & -1.522346 & 1.394072 \\
\hline C & 4.266759 & -1.905242 & -0.957309 \\
\hline C & 3.928858 & -3.267379 & -1.244191 \\
\hline C & 4.813512 & -4.055884 & -2.028898 \\
\hline C & 5.971198 & -3.520351 & -2.543205 \\
\hline C & 6.287726 & -2.164123 & -2.295198 \\
\hline C & 5.460837 & -1.378968 & -1.522060 \\
\hline $\mathrm{H}$ & 4.547550 & -5.091661 & -2.226330 \\
\hline $\mathrm{H}$ & 6.635977 & -4.130288 & -3.148666 \\
\hline $\mathrm{H}$ & 7.189891 & -1.735221 & -2.722882 \\
\hline $\mathrm{H}$ & 5.713176 & -0.339194 & -1.350317 \\
\hline $\mathrm{O}$ & -0.482832 & 1.007559 & 0.805359 \\
\hline $\mathrm{O}$ & -0.186667 & -0.501202 & -1.288836 \\
\hline $\mathrm{H}$ & -1.327388 & -0.677274 & -1.244422 \\
\hline $\mathrm{H}$ & 0.094929 & -4.574837 & -1.464441 \\
\hline $\mathrm{H}$ & -2.761194 & -5.348745 & 1.655586 \\
\hline $\mathrm{H}$ & 0.644018 & -2.840019 & 2.428754 \\
\hline $\mathrm{H}$ & 3.918541 & 4.815447 & -1.212728 \\
\hline $\mathrm{H}$ & 0.252130 & 7.047234 & -0.964594 \\
\hline $\mathrm{H}$ & 0.511712 & 3.136686 & 0.806332 \\
\hline C & -2.967038 & -1.558942 & -0.191236 \\
\hline 0 & -2.574914 & -0.875570 & -1.199455 \\
\hline $\mathrm{H}$ & -2.241247 & -2.123164 & 0.405017 \\
\hline C & -4.301334 & -2.288514 & -0.265910 \\
\hline 0 & -4.684491 & -3.061768 & 0.588459 \\
\hline O & -4.973614 & -2.003361 & -1.390296 \\
\hline C & -6.232035 & -2.684177 & -1.537658 \\
\hline $\mathrm{H}$ & -6.604295 & -2.395163 & -2.520615 \\
\hline $\mathrm{H}$ & -6.089039 & -3.766074 & -1.481229 \\
\hline C & -3.995564 & 0.705689 & 0.825315 \\
\hline C & -3.345617 & -0.368354 & 1.445647 \\
\hline $\mathrm{H}$ & -2.181747 & 1.414797 & 0.240260 \\
\hline $\mathrm{N}$ & -3.201340 & 1.573745 & 0.151480 \\
\hline C & -3.559370 & 2.730176 & -0.561041 \\
\hline 0 & -4.660395 & 3.223530 & -0.642145 \\
\hline $\mathrm{O}$ & -2.445689 & 3.209109 & -1.139335 \\
\hline C & -2.638647 & 4.364223 & -1.974641 \\
\hline $\mathrm{H}$ & -3.261376 & 4.104269 & -2.834766 \\
\hline $\mathrm{H}$ & -1.638608 & 4.655349 & -2.291452 \\
\hline
\end{tabular}




$\begin{array}{llll}\mathrm{H} & -3.118534 & 5.168372 & -1.411729 \\ \mathrm{H} & -3.934396 & -1.035883 & 2.063210 \\ \mathrm{H} & -2.302431 & -0.235088 & 1.717028 \\ \mathrm{C} & -5.476681 & 0.748231 & 0.779295 \\ \mathrm{C} & -6.184849 & 0.598393 & 1.982400 \\ \mathrm{C} & -6.188661 & 0.841478 & -0.427960 \\ \mathrm{C} & -7.578645 & 0.572893 & 1.984827 \\ \mathrm{H} & -5.639132 & 0.525554 & 2.918324 \\ \mathrm{C} & -7.579523 & 0.792289 & -0.422836 \\ \mathrm{H} & -5.652801 & 0.927648 & -1.364954 \\ \mathrm{C} & -8.278215 & 0.667456 & 0.781661 \\ \mathrm{H} & -8.114268 & 0.475277 & 2.924659 \\ \mathrm{H} & -8.121065 & 0.859503 & -1.362188 \\ \mathrm{H} & -9.364584 & 0.642510 & 0.779980 \\ \mathrm{H} & -6.927654 & -2.370332 & -0.755355\end{array}$

Catalyst (R)-1 TS Conformation 15

$B 3 L Y P / 6-31 G(d)$ Energy $=-2809.700788$

B3LYP-D3(BJ)/def2-TZVPP-IEF-PCM(DCM) Energy = -2810.990987

B3LYP-D3(BJ)/def2-TZVPP-IEF-PCM(DCM)//B3LYP/6-31G(d) Free Energy (Quasiharmonic) = 2810.348584

Frequencies (Top 3 out of 270)

1. $-472.4516 \mathrm{~cm}-1$

2. $\quad 10.8457 \mathrm{~cm}-1$

3. $12.6341 \mathrm{~cm}-1$

B3LYP/6-31G(d) Molecular Geometry in Cartesian Coordinates

$\begin{array}{llll}\text { C } & 3.464800 & -1.039675 & -0.023204 \\ \text { C } & 2.257209 & -1.657430 & 0.252557 \\ \text { C } & 1.990208 & -3.030649 & -0.018402 \\ \text { C } & 2.991217 & -3.757183 & -0.632300 \\ \text { H } & 2.833511 & -4.813875 & -0.831859 \\ \text { C } & 4.156122 & 3.107888 & 0.914832 \\ \text { C } & 3.677851 & 0.381173 & 0.383253 \\ \text { C } & 2.798235 & 1.371741 & -0.033519 \\ \text { C } & 3.034711 & 2.762210 & 0.185581 \\ \text { H } & 4.356070 & 4.159286 & 1.103324 \\ \text { O } & 1.243260 & -0.895144 & 0.828650 \\ \text { P } & 0.460556 & 0.156332 & -0.150876\end{array}$




\begin{tabular}{|c|c|c|c|}
\hline 0 & 1.686301 & 1.018971 & -0.792955 \\
\hline C & -1.721285 & -4.975297 & 0.974117 \\
\hline C & -1.149868 & -5.137680 & -0.289407 \\
\hline C & 0.045503 & -4.492225 & -0.607129 \\
\hline C & 0.694167 & -3.671280 & 0.330175 \\
\hline C & 0.108831 & -3.514192 & 1.598386 \\
\hline C & -1.084326 & -4.162986 & 1.916253 \\
\hline $\mathrm{H}$ & -1.641128 & -5.758605 & -1.033745 \\
\hline $\mathrm{H}$ & -1.515312 & -4.036882 & 2.906242 \\
\hline C & 0.620846 & 5.993461 & -1.315811 \\
\hline C & 0.021713 & 4.952288 & -0.603807 \\
\hline C & 0.782141 & 3.879631 & -0.137377 \\
\hline C & 2.165921 & 3.839297 & -0.367258 \\
\hline C & 2.758692 & 4.890240 & -1.087631 \\
\hline C & 1.994419 & 5.956368 & -1.560581 \\
\hline $\mathrm{H}$ & -1.045305 & 4.969740 & -0.400002 \\
\hline $\mathrm{H}$ & 2.472798 & 6.755636 & -2.120837 \\
\hline C & 4.783040 & 0.753549 & 1.225257 \\
\hline C & 5.025068 & 2.141789 & 1.475949 \\
\hline C & 6.118281 & 2.524610 & 2.299739 \\
\hline C & 6.931716 & 1.579340 & 2.879373 \\
\hline C & 6.674935 & 0.205068 & 2.662293 \\
\hline C & 5.631886 & -0.197085 & 1.857301 \\
\hline $\mathrm{H}$ & 6.290543 & 3.584378 & 2.472263 \\
\hline $\mathrm{H}$ & 7.761065 & 1.882648 & 3.512411 \\
\hline $\mathrm{H}$ & 7.302801 & -0.541783 & 3.140667 \\
\hline $\mathrm{H}$ & 5.443286 & -1.254304 & 1.711730 \\
\hline C & 4.467547 & -1.788595 & -0.732732 \\
\hline C & 4.220247 & -3.170058 & -1.022176 \\
\hline C & 5.206269 & -3.926424 & -1.711998 \\
\hline C & 6.378173 & -3.343582 & -2.134261 \\
\hline C & 6.607205 & -1.969848 & -1.886843 \\
\hline C & 5.679787 & -1.213820 & -1.203988 \\
\hline $\mathrm{H}$ & 5.007251 & -4.976641 & -1.911934 \\
\hline $\mathrm{H}$ & 7.121327 & -3.929848 & -2.667668 \\
\hline $\mathrm{H}$ & 7.521863 & -1.504032 & -2.243463 \\
\hline $\mathrm{H}$ & 5.867324 & -0.160522 & -1.032403 \\
\hline $\mathrm{O}$ & -0.497995 & 0.932934 & 0.695532 \\
\hline $\mathrm{O}$ & -0.106604 & -0.602341 & -1.370358 \\
\hline $\mathrm{H}$ & -1.235763 & -0.692064 & -1.406100 \\
\hline $\mathrm{H}$ & 0.595695 & -2.887949 & 2.338405 \\
\hline $\mathrm{H}$ & -2.658737 & -5.466908 & 1.217512 \\
\hline $\mathrm{H}$ & 0.472297 & -4.602417 & -1.599987 \\
\hline $\mathrm{H}$ & 3.826273 & 4.859827 & -1.288656 \\
\hline
\end{tabular}




\begin{tabular}{llll}
$\mathrm{H}$ & 0.023691 & 6.827573 & -1.675832 \\
$\mathrm{H}$ & 0.300286 & 3.082282 & 0.417395 \\
$\mathrm{C}$ & -3.025621 & -1.635075 & -0.623032 \\
$\mathrm{O}$ & -2.525030 & -0.783439 & -1.438684 \\
$\mathrm{H}$ & -2.396759 & -2.424769 & -0.194195 \\
$\mathrm{C}$ & -4.433520 & -2.141491 & -0.887450 \\
$\mathrm{O}$ & -4.888028 & -3.140169 & -0.361091 \\
$\mathrm{O}$ & -5.091191 & -1.364207 & -1.752975 \\
$\mathrm{C}$ & -6.430232 & -1.775787 & -2.077952 \\
$\mathrm{H}$ & -7.072249 & -1.714488 & -1.195710 \\
$\mathrm{H}$ & -6.768186 & -1.076556 & -2.842201 \\
$\mathrm{C}$ & -3.972479 & 0.374671 & 0.908290 \\
$\mathrm{C}$ & -3.252435 & -0.795079 & 1.202014 \\
$\mathrm{H}$ & -2.243350 & 1.266997 & 0.300047 \\
$\mathrm{~N}$ & -3.273242 & 1.349965 & 0.261766 \\
$\mathrm{C}$ & -3.754406 & 2.160550 & -0.784027 \\
$\mathrm{O}$ & -4.895751 & 2.241249 & -1.171287 \\
$\mathrm{O}$ & -2.706094 & 2.834085 & -1.289446 \\
$\mathrm{C}$ & -2.990483 & 3.612107 & -2.464957 \\
$\mathrm{H}$ & -2.047548 & 4.094720 & -2.719121 \\
$\mathrm{H}$ & -3.765703 & 4.353520 & -2.255379 \\
$\mathrm{H}$ & -3.322700 & 2.959476 & -3.276065 \\
$\mathrm{H}$ & -3.705580 & -1.531132 & 1.857046 \\
$\mathrm{H}$ & -2.178442 & -0.680044 & 1.314428 \\
$\mathrm{C}$ & -5.390901 & 0.549049 & 1.266028 \\
$\mathrm{C}$ & -5.897903 & 1.832906 & 1.541023 \\
$\mathrm{C}$ & -6.229967 & -0.564063 & 1.467613 \\
$\mathrm{C}$ & -7.204326 & 1.998778 & 1.988281 \\
$\mathrm{H}$ & -5.258059 & 2.699601 & 1.426757 \\
$\mathrm{C}$ & -7.543213 & -0.390731 & 1.896645 \\
$\mathrm{H}$ & -5.868311 & -1.566991 & 1.269857 \\
$\mathrm{H}$ & -8.035112 & 0.889529 & 2.159904 \\
$\mathrm{H}$ & -7.574255 & 2.996998 & 2.203696 \\
-8.180099 & -1.260063 & 2.033590 \\
-9.056835 & 1.021375 & 2.505212 \\
\hline & -6.432323 & -2.800469 & -2.457895
\end{tabular}

Catalyst (R)-1 TS Conformation 16

B3LYP/6-31G(d) Energy $=-2809.700247$

B3LYP-D3(BJ)/def2-TZVPP-IEF-PCM(DCM) Energy $=-2810.991118$

B3LYP-D3(BJ)/def2-TZVPP-IEF-PCM(DCM)//B3LYP/6-31G(d) Free Energy (Quasiharmonic) = 2810.348531 
Frequencies (Top 3 out of 270)

1. $-392.2392 \mathrm{~cm}-1$

2. $\quad 11.0506 \mathrm{~cm}-1$

3. $\quad 15.6987 \mathrm{~cm}-1$

B3LYP/6-31G(d) Molecular Geometry in Cartesian Coordinates

$\begin{array}{lrrr}\text { C } & 2.754653 & -1.506095 & -0.244474 \\ \text { C } & 1.440735 & -1.779265 & 0.095852 \\ \text { C } & 0.781239 & -3.004853 & -0.211031 \\ \text { C } & 1.503415 & -3.946425 & -0.917770 \\ \text { H } & 1.042864 & -4.903627 & -1.147647 \\ \text { C } & 4.630762 & 2.246093 & 0.735011 \\ \text { C } & 3.378425 & -0.218779 & 0.184332 \\ \text { C } & 2.784984 & 0.992375 & -0.147068 \\ \text { C } & 3.413671 & 2.253231 & 0.081054 \\ \text { H } & 5.128508 & 3.192645 & 0.928154 \\ \text { O } & 0.722859 & -0.800130 & 0.780202 \\ \text { P } & 0.206343 & 0.490379 & -0.082082 \\ \text { O } & 1.569837 & 0.988587 & -0.826113 \\ \text { C } & -3.286192 & -3.871395 & 0.900501 \\ \text { C } & -2.834380 & -4.125299 & -0.396077 \\ \text { C } & -1.517841 & -3.830330 & -0.748810 \\ \text { C } & -0.626686 & -3.274395 & 0.184869 \\ \text { C } & -1.094541 & -3.021267 & 1.485145 \\ \text { C } & -2.410466 & -3.319996 & 1.838730 \\ \text { H } & -3.515567 & -4.532744 & -1.137616 \\ \text { H } & -2.752406 & -3.114746 & 2.849654 \\ \text { C } & 1.913996 & 6.078230 & -1.203643 \\ \text { C } & 1.096604 & 5.227745 & -0.455812 \\ \text { C } & 1.552773 & 3.970765 & -0.056963 \\ \text { C } & 2.848791 & 3.548886 & -0.392201 \\ \text { C } & 3.662781 & 4.411305 & -1.145822 \\ \text { C } & 3.200194 & 5.662998 & -1.551169 \\ \text { H } & 0.096679 & 5.543401 & -0.169160 \\ \text { H } & 3.844783 & 6.311225 & -2.139220 \\ \text { C } & 4.594161 & -0.200387 & 0.952309 \\ \text { C } & 5.228449 & 1.055780 & 1.214298 \\ \text { C } & 6.434099 & 1.087725 & 1.966450 \\ \text { C } & 6.986169 & -0.068262 & 2.466687 \\ \text { C } & 6.344058 & -1.308268 & 2.238693 \\ \text { C } & 5.182403 & -1.373565 & 1.501181\end{array}$




\begin{tabular}{|c|c|c|c|}
\hline $\mathrm{H}$ & 6.905603 & 2.050554 & 2.148683 \\
\hline $\mathrm{H}$ & 7.904960 & -0.031846 & 3.045535 \\
\hline $\mathrm{H}$ & 6.768047 & -2.218262 & 2.654629 \\
\hline $\mathrm{H}$ & 4.698064 & -2.330514 & 1.345299 \\
\hline C & 3.465614 & -2.464506 & -1.048055 \\
\hline C & 2.824992 & -3.705805 & -1.367233 \\
\hline C & 3.518919 & -4.669444 & -2.148433 \\
\hline C & 4.781493 & -4.413971 & -2.629956 \\
\hline C & 5.399811 & -3.172355 & -2.352565 \\
\hline C & 4.761523 & -2.225019 & -1.582437 \\
\hline $\mathrm{H}$ & 3.022199 & -5.611082 & -2.370073 \\
\hline $\mathrm{H}$ & 5.299216 & -5.155073 & -3.232668 \\
\hline $\mathrm{H}$ & 6.386620 & -2.960712 & -2.755305 \\
\hline $\mathrm{H}$ & 5.246466 & -1.275597 & -1.389091 \\
\hline $\mathrm{O}$ & -0.370494 & 1.473799 & 0.885276 \\
\hline $\mathrm{O}$ & -0.646948 & -0.007201 & -1.266287 \\
\hline $\mathrm{H}$ & -1.753698 & 0.107166 & -1.329869 \\
\hline $\mathrm{H}$ & -0.423247 & -2.592751 & 2.221508 \\
\hline $\mathrm{H}$ & -4.316195 & -4.087457 & 1.169221 \\
\hline $\mathrm{H}$ & -1.178669 & -4.004419 & -1.766099 \\
\hline $\mathrm{H}$ & 4.661453 & 4.087586 & -1.426767 \\
\hline $\mathrm{H}$ & 1.552878 & 7.056320 & -1.511252 \\
\hline $\mathrm{H}$ & 0.905826 & 3.324958 & 0.526086 \\
\hline C & -3.888662 & -0.501678 & -0.964836 \\
\hline 0 & -3.035808 & 0.194132 & -1.618130 \\
\hline $\mathrm{H}$ & -3.554094 & -1.190504 & -0.179642 \\
\hline C & -5.080307 & -1.096545 & -1.711800 \\
\hline $\mathrm{O}$ & -5.679363 & -2.075710 & -1.315234 \\
\hline 0 & -5.367547 & -0.424893 & -2.833402 \\
\hline C & -6.469528 & -0.944723 & -3.596207 \\
\hline $\mathrm{H}$ & -7.386266 & -0.938699 & -3.000181 \\
\hline $\mathrm{H}$ & -6.564983 & -0.282182 & -4.456283 \\
\hline C & -4.027763 & 1.206420 & 0.973965 \\
\hline C & -5.046618 & 0.706939 & 0.148732 \\
\hline $\mathrm{H}$ & -2.157261 & 2.086581 & 0.858251 \\
\hline$N$ & -3.114401 & 2.083650 & 0.479474 \\
\hline C & -3.274845 & 2.866161 & -0.684194 \\
\hline $\mathrm{O}$ & -4.320632 & 3.108573 & -1.241835 \\
\hline $\mathrm{O}$ & -2.077807 & 3.366165 & -1.021404 \\
\hline C & -2.065066 & 4.146734 & -2.231207 \\
\hline $\mathrm{H}$ & -1.030336 & 4.464874 & -2.350051 \\
\hline $\mathrm{H}$ & -2.731962 & 5.007437 & -2.136703 \\
\hline $\mathrm{H}$ & -2.383074 & 3.529755 & -3.074811 \\
\hline $\mathrm{H}$ & -5.772325 & 0.039691 & 0.598772 \\
\hline
\end{tabular}




$\begin{array}{lrrr}\text { H } & -5.396465 & 1.324748 & -0.667175 \\ \mathrm{C} & -3.823948 & 0.668133 & 2.340459 \\ \mathrm{C} & -2.555459 & 0.564056 & 2.942562 \\ \mathrm{C} & -4.954991 & 0.271276 & 3.082185 \\ \mathrm{C} & -2.431519 & 0.061044 & 4.236473 \\ \mathrm{H} & -1.656478 & 0.840198 & 2.401243 \\ \mathrm{C} & -4.823715 & -0.221553 & 4.376879 \\ \mathrm{H} & -5.946711 & 0.382457 & 2.657483 \\ \mathrm{C} & -3.559105 & -0.333221 & 4.958461 \\ \mathrm{H} & -1.442869 & -0.022794 & 4.678670 \\ \mathrm{H} & -5.710739 & -0.509299 & 4.933967 \\ \mathrm{H} & -3.455010 & -0.717850 & 5.969390 \\ \mathrm{H} & -6.261414 & -1.968213 & -3.918983\end{array}$

Catalyst (R)-1 TS Conformation 17

B3LYP/6-31G(d) Energy $=-2809.701784$

B3LYP-D3(BJ)/def2-TZVPP-IEF-PCM(DCM) Energy $=-2810.9928$

B3LYP-D3(BJ)/def2-TZVPP-IEF-PCM(DCM)//B3LYP/6-31G(d) Free Energy (Quasiharmonic) = 2810.348482

Frequencies (Top 3 out of 270)

1. $-271.1618 \mathrm{~cm}-1$

2. $\quad 14.8767 \mathrm{~cm}-1$

3. $20.4080 \mathrm{~cm}-1$

B3LYP/6-31G(d) Molecular Geometry in Cartesian Coordinates

$\begin{array}{llll}\text { C } & -3.162490 & 0.226373 & -0.281462 \\ \text { C } & -2.265497 & 1.271849 & -0.113302 \\ \text { C } & -2.566854 & 2.618942 & -0.479718 \\ \text { C } & -3.785129 & 2.853517 & -1.087182 \\ \text { H } & -4.037243 & 3.869125 & -1.380279 \\ \text { C } & -2.410399 & -3.832392 & 0.936132 \\ \text { C } & -2.867225 & -1.133169 & 0.260392 \\ \text { C } & -1.704667 & -1.793190 & -0.105092 \\ \text { C } & -1.469641 & -3.172906 & 0.169078 \\ \text { H } & -2.258052 & -4.883414 & 1.167056 \\ \text { O } & -1.062547 & 1.026594 & 0.543011 \\ \text { P } & 0.092522 & 0.065135 & -0.099842 \\ \text { O } & -0.755854 & -1.101773 & -0.856246 \\ \text { C } & -0.072270 & 6.069351 & 0.157190\end{array}$




\begin{tabular}{|c|c|c|c|}
\hline$C$ & 0.441964 & 4.953699 & -0.508056 \\
\hline C & -0.346346 & 3.817804 & -0.692903 \\
\hline C & -1.664051 & 3.775426 & -0.213846 \\
\hline C & -2.168039 & 4.899755 & 0.462400 \\
\hline C & -1.380518 & 6.036932 & 0.645478 \\
\hline $\mathrm{H}$ & 1.461209 & 4.949857 & -0.882790 \\
\hline $\mathrm{H}$ & -1.790189 & 6.896627 & 1.169866 \\
\hline C & 1.783424 & -5.473703 & -1.460901 \\
\hline C & 2.053500 & -4.301521 & -0.751140 \\
\hline C & 1.013895 & -3.532143 & -0.226988 \\
\hline C & -0.320702 & -3.930331 & -0.403483 \\
\hline C & -0.580635 & -5.113124 & -1.115847 \\
\hline C & 0.460411 & -5.878168 & -1.641318 \\
\hline $\mathrm{H}$ & 3.081016 & -3.984715 & -0.592854 \\
\hline $\mathrm{H}$ & 0.235570 & -6.785690 & -2.195707 \\
\hline C & -3.783319 & -1.803824 & 1.144087 \\
\hline C & -3.543122 & -3.175574 & 1.476449 \\
\hline C & -4.440844 & -3.851025 & 2.346984 \\
\hline C & -5.521665 & -3.198673 & 2.892874 \\
\hline C & -5.744040 & -1.834427 & 2.591464 \\
\hline C & -4.901053 & -1.156408 & 1.738492 \\
\hline $\mathrm{H}$ & -4.247595 & -4.894956 & 2.582427 \\
\hline $\mathrm{H}$ & -6.197808 & -3.722963 & 3.562587 \\
\hline $\mathrm{H}$ & -6.585129 & -1.314134 & 3.041629 \\
\hline $\mathrm{H}$ & -5.079349 & -0.108735 & 1.525640 \\
\hline C & -4.377696 & 0.471841 & -1.013804 \\
\hline C & -4.692221 & 1.813408 & -1.399969 \\
\hline C & -5.893965 & 2.076160 & -2.111902 \\
\hline C & -6.747000 & 1.055157 & -2.459273 \\
\hline C & -6.421511 & -0.277293 & -2.113312 \\
\hline C & -5.271791 & -0.561568 & -1.409641 \\
\hline $\mathrm{H}$ & -6.117668 & 3.103661 & -2.388821 \\
\hline $\mathrm{H}$ & -7.660010 & 1.265396 & -3.009472 \\
\hline $\mathrm{H}$ & -7.081662 & -1.087193 & -2.411797 \\
\hline $\mathrm{H}$ & -5.034847 & -1.590216 & -1.165885 \\
\hline 0 & 0.967250 & -0.425766 & 1.006948 \\
\hline 0 & 0.745214 & 0.779796 & -1.313672 \\
\hline $\mathrm{H}$ & 1.673006 & 1.315834 & -1.176126 \\
\hline $\mathrm{H}$ & -3.183077 & 4.875845 & 0.850456 \\
\hline $\mathrm{H}$ & 0.541450 & 6.955782 & 0.296045 \\
\hline $\mathrm{H}$ & 0.057696 & 2.972329 & -1.233994 \\
\hline $\mathrm{H}$ & -1.610642 & -5.421904 & -1.272883 \\
\hline $\mathrm{H}$ & 2.597293 & -6.067565 & -1.869228 \\
\hline $\mathrm{H}$ & 1.237077 & -2.632260 & 0.335951 \\
\hline
\end{tabular}




$\begin{array}{llll}\mathrm{C} & 3.950075 & 2.061867 & -1.318460 \\ \mathrm{O} & 2.707937 & 2.259115 & -1.024394 \\ \mathrm{H} & 4.524421 & 2.935034 & -1.664678 \\ \mathrm{C} & 4.358046 & 0.855376 & -2.169483 \\ \mathrm{O} & 5.430783 & 0.766795 & -2.734926 \\ \mathrm{O} & 3.400760 & -0.078551 & -2.198727 \\ \mathrm{C} & 3.660390 & -1.240912 & -3.005874 \\ \mathrm{H} & 4.557942 & -1.755412 & -2.653793 \\ \mathrm{H} & 2.782008 & -1.874651 & -2.889468 \\ \mathrm{C} & 4.304591 & 0.861885 & 0.958059 \\ \mathrm{C} & 5.010377 & 1.845258 & 0.219829 \\ \mathrm{H} & 2.373450 & 0.483951 & 1.572112 \\ \mathrm{~N} & 3.129800 & 1.192820 & 1.536296 \\ \mathrm{C} & 2.725224 & 2.480612 & 1.958915 \\ \mathrm{O} & 3.422744 & 3.466611 & 2.031705 \\ \mathrm{O} & 1.452768 & 2.386139 & 2.353558 \\ \mathrm{C} & 0.873073 & 3.586058 & 2.899303 \\ \mathrm{H} & 0.983768 & 4.413509 & 2.198566 \\ \mathrm{H} & 1.354159 & 3.831950 & 3.850133 \\ \mathrm{H} & -0.178955 & 3.347067 & 3.045765 \\ \mathrm{H} & 6.014141 & 1.596381 & -0.108433 \\ \mathrm{H} & 4.906264 & 2.855801 & 0.595061 \\ \mathrm{C} & 4.691673 & -0.559699 & 0.998277 \\ \mathrm{C} & 4.097264 & -1.435811 & 1.929628 \\ \mathrm{C} & 5.710237 & -1.062806 & 0.162472 \\ \mathrm{C} & 4.500076 & -2.765162 & 2.014701 \\ \mathrm{H} & 3.331605 & -1.076316 & 2.607229 \\ \mathrm{C} & 6.105642 & -2.394159 & 0.248739 \\ \mathrm{H} & 6.181813 & -0.425926 & -0.576576 \\ \mathrm{C} & 5.505704 & -3.250256 & 1.176026 \\ \mathrm{H} & 4.030988 & -3.420557 & 2.742301 \\ \mathrm{H} & 6.889352 & -2.761766 & -0.407381 \\ \mathrm{H} & 5.824633 & -4.286263 & 1.249241 \\ \mathrm{H} & 3.797245 & -0.950128 & -4.050483\end{array}$

Catalyst (R)-1 TS Conformation 18

B3LYP/6-31G(d) Energy $=-2809.694854$

B3LYP-D3(BJ)/def2-TZVPP-IEF-PCM(DCM) Energy = -2810.989152

B3LYP-D3(BJ)/def2-TZVPP-IEF-PCM(DCM)//B3LYP/6-31G(d) Free Energy (Quasiharmonic) = 2810.3483

Frequencies (Top 3 out of 270) 
1. $-714.4353 \mathrm{~cm}-1$

2. $\quad 10.4173 \mathrm{~cm}-1$

3. $\quad 11.6710 \mathrm{~cm}-1$

B3LYP/6-31G(d) Molecular Geometry in Cartesian Coordinates

\begin{tabular}{|c|c|c|c|}
\hline C & -3.768516 & 0.129047 & -0.125621 \\
\hline C & -3.029217 & 1.223216 & 0.299120 \\
\hline C & -3.526803 & 2.559485 & 0.289866 \\
\hline C & -4.796094 & 2.756433 & -0.218424 \\
\hline $\mathrm{H}$ & -5.216463 & 3.758662 & -0.217337 \\
\hline C & -2.027510 & -3.815716 & 0.080366 \\
\hline C & -3.189248 & -1.242741 & -0.006625 \\
\hline C & -1.956638 & -1.512652 & -0.581214 \\
\hline C & -1.350554 & -2.803537 & -0.571721 \\
\hline $\mathrm{H}$ & -1.607985 & -4.818469 & 0.083031 \\
\hline $\mathrm{O}$ & -1.743905 & 1.011805 & 0.785667 \\
\hline$P$ & -0.545202 & 0.644850 & -0.266473 \\
\hline $\mathrm{O}$ & -1.279922 & -0.477842 & -1.213884 \\
\hline C & -1.341572 & 5.954939 & 1.775921 \\
\hline C & -1.989989 & 6.013898 & 0.541805 \\
\hline C & -2.679230 & 4.901903 & 0.059341 \\
\hline C & -2.733630 & 3.709856 & 0.799526 \\
\hline C & -2.070949 & 3.660873 & 2.037481 \\
\hline C & -1.384989 & 4.774068 & 2.520119 \\
\hline $\mathrm{H}$ & -1.952983 & 6.923267 & -0.052325 \\
\hline $\mathrm{H}$ & -0.884602 & 4.718546 & 3.483519 \\
\hline C & 2.426883 & -3.678557 & -2.442637 \\
\hline C & 1.464250 & -2.934675 & -3.129164 \\
\hline C & 0.245024 & -2.628936 & -2.525414 \\
\hline C & -0.039032 & -3.069132 & -1.221283 \\
\hline C & 0.938040 & -3.815966 & -0.542225 \\
\hline C & 2.159695 & -4.117900 & -1.144936 \\
\hline $\mathrm{H}$ & 1.659837 & -2.593341 & -4.142423 \\
\hline $\mathrm{H}$ & 2.906715 & -4.686382 & -0.597000 \\
\hline C & -3.844651 & -2.287860 & 0.731189 \\
\hline C & -3.253694 & -3.593164 & 0.753757 \\
\hline C & -3.898871 & -4.639255 & 1.467919 \\
\hline C & -5.062864 & -4.408856 & 2.163319 \\
\hline C & -5.626911 & -3.111460 & 2.176933 \\
\hline C & -5.035960 & -2.080512 & 1.480007 \\
\hline $\mathrm{H}$ & -3.444005 & -5.627124 & 1.462666 \\
\hline $\mathrm{H}$ & -5.543588 & -5.214912 & 2.710866 \\
\hline
\end{tabular}




\begin{tabular}{|c|c|c|c|}
\hline $\mathrm{H}$ & -6.533388 & -2.924686 & 2.746366 \\
\hline $\mathrm{H}$ & -5.476234 & -1.090669 & 1.508135 \\
\hline C & -5.057222 & 0.361020 & -0.718727 \\
\hline C & -5.573225 & 1.697233 & -0.747574 \\
\hline C & -6.851215 & 1.939816 & -1.320557 \\
\hline C & -7.584479 & 0.916919 & -1.875094 \\
\hline C & -7.060343 & -0.397061 & -1.884121 \\
\hline C & -5.832517 & -0.668048 & -1.321202 \\
\hline $\mathrm{H}$ & -7.232528 & 2.958251 & -1.322898 \\
\hline $\mathrm{H}$ & -8.557054 & 1.115880 & -2.316807 \\
\hline $\mathrm{H}$ & -7.629247 & -1.200336 & -2.344561 \\
\hline $\mathrm{H}$ & -5.441525 & -1.678522 & -1.346619 \\
\hline $\mathrm{O}$ & 0.605308 & 0.106852 & 0.519708 \\
\hline 0 & -0.303303 & 1.817700 & -1.221742 \\
\hline $\mathrm{H}$ & 0.817959 & 2.218261 & -1.414959 \\
\hline $\mathrm{H}$ & -2.100042 & 2.749499 & 2.624787 \\
\hline $\mathrm{H}$ & -0.802673 & 6.820216 & 2.153023 \\
\hline $\mathrm{H}$ & -3.162135 & 4.945473 & -0.912796 \\
\hline $\mathrm{H}$ & 0.741514 & -4.140835 & 0.475632 \\
\hline $\mathrm{H}$ & 3.377073 & -3.913990 & -2.914724 \\
\hline $\mathrm{H}$ & -0.495568 & -2.052161 & -3.068565 \\
\hline C & 2.756428 & 2.188358 & -0.725216 \\
\hline $\mathrm{O}$ & 1.942897 & 2.602996 & -1.617736 \\
\hline $\mathrm{H}$ & 2.373568 & 1.857045 & 0.244010 \\
\hline C & 4.129156 & 2.835979 & -0.722493 \\
\hline $\mathrm{O}$ & 4.702415 & 3.263129 & -1.695955 \\
\hline $\mathrm{O}$ & 4.607604 & 2.876812 & 0.538118 \\
\hline C & 5.897370 & 3.502171 & 0.680745 \\
\hline $\mathrm{H}$ & 6.107002 & 3.496827 & 1.750299 \\
\hline $\mathrm{H}$ & 6.656381 & 2.935322 & 0.136777 \\
\hline C & 3.969017 & -0.379401 & -0.290846 \\
\hline C & 3.328857 & 0.282206 & -1.341953 \\
\hline $\mathrm{H}$ & 2.181369 & -0.652704 & 0.673077 \\
\hline$N$ & 3.186736 & -0.902475 & 0.701028 \\
\hline C & 3.521335 & -1.943101 & 1.574653 \\
\hline $\mathrm{O}$ & 4.558869 & -2.566950 & 1.598872 \\
\hline $\mathrm{O}$ & 2.469131 & -2.154547 & 2.387396 \\
\hline C & 2.636212 & -3.222713 & 3.331818 \\
\hline $\mathrm{H}$ & 1.706467 & -3.250168 & 3.899722 \\
\hline $\mathrm{H}$ & 3.485357 & -3.023434 & 3.990691 \\
\hline $\mathrm{H}$ & 2.800576 & -4.171634 & 2.814393 \\
\hline $\mathrm{H}$ & 3.929904 & 0.614218 & -2.180097 \\
\hline $\mathrm{H}$ & 2.305007 & 0.002922 & -1.559212 \\
\hline C & 5.441533 & -0.373675 & -0.176663 \\
\hline
\end{tabular}




$\begin{array}{lrrr}\text { C } & 6.078635 & -0.122557 & 1.051858 \\ \text { C } & 6.227768 & -0.545448 & -1.328297 \\ \text { C } & 7.465029 & -0.042878 & 1.121197 \\ \text { H } & 5.482045 & 0.034937 & 1.943360 \\ \text { C } & 7.617629 & -0.481832 & -1.252547 \\ \text { H } & 5.747155 & -0.758429 & -2.277761 \\ \text { C } & 8.238826 & -0.227423 & -0.029096 \\ \text { H } & 7.945520 & 0.159054 & 2.074308 \\ \text { H } & 8.213303 & -0.631081 & -2.148286 \\ \text { H } & 9.322432 & -0.173780 & 0.030396 \\ \text { H } & 5.864392 & 4.525020 & 0.297901\end{array}$

Catalyst (R)-1 TS Conformation 19 (TS-1Re)

B3LYP/6-31G(d) Energy $=-2809.692308$

B3LYP-D3(BJ)/def2-TZVPP-IEF-PCM(DCM) Energy = -2810.990471

B3LYP-D3(BJ)/def2-TZVPP-IEF-PCM(DCM)//B3LYP/6-31G(d) Free Energy (Quasiharmonic) = 2810.348158

Frequencies (Top 3 out of 270)

1. $-653.4847 \mathrm{~cm}-1$

2. $\quad 11.7270 \mathrm{~cm}-1$

3. $20.4048 \mathrm{~cm}-1$

B3LYP/6-31G(d) Molecular Geometry in Cartesian Coordinates

$\begin{array}{llll}\text { C } & -2.857739 & -0.910381 & 0.078239 \\ \text { C } & -1.722922 & -1.636852 & -0.246760 \\ \text { C } & -1.550724 & -3.005787 & 0.103364 \\ \text { C } & -2.529457 & -3.596515 & 0.875579 \\ \text { H } & -2.425203 & -4.643513 & 1.148627 \\ \text { C } & -3.334605 & 3.179346 & -1.176453 \\ \text { C } & -3.011882 & 0.482822 & -0.429617 \\ \text { C } & -2.033760 & 1.431032 & -0.162084 \\ \text { C } & -2.183290 & 2.806300 & -0.511404 \\ \text { H } & -3.468463 & 4.222688 & -1.450318 \\ \text { O } & -0.695973 & -0.994858 & -0.941768 \\ \text { P } & 0.217781 & 0.049388 & -0.056452 \\ \text { O } & -0.913720 & 1.060607 & 0.568501 \\ \text { C } & 1.687519 & -5.511906 & -1.206183 \\ \text { C } & 0.810188 & -4.954242 & -2.139718 \\ \text { C } & -0.215360 & -4.107675 & -1.719535\end{array}$




\begin{tabular}{|c|c|c|c|}
\hline$C$ & -0.387209 & -3.815637 & -0.357903 \\
\hline C & 0.499826 & -4.377034 & 0.570789 \\
\hline C & 1.531826 & -5.216449 & 0.148759 \\
\hline $\mathrm{H}$ & 0.919961 & -5.184737 & -3.196497 \\
\hline $\mathrm{H}$ & 2.213897 & -5.639187 & 0.881757 \\
\hline C & 0.619591 & 5.974654 & 0.277319 \\
\hline C & -0.659357 & 6.004865 & 0.836305 \\
\hline C & -1.549715 & 4.955979 & 0.600213 \\
\hline C & -1.173827 & 3.854937 & -0.184933 \\
\hline C & 0.118777 & 3.825203 & -0.730484 \\
\hline C & 1.001421 & 4.883050 & -0.507235 \\
\hline $\mathrm{H}$ & -0.968703 & 6.847564 & 1.449336 \\
\hline $\mathrm{H}$ & 1.990149 & 4.859681 & -0.959814 \\
\hline C & -4.152950 & 0.865346 & -1.215979 \\
\hline C & -4.319494 & 2.241927 & -1.570433 \\
\hline C & -5.451215 & 2.637760 & -2.333623 \\
\hline C & -6.375867 & 1.712489 & -2.758042 \\
\hline C & -6.196753 & 0.345403 & -2.439973 \\
\hline C & -5.117805 & -0.067052 & -1.689583 \\
\hline $\mathrm{H}$ & -5.563743 & 3.689455 & -2.586480 \\
\hline $\mathrm{H}$ & -7.234516 & 2.024377 & -3.346278 \\
\hline $\mathrm{H}$ & -6.914752 & -0.388271 & -2.796488 \\
\hline $\mathrm{H}$ & -4.991429 & -1.119461 & -1.463820 \\
\hline C & -3.841313 & -1.517566 & 0.934117 \\
\hline C & -3.665138 & -2.882277 & 1.330927 \\
\hline C & -4.627551 & -3.494745 & 2.178284 \\
\hline C & -5.710018 & -2.787225 & 2.646444 \\
\hline C & -5.867818 & -1.428054 & 2.287230 \\
\hline C & -4.961153 & -0.810705 & 1.453964 \\
\hline $\mathrm{H}$ & -4.482724 & -4.535275 & 2.459148 \\
\hline $\mathrm{H}$ & -6.436340 & -3.263554 & 3.299273 \\
\hline $\mathrm{H}$ & -6.710285 & -0.862922 & 2.676861 \\
\hline $\mathrm{H}$ & -5.091767 & 0.234324 & 1.198999 \\
\hline $\mathrm{O}$ & 1.174469 & 0.750976 & -0.965048 \\
\hline $\mathrm{O}$ & 0.723262 & -0.675152 & 1.204573 \\
\hline $\mathrm{H}$ & 1.684676 & -1.278504 & 1.294812 \\
\hline $\mathrm{H}$ & 0.389711 & -4.136808 & 1.623825 \\
\hline $\mathrm{H}$ & 2.486012 & -6.172481 & -1.533835 \\
\hline $\mathrm{H}$ & -0.903113 & -3.683962 & -2.446430 \\
\hline $\mathrm{H}$ & 0.427520 & 2.976275 & -1.331218 \\
\hline $\mathrm{H}$ & 1.310342 & 6.796867 & 0.445729 \\
\hline $\mathrm{H}$ & -2.547324 & 4.984144 & 1.030462 \\
\hline C & 3.822883 & -1.965525 & 1.034630 \\
\hline $\mathrm{O}$ & 2.720343 & -1.954866 & 1.701412 \\
\hline
\end{tabular}




$\begin{array}{llll}\text { H } & 4.607672 & -2.634711 & 1.416386 \\ \mathrm{C} & 3.818308 & -2.017633 & -0.500341 \\ \mathrm{O} & 4.825850 & -2.180598 & -1.160223 \\ \mathrm{O} & 2.593083 & -1.864828 & -1.000045 \\ \mathrm{C} & 2.494233 & -1.816167 & -2.439201 \\ \mathrm{H} & 3.037086 & -0.946395 & -2.813093 \\ \mathrm{H} & 2.902055 & -2.732610 & -2.869161 \\ \mathrm{C} & 4.075951 & 0.664811 & 1.008263 \\ \mathrm{C} & 4.945244 & -0.407843 & 1.299389 \\ \mathrm{H} & 2.929612 & 1.250477 & -0.599047 \\ \mathrm{~N} & 3.903222 & 1.100133 & -0.282396 \\ \mathrm{C} & 4.902904 & 1.120188 & -1.262351 \\ \mathrm{O} & 6.090902 & 0.995158 & -1.071674 \\ \mathrm{O} & 4.326981 & 1.365525 & -2.455296 \\ \mathrm{C} & 5.246672 & 1.450671 & -3.558736 \\ \mathrm{H} & 5.787061 & 0.508135 & -3.673831 \\ \mathrm{H} & 5.962051 & 2.260952 & -3.397789 \\ \mathrm{H} & 4.626744 & 1.651746 & -4.432249 \\ \mathrm{H} & 5.241831 & -0.517098 & 2.337169 \\ \mathrm{H} & 5.728237 & -0.625278 & 0.583170 \\ \mathrm{C} & 3.188769 & 1.232531 & 2.017113 \\ \mathrm{C} & 2.970283 & 0.576355 & 3.249188 \\ \mathrm{C} & 2.543863 & 2.467083 & 1.784975 \\ \mathrm{C} & 2.123228 & 1.133785 & 4.200218 \\ \mathrm{H} & 3.419102 & -0.388522 & 3.441513 \\ \mathrm{C} & 1.703677 & 3.019994 & 2.741560 \\ \mathrm{H} & 2.715841 & 3.001776 & 0.858778 \\ \mathrm{C} & 1.489296 & 2.352289 & 3.951028 \\ \mathrm{H} & 1.949142 & 0.609269 & 5.134955 \\ \mathrm{H} & 1.214156 & 3.967363 & 2.539456 \\ \mathrm{H} & 0.828044 & 2.782889 & 4.698008 \\ \mathrm{H} & 1.431411 & -1.721459 & -2.645773 \\ \mathrm{H} & & & \end{array}$

Catalyst (R)-1 TS Conformation 20

B3LYP/6-31G(d) Energy $=-2809.696919$

B3LYP-D3(BJ)/def2-TZVPP-IEF-PCM(DCM) Energy $=-2810.988888$

B3LYP-D3(BJ)/def2-TZVPP-IEF-PCM(DCM)//B3LYP/6-31G(d) Free Energy (Quasiharmonic) = 2810.348132

Frequencies (Top 3 out of 270)

1. $-714.2763 \mathrm{~cm}-1$ 
2. $\quad 9.7366 \mathrm{~cm}-1$

3. $\quad 11.2298 \mathrm{~cm}-1$

B3LYP/6-31G(d) Molecular Geometry in Cartesian Coordinates

\begin{tabular}{|c|c|c|c|}
\hline C & -3.776015 & 0.147113 & -0.157307 \\
\hline C & -3.034989 & 1.218536 & 0.319558 \\
\hline C & -3.517717 & 2.560143 & 0.342411 \\
\hline C & -4.773184 & 2.787450 & -0.187360 \\
\hline $\mathrm{H}$ & -5.183094 & 3.793687 & -0.162759 \\
\hline C & -2.074661 & -3.818322 & -0.023855 \\
\hline C & -3.214322 & -1.234189 & -0.068088 \\
\hline C & -1.970752 & -1.499132 & -0.620676 \\
\hline C & -1.374004 & -2.794077 & -0.630296 \\
\hline $\mathrm{H}$ & -1.661515 & -4.823646 & -0.036500 \\
\hline $\mathrm{O}$ & -1.763802 & 0.976536 & 0.828825 \\
\hline$P$ & -0.544230 & 0.626566 & -0.204574 \\
\hline $\mathrm{O}$ & -1.270151 & -0.452224 & -1.207089 \\
\hline C & -1.327781 & 5.881829 & 1.980901 \\
\hline C & -1.394782 & 4.676907 & 2.683567 \\
\hline C & -2.082923 & 3.587587 & 2.152034 \\
\hline C & -2.723744 & 3.684805 & 0.905392 \\
\hline C & -2.645736 & 4.900827 & 0.207350 \\
\hline C & -1.954791 & 5.989043 & 0.738994 \\
\hline $\mathrm{H}$ & -0.910579 & 4.583539 & 3.652211 \\
\hline $\mathrm{H}$ & -1.899500 & 6.917744 & 0.176999 \\
\hline C & 2.447739 & -3.646078 & -2.419160 \\
\hline C & 2.146652 & -4.107008 & -1.136473 \\
\hline C & 0.910970 & -3.812173 & -0.559462 \\
\hline C & -0.046611 & -3.051269 & -1.250384 \\
\hline C & 0.271664 & -2.588213 & -2.538457 \\
\hline C & 1.505033 & -2.886765 & -3.116438 \\
\hline $\mathrm{H}$ & 2.877543 & -4.688547 & -0.580451 \\
\hline $\mathrm{H}$ & 1.727266 & -2.528122 & -4.118200 \\
\hline C & -3.896793 & -2.294216 & 0.622478 \\
\hline C & -3.316699 & -3.604621 & 0.622873 \\
\hline C & -3.988120 & -4.665072 & 1.290099 \\
\hline C & -5.167867 & -4.444696 & 1.961758 \\
\hline C & -5.721864 & -3.143433 & 1.998305 \\
\hline C & -5.105108 & -2.098077 & 1.346689 \\
\hline $\mathrm{H}$ & -3.540749 & -5.656119 & 1.268425 \\
\hline $\mathrm{H}$ & -5.668748 & -5.261871 & 2.473582 \\
\hline $\mathrm{H}$ & -6.641091 & -2.965182 & 2.549740 \\
\hline $\mathrm{H}$ & -5.538099 & -1.105705 & 1.392444 \\
\hline
\end{tabular}




\begin{tabular}{|c|c|c|c|}
\hline C & -5.047980 & 0.412755 & -0.771749 \\
\hline C & -5.549106 & 1.754897 & -0.768316 \\
\hline C & -6.810998 & 2.030267 & -1.361846 \\
\hline C & -7.541851 & 1.034269 & -1.966294 \\
\hline C & -7.031403 & -0.284531 & -2.006656 \\
\hline C & -5.819813 & -0.587436 & -1.425146 \\
\hline $\mathrm{H}$ & -7.181630 & 3.052395 & -1.339225 \\
\hline $\mathrm{H}$ & -8.501904 & 1.258386 & -2.423109 \\
\hline $\mathrm{H}$ & -7.597946 & -1.065944 & -2.505990 \\
\hline $\mathrm{H}$ & -5.438835 & -1.600866 & -1.474608 \\
\hline 0 & 0.580266 & 0.047335 & 0.588583 \\
\hline O & -0.266702 & 1.827292 & -1.117844 \\
\hline $\mathrm{H}$ & 0.842155 & 2.251582 & -1.237804 \\
\hline $\mathrm{H}$ & -3.111400 & 4.982184 & -0.770784 \\
\hline $\mathrm{H}$ & -0.786789 & 6.728117 & 2.396077 \\
\hline $\mathrm{H}$ & -2.130271 & 2.657382 & 2.707668 \\
\hline $\mathrm{H}$ & -0.453652 & -1.999507 & -3.089557 \\
\hline $\mathrm{H}$ & 3.408704 & -3.876927 & -2.871384 \\
\hline $\mathrm{H}$ & 0.688498 & -4.153099 & 0.447731 \\
\hline C & 2.758233 & 2.151446 & -0.486821 \\
\hline $\mathrm{O}$ & 1.986997 & 2.655942 & -1.371229 \\
\hline $\mathrm{H}$ & 2.334295 & 1.751290 & 0.438612 \\
\hline C & 4.137595 & 2.741563 & -0.289999 \\
\hline $\mathrm{O}$ & 4.690581 & 2.729840 & 0.791086 \\
\hline $\mathrm{O}$ & 4.651637 & 3.255905 & -1.413357 \\
\hline C & 5.965403 & 3.828909 & -1.280072 \\
\hline $\mathrm{H}$ & 5.954094 & 4.641571 & -0.549509 \\
\hline $\mathrm{H}$ & 6.681624 & 3.067316 & -0.960400 \\
\hline C & 3.964986 & -0.405450 & -0.179458 \\
\hline C & 3.320731 & 0.285275 & -1.209767 \\
\hline $\mathrm{H}$ & 2.180875 & -0.704606 & 0.779181 \\
\hline$N$ & 3.187972 & -0.941331 & 0.807828 \\
\hline C & 3.540202 & -1.964430 & 1.695152 \\
\hline $\mathrm{O}$ & 4.596301 & -2.554143 & 1.742498 \\
\hline $\mathrm{O}$ & 2.479970 & -2.203726 & 2.489769 \\
\hline C & 2.668122 & -3.251117 & 3.453410 \\
\hline $\mathrm{H}$ & 1.728345 & -3.306665 & 4.002449 \\
\hline $\mathrm{H}$ & 3.494532 & -3.008952 & 4.126635 \\
\hline $\mathrm{H}$ & 2.880292 & -4.200105 & 2.953823 \\
\hline $\mathrm{H}$ & 3.922458 & 0.632396 & -2.041333 \\
\hline $\mathrm{H}$ & 2.293854 & 0.020716 & -1.431459 \\
\hline C & 5.438980 & -0.409857 & -0.089493 \\
\hline C & 6.198708 & -0.637525 & -1.249500 \\
\hline C & 6.100350 & -0.100420 & 1.111817 \\
\hline
\end{tabular}




$\begin{array}{llrr}\mathrm{C} & 7.589949 & -0.578116 & -1.205700 \\ \mathrm{H} & 5.694648 & -0.892642 & -2.176677 \\ \mathrm{C} & 7.488398 & -0.022311 & 1.146743 \\ \mathrm{H} & 5.522743 & 0.113359 & 2.003382 \\ \mathrm{C} & 8.236798 & -0.266937 & -0.007987 \\ \mathrm{H} & 8.167162 & -0.776310 & -2.104341 \\ \mathrm{H} & 7.988264 & 0.231499 & 2.076904 \\ \mathrm{H} & 9.321665 & -0.214460 & 0.026377 \\ \mathrm{H} & 6.218234 & 4.205978 & -2.270892\end{array}$

Catalyst (R)-1 TS Conformation 21

B3LYP/6-31G(d) Energy $=-2809.698124$

B3LYP-D3(BJ)/def2-TZVPP-IEF-PCM(DCM) Energy = -2810.990676

B3LYP-D3(BJ)/def2-TZVPP-IEF-PCM(DCM)//B3LYP/6-31G(d) Free Energy (Quasiharmonic) = 2810.348085

Frequencies (Top 3 out of 270)

1. $-379.0410 \mathrm{~cm}-1$

2. $\quad 10.9783 \mathrm{~cm}-1$

3. $\quad 15.0396 \mathrm{~cm}-1$

B3LYP/6-31G(d) Molecular Geometry in Cartesian Coordinates

$\begin{array}{llll}\text { C } & 3.380632 & -0.294015 & 0.219032 \\ \text { C } & 2.827922 & 0.931540 & -0.129463 \\ \text { C } & 3.488267 & 2.175222 & 0.103355 \\ \text { C } & 4.692469 & 2.136835 & 0.779800 \\ \text { H } & 5.213495 & 3.069899 & 0.977029 \\ \text { C } & 1.422795 & -3.973413 & -0.899327 \\ \text { C } & 2.728792 & -1.565345 & -0.215248 \\ \text { C } & 1.401543 & -1.799262 & 0.101595 \\ \text { C } & 0.713668 & -3.007356 & -0.212474 \\ \text { H } & 0.940790 & -4.919223 & -1.132256 \\ \text { O } & 1.625129 & 0.957580 & -0.830253 \\ \text { P } & 0.235532 & 0.504579 & -0.106449 \\ \text { O } & 0.699720 & -0.797459 & 0.768990 \\ \text { C } & 2.127242 & 6.035959 & -1.227040 \\ \text { C } & 1.271180 & 5.214306 & -0.490390 \\ \text { C } & 1.682044 & 3.946302 & -0.077465 \\ \text { C } & 2.970652 & 3.484169 & -0.386940 \\ \text { C } & 3.823807 & 4.317764 & -1.129627\end{array}$




\begin{tabular}{|c|c|c|c|}
\hline C & 3.406448 & 5.580581 & -1.549179 \\
\hline $\mathrm{H}$ & 0.275902 & 5.560932 & -0.224319 \\
\hline $\mathrm{H}$ & 4.080655 & 6.206051 & -2.128578 \\
\hline C & -3.393662 & -3.770095 & 0.826876 \\
\hline C & -2.528314 & -3.214205 & 1.772108 \\
\hline C & -1.199629 & -2.948824 & 1.441596 \\
\hline C & -0.708439 & -3.236499 & 0.156959 \\
\hline C & -1.590686 & -3.791806 & -0.785281 \\
\hline C & -2.919140 & -4.057295 & -0.454437 \\
\hline $\mathrm{H}$ & -2.887636 & -2.982447 & 2.771088 \\
\hline $\mathrm{H}$ & -3.586708 & -4.476734 & -1.202309 \\
\hline C & 3.427508 & -2.547710 & -1.000360 \\
\hline C & 2.758858 & -3.772762 & -1.324462 \\
\hline C & 3.440234 & -4.760367 & -2.086547 \\
\hline C & 4.718192 & -4.542898 & -2.545517 \\
\hline C & 5.365322 & -3.317014 & -2.263828 \\
\hline C & 4.739327 & -2.347459 & -1.511501 \\
\hline $\mathrm{H}$ & 2.921778 & -5.689231 & -2.312247 \\
\hline $\mathrm{H}$ & 5.226368 & -5.301740 & -3.134078 \\
\hline $\mathrm{H}$ & 6.364897 & -3.135247 & -2.649251 \\
\hline $\mathrm{H}$ & 5.246667 & -1.410570 & -1.314660 \\
\hline C & 4.582080 & -0.306167 & 1.009255 \\
\hline C & 5.247011 & 0.932869 & 1.276423 \\
\hline C & 6.439002 & 0.934845 & 2.050700 \\
\hline C & 6.948519 & -0.233487 & 2.567140 \\
\hline C & 6.275579 & -1.456009 & 2.333712 \\
\hline C & 5.126328 & -1.492455 & 1.575069 \\
\hline $\mathrm{H}$ & 6.934357 & 1.884894 & 2.236632 \\
\hline $\mathrm{H}$ & 7.857147 & -0.219908 & 3.162764 \\
\hline $\mathrm{H}$ & 6.665678 & -2.375293 & 2.762201 \\
\hline $\mathrm{H}$ & 4.617854 & -2.436160 & 1.415293 \\
\hline 0 & -0.327107 & 1.508663 & 0.847613 \\
\hline $\mathrm{O}$ & -0.615396 & 0.022484 & -1.299054 \\
\hline $\mathrm{H}$ & -1.708899 & 0.200381 & -1.392833 \\
\hline $\mathrm{H}$ & 4.817179 & 3.962758 & -1.390875 \\
\hline $\mathrm{H}$ & 1.801182 & 7.022668 & -1.545996 \\
\hline $\mathrm{H}$ & 1.005543 & 3.323239 & 0.496690 \\
\hline $\mathrm{H}$ & -1.234446 & -3.991802 & -1.791752 \\
\hline $\mathrm{H}$ & -4.430483 & -3.969532 & 1.083440 \\
\hline $\mathrm{H}$ & -0.536221 & -2.519709 & 2.184430 \\
\hline C & -3.893718 & -0.302890 & -1.124674 \\
\hline $\mathrm{O}$ & -2.978865 & 0.363710 & -1.717006 \\
\hline $\mathrm{H}$ & -3.629337 & -1.034163 & -0.350298 \\
\hline C & -5.079285 & -0.741488 & -1.984431 \\
\hline
\end{tabular}




$\begin{array}{llll}\mathrm{O} & -5.361516 & -0.293055 & -3.067851 \\ \mathrm{O} & -5.768259 & -1.726331 & -1.358560 \\ \mathrm{C} & -6.904750 & -2.225422 & -2.084109 \\ \mathrm{H} & -7.622402 & -1.422471 & -2.273461 \\ \mathrm{H} & -6.590728 & -2.651259 & -3.040708 \\ \mathrm{C} & -3.998091 & 1.386243 & 0.845339 \\ \mathrm{C} & -5.023434 & 0.940481 & -0.002190 \\ \mathrm{H} & -2.089375 & 2.185076 & 0.774034 \\ \mathrm{~N} & -3.037633 & 2.224384 & 0.375486 \\ \mathrm{C} & -3.141846 & 3.016191 & -0.790238 \\ \mathrm{O} & -4.168126 & 3.316600 & -1.354630 \\ \mathrm{O} & -1.916142 & 3.447191 & -1.117269 \\ \mathrm{C} & -1.850080 & 4.215759 & -2.334069 \\ \mathrm{H} & -2.193616 & 3.608467 & -3.174565 \\ \mathrm{H} & -0.798755 & 4.476975 & -2.445077 \\ \mathrm{H} & -2.470711 & 5.111614 & -2.252931 \\ \mathrm{H} & -5.785144 & 0.302284 & 0.429214 \\ \mathrm{H} & -5.332177 & 1.581670 & -0.816988 \\ \mathrm{C} & -3.846453 & 0.830851 & 2.212579 \\ \mathrm{C} & -2.596638 & 0.662475 & 2.838192 \\ \mathrm{C} & -5.009338 & 0.487088 & 2.930985 \\ \mathrm{C} & -2.522080 & 0.148690 & 4.131829 \\ \mathrm{H} & -1.675272 & 0.899429 & 2.316295 \\ \mathrm{C} & -4.927232 & -0.017292 & 4.225418 \\ \mathrm{H} & -5.986003 & 0.650564 & 2.488510 \\ \mathrm{C} & -3.681043 & -0.193335 & 4.830368 \\ \mathrm{H} & -1.547343 & 0.016300 & 4.592718 \\ \mathrm{H} & -5.837823 & -0.262316 & 4.764745 \\ \mathrm{H} & -3.615272 & -0.586041 & 5.841425 \\ \mathrm{H} & -7.345576 & -2.993576 & -1.448029\end{array}$

Catalyst (R)-1 TS Conformation 22

B3LYP/6-31G(d) Energy $=-2809.698026$

B3LYP-D3(BJ)/def2-TZVPP-IEF-PCM(DCM) Energy = -2810.989756

B3LYP-D3(BJ)/def2-TZVPP-IEF-PCM(DCM)//B3LYP/6-31G(d) Free Energy (Quasiharmonic) = 2810.348067

Frequencies (Top 3 out of 270)

1. $-539.3501 \mathrm{~cm}-1$

2. $\quad 8.3872 \mathrm{~cm}-1$

3. $\quad 12.4146 \mathrm{~cm}-1$ 
B3LYP/6-31G(d) Molecular Geometry in Cartesian Coordinates

\begin{tabular}{|c|c|c|c|}
\hline C & 3.381980 & -1.123589 & -0.132900 \\
\hline C & 2.155750 & -1.684279 & 0.180160 \\
\hline C & 1.813411 & -3.038269 & -0.103770 \\
\hline C & 2.748011 & -3.796129 & -0.781820 \\
\hline $\mathrm{H}$ & 2.532741 & -4.840629 & -0.991190 \\
\hline C & 4.348749 & 2.924701 & 0.972010 \\
\hline C & 3.694610 & 0.263291 & 0.319660 \\
\hline C & 2.856520 & 1.320301 & -0.010400 \\
\hline C & 3.178159 & 2.680101 & 0.280290 \\
\hline $\mathrm{H}$ & 4.611929 & 3.951791 & 1.210230 \\
\hline 0 & 1.202840 & -0.881140 & 0.804960 \\
\hline$P$ & 0.451040 & 0.221430 & -0.149140 \\
\hline 0 & 1.704970 & 1.074861 & -0.751760 \\
\hline C & -1.871059 & -4.908080 & 1.102500 \\
\hline C & -1.171089 & -4.099400 & 2.001560 \\
\hline C & 0.009721 & -3.467940 & 1.611430 \\
\hline C & 0.518511 & -3.638530 & 0.312010 \\
\hline C & -0.198779 & -4.448640 & -0.584030 \\
\hline C & -1.380769 & -5.078200 & -0.193310 \\
\hline $\mathrm{H}$ & -1.541659 & -3.963780 & 3.014390 \\
\hline $\mathrm{H}$ & -1.921859 & -5.695430 & -0.905670 \\
\hline C & 0.872718 & 6.152160 & -0.780440 \\
\hline C & 2.212349 & 6.046171 & -1.157470 \\
\hline C & 2.938399 & 4.900271 & -0.834870 \\
\hline C & 2.338289 & 3.836421 & -0.140510 \\
\hline C & 0.985229 & 3.942710 & 0.215040 \\
\hline C & 0.266319 & 5.097260 & -0.095080 \\
\hline $\mathrm{H}$ & 2.694598 & 6.855461 & -1.699680 \\
\hline $\mathrm{H}$ & -0.773131 & 5.170810 & 0.211880 \\
\hline C & 4.853560 & 0.527981 & 1.130220 \\
\hline C & 5.187749 & 1.884901 & 1.437780 \\
\hline C & 6.336629 & 2.163232 & 2.226990 \\
\hline C & 7.117800 & 1.145282 & 2.721470 \\
\hline C & 6.770360 & -0.199228 & 2.450900 \\
\hline C & 5.671310 & -0.500098 & 1.676790 \\
\hline $\mathrm{H}$ & 6.577659 & 3.201462 & 2.442700 \\
\hline $\mathrm{H}$ & 7.990640 & 1.368322 & 3.328890 \\
\hline $\mathrm{H}$ & 7.372830 & -1.004078 & 2.863320 \\
\hline $\mathrm{H}$ & 5.415040 & -1.536309 & 1.490340 \\
\hline C & 4.311250 & -1.899729 & -0.909400 \\
\hline C & 3.982011 & -3.258189 & -1.222540 \\
\hline
\end{tabular}




\begin{tabular}{|c|c|c|c|}
\hline C & 4.894331 & -4.041149 & -1.980660 \\
\hline C & 6.071691 & -3.503198 & -2.445310 \\
\hline C & 6.380920 & -2.150098 & -2.172260 \\
\hline C & 5.526780 & -1.370599 & -1.423420 \\
\hline $\mathrm{H}$ & 4.634011 & -5.074259 & -2.198470 \\
\hline $\mathrm{H}$ & 6.757821 & -4.108598 & -3.031170 \\
\hline $\mathrm{H}$ & 7.299320 & -1.718988 & -2.561390 \\
\hline $\mathrm{H}$ & 5.774260 & -0.333078 & -1.232330 \\
\hline $\mathrm{O}$ & -0.495150 & 1.005890 & 0.705850 \\
\hline O & -0.129520 & -0.490360 & -1.386900 \\
\hline $\mathrm{H}$ & -1.273200 & -0.622770 & -1.392360 \\
\hline $\mathrm{H}$ & 0.166081 & -4.566950 & -1.600280 \\
\hline $\mathrm{H}$ & -2.794029 & -5.393130 & 1.407000 \\
\hline $\mathrm{H}$ & 0.548301 & -2.847290 & 2.319450 \\
\hline $\mathrm{H}$ & 0.497419 & 3.132430 & 0.745990 \\
\hline $\mathrm{H}$ & 0.307748 & 7.050620 & -1.016200 \\
\hline $\mathrm{H}$ & 3.981039 & 4.819421 & -1.130520 \\
\hline C & -3.006010 & -1.507211 & -0.478500 \\
\hline $\mathrm{O}$ & -2.533590 & -0.759610 & -1.400650 \\
\hline $\mathrm{H}$ & -2.344890 & -2.178950 & 0.080740 \\
\hline C & -4.402080 & -2.059841 & -0.721040 \\
\hline $\mathrm{O}$ & -5.123660 & -1.727991 & -1.632360 \\
\hline $\mathrm{O}$ & -4.724559 & -2.986201 & 0.208450 \\
\hline C & -6.038879 & -3.553781 & 0.070200 \\
\hline $\mathrm{H}$ & -6.800499 & -2.773551 & 0.148500 \\
\hline $\mathrm{H}$ & -6.139239 & -4.055051 & -0.895990 \\
\hline C & -4.005530 & 0.695249 & 0.712140 \\
\hline C & -3.350370 & -0.423451 & 1.244260 \\
\hline $\mathrm{H}$ & -2.203360 & 1.423220 & 0.119440 \\
\hline$N$ & -3.222580 & 1.589229 & 0.060950 \\
\hline C & -3.594781 & 2.765509 & -0.610810 \\
\hline $\mathrm{O}$ & -4.699841 & 3.252269 & -0.667280 \\
\hline $\mathrm{O}$ & -2.489391 & 3.270300 & -1.183470 \\
\hline C & -2.700941 & 4.442600 & -1.989810 \\
\hline $\mathrm{H}$ & -3.172881 & 5.232899 & -1.400970 \\
\hline $\mathrm{H}$ & -3.338111 & 4.199449 & -2.844120 \\
\hline $\mathrm{H}$ & -1.707501 & 4.743480 & -2.318490 \\
\hline $\mathrm{H}$ & -3.930370 & -1.107851 & 1.851730 \\
\hline $\mathrm{H}$ & -2.296940 & -0.321820 & 1.488490 \\
\hline C & -5.486750 & 0.768469 & 0.750170 \\
\hline C & -6.121760 & 0.609329 & 1.993140 \\
\hline C & -6.268930 & 0.893669 & -0.409280 \\
\hline C & -7.512850 & 0.607188 & 2.081510 \\
\hline $\mathrm{H}$ & -5.520210 & 0.513199 & 2.892360 \\
\hline
\end{tabular}




$\begin{array}{llll}\mathrm{C} & -7.657550 & 0.865018 & -0.318170 \\ \mathrm{H} & -5.792080 & 0.977159 & -1.377200 \\ \mathrm{C} & -8.282910 & 0.732048 & 0.924230 \\ \mathrm{H} & -7.991630 & 0.505788 & 3.051370 \\ \mathrm{H} & -8.253100 & 0.948218 & -1.222530 \\ \mathrm{H} & -9.367710 & 0.723128 & 0.988750 \\ \mathrm{H} & -6.135839 & -4.269951 & 0.886620\end{array}$

Catalyst (R)-1 TS Conformation 23

B3LYP/6-31G(d) Energy = -2809.699564

B3LYP-D3(BJ)/def2-TZVPP-IEF-PCM(DCM) Energy = -2810.989477

B3LYP-D3(BJ)/def2-TZVPP-IEF-PCM(DCM)//B3LYP/6-31G(d) Free Energy (Quasiharmonic) = 2810.348044

Frequencies (Top 3 out of 270)

1. $-503.9408 \mathrm{~cm}-1$

2. $\quad 9.0381 \mathrm{~cm}-1$

3. $12.0868 \mathrm{~cm}-1$

B3LYP/6-31G(d) Molecular Geometry in Cartesian Coordinates

$\begin{array}{llll}\text { C } & 3.672929 & 0.260042 & 0.336475 \\ \text { C } & 2.761008 & 1.296623 & 0.185403 \\ \text { C } & 3.060474 & 2.651097 & 0.522208 \\ \text { C } & 4.280760 & 2.902638 & 1.117891 \\ \text { H } & 4.532671 & 3.924016 & 1.390763 \\ \text { C } & 2.776604 & -3.694523 & -1.152018 \\ \text { C } & 3.383963 & -1.093174 & -0.227489 \\ \text { C } & 2.215453 & -1.748173 & 0.120630 \\ \text { C } & 1.882485 & -3.065559 & -0.308326 \\ \text { H } & 2.571862 & -4.710075 & -1.480655 \\ \text { O } & 1.535346 & 1.049092 & -0.423155 \\ \text { P } & 0.408064 & 0.085918 & 0.254719 \\ \text { O } & 1.314051 & -1.082868 & 0.946826 \\ \text { C } & 0.534337 & 6.009035 & -0.416910 \\ \text { C } & 1.868668 & 5.982394 & -0.825594 \\ \text { C } & 2.669473 & 4.881158 & -0.523405 \\ \text { C } & 2.153162 & 3.785998 & 0.189417 \\ \text { C } & 0.809817 & 3.822448 & 0.594983 \\ \text { C } & 0.011589 & 4.926433 & 0.294491 \\ \text { H } & 2.287463 & 6.816457 & -1.382883\end{array}$




\begin{tabular}{|c|c|c|c|}
\hline $\mathrm{H}$ & -1.023208 & 4.941029 & 0.627117 \\
\hline C & -1.732262 & -5.087874 & 0.866392 \\
\hline C & -1.320614 & -5.086172 & -0.467099 \\
\hline C & -0.154037 & -4.418058 & -0.840111 \\
\hline C & 0.625192 & -3.740200 & 0.111420 \\
\hline C & 0.200643 & -3.750033 & 1.451552 \\
\hline C & -0.965593 & -4.418004 & 1.823600 \\
\hline $\mathrm{H}$ & -1.911151 & -5.598918 & -1.221998 \\
\hline $\mathrm{H}$ & -1.273718 & -4.420908 & 2.865840 \\
\hline C & 4.265809 & -1.731149 & -1.168974 \\
\hline C & 3.954069 & -3.057005 & -1.615660 \\
\hline C & 4.822565 & -3.706308 & -2.534629 \\
\hline C & 5.937776 & -3.069213 & -3.026298 \\
\hline C & 6.224984 & -1.745154 & -2.620149 \\
\hline C & 5.413692 & -1.094880 & -1.716232 \\
\hline $\mathrm{H}$ & 4.577624 & -4.716989 & -2.852555 \\
\hline $\mathrm{H}$ & 6.590225 & -3.573157 & -3.734015 \\
\hline $\mathrm{H}$ & 7.091889 & -1.232965 & -3.028699 \\
\hline$H$ & 5.644090 & -0.077290 & -1.424172 \\
\hline C & 4.894225 & 0.524014 & 1.049731 \\
\hline C & 5.196594 & 1.869803 & 1.433389 \\
\hline C & 6.402113 & 2.143439 & 2.134613 \\
\hline C & 7.270023 & 1.131014 & 2.471179 \\
\hline C & 6.958766 & -0.204354 & 2.122976 \\
\hline C & 5.805256 & -0.499893 & 1.430191 \\
\hline $\mathrm{H}$ & 6.618185 & 3.172692 & 2.411184 \\
\hline $\mathrm{H}$ & 8.185636 & 1.350684 & 3.013324 \\
\hline $\mathrm{H}$ & 7.632892 & -1.006618 & 2.410627 \\
\hline $\mathrm{H}$ & 5.576810 & -1.529912 & 1.182052 \\
\hline $\mathrm{O}$ & -0.519434 & -0.396871 & -0.811795 \\
\hline $\mathrm{O}$ & -0.224627 & 0.792523 & 1.476819 \\
\hline $\mathrm{H}$ & -1.360808 & 0.693395 & 1.549676 \\
\hline $\mathrm{H}$ & 0.394050 & 2.994668 & 1.158054 \\
\hline $\mathrm{H}$ & -0.091249 & 6.867963 & -0.646497 \\
\hline $\mathrm{H}$ & 3.703304 & 4.856954 & -0.857486 \\
\hline $\mathrm{H}$ & 0.790790 & -3.238137 & 2.203964 \\
\hline $\mathrm{H}$ & -2.642184 & -5.604391 & 1.159670 \\
\hline $\mathrm{H}$ & 0.146954 & -4.397928 & -1.883726 \\
\hline C & -3.086032 & -0.598979 & 1.731806 \\
\hline $\mathrm{O}$ & -2.634531 & 0.591517 & 1.641548 \\
\hline $\mathrm{H}$ & -2.405102 & -1.434864 & 1.934923 \\
\hline C & -4.448670 & -0.833430 & 2.362433 \\
\hline $\mathrm{O}$ & -4.832670 & -1.932080 & 2.708763 \\
\hline $\mathrm{O}$ & -5.146358 & 0.301414 & 2.506756 \\
\hline
\end{tabular}




$\begin{array}{lrrr}\mathrm{C} & -6.446317 & 0.146318 & 3.102786 \\ \mathrm{H} & -6.851982 & 1.154902 & 3.180129 \\ \mathrm{H} & -7.083239 & -0.476233 & 2.469336 \\ \mathrm{C} & -4.008433 & -0.323753 & -0.814576 \\ \mathrm{C} & -3.503087 & -1.437145 & -0.133008 \\ \mathrm{H} & -2.102614 & 0.347166 & -1.048866 \\ \mathrm{~N} & -3.095932 & 0.591559 & -1.223722 \\ \mathrm{C} & -3.278231 & 1.728714 & -2.027797 \\ \mathrm{O} & -4.294787 & 2.073320 & -2.585173 \\ \mathrm{O} & -2.098079 & 2.368336 & -2.081732 \\ \mathrm{C} & -2.066526 & 3.548747 & -2.900729 \\ \mathrm{H} & -2.882772 & 4.222632 & -2.630240 \\ \mathrm{H} & -2.156065 & 3.278530 & -3.956605 \\ \mathrm{H} & -1.100033 & 4.009015 & -2.698963 \\ \mathrm{H} & -4.190338 & -2.228417 & 0.140942 \\ \mathrm{H} & -2.476257 & -1.728567 & -0.331175 \\ \mathrm{C} & -5.468415 & -0.093367 & -0.899016 \\ \mathrm{C} & -6.051725 & 1.121749 & -0.502781 \\ \mathrm{C} & -6.298231 & -1.150632 & -1.304872 \\ \mathrm{C} & -7.434805 & 1.271322 & -0.520261 \\ \mathrm{H} & -5.422740 & 1.933041 & -0.156727 \\ \mathrm{C} & -7.682609 & -0.989917 & -1.340292 \\ \mathrm{H} & -5.852719 & -2.090461 & -1.616700 \\ \mathrm{C} & -8.253196 & 0.220797 & -0.946173 \\ \mathrm{H} & -7.876405 & 2.212673 & -0.205608 \\ \mathrm{H} & -8.312174 & -1.809755 & -1.673966 \\ \mathrm{H} & -9.332265 & 0.347127 & -0.969194 \\ \mathrm{H} & -6.359988 & -0.313124 & 4.090543\end{array}$

Catalyst (R)-1 TS Conformation 24

B3LYP/6-31G(d) Energy $=-2809.699433$

B3LYP-D3(BJ)/def2-TZVPP-IEF-PCM(DCM) Energy = -2810.989662

B3LYP-D3(BJ)/def2-TZVPP-IEF-PCM(DCM)//B3LYP/6-31G(d) Free Energy (Quasiharmonic) = 2810.347713

Frequencies (Top 3 out of 270)

1. $-442.8940 \mathrm{~cm}-1$

2. $\quad 9.3868 \mathrm{~cm}-1$

3. $\quad 11.8444 \mathrm{~cm}-1$

B3LYP/6-31G(d) Molecular Geometry in Cartesian Coordinates 


\begin{tabular}{|c|c|c|c|}
\hline C & 3.319681 & -0.790997 & -0.165362 \\
\hline C & 2.237731 & -1.640558 & -0.006537 \\
\hline C & 2.190185 & -2.964161 & -0.531294 \\
\hline C & 3.268091 & -3.381394 & -1.286721 \\
\hline $\mathrm{H}$ & 3.275410 & -4.393096 & -1.683769 \\
\hline C & 3.371428 & 3.180767 & 1.500803 \\
\hline C & 3.315679 & 0.545846 & 0.498330 \\
\hline C & 2.273240 & 1.434316 & 0.271581 \\
\hline C & 2.294274 & 2.784776 & 0.732536 \\
\hline $\mathrm{H}$ & 3.409229 & 4.203668 & 1.866245 \\
\hline $\mathrm{O}$ & 1.135677 & -1.180148 & 0.712328 \\
\hline$P$ & 0.151889 & -0.110860 & -0.032484 \\
\hline $\mathrm{O}$ & 1.209240 & 1.040480 & -0.531532 \\
\hline C & -1.011267 & -5.748804 & 0.168644 \\
\hline C & -0.458529 & -5.037291 & 1.235690 \\
\hline C & 0.556660 & -4.108212 & 1.014168 \\
\hline C & 1.048154 & -3.883405 & -0.282046 \\
\hline C & 0.482137 & -4.601245 & -1.347142 \\
\hline C & -0.539715 & -5.523847 & -1.125072 \\
\hline $\mathrm{H}$ & -0.812661 & -5.214490 & 2.248218 \\
\hline $\mathrm{H}$ & -0.970275 & -6.062547 & -1.965048 \\
\hline C & -0.666966 & 5.764399 & -0.207427 \\
\hline C & 0.676631 & 5.971846 & -0.522890 \\
\hline C & 1.622806 & 4.989193 & -0.229222 \\
\hline C & 1.243494 & 3.780770 & 0.377710 \\
\hline C & -0.110949 & 3.578833 & 0.687137 \\
\hline C & -1.053364 & 4.566773 & 0.399637 \\
\hline $\mathrm{H}$ & 0.990503 & 6.897794 & -0.997841 \\
\hline $\mathrm{H}$ & -2.096363 & 4.402977 & 0.659574 \\
\hline C & 4.376008 & 0.941983 & 1.385352 \\
\hline C & 4.402502 & 2.286238 & 1.876973 \\
\hline C & 5.450207 & 2.693040 & 2.746923 \\
\hline C & 6.424751 & 1.806900 & 3.142475 \\
\hline C & 6.383319 & 0.468478 & 2.685583 \\
\hline C & 5.389078 & 0.047766 & 1.829963 \\
\hline $\mathrm{H}$ & 5.457743 & 3.720141 & 3.104121 \\
\hline $\mathrm{H}$ & 7.217734 & 2.126592 & 3.812934 \\
\hline $\mathrm{H}$ & 7.140118 & -0.237037 & 3.017762 \\
\hline $\mathrm{H}$ & 5.366484 & -0.983743 & 1.498027 \\
\hline C & 4.402114 & -1.213620 & -1.013927 \\
\hline C & 4.368070 & -2.534336 & -1.568118 \\
\hline C & 5.433300 & -2.969990 & -2.402110 \\
\hline C & 6.479136 & -2.131858 & -2.710575 \\
\hline
\end{tabular}




\begin{tabular}{|c|c|c|c|}
\hline C & 6.495638 & -0.813579 & -2.198127 \\
\hline C & 5.487383 & -0.367160 & -1.372163 \\
\hline $\mathrm{H}$ & 5.396635 & -3.979978 & -2.803493 \\
\hline $\mathrm{H}$ & 7.284309 & -2.473388 & -3.355243 \\
\hline $\mathrm{H}$ & 7.309343 & -0.143596 & -2.462432 \\
\hline $\mathrm{H}$ & 5.511732 & 0.649312 & -0.997742 \\
\hline 0 & -0.855702 & 0.392942 & 0.952994 \\
\hline $\mathrm{O}$ & -0.355317 & -0.744905 & -1.341782 \\
\hline $\mathrm{H}$ & -1.437415 & -0.573528 & -1.574293 \\
\hline $\mathrm{H}$ & 0.834577 & -4.415877 & -2.357760 \\
\hline $\mathrm{H}$ & -1.804230 & -6.471099 & 0.344253 \\
\hline $\mathrm{H}$ & 0.982653 & -3.561869 & 1.849416 \\
\hline $\mathrm{H}$ & -0.421174 & 2.653055 & 1.159961 \\
\hline $\mathrm{H}$ & -1.406112 & 6.529694 & -0.429381 \\
\hline $\mathrm{H}$ & 2.667345 & 5.150516 & -0.482423 \\
\hline C & -3.392884 & 0.551875 & -1.968224 \\
\hline $\mathrm{O}$ & -2.743304 & -0.535363 & -1.757528 \\
\hline $\mathrm{H}$ & -4.429883 & 0.449460 & -2.314170 \\
\hline C & -2.736989 & 1.747099 & -2.670129 \\
\hline $\mathrm{O}$ & -3.370427 & 2.579265 & -3.284918 \\
\hline $\mathrm{O}$ & -1.411352 & 1.749522 & -2.503854 \\
\hline C & -0.687519 & 2.836036 & -3.112588 \\
\hline $\mathrm{H}$ & -1.029988 & 3.790677 & -2.707089 \\
\hline $\mathrm{H}$ & 0.354632 & 2.660715 & -2.852137 \\
\hline C & -4.381075 & 0.500504 & 0.461487 \\
\hline C & -3.789500 & 1.511439 & -0.322046 \\
\hline $\mathrm{H}$ & -2.527023 & -0.145636 & 1.031851 \\
\hline$N$ & -3.547086 & -0.335170 & 1.115693 \\
\hline C & -3.885766 & -1.303995 & 2.080728 \\
\hline $\mathrm{O}$ & -4.992252 & -1.550129 & 2.500937 \\
\hline $\mathrm{O}$ & -2.748153 & -1.890293 & 2.480984 \\
\hline C & -2.903281 & -2.879715 & 3.510759 \\
\hline $\mathrm{H}$ & -1.893871 & -3.230084 & 3.722087 \\
\hline $\mathrm{H}$ & -3.532298 & -3.701106 & 3.158434 \\
\hline $\mathrm{H}$ & -3.353976 & -2.435780 & 4.401988 \\
\hline $\mathrm{H}$ & -4.452985 & 2.283694 & -0.698213 \\
\hline $\mathrm{H}$ & -2.792278 & 1.835761 & -0.035704 \\
\hline C & -5.834867 & 0.255288 & 0.351375 \\
\hline C & -6.328254 & -1.005688 & -0.024328 \\
\hline C & -6.729707 & 1.325754 & 0.506042 \\
\hline C & -7.691164 & -1.186342 & -0.236360 \\
\hline $\mathrm{H}$ & -5.639344 & -1.829847 & -0.173627 \\
\hline C & -8.097214 & 1.132254 & 0.320402 \\
\hline $\mathrm{H}$ & -6.353477 & 2.301876 & 0.797685 \\
\hline
\end{tabular}




$\begin{array}{lrrr}\mathrm{C} & -8.579157 & -0.122349 & -0.055311 \\ \mathrm{H} & -8.062384 & -2.160554 & -0.540954 \\ \mathrm{H} & -8.783207 & 1.962206 & 0.462743 \\ \mathrm{H} & -9.644050 & -0.271189 & -0.211335 \\ \mathrm{H} & -0.832663 & 2.822662 & -4.195749\end{array}$

Catalyst (R)-1 TS Conformation 25

B3LYP/6-31G(d) Energy = -2809.694609

B3LYP-D3(BJ)/def2-TZVPP-IEF-PCM(DCM) Energy = -2810.989279

B3LYP-D3(BJ)/def2-TZVPP-IEF-PCM(DCM)//B3LYP/6-31G(d) Free Energy (Quasiharmonic) = 2810.347703

Frequencies (Top 3 out of 270)

1. $-593.0641 \mathrm{~cm}-1$

2. $\quad 10.8033 \mathrm{~cm}-1$

3. $\quad 18.5284 \mathrm{~cm}-1$

B3LYP/6-31G(d) Molecular Geometry in Cartesian Coordinates

$\begin{array}{lrrr}\text { C } & 3.167808 & -0.059342 & 0.334684 \\ \text { C } & 2.545131 & 1.074652 & -0.162265 \\ \text { C } & 2.963903 & 2.401630 & 0.150668 \\ \text { C } & 3.996884 & 2.539158 & 1.057501 \\ \text { H } & 4.360851 & 3.534479 & 1.297966 \\ \text { C } & 1.908912 & -4.028487 & -0.775751 \\ \text { C } & 2.745934 & -1.414694 & -0.131977 \\ \text { C } & 1.423124 & -1.811769 & -0.002772 \\ \text { C } & 0.974289 & -3.139365 & -0.278580 \\ \text { H } & 1.614863 & -5.057573 & -0.963071 \\ \text { O } & 1.478627 & 0.919264 & -1.040648 \\ \text { P } & 0.047776 & 0.382638 & -0.466822 \\ \text { O } & 0.501103 & -0.892091 & 0.473506 \\ \text { C } & 1.417243 & 5.982438 & -1.664522 \\ \text { C } & 1.610256 & 5.914915 & -0.283774 \\ \mathrm{C} & 2.077774 & 4.738570 & 0.301079 \\ \mathrm{C} & 2.362926 & 3.607076 & -0.480423 \\ \mathrm{C} & 2.146623 & 3.681857 & -1.866884 \\ \mathrm{C} & 1.682496 & 4.859111 & -2.451255 \\ \mathrm{H} & 1.397034 & 6.778292 & 0.341362 \\ \mathrm{H} & 1.538858 & 4.901399 & -3.528022 \\ \mathrm{C} & -3.008972 & -4.592903 & 0.490119\end{array}$




\begin{tabular}{|c|c|c|c|}
\hline C & -2.315234 & -4.987432 & -0.654921 \\
\hline C & -1.040984 & -4.482551 & -0.913464 \\
\hline C & -0.420155 & -3.589923 & -0.023585 \\
\hline C & -1.128790 & -3.205906 & 1.129494 \\
\hline C & -2.410082 & -3.696783 & 1.378757 \\
\hline $\mathrm{H}$ & -2.766898 & -5.687404 & -1.353634 \\
\hline $\mathrm{H}$ & -2.941765 & -3.375236 & 2.270057 \\
\hline C & 3.681738 & -2.325705 & -0.732034 \\
\hline C & 3.246732 & -3.653266 & -1.046480 \\
\hline C & 4.164865 & -4.570342 & -1.626612 \\
\hline C & 5.454325 & -4.191270 & -1.918310 \\
\hline C & 5.876615 & -2.869394 & -1.642535 \\
\hline C & 5.016377 & -1.962789 & -1.062909 \\
\hline $\mathrm{H}$ & 3.821074 & -5.578190 & -1.847448 \\
\hline $\mathrm{H}$ & 6.145360 & -4.898273 & -2.369063 \\
\hline $\mathrm{H}$ & 6.888727 & -2.564353 & -1.894331 \\
\hline $\mathrm{H}$ & 5.353090 & -0.951524 & -0.866265 \\
\hline C & 4.190968 & 0.102470 & 1.332915 \\
\hline C & 4.607541 & 1.426668 & 1.685650 \\
\hline C & 5.623635 & 1.602790 & 2.663729 \\
\hline C & 6.190250 & 0.522148 & 3.298242 \\
\hline C & 5.754404 & -0.785392 & 2.979966 \\
\hline C & 4.784318 & -0.990259 & 2.023366 \\
\hline $\mathrm{H}$ & 5.935594 & 2.615093 & 2.909753 \\
\hline $\mathrm{H}$ & 6.960939 & 0.669156 & 4.049904 \\
\hline $\mathrm{H}$ & 6.185342 & -1.637522 & 3.498654 \\
\hline $\mathrm{H}$ & 4.455641 & -1.998443 & 1.800321 \\
\hline $\mathrm{O}$ & -0.806407 & 0.004294 & -1.627726 \\
\hline $\mathrm{O}$ & -0.455709 & 1.405589 & 0.567024 \\
\hline $\mathrm{H}$ & -1.386103 & 1.274988 & 1.224444 \\
\hline $\mathrm{H}$ & 2.357133 & 2.818788 & -2.488936 \\
\hline $\mathrm{H}$ & 1.065539 & 6.902768 & -2.124348 \\
\hline $\mathrm{H}$ & 2.210932 & 4.687082 & 1.377950 \\
\hline $\mathrm{H}$ & -0.668133 & -2.527741 & 1.838500 \\
\hline $\mathrm{H}$ & -4.005437 & -4.978155 & 0.688880 \\
\hline $\mathrm{H}$ & -0.523427 & -4.772413 & -1.823395 \\
\hline C & -3.252407 & 0.317445 & 1.833311 \\
\hline $\mathrm{O}$ & -2.399769 & 1.259390 & 1.999976 \\
\hline $\mathrm{H}$ & -2.947566 & -0.613339 & 1.337361 \\
\hline C & -4.228906 & 0.124488 & 2.989408 \\
\hline $\mathrm{O}$ & -4.619084 & 1.004187 & 3.719357 \\
\hline $\mathrm{O}$ & -4.600763 & -1.171051 & 3.078612 \\
\hline C & -5.540441 & -1.467030 & 4.128562 \\
\hline $\mathrm{H}$ & -5.747021 & -2.533853 & 4.044290 \\
\hline
\end{tabular}




$\begin{array}{llll}\mathrm{H} & -5.106561 & -1.232932 & 5.103992 \\ \mathrm{C} & -3.938259 & 1.031672 & -0.619532 \\ \mathrm{C} & -4.716795 & 0.750990 & 0.513689 \\ \mathrm{H} & -2.599430 & 0.088670 & -1.864803 \\ \mathrm{~N} & -3.564442 & 0.046666 & -1.496491 \\ \mathrm{C} & -4.270133 & -1.126233 & -1.777511 \\ \mathrm{O} & -5.327879 & -1.471830 & -1.294325 \\ \mathrm{O} & -3.598119 & -1.796171 & -2.728641 \\ \mathrm{C} & -4.215720 & -3.017915 & -3.162949 \\ \mathrm{H} & -3.540316 & -3.426797 & -3.914292 \\ \mathrm{H} & -5.198330 & -2.814953 & -3.597060 \\ \mathrm{H} & -4.321152 & -3.708476 & -2.324154 \\ \mathrm{H} & -5.207904 & 1.585917 & 1.000149 \\ \mathrm{H} & -5.263701 & -0.183640 & 0.519530 \\ \mathrm{C} & -3.356304 & 2.355452 & -0.845822 \\ \mathrm{C} & -2.812873 & 2.697168 & -2.103954 \\ \mathrm{C} & -3.335621 & 3.320042 & 0.185100 \\ \mathrm{C} & -2.259300 & 3.951629 & -2.316899 \\ \mathrm{H} & -2.842223 & 1.983126 & -2.919013 \\ \mathrm{C} & -2.770703 & 4.572352 & -0.036268 \\ \mathrm{H} & -3.719373 & 3.082309 & 1.168126 \\ \mathrm{C} & -2.230386 & 4.891242 & -1.281636 \\ \mathrm{H} & -1.844080 & 4.198622 & -3.289191 \\ \mathrm{H} & -2.744588 & 5.296476 & 0.772409 \\ \mathrm{H} & -1.781054 & 5.865659 & -1.447182 \\ \mathrm{H} & -6.455501 & -0.884195 & 3.995544\end{array}$

Catalyst (R)-1 TS Conformation 26

B3LYP/6-31G(d) Energy $=-2809.694771$

B3LYP-D3(BJ)/def2-TZVPP-IEF-PCM(DCM) Energy = -2810.988924

B3LYP-D3(BJ)/def2-TZVPP-IEF-PCM(DCM)//B3LYP/6-31G(d) Free Energy (Quasiharmonic) = 2810.347589

Frequencies (Top 3 out of 270)

1. $-706.4941 \mathrm{~cm}-1$

2. $\quad 10.2244 \mathrm{~cm}-1$

3. $\quad 16.8782 \mathrm{~cm}-1$

B3LYP/6-31G(d) Molecular Geometry in Cartesian Coordinates

$\begin{array}{llll}\text { C } & 2.811898 & -1.271072 & -0.218916\end{array}$ 


\begin{tabular}{|c|c|c|c|}
\hline C & 1.523144 & -1.759311 & -0.057340 \\
\hline C & 1.172179 & -3.118070 & -0.322906 \\
\hline C & 2.141213 & -3.925523 & -0.886650 \\
\hline $\mathrm{H}$ & 1.899819 & -4.961589 & -1.109485 \\
\hline C & 3.891389 & 2.669705 & 1.165614 \\
\hline C & 3.175146 & 0.076733 & 0.313261 \\
\hline C & 2.473232 & 1.201410 & -0.088799 \\
\hline C & 2.835531 & 2.528879 & 0.286216 \\
\hline $\mathrm{H}$ & 4.212770 & 3.667826 & 1.451016 \\
\hline $\mathrm{O}$ & 0.558211 & -0.926775 & 0.488171 \\
\hline$P$ & 0.009349 & 0.369202 & -0.367325 \\
\hline $\mathrm{O}$ & 1.385290 & 1.038601 & -0.937837 \\
\hline C & -2.559415 & -4.913463 & 0.859788 \\
\hline C & -2.568356 & -3.732313 & 0.113455 \\
\hline C & -1.370392 & -3.131792 & -0.280213 \\
\hline C & -0.138148 & -3.704325 & 0.075866 \\
\hline C & -0.144056 & -4.893320 & 0.824455 \\
\hline C & -1.341665 & -5.494984 & 1.210967 \\
\hline $\mathrm{H}$ & -3.517692 & -3.278236 & -0.159477 \\
\hline $\mathrm{H}$ & -1.319925 & -6.411070 & 1.795646 \\
\hline C & 1.095735 & 6.130100 & -1.297382 \\
\hline C & 1.390276 & 5.062843 & -2.149223 \\
\hline C & 1.913156 & 3.875950 & -1.638635 \\
\hline C & 2.161977 & 3.736145 & -0.262709 \\
\hline C & 1.845767 & 4.810269 & 0.584867 \\
\hline C & 1.318138 & 5.995714 & 0.074013 \\
\hline $\mathrm{H}$ & 1.224771 & 5.157877 & -3.219536 \\
\hline $\mathrm{H}$ & 1.082520 & 6.814345 & 0.749293 \\
\hline C & 4.224563 & 0.235518 & 1.285192 \\
\hline C & 4.581685 & 1.557431 & 1.705369 \\
\hline C & 5.621404 & 1.731948 & 2.658499 \\
\hline C & 6.268517 & 0.649054 & 3.206169 \\
\hline C & 5.892799 & -0.659382 & 2.822145 \\
\hline C & 4.901248 & -0.861105 & 1.887084 \\
\hline $\mathrm{H}$ & 5.886611 & 2.743791 & 2.955944 \\
\hline $\mathrm{H}$ & 7.056805 & 0.794005 & 3.939778 \\
\hline $\mathrm{H}$ & 6.387526 & -1.515469 & 3.272973 \\
\hline $\mathrm{H}$ & 4.619737 & -1.871098 & 1.614062 \\
\hline C & 3.780693 & -2.095465 & -0.888581 \\
\hline C & 3.428795 & -3.442149 & -1.224273 \\
\hline C & 4.376259 & -4.267002 & -1.888828 \\
\hline C & 5.617633 & -3.783748 & -2.231528 \\
\hline C & 5.958939 & -2.445282 & -1.925337 \\
\hline C & 5.067291 & -1.624640 & -1.269971 \\
\hline
\end{tabular}




\begin{tabular}{|c|c|c|c|}
\hline $\mathrm{H}$ & 4.094365 & -5.289250 & -2.130293 \\
\hline $\mathrm{H}$ & 6.332149 & -4.421536 & -2.744678 \\
\hline $\mathrm{H}$ & 6.932185 & -2.058433 & -2.215222 \\
\hline $\mathrm{H}$ & 5.339849 & -0.598333 & -1.052059 \\
\hline 0 & -0.824828 & -0.015947 & -1.546060 \\
\hline 0 & -0.567732 & 1.289525 & 0.714992 \\
\hline $\mathrm{H}$ & -1.573468 & 1.119769 & 1.317265 \\
\hline $\mathrm{H}$ & 0.802381 & -5.335250 & 1.123793 \\
\hline $\mathrm{H}$ & -3.495477 & -5.373241 & 1.165788 \\
\hline $\mathrm{H}$ & -1.382346 & -2.228341 & -0.880458 \\
\hline $\mathrm{H}$ & 2.004777 & 4.706714 & 1.654481 \\
\hline $\mathrm{H}$ & 0.699234 & 7.059115 & -1.699791 \\
\hline $\mathrm{H}$ & 2.146752 & 3.057200 & -2.310528 \\
\hline C & -3.388482 & 0.082674 & 1.738260 \\
\hline $\mathrm{O}$ & -2.593789 & 1.052156 & 1.996322 \\
\hline $\mathrm{H}$ & -3.020345 & -0.795977 & 1.196073 \\
\hline C & -4.421980 & -0.214162 & 2.816867 \\
\hline 0 & -4.846003 & 0.595906 & 3.606581 \\
\hline 0 & -4.794458 & -1.507219 & 2.755534 \\
\hline C & -5.774223 & -1.912152 & 3.728781 \\
\hline $\mathrm{H}$ & -5.386537 & -1.767378 & 4.740269 \\
\hline $\mathrm{H}$ & -6.691965 & -1.329961 & 3.610508 \\
\hline C & -4.027203 & 0.938827 & -0.711946 \\
\hline C & -4.844506 & 0.544230 & 0.353137 \\
\hline $\mathrm{H}$ & -2.583515 & 0.156428 & -1.946648 \\
\hline$N$ & -3.564463 & 0.042187 & -1.643234 \\
\hline C & -4.155479 & -1.168692 & -2.004772 \\
\hline 0 & -5.189684 & -1.635248 & -1.570703 \\
\hline 0 & -3.390307 & -1.735017 & -2.953798 \\
\hline C & -3.845725 & -3.009406 & -3.440886 \\
\hline $\mathrm{H}$ & -3.174915 & -3.254081 & -4.264045 \\
\hline $\mathrm{H}$ & -4.878983 & -2.939291 & -3.788229 \\
\hline $\mathrm{H}$ & -3.771429 & -3.763395 & -2.653618 \\
\hline $\mathrm{H}$ & -5.388198 & 1.318891 & 0.880978 \\
\hline $\mathrm{H}$ & -5.337489 & -0.416400 & 0.280470 \\
\hline C & -3.499254 & 2.301193 & -0.818118 \\
\hline C & -2.921215 & 2.756712 & -2.023453 \\
\hline C & -3.566720 & 3.188864 & 0.277529 \\
\hline C & -2.419885 & 4.046964 & -2.123138 \\
\hline $\mathrm{H}$ & -2.885556 & 2.103847 & -2.888321 \\
\hline C & -3.054683 & 4.478263 & 0.169782 \\
\hline $\mathrm{H}$ & -3.980192 & 2.865168 & 1.223349 \\
\hline C & -2.479318 & 4.910148 & -1.024804 \\
\hline $\mathrm{H}$ & -1.977141 & 4.381629 & -3.056165 \\
\hline
\end{tabular}




$\begin{array}{llrr}\mathrm{H} & -3.097111 & 5.142546 & 1.027604 \\ \mathrm{H} & -2.070812 & 5.913038 & -1.101567 \\ \mathrm{H} & -5.959160 & -2.968366 & 3.534257\end{array}$

Catalyst (R)-1 TS Conformation 27

B3LYP/6-31G(d) Energy $=-2809.697531$

B3LYP-D3(BJ)/def2-TZVPP-IEF-PCM(DCM) Energy = -2810.989301

B3LYP-D3(BJ)/def2-TZVPP-IEF-PCM(DCM)//B3LYP/6-31G(d) Free Energy (Quasiharmonic) = 2810.347586

Frequencies (Top 3 out of 270)

1. $-547.5710 \mathrm{~cm}-1$

2. $\quad 11.4446 \mathrm{~cm}-1$

3. $\quad 13.3818 \mathrm{~cm}-1$

B3LYP/6-31G(d) Molecular Geometry in Cartesian Coordinates

$\begin{array}{lrrr}\text { C } & 3.681679 & 0.410494 & 0.339347 \\ \text { C } & 2.825341 & 1.358044 & -0.205273 \\ \text { C } & 3.049009 & 2.763878 & -0.097015 \\ \text { C } & 4.116344 & 3.173953 & 0.679174 \\ \text { H } & 4.306079 & 4.238293 & 0.789076 \\ \text { C } & 3.089611 & -3.789491 & -0.469987 \\ \text { C } & 3.505617 & -1.036848 & 0.016006 \\ \text { C } & 2.288848 & -1.651982 & 0.255140 \\ \text { C } & 2.050306 & -3.041107 & 0.045545 \\ \text { H } & 2.950845 & -4.856893 & -0.621142 \\ \text { O } & 1.754612 & 0.930328 & -0.985416 \\ \text { P } & 0.498502 & 0.141606 & -0.310842 \\ \text { O } & 1.239090 & -0.875641 & 0.736833 \\ \text { C } & 0.819480 & 5.788564 & -2.194085 \\ \text { C } & 2.212706 & 5.748124 & -2.266137 \\ \text { C } & 2.917117 & 4.751968 & -1.591381 \\ \text { C } & 2.243494 & 3.778119 & -0.833853 \\ \text { C } & 0.842206 & 3.828671 & -0.770301 \\ \text { C } & 0.138986 & 4.827177 & -1.444679 \\ \text { H } & 2.753382 & 6.486372 & -2.853226 \\ \text { H } & -0.944065 & 4.842608 & -1.374122 \\ \text { C } & -1.698090 & -4.961786 & 0.941939 \\ \text { C } & -1.070550 & -5.168630 & -0.287765 \\ \text { C } & 0.137614 & -4.532522 & -0.575517\end{array}$




\begin{tabular}{|c|c|c|c|}
\hline C & 0.742153 & -3.675607 & 0.358518 \\
\hline C & 0.101858 & -3.475323 & 1.593608 \\
\hline C & -1.103153 & -4.115774 & 1.881959 \\
\hline $\mathrm{H}$ & -1.527248 & -5.817749 & -1.030190 \\
\hline $\mathrm{H}$ & -1.577837 & -3.955884 & 2.846809 \\
\hline C & 4.554978 & -1.813670 & -0.588788 \\
\hline C & 4.335758 & -3.211462 & -0.816778 \\
\hline C & 5.367203 & -3.994006 & -1.403159 \\
\hline C & 6.559089 & -3.423328 & -1.784025 \\
\hline C & 6.763220 & -2.036069 & -1.598086 \\
\hline C & 5.790330 & -1.253449 & -1.015905 \\
\hline $\mathrm{H}$ & 5.187745 & -5.055463 & -1.557187 \\
\hline $\mathrm{H}$ & 7.337597 & -4.030118 & -2.238236 \\
\hline $\mathrm{H}$ & 7.695051 & -1.580970 & -1.922693 \\
\hline $\mathrm{H}$ & 5.960131 & -0.190699 & -0.891172 \\
\hline C & 4.729375 & 0.856347 & 1.217403 \\
\hline C & 4.944945 & 2.262453 & 1.376972 \\
\hline C & 5.977623 & 2.717320 & 2.241228 \\
\hline C & 6.756484 & 1.827017 & 2.942962 \\
\hline C & 6.525675 & 0.437332 & 2.811627 \\
\hline C & 5.541532 & -0.035280 & 1.971381 \\
\hline $\mathrm{H}$ & 6.131782 & 3.788858 & 2.344511 \\
\hline $\mathrm{H}$ & 7.539271 & 2.186341 & 3.605401 \\
\hline $\mathrm{H}$ & 7.126353 & -0.264551 & 3.383898 \\
\hline $\mathrm{H}$ & 5.370262 & -1.102595 & 1.891085 \\
\hline $\mathrm{O}$ & -0.441585 & 0.984072 & 0.493056 \\
\hline $\mathrm{O}$ & -0.084460 & -0.659359 & -1.493265 \\
\hline $\mathrm{H}$ & -1.229147 & -0.688664 & -1.543190 \\
\hline $\mathrm{H}$ & 0.296030 & 3.098302 & -0.184258 \\
\hline $\mathrm{H}$ & 0.267825 & 6.562696 & -2.721799 \\
\hline $\mathrm{H}$ & 4.000646 & 4.711401 & -1.666102 \\
\hline $\mathrm{H}$ & 0.555823 & -2.821279 & 2.330741 \\
\hline $\mathrm{H}$ & -2.647041 & -5.442537 & 1.160147 \\
\hline $\mathrm{H}$ & 0.609188 & -4.678039 & -1.543283 \\
\hline C & -2.921888 & -1.623978 & -0.691899 \\
\hline $\mathrm{O}$ & -2.502346 & -0.769237 & -1.546985 \\
\hline $\mathrm{H}$ & -2.220639 & -2.347790 & -0.258250 \\
\hline C & -4.294547 & -2.257736 & -0.886280 \\
\hline $\mathrm{O}$ & -4.697404 & -3.183581 & -0.211003 \\
\hline $\mathrm{O}$ & -4.974821 & -1.700823 & -1.897440 \\
\hline C & -6.261385 & -2.286794 & -2.162778 \\
\hline $\mathrm{H}$ & -6.927676 & -2.145366 & -1.308127 \\
\hline $\mathrm{H}$ & -6.643083 & -1.762694 & -3.039072 \\
\hline C & -3.896915 & 0.376657 & 0.877505 \\
\hline
\end{tabular}




$\begin{array}{lrrr}\mathrm{C} & -3.190794 & -0.805911 & 1.138723 \\ \mathrm{H} & -2.163799 & 1.281961 & 0.277117 \\ \mathrm{~N} & -3.183098 & 1.435078 & 0.415807 \\ \mathrm{C} & -3.521442 & 2.796034 & 0.314517 \\ \mathrm{O} & -2.821835 & 3.584053 & -0.279918 \\ \mathrm{O} & -4.640193 & 3.109913 & 0.983870 \\ \mathrm{C} & -5.017882 & 4.497089 & 0.911718 \\ \mathrm{H} & -5.943150 & 4.570203 & 1.482792 \\ \mathrm{H} & -5.178646 & 4.796534 & -0.126766 \\ \mathrm{H} & -4.239525 & 5.124879 & 1.351549 \\ \mathrm{H} & -3.726156 & -1.621546 & 1.610463 \\ \mathrm{H} & -2.137944 & -0.707735 & 1.385265 \\ \mathrm{C} & -5.376562 & 0.384289 & 0.896178 \\ \mathrm{C} & -6.109077 & 0.875458 & -0.198665 \\ \mathrm{C} & -6.062561 & -0.177140 & 1.983537 \\ \mathrm{C} & -7.499197 & 0.812568 & -0.195076 \\ \mathrm{H} & -5.582964 & 1.268897 & -1.062440 \\ \mathrm{C} & -7.456012 & -0.221657 & 1.991198 \\ \mathrm{H} & -5.501967 & -0.555005 & 2.833019 \\ \mathrm{C} & -8.176460 & 0.272049 & 0.902795 \\ \mathrm{H} & -8.056700 & 1.183800 & -1.050518 \\ \mathrm{H} & -7.976679 & -0.644148 & 2.845604 \\ \mathrm{H} & -9.262313 & 0.232229 & 0.905827 \\ \mathrm{H} & -6.158133 & -3.355415 & -2.366722\end{array}$

Catalyst (R)-1 TS Conformation 28

B3LYP/6-31G(d) Energy $=-2809.697013$

B3LYP-D3(BJ)/def2-TZVPP-IEF-PCM(DCM) Energy $=-2810.988924$

B3LYP-D3(BJ)/def2-TZVPP-IEF-PCM(DCM)//B3LYP/6-31G(d) Free Energy (Quasiharmonic) = 2810.347564

Frequencies (Top 3 out of 270)

1. $-739.1164 \mathrm{~cm}-1$

2. $\quad 10.1170 \mathrm{~cm}-1$

3. $\quad 15.5087 \mathrm{~cm}-1$

B3LYP/6-31G(d) Molecular Geometry in Cartesian Coordinates

$\begin{array}{lrrr}\text { C } & 3.284380 & -0.372207 & 0.118173 \\ \text { C } & 2.722057 & 0.881417 & -0.083345 \\ \text { C } & 3.440233 & 2.092987 & 0.154683\end{array}$




\begin{tabular}{|c|c|c|c|}
\hline C & 4.720123 & 1.987646 & 0.664364 \\
\hline $\mathrm{H}$ & 5.282900 & 2.896417 & 0.860480 \\
\hline C & 1.160574 & -4.010238 & -0.786458 \\
\hline C & 2.547208 & -1.607330 & -0.278442 \\
\hline C & 1.281776 & -1.845147 & 0.231672 \\
\hline C & 0.573436 & -3.067094 & 0.034623 \\
\hline $\mathrm{H}$ & 0.660044 & -4.962886 & -0.938509 \\
\hline $\mathrm{O}$ & 1.453888 & 0.974277 & -0.641255 \\
\hline$P$ & 0.119720 & 0.464358 & 0.166558 \\
\hline $\mathrm{O}$ & 0.673371 & -0.844506 & 0.986740 \\
\hline C & 2.048764 & 6.098407 & -0.576660 \\
\hline C & 1.272683 & 5.220980 & 0.184349 \\
\hline C & 1.686391 & 3.905140 & 0.396849 \\
\hline C & 2.899832 & 3.449801 & -0.141323 \\
\hline C & 3.669984 & 4.337825 & -0.911680 \\
\hline C & 3.248733 & 5.649004 & -1.131182 \\
\hline $\mathrm{H}$ & 0.335018 & 5.559471 & 0.617289 \\
\hline $\mathrm{H}$ & 3.858728 & 6.318065 & -1.732817 \\
\hline C & -3.139246 & -4.070650 & 1.956413 \\
\hline C & -2.107516 & -3.483888 & 2.692551 \\
\hline C & -0.914567 & -3.122545 & 2.069714 \\
\hline C & -0.725594 & -3.356991 & 0.697400 \\
\hline C & -1.772710 & -3.942526 & -0.031885 \\
\hline C & -2.970870 & -4.291183 & 0.589311 \\
\hline $\mathrm{H}$ & -2.229179 & -3.306528 & 3.757968 \\
\hline $\mathrm{H}$ & -3.777311 & -4.721405 & 0.002250 \\
\hline C & 3.110089 & -2.565744 & -1.190847 \\
\hline C & 2.397308 & -3.783102 & -1.438417 \\
\hline C & 2.943512 & -4.741956 & -2.334192 \\
\hline C & 4.129355 & -4.503802 & -2.989080 \\
\hline C & 4.817145 & -3.286261 & -2.774982 \\
\hline C & 4.323553 & -2.344839 & -1.898556 \\
\hline $\mathrm{H}$ & 2.395309 & -5.666299 & -2.500797 \\
\hline $\mathrm{H}$ & 4.533411 & -5.240978 & -3.677566 \\
\hline $\mathrm{H}$ & 5.741933 & -3.089140 & -3.310544 \\
\hline $\mathrm{H}$ & 4.857511 & -1.412987 & -1.753316 \\
\hline C & 4.576818 & -0.460606 & 0.743840 \\
\hline C & 5.305537 & 0.743961 & 0.999326 \\
\hline C & 6.588700 & 0.673158 & 1.606474 \\
\hline C & 7.130265 & -0.535942 & 1.974973 \\
\hline C & 6.398313 & -1.726913 & 1.756840 \\
\hline C & 5.158393 & -1.691521 & 1.157640 \\
\hline $\mathrm{H}$ & 7.129068 & 1.599857 & 1.785162 \\
\hline $\mathrm{H}$ & 8.109506 & -0.579104 & 2.443875 \\
\hline
\end{tabular}




\begin{tabular}{|c|c|c|c|}
\hline $\mathrm{H}$ & 6.815323 & -2.679911 & 2.071212 \\
\hline $\mathrm{H}$ & 4.608336 & -2.613283 & 1.009771 \\
\hline 0 & -0.392042 & 1.457881 & 1.162782 \\
\hline 0 & -0.808301 & 0.020213 & -0.977509 \\
\hline $\mathrm{H}$ & -1.902785 & -0.461900 & -0.788996 \\
\hline $\mathrm{H}$ & 4.602193 & 3.989360 & -1.348244 \\
\hline $\mathrm{H}$ & 1.722039 & 7.123088 & -0.735656 \\
\hline $\mathrm{H}$ & 1.071594 & 3.234835 & 0.987827 \\
\hline $\mathrm{H}$ & -1.652099 & -4.100210 & -1.099973 \\
\hline $\mathrm{H}$ & -4.070802 & -4.348576 & 2.442983 \\
\hline $\mathrm{H}$ & -0.119297 & -2.666856 & 2.649998 \\
\hline C & -3.854570 & -0.286378 & -1.438471 \\
\hline $\mathrm{O}$ & -3.013097 & -0.916356 & -0.714190 \\
\hline $\mathrm{H}$ & -3.500162 & 0.381427 & -2.227736 \\
\hline C & -5.173435 & -0.987195 & -1.695157 \\
\hline $\mathrm{O}$ & -5.643709 & -1.857307 & -0.997484 \\
\hline $\mathrm{O}$ & -5.744349 & -0.501773 & -2.814023 \\
\hline C & -7.013639 & -1.083216 & -3.162075 \\
\hline $\mathrm{H}$ & -7.740245 & -0.919033 & -2.361835 \\
\hline $\mathrm{H}$ & -7.325098 & -0.577644 & -4.075849 \\
\hline C & -3.815005 & 1.720459 & 0.384037 \\
\hline C & -4.844873 & 1.352274 & -0.484640 \\
\hline $\mathrm{H}$ & -1.862807 & 2.325637 & 0.557520 \\
\hline$N$ & -2.733845 & 2.462959 & 0.009307 \\
\hline C & -2.549505 & 3.081453 & -1.234827 \\
\hline $\mathrm{O}$ & -3.345388 & 3.106049 & -2.151971 \\
\hline $\mathrm{O}$ & -1.337912 & 3.648588 & -1.248604 \\
\hline C & -0.944083 & 4.232478 & -2.505639 \\
\hline $\mathrm{H}$ & 0.044103 & 4.650407 & -2.323689 \\
\hline $\mathrm{H}$ & -1.653105 & 5.009954 & -2.800018 \\
\hline $\mathrm{H}$ & -0.905473 & 3.461243 & -3.278543 \\
\hline $\mathrm{H}$ & -5.727502 & 0.928060 & -0.020295 \\
\hline $\mathrm{H}$ & -4.993345 & 1.912922 & -1.395802 \\
\hline C & -3.776990 & 1.211688 & 1.766305 \\
\hline C & -4.344954 & -0.037054 & 2.083743 \\
\hline C & -3.191426 & 1.978847 & 2.791936 \\
\hline C & -4.331332 & -0.494363 & 3.398708 \\
\hline $\mathrm{H}$ & -4.753030 & -0.669886 & 1.303733 \\
\hline C & -3.198613 & 1.521871 & 4.104861 \\
\hline $\mathrm{H}$ & -2.756881 & 2.946317 & 2.563613 \\
\hline C & -3.768129 & 0.283710 & 4.411677 \\
\hline $\mathrm{H}$ & -4.754759 & -1.467449 & 3.627627 \\
\hline $\mathrm{H}$ & -2.756511 & 2.130300 & 4.888248 \\
\hline $\mathrm{H}$ & -3.767614 & -0.074845 & 5.437498 \\
\hline
\end{tabular}


$\begin{array}{llll}\mathrm{H} & -6.906212 & -2.157521 & -3.331908\end{array}$

Catalyst (R)-1 TS Conformation 29

B3LYP/6-31G(d) Energy $=-2809.69873$

B3LYP-D3(BJ)/def2-TZVPP-IEF-PCM(DCM) Energy $=-2810.989205$

B3LYP-D3(BJ)/def2-TZVPP-IEF-PCM(DCM)//B3LYP/6-31G(d) Free Energy (Quasiharmonic) = 2810.347536

Frequencies (Top 3 out of 270)

1. $-450.6007 \mathrm{~cm}-1$

2. $\quad 7.3456 \mathrm{~cm}-1$

3. $\quad 9.5815 \mathrm{~cm}-1$

B3LYP/6-31G(d) Molecular Geometry in Cartesian Coordinates

$\begin{array}{llll}\text { C } & -3.737661 & 0.335349 & -0.226917 \\ \text { C } & -2.834491 & 1.349368 & 0.055266 \\ \text { C } & -3.073042 & 2.722180 & -0.246794 \\ \text { C } & -4.250042 & 3.028498 & -0.901729 \\ \text { H } & -4.475540 & 4.067954 & -1.124862 \\ \text { C } & -2.796699 & -3.744471 & 0.821790 \\ \text { C } & -3.435320 & -1.066310 & 0.192137 \\ \text { C } & -2.246810 & -1.654566 & -0.209870 \\ \text { C } & -1.902492 & -3.009722 & 0.067633 \\ \text { H } & -2.580647 & -4.788725 & 1.031814 \\ \text { O } & -1.640848 & 1.026571 & 0.694918 \\ \text { P } & -0.472106 & 0.231314 & -0.120657 \\ \text { O } & -1.343981 & -0.887372 & -0.938790 \\ \text { C } & -0.405470 & 5.930830 & 0.801479 \\ \text { C } & -0.718065 & 4.948145 & 1.743008 \\ \text { C } & -1.561051 & 3.890578 & 1.406499 \\ \text { C } & -2.115118 & 3.799781 & 0.118716 \\ \text { C } & -1.790572 & 4.792259 & -0.820004 \\ \text { C } & -0.943551 & 5.847411 & -0.483108 \\ \text { H } & -0.306515 & 5.006768 & 2.747545 \\ \text { H } & -0.698303 & 6.599543 & -1.228358 \\ \text { C } & 1.709782 & -4.888408 & -1.330708 \\ \text { C } & 0.950906 & -4.101425 & -2.200846 \\ \text { C } & -0.210629 & -3.473733 & -1.752226 \\ \text { C } & -0.639152 & -3.623741 & -0.421681 \\ \text { C } & 0.134831 & -4.414817 & 0.442871\end{array}$




\begin{tabular}{|c|c|c|c|}
\hline C & 1.297159 & -5.041746 & -0.006337 \\
\hline $\mathrm{H}$ & 1.260305 & -3.981161 & -3.235806 \\
\hline $\mathrm{H}$ & 1.882829 & -5.645263 & 0.682351 \\
\hline C & -4.319563 & -1.821304 & 1.037169 \\
\hline C & -3.990517 & -3.183135 & 1.338342 \\
\hline C & -4.861723 & -3.944801 & 2.163782 \\
\hline C & -5.996931 & -3.384798 & 2.701641 \\
\hline C & -6.303825 & -2.029189 & 2.437831 \\
\hline C & -5.489524 & -1.268949 & 1.627419 \\
\hline $\mathrm{H}$ & -4.603807 & -4.980486 & 2.372189 \\
\hline $\mathrm{H}$ & -6.651534 & -3.975079 & 3.336941 \\
\hline $\mathrm{H}$ & -7.188397 & -1.581296 & 2.882500 \\
\hline $\mathrm{H}$ & -5.733925 & -0.229396 & 1.442448 \\
\hline C & -4.922502 & 0.662552 & -0.973197 \\
\hline C & -5.177489 & 2.034373 & -1.297856 \\
\hline C & -6.350624 & 2.373714 & -2.025203 \\
\hline C & -7.226952 & 1.402093 & -2.448661 \\
\hline C & -6.957572 & 0.042673 & -2.164684 \\
\hline C & -5.838385 & -0.317352 & -1.446593 \\
\hline $\mathrm{H}$ & -6.534254 & 3.421320 & -2.251850 \\
\hline $\mathrm{H}$ & -8.116833 & 1.672807 & -3.010243 \\
\hline $\mathrm{H}$ & -7.637396 & -0.726568 & -2.520972 \\
\hline $\mathrm{H}$ & -5.642609 & -1.364421 & -1.247507 \\
\hline $\mathrm{O}$ & 0.496601 & -0.343900 & 0.858407 \\
\hline $\mathrm{O}$ & 0.080099 & 1.125795 & -1.252123 \\
\hline $\mathrm{H}$ & 1.206421 & 1.170180 & -1.311457 \\
\hline $\mathrm{H}$ & -2.189402 & 4.720085 & -1.827934 \\
\hline $\mathrm{H}$ & 0.255602 & 6.752000 & 1.065817 \\
\hline $\mathrm{H}$ & -1.799271 & 3.133931 & 2.146256 \\
\hline $\mathrm{H}$ & -0.168347 & -4.518817 & 1.480859 \\
\hline $\mathrm{H}$ & 2.614123 & -5.377012 & -1.683743 \\
\hline $\mathrm{H}$ & -0.795829 & -2.870935 & -2.438165 \\
\hline C & 2.961571 & 0.067993 & -1.885775 \\
\hline $\mathrm{O}$ & 2.503741 & 1.160766 & -1.409888 \\
\hline $\mathrm{H}$ & 2.280579 & -0.647615 & -2.366497 \\
\hline C & 4.318656 & 0.061376 & -2.575928 \\
\hline $\mathrm{O}$ & 4.715872 & -0.875864 & -3.238088 \\
\hline $\mathrm{O}$ & 4.992349 & 1.204409 & -2.388997 \\
\hline C & 6.274490 & 1.268898 & -3.038030 \\
\hline $\mathrm{H}$ & 6.948064 & 0.513585 & -2.625570 \\
\hline $\mathrm{H}$ & 6.165356 & 1.107416 & -4.113289 \\
\hline C & 3.988371 & -0.548727 & 0.556292 \\
\hline C & 3.352645 & -1.314873 & -0.430043 \\
\hline $\mathrm{H}$ & 2.167150 & 0.149155 & 1.151678 \\
\hline
\end{tabular}




$\begin{array}{lrrr}\mathrm{N} & 3.187075 & 0.227167 & 1.329312 \\ \mathrm{C} & 3.520079 & 0.922010 & 2.502830 \\ \mathrm{O} & 4.596843 & 0.950722 & 3.053680 \\ \mathrm{O} & 2.409343 & 1.544186 & 2.933710 \\ \mathrm{C} & 2.558396 & 2.273496 & 4.161324 \\ \mathrm{H} & 1.578338 & 2.708653 & 4.355141 \\ \mathrm{H} & 3.314336 & 3.055503 & 4.052799 \\ \mathrm{H} & 2.849294 & 1.601816 & 4.973177 \\ \mathrm{H} & 3.952466 & -2.021526 & -0.991100 \\ \mathrm{H} & 2.316376 & -1.588882 & -0.257573 \\ \mathrm{C} & 5.465030 & -0.470146 & 0.608123 \\ \mathrm{C} & 6.212016 & -1.657015 & 0.537104 \\ \mathrm{C} & 6.139663 & 0.762318 & 0.638129 \\ \mathrm{C} & 7.605323 & -1.616356 & 0.523418 \\ \mathrm{H} & 5.697091 & -2.612654 & 0.519299 \\ \mathrm{C} & 7.529779 & 0.799408 & 0.603162 \\ \mathrm{H} & 5.572696 & 1.685267 & 0.661322 \\ \mathrm{C} & 8.266454 & -0.388140 & 0.554235 \\ \mathrm{H} & 8.171282 & -2.542674 & 0.486653 \\ \mathrm{H} & 8.041459 & 1.757552 & 0.619790 \\ \mathrm{H} & 9.352486 & -0.353960 & 0.539162 \\ \mathrm{H} & 6.651998 & 2.271074 & -2.834835\end{array}$

Catalyst (R)-1 TS Conformation 30

B3LYP/6-31G(d) Energy $=-2809.69474$

B3LYP-D3(BJ)/def2-TZVPP-IEF-PCM(DCM) Energy = -2810.988388

B3LYP-D3(BJ)/def2-TZVPP-IEF-PCM(DCM)//B3LYP/6-31G(d) Free Energy (Quasiharmonic) = 2810.347479

Frequencies (Top 3 out of 270)

1. $-718.3778 \mathrm{~cm}-1$

2. $\quad 9.9014 \mathrm{~cm}-1$

3. $\quad 11.6339 \mathrm{~cm}-1$

B3LYP/6-31G(d) Molecular Geometry in Cartesian Coordinates

$\begin{array}{llll}\text { C } & -3.734068 & 0.040439 & -0.225920 \\ \text { C } & -3.061524 & 1.202501 & 0.130055 \\ \text { C } & -3.693863 & 2.481840 & 0.171571 \\ \text { C } & -5.004882 & 2.556745 & -0.256755 \\ \text { H } & -5.508167 & 3.519856 & -0.241247\end{array}$




\begin{tabular}{|c|c|c|c|}
\hline C & -1.804052 & -3.804471 & 0.133084 \\
\hline C & -3.082029 & -1.291870 & -0.051680 \\
\hline C & -1.851743 & -1.537383 & -0.637741 \\
\hline C & -1.185826 & -2.796641 & -0.580830 \\
\hline $\mathrm{H}$ & -1.340827 & -4.786910 & 0.173504 \\
\hline $\mathrm{O}$ & -1.746755 & 1.119489 & 0.573523 \\
\hline$P$ & -0.531872 & 0.670954 & -0.423727 \\
\hline 0 & -1.235670 & -0.499200 & -1.328528 \\
\hline C & -1.897792 & 6.072493 & 1.723375 \\
\hline C & -3.114536 & 5.608937 & 2.224937 \\
\hline C & -3.674889 & 4.434608 & 1.722640 \\
\hline C & -3.029124 & 3.700937 & 0.713739 \\
\hline C & -1.804699 & 4.174902 & 0.217594 \\
\hline C & -1.248910 & 5.351811 & 0.718844 \\
\hline $\mathrm{H}$ & -3.627631 & 6.157650 & 3.010635 \\
\hline $\mathrm{H}$ & -0.304771 & 5.709628 & 0.315876 \\
\hline C & 2.590002 & -3.602845 & -2.484500 \\
\hline C & 2.363607 & -3.993671 & -1.163665 \\
\hline C & 1.141480 & -3.713346 & -0.551866 \\
\hline C & 0.123479 & -3.036406 & -1.244156 \\
\hline C & 0.367099 & -2.643145 & -2.571289 \\
\hline C & 1.586906 & -2.927823 & -3.184207 \\
\hline $\mathrm{H}$ & 3.141517 & -4.507096 & -0.604483 \\
\hline $\mathrm{H}$ & 1.751389 & -2.623970 & -4.214732 \\
\hline C & -3.673230 & -2.326888 & 0.754308 \\
\hline C & -3.023830 & -3.602387 & 0.824351 \\
\hline C & -3.604029 & -4.640218 & 1.603348 \\
\hline C & -4.759902 & -4.427594 & 2.317536 \\
\hline C & -5.379975 & -3.156602 & 2.285315 \\
\hline C & -4.853417 & -2.135892 & 1.524474 \\
\hline $\mathrm{H}$ & -3.105258 & -5.606213 & 1.632713 \\
\hline $\mathrm{H}$ & -5.190763 & -5.226421 & 2.914901 \\
\hline $\mathrm{H}$ & -6.278951 & -2.981434 & 2.870076 \\
\hline $\mathrm{H}$ & -5.336916 & -1.166372 & 1.519146 \\
\hline C & -5.063112 & 0.153724 & -0.763774 \\
\hline C & -5.702430 & 1.434478 & -0.765336 \\
\hline C & -7.017489 & 1.559412 & -1.289633 \\
\hline C & -7.674786 & 0.472667 & -1.817430 \\
\hline C & -7.033625 & -0.788101 & -1.847690 \\
\hline C & -5.765017 & -0.944322 & -1.333826 \\
\hline $\mathrm{H}$ & -7.489560 & 2.538965 & -1.275874 \\
\hline $\mathrm{H}$ & -8.677400 & 0.580978 & -2.221926 \\
\hline $\mathrm{H}$ & -7.543993 & -1.640992 & -2.287015 \\
\hline $\mathrm{H}$ & -5.284062 & -1.914743 & -1.376396 \\
\hline
\end{tabular}




\begin{tabular}{|c|c|c|c|}
\hline 0 & 0.604521 & 0.188852 & 0.416010 \\
\hline $\mathrm{O}$ & -0.253925 & 1.786118 & -1.445551 \\
\hline $\mathrm{H}$ & 0.875582 & 2.150191 & -1.621958 \\
\hline $\mathrm{H}$ & -1.298641 & 3.630241 & -0.571493 \\
\hline $\mathrm{H}$ & -1.458812 & 6.987851 & 2.111885 \\
\hline $\mathrm{H}$ & -4.615740 & 4.068819 & 2.125343 \\
\hline $\mathrm{H}$ & -0.405047 & -2.120445 & -3.125188 \\
\hline $\mathrm{H}$ & 3.540030 & -3.822189 & -2.964644 \\
\hline $\mathrm{H}$ & 0.976220 & -3.998731 & 0.483221 \\
\hline C & 2.794844 & 2.192923 & -0.854237 \\
\hline 0 & 2.013401 & 2.531264 & -1.803547 \\
\hline $\mathrm{H}$ & 2.380048 & 1.916353 & 0.118877 \\
\hline C & 4.162775 & 2.850234 & -0.846194 \\
\hline $\mathrm{O}$ & 4.764382 & 3.222236 & -1.825225 \\
\hline O & 4.597742 & 2.972049 & 0.424320 \\
\hline C & 5.879713 & 3.612670 & 0.571850 \\
\hline $\mathrm{H}$ & 6.053028 & 3.673197 & 1.646098 \\
\hline $\mathrm{H}$ & 6.658508 & 3.018103 & 0.088931 \\
\hline C & 4.010334 & -0.337613 & -0.196813 \\
\hline C & 3.417714 & 0.241071 & -1.319810 \\
\hline $\mathrm{H}$ & 2.181543 & -0.564841 & 0.700272 \\
\hline $\mathrm{N}$ & 3.184413 & -0.803734 & 0.790245 \\
\hline C & 3.481997 & -1.790829 & 1.735733 \\
\hline $\mathrm{O}$ & 4.523783 & -2.397494 & 1.850085 \\
\hline 0 & 2.388661 & -1.974190 & 2.499778 \\
\hline C & 2.518410 & -2.980861 & 3.515404 \\
\hline $\mathrm{H}$ & 3.321440 & -2.722866 & 4.210715 \\
\hline $\mathrm{H}$ & 2.732950 & -3.954586 & 3.067129 \\
\hline $\mathrm{H}$ & 1.556377 & -2.995897 & 4.027122 \\
\hline $\mathrm{H}$ & 4.054739 & 0.529589 & -2.147265 \\
\hline $\mathrm{H}$ & 2.405534 & -0.056945 & -1.564821 \\
\hline C & 5.474919 & -0.306180 & -0.009739 \\
\hline C & 6.320683 & -0.539002 & -1.107235 \\
\hline C & 6.045968 & 0.028249 & 1.231398 \\
\hline C & 7.704162 & -0.452466 & -0.965690 \\
\hline $\mathrm{H}$ & 5.891345 & -0.817455 & -2.064309 \\
\hline C & 7.426157 & 0.129631 & 1.365567 \\
\hline $\mathrm{H}$ & 5.402995 & 0.232272 & 2.080205 \\
\hline C & 8.259531 & -0.115219 & 0.269405 \\
\hline $\mathrm{H}$ & 8.346332 & -0.649295 & -1.819120 \\
\hline $\mathrm{H}$ & 7.855278 & 0.395691 & 2.327403 \\
\hline $\mathrm{H}$ & 9.338117 & -0.044313 & 0.380056 \\
\hline $\mathrm{H}$ & 5.855609 & 4.610169 & 0.126565 \\
\hline
\end{tabular}


Catalyst (R)-1 TS Conformation 31

B3LYP/6-31G(d) Energy $=-2809.694331$

B3LYP-D3(BJ)/def2-TZVPP-IEF-PCM(DCM) Energy = -2810.988469

B3LYP-D3(BJ)/def2-TZVPP-IEF-PCM(DCM)//B3LYP/6-31G(d) Free Energy (Quasiharmonic) = 2810.347469

Frequencies (Top 3 out of 270)

1. $-696.5249 \mathrm{~cm}-1$

2. $\quad 10.0400 \mathrm{~cm}-1$

3. $\quad 12.4737 \mathrm{~cm}-1$

B3LYP/6-31G(d) Molecular Geometry in Cartesian Coordinates

$\begin{array}{llll}\text { C } & 3.725782 & -0.084656 & 0.209869 \\ \text { C } & 3.194894 & 1.064878 & -0.355612 \\ \text { C } & 3.859671 & 2.326164 & -0.348585 \\ \text { C } & 5.074205 & 2.394123 & 0.305758 \\ \text { H } & 5.620855 & 3.333412 & 0.309276 \\ \text { C } & 1.558023 & -3.811737 & 0.043323 \\ \text { C } & 2.992445 & -1.380969 & 0.088451 \\ \text { C } & 1.677354 & -1.465896 & 0.520878 \\ \text { C } & 0.931243 & -2.682428 & 0.534951 \\ \text { H } & 1.034320 & -4.763700 & 0.069765 \\ \text { O } & 1.959445 & 0.987386 & -0.990820 \\ \text { P } & 0.608848 & 0.835396 & -0.087923 \\ \text { O } & 1.063182 & -0.316006 & 0.995485 \\ \text { C } & 2.337279 & 5.867491 & -2.259057 \\ \text { C } & 2.313454 & 4.646062 & -2.935466 \\ \text { C } & 2.783078 & 3.488375 & -2.317631 \\ \text { C } & 3.292311 & 3.532030 & -1.008999 \\ \text { C } & 3.307586 & 4.765647 & -0.338473 \\ \text { C } & 2.834535 & 5.922521 & -0.956525 \\ \text { H } & 1.929081 & 4.593051 & -3.950814 \\ \text { H } & 2.846459 & 6.864957 & -0.415268 \\ \text { C } & -3.088981 & -3.035071 & 2.042532 \\ \text { C } & -2.714234 & -3.673568 & 0.859321 \\ \text { C } & -1.416038 & -3.532612 & 0.368284 \\ \text { C } & -0.461710 & -2.760976 & 1.051596 \\ \text { C } & -0.853655 & -2.122712 & 2.242235 \\ \text { C } & -2.153287 & -2.257049 & 2.728857 \\ \text { H } & -3.432733 & -4.281722 & 0.315079\end{array}$




\begin{tabular}{|c|c|c|c|}
\hline $\mathrm{H}$ & -2.433968 & -1.755631 & 3.650986 \\
\hline C & 3.597929 & -2.545761 & -0.496616 \\
\hline C & 2.865734 & -3.777212 & -0.499008 \\
\hline C & 3.459274 & -4.941183 & -1.059097 \\
\hline C & 4.710800 & -4.894014 & -1.627368 \\
\hline C & 5.419852 & -3.670179 & -1.662685 \\
\hline C & 4.880334 & -2.528858 & -1.111269 \\
\hline $\mathrm{H}$ & 2.895281 & -5.870905 & -1.039809 \\
\hline $\mathrm{H}$ & 5.151505 & -5.788558 & -2.058831 \\
\hline $\mathrm{H}$ & 6.398459 & -3.628672 & -2.133204 \\
\hline $\mathrm{H}$ & 5.432969 & -1.597566 & -1.153877 \\
\hline C & 4.954000 & 0.021897 & 0.950559 \\
\hline C & 5.635140 & 1.281969 & 0.979694 \\
\hline C & 6.856329 & 1.399421 & 1.697550 \\
\hline C & 7.376362 & 0.331178 & 2.390244 \\
\hline C & 6.685397 & -0.903137 & 2.397355 \\
\hline C & 5.508755 & -1.054370 & 1.696889 \\
\hline $\mathrm{H}$ & 7.365830 & 2.360141 & 1.698174 \\
\hline $\mathrm{H}$ & 8.306950 & 0.435110 & 2.941413 \\
\hline $\mathrm{H}$ & 7.083468 & -1.739626 & 2.965449 \\
\hline $\mathrm{H}$ & 4.987712 & -2.004198 & 1.722932 \\
\hline $\mathrm{O}$ & -0.507055 & 0.407733 & -0.980556 \\
\hline $\mathrm{O}$ & 0.430997 & 2.087546 & 0.781236 \\
\hline $\mathrm{H}$ & -0.654577 & 2.428267 & 1.100761 \\
\hline $\mathrm{H}$ & 3.671286 & 4.809502 & 0.684256 \\
\hline $\mathrm{H}$ & 1.966093 & 6.767741 & -2.741754 \\
\hline $\mathrm{H}$ & 2.761812 & 2.545445 & -2.853242 \\
\hline $\mathrm{H}$ & -0.133977 & -1.526246 & 2.791225 \\
\hline $\mathrm{H}$ & -4.098693 & -3.145589 & 2.429593 \\
\hline $\mathrm{H}$ & -1.139271 & -4.010328 & -0.566611 \\
\hline C & -2.620201 & 1.793011 & 1.334371 \\
\hline $\mathrm{O}$ & -1.785789 & 2.750620 & 1.466448 \\
\hline $\mathrm{H}$ & -2.258478 & 0.762973 & 1.242176 \\
\hline C & -3.939277 & 1.953312 & 2.073217 \\
\hline $\mathrm{O}$ & -4.518612 & 2.998246 & 2.250712 \\
\hline $\mathrm{O}$ & -4.361687 & 0.751399 & 2.516353 \\
\hline C & -5.601424 & 0.774628 & 3.249582 \\
\hline $\mathrm{H}$ & -5.778800 & -0.256496 & 3.554867 \\
\hline $\mathrm{H}$ & -5.511964 & 1.426965 & 4.121648 \\
\hline C & -3.960604 & 0.759870 & -0.969677 \\
\hline C & -3.334172 & 1.952154 & -0.589939 \\
\hline $\mathrm{H}$ & -2.144657 & -0.101757 & -1.350809 \\
\hline$N$ & -3.166239 & -0.254035 & -1.427428 \\
\hline C & -3.552388 & -1.331442 & -2.233833 \\
\hline
\end{tabular}




$\begin{array}{lrrr}\mathrm{O} & -4.674309 & -1.606048 & -2.596237 \\ \mathrm{O} & -2.440292 & -2.008800 & -2.576113 \\ \mathrm{C} & -2.655503 & -3.114095 & -3.466534 \\ \mathrm{H} & -1.665110 & -3.530327 & -3.650145 \\ \mathrm{H} & -3.107844 & -2.771585 & -4.400736 \\ \mathrm{H} & -3.309257 & -3.858625 & -3.004501 \\ \mathrm{H} & -3.959405 & 2.813438 & -0.386203 \\ \mathrm{H} & -2.349007 & 2.148484 & -0.997874 \\ \mathrm{C} & -5.406094 & 0.559387 & -0.742218 \\ \mathrm{C} & -6.305716 & 1.600322 & -1.026270 \\ \mathrm{C} & -5.893064 & -0.626722 & -0.163555 \\ \mathrm{C} & -7.665156 & 1.452721 & -0.757502 \\ \mathrm{H} & -5.941879 & 2.513917 & -1.485585 \\ \mathrm{C} & -7.247401 & -0.762623 & 0.120249 \\ \mathrm{H} & -5.202052 & -1.424477 & 0.085057 \\ \mathrm{C} & -8.138091 & 0.272640 & -0.181853 \\ \mathrm{H} & -8.352272 & 2.258625 & -0.997894 \\ \mathrm{H} & -7.612780 & -1.679921 & 0.573322 \\ \mathrm{H} & -9.197463 & 0.157692 & 0.030931 \\ \mathrm{H} & -6.412599 & 1.131716 & 2.611077\end{array}$

Catalyst (R)-1 TS Conformation 32

B3LYP/6-31G(d) Energy = -2809.697671

B3LYP-D3(BJ)/def2-TZVPP-IEF-PCM(DCM) Energy = -2810.988892

B3LYP-D3(BJ)/def2-TZVPP-IEF-PCM(DCM)//B3LYP/6-31G(d) Free Energy (Quasiharmonic) = 2810.347301

Frequencies (Top 3 out of 270)

1. $-717.2215 \mathrm{~cm}-1$

2. $\quad 12.1942 \mathrm{~cm}-1$

3. $16.2629 \mathrm{~cm}-1$

B3LYP/6-31G(d) Molecular Geometry in Cartesian Coordinates

$\begin{array}{llll}\text { C } & 2.912452 & -1.106109 & -0.397678 \\ \text { C } & 1.682002 & -1.698274 & -0.151130 \\ \text { C } & 1.419000 & -3.074139 & -0.425834 \\ \text { C } & 2.416223 & -3.807491 & -1.037251 \\ \text { H } & 2.238353 & -4.856958 & -1.257083 \\ \text { C } & 3.880777 & 2.955072 & 0.642778 \\ \text { C } & 3.204934 & 0.278489 & 0.077474\end{array}$




\begin{tabular}{|c|c|c|c|}
\hline C & 2.386977 & 1.333433 & -0.296518 \\
\hline C & 2.730803 & 2.701285 & -0.079607 \\
\hline $\mathrm{H}$ & 4.165929 & 3.986760 & 0.830973 \\
\hline $\mathrm{O}$ & 0.695138 & -0.968659 & 0.497175 \\
\hline$P$ & -0.009152 & 0.345421 & -0.185866 \\
\hline $\mathrm{O}$ & 1.220269 & 1.048524 & -1.000010 \\
\hline C & -2.177541 & -5.198545 & 0.618030 \\
\hline C & -2.252099 & -4.066613 & -0.197930 \\
\hline C & -1.099259 & -3.348894 & -0.520229 \\
\hline C & 0.153231 & -3.759304 & -0.036090 \\
\hline C & 0.216987 & -4.901016 & 0.778682 \\
\hline C & -0.937892 & -5.614123 & 1.105891 \\
\hline $\mathrm{H}$ & -3.213954 & -3.751583 & -0.595298 \\
\hline $\mathrm{H}$ & -0.866517 & -6.494283 & 1.739962 \\
\hline C & 0.629115 & 6.053306 & -1.773145 \\
\hline C & -0.072356 & 5.103520 & -1.028367 \\
\hline C & 0.585030 & 4.002820 & -0.478732 \\
\hline C & 1.965683 & 3.836027 & -0.668832 \\
\hline C & 2.662898 & 4.799271 & -1.417933 \\
\hline C & 2.002355 & 5.898359 & -1.965482 \\
\hline $\mathrm{H}$ & -1.141611 & 5.214757 & -0.870795 \\
\hline $\mathrm{H}$ & 2.560006 & 6.626856 & -2.548572 \\
\hline C & 4.343334 & 0.556407 & 0.912327 \\
\hline C & 4.678255 & 1.920330 & 1.189706 \\
\hline C & 5.799672 & 2.211197 & 2.012924 \\
\hline C & 6.552502 & 1.201436 & 2.565629 \\
\hline C & 6.205728 & -0.147715 & 2.319027 \\
\hline C & 5.133598 & -0.461970 & 1.512824 \\
\hline $\mathrm{H}$ & 6.043733 & 3.253121 & 2.206470 \\
\hline $\mathrm{H}$ & 7.404026 & 1.435433 & 3.198730 \\
\hline $\mathrm{H}$ & 6.787387 & -0.944729 & 2.774435 \\
\hline $\mathrm{H}$ & 4.875327 & -1.500741 & 1.342648 \\
\hline C & 3.898704 & -1.852226 & -1.135123 \\
\hline C & 3.642891 & -3.227115 & -1.440292 \\
\hline C & 4.612296 & -3.979722 & -2.156854 \\
\hline C & 5.782718 & -3.398557 & -2.585160 \\
\hline C & 6.023925 & -2.030550 & -2.317860 \\
\hline C & 5.110536 & -1.279188 & -1.611491 \\
\hline $\mathrm{H}$ & 4.401618 & -5.024759 & -2.371688 \\
\hline $\mathrm{H}$ & 6.514469 & -3.980574 & -3.138649 \\
\hline $\mathrm{H}$ & 6.936514 & -1.564528 & -2.679570 \\
\hline $\mathrm{H}$ & 5.308000 & -0.229856 & -1.427796 \\
\hline $\mathrm{O}$ & -0.565194 & 1.189849 & 0.915720 \\
\hline $\mathrm{O}$ & -0.946115 & -0.140833 & -1.307654 \\
\hline
\end{tabular}




\begin{tabular}{|c|c|c|c|}
\hline $\mathrm{H}$ & -2.074697 & 0.184543 & -1.439973 \\
\hline $\mathrm{H}$ & 1.180850 & -5.224471 & 1.162749 \\
\hline $\mathrm{H}$ & -3.078560 & -5.752182 & 0.867833 \\
\hline $\mathrm{H}$ & -1.157516 & -2.477510 & -1.163740 \\
\hline $\mathrm{H}$ & 3.728562 & 4.670068 & -1.587372 \\
\hline $\mathrm{H}$ & 0.109553 & 6.905982 & -2.203028 \\
\hline $\mathrm{H}$ & 0.030909 & 3.282169 & 0.113035 \\
\hline C & -3.991566 & -0.567157 & -1.136629 \\
\hline 0 & -3.272766 & 0.334097 & -1.687944 \\
\hline $\mathrm{H}$ & -3.504515 & -1.409251 & -0.635560 \\
\hline C & -5.312842 & -0.880031 & -1.813986 \\
\hline 0 & -5.952645 & -0.101474 & -2.482213 \\
\hline O & -5.666930 & -2.156365 & -1.561269 \\
\hline C & -6.910904 & -2.580336 & -2.150210 \\
\hline $\mathrm{H}$ & -7.734368 & -1.961163 & -1.785022 \\
\hline $\mathrm{H}$ & -6.860375 & -2.503388 & -3.239112 \\
\hline C & -3.954534 & 0.759566 & 1.199524 \\
\hline C & -4.978668 & -0.009218 & 0.640525 \\
\hline $\mathrm{H}$ & -2.010676 & 0.696189 & 1.845771 \\
\hline$N$ & -2.930339 & 0.225496 & 1.926123 \\
\hline C & -2.890065 & -1.051311 & 2.505182 \\
\hline 0 & -3.785179 & -1.870263 & 2.510495 \\
\hline 0 & -1.687780 & -1.205945 & 3.073123 \\
\hline C & -1.442808 & -2.495873 & 3.663241 \\
\hline $\mathrm{H}$ & -2.146824 & -2.677905 & 4.479396 \\
\hline $\mathrm{H}$ & -0.421353 & -2.444049 & 4.038356 \\
\hline $\mathrm{H}$ & -1.538188 & -3.281274 & 2.911032 \\
\hline $\mathrm{H}$ & -5.851284 & 0.529336 & 0.290323 \\
\hline $\mathrm{H}$ & -5.145806 & -1.006321 & 1.023957 \\
\hline C & -3.856184 & 2.201675 & 0.924997 \\
\hline C & -4.443282 & 2.756708 & -0.229985 \\
\hline C & -3.207630 & 3.056244 & 1.839095 \\
\hline C & -4.385801 & 4.130085 & -0.452246 \\
\hline $\mathrm{H}$ & -4.911391 & 2.118608 & -0.969754 \\
\hline C & -3.168072 & 4.427902 & 1.617085 \\
\hline $\mathrm{H}$ & -2.764083 & 2.646879 & 2.740424 \\
\hline C & -3.758301 & 4.968891 & 0.470953 \\
\hline $\mathrm{H}$ & -4.831302 & 4.543963 & -1.351976 \\
\hline $\mathrm{H}$ & -2.679557 & 5.076000 & 2.338565 \\
\hline $\mathrm{H}$ & -3.729256 & 6.041737 & 0.300200 \\
\hline $\mathrm{H}$ & -7.041034 & -3.617378 & -1.841932 \\
\hline
\end{tabular}

Catalyst (R)-1 TS Conformation 33 
B3LYP/6-31G(d) Energy $=-2809.696725$

B3LYP-D3(BJ)/def2-TZVPP-IEF-PCM(DCM) Energy $=-2810.988387$

B3LYP-D3(BJ)/def2-TZVPP-IEF-PCM(DCM)//B3LYP/6-31G(d) Free Energy (Quasiharmonic) = 2810.347299

Frequencies (Top 3 out of 270)

1. $-663.1841 \mathrm{~cm}-1$

2. $\quad 9.1368 \mathrm{~cm}-1$

3. $\quad 13.4674 \mathrm{~cm}-1$

B3LYP/6-31G(d) Molecular Geometry in Cartesian Coordinates

$\begin{array}{llll}\mathrm{C} & -3.044530 & -1.338313 & -0.126402 \\ \mathrm{C} & -1.725701 & -1.459568 & -0.538839 \\ \mathrm{C} & -1.024207 & -2.702186 & -0.578101 \\ \mathrm{C} & -1.705119 & -3.821879 & -0.138542 \\ \mathrm{H} & -1.217382 & -4.791826 & -0.186720 \\ \mathrm{C} & -4.989332 & 2.513954 & -0.242713 \\ \mathrm{C} & -3.727668 & -0.012202 & -0.215937 \\ \mathrm{C} & -3.166661 & 1.098113 & 0.396673 \\ \mathrm{C} & -3.787742 & 2.381116 & 0.425431 \\ \mathrm{H} & -5.503963 & 3.470892 & -0.219893 \\ \mathrm{O} & -1.063674 & -0.318153 & -0.969526 \\ \mathrm{P} & -0.590436 & 0.790936 & 0.147619 \\ \mathrm{O} & -1.942200 & 0.957021 & 1.043966 \\ \mathrm{C} & 3.033021 & -3.142866 & -1.959174 \\ \mathrm{C} & 2.588787 & -3.822579 & -0.824156 \\ \mathrm{C} & 1.278599 & -3.655127 & -0.375268 \\ \mathrm{C} & 0.379949 & -2.817152 & -1.056382 \\ \mathrm{C} & 0.840000 & -2.143703 & -2.202669 \\ \mathrm{C} & 2.153067 & -2.301358 & -2.644153 \\ \mathrm{H} & 3.263932 & -4.480137 & -0.281743 \\ \mathrm{H} & 2.494330 & -1.762076 & -3.522691 \\ \mathrm{C} & -2.178612 & 5.798919 & 2.484447 \\ \mathrm{C} & -2.201910 & 4.553147 & 3.114919 \\ \mathrm{C} & -2.699820 & 3.434678 & 2.448828 \\ \mathrm{C} & -3.190401 & 3.542712 & 1.136788 \\ \mathrm{C} & -3.157764 & 4.800140 & 0.512615 \\ \mathrm{C} & -2.656842 & 5.917765 & 1.179032 \\ \mathrm{H} & -1.832786 & 4.450336 & 4.132102 \\ \mathrm{H} & -2.632628 & 6.879570 & 0.673343 \\ \mathrm{C} & -4.939626 & 0.163370 & -0.970398\end{array}$




\begin{tabular}{|c|c|c|c|}
\hline C & -5.576954 & 1.446431 & -0.964307 \\
\hline C & -6.781911 & 1.631350 & -1.695286 \\
\hline C & -7.326628 & 0.606960 & -2.433707 \\
\hline C & -6.677856 & -0.649394 & -2.475174 \\
\hline C & -5.518545 & -0.865978 & -1.763105 \\
\hline $\mathrm{H}$ & -7.258492 & 2.608468 & -1.668738 \\
\hline $\mathrm{H}$ & -8.244216 & 0.762409 & -2.994482 \\
\hline $\mathrm{H}$ & -7.094806 & -1.450893 & -3.079024 \\
\hline $\mathrm{H}$ & -5.029635 & -1.831637 & -1.815460 \\
\hline C & -3.704917 & -2.497132 & 0.409064 \\
\hline C & -3.020886 & -3.755460 & 0.380335 \\
\hline C & -3.668894 & -4.914071 & 0.888923 \\
\hline C & -4.927601 & -4.837694 & 1.437768 \\
\hline C & -5.589270 & -3.588904 & 1.504926 \\
\hline C & -4.996336 & -2.451208 & 1.003078 \\
\hline $\mathrm{H}$ & -3.140674 & -5.863801 & 0.846382 \\
\hline $\mathrm{H}$ & -5.410104 & -5.728719 & 1.830044 \\
\hline $\mathrm{H}$ & -6.573632 & -3.525290 & 1.960775 \\
\hline $\mathrm{H}$ & -5.513400 & -1.501097 & 1.069862 \\
\hline $\mathrm{O}$ & 0.512578 & 0.315508 & 1.031578 \\
\hline $\mathrm{O}$ & -0.383866 & 2.067166 & -0.684604 \\
\hline $\mathrm{H}$ & 0.679108 & 2.331755 & -1.085651 \\
\hline $\mathrm{H}$ & 0.163607 & -1.497938 & -2.750979 \\
\hline $\mathrm{H}$ & 4.054290 & -3.264658 & -2.309902 \\
\hline $\mathrm{H}$ & 0.949874 & -4.162582 & 0.526777 \\
\hline $\mathrm{H}$ & -3.506563 & 4.893322 & -0.511994 \\
\hline $\mathrm{H}$ & -1.786155 & 6.668548 & 3.005039 \\
\hline $\mathrm{H}$ & -2.715374 & 2.472542 & 2.949265 \\
\hline C & 2.607307 & 1.581505 & -1.334381 \\
\hline $\mathrm{O}$ & 1.826509 & 2.575239 & -1.524665 \\
\hline $\mathrm{H}$ & 2.190155 & 0.581691 & -1.168470 \\
\hline C & 3.907728 & 1.519403 & -2.111266 \\
\hline $\mathrm{O}$ & 4.374991 & 0.468810 & -2.502393 \\
\hline $\mathrm{O}$ & 4.455255 & 2.724464 & -2.309761 \\
\hline C & 5.692891 & 2.723692 & -3.044632 \\
\hline $\mathrm{H}$ & 5.549728 & 2.277807 & -4.031978 \\
\hline $\mathrm{H}$ & 5.976820 & 3.772183 & -3.133818 \\
\hline C & 3.981978 & 0.610553 & 0.940187 \\
\hline C & 3.354039 & 1.802196 & 0.555594 \\
\hline $\mathrm{H}$ & 2.167606 & -0.237221 & 1.351040 \\
\hline$N$ & 3.188638 & -0.400249 & 1.400431 \\
\hline C & 3.582973 & -1.510319 & 2.158241 \\
\hline $\mathrm{O}$ & 4.712383 & -1.821161 & 2.462304 \\
\hline $\mathrm{O}$ & 2.470077 & -2.170161 & 2.528797 \\
\hline
\end{tabular}




$\begin{array}{llll}\mathrm{C} & 2.696131 & -3.317432 & 3.361188 \\ \mathrm{H} & 3.204623 & -3.027574 & 4.284271 \\ \mathrm{H} & 3.303204 & -4.059314 & 2.835637 \\ \mathrm{H} & 1.704177 & -3.713650 & 3.577601 \\ \mathrm{H} & 3.985232 & 2.656760 & 0.342447 \\ \mathrm{H} & 2.375917 & 2.011113 & 0.974832 \\ \mathrm{C} & 5.428515 & 0.422171 & 0.708520 \\ \mathrm{C} & 6.320943 & 1.453205 & 1.047855 \\ \mathrm{C} & 5.920430 & -0.725434 & 0.062291 \\ \mathrm{C} & 7.680663 & 1.329879 & 0.769453 \\ \mathrm{H} & 5.950040 & 2.336404 & 1.559064 \\ \mathrm{C} & 7.274920 & -0.834333 & -0.233087 \\ \mathrm{H} & 5.233402 & -1.509293 & -0.234662 \\ \mathrm{C} & 8.158995 & 0.187121 & 0.125227 \\ \mathrm{H} & 8.364415 & 2.123403 & 1.057162 \\ \mathrm{H} & 7.643145 & -1.718526 & -0.745106 \\ \mathrm{H} & 9.218274 & 0.092076 & -0.097893 \\ \mathrm{H} & 6.456384 & 2.160276 & -2.501520\end{array}$

Catalyst (R)-1 TS Conformation 34

B3LYP/6-31G(d) Energy = -2809.692919

B3LYP-D3(BJ)/def2-TZVPP-IEF-PCM(DCM) Energy $=-2810.989173$

B3LYP-D3(BJ)/def2-TZVPP-IEF-PCM(DCM)//B3LYP/6-31G(d) Free Energy (Quasiharmonic) = 2810.347264

Frequencies (Top 3 out of 270)

1. $-727.5725 \mathrm{~cm}-1$

2. $12.4596 \mathrm{~cm}-1$

3. $\quad 18.0272 \mathrm{~cm}-1$

B3LYP/6-31G(d) Molecular Geometry in Cartesian Coordinates

$\begin{array}{llll}\text { C } & -2.686360 & -1.320220 & 0.134684 \\ \text { C } & -1.432605 & -1.811161 & -0.193262 \\ \text { C } & -0.986100 & -3.115272 & 0.170108 \\ \text { C } & -1.826230 & -3.875230 & 0.960335 \\ \text { H } & -1.525081 & -4.882915 & 1.234403 \\ \text { C } & -3.997480 & 2.544413 & -1.237370 \\ \text { C } & -3.126029 & -0.002240 & -0.407273 \\ \text { C } & -2.356458 & 1.133164 & -0.189607 \\ \text { C } & -2.785481 & 2.436350 & -0.584308\end{array}$




\begin{tabular}{|c|c|c|c|}
\hline $\mathrm{H}$ & -4.342090 & 3.527989 & -1.546089 \\
\hline $\mathrm{O}$ & -0.565275 & -0.991322 & -0.912543 \\
\hline$P$ & 0.131044 & 0.230179 & -0.062788 \\
\hline $\mathrm{O}$ & -1.179390 & 1.026277 & 0.532398 \\
\hline C & 2.615372 & -5.012560 & -1.207056 \\
\hline C & 1.799117 & -4.324097 & -2.107497 \\
\hline C & 0.657777 & -3.661757 & -1.659554 \\
\hline C & 0.301836 & -3.689975 & -0.301705 \\
\hline C & 1.142203 & -4.365341 & 0.597992 \\
\hline C & 2.289556 & -5.019929 & 0.150496 \\
\hline $\mathrm{H}$ & 2.046023 & -4.308509 & -3.166077 \\
\hline $\mathrm{H}$ & 2.925791 & -5.538987 & 0.862817 \\
\hline C & -0.672638 & 6.140440 & -0.009129 \\
\hline C & -1.936244 & 5.950565 & 0.553123 \\
\hline C & -2.597021 & 4.732152 & 0.390205 \\
\hline C & -2.003144 & 3.679219 & -0.323471 \\
\hline C & -0.723938 & 3.871448 & -0.868396 \\
\hline C & -0.072895 & 5.096868 & -0.719376 \\
\hline $\mathrm{H}$ & -2.412811 & 6.752275 & 1.111582 \\
\hline $\mathrm{H}$ & 0.905052 & 5.241327 & -1.173096 \\
\hline C & -4.330832 & 0.113254 & -1.183750 \\
\hline C & -4.778120 & 1.414113 & -1.578667 \\
\hline C & -5.976481 & 1.545971 & -2.331288 \\
\hline C & -6.699754 & 0.438745 & -2.708336 \\
\hline C & -6.241940 & -0.851736 & -2.351933 \\
\hline C & -5.092043 & -1.010793 & -1.610358 \\
\hline $\mathrm{H}$ & -6.303014 & 2.543861 & -2.614796 \\
\hline $\mathrm{H}$ & -7.611492 & 0.549824 & -3.288918 \\
\hline $\mathrm{H}$ & -6.799752 & -1.727795 & -2.671881 \\
\hline $\mathrm{H}$ & -4.751348 & -2.007553 & -1.356044 \\
\hline C & -3.519200 & -2.093162 & 1.016169 \\
\hline C & -3.072419 & -3.390265 & 1.426494 \\
\hline C & -3.885613 & -4.167388 & 2.295204 \\
\hline C & -5.079581 & -3.678878 & 2.772179 \\
\hline C & -5.505811 & -2.382434 & 2.399654 \\
\hline C & -4.748956 & -1.612048 & 1.544267 \\
\hline $\mathrm{H}$ & -3.536050 & -5.155285 & 2.586011 \\
\hline $\mathrm{H}$ & -5.689580 & -4.278810 & 3.442037 \\
\hline $\mathrm{H}$ & -6.437493 & -1.987619 & 2.795981 \\
\hline $\mathrm{H}$ & -5.085016 & -0.616818 & 1.277947 \\
\hline 0 & 0.926548 & 1.083464 & -0.996261 \\
\hline $\mathrm{O}$ & 0.757395 & -0.332423 & 1.220760 \\
\hline $\mathrm{H}$ & 1.805715 & -0.764530 & 1.418266 \\
\hline $\mathrm{H}$ & 0.895961 & -4.365393 & 1.655931 \\
\hline
\end{tabular}




\begin{tabular}{|c|c|c|c|}
\hline $\mathrm{H}$ & 3.498875 & -5.538962 & -1.559856 \\
\hline $\mathrm{H}$ & 0.027171 & -3.133245 & -2.366758 \\
\hline $\mathrm{H}$ & -0.244936 & 3.064234 & -1.412251 \\
\hline $\mathrm{H}$ & -0.162550 & 7.094336 & 0.099447 \\
\hline $\mathrm{H}$ & -3.583670 & 4.588712 & 0.822758 \\
\hline C & 4.010099 & -1.217925 & 1.401908 \\
\hline 0 & 2.865152 & -1.194522 & 1.988996 \\
\hline $\mathrm{H}$ & 4.831344 & -1.667877 & 1.974289 \\
\hline C & 4.076931 & -1.573123 & -0.076970 \\
\hline O & 3.202028 & -1.340058 & -0.881835 \\
\hline $\mathrm{O}$ & 5.255608 & -2.157753 & -0.358876 \\
\hline C & 5.495511 & -2.453324 & -1.746892 \\
\hline $\mathrm{H}$ & 4.654602 & -3.008933 & -2.166332 \\
\hline $\mathrm{H}$ & 5.642920 & -1.520194 & -2.296356 \\
\hline C & 3.869844 & 1.408404 & 0.873823 \\
\hline C & 4.900905 & 0.530295 & 1.282401 \\
\hline $\mathrm{H}$ & 2.546308 & 1.708841 & -0.667279 \\
\hline$N$ & 3.556919 & 1.625309 & -0.434219 \\
\hline C & 4.368361 & 1.372976 & -1.546176 \\
\hline $\mathrm{O}$ & 5.516280 & 0.975231 & -1.536194 \\
\hline O & 3.672581 & 1.698588 & -2.643786 \\
\hline C & 4.330395 & 1.443208 & -3.893506 \\
\hline $\mathrm{H}$ & 4.474681 & 0.368217 & -4.030487 \\
\hline $\mathrm{H}$ & 5.297503 & 1.950347 & -3.931403 \\
\hline $\mathrm{H}$ & 3.656917 & 1.833908 & -4.655854 \\
\hline $\mathrm{H}$ & 5.243711 & 0.659196 & 2.303415 \\
\hline $\mathrm{H}$ & 5.687122 & 0.323318 & 0.567256 \\
\hline C & 2.973993 & 2.028210 & 1.855026 \\
\hline C & 2.192038 & 3.149920 & 1.505114 \\
\hline C & 2.883360 & 1.528020 & 3.171842 \\
\hline C & 1.346859 & 3.744040 & 2.433374 \\
\hline $\mathrm{H}$ & 2.259932 & 3.569980 & 0.508454 \\
\hline C & 2.029407 & 2.123373 & 4.094032 \\
\hline $\mathrm{H}$ & 3.436123 & 0.644891 & 3.460353 \\
\hline C & 1.261519 & 3.230234 & 3.730160 \\
\hline $\mathrm{H}$ & 0.749812 & 4.601219 & 2.139620 \\
\hline $\mathrm{H}$ & 1.955922 & 1.713083 & 5.096782 \\
\hline $\mathrm{H}$ & 0.595456 & 3.692059 & 4.453802 \\
\hline $\mathrm{H}$ & 6.406169 & -3.053063 & -1.763849 \\
\hline
\end{tabular}

Catalyst (R)-1 TS Conformation 35

B3LYP/6-31G(d) Energy $=-2809.70051$ 
B3LYP-D3(BJ)/def2-TZVPP-IEF-PCM(DCM) Energy $=-2810.989638$

B3LYP-D3(BJ)/def2-TZVPP-IEF-PCM(DCM)//B3LYP/6-31G(d) Free Energy (Quasiharmonic) = 2810.347236

Frequencies (Top 3 out of 270)

1. $-388.7561 \mathrm{~cm}-1$

2. $\quad 5.1168 \mathrm{~cm}-1$

3. $\quad 12.6099 \mathrm{~cm}-1$

B3LYP/6-31G(d) Molecular Geometry in Cartesian Coordinates

$\begin{array}{lrrr}\text { C } & 3.255327 & -0.763999 & -0.285204 \\ \text { C } & 2.144774 & -1.588734 & -0.188798 \\ \text { C } & 2.130308 & -2.936782 & -0.654886 \\ \text { C } & 3.251889 & -3.386264 & -1.323632 \\ \text { H } & 3.269596 & -4.408052 & -1.693491 \\ \text { C } & 3.438841 & 3.121955 & 1.572107 \\ \text { C } & 3.289785 & 0.543973 & 0.434137 \\ \text { C } & 2.296160 & 1.490911 & 0.234693 \\ \text { C } & 2.360453 & 2.812501 & 0.767365 \\ \text { H } & 3.512497 & 4.121892 & 1.991503 \\ \text { O } & 1.018711 & -1.119266 & 0.481692 \\ \text { P } & 0.121847 & 0.071475 & -0.179476 \\ \text { O } & 1.235089 & 1.184378 & -0.612385 \\ \text { C } & -1.024171 & -5.776933 & 0.069646 \\ \text { C } & -1.313958 & -4.567933 & -0.566714 \\ \text { C } & -0.310361 & -3.625026 & -0.790274 \\ \text { C } & 1.008226 & -3.881447 & -0.383975 \\ \text { C } & 1.289356 & -5.100718 & 0.255163 \\ \text { C } & 0.283099 & -6.039889 & 0.482523 \\ \text { H } & -2.325936 & -4.356696 & -0.902667 \\ \text { H } & 0.522138 & -6.975732 & 0.981272 \\ \text { C } & -0.471804 & 5.961603 & 0.001177 \\ \text { C } & 0.877193 & 6.125637 & -0.317105 \\ \text { C } & 1.780885 & 5.088038 & -0.085294 \\ \text { C } & 1.352126 & 3.867340 & 0.461006 \\ \text { C } & -0.007784 & 3.708554 & 0.771096 \\ \text { C } & -0.907442 & 4.751165 & 0.546154 \\ \text { H } & 1.228549 & 7.061063 & -0.744864 \\ \text { H } & -1.954867 & 4.619635 & 0.806688 \\ \text { C } & 4.345964 & 0.847187 & 1.364964 \\ \text { C } & 4.422072 & 2.164538 & 1.920516 \\ \text { C } & 5.466610 & 2.483023 & 2.830177\end{array}$




\begin{tabular}{|c|c|c|c|}
\hline C & 6.389722 & 1.535719 & 3.206293 \\
\hline C & 6.295794 & 0.222283 & 2.689526 \\
\hline C & 5.304629 & -0.112530 & 1.793265 \\
\hline $\mathrm{H}$ & 5.511765 & 3.491571 & 3.234266 \\
\hline $\mathrm{H}$ & 7.180385 & 1.787590 & 3.907653 \\
\hline $\mathrm{H}$ & 7.009151 & -0.533247 & 3.007476 \\
\hline $\mathrm{H}$ & 5.242733 & -1.126873 & 1.417684 \\
\hline C & 4.370311 & -1.210919 & -1.077802 \\
\hline C & 4.360651 & -2.546811 & -1.592635 \\
\hline C & 5.456991 & -3.003677 & -2.373042 \\
\hline C & 6.514160 & -2.172712 & -2.661975 \\
\hline C & 6.511301 & -0.841543 & -2.183300 \\
\hline C & 5.470976 & -0.374166 & -1.410492 \\
\hline $\mathrm{H}$ & 5.435629 & -4.023703 & -2.749301 \\
\hline $\mathrm{H}$ & 7.343734 & -2.529961 & -3.265866 \\
\hline $\mathrm{H}$ & 7.335098 & -0.178292 & -2.432817 \\
\hline $\mathrm{H}$ & 5.479688 & 0.651873 & -1.061587 \\
\hline $\mathrm{O}$ & -0.861592 & 0.548121 & 0.841662 \\
\hline $\mathrm{O}$ & -0.429216 & -0.417588 & -1.540352 \\
\hline $\mathrm{H}$ & -1.514515 & -0.253391 & -1.696564 \\
\hline $\mathrm{H}$ & 2.304361 & -5.304395 & 0.585931 \\
\hline $\mathrm{H}$ & -1.808959 & -6.510133 & 0.238102 \\
\hline $\mathrm{H}$ & -0.544259 & -2.697516 & -1.299557 \\
\hline $\mathrm{H}$ & -0.355590 & 2.773915 & 1.197889 \\
\hline $\mathrm{H}$ & -1.177192 & 6.770445 & -0.170729 \\
\hline $\mathrm{H}$ & 2.830101 & 5.216831 & -0.337810 \\
\hline C & -3.564096 & 0.790975 & -1.872587 \\
\hline $\mathrm{O}$ & -2.850981 & -0.271395 & -1.805972 \\
\hline $\mathrm{H}$ & -4.614849 & 0.671897 & -2.167073 \\
\hline C & -3.003459 & 2.087308 & -2.465935 \\
\hline $\mathrm{O}$ & -3.707168 & 2.965510 & -2.918821 \\
\hline $\mathrm{O}$ & -1.667878 & 2.112735 & -2.416237 \\
\hline C & -1.024537 & 3.278536 & -2.965995 \\
\hline $\mathrm{H}$ & 0.038857 & 3.122870 & -2.791959 \\
\hline $\mathrm{H}$ & -1.242277 & 3.356319 & -4.034331 \\
\hline C & -4.399872 & 0.419005 & 0.587204 \\
\hline C & -3.930129 & 1.559965 & -0.089741 \\
\hline $\mathrm{H}$ & -2.474375 & -0.143956 & 0.953162 \\
\hline$N$ & -3.467019 & -0.430233 & 1.065825 \\
\hline C & -3.653005 & -1.578864 & 1.861209 \\
\hline $\mathrm{O}$ & -4.696143 & -1.976821 & 2.324642 \\
\hline $\mathrm{O}$ & -2.448873 & -2.141811 & 2.030572 \\
\hline C & -2.422052 & -3.316565 & 2.859343 \\
\hline $\mathrm{H}$ & -3.111741 & -4.070318 & 2.473419 \\
\hline
\end{tabular}




$\begin{array}{lrrr}\mathrm{H} & -2.699134 & -3.060044 & 3.885358 \\ \mathrm{H} & -1.395180 & -3.674835 & 2.809641 \\ \mathrm{H} & -4.662386 & 2.318918 & -0.344391 \\ \mathrm{H} & -2.936182 & 1.915722 & 0.169382 \\ \mathrm{C} & -5.840007 & 0.084416 & 0.537251 \\ \mathrm{C} & -6.282069 & -1.145885 & 0.022948 \\ \mathrm{C} & -6.784769 & 1.056446 & 0.901599 \\ \mathrm{C} & -7.643685 & -1.394457 & -0.118141 \\ \mathrm{H} & -5.557605 & -1.890972 & -0.286759 \\ \mathrm{C} & -8.148055 & 0.791983 & 0.784272 \\ \mathrm{H} & -6.447744 & 2.008781 & 1.300234 \\ \mathrm{C} & -8.579218 & -0.431748 & 0.270500 \\ \mathrm{H} & -7.976306 & -2.343000 & -0.529657 \\ \mathrm{H} & -8.870948 & 1.543568 & 1.088000 \\ \mathrm{H} & -9.641728 & -0.634710 & 0.168662 \\ \mathrm{H} & -1.369448 & 4.178762 & -2.453575\end{array}$

Catalyst (R)-1 TS Conformation 36

B3LYP/6-31G(d) Energy $=-2809.701834$

B3LYP-D3(BJ)/def2-TZVPP-IEF-PCM(DCM) Energy $=-2810.990966$

B3LYP-D3(BJ)/def2-TZVPP-IEF-PCM(DCM)//B3LYP/6-31G(d) Free Energy (Quasiharmonic) = 2810.347172

Frequencies (Top 3 out of 270)

1. $-283.9776 \mathrm{~cm}-1$

2. $\quad 13.3092 \mathrm{~cm}-1$

3. $\quad 18.8756 \mathrm{~cm}-1$

B3LYP/6-31G(d) Molecular Geometry in Cartesian Coordinates

$\begin{array}{llll}\text { C } & 2.987801 & -1.070101 & -0.335134 \\ \text { C } & 1.776644 & -1.697155 & -0.079876 \\ \text { C } & 1.556890 & -3.086855 & -0.326336 \\ \text { C } & 2.581849 & -3.795888 & -0.921750 \\ \text { H } & 2.438035 & -4.853866 & -1.124176 \\ \text { C } & 3.839312 & 3.041978 & 0.604581 \\ \text { C } & 3.236766 & 0.333171 & 0.109805 \\ \text { C } & 2.393893 & 1.356461 & -0.292939 \\ \text { C } & 2.698839 & 2.738195 & -0.113704 \\ \text { H } & 4.096810 & 4.085540 & 0.764883 \\ \text { O } & 0.765327 & -0.979103 & 0.553267\end{array}$




\begin{tabular}{|c|c|c|c|}
\hline$P$ & 0.039310 & 0.306918 & -0.146577 \\
\hline $\mathrm{O}$ & 1.231714 & 1.022685 & -0.988749 \\
\hline C & -1.980205 & -5.308763 & 0.713050 \\
\hline C & -2.091488 & -4.152615 & -0.063618 \\
\hline C & -0.952828 & -3.413972 & -0.386638 \\
\hline C & 0.313782 & -3.810341 & 0.065246 \\
\hline C & 0.411907 & -4.971359 & 0.851046 \\
\hline C & -0.724324 & -5.715593 & 1.170263 \\
\hline $\mathrm{H}$ & -3.057343 & -3.806066 & -0.418825 \\
\hline $\mathrm{H}$ & -0.627380 & -6.611465 & 1.778593 \\
\hline C & 0.515248 & 5.981243 & -1.912875 \\
\hline C & -0.163838 & 5.036277 & -1.141608 \\
\hline C & 0.520801 & 3.970702 & -0.557072 \\
\hline C & 1.906024 & 3.834599 & -0.737939 \\
\hline C & 2.580193 & 4.792969 & -1.513817 \\
\hline C & 1.892771 & 5.857025 & -2.096356 \\
\hline $\mathrm{H}$ & -1.235985 & 5.125572 & -0.989703 \\
\hline $\mathrm{H}$ & 2.433123 & 6.582119 & -2.699531 \\
\hline C & 4.363880 & 0.664250 & 0.940705 \\
\hline C & 4.661166 & 2.043642 & 1.182287 \\
\hline C & 5.771355 & 2.386143 & 2.000919 \\
\hline C & 6.548167 & 1.411571 & 2.582697 \\
\hline C & 6.238355 & 0.047506 & 2.371210 \\
\hline C & 5.178319 & -0.316713 & 1.570168 \\
\hline $\mathrm{H}$ & 5.987207 & 3.438880 & 2.167336 \\
\hline $\mathrm{H}$ & 7.390663 & 1.684769 & 3.212102 \\
\hline $\mathrm{H}$ & 6.839071 & -0.721175 & 2.849832 \\
\hline $\mathrm{H}$ & 4.948193 & -1.366041 & 1.426643 \\
\hline C & 4.001520 & -1.797304 & -1.054091 \\
\hline C & 3.790721 & -3.185124 & -1.332032 \\
\hline C & 4.786086 & -3.920437 & -2.030918 \\
\hline C & 5.938629 & -3.310626 & -2.467630 \\
\hline C & 6.135051 & -1.930509 & -2.227312 \\
\hline C & 5.195678 & -1.194876 & -1.538635 \\
\hline $\mathrm{H}$ & 4.609578 & -4.975708 & -2.225227 \\
\hline $\mathrm{H}$ & 6.690514 & -3.879787 & -3.007305 \\
\hline $\mathrm{H}$ & 7.033399 & -1.442745 & -2.595903 \\
\hline $\mathrm{H}$ & 5.359223 & -0.136266 & -1.376099 \\
\hline $\mathrm{O}$ & -0.562302 & 1.147733 & 0.930810 \\
\hline $\mathrm{O}$ & -0.881248 & -0.168858 & -1.308728 \\
\hline $\mathrm{H}$ & -1.888020 & -0.484148 & -1.073276 \\
\hline $\mathrm{H}$ & 1.385826 & -5.284301 & 1.218487 \\
\hline $\mathrm{H}$ & -2.865746 & -5.887879 & 0.962723 \\
\hline $\mathrm{H}$ & -1.049271 & -2.539131 & -1.015295 \\
\hline
\end{tabular}




$\begin{array}{llll}\mathrm{H} & 3.649463 & 4.687049 & -1.676197 \\ \mathrm{H} & -0.024969 & 6.806535 & -2.369809 \\ \mathrm{H} & -0.016034 & 3.253674 & 0.054559 \\ \mathrm{C} & -4.192453 & -0.379434 & -1.177004 \\ \mathrm{O} & -3.144366 & -1.049577 & -0.867831 \\ \mathrm{H} & -4.080907 & 0.595086 & -1.675246 \\ \mathrm{C} & -5.397882 & -1.106990 & -1.774688 \\ \mathrm{O} & -6.255475 & -0.531682 & -2.413111 \\ \mathrm{O} & -5.392712 & -2.420195 & -1.509281 \\ \mathrm{C} & -6.502312 & -3.159595 & -2.050278 \\ \mathrm{H} & -7.446685 & -2.776428 & -1.654665 \\ \mathrm{H} & -6.343679 & -4.191475 & -1.737734 \\ \mathrm{C} & -4.124977 & 0.963033 & 1.013556 \\ \mathrm{C} & -5.152145 & 0.204357 & 0.423205 \\ \mathrm{H} & -2.162611 & 0.782147 & 1.611797 \\ \mathrm{~N} & -3.105801 & 0.354890 & 1.663858 \\ \mathrm{C} & -3.130061 & -0.925907 & 2.259013 \\ \mathrm{O} & -4.107119 & -1.617111 & 2.437344 \\ \mathrm{O} & -1.885115 & -1.204129 & 2.656658 \\ \mathrm{C} & -1.708133 & -2.469786 & 3.320006 \\ \mathrm{H} & -2.257378 & -2.476835 & 4.265471 \\ \mathrm{H} & -0.635866 & -2.547506 & 3.492988 \\ \mathrm{H} & -2.053871 & -3.282990 & 2.680824 \\ \mathrm{H} & -3.777193 & 6.282389 & 0.347264 \\ \mathrm{H} & -6.028401 & 0.740275 & 0.075304 \\ \mathrm{H} & -5.343812 & -0.770550 & 0.853192 \\ \mathrm{C} & -4.000076 & 2.417482 & 0.801668 \\ \mathrm{H} & -4.695562 & 3.060185 & -0.241829 \\ \mathrm{H} & -3.217918 & 3.200148 & 1.672613 \\ \mathrm{H} & -4.608464 & 4.438823 & -0.405934 \\ \mathrm{H} & -5.292822 & 2.482242 & -0.938946 \\ \mathrm{H} & -2.690330 & 2.732364 & 2.496519 \\ \mathrm{H} & -2.539399 & 5.168570 & 2.195936 \\ \mathrm{H} & -3.083910 & -3.140534\end{array}$

Catalyst (R)-1 TS Conformation 37

B3LYP/6-31G(d) Energy $=-2809.696695$

B3LYP-D3(BJ)/def2-TZVPP-IEF-PCM(DCM) Energy = -2810.987971 
B3LYP-D3(BJ)/def2-TZVPP-IEF-PCM(DCM)//B3LYP/6-31G(d) Free Energy (Quasiharmonic) = 2810.347111

Frequencies (Top 3 out of 270)

1. $-704.0503 \mathrm{~cm}-1$

2. $\quad 9.2845 \mathrm{~cm}-1$

3. $\quad 9.6600 \mathrm{~cm}-1$

B3LYP/6-31G(d) Molecular Geometry in Cartesian Coordinates

$\begin{array}{llll}\mathrm{C} & -3.741624 & 0.050640 & -0.266413 \\ \mathrm{C} & -3.073808 & 1.195806 & 0.148381 \\ \mathrm{C} & -3.700774 & 2.476672 & 0.216662 \\ \mathrm{C} & -4.997913 & 2.574070 & -0.248152 \\ \mathrm{H} & -5.496824 & 3.538960 & -0.213791 \\ \mathrm{C} & -1.833812 & -3.810700 & 0.033520 \\ \mathrm{C} & -3.101466 & -1.290405 & -0.117080 \\ \mathrm{C} & -1.855837 & -1.523157 & -0.674891 \\ \mathrm{C} & -1.193770 & -2.784739 & -0.633629 \\ \mathrm{H} & -1.372407 & -4.794438 & 0.061235 \\ \mathrm{O} & -1.772273 & 1.089477 & 0.625457 \\ \mathrm{P} & -0.532535 & 0.665847 & -0.350970 \\ \mathrm{O} & -1.217072 & -0.466312 & -1.316174 \\ \mathrm{C} & -1.937548 & 5.993937 & 1.962478 \\ \mathrm{C} & -3.175217 & 5.522608 & 2.401693 \\ \mathrm{C} & -3.725076 & 4.372397 & 1.836112 \\ \mathrm{C} & -3.048119 & 3.670982 & 0.824625 \\ \mathrm{C} & -1.803264 & 4.152995 & 0.391084 \\ \mathrm{C} & -1.257594 & 5.305564 & 0.955906 \\ \mathrm{H} & -3.712546 & 6.045866 & 3.188541 \\ \mathrm{H} & -0.296097 & 5.669147 & 0.602299 \\ \mathrm{C} & 2.630746 & -3.551578 & -2.453305 \\ \mathrm{C} & 2.372326 & -3.964267 & -1.145065 \\ \mathrm{C} & 1.135276 & -3.695272 & -0.558679 \\ \mathrm{C} & 0.133826 & -3.008815 & -1.265368 \\ \mathrm{C} & 0.409918 & -2.591881 & -2.578758 \\ \mathrm{C} & 1.644846 & -2.864866 & -3.166031 \\ \mathrm{H} & 3.136170 & -4.488411 & -0.576444 \\ \mathrm{H} & 1.834489 & -2.543451 & -4.186898 \\ \mathrm{C} & -3.718831 & -2.346855 & 0.640011 \\ \mathrm{C} & -3.073799 & -3.625448 & 0.692912 \\ \mathrm{C} & -3.678768 & -4.683748 & 1.424004 \\ & -4.855467 & -4.488967 & 2.108643\end{array}$




\begin{tabular}{|c|c|c|c|}
\hline C & -5.472373 & -3.216126 & 2.094214 \\
\hline C & -4.921411 & -2.175178 & 1.379485 \\
\hline $\mathrm{H}$ & -3.182373 & -5.651241 & 1.440948 \\
\hline $\mathrm{H}$ & -5.305318 & -5.303518 & 2.669657 \\
\hline $\mathrm{H}$ & -6.388341 & -3.055651 & 2.656377 \\
\hline $\mathrm{H}$ & -5.402962 & -1.204731 & 1.387779 \\
\hline C & -5.053642 & 0.190105 & -0.838401 \\
\hline C & -5.685690 & 1.474247 & -0.815663 \\
\hline C & -6.983911 & 1.624895 & -1.374076 \\
\hline C & -7.631134 & 0.560426 & -1.956897 \\
\hline C & -6.996355 & -0.702839 & -2.010116 \\
\hline C & -5.744314 & -0.884088 & -1.464798 \\
\hline $\mathrm{H}$ & -7.451039 & 2.606368 & -1.341332 \\
\hline $\mathrm{H}$ & -8.620792 & 0.688474 & -2.386748 \\
\hline $\mathrm{H}$ & -7.498352 & -1.537491 & -2.492055 \\
\hline $\mathrm{H}$ & -5.267568 & -1.855684 & -1.525088 \\
\hline $\mathrm{O}$ & 0.578577 & 0.147421 & 0.499359 \\
\hline $\mathrm{O}$ & -0.224008 & 1.815269 & -1.328671 \\
\hline $\mathrm{H}$ & 0.892392 & 2.188900 & -1.455837 \\
\hline $\mathrm{H}$ & -1.272568 & 3.634030 & -0.399018 \\
\hline $\mathrm{H}$ & -1.505906 & 6.889761 & 2.401373 \\
\hline $\mathrm{H}$ & -4.682111 & 3.999435 & 2.191259 \\
\hline $\mathrm{H}$ & -0.349359 & -2.060596 & -3.142414 \\
\hline $\mathrm{H}$ & 3.592100 & -3.763711 & -2.913909 \\
\hline $\mathrm{H}$ & 0.945346 & -3.997302 & 0.467467 \\
\hline C & 2.797308 & 2.163939 & -0.637226 \\
\hline 0 & 2.053550 & 2.581119 & -1.586186 \\
\hline $\mathrm{H}$ & 2.347313 & 1.836473 & 0.304384 \\
\hline C & 4.169025 & 2.774560 & -0.449856 \\
\hline 0 & 4.685244 & 2.862169 & 0.645716 \\
\hline $\mathrm{O}$ & 4.718181 & 3.189647 & -1.597316 \\
\hline C & 6.026667 & 3.777348 & -1.473572 \\
\hline $\mathrm{H}$ & 6.733198 & 3.049124 & -1.066579 \\
\hline $\mathrm{H}$ & 6.309959 & 4.067516 & -2.485164 \\
\hline C & 4.001235 & -0.356691 & -0.068220 \\
\hline C & 3.400122 & 0.234342 & -1.181036 \\
\hline $\mathrm{H}$ & 2.178937 & -0.590505 & 0.834923 \\
\hline $\mathrm{N}$ & 3.183622 & -0.814609 & 0.927395 \\
\hline C & 3.499893 & -1.760458 & 1.908504 \\
\hline $\mathrm{O}$ & 4.560378 & -2.324185 & 2.060100 \\
\hline 0 & 2.398908 & -1.960127 & 2.657541 \\
\hline C & 2.548893 & -2.920767 & 3.714220 \\
\hline $\mathrm{H}$ & 1.577858 & -2.956602 & 4.207588 \\
\hline $\mathrm{H}$ & 3.325642 & -2.602121 & 4.414186 \\
\hline
\end{tabular}




$\begin{array}{llll}\mathrm{H} & 2.812970 & -3.900971 & 3.308592 \\ \mathrm{H} & 4.034869 & 0.518951 & -2.011636 \\ \mathrm{H} & 2.382840 & -0.050278 & -1.420975 \\ \mathrm{C} & 5.469604 & -0.339253 & 0.087049 \\ \mathrm{C} & 6.281811 & -0.658063 & -1.014486 \\ \mathrm{C} & 6.074580 & 0.078488 & 1.285286 \\ \mathrm{C} & 7.669293 & -0.580869 & -0.914820 \\ \mathrm{H} & 5.821005 & -0.997535 & -1.937137 \\ \mathrm{C} & 7.459168 & 0.173213 & 1.374446 \\ \mathrm{H} & 5.456280 & 0.361257 & 2.129073 \\ \mathrm{C} & 8.259957 & -0.161697 & 0.279050 \\ \mathrm{H} & 8.287436 & -0.849755 & -1.766661 \\ \mathrm{H} & 7.915329 & 0.510567 & 2.300498 \\ \mathrm{H} & 9.341852 & -0.095623 & 0.356527 \\ \mathrm{H} & 5.991487 & 4.650478 & -0.817349\end{array}$

Catalyst (R)-1 TS Conformation 38

B3LYP/6-31G(d) Energy $=-2809.694989$

B3LYP-D3(BJ)/def2-TZVPP-IEF-PCM(DCM) Energy $=-2810.988347$

B3LYP-D3(BJ)/def2-TZVPP-IEF-PCM(DCM)//B3LYP/6-31G(d) Free Energy (Quasiharmonic) = 2810.346966

Frequencies (Top 3 out of 270)

1. $-684.9440 \mathrm{~cm}-1$

2. $\quad 8.6902 \mathrm{~cm}-1$

3. $15.3343 \mathrm{~cm}-1$

B3LYP/6-31G(d) Molecular Geometry in Cartesian Coordinates

$\begin{array}{lrrr}\text { C } & 3.165293 & 0.260176 & 0.321871 \\ \text { C } & 2.388878 & 1.324818 & -0.106100 \\ \text { C } & 2.661256 & 2.682417 & 0.235856 \\ \text { C } & 3.705723 & 2.915843 & 1.109101 \\ \text { H } & 3.959205 & 3.940162 & 1.368937 \\ \text { C } & 2.402437 & -3.835510 & -0.757347 \\ \text { C } & 2.893276 & -1.122845 & -0.173184 \\ \text { C } & 1.641072 & -1.692229 & 0.007199 \\ \text { C } & 1.381844 & -3.079106 & -0.214175 \\ \text { H } & 2.231801 & -4.892208 & -0.946084 \\ \text { O } & 1.314673 & 1.069955 & -0.950181 \\ \text { P } & -0.011624 & 0.313284 & -0.372510\end{array}$




\begin{tabular}{|c|c|c|c|}
\hline $\mathrm{O}$ & 0.622869 & -0.907973 & 0.528910 \\
\hline C & 0.686555 & 6.121398 & -1.430321 \\
\hline C & 1.053397 & 5.057037 & -2.257343 \\
\hline C & 1.653304 & 3.919678 & -1.719525 \\
\hline C & 1.908410 & 3.828392 & -0.340733 \\
\hline C & 1.519509 & 4.898078 & 0.481887 \\
\hline C & 0.914621 & 6.033535 & -0.056129 \\
\hline $\mathrm{H}$ & 0.883813 & 5.116258 & -3.329580 \\
\hline $\mathrm{H}$ & 0.623509 & 6.849886 & 0.600024 \\
\hline C & -2.212761 & -5.071759 & 1.072275 \\
\hline C & -2.305872 & -3.926809 & 0.277068 \\
\hline C & -1.153502 & -3.265806 & -0.153543 \\
\hline C & 0.116702 & -3.739350 & 0.213865 \\
\hline C & 0.196049 & -4.895262 & 1.008450 \\
\hline C & -0.956233 & -5.557585 & 1.432048 \\
\hline $\mathrm{H}$ & -3.286093 & -3.547284 & -0.000273 \\
\hline $\mathrm{H}$ & -0.869449 & -6.444399 & 2.054563 \\
\hline C & 3.914517 & -1.899471 & -0.821576 \\
\hline C & 3.653467 & -3.276309 & -1.115422 \\
\hline C & 4.653344 & -4.054682 & -1.758898 \\
\hline C & 5.858501 & -3.499118 & -2.120926 \\
\hline C & 6.109356 & -2.132154 & -1.856035 \\
\hline C & 5.165570 & -1.354405 & -1.221663 \\
\hline $\mathrm{H}$ & 4.440886 & -5.100458 & -1.968570 \\
\hline $\mathrm{H}$ & 6.613419 & -4.102366 & -2.617759 \\
\hline $\mathrm{H}$ & 7.053708 & -1.689416 & -2.161145 \\
\hline $\mathrm{H}$ & 5.368509 & -0.305955 & -1.035201 \\
\hline C & 4.202136 & 0.513509 & 1.287434 \\
\hline C & 4.469997 & 1.866361 & 1.674102 \\
\hline C & 5.496577 & 2.134055 & 2.619850 \\
\hline C & 6.215574 & 1.111054 & 3.192398 \\
\hline C & 5.928036 & -0.228793 & 2.842008 \\
\hline C & 4.951393 & -0.519861 & 1.914848 \\
\hline $\mathrm{H}$ & 5.693533 & 3.168555 & 2.891292 \\
\hline $\mathrm{H}$ & 6.993198 & 1.326783 & 3.919974 \\
\hline $\mathrm{H}$ & 6.479422 & -1.038311 & 3.312671 \\
\hline $\mathrm{H}$ & 4.738128 & -1.552964 & 1.667939 \\
\hline $\mathrm{O}$ & -0.803432 & -0.166468 & -1.544790 \\
\hline $\mathrm{O}$ & -0.667724 & 1.223152 & 0.676838 \\
\hline $\mathrm{H}$ & -1.661348 & 0.993108 & 1.247898 \\
\hline $\mathrm{H}$ & 1.683778 & 4.829938 & 1.553569 \\
\hline $\mathrm{H}$ & 0.229899 & 7.012548 & -1.854072 \\
\hline $\mathrm{H}$ & 1.942291 & 3.103105 & -2.372256 \\
\hline $\mathrm{H}$ & 1.172107 & -5.260726 & 1.315913 \\
\hline
\end{tabular}




\begin{tabular}{llll}
$\mathrm{H}$ & -3.114315 & -5.573972 & 1.412145 \\
$\mathrm{H}$ & -1.229440 & -2.390205 & -0.789131 \\
$\mathrm{C}$ & -3.434272 & -0.163523 & 1.639038 \\
$\mathrm{O}$ & -2.710454 & 0.860405 & 1.910939 \\
$\mathrm{H}$ & -2.990338 & -1.022668 & 1.121535 \\
$\mathrm{C}$ & -4.434740 & -0.615439 & 2.695362 \\
$\mathrm{O}$ & -4.760569 & -1.774027 & 2.835544 \\
$\mathrm{O}$ & -4.894740 & 0.409339 & 3.428216 \\
$\mathrm{C}$ & -5.820047 & 0.048481 & 4.469637 \\
$\mathrm{H}$ & -6.092070 & 0.986073 & 4.954234 \\
$\mathrm{H}$ & -6.702134 & -0.439816 & 4.046635 \\
$\mathrm{C}$ & -4.065956 & 0.574836 & -0.835178 \\
$\mathrm{C}$ & -4.864777 & 0.177664 & 0.246209 \\
$\mathrm{H}$ & -2.561390 & -0.165813 & -2.014433 \\
$\mathrm{~N}$ & -3.536075 & -0.331956 & -1.717196 \\
$\mathrm{C}$ & -4.039640 & -1.599027 & -2.020065 \\
$\mathrm{O}$ & -5.053492 & -2.103167 & -1.582525 \\
$\mathrm{O}$ & -3.215303 & -2.167253 & -2.916302 \\
$\mathrm{C}$ & -3.572258 & -3.498149 & -3.330640 \\
$\mathrm{H}$ & -4.598495 & -3.519955 & -3.704070 \\
$\mathrm{H}$ & -3.468549 & -4.193492 & -2.494347 \\
$\mathrm{H}$ & -2.865298 & -3.747616 & -4.121433 \\
$\mathrm{H}$ & -5.462130 & 0.943455 & 0.727661 \\
$\mathrm{H}$ & -5.308930 & -0.808963 & 0.203971 \\
$\mathrm{C}$ & -3.625079 & 1.961362 & -1.004061 \\
$\mathrm{C}$ & -3.738326 & 2.889247 & 0.053309 \\
$\mathrm{C}$ & -3.089875 & 2.399570 & -2.235149 \\
$\mathrm{C}$ & -3.311393 & 4.202745 & -0.116058 \\
$\mathrm{H}$ & -4.116512 & 2.577615 & 1.017712 \\
$\mathrm{H}$ & -2.676474 & 3.714541 & -2.397511 \\
$\mathrm{H}$ & -3.020766 & 1.712155 & -3.070823 \\
& -2.780433 & 4.619148 & -1.336546 \\
$\mathrm{H}$ & -3.385292 & 4.899747 & 0.713251 \\
\hline & -2.268719 & 4.036511 & -3.350843 \\
$\mathrm{H}$ & -344102 & -0.629582 & 5.182421
\end{tabular}

Catalyst (R)-1 TS Conformation 39

B3LYP/6-31G(d) Energy $=-2809.694537$

B3LYP-D3(BJ)/def2-TZVPP-IEF-PCM(DCM) Energy $=-2810.987694$

B3LYP-D3(BJ)/def2-TZVPP-IEF-PCM(DCM)//B3LYP/6-31G(d) Free Energy (Quasiharmonic) = 2810.346665 
Frequencies (Top 3 out of 270)

1. $-703.6439 \mathrm{~cm}-1$

2. $\quad 8.0536 \mathrm{~cm}-1$

3. $\quad 11.9161 \mathrm{~cm}-1$

B3LYP/6-31G(d) Molecular Geometry in Cartesian Coordinates

$\begin{array}{llll}\text { C } & -3.698875 & -0.141383 & -0.298803 \\ \text { C } & -3.214191 & 1.072929 & 0.169690 \\ \text { C } & -4.001282 & 2.263676 & 0.200687 \\ \text { C } & -5.264342 & 2.203456 & -0.355047 \\ \text { H } & -5.882793 & 3.097060 & -0.351256 \\ \text { C } & -1.375966 & -3.763916 & 0.035560 \\ \text { C } & -2.907681 & -1.396163 & -0.120023 \\ \text { C } & -1.608713 & -1.465816 & -0.595237 \\ \text { C } & -0.812881 & -2.648701 & -0.554477 \\ \text { H } & -0.815261 & -4.694754 & 0.055007 \\ \text { O } & -1.947606 & 1.126888 & 0.740754 \\ \text { P } & -0.597259 & 0.872549 & -0.137217 \\ \text { O } & -1.058524 & -0.322599 & -1.161336 \\ \text { C } & -2.824264 & 5.949593 & 2.086163 \\ \text { C } & -1.988064 & 5.360546 & 1.135832 \\ \text { C } & -2.341924 & 4.156341 & 0.527517 \\ \text { C } & -3.548890 & 3.521554 & 0.860163 \\ \text { C } & -4.383922 & 4.123531 & 1.816248 \\ \text { C } & -4.025408 & 5.325772 & 2.425425 \\ \text { H } & -1.053504 & 5.842366 & 0.860009 \\ \text { H } & -4.682891 & 5.770558 & 3.168094 \\ \text { C } & 3.168183 & -2.936933 & -2.173231 \\ \text { C } & 2.174935 & -2.258147 & -2.883249 \\ \text { C } & 0.886687 & -2.144392 & -2.362078 \\ \text { C } & 0.564281 & -2.705981 & -1.113593 \\ \text { C } & 1.575198 & -3.378889 & -0.407697 \\ \text { C } & 2.862409 & -3.498076 & -0.932440 \\ \text { H } & 2.401089 & -1.820526 & -3.851830 \\ \text { H } & 3.625810 & -4.029905 & -0.369531 \\ \text { C } & -3.444631 & -2.539612 & 0.568389 \\ \text { C } & -2.663965 & -3.739892 & 0.624347 \\ \text { C } & -3.188398 & -4.884093 & 1.285034 \\ \text { C } & -4.417566 & -4.844695 & 1.900610 \\ \text { C } & -5.171972 & -3.648155 & 1.884225 \\ \text { C } & -4.700797 & -2.528260 & 1.234764\end{array}$




\begin{tabular}{|c|c|c|c|}
\hline $\mathrm{H}$ & -2.588757 & -5.791222 & 1.304577 \\
\hline $\mathrm{H}$ & -4.805173 & -5.723337 & 2.408881 \\
\hline $\mathrm{H}$ & -6.131556 & -3.610047 & 2.392639 \\
\hline $\mathrm{H}$ & -5.287979 & -1.617707 & 1.239696 \\
\hline C & -4.974832 & -0.159229 & -0.963465 \\
\hline C & -5.765140 & 1.034252 & -0.976870 \\
\hline C & -7.029653 & 1.029222 & -1.625639 \\
\hline C & -7.494012 & -0.098284 & -2.261745 \\
\hline C & -6.701195 & -1.269767 & -2.279697 \\
\hline C & -5.477668 & -1.300725 & -1.647244 \\
\hline $\mathrm{H}$ & -7.618598 & 1.943358 & -1.618878 \\
\hline $\mathrm{H}$ & -8.459332 & -0.088942 & -2.760390 \\
\hline $\mathrm{H}$ & -7.057373 & -2.152713 & -2.803586 \\
\hline $\mathrm{H}$ & -4.878497 & -2.203201 & -1.682200 \\
\hline $\mathrm{O}$ & 0.501738 & 0.479368 & 0.790955 \\
\hline $\mathrm{O}$ & -0.364327 & 2.066390 & -1.079746 \\
\hline $\mathrm{H}$ & 0.751689 & 2.366044 & -1.362705 \\
\hline $\mathrm{H}$ & -5.312745 & 3.632451 & 2.094314 \\
\hline $\mathrm{H}$ & -2.541680 & 6.886674 & 2.558948 \\
\hline $\mathrm{H}$ & -1.689196 & 3.715715 & -0.217549 \\
\hline $\mathrm{H}$ & 1.351647 & -3.792275 & 0.570841 \\
\hline $\mathrm{H}$ & 4.169494 & -3.029290 & -2.585615 \\
\hline $\mathrm{H}$ & 0.122295 & -1.624474 & -2.928503 \\
\hline C & 2.726761 & 1.725400 & -1.446222 \\
\hline $\mathrm{O}$ & 1.895493 & 2.663960 & -1.678538 \\
\hline $\mathrm{H}$ & 2.370575 & 0.700703 & -1.299693 \\
\hline C & 4.089813 & 1.863457 & -2.102757 \\
\hline 0 & 4.653370 & 2.908184 & -2.326565 \\
\hline 0 & 4.569676 & 0.642882 & -2.413606 \\
\hline C & 5.857383 & 0.641144 & -3.059463 \\
\hline $\mathrm{H}$ & 6.078519 & -0.406023 & -3.264834 \\
\hline $\mathrm{H}$ & 5.815028 & 1.217775 & -3.986681 \\
\hline C & 3.942253 & 0.846068 & 1.012293 \\
\hline C & 3.338393 & 2.010367 & 0.532148 \\
\hline $\mathrm{H}$ & 2.110989 & -0.014289 & 1.316634 \\
\hline$N$ & 3.124657 & -0.150942 & 1.471009 \\
\hline C & 3.462750 & -1.171513 & 2.366918 \\
\hline $\mathrm{O}$ & 4.555931 & -1.397828 & 2.835083 \\
\hline $\mathrm{O}$ & 2.339897 & -1.857939 & 2.653854 \\
\hline C & 2.499245 & -2.896115 & 3.633291 \\
\hline $\mathrm{H}$ & 1.506588 & -3.329434 & 3.754293 \\
\hline $\mathrm{H}$ & 2.854351 & -2.479025 & 4.579097 \\
\hline $\mathrm{H}$ & 3.211314 & -3.648615 & 3.284293 \\
\hline $\mathrm{H}$ & 3.970550 & 2.860869 & 0.306656 \\
\hline
\end{tabular}




$\begin{array}{lrrr}\mathrm{H} & 2.325728 & 2.220682 & 0.856410 \\ \mathrm{C} & 5.400557 & 0.643840 & 0.892258 \\ \mathrm{C} & 6.276052 & 1.705253 & 1.175366 \\ \mathrm{C} & 5.928962 & -0.570154 & 0.417382 \\ \mathrm{C} & 7.650869 & 1.552017 & 1.005843 \\ \mathrm{H} & 5.879566 & 2.640669 & 1.557275 \\ \mathrm{C} & 7.299583 & -0.713213 & 0.232753 \\ \mathrm{H} & 5.258309 & -1.385344 & 0.169460 \\ \mathrm{C} & 8.164921 & 0.344051 & 0.532309 \\ \mathrm{H} & 8.317984 & 2.375022 & 1.244686 \\ \mathrm{H} & 7.697179 & -1.652740 & -0.140634 \\ \mathrm{H} & 9.236478 & 0.224362 & 0.397521 \\ \mathrm{H} & 6.613246 & 1.071290 & -2.398547\end{array}$

Catalyst (R)-1 TS Conformation 40

B3LYP/6-31G(d) Energy = -2809.694394

B3LYP-D3(BJ)/def2-TZVPP-IEF-PCM(DCM) Energy = -2810.988145

B3LYP-D3(BJ)/def2-TZVPP-IEF-PCM(DCM)//B3LYP/6-31G(d) Free Energy (Quasiharmonic) = 2810.346655

Frequencies (Top 3 out of 270)

1. $-499.5900 \mathrm{~cm}-1$

2. $7.4918 \mathrm{~cm}-1$

3. $12.1438 \mathrm{~cm}-1$

B3LYP/6-31G(d) Molecular Geometry in Cartesian Coordinates

$\begin{array}{llll}\mathrm{C} & 3.618699 & -0.871255 & -0.057158 \\ \mathrm{C} & 2.453291 & -1.558617 & 0.241713 \\ \mathrm{C} & 2.299509 & -2.964161 & 0.062350 \\ \mathrm{C} & 3.366035 & -3.652991 & -0.480369 \\ \mathrm{H} & 3.291077 & -4.729546 & -0.610327 \\ \mathrm{C} & 3.823506 & 3.378721 & 0.653035 \\ \mathrm{C} & 3.703573 & 0.590487 & 0.236989 \\ \mathrm{C} & 2.747181 & 1.452647 & -0.279004 \\ \mathrm{C} & 2.789791 & 2.868250 & -0.108859 \\ \mathrm{H} & 3.903671 & 4.454986 & 0.780162 \\ \mathrm{O} & 1.373029 & -0.845970 & 0.752408 \\ \mathrm{P} & 0.516592 & 0.092725 & -0.283591 \\ \mathrm{O} & 1.706057 & 0.919757 & -1.034185 \\ \mathrm{C} & -1.296424 & -5.089865 & 1.107050\end{array}$




\begin{tabular}{|c|c|c|c|}
\hline$C$ & -0.695048 & -5.280827 & -0.137981 \\
\hline C & 0.464179 & -4.580161 & -0.472878 \\
\hline C & 1.044696 & -3.673640 & 0.428600 \\
\hline C & 0.431734 & -3.490481 & 1.680133 \\
\hline C & -0.724569 & -4.194509 & 2.015199 \\
\hline $\mathrm{H}$ & -1.134528 & -5.968020 & -0.856230 \\
\hline $\mathrm{H}$ & -1.180823 & -4.044231 & 2.990295 \\
\hline C & -0.065526 & 5.594919 & -1.817227 \\
\hline C & 0.337392 & 5.729523 & -0.488522 \\
\hline C & 1.249558 & 4.829792 & 0.060599 \\
\hline C & 1.777994 & 3.779107 & -0.707257 \\
\hline C & 1.363017 & 3.653866 & -2.043646 \\
\hline C & 0.451564 & 4.554536 & -2.590867 \\
\hline $\mathrm{H}$ & -0.066124 & 6.529493 & 0.127101 \\
\hline $\mathrm{H}$ & 0.142102 & 4.440128 & -3.626243 \\
\hline C & 4.725596 & 1.132186 & 1.090662 \\
\hline C & 4.784709 & 2.550584 & 1.281455 \\
\hline C & 5.798499 & 3.101760 & 2.111630 \\
\hline C & 6.701863 & 2.291570 & 2.758849 \\
\hline C & 6.621006 & 0.887539 & 2.604907 \\
\hline C & 5.661446 & 0.323518 & 1.793137 \\
\hline $\mathrm{H}$ & 5.836338 & 4.181602 & 2.234731 \\
\hline $\mathrm{H}$ & 7.468086 & 2.723942 & 3.396516 \\
\hline $\mathrm{H}$ & 7.319620 & 0.246629 & 3.136016 \\
\hline $\mathrm{H}$ & 5.607898 & -0.754377 & 1.694452 \\
\hline C & 4.693172 & -1.589240 & -0.687180 \\
\hline C & 4.558316 & -3.002364 & -0.883469 \\
\hline C & 5.617305 & -3.725967 & -1.495981 \\
\hline C & 6.753969 & -3.085281 & -1.930825 \\
\hline C & 6.873091 & -1.684320 & -1.774743 \\
\hline C & 5.872257 & -0.956717 & -1.169161 \\
\hline $\mathrm{H}$ & 5.503395 & -4.799624 & -1.626057 \\
\hline $\mathrm{H}$ & 7.553754 & -3.648070 & -2.404325 \\
\hline $\mathrm{H}$ & 7.760739 & -1.175536 & -2.140880 \\
\hline $\mathrm{H}$ & 5.975247 & 0.117217 & -1.066601 \\
\hline 0 & -0.437023 & 0.905329 & 0.529472 \\
\hline 0 & -0.058275 & -0.782296 & -1.418107 \\
\hline $\mathrm{H}$ & -1.189762 & -0.897381 & -1.412295 \\
\hline $\mathrm{H}$ & 0.867386 & -2.797471 & 2.392186 \\
\hline $\mathrm{H}$ & -2.209184 & -5.619875 & 1.362591 \\
\hline $\mathrm{H}$ & 0.913022 & -4.713149 & -1.453177 \\
\hline $\mathrm{H}$ & 1.758696 & 2.850676 & -2.655358 \\
\hline $\mathrm{H}$ & -0.783375 & 6.289459 & -2.245110 \\
\hline $\mathrm{H}$ & 1.539689 & 4.923724 & 1.103451 \\
\hline
\end{tabular}




$\begin{array}{llll}\mathrm{C} & -2.821586 & -1.808949 & -0.388051 \\ \mathrm{O} & -2.466234 & -1.061224 & -1.363294 \\ \mathrm{H} & -2.071543 & -2.413835 & 0.136853 \\ \mathrm{C} & -4.148156 & -2.554593 & -0.468302 \\ \mathrm{O} & -4.477759 & -3.408824 & 0.330079 \\ \mathrm{O} & -4.879734 & -2.183005 & -1.528503 \\ \mathrm{C} & -6.130494 & -2.876131 & -1.678743 \\ \mathrm{H} & -5.963730 & -3.954319 & -1.742265 \\ \mathrm{H} & -6.788469 & -2.662695 & -0.832498 \\ \mathrm{C} & -3.870560 & 0.363200 & 0.858995 \\ \mathrm{C} & -3.149878 & -0.750594 & 1.313702 \\ \mathrm{H} & -2.141705 & 1.204854 & 0.170825 \\ \mathrm{~N} & -3.168544 & 1.348433 & 0.249665 \\ \mathrm{C} & -3.550304 & 2.651972 & -0.126375 \\ \mathrm{O} & -2.892481 & 3.315201 & -0.891695 \\ \mathrm{O} & -4.663353 & 3.065040 & 0.502290 \\ \mathrm{C} & -5.097183 & 4.389093 & 0.145739 \\ \mathrm{H} & -5.303356 & 4.449656 & -0.925854 \\ \mathrm{H} & -4.330104 & 5.122321 & 0.405750 \\ \mathrm{H} & -6.005863 & 4.557507 & 0.723546 \\ \mathrm{H} & -3.681715 & -1.495563 & 1.893961 \\ \mathrm{H} & -2.104685 & -0.591375 & 1.561165 \\ \mathrm{C} & -5.351171 & 0.340148 & 0.842596 \\ \mathrm{C} & -6.055094 & -0.037872 & 1.995189 \\ \mathrm{C} & -6.062424 & 0.615732 & -0.337947 \\ \mathrm{C} & -7.447483 & -0.111410 & 1.978415 \\ \mathrm{H} & -5.509920 & -0.250206 & 2.909834 \\ \mathrm{C} & -7.451034 & 0.524222 & -0.355281 \\ \mathrm{H} & -5.519810 & 0.860859 & -1.245374 \\ \mathrm{C} & -8.147576 & 0.168967 & 0.804214 \\ \mathrm{H} & -7.983067 & -0.389923 & 2.881378 \\ \mathrm{H} & -7.992058 & 0.727560 & -1.275310 \\ \mathrm{H} & -9.232297 & 0.106309 & 0.789214 \\ & -6.562126 & -2.498061 & -2.605625\end{array}$

Catalyst (R)-1 TS Conformation 41

B3LYP/6-31G(d) Energy $=-2809.693642$

B3LYP-D3(BJ)/def2-TZVPP-IEF-PCM(DCM) Energy = -2810.987741

B3LYP-D3(BJ)/def2-TZVPP-IEF-PCM(DCM)//B3LYP/6-31G(d) Free Energy (Quasiharmonic) = 2810.346651

Frequencies (Top 3 out of 270) 
1. $-658.9817 \mathrm{~cm}-1$

2. $\quad 11.5488 \mathrm{~cm}-1$

3. $\quad 18.0611 \mathrm{~cm}-1$

B3LYP/6-31G(d) Molecular Geometry in Cartesian Coordinates

\begin{tabular}{|c|c|c|c|}
\hline C & 2.878366 & -1.426308 & -0.268009 \\
\hline C & 1.590071 & -1.792899 & 0.086996 \\
\hline C & 1.040248 & -3.084879 & -0.160987 \\
\hline C & 1.841706 & -3.993698 & -0.823969 \\
\hline $\mathrm{H}$ & 1.467385 & -4.997665 & -1.006398 \\
\hline C & 4.309328 & 2.535571 & 0.666905 \\
\hline C & 3.382777 & -0.070375 & 0.104965 \\
\hline C & 2.672042 & 1.059257 & -0.276239 \\
\hline C & 3.126917 & 2.389699 & -0.033019 \\
\hline $\mathrm{H}$ & 4.700278 & 3.534147 & 0.843102 \\
\hline 0 & 0.794337 & -0.859706 & 0.735789 \\
\hline$P$ & 0.157777 & 0.368212 & -0.144378 \\
\hline $\mathrm{O}$ & 1.474643 & 0.897565 & -0.962307 \\
\hline C & -2.946207 & -4.219202 & 1.010849 \\
\hline C & -2.460921 & -4.534627 & -0.259759 \\
\hline C & -1.171848 & -4.154732 & -0.632041 \\
\hline C & -0.340482 & -3.449029 & 0.254453 \\
\hline C & -0.841184 & -3.133348 & 1.529384 \\
\hline C & -2.128760 & -3.519649 & 1.902040 \\
\hline $\mathrm{H}$ & -3.093078 & -5.064647 & -0.967034 \\
\hline $\mathrm{H}$ & -2.486637 & -3.268502 & 2.897122 \\
\hline C & 1.157570 & 5.956317 & -1.421639 \\
\hline C & 1.284340 & 4.854293 & -2.270319 \\
\hline C & 1.892746 & 3.683352 & -1.821527 \\
\hline C & 2.392939 & 3.592150 & -0.511505 \\
\hline C & 2.248075 & 4.703375 & 0.335593 \\
\hline C & 1.638446 & 5.874470 & -0.113737 \\
\hline $\mathrm{H}$ & 0.914699 & 4.906961 & -3.291121 \\
\hline $\mathrm{H}$ & 1.540252 & 6.722370 & 0.559691 \\
\hline C & 4.568675 & 0.101021 & 0.899481 \\
\hline C & 5.036336 & 1.428247 & 1.166395 \\
\hline C & 6.215346 & 1.612006 & 1.938859 \\
\hline C & 6.894468 & 0.535998 & 2.460639 \\
\hline C & 6.412465 & -0.774572 & 2.233495 \\
\hline C & 5.283136 & -0.986728 & 1.473664 \\
\hline $\mathrm{H}$ & 6.562693 & 2.626494 & 2.120215 \\
\hline $\mathrm{H}$ & 7.790480 & 0.688795 & 3.056010 \\
\hline
\end{tabular}




\begin{tabular}{|c|c|c|c|}
\hline $\mathrm{H}$ & 6.935105 & -1.622921 & 2.667130 \\
\hline $\mathrm{H}$ & 4.922099 & -1.996662 & 1.318850 \\
\hline C & 3.670526 & -2.356617 & -1.025058 \\
\hline C & 3.139358 & -3.661893 & -1.285707 \\
\hline C & 3.917257 & -4.597335 & -2.020728 \\
\hline C & 5.156147 & -4.257675 & -2.512145 \\
\hline C & 5.665892 & -2.956666 & -2.291261 \\
\hline C & 4.944717 & -2.032688 & -1.567248 \\
\hline $\mathrm{H}$ & 3.504235 & -5.587541 & -2.198624 \\
\hline $\mathrm{H}$ & 5.738211 & -4.979220 & -3.078921 \\
\hline $\mathrm{H}$ & 6.634082 & -2.681188 & -2.700715 \\
\hline $\mathrm{H}$ & 5.345809 & -1.037395 & -1.415172 \\
\hline $\mathrm{O}$ & -0.408632 & 1.361028 & 0.815235 \\
\hline 0 & -0.706686 & -0.219765 & -1.269326 \\
\hline $\mathrm{H}$ & -1.857710 & -0.168619 & -1.413326 \\
\hline $\mathrm{H}$ & -0.226043 & -2.581607 & 2.230863 \\
\hline $\mathrm{H}$ & -3.956284 & -4.501416 & 1.293122 \\
\hline $\mathrm{H}$ & -0.810703 & -4.379950 & -1.631612 \\
\hline $\mathrm{H}$ & 2.603778 & 4.639346 & 1.360073 \\
\hline $\mathrm{H}$ & 0.690264 & 6.871281 & -1.777362 \\
\hline $\mathrm{H}$ & 1.990243 & 2.836824 & -2.491996 \\
\hline C & -3.784910 & -0.851888 & -0.816093 \\
\hline $\mathrm{O}$ & -3.074085 & -0.254970 & -1.699984 \\
\hline $\mathrm{H}$ & -3.291038 & -1.405989 & -0.009157 \\
\hline C & -5.057887 & -1.547157 & -1.277670 \\
\hline $\mathrm{O}$ & -5.551761 & -2.484940 & -0.687021 \\
\hline $\mathrm{O}$ & -5.559213 & -0.996307 & -2.394055 \\
\hline C & -6.752847 & -1.618106 & -2.901831 \\
\hline $\mathrm{H}$ & -6.559233 & -2.663744 & -3.154047 \\
\hline $\mathrm{H}$ & -7.555089 & -1.573090 & -2.160183 \\
\hline C & -3.760758 & 1.236932 & 0.844433 \\
\hline C & -4.797526 & 0.377231 & 0.451081 \\
\hline $\mathrm{H}$ & -1.898656 & 1.163303 & 1.695145 \\
\hline$N$ & -2.899010 & 0.930079 & 1.865746 \\
\hline C & -3.091459 & 0.119705 & 2.989906 \\
\hline O & -2.168771 & -0.290208 & 3.657744 \\
\hline $\mathrm{O}$ & -4.393827 & -0.083860 & 3.270403 \\
\hline C & -4.639738 & -0.860626 & 4.456433 \\
\hline $\mathrm{H}$ & -5.724514 & -0.889314 & 4.559077 \\
\hline $\mathrm{H}$ & -4.179844 & -0.385223 & 5.325670 \\
\hline $\mathrm{H}$ & -4.238166 & -1.870626 & 4.343434 \\
\hline $\mathrm{H}$ & -5.573885 & 0.803682 & -0.174199 \\
\hline $\mathrm{H}$ & -5.134183 & -0.379389 & 1.146829 \\
\hline C & -3.422982 & 2.425176 & 0.055653 \\
\hline
\end{tabular}




$\begin{array}{llll}\text { C } & -3.877400 & 2.564670 & -1.273636 \\ \text { C } & -2.643363 & 3.458862 & 0.617425 \\ \text { C } & -3.554248 & 3.700456 & -2.010198 \\ \text { H } & -4.441815 & 1.771882 & -1.746354 \\ \text { C } & -2.332439 & 4.591883 & -0.121653 \\ \text { H } & -2.291634 & 3.374364 & 1.638874 \\ \text { C } & -2.784139 & 4.714278 & -1.438768 \\ \text { H } & -3.896405 & 3.786780 & -3.037304 \\ \text { H } & -1.721508 & 5.372161 & 0.320692 \\ \text { H } & -2.530579 & 5.597606 & -2.018313 \\ \text { H } & -7.019011 & -1.051222 & -3.793842\end{array}$

Catalyst (R)-1 TS Conformation 42

B3LYP/6-31G(d) Energy $=-2809.696798$

B3LYP-D3(BJ)/def2-TZVPP-IEF-PCM(DCM) Energy = -2810.988943

B3LYP-D3(BJ)/def2-TZVPP-IEF-PCM(DCM)//B3LYP/6-31G(d) Free Energy (Quasiharmonic) = 2810.346591

Frequencies (Top 3 out of 270)

1. $-427.1816 \mathrm{~cm}-1$

2. $\quad 9.9531 \mathrm{~cm}-1$

3. $\quad 12.3970 \mathrm{~cm}-1$

B3LYP/6-31G(d) Molecular Geometry in Cartesian Coordinates

$\begin{array}{llll}\mathrm{C} & 3.429015 & -1.063504 & -0.025901 \\ \mathrm{C} & 2.214207 & -1.669391 & 0.243595 \\ \mathrm{C} & 1.931311 & -3.036334 & -0.042298 \\ \mathrm{C} & 2.922524 & -3.766990 & -0.667333 \\ \mathrm{H} & 2.753005 & -4.819743 & -0.877614 \\ \mathrm{C} & 4.179612 & 3.059319 & 0.968200 \\ \mathrm{C} & 3.661472 & 0.348203 & 0.400283 \\ \mathrm{C} & 2.796058 & 1.356533 & -0.003009 \\ \mathrm{C} & 3.054100 & 2.740453 & 0.232854 \\ \mathrm{H} & 4.395379 & 4.105079 & 1.169976 \\ \mathrm{O} & 1.210105 & -0.901843 & 0.830170 \\ \mathrm{P} & 0.441481 & 0.174812 & -0.132775 \\ \mathrm{O} & 1.678133 & 1.028603 & -0.765450 \\ \mathrm{C} & -1.778401 & -4.975058 & 0.962535 \\ \mathrm{C} & -1.138946 & -4.161766 & 1.901770 \\ \mathrm{C} & 0.052409 & -3.512692 & 1.578644\end{array}$




\begin{tabular}{|c|c|c|c|}
\hline$C$ & 0.632314 & -3.669522 & 0.307846 \\
\hline C & -0.022104 & -4.487471 & -0.627978 \\
\hline C & -1.214967 & -5.134432 & -0.304679 \\
\hline $\mathrm{H}$ & -1.565013 & -4.036581 & 2.893957 \\
\hline $\mathrm{H}$ & -1.707752 & -5.756329 & -1.047359 \\
\hline C & 0.706672 & 6.032081 & -1.241689 \\
\hline C & 2.081125 & 5.974179 & -1.477261 \\
\hline C & 2.822950 & 4.888619 & -1.013189 \\
\hline C & 2.206696 & 3.838926 & -0.310670 \\
\hline C & 0.822245 & 3.900343 & -0.090103 \\
\hline C & 0.084246 & 4.992335 & -0.547839 \\
\hline $\mathrm{H}$ & 2.577438 & 6.772056 & -2.023705 \\
\hline $\mathrm{H}$ & -0.984107 & 5.025533 & -0.353800 \\
\hline C & 4.771740 & 0.692484 & 1.247460 \\
\hline C & 5.033400 & 2.073360 & 1.517683 \\
\hline C & 6.131146 & 2.428985 & 2.347596 \\
\hline C & 6.930535 & 1.464107 & 2.914317 \\
\hline C & 6.654577 & 0.096826 & 2.677453 \\
\hline C & 5.606590 & -0.279057 & 1.866193 \\
\hline $\mathrm{H}$ & 6.318365 & 3.483647 & 2.535107 \\
\hline $\mathrm{H}$ & 7.763561 & 1.746581 & 3.552137 \\
\hline $\mathrm{H}$ & 7.271528 & -0.665541 & 3.145436 \\
\hline $\mathrm{H}$ & 5.403232 & -1.331347 & 1.705492 \\
\hline C & 4.421439 & -1.815086 & -0.746920 \\
\hline C & 4.157135 & -3.189555 & -1.053630 \\
\hline C & 5.132592 & -3.948686 & -1.755320 \\
\hline C & 6.310500 & -3.374335 & -2.172445 \\
\hline C & 6.556557 & -2.006825 & -1.907416 \\
\hline C & 5.639679 & -1.248717 & -1.212750 \\
\hline $\mathrm{H}$ & 4.920649 & -4.993743 & -1.968547 \\
\hline $\mathrm{H}$ & 7.045478 & -3.962322 & -2.715180 \\
\hline $\mathrm{H}$ & 7.476070 & -1.547431 & -2.259811 \\
\hline $\mathrm{H}$ & 5.840182 & -0.200106 & -1.027652 \\
\hline 0 & -0.508536 & 0.951663 & 0.722052 \\
\hline $\mathrm{O}$ & -0.135305 & -0.560857 & -1.363727 \\
\hline $\mathrm{H}$ & -1.255517 & -0.630304 & -1.403424 \\
\hline $\mathrm{H}$ & 0.399239 & -4.596175 & -1.623251 \\
\hline $\mathrm{H}$ & -2.710199 & -5.473695 & 1.214155 \\
\hline $\mathrm{H}$ & 0.542718 & -2.887466 & 2.317069 \\
\hline $\mathrm{H}$ & 0.322652 & 3.104419 & 0.450860 \\
\hline $\mathrm{H}$ & 0.126479 & 6.880786 & -1.595147 \\
\hline $\mathrm{H}$ & 3.891141 & 4.841754 & -1.207593 \\
\hline C & -3.077250 & -1.538184 & -0.619392 \\
\hline $\mathrm{O}$ & -2.562098 & -0.709588 & -1.445403 \\
\hline
\end{tabular}




$\begin{array}{llll}\mathrm{H} & -2.448761 & -2.300701 & -0.142827 \\ \mathrm{C} & -4.477188 & -2.027341 & -0.956957 \\ \mathrm{O} & -5.220800 & -1.516281 & -1.757960 \\ \mathrm{O} & -4.771945 & -3.147122 & -0.247333 \\ \mathrm{C} & -6.034934 & -3.754625 & -0.570237 \\ \mathrm{H} & -6.857479 & -3.055615 & -0.397591 \\ \mathrm{H} & -6.050378 & -4.062909 & -1.619048 \\ \mathrm{C} & -4.025292 & 0.572387 & 0.799214 \\ \mathrm{C} & -3.379673 & -0.618697 & 1.172037 \\ \mathrm{H} & -2.225905 & 1.348037 & 0.243225 \\ \mathrm{~N} & -3.246128 & 1.486781 & 0.158401 \\ \mathrm{C} & -3.632098 & 2.308762 & -0.919776 \\ \mathrm{O} & -4.751936 & 2.482406 & -1.334754 \\ \mathrm{O} & -2.515557 & 2.872611 & -1.413811 \\ \mathrm{C} & -2.702541 & 3.645762 & -2.612421 \\ \mathrm{H} & -3.434374 & 4.439999 & -2.445334 \\ \mathrm{H} & -3.047084 & 3.000175 & -3.424017 \\ \mathrm{H} & -1.720797 & 4.060761 & -2.836893 \\ \mathrm{H} & -3.898704 & -1.301250 & 1.836284 \\ \mathrm{H} & -2.308124 & -0.548735 & 1.335009 \\ \mathrm{C} & -5.449866 & 0.825463 & 1.073284 \\ \mathrm{C} & -5.908646 & 2.136351 & 1.299260 \\ \mathrm{C} & -6.352291 & -0.240617 & 1.241759 \\ \mathrm{C} & -7.228944 & 2.371459 & 1.667405 \\ \mathrm{H} & -5.222296 & 2.969325 & 1.207662 \\ \mathrm{C} & -7.676886 & -0.000632 & 1.593561 \\ \mathrm{H} & -6.019213 & -1.260210 & 1.088581 \\ \mathrm{C} & -8.120640 & 1.305958 & 1.807006 \\ \mathrm{H} & -7.562597 & 3.389728 & 1.844638 \\ \mathrm{H} & -8.363492 & -0.835148 & 1.703926 \\ \mathrm{H} & -9.153640 & 1.492149 & 2.087531 \\ \mathrm{H} & -6.120565 & -4.621302 & 0.085838\end{array}$

Catalyst (R)-1 TS Conformation 43 (TS-3Si)

B3LYP/6-31G(d) Energy = -2809.692687

B3LYP-D3(BJ)/def2-TZVPP-IEF-PCM(DCM) Energy $=-2810.988185$

B3LYP-D3(BJ)/def2-TZVPP-IEF-PCM(DCM)//B3LYP/6-31G(d) Free Energy (Quasiharmonic) = 2810.346469

Frequencies (Top 3 out of 270)

1. $-589.5612 \mathrm{~cm}-1$ 
2. $\quad 8.4550 \mathrm{~cm}-1$

3. $\quad 10.8216 \mathrm{~cm}-1$

B3LYP/6-31G(d) Molecular Geometry in Cartesian Coordinates

\begin{tabular}{|c|c|c|c|}
\hline C & -3.411084 & -1.117455 & 0.132716 \\
\hline C & -2.194656 & -1.708726 & -0.166018 \\
\hline C & -1.839506 & -3.026525 & 0.247277 \\
\hline C & -2.753339 & -3.715720 & 1.019772 \\
\hline $\mathrm{H}$ & -2.527149 & -4.732877 & 1.329078 \\
\hline C & -4.380952 & 2.850789 & -1.235066 \\
\hline C & -3.726281 & 0.232346 & -0.420390 \\
\hline C & -2.863799 & 1.299300 & -0.197202 \\
\hline C & -3.189689 & 2.639342 & -0.569395 \\
\hline $\mathrm{H}$ & -4.646194 & 3.862483 & -1.530982 \\
\hline $\mathrm{O}$ & -1.274976 & -0.982599 & -0.909337 \\
\hline$P$ & -0.452169 & 0.203320 & -0.113354 \\
\hline $\mathrm{O}$ & -1.690062 & 1.094717 & 0.508737 \\
\hline C & 1.868952 & -4.943838 & -0.798599 \\
\hline C & 1.390718 & -4.991088 & 0.511399 \\
\hline C & 0.197680 & -4.350030 & 0.845039 \\
\hline C & -0.542446 & -3.651486 & -0.122732 \\
\hline C & -0.046395 & -3.605486 & -1.437353 \\
\hline C & 1.145681 & -4.247643 & -1.770317 \\
\hline $\mathrm{H}$ & 1.949660 & -5.519891 & 1.279190 \\
\hline $\mathrm{H}$ & 1.508203 & -4.207013 & -2.794227 \\
\hline C & -0.802474 & 6.116589 & 0.287306 \\
\hline C & -2.132468 & 6.046889 & 0.703118 \\
\hline C & -2.887348 & 4.903773 & 0.438734 \\
\hline C & -2.326986 & 3.808393 & -0.238129 \\
\hline C & -0.985602 & 3.883623 & -0.646231 \\
\hline C & -0.236195 & 5.032621 & -0.388558 \\
\hline $\mathrm{H}$ & -2.584615 & 6.880790 & 1.234075 \\
\hline $\mathrm{H}$ & 0.796100 & 5.083777 & -0.726479 \\
\hline C & -4.909884 & 0.453580 & -1.207036 \\
\hline C & -5.242836 & 1.789012 & -1.600227 \\
\hline C & -6.415849 & 2.022352 & -2.368014 \\
\hline C & -7.223065 & 0.980455 & -2.760838 \\
\hline C & -6.878777 & -0.344929 & -2.405120 \\
\hline C & -5.756076 & -0.601438 & -1.649160 \\
\hline $\mathrm{H}$ & -6.655192 & 3.045115 & -2.650006 \\
\hline $\mathrm{H}$ & -8.114354 & 1.169281 & -3.353044 \\
\hline $\mathrm{H}$ & -7.502611 & -1.170551 & -2.737150 \\
\hline $\mathrm{H}$ & -5.501663 & -1.624046 & -1.396116 \\
\hline
\end{tabular}




\begin{tabular}{|c|c|c|c|}
\hline$C$ & -4.317717 & -1.815364 & 1.004423 \\
\hline C & -3.979111 & -3.139427 & 1.434541 \\
\hline C & -4.871021 & -3.847393 & 2.285065 \\
\hline C & -6.037011 & -3.268024 & 2.728308 \\
\hline C & -6.353862 & -1.945238 & 2.340064 \\
\hline C & -5.519546 & -1.239537 & 1.500972 \\
\hline $\mathrm{H}$ & -4.603590 & -4.856302 & 2.590714 \\
\hline $\mathrm{H}$ & -6.707389 & -3.816286 & 3.384633 \\
\hline $\mathrm{H}$ & -7.262272 & -1.478292 & 2.711244 \\
\hline $\mathrm{H}$ & -5.772850 & -0.223559 & 1.222103 \\
\hline $\mathrm{O}$ & 0.380452 & 0.935990 & -1.113853 \\
\hline O & 0.211228 & -0.390717 & 1.131904 \\
\hline $\mathrm{H}$ & 1.436473 & -0.582666 & 1.199357 \\
\hline $\mathrm{H}$ & -0.601179 & -3.069750 & -2.199747 \\
\hline $\mathrm{H}$ & 2.799176 & -5.440396 & -1.060728 \\
\hline $\mathrm{H}$ & -0.156577 & -4.368290 & 1.871680 \\
\hline $\mathrm{H}$ & -0.535058 & 3.047984 & -1.172235 \\
\hline $\mathrm{H}$ & -0.212805 & 7.008267 & 0.484789 \\
\hline $\mathrm{H}$ & -3.920837 & 4.849205 & 0.770445 \\
\hline C & 3.082822 & -1.161480 & 0.153276 \\
\hline O & 2.584242 & -0.795836 & 1.278164 \\
\hline $\mathrm{H}$ & 2.420197 & -1.562957 & -0.620133 \\
\hline C & 4.462872 & -1.790415 & 0.197635 \\
\hline 0 & 5.337714 & -1.497771 & 0.984021 \\
\hline $\mathrm{O}$ & 4.569539 & -2.711967 & -0.773557 \\
\hline C & 5.853369 & -3.346505 & -0.900340 \\
\hline $\mathrm{H}$ & 5.708026 & -4.159997 & -1.611349 \\
\hline $\mathrm{H}$ & 6.577840 & -2.626265 & -1.288137 \\
\hline C & 4.363268 & 1.217302 & -0.175780 \\
\hline C & 3.545018 & 0.447561 & -1.002926 \\
\hline $\mathrm{H}$ & 6.218773 & 1.874475 & 0.359872 \\
\hline$N$ & 5.731268 & 1.273286 & -0.292314 \\
\hline C & 6.566628 & 0.612549 & -1.188774 \\
\hline 0 & 6.232902 & -0.182634 & -2.039817 \\
\hline $\mathrm{O}$ & 7.828561 & 1.022541 & -0.952117 \\
\hline C & 8.834187 & 0.428244 & -1.791803 \\
\hline $\mathrm{H}$ & 8.606217 & 0.606033 & -2.845180 \\
\hline $\mathrm{H}$ & 8.894673 & -0.647524 & -1.608531 \\
\hline $\mathrm{H}$ & 9.767060 & 0.915900 & -1.510234 \\
\hline $\mathrm{H}$ & 2.491434 & 0.718956 & -1.057279 \\
\hline $\mathrm{H}$ & 3.978610 & 0.016269 & -1.897177 \\
\hline C & 3.821932 & 1.952208 & 0.977957 \\
\hline C & 2.548283 & 2.545423 & 0.912100 \\
\hline C & 4.557217 & 2.040855 & 2.178913 \\
\hline
\end{tabular}




$\begin{array}{llll}\mathrm{C} & 2.041419 & 3.241517 & 2.007375 \\ \mathrm{H} & 1.951385 & 2.462615 & 0.010724 \\ \mathrm{C} & 4.039986 & 2.727932 & 3.270909 \\ \mathrm{H} & 5.496180 & 1.504893 & 2.286087 \\ \mathrm{C} & 2.786047 & 3.339691 & 3.183439 \\ \mathrm{H} & 1.060955 & 3.701144 & 1.934544 \\ \mathrm{H} & 4.605051 & 2.768676 & 4.197578 \\ \mathrm{H} & 2.383682 & 3.876611 & 4.037988 \\ \mathrm{H} & 6.188886 & -3.729988 & 0.065989\end{array}$

Catalyst (R)-1 TS Conformation 44

B3LYP/6-31G(d) Energy $=-2809.69887$

B3LYP-D3(BJ)/def2-TZVPP-IEF-PCM(DCM) Energy = -2810.987956

B3LYP-D3(BJ)/def2-TZVPP-IEF-PCM(DCM)//B3LYP/6-31G(d) Free Energy (Quasiharmonic) = 2810.346434

Frequencies (Top 3 out of 270)

1. $-427.2978 \mathrm{~cm}-1$

2. $\quad 7.5227 \mathrm{~cm}-1$

3. $\quad 11.4013 \mathrm{~cm}-1$

B3LYP/6-31G(d) Molecular Geometry in Cartesian Coordinates

$\begin{array}{llll}\mathrm{C} & 3.684008 & 0.214248 & 0.334841 \\ \mathrm{C} & 2.781540 & 1.263629 & 0.221163 \\ \mathrm{C} & 3.099844 & 2.606513 & 0.585651 \\ \mathrm{C} & 4.330508 & 2.830540 & 1.170903 \\ \mathrm{H} & 4.597239 & 3.842425 & 1.464269 \\ \mathrm{C} & 2.723491 & -3.688298 & -1.248307 \\ \mathrm{C} & 3.372626 & -1.120507 & -0.260095 \\ \mathrm{C} & 2.201374 & -1.771963 & 0.085451 \\ \mathrm{C} & 1.848255 & -3.073228 & -0.375126 \\ \mathrm{H} & 2.502855 & -4.692066 & -1.601923 \\ \mathrm{O} & 1.545258 & 1.042133 & -0.376051 \\ \mathrm{P} & 0.417038 & 0.077607 & 0.298090 \\ \mathrm{O} & 1.317786 & -1.121256 & 0.942304 \\ \mathrm{C} & 0.598404 & 6.010353 & -0.247439 \\ \mathrm{C} & 0.073704 & 4.919502 & 0.449760 \\ \mathrm{C} & 0.864265 & 3.801436 & 0.716282 \\ \mathrm{C} & 2.200995 & 3.758399 & 0.290248 \\ \mathrm{C} & 2.719392 & 4.862050 & -0.407754\end{array}$




\begin{tabular}{|c|c|c|c|}
\hline C & 1.926431 & 5.977708 & -0.675940 \\
\hline $\mathrm{H}$ & -0.955994 & 4.938068 & 0.797358 \\
\hline $\mathrm{H}$ & 2.346383 & 6.818450 & -1.222233 \\
\hline C & -1.760149 & -5.104445 & 0.801393 \\
\hline C & -0.972695 & -4.468068 & 1.764287 \\
\hline C & 0.190251 & -3.795058 & 1.391704 \\
\hline C & 0.591113 & -3.747781 & 0.045300 \\
\hline C & -0.209974 & -4.390541 & -0.912371 \\
\hline C & -1.373762 & -5.062897 & -0.538989 \\
\hline $\mathrm{H}$ & -1.259828 & -4.502268 & 2.812111 \\
\hline $\mathrm{H}$ & -1.981178 & -5.548601 & -1.298340 \\
\hline C & 4.234645 & -1.741975 & -1.230646 \\
\hline C & 3.901921 & -3.051215 & -1.709946 \\
\hline C & 4.750664 & -3.684200 & -2.658276 \\
\hline C & 5.866556 & -3.046022 & -3.146935 \\
\hline C & 6.174255 & -1.737149 & -2.707909 \\
\hline C & 5.382475 & -1.103432 & -1.775396 \\
\hline $\mathrm{H}$ & 4.489907 & -4.682757 & -3.000966 \\
\hline $\mathrm{H}$ & 6.503797 & -3.537105 & -3.877183 \\
\hline $\mathrm{H}$ & 7.041508 & -1.223368 & -3.113685 \\
\hline $\mathrm{H}$ & 5.628387 & -0.097056 & -1.458322 \\
\hline C & 4.917358 & 0.447763 & 1.037680 \\
\hline C & 5.238995 & 1.780677 & 1.449653 \\
\hline C & 6.456364 & 2.024495 & 2.141319 \\
\hline C & 7.317624 & 0.995147 & 2.441785 \\
\hline C & 6.987735 & -0.328026 & 2.065315 \\
\hline C & 5.822246 & -0.594562 & 1.380849 \\
\hline $\mathrm{H}$ & 6.687059 & 3.044370 & 2.439900 \\
\hline $\mathrm{H}$ & 8.242451 & 1.192017 & 2.976998 \\
\hline $\mathrm{H}$ & 7.657023 & -1.143973 & 2.324373 \\
\hline $\mathrm{H}$ & 5.579563 & -1.615780 & 1.110655 \\
\hline 0 & -0.541557 & -0.357081 & -0.760393 \\
\hline $\mathrm{O}$ & -0.178170 & 0.757205 & 1.556606 \\
\hline $\mathrm{H}$ & -1.306089 & 0.746164 & 1.597768 \\
\hline $\mathrm{H}$ & 3.748016 & 4.833432 & -0.757265 \\
\hline $\mathrm{H}$ & -0.020920 & 6.880362 & -0.450654 \\
\hline $\mathrm{H}$ & 0.447934 & 2.967403 & 1.269464 \\
\hline $\mathrm{H}$ & 0.072443 & -4.340162 & -1.960104 \\
\hline $\mathrm{H}$ & -2.666104 & -5.628312 & 1.094727 \\
\hline $\mathrm{H}$ & 0.796674 & -3.309157 & 2.148363 \\
\hline C & -3.164884 & -0.386703 & 1.783818 \\
\hline $\mathrm{O}$ & -2.605873 & 0.749475 & 1.643806 \\
\hline $\mathrm{H}$ & -2.571022 & -1.264663 & 2.068649 \\
\hline C & -4.579907 & -0.381674 & 2.337188 \\
\hline
\end{tabular}




$\begin{array}{llll}\mathrm{O} & -5.278289 & 0.599246 & 2.441068 \\ \mathrm{O} & -4.944618 & -1.626202 & 2.719287 \\ \mathrm{C} & -6.274215 & -1.733519 & 3.256216 \\ \mathrm{H} & -7.012319 & -1.427616 & 2.509915 \\ \mathrm{H} & -6.401322 & -2.784725 & 3.516090 \\ \mathrm{C} & -4.031323 & -0.172970 & -0.785678 \\ \mathrm{C} & -3.565847 & -1.277757 & -0.061037 \\ \mathrm{H} & -2.109270 & 0.455319 & -0.990365 \\ \mathrm{~N} & -3.092558 & 0.717730 & -1.185112 \\ \mathrm{C} & -3.239803 & 1.865490 & -1.981882 \\ \mathrm{O} & -4.242596 & 2.239512 & -2.544277 \\ \mathrm{O} & -2.043324 & 2.475271 & -2.020704 \\ \mathrm{C} & -1.978373 & 3.666061 & -2.822396 \\ \mathrm{H} & -1.001470 & 4.098877 & -2.610267 \\ \mathrm{H} & -2.778351 & 4.356421 & -2.545015 \\ \mathrm{H} & -2.070431 & 3.413582 & -3.882462 \\ \mathrm{H} & -4.278461 & -2.051927 & 0.197451 \\ \mathrm{H} & -2.538946 & -1.592833 & -0.219735 \\ \mathrm{C} & -5.485479 & 0.064728 & -0.933575 \\ \mathrm{C} & -6.086899 & 1.267790 & -0.530341 \\ \mathrm{C} & -6.292880 & -0.982353 & -1.406516 \\ \mathrm{C} & -7.467999 & 1.416514 & -0.607981 \\ \mathrm{H} & -5.477322 & 2.065110 & -0.123343 \\ \mathrm{C} & -7.673849 & -0.820141 & -1.504080 \\ \mathrm{H} & -5.830583 & -1.912873 & -1.722990 \\ \mathrm{C} & -8.263290 & 0.379585 & -1.102509 \\ \mathrm{H} & -7.925178 & 2.345200 & -0.279376 \\ \mathrm{H} & -8.286267 & -1.629228 & -1.892131 \\ \mathrm{H} & -9.340488 & 0.506011 & -1.170801 \\ \mathrm{H} & -6.380538 & -1.102244 & 4.142229\end{array}$

Catalyst (R)-1 TS Conformation 45

B3LYP/6-31G(d) Energy $=-2809.698193$

B3LYP-D3(BJ)/def2-TZVPP-IEF-PCM(DCM) Energy $=-2810.987938$

B3LYP-D3(BJ)/def2-TZVPP-IEF-PCM(DCM)//B3LYP/6-31G(d) Free Energy (Quasiharmonic) = 2810.34628

Frequencies (Top 3 out of 270 )

1. $-411.3521 \mathrm{~cm}-1$

2. $\quad 7.0051 \mathrm{~cm}-1$

3. $\quad 8.1304 \mathrm{~cm}-1$ 
B3LYP/6-31G(d) Molecular Geometry in Cartesian Coordinates

\begin{tabular}{|c|c|c|c|}
\hline C & -3.763474 & 0.286944 & -0.227520 \\
\hline C & -2.879134 & 1.317039 & 0.055900 \\
\hline C & -3.147395 & 2.686974 & -0.234224 \\
\hline C & -4.336833 & 2.973729 & -0.875671 \\
\hline $\mathrm{H}$ & -4.585266 & 4.009936 & -1.089274 \\
\hline C & -2.720554 & -3.776009 & 0.789427 \\
\hline C & -3.426725 & -1.110689 & 0.177896 \\
\hline C & -2.228493 & -1.669176 & -0.237718 \\
\hline C & -1.850020 & -3.016766 & 0.031833 \\
\hline $\mathrm{H}$ & -2.477726 & -4.815585 & 0.993332 \\
\hline 0 & -1.674322 & 1.011625 & 0.683265 \\
\hline$P$ & -0.495698 & 0.254142 & -0.154704 \\
\hline $\mathrm{O}$ & -1.349487 & -0.878558 & -0.971549 \\
\hline C & -0.522917 & 5.936509 & 0.796275 \\
\hline C & -1.080982 & 5.853078 & -0.479747 \\
\hline C & -1.914617 & 4.785527 & -0.810542 \\
\hline C & -2.205748 & 3.780501 & 0.125946 \\
\hline C & -1.632419 & 3.872115 & 1.405206 \\
\hline C & -0.802452 & 4.941868 & 1.735526 \\
\hline $\mathrm{H}$ & -0.860618 & 6.614320 & -1.223477 \\
\hline $\mathrm{H}$ & -0.373553 & 4.999312 & 2.732695 \\
\hline C & 1.791953 & -4.811505 & -1.397977 \\
\hline C & 1.395403 & -4.972912 & -0.069683 \\
\hline C & 0.223405 & -4.372244 & 0.389536 \\
\hline C & -0.576157 & -3.599539 & -0.468264 \\
\hline C & -0.162964 & -3.439704 & -1.802228 \\
\hline C & 1.007852 & -4.041975 & -2.261043 \\
\hline $\mathrm{H}$ & 2.000788 & -5.562586 & 0.613908 \\
\hline $\mathrm{H}$ & 1.303621 & -3.915971 & -3.299463 \\
\hline C & -4.286147 & -1.890409 & 1.026110 \\
\hline C & -3.923337 & -3.245705 & 1.317564 \\
\hline C & -4.769918 & -4.031659 & 2.145870 \\
\hline C & -5.913232 & -3.500795 & 2.695902 \\
\hline C & -6.253279 & -2.151193 & 2.442033 \\
\hline C & -5.463457 & -1.368162 & 1.629128 \\
\hline $\mathrm{H}$ & -4.486402 & -5.062140 & 2.346703 \\
\hline $\mathrm{H}$ & -6.548828 & -4.109280 & 3.333324 \\
\hline $\mathrm{H}$ & -7.144089 & -1.726061 & 2.896469 \\
\hline $\mathrm{H}$ & -5.733152 & -0.333537 & 1.452022 \\
\hline C & -4.961572 & 0.595102 & -0.960234 \\
\hline C & -5.247661 & 1.964007 & -1.270926 \\
\hline
\end{tabular}




\begin{tabular}{|c|c|c|c|}
\hline C & -6.434407 & 2.284853 & -1.984516 \\
\hline C & -7.294490 & 1.298777 & -2.407910 \\
\hline C & -6.994547 & -0.057102 & -2.137853 \\
\hline C & -5.861397 & -0.399723 & -1.433269 \\
\hline $\mathrm{H}$ & -6.641770 & 3.330237 & -2.200694 \\
\hline $\mathrm{H}$ & -8.195073 & 1.555633 & -2.958851 \\
\hline $\mathrm{H}$ & -7.661839 & -0.837267 & -2.494113 \\
\hline $\mathrm{H}$ & -5.642193 & -1.444102 & -1.244532 \\
\hline $\mathrm{O}$ & 0.502828 & -0.299280 & 0.805311 \\
\hline O & 0.016679 & 1.168794 & -1.291562 \\
\hline $\mathrm{H}$ & 1.124312 & 1.338984 & -1.275143 \\
\hline $\mathrm{H}$ & -1.844452 & 3.106026 & 2.143178 \\
\hline $\mathrm{H}$ & 0.129380 & 6.766284 & 1.055211 \\
\hline $\mathrm{H}$ & -2.327997 & 4.713172 & -1.812597 \\
\hline $\mathrm{H}$ & -0.767139 & -2.849364 & -2.482520 \\
\hline $\mathrm{H}$ & 2.703076 & -5.281680 & -1.758931 \\
\hline $\mathrm{H}$ & -0.068115 & -4.482538 & 1.430169 \\
\hline C & 3.024848 & 0.508640 & -1.872344 \\
\hline $\mathrm{O}$ & 2.431817 & 1.465530 & -1.275232 \\
\hline $\mathrm{H}$ & 2.456709 & -0.163346 & -2.530324 \\
\hline C & 4.444484 & 0.777514 & -2.348351 \\
\hline $\mathrm{O}$ & 5.114046 & 1.729901 & -2.024071 \\
\hline $\mathrm{O}$ & 4.851841 & -0.191294 & -3.198770 \\
\hline C & 6.193599 & -0.043545 & -3.694898 \\
\hline $\mathrm{H}$ & 6.301929 & 0.905131 & -4.226790 \\
\hline $\mathrm{H}$ & 6.909628 & -0.074898 & -2.869277 \\
\hline C & 4.003711 & -0.427138 & 0.496009 \\
\hline C & 3.388356 & -1.054407 & -0.597044 \\
\hline $\mathrm{H}$ & 2.176823 & 0.213396 & 1.134185 \\
\hline$N$ & 3.192657 & 0.262802 & 1.335737 \\
\hline C & 3.513011 & 0.831207 & 2.579054 \\
\hline $\mathrm{O}$ & 4.584768 & 0.803436 & 3.139105 \\
\hline $\mathrm{O}$ & 2.397024 & 1.402996 & 3.062567 \\
\hline C & 2.535794 & 2.004026 & 4.359052 \\
\hline $\mathrm{H}$ & 2.831520 & 1.255573 & 5.098775 \\
\hline $\mathrm{H}$ & 1.551096 & 2.407692 & 4.593349 \\
\hline $\mathrm{H}$ & 3.284275 & 2.800217 & 4.333508 \\
\hline $\mathrm{H}$ & 4.001048 & -1.702906 & -1.212135 \\
\hline $\mathrm{H}$ & 2.344379 & -1.333326 & -0.491598 \\
\hline C & 5.480085 & -0.405523 & 0.603590 \\
\hline C & 6.184174 & -1.611973 & 0.455062 \\
\hline C & 6.197263 & 0.793076 & 0.753325 \\
\hline C & 7.577626 & -1.625081 & 0.482907 \\
\hline $\mathrm{H}$ & 5.634062 & -2.542032 & 0.346542 \\
\hline
\end{tabular}




$\begin{array}{lrrr}\mathrm{C} & 7.588326 & 0.777803 & 0.757234 \\ \mathrm{H} & 5.665448 & 1.733502 & 0.827525 \\ \mathrm{C} & 8.281770 & -0.428898 & 0.630870 \\ \mathrm{H} & 8.110498 & -2.567127 & 0.389080 \\ \mathrm{H} & 8.133079 & 1.711874 & 0.858180 \\ \mathrm{H} & 9.368395 & -0.435535 & 0.645872 \\ \mathrm{H} & 6.349462 & -0.883688 & -4.372153\end{array}$

Catalyst (R)-1 TS Conformation 46

B3LYP/6-31G(d) Energy $=-2809.692508$

B3LYP-D3(BJ)/def2-TZVPP-IEF-PCM(DCM) Energy = -2810.987256

B3LYP-D3(BJ)/def2-TZVPP-IEF-PCM(DCM)//B3LYP/6-31G(d) Free Energy (Quasiharmonic) = 2810.346226

Frequencies (Top 3 out of 270)

1. $-689.5934 \mathrm{~cm}-1$

2. $\quad 11.3578 \mathrm{~cm}-1$

3. $\quad 15.1017 \mathrm{~cm}-1$

B3LYP/6-31G(d) Molecular Geometry in Cartesian Coordinates

$\begin{array}{llll}\text { C } & 2.869635 & -1.466571 & -0.249391 \\ \text { C } & 1.570102 & -1.811387 & 0.086469 \\ \text { C } & 1.000427 & -3.091704 & -0.178043 \\ \text { C } & 1.796384 & -4.012585 & -0.831321 \\ \text { H } & 1.407916 & -5.009301 & -1.023533 \\ \text { C } & 4.354280 & 2.468590 & 0.712287 \\ \text { C } & 3.391648 & -0.120273 & 0.133989 \\ \text { C } & 2.704335 & 1.021616 & -0.254040 \\ \text { C } & 3.178176 & 2.343902 & -0.002269 \\ \text { H } & 4.759649 & 3.460164 & 0.895285 \\ \text { O } & 0.784157 & -0.867809 & 0.730685 \\ \text { P } & 0.176668 & 0.373174 & -0.153872 \\ \text { O } & 1.513520 & 0.880300 & -0.955211 \\ \text { C } & -3.019251 & -4.182618 & 0.919374 \\ \text { C } & -2.510039 & -4.512784 & -0.338104 \\ \text { C } & -1.211779 & -4.142305 & -0.687155 \\ \text { C } & -0.393634 & -3.434761 & 0.210316 \\ \text { C } & -0.920570 & -3.101123 & 1.470188 \\ \text { C } & -2.218122 & -3.475253 & 1.819182 \\ \text { H } & -3.126241 & -5.051816 & -1.053017\end{array}$




\begin{tabular}{|c|c|c|c|}
\hline $\mathrm{H}$ & -2.594679 & -3.211359 & 2.803823 \\
\hline C & 1.281462 & 5.944832 & -1.403234 \\
\hline C & 1.749045 & 5.853092 & -0.091173 \\
\hline C & 2.335095 & 4.671393 & 0.361714 \\
\hline C & 2.469472 & 3.559303 & -0.486005 \\
\hline C & 1.983184 & 3.660944 & -1.800500 \\
\hline C & 1.398007 & 4.842346 & -2.252716 \\
\hline $\mathrm{H}$ & 1.658565 & 6.701411 & 0.582825 \\
\hline $\mathrm{H}$ & 1.038050 & 4.902511 & -3.276517 \\
\hline C & 4.570118 & 0.029703 & 0.943563 \\
\hline C & 5.056547 & 1.348476 & 1.218622 \\
\hline C & 6.228854 & 1.511160 & 2.005875 \\
\hline C & 6.883406 & 0.423094 & 2.534050 \\
\hline C & 6.382345 & -0.878852 & 2.298678 \\
\hline C & 5.259071 & -1.070783 & 1.524617 \\
\hline $\mathrm{H}$ & 6.590899 & 2.519387 & 2.193298 \\
\hline $\mathrm{H}$ & 7.774474 & 0.559912 & 3.140625 \\
\hline $\mathrm{H}$ & 6.885341 & -1.736539 & 2.737173 \\
\hline $\mathrm{H}$ & 4.883048 & -2.074287 & 1.363591 \\
\hline C & 3.656217 & -2.407578 & -0.998861 \\
\hline C & 3.106740 & -3.702722 & -1.271345 \\
\hline C & 3.879049 & -4.649557 & -1.997664 \\
\hline C & 5.130412 & -4.329733 & -2.470304 \\
\hline C & 5.658781 & -3.038046 & -2.238538 \\
\hline C & 4.943238 & -2.103848 & -1.522125 \\
\hline $\mathrm{H}$ & 3.451721 & -5.632008 & -2.184598 \\
\hline $\mathrm{H}$ & 5.708201 & -5.059474 & -3.030905 \\
\hline $\mathrm{H}$ & 6.637107 & -2.777893 & -2.633643 \\
\hline $\mathrm{H}$ & 5.358855 & -1.115903 & -1.361609 \\
\hline $\mathrm{O}$ & -0.377260 & 1.377185 & 0.802640 \\
\hline $\mathrm{O}$ & -0.692620 & -0.203970 & -1.277265 \\
\hline $\mathrm{H}$ & -1.844966 & -0.054323 & -1.488090 \\
\hline $\mathrm{H}$ & -0.318464 & -2.545199 & 2.179211 \\
\hline $\mathrm{H}$ & -4.031748 & -4.468710 & 1.191753 \\
\hline $\mathrm{H}$ & -0.831976 & -4.379647 & -1.676792 \\
\hline $\mathrm{H}$ & 2.072901 & 2.814124 & -2.471649 \\
\hline $\mathrm{H}$ & 0.832009 & 6.867686 & -1.761510 \\
\hline $\mathrm{H}$ & 2.679874 & 4.599815 & 1.389428 \\
\hline C & -3.801078 & -0.684848 & -1.036920 \\
\hline $\mathrm{O}$ & -3.023585 & -0.045543 & -1.826425 \\
\hline $\mathrm{H}$ & -3.373913 & -1.338749 & -0.268714 \\
\hline C & -5.106772 & -1.161072 & -1.652751 \\
\hline $\mathrm{O}$ & -5.641199 & -0.657146 & -2.613227 \\
\hline $\mathrm{O}$ & -5.592645 & -2.218390 & -0.969051 \\
\hline
\end{tabular}




$\begin{array}{llll}\mathrm{C} & -6.835611 & -2.747616 & -1.464728 \\ \mathrm{H} & -7.617289 & -1.983956 & -1.430305 \\ \mathrm{H} & -6.719077 & -3.090850 & -2.495746 \\ \mathrm{C} & -3.754353 & 1.319859 & 0.756540 \\ \mathrm{C} & -4.808507 & 0.494894 & 0.343161 \\ \mathrm{H} & -1.892229 & 1.180339 & 1.612870 \\ \mathrm{~N} & -2.900300 & 0.966289 & 1.770809 \\ \mathrm{C} & -3.122977 & 0.150315 & 2.882947 \\ \mathrm{O} & -2.218465 & -0.298944 & 3.551028 \\ \mathrm{O} & -4.433598 & -0.013952 & 3.158279 \\ \mathrm{C} & -4.706129 & -0.780286 & 4.344467 \\ \mathrm{H} & -4.229586 & -0.321426 & 5.213644 \\ \mathrm{H} & -4.340648 & -1.804354 & 4.233724 \\ \mathrm{H} & -5.791289 & -0.770108 & 4.448336 \\ \mathrm{H} & -5.584936 & 0.952833 & -0.258447 \\ \mathrm{H} & -5.141064 & -0.293072 & 1.004966 \\ \mathrm{C} & -3.395632 & 2.523119 & 0.000894 \\ \mathrm{C} & -3.869863 & 2.720343 & -1.314915 \\ \mathrm{C} & -2.577193 & 3.515584 & 0.582196 \\ \mathrm{C} & -3.530368 & 3.872555 & -2.017451 \\ \mathrm{H} & -4.467552 & 1.963306 & -1.805848 \\ \mathrm{C} & -2.247544 & 4.663937 & -0.124384 \\ \mathrm{H} & -2.209099 & 3.387455 & 1.593079 \\ \mathrm{C} & -2.720891 & 4.844174 & -1.427206 \\ \mathrm{H} & -3.890410 & 4.003435 & -3.033558 \\ \mathrm{H} & -1.606442 & 5.411112 & 0.332178 \\ \mathrm{H} & -2.453836 & 5.739828 & -1.981330 \\ \mathrm{H} & -7.081809 & -3.581378 & -0.807122\end{array}$

Catalyst (R)-1 TS Conformation 47

B3LYP/6-31G(d) Energy $=-2809.701233$

B3LYP-D3(BJ)/def2-TZVPP-IEF-PCM(DCM) Energy = -2810.990296

B3LYP-D3(BJ)/def2-TZVPP-IEF-PCM(DCM)//B3LYP/6-31G(d) Free Energy (Quasiharmonic) = 2810.346226

Frequencies (Top 3 out of 270)

1. $-261.9468 \mathrm{~cm}-1$

2. $\quad 13.5842 \mathrm{~cm}-1$

3. $\quad 19.4070 \mathrm{~cm}-1$

B3LYP/6-31G(d) Molecular Geometry in Cartesian Coordinates 


\begin{tabular}{|c|c|c|c|}
\hline C & 3.024600 & -1.012718 & -0.372743 \\
\hline C & 1.829784 & -1.667893 & -0.110857 \\
\hline C & 1.636195 & -3.059661 & -0.367264 \\
\hline C & 2.669171 & -3.739692 & -0.982689 \\
\hline $\mathrm{H}$ & 2.545628 & -4.798588 & -1.193315 \\
\hline C & 3.804869 & 3.103560 & 0.611193 \\
\hline C & 3.250630 & 0.389804 & 0.086747 \\
\hline C & 2.384091 & 1.401456 & -0.294218 \\
\hline C & 2.663511 & 2.786531 & -0.099971 \\
\hline $\mathrm{H}$ & 4.043338 & 4.149826 & 0.782914 \\
\hline O & 0.810739 & -0.975619 & 0.540014 \\
\hline$P$ & 0.053569 & 0.301894 & -0.138879 \\
\hline $\mathrm{O}$ & 1.221487 & 1.053779 & -0.982903 \\
\hline C & -1.826197 & -5.384669 & 0.695519 \\
\hline C & -0.554924 & -5.756601 & 1.140200 \\
\hline C & 0.556390 & -4.978496 & 0.814217 \\
\hline C & 0.416459 & -3.817072 & 0.035078 \\
\hline C & -0.865506 & -3.455447 & -0.402261 \\
\hline C & -1.980206 & -4.228504 & -0.073978 \\
\hline $\mathrm{H}$ & -0.426266 & -6.652363 & 1.742942 \\
\hline $\mathrm{H}$ & -2.960138 & -3.912432 & -0.419717 \\
\hline C & 0.400090 & 6.010008 & -1.835007 \\
\hline C & 1.778392 & 5.916670 & -2.030478 \\
\hline C & 2.491718 & 4.858435 & -1.468874 \\
\hline C & 1.843394 & 3.875190 & -0.702084 \\
\hline C & 0.457042 & 3.980187 & -0.509191 \\
\hline C & -0.253540 & 5.039957 & -1.072957 \\
\hline $\mathrm{H}$ & 2.299284 & 6.661433 & -2.626774 \\
\hline $\mathrm{H}$ & -1.326171 & 5.104745 & -0.912092 \\
\hline C & 4.379434 & 0.732517 & 0.910679 \\
\hline C & 4.651965 & 2.114271 & 1.167521 \\
\hline C & 5.763423 & 2.468068 & 1.979617 \\
\hline C & 6.565107 & 1.501583 & 2.540745 \\
\hline C & 6.280100 & 0.134508 & 2.314281 \\
\hline C & 5.219407 & -0.240229 & 1.518999 \\
\hline $\mathrm{H}$ & 5.960172 & 3.522628 & 2.157801 \\
\hline $\mathrm{H}$ & 7.408391 & 1.783192 & 3.165380 \\
\hline $\mathrm{H}$ & 6.900653 & -0.628284 & 2.776732 \\
\hline $\mathrm{H}$ & 5.008598 & -1.291919 & 1.363757 \\
\hline C & 4.045049 & -1.710467 & -1.110870 \\
\hline C & 3.859648 & -3.099235 & -1.401423 \\
\hline C & 4.861742 & -3.805948 & -2.119956 \\
\hline C & 5.996195 & -3.167552 & -2.563203 \\
\hline
\end{tabular}




\begin{tabular}{|c|c|c|c|}
\hline C & 6.167050 & -1.786370 & -2.309733 \\
\hline C & 5.220793 & -1.078007 & -1.602142 \\
\hline $\mathrm{H}$ & 4.704835 & -4.862506 & -2.323798 \\
\hline $\mathrm{H}$ & 6.753256 & -3.715091 & -3.117836 \\
\hline $\mathrm{H}$ & 7.050856 & -1.276115 & -2.683052 \\
\hline $\mathrm{H}$ & 5.364325 & -0.018037 & -1.429583 \\
\hline 0 & -0.561406 & 1.117284 & 0.950513 \\
\hline 0 & -0.866464 & -0.177713 & -1.302346 \\
\hline $\mathrm{H}$ & -1.848315 & -0.522731 & -1.044080 \\
\hline $\mathrm{H}$ & -0.994122 & -2.580176 & -1.024449 \\
\hline $\mathrm{H}$ & -2.692317 & -5.991068 & 0.948111 \\
\hline $\mathrm{H}$ & 1.542711 & -5.265063 & 1.170165 \\
\hline $\mathrm{H}$ & -0.060551 & 3.243319 & 0.095430 \\
\hline $\mathrm{H}$ & -0.160287 & 6.830798 & -2.275526 \\
\hline $\mathrm{H}$ & 3.561600 & 4.776769 & -1.640844 \\
\hline C & -4.195584 & -0.605482 & -1.073299 \\
\hline $\mathrm{O}$ & -3.079423 & -1.152689 & -0.767926 \\
\hline $\mathrm{H}$ & -4.195704 & 0.339946 & -1.637382 \\
\hline C & -5.304849 & -1.550996 & -1.544702 \\
\hline 0 & -5.307935 & -2.750586 & -1.405218 \\
\hline $\mathrm{O}$ & -6.288966 & -0.850161 & -2.154361 \\
\hline C & -7.384510 & -1.638328 & -2.652546 \\
\hline $\mathrm{H}$ & -7.029549 & -2.357149 & -3.395467 \\
\hline $\mathrm{H}$ & -7.868386 & -2.180675 & -1.835802 \\
\hline C & -4.123558 & 0.804425 & 1.079783 \\
\hline C & -5.140562 & 0.004834 & 0.522860 \\
\hline $\mathrm{H}$ & -2.144922 & 0.695120 & 1.638766 \\
\hline$N$ & -3.072196 & 0.236307 & 1.710319 \\
\hline C & -3.039421 & -1.045444 & 2.308216 \\
\hline $\mathrm{O}$ & -3.991668 & -1.759743 & 2.522557 \\
\hline $\mathrm{O}$ & -1.775158 & -1.288033 & 2.661786 \\
\hline C & -1.538625 & -2.552784 & 3.309520 \\
\hline $\mathrm{H}$ & -2.052030 & -2.580256 & 4.274510 \\
\hline $\mathrm{H}$ & -0.458948 & -2.601429 & 3.441518 \\
\hline $\mathrm{H}$ & -1.885763 & -3.370674 & 2.677173 \\
\hline $\mathrm{H}$ & -6.038053 & 0.511198 & 0.185070 \\
\hline $\mathrm{H}$ & -5.301085 & -0.960327 & 0.987148 \\
\hline C & -4.046721 & 2.259583 & 0.848365 \\
\hline C & -4.778314 & 2.868755 & -0.189927 \\
\hline C & -3.274150 & 3.076170 & 1.696253 \\
\hline C & -4.735300 & 4.247066 & -0.372935 \\
\hline $\mathrm{H}$ & -5.370022 & 2.263785 & -0.868397 \\
\hline C & -3.241234 & 4.456088 & 1.515128 \\
\hline $\mathrm{H}$ & -2.718469 & 2.634597 & 2.516108 \\
\hline
\end{tabular}




$\begin{array}{llrr}\mathrm{C} & -3.971543 & 5.046501 & 0.481680 \\ \mathrm{H} & -5.298814 & 4.698441 & -1.184295 \\ \mathrm{H} & -2.646881 & 5.070326 & 2.184819 \\ \mathrm{H} & -3.948049 & 6.123981 & 0.344246 \\ \mathrm{H} & -8.075652 & -0.927357 & -3.105901\end{array}$

Catalyst (R)-1 TS Conformation 48 (TS-2Si)

B3LYP/6-31G(d) Energy = -2809.691941

B3LYP-D3(BJ)/def2-TZVPP-IEF-PCM(DCM) Energy = -2810.988349

B3LYP-D3(BJ)/def2-TZVPP-IEF-PCM(DCM)//B3LYP/6-31G(d) Free Energy (Quasiharmonic) = 2810.346169

Frequencies (Top 3 out of 270)

1. $-378.8137 \mathrm{~cm}-1$

2. $\quad 10.7744 \mathrm{~cm}-1$

3. $\quad 12.6789 \mathrm{~cm}-1$

B3LYP/6-31G(d) Molecular Geometry in Cartesian Coordinates

$\begin{array}{llll}\mathrm{C} & 3.270317 & 0.475819 & -0.078547 \\ \mathrm{C} & 2.305462 & 1.398695 & -0.453483 \\ \mathrm{C} & 2.446668 & 2.804282 & -0.257647 \\ \mathrm{C} & 3.590599 & 3.242846 & 0.379812 \\ \mathrm{H} & 3.740553 & 4.309671 & 0.524378 \\ \mathrm{C} & 2.590467 & -3.703532 & -0.901937 \\ \mathrm{C} & 3.059033 & -0.967286 & -0.400011 \\ \mathrm{C} & 1.896707 & -1.598413 & 0.022301 \\ \mathrm{C} & 1.636810 & -2.984456 & -0.206515 \\ \mathrm{H} & 2.440121 & -4.767938 & -1.062056 \\ \mathrm{O} & 1.146450 & 0.935242 & -1.057989 \\ \mathrm{P} & 0.017070 & 0.225375 & -0.089851 \\ \mathrm{O} & 0.957396 & -0.861786 & 0.726294 \\ \mathrm{C} & -0.487541 & 5.677811 & -1.540204 \\ \mathrm{C} & -0.078450 & 4.663559 & -2.408698 \\ \mathrm{C} & 0.857587 & 3.716582 & -1.996349 \\ \mathrm{C} & 1.409831 & 3.771648 & -0.705518 \\ \mathrm{C} & 0.989909 & 4.796135 & 0.158016 \\ \mathrm{C} & 0.049135 & 5.739398 & -0.253821 \\ \mathrm{H} & -0.488416 & 4.608494 & -3.414056 \\ \mathrm{H} & -0.273268 & 6.514870 & 0.435800 \\ \mathrm{C} & -1.894873 & -5.055755 & 1.142052\end{array}$




\begin{tabular}{|c|c|c|c|}
\hline$C$ & -1.387616 & -5.272202 & -0.139911 \\
\hline C & -0.257416 & -4.579171 & -0.573717 \\
\hline C & 0.397612 & -3.659624 & 0.263846 \\
\hline C & -0.125050 & -3.449434 & 1.551344 \\
\hline C & -1.258495 & -4.139727 & 1.984129 \\
\hline $\mathrm{H}$ & -1.875766 & -5.977082 & -0.807990 \\
\hline $\mathrm{H}$ & -1.634003 & -3.968115 & 2.989932 \\
\hline C & 4.000455 & -1.710609 & -1.191690 \\
\hline C & 3.762475 & -3.104118 & -1.421752 \\
\hline C & 4.695239 & -3.856788 & -2.186087 \\
\hline C & 5.804965 & -3.259135 & -2.735997 \\
\hline C & 6.021204 & -1.873715 & -2.546875 \\
\hline C & 5.145462 & -1.120923 & -1.795847 \\
\hline $\mathrm{H}$ & 4.504503 & -4.916567 & -2.338855 \\
\hline $\mathrm{H}$ & 6.507688 & -3.842454 & -3.324686 \\
\hline $\mathrm{H}$ & 6.884635 & -1.396811 & -3.002893 \\
\hline $\mathrm{H}$ & 5.321590 & -0.059244 & -1.669411 \\
\hline C & 4.420826 & 0.940359 & 0.646475 \\
\hline C & 4.578317 & 2.348421 & 0.861497 \\
\hline C & 5.716162 & 2.822791 & 1.569020 \\
\hline C & 6.650333 & 1.949846 & 2.076329 \\
\hline C & 6.477472 & 0.556905 & 1.899618 \\
\hline C & 5.394500 & 0.065951 & 1.203683 \\
\hline $\mathrm{H}$ & 5.826429 & 3.895225 & 1.712203 \\
\hline $\mathrm{H}$ & 7.512533 & 2.324635 & 2.621181 \\
\hline $\mathrm{H}$ & 7.203689 & -0.133377 & 2.320566 \\
\hline $\mathrm{H}$ & 5.272146 & -1.004520 & 1.085140 \\
\hline $\mathrm{O}$ & -1.019256 & -0.401783 & -0.959506 \\
\hline 0 & -0.418860 & 1.194691 & 1.013342 \\
\hline $\mathrm{H}$ & -1.493692 & 1.930072 & 0.796380 \\
\hline $\mathrm{H}$ & 1.386399 & 4.833762 & 1.168775 \\
\hline $\mathrm{H}$ & -1.224149 & 6.409746 & -1.860681 \\
\hline $\mathrm{H}$ & 1.167159 & 2.931517 & -2.677774 \\
\hline $\mathrm{H}$ & 0.358988 & -2.744983 & 2.215755 \\
\hline $\mathrm{H}$ & -2.775873 & -5.593724 & 1.481657 \\
\hline $\mathrm{H}$ & 0.115153 & -4.735753 & -1.582033 \\
\hline C & -3.252159 & 1.932047 & -0.149573 \\
\hline $\mathrm{O}$ & -2.424501 & 2.526126 & 0.621668 \\
\hline $\mathrm{H}$ & -2.912265 & 1.092062 & -0.758975 \\
\hline C & -4.361463 & 2.794405 & -0.720943 \\
\hline 0 & -4.707893 & 3.863926 & -0.282449 \\
\hline $\mathrm{O}$ & -4.889348 & 2.187982 & -1.803517 \\
\hline C & -5.942804 & 2.915025 & -2.459643 \\
\hline $\mathrm{H}$ & -5.575154 & 3.882452 & -2.811052 \\
\hline
\end{tabular}




$\begin{array}{llll}\mathrm{H} & -6.248648 & 2.290915 & -3.299069 \\ \mathrm{C} & -4.074377 & -0.427423 & 1.006577 \\ \mathrm{C} & -4.645655 & 0.839090 & 1.090939 \\ \mathrm{H} & -2.574554 & -1.721795 & 1.521296 \\ \mathrm{~N} & -3.017655 & -0.840052 & 1.765606 \\ \mathrm{C} & -2.418161 & -0.146975 & 2.833325 \\ \mathrm{O} & -2.811680 & 0.892541 & 3.307316 \\ \mathrm{O} & -1.367323 & -0.861332 & 3.256474 \\ \mathrm{C} & -0.507583 & -0.173718 & 4.189762 \\ \mathrm{H} & 0.253634 & -0.902600 & 4.466231 \\ \mathrm{H} & -1.076159 & 0.147173 & 5.065057 \\ \mathrm{H} & -0.057780 & 0.685565 & 3.689047 \\ \mathrm{H} & -5.573658 & 0.974051 & 0.548380 \\ \mathrm{H} & -4.469157 & 1.464492 & 1.954562 \\ \mathrm{C} & -4.552084 & -1.404674 & -0.002333 \\ \mathrm{C} & -5.934443 & -1.617667 & -0.149243 \\ \mathrm{C} & -3.651037 & -2.122883 & -0.807813 \\ \mathrm{C} & -6.408282 & -2.543838 & -1.074258 \\ \mathrm{H} & -6.632643 & -1.080229 & 0.485519 \\ \mathrm{C} & -4.137748 & -3.036305 & -1.742570 \\ \mathrm{H} & -2.586049 & -1.910272 & -0.760287 \\ \mathrm{C} & -5.509789 & -3.254421 & -1.874310 \\ \mathrm{H} & -7.477258 & -2.713457 & -1.167876 \\ \mathrm{H} & -3.435092 & -3.571463 & -2.374136 \\ \mathrm{H} & -5.880533 & -3.972220 & -2.601148 \\ \mathrm{H} & -6.778574 & 3.079860 & -1.774020\end{array}$

Catalyst (R)-1 TS Conformation 49

B3LYP/6-31G(d) Energy $=-2809.69716$

B3LYP-D3(BJ)/def2-TZVPP-IEF-PCM(DCM) Energy = -2810.990317

B3LYP-D3(BJ)/def2-TZVPP-IEF-PCM(DCM)//B3LYP/6-31G(d) Free Energy (Quasiharmonic) = 2810.346167

Frequencies (Top 3 out of 270)

1. $-265.2340 \mathrm{~cm}-1$

2. $\quad 11.2769 \mathrm{~cm}-1$

3. $\quad 14.7754 \mathrm{~cm}-1$

B3LYP/6-31G(d) Molecular Geometry in Cartesian Coordinates

$\begin{array}{llll}\text { C } & 3.089291 & -0.142052 & 0.269504\end{array}$ 


\begin{tabular}{|c|c|c|c|}
\hline C & 2.465428 & 1.014557 & -0.166377 \\
\hline C & 2.958762 & 2.319307 & 0.132182 \\
\hline C & 4.006383 & 2.407432 & 1.029103 \\
\hline $\mathrm{H}$ & 4.423983 & 3.384160 & 1.257710 \\
\hline C & 1.913063 & -4.045926 & -1.095804 \\
\hline C & 2.676966 & -1.463253 & -0.282856 \\
\hline C & 1.364743 & -1.896047 & -0.173803 \\
\hline C & 0.961604 & -3.217648 & -0.532585 \\
\hline $\mathrm{H}$ & 1.626107 & -5.053488 & -1.384706 \\
\hline O & 1.324022 & 0.896953 & -0.961374 \\
\hline$P$ & -0.046919 & 0.362530 & -0.239023 \\
\hline O & 0.426117 & -1.064551 & 0.423677 \\
\hline C & 1.999105 & 5.979200 & -1.902218 \\
\hline C & 2.079270 & 5.950638 & -0.508674 \\
\hline C & 2.324509 & 4.748342 & 0.155142 \\
\hline C & 2.494342 & 3.551309 & -0.559478 \\
\hline C & 2.372564 & 3.586081 & -1.959462 \\
\hline C & 2.136894 & 4.789802 & -2.623219 \\
\hline $\mathrm{H}$ & 1.956472 & 6.865955 & 0.064482 \\
\hline $\mathrm{H}$ & 2.071749 & 4.799389 & -3.708257 \\
\hline C & -2.927538 & -4.927414 & 0.123422 \\
\hline C & -2.809911 & -3.712018 & -0.554429 \\
\hline C & -1.560635 & -3.122982 & -0.748885 \\
\hline C & -0.401366 & -3.756253 & -0.275928 \\
\hline C & -0.530276 & -4.977319 & 0.408531 \\
\hline C & -1.781969 & -5.557924 & 0.610509 \\
\hline $\mathrm{H}$ & -3.695019 & -3.217905 & -0.939419 \\
\hline $\mathrm{H}$ & -1.859694 & -6.499933 & 1.147327 \\
\hline C & 3.632307 & -2.301379 & -0.957214 \\
\hline C & 3.235781 & -3.616689 & -1.357029 \\
\hline C & 4.168632 & -4.460244 & -2.018793 \\
\hline C & 5.441522 & -4.022008 & -2.299783 \\
\hline C & 5.828383 & -2.711315 & -1.933744 \\
\hline C & 4.950656 & -1.874928 & -1.279518 \\
\hline $\mathrm{H}$ & 3.849759 & -5.458707 & -2.308603 \\
\hline $\mathrm{H}$ & 6.145814 & -4.672476 & -2.811052 \\
\hline $\mathrm{H}$ & 6.826765 & -2.357596 & -2.176545 \\
\hline $\mathrm{H}$ & 5.261938 & -0.870636 & -1.017298 \\
\hline C & 4.133778 & -0.034604 & 1.251967 \\
\hline C & 4.580255 & 1.267693 & 1.642597 \\
\hline C & 5.606527 & 1.391840 & 2.617472 \\
\hline C & 6.156312 & 0.278750 & 3.209787 \\
\hline C & 5.696170 & -1.009041 & 2.847826 \\
\hline C & 4.715381 & -1.162806 & 1.892464 \\
\hline
\end{tabular}




\begin{tabular}{|c|c|c|c|}
\hline $\mathrm{H}$ & 5.941473 & 2.388695 & 2.894194 \\
\hline $\mathrm{H}$ & 6.934737 & 0.384962 & 3.960305 \\
\hline $\mathrm{H}$ & 6.117252 & -1.886278 & 3.331482 \\
\hline $\mathrm{H}$ & 4.366594 & -2.155889 & 1.634018 \\
\hline $\mathrm{O}$ & -1.130511 & 0.212713 & -1.253706 \\
\hline 0 & -0.272452 & 1.264564 & 0.998161 \\
\hline $\mathrm{H}$ & -1.256958 & 1.558178 & 1.318568 \\
\hline $\mathrm{H}$ & 2.493832 & 2.670791 & -2.529573 \\
\hline $\mathrm{H}$ & 1.824176 & 6.917595 & -2.421926 \\
\hline $\mathrm{H}$ & 2.386281 & 4.732092 & 1.239605 \\
\hline $\mathrm{H}$ & 0.361046 & -5.465051 & 0.794017 \\
\hline $\mathrm{H}$ & -3.905485 & -5.378509 & 0.271854 \\
\hline $\mathrm{H}$ & -1.485839 & -2.175620 & -1.273018 \\
\hline C & -3.472560 & 1.734781 & 2.283239 \\
\hline $\mathrm{O}$ & -2.395805 & 2.235355 & 1.781123 \\
\hline $\mathrm{H}$ & -3.982319 & 2.327252 & 3.060448 \\
\hline C & -3.521986 & 0.262527 & 2.706714 \\
\hline $\mathrm{O}$ & -4.429591 & -0.213203 & 3.363069 \\
\hline $\mathrm{O}$ & -2.455932 & -0.418535 & 2.275755 \\
\hline C & -2.375455 & -1.801437 & 2.677879 \\
\hline $\mathrm{H}$ & -3.205993 & -2.368428 & 2.252668 \\
\hline $\mathrm{H}$ & -1.427814 & -2.158229 & 2.280279 \\
\hline C & -4.423974 & 1.279031 & -0.088923 \\
\hline C & -4.902413 & 1.899871 & 1.093094 \\
\hline $\mathrm{H}$ & -2.685386 & 1.231018 & -1.199865 \\
\hline$N$ & -3.396181 & 1.844165 & -0.762003 \\
\hline C & -3.065923 & 3.220307 & -0.739092 \\
\hline $\mathrm{O}$ & -3.793366 & 4.116374 & -0.375729 \\
\hline $\mathrm{O}$ & -1.860450 & 3.368119 & -1.290869 \\
\hline C & -1.384396 & 4.726270 & -1.345315 \\
\hline $\mathrm{H}$ & -2.095287 & 5.353996 & -1.888208 \\
\hline $\mathrm{H}$ & -0.429915 & 4.672149 & -1.861732 \\
\hline $\mathrm{H}$ & -1.252372 & 5.112643 & -0.332513 \\
\hline $\mathrm{H}$ & -5.787253 & 1.465498 & 1.546757 \\
\hline $\mathrm{H}$ & -4.903896 & 2.982448 & 1.072513 \\
\hline C & -4.926766 & -0.016715 & -0.574577 \\
\hline C & -4.780356 & -0.352668 & -1.935705 \\
\hline C & -5.680263 & -0.872601 & 0.255012 \\
\hline C & -5.390178 & -1.491138 & -2.455592 \\
\hline $\mathrm{H}$ & -4.227144 & 0.304441 & -2.598009 \\
\hline C & -6.278517 & -2.014062 & -0.269452 \\
\hline $\mathrm{H}$ & -5.783087 & -0.659623 & 1.313210 \\
\hline C & -6.149039 & -2.320750 & -1.627142 \\
\hline $\mathrm{H}$ & -5.282177 & -1.722698 & -3.511138 \\
\hline
\end{tabular}




$\begin{array}{llll}\mathrm{H} & -6.853859 & -2.663204 & 0.384228 \\ \mathrm{H} & -6.635060 & -3.202154 & -2.036277 \\ \mathrm{H} & -2.403274 & -1.873351 & 3.767884\end{array}$

Catalyst (R)-1 TS Conformation 50

B3LYP/6-31G(d) Energy $=-2809.689906$

B3LYP-D3(BJ)/def2-TZVPP-IEF-PCM(DCM) Energy = -2810.987103

B3LYP-D3(BJ)/def2-TZVPP-IEF-PCM(DCM)//B3LYP/6-31G(d) Free Energy (Quasiharmonic) = 2810.346112

Frequencies (Top 3 out of 270)

1. $-702.7251 \mathrm{~cm}-1$

2. $\quad 6.4277 \mathrm{~cm}-1$

3. $\quad 13.6379 \mathrm{~cm}-1$

B3LYP/6-31G(d) Molecular Geometry in Cartesian Coordinates

$\begin{array}{llll}\text { C } & -2.761704 & -1.518856 & 0.063289 \\ \text { C } & -1.468005 & -1.831109 & -0.320113 \\ \text { C } & -0.857847 & -3.096038 & -0.074262 \\ \text { C } & -1.595767 & -4.025409 & 0.632714 \\ \text { H } & -1.174783 & -5.010942 & 0.813202 \\ \text { C } & -4.536996 & 2.285611 & -0.904304 \\ \text { C } & -3.356269 & -0.212341 & -0.344865 \\ \text { C } & -2.713928 & 0.980800 & -0.038240 \\ \text { C } & -3.301153 & 2.257180 & -0.289092 \\ \text { H } & -5.001907 & 3.247270 & -1.105216 \\ \text { O } & -0.723599 & -0.860282 & -0.983192 \\ \text { P } & -0.141608 & 0.368197 & -0.062116 \\ \text { O } & -1.502165 & 0.951586 & 0.638172 \\ \text { C } & 3.061631 & -4.207519 & -1.462550 \\ \text { C } & 2.659043 & -4.506878 & -0.159821 \\ \text { C } & 1.397238 & -4.118082 & 0.290000 \\ \text { C } & 0.509252 & -3.430347 & -0.553766 \\ \text { C } & 0.930769 & -3.126177 & -1.860313 \\ \text { C } & 2.193275 & -3.512652 & -2.308270 \\ \text { H } & 3.328208 & -5.036494 & 0.513420 \\ \text { H } & 2.495411 & -3.276150 & -3.325213 \\ \text { C } & -1.601832 & 6.090295 & 0.675264 \\ \text { C } & -0.896819 & 5.199142 & -0.137809 \\ \text { C } & -1.412117 & 3.933331 & -0.420468\end{array}$




\begin{tabular}{|c|c|c|c|}
\hline C & -2.659609 & 3.547663 & 0.093799 \\
\hline C & -3.360748 & 4.449285 & 0.910471 \\
\hline C & -2.834951 & 5.707408 & 1.205202 \\
\hline $\mathrm{H}$ & 0.056411 & 5.496553 & -0.569091 \\
\hline $\mathrm{H}$ & -3.391812 & 6.388846 & 1.843284 \\
\hline C & -4.589065 & -0.162180 & -1.084988 \\
\hline C & -5.192038 & 1.109988 & -1.342605 \\
\hline C & -6.418178 & 1.173725 & -2.058463 \\
\hline C & -7.020703 & 0.031687 & -2.531525 \\
\hline C & -6.408907 & -1.225053 & -2.312636 \\
\hline C & -5.228561 & -1.320304 & -1.608896 \\
\hline $\mathrm{H}$ & -6.863649 & 2.149663 & -2.236659 \\
\hline $\mathrm{H}$ & -7.954667 & 0.091727 & -3.083542 \\
\hline $\mathrm{H}$ & -6.871104 & -2.124895 & -2.709620 \\
\hline $\mathrm{H}$ & -4.769330 & -2.290670 & -1.461694 \\
\hline C & -3.484017 & -2.465307 & 0.870351 \\
\hline C & -2.886235 & -3.738646 & 1.140960 \\
\hline C & -3.592677 & -4.689377 & 1.926677 \\
\hline C & -4.825565 & -4.391756 & 2.458512 \\
\hline C & -5.400263 & -3.119881 & 2.227957 \\
\hline C & -4.749772 & -2.183917 & 1.454106 \\
\hline $\mathrm{H}$ & -3.129143 & -5.655698 & 2.111084 \\
\hline $\mathrm{H}$ & -5.352800 & -5.123406 & 3.064587 \\
\hline $\mathrm{H}$ & -6.362751 & -2.876190 & 2.669670 \\
\hline $\mathrm{H}$ & -5.199989 & -1.211023 & 1.295951 \\
\hline 0 & 0.522557 & 1.347197 & -0.974877 \\
\hline $\mathrm{O}$ & 0.621763 & -0.208103 & 1.136644 \\
\hline $\mathrm{H}$ & 1.738016 & -0.559556 & 1.215278 \\
\hline $\mathrm{H}$ & 0.263501 & -2.592644 & -2.528009 \\
\hline $\mathrm{H}$ & 4.044222 & -4.507959 & -1.815854 \\
\hline $\mathrm{H}$ & 1.101707 & -4.329799 & 1.313336 \\
\hline $\mathrm{H}$ & -4.322683 & 4.154240 & 1.321295 \\
\hline $\mathrm{H}$ & -1.196882 & 7.076485 & 0.888210 \\
\hline $\mathrm{H}$ & -0.853420 & 3.247604 & -1.048635 \\
\hline C & 3.743910 & -0.992670 & 0.545852 \\
\hline $\mathrm{O}$ & 2.876354 & -0.966279 & 1.485403 \\
\hline $\mathrm{H}$ & 3.417018 & -1.001692 & -0.500674 \\
\hline C & 4.985159 & -1.828100 & 0.836470 \\
\hline $\mathrm{O}$ & 5.354731 & -2.150757 & 1.940129 \\
\hline $\mathrm{O}$ & 5.624921 & -2.142831 & -0.310973 \\
\hline C & 6.821181 & -2.924244 & -0.148105 \\
\hline $\mathrm{H}$ & 6.589404 & -3.882347 & 0.324150 \\
\hline $\mathrm{H}$ & 7.211314 & -3.076391 & -1.154626 \\
\hline C & 3.760823 & 1.638432 & 0.205340 \\
\hline
\end{tabular}




$\begin{array}{llll}\mathrm{C} & 4.820080 & 0.733226 & 0.359562 \\ \mathrm{H} & 2.177635 & 1.926748 & -1.079124 \\ \mathrm{~N} & 3.214819 & 1.910699 & -1.026864 \\ \mathrm{C} & 3.812015 & 1.931820 & -2.290510 \\ \mathrm{O} & 3.163854 & 2.014507 & -3.308770 \\ \mathrm{O} & 5.160540 & 1.919432 & -2.238497 \\ \mathrm{C} & 5.805355 & 2.016298 & -3.521331 \\ \mathrm{H} & 5.517152 & 1.177896 & -4.159891 \\ \mathrm{H} & 6.873912 & 1.989839 & -3.307012 \\ \mathrm{H} & 5.533759 & 2.952515 & -4.014670 \\ \mathrm{H} & 5.374575 & 0.762869 & 1.290646 \\ \mathrm{H} & 5.400821 & 0.472765 & -0.514473 \\ \mathrm{C} & 3.059885 & 2.191779 & 1.365369 \\ \mathrm{C} & 3.260414 & 1.655075 & 2.657211 \\ \mathrm{C} & 2.173892 & 3.281250 & 1.217643 \\ \mathrm{C} & 2.589068 & 2.188461 & 3.752625 \\ \mathrm{H} & 3.905597 & 0.799566 & 2.804630 \\ \mathrm{C} & 1.510380 & 3.809803 & 2.316719 \\ \mathrm{H} & 2.016819 & 3.720303 & 0.239435 \\ \mathrm{C} & 1.714595 & 3.262892 & 3.587126 \\ \mathrm{H} & 2.742124 & 1.753962 & 4.735885 \\ \mathrm{H} & 0.824164 & 4.639157 & 2.179731 \\ \mathrm{H} & 1.189686 & 3.674317 & 4.444877 \\ \mathrm{H} & 7.546760 & -2.389933 & 0.471120\end{array}$

Catalyst (R)-1 TS Conformation 51

B3LYP/6-31G(d) Energy $=-2809.693926$

B3LYP-D3(BJ)/def2-TZVPP-IEF-PCM(DCM) Energy = -2810.987399

B3LYP-D3(BJ)/def2-TZVPP-IEF-PCM(DCM)//B3LYP/6-31G(d) Free Energy (Quasiharmonic) = 2810.345923

Frequencies (Top 3 out of 270)

1. $-673.9064 \mathrm{~cm}-1$

2. $\quad 7.4205 \mathrm{~cm}-1$

3. $20.8262 \mathrm{~cm}-1$

B3LYP/6-31G(d) Molecular Geometry in Cartesian Coordinates

$\begin{array}{llll}\text { C } & 2.678167 & -1.440161 & -0.142354 \\ \text { C } & 1.345441 & -1.780009 & 0.026647 \\ \text { C } & 0.825003 & -3.078282 & -0.262020\end{array}$




\begin{tabular}{|c|c|c|c|}
\hline C & 1.694448 & -3.989580 & -0.832219 \\
\hline $\mathrm{H}$ & 1.349231 & -5.000436 & -1.030635 \\
\hline C & 4.316205 & 2.337774 & 1.116025 \\
\hline C & 3.194245 & -0.138603 & 0.377581 \\
\hline C & 2.631236 & 1.064369 & -0.023713 \\
\hline C & 3.210458 & 2.331723 & 0.288031 \\
\hline $\mathrm{H}$ & 4.771089 & 3.289565 & 1.376983 \\
\hline 0 & 0.488341 & -0.825910 & 0.557803 \\
\hline$P$ & 0.078776 & 0.477887 & -0.360360 \\
\hline O & 1.522456 & 1.047797 & -0.860760 \\
\hline C & -3.146495 & -4.422763 & 0.735528 \\
\hline C & -2.533851 & -4.829294 & -0.450507 \\
\hline C & -1.265579 & -4.355336 & -0.785546 \\
\hline C & -0.566696 & -3.485247 & 0.068472 \\
\hline C & -1.193220 & -3.090845 & 1.264976 \\
\hline C & -2.469863 & -3.549440 & 1.589831 \\
\hline $\mathrm{H}$ & -3.044753 & -5.516357 & -1.120536 \\
\hline $\mathrm{H}$ & -2.936648 & -3.222199 & 2.514633 \\
\hline C & 1.953795 & 6.128983 & -1.299236 \\
\hline C & 1.019568 & 5.292102 & -0.686449 \\
\hline C & 1.397188 & 4.044713 & -0.189525 \\
\hline C & 2.730420 & 3.618325 & -0.290070 \\
\hline C & 3.662953 & 4.467109 & -0.910801 \\
\hline C & 3.279808 & 5.710049 & -1.413067 \\
\hline $\mathrm{H}$ & -0.014675 & 5.609144 & -0.587697 \\
\hline $\mathrm{H}$ & 4.016797 & 6.347270 & -1.895230 \\
\hline C & 4.284825 & -0.109132 & 1.316631 \\
\hline C & 4.851171 & 1.154326 & 1.678599 \\
\hline C & 5.930361 & 1.200285 & 2.602190 \\
\hline C & 6.423367 & 0.049565 & 3.171559 \\
\hline C & 5.845304 & -1.198596 & 2.841436 \\
\hline C & 4.807670 & -1.276852 & 1.938471 \\
\hline $\mathrm{H}$ & 6.351377 & 2.169591 & 2.858695 \\
\hline $\mathrm{H}$ & 7.244620 & 0.096404 & 3.881464 \\
\hline $\mathrm{H}$ & 6.218800 & -2.105334 & 3.309693 \\
\hline $\mathrm{H}$ & 4.370072 & -2.241046 & 1.707947 \\
\hline C & 3.541765 & -2.367822 & -0.821862 \\
\hline C & 3.031418 & -3.661592 & -1.161903 \\
\hline C & 3.876615 & -4.595439 & -1.820724 \\
\hline C & 5.165926 & -4.262169 & -2.164303 \\
\hline C & 5.661256 & -2.971732 & -1.862798 \\
\hline C & 4.873613 & -2.051553 & -1.206382 \\
\hline $\mathrm{H}$ & 3.476563 & -5.578043 & -2.059860 \\
\hline $\mathrm{H}$ & 5.800683 & -4.980798 & -2.675414 \\
\hline
\end{tabular}




\begin{tabular}{|c|c|c|c|}
\hline $\mathrm{H}$ & 6.672211 & -2.701586 & -2.155649 \\
\hline $\mathrm{H}$ & 5.265329 & -1.064416 & -0.990868 \\
\hline 0 & -0.729293 & 0.140998 & -1.567030 \\
\hline 0 & -0.480530 & 1.459405 & 0.686697 \\
\hline $\mathrm{H}$ & -1.492787 & 1.353839 & 1.263286 \\
\hline $\mathrm{H}$ & -0.671201 & -2.432000 & 1.949257 \\
\hline $\mathrm{H}$ & -4.139467 & -4.781764 & 0.991498 \\
\hline $\mathrm{H}$ & -0.812348 & -4.654676 & -1.726170 \\
\hline $\mathrm{H}$ & 4.693742 & 4.138200 & -1.012146 \\
\hline $\mathrm{H}$ & 1.651496 & 7.098991 & -1.686056 \\
\hline $\mathrm{H}$ & 0.661496 & 3.409690 & 0.291357 \\
\hline C & -3.338551 & 0.383566 & 1.805431 \\
\hline $\mathrm{O}$ & -2.534180 & 1.369197 & 1.944155 \\
\hline $\mathrm{H}$ & -2.980709 & -0.560103 & 1.376855 \\
\hline C & -4.375519 & 0.241934 & 2.912684 \\
\hline $\mathrm{O}$ & -4.819781 & 1.159186 & 3.561256 \\
\hline O & -4.729051 & -1.051605 & 3.062198 \\
\hline C & -5.720998 & -1.302283 & 4.076066 \\
\hline $\mathrm{H}$ & -5.347176 & -0.996872 & 5.056517 \\
\hline $\mathrm{H}$ & -6.638052 & -0.750260 & 3.854956 \\
\hline C & -3.964501 & 0.974038 & -0.718517 \\
\hline C & -4.785901 & 0.662031 & 0.370982 \\
\hline $\mathrm{H}$ & -2.496973 & 0.102028 & -1.872490 \\
\hline$N$ & -3.476792 & 0.004296 & -1.554945 \\
\hline C & -4.119470 & -1.189998 & -1.892006 \\
\hline $\mathrm{O}$ & -5.191654 & -1.577675 & -1.478120 \\
\hline $\mathrm{O}$ & -3.369556 & -1.820052 & -2.811841 \\
\hline C & -3.937906 & -3.032090 & -3.332017 \\
\hline $\mathrm{H}$ & -3.186904 & -3.429080 & -4.014916 \\
\hline $\mathrm{H}$ & -4.867239 & -2.816520 & -3.866424 \\
\hline $\mathrm{H}$ & -4.137099 & -3.737062 & -2.523363 \\
\hline $\mathrm{H}$ & -5.365595 & 1.466576 & 0.808109 \\
\hline $\mathrm{H}$ & -5.246664 & -0.317571 & 0.387649 \\
\hline C & -3.491110 & 2.341281 & -0.957664 \\
\hline C & -2.964873 & 2.703964 & -2.216622 \\
\hline C & -3.606477 & 3.332969 & 0.040214 \\
\hline C & -2.584385 & 4.014473 & -2.473213 \\
\hline $\mathrm{H}$ & -2.883252 & 1.962290 & -3.002855 \\
\hline C & -3.216340 & 4.642902 & -0.223580 \\
\hline $\mathrm{H}$ & -3.972867 & 3.079982 & 1.026514 \\
\hline C & -2.713839 & 4.989055 & -1.478902 \\
\hline $\mathrm{H}$ & -2.191668 & 4.279293 & -3.450206 \\
\hline $\mathrm{H}$ & -3.307150 & 5.394110 & 0.555319 \\
\hline $\mathrm{H}$ & -2.427106 & 6.016464 & -1.686283 \\
\hline
\end{tabular}


$\begin{array}{llll}H & -5.901180 & -2.376746 & 4.049106\end{array}$

Catalyst (R)-1 TS Conformation 52

B3LYP/6-31G(d) Energy $=-2809.695016$

B3LYP-D3(BJ)/def2-TZVPP-IEF-PCM(DCM) Energy = -2810.987035

B3LYP-D3(BJ)/def2-TZVPP-IEF-PCM(DCM)//B3LYP/6-31G(d) Free Energy (Quasiharmonic) = 2810.345908

Frequencies (Top 3 out of 270)

1. $-693.4947 \mathrm{~cm}-1$

2. $\quad 5.8653 \mathrm{~cm}-1$

3. $10.0955 \mathrm{~cm}-1$

B3LYP/6-31G(d) Molecular Geometry in Cartesian Coordinates

$\begin{array}{llll}\text { C } & -3.191312 & 1.240552 & 0.117368 \\ \text { C } & -1.884646 & 1.691960 & 0.190567 \\ \text { C } & -1.514112 & 3.063176 & 0.079056 \\ \text { C } & -2.526571 & 3.973987 & -0.148169 \\ \text { H } & -2.284125 & 5.031423 & -0.215103 \\ \text { C } & -4.180077 & -2.941425 & 0.413602 \\ \text { C } & -3.483138 & -0.212257 & 0.304855 \\ \text { C } & -2.852360 & -1.159616 & -0.491590 \\ \text { C } & -3.219365 & -2.539617 & -0.494689 \\ \text { H } & -4.472956 & -3.987660 & 0.439824 \\ \text { O } & -0.875481 & 0.755569 & 0.388758 \\ \text { P } & -0.449404 & -0.174846 & -0.892383 \\ \text { O } & -1.891973 & -0.743016 & -1.406344 \\ \text { C } & 2.549413 & 4.447509 & 0.385635 \\ \text { C } & 2.045073 & 3.550514 & 1.330859 \\ \text { C } & 0.734965 & 3.083766 & 1.231488 \\ \text { C } & -0.100034 & 3.510845 & 0.184524 \\ \text { C } & 0.419318 & 4.411758 & -0.758675 \\ \text { C } & 1.731013 & 4.876319 & -0.659873 \\ \text { H } & 2.673010 & 3.216335 & 2.152905 \\ \text { H } & 2.114582 & 5.566162 & -1.406948 \\ \text { C } & -1.727826 & -5.487987 & -3.254101 \\ \text { C } & -0.830306 & -4.695961 & -2.535685 \\ \text { C } & -1.291748 & -3.722253 & -1.650025 \\ \text { C } & -2.669940 & -3.527655 & -1.465815 \\ \text { C } & -3.564692 & -4.330324 & -2.193658\end{array}$




\begin{tabular}{|c|c|c|c|}
\hline C & -3.099562 & -5.300967 & -3.080230 \\
\hline $\mathrm{H}$ & 0.240192 & -4.836352 & -2.662829 \\
\hline $\mathrm{H}$ & -3.809890 & -5.904762 & -3.639214 \\
\hline C & -4.409760 & -0.664385 & 1.306911 \\
\hline C & -4.762991 & -2.051083 & 1.347322 \\
\hline C & -5.679921 & -2.510643 & 2.331410 \\
\hline C & -6.213991 & -1.647031 & 3.259136 \\
\hline C & -5.842591 & -0.281849 & 3.242335 \\
\hline C & -4.967067 & 0.196787 & 2.292460 \\
\hline $\mathrm{H}$ & -5.942981 & -3.565820 & 2.341534 \\
\hline $\mathrm{H}$ & -6.910159 & -2.010366 & 4.010149 \\
\hline $\mathrm{H}$ & -6.247687 & 0.395362 & 3.989496 \\
\hline $\mathrm{H}$ & -4.684982 & 1.243342 & 2.300078 \\
\hline C & -4.225587 & 2.191275 & -0.192929 \\
\hline C & -3.877097 & 3.576726 & -0.307895 \\
\hline C & -4.889859 & 4.529893 & -0.601078 \\
\hline C & -6.191909 & 4.138564 & -0.808029 \\
\hline C & -6.531502 & 2.767314 & -0.736788 \\
\hline C & -5.576706 & 1.820584 & -0.436729 \\
\hline $\mathrm{H}$ & -4.609192 & 5.578096 & -0.672490 \\
\hline $\mathrm{H}$ & -6.956222 & 4.875433 & -1.039089 \\
\hline $\mathrm{H}$ & -7.555164 & 2.455901 & -0.926361 \\
\hline $\mathrm{H}$ & -5.853244 & 0.773750 & -0.397394 \\
\hline $\mathrm{O}$ & 0.476424 & -1.233449 & -0.373069 \\
\hline $\mathrm{O}$ & 0.019336 & 0.709028 & -2.051940 \\
\hline $\mathrm{H}$ & 1.185868 & 0.768980 & -2.354376 \\
\hline $\mathrm{H}$ & -0.205176 & 4.728087 & -1.589156 \\
\hline $\mathrm{H}$ & 3.572220 & 4.805955 & 0.463213 \\
\hline $\mathrm{H}$ & 0.351151 & 2.389810 & 1.971788 \\
\hline $\mathrm{H}$ & -4.633784 & -4.175146 & -2.075367 \\
\hline $\mathrm{H}$ & -1.361450 & -6.242005 & -3.945962 \\
\hline $\mathrm{H}$ & -0.581895 & -3.120269 & -1.093498 \\
\hline C & 3.079574 & 0.867445 & -1.581896 \\
\hline O & 2.351836 & 0.882307 & -2.628785 \\
\hline $\mathrm{H}$ & 2.624736 & 1.041753 & -0.601078 \\
\hline C & 4.503565 & 1.367847 & -1.743843 \\
\hline $\mathrm{O}$ & 5.149012 & 1.313886 & -2.763248 \\
\hline $\mathrm{O}$ & 4.939016 & 1.888502 & -0.578898 \\
\hline C & 6.288366 & 2.391469 & -0.604332 \\
\hline $\mathrm{H}$ & 6.469099 & 2.792687 & 0.392507 \\
\hline $\mathrm{H}$ & 6.989333 & 1.583071 & -0.825077 \\
\hline C & 3.903987 & -1.315116 & 0.088247 \\
\hline C & 3.551626 & -1.149170 & -1.254604 \\
\hline $\mathrm{H}$ & 1.926224 & -1.329217 & 0.608243 \\
\hline
\end{tabular}




$\begin{array}{llrl}\text { N } & 2.885799 & -1.420665 & 0.995009 \\ \mathrm{C} & 2.946914 & -1.940676 & 2.295390 \\ \mathrm{O} & 3.926306 & -2.362415 & 2.868103 \\ \mathrm{O} & 1.702058 & -1.907871 & 2.804230 \\ \mathrm{C} & 1.566741 & -2.463623 & 4.122042 \\ \mathrm{H} & 0.510384 & -2.359485 & 4.368213 \\ \mathrm{H} & 2.186620 & -1.914070 & 4.835188 \\ \mathrm{H} & 1.861747 & -3.516048 & 4.125506 \\ \mathrm{H} & 4.333720 & -1.207038 & -2.002065 \\ \mathrm{H} & 2.559388 & -1.466406 & -1.554895 \\ \mathrm{C} & 5.317067 & -1.231306 & 0.513780 \\ \mathrm{C} & 6.306765 & -1.861165 & -0.259598 \\ \mathrm{C} & 5.707839 & -0.470040 & 1.629772 \\ \mathrm{C} & 7.653035 & -1.747715 & 0.083185 \\ \mathrm{H} & 6.016514 & -2.465935 & -1.112837 \\ \mathrm{C} & 7.052769 & -0.344355 & 1.959009 \\ \mathrm{H} & 4.957262 & 0.038255 & 2.223745 \\ \mathrm{C} & 8.028970 & -0.987011 & 1.191067 \\ \mathrm{H} & 8.405083 & -2.255108 & -0.513852 \\ \mathrm{H} & 7.341920 & 0.251001 & 2.820389 \\ \mathrm{H} & 9.078224 & -0.895840 & 1.458279 \\ \mathrm{H} & 6.385829 & 3.172780 & -1.361952\end{array}$

Catalyst (R)-1 TS Conformation 53

B3LYP/6-31G(d) Energy = -2809.694539

B3LYP-D3(BJ)/def2-TZVPP-IEF-PCM(DCM) Energy = -2810.986905

B3LYP-D3(BJ)/def2-TZVPP-IEF-PCM(DCM)//B3LYP/6-31G(d) Free Energy (Quasiharmonic) = 2810.345904

Frequencies (Top 3 out of 270)

1. $-698.7970 \mathrm{~cm}-1$

2. $\quad 4.9732 \mathrm{~cm}-1$

3. $\quad 9.7360 \mathrm{~cm}-1$

B3LYP/6-31G(d) Molecular Geometry in Cartesian Coordinates

$\begin{array}{llll}\text { C } & -3.336788 & 1.080545 & 0.121785 \\ \text { C } & -2.070043 & 1.631922 & 0.231804 \\ \text { C } & -1.815627 & 3.034023 & 0.199691 \\ \text { C } & -2.900025 & 3.869448 & 0.017862 \\ \text { H } & -2.745676 & 4.945366 & 0.011547\end{array}$




\begin{tabular}{|c|c|c|c|}
\hline C & -3.814212 & -3.206352 & 0.245232 \\
\hline C & -3.501615 & -0.401027 & 0.219918 \\
\hline C & -2.774374 & -1.229427 & -0.622939 \\
\hline C & -2.927078 & -2.647484 & -0.654754 \\
\hline $\mathrm{H}$ & -3.977271 & -4.280715 & 0.229102 \\
\hline $\mathrm{O}$ & -0.986951 & 0.776297 & 0.391064 \\
\hline$P$ & -0.464585 & -0.058529 & -0.923549 \\
\hline 0 & -1.870681 & -0.653621 & -1.508742 \\
\hline C & 2.125755 & 4.720535 & 0.582624 \\
\hline C & 1.701044 & 3.731987 & 1.473991 \\
\hline C & 0.430984 & 3.170027 & 1.350998 \\
\hline C & -0.442642 & 3.589854 & 0.333064 \\
\hline C & -0.003499 & 4.584391 & -0.555277 \\
\hline C & 1.267817 & 5.145140 & -0.432384 \\
\hline $\mathrm{H}$ & 2.360360 & 3.398991 & 2.271470 \\
\hline $\mathrm{H}$ & 1.590313 & 5.905956 & -1.138249 \\
\hline C & -0.852161 & -5.243900 & -3.388466 \\
\hline C & -1.413654 & -4.051700 & -3.850214 \\
\hline C & -2.068336 & -3.192146 & -2.969816 \\
\hline C & -2.178513 & -3.511998 & -1.605983 \\
\hline C & -1.606105 & -4.712362 & -1.154036 \\
\hline C & -0.949544 & -5.570410 & -2.035341 \\
\hline $\mathrm{H}$ & -1.344181 & -3.788376 & -4.902380 \\
\hline $\mathrm{H}$ & -0.507660 & -6.490658 & -1.661834 \\
\hline C & -4.361344 & -1.005829 & 1.200317 \\
\hline C & -4.522153 & -2.429346 & 1.194123 \\
\hline C & -5.379642 & -3.039145 & 2.149994 \\
\hline C & -6.030710 & -2.286529 & 3.099360 \\
\hline C & -5.842673 & -0.884673 & 3.133439 \\
\hline C & -5.032549 & -0.261546 & 2.209682 \\
\hline $\mathrm{H}$ & -5.501039 & -4.119521 & 2.121763 \\
\hline $\mathrm{H}$ & -6.678821 & -2.764635 & 3.828779 \\
\hline $\mathrm{H}$ & -6.339034 & -0.293408 & 3.898267 \\
\hline $\mathrm{H}$ & -4.892598 & 0.812192 & 2.255336 \\
\hline C & -4.445001 & 1.958275 & -0.139270 \\
\hline C & -4.212909 & 3.372148 & -0.172244 \\
\hline C & -5.301650 & 4.252612 & -0.416683 \\
\hline C & -6.566231 & 3.766532 & -0.653464 \\
\hline C & -6.790615 & 2.369826 & -0.662291 \\
\hline C & -5.760229 & 1.490469 & -0.411501 \\
\hline $\mathrm{H}$ & -5.109757 & 5.322996 & -0.426246 \\
\hline $\mathrm{H}$ & -7.389153 & 4.449237 & -0.846528 \\
\hline $\mathrm{H}$ & -7.784763 & 1.985797 & -0.874516 \\
\hline $\mathrm{H}$ & -5.947759 & 0.423312 & -0.432554 \\
\hline
\end{tabular}




\begin{tabular}{|c|c|c|c|}
\hline $\mathrm{O}$ & 0.496708 & -1.094882 & -0.438723 \\
\hline $\mathrm{O}$ & -0.020837 & 0.917936 & -2.019159 \\
\hline $\mathrm{H}$ & 1.138958 & 1.067947 & -2.263985 \\
\hline $\mathrm{H}$ & -0.656655 & 4.898398 & -1.364353 \\
\hline $\mathrm{H}$ & 3.117930 & 5.153430 & 0.678078 \\
\hline $\mathrm{H}$ & 0.109061 & 2.405156 & 2.049592 \\
\hline $\mathrm{H}$ & -1.659421 & -4.961183 & -0.097754 \\
\hline $\mathrm{H}$ & -0.339369 & -5.910218 & -4.077166 \\
\hline $\mathrm{H}$ & -2.502371 & -2.270460 & -3.341152 \\
\hline C & 3.011237 & 1.148535 & -1.415805 \\
\hline 0 & 2.318741 & 1.266221 & -2.481177 \\
\hline $\mathrm{H}$ & 2.514933 & 1.185340 & -0.439938 \\
\hline C & 4.409422 & 1.740165 & -1.454914 \\
\hline 0 & 5.104364 & 1.825306 & -2.439035 \\
\hline O & 4.758223 & 2.167364 & -0.223652 \\
\hline C & 6.069507 & 2.755978 & -0.133858 \\
\hline $\mathrm{H}$ & 6.834120 & 2.020793 & -0.395269 \\
\hline $\mathrm{H}$ & 6.145389 & 3.612679 & -0.807895 \\
\hline C & 3.919573 & -1.159972 & -0.004909 \\
\hline C & 3.554635 & -0.851148 & -1.320245 \\
\hline $\mathrm{H}$ & 1.945779 & -1.293257 & 0.511303 \\
\hline $\mathrm{N}$ & 2.909732 & -1.401907 & 0.883695 \\
\hline C & 2.994087 & -2.061296 & 2.117431 \\
\hline $\mathrm{O}$ & 3.987970 & -2.520159 & 2.634152 \\
\hline 0 & 1.753321 & -2.116186 & 2.634925 \\
\hline C & 1.644868 & -2.815865 & 3.884388 \\
\hline $\mathrm{H}$ & 2.258887 & -2.332951 & 4.649035 \\
\hline $\mathrm{H}$ & 1.964797 & -3.854855 & 3.770523 \\
\hline $\mathrm{H}$ & 0.588983 & -2.765178 & 4.148989 \\
\hline $\mathrm{H}$ & 4.336360 & -0.796298 & -2.068520 \\
\hline $\mathrm{H}$ & 2.576049 & -1.177557 & -1.654345 \\
\hline C & 5.330837 & -1.076463 & 0.426507 \\
\hline C & 6.338002 & -1.577319 & -0.415642 \\
\hline C & 5.700505 & -0.436502 & 1.622991 \\
\hline C & 7.681083 & -1.457635 & -0.063042 \\
\hline $\mathrm{H}$ & 6.064625 & -2.087906 & -1.333502 \\
\hline C & 7.041910 & -0.302879 & 1.963377 \\
\hline $\mathrm{H}$ & 4.935783 & -0.026620 & 2.272362 \\
\hline C & 8.035930 & -0.817849 & 1.125219 \\
\hline $\mathrm{H}$ & 8.447348 & -1.865003 & -0.715991 \\
\hline $\mathrm{H}$ & 7.314585 & 0.198775 & 2.887523 \\
\hline $\mathrm{H}$ & 9.082736 & -0.721316 & 1.400094 \\
\hline $\mathrm{H}$ & 6.178699 & 3.069149 & 0.904264 \\
\hline
\end{tabular}


Catalyst (R)-1 TS Conformation 54

B3LYP/6-31G(d) Energy $=-2809.69799$

B3LYP-D3(BJ)/def2-TZVPP-IEF-PCM(DCM) Energy = -2810.988225

B3LYP-D3(BJ)/def2-TZVPP-IEF-PCM(DCM)//B3LYP/6-31G(d) Free Energy (Quasiharmonic) = 2810.345892

Frequencies (Top 3 out of 270)

1. $-450.5152 \mathrm{~cm}-1$

2. $\quad 11.8390 \mathrm{~cm}-1$

3. $\quad 12.5942 \mathrm{~cm}-1$

B3LYP/6-31G(d) Molecular Geometry in Cartesian Coordinates

$\begin{array}{llll}\text { C } & 3.541018 & -0.987232 & 0.020289 \\ \text { C } & 2.336676 & -1.637730 & 0.225688 \\ \text { C } & 2.124562 & -3.018824 & -0.052190 \\ \text { C } & 3.180447 & -3.722015 & -0.596791 \\ \text { H } & 3.062535 & -4.783137 & -0.800669 \\ \text { C } & 4.051994 & 3.203916 & 0.869235 \\ \text { C } & 3.684407 & 0.448423 & 0.406903 \\ \text { C } & 2.809502 & 1.399315 & -0.100939 \\ \text { C } & 2.998533 & 2.804152 & 0.068755 \\ \text { H } & 4.215781 & 4.266364 & 1.027931 \\ \text { O } & 1.269957 & -0.906261 & 0.740728 \\ \text { P } & 0.511777 & 0.143265 & -0.257895 \\ \text { O } & 1.750741 & 0.978881 & -0.903161 \\ \text { C } & -1.599020 & -5.040234 & 0.713914 \\ \text { C } & -1.024963 & -4.234700 & 1.701385 \\ \text { C } & 0.172072 & -3.562134 & 1.456262 \\ \text { C } & 0.824589 & -3.689082 & 0.218060 \\ \text { C } & 0.239913 & -4.504177 & -0.764693 \\ \text { C } & -0.960305 & -5.172582 & -0.520534 \\ \text { H } & -1.507695 & -4.133855 & 2.670256 \\ \text { H } & -1.401227 & -5.789574 & -1.298953 \\ \text { C } & 0.710172 & 5.857734 & -1.921875 \\ \text { C } & 2.105178 & 5.866012 & -1.965671 \\ \text { C } & 2.829187 & 4.860764 & -1.326116 \\ \text { C } & 2.173937 & 3.830088 & -0.629915 \\ \text { C } & 0.770681 & 3.833775 & -0.592745 \\ \text { C } & 0.047394 & 4.839403 & -1.234408 \\ \text { H } & 2.632402 & 6.649037 & -2.505028\end{array}$




\begin{tabular}{|c|c|c|c|}
\hline $\mathrm{H}$ & -1.037081 & 4.811891 & -1.193128 \\
\hline C & 4.717837 & 0.879631 & 1.308635 \\
\hline C & 4.898773 & 2.282168 & 1.530792 \\
\hline C & 5.916467 & 2.722814 & 2.419895 \\
\hline C & 6.713335 & 1.821116 & 3.085916 \\
\hline C & 6.516576 & 0.433447 & 2.892410 \\
\hline C & 5.547663 & -0.024944 & 2.026986 \\
\hline $\mathrm{H}$ & 6.044480 & 3.792070 & 2.571164 \\
\hline $\mathrm{H}$ & 7.484339 & 2.169372 & 3.767774 \\
\hline $\mathrm{H}$ & 7.131436 & -0.278438 & 3.436541 \\
\hline $\mathrm{H}$ & 5.402191 & -1.091444 & 1.898980 \\
\hline C & 4.608058 & -1.714699 & -0.614216 \\
\hline C & 4.417155 & -3.104503 & -0.907811 \\
\hline C & 5.466496 & -3.838903 & -1.523996 \\
\hline C & 6.648692 & -3.228198 & -1.871469 \\
\hline C & 6.824738 & -1.847322 & -1.620636 \\
\hline C & 5.834038 & -1.111423 & -1.008351 \\
\hline $\mathrm{H}$ & 5.308625 & -4.895344 & -1.727953 \\
\hline $\mathrm{H}$ & 7.441054 & -3.798136 & -2.348837 \\
\hline $\mathrm{H}$ & 7.748980 & -1.359782 & -1.918709 \\
\hline $\mathrm{H}$ & 5.982447 & -0.052537 & -0.833586 \\
\hline $\mathrm{O}$ & -0.441525 & 0.933500 & 0.581117 \\
\hline $\mathrm{O}$ & -0.059808 & -0.620369 & -1.474413 \\
\hline $\mathrm{H}$ & -1.183395 & -0.639616 & -1.541502 \\
\hline $\mathrm{H}$ & 0.720806 & -4.591915 & -1.734803 \\
\hline $\mathrm{H}$ & -2.538055 & -5.553159 & 0.901637 \\
\hline $\mathrm{H}$ & 0.610275 & -2.940651 & 2.230148 \\
\hline $\mathrm{H}$ & 0.237799 & 3.060106 & -0.052303 \\
\hline $\mathrm{H}$ & 0.143625 & 6.637879 & -2.424301 \\
\hline $\mathrm{H}$ & 3.914573 & 4.858041 & -1.382294 \\
\hline C & -2.988599 & -1.599622 & -0.842096 \\
\hline 0 & -2.488922 & -0.678242 & -1.579215 \\
\hline $\mathrm{H}$ & -2.367810 & -2.447931 & -0.524226 \\
\hline C & -4.410990 & -2.056916 & -1.122787 \\
\hline $\mathrm{O}$ & -4.870855 & -3.096405 & -0.688469 \\
\hline 0 & -5.080825 & -1.190737 & -1.892600 \\
\hline C & -6.426809 & -1.568653 & -2.227847 \\
\hline $\mathrm{H}$ & -6.444058 & -2.563448 & -2.679446 \\
\hline $\mathrm{H}$ & -7.057751 & -1.566463 & -1.335033 \\
\hline C & -3.865864 & 0.236393 & 0.937765 \\
\hline C & -3.136076 & -0.961402 & 1.043088 \\
\hline $\mathrm{H}$ & -2.170680 & 1.243869 & 0.391186 \\
\hline $\mathrm{N}$ & -3.207054 & 1.294566 & 0.393408 \\
\hline C & -3.686704 & 2.324837 & -0.434854 \\
\hline
\end{tabular}




$\begin{array}{lrrr}\text { O } & -2.986831 & 3.255966 & -0.763076 \\ \text { O } & -4.952096 & 2.130684 & -0.828215 \\ \text { C } & -5.470511 & 3.143509 & -1.708170 \\ \text { H } & -5.431920 & 4.125317 & -1.229824 \\ \text { H } & -6.501764 & 2.850435 & -1.904360 \\ \text { H } & -4.892516 & 3.169712 & -2.634756 \\ \text { H } & -3.557166 & -1.765040 & 1.637854 \\ \text { H } & -2.058694 & -0.853798 & 1.124388 \\ \text { C } & -5.253255 & 0.361353 & 1.424613 \\ \text { C } & -5.696226 & 1.584669 & 1.962367 \\ \text { C } & -6.111289 & -0.752191 & 1.483769 \\ \mathrm{C} & -6.964434 & 1.695025 & 2.523596 \\ \text { H } & -5.029257 & 2.440373 & 1.973100 \\ \mathrm{C} & -7.387457 & -0.630698 & 2.029040 \\ \text { H } & -5.792931 & -1.711425 & 1.090736 \\ \mathrm{C} & -7.819172 & 0.590656 & 2.550423 \\ \mathrm{H} & -7.283291 & 2.643230 & 2.946983 \\ \mathrm{H} & -8.041866 & -1.497418 & 2.054868 \\ \mathrm{H} & -8.810307 & 0.678371 & 2.986724 \\ \mathrm{H} & -6.770349 & -0.816138 & -2.937619\end{array}$

Catalyst (R)-1 TS Conformation 55

B3LYP/6-31G(d) Energy = -2809.701977

B3LYP-D3(BJ)/def2-TZVPP-IEF-PCM(DCM) Energy = -2810.989782

B3LYP-D3(BJ)/def2-TZVPP-IEF-PCM(DCM)//B3LYP/6-31G(d) Free Energy (Quasiharmonic) = 2810.345887

Frequencies (Top 3 out of 270)

1. $-253.4217 \mathrm{~cm}-1$

2. $\quad 12.7212 \mathrm{~cm}-1$

3. $20.4959 \mathrm{~cm}-1$

B3LYP/6-31G(d) Molecular Geometry in Cartesian Coordinates

$\begin{array}{llll}\text { C } & 3.091242 & -0.929931 & -0.374457 \\ \text { C } & 1.912745 & -1.601324 & -0.077640 \\ \text { C } & 1.750860 & -3.005122 & -0.287211 \\ \text { C } & 2.790056 & -3.681307 & -0.896270 \\ \text { H } & 2.688390 & -4.748982 & -1.071590 \\ \text { C } & 3.676470 & 3.221179 & 0.630462 \\ \text { C } & 3.287848 & 0.488614 & 0.047382\end{array}$




\begin{tabular}{|c|c|c|c|}
\hline C & 2.383102 & 1.460052 & -0.345057 \\
\hline C & 2.564280 & 2.853343 & -0.102747 \\
\hline $\mathrm{H}$ & 3.867933 & 4.275824 & 0.808570 \\
\hline $\mathrm{O}$ & 0.881459 & -0.916100 & 0.558978 \\
\hline$P$ & 0.083759 & 0.323498 & -0.151034 \\
\hline $\mathrm{O}$ & 1.241870 & 1.052763 & -1.035898 \\
\hline C & -1.642350 & -5.344108 & 0.953250 \\
\hline C & -1.835072 & -4.217904 & 0.148976 \\
\hline C & -0.743455 & -3.442027 & -0.242212 \\
\hline C & 0.556313 & -3.772521 & 0.166187 \\
\hline C & 0.736617 & -4.905165 & 0.978352 \\
\hline C & -0.352624 & -5.685236 & 1.367508 \\
\hline $\mathrm{H}$ & -2.828641 & -3.922190 & -0.173844 \\
\hline $\mathrm{H}$ & -0.192621 & -6.556920 & 1.997266 \\
\hline C & 0.045187 & 5.985070 & -1.641121 \\
\hline C & 0.371081 & 4.892073 & -2.447476 \\
\hline C & 1.158876 & 3.856397 & -1.948064 \\
\hline C & 1.640036 & 3.893293 & -0.627701 \\
\hline C & 1.290964 & 4.989973 & 0.178099 \\
\hline C & 0.505285 & 6.027753 & -0.323239 \\
\hline $\mathrm{H}$ & 0.017460 & 4.847981 & -3.474113 \\
\hline $\mathrm{H}$ & 0.252793 & 6.868730 & 0.317728 \\
\hline C & 4.394028 & 0.880968 & 0.879250 \\
\hline C & 4.584221 & 2.272356 & 1.160335 \\
\hline C & 5.678851 & 2.678122 & 1.971277 \\
\hline C & 6.537202 & 1.751742 & 2.515620 \\
\hline C & 6.328936 & 0.373891 & 2.272067 \\
\hline C & 5.288953 & -0.050152 & 1.474196 \\
\hline $\mathrm{H}$ & 5.815787 & 3.739616 & 2.163585 \\
\hline $\mathrm{H}$ & 7.366082 & 2.072634 & 3.140504 \\
\hline $\mathrm{H}$ & 6.993514 & -0.358502 & 2.722258 \\
\hline $\mathrm{H}$ & 5.138916 & -1.109911 & 1.305440 \\
\hline C & 4.118381 & -1.627403 & -1.101548 \\
\hline C & 3.960275 & -3.027591 & -1.350493 \\
\hline C & 4.969888 & -3.731825 & -2.060822 \\
\hline C & 6.085439 & -3.081374 & -2.533847 \\
\hline C & 6.229845 & -1.690510 & -2.319070 \\
\hline C & 5.275564 & -0.983423 & -1.621079 \\
\hline $\mathrm{H}$ & 4.834571 & -4.796857 & -2.233725 \\
\hline $\mathrm{H}$ & 6.848336 & -3.627568 & -3.081725 \\
\hline $\mathrm{H}$ & 7.099379 & -1.172464 & -2.714486 \\
\hline $\mathrm{H}$ & 5.397748 & 0.083706 & -1.476899 \\
\hline $\mathrm{O}$ & -0.526976 & 1.166912 & 0.914258 \\
\hline $\mathrm{O}$ & -0.831292 & -0.212249 & -1.292075 \\
\hline
\end{tabular}




\begin{tabular}{|c|c|c|c|}
\hline $\mathrm{H}$ & -1.822380 & -0.554222 & -1.042393 \\
\hline $\mathrm{H}$ & 1.737176 & -5.165397 & 1.313887 \\
\hline $\mathrm{H}$ & -2.491541 & -5.950508 & 1.258357 \\
\hline $\mathrm{H}$ & -0.905374 & -2.588315 & -0.886246 \\
\hline $\mathrm{H}$ & 1.628791 & 5.020343 & 1.210035 \\
\hline $\mathrm{H}$ & -0.561840 & 6.795379 & -2.036586 \\
\hline $\mathrm{H}$ & 1.413288 & 3.019070 & -2.588262 \\
\hline C & -4.160352 & -0.675316 & -1.152993 \\
\hline 0 & -3.042915 & -1.188477 & -0.792927 \\
\hline $\mathrm{H}$ & -4.171122 & 0.256299 & -1.737861 \\
\hline C & -5.269547 & -1.599816 & -1.660052 \\
\hline 0 & -6.183770 & -1.208633 & -2.355406 \\
\hline O & -5.111652 & -2.867629 & -1.251269 \\
\hline C & -6.121575 & -3.786338 & -1.703782 \\
\hline $\mathrm{H}$ & -7.107948 & -3.476757 & -1.348132 \\
\hline $\mathrm{H}$ & -5.845741 & -4.752572 & -1.281789 \\
\hline C & -4.234928 & 0.839985 & 0.917330 \\
\hline C & -5.198188 & -0.039248 & 0.389092 \\
\hline $\mathrm{H}$ & -2.289761 & 0.893760 & 1.620651 \\
\hline$N$ & -3.167538 & 0.359010 & 1.597419 \\
\hline C & -3.071085 & -0.903890 & 2.226577 \\
\hline 0 & -3.974484 & -1.690304 & 2.397790 \\
\hline 0 & -1.818356 & -1.037139 & 2.671039 \\
\hline C & -1.533480 & -2.256007 & 3.382533 \\
\hline $\mathrm{H}$ & -1.766950 & -3.120767 & 2.760268 \\
\hline $\mathrm{H}$ & -2.114023 & -2.293610 & 4.308423 \\
\hline $\mathrm{H}$ & -0.466301 & -2.212157 & 3.594982 \\
\hline $\mathrm{H}$ & -6.073222 & 0.402815 & -0.073609 \\
\hline $\mathrm{H}$ & -5.347449 & -0.983004 & 0.897342 \\
\hline C & -4.254526 & 2.279470 & 0.575371 \\
\hline C & -5.499684 & 2.926167 & 0.442947 \\
\hline C & -3.078211 & 3.031504 & 0.393225 \\
\hline C & -5.567595 & 4.281326 & 0.135571 \\
\hline $\mathrm{H}$ & -6.417237 & 2.373886 & 0.615617 \\
\hline C & -3.154927 & 4.385101 & 0.071152 \\
\hline $\mathrm{H}$ & -2.100223 & 2.565740 & 0.468240 \\
\hline C & -4.394485 & 5.013984 & -0.056533 \\
\hline $\mathrm{H}$ & -6.536623 & 4.764859 & 0.050981 \\
\hline $\mathrm{H}$ & -2.236940 & 4.942748 & -0.087016 \\
\hline $\mathrm{H}$ & -4.447353 & 6.071190 & -0.302467 \\
\hline $\mathrm{H}$ & -6.134325 & -3.831521 & -2.795793 \\
\hline
\end{tabular}

Catalyst (R)-1 TS Conformation 56 
B3LYP/6-31G(d) Energy $=-2809.693641$

B3LYP-D3(BJ)/def2-TZVPP-IEF-PCM(DCM) Energy $=-2810.987082$

B3LYP-D3(BJ)/def2-TZVPP-IEF-PCM(DCM)//B3LYP/6-31G(d) Free Energy (Quasiharmonic) = 2810.345837

Frequencies (Top 3 out of 270)

1. $-480.7291 \mathrm{~cm}-1$

2. $\quad 6.6650 \mathrm{~cm}-1$

3. $\quad 11.8807 \mathrm{~cm}-1$

B3LYP/6-31G(d) Molecular Geometry in Cartesian Coordinates

$\begin{array}{llll}\text { C } & 3.623107 & -0.874558 & -0.035928 \\ \text { C } & 2.450277 & -1.565459 & 0.223035 \\ \text { C } & 2.300879 & -2.967935 & 0.018004 \\ \text { C } & 3.381447 & -3.649781 & -0.505579 \\ \text { H } & 3.310113 & -4.724330 & -0.652977 \\ \text { C } & 3.808753 & 3.366553 & 0.728046 \\ \text { C } & 3.699610 & 0.583342 & 0.278570 \\ \text { C } & 2.756325 & 1.451211 & -0.251921 \\ \text { C } & 2.794846 & 2.864938 & -0.065739 \\ \text { H } & 3.885875 & 4.441351 & 0.868685 \\ \text { O } & 1.357750 & -0.860291 & 0.716843 \\ \text { P } & 0.526194 & 0.091874 & -0.327963 \\ \text { O } & 1.734952 & 0.926454 & -1.038825 \\ \text { C } & -1.310273 & -5.122903 & 0.938656 \\ \text { C } & -0.774865 & -4.227705 & 1.868758 \\ \text { C } & 0.384922 & -3.512151 & 1.572702 \\ \text { C } & 1.037156 & -3.683069 & 0.339532 \\ \text { C } & 0.489346 & -4.585812 & -0.586020 \\ \text { C } & -0.672809 & -5.298813 & -0.290566 \\ \text { H } & -1.258686 & -4.089547 & 2.832406 \\ \text { H } & -1.084046 & -5.985342 & -1.025978 \\ \text { C } & -0.014099 & 5.610673 & -1.819358 \\ \text { C } & 0.521985 & 4.577630 & -2.589838 \\ \text { C } & 1.418607 & 3.670840 & -2.028426 \\ \text { C } & 1.799317 & 3.782596 & -0.680694 \\ \text { C } & 1.252193 & 4.826155 & 0.083777 \\ \text { C } & 0.354829 & 5.731896 & -0.479556 \\ \text { H } & 0.238755 & 4.473500 & -3.633750 \\ \text { H } & -0.064172 & 6.525871 & 0.133452 \\ \text { C } & 4.699393 & 1.115134 & 1.164077\end{array}$




\begin{tabular}{|c|c|c|c|}
\hline C & 4.753386 & 2.531310 & 1.372036 \\
\hline C & 5.745628 & 3.072995 & 2.233891 \\
\hline C & 6.632381 & 2.255518 & 2.894802 \\
\hline C & 6.555725 & 0.853299 & 2.723198 \\
\hline C & 5.617172 & 0.298535 & 1.881049 \\
\hline $\mathrm{H}$ & 5.780237 & 4.151394 & 2.369889 \\
\hline $\mathrm{H}$ & 7.382113 & 2.680670 & 3.556475 \\
\hline $\mathrm{H}$ & 7.240794 & 0.206429 & 3.264638 \\
\hline $\mathrm{H}$ & 5.566333 & -0.778200 & 1.768900 \\
\hline C & 4.713701 & -1.584072 & -0.647633 \\
\hline C & 4.584261 & -2.994286 & -0.866983 \\
\hline C & 5.659115 & -3.709860 & -1.461025 \\
\hline C & 6.806777 & -3.063576 & -1.856856 \\
\hline C & 6.921463 & -1.664880 & -1.678631 \\
\hline C & 5.904965 & -0.945315 & -1.089786 \\
\hline $\mathrm{H}$ & 5.548707 & -4.781575 & -1.608929 \\
\hline $\mathrm{H}$ & 7.618831 & -3.619981 & -2.316800 \\
\hline $\mathrm{H}$ & 7.818320 & -1.151344 & -2.014397 \\
\hline $\mathrm{H}$ & 6.005067 & 0.127070 & -0.969971 \\
\hline $\mathrm{O}$ & -0.448091 & 0.894592 & 0.469152 \\
\hline $\mathrm{O}$ & -0.020062 & -0.773388 & -1.484608 \\
\hline $\mathrm{H}$ & -1.152019 & -0.845940 & -1.525221 \\
\hline $\mathrm{H}$ & 0.967463 & -4.707870 & -1.553699 \\
\hline $\mathrm{H}$ & -2.218874 & -5.672560 & 1.168340 \\
\hline $\mathrm{H}$ & 0.793705 & -2.821275 & 2.302302 \\
\hline $\mathrm{H}$ & 1.515536 & 4.909510 & 1.134621 \\
\hline $\mathrm{H}$ & -0.720801 & 6.309637 & -2.258379 \\
\hline $\mathrm{H}$ & 1.829197 & 2.873389 & -2.637815 \\
\hline C & -2.881550 & -1.739060 & -0.632433 \\
\hline $\mathrm{O}$ & -2.438569 & -0.945446 & -1.530085 \\
\hline $\mathrm{H}$ & -2.198986 & -2.440063 & -0.135114 \\
\hline C & -4.276667 & -2.301966 & -0.863105 \\
\hline $\mathrm{O}$ & -5.049304 & -1.914146 & -1.707814 \\
\hline $\mathrm{O}$ & -4.532955 & -3.314127 & -0.002763 \\
\hline C & -5.835502 & -3.908483 & -0.132967 \\
\hline $\mathrm{H}$ & -5.870242 & -4.704744 & 0.611188 \\
\hline $\mathrm{H}$ & -6.614497 & -3.165972 & 0.060316 \\
\hline C & -3.892564 & 0.385225 & 0.739982 \\
\hline C & -3.187801 & -0.764302 & 1.130372 \\
\hline $\mathrm{H}$ & -2.157798 & 1.219093 & 0.066767 \\
\hline$N$ & -3.180310 & 1.376318 & 0.154569 \\
\hline C & -3.540590 & 2.692361 & -0.199648 \\
\hline $\mathrm{O}$ & -2.850538 & 3.366671 & -0.925799 \\
\hline $\mathrm{O}$ & -4.671267 & 3.099855 & 0.398406 \\
\hline
\end{tabular}




$\begin{array}{llll}\mathrm{C} & -5.081115 & 4.436153 & 0.058957 \\ \mathrm{H} & -5.241298 & 4.525733 & -1.018330 \\ \mathrm{H} & -4.320977 & 5.156533 & 0.370389 \\ \mathrm{H} & -6.012233 & 4.595968 & 0.602427 \\ \mathrm{H} & -3.728437 & -1.511345 & 1.699933 \\ \mathrm{H} & -2.134195 & -0.642321 & 1.362990 \\ \mathrm{C} & -5.373483 & 0.396488 & 0.785754 \\ \mathrm{C} & -6.029120 & 0.042680 & 1.974553 \\ \mathrm{C} & -6.132473 & 0.669633 & -0.364386 \\ \mathrm{C} & -7.421749 & -0.008688 & 2.022357 \\ \mathrm{H} & -5.445137 & -0.165867 & 2.866236 \\ \mathrm{C} & -7.521440 & 0.597341 & -0.317169 \\ \mathrm{H} & -5.629426 & 0.886348 & -1.300576 \\ \mathrm{C} & -8.169658 & 0.267293 & 0.876318 \\ \mathrm{H} & -7.920309 & -0.264577 & 2.953056 \\ \mathrm{H} & -8.099145 & 0.789771 & -1.216615 \\ \mathrm{H} & -9.254753 & 0.219095 & 0.910307 \\ \mathrm{H} & -5.971935 & -4.314995 & -1.138411\end{array}$

Catalyst (R)-1 TS Conformation 57

B3LYP/6-31G(d) Energy = -2809.692723

B3LYP-D3(BJ)/def2-TZVPP-IEF-PCM(DCM) Energy $=-2810.987779$

B3LYP-D3(BJ)/def2-TZVPP-IEF-PCM(DCM)//B3LYP/6-31G(d) Free Energy (Quasiharmonic) = 2810.345825

Frequencies (Top 3 out of 270)

1. $-428.7531 \mathrm{~cm}-1$

2. $\quad 12.6544 \mathrm{~cm}-1$

3. $\quad 14.1611 \mathrm{~cm}-1$

B3LYP/6-31G(d) Molecular Geometry in Cartesian Coordinates

$\begin{array}{lrrr}\text { C } & 3.243067 & 0.576787 & -0.037885 \\ \text { C } & 2.254053 & 1.452917 & -0.459716 \\ \text { C } & 2.338071 & 2.867367 & -0.293763 \\ \text { C } & 3.445945 & 3.361990 & 0.366687 \\ \text { H } & 3.554687 & 4.436701 & 0.487255 \\ \text { C } & 2.769716 & -3.641120 & -0.803475 \\ \text { C } & 3.102816 & -0.879013 & -0.339693 \\ \text { C } & 1.956611 & -1.552851 & 0.059301 \\ \text { C } & 1.764876 & -2.953025 & -0.149995\end{array}$




\begin{tabular}{|c|c|c|c|}
\hline $\mathrm{H}$ & 2.671283 & -4.713877 & -0.947197 \\
\hline $\mathrm{O}$ & 1.133422 & 0.932120 & -1.088438 \\
\hline$P$ & 0.004892 & 0.183117 & -0.148666 \\
\hline 0 & 0.965228 & -0.844473 & 0.719811 \\
\hline C & -0.616149 & 5.631248 & -1.759630 \\
\hline C & -0.177395 & 4.583841 & -2.572422 \\
\hline C & 0.762753 & 3.669955 & -2.099292 \\
\hline C & 1.288258 & 3.790213 & -0.801465 \\
\hline C & 0.834616 & 4.845117 & 0.007091 \\
\hline C & -0.108181 & 5.756878 & -0.466178 \\
\hline $\mathrm{H}$ & -0.566372 & 4.477220 & -3.581797 \\
\hline $\mathrm{H}$ & -0.452134 & 6.559560 & 0.180908 \\
\hline C & -1.702446 & -5.163794 & 1.142365 \\
\hline C & -1.134808 & -4.201888 & 1.982397 \\
\hline C & -0.023813 & -3.466048 & 1.566635 \\
\hline C & 0.544703 & -3.675791 & 0.298669 \\
\hline C & -0.041850 & -4.641698 & -0.537495 \\
\hline C & -1.149492 & -5.379986 & -0.120587 \\
\hline $\mathrm{H}$ & -1.546626 & -4.029143 & 2.973682 \\
\hline $\mathrm{H}$ & -1.584728 & -6.119862 & -0.787323 \\
\hline C & 4.099401 & -1.593407 & -1.089490 \\
\hline C & 3.929275 & -2.999729 & -1.300495 \\
\hline C & 4.916297 & -3.723765 & -2.023189 \\
\hline C & 6.014947 & -3.087440 & -2.551514 \\
\hline C & 6.165017 & -1.690820 & -2.381808 \\
\hline C & 5.235353 & -0.964431 & -1.670631 \\
\hline $\mathrm{H}$ & 4.776360 & -4.793349 & -2.161890 \\
\hline $\mathrm{H}$ & 6.759560 & -3.649300 & -3.108726 \\
\hline $\mathrm{H}$ & 7.020084 & -1.184294 & -2.821341 \\
\hline $\mathrm{H}$ & 5.361340 & 0.106006 & -1.559084 \\
\hline C & 4.351877 & 1.099683 & 0.711750 \\
\hline C & 4.449920 & 2.516709 & 0.899944 \\
\hline C & 5.546739 & 3.049032 & 1.630705 \\
\hline C & 6.496569 & 2.223124 & 2.185430 \\
\hline C & 6.381533 & 0.821161 & 2.034470 \\
\hline C & 5.339951 & 0.274791 & 1.317011 \\
\hline $\mathrm{H}$ & 5.612514 & 4.127700 & 1.752983 \\
\hline $\mathrm{H}$ & 7.326846 & 2.641808 & 2.747627 \\
\hline $\mathrm{H}$ & 7.119693 & 0.168069 & 2.492358 \\
\hline $\mathrm{H}$ & 5.261446 & -0.801788 & 1.218297 \\
\hline 0 & -0.970456 & -0.504594 & -1.040899 \\
\hline $\mathrm{O}$ & -0.513452 & 1.148598 & 0.923507 \\
\hline $\mathrm{H}$ & -1.616951 & 1.795686 & 0.666073 \\
\hline $\mathrm{H}$ & 1.208752 & 4.933768 & 1.023150 \\
\hline
\end{tabular}




$\begin{array}{lrrr}\mathrm{H} & -1.351641 & 6.340576 & -2.130278 \\ \mathrm{H} & 1.096825 & 2.860886 & -2.739413 \\ \mathrm{H} & 0.366002 & -4.799440 & -1.531863 \\ \mathrm{H} & -2.566102 & -5.736953 & 1.468656 \\ \mathrm{H} & 0.407106 & -2.726334 & 2.229291 \\ \mathrm{C} & -3.387586 & 1.726543 & -0.301859 \\ \mathrm{O} & -2.584059 & 2.345422 & 0.478947 \\ \mathrm{H} & -3.014005 & 0.919020 & -0.935000 \\ \mathrm{C} & -4.522717 & 2.516386 & -0.922620 \\ \mathrm{O} & -5.026718 & 2.204360 & -1.980136 \\ \mathrm{O} & -4.876517 & 3.569399 & -0.176336 \\ \mathrm{C} & -5.927547 & 4.383631 & -0.725491 \\ \mathrm{H} & -6.839600 & 3.794902 & -0.856896 \\ \mathrm{H} & -6.084365 & 5.181662 & -0.000210 \\ \mathrm{C} & -4.088488 & -0.666588 & 0.837760 \\ \mathrm{C} & -4.733272 & 0.567654 & 0.889921 \\ \mathrm{H} & -2.533345 & -1.864649 & 1.416320 \\ \mathrm{~N} & -3.034710 & -1.007530 & 1.634981 \\ \mathrm{C} & -2.514344 & -0.271476 & 2.715380 \\ \mathrm{O} & -2.986777 & 0.744214 & 3.168950 \\ \mathrm{O} & -1.434737 & -0.915448 & 3.177203 \\ \mathrm{C} & -0.647593 & -0.168992 & 4.128770 \\ \mathrm{H} & 0.145308 & -0.849020 & 4.438614 \\ \mathrm{H} & -1.262030 & 0.127702 & 4.981305 \\ \mathrm{H} & -0.231899 & 0.709464 & 3.631766 \\ \mathrm{H} & -5.647528 & 0.641939 & 0.312666 \\ \mathrm{H} & -4.630196 & 1.200513 & 1.760030 \\ \mathrm{C} & -4.474614 & -1.677151 & -0.175957 \\ \mathrm{C} & -5.837788 & -1.959884 & -0.376829 \\ \mathrm{C} & -3.506832 & -2.357548 & -0.935942 \\ \mathrm{C} & -6.226782 & -2.917093 & -1.309291 \\ \mathrm{H} & -6.587784 & -1.450717 & 0.220862 \\ \mathrm{H} & -3.909128 & -3.302531 & -1.879058 \\ \mathrm{H} & -2.456809 & -2.090059 & -0.850691 \\ \mathrm{H} & -7.281415 & -3.138484 & -1.446191 \\ \mathrm{H} & -3.155809 & -3.806407 & -2.476987 \\ \mathrm{H} & -4.330218 & -2.798296 \\ \mathrm{H} & -1.6956 & 4.793732 & -1.692477\end{array}$

Catalyst (R)-1 TS Conformation 58

$\mathrm{B} 3 \mathrm{LYP} / 6-31 \mathrm{G}(\mathrm{d})$ Energy $=-2809.693596$ 
B3LYP-D3(BJ)/def2-TZVPP-IEF-PCM(DCM) Energy = -2810.986907

B3LYP-D3(BJ)/def2-TZVPP-IEF-PCM(DCM)//B3LYP/6-31G(d) Free Energy (Quasiharmonic) = 2810.345791

Frequencies (Top 3 out of 270)

1. $-713.3048 \mathrm{~cm}-1$

2. $\quad 9.9693 \mathrm{~cm}-1$

3. $\quad 19.2523 \mathrm{~cm}-1$

B3LYP/6-31G(d) Molecular Geometry in Cartesian Coordinates

$\begin{array}{llll}\text { C } & 2.806985 & -1.449973 & -0.253816 \\ \text { C } & 1.495374 & -1.792174 & 0.028114 \\ \text { C } & 0.923105 & -3.055909 & -0.299728 \\ \text { C } & 1.726644 & -3.957603 & -0.969792 \\ \text { H } & 1.333095 & -4.941666 & -1.210657 \\ \text { C } & 4.445569 & 2.404467 & 0.737651 \\ \text { C } & 3.339144 & -0.127429 & 0.189819 \\ \text { C } & 2.700677 & 1.044833 & -0.193294 \\ \text { C } & 3.268123 & 2.338493 & 0.017047 \\ \text { H } & 4.893605 & 3.376853 & 0.924062 \\ \text { O } & 0.700162 & -0.860875 & 0.683152 \\ \text { P } & 0.150553 & 0.425783 & -0.170815 \\ \text { O } & 1.510355 & 0.963120 & -0.906186 \\ \text { C } & -3.102248 & -4.216190 & 0.695039 \\ \text { C } & -2.590004 & -4.449548 & -0.582594 \\ \text { C } & -1.290610 & -4.054604 & -0.898822 \\ \text { C } & -0.476848 & -3.412893 & 0.050722 \\ \text { C } & -1.006860 & -3.171193 & 1.329611 \\ \text { C } & -2.303364 & -3.577749 & 1.646555 \\ \text { H } & -3.208200 & -4.928335 & -1.336979 \\ \text { H } & -2.681508 & -3.397404 & 2.649240 \\ \text { C } & 1.748643 & 5.999572 & -1.663041 \\ \text { C } & 3.088543 & 5.642544 & -1.817130 \\ \text { C } & 3.556988 & 4.445765 & -1.276820 \\ \text { C } & 2.699598 & 3.583603 & -0.571217 \\ \text { C } & 1.352962 & 3.951983 & -0.422778 \\ \text { C } & 0.888311 & 5.149926 & -0.965577 \\ \text { H } & 3.768979 & 6.289343 & -2.365206 \\ \text { H } & -0.157950 & 5.415767 & -0.841907 \\ \text { C } & 4.513046 & -0.034654 & 1.014326 \\ \text { C } & 5.068575 & 1.256643 & 1.283586 \\ \text { C } & 6.228408 & 1.362854 & 2.098202\end{array}$




\begin{tabular}{|c|c|c|c|}
\hline C & 6.810728 & 0.245067 & 2.648791 \\
\hline C & 6.246579 & -1.030249 & 2.409603 \\
\hline C & 5.130711 & -1.167182 & 1.613430 \\
\hline $\mathrm{H}$ & 6.640668 & 2.351499 & 2.286239 \\
\hline $\mathrm{H}$ & 7.693799 & 0.338429 & 3.275042 \\
\hline $\mathrm{H}$ & 6.693769 & -1.910347 & 2.863906 \\
\hline $\mathrm{H}$ & 4.703659 & -2.149966 & 1.450140 \\
\hline C & 3.606311 & -2.369156 & -1.018907 \\
\hline C & 3.051279 & -3.644859 & -1.361540 \\
\hline C & 3.833033 & -4.570517 & -2.104722 \\
\hline C & 5.101141 & -4.247219 & -2.527472 \\
\hline C & 5.636645 & -2.972988 & -2.226639 \\
\hline C & 4.911403 & -2.060437 & -1.492254 \\
\hline $\mathrm{H}$ & 3.399830 & -5.538809 & -2.344493 \\
\hline $\mathrm{H}$ & 5.686788 & -4.960153 & -3.101415 \\
\hline $\mathrm{H}$ & 6.628703 & -2.708446 & -2.582650 \\
\hline $\mathrm{H}$ & 5.333904 & -1.085570 & -1.280112 \\
\hline $\mathrm{O}$ & -0.428370 & 1.394843 & 0.813432 \\
\hline $\mathrm{O}$ & -0.698116 & -0.073958 & -1.346044 \\
\hline $\mathrm{H}$ & -1.872143 & 0.028464 & -1.493518 \\
\hline $\mathrm{H}$ & -0.407036 & -2.666593 & 2.078620 \\
\hline $\mathrm{H}$ & -4.117912 & -4.514866 & 0.937303 \\
\hline $\mathrm{H}$ & -0.904597 & -4.220757 & -1.900628 \\
\hline $\mathrm{H}$ & 0.673012 & 3.309676 & 0.126297 \\
\hline $\mathrm{H}$ & 1.377817 & 6.929575 & -2.086716 \\
\hline $\mathrm{H}$ & 4.595876 & 4.160567 & -1.418964 \\
\hline C & -3.753769 & -0.730789 & -0.963737 \\
\hline $\mathrm{O}$ & -3.063241 & -0.001274 & -1.763192 \\
\hline $\mathrm{H}$ & -3.238053 & -1.392152 & -0.259096 \\
\hline C & -5.032086 & -1.355417 & -1.504649 \\
\hline $\mathrm{O}$ & -5.522726 & -2.364504 & -1.043855 \\
\hline $\mathrm{O}$ & -5.540991 & -0.654993 & -2.529466 \\
\hline C & -6.740818 & -1.198778 & -3.108806 \\
\hline $\mathrm{H}$ & -7.011529 & -0.513799 & -3.912040 \\
\hline $\mathrm{H}$ & -6.551642 & -2.199935 & -3.503930 \\
\hline C & -3.761035 & 1.137265 & 0.971856 \\
\hline C & -4.759300 & 0.274467 & 0.495897 \\
\hline $\mathrm{H}$ & -1.871856 & 1.065163 & 1.759932 \\
\hline$N$ & -2.854146 & 0.763649 & 1.928059 \\
\hline C & -2.993431 & -0.138025 & 2.989579 \\
\hline $\mathrm{O}$ & -2.045730 & -0.547213 & 3.620805 \\
\hline $\mathrm{O}$ & -4.282445 & -0.421393 & 3.261729 \\
\hline C & -4.486441 & -1.259618 & 4.413567 \\
\hline $\mathrm{H}$ & -5.568262 & -1.338330 & 4.520917 \\
\hline
\end{tabular}




$\begin{array}{lrrr}\mathrm{H} & -4.040431 & -0.803335 & 5.300151 \\ \mathrm{H} & -4.044252 & -2.245991 & 4.255253 \\ \mathrm{H} & -5.582762 & 0.735532 & -0.038443 \\ \mathrm{H} & -5.024487 & -0.588557 & 1.092100 \\ \mathrm{C} & -3.539068 & 2.448742 & 0.354279 \\ \mathrm{C} & -2.898989 & 3.471577 & 1.084961 \\ \mathrm{C} & -4.008554 & 2.731626 & -0.945764 \\ \mathrm{C} & -2.756507 & 4.742782 & 0.543068 \\ \mathrm{H} & -2.542816 & 3.272272 & 2.089427 \\ \mathrm{C} & -3.840470 & 4.001645 & -1.489907 \\ \mathrm{H} & -4.465832 & 1.953667 & -1.543248 \\ \mathrm{C} & -3.225225 & 5.010763 & -0.747027 \\ \mathrm{H} & -2.280802 & 5.525893 & 1.125988 \\ \mathrm{H} & -4.190575 & 4.202617 & -2.497990 \\ \mathrm{H} & -3.111795 & 6.005109 & -1.170451 \\ \mathrm{H} & -7.536923 & -1.254484 & -2.361383\end{array}$

Catalyst (R)-1 TS Conformation 59

B3LYP/6-31G(d) Energy $=-2809.697034$

B3LYP-D3(BJ)/def2-TZVPP-IEF-PCM(DCM) Energy $=-2810.98681$

B3LYP-D3(BJ)/def2-TZVPP-IEF-PCM(DCM)//B3LYP/6-31G(d) Free Energy (Quasiharmonic) = 2810.345769

Frequencies (Top 3 out of 270)

1. $-693.6229 \mathrm{~cm}-1$

2. $\quad 6.8255 \mathrm{~cm}-1$

3. $10.3649 \mathrm{~cm}-1$

B3LYP/6-31G(d) Molecular Geometry in Cartesian Coordinates

$\begin{array}{lrrr}\text { C } & -3.389665 & 1.025074 & 0.120697 \\ \text { C } & -2.144474 & 1.615339 & 0.269361 \\ \text { C } & -1.935483 & 3.025725 & 0.275796 \\ \text { C } & -3.045323 & 3.827974 & 0.095971 \\ \text { H } & -2.927945 & 4.908235 & 0.120347 \\ \text { C } & -3.734196 & -3.276956 & 0.137119 \\ \text { C } & -3.507982 & -0.463056 & 0.181965 \\ \text { C } & -2.737759 & -1.249566 & -0.662837 \\ \text { C } & -2.845663 & -2.670408 & -0.729940 \\ \text { H } & -3.863642 & -4.355109 & 0.093056 \\ \text { O } & -1.038258 & 0.790746 & 0.434162\end{array}$




\begin{tabular}{|c|c|c|c|}
\hline$P$ & -0.459993 & -0.006543 & -0.878919 \\
\hline $\mathrm{O}$ & -1.831561 & -0.627065 & -1.514952 \\
\hline C & 1.948440 & 4.825057 & 0.730718 \\
\hline C & 1.558398 & 3.787805 & 1.581573 \\
\hline C & 0.305108 & 3.193530 & 1.439465 \\
\hline C & -0.583878 & 3.624495 & 0.439290 \\
\hline C & -0.179218 & 4.668991 & -0.407654 \\
\hline C & 1.073316 & 5.265230 & -0.262742 \\
\hline $\mathrm{H}$ & 2.236864 & 3.436904 & 2.354059 \\
\hline $\mathrm{H}$ & 1.369053 & 6.064474 & -0.937325 \\
\hline C & -0.634633 & -5.139148 & -3.475416 \\
\hline C & -1.223329 & -3.954508 & -3.922570 \\
\hline C & -1.922316 & -3.135530 & -3.037539 \\
\hline C & -2.050592 & -3.489441 & -1.683732 \\
\hline C & -1.450329 & -4.681549 & -1.246285 \\
\hline C & -0.749454 & -5.498944 & -2.132132 \\
\hline $\mathrm{H}$ & -1.140899 & -3.665612 & -4.967095 \\
\hline $\mathrm{H}$ & -0.287031 & -6.413507 & -1.769673 \\
\hline C & -4.368526 & -1.116923 & 1.129896 \\
\hline C & -4.485477 & -2.544095 & 1.087750 \\
\hline C & -5.343491 & -3.201874 & 2.010778 \\
\hline C & -6.036464 & -2.491839 & 2.963225 \\
\hline C & -5.891666 & -1.086234 & 3.033825 \\
\hline C & -5.082328 & -0.417330 & 2.141987 \\
\hline $\mathrm{H}$ & -5.431129 & -4.284452 & 1.955151 \\
\hline $\mathrm{H}$ & -6.684396 & -3.006320 & 3.667624 \\
\hline $\mathrm{H}$ & -6.420789 & -0.528471 & 3.801827 \\
\hline $\mathrm{H}$ & -4.975620 & 0.658614 & 2.215803 \\
\hline C & -4.521756 & 1.871497 & -0.141092 \\
\hline C & -4.336860 & 3.292574 & -0.132184 \\
\hline C & -5.450009 & 4.142562 & -0.374897 \\
\hline C & -6.692668 & 3.621279 & -0.649780 \\
\hline C & -6.869468 & 2.218620 & -0.700261 \\
\hline C & -5.814872 & 1.367650 & -0.452096 \\
\hline $\mathrm{H}$ & -5.294251 & 5.218607 & -0.352197 \\
\hline $\mathrm{H}$ & -7.534402 & 4.281215 & -0.840992 \\
\hline $\mathrm{H}$ & -7.845790 & 1.807560 & -0.942546 \\
\hline $\mathrm{H}$ & -5.965796 & 0.295790 & -0.505058 \\
\hline 0 & 0.519346 & -1.019560 & -0.383855 \\
\hline 0 & -0.017916 & 0.997231 & -1.954085 \\
\hline $\mathrm{H}$ & 1.121545 & 1.284930 & -2.063985 \\
\hline $\mathrm{H}$ & -0.842986 & 4.993759 & -1.203840 \\
\hline $\mathrm{H}$ & 2.929714 & 5.278687 & 0.839844 \\
\hline $\mathrm{H}$ & 0.010097 & 2.391557 & 2.107502 \\
\hline
\end{tabular}




\begin{tabular}{|c|c|c|c|}
\hline $\mathrm{H}$ & -1.517623 & -4.955654 & -0.197104 \\
\hline $\mathrm{H}$ & -0.087702 & -5.773944 & -4.167650 \\
\hline $\mathrm{H}$ & -2.377205 & -2.219424 & -3.397585 \\
\hline C & 2.917395 & 1.300199 & -1.050703 \\
\hline 0 & 2.313860 & 1.601839 & -2.135209 \\
\hline $\mathrm{H}$ & 2.337859 & 1.117486 & -0.139232 \\
\hline C & 4.246789 & 1.955983 & -0.740345 \\
\hline 0 & 4.591015 & 2.202562 & 0.398190 \\
\hline 0 & 4.968489 & 2.218391 & -1.835907 \\
\hline C & 6.244332 & 2.839807 & -1.596832 \\
\hline $\mathrm{H}$ & 6.682837 & 2.989032 & -2.583396 \\
\hline $\mathrm{H}$ & 6.112294 & 3.796476 & -1.085249 \\
\hline C & 3.956671 & -1.098108 & -0.002301 \\
\hline C & 3.554000 & -0.640557 & -1.263394 \\
\hline $\mathrm{H}$ & 2.000858 & -1.336377 & 0.536441 \\
\hline$N$ & 2.973613 & -1.460322 & 0.872985 \\
\hline C & 3.106392 & -2.208992 & 2.050168 \\
\hline 0 & 4.127611 & -2.662391 & 2.514728 \\
\hline $\mathrm{O}$ & 1.877765 & -2.357380 & 2.578442 \\
\hline C & 1.822593 & -3.144927 & 3.778146 \\
\hline $\mathrm{H}$ & 2.429217 & -2.688337 & 4.564473 \\
\hline $\mathrm{H}$ & 2.184911 & -4.158541 & 3.587922 \\
\hline $\mathrm{H}$ & 0.770608 & -3.159059 & 4.062121 \\
\hline $\mathrm{H}$ & 4.323369 & -0.466207 & -2.006355 \\
\hline $\mathrm{H}$ & 2.583340 & -0.960242 & -1.626373 \\
\hline C & 5.379111 & -1.037502 & 0.393255 \\
\hline C & 6.357553 & -1.482979 & -0.512096 \\
\hline C & 5.785432 & -0.460990 & 1.609168 \\
\hline C & 7.711135 & -1.376808 & -0.199319 \\
\hline $\mathrm{H}$ & 6.051817 & -1.941571 & -1.447526 \\
\hline C & 7.137910 & -0.337245 & 1.908163 \\
\hline $\mathrm{H}$ & 5.042283 & -0.081933 & 2.300084 \\
\hline C & 8.103469 & -0.800284 & 1.010188 \\
\hline $\mathrm{H}$ & 8.456641 & -1.745102 & -0.898258 \\
\hline $\mathrm{H}$ & 7.439967 & 0.122292 & 2.844658 \\
\hline . & 9.158855 & -0.711107 & 1.253231 \\
\hline & 6.875882 & 2.189178 & -0.986063 \\
\hline
\end{tabular}

Catalyst (R)-1 TS Conformation 60

B3LYP/6-31G(d) Energy $=-2809.69886$

B3LYP-D3(BJ)/def2-TZVPP-IEF-PCM(DCM) Energy = -2810.988184 
B3LYP-D3(BJ)/def2-TZVPP-IEF-PCM(DCM)//B3LYP/6-31G(d) Free Energy (Quasiharmonic) = 2810.345688

Frequencies (Top 3 out of 270)

1. $-381.9127 \mathrm{~cm}-1$

2. $\quad 9.6030 \mathrm{~cm}-1$

3. $10.9353 \mathrm{~cm}-1$

B3LYP/6-31G(d) Molecular Geometry in Cartesian Coordinates

\begin{tabular}{|c|c|c|c|}
\hline C & 3.746625 & 0.214735 & 0.173629 \\
\hline C & 2.885614 & 1.261458 & -0.119676 \\
\hline C & 3.186023 & 2.626820 & 0.157896 \\
\hline C & 4.368205 & 2.892164 & 0.820693 \\
\hline $\mathrm{H}$ & 4.638057 & 3.924410 & 1.027671 \\
\hline C & 2.664814 & -3.832923 & -0.860968 \\
\hline C & 3.395141 & -1.176753 & -0.240539 \\
\hline C & 2.187091 & -1.721802 & 0.162620 \\
\hline C & 1.797786 & -3.066160 & -0.106993 \\
\hline $\mathrm{H}$ & 2.413552 & -4.870270 & -1.065944 \\
\hline 0 & 1.674714 & 0.983743 & -0.748798 \\
\hline$P$ & 0.483482 & 0.233387 & 0.075054 \\
\hline 0 & 1.312487 & -0.920414 & 0.888864 \\
\hline C & 0.758304 & 5.959612 & -1.067737 \\
\hline C & 1.218134 & 5.865695 & 0.246343 \\
\hline C & 1.982098 & 4.768804 & 0.644010 \\
\hline C & 2.295614 & 3.742523 & -0.261125 \\
\hline C & 1.813764 & 3.839652 & -1.576931 \\
\hline C & 1.059651 & 4.942133 & -1.976528 \\
\hline $\mathrm{H}$ & 0.980428 & 6.645116 & 0.965456 \\
\hline $\mathrm{H}$ & 0.718473 & 5.011978 & -3.006672 \\
\hline C & -1.847068 & -4.842279 & 1.338368 \\
\hline C & -1.055017 & -4.076504 & 2.197892 \\
\hline C & 0.115596 & -3.478607 & 1.732421 \\
\hline C & 0.520865 & -3.639770 & 0.395961 \\
\hline C & -0.286872 & -4.407974 & -0.458141 \\
\hline C & -1.459048 & -5.003652 & 0.007450 \\
\hline $\mathrm{H}$ & -1.344693 & -3.950643 & 3.237959 \\
\hline $\mathrm{H}$ & -2.071535 & -5.589432 & -0.673035 \\
\hline C & 4.253183 & -1.964215 & -1.082905 \\
\hline C & 3.876334 & -3.314269 & -1.381069 \\
\hline C & 4.720062 & -4.107876 & -2.204881 \\
\hline C & 5.874666 & -3.589534 & -2.743239 \\
\hline
\end{tabular}




\begin{tabular}{|c|c|c|c|}
\hline C & 6.229749 & -2.245383 & -2.481403 \\
\hline C & 5.442643 & -1.455046 & -1.672896 \\
\hline $\mathrm{H}$ & 4.425672 & -5.134156 & -2.411390 \\
\hline $\mathrm{H}$ & 6.508033 & -4.203830 & -3.377272 \\
\hline $\mathrm{H}$ & 7.130099 & -1.830240 & -2.926159 \\
\hline $\mathrm{H}$ & 5.724040 & -0.424577 & -1.489637 \\
\hline C & 4.940266 & 0.501234 & 0.922799 \\
\hline C & 5.248146 & 1.864191 & 1.238817 \\
\hline C & 6.428175 & 2.161741 & 1.973059 \\
\hline C & 7.261759 & 1.158894 & 2.409931 \\
\hline C & 6.941009 & -0.190629 & 2.132341 \\
\hline C & 5.813609 & -0.510979 & 1.408327 \\
\hline $\mathrm{H}$ & 6.652234 & 3.202796 & 2.193362 \\
\hline $\mathrm{H}$ & 8.157475 & 1.397876 & 2.976578 \\
\hline $\mathrm{H}$ & 7.587494 & -0.983690 & 2.498282 \\
\hline $\mathrm{H}$ & 5.577862 & -1.550751 & 1.214265 \\
\hline $\mathrm{O}$ & -0.521237 & -0.297161 & -0.891369 \\
\hline $\mathrm{O}$ & -0.018477 & 1.149153 & 1.217551 \\
\hline $\mathrm{H}$ & -1.124301 & 1.186751 & 1.315872 \\
\hline $\mathrm{H}$ & 2.044558 & 3.056415 & -2.291217 \\
\hline $\mathrm{H}$ & 0.170510 & 6.818318 & -1.381625 \\
\hline $\mathrm{H}$ & 2.326710 & 4.693350 & 1.671525 \\
\hline $\mathrm{H}$ & -0.001220 & -4.519349 & -1.500327 \\
\hline $\mathrm{H}$ & -2.757873 & -5.309001 & 1.704267 \\
\hline $\mathrm{H}$ & 0.727082 & -2.892586 & 2.410084 \\
\hline C & -2.990069 & 0.159101 & 1.926621 \\
\hline $\mathrm{O}$ & -2.451789 & 1.202846 & 1.418591 \\
\hline $\mathrm{H}$ & -2.383007 & -0.547839 & 2.509955 \\
\hline C & -4.384751 & 0.282524 & 2.519796 \\
\hline $\mathrm{O}$ & -4.859313 & -0.542529 & 3.277766 \\
\hline $\mathrm{O}$ & -5.007855 & 1.390904 & 2.106351 \\
\hline C & -6.329560 & 1.601756 & 2.631791 \\
\hline $\mathrm{H}$ & -6.311835 & 1.590897 & 3.724440 \\
\hline $\mathrm{H}$ & -6.635546 & 2.578255 & 2.257274 \\
\hline C & -3.991200 & -0.515838 & -0.481405 \\
\hline C & -3.300438 & -1.233379 & 0.511117 \\
\hline $\mathrm{H}$ & -2.220968 & 0.280537 & -1.095678 \\
\hline$N$ & -3.246432 & 0.394042 & -1.168398 \\
\hline C & -3.659965 & 1.673335 & -1.584754 \\
\hline $\mathrm{O}$ & -4.786617 & 2.110579 & -1.576830 \\
\hline $\mathrm{O}$ & -2.565170 & 2.336777 & -1.991782 \\
\hline C & -2.785246 & 3.706343 & -2.364547 \\
\hline $\mathrm{H}$ & -1.790229 & 4.120543 & -2.523110 \\
\hline $\mathrm{H}$ & -3.300523 & 4.240187 & -1.562886 \\
\hline
\end{tabular}




$\begin{array}{lrrr}\text { H } & -3.382486 & 3.761319 & -3.279211 \\ \mathrm{H} & -3.792272 & -2.083448 & 0.970952 \\ \mathrm{H} & -2.233959 & -1.360519 & 0.349577 \\ \mathrm{C} & -5.422196 & -0.723425 & -0.764029 \\ \mathrm{C} & -5.926837 & -0.513889 & -2.061035 \\ \mathrm{C} & -6.282093 & -1.258904 & 0.214599 \\ \mathrm{C} & -7.250394 & -0.815154 & -2.364471 \\ \mathrm{H} & -5.273585 & -0.134774 & -2.837320 \\ \mathrm{C} & -7.611551 & -1.539775 & -0.089283 \\ \mathrm{H} & -5.922147 & -1.440037 & 1.221267 \\ \mathrm{C} & -8.100703 & -1.320675 & -1.378884 \\ \mathrm{H} & -7.618522 & -0.654161 & -3.373602 \\ \mathrm{H} & -8.263523 & -1.939415 & 0.682356 \\ \mathrm{H} & -9.135688 & -1.550730 & -1.616620 \\ \mathrm{H} & -7.011002 & 0.826492 & 2.272526\end{array}$

Catalyst (R)-1 TS Conformation 61

B3LYP/6-31G(d) Energy $=-2809.694156$

B3LYP-D3(BJ)/def2-TZVPP-IEF-PCM(DCM) Energy $=-2810.987838$

B3LYP-D3(BJ)/def2-TZVPP-IEF-PCM(DCM)//B3LYP/6-31G(d) Free Energy (Quasiharmonic) = 2810.345619

Frequencies (Top 3 out of 270)

1. $-455.2162 \mathrm{~cm}-1$

2. $\quad 8.1629 \mathrm{~cm}-1$

3. $\quad 14.1792 \mathrm{~cm}-1$

B3LYP/6-31G(d) Molecular Geometry in Cartesian Coordinates

$\begin{array}{llll}\text { C } & 2.764542 & -1.504634 & -0.021380 \\ \text { C } & 1.466618 & -1.814140 & 0.350916 \\ \text { C } & 0.860169 & -3.081747 & 0.103754 \\ \text { C } & 1.608282 & -4.012399 & -0.591717 \\ \text { H } & 1.191167 & -4.999818 & -0.770665 \\ \text { C } & 4.542386 & 2.305429 & 0.908228 \\ \text { C } & 3.354991 & -0.194855 & 0.381725 \\ \text { C } & 2.721088 & 0.994667 & 0.045490 \\ \text { C } & 3.317543 & 2.272495 & 0.270856 \\ \text { H } & 5.012838 & 3.267802 & 1.092175 \\ \text { O } & 0.723738 & -0.842030 & 1.011641 \\ \text { P } & 0.145151 & 0.401616 & 0.104270\end{array}$




\begin{tabular}{|c|c|c|c|}
\hline $\mathrm{O}$ & 1.510223 & 0.951302 & -0.633174 \\
\hline C & -3.069318 & -4.212030 & 1.444187 \\
\hline C & -2.220281 & -3.502913 & 2.295454 \\
\hline C & -0.955099 & -3.109193 & 1.863647 \\
\hline C & -0.510951 & -3.421939 & 0.567527 \\
\hline C & -1.378732 & -4.129714 & -0.281105 \\
\hline C & -2.643970 & -4.522801 & 0.152398 \\
\hline $\mathrm{H}$ & -2.542094 & -3.256568 & 3.303988 \\
\hline $\mathrm{H}$ & -3.298167 & -5.068087 & -0.523443 \\
\hline C & 1.683918 & 6.063707 & -0.944058 \\
\hline C & 2.950196 & 5.664034 & -1.375377 \\
\hline C & 3.456896 & 4.421422 & -0.993644 \\
\hline C & 2.706482 & 3.554956 & -0.180757 \\
\hline C & 1.431422 & 3.962141 & 0.240973 \\
\hline C & 0.930736 & 5.208716 & -0.136800 \\
\hline $\mathrm{H}$ & 3.544708 & 6.317657 & -2.008674 \\
\hline $\mathrm{H}$ & -0.056488 & 5.511542 & 0.202340 \\
\hline C & 4.577041 & -0.137968 & 1.138202 \\
\hline C & 5.181016 & 1.135793 & 1.384817 \\
\hline C & 6.394668 & 1.206103 & 2.121091 \\
\hline C & 6.984127 & 0.069195 & 2.622312 \\
\hline C & 6.371967 & -1.188845 & 2.411462 \\
\hline C & 5.203455 & -1.290622 & 1.689105 \\
\hline $\mathrm{H}$ & 6.841609 & 2.182867 & 2.291045 \\
\hline $\mathrm{H}$ & 7.908696 & 0.134347 & 3.189399 \\
\hline $\mathrm{H}$ & 6.824577 & -2.084172 & 2.829174 \\
\hline $\mathrm{H}$ & 4.742973 & -2.261342 & 1.547606 \\
\hline C & 3.497403 & -2.452995 & -0.816081 \\
\hline C & 2.903728 & -3.727770 & -1.087622 \\
\hline C & 3.619855 & -4.681742 & -1.860653 \\
\hline C & 4.859010 & -4.386157 & -2.378951 \\
\hline C & 5.430729 & -3.113159 & -2.146816 \\
\hline C & 4.770458 & -2.173938 & -1.385238 \\
\hline $\mathrm{H}$ & 3.159066 & -5.649267 & -2.045829 \\
\hline $\mathrm{H}$ & 5.393857 & -5.120429 & -2.975142 \\
\hline $\mathrm{H}$ & 6.398855 & -2.871432 & -2.577203 \\
\hline $\mathrm{H}$ & 5.219063 & -1.200556 & -1.225295 \\
\hline $\mathrm{O}$ & -0.471908 & 1.398270 & 1.037522 \\
\hline $\mathrm{O}$ & -0.690016 & -0.142605 & -1.060583 \\
\hline $\mathrm{H}$ & -1.896113 & -0.562122 & -0.822176 \\
\hline $\mathrm{H}$ & -1.061644 & -4.356068 & -1.295320 \\
\hline $\mathrm{H}$ & -4.055165 & -4.517306 & 1.785204 \\
\hline $\mathrm{H}$ & -0.302268 & -2.563451 & 2.535791 \\
\hline $\mathrm{H}$ & 0.834266 & 3.303087 & 0.862143 \\
\hline
\end{tabular}




$\begin{array}{llll}\mathrm{H} & 1.287443 & 7.032973 & -1.235574 \\ \mathrm{H} & 4.440509 & 4.109336 & -1.334776 \\ \mathrm{C} & -3.814872 & -0.679672 & -1.509675 \\ \mathrm{O} & -2.946674 & -0.920503 & -0.599097 \\ \mathrm{H} & -3.486176 & -0.394782 & -2.509115 \\ \mathrm{C} & -5.115941 & -1.445443 & -1.486715 \\ \mathrm{O} & -5.759429 & -1.651266 & -2.494453 \\ \mathrm{O} & -5.448067 & -1.855414 & -0.256994 \\ \mathrm{C} & -6.666430 & -2.615021 & -0.173985 \\ \mathrm{H} & -6.784389 & -2.858120 & 0.881671 \\ \mathrm{H} & -7.513322 & -2.023034 & -0.531728 \\ \mathrm{C} & -4.010169 & 1.763324 & -0.359404 \\ \mathrm{C} & -4.852281 & 1.228151 & -1.333528 \\ \mathrm{H} & -2.091232 & 2.349627 & 0.131650 \\ \mathrm{~N} & -2.758405 & 2.222557 & -0.635577 \\ \mathrm{C} & -2.175561 & 2.338570 & -1.913231 \\ \mathrm{O} & -2.685271 & 1.990858 & -2.957911 \\ \mathrm{O} & -0.983756 & 2.917073 & -1.777491 \\ \mathrm{C} & -0.161506 & 2.938887 & -2.963541 \\ \mathrm{H} & -0.691996 & 3.434248 & -3.779449 \\ \mathrm{H} & 0.091636 & 1.914169 & -3.242463 \\ \mathrm{H} & 0.729759 & 3.492422 & -2.676030 \\ \mathrm{H} & -5.853520 & 0.965469 & -1.015822 \\ \mathrm{H} & -4.716194 & 1.482174 & -2.374117 \\ \mathrm{C} & -4.397401 & 1.719385 & 1.068541 \\ \mathrm{C} & -5.738116 & 1.966790 & 1.421451 \\ \mathrm{C} & -3.463598 & 1.440717 & 2.083927 \\ \mathrm{C} & -6.136311 & 1.939266 & 2.754007 \\ \mathrm{H} & -6.461291 & 2.217491 & 0.651872 \\ \mathrm{C} & -3.875880 & 1.400644 & 3.415035 \\ \mathrm{H} & -2.424236 & 1.231501 & 1.845297 \\ \mathrm{H} & -5.205742 & 1.650474 & 3.755445 \\ \mathrm{H} & -7.170462 & 2.149899 & 3.011480 \\ -3.147844 & 1.171230 & 4.187683 \\ -5.516905 & 1.625249 & 4.796323 \\ \mathrm{H} & -6.590071 & -3.525159 & -0.774331\end{array}$

Catalyst (R)-1 TS Conformation 62

B3LYP/6-31G(d) Energy $=-2809.697982$

B3LYP-D3(BJ)/def2-TZVPP-IEF-PCM(DCM) Energy $=-2810.989365$

B3LYP-D3(BJ)/def2-TZVPP-IEF-PCM(DCM)//B3LYP/6-31G(d) Free Energy (Quasiharmonic) = 2810.345579 
Frequencies (Top 3 out of 270)

1. $-246.2238 \mathrm{~cm}-1$

2. $\quad 11.8024 \mathrm{~cm}-1$

3. $\quad 15.3178 \mathrm{~cm}-1$

B3LYP/6-31G(d) Molecular Geometry in Cartesian Coordinates

$\begin{array}{lrrr}\mathrm{C} & 3.252822 & 0.124081 & 0.429949 \\ \mathrm{C} & 2.457713 & 1.222778 & 0.135557 \\ \mathrm{C} & 2.826573 & 2.556605 & 0.485801 \\ \mathrm{C} & 3.992152 & 2.728848 & 1.206649 \\ \mathrm{H} & 4.291780 & 3.735286 & 1.486846 \\ \mathrm{C} & 2.236285 & -3.847488 & -0.886235 \\ \mathrm{C} & 2.905925 & -1.225173 & -0.103627 \\ \mathrm{C} & 1.661211 & -1.772747 & 0.160011 \\ \mathrm{C} & 1.304445 & -3.111416 & -0.178900 \\ \mathrm{H} & 2.013549 & -4.881550 & -1.134589 \\ \mathrm{O} & 1.311183 & 1.041550 & -0.629304 \\ \mathrm{P} & 0.016672 & 0.220396 & -0.047640 \\ \mathrm{O} & 0.717154 & -0.979883 & 0.812339 \\ \mathrm{C} & 0.688199 & 6.139982 & -0.562903 \\ \mathrm{C} & 0.037404 & 5.121543 & 0.136290 \\ \mathrm{C} & 0.705362 & 3.938197 & 0.453254 \\ \mathrm{C} & 2.046392 & 3.760744 & 0.081422 \\ \mathrm{C} & 2.692600 & 4.790567 & -0.623170 \\ \mathrm{C} & 2.019532 & 5.968923 & -0.946152 \\ \mathrm{H} & -0.998395 & 5.248530 & 0.440912 \\ \mathrm{H} & 2.535899 & 6.751660 & -1.495940 \\ \mathrm{C} & -2.261640 & -5.167608 & 1.060561 \\ \mathrm{C} & -1.791408 & -5.293105 & -0.247717 \\ \mathrm{C} & -0.661012 & -4.586361 & -0.655276 \\ \mathrm{C} & 0.025141 & -3.745416 & 0.236147 \\ \mathrm{C} & -0.473197 & -3.609150 & 1.542690 \\ \mathrm{C} & -1.603225 & -4.315203 & 1.949140 \\ \mathrm{H} & -2.302621 & -5.942994 & -0.953574 \\ \mathrm{H} & -1.964827 & -4.205917 & 2.968254 \\ \mathrm{C} & 3.830593 & -1.976176 & -0.909412 \\ \mathrm{C} & 3.479223 & -3.308679 & -1.297444 \\ \mathrm{C} & 4.384344 & -4.067973 & -2.087682 \\ \mathrm{C} & 5.576963 & -3.529540 & -2.511076 \\ \mathrm{C} & 5.910015 & -2.199868 & -2.161366 \\ & 5.062809 & -1.444973 & -1.380047\end{array}$




\begin{tabular}{|c|c|c|c|}
\hline $\mathrm{H}$ & 4.106642 & -5.082826 & -2.362513 \\
\hline $\mathrm{H}$ & 6.257642 & -4.116239 & -3.121868 \\
\hline $\mathrm{H}$ & 6.841505 & -1.767286 & -2.516396 \\
\hline $\mathrm{H}$ & 5.328952 & -0.424658 & -1.130114 \\
\hline C & 4.405501 & 0.309919 & 1.270205 \\
\hline C & 4.781861 & 1.638933 & 1.644510 \\
\hline C & 5.925234 & 1.839489 & 2.464581 \\
\hline C & 6.660914 & 0.772440 & 2.924315 \\
\hline C & 6.272257 & -0.545074 & 2.585358 \\
\hline C & 5.177625 & -0.770808 & 1.780115 \\
\hline $\mathrm{H}$ & 6.199186 & 2.857449 & 2.731650 \\
\hline $\mathrm{H}$ & 7.529829 & 0.936055 & 3.555827 \\
\hline $\mathrm{H}$ & 6.839378 & -1.388830 & 2.969178 \\
\hline $\mathrm{H}$ & 4.888830 & -1.787264 & 1.539897 \\
\hline $\mathrm{O}$ & -0.841204 & 1.027467 & 0.872255 \\
\hline 0 & -0.581374 & -0.393225 & -1.333916 \\
\hline $\mathrm{H}$ & -1.617037 & -0.278194 & -1.611917 \\
\hline $\mathrm{H}$ & 3.728104 & 4.657463 & -0.925192 \\
\hline $\mathrm{H}$ & 0.162352 & 7.059441 & -0.807006 \\
\hline $\mathrm{H}$ & 0.189762 & 3.150924 & 0.992219 \\
\hline $\mathrm{H}$ & 0.037372 & -2.960060 & 2.245629 \\
\hline $\mathrm{H}$ & -3.133408 & -5.730131 & 1.386032 \\
\hline $\mathrm{H}$ & -0.308298 & -4.676913 & -1.678722 \\
\hline C & -3.991759 & -0.447897 & -2.027909 \\
\hline $\mathrm{O}$ & -2.804730 & -0.027576 & -2.314698 \\
\hline $\mathrm{H}$ & -4.652781 & -0.687610 & -2.875384 \\
\hline C & -4.109927 & -1.485439 & -0.911671 \\
\hline $\mathrm{O}$ & -3.264787 & -1.677900 & -0.067064 \\
\hline 0 & -5.291751 & -2.136335 & -0.971696 \\
\hline C & -5.518546 & -3.096189 & 0.076527 \\
\hline $\mathrm{H}$ & -4.708638 & -3.828403 & 0.103833 \\
\hline $\mathrm{H}$ & -5.575883 & -2.592015 & 1.045361 \\
\hline C & -4.309391 & 1.411534 & -0.306070 \\
\hline C & -5.069823 & 0.944290 & -1.414404 \\
\hline $\mathrm{H}$ & -2.367734 & 1.906657 & 0.167605 \\
\hline$N$ & -3.122777 & 2.005716 & -0.528618 \\
\hline C & -2.702741 & 2.566525 & -1.767677 \\
\hline $\mathrm{O}$ & -3.435362 & 2.982766 & -2.634274 \\
\hline $\mathrm{O}$ & -1.373163 & 2.657625 & -1.743953 \\
\hline C & -0.757303 & 3.174419 & -2.938106 \\
\hline $\mathrm{H}$ & -0.992984 & 2.521809 & -3.781586 \\
\hline $\mathrm{H}$ & 0.309713 & 3.169256 & -2.724218 \\
\hline $\mathrm{H}$ & -1.111329 & 4.187935 & -3.138564 \\
\hline $\mathrm{H}$ & -6.037655 & 0.510828 & -1.182776 \\
\hline
\end{tabular}




$\begin{array}{llll}\text { H } & -5.048557 & 1.555735 & -2.307948 \\ \mathrm{C} & -4.690342 & 1.073781 & 1.081043 \\ \mathrm{C} & -3.744251 & 0.782417 & 2.082844 \\ \mathrm{C} & -6.059126 & 1.069012 & 1.415205 \\ \mathrm{C} & -4.168425 & 0.491526 & 3.376964 \\ \mathrm{H} & -2.685284 & 0.738467 & 1.849168 \\ \mathrm{C} & -6.472586 & 0.787983 & 2.714443 \\ \mathrm{H} & -6.799520 & 1.322545 & 0.663609 \\ \mathrm{C} & -5.527154 & 0.495250 & 3.699413 \\ \mathrm{H} & -3.428607 & 0.253171 & 4.135598 \\ \mathrm{H} & -7.531128 & 0.805329 & 2.957801 \\ \mathrm{H} & -5.848227 & 0.272572 & 4.713428 \\ \mathrm{H} & -6.469373 & -3.573113 & -0.164021\end{array}$

Catalyst (R)-1 TS Conformation 63

B3LYP/6-31G(d) Energy $=-2809.69285$

B3LYP-D3(BJ)/def2-TZVPP-IEF-PCM(DCM) Energy $=-2810.988221$

B3LYP-D3(BJ)/def2-TZVPP-IEF-PCM(DCM)//B3LYP/6-31G(d) Free Energy (Quasiharmonic) = 2810.34557

Frequencies (Top 3 out of 270)

1. $-385.9444 \mathrm{~cm}-1$

2. $\quad 12.2070 \mathrm{~cm}-1$

3. $16.0949 \mathrm{~cm}-1$

B3LYP/6-31G(d) Molecular Geometry in Cartesian Coordinates

$\begin{array}{llll}\text { C } & 2.984831 & -1.005568 & -0.334618 \\ \text { C } & 1.805059 & -1.597350 & 0.096559 \\ \text { C } & 1.529427 & -2.990904 & -0.065140 \\ \text { C } & 2.470911 & -3.749665 & -0.735105 \\ \text { H } & 2.314530 & -4.819786 & -0.840514 \\ \text { C } & 3.722390 & 3.182424 & 0.391305 \\ \text { C } & 3.255646 & 0.430757 & -0.025177 \\ \text { C } & 2.337347 & 1.396840 & -0.407059 \\ \text { C } & 2.554280 & 2.796825 & -0.237245 \\ \text { H } & 3.933719 & 4.241583 & 0.512971 \\ \text { O } & 0.873197 & -0.826174 & 0.767576 \\ \text { P } & 0.002524 & 0.339651 & -0.012947 \\ \text { O } & 1.156390 & 0.980075 & -1.001266 \\ \text { C } & -1.942276 & -5.016550 & 1.501366\end{array}$




\begin{tabular}{|c|c|c|c|}
\hline C & -1.430949 & -5.344891 & 0.245150 \\
\hline C & -0.327119 & -4.661114 & -0.264449 \\
\hline C & 0.302489 & -3.640421 & 0.470761 \\
\hline C & -0.226691 & -3.317189 & 1.733541 \\
\hline C & -1.335819 & -3.997154 & 2.240215 \\
\hline $\mathrm{H}$ & -1.896238 & -6.130135 & -0.344943 \\
\hline $\mathrm{H}$ & -1.713809 & -3.735461 & 3.225518 \\
\hline C & -0.158835 & 5.838826 & -1.616470 \\
\hline C & 0.144908 & 4.751023 & -2.437896 \\
\hline C & 1.004508 & 3.748611 & -1.991578 \\
\hline C & 1.582439 & 3.817135 & -0.712481 \\
\hline C & 1.263764 & 4.913361 & 0.105401 \\
\hline C & 0.402589 & 5.914826 & -0.341225 \\
\hline $\mathrm{H}$ & -0.286404 & 4.682255 & -3.433216 \\
\hline $\mathrm{H}$ & 0.164716 & 6.750319 & 0.312220 \\
\hline C & 4.429154 & 0.844195 & 0.695165 \\
\hline C & 4.660203 & 2.244843 & 0.889503 \\
\hline C & 5.821396 & 2.670030 & 1.590344 \\
\hline C & 6.708721 & 1.757305 & 2.111405 \\
\hline C & 6.463146 & 0.372924 & 1.955308 \\
\hline C & 5.356272 & -0.071284 & 1.265526 \\
\hline $\mathrm{H}$ & 5.987427 & 3.737313 & 1.717296 \\
\hline $\mathrm{H}$ & 7.589322 & 2.094606 & 2.651290 \\
\hline $\mathrm{H}$ & 7.152028 & -0.348072 & 2.387335 \\
\hline $\mathrm{H}$ & 5.178681 & -1.135569 & 1.163477 \\
\hline C & 3.907488 & -1.791040 & -1.108143 \\
\hline C & 3.643990 & -3.186516 & -1.291192 \\
\hline C & 4.557929 & -3.979989 & -2.036693 \\
\hline C & 5.673940 & -3.420012 & -2.612979 \\
\hline C & 5.916429 & -2.033592 & -2.468693 \\
\hline C & 5.059903 & -1.241880 & -1.735613 \\
\hline $\mathrm{H}$ & 4.347732 & -5.040632 & -2.153781 \\
\hline $\mathrm{H}$ & 6.361773 & -4.034107 & -3.187751 \\
\hline $\mathrm{H}$ & 6.785016 & -1.586966 & -2.945089 \\
\hline $\mathrm{H}$ & 5.256034 & -0.180115 & -1.643496 \\
\hline $\mathrm{O}$ & -0.520579 & 1.284243 & 1.013920 \\
\hline $\mathrm{O}$ & -0.980271 & -0.335387 & -0.976740 \\
\hline $\mathrm{H}$ & -2.035606 & 0.362388 & -1.343931 \\
\hline $\mathrm{H}$ & 0.233703 & -2.534482 & 2.322628 \\
\hline $\mathrm{H}$ & -2.802843 & -5.547180 & 1.899695 \\
\hline $\mathrm{H}$ & 0.046663 & -4.909940 & -1.253606 \\
\hline $\mathrm{H}$ & 1.677993 & 4.965529 & 1.108303 \\
\hline $\mathrm{H}$ & -0.830145 & 6.618615 & -1.966997 \\
\hline $\mathrm{H}$ & 1.235425 & 2.910134 & -2.639334 \\
\hline
\end{tabular}




$\begin{array}{llll}\mathrm{C} & -3.334710 & 1.682487 & -0.627831 \\ \mathrm{O} & -2.951188 & 0.957522 & -1.609187 \\ \mathrm{H} & -2.668920 & 1.837813 & 0.224169 \\ \mathrm{C} & -4.318443 & 2.783728 & -0.972731 \\ \mathrm{O} & -4.966162 & 2.838034 & -1.991327 \\ \mathrm{O} & -4.345671 & 3.694567 & 0.016746 \\ \mathrm{C} & -5.224324 & 4.812188 & -0.199269 \\ \mathrm{H} & -5.119994 & 5.439185 & 0.685798 \\ \mathrm{H} & -4.928806 & 5.359039 & -1.098276 \\ \mathrm{C} & -4.210006 & -0.531091 & 0.760361 \\ \mathrm{C} & -4.827210 & 0.707865 & 0.660097 \\ \mathrm{H} & -2.753713 & -1.720172 & 1.578142 \\ \mathrm{~N} & -3.222995 & -0.822616 & 1.661246 \\ \mathrm{C} & -2.706039 & 0.033078 & 2.649356 \\ \mathrm{O} & -3.137900 & 1.129946 & 2.920118 \\ \mathrm{O} & -1.690839 & -0.592195 & 3.258258 \\ \mathrm{C} & -0.898668 & 0.252425 & 4.122483 \\ \mathrm{H} & -0.434829 & 1.032179 & 3.516045 \\ \mathrm{H} & -0.147347 & -0.408740 & 4.553704 \\ \mathrm{H} & -1.525639 & 0.689103 & 4.902938 \\ \mathrm{H} & -5.668857 & 0.772225 & -0.019398 \\ \mathrm{H} & -4.759168 & 1.421145 & 1.468377 \\ \mathrm{C} & -4.522040 & -1.596807 & -0.216968 \\ \mathrm{C} & -5.862342 & -1.840205 & -0.570285 \\ \mathrm{C} & -3.503680 & -2.356958 & -0.819145 \\ \mathrm{C} & -6.178666 & -2.829751 & -1.495192 \\ \mathrm{H} & -6.655088 & -1.271036 & -0.094852 \\ \mathrm{C} & -3.829371 & -3.334532 & -1.758409 \\ \mathrm{H} & -2.459865 & -2.142444 & -0.611693 \\ \mathrm{C} & -5.161164 & -3.577207 & -2.094569 \\ \mathrm{H} & -7.217979 & -3.018008 & -1.748705 \\ \mathrm{H} & -3.032485 & -3.899458 & -2.231651 \\ \mathrm{H} & -5.408057 & -4.342554 & -2.825339 \\ & -6.256544 & 4.469780 & -0.312773\end{array}$

Catalyst (R)-1 TS Conformation 64

B3LYP/6-31G(d) Energy $=-2809.691063$

B3LYP-D3(BJ)/def2-TZVPP-IEF-PCM(DCM) Energy = -2810.988395

B3LYP-D3(BJ)/def2-TZVPP-IEF-PCM(DCM)//B3LYP/6-31G(d) Free Energy (Quasiharmonic) = 2810.345547

Frequencies (Top 3 out of 270) 
1. $-541.4586 \mathrm{~cm}-1$

2. $\quad 11.3560 \mathrm{~cm}-1$

3. $\quad 19.5596 \mathrm{~cm}-1$

B3LYP/6-31G(d) Molecular Geometry in Cartesian Coordinates

\begin{tabular}{|c|c|c|c|}
\hline C & -2.882790 & -0.949225 & 0.094689 \\
\hline C & -1.736690 & -1.657243 & -0.231399 \\
\hline C & -1.530188 & -3.015711 & 0.140007 \\
\hline C & -2.486581 & -3.613689 & 0.934326 \\
\hline $\mathrm{H}$ & -2.356634 & -4.653339 & 1.223929 \\
\hline C & -3.456041 & 3.102089 & -1.244139 \\
\hline C & -3.073155 & 0.430298 & -0.437808 \\
\hline C & -2.110992 & 1.403460 & -0.204441 \\
\hline C & -2.288880 & 2.766185 & -0.587080 \\
\hline $\mathrm{H}$ & -3.611821 & 4.135426 & -1.543129 \\
\hline $\mathrm{O}$ & -0.730268 & -1.005921 & -0.947826 \\
\hline$P$ & 0.168188 & 0.069462 & -0.087002 \\
\hline 0 & -0.976272 & 1.073049 & 0.523422 \\
\hline C & 1.746920 & -5.470162 & -1.169147 \\
\hline C & 1.592659 & -5.168445 & 0.184516 \\
\hline C & 0.547624 & -4.345182 & 0.606163 \\
\hline C & -0.354184 & -3.806532 & -0.321840 \\
\hline C & -0.182733 & -4.103139 & -1.682612 \\
\hline C & 0.855755 & -4.933918 & -2.102147 \\
\hline $\mathrm{H}$ & 2.286100 & -5.573387 & 0.916915 \\
\hline $\mathrm{H}$ & 0.965269 & -5.168237 & -3.158071 \\
\hline C & 0.475238 & 6.001473 & 0.049887 \\
\hline C & -0.789757 & 6.024674 & 0.640399 \\
\hline C & -1.666538 & 4.954278 & 0.455445 \\
\hline C & -1.290139 & 3.838989 & -0.308960 \\
\hline C & -0.010740 & 3.816270 & -0.885248 \\
\hline C & 0.857843 & 4.895149 & -0.713485 \\
\hline $\mathrm{H}$ & -1.099524 & 6.879000 & 1.236985 \\
\hline $\mathrm{H}$ & 1.834335 & 4.876596 & -1.191978 \\
\hline C & -4.231739 & 0.773026 & -1.217031 \\
\hline C & -4.429348 & 2.137778 & -1.600225 \\
\hline C & -5.578993 & 2.494780 & -2.355757 \\
\hline C & -6.491651 & 1.542926 & -2.745890 \\
\hline C & -6.281805 & 0.187019 & -2.400078 \\
\hline C & -5.184781 & -0.187909 & -1.656264 \\
\hline $\mathrm{H}$ & -5.714797 & 3.538070 & -2.630971 \\
\hline $\mathrm{H}$ & -7.364112 & 1.825151 & -3.328758 \\
\hline
\end{tabular}




\begin{tabular}{|c|c|c|c|}
\hline $\mathrm{H}$ & -6.990232 & -0.568054 & -2.730082 \\
\hline $\mathrm{H}$ & -5.034981 & -1.232413 & -1.409285 \\
\hline$C$ & -3.842270 & -1.562299 & 0.973412 \\
\hline C & -3.631686 & -2.915776 & 1.391544 \\
\hline C & -4.570192 & -3.533517 & 2.261600 \\
\hline C & -5.661685 & -2.841035 & 2.731343 \\
\hline C & -5.853123 & -1.492032 & 2.350796 \\
\hline C & -4.970399 & -0.870356 & 1.495314 \\
\hline $\mathrm{H}$ & -4.399630 & -4.565672 & 2.558496 \\
\hline $\mathrm{H}$ & -6.369445 & -3.321209 & 3.401531 \\
\hline $\mathrm{H}$ & -6.702620 & -0.938171 & 2.741363 \\
\hline $\mathrm{H}$ & -5.126538 & 0.166991 & 1.223786 \\
\hline 0 & 1.118206 & 0.765726 & -1.003993 \\
\hline $\mathrm{O}$ & 0.683831 & -0.625105 & 1.190444 \\
\hline $\mathrm{H}$ & 1.648180 & -1.191376 & 1.277739 \\
\hline $\mathrm{H}$ & -0.880387 & -3.695526 & -2.409165 \\
\hline $\mathrm{H}$ & 2.555458 & -6.118663 & -1.496454 \\
\hline $\mathrm{H}$ & 0.438811 & -4.099311 & 1.658024 \\
\hline $\mathrm{H}$ & 0.298946 & 2.957699 & -1.471528 \\
\hline $\mathrm{H}$ & 1.153966 & 6.841092 & 0.176596 \\
\hline $\mathrm{H}$ & -2.654079 & 4.977398 & 0.908684 \\
\hline C & 3.834978 & -1.836129 & 1.048469 \\
\hline 0 & 2.722053 & -1.848154 & 1.699654 \\
\hline $\mathrm{H}$ & 4.628629 & -2.487377 & 1.447259 \\
\hline C & 3.855417 & -1.921717 & -0.488059 \\
\hline 0 & 4.884674 & -2.055679 & -1.125829 \\
\hline 0 & 2.638626 & -1.822566 & -1.011399 \\
\hline C & 2.556439 & -1.806757 & -2.456156 \\
\hline $\mathrm{H}$ & 2.980044 & -2.729416 & -2.856921 \\
\hline $\mathrm{H}$ & 1.493914 & -1.734755 & -2.673700 \\
\hline C & 4.022706 & 0.799341 & 0.941316 \\
\hline C & 4.886326 & -0.267791 & 1.289479 \\
\hline $\mathrm{H}$ & 2.856808 & 1.341179 & -0.652463 \\
\hline$N$ & 3.838347 & 1.193752 & -0.358945 \\
\hline C & 4.714467 & 1.114060 & -1.452820 \\
\hline $\mathrm{O}$ & 4.320418 & 1.224371 & -2.592853 \\
\hline $\mathrm{O}$ & 5.995986 & 0.983431 & -1.082529 \\
\hline C & 6.916159 & 0.765706 & -2.170497 \\
\hline $\mathrm{H}$ & 6.692193 & -0.188287 & -2.653147 \\
\hline $\mathrm{H}$ & 7.902842 & 0.741479 & -1.708237 \\
\hline $\mathrm{H}$ & 6.846281 & 1.577429 & -2.897235 \\
\hline $\mathrm{H}$ & 5.160529 & -0.322622 & 2.337914 \\
\hline $\mathrm{H}$ & 5.695991 & -0.497914 & 0.609524 \\
\hline C & 3.128892 & 1.400118 & 1.927268 \\
\hline
\end{tabular}




$\begin{array}{llll}\text { C } & 2.878459 & 0.766358 & 3.165065 \\ \text { C } & 2.507565 & 2.640547 & 1.663759 \\ \text { C } & 2.024528 & 1.352639 & 4.092337 \\ \text { H } & 3.300248 & -0.207240 & 3.375072 \\ \text { C } & 1.661490 & 3.222532 & 2.597952 \\ \text { H } & 2.703025 & 3.157282 & 0.731703 \\ \text { C } & 1.416806 & 2.578228 & 3.814244 \\ \text { H } & 1.823473 & 0.844308 & 5.030579 \\ \text { H } & 1.189533 & 4.173396 & 2.372118 \\ \text { H } & 0.750839 & 3.031784 & 4.543216 \\ \text { H } & 3.090960 & -0.938887 & -2.844869\end{array}$

Catalyst (R)-1 TS Conformation 65

B3LYP/6-31G(d) Energy $=-2809.697463$

B3LYP-D3(BJ)/def2-TZVPP-IEF-PCM(DCM) Energy = -2810.986628

B3LYP-D3(BJ)/def2-TZVPP-IEF-PCM(DCM)//B3LYP/6-31G(d) Free Energy (Quasiharmonic) = 2810.345496

Frequencies (Top 3 out of 270)

1. $-702.5914 \mathrm{~cm}-1$

2. $\quad 6.2603 \mathrm{~cm}-1$

3. $11.2498 \mathrm{~cm}-1$

B3LYP/6-31G(d) Molecular Geometry in Cartesian Coordinates

$\begin{array}{llll}\text { C } & -3.276038 & 1.163725 & 0.129286 \\ \text { C } & -1.996715 & 1.679082 & 0.249426 \\ \text { C } & -1.694171 & 3.070443 & 0.188834 \\ \text { C } & -2.748404 & 3.934214 & -0.033483 \\ \text { H } & -2.560159 & 5.004319 & -0.060922 \\ \text { C } & -4.063190 & -3.069038 & 0.281060 \\ \text { C } & -3.498311 & -0.306874 & 0.268072 \\ \text { C } & -2.801270 & -1.199250 & -0.536466 \\ \text { C } & -3.099637 & -2.594629 & -0.588333 \\ \text { H } & -4.304991 & -4.128510 & 0.269755 \\ \text { O } & -0.946509 & 0.788639 & 0.448769 \\ \text { P } & -0.441056 & -0.090849 & -0.837554 \\ \text { O } & -1.837399 & -0.710947 & -1.412327 \\ \text { C } & 2.295887 & 4.633735 & 0.590150 \\ \text { C } & 1.830442 & 3.673187 & 1.491805 \\ \text { C } & 0.542609 & 3.154093 & 1.366327\end{array}$




\begin{tabular}{|c|c|c|c|}
\hline$C$ & -0.306943 & 3.586255 & 0.332906 \\
\hline C & 0.172804 & 4.553188 & -0.565117 \\
\hline C & 1.460777 & 5.073515 & -0.437355 \\
\hline $\mathrm{H}$ & 2.476567 & 3.324456 & 2.292580 \\
\hline $\mathrm{H}$ & 1.814429 & 5.813117 & -1.150966 \\
\hline C & -1.390747 & -5.387861 & -3.383207 \\
\hline C & -2.774222 & -5.271517 & -3.244284 \\
\hline C & -3.310350 & -4.349808 & -2.345626 \\
\hline C & -2.476316 & -3.526348 & -1.570485 \\
\hline C & -1.085751 & -3.649475 & -1.720067 \\
\hline C & -0.553086 & -4.574439 & -2.617910 \\
\hline $\mathrm{H}$ & -3.438641 & -5.892533 & -3.839670 \\
\hline $\mathrm{H}$ & 0.526124 & -4.660207 & -2.717337 \\
\hline C & -4.426998 & -0.833068 & 1.231596 \\
\hline C & -4.712956 & -2.235712 & 1.223165 \\
\hline C & -5.631452 & -2.767899 & 2.168424 \\
\hline C & -6.230603 & -1.958858 & 3.105499 \\
\hline C & -5.925720 & -0.577581 & 3.137748 \\
\hline C & -5.050610 & -0.029356 & 2.225905 \\
\hline $\mathrm{H}$ & -5.842772 & -3.834350 & 2.141456 \\
\hline $\mathrm{H}$ & -6.927188 & -2.377328 & 3.826842 \\
\hline $\mathrm{H}$ & -6.381997 & 0.056793 & 3.892936 \\
\hline $\mathrm{H}$ & -4.819944 & 1.028731 & 2.271185 \\
\hline C & -4.350646 & 2.069278 & -0.179013 \\
\hline C & -4.072146 & 3.473769 & -0.240083 \\
\hline C & -5.125975 & 4.382868 & -0.528748 \\
\hline C & -6.400238 & 3.932282 & -0.782810 \\
\hline C & -6.669270 & 2.543738 & -0.765448 \\
\hline C & -5.673977 & 1.637906 & -0.470730 \\
\hline $\mathrm{H}$ & -4.898814 & 5.445937 & -0.558587 \\
\hline $\mathrm{H}$ & -7.196104 & 4.636276 & -1.009892 \\
\hline $\mathrm{H}$ & -7.670159 & 2.186578 & -0.992352 \\
\hline $\mathrm{H}$ & -5.896327 & 0.577490 & -0.472705 \\
\hline $\mathrm{O}$ & 0.521578 & -1.112043 & -0.313946 \\
\hline $\mathrm{O}$ & 0.014296 & 0.836853 & -1.972137 \\
\hline $\mathrm{H}$ & 1.165639 & 1.070034 & -2.135075 \\
\hline $\mathrm{H}$ & -0.461625 & 4.876073 & -1.385597 \\
\hline $\mathrm{H}$ & 3.304414 & 5.025995 & 0.685962 \\
\hline $\mathrm{H}$ & 0.189056 & 2.411359 & 2.073542 \\
\hline $\mathrm{H}$ & -0.422010 & -3.030071 & -1.126977 \\
\hline $\mathrm{H}$ & -0.969158 & -6.103839 & -4.083999 \\
\hline $\mathrm{H}$ & -4.388571 & -4.249546 & -2.254038 \\
\hline C & 2.989041 & 1.114137 & -1.179054 \\
\hline $\mathrm{O}$ & 2.358330 & 1.336060 & -2.266178 \\
\hline
\end{tabular}




$\begin{array}{llll}\mathrm{H} & 2.437037 & 1.029922 & -0.236806 \\ \mathrm{C} & 4.353034 & 1.739073 & -0.974710 \\ \mathrm{O} & 4.755860 & 2.055703 & 0.126477 \\ \mathrm{O} & 5.032881 & 1.891579 & -2.116737 \\ \mathrm{C} & 6.338760 & 2.481165 & -1.980334 \\ \mathrm{H} & 6.974607 & 1.855180 & -1.348644 \\ \mathrm{H} & 6.737032 & 2.539300 & -2.993134 \\ \mathrm{C} & 3.969234 & -1.231880 & 0.052874 \\ \mathrm{C} & 3.565537 & -0.871002 & -1.237754 \\ \mathrm{H} & 2.013955 & -1.362583 & 0.630064 \\ \mathrm{~N} & 2.985861 & -1.487537 & 0.966086 \\ \mathrm{C} & 3.107716 & -2.147733 & 2.196727 \\ \mathrm{O} & 4.119982 & -2.591760 & 2.688682 \\ \mathrm{O} & 1.879295 & -2.221632 & 2.740445 \\ \mathrm{C} & 1.809451 & -2.916864 & 3.995726 \\ \mathrm{H} & 0.758910 & -2.881988 & 4.282977 \\ \mathrm{H} & 2.432071 & -2.419549 & 4.743875 \\ \mathrm{H} & 2.143626 & -3.951009 & 3.879348 \\ \mathrm{H} & 4.329077 & -0.781288 & -2.001352 \\ \mathrm{H} & 2.578697 & -1.181364 & -1.562531 \\ \mathrm{C} & 5.397234 & -1.185631 & 0.428477 \\ \mathrm{C} & 6.350469 & -1.733694 & -0.447085 \\ \mathrm{C} & 5.835882 & -0.527578 & 1.590568 \\ \mathrm{C} & 7.710252 & -1.647147 & -0.156022 \\ \mathrm{H} & 6.019668 & -2.255912 & -1.339666 \\ \mathrm{C} & 7.194862 & -0.424806 & 1.866620 \\ \mathrm{H} & 5.113155 & -0.070851 & 2.255719 \\ \mathrm{C} & 8.134662 & -0.989287 & 0.999970 \\ \mathrm{H} & 8.435511 & -2.094475 & -0.829675 \\ \mathrm{H} & 7.522285 & 0.097734 & 2.760563 \\ \mathrm{H} & 9.195068 & -0.915701 & 1.225666 \\ \mathrm{H} & 6.262361 & 3.477782 & -1.538476\end{array}$

Catalyst (R)-1 TS Conformation 66

B3LYP/6-31G(d) Energy $=-2809.692499$

B3LYP-D3(BJ)/def2-TZVPP-IEF-PCM(DCM) Energy $=-2810.986695$

B3LYP-D3(BJ)/def2-TZVPP-IEF-PCM(DCM)//B3LYP/6-31G(d) Free Energy (Quasiharmonic) = 2810.345493

Frequencies (Top 3 out of 270)

1. $-688.0787 \mathrm{~cm}-1$ 
2. $\quad 10.6685 \mathrm{~cm}-1$

3. $\quad 18.0688 \mathrm{~cm}-1$

B3LYP/6-31G(d) Molecular Geometry in Cartesian Coordinates

\begin{tabular}{|c|c|c|c|}
\hline C & 2.789681 & -1.500334 & -0.226801 \\
\hline C & 1.466080 & -1.810602 & 0.036061 \\
\hline C & 0.868533 & -3.060352 & -0.301137 \\
\hline C & 1.662213 & -3.984137 & -0.952882 \\
\hline $\mathrm{H}$ & 1.249881 & -4.959389 & -1.198112 \\
\hline C & 4.496456 & 2.324994 & 0.761826 \\
\hline C & 3.343906 & -0.186781 & 0.216802 \\
\hline C & 2.735719 & 0.996020 & -0.183459 \\
\hline C & 3.327839 & 2.278890 & 0.025497 \\
\hline $\mathrm{H}$ & 4.962660 & 3.288950 & 0.947482 \\
\hline $\mathrm{O}$ & 0.685132 & -0.860533 & 0.679192 \\
\hline$P$ & 0.172408 & 0.434798 & -0.186812 \\
\hline $\mathrm{O}$ & 1.553585 & 0.933979 & -0.911115 \\
\hline C & -3.202116 & -4.129817 & 0.608161 \\
\hline C & -2.662563 & -4.390779 & -0.652821 \\
\hline C & -1.349295 & -4.021473 & -0.941872 \\
\hline C & -0.547305 & -3.381813 & 0.019066 \\
\hline C & -1.106180 & -3.109796 & 1.279670 \\
\hline C & -2.417465 & -3.487646 & 1.569110 \\
\hline $\mathrm{H}$ & -3.265409 & -4.876664 & -1.415509 \\
\hline $\mathrm{H}$ & -2.817419 & -3.285190 & 2.558881 \\
\hline C & 1.907709 & 5.956213 & -1.705385 \\
\hline C & 1.020457 & 5.130455 & -1.012956 \\
\hline C & 1.453136 & 3.928309 & -0.453312 \\
\hline C & 2.793824 & 3.531135 & -0.579851 \\
\hline C & 3.678557 & 4.369564 & -1.280232 \\
\hline C & 3.242158 & 5.570874 & -1.837120 \\
\hline $\mathrm{H}$ & -0.022008 & 5.418221 & -0.907014 \\
\hline $\mathrm{H}$ & 3.943215 & 6.198933 & -2.380986 \\
\hline C & 4.508035 & -0.113017 & 1.056789 \\
\hline C & 5.087206 & 1.168195 & 1.324553 \\
\hline C & 6.237687 & 1.255696 & 2.154500 \\
\hline C & 6.788413 & 0.129912 & 2.721119 \\
\hline C & 6.200552 & -1.134877 & 2.483174 \\
\hline C & 5.093068 & -1.253913 & 1.672531 \\
\hline $\mathrm{H}$ & 6.668336 & 2.236719 & 2.341235 \\
\hline $\mathrm{H}$ & 7.664568 & 0.209169 & 3.358925 \\
\hline $\mathrm{H}$ & 6.622573 & -2.020892 & 2.949909 \\
\hline $\mathrm{H}$ & 4.647360 & -2.228600 & 1.510337 \\
\hline
\end{tabular}




\begin{tabular}{|c|c|c|c|}
\hline C & 3.579624 & -2.441141 & -0.975080 \\
\hline C & 3.000967 & -3.705376 & -1.321075 \\
\hline C & 3.773357 & -4.653146 & -2.045989 \\
\hline C & 5.055558 & -4.361665 & -2.448741 \\
\hline C & 5.615154 & -3.098348 & -2.145624 \\
\hline C & 4.899122 & -2.165189 & -1.428330 \\
\hline $\mathrm{H}$ & 3.321770 & -5.612361 & -2.288365 \\
\hline $\mathrm{H}$ & 5.634112 & -5.091054 & -3.009014 \\
\hline $\mathrm{H}$ & 6.618795 & -2.858657 & -2.486404 \\
\hline $\mathrm{H}$ & 5.340427 & -1.199151 & -1.214293 \\
\hline $\mathrm{O}$ & -0.385981 & 1.425007 & 0.789390 \\
\hline $\mathrm{O}$ & -0.684677 & -0.054757 & -1.357010 \\
\hline $\mathrm{H}$ & -1.860828 & 0.148860 & -1.553032 \\
\hline $\mathrm{H}$ & -0.517813 & -2.603844 & 2.036464 \\
\hline $\mathrm{H}$ & -4.224509 & -4.418811 & 0.836657 \\
\hline $\mathrm{H}$ & -0.942032 & -4.209252 & -1.931206 \\
\hline $\mathrm{H}$ & 4.713267 & 4.062057 & -1.405467 \\
\hline $\mathrm{H}$ & 1.561815 & 6.889503 & -2.142654 \\
\hline$H$ & 0.752908 & 3.304960 & 0.092019 \\
\hline C & -3.772913 & -0.541195 & -1.146892 \\
\hline $\mathrm{O}$ & -3.016792 & 0.212140 & -1.856022 \\
\hline $\mathrm{H}$ & -3.321587 & -1.290983 & -0.489509 \\
\hline C & -5.087173 & -0.933941 & -1.801921 \\
\hline $\mathrm{O}$ & -5.636693 & -0.301555 & -2.673929 \\
\hline $\mathrm{O}$ & -5.559435 & -2.077284 & -1.265911 \\
\hline C & -6.808555 & -2.539095 & -1.812794 \\
\hline $\mathrm{H}$ & -7.591683 & -1.791574 & -1.660661 \\
\hline $\mathrm{H}$ & -6.705832 & -2.734611 & -2.883030 \\
\hline C & -3.750356 & 1.246092 & 0.890570 \\
\hline C & -4.767098 & 0.410321 & 0.411278 \\
\hline $\mathrm{H}$ & -1.855847 & 1.115490 & 1.674061 \\
\hline$N$ & -2.847321 & 0.838447 & 1.838590 \\
\hline C & -3.014912 & -0.053881 & 2.901405 \\
\hline O & -2.082184 & -0.495056 & 3.534127 \\
\hline $\mathrm{O}$ & -4.313457 & -0.293591 & 3.178081 \\
\hline C & -4.540564 & -1.107791 & 4.342028 \\
\hline $\mathrm{H}$ & -4.130374 & -2.110388 & 4.198832 \\
\hline $\mathrm{H}$ & -5.624122 & -1.150118 & 4.453835 \\
\hline $\mathrm{H}$ & -4.078027 & -0.653653 & 5.221252 \\
\hline $\mathrm{H}$ & -5.594620 & 0.890283 & -0.098504 \\
\hline $\mathrm{H}$ & -5.022608 & -0.473222 & 0.980811 \\
\hline C & -3.506804 & 2.560869 & 0.289639 \\
\hline C & -2.810563 & 3.549808 & 1.016498 \\
\hline C & -4.007430 & 2.882538 & -0.990620 \\
\hline
\end{tabular}




$\begin{array}{llll}\mathrm{C} & -2.641135 & 4.824413 & 0.490984 \\ \mathrm{H} & -2.429960 & 3.322215 & 2.005693 \\ \mathrm{C} & -3.815959 & 4.156543 & -1.517089 \\ \mathrm{H} & -4.513888 & 2.135467 & -1.588478 \\ \mathrm{C} & -3.141820 & 5.130631 & -0.778513 \\ \mathrm{H} & -2.120259 & 5.580517 & 1.070924 \\ \mathrm{H} & -4.193212 & 4.386636 & -2.508903 \\ \mathrm{H} & -3.007693 & 6.127823 & -1.189080 \\ \mathrm{H} & -7.041647 & -3.457479 & -1.274088\end{array}$

Catalyst (R)-1 TS Conformation 67

B3LYP/6-31G(d) Energy $=-2809.695093$

B3LYP-D3(BJ)/def2-TZVPP-IEF-PCM(DCM) Energy $=-2810.986098$

B3LYP-D3(BJ)/def2-TZVPP-IEF-PCM(DCM)//B3LYP/6-31G(d) Free Energy (Quasiharmonic) = 2810.34548

Frequencies (Top 3 out of 270)

1. $-697.2329 \mathrm{~cm}-1$

2. $\quad 7.1575 \mathrm{~cm}-1$

3. $\quad 13.7052 \mathrm{~cm}-1$

B3LYP/6-31G(d) Molecular Geometry in Cartesian Coordinates

$\begin{array}{llll}\text { C } & 2.959311 & -1.310947 & -0.048807 \\ \text { C } & 1.605707 & -1.603412 & 0.003853 \\ \text { C } & 1.076202 & -2.916930 & -0.160664 \\ \text { C } & 1.974714 & -3.932224 & -0.422346 \\ \text { H } & 1.607892 & -4.949525 & -0.532321 \\ \text { C } & 4.273120 & 2.760828 & 0.516072 \\ \text { C } & 3.414081 & 0.090750 & 0.197759 \\ \text { C } & 2.888499 & 1.127561 & -0.560295 \\ \text { C } & 3.319726 & 2.482507 & -0.444570 \\ \text { H } & 4.644518 & 3.777541 & 0.613023 \\ \text { O } & 0.714826 & -0.562475 & 0.237295 \\ \text { P } & 0.402619 & 0.469880 & -1.005382 \\ \text { O } & 1.914311 & 0.835490 & -1.508115 \\ \text { C } & -3.138677 & -3.768164 & 0.070088 \\ \text { C } & -2.371730 & -4.260964 & -0.987244 \\ \text { C } & -1.007699 & -3.976138 & -1.059582 \\ \text { C } & -0.382682 & -3.193337 & -0.075846 \\ \text { C } & -1.164760 & -2.710097 & 0.986668\end{array}$




\begin{tabular}{|c|c|c|c|}
\hline C & -2.528402 & -2.993790 & 1.061083 \\
\hline $\mathrm{H}$ & -2.838160 & -4.857520 & -1.766886 \\
\hline $\mathrm{H}$ & -3.110133 & -2.598542 & 1.889263 \\
\hline C & 1.882056 & 5.699507 & -2.913947 \\
\hline C & 2.214102 & 4.472572 & -3.491921 \\
\hline C & 2.658857 & 3.416220 & -2.699046 \\
\hline C & 2.785264 & 3.569287 & -1.308093 \\
\hline C & 2.444392 & 4.807163 & -0.738932 \\
\hline C & 1.997192 & 5.862324 & -1.532958 \\
\hline $\mathrm{H}$ & 2.127986 & 4.335481 & -4.566630 \\
\hline $\mathrm{H}$ & 1.730867 & 6.809007 & -1.069932 \\
\hline C & 4.348892 & 0.411082 & 1.241744 \\
\hline C & 4.786618 & 1.767637 & 1.385056 \\
\hline C & 5.719251 & 2.096092 & 2.406400 \\
\hline C & 6.182574 & 1.137920 & 3.277572 \\
\hline C & 5.722546 & -0.195160 & 3.163497 \\
\hline C & 4.832426 & -0.549209 & 2.173295 \\
\hline $\mathrm{H}$ & 6.050964 & 3.128244 & 2.491932 \\
\hline $\mathrm{H}$ & 6.890793 & 1.402370 & 4.058058 \\
\hline $\mathrm{H}$ & 6.072222 & -0.947239 & 3.865724 \\
\hline $\mathrm{H}$ & 4.484652 & -1.573420 & 2.104694 \\
\hline C & 3.874643 & -2.365236 & -0.390683 \\
\hline C & 3.364373 & -3.693489 & -0.562589 \\
\hline C & 4.259816 & -4.747661 & -0.889921 \\
\hline C & 5.601205 & -4.506055 & -1.074273 \\
\hline C & 6.101430 & -3.189187 & -0.944367 \\
\hline C & 5.262779 & -2.148277 & -0.611134 \\
\hline $\mathrm{H}$ & 3.857726 & -5.751505 & -1.005074 \\
\hline $\mathrm{H}$ & 6.274691 & -5.318983 & -1.331447 \\
\hline $\mathrm{H}$ & 7.157024 & -2.995217 & -1.114502 \\
\hline $\mathrm{H}$ & 5.660454 & -1.143716 & -0.525850 \\
\hline 0 & -0.369237 & 1.620979 & -0.440222 \\
\hline $\mathrm{O}$ & -0.185362 & -0.313813 & -2.184232 \\
\hline $\mathrm{H}$ & -1.338699 & -0.146757 & -2.475054 \\
\hline $\mathrm{H}$ & -0.697265 & -2.110670 & 1.760524 \\
\hline $\mathrm{H}$ & -4.204591 & -3.971152 & 0.113980 \\
\hline $\mathrm{H}$ & -0.422877 & -4.336781 & -1.901071 \\
\hline $\mathrm{H}$ & 2.509934 & 4.932488 & 0.338296 \\
\hline $\mathrm{H}$ & 1.531454 & 6.519842 & -3.534718 \\
\hline $\mathrm{H}$ & 2.915730 & 2.468839 & -3.159891 \\
\hline C & -3.299593 & -0.359997 & -1.828013 \\
\hline $\mathrm{O}$ & -2.501346 & -0.031451 & -2.772325 \\
\hline $\mathrm{H}$ & -2.940927 & -0.967724 & -0.992280 \\
\hline C & -4.727909 & -0.680805 & -2.221214 \\
\hline
\end{tabular}




$\begin{array}{llll}\mathrm{O} & -5.403963 & -1.502564 & -1.632366 \\ \mathrm{O} & -5.131936 & 0.014218 & -3.289048 \\ \mathrm{C} & -6.462438 & -0.278860 & -3.752073 \\ \mathrm{H} & -6.612751 & 0.360001 & -4.621894 \\ \mathrm{H} & -6.545889 & -1.333003 & -4.027719 \\ \mathrm{C} & -3.659274 & 1.160493 & 0.672792 \\ \mathrm{C} & -3.688713 & 1.372427 & -0.719110 \\ \mathrm{H} & -1.615669 & 1.393910 & 0.717412 \\ \mathrm{~N} & -2.449308 & 1.133514 & 1.289622 \\ \mathrm{C} & -2.151182 & 0.535117 & 2.527384 \\ \mathrm{O} & -2.882815 & -0.171658 & 3.183629 \\ \mathrm{O} & -0.891118 & 0.866500 & 2.848335 \\ \mathrm{C} & -0.383683 & 0.266036 & 4.051061 \\ \mathrm{H} & -0.973481 & 0.584386 & 4.914509 \\ \mathrm{H} & 0.644553 & 0.616649 & 4.132548 \\ \mathrm{H} & -0.412975 & -0.824000 & 3.977347 \\ \mathrm{H} & -4.625971 & 1.725562 & -1.135615 \\ \mathrm{H} & -2.793875 & 1.808785 & -1.150798 \\ \mathrm{C} & -4.900229 & 1.077396 & 1.476263 \\ \mathrm{C} & -5.023835 & 1.873495 & 2.629353 \\ \mathrm{C} & -5.993652 & 0.305236 & 1.056803 \\ \mathrm{C} & -6.218422 & 1.900445 & 3.340695 \\ \mathrm{H} & -4.190655 & 2.491338 & 2.949712 \\ \mathrm{C} & -7.179498 & 0.316970 & 1.790206 \\ \mathrm{H} & -5.905914 & -0.335719 & 0.187114 \\ \mathrm{C} & -7.298922 & 1.116751 & 2.927189 \\ \mathrm{H} & -6.305577 & 2.530864 & 4.221065 \\ \mathrm{H} & -8.011734 & -0.302860 & 1.468534 \\ \mathrm{H} & -8.228689 & 1.131551 & 3.489295 \\ \mathrm{H} & -7.197489 & -0.052433 & -2.974829\end{array}$

Catalyst (R)-1 TS Conformation 68

B3LYP/6-31G(d) Energy $=-2809.695937$

B3LYP-D3(BJ)/def2-TZVPP-IEF-PCM(DCM) Energy $=-2810.986105$

B3LYP-D3(BJ)/def2-TZVPP-IEF-PCM(DCM)//B3LYP/6-31G(d) Free Energy (Quasiharmonic) = 2810.345343

Frequencies (Top 3 out of 270 )

1. $-690.9390 \mathrm{~cm}-1$

2. $7.3914 \mathrm{~cm}-1$

3. $\quad 14.1459 \mathrm{~cm}-1$ 
B3LYP/6-31G(d) Molecular Geometry in Cartesian Coordinates

\begin{tabular}{|c|c|c|c|}
\hline C & 2.863790 & -1.376256 & -0.086612 \\
\hline C & 1.501266 & -1.621400 & -0.064270 \\
\hline C & 0.922087 & -2.895426 & -0.334102 \\
\hline C & 1.783266 & -3.920770 & -0.670698 \\
\hline $\mathrm{H}$ & 1.379012 & -4.911580 & -0.861380 \\
\hline C & 4.480578 & 2.535685 & 0.717581 \\
\hline C & 3.376066 & -0.019952 & 0.273506 \\
\hline C & 2.915981 & 1.103018 & -0.402379 \\
\hline C & 3.488874 & 2.400106 & -0.235042 \\
\hline $\mathrm{H}$ & 4.928779 & 3.513360 & 0.873406 \\
\hline 0 & 0.650150 & -0.564336 & 0.243144 \\
\hline$P$ & 0.400098 & 0.561617 & -0.925683 \\
\hline $\mathrm{O}$ & 1.922904 & 0.953397 & -1.363823 \\
\hline C & -3.319921 & -3.618428 & -0.181770 \\
\hline C & -2.565512 & -4.046294 & -1.275861 \\
\hline C & -1.192727 & -3.801132 & -1.322794 \\
\hline C & -0.546287 & -3.123775 & -0.276419 \\
\hline C & -1.316451 & -2.703451 & 0.820899 \\
\hline C & -2.688952 & -2.948087 & 0.870140 \\
\hline $\mathrm{H}$ & -3.048227 & -4.560870 & -2.102549 \\
\hline $\mathrm{H}$ & -3.260781 & -2.603678 & 1.727293 \\
\hline C & 2.519267 & 5.854548 & -2.613164 \\
\hline C & 1.497440 & 5.130271 & -1.996549 \\
\hline C & 1.786959 & 3.997315 & -1.236190 \\
\hline C & 3.115444 & 3.571341 & -1.077720 \\
\hline C & 4.136499 & 4.307661 & -1.702182 \\
\hline C & 3.842637 & 5.438242 & -2.463670 \\
\hline $\mathrm{H}$ & 0.463634 & 5.448199 & -2.105183 \\
\hline $\mathrm{H}$ & 4.647611 & 5.987946 & -2.944798 \\
\hline C & 4.341030 & 0.158759 & 1.324292 \\
\hline C & 4.901450 & 1.459182 & 1.535202 \\
\hline C & 5.857802 & 1.648909 & 2.569529 \\
\hline C & 6.235004 & 0.607230 & 3.384657 \\
\hline C & 5.660056 & -0.672260 & 3.199432 \\
\hline C & 4.740658 & -0.891261 & 2.197012 \\
\hline $\mathrm{H}$ & 6.278768 & 2.641785 & 2.709680 \\
\hline $\mathrm{H}$ & 6.963463 & 0.765111 & 4.175281 \\
\hline $\mathrm{H}$ & 5.942895 & -1.489783 & 3.857226 \\
\hline $\mathrm{H}$ & 4.303255 & -1.875462 & 2.074413 \\
\hline C & 3.741262 & -2.434902 & -0.509411 \\
\hline C & 3.181756 & -3.724903 & -0.786905 \\
\hline
\end{tabular}




\begin{tabular}{|c|c|c|c|}
\hline C & 4.037445 & -4.784371 & -1.193722 \\
\hline C & 5.387958 & -4.581290 & -1.355865 \\
\hline C & 5.937134 & -3.298745 & -1.122910 \\
\hline C & 5.137610 & -2.255439 & -0.710316 \\
\hline $\mathrm{H}$ & 3.597348 & -5.759598 & -1.388254 \\
\hline $\mathrm{H}$ & 6.031065 & -5.396993 & -1.674605 \\
\hline $\mathrm{H}$ & 6.999955 & -3.132445 & -1.276399 \\
\hline $\mathrm{H}$ & 5.573782 & -1.277082 & -0.547385 \\
\hline $\mathrm{O}$ & -0.368500 & 1.683620 & -0.291427 \\
\hline $\mathrm{O}$ & -0.178460 & -0.110102 & -2.174687 \\
\hline $\mathrm{H}$ & -1.330197 & 0.096922 & -2.470550 \\
\hline $\mathrm{H}$ & -0.832495 & -2.186193 & 1.642630 \\
\hline $\mathrm{H}$ & -4.391746 & -3.790732 & -0.155850 \\
\hline $\mathrm{H}$ & -0.616283 & -4.110448 & -2.190067 \\
\hline $\mathrm{H}$ & 5.166713 & 3.975899 & -1.603671 \\
\hline $\mathrm{H}$ & 2.286019 & 6.734057 & -3.207782 \\
\hline $\mathrm{H}$ & 0.981558 & 3.451443 & -0.757108 \\
\hline C & -3.305499 & -0.135260 & -1.883303 \\
\hline $\mathrm{O}$ & -2.479222 & 0.254868 & -2.777736 \\
\hline $\mathrm{H}$ & -2.978927 & -0.811778 & -1.088741 \\
\hline C & -4.731344 & -0.386542 & -2.331176 \\
\hline $\mathrm{O}$ & -5.440158 & -1.234710 & -1.824197 \\
\hline $\mathrm{O}$ & -5.092797 & 0.401281 & -3.348270 \\
\hline C & -6.418913 & 0.180786 & -3.862214 \\
\hline $\mathrm{H}$ & -6.520883 & -0.845374 & -4.223716 \\
\hline $\mathrm{H}$ & -7.166216 & 0.363171 & -3.085121 \\
\hline C & -3.693515 & 1.203248 & 0.731782 \\
\hline C & -3.694401 & 1.519772 & -0.639494 \\
\hline $\mathrm{H}$ & -1.648943 & 1.400713 & 0.829350 \\
\hline$N$ & -2.495501 & 1.115539 & 1.367051 \\
\hline C & -2.225661 & 0.433492 & 2.567563 \\
\hline $\mathrm{O}$ & -2.979334 & -0.297956 & 3.169341 \\
\hline $\mathrm{O}$ & -0.963919 & 0.719534 & 2.923403 \\
\hline C & -0.483598 & 0.037536 & 4.093604 \\
\hline $\mathrm{H}$ & -1.080932 & 0.311869 & 4.966859 \\
\hline $\mathrm{H}$ & 0.548662 & 0.365437 & 4.210614 \\
\hline $\mathrm{H}$ & -0.528975 & -1.045196 & 3.951841 \\
\hline $\mathrm{H}$ & -4.619232 & 1.914641 & -1.045779 \\
\hline $\mathrm{H}$ & -2.785825 & 1.970071 & -1.025019 \\
\hline C & -4.951516 & 1.075298 & 1.502262 \\
\hline C & -5.093170 & 1.785496 & 2.708076 \\
\hline C & -6.042172 & 0.347559 & 1.003578 \\
\hline C & -6.302753 & 1.772099 & 3.393991 \\
\hline $\mathrm{H}$ & -4.261908 & 2.369150 & 3.091252 \\
\hline
\end{tabular}




$\begin{array}{llll}\mathrm{C} & -7.243664 & 0.317331 & 1.710558 \\ \mathrm{H} & -5.941308 & -0.227380 & 0.090141 \\ \mathrm{C} & -7.380731 & 1.032156 & 2.900890 \\ \mathrm{H} & -6.403604 & 2.336598 & 4.316597 \\ \mathrm{H} & -8.074174 & -0.268141 & 1.326206 \\ \mathrm{H} & -8.322323 & 1.015019 & 3.442865 \\ \mathrm{H} & -6.533002 & 0.890954 & -4.680672\end{array}$

Catalyst (R)-1 TS Conformation 69

B3LYP/6-31G(d) Energy $=-2809.692871$

B3LYP-D3(BJ)/def2-TZVPP-IEF-PCM(DCM) Energy $=-2810.986077$

B3LYP-D3(BJ)/def2-TZVPP-IEF-PCM(DCM)//B3LYP/6-31G(d) Free Energy (Quasiharmonic) = 2810.345316

Frequencies (Top 3 out of 270)

1. $-720.3916 \mathrm{~cm}-1$

2. $8.4144 \mathrm{~cm}-1$

3. $11.3648 \mathrm{~cm}-1$

B3LYP/6-31G(d) Molecular Geometry in Cartesian Coordinates

$\begin{array}{llll}\text { C } & -3.824893 & 0.113957 & -0.093968 \\ \text { C } & -3.069000 & 1.196678 & 0.331594 \\ \text { C } & -3.552159 & 2.538470 & 0.336345 \\ \text { C } & -4.824005 & 2.752959 & -0.158586 \\ \text { H } & -5.233656 & 3.759547 & -0.145843 \\ \text { C } & -2.105925 & -3.841374 & 0.101757 \\ \text { C } & -3.259108 & -1.264281 & 0.013548 \\ \text { C } & -2.033655 & -1.542401 & -0.571498 \\ \text { C } & -1.431487 & -2.834350 & -0.560221 \\ \text { H } & -1.686606 & -4.844100 & 0.110269 \\ \text { O } & -1.782728 & 0.967309 & 0.805328 \\ \text { P } & -0.595844 & 0.589166 & -0.258121 \\ \text { O } & -1.355230 & -0.510912 & -1.210299 \\ \text { C } & -1.314052 & 5.898580 & 1.824875 \\ \text { C } & -1.981503 & 5.976729 & 0.602004 \\ \text { C } & -2.687975 & 4.876070 & 0.118493 \\ \text { C } & -2.741568 & 3.676396 & 0.846529 \\ \text { C } & -2.060066 & 3.608340 & 2.073473 \\ \text { C } & -1.356344 & 4.710087 & 2.556889 \\ \text { H } & -1.946029 & 6.892313 & 0.017278\end{array}$




\begin{tabular}{|c|c|c|c|}
\hline $\mathrm{H}$ & -0.840689 & 4.639226 & 3.511107 \\
\hline C & 2.318515 & -3.737839 & -2.470438 \\
\hline C & 1.346472 & -3.003195 & -3.153611 \\
\hline C & 0.136922 & -2.688290 & -2.535626 \\
\hline C & -0.126506 & -3.106513 & -1.220075 \\
\hline C & 0.861562 & -3.837996 & -0.540412 \\
\hline C & 2.071419 & -4.152249 & -1.160748 \\
\hline $\mathrm{H}$ & 1.526260 & -2.678687 & -4.175358 \\
\hline $\mathrm{H}$ & 2.823873 & -4.718054 & -0.616885 \\
\hline C & -3.915000 & -2.305213 & 0.756848 \\
\hline C & -3.327925 & -3.612290 & 0.780537 \\
\hline C & -3.971890 & -4.653807 & 1.502237 \\
\hline C & -5.131470 & -4.417676 & 2.202957 \\
\hline C & -5.691710 & -3.118692 & 2.214961 \\
\hline C & -5.101339 & -2.091723 & 1.511741 \\
\hline $\mathrm{H}$ & -3.518694 & -5.642378 & 1.499579 \\
\hline $\mathrm{H}$ & -5.610834 & -5.220149 & 2.756920 \\
\hline $\mathrm{H}$ & -6.594230 & -2.927131 & 2.789110 \\
\hline $\mathrm{H}$ & -5.538063 & -1.100349 & 1.540067 \\
\hline C & -5.116061 & 0.364349 & -0.673243 \\
\hline C & -5.617626 & 1.706258 & -0.688070 \\
\hline C & -6.898254 & 1.966450 & -1.247330 \\
\hline C & -7.647811 & 0.955292 & -1.801684 \\
\hline C & -7.138338 & -0.364351 & -1.824177 \\
\hline C & -5.908273 & -0.652330 & -1.274777 \\
\hline $\mathrm{H}$ & -7.268663 & 2.988906 & -1.239015 \\
\hline $\mathrm{H}$ & -8.622396 & 1.167763 & -2.232627 \\
\hline $\mathrm{H}$ & -7.720621 & -1.158394 & -2.283962 \\
\hline $\mathrm{H}$ & -5.528480 & -1.666849 & -1.309399 \\
\hline 0 & 0.548954 & 0.025287 & 0.518501 \\
\hline O & -0.335695 & 1.763448 & -1.207428 \\
\hline $\mathrm{H}$ & 0.773185 & 2.248721 & -1.285271 \\
\hline $\mathrm{H}$ & -2.087694 & 2.691136 & 2.651541 \\
\hline $\mathrm{H}$ & -0.761116 & 6.754663 & 2.202648 \\
\hline $\mathrm{H}$ & -3.185658 & 4.934541 & -0.845417 \\
\hline $\mathrm{H}$ & 0.689469 & -4.133779 & 0.490334 \\
\hline $\mathrm{H}$ & 3.259714 & -3.984618 & -2.955029 \\
\hline $\mathrm{H}$ & -0.612838 & -2.120946 & -3.076396 \\
\hline C & 2.647687 & 2.190145 & -0.472346 \\
\hline 0 & 1.886531 & 2.691768 & -1.370813 \\
\hline $\mathrm{H}$ & 2.206425 & 1.756311 & 0.428750 \\
\hline C & 3.994215 & 2.831726 & -0.218468 \\
\hline 0 & 4.516460 & 2.813914 & 0.877589 \\
\hline $\mathrm{O}$ & 4.517926 & 3.397658 & -1.312401 \\
\hline
\end{tabular}




$\begin{array}{llll}\mathrm{C} & 5.798519 & 4.027156 & -1.124082 \\ \mathrm{H} & 6.540963 & 3.290861 & -0.804713 \\ \mathrm{H} & 6.061219 & 4.444672 & -2.095930 \\ \mathrm{C} & 3.928834 & -0.338163 & -0.202939 \\ \mathrm{C} & 3.291808 & 0.376493 & -1.223037 \\ \mathrm{H} & 2.136200 & -0.729937 & 0.705670 \\ \mathrm{~N} & 3.146379 & -0.960929 & 0.728513 \\ \mathrm{C} & 3.427052 & -2.042737 & 1.573968 \\ \mathrm{O} & 2.628344 & -2.442249 & 2.390453 \\ \mathrm{O} & 4.631117 & -2.592672 & 1.338361 \\ \mathrm{C} & 4.964062 & -3.697873 & 2.195768 \\ \mathrm{H} & 4.255432 & -4.517601 & 2.054207 \\ \mathrm{H} & 4.948933 & -3.389268 & 3.243884 \\ \mathrm{H} & 5.967899 & -3.999344 & 1.896535 \\ \mathrm{H} & 3.909166 & 0.778864 & -2.017723 \\ \mathrm{H} & 2.285997 & 0.078472 & -1.494288 \\ \mathrm{C} & 5.396477 & -0.261112 & -0.046722 \\ \mathrm{C} & 5.975066 & 0.033789 & 1.200444 \\ \mathrm{C} & 6.226160 & -0.394819 & -1.171831 \\ \mathrm{C} & 7.353044 & 0.186969 & 1.314790 \\ \mathrm{H} & 5.337110 & 0.184047 & 2.064565 \\ \mathrm{C} & 7.607739 & -0.258756 & -1.049605 \\ \mathrm{H} & 5.786478 & -0.635311 & -2.135048 \\ \mathrm{C} & 8.173160 & 0.034823 & 0.193160 \\ \mathrm{H} & 7.788015 & 0.433392 & 2.279067 \\ \mathrm{H} & 8.241310 & -0.383031 & -1.923209 \\ \mathrm{H} & 9.249712 & 0.148546 & 0.287521 \\ \mathrm{H} & 5.727832 & 4.816454 & -0.371615\end{array}$

Catalyst (R)-1 TS Conformation 70

B3LYP/6-31G(d) Energy $=-2809.695563$

B3LYP-D3(BJ)/def2-TZVPP-IEF-PCM(DCM) Energy = -2810.988446

B3LYP-D3(BJ)/def2-TZVPP-IEF-PCM(DCM)//B3LYP/6-31G(d) Free Energy (Quasiharmonic) = 2810.345301

Frequencies (Top 3 out of 270)

1. $-302.4676 \mathrm{~cm}-1$

2. $\quad 10.9427 \mathrm{~cm}-1$

3. $\quad 14.7116 \mathrm{~cm}-1$

B3LYP/6-31G(d) Molecular Geometry in Cartesian Coordinates 


\begin{tabular}{|c|c|c|c|}
\hline C & 2.939501 & -1.356263 & -0.245823 \\
\hline C & 1.674493 & -1.734105 & 0.175695 \\
\hline C & 1.153900 & -3.052199 & 0.024406 \\
\hline C & 1.958458 & -3.980600 & -0.606147 \\
\hline $\mathrm{H}$ & 1.602319 & -5.001453 & -0.717787 \\
\hline C & 4.254747 & 2.707446 & 0.350666 \\
\hline C & 3.411996 & 0.037372 & 0.009582 \\
\hline C & 2.648176 & 1.110631 & -0.425976 \\
\hline C & 3.049975 & 2.472572 & -0.285312 \\
\hline $\mathrm{H}$ & 4.610451 & 3.729694 & 0.446726 \\
\hline $\mathrm{O}$ & 0.863768 & -0.780340 & 0.784509 \\
\hline$P$ & 0.168658 & 0.352815 & -0.170191 \\
\hline $\mathrm{O}$ & 1.439619 & 0.848371 & -1.065059 \\
\hline C & -2.771368 & -4.202623 & 1.367016 \\
\hline C & -1.921242 & -3.494816 & 2.220332 \\
\hline C & -0.652931 & -3.104545 & 1.791080 \\
\hline C & -0.205711 & -3.424422 & 0.498521 \\
\hline C & -1.066717 & -4.141776 & -0.348255 \\
\hline C & -2.337286 & -4.525216 & 0.080041 \\
\hline $\mathrm{H}$ & -2.245080 & -3.242225 & 3.226774 \\
\hline $\mathrm{H}$ & -2.994912 & -5.064867 & -0.596048 \\
\hline C & 0.768282 & 5.842523 & -1.685740 \\
\hline C & 0.883752 & 4.702657 & -2.482882 \\
\hline C & 1.606511 & 3.598161 & -2.035939 \\
\hline C & 2.228612 & 3.611434 & -0.776322 \\
\hline C & 2.098131 & 4.762766 & 0.019152 \\
\hline C & 1.378192 & 5.868167 & -0.430855 \\
\hline $\mathrm{H}$ & 0.405165 & 4.667829 & -3.457485 \\
\hline $\mathrm{H}$ & 1.286065 & 6.745392 & 0.204664 \\
\hline C & 4.618529 & 0.306369 & 0.742782 \\
\hline C & 5.045286 & 1.665391 & 0.892140 \\
\hline C & 6.246337 & 1.946228 & 1.599047 \\
\hline C & 6.984839 & 0.936000 & 2.169424 \\
\hline C & 6.543486 & -0.403784 & 2.059902 \\
\hline C & 5.394047 & -0.710561 & 1.365325 \\
\hline $\mathrm{H}$ & 6.562628 & 2.982654 & 1.691025 \\
\hline $\mathrm{H}$ & 7.897444 & 1.163482 & 2.713557 \\
\hline $\mathrm{H}$ & 7.114200 & -1.198860 & 2.532175 \\
\hline $\mathrm{H}$ & 5.065433 & -1.741139 & 1.298917 \\
\hline C & 3.734683 & -2.313824 & -0.965500 \\
\hline C & 3.233091 & -3.646499 & -1.126307 \\
\hline C & 4.014332 & -4.606744 & -1.824870 \\
\hline C & 5.227696 & -4.266922 & -2.375990 \\
\hline
\end{tabular}




\begin{tabular}{|c|c|c|c|}
\hline C & 5.706463 & -2.941243 & -2.255166 \\
\hline C & 4.981678 & -1.991761 & -1.568906 \\
\hline $\mathrm{H}$ & 3.623957 & -5.616655 & -1.926523 \\
\hline $\mathrm{H}$ & 5.812599 & -5.007809 & -2.914126 \\
\hline $\mathrm{H}$ & 6.653142 & -2.667029 & -2.712831 \\
\hline $\mathrm{H}$ & 5.358476 & -0.978402 & -1.494921 \\
\hline 0 & -0.445608 & 1.386600 & 0.708794 \\
\hline 0 & -0.691834 & -0.370946 & -1.237158 \\
\hline $\mathrm{H}$ & -1.768381 & -0.315295 & -1.262560 \\
\hline $\mathrm{H}$ & -0.743807 & -4.372344 & -1.359560 \\
\hline $\mathrm{H}$ & -3.767678 & -4.486514 & 1.692710 \\
\hline $\mathrm{H}$ & -0.003775 & -2.550384 & 2.460484 \\
\hline $\mathrm{H}$ & 2.546544 & 4.778729 & 1.008632 \\
\hline $\mathrm{H}$ & 0.200823 & 6.700623 & -2.036532 \\
\hline $\mathrm{H}$ & 1.688366 & 2.720741 & -2.666861 \\
\hline C & -3.854655 & -0.880077 & -0.513561 \\
\hline 0 & -3.149745 & -0.358952 & -1.449688 \\
\hline $\mathrm{H}$ & -3.354266 & -1.330406 & 0.355573 \\
\hline C & -5.075446 & -1.726115 & -0.876453 \\
\hline $\mathrm{O}$ & -5.546529 & -2.557718 & -0.126749 \\
\hline 0 & -5.557753 & -1.438614 & -2.094631 \\
\hline C & -6.698445 & -2.214277 & -2.499080 \\
\hline $\mathrm{H}$ & -7.533531 & -2.060047 & -1.810008 \\
\hline $\mathrm{H}$ & -6.952722 & -1.859657 & -3.498082 \\
\hline C & -3.836429 & 1.272703 & 0.886348 \\
\hline C & -4.900623 & 0.515059 & 0.360920 \\
\hline $\mathrm{H}$ & -2.033182 & 2.068255 & 0.376214 \\
\hline$N$ & -3.033190 & 2.027496 & 0.097446 \\
\hline C & -3.199855 & 2.465023 & -1.235100 \\
\hline 0 & -2.256755 & 2.826663 & -1.897346 \\
\hline $\mathrm{O}$ & -4.485430 & 2.524764 & -1.615854 \\
\hline C & -4.677925 & 2.868214 & -3.001130 \\
\hline $\mathrm{H}$ & -5.758582 & 2.907323 & -3.138568 \\
\hline $\mathrm{H}$ & -4.234443 & 2.098729 & -3.637273 \\
\hline $\mathrm{H}$ & -4.223046 & 3.836219 & -3.221157 \\
\hline $\mathrm{H}$ & -5.565410 & 0.049322 & 1.080429 \\
\hline $\mathrm{H}$ & -5.383175 & 0.880845 & -0.534138 \\
\hline C & -3.411059 & 1.130407 & 2.293471 \\
\hline C & -2.677108 & 2.153684 & 2.921167 \\
\hline C & -3.758280 & -0.010131 & 3.043627 \\
\hline C & -2.307531 & 2.042575 & 4.258309 \\
\hline $\mathrm{H}$ & -2.413073 & 3.047643 & 2.366881 \\
\hline C & -3.378450 & -0.119592 & 4.377427 \\
\hline $\mathrm{H}$ & -4.298743 & -0.827433 & 2.577965 \\
\hline
\end{tabular}




$\begin{array}{lrrr}\mathrm{C} & -2.655117 & 0.906612 & 4.990484 \\ \mathrm{H} & -1.745972 & 2.845054 & 4.727228 \\ \mathrm{H} & -3.645345 & -1.010115 & 4.939375 \\ \mathrm{H} & -2.363200 & 0.819606 & 6.033353 \\ \mathrm{H} & -6.448782 & -3.278225 & -2.521331\end{array}$

Catalyst (R)-1 TS Conformation 71

B3LYP/6-31G(d) Energy $=-2809.695391$

B3LYP-D3(BJ)/def2-TZVPP-IEF-PCM(DCM) Energy = -2810.987022

B3LYP-D3(BJ)/def2-TZVPP-IEF-PCM(DCM)//B3LYP/6-31G(d) Free Energy (Quasiharmonic) = 2810.345279

Frequencies (Top 3 out of 270)

1. $-586.1566 \mathrm{~cm}-1$

2. $\quad 6.8152 \mathrm{~cm}-1$

3. $21.9446 \mathrm{~cm}-1$

B3LYP/6-31G(d) Molecular Geometry in Cartesian Coordinates

$\begin{array}{llll}\mathrm{C} & 3.154634 & -0.002406 & 0.384687 \\ \mathrm{C} & 2.551762 & 1.151115 & -0.094316 \\ \mathrm{C} & 3.059921 & 2.458553 & 0.171271 \\ \mathrm{C} & 4.130730 & 2.558073 & 1.038433 \\ \mathrm{H} & 4.532149 & 3.541997 & 1.265842 \\ \mathrm{C} & 1.911858 & -3.971009 & -0.728066 \\ \mathrm{C} & 2.726712 & -1.349279 & -0.098595 \\ \mathrm{C} & 1.407873 & -1.755475 & 0.031454 \\ \mathrm{C} & 0.970031 & -3.090213 & -0.228652 \\ \mathrm{H} & 1.629999 & -5.005808 & -0.900909 \\ \mathrm{O} & 1.471285 & 1.037410 & -0.962187 \\ \mathrm{P} & 0.044900 & 0.436072 & -0.453419 \\ \mathrm{O} & 0.481172 & -0.831968 & 0.499047 \\ \mathrm{C} & 1.709859 & 6.095151 & -1.692753 \\ \mathrm{C} & 0.786967 & 5.254843 & -1.067694 \\ \mathrm{C} & 1.196340 & 4.059100 & -0.477719 \\ \mathrm{C} & 2.549695 & 3.688343 & -0.497647 \\ \mathrm{C} & 3.470820 & 4.540465 & -1.130819 \\ \mathrm{C} & 3.056651 & 5.732098 & -1.724470 \\ \mathrm{H} & -0.263685 & 5.528678 & -1.033173 \\ \mathrm{H} & 3.785806 & 6.372236 & -2.214591 \\ \mathrm{C} & -2.956706 & -4.637673 & 0.640809\end{array}$




\begin{tabular}{|c|c|c|c|}
\hline$C$ & -2.376455 & -3.694920 & 1.492543 \\
\hline C & -1.114537 & -3.172127 & 1.207352 \\
\hline C & -0.409971 & -3.566996 & 0.055417 \\
\hline C & -1.014614 & -4.506633 & -0.797179 \\
\hline C & -2.265998 & -5.046623 & -0.501019 \\
\hline $\mathrm{H}$ & -2.909757 & -3.358007 & 2.376639 \\
\hline $\mathrm{H}$ & -2.702456 & -5.786310 & -1.167947 \\
\hline C & 3.666752 & -2.251072 & -0.708047 \\
\hline C & 3.241647 & -3.582542 & -1.017031 \\
\hline C & 4.162217 & -4.491982 & -1.605277 \\
\hline C & 5.444724 & -4.100831 & -1.911011 \\
\hline C & 5.856790 & -2.774591 & -1.641240 \\
\hline C & 4.994355 & -1.875856 & -1.052603 \\
\hline $\mathrm{H}$ & 3.825593 & -5.503299 & -1.821182 \\
\hline $\mathrm{H}$ & 6.137800 & -4.801570 & -2.368397 \\
\hline $\mathrm{H}$ & 6.862822 & -2.459645 & -1.904881 \\
\hline $\mathrm{H}$ & 5.323649 & -0.861306 & -0.861440 \\
\hline C & 4.205108 & 0.124836 & 1.360277 \\
\hline C & 4.696157 & 1.430403 & 1.680567 \\
\hline C & 5.734214 & 1.572479 & 2.640790 \\
\hline C & 6.257708 & 0.475152 & 3.283696 \\
\hline C & 5.753490 & -0.814211 & 2.993026 \\
\hline C & 4.757759 & -0.985657 & 2.056416 \\
\hline $\mathrm{H}$ & 6.098781 & 2.572141 & 2.865275 \\
\hline $\mathrm{H}$ & 7.046802 & 0.595492 & 4.020911 \\
\hline $\mathrm{H}$ & 6.150885 & -1.678497 & 3.518365 \\
\hline $\mathrm{H}$ & 4.375856 & -1.979782 & 1.855747 \\
\hline $\mathrm{O}$ & -0.757586 & 0.055851 & -1.650007 \\
\hline 0 & -0.540142 & 1.433849 & 0.570156 \\
\hline $\mathrm{H}$ & -1.482307 & 1.259422 & 1.202727 \\
\hline $\mathrm{H}$ & 4.518164 & 4.253295 & -1.169945 \\
\hline $\mathrm{H}$ & 1.382707 & 7.024227 & -2.152843 \\
\hline $\mathrm{H}$ & 0.469456 & 3.422286 & 0.013886 \\
\hline $\mathrm{H}$ & -0.501626 & -4.808613 & -1.705783 \\
\hline $\mathrm{H}$ & -3.937689 & -5.046722 & 0.865997 \\
\hline $\mathrm{H}$ & -0.664499 & -2.461054 & 1.890818 \\
\hline C & -3.246679 & 0.142413 & 1.788455 \\
\hline $\mathrm{O}$ & -2.512506 & 1.182399 & 1.948470 \\
\hline $\mathrm{H}$ & -2.828116 & -0.752391 & 1.311193 \\
\hline C & -4.172453 & -0.225750 & 2.941791 \\
\hline 0 & -4.389874 & -1.372869 & 3.271882 \\
\hline $\mathrm{O}$ & -4.690757 & 0.854109 & 3.542494 \\
\hline C & -5.534308 & 0.581935 & 4.677019 \\
\hline $\mathrm{H}$ & -5.864749 & 1.557369 & 5.033414 \\
\hline
\end{tabular}




$\begin{array}{llll}\mathrm{H} & -6.388496 & -0.032498 & 4.380428 \\ \mathrm{C} & -4.001461 & 0.723304 & -0.685774 \\ \mathrm{C} & -4.742066 & 0.367436 & 0.450490 \\ \mathrm{H} & -2.547598 & -0.068967 & -1.909476 \\ \mathrm{~N} & -3.503214 & -0.219325 & -1.544850 \\ \mathrm{C} & -4.094133 & -1.450158 & -1.850509 \\ \mathrm{O} & -5.126198 & -1.889690 & -1.390683 \\ \mathrm{O} & -3.350249 & -2.042212 & -2.798620 \\ \mathrm{C} & -3.867778 & -3.290981 & -3.285785 \\ \mathrm{H} & -3.978773 & -4.001424 & -2.465316 \\ \mathrm{H} & -3.129061 & -3.643910 & -4.005217 \\ \mathrm{H} & -4.835054 & -3.136607 & -3.771718 \\ \mathrm{H} & -5.343844 & 1.140730 & 0.913805 \\ \mathrm{H} & -5.159136 & -0.632213 & 0.478163 \\ \mathrm{C} & -3.619611 & 2.113795 & -0.952396 \\ \mathrm{C} & -3.197617 & 2.501598 & -2.242542 \\ \mathrm{C} & -3.723443 & 3.099820 & 0.051797 \\ \mathrm{C} & -2.908007 & 3.830678 & -2.522224 \\ \mathrm{H} & -3.128149 & 1.763234 & -3.033198 \\ \mathrm{C} & -3.421884 & 4.428212 & -0.234526 \\ \mathrm{H} & -4.007709 & 2.826336 & 1.059282 \\ \mathrm{C} & -3.024255 & 4.798959 & -1.520156 \\ \mathrm{H} & -2.597043 & 4.114490 & -3.523068 \\ \mathrm{H} & -3.500028 & 5.175369 & 0.549686 \\ \mathrm{H} & -2.810214 & 5.840467 & -1.744615 \\ \mathrm{H} & -4.969424 & 0.059362 & 5.452901\end{array}$

Catalyst (R)-1 TS Conformation 72

B3LYP/6-31G(d) Energy $=-2809.69084$

B3LYP-D3(BJ)/def2-TZVPP-IEF-PCM(DCM) Energy $=-2810.986125$

B3LYP-D3(BJ)/def2-TZVPP-IEF-PCM(DCM)//B3LYP/6-31G(d) Free Energy (Quasiharmonic) = 2810.345215

Frequencies (Top 3 out of 270)

1. $-699.7163 \mathrm{~cm}-1$

2. $\quad 8.8368 \mathrm{~cm}-1$

3. $11.4022 \mathrm{~cm}-1$

B3LYP/6-31G(d) Molecular Geometry in Cartesian Coordinates

$\begin{array}{llll}\text { C } & 3.812142 & 0.107962 & 0.056899\end{array}$ 


\begin{tabular}{|c|c|c|c|}
\hline C & 3.049389 & 1.208786 & -0.304785 \\
\hline C & 3.538770 & 2.547873 & -0.272900 \\
\hline C & 4.825156 & 2.739181 & 0.192766 \\
\hline $\mathrm{H}$ & 5.238678 & 3.744185 & 0.206739 \\
\hline C & 2.078096 & -3.835535 & -0.221218 \\
\hline C & 3.236925 & -1.263354 & -0.084210 \\
\hline C & 2.029090 & -1.559545 & 0.528190 \\
\hline C & 1.426223 & -2.851028 & 0.495210 \\
\hline $\mathrm{H}$ & 1.659055 & -4.838038 & -0.247645 \\
\hline O & 1.748567 & 1.002577 & -0.747962 \\
\hline$P$ & 0.592536 & 0.591518 & 0.337732 \\
\hline O & 1.372857 & -0.550235 & 1.222053 \\
\hline C & 1.276666 & 5.969482 & -1.572772 \\
\hline C & 1.298461 & 4.811078 & -2.352451 \\
\hline C & 2.009398 & 3.689225 & -1.929605 \\
\hline C & 2.719329 & 3.706914 & -0.717168 \\
\hline C & 2.686171 & 4.876499 & 0.059275 \\
\hline C & 1.971975 & 5.997111 & -0.363327 \\
\hline $\mathrm{H}$ & 0.761769 & 4.779952 & -3.297251 \\
\hline $\mathrm{H}$ & 1.952464 & 6.888502 & 0.258291 \\
\hline C & -2.252002 & -3.824258 & 2.508863 \\
\hline C & -1.263431 & -3.095881 & 3.174686 \\
\hline C & -0.077295 & -2.758540 & 2.524005 \\
\hline C & 0.145640 & -3.146627 & 1.191675 \\
\hline C & -0.859061 & -3.872115 & 0.529993 \\
\hline C & -2.045015 & -4.209492 & 1.183444 \\
\hline $\mathrm{H}$ & -1.411751 & -2.793807 & 4.208250 \\
\hline $\mathrm{H}$ & -2.810379 & -4.771148 & 0.653450 \\
\hline C & 3.866757 & -2.278782 & -0.883137 \\
\hline C & 3.277019 & -3.583896 & -0.932289 \\
\hline C & 3.895721 & -4.600629 & -1.709319 \\
\hline C & 5.032677 & -4.341514 & -2.438440 \\
\hline C & 5.594771 & -3.043343 & -2.423877 \\
\hline C & 5.029060 & -2.040592 & -1.667432 \\
\hline $\mathrm{H}$ & 3.441234 & -5.588484 & -1.725645 \\
\hline $\mathrm{H}$ & 5.492667 & -5.124970 & -3.034466 \\
\hline $\mathrm{H}$ & 6.479033 & -2.833048 & -3.019489 \\
\hline $\mathrm{H}$ & 5.466694 & -1.049218 & -1.675358 \\
\hline C & 5.121028 & 0.331505 & 0.607004 \\
\hline C & 5.628969 & 1.670143 & 0.658528 \\
\hline C & 6.926351 & 1.904447 & 1.189828 \\
\hline C & 7.687113 & 0.870285 & 1.683120 \\
\hline C & 7.172556 & -0.447483 & 1.669941 \\
\hline C & 5.925833 & -0.710091 & 1.145946 \\
\hline
\end{tabular}




\begin{tabular}{|c|c|c|c|}
\hline $\mathrm{H}$ & 7.300831 & 2.925250 & 1.209955 \\
\hline $\mathrm{H}$ & 8.674640 & 1.062804 & 2.093469 \\
\hline $\mathrm{H}$ & 7.764252 & -1.260517 & 2.082042 \\
\hline $\mathrm{H}$ & 5.542733 & -1.723901 & 1.153067 \\
\hline 0 & -0.578528 & 0.065630 & -0.427862 \\
\hline $\mathrm{O}$ & 0.366950 & 1.728895 & 1.336422 \\
\hline $\mathrm{H}$ & -0.755969 & 2.197557 & 1.484759 \\
\hline $\mathrm{H}$ & 3.206169 & 4.895245 & 1.012908 \\
\hline $\mathrm{H}$ & 0.718479 & 6.841583 & -1.903327 \\
\hline $\mathrm{H}$ & 2.021188 & 2.795559 & -2.544052 \\
\hline $\mathrm{H}$ & -0.719568 & -4.144570 & -0.511994 \\
\hline $\mathrm{H}$ & -3.174924 & -4.088214 & 3.018794 \\
\hline $\mathrm{H}$ & 0.685482 & -2.196804 & 3.052040 \\
\hline C & -2.644257 & 2.213712 & 0.714680 \\
\hline 0 & -1.852964 & 2.627786 & 1.631288 \\
\hline $\mathrm{H}$ & -2.229988 & 1.842625 & -0.226020 \\
\hline C & -3.984250 & 2.922086 & 0.631600 \\
\hline 0 & -4.594213 & 3.378326 & 1.569050 \\
\hline 0 & -4.385463 & 2.978707 & -0.654562 \\
\hline C & -5.630466 & 3.668553 & -0.875720 \\
\hline $\mathrm{H}$ & -5.778324 & 3.663332 & -1.955533 \\
\hline $\mathrm{H}$ & -6.447968 & 3.147930 & -0.371644 \\
\hline C & -3.938306 & -0.317101 & 0.321599 \\
\hline C & -3.308762 & 0.366193 & 1.366255 \\
\hline $\mathrm{H}$ & -2.140119 & -0.705915 & -0.583552 \\
\hline $\mathrm{N}$ & -3.150234 & -0.942730 & -0.605345 \\
\hline C & -3.429710 & -2.036138 & -1.435449 \\
\hline $\mathrm{O}$ & -2.649205 & -2.424870 & -2.274444 \\
\hline $\mathrm{O}$ & -4.613237 & -2.612170 & -1.156461 \\
\hline C & -4.949257 & -3.730310 & -1.995318 \\
\hline $\mathrm{H}$ & -5.936308 & -4.051331 & -1.662390 \\
\hline $\mathrm{H}$ & -4.218993 & -4.533599 & -1.870696 \\
\hline $\mathrm{H}$ & -4.973957 & -3.429939 & -3.045729 \\
\hline $\mathrm{H}$ & -3.928327 & 0.764963 & 2.160963 \\
\hline $\mathrm{H}$ & -2.311506 & 0.044733 & 1.642282 \\
\hline C & -5.399083 & -0.210062 & 0.122418 \\
\hline C & -6.266484 & -0.260764 & 1.225414 \\
\hline C & -5.935542 & 0.018917 & -1.157892 \\
\hline C & -7.640319 & -0.102623 & 1.051896 \\
\hline $\mathrm{H}$ & -5.864386 & -0.451881 & 2.215224 \\
\hline C & -7.305585 & 0.191013 & -1.325839 \\
\hline $\mathrm{H}$ & -5.269446 & 0.092891 & -2.011529 \\
\hline C & -8.162516 & 0.125360 & -0.222284 \\
\hline $\mathrm{H}$ & -8.301250 & -0.157005 & 1.911936 \\
\hline
\end{tabular}




$\begin{array}{llll}\mathrm{H} & -7.707621 & 0.378778 & -2.317542 \\ \mathrm{H} & -9.233035 & 0.253750 & -0.356746 \\ \mathrm{H} & -5.565737 & 4.692190 & -0.499087\end{array}$

Catalyst (R)-1 TS Conformation 73

B3LYP/6-31G(d) Energy $=-2809.694147$

B3LYP-D3(BJ)/def2-TZVPP-IEF-PCM(DCM) Energy = -2810.986565

B3LYP-D3(BJ)/def2-TZVPP-IEF-PCM(DCM)//B3LYP/6-31G(d) Free Energy (Quasiharmonic) = 2810.345159

Frequencies (Top 3 out of 270)

1. $-695.9549 \mathrm{~cm}-1$

2. $\quad 7.6778 \mathrm{~cm}-1$

3. $\quad 14.1715 \mathrm{~cm}-1$

B3LYP/6-31G(d) Molecular Geometry in Cartesian Coordinates

$\begin{array}{lrrr}\text { C } & 2.817880 & -1.228140 & -0.179130 \\ \text { C } & 1.556040 & -1.719410 & 0.117540 \\ \text { C } & 1.175671 & -3.074840 & -0.119160 \\ \text { C } & 2.074621 & -3.876800 & -0.795120 \\ \text { H } & 1.810731 & -4.911870 & -0.996250 \\ \text { C } & 4.180110 & 2.640161 & 1.140230 \\ \text { C } & 3.252460 & 0.097191 & 0.353780 \\ \text { C } & 2.521870 & 1.249500 & 0.100320 \\ \text { C } & 2.988950 & 2.553460 & 0.446950 \\ \text { H } & 4.553899 & 3.621271 & 1.420740 \\ \text { O } & 0.654770 & -0.884010 & 0.763540 \\ \text { P } & 0.021770 & 0.374210 & -0.082790 \\ \text { O } & 1.342950 & 1.162210 & -0.627910 \\ \text { C } & -2.421769 & -4.878530 & 1.414820 \\ \text { C } & -2.503429 & -3.700691 & 0.667440 \\ \text { C } & -1.347069 & -3.096650 & 0.169810 \\ \text { C } & -0.085659 & -3.663120 & 0.412540 \\ \text { C } & -0.018149 & -4.848500 & 1.163200 \\ \text { C } & -1.174029 & -5.451750 & 1.659530 \\ \text { H } & -3.475269 & -3.255751 & 0.467220 \\ \text { H } & -1.096189 & -6.364630 & 2.244390 \\ \text { C } & 1.100689 & 6.284150 & -0.565110 \\ \text { C } & 2.426119 & 6.035960 & -0.924060 \\ \text { C } & 3.014659 & 4.810741 & -0.612460\end{array}$




\begin{tabular}{|c|c|c|c|}
\hline C & 2.289589 & 3.809810 & 0.055870 \\
\hline C & 0.952979 & 4.063490 & 0.399230 \\
\hline C & 0.370849 & 5.294280 & 0.095900 \\
\hline $\mathrm{H}$ & 3.004049 & 6.794670 & -1.445690 \\
\hline $\mathrm{H}$ & -0.659661 & 5.478570 & 0.386060 \\
\hline C & 4.435170 & 0.198471 & 1.170030 \\
\hline C & 4.905150 & 1.495841 & 1.549520 \\
\hline C & 6.076440 & 1.614041 & 2.345670 \\
\hline C & 6.751730 & 0.497661 & 2.780060 \\
\hline C & 6.270150 & -0.787809 & 2.439080 \\
\hline C & 5.146390 & -0.934039 & 1.655530 \\
\hline $\mathrm{H}$ & 6.420310 & 2.609731 & 2.615790 \\
\hline $\mathrm{H}$ & 7.642530 & 0.598551 & 3.394000 \\
\hline $\mathrm{H}$ & 6.787530 & -1.670749 & 2.804690 \\
\hline $\mathrm{H}$ & 4.787161 & -1.927919 & 1.417260 \\
\hline C & 3.699531 & -2.041729 & -0.973160 \\
\hline C & 3.311951 & -3.385639 & -1.279130 \\
\hline C & 4.173531 & -4.200309 & -2.062520 \\
\hline C & 5.361981 & -3.708349 & -2.549920 \\
\hline C & 5.733801 & -2.371399 & -2.274710 \\
\hline C & 4.927740 & -1.561669 & -1.504860 \\
\hline $\mathrm{H}$ & 3.866951 & -5.221139 & -2.278590 \\
\hline $\mathrm{H}$ & 6.009981 & -4.337949 & -3.153520 \\
\hline $\mathrm{H}$ & 6.662031 & -1.976959 & -2.679250 \\
\hline $\mathrm{H}$ & 5.221560 & -0.536429 & -1.311530 \\
\hline 0 & -0.779560 & -0.051110 & -1.268490 \\
\hline 0 & -0.637630 & 1.227060 & 1.013710 \\
\hline $\mathrm{H}$ & -1.783840 & 1.240590 & 1.296980 \\
\hline $\mathrm{H}$ & 0.953241 & -5.286990 & 1.374960 \\
\hline $\mathrm{H}$ & -3.324229 & -5.342731 & 1.803760 \\
\hline $\mathrm{H}$ & -1.411719 & -2.195670 & -0.429350 \\
\hline $\mathrm{H}$ & 0.376160 & 3.305740 & 0.917940 \\
\hline $\mathrm{H}$ & 0.641819 & 7.242210 & -0.796910 \\
\hline $\mathrm{H}$ & 4.045299 & 4.617601 & -0.898030 \\
\hline C & -3.698930 & 0.331389 & 1.572030 \\
\hline 0 & -2.931090 & 1.343369 & 1.732090 \\
\hline $\mathrm{H}$ & -3.271540 & -0.629881 & 1.263450 \\
\hline C & -4.856420 & 0.230159 & 2.557830 \\
\hline $\mathrm{O}$ & -5.372510 & 1.170479 & 3.113730 \\
\hline 0 & -5.219170 & -1.057981 & 2.711900 \\
\hline C & -6.309770 & -1.285951 & 3.623660 \\
\hline $\mathrm{H}$ & -7.205870 & -0.759721 & 3.284340 \\
\hline $\mathrm{H}$ & -6.470769 & -2.363751 & 3.621990 \\
\hline C & -4.051750 & 0.735549 & -1.047470 \\
\hline
\end{tabular}




$\begin{array}{llll}\mathrm{C} & -4.975900 & 0.489339 & -0.025420 \\ \mathrm{H} & -2.464760 & -0.158561 & -1.978560 \\ \mathrm{~N} & -3.463300 & -0.279201 & -1.756830 \\ \mathrm{C} & -3.970600 & -1.564341 & -1.961830 \\ \mathrm{O} & -5.020809 & -2.007381 & -1.543260 \\ \mathrm{O} & -3.100569 & -2.232761 & -2.736060 \\ \mathrm{C} & -3.451459 & -3.597951 & -3.027130 \\ \mathrm{H} & -2.686969 & -3.944231 & -3.722030 \\ \mathrm{H} & -4.442989 & -3.647761 & -3.482710 \\ \mathrm{H} & -3.433319 & -4.194021 & -2.111920 \\ \mathrm{H} & -5.599880 & 1.317239 & 0.290020 \\ \mathrm{H} & -5.434010 & -0.490431 & 0.012480 \\ \mathrm{C} & -3.563880 & 2.087349 & -1.336100 \\ \mathrm{C} & -2.893510 & 2.365739 & -2.547490 \\ \mathrm{C} & -3.788460 & 3.145149 & -0.428580 \\ \mathrm{C} & -2.468121 & 3.654139 & -2.841640 \\ \mathrm{H} & -2.731900 & 1.575639 & -3.271980 \\ \mathrm{C} & -3.355781 & 4.433049 & -0.731000 \\ \mathrm{H} & -4.270210 & 2.960829 & 0.522550 \\ \mathrm{C} & -2.697281 & 4.692169 & -1.933820 \\ \mathrm{H} & -1.958681 & 3.851460 & -3.779870 \\ \mathrm{H} & -3.532381 & 5.235119 & -0.020360 \\ \mathrm{H} & -2.361781 & 5.698840 & -2.165810 \\ \mathrm{H} & -6.046310 & -0.935711 & 4.624740\end{array}$

Catalyst (R)-1 TS Conformation 74

B3LYP/6-31G(d) Energy $=-2809.687449$

B3LYP-D3(BJ)/def2-TZVPP-IEF-PCM(DCM) Energy = -2810.986793

B3LYP-D3(BJ)/def2-TZVPP-IEF-PCM(DCM)//B3LYP/6-31G(d) Free Energy (Quasiharmonic) = 2810.345148

Frequencies (Top 3 out of 270)

1. $-622.3299 \mathrm{~cm}-1$

2. $\quad 8.9303 \mathrm{~cm}-1$

3. $\quad 9.4470 \mathrm{~cm}-1$

B3LYP/6-31G(d) Molecular Geometry in Cartesian Coordinates

$\begin{array}{llll}\text { C } & 3.405180 & -1.159969 & -0.083178 \\ \text { C } & 2.134372 & -1.690622 & 0.072619 \\ \text { C } & 1.776475 & -3.000325 & -0.363809\end{array}$




\begin{tabular}{|c|c|c|c|}
\hline C & 2.744946 & -3.739654 & -1.014203 \\
\hline $\mathrm{H}$ & 2.510924 & -4.750493 & -1.337982 \\
\hline C & 4.274018 & 2.831701 & 1.299845 \\
\hline C & 3.703384 & 0.198374 & 0.458971 \\
\hline C & 2.927493 & 1.277327 & 0.061207 \\
\hline C & 3.223532 & 2.623133 & 0.428499 \\
\hline $\mathrm{H}$ & 4.533840 & 3.848765 & 1.582126 \\
\hline 0 & 1.169480 & -0.924236 & 0.707861 \\
\hline$P$ & 0.495954 & 0.348827 & -0.094486 \\
\hline O & 1.830076 & 1.051747 & -0.758837 \\
\hline C & -2.075533 & -4.800895 & 0.287184 \\
\hline C & -1.431670 & -4.134750 & 1.333185 \\
\hline C & -0.195723 & -3.523763 & 1.124630 \\
\hline C & 0.424165 & -3.574708 & -0.135629 \\
\hline C & -0.238142 & -4.239777 & -1.179980 \\
\hline C & -1.476250 & -4.846720 & -0.972100 \\
\hline $\mathrm{H}$ & -1.891095 & -4.091477 & 2.317015 \\
\hline $\mathrm{H}$ & -1.975878 & -5.347242 & -1.797102 \\
\hline C & 1.220700 & 6.074586 & -1.178271 \\
\hline C & 1.688444 & 5.073497 & -2.033871 \\
\hline C & 2.303774 & 3.934884 & -1.514872 \\
\hline C & 2.475456 & 3.782110 & -0.128516 \\
\hline C & 1.996669 & 4.791839 & 0.720514 \\
\hline C & 1.372513 & 5.926807 & 0.201063 \\
\hline $\mathrm{H}$ & 1.580245 & 5.181825 & -3.110131 \\
\hline $\mathrm{H}$ & 1.003570 & 6.694420 & 0.876407 \\
\hline C & 4.754405 & 0.422378 & 1.413282 \\
\hline C & 5.035502 & 1.762871 & 1.833096 \\
\hline C & 6.073228 & 1.996601 & 2.775507 \\
\hline C & 6.791816 & 0.952907 & 3.310529 \\
\hline C & 6.494053 & -0.375067 & 2.924025 \\
\hline C & 5.505062 & -0.633506 & 2.000494 \\
\hline $\mathrm{H}$ & 6.280664 & 3.021591 & 3.074046 \\
\hline $\mathrm{H}$ & 7.578578 & 1.143202 & 4.035426 \\
\hline $\mathrm{H}$ & 7.047672 & -1.200427 & 3.363622 \\
\hline $\mathrm{H}$ & 5.282246 & -1.657206 & 1.722672 \\
\hline C & 4.382683 & -1.913916 & -0.819344 \\
\hline C & 4.039090 & -3.227509 & -1.276499 \\
\hline C & 4.998227 & -3.989576 & -1.997176 \\
\hline C & 6.239652 & -3.473523 & -2.287364 \\
\hline C & 6.568998 & -2.162500 & -1.870172 \\
\hline C & 5.667310 & -1.404350 & -1.155899 \\
\hline $\mathrm{H}$ & 4.723868 & -4.989122 & -2.326398 \\
\hline $\mathrm{H}$ & 6.962356 & -4.062975 & -2.844960 \\
\hline
\end{tabular}




\begin{tabular}{|c|c|c|c|}
\hline $\mathrm{H}$ & 7.541457 & -1.746625 & -2.119898 \\
\hline $\mathrm{H}$ & 5.932834 & -0.398272 & -0.852980 \\
\hline $\mathrm{O}$ & -0.250224 & 1.177353 & 0.886978 \\
\hline $\mathrm{O}$ & -0.233603 & -0.171325 & -1.353151 \\
\hline $\mathrm{H}$ & -1.386434 & -0.320001 & -1.277501 \\
\hline $\mathrm{H}$ & 0.214674 & -4.259832 & -2.167090 \\
\hline $\mathrm{H}$ & -3.037005 & -5.280647 & 0.451810 \\
\hline $\mathrm{H}$ & 0.299481 & -3.013323 & 1.943726 \\
\hline $\mathrm{H}$ & 2.102753 & 4.674636 & 1.795330 \\
\hline $\mathrm{H}$ & 0.741092 & 6.961327 & -1.584452 \\
\hline $\mathrm{H}$ & 2.667215 & 3.162986 & -2.185651 \\
\hline C & -2.976765 & -0.785020 & 0.017735 \\
\hline 0 & -2.621025 & -0.544638 & -1.197871 \\
\hline $\mathrm{H}$ & -2.198836 & -0.956819 & 0.773289 \\
\hline C & -4.178245 & -1.709750 & 0.182708 \\
\hline 0 & -4.936866 & -2.028874 & -0.703136 \\
\hline 0 & -4.294864 & -2.112991 & 1.467361 \\
\hline C & -5.408617 & -2.979666 & 1.739961 \\
\hline $\mathrm{H}$ & -5.344915 & -3.212915 & 2.803159 \\
\hline $\mathrm{H}$ & -6.351404 & -2.475605 & 1.511985 \\
\hline C & -4.674509 & 1.202703 & 0.103322 \\
\hline C & -3.566899 & 0.828948 & 0.888226 \\
\hline $\mathrm{H}$ & -5.414755 & 1.771442 & -1.695574 \\
\hline$N$ & -4.568722 & 1.726323 & -1.139006 \\
\hline C & -3.474564 & 2.269770 & -1.870560 \\
\hline 0 & -3.606989 & 2.513453 & -3.046914 \\
\hline 0 & -2.438668 & 2.533477 & -1.094847 \\
\hline C & -1.267975 & 3.076953 & -1.752171 \\
\hline $\mathrm{H}$ & -0.572834 & 3.283765 & -0.943528 \\
\hline $\mathrm{H}$ & -1.536820 & 3.984654 & -2.295280 \\
\hline $\mathrm{H}$ & -0.855173 & 2.329754 & -2.431267 \\
\hline $\mathrm{H}$ & -3.804195 & 0.504811 & 1.896671 \\
\hline $\mathrm{H}$ & -2.621998 & 1.351350 & 0.780959 \\
\hline C & -6.058146 & 0.881456 & 0.530253 \\
\hline C & -6.447879 & 1.135489 & 1.856228 \\
\hline C & -6.998230 & 0.344210 & -0.368179 \\
\hline C & -7.753297 & 0.877090 & 2.268805 \\
\hline $\mathrm{H}$ & -5.734308 & 1.564261 & 2.552708 \\
\hline C & -8.298717 & 0.077225 & 0.053105 \\
\hline $\mathrm{H}$ & -6.695457 & 0.067361 & -1.373655 \\
\hline C & -8.681374 & 0.348864 & 1.368817 \\
\hline $\mathrm{H}$ & -8.046295 & 1.093594 & 3.291999 \\
\hline $\mathrm{H}$ & -9.009571 & -0.355667 & -0.644480 \\
\hline $\mathrm{H}$ & -9.698064 & 0.144694 & 1.692658 \\
\hline
\end{tabular}


$\begin{array}{llll}H & -5.336887 & -3.891127 & 1.141000\end{array}$

Catalyst (R)-1 TS Conformation 75

B3LYP/6-31G(d) Energy $=-2809.695519$

B3LYP-D3(BJ)/def2-TZVPP-IEF-PCM(DCM) Energy $=-2810.987565$

B3LYP-D3(BJ)/def2-TZVPP-IEF-PCM(DCM)//B3LYP/6-31G(d) Free Energy (Quasiharmonic) = 2810.345134

Frequencies (Top 3 out of 270)

1. $-594.3752 \mathrm{~cm}-1$

2. $\quad 9.7809 \mathrm{~cm}-1$

3. $15.4439 \mathrm{~cm}-1$

B3LYP/6-31G(d) Molecular Geometry in Cartesian Coordinates

$\begin{array}{llll}\text { C } & -2.906150 & -0.851755 & 0.414659 \\ \text { C } & -1.851212 & -1.577186 & -0.113631 \\ \text { C } & -1.585988 & -2.933620 & 0.230346 \\ \text { C } & -2.371937 & -3.505006 & 1.210952 \\ \text { H } & -2.204788 & -4.544119 & 1.482570 \\ \text { C } & -3.755888 & 3.152271 & -0.920010 \\ \text { C } & -3.200750 & 0.511198 & -0.113952 \\ \text { C } & -2.218196 & 1.491814 & -0.111541 \\ \text { C } & -2.479831 & 2.842628 & -0.491394 \\ \text { H } & -3.976162 & 4.174187 & -1.217258 \\ \text { O } & -0.999315 & -0.947930 & -1.022998 \\ \text { P } & 0.047360 & 0.138411 & -0.375091 \\ \text { O } & -0.956053 & 1.190339 & 0.381951 \\ \text { C } & 1.295529 & -5.457607 & -1.718368 \\ \text { C } & 0.370544 & -4.733960 & -2.475648 \\ \text { C } & -0.533201 & -3.875492 & -1.851065 \\ \text { C } & -0.543108 & -3.744770 & -0.453180 \\ \text { C } & 0.393746 & -4.471347 & 0.296563 \\ \text { C } & 1.308782 & -5.316455 & -0.330607 \\ \text { H } & 0.342868 & -4.848716 & -3.556577 \\ \text { H } & 2.033523 & -5.863222 & 0.266580 \\ \text { C } & 0.319247 & 6.108948 & -0.457749 \\ \text { C } & -0.869517 & 6.185258 & 0.269203 \\ \text { C } & -1.753278 & 5.105960 & 0.276556 \\ \text { C } & -1.461461 & 3.928999 & -0.431751 \\ \text { C } & -0.255510 & 3.854062 & -1.146028\end{array}$




\begin{tabular}{|c|c|c|c|}
\hline C & 0.619916 & 4.940995 & -1.163680 \\
\hline $\mathrm{H}$ & -1.113038 & 7.085542 & 0.827545 \\
\hline $\mathrm{H}$ & 1.539132 & 4.876210 & -1.740458 \\
\hline C & -4.492938 & 0.825556 & -0.661793 \\
\hline C & -4.771654 & 2.175205 & -1.047319 \\
\hline C & -6.048908 & 2.504517 & -1.576695 \\
\hline C & -7.013342 & 1.539177 & -1.747205 \\
\hline C & -6.730176 & 0.196889 & -1.400898 \\
\hline C & -5.506453 & -0.150659 & -0.872419 \\
\hline $\mathrm{H}$ & -6.243131 & 3.537243 & -1.856689 \\
\hline $\mathrm{H}$ & -7.984756 & 1.799988 & -2.158193 \\
\hline $\mathrm{H}$ & -7.483701 & -0.569933 & -1.559285 \\
\hline $\mathrm{H}$ & -5.304427 & -1.185754 & -0.623408 \\
\hline C & -3.675014 & -1.436205 & 1.480431 \\
\hline C & -3.393854 & -2.783697 & 1.876159 \\
\hline C & -4.144630 & -3.373877 & 2.928577 \\
\hline C & -5.115560 & -2.660125 & 3.591649 \\
\hline C & -5.370613 & -1.317078 & 3.227946 \\
\hline C & -4.672341 & -0.722132 & 2.200138 \\
\hline $\mathrm{H}$ & -3.925952 & -4.401977 & 3.207459 \\
\hline $\mathrm{H}$ & -5.678408 & -3.119329 & 4.399706 \\
\hline $\mathrm{H}$ & -6.121673 & -0.746705 & 3.767830 \\
\hline $\mathrm{H}$ & -4.872819 & 0.310996 & 1.941531 \\
\hline $\mathrm{O}$ & 0.838198 & 0.776151 & -1.472557 \\
\hline $\mathrm{O}$ & 0.793462 & -0.502149 & 0.809319 \\
\hline $\mathrm{H}$ & 1.760133 & -1.099032 & 0.682441 \\
\hline $\mathrm{H}$ & 0.412474 & -4.355876 & 1.376338 \\
\hline $\mathrm{H}$ & 2.000802 & -6.124483 & -2.207239 \\
\hline $\mathrm{H}$ & -1.252646 & -3.319548 & -2.444521 \\
\hline $\mathrm{H}$ & -0.008673 & 2.952280 & -1.696437 \\
\hline $\mathrm{H}$ & 1.003599 & 6.953363 & -0.478479 \\
\hline $\mathrm{H}$ & -2.678944 & 5.167889 & 0.842553 \\
\hline C & 3.898141 & -1.789135 & 1.075228 \\
\hline $\mathrm{O}$ & 2.751832 & -1.903281 & 0.495046 \\
\hline $\mathrm{H}$ & 4.503533 & -2.702931 & 1.131923 \\
\hline C & 4.063606 & -0.998605 & 2.374944 \\
\hline $\mathrm{O}$ & 5.039264 & -1.098698 & 3.091345 \\
\hline $\mathrm{O}$ & 3.019148 & -0.199061 & 2.608784 \\
\hline C & 3.082516 & 0.595513 & 3.805204 \\
\hline $\mathrm{H}$ & 3.200549 & -0.046753 & 4.681449 \\
\hline $\mathrm{H}$ & 3.923807 & 1.291490 & 3.751288 \\
\hline C & 4.448228 & 0.165984 & -0.538069 \\
\hline C & 5.221799 & -0.894987 & -0.018564 \\
\hline $\mathrm{H}$ & 2.714515 & 0.524355 & -1.631572 \\
\hline
\end{tabular}




$\begin{array}{llll}\mathrm{N} & 3.542694 & -0.078203 & -1.513737 \\ \mathrm{C} & 3.548276 & -1.179872 & -2.401669 \\ \mathrm{O} & 4.387338 & -2.049641 & -2.469767 \\ \mathrm{O} & 2.498895 & -1.050336 & -3.217517 \\ \mathrm{C} & 2.368439 & -2.079014 & -4.213746 \\ \mathrm{H} & 2.260002 & -3.053394 & -3.734267 \\ \mathrm{H} & 3.242282 & -2.083869 & -4.870602 \\ \mathrm{H} & 1.467781 & -1.819824 & -4.769391 \\ \mathrm{H} & 6.004304 & -0.647948 & 0.688799 \\ \mathrm{H} & 5.441093 & -1.711459 & -0.692224 \\ \mathrm{C} & 4.457367 & 1.499483 & 0.098514 \\ \mathrm{C} & 5.645749 & 1.954564 & 0.705251 \\ \mathrm{C} & 3.325103 & 2.336894 & 0.122273 \\ \mathrm{C} & 5.698329 & 3.200030 & 1.323924 \\ \mathrm{H} & 6.542040 & 1.345792 & 0.667410 \\ \mathrm{C} & 3.380271 & 3.575572 & 0.756789 \\ \mathrm{H} & 2.387351 & 2.019402 & -0.321510 \\ \mathrm{C} & 4.562957 & 4.011851 & 1.357679 \\ \mathrm{H} & 6.627762 & 3.536335 & 1.774301 \\ \mathrm{H} & 2.491122 & 4.197523 & 0.777888 \\ \mathrm{H} & 4.600636 & 4.981861 & 1.846013 \\ \mathrm{H} & 2.136179 & 1.133825 & 3.842128\end{array}$

Catalyst (R)-1 TS Conformation 76

B3LYP/6-31G(d) Energy = -2809.697926

B3LYP-D3(BJ)/def2-TZVPP-IEF-PCM(DCM) Energy = -2810.986859

B3LYP-D3(BJ)/def2-TZVPP-IEF-PCM(DCM)//B3LYP/6-31G(d) Free Energy (Quasiharmonic) = 2810.345109

Frequencies (Top 3 out of 270)

1. $-430.3518 \mathrm{~cm}-1$

2. $\quad 6.6200 \mathrm{~cm}-1$

3. $\quad 9.4661 \mathrm{~cm}-1$

B3LYP/6-31G(d) Molecular Geometry in Cartesian Coordinates

$\begin{array}{llll}\text { C } & 3.602161 & -0.722766 & -0.217946 \\ \text { C } & 2.510078 & -1.524311 & 0.069111 \\ \text { C } & 2.445479 & -2.914617 & -0.236913 \\ \text { C } & 3.526241 & -3.461450 & -0.900750 \\ \text { H } & 3.524635 & -4.524203 & -1.127989\end{array}$




\begin{tabular}{|c|c|c|c|}
\hline C & 3.694965 & 3.467895 & 0.779672 \\
\hline C & 3.611744 & 0.704819 & 0.219449 \\
\hline C & 2.581668 & 1.557676 & -0.152582 \\
\hline C & 2.615213 & 2.965049 & 0.080458 \\
\hline $\mathrm{H}$ & 3.743855 & 4.535998 & 0.974494 \\
\hline 0 & 1.413220 & -0.942439 & 0.703565 \\
\hline$P$ & 0.446625 & 0.021541 & -0.190447 \\
\hline 0 & 1.509872 & 1.049562 & -0.880062 \\
\hline C & -0.856318 & -5.465059 & 0.811502 \\
\hline C & -0.338179 & -4.573292 & 1.752625 \\
\hline C & 0.716469 & -3.726418 & 1.416735 \\
\hline C & 1.279007 & -3.760708 & 0.129880 \\
\hline C & 0.746886 & -4.659653 & -0.808613 \\
\hline C & -0.310737 & -5.503484 & -0.472031 \\
\hline $\mathrm{H}$ & -0.755931 & -4.537454 & 2.755563 \\
\hline $\mathrm{H}$ & -0.714880 & -6.183419 & -1.217278 \\
\hline C & -0.306743 & 5.772588 & -1.370345 \\
\hline C & -0.714385 & 4.682546 & -0.598573 \\
\hline C & 0.215605 & 3.750493 & -0.138058 \\
\hline C & 1.578136 & 3.899862 & -0.441222 \\
\hline C & 1.978558 & 5.001085 & -1.215128 \\
\hline C & 1.045145 & 5.928692 & -1.678006 \\
\hline $\mathrm{H}$ & -1.764675 & 4.558111 & -0.345740 \\
\hline $\mathrm{H}$ & 1.375421 & 6.769992 & -2.281871 \\
\hline C & 4.674444 & 1.228802 & 1.034766 \\
\hline C & 4.714346 & 2.634892 & 1.301108 \\
\hline C & 5.763839 & 3.166353 & 2.098767 \\
\hline C & 6.726692 & 2.345999 & 2.638562 \\
\hline C & 6.671336 & 0.951556 & 2.405762 \\
\hline C & 5.675271 & 0.408006 & 1.624697 \\
\hline $\mathrm{H}$ & 5.782077 & 4.237791 & 2.283889 \\
\hline $\mathrm{H}$ & 7.521024 & 2.762129 & 3.252119 \\
\hline $\mathrm{H}$ & 7.418638 & 0.301331 & 2.852521 \\
\hline $\mathrm{H}$ & 5.641715 & -0.663492 & 1.465235 \\
\hline C & 4.684350 & -1.290142 & -0.977720 \\
\hline C & 4.639225 & -2.684246 & -1.305106 \\
\hline C & 5.706130 & -3.262883 & -2.044901 \\
\hline C & 6.763325 & -2.497843 & -2.478890 \\
\hline C & 6.790252 & -1.112699 & -2.193479 \\
\hline C & 5.780969 & -0.525403 & -1.462426 \\
\hline $\mathrm{H}$ & 5.661272 & -4.325153 & -2.273176 \\
\hline $\mathrm{H}$ & 7.569488 & -2.949696 & -3.050294 \\
\hline $\mathrm{H}$ & 7.612724 & -0.503736 & -2.558883 \\
\hline $\mathrm{H}$ & 5.813185 & 0.539005 & -1.262633 \\
\hline
\end{tabular}




\begin{tabular}{|c|c|c|c|}
\hline 0 & -0.546978 & 0.670942 & 0.719150 \\
\hline 0 & -0.101199 & -0.754635 & -1.410919 \\
\hline $\mathrm{H}$ & -1.197380 & -0.993629 & -1.352334 \\
\hline $\mathrm{H}$ & 1.152421 & -4.676656 & -1.816283 \\
\hline $\mathrm{H}$ & -1.683148 & -6.119453 & 1.074352 \\
\hline $\mathrm{H}$ & 1.112760 & -3.038538 & 2.155938 \\
\hline $\mathrm{H}$ & 3.029100 & 5.118491 & -1.467431 \\
\hline $\mathrm{H}$ & -1.036212 & 6.494533 & -1.728384 \\
\hline $\mathrm{H}$ & -0.112425 & 2.912151 & 0.467021 \\
\hline C & -3.154519 & -0.306056 & -1.915491 \\
\hline 0 & -2.488419 & -1.199117 & -1.295942 \\
\hline $\mathrm{H}$ & -2.652388 & 0.341565 & -2.647594 \\
\hline C & -4.584503 & -0.662847 & -2.295773 \\
\hline 0 & -5.191603 & -1.621838 & -1.880798 \\
\hline 0 & -5.079177 & 0.237398 & -3.173497 \\
\hline C & -6.437120 & 0.006377 & -3.588117 \\
\hline $\mathrm{H}$ & -7.110723 & 0.058171 & -2.728599 \\
\hline $\mathrm{H}$ & -6.663144 & 0.797790 & -4.303101 \\
\hline C & -4.077464 & 0.744070 & 0.431006 \\
\hline C & -3.500858 & 1.304953 & -0.719820 \\
\hline $\mathrm{H}$ & -2.226560 & 0.164370 & 1.065611 \\
\hline$N$ & -3.237289 & 0.119885 & 1.292110 \\
\hline C & -3.520368 & -0.364703 & 2.581092 \\
\hline 0 & -4.578137 & -0.306548 & 3.164281 \\
\hline 0 & -2.386816 & -0.890458 & 3.073148 \\
\hline C & -2.483303 & -1.395489 & 4.414133 \\
\hline $\mathrm{H}$ & -3.221373 & -2.199981 & 4.467425 \\
\hline $\mathrm{H}$ & -2.769954 & -0.597605 & 5.103965 \\
\hline $\mathrm{H}$ & -1.487165 & -1.768379 & 4.650801 \\
\hline $\mathrm{H}$ & -4.138975 & 1.911299 & -1.352334 \\
\hline $\mathrm{H}$ & -2.456072 & 1.595659 & -0.664127 \\
\hline C & -5.549959 & 0.715447 & 0.580266 \\
\hline C & -6.272663 & 1.902250 & 0.373276 \\
\hline C & -6.248006 & -0.478395 & 0.828011 \\
\hline C & -7.664782 & 1.902603 & 0.439424 \\
\hline $\mathrm{H}$ & -5.738149 & 2.829520 & 0.189376 \\
\hline C & -7.638516 & -0.477407 & 0.869559 \\
\hline $\mathrm{H}$ & -5.703045 & -1.406427 & 0.948376 \\
\hline C & -8.349830 & 0.711264 & 0.684415 \\
\hline $\mathrm{H}$ & -8.211354 & 2.830901 & 0.299605 \\
\hline $\mathrm{H}$ & -8.168817 & -1.408428 & 1.046647 \\
\hline $\mathrm{H}$ & -9.435595 & 0.707587 & 0.729570 \\
\hline $\mathrm{H}$ & -6.530520 & -0.975843 & -4.058258 \\
\hline
\end{tabular}


Catalyst (R)-1 TS Conformation 77

B3LYP/6-31G(d) Energy $=-2809.692536$

B3LYP-D3(BJ)/def2-TZVPP-IEF-PCM(DCM) Energy = -2810.987582

B3LYP-D3(BJ)/def2-TZVPP-IEF-PCM(DCM)//B3LYP/6-31G(d) Free Energy (Quasiharmonic) = 2810.345107

Frequencies (Top 3 out of 270)

1. $-420.9306 \mathrm{~cm}-1$

2. $\quad 11.8026 \mathrm{~cm}-1$

3. $16.7329 \mathrm{~cm}-1$

B3LYP/6-31G(d) Molecular Geometry in Cartesian Coordinates

$\begin{array}{lrrr}\text { C } & 3.283573 & 0.405825 & -0.060254 \\ \text { C } & 2.374095 & 1.402088 & -0.380096 \\ \text { C } & 2.621580 & 2.790258 & -0.163752 \\ \text { C } & 3.812655 & 3.131171 & 0.446900 \\ \text { H } & 4.045364 & 4.181124 & 0.604344 \\ \text { C } & 2.397961 & -3.732540 & -0.887402 \\ \text { C } & 2.975091 & -1.013027 & -0.411862 \\ \text { C } & 1.796902 & -1.597364 & 0.033795 \\ \text { C } & 1.491470 & -2.980088 & -0.164156 \\ \text { H } & 2.219161 & -4.795830 & -1.022229 \\ \text { O } & 1.168717 & 1.029334 & -0.955155 \\ \text { P } & 0.031280 & 0.378666 & 0.044451 \\ \text { O } & 0.898796 & -0.833147 & 0.756325 \\ \text { C } & -0.084265 & 5.919523 & -1.345187 \\ \text { C } & 0.498900 & 5.928330 & -0.077626 \\ \text { C } & 1.359980 & 4.900249 & 0.303841 \\ \text { C } & 1.654417 & 3.843225 & -0.572219 \\ \text { C } & 1.055509 & 3.842081 & -1.843218 \\ \text { C } & 0.197793 & 4.872304 & -2.224942 \\ \text { H } & 0.275656 & 6.730423 & 0.620952 \\ \text { H } & -0.249954 & 4.856699 & -3.215392 \\ \text { C } & -1.960625 & -4.999236 & 1.453445 \\ \text { C } & -1.314031 & -4.012203 & 2.202204 \\ \text { C } & -0.211174 & -3.333909 & 1.679852 \\ \text { C } & 0.271379 & -3.626297 & 0.391026 \\ \text { C } & -0.398350 & -4.614238 & -0.353321 \\ \text { C } & -1.495868 & -5.296563 & 0.171729 \\ \text { H } & -1.655094 & -3.775479 & 3.207126\end{array}$




\begin{tabular}{|c|c|c|c|}
\hline $\mathrm{H}$ & -1.992627 & -6.056366 & -0.425986 \\
\hline C & 3.859255 & -1.788363 & -1.238611 \\
\hline C & 3.563931 & -3.171755 & -1.460555 \\
\hline C & 4.440134 & -3.955530 & -2.259688 \\
\hline C & 5.549185 & -3.396346 & -2.850044 \\
\hline C & 5.822424 & -2.020350 & -2.666152 \\
\hline C & 5.003143 & -1.238940 & -1.881280 \\
\hline $\mathrm{H}$ & 4.206507 & -5.007622 & -2.405984 \\
\hline $\mathrm{H}$ & 6.207997 & -4.002701 & -3.465597 \\
\hline $\mathrm{H}$ & 6.685180 & -1.573497 & -3.152828 \\
\hline $\mathrm{H}$ & 5.222217 & -0.184744 & -1.758775 \\
\hline C & 4.484463 & 0.770756 & 0.641118 \\
\hline C & 4.746460 & 2.158731 & 0.882143 \\
\hline C & 5.934046 & 2.536265 & 1.565800 \\
\hline C & 6.818589 & 1.588914 & 2.026299 \\
\hline C & 6.543531 & 0.216085 & 1.824380 \\
\hline C & 5.410037 & -0.181912 & 1.149766 \\
\hline $\mathrm{H}$ & 6.122904 & 3.594801 & 1.728875 \\
\hline $\mathrm{H}$ & 7.719686 & 1.889869 & 2.553711 \\
\hline $\mathrm{H}$ & 7.230708 & -0.532896 & 2.208927 \\
\hline $\mathrm{H}$ & 5.210221 & -1.238257 & 1.012444 \\
\hline $\mathrm{O}$ & -0.443914 & 1.294139 & 1.118844 \\
\hline 0 & -0.993150 & -0.243012 & -0.913602 \\
\hline $\mathrm{H}$ & -2.042954 & 0.479804 & -1.208643 \\
\hline $\mathrm{H}$ & 1.268496 & 3.034085 & -2.534695 \\
\hline $\mathrm{H}$ & -0.757837 & 6.718840 & -1.642951 \\
\hline $\mathrm{H}$ & 1.791228 & 4.899006 & 1.300910 \\
\hline $\mathrm{H}$ & -0.060834 & -4.838621 & -1.361208 \\
\hline $\mathrm{H}$ & -2.816079 & -5.528853 & 1.863951 \\
\hline $\mathrm{H}$ & 0.280896 & -2.576907 & 2.276853 \\
\hline C & -3.334521 & 1.780897 & -0.412706 \\
\hline $\mathrm{O}$ & -2.968999 & 1.088304 & -1.427120 \\
\hline $\mathrm{H}$ & -2.645219 & 1.927438 & 0.421899 \\
\hline C & -4.301508 & 2.923040 & -0.646425 \\
\hline $\mathrm{O}$ & -4.402064 & 3.856846 & 0.118560 \\
\hline 0 & -5.001204 & 2.772824 & -1.780397 \\
\hline C & -5.910071 & 3.846812 & -2.081102 \\
\hline $\mathrm{H}$ & -6.392325 & 3.564760 & -3.016831 \\
\hline $\mathrm{H}$ & -6.648270 & 3.959725 & -1.282433 \\
\hline C & -4.165273 & -0.465418 & 0.931044 \\
\hline C & -4.770298 & 0.784275 & 0.881213 \\
\hline $\mathrm{H}$ & -2.693879 & -1.691309 & 1.659779 \\
\hline$N$ & -3.148994 & -0.790947 & 1.783637 \\
\hline C & -2.590804 & 0.030639 & 2.780604 \\
\hline
\end{tabular}




$\begin{array}{lrrr}\text { O } & -3.003459 & 1.122068 & 3.096289 \\ \text { O } & -1.564307 & -0.623344 & 3.337212 \\ \text { C } & -0.736026 & 0.187015 & 4.201127 \\ \text { H } & 0.020270 & -0.494785 & 4.589331 \\ \text { H } & -1.334045 & 0.607238 & 5.012629 \\ \text { H } & -0.282310 & 0.979175 & 3.603262 \\ \text { H } & -5.641125 & 0.865764 & 0.241341 \\ \text { H } & -4.670310 & 1.478297 & 1.703479 \\ \text { C } & -4.527217 & -1.501477 & -0.061453 \\ \text { C } & -5.883733 & -1.733597 & -0.354905 \\ \text { C } & -3.540832 & -2.242381 & -0.735945 \\ \mathrm{C} & -6.247026 & -2.695015 & -1.292324 \\ \text { H } & -6.650610 & -1.179236 & 0.177342 \\ \mathrm{C} & -3.914282 & -3.190571 & -1.687753 \\ \text { H } & -2.487826 & -2.034962 & -0.571735 \\ \mathrm{C} & -5.261429 & -3.423340 & -1.964366 \\ \mathrm{H} & -7.297962 & -2.877131 & -1.498259 \\ \mathrm{H} & -3.142747 & -3.741172 & -2.216640 \\ \mathrm{H} & -5.545328 & -4.166717 & -2.704357 \\ \mathrm{H} & -5.363757 & 4.786413 & -2.196135\end{array}$

Catalyst (R)-1 TS Conformation 78

B3LYP/6-31G(d) Energy = -2809.691052

B3LYP-D3(BJ)/def2-TZVPP-IEF-PCM(DCM) Energy = -2810.98622

B3LYP-D3(BJ)/def2-TZVPP-IEF-PCM(DCM)//B3LYP/6-31G(d) Free Energy (Quasiharmonic) = 2810.345104

Frequencies (Top 3 out of 270)

1. $-676.4718 \mathrm{~cm}-1$

2. $\quad 4.5494 \mathrm{~cm}-1$

3. $\quad 13.8002 \mathrm{~cm}-1$

B3LYP/6-31G(d) Molecular Geometry in Cartesian Coordinates

$\begin{array}{llll}\text { C } & 2.716993 & -1.546550 & -0.103640 \\ \text { C } & 1.432840 & -1.815122 & 0.340164 \\ \text { C } & 0.787028 & -3.074751 & 0.167500 \\ \text { C } & 1.475782 & -4.043911 & -0.535973 \\ \text { H } & 1.029039 & -5.026667 & -0.661065 \\ \text { C } & 4.634064 & 2.224833 & 0.711704 \\ \text { C } & 3.362651 & -0.247950 & 0.248356\end{array}$




\begin{tabular}{|c|c|c|c|}
\hline C & 2.742856 & 0.957151 & -0.057946 \\
\hline C & 3.374425 & 2.220763 & 0.145930 \\
\hline $\mathrm{H}$ & 5.132582 & 3.176420 & 0.876608 \\
\hline $\mathrm{O}$ & 0.737263 & -0.804902 & 0.997373 \\
\hline$P$ & 0.156515 & 0.414947 & 0.065792 \\
\hline $\mathrm{O}$ & 1.506133 & 0.950767 & -0.689098 \\
\hline C & -3.102216 & -4.023514 & 1.753778 \\
\hline C & -2.750615 & -4.404153 & 0.457417 \\
\hline C & -1.497131 & -4.073241 & -0.056085 \\
\hline C & -0.564524 & -3.360631 & 0.716841 \\
\hline C & -0.930798 & -2.981635 & 2.020296 \\
\hline C & -2.185951 & -3.311497 & 2.531205 \\
\hline $\mathrm{H}$ & -3.458796 & -4.950218 & -0.160319 \\
\hline $\mathrm{H}$ & -2.445784 & -3.012700 & 3.543436 \\
\hline C & 1.756946 & 6.095457 & -0.789415 \\
\hline C & 1.053807 & 5.230623 & 0.052724 \\
\hline C & 1.538443 & 3.950436 & 0.324334 \\
\hline C & 2.755088 & 3.524028 & -0.229845 \\
\hline C & 3.453849 & 4.398925 & -1.077351 \\
\hline C & 2.957263 & 5.671165 & -1.361285 \\
\hline $\mathrm{H}$ & 0.126606 & 5.559824 & 0.516473 \\
\hline $\mathrm{H}$ & 3.511719 & 6.331355 & -2.023354 \\
\hline C & 4.624456 & -0.219128 & 0.939859 \\
\hline C & 5.273103 & 1.039579 & 1.147020 \\
\hline C & 6.527911 & 1.082135 & 1.813091 \\
\hline C & 7.115940 & -0.067071 & 2.286891 \\
\hline C & 6.460032 & -1.309350 & 2.119503 \\
\hline C & 5.250656 & -1.384350 & 1.464260 \\
\hline $\mathrm{H}$ & 7.007405 & 2.048154 & 1.952899 \\
\hline $\mathrm{H}$ & 8.072286 & -0.023194 & 2.800793 \\
\hline $\mathrm{H}$ & 6.911206 & -2.214036 & 2.518144 \\
\hline $\mathrm{H}$ & 4.758610 & -2.343706 & 1.357017 \\
\hline C & 3.383295 & -2.534662 & -0.908816 \\
\hline C & 2.747777 & -3.802480 & -1.110123 \\
\hline C & 3.399695 & -4.793985 & -1.892627 \\
\hline C & 4.614160 & -4.541355 & -2.486590 \\
\hline C & 5.224871 & -3.275756 & -2.323917 \\
\hline C & 4.628324 & -2.300831 & -1.554719 \\
\hline $\mathrm{H}$ & 2.908916 & -5.755540 & -2.023920 \\
\hline $\mathrm{H}$ & 5.099262 & -5.304146 & -3.089485 \\
\hline $\mathrm{H}$ & 6.172141 & -3.068255 & -2.814328 \\
\hline $\mathrm{H}$ & 5.105101 & -1.333522 & -1.448247 \\
\hline 0 & -0.457029 & 1.430273 & 0.973986 \\
\hline $\mathrm{O}$ & -0.654511 & -0.170136 & -1.098600 \\
\hline
\end{tabular}




\begin{tabular}{|c|c|c|c|}
\hline $\mathrm{H}$ & -1.771047 & -0.487574 & -1.153112 \\
\hline $\mathrm{H}$ & -0.228332 & -2.431203 & 2.635973 \\
\hline $\mathrm{H}$ & -4.085436 & -4.265604 & 2.145980 \\
\hline $\mathrm{H}$ & -1.242459 & -4.347256 & -1.075860 \\
\hline $\mathrm{H}$ & 4.391205 & 4.072041 & -1.519696 \\
\hline $\mathrm{H}$ & 1.375984 & 7.093058 & -0.993399 \\
\hline $\mathrm{H}$ & 0.980451 & 3.286085 & 0.975590 \\
\hline C & -3.774076 & -0.959535 & -0.447295 \\
\hline 0 & -2.935486 & -0.871769 & -1.412116 \\
\hline $\mathrm{H}$ & -3.413709 & -1.050489 & 0.584571 \\
\hline C & -5.027818 & -1.794584 & -0.677741 \\
\hline 0 & -5.663609 & -2.300834 & 0.222918 \\
\hline O & -5.342616 & -1.881101 & -1.979044 \\
\hline C & -6.512042 & -2.664106 & -2.275496 \\
\hline $\mathrm{H}$ & -7.391507 & -2.244881 & -1.779088 \\
\hline $\mathrm{H}$ & -6.623032 & -2.622264 & -3.358936 \\
\hline C & -3.779949 & 1.638454 & 0.068284 \\
\hline C & -4.834259 & 0.726393 & -0.094612 \\
\hline $\mathrm{H}$ & -2.123312 & 1.894366 & 1.259139 \\
\hline$N$ & -3.159923 & 1.828667 & 1.277499 \\
\hline C & -3.659825 & 1.705404 & 2.579638 \\
\hline 0 & -2.936671 & 1.727995 & 3.548975 \\
\hline 0 & -5.004560 & 1.628300 & 2.624906 \\
\hline C & -5.553587 & 1.557124 & 3.953980 \\
\hline $\mathrm{H}$ & -5.289758 & 2.451790 & 4.522771 \\
\hline $\mathrm{H}$ & -5.177383 & 0.674426 & 4.476159 \\
\hline $\mathrm{H}$ & -6.632585 & 1.492349 & 3.814011 \\
\hline $\mathrm{H}$ & -5.441130 & 0.827920 & -0.987320 \\
\hline $\mathrm{H}$ & -5.367028 & 0.394463 & 0.786037 \\
\hline C & -3.162591 & 2.292074 & -1.088787 \\
\hline C & -3.411390 & 1.827361 & -2.399491 \\
\hline C & -2.315743 & 3.408561 & -0.918256 \\
\hline C & -2.825219 & 2.456826 & -3.492929 \\
\hline $\mathrm{H}$ & -4.024822 & 0.952212 & -2.564693 \\
\hline C & -1.740224 & 4.035160 & -2.015789 \\
\hline $\mathrm{H}$ & -2.122980 & 3.791854 & 0.077097 \\
\hline C & -1.991034 & 3.559231 & -3.305995 \\
\hline $\mathrm{H}$ & -3.012901 & 2.076316 & -4.492514 \\
\hline $\mathrm{H}$ & -1.082403 & 4.884539 & -1.864915 \\
\hline $\mathrm{H}$ & -1.533189 & 4.047227 & -4.161987 \\
\hline $\mathrm{H}$ & -6.374079 & -3.695981 & -1.942549 \\
\hline
\end{tabular}

Catalyst (R)-1 TS Conformation 79 
B3LYP/6-31G(d) Energy $=-2809.701777$

B3LYP-D3(BJ)/def2-TZVPP-IEF-PCM(DCM) Energy $=-2810.989245$

B3LYP-D3(BJ)/def2-TZVPP-IEF-PCM(DCM)//B3LYP/6-31G(d) Free Energy (Quasiharmonic) = 2810.345094

Frequencies (Top 3 out of 270)

1. $-235.7330 \mathrm{~cm}-1$

2. $\quad 13.4300 \mathrm{~cm}-1$

3. $20.3748 \mathrm{~cm}-1$

B3LYP/6-31G(d) Molecular Geometry in Cartesian Coordinates

$\begin{array}{llll}\mathrm{C} & 3.304467 & 0.538090 & 0.015809 \\ \mathrm{C} & 2.377002 & 1.493092 & -0.363273 \\ \mathrm{C} & 2.530952 & 2.888340 & -0.114571 \\ \mathrm{C} & 3.642845 & 3.275996 & 0.608628 \\ \mathrm{H} & 3.813211 & 4.333472 & 0.791505 \\ \mathrm{C} & 2.874372 & -3.637999 & -0.932075 \\ \mathrm{C} & 3.129829 & -0.882912 & -0.407749 \\ \mathrm{C} & 1.967555 & -1.577424 & -0.099541 \\ \mathrm{C} & 1.828831 & -2.983434 & -0.310130 \\ \mathrm{H} & 2.790762 & -4.707073 & -1.108195 \\ \mathrm{O} & 1.236795 & 1.066047 & -1.044371 \\ \mathrm{P} & 0.104035 & 0.314024 & -0.146856 \\ \mathrm{O} & 0.930697 & -0.911903 & 0.550502 \\ \mathrm{C} & -0.083591 & 5.967937 & -1.597817 \\ \mathrm{C} & 0.265361 & 4.893211 & -2.419172 \\ \mathrm{C} & 1.085226 & 3.874070 & -1.937743 \\ \mathrm{C} & 1.576552 & 3.909989 & -0.621152 \\ \mathrm{C} & 1.204996 & 4.987926 & 0.199582 \\ \mathrm{C} & 0.386433 & 6.008836 & -0.283386 \\ \mathrm{H} & -0.095299 & 4.850914 & -3.443471 \\ \mathrm{H} & 0.116027 & 6.835199 & 0.369129 \\ \mathrm{C} & -1.498187 & -5.404710 & 0.949348 \\ \mathrm{C} & -0.199274 & -5.707484 & 1.365220 \\ \mathrm{C} & 0.867961 & -4.899875 & 0.971150 \\ \mathrm{C} & 0.654731 & -3.776696 & 0.153689 \\ \mathrm{C} & -0.654340 & -3.483909 & -0.253911 \\ \mathrm{C} & -1.724857 & -4.288016 & 0.140446 \\ \mathrm{H} & -0.014595 & -6.571752 & 1.998607 \\ \mathrm{H} & -2.727727 & -4.026863 & -0.184574 \\ \mathrm{C} & 4.161959 & -1.559225 & -1.147438\end{array}$




\begin{tabular}{|c|c|c|c|}
\hline C & 4.027184 & -2.961595 & -1.397533 \\
\hline C & 5.042052 & -3.645360 & -2.120312 \\
\hline C & 6.140048 & -2.973259 & -2.604069 \\
\hline C & 6.260895 & -1.580349 & -2.387891 \\
\hline C & 5.301189 & -0.892634 & -1.678086 \\
\hline $\mathrm{H}$ & 4.924720 & -4.712391 & -2.293969 \\
\hline $\mathrm{H}$ & 6.906987 & -3.504087 & -3.161361 \\
\hline $\mathrm{H}$ & 7.116314 & -1.045388 & -2.791541 \\
\hline $\mathrm{H}$ & 5.405009 & 0.176340 & -1.532894 \\
\hline C & 4.411454 & 0.949691 & 0.837368 \\
\hline C & 4.576240 & 2.343512 & 1.122898 \\
\hline C & 5.671282 & 2.767989 & 1.923651 \\
\hline C & 6.554332 & 1.856977 & 2.454231 \\
\hline C & 6.371449 & 0.476227 & 2.206762 \\
\hline C & 5.331564 & 0.034486 & 1.418443 \\
\hline $\mathrm{H}$ & 5.788613 & 3.831205 & 2.119417 \\
\hline $\mathrm{H}$ & 7.383380 & 2.192013 & 3.071434 \\
\hline $\mathrm{H}$ & 7.055693 & -0.244409 & 2.646334 \\
\hline $\mathrm{H}$ & 5.201237 & -1.027334 & 1.246485 \\
\hline $\mathrm{O}$ & -0.512468 & 1.145468 & 0.924588 \\
\hline $\mathrm{O}$ & -0.815988 & -0.233466 & -1.280570 \\
\hline $\mathrm{H}$ & -1.782405 & -0.600181 & -1.002759 \\
\hline $\mathrm{H}$ & 1.550895 & 5.016068 & 1.228890 \\
\hline $\mathrm{H}$ & -0.715451 & 6.765931 & -1.979321 \\
\hline $\mathrm{H}$ & 1.356738 & 3.050673 & -2.588958 \\
\hline $\mathrm{H}$ & -0.840591 & -2.637274 & -0.900848 \\
\hline $\mathrm{H}$ & -2.330206 & -6.033852 & 1.255278 \\
\hline $\mathrm{H}$ & 1.876117 & -5.131445 & 1.305287 \\
\hline C & -4.141100 & -0.867013 & -1.022707 \\
\hline $\mathrm{O}$ & -2.978841 & -1.279761 & -0.683556 \\
\hline $\mathrm{H}$ & -4.239665 & 0.032866 & -1.648594 \\
\hline C & -5.151671 & -1.951733 & -1.409811 \\
\hline $\mathrm{O}$ & -5.032904 & -3.131967 & -1.180333 \\
\hline $\mathrm{O}$ & -6.201471 & -1.405678 & -2.064800 \\
\hline C & -7.209100 & -2.338065 & -2.492920 \\
\hline $\mathrm{H}$ & -7.637022 & -2.861365 & -1.633523 \\
\hline $\mathrm{H}$ & -7.968254 & -1.739034 & -2.996498 \\
\hline C & -4.211991 & 0.694037 & 1.014549 \\
\hline C & -5.163547 & -0.222959 & 0.527550 \\
\hline $\mathrm{H}$ & -2.250191 & 0.816655 & 1.659427 \\
\hline$N$ & -3.112129 & 0.255535 & 1.666970 \\
\hline C & -2.956683 & -1.003182 & 2.297881 \\
\hline $\mathrm{O}$ & -3.835341 & -1.804901 & 2.516466 \\
\hline $\mathrm{O}$ & -1.682495 & -1.106951 & 2.681316 \\
\hline
\end{tabular}




$\begin{array}{llll}\mathrm{C} & -1.334827 & -2.321995 & 3.372575 \\ \mathrm{H} & -0.257541 & -2.260834 & 3.518680 \\ \mathrm{H} & -1.592614 & -3.189523 & 2.764054 \\ \mathrm{H} & -1.857149 & -2.368540 & 4.332116 \\ \mathrm{H} & -6.063707 & 0.187871 & 0.085210 \\ \mathrm{H} & -5.275119 & -1.157489 & 1.062316 \\ \mathrm{C} & -4.284576 & 2.126725 & 0.650021 \\ \mathrm{C} & -5.551237 & 2.736417 & 0.552288 \\ \mathrm{C} & -3.137306 & 2.907452 & 0.412650 \\ \mathrm{C} & -5.668445 & 4.083486 & 0.224281 \\ \mathrm{H} & -6.445652 & 2.162098 & 0.769504 \\ \mathrm{C} & -3.263576 & 4.252388 & 0.070026 \\ \mathrm{H} & -2.144465 & 2.470689 & 0.463345 \\ \mathrm{C} & -4.524120 & 4.844480 & -0.023544 \\ \mathrm{H} & -6.652997 & 4.539155 & 0.168176 \\ \mathrm{H} & -2.367692 & 4.832484 & -0.129427 \\ \mathrm{H} & -4.615522 & 5.895280 & -0.285171 \\ \mathrm{H} & -6.781350 & -3.073425 & -3.179263\end{array}$

Catalyst (R)-1 TS Conformation 80

B3LYP/6-31G(d) Energy $=-2809.6984$

B3LYP-D3(BJ)/def2-TZVPP-IEF-PCM(DCM) Energy = -2810.989267

B3LYP-D3(BJ)/def2-TZVPP-IEF-PCM(DCM)//B3LYP/6-31G(d) Free Energy (Quasiharmonic) = 2810.345091

Frequencies (Top 3 out of 270)

1. $-244.8582 \mathrm{~cm}-1$

2. $\quad 12.2890 \mathrm{~cm}-1$

3. $\quad 18.7356 \mathrm{~cm}-1$

B3LYP/6-31G(d) Molecular Geometry in Cartesian Coordinates

$\begin{array}{llll}\text { C } & -3.229640 & 0.254697 & -0.294263 \\ \text { C } & -2.311857 & 1.286669 & -0.159524 \\ \text { C } & -2.597541 & 2.633272 & -0.541963 \\ \text { C } & -3.823807 & 2.879700 & -1.128383 \\ \text { H } & -4.063746 & 3.894331 & -1.434833 \\ \text { C } & -2.508142 & -3.805500 & 0.928191 \\ \text { C } & -2.941549 & -1.105783 & 0.250173 \\ \text { C } & -1.804481 & -1.788043 & -0.153021 \\ \text { C } & -1.589464 & -3.175087 & 0.109689\end{array}$




\begin{tabular}{|c|c|c|c|}
\hline $\mathrm{H}$ & -2.367724 & -4.856827 & 1.164472 \\
\hline 0 & -1.102455 & 1.032572 & 0.478517 \\
\hline$P$ & 0.024454 & 0.027138 & -0.153304 \\
\hline 0 & -0.864283 & -1.104073 & -0.921363 \\
\hline C & -0.018181 & 6.036047 & 0.013377 \\
\hline C & 0.469840 & 4.890685 & -0.620424 \\
\hline C & -0.347510 & 3.771994 & -0.783124 \\
\hline C & -1.668666 & 3.775980 & -0.310771 \\
\hline C & -2.146328 & 4.930609 & 0.333101 \\
\hline C & -1.330293 & 6.051148 & 0.492155 \\
\hline $\mathrm{H}$ & 1.492011 & 4.848798 & -0.984432 \\
\hline $\mathrm{H}$ & -1.720015 & 6.934167 & 0.992509 \\
\hline C & 1.476548 & -5.564285 & -1.749598 \\
\hline C & 1.811607 & -4.335657 & -1.177746 \\
\hline C & 0.835297 & -3.546463 & -0.570145 \\
\hline C & -0.502987 & -3.968751 & -0.530479 \\
\hline C & -0.827445 & -5.206771 & -1.113197 \\
\hline C & 0.151044 & -5.998714 & -1.712572 \\
\hline $\mathrm{H}$ & 2.837257 & -3.977954 & -1.208061 \\
\hline $\mathrm{H}$ & -0.126963 & -6.948301 & -2.162692 \\
\hline C & -3.837787 & -1.752508 & 1.170085 \\
\hline C & -3.604213 & -3.123318 & 1.510115 \\
\hline C & -4.476385 & -3.773839 & 2.424634 \\
\hline C & -5.526585 & -3.099005 & 3.002181 \\
\hline C & -5.743209 & -1.736366 & 2.689216 \\
\hline C & -4.924018 & -1.081677 & 1.795681 \\
\hline $\mathrm{H}$ & -4.288938 & -4.817337 & 2.666748 \\
\hline $\mathrm{H}$ & -6.183346 & -3.604690 & 3.704737 \\
\hline $\mathrm{H}$ & -6.560477 & -1.198908 & 3.162570 \\
\hline $\mathrm{H}$ & -5.096234 & -0.034728 & 1.573961 \\
\hline C & -4.457371 & 0.510852 & -1.001267 \\
\hline C & -4.756656 & 1.851610 & -1.402400 \\
\hline C & -5.969953 & 2.124831 & -2.090377 \\
\hline C & -6.849896 & 1.114472 & -2.399709 \\
\hline C & -6.540939 & -0.217833 & -2.038384 \\
\hline C & -5.379812 & -0.511934 & -1.357841 \\
\hline $\mathrm{H}$ & -6.181276 & 3.151620 & -2.379545 \\
\hline $\mathrm{H}$ & -7.771830 & 1.332651 & -2.931692 \\
\hline $\mathrm{H}$ & -7.223051 & -1.020050 & -2.306780 \\
\hline $\mathrm{H}$ & -5.156044 & -1.540630 & -1.102206 \\
\hline $\mathrm{O}$ & 0.860023 & -0.496579 & 0.968157 \\
\hline $\mathrm{O}$ & 0.721941 & 0.721677 & -1.351738 \\
\hline $\mathrm{H}$ & 1.667928 & 1.223229 & -1.178484 \\
\hline $\mathrm{H}$ & -3.163010 & 4.942839 & 0.717376 \\
\hline
\end{tabular}




$\begin{array}{lrrr}\mathrm{H} & 0.619149 & 6.907937 & 0.136808 \\ \mathrm{H} & 0.038583 & 2.901931 & -1.297994 \\ \mathrm{H} & -1.862629 & -5.536851 & -1.117276 \\ \mathrm{H} & 2.239487 & -6.173921 & -2.226910 \\ \mathrm{H} & 1.113046 & -2.604163 & -0.116220 \\ \mathrm{C} & 3.949770 & 1.919237 & -1.217922 \\ \mathrm{O} & 2.698776 & 2.145574 & -0.980974 \\ \mathrm{H} & 4.532191 & 2.753430 & -1.639700 \\ \mathrm{C} & 4.304151 & 0.598453 & -1.906322 \\ \mathrm{O} & 3.595626 & -0.382053 & -1.922476 \\ \mathrm{O} & 5.526321 & 0.663466 & -2.480570 \\ \mathrm{C} & 5.962172 & -0.541815 & -3.134172 \\ \mathrm{H} & 6.935467 & -0.306020 & -3.565505 \\ \mathrm{H} & 6.047874 & -1.357564 & -2.411131 \\ \mathrm{C} & 4.259848 & 0.852549 & 1.094397 \\ \mathrm{C} & 4.952127 & 1.843094 & 0.344634 \\ \mathrm{H} & 2.346943 & 0.411592 & 1.731527 \\ \mathrm{~N} & 3.055615 & 1.149640 & 1.620021 \\ \mathrm{C} & 2.575476 & 2.438901 & 1.964056 \\ \mathrm{O} & 3.223163 & 3.459642 & 1.993289 \\ \mathrm{O} & 1.306480 & 2.296178 & 2.348619 \\ \mathrm{C} & 0.652607 & 3.489052 & 2.823356 \\ \mathrm{H} & 1.095989 & 3.800474 & 3.773366 \\ \mathrm{H} & -0.389081 & 3.202228 & 2.955483 \\ \mathrm{H} & 0.741458 & 4.288384 & 2.087906 \\ \mathrm{H} & 5.962441 & 1.599648 & 0.032297 \\ \mathrm{H} & 4.815292 & 2.865739 & 0.673924 \\ \mathrm{C} & 4.725812 & -0.546929 & 1.153021 \\ \mathrm{C} & 6.111144 & -0.804544 & 1.124242 \\ \mathrm{C} & 3.839468 & -1.634876 & 1.278851 \\ \mathrm{C} & 6.595461 & -2.106368 & 1.216975 \\ \mathrm{H} & 6.815433 & 0.018321 & 1.068801 \\ \mathrm{C} & 4.331066 & -2.934556 & 1.362499 \\ \mathrm{H} & 2.766273 & -1.478598 & 1.268115 \\ 5.706439 & -3.176551 & 1.333292 \\ \mathrm{H} & 7.667339 & -2.282382 & 1.209388 \\ \mathrm{H} & 3.631276 & -3.761278 & 1.439365 \\ \mathrm{H} & & -4.193153 & 1.404825 \\ \mathrm{H} & -0.829819 & -3.914889\end{array}$

Catalyst (R)-1 TS Conformation 81

B3LYP/6-31G(d) Energy $=-2809.692499$ 
B3LYP-D3(BJ)/def2-TZVPP-IEF-PCM(DCM) Energy $=-2810.986402$

B3LYP-D3(BJ)/def2-TZVPP-IEF-PCM(DCM)//B3LYP/6-31G(d) Free Energy (Quasiharmonic) = 2810.34503

Frequencies (Top 3 out of 270)

1. $-666.6129 \mathrm{~cm}-1$

2. $\quad 7.3818 \mathrm{~cm}-1$

3. $\quad 10.2774 \mathrm{~cm}-1$

B3LYP/6-31G(d) Molecular Geometry in Cartesian Coordinates

$\begin{array}{llll}\text { C } & 3.480154 & -1.114597 & -0.080157 \\ \text { C } & 2.240085 & -1.707574 & 0.099046 \\ \text { C } & 1.951660 & -3.048479 & -0.293780 \\ \text { C } & 2.957261 & -3.755556 & -0.923567 \\ \text { H } & 2.779169 & -4.788477 & -1.211270 \\ \text { C } & 4.147903 & 2.942452 & 1.217319 \\ \text { C } & 3.710209 & 0.269452 & 0.429739 \\ \text { C } & 2.871425 & 1.297370 & 0.022480 \\ \text { C } & 3.093153 & 2.663967 & 0.369685 \\ \text { H } & 4.358900 & 3.976191 & 1.478361 \\ \text { O } & 1.239383 & -0.975159 & 0.715052 \\ \text { P } & 0.490789 & 0.226799 & -0.131818 \\ \text { O } & 1.790188 & 0.997681 & -0.791534 \\ \text { C } & -1.813767 & -5.006618 & 0.420174 \\ \text { C } & -1.191372 & -5.098769 & -0.825086 \\ \text { C } & 0.018076 & -4.442989 & -1.053789 \\ \text { C } & 0.630906 & -3.683649 & -0.043815 \\ \text { C } & -0.009629 & -3.592987 & 1.204326 \\ \text { C } & -1.217972 & -4.250509 & 1.432679 \\ \text { H } & -1.650464 & -5.674327 & -1.624765 \\ \text { H } & -1.693066 & -4.175565 & 2.407503 \\ \text { C } & 0.874771 & 5.999484 & -1.201633 \\ \text { C } & 1.278516 & 4.965261 & -2.050595 \\ \text { C } & 1.961782 & 3.861134 & -1.542744 \\ \text { C } & 2.266496 & 3.774636 & -0.173660 \\ \text { C } & 1.843097 & 4.814033 & 0.670828 \\ \text { C } & 1.153606 & 5.915184 & 0.163827 \\ \text { H } & 1.067816 & 5.020220 & -3.115642 \\ \text { H } & 0.833717 & 6.706567 & 0.836853 \\ \text { C } & 4.758510 & 0.565716 & 1.367216 \\ \text { C } & 4.975178 & 1.927167 & 1.755532 \\ \text { C } & 6.013617 & 2.234820 & 2.675887\end{array}$




\begin{tabular}{|c|c|c|c|}
\hline C & 6.793037 & 1.241633 & 3.221609 \\
\hline C & 6.557730 & -0.108098 & 2.868779 \\
\hline C & 5.570310 & -0.437068 & 1.966179 \\
\hline $\mathrm{H}$ & 6.171587 & 3.275465 & 2.949654 \\
\hline $\mathrm{H}$ & 7.579503 & 1.487954 & 3.929800 \\
\hline $\mathrm{H}$ & 7.158650 & -0.894356 & 3.317894 \\
\hline $\mathrm{H}$ & 5.396459 & -1.476835 & 1.714584 \\
\hline C & 4.492478 & -1.836685 & -0.800990 \\
\hline C & 4.219612 & -3.181756 & -1.212029 \\
\hline C & 5.215338 & -3.913025 & -1.914818 \\
\hline C & 6.423907 & -3.338591 & -2.232832 \\
\hline C & 6.681868 & -1.997788 & -1.862663 \\
\hline C & 5.744067 & -1.267821 & -1.165714 \\
\hline $\mathrm{H}$ & 4.995220 & -4.936854 & -2.208368 \\
\hline $\mathrm{H}$ & 7.174736 & -3.905299 & -2.776738 \\
\hline $\mathrm{H}$ & 7.627493 & -1.536657 & -2.135032 \\
\hline $\mathrm{H}$ & 5.954401 & -0.238742 & -0.898746 \\
\hline $\mathrm{O}$ & -0.295694 & 1.038808 & 0.837735 \\
\hline $\mathrm{O}$ & -0.198955 & -0.382349 & -1.360238 \\
\hline $\mathrm{H}$ & -1.408466 & -0.373818 & -1.453975 \\
\hline $\mathrm{H}$ & 0.446214 & -3.011416 & 1.998021 \\
\hline $\mathrm{H}$ & -2.757265 & -5.514371 & 0.600532 \\
\hline $\mathrm{H}$ & 0.485717 & -4.498419 & -2.032679 \\
\hline $\mathrm{H}$ & 2.045189 & 4.747068 & 1.736100 \\
\hline $\mathrm{H}$ & 0.347356 & 6.862298 & -1.600706 \\
\hline $\mathrm{H}$ & 2.273242 & 3.066058 & -2.211196 \\
\hline C & -3.076594 & -1.102504 & -0.534568 \\
\hline $\mathrm{O}$ & -2.601295 & -0.459300 & -1.538402 \\
\hline $\mathrm{H}$ & -2.401903 & -1.723819 & 0.065290 \\
\hline C & -4.473797 & -1.678065 & -0.696075 \\
\hline $\mathrm{O}$ & -5.389921 & -1.144617 & -1.284132 \\
\hline $\mathrm{O}$ & -4.539530 & -2.874016 & -0.087557 \\
\hline C & -5.822245 & -3.521385 & -0.109238 \\
\hline $\mathrm{H}$ & -6.510879 & -2.986929 & 0.550048 \\
\hline $\mathrm{H}$ & -6.223281 & -3.546342 & -1.125022 \\
\hline C & -4.347272 & 1.063375 & 0.536879 \\
\hline C & -3.419586 & 0.138420 & 1.020323 \\
\hline $\mathrm{H}$ & -6.261887 & 1.758648 & 0.439785 \\
\hline$N$ & -5.689881 & 1.019171 & 0.827633 \\
\hline C & -6.397692 & 0.087226 & 1.579964 \\
\hline $\mathrm{O}$ & -5.953523 & -0.912741 & 2.100697 \\
\hline $\mathrm{O}$ & -7.681565 & 0.495404 & 1.638530 \\
\hline C & -8.564444 & -0.363430 & 2.381130 \\
\hline $\mathrm{H}$ & -8.199225 & -0.496266 & 3.402024 \\
\hline
\end{tabular}




$\begin{array}{lrrr}\text { H } & -8.645585 & -1.338595 & 1.894149 \\ \text { H } & -9.528181 & 0.145137 & 2.378359 \\ \text { H } & -2.376620 & 0.451545 & 1.025576 \\ \text { H } & -3.730191 & -0.527101 & 1.817005 \\ \mathrm{C} & -3.971592 & 2.119286 & -0.415595 \\ \mathrm{C} & -2.719240 & 2.752733 & -0.322424 \\ \mathrm{C} & -4.858167 & 2.494391 & -1.447835 \\ \mathrm{C} & -2.382795 & 3.766127 & -1.218283 \\ \mathrm{H} & -2.004172 & 2.457237 & 0.437350 \\ \mathrm{C} & -4.508645 & 3.497413 & -2.343764 \\ \mathrm{H} & -5.783718 & 1.945739 & -1.598319 \\ \mathrm{C} & -3.274988 & 4.144275 & -2.221988 \\ \mathrm{H} & -1.415994 & 4.251721 & -1.132413 \\ \mathrm{H} & -5.188376 & 3.761204 & -3.148918 \\ \mathrm{H} & -3.004137 & 4.930363 & -2.921781 \\ \mathrm{H} & -5.647059 & -4.530766 & 0.263553\end{array}$

Catalyst (R)-1 TS Conformation 82

B3LYP/6-31G(d) Energy $=-2809.694894$

B3LYP-D3(BJ)/def2-TZVPP-IEF-PCM(DCM) Energy = -2810.987022

B3LYP-D3(BJ)/def2-TZVPP-IEF-PCM(DCM)//B3LYP/6-31G(d) Free Energy (Quasiharmonic) = 2810.344851

Frequencies (Top 3 out of 270)

1. $-427.3309 \mathrm{~cm}-1$

2. $\quad 7.4889 \mathrm{~cm}-1$

3. $12.0546 \mathrm{~cm}-1$

B3LYP/6-31G(d) Molecular Geometry in Cartesian Coordinates

$\begin{array}{llll}\text { C } & 3.637398 & -0.837865 & -0.031007 \\ \text { C } & 2.474024 & -1.534529 & 0.253812 \\ \text { C } & 2.323137 & -2.936443 & 0.046646 \\ \text { C } & 3.393124 & -3.612461 & -0.505416 \\ \text { H } & 3.321319 & -4.686511 & -0.656156 \\ \text { C } & 3.820763 & 3.399765 & 0.756708 \\ \text { C } & 3.716202 & 0.619004 & 0.288670 \\ \text { C } & 2.755906 & 1.486040 & -0.211694 \\ \text { C } & 2.788915 & 2.898158 & -0.013659 \\ \text { H } & 3.894305 & 4.473738 & 0.905230 \\ \text { O } & 1.390807 & -0.834527 & 0.776457\end{array}$




\begin{tabular}{|c|c|c|c|}
\hline$P$ & 0.532903 & 0.117000 & -0.244923 \\
\hline 0 & 1.718449 & 0.961522 & -0.978846 \\
\hline C & -1.276174 & -5.087598 & 1.025443 \\
\hline C & -0.715444 & -4.205097 & 1.952994 \\
\hline C & 0.441918 & -3.492729 & 1.639771 \\
\hline C & 1.066916 & -3.654386 & 0.391360 \\
\hline C & 0.496402 & -4.547063 & -0.530335 \\
\hline C & -0.663675 & -5.256260 & -0.217657 \\
\hline $\mathrm{H}$ & -1.178884 & -4.073396 & 2.927484 \\
\hline $\mathrm{H}$ & -1.094893 & -5.932969 & -0.950629 \\
\hline C & -0.100208 & 5.634596 & -1.648437 \\
\hline C & 0.419664 & 4.614077 & -2.446315 \\
\hline C & 1.343690 & 3.711324 & -1.924179 \\
\hline C & 1.767457 & 3.813483 & -0.588568 \\
\hline C & 1.235610 & 4.844031 & 0.203982 \\
\hline C & 0.311843 & 5.746710 & -0.320391 \\
\hline $\mathrm{H}$ & 0.102217 & 4.516612 & -3.480922 \\
\hline $\mathrm{H}$ & -0.094534 & 6.530199 & 0.314142 \\
\hline C & 4.735531 & 1.150294 & 1.152075 \\
\hline C & 4.787368 & 2.565354 & 1.368279 \\
\hline C & 5.798812 & 3.106749 & 2.207739 \\
\hline C & 6.706528 & 2.289719 & 2.840050 \\
\hline C & 6.632550 & 0.888248 & 2.661322 \\
\hline C & 5.675506 & 0.333936 & 1.839967 \\
\hline $\mathrm{H}$ & 5.831112 & 4.184366 & 2.350239 \\
\hline $\mathrm{H}$ & 7.470816 & 2.714511 & 3.485076 \\
\hline $\mathrm{H}$ & 7.334451 & 0.241507 & 3.180889 \\
\hline $\mathrm{H}$ & 5.627261 & -0.742299 & 1.722327 \\
\hline C & 4.715031 & -1.541429 & -0.671828 \\
\hline C & 4.584798 & -2.951356 & -0.893004 \\
\hline C & 5.647335 & -3.661024 & -1.515645 \\
\hline C & 6.782820 & -3.009384 & -1.937029 \\
\hline C & 6.897150 & -1.610921 & -1.756783 \\
\hline C & 5.892900 & -0.896964 & -1.140725 \\
\hline $\mathrm{H}$ & 5.537058 & -4.732608 & -1.664523 \\
\hline $\mathrm{H}$ & 7.585343 & -3.561436 & -2.418451 \\
\hline $\mathrm{H}$ & 7.783848 & -1.093146 & -2.112438 \\
\hline $\mathrm{H}$ & 5.992277 & 0.175352 & -1.019461 \\
\hline $\mathrm{O}$ & -0.430761 & 0.907990 & 0.575909 \\
\hline $\mathrm{O}$ & -0.028748 & -0.748304 & -1.397245 \\
\hline $\mathrm{H}$ & -1.145086 & -0.853891 & -1.414907 \\
\hline $\mathrm{H}$ & 0.954207 & -4.662807 & -1.508643 \\
\hline $\mathrm{H}$ & -2.186666 & -5.629258 & 1.265457 \\
\hline $\mathrm{H}$ & 0.869243 & -2.810815 & 2.367289 \\
\hline
\end{tabular}




$\begin{array}{llll}\mathrm{H} & 1.531692 & 4.919248 & 1.246647 \\ \mathrm{H} & -0.827633 & 6.330900 & -2.056886 \\ \mathrm{H} & 1.741597 & 2.924119 & -2.554881 \\ \mathrm{C} & -2.891506 & -1.787574 & -0.515765 \\ \mathrm{O} & -2.451798 & -0.979593 & -1.408898 \\ \mathrm{H} & -2.218417 & -2.530878 & -0.067981 \\ \mathrm{C} & -4.282145 & -2.376001 & -0.696386 \\ \mathrm{O} & -4.682450 & -3.339114 & -0.069307 \\ \mathrm{O} & -4.998432 & -1.716373 & -1.615552 \\ \mathrm{C} & -6.316249 & -2.233191 & -1.864519 \\ \mathrm{H} & -6.953620 & -2.093567 & -0.987232 \\ \mathrm{H} & -6.699034 & -1.656914 & -2.706906 \\ \mathrm{C} & -3.837695 & 0.291202 & 0.905874 \\ \mathrm{C} & -3.081306 & -0.850458 & 1.229815 \\ \mathrm{H} & -2.156208 & 1.229340 & 0.223386 \\ \mathrm{~N} & -3.192394 & 1.251047 & 0.190187 \\ \mathrm{C} & -3.670312 & 2.068687 & -0.852977 \\ \mathrm{O} & -2.973016 & 2.904738 & -1.376978 \\ \mathrm{O} & -4.934535 & 1.781485 & -1.197293 \\ \mathrm{C} & -5.446145 & 2.556794 & -2.294087 \\ \mathrm{H} & -4.861059 & 2.365830 & -3.196764 \\ \mathrm{H} & -5.411807 & 3.623987 & -2.060949 \\ \mathrm{H} & -6.475806 & 2.223481 & -2.424195 \\ \mathrm{H} & -3.495209 & -1.550687 & 1.947980 \\ \mathrm{H} & -2.009051 & -0.695059 & 1.308114 \\ \mathrm{H} & -5.238585 & 0.461430 & 1.335542 \\ \mathrm{H} & -6.066493 & -0.647640 & 1.589325 \\ \mathrm{H} & -5.728454 & 1.749339 & 1.623698 \\ \mathrm{H} & -7.357908 & -0.466534 & 2.079144 \\ \mathrm{H} & -5.711789 & -1.653238 & 1.391862 \\ \mathrm{H} & -7.012283 & 1.923080 & 2.130760 \\ \mathrm{H} & -7.836025 & 0.816916 & 2.351528 \\ \mathrm{H} & -1.333299 & 2.257668 \\ \mathrm{H} & -2.92350379 & -3.296649 & -2.111385\end{array}$

Catalyst (R)-1 TS Conformation 83

B3LYP/6-31G(d) Energy $=-2809.695133$

B3LYP-D3(BJ)/def2-TZVPP-IEF-PCM(DCM) Energy = -2810.985856 
B3LYP-D3(BJ)/def2-TZVPP-IEF-PCM(DCM)//B3LYP/6-31G(d) Free Energy (Quasiharmonic) = 2810.344848

Frequencies (Top 3 out of 270)

1. $-704.4730 \mathrm{~cm}-1$

2. $\quad 7.5889 \mathrm{~cm}-1$

3. $\quad 11.6140 \mathrm{~cm}-1$

B3LYP/6-31G(d) Molecular Geometry in Cartesian Coordinates

$\begin{array}{lrrr}\mathrm{C} & -3.597583 & -0.842546 & -0.014053 \\ \mathrm{C} & -2.488010 & -1.602003 & -0.343038 \\ \mathrm{C} & -2.449358 & -3.024016 & -0.266080 \\ \mathrm{C} & -3.578804 & -3.658999 & 0.210700 \\ \mathrm{H} & -3.594664 & -4.744562 & 0.262301 \\ \mathrm{C} & -3.589964 & 3.454176 & -0.346577 \\ \mathrm{C} & -3.565359 & 0.637213 & -0.213265 \\ \mathrm{C} & -2.564222 & 1.404151 & 0.369355 \\ \mathrm{C} & -2.573940 & 2.832147 & 0.352565 \\ \mathrm{H} & -3.617404 & 4.540198 & -0.379333 \\ \mathrm{O} & -1.341659 & -0.939742 & -0.773748 \\ \mathrm{P} & -0.454377 & -0.184109 & 0.376204 \\ \mathrm{O} & -1.560896 & 0.777619 & 1.098245 \\ \mathrm{C} & 0.964800 & -5.366120 & -1.435279 \\ \mathrm{C} & 0.330041 & -5.599964 & -0.215117 \\ \mathrm{C} & -0.767648 & -4.827236 & 0.162774 \\ \mathrm{C} & -1.249787 & -3.804736 & -0.669719 \\ \mathrm{C} & -0.597928 & -3.574091 & -1.893083 \\ \mathrm{C} & 0.495988 & -4.350690 & -2.272024 \\ \mathrm{H} & 0.695598 & -6.377093 & 0.450595 \\ \mathrm{H} & 0.980297 & -4.164371 & -3.227357 \\ \mathrm{C} & 0.234663 & 5.346012 & 2.432395 \\ \mathrm{C} & -1.138802 & 5.503705 & 2.621600 \\ \mathrm{C} & -2.036354 & 4.669412 & 1.955063 \\ \mathrm{C} & -1.579423 & 3.661548 & 1.089896 \\ \mathrm{C} & -0.195806 & 3.509814 & 0.907801 \\ \mathrm{C} & 0.699087 & 4.347723 & 1.573373 \\ \mathrm{H} & -1.514248 & 6.271627 & 3.293121 \\ \mathrm{H} & 1.766189 & 4.213837 & 1.415047 \\ \mathrm{C} & -4.554878 & 1.298637 & -1.021109 \\ \mathrm{C} & -4.567356 & 2.729228 & -1.069743 \\ \mathrm{C} & -5.545308 & 3.394751 & -1.857702 \\ \mathrm{C} & -6.463888 & 2.683755 & -2.593966\end{array}$




\begin{tabular}{|c|c|c|c|}
\hline C & -6.433059 & 1.269400 & -2.576155 \\
\hline C & -5.506839 & 0.595671 & -1.810691 \\
\hline $\mathrm{H}$ & -5.543959 & 4.482146 & -1.875225 \\
\hline $\mathrm{H}$ & -7.203498 & 3.202577 & -3.197656 \\
\hline $\mathrm{H}$ & -7.143288 & 0.708011 & -3.177240 \\
\hline $\mathrm{H}$ & -5.490794 & -0.487918 & -1.817618 \\
\hline C & -4.738546 & -1.512369 & 0.551159 \\
\hline C & -4.720841 & -2.942251 & 0.646598 \\
\hline C & -5.844700 & -3.619168 & 1.193274 \\
\hline C & -6.933397 & -2.921100 & 1.661239 \\
\hline C & -6.936524 & -1.507729 & 1.606407 \\
\hline C & -5.870693 & -0.822544 & 1.065461 \\
\hline $\mathrm{H}$ & -5.819195 & -4.705030 & 1.246605 \\
\hline $\mathrm{H}$ & -7.783464 & -3.449448 & 2.084135 \\
\hline $\mathrm{H}$ & -7.785797 & -0.955665 & 1.999887 \\
\hline $\mathrm{H}$ & -5.885658 & 0.260663 & 1.041558 \\
\hline 0 & 0.637602 & 0.553658 & -0.331793 \\
\hline 0 & -0.075303 & -1.163807 & 1.494880 \\
\hline $\mathrm{H}$ & 0.987136 & -1.700522 & 1.491945 \\
\hline $\mathrm{H}$ & -0.956523 & -2.789298 & -2.550818 \\
\hline $\mathrm{H}$ & 1.821324 & -5.966766 & -1.729799 \\
\hline $\mathrm{H}$ & -1.243530 & -4.997014 & 1.124421 \\
\hline $\mathrm{H}$ & 0.181521 & 2.744407 & 0.239489 \\
\hline $\mathrm{H}$ & 0.936398 & 5.993009 & 2.952682 \\
\hline $\mathrm{H}$ & -3.104604 & 4.785134 & 2.117888 \\
\hline C & 3.007301 & -1.318374 & 1.393990 \\
\hline 0 & 2.098868 & -2.202477 & 1.550981 \\
\hline $\mathrm{H}$ & 2.751094 & -0.259458 & 1.512024 \\
\hline C & 4.403065 & -1.705285 & 1.854661 \\
\hline 0 & 4.876191 & -2.814929 & 1.799564 \\
\hline $\mathrm{O}$ & 5.031153 & -0.619919 & 2.352272 \\
\hline C & 6.359408 & -0.860811 & 2.855767 \\
\hline $\mathrm{H}$ & 6.333366 & -1.625298 & 3.635872 \\
\hline $\mathrm{H}$ & 7.017332 & -1.188816 & 2.047699 \\
\hline C & 4.048430 & -0.026873 & -0.890025 \\
\hline C & 3.372592 & -1.224973 & -0.627173 \\
\hline $\mathrm{H}$ & 2.291502 & 0.997599 & -0.710403 \\
\hline$N$ & 3.297696 & 1.113408 & -0.928920 \\
\hline C & 3.640449 & 2.352676 & -1.488590 \\
\hline 0 & 4.661892 & 2.631110 & -2.073494 \\
\hline $\mathrm{O}$ & 2.609798 & 3.191886 & -1.274925 \\
\hline C & 2.746600 & 4.499524 & -1.857521 \\
\hline $\mathrm{H}$ & 3.659425 & 4.983162 & -1.501626 \\
\hline $\mathrm{H}$ & 1.863551 & 5.047326 & -1.530681 \\
\hline
\end{tabular}




$\begin{array}{llll}\mathrm{H} & 2.777347 & 4.427428 & -2.947820 \\ \mathrm{H} & 3.925140 & -2.153786 & -0.704797 \\ \mathrm{H} & 2.317756 & -1.266882 & -0.873932 \\ \mathrm{C} & 5.523313 & 0.012103 & -0.956205 \\ \mathrm{C} & 6.266786 & 1.003433 & -0.290867 \\ \mathrm{C} & 6.207368 & -1.009742 & -1.636553 \\ \mathrm{C} & 7.656655 & 0.969159 & -0.308180 \\ \mathrm{H} & 5.753475 & 1.783926 & 0.258647 \\ \mathrm{C} & 7.600224 & -1.030692 & -1.667425 \\ \mathrm{H} & 5.643981 & -1.771170 & -2.166313 \\ \mathrm{C} & 8.327457 & -0.043478 & -1.001259 \\ \mathrm{H} & 8.219876 & 1.736387 & 0.215320 \\ \mathrm{H} & 8.114998 & -1.817286 & -2.211116 \\ \mathrm{H} & 9.413674 & -0.060696 & -1.021339 \\ \mathrm{H} & 6.695004 & 0.093527 & 3.261278\end{array}$

Catalyst (R)-1 TS Conformation 84

B3LYP/6-31G(d) Energy $=-2809.69957$

B3LYP-D3(BJ)/def2-TZVPP-IEF-PCM(DCM) Energy $=-2810.987793$

B3LYP-D3(BJ)/def2-TZVPP-IEF-PCM(DCM)//B3LYP/6-31G(d) Free Energy (Quasiharmonic) = 2810.34484

Frequencies (Top 3 out of 270)

1. $-304.3169 \mathrm{~cm}-1$

2. $\quad 8.5978 \mathrm{~cm}-1$

3. $12.1264 \mathrm{~cm}-1$

B3LYP/6-31G(d) Molecular Geometry in Cartesian Coordinates

$\begin{array}{llll}\text { C } & 3.146174 & -0.909990 & -0.370921 \\ \text { C } & 1.908422 & -1.536081 & -0.405004 \\ \text { C } & 1.716056 & -2.854337 & -0.918486 \\ \text { C } & 2.806137 & -3.472708 & -1.498933 \\ \text { H } & 2.689058 & -4.474043 & -1.904995 \\ \text { C } & 3.639649 & 2.849111 & 1.697680 \\ \text { C } & 3.318989 & 0.366191 & 0.386306 \\ \text { C } & 2.514777 & 1.458511 & 0.106105 \\ \text { C } & 2.670695 & 2.734494 & 0.720757 \\ \text { H } & 3.801864 & 3.813622 & 2.171570 \\ \text { O } & 0.820048 & -0.906612 & 0.185855 \\ \text { P } & 0.186424 & 0.462088 & -0.448940\end{array}$




\begin{tabular}{|c|c|c|c|}
\hline $\mathrm{O}$ & 1.510739 & 1.319038 & -0.849949 \\
\hline C & -1.950791 & -5.080476 & -0.523294 \\
\hline C & -0.740564 & -5.611958 & -0.072415 \\
\hline C & 0.437771 & -4.874865 & -0.198070 \\
\hline C & 0.429600 & -3.594478 & -0.777043 \\
\hline C & -0.792020 & -3.073863 & -1.230652 \\
\hline C & -1.969345 & -3.809958 & -1.103738 \\
\hline $\mathrm{H}$ & -0.711853 & -6.600081 & 0.379990 \\
\hline $\mathrm{H}$ & -2.898129 & -3.380440 & -1.469956 \\
\hline C & 0.415025 & 6.234970 & -0.357804 \\
\hline C & 0.989400 & 5.439752 & -1.352382 \\
\hline C & 1.695251 & 4.286523 & -1.013261 \\
\hline C & 1.850459 & 3.912984 & 0.332174 \\
\hline C & 1.267378 & 4.719117 & 1.322205 \\
\hline C & 0.554218 & 5.868303 & 0.981128 \\
\hline $\mathrm{H}$ & 0.896943 & 5.724302 & -2.397614 \\
\hline $\mathrm{H}$ & 0.104425 & 6.474436 & 1.763154 \\
\hline C & 4.275456 & 0.482825 & 1.455976 \\
\hline C & 4.434535 & 1.750000 & 2.105775 \\
\hline C & 5.380930 & 1.882621 & 3.157882 \\
\hline C & 6.123144 & 0.805569 & 3.582469 \\
\hline C & 5.940112 & -0.456382 & 2.970489 \\
\hline C & 5.043752 & -0.613562 & 1.936117 \\
\hline $\mathrm{H}$ & 5.496892 & 2.855282 & 3.630092 \\
\hline $\mathrm{H}$ & 6.838869 & 0.917237 & 4.392264 \\
\hline $\mathrm{H}$ & 6.508992 & -1.312734 & 3.322422 \\
\hline $\mathrm{H}$ & 4.910637 & -1.590249 & 1.486626 \\
\hline C & 4.243921 & -1.525602 & -1.066408 \\
\hline C & 4.061459 & -2.829428 & -1.629698 \\
\hline C & 5.139281 & -3.450161 & -2.317252 \\
\hline C & 6.345794 & -2.807254 & -2.468554 \\
\hline C & 6.519583 & -1.506693 & -1.939572 \\
\hline C & 5.498789 & -0.883834 & -1.255491 \\
\hline $\mathrm{H}$ & 4.985296 & -4.443027 & -2.733231 \\
\hline $\mathrm{H}$ & 7.160689 & -3.288687 & -3.002098 \\
\hline $\mathrm{H}$ & 7.465645 & -0.990814 & -2.079685 \\
\hline $\mathrm{H}$ & 5.644312 & 0.117194 & -0.865837 \\
\hline $\mathrm{O}$ & -0.708943 & 1.068940 & 0.578778 \\
\hline $\mathrm{O}$ & -0.414519 & 0.165221 & -1.851047 \\
\hline $\mathrm{H}$ & -1.498836 & 0.152578 & -1.855271 \\
\hline $\mathrm{H}$ & -0.820458 & -2.100240 & -1.702077 \\
\hline $\mathrm{H}$ & -2.869160 & -5.654135 & -0.427446 \\
\hline $\mathrm{H}$ & 1.374550 & -5.286183 & 0.168942 \\
\hline $\mathrm{H}$ & 1.359803 & 4.428810 & 2.365024 \\
\hline
\end{tabular}




\begin{tabular}{llll}
$\mathrm{H}$ & -0.136079 & 7.132762 & -0.625112 \\
$\mathrm{H}$ & 2.142240 & 3.677877 & -1.792444 \\
$\mathrm{C}$ & -3.775672 & 0.771568 & -1.712892 \\
$\mathrm{O}$ & -2.859289 & -0.125841 & -1.736826 \\
$\mathrm{H}$ & -4.815127 & 0.434935 & -1.832822 \\
$\mathrm{C}$ & -3.592639 & 2.100405 & -2.454587 \\
$\mathrm{O}$ & -4.521201 & 2.788205 & -2.824207 \\
$\mathrm{O}$ & -2.298786 & 2.397858 & -2.631127 \\
$\mathrm{C}$ & -2.025860 & 3.631173 & -3.317329 \\
$\mathrm{H}$ & -2.499786 & 4.468556 & -2.798878 \\
$\mathrm{H}$ & -0.941712 & 3.734118 & -3.303771 \\
$\mathrm{C}$ & -4.198551 & 0.428270 & 0.840199 \\
$\mathrm{C}$ & -3.984629 & 1.573607 & 0.043992 \\
$\mathrm{H}$ & -2.183975 & 0.180444 & 0.987354 \\
$\mathrm{~N}$ & -3.099657 & -0.244408 & 1.234583 \\
$\mathrm{C}$ & -3.006031 & -1.379813 & 2.066615 \\
$\mathrm{O}$ & -3.918040 & -1.953353 & 2.615073 \\
$\mathrm{O}$ & -1.708944 & -1.695388 & 2.153705 \\
$\mathrm{C}$ & -1.402398 & -2.864449 & 2.931782 \\
$\mathrm{H}$ & -0.315966 & -2.935980 & 2.914148 \\
$\mathrm{H}$ & -1.850436 & -3.748231 & 2.471724 \\
$\mathrm{H}$ & -1.772190 & -2.750044 & 3.953733 \\
$\mathrm{H}$ & -4.843164 & 2.217215 & -0.119211 \\
$\mathrm{H}$ & -3.024349 & 2.073574 & 0.151024 \\
$\mathrm{C}$ & -5.574807 & -0.089346 & 1.007209 \\
$\mathrm{C}$ & -6.583084 & 0.784387 & 1.444974 \\
$\mathrm{C}$ & -5.917753 & -1.397447 & 0.626326 \\
$\mathrm{C}$ & -7.904357 & 0.349868 & 1.531117 \\
$\mathrm{H}$ & -6.323993 & 1.796638 & 1.740879 \\
$\mathrm{C}$ & -7.242955 & -1.817212 & 0.686654 \\
$\mathrm{H}$ & -5.149653 & -2.073462 & 0.268670 \\
$\mathrm{H}$ & -8.236989 & -0.949814 & 1.147311 \\
$\mathrm{H}$ & -8.672415 & 1.028526 & 1.890583 \\
-7.500408 & -2.826095 & 0.377452 \\
-9.268570 & -1.286355 & 1.203189 \\
\hline & -2.401107 & 3.584464 & -4.343155
\end{tabular}

Catalyst (R)-1 TS Conformation 85

B3LYP/6-31G(d) Energy $=-2809.699195$

B3LYP-D3(BJ)/def2-TZVPP-IEF-PCM(DCM) Energy $=-2810.988038$

B3LYP-D3(BJ)/def2-TZVPP-IEF-PCM(DCM)//B3LYP/6-31G(d) Free Energy (Quasiharmonic) = 2810.344797 
Frequencies (Top 3 out of 270)

1. $-294.0507 \mathrm{~cm}-1$

2. $\quad 7.7000 \mathrm{~cm}-1$

3. $\quad 12.7038 \mathrm{~cm}-1$

B3LYP/6-31G(d) Molecular Geometry in Cartesian Coordinates

$\begin{array}{llll}\text { C } & 3.311941 & -0.962899 & -0.368127 \\ \text { C } & 2.039215 & -1.506601 & -0.269009 \\ \text { C } & 1.752876 & -2.878419 & -0.542087 \\ \text { C } & 2.785731 & -3.656717 & -1.025815 \\ \text { H } & 2.597271 & -4.704060 & -1.246946 \\ \text { C } & 4.101225 & 3.043920 & 1.038686 \\ \text { C } & 3.587434 & 0.407032 & 0.161607 \\ \text { C } & 2.838398 & 1.489270 & -0.270084 \\ \text { C } & 3.084230 & 2.835731 & 0.127671 \\ \text { H } & 4.336855 & 4.059483 & 1.345322 \\ \text { O } & 1.005573 & -0.718780 & 0.225167 \\ \text { P } & 0.441493 & 0.560441 & -0.621330 \\ \text { O } & 1.799480 & 1.260720 & -1.170944 \\ \text { C } & -2.046683 & -4.719802 & 0.309214 \\ \text { C } & -0.866161 & -5.243848 & 0.841074 \\ \text { C } & 0.358797 & -4.634572 & 0.564412 \\ \text { C } & 0.425834 & -3.492954 & -0.251443 \\ \text { C } & -0.766211 & -2.984587 & -0.788035 \\ \text { C } & -1.991244 & -3.588133 & -0.508063 \\ \text { H } & -0.897051 & -6.125980 & 1.475797 \\ \text { H } & -2.894579 & -3.161966 & -0.936487 \\ \text { C } & 0.904588 & 6.234080 & -1.359830 \\ \text { C } & 1.155723 & 6.094846 & 0.005685 \\ \text { C } & 1.845558 & 4.979960 & 0.480399 \\ \text { C } & 2.297767 & 3.983020 & -0.399329 \\ \text { C } & 2.033503 & 4.131948 & -1.771295 \\ \text { C } & 1.345930 & 5.248068 & -2.244714 \\ \text { H } & 0.808129 & 6.850533 & 0.705330 \\ \text { H } & 1.157260 & 5.348309 & -3.310370 \\ \text { C } & 4.589678 & 0.634128 & 1.170181 \\ \text { C } & 4.849840 & 1.977839 & 1.594307 \\ \text { C } & 5.845817 & 2.220017 & 2.579159 \\ \text { C } & 6.539467 & 1.181614 & 3.154990 \\ \text { C } & 6.255354 & -0.149351 & 2.769878 \\ \text { C } & 5.309358 & -0.415956 & 1.804393\end{array}$




\begin{tabular}{|c|c|c|c|}
\hline $\mathrm{H}$ & 6.038628 & 3.247575 & 2.878196 \\
\hline $\mathrm{H}$ & 7.293704 & 1.378303 & 3.911921 \\
\hline $\mathrm{H}$ & 6.785293 & -0.971435 & 3.243334 \\
\hline $\mathrm{H}$ & 5.099360 & -1.442752 & 1.530272 \\
\hline C & 4.347640 & -1.757826 & -0.971699 \\
\hline C & 4.071617 & -3.125637 & -1.293873 \\
\hline C & 5.088548 & -3.922326 & -1.886159 \\
\hline C & 6.324049 & -3.391803 & -2.175996 \\
\hline C & 6.589583 & -2.032416 & -1.888073 \\
\hline C & 5.629950 & -1.238036 & -1.299870 \\
\hline $\mathrm{H}$ & 4.863986 & -4.960758 & -2.117988 \\
\hline $\mathrm{H}$ & 7.091546 & -4.008389 & -2.635637 \\
\hline $\mathrm{H}$ & 7.558032 & -1.608368 & -2.139174 \\
\hline $\mathrm{H}$ & 5.845465 & -0.195502 & -1.095619 \\
\hline $\mathrm{O}$ & -0.415040 & 1.372007 & 0.291136 \\
\hline 0 & -0.200151 & 0.087853 & -1.960265 \\
\hline $\mathrm{H}$ & -1.280332 & 0.006677 & -1.894394 \\
\hline $\mathrm{H}$ & -0.733983 & -2.124735 & -1.443074 \\
\hline $\mathrm{H}$ & -3.000546 & -5.193746 & 0.526862 \\
\hline $\mathrm{H}$ & 1.272664 & -5.034936 & 0.995805 \\
\hline $\mathrm{H}$ & 2.374944 & 3.374826 & -2.468819 \\
\hline $\mathrm{H}$ & 0.366025 & 7.101687 & -1.731827 \\
\hline $\mathrm{H}$ & 2.018316 & 4.865421 & 1.546865 \\
\hline C & -3.404980 & 0.798003 & -1.942113 \\
\hline $\mathrm{O}$ & -2.634535 & -0.196240 & -1.726651 \\
\hline $\mathrm{H}$ & -3.031664 & 1.672570 & -2.495224 \\
\hline C & -4.866915 & 0.547331 & -2.299898 \\
\hline $\mathrm{O}$ & -5.603702 & 1.417233 & -2.717231 \\
\hline 0 & -5.222262 & -0.735590 & -2.129897 \\
\hline C & -6.580925 & -1.042316 & -2.490610 \\
\hline $\mathrm{H}$ & -6.772037 & -0.759756 & -3.528743 \\
\hline $\mathrm{H}$ & -6.679548 & -2.120229 & -2.360426 \\
\hline C & -3.934543 & 1.009259 & 0.704517 \\
\hline C & -3.647481 & 1.943817 & -0.305839 \\
\hline $\mathrm{H}$ & -1.944230 & 0.619594 & 0.849852 \\
\hline$N$ & -2.875525 & 0.326158 & 1.197792 \\
\hline C & -2.818270 & -0.604794 & 2.252470 \\
\hline $\mathrm{O}$ & -3.735114 & -0.978720 & 2.947140 \\
\hline $\mathrm{O}$ & -1.541818 & -0.995861 & 2.359163 \\
\hline C & -1.276270 & -1.989602 & 3.362064 \\
\hline $\mathrm{H}$ & -1.586013 & -1.631203 & 4.346886 \\
\hline $\mathrm{H}$ & -0.199253 & -2.146259 & 3.323736 \\
\hline $\mathrm{H}$ & -1.804821 & -2.915177 & 3.121844 \\
\hline $\mathrm{H}$ & -4.448878 & 2.597425 & -0.630945 \\
\hline
\end{tabular}




$\begin{array}{llll}\text { H } & -2.644832 & 2.362788 & -0.317461 \\ \mathrm{C} & -5.339463 & 0.704778 & 1.059090 \\ \mathrm{C} & -5.841379 & -0.607558 & 1.083603 \\ \mathrm{C} & -6.216578 & 1.775882 & 1.298173 \\ \mathrm{C} & -7.188824 & -0.835490 & 1.345991 \\ \mathrm{H} & -5.181648 & -1.441112 & 0.878898 \\ \mathrm{C} & -7.560553 & 1.541518 & 1.582901 \\ \mathrm{H} & -5.835594 & 2.792391 & 1.285766 \\ \mathrm{C} & -8.049758 & 0.235255 & 1.604352 \\ \mathrm{H} & -7.567549 & -1.853614 & 1.356870 \\ \mathrm{H} & -8.222743 & 2.378674 & 1.783563 \\ \mathrm{H} & -9.098372 & 0.049891 & 1.820793 \\ \mathrm{H} & -7.277477 & -0.510929 & -1.837463\end{array}$

Catalyst (R)-1 TS Conformation 86

B3LYP/6-31G(d) Energy $=-2809.692182$

B3LYP-D3(BJ)/def2-TZVPP-IEF-PCM(DCM) Energy $=-2810.986746$

B3LYP-D3(BJ)/def2-TZVPP-IEF-PCM(DCM)//B3LYP/6-31G(d) Free Energy (Quasiharmonic) = 2810.344752

Frequencies (Top 3 out of 270)

1. $-451.0514 \mathrm{~cm}-1$

2. $\quad 9.7781 \mathrm{~cm}-1$

3. $12.1755 \mathrm{~cm}-1$

B3LYP/6-31G(d) Molecular Geometry in Cartesian Coordinates

$\begin{array}{llll}\mathrm{C} & -2.823488 & -1.398682 & 0.239988 \\ \mathrm{C} & -1.616464 & -1.877240 & -0.242748 \\ \mathrm{C} & -1.111338 & -3.179697 & 0.045805 \\ \mathrm{C} & -1.865513 & -3.976838 & 0.884304 \\ \mathrm{H} & -1.527353 & -4.986256 & 1.103513 \\ \mathrm{C} & -4.262944 & 2.555908 & -0.689104 \\ \mathrm{C} & -3.306345 & -0.048722 & -0.179718 \\ \mathrm{C} & -2.505041 & 1.071429 & 0.008144 \\ \mathrm{C} & -2.981039 & 2.402603 & -0.198532 \\ \mathrm{H} & -4.645364 & 3.558654 & -0.861539 \\ \mathrm{O} & -0.863334 & -1.052164 & -1.064130 \\ \mathrm{P} & -0.040867 & 0.183936 & -0.357492 \\ \mathrm{O} & -1.228858 & 0.918337 & 0.520502 \\ \mathrm{C} & 2.586755 & -4.711607 & -1.539128\end{array}$




\begin{tabular}{|c|c|c|c|}
\hline C & 2.265583 & -4.884484 & -0.192162 \\
\hline C & 1.073198 & -4.368983 & 0.315005 \\
\hline C & 0.175658 & -3.674073 & -0.512575 \\
\hline C & 0.514578 & -3.501006 & -1.866253 \\
\hline C & 1.707808 & -4.014434 & -2.372179 \\
\hline $\mathrm{H}$ & 2.946911 & -5.411940 & 0.470295 \\
\hline $\mathrm{H}$ & 1.951208 & -3.871480 & -3.421453 \\
\hline C & -0.766739 & 5.976433 & 0.734908 \\
\hline C & -0.188807 & 4.990121 & -0.068135 \\
\hline C & -0.880920 & 3.813878 & -0.359051 \\
\hline C & -2.176857 & 3.609913 & 0.142925 \\
\hline C & -2.748644 & 4.608689 & 0.947937 \\
\hline C & -2.050476 & 5.779914 & 1.244396 \\
\hline $\mathrm{H}$ & 0.802122 & 5.139633 & -0.490251 \\
\hline $\mathrm{H}$ & -2.510770 & 6.536182 & 1.875212 \\
\hline C & -4.598321 & 0.124316 & -0.787527 \\
\hline C & -5.079667 & 1.450752 & -1.030108 \\
\hline C & -6.357862 & 1.634313 & -1.623778 \\
\hline C & -7.128901 & 0.556276 & -1.991231 \\
\hline C & -6.642688 & -0.756123 & -1.784277 \\
\hline C & -5.414090 & -0.966636 & -1.197683 \\
\hline $\mathrm{H}$ & -6.709276 & 2.649553 & -1.793065 \\
\hline $\mathrm{H}$ & -8.101995 & 0.708231 & -2.450260 \\
\hline $\mathrm{H}$ & -7.241354 & -1.607411 & -2.097166 \\
\hline $\mathrm{H}$ & -5.052058 & -1.978520 & -1.057252 \\
\hline C & -3.555607 & -2.209796 & 1.176014 \\
\hline C & -3.067620 & -3.522416 & 1.480255 \\
\hline C & -3.788046 & -4.342061 & 2.391034 \\
\hline C & -4.926841 & -3.882200 & 3.010092 \\
\hline C & -5.387654 & -2.571471 & 2.744789 \\
\hline C & -4.722634 & -1.759148 & 1.852502 \\
\hline $\mathrm{H}$ & -3.409863 & -5.340267 & 2.599311 \\
\hline $\mathrm{H}$ & -5.465050 & -4.515509 & 3.710080 \\
\hline $\mathrm{H}$ & -6.272914 & -2.198883 & 3.253233 \\
\hline $\mathrm{H}$ & -5.084810 & -0.754552 & 1.669133 \\
\hline $\mathrm{O}$ & 0.528477 & 1.028399 & -1.446570 \\
\hline $\mathrm{O}$ & 0.871066 & -0.340942 & 0.754899 \\
\hline $\mathrm{H}$ & 2.026134 & -0.861794 & 0.612896 \\
\hline $\mathrm{H}$ & -0.161210 & -2.965272 & -2.523268 \\
\hline $\mathrm{H}$ & 3.513824 & -5.113096 & -1.940299 \\
\hline $\mathrm{H}$ & 0.842664 & -4.482638 & 1.370386 \\
\hline $\mathrm{H}$ & -3.744022 & 4.455351 & 1.356370 \\
\hline $\mathrm{H}$ & -0.222592 & 6.890406 & 0.959305 \\
\hline $\mathrm{H}$ & -0.420465 & 3.056595 & -0.984416 \\
\hline
\end{tabular}




$\begin{array}{llll}\mathrm{C} & 3.635929 & -0.979667 & -0.573387 \\ \mathrm{O} & 3.066335 & -1.316471 & 0.521769 \\ \mathrm{H} & 3.056262 & -0.526537 & -1.380555 \\ \mathrm{C} & 4.788504 & -1.837702 & -1.060550 \\ \mathrm{O} & 5.066868 & -1.948979 & -2.233810 \\ \mathrm{O} & 5.433120 & -2.441254 & -0.051888 \\ \mathrm{C} & 6.510784 & -3.306852 & -0.449393 \\ \mathrm{H} & 6.131416 & -4.126240 & -1.065304 \\ \mathrm{H} & 7.260815 & -2.751001 & -1.018439 \\ \mathrm{C} & 4.025394 & 1.652505 & 0.201064 \\ \mathrm{C} & 4.887146 & 0.729693 & -0.384939 \\ \mathrm{H} & 2.533239 & 3.035549 & 0.028647 \\ \mathrm{~N} & 3.162102 & 2.442242 & -0.500022 \\ \mathrm{C} & 2.947245 & 2.447812 & -1.889390 \\ \mathrm{O} & 3.493278 & 1.716298 & -2.682401 \\ \mathrm{O} & 2.083155 & 3.427928 & -2.174189 \\ \mathrm{C} & 1.534915 & 3.382523 & -3.509211 \\ \mathrm{H} & 0.892466 & 4.259398 & -3.581658 \\ \mathrm{H} & 0.955427 & 2.464011 & -3.617404 \\ \mathrm{H} & 2.336653 & 3.422389 & -4.249372 \\ \mathrm{H} & 5.622891 & 0.284199 & 0.274438 \\ \mathrm{H} & 5.124729 & 0.808483 & -1.437352 \\ \mathrm{C} & 3.932779 & 1.774727 & 1.672385 \\ \mathrm{C} & 2.685641 & 1.869655 & 2.317251 \\ \mathrm{C} & 5.108249 & 1.799290 & 2.444241 \\ \mathrm{C} & 2.624836 & 1.988814 & 3.704247 \\ \mathrm{H} & 1.765007 & 1.770126 & 1.752003 \\ \mathrm{C} & 5.039232 & 1.934312 & 3.827616 \\ \mathrm{H} & 6.074953 & 1.746683 & 1.953118 \\ \mathrm{C} & 3.797182 & 2.029104 & 4.460473 \\ \mathrm{H} & 1.655930 & 2.035880 & 4.191968 \\ \mathrm{H} & 5.954415 & 1.968964 & 4.411630 \\ \mathrm{H} & 3.744297 & 2.127144 & 5.541223 \\ \mathrm{H} & 6.933943 & -3.688854 & 0.479500\end{array}$

Catalyst (R)-1 TS Conformation 87

B3LYP/6-31G(d) Energy $=-2809.696698$

B3LYP-D3(BJ)/def2-TZVPP-IEF-PCM(DCM) Energy = -2810.987282

B3LYP-D3(BJ)/def2-TZVPP-IEF-PCM(DCM)//B3LYP/6-31G(d) Free Energy (Quasiharmonic) = 2810.344637

Frequencies (Top 3 out of 270) 
1. $-385.8229 \mathrm{~cm}-1$

2. $\quad 10.9198 \mathrm{~cm}-1$

3. $\quad 16.0833 \mathrm{~cm}-1$

B3LYP/6-31G(d) Molecular Geometry in Cartesian Coordinates

$\begin{array}{llll}\mathrm{C} & 3.362500 & 0.834638 & 0.030121 \\ \mathrm{C} & 2.246097 & 1.645247 & -0.092534 \\ \mathrm{C} & 2.183376 & 2.987422 & 0.385366 \\ \mathrm{C} & 3.301744 & 3.468326 & 1.039487 \\ \mathrm{H} & 3.307550 & 4.496890 & 1.389764 \\ \mathrm{C} & 3.460978 & -3.201768 & -1.475926 \\ \mathrm{C} & 3.364205 & -0.527609 & -0.581517 \\ \mathrm{C} & 2.366963 & -1.440444 & -0.265440 \\ \mathrm{C} & 2.411145 & -2.808039 & -0.669879 \\ \mathrm{H} & 3.516444 & -4.237872 & -1.799513 \\ \mathrm{O} & 1.126783 & 1.124234 & -0.737974 \\ \mathrm{P} & 0.213626 & 0.040174 & 0.064528 \\ \mathrm{O} & 1.326948 & -1.048518 & 0.571083 \\ \mathrm{C} & -1.185880 & 5.618340 & -0.107215 \\ \mathrm{C} & -0.787401 & 4.795814 & -1.162644 \\ \mathrm{C} & 0.288185 & 3.922082 & -1.008541 \\ \mathrm{C} & 0.988673 & 3.855347 & 0.207306 \\ \mathrm{C} & 0.567457 & 4.679009 & 1.265713 \\ \mathrm{C} & -0.506662 & 5.553056 & 1.110721 \\ \mathrm{H} & -1.317040 & 4.823217 & -2.110051 \\ \mathrm{H} & -0.817445 & 6.176500 & 1.945136 \\ \mathrm{C} & -0.397591 & -5.835161 & 0.546447 \\ \mathrm{C} & -0.853730 & -4.679085 & -0.091800 \\ \mathrm{C} & 0.039725 & -3.675898 & -0.468947 \\ \mathrm{C} & 1.413633 & -3.820121 & -0.219040 \\ \mathrm{C} & 1.862818 & -4.986966 & 0.420675 \\ \mathrm{C} & 0.965980 & -5.985025 & 0.803385 \\ \mathrm{H} & -1.912982 & -4.560414 & -0.306826 \\ \mathrm{H} & 1.333910 & -6.878142 & 1.301884 \\ \mathrm{C} & 4.388853 & -0.926967 & -1.508875 \\ \mathrm{C} & 4.437744 & -2.289915 & -1.944326 \\ \mathrm{C} & 5.451584 & -2.698837 & -2.852595 \\ \mathrm{C} & 6.370063 & -1.798203 & -3.339001 \\ \mathrm{C} & 5.303572 & -0.442893 & -2.938486 \\ \mathrm{H} & 5.477335 & -3.739891 & -3.165867 \\ \mathrm{C} & -2.136845 & -2.119925 & -4.038364\end{array}$




\begin{tabular}{|c|c|c|c|}
\hline $\mathrm{H}$ & 7.013913 & 0.273140 & -3.342863 \\
\hline $\mathrm{H}$ & 5.298936 & 1.024962 & -1.760029 \\
\hline C & 4.482411 & 1.323094 & 0.789741 \\
\hline C & 4.444618 & 2.668006 & 1.281160 \\
\hline C & 5.549209 & 3.173277 & 2.019606 \\
\hline C & 6.637081 & 2.379519 & 2.298361 \\
\hline C & 6.658597 & 1.037572 & 1.851554 \\
\hline C & 5.612552 & 0.524100 & 1.116510 \\
\hline $\mathrm{H}$ & 5.508764 & 4.200821 & 2.373279 \\
\hline $\mathrm{H}$ & 7.472189 & 2.774226 & 2.870550 \\
\hline $\mathrm{H}$ & 7.506661 & 0.402963 & 2.094321 \\
\hline $\mathrm{H}$ & 5.642438 & -0.509002 & 0.791228 \\
\hline $\mathrm{O}$ & -0.798897 & -0.525017 & -0.883023 \\
\hline 0 & -0.286274 & 0.678925 & 1.376561 \\
\hline $\mathrm{H}$ & -1.368124 & 0.555605 & 1.583379 \\
\hline $\mathrm{H}$ & 1.074209 & 4.613726 & 2.224284 \\
\hline $\mathrm{H}$ & -2.020655 & 6.304102 & -0.231212 \\
\hline $\mathrm{H}$ & 0.586054 & 3.291186 & -1.837985 \\
\hline $\mathrm{H}$ & 2.923239 & -5.103038 & 0.628529 \\
\hline $\mathrm{H}$ & -1.098374 & -6.613535 & 0.837127 \\
\hline $\mathrm{H}$ & -0.323869 & -2.784048 & -0.968088 \\
\hline C & -3.391061 & -0.492267 & 1.966657 \\
\hline $\mathrm{O}$ & -2.698712 & 0.565385 & 1.731550 \\
\hline $\mathrm{H}$ & -4.430728 & -0.334954 & 2.285272 \\
\hline C & -2.803311 & -1.662291 & 2.767354 \\
\hline $\mathrm{O}$ & -3.486349 & -2.423973 & 3.419662 \\
\hline $\mathrm{O}$ & -1.476011 & -1.731317 & 2.632374 \\
\hline C & -0.808447 & -2.801295 & 3.327829 \\
\hline $\mathrm{H}$ & 0.244576 & -2.687844 & 3.075478 \\
\hline $\mathrm{H}$ & -0.968979 & -2.706683 & 4.404731 \\
\hline C & -4.280502 & -0.541132 & -0.487365 \\
\hline C & -3.684345 & -1.498548 & 0.364933 \\
\hline $\mathrm{H}$ & -2.435151 & 0.098984 & -1.082568 \\
\hline$N$ & -3.444809 & 0.348077 & -1.068440 \\
\hline C & -3.659240 & 1.696464 & -1.431820 \\
\hline $\mathrm{O}$ & -2.865210 & 2.300053 & -2.114241 \\
\hline $\mathrm{O}$ & -4.778885 & 2.199989 & -0.900267 \\
\hline C & -5.005370 & 3.593627 & -1.180876 \\
\hline $\mathrm{H}$ & -5.082708 & 3.760288 & -2.258269 \\
\hline $\mathrm{H}$ & -4.186337 & 4.193036 & -0.776910 \\
\hline $\mathrm{H}$ & -5.944772 & 3.834970 & -0.684077 \\
\hline $\mathrm{H}$ & -4.288467 & -2.361067 & 0.630899 \\
\hline $\mathrm{H}$ & -2.639738 & -1.719257 & 0.158938 \\
\hline C & -5.735998 & -0.502337 & -0.710139 \\
\hline
\end{tabular}




$\begin{array}{lrrr}\text { C } & -6.249816 & -0.141673 & -1.969562 \\ \text { C } & -6.628704 & -0.921413 & 0.292227 \\ \text { C } & -7.618391 & -0.190014 & -2.213966 \\ \text { H } & -5.569560 & 0.141995 & -2.766565 \\ \text { C } & -7.999622 & -0.948405 & 0.049171 \\ \text { H } & -6.253138 & -1.209002 & 1.268735 \\ \text { C } & -8.498603 & -0.584969 & -1.203307 \\ \text { H } & -7.998699 & 0.076203 & -3.196021 \\ \text { H } & -8.678063 & -1.258093 & 0.838742 \\ \text { H } & -9.567651 & -0.617004 & -1.394071 \\ \text { H } & -1.183445 & -3.767631 & 2.983370\end{array}$

Catalyst (R)-1 TS Conformation 88

B3LYP/6-31G(d) Energy = -2809.697303

B3LYP-D3(BJ)/def2-TZVPP-IEF-PCM(DCM) Energy = -2810.985625

B3LYP-D3(BJ)/def2-TZVPP-IEF-PCM(DCM)//B3LYP/6-31G(d) Free Energy (Quasiharmonic) = 2810.344633

Frequencies (Top 3 out of 270)

1. $-693.0387 \mathrm{~cm}-1$

2. $\quad 7.3712 \mathrm{~cm}-1$

3. $\quad 11.6637 \mathrm{~cm}-1$

B3LYP/6-31G(d) Molecular Geometry in Cartesian Coordinates

$\begin{array}{llll}\text { C } & -3.585844 & -0.868209 & -0.035779 \\ \text { C } & -2.467316 & -1.616606 & -0.360520 \\ \text { C } & -2.422691 & -3.039646 & -0.304104 \\ \text { C } & -3.555100 & -3.686962 & 0.148976 \\ \text { H } & -3.567143 & -4.773256 & 0.182540 \\ \text { C } & -3.606387 & 3.432024 & -0.313284 \\ \text { C } & -3.562122 & 0.614035 & -0.216495 \\ \text { C } & -2.574054 & 1.380720 & 0.387977 \\ \text { C } & -2.593680 & 2.808608 & 0.389374 \\ \text { H } & -3.641653 & 4.518151 & -0.331954 \\ \text { O } & -1.319846 & -0.942279 & -0.768613 \\ \text { P } & -0.451201 & -0.188526 & 0.397003 \\ \text { O } & -1.575643 & 0.750471 & 1.120810 \\ \text { C } & 0.997749 & -5.367908 & -1.484255 \\ \text { C } & 0.342988 & -5.630724 & -0.280567 \\ \text { C } & -0.754236 & -4.860073 & 0.102815\end{array}$




\begin{tabular}{|c|c|c|c|}
\hline$C$ & -1.217825 & -3.811875 & -0.708238 \\
\hline C & -0.545478 & -3.552231 & -1.914692 \\
\hline C & 0.549027 & -4.325569 & -2.298556 \\
\hline $\mathrm{H}$ & 0.691079 & -6.430539 & 0.367656 \\
\hline $\mathrm{H}$ & 1.048791 & -4.116151 & -3.241030 \\
\hline C & 0.174351 & 5.315413 & 2.530392 \\
\hline C & 0.654962 & 4.338011 & 1.656413 \\
\hline C & -0.227088 & 3.502446 & 0.971126 \\
\hline C & -1.613193 & 3.635669 & 1.147930 \\
\hline C & -2.086527 & 4.623088 & 2.027599 \\
\hline C & -1.201851 & 5.454901 & 2.714181 \\
\hline $\mathrm{H}$ & 1.724385 & 4.219022 & 1.502244 \\
\hline $\mathrm{H}$ & -1.589407 & 6.206670 & 3.397009 \\
\hline C & -4.547042 & 1.278383 & -1.027544 \\
\hline C & -4.569801 & 2.709373 & -1.057332 \\
\hline C & -5.543459 & 3.377968 & -1.847993 \\
\hline C & -6.447752 & 2.670003 & -2.604602 \\
\hline C & -6.406313 & 1.255817 & -2.605239 \\
\hline C & -5.484140 & 0.578888 & -1.837702 \\
\hline $\mathrm{H}$ & -5.550202 & 4.465470 & -1.851093 \\
\hline $\mathrm{H}$ & -7.184079 & 3.191302 & -3.210167 \\
\hline $\mathrm{H}$ & -7.105026 & 0.697214 & -3.222213 \\
\hline $\mathrm{H}$ & -5.459751 & -0.504376 & -1.858865 \\
\hline C & -4.729676 & -1.551838 & 0.506643 \\
\hline C & -4.705747 & -2.982692 & 0.581950 \\
\hline C & -5.832479 & -3.673198 & 1.105254 \\
\hline C & -6.930198 & -2.987382 & 1.570171 \\
\hline C & -6.939929 & -1.573375 & 1.535582 \\
\hline C & -5.871421 & -0.875116 & 1.017135 \\
\hline $\mathrm{H}$ & -5.801994 & -4.759583 & 1.143241 \\
\hline $\mathrm{H}$ & -7.782493 & -3.525953 & 1.975301 \\
\hline $\mathrm{H}$ & -7.796592 & -1.031291 & 1.926881 \\
\hline $\mathrm{H}$ & -5.891708 & 0.208212 & 1.008559 \\
\hline 0 & 0.638554 & 0.570460 & -0.291046 \\
\hline $\mathrm{O}$ & -0.071085 & -1.181094 & 1.504887 \\
\hline $\mathrm{H}$ & 1.023691 & -1.626915 & 1.569496 \\
\hline $\mathrm{H}$ & -0.888943 & -2.747697 & -2.556235 \\
\hline $\mathrm{H}$ & 1.852943 & -5.967902 & -1.784294 \\
\hline $\mathrm{H}$ & -1.245667 & -5.053332 & 1.052100 \\
\hline $\mathrm{H}$ & -3.156985 & 4.724526 & 2.185568 \\
\hline $\mathrm{H}$ & 0.866025 & 5.960271 & 3.066468 \\
\hline $\mathrm{H}$ & 0.161884 & 2.753315 & 0.291238 \\
\hline C & 3.006107 & -1.086894 & 1.456617 \\
\hline $\mathrm{O}$ & 2.179043 & -2.031889 & 1.690996 \\
\hline
\end{tabular}




$\begin{array}{llll}\text { H } & 2.655012 & -0.049022 & 1.466358 \\ \mathrm{C} & 4.425703 & -1.207104 & 1.970267 \\ \mathrm{O} & 5.066845 & -0.233409 & 2.310504 \\ \mathrm{O} & 4.866209 & -2.469570 & 2.001348 \\ \mathrm{C} & 6.210476 & -2.638509 & 2.488303 \\ \mathrm{H} & 6.916636 & -2.101454 & 1.849543 \\ \mathrm{H} & 6.294299 & -2.264286 & 3.511605 \\ \mathrm{C} & 4.056132 & 0.079947 & -0.866080 \\ \mathrm{C} & 3.397210 & -1.118627 & -0.562663 \\ \mathrm{H} & 2.288647 & 1.083835 & -0.703055 \\ \mathrm{~N} & 3.291716 & 1.208863 & -0.922394 \\ \mathrm{C} & 3.631330 & 2.459298 & -1.457343 \\ \mathrm{O} & 4.661735 & 2.758313 & -2.014983 \\ \mathrm{O} & 2.584899 & 3.282142 & -1.254347 \\ \mathrm{C} & 2.723489 & 4.603923 & -1.803180 \\ \mathrm{H} & 1.827634 & 5.136412 & -1.485898 \\ \mathrm{H} & 2.781873 & 4.557678 & -2.893802 \\ \mathrm{H} & 3.622552 & 5.087216 & -1.413480 \\ \mathrm{H} & 3.968773 & -2.038091 & -0.608513 \\ \mathrm{H} & 2.343175 & -1.190322 & -0.805917 \\ \mathrm{C} & 5.529305 & 0.122609 & -0.958551 \\ \mathrm{C} & 6.194061 & -0.879381 & -1.686633 \\ \mathrm{C} & 6.288269 & 1.083579 & -0.268058 \\ \mathrm{C} & 7.585712 & -0.905978 & -1.744117 \\ \mathrm{H} & 5.614625 & -1.617286 & -2.233030 \\ \mathrm{C} & 7.677622 & 1.040476 & -0.310621 \\ \mathrm{H} & 5.789381 & 1.837634 & 0.328394 \\ \mathrm{C} & 8.329709 & 0.052427 & -1.053287 \\ \mathrm{H} & 8.086958 & -1.672474 & -2.328145 \\ \mathrm{H} & 8.253747 & 1.779532 & 0.238207 \\ \mathrm{H} & 9.415426 & 0.029592 & -1.091889 \\ \mathrm{H} & 6.397301 & -3.711692 & 2.454825\end{array}$

Catalyst (R)-1 TS Conformation 89

B3LYP/6-31G(d) Energy $=-2809.698103$

B3LYP-D3(BJ)/def2-TZVPP-IEF-PCM(DCM) Energy $=-2810.9874$

B3LYP-D3(BJ)/def2-TZVPP-IEF-PCM(DCM)//B3LYP/6-31G(d) Free Energy (Quasiharmonic) = 2810.344595

Frequencies (Top 3 out of 270)

1. $-340.0244 \mathrm{~cm}-1$ 
2. $\quad 6.4340 \mathrm{~cm}-1$

3. $11.2029 \mathrm{~cm}-1$

B3LYP/6-31G(d) Molecular Geometry in Cartesian Coordinates

\begin{tabular}{|c|c|c|c|}
\hline C & 3.541952 & 0.234434 & 0.042074 \\
\hline C & 2.663291 & 1.290916 & -0.144453 \\
\hline C & 2.955122 & 2.631958 & 0.239739 \\
\hline C & 4.154217 & 2.857137 & 0.887164 \\
\hline $\mathrm{H}$ & 4.417276 & 3.871897 & 1.174052 \\
\hline C & 2.419765 & -3.699920 & -1.328205 \\
\hline C & 3.183385 & -1.120330 & -0.473419 \\
\hline C & 1.985826 & -1.699178 & -0.084387 \\
\hline C & 1.578264 & -3.006319 & -0.480250 \\
\hline $\mathrm{H}$ & 2.151667 & -4.708694 & -1.631213 \\
\hline O & 1.438141 & 1.043731 & -0.759072 \\
\hline$P$ & 0.280059 & 0.247376 & 0.073531 \\
\hline $\mathrm{O}$ & 1.141092 & -0.971516 & 0.748797 \\
\hline C & 0.412160 & 6.001294 & -0.584740 \\
\hline C & 0.924826 & 5.799268 & 0.697030 \\
\hline C & 1.729528 & 4.691688 & 0.962604 \\
\hline C & 2.032370 & 3.763106 & -0.045465 \\
\hline C & 1.500762 & 3.969998 & -1.328998 \\
\hline C & 0.704419 & 5.082496 & -1.595195 \\
\hline $\mathrm{H}$ & 0.694434 & 6.500831 & 1.494417 \\
\hline $\mathrm{H}$ & 0.318626 & 5.237643 & -2.599840 \\
\hline C & -2.065752 & -4.891855 & 0.818800 \\
\hline C & -1.236754 & -4.260446 & 1.749121 \\
\hline C & -0.066360 & -3.625567 & 1.335577 \\
\hline C & 0.303043 & -3.618105 & -0.019847 \\
\hline C & -0.539300 & -4.255082 & -0.945172 \\
\hline C & -1.712788 & -4.884927 & -0.531240 \\
\hline $\mathrm{H}$ & -1.497947 & -4.272033 & 2.804372 \\
\hline $\mathrm{H}$ & -2.353528 & -5.365592 & -1.265923 \\
\hline C & 4.014713 & -1.826675 & -1.409161 \\
\hline C & 3.623214 & -3.141098 & -1.824024 \\
\hline C & 4.441144 & -3.856193 & -2.740588 \\
\hline C & 5.584452 & -3.292999 & -3.257397 \\
\hline C & 5.952760 & -1.980196 & -2.879977 \\
\hline C & 5.190656 & -1.267107 & -1.980860 \\
\hline $\mathrm{H}$ & 4.135677 & -4.857416 & -3.035260 \\
\hline $\mathrm{H}$ & 6.198298 & -3.846711 & -3.962472 \\
\hline $\mathrm{H}$ & 6.843396 & -1.527373 & -3.307203 \\
\hline $\mathrm{H}$ & 5.482065 & -0.259127 & -1.709717 \\
\hline
\end{tabular}




\begin{tabular}{|c|c|c|c|}
\hline C & 4.754521 & 0.473350 & 0.776028 \\
\hline C & 5.058104 & 1.810176 & 1.192162 \\
\hline C & 6.257055 & 2.061554 & 1.912988 \\
\hline C & 7.113287 & 1.036824 & 2.242187 \\
\hline C & 6.797675 & -0.289845 & 1.865604 \\
\hline C & 5.651814 & -0.564301 & 1.151812 \\
\hline $\mathrm{H}$ & 6.477719 & 3.084014 & 2.210376 \\
\hline $\mathrm{H}$ & 8.023604 & 1.240237 & 2.799411 \\
\hline $\mathrm{H}$ & 7.463186 & -1.101741 & 2.146287 \\
\hline $\mathrm{H}$ & 5.420236 & -1.587607 & 0.880051 \\
\hline 0 & -0.778652 & -0.213023 & -0.870170 \\
\hline O & -0.131689 & 1.099928 & 1.296872 \\
\hline $\mathrm{H}$ & -1.210218 & 1.209624 & 1.441234 \\
\hline $\mathrm{H}$ & 1.723979 & 3.262800 & -2.120982 \\
\hline $\mathrm{H}$ & -0.211735 & 6.866204 & -0.794341 \\
\hline $\mathrm{H}$ & 2.112749 & 4.529083 & 1.966035 \\
\hline $\mathrm{H}$ & -0.279119 & -4.235056 & -1.999682 \\
\hline $\mathrm{H}$ & -2.977934 & -5.384738 & 1.144554 \\
\hline $\mathrm{H}$ & 0.573403 & -3.141486 & 2.065808 \\
\hline C & -3.411098 & 0.591874 & 1.915335 \\
\hline $\mathrm{O}$ & -2.561951 & 1.439214 & 1.462788 \\
\hline $\mathrm{H}$ & -4.451824 & 0.934086 & 1.994945 \\
\hline C & -3.101061 & -0.290257 & 3.128873 \\
\hline $\mathrm{O}$ & -3.966146 & -0.805554 & 3.807876 \\
\hline $\mathrm{O}$ & -1.785289 & -0.410545 & 3.338672 \\
\hline C & -1.399692 & -1.197690 & 4.477435 \\
\hline $\mathrm{H}$ & -0.310191 & -1.186543 & 4.480274 \\
\hline $\mathrm{H}$ & -1.794162 & -0.755136 & 5.395839 \\
\hline C & -4.260085 & -0.199990 & -0.391880 \\
\hline C & -3.632939 & -0.880732 & 0.674231 \\
\hline $\mathrm{H}$ & -2.432345 & 0.346279 & -1.112309 \\
\hline$N$ & -3.449612 & 0.536631 & -1.190036 \\
\hline C & -3.765695 & 1.755651 & -1.821925 \\
\hline $\mathrm{O}$ & -4.838643 & 2.311654 & -1.827881 \\
\hline $\mathrm{O}$ & -2.647847 & 2.205306 & -2.413153 \\
\hline C & -2.766788 & 3.494877 & -3.034436 \\
\hline $\mathrm{H}$ & -3.039442 & 4.249745 & -2.292959 \\
\hline $\mathrm{H}$ & -3.522397 & 3.471324 & -3.823960 \\
\hline $\mathrm{H}$ & -1.780519 & 3.703236 & -3.447496 \\
\hline $\mathrm{H}$ & -4.211498 & -1.655241 & 1.166596 \\
\hline $\mathrm{H}$ & -2.580305 & -1.116421 & 0.542989 \\
\hline C & -5.720693 & -0.249632 & -0.573339 \\
\hline C & -6.566007 & -0.452375 & 0.534497 \\
\hline C & -6.287843 & -0.207082 & -1.859951 \\
\hline
\end{tabular}




$\begin{array}{llll}\text { C } & -7.941129 & -0.578930 & 0.358094 \\ \text { H } & -6.151414 & -0.495914 & 1.536617 \\ \text { C } & -7.659539 & -0.356619 & -2.031949 \\ \text { H } & -5.648525 & -0.080163 & -2.725935 \\ \text { C } & -8.491931 & -0.533723 & -0.924075 \\ \text { H } & -8.581785 & -0.716459 & 1.224271 \\ \text { H } & -8.080546 & -0.331943 & -3.032882 \\ \text { H } & -9.564564 & -0.640411 & -1.060459 \\ \text { H } & -1.779274 & -2.218409 & 4.381429\end{array}$

Catalyst (R)-1 TS Conformation 90

B3LYP/6-31G(d) Energy $=-2809.693879$

B3LYP-D3(BJ)/def2-TZVPP-IEF-PCM(DCM) Energy $=-2810.986704$

B3LYP-D3(BJ)/def2-TZVPP-IEF-PCM(DCM)//B3LYP/6-31G(d) Free Energy (Quasiharmonic) = 2810.344543

Frequencies (Top 3 out of 270)

1. $-468.0926 \mathrm{~cm}-1$

2. $8.5748 \mathrm{~cm}-1$

3. $\quad 13.9812 \mathrm{~cm}-1$

B3LYP/6-31G(d) Molecular Geometry in Cartesian Coordinates

$\begin{array}{lccc}\text { C } & 2.763114 & -1.516357 & -0.028128 \\ \text { C } & 1.483656 & -1.804580 & 0.417670 \\ \text { C } & 0.856934 & -3.074369 & 0.242567 \\ \text { C } & 1.565594 & -4.034050 & -0.454566 \\ \text { H } & 1.132713 & -5.022816 & -0.581321 \\ \text { C } & 4.604246 & 2.309503 & 0.694078 \\ \text { C } & 3.379415 & -0.198040 & 0.302268 \\ \text { C } & 2.734799 & 0.985424 & -0.036184 \\ \text { C } & 3.347404 & 2.265514 & 0.123276 \\ \text { H } & 5.087393 & 3.274069 & 0.826410 \\ \text { O } & 0.780294 & -0.805610 & 1.082228 \\ \text { P } & 0.162202 & 0.410984 & 0.167153 \\ \text { O } & 1.491006 & 0.931889 & -0.652395 \\ \text { C } & -3.060016 & -4.040943 & 1.739964 \\ \text { C } & -2.158401 & -3.345222 & 2.546657 \\ \text { C } & -0.892399 & -3.012609 & 2.067843 \\ \text { C } & -0.500324 & -3.376463 & 0.768487 \\ \text { C } & -1.415416 & -4.082466 & -0.030609\end{array}$




\begin{tabular}{|c|c|c|c|}
\hline C & -2.681986 & -4.410896 & 0.449291 \\
\hline $\mathrm{H}$ & -2.442466 & -3.055018 & 3.554900 \\
\hline $\mathrm{H}$ & -3.381286 & -4.941580 & -0.191399 \\
\hline C & 1.667756 & 6.038945 & -1.084182 \\
\hline C & 0.958563 & 5.208687 & -0.213642 \\
\hline C & 1.472517 & 3.966846 & 0.162074 \\
\hline C & 2.717439 & 3.540022 & -0.325274 \\
\hline C & 3.423306 & 4.381340 & -1.201870 \\
\hline C & 2.902895 & 5.618959 & -1.581570 \\
\hline $\mathrm{H}$ & -0.004500 & 5.526881 & 0.176929 \\
\hline $\mathrm{H}$ & 3.462749 & 6.253117 & -2.264344 \\
\hline C & 4.638939 & -0.126131 & 0.993661 \\
\hline C & 5.261638 & 1.150208 & 1.170136 \\
\hline C & 6.512283 & 1.234525 & 1.840079 \\
\hline C & 7.120804 & 0.109396 & 2.344989 \\
\hline C & 6.491386 & -1.150033 & 2.205310 \\
\hline C & 5.286587 & -1.265631 & 1.547566 \\
\hline $\mathrm{H}$ & 6.972460 & 2.212963 & 1.956790 \\
\hline $\mathrm{H}$ & 8.073844 & 0.185325 & 2.861348 \\
\hline $\mathrm{H}$ & 6.959730 & -2.035305 & 2.627089 \\
\hline $\mathrm{H}$ & 4.814026 & -2.236907 & 1.460621 \\
\hline C & 3.450755 & -2.496815 & -0.824446 \\
\hline C & 2.837718 & -3.776343 & -1.021034 \\
\hline C & 3.510443 & -4.761651 & -1.793820 \\
\hline C & 4.724035 & -4.492966 & -2.382562 \\
\hline C & 5.312756 & -3.216378 & -2.224621 \\
\hline C & 4.695364 & -2.246550 & -1.465415 \\
\hline $\mathrm{H}$ & 3.036366 & -5.732081 & -1.921424 \\
\hline $\mathrm{H}$ & 5.225272 & -5.251622 & -2.977490 \\
\hline $\mathrm{H}$ & 6.259622 & -2.996424 & -2.710459 \\
\hline $\mathrm{H}$ & 5.156127 & -1.271143 & -1.362400 \\
\hline 0 & -0.405987 & 1.438021 & 1.098576 \\
\hline $\mathrm{O}$ & -0.731492 & -0.162031 & -0.939610 \\
\hline $\mathrm{H}$ & -1.912710 & -0.602894 & -0.645977 \\
\hline $\mathrm{H}$ & -1.136258 & -4.349766 & -1.046242 \\
\hline $\mathrm{H}$ & -4.053299 & -4.281180 & 2.108028 \\
\hline $\mathrm{H}$ & -0.200770 & -2.470903 & 2.703653 \\
\hline $\mathrm{H}$ & 4.382848 & 4.053781 & -1.593355 \\
\hline $\mathrm{H}$ & 1.261350 & 7.004785 & -1.373459 \\
\hline $\mathrm{H}$ & 0.908578 & 3.326819 & 0.832235 \\
\hline C & -3.823815 & -0.718094 & -1.316023 \\
\hline $\mathrm{O}$ & -2.956789 & -0.985677 & -0.416771 \\
\hline $\mathrm{H}$ & -3.496315 & -0.360602 & -2.292305 \\
\hline C & -5.111162 & -1.510218 & -1.270806 \\
\hline
\end{tabular}




$\begin{array}{llll}\mathrm{O} & -5.509909 & -2.145041 & -0.323983 \\ \mathrm{O} & -5.738419 & -1.416163 & -2.462632 \\ \mathrm{C} & -6.979321 & -2.135939 & -2.560738 \\ \mathrm{H} & -7.695321 & -1.766638 & -1.821356 \\ \mathrm{H} & -7.342425 & -1.955717 & -3.572403 \\ \mathrm{C} & -4.014973 & 1.715321 & -0.112723 \\ \mathrm{C} & -4.901542 & 1.177659 & -1.044339 \\ \mathrm{H} & -2.080844 & 2.333382 & 0.276948 \\ \mathrm{~N} & -2.788355 & 2.203842 & -0.453589 \\ \mathrm{C} & -2.277189 & 2.334071 & -1.758445 \\ \mathrm{O} & -2.840932 & 1.993693 & -2.778520 \\ \mathrm{O} & -1.080580 & 2.914613 & -1.684914 \\ \mathrm{C} & -0.326288 & 2.947794 & -2.914747 \\ \mathrm{H} & -0.902845 & 3.446996 & -3.696381 \\ \mathrm{H} & -0.085914 & 1.926084 & -3.215633 \\ \mathrm{H} & 0.578103 & 3.502165 & -2.673926 \\ \mathrm{H} & -5.874496 & 0.884243 & -0.670693 \\ \mathrm{H} & -4.829188 & 1.444504 & -2.087836 \\ \mathrm{C} & -4.323314 & 1.650855 & 1.333287 \\ \mathrm{C} & -5.650629 & 1.854182 & 1.759056 \\ \mathrm{C} & -3.329858 & 1.394209 & 2.296798 \\ \mathrm{C} & -5.977426 & 1.803419 & 3.109860 \\ \mathrm{H} & -6.421363 & 2.087787 & 1.031627 \\ \mathrm{C} & -3.670208 & 1.330949 & 3.647015 \\ \mathrm{H} & -2.298225 & 1.219521 & 2.004039 \\ \mathrm{C} & -4.987422 & 1.535688 & 4.058658 \\ \mathrm{H} & -7.003040 & 1.977488 & 3.422504 \\ \mathrm{H} & -2.895893 & 1.117741 & 4.378154 \\ \mathrm{H} & -5.243119 & 1.490699 & 5.113832 \\ \mathrm{H} & -6.814918 & -3.203587 & -2.393806\end{array}$

Catalyst (R)-1 TS Conformation 91

B3LYP/6-31G(d) Energy $=-2809.693072$

B3LYP-D3(BJ)/def2-TZVPP-IEF-PCM(DCM) Energy $=-2810.986707$

B3LYP-D3(BJ)/def2-TZVPP-IEF-PCM(DCM)//B3LYP/6-31G(d) Free Energy (Quasiharmonic) = 2810.344536

Frequencies (Top 3 out of 270 )

1. $-673.5431 \mathrm{~cm}-1$

2. $\quad 11.5289 \mathrm{~cm}-1$

3. $\quad 14.0950 \mathrm{~cm}-1$ 
B3LYP/6-31G(d) Molecular Geometry in Cartesian Coordinates

\begin{tabular}{|c|c|c|c|}
\hline C & 2.966781 & -0.962530 & -0.382299 \\
\hline C & 1.814654 & -1.584278 & 0.079968 \\
\hline C & 1.551502 & -2.976304 & -0.108604 \\
\hline C & 2.471443 & -3.699996 & -0.844213 \\
\hline $\mathrm{H}$ & 2.325200 & -4.768774 & -0.974179 \\
\hline C & 3.679131 & 3.213044 & 0.435830 \\
\hline C & 3.232167 & 0.467969 & -0.041865 \\
\hline C & 2.287880 & 1.431822 & -0.359669 \\
\hline C & 2.492294 & 2.829213 & -0.157890 \\
\hline $\mathrm{H}$ & 3.881227 & 4.271126 & 0.580398 \\
\hline $\mathrm{O}$ & 0.898606 & -0.844427 & 0.808614 \\
\hline$P$ & -0.013630 & 0.323656 & 0.088000 \\
\hline O & 1.090873 & 1.014180 & -0.920859 \\
\hline C & -1.744457 & -5.157007 & 1.613385 \\
\hline C & -1.315642 & -5.423108 & 0.311697 \\
\hline C & -0.277165 & -4.681992 & -0.250541 \\
\hline C & 0.369823 & -3.666782 & 0.475778 \\
\hline C & -0.084470 & -3.397113 & 1.779617 \\
\hline C & -1.130090 & -4.132870 & 2.339374 \\
\hline $\mathrm{H}$ & -1.790574 & -6.208098 & -0.271259 \\
\hline $\mathrm{H}$ & -1.451547 & -3.912328 & 3.354038 \\
\hline C & -0.319443 & 5.865625 & -1.337362 \\
\hline C & -0.033259 & 4.806829 & -2.201855 \\
\hline C & 0.859233 & 3.806405 & -1.820311 \\
\hline C & 1.488002 & 3.847844 & -0.564229 \\
\hline C & 1.186967 & 4.915214 & 0.297335 \\
\hline C & 0.293070 & 5.914754 & -0.084530 \\
\hline $\mathrm{H}$ & -0.503632 & 4.759334 & -3.180608 \\
\hline $\mathrm{H}$ & 0.069616 & 6.727314 & 0.602048 \\
\hline C & 4.427956 & 0.877062 & 0.643134 \\
\hline C & 4.648162 & 2.274814 & 0.868932 \\
\hline C & 5.830911 & 2.696061 & 1.535282 \\
\hline C & 6.750359 & 1.781378 & 1.993395 \\
\hline C & 6.517130 & 0.398685 & 1.806280 \\
\hline C & 5.389317 & -0.041242 & 1.148457 \\
\hline $\mathrm{H}$ & 5.987972 & 3.761474 & 1.686925 \\
\hline $\mathrm{H}$ & 7.647444 & 2.115494 & 2.507498 \\
\hline $\mathrm{H}$ & 7.232485 & -0.324479 & 2.188808 \\
\hline $\mathrm{H}$ & 5.221815 & -1.104530 & 1.021736 \\
\hline C & 3.865456 & -1.711028 & -1.218175 \\
\hline C & 3.610569 & -3.103219 & -1.434704 \\
\hline
\end{tabular}




\begin{tabular}{|c|c|c|c|}
\hline C & 4.500382 & -3.860391 & -2.244328 \\
\hline C & 5.583930 & -3.267809 & -2.849276 \\
\hline C & 5.816715 & -1.883820 & -2.670068 \\
\hline C & 4.983473 & -1.127125 & -1.875719 \\
\hline $\mathrm{H}$ & 4.297604 & -4.919362 & -2.386722 \\
\hline $\mathrm{H}$ & 6.253267 & -3.854194 & -3.472762 \\
\hline $\mathrm{H}$ & 6.658942 & -1.411046 & -3.168079 \\
\hline $\mathrm{H}$ & 5.171194 & -0.066427 & -1.757446 \\
\hline 0 & -0.530620 & 1.233148 & 1.147837 \\
\hline $\mathrm{O}$ & -1.007646 & -0.359414 & -0.864555 \\
\hline $\mathrm{H}$ & -1.950368 & 0.338994 & -1.284280 \\
\hline $\mathrm{H}$ & 0.390086 & -2.616472 & 2.360753 \\
\hline $\mathrm{H}$ & -2.545613 & -5.741526 & 2.059030 \\
\hline $\mathrm{H}$ & 0.030786 & -4.882380 & -1.272473 \\
\hline $\mathrm{H}$ & 1.641310 & 4.945642 & 1.283628 \\
\hline $\mathrm{H}$ & -1.016348 & 6.644095 & -1.637234 \\
\hline $\mathrm{H}$ & 1.076083 & 2.990823 & -2.501289 \\
\hline C & -3.300510 & 1.702405 & -0.633590 \\
\hline $\mathrm{O}$ & -2.870428 & 0.991823 & -1.612041 \\
\hline $\mathrm{H}$ & -2.637743 & 1.908274 & 0.211094 \\
\hline C & -4.303182 & 2.776577 & -1.012557 \\
\hline 0 & -4.998024 & 2.750408 & -2.003129 \\
\hline 0 & -4.310584 & 3.751212 & -0.087026 \\
\hline C & -5.225908 & 4.832739 & -0.335004 \\
\hline $\mathrm{H}$ & -5.103621 & 5.515681 & 0.505267 \\
\hline $\mathrm{H}$ & -4.979850 & 5.329877 & -1.276720 \\
\hline C & -4.130318 & -0.544292 & 0.685410 \\
\hline C & -4.703922 & 0.725905 & 0.599157 \\
\hline $\mathrm{H}$ & -2.587358 & -1.672141 & 1.411768 \\
\hline$N$ & -3.179611 & -0.870896 & 1.610295 \\
\hline C & -2.741514 & -0.084800 & 2.693805 \\
\hline $\mathrm{O}$ & -3.240253 & 0.953962 & 3.059540 \\
\hline $\mathrm{O}$ & -1.708295 & -0.712958 & 3.267314 \\
\hline C & -0.968088 & 0.087516 & 4.214430 \\
\hline $\mathrm{H}$ & -0.513408 & 0.923909 & 3.680704 \\
\hline $\mathrm{H}$ & -0.206134 & -0.579994 & 4.616164 \\
\hline $\mathrm{H}$ & -1.628805 & 0.445125 & 5.006963 \\
\hline $\mathrm{H}$ & -5.611661 & 0.797860 & 0.012056 \\
\hline $\mathrm{H}$ & -4.611798 & 1.394788 & 1.443077 \\
\hline C & -4.455580 & -1.590611 & -0.298932 \\
\hline C & -4.331432 & -2.954842 & 0.029566 \\
\hline C & -4.912980 & -1.239482 & -1.585351 \\
\hline C & -4.661439 & -3.937565 & -0.897081 \\
\hline $\mathrm{H}$ & -4.005243 & -3.253840 & 1.020413 \\
\hline
\end{tabular}




$\begin{array}{llll}\mathrm{C} & -5.227028 & -2.230969 & -2.511298 \\ \mathrm{H} & -4.985234 & -0.199516 & -1.878298 \\ \mathrm{C} & -5.107256 & -3.579131 & -2.171498 \\ \mathrm{H} & -4.570579 & -4.984134 & -0.622628 \\ \mathrm{H} & -5.561769 & -1.945158 & -3.504014 \\ \mathrm{H} & -5.360385 & -4.348440 & -2.895836 \\ \mathrm{H} & -6.252412 & 4.459662 & -0.385487\end{array}$

Catalyst (R)-1 TS Conformation 92

B3LYP/6-31G(d) Energy $=-2809.694484$

B3LYP-D3(BJ)/def2-TZVPP-IEF-PCM(DCM) Energy $=-2810.986063$

B3LYP-D3(BJ)/def2-TZVPP-IEF-PCM(DCM)//B3LYP/6-31G(d) Free Energy (Quasiharmonic) = 2810.344532

Frequencies (Top 3 out of 270)

1. $-640.0647 \mathrm{~cm}-1$

2. $7.9059 \mathrm{~cm}-1$

3. $\quad 14.0655 \mathrm{~cm}-1$

B3LYP/6-31G(d) Molecular Geometry in Cartesian Coordinates

$\begin{array}{lrrr}\text { C } & 3.236632 & 0.193632 & 0.356039 \\ \text { C } & 2.471347 & 1.318934 & 0.084639 \\ \text { C } & 2.901948 & 2.642814 & 0.401641 \\ \text { C } & 4.094328 & 2.778297 & 1.085019 \\ \text { H } & 4.440927 & 3.775317 & 1.343479 \\ \text { C } & 2.166531 & -3.835719 & -0.700158 \\ \text { C } & 2.837435 & -1.155044 & -0.145613 \\ \text { C } & 1.593784 & -1.677326 & 0.173598 \\ \text { C } & 1.250325 & -3.047939 & -0.030355 \\ \text { H } & 1.931739 & -4.882041 & -0.877507 \\ \text { O } & 1.290417 & 1.183932 & -0.633668 \\ \text { P } & -0.000184 & 0.358812 & -0.073653 \\ \text { O } & 0.674089 & -0.850940 & 0.807700 \\ \text { C } & 0.898506 & 6.295024 & -0.674686 \\ \text { C } & 2.230304 & 6.080664 & -1.031837 \\ \text { C } & 2.856438 & 4.879982 & -0.698831 \\ \text { C } & 2.163672 & 3.869919 & -0.010189 \\ \text { C } & 0.820428 & 4.089115 & 0.331292 \\ \text { C } & 0.200547 & 5.295692 & 0.006208 \\ \text { H } & 2.783888 & 6.846678 & -1.568945\end{array}$




\begin{tabular}{|c|c|c|c|}
\hline $\mathrm{H}$ & -0.834720 & 5.454069 & 0.295086 \\
\hline C & -2.263130 & -4.925342 & 1.607504 \\
\hline C & -2.394941 & -3.765035 & 0.840319 \\
\hline C & -1.267007 & -3.139576 & 0.305256 \\
\hline C & 0.015526 & -3.664255 & 0.531537 \\
\hline C & 0.132795 & -4.833618 & 1.301155 \\
\hline C & -0.994726 & -5.459696 & 1.833103 \\
\hline $\mathrm{H}$ & -3.383291 & -3.347482 & 0.664569 \\
\hline $\mathrm{H}$ & -0.878283 & -6.358357 & 2.433398 \\
\hline C & 3.735963 & -1.958448 & -0.930784 \\
\hline C & 3.384351 & -3.318698 & -1.206303 \\
\hline C & 4.262104 & -4.123708 & -1.981708 \\
\hline C & 5.431583 & -3.607737 & -2.489798 \\
\hline C & 5.767456 & -2.255584 & -2.244252 \\
\hline C & 4.945189 & -1.454060 & -1.482973 \\
\hline $\mathrm{H}$ & 3.983263 & -5.157042 & -2.174661 \\
\hline $\mathrm{H}$ & 6.092082 & -4.230501 & -3.086933 \\
\hline $\mathrm{H}$ & 6.680543 & -1.843045 & -2.664895 \\
\hline $\mathrm{H}$ & 5.211156 & -0.417224 & -1.312369 \\
\hline C & 4.421188 & 0.346202 & 1.161587 \\
\hline C & 4.855297 & 1.664155 & 1.511816 \\
\hline C & 6.027844 & 1.832585 & 2.297029 \\
\hline C & 6.738563 & 0.745389 & 2.748519 \\
\hline C & 6.292813 & -0.560226 & 2.436535 \\
\hline C & 5.168676 & -0.755036 & 1.664220 \\
\hline $\mathrm{H}$ & 6.344092 & 2.843141 & 2.544803 \\
\hline $\mathrm{H}$ & 7.630071 & 0.884584 & 3.353871 \\
\hline $\mathrm{H}$ & 6.838391 & -1.420116 & 2.815807 \\
\hline $\mathrm{H}$ & 4.837350 & -1.763572 & 1.448238 \\
\hline $\mathrm{O}$ & -0.787165 & -0.124056 & -1.245223 \\
\hline 0 & -0.693381 & 1.221848 & 0.999037 \\
\hline $\mathrm{H}$ & -1.818913 & 1.159658 & 1.269460 \\
\hline $\mathrm{H}$ & 0.267548 & 3.323905 & 0.864847 \\
\hline $\mathrm{H}$ & 0.410066 & 7.234023 & -0.923409 \\
\hline $\mathrm{H}$ & 3.891888 & 4.713016 & -0.983449 \\
\hline $\mathrm{H}$ & 1.120657 & -5.239725 & 1.501154 \\
\hline $\mathrm{H}$ & -3.143479 & -5.402728 & 2.029058 \\
\hline $\mathrm{H}$ & -1.370038 & -2.252059 & -0.308397 \\
\hline C & -3.697488 & 0.112999 & 1.469980 \\
\hline $\mathrm{O}$ & -3.006686 & 1.171662 & 1.693202 \\
\hline $\mathrm{H}$ & -3.192136 & -0.797394 & 1.124878 \\
\hline C & -4.807830 & -0.228378 & 2.457716 \\
\hline $\mathrm{O}$ & -5.136831 & -1.369470 & 2.700247 \\
\hline $\mathrm{O}$ & -5.354399 & 0.865547 & 3.006302 \\
\hline
\end{tabular}




$\begin{array}{llll}\mathrm{C} & -6.386041 & 0.612643 & 3.977869 \\ \mathrm{H} & -6.717677 & 1.595670 & 4.311776 \\ \mathrm{H} & -7.211736 & 0.057728 & 3.524400 \\ \mathrm{C} & -4.050474 & 0.511462 & -1.129654 \\ \mathrm{C} & -4.955354 & 0.257920 & -0.088320 \\ \mathrm{H} & -2.445403 & -0.352751 & -2.043735 \\ \mathrm{~N} & -3.438478 & -0.500123 & -1.821231 \\ \mathrm{C} & -3.896799 & -1.812482 & -1.974453 \\ \mathrm{O} & -4.941170 & -2.268848 & -1.558683 \\ \mathrm{O} & -2.985861 & -2.485322 & -2.695378 \\ \mathrm{C} & -3.278440 & -3.877799 & -2.915305 \\ \mathrm{H} & -3.259926 & -4.418547 & -1.966362 \\ \mathrm{H} & -2.485237 & -4.233063 & -3.572446 \\ \mathrm{H} & -4.256432 & -3.991569 & -3.388268 \\ \mathrm{H} & -5.596346 & 1.076913 & 0.217492 \\ \mathrm{H} & -5.401999 & -0.727774 & -0.048150 \\ \mathrm{C} & -3.600627 & 1.868767 & -1.449714 \\ \mathrm{C} & -2.964422 & 2.142854 & -2.680115 \\ \mathrm{C} & -3.825331 & 2.934087 & -0.551876 \\ \mathrm{C} & -2.571062 & 3.434998 & -3.001397 \\ \mathrm{H} & -2.804770 & 1.345142 & -3.396888 \\ \mathrm{C} & -3.422417 & 4.225282 & -0.880296 \\ \mathrm{H} & -4.278325 & 2.750204 & 0.413280 \\ \mathrm{C} & -2.797182 & 4.480574 & -2.101535 \\ \mathrm{H} & -2.088163 & 3.629291 & -3.954218 \\ \mathrm{H} & -3.596181 & 5.033747 & -0.176136 \\ \mathrm{H} & -2.485004 & 5.489853 & -2.353685 \\ \mathrm{H} & -5.985417 & 0.036224 & 4.815412\end{array}$

Catalyst (R)-1 TS Conformation 93

B3LYP/6-31G(d) Energy $=-2809.697594$

B3LYP-D3(BJ)/def2-TZVPP-IEF-PCM(DCM) Energy = -2810.98684

B3LYP-D3(BJ)/def2-TZVPP-IEF-PCM(DCM)//B3LYP/6-31G(d) Free Energy (Quasiharmonic) = 2810.344512

Frequencies (Top 3 out of 270)

1. $-361.0506 \mathrm{~cm}-1$

2. $\quad 5.5877 \mathrm{~cm}-1$

3. $9.8709 \mathrm{~cm}-1$

B3LYP/6-31G(d) Molecular Geometry in Cartesian Coordinates 


\begin{tabular}{|c|c|c|c|}
\hline C & 3.396939 & -0.692024 & -0.126087 \\
\hline C & 2.292073 & -1.526044 & -0.051245 \\
\hline C & 2.291993 & -2.875354 & -0.511972 \\
\hline C & 3.452630 & -3.338520 & -1.101566 \\
\hline $\mathrm{H}$ & 3.497819 & -4.370065 & -1.440598 \\
\hline C & 3.119576 & 3.327681 & 1.417842 \\
\hline C & 3.318712 & 0.682009 & 0.453237 \\
\hline C & 2.311280 & 1.540715 & 0.041120 \\
\hline C & 2.197774 & 2.889733 & 0.487000 \\
\hline $\mathrm{H}$ & 3.075475 & 4.357882 & 1.761390 \\
\hline O & 1.125935 & -1.030962 & 0.524465 \\
\hline$P$ & 0.223394 & 0.043236 & -0.317320 \\
\hline $\mathrm{O}$ & 1.367643 & 1.072280 & -0.869930 \\
\hline C & -1.044150 & -5.566700 & -0.137359 \\
\hline C & -0.669415 & -4.766566 & 0.943701 \\
\hline C & 0.394021 & -3.873463 & 0.826363 \\
\hline C & 1.110157 & -3.768072 & -0.377674 \\
\hline C & 0.720002 & -4.574694 & -1.459032 \\
\hline C & -0.346329 & -5.465034 & -1.341206 \\
\hline $\mathrm{H}$ & -1.206391 & -4.840252 & 1.886108 \\
\hline $\mathrm{H}$ & -0.636997 & -6.072269 & -2.194399 \\
\hline C & -0.762136 & 5.671800 & -0.930555 \\
\hline C & -0.037190 & 4.899292 & -1.840876 \\
\hline C & 0.902642 & 3.973696 & -1.389951 \\
\hline C & 1.144367 & 3.811700 & -0.015830 \\
\hline C & 0.408248 & 4.592574 & 0.889253 \\
\hline C & -0.537619 & 5.512521 & 0.437336 \\
\hline $\mathrm{H}$ & -0.197095 & 5.024915 & -2.908748 \\
\hline $\mathrm{H}$ & -1.101465 & 6.101777 & 1.155849 \\
\hline C & 4.227676 & 1.131165 & 1.472279 \\
\hline C & 4.123851 & 2.479550 & 1.945206 \\
\hline C & 5.022063 & 2.939517 & 2.946243 \\
\hline C & 5.967417 & 2.100616 & 3.488461 \\
\hline C & 6.046871 & 0.757278 & 3.051738 \\
\hline C & 5.202322 & 0.285687 & 2.070887 \\
\hline $\mathrm{H}$ & 4.937364 & 3.969634 & 3.284300 \\
\hline $\mathrm{H}$ & 6.644420 & 2.461523 & 4.257864 \\
\hline $\mathrm{H}$ & 6.778540 & 0.088881 & 3.497552 \\
\hline $\mathrm{H}$ & 5.270374 & -0.748642 & 1.754706 \\
\hline C & 4.570316 & -1.165917 & -0.807185 \\
\hline C & 4.590657 & -2.515962 & -1.285995 \\
\hline C & 5.748530 & -3.002869 & -1.951422 \\
\hline C & 6.835082 & -2.188299 & -2.169123 \\
\hline
\end{tabular}




\begin{tabular}{|c|c|c|c|}
\hline C & 6.802692 & -0.843114 & -1.732076 \\
\hline C & 5.702451 & -0.345783 & -1.068775 \\
\hline $\mathrm{H}$ & 5.751768 & -4.033753 & -2.297622 \\
\hline $\mathrm{H}$ & 7.711827 & -2.569631 & -2.685328 \\
\hline $\mathrm{H}$ & 7.652204 & -0.193739 & -1.925718 \\
\hline $\mathrm{H}$ & 5.690290 & 0.689800 & -0.749298 \\
\hline 0 & -0.767750 & 0.663905 & 0.610690 \\
\hline $\mathrm{O}$ & -0.290869 & -0.625853 & -1.611610 \\
\hline $\mathrm{H}$ & -1.386649 & -0.682068 & -1.685331 \\
\hline $\mathrm{H}$ & 1.244343 & -4.482710 & -2.405947 \\
\hline $\mathrm{H}$ & -1.876792 & -6.258901 & -0.043923 \\
\hline $\mathrm{H}$ & 0.676851 & -3.256510 & 1.672311 \\
\hline $\mathrm{H}$ & 0.567969 & 4.459897 & 1.955613 \\
\hline $\mathrm{H}$ & -1.495794 & 6.390842 & -1.285343 \\
\hline $\mathrm{H}$ & 1.464242 & 3.380832 & -2.104367 \\
\hline C & -3.594832 & 0.020609 & -1.908322 \\
\hline $\mathrm{O}$ & -2.731610 & -0.883402 & -1.621271 \\
\hline $\mathrm{H}$ & -4.641490 & -0.300834 & -2.007889 \\
\hline C & -3.303216 & 1.081816 & -2.978659 \\
\hline $\mathrm{O}$ & -4.171460 & 1.721234 & -3.535303 \\
\hline $\mathrm{O}$ & -1.991554 & 1.200295 & -3.217342 \\
\hline C & -1.620675 & 2.156760 & -4.223273 \\
\hline $\mathrm{H}$ & -1.920242 & 3.162965 & -3.918504 \\
\hline $\mathrm{H}$ & -0.536494 & 2.084275 & -4.303339 \\
\hline C & -4.270502 & 0.412924 & 0.589398 \\
\hline C & -3.863558 & 1.267220 & -0.457469 \\
\hline $\mathrm{H}$ & -2.316056 & 0.010921 & 1.019835 \\
\hline$N$ & -3.298194 & -0.219056 & 1.280693 \\
\hline C & -3.433298 & -0.972098 & 2.461413 \\
\hline $\mathrm{O}$ & -4.451292 & -1.169211 & 3.083605 \\
\hline $\mathrm{O}$ & -2.212630 & -1.415562 & 2.802587 \\
\hline C & -2.157284 & -2.155118 & 4.032750 \\
\hline $\mathrm{H}$ & -1.106765 & -2.412879 & 4.163954 \\
\hline $\mathrm{H}$ & -2.772707 & -3.056076 & 3.965335 \\
\hline $\mathrm{H}$ & -2.510190 & -1.540533 & 4.864790 \\
\hline $\mathrm{H}$ & -4.633495 & 1.905160 & -0.879678 \\
\hline $\mathrm{H}$ & -2.871113 & 1.704952 & -0.374911 \\
\hline C & -5.702697 & 0.075747 & 0.734975 \\
\hline C & -6.653943 & 1.107682 & 0.773962 \\
\hline C & -6.139001 & -1.260065 & 0.718082 \\
\hline C & -8.014312 & 0.810310 & 0.826437 \\
\hline $\mathrm{H}$ & -6.322962 & 2.141790 & 0.789594 \\
\hline C & -7.499089 & -1.551118 & 0.741885 \\
\hline $\mathrm{H}$ & -5.412163 & -2.062991 & 0.661939 \\
\hline
\end{tabular}




$\begin{array}{lrrr}\mathrm{C} & -8.439009 & -0.518800 & 0.805717 \\ \mathrm{H} & -8.740489 & 1.616436 & 0.876562 \\ \mathrm{H} & -7.827051 & -2.586187 & 0.713558 \\ \mathrm{H} & -9.499977 & -0.751217 & 0.835042 \\ \mathrm{H} & -2.098466 & 1.911897 & -5.175326\end{array}$

Catalyst (R)-1 TS Conformation 94

B3LYP/6-31G(d) Energy $=-2809.692563$

B3LYP-D3(BJ)/def2-TZVPP-IEF-PCM(DCM) Energy = -2810.985323

B3LYP-D3(BJ)/def2-TZVPP-IEF-PCM(DCM)//B3LYP/6-31G(d) Free Energy (Quasiharmonic) = 2810.344441

Frequencies (Top 3 out of 270)

1. $-728.7569 \mathrm{~cm}-1$

2. $8.3593 \mathrm{~cm}-1$

3. $\quad 12.1313 \mathrm{~cm}-1$

B3LYP/6-31G(d) Molecular Geometry in Cartesian Coordinates

$\begin{array}{llll}\text { C } & -3.792313 & 0.021440 & -0.194526 \\ \text { C } & -3.109753 & 1.173944 & 0.173820 \\ \text { C } & -3.732878 & 2.457290 & 0.232418 \\ \text { C } & -5.044349 & 2.547313 & -0.191662 \\ \text { H } & -5.540421 & 3.513888 & -0.162975 \\ \text { C } & -1.870130 & -3.830196 & 0.137409 \\ \text { C } & -3.148422 & -1.316706 & -0.036462 \\ \text { C } & -1.920991 & -1.561848 & -0.627844 \\ \text { C } & -1.254666 & -2.820423 & -0.575555 \\ \text { H } & -1.403664 & -4.810975 & 0.178626 \\ \text { O } & -1.794954 & 1.075740 & 0.612332 \\ \text { P } & -0.585395 & 0.627903 & -0.393343 \\ \text { O } & -1.303532 & -0.519727 & -1.313737 \\ \text { C } & -1.902207 & 6.011702 & 1.827013 \\ \text { C } & -1.261716 & 5.298386 & 0.811910 \\ \text { C } & -1.829711 & 4.133763 & 0.296072 \\ \text { C } & -3.057512 & 3.664349 & 0.788045 \\ \text { C } & -3.694854 & 4.390814 & 1.807399 \\ \text { C } & -3.122670 & 5.553150 & 2.324075 \\ \text { H } & -0.313983 & 5.651442 & 0.413219 \\ \text { H } & -3.629017 & 6.095832 & 3.118293 \\ \text { C } & 2.507781 & -3.624443 & -2.505081\end{array}$




\begin{tabular}{|c|c|c|c|}
\hline C & 1.496961 & -2.955470 & -3.199313 \\
\hline C & 0.282032 & -2.672161 & -2.576432 \\
\hline C & 0.052143 & -3.057424 & -1.244603 \\
\hline C & 1.078830 & -3.723293 & -0.554333 \\
\hline C & 2.294162 & -4.005368 & -1.179333 \\
\hline $\mathrm{H}$ & 1.650815 & -2.657521 & -4.233271 \\
\hline $\mathrm{H}$ & 3.077741 & -4.517698 & -0.626531 \\
\hline C & -3.740186 & -2.355552 & 0.764147 \\
\hline C & -3.089957 & -3.630901 & 0.829332 \\
\hline C & -3.668770 & -4.671734 & 1.605116 \\
\hline C & -4.824842 & -4.462730 & 2.319917 \\
\hline C & -5.446143 & -3.192323 & 2.291969 \\
\hline C & -4.920296 & -2.168234 & 1.535240 \\
\hline $\mathrm{H}$ & -3.167726 & -5.636506 & 1.632889 \\
\hline $\mathrm{H}$ & -5.254105 & -5.263610 & 2.915671 \\
\hline $\mathrm{H}$ & -6.344918 & -3.019818 & 2.877868 \\
\hline $\mathrm{H}$ & -5.404088 & -1.198877 & 1.534634 \\
\hline C & -5.121770 & 0.151091 & -0.726856 \\
\hline C & -5.751621 & 1.436447 & -0.711749 \\
\hline C & -7.067145 & 1.576928 & -1.230929 \\
\hline C & -7.733914 & 0.501091 & -1.769173 \\
\hline C & -7.102319 & -0.764078 & -1.815327 \\
\hline C & -5.833450 & -0.935357 & -1.306975 \\
\hline $\mathrm{H}$ & -7.532139 & 2.559636 & -1.204364 \\
\hline $\mathrm{H}$ & -8.736946 & 0.621345 & -2.169326 \\
\hline $\mathrm{H}$ & -7.620515 & -1.608305 & -2.262221 \\
\hline $\mathrm{H}$ & -5.359704 & -1.908806 & -1.360760 \\
\hline $\mathrm{O}$ & 0.546338 & 0.121416 & 0.438638 \\
\hline $\mathrm{O}$ & -0.293086 & 1.752173 & -1.402016 \\
\hline $\mathrm{H}$ & 0.821567 & 2.202445 & -1.473295 \\
\hline $\mathrm{H}$ & -4.637964 & 4.028052 & 2.207492 \\
\hline $\mathrm{H}$ & -1.453319 & 6.916845 & 2.227905 \\
\hline $\mathrm{H}$ & -1.330308 & 3.594622 & -0.500903 \\
\hline $\mathrm{H}$ & 0.931114 & -3.990757 & 0.487976 \\
\hline $\mathrm{H}$ & 3.453123 & -3.846380 & -2.993577 \\
\hline $\mathrm{H}$ & -0.497620 & -2.156031 & -3.126162 \\
\hline C & 2.679230 & 2.216869 & -0.592389 \\
\hline $\mathrm{O}$ & 1.943964 & 2.650591 & -1.544506 \\
\hline $\mathrm{H}$ & 2.214645 & 1.831960 & 0.319097 \\
\hline C & 4.014747 & 2.881691 & -0.339845 \\
\hline $\mathrm{O}$ & 4.504165 & 2.934049 & 0.770012 \\
\hline $\mathrm{O}$ & 4.566130 & 3.385010 & -1.450645 \\
\hline C & 5.837486 & 4.034178 & -1.264563 \\
\hline $\mathrm{H}$ & 5.741276 & 4.865533 & -0.561889 \\
\hline
\end{tabular}




$\begin{array}{llll}\mathrm{H} & 6.124581 & 4.395932 & -2.251715 \\ \mathrm{C} & 3.961898 & -0.287288 & -0.121187 \\ \mathrm{C} & 3.366962 & 0.355542 & -1.210045 \\ \mathrm{H} & 2.134533 & -0.634329 & 0.736435 \\ \mathrm{~N} & 3.142176 & -0.858753 & 0.813336 \\ \mathrm{C} & 3.386879 & -1.900233 & 1.717811 \\ \mathrm{O} & 2.548854 & -2.273965 & 2.506860 \\ \mathrm{O} & 4.606688 & -2.446414 & 1.570753 \\ \mathrm{C} & 4.902944 & -3.509840 & 2.492539 \\ \mathrm{H} & 4.209039 & -4.342034 & 2.351050 \\ \mathrm{H} & 4.830846 & -3.155459 & 3.523627 \\ \mathrm{H} & 5.923348 & -3.813896 & 2.259267 \\ \mathrm{H} & 4.014838 & 0.718606 & -1.999228 \\ \mathrm{H} & 2.373665 & 0.037928 & -1.504091 \\ \mathrm{C} & 5.420157 & -0.188524 & 0.095726 \\ \mathrm{C} & 6.301064 & -0.377985 & -0.981498 \\ \mathrm{C} & 5.939455 & 0.181608 & 1.348972 \\ \mathrm{C} & 7.674629 & -0.221889 & -0.805165 \\ \mathrm{H} & 5.907299 & -0.677443 & -1.948061 \\ \mathrm{C} & 7.309686 & 0.353895 & 1.516379 \\ \mathrm{H} & 5.261807 & 0.373582 & 2.173734 \\ \mathrm{C} & 8.180913 & 0.146655 & 0.443181 \\ \mathrm{H} & 8.348218 & -0.389541 & -1.640764 \\ \mathrm{H} & 7.698691 & 0.658218 & 2.483737 \\ \mathrm{H} & 9.251251 & 0.275656 & 0.579274 \\ \mathrm{H} & 6.574954 & 3.323339 & -0.882276\end{array}$

Catalyst (R)-1 TS Conformation 95

B3LYP/6-31G(d) Energy $=-2809.69598$

B3LYP-D3(BJ)/def2-TZVPP-IEF-PCM(DCM) Energy = -2810.986331

B3LYP-D3(BJ)/def2-TZVPP-IEF-PCM(DCM)//B3LYP/6-31G(d) Free Energy (Quasiharmonic) = 2810.344423

Frequencies (Top 3 out of 270)

1. $-491.0421 \mathrm{~cm}-1$

2. $\quad 8.7862 \mathrm{~cm}-1$

3. $\quad 13.0594 \mathrm{~cm}-1$

B3LYP/6-31G(d) Molecular Geometry in Cartesian Coordinates

$\begin{array}{llll}\text { C } & 3.296686 & -0.980978 & -0.112233\end{array}$ 


\begin{tabular}{|c|c|c|c|}
\hline C & 2.126165 & -1.714967 & -0.013466 \\
\hline C & 1.973236 & -3.039789 & -0.519742 \\
\hline C & 3.064783 & -3.586001 & -1.168496 \\
\hline $\mathrm{H}$ & 3.004368 & -4.606073 & -1.537739 \\
\hline C & 3.654907 & 3.001866 & 1.495889 \\
\hline C & 3.385889 & 0.364507 & 0.529544 \\
\hline C & 2.453187 & 1.349958 & 0.232921 \\
\hline C & 2.585080 & 2.699946 & 0.676609 \\
\hline $\mathrm{H}$ & 3.776089 & 4.022707 & 1.848735 \\
\hline O & 1.043632 & -1.129515 & 0.637439 \\
\hline$P$ & 0.207942 & 0.024825 & -0.153045 \\
\hline O & 1.394784 & 1.053086 & -0.619095 \\
\hline C & -1.611300 & -5.397002 & -0.165654 \\
\hline C & -1.190037 & -4.610174 & 0.907348 \\
\hline C & -0.039971 & -3.829192 & 0.802081 \\
\hline C & 0.713039 & -3.818265 & -0.384271 \\
\hline C & 0.269668 & -4.606290 & -1.460864 \\
\hline C & -0.877269 & -5.390157 & -1.352771 \\
\hline $\mathrm{H}$ & -1.760050 & -4.588857 & 1.831405 \\
\hline $\mathrm{H}$ & -1.203658 & -5.985207 & -2.201893 \\
\hline C & -0.019904 & 5.944378 & -0.428045 \\
\hline C & 1.350995 & 6.015142 & -0.679916 \\
\hline C & 2.180540 & 4.947272 & -0.335949 \\
\hline C & 1.655664 & 3.788258 & 0.258893 \\
\hline C & 0.274587 & 3.723308 & 0.502490 \\
\hline C & -0.551131 & 4.796264 & 0.164938 \\
\hline $\mathrm{H}$ & 1.776954 & 6.900844 & -1.144282 \\
\hline $\mathrm{H}$ & -1.616675 & 4.737930 & 0.374111 \\
\hline C & 4.429298 & 0.670727 & 1.471720 \\
\hline C & 4.567323 & 2.015669 & 1.942300 \\
\hline C & 5.601343 & 2.332803 & 2.864430 \\
\hline C & 6.454390 & 1.360618 & 3.331770 \\
\hline C & 6.298414 & 0.023171 & 2.897509 \\
\hline C & 5.316028 & -0.312501 & 1.992090 \\
\hline $\mathrm{H}$ & 5.695145 & 3.361720 & 3.203800 \\
\hline $\mathrm{H}$ & 7.237315 & 1.612468 & 4.041849 \\
\hline $\mathrm{H}$ & 6.956130 & -0.749204 & 3.286979 \\
\hline $\mathrm{H}$ & 5.203825 & -1.343937 & 1.679195 \\
\hline C & 4.387456 & -1.531284 & -0.871586 \\
\hline C & 4.262852 & -2.862844 & -1.384511 \\
\hline C & 5.338201 & -3.430988 & -2.120554 \\
\hline C & 6.480158 & -2.708971 & -2.377249 \\
\hline C & 6.588183 & -1.378234 & -1.909839 \\
\hline C & 5.572134 & -0.806002 & -1.176096 \\
\hline
\end{tabular}




\begin{tabular}{|c|c|c|c|}
\hline $\mathrm{H}$ & 5.231590 & -4.447917 & -2.490832 \\
\hline $\mathrm{H}$ & 7.292179 & -3.151036 & -2.948080 \\
\hline $\mathrm{H}$ & 7.479558 & -0.799081 & -2.135535 \\
\hline $\mathrm{H}$ & 5.668492 & 0.217756 & -0.834431 \\
\hline $\mathrm{O}$ & -0.774010 & 0.632177 & 0.803214 \\
\hline $\mathrm{O}$ & -0.324251 & -0.547524 & -1.478556 \\
\hline $\mathrm{H}$ & -1.423284 & -0.377409 & -1.665760 \\
\hline $\mathrm{H}$ & 0.816242 & -4.581158 & -2.399210 \\
\hline $\mathrm{H}$ & -2.509397 & -6.003911 & -0.081692 \\
\hline $\mathrm{H}$ & 0.269463 & -3.223105 & 1.645108 \\
\hline $\mathrm{H}$ & -0.147552 & 2.837534 & 0.964962 \\
\hline $\mathrm{H}$ & -0.668325 & 6.776938 & -0.688523 \\
\hline $\mathrm{H}$ & 3.246712 & 5.002504 & -0.539411 \\
\hline C & -3.380703 & 0.759493 & -1.939832 \\
\hline $\mathrm{O}$ & -2.724351 & -0.336900 & -1.789778 \\
\hline $\mathrm{H}$ & -4.427962 & 0.661913 & -2.256234 \\
\hline C & -2.753456 & 1.969463 & -2.646625 \\
\hline 0 & -3.414771 & 2.843677 & -3.167204 \\
\hline $\mathrm{O}$ & -1.419716 & 1.930320 & -2.601338 \\
\hline C & -0.718759 & 3.016903 & -3.235897 \\
\hline $\mathrm{H}$ & 0.336152 & 2.812622 & -3.060288 \\
\hline $\mathrm{H}$ & -0.944953 & 3.034537 & -4.305103 \\
\hline C & -4.259200 & 0.622585 & 0.520089 \\
\hline C & -3.724715 & 1.659760 & -0.274808 \\
\hline $\mathrm{H}$ & -2.370342 & 0.011356 & 1.001066 \\
\hline$N$ & -3.385028 & -0.191445 & 1.145483 \\
\hline C & -3.588875 & -1.192417 & 2.117916 \\
\hline 0 & -2.702687 & -1.946003 & 2.445901 \\
\hline 0 & -4.817346 & -1.156334 & 2.652416 \\
\hline C & -5.066735 & -2.152820 & 3.661054 \\
\hline $\mathrm{H}$ & -4.380592 & -2.021808 & 4.500997 \\
\hline $\mathrm{H}$ & -4.941995 & -3.155799 & 3.245876 \\
\hline $\mathrm{H}$ & -6.097838 & -1.989722 & 3.973552 \\
\hline $\mathrm{H}$ & -4.425625 & 2.418492 & -0.609234 \\
\hline $\mathrm{H}$ & -2.731730 & 2.011969 & -0.006384 \\
\hline C & -5.699667 & 0.303007 & 0.415489 \\
\hline C & -6.106798 & -0.973274 & -0.009749 \\
\hline C & -6.662350 & 1.300923 & 0.625096 \\
\hline C & -7.457536 & -1.242410 & -0.211210 \\
\hline $\mathrm{H}$ & -5.358426 & -1.732038 & -0.217991 \\
\hline C & -8.015611 & 1.017793 & 0.447009 \\
\hline $\mathrm{H}$ & -6.349894 & 2.289150 & 0.949677 \\
\hline C & -8.414741 & -0.252037 & 0.026490 \\
\hline $\mathrm{H}$ & -7.763952 & -2.224861 & -0.558928 \\
\hline
\end{tabular}




$\begin{array}{llll}\mathrm{H} & -8.756248 & 1.791086 & 0.629222 \\ \mathrm{H} & -9.468755 & -0.467927 & -0.124706 \\ \mathrm{H} & -1.005844 & 3.968088 & -2.782854\end{array}$

Catalyst (R)-1 TS Conformation 96

B3LYP/6-31G(d) Energy $=-2809.68727$

B3LYP-D3(BJ)/def2-TZVPP-IEF-PCM(DCM) Energy = -2810.986589

B3LYP-D3(BJ)/def2-TZVPP-IEF-PCM(DCM)//B3LYP/6-31G(d) Free Energy (Quasiharmonic) = 2810.344353

Frequencies (Top 3 out of 270)

1. $-537.1022 \mathrm{~cm}-1$

2. $\quad 8.9689 \mathrm{~cm}-1$

3. $10.9469 \mathrm{~cm}-1$

B3LYP/6-31G(d) Molecular Geometry in Cartesian Coordinates

$\begin{array}{llll}\text { C } & 3.394268 & -1.190969 & -0.077003 \\ \text { C } & 2.119998 & -1.703644 & 0.110518 \\ \text { C } & 1.747177 & -3.027781 & -0.269006 \\ \text { C } & 2.705492 & -3.798564 & -0.898726 \\ \text { H } & 2.463891 & -4.821465 & -1.175111 \\ \text { C } & 4.342693 & 2.824859 & 1.177998 \\ \text { C } & 3.718154 & 0.178038 & 0.422180 \\ \text { C } & 2.953120 & 1.257425 & 0.006254 \\ \text { C } & 3.274188 & 2.608587 & 0.330596 \\ \text { H } & 4.623353 & 3.845140 & 1.426563 \\ \text { O } & 1.170396 & -0.907229 & 0.731785 \\ \text { P } & 0.508742 & 0.365731 & -0.077081 \\ \text { O } & 1.838698 & 1.024405 & -0.789547 \\ \text { C } & -2.102361 & -4.792279 & 0.493368 \\ \text { C } & -1.488602 & -4.939219 & -0.751008 \\ \text { C } & -0.253471 & -4.340507 & -0.997043 \\ \text { C } & 0.395681 & -3.588421 & -0.004181 \\ \text { C } & -0.237696 & -3.441046 & 1.242430 \\ \text { C } & -1.474065 & -4.037341 & 1.487116 \\ \text { H } & -1.973634 & -5.512662 & -1.536777 \\ \text { H } & -1.951901 & -3.908743 & 2.453968 \\ \text { C } & 1.292791 & 6.046718 & -1.331323 \\ \text { C } & 1.487370 & 5.942724 & 0.046691 \\ \text { C } & 2.103727 & 4.812184 & 0.584645\end{array}$




\begin{tabular}{|c|c|c|c|}
\hline C & 2.533084 & 3.763388 & -0.243753 \\
\hline C & 2.318154 & 3.872693 & -1.628277 \\
\hline C & 1.709732 & 5.006307 & -2.166105 \\
\hline $\mathrm{H}$ & 1.157773 & 6.740998 & 0.706656 \\
\hline $\mathrm{H}$ & 1.567580 & 5.079892 & -3.241317 \\
\hline C & 4.786954 & 0.412386 & 1.354442 \\
\hline C & 5.095807 & 1.759799 & 1.730078 \\
\hline C & 6.151736 & 2.004300 & 2.649287 \\
\hline C & 6.861472 & 0.965191 & 3.204565 \\
\hline C & 6.536120 & -0.368511 & 2.862727 \\
\hline C & 5.529211 & -0.637866 & 1.961951 \\
\hline $\mathrm{H}$ & 6.380020 & 3.034116 & 2.914058 \\
\hline $\mathrm{H}$ & 7.662157 & 1.163808 & 3.911759 \\
\hline $\mathrm{H}$ & 7.082549 & -1.189569 & 3.319016 \\
\hline $\mathrm{H}$ & 5.285533 & -1.665546 & 1.718760 \\
\hline C & 4.356413 & -1.978204 & -0.798405 \\
\hline C & 3.998508 & -3.305959 & -1.199156 \\
\hline C & 4.943039 & -4.102287 & -1.901998 \\
\hline C & 6.183351 & -3.606167 & -2.229193 \\
\hline C & 6.526306 & -2.281914 & -1.868429 \\
\hline C & 5.639357 & -1.490628 & -1.171840 \\
\hline $\mathrm{H}$ & 4.658076 & -5.112186 & -2.187761 \\
\hline $\mathrm{H}$ & 6.894737 & -4.221753 & -2.772939 \\
\hline $\mathrm{H}$ & 7.497586 & -1.882427 & -2.147733 \\
\hline $\mathrm{H}$ & 5.915225 & -0.475256 & -0.912223 \\
\hline $\mathrm{O}$ & -0.196812 & 1.227008 & 0.905388 \\
\hline $\mathrm{O}$ & -0.263332 & -0.157242 & -1.312361 \\
\hline $\mathrm{H}$ & -1.397789 & -0.266877 & -1.205673 \\
\hline $\mathrm{H}$ & 0.245954 & -2.864599 & 2.023335 \\
\hline $\mathrm{H}$ & -3.063690 & -5.259357 & 0.691151 \\
\hline $\mathrm{H}$ & 0.207282 & -4.437046 & -1.975974 \\
\hline $\mathrm{H}$ & 2.642258 & 3.070743 & -2.283592 \\
\hline $\mathrm{H}$ & 0.819315 & 6.929787 & -1.752442 \\
\hline $\mathrm{H}$ & 2.242230 & 4.729356 & 1.658965 \\
\hline C & -2.973533 & -0.698789 & 0.151986 \\
\hline $\mathrm{O}$ & -2.662606 & -0.463509 & -1.079363 \\
\hline $\mathrm{H}$ & -2.163433 & -0.852963 & 0.879279 \\
\hline C & -4.103317 & -1.685315 & 0.446587 \\
\hline $\mathrm{O}$ & -4.343503 & -2.106248 & 1.559967 \\
\hline $\mathrm{O}$ & -4.785440 & -2.029617 & -0.657264 \\
\hline C & -5.815647 & -3.011021 & -0.453739 \\
\hline $\mathrm{H}$ & -5.389131 & -3.926103 & -0.035533 \\
\hline $\mathrm{H}$ & -6.235019 & -3.201309 & -1.442138 \\
\hline C & -4.677949 & 1.263564 & 0.271550 \\
\hline
\end{tabular}




$\begin{array}{llll}\mathrm{C} & -3.561169 & 0.869796 & 1.036734 \\ \mathrm{H} & -5.424383 & 1.921277 & -1.494339 \\ \mathrm{~N} & -4.576150 & 1.843119 & -0.945542 \\ \mathrm{C} & -3.483692 & 2.402277 & -1.669328 \\ \mathrm{O} & -3.627887 & 2.679473 & -2.837248 \\ \mathrm{O} & -2.438812 & 2.636967 & -0.898592 \\ \mathrm{C} & -1.269554 & 3.184268 & -1.556926 \\ \mathrm{H} & -0.553585 & 3.339592 & -0.755295 \\ \mathrm{H} & -1.530430 & 4.119362 & -2.055314 \\ \mathrm{H} & -0.888441 & 2.459135 & -2.277273 \\ \mathrm{H} & -3.788009 & 0.505893 & 2.033852 \\ \mathrm{H} & -2.631282 & 1.420592 & 0.944194 \\ \mathrm{C} & -6.056124 & 0.898775 & 0.677549 \\ \mathrm{C} & -7.009210 & 0.464405 & -0.263142 \\ \mathrm{C} & -6.434594 & 1.005568 & 2.026454 \\ \mathrm{C} & -8.306179 & 0.154408 & 0.138051 \\ \mathrm{H} & -6.723984 & 0.309305 & -1.300196 \\ \mathrm{C} & -7.736032 & 0.704450 & 2.421287 \\ \mathrm{H} & -5.715173 & 1.352681 & 2.760523 \\ \mathrm{C} & -8.674902 & 0.279882 & 1.479797 \\ \mathrm{H} & -9.026925 & -0.193351 & -0.596332 \\ \mathrm{H} & -8.016197 & 0.804002 & 3.465689 \\ \mathrm{H} & -9.688476 & 0.042282 & 1.789891 \\ \mathrm{H} & -6.582560 & -2.629955 & 0.225599\end{array}$

Catalyst (R)-1 TS Conformation 97

B3LYP/6-31G(d) Energy $=-2809.690686$

B3LYP-D3(BJ)/def2-TZVPP-IEF-PCM(DCM) Energy $=-2810.985428$

B3LYP-D3(BJ)/def2-TZVPP-IEF-PCM(DCM)//B3LYP/6-31G(d) Free Energy (Quasiharmonic) = 2810.344351

Frequencies (Top 3 out of 270)

1. $-712.6089 \mathrm{~cm}-1$

2. $\quad 9.0252 \mathrm{~cm}-1$

3. $12.2086 \mathrm{~cm}-1$

B3LYP/6-31G(d) Molecular Geometry in Cartesian Coordinates
C $\quad-3.779565$
0.022349
$-0.146691$
C $\quad-3.081250$
1.187292
0.144998
C $\quad-3.699361$
2.474062
0.171497 


\begin{tabular}{|c|c|c|c|}
\hline C & -5.026868 & 2.550371 & -0.201999 \\
\hline $\mathrm{H}$ & -5.519601 & 3.519068 & -0.195658 \\
\hline C & -1.860654 & -3.824155 & 0.253801 \\
\hline C & -3.132090 & -1.310390 & 0.040037 \\
\hline C & -1.929886 & -1.584204 & -0.589638 \\
\hline C & -1.269000 & -2.845006 & -0.519651 \\
\hline $\mathrm{H}$ & -1.399288 & -4.806538 & 0.310565 \\
\hline 0 & -1.751161 & 1.104061 & 0.536934 \\
\hline$P$ & -0.580434 & 0.610218 & -0.494087 \\
\hline O & -1.335387 & -0.572403 & -1.337529 \\
\hline C & -1.796487 & 6.093367 & 1.515663 \\
\hline C & -2.990634 & 5.658967 & 2.092048 \\
\hline C & -3.586182 & 4.475144 & 1.656799 \\
\hline C & -2.998412 & 3.702759 & 0.641557 \\
\hline C & -1.796301 & 4.147726 & 0.069790 \\
\hline C & -1.205305 & 5.334099 & 0.503889 \\
\hline $\mathrm{H}$ & -3.458643 & 6.237959 & 2.884162 \\
\hline $\mathrm{H}$ & -0.279459 & 5.668601 & 0.042547 \\
\hline C & 2.407183 & -3.741260 & -2.571918 \\
\hline C & 1.378285 & -3.076367 & -3.242991 \\
\hline C & 0.190965 & -2.764313 & -2.581762 \\
\hline C & 0.007430 & -3.115171 & -1.233227 \\
\hline C & 1.051927 & -3.778089 & -0.567033 \\
\hline C & 2.239248 & -4.089414 & -1.230714 \\
\hline $\mathrm{H}$ & 1.496298 & -2.803753 & -4.288540 \\
\hline $\mathrm{H}$ & 3.037133 & -4.599229 & -0.696311 \\
\hline C & -3.695127 & -2.314966 & 0.902646 \\
\hline C & -3.049189 & -3.591227 & 0.988270 \\
\hline C & -3.600612 & -4.598846 & 1.825465 \\
\hline C & -4.724900 & -4.355931 & 2.579205 \\
\hline C & -5.340493 & -3.083388 & 2.529626 \\
\hline C & -4.841398 & -2.091548 & 1.714089 \\
\hline $\mathrm{H}$ & -3.103805 & -5.565264 & 1.868312 \\
\hline $\mathrm{H}$ & -5.133113 & -5.131419 & 3.221543 \\
\hline $\mathrm{H}$ & -6.213375 & -2.883471 & 3.145221 \\
\hline $\mathrm{H}$ & -5.319959 & -1.119721 & 1.697021 \\
\hline C & -5.129177 & 0.133681 & -0.630673 \\
\hline C & -5.756397 & 1.420374 & -0.644342 \\
\hline C & -7.091824 & 1.542855 & -1.115012 \\
\hline C & -7.781303 & 0.447410 & -1.580066 \\
\hline C & -7.153441 & -0.820283 & -1.599020 \\
\hline C & -5.865150 & -0.973835 & -1.135872 \\
\hline $\mathrm{H}$ & -7.554025 & 2.527229 & -1.111052 \\
\hline $\mathrm{H}$ & -8.799632 & 0.553722 & -1.943868 \\
\hline
\end{tabular}




\begin{tabular}{|c|c|c|c|}
\hline $\mathrm{H}$ & -7.690182 & -1.680923 & -1.989100 \\
\hline $\mathrm{H}$ & -5.395225 & -1.950029 & -1.168528 \\
\hline $\mathrm{O}$ & 0.577350 & 0.134666 & 0.321903 \\
\hline 0 & -0.317028 & 1.688486 & -1.555973 \\
\hline $\mathrm{H}$ & 0.813414 & 2.132456 & -1.679844 \\
\hline $\mathrm{H}$ & -1.335674 & 3.572161 & -0.725205 \\
\hline $\mathrm{H}$ & -1.330464 & 7.016061 & 1.851891 \\
\hline $\mathrm{H}$ & -4.508932 & 4.132371 & 2.117440 \\
\hline $\mathrm{H}$ & 0.941382 & -4.019092 & 0.486167 \\
\hline $\mathrm{H}$ & 3.331142 & -3.984764 & -3.090045 \\
\hline $\mathrm{H}$ & -0.602697 & -2.251651 & -3.114161 \\
\hline C & 2.672859 & 2.224117 & -0.827909 \\
\hline 0 & 1.915659 & 2.573375 & -1.797095 \\
\hline $\mathrm{H}$ & 2.227001 & 1.889416 & 0.111816 \\
\hline C & 4.001103 & 2.952183 & -0.730100 \\
\hline 0 & 4.636214 & 3.376870 & -1.665734 \\
\hline $\mathrm{O}$ & 4.356606 & 3.067874 & 0.564880 \\
\hline C & 5.586623 & 3.780177 & 0.799854 \\
\hline $\mathrm{H}$ & 5.524626 & 4.786895 & 0.379685 \\
\hline $\mathrm{H}$ & 5.697216 & 3.820148 & 1.883284 \\
\hline C & 3.977630 & -0.274832 & -0.248361 \\
\hline C & 3.395850 & 0.342431 & -1.357507 \\
\hline $\mathrm{H}$ & 2.141172 & -0.637276 & 0.590170 \\
\hline$N$ & 3.149295 & -0.863826 & 0.669914 \\
\hline C & 3.393791 & -1.924755 & 1.550708 \\
\hline 0 & 2.570166 & -2.298134 & 2.354997 \\
\hline 0 & 4.599304 & -2.491761 & 1.361235 \\
\hline C & 4.900218 & -3.575959 & 2.256583 \\
\hline $\mathrm{H}$ & 4.188541 & -4.393562 & 2.118481 \\
\hline $\mathrm{H}$ & 4.860478 & -3.239401 & 3.295454 \\
\hline $\mathrm{H}$ & 5.908820 & -3.893632 & 1.992107 \\
\hline $\mathrm{H}$ & 4.048852 & 0.715081 & -2.137860 \\
\hline $\mathrm{H}$ & 2.415144 & -0.000786 & -1.664799 \\
\hline C & 5.424350 & -0.137879 & 0.021046 \\
\hline C & 6.349458 & -0.225595 & -1.031687 \\
\hline C & 5.889636 & 0.155979 & 1.315948 \\
\hline C & 7.710095 & -0.039086 & -0.794119 \\
\hline $\mathrm{H}$ & 6.002842 & -0.467784 & -2.031275 \\
\hline C & 7.246646 & 0.355436 & 1.547218 \\
\hline $\mathrm{H}$ & 5.178453 & 0.257872 & 2.129352 \\
\hline C & 8.161407 & 0.253398 & 0.493974 \\
\hline $\mathrm{H}$ & 8.416219 & -0.122456 & -1.615037 \\
\hline $\mathrm{H}$ & 7.593382 & 0.593013 & 2.549053 \\
\hline $\mathrm{H}$ & 9.221676 & 0.403307 & 0.678174 \\
\hline
\end{tabular}


$\begin{array}{llll}H & 6.425752 & 3.248565 & 0.345292\end{array}$

Catalyst (R)-1 TS Conformation 98

B3LYP/6-31G(d) Energy $=-2809.69341$

B3LYP-D3(BJ)/def2-TZVPP-IEF-PCM(DCM) Energy = -2810.985461

B3LYP-D3(BJ)/def2-TZVPP-IEF-PCM(DCM)//B3LYP/6-31G(d) Free Energy (Quasiharmonic) = 2810.344321

Frequencies (Top 3 out of 270)

1. $-733.6350 \mathrm{~cm}-1$

2. $\quad 8.7822 \mathrm{~cm}-1$

3. $13.2234 \mathrm{~cm}-1$

B3LYP/6-31G(d) Molecular Geometry in Cartesian Coordinates

$\begin{array}{llll}\text { C } & 3.480726 & -0.826166 & 0.007662 \\ \text { C } & 2.279770 & -1.505210 & 0.138102 \\ \text { C } & 2.154768 & -2.918957 & 0.008334 \\ \text { C } & 3.299899 & -3.629770 & -0.291854 \\ \text { H } & 3.245581 & -4.712063 & -0.376609 \\ \text { C } & 3.556158 & 3.467799 & 0.435068 \\ \text { C } & 3.510145 & 0.654023 & 0.209388 \\ \text { C } & 2.662669 & 1.465274 & -0.531993 \\ \text { C } & 2.678136 & 2.889911 & -0.461722 \\ \text { H } & 3.614525 & 4.551398 & 0.494340 \\ \text { O } & 1.131818 & -0.772143 & 0.414347 \\ \text { P } & 0.464561 & 0.092464 & -0.813208 \\ \text { O } & 1.770363 & 0.869168 & -1.416621 \\ \text { C } & -1.589097 & -4.997960 & 0.440596 \\ \text { C } & -1.203681 & -4.051580 & 1.393717 \\ \text { C } & 0.001162 & -3.362778 & 1.255854 \\ \text { C } & 0.847419 & -3.611771 & 0.161925 \\ \text { C } & 0.446900 & -4.564091 & -0.789226 \\ \text { C } & -0.759562 & -5.250034 & -0.652730 \\ \text { H } & -1.842072 & -3.849005 & 2.249681 \\ \text { H } & -1.056489 & -5.972391 & -1.408071 \\ \text { C } & 0.217542 & 5.458294 & -2.884287 \\ \text { C } & 0.868835 & 4.367735 & -3.464337 \\ \text { C } & 1.649999 & 3.515966 & -2.685310 \\ \text { C } & 1.799232 & 3.742278 & -1.306539 \\ \text { C } & 1.135625 & 4.840309 & -0.734971\end{array}$




\begin{tabular}{|c|c|c|c|}
\hline C & 0.352693 & 5.690453 & -1.515019 \\
\hline $\mathrm{H}$ & 0.771260 & 4.178782 & -4.530203 \\
\hline $\mathrm{H}$ & -0.157319 & 6.530232 & -1.049929 \\
\hline C & 4.361492 & 1.269159 & 1.190731 \\
\hline C & 4.386173 & 2.698358 & 1.286087 \\
\hline C & 5.233508 & 3.319666 & 2.243553 \\
\hline C & 6.004536 & 2.568784 & 3.099823 \\
\hline C & 5.952289 & 1.156410 & 3.035282 \\
\hline C & 5.154933 & 0.524245 & 2.106623 \\
\hline $\mathrm{H}$ & 5.249841 & 4.405951 & 2.292798 \\
\hline $\mathrm{H}$ & 6.643579 & 3.054901 & 3.831926 \\
\hline $\mathrm{H}$ & 6.543817 & 0.563678 & 3.727871 \\
\hline $\mathrm{H}$ & 5.119759 & -0.558539 & 2.076722 \\
\hline C & 4.649622 & -1.571069 & -0.373788 \\
\hline C & 4.548299 & -2.994688 & -0.505576 \\
\hline C & 5.698830 & -3.745231 & -0.870663 \\
\hline C & 6.897646 & -3.122969 & -1.129811 \\
\hline C & 6.990588 & -1.714237 & -1.040270 \\
\hline C & 5.898519 & -0.959488 & -0.672035 \\
\hline $\mathrm{H}$ & 5.606983 & -4.825587 & -0.954432 \\
\hline $\mathrm{H}$ & 7.768379 & -3.706857 & -1.415230 \\
\hline $\mathrm{H}$ & 7.931506 & -1.221298 & -1.269494 \\
\hline $\mathrm{H}$ & 5.984704 & 0.119462 & -0.618323 \\
\hline $\mathrm{O}$ & -0.572929 & 0.980824 & -0.209064 \\
\hline $\mathrm{O}$ & 0.076115 & -0.842102 & -1.967897 \\
\hline $\mathrm{H}$ & -0.991558 & -1.381349 & -2.024051 \\
\hline $\mathrm{H}$ & 1.076529 & -4.745021 & -1.655674 \\
\hline $\mathrm{H}$ & -2.529471 & -5.532384 & 0.547109 \\
\hline $\mathrm{H}$ & 0.293557 & -2.631684 & 2.002105 \\
\hline $\mathrm{H}$ & 1.219177 & 5.013043 & 0.334438 \\
\hline $\mathrm{H}$ & -0.393193 & 6.118818 & -3.494206 \\
\hline $\mathrm{H}$ & 2.152969 & 2.673965 & -3.147852 \\
\hline C & -2.723077 & -1.511668 & -0.988848 \\
\hline $\mathrm{O}$ & -2.097707 & -1.892532 & -2.032279 \\
\hline $\mathrm{H}$ & -2.162752 & -1.137859 & -0.126481 \\
\hline C & -4.006799 & -2.234194 & -0.629706 \\
\hline $\mathrm{O}$ & -4.720656 & -2.837322 & -1.396976 \\
\hline $\mathrm{O}$ & -4.232620 & -2.083226 & 0.689988 \\
\hline C & -5.439116 & -2.673913 & 1.206639 \\
\hline $\mathrm{H}$ & -6.304129 & -2.347520 & 0.626224 \\
\hline $\mathrm{H}$ & -5.367243 & -3.764394 & 1.170501 \\
\hline C & -4.050078 & 0.880318 & -0.269984 \\
\hline C & -3.435379 & 0.395656 & -1.427392 \\
\hline $\mathrm{H}$ & -2.217593 & 1.289347 & 0.531516 \\
\hline
\end{tabular}




$\begin{array}{llll}\mathrm{N} & -3.223936 & 1.244263 & 0.762245 \\ \mathrm{C} & -3.502347 & 1.132874 & 2.132169 \\ \mathrm{O} & -4.538114 & 0.761470 & 2.637141 \\ \mathrm{O} & -2.398498 & 1.504968 & 2.805506 \\ \mathrm{C} & -2.489871 & 1.394538 & 4.234413 \\ \mathrm{H} & -3.289688 & 2.033280 & 4.617976 \\ \mathrm{H} & -1.520650 & 1.722939 & 4.608913 \\ \mathrm{H} & -2.684809 & 0.359573 & 4.527064 \\ \mathrm{H} & -4.036810 & 0.263030 & -2.319193 \\ \mathrm{H} & -2.402041 & 0.682425 & -1.587854 \\ \mathrm{C} & -5.513333 & 1.040600 & -0.176093 \\ \mathrm{C} & -6.375053 & 0.207376 & -0.914409 \\ \mathrm{C} & -6.067264 & 2.111879 & 0.548666 \\ \mathrm{C} & -7.750749 & 0.423682 & -0.900145 \\ \mathrm{H} & -5.976884 & -0.625029 & -1.484366 \\ \mathrm{C} & -7.439792 & 2.336931 & 0.540877 \\ \mathrm{H} & -5.418206 & 2.784884 & 1.096607 \\ \mathrm{C} & -8.288007 & 1.489266 & -0.175225 \\ \mathrm{H} & -8.401827 & -0.238889 & -1.463149 \\ \mathrm{H} & -7.848316 & 3.176011 & 1.096619 \\ \mathrm{H} & -9.360562 & 1.662717 & -0.173793 \\ \mathrm{H} & -5.513034 & -2.320247 & 2.234302\end{array}$

Catalyst (R)-1 TS Conformation 99

B3LYP/6-31G(d) Energy = -2809.693716

B3LYP-D3(BJ)/def2-TZVPP-IEF-PCM(DCM) Energy = -2810.985499

B3LYP-D3(BJ)/def2-TZVPP-IEF-PCM(DCM)//B3LYP/6-31G(d) Free Energy (Quasiharmonic) = 2810.344263

Frequencies (Top 3 out of 270)

1. $-732.9204 \mathrm{~cm}-1$

2. $\quad 8.4317 \mathrm{~cm}-1$

3. $\quad 11.4384 \mathrm{~cm}-1$

B3LYP/6-31G(d) Molecular Geometry in Cartesian Coordinates

$\begin{array}{llll}\text { C } & 3.380304 & -0.970351 & 0.016134 \\ \text { C } & 2.142861 & -1.583362 & 0.112578 \\ \text { C } & 1.932181 & -2.977775 & -0.090299 \\ \text { C } & 3.032533 & -3.738576 & -0.431934 \\ \text { H } & 2.914019 & -4.809913 & -0.571932\end{array}$




\begin{tabular}{|c|c|c|c|}
\hline C & 3.881486 & 3.270325 & 0.583970 \\
\hline C & 3.506353 & 0.490775 & 0.300247 \\
\hline C & 2.727884 & 1.407880 & -0.394550 \\
\hline C & 2.929364 & 2.818976 & -0.310027 \\
\hline $\mathrm{H}$ & 4.049843 & 4.339967 & 0.676463 \\
\hline 0 & 1.040970 & -0.793905 & 0.426354 \\
\hline$P$ & 0.443621 & 0.164537 & -0.762859 \\
\hline $\mathrm{O}$ & 1.776490 & 0.942848 & -1.296022 \\
\hline C & -1.916471 & -4.869349 & 0.270901 \\
\hline C & -1.110407 & -5.108370 & -0.842802 \\
\hline C & 0.129817 & -4.480899 & -0.956992 \\
\hline C & 0.588084 & -3.601583 & 0.037429 \\
\hline C & -0.235882 & -3.362961 & 1.150610 \\
\hline C & -1.474461 & -3.993464 & 1.266100 \\
\hline $\mathrm{H}$ & -1.450982 & -5.774881 & -1.630343 \\
\hline H & -2.094643 & -3.801685 & 2.137715 \\
\hline C & 0.961727 & 5.749536 & -2.774789 \\
\hline C & 2.352825 & 5.720863 & -2.670629 \\
\hline C & 2.973811 & 4.754426 & -1.880116 \\
\hline C & 2.218671 & 3.798117 & -1.180222 \\
\hline C & 0.819797 & 3.834282 & -1.294195 \\
\hline C & 0.201938 & 4.803930 & -2.083739 \\
\hline $\mathrm{H}$ & 2.957475 & 6.445653 & -3.209759 \\
\hline $\mathrm{H}$ & -0.882663 & 4.820382 & -2.156721 \\
\hline C & 4.423896 & 0.981458 & 1.292469 \\
\hline C & 4.612604 & 2.394535 & 1.422150 \\
\hline C & 5.518799 & 2.892388 & 2.397491 \\
\hline C & 6.198802 & 2.037400 & 3.233082 \\
\hline C & 5.990989 & 0.641709 & 3.129151 \\
\hline C & 5.129733 & 0.127650 & 2.184807 \\
\hline $\mathrm{H}$ & 5.655312 & 3.968416 & 2.476195 \\
\hline H & 6.885184 & 2.429307 & 3.978702 \\
\hline $\mathrm{H}$ & 6.511633 & -0.031698 & 3.804717 \\
\hline $\mathrm{H}$ & 4.973978 & -0.943378 & 2.125481 \\
\hline C & 4.502758 & -1.762262 & -0.411550 \\
\hline C & 4.316015 & -3.168195 & -0.618222 \\
\hline C & 5.418164 & -3.966491 & -1.028346 \\
\hline C & 6.651630 & -3.404646 & -1.261096 \\
\hline C & 6.828900 & -2.010749 & -1.098745 \\
\hline C & 5.785400 & -1.212183 & -0.684790 \\
\hline $\mathrm{H}$ & 5.260826 & -5.033355 & -1.168442 \\
\hline $\mathrm{H}$ & 7.484947 & -4.023791 & -1.581693 \\
\hline $\mathrm{H}$ & 7.796825 & -1.563400 & -1.308057 \\
\hline $\mathrm{H}$ & 5.937222 & -0.144922 & -0.576293 \\
\hline
\end{tabular}




\begin{tabular}{|c|c|c|c|}
\hline $\mathrm{O}$ & -0.579169 & 1.054328 & -0.125724 \\
\hline O & 0.039172 & -0.681465 & -1.976950 \\
\hline $\mathrm{H}$ & -1.050461 & -1.182588 & -2.091225 \\
\hline $\mathrm{H}$ & 0.101110 & -2.687562 & 1.929917 \\
\hline $\mathrm{H}$ & -2.882016 & -5.360151 & 0.361506 \\
\hline $\mathrm{H}$ & 0.742603 & -4.650867 & -1.837562 \\
\hline $\mathrm{H}$ & 0.215960 & 3.111243 & -0.757173 \\
\hline $\mathrm{H}$ & 0.474207 & 6.500020 & -3.391676 \\
\hline $\mathrm{H}$ & 4.058278 & 4.724138 & -1.816963 \\
\hline C & -2.797098 & -1.336116 & -1.096782 \\
\hline 0 & -2.163293 & -1.655466 & -2.154359 \\
\hline $\mathrm{H}$ & -2.244122 & -1.038988 & -0.200811 \\
\hline C & -4.112584 & -2.035887 & -0.817944 \\
\hline 0 & -4.825000 & -2.560022 & -1.642246 \\
\hline O & -4.366429 & -1.966347 & 0.502845 \\
\hline C & -5.601980 & -2.552534 & 0.951903 \\
\hline $\mathrm{H}$ & -5.558977 & -3.640176 & 0.847984 \\
\hline $\mathrm{H}$ & -5.692031 & -2.262183 & 1.997915 \\
\hline C & -4.067191 & 1.044310 & -0.225109 \\
\hline C & -3.448599 & 0.634911 & -1.407444 \\
\hline $\mathrm{H}$ & -2.237770 & 1.329187 & 0.635487 \\
\hline $\mathrm{N}$ & -3.248028 & 1.298975 & 0.846081 \\
\hline C & -3.552599 & 1.088207 & 2.198871 \\
\hline $\mathrm{O}$ & -4.608644 & 0.714775 & 2.657927 \\
\hline 0 & -2.447689 & 1.366857 & 2.914086 \\
\hline C & -2.566343 & 1.152298 & 4.329391 \\
\hline $\mathrm{H}$ & -1.592830 & 1.417311 & 4.741004 \\
\hline $\mathrm{H}$ & -2.801420 & 0.105755 & 4.539698 \\
\hline $\mathrm{H}$ & -3.350033 & 1.788373 & 4.748827 \\
\hline $\mathrm{H}$ & -4.037585 & 0.587905 & -2.315907 \\
\hline $\mathrm{H}$ & -2.402123 & 0.890510 & -1.529194 \\
\hline C & -5.526209 & 1.244185 & -0.140479 \\
\hline C & -6.400159 & 0.500089 & -0.955625 \\
\hline C & -6.059228 & 2.272180 & 0.658734 \\
\hline C & -7.768427 & 0.759259 & -0.945493 \\
\hline $\mathrm{H}$ & -6.017937 & -0.297388 & -1.583587 \\
\hline C & -7.423756 & 2.541642 & 0.647746 \\
\hline $\mathrm{H}$ & -5.399630 & 2.878106 & 1.268846 \\
\hline C & -8.284994 & 1.781305 & -0.146538 \\
\hline $\mathrm{H}$ & -8.429735 & 0.164757 & -1.569259 \\
\hline $\mathrm{H}$ & -7.815778 & 3.346927 & 1.262224 \\
\hline $\mathrm{H}$ & -9.351444 & 1.988907 & -0.147829 \\
\hline $\mathrm{H}$ & -6.442271 & -2.164969 & 0.372921 \\
\hline
\end{tabular}


Catalyst (R)-1 TS Conformation 100

B3LYP/6-31G(d) Energy $=-2809.694091$

B3LYP-D3(BJ)/def2-TZVPP-IEF-PCM(DCM) Energy = -2810.986683

B3LYP-D3(BJ)/def2-TZVPP-IEF-PCM(DCM)//B3LYP/6-31G(d) Free Energy (Quasiharmonic) = 2810.344247

Frequencies (Top 3 out of 270)

1. $-438.2268 \mathrm{~cm}-1$

2. $\quad 11.2175 \mathrm{~cm}-1$

3. $\quad 11.4256 \mathrm{~cm}-1$

B3LYP/6-31G(d) Molecular Geometry in Cartesian Coordinates

$\begin{array}{llll}\text { C } & -3.564571 & -0.278678 & -0.237173 \\ \text { C } & -3.004305 & 0.940245 & 0.113995 \\ \text { C } & -3.682018 & 2.184608 & -0.036008 \\ \text { C } & -4.926805 & 2.161077 & -0.633345 \\ \text { H } & -5.476583 & 3.092006 & -0.744823 \\ \text { C } & -1.342659 & -3.915843 & 0.426995 \\ \text { C } & -2.819998 & -1.542304 & 0.042301 \\ \text { C } & -1.537238 & -1.697671 & -0.457931 \\ \text { C } & -0.773361 & -2.891432 & -0.304397 \\ \text { H } & -0.798472 & -4.849580 & 0.542578 \\ \text { O } & -1.725598 & 0.958644 & 0.667427 \\ \text { P } & -0.438617 & 0.645815 & -0.290783 \\ \text { O } & -0.971994 & -0.638898 & -1.160786 \\ \text { C } & -2.197323 & 5.961368 & 1.387329 \\ \text { C } & -2.636688 & 5.826957 & 0.070020 \\ \text { C } & -3.092379 & 4.593018 & -0.394122 \\ \text { C } & -3.110201 & 3.470119 & 0.447123 \\ \text { C } & -2.653086 & 3.613115 & 1.767304 \\ \text { C } & -2.208746 & 4.849843 & 2.234103 \\ \text { H } & -2.621582 & 6.681906 & -0.600655 \\ \text { H } & -1.880419 & 4.947931 & 3.266069 \\ \text { C } & 3.120985 & -3.510093 & -2.027800 \\ \text { C } & 2.092019 & -2.970292 & -2.803289 \\ \text { C } & 0.834715 & -2.740096 & -2.246008 \\ \text { C } & 0.579244 & -3.055970 & -0.900824 \\ \text { C } & 1.623709 & -3.593889 & -0.130678 \\ \text { C } & 2.883315 & -3.817974 & -0.687056 \\ \text { H } & 2.265235 & -2.731709 & -3.849494\end{array}$




\begin{tabular}{|c|c|c|c|}
\hline $\mathrm{H}$ & 3.681089 & -4.225416 & -0.071578 \\
\hline C & -3.371456 & -2.590051 & 0.856589 \\
\hline C & -2.616447 & -3.794732 & 1.034722 \\
\hline C & -3.153564 & -4.843726 & 1.829395 \\
\hline C & -4.371747 & -4.706642 & 2.452938 \\
\hline C & -5.102383 & -3.503586 & 2.309699 \\
\hline C & -4.617328 & -2.474621 & 1.532705 \\
\hline $\mathrm{H}$ & -2.573295 & -5.756366 & 1.943566 \\
\hline $\mathrm{H}$ & -4.769477 & -5.512973 & 3.063000 \\
\hline $\mathrm{H}$ & -6.054171 & -3.388017 & 2.821105 \\
\hline $\mathrm{H}$ & -5.185534 & -1.556362 & 1.440249 \\
\hline C & -4.833145 & -0.281087 & -0.913373 \\
\hline C & -5.517342 & 0.962912 & -1.104099 \\
\hline C & -6.774045 & 0.974407 & -1.767816 \\
\hline C & -7.327951 & -0.186553 & -2.254478 \\
\hline C & -6.637800 & -1.411813 & -2.100181 \\
\hline C & -5.425665 & -1.458805 & -1.447333 \\
\hline $\mathrm{H}$ & -7.284597 & 1.926260 & -1.893581 \\
\hline $\mathrm{H}$ & -8.286040 & -0.164697 & -2.766430 \\
\hline $\mathrm{H}$ & -7.065250 & -2.324917 & -2.505582 \\
\hline $\mathrm{H}$ & -4.905493 & -2.404375 & -1.348073 \\
\hline 0 & 0.739374 & 0.338861 & 0.568286 \\
\hline $\mathrm{O}$ & -0.337075 & 1.752625 & -1.363265 \\
\hline $\mathrm{H}$ & 0.633702 & 2.229176 & -1.585413 \\
\hline $\mathrm{H}$ & -2.662747 & 2.755252 & 2.432204 \\
\hline $\mathrm{H}$ & -1.847849 & 6.923512 & 1.752326 \\
\hline $\mathrm{H}$ & -3.420994 & 4.488918 & -1.424301 \\
\hline $\mathrm{H}$ & 1.446988 & -3.817863 & 0.917656 \\
\hline $\mathrm{H}$ & 4.099948 & -3.690602 & -2.464097 \\
\hline $\mathrm{H}$ & 0.041485 & -2.323868 & -2.857850 \\
\hline C & 2.845678 & 2.511673 & -1.325464 \\
\hline 0 & 1.815376 & 2.713886 & -2.047433 \\
\hline $\mathrm{H}$ & 3.818177 & 2.837870 & -1.720191 \\
\hline C & 2.794697 & 2.744501 & 0.190415 \\
\hline $\mathrm{O}$ & 3.738731 & 2.558959 & 0.934388 \\
\hline $\mathrm{O}$ & 1.617347 & 3.243911 & 0.568033 \\
\hline C & 1.447112 & 3.440215 & 1.984160 \\
\hline $\mathrm{H}$ & 2.235796 & 4.087663 & 2.375329 \\
\hline $\mathrm{H}$ & 0.467498 & 3.903391 & 2.091578 \\
\hline C & 4.090186 & 0.075506 & -0.477897 \\
\hline C & 3.260966 & 0.555020 & -1.505135 \\
\hline $\mathrm{H}$ & 2.470315 & -0.200154 & 0.725063 \\
\hline$N$ & 3.491132 & -0.343509 & 0.666301 \\
\hline C & 4.055686 & -1.070291 & 1.719248 \\
\hline
\end{tabular}




$\begin{array}{llll}\mathrm{O} & 5.182863 & -1.504554 & 1.784962 \\ \mathrm{O} & 3.101922 & -1.238237 & 2.656525 \\ \mathrm{C} & 3.510480 & -1.994930 & 3.805822 \\ \mathrm{H} & 3.822834 & -3.000932 & 3.513291 \\ \mathrm{H} & 2.631354 & -2.036805 & 4.448702 \\ \mathrm{H} & 4.338980 & -1.497974 & 4.317185 \\ \mathrm{H} & 3.719543 & 0.654214 & -2.482271 \\ \mathrm{H} & 2.237510 & 0.202150 & -1.510953 \\ \mathrm{C} & 5.561982 & 0.138577 & -0.621669 \\ \mathrm{C} & 6.151482 & -0.372684 & -1.788782 \\ \mathrm{C} & 6.370981 & 0.767175 & 0.339461 \\ \mathrm{C} & 7.528950 & -0.280479 & -1.982254 \\ \mathrm{H} & 5.530307 & -0.870014 & -2.527840 \\ \mathrm{C} & 7.741532 & 0.877630 & 0.129884 \\ \mathrm{H} & 5.912855 & 1.198267 & 1.221008 \\ \mathrm{C} & 8.325351 & 0.348594 & -1.025006 \\ \mathrm{H} & 7.976752 & -0.696050 & -2.880535 \\ \mathrm{H} & 8.358195 & 1.378902 & 0.870517 \\ \mathrm{H} & 9.398054 & 0.430489 & -1.178371 \\ \mathrm{H} & 1.474733 & 2.472611 & 2.490622\end{array}$

Catalyst (R)-1 TS Conformation 101

B3LYP/6-31G(d) Energy = -2809.693361

B3LYP-D3(BJ)/def2-TZVPP-IEF-PCM(DCM) Energy $=-2810.985118$

B3LYP-D3(BJ)/def2-TZVPP-IEF-PCM(DCM)//B3LYP/6-31G(d) Free Energy (Quasiharmonic) = 2810.344224

Frequencies (Top 3 out of 270)

1. $-727.6809 \mathrm{~cm}-1$

2. $\quad 8.7430 \mathrm{~cm}-1$

3. $\quad 11.4894 \mathrm{~cm}-1$

B3LYP/6-31G(d) Molecular Geometry in Cartesian Coordinates

$\begin{array}{lrrr}\text { C } & -3.814204 & -0.064321 & -0.129597 \\ \text { C } & -3.220663 & 1.068586 & 0.408479 \\ \text { C } & -3.859481 & 2.342741 & 0.457427 \\ \text { C } & -5.113675 & 2.442878 & -0.112630 \\ \text { H } & -5.639667 & 3.392972 & -0.069852 \\ \text { C } & -1.682710 & -3.818859 & -0.111701 \\ \text { C } & -3.101527 & -1.376431 & -0.071125\end{array}$




\begin{tabular}{|c|c|c|c|}
\hline C & -1.821298 & -1.477082 & -0.592391 \\
\hline C & -1.084628 & -2.696010 & -0.649205 \\
\hline $\mathrm{H}$ & -1.159956 & -4.770693 & -0.156257 \\
\hline 0 & -1.949541 & 0.963083 & 0.962585 \\
\hline$P$ & -0.653643 & 0.761519 & -0.011171 \\
\hline 0 & -1.225051 & -0.328410 & -1.097883 \\
\hline C & -2.149868 & 5.833544 & 2.302917 \\
\hline C & -2.731106 & 5.913395 & 1.036969 \\
\hline C & -3.264103 & 4.772457 & 0.438217 \\
\hline C & -3.226411 & 3.530085 & 1.091530 \\
\hline C & -2.632335 & 3.461444 & 2.362872 \\
\hline C & -2.102742 & 4.603138 & 2.961692 \\
\hline $\mathrm{H}$ & -2.763145 & 6.862936 & 0.508954 \\
\hline $\mathrm{H}$ & -1.653674 & 4.530623 & 3.948960 \\
\hline C & 2.853383 & -2.993767 & -2.362519 \\
\hline C & 1.849314 & -2.296554 & -3.039816 \\
\hline C & 0.573849 & -2.186434 & -2.488862 \\
\hline C & 0.276839 & -2.769322 & -1.243774 \\
\hline C & 1.294805 & -3.462126 & -0.570369 \\
\hline C & 2.569838 & -3.576323 & -1.126804 \\
\hline $\mathrm{H}$ & 2.061346 & -1.837739 & -4.001682 \\
\hline $\mathrm{H}$ & 3.341916 & -4.116227 & -0.583996 \\
\hline C & -3.679931 & -2.537226 & 0.548404 \\
\hline C & -2.955907 & -3.773483 & 0.508276 \\
\hline C & -3.520855 & -4.931781 & 1.107951 \\
\hline C & -4.735047 & -4.875927 & 1.751609 \\
\hline C & -5.433711 & -3.648089 & 1.826816 \\
\hline C & -4.921756 & -2.511171 & 1.241006 \\
\hline $\mathrm{H}$ & -2.963529 & -5.864308 & 1.058381 \\
\hline $\mathrm{H}$ & -5.153035 & -5.766749 & 2.212499 \\
\hline $\mathrm{H}$ & -6.381477 & -3.599572 & 2.356275 \\
\hline $\mathrm{H}$ & -5.464856 & -1.576248 & 1.315911 \\
\hline C & -5.087026 & 0.075831 & -0.783809 \\
\hline C & -5.742339 & 1.349474 & -0.756460 \\
\hline C & -7.006634 & 1.498377 & -1.388797 \\
\hline C & -7.594475 & 0.447356 & -2.053039 \\
\hline C & -6.931487 & -0.800721 & -2.116684 \\
\hline C & -5.713482 & -0.982143 & -1.499099 \\
\hline $\mathrm{H}$ & -7.495047 & 2.469146 & -1.346936 \\
\hline $\mathrm{H}$ & -8.558001 & 0.575176 & -2.538798 \\
\hline $\mathrm{H}$ & -7.384651 & -1.623801 & -2.662694 \\
\hline $\mathrm{H}$ & -5.215038 & -1.941984 & -1.566960 \\
\hline $\mathrm{O}$ & 0.475389 & 0.242926 & 0.817244 \\
\hline $\mathrm{O}$ & -0.435410 & 2.029254 & -0.846977 \\
\hline
\end{tabular}




\begin{tabular}{|c|c|c|c|}
\hline $\mathrm{H}$ & 0.668385 & 2.300831 & -1.218127 \\
\hline $\mathrm{H}$ & -2.592345 & 2.511489 & 2.884688 \\
\hline $\mathrm{H}$ & -1.732689 & 6.721447 & 2.770871 \\
\hline $\mathrm{H}$ & -3.694676 & 4.835625 & -0.557193 \\
\hline $\mathrm{H}$ & 1.098741 & -3.876469 & 0.413026 \\
\hline $\mathrm{H}$ & 3.847016 & -3.073283 & -2.795122 \\
\hline $\mathrm{H}$ & -0.199747 & -1.647776 & -3.025488 \\
\hline C & 2.581616 & 1.548813 & -1.387295 \\
\hline O & 1.800515 & 2.541281 & -1.601198 \\
\hline $\mathrm{H}$ & 2.162461 & 0.547418 & -1.245236 \\
\hline C & 3.907460 & 1.506834 & -2.120192 \\
\hline 0 & 4.415920 & 0.462841 & -2.474519 \\
\hline O & 4.428890 & 2.723334 & -2.322171 \\
\hline C & 5.686459 & 2.744123 & -3.021424 \\
\hline $\mathrm{H}$ & 5.946356 & 3.798171 & -3.118057 \\
\hline $\mathrm{H}$ & 6.448585 & 2.207876 & -2.449500 \\
\hline C & 3.893089 & 0.580732 & 0.924326 \\
\hline C & 3.253870 & 1.761397 & 0.522982 \\
\hline $\mathrm{H}$ & 2.093220 & -0.354468 & 1.186101 \\
\hline$N$ & 3.113948 & -0.464565 & 1.330425 \\
\hline C & 3.434251 & -1.582399 & 2.114933 \\
\hline 0 & 2.647890 & -2.482816 & 2.304455 \\
\hline $\mathrm{O}$ & 4.660010 & -1.502827 & 2.659006 \\
\hline C & 5.028309 & -2.624485 & 3.480546 \\
\hline $\mathrm{H}$ & 5.006491 & -3.549598 & 2.899249 \\
\hline $\mathrm{H}$ & 4.344347 & -2.716367 & 4.327543 \\
\hline $\mathrm{H}$ & 6.040310 & -2.407657 & 3.822197 \\
\hline $\mathrm{H}$ & 3.877053 & 2.629495 & 0.341505 \\
\hline $\mathrm{H}$ & 2.258024 & 1.944934 & 0.910450 \\
\hline C & 5.350095 & 0.421733 & 0.732914 \\
\hline C & 6.223909 & 1.449772 & 1.121131 \\
\hline C & 5.868207 & -0.711040 & 0.080487 \\
\hline C & 7.593012 & 1.336811 & 0.885603 \\
\hline $\mathrm{H}$ & 5.830649 & 2.322203 & 1.634248 \\
\hline C & 7.233095 & -0.810737 & -0.169377 \\
\hline $\mathrm{H}$ & 5.190785 & -1.483899 & -0.267595 \\
\hline C & 8.099402 & 0.207603 & 0.238491 \\
\hline $\mathrm{H}$ & 8.262773 & 2.128880 & 1.208181 \\
\hline $\mathrm{H}$ & 7.621984 & -1.680454 & -0.691098 \\
\hline $\mathrm{H}$ & 9.165832 & 0.122782 & 0.047932 \\
\hline $\mathrm{H}$ & 5.582949 & 2.280971 & -4.005792 \\
\hline
\end{tabular}

Catalyst (R)-1 TS Conformation 102 
B3LYP/6-31G(d) Energy $=-2809.694054$

B3LYP-D3(BJ)/def2-TZVPP-IEF-PCM(DCM) Energy $=-2810.985852$

B3LYP-D3(BJ)/def2-TZVPP-IEF-PCM(DCM)//B3LYP/6-31G(d) Free Energy (Quasiharmonic) = 2810.344183

Frequencies (Top 3 out of 270)

1. $-468.4758 \mathrm{~cm}-1$

2. $\quad 7.6729 \mathrm{~cm}-1$

3. $\quad 10.6066 \mathrm{~cm}-1$

B3LYP/6-31G(d) Molecular Geometry in Cartesian Coordinates

\begin{tabular}{|c|c|c|c|}
\hline C & -3.769732 & 0.219651 & -0.256628 \\
\hline C & -2.932860 & 1.313954 & -0.081499 \\
\hline C & -3.334371 & 2.653647 & -0.369028 \\
\hline C & -4.579984 & 2.832431 & -0.938958 \\
\hline $\mathrm{H}$ & -4.908669 & 3.840855 & -1.175590 \\
\hline C & -2.582962 & -3.728381 & 1.024497 \\
\hline C & -3.372578 & -1.129652 & 0.246440 \\
\hline C & -2.171914 & -1.687980 & -0.156599 \\
\hline C & -1.751214 & -3.004086 & 0.193036 \\
\hline $\mathrm{H}$ & -2.311188 & -4.746275 & 1.291399 \\
\hline O & -1.683384 & 1.131398 & 0.503252 \\
\hline$P$ & -0.501906 & 0.276681 & -0.220604 \\
\hline O & -1.331457 & -0.922825 & -0.960359 \\
\hline C & -1.065641 & 6.177683 & 0.609754 \\
\hline C & -0.467754 & 5.152534 & -0.125291 \\
\hline C & -1.179831 & 3.994815 & -0.437462 \\
\hline C & -2.511008 & 3.845489 & -0.018607 \\
\hline C & -3.103545 & 4.883835 & 0.719560 \\
\hline C & -2.388280 & 6.039325 & 1.032159 \\
\hline $\mathrm{H}$ & 0.561220 & 5.251423 & -0.460906 \\
\hline $\mathrm{H}$ & -2.863556 & 6.826890 & 1.611420 \\
\hline C & 1.890941 & -4.812499 & -1.222709 \\
\hline C & 1.526149 & -4.908682 & 0.120988 \\
\hline C & 0.354257 & -4.302854 & 0.574780 \\
\hline C & -0.478714 & -3.591564 & -0.304545 \\
\hline C & -0.097963 & -3.498583 & -1.654974 \\
\hline C & 1.073995 & -4.103932 & -2.107711 \\
\hline $\mathrm{H}$ & 2.156374 & -5.451199 & 0.821085 \\
\hline $\mathrm{H}$ & 1.346380 & -4.028504 & -3.157149 \\
\hline C & -4.187960 & -1.866139 & 1.175243 \\
\hline
\end{tabular}




\begin{tabular}{|c|c|c|c|}
\hline C & -3.782749 & -3.188596 & 1.550099 \\
\hline C & -4.584753 & -3.933924 & 2.456540 \\
\hline C & -5.724402 & -3.392266 & 3.003499 \\
\hline C & -6.104701 & -2.071952 & 2.667338 \\
\hline C & -5.359501 & -1.330295 & 1.777071 \\
\hline $\mathrm{H}$ & -4.269218 & -4.940744 & 2.719903 \\
\hline $\mathrm{H}$ & -6.325462 & -3.968733 & 3.701333 \\
\hline $\mathrm{H}$ & -6.991183 & -1.635619 & 3.119570 \\
\hline $\mathrm{H}$ & -5.660107 & -0.317050 & 1.538467 \\
\hline C & -5.020052 & 0.415650 & -0.940873 \\
\hline C & -5.425419 & 1.747440 & -1.273757 \\
\hline C & -6.660027 & 1.955790 & -1.946313 \\
\hline C & -7.458950 & 0.894776 & -2.303363 \\
\hline C & -7.046015 & -0.425180 & -2.005774 \\
\hline C & -5.861715 & -0.658716 & -1.341815 \\
\hline $\mathrm{H}$ & -6.954409 & 2.975273 & -2.184124 \\
\hline $\mathrm{H}$ & -8.397816 & 1.065155 & -2.823081 \\
\hline $\mathrm{H}$ & -7.665758 & -1.264479 & -2.309744 \\
\hline $\mathrm{H}$ & -5.555578 & -1.677206 & -1.133017 \\
\hline $\mathrm{O}$ & 0.468940 & -0.195497 & 0.810552 \\
\hline $\mathrm{O}$ & 0.065591 & 1.077170 & -1.418741 \\
\hline $\mathrm{H}$ & 1.196204 & 1.075591 & -1.486448 \\
\hline $\mathrm{H}$ & -4.127632 & 4.771821 & 1.065706 \\
\hline $\mathrm{H}$ & -0.504296 & 7.075826 & 0.854072 \\
\hline $\mathrm{H}$ & -0.706770 & 3.212448 & -1.019617 \\
\hline $\mathrm{H}$ & -0.728741 & -2.958730 & -2.352809 \\
\hline $\mathrm{H}$ & 2.802876 & -5.283797 & -1.579490 \\
\hline $\mathrm{H}$ & 0.088263 & -4.361353 & 1.626406 \\
\hline C & 2.933728 & -0.119676 & -1.904217 \\
\hline $\mathrm{O}$ & 2.486756 & 1.033576 & -1.587242 \\
\hline $\mathrm{H}$ & 2.244476 & -0.895519 & -2.263429 \\
\hline C & 4.282564 & -0.231770 & -2.601803 \\
\hline $\mathrm{O}$ & 4.676026 & -1.259305 & -3.115626 \\
\hline $\mathrm{O}$ & 4.953382 & 0.928199 & -2.604784 \\
\hline C & 6.227471 & 0.892991 & -3.271371 \\
\hline $\mathrm{H}$ & 6.607091 & 1.913695 & -3.225299 \\
\hline $\mathrm{H}$ & 6.906081 & 0.206460 & -2.758820 \\
\hline C & 3.948846 & -0.379906 & 0.613420 \\
\hline C & 3.344748 & -1.287626 & -0.265180 \\
\hline $\mathrm{H}$ & 2.114685 & 0.384213 & 1.077651 \\
\hline$N$ & 3.129930 & 0.471962 & 1.280079 \\
\hline C & 3.371841 & 1.321101 & 2.376412 \\
\hline $\mathrm{O}$ & 2.572199 & 2.159153 & 2.720204 \\
\hline 0 & 4.529682 & 1.049804 & 3.000219 \\
\hline
\end{tabular}




$\begin{array}{llll}\mathrm{C} & 4.814810 & 1.894766 & 4.129322 \\ \mathrm{H} & 4.045697 & 1.775631 & 4.896071 \\ \mathrm{H} & 4.856879 & 2.942880 & 3.822955 \\ \mathrm{H} & 5.784460 & 1.560656 & 4.498174 \\ \mathrm{H} & 3.969524 & -2.039891 & -0.731459 \\ \mathrm{H} & 2.315993 & -1.568169 & -0.062298 \\ \mathrm{C} & 5.420487 & -0.217981 & 0.629594 \\ \mathrm{C} & 6.008141 & 1.048892 & 0.470953 \\ \mathrm{C} & 6.244450 & -1.349282 & 0.721753 \\ \mathrm{C} & 7.392873 & 1.176092 & 0.417818 \\ \mathrm{H} & 5.374422 & 1.921562 & 0.350892 \\ \mathrm{C} & 7.632085 & -1.215874 & 0.685348 \\ \mathrm{H} & 5.794909 & -2.329750 & 0.846241 \\ \mathrm{C} & 8.208534 & 0.045933 & 0.533268 \\ \mathrm{H} & 7.838138 & 2.158021 & 0.283473 \\ \mathrm{H} & 8.260583 & -2.097330 & 0.773895 \\ \mathrm{H} & 9.289670 & 0.149886 & 0.499695 \\ \mathrm{H} & 6.105706 & 0.572324 & -4.308922\end{array}$

Catalyst (R)-1 TS Conformation 103

B3LYP/6-31G(d) Energy = -2809.692525

B3LYP-D3(BJ)/def2-TZVPP-IEF-PCM(DCM) Energy = -2810.985777

B3LYP-D3(BJ)/def2-TZVPP-IEF-PCM(DCM)//B3LYP/6-31G(d) Free Energy (Quasiharmonic) = 2810.344176

Frequencies (Top 3 out of 270)

1. $-655.9231 \mathrm{~cm}-1$

2. $\quad 9.1468 \mathrm{~cm}-1$

3. $12.0391 \mathrm{~cm}-1$

B3LYP/6-31G(d) Molecular Geometry in Cartesian Coordinates

$\begin{array}{lrrr}\text { C } & 3.116880 & 0.934479 & 0.259589 \\ \text { C } & 2.045566 & 1.711492 & -0.152979 \\ \text { C } & 1.910464 & 3.095909 & 0.160723 \\ \text { C } & 2.891653 & 3.663398 & 0.949456 \\ \text { H } & 2.833178 & 4.722202 & 1.188056 \\ \text { C } & 3.306991 & -3.235513 & -0.831479 \\ \text { C } & 3.198203 & -0.492628 & -0.174484 \\ \text { C } & 2.134004 & -1.348206 & 0.076367 \\ \text { C } & 2.167750 & -2.744790 & -0.221944\end{array}$




\begin{tabular}{|c|c|c|c|}
\hline $\mathrm{H}$ & 3.382476 & -4.299584 & -1.039221 \\
\hline $\mathrm{O}$ & 1.055826 & 1.118290 & -0.923434 \\
\hline$P$ & -0.019644 & 0.128650 & -0.171135 \\
\hline $\mathrm{O}$ & 0.998190 & -0.842398 & 0.685974 \\
\hline C & -1.370693 & 5.525378 & -1.198165 \\
\hline C & -0.967195 & 5.561232 & 0.137059 \\
\hline C & 0.088489 & 4.760254 & 0.570827 \\
\hline C & 0.760035 & 3.906978 & -0.319619 \\
\hline C & 0.340389 & 3.875444 & -1.660244 \\
\hline C & -0.712624 & 4.679466 & -2.093727 \\
\hline $\mathrm{H}$ & -1.481877 & 6.203993 & 0.846198 \\
\hline $\mathrm{H}$ & -1.018076 & 4.645010 & -3.136364 \\
\hline C & -1.010811 & -5.503661 & 0.708331 \\
\hline C & -0.661020 & -4.506893 & 1.623592 \\
\hline C & 0.351252 & -3.593835 & 1.325270 \\
\hline C & 1.041468 & -3.661170 & 0.102215 \\
\hline C & 0.676403 & -4.667929 & -0.808427 \\
\hline C & -0.336093 & -5.579029 & -0.511038 \\
\hline $\mathrm{H}$ & -1.166643 & -4.444212 & 2.583743 \\
\hline $\mathrm{H}$ & -0.600658 & -6.345683 & -1.234694 \\
\hline C & 4.337428 & -1.003383 & -0.886671 \\
\hline C & 4.389209 & -2.400317 & -1.199144 \\
\hline C & 5.518967 & -2.921825 & -1.886505 \\
\hline C & 6.546412 & -2.099221 & -2.285221 \\
\hline C & 6.479373 & -0.712035 & -2.014859 \\
\hline C & 5.407155 & -0.179205 & -1.333553 \\
\hline $\mathrm{H}$ & 5.547443 & -3.987272 & -2.103014 \\
\hline $\mathrm{H}$ & 7.401676 & -2.507501 & -2.816677 \\
\hline $\mathrm{H}$ & 7.279766 & -0.058884 & -2.351940 \\
\hline $\mathrm{H}$ & 5.367370 & 0.886780 & -1.142553 \\
\hline C & 4.090289 & 1.520852 & 1.140458 \\
\hline C & 3.973205 & 2.910626 & 1.469864 \\
\hline C & 4.934683 & 3.507458 & 2.329843 \\
\hline C & 5.955564 & 2.764678 & 2.875594 \\
\hline C & 6.050110 & 1.383450 & 2.585372 \\
\hline C & 5.144443 & 0.778799 & 1.741361 \\
\hline $\mathrm{H}$ & 4.837407 & 4.566132 & 2.558894 \\
\hline $\mathrm{H}$ & 6.680347 & 3.230888 & 3.537425 \\
\hline $\mathrm{H}$ & 6.841968 & 0.791504 & 3.036567 \\
\hline $\mathrm{H}$ & 5.226025 & -0.282718 & 1.538718 \\
\hline 0 & -0.825131 & -0.561887 & -1.213105 \\
\hline $\mathrm{O}$ & -0.728043 & 0.887852 & 0.964814 \\
\hline $\mathrm{H}$ & -1.811706 & 1.307378 & 0.820370 \\
\hline $\mathrm{H}$ & 0.844082 & 3.221548 & -2.363790 \\
\hline
\end{tabular}




$\begin{array}{llll}\mathrm{H} & -2.194643 & 6.148043 & -1.536973 \\ \mathrm{H} & 0.381688 & 4.772349 & 1.616764 \\ \mathrm{H} & 1.183473 & -4.723089 & -1.767695 \\ \mathrm{H} & -1.795367 & -6.217796 & 0.945540 \\ \mathrm{H} & 0.615304 & -2.830980 & 2.048104 \\ \mathrm{C} & -3.520208 & 1.465778 & -0.401274 \\ \mathrm{O} & -2.950611 & 1.784673 & 0.706380 \\ \mathrm{H} & -2.918772 & 1.031059 & -1.205711 \\ \mathrm{C} & -4.610905 & 2.432198 & -0.855840 \\ \mathrm{O} & -5.291161 & 3.105405 & -0.117714 \\ \mathrm{O} & -4.707149 & 2.423884 & -2.199433 \\ \mathrm{C} & -5.705289 & 3.299758 & -2.750510 \\ \mathrm{H} & -5.486664 & 4.338253 & -2.488443 \\ \mathrm{H} & -5.656124 & 3.156021 & -3.829827 \\ \mathrm{C} & -4.063832 & -1.146139 & 0.317406 \\ \mathrm{C} & -4.781273 & -0.080958 & -0.253315 \\ \mathrm{H} & -2.631414 & -2.581459 & 0.091262 \\ \mathrm{~N} & -3.314198 & -2.018606 & -0.406914 \\ \mathrm{C} & -3.133029 & -2.036353 & -1.804941 \\ \mathrm{O} & -3.702328 & -1.324361 & -2.599473 \\ \mathrm{O} & -2.258092 & -3.003879 & -2.087803 \\ \mathrm{C} & -1.721146 & -2.964104 & -3.423091 \\ \mathrm{H} & -1.078710 & -3.840773 & -3.496751 \\ \mathrm{H} & -1.140239 & -2.047012 & -3.541270 \\ \mathrm{H} & -2.525033 & -3.005721 & -4.161256 \\ \mathrm{H} & -5.550562 & 0.343942 & 0.382166 \\ \mathrm{H} & -5.014726 & -0.156709 & -1.307552 \\ \mathrm{C} & -4.034531 & -1.345439 & 1.777279 \\ \mathrm{C} & -3.883958 & -2.633725 & 2.328584 \\ \mathrm{C} & -4.168697 & -0.241333 & 2.640530 \\ \mathrm{C} & -3.871431 & -2.811565 & 3.708049 \\ \mathrm{H} & -3.818752 & -3.502106 & 1.679689 \\ \mathrm{H} & -4.128075 & -0.427985 & 4.020895 \\ -4.251140 & 0.760038 & 2.233762 \\ \mathrm{H} & -3.986142 & -1.707843 & 4.558072 \\ \mathrm{H} & -4.208823 & 0.433408 & 4.677168 \\ \mathrm{H} & -3.970397 & -1.848279 & 5.635305 \\ \mathrm{H} & & 3.037926 & -2.369860\end{array}$

Catalyst (R)-1 TS Conformation 104

B3LYP/6-31G(d) Energy $=-2809.691862$ 
B3LYP-D3(BJ)/def2-TZVPP-IEF-PCM(DCM) Energy $=-2810.985983$

B3LYP-D3(BJ)/def2-TZVPP-IEF-PCM(DCM)//B3LYP/6-31G(d) Free Energy (Quasiharmonic) = 2810.344068

Frequencies (Top 3 out of 270)

1. $-615.2202 \mathrm{~cm}-1$

2. $\quad 11.4762 \mathrm{~cm}-1$

3. $\quad 14.9211 \mathrm{~cm}-1$

B3LYP/6-31G(d) Molecular Geometry in Cartesian Coordinates

$\begin{array}{lrrr}\text { C } & 3.284149 & 0.334423 & 0.349105 \\ \text { C } & 2.375784 & 1.355175 & 0.105048 \\ \text { C } & 2.589959 & 2.694351 & 0.548467 \\ \text { C } & 3.723902 & 2.945821 & 1.296082 \\ \text { H } & 3.908087 & 3.960247 & 1.639792 \\ \text { C } & 2.793444 & -3.642637 & -1.204455 \\ \text { C } & 3.099936 & -1.003215 & -0.280262 \\ \text { C } & 1.917035 & -1.703409 & -0.092892 \\ \text { C } & 1.745314 & -3.051562 & -0.525879 \\ \text { H } & 2.685447 & -4.670276 & -1.541350 \\ \text { O } & 1.256849 & 1.079304 & -0.683597 \\ \text { P } & 0.059888 & 0.128035 & -0.085525 \\ \text { O } & 0.890744 & -1.092242 & 0.626809 \\ \text { C } & 0.141833 & 6.155494 & -0.184205 \\ \text { C } & 1.421801 & 6.062206 & -0.734818 \\ \text { C } & 2.191102 & 4.917509 & -0.522617 \\ \text { C } & 1.691306 & 3.845413 & 0.234444 \\ \text { C } & 0.401910 & 3.945074 & 0.775971 \\ \text { C } & -0.362632 & 5.094096 & 0.570375 \\ \text { H } & 1.824810 & 6.881474 & -1.324755 \\ \text { H } & -1.356563 & 5.158081 & 1.005434 \\ \text { C } & -1.683434 & -5.594197 & 0.010421 \\ \text { C } & -1.797417 & -4.418921 & -0.736571 \\ \text { C } & -0.708029 & -3.557681 & -0.875690 \\ \text { C } & 0.521133 & -3.869035 & -0.275672 \\ \text { C } & 0.626397 & -5.050827 & 0.475072 \\ \text { C } & -0.467411 & -5.905208 & 0.621850 \\ \text { H } & -2.739199 & -4.176019 & -1.222807 \\ \text { H } & -0.365911 & -6.816131 & 1.206300 \\ \text { C } & 4.135041 & -1.591624 & -1.087068 \\ \text { C } & 3.977737 & -2.941311 & -1.534265 \\ \text { C } & 4.997313 & -3.543903 & -2.320055\end{array}$




\begin{tabular}{|c|c|c|c|}
\hline C & 6.120905 & -2.837579 & -2.679977 \\
\hline C & 6.263356 & -1.490368 & -2.271404 \\
\hline C & 5.300211 & -0.884578 & -1.495167 \\
\hline $\mathrm{H}$ & 4.862660 & -4.573452 & -2.643166 \\
\hline $\mathrm{H}$ & 6.891728 & -3.304381 & -3.286977 \\
\hline $\mathrm{H}$ & 7.139251 & -0.925173 & -2.578271 \\
\hline $\mathrm{H}$ & 5.421344 & 0.151085 & -1.200373 \\
\hline C & 4.397554 & 0.588692 & 1.223890 \\
\hline C & 4.623263 & 1.924222 & 1.683139 \\
\hline C & 5.727004 & 2.197083 & 2.535964 \\
\hline C & 6.565449 & 1.188634 & 2.949289 \\
\hline C & 6.323758 & -0.140541 & 2.528645 \\
\hline C & 5.272239 & -0.432959 & 1.688406 \\
\hline $\mathrm{H}$ & 5.885818 & 3.220709 & 2.866764 \\
\hline $\mathrm{H}$ & 7.402510 & 1.405491 & 3.607192 \\
\hline $\mathrm{H}$ & 6.970922 & -0.940932 & 2.877089 \\
\hline $\mathrm{H}$ & 5.096723 & -1.458615 & 1.386302 \\
\hline $\mathrm{O}$ & -0.838154 & -0.337337 & -1.188546 \\
\hline $\mathrm{O}$ & -0.620221 & 0.854669 & 1.096067 \\
\hline $\mathrm{H}$ & -1.625691 & 1.331358 & 0.820683 \\
\hline $\mathrm{H}$ & 0.006555 & 3.126381 & 1.365919 \\
\hline $\mathrm{H}$ & -0.457041 & 7.049007 & -0.340140 \\
\hline $\mathrm{H}$ & 3.190368 & 4.848777 & -0.944742 \\
\hline $\mathrm{H}$ & 1.575449 & -5.298935 & 0.943093 \\
\hline $\mathrm{H}$ & -2.533792 & -6.263906 & 0.109827 \\
\hline $\mathrm{H}$ & -0.799742 & -2.646377 & -1.457081 \\
\hline C & -3.455345 & 2.151066 & -0.348365 \\
\hline $\mathrm{O}$ & -2.834301 & 1.764179 & 0.715528 \\
\hline $\mathrm{H}$ & -4.460747 & 2.559497 & -0.187536 \\
\hline C & -2.758198 & 2.949882 & -1.451663 \\
\hline $\mathrm{O}$ & -3.358026 & 3.719416 & -2.173693 \\
\hline $\mathrm{O}$ & -1.457634 & 2.664883 & -1.534971 \\
\hline C & -0.729256 & 3.304998 & -2.601068 \\
\hline $\mathrm{H}$ & -1.211699 & 3.097011 & -3.559408 \\
\hline $\mathrm{H}$ & -0.691805 & 4.382749 & -2.432153 \\
\hline C & -4.395479 & -0.237152 & -0.544596 \\
\hline C & -3.973944 & 0.691190 & -1.520325 \\
\hline $\mathrm{H}$ & -2.458783 & -0.755193 & -0.284197 \\
\hline$N$ & -3.415688 & -0.914753 & 0.075522 \\
\hline C & -3.511297 & -1.838605 & 1.144549 \\
\hline $\mathrm{O}$ & -4.518002 & -2.386891 & 1.523894 \\
\hline $\mathrm{O}$ & -2.280831 & -1.998119 & 1.634395 \\
\hline C & -2.144558 & -2.947310 & 2.707474 \\
\hline $\mathrm{H}$ & -2.421220 & -3.944767 & 2.360848 \\
\hline
\end{tabular}




$\begin{array}{lrrr}\mathrm{H} & -2.775248 & -2.654098 & 3.550091 \\ \mathrm{H} & -1.090265 & -2.912801 & 2.976304 \\ \mathrm{H} & -4.744085 & 1.147469 & -2.133889 \\ \mathrm{H} & -3.030838 & 0.475715 & -2.018091 \\ \mathrm{C} & -5.795640 & -0.219246 & -0.068787 \\ \mathrm{C} & -6.100452 & 0.075652 & 1.270016 \\ \mathrm{C} & -6.836009 & -0.380664 & -0.996115 \\ \mathrm{C} & -7.428041 & 0.194961 & 1.669831 \\ \mathrm{H} & -5.298083 & 0.242481 & 1.980270 \\ \mathrm{C} & -8.164083 & -0.288350 & -0.583352 \\ \mathrm{H} & -6.601310 & -0.600443 & -2.033645 \\ \mathrm{C} & -8.461326 & 0.002286 & 0.748899 \\ \mathrm{H} & -7.657062 & 0.437214 & 2.703529 \\ \mathrm{H} & -8.963860 & -0.435285 & -1.303398 \\ \mathrm{H} & -9.496280 & 0.085502 & 1.068952 \\ \mathrm{H} & 0.267961 & 2.872313 & -2.559337\end{array}$

Catalyst (R)-1 TS Conformation 105

B3LYP/6-31G(d) Energy $=-2809.690847$

B3LYP-D3(BJ)/def2-TZVPP-IEF-PCM(DCM) Energy = -2810.986133

B3LYP-D3(BJ)/def2-TZVPP-IEF-PCM(DCM)//B3LYP/6-31G(d) Free Energy (Quasiharmonic) = 2810.344024

Frequencies (Top 3 out of 270)

1. $-616.6133 \mathrm{~cm}-1$

2. $\quad 9.1155 \mathrm{~cm}-1$

3. $\quad 9.9534 \mathrm{~cm}-1$

B3LYP/6-31G(d) Molecular Geometry in Cartesian Coordinates

$\begin{array}{lrrr}\text { C } & 3.470239 & 1.068746 & 0.162182 \\ \text { C } & 2.261622 & 1.713078 & -0.044504 \\ \text { C } & 1.971649 & 3.018864 & 0.449797 \\ \text { C } & 2.947395 & 3.640516 & 1.203826 \\ \text { H } & 2.771114 & 4.647290 & 1.573581 \\ \text { C } & 4.228274 & -2.882166 & -1.375935 \\ \text { C } & 3.707675 & -0.269059 & -0.456415 \\ \text { C } & 2.824487 & -1.314525 & -0.216328 \\ \text { C } & 3.086446 & -2.655770 & -0.632019 \\ \text { H } & 4.445698 & -3.892812 & -1.711467 \\ \text { O } & 1.283576 & 1.057817 & -0.780001\end{array}$




\begin{tabular}{|c|c|c|c|}
\hline$P$ & 0.460281 & -0.156139 & -0.033885 \\
\hline $\mathrm{O}$ & 1.690604 & -1.081870 & 0.547244 \\
\hline C & -1.724831 & 5.094350 & -0.289411 \\
\hline C & -1.176446 & 5.057124 & 0.992958 \\
\hline C & 0.012180 & 4.365677 & 1.226108 \\
\hline C & 0.677338 & 3.700328 & 0.183563 \\
\hline C & 0.111009 & 3.739823 & -1.102475 \\
\hline C & -1.076803 & 4.431733 & -1.334797 \\
\hline $\mathrm{H}$ & -1.677696 & 5.557988 & 1.817117 \\
\hline $\mathrm{H}$ & -1.495728 & 4.454650 & -2.337335 \\
\hline C & 0.689048 & -6.082866 & 0.387280 \\
\hline C & 0.087526 & -4.962780 & -0.190713 \\
\hline C & 0.842049 & -3.832208 & -0.506689 \\
\hline C & 2.222910 & -3.809342 & -0.252195 \\
\hline C & 2.817848 & -4.941032 & 0.330377 \\
\hline C & 2.059490 & -6.067440 & 0.648932 \\
\hline $\mathrm{H}$ & -0.978491 & -4.967434 & -0.403194 \\
\hline $\mathrm{H}$ & 2.540181 & -6.929568 & 1.104484 \\
\hline C & 4.837498 & -0.503859 & -1.314111 \\
\hline C & 5.099399 & -1.836682 & -1.765831 \\
\hline C & 6.216225 & -2.083206 & -2.609628 \\
\hline C & 7.034999 & -1.056223 & -3.017692 \\
\hline C & 6.760302 & 0.267514 & -2.600422 \\
\hline C & 5.693549 & 0.536365 & -1.771261 \\
\hline $\mathrm{H}$ & 6.403046 & -3.103513 & -2.936557 \\
\hline $\mathrm{H}$ & 7.882584 & -1.255144 & -3.667912 \\
\hline $\mathrm{H}$ & 7.393215 & 1.081964 & -2.942662 \\
\hline $\mathrm{H}$ & 5.490597 & 1.557712 & -1.470600 \\
\hline C & 4.445199 & 1.696287 & 1.013541 \\
\hline C & 4.174333 & 3.008205 & 1.521996 \\
\hline C & 5.133836 & 3.647548 & 2.353151 \\
\hline C & 6.302674 & 3.012935 & 2.703300 \\
\hline C & 6.554438 & 1.701243 & 2.237518 \\
\hline C & 5.652867 & 1.061553 & 1.415274 \\
\hline $\mathrm{H}$ & 4.916573 & 4.648360 & 2.719170 \\
\hline $\mathrm{H}$ & 7.025455 & 3.508885 & 3.345452 \\
\hline $\mathrm{H}$ & 7.466114 & 1.190096 & 2.535133 \\
\hline $\mathrm{H}$ & 5.857719 & 0.052992 & 1.076374 \\
\hline $\mathrm{O}$ & -0.395572 & -0.828056 & -1.056586 \\
\hline $\mathrm{O}$ & -0.208599 & 0.368749 & 1.242493 \\
\hline $\mathrm{H}$ & -1.434500 & 0.580991 & 1.216168 \\
\hline $\mathrm{H}$ & 0.608081 & 3.231919 & -1.921697 \\
\hline $\mathrm{H}$ & -2.650693 & 5.633147 & -0.473366 \\
\hline $\mathrm{H}$ & 0.420804 & 4.317756 & 2.231363 \\
\hline
\end{tabular}




\begin{tabular}{|c|c|c|c|}
\hline $\mathrm{H}$ & 3.882440 & -4.927252 & 0.548403 \\
\hline $\mathrm{H}$ & 0.094914 & -6.960085 & 0.631069 \\
\hline $\mathrm{H}$ & 0.362288 & -2.971813 & -0.961889 \\
\hline C & -2.995703 & 1.076295 & 0.001807 \\
\hline 0 & -2.586075 & 0.793477 & 1.189676 \\
\hline $\mathrm{H}$ & -2.253346 & 1.305636 & -0.768783 \\
\hline C & -4.271521 & 1.892909 & -0.092337 \\
\hline 0 & -5.196772 & 1.840079 & 0.688089 \\
\hline 0 & -4.220319 & 2.676755 & -1.183546 \\
\hline C & -5.387325 & 3.474951 & -1.443504 \\
\hline $\mathrm{H}$ & -5.686607 & 4.019924 & -0.545297 \\
\hline $\mathrm{H}$ & -6.202987 & 2.829147 & -1.777955 \\
\hline C & -4.508653 & -1.216500 & -0.170329 \\
\hline C & -3.639056 & -0.527173 & -1.029070 \\
\hline $\mathrm{H}$ & -6.375810 & -1.289726 & 0.655323 \\
\hline$N$ & -5.862626 & -0.989541 & -0.162831 \\
\hline C & -6.648465 & -0.278367 & -1.069521 \\
\hline 0 & -6.279171 & 0.259889 & -2.089689 \\
\hline 0 & -7.917518 & -0.318981 & -0.620922 \\
\hline C & -8.878744 & 0.386372 & -1.425703 \\
\hline $\mathrm{H}$ & -9.845471 & 0.171432 & -0.971206 \\
\hline $\mathrm{H}$ & -8.847176 & 0.031519 & -2.458152 \\
\hline $\mathrm{H}$ & -8.676392 & 1.460123 & -1.400696 \\
\hline $\mathrm{H}$ & -2.649984 & -0.946008 & -1.189592 \\
\hline $\mathrm{H}$ & -4.081133 & -0.031289 & -1.884578 \\
\hline C & -4.028353 & -2.152526 & 0.855032 \\
\hline C & -2.651865 & -2.224368 & 1.149441 \\
\hline C & -4.910062 & -2.993239 & 1.573523 \\
\hline C & -2.182768 & -3.068877 & 2.153648 \\
\hline $\mathrm{H}$ & -1.937788 & -1.640270 & 0.587263 \\
\hline C & -4.435324 & -3.839420 & 2.566334 \\
\hline $\mathrm{H}$ & -5.968938 & -3.034598 & 1.334329 \\
\hline C & -3.069598 & -3.870618 & 2.869700 \\
\hline $\mathrm{H}$ & -1.118137 & -3.099532 & 2.360966 \\
\hline $\mathrm{H}$ & -5.128635 & -4.483781 & 3.098995 \\
\hline $\mathrm{H}$ & -2.701146 & -4.531607 & 3.649129 \\
\hline $\mathrm{H}$ & -5.099149 & 4.163863 & -2.237715 \\
\hline
\end{tabular}

Catalyst (R)-1 TS Conformation 106

B3LYP/6-31G(d) Energy $=-2809.696083$

B3LYP-D3(BJ)/def2-TZVPP-IEF-PCM(DCM) Energy = -2810.986067 
B3LYP-D3(BJ)/def2-TZVPP-IEF-PCM(DCM)//B3LYP/6-31G(d) Free Energy (Quasiharmonic) = 2810.343959

Frequencies (Top 3 out of 270)

1. $-549.3306 \mathrm{~cm}-1$

2. $\quad 14.7302 \mathrm{~cm}-1$

3. $\quad 15.3520 \mathrm{~cm}-1$

B3LYP/6-31G(d) Molecular Geometry in Cartesian Coordinates

$\begin{array}{llll}\text { C } & 2.923321 & -1.072756 & -0.381493 \\ \text { C } & 1.693574 & -1.702465 & -0.241411 \\ \text { C } & 1.489280 & -3.077869 & -0.570725 \\ \text { C } & 2.558997 & -3.772011 & -1.101111 \\ \text { H } & 2.425715 & -4.818409 & -1.362346 \\ \text { C } & 3.716016 & 3.032748 & 0.627036 \\ \mathrm{C} & 3.137830 & 0.324571 & 0.099252 \\ \mathrm{C} & 2.329047 & 1.349583 & -0.364633 \\ \mathrm{C} & 2.630628 & 2.730735 & -0.172651 \\ \mathrm{H} & 3.968965 & 4.075549 & 0.799725 \\ \mathrm{O} & 0.640996 & -1.016133 & 0.352782 \\ \mathrm{P} & -0.024236 & 0.336311 & -0.285295 \\ \mathrm{O} & 1.205865 & 1.013854 & -1.118393 \\ \mathrm{C} & -2.140152 & -5.338146 & -0.091675 \\ \mathrm{C} & -0.951699 & -5.768180 & 0.503775 \\ \mathrm{C} & 0.210533 & -5.007556 & 0.374082 \\ \mathrm{C} & 0.206432 & -3.806387 & -0.354939 \\ \mathrm{C} & -0.994669 & -3.382862 & -0.940888 \\ \mathrm{C} & -2.159414 & -4.139978 & -0.809456 \\ \mathrm{H} & -0.926853 & -6.697443 & 1.067873 \\ \mathrm{H} & -3.078298 & -3.778873 & -1.262077 \\ \mathrm{C} & 0.625203 & 5.935895 & -2.233516 \\ \mathrm{C} & -0.122540 & 5.003582 & -1.511853 \\ \mathrm{C} & 0.503442 & 3.957890 & -0.833549 \\ \mathrm{C} & 1.899922 & 3.822321 & -0.876009 \\ \mathrm{C} & 2.643569 & 4.768370 & -1.602153 \\ \mathrm{C} & 2.014650 & 5.817143 & -2.272222 \\ \mathrm{H} & -1.205707 & 5.084305 & -1.481314 \\ \mathrm{H} & 2.610332 & 6.532043 & -2.833947 \\ \mathrm{C} & 4.201466 & 0.653431 & 1.009913 \\ \mathrm{C} & 4.484859 & 2.032312 & 1.271172 \\ \mathrm{C} & 5.531076 & 2.371324 & 2.171393 \\ \mathrm{C} & 6.257689 & 1.394358 & 2.811445\end{array}$




\begin{tabular}{|c|c|c|c|}
\hline C & 5.960330 & 0.031062 & 2.577823 \\
\hline C & 4.962763 & -0.329993 & 1.698855 \\
\hline $\mathrm{H}$ & 5.738410 & 3.423403 & 2.352552 \\
\hline $\mathrm{H}$ & 7.051107 & 1.665257 & 3.502663 \\
\hline $\mathrm{H}$ & 6.520911 & -0.739203 & 3.100628 \\
\hline $\mathrm{H}$ & 4.739851 & -1.378405 & 1.537188 \\
\hline C & 3.991478 & -1.780678 & -1.039373 \\
\hline C & 3.802962 & -3.157889 & -1.378143 \\
\hline C & 4.852101 & -3.876845 & -2.012445 \\
\hline C & 6.038982 & -3.260254 & -2.331513 \\
\hline C & 6.215957 & -1.888534 & -2.035013 \\
\hline C & 5.223090 & -1.169605 & -1.406306 \\
\hline $\mathrm{H}$ & 4.689434 & -4.924734 & -2.253409 \\
\hline $\mathrm{H}$ & 6.832776 & -3.816530 & -2.822473 \\
\hline $\mathrm{H}$ & 7.142528 & -1.393221 & -2.312596 \\
\hline $\mathrm{H}$ & 5.375262 & -0.116963 & -1.200987 \\
\hline $\mathrm{O}$ & -0.524320 & 1.177511 & 0.843818 \\
\hline $\mathrm{O}$ & -1.000039 & -0.038913 & -1.424976 \\
\hline $\mathrm{H}$ & -2.038546 & -0.440739 & -1.195857 \\
\hline $\mathrm{H}$ & -1.014148 & -2.468672 & -1.520953 \\
\hline $\mathrm{H}$ & -3.045021 & -5.933758 & 0.001834 \\
\hline $\mathrm{H}$ & 1.132410 & -5.341219 & 0.843432 \\
\hline $\mathrm{H}$ & 3.723585 & 4.662816 & -1.658748 \\
\hline $\mathrm{H}$ & 0.129581 & 6.744638 & -2.764414 \\
\hline $\mathrm{H}$ & -0.087514 & 3.258215 & -0.254014 \\
\hline C & -4.230053 & -0.233736 & -1.106472 \\
\hline $\mathrm{O}$ & -3.197309 & -0.993592 & -1.069603 \\
\hline $\mathrm{H}$ & -4.122277 & 0.799628 & -1.461084 \\
\hline C & -5.514905 & -0.921551 & -1.556784 \\
\hline $\mathrm{O}$ & -5.725138 & -2.109760 & -1.468159 \\
\hline $\mathrm{O}$ & -6.382648 & -0.021682 & -2.058597 \\
\hline C & -7.639081 & -0.559247 & -2.510016 \\
\hline $\mathrm{H}$ & -8.163018 & -1.048635 & -1.684672 \\
\hline $\mathrm{H}$ & -8.208018 & 0.295576 & -2.875298 \\
\hline C & -3.804021 & 0.592321 & 1.388123 \\
\hline C & -4.978665 & 0.302594 & 0.670866 \\
\hline $\mathrm{H}$ & -2.134656 & 1.768904 & 1.360530 \\
\hline$N$ & -3.167714 & 1.798084 & 1.304283 \\
\hline C & -3.738298 & 3.020804 & 0.938892 \\
\hline $\mathrm{O}$ & -4.902068 & 3.225486 & 0.667038 \\
\hline $\mathrm{O}$ & -2.775925 & 3.959604 & 0.972370 \\
\hline C & -3.220180 & 5.298653 & 0.689839 \\
\hline $\mathrm{H}$ & -2.317051 & 5.907197 & 0.708218 \\
\hline $\mathrm{H}$ & -3.928462 & 5.630968 & 1.453153 \\
\hline
\end{tabular}




$\begin{array}{lrrr}\mathrm{H} & -3.700152 & 5.344312 & -0.290712 \\ \mathrm{H} & -5.527448 & -0.571008 & 1.006115 \\ \mathrm{H} & -5.585366 & 1.137387 & 0.344628 \\ \mathrm{C} & -3.106366 & -0.436254 & 2.161588 \\ \mathrm{C} & -3.287500 & -1.804635 & 1.872765 \\ \mathrm{C} & -2.260242 & -0.069182 & 3.230891 \\ \mathrm{C} & -2.629495 & -2.770673 & 2.628761 \\ \mathrm{H} & -3.896580 & -2.110574 & 1.031619 \\ \mathrm{C} & -1.628448 & -1.040566 & 3.994447 \\ \mathrm{H} & -2.123654 & 0.978016 & 3.477179 \\ \mathrm{C} & -1.806976 & -2.393705 & 3.690841 \\ \mathrm{H} & -2.743636 & -3.817944 & 2.370337 \\ \mathrm{H} & -0.990617 & -0.744375 & 4.821836 \\ \mathrm{H} & -1.300483 & -3.152997 & 4.280340 \\ \mathrm{H} & -7.476083 & -1.285597 & -3.310193\end{array}$

Catalyst (R)-1 TS Conformation 107

$B 3 L Y P / 6-31 G(d)$ Energy $=-2809.688535$

B3LYP-D3(BJ)/def2-TZVPP-IEF-PCM(DCM) Energy $=-2810.985372$

B3LYP-D3(BJ)/def2-TZVPP-IEF-PCM(DCM)//B3LYP/6-31G(d) Free Energy (Quasiharmonic) = 2810.343957

Frequencies (Top 3 out of 270)

1. $-639.5253 \mathrm{~cm}-1$

2. $\quad 5.9760 \mathrm{~cm}-1$

3. $14.3981 \mathrm{~cm}-1$

B3LYP/6-31G(d) Molecular Geometry in Cartesian Coordinates

$\begin{array}{llll}\text { C } & 3.006506 & -0.960303 & -0.317575 \\ \text { C } & 1.855111 & -1.560965 & 0.170784 \\ \text { C } & 1.481118 & -2.895547 & -0.155523 \\ \text { C } & 2.272653 & -3.592946 & -1.043359 \\ \text { H } & 2.011551 & -4.617150 & -1.298432 \\ \text { C } & 3.925732 & 3.104521 & 0.784868 \\ \text { C } & 3.354542 & 0.425375 & 0.116067 \\ \text { C } & 2.426283 & 1.439932 & -0.065890 \\ \text { C } & 2.693479 & 2.808584 & 0.234398 \\ \text { H } & 4.171968 & 4.140286 & 1.003624 \\ \text { O } & 1.028353 & -0.852965 & 1.029210 \\ \text { P } & 0.104143 & 0.366390 & 0.410111\end{array}$




\begin{tabular}{|c|c|c|c|}
\hline $\mathrm{O}$ & 1.186641 & 1.106469 & -0.590695 \\
\hline C & -1.933169 & -4.890090 & 1.547641 \\
\hline C & -0.876049 & -4.485407 & 2.366312 \\
\hline C & 0.216835 & -3.810558 & 1.821601 \\
\hline C & 0.279122 & -3.540309 & 0.445633 \\
\hline C & -0.789310 & -3.945134 & -0.367333 \\
\hline C & -1.889158 & -4.613053 & 0.179235 \\
\hline $\mathrm{H}$ & -0.900631 & -4.699851 & 3.431494 \\
\hline $\mathrm{H}$ & -2.704945 & -4.922614 & -0.469374 \\
\hline C & -0.066657 & 6.019570 & -0.526629 \\
\hline C & 0.147162 & 5.038766 & -1.497331 \\
\hline C & 1.022078 & 3.982056 & -1.251676 \\
\hline C & 1.706607 & 3.889325 & -0.028326 \\
\hline C & 1.480232 & 4.879972 & 0.940591 \\
\hline C & 0.602234 & 5.934765 & 0.694924 \\
\hline $\mathrm{H}$ & -0.368140 & 5.095630 & -2.452796 \\
\hline $\mathrm{H}$ & 0.433349 & 6.684455 & 1.463554 \\
\hline C & 4.603384 & 0.738742 & 0.752469 \\
\hline C & 4.885825 & 2.105062 & 1.078191 \\
\hline C & 6.121446 & 2.432076 & 1.699950 \\
\hline C & 7.034936 & 1.454438 & 2.019049 \\
\hline C & 6.743017 & 0.100244 & 1.731644 \\
\hline C & 5.561422 & -0.248007 & 1.114716 \\
\hline $\mathrm{H}$ & 6.324967 & 3.475319 & 1.930105 \\
\hline $\mathrm{H}$ & 7.973177 & 1.716478 & 2.500468 \\
\hline $\mathrm{H}$ & 7.455614 & -0.673625 & 2.004434 \\
\hline $\mathrm{H}$ & 5.348329 & -1.290998 & 0.909881 \\
\hline C & 3.793999 & -1.674231 & -1.286029 \\
\hline C & 3.419456 & -3.011667 & -1.639491 \\
\hline C & 4.193834 & -3.727052 & -2.592345 \\
\hline C & 5.280557 & -3.145016 & -3.202103 \\
\hline C & 5.631219 & -1.811734 & -2.884689 \\
\hline C & 4.910016 & -1.096964 & -1.953914 \\
\hline $\mathrm{H}$ & 3.901009 & -4.745253 & -2.838204 \\
\hline $\mathrm{H}$ & 5.862109 & -3.699619 & -3.933459 \\
\hline $\mathrm{H}$ & 6.475442 & -1.343999 & -3.384132 \\
\hline $\mathrm{H}$ & 5.186514 & -0.073221 & -1.731179 \\
\hline $\mathrm{O}$ & -0.422047 & 1.213967 & 1.503942 \\
\hline $\mathrm{O}$ & -0.881981 & -0.315400 & -0.572006 \\
\hline $\mathrm{H}$ & -1.765811 & 0.332170 & -0.995929 \\
\hline $\mathrm{H}$ & -0.762819 & -3.716963 & -1.428094 \\
\hline $\mathrm{H}$ & -2.782830 & -5.417603 & 1.972871 \\
\hline $\mathrm{H}$ & 1.037919 & -3.499868 & 2.461232 \\
\hline $\mathrm{H}$ & 1.978515 & 4.804821 & 1.902983 \\
\hline
\end{tabular}




\begin{tabular}{llll}
$\mathrm{H}$ & -0.754140 & 6.839289 & -0.718216 \\
$\mathrm{H}$ & 1.181196 & 3.226206 & -2.013038 \\
$\mathrm{C}$ & -3.387858 & 1.608948 & -0.550711 \\
$\mathrm{O}$ & -2.733684 & 0.955847 & -1.448743 \\
$\mathrm{H}$ & -2.919681 & 1.785639 & 0.425029 \\
$\mathrm{C}$ & -4.209398 & 2.817724 & -0.993967 \\
$\mathrm{O}$ & -4.627871 & 3.647881 & -0.214910 \\
$\mathrm{O}$ & -4.407049 & 2.839184 & -2.317999 \\
$\mathrm{C}$ & -5.168669 & 3.958086 & -2.802665 \\
$\mathrm{H}$ & -5.236288 & 3.817356 & -3.881366 \\
$\mathrm{H}$ & -6.164457 & 3.969158 & -2.351060 \\
$\mathrm{C}$ & -4.301796 & -0.564271 & 0.517066 \\
$\mathrm{C}$ & -4.965930 & 0.587139 & 0.068236 \\
$\mathrm{H}$ & -3.151448 & -2.170394 & -0.019932 \\
$\mathrm{~N}$ & -3.825878 & -1.487519 & -0.357695 \\
$\mathrm{C}$ & -4.150696 & -1.610295 & -1.724187 \\
$\mathrm{O}$ & -5.057325 & -1.054261 & -2.295923 \\
$\mathrm{O}$ & -3.321037 & -2.516359 & -2.266668 \\
$\mathrm{C}$ & -3.512021 & -2.738105 & -3.677342 \\
$\mathrm{H}$ & -2.763828 & -3.480248 & -3.953920 \\
$\mathrm{H}$ & -3.354626 & -1.807167 & -4.226206 \\
$\mathrm{H}$ & -4.520339 & -3.111659 & -3.871351 \\
$\mathrm{H}$ & -5.374620 & 1.240802 & 0.830387 \\
$\mathrm{H}$ & -5.501516 & 0.533417 & -0.870728 \\
$\mathrm{C}$ & -3.927635 & -0.725614 & 1.935092 \\
$\mathrm{C}$ & -4.847840 & -0.344962 & 2.930823 \\
$\mathrm{C}$ & -2.674317 & -1.233314 & 2.319201 \\
$\mathrm{H}$ & -4.523441 & -0.476920 & 4.276780 \\
$\mathrm{H}$ & -5.827075 & 0.026508 & 2.646235 \\
$\mathrm{H}$ & -2.349584 & -1.343583 & 3.668671 \\
$\mathrm{H}$ & -1.926955 & -1.485730 & 1.575289 \\
& -3.270466 & -0.971326 & 4.648322 \\
$\mathrm{H}$ & -5.246730 & -0.191878 & 5.035220 \\
\hline & -3.011082 & -1.058451 & 5.699760 \\
\hline & & & -2.566313
\end{tabular}

Catalyst (R)-1 TS Conformation 108

B3LYP/6-31G(d) Energy $=-2809.69114$

B3LYP-D3(BJ)/def2-TZVPP-IEF-PCM(DCM) Energy $=-2810.984914$

B3LYP-D3(BJ)/def2-TZVPP-IEF-PCM(DCM)//B3LYP/6-31G(d) Free Energy (Quasiharmonic) = 2810.343946 
Frequencies (Top 3 out of 270)

1. $-721.9965 \mathrm{~cm}-1$

2. $\quad 6.9000 \mathrm{~cm}-1$

3. $11.3451 \mathrm{~cm}-1$

B3LYP/6-31G(d) Molecular Geometry in Cartesian Coordinates

\begin{tabular}{|c|c|c|c|}
\hline C & 3.058449 & -1.410884 & 0.033793 \\
\hline C & 1.776504 & -1.495770 & 0.554097 \\
\hline C & 1.011956 & -2.698569 & 0.575004 \\
\hline C & 1.580309 & -3.817829 & -0.000930 \\
\hline $\mathrm{H}$ & 1.035331 & -4.758010 & 0.016284 \\
\hline C & 5.162288 & 2.354807 & 0.190342 \\
\hline C & 3.804226 & -0.119905 & 0.131923 \\
\hline C & 3.237722 & 1.042285 & -0.371116 \\
\hline C & 3.905990 & 2.302042 & -0.381469 \\
\hline $\mathrm{H}$ & 5.710266 & 3.293269 & 0.176930 \\
\hline 0 & 1.207249 & -0.350681 & 1.096497 \\
\hline$P$ & 0.665613 & 0.791087 & 0.047166 \\
\hline 0 & 1.964476 & 0.981405 & -0.926235 \\
\hline C & -2.900476 & -3.012998 & 2.341968 \\
\hline C & -1.878280 & -2.348587 & 3.025162 \\
\hline C & -0.613129 & -2.225757 & 2.452965 \\
\hline C & -0.344342 & -2.765352 & 1.182467 \\
\hline C & -1.382559 & -3.419283 & 0.500793 \\
\hline C & -2.647673 & -3.544783 & 1.076711 \\
\hline $\mathrm{H}$ & -2.063643 & -1.930531 & 4.011090 \\
\hline $\mathrm{H}$ & -3.434495 & -4.058176 & 0.529320 \\
\hline C & 2.273217 & 5.886391 & -2.113047 \\
\hline C & 2.855711 & 5.913011 & -0.845446 \\
\hline C & 3.364163 & 4.742279 & -0.284069 \\
\hline C & 3.299847 & 3.522783 & -0.977139 \\
\hline C & 2.704869 & 3.507742 & -2.249804 \\
\hline C & 2.200064 & 4.679247 & -2.811288 \\
\hline $\mathrm{H}$ & 2.907265 & 6.844010 & -0.286926 \\
\hline $\mathrm{H}$ & 1.749634 & 4.648344 & -3.800106 \\
\hline C & 5.080464 & -0.030832 & 0.788110 \\
\hline C & 5.765416 & 1.227412 & 0.799227 \\
\hline C & 7.033213 & 1.326857 & 1.434220 \\
\hline C & 7.596742 & 0.242143 & 2.064546 \\
\hline C & 6.904925 & -0.991560 & 2.090017 \\
\hline C & 5.682515 & -1.125078 & 1.468891 \\
\hline
\end{tabular}




\begin{tabular}{|c|c|c|c|}
\hline $\mathrm{H}$ & 7.544214 & 2.286752 & 1.422054 \\
\hline $\mathrm{H}$ & 8.563288 & 0.332231 & 2.552748 \\
\hline $\mathrm{H}$ & 7.339270 & -1.841692 & 2.609226 \\
\hline $\mathrm{H}$ & 5.161871 & -2.074762 & 1.507260 \\
\hline C & 3.606766 & -2.565059 & -0.624227 \\
\hline C & 2.852475 & -3.783630 & -0.623411 \\
\hline C & 3.387385 & -4.935282 & -1.262106 \\
\hline C & 4.601739 & -4.888360 & -1.906112 \\
\hline C & 5.330694 & -3.676433 & -1.942093 \\
\hline C & 4.848084 & -2.547074 & -1.318056 \\
\hline $\mathrm{H}$ & 2.807120 & -5.854829 & -1.242010 \\
\hline $\mathrm{H}$ & 4.996866 & -5.773537 & -2.397032 \\
\hline $\mathrm{H}$ & 6.278736 & -3.634086 & -2.471560 \\
\hline $\mathrm{H}$ & 5.414214 & -1.624006 & -1.363141 \\
\hline $\mathrm{O}$ & -0.479059 & 0.333024 & -0.795489 \\
\hline $\mathrm{O}$ & 0.485015 & 2.033345 & 0.925835 \\
\hline $\mathrm{H}$ & -0.626605 & 2.404042 & 1.199060 \\
\hline $\mathrm{H}$ & -1.208689 & -3.796739 & -0.501274 \\
\hline $\mathrm{H}$ & -3.883771 & -3.114791 & 2.794597 \\
\hline $\mathrm{H}$ & 0.175356 & -1.714889 & 2.994930 \\
\hline $\mathrm{H}$ & 2.644680 & 2.576095 & -2.801886 \\
\hline $\mathrm{H}$ & 1.874658 & 6.797504 & -2.551606 \\
\hline $\mathrm{H}$ & 3.795452 & 4.764019 & 0.712794 \\
\hline C & -2.582460 & 1.779422 & 1.360994 \\
\hline $\mathrm{O}$ & -1.746825 & 2.738236 & 1.507594 \\
\hline $\mathrm{H}$ & -2.217480 & 0.749008 & 1.300580 \\
\hline C & -3.915526 & 1.956426 & 2.070963 \\
\hline $\mathrm{O}$ & -4.509482 & 3.000996 & 2.195279 \\
\hline $\mathrm{O}$ & -4.329732 & 0.769618 & 2.558125 \\
\hline C & -5.570361 & 0.809543 & 3.288522 \\
\hline $\mathrm{H}$ & -5.489918 & 1.500367 & 4.131304 \\
\hline $\mathrm{H}$ & -6.385421 & 1.128917 & 2.634960 \\
\hline C & -3.876310 & 0.731134 & -0.946325 \\
\hline C & -3.232583 & 1.915568 & -0.569217 \\
\hline $\mathrm{H}$ & -2.082726 & -0.222832 & -1.199775 \\
\hline$N$ & -3.103823 & -0.320497 & -1.354884 \\
\hline C & -3.431639 & -1.413850 & -2.168843 \\
\hline $\mathrm{O}$ & -2.667567 & -2.334216 & -2.354997 \\
\hline $\mathrm{O}$ & -4.638634 & -1.286757 & -2.746841 \\
\hline C & -5.015883 & -2.380495 & -3.601125 \\
\hline $\mathrm{H}$ & -4.308606 & -2.478608 & -4.427994 \\
\hline $\mathrm{H}$ & -6.009124 & -2.125045 & -3.970098 \\
\hline $\mathrm{H}$ & -5.041929 & -3.316742 & -3.037972 \\
\hline $\mathrm{H}$ & -3.846640 & 2.791858 & -0.396056 \\
\hline
\end{tabular}




$\begin{array}{lrrr}\text { H } & -2.236143 & 2.082693 & -0.961906 \\ \mathrm{C} & -5.328124 & 0.558308 & -0.728694 \\ \mathrm{C} & -6.219013 & 1.595419 & -1.046545 \\ \mathrm{C} & -5.825465 & -0.613181 & -0.128692 \\ \mathrm{C} & -7.582373 & 1.456786 & -0.791745 \\ \mathrm{H} & -5.845081 & 2.498507 & -1.518460 \\ \mathrm{C} & -7.184664 & -0.741006 & 0.138497 \\ \mathrm{H} & -5.135563 & -1.400832 & 0.158602 \\ \mathrm{C} & -8.067712 & 0.290121 & -0.198648 \\ \mathrm{H} & -8.263661 & 2.260313 & -1.055602 \\ \mathrm{H} & -7.558162 & -1.644381 & 0.612732 \\ \mathrm{H} & -9.129923 & 0.184352 & 0.004232 \\ \mathrm{H} & -5.734577 & -0.209390 & 3.638875\end{array}$

Catalyst (R)-1 TS Conformation 109

$B 3 L Y P / 6-31 G(d)$ Energy $=-2809.68957$

B3LYP-D3(BJ)/def2-TZVPP-IEF-PCM(DCM) Energy $=-2810.985743$

B3LYP-D3(BJ)/def2-TZVPP-IEF-PCM(DCM)//B3LYP/6-31G(d) Free Energy (Quasiharmonic) = 2810.343941

Frequencies (Top 3 out of 270)

1. $-669.2910 \mathrm{~cm}-1$

2. $9.2759 \mathrm{~cm}-1$

3. $\quad 10.8347 \mathrm{~cm}-1$

B3LYP/6-31G(d) Molecular Geometry in Cartesian Coordinates

$\begin{array}{llll}\text { C } & -3.396250 & -1.114921 & 0.105232 \\ \text { C } & -2.173517 & -1.682792 & -0.210287 \\ \text { C } & -1.782230 & -2.993218 & 0.191059 \\ \text { C } & -2.675426 & -3.709737 & 0.962201 \\ \text { H } & -2.421273 & -4.721531 & 1.267561 \\ \text { C } & -4.412167 & 2.872604 & -1.179701 \\ \text { C } & -3.730989 & 0.243124 & -0.418828 \\ \text { C } & -2.880505 & 1.315826 & -0.177578 \\ \text { C } & -3.218267 & 2.661122 & -0.518039 \\ \text { H } & -4.688741 & 3.886813 & -1.455689 \\ \text { O } & -1.274837 & -0.933059 & -0.957113 \\ \text { P } & -0.462005 & 0.254124 & -0.163449 \\ \text { O } & -1.696105 & 1.105366 & 0.514107 \\ \text { C } & 2.025645 & -4.717556 & -0.833789\end{array}$




\begin{tabular}{|c|c|c|c|}
\hline C & 1.259694 & -4.085834 & -1.816951 \\
\hline C & 0.030004 & -3.513349 & -1.493041 \\
\hline C & -0.460041 & -3.566342 & -0.176975 \\
\hline C & 0.321290 & -4.201973 & 0.801619 \\
\hline C & 1.552337 & -4.771251 & 0.477929 \\
\hline $\mathrm{H}$ & 1.617253 & -4.040722 & -2.842507 \\
\hline $\mathrm{H}$ & 2.147311 & -5.244747 & 1.254042 \\
\hline C & -0.871123 & 6.128035 & 0.488306 \\
\hline C & -0.274306 & 5.054850 & -0.177334 \\
\hline C & -1.011775 & 3.912490 & -0.492983 \\
\hline C & -2.371082 & 3.829891 & -0.147293 \\
\hline C & -2.961380 & 4.915226 & 0.521387 \\
\hline C & -2.219802 & 6.053570 & 0.837914 \\
\hline $\mathrm{H}$ & 0.773861 & 5.106430 & -0.461889 \\
\hline $\mathrm{H}$ & -2.696164 & 6.878591 & 1.361472 \\
\hline C & -4.919477 & 0.469307 & -1.196332 \\
\hline C & -5.263879 & 1.809323 & -1.564127 \\
\hline C & -6.440367 & 2.046379 & -2.325620 \\
\hline C & -7.239571 & 1.004935 & -2.735559 \\
\hline C & -6.884123 & -0.323830 & -2.404190 \\
\hline C & -5.757736 & -0.584663 & -1.655267 \\
\hline $\mathrm{H}$ & -6.689083 & 3.071926 & -2.588597 \\
\hline $\mathrm{H}$ & -8.133555 & 1.197030 & -3.322581 \\
\hline $\mathrm{H}$ & -7.502181 & -1.148298 & -2.749510 \\
\hline $\mathrm{H}$ & -5.494244 & -1.609408 & -1.420699 \\
\hline C & -4.284013 & -1.843359 & 0.971488 \\
\hline C & -3.914020 & -3.165316 & 1.384004 \\
\hline C & -4.786943 & -3.902523 & 2.229393 \\
\hline C & -5.963869 & -3.354592 & 2.683646 \\
\hline C & -6.311582 & -2.034670 & 2.312736 \\
\hline C & -5.496097 & -1.300333 & 1.479714 \\
\hline $\mathrm{H}$ & -4.496111 & -4.908727 & 2.522159 \\
\hline $\mathrm{H}$ & -6.619361 & -3.925560 & 3.335576 \\
\hline $\mathrm{H}$ & -7.228876 & -1.592727 & 2.692514 \\
\hline $\mathrm{H}$ & -5.773223 & -0.287050 & 1.213954 \\
\hline $\mathrm{O}$ & 0.354138 & 1.005521 & -1.157604 \\
\hline $\mathrm{O}$ & 0.230714 & -0.340172 & 1.079051 \\
\hline $\mathrm{H}$ & 1.392398 & -0.611338 & 1.004030 \\
\hline $\mathrm{H}$ & -0.029716 & -4.221988 & 1.829342 \\
\hline $\mathrm{H}$ & 2.984678 & -5.162567 & -1.086417 \\
\hline $\mathrm{H}$ & -0.556829 & -3.025021 & -2.263482 \\
\hline $\mathrm{H}$ & -4.007884 & 4.855350 & 0.808311 \\
\hline $\mathrm{H}$ & -0.290438 & 7.014178 & 0.731698 \\
\hline $\mathrm{H}$ & -0.533545 & 3.089903 & -1.015184 \\
\hline
\end{tabular}




$\begin{array}{llll}\mathrm{C} & 2.976778 & -0.780097 & -0.297844 \\ \mathrm{O} & 2.570051 & -0.909414 & 0.916027 \\ \mathrm{H} & 2.238207 & -0.669441 & -1.099365 \\ \mathrm{C} & 4.195295 & -1.606052 & -0.678626 \\ \mathrm{O} & 4.939314 & -2.150858 & 0.103896 \\ \mathrm{O} & 4.335125 & -1.640693 & -2.019975 \\ \mathrm{C} & 5.461741 & -2.392398 & -2.502631 \\ \mathrm{H} & 5.413546 & -2.325586 & -3.589642 \\ \mathrm{H} & 6.395590 & -1.963256 & -2.130123 \\ \mathrm{C} & 4.645547 & 1.177881 & 0.312809 \\ \mathrm{C} & 3.598367 & 1.072570 & -0.611757 \\ \mathrm{H} & 5.280431 & 1.177323 & 2.236547 \\ \mathrm{~N} & 4.462726 & 1.301809 & 1.650731 \\ \mathrm{C} & 3.335423 & 1.591522 & 2.466346 \\ \mathrm{O} & 3.432598 & 1.482890 & 3.666682 \\ \mathrm{O} & 2.300468 & 2.049608 & 1.778236 \\ \mathrm{C} & 1.123231 & 2.369961 & 2.567441 \\ \mathrm{H} & 0.446634 & 2.862654 & 1.872276 \\ \mathrm{H} & 1.403138 & 3.031257 & 3.389185 \\ \mathrm{H} & 0.679523 & 1.447833 & 2.941903 \\ \mathrm{H} & 3.886945 & 1.059311 & -1.657551 \\ \mathrm{H} & 2.629618 & 1.509823 & -0.403060 \\ \mathrm{C} & 6.057500 & 0.998724 & -0.107396 \\ \mathrm{C} & 6.951200 & 0.208331 & 0.638037 \\ \mathrm{C} & 6.520153 & 1.644696 & -1.266309 \\ \mathrm{C} & 8.277533 & 0.076989 & 0.233363 \\ \mathrm{H} & 6.594996 & -0.360665 & 1.491609 \\ \mathrm{C} & 7.850474 & 1.518001 & -1.660485 \\ \mathrm{H} & 5.842588 & 2.269974 & -1.839151 \\ \mathrm{C} & 8.731983 & 0.735477 & -0.911549 \\ \mathrm{H} & 8.952691 & -0.551389 & 0.806622 \\ \mathrm{H} & 8.199203 & 2.035672 & -2.549337 \\ \mathrm{H} & 9.768394 & 0.635241 & -1.221380 \\ \mathrm{H} & 5.391552 & -3.433493 & -2.177269\end{array}$

Catalyst (R)-1 TS Conformation 110

B3LYP/6-31G(d) Energy $=-2809.689994$

B3LYP-D3(BJ)/def2-TZVPP-IEF-PCM(DCM) Energy = -2810.985556

B3LYP-D3(BJ)/def2-TZVPP-IEF-PCM(DCM)//B3LYP/6-31G(d) Free Energy (Quasiharmonic) = 2810.343906

Frequencies (Top 3 out of 270) 
1. $-652.3700 \mathrm{~cm}-1$

2. $\quad 7.7059 \mathrm{~cm}-1$

3. $\quad 12.1056 \mathrm{~cm}-1$

B3LYP/6-31G(d) Molecular Geometry in Cartesian Coordinates

\begin{tabular}{|c|c|c|c|}
\hline C & 3.406398 & -1.229511 & -0.125397 \\
\hline C & 2.136187 & -1.713071 & 0.141003 \\
\hline C & 1.697301 & -3.019158 & -0.226397 \\
\hline C & 2.588376 & -3.813138 & -0.920788 \\
\hline $\mathrm{H}$ & 2.297692 & -4.824379 & -1.193450 \\
\hline C & 4.619772 & 2.717240 & 1.107329 \\
\hline C & 3.801348 & 0.118340 & 0.380585 \\
\hline C & 3.034921 & 1.235960 & 0.072288 \\
\hline C & 3.444396 & 2.564470 & 0.398638 \\
\hline $\mathrm{H}$ & 4.949098 & 3.719063 & 1.370475 \\
\hline 0 & 1.242454 & -0.884260 & 0.806072 \\
\hline$P$ & 0.554822 & 0.325322 & -0.071217 \\
\hline $\mathrm{O}$ & 1.878182 & 1.086468 & -0.676731 \\
\hline C & -2.218219 & -4.551648 & 0.705998 \\
\hline C & -1.678755 & -4.708740 & -0.571924 \\
\hline C & -0.414899 & -4.197750 & -0.868291 \\
\hline C & 0.337262 & -3.520070 & 0.105612 \\
\hline C & -0.215996 & -3.368894 & 1.389143 \\
\hline C & -1.479057 & -3.881740 & 1.684674 \\
\hline $\mathrm{H}$ & -2.247441 & -5.219272 & -1.344854 \\
\hline $\mathrm{H}$ & -1.887901 & -3.756995 & 2.684025 \\
\hline C & 1.368533 & 6.169887 & -0.703613 \\
\hline C & 0.693087 & 5.161874 & -0.011375 \\
\hline C & 1.339013 & 3.970617 & 0.322219 \\
\hline C & 2.686577 & 3.777420 & -0.020987 \\
\hline C & 3.357114 & 4.797091 & -0.715876 \\
\hline C & 2.704348 & 5.981309 & -1.058979 \\
\hline $\mathrm{H}$ & -0.343194 & 5.306783 & 0.284605 \\
\hline $\mathrm{H}$ & 3.240771 & 6.754422 & -1.603241 \\
\hline C & 4.964595 & 0.288015 & 1.209577 \\
\hline C & 5.381945 & 1.612432 & 1.557107 \\
\hline C & 6.536390 & 1.794212 & 2.365940 \\
\hline C & 7.244079 & 0.715146 & 2.841543 \\
\hline C & 6.814207 & -0.596463 & 2.530885 \\
\hline C & 5.707831 & -0.804642 & 1.736954 \\
\hline $\mathrm{H}$ & 6.841494 & 2.808642 & 2.612186 \\
\hline $\mathrm{H}$ & 8.121676 & 0.865311 & 3.464449 \\
\hline
\end{tabular}




\begin{tabular}{|c|c|c|c|}
\hline $\mathrm{H}$ & 7.358213 & -1.449351 & 2.927963 \\
\hline $\mathrm{H}$ & 5.386620 & -1.816485 & 1.519128 \\
\hline C & 4.293399 & -2.036925 & -0.919593 \\
\hline C & 3.872379 & -3.351955 & -1.302517 \\
\hline C & 4.743313 & -4.166940 & -2.075450 \\
\hline C & 5.968900 & -3.699915 & -2.489510 \\
\hline C & 6.369823 & -2.386756 & -2.149392 \\
\hline C & 5.556700 & -1.578868 & -1.385007 \\
\hline $\mathrm{H}$ & 4.412300 & -5.167037 & -2.345691 \\
\hline $\mathrm{H}$ & 6.622929 & -4.329443 & -3.086726 \\
\hline $\mathrm{H}$ & 7.326894 & -2.008653 & -2.498706 \\
\hline $\mathrm{H}$ & 5.875423 & -0.572005 & -1.142638 \\
\hline $\mathrm{O}$ & -0.267406 & 1.156373 & 0.858269 \\
\hline $\mathrm{O}$ & -0.104577 & -0.271359 & -1.322965 \\
\hline $\mathrm{H}$ & -1.302501 & -0.278664 & -1.431828 \\
\hline $\mathrm{H}$ & 0.347426 & -2.849293 & 2.156419 \\
\hline $\mathrm{H}$ & -3.210491 & -4.929810 & 0.932599 \\
\hline $\mathrm{H}$ & -0.012902 & -4.298488 & -1.872459 \\
\hline $\mathrm{H}$ & 4.396143 & 4.650639 & -0.998956 \\
\hline $\mathrm{H}$ & 0.858989 & 7.095129 & -0.960787 \\
\hline $\mathrm{H}$ & 0.801813 & 3.195351 & 0.858643 \\
\hline C & -3.045203 & -1.022891 & -0.610770 \\
\hline $\mathrm{O}$ & -2.500032 & -0.345613 & -1.556764 \\
\hline $\mathrm{H}$ & -2.434193 & -1.713179 & -0.017966 \\
\hline C & -4.444789 & -1.569704 & -0.835728 \\
\hline $\mathrm{O}$ & -4.931260 & -2.457468 & -0.165951 \\
\hline $\mathrm{O}$ & -5.079596 & -0.945363 & -1.841598 \\
\hline C & -6.405891 & -1.426719 & -2.115396 \\
\hline $\mathrm{H}$ & -6.384267 & -2.491297 & -2.361381 \\
\hline $\mathrm{H}$ & -7.056024 & -1.277030 & -1.248233 \\
\hline C & -4.391317 & 0.963959 & 0.618987 \\
\hline C & -3.354274 & 0.106369 & 1.004580 \\
\hline $\mathrm{H}$ & -6.414099 & 1.299829 & 0.575097 \\
\hline$N$ & -5.696366 & 0.710122 & 0.973187 \\
\hline C & -6.188455 & -0.187312 & 1.930938 \\
\hline O & -5.546897 & -0.872037 & 2.689299 \\
\hline $\mathrm{O}$ & -7.536685 & -0.135257 & 1.868698 \\
\hline C & -8.215888 & -0.992790 & 2.806153 \\
\hline $\mathrm{H}$ & -7.936842 & -2.034773 & 2.634446 \\
\hline $\mathrm{H}$ & -9.278048 & -0.839237 & 2.616981 \\
\hline $\mathrm{H}$ & -7.961622 & -0.712492 & 3.831112 \\
\hline $\mathrm{H}$ & -2.339585 & 0.495832 & 1.005200 \\
\hline $\mathrm{H}$ & -3.576416 & -0.624487 & 1.771528 \\
\hline C & -4.175952 & 2.081586 & -0.312885 \\
\hline
\end{tabular}




$\begin{array}{lrrr}\text { C } & -2.881123 & 2.614618 & -0.477438 \\ \text { C } & -5.225444 & 2.620557 & -1.090104 \\ \text { C } & -2.655322 & 3.657700 & -1.374285 \\ \text { H } & -2.043971 & 2.233457 & 0.097951 \\ \text { C } & -4.992641 & 3.659208 & -1.981555 \\ \text { H } & -6.228020 & 2.202550 & -1.055667 \\ \text { C } & -3.704899 & 4.185984 & -2.123428 \\ \text { H } & -1.648851 & 4.049936 & -1.483178 \\ \text { H } & -5.812160 & 4.048919 & -2.578380 \\ \text { H } & -3.523753 & 4.997014 & -2.823299 \\ \text { H } & -6.756853 & -0.843446 & -2.966884\end{array}$

Catalyst (R)-1 TS Conformation 111

B3LYP/6-31G(d) Energy $=-2809.695813$

B3LYP-D3(BJ)/def2-TZVPP-IEF-PCM(DCM) Energy = -2810.987738

B3LYP-D3(BJ)/def2-TZVPP-IEF-PCM(DCM)//B3LYP/6-31G(d) Free Energy (Quasiharmonic) = 2810.343812

Frequencies (Top 3 out of 270)

1. $-216.9356 \mathrm{~cm}-1$

2. $\quad 11.0968 \mathrm{~cm}-1$

3. $\quad 16.8446 \mathrm{~cm}-1$

B3LYP/6-31G(d) Molecular Geometry in Cartesian Coordinates

$\begin{array}{llll}\text { C } & 3.152039 & -0.222891 & 0.322855 \\ \text { C } & 2.588299 & 0.964646 & -0.111472 \\ \text { C } & 3.117871 & 2.244203 & 0.229030 \\ \text { C } & 4.151537 & 2.278393 & 1.144827 \\ \text { H } & 4.592498 & 3.236455 & 1.406895 \\ \text { C } & 1.765702 & -4.056170 & -1.034599 \\ \text { C } & 2.674314 & -1.523081 & -0.229997 \\ \text { C } & 1.341194 & -1.885031 & -0.111279 \\ \text { C } & 0.856533 & -3.184908 & -0.460344 \\ \text { H } & 1.450438 & -5.068035 & -1.271275 \\ \text { O } & 1.474800 & 0.908237 & -0.946778 \\ \text { P } & 0.048875 & 0.421578 & -0.302212 \\ \text { O } & 0.458658 & -0.975402 & 0.452979 \\ \text { C } & 2.213364 & 5.987789 & -1.675312 \\ \text { C } & 2.238304 & 5.896375 & -0.282637 \\ \text { C } & 2.474724 & 4.667914 & 0.335153\end{array}$




\begin{tabular}{|c|c|c|c|}
\hline C & 2.685531 & 3.507508 & -0.426248 \\
\hline C & 2.621878 & 3.604816 & -1.826689 \\
\hline C & 2.398745 & 4.835217 & -2.444021 \\
\hline $\mathrm{H}$ & 2.079709 & 6.782841 & 0.325985 \\
\hline $\mathrm{H}$ & 2.380135 & 4.894869 & -3.529383 \\
\hline C & -3.008108 & -4.843385 & 0.464355 \\
\hline C & -2.356676 & -5.177663 & -0.724747 \\
\hline C & -1.134528 & -4.587693 & -1.042042 \\
\hline C & -0.522663 & -3.664630 & -0.172516 \\
\hline C & -1.204513 & -3.316659 & 1.006575 \\
\hline C & -2.431276 & -3.902169 & 1.317173 \\
\hline $\mathrm{H}$ & -2.799880 & -5.896973 & -1.409266 \\
\hline $\mathrm{H}$ & -2.931635 & -3.619241 & 2.238705 \\
\hline C & 3.579655 & -2.408673 & -0.908544 \\
\hline C & 3.105473 & -3.696857 & -1.310536 \\
\hline C & 3.989449 & -4.593636 & -1.970038 \\
\hline C & 5.284712 & -4.228194 & -2.253136 \\
\hline C & 5.747033 & -2.941961 & -1.887169 \\
\hline C & 4.919832 & -2.057694 & -1.229982 \\
\hline $\mathrm{H}$ & 3.615167 & -5.573419 & -2.257511 \\
\hline $\mathrm{H}$ & 5.950149 & -4.918088 & -2.764824 \\
\hline $\mathrm{H}$ & 6.764117 & -2.646606 & -2.130376 \\
\hline $\mathrm{H}$ & 5.287670 & -1.073350 & -0.964686 \\
\hline C & 4.186289 & -0.171841 & 1.320589 \\
\hline C & 4.678129 & 1.105799 & 1.738907 \\
\hline C & 5.696712 & 1.173581 & 2.727369 \\
\hline C & 6.196843 & 0.030540 & 3.306405 \\
\hline C & 5.691212 & -1.232177 & 2.917818 \\
\hline C & 4.715822 & -1.331886 & 1.949904 \\
\hline $\mathrm{H}$ & 6.066218 & 2.152129 & 3.024841 \\
\hline $\mathrm{H}$ & 6.970384 & 0.094124 & 4.066783 \\
\hline $\mathrm{H}$ & 6.072428 & -2.133126 & 3.390899 \\
\hline $\mathrm{H}$ & 4.331892 & -2.306497 & 1.671927 \\
\hline $\mathrm{O}$ & -0.950318 & 0.258526 & -1.395772 \\
\hline $\mathrm{O}$ & -0.249083 & 1.372178 & 0.883467 \\
\hline $\mathrm{H}$ & -1.248329 & 1.686405 & 1.109865 \\
\hline $\mathrm{H}$ & 2.776441 & 2.717143 & -2.431602 \\
\hline $\mathrm{H}$ & 2.046300 & 6.947063 & -2.158370 \\
\hline $\mathrm{H}$ & 2.493653 & 4.601249 & 1.419285 \\
\hline $\mathrm{H}$ & -0.776302 & -2.590670 & 1.685841 \\
\hline $\mathrm{H}$ & -3.959902 & -5.303794 & 0.716472 \\
\hline $\mathrm{H}$ & -0.646893 & -4.842554 & -1.978587 \\
\hline C & -3.514861 & 1.940957 & 1.934252 \\
\hline $\mathrm{O}$ & -2.414795 & 2.410265 & 1.452852 \\
\hline
\end{tabular}




$\begin{array}{lrrr}\mathrm{H} & -4.043702 & 2.565914 & 2.671434 \\ \mathrm{C} & -3.527390 & 0.470547 & 2.357020 \\ \mathrm{O} & -2.721272 & -0.359440 & 1.999434 \\ \mathrm{O} & -4.568957 & 0.212156 & 3.179118 \\ \mathrm{C} & -4.691796 & -1.152073 & 3.613658 \\ \mathrm{H} & -5.568892 & -1.176660 & 4.261139 \\ \mathrm{H} & -4.827776 & -1.814982 & 2.754884 \\ \mathrm{C} & -4.343484 & 1.334024 & -0.420700 \\ \mathrm{C} & -4.901749 & 2.028801 & 0.687947 \\ \mathrm{H} & -2.592518 & 1.268819 & -1.513067 \\ \mathrm{~N} & -3.298767 & 1.878530 & -1.075567 \\ \mathrm{C} & -2.965141 & 3.256054 & -1.085849 \\ \mathrm{O} & -3.705517 & 4.165232 & -0.787929 \\ \mathrm{O} & -1.738369 & 3.380966 & -1.594171 \\ \mathrm{C} & -1.252948 & 4.733900 & -1.675694 \\ \mathrm{H} & -1.928402 & 5.342212 & -2.282416 \\ \mathrm{H} & -0.270273 & 4.655918 & -2.133833 \\ \mathrm{H} & -1.174279 & 5.159707 & -0.673145 \\ \mathrm{H} & -5.768856 & 1.572354 & 1.154404 \\ \mathrm{H} & -4.948159 & 3.107039 & 0.603510 \\ \mathrm{C} & -4.759419 & -0.038414 & -0.765911 \\ \mathrm{C} & -6.113822 & -0.389229 & -0.591657 \\ \mathrm{C} & -3.878676 & -0.985608 & -1.323149 \\ \mathrm{C} & -6.577040 & -1.645394 & -0.971331 \\ \mathrm{H} & -6.815544 & 0.339108 & -0.199525 \\ \mathrm{C} & -4.349548 & -2.242239 & -1.692329 \\ \mathrm{H} & -2.821102 & -0.766077 & -1.431293 \\ \mathrm{C} & -5.694744 & -2.576117 & -1.522847 \\ \mathrm{H} & -7.627827 & -1.891370 & -0.846407 \\ \mathrm{H} & -3.653157 & -2.969168 & -2.096091 \\ \mathrm{H} & -6.054028 & -3.557983 & -1.819217 \\ \mathrm{H} & -3.799571 & -1.458615 & 4.166189\end{array}$

Catalyst (R)-1 TS Conformation 112

B3LYP/6-31G(d) Energy $=-2809.694675$

B3LYP-D3(BJ)/def2-TZVPP-IEF-PCM(DCM) Energy = -2810.986026

B3LYP-D3(BJ)/def2-TZVPP-IEF-PCM(DCM)//B3LYP/6-31G(d) Free Energy (Quasiharmonic) = 2810.343797

Frequencies (Top 3 out of 270)

1. $-381.5013 \mathrm{~cm}-1$ 
2. $\quad 9.8858 \mathrm{~cm}-1$

3. $\quad 19.9107 \mathrm{~cm}-1$

B3LYP/6-31G(d) Molecular Geometry in Cartesian Coordinates

\begin{tabular}{|c|c|c|c|}
\hline$C$ & 3.279389 & -0.142236 & 0.278484 \\
\hline C & 2.723226 & 0.991089 & -0.293221 \\
\hline C & 3.254952 & 2.302445 & -0.115247 \\
\hline C & 4.329877 & 2.436341 & 0.741833 \\
\hline $\mathrm{H}$ & 4.778529 & 3.416581 & 0.878672 \\
\hline C & 1.706338 & -4.097257 & -0.387731 \\
\hline C & 2.744823 & -1.498750 & -0.049009 \\
\hline C & 1.404547 & -1.785546 & 0.161417 \\
\hline C & 0.854227 & -3.098563 & 0.046142 \\
\hline $\mathrm{H}$ & 1.336949 & -5.116875 & -0.453993 \\
\hline $\mathrm{O}$ & 1.611817 & 0.850717 & -1.119566 \\
\hline$P$ & 0.170336 & 0.449693 & -0.474125 \\
\hline $\mathrm{O}$ & 0.567664 & -0.756184 & 0.567399 \\
\hline C & 1.950285 & 5.826154 & -2.211456 \\
\hline C & 2.096049 & 4.618014 & -2.898569 \\
\hline C & 2.477292 & 3.461429 & -2.219442 \\
\hline C & 2.730577 & 3.492439 & -0.837583 \\
\hline C & 2.564997 & 4.709537 & -0.156162 \\
\hline C & 2.179086 & 5.865117 & -0.834715 \\
\hline $\mathrm{H}$ & 1.921597 & 4.576147 & -3.970649 \\
\hline $\mathrm{H}$ & 2.056807 & 6.795576 & -0.286324 \\
\hline C & -3.192452 & -4.149311 & 1.086106 \\
\hline C & -2.498525 & -3.212310 & 1.855037 \\
\hline C & -1.193101 & -2.854243 & 1.517337 \\
\hline C & -0.556360 & -3.416940 & 0.396062 \\
\hline C & -1.272028 & -4.353425 & -0.369440 \\
\hline C & -2.572008 & -4.721278 & -0.024830 \\
\hline $\mathrm{H}$ & -2.977586 & -2.747940 & 2.712886 \\
\hline $\mathrm{H}$ & -3.104968 & -5.445493 & -0.635421 \\
\hline C & 3.590954 & -2.529555 & -0.584988 \\
\hline C & 3.053216 & -3.847064 & -0.745419 \\
\hline C & 3.881692 & -4.880860 & -1.260705 \\
\hline C & 5.180310 & -4.626314 & -1.635479 \\
\hline C & 5.703167 & -3.317512 & -1.511585 \\
\hline C & 4.931980 & -2.298222 & -0.997447 \\
\hline $\mathrm{H}$ & 3.461425 & -5.878510 & -1.364358 \\
\hline $\mathrm{H}$ & 5.801823 & -5.422655 & -2.035629 \\
\hline $\mathrm{H}$ & 6.722117 & -3.112849 & -1.828848 \\
\hline $\mathrm{H}$ & 5.344771 & -1.299228 & -0.916738 \\
\hline
\end{tabular}




\begin{tabular}{|c|c|c|c|}
\hline C & 4.349352 & 0.025266 & 1.226460 \\
\hline C & 4.877715 & 1.337944 & 1.447439 \\
\hline C & 5.940420 & 1.518004 & 2.373874 \\
\hline C & 6.447134 & 0.455231 & 3.084500 \\
\hline C & 5.901693 & -0.836432 & 2.897790 \\
\hline C & 4.883900 & -1.046676 & 1.993355 \\
\hline $\mathrm{H}$ & 6.336912 & 2.520194 & 2.518672 \\
\hline $\mathrm{H}$ & 7.254430 & 0.605615 & 3.795963 \\
\hline $\mathrm{H}$ & 6.285543 & -1.671636 & 3.477344 \\
\hline $\mathrm{H}$ & 4.471778 & -2.041372 & 1.872364 \\
\hline 0 & -0.752645 & 0.040365 & -1.569711 \\
\hline O & -0.253635 & 1.584753 & 0.485686 \\
\hline $\mathrm{H}$ & -1.274999 & 1.563908 & 0.923337 \\
\hline $\mathrm{H}$ & 2.727852 & 4.742932 & 0.917343 \\
\hline $\mathrm{H}$ & 1.659946 & 6.727942 & -2.744475 \\
\hline $\mathrm{H}$ & 2.594996 & 2.531577 & -2.765022 \\
\hline $\mathrm{H}$ & -0.809673 & -4.782274 & -1.254241 \\
\hline $\mathrm{H}$ & -4.210103 & -4.425306 & 1.348627 \\
\hline $\mathrm{H}$ & -0.660322 & -2.138339 & 2.132408 \\
\hline C & -3.282815 & 0.724260 & 1.645512 \\
\hline $\mathrm{O}$ & -2.460125 & 1.700619 & 1.503154 \\
\hline $\mathrm{H}$ & -2.977689 & -0.293217 & 1.363550 \\
\hline C & -4.098940 & 0.656787 & 2.938214 \\
\hline $\mathrm{O}$ & -4.416303 & -0.394048 & 3.458416 \\
\hline $\mathrm{O}$ & -4.403286 & 1.868403 & 3.417667 \\
\hline C & -5.136766 & 1.876095 & 4.654376 \\
\hline $\mathrm{H}$ & -5.292351 & 2.928163 & 4.892707 \\
\hline $\mathrm{H}$ & -6.094060 & 1.360707 & 4.536944 \\
\hline C & -4.204957 & 0.641331 & -0.739469 \\
\hline C & -4.813125 & 1.003525 & 0.479326 \\
\hline $\mathrm{H}$ & -2.508002 & 1.021924 & -1.839519 \\
\hline$N$ & -3.274071 & 1.449148 & -1.308721 \\
\hline C & -3.146460 & 2.840253 & -1.105814 \\
\hline $\mathrm{O}$ & -3.970322 & 3.562781 & -0.594581 \\
\hline $\mathrm{O}$ & -1.992995 & 3.228998 & -1.660411 \\
\hline C & -1.672196 & 4.622096 & -1.490416 \\
\hline $\mathrm{H}$ & -0.704043 & 4.752429 & -1.970205 \\
\hline $\mathrm{H}$ & -1.607852 & 4.860322 & -0.426511 \\
\hline $\mathrm{H}$ & -2.435560 & 5.246533 & -1.961655 \\
\hline $\mathrm{H}$ & -5.599725 & 0.346529 & 0.836158 \\
\hline $\mathrm{H}$ & -4.938787 & 2.055801 & 0.699141 \\
\hline C & -4.456506 & -0.675646 & -1.365876 \\
\hline C & -3.479970 & -1.371345 & -2.104166 \\
\hline C & -5.755710 & -1.216073 & -1.283325 \\
\hline
\end{tabular}




$\begin{array}{llll}\mathrm{C} & -3.804572 & -2.569310 & -2.735725 \\ \mathrm{H} & -2.457207 & -1.011834 & -2.147352 \\ \mathrm{C} & -6.073230 & -2.408232 & -1.926928 \\ \mathrm{H} & -6.533007 & -0.678027 & -0.751521 \\ \mathrm{C} & -5.097664 & -3.089032 & -2.657132 \\ \mathrm{H} & -3.035307 & -3.101279 & -3.287403 \\ \mathrm{H} & -7.085221 & -2.798321 & -1.866050 \\ \mathrm{H} & -5.344707 & -4.019050 & -3.162080 \\ \mathrm{H} & -4.561093 & 1.383304 & 5.442085\end{array}$

Catalyst (R)-1 TS Conformation 113

B3LYP/6-31G(d) Energy $=-2809.687961$

B3LYP-D3(BJ)/def2-TZVPP-IEF-PCM(DCM) Energy $=-2810.985197$

B3LYP-D3(BJ)/def2-TZVPP-IEF-PCM(DCM)//B3LYP/6-31G(d) Free Energy (Quasiharmonic) = 2810.343789

Frequencies (Top 3 out of 270)

1. $-617.0728 \mathrm{~cm}-1$

2. $\quad 6.4279 \mathrm{~cm}-1$

3. $14.5108 \mathrm{~cm}-1$

B3LYP/6-31G(d) Molecular Geometry in Cartesian Coordinates

$\begin{array}{lccc}\text { C } & 3.071564 & -0.914598 & -0.125839 \\ \text { C } & 1.959711 & -1.567215 & 0.386084 \\ \text { C } & 1.645330 & -2.924295 & 0.089588 \\ \text { C } & 2.481965 & -3.606920 & -0.768442 \\ \text { H } & 2.273164 & -4.648714 & -0.999200 \\ \text { C } & 3.707685 & 3.268527 & 0.711778 \\ \text { C } & 3.320986 & 0.514550 & 0.233664 \\ \text { C } & 2.321076 & 1.448981 & 0.003173 \\ \text { C } & 2.490664 & 2.850980 & 0.207258 \\ \text { H } & 3.886058 & 4.331070 & 0.854380 \\ \text { O } & 1.100652 & -0.881606 & 1.232417 \\ \text { P } & 0.089845 & 0.236146 & 0.575659 \\ \text { O } & 1.103080 & 0.997682 & -0.478902 \\ \text { C } & -1.793821 & -4.940327 & 1.715306 \\ \text { C } & -1.631698 & -4.819743 & 0.333371 \\ \text { C } & -0.519818 & -4.152380 & -0.186429 \\ \text { C } & 0.443338 & -3.589378 & 0.664326 \\ \text { C } & 0.262266 & -3.704282 & 2.051773\end{array}$




\begin{tabular}{|c|c|c|c|}
\hline C & -0.841575 & -4.380774 & 2.571245 \\
\hline $\mathrm{H}$ & -2.365288 & -5.250438 & -0.343893 \\
\hline $\mathrm{H}$ & -0.955634 & -4.476708 & 3.648001 \\
\hline C & -0.542626 & 5.775674 & -0.677134 \\
\hline C & 0.208601 & 5.863859 & 0.495702 \\
\hline C & 1.175956 & 4.901527 & 0.781530 \\
\hline C & 1.417612 & 3.834695 & -0.099979 \\
\hline C & 0.651124 & 3.756600 & -1.275916 \\
\hline C & -0.319443 & 4.716508 & -1.559847 \\
\hline $\mathrm{H}$ & 0.035450 & 6.676462 & 1.196666 \\
\hline $\mathrm{H}$ & -0.904719 & 4.630563 & -2.471638 \\
\hline C & 4.549498 & 0.957478 & 0.830689 \\
\hline C & 4.738347 & 2.359809 & 1.057027 \\
\hline C & 5.954719 & 2.813644 & 1.635861 \\
\hline C & 6.937089 & 1.925896 & 2.008608 \\
\hline C & 6.737587 & 0.537888 & 1.820382 \\
\hline C & 5.577323 & 0.066802 & 1.246069 \\
\hline $\mathrm{H}$ & 6.087545 & 3.881938 & 1.790348 \\
\hline $\mathrm{H}$ & 7.859405 & 2.285086 & 2.456964 \\
\hline $\mathrm{H}$ & 7.504878 & -0.163936 & 2.136198 \\
\hline $\mathrm{H}$ & 5.434661 & -1.000107 & 1.116515 \\
\hline C & 3.903011 & -1.618079 & -1.065967 \\
\hline C & 3.605918 & -2.987369 & -1.369290 \\
\hline C & 4.427000 & -3.694900 & -2.288547 \\
\hline C & 5.483281 & -3.077001 & -2.916087 \\
\hline C & 5.753979 & -1.713902 & -2.652362 \\
\hline C & 4.986901 & -1.004927 & -1.754254 \\
\hline $\mathrm{H}$ & 4.193581 & -4.736903 & -2.495097 \\
\hline $\mathrm{H}$ & 6.100718 & -3.626490 & -3.621419 \\
\hline $\mathrm{H}$ & 6.572508 & -1.218308 & -3.167440 \\
\hline $\mathrm{H}$ & 5.203082 & 0.041177 & -1.573660 \\
\hline 0 & -0.487042 & 1.095414 & 1.633498 \\
\hline 0 & -0.856866 & -0.546487 & -0.375285 \\
\hline $\mathrm{H}$ & -1.594430 & 0.108654 & -0.999465 \\
\hline $\mathrm{H}$ & 0.996784 & -3.268720 & 2.722122 \\
\hline $\mathrm{H}$ & -2.653096 & -5.466501 & 2.122602 \\
\hline $\mathrm{H}$ & -0.404045 & -4.043775 & -1.260497 \\
\hline $\mathrm{H}$ & 0.815552 & 2.941775 & -1.971403 \\
\hline $\mathrm{H}$ & -1.297162 & 6.525915 & -0.901039 \\
\hline $\mathrm{H}$ & 1.734605 & 4.959696 & 1.711369 \\
\hline C & -3.171269 & 1.477921 & -0.829534 \\
\hline $\mathrm{O}$ & -2.427217 & 0.793580 & -1.623770 \\
\hline $\mathrm{H}$ & -2.860196 & 1.599814 & 0.215432 \\
\hline C & -3.794153 & 2.741063 & -1.424328 \\
\hline
\end{tabular}




$\begin{array}{llll}\mathrm{O} & -3.759102 & 3.049300 & -2.590334 \\ \mathrm{O} & -4.362525 & 3.482019 & -0.448542 \\ \mathrm{C} & -4.916699 & 4.737275 & -0.876495 \\ \mathrm{H} & -4.129397 & 5.379052 & -1.280542 \\ \mathrm{H} & -5.678933 & 4.579961 & -1.644276 \\ \mathrm{C} & -4.355670 & -0.636198 & 0.055157 \\ \mathrm{C} & -4.894841 & 0.527000 & -0.511983 \\ \mathrm{H} & -3.152485 & -2.261222 & -0.248082 \\ \mathrm{~N} & -3.755098 & -1.584275 & -0.708445 \\ \mathrm{C} & -3.837230 & -1.728879 & -2.109248 \\ \mathrm{O} & -4.623423 & -1.172728 & -2.837030 \\ \mathrm{O} & -2.936982 & -2.652715 & -2.479598 \\ \mathrm{C} & -2.876622 & -2.898557 & -3.898187 \\ \mathrm{H} & -3.837720 & -3.270505 & -4.261327 \\ \mathrm{H} & -2.097359 & -3.649317 & -4.025194 \\ \mathrm{H} & -2.617135 & -1.978239 & -4.425725 \\ \mathrm{H} & -5.420864 & 1.193446 & 0.161547 \\ \mathrm{H} & -5.240142 & 0.489050 & -1.537346 \\ \mathrm{C} & -4.247745 & -0.794469 & 1.519857 \\ \mathrm{C} & -5.335959 & -0.417787 & 2.329091 \\ \mathrm{C} & -3.086403 & -1.305473 & 2.125542 \\ \mathrm{C} & -5.267048 & -0.559537 & 3.711473 \\ \mathrm{H} & -6.245184 & -0.043720 & 1.868992 \\ \mathrm{C} & -3.019125 & -1.427481 & 3.511256 \\ \mathrm{H} & -2.213598 & -1.546662 & 1.528349 \\ \mathrm{C} & -4.106270 & -1.061083 & 4.305627 \\ \mathrm{H} & -6.118593 & -0.278969 & 4.324605 \\ \mathrm{H} & -2.104716 & -1.794672 & 3.965356 \\ \mathrm{H} & -4.047954 & -1.158870 & 5.386108 \\ \mathrm{H} & -5.353022 & 5.184444 & 0.016842\end{array}$

Catalyst (R)-1 TS Conformation 114

B3LYP/6-31G(d) Energy $=-2809.692184$

B3LYP-D3(BJ)/def2-TZVPP-IEF-PCM(DCM) Energy = -2810.985737

B3LYP-D3(BJ)/def2-TZVPP-IEF-PCM(DCM)//B3LYP/6-31G(d) Free Energy (Quasiharmonic) = 2810.343788

Frequencies (Top 3 out of 270)

1. $-733.9456 \mathrm{~cm}-1$

2. $\quad 11.4807 \mathrm{~cm}-1$

3. $\quad 13.7960 \mathrm{~cm}-1$ 
B3LYP/6-31G(d) Molecular Geometry in Cartesian Coordinates

\begin{tabular}{|c|c|c|c|}
\hline C & 2.940203 & -0.980660 & -0.456114 \\
\hline C & 1.787005 & -1.587290 & 0.023463 \\
\hline C & 1.488002 & -2.968893 & -0.187939 \\
\hline C & 2.367776 & -3.693724 & -0.970226 \\
\hline $\mathrm{H}$ & 2.195435 & -4.756067 & -1.119271 \\
\hline C & 3.787685 & 3.144265 & 0.484069 \\
\hline C & 3.255193 & 0.430542 & -0.079358 \\
\hline C & 2.329156 & 1.429518 & -0.335266 \\
\hline C & 2.575118 & 2.812604 & -0.088345 \\
\hline $\mathrm{H}$ & 4.019834 & 4.190844 & 0.663222 \\
\hline 0 & 0.908398 & -0.846490 & 0.795573 \\
\hline$P$ & 0.011642 & 0.369905 & 0.139212 \\
\hline $\mathrm{O}$ & 1.105771 & 1.063206 & -0.876635 \\
\hline C & -1.780648 & -5.129141 & 1.611151 \\
\hline C & -1.129472 & -4.122995 & 2.330130 \\
\hline C & -0.093208 & -3.392669 & 1.746234 \\
\hline C & 0.314741 & -3.649750 & 0.424314 \\
\hline C & -0.369942 & -4.645888 & -0.293882 \\
\hline C & -1.398698 & -5.381857 & 0.292416 \\
\hline $\mathrm{H}$ & -1.413773 & -3.913074 & 3.358092 \\
\hline $\mathrm{H}$ & -1.902927 & -6.152286 & -0.285328 \\
\hline C & -0.210079 & 5.946522 & -1.053416 \\
\hline C & 0.043692 & 4.930375 & -1.977055 \\
\hline C & 0.928670 & 3.899389 & -1.666223 \\
\hline C & 1.583219 & 3.868438 & -0.423370 \\
\hline C & 1.317817 & 4.895107 & 0.497002 \\
\hline C & 0.429807 & 5.924021 & 0.186273 \\
\hline $\mathrm{H}$ & -0.447985 & 4.939416 & -2.946502 \\
\hline $\mathrm{H}$ & 0.229502 & 6.701673 & 0.918602 \\
\hline C & 4.481204 & 0.783879 & 0.583375 \\
\hline C & 4.744365 & 2.166498 & 0.852687 \\
\hline C & 5.956687 & 2.533125 & 1.497838 \\
\hline C & 6.865091 & 1.579557 & 1.894578 \\
\hline C & 6.590374 & 0.210995 & 1.665089 \\
\hline C & 5.432552 & -0.176078 & 1.026425 \\
\hline $\mathrm{H}$ & 6.145705 & 3.587964 & 1.683120 \\
\hline $\mathrm{H}$ & 7.785258 & 1.872035 & 2.393028 \\
\hline $\mathrm{H}$ & 7.297379 & -0.543487 & 1.999661 \\
\hline $\mathrm{H}$ & 5.233778 & -1.229535 & 0.867222 \\
\hline C & 3.794026 & -1.727017 & -1.339452 \\
\hline C & 3.499803 & -3.106750 & -1.583747 \\
\hline
\end{tabular}




\begin{tabular}{|c|c|c|c|}
\hline C & 4.345423 & -3.861753 & -2.441342 \\
\hline C & 5.422740 & -3.277648 & -3.065410 \\
\hline C & 5.693844 & -1.904692 & -2.857314 \\
\hline C & 4.904400 & -1.151103 & -2.016626 \\
\hline $\mathrm{H}$ & 4.113647 & -4.911732 & -2.604619 \\
\hline $\mathrm{H}$ & 6.057953 & -3.861995 & -3.725448 \\
\hline $\mathrm{H}$ & 6.530912 & -1.437960 & -3.369518 \\
\hline $\mathrm{H}$ & 5.120740 & -0.098578 & -1.875987 \\
\hline $\mathrm{O}$ & -0.457002 & 1.252495 & 1.241988 \\
\hline O & -1.024425 & -0.257209 & -0.810926 \\
\hline $\mathrm{H}$ & -1.941936 & 0.469901 & -1.178983 \\
\hline $\mathrm{H}$ & -0.098938 & -4.835983 & -1.328167 \\
\hline $\mathrm{H}$ & -2.573998 & -5.709987 & 2.075191 \\
\hline $\mathrm{H}$ & 0.410419 & -2.626976 & 2.322730 \\
\hline $\mathrm{H}$ & 1.793224 & 4.868519 & 1.473454 \\
\hline $\mathrm{H}$ & -0.905972 & 6.745497 & -1.295252 \\
\hline $\mathrm{H}$ & 1.118902 & 3.115738 & -2.391502 \\
\hline C & -3.284724 & 1.819265 & -0.442166 \\
\hline $\mathrm{O}$ & -2.869508 & 1.161864 & -1.466636 \\
\hline $\mathrm{H}$ & -2.605264 & 1.985354 & 0.398533 \\
\hline C & -4.238920 & 2.972783 & -0.692962 \\
\hline $\mathrm{O}$ & -4.340948 & 3.919146 & 0.055299 \\
\hline $\mathrm{O}$ & -4.943413 & 2.809528 & -1.826529 \\
\hline C & -5.851417 & 3.880978 & -2.138241 \\
\hline $\mathrm{H}$ & -5.304211 & 4.818725 & -2.262950 \\
\hline $\mathrm{H}$ & -6.334417 & 3.590888 & -3.071289 \\
\hline C & -4.093596 & -0.474776 & 0.809589 \\
\hline C & -4.655601 & 0.804136 & 0.738317 \\
\hline $\mathrm{H}$ & -2.564789 & -1.635101 & 1.510628 \\
\hline$N$ & -3.138120 & -0.822407 & 1.719216 \\
\hline C & -2.673718 & -0.050453 & 2.803746 \\
\hline $\mathrm{O}$ & -3.155167 & 0.990696 & 3.183299 \\
\hline $\mathrm{O}$ & -1.640102 & -0.696522 & 3.355433 \\
\hline C & -0.876775 & 0.086579 & 4.299594 \\
\hline $\mathrm{H}$ & -1.522613 & 0.446286 & 5.103278 \\
\hline $\mathrm{H}$ & -0.418590 & 0.921315 & 3.766343 \\
\hline $\mathrm{H}$ & -0.118658 & -0.594353 & 4.685715 \\
\hline $\mathrm{H}$ & -5.569382 & 0.881462 & 0.160518 \\
\hline $\mathrm{H}$ & -4.567584 & 1.456315 & 1.596423 \\
\hline C & -4.444358 & -1.511789 & -0.176684 \\
\hline C & -4.373038 & -2.877973 & 0.157429 \\
\hline C & -4.876082 & -1.148091 & -1.467637 \\
\hline C & -4.732255 & -3.850979 & -0.769090 \\
\hline $\mathrm{H}$ & -4.065651 & -3.183765 & 1.152215 \\
\hline
\end{tabular}




$\begin{array}{llll}\mathrm{C} & -5.216857 & -2.130095 & -2.394235 \\ \mathrm{H} & -4.901877 & -0.106199 & -1.760795 \\ \mathrm{C} & -5.152390 & -3.480710 & -2.048629 \\ \mathrm{H} & -4.684172 & -4.899257 & -0.490438 \\ \mathrm{H} & -5.529670 & -1.836455 & -3.391942 \\ \mathrm{H} & -5.428146 & -4.242502 & -2.772631 \\ \mathrm{H} & -6.589648 & 4.003099 & -1.340926\end{array}$

Catalyst (R)-1 TS Conformation 115

$B 3 L Y P / 6-31 G(d)$ Energy $=-2809.688276$

B3LYP-D3(BJ)/def2-TZVPP-IEF-PCM(DCM) Energy $=-2810.984938$

B3LYP-D3(BJ)/def2-TZVPP-IEF-PCM(DCM)//B3LYP/6-31G(d) Free Energy (Quasiharmonic) = 2810.343675

Frequencies (Top 3 out of 270)

1. $-657.2749 \mathrm{~cm}-1$

2. $\quad 7.4544 \mathrm{~cm}-1$

3. $10.9205 \mathrm{~cm}-1$

B3LYP/6-31G(d) Molecular Geometry in Cartesian Coordinates

$\begin{array}{llll}\text { C } & 3.060487 & -0.842014 & -0.218588 \\ \text { C } & 1.956806 & -1.539624 & 0.250051 \\ \text { C } & 1.723524 & -2.915843 & -0.035770 \\ \text { C } & 2.628829 & -3.564233 & -0.850705 \\ \text { H } & 2.485710 & -4.619418 & -1.069875 \\ \text { C } & 3.489664 & 3.360574 & 0.653743 \\ \text { C } & 3.237623 & 0.595918 & 0.147634 \\ \text { C } & 2.213515 & 1.490220 & -0.128017 \\ \text { C } & 2.316255 & 2.896221 & 0.090717 \\ \text { H } & 3.616513 & 4.428644 & 0.809942 \\ \text { O } & 1.029539 & -0.884199 & 1.048258 \\ \text { P } & 0.010845 & 0.196043 & 0.349465 \\ \text { O } & 1.038319 & 0.991369 & -0.666845 \\ \text { C } & -1.599342 & -5.155342 & 1.532941 \\ \text { C } & -0.768336 & -4.437441 & 2.397513 \\ \text { C } & 0.290080 & -3.683016 & 1.893758 \\ \text { C } & 0.549202 & -3.646222 & 0.514229 \\ \text { C } & -0.296491 & -4.363812 & -0.345998 \\ \text { C } & -1.364544 & -5.108912 & 0.157079 \\ \text { H } & -0.939884 & -4.469114 & 3.470278\end{array}$




\begin{tabular}{|c|c|c|c|}
\hline $\mathrm{H}$ & -2.009216 & -5.655361 & -0.526477 \\
\hline C & -0.784344 & 5.704702 & -0.925298 \\
\hline C & -0.109434 & 5.802071 & 0.292335 \\
\hline C & 0.880390 & 4.876511 & 0.620218 \\
\hline C & 1.219583 & 3.837379 & -0.261989 \\
\hline C & 0.528786 & 3.748389 & -1.482972 \\
\hline C & -0.462469 & 4.672794 & -1.809950 \\
\hline $\mathrm{H}$ & -0.358162 & 6.594332 & 0.993893 \\
\hline $\mathrm{H}$ & -0.982631 & 4.585271 & -2.760302 \\
\hline C & 4.418832 & 1.085049 & 0.801758 \\
\hline C & 4.540063 & 2.492609 & 1.041762 \\
\hline C & 5.709067 & 2.992385 & 1.677489 \\
\hline C & 6.708680 & 2.143186 & 2.091807 \\
\hline C & 6.574509 & 0.749298 & 1.889752 \\
\hline C & 5.461946 & 0.234581 & 1.261088 \\
\hline $\mathrm{H}$ & 5.791083 & 4.064366 & 1.841514 \\
\hline $\mathrm{H}$ & 7.594241 & 2.536974 & 2.583138 \\
\hline $\mathrm{H}$ & 7.354478 & 0.077409 & 2.237920 \\
\hline $\mathrm{H}$ & 5.369270 & -0.836476 & 1.121461 \\
\hline C & 3.962503 & -1.512549 & -1.116341 \\
\hline C & 3.742513 & -2.896501 & -1.417135 \\
\hline C & 4.632919 & -3.572000 & -2.295089 \\
\hline C & 5.684061 & -2.909920 & -2.885095 \\
\hline C & 5.880325 & -1.533678 & -2.623525 \\
\hline C & 5.044639 & -0.854483 & -1.764419 \\
\hline $\mathrm{H}$ & 4.457185 & -4.625415 & -2.500709 \\
\hline $\mathrm{H}$ & 6.354769 & -3.435237 & -3.559508 \\
\hline $\mathrm{H}$ & 6.695684 & -1.004454 & -3.109341 \\
\hline $\mathrm{H}$ & 5.204207 & 0.202008 & -1.584876 \\
\hline $\mathrm{O}$ & -0.625073 & 1.049931 & 1.380305 \\
\hline 0 & -0.883731 & -0.604726 & -0.634039 \\
\hline $\mathrm{H}$ & -1.688188 & 0.021263 & -1.203138 \\
\hline $\mathrm{H}$ & -0.121370 & -4.319651 & -1.416971 \\
\hline $\mathrm{H}$ & -2.419231 & -5.749985 & 1.928422 \\
\hline $\mathrm{H}$ & 0.928168 & -3.125388 & 2.571483 \\
\hline $\mathrm{H}$ & 0.771677 & 2.954578 & -2.180141 \\
\hline $\mathrm{H}$ & -1.554130 & 6.427711 & -1.183875 \\
\hline $\mathrm{H}$ & 1.381921 & 4.941757 & 1.581633 \\
\hline C & -3.190541 & 1.432815 & -0.876518 \\
\hline $\mathrm{O}$ & -2.609612 & 0.678236 & -1.740610 \\
\hline $\mathrm{H}$ & -2.677272 & 1.638968 & 0.069480 \\
\hline C & -3.951852 & 2.634504 & -1.428930 \\
\hline $\mathrm{O}$ & -4.190488 & 2.836335 & -2.594114 \\
\hline $\mathrm{O}$ & -4.302872 & 3.458849 & -0.416061 \\
\hline
\end{tabular}




$\begin{array}{lrrr}\mathrm{C} & -4.979037 & 4.663307 & -0.813299 \\ \mathrm{H} & -5.891935 & 4.427411 & -1.366659 \\ \mathrm{H} & -5.212759 & 5.187733 & 0.113408 \\ \mathrm{C} & -4.161427 & -0.615872 & 0.398399 \\ \mathrm{C} & -4.805072 & 0.498038 & -0.156886 \\ \mathrm{H} & -2.874199 & -2.127748 & -0.078434 \\ \mathrm{~N} & -3.696838 & -1.620611 & -0.395592 \\ \mathrm{C} & -4.087148 & -1.907143 & -1.718914 \\ \mathrm{O} & -5.067775 & -1.481024 & -2.281221 \\ \mathrm{O} & -3.213801 & -2.792418 & -2.221931 \\ \mathrm{C} & -3.452632 & -3.162446 & -3.592709 \\ \mathrm{H} & -3.409867 & -2.278031 & -4.232201 \\ \mathrm{H} & -4.430277 & -3.639988 & -3.694270 \\ \mathrm{H} & -2.653273 & -3.858983 & -3.843780 \\ \mathrm{H} & -5.282656 & 1.181940 & 0.534785 \\ \mathrm{H} & -5.295934 & 0.367783 & -1.112826 \\ \mathrm{C} & -3.819318 & -0.704531 & 1.827594 \\ \mathrm{C} & -3.674838 & -1.961409 & 2.444269 \\ \mathrm{C} & -3.666930 & 0.457092 & 2.607844 \\ \mathrm{C} & -3.398312 & -2.051351 & 3.805574 \\ \mathrm{H} & -3.808389 & -2.870731 & 1.866947 \\ \mathrm{C} & -3.377180 & 0.360042 & 3.963587 \\ \mathrm{H} & -3.735752 & 1.436284 & 2.148180 \\ \mathrm{C} & -3.247119 & -0.892477 & 4.568148 \\ \mathrm{H} & -3.303782 & -3.028440 & 4.269795 \\ \mathrm{H} & -3.237302 & 1.265062 & 4.546605 \\ \mathrm{H} & -3.023800 & -0.963927 & 5.628934 \\ \mathrm{H} & -4.326381 & 5.272472 & -1.444066\end{array}$

Catalyst (R)-1 TS Conformation 116

B3LYP/6-31G(d) Energy $=-2809.690051$

B3LYP-D3(BJ)/def2-TZVPP-IEF-PCM(DCM) Energy = -2810.985249

B3LYP-D3(BJ)/def2-TZVPP-IEF-PCM(DCM)//B3LYP/6-31G(d) Free Energy (Quasiharmonic) = 2810.343633

Frequencies (Top 3 out of 270)

1. $-541.4221 \mathrm{~cm}-1$

2. $\quad 10.5598 \mathrm{~cm}-1$

3. $18.0426 \mathrm{~cm}-1$

B3LYP/6-31G(d) Molecular Geometry in Cartesian Coordinates 


\begin{tabular}{|c|c|c|c|}
\hline C & 3.260802 & -0.176093 & 0.309931 \\
\hline C & 2.672063 & 1.000055 & -0.128325 \\
\hline C & 3.153279 & 2.296498 & 0.219917 \\
\hline C & 4.221204 & 2.360034 & 1.093671 \\
\hline $\mathrm{H}$ & 4.630082 & 3.331197 & 1.359704 \\
\hline C & 1.727097 & -4.025214 & -0.888568 \\
\hline C & 2.752385 & -1.494654 & -0.175913 \\
\hline C & 1.415983 & -1.820845 & -0.002487 \\
\hline C & 0.874278 & -3.103487 & -0.312272 \\
\hline $\mathrm{H}$ & 1.356298 & -5.021574 & -1.113969 \\
\hline 0 & 1.577719 & 0.923360 & -0.981958 \\
\hline$P$ & 0.137381 & 0.418876 & -0.404324 \\
\hline O & 0.567654 & -0.862117 & 0.535041 \\
\hline C & 1.635466 & 5.993061 & -1.374189 \\
\hline C & 1.861185 & 4.907007 & -2.223149 \\
\hline C & 2.319058 & 3.694220 & -1.711028 \\
\hline C & 2.569427 & 3.546456 & -0.336455 \\
\hline C & 2.327661 & 4.642224 & 0.507816 \\
\hline C & 1.864856 & 5.853697 & -0.004582 \\
\hline $\mathrm{H}$ & 1.689912 & 5.005784 & -3.292167 \\
\hline $\mathrm{H}$ & 1.682431 & 6.687668 & 0.668321 \\
\hline C & -3.161381 & -4.309651 & 0.572124 \\
\hline C & -2.581866 & -4.621976 & -0.657889 \\
\hline C & -1.284534 & -4.200882 & -0.948732 \\
\hline C & -0.536105 & -3.468736 & -0.013878 \\
\hline C & -1.134454 & -3.153553 & 1.219425 \\
\hline C & -2.434100 & -3.568158 & 1.507538 \\
\hline $\mathrm{H}$ & -3.141508 & -5.181964 & -1.401968 \\
\hline $\mathrm{H}$ & -2.879219 & -3.309885 & 2.464535 \\
\hline C & 3.606650 & -2.437563 & -0.844199 \\
\hline C & 3.075964 & -3.721103 & -1.195339 \\
\hline C & 3.912093 & -4.666567 & -1.848996 \\
\hline C & 5.211833 & -4.356233 & -2.174736 \\
\hline C & 5.727868 & -3.076824 & -1.861114 \\
\hline C & 4.948648 & -2.144325 & -1.212153 \\
\hline $\mathrm{H}$ & 3.496742 & -5.640228 & -2.098258 \\
\hline $\mathrm{H}$ & 5.839199 & -5.084582 & -2.681226 \\
\hline $\mathrm{H}$ & 6.747745 & -2.824959 & -2.139131 \\
\hline $\mathrm{H}$ & 5.355751 & -1.165233 & -0.987566 \\
\hline C & 4.325042 & -0.091371 & 1.273764 \\
\hline C & 4.809458 & 1.201306 & 1.656320 \\
\hline C & 5.867199 & 1.300181 & 2.600561 \\
\hline C & 6.411099 & 0.175083 & 3.174806 \\
\hline
\end{tabular}




\begin{tabular}{|c|c|c|c|}
\hline C & 5.909338 & -1.101297 & 2.828177 \\
\hline C & 4.896711 & -1.231627 & 1.903186 \\
\hline $\mathrm{H}$ & 6.230161 & 2.289378 & 2.869625 \\
\hline $\mathrm{H}$ & 7.214601 & 0.263265 & 3.900905 \\
\hline $\mathrm{H}$ & 6.323182 & -1.988550 & 3.299794 \\
\hline $\mathrm{H}$ & 4.518088 & -2.216803 & 1.657606 \\
\hline 0 & -0.725909 & 0.055364 & -1.562619 \\
\hline 0 & -0.339756 & 1.458238 & 0.627311 \\
\hline $\mathrm{H}$ & -1.313834 & 1.384529 & 1.210066 \\
\hline $\mathrm{H}$ & 2.488789 & 4.534090 & 1.576667 \\
\hline $\mathrm{H}$ & 1.286336 & 6.940561 & -1.777346 \\
\hline $\mathrm{H}$ & 2.496432 & 2.859387 & -2.380276 \\
\hline $\mathrm{H}$ & -0.573290 & -2.591722 & 1.958118 \\
\hline $\mathrm{H}$ & -4.171171 & -4.640316 & 0.803173 \\
\hline $\mathrm{H}$ & -0.853726 & -4.420216 & -1.921040 \\
\hline C & -3.225979 & 0.464193 & 1.786445 \\
\hline $\mathrm{O}$ & -2.383740 & 1.423308 & 1.927484 \\
\hline $\mathrm{H}$ & -2.889447 & -0.495065 & 1.369672 \\
\hline C & -4.220434 & 0.321038 & 2.938357 \\
\hline 0 & -4.628097 & 1.231569 & 3.618795 \\
\hline $\mathrm{O}$ & -4.589465 & -0.971532 & 3.085858 \\
\hline C & -5.529565 & -1.219827 & 4.147330 \\
\hline $\mathrm{H}$ & -5.726735 & -2.291595 & 4.119830 \\
\hline $\mathrm{H}$ & -5.100715 & -0.931392 & 5.110297 \\
\hline C & -3.852018 & 1.009642 & -0.725051 \\
\hline C & -4.624074 & 0.805089 & 0.434773 \\
\hline $\mathrm{H}$ & -2.489634 & -0.017529 & -1.858459 \\
\hline$N$ & -3.475022 & -0.027840 & -1.541772 \\
\hline C & -4.142625 & -1.205561 & -1.888682 \\
\hline $\mathrm{O}$ & -3.634029 & -2.044850 & -2.596205 \\
\hline $\mathrm{O}$ & -5.404107 & -1.259883 & -1.415591 \\
\hline C & -6.136955 & -2.433114 & -1.811189 \\
\hline $\mathrm{H}$ & -7.126314 & -2.315269 & -1.368644 \\
\hline $\mathrm{H}$ & -5.646101 & -3.331770 & -1.430876 \\
\hline $\mathrm{H}$ & -6.205465 & -2.491829 & -2.899969 \\
\hline $\mathrm{H}$ & -5.129079 & 1.669798 & 0.851221 \\
\hline $\mathrm{H}$ & -5.179625 & -0.121621 & 0.502041 \\
\hline C & -3.254993 & 2.310460 & -1.021706 \\
\hline C & -2.698559 & 2.570713 & -2.294830 \\
\hline C & -3.231978 & 3.336690 & -0.050470 \\
\hline C & -2.130960 & 3.804030 & -2.578878 \\
\hline $\mathrm{H}$ & -2.727867 & 1.807710 & -3.063884 \\
\hline C & -2.649046 & 4.566118 & -0.342014 \\
\hline $\mathrm{H}$ & -3.626543 & 3.164382 & 0.941547 \\
\hline
\end{tabular}




$\begin{array}{lrrr}\mathrm{C} & -2.096934 & 4.803195 & -1.600464 \\ \mathrm{H} & -1.708999 & 3.988119 & -3.562234 \\ \mathrm{H} & -2.618774 & 5.337048 & 0.421863 \\ \mathrm{H} & -1.636416 & 5.761716 & -1.820297 \\ \mathrm{H} & -6.449547 & -0.652393 & 3.983523\end{array}$

Catalyst (R)-1 TS Conformation 117

B3LYP/6-31G(d) Energy $=-2809.694347$

B3LYP-D3(BJ)/def2-TZVPP-IEF-PCM(DCM) Energy = -2810.988718

B3LYP-D3(BJ)/def2-TZVPP-IEF-PCM(DCM)//B3LYP/6-31G(d) Free Energy (Quasiharmonic) = 2810.343619

Frequencies (Top 3 out of 270)

1. $-202.1533 \mathrm{~cm}-1$

2. $\quad 9.4766 \mathrm{~cm}-1$

3. $\quad 16.1071 \mathrm{~cm}-1$

B3LYP/6-31G(d) Molecular Geometry in Cartesian Coordinates

$\begin{array}{llll}\mathrm{C} & -3.160079 & 0.410164 & -0.208897 \\ \mathrm{C} & -2.163806 & 1.365860 & -0.052743 \\ \mathrm{C} & -2.390344 & 2.755522 & -0.282942 \\ \mathrm{C} & -3.639898 & 3.135609 & -0.731569 \\ \mathrm{H} & -3.833781 & 4.190045 & -0.909927 \\ \mathrm{C} & -2.423162 & -3.707714 & 0.819331 \\ \mathrm{C} & -2.917440 & -1.003251 & 0.200707 \\ \mathrm{C} & -1.833485 & -1.688461 & -0.322087 \\ \mathrm{C} & -1.558602 & -3.059691 & -0.042797 \\ \mathrm{H} & -2.265965 & -4.762158 & 1.029785 \\ \mathrm{O} & -0.920931 & 0.980834 & 0.445580 \\ \mathrm{P} & 0.082672 & 0.003373 & -0.410622 \\ \mathrm{O} & -0.968994 & -0.989240 & -1.166628 \\ \mathrm{C} & 0.413744 & 5.960795 & 0.332604 \\ \mathrm{C} & 0.691836 & 4.963823 & -0.605236 \\ \mathrm{C} & -0.187408 & 3.895487 & -0.785610 \\ \mathrm{C} & -1.369626 & 3.816092 & -0.034942 \\ \mathrm{C} & -1.641929 & 4.823656 & 0.904419 \\ \mathrm{C} & -0.755846 & 5.885200 & 1.091345 \\ \mathrm{H} & 1.597408 & 5.017035 & -1.203890 \\ \mathrm{H} & -0.982084 & 6.653731 & 1.826074 \\ \mathrm{C} & 1.715664 & -5.314315 & -1.687299\end{array}$




\begin{tabular}{|c|c|c|c|}
\hline C & 1.405692 & -5.399217 & -0.328369 \\
\hline C & 0.357395 & -4.645326 & 0.197121 \\
\hline C & -0.402849 & -3.793219 & -0.623313 \\
\hline C & -0.072203 & -3.708025 & -1.984708 \\
\hline C & 0.974825 & -4.464270 & -2.509365 \\
\hline $\mathrm{H}$ & 1.980768 & -6.051443 & 0.324368 \\
\hline $\mathrm{H}$ & 1.215142 & -4.379696 & -3.565205 \\
\hline C & -3.755618 & -1.668778 & 1.161177 \\
\hline C & -3.504657 & -3.048315 & 1.451658 \\
\hline C & -4.333095 & -3.727703 & 2.386016 \\
\hline C & -5.348458 & -3.070098 & 3.040046 \\
\hline C & -5.571071 & -1.695920 & 2.787895 \\
\hline C & -4.798414 & -1.014503 & 1.873275 \\
\hline $\mathrm{H}$ & -4.136995 & -4.778972 & 2.583546 \\
\hline $\mathrm{H}$ & -5.970895 & -3.597479 & 3.757733 \\
\hline $\mathrm{H}$ & -6.357008 & -1.170847 & 3.324019 \\
\hline $\mathrm{H}$ & -4.977398 & 0.039845 & 1.699244 \\
\hline C & -4.417129 & 0.808704 & -0.782265 \\
\hline C & -4.658564 & 2.197886 & -1.025060 \\
\hline C & -5.902150 & 2.607795 & -1.577757 \\
\hline C & -6.866622 & 1.684873 & -1.907985 \\
\hline C & -6.617867 & 0.306936 & -1.704058 \\
\hline C & -5.428755 & -0.119775 & -1.155349 \\
\hline $\mathrm{H}$ & -6.069270 & 3.668848 & -1.747365 \\
\hline $\mathrm{H}$ & -7.811360 & 2.007615 & -2.336787 \\
\hline $\mathrm{H}$ & -7.370057 & -0.423490 & -1.989606 \\
\hline $\mathrm{H}$ & -5.251067 & -1.179871 & -1.017234 \\
\hline $\mathrm{O}$ & 1.017901 & -0.683622 & 0.522724 \\
\hline $\mathrm{O}$ & 0.658474 & 0.828463 & -1.598517 \\
\hline $\mathrm{H}$ & 1.674246 & 1.124098 & -1.548301 \\
\hline $\mathrm{H}$ & -2.554090 & 4.767697 & 1.492787 \\
\hline $\mathrm{H}$ & 1.102550 & 6.790303 & 0.469425 \\
\hline $\mathrm{H}$ & 0.036111 & 3.126738 & -1.516418 \\
\hline $\mathrm{H}$ & -0.634253 & -3.046695 & -2.634236 \\
\hline $\mathrm{H}$ & 2.531922 & -5.901598 & -2.100106 \\
\hline $\mathrm{H}$ & 0.131324 & -4.700360 & 1.258392 \\
\hline C & 3.932620 & 2.021826 & -0.986225 \\
\hline $\mathrm{O}$ & 3.060182 & 1.514896 & -1.796158 \\
\hline $\mathrm{H}$ & 4.688867 & 2.693586 & -1.427785 \\
\hline C & 3.493375 & 2.636524 & 0.348831 \\
\hline $\mathrm{O}$ & 4.190630 & 3.402268 & 0.987733 \\
\hline $\mathrm{O}$ & 2.291158 & 2.198714 & 0.730878 \\
\hline C & 1.800249 & 2.677042 & 2.000383 \\
\hline $\mathrm{H}$ & 2.472542 & 2.360905 & 2.801319 \\
\hline
\end{tabular}




$\begin{array}{llcl}\mathrm{H} & 1.725583 & 3.765688 & 1.983822 \\ \mathrm{C} & 4.364626 & -0.276459 & 0.111033 \\ \mathrm{C} & 5.160347 & 0.755102 & -0.464829 \\ \mathrm{H} & 2.606664 & -1.232176 & -0.217915 \\ \mathrm{~N} & 3.512207 & -0.989253 & -0.658362 \\ \mathrm{C} & 3.459048 & -1.156019 & -2.062556 \\ \mathrm{O} & 2.450246 & -1.529936 & -2.609718 \\ \mathrm{O} & 4.648808 & -0.984472 & -2.658961 \\ \mathrm{C} & 4.599329 & -1.033491 & -4.097719 \\ \mathrm{H} & 3.965693 & -0.225502 & -4.470858 \\ \mathrm{H} & 4.206899 & -1.995507 & -4.433491 \\ \mathrm{H} & 5.630744 & -0.900367 & -4.424447 \\ \mathrm{H} & 5.889127 & 1.218960 & 0.192489 \\ \mathrm{H} & 5.554005 & 0.541306 & -1.449500 \\ \mathrm{C} & 4.276058 & -0.504810 & 1.563539 \\ \mathrm{C} & 3.719700 & -1.701348 & 2.060774 \\ \mathrm{C} & 4.790867 & 0.429859 & 2.485913 \\ \mathrm{C} & 3.672341 & -1.947820 & 3.428754 \\ \mathrm{H} & 3.340662 & -2.453058 & 1.377540 \\ \mathrm{C} & 4.731531 & 0.180573 & 3.853427 \\ \mathrm{H} & 5.202544 & 1.372278 & 2.144731 \\ \mathrm{C} & 4.175529 & -1.008774 & 4.330620 \\ \mathrm{H} & 3.242816 & -2.877445 & 3.790000 \\ \mathrm{H} & 5.121894 & 0.918934 & 4.547796 \\ \mathrm{H} & 4.138495 & -1.203621 & 5.398829 \\ \mathrm{H} & 0.818682 & 2.221466 & 2.112443\end{array}$

Catalyst (R)-1 TS Conformation 118

B3LYP/6-31G(d) Energy $=-2809.688725$

B3LYP-D3(BJ)/def2-TZVPP-IEF-PCM(DCM) Energy = -2810.985667

B3LYP-D3(BJ)/def2-TZVPP-IEF-PCM(DCM)//B3LYP/6-31G(d) Free Energy (Quasiharmonic) = 2810.343594

Frequencies (Top 3 out of 270)

1. $-664.9637 \mathrm{~cm}-1$

2. $\quad 8.6413 \mathrm{~cm}-1$

3. $\quad 11.9843 \mathrm{~cm}-1$

B3LYP/6-31G(d) Molecular Geometry in Cartesian Coordinates

$\begin{array}{llll}\text { C } & -3.376351 & -1.146284 & 0.107897\end{array}$ 


\begin{tabular}{|c|c|c|c|}
\hline C & -2.151811 & -1.688252 & -0.244969 \\
\hline C & -1.736204 & -3.004372 & 0.112799 \\
\hline C & -2.606274 & -3.751296 & 0.882409 \\
\hline $\mathrm{H}$ & -2.336845 & -4.769179 & 1.152003 \\
\hline C & -4.494275 & 2.841555 & -1.088448 \\
\hline C & -3.746972 & 0.214088 & -0.384805 \\
\hline C & -2.911695 & 1.298838 & -0.145589 \\
\hline C & -3.280987 & 2.642135 & -0.459348 \\
\hline $\mathrm{H}$ & -4.795308 & 3.854543 & -1.342443 \\
\hline O & -1.280539 & -0.907759 & -0.992734 \\
\hline$P$ & -0.475087 & 0.283678 & -0.199294 \\
\hline O & -1.708924 & 1.100226 & 0.518444 \\
\hline C & 2.047762 & -4.696531 & -1.047538 \\
\hline C & 1.584093 & -4.824891 & 0.262392 \\
\hline C & 0.363884 & -4.260183 & 0.631423 \\
\hline C & -0.419418 & -3.559011 & -0.300226 \\
\hline C & 0.061563 & -3.432405 & -1.615120 \\
\hline C & 1.282806 & -3.995897 & -1.983446 \\
\hline $\mathrm{H}$ & 2.176446 & -5.355463 & 1.003212 \\
\hline $\mathrm{H}$ & 1.636156 & -3.889068 & -3.005518 \\
\hline C & -0.969107 & 6.141202 & 0.514976 \\
\hline C & -0.376665 & 5.091757 & -0.191213 \\
\hline C & -1.101870 & 3.938468 & -0.495629 \\
\hline C & -2.444224 & 3.821386 & -0.097970 \\
\hline C & -3.030400 & 4.882907 & 0.611107 \\
\hline C & -2.300783 & 6.031936 & 0.916839 \\
\hline $\mathrm{H}$ & 0.657879 & 5.170590 & -0.516391 \\
\hline $\mathrm{H}$ & -2.773147 & 6.838368 & 1.472024 \\
\hline C & -4.956996 & 0.429709 & -1.131990 \\
\hline C & -5.335366 & 1.768569 & -1.469166 \\
\hline C & -6.533703 & 1.995524 & -2.198984 \\
\hline C & -7.322186 & 0.945745 & -2.608311 \\
\hline C & -6.933432 & -0.381159 & -2.308506 \\
\hline C & -5.785218 & -0.632542 & -1.590133 \\
\hline $\mathrm{H}$ & -6.807768 & 3.020292 & -2.438715 \\
\hline $\mathrm{H}$ & -8.233072 & 1.130133 & -3.171311 \\
\hline $\mathrm{H}$ & -7.543071 & -1.211683 & -2.654246 \\
\hline $\mathrm{H}$ & -5.496795 & -1.655837 & -1.380115 \\
\hline C & -4.235257 & -1.906114 & 0.976053 \\
\hline C & -3.840521 & -3.233009 & 1.346678 \\
\hline C & -4.685586 & -4.002082 & 2.192093 \\
\hline C & -5.858261 & -3.480117 & 2.686109 \\
\hline C & -6.229772 & -2.155683 & 2.356444 \\
\hline C & -5.442083 & -1.390897 & 1.524083 \\
\hline
\end{tabular}




\begin{tabular}{|c|c|c|c|}
\hline $\mathrm{H}$ & -4.376577 & -5.011741 & 2.452576 \\
\hline $\mathrm{H}$ & -6.492237 & -4.075221 & 3.337734 \\
\hline $\mathrm{H}$ & -7.143433 & -1.734742 & 2.767530 \\
\hline $\mathrm{H}$ & -5.737113 & -0.374901 & 1.289745 \\
\hline $\mathrm{O}$ & 0.306438 & 1.065537 & -1.196851 \\
\hline 0 & 0.255333 & -0.315846 & 1.021218 \\
\hline $\mathrm{H}$ & 1.406723 & -0.560630 & 0.914142 \\
\hline $\mathrm{H}$ & -0.525449 & -2.893941 & -2.350781 \\
\hline $\mathrm{H}$ & 2.996645 & -5.139619 & -1.339514 \\
\hline $\mathrm{H}$ & 0.022239 & -4.338402 & 1.659520 \\
\hline $\mathrm{H}$ & -4.063586 & 4.796163 & 0.936853 \\
\hline $\mathrm{H}$ & -0.398209 & 7.036164 & 0.749057 \\
\hline $\mathrm{H}$ & -0.627497 & 3.133808 & -1.048465 \\
\hline C & 2.976717 & -0.668990 & -0.432562 \\
\hline $\mathrm{O}$ & 2.602126 & -0.840288 & 0.788232 \\
\hline $\mathrm{H}$ & 2.214482 & -0.532038 & -1.208884 \\
\hline C & 4.144688 & -1.489189 & -0.962899 \\
\hline $\mathrm{O}$ & 4.427840 & -1.544435 & -2.141429 \\
\hline $\mathrm{O}$ & 4.800817 & -2.141096 & 0.009949 \\
\hline C & 5.864759 & -2.995173 & -0.444190 \\
\hline $\mathrm{H}$ & 5.479564 & -3.738475 & -1.146571 \\
\hline $\mathrm{H}$ & 6.251541 & -3.479291 & 0.452929 \\
\hline C & 4.637851 & 1.279287 & 0.195294 \\
\hline C & 3.586748 & 1.167656 & -0.724602 \\
\hline $\mathrm{H}$ & 5.275155 & 1.328435 & 2.118419 \\
\hline$N$ & 4.455288 & 1.426570 & 1.531450 \\
\hline C & 3.327761 & 1.706927 & 2.350129 \\
\hline $\mathrm{O}$ & 3.436994 & 1.611388 & 3.551021 \\
\hline $\mathrm{O}$ & 2.279200 & 2.137515 & 1.666906 \\
\hline C & 1.102687 & 2.441664 & 2.464546 \\
\hline $\mathrm{H}$ & 1.377143 & 3.116487 & 3.277025 \\
\hline $\mathrm{H}$ & 0.682359 & 1.514083 & 2.852269 \\
\hline $\mathrm{H}$ & 0.409925 & 2.913726 & 1.771379 \\
\hline $\mathrm{H}$ & 3.868657 & 1.138433 & -1.771672 \\
\hline $\mathrm{H}$ & 2.625435 & 1.619223 & -0.511959 \\
\hline C & 6.047705 & 1.076395 & -0.219788 \\
\hline C & 6.502332 & 1.628313 & -1.429181 \\
\hline C & 6.954134 & 0.356777 & 0.581360 \\
\hline C & 7.831151 & 1.478488 & -1.819463 \\
\hline $\mathrm{H}$ & 5.819485 & 2.199347 & -2.049401 \\
\hline C & 8.279635 & 0.202065 & 0.182808 \\
\hline $\mathrm{H}$ & 6.612984 & -0.134418 & 1.488642 \\
\hline C & 8.723152 & 0.767235 & -1.015347 \\
\hline $\mathrm{H}$ & 8.169471 & 1.921175 & -2.751534 \\
\hline
\end{tabular}




$\begin{array}{rrrr}\mathrm{H} & 8.964452 & -0.367149 & 0.804723 \\ \mathrm{H} & 9.758507 & 0.649439 & -1.322074 \\ \mathrm{H} & 6.645791 & -2.408995 & -0.935101\end{array}$

Catalyst (R)-1 TS Conformation 119

B3LYP/6-31G(d) Energy $=-2809.691853$

B3LYP-D3(BJ)/def2-TZVPP-IEF-PCM(DCM) Energy = -2810.985565

B3LYP-D3(BJ)/def2-TZVPP-IEF-PCM(DCM)//B3LYP/6-31G(d) Free Energy (Quasiharmonic) = 2810.343592

Frequencies (Top 3 out of 270)

1. $-468.6001 \mathrm{~cm}-1$

2. $\quad 10.8871 \mathrm{~cm}-1$

3. $\quad 18.8666 \mathrm{~cm}-1$

B3LYP/6-31G(d) Molecular Geometry in Cartesian Coordinates

$\begin{array}{lrrr}\text { C } & 3.244457 & -0.046526 & 0.313304 \\ \text { C } & 2.612142 & 1.082726 & -0.183043 \\ \text { C } & 3.028609 & 2.413292 & 0.116523 \\ \text { C } & 4.079369 & 2.561390 & 1.000829 \\ \text { H } & 4.441063 & 3.560132 & 1.230605 \\ \text { C } & 1.917338 & -4.011834 & -0.741005 \\ \text { C } & 2.805448 & -1.406293 & -0.124930 \\ \text { C } & 1.482816 & -1.789452 & 0.039728 \\ \text { C } & 1.008467 & -3.109385 & -0.221961 \\ \text { H } & 1.600175 & -5.034427 & -0.926882 \\ \text { O } & 1.534819 & 0.920555 & -1.047219 \\ \text { P } & 0.112594 & 0.379915 & -0.460775 \\ \text { O } & 0.580889 & -0.850641 & 0.524082 \\ \text { C } & 1.358676 & 5.965732 & -1.645874 \\ \text { C } & 1.585928 & 5.896618 & -0.270551 \\ \text { C } & 2.099257 & 4.730649 & 0.296345 \\ \text { C } & 2.395631 & 3.611038 & -0.497953 \\ \text { C } & 2.147975 & 3.687919 & -1.878868 \\ \text { C } & 1.638633 & 4.855133 & -2.445418 \\ \text { H } & 1.362408 & 6.750164 & 0.364420 \\ \text { H } & 1.469321 & 4.899121 & -3.518368 \\ \text { C } & -2.981589 & -4.480553 & 0.627830 \\ \text { C } & -2.324249 & -3.647932 & 1.538037 \\ \text { C } & -1.039142 & -3.182463 & 1.260187\end{array}$




\begin{tabular}{|c|c|c|c|}
\hline C & -0.388670 & -3.532594 & 0.063127 \\
\hline C & -1.070048 & -4.355566 & -0.847758 \\
\hline C & -2.350538 & -4.830564 & -0.566366 \\
\hline $\mathrm{H}$ & -2.816504 & -3.351975 & 2.459968 \\
\hline $\mathrm{H}$ & -2.857516 & -5.462248 & -1.290726 \\
\hline C & 3.716479 & -2.333596 & -0.737804 \\
\hline C & 3.255147 & -3.655762 & -1.039281 \\
\hline C & 4.147916 & -4.586857 & -1.636322 \\
\hline C & 5.436662 & -4.227496 & -1.955212 \\
\hline C & 5.884153 & -2.911521 & -1.691563 \\
\hline C & 5.049024 & -1.990950 & -1.097416 \\
\hline $\mathrm{H}$ & 3.784836 & -5.589860 & -1.847972 \\
\hline $\mathrm{H}$ & 6.107673 & -4.945704 & -2.418408 \\
\hline $\mathrm{H}$ & 6.895342 & -2.622044 & -1.964696 \\
\hline $\mathrm{H}$ & 5.404180 & -0.984026 & -0.910879 \\
\hline C & 4.287811 & 0.126785 & 1.288237 \\
\hline C & 4.709007 & 1.454926 & 1.620962 \\
\hline C & 5.746087 & 1.641027 & 2.574944 \\
\hline C & 6.328917 & 0.566813 & 3.205637 \\
\hline C & 5.888722 & -0.744228 & 2.908182 \\
\hline C & 4.898084 & -0.958923 & 1.975154 \\
\hline $\mathrm{H}$ & 6.061289 & 2.655972 & 2.805621 \\
\hline $\mathrm{H}$ & 7.115949 & 0.721579 & 3.938616 \\
\hline $\mathrm{H}$ & 6.332819 & -1.591169 & 3.424266 \\
\hline $\mathrm{H}$ & 4.566634 & -1.969448 & 1.767440 \\
\hline 0 & -0.735460 & -0.046541 & -1.607889 \\
\hline 0 & -0.404070 & 1.438534 & 0.536539 \\
\hline $\mathrm{H}$ & -1.342214 & 1.312907 & 1.142096 \\
\hline $\mathrm{H}$ & 2.367048 & 2.833984 & -2.510487 \\
\hline $\mathrm{H}$ & 0.969426 & 6.877861 & -2.091623 \\
\hline $\mathrm{H}$ & 2.257922 & 4.676521 & 1.369657 \\
\hline $\mathrm{H}$ & -0.600512 & -4.605056 & -1.794640 \\
\hline $\mathrm{H}$ & -3.978818 & -4.851438 & 0.852086 \\
\hline $\mathrm{H}$ & -0.530433 & -2.551051 & 1.980450 \\
\hline C & -3.196068 & 0.263872 & 1.731781 \\
\hline 0 & -2.420032 & 1.278073 & 1.890165 \\
\hline $\mathrm{H}$ & -2.795673 & -0.659751 & 1.290443 \\
\hline C & -4.126127 & -0.071350 & 2.897344 \\
\hline $\mathrm{O}$ & -4.417565 & -1.208231 & 3.207270 \\
\hline $\mathrm{O}$ & -4.569499 & 1.026902 & 3.525601 \\
\hline C & -5.414387 & 0.785104 & 4.664493 \\
\hline $\mathrm{H}$ & -4.875765 & 0.211041 & 5.422629 \\
\hline $\mathrm{H}$ & -5.677980 & 1.771604 & 5.045736 \\
\hline C & -3.890103 & 0.754069 & -0.759726 \\
\hline
\end{tabular}




$\begin{array}{llll}\mathrm{C} & -4.620194 & 0.536168 & 0.426969 \\ \mathrm{H} & -2.507317 & -0.224085 & -1.906189 \\ \mathrm{~N} & -3.481037 & -0.280096 & -1.562981 \\ \mathrm{C} & -4.087912 & -1.505243 & -1.860865 \\ \mathrm{O} & -3.549952 & -2.327679 & -2.565814 \\ \mathrm{O} & -5.327254 & -1.621449 & -1.346224 \\ \mathrm{C} & -5.998144 & -2.850502 & -1.680028 \\ \mathrm{H} & -6.100137 & -2.947076 & -2.763478 \\ \mathrm{H} & -6.976607 & -2.780056 & -1.204695 \\ \mathrm{H} & -5.438029 & -3.703169 & -1.290434 \\ \mathrm{H} & -5.155498 & 1.386057 & 0.836403 \\ \mathrm{H} & -5.138247 & -0.410546 & 0.517440 \\ \mathrm{C} & -3.365257 & 2.075413 & -1.100853 \\ \mathrm{C} & -3.356517 & 3.120240 & -0.150148 \\ \mathrm{C} & -2.863932 & 2.335297 & -2.396484 \\ \mathrm{C} & -2.838858 & 4.368269 & -0.482949 \\ \mathrm{H} & -3.706374 & 2.946567 & 0.858272 \\ \mathrm{C} & -2.362351 & 3.587004 & -2.722091 \\ \mathrm{H} & -2.884612 & 1.556767 & -3.150243 \\ \mathrm{C} & -2.340427 & 4.605487 & -1.763672 \\ \mathrm{H} & -2.816429 & 5.154454 & 0.265598 \\ \mathrm{H} & -1.982295 & 3.770357 & -3.722547 \\ \mathrm{H} & -1.931018 & 5.579060 & -2.016157 \\ \mathrm{H} & -6.310202 & 0.232476 & 4.368238\end{array}$

Catalyst (R)-1 TS Conformation 120

B3LYP/6-31G(d) Energy $=-2809.695457$

B3LYP-D3(BJ)/def2-TZVPP-IEF-PCM(DCM) Energy = -2810.986263

B3LYP-D3(BJ)/def2-TZVPP-IEF-PCM(DCM)//B3LYP/6-31G(d) Free Energy (Quasiharmonic) = 2810.343459

Frequencies (Top 3 out of 270)

1. $-420.4958 \mathrm{~cm}-1$

2. $\quad 9.4454 \mathrm{~cm}-1$

3. $\quad 11.7276 \mathrm{~cm}-1$

B3LYP/6-31G(d) Molecular Geometry in Cartesian Coordinates

$\begin{array}{llll}C & -3.546448 & -0.198284 & -0.260654 \\ C & -2.914258 & 1.017452 & -0.030268 \\ C & -3.600523 & 2.268108 & -0.082018\end{array}$




\begin{tabular}{|c|c|c|c|}
\hline C & -4.928375 & 2.250872 & -0.461668 \\
\hline $\mathrm{H}$ & -5.471789 & 3.190645 & -0.512687 \\
\hline C & -1.414482 & -3.904984 & 0.334285 \\
\hline C & -2.829828 & -1.483435 & -0.006057 \\
\hline C & -1.612411 & -1.719979 & -0.619956 \\
\hline C & -0.875360 & -2.931526 & -0.483594 \\
\hline $\mathrm{H}$ & -0.895086 & -4.853611 & 0.442408 \\
\hline 0 & -1.583093 & 1.031479 & 0.378165 \\
\hline$P$ & -0.370765 & 0.517680 & -0.592204 \\
\hline O & -1.072989 & -0.706849 & -1.411252 \\
\hline C & -1.907612 & 6.068877 & 1.020879 \\
\hline C & -1.280510 & 5.286761 & 0.048582 \\
\hline C & -1.804175 & 4.042876 & -0.305517 \\
\hline C & -2.970441 & 3.561451 & 0.308553 \\
\hline C & -3.594201 & 4.356903 & 1.284317 \\
\hline C & -3.067706 & 5.599019 & 1.638929 \\
\hline $\mathrm{H}$ & -0.377138 & 5.640500 & -0.440704 \\
\hline $\mathrm{H}$ & -3.562679 & 6.196503 & 2.400269 \\
\hline C & 2.892602 & -3.659556 & -2.430458 \\
\hline C & 2.732014 & -3.933093 & -1.071157 \\
\hline C & 1.510796 & -3.680244 & -0.446130 \\
\hline C & 0.427647 & -3.149997 & -1.166391 \\
\hline C & 0.604097 & -2.873325 & -2.532488 \\
\hline C & 1.824235 & -3.128803 & -3.156947 \\
\hline $\mathrm{H}$ & 3.559964 & -4.337230 & -0.494266 \\
\hline $\mathrm{H}$ & 1.938172 & -2.915380 & -4.216533 \\
\hline C & -3.339444 & -2.476164 & 0.902189 \\
\hline C & -2.620848 & -3.707283 & 1.050681 \\
\hline C & -3.118738 & -4.704060 & 1.933346 \\
\hline C & -4.259552 & -4.490624 & 2.671159 \\
\hline C & -4.947040 & -3.259486 & 2.559286 \\
\hline C & -4.501165 & -2.280522 & 1.698566 \\
\hline $\mathrm{H}$ & -2.568720 & -5.637933 & 2.022758 \\
\hline $\mathrm{H}$ & -4.626963 & -5.257447 & 3.347575 \\
\hline $\mathrm{H}$ & -5.833947 & -3.081709 & 3.161400 \\
\hline $\mathrm{H}$ & -5.035433 & -1.340296 & 1.632289 \\
\hline C & -4.897080 & -0.187134 & -0.755067 \\
\hline C & -5.593733 & 1.060221 & -0.840493 \\
\hline C & -6.931478 & 1.083892 & -1.319925 \\
\hline C & -7.557141 & -0.071310 & -1.726596 \\
\hline C & -6.860257 & -1.301550 & -1.676209 \\
\hline C & -5.568043 & -1.359060 & -1.202385 \\
\hline $\mathrm{H}$ & -7.446735 & 2.040143 & -1.370655 \\
\hline $\mathrm{H}$ & -8.577740 & -0.041144 & -2.098031 \\
\hline
\end{tabular}




\begin{tabular}{|c|c|c|c|}
\hline $\mathrm{H}$ & -7.346564 & -2.209944 & -2.021377 \\
\hline $\mathrm{H}$ & -5.045332 & -2.308307 & -1.182411 \\
\hline $\mathrm{O}$ & 0.779011 & 0.110194 & 0.261768 \\
\hline 0 & -0.136112 & 1.550730 & -1.724637 \\
\hline $\mathrm{H}$ & 0.805763 & 2.119864 & -1.753598 \\
\hline $\mathrm{H}$ & -4.490439 & 3.988211 & 1.776274 \\
\hline $\mathrm{H}$ & -1.495861 & 7.036915 & 1.294474 \\
\hline $\mathrm{H}$ & -1.313716 & 3.450274 & -1.068565 \\
\hline $\mathrm{H}$ & -0.219478 & -2.462755 & -3.106765 \\
\hline $\mathrm{H}$ & 3.842754 & -3.857497 & -2.919615 \\
\hline $\mathrm{H}$ & 1.397711 & -3.868268 & 0.617808 \\
\hline C & 2.924291 & 2.534994 & -1.146353 \\
\hline 0 & 1.988536 & 2.756052 & -1.980358 \\
\hline $\mathrm{H}$ & 3.921310 & 2.936602 & -1.374303 \\
\hline C & 2.662594 & 2.603172 & 0.364206 \\
\hline 0 & 3.513502 & 2.387531 & 1.205122 \\
\hline $\mathrm{O}$ & 1.416913 & 3.004572 & 0.628408 \\
\hline C & 1.051101 & 3.035918 & 2.023421 \\
\hline $\mathrm{H}$ & 1.076795 & 2.021046 & 2.425623 \\
\hline $\mathrm{H}$ & 1.739812 & 3.676536 & 2.579205 \\
\hline C & 4.218430 & 0.084255 & -0.390798 \\
\hline C & 3.475181 & 0.607191 & -1.459017 \\
\hline $\mathrm{H}$ & 2.501721 & -0.398729 & 0.589041 \\
\hline$N$ & 3.528580 & -0.479651 & 0.635503 \\
\hline C & 4.022922 & -1.252644 & 1.690249 \\
\hline 0 & 5.167905 & -1.600278 & 1.867296 \\
\hline 0 & 2.979956 & -1.580870 & 2.479210 \\
\hline C & 3.314245 & -2.392475 & 3.615425 \\
\hline $\mathrm{H}$ & 3.754256 & -3.340613 & 3.295238 \\
\hline $\mathrm{H}$ & 2.370811 & -2.561213 & 4.134424 \\
\hline $\mathrm{H}$ & 4.022687 & -1.870345 & 4.263719 \\
\hline $\mathrm{H}$ & 4.025813 & 0.835080 & -2.364248 \\
\hline $\mathrm{H}$ & 2.476070 & 0.215736 & -1.605017 \\
\hline C & 5.689049 & 0.252412 & -0.358568 \\
\hline C & 6.437968 & -0.105773 & -1.490845 \\
\hline C & 6.340221 & 0.838296 & 0.739765 \\
\hline C & 7.817452 & 0.093576 & -1.516710 \\
\hline $\mathrm{H}$ & 5.940240 & -0.568078 & -2.338242 \\
\hline C & 7.713231 & 1.056871 & 0.698750 \\
\hline $\mathrm{H}$ & 5.759100 & 1.152045 & 1.598023 \\
\hline C & 8.456419 & 0.678887 & -0.423377 \\
\hline $\mathrm{H}$ & 8.389323 & -0.204770 & -2.390791 \\
\hline $\mathrm{H}$ & 8.206860 & 1.524136 & 1.546129 \\
\hline $\mathrm{H}$ & 9.530256 & 0.844086 & -0.445172 \\
\hline
\end{tabular}


$\begin{array}{llll}H & 0.038703 & 3.434655 & 2.043431\end{array}$

Catalyst (R)-1 TS Conformation 121

$B 3 L Y P / 6-31 G(d)$ Energy $=-2809.694991$

B3LYP-D3(BJ)/def2-TZVPP-IEF-PCM(DCM) Energy $=-2810.987925$

B3LYP-D3(BJ)/def2-TZVPP-IEF-PCM(DCM)//B3LYP/6-31G(d) Free Energy (Quasiharmonic) = 2810.343414

Frequencies (Top 3 out of 270)

1. $-213.8512 \mathrm{~cm}-1$

2. $\quad 7.4187 \mathrm{~cm}-1$

3. $\quad 16.5413 \mathrm{~cm}-1$

B3LYP/6-31G(d) Molecular Geometry in Cartesian Coordinates

$\begin{array}{llll}\text { C } & 3.200207 & 0.346819 & 0.161425 \\ \text { C } & 2.305182 & 1.353536 & -0.160070 \\ \text { C } & 2.503321 & 2.720509 & 0.195317 \\ \text { C } & 3.616815 & 3.014571 & 0.959517 \\ \text { H } & 3.814891 & 4.049827 & 1.223516 \\ \text { C } & 2.606874 & -3.757186 & -0.974189 \\ \text { C } & 2.973333 & -1.039720 & -0.338751 \\ \text { C } & 1.787450 & -1.698886 & -0.049036 \\ \text { C } & 1.597649 & -3.090106 & -0.306037 \\ \text { H } & 2.482936 & -4.814928 & -1.190734 \\ \text { O } & 1.168918 & 1.011754 & -0.892946 \\ \text { P } & -0.028088 & 0.202113 & -0.133878 \\ \text { O } & 0.779928 & -1.009571 & 0.618608 \\ \text { C } & 0.111393 & 6.055289 & -1.080948 \\ \text { C } & 0.452484 & 5.053401 & -1.991322 \\ \text { C } & 1.188195 & 3.944584 & -1.577820 \\ \text { C } & 1.606615 & 3.822482 & -0.243596 \\ \text { C } & 1.240151 & 4.826842 & 0.668069 \\ \text { C } & 0.499445 & 5.932900 & 0.254861 \\ \text { H } & 0.144205 & 5.131344 & -3.030175 \\ \text { H } & 0.226638 & 6.698242 & 0.977049 \\ \text { C } & -1.743879 & -5.447624 & 1.031862 \\ \text { C } & -1.970768 & -4.274914 & 0.308444 \\ \text { C } & -0.903929 & -3.480586 & -0.114439 \\ \text { C } & 0.416276 & -3.858338 & 0.175817 \\ \text { C } & 0.633227 & -5.039848 & 0.905972\end{array}$




\begin{tabular}{|c|c|c|c|}
\hline C & -0.435337 & -5.827629 & 1.332200 \\
\hline $\mathrm{H}$ & -2.985364 & -3.974830 & 0.064529 \\
\hline $\mathrm{H}$ & -0.243984 & -6.733979 & 1.901011 \\
\hline C & 3.971520 & -1.722136 & -1.116011 \\
\hline C & 3.777127 & -3.104606 & -1.430204 \\
\hline C & 4.756300 & -3.792241 & -2.197269 \\
\hline C & 5.876387 & -3.141612 & -2.659497 \\
\hline C & 6.057712 & -1.767320 & -2.375465 \\
\hline C & 5.133327 & -1.076878 & -1.622856 \\
\hline $\mathrm{H}$ & 4.595149 & -4.844285 & -2.420661 \\
\hline $\mathrm{H}$ & 6.615984 & -3.674999 & -3.250369 \\
\hline $\mathrm{H}$ & 6.932076 & -1.249315 & -2.760160 \\
\hline $\mathrm{H}$ & 5.281329 & -0.021810 & -1.423331 \\
\hline C & 4.312688 & 0.658123 & 1.018242 \\
\hline C & 4.516933 & 2.019662 & 1.410392 \\
\hline C & 5.616090 & 2.348909 & 2.249272 \\
\hline C & 6.467122 & 1.374158 & 2.714934 \\
\hline C & 6.245407 & 0.022471 & 2.361389 \\
\hline C & 5.199657 & -0.326279 & 1.535071 \\
\hline $\mathrm{H}$ & 5.762481 & 3.390275 & 2.526231 \\
\hline $\mathrm{H}$ & 7.299992 & 1.636008 & 3.361771 \\
\hline $\mathrm{H}$ & 6.903706 & -0.750164 & 2.749427 \\
\hline $\mathrm{H}$ & 5.039411 & -1.368029 & 1.283993 \\
\hline 0 & -1.021561 & -0.277804 & -1.139602 \\
\hline $\mathrm{O}$ & -0.496624 & 1.057105 & 1.071268 \\
\hline $\mathrm{H}$ & -1.505294 & 1.385105 & 1.154003 \\
\hline $\mathrm{H}$ & 1.528528 & 4.728698 & 1.710789 \\
\hline $\mathrm{H}$ & -0.454137 & 6.924228 & -1.408943 \\
\hline $\mathrm{H}$ & 1.446199 & 3.172672 & -2.294407 \\
\hline $\mathrm{H}$ & 1.650804 & -5.330495 & 1.152679 \\
\hline $\mathrm{H}$ & -2.580244 & -6.060100 & 1.359516 \\
\hline $\mathrm{H}$ & -1.094497 & -2.574890 & -0.680783 \\
\hline C & -3.856721 & 1.580113 & 1.781657 \\
\hline 0 & -2.760378 & 2.074928 & 1.308522 \\
\hline $\mathrm{H}$ & -4.494170 & 2.258571 & 2.374523 \\
\hline C & -3.848993 & 0.222672 & 2.498468 \\
\hline 0 & -4.779382 & -0.183487 & 3.169574 \\
\hline $\mathrm{O}$ & -2.711268 & -0.446090 & 2.290933 \\
\hline C & -2.572151 & -1.709161 & 2.968948 \\
\hline $\mathrm{H}$ & -1.574656 & -2.062525 & 2.713857 \\
\hline $\mathrm{H}$ & -2.679365 & -1.568377 & 4.047305 \\
\hline C & -4.429739 & 0.606006 & -0.543675 \\
\hline C & -5.112156 & 1.357386 & 0.453844 \\
\hline $\mathrm{H}$ & -2.594309 & 0.520169 & -1.453833 \\
\hline
\end{tabular}




$\begin{array}{llll}\mathrm{N} & -3.387876 & 1.144277 & -1.211528 \\ \mathrm{C} & -3.012770 & 2.493859 & -1.419490 \\ \mathrm{O} & -1.922477 & 2.766701 & -1.859255 \\ \mathrm{O} & -4.005061 & 3.367894 & -1.205902 \\ \mathrm{C} & -3.618170 & 4.748832 & -1.356903 \\ \mathrm{H} & -2.795399 & 4.981657 & -0.678197 \\ \mathrm{H} & -4.510201 & 5.322845 & -1.105753 \\ \mathrm{H} & -3.308945 & 4.944411 & -2.386102 \\ \mathrm{H} & -5.997301 & 0.895455 & 0.879463 \\ \mathrm{H} & -5.246981 & 2.406321 & 0.227810 \\ \mathrm{C} & -4.702932 & -0.821313 & -0.791080 \\ \mathrm{C} & -5.453549 & -1.595157 & 0.118196 \\ \mathrm{C} & -4.292706 & -1.416424 & -2.001684 \\ \mathrm{C} & -5.779125 & -2.915077 & -0.179117 \\ \mathrm{H} & -5.761865 & -1.180429 & 1.071058 \\ \mathrm{C} & -4.627205 & -2.735017 & -2.295365 \\ \mathrm{H} & -3.739951 & -0.836145 & -2.732227 \\ \mathrm{C} & -5.375567 & -3.488033 & -1.388449 \\ \mathrm{H} & -6.353803 & -3.496653 & 0.535941 \\ \mathrm{H} & -4.310135 & -3.170740 & -3.238083 \\ \mathrm{H} & -5.643943 & -4.514392 & -1.622722 \\ \mathrm{H} & -3.329225 & -2.414015 & 2.617539\end{array}$

Catalyst (R)-1 TS Conformation 122

B3LYP/6-31G(d) Energy $=-2809.69372$

B3LYP-D3(BJ)/def2-TZVPP-IEF-PCM(DCM) Energy = -2810.984387

B3LYP-D3(BJ)/def2-TZVPP-IEF-PCM(DCM)//B3LYP/6-31G(d) Free Energy (Quasiharmonic) = 2810.3434

Frequencies (Top 3 out of 270)

1. $-723.3841 \mathrm{~cm}-1$

2. $\quad 9.7741 \mathrm{~cm}-1$

3. $\quad 11.1842 \mathrm{~cm}-1$

B3LYP/6-31G(d) Molecular Geometry in Cartesian Coordinates

$\begin{array}{llll}\text { C } & -3.790064 & -0.097620 & -0.212457 \\ \text { C } & -3.229308 & 1.093263 & 0.232676 \\ \text { C } & -3.966786 & 2.312986 & 0.319315 \\ \text { C } & -5.264489 & 2.306388 & -0.153702 \\ \text { H } & -5.845723 & 3.223448 & -0.106161\end{array}$




\begin{tabular}{|c|c|c|c|}
\hline C & -1.548677 & -3.785338 & -0.038043 \\
\hline C & -3.035068 & -1.381954 & -0.099382 \\
\hline C & -1.773771 & -1.486097 & -0.659689 \\
\hline C & -1.002398 & -2.683789 & -0.666075 \\
\hline $\mathrm{H}$ & -0.999774 & -4.723375 & -0.039738 \\
\hline 0 & -1.929433 & 1.097906 & 0.725411 \\
\hline$P$ & -0.639282 & 0.780460 & -0.222593 \\
\hline 0 & -1.226821 & -0.350737 & -1.249823 \\
\hline C & -2.525696 & 5.944296 & 2.126871 \\
\hline C & -3.728807 & 5.370226 & 2.539054 \\
\hline C & -4.172870 & 4.184450 & 1.954382 \\
\hline C & -3.423321 & 3.549258 & 0.950140 \\
\hline C & -2.213086 & 4.133745 & 0.544634 \\
\hline C & -1.773668 & 5.321639 & 1.128782 \\
\hline $\mathrm{H}$ & -4.321202 & 5.840891 & 3.319621 \\
\hline $\mathrm{H}$ & -0.838088 & 5.764425 & 0.796379 \\
\hline C & 2.893100 & -2.953938 & -2.477398 \\
\hline C & 1.841692 & -2.349620 & -3.171446 \\
\hline C & 0.578629 & -2.249923 & -2.590186 \\
\hline C & 0.341670 & -2.752973 & -1.298832 \\
\hline C & 1.405298 & -3.356859 & -0.609989 \\
\hline C & 2.668017 & -3.458485 & -1.195984 \\
\hline $\mathrm{H}$ & 2.005681 & -1.955317 & -4.170811 \\
\hline $\mathrm{H}$ & 3.477316 & -3.928047 & -0.641783 \\
\hline C & -3.557362 & -2.515959 & 0.615571 \\
\hline C & -2.800115 & -3.732984 & 0.624686 \\
\hline C & -3.308294 & -4.865582 & 1.316970 \\
\hline C & -4.497954 & -4.801115 & 2.004012 \\
\hline C & -5.227025 & -3.589343 & 2.031502 \\
\hline C & -4.771028 & -2.478781 & 1.355656 \\
\hline $\mathrm{H}$ & -2.726341 & -5.784144 & 1.303421 \\
\hline $\mathrm{H}$ & -4.872360 & -5.671650 & 2.535686 \\
\hline $\mathrm{H}$ & -6.153968 & -3.531469 & 2.595714 \\
\hline $\mathrm{H}$ & -5.337298 & -1.555885 & 1.395981 \\
\hline C & -5.106052 & -0.060146 & -0.792443 \\
\hline C & -5.849646 & 1.162179 & -0.747299 \\
\hline C & -7.152936 & 1.210149 & -1.312235 \\
\hline C & -7.700205 & 0.106267 & -1.923335 \\
\hline C & -6.955330 & -1.094065 & -1.999892 \\
\hline C & -5.695377 & -1.176161 & -1.448887 \\
\hline $\mathrm{H}$ & -7.705083 & 2.145685 & -1.261495 \\
\hline $\mathrm{H}$ & -8.694946 & 0.156012 & -2.357722 \\
\hline $\mathrm{H}$ & -7.378195 & -1.958723 & -2.504376 \\
\hline $\mathrm{H}$ & -5.134356 & -2.100139 & -1.527230 \\
\hline
\end{tabular}




\begin{tabular}{|c|c|c|c|}
\hline $\mathrm{O}$ & 0.472604 & 0.289601 & 0.644346 \\
\hline $\mathrm{O}$ & -0.364532 & 1.987184 & -1.136973 \\
\hline $\mathrm{H}$ & 0.767168 & 2.216883 & -1.462900 \\
\hline $\mathrm{H}$ & -1.623939 & 3.666483 & -0.236432 \\
\hline $\mathrm{H}$ & -2.176603 & 6.868529 & 2.580267 \\
\hline $\mathrm{H}$ & -5.102507 & 3.731821 & 2.289094 \\
\hline $\mathrm{H}$ & 1.253959 & -3.706010 & 0.406041 \\
\hline $\mathrm{H}$ & 3.878157 & -3.020621 & -2.930689 \\
\hline $\mathrm{H}$ & -0.231215 & -1.781131 & -3.139050 \\
\hline C & 2.691265 & 1.468451 & -1.482156 \\
\hline 0 & 1.915867 & 2.437140 & -1.792250 \\
\hline $\mathrm{H}$ & 2.275628 & 0.473611 & -1.296189 \\
\hline C & 4.063532 & 1.408444 & -2.120285 \\
\hline $\mathrm{O}$ & 4.612294 & 0.354631 & -2.369402 \\
\hline $\mathrm{O}$ & 4.574813 & 2.620474 & -2.368201 \\
\hline C & 5.876528 & 2.623823 & -2.982436 \\
\hline $\mathrm{H}$ & 6.606880 & 2.140220 & -2.328147 \\
\hline $\mathrm{H}$ & 5.847192 & 2.098040 & -3.939965 \\
\hline C & 3.876792 & 0.644840 & 0.965767 \\
\hline C & 3.258054 & 1.799589 & 0.475775 \\
\hline $\mathrm{H}$ & 2.071206 & -0.298130 & 1.149326 \\
\hline$N$ & 3.079843 & -0.391997 & 1.363420 \\
\hline C & 3.357874 & -1.474892 & 2.209735 \\
\hline $\mathrm{O}$ & 2.575774 & -2.385174 & 2.369742 \\
\hline $\mathrm{O}$ & 4.536126 & -1.351543 & 2.842489 \\
\hline C & 4.861896 & -2.437956 & 3.727286 \\
\hline $\mathrm{H}$ & 4.117560 & -2.516035 & 4.523173 \\
\hline $\mathrm{H}$ & 5.840945 & -2.188824 & 4.136214 \\
\hline $\mathrm{H}$ & 4.901110 & -3.381820 & 3.177942 \\
\hline $\mathrm{H}$ & 3.884320 & 2.661974 & 0.279326 \\
\hline $\mathrm{H}$ & 2.235849 & 1.990046 & 0.781954 \\
\hline C & 5.344535 & 0.491664 & 0.878056 \\
\hline C & 6.183154 & 1.543590 & 1.279570 \\
\hline C & 5.913536 & -0.662894 & 0.312229 \\
\hline C & 7.565793 & 1.434103 & 1.141604 \\
\hline $\mathrm{H}$ & 5.750003 & 2.432974 & 1.727309 \\
\hline C & 7.292889 & -0.760236 & 0.159581 \\
\hline $\mathrm{H}$ & 5.266788 & -1.456502 & -0.047048 \\
\hline C & 8.122612 & 0.283143 & 0.579894 \\
\hline $\mathrm{H}$ & 8.206749 & 2.245737 & 1.473922 \\
\hline $\mathrm{H}$ & 7.722018 & -1.647969 & -0.296052 \\
\hline $\mathrm{H}$ & 9.200051 & 0.200558 & 0.465591 \\
\hline $\mathrm{H}$ & 6.124634 & 3.674966 & -3.128487 \\
\hline
\end{tabular}


Catalyst (R)-1 TS Conformation 123

B3LYP/6-31G(d) Energy $=-2809.692678$

B3LYP-D3(BJ)/def2-TZVPP-IEF-PCM(DCM) Energy $=-2810.984348$

B3LYP-D3(BJ)/def2-TZVPP-IEF-PCM(DCM)//B3LYP/6-31G(d) Free Energy (Quasiharmonic) = 2810.343375

Frequencies (Top 3 out of 270)

1. $-713.6749 \mathrm{~cm}-1$

2. $\quad 6.7530 \mathrm{~cm}-1$

3. $\quad 10.3146 \mathrm{~cm}-1$

B3LYP/6-31G(d) Molecular Geometry in Cartesian Coordinates

$\begin{array}{lrrr}\text { C } & 3.493844 & 0.918622 & -0.167542 \\ \text { C } & 2.273397 & 1.559005 & -0.314042 \\ \text { C } & 2.122408 & 2.976803 & -0.325028 \\ \text { C } & 3.264575 & 3.733620 & -0.150803 \\ \text { H } & 3.191788 & 4.817706 & -0.179331 \\ \text { C } & 3.653162 & -3.394373 & -0.193930 \\ \text { C } & 3.550812 & -0.573077 & -0.229092 \\ \text { C } & 2.749719 & -1.327778 & 0.615890 \\ \text { C } & 2.794207 & -2.752006 & 0.676859 \\ \text { H } & 3.732759 & -4.477555 & -0.155605 \\ \text { O } & 1.133714 & 0.780477 & -0.471365 \\ \text { P } & 0.529891 & 0.015713 & 0.849058 \\ \text { O } & 1.875108 & -0.669466 & 1.474470 \\ \text { C } & -1.685312 & 4.931748 & -0.783018 \\ \text { C } & -0.789154 & 5.343875 & 0.203747 \\ \text { C } & 0.437901 & 4.697219 & 0.350018 \\ \text { C } & 0.795958 & 3.629358 & -0.488859 \\ \text { C } & -0.113998 & 3.226433 & -1.481962 \\ \text { C } & -1.342001 & 3.871203 & -1.625276 \\ \text { H } & -1.048799 & 6.160940 & 0.871862 \\ \text { H } & -2.036559 & 3.541712 & -2.392926 \\ \text { C } & 0.476303 & -5.132113 & 3.412219 \\ \text { C } & 0.565994 & -5.484485 & 2.065030 \\ \text { C } & 1.301967 & -4.694856 & 1.182317 \\ \text { C } & 1.963496 & -3.538644 & 1.627564 \\ \text { C } & 1.859664 & -3.190989 & 2.985038 \\ \text { C } & 1.125249 & -3.982178 & 3.866699 \\ \text { H } & 0.056921 & -6.371630 & 1.696828\end{array}$




\begin{tabular}{|c|c|c|c|}
\hline $\mathrm{H}$ & 1.062718 & -3.699227 & 4.914288 \\
\hline C & 4.380638 & -1.261058 & -1.180375 \\
\hline C & 4.435253 & -2.692034 & -1.142588 \\
\hline C & 5.262295 & -3.384126 & -2.068641 \\
\hline C & 5.984443 & -2.702432 & -3.019998 \\
\hline C & 5.900857 & -1.291739 & -3.086557 \\
\hline C & 5.122578 & -0.590610 & -2.191914 \\
\hline $\mathrm{H}$ & 5.301290 & -4.469710 & -2.017017 \\
\hline $\mathrm{H}$ & 6.607492 & -3.242796 & -3.727454 \\
\hline $\mathrm{H}$ & 6.451883 & -0.755490 & -3.854488 \\
\hline $\mathrm{H}$ & 5.061888 & 0.488988 & -2.263825 \\
\hline C & 4.659996 & 1.718912 & 0.089270 \\
\hline C & 4.533540 & 3.146352 & 0.076550 \\
\hline C & 5.681282 & 3.950505 & 0.314311 \\
\hline C & 6.902086 & 3.379382 & 0.588202 \\
\hline C & 7.021262 & 1.970776 & 0.642430 \\
\hline C & 5.932028 & 1.163224 & 0.398902 \\
\hline $\mathrm{H}$ & 5.569892 & 5.032004 & 0.288568 \\
\hline $\mathrm{H}$ & 7.770684 & 4.004752 & 0.775566 \\
\hline $\mathrm{H}$ & 7.980474 & 1.520623 & 0.883657 \\
\hline $\mathrm{H}$ & 6.038631 & 0.086146 & 0.454055 \\
\hline $\mathrm{O}$ & -0.502513 & -0.950312 & 0.366676 \\
\hline $\mathrm{O}$ & 0.143148 & 1.041049 & 1.924268 \\
\hline $\mathrm{H}$ & -0.989049 & 1.389107 & 2.030538 \\
\hline $\mathrm{H}$ & 0.144313 & 2.406729 & -2.143529 \\
\hline $\mathrm{H}$ & -2.646599 & 5.426190 & -0.893910 \\
\hline $\mathrm{H}$ & 1.117424 & 5.001278 & 1.141088 \\
\hline $\mathrm{H}$ & 2.361394 & -2.301745 & 3.350367 \\
\hline $\mathrm{H}$ & -0.097428 & -5.745688 & 4.102014 \\
\hline $\mathrm{H}$ & 1.349163 & -4.961019 & 0.130068 \\
\hline C & -2.783026 & 1.435033 & 1.027968 \\
\hline $\mathrm{O}$ & -2.156587 & 1.755312 & 2.096641 \\
\hline $\mathrm{H}$ & -2.218398 & 1.202174 & 0.118872 \\
\hline C & -4.083842 & 2.141974 & 0.707110 \\
\hline $\mathrm{O}$ & -4.433318 & 2.361023 & -0.435426 \\
\hline $\mathrm{O}$ & -4.776533 & 2.481393 & 1.800565 \\
\hline C & -6.019829 & 3.162155 & 1.553716 \\
\hline $\mathrm{H}$ & -5.843367 & 4.090379 & 1.004517 \\
\hline $\mathrm{H}$ & -6.435609 & 3.372014 & 2.539102 \\
\hline C & -3.930060 & -0.957750 & 0.088525 \\
\hline C & -3.484949 & -0.453374 & 1.318908 \\
\hline $\mathrm{H}$ & -1.999056 & -1.257390 & -0.508974 \\
\hline$N$ & -2.987480 & -1.402176 & -0.791744 \\
\hline C & -3.102524 & -2.225220 & -1.924387 \\
\hline
\end{tabular}




$\begin{array}{lrrr}\text { O } & -2.173792 & -2.406275 & -2.677356 \\ \text { O } & -4.310114 & -2.803823 & -2.029305 \\ \text { C } & -4.469922 & -3.655949 & -3.177410 \\ \text { H } & -5.496433 & -4.018202 & -3.123149 \\ \text { H } & -3.762461 & -4.487424 & -3.134612 \\ \text { H } & -4.306263 & -3.092393 & -4.099207 \\ \text { H } & -4.235793 & -0.217583 & 2.064283 \\ \text { H } & -2.526223 & -0.806473 & 1.682614 \\ \text { C } & -5.353031 & -0.833460 & -0.294423 \\ \text { C } & -6.351819 & -1.192288 & 0.625071 \\ \text { C } & -5.727657 & -0.280073 & -1.531333 \\ \text { C } & -7.698169 & -1.025489 & 0.305378 \\ \text { H } & -6.069859 & -1.629374 & 1.578177 \\ \text { C } & -7.072010 & -0.097336 & -1.838948 \\ \text { H } & -4.962371 & 0.044946 & -2.227715 \\ \text { C } & -8.060433 & -0.475760 & -0.925953 \\ \text { H } & -8.462231 & -1.325096 & 1.017010 \\ \text { H } & -7.349654 & 0.348456 & -2.789714 \\ \text { H } & -9.109707 & -0.338078 & -1.172605 \\ \text { H } & -6.694814 & 2.525224 & 0.975705\end{array}$

Catalyst (R)-1 TS Conformation 124

B3LYP/6-31G(d) Energy = -2809.691842

B3LYP-D3(BJ)/def2-TZVPP-IEF-PCM(DCM) Energy = -2810.984222

B3LYP-D3(BJ)/def2-TZVPP-IEF-PCM(DCM)//B3LYP/6-31G(d) Free Energy (Quasiharmonic) = 2810.343373

Frequencies (Top 3 out of 270)

1. $-670.8988 \mathrm{~cm}-1$

2. $\quad 7.2810 \mathrm{~cm}-1$

3. $\quad 12.9758 \mathrm{~cm}-1$

B3LYP/6-31G(d) Molecular Geometry in Cartesian Coordinates

$\begin{array}{llll}\text { C } & 2.863253 & -1.402526 & -0.033844 \\ \text { C } & 1.497028 & -1.626912 & -0.013766 \\ \text { C } & 0.901122 & -2.898721 & -0.257576 \\ \text { C } & 1.749875 & -3.944949 & -0.560684 \\ \text { H } & 1.333208 & -4.934784 & -0.728160 \\ \text { C } & 4.535254 & 2.504519 & 0.672510 \\ \text { C } & 3.393490 & -0.044866 & 0.293594\end{array}$




\begin{tabular}{|c|c|c|c|}
\hline C & 2.953277 & 1.065967 & -0.414927 \\
\hline C & 3.545964 & 2.358102 & -0.281044 \\
\hline $\mathrm{H}$ & 4.998123 & 3.479023 & 0.803297 \\
\hline $\mathrm{O}$ & 0.660625 & -0.551316 & 0.265406 \\
\hline$P$ & 0.430345 & 0.551906 & -0.929760 \\
\hline $\mathrm{O}$ & 1.961283 & 0.904497 & -1.375242 \\
\hline C & -3.347407 & -3.581693 & -0.118174 \\
\hline C & -2.585082 & -4.065561 & -1.182988 \\
\hline C & -1.210982 & -3.829095 & -1.227410 \\
\hline C & -0.570411 & -3.106960 & -0.207399 \\
\hline C & -1.350192 & -2.627141 & 0.858337 \\
\hline C & -2.724663 & -2.860908 & 0.904693 \\
\hline $\mathrm{H}$ & -3.060696 & -4.620131 & -1.987750 \\
\hline $\mathrm{H}$ & -3.302817 & -2.473019 & 1.738760 \\
\hline C & 2.645692 & 5.757021 & -2.764005 \\
\hline C & 1.608796 & 5.067996 & -2.132349 \\
\hline C & 1.875686 & 3.953403 & -1.337361 \\
\hline C & 3.196093 & 3.510625 & -1.158901 \\
\hline C & 4.232490 & 4.211615 & -1.798599 \\
\hline C & 3.961259 & 5.323946 & -2.594561 \\
\hline $\mathrm{H}$ & 0.580959 & 5.399161 & -2.256654 \\
\hline $\mathrm{H}$ & 4.777672 & 5.846075 & -3.086994 \\
\hline C & 4.356499 & 0.147613 & 1.343642 \\
\hline C & 4.935627 & 1.444730 & 1.521695 \\
\hline C & 5.890052 & 1.648230 & 2.555168 \\
\hline C & 6.247827 & 0.623652 & 3.400200 \\
\hline C & 5.654534 & -0.651685 & 3.247004 \\
\hline C & 4.736397 & -0.884102 & 2.246449 \\
\hline $\mathrm{H}$ & 6.325362 & 2.638131 & 2.670287 \\
\hline $\mathrm{H}$ & 6.975028 & 0.792141 & 4.189792 \\
\hline $\mathrm{H}$ & 5.922129 & -1.455129 & 3.928125 \\
\hline $\mathrm{H}$ & 4.284710 & -1.864635 & 2.148528 \\
\hline C & 3.727845 & -2.483898 & -0.424313 \\
\hline C & 3.151686 & -3.772641 & -0.671530 \\
\hline C & 3.994392 & -4.854732 & -1.044614 \\
\hline C & 5.348577 & -4.675167 & -1.203516 \\
\hline C & 5.914582 & -3.394704 & -1.001242 \\
\hline C & 5.127747 & -2.329583 & -0.621310 \\
\hline $\mathrm{H}$ & 3.541488 & -5.828396 & -1.216291 \\
\hline $\mathrm{H}$ & 5.981851 & -5.507997 & -1.496587 \\
\hline $\mathrm{H}$ & 6.980513 & -3.247552 & -1.152616 \\
\hline $\mathrm{H}$ & 5.576927 & -1.353556 & -0.481628 \\
\hline $\mathrm{O}$ & -0.312085 & 1.704573 & -0.318873 \\
\hline $\mathrm{O}$ & -0.165337 & -0.139142 & -2.157986 \\
\hline
\end{tabular}




\begin{tabular}{|c|c|c|c|}
\hline $\mathrm{H}$ & -1.304928 & 0.129809 & -2.503646 \\
\hline $\mathrm{H}$ & -0.871913 & -2.072349 & 1.658231 \\
\hline $\mathrm{H}$ & -4.418832 & -3.759401 & -0.086870 \\
\hline $\mathrm{H}$ & -0.628121 & -4.183337 & -2.072786 \\
\hline $\mathrm{H}$ & 5.256573 & 3.866085 & -1.684582 \\
\hline $\mathrm{H}$ & 2.429992 & 6.622074 & -3.385795 \\
\hline H & 1.059107 & 3.435168 & -0.846711 \\
\hline$C$ & -3.302073 & -0.017662 & -2.005672 \\
\hline O & -2.416761 & 0.343706 & -2.854369 \\
\hline $\mathrm{H}$ & -3.045635 & -0.729839 & -1.216307 \\
\hline C & -4.706565 & -0.115898 & -2.578658 \\
\hline 0 & -5.160712 & 0.601306 & -3.435640 \\
\hline O & -5.363751 & -1.159909 & -2.022736 \\
\hline C & -6.682135 & -1.398446 & -2.554071 \\
\hline $\mathrm{H}$ & -6.626211 & -1.590403 & -3.628131 \\
\hline $\mathrm{H}$ & -7.056093 & -2.273980 & -2.023586 \\
\hline C & -3.667594 & 1.347892 & 0.619513 \\
\hline C & -3.625649 & 1.654493 & -0.751410 \\
\hline $\mathrm{H}$ & -1.621085 & 1.478948 & 0.773704 \\
\hline$N$ & -2.492066 & 1.228235 & 1.290622 \\
\hline C & -2.284042 & 0.555875 & 2.507850 \\
\hline $\mathrm{O}$ & -3.084099 & -0.136068 & 3.097394 \\
\hline $\mathrm{O}$ & -1.023692 & 0.798218 & 2.898486 \\
\hline C & -0.608847 & 0.123651 & 4.097828 \\
\hline $\mathrm{H}$ & -1.225060 & 0.437481 & 4.944214 \\
\hline $\mathrm{H}$ & 0.430119 & 0.416636 & 4.244189 \\
\hline $\mathrm{H}$ & -0.689113 & -0.959477 & 3.975694 \\
\hline $\mathrm{H}$ & -4.523221 & 2.078457 & -1.187610 \\
\hline $\mathrm{H}$ & -2.689357 & 2.058848 & -1.120637 \\
\hline C & -4.951490 & 1.262382 & 1.353502 \\
\hline C & -5.122040 & 2.003915 & 2.535672 \\
\hline C & -6.037140 & 0.542038 & 0.836348 \\
\hline C & -6.355237 & 2.028054 & 3.178363 \\
\hline $\mathrm{H}$ & -4.293613 & 2.581683 & 2.933608 \\
\hline C & -7.264131 & 0.549636 & 1.498328 \\
\hline $\mathrm{H}$ & -5.905319 & -0.055477 & -0.057904 \\
\hline C & -7.429275 & 1.296204 & 2.665321 \\
\hline $\mathrm{H}$ & -6.478003 & 2.616471 & 4.083127 \\
\hline $\mathrm{H}$ & -8.092940 & -0.028836 & 1.099738 \\
\hline $\mathrm{H}$ & -8.389409 & 1.309288 & 3.173582 \\
\hline $\mathrm{H}$ & -7.326429 & -0.532602 & -2.379691 \\
\hline
\end{tabular}

Catalyst (R)-1 TS Conformation 125 
B3LYP/6-31G(d) Energy $=-2809.6915$

B3LYP-D3(BJ)/def2-TZVPP-IEF-PCM(DCM) Energy $=-2810.984438$

B3LYP-D3(BJ)/def2-TZVPP-IEF-PCM(DCM)//B3LYP/6-31G(d) Free Energy (Quasiharmonic) = 2810.343354

Frequencies (Top 3 out of 270)

1. $-717.9405 \mathrm{~cm}-1$

2. $\quad 8.8752 \mathrm{~cm}-1$

3. $\quad 11.7469 \mathrm{~cm}-1$

B3LYP/6-31G(d) Molecular Geometry in Cartesian Coordinates

$\begin{array}{llll}\text { C } & -2.975702 & -1.422552 & -0.064911 \\ \text { C } & -1.708331 & -1.502009 & -0.616079 \\ \text { C } & -0.900948 & -2.675571 & -0.583952 \\ \text { C } & -1.414885 & -3.773976 & 0.076495 \\ \text { H } & -0.838544 & -4.694986 & 0.102824 \\ \text { C } & -5.328154 & 2.183763 & -0.237762 \\ \text { C } & -3.773379 & -0.169103 & -0.221163 \\ \text { C } & -3.255588 & 1.052018 & 0.192121 \\ \mathrm{C} & -4.034000 & 2.248103 & 0.240658 \\ \text { H } & -5.940350 & 3.081508 & -0.218952 \\ \text { O } & -1.194289 & -0.369326 & -1.238975 \\ \text { P } & -0.655697 & 0.819050 & -0.248501 \\ \text { O } & -1.959312 & 1.111998 & 0.689763 \\ \text { C } & 2.979589 & -2.959628 & -2.424589 \\ \text { C } & 1.919322 & -2.373571 & -3.120744 \\ \mathrm{C} & 0.663077 & -2.261243 & -2.526668 \\ \mathrm{C} & 0.441869 & -2.733499 & -1.220953 \\ \mathrm{C} & 1.517608 & -3.310303 & -0.527042 \\ \mathrm{C} & 2.773301 & -3.425417 & -1.125223 \\ \mathrm{H} & 2.067711 & -2.008806 & -4.133761 \\ \mathrm{H} & 3.589953 & -3.880449 & -0.569520 \\ \mathrm{C} & -2.724154 & 5.974606 & 1.951041 \\ \mathrm{C} & -1.948731 & 5.351969 & 0.970989 \\ \mathrm{C} & -2.345672 & 4.134233 & 0.418771 \\ \mathrm{C} & -3.535684 & 3.519239 & 0.838548 \\ \mathrm{C} & -4.309218 & 4.154776 & 1.824157 \\ \mathrm{C} & -3.907612 & 5.370543 & 2.377102 \\ \mathrm{H} & -1.028477 & 5.817849 & 0.627720 \\ \mathrm{H} & -4.517663 & 5.841400 & 3.143832 \\ \mathrm{C} & -5.086690 & -0.193563 & -0.807505\end{array}$




\begin{tabular}{|c|c|c|c|}
\hline C & -5.871201 & 1.003772 & -0.800789 \\
\hline C & -7.172497 & 0.991165 & -1.372154 \\
\hline C & -7.679262 & -0.147936 & -1.952845 \\
\hline C & -6.894142 & -1.324196 & -1.991193 \\
\hline C & -5.634821 & -1.347577 & -1.433115 \\
\hline $\mathrm{H}$ & -7.756113 & 1.908546 & -1.351035 \\
\hline $\mathrm{H}$ & -8.672932 & -0.144478 & -2.392465 \\
\hline $\mathrm{H}$ & -7.285312 & -2.217003 & -2.471656 \\
\hline $\mathrm{H}$ & -5.042652 & -2.254035 & -1.482011 \\
\hline C & -3.464595 & -2.549634 & 0.683746 \\
\hline C & -2.669211 & -3.740801 & 0.734378 \\
\hline C & -3.143852 & -4.866834 & 1.460362 \\
\hline C & -4.338060 & -4.818782 & 2.140742 \\
\hline C & -5.105602 & -3.630722 & 2.126901 \\
\hline C & -4.682369 & -2.528030 & 1.417720 \\
\hline $\mathrm{H}$ & -2.532806 & -5.766235 & 1.477982 \\
\hline $\mathrm{H}$ & -4.686961 & -5.683528 & 2.698538 \\
\hline $\mathrm{H}$ & -6.036513 & -3.584820 & 2.685625 \\
\hline $\mathrm{H}$ & -5.278029 & -1.623016 & 1.426619 \\
\hline $\mathrm{O}$ & 0.471804 & 0.401315 & 0.636508 \\
\hline $\mathrm{O}$ & -0.424913 & 2.001449 & -1.202909 \\
\hline $\mathrm{H}$ & 0.710281 & 2.335118 & -1.445240 \\
\hline $\mathrm{H}$ & 1.379240 & -3.632124 & 0.499669 \\
\hline $\mathrm{H}$ & 3.956275 & -3.051651 & -2.893007 \\
\hline $\mathrm{H}$ & -0.154781 & -1.811072 & -3.078910 \\
\hline $\mathrm{H}$ & -5.223501 & 3.679464 & 2.169614 \\
\hline $\mathrm{H}$ & -2.408271 & 6.922279 & 2.379677 \\
\hline $\mathrm{H}$ & -1.739653 & 3.666789 & -0.349154 \\
\hline C & 2.675475 & 1.714182 & -1.472593 \\
\hline $\mathrm{O}$ & 1.841154 & 2.652080 & -1.713526 \\
\hline $\mathrm{H}$ & 2.319494 & 0.685913 & -1.357944 \\
\hline C & 4.046070 & 1.871852 & -2.109665 \\
\hline $\mathrm{O}$ & 4.620033 & 2.920718 & -2.282073 \\
\hline $\mathrm{O}$ & 4.518123 & 0.662564 & -2.471010 \\
\hline C & 5.802359 & 0.678843 & -3.123083 \\
\hline $\mathrm{H}$ & 5.759900 & 1.295836 & -4.023906 \\
\hline $\mathrm{H}$ & 6.565414 & 1.074099 & -2.448622 \\
\hline C & 3.855258 & 0.813256 & 0.975504 \\
\hline C & 3.232610 & 1.972458 & 0.504908 \\
\hline $\mathrm{H}$ & 2.054019 & -0.141226 & 1.165857 \\
\hline$N$ & 3.063089 & -0.224231 & 1.386248 \\
\hline C & 3.346070 & -1.276109 & 2.268237 \\
\hline $\mathrm{O}$ & 2.584036 & -2.201724 & 2.437785 \\
\hline $\mathrm{O}$ & 4.505977 & -1.103977 & 2.924912 \\
\hline
\end{tabular}




$\begin{array}{llll}\mathrm{C} & 4.838222 & -2.155749 & 3.848105 \\ \mathrm{H} & 4.074970 & -2.233830 & 4.625811 \\ \mathrm{H} & 5.798221 & -1.867221 & 4.275918 \\ \mathrm{H} & 4.919455 & -3.112951 & 3.327000 \\ \mathrm{H} & 3.851676 & 2.840111 & 0.308951 \\ \mathrm{H} & 2.212046 & 2.152954 & 0.821810 \\ \mathrm{C} & 5.318816 & 0.639718 & 0.858046 \\ \mathrm{C} & 6.183417 & 1.697967 & 1.178646 \\ \mathrm{C} & 5.858652 & -0.557221 & 0.352787 \\ \mathrm{C} & 7.560880 & 1.556873 & 1.017981 \\ \mathrm{H} & 5.776332 & 2.620700 & 1.579888 \\ \mathrm{C} & 7.232670 & -0.688716 & 0.179687 \\ \mathrm{H} & 5.191973 & -1.363790 & 0.063317 \\ \mathrm{C} & 8.088082 & 0.365047 & 0.517959 \\ \mathrm{H} & 8.220570 & 2.377788 & 1.283236 \\ \mathrm{H} & 7.639447 & -1.612689 & -0.221929 \\ \mathrm{H} & 9.161506 & 0.256901 & 0.388818 \\ \mathrm{H} & 6.013082 & -0.360077 & -3.376001\end{array}$

Catalyst (R)-1 TS Conformation 126

B3LYP/6-31G(d) Energy = -2809.693468

B3LYP-D3(BJ)/def2-TZVPP-IEF-PCM(DCM) Energy $=-2810.985756$

B3LYP-D3(BJ)/def2-TZVPP-IEF-PCM(DCM)//B3LYP/6-31G(d) Free Energy (Quasiharmonic) = 2810.343313

Frequencies (Top 3 out of 270)

1. $-512.2403 \mathrm{~cm}-1$

2. $\quad 9.4521 \mathrm{~cm}-1$

3. $\quad 13.6639 \mathrm{~cm}-1$

B3LYP/6-31G(d) Molecular Geometry in Cartesian Coordinates

$\begin{array}{lrrr}\text { C } & 3.261206 & 0.487922 & 0.033297 \\ \text { C } & 2.291243 & 1.481030 & 0.031647 \\ \text { C } & 2.579618 & 2.836517 & 0.374388 \\ \text { C } & 3.869352 & 3.137956 & 0.766538 \\ \text { H } & 4.109862 & 4.163170 & 1.035396 \\ \text { C } & 2.346401 & -3.543212 & -1.184197 \\ \text { C } & 2.936131 & -0.881933 & -0.457628 \\ \text { C } & 1.884545 & -1.580701 & 0.111759 \\ \text { C } & 1.593133 & -2.939988 & -0.197233\end{array}$




\begin{tabular}{|c|c|c|c|}
\hline $\mathrm{H}$ & 2.157517 & -4.585088 & -1.429873 \\
\hline $\mathrm{O}$ & 1.014713 & 1.185224 & -0.425175 \\
\hline$P$ & 0.015173 & 0.165256 & 0.377134 \\
\hline $\mathrm{O}$ & 1.063122 & -0.920392 & 1.027014 \\
\hline C & -0.171899 & 6.142584 & 0.330301 \\
\hline C & -0.475827 & 4.993274 & 1.064669 \\
\hline C & 0.382976 & 3.893185 & 1.051747 \\
\hline C & 1.575645 & 3.936023 & 0.313056 \\
\hline C & 1.870609 & 5.094309 & -0.424151 \\
\hline C & 1.003231 & 6.186721 & -0.421008 \\
\hline $\mathrm{H}$ & -1.385196 & 4.952910 & 1.658961 \\
\hline $\mathrm{H}$ & 1.248507 & 7.071751 & -1.002499 \\
\hline C & -1.263602 & -5.393955 & 1.872892 \\
\hline C & -0.298046 & -4.683131 & 2.590770 \\
\hline C & 0.597467 & -3.845412 & 1.927276 \\
\hline C & 0.558071 & -3.723680 & 0.529238 \\
\hline C & -0.419791 & -4.435846 & -0.180603 \\
\hline C & -1.326403 & -5.259881 & 0.485744 \\
\hline $\mathrm{H}$ & -0.232682 & -4.791661 & 3.670757 \\
\hline $\mathrm{H}$ & -2.083142 & -5.796229 & -0.080457 \\
\hline C & 3.670815 & -1.499625 & -1.528637 \\
\hline C & 3.361858 & -2.850903 & -1.888841 \\
\hline C & 4.078884 & -3.473728 & -2.945907 \\
\hline C & 5.043316 & -2.787968 & -3.646872 \\
\hline C & 5.325151 & -1.441247 & -3.318251 \\
\hline C & 4.659928 & -0.814941 & -2.287214 \\
\hline $\mathrm{H}$ & 3.839212 & -4.504168 & -3.197665 \\
\hline $\mathrm{H}$ & 5.580082 & -3.271882 & -4.458281 \\
\hline $\mathrm{H}$ & 6.070173 & -0.892783 & -3.888362 \\
\hline $\mathrm{H}$ & 4.879828 & 0.220794 & -2.056434 \\
\hline C & 4.569965 & 0.796640 & 0.543389 \\
\hline C & 4.875156 & 2.150477 & 0.892207 \\
\hline C & 6.168725 & 2.474026 & 1.384197 \\
\hline C & 7.124464 & 1.499816 & 1.553408 \\
\hline C & 6.815907 & 0.154216 & 1.243508 \\
\hline C & 5.575566 & -0.188249 & 0.751703 \\
\hline $\mathrm{H}$ & 6.382856 & 3.509976 & 1.636483 \\
\hline $\mathrm{H}$ & 8.108679 & 1.756527 & 1.935586 \\
\hline $\mathrm{H}$ & 7.563095 & -0.619024 & 1.400893 \\
\hline $\mathrm{H}$ & 5.354311 & -1.225673 & 0.530181 \\
\hline 0 & -0.741445 & 0.840053 & 1.476991 \\
\hline $\mathrm{O}$ & -0.766583 & -0.496586 & -0.771921 \\
\hline $\mathrm{H}$ & -1.739886 & -1.048475 & -0.601135 \\
\hline $\mathrm{H}$ & 2.785111 & 5.130718 & -1.010104 \\
\hline
\end{tabular}




\begin{tabular}{|c|c|c|c|}
\hline $\mathrm{H}$ & -0.843619 & 6.997205 & 0.346924 \\
\hline $\mathrm{H}$ & 0.133321 & 3.005987 & 1.624099 \\
\hline $\mathrm{H}$ & -0.476122 & -4.325680 & -1.259568 \\
\hline $\mathrm{H}$ & -1.961832 & -6.045461 & 2.391822 \\
\hline H & 1.349108 & -3.299568 & 2.489567 \\
\hline$C$ & -3.908975 & -1.707364 & -0.913334 \\
\hline 0 & -2.756415 & -1.830694 & -0.341435 \\
\hline $\mathrm{H}$ & -4.519768 & -2.618820 & -0.963793 \\
\hline C & -3.985998 & -0.908393 & -2.213875 \\
\hline O & -3.170375 & -0.096438 & -2.580922 \\
\hline 0 & -5.105999 & -1.229212 & -2.904407 \\
\hline C & -5.282710 & -0.517299 & -4.141378 \\
\hline $\mathrm{H}$ & -5.344417 & 0.558795 & -3.957466 \\
\hline $\mathrm{H}$ & -4.446926 & -0.713776 & -4.817797 \\
\hline C & -4.375066 & 0.291113 & 0.652771 \\
\hline C & -5.173929 & -0.769055 & 0.154352 \\
\hline $\mathrm{H}$ & -2.606368 & 0.630048 & 1.690650 \\
\hline $\mathrm{N}$ & -3.447908 & 0.038852 & 1.600412 \\
\hline C & -3.445759 & -1.061795 & 2.493049 \\
\hline O & -4.307847 & -1.904390 & 2.600564 \\
\hline O & -2.363230 & -0.956715 & 3.265922 \\
\hline C & -2.225077 & -1.979308 & 4.267649 \\
\hline $\mathrm{H}$ & -1.295430 & -1.742818 & 4.784172 \\
\hline $\mathrm{H}$ & -2.165609 & -2.961059 & 3.795051 \\
\hline $\mathrm{H}$ & -3.072020 & -1.949549 & 4.958292 \\
\hline $\mathrm{H}$ & -5.973520 & -0.498881 & -0.526452 \\
\hline $\mathrm{H}$ & -5.412833 & -1.560185 & 0.851980 \\
\hline C & -4.390819 & 1.619090 & 0.009873 \\
\hline C & -5.609671 & 2.105680 & -0.504861 \\
\hline C & -3.238622 & 2.418815 & -0.108617 \\
\hline C & -5.673084 & 3.348960 & -1.125799 \\
\hline $\mathrm{H}$ & -6.517981 & 1.524538 & -0.385853 \\
\hline C & -3.305579 & 3.653430 & -0.749196 \\
\hline $\mathrm{H}$ & -2.281076 & 2.071898 & 0.264445 \\
\hline C & -4.518104 & 4.122623 & -1.257563 \\
\hline$H$ & -6.624599 & 3.714782 & -1.501237 \\
\hline $\mathrm{H}$ & -2.401692 & 4.245188 & -0.850132 \\
\hline $\mathrm{H}$ & -4.563539 & 5.089110 & -1.752107 \\
\hline $\mathrm{H}$ & -6.215595 & -0.890964 & -4.564594 \\
\hline
\end{tabular}

Catalyst (R)-1 TS Conformation 127

$\mathrm{B} 3 \mathrm{LYP} / 6-31 \mathrm{G}(\mathrm{d})$ Energy $=-2809.690324$ 
B3LYP-D3(BJ)/def2-TZVPP-IEF-PCM(DCM) Energy $=-2810.985273$

B3LYP-D3(BJ)/def2-TZVPP-IEF-PCM(DCM)//B3LYP/6-31G(d) Free Energy (Quasiharmonic) = 2810.34331

Frequencies (Top 3 out of 270)

1. $-681.9636 \mathrm{~cm}-1$

2. $\quad 10.0773 \mathrm{~cm}-1$

3. $\quad 14.5870 \mathrm{~cm}-1$

B3LYP/6-31G(d) Molecular Geometry in Cartesian Coordinates

\begin{tabular}{|c|c|c|c|}
\hline C & 2.911157 & 1.231431 & 0.148096 \\
\hline C & 1.730654 & 1.839603 & -0.245611 \\
\hline C & 1.378493 & 3.178424 & 0.095238 \\
\hline C & 2.264766 & 3.881231 & 0.886959 \\
\hline $\mathrm{H}$ & 2.042662 & 4.913335 & 1.145649 \\
\hline C & 3.832669 & -2.829352 & -0.979571 \\
\hline C & 3.216585 & -0.152428 & -0.322938 \\
\hline C & 2.308085 & -1.183772 & -0.112610 \\
\hline C & 2.607080 & -2.545879 & -0.412768 \\
\hline $\mathrm{H}$ & 4.080884 & -3.861872 & -1.211791 \\
\hline $\mathrm{O}$ & 0.836508 & 1.103093 & -1.011060 \\
\hline$P$ & -0.067805 & -0.009425 & -0.206389 \\
\hline $\mathrm{O}$ & 1.099282 & -0.924344 & 0.511626 \\
\hline C & -2.287277 & 5.047603 & -1.166967 \\
\hline C & -1.862579 & 5.141007 & 0.158948 \\
\hline C & -0.679347 & 4.521903 & 0.560231 \\
\hline C & 0.103270 & 3.798082 & -0.354149 \\
\hline C & -0.338461 & 3.706750 & -1.685276 \\
\hline C & -1.521083 & 4.326719 & -2.086107 \\
\hline $\mathrm{H}$ & -2.456984 & 5.686875 & 0.886870 \\
\hline $\mathrm{H}$ & -1.843465 & 4.248131 & -3.121034 \\
\hline C & 0.001738 & -5.885153 & 0.355715 \\
\hline C & -0.397959 & -4.878374 & -0.527610 \\
\hline C & 0.418654 & -3.767540 & -0.752589 \\
\hline C & 1.663595 & -3.661931 & -0.111513 \\
\hline C & 2.057744 & -4.681984 & 0.768017 \\
\hline C & 1.231114 & -5.781434 & 1.007007 \\
\hline $\mathrm{H}$ & -1.332237 & -4.961201 & -1.076939 \\
\hline $\mathrm{H}$ & 1.553188 & -6.558283 & 1.695925 \\
\hline C & 4.440337 & -0.449016 & -1.019129 \\
\hline C & 4.754396 & -1.811758 & -1.326914 \\
\hline C & 5.968653 & -2.117063 & -1.999288 \\
\hline
\end{tabular}




\begin{tabular}{|c|c|c|c|}
\hline C & 6.834434 & -1.120174 & -2.384070 \\
\hline C & 6.510277 & 0.230694 & -2.116511 \\
\hline C & 5.348492 & 0.557218 & -1.452315 \\
\hline $\mathrm{H}$ & 6.192286 & -3.158984 & -2.216419 \\
\hline $\mathrm{H}$ & 7.756864 & -1.364247 & -2.903907 \\
\hline $\mathrm{H}$ & 7.181305 & 1.020230 & -2.444174 \\
\hline $\mathrm{H}$ & 5.111340 & 1.598161 & -1.266273 \\
\hline C & 3.784374 & 1.948341 & 1.038919 \\
\hline C & 3.454035 & 3.297958 & 1.390249 \\
\hline C & 4.314513 & 4.024277 & 2.257599 \\
\hline C & 5.439704 & 3.440777 & 2.791627 \\
\hline C & 5.745091 & 2.094893 & 2.481850 \\
\hline C & 4.941718 & 1.369844 & 1.629097 \\
\hline $\mathrm{H}$ & 4.055109 & 5.051693 & 2.502362 \\
\hline $\mathrm{H}$ & 6.085851 & 4.004110 & 3.459370 \\
\hline $\mathrm{H}$ & 6.619823 & 1.625737 & 2.924299 \\
\hline $\mathrm{H}$ & 5.185843 & 0.337043 & 1.410447 \\
\hline $\mathrm{O}$ & -0.896637 & -0.748500 & -1.201772 \\
\hline $\mathrm{O}$ & -0.745500 & 0.645063 & 1.005088 \\
\hline $\mathrm{H}$ & -1.892697 & 1.067778 & 0.947599 \\
\hline $\mathrm{H}$ & 0.249038 & 3.150103 & -2.407091 \\
\hline $\mathrm{H}$ & -3.207893 & 5.531577 & -1.483507 \\
\hline $\mathrm{H}$ & -0.368229 & 4.573943 & 1.599629 \\
\hline $\mathrm{H}$ & 3.018493 & -4.606058 & 1.270669 \\
\hline $\mathrm{H}$ & -0.635984 & -6.748953 & 0.526200 \\
\hline $\mathrm{H}$ & 0.092581 & -2.991269 & -1.437176 \\
\hline C & -3.542766 & 1.033823 & -0.217353 \\
\hline $\mathrm{O}$ & -2.999253 & 1.483128 & 0.852221 \\
\hline $\mathrm{H}$ & -2.927232 & 0.537590 & -0.970007 \\
\hline C & -4.683097 & 1.830636 & -0.828966 \\
\hline $\mathrm{O}$ & -4.920094 & 1.826413 & -2.019638 \\
\hline $\mathrm{O}$ & -5.372418 & 2.524597 & 0.085679 \\
\hline C & -6.436544 & 3.339397 & -0.435850 \\
\hline $\mathrm{H}$ & -6.889667 & 3.816567 & 0.432958 \\
\hline $\mathrm{H}$ & -7.168379 & 2.723571 & -0.965667 \\
\hline C & -3.859182 & -1.638582 & 0.493009 \\
\hline C & -4.742153 & -0.600314 & 0.184622 \\
\hline $\mathrm{H}$ & -2.712868 & -3.219679 & -0.074629 \\
\hline$N$ & -3.317676 & -2.487349 & -0.430029 \\
\hline C & -3.232869 & -2.420987 & -1.835146 \\
\hline $\mathrm{O}$ & -2.663779 & -3.284743 & -2.463439 \\
\hline $\mathrm{O}$ & -3.844717 & -1.350518 & -2.335369 \\
\hline C & -3.609997 & -1.095602 & -3.737925 \\
\hline $\mathrm{H}$ & -4.113392 & -0.149200 & -3.928892 \\
\hline
\end{tabular}




$\begin{array}{llll}\mathrm{H} & -4.028497 & -1.902701 & -4.343269 \\ \mathrm{H} & -2.535784 & -1.011466 & -3.912487 \\ \mathrm{H} & -5.242730 & -0.134425 & 1.024800 \\ \mathrm{H} & -5.290287 & -0.647125 & -0.746623 \\ \mathrm{C} & -3.398273 & -1.856555 & 1.879834 \\ \mathrm{C} & -2.068893 & -2.238883 & 2.144624 \\ \mathrm{C} & -4.282993 & -1.675407 & 2.959030 \\ \mathrm{C} & -1.640966 & -2.429829 & 3.455336 \\ \mathrm{H} & -1.351970 & -2.338964 & 1.336726 \\ \mathrm{C} & -3.852138 & -1.879877 & 4.266087 \\ \mathrm{H} & -5.317597 & -1.407971 & 2.770351 \\ \mathrm{C} & -2.529974 & -2.255104 & 4.517230 \\ \mathrm{H} & -0.606318 & -2.699898 & 3.641649 \\ \mathrm{H} & -4.549041 & -1.749717 & 5.088925 \\ \mathrm{H} & -2.193235 & -2.406601 & 5.539019 \\ \mathrm{H} & -6.037533 & 4.089784 & -1.123108\end{array}$

Catalyst (R)-1 TS Conformation 128

B3LYP/6-31G(d) Energy $=-2809.690092$

B3LYP-D3(BJ)/def2-TZVPP-IEF-PCM(DCM) Energy = -2810.984231

B3LYP-D3(BJ)/def2-TZVPP-IEF-PCM(DCM)//B3LYP/6-31G(d) Free Energy (Quasiharmonic) = 2810.343275

Frequencies (Top 3 out of 270)

1. $-713.2709 \mathrm{~cm}-1$

2. $\quad 4.1579 \mathrm{~cm}-1$

3. $10.3497 \mathrm{~cm}-1$

B3LYP/6-31G(d) Molecular Geometry in Cartesian Coordinates

$\begin{array}{llll}\text { C } & -3.542755 & -0.593850 & 0.261899 \\ \text { C } & -2.732816 & -1.356324 & -0.567588 \\ \text { C } & -2.755071 & -2.782247 & -0.592888 \\ \text { C } & -3.601003 & -3.416051 & 0.296776 \\ \text { H } & -3.663682 & -4.500967 & 0.285665 \\ \text { C } & -3.314982 & 3.713234 & 0.067525 \\ \text { C } & -3.507284 & 0.896403 & 0.163242 \\ \text { C } & -2.295244 & 1.556530 & 0.289723 \\ \text { C } & -2.163881 & 2.975643 & 0.262222 \\ \text { H } & -3.255714 & 4.798563 & 0.064915 \\ \text { O } & -1.873853 & -0.705573 & -1.446420\end{array}$




\begin{tabular}{|c|c|c|c|}
\hline$P$ & -0.535693 & 0.020471 & -0.850467 \\
\hline 0 & -1.143507 & 0.798859 & 0.460964 \\
\hline C & -0.405438 & -5.192030 & -3.274796 \\
\hline C & -1.073237 & -4.063864 & -3.755741 \\
\hline C & -1.818615 & -3.263130 & -2.892071 \\
\hline C & -1.914557 & -3.579138 & -1.526286 \\
\hline C & -1.234229 & -4.713740 & -1.054490 \\
\hline C & -0.487430 & -5.512981 & -1.919284 \\
\hline $\mathrm{H}$ & -1.016807 & -3.805448 & -4.809973 \\
\hline $\mathrm{H}$ & 0.036014 & -6.382947 & -1.530767 \\
\hline C & 1.610026 & 4.998786 & 0.697348 \\
\hline C & 0.727543 & 5.354932 & -0.322971 \\
\hline C & -0.488057 & 4.685476 & -0.462814 \\
\hline C & -0.846341 & 3.648781 & 0.413750 \\
\hline C & 0.051723 & 3.298252 & 1.436700 \\
\hline C & 1.266361 & 3.968480 & 1.576186 \\
\hline $\mathrm{H}$ & 0.988456 & 6.146967 & -1.019898 \\
\hline $\mathrm{H}$ & 1.945304 & 3.686291 & 2.376680 \\
\hline C & -4.684384 & 1.674333 & -0.111958 \\
\hline C & -4.576594 & 3.103158 & -0.140626 \\
\hline C & -5.735063 & 3.885216 & -0.398880 \\
\hline C & -6.948897 & 3.290658 & -0.653187 \\
\hline C & -7.049883 & 1.879667 & -0.666228 \\
\hline C & -5.949777 & 1.093588 & -0.402227 \\
\hline $\mathrm{H}$ & -5.637688 & 4.968349 & -0.404772 \\
\hline $\mathrm{H}$ & -7.825888 & 3.899044 & -0.856611 \\
\hline $\mathrm{H}$ & -8.003675 & 1.410385 & -0.891957 \\
\hline $\mathrm{H}$ & -6.042461 & 0.014091 & -0.426054 \\
\hline C & -4.359033 & -1.270567 & 1.232540 \\
\hline C & -4.391344 & -2.702728 & 1.230322 \\
\hline C & -5.204968 & -3.384359 & 2.175815 \\
\hline C & -5.935342 & -2.690572 & 3.112059 \\
\hline C & -5.873913 & -1.277503 & 3.143209 \\
\hline C & -5.108931 & -0.586797 & 2.229183 \\
\hline $\mathrm{H}$ & -5.227183 & -4.471367 & 2.151228 \\
\hline $\mathrm{H}$ & -6.548122 & -3.222845 & 3.834457 \\
\hline $\mathrm{H}$ & -6.431685 & -0.730997 & 3.898953 \\
\hline $\mathrm{H}$ & -5.065306 & 0.495134 & 2.273749 \\
\hline 0 & 0.518214 & -0.918487 & -0.361240 \\
\hline 0 & -0.178688 & 1.032883 & -1.945114 \\
\hline $\mathrm{H}$ & 0.965565 & 1.339830 & -2.132106 \\
\hline $\mathrm{H}$ & -1.275503 & -4.955012 & 0.004010 \\
\hline $\mathrm{H}$ & 0.176822 & -5.812995 & -3.950672 \\
\hline $\mathrm{H}$ & -2.334844 & -2.391051 & -3.277929 \\
\hline
\end{tabular}




\begin{tabular}{|c|c|c|c|}
\hline $\mathrm{H}$ & -0.207092 & 2.501743 & 2.125980 \\
\hline $\mathrm{H}$ & 2.558629 & 5.517960 & 0.806592 \\
\hline $\mathrm{H}$ & -1.158550 & 4.947541 & -1.276211 \\
\hline C & 2.813648 & 1.451912 & -1.240962 \\
\hline 0 & 2.119340 & 1.673435 & -2.291694 \\
\hline $\mathrm{H}$ & 2.308208 & 1.314940 & -0.279159 \\
\hline C & 4.153724 & 2.164826 & -1.170537 \\
\hline 0 & 4.862126 & 2.417054 & -2.115649 \\
\hline 0 & 4.432786 & 2.486783 & 0.110003 \\
\hline C & 5.671429 & 3.195613 & 0.301719 \\
\hline $\mathrm{H}$ & 6.515831 & 2.577927 & -0.012801 \\
\hline $\mathrm{H}$ & 5.667864 & 4.123675 & -0.275095 \\
\hline C & 3.948185 & -0.931382 & -0.184904 \\
\hline C & 3.488700 & -0.470158 & -1.425256 \\
\hline $\mathrm{H}$ & 2.024949 & -1.212940 & 0.454273 \\
\hline$N$ & 3.019001 & -1.362625 & 0.718044 \\
\hline C & 3.155880 & -2.202339 & 1.835700 \\
\hline 0 & 2.260954 & -2.357833 & 2.633909 \\
\hline $\mathrm{O}$ & 4.343752 & -2.830548 & 1.871089 \\
\hline C & 4.528526 & -3.702787 & 2.999990 \\
\hline $\mathrm{H}$ & 5.533175 & -4.109555 & 2.885274 \\
\hline $\mathrm{H}$ & 3.783246 & -4.501530 & 2.988619 \\
\hline $\mathrm{H}$ & 4.441556 & -3.144308 & 3.935343 \\
\hline $\mathrm{H}$ & 4.224941 & -0.254991 & -2.191009 \\
\hline $\mathrm{H}$ & 2.524353 & -0.836178 & -1.759353 \\
\hline C & 5.368278 & -0.778534 & 0.198524 \\
\hline C & 6.379801 & -1.066956 & -0.731368 \\
\hline C & 5.726672 & -0.276636 & 1.462851 \\
\hline C & 7.720277 & -0.876953 & -0.399391 \\
\hline $\mathrm{H}$ & 6.114965 & -1.466417 & -1.705151 \\
\hline C & 7.064345 & -0.073775 & 1.785766 \\
\hline $\mathrm{H}$ & 4.951020 & -0.016659 & 2.176093 \\
\hline C & 8.065459 & -0.379028 & 0.857883 \\
\hline $\mathrm{H}$ & 8.493133 & -1.117525 & -1.123447 \\
\hline $\mathrm{H}$ & 7.328706 & 0.324807 & 2.761279 \\
\hline 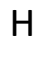 & 9.110045 & -0.226252 & 1.114917 \\
\hline & 5.725794 & 3.405131 & 1.369993 \\
\hline
\end{tabular}

Catalyst (R)-1 TS Conformation 129

B3LYP/6-31G(d) Energy $=-2809.691428$

B3LYP-D3(BJ)/def2-TZVPP-IEF-PCM(DCM) Energy = -2810.986881 
B3LYP-D3(BJ)/def2-TZVPP-IEF-PCM(DCM)//B3LYP/6-31G(d) Free Energy (Quasiharmonic) = 2810.343236

Frequencies (Top 3 out of 270)

1. $-362.8279 \mathrm{~cm}-1$

2. $\quad 12.7619 \mathrm{~cm}-1$

3. $20.5529 \mathrm{~cm}-1$

B3LYP/6-31G(d) Molecular Geometry in Cartesian Coordinates

\begin{tabular}{|c|c|c|c|}
\hline C & 2.939175 & -0.833300 & -0.153020 \\
\hline C & 1.807252 & -1.631660 & -0.223760 \\
\hline C & 1.845005 & -2.975773 & -0.703513 \\
\hline C & 3.056046 & -3.459295 & -1.157671 \\
\hline $\mathrm{H}$ & 3.106543 & -4.480918 & -1.525059 \\
\hline C & 2.910232 & 3.175520 & 1.397386 \\
\hline C & 2.878384 & 0.515515 & 0.479146 \\
\hline C & 1.984756 & 1.460825 & 0.001298 \\
\hline C & 2.025453 & 2.832974 & 0.391807 \\
\hline $\mathrm{H}$ & 2.991660 & 4.216644 & 1.697192 \\
\hline 0 & 0.612861 & -1.155131 & 0.303681 \\
\hline$P$ & -0.193683 & 0.132044 & -0.324273 \\
\hline 0 & 1.023585 & 1.054993 & -0.925145 \\
\hline C & -1.450785 & -5.736761 & -0.835023 \\
\hline C & -1.514981 & -4.541525 & -1.553678 \\
\hline C & -0.468704 & -3.621288 & -1.489615 \\
\hline C & 0.665368 & -3.888284 & -0.710721 \\
\hline C & 0.723206 & -5.094696 & 0.006420 \\
\hline C & -0.327939 & -6.010198 & -0.050817 \\
\hline $\mathrm{H}$ & -2.381343 & -4.312558 & -2.167768 \\
\hline $\mathrm{H}$ & -0.267869 & -6.936646 & 0.514713 \\
\hline C & 0.114374 & 6.133853 & -1.590682 \\
\hline C & 0.626585 & 5.069178 & -2.336181 \\
\hline C & 1.186604 & 3.963815 & -1.697305 \\
\hline C & 1.257733 & 3.905753 & -0.294858 \\
\hline C & 0.709563 & 4.968007 & 0.443826 \\
\hline C & 0.146732 & 6.072416 & -0.195799 \\
\hline $\mathrm{H}$ & 0.606333 & 5.104771 & -3.422455 \\
\hline $\mathrm{H}$ & -0.259912 & 6.887928 & 0.397128 \\
\hline C & 3.737113 & 0.870319 & 1.576180 \\
\hline C & 3.736930 & 2.223703 & 2.041079 \\
\hline C & 4.579189 & 2.590597 & 3.125347 \\
\hline C & 5.370854 & 1.656587 & 3.751984 \\
\hline
\end{tabular}




\begin{tabular}{|c|c|c|c|}
\hline C & 5.348657 & 0.310828 & 3.316067 \\
\hline C & 4.557619 & -0.071760 & 2.254972 \\
\hline $\mathrm{H}$ & 4.575614 & 3.625948 & 3.457928 \\
\hline $\mathrm{H}$ & 6.004662 & 1.945693 & 4.585801 \\
\hline $\mathrm{H}$ & 5.958503 & -0.429904 & 3.826130 \\
\hline $\mathrm{H}$ & 4.544274 & -1.108458 & 1.939162 \\
\hline C & 4.167494 & -1.314336 & -0.727410 \\
\hline C & 4.221266 & -2.658154 & -1.215791 \\
\hline C & 5.430867 & -3.155649 & -1.771728 \\
\hline C & 6.544779 & -2.355282 & -1.870306 \\
\hline C & 6.486082 & -1.014906 & -1.421484 \\
\hline C & 5.332253 & -0.508569 & -0.864733 \\
\hline $\mathrm{H}$ & 5.452470 & -4.182096 & -2.130202 \\
\hline $\mathrm{H}$ & 7.463191 & -2.742980 & -2.302495 \\
\hline $\mathrm{H}$ & 7.358601 & -0.375049 & -1.522559 \\
\hline $\mathrm{H}$ & 5.304579 & 0.523989 & -0.537443 \\
\hline $\mathrm{O}$ & -0.975080 & 0.787054 & 0.759598 \\
\hline $\mathrm{O}$ & -0.906246 & -0.308694 & -1.629484 \\
\hline $\mathrm{H}$ & -1.892366 & -0.790328 & -1.595009 \\
\hline $\mathrm{H}$ & 1.597078 & -5.308232 & 0.616564 \\
\hline $\mathrm{H}$ & -2.268818 & -6.450756 & -0.885435 \\
\hline $\mathrm{H}$ & -0.530227 & -2.697331 & -2.052250 \\
\hline $\mathrm{H}$ & 0.728814 & 4.925565 & 1.529203 \\
\hline $\mathrm{H}$ & -0.306958 & 7.001914 & -2.091428 \\
\hline $\mathrm{H}$ & 1.595743 & 3.151116 & -2.287723 \\
\hline C & -4.014498 & -1.682867 & -0.998732 \\
\hline 0 & -3.108234 & -1.379546 & -1.871222 \\
\hline $\mathrm{H}$ & -4.852253 & -2.291318 & -1.379023 \\
\hline C & -3.625866 & -2.249672 & 0.380378 \\
\hline $\mathrm{O}$ & -4.433837 & -2.780962 & 1.121170 \\
\hline 0 & -2.334804 & -2.085614 & 0.654402 \\
\hline C & -1.868306 & -2.629260 & 1.911935 \\
\hline $\mathrm{H}$ & -2.074753 & -3.700888 & 1.943531 \\
\hline $\mathrm{H}$ & -0.799253 & -2.434050 & 1.918000 \\
\hline C & -4.259740 & 0.750381 & -0.029152 \\
\hline C & -5.123684 & -0.286652 & -0.476484 \\
\hline $\mathrm{H}$ & -2.724419 & 1.016400 & 1.277765 \\
\hline$N$ & -3.731416 & 0.781506 & 1.229947 \\
\hline C & -4.215265 & 0.215889 & 2.422458 \\
\hline $\mathrm{O}$ & -3.494086 & 0.032174 & 3.377252 \\
\hline 0 & -5.534618 & -0.013802 & 2.385131 \\
\hline C & -6.055362 & -0.733470 & 3.521458 \\
\hline $\mathrm{H}$ & -5.652927 & -1.749031 & 3.521822 \\
\hline $\mathrm{H}$ & -7.135609 & -0.748023 & 3.378279 \\
\hline
\end{tabular}




$\begin{array}{lrrr}\text { H } & -5.791180 & -0.222695 & 4.449206 \\ \mathrm{H} & -5.677924 & -0.053167 & -1.380301 \\ \mathrm{H} & -5.718599 & -0.790043 & 0.275212 \\ \mathrm{C} & -3.736106 & 1.739812 & -0.964433 \\ \mathrm{C} & -3.761258 & 1.507482 & -2.357105 \\ \mathrm{C} & -3.233151 & 2.969460 & -0.485608 \\ \mathrm{C} & -3.289549 & 2.477639 & -3.235369 \\ \mathrm{H} & -4.087371 & 0.550322 & -2.742244 \\ \mathrm{C} & -2.785735 & 3.938839 & -1.370744 \\ \mathrm{H} & -3.223606 & 3.169051 & 0.580289 \\ \mathrm{C} & -2.810061 & 3.693729 & -2.747400 \\ \mathrm{H} & -3.291770 & 2.279492 & -4.303054 \\ \mathrm{H} & -2.401052 & 4.879243 & -0.992348 \\ \mathrm{H} & -2.449265 & 4.452644 & -3.435643 \\ \mathrm{H} & -2.363236 & -2.119826 & 2.740232\end{array}$

Catalyst (R)-1 TS Conformation 130

B3LYP/6-31G(d) Energy $=-2809.692329$

B3LYP-D3(BJ)/def2-TZVPP-IEF-PCM(DCM) Energy $=-2810.985254$

B3LYP-D3(BJ)/def2-TZVPP-IEF-PCM(DCM)//B3LYP/6-31G(d) Free Energy (Quasiharmonic) = 2810.343234

Frequencies (Top 3 out of 270)

1. $-416.1332 \mathrm{~cm}-1$

2. $\quad 7.8149 \mathrm{~cm}-1$

3. $\quad 11.6656 \mathrm{~cm}-1$

B3LYP/6-31G(d) Molecular Geometry in Cartesian Coordinates

$\begin{array}{llll}\text { C } & 3.627532 & -0.835664 & -0.037131 \\ \text { C } & 2.467759 & -1.537215 & 0.250372 \\ \text { C } & 2.316343 & -2.936396 & 0.025709 \\ \text { C } & 3.382163 & -3.604130 & -0.544425 \\ \text { H } & 3.310631 & -4.676338 & -0.707801 \\ \text { C } & 3.815343 & 3.390402 & 0.804701 \\ \text { C } & 3.708263 & 0.616805 & 0.300916 \\ \text { C } & 2.741187 & 1.488977 & -0.177227 \\ \text { C } & 2.773786 & 2.898356 & 0.040939 \\ \text { H } & 3.889728 & 4.462301 & 0.966860 \\ \text { O } & 1.389024 & -0.845453 & 0.792955 \\ \text { P } & 0.519766 & 0.115435 & -0.209980\end{array}$




\begin{tabular}{|c|c|c|c|}
\hline $\mathrm{O}$ & 1.697964 & 0.972336 & -0.941859 \\
\hline C & -1.263650 & -5.115398 & 1.009780 \\
\hline C & -0.656288 & -5.273626 & -0.237060 \\
\hline C & 0.496157 & -4.553404 & -0.551811 \\
\hline C & 1.064617 & -3.661225 & 0.371667 \\
\hline C & 0.442809 & -3.508443 & 1.622764 \\
\hline C & -0.707714 & -4.230730 & 1.937897 \\
\hline $\mathrm{H}$ & -1.083592 & -5.952055 & -0.970843 \\
\hline $\mathrm{H}$ & -1.167528 & -4.106493 & 2.915096 \\
\hline C & -0.145200 & 5.656088 & -1.502679 \\
\hline C & 0.353120 & 4.641698 & -2.321666 \\
\hline C & 1.287767 & 3.732862 & -1.830069 \\
\hline C & 1.742344 & 3.821007 & -0.503598 \\
\hline C & 1.230649 & 4.844862 & 0.310972 \\
\hline C & 0.297760 & 5.754930 & -0.183525 \\
\hline $\mathrm{H}$ & 0.009086 & 4.552670 & -3.348296 \\
\hline $\mathrm{H}$ & -0.091565 & 6.533507 & 0.467619 \\
\hline C & 4.736857 & 1.137273 & 1.159805 \\
\hline C & 4.790329 & 2.549426 & 1.393245 \\
\hline C & 5.811388 & 3.081043 & 2.227349 \\
\hline C & 6.726905 & 2.256818 & 2.838703 \\
\hline C & 6.651421 & 0.857606 & 2.643528 \\
\hline C & 5.685111 & 0.312972 & 1.826554 \\
\hline $\mathrm{H}$ & 5.844722 & 4.156815 & 2.382935 \\
\hline $\mathrm{H}$ & 7.498547 & 2.674048 & 3.479899 \\
\hline $\mathrm{H}$ & 7.359633 & 0.204886 & 3.146810 \\
\hline $\mathrm{H}$ & 5.636041 & -0.761755 & 1.696145 \\
\hline C & 4.699466 & -1.529504 & -0.697807 \\
\hline C & 4.569216 & -2.936753 & -0.934998 \\
\hline C & 5.626577 & -3.637139 & -1.576700 \\
\hline C & 6.756659 & -2.978464 & -2.001579 \\
\hline C & 6.870424 & -1.582035 & -1.805746 \\
\hline C & 5.871381 & -0.877311 & -1.170901 \\
\hline $\mathrm{H}$ & 5.516460 & -4.707008 & -1.737573 \\
\hline $\mathrm{H}$ & 7.555157 & -3.523210 & -2.497776 \\
\hline $\mathrm{H}$ & 7.752498 & -1.058421 & -2.164310 \\
\hline $\mathrm{H}$ & 5.970105 & 0.193649 & -1.037852 \\
\hline $\mathrm{O}$ & -0.441985 & 0.895055 & 0.623757 \\
\hline $\mathrm{O}$ & -0.047063 & -0.741299 & -1.366493 \\
\hline $\mathrm{H}$ & -1.162635 & -0.824644 & -1.395862 \\
\hline $\mathrm{H}$ & 0.867490 & -2.826201 & 2.351294 \\
\hline $\mathrm{H}$ & -2.164044 & -5.671928 & 1.255217 \\
\hline $\mathrm{H}$ & 0.950025 & -4.661198 & -1.532764 \\
\hline $\mathrm{H}$ & 1.549816 & 4.909127 & 1.347535 \\
\hline
\end{tabular}




$\begin{array}{llll}\mathrm{H} & -0.880536 & 6.357384 & -1.887788 \\ \mathrm{H} & 1.668693 & 2.951065 & -2.477557 \\ \mathrm{C} & -2.957045 & -1.708884 & -0.523129 \\ \mathrm{O} & -2.475381 & -0.920995 & -1.411178 \\ \mathrm{H} & -2.308362 & -2.457740 & -0.049214 \\ \mathrm{C} & -4.363367 & -2.223549 & -0.796129 \\ \mathrm{O} & -5.148931 & -1.737704 & -1.573644 \\ \mathrm{O} & -4.614249 & -3.331884 & -0.052736 \\ \mathrm{C} & -5.880413 & -3.963211 & -0.308632 \\ \mathrm{H} & -5.937710 & -4.290096 & -1.350336 \\ \mathrm{H} & -5.923616 & -4.819545 & 0.364946 \\ \mathrm{C} & -3.882599 & 0.433582 & 0.809605 \\ \mathrm{C} & -3.187616 & -0.726615 & 1.200153 \\ \mathrm{H} & -2.141055 & 1.284240 & 0.169928 \\ \mathrm{~N} & -3.172103 & 1.342227 & 0.089818 \\ \mathrm{C} & -3.573100 & 2.100240 & -1.031629 \\ \mathrm{O} & -2.814382 & 2.857966 & -1.588611 \\ \mathrm{O} & -4.835148 & 1.846141 & -1.396246 \\ \mathrm{C} & -5.265575 & 2.514704 & -2.593641 \\ \mathrm{H} & -4.643631 & 2.209765 & -3.438229 \\ \mathrm{H} & -5.206046 & 3.599243 & -2.471164 \\ \mathrm{H} & -6.297186 & 2.196522 & -2.741682 \\ \mathrm{H} & -3.655584 & -1.380837 & 1.929100 \\ \mathrm{H} & -2.113269 & -0.612205 & 1.315236 \\ \mathrm{C} & -5.291081 & 0.674538 & 1.170053 \\ \mathrm{C} & -6.173311 & -0.389588 & 1.425567 \\ \mathrm{C} & -5.741446 & 1.990142 & 1.388005 \\ \mathrm{C} & -7.474887 & -0.143723 & 1.853413 \\ \mathrm{H} & -5.843055 & -1.411609 & 1.282134 \\ \mathrm{C} & -7.038020 & 2.231639 & 1.830268 \\ \mathrm{H} & -5.059168 & 2.820615 & 1.241040 \\ \mathrm{H} & -7.913006 & 1.166572 & 2.055870 \\ & -8.147934 & -0.977391 & 2.032574 \\ -7.364411 & 3.252938 & 2.004712 \\ \mathrm{H} & -6.926736 & 1.356092 & 2.397679 \\ \mathrm{H} & & -3.273809 & -0.110841\end{array}$

Catalyst (R)-1 TS Conformation 131

B3LYP/6-31G(d) Energy $=-2809.694738$

B3LYP-D3(BJ)/def2-TZVPP-IEF-PCM(DCM) Energy $=-2810.985003$

B3LYP-D3(BJ)/def2-TZVPP-IEF-PCM(DCM)//B3LYP/6-31G(d) Free Energy (Quasiharmonic) = 2810.343226 
Frequencies (Top 3 out of 270)

1. $-501.0519 \mathrm{~cm}-1$

2. $\quad 7.9384 \mathrm{~cm}-1$

3. $\quad 10.5400 \mathrm{~cm}-1$

B3LYP/6-31G(d) Molecular Geometry in Cartesian Coordinates

$\begin{array}{llll}\text { C } & 3.598317 & -0.805007 & -0.159128 \\ \text { C } & 2.432137 & -1.531269 & 0.028845 \\ \text { C } & 2.319127 & -2.930146 & -0.228833 \\ \text { C } & 3.442712 & -3.564277 & -0.725429 \\ \text { H } & 3.410796 & -4.635926 & -0.901917 \\ \text { C } & 3.690573 & 3.402468 & 0.807459 \\ \text { C } & 3.640320 & 0.638268 & 0.225561 \\ \text { C } & 2.699155 & 1.517292 & -0.288350 \\ \text { C } & 2.707880 & 2.920396 & -0.035143 \\ \text { H } & 3.744689 & 4.470469 & 1.001383 \\ \text { O } & 1.317062 & -0.869578 & 0.530042 \\ \text { P } & 0.490612 & 0.160264 & -0.428635 \\ \text { O } & 1.698300 & 1.015669 & -1.116415 \\ \text { C } & -1.257004 & -5.237923 & 0.425501 \\ \text { C } & -0.888275 & -4.254244 & 1.344400 \\ \text { C } & 0.259714 & -3.490360 & 1.139719 \\ \text { C } & 1.063295 & -3.693309 & 0.004221 \\ \text { C } & 0.673255 & -4.680203 & -0.918093 \\ \text { C } & -0.471397 & -5.447079 & -0.708970 \\ \text { H } & -1.496505 & -4.064681 & 2.224112 \\ \text { H } & -0.756018 & -6.198518 & -1.441062 \\ \text { C } & -0.107125 & 5.689375 & -1.747508 \\ \text { C } & 0.204055 & 5.743110 & -0.388273 \\ \text { C } & 1.103431 & 4.829713 & 0.160851 \\ \text { C } & 1.710117 & 3.845468 & -0.636369 \\ \text { C } & 1.384737 & 3.798935 & -2.002641 \\ \text { C } & 0.486947 & 4.713503 & -2.550828 \\ \text { H } & -0.258464 & 6.492304 & 0.249237 \\ \text { H } & 0.254087 & 4.665337 & -3.611443 \\ \text { C } & 4.606797 & 1.145623 & 1.162108 \\ \text { C } & 4.631957 & 2.551664 & 1.436433 \\ \text { C } & 5.591209 & 3.068125 & 2.349515 \\ \text { C } & 6.472173 & 2.234448 & 2.997707 \\ \text { C } & 6.422162 & 0.840610 & 2.761078 \\ \text { C } & 5.516806 & 0.310998 & 1.867989\end{array}$




\begin{tabular}{|c|c|c|c|}
\hline $\mathrm{H}$ & 5.604526 & 4.139542 & 2.535365 \\
\hline $\mathrm{H}$ & 7.196273 & 2.639856 & 3.699108 \\
\hline $\mathrm{H}$ & 7.101306 & 0.179642 & 3.292792 \\
\hline $\mathrm{H}$ & 5.485663 & -0.760041 & 1.706582 \\
\hline C & 4.725746 & -1.464008 & -0.759567 \\
\hline C & 4.639624 & -2.869182 & -1.024237 \\
\hline C & 5.752985 & -3.539739 & -1.600257 \\
\hline C & 6.896188 & -2.853581 & -1.937491 \\
\hline C & 6.968300 & -1.458163 & -1.715844 \\
\hline C & 5.914033 & -0.782438 & -1.141499 \\
\hline $\mathrm{H}$ & 5.675503 & -4.609034 & -1.782640 \\
\hline $\mathrm{H}$ & 7.737639 & -3.375775 & -2.384623 \\
\hline $\mathrm{H}$ & 7.862165 & -0.912465 & -2.005863 \\
\hline $\mathrm{H}$ & 5.982241 & 0.288166 & -0.987285 \\
\hline $\mathrm{O}$ & -0.434725 & 0.952340 & 0.439373 \\
\hline $\mathrm{O}$ & -0.120016 & -0.584346 & -1.635251 \\
\hline $\mathrm{H}$ & -1.251968 & -0.667700 & -1.600378 \\
\hline $\mathrm{H}$ & 1.259753 & -4.826939 & -1.820624 \\
\hline $\mathrm{H}$ & -2.154420 & -5.830185 & 0.585778 \\
\hline $\mathrm{H}$ & 0.524802 & -2.729805 & 1.863944 \\
\hline $\mathrm{H}$ & 1.842570 & 3.047876 & -2.637053 \\
\hline $\mathrm{H}$ & -0.808428 & 6.399664 & -2.177600 \\
\hline $\mathrm{H}$ & 1.324092 & 4.861389 & 1.224138 \\
\hline C & -3.106390 & 0.363402 & -1.961542 \\
\hline $\mathrm{O}$ & -2.541902 & -0.713949 & -1.561816 \\
\hline $\mathrm{H}$ & -2.516251 & 1.113587 & -2.506408 \\
\hline C & -4.519091 & 0.290202 & -2.532946 \\
\hline $\mathrm{O}$ & -5.053492 & 1.223661 & -3.096669 \\
\hline 0 & -5.075846 & -0.917159 & -2.364833 \\
\hline C & -6.399584 & -1.057981 & -2.908806 \\
\hline $\mathrm{H}$ & -7.094972 & -0.387687 & -2.397046 \\
\hline $\mathrm{H}$ & -6.399038 & -0.828737 & -3.977273 \\
\hline C & -3.888274 & 0.863562 & 0.576168 \\
\hline C & -3.427726 & 1.673423 & -0.475807 \\
\hline $\mathrm{H}$ & -1.966145 & 0.305597 & 0.957139 \\
\hline$N$ & -2.952440 & 0.165933 & 1.262859 \\
\hline C & -3.030730 & -0.566644 & 2.461559 \\
\hline $\mathrm{O}$ & -2.132136 & -1.291333 & 2.823693 \\
\hline $\mathrm{O}$ & -4.153302 & -0.320976 & 3.153229 \\
\hline C & -4.269876 & -1.044685 & 4.391547 \\
\hline $\mathrm{H}$ & -5.230923 & -0.743838 & 4.808109 \\
\hline $\mathrm{H}$ & -3.453208 & -0.776477 & 5.065793 \\
\hline $\mathrm{H}$ & -4.247168 & -2.121927 & 4.209239 \\
\hline $\mathrm{H}$ & -4.145016 & 2.330781 & -0.953906 \\
\hline
\end{tabular}




$\begin{array}{lrrr}\text { H } & -2.406924 & 2.036906 & -0.400143 \\ \mathrm{C} & -5.337126 & 0.619732 & 0.753389 \\ \mathrm{C} & -5.847071 & -0.689290 & 0.800265 \\ \mathrm{C} & -6.225663 & 1.704564 & 0.789697 \\ \mathrm{C} & -7.219104 & -0.901631 & 0.894682 \\ \mathrm{H} & -5.167887 & -1.531891 & 0.720933 \\ \mathrm{C} & -7.598321 & 1.487457 & 0.903470 \\ \mathrm{H} & -5.836224 & 2.717416 & 0.752663 \\ \mathrm{C} & -8.097178 & 0.185172 & 0.955881 \\ \mathrm{H} & -7.605943 & -1.916652 & 0.917562 \\ \mathrm{H} & -8.275905 & 2.335175 & 0.947391 \\ \mathrm{H} & -9.167314 & 0.015439 & 1.038032 \\ \mathrm{H} & -6.673918 & -2.099104 & -2.738233\end{array}$

Catalyst (R)-1 TS Conformation 132

B3LYP/6-31G(d) Energy $=-2809.69103$

B3LYP-D3(BJ)/def2-TZVPP-IEF-PCM(DCM) Energy $=-2810.983877$

B3LYP-D3(BJ)/def2-TZVPP-IEF-PCM(DCM)//B3LYP/6-31G(d) Free Energy (Quasiharmonic) = 2810.343213

Frequencies (Top 3 out of 270)

1. $-687.6156 \mathrm{~cm}-1$

2. $\quad 7.2595 \mathrm{~cm}-1$

3. $12.8045 \mathrm{~cm}-1$

B3LYP/6-31G(d) Molecular Geometry in Cartesian Coordinates

$\begin{array}{llll}\text { C } & 2.976399 & -1.325716 & -0.006858 \\ \text { C } & 1.620408 & -1.607720 & 0.045045 \\ \text { C } & 1.082664 & -2.920287 & -0.101546 \\ \text { C } & 1.976081 & -3.946235 & -0.339276 \\ \text { H } & 1.603817 & -4.963234 & -0.432158 \\ \text { C } & 4.318704 & 2.745437 & 0.489313 \\ \text { C } & 3.440392 & 0.076750 & 0.217134 \\ \text { C } & 2.923974 & 1.103696 & -0.560466 \\ \text { C } & 3.364852 & 2.457338 & -0.467995 \\ \text { H } & 4.697487 & 3.760923 & 0.568959 \\ \text { O } & 0.736508 & -0.557935 & 0.260923 \\ \text { P } & 0.433306 & 0.460175 & -0.996038 \\ \text { O } & 1.949394 & 0.801271 & -1.504351 \\ \text { C } & -3.133804 & -3.763971 & 0.120217\end{array}$




\begin{tabular}{|c|c|c|c|}
\hline C & -2.355717 & -4.299583 & -0.907619 \\
\hline C & -0.992299 & -4.013098 & -0.978741 \\
\hline C & -0.378060 & -3.188135 & -0.022733 \\
\hline C & -1.173066 & -2.659002 & 1.007977 \\
\hline C & -2.536914 & -2.942232 & 1.080518 \\
\hline $\mathrm{H}$ & -2.811231 & -4.933372 & -1.664085 \\
\hline $\mathrm{H}$ & -3.127835 & -2.513798 & 1.885460 \\
\hline C & 1.950328 & 5.639950 & -2.994585 \\
\hline C & 2.273564 & 4.400595 & -3.550601 \\
\hline C & 2.711224 & 3.355538 & -2.739030 \\
\hline C & 2.839000 & 3.532528 & -1.351039 \\
\hline C & 2.507241 & 4.782832 & -0.804057 \\
\hline C & 2.067272 & 5.826718 & -1.616778 \\
\hline $\mathrm{H}$ & 2.185610 & 4.244780 & -4.622574 \\
\hline $\mathrm{H}$ & 1.807650 & 6.783370 & -1.170752 \\
\hline C & 4.375495 & 0.408539 & 1.257229 \\
\hline C & 4.823140 & 1.764138 & 1.376938 \\
\hline C & 5.756358 & 2.103921 & 2.394023 \\
\hline C & 6.210838 & 1.158204 & 3.283274 \\
\hline C & 5.740879 & -0.173180 & 3.192419 \\
\hline C & 4.849935 & -0.538310 & 2.206996 \\
\hline $\mathrm{H}$ & 6.095657 & 3.134934 & 2.461588 \\
\hline $\mathrm{H}$ & 6.919592 & 1.431390 & 4.060259 \\
\hline $\mathrm{H}$ & 6.083452 & -0.915039 & 3.908885 \\
\hline $\mathrm{H}$ & 4.494352 & -1.560901 & 2.156441 \\
\hline C & 3.885957 & -2.391740 & -0.327000 \\
\hline C & 3.367830 & -3.719570 & -0.476519 \\
\hline C & 4.257551 & -4.785617 & -0.780304 \\
\hline C & 5.601120 & -4.556126 & -0.963923 \\
\hline C & 6.109264 & -3.240193 & -0.856994 \\
\hline C & 5.276237 & -2.187845 & -0.546379 \\
\hline $\mathrm{H}$ & 3.849333 & -5.788805 & -0.878455 \\
\hline $\mathrm{H}$ & 6.270315 & -5.377978 & -1.203275 \\
\hline $\mathrm{H}$ & 7.166648 & -3.056170 & -1.026986 \\
\hline $\mathrm{H}$ & 5.680092 & -1.184460 & -0.478459 \\
\hline $\mathrm{O}$ & -0.319909 & 1.630392 & -0.444293 \\
\hline $\mathrm{O}$ & -0.169005 & -0.334819 & -2.158080 \\
\hline $\mathrm{H}$ & -1.309102 & -0.110052 & -2.504732 \\
\hline $\mathrm{H}$ & -0.715099 & -2.023936 & 1.758330 \\
\hline $\mathrm{H}$ & -4.197515 & -3.979641 & 0.171047 \\
\hline $\mathrm{H}$ & -0.398825 & -4.408390 & -1.798165 \\
\hline $\mathrm{H}$ & 2.573803 & 4.926930 & 0.270766 \\
\hline $\mathrm{H}$ & 1.604791 & 6.451271 & -3.629829 \\
\hline $\mathrm{H}$ & 2.961147 & 2.398299 & -3.182999 \\
\hline
\end{tabular}




$\begin{array}{llcc}\mathrm{C} & -3.297321 & -0.250053 & -1.957580 \\ \mathrm{O} & -2.437554 & 0.058081 & -2.853255 \\ \mathrm{H} & -3.008184 & -0.896574 & -1.123685 \\ \mathrm{C} & -4.709473 & -0.431205 & -2.491149 \\ \mathrm{O} & -5.202608 & 0.204143 & -3.390209 \\ \mathrm{O} & -5.324069 & -1.448435 & -1.843190 \\ \mathrm{C} & -6.642735 & -1.767662 & -2.328736 \\ \mathrm{H} & -7.310543 & -0.909690 & -2.213811 \\ \mathrm{H} & -6.598429 & -2.045166 & -3.384555 \\ \mathrm{C} & -3.649692 & 1.284211 & 0.553396 \\ \mathrm{C} & -3.624828 & 1.496393 & -0.836475 \\ \mathrm{H} & -1.602060 & 1.443178 & 0.674362 \\ \mathrm{~N} & -2.465650 & 1.214241 & 1.216064 \\ \mathrm{C} & -2.241195 & 0.612996 & 2.466819 \\ \mathrm{O} & -3.029360 & -0.054304 & 3.099470 \\ \mathrm{O} & -0.980523 & 0.888755 & 2.834353 \\ \mathrm{C} & -0.551687 & 0.285129 & 4.065904 \\ \mathrm{H} & 0.486284 & 0.592787 & 4.187367 \\ \mathrm{H} & -0.625219 & -0.803667 & 4.005424 \\ \mathrm{H} & -1.163543 & 0.641525 & 4.898552 \\ \mathrm{H} & -4.530545 & 1.883038 & -1.290538 \\ \mathrm{H} & -2.696177 & 1.886892 & -1.239174 \\ \mathrm{C} & -4.923097 & 1.244377 & 1.308866 \\ \mathrm{C} & -5.076387 & 2.059206 & 2.444380 \\ \mathrm{C} & -6.016743 & 0.494620 & 0.854173 \\ \mathrm{C} & -6.300120 & 2.125768 & 3.101980 \\ \mathrm{H} & -4.242027 & 2.660132 & 2.792528 \\ \mathrm{C} & -7.234010 & 0.545825 & 1.531790 \\ \mathrm{H} & -5.897894 & -0.159306 & -0.001367 \\ \mathrm{C} & -7.381958 & 1.364793 & 2.651589 \\ \mathrm{H} & -6.409448 & 2.770400 & 3.969412 \\ \mathrm{H} & -8.068769 & -0.055404 & 1.182330 \\ \mathrm{H} & -8.334743 & 1.411475 & 3.171591 \\ \mathrm{H} & -6.981484 & -2.607375 & -1.722096\end{array}$

Catalyst (R)-1 TS Conformation 133

B3LYP/6-31G(d) Energy $=-2809.69914$

B3LYP-D3(BJ)/def2-TZVPP-IEF-PCM(DCM) Energy = -2810.987236

B3LYP-D3(BJ)/def2-TZVPP-IEF-PCM(DCM)//B3LYP/6-31G(d) Free Energy (Quasiharmonic) = 2810.34316

Frequencies (Top 3 out of 270) 
1. $-253.6909 \mathrm{~cm}-1$

2. $\quad 14.9862 \mathrm{~cm}-1$

3. $\quad 19.9943 \mathrm{~cm}-1$

B3LYP/6-31G(d) Molecular Geometry in Cartesian Coordinates

\begin{tabular}{|c|c|c|c|}
\hline$C$ & 3.036618 & -1.023131 & -0.280520 \\
\hline C & 1.825615 & -1.664028 & -0.062624 \\
\hline C & 1.629489 & -3.056806 & -0.312383 \\
\hline C & 2.682271 & -3.754859 & -0.871440 \\
\hline $\mathrm{H}$ & 2.557108 & -4.814478 & -1.077404 \\
\hline C & 3.808942 & 3.112708 & 0.614183 \\
\hline C & 3.251638 & 0.389179 & 0.154267 \\
\hline C & 2.414107 & 1.394674 & -0.300666 \\
\hline C & 2.703913 & 2.783766 & -0.148136 \\
\hline $\mathrm{H}$ & 4.052083 & 4.161382 & 0.762602 \\
\hline $\mathrm{O}$ & 0.785890 & -0.956686 & 0.536411 \\
\hline$P$ & 0.070401 & 0.324253 & -0.181205 \\
\hline $\mathrm{O}$ & 1.274965 & 1.030307 & -1.018495 \\
\hline C & -1.911511 & -5.317359 & 0.625642 \\
\hline C & -0.661369 & -5.722714 & 1.099336 \\
\hline C & 0.475005 & -4.966139 & 0.811637 \\
\hline C & 0.383451 & -3.794363 & 0.040730 \\
\hline C & -0.877809 & -3.399909 & -0.428438 \\
\hline C & -2.016825 & -4.150845 & -0.136108 \\
\hline $\mathrm{H}$ & -0.569194 & -6.626036 & 1.697290 \\
\hline $\mathrm{H}$ & -2.979123 & -3.804204 & -0.500291 \\
\hline C & 0.608511 & 5.950099 & -2.181863 \\
\hline C & -0.114296 & 4.987170 & -1.475150 \\
\hline C & 0.542980 & 3.951651 & -0.810910 \\
\hline C & 1.943058 & 3.856909 & -0.847522 \\
\hline C & 2.659368 & 4.831971 & -1.563240 \\
\hline C & 2.000715 & 5.869797 & -2.221469 \\
\hline $\mathrm{H}$ & -1.199381 & 5.037526 & -1.441294 \\
\hline $\mathrm{H}$ & 2.576366 & 6.607310 & -2.774728 \\
\hline C & 4.342151 & 0.748082 & 1.020818 \\
\hline C & 4.613242 & 2.135100 & 1.248932 \\
\hline C & 5.683891 & 2.505338 & 2.107238 \\
\hline C & 6.447235 & 1.550394 & 2.737429 \\
\hline C & 6.163651 & 0.179036 & 2.536199 \\
\hline C & 5.142049 & -0.212081 & 1.698704 \\
\hline $\mathrm{H}$ & 5.880601 & 3.563291 & 2.263963 \\
\hline $\mathrm{H}$ & 7.259333 & 1.844739 & 3.396519 \\
\hline
\end{tabular}




\begin{tabular}{|c|c|c|c|}
\hline $\mathrm{H}$ & 6.753930 & -0.573672 & 3.051731 \\
\hline $\mathrm{H}$ & 4.930611 & -1.266439 & 1.562942 \\
\hline C & 4.083892 & -1.741185 & -0.959604 \\
\hline C & 3.898241 & -3.132090 & -1.239978 \\
\hline C & 4.925730 & -3.858782 & -1.900381 \\
\hline C & 6.086720 & -3.238068 & -2.297437 \\
\hline C & 6.259624 & -1.855220 & -2.054931 \\
\hline C & 5.288195 & -1.127489 & -1.403294 \\
\hline $\mathrm{H}$ & 4.767476 & -4.916467 & -2.097212 \\
\hline $\mathrm{H}$ & 6.863558 & -3.800766 & -2.807728 \\
\hline $\mathrm{H}$ & 7.165456 & -1.358947 & -2.392532 \\
\hline $\mathrm{H}$ & 5.434873 & -0.066712 & -1.239158 \\
\hline $\mathrm{O}$ & -0.543612 & 1.173425 & 0.881549 \\
\hline $\mathrm{O}$ & -0.836951 & -0.155151 & -1.352530 \\
\hline $\mathrm{H}$ & -1.848615 & -0.444998 & -1.120788 \\
\hline $\mathrm{H}$ & -0.970788 & -2.515407 & -1.044196 \\
\hline $\mathrm{H}$ & -2.797792 & -5.904348 & 0.853078 \\
\hline $\mathrm{H}$ & 1.443806 & -5.277053 & 1.193978 \\
\hline $\mathrm{H}$ & 3.741834 & 4.758542 & -1.621830 \\
\hline $\mathrm{H}$ & 0.090881 & 6.751997 & -2.701749 \\
\hline $\mathrm{H}$ & -0.026479 & 3.220308 & -0.250192 \\
\hline C & -4.194426 & -0.420218 & -1.197300 \\
\hline $\mathrm{O}$ & -3.102438 & -1.019126 & -0.895625 \\
\hline $\mathrm{H}$ & -4.160993 & 0.566868 & -1.682493 \\
\hline C & -5.340555 & -1.235633 & -1.804052 \\
\hline $\mathrm{O}$ & -6.234068 & -0.731225 & -2.451733 \\
\hline $\mathrm{O}$ & -5.238182 & -2.545670 & -1.536708 \\
\hline C & -6.282634 & -3.366404 & -2.089015 \\
\hline $\mathrm{H}$ & -6.049547 & -4.383667 & -1.775083 \\
\hline $\mathrm{H}$ & -7.257524 & -3.056543 & -1.703242 \\
\hline C & -4.230544 & 0.888642 & 1.020259 \\
\hline C & -5.199487 & 0.076271 & 0.401212 \\
\hline $\mathrm{H}$ & -2.273715 & 0.819712 & 1.686400 \\
\hline$N$ & -3.167251 & 0.317320 & 1.636265 \\
\hline C & -3.097739 & -0.992524 & 2.162563 \\
\hline $\mathrm{O}$ & -4.017099 & -1.770149 & 2.277865 \\
\hline $\mathrm{O}$ & -1.845432 & -1.182629 & 2.587811 \\
\hline C & -1.581175 & -2.452165 & 3.214285 \\
\hline $\mathrm{H}$ & -2.125351 & -2.520620 & 4.160448 \\
\hline $\mathrm{H}$ & -0.505714 & -2.461407 & 3.384031 \\
\hline $\mathrm{H}$ & -1.874650 & -3.268966 & 2.554547 \\
\hline $\mathrm{H}$ & -6.082016 & 0.561817 & 0.001651 \\
\hline $\mathrm{H}$ & -5.348031 & -0.914101 & 0.812467 \\
\hline C & -4.239480 & 2.361354 & 0.872562 \\
\hline
\end{tabular}




$\begin{array}{lrrr}\text { C } & -3.067356 & 3.138251 & 0.963084 \\ \text { C } & -5.469501 & 3.024764 & 0.687262 \\ \text { C } & -3.131590 & 4.526104 & 0.862308 \\ \text { H } & -2.095696 & 2.670420 & 1.076730 \\ \text { C } & -5.526507 & 4.411586 & 0.589834 \\ \text { H } & -6.393373 & 2.458607 & 0.654503 \\ \text { C } & -4.356972 & 5.168675 & 0.675577 \\ \text { H } & -2.214630 & 5.104387 & 0.926298 \\ \text { H } & -6.487389 & 4.900231 & 0.457252 \\ \text { H } & -4.400840 & 6.251843 & 0.603113 \\ \text { H } & -6.290094 & -3.291004 & -3.179362\end{array}$

Catalyst (R)-1 TS Conformation 134

B3LYP/6-31G(d) Energy $=-2809.690402$

B3LYP-D3(BJ)/def2-TZVPP-IEF-PCM(DCM) Energy = -2810.984208

B3LYP-D3(BJ)/def2-TZVPP-IEF-PCM(DCM)//B3LYP/6-31G(d) Free Energy (Quasiharmonic) = 2810.343152

Frequencies (Top 3 out of 270)

1. $-699.1938 \mathrm{~cm}-1$

2. $\quad 5.2252 \mathrm{~cm}-1$

3. $\quad 9.9973 \mathrm{~cm}-1$

B3LYP/6-31G(d) Molecular Geometry in Cartesian Coordinates

$\begin{array}{llll}\text { C } & -3.326121 & 1.133423 & 0.183175 \\ \text { C } & -2.045946 & 1.653860 & 0.264786 \\ \text { C } & -1.749806 & 3.044783 & 0.176371 \\ \text { C } & -2.809951 & 3.903014 & -0.037710 \\ \text { H } & -2.625404 & 4.973070 & -0.086148 \\ \text { C } & -4.090148 & -3.098783 & 0.431235 \\ \text { C } & -3.540030 & -0.335090 & 0.352655 \\ \text { C } & -2.857780 & -1.238952 & -0.451700 \\ \text { C } & -3.149798 & -2.636496 & -0.469371 \\ \text { H } & -4.325683 & -4.159595 & 0.446700 \\ \text { O } & -0.987239 & 0.770989 & 0.448027 \\ \text { P } & -0.513640 & -0.112994 & -0.847343 \\ \text { O } & -1.920588 & -0.763148 & -1.361931 \\ \text { C } & 2.233119 & 4.639947 & 0.512926 \\ \text { C } & 1.781122 & 3.692789 & 1.435350 \\ \text { C } & 0.497977 & 3.158207 & 1.326508\end{array}$




\begin{tabular}{|c|c|c|c|}
\hline C & -0.361964 & 3.565957 & 0.291930 \\
\hline C & 0.105112 & 4.517460 & -0.628824 \\
\hline C & 1.389716 & 5.050263 & -0.520067 \\
\hline $\mathrm{H}$ & 2.428204 & 3.371568 & 2.247593 \\
\hline $\mathrm{H}$ & 1.733030 & 5.778806 & -1.249845 \\
\hline C & -1.487994 & -5.473297 & -3.248785 \\
\hline C & -2.868551 & -5.363905 & -3.078816 \\
\hline C & -3.389796 & -4.428222 & -2.185840 \\
\hline C & -2.543693 & -3.583807 & -1.447219 \\
\hline C & -1.156217 & -3.700349 & -1.627631 \\
\hline C & -0.638421 & -4.639081 & -2.519841 \\
\hline $\mathrm{H}$ & -3.542433 & -6.001168 & -3.645767 \\
\hline $\mathrm{H}$ & 0.438733 & -4.719062 & -2.643811 \\
\hline C & -4.443540 & -0.846910 & 1.347273 \\
\hline C & -4.722606 & -2.250687 & 1.371822 \\
\hline C & -5.616633 & -2.769136 & 2.347555 \\
\hline C & -6.198617 & -1.945321 & 3.282505 \\
\hline C & -5.899933 & -0.562381 & 3.281825 \\
\hline C & -5.048283 & -0.027532 & 2.340362 \\
\hline $\mathrm{H}$ & -5.822191 & -3.837033 & 2.346090 \\
\hline $\mathrm{H}$ & -6.875931 & -2.353403 & 4.027755 \\
\hline $\mathrm{H}$ & -6.341449 & 0.083955 & 4.035654 \\
\hline $\mathrm{H}$ & -4.821045 & 1.032038 & 2.361477 \\
\hline C & -4.409625 & 2.031672 & -0.115393 \\
\hline C & -4.136579 & 3.435620 & -0.207579 \\
\hline C & -5.199087 & 4.336910 & -0.488581 \\
\hline C & -6.477490 & 3.878842 & -0.705852 \\
\hline C & -6.742222 & 2.490208 & -0.657497 \\
\hline C & -5.738060 & 1.592137 & -0.369224 \\
\hline $\mathrm{H}$ & -4.975644 & 5.399847 & -0.542375 \\
\hline $\mathrm{H}$ & -7.280205 & 4.576785 & -0.927496 \\
\hline $\mathrm{H}$ & -7.747025 & 2.126691 & -0.855148 \\
\hline $\mathrm{H}$ & -5.957220 & 0.531306 & -0.346896 \\
\hline $\mathrm{O}$ & 0.481462 & -1.118642 & -0.350234 \\
\hline $\mathrm{O}$ & -0.107653 & 0.811258 & -1.999184 \\
\hline $\mathrm{H}$ & 1.053166 & 0.950482 & -2.302561 \\
\hline $\mathrm{H}$ & -0.537793 & 4.820207 & -1.450297 \\
\hline $\mathrm{H}$ & 3.234837 & 5.052486 & 0.598658 \\
\hline $\mathrm{H}$ & 0.155571 & 2.425685 & 2.049618 \\
\hline $\mathrm{H}$ & -0.483161 & -3.064732 & -1.062887 \\
\hline $\mathrm{H}$ & -1.077983 & -6.199839 & -3.945612 \\
\hline $\mathrm{H}$ & -4.466232 & -4.333576 & -2.070352 \\
\hline C & 2.944103 & 1.068745 & -1.531125 \\
\hline $\mathrm{O}$ & 2.209220 & 1.135526 & -2.573761 \\
\hline
\end{tabular}




$\begin{array}{llll}\text { H } & 2.485935 & 1.157577 & -0.540268 \\ \mathrm{C} & 4.337929 & 1.658835 & -1.659416 \\ \mathrm{O} & 4.993025 & 1.687101 & -2.673674 \\ \mathrm{O} & 4.734058 & 2.156187 & -0.470027 \\ \mathrm{C} & 6.042482 & 2.757676 & -0.468363 \\ \mathrm{H} & 6.802255 & 2.014352 & -0.721090 \\ \mathrm{H} & 6.082499 & 3.575896 & -1.191436 \\ \mathrm{C} & 3.904283 & -1.174166 & -0.050951 \\ \mathrm{C} & 3.490901 & -0.919533 & -1.363688 \\ \mathrm{H} & 1.957561 & -1.234319 & 0.577664 \\ \mathrm{~N} & 2.937993 & -1.376019 & 0.893225 \\ \mathrm{C} & 3.006775 & -1.996553 & 2.152183 \\ \mathrm{O} & 2.092945 & -1.942126 & 2.942134 \\ \mathrm{O} & 4.150383 & -2.678075 & 2.334388 \\ \mathrm{C} & 4.262373 & -3.333625 & 3.610545 \\ \mathrm{H} & 4.198951 & -2.605562 & 4.423047 \\ \mathrm{H} & 5.239870 & -3.815512 & 3.599107 \\ \mathrm{H} & 3.466765 & -4.072951 & 3.728168 \\ \mathrm{H} & 4.245739 & -0.893500 & -2.140800 \\ \mathrm{H} & 2.503629 & -1.265865 & -1.647662 \\ \mathrm{C} & 5.327076 & -1.043131 & 0.331478 \\ \mathrm{C} & 5.704318 & -0.339782 & 1.489746 \\ \mathrm{C} & 6.327188 & -1.562823 & -0.505529 \\ \mathrm{C} & 7.048833 & -0.166472 & 1.800985 \\ \mathrm{H} & 4.940211 & 0.096589 & 2.125088 \\ \mathrm{C} & 7.673838 & -1.400311 & -0.183204 \\ \mathrm{H} & 6.047092 & -2.118740 & -1.394675 \\ \mathrm{C} & 8.037599 & -0.701272 & 0.968729 \\ \mathrm{H} & 7.328350 & 0.387819 & 2.692608 \\ \mathrm{H} & 8.436763 & -1.820523 & -0.831931 \\ \mathrm{H} & 9.087122 & -0.570941 & 1.217858 \\ \mathrm{H} & 6.191731 & 3.129245 & 0.545205 \\ & & & \end{array}$

Catalyst (R)-1 TS Conformation 135

B3LYP/6-31G(d) Energy $=-2809.689745$

B3LYP-D3(BJ)/def2-TZVPP-IEF-PCM(DCM) Energy = -2810.985141

B3LYP-D3(BJ)/def2-TZVPP-IEF-PCM(DCM)//B3LYP/6-31G(d) Free Energy (Quasiharmonic) = 2810.343136

Frequencies (Top 3 out of 270)

1. $-537.3628 \mathrm{~cm}-1$ 
2. $\quad 13.1543 \mathrm{~cm}-1$

3. $\quad 15.2880 \mathrm{~cm}-1$

B3LYP/6-31G(d) Molecular Geometry in Cartesian Coordinates

\begin{tabular}{|c|c|c|c|}
\hline C & 3.282854 & 0.464590 & -0.051909 \\
\hline C & 2.328487 & 1.385468 & -0.456672 \\
\hline C & 2.478736 & 2.794317 & -0.291387 \\
\hline C & 3.619347 & 3.238083 & 0.348877 \\
\hline $\mathrm{H}$ & 3.778353 & 4.306723 & 0.467917 \\
\hline C & 2.625989 & -3.734665 & -0.780522 \\
\hline C & 3.073107 & -0.983862 & -0.349097 \\
\hline C & 1.906142 & -1.608460 & 0.069525 \\
\hline C & 1.657729 & -3.002605 & -0.119316 \\
\hline $\mathrm{H}$ & 2.486870 & -4.804879 & -0.908089 \\
\hline $\mathrm{O}$ & 1.174263 & 0.917638 & -1.067623 \\
\hline$P$ & 0.031798 & 0.214201 & -0.112007 \\
\hline $\mathrm{O}$ & 0.951794 & -0.857252 & 0.736412 \\
\hline C & -0.388647 & 5.682269 & -1.690497 \\
\hline C & -0.002544 & 4.625537 & -2.517746 \\
\hline C & 0.909570 & 3.672813 & -2.066831 \\
\hline C & 1.460368 & 3.763053 & -0.777164 \\
\hline C & 1.061928 & 4.829508 & 0.045220 \\
\hline C & 0.146155 & 5.779475 & -0.405499 \\
\hline $\mathrm{H}$ & -0.411152 & 4.541920 & -3.521655 \\
\hline $\mathrm{H}$ & -0.157081 & 6.589735 & 0.252317 \\
\hline C & -1.850184 & -5.088140 & 1.268331 \\
\hline C & -1.249817 & -4.118670 & 2.076448 \\
\hline C & -0.127696 & -3.417404 & 1.629543 \\
\hline C & 0.421373 & -3.676071 & 0.361766 \\
\hline C & -0.200281 & -4.646995 & -0.444044 \\
\hline C & -1.320305 & -5.347375 & 0.003170 \\
\hline $\mathrm{H}$ & -1.641159 & -3.906203 & 3.067781 \\
\hline $\mathrm{H}$ & -1.781518 & -6.092324 & -0.640246 \\
\hline C & 4.028246 & -1.742661 & -1.109154 \\
\hline C & 3.799968 & -3.142870 & -1.304444 \\
\hline C & 4.745807 & -3.910787 & -2.036875 \\
\hline C & 5.859171 & -3.322239 & -2.589323 \\
\hline C & 6.066417 & -1.931214 & -2.434585 \\
\hline C & 5.177994 & -1.163373 & -1.714252 \\
\hline $\mathrm{H}$ & 4.562314 & -4.975327 & -2.163152 \\
\hline $\mathrm{H}$ & 6.571872 & -3.917438 & -3.153656 \\
\hline $\mathrm{H}$ & 6.933071 & -1.462108 & -2.892613 \\
\hline $\mathrm{H}$ & 5.347571 & -0.097825 & -1.613824 \\
\hline
\end{tabular}




\begin{tabular}{|c|c|c|c|}
\hline C & 4.426913 & 0.936537 & 0.678928 \\
\hline C & 4.593304 & 2.347603 & 0.863882 \\
\hline C & 5.726215 & 2.829372 & 1.574344 \\
\hline C & 6.646477 & 1.960865 & 2.113494 \\
\hline C & 6.463770 & 0.565658 & 1.967234 \\
\hline C & 5.385833 & 0.067394 & 1.268803 \\
\hline $\mathrm{H}$ & 5.843558 & 3.903952 & 1.694104 \\
\hline $\mathrm{H}$ & 7.504823 & 2.341079 & 2.660687 \\
\hline $\mathrm{H}$ & 7.177962 & -0.120600 & 2.414420 \\
\hline $\mathrm{H}$ & 5.255231 & -1.004432 & 1.174906 \\
\hline 0 & -0.995263 & -0.412686 & -0.991428 \\
\hline O & -0.422701 & 1.198421 & 0.976331 \\
\hline $\mathrm{H}$ & -1.472540 & 1.884476 & 0.746110 \\
\hline $\mathrm{H}$ & 1.458002 & 4.897198 & 1.054647 \\
\hline $\mathrm{H}$ & -1.105057 & 6.420063 & -2.041995 \\
\hline $\mathrm{H}$ & 1.202159 & 2.856163 & -2.717663 \\
\hline $\mathrm{H}$ & 0.191266 & -4.839786 & -1.438897 \\
\hline $\mathrm{H}$ & -2.720944 & -5.634956 & 1.620646 \\
\hline $\mathrm{H}$ & 0.317700 & -2.667744 & 2.271384 \\
\hline C & -3.262465 & 1.884329 & -0.187301 \\
\hline $\mathrm{O}$ & -2.436601 & 2.483279 & 0.585389 \\
\hline $\mathrm{H}$ & -2.907159 & 1.075695 & -0.830312 \\
\hline C & -4.385671 & 2.746885 & -0.736832 \\
\hline $\mathrm{O}$ & -4.771097 & 3.781499 & -0.248580 \\
\hline $\mathrm{O}$ & -4.882095 & 2.184472 & -1.857411 \\
\hline C & -5.944638 & 2.917065 & -2.492468 \\
\hline $\mathrm{H}$ & -6.794402 & 3.025830 & -1.812858 \\
\hline $\mathrm{H}$ & -5.597301 & 3.910060 & -2.788877 \\
\hline C & -4.026927 & -0.532391 & 0.959674 \\
\hline C & -4.587201 & 0.745739 & 0.998462 \\
\hline $\mathrm{H}$ & -2.687303 & -1.930989 & 1.585148 \\
\hline$N$ & -3.029676 & -0.990768 & 1.768685 \\
\hline C & -2.325582 & -0.407279 & 2.844755 \\
\hline $\mathrm{O}$ & -1.505052 & -1.047882 & 3.461111 \\
\hline $\mathrm{O}$ & -2.692320 & 0.848100 & 3.087588 \\
\hline C & -1.851247 & 1.557925 & 4.025232 \\
\hline $\mathrm{H}$ & -2.296165 & 2.548828 & 4.105689 \\
\hline $\mathrm{H}$ & -0.840254 & 1.616038 & 3.618575 \\
\hline $\mathrm{H}$ & -1.847414 & 1.047655 & 4.990406 \\
\hline $\mathrm{H}$ & -5.504252 & 0.854649 & 0.431581 \\
\hline $\mathrm{H}$ & -4.474057 & 1.373003 & 1.870418 \\
\hline C & -4.481738 & -1.506131 & -0.064931 \\
\hline C & -3.555491 & -2.233379 & -0.832994 \\
\hline C & -5.859118 & -1.708135 & -0.264138 \\
\hline
\end{tabular}




$\begin{array}{llll}\mathrm{C} & -4.012779 & -3.145034 & -1.783966 \\ \mathrm{H} & -2.492510 & -2.026555 & -0.743218 \\ \mathrm{C} & -6.303866 & -2.633258 & -1.204441 \\ \mathrm{H} & -6.577610 & -1.164482 & 0.342183 \\ \mathrm{C} & -5.380487 & -3.352635 & -1.967601 \\ \mathrm{H} & -3.290505 & -3.687086 & -2.386752 \\ \mathrm{H} & -7.369628 & -2.795416 & -1.338732 \\ \mathrm{H} & -5.728632 & -4.069445 & -2.706441 \\ \mathrm{H} & -6.222072 & 2.329058 & -3.367136\end{array}$

Catalyst (R)-1 TS Conformation 136

B3LYP/6-31G(d) Energy $=-2809.692445$

B3LYP-D3(BJ)/def2-TZVPP-IEF-PCM(DCM) Energy $=-2810.985472$

B3LYP-D3(BJ)/def2-TZVPP-IEF-PCM(DCM)//B3LYP/6-31G(d) Free Energy (Quasiharmonic) = 2810.34311

Frequencies (Top 3 out of 270)

1. $-348.3505 \mathrm{~cm}-1$

2. $\quad 10.6194 \mathrm{~cm}-1$

3. $\quad 17.9294 \mathrm{~cm}-1$

B3LYP/6-31G(d) Molecular Geometry in Cartesian Coordinates

$\begin{array}{lrrr}\text { C } & 3.294381 & -0.230381 & 0.289620 \\ \text { C } & 2.768686 & 0.945334 & -0.222299 \\ \text { C } & 3.343632 & 2.229212 & 0.012172 \\ \text { C } & 4.425566 & 2.289145 & 0.868789 \\ \text { H } & 4.905371 & 3.247507 & 1.048100 \\ \text { C } & 1.598964 & -4.099123 & -0.557950 \\ \text { C } & 2.717984 & -1.552665 & -0.099718 \\ \text { C } & 1.371520 & -1.809200 & 0.107831 \\ \text { C } & 0.781566 & -3.098008 & -0.066889 \\ \text { H } & 1.198658 & -5.102878 & -0.670849 \\ \text { O } & 1.647354 & 0.879018 & -1.044888 \\ \text { P } & 0.197701 & 0.485117 & -0.413416 \\ \text { O } & 0.568619 & -0.776674 & 0.570188 \\ \text { C } & 2.177751 & 5.885960 & -1.930358 \\ \text { C } & 2.395773 & 5.855513 & -0.551694 \\ \text { C } & 2.734083 & 4.657727 & 0.077326 \\ \text { C } & 2.860965 & 3.467056 & -0.656808 \\ \text { C } & 2.616766 & 3.505929 & -2.040072\end{array}$




\begin{tabular}{|c|c|c|c|}
\hline C & 2.284255 & 4.704792 & -2.669686 \\
\hline $\mathrm{H}$ & 2.302281 & 6.764506 & 0.036786 \\
\hline $\mathrm{H}$ & 2.116900 & 4.716954 & -3.743647 \\
\hline C & -3.279904 & -4.083783 & 0.980066 \\
\hline C & -2.547236 & -3.205546 & 1.781322 \\
\hline C & -1.237914 & -2.865777 & 1.441971 \\
\hline C & -0.633592 & -3.391436 & 0.285404 \\
\hline C & -1.386827 & -4.268879 & -0.513107 \\
\hline C & -2.691999 & -4.616646 & -0.167262 \\
\hline $\mathrm{H}$ & -2.996379 & -2.777625 & 2.673799 \\
\hline $\mathrm{H}$ & -3.254006 & -5.294945 & -0.803804 \\
\hline C & 3.528695 & -2.580484 & -0.693069 \\
\hline C & 2.950133 & -3.871609 & -0.914722 \\
\hline C & 3.743189 & -4.902619 & -1.487988 \\
\hline C & 5.046389 & -4.668563 & -1.860157 \\
\hline C & 5.609659 & -3.383975 & -1.675009 \\
\hline C & 4.873361 & -2.369057 & -1.104221 \\
\hline $\mathrm{H}$ & 3.292181 & -5.880752 & -1.638039 \\
\hline $\mathrm{H}$ & 5.640730 & -5.461997 & -2.304834 \\
\hline $\mathrm{H}$ & 6.632252 & -3.194416 & -1.989855 \\
\hline $\mathrm{H}$ & 5.316817 & -1.388257 & -0.976772 \\
\hline C & 4.374183 & -0.141659 & 1.237004 \\
\hline C & 4.942367 & 1.142382 & 1.518577 \\
\hline C & 6.014128 & 1.245539 & 2.446278 \\
\hline C & 6.492657 & 0.134688 & 3.100696 \\
\hline C & 5.908747 & -1.129766 & 2.853869 \\
\hline C & 4.880803 & -1.265372 & 1.946638 \\
\hline $\mathrm{H}$ & 6.440651 & 2.227348 & 2.637660 \\
\hline $\mathrm{H}$ & 7.307290 & 0.226216 & 3.813774 \\
\hline $\mathrm{H}$ & 6.270835 & -2.003411 & 3.389070 \\
\hline $\mathrm{H}$ & 4.439154 & -2.240559 & 1.779517 \\
\hline $\mathrm{O}$ & -0.738521 & 0.148240 & -1.522194 \\
\hline $\mathrm{O}$ & -0.194809 & 1.583975 & 0.600843 \\
\hline $\mathrm{H}$ & -1.232442 & 1.622864 & 0.973970 \\
\hline $\mathrm{H}$ & 2.704862 & 2.597151 & -2.625509 \\
\hline $\mathrm{H}$ & 1.924858 & 6.820512 & -2.424541 \\
\hline $\mathrm{H}$ & 2.889936 & 4.637673 & 1.152202 \\
\hline $\mathrm{H}$ & -0.948940 & -4.667659 & -1.423978 \\
\hline $\mathrm{H}$ & -4.300730 & -4.345542 & 1.244947 \\
\hline $\mathrm{H}$ & -0.676577 & -2.195300 & 2.082100 \\
\hline C & -3.330867 & 0.924390 & 1.663006 \\
\hline $\mathrm{O}$ & -2.446126 & 1.837697 & 1.498649 \\
\hline $\mathrm{H}$ & -3.087325 & -0.121257 & 1.423628 \\
\hline C & -4.184357 & 1.034241 & 2.931500 \\
\hline
\end{tabular}




$\begin{array}{llll}\mathrm{O} & -4.416105 & 2.049922 & 3.538615 \\ \mathrm{O} & -4.645454 & -0.191448 & 3.283551 \\ \mathrm{C} & -5.457940 & -0.216116 & 4.470193 \\ \mathrm{H} & -6.334161 & 0.426505 & 4.348754 \\ \mathrm{H} & -5.757666 & -1.256380 & 4.599930 \\ \mathrm{C} & -4.189335 & 0.876284 & -0.748444 \\ \mathrm{C} & -4.818802 & 1.255310 & 0.454538 \\ \mathrm{H} & -2.443915 & 1.195744 & -1.791207 \\ \mathrm{~N} & -3.209171 & 1.648376 & -1.279973 \\ \mathrm{C} & -3.032441 & 3.031805 & -1.052518 \\ \mathrm{O} & -3.855128 & 3.783072 & -0.583903 \\ \mathrm{O} & -1.833381 & 3.376304 & -1.534177 \\ \mathrm{C} & -1.471190 & 4.755832 & -1.334265 \\ \mathrm{H} & -2.182766 & 5.411041 & -1.843203 \\ \mathrm{H} & -0.473244 & 4.852739 & -1.757209 \\ \mathrm{H} & -1.460763 & 4.984615 & -0.266414 \\ \mathrm{H} & -5.639011 & 0.626830 & 0.785397 \\ \mathrm{H} & -4.912177 & 2.310751 & 0.677405 \\ \mathrm{C} & -4.478863 & -0.423995 & -1.394306 \\ \mathrm{C} & -5.803123 & -0.905199 & -1.358027 \\ \mathrm{C} & -3.512105 & -1.157008 & -2.108460 \\ \mathrm{C} & -6.153825 & -2.076507 & -2.022642 \\ \mathrm{H} & -6.571644 & -0.335395 & -0.846841 \\ \mathrm{C} & -3.870576 & -2.333491 & -2.762037 \\ \mathrm{H} & -2.473877 & -0.842045 & -2.118983 \\ \mathrm{C} & -5.187519 & -2.794885 & -2.728729 \\ \mathrm{H} & -7.184130 & -2.420015 & -1.998278 \\ \mathrm{H} & -3.109332 & -2.894308 & -3.295918 \\ \mathrm{H} & -5.460439 & -3.707919 & -3.251098 \\ \mathrm{H} & -4.882897 & 0.129130 & 5.333349\end{array}$

Catalyst (R)-1 TS Conformation 137

B3LYP/6-31G(d) Energy $=-2809.688643$

B3LYP-D3(BJ)/def2-TZVPP-IEF-PCM(DCM) Energy = -2810.984938

B3LYP-D3(BJ)/def2-TZVPP-IEF-PCM(DCM)//B3LYP/6-31G(d) Free Energy (Quasiharmonic) = 2810.343087

Frequencies (Top 3 out of 270)

1. $-647.4372 \mathrm{~cm}-1$

2. $8.9172 \mathrm{~cm}-1$

3. $\quad 13.4681 \mathrm{~cm}-1$ 
B3LYP/6-31G(d) Molecular Geometry in Cartesian Coordinates

\begin{tabular}{|c|c|c|c|}
\hline C & -2.897561 & -1.223398 & 0.176430 \\
\hline C & -1.702161 & -1.826459 & -0.176820 \\
\hline C & -1.333722 & -3.144809 & 0.220430 \\
\hline C & -2.216762 & -3.830908 & 1.029650 \\
\hline $\mathrm{H}$ & -1.979243 & -4.847249 & 1.333330 \\
\hline C & -3.880299 & 2.786683 & -1.067120 \\
\hline C & -3.217370 & 0.139142 & -0.344900 \\
\hline C & -2.332430 & 1.193092 & -0.147320 \\
\hline C & -2.659879 & 2.544122 & -0.469980 \\
\hline $\mathrm{H}$ & -4.149688 & 3.808833 & -1.320480 \\
\hline 0 & -0.808671 & -1.107089 & -0.958840 \\
\hline$P$ & 0.063790 & 0.058120 & -0.194210 \\
\hline 0 & -1.123950 & 0.969611 & 0.490640 \\
\hline C & 2.373147 & -4.997911 & -0.939540 \\
\hline C & 1.583708 & -4.357980 & -1.898500 \\
\hline C & 0.388518 & -3.741310 & -1.530410 \\
\hline C & -0.044332 & -3.759830 & -0.193710 \\
\hline C & 0.760078 & -4.403980 & 0.760230 \\
\hline C & 1.958327 & -5.015031 & 0.392690 \\
\hline $\mathrm{H}$ & 1.895448 & -4.342141 & -2.939900 \\
\hline $\mathrm{H}$ & 2.574137 & -5.492301 & 1.149810 \\
\hline C & -0.176497 & 5.952481 & 0.390720 \\
\hline C & -1.456647 & 5.850391 & 0.935720 \\
\hline C & -2.243628 & 4.730162 & 0.664170 \\
\hline C & -1.761158 & 3.688451 & -0.143710 \\
\hline C & -0.467378 & 3.794591 & -0.679190 \\
\hline C & 0.311442 & 4.924440 & -0.420370 \\
\hline $\mathrm{H}$ & -1.847547 & 6.643041 & 1.568800 \\
\hline $\mathrm{H}$ & 1.289323 & 5.004140 & -0.887510 \\
\hline C & -4.434830 & 0.393243 & -1.067930 \\
\hline C & -4.770499 & 1.741403 & -1.414380 \\
\hline C & -5.976999 & 2.004424 & -2.117850 \\
\hline C & -6.814640 & 0.980414 & -2.493950 \\
\hline C & -6.469450 & -0.356376 & -2.185110 \\
\hline C & -5.314440 & -0.642077 & -1.490800 \\
\hline $\mathrm{H}$ & -6.217899 & 3.035794 & -2.364880 \\
\hline $\mathrm{H}$ & -7.731360 & 1.192395 & -3.037440 \\
\hline $\mathrm{H}$ & -7.118611 & -1.167366 & -2.504360 \\
\hline $\mathrm{H}$ & -5.060101 & -1.672797 & -1.272610 \\
\hline C & -3.772081 & -1.920858 & 1.081710 \\
\hline C & -3.423312 & -3.249138 & 1.492270 \\
\hline
\end{tabular}




\begin{tabular}{|c|c|c|c|}
\hline C & -4.283662 & -3.955667 & 2.375860 \\
\hline C & -5.427412 & -3.372267 & 2.868980 \\
\hline C & -5.752221 & -2.046026 & 2.500090 \\
\hline C & -4.948841 & -1.340927 & 1.630780 \\
\hline $\mathrm{H}$ & -4.009493 & -4.967307 & 2.665970 \\
\hline $\mathrm{H}$ & -6.073532 & -3.920136 & 3.549500 \\
\hline $\mathrm{H}$ & -6.642121 & -1.575816 & 2.909980 \\
\hline $\mathrm{H}$ & -5.208260 & -0.322487 & 1.367250 \\
\hline $\mathrm{O}$ & 0.876250 & 0.770610 & -1.222960 \\
\hline O & 0.755220 & -0.524800 & 1.044630 \\
\hline $\mathrm{H}$ & 1.890359 & -1.006231 & 1.010500 \\
\hline $\mathrm{H}$ & 0.454048 & -4.397740 & 1.802420 \\
\hline $\mathrm{H}$ & 3.305727 & -5.477211 & -1.226210 \\
\hline $\mathrm{H}$ & -0.217122 & -3.246189 & -2.281860 \\
\hline $\mathrm{H}$ & -0.074709 & 3.005790 & -1.312570 \\
\hline $\mathrm{H}$ & 0.433233 & 6.830710 & 0.588150 \\
\hline $\mathrm{H}$ & -3.241008 & 4.652522 & 1.089140 \\
\hline C & 3.523519 & -1.120491 & -0.154660 \\
\hline $\mathrm{O}$ & 2.967659 & -1.470611 & 0.942740 \\
\hline $\mathrm{H}$ & 2.926430 & -0.649661 & -0.938400 \\
\hline C & 4.664179 & -2.008372 & -0.628880 \\
\hline $\mathrm{O}$ & 5.342298 & -2.710352 & 0.081650 \\
\hline $\mathrm{O}$ & 4.809029 & -1.899812 & -1.967850 \\
\hline C & 5.848368 & -2.717923 & -2.533830 \\
\hline $\mathrm{H}$ & 5.642948 & -3.774983 & -2.346990 \\
\hline $\mathrm{H}$ & 5.837829 & -2.507963 & -3.603420 \\
\hline C & 3.949241 & 1.554378 & 0.523720 \\
\hline C & 4.782660 & 0.507168 & 0.127830 \\
\hline $\mathrm{H}$ & 2.820412 & 3.187989 & 0.085440 \\
\hline$N$ & 3.358981 & 2.438959 & -0.334370 \\
\hline C & 3.172141 & 2.426039 & -1.729810 \\
\hline $\mathrm{O}$ & 2.603132 & 3.338589 & -2.284570 \\
\hline $\mathrm{O}$ & 3.694161 & 1.349068 & -2.314650 \\
\hline C & 3.289270 & 1.151579 & -3.687370 \\
\hline $\mathrm{H}$ & 3.786650 & 0.231848 & -3.992580 \\
\hline $\mathrm{H}$ & 3.605921 & 1.996259 & -4.302480 \\
\hline $\mathrm{H}$ & 2.204180 & 1.038909 & -3.721560 \\
\hline $\mathrm{H}$ & 5.344850 & 0.021638 & 0.916520 \\
\hline $\mathrm{H}$ & 5.243630 & 0.548298 & -0.849820 \\
\hline C & 3.596511 & 1.746439 & 1.945320 \\
\hline C & 4.554531 & 1.523398 & 2.951620 \\
\hline C & 2.296711 & 2.143659 & 2.316250 \\
\hline C & 4.224851 & 1.702668 & 4.291330 \\
\hline $\mathrm{H}$ & 5.567011 & 1.242217 & 2.681090 \\
\hline
\end{tabular}




$\begin{array}{llll}\mathrm{C} & 1.970341 & 2.309049 & 3.659310 \\ \mathrm{H} & 1.522641 & 2.269870 & 1.566510 \\ \mathrm{C} & 2.932051 & 2.093859 & 4.648070 \\ \mathrm{H} & 4.977621 & 1.539578 & 5.056990 \\ \mathrm{H} & 0.957451 & 2.590290 & 3.930020 \\ \mathrm{H} & 2.673951 & 2.225499 & 5.695150 \\ \mathrm{H} & 6.817859 & -2.461493 & -2.098440\end{array}$

Catalyst (R)-1 TS Conformation 138

B3LYP/6-31G(d) Energy $=-2809.692814$

B3LYP-D3(BJ)/def2-TZVPP-IEF-PCM(DCM) Energy $=-2810.988035$

B3LYP-D3(BJ)/def2-TZVPP-IEF-PCM(DCM)//B3LYP/6-31G(d) Free Energy (Quasiharmonic) = 2810.343078

Frequencies (Top 3 out of 270)

1. $-190.9417 \mathrm{~cm}-1$

2. $\quad 11.4005 \mathrm{~cm}-1$

3. $19.9028 \mathrm{~cm}-1$

B3LYP/6-31G(d) Molecular Geometry in Cartesian Coordinates

$\begin{array}{lrrr}\text { C } & 2.924310 & -0.918114 & -0.150410 \\ \text { C } & 1.752233 & -1.656181 & -0.218636 \\ \text { C } & 1.723750 & -3.016603 & -0.650521 \\ \text { C } & 2.919223 & -3.587620 & -1.041069 \\ \text { H } & 2.920229 & -4.622704 & -1.372229 \\ \text { C } & 3.169800 & 3.184501 & 1.073804 \\ \text { C } & 2.924964 & 0.468195 & 0.397972 \\ \text { C } & 2.105772 & 1.433259 & -0.168254 \\ \text { C } & 2.265030 & 2.829613 & 0.089438 \\ \text { H } & 3.299969 & 4.237280 & 1.308986 \\ \text { O } & 0.572318 & -1.089167 & 0.257856 \\ \text { P } & -0.135256 & 0.206392 & -0.458267 \\ \text { O } & 1.137817 & 1.017663 & -1.086923 \\ \text { C } & -1.696486 & -5.613982 & -0.906853 \\ \text { C } & -1.674068 & -4.418755 & -1.629097 \\ \text { C } & -0.591480 & -3.545270 & -1.521079 \\ \text { C } & 0.495430 & -3.861751 & -0.692563 \\ \text { C } & 0.465928 & -5.067609 & 0.026959 \\ \text { C } & -0.622108 & -5.935441 & -0.074951 \\ \text { H } & -2.502672 & -4.162806 & -2.284182\end{array}$




\begin{tabular}{|c|c|c|c|}
\hline $\mathrm{H}$ & -0.628290 & -6.862111 & 0.493321 \\
\hline C & 0.454805 & 6.009728 & -2.178510 \\
\hline C & 1.824176 & 6.010031 & -1.907677 \\
\hline C & 2.391454 & 4.964024 & -1.182497 \\
\hline C & 1.602912 & 3.900306 & -0.706220 \\
\hline C & 0.229481 & 3.911802 & -0.986921 \\
\hline C & -0.335701 & 4.956283 & -1.718089 \\
\hline $\mathrm{H}$ & 2.454963 & 6.817378 & -2.271121 \\
\hline $\mathrm{H}$ & -1.399151 & 4.929026 & -1.934260 \\
\hline C & 3.796417 & 0.846482 & 1.476384 \\
\hline C & 3.904865 & 2.231190 & 1.818292 \\
\hline C & 4.752043 & 2.621194 & 2.890833 \\
\hline C & 5.451396 & 1.684079 & 3.615283 \\
\hline C & 5.326301 & 0.311355 & 3.295517 \\
\hline C & 4.524120 & -0.096733 & 2.252409 \\
\hline $\mathrm{H}$ & 4.828743 & 3.678586 & 3.133136 \\
\hline $\mathrm{H}$ & 6.091836 & 1.992568 & 4.437111 \\
\hline $\mathrm{H}$ & 5.864122 & -0.428841 & 3.881823 \\
\hline $\mathrm{H}$ & 4.429795 & -1.152609 & 2.025420 \\
\hline C & 4.139817 & -1.493398 & -0.664577 \\
\hline C & 4.131227 & -2.859685 & -1.088460 \\
\hline C & 5.326004 & -3.451906 & -1.580180 \\
\hline C & 6.486413 & -2.721287 & -1.680645 \\
\hline C & 6.490429 & -1.358590 & -1.300671 \\
\hline C & 5.351920 & -0.761368 & -0.806088 \\
\hline $\mathrm{H}$ & 5.298354 & -4.494122 & -1.889320 \\
\hline $\mathrm{H}$ & 7.393486 & -3.180569 & -2.063853 \\
\hline $\mathrm{H}$ & 7.399831 & -0.773293 & -1.406790 \\
\hline $\mathrm{H}$ & 5.374252 & 0.286608 & -0.533200 \\
\hline $\mathrm{O}$ & -0.899361 & 0.971485 & 0.572937 \\
\hline $\mathrm{O}$ & -0.880782 & -0.283445 & -1.728769 \\
\hline $\mathrm{H}$ & -1.946190 & -0.468629 & -1.651879 \\
\hline $\mathrm{H}$ & 1.302664 & -5.319945 & 0.673214 \\
\hline $\mathrm{H}$ & -2.544598 & -6.288027 & -0.991375 \\
\hline $\mathrm{H}$ & -0.583346 & -2.620988 & -2.087537 \\
\hline$H$ & -0.402153 & 3.111536 & -0.627535 \\
\hline $\mathrm{H}$ & 0.010432 & 6.819638 & -2.751569 \\
\hline $\mathrm{H}$ & 3.462715 & 4.954369 & -1.000937 \\
\hline C & -4.221106 & -1.210951 & -1.096215 \\
\hline $\mathrm{O}$ & -3.327455 & -0.619314 & -1.841610 \\
\hline $\mathrm{H}$ & -5.029735 & -1.729843 & -1.639475 \\
\hline C & -3.790020 & -2.136351 & 0.049583 \\
\hline $\mathrm{O}$ & -4.517595 & -2.993864 & 0.513166 \\
\hline $\mathrm{O}$ & -2.570528 & -1.840860 & 0.508417 \\
\hline
\end{tabular}




$\begin{array}{llll}\mathrm{C} & -2.096821 & -2.629405 & 1.621226 \\ \mathrm{H} & -1.097848 & -2.252520 & 1.827172 \\ \mathrm{H} & -2.755867 & -2.490043 & 2.481313 \\ \mathrm{C} & -4.367349 & 0.796080 & 0.465187 \\ \mathrm{C} & -5.275347 & -0.027343 & -0.277331 \\ \mathrm{H} & -2.529752 & 1.632897 & 0.205822 \\ \mathrm{~N} & -3.488463 & 1.579441 & -0.192758 \\ \mathrm{C} & -3.508031 & 2.065822 & -1.521999 \\ \mathrm{O} & -2.508545 & 2.513916 & -2.031692 \\ \mathrm{O} & -4.733275 & 2.102449 & -2.060999 \\ \mathrm{C} & -4.760119 & 2.502967 & -3.446050 \\ \mathrm{H} & -5.814028 & 2.498010 & -3.723711 \\ \mathrm{H} & -4.195609 & 1.785619 & -4.045792 \\ \mathrm{H} & -4.331960 & 3.500480 & -3.562633 \\ \mathrm{H} & -6.017724 & -0.557647 & 0.311884 \\ \mathrm{H} & -5.706435 & 0.446442 & -1.149771 \\ \mathrm{C} & -4.194998 & 0.693437 & 1.921658 \\ \mathrm{C} & -4.797225 & -0.347008 & 2.660995 \\ \mathrm{C} & -3.464276 & 1.676289 & 2.622118 \\ \mathrm{C} & -4.654774 & -0.407027 & 4.043335 \\ \mathrm{H} & -5.344639 & -1.135961 & 2.159281 \\ \mathrm{C} & -3.330764 & 1.613439 & 4.004653 \\ \mathrm{H} & -3.015874 & 2.506290 & 2.088627 \\ \mathrm{C} & -3.923893 & 0.572139 & 4.720863 \\ \mathrm{H} & -5.116601 & -1.222293 & 4.592480 \\ \mathrm{H} & -2.765418 & 2.382049 & 4.522819 \\ \mathrm{H} & -3.821483 & 0.525930 & 5.801424 \\ \mathrm{H} & -2.068629 & -3.683639 & 1.341907\end{array}$

Catalyst (R)-1 TS Conformation 139

B3LYP/6-31G(d) Energy $=-2809.690781$

B3LYP-D3(BJ)/def2-TZVPP-IEF-PCM(DCM) Energy = -2810.985113

B3LYP-D3(BJ)/def2-TZVPP-IEF-PCM(DCM)//B3LYP/6-31G(d) Free Energy (Quasiharmonic) = 2810.343037

Frequencies (Top 3 out of 270)

1. $-653.6709 \mathrm{~cm}-1$

2. $\quad 6.9173 \mathrm{~cm}-1$

3. $12.0888 \mathrm{~cm}-1$

B3LYP/6-31G(d) Molecular Geometry in Cartesian Coordinates 


\begin{tabular}{|c|c|c|c|}
\hline C & 3.422677 & -1.241116 & -0.107886 \\
\hline C & 2.146168 & -1.721199 & 0.133256 \\
\hline C & 1.716680 & -3.033028 & -0.224035 \\
\hline C & 2.624983 & -3.838083 & -0.882221 \\
\hline $\mathrm{H}$ & 2.340712 & -4.853327 & -1.146732 \\
\hline C & 4.597135 & 2.732332 & 1.074863 \\
\hline C & 3.802862 & 0.117103 & 0.381851 \\
\hline C & 3.044534 & 1.226716 & 0.028547 \\
\hline C & 3.443596 & 2.563259 & 0.334289 \\
\hline $\mathrm{H}$ & 4.918523 & 3.739972 & 1.325172 \\
\hline $\mathrm{O}$ & 1.234896 & -0.883351 & 0.762404 \\
\hline$P$ & 0.569936 & 0.316660 & -0.143377 \\
\hline $\mathrm{O}$ & 1.906619 & 1.055694 & -0.745377 \\
\hline C & -2.226211 & -4.539397 & 0.629999 \\
\hline C & -1.657844 & -4.711060 & -0.633321 \\
\hline C & -0.384558 & -4.209582 & -0.904433 \\
\hline C & 0.347658 & -3.526697 & 0.080681 \\
\hline C & -0.234301 & -3.361280 & 1.349605 \\
\hline C & -1.506574 & -3.864980 & 1.620089 \\
\hline $\mathrm{H}$ & -2.210983 & -5.225635 & -1.414813 \\
\hline $\mathrm{H}$ & -1.937735 & -3.730071 & 2.608732 \\
\hline C & 1.416109 & 6.136726 & -0.948306 \\
\hline C & 0.708764 & 5.142636 & -0.268434 \\
\hline C & 1.339447 & 3.962113 & 0.126355 \\
\hline C & 2.703189 & 3.765244 & -0.143853 \\
\hline C & 3.405646 & 4.770998 & -0.827981 \\
\hline C & 2.768828 & 5.944890 & -1.230637 \\
\hline $\mathrm{H}$ & -0.342340 & 5.288065 & -0.031579 \\
\hline $\mathrm{H}$ & 3.330460 & 6.706788 & -1.765241 \\
\hline C & 4.942252 & 0.306216 & 1.238984 \\
\hline C & 5.346524 & 1.638671 & 1.571047 \\
\hline C & 6.476420 & 1.839676 & 2.409490 \\
\hline C & 7.172133 & 0.772274 & 2.927258 \\
\hline C & 6.754657 & -0.546558 & 2.630523 \\
\hline C & 5.672281 & -0.773674 & 1.809167 \\
\hline $\mathrm{H}$ & 6.772284 & 2.859641 & 2.643845 \\
\hline $\mathrm{H}$ & 8.030811 & 0.937365 & 3.572360 \\
\hline $\mathrm{H}$ & 7.288988 & -1.389744 & 3.060125 \\
\hline $\mathrm{H}$ & 5.359704 & -1.790517 & 1.602149 \\
\hline C & 4.330436 & -2.061992 & -0.863967 \\
\hline C & 3.919142 & -3.383196 & -1.236450 \\
\hline C & 4.810230 & -4.210871 & -1.972011 \\
\hline C & 6.047010 & -3.751054 & -2.360020 \\
\hline
\end{tabular}




\begin{tabular}{|c|c|c|c|}
\hline C & 6.439503 & -2.432654 & -2.030550 \\
\hline C & 5.606340 & -1.612033 & -1.302163 \\
\hline $\mathrm{H}$ & 4.486018 & -5.215187 & -2.234740 \\
\hline $\mathrm{H}$ & 6.716639 & -4.390476 & -2.928755 \\
\hline $\mathrm{H}$ & 7.406100 & -2.060656 & -2.359593 \\
\hline $\mathrm{H}$ & 5.919148 & -0.601463 & -1.067681 \\
\hline 0 & -0.267278 & 1.166334 & 0.753701 \\
\hline 0 & -0.081390 & -0.293377 & -1.395947 \\
\hline $\mathrm{H}$ & -1.269866 & -0.235190 & -1.486165 \\
\hline $\mathrm{H}$ & 0.314031 & -2.837719 & 2.125158 \\
\hline $\mathrm{H}$ & -3.225387 & -4.910656 & 0.836797 \\
\hline $\mathrm{H}$ & 0.040614 & -4.321452 & -1.897826 \\
\hline $\mathrm{H}$ & 4.457478 & 4.620929 & -1.056633 \\
\hline $\mathrm{H}$ & 0.918038 & 7.053543 & -1.253807 \\
\hline $\mathrm{H}$ & 0.775924 & 3.199502 & 0.654020 \\
\hline C & -3.023982 & -0.935297 & -0.637134 \\
\hline $\mathrm{O}$ & -2.483610 & -0.229652 & -1.573132 \\
\hline $\mathrm{H}$ & -2.397637 & -1.651565 & -0.090741 \\
\hline C & -4.406516 & -1.514257 & -0.901250 \\
\hline 0 & -4.888759 & -2.418474 & -0.248668 \\
\hline $\mathrm{O}$ & -5.031792 & -0.898765 & -1.916295 \\
\hline C & -6.336440 & -1.414107 & -2.232755 \\
\hline $\mathrm{H}$ & -6.273437 & -2.469591 & -2.509295 \\
\hline $\mathrm{H}$ & -7.008890 & -1.311942 & -1.375985 \\
\hline C & -4.420087 & 0.951321 & 0.679095 \\
\hline C & -3.355569 & 0.083369 & 0.987072 \\
\hline $\mathrm{H}$ & -6.446042 & 1.018011 & 0.365305 \\
\hline$N$ & -5.720662 & 0.565332 & 0.905389 \\
\hline C & -6.200691 & -0.419253 & 1.782971 \\
\hline $\mathrm{O}$ & -5.573465 & -0.999944 & 2.633576 \\
\hline $\mathrm{O}$ & -7.516429 & -0.575600 & 1.527410 \\
\hline C & -8.173147 & -1.565504 & 2.343573 \\
\hline $\mathrm{H}$ & -9.212960 & -1.561149 & 2.017637 \\
\hline $\mathrm{H}$ & -8.097493 & -1.298077 & 3.400022 \\
\hline $\mathrm{H}$ & -7.718380 & -2.545148 & 2.180933 \\
\hline $\mathrm{H}$ & -2.364490 & 0.519031 & 1.093789 \\
\hline $\mathrm{H}$ & -3.581096 & -0.721862 & 1.675698 \\
\hline C & -4.236842 & 2.215389 & -0.037254 \\
\hline C & -2.966115 & 2.554395 & -0.549711 \\
\hline C & -5.307983 & 3.116496 & -0.245198 \\
\hline C & -2.794827 & 3.724420 & -1.288163 \\
\hline $\mathrm{H}$ & -2.104625 & 1.929456 & -0.357143 \\
\hline C & -5.124651 & 4.284771 & -0.970655 \\
\hline $\mathrm{H}$ & -6.285152 & 2.937768 & 0.194642 \\
\hline
\end{tabular}




$\begin{array}{llll}\mathrm{C} & -3.867541 & 4.586150 & -1.507965 \\ \mathrm{H} & -1.809786 & 3.961596 & -1.677780 \\ \mathrm{H} & -5.957520 & 4.967603 & -1.110947 \\ \mathrm{H} & -3.726670 & 5.499897 & -2.078706 \\ \mathrm{H} & -6.687690 & -0.817649 & -3.074847\end{array}$

Catalyst (R)-1 TS Conformation 140

B3LYP/6-31G(d) Energy $=-2809.693505$

B3LYP-D3(BJ)/def2-TZVPP-IEF-PCM(DCM) Energy = -2810.984606

B3LYP-D3(BJ)/def2-TZVPP-IEF-PCM(DCM)//B3LYP/6-31G(d) Free Energy (Quasiharmonic) = 2810.343034

Frequencies (Top 3 out of 270)

1. $-424.9901 \mathrm{~cm}-1$

2. $\quad 7.9758 \mathrm{~cm}-1$

3. $\quad 9.7601 \mathrm{~cm}-1$

B3LYP/6-31G(d) Molecular Geometry in Cartesian Coordinates

$\begin{array}{llll}\text { C } & -3.785499 & 0.147868 & -0.255833 \\ \text { C } & -2.978142 & 1.269399 & -0.118473 \\ \text { C } & -3.419905 & 2.589229 & -0.437056 \\ \text { C } & -4.675592 & 2.717742 & -0.998368 \\ \text { H } & -5.034916 & 3.709948 & -1.257916 \\ \text { C } & -2.469821 & -3.724839 & 1.126263 \\ \text { C } & -3.344863 & -1.175042 & 0.279861 \\ \text { C } & -2.132100 & -1.709319 & -0.119458 \\ \text { C } & -1.668641 & -3.001023 & 0.264990 \\ \text { H } & -2.164669 & -4.725582 & 1.420579 \\ \text { O } & -1.718582 & 1.136876 & 0.457900 \\ \text { P } & -0.519833 & 0.297685 & -0.255881 \\ \text { O } & -1.322024 & -0.944409 & -0.954193 \\ \text { C } & -1.240003 & 6.197914 & 0.427657 \\ \text { C } & -2.553083 & 6.033203 & 0.870038 \\ \text { C } & -3.239531 & 4.851157 & 0.594221 \\ \text { C } & -2.626835 & 3.812233 & -0.126381 \\ \text { C } & -1.305741 & 3.988526 & -0.565984 \\ \text { C } & -0.622371 & 5.172579 & -0.290647 \\ \text { H } & -3.043139 & 6.821066 & 1.436439 \\ \text { H } & 0.399222 & 5.291716 & -0.641701 \\ \text { C } & 2.006368 & -4.750685 & -1.138355\end{array}$




\begin{tabular}{|c|c|c|c|}
\hline C & 1.662150 & -4.811060 & 0.212861 \\
\hline C & 0.479492 & -4.223326 & 0.662002 \\
\hline C & -0.384497 & -3.565712 & -0.229053 \\
\hline C & -0.023178 & -3.506221 & -1.586503 \\
\hline C & 1.158979 & -4.094490 & -2.034843 \\
\hline $\mathrm{H}$ & 2.316105 & -5.312330 & 0.921865 \\
\hline $\mathrm{H}$ & 1.413579 & -4.048185 & -3.090588 \\
\hline C & -4.128974 & -1.907917 & 1.238074 \\
\hline C & -3.680579 & -3.205931 & 1.647645 \\
\hline C & -4.451188 & -3.947729 & 2.583712 \\
\hline C & -5.601580 & -3.424454 & 3.126006 \\
\hline C & -6.024657 & -2.126671 & 2.755038 \\
\hline C & -5.310487 & -1.389737 & 1.835891 \\
\hline $\mathrm{H}$ & -4.102875 & -4.936344 & 2.873417 \\
\hline $\mathrm{H}$ & -6.178458 & -3.997647 & 3.846567 \\
\hline $\mathrm{H}$ & -6.919644 & -1.703801 & 3.203267 \\
\hline $\mathrm{H}$ & -5.643768 & -0.393451 & 1.570847 \\
\hline C & -5.047543 & 0.290328 & -0.931534 \\
\hline C & -5.493388 & 1.600951 & -1.295348 \\
\hline C & -6.740025 & 1.756607 & -1.959927 \\
\hline C & -7.512416 & 0.664550 & -2.279890 \\
\hline C & -7.059744 & -0.634926 & -1.951536 \\
\hline C & -5.862722 & -0.817437 & -1.294433 \\
\hline $\mathrm{H}$ & -7.065326 & 2.760719 & -2.221630 \\
\hline $\mathrm{H}$ & -8.460872 & 0.794736 & -2.793782 \\
\hline $\mathrm{H}$ & -7.658848 & -1.498986 & -2.226107 \\
\hline $\mathrm{H}$ & -5.526060 & -1.820997 & -1.061574 \\
\hline $\mathrm{O}$ & 0.477446 & -0.114083 & 0.774741 \\
\hline $\mathrm{O}$ & 0.010398 & 1.078392 & -1.485852 \\
\hline $\mathrm{H}$ & 1.131269 & 1.162626 & -1.518352 \\
\hline $\mathrm{H}$ & -0.818468 & 3.206047 & -1.136063 \\
\hline $\mathrm{H}$ & -0.701076 & 7.116811 & 0.643509 \\
\hline $\mathrm{H}$ & -4.255836 & 4.719108 & 0.955945 \\
\hline $\mathrm{H}$ & -0.677118 & -3.006594 & -2.292876 \\
\hline $\mathrm{H}$ & 2.925299 & -5.211525 & -1.491397 \\
\hline $\mathrm{H}$ & 0.228360 & -4.254120 & 1.718395 \\
\hline C & 2.981554 & 0.125110 & -1.930809 \\
\hline $\mathrm{O}$ & 2.436358 & 1.218405 & -1.567533 \\
\hline $\mathrm{H}$ & 2.370971 & -0.672865 & -2.374292 \\
\hline C & 4.382032 & 0.226368 & -2.515633 \\
\hline $\mathrm{O}$ & 5.084735 & 1.208272 & -2.463062 \\
\hline $\mathrm{O}$ & 4.727685 & -0.930367 & -3.124461 \\
\hline C & 6.040574 & -0.942848 & -3.710734 \\
\hline $\mathrm{H}$ & 6.130137 & -0.156116 & -4.464189 \\
\hline
\end{tabular}




$\begin{array}{llrl}\mathrm{H} & 6.802425 & -0.789104 & -2.941672 \\ \mathrm{C} & 3.965712 & -0.207530 & 0.596345 \\ \mathrm{C} & 3.385851 & -1.094792 & -0.320523 \\ \mathrm{H} & 2.119095 & 0.533753 & 1.034829 \\ \mathrm{~N} & 3.128220 & 0.631729 & 1.253843 \\ \mathrm{C} & 3.339659 & 1.493104 & 2.347348 \\ \mathrm{O} & 2.505582 & 2.297638 & 2.689274 \\ \mathrm{O} & 4.509812 & 1.275500 & 2.967155 \\ \mathrm{C} & 4.762394 & 2.137552 & 4.091187 \\ \mathrm{H} & 4.753535 & 3.184956 & 3.780008 \\ \mathrm{H} & 5.748960 & 1.850382 & 4.454626 \\ \mathrm{H} & 4.004621 & 1.985830 & 4.863513 \\ \mathrm{H} & 4.027968 & -1.840812 & -0.773514 \\ \mathrm{H} & 2.352044 & -1.381431 & -0.154731 \\ \mathrm{C} & 5.439150 & -0.074257 & 0.669888 \\ \mathrm{C} & 6.064968 & 1.170529 & 0.490559 \\ \mathrm{C} & 6.227598 & -1.223475 & 0.831255 \\ \mathrm{C} & 7.453677 & 1.258813 & 0.483374 \\ \mathrm{H} & 5.461347 & 2.052890 & 0.307977 \\ \mathrm{C} & 7.618608 & -1.127275 & 0.843692 \\ \mathrm{H} & 5.746177 & -2.186725 & 0.972847 \\ \mathrm{C} & 8.233420 & 0.113779 & 0.668647 \\ \mathrm{H} & 7.928927 & 2.222297 & 0.323353 \\ \mathrm{H} & 8.219833 & -2.020393 & 0.989174 \\ \mathrm{H} & 9.317535 & 0.188637 & 0.669494 \\ \mathrm{H} & 6.147868 & -1.926755 & -4.168092\end{array}$

Catalyst (R)-1 TS Conformation 141

B3LYP/6-31G(d) Energy $=-2809.692998$

B3LYP-D3(BJ)/def2-TZVPP-IEF-PCM(DCM) Energy = -2810.984073

B3LYP-D3(BJ)/def2-TZVPP-IEF-PCM(DCM)//B3LYP/6-31G(d) Free Energy (Quasiharmonic) = 2810.342994

Frequencies (Top 3 out of 270)

1. $-714.1716 \mathrm{~cm}-1$

2. $\quad 6.9684 \mathrm{~cm}-1$

3. $\quad 10.4312 \mathrm{~cm}-1$

B3LYP/6-31G(d) Molecular Geometry in Cartesian Coordinates

$\begin{array}{llll}\text { C } & -3.368251 & 1.086760 & 0.186765\end{array}$ 


\begin{tabular}{|c|c|c|c|}
\hline C & -2.103558 & 1.638076 & 0.301643 \\
\hline C & -1.841556 & 3.038043 & 0.250345 \\
\hline C & -2.921518 & 3.872996 & 0.042313 \\
\hline $\mathrm{H}$ & -2.764542 & 4.948324 & 0.022631 \\
\hline C & -4.031457 & -3.168060 & 0.322719 \\
\hline C & -3.547250 & -0.390391 & 0.318538 \\
\hline C & -2.829185 & -1.258796 & -0.493637 \\
\hline C & -3.086526 & -2.662042 & -0.549022 \\
\hline $\mathrm{H}$ & -4.241389 & -4.234257 & 0.309054 \\
\hline O & -1.026319 & 0.777644 & 0.484888 \\
\hline$P$ & -0.506574 & -0.072420 & -0.814425 \\
\hline O & -1.886382 & -0.740243 & -1.375164 \\
\hline C & 2.107048 & 4.707172 & 0.636230 \\
\hline C & 1.676098 & 3.723891 & 1.530521 \\
\hline C & 0.402010 & 3.170656 & 1.410269 \\
\hline C & -0.468233 & 3.591144 & 0.389197 \\
\hline C & -0.023184 & 4.581129 & -0.501603 \\
\hline C & 1.251050 & 5.135391 & -0.378937 \\
\hline $\mathrm{H}$ & 2.337699 & 3.384323 & 2.322607 \\
\hline $\mathrm{H}$ & 1.577713 & 5.892753 & -1.086831 \\
\hline C & -1.303437 & -5.392245 & -3.359955 \\
\hline C & -2.689347 & -5.317881 & -3.216782 \\
\hline C & -3.250197 & -4.416076 & -2.312969 \\
\hline C & -2.439128 & -3.571172 & -1.536650 \\
\hline C & -1.045927 & -3.652236 & -1.690313 \\
\hline C & -0.488445 & -4.557191 & -2.593423 \\
\hline $\mathrm{H}$ & -3.336619 & -5.956238 & -3.812772 \\
\hline $\mathrm{H}$ & 0.592636 & -4.610400 & -2.695973 \\
\hline C & -4.454919 & -0.947654 & 1.284757 \\
\hline C & -4.700476 & -2.357833 & 1.271348 \\
\hline C & -5.598346 & -2.920606 & 2.218584 \\
\hline C & -6.215651 & -2.133493 & 3.162429 \\
\hline C & -5.950119 & -0.744314 & 3.199827 \\
\hline C & -5.095821 & -0.166958 & 2.286299 \\
\hline $\mathrm{H}$ & -5.777999 & -3.992738 & 2.188346 \\
\hline $\mathrm{H}$ & -6.895425 & -2.575271 & 3.885908 \\
\hline $\mathrm{H}$ & -6.419452 & -0.126964 & 3.961095 \\
\hline $\mathrm{H}$ & -4.894339 & 0.896806 & 2.336618 \\
\hline C & -4.470264 & 1.963588 & -0.107720 \\
\hline C & -4.232754 & 3.375993 & -0.159567 \\
\hline C & -5.314227 & 4.256420 & -0.434531 \\
\hline C & -6.576585 & 3.771249 & -0.684363 \\
\hline C & -6.805349 & 2.375422 & -0.676271 \\
\hline C & -5.782476 & 1.496532 & -0.394676 \\
\hline
\end{tabular}




\begin{tabular}{|c|c|c|c|}
\hline $\mathrm{H}$ & -5.117996 & 5.325830 & -0.457268 \\
\hline $\mathrm{H}$ & -7.393861 & 4.453745 & -0.900918 \\
\hline $\mathrm{H}$ & -7.796975 & 1.991207 & -0.899707 \\
\hline $\mathrm{H}$ & -5.974038 & 0.430162 & -0.403198 \\
\hline 0 & 0.501891 & -1.061016 & -0.312690 \\
\hline $\mathrm{O}$ & -0.098760 & 0.878328 & -1.947188 \\
\hline $\mathrm{H}$ & 1.050937 & 1.140049 & -2.131173 \\
\hline $\mathrm{H}$ & -0.673488 & 4.895610 & -1.312877 \\
\hline $\mathrm{H}$ & 3.105018 & 5.126627 & 0.728179 \\
\hline $\mathrm{H}$ & 0.076121 & 2.410126 & 2.111741 \\
\hline $\mathrm{H}$ & -0.399592 & -3.015707 & -1.096134 \\
\hline $\mathrm{H}$ & -0.862603 & -6.092549 & -4.064806 \\
\hline $\mathrm{H}$ & -4.330655 & -4.348581 & -2.217774 \\
\hline C & 2.880918 & 1.210682 & -1.202828 \\
\hline 0 & 2.226739 & 1.430875 & -2.278911 \\
\hline $\mathrm{H}$ & 2.344495 & 1.110957 & -0.253153 \\
\hline C & 4.226865 & 1.879959 & -1.016027 \\
\hline 0 & 4.641590 & 2.197790 & 0.080402 \\
\hline 0 & 4.878251 & 2.069482 & -2.169302 \\
\hline C & 6.161482 & 2.710037 & -2.052521 \\
\hline $\mathrm{H}$ & 6.536916 & 2.793940 & -3.072225 \\
\hline $\mathrm{H}$ & 6.053787 & 3.698535 & -1.599089 \\
\hline C & 3.933818 & -1.119758 & -0.014726 \\
\hline C & 3.499947 & -0.740703 & -1.292170 \\
\hline $\mathrm{H}$ & 1.996836 & -1.264547 & 0.620385 \\
\hline $\mathrm{N}$ & 2.980047 & -1.414565 & 0.915925 \\
\hline C & 3.066643 & -2.102565 & 2.138368 \\
\hline $\mathrm{O}$ & 2.136987 & -2.145680 & 2.910395 \\
\hline 0 & 4.245009 & -2.723653 & 2.306234 \\
\hline C & 4.373659 & -3.442921 & 3.546125 \\
\hline $\mathrm{H}$ & 3.625622 & -4.237100 & 3.603299 \\
\hline $\mathrm{H}$ & 4.246708 & -2.767786 & 4.395876 \\
\hline $\mathrm{H}$ & 5.380514 & -3.859812 & 3.530677 \\
\hline $\mathrm{H}$ & 4.251658 & -0.622550 & -2.064057 \\
\hline $\mathrm{H}$ & 2.520324 & -1.081773 & -1.607986 \\
\hline C & 5.364732 & -1.021385 & 0.344616 \\
\hline C & 5.778716 & -0.349230 & 1.507867 \\
\hline C & 6.335238 & -1.532374 & -0.532217 \\
\hline C & 7.133388 & -0.199429 & 1.786140 \\
\hline $\mathrm{H}$ & 5.037456 & 0.090996 & 2.165887 \\
\hline C & 7.691366 & -1.397098 & -0.240142 \\
\hline $\mathrm{H}$ & 6.022491 & -2.061616 & -1.427252 \\
\hline C & 8.092635 & -0.728613 & 0.918124 \\
\hline $\mathrm{H}$ & 7.442341 & 0.338098 & 2.677961 \\
\hline
\end{tabular}




$\begin{array}{rrrr}\mathrm{H} & 8.432501 & -1.814014 & -0.916048 \\ \mathrm{H} & 9.149841 & -0.615798 & 1.142423 \\ \mathrm{H} & 6.835040 & 2.104944 & -1.439715\end{array}$

Catalyst (R)-1 TS Conformation 142

B3LYP/6-31G(d) Energy $=-2809.688931$

B3LYP-D3(BJ)/def2-TZVPP-IEF-PCM(DCM) Energy = -2810.984267

B3LYP-D3(BJ)/def2-TZVPP-IEF-PCM(DCM)//B3LYP/6-31G(d) Free Energy (Quasiharmonic) = 2810.342853

Frequencies (Top 3 out of 270)

1. $-629.1333 \mathrm{~cm}-1$

2. $\quad 7.9759 \mathrm{~cm}-1$

3. $\quad 13.9269 \mathrm{~cm}-1$

B3LYP/6-31G(d) Molecular Geometry in Cartesian Coordinates

$\begin{array}{llll}\text { C } & 2.996489 & -0.892167 & -0.348533 \\ \text { C } & 1.878129 & -1.545623 & 0.147640 \\ \text { C } & 1.571214 & -2.903254 & -0.156920 \\ \text { C } & 2.401433 & -3.568508 & -1.035788 \\ \text { H } & 2.200356 & -4.610698 & -1.271154 \\ \text { C } & 3.707001 & 3.226250 & 0.714192 \\ \text { C } & 3.273964 & 0.514619 & 0.069336 \\ \text { C } & 2.295587 & 1.479118 & -0.121055 \\ \text { C } & 2.490678 & 2.861952 & 0.169403 \\ \text { H } & 3.899454 & 4.274999 & 0.924962 \\ \text { O } & 1.015062 & -0.865226 & 0.994729 \\ \text { P } & 0.030844 & 0.286132 & 0.355561 \\ \text { O } & 1.075660 & 1.079207 & -0.644609 \\ \text { C } & -1.687165 & -5.098488 & 1.597532 \\ \text { C } & -0.772666 & -4.427340 & 2.414336 \\ \text { C } & 0.260485 & -3.680412 & 1.850555 \\ \text { C } & 0.412107 & -3.607079 & 0.456336 \\ \text { C } & -0.517980 & -4.275251 & -0.354945 \\ \text { C } & -1.562102 & -5.010948 & 0.209372 \\ \text { H } & -0.858188 & -4.491699 & 3.495962 \\ \text { H } & -2.273245 & -5.519010 & -0.436735 \\ \text { C } & -0.459503 & 5.902553 & -0.583686 \\ \text { C } & -0.197029 & 4.930455 & -1.551304 \\ \text { C } & 0.742510 & 3.929697 & -1.309641\end{array}$




\begin{tabular}{|c|c|c|c|}
\hline C & 1.443659 & 3.884737 & -0.092844 \\
\hline C & 1.169370 & 4.867124 & 0.872189 \\
\hline C & 0.227434 & 5.866242 & 0.630197 \\
\hline $\mathrm{H}$ & -0.724096 & 4.951067 & -2.501831 \\
\hline $\mathrm{H}$ & 0.023097 & 6.610098 & 1.395934 \\
\hline C & 4.505798 & 0.897941 & 0.700843 \\
\hline C & 4.718289 & 2.280200 & 1.012781 \\
\hline C & 5.936782 & 2.676314 & 1.628191 \\
\hline C & 6.899846 & 1.750047 & 1.954574 \\
\hline C & 6.677101 & 0.379864 & 1.681414 \\
\hline C & 5.513785 & -0.034693 & 1.070811 \\
\hline $\mathrm{H}$ & 6.086971 & 3.730863 & 1.847583 \\
\hline $\mathrm{H}$ & 7.824408 & 2.064641 & 2.430947 \\
\hline $\mathrm{H}$ & 7.428876 & -0.353725 & 1.960206 \\
\hline $\mathrm{H}$ & 5.354151 & -1.089186 & 0.876789 \\
\hline C & 3.819851 & -1.576351 & -1.308641 \\
\hline C & 3.514521 & -2.936070 & -1.642653 \\
\hline C & 4.325049 & -3.623550 & -2.586122 \\
\hline C & 5.379372 & -2.994136 & -3.205667 \\
\hline C & 5.660359 & -1.640081 & -2.907652 \\
\hline C & 4.903617 & -0.950987 & -1.985587 \\
\hline $\mathrm{H}$ & 4.085783 & -4.659039 & -2.817202 \\
\hline $\mathrm{H}$ & 5.988470 & -3.527943 & -3.930039 \\
\hline $\mathrm{H}$ & 6.478644 & -1.136051 & -3.414879 \\
\hline $\mathrm{H}$ & 5.126500 & 0.088785 & -1.777325 \\
\hline 0 & -0.556929 & 1.120484 & 1.428961 \\
\hline 0 & -0.907696 & -0.448554 & -0.638888 \\
\hline $\mathrm{H}$ & -1.756711 & 0.179537 & -1.119426 \\
\hline $\mathrm{H}$ & -0.426071 & -4.201562 & -1.434520 \\
\hline $\mathrm{H}$ & -2.486941 & -5.688014 & 2.039015 \\
\hline $\mathrm{H}$ & 0.964927 & -3.160114 & 2.491389 \\
\hline $\mathrm{H}$ & 1.681955 & 4.828419 & 1.829261 \\
\hline $\mathrm{H}$ & -1.198011 & 6.677331 & -0.771770 \\
\hline $\mathrm{H}$ & 0.938798 & 3.180622 & -2.068918 \\
\hline C & -3.305629 & 1.551381 & -0.705004 \\
\hline 0 & -2.738714 & 0.811733 & -1.595635 \\
\hline $\mathrm{H}$ & -2.744762 & 1.805645 & 0.201994 \\
\hline C & -4.156476 & 2.731901 & -1.163243 \\
\hline $\mathrm{O}$ & -4.480948 & 3.630832 & -0.415297 \\
\hline 0 & -4.498149 & 2.646264 & -2.454842 \\
\hline C & -5.303375 & 3.731061 & -2.947246 \\
\hline $\mathrm{H}$ & -6.243490 & 3.793604 & -2.392396 \\
\hline $\mathrm{H}$ & -4.768360 & 4.679131 & -2.848420 \\
\hline C & -4.121270 & -0.508809 & 0.645746 \\
\hline
\end{tabular}




$\begin{array}{lrrr}\mathrm{C} & -4.816152 & 0.590221 & 0.116988 \\ \mathrm{H} & -2.851330 & -2.014688 & 0.103491 \\ \mathrm{~N} & -3.692768 & -1.512395 & -0.168721 \\ \mathrm{C} & -4.156177 & -1.811003 & -1.465648 \\ \mathrm{O} & -5.173420 & -1.401319 & -1.973123 \\ \mathrm{O} & -3.303753 & -2.688850 & -2.015415 \\ \mathrm{C} & -3.619557 & -3.070469 & -3.366885 \\ \mathrm{H} & -4.597239 & -3.556906 & -3.407917 \\ \mathrm{H} & -2.830246 & -3.761832 & -3.660484 \\ \mathrm{H} & -3.621976 & -2.190325 & -4.013710 \\ \mathrm{H} & -5.262026 & 1.275515 & 0.828816 \\ \mathrm{H} & -5.376166 & 0.427261 & -0.794825 \\ \mathrm{C} & -3.686834 & -0.570664 & 2.049182 \\ \mathrm{C} & -3.458216 & -1.814362 & 2.667631 \\ \mathrm{C} & -3.527999 & 0.605484 & 2.807110 \\ \mathrm{C} & -3.092170 & -1.877533 & 4.008876 \\ \mathrm{H} & -3.595493 & -2.735725 & 2.110705 \\ \mathrm{C} & -3.149000 & 0.535079 & 4.142013 \\ \mathrm{H} & -3.662494 & 1.576621 & 2.344788 \\ \mathrm{C} & -2.934799 & -0.704757 & 4.748735 \\ \mathrm{H} & -2.932249 & -2.844882 & 4.475394 \\ \mathrm{H} & -3.006335 & 1.451531 & 4.706060 \\ \mathrm{H} & -2.641644 & -0.755528 & 5.793592 \\ \mathrm{H} & -5.489495 & 3.501239 & -3.996276\end{array}$

Catalyst (R)-1 TS Conformation 143

B3LYP/6-31G(d) Energy $=-2809.692143$

B3LYP-D3(BJ)/def2-TZVPP-IEF-PCM(DCM) Energy = -2810.985455

B3LYP-D3(BJ)/def2-TZVPP-IEF-PCM(DCM)//B3LYP/6-31G(d) Free Energy (Quasiharmonic) = 2810.34283

Frequencies (Top 3 out of 270)

1. $-341.8256 \mathrm{~cm}-1$

2. $\quad 8.4707 \mathrm{~cm}-1$

3. $\quad 9.9582 \mathrm{~cm}-1$

B3LYP/6-31G(d) Molecular Geometry in Cartesian Coordinates

$\begin{array}{llll}\text { C } & 2.821264 & -1.334049 & -0.130873 \\ \text { C } & 1.545191 & -1.800347 & 0.138029 \\ C & 1.162303 & -3.161730 & -0.055712\end{array}$




\begin{tabular}{|c|c|c|c|}
\hline C & 2.073103 & -3.990615 & -0.682578 \\
\hline $\mathrm{H}$ & 1.805864 & -5.029755 & -0.855401 \\
\hline C & 4.143260 & 2.592805 & 1.036313 \\
\hline C & 3.245248 & 0.013411 & 0.349579 \\
\hline C & 2.552457 & 1.151107 & -0.030755 \\
\hline C & 3.023660 & 2.472062 & 0.235280 \\
\hline $\mathrm{H}$ & 4.546188 & 3.582262 & 1.233909 \\
\hline 0 & 0.634827 & -0.934683 & 0.731425 \\
\hline$P$ & 0.042113 & 0.335517 & -0.114048 \\
\hline O & 1.379502 & 1.010291 & -0.767278 \\
\hline C & -2.413155 & -4.912572 & 1.577369 \\
\hline C & -1.162888 & -5.485135 & 1.810638 \\
\hline C & -0.018228 & -4.897542 & 1.274300 \\
\hline C & -0.098743 & -3.731055 & 0.493696 \\
\hline C & -1.362120 & -3.166277 & 0.259817 \\
\hline C & -2.504866 & -3.756155 & 0.800822 \\
\hline $\mathrm{H}$ & -1.074541 & -6.382076 & 2.418254 \\
\hline $\mathrm{H}$ & -3.475083 & -3.310249 & 0.605955 \\
\hline C & 1.692736 & 6.111727 & -1.625045 \\
\hline C & 1.786536 & 4.935629 & -2.373644 \\
\hline C & 2.152132 & 3.736962 & -1.762394 \\
\hline C & 2.445630 & 3.692817 & -0.388242 \\
\hline C & 2.319041 & 4.876197 & 0.358337 \\
\hline C & 1.948244 & 6.074117 & -0.252825 \\
\hline $\mathrm{H}$ & 1.582753 & 4.951700 & -3.441140 \\
\hline $\mathrm{H}$ & 1.860412 & 6.977851 & 0.344591 \\
\hline C & 4.366710 & 0.155880 & 1.240175 \\
\hline C & 4.807802 & 1.472001 & 1.588794 \\
\hline C & 5.914083 & 1.630925 & 2.466420 \\
\hline C & 6.548763 & 0.537655 & 3.008098 \\
\hline C & 6.094917 & -0.764256 & 2.692213 \\
\hline C & 5.036583 & -0.951174 & 1.830061 \\
\hline $\mathrm{H}$ & 6.241841 & 2.638710 & 2.710224 \\
\hline $\mathrm{H}$ & 7.388615 & 0.670030 & 3.684563 \\
\hline $\mathrm{H}$ & 6.582549 & -1.626871 & 3.138165 \\
\hline $\mathrm{H}$ & 4.695796 & -1.955704 & 1.609234 \\
\hline C & 3.726951 & -2.182778 & -0.856563 \\
\hline C & 3.332141 & -3.529579 & -1.138488 \\
\hline C & 4.212968 & -4.378623 & -1.861527 \\
\hline C & 5.429714 & -3.918694 & -2.308934 \\
\hline C & 5.812593 & -2.581086 & -2.052504 \\
\hline C & 4.986292 & -1.736913 & -1.343382 \\
\hline $\mathrm{H}$ & 3.899943 & -5.400675 & -2.061710 \\
\hline $\mathrm{H}$ & 6.093082 & -4.574932 & -2.865607 \\
\hline
\end{tabular}




\begin{tabular}{|c|c|c|c|}
\hline $\mathrm{H}$ & 6.765666 & -2.213753 & -2.423361 \\
\hline $\mathrm{H}$ & 5.289564 & -0.711702 & -1.164313 \\
\hline $\mathrm{O}$ & -0.885037 & -0.041488 & -1.223554 \\
\hline $\mathrm{O}$ & -0.488317 & 1.258460 & 1.009011 \\
\hline $\mathrm{H}$ & -1.571864 & 1.360856 & 1.152588 \\
\hline $\mathrm{H}$ & -1.449240 & -2.278147 & -0.357294 \\
\hline $\mathrm{H}$ & -3.308668 & -5.361999 & 1.998956 \\
\hline $\mathrm{H}$ & 0.956869 & -5.330226 & 1.480435 \\
\hline $\mathrm{H}$ & 2.511512 & 4.853096 & 1.427245 \\
\hline $\mathrm{H}$ & 1.414301 & 7.046136 & -2.105209 \\
\hline $\mathrm{H}$ & 2.235966 & 2.833449 & -2.356693 \\
\hline C & -3.788277 & 0.728846 & 1.474731 \\
\hline 0 & -2.875265 & 1.631613 & 1.432234 \\
\hline $\mathrm{H}$ & -3.511877 & -0.323888 & 1.308503 \\
\hline C & -4.829629 & 0.859364 & 2.592877 \\
\hline 0 & -5.061261 & 1.858260 & 3.226544 \\
\hline 0 & -5.462629 & -0.327340 & 2.771486 \\
\hline C & -6.456870 & -0.336002 & 3.810420 \\
\hline $\mathrm{H}$ & -6.003206 & -0.089954 & 4.773896 \\
\hline $\mathrm{H}$ & -7.245267 & 0.390180 & 3.593932 \\
\hline C & -4.202380 & 0.698758 & -1.034051 \\
\hline C & -5.045966 & 1.028619 & 0.048024 \\
\hline $\mathrm{H}$ & -2.289068 & 1.084708 & -1.624172 \\
\hline$N$ & -3.190156 & 1.530400 & -1.378744 \\
\hline C & -3.142758 & 2.912004 & -1.085615 \\
\hline 0 & -4.100674 & 3.616809 & -0.865983 \\
\hline 0 & -1.873507 & 3.318330 & -1.175785 \\
\hline C & -1.659400 & 4.696125 & -0.809363 \\
\hline $\mathrm{H}$ & -2.013334 & 4.863539 & 0.210230 \\
\hline $\mathrm{H}$ & -2.195520 & 5.356310 & -1.495913 \\
\hline $\mathrm{H}$ & -0.585947 & 4.846946 & -0.880726 \\
\hline $\mathrm{H}$ & -5.919644 & 0.402933 & 0.193923 \\
\hline $\mathrm{H}$ & -5.208185 & 2.081131 & 0.242914 \\
\hline C & -4.253135 & -0.607392 & -1.713066 \\
\hline C & -3.632247 & -0.780799 & -2.965039 \\
\hline C & -4.975363 & -1.686651 & -1.165843 \\
\hline C & -3.729472 & -1.991317 & -3.644646 \\
\hline $\mathrm{H}$ & -3.092477 & 0.042318 & -3.419336 \\
\hline C & -5.068790 & -2.894784 & -1.848967 \\
\hline $\mathrm{H}$ & -5.445280 & -1.590722 & -0.192620 \\
\hline C & -4.447800 & -3.051754 & -3.090809 \\
\hline $\mathrm{H}$ & -3.246093 & -2.103531 & -4.610514 \\
\hline $\mathrm{H}$ & -5.622812 & -3.718779 & -1.408877 \\
\hline $\mathrm{H}$ & -4.524508 & -3.995899 & -3.622478 \\
\hline
\end{tabular}


$\begin{array}{llll}H & -6.859415 & -1.349277 & 3.824184\end{array}$

Catalyst (R)-1 TS Conformation 144

B3LYP/6-31G(d) Energy $=-2809.693896$

B3LYP-D3(BJ)/def2-TZVPP-IEF-PCM(DCM) Energy = -2810.986834

B3LYP-D3(BJ)/def2-TZVPP-IEF-PCM(DCM)//B3LYP/6-31G(d) Free Energy (Quasiharmonic) = 2810.34279

Frequencies (Top 3 out of 270)

1. $-227.0724 \mathrm{~cm}-1$

2. $\quad 10.7295 \mathrm{~cm}-1$

3. $16.3459 \mathrm{~cm}-1$

B3LYP/6-31G(d) Molecular Geometry in Cartesian Coordinates

\begin{tabular}{|c|c|c|c|}
\hline C & 3.234003 & 0.338841 & 0.227963 \\
\hline C & 2.319215 & 1.335877 & -0.070284 \\
\hline C & 2.503254 & 2.699525 & 0.307553 \\
\hline C & 3.618935 & 2.996047 & 1.068229 \\
\hline $\mathrm{H}$ & 3.805717 & 4.029422 & 1.347272 \\
\hline C & 2.610633 & -3.726130 & -1.041131 \\
\hline C & 3.017503 & -1.042957 & -0.289631 \\
\hline C & 1.843694 & -1.713629 & 0.016415 \\
\hline C & 1.632265 & -3.088937 & -0.301112 \\
\hline $\mathrm{H}$ & 2.494886 & -4.781426 & -1.272979 \\
\hline $\mathrm{O}$ & 1.190295 & 0.994241 & -0.808493 \\
\hline$P$ & -0.001970 & 0.125426 & -0.099384 \\
\hline $\mathrm{O}$ & 0.845523 & -1.030805 & 0.703998 \\
\hline C & 0.080968 & 6.032582 & -0.914871 \\
\hline C & 0.405438 & 5.032217 & -1.833409 \\
\hline C & 1.147217 & 3.921136 & -1.435932 \\
\hline C & 1.592377 & 3.797859 & -0.110370 \\
\hline C & 1.240692 & 4.800051 & 0.810168 \\
\hline C & 0.491733 & 5.906141 & 0.413785 \\
\hline $\mathrm{H}$ & 0.081463 & 5.112071 & -2.867301 \\
\hline $\mathrm{H}$ & 0.229278 & 6.668242 & 1.143009 \\
\hline C & -1.582839 & -5.552963 & 1.150068 \\
\hline C & -1.180009 & -5.629350 & -0.184388 \\
\hline C & -0.171165 & -4.791480 & -0.661674 \\
\hline C & 0.461680 & -3.866359 & 0.185025 \\
\hline C & 0.035423 & -3.788091 & 1.522372 \\
\hline
\end{tabular}




\begin{tabular}{|c|c|c|c|}
\hline C & -0.972506 & -4.626125 & 1.998442 \\
\hline $\mathrm{H}$ & -1.646827 & -6.345322 & -0.856517 \\
\hline $\mathrm{H}$ & -1.269852 & -4.566951 & 3.042446 \\
\hline C & 3.992031 & -1.696659 & -1.118612 \\
\hline C & 3.773921 & -3.060192 & -1.495845 \\
\hline C & 4.731534 & -3.721607 & -2.311628 \\
\hline C & 5.848859 & -3.060972 & -2.766300 \\
\hline C & 6.050627 & -1.703270 & -2.422806 \\
\hline C & 5.149751 & -1.039722 & -1.619165 \\
\hline $\mathrm{H}$ & 4.555945 & -4.761025 & -2.578913 \\
\hline $\mathrm{H}$ & 6.570960 & -3.573730 & -3.395751 \\
\hline $\mathrm{H}$ & 6.922934 & -1.176830 & -2.800577 \\
\hline $\mathrm{H}$ & 5.313389 & 0.003025 & -1.372970 \\
\hline C & 4.350895 & 0.650743 & 1.076880 \\
\hline C & 4.538496 & 2.007530 & 1.492706 \\
\hline C & 5.642114 & 2.337427 & 2.325454 \\
\hline C & 6.514325 & 1.367352 & 2.760942 \\
\hline C & 6.311061 & 0.019627 & 2.381549 \\
\hline C & 5.260595 & -0.329457 & 1.561387 \\
\hline $\mathrm{H}$ & 5.775632 & 3.375261 & 2.621568 \\
\hline $\mathrm{H}$ & 7.350687 & 1.629639 & 3.403066 \\
\hline $\mathrm{H}$ & 6.987670 & -0.749417 & 2.744451 \\
\hline $\mathrm{H}$ & 5.114582 & -1.368247 & 1.289257 \\
\hline $\mathrm{O}$ & -0.903594 & -0.414371 & -1.157276 \\
\hline $\mathrm{O}$ & -0.586271 & 0.939039 & 1.079367 \\
\hline $\mathrm{H}$ & -1.574065 & 1.385680 & 1.011685 \\
\hline $\mathrm{H}$ & 1.547426 & 4.700002 & 1.847460 \\
\hline $\mathrm{H}$ & -0.488804 & 6.903465 & -1.230294 \\
\hline $\mathrm{H}$ & 1.388596 & 3.150572 & -2.159041 \\
\hline $\mathrm{H}$ & 0.513242 & -3.083344 & 2.194397 \\
\hline $\mathrm{H}$ & -2.361934 & -6.210362 & 1.526766 \\
\hline $\mathrm{H}$ & 0.130457 & -4.849793 & -1.703682 \\
\hline C & -3.890303 & 1.851832 & 1.422208 \\
\hline $\mathrm{O}$ & -2.723148 & 2.164706 & 0.946783 \\
\hline $\mathrm{H}$ & -4.471391 & 2.675632 & 1.867728 \\
\hline C & -4.056477 & 0.632960 & 2.337151 \\
\hline $\mathrm{O}$ & -4.974746 & 0.510989 & 3.121936 \\
\hline $\mathrm{O}$ & -3.092664 & -0.278453 & 2.145038 \\
\hline C & -3.179853 & -1.462186 & 2.956974 \\
\hline $\mathrm{H}$ & -2.358996 & -2.098586 & 2.629689 \\
\hline $\mathrm{H}$ & -3.075542 & -1.201815 & 4.013578 \\
\hline C & -4.410714 & 0.587831 & -0.744034 \\
\hline C & -5.107182 & 1.505619 & 0.098862 \\
\hline $\mathrm{H}$ & -2.594398 & 0.307340 & -1.665246 \\
\hline
\end{tabular}




$\begin{array}{llll}\mathrm{N} & -3.336753 & 0.989155 & -1.448581 \\ \mathrm{C} & -2.889739 & 2.291648 & -1.799515 \\ \mathrm{O} & -1.782966 & 2.464088 & -2.246731 \\ \mathrm{O} & -3.847339 & 3.222483 & -1.709903 \\ \mathrm{C} & -3.405905 & 4.562644 & -2.005273 \\ \mathrm{H} & -2.609753 & 4.851656 & -1.316779 \\ \mathrm{H} & -4.288484 & 5.188164 & -1.870291 \\ \mathrm{H} & -3.043179 & 4.622836 & -3.033898 \\ \mathrm{H} & -5.988900 & 1.113243 & 0.596056 \\ \mathrm{H} & -5.232747 & 2.508815 & -0.283798 \\ \mathrm{C} & -4.717914 & -0.856551 & -0.705919 \\ \mathrm{C} & -6.061226 & -1.252280 & -0.546558 \\ \mathrm{C} & -3.730827 & -1.850422 & -0.858792 \\ \mathrm{C} & -6.410392 & -2.599550 & -0.545060 \\ \mathrm{H} & -6.840283 & -0.502679 & -0.459379 \\ \mathrm{C} & -4.087581 & -3.196137 & -0.840613 \\ \mathrm{H} & -2.681538 & -1.584439 & -0.946706 \\ \mathrm{C} & -5.423217 & -3.575766 & -0.688547 \\ \mathrm{H} & -7.452853 & -2.884151 & -0.435214 \\ \mathrm{H} & -3.311035 & -3.948629 & -0.932732 \\ \mathrm{H} & -5.693566 & -4.628313 & -0.681457 \\ \mathrm{H} & -4.140955 & -1.959007 & 2.802185\end{array}$

Catalyst (R)-1 TS Conformation 145

B3LYP/6-31G(d) Energy = -2809.694142

B3LYP-D3(BJ)/def2-TZVPP-IEF-PCM(DCM) Energy = -2810.984099

B3LYP-D3(BJ)/def2-TZVPP-IEF-PCM(DCM)//B3LYP/6-31G(d) Free Energy (Quasiharmonic) = 2810.342789

Frequencies (Top 3 out of 270)

1. $-680.1230 \mathrm{~cm}-1$

2. $\quad 6.4253 \mathrm{~cm}-1$

3. $\quad 7.7825 \mathrm{~cm}-1$

B3LYP/6-31G(d) Molecular Geometry in Cartesian Coordinates

$\begin{array}{llll}\text { C } & -3.417774 & 0.917896 & -0.018856 \\ \text { C } & -2.240930 & 1.653790 & 0.013197 \\ \text { C } & -2.217857 & 3.081211 & 0.015015 \\ \text { C } & -3.425929 & 3.738495 & -0.102969 \\ \text { H } & -3.435603 & 4.825359 & -0.104487\end{array}$




\begin{tabular}{|c|c|c|c|}
\hline C & -3.385067 & -3.376653 & 0.420720 \\
\hline C & -3.391660 & -0.561153 & 0.190978 \\
\hline C & -2.596184 & -1.365080 & -0.609127 \\
\hline C & -2.587496 & -2.789423 & -0.542314 \\
\hline $\mathrm{H}$ & -3.429820 & -4.460779 & 0.481975 \\
\hline $\mathrm{O}$ & -1.030257 & 0.989348 & 0.162802 \\
\hline$P$ & -0.437641 & -0.000736 & -1.004651 \\
\hline 0 & -1.774233 & -0.752506 & -1.551942 \\
\hline C & 1.357778 & 5.420680 & 0.534243 \\
\hline C & 1.271353 & 4.508724 & -0.520361 \\
\hline C & 0.119745 & 3.739706 & -0.689460 \\
\hline C & -0.961971 & 3.864276 & 0.194748 \\
\hline C & -0.865854 & 4.787715 & 1.247761 \\
\hline C & 0.284364 & 5.559911 & 1.415877 \\
\hline $\mathrm{H}$ & 2.095825 & 4.385534 & -1.217505 \\
\hline $\mathrm{H}$ & 0.341974 & 6.266723 & 2.239877 \\
\hline C & -0.311858 & -5.326752 & -3.169804 \\
\hline C & -1.005892 & -4.231352 & -3.687484 \\
\hline C & -1.727567 & -3.389490 & -2.843029 \\
\hline C & -1.772514 & -3.630138 & -1.459320 \\
\hline C & -1.066258 & -4.732831 & -0.951372 \\
\hline C & -0.343608 & -5.573509 & -1.796776 \\
\hline $\mathrm{H}$ & -0.988648 & -4.030625 & -4.755457 \\
\hline $\mathrm{H}$ & 0.200674 & -6.417512 & -1.380673 \\
\hline C & -4.149910 & -1.186007 & 1.242905 \\
\hline C & -4.149073 & -2.615508 & 1.338705 \\
\hline C & -4.905176 & -3.247806 & 2.363015 \\
\hline C & -5.608750 & -2.507003 & 3.283591 \\
\hline C & -5.577005 & -1.094373 & 3.218082 \\
\hline C & -4.870229 & -0.451925 & 2.225196 \\
\hline $\mathrm{H}$ & -4.904819 & -4.334283 & 2.410935 \\
\hline $\mathrm{H}$ & -6.177496 & -3.001176 & 4.066508 \\
\hline $\mathrm{H}$ & -6.112116 & -0.508899 & 3.960833 \\
\hline $\mathrm{H}$ & -4.850080 & 0.630916 & 2.196491 \\
\hline C & -4.654531 & 1.614799 & -0.252750 \\
\hline C & -4.649194 & 3.046401 & -0.279092 \\
\hline C & -5.866154 & 3.746604 & -0.499039 \\
\hline C & -7.043800 & 3.068865 & -0.712409 \\
\hline C & -7.047067 & 1.654242 & -0.721308 \\
\hline C & -5.886655 & 0.946887 & -0.495610 \\
\hline $\mathrm{H}$ & -5.843560 & 4.833784 & -0.508474 \\
\hline $\mathrm{H}$ & -7.967111 & 3.614428 & -0.886825 \\
\hline $\mathrm{H}$ & -7.973009 & 1.119394 & -0.914810 \\
\hline $\mathrm{H}$ & -5.905377 & -0.136607 & -0.517459 \\
\hline
\end{tabular}




\begin{tabular}{|c|c|c|c|}
\hline $\mathrm{O}$ & 0.575907 & -0.878598 & -0.349914 \\
\hline $\mathrm{O}$ & -0.002510 & 0.817061 & -2.237825 \\
\hline $\mathrm{H}$ & 1.108442 & 1.167315 & -2.267981 \\
\hline $\mathrm{H}$ & -1.693280 & 4.887166 & 1.945542 \\
\hline $\mathrm{H}$ & 2.254108 & 6.021512 & 0.666024 \\
\hline $\mathrm{H}$ & 0.048662 & 3.053458 & -1.523828 \\
\hline $\mathrm{H}$ & -1.069419 & -4.916482 & 0.119508 \\
\hline $\mathrm{H}$ & 0.252109 & -5.979604 & -3.830813 \\
\hline $\mathrm{H}$ & -2.265043 & -2.544205 & -3.258268 \\
\hline C & 3.121896 & 0.793739 & -1.739850 \\
\hline 0 & 2.284789 & 1.603753 & -2.270652 \\
\hline $\mathrm{H}$ & 2.868190 & -0.269733 & -1.671494 \\
\hline C & 4.587695 & 1.100591 & -2.004913 \\
\hline $\mathrm{O}$ & 5.060130 & 2.207527 & -2.111417 \\
\hline O & 5.282479 & -0.049984 & -2.117662 \\
\hline C & 6.686807 & 0.108953 & -2.396476 \\
\hline $\mathrm{H}$ & 7.180311 & 0.631214 & -1.573576 \\
\hline $\mathrm{H}$ & 7.079725 & -0.902359 & -2.500273 \\
\hline C & 3.689805 & 0.081149 & 0.935473 \\
\hline C & 3.095630 & 1.158072 & 0.261356 \\
\hline $\mathrm{H}$ & 2.000731 & -1.043371 & 0.664480 \\
\hline $\mathrm{N}$ & 2.930294 & -1.036929 & 1.125159 \\
\hline C & 3.136278 & -2.055527 & 2.067220 \\
\hline $\mathrm{O}$ & 4.037494 & -2.130411 & 2.871393 \\
\hline 0 & 2.130505 & -2.938768 & 1.940706 \\
\hline C & 2.154756 & -4.024988 & 2.880011 \\
\hline $\mathrm{H}$ & 2.090716 & -3.647505 & 3.903757 \\
\hline $\mathrm{H}$ & 3.072473 & -4.608165 & 2.768311 \\
\hline $\mathrm{H}$ & 1.281450 & -4.630302 & 2.638414 \\
\hline $\mathrm{H}$ & 3.637622 & 2.095960 & 0.230925 \\
\hline $\mathrm{H}$ & 2.016351 & 1.239894 & 0.312618 \\
\hline C & 5.124893 & 0.108541 & 1.281643 \\
\hline C & 5.688147 & 1.288840 & 1.796085 \\
\hline C & 5.961918 & -0.994347 & 1.033081 \\
\hline C & 7.051879 & 1.359652 & 2.073197 \\
\hline $\mathrm{H}$ & 5.049194 & 2.140263 & 2.007298 \\
\hline C & 7.325314 & -0.913578 & 1.292479 \\
\hline $\mathrm{H}$ & 5.544343 & -1.902680 & 0.614242 \\
\hline C & 7.873305 & 0.260565 & 1.819065 \\
\hline $\mathrm{H}$ & 7.470589 & 2.272395 & 2.486612 \\
\hline $\mathrm{H}$ & 7.963036 & -1.769127 & 1.089292 \\
\hline $\mathrm{H}$ & 8.937606 & 0.316127 & 2.030749 \\
\hline $\mathrm{H}$ & 6.825769 & 0.674982 & -3.320670 \\
\hline
\end{tabular}


Catalyst (R)-1 TS Conformation 146

B3LYP/6-31G(d) Energy $=-2809.690931$

B3LYP-D3(BJ)/def2-TZVPP-IEF-PCM(DCM) Energy = -2810.985542

B3LYP-D3(BJ)/def2-TZVPP-IEF-PCM(DCM)//B3LYP/6-31G(d) Free Energy (Quasiharmonic) = 2810.342758

Frequencies (Top 3 out of 270)

1. $-518.0802 \mathrm{~cm}-1$

2. $\quad 14.2234 \mathrm{~cm}-1$

3. $\quad 19.2400 \mathrm{~cm}-1$

B3LYP/6-31G(d) Molecular Geometry in Cartesian Coordinates

$\begin{array}{llll}\text { C } & 3.262621 & 0.284648 & 0.097516 \\ \text { C } & 2.400933 & 1.313477 & -0.257555 \\ \text { C } & 2.748368 & 2.693411 & -0.134985 \\ \text { C } & 3.964716 & 2.992892 & 0.446763 \\ \text { H } & 4.252705 & 4.035091 & 0.557699 \\ \text { C } & 2.306013 & -3.841962 & -0.709477 \\ \text { C } & 2.927553 & -1.129647 & -0.248498 \\ \text { C } & 1.725845 & -1.685846 & 0.164024 \\ \text { C } & 1.390194 & -3.061434 & -0.028799 \\ \text { H } & 2.109517 & -4.902810 & -0.837555 \\ \text { O } & 1.188041 & 0.991759 & -0.847729 \\ \text { P } & 0.007064 & 0.302904 & 0.067790 \\ \text { O } & 0.824822 & -0.885459 & 0.847805 \\ \text { C } & 0.359246 & 5.952663 & -1.620237 \\ \text { C } & -0.209393 & 5.009361 & -0.761934 \\ \text { C } & 0.545729 & 3.939045 & -0.283018 \\ \text { C } & 1.890864 & 3.794692 & -0.658021 \\ \text { C } & 2.454390 & 4.750648 & -1.519006 \\ \text { C } & 1.696420 & 5.819993 & -1.996532 \\ \text { H } & -1.250052 & 5.101260 & -0.459316 \\ \text { H } & 2.150055 & 6.544080 & -2.668541 \\ \text { C } & -2.174524 & -4.987792 & 1.451878 \\ \text { C } & -1.650722 & -5.318005 & 0.200496 \\ \text { C } & -0.516541 & -4.664091 & -0.279211 \\ \text { C } & 0.132189 & -3.672384 & 0.480875 \\ \text { C } & -0.412506 & -3.343065 & 1.735199 \\ \text { C } & -1.551941 & -3.994932 & 2.212763 \\ \text { H } & -2.128894 & -6.081570 & -0.407673\end{array}$




\begin{tabular}{|c|c|c|c|}
\hline $\mathrm{H}$ & -1.939844 & -3.722695 & 3.190506 \\
\hline C & 3.819604 & -1.933422 & -1.041011 \\
\hline C & 3.501617 & -3.313521 & -1.251491 \\
\hline C & 4.384065 & -4.127826 & -2.012406 \\
\hline C & 5.520538 & -3.600832 & -2.579538 \\
\hline C & 5.815602 & -2.227656 & -2.410456 \\
\hline C & 4.991239 & -1.417547 & -1.660691 \\
\hline $\mathrm{H}$ & 4.132477 & -5.177003 & -2.149317 \\
\hline $\mathrm{H}$ & 6.183859 & -4.230167 & -3.166523 \\
\hline $\mathrm{H}$ & 6.699534 & -1.805416 & -2.880810 \\
\hline $\mathrm{H}$ & 5.228426 & -0.366181 & -1.550521 \\
\hline C & 4.476829 & 0.614260 & 0.794568 \\
\hline C & 4.828684 & 1.992776 & 0.955842 \\
\hline C & 6.028524 & 2.333241 & 1.637295 \\
\hline C & 6.843466 & 1.359167 & 2.165380 \\
\hline C & 6.482047 & -0.002594 & 2.037397 \\
\hline C & 5.333131 & -0.365337 & 1.369269 \\
\hline $\mathrm{H}$ & 6.283122 & 3.385250 & 1.743272 \\
\hline $\mathrm{H}$ & 7.755207 & 1.631369 & 2.690114 \\
\hline $\mathrm{H}$ & 7.113529 & -0.770582 & 2.476034 \\
\hline $\mathrm{H}$ & 5.065407 & -1.412675 & 1.290741 \\
\hline $\mathrm{O}$ & -0.565589 & 1.218450 & 1.100795 \\
\hline 0 & -0.943701 & -0.329134 & -0.957913 \\
\hline $\mathrm{H}$ & -1.948191 & 0.367495 & -1.356317 \\
\hline $\mathrm{H}$ & 3.490147 & 4.640949 & -1.829475 \\
\hline $\mathrm{H}$ & -0.234091 & 6.783024 & -1.994728 \\
\hline $\mathrm{H}$ & 0.098369 & 3.218300 & 0.392934 \\
\hline $\mathrm{H}$ & 0.050653 & -2.577488 & 2.344552 \\
\hline $\mathrm{H}$ & -3.057144 & -5.497774 & 1.828971 \\
\hline $\mathrm{H}$ & -0.132796 & -4.913309 & -1.264439 \\
\hline C & -3.214759 & 1.740318 & -0.665492 \\
\hline $\mathrm{O}$ & -2.855506 & 1.002724 & -1.645729 \\
\hline $\mathrm{H}$ & -2.548513 & 1.858444 & 0.191446 \\
\hline C & -4.127510 & 2.900760 & -1.012138 \\
\hline $\mathrm{O}$ & -4.819470 & 2.974588 & -1.998671 \\
\hline 0 & -4.041555 & 3.847326 & -0.053120 \\
\hline C & -4.861391 & 5.011197 & -0.269393 \\
\hline $\mathrm{H}$ & -4.669863 & 5.665013 & 0.581167 \\
\hline $\mathrm{H}$ & -4.584574 & 5.502194 & -1.205488 \\
\hline C & -4.244816 & -0.451493 & 0.689886 \\
\hline C & -4.746296 & 0.840134 & 0.582317 \\
\hline $\mathrm{H}$ & -3.060711 & -1.856078 & 1.571411 \\
\hline$N$ & -3.365767 & -0.888940 & 1.641072 \\
\hline C & -2.722435 & -0.245767 & 2.719008 \\
\hline
\end{tabular}




$\begin{array}{lrrr}\text { O } & -1.985472 & -0.867151 & 3.450678 \\ \text { O } & -3.048171 & 1.041179 & 2.830085 \\ \text { C } & -2.234983 & 1.788514 & 3.765927 \\ \text { H } & -1.211669 & 1.812390 & 3.389485 \\ \text { H } & -2.278019 & 1.327172 & 4.754184 \\ \text { H } & -2.671368 & 2.786971 & 3.781907 \\ \text { H } & -5.557505 & 0.973163 & -0.123340 \\ \text { H } & -4.681465 & 1.529649 & 1.411097 \\ \text { C } & -4.585334 & -1.452199 & -0.346599 \\ \text { C } & -3.593238 & -2.276860 & -0.907209 \\ \text { C } & -5.912908 & -1.568673 & -0.798041 \\ \text { C } & -3.931336 & -3.192923 & -1.902045 \\ \text { H } & -2.553206 & -2.159936 & -0.619258 \\ \text { C } & -6.243772 & -2.498039 & -1.778589 \\ \text { H } & -6.688295 & -0.950711 & -0.356015 \\ \text { C } & -5.251975 & -3.310130 & -2.335547 \\ \text { H } & -3.152577 & -3.808473 & -2.341007 \\ \text { H } & -7.274605 & -2.589284 & -2.108445 \\ \text { H } & -5.509657 & -4.028249 & -3.109176 \\ \text { H } & -5.917028 & 4.730019 & -0.312455\end{array}$

Catalyst (R)-1 TS Conformation 147

B3LYP/6-31G(d) Energy $=-2809.69458$

B3LYP-D3(BJ)/def2-TZVPP-IEF-PCM(DCM) Energy = -2810.986114

B3LYP-D3(BJ)/def2-TZVPP-IEF-PCM(DCM)//B3LYP/6-31G(d) Free Energy (Quasiharmonic) = 2810.342628

Frequencies (Top 3 out of 270)

1. $-270.7350 \mathrm{~cm}-1$

2. $\quad 8.9223 \mathrm{~cm}-1$

3. $\quad 10.8336 \mathrm{~cm}-1$

B3LYP/6-31G(d) Molecular Geometry in Cartesian Coordinates

$\begin{array}{llll}\text { C } & 2.958717 & -1.356184 & -0.273256 \\ \text { C } & 1.700398 & -1.745099 & 0.157945 \\ \text { C } & 1.179866 & -3.060517 & -0.014224 \\ \text { C } & 1.976417 & -3.973639 & -0.676629 \\ \text { H } & 1.621002 & -4.992845 & -0.804258 \\ \text { C } & 4.276864 & 2.694995 & 0.392360 \\ \text { C } & 3.433462 & 0.032076 & 0.005588\end{array}$




\begin{tabular}{|c|c|c|c|}
\hline C & 2.662261 & 1.113111 & -0.396050 \\
\hline C & 3.062963 & 2.472589 & -0.230936 \\
\hline $\mathrm{H}$ & 4.632380 & 3.715473 & 0.505894 \\
\hline $\mathrm{O}$ & 0.895655 & -0.805653 & 0.797439 \\
\hline$P$ & 0.187593 & 0.344547 & -0.125194 \\
\hline $\mathrm{O}$ & 1.445851 & 0.860282 & -1.025075 \\
\hline C & -2.699350 & -4.290006 & 1.387322 \\
\hline C & -2.290275 & -4.580397 & 0.084466 \\
\hline C & -1.036925 & -4.165159 & -0.364752 \\
\hline C & -0.168809 & -3.450414 & 0.476782 \\
\hline C & -0.594527 & -3.157444 & 1.782947 \\
\hline C & -1.845526 & -3.577470 & 2.233003 \\
\hline $\mathrm{H}$ & -2.949234 & -5.125204 & -0.586469 \\
\hline $\mathrm{H}$ & -2.150631 & -3.349098 & 3.250865 \\
\hline C & 0.750260 & 5.868757 & -1.511310 \\
\hline C & 0.851111 & 4.747223 & -2.335810 \\
\hline C & 1.584685 & 3.634586 & -1.928442 \\
\hline C & 2.231737 & 3.620915 & -0.681533 \\
\hline C & 2.115688 & 4.754033 & 0.142068 \\
\hline C & 1.385472 & 5.867819 & -0.268723 \\
\hline $\mathrm{H}$ & 0.351232 & 4.732175 & -3.300016 \\
\hline $\mathrm{H}$ & 1.304665 & 6.730418 & 0.387996 \\
\hline C & 4.650024 & 0.286666 & 0.727043 \\
\hline C & 5.076912 & 1.642896 & 0.899249 \\
\hline C & 6.287930 & 1.910476 & 1.594252 \\
\hline C & 7.036221 & 0.889440 & 2.131655 \\
\hline C & 6.595211 & -0.448457 & 1.999838 \\
\hline C & 5.435987 & -0.742176 & 1.315961 \\
\hline $\mathrm{H}$ & 6.604122 & 2.945195 & 1.703877 \\
\hline $\mathrm{H}$ & 7.956509 & 1.106707 & 2.666929 \\
\hline $\mathrm{H}$ & 7.174072 & -1.252517 & 2.446272 \\
\hline $\mathrm{H}$ & 5.107998 & -1.771709 & 1.232192 \\
\hline C & 3.744538 & -2.296470 & -1.025301 \\
\hline C & 3.242526 & -3.626032 & -1.208273 \\
\hline C & 4.014511 & -4.569435 & -1.939307 \\
\hline C & 5.219066 & -4.215354 & -2.500577 \\
\hline C & 5.697776 & -2.891871 & -2.357357 \\
\hline C & 4.982092 & -1.958977 & -1.639564 \\
\hline $\mathrm{H}$ & 3.623991 & -5.577449 & -2.057704 \\
\hline $\mathrm{H}$ & 5.796885 & -4.943008 & -3.063786 \\
\hline $\mathrm{H}$ & 6.637140 & -2.606014 & -2.822840 \\
\hline $\mathrm{H}$ & 5.358610 & -0.946929 & -1.548672 \\
\hline O & -0.430042 & 1.359202 & 0.770281 \\
\hline $\mathrm{O}$ & -0.679005 & -0.380968 & -1.192551 \\
\hline
\end{tabular}




\begin{tabular}{|c|c|c|c|}
\hline $\mathrm{H}$ & -1.725407 & -0.232387 & -1.258897 \\
\hline $\mathrm{H}$ & 0.059080 & -2.603200 & 2.447721 \\
\hline $\mathrm{H}$ & -3.674581 & -4.615809 & 1.739758 \\
\hline $\mathrm{H}$ & -0.732439 & -4.373279 & -1.386450 \\
\hline $\mathrm{H}$ & 2.583267 & 4.748723 & 1.122761 \\
\hline $\mathrm{H}$ & 0.173824 & 6.732930 & -1.831070 \\
\hline $\mathrm{H}$ & 1.654662 & 2.771812 & -2.580561 \\
\hline$C$ & -3.982920 & -0.724464 & -0.777726 \\
\hline 0 & -3.135390 & -0.131430 & -1.529914 \\
\hline $\mathrm{H}$ & -3.629360 & -1.410310 & 0.006189 \\
\hline C & -5.257998 & -1.221077 & -1.460934 \\
\hline 0 & -5.700535 & -0.802627 & -2.505320 \\
\hline $\mathrm{O}$ & -5.836212 & -2.197362 & -0.724096 \\
\hline$C$ & -7.051503 & -2.737511 & -1.270280 \\
\hline $\mathrm{H}$ & -7.806900 & -1.953848 & -1.375168 \\
\hline $\mathrm{H}$ & -6.864783 & -3.182733 & -2.250992 \\
\hline C & -3.825282 & 1.276403 & 0.899496 \\
\hline C & -4.925879 & 0.590378 & 0.349718 \\
\hline $\mathrm{H}$ & -2.027159 & 2.100755 & 0.443815 \\
\hline $\mathrm{N}$ & -3.019781 & 2.063719 & 0.149359 \\
\hline C & -3.157856 & 2.508285 & -1.191001 \\
\hline $\mathrm{O}$ & -2.194335 & 2.864943 & -1.825002 \\
\hline $\mathrm{O}$ & -4.434431 & 2.573791 & -1.589404 \\
\hline C & -4.620026 & 2.704915 & -3.014886 \\
\hline $\mathrm{H}$ & -4.359472 & 1.755359 & -3.487458 \\
\hline $\mathrm{H}$ & -4.003201 & 3.515337 & -3.405949 \\
\hline $\mathrm{H}$ & -5.680091 & 2.920177 & -3.148142 \\
\hline $\mathrm{H}$ & -5.562854 & 0.060344 & 1.049924 \\
\hline $\mathrm{H}$ & -5.448016 & 1.074863 & -0.462741 \\
\hline C & -3.382778 & 1.042344 & 2.290547 \\
\hline C & -3.709427 & -0.149301 & 2.964330 \\
\hline C & -2.657747 & 2.030408 & 2.981138 \\
\hline C & -3.317803 & -0.344614 & 4.285103 \\
\hline $\mathrm{H}$ & -4.243550 & -0.939227 & 2.447240 \\
\hline C & -2.277403 & 1.834758 & 4.305603 \\
\hline $\mathrm{H}$ & -2.409782 & 2.963499 & 2.486947 \\
\hline C & -2.604232 & 0.647503 & 4.961910 \\
\hline $\mathrm{H}$ & -3.569141 & -1.274565 & 4.787366 \\
\hline $\mathrm{H}$ & -1.723645 & 2.611822 & 4.824015 \\
\hline $\mathrm{H}$ & -2.304375 & 0.494738 & 5.994910 \\
\hline $\mathrm{H}$ & -7.381262 & -3.496880 & -0.560671 \\
\hline
\end{tabular}

Catalyst (R)-1 TS Conformation 148 
B3LYP/6-31G(d) Energy $=-2809.696056$

B3LYP-D3(BJ)/def2-TZVPP-IEF-PCM(DCM) Energy $=-2810.983887$

B3LYP-D3(BJ)/def2-TZVPP-IEF-PCM(DCM)//B3LYP/6-31G(d) Free Energy (Quasiharmonic) = 2810.342563

Frequencies (Top 3 out of 270)

1. $-644.9210 \mathrm{~cm}-1$

2. $\quad 6.2204 \mathrm{~cm}-1$

3. $\quad 8.7131 \mathrm{~cm}-1$

B3LYP/6-31G(d) Molecular Geometry in Cartesian Coordinates

$\begin{array}{llll}\text { C } & -3.437014 & -0.938059 & -0.002524 \\ \text { C } & -2.257136 & -1.666561 & -0.070298 \\ \text { C } & -2.226698 & -3.093459 & -0.099912 \\ \text { C } & -3.428722 & -3.759981 & 0.027616 \\ \text { H } & -3.432715 & -4.846728 & 0.008596 \\ \text { C } & -3.431448 & 3.363999 & -0.359852 \\ \text { C } & -3.422117 & 0.544830 & -0.184008 \\ \text { C } & -2.615026 & 1.336910 & 0.616283 \\ \text { C } & -2.613052 & 2.762261 & 0.576394 \\ \text { H } & -3.481380 & 4.448873 & -0.399891 \\ \text { O } & -1.052615 & -0.993568 & -0.228920 \\ \text { P } & -0.443386 & -0.025037 & 0.947317 \\ \text { O } & -1.773552 & 0.709809 & 1.532118 \\ \text { C } & 1.350147 & -5.404193 & -0.728977 \\ \text { C } & 1.280193 & -4.508537 & 0.340595 \\ \text { C } & 0.129442 & -3.747490 & 0.545369 \\ \text { C } & -0.970089 & -3.865445 & -0.317674 \\ \text { C } & -0.890801 & -4.772448 & -1.386221 \\ \text { C } & 0.259608 & -5.535579 & -1.590361 \\ \text { H } & 2.116893 & -4.394013 & 1.024653 \\ \text { H } & 0.303779 & -6.229202 & -2.426264 \\ \text { C } & -0.292338 & 5.258010 & 3.204175 \\ \text { C } & -0.353061 & 5.530305 & 1.836977 \\ \text { C } & -1.090434 & 4.703243 & 0.990871 \\ \text { C } & -1.782874 & 3.588937 & 1.492507 \\ \text { C } & -1.709271 & 3.322898 & 2.870314 \\ \text { C } & -0.972736 & 4.151128 & 3.715416 \\ \text { H } & 0.180479 & 6.383550 & 1.425888 \\ \text { H } & -0.932792 & 3.930565 & 4.778847 \\ \text { C } & -4.202997 & 1.186056 & -1.209151\end{array}$




\begin{tabular}{|c|c|c|c|}
\hline C & -4.209991 & 2.617112 & -1.277326 \\
\hline C & -4.988232 & 3.265492 & -2.274639 \\
\hline C & -5.706194 & 2.539307 & -3.195739 \\
\hline C & -5.667178 & 1.125849 & -3.158187 \\
\hline C & -4.938767 & 0.467687 & -2.191583 \\
\hline $\mathrm{H}$ & -4.993139 & 4.352660 & -2.301745 \\
\hline $\mathrm{H}$ & -6.291781 & 3.045834 & -3.958065 \\
\hline $\mathrm{H}$ & -6.213792 & 0.552317 & -3.901883 \\
\hline $\mathrm{H}$ & -4.913285 & -0.615403 & -2.184419 \\
\hline C & -4.665455 & -1.646434 & 0.240620 \\
\hline C & -4.652130 & -3.078252 & 0.239447 \\
\hline C & -5.861085 & -3.789371 & 0.468339 \\
\hline C & -7.038103 & -3.122438 & 0.716354 \\
\hline C & -7.048625 & -1.708276 & 0.752435 \\
\hline C & -5.896360 & -0.990224 & 0.518946 \\
\hline $\mathrm{H}$ & -5.832641 & -4.876398 & 0.456449 \\
\hline $\mathrm{H}$ & -7.955157 & -3.676381 & 0.897236 \\
\hline $\mathrm{H}$ & -7.973619 & -1.182428 & 0.973177 \\
\hline $\mathrm{H}$ & -5.920333 & 0.092527 & 0.561758 \\
\hline $\mathrm{O}$ & 0.557700 & 0.868000 & 0.295810 \\
\hline $\mathrm{O}$ & 0.010049 & -0.869254 & 2.157786 \\
\hline $\mathrm{H}$ & 1.123409 & -1.186981 & 2.196469 \\
\hline $\mathrm{H}$ & -1.732049 & -4.866007 & -2.068037 \\
\hline $\mathrm{H}$ & 2.246378 & -5.998498 & -0.888539 \\
\hline $\mathrm{H}$ & 0.072675 & -3.073410 & 1.390796 \\
\hline $\mathrm{H}$ & -2.235945 & 2.468435 & 3.280619 \\
\hline $\mathrm{H}$ & 0.283898 & 5.899733 & 3.865428 \\
\hline $\mathrm{H}$ & -1.116074 & 4.906614 & -0.076160 \\
\hline C & 3.106003 & -0.691256 & 1.692469 \\
\hline $\mathrm{O}$ & 2.329826 & -1.568347 & 2.208958 \\
\hline $\mathrm{H}$ & 2.766944 & 0.347752 & 1.615655 \\
\hline C & 4.593079 & -0.780317 & 1.971265 \\
\hline $\mathrm{O}$ & 5.292778 & 0.208791 & 2.051664 \\
\hline $\mathrm{O}$ & 5.023589 & -2.040554 & 2.111030 \\
\hline C & 6.431159 & -2.181141 & 2.377268 \\
\hline $\mathrm{H}$ & 7.017424 & -1.769499 & 1.551376 \\
\hline $\mathrm{H}$ & 6.697839 & -1.662240 & 3.301309 \\
\hline C & 3.743200 & 0.080751 & -0.930011 \\
\hline C & 3.142075 & -1.028237 & -0.316734 \\
\hline $\mathrm{H}$ & 2.041467 & 1.177410 & -0.645682 \\
\hline$N$ & 2.985146 & 1.206042 & -1.070571 \\
\hline C & 3.230292 & 2.300294 & -1.912690 \\
\hline $\mathrm{O}$ & 4.170344 & 2.445788 & -2.660181 \\
\hline $\mathrm{O}$ & 2.212158 & 3.166140 & -1.763282 \\
\hline
\end{tabular}




$\begin{array}{llll}\mathrm{C} & 2.281822 & 4.333709 & -2.596561 \\ \mathrm{H} & 1.394895 & 4.915506 & -2.346832 \\ \mathrm{H} & 2.273245 & 4.051793 & -3.652589 \\ \mathrm{H} & 3.190209 & 4.902980 & -2.383399 \\ \mathrm{H} & 3.694773 & -1.960370 & -0.314089 \\ \mathrm{H} & 2.064414 & -1.116640 & -0.387313 \\ \mathrm{C} & 5.181594 & 0.059680 & -1.261969 \\ \mathrm{C} & 5.721226 & -1.075900 & -1.890557 \\ \mathrm{C} & 6.041569 & 1.105090 & -0.882142 \\ \mathrm{C} & 7.086608 & -1.154243 & -2.156170 \\ \mathrm{H} & 5.061564 & -1.880983 & -2.199588 \\ \mathrm{C} & 7.406765 & 1.012837 & -1.129181 \\ \mathrm{H} & 5.642662 & 1.968462 & -0.363431 \\ \mathrm{C} & 7.931921 & -0.111327 & -1.772451 \\ \mathrm{H} & 7.488317 & -2.027013 & -2.662910 \\ \mathrm{H} & 8.063653 & 1.819758 & -0.818172 \\ \mathrm{H} & 8.998102 & -0.173866 & -1.972932 \\ \mathrm{H} & 6.601643 & -3.253165 & 2.475629\end{array}$

Catalyst (R)-1 TS Conformation 149

B3LYP/6-31G(d) Energy = -2809.690156

B3LYP-D3(BJ)/def2-TZVPP-IEF-PCM(DCM) Energy = -2810.984454

B3LYP-D3(BJ)/def2-TZVPP-IEF-PCM(DCM)//B3LYP/6-31G(d) Free Energy (Quasiharmonic) = 2810.342558

Frequencies (Top 3 out of 270)

1. $-588.7234 \mathrm{~cm}-1$

2. $\quad 13.1307 \mathrm{~cm}-1$

3. $\quad 15.3462 \mathrm{~cm}-1$

B3LYP/6-31G(d) Molecular Geometry in Cartesian Coordinates

$\begin{array}{llll}\text { C } & -3.253119 & -0.583657 & -0.015842 \\ \text { C } & -2.266127 & -1.447474 & -0.466048 \\ \text { C } & -2.343868 & -2.865506 & -0.329270 \\ \text { C } & -3.443997 & -3.377516 & 0.331056 \\ \text { H } & -3.549787 & -4.454910 & 0.427972 \\ \text { C } & -2.831933 & 3.655322 & -0.684774 \\ \text { C } & -3.126066 & 0.878685 & -0.290791 \\ \text { C } & -1.980765 & 1.555145 & 0.106182 \\ \text { C } & -1.808635 & 2.962978 & -0.064993\end{array}$




\begin{tabular}{|c|c|c|c|}
\hline $\mathrm{H}$ & -2.750653 & 4.733128 & -0.797430 \\
\hline 0 & -1.154485 & -0.910487 & -1.098132 \\
\hline$P$ & -0.022306 & -0.163779 & -0.163133 \\
\hline 0 & -0.970948 & 0.842059 & 0.732456 \\
\hline C & 0.598343 & -5.595479 & -1.882795 \\
\hline C & 0.160629 & -4.523862 & -2.663863 \\
\hline C & -0.775388 & -3.620879 & -2.162399 \\
\hline C & -1.297622 & -3.775536 & -0.866782 \\
\hline C & -0.844661 & -4.854792 & -0.090237 \\
\hline C & 0.093281 & -5.756185 & -0.592078 \\
\hline $\mathrm{H}$ & 0.547062 & -4.389674 & -3.670900 \\
\hline $\mathrm{H}$ & 0.435061 & -6.579261 & 0.030260 \\
\hline C & 1.629093 & 5.204328 & 1.253060 \\
\hline C & 1.102670 & 4.194375 & 2.063096 \\
\hline C & 0.004741 & 3.443063 & 1.637890 \\
\hline C & -0.593906 & 3.691192 & 0.390726 \\
\hline C & -0.046143 & 4.703544 & -0.417751 \\
\hline C & 1.049789 & 5.453740 & 0.007728 \\
\hline $\mathrm{H}$ & 1.533569 & 3.988221 & 3.039213 \\
\hline $\mathrm{H}$ & 1.453860 & 6.229774 & -0.637331 \\
\hline C & -4.140576 & 1.600032 & -1.009389 \\
\hline C & -3.989502 & 3.013170 & -1.185302 \\
\hline C & -4.994159 & 3.743994 & -1.876176 \\
\hline C & -6.091974 & 3.108660 & -2.407486 \\
\hline C & -6.223637 & 1.706409 & -2.272724 \\
\hline C & -5.276643 & 0.972954 & -1.592273 \\
\hline $\mathrm{H}$ & -4.868556 & 4.818490 & -1.988073 \\
\hline $\mathrm{H}$ & -6.850164 & 3.676030 & -2.940310 \\
\hline $\mathrm{H}$ & -7.078296 & 1.201293 & -2.714711 \\
\hline $\mathrm{H}$ & -5.388889 & -0.101457 & -1.507211 \\
\hline C & -4.351109 & -1.126062 & 0.736269 \\
\hline C & -4.444002 & -2.547048 & 0.893764 \\
\hline C & -5.531405 & -3.098553 & 1.624377 \\
\hline C & -6.476213 & -2.287558 & 2.208723 \\
\hline C & -6.365123 & -0.882273 & 2.089070 \\
\hline C & -5.333253 & -0.317335 & 1.372068 \\
\hline $\mathrm{H}$ & -5.593550 & -4.179901 & 1.722779 \\
\hline $\mathrm{H}$ & -7.299075 & -2.720667 & 2.770917 \\
\hline $\mathrm{H}$ & -7.098213 & -0.241318 & 2.571506 \\
\hline $\mathrm{H}$ & -5.257113 & 0.761329 & 1.298614 \\
\hline $\mathrm{O}$ & 0.946267 & 0.529847 & -1.056942 \\
\hline $\mathrm{O}$ & 0.512133 & -1.143331 & 0.894687 \\
\hline $\mathrm{H}$ & 1.581139 & -1.757184 & 0.623424 \\
\hline $\mathrm{H}$ & -1.217367 & -4.971969 & 0.923531 \\
\hline
\end{tabular}




$\begin{array}{llll}\mathrm{H} & 1.330169 & -6.296486 & -2.275861 \\ \mathrm{H} & -1.108759 & -2.793434 & -2.778750 \\ \mathrm{H} & -0.475908 & 4.889667 & -1.397973 \\ \mathrm{H} & 2.481229 & 5.789765 & 1.588444 \\ \mathrm{H} & -0.383091 & 2.662696 & 2.280506 \\ \mathrm{C} & 3.373842 & -1.670811 & -0.339452 \\ \mathrm{O} & 2.578777 & -2.310345 & 0.436634 \\ \mathrm{H} & 2.979927 & -0.884249 & -0.987505 \\ \mathrm{C} & 4.518370 & -2.448045 & -0.964266 \\ \mathrm{O} & 5.006907 & -2.145650 & -2.031474 \\ \mathrm{O} & 4.904719 & -3.482114 & -0.204316 \\ \mathrm{C} & 5.963054 & -4.284154 & -0.757155 \\ \mathrm{H} & 6.147232 & -5.068020 & -0.022677 \\ \mathrm{H} & 6.861500 & -3.680446 & -0.912549 \\ \mathrm{C} & 4.027578 & 0.768516 & 0.806663 \\ \mathrm{C} & 4.650968 & -0.482348 & 0.815111 \\ \mathrm{H} & 2.640543 & 2.091123 & 1.490490 \\ \mathrm{~N} & 3.034174 & 1.166939 & 1.651364 \\ \mathrm{C} & 2.390793 & 0.536492 & 2.738358 \\ \mathrm{O} & 1.556757 & 1.127276 & 3.385622 \\ \mathrm{O} & 2.825498 & -0.702249 & 2.955452 \\ \mathrm{C} & 2.042519 & -1.463692 & 3.902395 \\ \mathrm{H} & 2.035816 & -0.966134 & 4.874181 \\ \mathrm{H} & 2.537177 & -2.432420 & 3.959965 \\ \mathrm{H} & 1.026410 & -1.567262 & 3.518106 \\ \mathrm{H} & 5.554543 & -0.537392 & 0.218888 \\ \mathrm{H} & 4.602575 & -1.113511 & 1.690381 \\ \mathrm{H} & 4.399611 & 1.772333 & -0.220689 \\ \mathrm{C} & 5.758271 & 2.031561 & -0.475854 \\ \mathrm{C} & 3.413379 & 2.471714 & -0.938946 \\ \mathrm{C} & 6.125284 & 2.984799 & -1.421162 \\ \mathrm{H} & 6.523669 & 1.509009 & 0.090018 \\ \mathrm{C} & 3.793055 & 3.412222 & -1.895520 \\ \mathrm{H} & 2.364419 & 2.219816 & -0.810215 \\ 5.142425 & 3.676122 & -2.134153 \\ \mathrm{H} & 3.177057 & 3.188852 & -1.600237 \\ \mathrm{H} & 5.430162 & 4.413744 & -2.878419 \\ \mathrm{H} & & -4.715535 & -1.712750\end{array}$

Catalyst (R)-1 TS Conformation 150

B3LYP/6-31G(d) Energy $=-2809.690148$ 
B3LYP-D3(BJ)/def2-TZVPP-IEF-PCM(DCM) Energy $=-2810.985196$

B3LYP-D3(BJ)/def2-TZVPP-IEF-PCM(DCM)//B3LYP/6-31G(d) Free Energy (Quasiharmonic) = 2810.342536

Frequencies (Top 3 out of 270)

1. $-492.9453 \mathrm{~cm}-1$

2. $\quad 13.2307 \mathrm{~cm}-1$

3. $\quad 15.8378 \mathrm{~cm}-1$

B3LYP/6-31G(d) Molecular Geometry in Cartesian Coordinates

$\begin{array}{lrrr}\text { C } & 3.264055 & 0.434751 & 0.001187 \\ \text { C } & 2.344237 & 1.386295 & -0.411686 \\ \text { C } & 2.548230 & 2.790964 & -0.265912 \\ \text { C } & 3.706706 & 3.197585 & 0.367436 \\ \text { H } & 3.909858 & 4.260392 & 0.469693 \\ \text { C } & 2.529008 & -3.766059 & -0.633058 \\ \text { C } & 3.009536 & -1.009544 & -0.283998 \\ \text { C } & 1.828865 & -1.604240 & 0.140619 \\ \text { C } & 1.568943 & -3.003456 & 0.005559 \\ \text { H } & 2.385568 & -4.839844 & -0.716831 \\ \text { O } & 1.174773 & 0.949107 & -1.015016 \\ \text { P } & 0.014907 & 0.312673 & -0.032428 \\ \text { O } & 0.878394 & -0.828361 & 0.780150 \\ \text { C } & -0.174564 & 5.788888 & -1.723794 \\ \text { C } & 0.384245 & 5.897098 & -0.449658 \\ \text { C } & 1.248126 & 4.909568 & 0.022195 \\ \text { C } & 1.573606 & 3.795397 & -0.768759 \\ \text { C } & 0.998764 & 3.695291 & -2.047295 \\ \text { C } & 0.135612 & 4.683234 & -2.518532 \\ \text { H } & 0.143430 & 6.748001 & 0.182697 \\ \text { H } & -0.292996 & 4.589308 & -3.512947 \\ \text { C } & -1.896611 & -5.046674 & 1.560686 \\ \text { C } & -1.361862 & -5.392400 & 0.318309 \\ \text { C } & -0.261164 & -4.701650 & -0.187708 \\ \text { C } & 0.340836 & -3.655609 & 0.536381 \\ \text { C } & -0.214752 & -3.310970 & 1.781735 \\ \text { C } & -1.319653 & -4.000820 & 2.285988 \\ \text { H } & -1.804985 & -6.197511 & -0.262221 \\ \text { H } & -1.715586 & -3.717142 & 3.257445 \\ \text { C } & 3.951488 & -1.801414 & -1.027251 \\ \text { C } & 3.704516 & -3.202970 & -1.184028 \\ \text { C } & 4.637274 & -4.002745 & -1.898850\end{array}$




\begin{tabular}{|c|c|c|c|}
\hline C & 5.756009 & -3.443876 & -2.470966 \\
\hline C & 5.982462 & -2.052268 & -2.353281 \\
\hline C & 5.107406 & -1.253984 & -1.649772 \\
\hline $\mathrm{H}$ & 4.439431 & -5.067788 & -1.995827 \\
\hline $\mathrm{H}$ & 6.458348 & -4.063135 & -3.022209 \\
\hline $\mathrm{H}$ & 6.853424 & -1.606966 & -2.826614 \\
\hline $\mathrm{H}$ & 5.291681 & -0.188532 & -1.577823 \\
\hline C & 4.424895 & 0.871290 & 0.728474 \\
\hline C & 4.644918 & 2.277130 & 0.895487 \\
\hline C & 5.795047 & 2.724864 & 1.600555 \\
\hline C & 6.681229 & 1.829152 & 2.152016 \\
\hline C & 6.445393 & 0.440215 & 2.023760 \\
\hline C & 5.349894 & -0.025832 & 1.330385 \\
\hline $\mathrm{H}$ & 5.953044 & 3.795685 & 1.706381 \\
\hline $\mathrm{H}$ & 7.553080 & 2.183469 & 2.695200 \\
\hline $\mathrm{H}$ & 7.132428 & -0.266902 & 2.480851 \\
\hline $\mathrm{H}$ & 5.179070 & -1.093043 & 1.250621 \\
\hline $\mathrm{O}$ & -0.537096 & 1.275593 & 0.962575 \\
\hline $\mathrm{O}$ & -0.948177 & -0.387041 & -1.001550 \\
\hline $\mathrm{H}$ & -1.990278 & 0.277953 & -1.379225 \\
\hline $\mathrm{H}$ & 1.234739 & 2.843359 & -2.675163 \\
\hline $\mathrm{H}$ & -0.847607 & 6.557842 & -2.094437 \\
\hline $\mathrm{H}$ & 1.661276 & 4.987729 & 1.023920 \\
\hline $\mathrm{H}$ & 0.212834 & -2.503648 & 2.362564 \\
\hline $\mathrm{H}$ & -2.752744 & -5.585348 & 1.958362 \\
\hline $\mathrm{H}$ & 0.132460 & -4.965181 & -1.165371 \\
\hline C & -3.284105 & 1.607759 & -0.662693 \\
\hline $\mathrm{O}$ & -2.922861 & 0.876370 & -1.647725 \\
\hline $\mathrm{H}$ & -2.594975 & 1.767828 & 0.169429 \\
\hline C & -4.258575 & 2.722241 & -0.993723 \\
\hline $\mathrm{O}$ & -4.913975 & 2.794398 & -2.005718 \\
\hline $\mathrm{O}$ & -4.272712 & 3.628196 & 0.004761 \\
\hline C & -5.137434 & 4.757835 & -0.206791 \\
\hline $\mathrm{H}$ & -4.836497 & 5.303266 & -1.104738 \\
\hline $\mathrm{H}$ & -6.174447 & 4.429975 & -0.319499 \\
\hline C & -4.160912 & -0.613137 & 0.758159 \\
\hline C & -4.732147 & 0.647584 & 0.635763 \\
\hline $\mathrm{H}$ & -2.879754 & -1.931069 & 1.638644 \\
\hline$N$ & -3.229863 & -0.978121 & 1.690505 \\
\hline C & -2.576327 & -0.267194 & 2.718791 \\
\hline $\mathrm{O}$ & -1.783819 & -0.827623 & 3.441905 \\
\hline $\mathrm{O}$ & -2.956036 & 1.006971 & 2.795375 \\
\hline C & -2.135606 & 1.831437 & 3.657981 \\
\hline $\mathrm{H}$ & -1.139531 & 1.898858 & 3.218873 \\
\hline
\end{tabular}




$\begin{array}{lrrr}\mathrm{H} & -2.096429 & 1.403382 & 4.661226 \\ \mathrm{H} & -2.627794 & 2.803680 & 3.666390 \\ \mathrm{H} & -5.569335 & 0.720881 & -0.048300 \\ \mathrm{H} & -4.680474 & 1.359883 & 1.445490 \\ \mathrm{C} & -4.484372 & -1.660107 & -0.237576 \\ \mathrm{C} & -3.470734 & -2.448246 & -0.811853 \\ \mathrm{C} & -5.819475 & -1.859660 & -0.634293 \\ \mathrm{C} & -3.795811 & -3.411019 & -1.766163 \\ \mathrm{H} & -2.428792 & -2.266360 & -0.567892 \\ \mathrm{C} & -6.136018 & -2.834586 & -1.574628 \\ \mathrm{H} & -6.609920 & -1.269930 & -0.180427 \\ \mathrm{C} & -5.123324 & -3.610539 & -2.145322 \\ \mathrm{H} & -3.001905 & -3.998521 & -2.216372 \\ \mathrm{H} & -7.171935 & -2.989818 & -1.862026 \\ \mathrm{H} & -5.370489 & -4.364866 & -2.887320 \\ \mathrm{H} & -5.023813 & 5.382505 & 0.679047\end{array}$

Catalyst (R)-1 TS Conformation 151

B3LYP/6-31G(d) Energy $=-2809.685908$

B3LYP-D3(BJ)/def2-TZVPP-IEF-PCM(DCM) Energy $=-2810.984623$

B3LYP-D3(BJ)/def2-TZVPP-IEF-PCM(DCM)//B3LYP/6-31G(d) Free Energy (Quasiharmonic) = 2810.342449

Frequencies (Top 3 out of 270)

1. $-565.8486 \mathrm{~cm}-1$

2. $12.0058 \mathrm{~cm}-1$

3. $\quad 18.9487 \mathrm{~cm}-1$

B3LYP/6-31G(d) Molecular Geometry in Cartesian Coordinates

$\begin{array}{llll}\text { C } & -2.848954 & -1.062367 & 0.108922 \\ \text { C } & -1.657363 & -1.692261 & -0.214225 \\ \text { C } & -1.371902 & -3.044626 & 0.134701 \\ \text { C } & -2.295723 & -3.705149 & 0.920467 \\ \text { H } & -2.116129 & -4.743813 & 1.185559 \\ \text { C } & -3.709215 & 2.915448 & -1.299209 \\ \text { C } & -3.136597 & 0.294388 & -0.438819 \\ \text { C } & -2.245919 & 1.337887 & -0.225197 \\ \text { C } & -2.520582 & 2.676196 & -0.638714 \\ \text { H } & -3.937021 & 3.928312 & -1.621254 \\ \text { O } & -0.690902 & -0.971195 & -0.913861\end{array}$




\begin{tabular}{|c|c|c|c|}
\hline$P$ & 0.123380 & 0.156761 & -0.042552 \\
\hline 0 & -1.096045 & 1.110216 & 0.512144 \\
\hline C & 1.956642 & -5.353914 & -1.297363 \\
\hline C & 1.665573 & -5.310350 & 0.067460 \\
\hline C & 0.609760 & -4.527024 & 0.533266 \\
\hline C & -0.169223 & -3.769768 & -0.355460 \\
\hline C & 0.151063 & -3.798275 & -1.721663 \\
\hline C & 1.198272 & -4.590418 & -2.188206 \\
\hline $\mathrm{H}$ & 2.257227 & -5.889991 & 0.771556 \\
\hline $\mathrm{H}$ & 1.416935 & -4.616271 & -3.252852 \\
\hline C & 0.016124 & 6.111744 & -0.114049 \\
\hline C & 0.480997 & 5.000728 & -0.823203 \\
\hline C & -0.311192 & 3.859318 & -0.955042 \\
\hline C & -1.597318 & 3.821805 & -0.394035 \\
\hline C & -2.055567 & 4.941581 & 0.317517 \\
\hline C & -1.254390 & 6.075277 & 0.463576 \\
\hline $\mathrm{H}$ & 1.463166 & 5.026462 & -1.289684 \\
\hline $\mathrm{H}$ & -1.627266 & 6.931427 & 1.020139 \\
\hline C & -4.316744 & 0.538359 & -1.223999 \\
\hline C & -4.612528 & 1.877850 & -1.632308 \\
\hline C & -5.785321 & 2.137886 & -2.391763 \\
\hline C & -6.627849 & 1.116412 & -2.763083 \\
\hline C & -6.319955 & -0.214344 & -2.394238 \\
\hline C & -5.198249 & -0.496009 & -1.645947 \\
\hline $\mathrm{H}$ & -5.995372 & 3.163746 & -2.685459 \\
\hline $\mathrm{H}$ & -7.518842 & 1.324791 & -3.349070 \\
\hline $\mathrm{H}$ & -6.971605 & -1.024617 & -2.710151 \\
\hline $\mathrm{H}$ & -4.973500 & -1.522798 & -1.382686 \\
\hline C & -3.768442 & -1.737671 & 0.984442 \\
\hline C & -3.475703 & -3.079013 & 1.391167 \\
\hline C & -4.374814 & -3.758919 & 2.256590 \\
\hline C & -5.505080 & -3.136696 & 2.733283 \\
\hline C & -5.778150 & -1.798844 & 2.363414 \\
\hline C & -4.935695 & -1.119059 & 1.511236 \\
\hline $\mathrm{H}$ & -4.142714 & -4.781561 & 2.544769 \\
\hline $\mathrm{H}$ & -6.181574 & -3.663810 & 3.400566 \\
\hline $\mathrm{H}$ & -6.658884 & -1.300098 & 2.759111 \\
\hline $\mathrm{H}$ & -5.153773 & -0.090964 & 1.246716 \\
\hline $\mathrm{O}$ & 1.051854 & 0.909761 & -0.937316 \\
\hline $\mathrm{O}$ & 0.625160 & -0.472522 & 1.271400 \\
\hline $\mathrm{H}$ & 1.606973 & -0.992255 & 1.448177 \\
\hline $\mathrm{H}$ & -0.433374 & -3.208563 & -2.420428 \\
\hline $\mathrm{H}$ & 2.767420 & -5.978975 & -1.663832 \\
\hline $\mathrm{H}$ & 0.391028 & -4.487866 & 1.596543 \\
\hline
\end{tabular}




\begin{tabular}{|c|c|c|c|}
\hline $\mathrm{H}$ & -3.047658 & 4.917998 & 0.760700 \\
\hline $\mathrm{H}$ & 0.635883 & 6.999748 & -0.018282 \\
\hline $\mathrm{H}$ & 0.064189 & 2.997691 & -1.496674 \\
\hline C & 3.781264 & -1.618030 & 1.283779 \\
\hline 0 & 2.689593 & -1.550602 & 1.974340 \\
\hline $\mathrm{H}$ & 4.575714 & -2.252135 & 1.708180 \\
\hline C & 3.628029 & -1.855657 & -0.222217 \\
\hline 0 & 2.591180 & -1.717732 & -0.825586 \\
\hline 0 & 4.794025 & -2.233868 & -0.791604 \\
\hline C & 4.720339 & -2.496843 & -2.209469 \\
\hline $\mathrm{H}$ & 3.980789 & -3.275700 & -2.406705 \\
\hline $\mathrm{H}$ & 4.441784 & -1.587742 & -2.748711 \\
\hline$C$ & 3.941791 & 0.977217 & 0.906481 \\
\hline C & 4.821130 & -0.062722 & 1.318326 \\
\hline $\mathrm{H}$ & 2.751992 & 1.308405 & -0.735757 \\
\hline$N$ & 3.746210 & 1.256847 & -0.421531 \\
\hline C & 4.665511 & 1.171537 & -1.472163 \\
\hline 0 & 4.331881 & 1.110700 & -2.634223 \\
\hline 0 & 5.941410 & 1.250384 & -1.041384 \\
\hline C & 6.930500 & 1.225419 & -2.085495 \\
\hline $\mathrm{H}$ & 7.888094 & 1.327145 & -1.574764 \\
\hline $\mathrm{H}$ & 6.772212 & 2.053384 & -2.780260 \\
\hline $\mathrm{H}$ & 6.886027 & 0.281720 & -2.634799 \\
\hline $\mathrm{H}$ & 5.144776 & -0.018054 & 2.353596 \\
\hline $\mathrm{H}$ & 5.619922 & -0.323062 & 0.634430 \\
\hline C & 3.050491 & 1.631430 & 1.851827 \\
\hline C & 2.360395 & 2.809568 & 1.484686 \\
\hline C & 2.867916 & 1.118781 & 3.157618 \\
\hline C & 1.514557 & 3.444098 & 2.382507 \\
\hline $\mathrm{H}$ & 2.499541 & 3.231103 & 0.496712 \\
\hline C & 2.012446 & 1.756866 & 4.048111 \\
\hline $\mathrm{H}$ & 3.347891 & 0.197419 & 3.455725 \\
\hline C & 1.336843 & 2.916772 & 3.665776 \\
\hline $\mathrm{H}$ & 0.988974 & 4.343315 & 2.078392 \\
\hline $\mathrm{H}$ & 1.865117 & 1.340757 & 5.040131 \\
\hline $\mathrm{H}$ & 0.670187 & 3.412253 & 4.366331 \\
\hline & 5.719425 & -2.829551 & -2.493968 \\
\hline
\end{tabular}

Catalyst (R)-1 TS Conformation 152

B3LYP/6-31G(d) Energy $=-2809.690687$

B3LYP-D3(BJ)/def2-TZVPP-IEF-PCM(DCM) Energy = -2810.984906 
B3LYP-D3(BJ)/def2-TZVPP-IEF-PCM(DCM)//B3LYP/6-31G(d) Free Energy (Quasiharmonic) = 2810.342405

Frequencies (Top 3 out of 270)

1. $-540.6884 \mathrm{~cm}-1$

2. $\quad 12.4817 \mathrm{~cm}-1$

3. $\quad 17.7849 \mathrm{~cm}-1$

B3LYP/6-31G(d) Molecular Geometry in Cartesian Coordinates

$\begin{array}{llll}\text { C } & 2.998645 & -1.017476 & -0.353365 \\ \text { C } & 1.818159 & -1.604946 & 0.081935 \\ \text { C } & 1.533056 & -2.995897 & -0.085629 \\ \text { C } & 2.463149 & -3.754060 & -0.772126 \\ \text { H } & 2.300849 & -4.822773 & -0.882167 \\ \text { C } & 3.791204 & 3.151131 & 0.425387 \\ \text { C } & 3.288200 & 0.411302 & -0.026850 \\ \text { C } & 2.377747 & 1.393449 & -0.384379 \\ \text { C } & 2.611856 & 2.787966 & -0.195354 \\ \text { H } & 4.015514 & 4.205945 & 0.560982 \\ \text { O } & 0.895934 & -0.834463 & 0.766898 \\ \text { P } & 0.038326 & 0.354795 & 0.018813 \\ \text { O } & 1.185227 & 0.998994 & -0.972855 \\ \text { C } & -1.910895 & -5.036397 & 1.520715 \\ \mathrm{C} & -1.299689 & -4.015783 & 2.253999 \\ \mathrm{C} & -0.202009 & -3.326157 & 1.733898 \\ \mathrm{C} & 0.312019 & -3.645737 & 0.464061 \\ \mathrm{C} & -0.324289 & -4.666195 & -0.267114 \\ \mathrm{C} & -1.417792 & -5.356761 & 0.254622 \\ \mathrm{H} & -1.662464 & -3.752520 & 3.244022 \\ \mathrm{H} & -1.887893 & -6.141828 & -0.332101 \\ \mathrm{C} & -0.090298 & 5.877606 & -1.487950 \\ \mathrm{C} & 0.198126 & 4.804576 & -2.333844 \\ \mathrm{C} & 1.054315 & 3.787023 & -1.916186 \\ \mathrm{C} & 1.645089 & 3.825835 & -0.641835 \\ \mathrm{C} & 1.343382 & 4.908495 & 0.200240 \\ \mathrm{C} & 0.484716 & 5.924491 & -0.217427 \\ \mathrm{H} & -0.242785 & 4.758979 & -3.326411 \\ \mathrm{H} & 0.258344 & 6.748195 & 0.454696 \\ \mathrm{C} & 4.474002 & 0.800777 & 0.687029 \\ \mathrm{C} & 4.723774 & 2.195655 & 0.898624 \\ \mathrm{C} & 5.897635 & 2.597333 & 1.592152 \\ & 6.779538 & 1.666918 & 2.090485\end{array}$




\begin{tabular}{|c|c|c|c|}
\hline C & 6.515364 & 0.287905 & 1.918330 \\
\hline C & 5.395891 & -0.133518 & 1.234724 \\
\hline $\mathrm{H}$ & 6.077537 & 3.660697 & 1.732463 \\
\hline $\mathrm{H}$ & 7.669802 & 1.986083 & 2.625540 \\
\hline $\mathrm{H}$ & 7.199461 & -0.447225 & 2.333755 \\
\hline $\mathrm{H}$ & 5.203700 & -1.194030 & 1.121363 \\
\hline C & 3.907361 & -1.801390 & -1.144793 \\
\hline C & 3.632500 & -3.193109 & -1.338129 \\
\hline C & 4.532536 & -3.985209 & -2.101761 \\
\hline C & 5.645587 & -3.427022 & -2.685550 \\
\hline C & 5.899124 & -2.043754 & -2.530501 \\
\hline C & 5.056388 & -1.253751 & -1.779765 \\
\hline $\mathrm{H}$ & 4.314115 & -5.043360 & -2.226245 \\
\hline $\mathrm{H}$ & 6.322755 & -4.040088 & -3.273972 \\
\hline $\mathrm{H}$ & 6.765356 & -1.598224 & -3.012233 \\
\hline $\mathrm{H}$ & 5.260882 & -0.194307 & -1.679151 \\
\hline 0 & -0.467878 & 1.290669 & 1.061544 \\
\hline $\mathrm{O}$ & -0.965603 & -0.290214 & -0.949052 \\
\hline $\mathrm{H}$ & -1.999358 & 0.403565 & -1.259109 \\
\hline $\mathrm{H}$ & 0.036967 & -4.910076 & -1.262245 \\
\hline $\mathrm{H}$ & -2.761174 & -5.575122 & 1.930672 \\
\hline $\mathrm{H}$ & 0.252729 & -2.539019 & 2.321783 \\
\hline $\mathrm{H}$ & 1.769332 & 4.938144 & 1.199208 \\
\hline $\mathrm{H}$ & -0.761118 & 6.667989 & -1.814578 \\
\hline $\mathrm{H}$ & 1.272554 & 2.959586 & -2.582351 \\
\hline C & -3.284620 & 1.699916 & -0.443661 \\
\hline $\mathrm{O}$ & -2.939577 & 1.024534 & -1.476101 \\
\hline $\mathrm{H}$ & -2.577865 & 1.823229 & 0.379744 \\
\hline C & -4.233425 & 2.866753 & -0.632447 \\
\hline $\mathrm{O}$ & -4.344603 & 3.752967 & 0.187793 \\
\hline 0 & -4.908176 & 2.796001 & -1.787891 \\
\hline C & -5.799479 & 3.896281 & -2.042682 \\
\hline $\mathrm{H}$ & -6.556847 & 3.966370 & -1.257142 \\
\hline $\mathrm{H}$ & -5.241965 & 4.835382 & -2.084510 \\
\hline C & -4.125914 & -0.571724 & 0.899047 \\
\hline C & -4.696093 & 0.694471 & 0.823244 \\
\hline $\mathrm{H}$ & -2.823486 & -1.914488 & 1.706564 \\
\hline$N$ & -3.169483 & -0.962282 & 1.792332 \\
\hline C & -2.487422 & -0.277901 & 2.822569 \\
\hline $\mathrm{O}$ & -1.680214 & -0.859661 & 3.511457 \\
\hline $\mathrm{O}$ & -2.860836 & 0.993907 & 2.935963 \\
\hline C & -2.022095 & 1.800974 & 3.798544 \\
\hline $\mathrm{H}$ & -1.969173 & 1.355587 & 4.793625 \\
\hline $\mathrm{H}$ & -2.509691 & 2.774828 & 3.829427 \\
\hline
\end{tabular}




$\begin{array}{lrrr}\mathrm{H} & -1.033135 & 1.870446 & 3.344133 \\ \mathrm{H} & -5.552515 & 0.781973 & 0.164867 \\ \mathrm{H} & -4.628958 & 1.385780 & 1.650249 \\ \mathrm{C} & -4.482289 & -1.591045 & -0.114645 \\ \mathrm{C} & -5.831220 & -1.788944 & -0.461997 \\ \mathrm{C} & -3.487648 & -2.352549 & -0.753573 \\ \mathrm{C} & -6.179673 & -2.737557 & -1.418030 \\ \mathrm{H} & -6.605741 & -1.219805 & 0.043031 \\ \mathrm{C} & -3.845272 & -3.287865 & -1.723714 \\ \mathrm{H} & -2.438129 & -2.170374 & -0.544676 \\ \mathrm{C} & -5.185840 & -3.486839 & -2.053986 \\ \mathrm{H} & -7.225614 & -2.893955 & -1.666107 \\ \mathrm{H} & -3.066680 & -3.855174 & -2.223818 \\ \mathrm{H} & -5.458110 & -4.220602 & -2.807765 \\ \mathrm{H} & -6.260301 & 3.678729 & -3.005994\end{array}$

Catalyst (R)-1 TS Conformation 153

B3LYP/6-31G(d) Energy $=-2809.694344$

B3LYP-D3(BJ)/def2-TZVPP-IEF-PCM(DCM) Energy = -2810.983963

B3LYP-D3(BJ)/def2-TZVPP-IEF-PCM(DCM)//B3LYP/6-31G(d) Free Energy (Quasiharmonic) = 2810.342348

Frequencies (Top 3 out of 270)

1. $-481.7583 \mathrm{~cm}-1$

2. $\quad 7.7304 \mathrm{~cm}-1$

3. $10.4529 \mathrm{~cm}-1$

B3LYP/6-31G(d) Molecular Geometry in Cartesian Coordinates

$\begin{array}{llll}\text { C } & 3.636799 & -0.718431 & -0.180058 \\ \text { C } & 2.501443 & -1.497413 & -0.016814 \\ \text { C } & 2.444134 & -2.889920 & -0.322574 \\ \text { C } & 3.592277 & -3.460915 & -0.839253 \\ \text { H } & 3.603084 & -4.526212 & -1.052817 \\ \text { C } & 3.558914 & 3.456254 & 0.920532 \\ \text { C } & 3.619388 & 0.712043 & 0.251323 \\ \text { C } & 2.642615 & 1.568013 & -0.234588 \\ \text { C } & 2.596013 & 2.961799 & 0.062394 \\ \text { H } & 3.570759 & 4.519054 & 1.147430 \\ \text { O } & 1.361641 & -0.898214 & 0.507047 \\ \text { P } & 0.491161 & 0.126040 & -0.417381\end{array}$




\begin{tabular}{|c|c|c|c|}
\hline $\mathrm{O}$ & 1.661062 & 1.053582 & -1.077718 \\
\hline C & -1.043934 & -5.352060 & 0.235473 \\
\hline C & -0.248540 & -5.490383 & -0.902962 \\
\hline C & 0.867712 & -4.675050 & -1.079494 \\
\hline C & 1.218753 & -3.709072 & -0.120135 \\
\hline C & 0.406260 & -3.578308 & 1.019593 \\
\hline C & -0.713305 & -4.390786 & 1.191748 \\
\hline $\mathrm{H}$ & -0.504610 & -6.223319 & -1.663726 \\
\hline $\mathrm{H}$ & -1.330757 & -4.255974 & 2.075061 \\
\hline C & -0.315215 & 5.677286 & -1.573210 \\
\hline C & 0.314290 & 4.747341 & -2.403572 \\
\hline C & 1.242789 & 3.848882 & -1.880477 \\
\hline C & 1.564302 & 3.866098 & -0.512590 \\
\hline C & 0.921182 & 4.803544 & 0.312012 \\
\hline C & -0.008980 & 5.700714 & -0.211995 \\
\hline $\mathrm{H}$ & 0.085973 & 4.723210 & -3.466055 \\
\hline $\mathrm{H}$ & -0.498676 & 6.413689 & 0.446428 \\
\hline C & 4.564980 & 1.228071 & 1.204307 \\
\hline C & 4.533694 & 2.624465 & 1.523404 \\
\hline C & 5.471674 & 3.149778 & 2.453373 \\
\hline C & 6.385624 & 2.331933 & 3.075518 \\
\hline C & 6.391643 & 0.945465 & 2.794475 \\
\hline C & 5.508102 & 0.408618 & 1.884042 \\
\hline $\mathrm{H}$ & 5.441935 & 4.214400 & 2.673296 \\
\hline $\mathrm{H}$ & 7.093016 & 2.743512 & 3.790248 \\
\hline $\mathrm{H}$ & 7.096926 & 0.295710 & 3.305570 \\
\hline $\mathrm{H}$ & 5.519919 & -0.657117 & 1.688570 \\
\hline C & 4.789832 & -1.310635 & -0.801106 \\
\hline C & 4.760270 & -2.708519 & -1.112746 \\
\hline C & 5.899686 & -3.313972 & -1.709579 \\
\hline C & 7.014325 & -2.571483 & -2.022240 \\
\hline C & 7.030204 & -1.182488 & -1.754032 \\
\hline C & 5.949585 & -0.569367 & -1.158769 \\
\hline $\mathrm{H}$ & 5.865288 & -4.378809 & -1.927721 \\
\hline $\mathrm{H}$ & 7.876087 & -3.044174 & -2.485485 \\
\hline $\mathrm{H}$ & 7.901348 & -0.591842 & -2.024513 \\
\hline $\mathrm{H}$ & 5.974663 & 0.497383 & -0.968853 \\
\hline $\mathrm{O}$ & -0.467580 & 0.848134 & 0.474448 \\
\hline $\mathrm{O}$ & -0.088515 & -0.602955 & -1.649654 \\
\hline $\mathrm{H}$ & -1.209682 & -0.754158 & -1.596061 \\
\hline $\mathrm{H}$ & 0.641619 & -2.835781 & 1.772290 \\
\hline $\mathrm{H}$ & -1.920595 & -5.980638 & 0.369398 \\
\hline $\mathrm{H}$ & 1.460908 & -4.766241 & -1.984991 \\
\hline $\mathrm{H}$ & 1.138818 & 4.811196 & 1.376341 \\
\hline
\end{tabular}




$\begin{array}{llll}\mathrm{H} & -1.039486 & 6.375986 & -1.983964 \\ \mathrm{H} & 1.728083 & 3.133852 & -2.535734 \\ \mathrm{C} & -3.134549 & 0.157397 & -1.932118 \\ \mathrm{O} & -2.498085 & -0.873755 & -1.522707 \\ \mathrm{H} & -2.605983 & 0.923596 & -2.516106 \\ \mathrm{C} & -4.562298 & -0.078995 & -2.407254 \\ \mathrm{O} & -5.201919 & -1.085729 & -2.212934 \\ \mathrm{O} & -5.015775 & 0.992803 & -3.096756 \\ \mathrm{C} & -6.360526 & 0.876898 & -3.591663 \\ \mathrm{H} & -7.062606 & 0.752942 & -2.762605 \\ \mathrm{H} & -6.556956 & 1.806084 & -4.127215 \\ \mathrm{C} & -3.917444 & 0.650238 & 0.611383 \\ \mathrm{C} & -3.477826 & 1.467861 & -0.445796 \\ \mathrm{H} & -1.987075 & 0.111768 & 0.959334 \\ \mathrm{~N} & -2.966835 & -0.053073 & 1.268424 \\ \mathrm{C} & -3.018970 & -0.840109 & 2.434378 \\ \mathrm{O} & -2.087799 & -1.536180 & 2.769005 \\ \mathrm{O} & -4.155871 & -0.682319 & 3.125977 \\ \mathrm{C} & -4.244537 & -1.466871 & 4.329243 \\ \mathrm{H} & -4.162253 & -2.531719 & 4.098376 \\ \mathrm{H} & -5.224214 & -1.236834 & 4.747452 \\ \mathrm{H} & -3.449652 & -1.186317 & 5.024244 \\ \mathrm{H} & -4.209110 & 2.132299 & -0.892479 \\ \mathrm{H} & -2.457928 & 1.837585 & -0.386996 \\ \mathrm{C} & -5.366028 & 0.433635 & 0.828694 \\ \mathrm{C} & -5.918333 & -0.857799 & 0.806241 \\ \mathrm{C} & -6.213523 & 1.543058 & 0.968302 \\ \mathrm{C} & -7.293305 & -1.029827 & 0.932791 \\ \mathrm{H} & -5.274259 & -1.713963 & 0.637832 \\ \mathrm{H} & -7.588334 & 1.364016 & 1.116967 \\ \mathrm{H} & -5.788853 & 2.542596 & 0.986147 \\ \mathrm{H} & -8.129878 & 0.077553 & 1.098179 \\ -7.714378 & -2.030223 & 0.892338 \\ \mathrm{H} & -9.234019 & 2.228252 & 1.244854 \\ \mathrm{H} & -0.447681 & 0.019345 & -4.263774\end{array}$

Catalyst (R)-1 TS Conformation 154

B3LYP/6-31G(d) Energy $=-2809.691628$

B3LYP-D3(BJ)/def2-TZVPP-IEF-PCM(DCM) Energy $=-2810.983819$

B3LYP-D3(BJ)/def2-TZVPP-IEF-PCM(DCM)//B3LYP/6-31G(d) Free Energy (Quasiharmonic) = 2810.342325 
Frequencies (Top 3 out of 270)

1. $-724.4818 \mathrm{~cm}-1$

2. $\quad 11.2994 \mathrm{~cm}-1$

3. $\quad 15.6890 \mathrm{~cm}-1$

B3LYP/6-31G(d) Molecular Geometry in Cartesian Coordinates

$\begin{array}{llll}\text { C } & -3.191474 & 0.471149 & -0.353624 \\ \text { C } & -2.248398 & 1.479020 & -0.204923 \\ \text { C } & -2.513672 & 2.840590 & -0.542970 \\ \text { C } & -3.741084 & 3.133470 & -1.103390 \\ \text { H } & -3.964388 & 4.162810 & -1.371355 \\ \text { C } & -2.565089 & -3.629208 & 0.788990 \\ \text { C } & -2.933997 & -0.906206 & 0.161954 \\ \text { C } & -1.808895 & -1.604215 & -0.250216 \\ \text { C } & -1.622111 & -2.997684 & 0.001118 \\ \text { H } & -2.448116 & -4.688541 & 1.002569 \\ \text { O } & -1.034272 & 1.191179 & 0.402374 \\ \text { P } & 0.072450 & 0.184182 & -0.272964 \\ \text { O } & -0.864367 & -0.937673 & -1.020236 \\ \text { C } & 0.132653 & 6.176172 & 0.076243 \\ \text { C } & -1.146739 & 6.170651 & 0.634405 \\ \text { C } & -1.983254 & 5.069237 & 0.450678 \\ \text { C } & -1.554990 & 3.953134 & -0.287111 \\ \text { C } & -0.261483 & 3.962407 & -0.831905 \\ \text { C } & 0.569675 & 5.068799 & -0.654389 \\ \text { H } & -1.497310 & 7.023843 & 1.209815 \\ \text { H } & 1.563573 & 5.063751 & -1.093892 \\ \text { C } & 1.512472 & -5.381758 & -1.740198 \\ \text { C } & 0.175583 & -5.764292 & -1.856633 \\ \text { C } & -0.830181 & -4.976263 & -1.296302 \\ \text { C } & -0.518194 & -3.791957 & -0.608482 \\ \text { C } & 0.831525 & -3.421151 & -0.493653 \\ \text { C } & 1.838141 & -4.209014 & -1.054675 \\ \text { H } & -0.089031 & -6.672101 & -2.393070 \\ \text { H } & 2.875242 & -3.898451 & -0.961659 \\ \text { C } & -3.848611 & -1.551477 & 1.065622 \\ \text { C } & -3.654290 & -2.936396 & 1.372161 \\ \text { C } & -4.551542 & -3.587710 & 2.261396 \\ \text { C } & -5.587763 & -2.900831 & 2.850053 \\ \text { C } & -5.763423 & -1.524411 & 2.574289 \\ \text { C } & -4.920121 & -0.868712 & 1.704186\end{array}$




\begin{tabular}{|c|c|c|c|}
\hline $\mathrm{H}$ & -4.394215 & -4.642289 & 2.475828 \\
\hline $\mathrm{H}$ & -6.264016 & -3.407628 & 3.533129 \\
\hline $\mathrm{H}$ & -6.568447 & -0.977179 & 3.057430 \\
\hline $\mathrm{H}$ & -5.062149 & 0.188287 & 1.510824 \\
\hline C & -4.419759 & 0.774539 & -1.041914 \\
\hline C & -4.696836 & 2.132455 & -1.399415 \\
\hline C & -5.911049 & 2.450102 & -2.066181 \\
\hline C & -6.813329 & 1.466970 & -2.398333 \\
\hline C & -6.526495 & 0.118459 & -2.081944 \\
\hline C & -5.365322 & -0.218496 & -1.421592 \\
\hline $\mathrm{H}$ & -6.104930 & 3.489318 & -2.321381 \\
\hline $\mathrm{H}$ & -7.735661 & 1.719235 & -2.914383 \\
\hline $\mathrm{H}$ & -7.225868 & -0.662132 & -2.369158 \\
\hline $\mathrm{H}$ & -5.158783 & -1.258741 & -1.200525 \\
\hline O & 0.923129 & -0.365432 & 0.824820 \\
\hline $\mathrm{O}$ & 0.764521 & 0.906858 & -1.441020 \\
\hline $\mathrm{H}$ & 1.974055 & 0.876297 & -1.516577 \\
\hline $\mathrm{H}$ & 0.086488 & 3.109737 & -1.404735 \\
\hline $\mathrm{H}$ & 0.782556 & 7.038046 & 0.206723 \\
\hline $\mathrm{H}$ & -2.978350 & 5.065917 & 0.887701 \\
\hline $\mathrm{H}$ & 1.086629 & -2.516502 & 0.046912 \\
\hline $\mathrm{H}$ & 2.296494 & -5.990095 & -2.183448 \\
\hline $\mathrm{H}$ & -1.871302 & -5.266559 & -1.409994 \\
\hline C & 3.672518 & -0.293591 & -1.318798 \\
\hline $\mathrm{O}$ & 3.153333 & 0.799455 & -1.736673 \\
\hline $\mathrm{H}$ & 3.042502 & -1.046896 & -0.840377 \\
\hline C & 4.769049 & -0.924317 & -2.166132 \\
\hline $\mathrm{O}$ & 4.899244 & -2.124810 & -2.270299 \\
\hline 0 & 5.531820 & -0.010741 & -2.781564 \\
\hline C & 6.547269 & -0.545647 & -3.650052 \\
\hline $\mathrm{H}$ & 7.064813 & 0.321609 & -4.059666 \\
\hline $\mathrm{H}$ & 7.237792 & -1.179782 & -3.087471 \\
\hline C & 4.105859 & 0.393891 & 1.329439 \\
\hline C & 4.938918 & -0.025602 & 0.290708 \\
\hline $\mathrm{H}$ & 2.776302 & -0.058038 & 2.801875 \\
\hline$N$ & 3.460246 & -0.460861 & 2.172732 \\
\hline C & 3.408996 & -1.857633 & 2.100166 \\
\hline $\mathrm{O}$ & 4.016088 & -2.548017 & 1.310945 \\
\hline $\mathrm{O}$ & 2.598235 & -2.294372 & 3.071991 \\
\hline C & 2.383973 & -3.720062 & 3.098700 \\
\hline $\mathrm{H}$ & 1.916767 & -4.045996 & 2.167012 \\
\hline $\mathrm{H}$ & 1.719305 & -3.890171 & 3.945026 \\
\hline $\mathrm{H}$ & 3.333307 & -4.242543 & 3.238809 \\
\hline $\mathrm{H}$ & 5.542495 & 0.743153 & -0.177071 \\
\hline
\end{tabular}




$\begin{array}{llll}\mathrm{H} & 5.345391 & -1.028019 & 0.328922 \\ \mathrm{C} & 3.820646 & 1.825793 & 1.553508 \\ \mathrm{C} & 4.856438 & 2.770184 & 1.436817 \\ \mathrm{C} & 2.528688 & 2.262965 & 1.905044 \\ \mathrm{C} & 4.610167 & 4.117960 & 1.682576 \\ \mathrm{H} & 5.861158 & 2.442202 & 1.190311 \\ \mathrm{C} & 2.286460 & 3.615624 & 2.130860 \\ \mathrm{H} & 1.704003 & 1.555739 & 1.923290 \\ \mathrm{C} & 3.325648 & 4.542914 & 2.029240 \\ \mathrm{H} & 5.421869 & 4.835746 & 1.606114 \\ \mathrm{H} & 1.279622 & 3.947447 & 2.362346 \\ \mathrm{H} & 3.131264 & 5.596338 & 2.210019 \\ \mathrm{H} & 6.091151 & -1.135205 & -4.449186\end{array}$

Catalyst (R)-1 TS Conformation 155

B3LYP/6-31G(d) Energy = -2809.689947

B3LYP-D3(BJ)/def2-TZVPP-IEF-PCM(DCM) Energy = -2810.983601

B3LYP-D3(BJ)/def2-TZVPP-IEF-PCM(DCM)//B3LYP/6-31G(d) Free Energy (Quasiharmonic) = 2810.342299

Frequencies (Top 3 out of 270)

1. $-632.3385 \mathrm{~cm}-1$

2. $\quad 7.4452 \mathrm{~cm}-1$

3. $19.3458 \mathrm{~cm}-1$

B3LYP/6-31G(d) Molecular Geometry in Cartesian Coordinates

$\begin{array}{llll}\text { C } & 3.285523 & -0.284839 & 0.349362 \\ \mathrm{C} & 2.756546 & 0.956967 & 0.024006 \\ \mathrm{C} & 3.410801 & 2.185102 & 0.345309 \\ \mathrm{C} & 4.567603 & 2.111744 & 1.096589 \\ \mathrm{H} & 5.080211 & 3.032344 & 1.362501 \\ \mathrm{C} & 1.467728 & -3.992413 & -0.892515 \\ \mathrm{C} & 2.667507 & -1.542716 & -0.167982 \\ \mathrm{C} & 1.331626 & -1.809455 & 0.081367 \\ \mathrm{C} & 0.704421 & -3.052371 & -0.227308 \\ \mathrm{H} & 1.034677 & -4.962720 & -1.120226 \\ \mathrm{O} & 1.604548 & 1.027953 & -0.748400 \\ \mathrm{P} & 0.160652 & 0.481571 & -0.222827 \\ \mathrm{O} & 0.570213 & -0.820046 & 0.692399 \\ \mathrm{C} & 2.195757 & 6.097582 & -0.973956\end{array}$




\begin{tabular}{|c|c|c|c|}
\hline C & 1.274531 & 5.264399 & -0.336625 \\
\hline C & 1.638329 & 3.981730 & 0.073264 \\
\hline C & 2.944247 & 3.514241 & -0.140984 \\
\hline C & 3.863265 & 4.359555 & -0.785801 \\
\hline C & 3.493744 & 5.638454 & -1.200858 \\
\hline $\mathrm{H}$ & 0.262264 & 5.612386 & -0.149618 \\
\hline $\mathrm{H}$ & 4.219583 & 6.272873 & -1.703232 \\
\hline C & -3.301726 & -4.110374 & 0.940369 \\
\hline C & -2.825357 & -4.430998 & -0.330969 \\
\hline C & -1.538237 & -4.054225 & -0.714660 \\
\hline C & -0.694431 & -3.363708 & 0.169209 \\
\hline C & -1.187951 & -3.042095 & 1.447074 \\
\hline C & -2.478540 & -3.408959 & 1.825981 \\
\hline $\mathrm{H}$ & -3.456348 & -4.965690 & -1.035849 \\
\hline $\mathrm{H}$ & -2.841306 & -3.148594 & 2.816598 \\
\hline C & 3.423006 & -2.498097 & -0.932836 \\
\hline C & 2.803599 & -3.739556 & -1.289739 \\
\hline C & 3.540329 & -4.697474 & -2.037945 \\
\hline C & 4.826320 & -4.436652 & -2.450031 \\
\hline C & 5.427639 & -3.196644 & -2.130753 \\
\hline C & 4.747112 & -2.255008 & -1.390306 \\
\hline $\mathrm{H}$ & 3.058815 & -5.639377 & -2.290148 \\
\hline $\mathrm{H}$ & 5.376881 & -5.173199 & -3.028820 \\
\hline $\mathrm{H}$ & 6.435094 & -2.982152 & -2.476978 \\
\hline $\mathrm{H}$ & 5.218683 & -1.306233 & -1.162555 \\
\hline C & 4.434802 & -0.337266 & 1.214329 \\
\hline C & 5.083849 & 0.885233 & 1.578487 \\
\hline C & 6.222880 & 0.848702 & 2.427699 \\
\hline C & 6.696771 & -0.342920 & 2.924483 \\
\hline C & 6.038404 & -1.550669 & 2.594274 \\
\hline C & 4.940549 & -1.548985 & 1.761952 \\
\hline $\mathrm{H}$ & 6.705903 & 1.788012 & 2.686612 \\
\hline $\mathrm{H}$ & 7.564705 & -0.359113 & 3.577990 \\
\hline $\mathrm{H}$ & 6.397887 & -2.489713 & 3.006495 \\
\hline $\mathrm{H}$ & 4.442570 & -2.483139 & 1.530436 \\
\hline $\mathrm{O}$ & -0.671534 & 0.147839 & -1.412623 \\
\hline $\mathrm{O}$ & -0.366945 & 1.480006 & 0.826892 \\
\hline $\mathrm{H}$ & -1.435202 & 1.469652 & 1.272487 \\
\hline $\mathrm{H}$ & 4.871477 & 4.000708 & -0.974888 \\
\hline $\mathrm{H}$ & 1.905467 & 7.095996 & -1.291590 \\
\hline $\mathrm{H}$ & 0.913047 & 3.349505 & 0.572918 \\
\hline $\mathrm{H}$ & -0.552524 & -2.512587 & 2.148418 \\
\hline $\mathrm{H}$ & -4.304574 & -4.402721 & 1.241604 \\
\hline $\mathrm{H}$ & -1.192674 & -4.273807 & -1.719975 \\
\hline
\end{tabular}




\begin{tabular}{llll}
$\mathrm{C}$ & -3.366305 & 0.586731 & 1.718714 \\
$\mathrm{O}$ & -2.550366 & 1.567648 & 1.850789 \\
$\mathrm{H}$ & -2.994192 & -0.386985 & 1.375217 \\
$\mathrm{C}$ & -4.442474 & 0.505779 & 2.798585 \\
$\mathrm{O}$ & -4.899092 & 1.454089 & 3.391008 \\
$\mathrm{O}$ & -4.816968 & -0.777032 & 2.993628 \\
$\mathrm{C}$ & -5.831176 & -0.971211 & 3.997045 \\
$\mathrm{H}$ & -6.020306 & -2.044473 & 4.018283 \\
$\mathrm{H}$ & -5.474919 & -0.622877 & 4.969692 \\
$\mathrm{C}$ & -3.858068 & 1.017102 & -0.860459 \\
$\mathrm{C}$ & -4.705301 & 0.822552 & 0.242766 \\
$\mathrm{H}$ & -2.392454 & -0.013084 & -1.854579 \\
$\mathrm{~N}$ & -3.399557 & -0.032770 & -1.618897 \\
$\mathrm{C}$ & -4.036220 & -1.212774 & -2.008885 \\
$\mathrm{O}$ & -3.471813 & -2.062307 & -2.660199 \\
$\mathrm{O}$ & -5.334503 & -1.256344 & -1.647029 \\
$\mathrm{C}$ & -6.040126 & -2.426232 & -2.097526 \\
$\mathrm{H}$ & -5.998569 & -2.502284 & -3.186524 \\
$\mathrm{H}$ & -7.067449 & -2.288600 & -1.759543 \\
$\mathrm{H}$ & -5.604542 & -3.325123 & -1.655363 \\
$\mathrm{H}$ & -5.266419 & 1.678937 & 0.599408 \\
$\mathrm{H}$ & -5.220374 & -0.126695 & 0.316415 \\
$\mathrm{C}$ & -3.289770 & 2.331244 & -1.162825 \\
$\mathrm{C}$ & -2.664775 & 2.570338 & -2.407666 \\
$\mathrm{C}$ & -3.389947 & 3.396782 & -0.240401 \\
$\mathrm{C}$ & -2.164616 & 3.826679 & -2.718809 \\
$\mathrm{H}$ & -2.592249 & 1.772889 & -3.137700 \\
$\mathrm{C}$ & -2.881045 & 4.652407 & -0.559735 \\
$\mathrm{H}$ & -3.834969 & 3.241957 & 0.733238 \\
$\mathrm{C}$ & -2.271673 & 4.872070 & -1.795835 \\
$\mathrm{H}$ & -1.691474 & 3.994270 & -3.681477 \\
$\mathrm{H}$ & -2.960955 & 5.459750 & 0.162176 \\
& -1.882558 & 5.855526 & -2.044348 \\
\hline & -6.739301 & -0.422774 & 3.733156
\end{tabular}

Catalyst (R)-1 TS Conformation 156

B3LYP/6-31G(d) Energy $=-2809.688222$

B3LYP-D3(BJ)/def2-TZVPP-IEF-PCM(DCM) Energy = -2810.985106

B3LYP-D3(BJ)/def2-TZVPP-IEF-PCM(DCM)//B3LYP/6-31G(d) Free Energy (Quasiharmonic) = 2810.342291

Frequencies (Top 3 out of 270) 
1. $-392.4255 \mathrm{~cm}-1$

2. $\quad 9.4953 \mathrm{~cm}-1$

3. $\quad 12.4438 \mathrm{~cm}-1$

B3LYP/6-31G(d) Molecular Geometry in Cartesian Coordinates

\begin{tabular}{llll}
$\mathrm{C}$ & 3.472761 & -1.088045 & -0.031359 \\
$\mathrm{C}$ & 2.224905 & -1.668504 & 0.132632 \\
$\mathrm{C}$ & 1.930403 & -3.011236 & -0.249092 \\
$\mathrm{C}$ & 2.942504 & -3.733257 & -0.851613 \\
$\mathrm{H}$ & 2.760294 & -4.767909 & -1.129847 \\
$\mathrm{C}$ & 4.170208 & 2.988907 & 1.190342 \\
$\mathrm{C}$ & 3.708712 & 0.302006 & 0.458631 \\
$\mathrm{C}$ & 2.894106 & 1.332243 & 0.013420 \\
$\mathrm{C}$ & 3.133325 & 2.703111 & 0.324390 \\
$\mathrm{H}$ & 4.389092 & 4.026267 & 1.430059 \\
$\mathrm{O}$ & 1.220020 & -0.920876 & 0.730132 \\
$\mathrm{P}$ & 0.507024 & 0.306487 & -0.099339 \\
$\mathrm{O}$ & 1.808039 & 1.027789 & -0.799496 \\
$\mathrm{C}$ & -1.863793 & -4.934020 & 0.397994 \\
$\mathrm{C}$ & -1.288418 & -4.169503 & 1.416060 \\
$\mathrm{C}$ & -0.068956 & -3.526098 & 1.210512 \\
$\mathrm{C}$ & 0.600375 & -3.635302 & -0.021004 \\
$\mathrm{C}$ & 0.007802 & -4.402444 & -1.037026 \\
$\mathrm{C}$ & -1.211107 & -5.047778 & -0.829722 \\
$\mathrm{H}$ & -1.797224 & -4.068040 & 2.370153 \\
$\mathrm{H}$ & -1.654172 & -5.629905 & -1.633716 \\
$\mathrm{C}$ & 1.007792 & 6.005102 & -1.432033 \\
$\mathrm{C}$ & 1.172561 & 5.929010 & -0.048316 \\
$\mathrm{C}$ & 1.836297 & 4.840993 & 0.520195 \\
$\mathrm{C}$ & 2.343422 & 3.807592 & -0.283064 \\
$\mathrm{C}$ & 2.157887 & 3.887539 & -1.673807 \\
$\mathrm{C}$ & 1.502132 & 4.979127 & -2.241990 \\
$\mathrm{H}$ & 0.782911 & 6.715894 & 0.592292 \\
$\mathrm{H}$ & 1.383198 & 5.031284 & -3.321248 \\
$\mathrm{C}$ & 4.743067 & 0.607132 & 1.408993 \\
$\mathrm{C}$ & 4.968812 & 1.974184 & 1.772539 \\
$\mathrm{C}$ & 5.990051 & 2.288242 & 2.709665 \\
$\mathrm{C}$ & 6.744258 & 1.296993 & 3.293089 \\
6.500464 & -0.056875 & 2.962743 \\
$\mathrm{C}$ & 5.529181 & -0.392836 & 2.045413 \\
$\mathrm{C}$ & 7.155569 & 3.332295 & 2.965116 \\
$\mathrm{C}$ & & 1.548449 & 4.013621 \\
\hline
\end{tabular}




\begin{tabular}{|c|c|c|c|}
\hline $\mathrm{H}$ & 7.081772 & -0.840573 & 3.441056 \\
\hline $\mathrm{H}$ & 5.347764 & -1.435354 & 1.811040 \\
\hline C & 4.492158 & -1.827088 & -0.724851 \\
\hline C & 4.214887 & -3.174632 & -1.123709 \\
\hline C & 5.216723 & -3.923682 & -1.798644 \\
\hline C & 6.436017 & -3.363932 & -2.101195 \\
\hline C & 6.699185 & -2.020835 & -1.743207 \\
\hline C & 5.755315 & -1.273704 & -1.073183 \\
\hline $\mathrm{H}$ & 4.992755 & -4.949134 & -2.083239 \\
\hline $\mathrm{H}$ & 7.191694 & -3.944047 & -2.623761 \\
\hline $\mathrm{H}$ & 7.653838 & -1.571608 & -2.003585 \\
\hline $\mathrm{H}$ & 5.970621 & -0.243330 & -0.815517 \\
\hline $\mathrm{O}$ & -0.269588 & 1.136312 & 0.855243 \\
\hline $\mathrm{O}$ & -0.214869 & -0.271904 & -1.345821 \\
\hline $\mathrm{H}$ & -1.320166 & -0.399598 & -1.250429 \\
\hline $\mathrm{H}$ & 0.497784 & -4.471825 & -2.004045 \\
\hline $\mathrm{H}$ & -2.817234 & -5.428444 & 0.562854 \\
\hline $\mathrm{H}$ & 0.372654 & -2.940048 & 2.009171 \\
\hline $\mathrm{H}$ & 2.542116 & 3.096740 & -2.309959 \\
\hline $\mathrm{H}$ & 0.497254 & 6.855347 & -1.876711 \\
\hline $\mathrm{H}$ & 1.952060 & 4.779296 & 1.598620 \\
\hline C & -2.966601 & -0.903655 & 0.079312 \\
\hline 0 & -2.629512 & -0.611910 & -1.136622 \\
\hline $\mathrm{H}$ & -2.172370 & -1.120790 & 0.810010 \\
\hline C & -4.097252 & -1.912522 & 0.269536 \\
\hline 0 & -4.280663 & -2.526313 & 1.304085 \\
\hline $\mathrm{O}$ & -4.869134 & -2.027609 & -0.820855 \\
\hline C & -5.933797 & -2.988938 & -0.725807 \\
\hline $\mathrm{H}$ & -5.532539 & -3.979343 & -0.497198 \\
\hline $\mathrm{H}$ & -6.415319 & -2.986373 & -1.703879 \\
\hline C & -4.704813 & 1.032862 & 0.275891 \\
\hline C & -3.546345 & 0.613557 & 0.976765 \\
\hline $\mathrm{H}$ & -5.465572 & 1.430508 & -1.562362 \\
\hline$N$ & -4.635577 & 1.516291 & -0.986634 \\
\hline C & -3.567854 & 2.066898 & -1.752012 \\
\hline $\mathrm{O}$ & -3.702864 & 2.215906 & -2.943502 \\
\hline $\mathrm{O}$ & -2.563588 & 2.463837 & -0.989685 \\
\hline C & -1.416810 & 3.011111 & -1.683284 \\
\hline $\mathrm{H}$ & -1.718616 & 3.882878 & -2.266809 \\
\hline $\mathrm{H}$ & -0.986563 & 2.247318 & -2.332603 \\
\hline $\mathrm{H}$ & -0.720372 & 3.278231 & -0.893669 \\
\hline $\mathrm{H}$ & -3.710054 & 0.353058 & 2.018469 \\
\hline $\mathrm{H}$ & -2.624452 & 1.166568 & 0.817956 \\
\hline C & -6.072765 & 0.849212 & 0.805829 \\
\hline
\end{tabular}




$\begin{array}{lrrr}\text { C } & -7.129345 & 1.651177 & 0.326140 \\ \text { C } & -6.349726 & -0.082834 & 1.825992 \\ \text { C } & -8.418502 & 1.511285 & 0.832057 \\ \text { H } & -6.937240 & 2.425742 & -0.410244 \\ \text { C } & -7.644028 & -0.225781 & 2.318917 \\ \text { H } & -5.566802 & -0.724716 & 2.210958 \\ \text { C } & -8.682569 & 0.567258 & 1.825872 \\ \text { H } & -9.213621 & 2.149422 & 0.457758 \\ \text { H } & -7.839047 & -0.960318 & 3.094759 \\ \text { H } & -9.688384 & 0.458194 & 2.221413 \\ \text { H } & -6.644159 & -2.701572 & 0.054117\end{array}$

Catalyst (R)-1 TS Conformation 157

B3LYP/6-31G(d) Energy = -2809.689755

B3LYP-D3(BJ)/def2-TZVPP-IEF-PCM(DCM) Energy = -2810.984743

B3LYP-D3(BJ)/def2-TZVPP-IEF-PCM(DCM)//B3LYP/6-31G(d) Free Energy (Quasiharmonic) = 2810.342246

Frequencies (Top 3 out of 270)

1. $-544.9774 \mathrm{~cm}-1$

2. $\quad 9.8520 \mathrm{~cm}-1$

3. $\quad 13.6610 \mathrm{~cm}-1$

B3LYP/6-31G(d) Molecular Geometry in Cartesian Coordinates

$\begin{array}{llll}\text { C } & -3.441717 & -1.060011 & 0.088629 \\ \text { C } & -2.235026 & -1.654182 & -0.240598 \\ \text { C } & -1.882865 & -2.987079 & 0.122858 \\ \text { C } & -2.800803 & -3.696959 & 0.871818 \\ \text { H } & -2.580851 & -4.725767 & 1.144658 \\ \text { C } & -4.363640 & 2.977432 & -1.107635 \\ \text { C } & -3.743386 & 0.316605 & -0.405965 \\ \text { C } & -2.867641 & 1.363459 & -0.145092 \\ \text { C } & -3.172556 & 2.723197 & -0.456081 \\ \text { H } & -4.616406 & 4.003732 & -1.360700 \\ \text { O } & -1.316279 & -0.911068 & -0.971571 \\ \text { P } & -0.479182 & 0.249326 & -0.170098 \\ \text { O } & -1.685272 & 1.108376 & 0.538430 \\ \text { C } & 1.859085 & -4.826852 & -0.945618 \\ \text { C } & 1.354899 & -4.942400 & 0.350386 \\ \text { C } & 0.148402 & -4.330915 & 0.689409\end{array}$




\begin{tabular}{|c|c|c|c|}
\hline C & -0.581038 & -3.596064 & -0.259704 \\
\hline C & -0.061285 & -3.486005 & -1.561423 \\
\hline C & 1.146880 & -4.094727 & -1.898867 \\
\hline $\mathrm{H}$ & 1.905623 & -5.498429 & 1.104614 \\
\hline $\mathrm{H}$ & 1.534305 & -3.995998 & -2.909137 \\
\hline C & -0.738038 & 6.115166 & 0.595458 \\
\hline C & -2.081911 & 6.059436 & 0.966421 \\
\hline C & -2.851954 & 4.944273 & 0.635553 \\
\hline C & -2.294882 & 3.863694 & -0.068194 \\
\hline C & -0.940144 & 3.926784 & -0.434567 \\
\hline C & -0.174207 & 5.046472 & -0.105392 \\
\hline $\mathrm{H}$ & -2.532549 & 6.881262 & 1.517044 \\
\hline $\mathrm{H}$ & 0.869669 & 5.083914 & -0.407277 \\
\hline C & -4.928304 & 0.587753 & -1.174944 \\
\hline C & -5.241864 & 1.943381 & -1.511615 \\
\hline C & -6.414658 & 2.225260 & -2.263489 \\
\hline C & -7.239171 & 1.212354 & -2.694136 \\
\hline C & -6.914006 & -0.131535 & -2.394236 \\
\hline C & -5.792174 & -0.435671 & -1.654909 \\
\hline $\mathrm{H}$ & -6.639733 & 3.262003 & -2.502664 \\
\hline $\mathrm{H}$ & -8.129929 & 1.438533 & -3.273835 \\
\hline $\mathrm{H}$ & -7.551925 & -0.933263 & -2.756480 \\
\hline $\mathrm{H}$ & -5.552237 & -1.471390 & -1.444773 \\
\hline C & -4.350339 & -1.783465 & 0.937147 \\
\hline C & -4.021076 & -3.127003 & 1.311515 \\
\hline C & -4.915907 & -3.860780 & 2.136899 \\
\hline C & -6.074749 & -3.289586 & 2.608490 \\
\hline C & -6.381570 & -1.949428 & 2.275814 \\
\hline C & -5.544566 & -1.217521 & 1.462250 \\
\hline $\mathrm{H}$ & -4.656277 & -4.883450 & 2.400410 \\
\hline $\mathrm{H}$ & -6.747198 & -3.858158 & 3.245045 \\
\hline $\mathrm{H}$ & -7.284257 & -1.490155 & 2.669710 \\
\hline $\mathrm{H}$ & -5.790404 & -0.189049 & 1.225653 \\
\hline $\mathrm{O}$ & 0.351287 & 0.997819 & -1.151979 \\
\hline $\mathrm{O}$ & 0.213724 & -0.378941 & 1.063846 \\
\hline $\mathrm{H}$ & 1.325709 & -0.636293 & 0.960718 \\
\hline $\mathrm{H}$ & -0.607392 & -2.923635 & -2.310627 \\
\hline $\mathrm{H}$ & 2.800302 & -5.299909 & -1.213568 \\
\hline $\mathrm{H}$ & -0.222781 & -4.398162 & 1.708004 \\
\hline $\mathrm{H}$ & -0.487420 & 3.107212 & -0.983455 \\
\hline $\mathrm{H}$ & -0.135565 & 6.983719 & 0.849008 \\
\hline $\mathrm{H}$ & -3.894940 & 4.898976 & 0.937571 \\
\hline C & 2.962471 & -0.870423 & -0.375355 \\
\hline 0 & 2.564172 & -0.943340 & 0.851624 \\
\hline
\end{tabular}




$\begin{array}{llll}\mathrm{H} & 2.214444 & -0.826166 & -1.177938 \\ \mathrm{C} & 4.121030 & -1.767102 & -0.789009 \\ \mathrm{O} & 4.338823 & -2.080601 & -1.943243 \\ \mathrm{O} & 4.867951 & -2.154006 & 0.255182 \\ \mathrm{C} & 5.953590 & -3.043472 & -0.058339 \\ \mathrm{H} & 5.577863 & -3.940397 & -0.556764 \\ \mathrm{H} & 6.406406 & -3.297593 & 0.900171 \\ \mathrm{C} & 4.668997 & 1.076533 & 0.107466 \\ \mathrm{C} & 3.566732 & 0.897821 & -0.752327 \\ \mathrm{H} & 5.330296 & 0.902456 & 2.015900 \\ \mathrm{~N} & 4.526942 & 1.161244 & 1.454387 \\ \mathrm{C} & 3.427721 & 1.450042 & 2.308550 \\ \mathrm{O} & 3.535307 & 1.251702 & 3.496168 \\ \mathrm{O} & 2.415903 & 2.026194 & 1.675056 \\ \mathrm{C} & 1.272577 & 2.354863 & 2.508248 \\ \mathrm{H} & 0.609207 & 2.923192 & 1.859365 \\ \mathrm{H} & 1.600430 & 2.949483 & 3.362763 \\ \mathrm{H} & 0.789773 & 1.434816 & 2.837452 \\ \mathrm{H} & 3.781813 & 0.959257 & -1.814581 \\ \mathrm{H} & 2.613770 & 1.340228 & -0.483619 \\ \mathrm{C} & 6.068070 & 1.053773 & -0.374034 \\ \mathrm{C} & 6.413810 & 0.454155 & -1.601260 \\ \mathrm{C} & 7.083769 & 1.682495 & 0.374790 \\ \mathrm{C} & 7.734472 & 0.459484 & -2.042120 \\ \mathrm{H} & 5.662482 & -0.049211 & -2.197815 \\ \mathrm{C} & 8.400519 & 1.694207 & -0.077533 \\ \mathrm{H} & 6.840010 & 2.210357 & 1.291936 \\ \mathrm{C} & 8.732363 & 1.077067 & -1.284583 \\ \mathrm{H} & 7.982369 & -0.020451 & -2.984312 \\ \mathrm{H} & 9.164310 & 2.196624 & 0.508757 \\ \mathrm{H} & 9.759506 & 1.086302 & -1.637931 \\ \mathrm{H} & 6.680334 & -2.549420 & -0.708694 \\ & & & \end{array}$

Catalyst (R)-1 TS Conformation 158

B3LYP/6-31G(d) Energy $=-2809.691393$

B3LYP-D3(BJ)/def2-TZVPP-IEF-PCM(DCM) Energy = -2810.984174

B3LYP-D3(BJ)/def2-TZVPP-IEF-PCM(DCM)//B3LYP/6-31G(d) Free Energy (Quasiharmonic) = 2810.342235

Frequencies (Top 3 out of 270)

1. $-569.9055 \mathrm{~cm}-1$ 
2. $\quad 9.6527 \mathrm{~cm}-1$

3. $\quad 10.7232 \mathrm{~cm}-1$

B3LYP/6-31G(d) Molecular Geometry in Cartesian Coordinates

\begin{tabular}{|c|c|c|c|}
\hline C & 2.999502 & -0.866218 & -0.250637 \\
\hline C & 1.839799 & -1.549060 & 0.077922 \\
\hline C & 1.658639 & -2.948907 & -0.142026 \\
\hline C & 2.636110 & -3.588869 & -0.881652 \\
\hline $\mathrm{H}$ & 2.529404 & -4.649555 & -1.092987 \\
\hline C & 3.655928 & 3.085513 & 1.371882 \\
\hline C & 3.230963 & 0.497366 & 0.319155 \\
\hline C & 2.319958 & 1.526479 & 0.129620 \\
\hline C & 2.521957 & 2.850792 & 0.620544 \\
\hline $\mathrm{H}$ & 3.848991 & 4.090846 & 1.736681 \\
\hline $\mathrm{O}$ & 0.833507 & -0.839667 & 0.722062 \\
\hline$P$ & 0.016699 & 0.242830 & -0.199548 \\
\hline $\mathrm{O}$ & 1.173521 & 1.305783 & -0.624589 \\
\hline C & -1.420482 & -5.207166 & 1.859489 \\
\hline C & -1.741401 & -3.986701 & 1.261865 \\
\hline C & -0.765400 & -3.261703 & 0.577512 \\
\hline C & 0.559477 & -3.721635 & 0.503053 \\
\hline C & 0.865785 & -4.952832 & 1.111785 \\
\hline C & -0.114364 & -5.692801 & 1.771721 \\
\hline $\mathrm{H}$ & -2.743296 & -3.573287 & 1.346993 \\
\hline $\mathrm{H}$ & 0.150736 & -6.637446 & 2.239933 \\
\hline C & -0.031556 & 6.218673 & -0.178511 \\
\hline C & 0.359533 & 5.376400 & -1.221554 \\
\hline C & 1.152755 & 4.258964 & -0.967968 \\
\hline C & 1.583810 & 3.970367 & 0.337009 \\
\hline C & 1.178259 & 4.820478 & 1.378468 \\
\hline C & 0.376294 & 5.932838 & 1.124796 \\
\hline $\mathrm{H}$ & 0.052488 & 5.593270 & -2.241265 \\
\hline $\mathrm{H}$ & 0.070381 & 6.574672 & 1.946974 \\
\hline C & 4.370217 & 0.742479 & 1.167703 \\
\hline C & 4.582639 & 2.062111 & 1.682048 \\
\hline C & 5.710238 & 2.322692 & 2.506985 \\
\hline C & 6.585318 & 1.318198 & 2.847187 \\
\hline C & 6.356290 & 0.003955 & 2.377950 \\
\hline C & 5.282050 & -0.276257 & 1.562072 \\
\hline $\mathrm{H}$ & 5.858759 & 3.335151 & 2.875106 \\
\hline $\mathrm{H}$ & 7.440589 & 1.526508 & 3.484117 \\
\hline $\mathrm{H}$ & 7.031242 & -0.796588 & 2.668507 \\
\hline $\mathrm{H}$ & 5.120169 & -1.292776 & 1.225804 \\
\hline
\end{tabular}




\begin{tabular}{|c|c|c|c|}
\hline C & 3.967012 & -1.527372 & -1.081029 \\
\hline C & 3.762243 & -2.907209 & -1.407438 \\
\hline C & 4.702437 & -3.569398 & -2.242591 \\
\hline C & 5.791333 & -2.900791 & -2.752742 \\
\hline C & 5.983302 & -1.532541 & -2.448166 \\
\hline C & 5.097192 & -0.864525 & -1.631440 \\
\hline $\mathrm{H}$ & 4.538230 & -4.618447 & -2.477776 \\
\hline $\mathrm{H}$ & 6.499722 & -3.417164 & -3.394803 \\
\hline $\mathrm{H}$ & 6.834552 & -1.002246 & -2.866568 \\
\hline $\mathrm{H}$ & 5.249376 & 0.186760 & -1.412898 \\
\hline 0 & -0.566123 & -0.334776 & -1.448622 \\
\hline $\mathrm{O}$ & -0.946465 & 0.909431 & 0.811491 \\
\hline $\mathrm{H}$ & -1.851877 & 0.261911 & 1.063263 \\
\hline $\mathrm{H}$ & 1.890397 & -5.314204 & 1.097062 \\
\hline $\mathrm{H}$ & -2.178570 & -5.768571 & 2.399343 \\
\hline $\mathrm{H}$ & -1.041318 & -2.342321 & 0.084389 \\
\hline $\mathrm{H}$ & 1.484995 & 4.595400 & 2.396121 \\
\hline $\mathrm{H}$ & -0.648784 & 7.090592 & -0.379905 \\
\hline $\mathrm{H}$ & 1.454130 & 3.613192 & -1.785852 \\
\hline C & -3.976217 & 0.174746 & 1.443980 \\
\hline $\mathrm{O}$ & -2.882973 & -0.484454 & 1.314203 \\
\hline $\mathrm{H}$ & -3.924754 & 1.263159 & 1.581319 \\
\hline C & -5.053422 & -0.491421 & 2.294713 \\
\hline O & -5.078287 & -1.659414 & 2.597430 \\
\hline $\mathrm{O}$ & -5.981653 & 0.420102 & 2.665389 \\
\hline C & -7.054091 & -0.094497 & 3.474193 \\
\hline $\mathrm{H}$ & -6.662751 & -0.509589 & 4.406529 \\
\hline $\mathrm{H}$ & -7.704323 & 0.757027 & 3.675964 \\
\hline C & -4.041585 & 0.398374 & -1.164008 \\
\hline C & -5.071698 & 0.227251 & -0.222190 \\
\hline $\mathrm{H}$ & -2.285475 & -0.500488 & -1.777400 \\
\hline$N$ & -3.291870 & -0.656727 & -1.567378 \\
\hline C & -3.691379 & -2.007575 & -1.586518 \\
\hline O & -4.765333 & -2.450786 & -1.244691 \\
\hline $\mathrm{O}$ & -2.689498 & -2.720511 & -2.115745 \\
\hline C & -2.931177 & -4.135373 & -2.229402 \\
\hline $\mathrm{H}$ & -2.036947 & -4.536085 & -2.705216 \\
\hline $\mathrm{H}$ & -3.816453 & -4.319256 & -2.842964 \\
\hline $\mathrm{H}$ & -3.065464 & -4.575366 & -1.239593 \\
\hline $\mathrm{H}$ & -5.762460 & 1.050543 & -0.078746 \\
\hline $\mathrm{H}$ & -5.508554 & -0.761915 & -0.171092 \\
\hline C & -3.612330 & 1.724913 & -1.640207 \\
\hline C & -2.857459 & 1.847046 & -2.823271 \\
\hline C & -3.995526 & 2.899304 & -0.962869 \\
\hline
\end{tabular}




$\begin{array}{llll}\mathrm{C} & -2.507389 & 3.101258 & -3.313930 \\ \mathrm{H} & -2.565939 & 0.960941 & -3.375517 \\ \mathrm{C} & -3.634544 & 4.149481 & -1.451060 \\ \mathrm{H} & -4.563232 & 2.837226 & -0.041078 \\ \mathrm{C} & -2.894658 & 4.255158 & -2.631378 \\ \mathrm{H} & -1.934340 & 3.175137 & -4.233390 \\ \mathrm{H} & -3.926797 & 5.043185 & -0.907988 \\ \mathrm{H} & -2.623211 & 5.233699 & -3.016772 \\ \mathrm{H} & -7.596751 & -0.876823 & 2.936750\end{array}$

Catalyst (R)-1 TS Conformation 159

B3LYP/6-31G(d) Energy $=-2809.691584$

B3LYP-D3(BJ)/def2-TZVPP-IEF-PCM(DCM) Energy $=-2810.983915$

B3LYP-D3(BJ)/def2-TZVPP-IEF-PCM(DCM)//B3LYP/6-31G(d) Free Energy (Quasiharmonic) = 2810.342229

Frequencies (Top 3 out of 270)

1. $-552.9536 \mathrm{~cm}-1$

2. $8.5878 \mathrm{~cm}-1$

3. $22.6152 \mathrm{~cm}-1$

B3LYP/6-31G(d) Molecular Geometry in Cartesian Coordinates

$\begin{array}{llll}\text { C } & 3.251365 & -0.162605 & 0.366363 \\ \text { C } & 2.690252 & 1.039072 & -0.042385 \\ \text { C } & 3.282051 & 2.307092 & 0.241942 \\ \text { C } & 4.403049 & 2.317505 & 1.049168 \\ \text { H } & 4.868445 & 3.269768 & 1.289140 \\ \text { C } & 1.674269 & -4.000974 & -0.796098 \\ \text { C } & 2.714351 & -1.467285 & -0.124886 \\ \text { C } & 1.381293 & -1.789092 & 0.071597 \\ \text { C } & 0.831543 & -3.075111 & -0.210568 \\ \text { H } & 1.302628 & -5.001852 & -0.997785 \\ \text { O } & 1.567334 & 1.021157 & -0.861199 \\ \text { P } & 0.130862 & 0.457216 & -0.338434 \\ \text { O } & 0.547426 & -0.816055 & 0.611494 \\ \text { C } & 2.006727 & 6.087795 & -1.372861 \\ \text { C } & 1.081297 & 5.260495 & -0.734156 \\ \text { C } & 1.465568 & 4.019512 & -0.226406 \\ \text { C } & 2.796240 & 3.588714 & -0.343133 \\ \text { C } & 3.719655 & 4.427938 & -0.989856\end{array}$




\begin{tabular}{|c|c|c|c|}
\hline C & 3.330179 & 5.665044 & -1.501837 \\
\hline $\mathrm{H}$ & 0.048742 & 5.580445 & -0.623775 \\
\hline $\mathrm{H}$ & 4.060298 & 6.294631 & -2.004062 \\
\hline C & -3.160791 & -4.324381 & 0.805817 \\
\hline C & -2.592157 & -4.687035 & -0.415576 \\
\hline C & -1.312911 & -4.245881 & -0.753026 \\
\hline C & -0.566605 & -3.449835 & 0.130579 \\
\hline C & -1.153190 & -3.088876 & 1.357664 \\
\hline C & -2.438579 & -3.516837 & 1.689124 \\
\hline $\mathrm{H}$ & -3.145892 & -5.304067 & -1.118311 \\
\hline $\mathrm{H}$ & -2.881230 & -3.213820 & 2.633392 \\
\hline C & 3.552379 & -2.412440 & -0.812448 \\
\hline C & 3.013227 & -3.697512 & -1.142479 \\
\hline C & 3.831671 & -4.647180 & -1.812310 \\
\hline C & 5.121824 & -4.338311 & -2.175070 \\
\hline C & 5.645079 & -3.056759 & -1.883355 \\
\hline C & 4.883763 & -2.121074 & -1.217841 \\
\hline $\mathrm{H}$ & 3.409815 & -5.622227 & -2.044573 \\
\hline$H$ & 5.735595 & -5.069270 & -2.694313 \\
\hline $\mathrm{H}$ & 6.656415 & -2.805542 & -2.191487 \\
\hline $\mathrm{H}$ & 5.296571 & -1.140703 & -1.010934 \\
\hline C & 4.359176 & -0.126383 & 1.284431 \\
\hline C & 4.940931 & 1.138120 & 1.617560 \\
\hline C & 6.037887 & 1.189134 & 2.519774 \\
\hline C & 6.533605 & 0.042915 & 3.095823 \\
\hline C & 5.940748 & -1.205667 & 2.794492 \\
\hline C & 4.885530 & -1.289080 & 1.912691 \\
\hline $\mathrm{H}$ & 6.470692 & 2.158822 & 2.754405 \\
\hline $\mathrm{H}$ & 7.368727 & 0.093746 & 3.789111 \\
\hline $\mathrm{H}$ & 6.316988 & -2.108416 & 3.268211 \\
\hline $\mathrm{H}$ & 4.436819 & -2.253009 & 1.703375 \\
\hline $\mathrm{O}$ & -0.689979 & 0.091703 & -1.526178 \\
\hline $\mathrm{O}$ & -0.418322 & 1.473949 & 0.687602 \\
\hline $\mathrm{H}$ & -1.430940 & 1.382619 & 1.205217 \\
\hline $\mathrm{H}$ & 4.748061 & 4.095904 & -1.104242 \\
\hline $\mathrm{H}$ & 1.699820 & 7.053008 & -1.767977 \\
\hline $\mathrm{H}$ & 0.736802 & 3.392303 & 0.274413 \\
\hline $\mathrm{H}$ & -0.593825 & -2.479687 & 2.059188 \\
\hline $\mathrm{H}$ & -4.158315 & -4.664851 & 1.072061 \\
\hline $\mathrm{H}$ & -0.896392 & -4.501060 & -1.722589 \\
\hline C & -3.290839 & 0.356827 & 1.708842 \\
\hline $\mathrm{O}$ & -2.537665 & 1.387516 & 1.856948 \\
\hline $\mathrm{H}$ & -2.864360 & -0.574730 & 1.314054 \\
\hline C & -4.280710 & 0.064257 & 2.833673 \\
\hline
\end{tabular}




$\begin{array}{llll}\mathrm{O} & -4.588759 & -1.061143 & 3.167029 \\ \mathrm{O} & -4.752724 & 1.184702 & 3.397950 \\ \mathrm{C} & -5.655676 & 0.985135 & 4.500640 \\ \mathrm{H} & -5.157558 & 0.438504 & 5.305208 \\ \mathrm{H} & -5.935256 & 1.985135 & 4.831757 \\ \mathrm{C} & -3.902549 & 0.789059 & -0.831816 \\ \mathrm{C} & -4.684148 & 0.551057 & 0.313240 \\ \mathrm{H} & -2.431918 & -0.151261 & -1.902221 \\ \mathrm{~N} & -3.420454 & -0.232998 & -1.609955 \\ \mathrm{C} & -3.998000 & -1.457036 & -1.963365 \\ \mathrm{O} & -3.414737 & -2.263421 & -2.650714 \\ \mathrm{O} & -5.264280 & -1.588348 & -1.523346 \\ \mathrm{C} & -5.912464 & -2.809330 & -1.924339 \\ \mathrm{H} & -6.921122 & -2.744584 & -1.515971 \\ \mathrm{H} & -5.382151 & -3.670256 & -1.512146 \\ \mathrm{H} & -5.940140 & -2.886493 & -3.013744 \\ \mathrm{H} & -5.272847 & 1.379432 & 0.691562 \\ \mathrm{H} & -5.153589 & -0.420767 & 0.401212 \\ \mathrm{C} & -3.425806 & 2.132960 & -1.164415 \\ \mathrm{C} & -2.900543 & 2.406410 & -2.447247 \\ \mathrm{C} & -3.522233 & 3.190380 & -0.233280 \\ \mathrm{C} & -2.496306 & 3.689707 & -2.787684 \\ \mathrm{H} & -2.833159 & 1.613963 & -3.183416 \\ \mathrm{C} & -3.107634 & 4.472864 & -0.581126 \\ \mathrm{H} & -3.886569 & 3.006868 & 0.768476 \\ \mathrm{C} & -2.600457 & 4.727621 & -1.856174 \\ \mathrm{H} & -2.101577 & 3.883988 & -3.780247 \\ \mathrm{H} & -3.181492 & 5.274413 & 0.147916 \\ \mathrm{H} & -2.290011 & 5.732705 & -2.128206 \\ \mathrm{H} & -6.536525 & 0.423055 & 4.178698\end{array}$

Catalyst (R)-1 TS Conformation 160

B3LYP/6-31G(d) Energy $=-2809.69562$

B3LYP-D3(BJ)/def2-TZVPP-IEF-PCM(DCM) Energy = -2810.985065

B3LYP-D3(BJ)/def2-TZVPP-IEF-PCM(DCM)//B3LYP/6-31G(d) Free Energy (Quasiharmonic) = 2810.34218

Frequencies (Top 3 out of 270)

1. $-367.4799 \mathrm{~cm}-1$

2. $\quad 10.6077 \mathrm{~cm}-1$

3. $\quad 14.9532 \mathrm{~cm}-1$ 
B3LYP/6-31G(d) Molecular Geometry in Cartesian Coordinates

\begin{tabular}{|c|c|c|c|}
\hline C & 3.467432 & 0.639329 & 0.021793 \\
\hline C & 2.374826 & 1.490184 & -0.048290 \\
\hline C & 2.408536 & 2.854347 & 0.367774 \\
\hline C & 3.594008 & 3.312715 & 0.911160 \\
\hline $\mathrm{H}$ & 3.670293 & 4.354561 & 1.210226 \\
\hline C & 3.119933 & -3.410880 & -1.430215 \\
\hline C & 3.360315 & -0.745395 & -0.527936 \\
\hline C & 2.350508 & -1.584685 & -0.083693 \\
\hline C & 2.215886 & -2.942111 & -0.497134 \\
\hline $\mathrm{H}$ & 3.061313 & -4.448161 & -1.749412 \\
\hline $\mathrm{O}$ & 1.189016 & 1.000951 & -0.585077 \\
\hline$P$ & 0.287839 & -0.053997 & 0.275706 \\
\hline $\mathrm{O}$ & 1.424697 & -1.088301 & 0.830597 \\
\hline C & -0.869390 & 5.616148 & -0.021987 \\
\hline C & -0.590134 & 4.718657 & -1.054185 \\
\hline C & 0.452886 & 3.801837 & -0.929935 \\
\hline C & 1.242490 & 3.768004 & 0.231851 \\
\hline C & 0.941813 & 4.668915 & 1.268133 \\
\hline C & -0.101504 & 5.584316 & 1.143252 \\
\hline $\mathrm{H}$ & -1.185266 & 4.719458 & -1.962645 \\
\hline $\mathrm{H}$ & -0.319344 & 6.266378 & 1.961070 \\
\hline C & -0.763307 & -5.648633 & 1.024785 \\
\hline C & -0.027732 & -4.852754 & 1.905970 \\
\hline C & 0.920293 & -3.953120 & 1.421020 \\
\hline C & 1.158430 & -3.839134 & 0.041182 \\
\hline C & 0.410808 & -4.642706 & -0.834330 \\
\hline C & -0.541812 & -5.538000 & -0.348410 \\
\hline $\mathrm{H}$ & -0.185865 & -4.939252 & 2.978107 \\
\hline $\mathrm{H}$ & -1.114091 & -6.145376 & -1.044851 \\
\hline C & 4.247904 & -1.226764 & -1.551729 \\
\hline C & 4.123985 & -2.584658 & -1.991676 \\
\hline C & 5.001911 & -3.076461 & -2.995557 \\
\hline C & 5.945899 & -2.259462 & -3.572384 \\
\hline C & 6.044027 & -0.907030 & -3.169070 \\
\hline C & 5.219985 & -0.404778 & -2.186010 \\
\hline $\mathrm{H}$ & 4.902012 & -4.113237 & -3.308195 \\
\hline $\mathrm{H}$ & 6.606832 & -2.644499 & -4.344078 \\
\hline $\mathrm{H}$ & 6.773340 & -0.255656 & -3.643011 \\
\hline $\mathrm{H}$ & 5.301733 & 0.636292 & -1.896639 \\
\hline C & 4.663899 & 1.110618 & 0.663485 \\
\hline C & 4.719817 & 2.474402 & 1.097852 \\
\hline
\end{tabular}




\begin{tabular}{|c|c|c|c|}
\hline C & 5.901546 & 2.959938 & 1.721192 \\
\hline C & 6.977360 & 2.131932 & 1.941578 \\
\hline C & 6.910068 & 0.774271 & 1.549402 \\
\hline C & 5.786180 & 0.277584 & 0.926405 \\
\hline $\mathrm{H}$ & 5.931815 & 4.001218 & 2.033365 \\
\hline $\mathrm{H}$ & 7.872481 & 2.512677 & 2.425752 \\
\hline $\mathrm{H}$ & 7.751357 & 0.114981 & 1.745552 \\
\hline $\mathrm{H}$ & 5.747546 & -0.767228 & 0.640787 \\
\hline 0 & -0.717009 & -0.668226 & -0.644045 \\
\hline 0 & -0.213936 & 0.617025 & 1.573965 \\
\hline $\mathrm{H}$ & -1.310535 & 0.710960 & 1.648805 \\
\hline $\mathrm{H}$ & 1.518480 & 4.633029 & 2.188087 \\
\hline $\mathrm{H}$ & -1.682105 & 6.331651 & -0.120743 \\
\hline $\mathrm{H}$ & 0.653317 & 3.111645 & -1.740874 \\
\hline $\mathrm{H}$ & 0.566457 & -4.546660 & -1.905186 \\
\hline $\mathrm{H}$ & -1.503026 & -6.347829 & 1.405848 \\
\hline $\mathrm{H}$ & 1.489563 & -3.342090 & 2.113497 \\
\hline C & -3.530454 & 0.062138 & 1.872307 \\
\hline $\mathrm{O}$ & -2.641545 & 0.947845 & 1.587875 \\
\hline $\mathrm{H}$ & -4.568433 & 0.419270 & 1.929757 \\
\hline C & -3.316965 & -0.949031 & 3.006268 \\
\hline $\mathrm{O}$ & -4.234160 & -1.520317 & 3.560392 \\
\hline $\mathrm{O}$ & -2.021296 & -1.116288 & 3.290286 \\
\hline C & -1.722469 & -2.047873 & 4.343504 \\
\hline $\mathrm{H}$ & -0.639819 & -2.012505 & 4.460276 \\
\hline $\mathrm{H}$ & -2.223447 & -1.750380 & 5.268086 \\
\hline C & -4.157070 & -0.423994 & -0.571165 \\
\hline C & -3.677206 & -1.229822 & 0.488444 \\
\hline $\mathrm{H}$ & -2.245144 & 0.049617 & -1.094719 \\
\hline$N$ & -3.238962 & 0.335245 & -1.212924 \\
\hline C & -3.358334 & 1.632410 & -1.754738 \\
\hline $\mathrm{O}$ & -2.468001 & 2.135504 & -2.399529 \\
\hline $\mathrm{O}$ & -4.517188 & 2.219743 & -1.430073 \\
\hline C & -4.662651 & 3.572462 & -1.897835 \\
\hline $\mathrm{H}$ & -4.559289 & 3.616944 & -2.984762 \\
\hline $\mathrm{H}$ & -3.907651 & 4.210725 & -1.432944 \\
\hline $\mathrm{H}$ & -5.664141 & 3.873998 & -1.591495 \\
\hline $\mathrm{H}$ & -4.338126 & -2.019423 & 0.832739 \\
\hline $\mathrm{H}$ & -2.627228 & -1.508502 & 0.429541 \\
\hline C & -5.585819 & -0.391417 & -0.924642 \\
\hline C & -5.981055 & -0.206020 & -2.262528 \\
\hline C & -6.571945 & -0.647308 & 0.045997 \\
\hline C & -7.324945 & -0.264708 & -2.616439 \\
\hline $\mathrm{H}$ & -5.227601 & -0.051663 & -3.028407 \\
\hline
\end{tabular}




$\begin{array}{lllr}\text { C } & -7.917412 & -0.684721 & -0.310742 \\ \text { H } & -6.288940 & -0.802559 & 1.082225 \\ \text { C } & -8.298295 & -0.495055 & -1.640796 \\ \text { H } & -7.613378 & -0.135384 & -3.655699 \\ \text { H } & -8.668793 & -0.867210 & 0.451970 \\ \text { H } & -9.348070 & -0.534991 & -1.917832 \\ \text { H } & -2.049197 & -3.053153 & 4.063980\end{array}$

Catalyst (R)-1 TS Conformation 161

B3LYP/6-31G(d) Energy = -2809.68555

B3LYP-D3(BJ)/def2-TZVPP-IEF-PCM(DCM) Energy = -2810.983599

B3LYP-D3(BJ)/def2-TZVPP-IEF-PCM(DCM)//B3LYP/6-31G(d) Free Energy (Quasiharmonic) = 2810.342131

Frequencies (Top 3 out of 270)

1. $-727.3659 \mathrm{~cm}-1$

2. $\quad 7.1030 \mathrm{~cm}-1$

3. $\quad 9.0847 \mathrm{~cm}-1$

B3LYP/6-31G(d) Molecular Geometry in Cartesian Coordinates

$\begin{array}{llll}\text { C } & -3.423232 & -1.200686 & 0.209590 \\ \text { C } & -2.190691 & -1.752667 & -0.098776 \\ \text { C } & -1.856605 & -3.116651 & 0.152529 \\ \text { C } & -2.805730 & -3.890962 & 0.791340 \\ \text { H } & -2.597585 & -4.941961 & 0.974101 \\ \text { C } & -4.307438 & 2.905758 & -0.766399 \\ \text { C } & -3.716300 & 0.207581 & -0.192345 \\ \text { C } & -2.883834 & 1.239805 & 0.219219 \\ \text { C } & -3.187695 & 2.616432 & -0.011029 \\ \text { H } & -4.579747 & 3.944484 & -0.933719 \\ \text { O } & -1.247055 & -0.939655 & -0.703949 \\ \text { P } & -0.466883 & 0.154688 & 0.255857 \\ \text { O } & -1.737206 & 0.947383 & 0.939973 \\ \text { C } & 1.836459 & -4.965676 & -1.056937 \\ \text { C } & 1.312492 & -5.195533 & 0.215843 \\ \text { C } & 0.129373 & -4.571326 & 0.609310 \\ \text { C } & -0.556278 & -3.707740 & -0.260616 \\ \text { C } & -0.011722 & -3.475945 & -1.535744 \\ \text { C } & 1.170979 & -4.100858 & -1.928918 \\ \text { H } & 1.826517 & -5.857810 & 0.907919\end{array}$




\begin{tabular}{|c|c|c|c|}
\hline $\mathrm{H}$ & 1.567860 & -3.916740 & -2.924050 \\
\hline C & -1.060786 & 5.946094 & 1.698910 \\
\hline C & -1.340751 & 4.820159 & 2.477330 \\
\hline C & -1.992271 & 3.720035 & 1.920318 \\
\hline C & -2.386371 & 3.726703 & 0.570541 \\
\hline C & -2.086316 & 4.859665 & -0.204109 \\
\hline C & -1.431216 & 5.958785 & 0.352986 \\
\hline $\mathrm{H}$ & -1.057749 & 4.799291 & 3.526638 \\
\hline $\mathrm{H}$ & -1.210870 & 6.824289 & -0.266689 \\
\hline C & -4.834767 & 0.521951 & -1.040138 \\
\hline C & -5.127498 & 1.894837 & -1.322355 \\
\hline C & -6.234710 & 2.218933 & -2.152291 \\
\hline C & -7.011311 & 1.232010 & -2.713029 \\
\hline C & -6.703654 & -0.126580 & -2.466362 \\
\hline C & -5.647803 & -0.472328 & -1.651691 \\
\hline $\mathrm{H}$ & -6.448147 & 3.267785 & -2.345028 \\
\hline $\mathrm{H}$ & -7.850900 & 1.490843 & -3.352362 \\
\hline $\mathrm{H}$ & -7.303050 & -0.906493 & -2.928336 \\
\hline $\mathrm{H}$ & -5.420235 & -1.518283 & -1.482788 \\
\hline C & -4.371535 & -1.997237 & 0.938828 \\
\hline C & -4.049591 & -3.364977 & 1.219317 \\
\hline C & -4.981233 & -4.169199 & 1.930232 \\
\hline C & -6.171911 & -3.646129 & 2.378174 \\
\hline C & -6.476299 & -2.286180 & 2.135004 \\
\hline C & -5.602272 & -1.484675 & 1.433687 \\
\hline $\mathrm{H}$ & -4.726020 & -5.208480 & 2.124130 \\
\hline $\mathrm{H}$ & -6.873006 & -4.269132 & 2.926859 \\
\hline $\mathrm{H}$ & -7.406933 & -1.867741 & 2.508945 \\
\hline $\mathrm{H}$ & -5.846610 & -0.442459 & 1.263948 \\
\hline 0 & 0.359070 & -0.458064 & 1.329781 \\
\hline O & 0.211931 & 1.085744 & -0.767470 \\
\hline $\mathrm{H}$ & 1.351756 & 0.767589 & -1.080322 \\
\hline $\mathrm{H}$ & -0.523055 & -2.811635 & -2.223442 \\
\hline $\mathrm{H}$ & 2.754189 & -5.458077 & -1.368786 \\
\hline $\mathrm{H}$ & -0.261228 & -4.736494 & 1.609371 \\
\hline $\mathrm{H}$ & -2.360964 & 4.871422 & -1.255200 \\
\hline $\mathrm{H}$ & -0.556042 & 6.803396 & 2.136611 \\
\hline $\mathrm{H}$ & -2.209849 & 2.854391 & 2.536108 \\
\hline C & 2.903855 & -0.465344 & -0.554217 \\
\hline 0 & 2.462742 & 0.423297 & -1.375917 \\
\hline $\mathrm{H}$ & 2.196385 & -0.977128 & 0.107367 \\
\hline C & 4.050922 & -1.322186 & -1.064357 \\
\hline 0 & 4.684075 & -1.106984 & -2.072840 \\
\hline $\mathrm{O}$ & 4.263627 & -2.358750 & -0.230747 \\
\hline
\end{tabular}




$\begin{array}{llll}\mathrm{C} & 5.316702 & -3.257942 & -0.616008 \\ \mathrm{H} & 5.315996 & -4.046013 & 0.136940 \\ \mathrm{H} & 5.118029 & -3.672576 & -1.607351 \\ \mathrm{C} & 4.799435 & 1.086412 & 0.473953 \\ \mathrm{C} & 3.704852 & 0.425510 & 1.041527 \\ \mathrm{H} & 5.536051 & 2.501238 & -0.777939 \\ \mathrm{~N} & 4.702507 & 2.211850 & -0.279771 \\ \mathrm{C} & 3.648322 & 3.125351 & -0.542094 \\ \mathrm{O} & 3.799334 & 3.976244 & -1.388309 \\ \mathrm{O} & 2.612599 & 2.967857 & 0.267753 \\ \mathrm{C} & 1.497140 & 3.865349 & 0.026190 \\ \mathrm{H} & 1.844851 & 4.898653 & 0.066234 \\ \mathrm{H} & 0.786347 & 3.653586 & 0.819960 \\ \mathrm{H} & 1.054469 & 3.642034 & -0.943564 \\ \mathrm{H} & 3.931921 & -0.416478 & 1.685736 \\ \mathrm{H} & 2.800421 & 0.968714 & 1.279588 \\ \mathrm{C} & 6.162180 & 0.501306 & 0.538061 \\ \mathrm{C} & 7.007160 & 0.484646 & -0.586736 \\ \mathrm{C} & 6.629793 & -0.031343 & 1.751355 \\ \mathrm{C} & 8.291469 & -0.047157 & -0.492361 \\ \mathrm{H} & 6.639526 & 0.822014 & -1.551267 \\ \mathrm{C} & 7.918554 & -0.552441 & 1.842424 \\ \mathrm{H} & 5.991610 & -0.008289 & 2.628986 \\ \mathrm{C} & 8.752451 & -0.560560 & 0.722095 \\ \mathrm{H} & 8.927517 & -0.070340 & -1.372301 \\ \mathrm{H} & 8.272941 & -0.946700 & 2.790357 \\ \mathrm{H} & 9.756530 & -0.969046 & 0.793909 \\ \mathrm{H} & 6.277939 & -2.737695 & -0.629732\end{array}$

Catalyst (R)-1 TS Conformation 162

B3LYP/6-31G(d) Energy $=-2809.694864$

B3LYP-D3(BJ)/def2-TZVPP-IEF-PCM(DCM) Energy = -2810.983599

B3LYP-D3(BJ)/def2-TZVPP-IEF-PCM(DCM)//B3LYP/6-31G(d) Free Energy (Quasiharmonic) = 2810.34212

Frequencies (Top 3 out of 270)

1. $-654.7107 \mathrm{~cm}-1$

2. $\quad 4.1766 \mathrm{~cm}-1$

3. $\quad 10.0616 \mathrm{~cm}-1$

B3LYP/6-31G(d) Molecular Geometry in Cartesian Coordinates 


\begin{tabular}{|c|c|c|c|}
\hline C & 3.377077 & -1.023941 & -0.021896 \\
\hline C & 2.175224 & -1.715073 & 0.018690 \\
\hline C & 2.092685 & -3.138832 & -0.028060 \\
\hline C & 3.268703 & -3.838327 & -0.207850 \\
\hline $\mathrm{H}$ & 3.234723 & -4.924054 & -0.245156 \\
\hline C & 3.676545 & 3.239410 & 0.536710 \\
\hline C & 3.422216 & 0.443302 & 0.254802 \\
\hline C & 2.645297 & 1.328276 & -0.477689 \\
\hline C & 2.781462 & 2.745944 & -0.392205 \\
\hline $\mathrm{H}$ & 3.801383 & 4.315309 & 0.626601 \\
\hline $\mathrm{O}$ & 0.997840 & -1.004330 & 0.225910 \\
\hline$P$ & 0.426135 & 0.033847 & -0.903421 \\
\hline O & 1.754535 & 0.816702 & -1.418465 \\
\hline C & -1.558407 & -5.347389 & 0.535367 \\
\hline C & -0.476768 & -5.533166 & 1.398340 \\
\hline C & 0.698918 & -4.803493 & 1.216541 \\
\hline C & 0.811934 & -3.877148 & 0.167949 \\
\hline C & -0.277728 & -3.706869 & -0.697969 \\
\hline C & -1.455309 & -4.432392 & -0.515079 \\
\hline $\mathrm{H}$ & -0.547533 & -6.243490 & 2.218292 \\
\hline $\mathrm{H}$ & -2.285649 & -4.271860 & -1.197432 \\
\hline C & 0.787690 & 5.579908 & -2.945929 \\
\hline C & 0.037441 & 4.642548 & -2.233374 \\
\hline C & 0.664683 & 3.703376 & -1.414610 \\
\hline C & 2.063405 & 3.690740 & -1.294537 \\
\hline C & 2.809110 & 4.639578 & -2.013574 \\
\hline C & 2.178419 & 5.575408 & -2.833065 \\
\hline $\mathrm{H}$ & -1.046842 & 4.640997 & -2.312688 \\
\hline $\mathrm{H}$ & 2.775186 & 6.295255 & -3.387361 \\
\hline C & 4.268838 & 0.975939 & 1.290696 \\
\hline C & 4.399741 & 2.396278 & 1.414932 \\
\hline C & 5.238597 & 2.936359 & 2.427257 \\
\hline C & 5.904934 & 2.115093 & 3.306365 \\
\hline C & 5.749271 & 0.712391 & 3.210294 \\
\hline C & 4.956472 & 0.158025 & 2.229423 \\
\hline $\mathrm{H}$ & 5.332784 & 4.017369 & 2.499455 \\
\hline $\mathrm{H}$ & 6.538903 & 2.538795 & 4.080440 \\
\hline $\mathrm{H}$ & 6.255602 & 0.064779 & 3.920962 \\
\hline $\mathrm{H}$ & 4.840777 & -0.918063 & 2.178073 \\
\hline C & 4.576712 & -1.759725 & -0.325407 \\
\hline C & 4.512201 & -3.188102 & -0.402557 \\
\hline C & 5.691307 & -3.927525 & -0.689799 \\
\hline C & 6.887495 & -3.289526 & -0.921496 \\
\hline
\end{tabular}




\begin{tabular}{|c|c|c|c|}
\hline C & 6.947719 & -1.876848 & -0.881723 \\
\hline C & 5.825777 & -1.132819 & -0.589212 \\
\hline $\mathrm{H}$ & 5.623896 & -5.011855 & -0.736692 \\
\hline $\mathrm{H}$ & 7.781256 & -3.864378 & -1.147982 \\
\hline $\mathrm{H}$ & 7.887087 & -1.372150 & -1.090777 \\
\hline $\mathrm{H}$ & 5.888077 & -0.051009 & -0.574955 \\
\hline 0 & -0.588434 & 0.890026 & -0.215383 \\
\hline $\mathrm{O}$ & -0.017642 & -0.724732 & -2.171051 \\
\hline $\mathrm{H}$ & -1.120906 & -1.076546 & -2.204118 \\
\hline $\mathrm{H}$ & -0.193738 & -3.019750 & -1.530095 \\
\hline $\mathrm{H}$ & -2.474344 & -5.915252 & 0.678233 \\
\hline $\mathrm{H}$ & 1.533716 & -4.939194 & 1.899276 \\
\hline $\mathrm{H}$ & 3.893384 & 4.628080 & -1.940823 \\
\hline $\mathrm{H}$ & 0.292972 & 6.306056 & -3.585823 \\
\hline $\mathrm{H}$ & 0.068498 & 2.988808 & -0.857446 \\
\hline C & -3.170450 & -0.741626 & -1.715900 \\
\hline $\mathrm{O}$ & -2.298833 & -1.533911 & -2.217252 \\
\hline $\mathrm{H}$ & -2.953190 & 0.331836 & -1.669183 \\
\hline C & -4.620084 & -1.095698 & -2.012968 \\
\hline $\mathrm{O}$ & -5.057369 & -2.218123 & -2.107391 \\
\hline $\mathrm{O}$ & -5.345183 & 0.031155 & -2.167250 \\
\hline C & -6.737743 & -0.175110 & -2.473683 \\
\hline $\mathrm{H}$ & -7.157526 & 0.821563 & -2.608883 \\
\hline $\mathrm{H}$ & -6.839049 & -0.765198 & -3.387602 \\
\hline C & -3.797396 & 0.035603 & 0.909311 \\
\hline C & -3.187100 & -1.062624 & 0.281838 \\
\hline $\mathrm{H}$ & -2.088526 & 1.124477 & 0.658568 \\
\hline$N$ & -3.038277 & 1.156611 & 1.072225 \\
\hline C & -3.266179 & 2.236826 & 1.939069 \\
\hline $\mathrm{O}$ & -4.190288 & 2.371044 & 2.707968 \\
\hline $\mathrm{O}$ & -2.250157 & 3.103041 & 1.779969 \\
\hline C & -2.285466 & 4.252191 & 2.642646 \\
\hline $\mathrm{H}$ & -1.404431 & 4.835113 & 2.376104 \\
\hline $\mathrm{H}$ & -2.242618 & 3.944012 & 3.690354 \\
\hline $\mathrm{H}$ & -3.198037 & 4.829380 & 2.473554 \\
\hline $\mathrm{H}$ & -3.724971 & -2.003383 & 0.274405 \\
\hline $\mathrm{H}$ & -2.109002 & -1.139271 & 0.362005 \\
\hline C & -5.239004 & 0.018154 & 1.226397 \\
\hline C & -6.075614 & 1.106896 & 0.920719 \\
\hline C & -5.807343 & -1.144893 & 1.774124 \\
\hline C & -7.443329 & 1.029334 & 1.157588 \\
\hline $\mathrm{H}$ & -5.655048 & 2.001182 & 0.475931 \\
\hline C & -7.175592 & -1.211452 & 2.028817 \\
\hline $\mathrm{H}$ & -5.169232 & -1.985070 & 2.028502 \\
\hline
\end{tabular}




$\begin{array}{llll}\mathrm{C} & -7.996381 & -0.126453 & 1.718157 \\ \mathrm{H} & -8.080462 & 1.873562 & 0.910212 \\ \mathrm{H} & -7.598255 & -2.109840 & 2.468751 \\ \mathrm{H} & -9.064188 & -0.178797 & 1.912166 \\ \mathrm{H} & -7.234391 & -0.693651 & -1.650261\end{array}$

Catalyst (R)-1 TS Conformation 163

B3LYP/6-31G(d) Energy $=-2809.696131$

B3LYP-D3(BJ)/def2-TZVPP-IEF-PCM(DCM) Energy = -2810.985832

B3LYP-D3(BJ)/def2-TZVPP-IEF-PCM(DCM)//B3LYP/6-31G(d) Free Energy (Quasiharmonic) = 2810.342109

Frequencies (Top 3 out of 270)

1. $-272.7105 \mathrm{~cm}-1$

2. $\quad 11.5953 \mathrm{~cm}-1$

3. $\quad 15.6136 \mathrm{~cm}-1$

B3LYP/6-31G(d) Molecular Geometry in Cartesian Coordinates

$\begin{array}{llll}\mathrm{C} & 2.882009 & -1.368249 & -0.339020 \\ \mathrm{C} & 1.576780 & -1.740650 & -0.065896 \\ \mathrm{C} & 1.003131 & -2.979914 & -0.472769 \\ \mathrm{C} & 1.805711 & -3.834613 & -1.202221 \\ \mathrm{H} & 1.410107 & -4.799033 & -1.510055 \\ \mathrm{C} & 4.464437 & 2.467630 & 0.814902 \\ \mathrm{C} & 3.402690 & -0.060021 & 0.161449 \\ \mathrm{C} & 2.742715 & 1.118425 & -0.160089 \\ \mathrm{C} & 3.280204 & 2.414614 & 0.103495 \\ \mathrm{H} & 4.894702 & 3.438464 & 1.045380 \\ \mathrm{O} & 0.778217 & -0.858278 & 0.657451 \\ \mathrm{P} & 0.216904 & 0.479616 & -0.093840 \\ \mathrm{O} & 1.539157 & 1.040351 & -0.859057 \\ \mathrm{C} & -3.064323 & -4.095905 & 0.388026 \\ \mathrm{C} & -2.248339 & -3.598520 & 1.407181 \\ \mathrm{C} & -0.932536 & -3.223041 & 1.136690 \\ \mathrm{C} & -0.404651 & -3.344139 & -0.159355 \\ \mathrm{C} & -1.234365 & -3.849486 & -1.174084 \\ \mathrm{C} & -2.551576 & -4.219976 & -0.904669 \\ \mathrm{H} & -2.636871 & -3.496201 & 2.417045 \\ \mathrm{H} & -3.184552 & -4.588708 & -1.706960 \\ \mathrm{C} & 1.645730 & 6.100946 & -1.406744\end{array}$




\begin{tabular}{|c|c|c|c|}
\hline C & 0.808552 & 5.189743 & -0.761102 \\
\hline C & 1.315315 & 3.987318 & -0.268487 \\
\hline C & 2.675033 & 3.672065 & -0.420208 \\
\hline C & 3.508057 & 4.597157 & -1.074265 \\
\hline C & 3.000228 & 5.800892 & -1.560671 \\
\hline $\mathrm{H}$ & -0.250403 & 5.399230 & -0.641426 \\
\hline $\mathrm{H}$ & 3.661713 & 6.497507 & -2.069670 \\
\hline C & 4.585651 & 0.017574 & 0.974006 \\
\hline C & 5.117066 & 1.307182 & 1.296839 \\
\hline C & 6.284576 & 1.398648 & 2.102543 \\
\hline C & 6.896303 & 0.268621 & 2.593064 \\
\hline C & 6.356225 & -1.005981 & 2.300264 \\
\hline C & 5.233541 & -1.128782 & 1.511351 \\
\hline $\mathrm{H}$ & 6.679241 & 2.385598 & 2.332224 \\
\hline $\mathrm{H}$ & 7.785185 & 0.351234 & 3.212527 \\
\hline $\mathrm{H}$ & 6.828062 & -1.896729 & 2.706295 \\
\hline $\mathrm{H}$ & 4.825545 & -2.111648 & 1.304698 \\
\hline C & 3.680736 & -2.237704 & -1.161477 \\
\hline C & 3.129076 & -3.493982 & -1.575769 \\
\hline C & 3.910973 & -4.370443 & -2.376305 \\
\hline C & 5.175243 & -4.016798 & -2.785819 \\
\hline C & 5.706447 & -2.759627 & -2.414217 \\
\hline C & 4.981167 & -1.894946 & -1.624166 \\
\hline $\mathrm{H}$ & 3.480642 & -5.324769 & -2.670696 \\
\hline $\mathrm{H}$ & 5.760860 & -4.692005 & -3.403653 \\
\hline $\mathrm{H}$ & 6.694976 & -2.469617 & -2.759895 \\
\hline $\mathrm{H}$ & 5.400481 & -0.931972 & -1.358596 \\
\hline $\mathrm{O}$ & -0.350070 & 1.373518 & 0.957309 \\
\hline $\mathrm{O}$ & -0.672165 & 0.040515 & -1.286863 \\
\hline $\mathrm{H}$ & -1.728647 & 0.235008 & -1.288896 \\
\hline $\mathrm{H}$ & -0.847986 & -3.922368 & -2.186805 \\
\hline $\mathrm{H}$ & -4.094867 & -4.371450 & 0.593115 \\
\hline $\mathrm{H}$ & -0.308389 & -2.835479 & 1.934746 \\
\hline $\mathrm{H}$ & 4.557537 & 4.356420 & -1.221880 \\
\hline $\mathrm{H}$ & 1.245868 & 7.035385 & -1.792566 \\
\hline $\mathrm{H}$ & 0.648607 & 3.304837 & 0.244041 \\
\hline C & -3.893287 & -0.443155 & -0.915999 \\
\hline $\mathrm{O}$ & -3.107651 & 0.410682 & -1.463551 \\
\hline $\mathrm{H}$ & -3.475412 & -1.271934 & -0.328401 \\
\hline C & -5.099015 & -0.944251 & -1.712966 \\
\hline $\mathrm{O}$ & -5.616413 & -2.024619 & -1.519069 \\
\hline $\mathrm{O}$ & -5.505890 & -0.060216 & -2.638843 \\
\hline C & -6.616139 & -0.489957 & -3.445034 \\
\hline $\mathrm{H}$ & -6.807132 & 0.328818 & -4.139023 \\
\hline
\end{tabular}




$\begin{array}{llll}\mathrm{H} & -6.361984 & -1.402979 & -3.989465 \\ \mathrm{C} & -3.951291 & 0.901567 & 1.300172 \\ \mathrm{C} & -4.980389 & 0.414879 & 0.469884 \\ \mathrm{H} & -2.188580 & 1.949988 & 1.293747 \\ \mathrm{~N} & -3.139517 & 1.915250 & 0.910339 \\ \mathrm{C} & -3.238914 & 2.815240 & -0.179331 \\ \mathrm{O} & -2.286251 & 3.466507 & -0.536523 \\ \mathrm{O} & -4.484890 & 2.930528 & -0.654504 \\ \mathrm{C} & -4.587353 & 3.660058 & -1.893137 \\ \mathrm{H} & -5.656282 & 3.738617 & -2.091039 \\ \mathrm{H} & -4.088885 & 3.094322 & -2.683447 \\ \mathrm{H} & -4.135490 & 4.648435 & -1.793345 \\ \mathrm{H} & -5.591969 & -0.383039 & 0.876305 \\ \mathrm{H} & -5.490022 & 1.112586 & -0.178458 \\ \mathrm{C} & -3.617461 & 0.198917 & 2.563445 \\ \mathrm{C} & -4.670166 & -0.346531 & 3.325273 \\ \mathrm{C} & -2.301445 & 0.079414 & 3.049534 \\ \mathrm{C} & -4.417218 & -0.995354 & 4.530300 \\ \mathrm{H} & -5.695587 & -0.231032 & 2.990682 \\ \mathrm{C} & -2.055751 & -0.580673 & 4.252121 \\ \mathrm{H} & -1.460088 & 0.461696 & 2.479975 \\ \mathrm{C} & -3.106776 & -1.118771 & 4.996762 \\ \mathrm{H} & -5.244899 & -1.396633 & 5.108088 \\ \mathrm{H} & -1.032429 & -0.674963 & 4.603920 \\ \mathrm{H} & -2.907615 & -1.626055 & 5.936786 \\ \mathrm{H} & -7.494327 & -0.680950 & -2.821904\end{array}$

Catalyst (R)-1 TS Conformation 164

B3LYP/6-31G(d) Energy $=-2809.69455$

B3LYP-D3(BJ)/def2-TZVPP-IEF-PCM(DCM) Energy = -2810.984311

B3LYP-D3(BJ)/def2-TZVPP-IEF-PCM(DCM)//B3LYP/6-31G(d) Free Energy (Quasiharmonic) = 2810.342063

Frequencies (Top 3 out of 270)

1. $-401.6735 \mathrm{~cm}-1$

2. $\quad 10.4022 \mathrm{~cm}-1$

3. $11.4728 \mathrm{~cm}-1$

B3LYP/6-31G(d) Molecular Geometry in Cartesian Coordinates

$\begin{array}{llll}\text { C } & 3.337747 & -0.890437 & -0.115686\end{array}$ 


\begin{tabular}{|c|c|c|c|}
\hline C & 2.152168 & -1.608985 & -0.114307 \\
\hline C & 2.035123 & -2.943278 & -0.605981 \\
\hline C & 3.175267 & -3.510837 & -1.143885 \\
\hline $\mathrm{H}$ & 3.138158 & -4.537356 & -1.498158 \\
\hline C & 3.425814 & 3.087583 & 1.558921 \\
\hline C & 3.376017 & 0.466031 & 0.508569 \\
\hline C & 2.481739 & 1.441607 & 0.094594 \\
\hline C & 2.498924 & 2.781017 & 0.582052 \\
\hline $\mathrm{H}$ & 3.481228 & 4.105900 & 1.934771 \\
\hline O & 1.021720 & -1.009500 & 0.428101 \\
\hline$P$ & 0.267170 & 0.179702 & -0.398383 \\
\hline O & 1.525513 & 1.112323 & -0.863284 \\
\hline C & -1.582331 & -5.274976 & -0.496581 \\
\hline C & -1.246192 & -4.462748 & 0.587486 \\
\hline C & -0.087668 & -3.687969 & 0.559186 \\
\hline C & 0.761659 & -3.710938 & -0.560488 \\
\hline C & 0.404647 & -4.524542 & -1.649963 \\
\hline C & -0.752504 & -5.300420 & -1.618512 \\
\hline $\mathrm{H}$ & -1.886455 & -4.418821 & 1.463980 \\
\hline $\mathrm{H}$ & -1.011150 & -5.915101 & -2.476901 \\
\hline C & -0.065311 & 5.923294 & -0.854587 \\
\hline C & 0.603334 & 5.097673 & -1.761460 \\
\hline C & 1.411177 & 4.056917 & -1.305708 \\
\hline C & 1.576112 & 3.829668 & 0.070588 \\
\hline C & 0.897084 & 4.664745 & 0.971983 \\
\hline C & 0.082313 & 5.700322 & 0.514876 \\
\hline $\mathrm{H}$ & 0.503685 & 5.270882 & -2.830045 \\
\hline $\mathrm{H}$ & -0.439607 & 6.330491 & 1.230389 \\
\hline C & 4.286374 & 0.782480 & 1.576102 \\
\hline C & 4.310283 & 2.118686 & 2.092292 \\
\hline C & 5.212317 & 2.447021 & 3.140579 \\
\hline C & 6.038819 & 1.493650 & 3.687602 \\
\hline C & 5.989096 & 0.163666 & 3.208024 \\
\hline C & 5.138683 & -0.182356 & 2.181013 \\
\hline $\mathrm{H}$ & 5.225798 & 3.469481 & 3.510793 \\
\hline $\mathrm{H}$ & 6.719437 & 1.754546 & 4.493409 \\
\hline $\mathrm{H}$ & 6.624471 & -0.594668 & 3.657533 \\
\hline $\mathrm{H}$ & 5.106237 & -1.208101 & 1.833325 \\
\hline C & 4.488398 & -1.465806 & -0.755752 \\
\hline C & 4.396724 & -2.803756 & -1.258990 \\
\hline C & 5.531075 & -3.394107 & -1.880019 \\
\hline C & 6.701882 & -2.688889 & -2.033200 \\
\hline C & 6.782393 & -1.353477 & -1.572948 \\
\hline C & 5.706972 & -0.758901 & -0.950094 \\
\hline
\end{tabular}




\begin{tabular}{|c|c|c|c|}
\hline $\mathrm{H}$ & 5.448471 & -4.415060 & -2.245375 \\
\hline $\mathrm{H}$ & 7.559731 & -3.148379 & -2.516547 \\
\hline $\mathrm{H}$ & 7.699970 & -0.789135 & -1.716106 \\
\hline $\mathrm{H}$ & 5.782268 & 0.267928 & -0.611332 \\
\hline 0 & -0.696493 & 0.845557 & 0.531616 \\
\hline 0 & -0.267579 & -0.364993 & -1.740174 \\
\hline $\mathrm{H}$ & -1.373681 & -0.372928 & -1.808438 \\
\hline $\mathrm{H}$ & 1.028223 & -4.526773 & -2.539471 \\
\hline $\mathrm{H}$ & -2.487735 & -5.876302 & -0.472702 \\
\hline $\mathrm{H}$ & 0.149346 & -3.060336 & 1.409487 \\
\hline $\mathrm{H}$ & 0.996758 & 4.484839 & 2.038740 \\
\hline $\mathrm{H}$ & -0.695890 & 6.732664 & -1.213086 \\
\hline $\mathrm{H}$ & 1.929898 & 3.423279 & -2.017494 \\
\hline C & -3.543767 & 0.437251 & -1.908519 \\
\hline $\mathrm{O}$ & -2.709621 & -0.527648 & -1.744378 \\
\hline $\mathrm{H}$ & -4.598484 & 0.157100 & -2.046724 \\
\hline C & -3.224957 & 1.604438 & -2.856327 \\
\hline 0 & -4.069621 & 2.367712 & -3.277584 \\
\hline 0 & -1.922684 & 1.661308 & -3.155009 \\
\hline C & -1.527490 & 2.716940 & -4.046562 \\
\hline $\mathrm{H}$ & -0.460851 & 2.568806 & -4.211804 \\
\hline $\mathrm{H}$ & -2.081349 & 2.648194 & -4.986250 \\
\hline C & -4.146203 & 0.523078 & 0.624307 \\
\hline C & -3.778239 & 1.489940 & -0.339406 \\
\hline $\mathrm{H}$ & -2.178073 & 0.098384 & 0.956223 \\
\hline$N$ & -3.153872 & -0.154107 & 1.234625 \\
\hline C & -3.188060 & -1.054904 & 2.318199 \\
\hline 0 & -2.246503 & -1.764039 & 2.588149 \\
\hline 0 & -4.327226 & -0.977055 & 3.020526 \\
\hline C & -4.409052 & -1.875683 & 4.141948 \\
\hline $\mathrm{H}$ & -3.608385 & -1.665950 & 4.854883 \\
\hline $\mathrm{H}$ & -4.331295 & -2.912969 & 3.807001 \\
\hline $\mathrm{H}$ & -5.385199 & -1.686639 & 4.587880 \\
\hline $\mathrm{H}$ & -4.569350 & 2.156998 & -0.668126 \\
\hline $\mathrm{H}$ & -2.795065 & 1.939782 & -0.218024 \\
\hline C & -5.560775 & 0.102093 & 0.722888 \\
\hline C & -5.911800 & -1.243659 & 0.518724 \\
\hline C & -6.570795 & 1.057322 & 0.908317 \\
\hline C & -7.251371 & -1.621870 & 0.510277 \\
\hline $\mathrm{H}$ & -5.134125 & -1.977451 & 0.328294 \\
\hline C & -7.909377 & 0.668831 & 0.924402 \\
\hline $\mathrm{H}$ & -6.303310 & 2.098480 & 1.062566 \\
\hline C & -8.251805 & -0.669368 & 0.723071 \\
\hline $\mathrm{H}$ & -7.515915 & -2.660293 & 0.332093 \\
\hline
\end{tabular}




$\begin{array}{rrrr}\mathrm{H} & -8.684054 & 1.412715 & 1.086418 \\ \mathrm{H} & -9.296135 & -0.969045 & 0.722786 \\ \mathrm{H} & -1.714728 & 3.690676 & -3.586464\end{array}$

Catalyst (R)-1 TS Conformation 165

B3LYP/6-31G(d) Energy $=-2809.687914$

B3LYP-D3(BJ)/def2-TZVPP-IEF-PCM(DCM) Energy = -2810.984606

B3LYP-D3(BJ)/def2-TZVPP-IEF-PCM(DCM)//B3LYP/6-31G(d) Free Energy (Quasiharmonic) = 2810.341994

Frequencies (Top 3 out of 270)

1. $-452.1167 \mathrm{~cm}-1$

2. $\quad 3.8832 \mathrm{~cm}-1$

3. $\quad 8.9411 \mathrm{~cm}-1$

B3LYP/6-31G(d) Molecular Geometry in Cartesian Coordinates

$\begin{array}{llll}\text { C } & -3.227732 & 0.078512 & 0.253502 \\ \text { C } & -2.874966 & -0.941143 & -0.617143 \\ \text { C } & -3.267458 & -2.301245 & -0.434741 \\ \text { C } & -3.987467 & -2.602467 & 0.705057 \\ \text { H } & -4.328854 & -3.622381 & 0.861867 \\ \text { C } & -2.058163 & 4.159465 & -0.484513 \\ \text { C } & -2.859166 & 1.487891 & -0.074465 \\ \text { C } & -1.531938 & 1.819064 & -0.320092 \\ \text { C } & -1.097037 & 3.167835 & -0.500748 \\ \text { H } & -1.751071 & 5.192775 & -0.624236 \\ \text { O } & -2.112453 & -0.621122 & -1.729466 \\ \text { P } & -0.509544 & -0.345098 & -1.488041 \\ \text { O } & -0.575024 & 0.820369 & -0.287139 \\ \text { C } & -2.398007 & -5.456573 & -3.227744 \\ \text { C } & -2.226195 & -5.655374 & -1.857321 \\ \text { C } & -2.490508 & -4.620205 & -0.961748 \\ \text { C } & -2.932097 & -3.366758 & -1.415949 \\ \text { C } & -3.093919 & -3.177253 & -2.798726 \\ \text { C } & -2.831424 & -4.213515 & -3.692994 \\ \text { H } & -1.876247 & -6.614349 & -1.483725 \\ \text { H } & -2.966261 & -4.047262 & -4.758539 \\ \text { C } & 2.999507 & 4.400364 & -0.987203 \\ \text { C } & 2.211464 & 4.936453 & 0.032341 \\ \text { C } & 0.891595 & 4.512772 & 0.190859\end{array}$




\begin{tabular}{|c|c|c|c|}
\hline C & 0.336568 & 3.543875 & -0.661625 \\
\hline C & 1.137480 & 3.007389 & -1.683481 \\
\hline C & 2.455869 & 3.438305 & -1.842253 \\
\hline $\mathrm{H}$ & 2.622368 & 5.684032 & 0.706397 \\
\hline $\mathrm{H}$ & 3.059225 & 3.019966 & -2.644300 \\
\hline C & -3.857648 & 2.518474 & -0.162216 \\
\hline C & -3.438727 & 3.874312 & -0.352678 \\
\hline C & -4.414571 & 4.904694 & -0.429898 \\
\hline C & -5.756752 & 4.615734 & -0.348458 \\
\hline C & -6.176552 & 3.273347 & -0.194812 \\
\hline C & -5.254398 & 2.254059 & -0.103169 \\
\hline $\mathrm{H}$ & -4.076235 & 5.928988 & -0.568455 \\
\hline $\mathrm{H}$ & -6.494600 & 5.410623 & -0.415329 \\
\hline $\mathrm{H}$ & -7.237805 & 3.042495 & -0.156173 \\
\hline $\mathrm{H}$ & -5.594212 & 1.230214 & 0.001467 \\
\hline C & -3.907174 & -0.265291 & 1.473643 \\
\hline C & -4.297045 & -1.627941 & 1.685775 \\
\hline C & -4.978697 & -1.980606 & 2.882422 \\
\hline C & -5.240222 & -1.041429 & 3.853015 \\
\hline C & -4.821271 & 0.296591 & 3.664574 \\
\hline C & -4.175362 & 0.674437 & 2.507476 \\
\hline $\mathrm{H}$ & -5.281157 & -3.016371 & 3.019413 \\
\hline $\mathrm{H}$ & -5.757352 & -1.324791 & 4.765804 \\
\hline $\mathrm{H}$ & -5.008520 & 1.033899 & 4.440759 \\
\hline $\mathrm{H}$ & -3.855664 & 1.702329 & 2.381788 \\
\hline $\mathrm{O}$ & 0.112364 & 0.163710 & -2.738514 \\
\hline $\mathrm{O}$ & 0.087780 & -1.541481 & -0.745450 \\
\hline $\mathrm{H}$ & 1.324459 & -1.870770 & -0.866154 \\
\hline $\mathrm{H}$ & -3.428754 & -2.216124 & -3.172478 \\
\hline $\mathrm{H}$ & -2.189298 & -6.260929 & -3.928289 \\
\hline $\mathrm{H}$ & -2.330080 & -4.772804 & 0.101853 \\
\hline $\mathrm{H}$ & 0.728739 & 2.257742 & -2.353956 \\
\hline $\mathrm{H}$ & 4.027405 & 4.729749 & -1.115715 \\
\hline $\mathrm{H}$ & 0.282828 & 4.926406 & 0.990831 \\
\hline C & 3.050658 & -0.978593 & -1.235086 \\
\hline $\mathrm{O}$ & 2.445829 & -2.050199 & -0.859177 \\
\hline $\mathrm{H}$ & 2.529831 & -0.286810 & -1.903919 \\
\hline C & 4.547683 & -1.093294 & -1.432577 \\
\hline $\mathrm{O}$ & 5.278716 & -1.819803 & -0.794529 \\
\hline $\mathrm{O}$ & 4.933275 & -0.265249 & -2.415047 \\
\hline C & 6.346232 & -0.219161 & -2.681716 \\
\hline $\mathrm{H}$ & 6.858276 & 0.258018 & -1.842610 \\
\hline $\mathrm{H}$ & 6.739065 & -1.227022 & -2.834473 \\
\hline C & 3.514334 & -0.275364 & 1.367684 \\
\hline
\end{tabular}




$\begin{array}{llll}\mathrm{C} & 3.053409 & 0.432598 & 0.259053 \\ \mathrm{H} & 5.030302 & -0.801396 & 2.625991 \\ \mathrm{~N} & 4.809124 & -0.233970 & 1.817397 \\ \mathrm{C} & 5.889443 & 0.490578 & 1.314939 \\ \mathrm{O} & 5.879920 & 1.228506 & 0.355011 \\ \mathrm{O} & 6.952594 & 0.237227 & 2.101265 \\ \mathrm{C} & 8.171374 & 0.899219 & 1.717665 \\ \mathrm{H} & 8.021992 & 1.980501 & 1.677305 \\ \mathrm{H} & 8.505921 & 0.539561 & 0.741441 \\ \mathrm{H} & 8.894617 & 0.636899 & 2.489233 \\ \mathrm{H} & 1.979156 & 0.555917 & 0.183062 \\ \mathrm{H} & 3.653471 & 1.235120 & -0.150226 \\ \mathrm{C} & 2.647574 & -1.229992 & 2.077898 \\ \mathrm{C} & 1.278509 & -0.957668 & 2.250688 \\ \mathrm{C} & 3.169895 & -2.447360 & 2.562699 \\ \mathrm{C} & 0.462115 & -1.864277 & 2.921390 \\ \mathrm{H} & 0.849333 & -0.036998 & 1.872723 \\ \mathrm{C} & 2.346812 & -3.351430 & 3.224285 \\ \mathrm{H} & 4.200691 & -2.720939 & 2.354592 \\ \mathrm{C} & 0.993553 & -3.056747 & 3.413902 \\ \mathrm{H} & -0.592760 & -1.640388 & 3.045068 \\ \mathrm{H} & 2.755227 & -4.295263 & 3.573323 \\ \mathrm{H} & 0.351651 & -3.765051 & 3.930216 \\ \mathrm{H} & 6.452154 & 0.379316 & -3.586423\end{array}$

Catalyst (R)-1 TS Conformation 166

B3LYP/6-31G(d) Energy $=-2809.690068$

B3LYP-D3(BJ)/def2-TZVPP-IEF-PCM(DCM) Energy = -2810.983561

B3LYP-D3(BJ)/def2-TZVPP-IEF-PCM(DCM)//B3LYP/6-31G(d) Free Energy (Quasiharmonic) = 2810.341968

Frequencies (Top 3 out of 270)

1. $-719.4638 \mathrm{~cm}-1$

2. $\quad 12.6373 \mathrm{~cm}-1$

3. $16.4350 \mathrm{~cm}-1$

B3LYP/6-31G(d) Molecular Geometry in Cartesian Coordinates

$\begin{array}{lrrr}C & 3.140833 & -0.332052 & 0.365010 \\ C & 2.693665 & 0.872464 & -0.155911 \\ C & 3.296637 & 2.125678 & 0.166303\end{array}$




\begin{tabular}{|c|c|c|c|}
\hline C & 4.276156 & 2.129700 & 1.140131 \\
\hline $\mathrm{H}$ & 4.772586 & 3.064339 & 1.387144 \\
\hline C & 1.550729 & -4.149227 & -0.815069 \\
\hline C & 2.604230 & -1.629061 & -0.144760 \\
\hline C & 1.243355 & -1.887179 & -0.088309 \\
\hline C & 0.679127 & -3.170662 & -0.371083 \\
\hline $\mathrm{H}$ & 1.174287 & -5.151320 & -0.998757 \\
\hline 0 & 1.650661 & 0.868131 & -1.073552 \\
\hline$P$ & 0.136110 & 0.464069 & -0.584320 \\
\hline O & 0.406675 & -0.873480 & 0.341800 \\
\hline C & 2.703213 & 5.839164 & -1.919833 \\
\hline C & 2.702816 & 5.807569 & -0.524112 \\
\hline C & 2.843934 & 4.593492 & 0.149501 \\
\hline C & 2.984470 & 3.387513 & -0.557017 \\
\hline C & 2.953403 & 3.429578 & -1.961742 \\
\hline C & 2.823695 & 4.644117 & -2.634196 \\
\hline $\mathrm{H}$ & 2.597555 & 6.728578 & 0.043497 \\
\hline $\mathrm{H}$ & 2.826222 & 4.656916 & -3.721254 \\
\hline C & -3.415903 & -4.323850 & 0.323711 \\
\hline C & -2.812661 & -3.368799 & 1.142409 \\
\hline C & -1.498567 & -2.964571 & 0.911282 \\
\hline C & -0.756499 & -3.500340 & -0.157166 \\
\hline C & -1.389371 & -4.441127 & -0.991234 \\
\hline C & -2.697347 & -4.856847 & -0.748190 \\
\hline $\mathrm{H}$ & -3.363182 & -2.920418 & 1.964727 \\
\hline $\mathrm{H}$ & -3.157396 & -5.592026 & -1.404135 \\
\hline C & 3.476752 & -2.628278 & -0.696204 \\
\hline C & 2.928733 & -3.907922 & -1.028849 \\
\hline C & 3.779341 & -4.914939 & -1.560839 \\
\hline C & 5.113084 & -4.666978 & -1.787568 \\
\hline C & 5.650477 & -3.392215 & -1.490773 \\
\hline C & 4.856197 & -2.401469 & -0.956220 \\
\hline $\mathrm{H}$ & 3.349033 & -5.885374 & -1.797260 \\
\hline $\mathrm{H}$ & 5.752305 & -5.441523 & -2.202431 \\
\hline $\mathrm{H}$ & 6.699615 & -3.190951 & -1.690044 \\
\hline $\mathrm{H}$ & 5.281383 & -1.427707 & -0.741868 \\
\hline C & 4.111803 & -0.304200 & 1.426944 \\
\hline C & 4.677032 & 0.952245 & 1.815975 \\
\hline C & 5.637708 & 0.994918 & 2.862234 \\
\hline C & 6.010925 & -0.150108 & 3.526498 \\
\hline C & 5.429495 & -1.388894 & 3.168482 \\
\hline C & 4.508967 & -1.465265 & 2.146192 \\
\hline $\mathrm{H}$ & 6.064600 & 1.957281 & 3.134831 \\
\hline $\mathrm{H}$ & 6.740767 & -0.105352 & 4.330194 \\
\hline
\end{tabular}




\begin{tabular}{|c|c|c|c|}
\hline $\mathrm{H}$ & 5.707857 & -2.289960 & 3.708366 \\
\hline $\mathrm{H}$ & 4.066060 & -2.421377 & 1.893680 \\
\hline 0 & -0.694487 & 0.202934 & -1.796594 \\
\hline 0 & -0.357013 & 1.484586 & 0.458187 \\
\hline $\mathrm{H}$ & -1.357851 & 1.098730 & 1.103618 \\
\hline $\mathrm{H}$ & 3.054494 & 2.508639 & -2.526064 \\
\hline $\mathrm{H}$ & 2.608704 & 6.785331 & -2.446375 \\
\hline $\mathrm{H}$ & 2.841646 & 4.574514 & 1.235800 \\
\hline $\mathrm{H}$ & -0.853124 & -4.843007 & -1.846076 \\
\hline $\mathrm{H}$ & -4.439144 & -4.639990 & 0.508961 \\
\hline $\mathrm{H}$ & -1.050296 & -2.228024 & 1.565530 \\
\hline C & -3.199487 & 1.493469 & 2.008346 \\
\hline $\mathrm{O}$ & -2.302238 & 0.655831 & 1.639252 \\
\hline $\mathrm{H}$ & -2.941386 & 2.548792 & 2.103390 \\
\hline C & -4.237736 & 1.045618 & 3.013759 \\
\hline $\mathrm{O}$ & -4.840629 & 1.831070 & 3.714876 \\
\hline O & -4.397490 & -0.285530 & 3.036968 \\
\hline C & -5.357572 & -0.764515 & 3.996103 \\
\hline $\mathrm{H}$ & -6.346517 & -0.346083 & 3.790494 \\
\hline $\mathrm{H}$ & -5.366468 & -1.848326 & 3.882518 \\
\hline C & -4.098735 & 1.423389 & -0.591514 \\
\hline C & -4.673065 & 1.991470 & 0.551783 \\
\hline $\mathrm{H}$ & -2.468954 & 1.378189 & -1.858283 \\
\hline$N$ & -3.005705 & 1.951589 & -1.202227 \\
\hline C & -2.409807 & 3.195182 & -0.922091 \\
\hline $\mathrm{O}$ & -2.714475 & 3.938503 & -0.012995 \\
\hline $\mathrm{O}$ & -1.486959 & 3.434382 & -1.851961 \\
\hline C & -0.695001 & 4.619502 & -1.634474 \\
\hline $\mathrm{H}$ & -1.341013 & 5.498010 & -1.568975 \\
\hline $\mathrm{H}$ & -0.032658 & 4.680403 & -2.494393 \\
\hline $\mathrm{H}$ & -0.114470 & 4.509486 & -0.717234 \\
\hline $\mathrm{H}$ & -5.590779 & 1.534061 & 0.900494 \\
\hline $\mathrm{H}$ & -4.564608 & 3.051059 & 0.732468 \\
\hline C & -4.602235 & 0.149330 & -1.147724 \\
\hline C & -5.989385 & -0.096297 & -1.134572 \\
\hline C & -3.745965 & -0.797293 & -1.741352 \\
\hline C & -6.508951 & -1.252185 & -1.708218 \\
\hline $\mathrm{H}$ & -6.665400 & 0.641045 & -0.714134 \\
\hline C & -4.275404 & -1.956866 & -2.303414 \\
\hline $\mathrm{H}$ & -2.668116 & -0.655330 & -1.739841 \\
\hline C & -5.651841 & -2.186703 & -2.293844 \\
\hline $\mathrm{H}$ & -7.582647 & -1.417692 & -1.707283 \\
\hline $\mathrm{H}$ & -3.601268 & -2.688390 & -2.736190 \\
\hline $\mathrm{H}$ & -6.056890 & -3.090176 & -2.741794 \\
\hline
\end{tabular}


$\begin{array}{llll}H & -5.056482 & -0.485242 & 5.008899\end{array}$

Catalyst (R)-1 TS Conformation 167

B3LYP/6-31G(d) Energy $=-2809.692927$

B3LYP-D3(BJ)/def2-TZVPP-IEF-PCM(DCM) Energy = -2810.984469

B3LYP-D3(BJ)/def2-TZVPP-IEF-PCM(DCM)//B3LYP/6-31G(d) Free Energy (Quasiharmonic) = 2810.341909

Frequencies (Top 3 out of 270)

1. $-611.6440 \mathrm{~cm}-1$

2. $\quad 15.2041 \mathrm{~cm}-1$

3. $\quad 15.6831 \mathrm{~cm}-1$

B3LYP/6-31G(d) Molecular Geometry in Cartesian Coordinates

$\begin{array}{llll}\mathrm{C} & 2.798190 & -1.330418 & -0.255421 \\ \mathrm{C} & 1.514646 & -1.841614 & -0.125379 \\ \mathrm{C} & 1.182572 & -3.191277 & -0.454262 \\ \mathrm{C} & 2.174941 & -3.970837 & -1.016010 \\ \mathrm{H} & 1.945223 & -4.998489 & -1.284308 \\ \mathrm{C} & 4.001057 & 2.644063 & 0.861051 \\ \mathrm{C} & 3.150890 & 0.024816 & 0.262695 \\ \mathrm{C} & 2.453871 & 1.138025 & -0.176480 \\ \mathrm{C} & 2.902773 & 2.475763 & 0.039518 \\ \mathrm{H} & 4.362796 & 3.649797 & 1.058100 \\ \mathrm{O} & 0.525800 & -1.064250 & 0.463761 \\ \mathrm{P} & -0.004900 & 0.354708 & -0.152651 \\ \mathrm{O} & 1.306484 & 0.937274 & -0.938248 \\ \mathrm{C} & -2.580363 & -5.138008 & 0.290641 \\ \mathrm{C} & -1.385275 & -5.694295 & 0.749982 \\ \mathrm{C} & -0.178157 & -5.034834 & 0.521816 \\ \mathrm{C} & -0.142221 & -3.808696 & -0.165789 \\ \mathrm{C} & -1.351208 & -3.252283 & -0.611011 \\ \mathrm{C} & -2.557079 & -3.917681 & -0.386926 \\ \mathrm{H} & -1.389683 & -6.640569 & 1.285590 \\ \mathrm{H} & -3.473870 & -3.465595 & -0.750587 \\ \mathrm{C} & 1.334043 & 5.861272 & -2.110315 \\ \mathrm{C} & 0.457592 & 4.989926 & -1.461097 \\ \mathrm{C} & 0.940591 & 3.895460 & -0.743273 \\ \mathrm{C} & 2.320240 & 3.642947 & -0.678911 \\ \mathrm{C} & 3.193450 & 4.528820 & -1.334419\end{array}$




\begin{tabular}{|c|c|c|c|}
\hline C & 2.707932 & 5.630302 & -2.037821 \\
\hline $\mathrm{H}$ & -0.614683 & 5.154791 & -1.522128 \\
\hline $\mathrm{H}$ & 3.403117 & 6.296003 & -2.542882 \\
\hline C & 4.235720 & 0.218665 & 1.186926 \\
\hline C & 4.652909 & 1.554560 & 1.489551 \\
\hline C & 5.717159 & 1.761570 & 2.408341 \\
\hline C & 6.336224 & 0.699086 & 3.024944 \\
\hline C & 5.908597 & -0.620601 & 2.747600 \\
\hline C & 4.889314 & -0.855147 & 1.850707 \\
\hline $\mathrm{H}$ & 6.026404 & 2.782086 & 2.621968 \\
\hline $\mathrm{H}$ & 7.144756 & 0.869767 & 3.730524 \\
\hline $\mathrm{H}$ & 6.385042 & -1.457609 & 3.250907 \\
\hline $\mathrm{H}$ & 4.565560 & -1.871149 & 1.655764 \\
\hline C & 3.789978 & -2.124350 & -0.934287 \\
\hline C & 3.465591 & -3.467966 & -1.304481 \\
\hline C & 4.435049 & -4.267601 & -1.968195 \\
\hline C & 5.674098 & -3.760840 & -2.282794 \\
\hline C & 5.987211 & -2.422035 & -1.950735 \\
\hline C & 5.073429 & -1.627003 & -1.294144 \\
\hline $\mathrm{H}$ & 4.169997 & -5.288323 & -2.233786 \\
\hline $\mathrm{H}$ & 6.406147 & -4.378335 & -2.796083 \\
\hline $\mathrm{H}$ & 6.956410 & -2.012645 & -2.222740 \\
\hline $\mathrm{H}$ & 5.328715 & -0.600214 & -1.061451 \\
\hline $\mathrm{O}$ & -0.451315 & 1.199171 & 0.999854 \\
\hline $\mathrm{O}$ & -1.009392 & 0.060883 & -1.284218 \\
\hline $\mathrm{H}$ & -1.955316 & 0.699805 & -1.385983 \\
\hline $\mathrm{H}$ & -1.358691 & -2.309074 & -1.145416 \\
\hline $\mathrm{H}$ & -3.523083 & -5.652849 & 0.460542 \\
\hline $\mathrm{H}$ & 0.750309 & -5.464888 & 0.888287 \\
\hline $\mathrm{H}$ & 4.261792 & 4.331844 & -1.314066 \\
\hline $\mathrm{H}$ & 0.949225 & 6.708028 & -2.672741 \\
\hline $\mathrm{H}$ & 0.249565 & 3.247560 & -0.217473 \\
\hline C & -4.160667 & 1.214739 & -1.627603 \\
\hline $\mathrm{O}$ & -2.915390 & 1.552688 & -1.564092 \\
\hline $\mathrm{H}$ & -4.811899 & 1.898878 & -2.184976 \\
\hline C & -4.508502 & -0.243323 & -1.906711 \\
\hline $\mathrm{O}$ & -3.786197 & -1.188450 & -1.687335 \\
\hline $\mathrm{O}$ & -5.748634 & -0.339535 & -2.434489 \\
\hline C & -6.185922 & -1.673446 & -2.747296 \\
\hline $\mathrm{H}$ & -6.243552 & -2.280683 & -1.839502 \\
\hline $\mathrm{H}$ & -7.173148 & -1.560200 & -3.195619 \\
\hline C & -4.116363 & 1.139276 & 0.986540 \\
\hline C & -5.118438 & 1.443245 & 0.031662 \\
\hline $\mathrm{H}$ & -2.169259 & 1.684517 & 1.460520 \\
\hline
\end{tabular}




$\begin{array}{llll}\mathrm{N} & -3.105270 & 2.017647 & 1.179104 \\ \mathrm{C} & -3.146816 & 3.404532 & 0.923919 \\ \mathrm{O} & -4.094443 & 4.039699 & 0.517135 \\ \mathrm{O} & -1.972228 & 3.926607 & 1.296838 \\ \mathrm{C} & -1.891654 & 5.362627 & 1.242252 \\ \mathrm{H} & -0.839531 & 5.595517 & 1.397023 \\ \mathrm{H} & -2.508851 & 5.798734 & 2.032825 \\ \mathrm{H} & -2.231784 & 5.729696 & 0.272580 \\ \mathrm{H} & -5.970354 & 0.775448 & -0.022821 \\ \mathrm{H} & -5.359235 & 2.491131 & -0.085291 \\ \mathrm{C} & -4.038761 & -0.172859 & 1.654966 \\ \mathrm{C} & -5.224466 & -0.911993 & 1.850776 \\ \mathrm{C} & -2.831210 & -0.699920 & 2.157420 \\ \mathrm{C} & -5.202064 & -2.134312 & 2.513649 \\ \mathrm{H} & -6.176530 & -0.511988 & 1.520381 \\ \mathrm{C} & -2.813713 & -1.932345 & 2.802112 \\ \mathrm{H} & -1.890765 & -0.179294 & 2.016119 \\ \mathrm{C} & -3.994623 & -2.653310 & 2.985095 \\ \mathrm{H} & -6.129479 & -2.678927 & 2.666379 \\ \mathrm{H} & -1.867133 & -2.335050 & 3.148019 \\ \mathrm{H} & -3.973559 & -3.614064 & 3.491314 \\ \mathrm{H} & -5.495139 & -2.146700 & -3.449431\end{array}$

Catalyst (R)-1 TS Conformation 168

B3LYP/6-31G(d) Energy = -2809.689395

B3LYP-D3(BJ)/def2-TZVPP-IEF-PCM(DCM) Energy = -2810.983923

B3LYP-D3(BJ)/def2-TZVPP-IEF-PCM(DCM)//B3LYP/6-31G(d) Free Energy (Quasiharmonic) = 2810.34188

Frequencies (Top 3 out of 270)

1. $-662.0870 \mathrm{~cm}-1$

2. $\quad 9.5594 \mathrm{~cm}-1$

3. $\quad 12.3061 \mathrm{~cm}-1$

B3LYP/6-31G(d) Molecular Geometry in Cartesian Coordinates

$\begin{array}{llll}\text { C } & 3.339731 & -1.238091 & -0.172184 \\ \text { C } & 2.079210 & -1.729308 & 0.124047 \\ \text { C } & 1.627577 & -3.024046 & -0.266348 \\ \text { C } & 2.492425 & -3.797152 & -1.015064 \\ \text { H } & 2.190838 & -4.799580 & -1.307800\end{array}$




\begin{tabular}{|c|c|c|c|}
\hline C & 4.594694 & 2.673103 & 1.128614 \\
\hline C & 3.751865 & 0.095262 & 0.357331 \\
\hline C & 2.975702 & 1.220249 & 0.105401 \\
\hline C & 3.396305 & 2.539181 & 0.455591 \\
\hline $\mathrm{H}$ & 4.932640 & 3.667485 & 1.408527 \\
\hline 0 & 1.207826 & -0.919307 & 0.840670 \\
\hline$P$ & 0.491762 & 0.309594 & 0.012391 \\
\hline 0 & 1.795479 & 1.091262 & -0.610123 \\
\hline C & -2.245176 & -4.596399 & 0.768755 \\
\hline C & -1.464456 & -3.965208 & 1.740845 \\
\hline C & -0.216122 & -3.437440 & 1.411921 \\
\hline C & 0.280772 & -3.535895 & 0.100619 \\
\hline C & -0.513131 & -4.173155 & -0.866896 \\
\hline C & -1.762879 & -4.698391 & -0.537094 \\
\hline $\mathrm{H}$ & -1.827659 & -3.884723 & 2.762263 \\
\hline $\mathrm{H}$ & -2.363692 & -5.179073 & -1.304862 \\
\hline C & 1.283006 & 6.172796 & -0.468010 \\
\hline C & 0.633606 & 5.145821 & 0.221682 \\
\hline C & 1.291372 & 3.946114 & 0.497484 \\
\hline C & 2.624571 & 3.762980 & 0.097642 \\
\hline C & 3.268911 & 4.801646 & -0.593802 \\
\hline C & 2.604291 & 5.994625 & -0.878957 \\
\hline $\mathrm{H}$ & -0.390936 & 5.282251 & 0.559673 \\
\hline $\mathrm{H}$ & 3.120155 & 6.782870 & -1.421347 \\
\hline C & 4.942043 & 0.242416 & 1.151577 \\
\hline C & 5.371305 & 1.556817 & 1.521715 \\
\hline C & 6.552133 & 1.716733 & 2.296331 \\
\hline C & 7.274894 & 0.625205 & 2.717744 \\
\hline C & 6.834454 & -0.677490 & 2.385081 \\
\hline C & 5.702111 & -0.864137 & 1.623045 \\
\hline $\mathrm{H}$ & 6.865674 & 2.724065 & 2.560417 \\
\hline $\mathrm{H}$ & 8.172880 & 0.758415 & 3.314890 \\
\hline $\mathrm{H}$ & 7.391259 & -1.540761 & 2.739696 \\
\hline $\mathrm{H}$ & 5.373531 & -1.869701 & 1.387784 \\
\hline C & 4.198372 & -2.022000 & -1.019366 \\
\hline C & 3.763073 & -3.324932 & -1.426889 \\
\hline C & 4.605936 & -4.116490 & -2.253377 \\
\hline C & 5.817142 & -3.637368 & -2.694990 \\
\hline C & 6.231019 & -2.335099 & -2.329481 \\
\hline C & 5.445542 & -1.550357 & -1.513810 \\
\hline $\mathrm{H}$ & 4.264700 & -5.107956 & -2.542028 \\
\hline $\mathrm{H}$ & 6.449580 & -4.248698 & -3.332942 \\
\hline $\mathrm{H}$ & 7.176029 & -1.946868 & -2.699851 \\
\hline $\mathrm{H}$ & 5.773578 & -0.551271 & -1.252467 \\
\hline
\end{tabular}




\begin{tabular}{|c|c|c|c|}
\hline $\mathrm{O}$ & -0.307073 & 1.115825 & 0.982482 \\
\hline 0 & -0.193993 & -0.261374 & -1.237269 \\
\hline $\mathrm{H}$ & -1.387191 & -0.337357 & -1.312275 \\
\hline $\mathrm{H}$ & -0.154768 & -4.232144 & -1.890636 \\
\hline $\mathrm{H}$ & -3.224548 & -4.990360 & 1.023756 \\
\hline $\mathrm{H}$ & 0.380857 & -2.948756 & 2.174284 \\
\hline $\mathrm{H}$ & 4.296419 & 4.663546 & -0.919820 \\
\hline $\mathrm{H}$ & 0.764694 & 7.104683 & -0.679502 \\
\hline $\mathrm{H}$ & 0.775202 & 3.155788 & 1.032632 \\
\hline C & -3.112433 & -1.005237 & -0.376804 \\
\hline $\mathrm{O}$ & -2.587326 & -0.463538 & -1.414551 \\
\hline $\mathrm{H}$ & -2.486549 & -1.595674 & 0.302812 \\
\hline C & -4.507922 & -1.596494 & -0.495294 \\
\hline 0 & -4.967564 & -2.379816 & 0.313589 \\
\hline $\mathrm{O}$ & -5.168673 & -1.140486 & -1.567967 \\
\hline C & -6.497837 & -1.668869 & -1.745434 \\
\hline $\mathrm{H}$ & -6.473012 & -2.760694 & -1.772456 \\
\hline $\mathrm{H}$ & -7.151787 & -1.342978 & -0.931718 \\
\hline C & -4.409697 & 1.192225 & 0.532436 \\
\hline C & -3.437751 & 0.339369 & 1.067061 \\
\hline $\mathrm{H}$ & -6.374006 & 1.669443 & 0.272544 \\
\hline$N$ & -5.751694 & 1.077625 & 0.807538 \\
\hline C & -6.508302 & 0.199833 & 1.606259 \\
\hline $\mathrm{O}$ & -7.705057 & 0.100703 & 1.431982 \\
\hline 0 & -5.790631 & -0.430875 & 2.531505 \\
\hline C & -6.485275 & -1.479791 & 3.241474 \\
\hline $\mathrm{H}$ & -5.796463 & -1.794628 & 4.024317 \\
\hline $\mathrm{H}$ & -6.688270 & -2.302964 & 2.553563 \\
\hline $\mathrm{H}$ & -7.414841 & -1.097873 & 3.666310 \\
\hline $\mathrm{H}$ & -2.404881 & 0.678940 & 1.053440 \\
\hline $\mathrm{H}$ & -3.711613 & -0.277575 & 1.911544 \\
\hline C & -4.065023 & 2.181343 & -0.504501 \\
\hline C & -2.771667 & 2.738290 & -0.543883 \\
\hline C & -4.992941 & 2.562315 & -1.498038 \\
\hline C & -2.432529 & 3.665003 & -1.527948 \\
\hline $\mathrm{H}$ & -2.024560 & 2.454778 & 0.189407 \\
\hline C & -4.646488 & 3.483653 & -2.478417 \\
\hline $\mathrm{H}$ & -5.971260 & 2.093444 & -1.559288 \\
\hline C & -3.366343 & 4.044923 & -2.491323 \\
\hline $\mathrm{H}$ & -1.430511 & 4.082613 & -1.537237 \\
\hline $\mathrm{H}$ & -5.368876 & 3.750222 & -3.244365 \\
\hline $\mathrm{H}$ & -3.096105 & 4.763938 & -3.259649 \\
\hline $\mathrm{H}$ & -6.841524 & -1.268615 & -2.699252 \\
\hline
\end{tabular}


Catalyst (R)-1 TS Conformation 169

B3LYP/6-31G(d) Energy $=-2809.689687$

B3LYP-D3(BJ)/def2-TZVPP-IEF-PCM(DCM) Energy $=-2810.983842$

B3LYP-D3(BJ)/def2-TZVPP-IEF-PCM(DCM)//B3LYP/6-31G(d) Free Energy (Quasiharmonic) = 2810.341872

Frequencies (Top 3 out of 270)

1. $-665.7124 \mathrm{~cm}-1$

2. $\quad 10.1459 \mathrm{~cm}-1$

3. $\quad 11.2820 \mathrm{~cm}-1$

B3LYP/6-31G(d) Molecular Geometry in Cartesian Coordinates

$\begin{array}{lccc}\text { C } & 3.442023 & -1.161781 & -0.142262 \\ \text { C } & 2.184063 & -1.703690 & 0.071129 \\ \text { C } & 1.827307 & -3.030492 & -0.311213 \\ \text { C } & 2.785894 & -3.784742 & -0.958157 \\ \text { H } & 2.553863 & -4.808017 & -1.242298 \\ \text { C } & 4.258519 & 2.881951 & 1.120468 \\ \text { C } & 3.733934 & 0.218777 & 0.346931 \\ \text { C } & 2.915864 & 1.269724 & -0.044161 \\ \text { C } & 3.172824 & 2.629549 & 0.304397 \\ \text { H } & 4.497542 & 3.909532 & 1.381701 \\ \text { O } & 1.225944 & -0.926369 & 0.701752 \\ \text { P } & 0.501142 & 0.275735 & -0.162976 \\ \text { O } & 1.813906 & 1.000085 & -0.841249 \\ \text { C } & -2.062769 & -4.721553 & 0.430961 \\ \text { C } & -1.384753 & -4.052123 & 1.453467 \\ \text { C } & -0.130593 & -3.488895 & 1.219494 \\ \text { C } & 0.475411 & -3.589774 & -0.044721 \\ \text { C } & -0.213649 & -4.269036 & -1.062188 \\ \text { C } & -1.469979 & -4.828747 & -0.827960 \\ \text { H } & -1.833574 & -3.969384 & 2.440193 \\ \text { H } & -1.989969 & -5.339482 & -1.634308 \\ \text { C } & 0.874171 & 5.982375 & -1.110379 \\ \text { C } & 1.228337 & 5.882973 & 0.236523 \\ \text { C } & 1.950458 & 4.779809 & 0.690633 \\ \text { C } & 2.333099 & 3.753847 & -0.189109 \\ \text { C } & 1.958387 & 3.858609 & -1.539378 \\ \text { C } & 1.240229 & 4.963569 & -1.994224 \\ \text { H } & 0.940479 & 6.663152 & 0.936550\end{array}$




\begin{tabular}{|c|c|c|c|}
\hline $\mathrm{H}$ & 0.972475 & 5.031369 & -3.045585 \\
\hline C & 4.814514 & 0.489779 & 1.255056 \\
\hline C & 5.078232 & 1.846553 & 1.631485 \\
\hline C & 6.150931 & 2.129395 & 2.520079 \\
\hline C & 6.918749 & 1.117707 & 3.047845 \\
\hline C & 6.636429 & -0.226582 & 2.709048 \\
\hline C & 5.614883 & -0.532208 & 1.836750 \\
\hline $\mathrm{H}$ & 6.344373 & 3.166386 & 2.784726 \\
\hline $\mathrm{H}$ & 7.731779 & 1.345471 & 3.731808 \\
\hline $\mathrm{H}$ & 7.228120 & -1.027113 & 3.144986 \\
\hline $\mathrm{H}$ & 5.405760 & -1.567932 & 1.595688 \\
\hline C & 4.406025 & -1.932550 & -0.879058 \\
\hline C & 4.066757 & -3.267888 & -1.273598 \\
\hline C & 5.014757 & -4.045751 & -1.992156 \\
\hline C & 6.239230 & -3.525670 & -2.341328 \\
\hline C & 6.561876 & -2.194295 & -1.988435 \\
\hline C & 5.671700 & -1.419996 & -1.277058 \\
\hline $\mathrm{H}$ & 4.744861 & -5.061252 & -2.272746 \\
\hline $\mathrm{H}$ & 6.952992 & -4.127825 & -2.896887 \\
\hline $\mathrm{H}$ & 7.519655 & -1.775691 & -2.285793 \\
\hline $\mathrm{H}$ & 5.931132 & -0.398708 & -1.023734 \\
\hline $\mathrm{O}$ & -0.266444 & 1.122460 & 0.791568 \\
\hline 0 & -0.205041 & -0.341297 & -1.380027 \\
\hline $\mathrm{H}$ & -1.401088 & -0.318176 & -1.457479 \\
\hline $\mathrm{H}$ & 0.230640 & -4.332063 & -2.051458 \\
\hline $\mathrm{H}$ & -3.047978 & -5.141702 & 0.611022 \\
\hline $\mathrm{H}$ & 0.385642 & -2.968987 & 2.019285 \\
\hline $\mathrm{H}$ & 2.239038 & 3.075570 & -2.234918 \\
\hline $\mathrm{H}$ & 0.320188 & 6.846477 & -1.468759 \\
\hline $\mathrm{H}$ & 2.207013 & 4.698906 & 1.743115 \\
\hline C & -3.091622 & -1.046688 & -0.545773 \\
\hline $\mathrm{O}$ & -2.608844 & -0.380455 & -1.530771 \\
\hline $\mathrm{H}$ & -2.438066 & -1.722089 & 0.019235 \\
\hline C & -4.493197 & -1.619971 & -0.672975 \\
\hline $\mathrm{O}$ & -4.908255 & -2.516776 & 0.036261 \\
\hline 0 & -5.211038 & -1.018393 & -1.630970 \\
\hline C & -6.546565 & -1.528789 & -1.814325 \\
\hline $\mathrm{H}$ & -6.519846 & -2.603968 & -2.005979 \\
\hline $\mathrm{H}$ & -6.942573 & -0.994456 & -2.677908 \\
\hline C & -4.350151 & 0.996493 & 0.735372 \\
\hline C & -3.329765 & 0.100314 & 1.073545 \\
\hline $\mathrm{H}$ & -6.331960 & 1.461007 & 0.670051 \\
\hline$N$ & -5.670068 & 0.807113 & 1.068378 \\
\hline C & -6.360558 & -0.196395 & 1.773206 \\
\hline
\end{tabular}




$\begin{array}{llll}\text { O } & -7.564526 & -0.297996 & 1.661325 \\ \text { O } & -5.574520 & -0.937460 & 2.549213 \\ \text { C } & -6.205358 & -2.096524 & 3.136498 \\ \text { H } & -7.109627 & -1.804394 & 3.672663 \\ \text { H } & -5.461535 & -2.507905 & 3.817677 \\ \text { H } & -6.442319 & -2.812503 & 2.347101 \\ \text { H } & -2.308843 & 0.472572 & 1.029259 \\ \text { H } & -3.529747 & -0.631017 & 1.844464 \\ \text { C } & -4.091889 & 2.149763 & -0.145578 \\ \text { C } & -2.835474 & 2.785603 & -0.122089 \\ \text { C } & -5.077288 & 2.627599 & -1.036643 \\ \text { C } & -2.589800 & 3.885757 & -0.941944 \\ \text { H } & -2.043205 & 2.429962 & 0.527134 \\ \text { C } & -4.821586 & 3.719369 & -1.856721 \\ \text { H } & -6.025869 & 2.109158 & -1.148176 \\ \text { C } & -3.579162 & 4.358471 & -1.803538 \\ \text { H } & -1.615842 & 4.364344 & -0.907217 \\ \text { H } & -5.584515 & 4.061701 & -2.549895 \\ \text { H } & -3.381518 & 5.213330 & -2.444544 \\ \text { H } & -7.156263 & -1.335568 & -0.927274\end{array}$

Catalyst (R)-1 TS Conformation 170

B3LYP/6-31G(d) Energy = -2809.692825

B3LYP-D3(BJ)/def2-TZVPP-IEF-PCM(DCM) Energy = -2810.984011

B3LYP-D3(BJ)/def2-TZVPP-IEF-PCM(DCM)//B3LYP/6-31G(d) Free Energy (Quasiharmonic) = 2810.341855

Frequencies (Top 3 out of 270)

1. $-404.5134 \mathrm{~cm}-1$

2. $\quad 10.7126 \mathrm{~cm}-1$

3. $\quad 14.9438 \mathrm{~cm}-1$

B3LYP/6-31G(d) Molecular Geometry in Cartesian Coordinates

$\begin{array}{rrrr}\text { C } & 3.345149 & -0.159901 & 0.296348 \\ \text { C } & 2.796364 & 1.042165 & -0.130365 \\ \text { C } & 3.456754 & 2.296516 & 0.034514 \\ \text { C } & 4.661279 & 2.301816 & 0.708673 \\ \text { H } & 5.181696 & 3.245788 & 0.846917 \\ \text { C } & 1.510997 & -4.014849 & -0.268592 \\ \text { C } & 2.704221 & -1.470730 & -0.025168\end{array}$




\begin{tabular}{|c|c|c|c|}
\hline C & 1.385172 & -1.702046 & 0.329465 \\
\hline C & 0.762217 & -2.985209 & 0.270784 \\
\hline $\mathrm{H}$ & 1.092187 & -5.016943 & -0.298186 \\
\hline $\mathrm{O}$ & 1.611844 & 1.044306 & -0.857987 \\
\hline$P$ & 0.190866 & 0.526306 & -0.257893 \\
\hline $\mathrm{O}$ & 0.642901 & -0.630363 & 0.811353 \\
\hline C & 2.095613 & 6.108002 & -1.423372 \\
\hline C & 1.272191 & 5.348004 & -0.589437 \\
\hline C & 1.677358 & 4.089066 & -0.144533 \\
\hline C & 2.931925 & 3.579892 & -0.512964 \\
\hline C & 3.752777 & 4.351020 & -1.351928 \\
\hline C & 3.337207 & 5.601488 & -1.809217 \\
\hline $\mathrm{H}$ & 0.310814 & 5.741459 & -0.269541 \\
\hline $\mathrm{H}$ & 3.985352 & 6.179465 & -2.462923 \\
\hline C & -3.194840 & -3.822318 & 1.759470 \\
\hline C & -2.374166 & -2.916351 & 2.435279 \\
\hline C & -1.095415 & -2.630834 & 1.957042 \\
\hline C & -0.611959 & -3.237055 & 0.782468 \\
\hline C & -1.452084 & -4.144269 & 0.114837 \\
\hline C & -2.725360 & -4.439379 & 0.600118 \\
\hline $\mathrm{H}$ & -2.736465 & -2.422689 & 3.332693 \\
\hline $\mathrm{H}$ & -3.357940 & -5.136885 & 0.057889 \\
\hline C & 3.428936 & -2.527980 & -0.677220 \\
\hline C & 2.813736 & -3.816615 & -0.787788 \\
\hline C & 3.523057 & -4.876085 & -1.416423 \\
\hline C & 4.774808 & -4.671731 & -1.948468 \\
\hline C & 5.368786 & -3.389874 & -1.874359 \\
\hline C & 4.716667 & -2.348064 & -1.251911 \\
\hline $\mathrm{H}$ & 3.047543 & -5.852056 & -1.480135 \\
\hline $\mathrm{H}$ & 5.303738 & -5.486859 & -2.434652 \\
\hline $\mathrm{H}$ & 6.347588 & -3.223970 & -2.316127 \\
\hline $\mathrm{H}$ & 5.181330 & -1.369777 & -1.209998 \\
\hline C & 4.542855 & -0.119590 & 1.097065 \\
\hline C & 5.213728 & 1.131203 & 1.280585 \\
\hline C & 6.404605 & 1.183997 & 2.054409 \\
\hline C & 6.907960 & 0.054189 & 2.655208 \\
\hline C & 6.226650 & -1.176877 & 2.510965 \\
\hline C & 5.079344 & -1.262628 & 1.753110 \\
\hline $\mathrm{H}$ & 6.902450 & 2.143474 & 2.173094 \\
\hline $\mathrm{H}$ & 7.815324 & 0.106186 & 3.250616 \\
\hline $\mathrm{H}$ & 6.607611 & -2.064432 & 3.008925 \\
\hline $\mathrm{H}$ & 4.566800 & -2.213099 & 1.667250 \\
\hline $\mathrm{O}$ & -0.660604 & 0.035502 & -1.378365 \\
\hline $\mathrm{O}$ & -0.367998 & 1.629405 & 0.672560 \\
\hline
\end{tabular}




\begin{tabular}{|c|c|c|c|}
\hline $\mathrm{H}$ & -1.459149 & 1.640630 & 0.916144 \\
\hline $\mathrm{H}$ & 4.720464 & 3.958513 & -1.652953 \\
\hline $\mathrm{H}$ & 1.774202 & 7.088390 & -1.765756 \\
\hline $\mathrm{H}$ & 1.027750 & 3.509308 & 0.502063 \\
\hline $\mathrm{H}$ & -1.111654 & -4.604549 & -0.808305 \\
\hline $\mathrm{H}$ & -4.192373 & -4.037918 & 2.132167 \\
\hline $\mathrm{H}$ & -0.465850 & -1.935970 & 2.500264 \\
\hline C & -3.498052 & 0.820385 & 1.480948 \\
\hline 0 & -2.707943 & 1.812409 & 1.291511 \\
\hline $\mathrm{H}$ & -3.129582 & -0.207505 & 1.362310 \\
\hline C & -4.462364 & 0.879542 & 2.666206 \\
\hline 0 & -4.811321 & -0.112113 & 3.273553 \\
\hline $\mathrm{O}$ & -4.851347 & 2.128396 & 2.949745 \\
\hline$C$ & -5.729230 & 2.258333 & 4.081284 \\
\hline $\mathrm{H}$ & -5.240867 & 1.889451 & 4.986899 \\
\hline $\mathrm{H}$ & -5.939093 & 3.324540 & 4.164582 \\
\hline C & -4.164260 & 0.435257 & -0.980828 \\
\hline C & -4.924748 & 0.869546 & 0.118376 \\
\hline $\mathrm{H}$ & -2.364435 & 0.848061 & -1.898263 \\
\hline $\mathrm{N}$ & -3.230122 & 1.258968 & -1.530690 \\
\hline C & -3.256538 & 2.664509 & -1.518340 \\
\hline $\mathrm{O}$ & -4.191188 & 3.361011 & -1.194108 \\
\hline $\mathrm{O}$ & -2.091899 & 3.100856 & -2.020637 \\
\hline C & -1.980221 & 4.528642 & -2.147030 \\
\hline $\mathrm{H}$ & -2.682700 & 4.896714 & -2.899992 \\
\hline $\mathrm{H}$ & -0.950758 & 4.709009 & -2.452254 \\
\hline $\mathrm{H}$ & -2.190906 & 5.010476 & -1.189747 \\
\hline $\mathrm{H}$ & -5.704335 & 0.202945 & 0.471069 \\
\hline $\mathrm{H}$ & -5.123557 & 1.928504 & 0.219167 \\
\hline C & -4.265538 & -0.943650 & -1.509999 \\
\hline C & -5.512243 & -1.598845 & -1.444757 \\
\hline C & -3.200606 & -1.590307 & -2.167547 \\
\hline C & -5.692969 & -2.850666 & -2.024783 \\
\hline $\mathrm{H}$ & -6.359873 & -1.107398 & -0.980306 \\
\hline C & -3.389172 & -2.844632 & -2.741770 \\
\hline $\mathrm{H}$ & -2.212368 & -1.145373 & -2.193117 \\
\hline C & -4.631868 & -3.477349 & -2.680208 \\
\hline $\mathrm{H}$ & -6.667506 & -3.328131 & -1.977217 \\
\hline $\mathrm{H}$ & -2.553765 & -3.329885 & -3.238035 \\
\hline $\mathrm{H}$ & -4.773879 & -4.450844 & -3.141832 \\
\hline $\mathrm{H}$ & -6.651815 & 1.694292 & 3.918636 \\
\hline
\end{tabular}

Catalyst (R)-1 TS Conformation 171 
B3LYP/6-31G(d) Energy $=-2809.690582$

B3LYP-D3(BJ)/def2-TZVPP-IEF-PCM(DCM) Energy $=-2810.982537$

B3LYP-D3(BJ)/def2-TZVPP-IEF-PCM(DCM)//B3LYP/6-31G(d) Free Energy (Quasiharmonic) = 2810.341834

Frequencies (Top 3 out of 270)

1. $-711.0345 \mathrm{~cm}-1$

2. $\quad 10.2267 \mathrm{~cm}-1$

3. $\quad 12.9981 \mathrm{~cm}-1$

B3LYP/6-31G(d) Molecular Geometry in Cartesian Coordinates

$\begin{array}{llll}\mathrm{C} & 3.156473 & -1.178272 & 0.040541 \\ \mathrm{C} & 1.829663 & -1.576311 & 0.076602 \\ \mathrm{C} & 1.407005 & -2.930082 & -0.069085 \\ \mathrm{C} & 2.387517 & -3.877877 & -0.286152 \\ \mathrm{H} & 2.104812 & -4.923453 & -0.377656 \\ \mathrm{C} & 4.148615 & 2.991654 & 0.547394 \\ \mathrm{C} & 3.496987 & 0.258794 & 0.267550 \\ \mathrm{C} & 2.901910 & 1.240782 & -0.511769 \\ \mathrm{C} & 3.227014 & 2.626108 & -0.414722 \\ \mathrm{H} & 4.440460 & 4.035197 & 0.630375 \\ \mathrm{O} & 0.854515 & -0.608745 & 0.276901 \\ \mathrm{P} & 0.479628 & 0.386137 & -0.972505 \\ \mathrm{O} & 1.961803 & 0.862740 & -1.465418 \\ \mathrm{C} & -2.742687 & -4.080262 & 0.015877 \\ \mathrm{C} & -2.237778 & -3.217036 & 0.992270 \\ \mathrm{C} & -0.895844 & -2.836149 & 0.975014 \\ \mathrm{C} & -0.029319 & -3.313102 & -0.024430 \\ \mathrm{C} & -0.547362 & -4.186482 & -0.994237 \\ \mathrm{C} & -1.889182 & -4.567692 & -0.974492 \\ \mathrm{H} & -2.896777 & -2.828288 & 1.764202 \\ \mathrm{H} & -2.270136 & -5.233778 & -1.744239 \\ \mathrm{C} & 1.566876 & 5.686783 & -2.943190 \\ \mathrm{C} & 2.001246 & 4.482555 & -3.500811 \\ \mathrm{C} & 2.519395 & 3.475155 & -2.688940 \\ \mathrm{C} & 2.617737 & 3.655498 & -1.298967 \\ \mathrm{C} & 2.173433 & 4.869641 & -0.750354 \\ \mathrm{C} & 1.653309 & 5.875833 & -1.563435 \\ \mathrm{H} & 1.938486 & 4.325267 & -4.574421 \\ \mathrm{H} & 1.308067 & 6.804444 & -1.116108 \\ \mathrm{C} & 4.393959 & 0.666973 & 1.314560\end{array}$




\begin{tabular}{|c|c|c|c|}
\hline C & 4.728051 & 2.054564 & 1.436706 \\
\hline C & 5.624583 & 2.469971 & 2.458579 \\
\hline C & 6.149470 & 1.564803 & 3.351007 \\
\hline C & 5.789127 & 0.199865 & 3.259120 \\
\hline C & 4.937092 & -0.237214 & 2.268813 \\
\hline $\mathrm{H}$ & 5.876905 & 3.525520 & 2.528014 \\
\hline $\mathrm{H}$ & 6.828098 & 1.895225 & 4.132653 \\
\hline $\mathrm{H}$ & 6.183896 & -0.510834 & 3.980226 \\
\hline $\mathrm{H}$ & 4.663128 & -1.284545 & 2.220246 \\
\hline C & 4.157194 & -2.164887 & -0.262789 \\
\hline C & 3.756503 & -3.533421 & -0.407324 \\
\hline C & 4.737882 & -4.521267 & -0.692717 \\
\hline C & 6.058844 & -4.178837 & -0.864100 \\
\hline C & 6.450946 & -2.823400 & -0.762892 \\
\hline C & 5.527272 & -1.844322 & -0.469477 \\
\hline $\mathrm{H}$ & 4.418222 & -5.556483 & -0.786876 \\
\hline $\mathrm{H}$ & 6.798669 & -4.942081 & -1.089356 \\
\hline $\mathrm{H}$ & 7.490481 & -2.550396 & -0.923235 \\
\hline $\mathrm{H}$ & 5.843007 & -0.809629 & -0.404883 \\
\hline 0 & -0.388201 & 1.473869 & -0.418632 \\
\hline $\mathrm{O}$ & -0.038047 & -0.440643 & -2.156628 \\
\hline $\mathrm{H}$ & -1.184218 & -0.347560 & -2.477548 \\
\hline $\mathrm{H}$ & 0.102998 & -4.541721 & -1.788468 \\
\hline $\mathrm{H}$ & -3.793319 & -4.355649 & 0.020608 \\
\hline $\mathrm{H}$ & -0.515395 & -2.162164 & 1.735546 \\
\hline $\mathrm{H}$ & 2.216658 & 5.013124 & 0.325702 \\
\hline $\mathrm{H}$ & 1.159823 & 6.468875 & -3.578775 \\
\hline $\mathrm{H}$ & 2.855737 & 2.545241 & -3.134034 \\
\hline C & -3.144054 & -0.560446 & -1.823922 \\
\hline $\mathrm{O}$ & -2.355231 & -0.305364 & -2.799343 \\
\hline $\mathrm{H}$ & -2.764124 & -1.075016 & -0.935240 \\
\hline C & -4.560467 & -0.972461 & -2.171349 \\
\hline $\mathrm{O}$ & -5.219348 & -1.717190 & -1.470400 \\
\hline $\mathrm{O}$ & -4.977501 & -0.444240 & -3.326353 \\
\hline C & -6.297386 & -0.832319 & -3.746087 \\
\hline $\mathrm{H}$ & -6.362179 & -1.918600 & -3.845323 \\
\hline $\mathrm{H}$ & -7.045371 & -0.493319 & -3.023748 \\
\hline C & -3.677406 & 1.088103 & 0.515660 \\
\hline C & -3.563383 & 1.227653 & -0.881672 \\
\hline $\mathrm{H}$ & -1.639084 & 1.174624 & 0.734207 \\
\hline$N$ & -2.530614 & 0.965058 & 1.236241 \\
\hline C & -2.316193 & 0.428140 & 2.518511 \\
\hline $\mathrm{O}$ & -1.259532 & 0.553194 & 3.093124 \\
\hline $\mathrm{O}$ & -3.374027 & -0.258323 & 2.981812 \\
\hline
\end{tabular}




$\begin{array}{llll}\mathrm{C} & -3.214299 & -0.784151 & 4.312706 \\ \mathrm{H} & -3.006922 & 0.022800 & 5.019523 \\ \mathrm{H} & -2.395379 & -1.506676 & 4.341001 \\ \mathrm{H} & -4.163918 & -1.266129 & 4.543951 \\ \mathrm{H} & -4.431998 & 1.613182 & -1.405545 \\ \mathrm{H} & -2.603920 & 1.593385 & -1.234031 \\ \mathrm{C} & -4.983558 & 1.199296 & 1.205886 \\ \mathrm{C} & -6.123236 & 0.519759 & 0.752250 \\ \mathrm{C} & -5.101392 & 2.096390 & 2.283587 \\ \mathrm{C} & -7.352656 & 0.723708 & 1.378298 \\ \mathrm{H} & -6.041197 & -0.200283 & -0.053551 \\ \mathrm{C} & -6.336413 & 2.313521 & 2.886414 \\ \mathrm{H} & -4.228281 & 2.644861 & 2.624947 \\ \mathrm{C} & -7.466002 & 1.623035 & 2.439280 \\ \mathrm{H} & -8.224751 & 0.175520 & 1.032852 \\ \mathrm{H} & -6.417561 & 3.022794 & 3.705344 \\ \mathrm{H} & -8.428936 & 1.788215 & 2.914737 \\ \mathrm{H} & -6.448473 & -0.347084 & -4.709989\end{array}$

Catalyst (R)-1 TS Conformation 172

B3LYP/6-31G(d) Energy $=-2809.689518$

B3LYP-D3(BJ)/def2-TZVPP-IEF-PCM(DCM) Energy $=-2810.983615$

B3LYP-D3(BJ)/def2-TZVPP-IEF-PCM(DCM)//B3LYP/6-31G(d) Free Energy (Quasiharmonic) = 2810.341831

Frequencies (Top 3 out of 270)

1. $-673.5342 \mathrm{~cm}-1$

2. $\quad 6.1534 \mathrm{~cm}-1$

3. $9.6188 \mathrm{~cm}-1$

B3LYP/6-31G(d) Molecular Geometry in Cartesian Coordinates

$\begin{array}{llll}\text { C } & -3.550102 & -0.831887 & 0.100984 \\ \text { C } & -2.469131 & -1.623348 & -0.251231 \\ \text { C } & -2.331646 & -2.988555 & 0.136413 \\ \text { C } & -3.318392 & -3.516370 & 0.945618 \\ \text { H } & -3.260109 & -4.561095 & 1.239710 \\ \text { C } & -3.855475 & 3.276044 & -1.165371 \\ \text { C } & -3.644866 & 0.562978 & -0.423608 \\ \text { C } & -2.603205 & 1.458372 & -0.216504 \\ \text { C } & -2.699288 & 2.844965 & -0.544781\end{array}$




\begin{tabular}{|c|c|c|c|}
\hline $\mathrm{H}$ & -3.950786 & 4.325615 & -1.431208 \\
\hline $\mathrm{O}$ & -1.470071 & -1.061554 & -1.035071 \\
\hline$P$ & -0.421554 & -0.028225 & -0.307978 \\
\hline $\mathrm{O}$ & -1.455429 & 1.023944 & 0.430406 \\
\hline C & 0.928265 & -5.512198 & -1.096055 \\
\hline C & 0.287712 & -4.694770 & -2.029865 \\
\hline C & -0.755067 & -3.857374 & -1.636734 \\
\hline C & -1.182664 & -3.826416 & -0.298503 \\
\hline C & -0.527272 & -4.650031 & 0.631128 \\
\hline C & 0.518047 & -5.484693 & 0.237380 \\
\hline $\mathrm{H}$ & 0.597923 & -4.710128 & -3.071640 \\
\hline $\mathrm{H}$ & 1.018097 & -6.105631 & 0.976010 \\
\hline C & 0.275742 & 5.806795 & 0.412671 \\
\hline C & 0.642468 & 4.654963 & -0.286713 \\
\hline C & -0.302686 & 3.674061 & -0.590475 \\
\hline C & -1.641508 & 3.835301 & -0.196106 \\
\hline C & -2.000005 & 4.998117 & 0.506443 \\
\hline C & -1.051534 & 5.975213 & 0.809116 \\
\hline $\mathrm{H}$ & 1.672823 & 4.517976 & -0.605867 \\
\hline $\mathrm{H}$ & -1.350247 & 6.864303 & 1.358656 \\
\hline C & -4.797511 & 1.007133 & -1.159789 \\
\hline C & -4.900482 & 2.389030 & -1.519746 \\
\hline C & -6.038206 & 2.841692 & -2.241373 \\
\hline C & -7.029744 & 1.967060 & -2.620021 \\
\hline C & -6.915516 & 0.594620 & -2.295749 \\
\hline C & -5.831879 & 0.127758 & -1.584796 \\
\hline $\mathrm{H}$ & -6.102038 & 3.896286 & -2.499304 \\
\hline $\mathrm{H}$ & -7.892267 & 2.322826 & -3.176964 \\
\hline $\mathrm{H}$ & -7.687202 & -0.100116 & -2.616382 \\
\hline $\mathrm{H}$ & -5.754663 & -0.928552 & -1.354844 \\
\hline C & -4.529187 & -1.373157 & 1.005219 \\
\hline C & -4.407099 & -2.740828 & 1.414990 \\
\hline C & -5.372732 & -3.293801 & 2.299284 \\
\hline C & -6.402870 & -2.527520 & 2.792532 \\
\hline C & -6.503022 & -1.166018 & 2.422302 \\
\hline C & -5.593626 & -0.604989 & 1.552541 \\
\hline $\mathrm{H}$ & -5.271195 & -4.336967 & 2.589501 \\
\hline $\mathrm{H}$ & -7.130789 & -2.959564 & 3.473838 \\
\hline $\mathrm{H}$ & -7.302511 & -0.554256 & 2.831653 \\
\hline $\mathrm{H}$ & -5.680176 & 0.442194 & 1.287777 \\
\hline 0 & 0.442730 & 0.584908 & -1.356323 \\
\hline $\mathrm{O}$ & 0.244238 & -0.723307 & 0.893496 \\
\hline $\mathrm{H}$ & 1.425676 & -0.971098 & 0.830564 \\
\hline $\mathrm{H}$ & -0.826220 & -4.614205 & 1.674869 \\
\hline
\end{tabular}




\begin{tabular}{|c|c|c|c|}
\hline $\mathrm{H}$ & 1.743550 & -6.161602 & -1.404330 \\
\hline $\mathrm{H}$ & -1.246223 & -3.227477 & -2.370411 \\
\hline $\mathrm{H}$ & -3.029699 & 5.125808 & 0.829780 \\
\hline $\mathrm{H}$ & 1.017344 & 6.566456 & 0.646497 \\
\hline $\mathrm{H}$ & -0.004470 & 2.787315 & -1.140680 \\
\hline C & 3.063175 & -0.958527 & -0.405031 \\
\hline 0 & 2.601286 & -1.228654 & 0.765230 \\
\hline $\mathrm{H}$ & 2.360101 & -0.770986 & -1.223764 \\
\hline C & 4.331768 & -1.697212 & -0.798846 \\
\hline O & 5.053662 & -2.295809 & -0.034862 \\
\hline 0 & 4.539486 & -1.590165 & -2.126888 \\
\hline C & 5.714567 & -2.254521 & -2.624030 \\
\hline $\mathrm{H}$ & 5.706492 & -2.093082 & -3.702021 \\
\hline $\mathrm{H}$ & 6.614255 & -1.824813 & -2.175762 \\
\hline C & 4.652992 & 0.977599 & 0.479778 \\
\hline C & 3.643061 & 0.945173 & -0.488832 \\
\hline $\mathrm{H}$ & 5.222754 & 0.802090 & 2.416305 \\
\hline $\mathrm{N}$ & 4.420950 & 0.958213 & 1.816390 \\
\hline C & 3.259437 & 1.134791 & 2.615560 \\
\hline O & 3.324934 & 0.923921 & 3.804458 \\
\hline O & 2.225996 & 1.609391 & 1.936385 \\
\hline C & 1.017831 & 1.819383 & 2.716950 \\
\hline $\mathrm{H}$ & 0.322580 & 2.298374 & 2.032167 \\
\hline $\mathrm{H}$ & 1.244767 & 2.457288 & 3.572902 \\
\hline $\mathrm{H}$ & 0.627089 & 0.855592 & 3.042228 \\
\hline $\mathrm{H}$ & 3.963936 & 1.049086 & -1.519716 \\
\hline $\mathrm{H}$ & 2.655453 & 1.326717 & -0.265873 \\
\hline C & 6.083296 & 0.880834 & 0.096042 \\
\hline C & 6.975506 & 0.044638 & 0.791674 \\
\hline C & 6.564811 & 1.652544 & -0.975017 \\
\hline C & 8.318237 & -0.008812 & 0.424997 \\
\hline $\mathrm{H}$ & 6.608871 & -0.616518 & 1.571163 \\
\hline C & 7.910910 & 1.602625 & -1.330825 \\
\hline $\mathrm{H}$ & 5.888264 & 2.313604 & -1.507427 \\
\hline C & 8.790468 & 0.773339 & -0.631498 \\
\hline $\mathrm{H}$ & 8.992821 & -0.672517 & 0.957658 \\
\hline $\mathrm{H}$ & 8.273205 & 2.216313 & -2.150431 \\
\hline $\mathrm{H}$ & 9.839366 & 0.733267 & -0.911462 \\
\hline $\mathrm{H}$ & 5.673780 & -3.322025 & -2.393630 \\
\hline
\end{tabular}

Catalyst (R)-1 TS Conformation 173

B3LYP/6-31G(d) Energy $=-2809.693628$ 
B3LYP-D3(BJ)/def2-TZVPP-IEF-PCM(DCM) Energy $=-2810.984734$

B3LYP-D3(BJ)/def2-TZVPP-IEF-PCM(DCM)//B3LYP/6-31G(d) Free Energy (Quasiharmonic) = 2810.341782

Frequencies (Top 3 out of 270)

1. $-369.5652 \mathrm{~cm}-1$

2. $\quad 7.5146 \mathrm{~cm}-1$

3. $\quad 11.8259 \mathrm{~cm}-1$

B3LYP/6-31G(d) Molecular Geometry in Cartesian Coordinates

$\begin{array}{lrrr}\text { C } & -3.092029 & -1.095055 & 0.219691 \\ \text { C } & -1.915639 & -1.736463 & -0.131611 \\ \text { C } & -1.659859 & -3.111670 & 0.148630 \\ \text { C } & -2.624598 & -3.796620 & 0.863309 \\ \text { H } & -2.477512 & -4.853774 & 1.066756 \\ \text { C } & -3.859225 & 3.054695 & -0.598366 \\ \text { C } & -3.323374 & 0.322270 & -0.184954 \\ \text { C } & -2.421168 & 1.305659 & 0.191827 \\ \text { C } & -2.697125 & 2.700073 & 0.060594 \\ \text { H } & -4.090028 & 4.109057 & -0.725156 \\ \text { O } & -0.952241 & -1.010170 & -0.827812 \\ \text { P } & -0.097508 & 0.142655 & -0.046053 \\ \text { O } & -1.239584 & 0.923863 & 0.821410 \\ \text { C } & 1.709942 & -5.405210 & -1.217017 \\ \text { C } & 1.087028 & -4.501315 & -2.079447 \\ \text { C } & 0.024696 & -3.715846 & -1.633768 \\ \text { C } & -0.445533 & -3.833098 & -0.316458 \\ \text { C } & 0.203603 & -4.731765 & 0.548339 \\ \text { C } & 1.270978 & -5.509258 & 0.104459 \\ \text { H } & 1.425551 & -4.399494 & -3.106310 \\ \text { H } & 1.760312 & -6.194660 & 0.791620 \\ \text { C } & -0.371125 & 5.828297 & 1.883516 \\ \text { C } & 0.264277 & 4.865592 & 1.097275 \\ \text { C } & -0.465868 & 3.837648 & 0.500516 \\ \text { C } & -1.854797 & 3.757250 & 0.685353 \\ \text { C } & -2.484394 & 4.732639 & 1.478368 \\ \text { C } & -1.751822 & 5.759707 & 2.071357 \\ \text { H } & 1.338235 & 4.911382 & 0.943968 \\ \text { H } & -2.259294 & 6.497881 & 2.687187 \\ \text { C } & -4.482268 & 0.704650 & -0.943879 \\ \text { C } & -4.743041 & 2.096610 & -1.151060 \\ \text { C } & -5.882551 & 2.488854 & -1.904453\end{array}$




\begin{tabular}{|c|c|c|c|}
\hline C & -6.724931 & 1.549797 & -2.452660 \\
\hline C & -6.455230 & 0.172625 & -2.271616 \\
\hline C & -5.366106 & -0.239300 & -1.535428 \\
\hline $\mathrm{H}$ & -6.069515 & 3.550663 & -2.046928 \\
\hline $\mathrm{H}$ & -7.590011 & 1.860816 & -3.031968 \\
\hline $\mathrm{H}$ & -7.110200 & -0.567797 & -2.722891 \\
\hline $\mathrm{H}$ & -5.166079 & -1.297873 & -1.414581 \\
\hline C & -4.050329 & -1.801577 & 1.026984 \\
\hline C & -3.805052 & -3.177254 & 1.338140 \\
\hline C & -4.746203 & -3.896069 & 2.124227 \\
\hline C & -5.872966 & -3.280512 & 2.616681 \\
\hline C & -6.098759 & -1.910750 & 2.344789 \\
\hline C & -5.214522 & -1.191642 & 1.570848 \\
\hline $\mathrm{H}$ & -4.548607 & -4.943621 & 2.339224 \\
\hline $\mathrm{H}$ & -6.582297 & -3.837405 & 3.222792 \\
\hline $\mathrm{H}$ & -6.976357 & -1.418283 & 2.754890 \\
\hline $\mathrm{H}$ & -5.399330 & -0.140802 & 1.382985 \\
\hline $\mathrm{O}$ & 0.589436 & 0.994599 & -1.063943 \\
\hline $\mathrm{O}$ & 0.742417 & -0.501942 & 1.084549 \\
\hline $\mathrm{H}$ & 1.789735 & -0.798865 & 0.917290 \\
\hline $\mathrm{H}$ & -0.125976 & -4.807080 & 1.580720 \\
\hline $\mathrm{H}$ & 2.532487 & -6.023033 & -1.569598 \\
\hline $\mathrm{H}$ & -0.445438 & -3.015516 & -2.314403 \\
\hline $\mathrm{H}$ & -3.555738 & 4.667247 & 1.647647 \\
\hline $\mathrm{H}$ & 0.205552 & 6.623456 & 2.349462 \\
\hline $\mathrm{H}$ & 0.039141 & 3.105839 & -0.120665 \\
\hline C & 3.907230 & -0.301292 & 1.323926 \\
\hline $\mathrm{O}$ & 3.084196 & -1.180225 & 0.876955 \\
\hline $\mathrm{H}$ & 3.515197 & 0.654573 & 1.702686 \\
\hline C & 5.069628 & -0.740601 & 2.217826 \\
\hline $\mathrm{O}$ & 5.638820 & 0.024966 & 2.969247 \\
\hline $\mathrm{O}$ & 5.377890 & -2.034436 & 2.063986 \\
\hline C & 6.451660 & -2.510676 & 2.894250 \\
\hline $\mathrm{H}$ & 6.200532 & -2.386208 & 3.950617 \\
\hline $\mathrm{H}$ & 6.563007 & -3.566602 & 2.647835 \\
\hline C & 4.084248 & 0.975585 & -0.887618 \\
\hline C & 5.050776 & 0.311696 & -0.107034 \\
\hline $\mathrm{H}$ & 2.220024 & 0.672092 & -1.687110 \\
\hline$N$ & 3.188151 & 0.296895 & -1.646589 \\
\hline C & 3.256117 & -0.988820 & -2.220317 \\
\hline $\mathrm{O}$ & 2.285388 & -1.496057 & -2.730357 \\
\hline $\mathrm{O}$ & 4.493061 & -1.507099 & -2.218780 \\
\hline C & 4.590980 & -2.828525 & -2.785243 \\
\hline $\mathrm{H}$ & 5.646005 & -3.092137 & -2.710393 \\
\hline
\end{tabular}




$\begin{array}{llll}\mathrm{H} & 4.268309 & -2.818450 & -3.828944 \\ \mathrm{H} & 3.973057 & -3.525193 & -2.215230 \\ \mathrm{H} & 5.830243 & 0.928568 & 0.326858 \\ \mathrm{H} & 5.375736 & -0.665740 & -0.434091 \\ \mathrm{C} & 3.882868 & 2.432839 & -0.782387 \\ \mathrm{C} & 4.380634 & 3.159380 & 0.318128 \\ \mathrm{C} & 3.251517 & 3.135489 & -1.826575 \\ \mathrm{C} & 4.261299 & 4.544566 & 0.360370 \\ \mathrm{H} & 4.844519 & 2.642155 & 1.151684 \\ \mathrm{C} & 3.137819 & 4.522114 & -1.780254 \\ \mathrm{H} & 2.877780 & 2.597651 & -2.691094 \\ \mathrm{C} & 3.646917 & 5.231483 & -0.691063 \\ \mathrm{H} & 4.646289 & 5.089198 & 1.217548 \\ \mathrm{H} & 2.656333 & 5.048468 & -2.598862 \\ \mathrm{H} & 3.562278 & 6.314086 & -0.658739 \\ \mathrm{H} & 7.374345 & -1.963894 & 2.680908\end{array}$

Catalyst (R)-1 TS Conformation 174

B3LYP/6-31G(d) Energy $=-2809.690606$

B3LYP-D3(BJ)/def2-TZVPP-IEF-PCM(DCM) Energy = -2810.983411

B3LYP-D3(BJ)/def2-TZVPP-IEF-PCM(DCM)//B3LYP/6-31G(d) Free Energy (Quasiharmonic) = 2810.341754

Frequencies (Top 3 out of 270)

1. $-793.3274 \mathrm{~cm}-1$

2. $\quad 13.2828 \mathrm{~cm}-1$

3. $\quad 19.8280 \mathrm{~cm}-1$

B3LYP/6-31G(d) Molecular Geometry in Cartesian Coordinates

$\begin{array}{lrrr}\text { C } & 3.169520 & -0.264239 & 0.381515 \\ \text { C } & 2.706155 & 0.915364 & -0.181001 \\ \text { C } & 3.285858 & 2.188985 & 0.101533 \\ \text { C } & 4.265207 & 2.241494 & 1.074030 \\ \text { H } & 4.745589 & 3.191898 & 1.290785 \\ \text { C } & 1.637918 & -4.148027 & -0.649423 \\ \text { C } & 2.653640 & -1.587575 & -0.081324 \\ \text { C } & 1.296198 & -1.863345 & -0.022141 \\ \text { C } & 0.748503 & -3.164161 & -0.254501 \\ \text { H } & 1.276984 & -5.162245 & -0.792751 \\ \text { O } & 1.667981 & 0.866046 & -1.103047\end{array}$




\begin{tabular}{|c|c|c|c|}
\hline$P$ & 0.158674 & 0.449654 & -0.612706 \\
\hline O & 0.444601 & -0.843707 & 0.363234 \\
\hline C & 2.584813 & 5.826375 & -2.085350 \\
\hline C & 2.604799 & 5.835519 & -0.689447 \\
\hline C & 2.783809 & 4.645229 & 0.016695 \\
\hline C & 2.943319 & 3.422412 & -0.656321 \\
\hline C & 2.893420 & 3.423182 & -2.061199 \\
\hline C & 2.724767 & 4.614140 & -2.766472 \\
\hline $\mathrm{H}$ & 2.485542 & 6.770011 & -0.147141 \\
\hline $\mathrm{H}$ & 2.711982 & 4.595103 & -3.853340 \\
\hline C & -3.348827 & -4.320303 & 0.422596 \\
\hline C & -2.774193 & -3.315511 & 1.201651 \\
\hline C & -1.456963 & -2.915850 & 0.976677 \\
\hline C & -0.686912 & -3.500452 & -0.045616 \\
\hline C & -1.293352 & -4.491501 & -0.840791 \\
\hline C & -2.602585 & -4.905512 & -0.602440 \\
\hline $\mathrm{H}$ & -3.347592 & -2.821678 & 1.980668 \\
\hline $\mathrm{H}$ & -3.042228 & -5.679711 & -1.226998 \\
\hline C & 3.542970 & -2.596476 & -0.586275 \\
\hline C & 3.013868 & -3.896713 & -0.865551 \\
\hline C & 3.881356 & -4.913748 & -1.349231 \\
\hline C & 5.212695 & -4.657249 & -1.580732 \\
\hline C & 5.730991 & -3.363335 & -1.337800 \\
\hline C & 4.920284 & -2.361686 & -0.850232 \\
\hline $\mathrm{H}$ & 3.465712 & -5.899504 & -1.545032 \\
\hline $\mathrm{H}$ & 5.864584 & -5.440205 & -1.958515 \\
\hline $\mathrm{H}$ & 6.778165 & -3.156094 & -1.541351 \\
\hline $\mathrm{H}$ & 5.330780 & -1.373539 & -0.676753 \\
\hline C & 4.137286 & -0.183677 & 1.444179 \\
\hline C & 4.684162 & 1.093783 & 1.788833 \\
\hline C & 5.643057 & 1.187391 & 2.833479 \\
\hline C & 6.031013 & 0.072450 & 3.539088 \\
\hline C & 5.466384 & -1.186123 & 3.226097 \\
\hline C & 4.548639 & -1.312080 & 2.206240 \\
\hline $\mathrm{H}$ & 6.056168 & 2.164848 & 3.071510 \\
\hline $\mathrm{H}$ & 6.759173 & 0.156224 & 4.341210 \\
\hline $\mathrm{H}$ & 5.755403 & -2.063066 & 3.799067 \\
\hline $\mathrm{H}$ & 4.118719 & -2.282527 & 1.988778 \\
\hline $\mathrm{O}$ & -0.657383 & 0.138578 & -1.822864 \\
\hline $\mathrm{O}$ & -0.363884 & 1.497726 & 0.392063 \\
\hline $\mathrm{H}$ & -1.350267 & 1.098441 & 1.016355 \\
\hline $\mathrm{H}$ & 3.008682 & 2.489075 & -2.600375 \\
\hline $\mathrm{H}$ & 2.459847 & 6.754164 & -2.637652 \\
\hline $\mathrm{H}$ & 2.795657 & 4.657960 & 1.103033 \\
\hline
\end{tabular}




\begin{tabular}{|c|c|c|c|}
\hline $\mathrm{H}$ & -0.736586 & -4.933457 & -1.662225 \\
\hline $\mathrm{H}$ & -4.373978 & -4.634055 & 0.601626 \\
\hline $\mathrm{H}$ & -1.031783 & -2.140417 & 1.600125 \\
\hline C & -3.264634 & 1.304134 & 1.927845 \\
\hline 0 & -2.290076 & 0.576803 & 1.524297 \\
\hline $\mathrm{H}$ & -3.095936 & 2.365464 & 2.117996 \\
\hline C & -4.253089 & 0.624062 & 2.855978 \\
\hline 0 & -4.380538 & -0.569765 & 2.996057 \\
\hline $\mathrm{O}$ & -4.968276 & 1.555402 & 3.523007 \\
\hline C & -5.938797 & 1.037787 & 4.449191 \\
\hline $\mathrm{H}$ & -6.675523 & 0.420529 & 3.927653 \\
\hline $\mathrm{H}$ & -5.448675 & 0.433268 & 5.216661 \\
\hline C & -4.113493 & 1.222521 & -0.666313 \\
\hline C & -4.715657 & 1.766219 & 0.478942 \\
\hline $\mathrm{H}$ & -2.466169 & 1.240228 & -1.908158 \\
\hline$N$ & -3.030896 & 1.789808 & -1.254535 \\
\hline C & -2.479952 & 3.052680 & -0.959173 \\
\hline $\mathrm{O}$ & -2.816801 & 3.775998 & -0.045562 \\
\hline $\mathrm{O}$ & -1.561838 & 3.331785 & -1.881501 \\
\hline C & -0.795849 & 4.529188 & -1.637689 \\
\hline $\mathrm{H}$ & -1.460503 & 5.392528 & -1.558815 \\
\hline $\mathrm{H}$ & -0.130572 & 4.620409 & -2.492721 \\
\hline $\mathrm{H}$ & -0.217986 & 4.411580 & -0.719715 \\
\hline $\mathrm{H}$ & -5.627932 & 1.281807 & 0.805356 \\
\hline $\mathrm{H}$ & -4.651135 & 2.831245 & 0.649486 \\
\hline C & -4.565666 & -0.063837 & -1.234098 \\
\hline C & -3.668673 & -0.976704 & -1.821128 \\
\hline C & -5.943240 & -0.358676 & -1.237498 \\
\hline C & -4.149846 & -2.151514 & -2.393969 \\
\hline $\mathrm{H}$ & -2.596590 & -0.798028 & -1.801902 \\
\hline C & -6.414451 & -1.528870 & -1.823263 \\
\hline $\mathrm{H}$ & -6.649925 & 0.350826 & -0.819632 \\
\hline C & -5.517514 & -2.429225 & -2.402638 \\
\hline $\mathrm{H}$ & -3.445078 & -2.858178 & -2.819219 \\
\hline $\mathrm{H}$ & -7.481226 & -1.733609 & -1.834421 \\
\hline $\mathrm{H}$ & -5.884759 & -3.345020 & -2.857994 \\
\hline $\mathrm{H}$ & -6.414312 & 1.912168 & 4.893553 \\
\hline
\end{tabular}

Catalyst (R)-1 TS Conformation 175

B3LYP/6-31G(d) Energy $=-2809.691507$

B3LYP-D3(BJ)/def2-TZVPP-IEF-PCM(DCM) Energy = -2810.983793 
B3LYP-D3(BJ)/def2-TZVPP-IEF-PCM(DCM)//B3LYP/6-31G(d) Free Energy (Quasiharmonic) = 2810.341733

Frequencies (Top 3 out of 270)

1. $-552.1094 \mathrm{~cm}-1$

2. $\quad 7.8125 \mathrm{~cm}-1$

3. $\quad 15.0115 \mathrm{~cm}-1$

B3LYP/6-31G(d) Molecular Geometry in Cartesian Coordinates

$\begin{array}{llll}\text { C } & 2.974888 & -0.986268 & -0.162030 \\ \text { C } & 1.753211 & -1.626988 & -0.024311 \\ \text { C } & 1.559403 & -3.026285 & -0.250276 \\ \text { C } & 2.649862 & -3.718128 & -0.749716 \\ \text { H } & 2.580174 & -4.792056 & -0.891833 \\ \text { C } & 3.695158 & 3.029995 & 1.238156 \\ \mathrm{C} & 3.171451 & 0.390807 & 0.386324 \\ \mathrm{C} & 2.362460 & 1.454172 & 0.011522 \\ \mathrm{C} & 2.629780 & 2.804741 & 0.389389 \\ \mathrm{H} & 3.916488 & 4.048727 & 1.544926 \\ \mathrm{O} & 0.684783 & -0.876250 & 0.442214 \\ \mathrm{P} & 0.031679 & 0.301935 & -0.487589 \\ \mathrm{O} & 1.304104 & 1.239822 & -0.865688 \\ \mathrm{C} & -1.996615 & -5.262577 & 0.756338 \\ \mathrm{C} & -1.148721 & -5.687053 & -0.269696 \\ \mathrm{C} & -0.031247 & -4.930549 & -0.616633 \\ \mathrm{C} & 0.296770 & -3.749085 & 0.076659 \\ \mathrm{C} & -0.568209 & -3.339793 & 1.109796 \\ \mathrm{C} & -1.707615 & -4.076727 & 1.432655 \\ \mathrm{H} & -1.365350 & -6.602688 & -0.815016 \\ \mathrm{H} & -2.371564 & -3.706262 & 2.208740 \\ \mathrm{C} & 0.502696 & 6.278045 & -0.996705 \\ \mathrm{C} & -0.202733 & 5.211520 & -0.436250 \\ \mathrm{C} & 0.464020 & 4.062856 & -0.010412 \\ \mathrm{C} & 1.859163 & 3.969320 & -0.129462 \\ \mathrm{C} & 2.559381 & 5.046870 & -0.697701 \\ \mathrm{C} & 1.888812 & 6.190427 & -1.130061 \\ \mathrm{H} & -1.281670 & 5.269606 & -0.325759 \\ \mathrm{H} & 2.449986 & 7.009715 & -1.572231 \\ \mathrm{C} & 4.208917 & 0.632008 & 1.358467 \\ \mathrm{C} & 4.475866 & 1.976561 & 1.769909 \\ \mathrm{C} & 5.502593 & 2.231439 & 2.718984 \\ \mathrm{C} & 6.226613 & 1.201099 & 3.271167\end{array}$




\begin{tabular}{|c|c|c|c|}
\hline C & 5.940031 & -0.132716 & 2.898300 \\
\hline C & 4.962190 & -0.409825 & 1.968120 \\
\hline $\mathrm{H}$ & 5.694132 & 3.261655 & 3.009814 \\
\hline $\mathrm{H}$ & 7.005032 & 1.405753 & 4.001083 \\
\hline $\mathrm{H}$ & 6.491813 & -0.949794 & 3.355193 \\
\hline $\mathrm{H}$ & 4.750685 & -1.439807 & 1.708163 \\
\hline C & 4.051677 & -1.698549 & -0.792898 \\
\hline C & 3.873392 & -3.088763 & -1.081700 \\
\hline C & 4.934294 & -3.816138 & -1.687340 \\
\hline C & 6.112956 & -3.194970 & -2.028743 \\
\hline C & 6.277648 & -1.812505 & -1.776325 \\
\hline C & 5.277366 & -1.085122 & -1.169291 \\
\hline $\mathrm{H}$ & 4.788365 & -4.874795 & -1.888977 \\
\hline $\mathrm{H}$ & 6.913118 & -3.758680 & -2.500538 \\
\hline $\mathrm{H}$ & 7.200818 & -1.318632 & -2.067261 \\
\hline $\mathrm{H}$ & 5.414756 & -0.025151 & -0.988442 \\
\hline 0 & -0.610006 & -0.153082 & -1.755064 \\
\hline $\mathrm{O}$ & -0.855751 & 1.043669 & 0.549824 \\
\hline $\mathrm{H}$ & -1.645692 & 0.375611 & 1.031715 \\
\hline $\mathrm{H}$ & -0.360109 & -2.437712 & 1.667747 \\
\hline $\mathrm{H}$ & -2.876980 & -5.843794 & 1.018144 \\
\hline $\mathrm{H}$ & 0.587992 & -5.256804 & -1.446802 \\
\hline $\mathrm{H}$ & 3.637783 & 4.976868 & -0.812101 \\
\hline $\mathrm{H}$ & -0.023011 & 7.170235 & -1.327847 \\
\hline $\mathrm{H}$ & -0.096844 & 3.245610 & 0.429600 \\
\hline C & -3.652793 & 0.230412 & 1.778099 \\
\hline $\mathrm{O}$ & -2.562473 & -0.386540 & 1.528161 \\
\hline $\mathrm{H}$ & -3.646539 & 1.325496 & 1.856394 \\
\hline C & -4.595256 & -0.451698 & 2.763442 \\
\hline $\mathrm{O}$ & -4.516623 & -1.603187 & 3.117509 \\
\hline $\mathrm{O}$ & -5.529194 & 0.424836 & 3.196457 \\
\hline C & -6.475689 & -0.106740 & 4.140709 \\
\hline $\mathrm{H}$ & -7.029386 & -0.939287 & 3.698576 \\
\hline $\mathrm{H}$ & -5.961160 & -0.458172 & 5.038685 \\
\hline C & -4.087085 & 0.469424 & -0.820023 \\
\hline C & -4.973806 & 0.181199 & 0.227332 \\
\hline $\mathrm{H}$ & -2.390301 & -0.307058 & -1.740205 \\
\hline$N$ & -3.340963 & -0.518631 & -1.380559 \\
\hline C & -3.725182 & -1.866855 & -1.516570 \\
\hline $\mathrm{O}$ & -4.735443 & -2.377530 & -1.085596 \\
\hline $\mathrm{O}$ & -2.811567 & -2.474418 & -2.281887 \\
\hline C & -3.109730 & -3.840546 & -2.619246 \\
\hline $\mathrm{H}$ & -2.238794 & -4.192110 & -3.170701 \\
\hline $\mathrm{H}$ & -4.007657 & -3.884318 & -3.242261 \\
\hline
\end{tabular}




$\begin{array}{lrrr}\text { H } & -3.254922 & -4.431797 & -1.715038 \\ \text { H } & -5.709841 & 0.929705 & 0.495669 \\ \text { H } & -5.294970 & -0.848498 & 0.317583 \\ \text { C } & -3.819890 & 1.845901 & -1.280363 \\ \text { C } & -3.156266 & 2.079587 & -2.501155 \\ \text { C } & -4.282638 & 2.957218 & -0.547676 \\ \text { C } & -2.967787 & 3.375959 & -2.970898 \\ \text { H } & -2.798840 & 1.248081 & -3.097023 \\ \text { C } & -4.095912 & 4.250824 & -1.022569 \\ \text { H } & -4.787366 & 2.815054 & 0.401440 \\ \text { C } & -3.440206 & 4.465349 & -2.237950 \\ \text { H } & -2.453653 & 3.533149 & -3.914126 \\ \text { H } & -4.462615 & 5.093256 & -0.443025 \\ \text { H } & -3.297949 & 5.475867 & -2.610320 \\ \text { H } & -7.146309 & 0.718705 & 4.380143\end{array}$

Catalyst (R)-1 TS Conformation 176

B3LYP/6-31G(d) Energy $=-2809.692626$

B3LYP-D3(BJ)/def2-TZVPP-IEF-PCM(DCM) Energy $=-2810.982754$

B3LYP-D3(BJ)/def2-TZVPP-IEF-PCM(DCM)//B3LYP/6-31G(d) Free Energy (Quasiharmonic) = 2810.341715

Frequencies (Top 3 out of 270)

1. $-731.3508 \mathrm{~cm}-1$

2. $\quad 7.4498 \mathrm{~cm}-1$

3. $10.2516 \mathrm{~cm}-1$

B3LYP/6-31G(d) Molecular Geometry in Cartesian Coordinates

$\begin{array}{llll}\text { C } & 3.599428 & -0.832242 & 0.061697 \\ \text { C } & 2.459186 & -1.596149 & 0.248852 \\ \text { C } & 2.421745 & -3.011465 & 0.087124 \\ \text { C } & 3.586127 & -3.630466 & -0.322349 \\ \text { H } & 3.600450 & -4.711451 & -0.434997 \\ \text { C } & 3.468438 & 3.433726 & 0.683730 \\ \text { C } & 3.551167 & 0.636164 & 0.332195 \\ \text { C } & 2.605936 & 1.427399 & -0.306016 \\ \text { C } & 2.555197 & 2.847946 & -0.172721 \\ \text { H } & 3.482118 & 4.515704 & 0.783074 \\ \text { O } & 1.285185 & -0.949767 & 0.619258 \\ \text { P } & 0.490184 & -0.106153 & -0.542222\end{array}$




\begin{tabular}{|c|c|c|c|}
\hline $\mathrm{O}$ & 1.689574 & 0.822346 & -1.157540 \\
\hline C & -1.095356 & -5.382840 & 0.809305 \\
\hline C & -0.355180 & -5.551960 & -0.361386 \\
\hline C & 0.775473 & -4.769486 & -0.594513 \\
\hline C & 1.186724 & -3.801857 & 0.335951 \\
\hline C & 0.429777 & -3.636491 & 1.508273 \\
\hline C & -0.697715 & -4.422456 & 1.742579 \\
\hline $\mathrm{H}$ & -0.662800 & -6.286464 & -1.100791 \\
\hline $\mathrm{H}$ & -1.263595 & -4.287764 & 2.661013 \\
\hline C & -0.127558 & 5.441028 & -2.323384 \\
\hline C & 0.468777 & 4.360086 & -2.975423 \\
\hline C & 1.317450 & 3.497226 & -2.283582 \\
\hline C & 1.588337 & 3.697716 & -0.918987 \\
\hline C & 0.972544 & 4.782753 & -0.272265 \\
\hline C & 0.128370 & 5.648754 & -0.966872 \\
\hline $\mathrm{H}$ & 0.279589 & 4.189858 & -4.032056 \\
\hline $\mathrm{H}$ & -0.325661 & 6.489192 & -0.446845 \\
\hline C & 4.436757 & 1.254389 & 1.280982 \\
\hline C & 4.394911 & 2.676896 & 1.440085 \\
\hline C & 5.276079 & 3.303643 & 2.362820 \\
\hline C & 6.144494 & 2.560852 & 3.127874 \\
\hline C & 6.160375 & 1.151677 & 3.002456 \\
\hline C & 5.332037 & 0.516177 & 2.103710 \\
\hline $\mathrm{H}$ & 5.239537 & 4.386156 & 2.460455 \\
\hline $\mathrm{H}$ & 6.808533 & 3.049845 & 3.835357 \\
\hline $\mathrm{H}$ & 6.829657 & 0.563583 & 3.624594 \\
\hline $\mathrm{H}$ & 5.350850 & -0.564630 & 2.027266 \\
\hline C & 4.783728 & -1.480961 & -0.431873 \\
\hline C & 4.767549 & -2.902911 & -0.610077 \\
\hline C & 5.933966 & -3.559102 & -1.088649 \\
\hline C & 7.065234 & -2.846833 & -1.412074 \\
\hline C & 7.071160 & -1.438964 & -1.274492 \\
\hline C & 5.962821 & -0.774598 & -0.796805 \\
\hline $\mathrm{H}$ & 5.908251 & -4.639841 & -1.206746 \\
\hline $\mathrm{H}$ & 7.948320 & -3.359076 & -1.784026 \\
\hline $\mathrm{H}$ & 7.956990 & -0.874638 & -1.553270 \\
\hline $\mathrm{H}$ & 5.980922 & 0.305317 & -0.707301 \\
\hline $\mathrm{O}$ & -0.606762 & 0.647656 & 0.134389 \\
\hline $\mathrm{O}$ & 0.149960 & -1.029419 & -1.721250 \\
\hline $\mathrm{H}$ & -0.941067 & -1.479584 & -1.884346 \\
\hline $\mathrm{H}$ & 0.732904 & -2.895615 & 2.240578 \\
\hline $\mathrm{H}$ & -1.976580 & -5.992179 & 0.992034 \\
\hline $\mathrm{H}$ & 1.334480 & -4.888275 & -1.518328 \\
\hline $\mathrm{H}$ & 1.148878 & 4.938544 & 0.788257 \\
\hline
\end{tabular}




\begin{tabular}{llll}
$\mathrm{H}$ & -0.783835 & 6.115145 & -2.867682 \\
$\mathrm{H}$ & 1.781376 & 2.668231 & -2.805646 \\
$\mathrm{C}$ & -2.890953 & -0.965988 & -1.647404 \\
$\mathrm{O}$ & -2.088970 & -1.859367 & -2.079423 \\
$\mathrm{H}$ & -2.518466 & 0.048693 & -1.473521 \\
$\mathrm{C}$ & -4.335568 & -1.038365 & -2.104675 \\
$\mathrm{O}$ & -4.923097 & -2.037141 & -2.450755 \\
$\mathrm{O}$ & -4.865007 & 0.199646 & -2.056347 \\
$\mathrm{C}$ & -6.250077 & 0.319846 & -2.430976 \\
$\mathrm{H}$ & -6.371893 & 0.091574 & -3.493127 \\
$\mathrm{H}$ & -6.866078 & -0.360050 & -1.839203 \\
$\mathrm{C}$ & -3.905661 & -0.265048 & 0.880999 \\
$\mathrm{C}$ & -3.114098 & -1.306209 & 0.385158 \\
$\mathrm{H}$ & -2.300411 & 0.988416 & 0.783152 \\
$\mathrm{~N}$ & -3.318753 & 0.971557 & 0.952472 \\
$\mathrm{C}$ & -3.952175 & 2.209787 & 0.755427 \\
$\mathrm{O}$ & -5.137311 & 2.405508 & 0.606585 \\
$\mathrm{O}$ & -2.997000 & 3.154304 & 0.745362 \\
$\mathrm{C}$ & -3.453983 & 4.489149 & 0.476805 \\
$\mathrm{H}$ & -4.042276 & 4.514142 & -0.443472 \\
$\mathrm{H}$ & -2.546377 & 5.081679 & 0.368731 \\
$\mathrm{H}$ & -4.065057 & 4.856618 & 1.306016 \\
$\mathrm{H}$ & -3.476336 & -2.324394 & 0.464934 \\
$\mathrm{H}$ & -2.041915 & -1.182436 & 0.475042 \\
$\mathrm{C}$ & -5.287745 & -0.489851 & 1.342198 \\
$\mathrm{C}$ & -6.067011 & -1.526453 & 0.793606 \\
$\mathrm{H}$ & -5.803682 & 0.240919 & 2.428463 \\
$\mathrm{H}$ & -7.336002 & -1.798725 & 1.298450 \\
$\mathrm{H}$ & -5.695102 & -2.107361 & -0.043351 \\
$\mathrm{H}$ & -7.061856 & -0.051700 & 2.944002 \\
$\mathrm{H}$ & -5.207029 & 1.021843 & 2.884820 \\
\hline & -7.836884 & -1.065408 & 2.376055 \\
$\mathrm{H}$ & -7.930198 & -2.590834 & 0.851961 \\
$\mathrm{H}$ & -6.514135 & 1.355428 & -2.220320
\end{tabular}

Catalyst (R)-1 TS Conformation 177

B3LYP/6-31G(d) Energy $=-2809.691304$

B3LYP-D3(BJ)/def2-TZVPP-IEF-PCM(DCM) Energy $=-2810.982579$

B3LYP-D3(BJ)/def2-TZVPP-IEF-PCM(DCM)//B3LYP/6-31G(d) Free Energy (Quasiharmonic) = 2810.341689 
Frequencies (Top 3 out of 270)

1. $-709.4131 \mathrm{~cm}-1$

2. $\quad 10.7991 \mathrm{~cm}-1$

3. $\quad 14.1322 \mathrm{~cm}-1$

B3LYP/6-31G(d) Molecular Geometry in Cartesian Coordinates

$\begin{array}{llll}\text { C } & 3.065341 & -1.262835 & 0.018700 \\ \text { C } & 1.725422 & -1.611036 & 0.023261 \\ \text { C } & 1.248728 & -2.932135 & -0.219154 \\ \text { C } & 2.192010 & -3.900440 & -0.500394 \\ \text { H } & 1.868703 & -4.924915 & -0.665883 \\ \text { C } & 4.376727 & 2.778961 & 0.734547 \\ \text { C } & 3.467482 & 0.137714 & 0.348338 \\ \text { C } & 2.933090 & 1.206516 & -0.359932 \\ \text { C } & 3.405877 & 2.546221 & -0.220438 \\ \text { H } & 4.749964 & 3.790788 & 0.868456 \\ \text { O } & 0.789749 & -0.617893 & 0.286939 \\ \text { P } & 0.472093 & 0.464128 & -0.900140 \\ \text { O } & 1.964762 & 0.962525 & -1.329031 \\ \text { C } & -2.940132 & -3.933617 & -0.224265 \\ \text { C } & -2.408951 & -3.161403 & 0.812535 \\ \text { C } & -1.054374 & -2.827287 & 0.824591 \\ \text { C } & -0.201245 & -3.261840 & -0.205215 \\ \text { C } & -0.746192 & -4.043305 & -1.236920 \\ \text { C } & -2.100619 & -4.377241 & -1.246730 \\ \text { H } & -3.057029 & -2.807001 & 1.609728 \\ \text { H } & -2.501824 & -4.971929 & -2.063216 \\ \text { C } & 2.194317 & 5.860217 & -2.686250 \\ \text { C } & 3.544125 & 5.546184 & -2.524123 \\ \text { C } & 3.917663 & 4.459324 & -1.734285 \\ \text { C } & 2.951519 & 3.665524 & -1.093372 \\ \text { C } & 1.595958 & 3.988893 & -1.264460 \\ \text { C } & 1.226379 & 5.078207 & -2.053316 \\ \text { H } & 4.308215 & 6.141757 & -3.017235 \\ \text { H } & 0.172387 & 5.316854 & -2.171253 \\ \text { C } & 4.404285 & 0.415068 & 1.403705 \\ \text { C } & 4.867243 & 1.757674 & 1.583326 \\ \text { C } & 5.797306 & 2.044189 & 2.619211 \\ \text { C } & 6.239623 & 1.055165 & 3.466334 \\ \text { C } & 5.758172 & -0.266381 & 3.313531 \\ \text { C } & 4.867371 & -0.578486 & 2.310171\end{array}$




\begin{tabular}{|c|c|c|c|}
\hline $\mathrm{H}$ & 6.143544 & 3.068523 & 2.735403 \\
\hline $\mathrm{H}$ & 6.946023 & 1.286745 & 4.258836 \\
\hline $\mathrm{H}$ & 6.088836 & -1.042284 & 3.998791 \\
\hline $\mathrm{H}$ & 4.499063 & -1.593388 & 2.215301 \\
\hline C & 4.028112 & -2.264656 & -0.354812 \\
\hline$C$ & 3.573870 & -3.602614 & -0.595404 \\
\hline C & 4.515384 & -4.606893 & -0.949435 \\
\hline C & 5.849261 & -4.306575 & -1.097404 \\
\hline C & 6.294379 & -2.978111 & -0.902980 \\
\hline C & 5.410133 & -1.985726 & -0.540708 \\
\hline $\mathrm{H}$ & 4.154477 & -5.619203 & -1.115742 \\
\hline$H$ & 6.558530 & -5.081152 & -1.375930 \\
\hline $\mathrm{H}$ & 7.343986 & -2.735819 & -1.045996 \\
\hline $\mathrm{H}$ & 5.767415 & -0.971780 & -0.406100 \\
\hline 0 & -0.391756 & 1.529768 & -0.289348 \\
\hline $\mathrm{O}$ & -0.041260 & -0.262053 & -2.148603 \\
\hline $\mathrm{H}$ & -1.188075 & -0.129246 & -2.480156 \\
\hline $\mathrm{H}$ & -0.105425 & -4.363083 & -2.053658 \\
\hline $\mathrm{H}$ & -3.999697 & -4.171392 & -0.241097 \\
\hline $\mathrm{H}$ & -0.653534 & -2.223936 & 1.632591 \\
\hline $\mathrm{H}$ & 0.831818 & 3.397232 & -0.772294 \\
\hline $\mathrm{H}$ & 1.899137 & 6.705317 & -3.302889 \\
\hline $\mathrm{H}$ & 4.969110 & 4.206997 & -1.625244 \\
\hline C & -3.160265 & -0.355877 & -1.880784 \\
\hline $\mathrm{O}$ & -2.344914 & -0.044800 & -2.816509 \\
\hline $\mathrm{H}$ & -2.811803 & -0.937731 & -1.021766 \\
\hline C & -4.578004 & -0.703695 & -2.286592 \\
\hline $\mathrm{O}$ & -5.269953 & -1.480491 & -1.655990 \\
\hline 0 & -4.955169 & -0.081531 & -3.407585 \\
\hline C & -6.274486 & -0.402913 & -3.882879 \\
\hline $\mathrm{H}$ & -6.362723 & -1.476602 & -4.065611 \\
\hline $\mathrm{H}$ & -7.029889 & -0.100262 & -3.152240 \\
\hline C & -3.711029 & 1.146943 & 0.567528 \\
\hline C & -3.568538 & 1.378423 & -0.813963 \\
\hline $\mathrm{H}$ & -1.676613 & 1.176692 & 0.826605 \\
\hline$N$ & -2.579858 & 0.955593 & 1.298941 \\
\hline C & -2.395006 & 0.337533 & 2.549032 \\
\hline $\mathrm{O}$ & -1.339363 & 0.394999 & 3.136161 \\
\hline $\mathrm{O}$ & -3.478342 & -0.338040 & 2.965741 \\
\hline C & -3.346098 & -0.945353 & 4.264945 \\
\hline $\mathrm{H}$ & -3.113920 & -0.188514 & 5.017880 \\
\hline $\mathrm{H}$ & -2.554165 & -1.697792 & 4.254617 \\
\hline $\mathrm{H}$ & -4.314042 & -1.404754 & 4.463758 \\
\hline $\mathrm{H}$ & -4.420184 & 1.813129 & -1.326803 \\
\hline
\end{tabular}




$\begin{array}{llll}\mathrm{H} & -2.595625 & 1.743305 & -1.127070 \\ \mathrm{C} & -5.029210 & 1.235226 & 1.238204 \\ \mathrm{C} & -6.168090 & 0.602064 & 0.720146 \\ \mathrm{C} & -5.157365 & 2.066258 & 2.366394 \\ \mathrm{C} & -7.407666 & 0.785623 & 1.332458 \\ \mathrm{H} & -6.079007 & -0.067421 & -0.127543 \\ \mathrm{C} & -6.401829 & 2.264564 & 2.956087 \\ \mathrm{H} & -4.284232 & 2.579214 & 2.759038 \\ \mathrm{C} & -7.531036 & 1.619772 & 2.444317 \\ \mathrm{H} & -8.279712 & 0.272990 & 0.936092 \\ \mathrm{H} & -6.490635 & 2.923392 & 3.815344 \\ \mathrm{H} & -8.501459 & 1.769950 & 2.909380 \\ \mathrm{H} & -6.391887 & 0.157317 & -4.810043\end{array}$

Catalyst (R)-1 TS Conformation 178

B3LYP/6-31G(d) Energy = -2809.690359

B3LYP-D3(BJ)/def2-TZVPP-IEF-PCM(DCM) Energy $=-2810.98408$

B3LYP-D3(BJ)/def2-TZVPP-IEF-PCM(DCM)//B3LYP/6-31G(d) Free Energy (Quasiharmonic) = 2810.341686

Frequencies (Top 3 out of 270)

1. $-463.1749 \mathrm{~cm}-1$

2. $\quad 10.5593 \mathrm{~cm}-1$

3. $12.1678 \mathrm{~cm}-1$

B3LYP/6-31G(d) Molecular Geometry in Cartesian Coordinates

$\begin{array}{llll}\text { C } & -3.609117 & -0.335145 & -0.196542 \\ \text { C } & -3.069216 & 0.897686 & 0.138041 \\ \text { C } & -3.773402 & 2.126734 & -0.016973 \\ \text { C } & -5.022474 & 2.073323 & -0.603336 \\ \text { H } & -5.591429 & 2.992266 & -0.718089 \\ \text { C } & -1.306542 & -3.918185 & 0.484270 \\ \text { C } & -2.837481 & -1.581179 & 0.087673 \\ \text { C } & -1.557355 & -1.715610 & -0.424553 \\ \text { C } & -0.766980 & -2.890990 & -0.265393 \\ \text { H } & -0.740903 & -4.838133 & 0.606679 \\ \text { O } & -1.786395 & 0.946672 & 0.679354 \\ \text { P } & -0.500989 & 0.646301 & -0.285632 \\ \text { O } & -1.021374 & -0.651972 & -1.143450 \\ C & -2.362933 & 5.946177 & 1.366633\end{array}$




\begin{tabular}{|c|c|c|c|}
\hline C & -2.803276 & 5.790713 & 0.051995 \\
\hline C & -3.234072 & 4.543241 & -0.399658 \\
\hline C & -3.225209 & 3.427848 & 0.451583 \\
\hline C & -2.766910 & 3.592123 & 1.768851 \\
\hline C & -2.347951 & 4.842274 & 2.223235 \\
\hline $\mathrm{H}$ & -2.808585 & 6.639812 & -0.626258 \\
\hline $\mathrm{H}$ & -2.018687 & 4.956528 & 3.253229 \\
\hline C & 3.112683 & -3.461664 & -2.037685 \\
\hline C & 2.064899 & -2.943217 & -2.802462 \\
\hline C & 0.812370 & -2.728302 & -2.228675 \\
\hline C & 0.580977 & -3.035844 & -0.877078 \\
\hline C & 1.644782 & -3.548656 & -0.116143 \\
\hline C & 2.898441 & -3.759931 & -0.690874 \\
\hline $\mathrm{H}$ & 2.219180 & -2.711285 & -3.853130 \\
\hline $\mathrm{H}$ & 3.709682 & -4.153964 & -0.084050 \\
\hline C & -3.359000 & -2.630977 & 0.918701 \\
\hline C & -2.576458 & -3.816889 & 1.103452 \\
\hline C & -3.082779 & -4.867416 & 1.916001 \\
\hline C & -4.297644 & -4.749180 & 2.549713 \\
\hline C & -5.055767 & -3.564206 & 2.399061 \\
\hline C & -4.600626 & -2.534344 & 1.605365 \\
\hline $\mathrm{H}$ & -2.481051 & -5.765179 & 2.036458 \\
\hline $\mathrm{H}$ & -4.671400 & -5.556056 & 3.174037 \\
\hline $\mathrm{H}$ & -6.004773 & -3.462975 & 2.918629 \\
\hline $\mathrm{H}$ & -5.189280 & -1.629559 & 1.508084 \\
\hline C & -4.883396 & -0.368851 & -0.860871 \\
\hline C & -5.593498 & 0.859518 & -1.057682 \\
\hline C & -6.856016 & 0.839834 & -1.710067 \\
\hline C & -7.391523 & -0.336587 & -2.179933 \\
\hline C & -6.676304 & -1.546615 & -2.019498 \\
\hline C & -5.457650 & -1.563306 & -1.377413 \\
\hline $\mathrm{H}$ & -7.386238 & 1.780252 & -1.840528 \\
\hline $\mathrm{H}$ & -8.354479 & -0.338589 & -2.683186 \\
\hline $\mathrm{H}$ & -7.089637 & -2.472031 & -2.411439 \\
\hline $\mathrm{H}$ & -4.918303 & -2.497509 & -1.272940 \\
\hline $\mathrm{O}$ & 0.688232 & 0.361267 & 0.565494 \\
\hline $\mathrm{O}$ & -0.418920 & 1.746660 & -1.366010 \\
\hline $\mathrm{H}$ & 0.545708 & 2.251540 & -1.573497 \\
\hline $\mathrm{H}$ & -2.755956 & 2.740113 & 2.441255 \\
\hline $\mathrm{H}$ & -2.033014 & 6.918774 & 1.722034 \\
\hline $\mathrm{H}$ & -3.564211 & 4.422957 & -1.427604 \\
\hline $\mathrm{H}$ & 1.490077 & -3.759692 & 0.938182 \\
\hline $\mathrm{H}$ & 4.086955 & -3.634080 & -2.487959 \\
\hline $\mathrm{H}$ & 0.003799 & -2.330628 & -2.832681 \\
\hline
\end{tabular}




$\begin{array}{llll}\mathrm{C} & 2.741527 & 2.567776 & -1.279426 \\ \mathrm{O} & 1.714967 & 2.764749 & -2.010918 \\ \mathrm{H} & 3.709729 & 2.924756 & -1.658614 \\ \mathrm{C} & 2.671517 & 2.784630 & 0.238749 \\ \mathrm{O} & 3.611508 & 2.599567 & 0.988691 \\ \mathrm{O} & 1.488620 & 3.271094 & 0.610717 \\ \mathrm{C} & 1.302612 & 3.444828 & 2.028934 \\ \mathrm{H} & 2.082274 & 4.092647 & 2.437009 \\ \mathrm{H} & 0.318508 & 3.898966 & 2.132429 \\ \mathrm{C} & 4.030389 & 0.154925 & -0.456974 \\ \mathrm{C} & 3.191978 & 0.636628 & -1.478059 \\ \mathrm{H} & 2.420305 & -0.163271 & 0.743786 \\ \mathrm{~N} & 3.441720 & -0.304589 & 0.676892 \\ \mathrm{C} & 3.938760 & -1.050154 & 1.754319 \\ \mathrm{O} & 3.258528 & -1.287821 & 2.726931 \\ \mathrm{O} & 5.188976 & -1.496257 & 1.557014 \\ \mathrm{C} & 5.734887 & -2.255440 & 2.649521 \\ \mathrm{H} & 6.748523 & -2.510795 & 2.340825 \\ \mathrm{H} & 5.142727 & -3.157734 & 2.820935 \\ \mathrm{H} & 5.747886 & -1.656679 & 3.563430 \\ \mathrm{H} & 3.653527 & 0.754398 & -2.452035 \\ \mathrm{H} & 2.178952 & 0.255038 & -1.493477 \\ \mathrm{C} & 5.501117 & 0.273448 & -0.600083 \\ \mathrm{C} & 6.117959 & -0.241672 & -1.750035 \\ \mathrm{C} & 6.276317 & 0.957736 & 0.350945 \\ \mathrm{C} & 7.492758 & -0.099808 & -1.935946 \\ \mathrm{H} & 5.520978 & -0.777287 & -2.482382 \\ \mathrm{C} & 7.644198 & 1.115577 & 0.148922 \\ \mathrm{H} & 5.789855 & 1.398169 & 1.213299 \\ \mathrm{C} & 8.257358 & 0.581741 & -0.988571 \\ \mathrm{H} & 7.963013 & -0.516685 & -2.822097 \\ \mathrm{H} & 8.234388 & 1.662905 & 0.878726 \\ \mathrm{H} & 9.326804 & 0.703646 & -1.137953 \\ \mathrm{H} & 1.333035 & 2.469726 & 2.520321\end{array}$

Catalyst (R)-1 TS Conformation 179

B3LYP/6-31G(d) Energy $=-2809.690948$

B3LYP-D3(BJ)/def2-TZVPP-IEF-PCM(DCM) Energy = -2810.982555

B3LYP-D3(BJ)/def2-TZVPP-IEF-PCM(DCM)//B3LYP/6-31G(d) Free Energy (Quasiharmonic) = 2810.341648

Frequencies (Top 3 out of 270) 
1. $-709.7603 \mathrm{~cm}-1$

2. $\quad 6.8908 \mathrm{~cm}-1$

3. $\quad 11.0396 \mathrm{~cm}-1$

B3LYP/6-31G(d) Molecular Geometry in Cartesian Coordinates

\begin{tabular}{|c|c|c|c|}
\hline C & -3.660818 & -0.765913 & -0.031331 \\
\hline C & -2.561159 & -1.528139 & -0.386923 \\
\hline C & -2.532951 & -2.951626 & -0.334147 \\
\hline C & -3.661039 & -3.586682 & 0.145441 \\
\hline $\mathrm{H}$ & -3.684732 & -4.672854 & 0.178467 \\
\hline C & -3.627498 & 3.536473 & -0.301880 \\
\hline C & -3.621359 & 0.716177 & -0.209223 \\
\hline C & -2.603072 & 1.468873 & 0.362353 \\
\hline C & -2.598926 & 2.895827 & 0.359479 \\
\hline $\mathrm{H}$ & -3.645714 & 4.623083 & -0.317493 \\
\hline $\mathrm{O}$ & -1.413053 & -0.868803 & -0.817298 \\
\hline$P$ & -0.509882 & -0.148741 & 0.344624 \\
\hline $\mathrm{O}$ & -1.593118 & 0.831488 & 1.072169 \\
\hline C & 0.850112 & -5.298913 & -1.581954 \\
\hline C & 0.226893 & -5.549191 & -0.359113 \\
\hline C & -0.860531 & -4.774787 & 0.044265 \\
\hline C & -1.343963 & -3.734180 & -0.764761 \\
\hline C & -0.703296 & -3.486893 & -1.990840 \\
\hline C & 0.380302 & -4.265082 & -2.395365 \\
\hline $\mathrm{H}$ & 0.593470 & -6.340662 & 0.288935 \\
\hline $\mathrm{H}$ & 0.855515 & -4.065628 & -3.352666 \\
\hline C & 0.318812 & 5.356876 & 2.341593 \\
\hline C & -1.034731 & 5.460582 & 2.665944 \\
\hline C & -1.969703 & 4.643337 & 2.030321 \\
\hline C & -1.566061 & 3.703632 & 1.068404 \\
\hline C & -0.202580 & 3.604024 & 0.753411 \\
\hline C & 0.729453 & 4.429231 & 1.382132 \\
\hline $\mathrm{H}$ & -1.365365 & 6.176616 & 3.414227 \\
\hline $\mathrm{H}$ & 1.775523 & 4.347457 & 1.101648 \\
\hline C & -4.622793 & 1.397084 & -0.986301 \\
\hline C & -4.628198 & 2.828503 & -1.010647 \\
\hline C & -5.620508 & 3.512387 & -1.764041 \\
\hline C & -6.559555 & 2.819263 & -2.491566 \\
\hline C & -6.535402 & 1.404774 & -2.499800 \\
\hline C & -5.595705 & 0.713241 & -1.767324 \\
\hline $\mathrm{H}$ & -5.612913 & 4.599883 & -1.763073 \\
\hline $\mathrm{H}$ & -7.309806 & 3.352458 & -3.069111 \\
\hline
\end{tabular}




\begin{tabular}{|c|c|c|c|}
\hline $\mathrm{H}$ & -7.261492 & 0.857396 & -3.094922 \\
\hline $\mathrm{H}$ & -5.585511 & -0.370122 & -1.794355 \\
\hline C & -4.798560 & -1.437402 & 0.539036 \\
\hline C & -4.791278 & -2.868806 & 0.609268 \\
\hline C & -5.912590 & -3.546458 & 1.160260 \\
\hline C & -6.988281 & -2.848237 & 1.657175 \\
\hline C & -6.980070 & -1.434127 & 1.628244 \\
\hline C & -5.916891 & -0.747985 & 1.083308 \\
\hline $\mathrm{H}$ & -5.895232 & -4.633306 & 1.193771 \\
\hline $\mathrm{H}$ & -7.836352 & -3.377271 & 2.083286 \\
\hline $\mathrm{H}$ & -7.818356 & -0.882282 & 2.044937 \\
\hline $\mathrm{H}$ & -5.922844 & 0.335515 & 1.079282 \\
\hline $\mathrm{O}$ & 0.606254 & 0.563281 & -0.352678 \\
\hline $\mathrm{O}$ & -0.163878 & -1.152590 & 1.452523 \\
\hline $\mathrm{H}$ & 0.879006 & -1.730582 & 1.452042 \\
\hline $\mathrm{H}$ & -1.062475 & -2.687457 & -2.630306 \\
\hline $\mathrm{H}$ & 1.698285 & -5.901272 & -1.896677 \\
\hline $\mathrm{H}$ & -1.327164 & -4.957698 & 1.008007 \\
\hline $\mathrm{H}$ & 0.131634 & 2.893756 & 0.005722 \\
\hline $\mathrm{H}$ & 1.047911 & 5.997234 & 2.831998 \\
\hline $\mathrm{H}$ & -3.022689 & 4.720496 & 2.288644 \\
\hline C & 2.897380 & -1.384960 & 1.397165 \\
\hline $\mathrm{O}$ & 1.972603 & -2.261843 & 1.519623 \\
\hline $\mathrm{H}$ & 2.649251 & -0.327598 & 1.545363 \\
\hline C & 4.271973 & -1.800260 & 1.899674 \\
\hline $\mathrm{O}$ & 4.754688 & -2.902201 & 1.793636 \\
\hline $\mathrm{O}$ & 4.868421 & -0.750394 & 2.501424 \\
\hline C & 6.165684 & -1.024894 & 3.064477 \\
\hline $\mathrm{H}$ & 6.096243 & -1.836777 & 3.792271 \\
\hline $\mathrm{H}$ & 6.869824 & -1.303593 & 2.276946 \\
\hline C & 3.998943 & -0.068899 & -0.814275 \\
\hline C & 3.302447 & -1.263700 & -0.584819 \\
\hline $\mathrm{H}$ & 2.261137 & 0.994369 & -0.636410 \\
\hline$N$ & 3.270878 & 1.083950 & -0.864617 \\
\hline C & 3.592433 & 2.347435 & -1.384612 \\
\hline $\mathrm{O}$ & 2.913965 & 3.324560 & -1.157410 \\
\hline $\mathrm{O}$ & 4.671626 & 2.324292 & -2.181041 \\
\hline C & 5.040239 & 3.600338 & -2.736887 \\
\hline $\mathrm{H}$ & 5.255474 & 4.317343 & -1.940850 \\
\hline $\mathrm{H}$ & 4.232848 & 3.988194 & -3.362056 \\
\hline $\mathrm{H}$ & 5.931714 & 3.404795 & -3.332359 \\
\hline $\mathrm{H}$ & 3.850105 & -2.195825 & -0.661823 \\
\hline $\mathrm{H}$ & 2.258835 & -1.290685 & -0.877815 \\
\hline C & 5.476591 & -0.039406 & -0.796039 \\
\hline
\end{tabular}




$\begin{array}{lrrr}\text { C } & 6.173926 & 0.940183 & -0.065807 \\ \text { C } & 6.202752 & -1.044430 & -1.454871 \\ \text { C } & 7.563272 & 0.913704 & -0.003229 \\ \text { H } & 5.621450 & 1.698625 & 0.479676 \\ \text { C } & 7.595522 & -1.058436 & -1.403782 \\ \text { H } & 5.674200 & -1.798679 & -2.029056 \\ \text { C } & 8.278217 & -0.081563 & -0.677456 \\ \text { H } & 8.091030 & 1.667915 & 0.573715 \\ \text { H } & 8.145552 & -1.833113 & -1.929783 \\ \text { H } & 9.363702 & -0.095873 & -0.632771 \\ \text { H } & 6.475352 & -0.098587 & 3.548215\end{array}$

Catalyst (R)-1 TS Conformation 180

B3LYP/6-31G(d) Energy $=-2809.683532$

B3LYP-D3(BJ)/def2-TZVPP-IEF-PCM(DCM) Energy = -2810.983866

B3LYP-D3(BJ)/def2-TZVPP-IEF-PCM(DCM)//B3LYP/6-31G(d) Free Energy (Quasiharmonic) = 2810.341647

Frequencies (Top 3 out of 270)

1. $-500.6827 \mathrm{~cm}-1$

2. $\quad 9.0779 \mathrm{~cm}-1$

3. $\quad 11.4913 \mathrm{~cm}-1$

B3LYP/6-31G(d) Molecular Geometry in Cartesian Coordinates

$\begin{array}{llll}\text { C } & -3.126499 & 0.143399 & 0.331007 \\ \text { C } & -2.871829 & -0.891285 & -0.556832 \\ \text { C } & -3.266996 & -2.242968 & -0.321795 \\ \text { C } & -3.881954 & -2.520375 & 0.883951 \\ \text { H } & -4.224284 & -3.532534 & 1.083324 \\ \text { C } & -1.911267 & 4.190748 & -0.507912 \\ \text { C } & -2.754834 & 1.542292 & -0.037622 \\ \text { C } & -1.443830 & 1.836775 & -0.390623 \\ \text { C } & -0.982205 & 3.172783 & -0.597246 \\ \text { H } & -1.586045 & 5.215909 & -0.665557 \\ \text { O } & -2.220184 & -0.596052 & -1.741997 \\ \text { P } & -0.599925 & -0.321577 & -1.687535 \\ \text { O } & -0.523122 & 0.804603 & -0.445499 \\ \text { C } & -2.720603 & -5.443359 & -3.145352 \\ \text { C } & -2.425355 & -5.631391 & -1.794616 \\ \text { C } & -2.585426 & -4.581898 & -0.891164\end{array}$




\begin{tabular}{|c|c|c|c|}
\hline C & -3.043712 & -3.324592 & -1.317327 \\
\hline C & -3.330365 & -3.146250 & -2.681206 \\
\hline C & -3.172046 & -4.196815 & -3.583218 \\
\hline $\mathrm{H}$ & -2.060325 & -6.593302 & -1.443626 \\
\hline $\mathrm{H}$ & -3.402298 & -4.038818 & -4.633508 \\
\hline C & 3.138191 & 4.228757 & -1.269193 \\
\hline C & 2.514221 & 3.300802 & -2.107515 \\
\hline C & 1.181895 & 2.938453 & -1.898683 \\
\hline C & 0.451859 & 3.502008 & -0.838406 \\
\hline C & 1.087090 & 4.438663 & -0.006136 \\
\hline C & 2.418130 & 4.799741 & -0.218636 \\
\hline $\mathrm{H}$ & 3.068993 & 2.849438 & -2.926079 \\
\hline $\mathrm{H}$ & 2.892080 & 5.523035 & 0.440453 \\
\hline C & -3.727301 & 2.600424 & -0.045425 \\
\hline C & -3.285855 & 3.943664 & -0.272449 \\
\hline C & -4.235844 & 5.000707 & -0.275340 \\
\hline C & -5.574894 & 4.749578 & -0.086189 \\
\hline C & -6.018856 & 3.420047 & 0.106294 \\
\hline C & -5.121225 & 2.375256 & 0.127582 \\
\hline $\mathrm{H}$ & -3.881432 & 6.015010 & -0.443802 \\
\hline $\mathrm{H}$ & -6.293121 & 5.564900 & -0.097283 \\
\hline $\mathrm{H}$ & -7.079665 & 3.219676 & 0.231068 \\
\hline $\mathrm{H}$ & -5.479481 & 1.361189 & 0.263140 \\
\hline C & -3.698223 & -0.175643 & 1.611866 \\
\hline C & -4.086914 & -1.529829 & 1.876383 \\
\hline C & -4.662941 & -1.857968 & 3.134280 \\
\hline C & -4.823447 & -0.903311 & 4.111620 \\
\hline C & -4.404839 & 0.425931 & 3.868304 \\
\hline C & -3.859816 & 0.780128 & 2.653330 \\
\hline $\mathrm{H}$ & -4.967271 & -2.887144 & 3.311178 \\
\hline $\mathrm{H}$ & -5.260803 & -1.167730 & 5.070606 \\
\hline $\mathrm{H}$ & -4.511966 & 1.175405 & 4.647977 \\
\hline $\mathrm{H}$ & -3.539053 & 1.801627 & 2.486117 \\
\hline O & -0.136652 & 0.232572 & -2.983819 \\
\hline $\mathrm{O}$ & 0.078112 & -1.539468 & -1.054773 \\
\hline $\mathrm{H}$ & 1.331394 & -1.755460 & -1.184104 \\
\hline $\mathrm{H}$ & -3.680348 & -2.182698 & -3.034013 \\
\hline $\mathrm{H}$ & -2.593311 & -6.258820 & -3.852512 \\
\hline $\mathrm{H}$ & -2.329216 & -4.726868 & 0.154670 \\
\hline $\mathrm{H}$ & 0.533813 & 4.873494 & 0.822456 \\
\hline $\mathrm{H}$ & 4.176642 & 4.503213 & -1.435021 \\
\hline $\mathrm{H}$ & 0.705613 & 2.220600 & -2.559575 \\
\hline C & 2.988713 & -0.686997 & -1.397930 \\
\hline $\mathrm{O}$ & 2.470446 & -1.848195 & -1.189441 \\
\hline
\end{tabular}




$\begin{array}{llll}\mathrm{H} & 2.404367 & 0.060821 & -1.941894 \\ \mathrm{C} & 4.456282 & -0.620079 & -1.764066 \\ \mathrm{O} & 4.874528 & 0.164517 & -2.585365 \\ \mathrm{O} & 5.202794 & -1.530416 & -1.116739 \\ \mathrm{C} & 6.592279 & -1.539537 & -1.494204 \\ \mathrm{H} & 6.695243 & -1.769466 & -2.557493 \\ \mathrm{H} & 7.043729 & -0.564766 & -1.292480 \\ \mathrm{C} & 3.368186 & -0.349854 & 1.326229 \\ \mathrm{C} & 2.946915 & 0.470685 & 0.280848 \\ \mathrm{H} & 4.810569 & -0.923374 & 2.652583 \\ \mathrm{~N} & 4.637258 & -0.326345 & 1.853997 \\ \mathrm{C} & 5.715328 & 0.483455 & 1.497987 \\ \mathrm{O} & 5.757876 & 1.263636 & 0.574822 \\ \mathrm{O} & 6.716513 & 0.240366 & 2.368750 \\ \mathrm{C} & 7.913924 & 1.009820 & 2.149621 \\ \mathrm{H} & 8.598893 & 0.704472 & 2.940061 \\ \mathrm{H} & 7.696679 & 2.078274 & 2.216631 \\ \mathrm{H} & 8.335527 & 0.787587 & 1.166340 \\ \mathrm{H} & 1.874452 & 0.596129 & 0.182135 \\ \mathrm{H} & 3.550449 & 1.324142 & -0.002316 \\ \mathrm{C} & 2.493241 & -1.390350 & 1.891197 \\ \mathrm{C} & 1.103703 & -1.186583 & 1.978542 \\ \mathrm{C} & 3.029309 & -2.619403 & 2.332244 \\ \mathrm{C} & 0.280254 & -2.171258 & 2.518035 \\ \mathrm{H} & 0.660810 & -0.258794 & 1.636835 \\ \mathrm{C} & 2.200936 & -3.601467 & 2.862188 \\ \mathrm{H} & 4.085732 & -2.836126 & 2.198959 \\ \mathrm{C} & 0.825206 & -3.375107 & 2.965102 \\ \mathrm{H} & -0.789458 & -1.996897 & 2.576604 \\ \mathrm{H} & 2.624484 & -4.550339 & 3.178056 \\ \mathrm{H} & 0.179036 & -4.143463 & 3.380297 \\ \mathrm{H} & 7.053638 & -2.319551 & -0.887857 \\ & & & \end{array}$

Catalyst (R)-1 TS Conformation 181

B3LYP/6-31G(d) Energy $=-2809.698147$

B3LYP-D3(BJ)/def2-TZVPP-IEF-PCM(DCM) Energy = -2810.985609

B3LYP-D3(BJ)/def2-TZVPP-IEF-PCM(DCM)//B3LYP/6-31G(d) Free Energy (Quasiharmonic) = 2810.341622

Frequencies (Top 3 out of 270)

1. $-237.9122 \mathrm{~cm}-1$ 
2. $\quad 9.3271 \mathrm{~cm}-1$

3. $\quad 19.6670 \mathrm{~cm}-1$

B3LYP/6-31G(d) Molecular Geometry in Cartesian Coordinates

\begin{tabular}{|c|c|c|c|}
\hline$C$ & 2.967701 & -1.054130 & -0.474149 \\
\hline C & 1.787350 & -1.634192 & -0.031476 \\
\hline C & 1.498137 & -3.020096 & -0.209261 \\
\hline C & 2.387466 & -3.765620 & -0.957620 \\
\hline $\mathrm{H}$ & 2.187597 & -4.823647 & -1.104831 \\
\hline C & 4.173775 & 2.934706 & 0.605717 \\
\hline C & 3.363054 & 0.308832 & -0.018077 \\
\hline C & 2.520819 & 1.394162 & -0.202227 \\
\hline C & 2.912835 & 2.734710 & 0.080352 \\
\hline $\mathrm{H}$ & 4.495861 & 3.949274 & 0.824934 \\
\hline $\mathrm{O}$ & 0.893941 & -0.865145 & 0.716780 \\
\hline$P$ & 0.109915 & 0.397383 & 0.035401 \\
\hline $\mathrm{O}$ & 1.273692 & 1.184532 & -0.787907 \\
\hline C & -1.809651 & -5.164913 & 1.509307 \\
\hline C & -0.496732 & -5.473968 & 1.874118 \\
\hline C & 0.568221 & -4.753449 & 1.332013 \\
\hline C & 0.335252 & -3.710014 & 0.421067 \\
\hline C & -0.985150 & -3.406753 & 0.067813 \\
\hline C & -2.052982 & -4.127171 & 0.605570 \\
\hline $\mathrm{H}$ & -0.299134 & -6.278796 & 2.578037 \\
\hline $\mathrm{H}$ & -3.063812 & -3.868382 & 0.304764 \\
\hline C & 0.604548 & 6.316876 & -0.483551 \\
\hline C & 1.772074 & 6.105218 & -1.217893 \\
\hline C & 2.493253 & 4.922013 & -1.055489 \\
\hline C & 2.050741 & 3.925563 & -0.171775 \\
\hline C & 0.864022 & 4.135656 & 0.545879 \\
\hline C & 0.156668 & 5.329816 & 0.398151 \\
\hline $\mathrm{H}$ & 2.128091 & 6.863395 & -1.910570 \\
\hline $\mathrm{H}$ & -0.743334 & 5.492942 & 0.985195 \\
\hline C & 4.625355 & 0.521826 & 0.642235 \\
\hline C & 5.037472 & 1.861477 & 0.930651 \\
\hline C & 6.288832 & 2.091229 & 1.564123 \\
\hline C & 7.097300 & 1.041523 & 1.931747 \\
\hline C & 6.675775 & -0.286342 & 1.686090 \\
\hline C & 5.476530 & -0.539931 & 1.057578 \\
\hline $\mathrm{H}$ & 6.586743 & 3.117455 & 1.765632 \\
\hline $\mathrm{H}$ & 8.049074 & 1.226777 & 2.422000 \\
\hline $\mathrm{H}$ & 7.301726 & -1.116536 & 2.001937 \\
\hline $\mathrm{H}$ & 5.167305 & -1.564292 & 0.888621 \\
\hline
\end{tabular}




\begin{tabular}{|c|c|c|c|}
\hline C & 3.820321 & -1.813117 & -1.350668 \\
\hline C & 3.520685 & -3.192304 & -1.583414 \\
\hline C & 4.358040 & -3.956567 & -2.440263 \\
\hline C & 5.437015 & -3.381322 & -3.069939 \\
\hline C & 5.717189 & -2.009201 & -2.868955 \\
\hline C & 4.934305 & -1.246959 & -2.030040 \\
\hline $\mathrm{H}$ & 4.118326 & -5.005348 & -2.598514 \\
\hline $\mathrm{H}$ & 6.066455 & -3.972135 & -3.729742 \\
\hline $\mathrm{H}$ & 6.554917 & -1.549695 & -3.386559 \\
\hline $\mathrm{H}$ & 5.156604 & -0.194579 & -1.896628 \\
\hline $\mathrm{O}$ & -0.538879 & 1.205592 & 1.109341 \\
\hline $\mathrm{O}$ & -0.785899 & -0.098112 & -1.139270 \\
\hline $\mathrm{H}$ & -1.773018 & -0.464139 & -0.908589 \\
\hline $\mathrm{H}$ & -1.189148 & -2.622231 & -0.647985 \\
\hline $\mathrm{H}$ & -2.639035 & -5.731757 & 1.925097 \\
\hline $\mathrm{H}$ & 1.589275 & -4.993692 & 1.617357 \\
\hline $\mathrm{H}$ & 0.507398 & 3.371667 & 1.228910 \\
\hline $\mathrm{H}$ & 0.051277 & 7.246334 & -0.592075 \\
\hline$H$ & 3.409035 & 4.762621 & -1.618469 \\
\hline C & -4.119252 & -0.729736 & -1.100325 \\
\hline $\mathrm{O}$ & -2.983330 & -1.119910 & -0.640829 \\
\hline $\mathrm{H}$ & -4.149397 & 0.102020 & -1.820910 \\
\hline C & -5.096554 & -1.846534 & -1.489140 \\
\hline $\mathrm{O}$ & -5.021792 & -2.999341 & -1.135741 \\
\hline $\mathrm{O}$ & -6.065708 & -1.360608 & -2.297530 \\
\hline C & -7.039207 & -2.324093 & -2.736307 \\
\hline $\mathrm{H}$ & -7.734893 & -1.771381 & -3.368167 \\
\hline $\mathrm{H}$ & -6.555526 & -3.123211 & -3.303904 \\
\hline C & -4.286458 & 0.966728 & 0.764104 \\
\hline C & -5.225009 & 0.034619 & 0.266028 \\
\hline $\mathrm{H}$ & -2.391564 & 1.089379 & 1.589993 \\
\hline$N$ & -3.275723 & 0.562163 & 1.558527 \\
\hline C & -3.239301 & -0.637423 & 2.319390 \\
\hline $\mathrm{O}$ & -4.166883 & -1.391054 & 2.502165 \\
\hline $\mathrm{O}$ & -2.027094 & -0.734479 & 2.863705 \\
\hline C & -1.806206 & -1.891914 & 3.693505 \\
\hline $\mathrm{H}$ & -1.962312 & -2.803750 & 3.115279 \\
\hline $\mathrm{H}$ & -2.482145 & -1.872015 & 4.552473 \\
\hline $\mathrm{H}$ & -0.768230 & -1.811180 & 4.013069 \\
\hline $\mathrm{H}$ & -6.067345 & 0.441501 & -0.282653 \\
\hline $\mathrm{H}$ & -5.431349 & -0.835851 & 0.875733 \\
\hline C & -4.256655 & 2.339249 & 0.214556 \\
\hline C & -3.056605 & 2.996147 & -0.112303 \\
\hline C & -5.479979 & 2.996680 & -0.022145 \\
\hline
\end{tabular}




$\begin{array}{lllr}\mathrm{C} & -3.090905 & 4.262731 & -0.693687 \\ \mathrm{H} & -2.098381 & 2.514442 & 0.054630 \\ \mathrm{C} & -5.504262 & 4.273134 & -0.574969 \\ \mathrm{H} & -6.412453 & 2.516297 & 0.255937 \\ \mathrm{C} & -4.308720 & 4.904995 & -0.923260 \\ \mathrm{H} & -2.157358 & 4.742633 & -0.968442 \\ \mathrm{H} & -6.455706 & 4.771961 & -0.735725 \\ \mathrm{H} & -4.326339 & 5.894810 & -1.371162 \\ \mathrm{H} & -7.558876 & -2.761439 & -1.879460\end{array}$

Catalyst (R)-1 TS Conformation 182

B3LYP/6-31G(d) Energy $=-2809.687344$

B3LYP-D3(BJ)/def2-TZVPP-IEF-PCM(DCM) Energy $=-2810.983652$

B3LYP-D3(BJ)/def2-TZVPP-IEF-PCM(DCM)//B3LYP/6-31G(d) Free Energy (Quasiharmonic) = 2810.341622

Frequencies (Top 3 out of 270)

1. $-663.8041 \mathrm{~cm}-1$

2. $\quad 5.4031 \mathrm{~cm}-1$

3. $\quad 10.3647 \mathrm{~cm}-1$

B3LYP/6-31G(d) Molecular Geometry in Cartesian Coordinates

$\begin{array}{llll}\mathrm{C} & -3.380256 & 0.030073 & 0.262860 \\ \mathrm{C} & -2.971642 & -1.050199 & -0.504517 \\ \mathrm{C} & -3.367461 & -2.396401 & -0.244500 \\ \mathrm{C} & -4.156770 & -2.616036 & 0.868044 \\ \mathrm{H} & -4.502127 & -3.624259 & 1.080922 \\ \mathrm{C} & -2.170171 & 4.057665 & -0.674545 \\ \mathrm{C} & -2.994946 & 1.414956 & -0.142227 \\ \mathrm{C} & -1.656011 & 1.735787 & -0.328695 \\ \mathrm{C} & -1.209773 & 3.070703 & -0.569277 \\ \mathrm{H} & -1.855395 & 5.081264 & -0.860765 \\ \mathrm{O} & -2.146584 & -0.809786 & -1.594951 \\ \mathrm{P} & -0.569509 & -0.474311 & -1.304187 \\ \mathrm{O} & -0.702751 & 0.742156 & -0.175267 \\ \mathrm{C} & -2.300068 & -5.748261 & -2.722030 \\ \mathrm{C} & -2.713287 & -4.551040 & -3.309731 \\ \mathrm{C} & -3.040337 & -3.451796 & -2.517831 \\ \mathrm{C} & -2.964741 & -3.531189 & -1.117062 \\ \mathrm{C} & -2.544153 & -4.740142 & -0.538877\end{array}$




\begin{tabular}{|c|c|c|c|}
\hline C & -2.214798 & -5.838153 & -1.332200 \\
\hline $\mathrm{H}$ & -2.781873 & -4.470169 & -4.391351 \\
\hline $\mathrm{H}$ & -1.881959 & -6.760427 & -0.863164 \\
\hline C & 2.899453 & 4.308898 & -0.919823 \\
\hline C & 2.061931 & 4.885292 & 0.036857 \\
\hline C & 0.739294 & 4.456930 & 0.155761 \\
\hline C & 0.230629 & 3.443291 & -0.673150 \\
\hline C & 1.082223 & 2.863704 & -1.627978 \\
\hline C & 2.403310 & 3.299138 & -1.749247 \\
\hline $\mathrm{H}$ & 2.434515 & 5.671158 & 0.689218 \\
\hline $\mathrm{H}$ & 3.044530 & 2.846882 & -2.502179 \\
\hline C & -3.986319 & 2.433318 & -0.358816 \\
\hline C & -3.556257 & 3.775618 & -0.610342 \\
\hline C & -4.525449 & 4.794870 & -0.814714 \\
\hline C & -5.869911 & 4.505751 & -0.798894 \\
\hline C & -6.298341 & 3.174317 & -0.585269 \\
\hline C & -5.383775 & 2.166970 & -0.369913 \\
\hline $\mathrm{H}$ & -4.179496 & 5.809527 & -0.997799 \\
\hline $\mathrm{H}$ & -6.602337 & 5.291386 & -0.963034 \\
\hline $\mathrm{H}$ & -7.359856 & 2.942102 & -0.598280 \\
\hline $\mathrm{H}$ & -5.729233 & 1.150670 & -0.220037 \\
\hline C & -4.134316 & -0.226975 & 1.461202 \\
\hline C & -4.532363 & -1.572923 & 1.749880 \\
\hline C & -5.286804 & -1.841441 & 2.924392 \\
\hline C & -5.611841 & -0.834802 & 3.803559 \\
\hline C & -5.185930 & 0.488627 & 3.542376 \\
\hline C & -4.469605 & 0.784894 & 2.403224 \\
\hline $\mathrm{H}$ & -5.592261 & -2.866692 & 3.120020 \\
\hline $\mathrm{H}$ & -6.183375 & -1.053698 & 4.701389 \\
\hline $\mathrm{H}$ & -5.423138 & 1.279792 & 4.248632 \\
\hline $\mathrm{H}$ & -4.145398 & 1.803081 & 2.222855 \\
\hline $\mathrm{O}$ & 0.103815 & -0.038040 & -2.553906 \\
\hline $\mathrm{O}$ & 0.020353 & -1.626770 & -0.470282 \\
\hline $\mathrm{H}$ & 1.199366 & -1.863717 & -0.518599 \\
\hline $\mathrm{H}$ & -2.452871 & -4.809606 & 0.541575 \\
\hline $\mathrm{H}$ & -2.040320 & -6.601690 & -3.342795 \\
\hline $\mathrm{H}$ & -3.359779 & -2.527626 & -2.986365 \\
\hline $\mathrm{H}$ & 0.709235 & 2.079309 & -2.278988 \\
\hline $\mathrm{H}$ & 3.926235 & 4.651213 & -1.025820 \\
\hline $\mathrm{H}$ & 0.091166 & 4.904419 & 0.904752 \\
\hline C & 2.957323 & -0.977224 & -1.004361 \\
\hline $\mathrm{O}$ & 2.396357 & -2.025231 & -0.518699 \\
\hline $\mathrm{H}$ & 2.358231 & -0.286297 & -1.608538 \\
\hline C & 4.392768 & -1.143071 & -1.471981 \\
\hline
\end{tabular}




\begin{tabular}{llll} 
O & 5.107750 & -2.080132 & -1.201231 \\
O & 4.756123 & -0.093606 & -2.236404 \\
$\mathrm{C}$ & 6.098666 & -0.141582 & -2.752578 \\
$\mathrm{H}$ & 6.204547 & 0.748882 & -3.372160 \\
$\mathrm{H}$ & 6.822253 & -0.130853 & -1.933345 \\
$\mathrm{C}$ & 4.018829 & -0.218042 & 1.334900 \\
$\mathrm{C}$ & 3.150368 & 0.417129 & 0.442753 \\
$\mathrm{H}$ & 4.384793 & -1.712939 & 2.657875 \\
$\mathrm{~N}$ & 3.643375 & -1.213452 & 2.180897 \\
$\mathrm{C}$ & 2.383243 & -1.713211 & 2.600859 \\
$\mathrm{O}$ & 2.335837 & -2.705147 & 3.291224 \\
$\mathrm{O}$ & 1.371889 & -0.946216 & 2.222127 \\
$\mathrm{C}$ & 0.055756 & -1.403027 & 2.623227 \\
$\mathrm{H}$ & -0.142234 & -2.381020 & 2.185740 \\
$\mathrm{H}$ & -0.628504 & -0.663578 & 2.215570 \\
$\mathrm{H}$ & 0.003153 & -1.449914 & 3.713025 \\
$\mathrm{H}$ & 3.544714 & 1.266120 & -0.103375 \\
$\mathrm{H}$ & 2.091704 & 0.451876 & 0.662817 \\
$\mathrm{C}$ & 5.473791 & 0.071363 & 1.318971 \\
$\mathrm{C}$ & 5.910336 & 1.403606 & 1.217791 \\
$\mathrm{C}$ & 6.429773 & -0.955879 & 1.419562 \\
$\mathrm{C}$ & 7.271194 & 1.701653 & 1.234977 \\
$\mathrm{H}$ & 5.180721 & 2.204842 & 1.154406 \\
$\mathrm{C}$ & 7.789144 & -0.652179 & 1.426650 \\
$\mathrm{H}$ & 6.116514 & -1.995647 & 1.421095 \\
$\mathrm{C}$ & 8.213137 & 0.675924 & 1.340856 \\
$\mathrm{H}$ & 7.595314 & 2.736407 & 1.172234 \\
$\mathrm{H}$ & 8.517279 & -1.455659 & 1.486180 \\
$\mathrm{H}$ & 9.273933 & 0.910009 & 1.352151 \\
$\mathrm{H}$ & 6.243555 & -1.045558 & -3.349094 \\
& & & \\
\hline
\end{tabular}

Catalyst (R)-1 TS Conformation 183

B3LYP/6-31G(d) Energy $=-2809.686606$

B3LYP-D3(BJ)/def2-TZVPP-IEF-PCM(DCM) Energy $=-2810.983597$

B3LYP-D3(BJ)/def2-TZVPP-IEF-PCM(DCM)//B3LYP/6-31G(d) Free Energy (Quasiharmonic) = 2810.3416

Frequencies (Top 3 out of 270 )

1. $-622.7829 \mathrm{~cm}-1$

2. $\quad 7.7935 \mathrm{~cm}-1$

3. $\quad 10.1941 \mathrm{~cm}-1$ 
B3LYP/6-31G(d) Molecular Geometry in Cartesian Coordinates

\begin{tabular}{|c|c|c|c|}
\hline C & 3.698839 & 0.224002 & 0.111118 \\
\hline C & 2.930769 & 1.260408 & -0.400617 \\
\hline C & 3.214869 & 2.637828 & -0.158452 \\
\hline C & 4.282922 & 2.927370 & 0.668747 \\
\hline $\mathrm{H}$ & 4.543299 & 3.966491 & 0.852377 \\
\hline C & 2.633498 & -3.840936 & -0.873433 \\
\hline C & 3.367691 & -1.183801 & -0.261570 \\
\hline C & 2.084484 & -1.660022 & -0.036624 \\
\hline C & 1.689436 & -3.001762 & -0.315477 \\
\hline $\mathrm{H}$ & 2.368914 & -4.875312 & -1.077803 \\
\hline 0 & 1.850469 & 0.949924 & -1.211588 \\
\hline$P$ & 0.483589 & 0.333513 & -0.534551 \\
\hline 0 & 1.140116 & -0.792358 & 0.492248 \\
\hline C & 0.990670 & 5.895890 & -1.877411 \\
\hline C & 1.362399 & 4.809627 & -2.672260 \\
\hline C & 2.062974 & 3.738269 & -2.120891 \\
\hline C & 2.411523 & 3.735584 & -0.759693 \\
\hline C & 2.028395 & 4.832375 & 0.029325 \\
\hline C & 1.324859 & 5.902102 & -0.522723 \\
\hline $\mathrm{H}$ & 1.107429 & 4.795161 & -3.728818 \\
\hline $\mathrm{H}$ & 1.030075 & 6.735844 & 0.109288 \\
\hline C & -2.233552 & -4.568325 & 0.510949 \\
\hline C & -1.544603 & -3.855646 & 1.495638 \\
\hline C & -0.282906 & -3.326329 & 1.228024 \\
\hline C & 0.317763 & -3.501624 & -0.029424 \\
\hline C & -0.386955 & -4.215659 & -1.011157 \\
\hline C & -1.649847 & -4.744735 & -0.744494 \\
\hline $\mathrm{H}$ & -1.986796 & -3.717660 & 2.479068 \\
\hline $\mathrm{H}$ & -2.177889 & -5.292376 & -1.521056 \\
\hline C & 4.319801 & -2.048650 & -0.902705 \\
\hline C & 3.940238 & -3.399039 & -1.195502 \\
\hline C & 4.875545 & -4.267746 & -1.820560 \\
\hline C & 6.127427 & -3.822717 & -2.175940 \\
\hline C & 6.491694 & -2.479008 & -1.924339 \\
\hline C & 5.613969 & -1.616592 & -1.305038 \\
\hline $\mathrm{H}$ & 4.574336 & -5.292726 & -2.024283 \\
\hline $\mathrm{H}$ & 6.831695 & -4.494137 & -2.659559 \\
\hline $\mathrm{H}$ & 7.472098 & -2.121449 & -2.227489 \\
\hline $\mathrm{H}$ & 5.905246 & -0.587662 & -1.129316 \\
\hline C & 4.760263 & 0.540246 & 1.026586 \\
\hline C & 5.055299 & 1.916880 & 1.291949 \\
\hline
\end{tabular}




\begin{tabular}{|c|c|c|c|}
\hline C & 6.109816 & 2.244596 & 2.186972 \\
\hline C & 6.829670 & 1.261127 & 2.824565 \\
\hline C & 6.515550 & -0.098983 & 2.594325 \\
\hline C & 5.510563 & -0.449803 & 1.719651 \\
\hline $\mathrm{H}$ & 6.328290 & 3.294676 & 2.366998 \\
\hline $\mathrm{H}$ & 7.629256 & 1.524389 & 3.511655 \\
\hline $\mathrm{H}$ & 7.069495 & -0.875135 & 3.115689 \\
\hline $\mathrm{H}$ & 5.276833 & -1.496336 & 1.561424 \\
\hline 0 & -0.370505 & -0.253279 & -1.601480 \\
\hline O & -0.118235 & 1.359628 & 0.437257 \\
\hline $\mathrm{H}$ & -1.322397 & 1.661708 & 0.306945 \\
\hline $\mathrm{H}$ & 2.265208 & 4.831922 & 1.089638 \\
\hline $\mathrm{H}$ & 0.440066 & 6.727516 & -2.309330 \\
\hline $\mathrm{H}$ & 2.346555 & 2.900266 & -2.747932 \\
\hline $\mathrm{H}$ & 0.054054 & -4.336215 & -1.996384 \\
\hline $\mathrm{H}$ & -3.214094 & -4.987270 & 0.723681 \\
\hline $\mathrm{H}$ & 0.251584 & -2.786914 & 2.002854 \\
\hline C & -2.965388 & 1.173351 & -0.747950 \\
\hline $\mathrm{O}$ & -2.462784 & 1.904417 & 0.183423 \\
\hline $\mathrm{H}$ & -2.290337 & 0.678136 & -1.454937 \\
\hline C & -4.299424 & 1.638321 & -1.300662 \\
\hline 0 & -5.017673 & 2.463999 & -0.784376 \\
\hline $\mathrm{O}$ & -4.565494 & 1.001261 & -2.457226 \\
\hline C & -5.801157 & 1.367415 & -3.096884 \\
\hline $\mathrm{H}$ & -5.829294 & 0.794646 & -4.023766 \\
\hline $\mathrm{H}$ & -6.651181 & 1.112234 & -2.458925 \\
\hline C & -4.462553 & -0.351526 & 0.890859 \\
\hline C & -3.431304 & -0.660138 & 0.003847 \\
\hline $\mathrm{H}$ & -5.116818 & 0.539229 & 2.592110 \\
\hline $\mathrm{N}$ & -4.281847 & 0.230176 & 2.108744 \\
\hline C & -3.144591 & 0.502562 & 2.908726 \\
\hline 0 & -3.274576 & 1.146877 & 3.924682 \\
\hline 0 & -2.035279 & -0.064667 & 2.455526 \\
\hline C & -0.842027 & 0.210196 & 3.233945 \\
\hline $\mathrm{H}$ & -0.033194 & -0.255130 & 2.677489 \\
\hline $\mathrm{H}$ & -0.955081 & -0.216188 & 4.233371 \\
\hline $\mathrm{H}$ & -0.684736 & 1.286851 & 3.297293 \\
\hline $\mathrm{H}$ & -3.707168 & -1.199809 & -0.894687 \\
\hline $\mathrm{H}$ & -2.431033 & -0.840741 & 0.371117 \\
\hline C & -5.883640 & -0.531753 & 0.500549 \\
\hline C & -6.856277 & 0.441731 & 0.792777 \\
\hline C & -6.273172 & -1.710251 & -0.158471 \\
\hline C & -8.187027 & 0.233946 & 0.435961 \\
\hline $\mathrm{H}$ & -6.564691 & 1.389309 & 1.235713 \\
\hline
\end{tabular}




$\begin{array}{llll}\mathrm{C} & -7.606799 & -1.916500 & -0.504416 \\ \mathrm{H} & -5.532911 & -2.475490 & -0.369804 \\ \mathrm{C} & -8.566508 & -0.946154 & -0.207700 \\ \mathrm{H} & -8.925326 & 1.000708 & 0.651425 \\ \mathrm{H} & -7.897064 & -2.838243 & -1.000209 \\ \mathrm{H} & -9.605854 & -1.107439 & -0.479657 \\ \mathrm{H} & -5.816968 & 2.440023 & -3.305564\end{array}$

Catalyst (R)-1 TS Conformation 184

B3LYP/6-31G(d) Energy = -2809.68959

B3LYP-D3(BJ)/def2-TZVPP-IEF-PCM(DCM) Energy = -2810.982529

B3LYP-D3(BJ)/def2-TZVPP-IEF-PCM(DCM)//B3LYP/6-31G(d) Free Energy (Quasiharmonic) = 2810.341579

Frequencies (Top 3 out of 270)

1. $-759.9989 \mathrm{~cm}-1$

2. $\quad 10.1324 \mathrm{~cm}-1$

3. $11.0522 \mathrm{~cm}-1$

B3LYP/6-31G(d) Molecular Geometry in Cartesian Coordinates

$\begin{array}{llll}\text { C } & 3.524494 & 0.139990 & 0.265769 \\ \text { C } & 2.875002 & 1.290602 & -0.162191 \\ \text { C } & 3.283466 & 2.602058 & 0.227849 \\ \text { C } & 4.317263 & 2.703590 & 1.137442 \\ \text { H } & 4.645122 & 3.690718 & 1.452613 \\ \text { C } & 2.433858 & -3.755172 & -1.242138 \\ \text { C } & 3.177316 & -1.191537 & -0.315901 \\ \text { C } & 1.867046 & -1.637894 & -0.279787 \\ \text { C } & 1.459795 & -2.935239 & -0.707178 \\ \text { H } & 2.167133 & -4.760928 & -1.556096 \\ \text { O } & 1.855026 & 1.193541 & -1.099550 \\ \text { P } & 0.435924 & 0.447104 & -0.785176 \\ \text { O } & 0.892804 & -0.774336 & 0.211384 \\ \text { C } & 1.648332 & 6.246145 & -1.375080 \\ \text { C } & 3.018701 & 5.991431 & -1.439932 \\ \text { C } & 3.533048 & 4.799310 & -0.929974 \\ \text { C } & 2.687554 & 3.840118 & -0.349427 \\ \text { C } & 1.311278 & 4.107196 & -0.288463 \\ \text { C } & 0.799330 & 5.300781 & -0.796112 \\ \text { H } & 3.689289 & 6.717276 & -1.892745\end{array}$




\begin{tabular}{|c|c|c|c|}
\hline $\mathrm{H}$ & -0.269067 & 5.491604 & -0.735384 \\
\hline C & -2.560894 & -4.431022 & -0.350657 \\
\hline C & -1.970642 & -3.756675 & 0.721371 \\
\hline C & -0.676647 & -3.249499 & 0.606079 \\
\hline C & 0.055446 & -3.410037 & -0.583349 \\
\hline C & -0.553000 & -4.084933 & -1.654032 \\
\hline C & -1.847336 & -4.591818 & -1.539227 \\
\hline $\mathrm{H}$ & -2.521692 & -3.624012 & 1.649151 \\
\hline $\mathrm{H}$ & -2.299323 & -5.106698 & -2.383053 \\
\hline C & 4.163882 & -2.027100 & -0.947191 \\
\hline C & 3.775637 & -3.329266 & -1.402333 \\
\hline C & 4.741598 & -4.170062 & -2.018917 \\
\hline C & 6.033210 & -3.739769 & -2.213971 \\
\hline C & 6.409212 & -2.439821 & -1.802186 \\
\hline C & 5.501678 & -1.607643 & -1.184256 \\
\hline $\mathrm{H}$ & 4.432618 & -5.159679 & -2.347198 \\
\hline $\mathrm{H}$ & 6.760894 & -4.388313 & -2.693974 \\
\hline $\mathrm{H}$ & 7.422986 & -2.091253 & -1.979768 \\
\hline $\mathrm{H}$ & 5.803907 & -0.611094 & -0.884891 \\
\hline C & 4.528191 & 0.260482 & 1.289932 \\
\hline C & 4.932157 & 1.566483 & 1.715166 \\
\hline C & 5.928358 & 1.698971 & 2.720105 \\
\hline C & 6.492312 & 0.590836 & 3.308018 \\
\hline C & 6.071493 & -0.701389 & 2.915164 \\
\hline C & 5.118563 & -0.862633 & 1.933337 \\
\hline $\mathrm{H}$ & 6.227711 & 2.699475 & 3.023474 \\
\hline $\mathrm{H}$ & 7.249151 & 0.703836 & 4.079420 \\
\hline $\mathrm{H}$ & 6.499956 & -1.576481 & 3.396418 \\
\hline $\mathrm{H}$ & 4.801073 & -1.860156 & 1.652812 \\
\hline 0 & -0.209127 & 0.040729 & -2.059285 \\
\hline O & -0.414172 & 1.301185 & 0.202757 \\
\hline $\mathrm{H}$ & -1.389396 & 1.842468 & -0.234033 \\
\hline $\mathrm{H}$ & 0.646545 & 3.386231 & 0.173347 \\
\hline $\mathrm{H}$ & 1.244840 & 7.173462 & -1.773390 \\
\hline $\mathrm{H}$ & 4.598791 & 4.597039 & -0.996297 \\
\hline $\mathrm{H}$ & -0.011769 & -4.191612 & -2.589727 \\
\hline $\mathrm{H}$ & -3.568261 & -4.828611 & -0.257332 \\
\hline $\mathrm{H}$ & -0.223958 & -2.731477 & 1.445199 \\
\hline C & -3.039525 & 1.650243 & -1.496815 \\
\hline 0 & -2.514005 & 2.229821 & -0.484932 \\
\hline $\mathrm{H}$ & -2.417278 & 1.355137 & -2.346281 \\
\hline C & -4.461725 & 2.004506 & -1.884263 \\
\hline 0 & -4.930444 & 1.728265 & -2.968597 \\
\hline $\mathrm{O}$ & -5.112068 & 2.647165 & -0.904764 \\
\hline
\end{tabular}




$\begin{array}{lrrr}\mathrm{C} & -6.469610 & 3.012920 & -1.212951 \\ \mathrm{H} & -6.825640 & 3.564270 & -0.342920 \\ \mathrm{H} & -6.501261 & 3.638947 & -2.107919 \\ \mathrm{C} & -3.779900 & -0.448584 & 0.169343 \\ \mathrm{C} & -3.316416 & -0.407038 & -1.142259 \\ \mathrm{H} & -1.966792 & 0.185333 & 0.909317 \\ \mathrm{~N} & -2.891470 & -0.170377 & 1.172414 \\ \mathrm{C} & -2.991215 & -0.559930 & 2.516731 \\ \mathrm{O} & -3.870984 & -1.229077 & 3.008775 \\ \mathrm{O} & -1.912266 & -0.086386 & 3.162315 \\ \mathrm{C} & -1.826342 & -0.441514 & 4.552607 \\ \mathrm{H} & -0.899798 & 0.010400 & 4.905185 \\ \mathrm{H} & -1.795202 & -1.527810 & 4.668798 \\ \mathrm{H} & -2.684209 & -0.044760 & 5.101264 \\ \mathrm{H} & -4.018283 & -0.640262 & -1.934737 \\ \mathrm{H} & -2.269594 & -0.612389 & -1.351368 \\ \mathrm{C} & -5.218575 & -0.604404 & 0.463508 \\ \mathrm{C} & -5.872818 & 0.250359 & 1.367686 \\ \mathrm{C} & -5.966089 & -1.566527 & -0.234465 \\ \mathrm{C} & -7.245576 & 0.142531 & 1.563401 \\ \mathrm{H} & -5.306917 & 1.015789 & 1.887504 \\ \mathrm{C} & -7.338289 & -1.683451 & -0.021307 \\ \mathrm{H} & -5.460810 & -2.239467 & -0.920432 \\ \mathrm{C} & -7.980540 & -0.827768 & 0.875011 \\ \mathrm{H} & -7.744690 & 0.813737 & 2.256556 \\ \mathrm{H} & -7.904150 & -2.441856 & -0.554520 \\ \mathrm{H} & -9.051225 & -0.915318 & 1.038243 \\ \mathrm{H} & -7.075862 & 2.118314 & -1.376274\end{array}$

Catalyst (R)-1 TS Conformation 185

B3LYP/6-31G(d) Energy $=-2809.692721$

B3LYP-D3(BJ)/def2-TZVPP-IEF-PCM(DCM) Energy = -2810.984672

B3LYP-D3(BJ)/def2-TZVPP-IEF-PCM(DCM)//B3LYP/6-31G(d) Free Energy (Quasiharmonic) = 2810.341547

Frequencies (Top 3 out of 270)

1. $-329.4467 \mathrm{~cm}-1$

2. $\quad 7.5834 \mathrm{~cm}-1$

3. $\quad 11.6479 \mathrm{~cm}-1$

B3LYP/6-31G(d) Molecular Geometry in Cartesian Coordinates 


\begin{tabular}{|c|c|c|c|}
\hline C & -3.132724 & -1.009393 & 0.255618 \\
\hline C & -1.985455 & -1.698123 & -0.101877 \\
\hline C & -1.772406 & -3.075463 & 0.201606 \\
\hline C & -2.747704 & -3.712007 & 0.946062 \\
\hline $\mathrm{H}$ & -2.632628 & -4.769182 & 1.169044 \\
\hline C & -3.769605 & 3.149880 & -0.620217 \\
\hline C & -3.320621 & 0.407748 & -0.170921 \\
\hline C & -2.379367 & 1.365121 & 0.175812 \\
\hline C & -2.610563 & 2.765904 & 0.027707 \\
\hline $\mathrm{H}$ & -3.966684 & 4.209455 & -0.759765 \\
\hline 0 & -1.009154 & -1.018631 & -0.828123 \\
\hline$P$ & -0.103154 & 0.118588 & -0.084527 \\
\hline O & -1.200278 & 0.952452 & 0.791585 \\
\hline C & 1.490934 & -5.513169 & -1.169165 \\
\hline C & 0.877514 & -4.614687 & -2.043985 \\
\hline C & -0.148870 & -3.783042 & -1.598296 \\
\hline C & -0.592034 & -3.848139 & -0.268182 \\
\hline C & 0.047230 & -4.742369 & 0.608236 \\
\hline C & 1.079606 & -5.565593 & 0.164153 \\
\hline $\mathrm{H}$ & 1.197082 & -4.552541 & -3.080077 \\
\hline $\mathrm{H}$ & 1.564565 & -6.244827 & 0.860242 \\
\hline C & -0.161028 & 5.840545 & 1.778379 \\
\hline C & 0.433009 & 4.846081 & 0.999383 \\
\hline C & -0.337387 & 3.834581 & 0.425538 \\
\hline C & -1.725976 & 3.803160 & 0.626693 \\
\hline C & -2.313688 & 4.810074 & 1.412545 \\
\hline C & -1.540963 & 5.820612 & 1.982422 \\
\hline $\mathrm{H}$ & 1.505905 & 4.854079 & 0.833320 \\
\hline $\mathrm{H}$ & -2.016753 & 6.583980 & 2.592809 \\
\hline C & -4.477115 & 0.817657 & -0.918921 \\
\hline C & -4.693264 & 2.214202 & -1.145359 \\
\hline C & -5.829710 & 2.633189 & -1.888915 \\
\hline C & -6.711565 & 1.714804 & -2.409361 \\
\hline C & -6.486485 & 0.332258 & -2.209135 \\
\hline C & -5.401351 & -0.104919 & -1.481693 \\
\hline $\mathrm{H}$ & -5.982486 & 3.698339 & -2.046411 \\
\hline $\mathrm{H}$ & -7.573945 & 2.045916 & -2.981509 \\
\hline $\mathrm{H}$ & -7.172981 & -0.392373 & -2.638632 \\
\hline $\mathrm{H}$ & -5.235670 & -1.167612 & -1.345903 \\
\hline C & -4.101673 & -1.666251 & 1.091622 \\
\hline C & -3.898316 & -3.043088 & 1.426862 \\
\hline C & -4.850423 & -3.713341 & 2.242123 \\
\hline C & -5.947497 & -3.049831 & 2.739322 \\
\hline
\end{tabular}




\begin{tabular}{|c|c|c|c|}
\hline$C$ & -6.131043 & -1.678825 & 2.443002 \\
\hline C & -5.235486 & -1.005996 & 1.640964 \\
\hline $\mathrm{H}$ & -4.685067 & -4.762570 & 2.475316 \\
\hline $\mathrm{H}$ & -6.665454 & -3.569947 & 3.367555 \\
\hline $\mathrm{H}$ & -6.984739 & -1.148521 & 2.856388 \\
\hline $\mathrm{H}$ & -5.387665 & 0.046614 & 1.434612 \\
\hline 0 & 0.598183 & 0.927917 & -1.126065 \\
\hline 0 & 0.735284 & -0.533746 & 1.046874 \\
\hline $\mathrm{H}$ & 1.746076 & -0.885692 & 0.843372 \\
\hline $\mathrm{H}$ & -0.261172 & -4.777536 & 1.649296 \\
\hline $\mathrm{H}$ & 2.286411 & -6.165787 & -1.520897 \\
\hline $\mathrm{H}$ & -0.612304 & -3.087080 & -2.288160 \\
\hline $\mathrm{H}$ & -3.384550 & 4.782599 & 1.594623 \\
\hline $\mathrm{H}$ & 0.446933 & 6.622908 & 2.225935 \\
\hline $\mathrm{H}$ & 0.135979 & 3.077777 & -0.190642 \\
\hline C & 3.925482 & -0.558543 & 1.229594 \\
\hline 0 & 3.037462 & -1.345199 & 0.740670 \\
\hline $\mathrm{H}$ & 3.603086 & 0.384153 & 1.697808 \\
\hline C & 5.073919 & -1.211649 & 2.006081 \\
\hline 0 & 5.451498 & -2.350793 & 1.879385 \\
\hline 0 & 5.618389 & -0.312714 & 2.860437 \\
\hline C & 6.706305 & -0.809334 & 3.659429 \\
\hline $\mathrm{H}$ & 6.372059 & -1.644143 & 4.280664 \\
\hline $\mathrm{H}$ & 7.527499 & -1.147909 & 3.021626 \\
\hline C & 4.102166 & 0.788089 & -0.955635 \\
\hline C & 5.062941 & 0.103684 & -0.184255 \\
\hline $\mathrm{H}$ & 2.230327 & 0.540826 & -1.749807 \\
\hline $\mathrm{N}$ & 3.181679 & 0.128649 & -1.698599 \\
\hline C & 3.189573 & -1.181273 & -2.227575 \\
\hline 0 & 2.191517 & -1.660167 & -2.710814 \\
\hline $\mathrm{O}$ & 4.402170 & -1.748766 & -2.218575 \\
\hline C & 4.435378 & -3.110041 & -2.692276 \\
\hline $\mathrm{H}$ & 3.799420 & -3.736025 & -2.063595 \\
\hline $\mathrm{H}$ & 5.479356 & -3.412472 & -2.612468 \\
\hline $\mathrm{H}$ & 4.095497 & -3.158094 & -3.729404 \\
\hline $\mathrm{H}$ & 5.849709 & 0.709248 & 0.253464 \\
\hline $\mathrm{H}$ & 5.383657 & -0.867486 & -0.533593 \\
\hline C & 3.941709 & 2.252478 & -0.866181 \\
\hline C & 3.335769 & 2.961682 & -1.920649 \\
\hline C & 4.458394 & 2.977395 & 0.225623 \\
\hline C & 3.266023 & 4.351878 & -1.892269 \\
\hline $\mathrm{H}$ & 2.948103 & 2.425314 & -2.779938 \\
\hline C & 4.383208 & 4.366111 & 0.251020 \\
\hline $\mathrm{H}$ & 4.904212 & 2.455047 & 1.065555 \\
\hline
\end{tabular}




$\begin{array}{llll}\mathrm{C} & 3.794522 & 5.058986 & -0.811075 \\ \mathrm{H} & 2.803963 & 4.882506 & -2.719266 \\ \mathrm{H} & 4.782696 & 4.909413 & 1.102503 \\ \mathrm{H} & 3.745014 & 6.144070 & -0.793171 \\ \mathrm{H} & 7.021367 & 0.029113 & 4.281059\end{array}$

Catalyst (R)-1 TS Conformation 186

B3LYP/6-31G(d) Energy $=-2809.693162$

B3LYP-D3(BJ)/def2-TZVPP-IEF-PCM(DCM) Energy = -2810.98242

B3LYP-D3(BJ)/def2-TZVPP-IEF-PCM(DCM)//B3LYP/6-31G(d) Free Energy (Quasiharmonic) = 2810.341525

Frequencies (Top 3 out of 270)

1. $-703.2709 \mathrm{~cm}-1$

2. $\quad 6.6727 \mathrm{~cm}-1$

3. $\quad 11.3171 \mathrm{~cm}-1$

B3LYP/6-31G(d) Molecular Geometry in Cartesian Coordinates

$\begin{array}{llll}\text { C } & -3.643873 & -0.802689 & -0.060391 \\ \text { C } & -2.526078 & -1.543822 & -0.404525 \\ \text { C } & -2.479851 & -2.967700 & -0.373081 \\ \text { C } & -3.608485 & -3.625083 & 0.074501 \\ \text { H } & -3.618941 & -4.711854 & 0.088795 \\ \text { C } & -3.671298 & 3.502677 & -0.274904 \\ \text { C } & -3.624073 & 0.681975 & -0.218437 \\ \text { C } & -2.628874 & 1.442269 & 0.382685 \\ \text { C } & -2.645769 & 2.868967 & 0.397676 \\ \text { H } & -3.705634 & 4.589006 & -0.276876 \\ \text { O } & -1.379645 & -0.862367 & -0.802899 \\ \text { P } & -0.509721 & -0.140526 & 0.384120 \\ \text { O } & -1.624289 & 0.809577 & 1.104252 \\ \text { C } & 0.939999 & -5.267812 & -1.610065 \\ \text { C } & 0.291575 & -5.552914 & -0.408036 \\ \text { C } & -0.805524 & -4.791510 & -0.006136 \\ \text { C } & -1.275525 & -3.730419 & -0.796484 \\ \text { C } & -0.609182 & -3.448152 & -2.001253 \\ \text { C } & 0.485146 & -4.212249 & -2.403769 \\ \text { H } & 0.644466 & -6.363035 & 0.224632 \\ \text { H } & 0.979683 & -3.985382 & -3.345030 \\ \text { C } & 0.200321 & 5.345184 & 2.462771\end{array}$




\begin{tabular}{|c|c|c|c|}
\hline C & -1.158861 & 5.418301 & 2.771536 \\
\hline C & -2.070813 & 4.596492 & 2.108862 \\
\hline C & -1.637649 & 3.682513 & 1.135215 \\
\hline C & -0.268902 & 3.613855 & 0.835491 \\
\hline C & 0.639986 & 4.443726 & 1.491303 \\
\hline $\mathrm{H}$ & -1.511757 & 6.113952 & 3.528818 \\
\hline $\mathrm{H}$ & 1.690970 & 4.386448 & 1.223392 \\
\hline C & -4.620773 & 1.357738 & -1.005990 \\
\hline C & -4.647575 & 2.789131 & -1.011723 \\
\hline C & -5.635655 & 3.467946 & -1.775185 \\
\hline C & -6.549818 & 2.770550 & -2.529838 \\
\hline C & -6.503829 & 1.356833 & -2.556140 \\
\hline C & -5.567899 & 0.669817 & -1.814637 \\
\hline $\mathrm{H}$ & -5.644715 & 4.555316 & -1.759884 \\
\hline $\mathrm{H}$ & -7.296908 & 3.300072 & -3.114813 \\
\hline $\mathrm{H}$ & -7.209875 & 0.806584 & -3.172371 \\
\hline $\mathrm{H}$ & -5.540607 & -0.412822 & -1.855711 \\
\hline C & -4.782608 & -1.498072 & 0.478418 \\
\hline C & -4.756914 & -2.930017 & 0.527784 \\
\hline C & -5.878950 & -3.631123 & 1.047064 \\
\hline C & -6.973362 & -2.955049 & 1.533566 \\
\hline C & -6.984151 & -1.540658 & 1.525559 \\
\hline C & -5.920525 & -0.832059 & 1.011112 \\
\hline $\mathrm{H}$ & -5.847214 & -4.718027 & 1.064844 \\
\hline $\mathrm{H}$ & -7.821944 & -3.501800 & 1.935608 \\
\hline $\mathrm{H}$ & -7.837696 & -1.006535 & 1.934268 \\
\hline $\mathrm{H}$ & -5.941360 & 0.251186 & 1.022827 \\
\hline O & 0.605525 & 0.600950 & -0.282698 \\
\hline 0 & -0.165385 & -1.156186 & 1.481859 \\
\hline $\mathrm{H}$ & 0.914583 & -1.654520 & 1.542182 \\
\hline $\mathrm{H}$ & -0.957163 & -2.632863 & -2.626532 \\
\hline $\mathrm{H}$ & 1.794739 & -5.860982 & -1.924839 \\
\hline $\mathrm{H}$ & -1.291927 & -5.002236 & 0.941995 \\
\hline $\mathrm{H}$ & 0.087262 & 2.924316 & 0.078654 \\
\hline $\mathrm{H}$ & 0.911517 & 5.988690 & 2.974744 \\
\hline $\mathrm{H}$ & -3.128266 & 4.649820 & 2.354744 \\
\hline C & 2.901366 & -1.168178 & 1.477153 \\
\hline $\mathrm{O}$ & 2.044120 & -2.100771 & 1.662913 \\
\hline $\mathrm{H}$ & 2.575325 & -0.123429 & 1.533678 \\
\hline C & 4.301389 & -1.349150 & 2.027925 \\
\hline $\mathrm{O}$ & 4.962758 & -0.409516 & 2.421083 \\
\hline $\mathrm{O}$ & 4.702012 & -2.625490 & 2.027474 \\
\hline C & 6.021005 & -2.855204 & 2.555914 \\
\hline $\mathrm{H}$ & 6.175170 & -3.932135 & 2.490914 \\
\hline
\end{tabular}




$\begin{array}{llll}\mathrm{H} & 6.078626 & -2.519575 & 3.594301 \\ \mathrm{C} & 4.006887 & 0.060508 & -0.771774 \\ \mathrm{C} & 3.325009 & -1.137150 & -0.507823 \\ \mathrm{H} & 2.260338 & 1.100201 & -0.585743 \\ \mathrm{~N} & 3.265883 & 1.203945 & -0.818179 \\ \mathrm{C} & 3.569876 & 2.484284 & -1.306612 \\ \mathrm{O} & 2.853231 & 3.435477 & -1.086229 \\ \mathrm{O} & 4.677065 & 2.508619 & -2.061737 \\ \mathrm{C} & 5.026553 & 3.805739 & -2.580175 \\ \mathrm{H} & 5.948449 & 3.649451 & -3.139817 \\ \mathrm{H} & 5.183960 & 4.514497 & -1.763638 \\ \mathrm{H} & 4.234039 & 4.178466 & -3.233067 \\ \mathrm{H} & 3.887589 & -2.061329 & -0.574002 \\ \mathrm{H} & 2.279200 & -1.187510 & -0.789746 \\ \mathrm{C} & 5.484039 & 0.087578 & -0.806464 \\ \mathrm{C} & 6.174266 & -0.885807 & -1.547086 \\ \mathrm{C} & 6.215585 & 1.017717 & -0.047124 \\ \mathrm{C} & 7.567650 & -0.912531 & -1.550922 \\ \mathrm{H} & 5.615251 & -1.601352 & -2.142447 \\ \mathrm{C} & 7.605995 & 0.975058 & -0.038084 \\ \mathrm{H} & 5.691103 & 1.739191 & 0.569734 \\ \mathrm{C} & 8.285487 & 0.016366 & -0.795017 \\ \mathrm{H} & 8.090964 & -1.657588 & -2.143291 \\ \mathrm{H} & 8.161062 & 1.685578 & 0.567480 \\ \mathrm{H} & 9.371773 & -0.009251 & -0.790750 \\ \mathrm{H} & 6.767533 & -2.319885 & 1.963107\end{array}$

Catalyst (R)-1 TS Conformation 187

B3LYP/6-31G(d) Energy $=-2809.691805$

B3LYP-D3(BJ)/def2-TZVPP-IEF-PCM(DCM) Energy = -2810.983246

B3LYP-D3(BJ)/def2-TZVPP-IEF-PCM(DCM)//B3LYP/6-31G(d) Free Energy (Quasiharmonic) = 2810.341479

Frequencies (Top 3 out of 270)

1. $-843.6248 \mathrm{~cm}-1$

2. $\quad 10.3030 \mathrm{~cm}-1$

3. $12.6010 \mathrm{~cm}-1$

B3LYP/6-31G(d) Molecular Geometry in Cartesian Coordinates

$\begin{array}{llll}\text { C } & 3.295813 & -0.018242 & 0.340229\end{array}$ 


\begin{tabular}{|c|c|c|c|}
\hline C & 2.594393 & 1.104420 & -0.081098 \\
\hline C & 3.134620 & 2.424168 & -0.000918 \\
\hline C & 4.371441 & 2.573855 & 0.595909 \\
\hline $\mathrm{H}$ & 4.800094 & 3.569550 & 0.673924 \\
\hline C & 1.710407 & -3.979344 & -0.279816 \\
\hline C & 2.763254 & -1.385989 & 0.068027 \\
\hline C & 1.493025 & -1.726350 & 0.502799 \\
\hline C & 0.938621 & -3.033403 & 0.366881 \\
\hline $\mathrm{H}$ & 1.332489 & -4.993652 & -0.376827 \\
\hline $\mathrm{O}$ & 1.364294 & 0.942041 & -0.704745 \\
\hline$P$ & 0.060926 & 0.399816 & 0.136022 \\
\hline $\mathrm{O}$ & 0.723666 & -0.741363 & 1.113368 \\
\hline C & 1.296230 & 5.978092 & -1.587479 \\
\hline C & 2.593863 & 5.620900 & -1.957764 \\
\hline C & 3.167552 & 4.454511 & -1.451848 \\
\hline C & 2.456079 & 3.622450 & -0.570687 \\
\hline C & 1.149616 & 3.986737 & -0.209280 \\
\hline C & 0.580458 & 5.157010 & -0.713510 \\
\hline $\mathrm{H}$ & 3.160048 & 6.247200 & -2.642522 \\
\hline $\mathrm{H}$ & -0.430884 & 5.426119 & -0.419962 \\
\hline C & -2.899018 & -4.236419 & 1.895603 \\
\hline C & -2.051788 & -3.450616 & 2.679442 \\
\hline C & -0.817899 & -3.033174 & 2.184310 \\
\hline C & -0.404243 & -3.397396 & 0.892077 \\
\hline C & -1.270369 & -4.178448 & 0.109312 \\
\hline C & -2.504121 & -4.596480 & 0.606302 \\
\hline $\mathrm{H}$ & -2.349874 & -3.164548 & 3.684866 \\
\hline $\mathrm{H}$ & -3.158031 & -5.201008 & -0.017503 \\
\hline C & 3.520563 & -2.359483 & -0.671647 \\
\hline C & 2.979770 & -3.676392 & -0.829667 \\
\hline C & 3.720394 & -4.654390 & -1.547540 \\
\hline C & 4.932311 & -4.345649 & -2.119732 \\
\hline C & 5.450377 & -3.034779 & -2.000138 \\
\hline C & 4.765580 & -2.069520 & -1.294864 \\
\hline $\mathrm{H}$ & 3.299791 & -5.652359 & -1.646810 \\
\hline $\mathrm{H}$ & 5.485981 & -5.099432 & -2.672877 \\
\hline $\mathrm{H}$ & 6.396040 & -2.784514 & -2.473490 \\
\hline $\mathrm{H}$ & 5.172758 & -1.067988 & -1.222067 \\
\hline C & 4.533163 & 0.166655 & 1.049363 \\
\hline C & 5.077652 & 1.485481 & 1.161473 \\
\hline C & 6.304124 & 1.681000 & 1.852615 \\
\hline C & 6.962993 & 0.624265 & 2.436203 \\
\hline C & 6.411108 & -0.676140 & 2.356817 \\
\hline C & 5.231383 & -0.899616 & 1.681582 \\
\hline
\end{tabular}




\begin{tabular}{|c|c|c|c|}
\hline $\mathrm{H}$ & 6.705419 & 2.689512 & 1.920529 \\
\hline $\mathrm{H}$ & 7.897021 & 0.785573 & 2.967499 \\
\hline $\mathrm{H}$ & 6.919608 & -1.506823 & 2.838855 \\
\hline $\mathrm{H}$ & 4.817380 & -1.900328 & 1.640214 \\
\hline $\mathrm{O}$ & -0.561496 & 1.440341 & 1.016876 \\
\hline $\mathrm{O}$ & -0.786208 & -0.268511 & -0.959408 \\
\hline $\mathrm{H}$ & -1.879772 & -0.683158 & -0.614782 \\
\hline $\mathrm{H}$ & 0.582469 & 3.356968 & 0.467541 \\
\hline $\mathrm{H}$ & 0.846637 & 6.887817 & -1.977331 \\
\hline $\mathrm{H}$ & 4.173747 & 4.172929 & -1.750833 \\
\hline $\mathrm{H}$ & -0.980028 & -4.439159 & -0.904346 \\
\hline $\mathrm{H}$ & -3.858973 & -4.564312 & 2.286700 \\
\hline $\mathrm{H}$ & -0.165448 & -2.427832 & 2.804095 \\
\hline C & -4.049770 & -1.114529 & -0.484845 \\
\hline $\mathrm{O}$ & -2.865027 & -0.993707 & -0.003782 \\
\hline $\mathrm{H}$ & -4.785558 & -1.559559 & 0.191426 \\
\hline C & -4.185979 & -1.575752 & -1.931772 \\
\hline 0 & -3.256727 & -1.718652 & -2.688325 \\
\hline $\mathrm{O}$ & -5.475148 & -1.842296 & -2.232195 \\
\hline C & -5.705442 & -2.294500 & -3.578511 \\
\hline $\mathrm{H}$ & -5.167769 & -3.227871 & -3.764766 \\
\hline $\mathrm{H}$ & -6.781882 & -2.449153 & -3.655539 \\
\hline C & -4.228243 & 1.402146 & 0.169844 \\
\hline C & -5.090723 & 0.622490 & -0.622986 \\
\hline $\mathrm{H}$ & -2.314346 & 2.153679 & 0.318799 \\
\hline$N$ & -3.079653 & 1.915544 & -0.323608 \\
\hline C & -2.707268 & 1.985949 & -1.688546 \\
\hline $\mathrm{O}$ & -3.362184 & 1.582562 & -2.623005 \\
\hline 0 & -1.533734 & 2.610987 & -1.762121 \\
\hline C & -0.896221 & 2.582317 & -3.057778 \\
\hline $\mathrm{H}$ & 0.014518 & 3.164129 & -2.932477 \\
\hline $\mathrm{H}$ & -1.551926 & 3.026997 & -3.809415 \\
\hline $\mathrm{H}$ & -0.666521 & 1.547255 & -3.318002 \\
\hline $\mathrm{H}$ & -6.039179 & 0.345328 & -0.177752 \\
\hline $\mathrm{H}$ & -5.101625 & 0.799590 & -1.688219 \\
\hline C & -4.436915 & 1.507282 & 1.628958 \\
\hline C & -5.746295 & 1.670427 & 2.120132 \\
\hline C & -3.364229 & 1.445526 & 2.538785 \\
\hline C & -5.979275 & 1.781177 & 3.487516 \\
\hline $\mathrm{H}$ & -6.577799 & 1.746084 & 1.426439 \\
\hline C & -3.610837 & 1.540960 & 3.907049 \\
\hline $\mathrm{H}$ & -2.347047 & 1.289132 & 2.189385 \\
\hline C & -4.911118 & 1.712482 & 4.385207 \\
\hline $\mathrm{H}$ & -6.992549 & 1.924841 & 3.851613 \\
\hline
\end{tabular}




$\begin{array}{rrrr}\mathrm{H} & -2.777988 & 1.476922 & 4.601235 \\ \mathrm{H} & -5.092982 & 1.793383 & 5.453467 \\ \mathrm{H} & -5.369849 & -1.540716 & -4.295474\end{array}$

Catalyst (R)-1 TS Conformation 188

B3LYP/6-31G(d) Energy $=-2809.686787$

B3LYP-D3(BJ)/def2-TZVPP-IEF-PCM(DCM) Energy $=-2810.983868$

B3LYP-D3(BJ)/def2-TZVPP-IEF-PCM(DCM)//B3LYP/6-31G(d) Free Energy (Quasiharmonic) = 2810.341428

Frequencies (Top 3 out of 270)

1. $-658.8515 \mathrm{~cm}-1$

2. $\quad 7.5290 \mathrm{~cm}-1$

3. $\quad 13.9081 \mathrm{~cm}-1$

B3LYP/6-31G(d) Molecular Geometry in Cartesian Coordinates

$\begin{array}{lrrr}\text { C } & 3.365197 & 0.047082 & 0.275342 \\ \text { C } & 2.928153 & 1.124168 & -0.480919 \\ \text { C } & 3.262224 & 2.480477 & -0.187703 \\ \text { C } & 4.017555 & 2.711219 & 0.946153 \\ \text { H } & 4.316532 & 3.728487 & 1.184625 \\ \text { C } & 2.326689 & -4.011572 & -0.727592 \\ \text { C } & 3.042335 & -1.345545 & -0.157819 \\ \text { C } & 1.720009 & -1.715568 & -0.368166 \\ \text { C } & 1.326568 & -3.064683 & -0.622189 \\ \text { H } & 2.054228 & -5.045100 & -0.925155 \\ \text { O } & 2.142005 & 0.871879 & -1.596353 \\ \text { P } & 0.577564 & 0.444747 & -1.370446 \\ \text { O } & 0.730279 & -0.754827 & -0.226860 \\ \text { C } & 2.115882 & 5.834126 & -2.627634 \\ \text { C } & 1.998663 & 5.894821 & -1.238564 \\ \text { C } & 2.354055 & 4.795699 & -0.458127 \\ \text { C } & 2.833040 & 3.614663 & -1.048587 \\ \text { C } & 2.940521 & 3.564410 & -2.448648 \\ \text { C } & 2.587320 & 4.664820 & -3.227569 \\ \text { H } & 1.621114 & 6.794862 & -0.760235 \\ \text { H } & 2.681243 & 4.606689 & -4.308725 \\ \text { C } & -2.743759 & -4.434141 & -0.938274 \\ \text { C } & -2.295412 & -3.395992 & -1.759932 \\ \text { C } & -0.984321 & -2.925942 & -1.656450\end{array}$




\begin{tabular}{|c|c|c|c|}
\hline$C$ & -0.098752 & -3.491641 & -0.724254 \\
\hline C & -0.560332 & -4.535285 & 0.095234 \\
\hline C & -1.870609 & -5.003312 & -0.009505 \\
\hline $\mathrm{H}$ & -2.970029 & -2.941965 & -2.481312 \\
\hline $\mathrm{H}$ & -2.206778 & -5.811811 & 0.635080 \\
\hline C & 4.075285 & -2.322118 & -0.370942 \\
\hline C & 3.700104 & -3.676337 & -0.645534 \\
\hline C & 4.710746 & -4.654496 & -0.849946 \\
\hline C & 6.042758 & -4.314130 & -0.811270 \\
\hline C & 6.416901 & -2.970561 & -0.573123 \\
\hline C & 5.461283 & -2.002100 & -0.357474 \\
\hline $\mathrm{H}$ & 4.406853 & -5.679111 & -1.051218 \\
\hline $\mathrm{H}$ & 6.807025 & -5.068759 & -0.975754 \\
\hline $\mathrm{H}$ & 7.468827 & -2.697910 & -0.567418 \\
\hline $\mathrm{H}$ & 5.764925 & -0.975343 & -0.188828 \\
\hline C & 4.082847 & 0.312261 & 1.494236 \\
\hline C & 4.418212 & 1.667740 & 1.816373 \\
\hline C & 5.136604 & 1.944575 & 3.011410 \\
\hline C & 5.485673 & 0.935427 & 3.878375 \\
\hline C & 5.121105 & -0.399235 & 3.583631 \\
\hline C & 4.441115 & -0.702891 & 2.424333 \\
\hline $\mathrm{H}$ & 5.394957 & 2.977628 & 3.232278 \\
\hline $\mathrm{H}$ & 6.029348 & 1.160343 & 4.791883 \\
\hline $\mathrm{H}$ & 5.377140 & -1.193498 & 4.279752 \\
\hline $\mathrm{H}$ & 4.164115 & -1.730015 & 2.218138 \\
\hline $\mathrm{O}$ & -0.017948 & -0.029982 & -2.643067 \\
\hline 0 & -0.108993 & 1.569061 & -0.565334 \\
\hline $\mathrm{H}$ & -1.280321 & 1.685360 & -0.631664 \\
\hline $\mathrm{H}$ & 3.305234 & 2.662262 & -2.926823 \\
\hline $\mathrm{H}$ & 1.836248 & 6.688384 & -3.238559 \\
\hline $\mathrm{H}$ & 2.238591 & 4.842041 & 0.621294 \\
\hline $\mathrm{H}$ & 0.113581 & -4.972922 & 0.827178 \\
\hline $\mathrm{H}$ & -3.763123 & -4.801784 & -1.028748 \\
\hline $\mathrm{H}$ & -0.643913 & -2.125508 & -2.305925 \\
\hline C & -2.974288 & 0.587496 & -1.020225 \\
\hline 0 & -2.516272 & 1.731732 & -0.649518 \\
\hline $\mathrm{H}$ & -2.298226 & -0.114285 & -1.523884 \\
\hline C & -4.364564 & 0.508889 & -1.636768 \\
\hline 0 & -4.789825 & -0.495465 & -2.170225 \\
\hline 0 & -5.037603 & 1.664134 & -1.539852 \\
\hline C & -6.326703 & 1.673956 & -2.180057 \\
\hline $\mathrm{H}$ & -6.226931 & 1.414435 & -3.236681 \\
\hline $\mathrm{H}$ & -6.697889 & 2.692744 & -2.067520 \\
\hline C & -4.012409 & 0.070014 & 1.358626 \\
\hline
\end{tabular}




$\begin{array}{lrrr}\mathrm{C} & -3.145387 & -0.636672 & 0.516194 \\ \mathrm{H} & -4.352634 & 1.654806 & 2.579303 \\ \mathrm{~N} & -3.621425 & 1.118071 & 2.128181 \\ \mathrm{C} & -2.355117 & 1.644964 & 2.498592 \\ \mathrm{O} & -2.304498 & 2.688011 & 3.109014 \\ \mathrm{O} & -1.347417 & 0.850598 & 2.175020 \\ \mathrm{C} & -0.028487 & 1.337523 & 2.533027 \\ \mathrm{H} & 0.653558 & 0.566417 & 2.184487 \\ \mathrm{H} & 0.027983 & 1.471354 & 3.615291 \\ \mathrm{H} & 0.167509 & 2.275350 & 2.015037 \\ \mathrm{H} & -3.542404 & -1.523210 & 0.035561 \\ \mathrm{H} & -2.091086 & -0.667955 & 0.757105 \\ \mathrm{C} & -5.472861 & -0.185004 & 1.345936 \\ \mathrm{C} & -6.403994 & 0.867517 & 1.427368 \\ \mathrm{C} & -5.946322 & -1.505780 & 1.267708 \\ \mathrm{C} & -7.770871 & 0.600953 & 1.439062 \\ \mathrm{H} & -6.065986 & 1.900305 & 1.422067 \\ \mathrm{C} & -7.314320 & -1.767579 & 1.288742 \\ \mathrm{H} & -5.240222 & -2.327987 & 1.217783 \\ \mathrm{C} & -8.229496 & -0.717244 & 1.376212 \\ \mathrm{H} & -8.478136 & 1.423744 & 1.488958 \\ \mathrm{H} & -7.664616 & -2.794260 & 1.239603 \\ \mathrm{H} & -9.295901 & -0.923414 & 1.390468 \\ \mathrm{H} & -6.999178 & 0.960972 & -1.696302\end{array}$

Catalyst (R)-1 TS Conformation 189

B3LYP/6-31G(d) Energy $=-2809.688623$

B3LYP-D3(BJ)/def2-TZVPP-IEF-PCM(DCM) Energy = -2810.98349

B3LYP-D3(BJ)/def2-TZVPP-IEF-PCM(DCM)//B3LYP/6-31G(d) Free Energy (Quasiharmonic) = 2810.341392

Frequencies (Top 3 out of 270)

1. $-683.6278 \mathrm{~cm}-1$

2. $\quad 7.3820 \mathrm{~cm}-1$

3. $\quad 9.3127 \mathrm{~cm}-1$

B3LYP/6-31G(d) Molecular Geometry in Cartesian Coordinates

$\begin{array}{llll}\text { C } & 3.518928 & 0.896683 & 0.122773 \\ \text { C } & 2.422931 & 1.647300 & -0.270582 \\ \text { C } & 2.231526 & 3.013129 & 0.092040\end{array}$




\begin{tabular}{|c|c|c|c|}
\hline C & 3.177868 & 3.583119 & 0.920972 \\
\hline $\mathrm{H}$ & 3.079841 & 4.630046 & 1.195895 \\
\hline C & 4.004419 & -3.208895 & -1.094239 \\
\hline C & 3.677966 & -0.498883 & -0.383875 \\
\hline C & 2.662311 & -1.428293 & -0.199921 \\
\hline C & 2.815216 & -2.812864 & -0.514149 \\
\hline $\mathrm{H}$ & 4.143418 & -4.256547 & -1.348115 \\
\hline $\mathrm{O}$ & 1.465859 & 1.042967 & -1.074856 \\
\hline$P$ & 0.434403 & -0.021784 & -0.369695 \\
\hline $\mathrm{O}$ & 1.481598 & -1.028723 & 0.409963 \\
\hline C & -1.054949 & 5.429415 & -1.278081 \\
\hline C & -0.376977 & 4.601596 & -2.175498 \\
\hline C & 0.674497 & 3.797986 & -1.737615 \\
\hline C & 1.072649 & 3.810703 & -0.389886 \\
\hline C & 0.378422 & 4.643292 & 0.503096 \\
\hline C & -0.674443 & 5.445267 & 0.064341 \\
\hline $\mathrm{H}$ & -0.664820 & 4.582051 & -3.223464 \\
\hline $\mathrm{H}$ & -1.202627 & 6.075491 & 0.775193 \\
\hline C & -0.088505 & -5.869775 & 0.358872 \\
\hline C & 1.226319 & -5.985390 & 0.811759 \\
\hline C & 2.150851 & -4.977704 & 0.536275 \\
\hline C & 1.779911 & -3.836253 & -0.194195 \\
\hline C & 0.453615 & -3.727784 & -0.644998 \\
\hline C & -0.467300 & -4.739581 & -0.368910 \\
\hline $\mathrm{H}$ & 1.533848 & -6.857311 & 1.383503 \\
\hline $\mathrm{H}$ & -1.487412 & -4.644359 & -0.732954 \\
\hline C & 4.867465 & -0.908749 & -1.080488 \\
\hline C & 5.029206 & -2.289273 & -1.423692 \\
\hline C & 6.203799 & -2.708438 & -2.105366 \\
\hline C & 7.175844 & -1.803191 & -2.461866 \\
\hline C & 7.004124 & -0.432762 & -2.154991 \\
\hline C & 5.883454 & 0.002348 & -1.482353 \\
\hline $\mathrm{H}$ & 6.311814 & -3.762346 & -2.351042 \\
\hline $\mathrm{H}$ & 8.066976 & -2.133560 & -2.988577 \\
\hline $\mathrm{H}$ & 7.760763 & 0.285636 & -2.458881 \\
\hline $\mathrm{H}$ & 5.762675 & 1.057359 & -1.265711 \\
\hline C & 4.452581 & 1.480735 & 1.048064 \\
\hline C & 4.275431 & 2.849147 & 1.434147 \\
\hline C & 5.196484 & 3.444619 & 2.338218 \\
\hline C & 6.234866 & 2.718174 & 2.872726 \\
\hline C & 6.388566 & 1.355554 & 2.525578 \\
\hline C & 5.523698 & 0.754195 & 1.637542 \\
\hline $\mathrm{H}$ & 5.053840 & 4.487969 & 2.609909 \\
\hline $\mathrm{H}$ & 6.928310 & 3.182369 & 3.568689 \\
\hline
\end{tabular}




\begin{tabular}{|c|c|c|c|}
\hline $\mathrm{H}$ & 7.194193 & 0.775108 & 2.967216 \\
\hline $\mathrm{H}$ & 5.650888 & -0.293228 & 1.390670 \\
\hline 0 & -0.377923 & -0.674118 & -1.434802 \\
\hline 0 & -0.290545 & 0.659508 & 0.807543 \\
\hline $\mathrm{H}$ & -1.460966 & 0.882602 & 0.694645 \\
\hline $\mathrm{H}$ & 0.654134 & 4.641222 & 1.553839 \\
\hline $\mathrm{H}$ & -1.875596 & 6.053658 & -1.622217 \\
\hline $\mathrm{H}$ & 1.195093 & 3.160818 & -2.444001 \\
\hline $\mathrm{H}$ & 0.146255 & -2.857821 & -1.216635 \\
\hline $\mathrm{H}$ & -0.811141 & -6.653820 & 0.570521 \\
\hline $\mathrm{H}$ & 3.170580 & -5.064753 & 0.901967 \\
\hline C & -3.077180 & 0.766630 & -0.585706 \\
\hline $\mathrm{O}$ & -2.650804 & 1.119121 & 0.577959 \\
\hline $\mathrm{H}$ & -2.346011 & 0.524062 & -1.366130 \\
\hline C & -4.299449 & 1.468335 & -1.160944 \\
\hline $\mathrm{O}$ & -4.663002 & 1.318844 & -2.308927 \\
\hline O & -4.900272 & 2.271273 & -0.269047 \\
\hline C & -6.013049 & 3.024569 & -0.783122 \\
\hline $\mathrm{H}$ & -6.819067 & 2.354378 & -1.092698 \\
\hline $\mathrm{H}$ & -5.699976 & 3.628044 & -1.638571 \\
\hline C & -4.654157 & -1.116548 & 0.395424 \\
\hline C & -3.656660 & -1.119208 & -0.586472 \\
\hline $\mathrm{H}$ & -5.188847 & -0.929385 & 2.341792 \\
\hline$N$ & -4.398581 & -1.088592 & 1.728312 \\
\hline C & -3.226865 & -1.258317 & 2.513753 \\
\hline $\mathrm{O}$ & -3.279713 & -1.033516 & 3.701199 \\
\hline $\mathrm{O}$ & -2.200307 & -1.736960 & 1.828806 \\
\hline C & -0.983493 & -1.937189 & 2.599765 \\
\hline $\mathrm{H}$ & -0.586231 & -0.968388 & 2.901025 \\
\hline $\mathrm{H}$ & -0.298590 & -2.432082 & 1.916055 \\
\hline $\mathrm{H}$ & -1.203486 & -2.557848 & 3.469990 \\
\hline $\mathrm{H}$ & -3.988679 & -1.230566 & -1.612683 \\
\hline $\mathrm{H}$ & -2.677360 & -1.519723 & -0.360357 \\
\hline C & -6.086792 & -0.977935 & 0.035824 \\
\hline C & -6.599209 & -1.682219 & -1.066520 \\
\hline C & -6.957056 & -0.166045 & 0.787317 \\
\hline C & -7.948872 & -1.590449 & -1.398722 \\
\hline $\mathrm{H}$ & -5.943964 & -2.323894 & -1.646094 \\
\hline C & -8.304037 & -0.070551 & 0.446182 \\
\hline $\mathrm{H}$ & -6.573216 & 0.439104 & 1.604213 \\
\hline C & -8.804725 & -0.786864 & -0.643716 \\
\hline $\mathrm{H}$ & -8.331631 & -2.150145 & -2.246890 \\
\hline $\mathrm{H}$ & -8.961069 & 0.570016 & 1.027319 \\
\hline $\mathrm{H}$ & -9.856521 & -0.714792 & -0.905319 \\
\hline
\end{tabular}


$\begin{array}{llll}H & -6.335893 & 3.662558 & 0.039890\end{array}$

Catalyst (R)-1 TS Conformation 190

B3LYP/6-31G(d) Energy $=-2809.688695$

B3LYP-D3(BJ)/def2-TZVPP-IEF-PCM(DCM) Energy = -2810.982657

B3LYP-D3(BJ)/def2-TZVPP-IEF-PCM(DCM)//B3LYP/6-31G(d) Free Energy (Quasiharmonic) = 2810.341306

Frequencies (Top 3 out of 270)

1. $-661.0126 \mathrm{~cm}-1$

2. $10.8326 \mathrm{~cm}-1$

3. $18.4258 \mathrm{~cm}-1$

B3LYP/6-31G(d) Molecular Geometry in Cartesian Coordinates

$\begin{array}{llll}\text { C } & 3.302358 & -0.049032 & 0.221345 \\ \text { C } & 2.655414 & 1.026322 & -0.369695 \\ \text { C } & 3.074851 & 2.381017 & -0.206211 \\ \text { C } & 4.163527 & 2.607478 & 0.614665 \\ \text { H } & 4.534027 & 3.622018 & 0.733803 \\ \text { C } & 1.924945 & -4.090270 & -0.373457 \\ \text { C } & 2.844483 & -1.443494 & -0.058498 \\ \text { C } & 1.522093 & -1.792260 & 0.176226 \\ \text { C } & 1.029406 & -3.126865 & 0.052251 \\ \text { H } & 1.597228 & -5.123858 & -0.444699 \\ \text { O } & 1.564026 & 0.774441 & -1.192077 \\ \text { P } & 0.145353 & 0.314652 & -0.522218 \\ \text { O } & 0.644408 & -0.799361 & 0.587304 \\ \text { C } & 1.240982 & 5.779398 & -2.110383 \\ \text { C } & 1.425875 & 4.596364 & -2.827724 \\ \text { C } & 1.998151 & 3.481338 & -2.218049 \\ \text { C } & 2.396825 & 3.525771 & -0.871487 \\ \text { C } & 2.193042 & 4.719322 & -0.156684 \\ \text { C } & 1.625129 & 5.836088 & -0.769381 \\ \text { H } & 1.121317 & 4.537556 & -3.868808 \\ \text { H } & 1.480242 & 6.748617 & -0.196074 \\ \text { C } & -3.012049 & -4.322127 & 0.945465 \\ \text { C } & -2.342968 & -4.843617 & -0.162261 \\ \text { C } & -1.043537 & -4.430908 & -0.454990 \\ \text { C } & -0.377613 & -3.498967 & 0.359638 \\ \text { C } & -1.062846 & -2.986850 & 1.475944\end{array}$




\begin{tabular}{|c|c|c|c|}
\hline C & -2.367264 & -3.390656 & 1.762282 \\
\hline $\mathrm{H}$ & -2.835583 & -5.566343 & -0.808074 \\
\hline $\mathrm{H}$ & -2.886491 & -2.968133 & 2.617926 \\
\hline C & 3.735320 & -2.439537 & -0.587016 \\
\hline C & 3.260948 & -3.783537 & -0.727100 \\
\hline C & 4.136151 & -4.784049 & -1.230972 \\
\hline C & 5.419146 & -4.473099 & -1.616521 \\
\hline C & 5.877739 & -3.138269 & -1.517163 \\
\hline C & 5.060528 & -2.149764 & -1.014380 \\
\hline $\mathrm{H}$ & 3.763509 & -5.802036 & -1.318396 \\
\hline $\mathrm{H}$ & 6.076667 & -5.244584 & -2.007874 \\
\hline $\mathrm{H}$ & 6.883361 & -2.888935 & -1.844968 \\
\hline $\mathrm{H}$ & 5.424062 & -1.130563 & -0.953190 \\
\hline C & 4.377065 & 0.214884 & 1.139870 \\
\hline C & 4.817337 & 1.566154 & 1.315695 \\
\hline C & 5.891540 & 1.841952 & 2.204978 \\
\hline C & 6.491086 & 0.835002 & 2.924535 \\
\hline C & 6.030307 & -0.495358 & 2.785958 \\
\hline C & 5.004247 & -0.797580 & 1.917720 \\
\hline $\mathrm{H}$ & 6.220972 & 2.872563 & 2.314885 \\
\hline $\mathrm{H}$ & 7.306463 & 1.058492 & 3.607113 \\
\hline $\mathrm{H}$ & 6.486921 & -1.287127 & 3.373796 \\
\hline $\mathrm{H}$ & 4.658327 & -1.820866 & 1.832237 \\
\hline 0 & -0.742115 & -0.244134 & -1.576051 \\
\hline $\mathrm{O}$ & -0.348333 & 1.482849 & 0.356412 \\
\hline $\mathrm{H}$ & -1.258344 & 1.390219 & 1.088330 \\
\hline $\mathrm{H}$ & 2.468004 & 4.763134 & 0.893448 \\
\hline $\mathrm{H}$ & 0.796797 & 6.647324 & -2.590940 \\
\hline $\mathrm{H}$ & 2.138203 & 2.571039 & -2.789186 \\
\hline $\mathrm{H}$ & -0.567713 & -2.273747 & 2.125224 \\
\hline $\mathrm{H}$ & -4.029284 & -4.632047 & 1.168860 \\
\hline $\mathrm{H}$ & -0.542067 & -4.818974 & -1.337161 \\
\hline C & -3.131629 & 0.558548 & 1.705958 \\
\hline O & -2.215150 & 1.436915 & 1.868261 \\
\hline $\mathrm{H}$ & -2.909938 & -0.381005 & 1.186950 \\
\hline C & -4.082070 & 0.320904 & 2.872545 \\
\hline 0 & -4.537185 & -0.772990 & 3.136477 \\
\hline $\mathrm{O}$ & -4.336577 & 1.441807 & 3.559228 \\
\hline C & -5.190034 & 1.279795 & 4.706094 \\
\hline $\mathrm{H}$ & -6.167899 & 0.893438 & 4.405796 \\
\hline $\mathrm{H}$ & -5.285127 & 2.275052 & 5.139894 \\
\hline C & -4.112371 & 0.843473 & -0.800145 \\
\hline C & -4.562921 & 1.274029 & 0.457628 \\
\hline $\mathrm{H}$ & -2.803110 & 0.965462 & -2.344535 \\
\hline
\end{tabular}




$\begin{array}{llll}\mathrm{N} & -3.188433 & 1.482928 & -1.560586 \\ \mathrm{C} & -2.523930 & 2.727119 & -1.447838 \\ \mathrm{O} & -1.761096 & 3.082268 & -2.313703 \\ \mathrm{O} & -2.865522 & 3.409571 & -0.356879 \\ \mathrm{C} & -2.067421 & 4.590706 & -0.113472 \\ \mathrm{H} & -2.465741 & 5.012626 & 0.808541 \\ \mathrm{H} & -2.168383 & 5.292010 & -0.944052 \\ \mathrm{H} & -1.021881 & 4.302662 & 0.005920 \\ \mathrm{H} & -5.450583 & 0.764768 & 0.817406 \\ \mathrm{H} & -4.457182 & 2.311410 & 0.741324 \\ \mathrm{C} & -4.582984 & -0.450736 & -1.354312 \\ \mathrm{C} & -5.949704 & -0.776005 & -1.282048 \\ \mathrm{C} & -3.690780 & -1.348252 & -1.970092 \\ \mathrm{C} & -6.419491 & -1.966184 & -1.829732 \\ \mathrm{H} & -6.649050 & -0.078976 & -0.830893 \\ \mathrm{C} & -4.170439 & -2.545190 & -2.499710 \\ \mathrm{H} & -2.622927 & -1.139388 & -1.983438 \\ \mathrm{C} & -5.530089 & -2.854154 & -2.439269 \\ \mathrm{H} & -7.479804 & -2.197774 & -1.784436 \\ \mathrm{H} & -3.470717 & -3.242111 & -2.950456 \\ \mathrm{H} & -5.897075 & -3.785427 & -2.862162 \\ \mathrm{H} & -4.738236 & 0.588855 & 5.422240\end{array}$

Catalyst (R)-1 TS Conformation 191

B3LYP/6-31G(d) Energy $=-2809.69113$

B3LYP-D3(BJ)/def2-TZVPP-IEF-PCM(DCM) Energy = -2810.982317

B3LYP-D3(BJ)/def2-TZVPP-IEF-PCM(DCM)//B3LYP/6-31G(d) Free Energy (Quasiharmonic) = 2810.341287

Frequencies (Top 3 out of 270)

1. $-689.1519 \mathrm{~cm}-1$

2. $\quad 8.9779 \mathrm{~cm}-1$

3. $\quad 11.2984 \mathrm{~cm}-1$

B3LYP/6-31G(d) Molecular Geometry in Cartesian Coordinates

$\begin{array}{llll}\text { C } & -3.214927 & -0.896737 & 0.328486 \\ \text { C } & -2.131119 & -1.633906 & -0.118428 \\ \text { C } & -1.906416 & -2.996125 & 0.238531 \\ \text { C } & -2.781196 & -3.557250 & 1.149630 \\ \text { H } & -2.659969 & -4.601851 & 1.423207\end{array}$




\begin{tabular}{|c|c|c|c|}
\hline C & -3.969428 & 3.086647 & -1.120890 \\
\hline C & -3.467770 & 0.460155 & -0.236660 \\
\hline C & -2.487968 & 1.442216 & -0.185357 \\
\hline C & -2.724438 & 2.786781 & -0.603086 \\
\hline $\mathrm{H}$ & -4.169959 & 4.103499 & -1.447831 \\
\hline $\mathrm{O}$ & -1.217862 & -1.013371 & -0.971858 \\
\hline$P$ & -0.215403 & 0.087550 & -0.290158 \\
\hline 0 & -1.257895 & 1.148210 & 0.394929 \\
\hline C & 1.104714 & -5.545092 & -1.467499 \\
\hline C & 0.396795 & -4.660362 & -2.282656 \\
\hline C & -0.553260 & -3.802460 & -1.732711 \\
\hline C & -0.818774 & -3.818747 & -0.353189 \\
\hline C & -0.087235 & -4.701755 & 0.457618 \\
\hline C & 0.864512 & -5.557669 & -0.093383 \\
\hline $\mathrm{H}$ & 0.578814 & -4.640680 & -3.354061 \\
\hline $\mathrm{H}$ & 1.420264 & -6.231653 & 0.553552 \\
\hline C & 0.046960 & 6.072006 & -0.420959 \\
\hline C & -1.189833 & 6.149998 & 0.222037 \\
\hline C & -2.065259 & 5.064436 & 0.183184 \\
\hline C & -1.718297 & 3.880986 & -0.491467 \\
\hline C & -0.467645 & 3.808109 & -1.123091 \\
\hline C & 0.401400 & 4.899173 & -1.090158 \\
\hline $\mathrm{H}$ & -1.476035 & 7.055277 & 0.751409 \\
\hline $\mathrm{H}$ & 1.362184 & 4.829842 & -1.593862 \\
\hline C & -4.720289 & 0.763588 & -0.876850 \\
\hline C & -4.973394 & 2.106280 & -1.301402 \\
\hline C & -6.211655 & 2.425697 & -1.921714 \\
\hline C & -7.160984 & 1.456071 & -2.143924 \\
\hline C & -6.900305 & 0.119540 & -1.759961 \\
\hline C & -5.715682 & -0.217761 & -1.143179 \\
\hline $\mathrm{H}$ & -6.386823 & 3.453818 & -2.229736 \\
\hline $\mathrm{H}$ & -8.102103 & 1.708730 & -2.624570 \\
\hline $\mathrm{H}$ & -7.639614 & -0.651439 & -1.959600 \\
\hline $\mathrm{H}$ & -5.530441 & -1.249017 & -0.867387 \\
\hline C & -4.066461 & -1.469001 & 1.335756 \\
\hline C & -3.837004 & -2.822685 & 1.741979 \\
\hline C & -4.673799 & -3.405509 & 2.732129 \\
\hline C & -5.678333 & -2.678225 & 3.326836 \\
\hline C & -5.883362 & -1.328930 & 2.954318 \\
\hline C & -5.101891 & -0.741214 & 1.983784 \\
\hline $\mathrm{H}$ & -4.493769 & -4.438639 & 3.019896 \\
\hline $\mathrm{H}$ & -6.306590 & -3.131723 & 4.088578 \\
\hline $\mathrm{H}$ & -6.662194 & -0.748505 & 3.441542 \\
\hline $\mathrm{H}$ & -5.265732 & 0.296258 & 1.716446 \\
\hline
\end{tabular}




\begin{tabular}{|c|c|c|c|}
\hline $\mathrm{O}$ & 0.648668 & 0.677609 & -1.362260 \\
\hline $\mathrm{O}$ & 0.502095 & -0.527148 & 0.933904 \\
\hline $\mathrm{H}$ & 1.386552 & -1.218823 & 0.644095 \\
\hline $\mathrm{H}$ & -0.257994 & -4.703707 & 1.530503 \\
\hline $\mathrm{H}$ & 1.838619 & -6.220209 & -1.900615 \\
\hline $\mathrm{H}$ & -1.103686 & -3.125455 & -2.376875 \\
\hline $\mathrm{H}$ & -0.176000 & 2.900076 & -1.640048 \\
\hline $\mathrm{H}$ & 0.728307 & 6.918768 & -0.400218 \\
\hline $\mathrm{H}$ & -3.028354 & 5.126526 & 0.683107 \\
\hline C & 3.519093 & -1.708984 & 0.270432 \\
\hline 0 & 2.269612 & -1.989481 & 0.173476 \\
\hline $\mathrm{H}$ & 3.890786 & -1.205705 & 1.172700 \\
\hline C & 4.510989 & -2.780351 & -0.173329 \\
\hline $\mathrm{O}$ & 5.624438 & -2.887503 & 0.305300 \\
\hline $\mathrm{O}$ & 4.021713 & -3.561369 & -1.138779 \\
\hline C & 4.903782 & -4.598953 & -1.600032 \\
\hline $\mathrm{H}$ & 5.821231 & -4.168491 & -2.010889 \\
\hline $\mathrm{H}$ & 5.162753 & -5.272641 & -0.779325 \\
\hline C & 4.152020 & 0.814341 & -0.369287 \\
\hline C & 3.997268 & -0.383276 & -1.107386 \\
\hline $\mathrm{H}$ & 2.160656 & 1.262797 & -0.570397 \\
\hline$N$ & 3.030142 & 1.508201 & -0.054971 \\
\hline C & 2.814081 & 2.229918 & 1.144950 \\
\hline $\mathrm{O}$ & 3.606395 & 2.371040 & 2.046127 \\
\hline $\mathrm{O}$ & 1.563671 & 2.695768 & 1.108271 \\
\hline C & 1.099035 & 3.352718 & 2.301530 \\
\hline $\mathrm{H}$ & 1.089045 & 2.645328 & 3.134077 \\
\hline $\mathrm{H}$ & 0.091253 & 3.686021 & 2.061997 \\
\hline $\mathrm{H}$ & 1.746113 & 4.198770 & 2.543550 \\
\hline $\mathrm{H}$ & 4.884684 & -0.732741 & -1.626392 \\
\hline $\mathrm{H}$ & 3.071451 & -0.502294 & -1.663223 \\
\hline C & 5.478296 & 1.291413 & 0.055957 \\
\hline C & 6.505438 & 0.383947 & 0.373249 \\
\hline C & 5.760751 & 2.670628 & 0.047631 \\
\hline C & 7.776691 & 0.853524 & 0.695513 \\
\hline $\mathrm{H}$ & 6.308523 & -0.683231 & 0.401616 \\
\hline C & 7.038596 & 3.129112 & 0.344551 \\
\hline $\mathrm{H}$ & 4.982662 & 3.377299 & -0.220376 \\
\hline C & 8.048812 & 2.222549 & 0.677642 \\
\hline $\mathrm{H}$ & 8.555809 & 0.144505 & 0.959901 \\
\hline $\mathrm{H}$ & 7.246661 & 4.194870 & 0.320620 \\
\hline $\mathrm{H}$ & 9.044648 & 2.583461 & 0.919916 \\
\hline $\mathrm{H}$ & 4.346544 & -5.128793 & -2.371904 \\
\hline
\end{tabular}


Catalyst (R)-1 TS Conformation 192

B3LYP/6-31G(d) Energy $=-2809.692093$

B3LYP-D3(BJ)/def2-TZVPP-IEF-PCM(DCM) Energy = -2810.983153

B3LYP-D3(BJ)/def2-TZVPP-IEF-PCM(DCM)//B3LYP/6-31G(d) Free Energy (Quasiharmonic) = 2810.341224

Frequencies (Top 3 out of 270)

1. $-482.3939 \mathrm{~cm}-1$

2. $\quad 10.4595 \mathrm{~cm}-1$

3. $\quad 13.1285 \mathrm{~cm}-1$

B3LYP/6-31G(d) Molecular Geometry in Cartesian Coordinates

$\begin{array}{llll}\mathrm{C} & 3.161041 & -1.066911 & -0.370946 \\ \mathrm{C} & 1.869307 & -1.552217 & -0.221597 \\ \mathrm{C} & 1.504873 & -2.900640 & -0.515058 \\ \mathrm{C} & 2.475590 & -3.714333 & -1.065251 \\ \mathrm{H} & 2.225843 & -4.745002 & -1.303354 \\ \mathrm{C} & 4.197906 & 2.879968 & 1.035896 \\ \mathrm{C} & 3.523719 & 0.280533 & 0.162902 \\ \mathrm{C} & 2.803099 & 1.398750 & -0.224655 \\ \mathrm{C} & 3.129113 & 2.728553 & 0.173791 \\ \mathrm{H} & 4.495155 & 3.880331 & 1.339006 \\ \mathrm{O} & 0.900175 & -0.731942 & 0.342443 \\ \mathrm{P} & 0.347439 & 0.585551 & -0.452742 \\ \mathrm{O} & 1.716409 & 1.218629 & -1.074732 \\ \mathrm{C} & -2.314572 & -4.659558 & 0.417344 \\ \mathrm{C} & -1.132445 & -5.216180 & 0.909972 \\ \mathrm{C} & 0.095799 & -4.625971 & 0.608976 \\ \mathrm{C} & 0.165357 & -3.467439 & -0.183339 \\ \mathrm{C} & -1.029719 & -2.914611 & -0.670393 \\ \mathrm{C} & -2.256560 & -3.510215 & -0.375034 \\ \mathrm{H} & -1.163651 & -6.110554 & 1.527373 \\ \mathrm{H} & -3.161628 & -3.070926 & -0.785687 \\ \mathrm{C} & 1.047538 & 6.245780 & -1.170873 \\ \mathrm{C} & 1.375346 & 5.239821 & -2.081937 \\ \mathrm{C} & 2.029536 & 4.085995 & -1.654055 \\ \mathrm{C} & 2.373018 & 3.917498 & -0.302182 \\ \mathrm{C} & 2.032910 & 4.934581 & 0.604875 \\ \mathrm{C} & 1.377372 & 6.087745 & 0.175773 \\ \mathrm{H} & 1.121524 & 5.352030 & -3.132660\end{array}$




\begin{tabular}{|c|c|c|c|}
\hline $\mathrm{H}$ & 1.117500 & 6.858721 & 0.896681 \\
\hline C & 4.582035 & 0.449909 & 1.123415 \\
\hline C & 4.923006 & 1.775705 & 1.546210 \\
\hline C & 5.974983 & 1.961555 & 2.483973 \\
\hline C & 6.647531 & 0.886580 & 3.016303 \\
\hline C & 6.285509 & -0.425955 & 2.632981 \\
\hline C & 5.283160 & -0.638656 & 1.711962 \\
\hline $\mathrm{H}$ & 6.228537 & 2.976010 & 2.782669 \\
\hline $\mathrm{H}$ & 7.445290 & 1.040714 & 3.737735 \\
\hline $\mathrm{H}$ & 6.800102 & -1.276310 & 3.072341 \\
\hline $\mathrm{H}$ & 5.013932 & -1.651654 & 1.437762 \\
\hline C & 4.128661 & -1.894726 & -1.039425 \\
\hline C & 3.772670 & -3.239399 & -1.379336 \\
\hline C & 4.721892 & -4.068866 & -2.035639 \\
\hline C & 5.967568 & -3.591051 & -2.370028 \\
\hline C & 6.311336 & -2.253169 & -2.064425 \\
\hline C & 5.418704 & -1.428686 & -1.415365 \\
\hline $\mathrm{H}$ & 4.436578 & -5.089396 & -2.280091 \\
\hline $\mathrm{H}$ & 6.682814 & -4.232042 & -2.878136 \\
\hline $\mathrm{H}$ & 7.286943 & -1.869423 & -2.350425 \\
\hline $\mathrm{H}$ & 5.693448 & -0.402775 & -1.198696 \\
\hline $\mathrm{O}$ & -0.367469 & 1.469368 & 0.516200 \\
\hline 0 & -0.432006 & 0.105265 & -1.700512 \\
\hline $\mathrm{H}$ & -1.315142 & 0.747124 & -1.952456 \\
\hline $\mathrm{H}$ & -1.004317 & -2.028856 & -1.294111 \\
\hline $\mathrm{H}$ & -3.271731 & -5.122589 & 0.644632 \\
\hline $\mathrm{H}$ & 1.013541 & -5.057170 & 1.000678 \\
\hline $\mathrm{H}$ & 2.265492 & 4.806268 & 1.658329 \\
\hline $\mathrm{H}$ & 0.534608 & 7.142989 & -1.507467 \\
\hline $\mathrm{H}$ & 2.280577 & 3.313137 & -2.372039 \\
\hline C & -3.426629 & 1.705303 & -2.000431 \\
\hline $\mathrm{O}$ & -2.166409 & 1.705280 & -2.238208 \\
\hline $\mathrm{H}$ & -3.993180 & 2.537697 & -2.438452 \\
\hline C & -4.178018 & 0.382619 & -2.133265 \\
\hline $\mathrm{O}$ & -3.716779 & -0.708807 & -1.874795 \\
\hline 0 & -5.419462 & 0.595945 & -2.608603 \\
\hline C & -6.212938 & -0.580913 & -2.849983 \\
\hline $\mathrm{H}$ & -5.673821 & -1.273969 & -3.500398 \\
\hline $\mathrm{H}$ & -6.452290 & -1.077058 & -1.906788 \\
\hline C & -3.961177 & 1.177690 & 0.724077 \\
\hline C & -3.779715 & 2.258685 & -0.182671 \\
\hline $\mathrm{H}$ & -1.930745 & 0.956303 & 0.957712 \\
\hline$N$ & -2.869318 & 0.600989 & 1.258123 \\
\hline C & -2.804291 & -0.370747 & 2.285801 \\
\hline
\end{tabular}




$\begin{array}{lrrr}\text { O } & -3.719780 & -0.751129 & 2.977918 \\ \text { O } & -1.532916 & -0.767161 & 2.369835 \\ \text { C } & -1.254041 & -1.785305 & 3.345769 \\ \text { H } & -0.178025 & -1.940177 & 3.286762 \\ \text { H } & -1.787575 & -2.703588 & 3.089512 \\ \text { H } & -1.549831 & -1.448698 & 4.342451 \\ \text { H } & -4.672952 & 2.856858 & -0.335406 \\ \text { H } & -2.862476 & 2.832076 & -0.073301 \\ \text { C } & -5.326450 & 0.652359 & 0.963387 \\ \text { C } & -5.618186 & -0.719876 & 0.869337 \\ \mathrm{C} & -6.368801 & 1.554401 & 1.234257 \\ \mathrm{C} & -6.923257 & -1.170755 & 1.041206 \\ \mathrm{H} & -4.827973 & -1.424605 & 0.641008 \\ \mathrm{C} & -7.670335 & 1.095528 & 1.428751 \\ \mathrm{H} & -6.152502 & 2.614101 & 1.328775 \\ \mathrm{C} & -7.950912 & -0.267172 & 1.327963 \\ \mathrm{H} & -7.137936 & -2.232669 & 0.961541 \\ \mathrm{H} & -8.461954 & 1.802757 & 1.658448 \\ \mathrm{H} & -8.965832 & -0.626518 & 1.474330 \\ \mathrm{H} & -7.121973 & -0.224168 & -3.334581\end{array}$

Catalyst (R)-1 TS Conformation 193

B3LYP/6-31G(d) Energy = -2809.691456

B3LYP-D3(BJ)/def2-TZVPP-IEF-PCM(DCM) Energy = -2810.982676

B3LYP-D3(BJ)/def2-TZVPP-IEF-PCM(DCM)//B3LYP/6-31G(d) Free Energy (Quasiharmonic) = 2810.341088

Frequencies (Top 3 out of 270)

1. $-695.5649 \mathrm{~cm}-1$

2. $\quad 10.5891 \mathrm{~cm}-1$

3. $\quad 13.2630 \mathrm{~cm}-1$

B3LYP/6-31G(d) Molecular Geometry in Cartesian Coordinates

$\begin{array}{llll}\text { C } & -3.298222 & -0.791068 & 0.196597 \\ \text { C } & -2.282925 & -1.561762 & -0.344616 \\ \text { C } & -2.154460 & -2.964935 & -0.123730 \\ \text { C } & -3.060659 & -3.547287 & 0.741849 \\ \text { H } & -3.013003 & -4.619315 & 0.913293 \\ \text { C } & -3.744923 & 3.375566 & -0.801695 \\ \text { C } & -3.445590 & 0.634362 & -0.219471\end{array}$




\begin{tabular}{|c|c|c|c|}
\hline C & -2.387177 & 1.524239 & -0.091759 \\
\hline C & -2.520215 & 2.921474 & -0.352786 \\
\hline $\mathrm{H}$ & -3.867705 & 4.435195 & -1.009661 \\
\hline 0 & -1.342323 & -0.932473 & -1.158992 \\
\hline$P$ & -0.236961 & 0.013750 & -0.410392 \\
\hline 0 & -1.172145 & 1.074973 & 0.414385 \\
\hline C & 0.756041 & -5.479204 & -2.048788 \\
\hline C & 0.082573 & -4.502167 & -2.784647 \\
\hline C & -0.843059 & -3.665441 & -2.164807 \\
\hline C & -1.117614 & -3.793840 & -0.793274 \\
\hline C & -0.429419 & -4.776333 & -0.063412 \\
\hline C & 0.497978 & -5.611382 & -0.683975 \\
\hline $\mathrm{H}$ & 0.274362 & -4.392656 & -3.849044 \\
\hline $\mathrm{H}$ & 1.024154 & -6.360717 & -0.098088 \\
\hline C & 0.522692 & 5.923257 & 0.139915 \\
\hline C & -0.698660 & 6.033343 & 0.807273 \\
\hline C & -1.663867 & 5.036407 & 0.663626 \\
\hline C & -1.424451 & 3.909966 & -0.142323 \\
\hline C & -0.188011 & 3.801428 & -0.796921 \\
\hline C & 0.771284 & 4.805360 & -0.658714 \\
\hline $\mathrm{H}$ & -0.902864 & 6.895137 & 1.437586 \\
\hline $\mathrm{H}$ & 1.719215 & 4.710911 & -1.182220 \\
\hline C & -4.679284 & 1.106281 & -0.790987 \\
\hline C & -4.828279 & 2.503411 & -1.062023 \\
\hline C & -6.046329 & 2.986346 & -1.612711 \\
\hline C & -7.075524 & 2.125690 & -1.914151 \\
\hline C & -6.919042 & 0.738678 & -1.683248 \\
\hline C & -5.756126 & 0.242651 & -1.136329 \\
\hline $\mathrm{H}$ & -6.141687 & 4.052683 & -1.803638 \\
\hline $\mathrm{H}$ & -8.000476 & 2.503712 & -2.340931 \\
\hline $\mathrm{H}$ & -7.722130 & 0.055521 & -1.946297 \\
\hline $\mathrm{H}$ & -5.651262 & -0.824032 & -0.977996 \\
\hline C & -4.179700 & -1.396086 & 1.158322 \\
\hline C & -4.052729 & -2.798291 & 1.420535 \\
\hline C & -4.922149 & -3.413563 & 2.361789 \\
\hline C & -5.859805 & -2.676318 & 3.046614 \\
\hline C & -5.961380 & -1.283927 & 2.818182 \\
\hline C & -5.146651 & -0.661399 & 1.897976 \\
\hline $\mathrm{H}$ & -4.820654 & -4.481640 & 2.539334 \\
\hline $\mathrm{H}$ & -6.513617 & -3.156260 & 3.769693 \\
\hline $\mathrm{H}$ & -6.686236 & -0.698237 & 3.377158 \\
\hline $\mathrm{H}$ & -5.230965 & 0.407737 & 1.741705 \\
\hline $\mathrm{O}$ & 0.632612 & 0.636265 & -1.460645 \\
\hline $\mathrm{O}$ & 0.468536 & -0.760825 & 0.725618 \\
\hline
\end{tabular}




\begin{tabular}{|c|c|c|c|}
\hline $\mathrm{H}$ & 1.268281 & -1.480379 & 0.317596 \\
\hline $\mathrm{H}$ & -0.608620 & -4.868389 & 1.004186 \\
\hline $\mathrm{H}$ & 1.477265 & -6.131116 & -2.535224 \\
\hline $\mathrm{H}$ & -1.362370 & -2.912512 & -2.747631 \\
\hline $\mathrm{H}$ & 0.022530 & 2.934459 & -1.414017 \\
\hline $\mathrm{H}$ & 1.273840 & 6.702421 & 0.242036 \\
\hline $\mathrm{H}$ & -2.613990 & 5.123068 & 1.184174 \\
\hline$C$ & 3.238912 & -2.328542 & -0.522520 \\
\hline 0 & 1.955218 & -2.288712 & -0.388363 \\
\hline $\mathrm{H}$ & 3.615320 & -3.118795 & -1.187369 \\
\hline C & 4.113168 & -2.283174 & 0.728637 \\
\hline 0 & 5.184267 & -2.851946 & 0.815645 \\
\hline $\mathrm{O}$ & 3.557380 & -1.550136 & 1.700408 \\
\hline C & 4.318734 & -1.433345 & 2.918515 \\
\hline $\mathrm{H}$ & 4.504382 & -2.423245 & 3.341950 \\
\hline $\mathrm{H}$ & 5.267356 & -0.930303 & 2.721272 \\
\hline C & 4.196411 & 0.218564 & -0.840179 \\
\hline C & 3.831865 & -0.919605 & -1.620717 \\
\hline $\mathrm{H}$ & 2.247171 & 0.864448 & -0.781906 \\
\hline $\mathrm{N}$ & 3.191609 & 0.984401 & -0.354742 \\
\hline C & 3.174683 & 1.635034 & 0.902742 \\
\hline $\mathrm{O}$ & 4.068133 & 1.645953 & 1.717941 \\
\hline 0 & 1.977762 & 2.209619 & 1.035125 \\
\hline C & 1.695668 & 2.804798 & 2.314386 \\
\hline $\mathrm{H}$ & 0.710973 & 3.254117 & 2.202301 \\
\hline $\mathrm{H}$ & 2.447568 & 3.559430 & 2.555596 \\
\hline $\mathrm{H}$ & 1.684993 & 2.032026 & 3.086759 \\
\hline $\mathrm{H}$ & 4.630919 & -1.319648 & -2.238664 \\
\hline $\mathrm{H}$ & 2.883206 & -0.833766 & -2.146103 \\
\hline C & 5.603828 & 0.565983 & -0.596039 \\
\hline C & 5.982179 & 1.919965 & -0.489601 \\
\hline C & 6.610151 & -0.420531 & -0.597626 \\
\hline C & 7.321235 & 2.273546 & -0.381473 \\
\hline $\mathrm{H}$ & 5.225285 & 2.694851 & -0.526865 \\
\hline C & 7.947930 & -0.059950 & -0.461735 \\
\hline $\mathrm{H}$ & 6.346692 & -1.469496 & -0.658700 \\
\hline C & 8.308586 & 1.284572 & -0.357531 \\
\hline $\mathrm{H}$ & 7.596206 & 3.322129 & -0.315344 \\
\hline $\mathrm{H}$ & 8.709468 & -0.833857 & -0.440781 \\
\hline $\mathrm{H}$ & 9.354782 & 1.562616 & -0.264298 \\
\hline $\mathrm{H}$ & 3.703210 & -0.831555 & 3.585219 \\
\hline
\end{tabular}

Catalyst (R)-1 TS Conformation 194 
B3LYP/6-31G(d) Energy $=-2809.691949$

B3LYP-D3(BJ)/def2-TZVPP-IEF-PCM(DCM) Energy $=-2810.983652$

B3LYP-D3(BJ)/def2-TZVPP-IEF-PCM(DCM)//B3LYP/6-31G(d) Free Energy (Quasiharmonic) = 2810.340881

Frequencies (Top 3 out of 270)

1. $-438.2271 \mathrm{~cm}-1$

2. $\quad 9.9258 \mathrm{~cm}-1$

3. $\quad 12.1831 \mathrm{~cm}-1$

B3LYP/6-31G(d) Molecular Geometry in Cartesian Coordinates

$\begin{array}{llll}\text { C } & -3.591699 & -0.236673 & -0.218022 \\ \text { C } & -2.963209 & 0.985162 & -0.011374 \\ \text { C } & -3.657524 & 2.231139 & -0.069191 \\ \text { C } & -4.990283 & 2.201866 & -0.430537 \\ \text { H } & -5.539727 & 3.137926 & -0.485522 \\ \text { C } & -1.414753 & -3.910042 & 0.418052 \\ \text { C } & -2.863205 & -1.513127 & 0.045248 \\ \text { C } & -1.652771 & -1.749921 & -0.581785 \\ \text { C } & -0.900120 & -2.949308 & -0.429669 \\ \text { H } & -0.879800 & -4.847818 & 0.542869 \\ \text { O } & -1.626733 & 1.010998 & 0.378537 \\ \text { P } & -0.425176 & 0.489927 & -0.602342 \\ \text { O } & -1.133026 & -0.745024 & -1.398793 \\ \text { C } & -1.966781 & 6.051477 & 0.966994 \\ \text { C } & -3.114804 & 5.582845 & 1.608320 \\ \text { C } & -3.641142 & 4.334721 & 1.275060 \\ \text { C } & -3.029306 & 3.532397 & 0.297257 \\ \text { C } & -1.875773 & 4.013234 & -0.340493 \\ \text { C } & -1.351669 & 5.262486 & -0.007211 \\ \text { H } & -3.600123 & 6.185787 & 2.371596 \\ \text { H } & -0.456726 & 5.613693 & -0.513345 \\ \text { C } & 2.832895 & -3.697932 & -2.433101 \\ \text { C } & 1.740876 & -3.209100 & -3.153784 \\ \text { C } & 0.532855 & -2.945385 & -2.509613 \\ \text { C } & 0.393100 & -3.170421 & -1.129987 \\ \text { C } & 1.500370 & -3.653683 & -0.413383 \\ \text { C } & 2.708419 & -3.916545 & -1.060156 \\ \text { H } & 1.826606 & -3.036292 & -4.223420 \\ \text { H } & 3.554839 & -4.288229 & -0.487887 \\ \text { C } & -3.350362 & -2.493031 & 0.979362\end{array}$




\begin{tabular}{|c|c|c|c|}
\hline$C$ & -2.614267 & -3.711438 & 1.145475 \\
\hline C & -3.087716 & -4.694569 & 2.056269 \\
\hline C & -4.222203 & -4.479740 & 2.803265 \\
\hline C & -4.927352 & -3.260549 & 2.672728 \\
\hline C & -4.504746 & -2.294858 & 1.785722 \\
\hline $\mathrm{H}$ & -2.523195 & -5.618100 & 2.160541 \\
\hline $\mathrm{H}$ & -4.570473 & -5.235627 & 3.501747 \\
\hline $\mathrm{H}$ & -5.808983 & -3.080868 & 3.282021 \\
\hline $\mathrm{H}$ & -5.051781 & -1.363040 & 1.706499 \\
\hline C & -4.948889 & -0.239379 & -0.693385 \\
\hline C & -5.653873 & 1.002816 & -0.785349 \\
\hline C & -6.998181 & 1.012412 & -1.246569 \\
\hline C & -7.622560 & -0.151721 & -1.629118 \\
\hline C & -6.918082 & -1.377378 & -1.571602 \\
\hline C & -5.619147 & -1.421160 & -1.115074 \\
\hline $\mathrm{H}$ & -7.519828 & 1.964912 & -1.302717 \\
\hline $\mathrm{H}$ & -8.648384 & -0.132312 & -1.986691 \\
\hline $\mathrm{H}$ & -7.404090 & -2.293139 & -1.897217 \\
\hline $\mathrm{H}$ & -5.090518 & -2.367007 & -1.088464 \\
\hline 0 & 0.738382 & 0.096665 & 0.239672 \\
\hline $\mathrm{O}$ & -0.203180 & 1.511836 & -1.748474 \\
\hline $\mathrm{H}$ & 0.707002 & 2.133800 & -1.737907 \\
\hline $\mathrm{H}$ & -1.394914 & 3.414855 & -1.104949 \\
\hline $\mathrm{H}$ & -1.554785 & 7.023748 & 1.224834 \\
\hline $\mathrm{H}$ & -4.527382 & 3.966706 & 1.785300 \\
\hline $\mathrm{H}$ & 1.420883 & -3.790772 & 0.661129 \\
\hline $\mathrm{H}$ & 3.773109 & -3.904864 & -2.937799 \\
\hline $\mathrm{H}$ & -0.310547 & -2.569028 & -3.078887 \\
\hline C & 2.788669 & 2.608326 & -1.064758 \\
\hline 0 & 1.858373 & 2.837267 & -1.905686 \\
\hline $\mathrm{H}$ & 3.770296 & 3.065653 & -1.254234 \\
\hline C & 2.500347 & 2.607359 & 0.443973 \\
\hline 0 & 3.341611 & 2.367811 & 1.288485 \\
\hline 0 & 1.248036 & 2.985977 & 0.702728 \\
\hline C & 0.856859 & 2.958539 & 2.091642 \\
\hline $\mathrm{H}$ & 1.523941 & 3.590574 & 2.682504 \\
\hline $\mathrm{H}$ & -0.162780 & 3.338358 & 2.106999 \\
\hline C & 4.161807 & 0.181234 & -0.402970 \\
\hline C & 3.408843 & 0.739055 & -1.449090 \\
\hline $\mathrm{H}$ & 2.459434 & -0.409529 & 0.539352 \\
\hline$N$ & 3.488563 & -0.480443 & 0.575877 \\
\hline C & 3.917434 & -1.363583 & 1.574651 \\
\hline 0 & 3.146168 & -1.822496 & 2.387868 \\
\hline 0 & 5.221025 & -1.669113 & 1.487883 \\
\hline
\end{tabular}




$\begin{array}{llll}\mathrm{C} & 5.695392 & -2.574119 & 2.499919 \\ \mathrm{H} & 5.181686 & -3.535615 & 2.423405 \\ \mathrm{H} & 5.528344 & -2.156739 & 3.495742 \\ \mathrm{H} & 6.761154 & -2.688699 & 2.302665 \\ \mathrm{H} & 3.964798 & 1.029513 & -2.333293 \\ \mathrm{H} & 2.432448 & 0.308301 & -1.634280 \\ \mathrm{C} & 5.621072 & 0.430058 & -0.335102 \\ \mathrm{C} & 6.208587 & 1.007611 & 0.803224 \\ \mathrm{C} & 6.416869 & 0.160515 & -1.458775 \\ \mathrm{C} & 7.568460 & 1.302594 & 0.810177 \\ \mathrm{H} & 5.583349 & 1.261419 & 1.651169 \\ \mathrm{C} & 7.783373 & 0.437742 & -1.437747 \\ \mathrm{H} & 5.967413 & -0.291398 & -2.338202 \\ \mathrm{C} & 8.360621 & 1.011872 & -0.304702 \\ \mathrm{H} & 8.012034 & 1.767055 & 1.686512 \\ \mathrm{H} & 8.393192 & 0.209604 & -2.307321 \\ \mathrm{H} & 9.423158 & 1.239215 & -0.291210 \\ \mathrm{H} & 0.894223 & 1.930016 & 2.455956\end{array}$

Catalyst (R)-1 TS Conformation 195

B3LYP/6-31G(d) Energy = -2809.688916

B3LYP-D3(BJ)/def2-TZVPP-IEF-PCM(DCM) Energy $=-2810.982132$

B3LYP-D3(BJ)/def2-TZVPP-IEF-PCM(DCM)//B3LYP/6-31G(d) Free Energy (Quasiharmonic) = 2810.340835

Frequencies (Top 3 out of 270)

1. $-714.5139 \mathrm{~cm}-1$

2. $\quad 6.9880 \mathrm{~cm}-1$

3. $10.1788 \mathrm{~cm}-1$

B3LYP/6-31G(d) Molecular Geometry in Cartesian Coordinates

$\begin{array}{llll}\text { C } & 3.427568 & -0.968419 & 0.068793 \\ \text { C } & 2.185078 & -1.574032 & 0.143268 \\ \text { C } & 1.968977 & -2.966818 & -0.064263 \\ \text { C } & 3.069733 & -3.733962 & -0.389923 \\ \text { H } & 2.947140 & -4.804511 & -0.532376 \\ \text { C } & 3.947810 & 3.266445 & 0.662439 \\ \text { C } & 3.559107 & 0.490584 & 0.360808 \\ \text { C } & 2.797038 & 1.415980 & -0.340646 \\ \text { C } & 3.005234 & 2.825186 & -0.246417\end{array}$




\begin{tabular}{|c|c|c|c|}
\hline $\mathrm{H}$ & 4.120982 & 4.334593 & 0.762705 \\
\hline $\mathrm{O}$ & 1.081915 & -0.778956 & 0.439054 \\
\hline$P$ & 0.512616 & 0.186134 & -0.755121 \\
\hline $\mathrm{O}$ & 1.856436 & 0.961499 & -1.259753 \\
\hline C & -1.894161 & -4.836672 & 0.246940 \\
\hline C & -1.072759 & -5.085453 & -0.853232 \\
\hline C & 0.171956 & -4.463839 & -0.952161 \\
\hline C & 0.619624 & -3.582462 & 0.044977 \\
\hline C & -0.219532 & -3.334593 & 1.145050 \\
\hline C & -1.462582 & -3.958333 & 1.244370 \\
\hline $\mathrm{H}$ & -1.403522 & -5.755602 & -1.642068 \\
\hline $\mathrm{H}$ & -2.094443 & -3.759684 & 2.106074 \\
\hline C & 1.085147 & 5.778041 & -2.721799 \\
\hline C & 0.311293 & 4.836584 & -2.040752 \\
\hline C & 0.913830 & 3.859959 & -1.248006 \\
\hline C & 2.311182 & 3.812457 & -1.120800 \\
\hline C & 3.080579 & 4.764753 & -1.810425 \\
\hline C & 2.474887 & 5.738249 & -2.604174 \\
\hline $\mathrm{H}$ & -0.772414 & 4.862025 & -2.123803 \\
\hline $\mathrm{H}$ & 3.090374 & 6.459987 & -3.135101 \\
\hline C & 4.465471 & 0.970953 & 1.368345 \\
\hline C & 4.661635 & 2.382169 & 1.506549 \\
\hline C & 5.557312 & 2.870054 & 2.496453 \\
\hline C & 6.219752 & 2.007176 & 3.337932 \\
\hline C & 6.003898 & 0.613418 & 3.225552 \\
\hline C & 5.152620 & 0.108887 & 2.267188 \\
\hline $\mathrm{H}$ & 5.699081 & 3.944845 & 2.582061 \\
\hline $\mathrm{H}$ & 6.897576 & 2.391494 & 4.095225 \\
\hline $\mathrm{H}$ & 6.509593 & -0.066097 & 3.906317 \\
\hline $\mathrm{H}$ & 4.989708 & -0.960723 & 2.202307 \\
\hline C & 4.551402 & -1.766688 & -0.343433 \\
\hline C & 4.359223 & -3.170978 & -0.556061 \\
\hline C & 5.462577 & -3.975130 & -0.951230 \\
\hline C & 6.702795 & -3.420338 & -1.164182 \\
\hline C & 6.886087 & -2.027913 & -0.996055 \\
\hline C & 5.841356 & -1.223911 & -0.595976 \\
\hline $\mathrm{H}$ & 5.300902 & -5.040740 & -1.095930 \\
\hline $\mathrm{H}$ & 7.537082 & -4.043907 & -1.473526 \\
\hline $\mathrm{H}$ & 7.859772 & -1.586027 & -1.189682 \\
\hline $\mathrm{H}$ & 5.997964 & -0.157883 & -0.482468 \\
\hline O & -0.525149 & 1.074756 & -0.141711 \\
\hline $\mathrm{O}$ & 0.133024 & -0.654856 & -1.983309 \\
\hline $\mathrm{H}$ & -0.963859 & -1.051671 & -2.164571 \\
\hline $\mathrm{H}$ & 0.108478 & -2.657221 & 1.926400 \\
\hline
\end{tabular}




$\begin{array}{llll}\mathrm{H} & -2.863193 & -5.322596 & 0.326764 \\ \mathrm{H} & 0.796826 & -4.640886 & -1.822771 \\ \mathrm{H} & 4.164089 & 4.725984 & -1.736297 \\ \mathrm{H} & 0.609518 & 6.534169 & -3.341107 \\ \mathrm{H} & 0.299086 & 3.140658 & -0.718411 \\ \mathrm{C} & -2.800997 & -1.247226 & -1.268575 \\ \mathrm{O} & -2.118478 & -1.462093 & -2.324873 \\ \mathrm{H} & -2.289973 & -1.108688 & -0.309226 \\ \mathrm{C} & -4.143131 & -1.947855 & -1.164442 \\ \mathrm{O} & -4.838332 & -2.285700 & -2.094436 \\ \mathrm{O} & -4.451173 & -2.133346 & 0.135981 \\ \mathrm{C} & -5.699057 & -2.801665 & 0.391717 \\ \mathrm{H} & -5.721612 & -3.769787 & -0.114371 \\ \mathrm{H} & -5.744121 & -2.928564 & 1.473252 \\ \mathrm{C} & -3.980904 & 1.069855 & -0.151350 \\ \mathrm{C} & -3.388337 & 0.713786 & -1.369733 \\ \mathrm{H} & -2.135600 & 1.282786 & 0.695239 \\ \mathrm{~N} & -3.143692 & 1.232517 & 0.919465 \\ \mathrm{C} & -3.365351 & 1.035089 & 2.293102 \\ \mathrm{O} & -2.527664 & 1.314057 & 3.119462 \\ \mathrm{O} & -4.560079 & 0.480485 & 2.556395 \\ \mathrm{C} & -4.830224 & 0.278973 & 3.955152 \\ \mathrm{H} & -4.785427 & 1.227463 & 4.495906 \\ \mathrm{H} & -4.103953 & -0.413882 & 4.386627 \\ \mathrm{H} & -5.835823 & -0.139733 & 3.994617 \\ \mathrm{H} & -3.989210 & 0.769322 & -2.270482 \\ \mathrm{H} & -2.340665 & 0.971043 & -1.481664 \\ \mathrm{C} & -5.428560 & 1.338363 & -0.045089 \\ \mathrm{C} & -6.350579 & 0.668415 & -0.869669 \\ \mathrm{C} & -5.894129 & 2.369858 & 0.791649 \\ \mathrm{C} & -7.703472 & 0.998299 & -0.828093 \\ \mathrm{H} & -6.017716 & -0.118592 & -1.537751 \\ \mathrm{C} & -7.243080 & 2.709894 & 0.812758 \\ \mathrm{H} & -5.190468 & 2.930289 & 1.398253 \\ -8.154906 & 2.018563 & 0.011528 \\ \mathrm{H} & -8.403761 & 0.462121 & -1.462140 \\ \mathrm{H} & -9.208676 & 2.282073 & 0.032572 \\ \mathrm{H} & & -2.192593 & 0.044840\end{array}$

Catalyst (R)-1 TS Conformation 196

$\mathrm{B} 3 \mathrm{LYP} / 6-31 \mathrm{G}(\mathrm{d})$ Energy $=-2809.690378$ 
B3LYP-D3(BJ)/def2-TZVPP-IEF-PCM(DCM) Energy = -2810.98333

B3LYP-D3(BJ)/def2-TZVPP-IEF-PCM(DCM)//B3LYP/6-31G(d) Free Energy (Quasiharmonic) = 2810.340834

Frequencies (Top 3 out of 270)

1. $-649.4426 \mathrm{~cm}-1$

2. $8.5735 \mathrm{~cm}-1$

3. $11.4568 \mathrm{~cm}-1$

B3LYP/6-31G(d) Molecular Geometry in Cartesian Coordinates

$\begin{array}{lccc}\text { C } & 3.403471 & -1.195908 & -0.136112 \\ \text { C } & 2.144175 & -1.722871 & 0.096876 \\ \text { C } & 1.752317 & -3.033784 & -0.303364 \\ \text { C } & 2.679606 & -3.787931 & -0.994444 \\ \text { H } & 2.423412 & -4.801184 & -1.293071 \\ \text { C } & 4.460925 & 2.778774 & 1.144929 \\ \text { C } & 3.743686 & 0.159057 & 0.390302 \\ \text { C } & 2.950208 & 1.253167 & 0.068055 \\ \text { C } & 3.310840 & 2.593744 & 0.402427 \\ \text { H } & 4.753432 & 3.789204 & 1.418231 \\ \text { O } & 1.211723 & -0.934928 & 0.760240 \\ \text { P } & 0.504751 & 0.274867 & -0.099012 \\ \text { O } & 1.811694 & 1.063309 & -0.702069 \\ \text { C } & -2.131549 & -4.697245 & 0.524237 \\ \text { C } & -1.575867 & -4.791534 & -0.752434 \\ \text { C } & -0.322360 & -4.238103 & -1.015029 \\ \text { C } & 0.401415 & -3.579880 & -0.007809 \\ \text { C } & -0.168258 & -3.490741 & 1.274214 \\ \text { C } & -1.420308 & -4.046287 & 1.535811 \\ \text { H } & -2.121937 & -5.287948 & -1.550511 \\ \text { H } & -1.841687 & -3.972031 & 2.535057 \\ \text { C } & 1.188123 & 6.133019 & -0.820210 \\ \text { C } & 0.504017 & 5.103380 & -0.170108 \\ \text { C } & 1.166670 & 3.934655 & 0.207337 \\ \text { C } & 2.538413 & 3.784503 & -0.052340 \\ \text { C } & 3.216988 & 4.825869 & -0.707033 \\ \text { C } & 2.549185 & 5.988724 & -1.090748 \\ \text { H } & -0.554352 & 5.210095 & 0.054014 \\ \text { H } & 3.093059 & 6.778834 & -1.602252 \\ \text { C } & 4.880617 & 0.361041 & 1.247310 \\ \text { C } & 5.244298 & 1.696444 & 1.612655 \\ \text { C } & 6.370348 & 1.910584 & 2.453052\end{array}$




\begin{tabular}{|c|c|c|c|}
\hline C & 7.100970 & 0.852141 & 2.940261 \\
\hline C & 6.724396 & -0.470934 & 2.609447 \\
\hline C & 5.646531 & -0.710220 & 1.785628 \\
\hline $\mathrm{H}$ & 6.635312 & 2.932739 & 2.713323 \\
\hline $\mathrm{H}$ & 7.956463 & 1.027010 & 3.586991 \\
\hline $\mathrm{H}$ & 7.287058 & -1.307838 & 3.014423 \\
\hline $\mathrm{H}$ & 5.365408 & -1.730482 & 1.551793 \\
\hline C & 4.331273 & -1.963192 & -0.923546 \\
\hline C & 3.957596 & -3.282773 & -1.338911 \\
\hline C & 4.868579 & -4.057831 & -2.106714 \\
\hline C & 6.088720 & -3.548048 & -2.484728 \\
\hline C & 6.443548 & -2.230410 & -2.112263 \\
\hline C & 5.590558 & -1.460357 & -1.352324 \\
\hline $\mathrm{H}$ & 4.572968 & -5.061875 & -2.402112 \\
\hline $\mathrm{H}$ & 6.773810 & -4.147248 & -3.078265 \\
\hline $\mathrm{H}$ & 7.396666 & -1.818597 & -2.433050 \\
\hline $\mathrm{H}$ & 5.874483 & -0.449392 & -1.085193 \\
\hline $\mathrm{O}$ & -0.341398 & 1.076924 & 0.831581 \\
\hline $\mathrm{O}$ & -0.149487 & -0.313075 & -1.362485 \\
\hline $\mathrm{H}$ & -1.328726 & -0.341345 & -1.408257 \\
\hline $\mathrm{H}$ & 0.375055 & -2.987219 & 2.066593 \\
\hline $\mathrm{H}$ & -3.113997 & -5.113075 & 0.727532 \\
\hline $\mathrm{H}$ & 0.093029 & -4.290819 & -2.017337 \\
\hline $\mathrm{H}$ & 4.274896 & 4.712299 & -0.928461 \\
\hline $\mathrm{H}$ & 0.665474 & 7.040606 & -1.111903 \\
\hline $\mathrm{H}$ & 0.621514 & 3.145062 & 0.714209 \\
\hline C & -3.051587 & -0.976601 & -0.411993 \\
\hline $\mathrm{O}$ & -2.557972 & -0.407628 & -1.458339 \\
\hline $\mathrm{H}$ & -2.378859 & -1.547664 & 0.241915 \\
\hline C & -4.391701 & -1.690480 & -0.548559 \\
\hline $\mathrm{O}$ & -4.822079 & -2.455414 & 0.295046 \\
\hline $\mathrm{O}$ & -5.034471 & -1.367215 & -1.675185 \\
\hline C & -6.304892 & -2.020429 & -1.872754 \\
\hline $\mathrm{H}$ & -7.008513 & -1.734555 & -1.086519 \\
\hline $\mathrm{H}$ & -6.177924 & -3.105661 & -1.865908 \\
\hline C & -4.505777 & 1.094623 & 0.544614 \\
\hline C & -3.475851 & 0.259955 & 1.021116 \\
\hline $\mathrm{H}$ & -6.474277 & 1.174918 & 0.016130 \\
\hline$N$ & -5.834296 & 0.768396 & 0.686945 \\
\hline C & -6.521387 & -0.163968 & 1.487804 \\
\hline $\mathrm{O}$ & -7.664335 & -0.468181 & 1.218803 \\
\hline $\mathrm{O}$ & -5.815738 & -0.586577 & 2.533161 \\
\hline C & -6.417913 & -1.667269 & 3.279017 \\
\hline $\mathrm{H}$ & -5.751114 & -1.832317 & 4.124416 \\
\hline
\end{tabular}




$\begin{array}{lrrr}\mathrm{H} & -6.469230 & -2.555379 & 2.646042 \\ \mathrm{H} & -7.416003 & -1.383537 & 3.617119 \\ \mathrm{H} & -2.489622 & 0.702570 & 1.139551 \\ \mathrm{H} & -3.747654 & -0.455396 & 1.785935 \\ \mathrm{C} & -4.237256 & 2.278081 & -0.278695 \\ \mathrm{C} & -2.938262 & 2.508981 & -0.778691 \\ \mathrm{C} & -5.256695 & 3.205546 & -0.599212 \\ \mathrm{C} & -2.687385 & 3.599036 & -1.610600 \\ \mathrm{H} & -2.118833 & 1.857187 & -0.510671 \\ \mathrm{C} & -4.994565 & 4.295085 & -1.417728 \\ \mathrm{H} & -6.251448 & 3.111826 & -0.173064 \\ \mathrm{C} & -3.709688 & 4.487963 & -1.938255 \\ \mathrm{H} & -1.681383 & 3.755152 & -1.986980 \\ \mathrm{H} & -5.787877 & 5.001848 & -1.642844 \\ \mathrm{H} & -3.507058 & 5.340013 & -2.581208 \\ \mathrm{H} & -6.653271 & -1.680767 & -2.848044\end{array}$

Catalyst (R)-1 TS Conformation 197

B3LYP/6-31G(d) Energy $=-2809.687128$

B3LYP-D3(BJ)/def2-TZVPP-IEF-PCM(DCM) Energy $=-2810.983494$

B3LYP-D3(BJ)/def2-TZVPP-IEF-PCM(DCM)//B3LYP/6-31G(d) Free Energy (Quasiharmonic) = 2810.340811

Frequencies (Top 3 out of 270)

1. $-590.2925 \mathrm{~cm}-1$

2. $\quad 7.8689 \mathrm{~cm}-1$

3. $\quad 14.5839 \mathrm{~cm}-1$

B3LYP/6-31G(d) Molecular Geometry in Cartesian Coordinates

$\begin{array}{llll}\text { C } & -3.297907 & 0.087198 & 0.344399 \\ \text { C } & -2.979154 & -1.010500 & -0.440614 \\ \text { C } & -3.377300 & -2.345257 & -0.129073 \\ \text { C } & -4.069765 & -2.535410 & 1.051597 \\ \text { H } & -4.415878 & -3.533462 & 1.306882 \\ \text { C } & -2.080606 & 4.080805 & -0.717491 \\ \text { C } & -2.919364 & 1.460074 & -0.106496 \\ \text { C } & -1.593596 & 1.750438 & -0.402084 \\ \text { C } & -1.135599 & 3.074160 & -0.679382 \\ \text { H } & -1.758857 & 5.096896 & -0.930731 \\ \text { O } & -2.253459 & -0.801292 & -1.605256\end{array}$




\begin{tabular}{|c|c|c|c|}
\hline$P$ & -0.656673 & -0.466304 & -1.484970 \\
\hline $\mathrm{O}$ & -0.657991 & 0.729345 & -0.328822 \\
\hline C & -2.601505 & -5.748401 & -2.645108 \\
\hline C & -2.399182 & -5.824890 & -1.266671 \\
\hline C & -2.634972 & -4.710831 & -0.462509 \\
\hline C & -3.076493 & -3.498745 & -1.018302 \\
\hline C & -3.270599 & -3.433275 & -2.408361 \\
\hline C & -3.037265 & -4.548597 & -3.210801 \\
\hline $\mathrm{H}$ & -2.047848 & -6.749310 & -0.815730 \\
\hline $\mathrm{H}$ & -3.196660 & -4.478090 & -4.283497 \\
\hline C & 2.985105 & 4.186548 & -1.248610 \\
\hline C & 2.420828 & 3.185450 & -2.044432 \\
\hline C & 1.091078 & 2.799465 & -1.860974 \\
\hline C & 0.303863 & 3.412922 & -0.872447 \\
\hline C & 0.881385 & 4.418892 & -0.079796 \\
\hline C & 2.209797 & 4.803237 & -0.264766 \\
\hline $\mathrm{H}$ & 3.018517 & 2.694619 & -2.808127 \\
\hline $\mathrm{H}$ & 2.637327 & 5.582741 & 0.360989 \\
\hline C & -3.902354 & 2.498970 & -0.249777 \\
\hline C & -3.463695 & 3.829333 & -0.546195 \\
\hline C & -4.423806 & 4.868358 & -0.682421 \\
\hline C & -5.768778 & 4.609534 & -0.557234 \\
\hline C & -6.208076 & 3.289966 & -0.297231 \\
\hline C & -5.301451 & 2.263895 & -0.146066 \\
\hline $\mathrm{H}$ & -4.071624 & 5.873654 & -0.901558 \\
\hline $\mathrm{H}$ & -6.494548 & 5.410221 & -0.670196 \\
\hline $\mathrm{H}$ & -7.272087 & 3.081890 & -0.223163 \\
\hline $\mathrm{H}$ & -5.655728 & 1.256612 & 0.040392 \\
\hline C & -3.948771 & -0.140343 & 1.607628 \\
\hline C & -4.346408 & -1.474339 & 1.948482 \\
\hline C & -5.000884 & -1.713019 & 3.187693 \\
\hline C & -5.228320 & -0.689307 & 4.077727 \\
\hline C & -4.800675 & 0.621753 & 3.762449 \\
\hline C & -4.180592 & 0.889505 & 2.561464 \\
\hline $\mathrm{H}$ & -5.308751 & -2.729187 & 3.422941 \\
\hline $\mathrm{H}$ & -5.724144 & -0.885376 & 5.024497 \\
\hline $\mathrm{H}$ & -4.960017 & 1.426113 & 4.475596 \\
\hline $\mathrm{H}$ & -3.853718 & 1.898503 & 2.339451 \\
\hline $\mathrm{O}$ & -0.116078 & -0.022982 & -2.791535 \\
\hline 0 & 0.006124 & -1.640427 & -0.726372 \\
\hline $\mathrm{H}$ & 1.152961 & -1.769926 & -0.793174 \\
\hline $\mathrm{H}$ & -3.608697 & -2.507462 & -2.860120 \\
\hline $\mathrm{H}$ & -2.414954 & -6.614389 & -3.274706 \\
\hline $\mathrm{H}$ & -2.453681 & -4.771373 & 0.607145 \\
\hline
\end{tabular}




\begin{tabular}{|c|c|c|c|}
\hline $\mathrm{H}$ & 0.284131 & 4.892322 & 0.695158 \\
\hline $\mathrm{H}$ & 4.018665 & 4.488525 & -1.399748 \\
\hline $\mathrm{H}$ & 0.660776 & 2.026939 & -2.490610 \\
\hline C & 2.922217 & -0.715439 & -1.146879 \\
\hline 0 & 2.414681 & -1.848431 & -0.794201 \\
\hline $\mathrm{H}$ & 2.292302 & 0.003662 & -1.686718 \\
\hline C & 4.325095 & -0.717858 & -1.734290 \\
\hline 0 & 4.758398 & 0.194316 & -2.411845 \\
\hline $\mathrm{O}$ & 5.013000 & -1.822307 & -1.417719 \\
\hline C & 6.331342 & -1.915444 & -1.988018 \\
\hline $\mathrm{H}$ & 6.974352 & -1.122822 & -1.596480 \\
\hline $\mathrm{H}$ & 6.280697 & -1.833534 & -3.076287 \\
\hline C & 3.940185 & -0.244919 & 1.251200 \\
\hline C & 3.060897 & 0.443658 & 0.394354 \\
\hline $\mathrm{H}$ & 4.312424 & -2.026885 & 2.153661 \\
\hline$N$ & 3.571677 & -1.390658 & 1.882351 \\
\hline C & 2.311755 & -1.959502 & 2.209734 \\
\hline $\mathrm{O}$ & 2.261377 & -3.088787 & 2.638061 \\
\hline $\mathrm{O}$ & 1.310540 & -1.100003 & 2.083580 \\
\hline C & -0.002370 & -1.618336 & 2.414713 \\
\hline $\mathrm{H}$ & -0.679119 & -0.783273 & 2.248876 \\
\hline $\mathrm{H}$ & -0.014212 & -1.944400 & 3.456818 \\
\hline $\mathrm{H}$ & -0.249531 & -2.441423 & 1.745733 \\
\hline $\mathrm{H}$ & 3.380765 & 1.418934 & 0.043811 \\
\hline $\mathrm{H}$ & 2.002133 & 0.385566 & 0.613267 \\
\hline C & 5.354714 & 0.148670 & 1.429759 \\
\hline C & 6.003332 & 0.990958 & 0.504646 \\
\hline C & 6.072202 & -0.273303 & 2.567956 \\
\hline C & 7.330338 & 1.364605 & 0.698915 \\
\hline $\mathrm{H}$ & 5.486757 & 1.331490 & -0.384304 \\
\hline C & 7.395779 & 0.112264 & 2.761442 \\
\hline $\mathrm{H}$ & 5.584051 & -0.865340 & 3.336202 \\
\hline C & 8.032718 & 0.926974 & 1.824066 \\
\hline $\mathrm{H}$ & 7.815353 & 2.003615 & -0.033156 \\
\hline $\mathrm{H}$ & 7.924564 & -0.214808 & 3.651877 \\
\hline $\mathrm{H}$ & 9.065340 & 1.228387 & 1.975026 \\
\hline $\mathrm{H}$ & 6.705683 & -2.895436 & -1.692233 \\
\hline
\end{tabular}

Catalyst (R)-1 TS Conformation 198

B3LYP/6-31G(d) Energy $=-2809.688724$

B3LYP-D3(BJ)/def2-TZVPP-IEF-PCM(DCM) Energy = -2810.981969 
B3LYP-D3(BJ)/def2-TZVPP-IEF-PCM(DCM)//B3LYP/6-31G(d) Free Energy (Quasiharmonic) = 2810.340766

Frequencies (Top 3 out of 270)

1. $-701.3438 \mathrm{~cm}-1$

2. $\quad 7.1207 \mathrm{~cm}-1$

3. $12.3534 \mathrm{~cm}-1$

B3LYP/6-31G(d) Molecular Geometry in Cartesian Coordinates

$\begin{array}{llll}\text { C } & 3.536423 & -0.803676 & 0.062654 \\ \text { C } & 2.336865 & -1.489663 & 0.167276 \\ \text { C } & 2.223002 & -2.904331 & 0.036921 \\ \text { C } & 3.378472 & -3.608292 & -0.239281 \\ \text { H } & 3.332924 & -4.691084 & -0.322496 \\ \text { C } & 3.577250 & 3.488872 & 0.507750 \\ \text { C } & 3.554770 & 0.675912 & 0.269193 \\ \text { C } & 2.718007 & 1.485165 & -0.485707 \\ \text { C } & 2.721225 & 2.909125 & -0.408732 \\ \text { H } & 3.625331 & 4.572532 & 0.574334 \\ \text { O } & 1.178277 & -0.763920 & 0.419277 \\ \text { P } & 0.534113 & 0.104299 & -0.814809 \\ \text { O } & 1.846827 & 0.886373 & -1.390917 \\ \text { C } & -1.509507 & -5.014287 & 0.410578 \\ \text { C } & -1.155457 & -4.051462 & 1.359166 \\ \mathrm{C} & 0.045076 & -3.352246 & 1.240083 \\ \mathrm{C} & 0.918352 & -3.606429 & 0.168483 \\ \mathrm{C} & 0.548966 & -4.574797 & -0.778934 \\ \mathrm{C} & -0.652815 & -5.272364 & -0.660099 \\ \mathrm{H} & -1.815099 & -3.844408 & 2.197786 \\ \mathrm{H} & -0.923960 & -6.008819 & -1.411693 \\ \mathrm{C} & 0.284607 & 5.469249 & -2.863431 \\ \mathrm{C} & 0.961800 & 4.391755 & -3.438290 \\ \mathrm{C} & 1.735720 & 3.542608 & -2.649217 \\ \mathrm{C} & 1.851347 & 3.758647 & -1.265630 \\ \mathrm{C} & 1.161740 & 4.843167 & -0.699203 \\ \mathrm{C} & 0.386158 & 5.690683 & -1.489472 \\ \mathrm{H} & 0.890249 & 4.211124 & -4.507681 \\ \mathrm{H} & -0.144546 & 6.519864 & -1.028541 \\ \mathrm{C} & 4.383038 & 1.292289 & 1.269393 \\ \mathrm{C} & 4.396251 & 2.721190 & 1.370903 \\ \mathrm{C} & 5.220649 & 3.344184 & 2.347032 \\ \mathrm{C} & 5.980028 & 2.594906 & 3.214936\end{array}$




\begin{tabular}{|c|c|c|c|}
\hline C & 5.938360 & 1.182553 & 3.143885 \\
\hline C & 5.163272 & 0.548870 & 2.197637 \\
\hline $\mathrm{H}$ & 5.227854 & 4.430276 & 2.401592 \\
\hline $\mathrm{H}$ & 6.600904 & 3.082201 & 3.961723 \\
\hline $\mathrm{H}$ & 6.519611 & 0.590910 & 3.846026 \\
\hline $\mathrm{H}$ & 5.135144 & -0.533971 & 2.163755 \\
\hline C & 4.716877 & -1.541728 & -0.295760 \\
\hline C & 4.626796 & -2.965837 & -0.429354 \\
\hline C & 5.788815 & -3.709420 & -0.771653 \\
\hline C & 6.988629 & -3.079840 & -1.007396 \\
\hline C & 7.071256 & -1.670553 & -0.916134 \\
\hline C & 5.967645 & -0.922502 & -0.569319 \\
\hline $\mathrm{H}$ & 5.705225 & -4.790338 & -0.856948 \\
\hline $\mathrm{H}$ & 7.868348 & -3.658412 & -1.275614 \\
\hline $\mathrm{H}$ & 8.013491 & -1.171893 & -1.126834 \\
\hline $\mathrm{H}$ & 6.046108 & 0.156929 & -0.513627 \\
\hline $\mathrm{O}$ & -0.522665 & 0.985059 & -0.234470 \\
\hline $\mathrm{O}$ & 0.173287 & -0.828339 & -1.983081 \\
\hline $\mathrm{H}$ & -0.903460 & -1.274435 & -2.104187 \\
\hline $\mathrm{H}$ & 1.199446 & -4.760206 & -1.628849 \\
\hline $\mathrm{H}$ & -2.446155 & -5.557781 & 0.504424 \\
\hline $\mathrm{H}$ & 0.312619 & -2.609029 & 1.983549 \\
\hline $\mathrm{H}$ & 1.218477 & 5.006423 & 0.373387 \\
\hline $\mathrm{H}$ & -0.320273 & 6.127916 & -3.481208 \\
\hline $\mathrm{H}$ & 2.259217 & 2.710732 & -3.107477 \\
\hline C & -2.723574 & -1.456264 & -1.151751 \\
\hline 0 & -2.056332 & -1.738590 & -2.203187 \\
\hline $\mathrm{H}$ & -2.196157 & -1.223010 & -0.219736 \\
\hline C & -4.030812 & -2.201598 & -0.951718 \\
\hline $\mathrm{O}$ & -4.739634 & -2.636947 & -1.829665 \\
\hline 0 & -4.291718 & -2.302058 & 0.368793 \\
\hline C & -5.503571 & -2.996193 & 0.712999 \\
\hline $\mathrm{H}$ & -6.375562 & -2.445257 & 0.352097 \\
\hline $\mathrm{H}$ & -5.503919 & -3.998403 & 0.277691 \\
\hline C & -3.968672 & 0.900546 & -0.211258 \\
\hline C & -3.382574 & 0.450992 & -1.403540 \\
\hline $\mathrm{H}$ & -2.118720 & 1.258444 & 0.573291 \\
\hline$N$ & -3.121661 & 1.196451 & 0.820766 \\
\hline C & -3.317657 & 1.136476 & 2.211007 \\
\hline $\mathrm{O}$ & -2.487132 & 1.543291 & 2.990232 \\
\hline 0 & -4.479223 & 0.553078 & 2.550819 \\
\hline C & -4.723643 & 0.488073 & 3.966915 \\
\hline $\mathrm{H}$ & -3.957621 & -0.117082 & 4.457555 \\
\hline $\mathrm{H}$ & -5.705479 & 0.025287 & 4.066737 \\
\hline
\end{tabular}




$\begin{array}{llll}\mathrm{H} & -4.722861 & 1.489746 & 4.403741 \\ \mathrm{H} & -4.001454 & 0.404731 & -2.292664 \\ \mathrm{H} & -2.350237 & 0.744625 & -1.561030 \\ \mathrm{C} & -5.423806 & 1.123950 & -0.101366 \\ \mathrm{C} & -5.914596 & 2.215331 & 0.639599 \\ \mathrm{C} & -6.333328 & 0.341280 & -0.835418 \\ \mathrm{C} & -7.275363 & 2.504546 & 0.657217 \\ \mathrm{H} & -5.222607 & 2.859975 & 1.171456 \\ \mathrm{C} & -7.697376 & 0.622146 & -0.796033 \\ \mathrm{H} & -5.981603 & -0.494472 & -1.430525 \\ \mathrm{C} & -8.173618 & 1.702811 & -0.051146 \\ \mathrm{H} & -7.634729 & 3.360870 & 1.220829 \\ \mathrm{H} & -8.387273 & -0.000504 & -1.358427 \\ \mathrm{H} & -9.236523 & 1.926974 & -0.032546 \\ \mathrm{H} & -5.510456 & -3.046730 & 1.801750\end{array}$

Catalyst (R)-1 TS Conformation 199

B3LYP/6-31G(d) Energy $=-2809.688639$

B3LYP-D3(BJ)/def2-TZVPP-IEF-PCM(DCM) Energy $=-2810.981704$

B3LYP-D3(BJ)/def2-TZVPP-IEF-PCM(DCM)//B3LYP/6-31G(d) Free Energy (Quasiharmonic) = 2810.340756

Frequencies (Top 3 out of 270)

1. $-693.6397 \mathrm{~cm}-1$

2. $\quad 5.3780 \mathrm{~cm}-1$

3. $\quad 10.4479 \mathrm{~cm}-1$

B3LYP/6-31G(d) Molecular Geometry in Cartesian Coordinates

$\begin{array}{llll}\text { C } & 3.051219 & -1.074778 & -0.388663 \\ \text { C } & 1.884838 & -1.688894 & 0.038733 \\ \text { C } & 1.564199 & -3.046158 & -0.256857 \\ \text { C } & 2.439454 & -3.742974 & -1.066899 \\ \text { H } & 2.233568 & -4.786200 & -1.291877 \\ \text { C } & 3.883891 & 3.023056 & 0.644463 \\ \text { C } & 3.347684 & 0.324559 & 0.036766 \\ \text { C } & 2.433502 & 1.330677 & -0.236685 \\ \text { C } & 2.693141 & 2.710782 & 0.015926 \\ \text { H } & 4.125707 & 4.066641 & 0.827170 \\ \text { O } & 0.991388 & -0.956352 & 0.813227 \\ \text { P } & 0.098973 & 0.212289 & 0.083483\end{array}$




\begin{tabular}{|c|c|c|c|}
\hline $\mathrm{O}$ & 1.222580 & 0.984789 & -0.826139 \\
\hline C & -1.812521 & -5.182675 & 1.327480 \\
\hline C & -1.007984 & -4.418581 & 2.175631 \\
\hline C & 0.062883 & -3.688441 & 1.663664 \\
\hline C & 0.359997 & -3.724679 & 0.291595 \\
\hline C & -0.461085 & -4.489233 & -0.552359 \\
\hline C & -1.540343 & -5.208548 & -0.040572 \\
\hline $\mathrm{H}$ & -1.211133 & -4.391999 & 3.242942 \\
\hline $\mathrm{H}$ & -2.171137 & -5.784378 & -0.712355 \\
\hline C & 0.179416 & 5.970349 & -1.226042 \\
\hline C & 0.726293 & 5.948857 & 0.056819 \\
\hline C & 1.512606 & 4.872485 & 0.464317 \\
\hline C & 1.767226 & 3.796617 & -0.401344 \\
\hline C & 1.198415 & 3.823447 & -1.685680 \\
\hline C & 0.416558 & 4.902379 & -2.092769 \\
\hline $\mathrm{H}$ & 0.535621 & 6.767373 & 0.746216 \\
\hline $\mathrm{H}$ & -0.006912 & 4.908697 & -3.093943 \\
\hline C & 4.547751 & 0.658477 & 0.752566 \\
\hline C & 4.810599 & 2.033657 & 1.053096 \\
\hline C & 5.997197 & 2.379921 & 1.754864 \\
\hline C & 6.880044 & 1.411815 & 2.173430 \\
\hline C & 6.605828 & 0.049323 & 1.908264 \\
\hline C & 5.472955 & -0.317486 & 1.215477 \\
\hline $\mathrm{H}$ & 6.187277 & 3.430014 & 1.964462 \\
\hline $\mathrm{H}$ & 7.780543 & 1.688019 & 2.715253 \\
\hline $\mathrm{H}$ & 7.293234 & -0.716108 & 2.258349 \\
\hline $\mathrm{H}$ & 5.272239 & -1.366129 & 1.028427 \\
\hline C & 3.920946 & -1.791708 & -1.280930 \\
\hline C & 3.602786 & -3.148215 & -1.613046 \\
\hline C & 4.456345 & -3.871730 & -2.489437 \\
\hline C & 5.566112 & -3.279444 & -3.045504 \\
\hline C & 5.863080 & -1.928447 & -2.748753 \\
\hline C & 5.064622 & -1.205085 & -1.890218 \\
\hline $\mathrm{H}$ & 4.205663 & -4.904389 & -2.720765 \\
\hline $\mathrm{H}$ & 6.207902 & -3.840431 & -3.719392 \\
\hline $\mathrm{H}$ & 6.727184 & -1.454269 & -3.206399 \\
\hline $\mathrm{H}$ & 5.301174 & -0.168229 & -1.682047 \\
\hline $\mathrm{O}$ & -0.515364 & 1.047568 & 1.157913 \\
\hline $\mathrm{O}$ & -0.793300 & -0.408915 & -1.008130 \\
\hline $\mathrm{H}$ & -1.816907 & -0.930242 & -0.806786 \\
\hline $\mathrm{H}$ & -0.258120 & -4.502799 & -1.619557 \\
\hline $\mathrm{H}$ & -2.648313 & -5.750436 & 1.728568 \\
\hline $\mathrm{H}$ & 0.683066 & -3.097928 & 2.329959 \\
\hline $\mathrm{H}$ & 1.381311 & 3.001588 & -2.369446 \\
\hline
\end{tabular}




$\begin{array}{llll}\mathrm{H} & -0.435074 & 6.808190 & -1.544838 \\ \mathrm{H} & 1.922023 & 4.852808 & 1.470574 \\ \mathrm{C} & -3.827675 & -0.677480 & -1.310758 \\ \mathrm{O} & -2.952985 & -1.451330 & -0.783256 \\ \mathrm{H} & -3.485613 & 0.186252 & -1.893913 \\ \mathrm{C} & -5.071450 & -1.363940 & -1.855843 \\ \mathrm{O} & -5.513850 & -2.416187 & -1.457234 \\ \mathrm{O} & -5.619734 & -0.623018 & -2.841894 \\ \mathrm{C} & -6.810220 & -1.173334 & -3.433999 \\ \mathrm{H} & -7.593506 & -1.289257 & -2.680044 \\ \mathrm{H} & -7.113689 & -0.458963 & -4.199338 \\ \mathrm{C} & -3.898184 & 0.846740 & 0.894838 \\ \mathrm{C} & -4.900728 & 0.459881 & -0.010442 \\ \mathrm{H} & -2.091847 & 1.807481 & 1.002995 \\ \mathrm{~N} & -3.081815 & 1.925091 & 0.700580 \\ \mathrm{C} & -3.283968 & 3.109561 & -0.019725 \\ \mathrm{O} & -2.399484 & 3.917397 & -0.179333 \\ \mathrm{O} & -4.552367 & 3.264478 & -0.450685 \\ \mathrm{C} & -4.798095 & 4.506060 & -1.137017 \\ \mathrm{H} & -4.605450 & 5.352107 & -0.473203 \\ \mathrm{H} & -5.849485 & 4.471635 & -1.422741 \\ \mathrm{H} & -4.158410 & 4.588105 & -2.018715 \\ \mathrm{H} & -5.647379 & -0.226045 & 0.373499 \\ \mathrm{H} & -5.268828 & 1.191131 & -0.716220 \\ \mathrm{C} & -3.570943 & 0.001095 & 2.048591 \\ \mathrm{C} & -2.932432 & 0.558211 & 3.177067 \\ \mathrm{C} & -3.932653 & -1.362412 & 2.074199 \\ \mathrm{C} & -2.686055 & -0.216493 & 4.302914 \\ \mathrm{H} & -2.655402 & 1.606223 & 3.177943 \\ \mathrm{C} & -3.670092 & -2.133368 & 3.202636 \\ \mathrm{H} & -4.378825 & -1.830662 & 1.205878 \\ \mathrm{H} & -3.055476 & -1.564392 & 4.319240 \\ & -2.205559 & 0.230077 & 5.168260 \\ -3.940276 & -3.184554 & 3.202886 \\ \mathrm{H} & -2.862060 & -2.169056 & 5.201354 \\ \mathrm{H} & & -2.148408 & -3.879408\end{array}$

Catalyst (R)-1 TS Conformation 200

B3LYP/6-31G(d) Energy $=-2809.686073$

B3LYP-D3(BJ)/def2-TZVPP-IEF-PCM(DCM) Energy $=-2810.982402$

B3LYP-D3(BJ)/def2-TZVPP-IEF-PCM(DCM)//B3LYP/6-31G(d) Free Energy (Quasiharmonic) = 2810.340737 
Frequencies (Top 3 out of 270)

1. $-557.2882 \mathrm{~cm}-1$

2. $\quad 7.1549 \mathrm{~cm}-1$

3. $\quad 12.2511 \mathrm{~cm}-1$

B3LYP/6-31G(d) Molecular Geometry in Cartesian Coordinates

$\begin{array}{llll}\text { C } & -3.137251 & -0.925894 & -0.102200 \\ \text { C } & -1.988590 & -1.610921 & -0.463281 \\ \text { C } & -1.802049 & -3.008461 & -0.251527 \\ \text { C } & -2.819176 & -3.692531 & 0.383514 \\ \text { H } & -2.722066 & -4.763878 & 0.539734 \\ \text { C } & -3.565551 & 3.299821 & -0.851102 \\ \text { C } & -3.268188 & 0.522741 & -0.441533 \\ \text { C } & -2.290359 & 1.427794 & -0.045122 \\ \text { C } & -2.429557 & 2.838635 & -0.216849 \\ \text { H } & -3.692483 & 4.370045 & -0.992863 \\ \text { O } & -0.956948 & -0.900179 & -1.062251 \\ \text { P } & -0.039404 & 0.035509 & -0.068546 \\ \text { O } & -1.178023 & 0.977252 & 0.645471 \\ \text { C } & 1.767430 & -5.099369 & -1.439861 \\ \text { C } & 1.140093 & -4.227516 & -2.333215 \\ \text { C } & -0.009133 & -3.535216 & -1.953819 \\ \text { C } & -0.558820 & -3.708431 & -0.672141 \\ \text { C } & 0.081159 & -4.588981 & 0.215211 \\ \text { C } & 1.234337 & -5.275807 & -0.162570 \\ \text { H } & 1.544029 & -4.086225 & -3.332619 \\ \text { H } & 1.724446 & -5.937126 & 0.546481 \\ \text { C } & 0.417447 & 5.774345 & 1.127010 \\ \text { C } & -0.907662 & 5.822695 & 1.559155 \\ \text { C } & -1.818395 & 4.854033 & 1.134574 \\ \text { C } & -1.419164 & 3.816035 & 0.279387 \\ \text { C } & -0.082222 & 3.772324 & -0.146497 \\ \text { C } & 0.823571 & 4.747814 & 0.270589 \\ \text { H } & -1.235527 & 6.613282 & 2.229187 \\ \text { H } & 1.849454 & 4.717314 & -0.092417 \\ \text { C } & -4.389531 & 1.011412 & -1.198977 \\ \text { C } & -4.543264 & 2.423287 & -1.381064 \\ \text { C } & -5.655553 & 2.918457 & -2.114218 \\ \text { C } & -6.572460 & 2.060312 & -2.674928 \\ \text { C } & -6.403896 & 0.663169 & -2.529977 \\ \text { C } & -5.344565 & 0.153179 & -1.811995\end{array}$




\begin{tabular}{|c|c|c|c|}
\hline $\mathrm{H}$ & -5.758953 & 3.994465 & -2.233975 \\
\hline $\mathrm{H}$ & -7.415765 & 2.449626 & -3.238838 \\
\hline $\mathrm{H}$ & -7.113627 & -0.015740 & -2.995154 \\
\hline $\mathrm{H}$ & -5.225318 & -0.920106 & -1.721001 \\
\hline C & -4.152312 & -1.635666 & 0.630166 \\
\hline C & -3.986709 & -3.041642 & 0.854051 \\
\hline C & -4.987758 & -3.758275 & 1.564392 \\
\hline C & -6.094688 & -3.117051 & 2.069634 \\
\hline C & -6.239600 & -1.721745 & 1.888625 \\
\hline C & -5.296800 & -1.001867 & 1.187813 \\
\hline $\mathrm{H}$ & -4.851907 & -4.827076 & 1.712791 \\
\hline $\mathrm{H}$ & -6.849500 & -3.674539 & 2.617546 \\
\hline $\mathrm{H}$ & -7.100718 & -1.210627 & 2.310768 \\
\hline $\mathrm{H}$ & -5.418828 & 0.068095 & 1.067948 \\
\hline $\mathrm{O}$ & 0.940962 & 0.776772 & -0.915061 \\
\hline 0 & 0.482820 & -0.802714 & 1.108000 \\
\hline $\mathrm{H}$ & 1.548851 & -1.464904 & 1.003295 \\
\hline $\mathrm{H}$ & -0.315320 & -4.710315 & 1.219323 \\
\hline $\mathrm{H}$ & 2.666989 & -5.633781 & -1.734017 \\
\hline $\mathrm{H}$ & -0.486479 & -2.858141 & -2.653844 \\
\hline $\mathrm{H}$ & 0.239615 & 2.976946 & -0.809928 \\
\hline $\mathrm{H}$ & 1.127116 & 6.530864 & 1.451870 \\
\hline $\mathrm{H}$ & -2.848388 & 4.891028 & 1.479371 \\
\hline C & 3.370493 & -1.574351 & 0.128145 \\
\hline $\mathrm{O}$ & 2.535197 & -2.061455 & 0.964774 \\
\hline $\mathrm{H}$ & 3.020802 & -0.877768 & -0.637806 \\
\hline C & 4.507608 & -2.494349 & -0.282493 \\
\hline 0 & 4.877025 & -3.462384 & 0.336510 \\
\hline 0 & 5.037671 & -2.068216 & -1.447196 \\
\hline C & 6.116992 & -2.869222 & -1.958850 \\
\hline $\mathrm{H}$ & 6.943730 & -2.900380 & -1.243853 \\
\hline $\mathrm{H}$ & 5.774840 & -3.889339 & -2.151013 \\
\hline C & 4.079290 & 0.981726 & 0.869899 \\
\hline C & 4.644474 & -0.261431 & 1.164395 \\
\hline $\mathrm{H}$ & 2.660900 & 2.413434 & 1.124742 \\
\hline$N$ & 3.030211 & 1.553792 & 1.518789 \\
\hline C & 2.262533 & 1.170632 & 2.645733 \\
\hline $\mathrm{O}$ & 1.369192 & 1.880135 & 3.037874 \\
\hline $\mathrm{O}$ & 2.667585 & 0.021187 & 3.182627 \\
\hline C & 1.790405 & -0.507619 & 4.203912 \\
\hline $\mathrm{H}$ & 2.264643 & -1.432585 & 4.529692 \\
\hline $\mathrm{H}$ & 0.811568 & -0.703036 & 3.763051 \\
\hline $\mathrm{H}$ & 1.702869 & 0.201721 & 5.029262 \\
\hline $\mathrm{H}$ & 5.596389 & -0.452775 & 0.682687 \\
\hline
\end{tabular}




$\begin{array}{llll}\text { H } & 4.481448 & -0.726528 & 2.125672 \\ \mathrm{C} & 4.583746 & 1.763918 & -0.289258 \\ \mathrm{C} & 3.698191 & 2.272213 & -1.256184 \\ \mathrm{C} & 5.962312 & 2.003895 & -0.414660 \\ \mathrm{C} & 4.197514 & 3.013967 & -2.327017 \\ \mathrm{H} & 2.642012 & 2.018002 & -1.205700 \\ \mathrm{C} & 6.447570 & 2.761402 & -1.478137 \\ \mathrm{H} & 6.646819 & 1.624517 & 0.338421 \\ \mathrm{C} & 5.565962 & 3.268037 & -2.435976 \\ \mathrm{H} & 3.511716 & 3.383947 & -3.083741 \\ \mathrm{H} & 7.512969 & 2.958430 & -1.556967 \\ \mathrm{H} & 5.946615 & 3.853610 & -3.268334 \\ \mathrm{H} & 6.425542 & -2.385813 & -2.885641\end{array}$

Catalyst (R)-1 TS Conformation 201

B3LYP/6-31G(d) Energy $=-2809.69168$

B3LYP-D3(BJ)/def2-TZVPP-IEF-PCM(DCM) Energy $=-2810.982109$

B3LYP-D3(BJ)/def2-TZVPP-IEF-PCM(DCM)//B3LYP/6-31G(d) Free Energy (Quasiharmonic) = 2810.34063

Frequencies (Top 3 out of 270)

1. $-737.0551 \mathrm{~cm}-1$

2. $\quad 10.2833 \mathrm{~cm}-1$

3. $14.9653 \mathrm{~cm}-1$

B3LYP/6-31G(d) Molecular Geometry in Cartesian Coordinates

$\begin{array}{llll}\text { C } & 2.877325 & -1.275400 & -0.458615 \\ \text { C } & 1.599936 & -1.770800 & -0.236637 \\ \text { C } & 1.228797 & -3.112745 & -0.556965 \\ \text { C } & 2.163926 & -3.899569 & -1.198657 \\ \text { H } & 1.902216 & -4.923397 & -1.452837 \\ \text { C } & 4.155908 & 2.615232 & 0.876605 \\ \text { C } & 3.290145 & 0.050450 & 0.089745 \\ \text { C } & 2.573826 & 1.193509 & -0.226703 \\ \text { C } & 3.011807 & 2.510475 & 0.108000 \\ \text { H } & 4.542255 & 3.600974 & 1.120441 \\ \text { O } & 0.674981 & -0.987997 & 0.438017 \\ \text { P } & 0.097049 & 0.434069 & -0.153356 \\ \text { O } & 1.390597 & 1.053903 & -0.944128 \\ \text { C } & -2.537870 & -4.909988 & 0.481503\end{array}$




\begin{tabular}{|c|c|c|c|}
\hline$C$ & -2.513896 & -3.757510 & -0.306844 \\
\hline C & -1.295889 & -3.161535 & -0.633264 \\
\hline C & -0.086200 & -3.701553 & -0.176561 \\
\hline C & -0.122610 & -4.862256 & 0.613008 \\
\hline C & -1.339615 & -5.461595 & 0.939645 \\
\hline $\mathrm{H}$ & -3.434112 & -3.309465 & -0.670290 \\
\hline $\mathrm{H}$ & -1.349747 & -6.358572 & 1.554290 \\
\hline C & 1.316595 & 6.186142 & -1.357725 \\
\hline C & 1.749509 & 6.082829 & -0.033976 \\
\hline C & 2.249599 & 4.873058 & 0.447394 \\
\hline C & 2.341086 & 3.743557 & -0.384317 \\
\hline C & 1.882406 & 3.856392 & -1.708620 \\
\hline C & 1.377543 & 5.064678 & -2.187822 \\
\hline $\mathrm{H}$ & 1.700792 & 6.945146 & 0.626582 \\
\hline $\mathrm{H}$ & 1.043656 & 5.132029 & -3.220042 \\
\hline C & 4.427142 & 0.173883 & 0.962939 \\
\hline C & 4.858071 & 1.482202 & 1.352910 \\
\hline C & 5.985646 & 1.622072 & 2.206889 \\
\hline C & 6.647955 & 0.517816 & 2.689974 \\
\hline C & 6.201592 & -0.777417 & 2.337429 \\
\hline C & 5.124519 & -0.945425 & 1.494882 \\
\hline $\mathrm{H}$ & 6.306622 & 2.624178 & 2.481577 \\
\hline $\mathrm{H}$ & 7.503799 & 0.635949 & 3.348915 \\
\hline $\mathrm{H}$ & 6.710858 & -1.649669 & 2.738277 \\
\hline $\mathrm{H}$ & 4.790697 & -1.944908 & 1.242516 \\
\hline C & 3.800851 & -2.069444 & -1.225614 \\
\hline C & 3.433204 & -3.405122 & -1.585333 \\
\hline C & 4.339248 & -4.204060 & -2.333761 \\
\hline C & 5.554929 & -3.704239 & -2.738868 \\
\hline C & 5.908740 & -2.373731 & -2.413916 \\
\hline C & 5.058095 & -1.579656 & -1.676355 \\
\hline $\mathrm{H}$ & 4.044003 & -5.218607 & -2.591039 \\
\hline $\mathrm{H}$ & 6.237395 & -4.321466 & -3.316746 \\
\hline $\mathrm{H}$ & 6.858686 & -1.970812 & -2.754863 \\
\hline $\mathrm{H}$ & 5.341582 & -0.559011 & -1.447164 \\
\hline 0 & -0.355675 & 1.228021 & 1.027958 \\
\hline 0 & -0.881749 & 0.184115 & -1.314199 \\
\hline $\mathrm{H}$ & -2.021732 & -0.156781 & -1.160709 \\
\hline $\mathrm{H}$ & 0.808660 & -5.286092 & 0.980220 \\
\hline $\mathrm{H}$ & -3.485938 & -5.376835 & 0.736709 \\
\hline $\mathrm{H}$ & -1.281894 & -2.281358 & -1.262872 \\
\hline $\mathrm{H}$ & 1.937747 & 2.998806 & -2.369380 \\
\hline $\mathrm{H}$ & 0.934600 & 7.130099 & -1.738079 \\
\hline $\mathrm{H}$ & 2.568367 & 4.797606 & 1.483021 \\
\hline
\end{tabular}




$\begin{array}{llll}\mathrm{C} & -4.112589 & 0.184421 & -1.377956 \\ \mathrm{O} & -3.141640 & -0.614406 & -1.139985 \\ \mathrm{H} & -3.905282 & 1.196736 & -1.736188 \\ \mathrm{C} & -5.371582 & -0.462823 & -1.929585 \\ \mathrm{O} & -5.641172 & -1.638340 & -1.843765 \\ \mathrm{O} & -6.142470 & 0.463312 & -2.534284 \\ \mathrm{C} & -7.366637 & -0.031695 & -3.104958 \\ \mathrm{H} & -7.998331 & -0.473914 & -2.329721 \\ \mathrm{H} & -7.853111 & 0.836170 & -3.549942 \\ \mathrm{C} & -4.034715 & 0.936594 & 1.191333 \\ \mathrm{C} & -5.115530 & 0.928377 & 0.300001 \\ \mathrm{H} & -2.155952 & 1.721962 & 1.579432 \\ \mathrm{~N} & -3.081389 & 1.909887 & 1.177114 \\ \mathrm{C} & -3.133701 & 3.120293 & 0.465999 \\ \mathrm{O} & -3.994829 & 3.454607 & -0.322509 \\ \mathrm{O} & -2.080410 & 3.858297 & 0.822186 \\ \mathrm{C} & -1.945902 & 5.114359 & 0.132362 \\ \mathrm{H} & -2.802732 & 5.757765 & 0.348481 \\ \mathrm{H} & -1.873359 & 4.947684 & -0.944400 \\ \mathrm{H} & -1.020967 & 5.546067 & 0.508814 \\ \mathrm{H} & -5.873639 & 0.176412 & 0.479573 \\ \mathrm{H} & -5.440088 & 1.852203 & -0.156353 \\ \mathrm{C} & -3.813809 & -0.209673 & 2.096640 \\ \mathrm{C} & -4.930283 & -0.884660 & 2.632716 \\ \mathrm{C} & -2.524677 & -0.654687 & 2.448717 \\ \mathrm{C} & -4.763053 & -1.970053 & 3.484723 \\ \mathrm{H} & -5.933243 & -0.535990 & 2.411724 \\ \mathrm{C} & -2.365894 & -1.757142 & 3.284797 \\ \mathrm{H} & -1.638703 & -0.171529 & 2.051479 \\ \mathrm{C} & -3.478757 & -2.416929 & 3.805685 \\ \mathrm{H} & -5.635588 & -2.467035 & 3.898854 \\ \mathrm{H} & -1.363742 & -2.104323 & 3.515904 \\ \mathrm{H} & -3.348097 & -3.274376 & 4.459968 \\ & -7.153886 & -0.787750 & -3.864983\end{array}$

Catalyst (R)-1 TS Conformation 202

B3LYP/6-31G(d) Energy $=-2809.686452$

B3LYP-D3(BJ)/def2-TZVPP-IEF-PCM(DCM) Energy = -2810.982114

B3LYP-D3(BJ)/def2-TZVPP-IEF-PCM(DCM)//B3LYP/6-31G(d) Free Energy (Quasiharmonic) = 2810.340623

Frequencies (Top 3 out of 270) 
1. $-669.9928 \mathrm{~cm}-1$

2. $\quad 8.5268 \mathrm{~cm}-1$

3. $\quad 16.0523 \mathrm{~cm}-1$

B3LYP/6-31G(d) Molecular Geometry in Cartesian Coordinates

$\begin{array}{llll}\mathrm{C} & 3.313201 & -0.119785 & 0.139545 \\ \mathrm{C} & 2.655512 & 1.042706 & -0.231581 \\ \mathrm{C} & 3.145753 & 2.349413 & 0.069745 \\ \mathrm{C} & 4.308629 & 2.428944 & 0.812702 \\ \mathrm{H} & 4.730958 & 3.406367 & 1.029175 \\ \mathrm{C} & 1.843803 & -4.064657 & -0.744985 \\ \mathrm{C} & 2.789385 & -1.451216 & -0.286694 \\ \mathrm{C} & 1.489943 & -1.819918 & 0.033532 \\ \mathrm{C} & 1.004318 & -3.152549 & -0.134816 \\ \mathrm{H} & 1.495448 & -5.083601 & -0.892727 \\ \mathrm{O} & 1.484733 & 0.931695 & -0.972552 \\ \mathrm{P} & 0.116961 & 0.397715 & -0.251061 \\ \mathrm{O} & 0.660840 & -0.884923 & 0.634763 \\ \mathrm{C} & 1.410062 & 6.057261 & -1.258298 \\ \mathrm{C} & 1.875344 & 5.918688 & 0.050790 \\ \mathrm{C} & 2.402426 & 4.701096 & 0.480240 \\ \mathrm{C} & 2.483229 & 3.599200 & -0.389973 \\ \mathrm{C} & 1.998066 & 3.749470 & -1.699719 \\ \mathrm{C} & 1.468375 & 4.965960 & -2.126577 \\ \mathrm{H} & 1.826897 & 6.757280 & 0.741224 \\ \mathrm{H} & 1.095772 & 5.058065 & -3.142656 \\ \mathrm{C} & -2.785433 & -4.589060 & 1.315917 \\ \mathrm{C} & -1.598628 & -5.238216 & 1.656787 \\ \mathrm{C} & -0.377231 & -4.750580 & 1.191577 \\ \mathrm{C} & -0.318473 & -3.606201 & 0.379183 \\ \mathrm{C} & -1.518940 & -2.960409 & 0.043096 \\ \mathrm{C} & -2.739863 & -3.451133 & 0.507231 \\ \mathrm{H} & -1.619789 & -6.121564 & 2.290022 \\ \mathrm{H} & -3.660271 & -2.942252 & 0.233491 \\ \mathrm{C} & 3.612834 & -2.381781 & -1.009226 \\ \mathrm{C} & 3.124770 & -3.708860 & -1.232311 \\ \mathrm{C} & 3.929559 & -4.639429 & -1.943835 \\ \mathrm{C} & 5.159953 & -4.276101 & -2.439850 \\ \mathrm{H} & 5.632873 & -2.956568 & -2.246821 \\ \mathrm{H} & 3.5456697 & -2.035893 & -1.548910 \\ \mathrm{H} & -5.645284 & -2.097867 \\ \mathrm{C} & -4.993781 & -2.987935\end{array}$




\begin{tabular}{|c|c|c|c|}
\hline $\mathrm{H}$ & 6.595241 & -2.664332 & -2.658389 \\
\hline $\mathrm{H}$ & 5.253861 & -1.025850 & -1.418612 \\
\hline C & 4.473153 & -0.016958 & 0.984752 \\
\hline C & 4.977645 & 1.283745 & 1.305833 \\
\hline C & 6.133556 & 1.404903 & 2.124216 \\
\hline C & 6.754734 & 0.291866 & 2.640225 \\
\hline C & 6.234256 & -0.993387 & 2.360432 \\
\hline C & 5.127013 & -1.144391 & 1.554646 \\
\hline $\mathrm{H}$ & 6.509104 & 2.401247 & 2.345552 \\
\hline $\mathrm{H}$ & 7.633259 & 0.396151 & 3.271100 \\
\hline $\mathrm{H}$ & 6.709387 & -1.871506 & 2.789512 \\
\hline $\mathrm{H}$ & 4.737350 & -2.136516 & 1.361032 \\
\hline 0 & -0.866269 & 0.004030 & -1.300922 \\
\hline $\mathrm{O}$ & -0.295011 & 1.429855 & 0.810850 \\
\hline $\mathrm{H}$ & -1.314388 & 1.317824 & 1.472937 \\
\hline $\mathrm{H}$ & 2.040177 & 2.911957 & -2.386477 \\
\hline $\mathrm{H}$ & 1.000224 & 7.005303 & -1.597213 \\
\hline $\mathrm{H}$ & 2.745334 & 4.594410 & 1.505585 \\
\hline$H$ & -1.488819 & -2.082698 & -0.593474 \\
\hline $\mathrm{H}$ & -3.738581 & -4.967329 & 1.676967 \\
\hline $\mathrm{H}$ & 0.546337 & -5.249157 & 1.473232 \\
\hline C & -3.194744 & 0.484176 & 1.718784 \\
\hline 0 & -2.291820 & 1.281167 & 2.143129 \\
\hline $\mathrm{H}$ & -2.940081 & -0.284478 & 0.983616 \\
\hline C & -4.243318 & 0.067874 & 2.740357 \\
\hline 0 & -4.495752 & 0.664418 & 3.758084 \\
\hline 0 & -4.845636 & -1.072738 & 2.340572 \\
\hline C & -5.837792 & -1.589265 & 3.245665 \\
\hline $\mathrm{H}$ & -6.217633 & -2.496507 & 2.776110 \\
\hline $\mathrm{H}$ & -5.385625 & -1.816655 & 4.214186 \\
\hline C & -4.130329 & 1.310672 & -0.740046 \\
\hline C & -4.565261 & 1.545346 & 0.569246 \\
\hline $\mathrm{H}$ & -2.865644 & 1.653600 & -2.285081 \\
\hline$N$ & -3.171065 & 2.018059 & -1.389863 \\
\hline C & -2.369909 & 3.128015 & -1.034350 \\
\hline 0 & -1.573327 & 3.568779 & -1.828108 \\
\hline 0 & -2.628178 & 3.589184 & 0.185242 \\
\hline C & -1.702184 & 4.594249 & 0.665174 \\
\hline $\mathrm{H}$ & -0.705627 & 4.156906 & 0.737256 \\
\hline $\mathrm{H}$ & -2.079641 & 4.873842 & 1.647906 \\
\hline $\mathrm{H}$ & -1.689877 & 5.448687 & -0.013339 \\
\hline $\mathrm{H}$ & -5.488733 & 1.045861 & 0.836912 \\
\hline $\mathrm{H}$ & -4.377177 & 2.498999 & 1.041081 \\
\hline C & -4.669722 & 0.162216 & -1.512222 \\
\hline
\end{tabular}




$\begin{array}{llll}\text { C } & -3.814993 & -0.658818 & -2.272267 \\ \text { C } & -6.049823 & -0.104992 & -1.497978 \\ \text { C } & -4.342795 & -1.727586 & -2.995903 \\ \text { H } & -2.739465 & -0.498915 & -2.242246 \\ \text { C } & -6.568379 & -1.164632 & -2.237677 \\ \text { H } & -6.719790 & 0.539222 & -0.936942 \\ \text { C } & -5.715928 & -1.979684 & -2.986308 \\ \text { H } & -3.673527 & -2.369536 & -3.561032 \\ \text { H } & -7.638616 & -1.350519 & -2.233893 \\ \text { H } & -6.121291 & -2.809810 & -3.558135 \\ \text { H } & -6.641230 & -0.861684 & 3.389646\end{array}$

Catalyst (R)-1 TS Conformation 203

B3LYP/6-31G(d) Energy = -2809.692902

B3LYP-D3(BJ)/def2-TZVPP-IEF-PCM(DCM) Energy = -2810.984926

B3LYP-D3(BJ)/def2-TZVPP-IEF-PCM(DCM)//B3LYP/6-31G(d) Free Energy (Quasiharmonic) = 2810.340616

Frequencies (Top 3 out of 270)

1. $-164.6675 \mathrm{~cm}-1$

2. $\quad 9.5855 \mathrm{~cm}-1$

3. $\quad 12.0681 \mathrm{~cm}-1$

B3LYP/6-31G(d) Molecular Geometry in Cartesian Coordinates

$\begin{array}{llll}\text { C } & 3.302297 & 0.170357 & 0.221351 \\ \text { C } & 2.486096 & 1.227932 & -0.147426 \\ \text { C } & 2.771336 & 2.586997 & 0.180623 \\ \text { C } & 3.888372 & 2.824758 & 0.958927 \\ \text { H } & 4.152127 & 3.850469 & 1.202103 \\ \text { C } & 2.389467 & -3.890300 & -0.868892 \\ \text { C } & 2.986343 & -1.212127 & -0.243309 \\ \text { C } & 1.746074 & -1.766570 & 0.036004 \\ \text { C } & 1.424469 & -3.133724 & -0.228257 \\ \text { H } & 2.202090 & -4.944969 & -1.049121 \\ \text { O } & 1.349742 & 0.953332 & -0.902428 \\ \text { P } & 0.070724 & 0.237302 & -0.178003 \\ \text { O } & 0.793622 & -0.971659 & 0.660275 \\ \text { C } & 0.591024 & 6.026545 & -1.198344 \\ \text { C } & 0.970023 & 5.918234 & 0.141179 \\ \text { C } & 1.643582 & 4.782055 & 0.586552\end{array}$




\begin{tabular}{|c|c|c|c|}
\hline C & 1.951674 & 3.732799 & -0.295797 \\
\hline C & 1.544580 & 3.844141 & -1.634694 \\
\hline C & 0.875280 & 4.982323 & -2.080203 \\
\hline $\mathrm{H}$ & 0.741596 & 6.717634 & 0.841649 \\
\hline $\mathrm{H}$ & 0.574436 & 5.049963 & -3.122016 \\
\hline C & -2.150125 & -5.180515 & 1.033848 \\
\hline C & -1.603130 & -4.176109 & 1.833284 \\
\hline C & -0.467099 & -3.480814 & 1.421281 \\
\hline C & 0.147801 & -3.773092 & 0.191038 \\
\hline C & -0.430746 & -4.769473 & -0.616749 \\
\hline C & -1.559666 & -5.472141 & -0.197680 \\
\hline $\mathrm{H}$ & -2.057716 & -3.929583 & 2.788793 \\
\hline $\mathrm{H}$ & -1.978592 & -6.246012 & -0.836626 \\
\hline C & 3.937883 & -1.987250 & -0.989945 \\
\hline C & 3.626024 & -3.350305 & -1.294840 \\
\hline C & 4.563306 & -4.136300 & -2.019127 \\
\hline C & 5.749545 & -3.595938 & -2.457628 \\
\hline C & 6.044376 & -2.238176 & -2.189645 \\
\hline C & 5.165426 & -1.456083 & -1.473013 \\
\hline $\mathrm{H}$ & 4.315812 & -5.173845 & -2.231287 \\
\hline $\mathrm{H}$ & 6.455131 & -4.203400 & -3.017806 \\
\hline $\mathrm{H}$ & 6.971666 & -1.806426 & -2.556489 \\
\hline $\mathrm{H}$ & 5.401738 & -0.415437 & -1.283367 \\
\hline C & 4.416649 & 0.428025 & 1.092943 \\
\hline C & 4.709231 & 1.782597 & 1.452429 \\
\hline C & 5.813401 & 2.057429 & 2.304242 \\
\hline C & 6.584907 & 1.039141 & 2.813382 \\
\hline C & 6.274740 & -0.303222 & 2.492216 \\
\hline C & 5.222199 & -0.600979 & 1.654640 \\
\hline $\mathrm{H}$ & 6.027792 & 3.093453 & 2.555985 \\
\hline $\mathrm{H}$ & 7.422196 & 1.260342 & 3.469676 \\
\hline $\mathrm{H}$ & 6.869494 & -1.108865 & 2.914306 \\
\hline $\mathrm{H}$ & 4.993231 & -1.635700 & 1.428617 \\
\hline $\mathrm{O}$ & -0.887360 & -0.224260 & -1.220876 \\
\hline $\mathrm{O}$ & -0.401004 & 1.164403 & 0.971940 \\
\hline $\mathrm{H}$ & -1.405820 & 1.491996 & 1.026974 \\
\hline $\mathrm{H}$ & 1.757449 & 3.039451 & -2.329401 \\
\hline $\mathrm{H}$ & 0.076138 & 6.916996 & -1.551110 \\
\hline $\mathrm{H}$ & 1.922406 & 4.695262 & 1.632889 \\
\hline $\mathrm{H}$ & 0.005283 & -4.988548 & -1.587166 \\
\hline $\mathrm{H}$ & -3.030770 & -5.726213 & 1.362786 \\
\hline $\mathrm{H}$ & -0.053476 & -2.710418 & 2.060124 \\
\hline C & -3.766804 & 1.743205 & 1.599192 \\
\hline $\mathrm{O}$ & -2.653012 & 2.222321 & 1.151573 \\
\hline
\end{tabular}




$\begin{array}{lrrr}\text { H } & -4.379704 & 2.410365 & 2.229197 \\ \mathrm{C} & -3.732531 & 0.332066 & 2.198571 \\ \mathrm{O} & -2.858412 & -0.482213 & 2.005100 \\ \mathrm{O} & -4.822211 & 0.104728 & 2.967208 \\ \mathrm{C} & -4.898134 & -1.206290 & 3.552577 \\ \mathrm{H} & -4.901244 & -1.973246 & 2.773553 \\ \mathrm{H} & -4.047060 & -1.376485 & 4.217340 \\ \mathrm{C} & -4.353901 & 0.810051 & -0.708577 \\ \mathrm{C} & -5.021496 & 1.610527 & 0.265716 \\ \mathrm{H} & -2.557925 & 0.606300 & -1.677311 \\ \mathrm{~N} & -3.275309 & 1.276171 & -1.362921 \\ \mathrm{C} & -2.780521 & 2.599546 & -1.513221 \\ \mathrm{O} & -1.661779 & 2.794256 & -1.919266 \\ \mathrm{O} & -3.708427 & 3.541207 & -1.301866 \\ \mathrm{C} & -3.194524 & 4.888056 & -1.335132 \\ \mathrm{H} & -2.418227 & 5.005504 & -0.576469 \\ \mathrm{H} & -4.052822 & 5.525261 & -1.121149 \\ \mathrm{H} & -2.780740 & 5.111859 & -2.320528 \\ \mathrm{H} & -5.907295 & 1.162876 & 0.706269 \\ \mathrm{H} & -5.123973 & 2.664041 & 0.043287 \\ \mathrm{C} & -4.705893 & -0.614730 & -0.878707 \\ \mathrm{C} & -6.068362 & -0.973347 & -0.840909 \\ \mathrm{C} & -3.742432 & -1.614300 & -1.112998 \\ \mathrm{C} & -6.459823 & -2.293215 & -1.044597 \\ \mathrm{H} & -6.824503 & -0.209415 & -0.691472 \\ \mathrm{C} & -4.143330 & -2.934643 & -1.301329 \\ \mathrm{H} & -2.682775 & -1.376914 & -1.103625 \\ \mathrm{C} & -5.496574 & -3.277954 & -1.273133 \\ \mathrm{H} & -7.515368 & -2.549802 & -1.030997 \\ \mathrm{H} & -3.387347 & -3.697789 & -1.453113 \\ \mathrm{H} & -5.800204 & -4.309985 & -1.427567 \\ \mathrm{H} & -5.832082 & -1.223466 & 4.115262\end{array}$

Catalyst (R)-1 TS Conformation 204

$B 3 L Y P / 6-31 G(d)$ Energy $=-2809.685615$

B3LYP-D3(BJ)/def2-TZVPP-IEF-PCM(DCM) Energy $=-2810.983609$

B3LYP-D3(BJ)/def2-TZVPP-IEF-PCM(DCM)//B3LYP/6-31G(d) Free Energy (Quasiharmonic) = 2810.340612

Frequencies (Top 3 out of 270)

1. $-383.9961 \mathrm{~cm}-1$ 
2. $\quad 9.0248 \mathrm{~cm}-1$

3. $\quad 16.3335 \mathrm{~cm}-1$

B3LYP/6-31G(d) Molecular Geometry in Cartesian Coordinates

\begin{tabular}{|c|c|c|c|}
\hline C & 2.870537 & -1.054979 & -0.141746 \\
\hline C & 1.655930 & -1.721596 & -0.230164 \\
\hline C & 1.552822 & -3.062613 & -0.709462 \\
\hline C & 2.711194 & -3.688517 & -1.124318 \\
\hline $\mathrm{H}$ & 2.652572 & -4.710755 & -1.489057 \\
\hline C & 3.247040 & 2.967841 & 1.329439 \\
\hline C & 2.948170 & 0.305258 & 0.464284 \\
\hline C & 2.163650 & 1.328793 & -0.044277 \\
\hline C & 2.334247 & 2.696559 & 0.327172 \\
\hline $\mathrm{H}$ & 3.429707 & 4.000485 & 1.613728 \\
\hline $\mathrm{O}$ & 0.512226 & -1.120762 & 0.270763 \\
\hline$P$ & -0.139330 & 0.240803 & -0.363736 \\
\hline 0 & 1.181065 & 1.006485 & -0.977478 \\
\hline C & -2.024786 & -5.421696 & -1.075148 \\
\hline C & -1.900732 & -4.226333 & -1.787223 \\
\hline C & -0.765168 & -3.430329 & -1.638210 \\
\hline C & 0.272117 & -3.824242 & -0.781537 \\
\hline C & 0.138719 & -5.025791 & -0.068783 \\
\hline C & -1.002280 & -5.817233 & -0.209690 \\
\hline $\mathrm{H}$ & -2.686582 & -3.904545 & -2.465053 \\
\hline $\mathrm{H}$ & -1.086546 & -6.746163 & 0.349117 \\
\hline C & 0.637254 & 6.109679 & -1.667514 \\
\hline C & 0.719468 & 6.073715 & -0.273791 \\
\hline C & 1.217022 & 4.940583 & 0.369534 \\
\hline C & 1.652016 & 3.823104 & -0.363592 \\
\hline C & 1.536251 & 3.861624 & -1.763913 \\
\hline C & 1.038306 & 4.994224 & -2.406573 \\
\hline $\mathrm{H}$ & 0.400847 & 6.930267 & 0.315304 \\
\hline $\mathrm{H}$ & 0.978378 & 5.009071 & -3.491864 \\
\hline C & 3.828573 & 0.592882 & 1.563658 \\
\hline C & 3.969779 & 1.949689 & 1.996400 \\
\hline C & 4.840169 & 2.251114 & 3.078758 \\
\hline C & 5.522507 & 1.253731 & 3.735558 \\
\hline C & 5.356947 & -0.092630 & 3.333592 \\
\hline C & 4.536558 & -0.414462 & 2.274667 \\
\hline $\mathrm{H}$ & 4.945350 & 3.288942 & 3.386282 \\
\hline $\mathrm{H}$ & 6.178391 & 1.494175 & 4.567835 \\
\hline $\mathrm{H}$ & 5.878452 & -0.881791 & 3.868489 \\
\hline $\mathrm{H}$ & 4.411956 & -1.451408 & 1.985088 \\
\hline
\end{tabular}




\begin{tabular}{|c|c|c|c|}
\hline C & 4.048929 & -1.679868 & -0.682098 \\
\hline C & 3.962614 & -3.028256 & -1.153003 \\
\hline C & 5.121037 & -3.667987 & -1.671079 \\
\hline C & 6.320511 & -3.000373 & -1.752427 \\
\hline C & 6.402186 & -1.654337 & -1.324792 \\
\hline C & 5.300127 & -1.012609 & -0.803877 \\
\hline $\mathrm{H}$ & 5.034344 & -4.695803 & -2.015776 \\
\hline $\mathrm{H}$ & 7.199203 & -3.496135 & -2.155928 \\
\hline $\mathrm{H}$ & 7.342928 & -1.117591 & -1.413970 \\
\hline $\mathrm{H}$ & 5.381644 & 0.022039 & -0.492969 \\
\hline $\mathrm{O}$ & -0.812441 & 1.023393 & 0.709917 \\
\hline $\mathrm{O}$ & -0.900527 & -0.110678 & -1.667291 \\
\hline $\mathrm{H}$ & -1.938421 & -0.486189 & -1.665523 \\
\hline $\mathrm{H}$ & 0.936057 & -5.336627 & 0.601177 \\
\hline $\mathrm{H}$ & -2.908796 & -6.042701 & -1.197465 \\
\hline $\mathrm{H}$ & -0.679524 & -2.505011 & -2.196125 \\
\hline $\mathrm{H}$ & 1.856760 & 3.008032 & -2.350755 \\
\hline $\mathrm{H}$ & 0.264282 & 6.997539 & -2.172049 \\
\hline$H$ & 1.268970 & 4.916736 & 1.454335 \\
\hline C & -4.066163 & -1.283728 & -1.086504 \\
\hline $\mathrm{O}$ & -3.200049 & -0.916815 & -1.983715 \\
\hline $\mathrm{H}$ & -4.941939 & -1.828785 & -1.474033 \\
\hline C & -3.515959 & -1.972226 & 0.164144 \\
\hline $\mathrm{O}$ & -2.441956 & -1.725221 & 0.664363 \\
\hline $\mathrm{O}$ & -4.390878 & -2.873895 & 0.655776 \\
\hline C & -3.934879 & -3.594228 & 1.817652 \\
\hline $\mathrm{H}$ & -3.072003 & -4.211910 & 1.557167 \\
\hline $\mathrm{H}$ & -3.649989 & -2.900505 & 2.613197 \\
\hline C & -4.085753 & 1.055155 & 0.120637 \\
\hline C & -5.030384 & 0.079266 & -0.328044 \\
\hline $\mathrm{H}$ & -2.455254 & 1.191276 & 1.326474 \\
\hline$N$ & -3.478622 & 1.000581 & 1.338296 \\
\hline C & -3.907385 & 0.448839 & 2.553974 \\
\hline $\mathrm{O}$ & -3.172958 & 0.351278 & 3.507906 \\
\hline $\mathrm{O}$ & -5.216642 & 0.126499 & 2.553579 \\
\hline C & -5.716238 & -0.345263 & 3.818613 \\
\hline $\mathrm{H}$ & -5.584616 & 0.419142 & 4.587915 \\
\hline $\mathrm{H}$ & -5.192602 & -1.254438 & 4.122757 \\
\hline $\mathrm{H}$ & -6.774204 & -0.546859 & 3.651019 \\
\hline $\mathrm{H}$ & -5.660294 & 0.415887 & -1.146583 \\
\hline $\mathrm{H}$ & -5.591613 & -0.432537 & 0.445131 \\
\hline C & -3.581662 & 2.073574 & -0.793283 \\
\hline C & -2.940038 & 3.226927 & -0.286496 \\
\hline C & -3.753297 & 1.949979 & -2.190440 \\
\hline
\end{tabular}




$\begin{array}{llll}\mathrm{C} & -2.490426 & 4.218527 & -1.144282 \\ \mathrm{H} & -2.817145 & 3.349299 & 0.783436 \\ \mathrm{C} & -3.281897 & 2.942162 & -3.044076 \\ \mathrm{H} & -4.193665 & 1.055120 & -2.607774 \\ \mathrm{C} & -2.655727 & 4.076003 & -2.525975 \\ \mathrm{H} & -1.993079 & 5.094694 & -0.743299 \\ \mathrm{H} & -3.398941 & 2.824157 & -4.117180 \\ \mathrm{H} & -2.291741 & 4.851051 & -3.194370 \\ \mathrm{H} & -4.776722 & -4.216139 & 2.124120\end{array}$

Catalyst (R)-1 TS Conformation 205

B3LYP/6-31G(d) Energy $=-2809.693894$

B3LYP-D3(BJ)/def2-TZVPP-IEF-PCM(DCM) Energy $=-2810.98441$

B3LYP-D3(BJ)/def2-TZVPP-IEF-PCM(DCM)//B3LYP/6-31G(d) Free Energy (Quasiharmonic) = 2810.340602

Frequencies (Top 3 out of 270)

1. $-253.2195 \mathrm{~cm}-1$

2. $\quad 6.9358 \mathrm{~cm}-1$

3. $12.6922 \mathrm{~cm}-1$

B3LYP/6-31G(d) Molecular Geometry in Cartesian Coordinates

$\begin{array}{lrrr}\text { C } & 2.944842 & -1.361922 & -0.256514 \\ \text { C } & 1.656950 & -1.699699 & 0.127290 \\ \text { C } & 1.085274 & -2.989646 & -0.074460 \\ \text { C } & 1.863497 & -3.929696 & -0.720927 \\ \text { H } & 1.468758 & -4.931163 & -0.871302 \\ \text { C } & 4.428402 & 2.615117 & 0.512907 \\ \text { C } & 3.471909 & -0.000209 & 0.058771 \\ \text { C } & 2.769450 & 1.122469 & -0.354390 \\ \text { C } & 3.232596 & 2.457851 & -0.162236 \\ \text { H } & 4.828230 & 3.615964 & 0.651536 \\ \text { O } & 0.875431 & -0.730701 & 0.750898 \\ \text { P } & 0.255061 & 0.470417 & -0.173715 \\ \text { O } & 1.561018 & 0.942321 & -1.024102 \\ \text { C } & -2.904324 & -4.020207 & 1.170983 \\ \text { C } & -2.045841 & -3.363095 & 2.055819 \\ \text { C } & -0.755529 & -3.013893 & 1.657867 \\ \text { C } & -0.296029 & -3.321241 & 0.366322 \\ \text { C } & -1.167844 & -3.985681 & -0.512305\end{array}$




\begin{tabular}{|c|c|c|c|}
\hline C & -2.459606 & -4.330494 & -0.115580 \\
\hline $\mathrm{H}$ & -2.381673 & -3.115373 & 3.059427 \\
\hline $\mathrm{H}$ & -3.127675 & -4.823397 & -0.816187 \\
\hline C & 1.175323 & 5.971633 & -1.552151 \\
\hline C & 1.719074 & 5.928284 & -0.267901 \\
\hline C & 2.365836 & 4.777228 & 0.178957 \\
\hline C & 2.484600 & 3.647968 & -0.648367 \\
\hline C & 1.928523 & 3.703243 & -1.937262 \\
\hline C & 1.281720 & 4.854463 & -2.382219 \\
\hline $\mathrm{H}$ & 1.631715 & 6.787238 & 0.392541 \\
\hline $\mathrm{H}$ & 0.857027 & 4.875955 & -3.382113 \\
\hline C & 4.671330 & 0.187385 & 0.828604 \\
\hline C & 5.154674 & 1.519309 & 1.038352 \\
\hline C & 6.347838 & 1.719420 & 1.784913 \\
\hline C & 7.025280 & 0.656647 & 2.335251 \\
\hline C & 6.527967 & -0.656841 & 2.164594 \\
\hline C & 5.384528 & -0.885691 & 1.431133 \\
\hline $\mathrm{H}$ & 6.707640 & 2.736321 & 1.922977 \\
\hline$H$ & 7.932460 & 0.822557 & 2.909829 \\
\hline $\mathrm{H}$ & 7.050382 & -1.493681 & 2.620296 \\
\hline $\mathrm{H}$ & 5.012491 & -1.897274 & 1.318171 \\
\hline C & 3.713806 & -2.327864 & -0.993125 \\
\hline C & 3.160262 & -3.632132 & -1.207629 \\
\hline C & 3.914477 & -4.600960 & -1.923850 \\
\hline C & 5.151638 & -4.294697 & -2.440690 \\
\hline C & 5.683108 & -2.995361 & -2.265927 \\
\hline C & 4.985179 & -2.039193 & -1.561348 \\
\hline $\mathrm{H}$ & 3.484534 & -5.589560 & -2.066757 \\
\hline $\mathrm{H}$ & 5.715623 & -5.041458 & -2.992821 \\
\hline $\mathrm{H}$ & 6.649481 & -2.746745 & -2.696196 \\
\hline $\mathrm{H}$ & 5.402547 & -1.045807 & -1.445556 \\
\hline $\mathrm{O}$ & -0.339309 & 1.486419 & 0.736799 \\
\hline $\mathrm{O}$ & -0.609373 & -0.177232 & -1.290349 \\
\hline $\mathrm{H}$ & -1.667007 & -0.088266 & -1.293306 \\
\hline $\mathrm{H}$ & -0.835636 & -4.204589 & -1.523238 \\
\hline $\mathrm{H}$ & -3.916305 & -4.274822 & 1.472363 \\
\hline $\mathrm{H}$ & -0.097607 & -2.501928 & 2.351893 \\
\hline $\mathrm{H}$ & 2.005412 & 2.843347 & -2.593021 \\
\hline $\mathrm{H}$ & 0.665483 & 6.865864 & -1.900913 \\
\hline $\mathrm{H}$ & 2.764185 & 4.740404 & 1.189113 \\
\hline C & -3.866661 & -0.746017 & -0.749562 \\
\hline $\mathrm{O}$ & -3.084570 & -0.059707 & -1.498649 \\
\hline $\mathrm{H}$ & -3.449120 & -1.380798 & 0.044122 \\
\hline C & -5.052185 & -1.464696 & -1.397347 \\
\hline
\end{tabular}




$\begin{array}{llll}\mathrm{O} & -5.549665 & -2.471372 & -0.936810 \\ \mathrm{O} & -5.467019 & -0.858949 & -2.523009 \\ \mathrm{C} & -6.559237 & -1.506716 & -3.196342 \\ \mathrm{H} & -7.439611 & -1.552040 & -2.549091 \\ \mathrm{H} & -6.760986 & -0.898198 & -4.078178 \\ \mathrm{C} & -3.960334 & 1.125262 & 1.031304 \\ \mathrm{C} & -4.977404 & 0.442365 & 0.332509 \\ \mathrm{H} & -2.178470 & 2.117224 & 0.792169 \\ \mathrm{~N} & -3.122163 & 1.987214 & 0.406982 \\ \mathrm{C} & -3.182286 & 2.541360 & -0.899055 \\ \mathrm{O} & -2.202325 & 3.006572 & -1.426464 \\ \mathrm{O} & -4.431207 & 2.590072 & -1.384456 \\ \mathrm{C} & -4.511484 & 2.921631 & -2.783919 \\ \mathrm{H} & -3.990506 & 3.859258 & -2.985374 \\ \mathrm{H} & -5.576723 & 3.014874 & -2.996037 \\ \mathrm{H} & -4.070668 & 2.110462 & -3.368095 \\ \mathrm{H} & -5.608475 & -0.212810 & 0.923270 \\ \mathrm{H} & -5.465530 & 0.947235 & -0.488411 \\ \mathrm{C} & -3.673482 & 0.776240 & 2.444927 \\ \mathrm{C} & -4.760196 & 0.493158 & 3.296330 \\ \mathrm{C} & -2.371062 & 0.738295 & 2.977393 \\ \mathrm{C} & -4.553388 & 0.177366 & 4.635882 \\ \mathrm{H} & -5.774279 & 0.554727 & 2.915645 \\ \mathrm{C} & -2.172271 & 0.408671 & 4.317078 \\ \mathrm{H} & -1.507321 & 0.929930 & 2.348283 \\ \mathrm{C} & -3.256320 & 0.128726 & 5.150526 \\ \mathrm{H} & -5.406041 & -0.024285 & 5.278020 \\ \mathrm{H} & -1.159171 & 0.369765 & 4.707070 \\ \mathrm{H} & -3.092906 & -0.121048 & 6.195360 \\ \mathrm{H} & -6.280491 & -2.522851 & -3.487147\end{array}$

Catalyst (R)-1 TS Conformation 206

B3LYP/6-31G(d) Energy $=-2809.69205$

B3LYP-D3(BJ)/def2-TZVPP-IEF-PCM(DCM) Energy $=-2810.981723$

B3LYP-D3(BJ)/def2-TZVPP-IEF-PCM(DCM)//B3LYP/6-31G(d) Free Energy (Quasiharmonic) = 2810.340581

Frequencies (Top 3 out of 270 )

1. $-731.9633 \mathrm{~cm}-1$

2. $\quad 7.8840 \mathrm{~cm}-1$

3. $\quad 10.7332 \mathrm{~cm}-1$ 
B3LYP/6-31G(d) Molecular Geometry in Cartesian Coordinates

\begin{tabular}{|c|c|c|c|}
\hline C & -3.354877 & -1.025483 & 0.243986 \\
\hline C & -2.196602 & -1.530250 & -0.330795 \\
\hline C & -1.862231 & -2.918239 & -0.319766 \\
\hline C & -2.693077 & -3.764130 & 0.388320 \\
\hline $\mathrm{H}$ & -2.460584 & -4.825362 & 0.419801 \\
\hline C & -4.457199 & 3.109836 & -0.338040 \\
\hline C & -3.754834 & 0.393800 & 0.001506 \\
\hline C & -2.878643 & 1.425365 & 0.297011 \\
\hline C & -3.207046 & 2.806066 & 0.163767 \\
\hline $\mathrm{H}$ & -4.752690 & 4.151792 & -0.428611 \\
\hline 0 & -1.372003 & -0.667850 & -1.042502 \\
\hline$P$ & -0.512845 & 0.482539 & -0.253883 \\
\hline 0 & -1.612598 & 1.104146 & 0.776847 \\
\hline C & 1.389500 & -4.600686 & -2.584550 \\
\hline C & 1.635462 & -3.553357 & -1.693932 \\
\hline C & 0.592384 & -2.997890 & -0.952836 \\
\hline C & -0.719609 & -3.475511 & -1.097889 \\
\hline C & -0.953385 & -4.533667 & -1.991087 \\
\hline C & 0.091742 & -5.093293 & -2.726523 \\
\hline $\mathrm{H}$ & 2.642262 & -3.157799 & -1.582291 \\
\hline $\mathrm{H}$ & -0.112206 & -5.906545 & -3.418493 \\
\hline C & -0.582380 & 6.029320 & 1.276081 \\
\hline C & -0.749624 & 4.939187 & 2.132831 \\
\hline C & -1.579335 & 3.878951 & 1.771809 \\
\hline C & -2.264430 & 3.891535 & 0.545133 \\
\hline C & -2.084391 & 4.991435 & -0.308972 \\
\hline C & -1.251804 & 6.050240 & 0.051964 \\
\hline $\mathrm{H}$ & -0.235366 & 4.914734 & 3.090279 \\
\hline $\mathrm{H}$ & -1.121006 & 6.887715 & -0.628452 \\
\hline C & -5.023019 & 0.727205 & -0.592320 \\
\hline C & -5.372406 & 2.108440 & -0.745012 \\
\hline C & -6.626981 & 2.453315 & -1.317221 \\
\hline C & -7.495892 & 1.482175 & -1.756624 \\
\hline C & -7.136307 & 0.118681 & -1.646415 \\
\hline C & -5.935658 & -0.248820 & -1.079458 \\
\hline $\mathrm{H}$ & -6.879939 & 3.506650 & -1.412926 \\
\hline $\mathrm{H}$ & -8.449116 & 1.758021 & -2.199263 \\
\hline $\mathrm{H}$ & -7.811339 & -0.647752 & -2.017625 \\
\hline $\mathrm{H}$ & -5.673197 & -1.297841 & -1.013826 \\
\hline C & -4.152233 & -1.902054 & 1.058492 \\
\hline C & -3.811107 & -3.291552 & 1.118547 \\
\hline
\end{tabular}




\begin{tabular}{|c|c|c|c|}
\hline$C$ & -4.593358 & -4.168573 & 1.917787 \\
\hline C & -5.657497 & -3.698056 & 2.651378 \\
\hline C & -5.978282 & -2.320534 & 2.618575 \\
\hline C & -5.248190 & -1.447273 & 1.842513 \\
\hline $\mathrm{H}$ & -4.323968 & -5.221788 & 1.946403 \\
\hline $\mathrm{H}$ & -6.244362 & -4.376944 & 3.264076 \\
\hline $\mathrm{H}$ & -6.804940 & -1.945976 & 3.216323 \\
\hline $\mathrm{H}$ & -5.499894 & -0.392909 & 1.836694 \\
\hline 0 & 0.613393 & -0.066923 & 0.564072 \\
\hline O & -0.186873 & 1.512372 & -1.343721 \\
\hline $\mathrm{H}$ & 0.895310 & 1.537136 & -1.856927 \\
\hline $\mathrm{H}$ & -1.966882 & -4.903068 & -2.123732 \\
\hline $\mathrm{H}$ & 2.203347 & -5.028216 & -3.164570 \\
\hline $\mathrm{H}$ & 0.792444 & -2.199992 & -0.246956 \\
\hline $\mathrm{H}$ & -2.585050 & 5.001858 & -1.272990 \\
\hline $\mathrm{H}$ & 0.066978 & 6.853717 & 1.559217 \\
\hline $\mathrm{H}$ & -1.704882 & 3.039035 & 2.446556 \\
\hline C & 2.748097 & 0.681432 & -1.735438 \\
\hline $\mathrm{O}$ & 2.017393 & 1.546221 & -2.331096 \\
\hline $\mathrm{H}$ & 2.277036 & -0.158452 & -1.217905 \\
\hline C & 4.080030 & 0.298115 & -2.342786 \\
\hline 0 & 4.543657 & -0.818026 & -2.212041 \\
\hline $\mathrm{O}$ & 4.660436 & 1.299095 & -3.011138 \\
\hline C & 5.927402 & 0.982849 & -3.618089 \\
\hline $\mathrm{H}$ & 5.812851 & 0.162386 & -4.330662 \\
\hline $\mathrm{H}$ & 6.239018 & 1.894392 & -4.127559 \\
\hline C & 4.031495 & 0.623924 & 0.785102 \\
\hline C & 3.387707 & 1.582602 & -0.006866 \\
\hline $\mathrm{H}$ & 2.241631 & -0.255962 & 1.238097 \\
\hline $\mathrm{N}$ & 3.252648 & -0.269629 & 1.461702 \\
\hline C & 3.547263 & -1.105987 & 2.551411 \\
\hline 0 & 2.772345 & -1.952690 & 2.931444 \\
\hline 0 & 4.726463 & -0.816983 & 3.124899 \\
\hline C & 5.068647 & -1.650890 & 4.246933 \\
\hline $\mathrm{H}$ & 6.049480 & -1.303834 & 4.571455 \\
\hline $\mathrm{H}$ & 5.108833 & -2.700551 & 3.946049 \\
\hline $\mathrm{H}$ & 4.331968 & -1.533849 & 5.045169 \\
\hline $\mathrm{H}$ & 3.999335 & 2.350779 & -0.465534 \\
\hline $\mathrm{H}$ & 2.375185 & 1.863721 & 0.260323 \\
\hline C & 5.502299 & 0.483133 & 0.731979 \\
\hline C & 6.103797 & -0.769529 & 0.517068 \\
\hline C & 6.312614 & 1.627527 & 0.810320 \\
\hline C & 7.485593 & -0.869834 & 0.388077 \\
\hline $\mathrm{H}$ & 5.482693 & -1.651752 & 0.407861 \\
\hline
\end{tabular}




$\begin{array}{llll}\mathrm{C} & 7.697602 & 1.520033 & 0.699909 \\ \mathrm{H} & 5.855108 & 2.596271 & 0.986844 \\ \mathrm{C} & 8.286131 & 0.271867 & 0.485994 \\ \mathrm{H} & 7.938727 & -1.839687 & 0.204196 \\ \mathrm{H} & 8.315550 & 2.409662 & 0.780954 \\ \mathrm{H} & 9.365471 & 0.188507 & 0.392151 \\ \mathrm{H} & 6.654435 & 0.697776 & -2.853140\end{array}$

Catalyst (R)-1 TS Conformation 207

B3LYP/6-31G(d) Energy $=-2809.689999$

B3LYP-D3(BJ)/def2-TZVPP-IEF-PCM(DCM) Energy = -2810.982919

B3LYP-D3(BJ)/def2-TZVPP-IEF-PCM(DCM)//B3LYP/6-31G(d) Free Energy (Quasiharmonic) = 2810.340574

Frequencies (Top 3 out of 270)

1. $-628.7750 \mathrm{~cm}-1$

2. $\quad 9.2563 \mathrm{~cm}-1$

3. $11.2575 \mathrm{~cm}-1$

B3LYP/6-31G(d) Molecular Geometry in Cartesian Coordinates

$\begin{array}{lrrr}\text { C } & 3.495233 & -1.126334 & -0.089691 \\ \text { C } & 2.243869 & -1.691574 & 0.100828 \\ \text { C } & 1.928184 & -3.037053 & -0.250695 \\ \text { C } & 2.924742 & -3.789501 & -0.839665 \\ \text { H } & 2.724386 & -4.825971 & -1.098919 \\ \text { C } & 4.178397 & 2.981228 & 1.042024 \\ \text { C } & 3.739687 & 0.277615 & 0.357808 \\ \text { C } & 2.910167 & 1.293392 & -0.096173 \\ \text { C } & 3.123101 & 2.671504 & 0.206055 \\ \text { H } & 4.385261 & 4.023441 & 1.270643 \\ \text { O } & 1.246691 & -0.919178 & 0.676878 \\ \text { P } & 0.524067 & 0.243832 & -0.235772 \\ \text { O } & 1.836942 & 0.965815 & -0.912120 \\ \text { C } & -1.961829 & -4.768374 & 0.390036 \\ \text { C } & -1.332887 & -4.062911 & 1.419543 \\ \text { C } & -0.077863 & -3.488987 & 1.219099 \\ \text { C } & 0.577519 & -3.614275 & -0.017903 \\ \text { C } & -0.061610 & -4.331214 & -1.041919 \\ \text { C } & -1.318604 & -4.902141 & -0.841116 \\ \text { H } & -1.821268 & -3.959936 & 2.385322\end{array}$




\begin{tabular}{|c|c|c|c|}
\hline $\mathrm{H}$ & -1.799956 & -5.441661 & -1.652689 \\
\hline C & 0.763995 & 5.896812 & -1.394299 \\
\hline C & 1.181549 & 4.856482 & -2.228726 \\
\hline C & 1.922220 & 3.792986 & -1.714082 \\
\hline C & 2.267384 & 3.752608 & -0.352457 \\
\hline C & 1.834623 & 4.800779 & 0.476279 \\
\hline C & 1.090577 & 5.862114 & -0.037658 \\
\hline $\mathrm{H}$ & 0.938502 & 4.875811 & -3.288152 \\
\hline $\mathrm{H}$ & 0.762293 & 6.659298 & 0.624312 \\
\hline C & 4.786067 & 0.609610 & 1.285515 \\
\hline C & 5.006538 & 1.986060 & 1.615936 \\
\hline C & 6.045570 & 2.328710 & 2.523340 \\
\hline C & 6.820629 & 1.356990 & 3.112107 \\
\hline C & 6.579885 & -0.005828 & 2.818285 \\
\hline C & 5.592154 & -0.369521 & 1.929485 \\
\hline $\mathrm{H}$ & 6.206958 & 3.379453 & 2.752830 \\
\hline $\mathrm{H}$ & 7.607432 & 1.630632 & 3.809778 \\
\hline $\mathrm{H}$ & 7.176762 & -0.774322 & 3.302143 \\
\hline $\mathrm{H}$ & 5.414317 & -1.418504 & 1.723042 \\
\hline C & 4.500176 & -1.898444 & -0.768582 \\
\hline C & 4.204210 & -3.253831 & -1.128282 \\
\hline C & 5.193006 & -4.032878 & -1.788217 \\
\hline C & 6.416485 & -3.496164 & -2.114858 \\
\hline C & 6.696985 & -2.146338 & -1.798021 \\
\hline C & 5.766398 & -1.369754 & -1.143100 \\
\hline $\mathrm{H}$ & 4.955394 & -5.063240 & -2.042515 \\
\hline $\mathrm{H}$ & 7.161776 & -4.099698 & -2.625702 \\
\hline $\mathrm{H}$ & 7.654338 & -1.715343 & -2.078538 \\
\hline $\mathrm{H}$ & 5.994366 & -0.334665 & -0.917195 \\
\hline $\mathrm{O}$ & -0.292467 & 1.102300 & 0.664735 \\
\hline 0 & -0.152414 & -0.415485 & -1.453473 \\
\hline $\mathrm{H}$ & -1.319360 & -0.332847 & -1.513002 \\
\hline $\mathrm{H}$ & 0.421420 & -4.413990 & -2.011389 \\
\hline $\mathrm{H}$ & -2.948115 & -5.196533 & 0.543404 \\
\hline $\mathrm{H}$ & 0.400020 & -2.940853 & 2.023908 \\
\hline $\mathrm{H}$ & 2.067684 & 4.768984 & 1.536800 \\
\hline $\mathrm{H}$ & 0.191272 & 6.727581 & -1.798937 \\
\hline $\mathrm{H}$ & 2.243634 & 2.993192 & -2.371913 \\
\hline C & -3.042465 & -1.011934 & -0.572135 \\
\hline $\mathrm{O}$ & -2.562035 & -0.322028 & -1.548904 \\
\hline $\mathrm{H}$ & -2.363444 & -1.672673 & -0.015750 \\
\hline C & -4.394717 & -1.688999 & -0.762380 \\
\hline $\mathrm{O}$ & -4.801836 & -2.568862 & -0.025823 \\
\hline $\mathrm{O}$ & -5.074272 & -1.201043 & -1.805261 \\
\hline
\end{tabular}




$\begin{array}{llll}\mathrm{C} & -6.355849 & -1.814634 & -2.050961 \\ \mathrm{H} & -6.737000 & -1.332150 & -2.950928 \\ \mathrm{H} & -6.236895 & -2.888924 & -2.211374 \\ \mathrm{C} & -4.458583 & 0.923374 & 0.699406 \\ \mathrm{C} & -3.406937 & 0.039682 & 1.015308 \\ \mathrm{H} & -6.447736 & 1.058376 & 0.269383 \\ \mathrm{~N} & -5.778859 & 0.565607 & 0.847597 \\ \mathrm{C} & -6.430895 & -0.471055 & 1.540758 \\ \mathrm{O} & -7.585755 & -0.739764 & 1.284257 \\ \mathrm{O} & -5.680439 & -1.032942 & 2.485074 \\ \mathrm{C} & -6.252204 & -2.209063 & 3.098022 \\ \mathrm{H} & -6.331875 & -3.000832 & 2.350500 \\ \mathrm{H} & -7.234581 & -1.979567 & 3.514313 \\ \mathrm{H} & -5.550607 & -2.487347 & 3.883534 \\ \mathrm{H} & -2.419762 & 0.476238 & 1.144813 \\ \mathrm{H} & -3.642465 & -0.766865 & 1.696992 \\ \mathrm{C} & -4.229845 & 2.217846 & 0.049690 \\ \mathrm{C} & -2.947423 & 2.545128 & -0.439900 \\ \mathrm{C} & -5.269481 & 3.167406 & -0.095613 \\ \mathrm{C} & -2.730059 & 3.761075 & -1.085842 \\ \mathrm{H} & -2.108646 & 1.876168 & -0.300061 \\ \mathrm{C} & -5.041810 & 4.377295 & -0.735447 \\ \mathrm{H} & -6.251790 & 2.993250 & 0.334173 \\ \mathrm{C} & -3.771343 & 4.673559 & -1.243159 \\ \mathrm{H} & -1.733662 & 3.995002 & -1.447953 \\ \mathrm{H} & -5.849650 & 5.097536 & -0.826967 \\ \mathrm{H} & -3.594618 & 5.623662 & -1.739973 \\ \mathrm{H} & -7.028357 & -1.648634 & -1.205296\end{array}$

Catalyst (R)-1 TS Conformation 208

B3LYP/6-31G(d) Energy $=-2809.692048$

B3LYP-D3(BJ)/def2-TZVPP-IEF-PCM(DCM) Energy $=-2810.981632$

B3LYP-D3(BJ)/def2-TZVPP-IEF-PCM(DCM)//B3LYP/6-31G(d) Free Energy (Quasiharmonic) = 2810.340482

Frequencies (Top 3 out of 270)

1. $-726.2613 \mathrm{~cm}-1$

2. $\quad 5.3828 \mathrm{~cm}-1$

3. $\quad 9.8245 \mathrm{~cm}-1$

B3LYP/6-31G(d) Molecular Geometry in Cartesian Coordinates 


\begin{tabular}{|c|c|c|c|}
\hline C & 3.717375 & 0.369772 & 0.085993 \\
\hline C & 2.845133 & 1.436662 & -0.081629 \\
\hline C & 3.259347 & 2.799797 & 0.007036 \\
\hline C & 4.569635 & 3.043210 & 0.368928 \\
\hline $\mathrm{H}$ & 4.910451 & 4.072144 & 0.448191 \\
\hline C & 2.475924 & -3.704278 & -0.603013 \\
\hline C & 3.279829 & -1.025292 & -0.220660 \\
\hline C & 2.157474 & -1.552358 & 0.396996 \\
\hline C & 1.739146 & -2.908591 & 0.253392 \\
\hline $\mathrm{H}$ & 2.211134 & -4.752516 & -0.712740 \\
\hline $\mathrm{O}$ & 1.532418 & 1.186927 & -0.463194 \\
\hline$P$ & 0.479553 & 0.422928 & 0.525182 \\
\hline O & 1.414964 & -0.721132 & 1.228651 \\
\hline C & 0.795245 & 6.190256 & -0.972610 \\
\hline C & 0.355212 & 5.264929 & -0.023986 \\
\hline C & 1.130286 & 4.149064 & 0.291521 \\
\hline C & 2.368089 & 3.943941 & -0.337642 \\
\hline C & 2.802925 & 4.882134 & -1.288147 \\
\hline C & 2.023500 & 5.994643 & -1.605067 \\
\hline $\mathrm{H}$ & -0.595796 & 5.414283 & 0.481176 \\
\hline $\mathrm{H}$ & 2.375586 & 6.704979 & -2.348775 \\
\hline C & -1.556024 & -4.684506 & 2.382401 \\
\hline C & -0.692811 & -3.806160 & 3.040220 \\
\hline C & 0.363240 & -3.207114 & 2.355084 \\
\hline C & 0.578804 & -3.474515 & 0.991944 \\
\hline C & -0.301787 & -4.354884 & 0.341027 \\
\hline C & -1.355167 & -4.956874 & 1.028461 \\
\hline $\mathrm{H}$ & -0.836129 & -3.590044 & 4.095694 \\
\hline $\mathrm{H}$ & -2.019961 & -5.639724 & 0.504991 \\
\hline C & 3.981416 & -1.842997 & -1.174278 \\
\hline C & 3.571289 & -3.204463 & -1.348509 \\
\hline C & 4.264458 & -4.029997 & -2.275108 \\
\hline C & 5.299829 & -3.531336 & -3.030503 \\
\hline C & 5.680140 & -2.175992 & -2.891057 \\
\hline C & 5.041572 & -1.355564 & -1.987094 \\
\hline $\mathrm{H}$ & 3.948630 & -5.064959 & -2.383860 \\
\hline $\mathrm{H}$ & 5.817568 & -4.169593 & -3.741250 \\
\hline $\mathrm{H}$ & 6.481533 & -1.775915 & -3.506262 \\
\hline $\mathrm{H}$ & 5.340026 & -0.317626 & -1.900168 \\
\hline C & 5.047529 & 0.640801 & 0.563089 \\
\hline C & 5.472771 & 2.001647 & 0.692281 \\
\hline C & 6.786174 & 2.283605 & 1.156249 \\
\hline C & 7.645780 & 1.268736 & 1.506501 \\
\hline
\end{tabular}




\begin{tabular}{|c|c|c|c|}
\hline C & 7.217795 & -0.076330 & 1.412372 \\
\hline C & 5.955978 & -0.382386 & 0.951835 \\
\hline $\mathrm{H}$ & 7.093361 & 3.323339 & 1.240788 \\
\hline$H$ & 8.645415 & 1.495901 & 1.866635 \\
\hline $\mathrm{H}$ & 7.888537 & -0.876794 & 1.712789 \\
\hline $\mathrm{H}$ & 5.641050 & -1.418032 & 0.897971 \\
\hline 0 & -0.630246 & -0.118580 & -0.314535 \\
\hline $\mathrm{O}$ & 0.121889 & 1.348547 & 1.702227 \\
\hline $\mathrm{H}$ & -0.993327 & 1.446560 & 2.122328 \\
\hline $\mathrm{H}$ & 3.752964 & 4.725602 & -1.792224 \\
\hline $\mathrm{H}$ & 0.186182 & 7.056955 & -1.216260 \\
\hline $\mathrm{H}$ & 0.785441 & 3.443311 & 1.038846 \\
\hline $\mathrm{H}$ & -0.163449 & -4.555007 & -0.717815 \\
\hline $\mathrm{H}$ & -2.376998 & -5.151622 & 2.919883 \\
\hline $\mathrm{H}$ & 1.031152 & -2.534630 & 2.881311 \\
\hline C & -2.889906 & 0.759346 & 1.846976 \\
\hline 0 & -2.145544 & 1.552007 & 2.510037 \\
\hline $\mathrm{H}$ & -2.448759 & -0.102165 & 1.337880 \\
\hline C & -4.317176 & 0.567238 & 2.320524 \\
\hline $\mathrm{O}$ & -4.954872 & 1.351066 & 2.985190 \\
\hline $\mathrm{O}$ & -4.761053 & -0.621604 & 1.872779 \\
\hline C & -6.120092 & -0.966583 & 2.200560 \\
\hline $\mathrm{H}$ & -6.800159 & -0.167881 & 1.898449 \\
\hline $\mathrm{H}$ & -6.326234 & -1.877019 & 1.639406 \\
\hline C & -3.968180 & 0.833924 & -0.790109 \\
\hline C & -3.220871 & 1.714577 & -0.008879 \\
\hline $\mathrm{H}$ & -2.299040 & -0.288081 & -1.140231 \\
\hline$N$ & -3.320847 & -0.273144 & -1.276222 \\
\hline C & -3.891825 & -1.533134 & -1.511859 \\
\hline $\mathrm{O}$ & -5.050085 & -1.846361 & -1.352442 \\
\hline $\mathrm{O}$ & -2.917039 & -2.350116 & -1.948581 \\
\hline C & -3.320708 & -3.709589 & -2.173594 \\
\hline $\mathrm{H}$ & -3.628327 & -4.174746 & -1.233648 \\
\hline $\mathrm{H}$ & -2.438036 & -4.207088 & -2.574805 \\
\hline $\mathrm{H}$ & -4.146933 & -3.751674 & -2.887460 \\
\hline $\mathrm{H}$ & -3.648982 & 2.675602 & 0.250365 \\
\hline $\mathrm{H}$ & -2.144510 & 1.685687 & -0.124445 \\
\hline C & -5.378720 & 1.106418 & -1.128826 \\
\hline C & -6.200382 & 1.833156 & -0.247119 \\
\hline C & -5.886283 & 0.758309 & -2.393847 \\
\hline C & -7.501251 & 2.172096 & -0.611759 \\
\hline $\mathrm{H}$ & -5.834898 & 2.117241 & 0.733800 \\
\hline C & -7.178205 & 1.119455 & -2.761411 \\
\hline $\mathrm{H}$ & -5.257708 & 0.228435 & -3.100303 \\
\hline
\end{tabular}




$\begin{array}{rrrr}\mathrm{C} & -7.994139 & 1.819110 & -1.869437 \\ \mathrm{H} & -8.126911 & 2.719277 & 0.087543 \\ \mathrm{H} & -7.549233 & 0.852879 & -3.746838 \\ \mathrm{H} & -9.005567 & 2.093543 & -2.156011 \\ \mathrm{H} & -6.213108 & -1.137857 & 3.276344\end{array}$

Catalyst (R)-1 TS Conformation 209

B3LYP/6-31G(d) Energy $=-2809.688167$

B3LYP-D3(BJ)/def2-TZVPP-IEF-PCM(DCM) Energy = -2810.982507

B3LYP-D3(BJ)/def2-TZVPP-IEF-PCM(DCM)//B3LYP/6-31G(d) Free Energy (Quasiharmonic) = 2810.340475

Frequencies (Top 3 out of 270)

1. $-533.5820 \mathrm{~cm}-1$

2. $\quad 9.1423 \mathrm{~cm}-1$

3. $\quad 17.9321 \mathrm{~cm}-1$

B3LYP/6-31G(d) Molecular Geometry in Cartesian Coordinates

$\begin{array}{llll}\mathrm{C} & -3.438604 & 0.053936 & -0.228242 \\ \mathrm{C} & -2.623861 & 1.175446 & -0.161883 \\ \mathrm{C} & -3.056510 & 2.463608 & -0.603298 \\ \mathrm{C} & -4.323222 & 2.558737 & -1.147621 \\ \mathrm{H} & -4.671175 & 3.528759 & -1.492520 \\ \mathrm{C} & -2.154925 & -3.807800 & 1.157184 \\ \mathrm{C} & -2.980664 & -1.244760 & 0.341417 \\ \mathrm{C} & -1.792569 & -1.802739 & -0.101979 \\ \mathrm{C} & -1.372881 & -3.120638 & 0.247259 \\ \mathrm{H} & -1.882989 & -4.825869 & 1.421995 \\ \mathrm{O} & -1.379750 & 1.066408 & 0.455100 \\ \mathrm{P} & -0.161511 & 0.169809 & -0.187333 \\ \mathrm{O} & -0.977987 & -1.035592 & -0.939649 \\ \mathrm{C} & -0.871901 & 6.168167 & -0.464217 \\ \mathrm{C} & -2.105441 & 6.045675 & 0.178778 \\ \mathrm{C} & -2.785695 & 4.827835 & 0.157109 \\ \mathrm{C} & -2.244361 & 3.710651 & -0.501245 \\ \mathrm{C} & -1.000814 & 3.842209 & -1.137341 \\ \mathrm{C} & -0.325153 & 5.062904 & -1.120106 \\ \mathrm{H} & -2.540182 & 6.897305 & 0.695906 \\ \mathrm{H} & 0.633209 & 5.148612 & -1.625590 \\ \mathrm{C} & 1.840634 & -5.345072 & -1.536674\end{array}$




\begin{tabular}{|c|c|c|c|}
\hline$C$ & 1.027068 & -4.534661 & -2.330793 \\
\hline C & 0.019421 & -3.765594 & -1.753276 \\
\hline C & -0.201194 & -3.799755 & -0.366272 \\
\hline C & 0.642917 & -4.596230 & 0.425407 \\
\hline C & 1.653301 & -5.363610 & -0.153376 \\
\hline $\mathrm{H}$ & 1.174725 & -4.501818 & -3.406650 \\
\hline $\mathrm{H}$ & 2.288747 & -5.980171 & 0.477734 \\
\hline C & -3.740008 & -1.940537 & 1.343637 \\
\hline C & -3.308068 & -3.242241 & 1.752347 \\
\hline C & -4.048741 & -3.945444 & 2.740829 \\
\hline C & -5.155010 & -3.379537 & 3.330435 \\
\hline C & -5.563953 & -2.078493 & 2.953646 \\
\hline C & -4.878345 & -1.379191 & 1.984735 \\
\hline $\mathrm{H}$ & -3.714094 & -4.938714 & 3.030697 \\
\hline $\mathrm{H}$ & -5.709312 & -3.922716 & 4.090917 \\
\hline $\mathrm{H}$ & -6.425156 & -1.624358 & 3.436255 \\
\hline $\mathrm{H}$ & -5.198529 & -0.379850 & 1.713507 \\
\hline C & -4.711512 & 0.151373 & -0.890380 \\
\hline C & -5.161760 & 1.434829 & -1.332656 \\
\hline C & -6.423892 & 1.554082 & -1.975317 \\
\hline C & -7.208345 & 0.447534 & -2.200882 \\
\hline C & -6.750946 & -0.829462 & -1.798245 \\
\hline C & -5.538574 & -0.974639 & -1.160688 \\
\hline $\mathrm{H}$ & -6.750416 & 2.540136 & -2.297241 \\
\hline $\mathrm{H}$ & -8.169134 & 0.547547 & -2.698326 \\
\hline $\mathrm{H}$ & -7.359331 & -1.706948 & -2.000142 \\
\hline $\mathrm{H}$ & -5.201077 & -1.962596 & -0.870964 \\
\hline O & 0.750235 & -0.305598 & 0.898867 \\
\hline 0 & 0.487708 & 0.964356 & -1.343311 \\
\hline $\mathrm{H}$ & 1.463449 & 1.452606 & -1.032387 \\
\hline $\mathrm{H}$ & -0.569318 & 2.992290 & -1.653263 \\
\hline $\mathrm{H}$ & -0.341171 & 7.116575 & -0.454370 \\
\hline $\mathrm{H}$ & -3.745713 & 4.734513 & 0.658217 \\
\hline $\mathrm{H}$ & 0.504708 & -4.609047 & 1.502960 \\
\hline $\mathrm{H}$ & 2.614826 & -5.957111 & -1.993309 \\
\hline $\mathrm{H}$ & -0.612651 & -3.147211 & -2.381371 \\
\hline C & 3.158498 & 2.441069 & 0.240231 \\
\hline $\mathrm{O}$ & 2.672789 & 1.895738 & -0.823943 \\
\hline $\mathrm{H}$ & 4.150251 & 2.898675 & 0.129273 \\
\hline C & 2.314327 & 3.318358 & 1.167993 \\
\hline $\mathrm{O}$ & 2.785495 & 4.255738 & 1.778315 \\
\hline $\mathrm{O}$ & 1.050067 & 2.897436 & 1.256509 \\
\hline C & 0.212095 & 3.601925 & 2.194719 \\
\hline $\mathrm{H}$ & 0.063839 & 4.631397 & 1.864593 \\
\hline
\end{tabular}




$\begin{array}{llll}\mathrm{H} & -0.728799 & 3.056791 & 2.195308 \\ \mathrm{C} & 4.250526 & 0.179951 & 0.826848 \\ \mathrm{C} & 3.620236 & 1.168380 & 1.613024 \\ \mathrm{H} & 2.424117 & -0.570779 & 0.332472 \\ \mathrm{~N} & 3.449807 & -0.677155 & 0.177350 \\ \mathrm{C} & 3.780455 & -1.719742 & -0.722699 \\ \mathrm{O} & 3.039482 & -2.048285 & -1.614996 \\ \mathrm{O} & 4.950850 & -2.293472 & -0.414666 \\ \mathrm{C} & 5.361841 & -3.341985 & -1.312521 \\ \mathrm{H} & 4.610232 & -4.133782 & -1.331913 \\ \mathrm{H} & 6.307011 & -3.706986 & -0.911234 \\ \mathrm{H} & 5.498818 & -2.945635 & -2.321945 \\ \mathrm{H} & 4.262764 & 1.756934 & 2.260994 \\ \mathrm{H} & 2.642955 & 0.910859 & 2.014678 \\ \mathrm{C} & 5.687845 & 0.312080 & 0.496498 \\ \mathrm{C} & 6.645494 & 0.369297 & 1.518042 \\ \mathrm{C} & 6.085043 & 0.489848 & -0.839402 \\ \mathrm{C} & 7.990235 & 0.564006 & 1.205643 \\ \mathrm{H} & 6.337147 & 0.240337 & 2.551525 \\ \mathrm{C} & 7.426649 & 0.707690 & -1.142745 \\ \mathrm{H} & 5.333843 & 0.501285 & -1.624130 \\ \mathrm{C} & 8.382179 & 0.734594 & -0.123380 \\ \mathrm{H} & 8.729749 & 0.589778 & 2.000828 \\ \mathrm{H} & 7.725948 & 0.863124 & -2.175392 \\ \mathrm{H} & 9.428917 & 0.898253 & -0.364244 \\ \mathrm{H} & 0.675799 & 3.594619 & 3.184606\end{array}$

Catalyst (R)-1 TS Conformation 210

B3LYP/6-31G(d) Energy $=-2809.695656$

B3LYP-D3(BJ)/def2-TZVPP-IEF-PCM(DCM) Energy = -2810.984318

B3LYP-D3(BJ)/def2-TZVPP-IEF-PCM(DCM)//B3LYP/6-31G(d) Free Energy (Quasiharmonic) = 2810.340423

Frequencies (Top 3 out of 270)

1. $-256.3883 \mathrm{~cm}-1$

2. $\quad 11.0106 \mathrm{~cm}-1$

3. $12.8495 \mathrm{~cm}-1$

B3LYP/6-31G(d) Molecular Geometry in Cartesian Coordinates

$\begin{array}{llll}\text { C } & 3.417048 & -0.083746 & 0.175100\end{array}$ 


\begin{tabular}{|c|c|c|c|}
\hline C & 2.761537 & 1.096167 & -0.149852 \\
\hline C & 3.302759 & 2.390967 & 0.112677 \\
\hline C & 4.483912 & 2.440650 & 0.829599 \\
\hline $\mathrm{H}$ & 4.916749 & 3.410375 & 1.059815 \\
\hline C & 1.823570 & -3.854554 & -1.200447 \\
\hline C & 2.896344 & -1.390199 & -0.329429 \\
\hline C & 1.589079 & -1.760972 & -0.063866 \\
\hline C & 1.016664 & -2.999305 & -0.475994 \\
\hline $\mathrm{H}$ & 1.430200 & -4.819379 & -1.509746 \\
\hline $\mathrm{O}$ & 1.558684 & 1.019121 & -0.851007 \\
\hline$P$ & 0.235304 & 0.466433 & -0.081959 \\
\hline $\mathrm{O}$ & 0.788899 & -0.880230 & 0.659249 \\
\hline C & 1.699405 & 6.081182 & -1.419972 \\
\hline C & 0.852589 & 5.177914 & -0.775847 \\
\hline C & 1.348808 & 3.973959 & -0.276049 \\
\hline C & 2.707306 & 3.649751 & -0.418699 \\
\hline C & 3.550119 & 4.567016 & -1.071473 \\
\hline C & 3.052826 & 5.772032 & -1.565277 \\
\hline $\mathrm{H}$ & -0.205625 & 5.393750 & -0.663051 \\
\hline $\mathrm{H}$ & 3.721573 & 6.462395 & -2.073316 \\
\hline C & -3.047899 & -4.143184 & 0.361236 \\
\hline C & -2.519216 & -4.285084 & -0.923140 \\
\hline C & -1.204931 & -3.899715 & -1.185913 \\
\hline C & -0.392227 & -3.366499 & -0.171855 \\
\hline C & -0.937079 & -3.226766 & 1.115478 \\
\hline C & -2.251029 & -3.612219 & 1.378492 \\
\hline $\mathrm{H}$ & -3.132608 & -4.687390 & -1.725084 \\
\hline $\mathrm{H}$ & -2.652210 & -3.495133 & 2.381610 \\
\hline C & 3.698712 & -2.259055 & -1.148951 \\
\hline C & 3.149002 & -3.514918 & -1.566551 \\
\hline C & 3.934731 & -4.391688 & -2.363026 \\
\hline C & 5.201121 & -4.038212 & -2.765931 \\
\hline C & 5.730574 & -2.781131 & -2.391428 \\
\hline C & 5.001562 & -1.916436 & -1.604860 \\
\hline $\mathrm{H}$ & 3.505650 & -5.345807 & -2.659912 \\
\hline $\mathrm{H}$ & 5.789787 & -4.713334 & -3.380930 \\
\hline $\mathrm{H}$ & 6.720815 & -2.491188 & -2.732167 \\
\hline $\mathrm{H}$ & 5.419719 & -0.953629 & -1.337020 \\
\hline C & 4.596771 & -0.009403 & 0.992548 \\
\hline C & 5.130370 & 1.278907 & 1.316641 \\
\hline C & 6.294355 & 1.367666 & 2.127724 \\
\hline C & 6.900556 & 0.236259 & 2.621937 \\
\hline C & 6.358329 & -1.037053 & 2.327495 \\
\hline C & 5.238951 & -1.157250 & 1.533481 \\
\hline
\end{tabular}




\begin{tabular}{|c|c|c|c|}
\hline $\mathrm{H}$ & 6.690809 & 2.353651 & 2.358417 \\
\hline $\mathrm{H}$ & 7.786774 & 0.316826 & 3.245469 \\
\hline $\mathrm{H}$ & 6.825845 & -1.928819 & 2.736285 \\
\hline $\mathrm{H}$ & 4.829150 & -2.139145 & 1.325653 \\
\hline $\mathrm{O}$ & -0.323016 & 1.360955 & 0.972036 \\
\hline $\mathrm{O}$ & -0.665310 & 0.029671 & -1.269559 \\
\hline $\mathrm{H}$ & -1.697396 & 0.301093 & -1.286243 \\
\hline $\mathrm{H}$ & 4.598823 & 4.318925 & -1.212337 \\
\hline $\mathrm{H}$ & 1.307646 & 7.016615 & -1.811641 \\
\hline $\mathrm{H}$ & 0.674313 & 3.298301 & 0.235266 \\
\hline $\mathrm{H}$ & -0.327038 & -2.817442 & 1.913218 \\
\hline $\mathrm{H}$ & -4.072697 & -4.440900 & 0.567037 \\
\hline $\mathrm{H}$ & -0.807230 & -3.987063 & -2.192956 \\
\hline C & -3.963753 & -0.209753 & -1.071427 \\
\hline $\mathrm{O}$ & -3.066510 & 0.608715 & -1.478285 \\
\hline $\mathrm{H}$ & -3.663862 & -1.154454 & -0.596131 \\
\hline C & -5.184456 & -0.365808 & -1.981863 \\
\hline $\mathrm{O}$ & -5.554190 & 0.444728 & -2.799167 \\
\hline $\mathrm{O}$ & -5.802798 & -1.543707 & -1.741850 \\
\hline C & -6.965561 & -1.800504 & -2.547994 \\
\hline $\mathrm{H}$ & -7.336637 & -2.774162 & -2.226957 \\
\hline $\mathrm{H}$ & -7.721987 & -1.027217 & -2.388056 \\
\hline C & -3.952061 & 0.973589 & 1.265088 \\
\hline C & -4.999248 & 0.561071 & 0.415237 \\
\hline $\mathrm{H}$ & -2.172592 & 1.986665 & 1.323263 \\
\hline$N$ & -3.115431 & 1.980744 & 0.921379 \\
\hline C & -3.175777 & 2.910868 & -0.152154 \\
\hline $\mathrm{O}$ & -2.197565 & 3.540020 & -0.477017 \\
\hline 0 & -4.411430 & 3.070354 & -0.633496 \\
\hline C & -4.488606 & 3.751065 & -1.905068 \\
\hline $\mathrm{H}$ & -4.093701 & 3.088287 & -2.677307 \\
\hline $\mathrm{H}$ & -3.928463 & 4.686485 & -1.869293 \\
\hline $\mathrm{H}$ & -5.550332 & 3.934516 & -2.066917 \\
\hline $\mathrm{H}$ & -5.623808 & -0.247627 & 0.778209 \\
\hline $\mathrm{H}$ & -5.505883 & 1.318966 & -0.164312 \\
\hline C & -3.640870 & 0.208424 & 2.498027 \\
\hline C & -4.709934 & -0.344804 & 3.230867 \\
\hline C & -2.331746 & 0.043705 & 2.989069 \\
\hline C & -4.479683 & -1.045027 & 4.411544 \\
\hline $\mathrm{H}$ & -5.730278 & -0.193852 & 2.894893 \\
\hline C & -2.108666 & -0.666043 & 4.167625 \\
\hline $\mathrm{H}$ & -1.478511 & 0.431489 & 2.441324 \\
\hline C & -3.175886 & -1.211736 & 4.883208 \\
\hline $\mathrm{H}$ & -5.319855 & -1.450846 & 4.967822 \\
\hline
\end{tabular}




$\begin{array}{llll}\mathrm{H} & -1.090328 & -0.792345 & 4.523918 \\ \mathrm{H} & -2.994474 & -1.757243 & 5.805277 \\ \mathrm{H} & -6.698222 & -1.820870 & -3.607646\end{array}$

Catalyst (R)-1 TS Conformation 211

B3LYP/6-31G(d) Energy $=-2809.688857$

B3LYP-D3(BJ)/def2-TZVPP-IEF-PCM(DCM) Energy $=-2810.981672$

B3LYP-D3(BJ)/def2-TZVPP-IEF-PCM(DCM)//B3LYP/6-31G(d) Free Energy (Quasiharmonic) = 2810.340423

Frequencies (Top 3 out of 270)

1. $-690.6556 \mathrm{~cm}-1$

2. $\quad 9.5062 \mathrm{~cm}-1$

3. $\quad 10.8179 \mathrm{~cm}-1$

B3LYP/6-31G(d) Molecular Geometry in Cartesian Coordinates

$\begin{array}{llll}\text { C } & -3.566009 & 0.652716 & 0.022121 \\ \text { C } & -2.556291 & 1.568950 & 0.261588 \\ \text { C } & -2.698862 & 2.972600 & 0.059358 \\ \text { C } & -3.901609 & 3.415505 & -0.454554 \\ \text { H } & -4.055682 & 4.481666 & -0.599172 \\ \text { C } & -3.040461 & -3.562776 & 0.727205 \\ \text { C } & -3.351059 & -0.787342 & 0.353883 \\ \text { C } & -2.272407 & -1.477923 & -0.184165 \\ \text { C } & -2.120807 & -2.893678 & -0.057993 \\ \text { H } & -2.941910 & -4.637900 & 0.851712 \\ \text { O } & -1.339448 & 1.095066 & 0.736706 \\ \text { P } & -0.357262 & 0.332130 & -0.332721 \\ \text { O } & -1.355691 & -0.795993 & -0.972441 \\ \text { C } & 0.348970 & 5.856056 & 1.011646 \\ \text { C } & -0.316003 & 5.906837 & -0.213898 \\ \text { C } & -1.288357 & 4.956388 & -0.523099 \\ \text { C } & -1.614792 & 3.936859 & 0.385284 \\ \text { C } & -0.931763 & 3.890858 & 1.612440 \\ \text { C } & 0.037470 & 4.843660 & 1.921962 \\ \text { H } & -0.072507 & 6.681499 & -0.936266 \\ \text { H } & 0.546603 & 4.797642 & 2.881505 \\ \text { C } & 0.846265 & -5.252452 & -2.102103 \\ \text { C } & 1.229533 & -4.098688 & -1.415947 \\ \text { C } & 0.282517 & -3.312607 & -0.759673\end{array}$




\begin{tabular}{|c|c|c|c|}
\hline C & -1.074496 & -3.670666 & -0.779520 \\
\hline C & -1.449986 & -4.832440 & -1.476459 \\
\hline C & -0.500558 & -5.617102 & -2.130045 \\
\hline $\mathrm{H}$ & 2.272553 & -3.794492 & -1.392198 \\
\hline $\mathrm{H}$ & -0.816171 & -6.506568 & -2.669468 \\
\hline C & -4.242829 & -1.484614 & 1.240744 \\
\hline C & -4.080279 & -2.895566 & 1.417520 \\
\hline C & -4.955420 & -3.597203 & 2.290478 \\
\hline C & -5.941375 & -2.936180 & 2.985106 \\
\hline C & -6.085077 & -1.536415 & 2.837446 \\
\hline C & -5.261139 & -0.830626 & 1.988382 \\
\hline $\mathrm{H}$ & -4.821398 & -4.670336 & 2.405740 \\
\hline $\mathrm{H}$ & -6.601485 & -3.481585 & 3.654084 \\
\hline $\mathrm{H}$ & -6.849185 & -1.011091 & 3.404133 \\
\hline $\mathrm{H}$ & -5.377716 & 0.242910 & 1.895872 \\
\hline C & -4.784858 & 1.120306 & -0.581869 \\
\hline C & -4.946649 & 2.526171 & -0.807171 \\
\hline C & -6.149446 & 3.005345 & -1.393459 \\
\hline C & -7.145533 & 2.137687 & -1.776357 \\
\hline C & -6.972152 & 0.746021 & -1.592121 \\
\hline C & -5.825693 & 0.251080 & -1.010062 \\
\hline $\mathrm{H}$ & -6.259955 & 4.076434 & -1.545950 \\
\hline $\mathrm{H}$ & -8.057475 & 2.515330 & -2.230709 \\
\hline $\mathrm{H}$ & -7.748594 & 0.059061 & -1.917940 \\
\hline $\mathrm{H}$ & -5.705233 & -0.818706 & -0.886733 \\
\hline O & 0.780015 & -0.220999 & 0.466769 \\
\hline $\mathrm{O}$ & -0.079031 & 1.256323 & -1.525344 \\
\hline $\mathrm{H}$ & 0.969229 & 1.704046 & -1.705150 \\
\hline $\mathrm{H}$ & -1.169033 & 3.110642 & 2.327771 \\
\hline $\mathrm{H}$ & 1.106332 & 6.597038 & 1.254464 \\
\hline $\mathrm{H}$ & -1.785948 & 4.986047 & -1.488206 \\
\hline $\mathrm{H}$ & -2.500096 & -5.108113 & -1.522466 \\
\hline $\mathrm{H}$ & 1.587780 & -5.858084 & -2.617243 \\
\hline $\mathrm{H}$ & 0.601208 & -2.425627 & -0.226563 \\
\hline C & 3.170100 & 1.791722 & -1.645884 \\
\hline $\mathrm{O}$ & 2.041249 & 2.366313 & -1.869715 \\
\hline $\mathrm{H}$ & 4.066641 & 2.389611 & -1.849872 \\
\hline C & 3.340632 & 0.348663 & -2.121823 \\
\hline $\mathrm{O}$ & 2.451178 & -0.455344 & -2.269962 \\
\hline $\mathrm{O}$ & 4.643279 & 0.095952 & -2.390144 \\
\hline C & 4.913261 & -1.210442 & -2.928142 \\
\hline $\mathrm{H}$ & 5.988983 & -1.239113 & -3.102898 \\
\hline $\mathrm{H}$ & 4.614222 & -1.989059 & -2.220923 \\
\hline C & 4.153370 & 0.606559 & 0.715426 \\
\hline
\end{tabular}




$\begin{array}{llll}\mathrm{C} & 3.367306 & 1.701413 & 0.276284 \\ \mathrm{H} & 2.489770 & -0.561087 & 0.628758 \\ \mathrm{~N} & 3.507766 & -0.578784 & 0.846409 \\ \mathrm{C} & 3.948198 & -1.752678 & 1.487693 \\ \mathrm{O} & 4.993781 & -1.913214 & 2.073111 \\ \mathrm{O} & 2.979376 & -2.669614 & 1.345635 \\ \mathrm{C} & 3.208016 & -3.928394 & 2.003513 \\ \mathrm{H} & 4.158584 & -4.360075 & 1.681444 \\ \mathrm{H} & 2.371824 & -4.557692 & 1.702113 \\ \mathrm{H} & 3.221007 & -3.790157 & 3.087703 \\ \mathrm{H} & 3.805274 & 2.683495 & 0.416394 \\ \mathrm{H} & 2.311330 & 1.634302 & 0.514011 \\ \mathrm{C} & 5.613760 & 0.750946 & 0.875004 \\ \mathrm{C} & 6.522210 & -0.188899 & 0.356843 \\ \mathrm{C} & 6.115720 & 1.906832 & 1.499782 \\ \mathrm{C} & 7.891570 & 0.028664 & 0.455384 \\ \mathrm{H} & 6.154625 & -1.079772 & -0.136516 \\ \mathrm{C} & 7.488590 & 2.108861 & 1.619607 \\ \mathrm{H} & 5.427136 & 2.630531 & 1.924181 \\ \mathrm{C} & 8.379261 & 1.173620 & 1.091591 \\ \mathrm{H} & 8.582148 & -0.699266 & 0.039711 \\ \mathrm{H} & 7.860331 & 2.996313 & 2.123222 \\ \mathrm{H} & 9.450513 & 1.334021 & 1.175693 \\ \mathrm{H} & 4.366129 & -1.356021 & -3.862873\end{array}$

Catalyst (R)-1 TS Conformation 212

B3LYP/6-31G(d) Energy $=-2809.693775$

B3LYP-D3(BJ)/def2-TZVPP-IEF-PCM(DCM) Energy $=-2810.98312$

B3LYP-D3(BJ)/def2-TZVPP-IEF-PCM(DCM)//B3LYP/6-31G(d) Free Energy (Quasiharmonic) = 2810.340412

Frequencies (Top 3 out of 270)

1. $-485.7105 \mathrm{~cm}-1$

2. $\quad 5.8944 \mathrm{~cm}-1$

3. $11.1001 \mathrm{~cm}-1$

B3LYP/6-31G(d) Molecular Geometry in Cartesian Coordinates

$\begin{array}{llll}\text { C } & -3.466102 & 0.261651 & -0.124121 \\ \text { C } & -2.577872 & 1.325902 & -0.065999 \\ \text { C } & -2.983341 & 2.683506 & -0.232493\end{array}$




\begin{tabular}{|c|c|c|c|}
\hline C & -4.311075 & 2.922340 & -0.524497 \\
\hline $\mathrm{H}$ & -4.643912 & 3.949031 & -0.652352 \\
\hline C & -2.372384 & -3.845966 & 0.540169 \\
\hline C & -3.028325 & -1.123730 & 0.217265 \\
\hline C & -1.957899 & -1.701630 & -0.447775 \\
\hline C & -1.635645 & -3.088187 & -0.349464 \\
\hline $\mathrm{H}$ & -2.147623 & -4.904534 & 0.640571 \\
\hline 0 & -1.250910 & 1.083066 & 0.281190 \\
\hline$P$ & -0.246955 & 0.233936 & -0.691953 \\
\hline O & -1.218688 & -0.913334 & -1.326617 \\
\hline C & -0.443564 & 6.130313 & 0.194270 \\
\hline C & -0.155335 & 5.170442 & -0.777781 \\
\hline C & -0.954361 & 4.034343 & -0.907871 \\
\hline C & -2.059304 & 3.842503 & -0.065859 \\
\hline C & -2.342453 & 4.814362 & 0.908294 \\
\hline C & -1.539956 & 5.948265 & 1.039425 \\
\hline $\mathrm{H}$ & 0.696262 & 5.298333 & -1.440253 \\
\hline $\mathrm{H}$ & -1.772402 & 6.688036 & 1.801262 \\
\hline C & 1.277666 & -5.123467 & -2.778803 \\
\hline C & 1.654078 & -3.998498 & -2.042616 \\
\hline C & 0.720215 & -3.315443 & -1.264101 \\
\hline C & -0.612343 & -3.751340 & -1.206622 \\
\hline C & -0.980077 & -4.885724 & -1.948946 \\
\hline C & -0.044853 & -5.565398 & -2.729161 \\
\hline $\mathrm{H}$ & 2.683734 & -3.650400 & -2.070892 \\
\hline $\mathrm{H}$ & -0.352564 & -6.436245 & -3.302187 \\
\hline C & -3.713303 & -1.900455 & 1.216134 \\
\hline C & -3.376198 & -3.283632 & 1.366062 \\
\hline C & -4.046882 & -4.064363 & 2.346206 \\
\hline C & -4.995958 & -3.503565 & 3.168707 \\
\hline C & -5.307997 & -2.129172 & 3.045362 \\
\hline C & -4.687206 & -1.349856 & 2.093916 \\
\hline $\mathrm{H}$ & -3.784218 & -5.115455 & 2.440106 \\
\hline $\mathrm{H}$ & -5.498030 & -4.108216 & 3.918989 \\
\hline $\mathrm{H}$ & -6.041134 & -1.682003 & 3.711224 \\
\hline $\mathrm{H}$ & -4.930636 & -0.296388 & 2.018945 \\
\hline C & -4.819674 & 0.519592 & -0.543324 \\
\hline C & -5.242776 & 1.875123 & -0.722678 \\
\hline C & -6.579846 & 2.146986 & -1.120273 \\
\hline C & -7.466484 & 1.124429 & -1.363385 \\
\hline C & -7.041855 & -0.217848 & -1.225933 \\
\hline C & -5.757141 & -0.512690 & -0.825602 \\
\hline $\mathrm{H}$ & -6.882892 & 3.184118 & -1.242714 \\
\hline $\mathrm{H}$ & -8.484500 & 1.342440 & -1.674220 \\
\hline
\end{tabular}




\begin{tabular}{|c|c|c|c|}
\hline $\mathrm{H}$ & -7.734038 & -1.026257 & -1.445387 \\
\hline $\mathrm{H}$ & -5.448348 & -1.547484 & -0.738880 \\
\hline $\mathrm{O}$ & 0.865855 & -0.300487 & 0.147951 \\
\hline 0 & 0.102365 & 1.063929 & -1.950662 \\
\hline $\mathrm{H}$ & 1.084320 & 1.583946 & -2.020516 \\
\hline $\mathrm{H}$ & -3.193969 & 4.671871 & 1.568625 \\
\hline $\mathrm{H}$ & 0.180989 & 7.014512 & 0.292582 \\
\hline $\mathrm{H}$ & -0.725596 & 3.297056 & -1.668551 \\
\hline $\mathrm{H}$ & -2.012730 & -5.223409 & -1.925717 \\
\hline $\mathrm{H}$ & 2.008292 & -5.650257 & -3.387036 \\
\hline $\mathrm{H}$ & 1.021791 & -2.450718 & -0.684140 \\
\hline C & 3.216825 & 2.005615 & -1.462323 \\
\hline 0 & 2.268743 & 2.136842 & -2.308765 \\
\hline $\mathrm{H}$ & 4.217729 & 2.340416 & -1.766500 \\
\hline C & 2.997765 & 2.330902 & 0.020069 \\
\hline 0 & 3.904679 & 2.380886 & 0.829068 \\
\hline $\mathrm{O}$ & 1.719274 & 2.582313 & 0.296250 \\
\hline C & 1.405894 & 2.843624 & 1.680069 \\
\hline $\mathrm{H}$ & 1.966720 & 3.711891 & 2.032727 \\
\hline $\mathrm{H}$ & 0.335030 & 3.032449 & 1.697438 \\
\hline C & 4.362558 & -0.290103 & -0.266407 \\
\hline C & 3.664667 & 0.065352 & -1.436859 \\
\hline $\mathrm{H}$ & 2.590499 & -0.498437 & 0.710762 \\
\hline$N$ & 3.613153 & -0.584403 & 0.826804 \\
\hline C & 4.027842 & -1.093815 & 2.066660 \\
\hline 0 & 5.139924 & -1.455921 & 2.370282 \\
\hline 0 & 2.944865 & -1.136955 & 2.864560 \\
\hline C & 3.173388 & -1.694859 & 4.169425 \\
\hline $\mathrm{H}$ & 3.531423 & -2.724162 & 4.087010 \\
\hline $\mathrm{H}$ & 2.204641 & -1.662964 & 4.667233 \\
\hline $\mathrm{H}$ & 3.909529 & -1.099434 & 4.715318 \\
\hline $\mathrm{H}$ & 4.238654 & 0.074097 & -2.356452 \\
\hline $\mathrm{H}$ & 2.646217 & -0.294174 & -1.525880 \\
\hline C & 5.839551 & -0.217101 & -0.232143 \\
\hline C & 6.566312 & -0.832719 & -1.264989 \\
\hline C & 6.527558 & 0.514895 & 0.750436 \\
\hline C & 7.956586 & -0.743523 & -1.300720 \\
\hline $\mathrm{H}$ & 6.041434 & -1.406815 & -2.022839 \\
\hline C & 7.913063 & 0.622283 & 0.694336 \\
\hline $\mathrm{H}$ & 5.970374 & 1.026647 & 1.524524 \\
\hline C & 8.631658 & -0.012142 & -0.323053 \\
\hline $\mathrm{H}$ & 8.508656 & -1.240899 & -2.092946 \\
\hline $\mathrm{H}$ & 8.435500 & 1.203491 & 1.448684 \\
\hline $\mathrm{H}$ & 9.714912 & 0.067491 & -0.354446 \\
\hline
\end{tabular}


$\mathrm{H}$

Catalyst (R)-1 TS Conformation 213

B3LYP/6-31G(d) Energy $=-2809.686818$

B3LYP-D3(BJ)/def2-TZVPP-IEF-PCM(DCM) Energy $=-2810.982453$

B3LYP-D3(BJ)/def2-TZVPP-IEF-PCM(DCM)//B3LYP/6-31G(d) Free Energy (Quasiharmonic) = 2810.340407

Frequencies (Top 3 out of 270)

1. $-549.1032 \mathrm{~cm}-1$

2. $8.6376 \mathrm{~cm}-1$

3. $10.6192 \mathrm{~cm}-1$

B3LYP/6-31G(d) Molecular Geometry in Cartesian Coordinates

$\begin{array}{llll}\mathrm{C} & 3.419244 & -1.111146 & -0.147067 \\ \mathrm{C} & 2.135157 & -1.577920 & 0.079418 \\ \mathrm{C} & 1.727495 & -2.917696 & -0.185747 \\ \mathrm{C} & 2.665960 & -3.773537 & -0.725248 \\ \mathrm{H} & 2.392071 & -4.807104 & -0.921781 \\ \mathrm{C} & 4.483366 & 2.991861 & 0.618421 \\ \mathrm{C} & 3.758485 & 0.300027 & 0.204619 \\ \mathrm{C} & 3.009136 & 1.345416 & -0.323084 \\ \mathrm{C} & 3.381478 & 2.716451 & -0.168591 \\ \mathrm{H} & 4.782052 & 4.027097 & 0.760955 \\ \mathrm{O} & 1.194014 & -0.694650 & 0.587155 \\ \mathrm{P} & 0.550141 & 0.404332 & -0.469499 \\ \mathrm{O} & 1.912747 & 1.057405 & -1.119089 \\ \mathrm{C} & -2.276011 & -4.311606 & 0.566006 \\ \mathrm{C} & -1.565090 & -3.651203 & 1.572107 \\ \mathrm{C} & -0.271621 & -3.188515 & 1.332911 \\ \mathrm{C} & 0.339787 & -3.380756 & 0.082684 \\ \mathrm{C} & -0.381301 & -4.051369 & -0.917008 \\ \mathrm{C} & -1.676882 & -4.512100 & -0.678447 \\ \mathrm{H} & -2.019827 & -3.501635 & 2.548307 \\ \mathrm{H} & -2.220382 & -5.020348 & -1.470843 \\ \mathrm{C} & 1.459659 & 6.035356 & -2.125049 \\ \mathrm{C} & 2.841445 & 5.859892 & -2.207144 \\ \mathrm{C} & 3.444295 & 4.769460 & -1.581013 \\ \mathrm{C} & 2.680489 & 3.833534 & -0.862884 \\ \mathrm{C} & 1.290026 & 4.016830 & -0.789422\end{array}$




\begin{tabular}{|c|c|c|c|}
\hline C & 0.691691 & 5.110664 & -1.414953 \\
\hline $\mathrm{H}$ & 3.451564 & 6.566703 & -2.763933 \\
\hline $\mathrm{H}$ & -0.385477 & 5.240025 & -1.343396 \\
\hline C & 4.844383 & 0.609228 & 1.094063 \\
\hline C & 5.210131 & 1.979384 & 1.289948 \\
\hline C & 6.283535 & 2.298490 & 2.165272 \\
\hline C & 6.960846 & 1.312323 & 2.843966 \\
\hline C & 6.581730 & -0.040645 & 2.677472 \\
\hline C & 5.554131 & -0.382959 & 1.826098 \\
\hline $\mathrm{H}$ & 6.551884 & 3.344380 & 2.295557 \\
\hline $\mathrm{H}$ & 7.776502 & 1.568494 & 3.514702 \\
\hline $\mathrm{H}$ & 7.102307 & -0.817561 & 3.231122 \\
\hline $\mathrm{H}$ & 5.269286 & -1.423276 & 1.718168 \\
\hline C & 4.367953 & -1.993434 & -0.772112 \\
\hline C & 3.978840 & -3.345896 & -1.044535 \\
\hline C & 4.909552 & -4.231924 & -1.651635 \\
\hline C & 6.166045 & -3.802832 & -2.010440 \\
\hline C & 6.539101 & -2.457854 & -1.781159 \\
\hline C & 5.666127 & -1.578530 & -1.178901 \\
\hline $\mathrm{H}$ & 4.600691 & -5.257641 & -1.839627 \\
\hline $\mathrm{H}$ & 6.866533 & -4.487756 & -2.480468 \\
\hline $\mathrm{H}$ & 7.522562 & -2.112235 & -2.088290 \\
\hline $\mathrm{H}$ & 5.965012 & -0.549078 & -1.021234 \\
\hline $\mathrm{O}$ & -0.270575 & 1.351859 & 0.341409 \\
\hline $\mathrm{O}$ & -0.082459 & -0.338882 & -1.646162 \\
\hline $\mathrm{H}$ & -1.326657 & -0.420900 & -1.747032 \\
\hline $\mathrm{H}$ & 0.070485 & -4.184762 & -1.895700 \\
\hline $\mathrm{H}$ & -3.289069 & -4.657273 & 0.750808 \\
\hline $\mathrm{H}$ & 0.276362 & -2.679999 & 2.119555 \\
\hline $\mathrm{H}$ & 0.678119 & 3.311360 & -0.237118 \\
\hline $\mathrm{H}$ & 0.985533 & 6.883244 & -2.613054 \\
\hline $\mathrm{H}$ & 4.518479 & 4.626332 & -1.663217 \\
\hline C & -3.100612 & -0.726544 & -0.768369 \\
\hline $\mathrm{O}$ & -2.469589 & -0.563185 & -1.879958 \\
\hline $\mathrm{H}$ & -2.550351 & -1.032269 & 0.126102 \\
\hline C & -4.461202 & -1.399567 & -0.844255 \\
\hline $\mathrm{O}$ & -4.976226 & -1.946264 & 0.112579 \\
\hline $\mathrm{O}$ & -5.000130 & -1.321647 & -2.063878 \\
\hline C & -6.265368 & -1.985827 & -2.231188 \\
\hline $\mathrm{H}$ & -6.510109 & -1.877565 & -3.287621 \\
\hline $\mathrm{H}$ & -6.179395 & -3.041168 & -1.960788 \\
\hline C & -4.629585 & 1.038209 & 0.779862 \\
\hline C & -3.537982 & 1.082682 & -0.103083 \\
\hline $\mathrm{H}$ & -5.441779 & 0.733250 & 2.613988 \\
\hline
\end{tabular}




$\begin{array}{llll}\text { N } & -4.566593 & 0.727766 & 2.103951 \\ \mathrm{C} & -3.495821 & 0.440006 & 2.986122 \\ \mathrm{O} & -3.720740 & 0.259491 & 4.161918 \\ \mathrm{O} & -2.327623 & 0.417639 & 2.370093 \\ \mathrm{C} & -1.162143 & 0.222314 & 3.210174 \\ \mathrm{H} & -0.322501 & 0.338194 & 2.530432 \\ \mathrm{H} & -1.196977 & -0.774529 & 3.654771 \\ \mathrm{H} & -1.150433 & 0.977966 & 3.998107 \\ \mathrm{H} & -3.768139 & 1.505599 & -1.074784 \\ \mathrm{H} & -2.537701 & 1.286728 & 0.271861 \\ \mathrm{C} & -6.012121 & 1.257345 & 0.287377 \\ \mathrm{C} & -7.080910 & 0.466409 & 0.751204 \\ \mathrm{C} & -6.274506 & 2.281189 & -0.639470 \\ \mathrm{C} & -8.377844 & 0.700930 & 0.298761 \\ \mathrm{H} & -6.888401 & -0.371024 & 1.414958 \\ \mathrm{C} & -7.574528 & 2.517916 & -1.079201 \\ \mathrm{H} & -5.463789 & 2.911789 & -0.989461 \\ \mathrm{C} & -8.628646 & 1.729893 & -0.611848 \\ \mathrm{H} & -9.191307 & 0.074488 & 0.653136 \\ \mathrm{H} & -7.764639 & 3.322367 & -1.783464 \\ \mathrm{H} & -9.641556 & 1.915330 & -0.957778 \\ \mathrm{H} & -7.029720 & -1.514383 & -1.608459\end{array}$

Catalyst (R)-1 TS Conformation 214

B3LYP/6-31G(d) Energy = -2809.694304

B3LYP-D3(BJ)/def2-TZVPP-IEF-PCM(DCM) Energy = -2810.981686

B3LYP-D3(BJ)/def2-TZVPP-IEF-PCM(DCM)//B3LYP/6-31G(d) Free Energy (Quasiharmonic) = 2810.340355

Frequencies (Top 3 out of 270)

1. $-511.5393 \mathrm{~cm}-1$

2. $\quad 9.6956 \mathrm{~cm}-1$

3. $\quad 11.3835 \mathrm{~cm}-1$

B3LYP/6-31G(d) Molecular Geometry in Cartesian Coordinates

$\begin{array}{llll}\text { C } & 3.553029 & 0.274828 & 0.323407 \\ \text { C } & 2.635445 & 1.315521 & 0.243171 \\ \text { C } & 2.907446 & 2.629279 & 0.730194 \\ \text { C } & 4.109059 & 2.832027 & 1.379997 \\ \text { H } & 4.338606 & 3.822507 & 1.763852\end{array}$




\begin{tabular}{|c|c|c|c|}
\hline C & 2.767164 & -3.550902 & -1.512561 \\
\hline C & 3.299765 & -1.026008 & -0.367962 \\
\hline C & 2.128251 & -1.719798 & -0.117036 \\
\hline C & 1.821616 & -2.998248 & -0.669318 \\
\hline $\mathrm{H}$ & 2.593709 & -4.539842 & -1.928025 \\
\hline $\mathrm{O}$ & 1.432639 & 1.125592 & -0.432596 \\
\hline$P$ & 0.304573 & 0.079239 & 0.100872 \\
\hline $\mathrm{O}$ & 1.201777 & -1.126037 & 0.736181 \\
\hline C & 0.364826 & 6.067789 & 0.227637 \\
\hline C & 1.687361 & 6.087153 & -0.217742 \\
\hline C & 2.491269 & 4.956972 & -0.068214 \\
\hline C & 1.988753 & 3.785666 & 0.522665 \\
\hline C & 0.654652 & 3.772950 & 0.959100 \\
\hline C & -0.145262 & 4.907669 & 0.816022 \\
\hline $\mathrm{H}$ & 2.095838 & 6.981490 & -0.681338 \\
\hline $\mathrm{H}$ & -1.170834 & 4.886482 & 1.176573 \\
\hline C & -1.877578 & -5.083508 & 0.048494 \\
\hline C & -1.299989 & -5.071627 & -1.222199 \\
\hline C & -0.107919 & -4.383987 & -1.442338 \\
\hline C & 0.540677 & -3.703624 & -0.396900 \\
\hline C & -0.049582 & -3.729200 & 0.878531 \\
\hline C & -1.248824 & -4.406474 & 1.095292 \\
\hline $\mathrm{H}$ & -1.784912 & -5.584938 & -2.048644 \\
\hline $\mathrm{H}$ & -1.695864 & -4.390265 & 2.085008 \\
\hline C & 4.225890 & -1.574731 & -1.321973 \\
\hline C & 3.954074 & -2.868291 & -1.875227 \\
\hline C & 4.869684 & -3.436744 & -2.802402 \\
\hline C & 5.991437 & -2.748979 & -3.202243 \\
\hline C & 6.238847 & -1.453147 & -2.691709 \\
\hline C & 5.381987 & -0.882665 & -1.776055 \\
\hline $\mathrm{H}$ & 4.655000 & -4.425035 & -3.202122 \\
\hline $\mathrm{H}$ & 6.679730 & -3.190567 & -3.917665 \\
\hline $\mathrm{H}$ & 7.111301 & -0.899597 & -3.028195 \\
\hline $\mathrm{H}$ & 5.582604 & 0.114299 & -1.402024 \\
\hline C & 4.748691 & 0.477489 & 1.098590 \\
\hline C & 5.028519 & 1.782186 & 1.616537 \\
\hline C & 6.211028 & 1.996710 & 2.375302 \\
\hline C & 7.076969 & 0.962316 & 2.642253 \\
\hline C & 6.785604 & -0.336774 & 2.163802 \\
\hline C & 5.655746 & -0.572782 & 1.411906 \\
\hline $\mathrm{H}$ & 6.409703 & 2.996936 & 2.752949 \\
\hline $\mathrm{H}$ & 7.974661 & 1.135471 & 3.229366 \\
\hline $\mathrm{H}$ & 7.456309 & -1.159220 & 2.397361 \\
\hline $\mathrm{H}$ & 5.442880 & -1.576923 & 1.064524 \\
\hline
\end{tabular}




\begin{tabular}{|c|c|c|c|}
\hline $\mathrm{O}$ & -0.558181 & -0.354221 & -1.037145 \\
\hline $\mathrm{O}$ & -0.386406 & 0.714699 & 1.336025 \\
\hline $\mathrm{H}$ & -1.220129 & 0.081136 & 1.767364 \\
\hline $\mathrm{H}$ & 0.249275 & 2.882413 & 1.425810 \\
\hline $\mathrm{H}$ & -0.261956 & 6.949553 & 0.121498 \\
\hline $\mathrm{H}$ & 3.518472 & 4.973262 & -0.422776 \\
\hline $\mathrm{H}$ & 0.425213 & -3.211604 & 1.703267 \\
\hline $\mathrm{H}$ & -2.812970 & -5.610361 & 0.219384 \\
\hline $\mathrm{H}$ & 0.312369 & -4.346194 & -2.443171 \\
\hline C & -3.351887 & -0.461470 & 1.949609 \\
\hline 0 & -2.128213 & -0.739790 & 2.187896 \\
\hline $\mathrm{H}$ & -3.669582 & 0.584729 & 1.860007 \\
\hline C & -4.407130 & -1.294145 & 2.664397 \\
\hline 0 & -5.506297 & -0.862082 & 2.954049 \\
\hline O & -3.981295 & -2.530126 & 2.947626 \\
\hline C & -4.922648 & -3.355784 & 3.657332 \\
\hline $\mathrm{H}$ & -4.418722 & -4.311027 & 3.802826 \\
\hline $\mathrm{H}$ & -5.176321 & -2.903504 & 4.619266 \\
\hline C & -4.103432 & 0.075233 & -0.714689 \\
\hline C & -3.817417 & -1.073800 & 0.055461 \\
\hline $\mathrm{H}$ & -2.126048 & 0.304530 & -1.249956 \\
\hline $\mathrm{N}$ & -3.066883 & 0.755159 & -1.263953 \\
\hline C & -3.042992 & 2.122982 & -1.614402 \\
\hline $\mathrm{O}$ & -3.901245 & 2.941117 & -1.378965 \\
\hline 0 & -1.878398 & 2.358034 & -2.234701 \\
\hline C & -1.628855 & 3.730669 & -2.587772 \\
\hline $\mathrm{H}$ & -0.692444 & 3.713192 & -3.144108 \\
\hline $\mathrm{H}$ & -1.521069 & 4.338903 & -1.687185 \\
\hline $\mathrm{H}$ & -2.443641 & 4.119101 & -3.203519 \\
\hline $\mathrm{H}$ & -4.635947 & -1.777978 & 0.165338 \\
\hline $\mathrm{H}$ & -2.842489 & -1.531316 & -0.083180 \\
\hline C & -5.495612 & 0.502524 & -0.964965 \\
\hline C & -6.472464 & 0.409953 & 0.040330 \\
\hline C & -5.878029 & 0.907899 & -2.257066 \\
\hline C & -7.797046 & 0.741047 & -0.240061 \\
\hline $\mathrm{H}$ & -6.199280 & 0.107536 & 1.045990 \\
\hline C & -7.205870 & 1.211005 & -2.535488 \\
\hline $\mathrm{H}$ & -5.137310 & 0.955838 & -3.048621 \\
\hline C & -8.168850 & 1.137143 & -1.525411 \\
\hline $\mathrm{H}$ & -8.539048 & 0.685372 & 0.551304 \\
\hline $\mathrm{H}$ & -7.489743 & 1.508815 & -3.540810 \\
\hline $\mathrm{H}$ & -9.204511 & 1.384460 & -1.742150 \\
\hline $\mathrm{H}$ & -5.836722 & -3.485758 & 3.071674 \\
\hline
\end{tabular}


Catalyst (R)-1 TS Conformation 215

B3LYP/6-31G(d) Energy $=-2809.693041$

B3LYP-D3(BJ)/def2-TZVPP-IEF-PCM(DCM) Energy = -2810.981532

B3LYP-D3(BJ)/def2-TZVPP-IEF-PCM(DCM)//B3LYP/6-31G(d) Free Energy (Quasiharmonic) = 2810.340346

Frequencies (Top 3 out of 270)

1. $-515.8530 \mathrm{~cm}-1$

2. $\quad 8.5447 \mathrm{~cm}-1$

3. $\quad 15.2728 \mathrm{~cm}-1$

B3LYP/6-31G(d) Molecular Geometry in Cartesian Coordinates

$\begin{array}{llll}\text { C } & 3.567011 & 0.326731 & 0.254161 \\ \text { C } & 2.683762 & 1.377573 & 0.054086 \\ \text { C } & 2.883489 & 2.682760 & 0.589728 \\ \text { C } & 3.984629 & 2.874767 & 1.400365 \\ \text { H } & 4.175976 & 3.864604 & 1.806434 \\ \text { C } & 2.804808 & -3.536754 & -1.502355 \\ \text { C } & 3.328675 & -0.989780 & -0.411371 \\ \text { C } & 2.117561 & -1.636552 & -0.222522 \\ \text { C } & 1.819124 & -2.929702 & -0.746113 \\ \text { H } & 2.634278 & -4.537331 & -1.890155 \\ \text { O } & 1.547464 & 1.169826 & -0.727214 \\ \text { P } & 0.338877 & 0.253697 & -0.130218 \\ \text { O } & 1.154167 & -0.994108 & 0.545858 \\ \text { C } & 0.383361 & 6.079945 & -0.252076 \\ \text { C } & 0.848744 & 5.277881 & -1.297044 \\ \text { C } & 1.627755 & 4.152857 & -1.030365 \\ \text { C } & 1.970999 & 3.818814 & 0.289712 \\ \text { C } & 1.495146 & 4.630111 & 1.331604 \\ \text { C } & 0.705500 & 5.748257 & 1.064552 \\ \text { H } & 0.614315 & 5.535718 & -2.326880 \\ \text { H } & 0.340642 & 6.358537 & 1.886498 \\ \text { C } & -1.923574 & -4.976620 & -0.147394 \\ \text { C } & -1.276147 & -5.020706 & -1.383130 \\ \text { C } & -0.074347 & -4.339496 & -1.567960 \\ \text { C } & 0.514098 & -3.607578 & -0.521581 \\ \text { C } & -0.150128 & -3.570198 & 0.717029 \\ \text { C } & -1.356858 & -4.245243 & 0.898508 \\ \text { H } & -1.712592 & -5.574757 & -2.210267\end{array}$




\begin{tabular}{|c|c|c|c|}
\hline $\mathrm{H}$ & -1.856719 & -4.182841 & 1.860778 \\
\hline C & 4.304937 & -1.598470 & -1.271646 \\
\hline C & 4.034020 & -2.901038 & -1.802921 \\
\hline C & 4.998099 & -3.526409 & -2.639938 \\
\hline C & 6.169167 & -2.886242 & -2.972011 \\
\hline C & 6.421086 & -1.583436 & -2.480997 \\
\hline C & 5.515718 & -0.957434 & -1.652586 \\
\hline $\mathrm{H}$ & 4.782838 & -4.520451 & -3.024882 \\
\hline $\mathrm{H}$ & 6.895041 & -3.371445 & -3.618752 \\
\hline $\mathrm{H}$ & 7.335921 & -1.069449 & -2.763377 \\
\hline $\mathrm{H}$ & 5.719858 & 0.043778 & -1.291045 \\
\hline C & 4.670215 & 0.524944 & 1.155931 \\
\hline C & 4.877302 & 1.823993 & 1.723147 \\
\hline C & 5.968362 & 2.034591 & 2.609385 \\
\hline C & 6.808790 & 1.002392 & 2.954919 \\
\hline C & 6.583541 & -0.291194 & 2.428578 \\
\hline C & 5.545430 & -0.523696 & 1.553393 \\
\hline $\mathrm{H}$ & 6.117041 & 3.030539 & 3.019932 \\
\hline $\mathrm{H}$ & 7.635440 & 1.173304 & 3.639020 \\
\hline $\mathrm{H}$ & 7.232598 & -1.111975 & 2.721594 \\
\hline $\mathrm{H}$ & 5.381605 & -1.523594 & 1.169452 \\
\hline $\mathrm{O}$ & -0.568518 & -0.165255 & -1.239560 \\
\hline $\mathrm{O}$ & -0.274896 & 0.995690 & 1.081702 \\
\hline $\mathrm{H}$ & -1.030547 & 0.371995 & 1.644165 \\
\hline $\mathrm{H}$ & 1.733681 & 4.367839 & 2.358465 \\
\hline $\mathrm{H}$ & -0.223577 & 6.956707 & -0.462666 \\
\hline $\mathrm{H}$ & 1.987305 & 3.537137 & -1.848424 \\
\hline $\mathrm{H}$ & 0.271066 & -3.006696 & 1.540530 \\
\hline $\mathrm{H}$ & -2.864539 & -5.501752 & -0.003592 \\
\hline $\mathrm{H}$ & 0.403032 & -4.350624 & -2.543565 \\
\hline C & -3.106707 & -0.310761 & 2.028147 \\
\hline $\mathrm{O}$ & -1.847271 & -0.472965 & 2.203237 \\
\hline $\mathrm{H}$ & -3.510167 & 0.702028 & 1.898985 \\
\hline C & -4.034057 & -1.143045 & 2.907012 \\
\hline $\mathrm{O}$ & -5.137841 & -0.765961 & 3.250810 \\
\hline $\mathrm{O}$ & -3.491904 & -2.312481 & 3.267990 \\
\hline C & -4.303901 & -3.122469 & 4.137668 \\
\hline $\mathrm{H}$ & -3.713039 & -4.016157 & 4.337365 \\
\hline $\mathrm{H}$ & -4.518356 & -2.587079 & 5.065797 \\
\hline C & -4.099315 & -0.045014 & -0.564727 \\
\hline C & -3.633511 & -1.093454 & 0.266089 \\
\hline $\mathrm{H}$ & -2.201767 & 0.352715 & -1.277006 \\
\hline$N$ & -3.186991 & 0.698866 & -1.234055 \\
\hline C & -3.355985 & 2.032148 & -1.668253 \\
\hline
\end{tabular}




$\begin{array}{llll}\text { O } & -4.285105 & 2.759313 & -1.406820 \\ \text { O } & -2.283950 & 2.360219 & -2.403413 \\ \text { C } & -2.242755 & 3.727818 & -2.845190 \\ \text { H } & -3.156499 & 3.981797 & -3.387605 \\ \text { H } & -1.372494 & 3.788656 & -3.497750 \\ \text { H } & -2.123777 & 4.397038 & -1.989747 \\ \text { H } & -4.362008 & -1.869974 & 0.478836 \\ \text { H } & -2.635975 & -1.469483 & 0.059458 \\ \text { C } & -5.543703 & 0.208065 & -0.741528 \\ \text { C } & -6.436839 & 0.102731 & 0.337511 \\ \text { C } & -6.051391 & 0.451051 & -2.031480 \\ \text { C } & -7.805468 & 0.263664 & 0.128668 \\ \text { H } & -6.066405 & -0.073697 & 1.341988 \\ \text { C } & -7.420060 & 0.582757 & -2.235611 \\ \text { H } & -5.372627 & 0.505338 & -2.876597 \\ \text { C } & -8.301509 & 0.498423 & -1.154364 \\ \text { H } & -8.484114 & 0.201848 & 0.974553 \\ \text { H } & -7.799892 & 0.754956 & -3.238622 \\ \text { H } & -9.370311 & 0.612157 & -1.313888 \\ \text { H } & -5.247077 & -3.383009 & 3.649727\end{array}$

Catalyst (R)-1 TS Conformation 216

B3LYP/6-31G(d) Energy = -2809.690203

B3LYP-D3(BJ)/def2-TZVPP-IEF-PCM(DCM) Energy = -2810.983577

B3LYP-D3(BJ)/def2-TZVPP-IEF-PCM(DCM)//B3LYP/6-31G(d) Free Energy (Quasiharmonic) = 2810.340304

Frequencies (Top 3 out of 270)

1. $-380.5208 \mathrm{~cm}-1$

2. $\quad 10.0538 \mathrm{~cm}-1$

3. $\quad 13.9499 \mathrm{~cm}-1$

B3LYP/6-31G(d) Molecular Geometry in Cartesian Coordinates

$\begin{array}{llll}\text { C } & -2.963161 & -0.834554 & 0.365989 \\ \text { C } & -1.899195 & -1.563798 & -0.139092 \\ \text { C } & -1.660998 & -2.930625 & 0.189991 \\ \text { C } & -2.494405 & -3.504537 & 1.131350 \\ \text { H } & -2.361786 & -4.553016 & 1.383951 \\ \text { C } & -3.767147 & 3.175631 & -0.977732 \\ \text { C } & -3.238150 & 0.531909 & -0.163148\end{array}$




\begin{tabular}{|c|c|c|c|}
\hline C & -2.253027 & 1.509297 & -0.137011 \\
\hline C & -2.500778 & 2.859600 & -0.526199 \\
\hline $\mathrm{H}$ & -3.976135 & 4.198310 & -1.280429 \\
\hline 0 & -1.019489 & -0.927997 & -1.017328 \\
\hline$P$ & 0.013325 & 0.147009 & -0.337864 \\
\hline 0 & -1.003558 & 1.205702 & 0.388679 \\
\hline C & 1.184978 & -5.533586 & -1.703542 \\
\hline C & 0.453572 & -4.623419 & -2.470276 \\
\hline C & -0.432599 & -3.738478 & -1.858944 \\
\hline C & -0.613357 & -3.756375 & -0.466322 \\
\hline C & 0.150822 & -4.655338 & 0.296549 \\
\hline C & 1.040716 & -5.536301 & -0.314699 \\
\hline $\mathrm{H}$ & 0.566529 & -4.603110 & -3.550775 \\
\hline $\mathrm{H}$ & 1.620085 & -6.225199 & 0.294545 \\
\hline C & 0.299168 & 6.123084 & -0.530107 \\
\hline C & 0.587756 & 4.955197 & -1.241241 \\
\hline C & -0.284009 & 3.865898 & -1.203310 \\
\hline C & -1.476693 & 3.940877 & -0.467570 \\
\hline C & -1.756261 & 5.117076 & 0.246515 \\
\hline C & -0.873736 & 6.197181 & 0.222401 \\
\hline $\mathrm{H}$ & 1.492953 & 4.892840 & -1.839951 \\
\hline $\mathrm{H}$ & -1.107302 & 7.097405 & 0.785069 \\
\hline C & -4.517032 & 0.851444 & -0.739703 \\
\hline C & -4.784308 & 2.203146 & -1.125532 \\
\hline C & -6.049341 & 2.538734 & -1.679707 \\
\hline C & -7.012248 & 1.576789 & -1.875516 \\
\hline C & -6.739019 & 0.231976 & -1.531188 \\
\hline C & -5.527823 & -0.121280 & -0.978290 \\
\hline $\mathrm{H}$ & -6.234593 & 3.573276 & -1.959055 \\
\hline $\mathrm{H}$ & -7.974097 & 1.842001 & -2.305747 \\
\hline $\mathrm{H}$ & -7.490058 & -0.532562 & -1.710915 \\
\hline $\mathrm{H}$ & -5.333653 & -1.158409 & -0.732083 \\
\hline C & -3.770013 & -1.420955 & 1.401684 \\
\hline C & -3.522776 & -2.779218 & 1.780090 \\
\hline C & -4.314463 & -3.375841 & 2.798612 \\
\hline C & -5.291500 & -2.657069 & 3.447032 \\
\hline C & -5.512594 & -1.303057 & 3.101812 \\
\hline C & -4.775270 & -0.702195 & 2.105127 \\
\hline $\mathrm{H}$ & -4.121614 & -4.412575 & 3.064317 \\
\hline $\mathrm{H}$ & -5.885290 & -3.120865 & 4.229949 \\
\hline $\mathrm{H}$ & -6.268656 & -0.729315 & 3.631034 \\
\hline $\mathrm{H}$ & -4.950478 & 0.338749 & 1.859666 \\
\hline $\mathrm{O}$ & 0.853012 & 0.784999 & -1.396864 \\
\hline $\mathrm{O}$ & 0.704996 & -0.508367 & 0.876860 \\
\hline
\end{tabular}




\begin{tabular}{|c|c|c|c|}
\hline $\mathrm{H}$ & 1.678243 & -1.037095 & 0.800987 \\
\hline $\mathrm{H}$ & 0.051016 & -4.652727 & 1.378091 \\
\hline $\mathrm{H}$ & 1.862021 & -6.235986 & -2.184230 \\
\hline $\mathrm{H}$ & -0.998434 & -3.040350 & -2.465638 \\
\hline $\mathrm{H}$ & -2.672807 & 5.178872 & 0.827212 \\
\hline $\mathrm{H}$ & 0.979932 & 6.969886 & -0.567443 \\
\hline $\mathrm{H}$ & -0.046132 & 2.963228 & -1.756146 \\
\hline C & 3.891046 & -1.608676 & 1.297404 \\
\hline 0 & 2.761744 & -1.829580 & 0.702753 \\
\hline $\mathrm{H}$ & 4.495005 & -2.498696 & 1.531354 \\
\hline C & 3.985723 & -0.654258 & 2.494495 \\
\hline 0 & 4.928828 & -0.643711 & 3.259900 \\
\hline 0 & 2.924144 & 0.153890 & 2.578306 \\
\hline C & 2.920579 & 1.086467 & 3.672162 \\
\hline $\mathrm{H}$ & 3.751379 & 1.790054 & 3.572202 \\
\hline $\mathrm{H}$ & 1.964399 & 1.604252 & 3.604876 \\
\hline C & 4.435288 & 0.122921 & -0.519762 \\
\hline C & 5.179640 & -0.883014 & 0.155527 \\
\hline $\mathrm{H}$ & 2.682937 & 0.412329 & -1.581978 \\
\hline$N$ & 3.493340 & -0.209398 & -1.425723 \\
\hline C & 3.299451 & -1.410541 & -2.162010 \\
\hline 0 & 2.289123 & -1.599905 & -2.790840 \\
\hline $\mathrm{O}$ & 4.376923 & -2.207380 & -2.167899 \\
\hline C & 4.217551 & -3.422604 & -2.928150 \\
\hline $\mathrm{H}$ & 5.174136 & -3.938155 & -2.841164 \\
\hline $\mathrm{H}$ & 3.997826 & -3.187829 & -3.972142 \\
\hline $\mathrm{H}$ & 3.408331 & -4.021788 & -2.507104 \\
\hline $\mathrm{H}$ & 5.969903 & -0.540326 & 0.814231 \\
\hline $\mathrm{H}$ & 5.427676 & -1.768958 & -0.409999 \\
\hline C & 4.512545 & 1.527339 & -0.064617 \\
\hline C & 5.754868 & 2.022534 & 0.381179 \\
\hline C & 3.397872 & 2.388067 & -0.053112 \\
\hline C & 5.879654 & 3.333526 & 0.830747 \\
\hline $\mathrm{H}$ & 6.634084 & 1.388589 & 0.347760 \\
\hline C & 3.526086 & 3.692052 & 0.419843 \\
\hline $\mathrm{H}$ & 2.422090 & 2.039621 & -0.376447 \\
\hline C & 4.762491 & 4.169854 & 0.859822 \\
\hline $\mathrm{H}$ & 6.848808 & 3.699235 & 1.157380 \\
\hline $\mathrm{H}$ & 2.650249 & 4.332338 & 0.444132 \\
\hline $\mathrm{H}$ & 4.854859 & 5.190392 & 1.221471 \\
\hline $\mathrm{H}$ & 3.010112 & 0.555742 & 4.623205 \\
\hline
\end{tabular}

Catalyst (R)-1 TS Conformation 217 
B3LYP/6-31G(d) Energy $=-2809.687005$

B3LYP-D3(BJ)/def2-TZVPP-IEF-PCM(DCM) Energy $=-2810.981182$

B3LYP-D3(BJ)/def2-TZVPP-IEF-PCM(DCM)//B3LYP/6-31G(d) Free Energy (Quasiharmonic) = 2810.340274

Frequencies (Top 3 out of 270)

1. $-702.2274 \mathrm{~cm}-1$

2. $\quad 5.4173 \mathrm{~cm}-1$

3. $12.0239 \mathrm{~cm}-1$

B3LYP/6-31G(d) Molecular Geometry in Cartesian Coordinates

$\begin{array}{llll}\mathrm{C} & 3.170747 & -0.104561 & 0.277709 \\ \mathrm{C} & 2.586009 & 1.088087 & -0.119183 \\ \mathrm{C} & 3.116365 & 2.364809 & 0.235646 \\ \mathrm{C} & 4.178619 & 2.386885 & 1.118688 \\ \mathrm{H} & 4.596440 & 3.345829 & 1.413412 \\ \mathrm{C} & 1.940967 & -3.981342 & -1.127925 \\ \mathrm{C} & 2.738404 & -1.401107 & -0.320453 \\ \mathrm{C} & 1.413948 & -1.806997 & -0.254457 \\ \mathrm{C} & 0.994536 & -3.123470 & -0.605182 \\ \mathrm{H} & 1.643182 & -4.990453 & -1.400647 \\ \mathrm{O} & 1.500418 & 1.046451 & -0.987954 \\ \mathrm{P} & 0.067711 & 0.459244 & -0.472635 \\ \mathrm{O} & 0.469827 & -0.945272 & 0.285955 \\ \mathrm{C} & 1.898161 & 6.130977 & -1.452343 \\ \mathrm{C} & 3.234068 & 5.730488 & -1.483383 \\ \mathrm{C} & 3.603280 & 4.498613 & -0.945232 \\ \mathrm{C} & 2.648213 & 3.643197 & -0.368985 \\ \mathrm{C} & 1.306151 & 4.052316 & -0.348271 \\ \mathrm{C} & 0.942130 & 5.288110 & -0.883211 \\ \mathrm{H} & 3.989177 & 6.372128 & -1.930299 \\ \mathrm{H} & -0.099565 & 5.592525 & -0.849437 \\ \mathrm{C} & -2.934830 & -4.748988 & 0.035091 \\ \mathrm{C} & -2.767515 & -3.659134 & -0.822017 \\ \mathrm{C} & -1.507064 & -3.090183 & -1.014036 \\ \mathrm{C} & -0.387191 & -3.626414 & -0.360329 \\ \mathrm{C} & -0.564236 & -4.725871 & 0.494712 \\ \mathrm{C} & -1.828255 & -5.280072 & 0.697625 \\ \mathrm{H} & -3.612873 & -3.261242 & -1.374188 \\ \mathrm{H} & -1.944321 & -6.128431 & 1.367463 \\ \mathrm{C} & 3.689584 & -2.264531 & -0.969850\end{array}$




\begin{tabular}{|c|c|c|c|}
\hline C & 3.276572 & -3.576128 & -1.367373 \\
\hline C & 4.207577 & -4.442561 & -2.001246 \\
\hline C & 5.493523 & -4.029829 & -2.261080 \\
\hline C & 5.896526 & -2.722812 & -1.899811 \\
\hline C & 5.021676 & -1.865483 & -1.269401 \\
\hline $\mathrm{H}$ & 3.876243 & -5.437543 & -2.289147 \\
\hline $\mathrm{H}$ & 6.195584 & -4.697459 & -2.753048 \\
\hline $\mathrm{H}$ & 6.905089 & -2.388493 & -2.127723 \\
\hline $\mathrm{H}$ & 5.344545 & -0.863889 & -1.010786 \\
\hline C & 4.211255 & -0.063261 & 1.271480 \\
\hline C & 4.716020 & 1.208600 & 1.690326 \\
\hline C & 5.742378 & 1.266557 & 2.671575 \\
\hline C & 6.241173 & 0.118488 & 3.241446 \\
\hline C & 5.723314 & -1.139216 & 2.852697 \\
\hline C & 4.738887 & -1.228624 & 1.892962 \\
\hline $\mathrm{H}$ & 6.117942 & 2.242121 & 2.971391 \\
\hline $\mathrm{H}$ & 7.021305 & 0.174230 & 3.995751 \\
\hline $\mathrm{H}$ & 6.101260 & -2.044538 & 3.320142 \\
\hline $\mathrm{H}$ & 4.346022 & -2.199855 & 1.616007 \\
\hline 0 & -0.810021 & 0.259094 & -1.666445 \\
\hline $\mathrm{O}$ & -0.434625 & 1.346780 & 0.677807 \\
\hline $\mathrm{H}$ & -1.338244 & 1.070187 & 1.433119 \\
\hline $\mathrm{H}$ & 0.554863 & 3.413982 & 0.104078 \\
\hline $\mathrm{H}$ & 1.604559 & 7.090860 & -1.869850 \\
\hline $\mathrm{H}$ & 4.641934 & 4.181745 & -0.984767 \\
\hline $\mathrm{H}$ & 0.299064 & -5.141043 & 1.007924 \\
\hline $\mathrm{H}$ & -3.919575 & -5.187647 & 0.176908 \\
\hline $\mathrm{H}$ & -1.389883 & -2.249897 & -1.691382 \\
\hline C & -3.019235 & -0.085608 & 1.854708 \\
\hline $\mathrm{O}$ & -2.242258 & 0.875327 & 2.195430 \\
\hline $\mathrm{H}$ & -2.669357 & -0.842530 & 1.143685 \\
\hline C & -3.922541 & -0.605757 & 2.965960 \\
\hline $\mathrm{O}$ & -4.282969 & 0.042233 & 3.919397 \\
\hline $\mathrm{O}$ & -4.259277 & -1.886383 & 2.723281 \\
\hline C & -5.096209 & -2.503204 & 3.718984 \\
\hline $\mathrm{H}$ & -6.045983 & -1.968220 & 3.803638 \\
\hline $\mathrm{H}$ & -5.255426 & -3.524024 & 3.372591 \\
\hline C & -3.950001 & 1.116724 & -0.360364 \\
\hline C & -4.617294 & 0.506742 & 0.708027 \\
\hline $\mathrm{H}$ & -2.577796 & 0.476379 & -1.775356 \\
\hline$N$ & -3.569112 & 0.393948 & -1.471582 \\
\hline C & -4.278934 & -0.600383 & -2.140690 \\
\hline $\mathrm{O}$ & -3.784435 & -1.286887 & -3.008261 \\
\hline $\mathrm{O}$ & -5.574626 & -0.653898 & -1.765636 \\
\hline
\end{tabular}




$\begin{array}{llll}\mathrm{C} & -6.375833 & -1.594477 & -2.503092 \\ \mathrm{H} & -6.025580 & -2.616028 & -2.335207 \\ \mathrm{H} & -6.337142 & -1.373468 & -3.572090 \\ \mathrm{H} & -7.388370 & -1.469123 & -2.119088 \\ \mathrm{H} & -5.148183 & 1.141111 & 1.408792 \\ \mathrm{H} & -5.056071 & -0.468835 & 0.540136 \\ \mathrm{C} & -3.511762 & 2.510060 & -0.298767 \\ \mathrm{C} & -3.512471 & 3.223806 & 0.920468 \\ \mathrm{C} & -3.152499 & 3.187893 & -1.484068 \\ \mathrm{C} & -3.174328 & 4.572761 & 0.942790 \\ \mathrm{H} & -3.748694 & 2.722537 & 1.850110 \\ \mathrm{C} & -2.829877 & 4.538239 & -1.454030 \\ \mathrm{H} & -3.160400 & 2.657382 & -2.429522 \\ \mathrm{C} & -2.844584 & 5.235192 & -0.241322 \\ \mathrm{H} & -3.170954 & 5.108397 & 1.887218 \\ \mathrm{H} & -2.572052 & 5.050459 & -2.376066 \\ \mathrm{H} & -2.601969 & 6.294235 & -0.220682 \\ \mathrm{H} & -4.595449 & -2.498445 & 4.690184\end{array}$

Catalyst (R)-1 TS Conformation 218

B3LYP/6-31G(d) Energy = -2809.685511

B3LYP-D3(BJ)/def2-TZVPP-IEF-PCM(DCM) Energy $=-2810.982059$

B3LYP-D3(BJ)/def2-TZVPP-IEF-PCM(DCM)//B3LYP/6-31G(d) Free Energy (Quasiharmonic) = 2810.340251

Frequencies (Top 3 out of 270)

1. $-565.0021 \mathrm{~cm}-1$

2. $\quad 9.3363 \mathrm{~cm}-1$

3. $10.9338 \mathrm{~cm}-1$

B3LYP/6-31G(d) Molecular Geometry in Cartesian Coordinates

$\begin{array}{llll}\text { C } & 3.493851 & -1.034744 & -0.146322 \\ \text { C } & 2.225520 & -1.538207 & 0.097912 \\ \text { C } & 1.874591 & -2.905842 & -0.100894 \\ \text { C } & 2.850790 & -3.750571 & -0.588987 \\ \text { H } & 2.619231 & -4.802875 & -0.733886 \\ \text { C } & 4.257099 & 3.161918 & 0.497543 \\ \text { C } & 3.767704 & 0.407375 & 0.129664 \\ \text { C } & 2.965986 & 1.378150 & -0.456848 \\ \text { C } & 3.205163 & 2.778435 & -0.312137\end{array}$




\begin{tabular}{|c|c|c|c|}
\hline $\mathrm{H}$ & 4.483628 & 4.219418 & 0.605510 \\
\hline $\mathrm{O}$ & 1.247397 & -0.672547 & 0.558416 \\
\hline$P$ & 0.553953 & 0.356629 & -0.543138 \\
\hline $\mathrm{O}$ & 1.904872 & 0.978803 & -1.251962 \\
\hline C & -2.081512 & -4.410903 & 0.686904 \\
\hline C & -1.409692 & -3.667072 & 1.661141 \\
\hline C & -0.131791 & -3.169037 & 1.410063 \\
\hline C & 0.502898 & -3.408178 & 0.179583 \\
\hline C & -0.178990 & -4.162242 & -0.787565 \\
\hline C & -1.459043 & -4.658585 & -0.537314 \\
\hline $\mathrm{H}$ & -1.883236 & -3.478764 & 2.621477 \\
\hline $\mathrm{H}$ & -1.972566 & -5.231016 & -1.305546 \\
\hline C & 0.916909 & 5.843339 & -2.285621 \\
\hline C & 1.311678 & 4.704744 & -2.991073 \\
\hline C & 2.031551 & 3.694449 & -2.355846 \\
\hline C & 2.376975 & 3.806024 & -0.998347 \\
\hline C & 1.969040 & 4.953911 & -0.299287 \\
\hline C & 1.246730 & 5.962874 & -0.935133 \\
\hline $\mathrm{H}$ & 1.060291 & 4.601421 & -4.043533 \\
\hline $\mathrm{H}$ & 0.935818 & 6.839004 & -0.371615 \\
\hline C & 4.809128 & 0.824464 & 1.027691 \\
\hline C & 5.056567 & 2.225306 & 1.196661 \\
\hline C & 6.091707 & 2.650983 & 2.072908 \\
\hline C & 6.837437 & 1.739954 & 2.784073 \\
\hline C & 6.569831 & 0.357199 & 2.649448 \\
\hline C & 5.585132 & -0.088138 & 1.795004 \\
\hline $\mathrm{H}$ & 6.274065 & 3.717966 & 2.178749 \\
\hline $\mathrm{H}$ & 7.621733 & 2.077839 & 3.456022 \\
\hline $\mathrm{H}$ & 7.143703 & -0.361102 & 3.228948 \\
\hline $\mathrm{H}$ & 5.386847 & -1.150356 & 1.710395 \\
\hline C & 4.481933 & -1.909670 & -0.715823 \\
\hline C & 4.149125 & -3.288892 & -0.920094 \\
\hline C & 5.120591 & -4.166908 & -1.472598 \\
\hline C & 6.362922 & -3.706940 & -1.842637 \\
\hline C & 6.680672 & -2.338094 & -1.680099 \\
\hline C & 5.767111 & -1.464505 & -1.132215 \\
\hline $\mathrm{H}$ & 4.854799 & -5.212621 & -1.609406 \\
\hline $\mathrm{H}$ & 7.094811 & -4.386757 & -2.270353 \\
\hline $\mathrm{H}$ & 7.653352 & -1.970136 & -1.995586 \\
\hline $\mathrm{H}$ & 6.023101 & -0.416945 & -1.024626 \\
\hline 0 & -0.267694 & 1.329731 & 0.228140 \\
\hline $\mathrm{O}$ & -0.074713 & -0.468137 & -1.667775 \\
\hline $\mathrm{H}$ & -1.314077 & -0.590391 & -1.735615 \\
\hline $\mathrm{H}$ & 0.289863 & -4.333076 & -1.752326 \\
\hline
\end{tabular}




\begin{tabular}{|c|c|c|c|}
\hline $\mathrm{H}$ & -3.082577 & -4.785553 & 0.881259 \\
\hline $\mathrm{H}$ & 0.385440 & -2.594981 & 2.171912 \\
\hline $\mathrm{H}$ & 2.203233 & 5.042596 & 0.757926 \\
\hline $\mathrm{H}$ & 0.353340 & 6.628223 & -2.783576 \\
\hline $\mathrm{H}$ & 2.332904 & 2.815415 & -2.914369 \\
\hline C & -3.057721 & -0.849892 & -0.689941 \\
\hline 0 & -2.459052 & -0.769156 & -1.829356 \\
\hline $\mathrm{H}$ & -2.476852 & -1.074411 & 0.209329 \\
\hline C & -4.402283 & -1.558920 & -0.671066 \\
\hline 0 & -4.882708 & -2.027040 & 0.343916 \\
\hline 0 & -4.969993 & -1.607769 & -1.879472 \\
\hline C & -6.219722 & -2.316009 & -1.953761 \\
\hline $\mathrm{H}$ & -6.489074 & -2.315497 & -3.009807 \\
\hline $\mathrm{H}$ & -6.100211 & -3.338195 & -1.586107 \\
\hline C & -4.589394 & 1.004305 & 0.735061 \\
\hline C & -3.508342 & 0.989537 & -0.163210 \\
\hline $\mathrm{H}$ & -5.377747 & 0.837131 & 2.596866 \\
\hline$N$ & -4.508986 & 0.795966 & 2.077546 \\
\hline C & -3.425642 & 0.576019 & 2.964239 \\
\hline 0 & -3.633414 & 0.491159 & 4.153980 \\
\hline $\mathrm{O}$ & -2.268004 & 0.499882 & 2.333922 \\
\hline C & -1.087880 & 0.371776 & 3.165949 \\
\hline $\mathrm{H}$ & -0.260616 & 0.449136 & 2.465722 \\
\hline $\mathrm{H}$ & -1.106681 & -0.593102 & 3.677482 \\
\hline $\mathrm{H}$ & -1.070717 & 1.178963 & 3.900836 \\
\hline $\mathrm{H}$ & -3.757177 & 1.337177 & -1.159942 \\
\hline $\mathrm{H}$ & -2.506396 & 1.238379 & 0.180930 \\
\hline C & -5.979335 & 1.175341 & 0.244389 \\
\hline C & -7.035041 & 0.410524 & 0.776782 \\
\hline C & -6.261617 & 2.127002 & -0.750930 \\
\hline C & -8.339065 & 0.599757 & 0.323390 \\
\hline $\mathrm{H}$ & -6.826484 & -0.374392 & 1.497488 \\
\hline C & -7.568708 & 2.319587 & -1.191305 \\
\hline $\mathrm{H}$ & -5.460689 & 2.737547 & -1.154900 \\
\hline C & -8.609829 & 1.557842 & -0.656203 \\
\hline $\mathrm{H}$ & -9.142488 & -0.006696 & 0.731451 \\
\hline $\mathrm{H}$ & -7.774447 & 3.069231 & -1.949595 \\
\hline $\mathrm{H}$ & -9.628214 & 1.708485 & -1.003008 \\
\hline $\mathrm{H}$ & -6.984030 & -1.806478 & -1.361632 \\
\hline
\end{tabular}

Catalyst (R)-1 TS Conformation 219

B3LYP/6-31G(d) Energy $=-2809.689231$ 
B3LYP-D3(BJ)/def2-TZVPP-IEF-PCM(DCM) Energy $=-2810.981543$

B3LYP-D3(BJ)/def2-TZVPP-IEF-PCM(DCM)//B3LYP/6-31G(d) Free Energy (Quasiharmonic) = 2810.34024

Frequencies (Top 3 out of 270)

1. $-608.2002 \mathrm{~cm}-1$

2. $\quad 3.9259 \mathrm{~cm}-1$

3. $10.9848 \mathrm{~cm}-1$

B3LYP/6-31G(d) Molecular Geometry in Cartesian Coordinates

$\begin{array}{llll}\text { C } & 3.415267 & -0.945988 & 0.104571 \\ \text { C } & 2.162044 & -1.529423 & 0.202955 \\ \text { C } & 1.938687 & -2.935981 & 0.140213 \\ \text { C } & 3.042480 & -3.741111 & -0.061948 \\ \text { H } & 2.913722 & -4.819983 & -0.090347 \\ \text { C } & 3.801933 & 3.344991 & 0.359696 \\ \text { C } & 3.549400 & 0.535279 & 0.246201 \\ \text { C } & 2.802382 & 1.375081 & -0.566860 \\ \text { C } & 2.923132 & 2.795888 & -0.554101 \\ \text { H } & 3.939812 & 4.422791 & 0.378739 \\ \text { O } & 1.059127 & -0.703144 & 0.385875 \\ \text { P } & 0.519159 & 0.169110 & -0.891946 \\ \text { O } & 1.904997 & 0.808722 & -1.468416 \\ \text { C } & -1.969517 & -4.710299 & 0.468236 \\ \text { C } & -1.576558 & -3.719555 & 1.371686 \\ \text { C } & -0.315757 & -3.132858 & 1.271012 \\ \text { C } & 0.578770 & -3.526112 & 0.260007 \\ \text { C } & 0.171805 & -4.524311 & -0.639793 \\ \text { C } & -1.088828 & -5.112374 & -0.536340 \\ \text { H } & -2.258924 & -3.399585 & 2.154277 \\ \text { H } & -1.385809 & -5.875290 & -1.251289 \\ \text { C } & 0.775604 & 5.431444 & -3.192038 \\ \text { C } & 1.370474 & 4.273419 & -3.697036 \\ \text { C } & 2.049123 & 3.400861 & -2.848128 \\ \text { C } & 2.150157 & 3.673373 & -1.473409 \\ \text { C } & 1.543782 & 4.839144 & -0.977557 \\ \text { C } & 0.863373 & 5.710158 & -1.827604 \\ \text { H } & 1.308682 & 4.047444 & -4.758379 \\ \text { H } & 0.395321 & 6.602884 & -1.420687 \\ \text { C } & 4.400717 & 1.127421 & 1.241974 \\ \text { C } & 4.531174 & 2.553493 & 1.279895 \\ \text { C } & 5.379797 & 3.151478 & 2.250893\end{array}$




\begin{tabular}{|c|c|c|c|}
\hline C & 6.050961 & 2.383672 & 3.173539 \\
\hline C & 5.892487 & 0.977874 & 3.164696 \\
\hline C & 5.091603 & 0.366587 & 2.225229 \\
\hline $\mathrm{H}$ & 5.476709 & 4.234617 & 2.256947 \\
\hline $\mathrm{H}$ & 6.691105 & 2.852558 & 3.915832 \\
\hline $\mathrm{H}$ & 6.403378 & 0.373907 & 3.909737 \\
\hline $\mathrm{H}$ & 4.973358 & -0.710543 & 2.239415 \\
\hline C & 4.542147 & -1.791607 & -0.181508 \\
\hline C & 4.342554 & -3.209269 & -0.245723 \\
\hline C & 5.450475 & -4.058369 & -0.514068 \\
\hline C & 6.702347 & -3.537727 & -0.744790 \\
\hline C & 6.894321 & -2.136315 & -0.722830 \\
\hline C & 5.844946 & -1.287168 & -0.447869 \\
\hline $\mathrm{H}$ & 5.283465 & -5.132469 & -0.546836 \\
\hline $\mathrm{H}$ & 7.540070 & -4.196591 & -0.956281 \\
\hline $\mathrm{H}$ & 7.878387 & -1.724528 & -0.929972 \\
\hline $\mathrm{H}$ & 6.007486 & -0.215707 & -0.444598 \\
\hline $\mathrm{O}$ & -0.471829 & 1.158000 & -0.371330 \\
\hline $\mathrm{O}$ & 0.099569 & -0.775543 & -2.033811 \\
\hline $\mathrm{H}$ & -1.008507 & -1.030832 & -2.200354 \\
\hline $\mathrm{H}$ & 0.840649 & -4.818596 & -1.443552 \\
\hline $\mathrm{H}$ & -2.957334 & -5.156060 & 0.545508 \\
\hline $\mathrm{H}$ & -0.019559 & -2.366488 & 1.979248 \\
\hline $\mathrm{H}$ & 1.589029 & 5.049150 & 0.087422 \\
\hline $\mathrm{H}$ & 0.244422 & 6.108189 & -3.856272 \\
\hline $\mathrm{H}$ & 2.509478 & 2.506141 & -3.252594 \\
\hline C & -2.883699 & -1.168889 & -1.265772 \\
\hline $\mathrm{O}$ & -2.235722 & -1.345640 & -2.353530 \\
\hline $\mathrm{H}$ & -2.341968 & -1.113415 & -0.312954 \\
\hline C & -4.203804 & -1.896768 & -1.085908 \\
\hline $\mathrm{O}$ & -4.623936 & -2.224928 & 0.004704 \\
\hline $\mathrm{O}$ & -4.827188 & -2.139572 & -2.249329 \\
\hline C & -6.025559 & -2.928970 & -2.152416 \\
\hline $\mathrm{H}$ & -6.396720 & -3.019905 & -3.173102 \\
\hline $\mathrm{H}$ & -6.764465 & -2.437916 & -1.513295 \\
\hline C & -3.878826 & 1.083206 & 0.078548 \\
\hline C & -3.458505 & 0.757389 & -1.223330 \\
\hline $\mathrm{H}$ & -1.933619 & 1.292412 & 0.664737 \\
\hline$N$ & -2.902819 & 1.221626 & 1.024711 \\
\hline C & -2.934117 & 0.982738 & 2.410951 \\
\hline $\mathrm{O}$ & -1.993111 & 1.248022 & 3.123171 \\
\hline $\mathrm{O}$ & -4.074837 & 0.403262 & 2.812008 \\
\hline C & -4.148871 & 0.125646 & 4.221207 \\
\hline $\mathrm{H}$ & -5.127901 & -0.328934 & 4.370623 \\
\hline
\end{tabular}




$\begin{array}{lrrr}\mathrm{H} & -4.056619 & 1.048276 & 4.799817 \\ \mathrm{H} & -3.353264 & -0.563196 & 4.514541 \\ \mathrm{H} & -4.176129 & 0.865490 & -2.029591 \\ \mathrm{H} & -2.439342 & 1.040225 & -1.466934 \\ \mathrm{C} & -5.294675 & 1.346391 & 0.394505 \\ \mathrm{C} & -6.326347 & 0.701972 & -0.309868 \\ \mathrm{C} & -5.635379 & 2.349922 & 1.321372 \\ \mathrm{C} & -7.658562 & 1.027839 & -0.069585 \\ \mathrm{H} & -6.087213 & -0.056871 & -1.044757 \\ \mathrm{C} & -6.966389 & 2.686080 & 1.544186 \\ \mathrm{H} & -4.851270 & 2.892707 & 1.838695 \\ \mathrm{C} & -7.984155 & 2.018565 & 0.858319 \\ \mathrm{H} & -8.443942 & 0.509788 & -0.612480 \\ \mathrm{H} & -7.209985 & 3.474209 & 2.250960 \\ \mathrm{H} & -9.023856 & 2.277693 & 1.037731 \\ \mathrm{H} & -5.797236 & -3.913935 & -1.736931\end{array}$

Catalyst (R)-1 TS Conformation 220

B3LYP/6-31G(d) Energy $=-2809.691053$

B3LYP-D3(BJ)/def2-TZVPP-IEF-PCM(DCM) Energy = -2810.983315

B3LYP-D3(BJ)/def2-TZVPP-IEF-PCM(DCM)//B3LYP/6-31G(d) Free Energy (Quasiharmonic) = 2810.340228

Frequencies (Top 3 out of 270)

1. $-317.3558 \mathrm{~cm}-1$

2. $\quad 11.0221 \mathrm{~cm}-1$

3. $\quad 11.8679 \mathrm{~cm}-1$

B3LYP/6-31G(d) Molecular Geometry in Cartesian Coordinates

$\begin{array}{llll}\text { C } & -2.730347 & -1.454924 & 0.349733 \\ \text { C } & -1.509313 & -1.793948 & -0.209088 \\ \text { C } & -0.864484 & -3.046163 & 0.012181 \\ \text { C } & -1.467557 & -3.912428 & 0.904466 \\ \text { H } & -1.022166 & -4.888758 & 1.075023 \\ \text { C } & -4.733478 & 2.213100 & -0.686973 \\ \text { C } & -3.415287 & -0.199873 & -0.074472 \\ \text { C } & -2.770841 & 1.025226 & 0.024133 \\ \text { C } & -3.421049 & 2.263071 & -0.259597 \\ \text { H } & -5.247839 & 3.143963 & -0.910575 \\ \text { O } & -0.879710 & -0.863766 & -1.039540\end{array}$




\begin{tabular}{|c|c|c|c|}
\hline$P$ & -0.214376 & 0.434876 & -0.301982 \\
\hline $\mathrm{O}$ & -1.472471 & 1.074143 & 0.521189 \\
\hline C & 2.622194 & -4.473005 & -2.055842 \\
\hline C & 2.499448 & -4.644562 & -0.675938 \\
\hline C & 1.386079 & -4.141993 & -0.005924 \\
\hline C & 0.373376 & -3.459323 & -0.700289 \\
\hline C & 0.524663 & -3.264524 & -2.083292 \\
\hline C & 1.636320 & -3.771335 & -2.753427 \\
\hline $\mathrm{H}$ & 3.271495 & -5.168136 & -0.118304 \\
\hline $\mathrm{H}$ & 1.727664 & -3.619296 & -3.825304 \\
\hline C & -1.728161 & 6.205855 & 0.028928 \\
\hline C & -2.864951 & 5.866566 & 0.763815 \\
\hline C & -3.383547 & 4.573759 & 0.689340 \\
\hline C & -2.770050 & 3.595369 & -0.109437 \\
\hline C & -1.615922 & 3.939441 & -0.830119 \\
\hline C & -1.108664 & 5.238159 & -0.766328 \\
\hline $\mathrm{H}$ & -3.352618 & 6.607982 & 1.391496 \\
\hline $\mathrm{H}$ & -0.227800 & 5.495585 & -1.348913 \\
\hline C & -4.744126 & -0.240365 & -0.625026 \\
\hline C & -5.413451 & 0.992142 & -0.908739 \\
\hline C & -6.732604 & 0.969632 & -1.437332 \\
\hline C & -7.365803 & -0.221158 & -1.705473 \\
\hline C & -6.693768 & -1.442191 & -1.462359 \\
\hline C & -5.420749 & -1.452745 & -0.936249 \\
\hline $\mathrm{H}$ & -7.226265 & 1.917445 & -1.638595 \\
\hline $\mathrm{H}$ & -8.371946 & -0.227992 & -2.115569 \\
\hline $\mathrm{H}$ & -7.184067 & -2.382548 & -1.699376 \\
\hline $\mathrm{H}$ & -4.918676 & -2.398031 & -0.768117 \\
\hline C & -3.300487 & -2.331658 & 1.336618 \\
\hline C & -2.650848 & -3.578586 & 1.606662 \\
\hline C & -3.205151 & -4.459443 & 2.574718 \\
\hline C & -4.336462 & -4.116236 & 3.277496 \\
\hline C & -4.958708 & -2.868047 & 3.040336 \\
\hline C & -4.457407 & -2.001065 & 2.094297 \\
\hline $\mathrm{H}$ & -2.706157 & -5.408101 & 2.758078 \\
\hline $\mathrm{H}$ & -4.746655 & -4.793731 & 4.021369 \\
\hline $\mathrm{H}$ & -5.838393 & -2.587778 & 3.613401 \\
\hline $\mathrm{H}$ & -4.940182 & -1.044451 & 1.932042 \\
\hline $\mathrm{O}$ & 0.368003 & 1.356622 & -1.319799 \\
\hline 0 & 0.695092 & -0.042573 & 0.863890 \\
\hline $\mathrm{H}$ & 1.700306 & -0.418584 & 0.651722 \\
\hline $\mathrm{H}$ & -0.236211 & -2.726432 & -2.637339 \\
\hline $\mathrm{H}$ & 3.480622 & -4.881850 & -2.583731 \\
\hline $\mathrm{H}$ & 1.302783 & -4.265320 & 1.070010 \\
\hline
\end{tabular}




\begin{tabular}{|c|c|c|c|}
\hline $\mathrm{H}$ & -1.123481 & 3.197514 & -1.449927 \\
\hline $\mathrm{H}$ & -1.330190 & 7.216582 & 0.071711 \\
\hline $\mathrm{H}$ & -4.270764 & 4.312144 & 1.259806 \\
\hline C & 3.819191 & -0.358066 & 1.315647 \\
\hline 0 & 2.971312 & -0.903167 & 0.524415 \\
\hline $\mathrm{H}$ & 3.468283 & 0.325304 & 2.102074 \\
\hline C & 4.980253 & -1.197712 & 1.843901 \\
\hline 0 & 5.556388 & -0.944241 & 2.880944 \\
\hline 0 & 5.281030 & -2.227405 & 1.036018 \\
\hline C & 6.353923 & -3.065815 & 1.496920 \\
\hline $\mathrm{H}$ & 6.106660 & -3.505543 & 2.466628 \\
\hline $\mathrm{H}$ & 6.462489 & -3.842826 & 0.739887 \\
\hline C & 3.991642 & 1.696328 & -0.252201 \\
\hline C & 4.990329 & 0.912445 & 0.355680 \\
\hline $\mathrm{H}$ & 2.302378 & 1.605914 & -1.440421 \\
\hline$N$ & 3.247225 & 1.228731 & -1.284999 \\
\hline C & 3.460566 & 0.126207 & -2.151108 \\
\hline 0 & 2.589280 & -0.274784 & -2.882347 \\
\hline 0 & 4.724538 & -0.318733 & -2.131411 \\
\hline C & 4.963424 & -1.477360 & -2.953826 \\
\hline $\mathrm{H}$ & 4.365842 & -2.315893 & -2.591542 \\
\hline $\mathrm{H}$ & 6.028906 & -1.683700 & -2.850364 \\
\hline $\mathrm{H}$ & 4.709593 & -1.262586 & -3.994210 \\
\hline $\mathrm{H}$ & 5.562983 & 1.378024 & 1.149491 \\
\hline $\mathrm{H}$ & 5.522979 & 0.194804 & -0.250050 \\
\hline C & 3.595978 & 2.981690 & 0.370029 \\
\hline C & 2.263909 & 3.432214 & 0.412323 \\
\hline C & 4.599737 & 3.785322 & 0.947639 \\
\hline C & 1.949445 & 4.633058 & 1.046147 \\
\hline $\mathrm{H}$ & 1.463233 & 2.843677 & -0.022747 \\
\hline C & 4.281233 & 4.993054 & 1.560175 \\
\hline $\mathrm{H}$ & 5.638344 & 3.477785 & 0.888515 \\
\hline C & 2.952090 & 5.415744 & 1.620430 \\
\hline $\mathrm{H}$ & 0.912921 & 4.951320 & 1.087993 \\
\hline $\mathrm{H}$ & 5.071563 & 5.603085 & 1.988218 \\
\hline 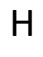 & 2.699421 & 6.352746 & 2.109175 \\
\hline & 7.278810 & -2.490481 & 1.594852 \\
\hline
\end{tabular}

Catalyst (R)-1 TS Conformation 221

B3LYP/6-31G(d) Energy $=-2809.690059$

B3LYP-D3(BJ)/def2-TZVPP-IEF-PCM(DCM) Energy = -2810.981435 
B3LYP-D3(BJ)/def2-TZVPP-IEF-PCM(DCM)//B3LYP/6-31G(d) Free Energy (Quasiharmonic) = 2810.340223

Frequencies (Top 3 out of 270)

1. $-743.3154 \mathrm{~cm}-1$

2. $\quad 7.6333 \mathrm{~cm}-1$

3. $\quad 10.0691 \mathrm{~cm}-1$

B3LYP/6-31G(d) Molecular Geometry in Cartesian Coordinates

$\begin{array}{llll}\text { C } & 2.916545 & -1.213502 & -0.354072 \\ \text { C } & 1.689472 & -1.740240 & 0.010452 \\ \text { C } & 1.261835 & -3.046603 & -0.365525 \\ \text { C } & 2.087297 & -3.769007 & -1.204605 \\ \text { H } & 1.795611 & -4.775974 & -1.491444 \\ \text { C } & 4.227348 & 2.715956 & 0.771705 \\ \text { C } & 3.335331 & 0.123585 & 0.155962 \\ \text { C } & 2.551083 & 1.238599 & -0.102817 \\ \text { C } & 3.014237 & 2.570824 & 0.123920 \\ \text { H } & 4.595668 & 3.718197 & 0.973325 \\ \text { O } & 0.843594 & -0.964562 & 0.799527 \\ \text { P } & 0.097288 & 0.318228 & 0.096655 \\ \text { O } & 1.314935 & 1.059303 & -0.713086 \\ \text { C } & -2.212845 & -5.097772 & 1.105403 \\ \text { C } & -1.336673 & -4.475255 & 1.997689 \\ \text { C } & -0.240294 & -3.757572 & 1.523869 \\ \text { C } & 0.012782 & -3.671405 & 0.145567 \\ \text { C } & -0.881784 & -4.288647 & -0.742239 \\ \text { C } & -1.989108 & -4.990940 & -0.267417 \\ \text { H } & -1.502410 & -4.553344 & 3.068992 \\ \text { H } & -2.676025 & -5.453421 & -0.970914 \\ \text { C } & 1.161667 & 6.157352 & -1.364127 \\ \text { C } & 0.394515 & 5.236539 & -0.648837 \\ \text { C } & 0.965128 & 4.056138 & -0.169866 \\ \text { C } & 2.322604 & 3.783196 & -0.395901 \\ \text { C } & 3.083691 & 4.717707 & -1.121660 \\ \text { C } & 2.511021 & 5.893732 & -1.602017 \\ \text { H } & -0.655350 & 5.425485 & -0.454862 \\ \text { H } & 3.117797 & 6.597567 & -2.166393 \\ \text { C } & 4.554972 & 0.287935 & 0.896589 \\ \text { C } & 4.995242 & 1.611901 & 1.212870 \\ \text { C } & 6.194782 & 1.790704 & 1.953790 \\ \text { C } & 6.927485 & 0.709050 & 2.384385\end{array}$




\begin{tabular}{|c|c|c|c|}
\hline C & 6.482798 & -0.602229 & 2.092485 \\
\hline C & 5.330143 & -0.807929 & 1.366462 \\
\hline $\mathrm{H}$ & 6.517755 & 2.804066 & 2.180810 \\
\hline $\mathrm{H}$ & 7.840485 & 0.857105 & 2.954750 \\
\hline $\mathrm{H}$ & 7.052937 & -1.455735 & 2.449561 \\
\hline $\mathrm{H}$ & 4.995923 & -1.818461 & 1.160051 \\
\hline C & 3.741197 & -1.952169 & -1.272391 \\
\hline C & 3.309245 & -3.249892 & -1.696538 \\
\hline C & 4.112691 & -3.994036 & -2.602321 \\
\hline C & 5.285008 & -3.474159 & -3.099090 \\
\hline C & 5.697329 & -2.178038 & -2.710238 \\
\hline C & 4.948583 & -1.438214 & -1.821457 \\
\hline $\mathrm{H}$ & 3.773716 & -4.982517 & -2.903526 \\
\hline $\mathrm{H}$ & 5.888538 & -4.049114 & -3.796162 \\
\hline $\mathrm{H}$ & 6.611918 & -1.758589 & -3.120757 \\
\hline $\mathrm{H}$ & 5.274689 & -0.442990 & -1.543998 \\
\hline $\mathrm{O}$ & -0.498367 & 1.148739 & 1.190986 \\
\hline O & -0.800265 & -0.163763 & -1.055822 \\
\hline $\mathrm{H}$ & -1.852332 & -0.703350 & -0.913272 \\
\hline $\mathrm{H}$ & -0.709206 & -4.205647 & -1.811570 \\
\hline $\mathrm{H}$ & -3.065768 & -5.660307 & 1.477156 \\
\hline $\mathrm{H}$ & 0.439086 & -3.279924 & 2.222861 \\
\hline $\mathrm{H}$ & 4.129517 & 4.504781 & -1.325870 \\
\hline $\mathrm{H}$ & 0.709965 & 7.073603 & -1.736701 \\
\hline $\mathrm{H}$ & 0.356584 & 3.358298 & 0.394333 \\
\hline C & -3.822010 & -0.372045 & -1.424870 \\
\hline 0 & -2.967342 & -1.200941 & -0.948940 \\
\hline $\mathrm{H}$ & -3.456767 & 0.534915 & -1.919932 \\
\hline C & -5.064492 & -0.992054 & -2.045063 \\
\hline 0 & -5.523536 & -2.069875 & -1.746012 \\
\hline O & -5.587567 & -0.160186 & -2.968614 \\
\hline C & -6.773775 & -0.640482 & -3.627897 \\
\hline $\mathrm{H}$ & -7.570869 & -0.814368 & -2.900105 \\
\hline $\mathrm{H}$ & -7.055737 & 0.143909 & -4.330112 \\
\hline C & -3.930550 & 0.937400 & 0.918616 \\
\hline C & -4.915367 & 0.666492 & -0.043749 \\
\hline $\mathrm{H}$ & -2.110170 & 1.865296 & 1.137453 \\
\hline $\mathrm{N}$ & -3.099702 & 2.024010 & 0.853191 \\
\hline C & -3.321290 & 3.303628 & 0.340495 \\
\hline 0 & -2.454074 & 4.148929 & 0.341467 \\
\hline $\mathrm{O}$ & -4.581758 & 3.505396 & -0.085207 \\
\hline C & -4.849987 & 4.842162 & -0.551332 \\
\hline $\mathrm{H}$ & -4.678148 & 5.565416 & 0.248997 \\
\hline $\mathrm{H}$ & -5.899040 & 4.835497 & -0.846823 \\
\hline
\end{tabular}




$\begin{array}{lrrr}\mathrm{H} & -4.209122 & 5.084788 & -1.401983 \\ \mathrm{H} & -5.687338 & -0.037356 & 0.245447 \\ \mathrm{H} & -5.243475 & 1.469677 & -0.688473 \\ \mathrm{C} & -3.642385 & -0.021396 & 1.988495 \\ \mathrm{C} & -2.993501 & 0.407716 & 3.166855 \\ \mathrm{C} & -4.068160 & -1.363844 & 1.895498 \\ \mathrm{C} & -2.804204 & -0.468451 & 4.227429 \\ \mathrm{H} & -2.666451 & 1.436767 & 3.260136 \\ \mathrm{C} & -3.869982 & -2.234331 & 2.961882 \\ \mathrm{H} & -4.518714 & -1.737653 & 0.984363 \\ \mathrm{C} & -3.246941 & -1.790306 & 4.129743 \\ \mathrm{H} & -2.314905 & -0.119892 & 5.131900 \\ \mathrm{H} & -4.193032 & -3.266182 & 2.872860 \\ \mathrm{H} & -3.102721 & -2.473320 & 4.962651 \\ \mathrm{H} & -6.563056 & -1.573633 & -4.156093\end{array}$

Catalyst (R)-1 TS Conformation 222

B3LYP/6-31G(d) Energy $=-2809.687639$

B3LYP-D3(BJ)/def2-TZVPP-IEF-PCM(DCM) Energy $=-2810.982874$

B3LYP-D3(BJ)/def2-TZVPP-IEF-PCM(DCM)//B3LYP/6-31G(d) Free Energy (Quasiharmonic) = 2810.340176

Frequencies (Top 3 out of 270)

1. $-405.3509 \mathrm{~cm}-1$

2. $\quad 8.2773 \mathrm{~cm}-1$

3. $9.3556 \mathrm{~cm}-1$

B3LYP/6-31G(d) Molecular Geometry in Cartesian Coordinates

$\begin{array}{llll}\text { C } & 3.417957 & -0.743032 & -0.375076 \\ \text { C } & 2.253940 & -1.502326 & -0.347331 \\ \text { C } & 2.239823 & -2.893687 & -0.672806 \\ \text { C } & 3.417763 & -3.468353 & -1.106087 \\ \text { H } & 3.427114 & -4.524806 & -1.362004 \\ \text { C } & 3.423401 & 3.354751 & 0.972737 \\ \text { C } & 3.419508 & 0.654276 & 0.151265 \\ \text { C } & 2.513136 & 1.575304 & -0.349769 \\ \text { C } & 2.505845 & 2.953070 & 0.021760 \\ \text { H } & 3.465862 & 4.402408 & 1.259047 \\ \text { O } & 1.079888 & -0.945100 & 0.121127 \\ \text { P } & 0.298265 & 0.283616 & -0.670570\end{array}$




\begin{tabular}{|c|c|c|c|}
\hline $\mathrm{O}$ & 1.576147 & 1.135411 & -1.270777 \\
\hline C & -1.187795 & -5.467434 & -0.259043 \\
\hline C & 0.009037 & -5.766221 & 0.392583 \\
\hline C & 1.106371 & -4.913267 & 0.264371 \\
\hline C & 1.027104 & -3.744916 & -0.510611 \\
\hline C & -0.183209 & -3.449741 & -1.159753 \\
\hline C & -1.276355 & -4.309205 & -1.036349 \\
\hline $\mathrm{H}$ & 0.091498 & -6.662893 & 1.001672 \\
\hline $\mathrm{H}$ & -2.199316 & -4.079135 & -1.563543 \\
\hline C & -0.127430 & 5.896860 & -1.685856 \\
\hline C & 0.500931 & 4.961209 & -2.510266 \\
\hline C & 1.337166 & 3.988739 & -1.964667 \\
\hline C & 1.566050 & 3.936067 & -0.579290 \\
\hline C & 0.923457 & 4.879293 & 0.238997 \\
\hline C & 0.085565 & 5.850425 & -0.307578 \\
\hline $\mathrm{H}$ & 0.341641 & 4.988025 & -3.585168 \\
\hline $\mathrm{H}$ & -0.407719 & 6.565316 & 0.346161 \\
\hline C & 4.314198 & 1.070986 & 1.197721 \\
\hline C & 4.314410 & 2.447155 & 1.596602 \\
\hline C & 5.200731 & 2.877284 & 2.621149 \\
\hline C & 6.034150 & 1.987182 & 3.257673 \\
\hline C & 6.007504 & 0.620295 & 2.894626 \\
\hline C & 5.173213 & 0.175194 & 1.892423 \\
\hline $\mathrm{H}$ & 5.196682 & 3.928291 & 2.901003 \\
\hline $\mathrm{H}$ & 6.702681 & 2.327092 & 4.044072 \\
\hline $\mathrm{H}$ & 6.648824 & -0.087253 & 3.413562 \\
\hline $\mathrm{H}$ & 5.159804 & -0.876912 & 1.633172 \\
\hline C & 4.609122 & -1.328054 & -0.930502 \\
\hline C & 4.603470 & -2.715334 & -1.284447 \\
\hline C & 5.777699 & -3.306255 & -1.824398 \\
\hline C & 6.912917 & -2.559063 & -2.035783 \\
\hline C & 6.912372 & -1.180000 & -1.720100 \\
\hline C & 5.794308 & -0.581899 & -1.181503 \\
\hline $\mathrm{H}$ & 5.754959 & -4.363153 & -2.080083 \\
\hline $\mathrm{H}$ & 7.803172 & -3.019411 & -2.455649 \\
\hline $\mathrm{H}$ & 7.800827 & -0.583911 & -1.910872 \\
\hline $\mathrm{H}$ & 5.807973 & 0.478313 & -0.957201 \\
\hline $\mathrm{O}$ & -0.526549 & 1.021154 & 0.324177 \\
\hline $\mathrm{O}$ & -0.379341 & -0.290916 & -1.921659 \\
\hline $\mathrm{H}$ & -1.590701 & 0.138993 & -2.189447 \\
\hline $\mathrm{H}$ & -0.258741 & -2.554701 & -1.768692 \\
\hline $\mathrm{H}$ & -2.042347 & -6.133068 & -0.167590 \\
\hline $\mathrm{H}$ & 2.035308 & -5.145527 & 0.778622 \\
\hline $\mathrm{H}$ & 1.065436 & 4.832006 & 1.314975 \\
\hline
\end{tabular}




$\begin{array}{llll}\mathrm{H} & -0.781571 & 6.652050 & -2.114024 \\ \mathrm{H} & 1.820197 & 3.267739 & -2.614830 \\ \mathrm{C} & -3.216934 & 0.704376 & -1.214078 \\ \mathrm{O} & -2.667546 & 0.425785 & -2.343583 \\ \mathrm{H} & -2.580152 & 1.004177 & -0.376922 \\ \mathrm{C} & -4.595153 & 1.327935 & -1.225223 \\ \mathrm{O} & -5.098254 & 1.799000 & -0.221650 \\ \mathrm{O} & -5.153608 & 1.304895 & -2.435479 \\ \mathrm{C} & -6.481211 & 1.849295 & -2.523638 \\ \mathrm{H} & -6.514408 & 2.852978 & -2.093242 \\ \mathrm{H} & -6.712867 & 1.875780 & -3.588260 \\ \mathrm{C} & -4.097980 & -0.899960 & 0.922360 \\ \mathrm{C} & -3.719400 & -1.137013 & -0.397072 \\ \mathrm{H} & -5.549559 & -0.534107 & 2.304105 \\ \mathrm{~N} & -5.398017 & -0.732054 & 1.322746 \\ \mathrm{C} & -6.564945 & -0.798389 & 0.562427 \\ \mathrm{O} & -6.640719 & -1.030066 & -0.623983 \\ \mathrm{O} & -7.605526 & -0.585646 & 1.389793 \\ \mathrm{C} & -8.902299 & -0.618800 & 0.767480 \\ \mathrm{H} & -9.005047 & 0.210510 & 0.063071 \\ \mathrm{H} & -9.615052 & -0.514376 & 1.585014 \\ \mathrm{H} & -9.049988 & -1.564773 & 0.241793 \\ \mathrm{H} & -2.701536 & -1.476265 & -0.546096 \\ \mathrm{H} & -4.459353 & -1.456467 & -1.119033 \\ \mathrm{C} & -3.101435 & -0.714928 & 1.994490 \\ \mathrm{C} & -1.947066 & -1.514819 & 2.033226 \\ \mathrm{C} & -3.282945 & 0.279465 & 2.975460 \\ \mathrm{C} & -1.004731 & -1.334784 & 3.040797 \\ \mathrm{H} & -1.792460 & -2.289176 & 1.289134 \\ \mathrm{H} & -2.331839 & 0.458970 & 3.974550 \\ \mathrm{H} & -4.127591 & 0.960934 & 2.912447 \\ \mathrm{H} & -1.194895 & -0.351723 & 4.012553 \\ \mathrm{H} & -0.114094 & -1.954390 & 3.051795 \\ -2.466866 & 1.246035 & 4.710630 \\ -0.450058 & -0.204908 & 4.789493 \\ \mathrm{H} & -7.179478 & 1.194986 & -1.995677\end{array}$

Catalyst (R)-1 TS Conformation 223

B3LYP/6-31G(d) Energy $=-2809.688332$

B3LYP-D3(BJ)/def2-TZVPP-IEF-PCM(DCM) Energy $=-2810.982974$

B3LYP-D3(BJ)/def2-TZVPP-IEF-PCM(DCM)//B3LYP/6-31G(d) Free Energy (Quasiharmonic) = 2810.340099 
Frequencies (Top 3 out of 270)

1. $-431.6148 \mathrm{~cm}-1$

2. $\quad 4.6507 \mathrm{~cm}-1$

3. $\quad 10.1491 \mathrm{~cm}-1$

B3LYP/6-31G(d) Molecular Geometry in Cartesian Coordinates

$\begin{array}{lrrr}\text { C } & 3.695011 & 0.416323 & 0.148907 \\ \text { C } & 2.820462 & 1.440400 & -0.185009 \\ \text { C } & 2.988082 & 2.786964 & 0.256924 \\ \text { C } & 4.053044 & 3.050565 & 1.096267 \\ \text { H } & 4.225149 & 4.070810 & 1.429271 \\ \text { C } & 2.990725 & -3.550686 & -1.394730 \\ \text { C } & 3.481246 & -0.945384 & -0.426101 \\ \text { C } & 2.254719 & -1.571351 & -0.254868 \\ \text { C } & 1.983541 & -2.895522 & -0.713181 \\ \text { H } & 2.825288 & -4.570126 & -1.733647 \\ \text { O } & 1.744967 & 1.153565 & -1.009389 \\ \text { P } & 0.463681 & 0.324075 & -0.387280 \\ \text { O } & 1.250149 & -0.890610 & 0.413484 \\ \text { C } & 0.420115 & 6.038264 & -0.907473 \\ \text { C } & 0.796487 & 5.874367 & 0.426135 \\ \text { C } & 1.612285 & 4.806057 & 0.796974 \\ \text { C } & 2.068355 & 3.880465 & -0.155740 \\ \text { C } & 1.676126 & 4.052476 & -1.494122 \\ \text { C } & 0.862987 & 5.122400 & -1.864154 \\ \text { H } & 0.448109 & 6.573198 & 1.182345 \\ \text { H } & 0.576487 & 5.241241 & -2.906009 \\ \text { C } & -1.740485 & -4.954063 & -0.061388 \\ \text { C } & -1.136214 & -4.961172 & -1.319168 \\ \text { C } & 0.059534 & -4.274025 & -1.525744 \\ \text { C } & 0.677086 & -3.567362 & -0.481015 \\ \text { C } & 0.054919 & -3.562973 & 0.778834 \\ \text { C } & -1.140057 & -4.250809 & 0.985484 \\ \text { H } & -1.599178 & -5.495071 & -2.145138 \\ \text { H } & -1.600998 & -4.238564 & 1.969802 \\ \text { C } & 4.492188 & -1.611419 & -1.200647 \\ \text { C } & 4.237255 & -2.939376 & -1.674124 \\ \text { C } & 5.233441 & -3.614813 & -2.430262 \\ \text { C } & 6.424555 & -3.001204 & -2.740705 \\ \text { C } & 6.663513 & -1.675249 & -2.309072 \\ \text { C } & 5.725267 & -0.999857 & -1.559802\end{array}$




\begin{tabular}{|c|c|c|c|}
\hline $\mathrm{H}$ & 5.027275 & -4.626919 & -2.770911 \\
\hline $\mathrm{H}$ & 7.175695 & -3.525008 & -3.325688 \\
\hline $\mathrm{H}$ & 7.594479 & -1.181975 & -2.575587 \\
\hline $\mathrm{H}$ & 5.920129 & 0.019038 & -1.246121 \\
\hline C & 4.753489 & 0.691790 & 1.081200 \\
\hline C & 4.933371 & 2.035565 & 1.544515 \\
\hline C & 5.983840 & 2.324530 & 2.457391 \\
\hline C & 6.809298 & 1.329189 & 2.926286 \\
\hline C & 6.609589 & -0.005396 & 2.501428 \\
\hline C & 5.611382 & -0.315337 & 1.603852 \\
\hline $\mathrm{H}$ & 6.113658 & 3.352407 & 2.788354 \\
\hline $\mathrm{H}$ & 7.604817 & 1.561586 & 3.629128 \\
\hline $\mathrm{H}$ & 7.247015 & -0.795207 & 2.890064 \\
\hline $\mathrm{H}$ & 5.466061 & -1.344262 & 1.295773 \\
\hline $\mathrm{O}$ & -0.397061 & -0.137450 & -1.511641 \\
\hline $\mathrm{O}$ & -0.168930 & 1.120964 & 0.761230 \\
\hline $\mathrm{H}$ & -1.396405 & 1.535148 & 0.629593 \\
\hline $\mathrm{H}$ & 2.014201 & 3.347592 & -2.245565 \\
\hline $\mathrm{H}$ & -0.217003 & 6.869457 & -1.198504 \\
\hline $\mathrm{H}$ & 1.882562 & 4.669821 & 1.840349 \\
\hline $\mathrm{H}$ & 0.515166 & -3.023207 & 1.599101 \\
\hline $\mathrm{H}$ & -2.672504 & -5.489345 & 0.101607 \\
\hline $\mathrm{H}$ & 0.511893 & -4.262168 & -2.513227 \\
\hline C & -2.969270 & 1.375140 & -0.581652 \\
\hline $\mathrm{O}$ & -2.490484 & 1.800859 & 0.538993 \\
\hline $\mathrm{H}$ & -2.269668 & 1.117175 & -1.381430 \\
\hline C & -4.290223 & 1.985443 & -1.003619 \\
\hline $\mathrm{O}$ & -5.182571 & 2.315974 & -0.253196 \\
\hline 0 & -4.311287 & 2.102801 & -2.340692 \\
\hline C & -5.521518 & 2.629069 & -2.912770 \\
\hline $\mathrm{H}$ & -5.811883 & 3.553784 & -2.408774 \\
\hline $\mathrm{H}$ & -6.318271 & 1.886813 & -2.821565 \\
\hline C & -4.369250 & -0.751195 & 0.594324 \\
\hline C & -3.565219 & -0.578770 & -0.536776 \\
\hline $\mathrm{H}$ & -6.185650 & -0.435198 & 1.469907 \\
\hline$N$ & -5.729498 & -0.566121 & 0.575867 \\
\hline C & -6.585926 & -0.409748 & -0.514969 \\
\hline $\mathrm{O}$ & -6.283496 & -0.453007 & -1.686685 \\
\hline $\mathrm{O}$ & -7.828786 & -0.230397 & -0.030880 \\
\hline C & -8.851734 & -0.022807 & -1.021050 \\
\hline $\mathrm{H}$ & -9.787437 & 0.009544 & -0.463648 \\
\hline $\mathrm{H}$ & -8.857294 & -0.842382 & -1.742922 \\
\hline $\mathrm{H}$ & -8.685099 & 0.923726 & -1.541336 \\
\hline $\mathrm{H}$ & -2.565077 & -0.998051 & -0.512049 \\
\hline
\end{tabular}




$\begin{array}{llll}\mathrm{H} & -4.050932 & -0.594534 & -1.504790 \\ \mathrm{C} & -3.820400 & -1.081974 & 1.920177 \\ \mathrm{C} & -2.474847 & -0.806213 & 2.227554 \\ \mathrm{C} & -4.626444 & -1.689521 & 2.908896 \\ \mathrm{C} & -1.967668 & -1.089822 & 3.493951 \\ \mathrm{H} & -1.816007 & -0.349777 & 1.503815 \\ \mathrm{C} & -4.107841 & -1.988812 & 4.163041 \\ \mathrm{H} & -5.648179 & -1.983914 & 2.685656 \\ \mathrm{C} & -2.777762 & -1.678553 & 4.464439 \\ \mathrm{H} & -0.932243 & -0.845374 & 3.709878 \\ \mathrm{H} & -4.738402 & -2.471843 & 4.903860 \\ \mathrm{H} & -2.376015 & -1.906172 & 5.447870 \\ \mathrm{H} & -5.290796 & 2.814312 & -3.961757\end{array}$

Catalyst (R)-1 TS Conformation 224

B3LYP/6-31G(d) Energy = -2809.686301

B3LYP-D3(BJ)/def2-TZVPP-IEF-PCM(DCM) Energy = -2810.982051

B3LYP-D3(BJ)/def2-TZVPP-IEF-PCM(DCM)//B3LYP/6-31G(d) Free Energy (Quasiharmonic) = 2810.340091

Frequencies (Top 3 out of 270)

1. $-501.0124 \mathrm{~cm}-1$

2. $\quad 5.7946 \mathrm{~cm}-1$

3. $\quad 8.7740 \mathrm{~cm}-1$

B3LYP/6-31G(d) Molecular Geometry in Cartesian Coordinates

$\begin{array}{llll}\text { C } & 3.403951 & -1.076740 & -0.204614 \\ \text { C } & 2.160423 & -1.642307 & 0.035800 \\ \text { C } & 1.879798 & -3.023584 & -0.180157 \\ \text { C } & 2.885929 & -3.808794 & -0.705073 \\ \text { H } & 2.704694 & -4.868961 & -0.863826 \\ \text { C } & 4.003540 & 3.126203 & 0.552291 \\ \text { C } & 3.623393 & 0.366002 & 0.112153 \\ \text { C } & 2.780675 & 1.318259 & -0.444734 \\ \text { C } & 2.964446 & 2.722748 & -0.264126 \\ \text { H } & 4.188111 & 4.188688 & 0.688119 \\ \text { O } & 1.142495 & -0.839586 & 0.520907 \\ \text { P } & 0.408025 & 0.211547 & -0.530547 \\ \text { O } & 1.735082 & 0.891329 & -1.242878 \\ \text { C } & -1.897582 & -4.847404 & 0.784030\end{array}$




\begin{tabular}{|c|c|c|c|}
\hline$C$ & -1.226982 & -4.078653 & 1.739507 \\
\hline C & -0.014826 & -3.464981 & 1.424282 \\
\hline C & 0.555585 & -3.615824 & 0.149128 \\
\hline C & -0.127336 & -4.390202 & -0.800394 \\
\hline C & -1.343360 & -4.999286 & -0.487260 \\
\hline $\mathrm{H}$ & -1.643296 & -3.966333 & 2.737881 \\
\hline $\mathrm{H}$ & -1.859530 & -5.588108 & -1.241041 \\
\hline C & 0.545929 & 5.739096 & -2.154629 \\
\hline C & 0.985410 & 4.635887 & -2.889249 \\
\hline C & 1.748545 & 3.640921 & -2.280886 \\
\hline C & 2.093086 & 3.732818 & -0.921709 \\
\hline C & 1.640458 & 4.845025 & -0.193381 \\
\hline C & 0.874953 & 5.838558 & -0.802333 \\
\hline $\mathrm{H}$ & 0.734779 & 4.548364 & -3.943333 \\
\hline $\mathrm{H}$ & 0.528805 & 6.686286 & -0.216367 \\
\hline C & 4.652776 & 0.799104 & 1.015947 \\
\hline C & 4.843773 & 2.203870 & 1.222506 \\
\hline C & 5.866021 & 2.646839 & 2.105215 \\
\hline C & 6.653329 & 1.747775 & 2.786371 \\
\hline C & 6.442401 & 0.359465 & 2.613661 \\
\hline C & 5.471090 & -0.101867 & 1.752305 \\
\hline $\mathrm{H}$ & 6.005419 & 3.717080 & 2.239988 \\
\hline $\mathrm{H}$ & 7.427616 & 2.098864 & 3.463212 \\
\hline $\mathrm{H}$ & 7.049853 & -0.350547 & 3.168725 \\
\hline $\mathrm{H}$ & 5.316505 & -1.168596 & 1.637720 \\
\hline C & 4.423877 & -1.889983 & -0.808699 \\
\hline C & 4.153607 & -3.276894 & -1.048252 \\
\hline C & 5.156466 & -4.092522 & -1.638731 \\
\hline C & 6.370843 & -3.564653 & -2.010929 \\
\hline C & 6.627186 & -2.187807 & -1.811505 \\
\hline C & 5.681862 & -1.373912 & -1.226832 \\
\hline $\mathrm{H}$ & 4.937514 & -5.145259 & -1.802252 \\
\hline $\mathrm{H}$ & 7.127312 & -4.196862 & -2.467925 \\
\hline $\mathrm{H}$ & 7.577446 & -1.765905 & -2.127853 \\
\hline $\mathrm{H}$ & 5.890519 & -0.319067 & -1.091803 \\
\hline 0 & -0.425518 & 1.152791 & 0.264736 \\
\hline 0 & -0.232401 & -0.601993 & -1.658757 \\
\hline $\mathrm{H}$ & -1.411332 & -0.295126 & -2.042304 \\
\hline $\mathrm{H}$ & 0.291102 & -4.494290 & -1.797264 \\
\hline $\mathrm{H}$ & -2.842377 & -5.324979 & 1.030470 \\
\hline $\mathrm{H}$ & 0.506431 & -2.876116 & 2.172633 \\
\hline $\mathrm{H}$ & 1.873245 & 4.916093 & 0.865444 \\
\hline $\mathrm{H}$ & -0.052256 & 6.511458 & -2.631254 \\
\hline $\mathrm{H}$ & 2.084371 & 2.789104 & -2.861592 \\
\hline
\end{tabular}




$\begin{array}{llll}\mathrm{C} & -3.114611 & 0.504776 & -1.353866 \\ \mathrm{O} & -2.499869 & -0.082108 & -2.321778 \\ \mathrm{H} & -2.533193 & 1.095548 & -0.638986 \\ \mathrm{C} & -4.499591 & 1.055519 & -1.636600 \\ \mathrm{O} & -5.105770 & 1.744266 & -0.835400 \\ \mathrm{O} & -4.942839 & 0.712778 & -2.846342 \\ \mathrm{C} & -6.262926 & 1.168422 & -3.182055 \\ \mathrm{H} & -6.352805 & 2.245095 & -3.019322 \\ \mathrm{H} & -6.395332 & 0.922461 & -4.235540 \\ \mathrm{C} & -4.165632 & -0.357775 & 1.074507 \\ \mathrm{C} & -3.559480 & -0.955213 & -0.033478 \\ \mathrm{H} & -5.850528 & 0.179634 & 2.083901 \\ \mathrm{~N} & -5.522573 & -0.285775 & 1.246748 \\ \mathrm{C} & -6.540770 & -0.741160 & 0.409288 \\ \mathrm{O} & -6.404477 & -1.294432 & -0.658786 \\ \mathrm{O} & -7.715599 & -0.472029 & 1.011029 \\ \mathrm{C} & -8.886226 & -0.878454 & 0.279733 \\ \mathrm{H} & -8.967422 & -0.312060 & -0.651459 \\ \mathrm{H} & -9.726312 & -0.654627 & 0.936575 \\ \mathrm{H} & -8.843663 & -1.946213 & 0.053580 \\ \mathrm{H} & -2.509348 & -1.201401 & 0.072404 \\ \mathrm{H} & -4.146525 & -1.608672 & -0.665409 \\ \mathrm{C} & -3.387019 & 0.334847 & 2.118147 \\ \mathrm{C} & -2.153796 & -0.182699 & 2.547390 \\ \mathrm{C} & -3.862242 & 1.535702 & 2.683785 \\ \mathrm{C} & -1.429092 & 0.468706 & 3.540934 \\ \mathrm{H} & -1.769724 & -1.101673 & 2.118872 \\ \mathrm{C} & -3.127420 & 2.185979 & 3.669103 \\ \mathrm{H} & -4.766295 & 1.999084 & 2.297780 \\ \mathrm{C} & -1.913865 & 1.648111 & 4.106244 \\ \mathrm{H} & -0.475053 & 0.060849 & 3.859287 \\ \mathrm{H} & -3.490559 & 3.122875 & 4.081335 \\ \mathrm{H} & -1.338979 & 2.159127 & 4.873384 \\ \mathrm{H} & -6.999935 & 0.639780 & -2.571664\end{array}$

Catalyst (R)-1 TS Conformation 225

B3LYP/6-31G(d) Energy $=-2809.690283$

B3LYP-D3(BJ)/def2-TZVPP-IEF-PCM(DCM) Energy = -2810.981297

B3LYP-D3(BJ)/def2-TZVPP-IEF-PCM(DCM)//B3LYP/6-31G(d) Free Energy (Quasiharmonic) = 2810.340078

Frequencies (Top 3 out of 270) 
1. $-724.1563 \mathrm{~cm}-1$

2. $\quad 5.3538 \mathrm{~cm}-1$

3. $\quad 7.3776 \mathrm{~cm}-1$

B3LYP/6-31G(d) Molecular Geometry in Cartesian Coordinates

\begin{tabular}{|c|c|c|c|}
\hline C & -3.089870 & -0.461453 & 0.248018 \\
\hline C & -2.500823 & -1.316829 & -0.669056 \\
\hline C & -2.485060 & -2.736120 & -0.530690 \\
\hline C & -3.049119 & -3.261530 & 0.615562 \\
\hline $\mathrm{H}$ & -3.083377 & -4.340493 & 0.741970 \\
\hline C & -3.110070 & 3.810424 & -0.324256 \\
\hline C & -3.136302 & 1.005696 & -0.028671 \\
\hline C & -1.964044 & 1.702001 & -0.291526 \\
\hline C & -1.915124 & 3.123289 & -0.411586 \\
\hline $\mathrm{H}$ & -3.102328 & 4.893340 & -0.416522 \\
\hline $\mathrm{O}$ & -1.897230 & -0.764219 & -1.794375 \\
\hline$P$ & -0.449281 & -0.033002 & -1.591101 \\
\hline $\mathrm{O}$ & -0.765729 & 1.002351 & -0.343012 \\
\hline C & -0.839574 & -5.425184 & -3.458642 \\
\hline C & -0.564238 & -5.599389 & -2.101804 \\
\hline C & -1.086072 & -4.711096 & -1.162479 \\
\hline C & -1.893405 & -3.632397 & -1.559098 \\
\hline C & -2.157660 & -3.464272 & -2.928849 \\
\hline C & -1.636960 & -4.354109 & -3.866764 \\
\hline $\mathrm{H}$ & 0.065424 & -6.422184 & -1.773124 \\
\hline $\mathrm{H}$ & -1.856402 & -4.208851 & -4.921168 \\
\hline C & 1.691225 & 5.428287 & -0.875446 \\
\hline C & 1.407711 & 4.395075 & -1.771697 \\
\hline C & 0.253951 & 3.623079 & -1.624751 \\
\hline C & -0.640714 & 3.879842 & -0.572500 \\
\hline C & -0.347389 & 4.922922 & 0.321324 \\
\hline C & 0.808509 & 5.689956 & 0.173271 \\
\hline $\mathrm{H}$ & 2.083707 & 4.190901 & -2.598349 \\
\hline$H$ & 1.018451 & 6.489615 & 0.879161 \\
\hline C & -4.380909 & 1.725476 & -0.041440 \\
\hline C & -4.354432 & 3.150753 & -0.176704 \\
\hline C & -5.576976 & 3.875633 & -0.181981 \\
\hline C & -6.785095 & 3.225850 & -0.083445 \\
\hline C & -6.816728 & 1.814913 & 0.016331 \\
\hline C & -5.648598 & 1.085092 & 0.038238 \\
\hline $\mathrm{H}$ & -5.536887 & 4.958018 & -0.279016 \\
\hline $\mathrm{H}$ & -7.713911 & 3.789512 & -0.095275 \\
\hline
\end{tabular}




\begin{tabular}{|c|c|c|c|}
\hline $\mathrm{H}$ & -7.772498 & 1.300523 & 0.069004 \\
\hline $\mathrm{H}$ & -5.691645 & 0.004009 & 0.102860 \\
\hline C & -3.601032 & -1.019678 & 1.471452 \\
\hline C & -3.584632 & -2.442629 & 1.640177 \\
\hline C & -4.094571 & -3.009311 & 2.840368 \\
\hline C & -4.571766 & -2.211115 & 3.854051 \\
\hline C & -4.551912 & -0.804322 & 3.707035 \\
\hline C & -4.082353 & -0.225102 & 2.548346 \\
\hline $\mathrm{H}$ & -4.091244 & -4.092067 & 2.943775 \\
\hline $\mathrm{H}$ & -4.954395 & -2.655693 & 4.768769 \\
\hline $\mathrm{H}$ & -4.907835 & -0.173300 & 4.516972 \\
\hline $\mathrm{H}$ & -4.067091 & 0.854453 & 2.456159 \\
\hline $\mathrm{O}$ & -0.012929 & 0.624350 & -2.846789 \\
\hline $\mathrm{O}$ & 0.521068 & -1.026813 & -0.897028 \\
\hline $\mathrm{H}$ & 1.631585 & -1.194593 & -1.383369 \\
\hline $\mathrm{H}$ & -2.776267 & -2.636853 & -3.258354 \\
\hline $\mathrm{H}$ & -0.431283 & -6.114409 & -4.193058 \\
\hline $\mathrm{H}$ & -0.847845 & -4.836716 & -0.109961 \\
\hline $\mathrm{H}$ & -1.026962 & 5.122032 & 1.145874 \\
\hline $\mathrm{H}$ & 2.590654 & 6.026675 & -0.996330 \\
\hline $\mathrm{H}$ & 0.044100 & 2.827985 & -2.333010 \\
\hline C & 3.232567 & -0.038907 & -1.807694 \\
\hline 0 & 2.806468 & -1.217605 & -1.564804 \\
\hline $\mathrm{H}$ & 2.598635 & 0.672206 & -2.344386 \\
\hline C & 4.714850 & 0.184434 & -2.019532 \\
\hline 0 & 5.156712 & 1.212277 & -2.489441 \\
\hline 0 & 5.447085 & -0.868728 & -1.638562 \\
\hline C & 6.868669 & -0.718288 & -1.808894 \\
\hline $\mathrm{H}$ & 7.106509 & -0.516088 & -2.855988 \\
\hline $\mathrm{H}$ & 7.239300 & 0.101479 & -1.188383 \\
\hline C & 3.286575 & 0.369062 & 0.959141 \\
\hline C & 2.994470 & 1.241120 & -0.085087 \\
\hline $\mathrm{H}$ & 1.503373 & -0.609991 & 0.688250 \\
\hline$N$ & 2.329513 & -0.545484 & 1.298771 \\
\hline C & 2.207839 & -1.250309 & 2.506930 \\
\hline 0 & 2.967632 & -1.214915 & 3.446825 \\
\hline $\mathrm{O}$ & 1.066608 & -1.957663 & 2.445633 \\
\hline C & 0.738358 & -2.699795 & 3.631513 \\
\hline $\mathrm{H}$ & 1.481071 & -3.482184 & 3.809283 \\
\hline $\mathrm{H}$ & -0.241435 & -3.133220 & 3.432871 \\
\hline $\mathrm{H}$ & 0.698187 & -2.036338 & 4.498724 \\
\hline $\mathrm{H}$ & 3.717407 & 2.004746 & -0.344204 \\
\hline $\mathrm{H}$ & 1.955743 & 1.473764 & -0.296015 \\
\hline C & 4.640775 & 0.319040 & 1.547367 \\
\hline
\end{tabular}




$\begin{array}{lrrr}\text { C } & 5.305170 & 1.517687 & 1.853728 \\ \text { C } & 5.314378 & -0.902702 & 1.719398 \\ \text { C } & 6.610752 & 1.495613 & 2.341044 \\ \text { H } & 4.785078 & 2.463297 & 1.734940 \\ \text { C } & 6.623612 & -0.919002 & 2.188193 \\ \text { H } & 4.818602 & -1.830403 & 1.457308 \\ \text { C } & 7.272642 & 0.278018 & 2.506576 \\ \text { H } & 7.108451 & 2.427906 & 2.591600 \\ \text { H } & 7.138965 & -1.867422 & 2.310323 \\ \text { H } & 8.291678 & 0.259893 & 2.883412 \\ \text { H } & 7.299885 & -1.666758 & -1.490027\end{array}$

Catalyst (R)-1 TS Conformation 226

B3LYP/6-31G(d) Energy $=-2809.688261$

B3LYP-D3(BJ)/def2-TZVPP-IEF-PCM(DCM) Energy = -2810.982914

B3LYP-D3(BJ)/def2-TZVPP-IEF-PCM(DCM)//B3LYP/6-31G(d) Free Energy (Quasiharmonic) = 2810.340029

Frequencies (Top 3 out of 270)

1. $-410.3544 \mathrm{~cm}-1$

2. $\quad 5.2446 \mathrm{~cm}-1$

3. $\quad 9.8829 \mathrm{~cm}-1$

B3LYP/6-31G(d) Molecular Geometry in Cartesian Coordinates

$\begin{array}{lrrr}\text { C } & 3.704668 & 0.160466 & 0.205338 \\ \text { C } & 2.963567 & 1.304185 & -0.066421 \\ \text { C } & 3.386586 & 2.608692 & 0.335813 \\ \text { C } & 4.528380 & 2.700383 & 1.107626 \\ \text { H } & 4.866330 & 3.681133 & 1.432101 \\ \text { C } & 2.529890 & -3.642389 & -1.462410 \\ \text { C } & 3.324548 & -1.143723 & -0.414438 \\ \text { C } & 2.042585 & -1.638905 & -0.238828 \\ \text { C } & 1.615603 & -2.906079 & -0.735132 \\ \text { H } & 2.245940 & -4.624045 & -1.832832 \\ \text { O } & 1.827951 & 1.207296 & -0.851987 \\ \text { P } & 0.477373 & 0.420608 & -0.335891 \\ \text { O } & 1.130925 & -0.865373 & 0.465539 \\ \text { C } & 1.481895 & 6.283604 & -0.846269 \\ \text { C } & 0.726638 & 5.271873 & -0.249886 \\ \text { C } & 1.322198 & 4.066707 & 0.121407\end{array}$




\begin{tabular}{|c|c|c|c|}
\hline C & 2.692826 & 3.855368 & -0.094925 \\
\hline C & 3.443759 & 4.880256 & -0.694164 \\
\hline C & 2.844829 & 6.083116 & -1.068092 \\
\hline $\mathrm{H}$ & -0.334784 & 5.420434 & -0.067346 \\
\hline $\mathrm{H}$ & 3.443253 & 6.859898 & -1.537497 \\
\hline C & -2.295324 & -4.570393 & -0.057263 \\
\hline C & -1.591467 & -3.989938 & 1.000665 \\
\hline C & -0.334009 & -3.426698 & 0.785804 \\
\hline C & 0.248342 & -3.438093 & -0.492846 \\
\hline C & -0.472668 & -4.019787 & -1.548273 \\
\hline C & -1.731299 & -4.580786 & -1.333794 \\
\hline $\mathrm{H}$ & -2.019584 & -3.978024 & 1.999609 \\
\hline $\mathrm{H}$ & -2.273680 & -5.019429 & -2.167444 \\
\hline C & 4.240551 & -1.887071 & -1.237844 \\
\hline C & 3.830244 & -3.160513 & -1.750630 \\
\hline C & 4.728651 & -3.913035 & -2.554837 \\
\hline C & 5.972963 & -3.422644 & -2.875200 \\
\hline C & 6.365579 & -2.147387 & -2.405633 \\
\hline C & 5.524858 & -1.401468 & -1.608864 \\
\hline $\mathrm{H}$ & 4.404148 & -4.883026 & -2.924528 \\
\hline $\mathrm{H}$ & 6.648523 & -4.003590 & -3.497199 \\
\hline $\mathrm{H}$ & 7.338473 & -1.748730 & -2.680463 \\
\hline $\mathrm{H}$ & 5.838151 & -0.422093 & -1.267487 \\
\hline C & 4.832966 & 0.263467 & 1.090590 \\
\hline C & 5.248600 & 1.558984 & 1.535672 \\
\hline C & 6.365168 & 1.674652 & 2.407286 \\
\hline C & 7.038080 & 0.558778 & 2.847790 \\
\hline C & 6.611010 & -0.725489 & 2.435527 \\
\hline C & 5.540618 & -0.869432 & 1.580173 \\
\hline $\mathrm{H}$ & 6.670440 & 2.667874 & 2.728534 \\
\hline $\mathrm{H}$ & 7.887097 & 0.658824 & 3.518606 \\
\hline $\mathrm{H}$ & 7.128642 & -1.608179 & 2.801695 \\
\hline $\mathrm{H}$ & 5.219929 & -1.861240 & 1.282732 \\
\hline $\mathrm{O}$ & -0.347391 & 0.050621 & -1.519402 \\
\hline $\mathrm{O}$ & -0.188440 & 1.213564 & 0.803048 \\
\hline $\mathrm{H}$ & -1.411759 & 1.633893 & 0.605919 \\
\hline $\mathrm{H}$ & 4.502175 & 4.721479 & -0.883161 \\
\hline $\mathrm{H}$ & 1.011957 & 7.219768 & -1.136892 \\
\hline $\mathrm{H}$ & 0.730093 & 3.291527 & 0.594397 \\
\hline $\mathrm{H}$ & -0.048778 & -4.008822 & -2.548237 \\
\hline $\mathrm{H}$ & -3.275276 & -5.009380 & 0.112124 \\
\hline $\mathrm{H}$ & 0.206532 & -2.981912 & 1.614351 \\
\hline C & -2.949305 & 1.449589 & -0.643226 \\
\hline $\mathrm{O}$ & -2.488818 & 1.930338 & 0.460421 \\
\hline
\end{tabular}




$\begin{array}{llll}\text { H } & -2.237754 & 1.102624 & -1.398101 \\ \mathrm{C} & -4.245229 & 2.057352 & -1.136856 \\ \mathrm{O} & -5.136264 & 2.478223 & -0.431331 \\ \mathrm{O} & -4.241884 & 2.059705 & -2.478398 \\ \mathrm{C} & -5.424228 & 2.573557 & -3.117021 \\ \mathrm{H} & -5.693639 & 3.545180 & -2.696609 \\ \mathrm{H} & -5.168062 & 2.664332 & -4.172415 \\ \mathrm{C} & -4.446044 & -0.558745 & 0.650810 \\ \mathrm{C} & -3.626293 & -0.511130 & -0.477381 \\ \mathrm{H} & -6.254240 & -0.090337 & 1.476331 \\ \mathrm{~N} & -5.797427 & -0.314304 & 0.601372 \\ \mathrm{C} & -6.635473 & -0.210255 & -0.508743 \\ \mathrm{O} & -6.322855 & -0.358910 & -1.669427 \\ \mathrm{O} & -7.874726 & 0.058248 & -0.057664 \\ \mathrm{C} & -8.877461 & 0.229995 & -1.074965 \\ \mathrm{H} & -8.666358 & 1.126113 & -1.663881 \\ \mathrm{H} & -9.816967 & 0.343150 & -0.534766 \\ \mathrm{H} & -8.909309 & -0.641909 & -1.731915 \\ \mathrm{H} & -2.643431 & -0.962677 & -0.403882 \\ \mathrm{H} & -4.096041 & -0.564973 & -1.451374 \\ \mathrm{C} & -3.925458 & -0.810365 & 2.006134 \\ \mathrm{C} & -4.768458 & -1.302342 & 3.027331 \\ \mathrm{C} & -2.571840 & -0.573576 & 2.310510 \\ \mathrm{C} & -4.277209 & -1.526978 & 4.308093 \\ \mathrm{H} & -5.800583 & -1.565589 & 2.813373 \\ \mathrm{C} & -2.090863 & -0.782009 & 3.601369 \\ \mathrm{H} & -1.883956 & -0.207201 & 1.562852 \\ \mathrm{C} & -2.937491 & -1.255788 & 4.603222 \\ \mathrm{H} & -4.937445 & -1.921503 & 5.075015 \\ \mathrm{H} & -1.047389 & -0.569352 & 3.812120 \\ \mathrm{H} & -2.556862 & -1.424384 & 5.606702 \\ \mathrm{H} & -6.245270 & 1.865444 & -2.981389\end{array}$

Catalyst (R)-1 TS Conformation 227

B3LYP/6-31G(d) Energy $=-2809.690459$

B3LYP-D3(BJ)/def2-TZVPP-IEF-PCM(DCM) Energy = -2810.981341

B3LYP-D3(BJ)/def2-TZVPP-IEF-PCM(DCM)//B3LYP/6-31G(d) Free Energy (Quasiharmonic) = 2810.340014

Frequencies (Top 3 out of 270)

1. $-706.8057 \mathrm{~cm}-1$ 
2. $\quad 5.7979 \mathrm{~cm}-1$

3. $\quad 9.7786 \mathrm{~cm}-1$

B3LYP/6-31G(d) Molecular Geometry in Cartesian Coordinates

\begin{tabular}{|c|c|c|c|}
\hline C & -3.374955 & 0.996443 & 0.019136 \\
\hline C & -2.167095 & 1.678128 & -0.004665 \\
\hline C & -2.076888 & 3.100802 & -0.067961 \\
\hline C & -3.254941 & 3.808980 & -0.191589 \\
\hline $\mathrm{H}$ & -3.214321 & 4.894063 & -0.239920 \\
\hline C & -3.687638 & -3.264104 & 0.588544 \\
\hline C & -3.418432 & -0.469965 & 0.300154 \\
\hline C & -2.687909 & -1.361567 & -0.470849 \\
\hline C & -2.835116 & -2.777515 & -0.382763 \\
\hline $\mathrm{H}$ & -3.818294 & -4.338877 & 0.682455 \\
\hline 0 & -0.986145 & 0.960491 & 0.150358 \\
\hline$P$ & -0.476797 & -0.094001 & -0.996317 \\
\hline 0 & -1.837210 & -0.856534 & -1.452201 \\
\hline C & 1.609277 & 5.298794 & 0.262631 \\
\hline C & 0.580294 & 5.496761 & 1.185182 \\
\hline C & -0.605852 & 4.769003 & 1.079538 \\
\hline C & -0.782560 & 3.832104 & 0.049230 \\
\hline C & 0.254869 & 3.648238 & -0.876342 \\
\hline C & 1.442635 & 4.372655 & -0.769790 \\
\hline $\mathrm{H}$ & 0.700143 & 6.215832 & 1.991728 \\
\hline $\mathrm{H}$ & 2.231863 & 4.203280 & -1.497315 \\
\hline C & -1.004339 & -5.616049 & -3.048822 \\
\hline C & -0.206970 & -4.703981 & -2.354941 \\
\hline C & -0.781814 & -3.763448 & -1.500316 \\
\hline C & -2.173841 & -3.725113 & -1.324556 \\
\hline C & -2.967436 & -4.649020 & -2.024192 \\
\hline C & -2.389129 & -5.585729 & -2.880485 \\
\hline $\mathrm{H}$ & 0.873268 & -4.725311 & -2.474374 \\
\hline $\mathrm{H}$ & -3.021871 & -6.286765 & -3.418853 \\
\hline C & -4.218050 & -0.996122 & 1.375760 \\
\hline C & -4.356473 & -2.415421 & 1.503963 \\
\hline C & -5.148664 & -2.949120 & 2.556411 \\
\hline C & -5.762292 & -2.123139 & 3.468894 \\
\hline C & -5.598519 & -0.721790 & 3.366952 \\
\hline C & -4.850239 & -0.173301 & 2.348505 \\
\hline $\mathrm{H}$ & -5.248679 & -4.029306 & 2.632233 \\
\hline $\mathrm{H}$ & -6.360373 & -2.542343 & 4.273410 \\
\hline $\mathrm{H}$ & -6.062665 & -0.070650 & 4.102828 \\
\hline $\mathrm{H}$ & -4.726752 & 0.901797 & 2.292794 \\
\hline
\end{tabular}




\begin{tabular}{|c|c|c|c|}
\hline$C$ & -4.582755 & 1.740345 & -0.227474 \\
\hline C & -4.511808 & 3.167712 & -0.316418 \\
\hline C & -5.698441 & 3.914973 & -0.546873 \\
\hline C & -6.909749 & 3.285230 & -0.713061 \\
\hline C & -6.978327 & 1.873260 & -0.662467 \\
\hline C & -5.848518 & 1.122009 & -0.423768 \\
\hline $\mathrm{H}$ & -5.625196 & 4.998486 & -0.603492 \\
\hline $\mathrm{H}$ & -7.809655 & 3.865840 & -0.896520 \\
\hline $\mathrm{H}$ & -7.930900 & 1.374733 & -0.820326 \\
\hline $\mathrm{H}$ & -5.918265 & 0.040897 & -0.400309 \\
\hline $\mathrm{O}$ & 0.552026 & -0.961630 & -0.342589 \\
\hline $\mathrm{O}$ & -0.067746 & 0.654122 & -2.280208 \\
\hline $\mathrm{H}$ & 1.054334 & 0.979634 & -2.357513 \\
\hline $\mathrm{H}$ & 0.120896 & 2.950916 & -1.693731 \\
\hline $\mathrm{H}$ & 2.533062 & 5.866008 & 0.344955 \\
\hline $\mathrm{H}$ & -1.399725 & 4.915364 & 1.807366 \\
\hline $\mathrm{H}$ & -4.047392 & -4.617784 & -1.906118 \\
\hline $\mathrm{H}$ & -0.550261 & -6.344200 & -3.716046 \\
\hline $\mathrm{H}$ & -0.149760 & -3.070056 & -0.956256 \\
\hline C & 3.070313 & 0.599949 & -1.849613 \\
\hline $\mathrm{O}$ & 2.232052 & 1.391249 & -2.409521 \\
\hline $\mathrm{H}$ & 2.804796 & -0.455343 & -1.723962 \\
\hline C & 4.532092 & 0.870051 & -2.173366 \\
\hline 0 & 5.021572 & 1.963558 & -2.330089 \\
\hline $\mathrm{O}$ & 5.201226 & -0.296791 & -2.274246 \\
\hline C & 6.595732 & -0.174363 & -2.614223 \\
\hline $\mathrm{H}$ & 6.966184 & -1.195951 & -2.698247 \\
\hline $\mathrm{H}$ & 6.707126 & 0.356655 & -3.562570 \\
\hline C & 3.685943 & 0.016499 & 0.835540 \\
\hline C & 3.097742 & 1.069363 & 0.117666 \\
\hline $\mathrm{H}$ & 1.993129 & -1.114531 & 0.627404 \\
\hline$N$ & 2.917930 & -1.079141 & 1.098109 \\
\hline C & 3.068300 & -2.093853 & 2.059407 \\
\hline O & 2.398512 & -3.100176 & 2.035210 \\
\hline $\mathrm{O}$ & 3.973395 & -1.784073 & 3.001797 \\
\hline C & 4.156769 & -2.791227 & 4.013535 \\
\hline $\mathrm{H}$ & 4.923001 & -2.392070 & 4.677824 \\
\hline $\mathrm{H}$ & 4.485421 & -3.731355 & 3.563696 \\
\hline $\mathrm{H}$ & 3.222839 & -2.958870 & 4.554851 \\
\hline $\mathrm{H}$ & 3.659245 & 1.991893 & 0.026251 \\
\hline $\mathrm{H}$ & 2.023022 & 1.181674 & 0.200190 \\
\hline C & 5.135228 & 0.017771 & 1.124060 \\
\hline C & 5.760119 & 1.196026 & 1.563441 \\
\hline C & 5.919798 & -1.127325 & 0.894682 \\
\hline
\end{tabular}




$\begin{array}{lrrr}\mathrm{C} & 7.135369 & 1.224191 & 1.788308 \\ \mathrm{H} & 5.161677 & 2.080887 & 1.755311 \\ \mathrm{C} & 7.294348 & -1.090839 & 1.104098 \\ \mathrm{H} & 5.452331 & -2.032060 & 0.519304 \\ \mathrm{C} & 7.905058 & 0.082951 & 1.557613 \\ \mathrm{H} & 7.604136 & 2.137593 & 2.142310 \\ \mathrm{H} & 7.892397 & -1.977201 & 0.911912 \\ \mathrm{H} & 8.977978 & 0.106756 & 1.727310 \\ \mathrm{H} & 7.131406 & 0.367154 & -1.830969\end{array}$

Catalyst (R)-1 TS Conformation 228

B3LYP/6-31G(d) Energy $=-2809.690279$

B3LYP-D3(BJ)/def2-TZVPP-IEF-PCM(DCM) Energy = -2810.981118

B3LYP-D3(BJ)/def2-TZVPP-IEF-PCM(DCM)//B3LYP/6-31G(d) Free Energy (Quasiharmonic) = 2810.340013

Frequencies (Top 3 out of 270)

1. $-751.3999 \mathrm{~cm}-1$

2. $\quad 4.5794 \mathrm{~cm}-1$

3. $\quad 11.3821 \mathrm{~cm}-1$

B3LYP/6-31G(d) Molecular Geometry in Cartesian Coordinates

$\begin{array}{llll}\mathrm{C} & 3.473510 & -0.782269 & 0.019745 \\ \mathrm{C} & 2.365073 & -1.580230 & 0.248863 \\ \mathrm{C} & 2.349343 & -2.988781 & 0.025921 \\ \mathrm{C} & 3.489735 & -3.552771 & -0.512339 \\ \mathrm{H} & 3.523751 & -4.627200 & -0.672380 \\ \mathrm{C} & 3.407198 & 3.434993 & 0.908665 \\ \mathrm{C} & 3.434121 & 0.662892 & 0.394820 \\ \mathrm{C} & 2.444890 & 1.491057 & -0.116490 \\ \mathrm{C} & 2.431760 & 2.904803 & 0.085323 \\ \mathrm{H} & 3.447911 & 4.510690 & 1.056347 \\ \mathrm{O} & 1.215580 & -0.981977 & 0.748441 \\ \mathrm{P} & 0.320057 & -0.048839 & -0.262347 \\ \mathrm{O} & 1.450589 & 0.940820 & -0.914474 \\ \mathrm{C} & -0.958180 & -5.553619 & 1.021734 \\ \mathrm{C} & -0.310304 & -5.678510 & -0.207313 \\ \mathrm{C} & 0.746268 & -4.828986 & -0.531578 \\ \mathrm{C} & 1.175972 & -3.837458 & 0.364350 \\ \mathrm{C} & 0.510298 & -3.716051 & 1.596037\end{array}$




\begin{tabular}{|c|c|c|c|}
\hline C & -0.543663 & -4.568345 & 1.920710 \\
\hline $\mathrm{H}$ & -0.631628 & -6.433182 & -0.920413 \\
\hline $\mathrm{H}$ & -1.035967 & -4.468014 & 2.884982 \\
\hline C & -0.187340 & 5.699061 & -1.880344 \\
\hline C & 0.321964 & 4.605334 & -2.584021 \\
\hline C & 1.137449 & 3.671929 & -1.946386 \\
\hline C & 1.463663 & 3.813352 & -0.586102 \\
\hline C & 0.926319 & 4.905750 & 0.115327 \\
\hline C & 0.114586 & 5.842428 & -0.524413 \\
\hline $\mathrm{H}$ & 0.095162 & 4.483804 & -3.640109 \\
\hline $\mathrm{H}$ & -0.277937 & 6.686435 & 0.037746 \\
\hline C & 4.390752 & 1.219997 & 1.312455 \\
\hline C & 4.370666 & 2.629678 & 1.561378 \\
\hline C & 5.317750 & 3.195836 & 2.457369 \\
\hline C & 6.232651 & 2.404669 & 3.111852 \\
\hline C & 6.231602 & 1.006356 & 2.896670 \\
\hline C & 5.338495 & 0.430069 & 2.020220 \\
\hline $\mathrm{H}$ & 5.295489 & 4.270271 & 2.624112 \\
\hline $\mathrm{H}$ & 6.947360 & 2.846859 & 3.800512 \\
\hline $\mathrm{H}$ & 6.939618 & 0.379130 & 3.431591 \\
\hline $\mathrm{H}$ & 5.345495 & -0.643761 & 1.874709 \\
\hline C & 4.625597 & -1.371033 & -0.607077 \\
\hline C & 4.623763 & -2.780410 & -0.864669 \\
\hline C & 5.758681 & -3.379294 & -1.475781 \\
\hline C & 6.844057 & -2.621784 & -1.849848 \\
\hline C & 6.833549 & -1.224353 & -1.630317 \\
\hline C & 5.756115 & -0.616000 & -1.024356 \\
\hline $\mathrm{H}$ & 5.745287 & -4.452111 & -1.653364 \\
\hline $\mathrm{H}$ & 7.702916 & -3.089951 & -2.322930 \\
\hline $\mathrm{H}$ & 7.681701 & -0.623346 & -1.947086 \\
\hline $\mathrm{H}$ & 5.760403 & 0.457144 & -0.872734 \\
\hline $\mathrm{O}$ & -0.699052 & 0.628720 & 0.595431 \\
\hline $\mathrm{O}$ & -0.132502 & -0.850373 & -1.491864 \\
\hline $\mathrm{H}$ & -1.021795 & -1.599956 & -1.361201 \\
\hline $\mathrm{H}$ & 0.829207 & -2.959210 & 2.304613 \\
\hline $\mathrm{H}$ & -1.779613 & -6.218089 & 1.277738 \\
\hline $\mathrm{H}$ & 1.231308 & -4.916257 & -1.499695 \\
\hline $\mathrm{H}$ & 1.142403 & 5.015695 & 1.174171 \\
\hline $\mathrm{H}$ & -0.811096 & 6.433071 & -2.384349 \\
\hline $\mathrm{H}$ & 1.537225 & 2.835620 & -2.508416 \\
\hline C & -3.080016 & -2.309522 & -0.925269 \\
\hline $\mathrm{O}$ & -1.824654 & -2.517870 & -1.111468 \\
\hline $\mathrm{H}$ & -3.678606 & -3.202181 & -0.711655 \\
\hline C & -3.860733 & -1.394978 & -1.861515 \\
\hline
\end{tabular}




$\begin{array}{llll}\mathrm{O} & -5.018742 & -1.608255 & -2.162015 \\ \mathrm{O} & -3.128223 & -0.371674 & -2.313001 \\ \mathrm{C} & -3.793398 & 0.511616 & -3.239406 \\ \mathrm{H} & -4.623413 & 1.019432 & -2.741841 \\ \mathrm{H} & -3.030162 & 1.223935 & -3.551860 \\ \mathrm{C} & -4.085470 & -0.312136 & 0.873548 \\ \mathrm{C} & -3.317630 & -1.506340 & 0.854882 \\ \mathrm{H} & -2.397389 & 0.830795 & 0.621505 \\ \mathrm{~N} & -3.441769 & 0.854031 & 0.638908 \\ \mathrm{C} & -4.016550 & 2.038033 & 0.132697 \\ \mathrm{O} & -5.139576 & 2.159887 & -0.302371 \\ \mathrm{O} & -3.087850 & 3.000154 & 0.183565 \\ \mathrm{C} & -3.484683 & 4.265973 & -0.372679 \\ \mathrm{H} & -2.590360 & 4.885147 & -0.331814 \\ \mathrm{H} & -4.295245 & 4.700813 & 0.218318 \\ \mathrm{H} & -3.820128 & 4.139878 & -1.404958 \\ \mathrm{H} & -3.746484 & -2.334694 & 1.409828 \\ \mathrm{H} & -2.254362 & -1.367010 & 1.019971 \\ \mathrm{C} & -5.522469 & -0.335400 & 1.204976 \\ \mathrm{C} & -6.045774 & 0.618384 & 2.097707 \\ \mathrm{C} & -6.355161 & -1.368662 & 0.742342 \\ \mathrm{C} & -7.367709 & 0.535745 & 2.519940 \\ \mathrm{H} & -5.404133 & 1.403047 & 2.485500 \\ \mathrm{C} & -7.685976 & -1.429647 & 1.149109 \\ \mathrm{H} & -5.978296 & -2.084938 & 0.021518 \\ \mathrm{C} & -8.194152 & -0.484554 & 2.041688 \\ \mathrm{H} & -7.754653 & 1.268898 & 3.221773 \\ \mathrm{H} & -8.326725 & -2.217855 & 0.764658 \\ \mathrm{H} & -9.229934 & -0.541743 & 2.364827 \\ \mathrm{H} & -4.170056 & -0.053178 & -4.095278\end{array}$

Catalyst (R)-1 TS Conformation 229

B3LYP/6-31G(d) Energy $=-2809.692903$

B3LYP-D3(BJ)/def2-TZVPP-IEF-PCM(DCM) Energy = -2810.9851

B3LYP-D3(BJ)/def2-TZVPP-IEF-PCM(DCM)//B3LYP/6-31G(d) Free Energy (Quasiharmonic) = 2810.339972

Frequencies (Top 3 out of 270)

1. $-210.2280 \mathrm{~cm}-1$

2. $\quad 9.8569 \mathrm{~cm}-1$

3. $\quad 17.0141 \mathrm{~cm}-1$ 
B3LYP/6-31G(d) Molecular Geometry in Cartesian Coordinates

\begin{tabular}{|c|c|c|c|}
\hline C & 3.157952 & 0.014598 & 0.260653 \\
\hline C & 2.472405 & 1.148656 & -0.144685 \\
\hline C & 2.958259 & 2.470095 & 0.097821 \\
\hline C & 4.061165 & 2.589823 & 0.923551 \\
\hline $\mathrm{H}$ & 4.442582 & 3.583082 & 1.143570 \\
\hline C & 2.121839 & -3.947376 & -1.051875 \\
\hline C & 2.785336 & -1.322819 & -0.280610 \\
\hline C & 1.500817 & -1.818927 & -0.128445 \\
\hline C & 1.149942 & -3.160136 & -0.465625 \\
\hline $\mathrm{H}$ & 1.875234 & -4.970663 & -1.322259 \\
\hline $\mathrm{O}$ & 1.311705 & 0.985150 & -0.905374 \\
\hline$P$ & -0.015817 & 0.354756 & -0.198039 \\
\hline $\mathrm{O}$ & 0.541261 & -1.024480 & 0.492286 \\
\hline C & 1.569903 & 6.054367 & -1.837588 \\
\hline C & 2.927164 & 5.729947 & -1.812358 \\
\hline C & 3.349872 & 4.556844 & -1.190856 \\
\hline C & 2.428881 & 3.687654 & -0.576695 \\
\hline C & 1.068629 & 4.023529 & -0.610821 \\
\hline C & 0.647673 & 5.196177 & -1.238408 \\
\hline $\mathrm{H}$ & 3.656803 & 6.382336 & -2.285495 \\
\hline $\mathrm{H}$ & -0.413120 & 5.421617 & -1.263877 \\
\hline C & -2.629033 & -5.059766 & 0.301009 \\
\hline C & -2.587498 & -3.862003 & -0.416307 \\
\hline C & -1.375553 & -3.210082 & -0.644127 \\
\hline C & -0.177679 & -3.762300 & -0.166662 \\
\hline C & -0.229639 & -4.965998 & 0.557101 \\
\hline C & -1.444501 & -5.608757 & 0.793666 \\
\hline $\mathrm{H}$ & -3.503101 & -3.432151 & -0.806983 \\
\hline $\mathrm{H}$ & -1.463184 & -6.536317 & 1.360130 \\
\hline C & 3.755685 & -2.118358 & -0.986222 \\
\hline C & 3.411641 & -3.455304 & -1.362145 \\
\hline C & 4.361080 & -4.257699 & -2.051001 \\
\hline C & 5.598684 & -3.758538 & -2.382887 \\
\hline C & 5.931132 & -2.426104 & -2.042989 \\
\hline C & 5.037379 & -1.628950 & -1.362160 \\
\hline $\mathrm{H}$ & 4.082417 & -5.273557 & -2.321187 \\
\hline $\mathrm{H}$ & 6.315706 & -4.377540 & -2.915154 \\
\hline $\mathrm{H}$ & 6.899684 & -2.024056 & -2.327681 \\
\hline $\mathrm{H}$ & 5.306033 & -0.607414 & -1.121187 \\
\hline C & 4.251395 & 0.158463 & 1.183562 \\
\hline C & 4.694106 & 1.475231 & 1.523253 \\
\hline
\end{tabular}




\begin{tabular}{|c|c|c|c|}
\hline C & 5.764092 & 1.637504 & 2.444347 \\
\hline C & 6.365558 & 0.546533 & 3.027414 \\
\hline C & 5.913472 & -0.756598 & 2.712547 \\
\hline C & 4.887456 & -0.946587 & 1.812826 \\
\hline $\mathrm{H}$ & 6.091499 & 2.645850 & 2.686400 \\
\hline $\mathrm{H}$ & 7.178650 & 0.681661 & 3.735435 \\
\hline $\mathrm{H}$ & 6.375816 & -1.616450 & 3.189828 \\
\hline $\mathrm{H}$ & 4.544891 & -1.950928 & 1.591699 \\
\hline 0 & -1.088271 & 0.125532 & -1.209440 \\
\hline O & -0.321610 & 1.251143 & 1.037576 \\
\hline $\mathrm{H}$ & -1.313407 & 1.476894 & 1.306689 \\
\hline $\mathrm{H}$ & 0.337129 & 3.381597 & -0.138408 \\
\hline $\mathrm{H}$ & 1.234212 & 6.964727 & -2.328106 \\
\hline $\mathrm{H}$ & 4.404145 & 4.293909 & -1.197835 \\
\hline $\mathrm{H}$ & 0.692603 & -5.391483 & 0.943611 \\
\hline $\mathrm{H}$ & -3.578068 & -5.560799 & 0.474937 \\
\hline $\mathrm{H}$ & -1.357927 & -2.278048 & -1.199940 \\
\hline C & -3.628071 & 1.515972 & 2.200181 \\
\hline 0 & -2.580739 & 2.103317 & 1.727287 \\
\hline $\mathrm{H}$ & -4.200256 & 2.058230 & 2.973718 \\
\hline C & -3.567859 & 0.042889 & 2.631845 \\
\hline 0 & -4.482959 & -0.521953 & 3.202428 \\
\hline $\mathrm{O}$ & -2.398661 & -0.522185 & 2.322954 \\
\hline C & -2.210183 & -1.884918 & 2.758136 \\
\hline $\mathrm{H}$ & -2.952734 & -2.537397 & 2.295522 \\
\hline $\mathrm{H}$ & -1.208844 & -2.152097 & 2.427385 \\
\hline C & -4.461034 & 1.017472 & -0.201737 \\
\hline C & -5.014252 & 1.571130 & 0.985299 \\
\hline $\mathrm{H}$ & -2.697720 & 1.059311 & -1.256747 \\
\hline $\mathrm{N}$ & -3.443651 & 1.644234 & -0.837745 \\
\hline C & -3.047587 & 3.000271 & -0.795903 \\
\hline 0 & -1.967885 & 3.348079 & -1.210100 \\
\hline 0 & -4.025950 & 3.825006 & -0.396362 \\
\hline C & -3.635791 & 5.206645 & -0.281688 \\
\hline $\mathrm{H}$ & -4.531671 & 5.729262 & 0.053520 \\
\hline $\mathrm{H}$ & -3.304960 & 5.590365 & -1.249210 \\
\hline $\mathrm{H}$ & -2.832477 & 5.305545 & 0.451869 \\
\hline $\mathrm{H}$ & -5.872396 & 1.051924 & 1.398837 \\
\hline $\mathrm{H}$ & -5.126609 & 2.646334 & 0.987070 \\
\hline C & -4.866184 & -0.297873 & -0.725364 \\
\hline C & -4.642010 & -0.606715 & -2.082925 \\
\hline C & -5.597321 & -1.211419 & 0.062741 \\
\hline C & -5.152581 & -1.776226 & -2.638990 \\
\hline $\mathrm{H}$ & -4.105987 & 0.091828 & -2.716292 \\
\hline
\end{tabular}




$\begin{array}{lllr}\text { C } & -6.100760 & -2.380135 & -0.499364 \\ \text { H } & -5.750971 & -1.024270 & 1.119586 \\ \text { C } & -5.892671 & -2.661759 & -1.852815 \\ \text { H } & -4.983087 & -1.988023 & -3.690483 \\ \text { H } & -6.659875 & -3.073115 & 0.122584 \\ \text { H } & -6.302396 & -3.567569 & -2.290961 \\ \text { H } & -2.298790 & -1.941167 & 3.845970\end{array}$

Catalyst (R)-1 TS Conformation 230

B3LYP/6-31G(d) Energy $=-2809.689484$

B3LYP-D3(BJ)/def2-TZVPP-IEF-PCM(DCM) Energy $=-2810.982209$

B3LYP-D3(BJ)/def2-TZVPP-IEF-PCM(DCM)//B3LYP/6-31G(d) Free Energy (Quasiharmonic) = 2810.339928

Frequencies (Top 3 out of 270)

1. $-740.8144 \mathrm{~cm}-1$

2. $\quad 10.5470 \mathrm{~cm}-1$

3. $13.0352 \mathrm{~cm}-1$

B3LYP/6-31G(d) Molecular Geometry in Cartesian Coordinates

$\begin{array}{llll}\text { C } & 3.294710 & 0.343393 & -0.006673 \\ \text { C } & 2.396996 & 1.337716 & -0.364111 \\ \text { C } & 2.650159 & 2.729170 & -0.175514 \\ \text { C } & 3.834990 & 3.076031 & 0.444679 \\ \text { H } & 4.075006 & 4.127581 & 0.578460 \\ \text { C } & 2.396550 & -3.803549 & -0.773883 \\ \text { C } & 2.986434 & -1.081191 & -0.334930 \\ \text { C } & 1.797789 & -1.651166 & 0.099516 \\ \text { C } & 1.482749 & -3.033121 & -0.079337 \\ \text { H } & 2.210667 & -4.867167 & -0.895323 \\ \text { O } & 1.201362 & 0.959855 & -0.956745 \\ \text { P } & 0.042399 & 0.312647 & 0.018222 \\ \text { O } & 0.890551 & -0.863413 & 0.788752 \\ \text { C } & 0.001019 & 5.863686 & -1.472283 \\ \text { C } & 0.256726 & 4.775985 & -2.309948 \\ \text { C } & 1.094996 & 3.744169 & -1.890811 \\ \text { C } & 1.699269 & 3.781604 & -0.622549 \\ \text { C } & 1.428649 & 4.878571 & 0.211916 \\ \text { C } & 0.589383 & 5.909860 & -0.207784 \\ \text { H } & -0.194910 & 4.730294 & -3.297558\end{array}$




\begin{tabular}{|c|c|c|c|}
\hline $\mathrm{H}$ & 0.390676 & 6.746245 & 0.457671 \\
\hline C & -1.977919 & -5.034724 & 1.529798 \\
\hline C & -1.512551 & -5.334933 & 0.248235 \\
\hline C & -0.415367 & -4.653288 & -0.275693 \\
\hline C & 0.250296 & -3.662479 & 0.467871 \\
\hline C & -0.242473 & -3.353914 & 1.748473 \\
\hline C & -1.343686 & -4.034395 & 2.272004 \\
\hline $\mathrm{H}$ & -2.005444 & -6.097918 & -0.348748 \\
\hline $\mathrm{H}$ & -1.690787 & -3.782655 & 3.270496 \\
\hline C & 3.880768 & -1.876959 & -1.130824 \\
\hline C & 3.577441 & -3.261402 & -1.334711 \\
\hline C & 4.461575 & -4.065494 & -2.104353 \\
\hline C & 5.586065 & -3.525579 & -2.683409 \\
\hline C & 5.867719 & -2.149044 & -2.517737 \\
\hline C & 5.040694 & -1.347780 & -1.761462 \\
\hline $\mathrm{H}$ & 4.221551 & -5.117873 & -2.237424 \\
\hline $\mathrm{H}$ & 6.250758 & -4.147758 & -3.276472 \\
\hline $\mathrm{H}$ & 6.743020 & -1.717561 & -2.995852 \\
\hline $\mathrm{H}$ & 5.266476 & -0.293415 & -1.653223 \\
\hline C & 4.485248 & 0.716914 & 0.707277 \\
\hline C & 4.754339 & 2.108226 & 0.918283 \\
\hline C & 5.933972 & 2.493840 & 1.611232 \\
\hline C & 6.803019 & 1.551350 & 2.109404 \\
\hline C & 6.519850 & 0.175997 & 1.937506 \\
\hline C & 5.394421 & -0.230076 & 1.254460 \\
\hline $\mathrm{H}$ & 6.128879 & 3.554640 & 1.750980 \\
\hline $\mathrm{H}$ & 7.697937 & 1.858236 & 2.643875 \\
\hline $\mathrm{H}$ & 7.194168 & -0.568362 & 2.352462 \\
\hline $\mathrm{H}$ & 5.187582 & -1.287789 & 1.140536 \\
\hline $\mathrm{O}$ & -0.497198 & 1.255420 & 1.037198 \\
\hline 0 & -0.930713 & -0.360482 & -0.965811 \\
\hline $\mathrm{H}$ & -1.871694 & 0.297810 & -1.352083 \\
\hline $\mathrm{H}$ & 1.865160 & 4.909029 & 1.206316 \\
\hline $\mathrm{H}$ & -0.652952 & 6.666915 & -1.802109 \\
\hline $\mathrm{H}$ & 1.288655 & 2.906724 & -2.551758 \\
\hline $\mathrm{H}$ & 0.234237 & -2.584525 & 2.342573 \\
\hline $\mathrm{H}$ & -2.823632 & -5.575895 & 1.947528 \\
\hline $\mathrm{H}$ & -0.076855 & -4.878710 & -1.282748 \\
\hline C & -3.205441 & 1.713281 & -0.708240 \\
\hline $\mathrm{O}$ & -2.826716 & 0.956661 & -1.676214 \\
\hline $\mathrm{H}$ & -2.496164 & 1.941719 & 0.092008 \\
\hline C & -4.165114 & 2.824066 & -1.103780 \\
\hline $\mathrm{O}$ & -4.869250 & 2.812052 & -2.087140 \\
\hline $\mathrm{O}$ & -4.127351 & 3.819303 & -0.196068 \\
\hline
\end{tabular}




$\begin{array}{llll}\mathrm{C} & -4.993794 & 4.934246 & -0.469944 \\ \mathrm{H} & -4.729730 & 5.394993 & -1.425121 \\ \mathrm{H} & -6.036757 & 4.608054 & -0.507998 \\ \mathrm{C} & -4.112251 & -0.469027 & 0.729485 \\ \mathrm{C} & -4.554235 & 0.853040 & 0.573204 \\ \mathrm{H} & -2.797411 & -1.805688 & 1.521232 \\ \mathrm{~N} & -3.197382 & -0.879645 & 1.651371 \\ \mathrm{C} & -2.539793 & -0.223540 & 2.719733 \\ \mathrm{O} & -1.748871 & -0.830344 & 3.404290 \\ \mathrm{O} & -2.915179 & 1.042945 & 2.874982 \\ \mathrm{C} & -2.082294 & 1.810848 & 3.777284 \\ \mathrm{H} & -1.086261 & 1.887120 & 3.339142 \\ \mathrm{H} & -2.045279 & 1.330638 & 4.756689 \\ \mathrm{H} & -2.561747 & 2.787449 & 3.838712 \\ \mathrm{H} & -5.482322 & 0.955546 & 0.022523 \\ \mathrm{H} & -4.411245 & 1.545671 & 1.389378 \\ \mathrm{C} & -4.592798 & -1.520210 & -0.188363 \\ \mathrm{C} & -4.694760 & -2.859537 & 0.236974 \\ \mathrm{C} & -4.975878 & -1.191649 & -1.504248 \\ \mathrm{C} & -5.168322 & -3.840906 & -0.627027 \\ \mathrm{H} & -4.439168 & -3.133299 & 1.255620 \\ \mathrm{C} & -5.430735 & -2.185543 & -2.367599 \\ \mathrm{H} & -4.877040 & -0.176190 & -1.867360 \\ \mathrm{C} & -5.532968 & -3.507878 & -1.933724 \\ \mathrm{H} & -5.256089 & -4.865621 & -0.278394 \\ \mathrm{H} & -5.703538 & -1.921659 & -3.385025 \\ \mathrm{H} & -5.898225 & -4.276632 & -2.609077 \\ \mathrm{H} & -4.837622 & 5.634240 & 0.350786\end{array}$

Catalyst (R)-1 TS Conformation 231

B3LYP/6-31G(d) Energy $=-2809.684745$

B3LYP-D3(BJ)/def2-TZVPP-IEF-PCM(DCM) Energy = -2810.981245

B3LYP-D3(BJ)/def2-TZVPP-IEF-PCM(DCM)//B3LYP/6-31G(d) Free Energy (Quasiharmonic) = 2810.339921

Frequencies (Top 3 out of 270)

1. $-517.5216 \mathrm{~cm}-1$

2. $\quad 11.1136 \mathrm{~cm}-1$

3. $15.3518 \mathrm{~cm}-1$

B3LYP/6-31G(d) Molecular Geometry in Cartesian Coordinates 


\begin{tabular}{|c|c|c|c|}
\hline C & 2.853149 & -1.430228 & -0.262690 \\
\hline C & 1.566637 & -1.746230 & 0.141346 \\
\hline C & 0.941411 & -2.999987 & -0.126030 \\
\hline C & 1.663771 & -3.919491 & -0.861820 \\
\hline $\mathrm{H}$ & 1.236066 & -4.899505 & -1.056019 \\
\hline C & 4.665892 & 2.358459 & 0.700726 \\
\hline C & 3.459068 & -0.131129 & 0.153972 \\
\hline C & 2.809735 & 1.067713 & -0.114792 \\
\hline C & 3.411629 & 2.339693 & 0.124133 \\
\hline $\mathrm{H}$ & 5.142593 & 3.316378 & 0.891801 \\
\hline 0 & 0.849904 & -0.794706 & 0.855204 \\
\hline$P$ & 0.235491 & 0.466102 & 0.005234 \\
\hline $\mathrm{O}$ & 1.572826 & 1.051149 & -0.742780 \\
\hline C & -2.999255 & -4.073238 & 1.243345 \\
\hline C & -2.582825 & -4.394717 & -0.050286 \\
\hline C & -1.312303 & -4.023962 & -0.489348 \\
\hline C & -0.427440 & -3.327551 & 0.353048 \\
\hline C & -0.862922 & -3.000931 & 1.649307 \\
\hline C & -2.133710 & -3.373664 & 2.087323 \\
\hline $\mathrm{H}$ & -3.250578 & -4.926562 & -0.722734 \\
\hline $\mathrm{H}$ & -2.438018 & -3.117967 & 3.098718 \\
\hline C & 1.682295 & 6.158733 & -0.844802 \\
\hline C & 0.996481 & 5.275485 & -0.007305 \\
\hline C & 1.525211 & 4.017382 & 0.284738 \\
\hline C & 2.764833 & 3.630549 & -0.247419 \\
\hline C & 3.447811 & 4.525926 & -1.085767 \\
\hline C & 2.909817 & 5.777359 & -1.387412 \\
\hline $\mathrm{H}$ & 0.047998 & 5.571295 & 0.434590 \\
\hline $\mathrm{H}$ & 3.451541 & 6.453038 & -2.044341 \\
\hline C & 4.714149 & -0.091802 & 0.856471 \\
\hline C & 5.328167 & 1.176113 & 1.109962 \\
\hline C & 6.575016 & 1.228354 & 1.790011 \\
\hline C & 7.187807 & 0.079581 & 2.232823 \\
\hline C & 6.566239 & -1.173044 & 2.018294 \\
\hline C & 5.365495 & -1.257223 & 1.348390 \\
\hline $\mathrm{H}$ & 7.028675 & 2.201034 & 1.965435 \\
\hline $\mathrm{H}$ & 8.137744 & 0.131184 & 2.757809 \\
\hline $\mathrm{H}$ & 7.037085 & -2.078442 & 2.391837 \\
\hline $\mathrm{H}$ & 4.898779 & -2.224588 & 1.204453 \\
\hline C & 3.554580 & -2.362558 & -1.104170 \\
\hline C & 2.947487 & -3.629427 & -1.384884 \\
\hline C & 3.635576 & -4.568947 & -2.199942 \\
\hline C & 4.858302 & -4.265691 & -2.751582 \\
\hline
\end{tabular}




\begin{tabular}{|c|c|c|c|}
\hline C & 5.440422 & -2.998826 & -2.512383 \\
\hline C & 4.808397 & -2.074358 & -1.709913 \\
\hline $\mathrm{H}$ & 3.165605 & -5.530878 & -2.391171 \\
\hline $\mathrm{H}$ & 5.371292 & -4.988508 & -3.380070 \\
\hline $\mathrm{H}$ & 6.393959 & -2.749678 & -2.970144 \\
\hline $\mathrm{H}$ & 5.264267 & -1.105267 & -1.545340 \\
\hline 0 & -0.350519 & 1.430068 & 0.993373 \\
\hline 0 & -0.618726 & -0.065566 & -1.140753 \\
\hline $\mathrm{H}$ & -1.830103 & 0.012205 & -1.442352 \\
\hline $\mathrm{H}$ & -0.208431 & -2.453982 & 2.317372 \\
\hline $\mathrm{H}$ & -3.989214 & -4.361545 & 1.587009 \\
\hline $\mathrm{H}$ & -1.005151 & -4.256630 & -1.504962 \\
\hline $\mathrm{H}$ & 4.403301 & 4.230162 & -1.510912 \\
\hline $\mathrm{H}$ & 1.265603 & 7.137540 & -1.068481 \\
\hline $\mathrm{H}$ & 0.984069 & 3.338660 & 0.935456 \\
\hline C & -3.654360 & -0.799979 & -1.084808 \\
\hline 0 & -2.918196 & -0.070487 & -1.825888 \\
\hline $\mathrm{H}$ & -3.210438 & -1.373646 & -0.266916 \\
\hline C & -4.887963 & -1.387023 & -1.743227 \\
\hline 0 & -5.369081 & -0.997211 & -2.779857 \\
\hline 0 & -5.366007 & -2.411407 & -1.005346 \\
\hline C & -6.538100 & -3.052031 & -1.540675 \\
\hline $\mathrm{H}$ & -6.783766 & -3.847186 & -0.836885 \\
\hline $\mathrm{H}$ & -7.361897 & -2.337490 & -1.619465 \\
\hline C & -3.972933 & 1.270274 & 0.639260 \\
\hline C & -4.920729 & 0.304167 & 0.314782 \\
\hline $\mathrm{H}$ & -2.074095 & 1.396582 & 1.506684 \\
\hline$N$ & -3.049523 & 1.071665 & 1.640889 \\
\hline C & -3.168425 & 0.306923 & 2.806757 \\
\hline 0 & -2.219146 & 0.029224 & 3.503472 \\
\hline $\mathrm{O}$ & -4.448782 & -0.009525 & 3.097307 \\
\hline C & -4.623470 & -0.706046 & 4.343000 \\
\hline $\mathrm{H}$ & -5.700730 & -0.836313 & 4.449123 \\
\hline $\mathrm{H}$ & -4.221582 & -0.116570 & 5.170151 \\
\hline $\mathrm{H}$ & -4.120076 & -1.675596 & 4.316065 \\
\hline $\mathrm{H}$ & -5.717644 & 0.574147 & -0.365152 \\
\hline $\mathrm{H}$ & -5.127005 & -0.508631 & 0.995702 \\
\hline C & -3.833629 & 2.472466 & -0.210326 \\
\hline C & -4.972395 & 2.989586 & -0.865253 \\
\hline C & -2.602729 & 3.133288 & -0.392863 \\
\hline C & -4.882265 & 4.115183 & -1.675196 \\
\hline $\mathrm{H}$ & -5.944450 & 2.535025 & -0.711219 \\
\hline C & -2.514775 & 4.246282 & -1.226224 \\
\hline $\mathrm{H}$ & -1.699352 & 2.764355 & 0.079387 \\
\hline
\end{tabular}




$\begin{array}{llll}\mathrm{C} & -3.649364 & 4.742831 & -1.867773 \\ \mathrm{H} & -5.775828 & 4.502368 & -2.156181 \\ \mathrm{H} & -1.548151 & 4.718281 & -1.373689 \\ \mathrm{H} & -3.576122 & 5.615009 & -2.511647 \\ \mathrm{H} & -6.328516 & -3.463354 & -2.531251\end{array}$

Catalyst (R)-1 TS Conformation 232

B3LYP/6-31G(d) Energy $=-2809.692957$

B3LYP-D3(BJ)/def2-TZVPP-IEF-PCM(DCM) Energy = -2810.981465

B3LYP-D3(BJ)/def2-TZVPP-IEF-PCM(DCM)//B3LYP/6-31G(d) Free Energy (Quasiharmonic) = 2810.339902

Frequencies (Top 3 out of 270)

1. $-646.4248 \mathrm{~cm}-1$

2. $\quad 5.3848 \mathrm{~cm}-1$

3. $\quad 10.3904 \mathrm{~cm}-1$

B3LYP/6-31G(d) Molecular Geometry in Cartesian Coordinates

$\begin{array}{llll}\text { C } & -3.586555 & 0.518706 & -0.130736 \\ \text { C } & -2.531548 & 1.418876 & -0.062309 \\ \text { C } & -2.711505 & 2.832632 & -0.135663 \\ \text { C } & -3.989975 & 3.302180 & -0.360418 \\ \text { H } & -4.153547 & 4.375046 & -0.420069 \\ \text { C } & -2.944665 & -3.701122 & 0.516006 \\ \text { C } & -3.361972 & -0.931399 & 0.148774 \\ \text { C } & -2.403397 & -1.634325 & -0.562392 \\ \text { C } & -2.180424 & -3.035436 & -0.422648 \\ \text { H } & -2.825150 & -4.775170 & 0.630763 \\ \text { O } & -1.250810 & 0.947113 & 0.199313 \\ \text { P } & -0.442043 & 0.010506 & -0.873405 \\ \text { O } & -1.620970 & -0.936803 & -1.480486 \\ \text { C } & 0.434353 & 5.711852 & 0.447956 \\ \text { C } & 0.543916 & 4.758616 & -0.566951 \\ \text { C } & -0.461152 & 3.809963 & -0.753480 \\ \text { C } & -1.595180 & 3.799138 & 0.072402 \\ \text { C } & -1.697911 & 4.764827 & 1.085819 \\ \text { C } & -0.690887 & 5.712542 & 1.273482 \\ \text { H } & 1.408915 & 4.751750 & -1.225255 \\ \text { H } & -0.786191 & 6.449318 & 2.067098 \\ \text { C } & 0.662639 & -5.275177 & -2.750692\end{array}$




\begin{tabular}{|c|c|c|c|}
\hline$C$ & 0.570996 & -5.462055 & -1.370834 \\
\hline C & -0.339509 & -4.716948 & -0.622507 \\
\hline C & -1.177205 & -3.771686 & -1.237120 \\
\hline C & -1.071087 & -3.589037 & -2.626372 \\
\hline C & -0.161448 & -4.335535 & -3.373503 \\
\hline $\mathrm{H}$ & 1.213576 & -6.183867 & -0.873110 \\
\hline $\mathrm{H}$ & -0.099249 & -4.183319 & -4.447821 \\
\hline C & -4.089671 & -1.624638 & 1.178934 \\
\hline C & -3.879512 & -3.032346 & 1.343525 \\
\hline C & -4.601774 & -3.734116 & 2.346800 \\
\hline C & -5.472605 & -3.076071 & 3.183391 \\
\hline C & -5.649977 & -1.678869 & 3.052003 \\
\hline C & -4.979687 & -0.973296 & 2.076837 \\
\hline $\mathrm{H}$ & -4.440267 & -4.804826 & 2.447447 \\
\hline $\mathrm{H}$ & -6.014147 & -3.621892 & 3.951136 \\
\hline $\mathrm{H}$ & -6.318762 & -1.155087 & 3.729659 \\
\hline $\mathrm{H}$ & -5.121193 & 0.097888 & 1.997215 \\
\hline C & -4.891034 & 1.018282 & -0.474832 \\
\hline C & -5.087954 & 2.433079 & -0.573244 \\
\hline C & -6.374608 & 2.939326 & -0.901814 \\
\hline C & -7.426496 & 2.089323 & -1.152083 \\
\hline C & -7.227454 & 0.690063 & -1.090201 \\
\hline C & -5.996073 & 0.168821 & -0.758935 \\
\hline $\mathrm{H}$ & -6.506488 & 4.016909 & -0.964793 \\
\hline $\mathrm{H}$ & -8.404215 & 2.487126 & -1.409693 \\
\hline $\mathrm{H}$ & -8.052458 & 0.018777 & -1.312907 \\
\hline $\mathrm{H}$ & -5.858626 & -0.905826 & -0.727572 \\
\hline O & 0.627724 & -0.707655 & -0.121037 \\
\hline 0 & -0.037722 & 0.839348 & -2.112439 \\
\hline $\mathrm{H}$ & 1.024070 & 1.286243 & -2.193038 \\
\hline $\mathrm{H}$ & -2.567826 & 4.760940 & 1.737420 \\
\hline $\mathrm{H}$ & 1.218258 & 6.450965 & 0.592033 \\
\hline $\mathrm{H}$ & -0.378855 & 3.086628 & -1.555649 \\
\hline $\mathrm{H}$ & -1.707906 & -2.864868 & -3.122402 \\
\hline $\mathrm{H}$ & 1.372478 & -5.853847 & -3.335918 \\
\hline $\mathrm{H}$ & -0.390534 & -4.850442 & 0.454509 \\
\hline C & 2.805604 & 1.548780 & -1.153828 \\
\hline $\mathrm{O}$ & 2.183571 & 1.810005 & -2.237301 \\
\hline $\mathrm{H}$ & 2.239029 & 1.291663 & -0.252142 \\
\hline C & 4.082720 & 2.321541 & -0.872264 \\
\hline $\mathrm{O}$ & 4.796497 & 2.839874 & -1.699834 \\
\hline $\mathrm{O}$ & 4.298352 & 2.332798 & 0.457574 \\
\hline C & 5.486876 & 3.007178 & 0.909759 \\
\hline $\mathrm{H}$ & 5.539394 & 2.807617 & 1.979348 \\
\hline
\end{tabular}




$\begin{array}{llrr}\mathrm{H} & 6.368458 & 2.610587 & 0.402150 \\ \mathrm{C} & 4.110941 & -0.715003 & -0.132126 \\ \mathrm{C} & 3.512181 & -0.364205 & -1.348547 \\ \mathrm{H} & 2.265220 & -0.996338 & 0.685176 \\ \mathrm{~N} & 3.268050 & -0.945945 & 0.922564 \\ \mathrm{C} & 3.526527 & -0.680248 & 2.277343 \\ \mathrm{O} & 4.563427 & -0.279445 & 2.755126 \\ \mathrm{O} & 2.400822 & -0.942112 & 2.964273 \\ \mathrm{C} & 2.463234 & -0.655432 & 4.370706 \\ \mathrm{H} & 3.241491 & -1.255194 & 4.849552 \\ \mathrm{H} & 1.479434 & -0.917252 & 4.759144 \\ \mathrm{H} & 2.671997 & 0.404677 & 4.535282 \\ \mathrm{H} & 4.127638 & -0.345785 & -2.240624 \\ \mathrm{H} & 2.485591 & -0.683530 & -1.489752 \\ \mathrm{C} & 5.570944 & -0.868342 & -0.000015 \\ \mathrm{C} & 6.110366 & -1.848435 & 0.853561 \\ \mathrm{C} & 6.445962 & -0.130797 & -0.820387 \\ \mathrm{C} & 7.481698 & -2.077328 & 0.890332 \\ \mathrm{H} & 5.451380 & -2.449401 & 1.469053 \\ \mathrm{C} & 7.820215 & -0.347835 & -0.761731 \\ \mathrm{H} & 6.059232 & 0.629605 & -1.490142 \\ \mathrm{C} & 8.342903 & -1.322375 & 0.090847 \\ \mathrm{H} & 7.879170 & -2.846177 & 1.546558 \\ \mathrm{H} & 8.481716 & 0.241932 & -1.389732 \\ \mathrm{H} & 9.414539 & -1.497632 & 0.127197 \\ \mathrm{H} & 5.406135 & 4.079808 & 0.714448\end{array}$

Catalyst (R)-1 TS Conformation 233

B3LYP/6-31G(d) Energy $=-2809.684485$

B3LYP-D3(BJ)/def2-TZVPP-IEF-PCM(DCM) Energy $=-2810.981248$

B3LYP-D3(BJ)/def2-TZVPP-IEF-PCM(DCM)//B3LYP/6-31G(d) Free Energy (Quasiharmonic) = 2810.339843

Frequencies (Top 3 out of 270)

1. $-701.6984 \mathrm{~cm}-1$

2. $\quad 13.5808 \mathrm{~cm}-1$

3. $\quad 17.0841 \mathrm{~cm}-1$

B3LYP/6-31G(d) Molecular Geometry in Cartesian Coordinates

$\begin{array}{llll}\text { C } & 2.782960 & 0.671923 & -0.128613\end{array}$ 


\begin{tabular}{|c|c|c|c|}
\hline C & 2.007559 & 1.569863 & -0.847108 \\
\hline C & 2.019096 & 2.978799 & -0.617741 \\
\hline C & 2.811008 & 3.442732 & 0.414673 \\
\hline $\mathrm{H}$ & 2.867148 & 4.512183 & 0.599410 \\
\hline C & 2.663075 & -3.574867 & -0.850433 \\
\hline C & 2.766883 & -0.779507 & -0.482408 \\
\hline C & 1.560347 & -1.466116 & -0.516499 \\
\hline C & 1.482131 & -2.885618 & -0.657533 \\
\hline $\mathrm{H}$ & 2.631522 & -4.655173 & -0.967083 \\
\hline O & 1.202912 & 1.083424 & -1.865425 \\
\hline$P$ & -0.168653 & 0.268139 & -1.489212 \\
\hline O & 0.387486 & -0.762359 & -0.307489 \\
\hline C & -0.198833 & 5.830763 & -2.955632 \\
\hline C & -0.171289 & 5.922467 & -1.563577 \\
\hline C & 0.533427 & 4.981295 & -0.814532 \\
\hline C & 1.224751 & 3.930347 & -1.439639 \\
\hline C & 1.184241 & 3.846171 & -2.841684 \\
\hline C & 0.481067 & 4.788958 & -3.589485 \\
\hline $\mathrm{H}$ & -0.705905 & 6.722440 & -1.057781 \\
\hline $\mathrm{H}$ & 0.465370 & 4.707842 & -4.673113 \\
\hline C & -2.175960 & -5.137565 & -0.308732 \\
\hline C & -1.070751 & -5.444215 & 0.487403 \\
\hline C & 0.102949 & -4.698265 & 0.372641 \\
\hline C & 0.197916 & -3.634299 & -0.541007 \\
\hline C & -0.917526 & -3.339108 & -1.344631 \\
\hline C & -2.094288 & -4.085023 & -1.225542 \\
\hline $\mathrm{H}$ & -1.121950 & -6.260524 & 1.203429 \\
\hline $\mathrm{H}$ & -2.946457 & -3.839193 & -1.854476 \\
\hline C & 3.975297 & -1.496464 & -0.786130 \\
\hline C & 3.912921 & -2.916745 & -0.960112 \\
\hline C & 5.101712 & -3.637728 & -1.254608 \\
\hline C & 6.305875 & -2.988475 & -1.397609 \\
\hline C & 6.365697 & -1.581839 & -1.257894 \\
\hline C & 5.233542 & -0.856171 & -0.958789 \\
\hline $\mathrm{H}$ & 5.036543 & -4.716240 & -1.378262 \\
\hline $\mathrm{H}$ & 7.207150 & -3.548994 & -1.630158 \\
\hline $\mathrm{H}$ & 7.312938 & -1.067351 & -1.395353 \\
\hline $\mathrm{H}$ & 5.293635 & 0.222311 & -0.867311 \\
\hline C & 3.540903 & 1.164286 & 0.991098 \\
\hline C & 3.556080 & 2.573627 & 1.248382 \\
\hline C & 4.307648 & 3.076591 & 2.344990 \\
\hline C & 4.994598 & 2.229434 & 3.182927 \\
\hline C & 4.951716 & 0.834130 & 2.955502 \\
\hline C & 4.247833 & 0.316466 & 1.889346 \\
\hline
\end{tabular}




\begin{tabular}{|c|c|c|c|}
\hline $\mathrm{H}$ & 4.317547 & 4.150569 & 2.515659 \\
\hline $\mathrm{H}$ & 5.559928 & 2.625768 & 4.021858 \\
\hline $\mathrm{H}$ & 5.479933 & 0.162779 & 3.627454 \\
\hline $\mathrm{H}$ & 4.228249 & -0.755243 & 1.730226 \\
\hline 0 & -0.679248 & -0.438163 & -2.690758 \\
\hline 0 & -1.111296 & 1.183120 & -0.685022 \\
\hline $\mathrm{H}$ & -2.329622 & 1.098949 & -0.929794 \\
\hline $\mathrm{H}$ & 1.708345 & 3.042376 & -3.346265 \\
\hline $\mathrm{H}$ & -0.750229 & 6.561197 & -3.541783 \\
\hline $\mathrm{H}$ & 0.532623 & 5.045265 & 0.270168 \\
\hline $\mathrm{H}$ & -0.856036 & -2.537040 & -2.074225 \\
\hline $\mathrm{H}$ & -3.091029 & -5.717766 & -0.221978 \\
\hline $\mathrm{H}$ & 0.954505 & -4.929891 & 1.006816 \\
\hline C & -3.658042 & -0.371657 & -1.171924 \\
\hline 0 & -3.476965 & 0.891429 & -1.085225 \\
\hline $\mathrm{H}$ & -2.805021 & -1.021590 & -1.377015 \\
\hline C & -4.937848 & -0.890859 & -1.799178 \\
\hline $\mathrm{O}$ & -5.035754 & -2.021965 & -2.230102 \\
\hline 0 & -5.911635 & 0.024908 & -1.813513 \\
\hline C & -7.141876 & -0.395406 & -2.432180 \\
\hline $\mathrm{H}$ & -7.811115 & 0.461057 & -2.355302 \\
\hline $\mathrm{H}$ & -6.969141 & -0.658421 & -3.478650 \\
\hline C & -3.165912 & -0.720039 & 1.565288 \\
\hline C & -4.064680 & -1.304913 & 0.669272 \\
\hline $\mathrm{H}$ & -1.661503 & -2.008756 & 1.057730 \\
\hline$N$ & -1.922660 & -1.264266 & 1.700666 \\
\hline C & -0.975772 & -1.024078 & 2.713989 \\
\hline 0 & -1.076072 & -0.226129 & 3.614238 \\
\hline 0 & 0.043738 & -1.876955 & 2.526883 \\
\hline C & 1.133493 & -1.738337 & 3.457022 \\
\hline $\mathrm{H}$ & 1.816954 & -2.551739 & 3.215286 \\
\hline $\mathrm{H}$ & 0.771808 & -1.825151 & 4.484104 \\
\hline $\mathrm{H}$ & 1.626162 & -0.772811 & 3.319856 \\
\hline $\mathrm{H}$ & -5.092377 & -0.969334 & 0.747783 \\
\hline $\mathrm{H}$ & -3.909907 & -2.332674 & 0.352347 \\
\hline C & -3.528687 & 0.548134 & 2.223191 \\
\hline C & -2.691149 & 1.674682 & 2.131782 \\
\hline C & -4.780465 & 0.664900 & 2.852514 \\
\hline C & -3.108895 & 2.890211 & 2.664685 \\
\hline $\mathrm{H}$ & -1.745432 & 1.604276 & 1.607153 \\
\hline C & -5.176173 & 1.877052 & 3.410272 \\
\hline $\mathrm{H}$ & -5.424522 & -0.205863 & 2.933820 \\
\hline C & -4.342162 & 2.993044 & 3.312174 \\
\hline $\mathrm{H}$ & -2.466520 & 3.760978 & 2.573417 \\
\hline
\end{tabular}




$\begin{array}{llrr}H & -6.134349 & 1.951658 & 3.916352 \\ H & -4.655559 & 3.943146 & 3.736348 \\ H & -7.557074 & -1.261246 & -1.909425\end{array}$

Catalyst (R)-1 TS Conformation 234

B3LYP/6-31G(d) Energy $=-2809.694686$

B3LYP-D3(BJ)/def2-TZVPP-IEF-PCM(DCM) Energy = -2810.982695

B3LYP-D3(BJ)/def2-TZVPP-IEF-PCM(DCM)//B3LYP/6-31G(d) Free Energy (Quasiharmonic) = 2810.339786

Frequencies (Top 3 out of 270)

1. $-401.0103 \mathrm{~cm}-1$

2. $\quad 10.9753 \mathrm{~cm}-1$

3. $16.0688 \mathrm{~cm}-1$

B3LYP/6-31G(d) Molecular Geometry in Cartesian Coordinates

$\begin{array}{lrrr}\text { C } & 3.480013 & 0.678210 & 0.379710 \\ \text { C } & 2.531289 & 1.543080 & -0.147352 \\ \text { C } & 2.650704 & 2.963309 & -0.081842 \\ \text { C } & 3.719326 & 3.475599 & 0.627858 \\ \text { H } & 3.832475 & 4.554084 & 0.698774 \\ \text { C } & 3.264685 & -3.590897 & -0.187932 \\ \text { C } & 3.410227 & -0.787806 & 0.103926 \\ \text { C } & 2.264690 & -1.501113 & 0.414967 \\ \text { C } & 2.166487 & -2.921273 & 0.317599 \\ \text { H } & 3.245346 & -4.675881 & -0.243616 \\ \text { O } & 1.466886 & 1.013902 & -0.872122 \\ \text { P } & 0.306315 & 0.141478 & -0.131507 \\ \text { O } & 1.159585 & -0.802441 & 0.890311 \\ \text { C } & 0.085790 & 5.770069 & -2.091758 \\ \text { C } & -0.470444 & 4.820047 & -1.233291 \\ \text { C } & 0.341526 & 3.884728 & -0.591069 \\ \text { C } & 1.729966 & 3.894082 & -0.793594 \\ \text { C } & 2.279522 & 4.856421 & -1.657464 \\ \text { C } & 1.465035 & 5.785135 & -2.304177 \\ \text { H } & -1.539547 & 4.800969 & -1.045811 \\ \text { H } & 1.908883 & 6.516407 & -2.975133 \\ \text { C } & -1.213170 & -5.247709 & 1.632234 \\ \text { C } & -0.793659 & -4.143514 & 2.376973 \\ \text { C } & 0.283340 & -3.368633 & 1.948490\end{array}$




\begin{tabular}{|c|c|c|c|}
\hline C & 0.965616 & -3.680186 & 0.758885 \\
\hline C & 0.527283 & -4.789386 & 0.015707 \\
\hline C & -0.545490 & -5.568262 & 0.449127 \\
\hline $\mathrm{H}$ & -1.299834 & -3.888118 & 3.304364 \\
\hline $\mathrm{H}$ & -0.859479 & -6.426762 & -0.139507 \\
\hline C & 4.507433 & -1.491436 & -0.505322 \\
\hline C & 4.425096 & -2.915196 & -0.637003 \\
\hline C & 5.507449 & -3.626786 & -1.222366 \\
\hline C & 6.616393 & -2.964470 & -1.694423 \\
\hline C & 6.683062 & -1.554417 & -1.602852 \\
\hline C & 5.659707 & -0.837899 & -1.022013 \\
\hline $\mathrm{H}$ & 5.433559 & -4.708859 & -1.301892 \\
\hline $\mathrm{H}$ & 7.434257 & -3.517754 & -2.147782 \\
\hline $\mathrm{H}$ & 7.548262 & -1.029777 & -1.998968 \\
\hline $\mathrm{H}$ & 5.723180 & 0.242443 & -0.968879 \\
\hline C & 4.527540 & 1.226829 & 1.199577 \\
\hline C & 4.645045 & 2.649206 & 1.309602 \\
\hline C & 5.677992 & 3.206015 & 2.111476 \\
\hline C & 6.550541 & 2.398124 & 2.802489 \\
\hline C & 6.416829 & 0.992029 & 2.723011 \\
\hline C & 5.435183 & 0.421978 & 1.942382 \\
\hline $\mathrm{H}$ & 5.755893 & 4.288707 & 2.176684 \\
\hline $\mathrm{H}$ & 7.332544 & 2.834629 & 3.417775 \\
\hline $\mathrm{H}$ & 7.091040 & 0.354381 & 3.288491 \\
\hline $\mathrm{H}$ & 5.340485 & -0.656950 & 1.903122 \\
\hline 0 & -0.662985 & 0.927958 & 0.687169 \\
\hline 0 & -0.251127 & -0.752398 & -1.266983 \\
\hline $\mathrm{H}$ & -1.270516 & -0.527667 & -1.616589 \\
\hline $\mathrm{H}$ & 3.352131 & 4.861666 & -1.833109 \\
\hline $\mathrm{H}$ & -0.551108 & 6.495135 & -2.592544 \\
\hline $\mathrm{H}$ & -0.107346 & 3.161088 & 0.080481 \\
\hline $\mathrm{H}$ & 1.026807 & -5.033641 & -0.917586 \\
\hline $\mathrm{H}$ & -2.049749 & -5.852869 & 1.971293 \\
\hline $\mathrm{H}$ & 0.605111 & -2.522708 & 2.544854 \\
\hline C & -3.504335 & -0.896519 & -1.574334 \\
\hline 0 & -2.533254 & -0.139369 & -1.926586 \\
\hline $\mathrm{H}$ & -4.516973 & -0.506316 & -1.747542 \\
\hline C & -3.515177 & -2.399647 & -1.884415 \\
\hline $\mathrm{O}$ & -4.511701 & -3.087815 & -1.772029 \\
\hline $\mathrm{O}$ & -2.329076 & -2.830154 & -2.315145 \\
\hline C & -2.257559 & -4.224508 & -2.662888 \\
\hline $\mathrm{H}$ & -1.240377 & -4.379274 & -3.020752 \\
\hline $\mathrm{H}$ & -2.453971 & -4.842668 & -1.784019 \\
\hline C & -4.151812 & 0.132870 & 0.684838 \\
\hline
\end{tabular}




$\begin{array}{lrrr}\mathrm{C} & -3.499450 & -1.075040 & 0.361011 \\ \mathrm{H} & -2.385403 & 1.181403 & 0.666136 \\ \mathrm{~N} & -3.421385 & 1.274360 & 0.640009 \\ \mathrm{C} & -3.825619 & 2.571813 & 0.268489 \\ \mathrm{O} & -3.117434 & 3.537130 & 0.441347 \\ \mathrm{O} & -5.026775 & 2.585344 & -0.325457 \\ \mathrm{C} & -5.486871 & 3.885392 & -0.737113 \\ \mathrm{H} & -6.484574 & 3.719363 & -1.142703 \\ \mathrm{H} & -4.822750 & 4.295519 & -1.501520 \\ \mathrm{H} & -5.522820 & 4.567346 & 0.115774 \\ \mathrm{H} & -4.010087 & -1.989722 & 0.641965 \\ \mathrm{H} & -2.421089 & -1.107633 & 0.476992 \\ \mathrm{C} & -5.585331 & 0.143928 & 1.030856 \\ \mathrm{C} & -6.069564 & 1.045290 & 1.996568 \\ \mathrm{C} & -6.465038 & -0.805904 & 0.479743 \\ \mathrm{C} & -7.401514 & 1.002061 & 2.395901 \\ \mathrm{H} & -5.389975 & 1.754770 & 2.458833 \\ \mathrm{C} & -7.801844 & -0.830151 & 0.870411 \\ \mathrm{H} & -6.109736 & -1.514513 & -0.262969 \\ \mathrm{C} & -8.273937 & 0.070144 & 1.827880 \\ \mathrm{H} & -7.758232 & 1.693077 & 3.154365 \\ \mathrm{H} & -8.474903 & -1.557865 & 0.426434 \\ \mathrm{H} & -9.315418 & 0.041538 & 2.136020 \\ \mathrm{H} & -2.985803 & -4.457132 & -3.443931\end{array}$

Catalyst (R)-1 TS Conformation 235

B3LYP/6-31G(d) Energy $=-2809.686352$

B3LYP-D3(BJ)/def2-TZVPP-IEF-PCM(DCM) Energy = -2810.980633

B3LYP-D3(BJ)/def2-TZVPP-IEF-PCM(DCM)//B3LYP/6-31G(d) Free Energy (Quasiharmonic) = 2810.339767

Frequencies (Top 3 out of 270)

1. $-714.1282 \mathrm{~cm}-1$

2. $\quad 11.6903 \mathrm{~cm}-1$

3. $16.4843 \mathrm{~cm}-1$

B3LYP/6-31G(d) Molecular Geometry in Cartesian Coordinates

$\begin{array}{llll}\text { C } & 2.935772 & -1.228044 & -0.242438 \\ \text { C } & 1.686002 & -1.600473 & 0.229210 \\ \text { C } & 1.213828 & -2.946428 & 0.211058\end{array}$




\begin{tabular}{|c|c|c|c|}
\hline C & 2.031422 & -3.902284 & -0.358385 \\
\hline $\mathrm{H}$ & 1.710379 & -4.940833 & -0.366586 \\
\hline C & 4.150664 & 2.903615 & 0.017608 \\
\hline C & 3.376385 & 0.192731 & -0.104693 \\
\hline C & 2.582675 & 1.206634 & -0.621903 \\
\hline C & 2.956768 & 2.583627 & -0.599794 \\
\hline $\mathrm{H}$ & 4.479513 & 3.939450 & 0.028500 \\
\hline 0 & 0.856405 & -0.628188 & 0.763678 \\
\hline$P$ & 0.115338 & 0.429711 & -0.266581 \\
\hline O & 1.379983 & 0.865746 & -1.221354 \\
\hline C & -2.554386 & -4.177714 & 1.899205 \\
\hline C & -1.702795 & -3.336263 & 2.623904 \\
\hline C & -0.493595 & -2.909147 & 2.071548 \\
\hline C & -0.102651 & -3.329704 & 0.787988 \\
\hline C & -0.968927 & -4.172137 & 0.071898 \\
\hline C & -2.185587 & -4.588418 & 0.616691 \\
\hline $\mathrm{H}$ & -1.969622 & -3.023705 & 3.631022 \\
\hline $\mathrm{H}$ & -2.852517 & -5.214393 & 0.031679 \\
\hline C & 0.629266 & 5.742983 & -2.365772 \\
\hline C & 0.826318 & 4.549171 & -3.062966 \\
\hline C & 1.559610 & 3.510857 & -2.491483 \\
\hline C & 2.116379 & 3.649107 & -1.208807 \\
\hline C & 1.907522 & 4.853290 & -0.516972 \\
\hline C & 1.171559 & 5.890442 & -1.088566 \\
\hline $\mathrm{H}$ & 0.408714 & 4.424338 & -4.058648 \\
\hline $\mathrm{H}$ & 1.015822 & 6.810468 & -0.531043 \\
\hline C & 4.578167 & 0.550545 & 0.597804 \\
\hline C & 4.967078 & 1.928840 & 0.641553 \\
\hline C & 6.159320 & 2.296449 & 1.322708 \\
\hline C & 6.927402 & 1.353974 & 1.965813 \\
\hline C & 6.525571 & -0.002475 & 1.957678 \\
\hline C & 5.384553 & -0.393600 & 1.291903 \\
\hline $\mathrm{H}$ & 6.446104 & 3.345426 & 1.334631 \\
\hline $\mathrm{H}$ & 7.833427 & 1.648190 & 2.488514 \\
\hline $\mathrm{H}$ & 7.120475 & -0.743275 & 2.485242 \\
\hline $\mathrm{H}$ & 5.086686 & -1.435646 & 1.303382 \\
\hline C & 3.746764 & -2.220152 & -0.893880 \\
\hline C & 3.282834 & -3.575417 & -0.936357 \\
\hline C & 4.079826 & -4.567342 & -1.569498 \\
\hline C & 5.273807 & -4.239917 & -2.168492 \\
\hline C & 5.716247 & -2.896210 & -2.162408 \\
\hline C & 4.975328 & -1.914398 & -1.541981 \\
\hline $\mathrm{H}$ & 3.717820 & -5.592788 & -1.581641 \\
\hline $\mathrm{H}$ & 5.871191 & -5.005433 & -2.655994 \\
\hline
\end{tabular}




\begin{tabular}{|c|c|c|c|}
\hline $\mathrm{H}$ & 6.647816 & -2.634303 & -2.656815 \\
\hline $\mathrm{H}$ & 5.323746 & -0.888291 & -1.555562 \\
\hline $\mathrm{O}$ & -0.471762 & 1.524086 & 0.550058 \\
\hline $\mathrm{O}$ & -0.756843 & -0.384361 & -1.236601 \\
\hline $\mathrm{H}$ & -1.918494 & -0.240597 & -1.406100 \\
\hline $\mathrm{H}$ & -0.694436 & -4.482281 & -0.932369 \\
\hline $\mathrm{H}$ & -3.493812 & -4.512581 & 2.331378 \\
\hline $\mathrm{H}$ & 0.153926 & -2.251758 & 2.639989 \\
\hline $\mathrm{H}$ & 2.307307 & 4.965270 & 0.487019 \\
\hline $\mathrm{H}$ & 0.054531 & 6.549753 & -2.813276 \\
\hline $\mathrm{H}$ & 1.706936 & 2.588929 & -3.042970 \\
\hline C & -3.570085 & -1.379288 & -1.051893 \\
\hline $\mathrm{O}$ & -3.116360 & -0.343447 & -1.649939 \\
\hline $\mathrm{H}$ & -2.868220 & -2.038760 & -0.530157 \\
\hline C & -4.702231 & -2.165527 & -1.689405 \\
\hline 0 & -4.892507 & -3.341459 & -1.452076 \\
\hline $\mathrm{O}$ & -5.440335 & -1.421225 & -2.521940 \\
\hline C & -6.510990 & -2.117595 & -3.183682 \\
\hline $\mathrm{H}$ & -7.211108 & -2.530620 & -2.452265 \\
\hline $\mathrm{H}$ & -7.000590 & -1.370164 & -3.807616 \\
\hline C & -4.050729 & 0.127853 & 1.213866 \\
\hline C & -4.665011 & -1.009145 & 0.668790 \\
\hline $\mathrm{H}$ & -2.548121 & -0.988402 & 2.022088 \\
\hline $\mathrm{N}$ & -2.933128 & -0.046749 & 1.968131 \\
\hline C & -2.258202 & 0.894192 & 2.778829 \\
\hline 0 & -2.622722 & 2.017676 & 3.014158 \\
\hline 0 & -1.182102 & 0.277827 & 3.288859 \\
\hline C & -0.246836 & 1.153993 & 3.948517 \\
\hline $\mathrm{H}$ & 0.536960 & 0.500554 & 4.330625 \\
\hline $\mathrm{H}$ & -0.737298 & 1.692350 & 4.762608 \\
\hline $\mathrm{H}$ & 0.156330 & 1.854849 & 3.215192 \\
\hline $\mathrm{H}$ & -5.641071 & -0.846409 & 0.227475 \\
\hline $\mathrm{H}$ & -4.512187 & -1.973993 & 1.145121 \\
\hline C & -4.506563 & 1.463196 & 0.796860 \\
\hline C & -3.593561 & 2.426305 & 0.326353 \\
\hline C & -5.886726 & 1.736842 & 0.757275 \\
\hline C & -4.068827 & 3.633373 & -0.179165 \\
\hline $\mathrm{H}$ & -2.527005 & 2.224648 & 0.337274 \\
\hline C & -6.347718 & 2.959076 & 0.280159 \\
\hline $\mathrm{H}$ & -6.592451 & 1.003067 & 1.135654 \\
\hline C & -5.437867 & 3.906724 & -0.196553 \\
\hline $\mathrm{H}$ & -3.360081 & 4.364890 & -0.555930 \\
\hline $\mathrm{H}$ & -7.413036 & 3.171322 & 0.276838 \\
\hline $\mathrm{H}$ & -5.797780 & 4.857621 & -0.580625 \\
\hline
\end{tabular}


$\mathrm{H}$

Catalyst (R)-1 TS Conformation 236

$B 3 L Y P / 6-31 G(d)$ Energy $=-2809.685238$

B3LYP-D3(BJ)/def2-TZVPP-IEF-PCM(DCM) Energy = -2810.981772

B3LYP-D3(BJ)/def2-TZVPP-IEF-PCM(DCM)//B3LYP/6-31G(d) Free Energy (Quasiharmonic) = 2810.339733

Frequencies (Top 3 out of 270)

1. $-695.0118 \mathrm{~cm}-1$

2. $\quad 6.7539 \mathrm{~cm}-1$

3. $8.9419 \mathrm{~cm}-1$

B3LYP/6-31G(d) Molecular Geometry in Cartesian Coordinates

$\begin{array}{llll}\text { C } & 3.692037 & 0.204564 & 0.212850 \\ \mathrm{C} & 2.931048 & 1.284354 & -0.218675 \\ \mathrm{C} & 3.304893 & 2.640410 & 0.033545 \\ \mathrm{C} & 4.413768 & 2.857700 & 0.828447 \\ \mathrm{H} & 4.714004 & 3.879963 & 1.043096 \\ \mathrm{C} & 2.656609 & -3.788205 & -1.061965 \\ \mathrm{C} & 3.367483 & -1.174243 & -0.259489 \\ \mathrm{C} & 2.093911 & -1.682246 & -0.064704 \\ \mathrm{C} & 1.708841 & -3.002677 & -0.437623 \\ \mathrm{H} & 2.400249 & -4.806814 & -1.341983 \\ \mathrm{O} & 1.823955 & 1.057575 & -1.020307 \\ \mathrm{P} & 0.480488 & 0.297868 & -0.457434 \\ \mathrm{O} & 1.141829 & -0.857056 & 0.522672 \\ \mathrm{C} & 1.373844 & 6.086163 & -1.678429 \\ \mathrm{C} & 0.612778 & 5.130622 & -1.002392 \\ \mathrm{C} & 1.216802 & 3.998051 & -0.457020 \\ \mathrm{C} & 2.601946 & 3.804652 & -0.576151 \\ \mathrm{C} & 3.358482 & 4.772932 & -1.257521 \\ \mathrm{C} & 2.751311 & 5.902845 & -1.804874 \\ \mathrm{H} & -0.460437 & 5.265929 & -0.894255 \\ \mathrm{H} & 3.354881 & 6.635227 & -2.335045 \\ \mathrm{C} & -2.193726 & -4.657374 & 0.302289 \\ \mathrm{C} & -1.638488 & -4.697856 & -0.977588 \\ \mathrm{C} & -0.381463 & -4.141212 & -1.214807 \\ \mathrm{C} & 0.344243 & -3.535080 & -0.177917 \\ \mathrm{C} & -0.226807 & -3.496620 & 1.104338\end{array}$




\begin{tabular}{|c|c|c|c|}
\hline C & -1.482688 & -4.053544 & 1.342469 \\
\hline $\mathrm{H}$ & -2.184625 & -5.159803 & -1.796104 \\
\hline $\mathrm{H}$ & -1.902771 & -4.023610 & 2.344649 \\
\hline C & 4.324898 & -1.979605 & -0.969866 \\
\hline C & 3.956352 & -3.308750 & -1.358827 \\
\hline C & 4.894566 & -4.119797 & -2.052989 \\
\hline C & 6.138972 & -3.637179 & -2.384433 \\
\hline C & 6.491509 & -2.311724 & -2.038438 \\
\hline C & 5.610949 & -1.506072 & -1.350400 \\
\hline $\mathrm{H}$ & 4.601158 & -5.129895 & -2.329281 \\
\hline $\mathrm{H}$ & 6.845590 & -4.263972 & -2.921531 \\
\hline $\mathrm{H}$ & 7.465151 & -1.922094 & -2.323210 \\
\hline $\mathrm{H}$ & 5.894178 & -0.489820 & -1.103903 \\
\hline C & 4.785093 & 0.446793 & 1.114467 \\
\hline C & 5.147509 & 1.798529 & 1.415407 \\
\hline C & 6.227012 & 2.051799 & 2.304450 \\
\hline C & 6.913929 & 1.017609 & 2.896600 \\
\hline C & 6.539475 & -0.319476 & 2.624948 \\
\hline C & 5.506046 & -0.597558 & 1.757312 \\
\hline $\mathrm{H}$ & 6.492401 & 3.085120 & 2.515614 \\
\hline $\mathrm{H}$ & 7.734042 & 1.223154 & 3.579164 \\
\hline $\mathrm{H}$ & 7.068476 & -1.135650 & 3.109827 \\
\hline $\mathrm{H}$ & 5.225171 & -1.627339 & 1.567967 \\
\hline 0 & -0.298305 & -0.244162 & -1.601113 \\
\hline $\mathrm{O}$ & -0.236431 & 1.213225 & 0.558902 \\
\hline $\mathrm{H}$ & -1.417133 & 1.462345 & 0.349845 \\
\hline $\mathrm{H}$ & 4.428902 & 4.625115 & -1.373496 \\
\hline $\mathrm{H}$ & 0.897279 & 6.965107 & -2.105024 \\
\hline $\mathrm{H}$ & 0.617553 & 3.268404 & 0.075292 \\
\hline $\mathrm{H}$ & 0.327622 & -3.044234 & 1.920386 \\
\hline $\mathrm{H}$ & -3.170368 & -5.096447 & 0.490239 \\
\hline $\mathrm{H}$ & 0.037870 & -4.154155 & -2.216544 \\
\hline C & -3.017103 & 0.964839 & -0.809978 \\
\hline 0 & -2.567890 & 1.705092 & 0.140721 \\
\hline $\mathrm{H}$ & -2.301116 & 0.438761 & -1.453169 \\
\hline C & -4.265848 & 1.404454 & -1.555381 \\
\hline 0 & -4.665822 & 0.839753 & -2.551561 \\
\hline $\mathrm{O}$ & -4.839210 & 2.487148 & -1.007154 \\
\hline C & -5.966166 & 3.011147 & -1.733632 \\
\hline $\mathrm{H}$ & -6.779381 & 2.281495 & -1.756651 \\
\hline $\mathrm{H}$ & -6.266594 & 3.908903 & -1.193028 \\
\hline C & -4.624898 & -0.493431 & 0.781092 \\
\hline C & -3.596447 & -0.845227 & -0.090957 \\
\hline $\mathrm{H}$ & -5.256887 & 0.328408 & 2.526069 \\
\hline
\end{tabular}




$\begin{array}{llll}\mathrm{N} & -4.430996 & 0.013034 & 2.032312 \\ \mathrm{C} & -3.298958 & 0.184889 & 2.864977 \\ \mathrm{O} & -3.425127 & 0.763214 & 3.921131 \\ \mathrm{O} & -2.199123 & -0.380551 & 2.388656 \\ \mathrm{C} & -1.015528 & -0.205984 & 3.210610 \\ \mathrm{H} & -0.832378 & 0.856375 & 3.370010 \\ \mathrm{H} & -0.207244 & -0.644068 & 2.632167 \\ \mathrm{H} & -1.161287 & -0.713636 & 4.166884 \\ \mathrm{H} & -3.884086 & -1.319862 & -1.021542 \\ \mathrm{H} & -2.623217 & -1.108495 & 0.299575 \\ \mathrm{C} & -6.044516 & -0.526104 & 0.349041 \\ \mathrm{C} & -6.951044 & 0.479893 & 0.732777 \\ \mathrm{C} & -6.507945 & -1.588649 & -0.444585 \\ \mathrm{C} & -8.284980 & 0.417497 & 0.336210 \\ \mathrm{H} & -6.605194 & 1.343361 & 1.294726 \\ \mathrm{C} & -7.844204 & -1.650856 & -0.832615 \\ \mathrm{H} & -5.824936 & -2.380567 & -0.733204 \\ \mathrm{C} & -8.736220 & -0.650394 & -0.443019 \\ \mathrm{H} & -8.970215 & 1.207399 & 0.630005 \\ \mathrm{H} & -8.188774 & -2.484306 & -1.437454 \\ \mathrm{H} & -9.777631 & -0.699782 & -0.747829 \\ \mathrm{H} & -5.675286 & 3.257042 & -2.757829\end{array}$

Catalyst (R)-1 TS Conformation 237

B3LYP/6-31G(d) Energy $=-2809.688972$

B3LYP-D3(BJ)/def2-TZVPP-IEF-PCM(DCM) Energy = -2810.981969

B3LYP-D3(BJ)/def2-TZVPP-IEF-PCM(DCM)//B3LYP/6-31G(d) Free Energy (Quasiharmonic) = 2810.339598

Frequencies (Top 3 out of 270)

1. $-619.1438 \mathrm{~cm}-1$

2. $\quad 7.9951 \mathrm{~cm}-1$

3. $\quad 11.8158 \mathrm{~cm}-1$

B3LYP/6-31G(d) Molecular Geometry in Cartesian Coordinates

$\begin{array}{llll}\text { C } & 3.750415 & 0.162007 & 0.276688 \\ \text { C } & 2.959249 & 1.250793 & -0.059318 \\ \text { C } & 3.255622 & 2.589147 & 0.334234 \\ \text { C } & 4.363418 & 2.782839 & 1.135627 \\ \text { H } & 4.632660 & 3.792957 & 1.433209\end{array}$




\begin{tabular}{|c|c|c|c|}
\hline C & 2.668743 & -3.780769 & -1.108876 \\
\hline C & 3.405960 & -1.193405 & -0.250103 \\
\hline C & 2.136190 & -1.706933 & -0.030918 \\
\hline C & 1.736882 & -3.016094 & -0.434081 \\
\hline $\mathrm{H}$ & 2.409547 & -4.793564 & -1.406171 \\
\hline 0 & 1.831987 & 1.044656 & -0.842486 \\
\hline$P$ & 0.514017 & 0.330387 & -0.179990 \\
\hline $\mathrm{O}$ & 1.212328 & -0.918965 & 0.636934 \\
\hline C & 0.941434 & 6.010739 & -0.876273 \\
\hline C & 1.297054 & 5.040361 & -1.816679 \\
\hline C & 2.025896 & 3.916247 & -1.429661 \\
\hline C & 2.421259 & 3.744558 & -0.092273 \\
\hline C & 2.054597 & 4.725648 & 0.842922 \\
\hline C & 1.321565 & 5.847214 & 0.456354 \\
\hline $\mathrm{H}$ & 1.016446 & 5.162901 & -2.860024 \\
\hline $\mathrm{H}$ & 1.041754 & 6.589353 & 1.199490 \\
\hline C & -2.174902 & -4.650931 & 0.318071 \\
\hline C & -1.508263 & -3.950881 & 1.327292 \\
\hline C & -0.245264 & -3.408324 & 1.091274 \\
\hline C & 0.375059 & -3.549806 & -0.162796 \\
\hline C & -0.310358 & -4.250968 & -1.168251 \\
\hline C & -1.570419 & -4.799550 & -0.930707 \\
\hline $\mathrm{H}$ & -1.974395 & -3.826684 & 2.301033 \\
\hline $\mathrm{H}$ & -2.081864 & -5.334808 & -1.726715 \\
\hline C & 4.336026 & -1.971497 & -1.021845 \\
\hline C & 3.956254 & -3.289595 & -1.436468 \\
\hline C & 4.871930 & -4.076288 & -2.186927 \\
\hline C & 6.102503 & -3.579485 & -2.548047 \\
\hline C & 6.464464 & -2.263644 & -2.175221 \\
\hline C & 5.606859 & -1.482248 & -1.432365 \\
\hline $\mathrm{H}$ & 4.571950 & -5.079054 & -2.482326 \\
\hline $\mathrm{H}$ & 6.791146 & -4.187742 & -3.128090 \\
\hline $\mathrm{H}$ & 7.426886 & -1.862844 & -2.481889 \\
\hline $\mathrm{H}$ & 5.896075 & -0.473053 & -1.163286 \\
\hline C & 4.856318 & 0.371385 & 1.171649 \\
\hline C & 5.165011 & 1.706797 & 1.589561 \\
\hline C & 6.262584 & 1.928528 & 2.464996 \\
\hline C & 7.011986 & 0.878444 & 2.941788 \\
\hline C & 6.685059 & -0.444821 & 2.563383 \\
\hline C & 5.638417 & -0.691615 & 1.702209 \\
\hline $\mathrm{H}$ & 6.489904 & 2.949869 & 2.761531 \\
\hline $\mathrm{H}$ & 7.844244 & 1.059911 & 3.616387 \\
\hline $\mathrm{H}$ & 7.261811 & -1.276161 & 2.959856 \\
\hline $\mathrm{H}$ & 5.395475 & -1.712371 & 1.431145 \\
\hline
\end{tabular}




\begin{tabular}{|c|c|c|c|}
\hline 0 & -0.417719 & -0.080206 & -1.264008 \\
\hline 0 & -0.018849 & 1.221304 & 0.959775 \\
\hline $\mathrm{H}$ & -1.173557 & 1.213632 & 1.130977 \\
\hline $\mathrm{H}$ & 2.328367 & 4.592503 & 1.885694 \\
\hline $\mathrm{H}$ & 0.373725 & 6.886510 & -1.180148 \\
\hline $\mathrm{H}$ & 2.298353 & 3.170559 & -2.168446 \\
\hline $\mathrm{H}$ & 0.140926 & -4.343989 & -2.151882 \\
\hline $\mathrm{H}$ & -3.155492 & -5.079945 & 0.508616 \\
\hline $\mathrm{H}$ & 0.267839 & -2.875663 & 1.884229 \\
\hline C & -2.866356 & -0.034540 & 1.286742 \\
\hline O & -2.403995 & 1.168275 & 1.338928 \\
\hline $\mathrm{H}$ & -2.157321 & -0.873749 & 1.328654 \\
\hline C & -4.109895 & -0.357536 & 2.109060 \\
\hline $\mathrm{O}$ & -4.455064 & -1.496779 & 2.364675 \\
\hline $\mathrm{O}$ & -4.768506 & 0.739184 & 2.497693 \\
\hline C & -5.941809 & 0.507576 & 3.303765 \\
\hline $\mathrm{H}$ & -5.686523 & -0.089769 & 4.182170 \\
\hline $\mathrm{H}$ & -6.286449 & 1.498500 & 3.599308 \\
\hline C & -4.516580 & 0.285821 & -0.821577 \\
\hline C & -3.463186 & -0.579459 & -0.465682 \\
\hline $\mathrm{H}$ & -6.447626 & 0.810338 & -0.422264 \\
\hline$N$ & -5.827289 & 0.014251 & -0.502577 \\
\hline C & -6.490778 & -1.147875 & -0.068379 \\
\hline $\mathrm{O}$ & -7.585504 & -1.066892 & 0.448968 \\
\hline O & -5.823659 & -2.267890 & -0.332316 \\
\hline C & -6.381450 & -3.464547 & 0.252380 \\
\hline $\mathrm{H}$ & -7.418771 & -3.592132 & -0.061988 \\
\hline $\mathrm{H}$ & -6.318835 & -3.395956 & 1.340290 \\
\hline $\mathrm{H}$ & -5.756987 & -4.275711 & -0.119821 \\
\hline $\mathrm{H}$ & -2.519899 & -0.456545 & -0.992388 \\
\hline $\mathrm{H}$ & -3.723234 & -1.607202 & -0.248313 \\
\hline C & -4.275385 & 1.609664 & -1.402497 \\
\hline C & -2.966137 & 2.135379 & -1.437619 \\
\hline C & -5.330419 & 2.394638 & -1.925237 \\
\hline C & -2.735135 & 3.420001 & -1.926837 \\
\hline $\mathrm{H}$ & -2.125086 & 1.545566 & -1.102853 \\
\hline C & -5.088495 & 3.665857 & -2.425850 \\
\hline $\mathrm{H}$ & -6.340392 & 1.999911 & -1.989998 \\
\hline C & -3.789954 & 4.189173 & -2.413932 \\
\hline $\mathrm{H}$ & -1.721989 & 3.810945 & -1.926463 \\
\hline $\mathrm{H}$ & -5.909121 & 4.248270 & -2.834519 \\
\hline $\mathrm{H}$ & -3.604806 & 5.187205 & -2.801566 \\
\hline $\mathrm{H}$ & -6.707973 & -0.011077 & 2.721686 \\
\hline
\end{tabular}


Catalyst (R)-1 TS Conformation 238

B3LYP/6-31G(d) Energy $=-2809.683045$

B3LYP-D3(BJ)/def2-TZVPP-IEF-PCM(DCM) Energy = -2810.981025

B3LYP-D3(BJ)/def2-TZVPP-IEF-PCM(DCM)//B3LYP/6-31G(d) Free Energy (Quasiharmonic) = 2810.339597

Frequencies (Top 3 out of 270)

1. $-597.6046 \mathrm{~cm}-1$

2. $\quad 13.6492 \mathrm{~cm}-1$

3. $\quad 16.6205 \mathrm{~cm}-1$

B3LYP/6-31G(d) Molecular Geometry in Cartesian Coordinates

$\begin{array}{lrrr}\text { C } & 2.813714 & 0.573805 & -0.127468 \\ \text { C } & 2.077179 & 1.481435 & -0.873657 \\ \text { C } & 2.151942 & 2.894949 & -0.690535 \\ \text { C } & 2.966119 & 3.356150 & 0.325673 \\ \text { H } & 3.069763 & 4.427462 & 0.475931 \\ \text { C } & 2.513829 & -3.681075 & -0.742627 \\ \text { C } & 2.734652 & -0.884941 & -0.439031 \\ \text { C } & 1.499885 & -1.520386 & -0.454400 \\ \text { C } & 1.363216 & -2.938300 & -0.565140 \\ \text { H } & 2.436679 & -4.761310 & -0.836630 \\ \text { O } & 1.243187 & 0.995708 & -1.869542 \\ \text { P } & -0.166871 & 0.278070 & -1.438050 \\ \text { O } & 0.357999 & -0.766581 & -0.254065 \\ \text { C } & 0.050974 & 5.759701 & -3.118385 \\ \text { C } & 0.687556 & 4.671608 & -3.718584 \\ \text { C } & 1.352474 & 3.725377 & -2.940749 \\ \text { C } & 1.397552 & 3.852636 & -1.542140 \\ \text { C } & 0.750129 & 4.950012 & -0.950912 \\ \text { C } & 0.083417 & 5.894532 & -1.729947 \\ \text { H } & 0.667378 & 4.556753 & -4.799092 \\ \text { H } & -0.418629 & 6.730746 & -1.250158 \\ \text { C } & -2.381913 & -5.040801 & -0.204773 \\ \text { C } & -2.254575 & -3.999684 & -1.128873 \\ \text { C } & -1.051304 & -3.298587 & -1.250018 \\ \text { C } & 0.049246 & -3.631200 & -0.440683 \\ \text { C } & -0.090733 & -4.682524 & 0.481608 \\ \text { C } & -1.292486 & -5.381638 & 0.598850 \\ \text { H } & -3.090786 & -3.731622 & -1.770350\end{array}$




\begin{tabular}{|c|c|c|c|}
\hline $\mathrm{H}$ & -1.377879 & -6.188480 & 1.322167 \\
\hline C & 3.911543 & -1.658983 & -0.726119 \\
\hline C & 3.790155 & -3.079127 & -0.866031 \\
\hline C & 4.947433 & -3.856243 & -1.142848 \\
\hline C & 6.177554 & -3.261580 & -1.300980 \\
\hline C & 6.295997 & -1.855668 & -1.195229 \\
\hline C & 5.195409 & -1.076285 & -0.914091 \\
\hline $\mathrm{H}$ & 4.837095 & -4.933772 & -1.240413 \\
\hline $\mathrm{H}$ & 7.054539 & -3.864650 & -1.519490 \\
\hline $\mathrm{H}$ & 7.263795 & -1.384616 & -1.344617 \\
\hline $\mathrm{H}$ & 5.300835 & 0.000520 & -0.848435 \\
\hline C & 3.594423 & 1.067113 & 0.975739 \\
\hline C & 3.672646 & 2.481929 & 1.187381 \\
\hline C & 4.446755 & 2.985424 & 2.267931 \\
\hline C & 5.095156 & 2.135334 & 3.133245 \\
\hline C & 4.989286 & 0.736731 & 2.950966 \\
\hline C & 4.262436 & 0.217342 & 1.901274 \\
\hline $\mathrm{H}$ & 4.505003 & 4.062757 & 2.404323 \\
\hline $\mathrm{H}$ & 5.678009 & 2.532550 & 3.959684 \\
\hline $\mathrm{H}$ & 5.486439 & 0.064323 & 3.645185 \\
\hline $\mathrm{H}$ & 4.193293 & -0.856997 & 1.776982 \\
\hline $\mathrm{O}$ & -0.752313 & -0.421994 & -2.611335 \\
\hline 0 & -1.029770 & 1.262019 & -0.631986 \\
\hline $\mathrm{H}$ & -2.273611 & 1.300203 & -0.884710 \\
\hline $\mathrm{H}$ & 0.752026 & 5.047808 & 0.131218 \\
\hline $\mathrm{H}$ & -0.471419 & 6.492531 & -3.727607 \\
\hline $\mathrm{H}$ & 1.843011 & 2.885052 & -3.419061 \\
\hline $\mathrm{H}$ & 0.749045 & -4.941783 & 1.120669 \\
\hline $\mathrm{H}$ & -3.318379 & -5.585660 & -0.116805 \\
\hline $\mathrm{H}$ & -0.958234 & -2.503720 & -1.984062 \\
\hline C & -3.705727 & -0.025732 & -1.207542 \\
\hline 0 & -3.414754 & 1.206230 & -1.039672 \\
\hline $\mathrm{H}$ & -2.914082 & -0.729709 & -1.469777 \\
\hline C & -5.077519 & -0.322285 & -1.781828 \\
\hline $\mathrm{O}$ & -6.003755 & 0.450992 & -1.811824 \\
\hline 0 & -5.106202 & -1.584267 & -2.261598 \\
\hline C & -6.351117 & -1.980049 & -2.866531 \\
\hline $\mathrm{H}$ & -6.588402 & -1.324306 & -3.707732 \\
\hline $\mathrm{H}$ & -6.198082 & -3.003677 & -3.207553 \\
\hline C & -3.241328 & -0.508225 & 1.546376 \\
\hline C & -4.142562 & -1.052456 & 0.631168 \\
\hline $\mathrm{H}$ & -1.770189 & -1.844543 & 1.058303 \\
\hline$N$ & -2.019800 & -1.098524 & 1.703637 \\
\hline C & -1.091540 & -0.907268 & 2.742638 \\
\hline
\end{tabular}




$\begin{array}{llll}\mathrm{O} & -1.180970 & -0.114933 & 3.649215 \\ \mathrm{O} & -0.101617 & -1.799148 & 2.572531 \\ \mathrm{C} & 0.973827 & -1.704642 & 3.523860 \\ \mathrm{H} & 0.589426 & -1.775647 & 4.543862 \\ \mathrm{H} & 1.508047 & -0.759901 & 3.396496 \\ \mathrm{H} & 1.628715 & -2.545073 & 3.295591 \\ \mathrm{H} & -5.161336 & -0.689044 & 0.696264 \\ \mathrm{H} & -4.004490 & -2.073633 & 0.287106 \\ \mathrm{C} & -3.569892 & 0.766495 & 2.209395 \\ \mathrm{C} & -4.832369 & 0.931032 & 2.805707 \\ \mathrm{C} & -2.683529 & 1.857640 & 2.151654 \\ \mathrm{C} & -5.192213 & 2.154363 & 3.362921 \\ \mathrm{H} & -5.515149 & 0.088274 & 2.860994 \\ \mathrm{C} & -3.063935 & 3.085198 & 2.684681 \\ \mathrm{H} & -1.726678 & 1.750960 & 1.653902 \\ \mathrm{C} & -4.309581 & 3.234814 & 3.298343 \\ \mathrm{H} & -6.160830 & 2.265780 & 3.841455 \\ \mathrm{H} & -2.383102 & 3.928706 & 2.619912 \\ \mathrm{H} & -4.594900 & 4.193994 & 3.721830 \\ \mathrm{H} & -7.162794 & -1.931511 & -2.135621\end{array}$

Catalyst (R)-1 TS Conformation 239

B3LYP/6-31G(d) Energy = -2809.690114

B3LYP-D3(BJ)/def2-TZVPP-IEF-PCM(DCM) Energy = -2810.981529

B3LYP-D3(BJ)/def2-TZVPP-IEF-PCM(DCM)//B3LYP/6-31G(d) Free Energy (Quasiharmonic) = 2810.339589

Frequencies (Top 3 out of 270)

1. $-785.9691 \mathrm{~cm}-1$

2. $\quad 13.8454 \mathrm{~cm}-1$

3. $20.0947 \mathrm{~cm}-1$

B3LYP/6-31G(d) Molecular Geometry in Cartesian Coordinates

$\begin{array}{llll}\text { C } & 3.102597 & -0.747888 & -0.187693 \\ \text { C } & 1.995845 & -1.554241 & 0.039803 \\ \text { C } & 2.005902 & -2.962461 & -0.199475 \\ \text { C } & 3.157046 & -3.511694 & -0.729583 \\ \text { H } & 3.186322 & -4.580520 & -0.924084 \\ \text { C } & 3.225512 & 3.489211 & 0.517412 \\ \text { C } & 3.093172 & 0.695871 & 0.190911\end{array}$




\begin{tabular}{|c|c|c|c|}
\hline C & 2.112978 & 1.535373 & -0.316297 \\
\hline C & 2.192828 & 2.959344 & -0.233439 \\
\hline $\mathrm{H}$ & 3.305400 & 4.568670 & 0.614699 \\
\hline $\mathrm{O}$ & 0.866904 & -1.003936 & 0.631057 \\
\hline$P$ & -0.051804 & 0.135315 & -0.110760 \\
\hline 0 & 1.049958 & 0.963775 & -1.005911 \\
\hline C & -1.177736 & -5.751676 & 0.576090 \\
\hline C & -1.421743 & -4.623044 & -0.210678 \\
\hline C & -0.412625 & -3.684880 & -0.436913 \\
\hline C & 0.865152 & -3.869946 & 0.114636 \\
\hline C & 1.097075 & -5.005014 & 0.910570 \\
\hline C & 0.085103 & -5.937109 & 1.142517 \\
\hline $\mathrm{H}$ & -2.397401 & -4.457143 & -0.656385 \\
\hline $\mathrm{H}$ & 0.285708 & -6.807711 & 1.762184 \\
\hline C & -0.330298 & 5.682773 & -2.419529 \\
\hline C & -0.906802 & 4.638980 & -1.693271 \\
\hline C & -0.107898 & 3.743032 & -0.983041 \\
\hline C & 1.289783 & 3.872433 & -0.988378 \\
\hline C & 1.857819 & 4.925998 & -1.726068 \\
\hline C & 1.057785 & 5.823687 & -2.432030 \\
\hline $\mathrm{H}$ & -1.986458 & 4.515197 & -1.678573 \\
\hline $\mathrm{H}$ & 1.521740 & 6.625239 & -3.001174 \\
\hline C & 4.105945 & 1.256949 & 1.043091 \\
\hline C & 4.160321 & 2.678022 & 1.205408 \\
\hline C & 5.151209 & 3.246890 & 2.050668 \\
\hline C & 6.043383 & 2.450272 & 2.730043 \\
\hline C & 5.974706 & 1.043740 & 2.592974 \\
\hline C & 5.034774 & 0.462911 & 1.769979 \\
\hline $\mathrm{H}$ & 5.182805 & 4.328765 & 2.157216 \\
\hline $\mathrm{H}$ & 6.792989 & 2.895686 & 3.378466 \\
\hline $\mathrm{H}$ & 6.666667 & 0.414763 & 3.146653 \\
\hline $\mathrm{H}$ & 4.987553 & -0.616584 & 1.682852 \\
\hline C & 4.253007 & -1.318566 & -0.839274 \\
\hline C & 4.278442 & -2.727354 & -1.088654 \\
\hline C & 5.412237 & -3.310386 & -1.716792 \\
\hline C & 6.476682 & -2.535719 & -2.113812 \\
\hline C & 6.439917 & -1.137124 & -1.905033 \\
\hline C & 5.361231 & -0.545357 & -1.285260 \\
\hline $\mathrm{H}$ & 5.413264 & -4.384131 & -1.889408 \\
\hline $\mathrm{H}$ & 7.336284 & -2.989935 & -2.599062 \\
\hline $\mathrm{H}$ & 7.268232 & -0.520555 & -2.243754 \\
\hline $\mathrm{H}$ & 5.347956 & 0.528995 & -1.147473 \\
\hline $\mathrm{O}$ & -0.688248 & 0.987985 & 0.945036 \\
\hline $\mathrm{O}$ & -0.942895 & -0.565521 & -1.142561 \\
\hline
\end{tabular}




\begin{tabular}{|c|c|c|c|}
\hline $\mathrm{H}$ & -2.097102 & -0.210267 & -1.318959 \\
\hline $\mathrm{H}$ & 2.079345 & -5.151189 & 1.352567 \\
\hline $\mathrm{H}$ & -1.966104 & -6.480245 & 0.748722 \\
\hline $\mathrm{H}$ & -0.620614 & -2.817424 & -1.053056 \\
\hline $\mathrm{H}$ & 2.939216 & 5.024760 & -1.763527 \\
\hline $\mathrm{H}$ & -0.956451 & 6.375428 & -2.976043 \\
\hline$H$ & -0.564114 & 2.945227 & -0.411275 \\
\hline$C$ & -4.293228 & -0.215658 & -1.497070 \\
\hline $\mathrm{O}$ & -3.136707 & 0.346812 & -1.512300 \\
\hline $\mathrm{H}$ & -5.104438 & 0.373728 & -1.933154 \\
\hline$C$ & -4.382318 & -1.704093 & -1.798408 \\
\hline 0 & -3.440672 & -2.462371 & -1.783548 \\
\hline O & -5.648684 & -2.051601 & -2.100072 \\
\hline C & -5.852763 & -3.446356 & -2.392587 \\
\hline $\mathrm{H}$ & -5.225562 & -3.755078 & -3.232437 \\
\hline $\mathrm{H}$ & -5.609885 & -4.056753 & -1.518611 \\
\hline C & -4.322480 & 0.495763 & 1.033011 \\
\hline C & -5.229863 & -0.302590 & 0.310234 \\
\hline $\mathrm{H}$ & -2.368527 & 0.539516 & 1.719169 \\
\hline$N$ & -3.213228 & -0.036733 & 1.594315 \\
\hline C & -3.013411 & -1.390406 & 1.955077 \\
\hline O & -3.803406 & -2.295924 & 1.804228 \\
\hline 0 & -1.820975 & -1.469660 & 2.543447 \\
\hline C & -1.432626 & -2.770303 & 3.031317 \\
\hline $\mathrm{H}$ & -2.007552 & -3.008874 & 3.930744 \\
\hline $\mathrm{H}$ & -0.372921 & -2.677102 & 3.261227 \\
\hline $\mathrm{H}$ & -1.597058 & -3.528556 & 2.266799 \\
\hline $\mathrm{H}$ & -6.182396 & 0.140985 & 0.047636 \\
\hline $\mathrm{H}$ & -5.257188 & -1.357014 & 0.546986 \\
\hline C & -4.445716 & 1.966983 & 1.039863 \\
\hline C & -5.729478 & 2.547934 & 1.040063 \\
\hline C & -3.318639 & 2.810975 & 1.068055 \\
\hline C & -5.882949 & 3.930358 & 1.071731 \\
\hline $\mathrm{H}$ & -6.611704 & 1.916784 & 1.056218 \\
\hline C & -3.481029 & 4.194349 & 1.083077 \\
\hline $\mathrm{H}$ & -2.315696 & 2.397409 & 1.040788 \\
\hline C & -4.758357 & 4.758333 & 1.087835 \\
\hline $\mathrm{H}$ & -6.880225 & 4.360349 & 1.089294 \\
\hline $\mathrm{H}$ & -2.601088 & 4.830440 & 1.082201 \\
\hline $\mathrm{H}$ & -4.877531 & 5.838136 & 1.107188 \\
\hline $\mathrm{H}$ & -6.908966 & -3.539935 & -2.644926 \\
\hline
\end{tabular}

Catalyst (R)-1 TS Conformation 240 
B3LYP/6-31G(d) Energy $=-2809.681952$

B3LYP-D3(BJ)/def2-TZVPP-IEF-PCM(DCM) Energy $=-2810.980302$

B3LYP-D3(BJ)/def2-TZVPP-IEF-PCM(DCM)//B3LYP/6-31G(d) Free Energy (Quasiharmonic) = 2810.339574

Frequencies (Top 3 out of 270)

1. $-705.7010 \mathrm{~cm}-1$

2. $\quad 8.1527 \mathrm{~cm}-1$

3. $12.0790 \mathrm{~cm}-1$

B3LYP/6-31G(d) Molecular Geometry in Cartesian Coordinates

$\begin{array}{llll}\text { C } & -2.913657 & -1.253029 & 0.238418 \\ \text { C } & -1.717730 & -1.834787 & -0.146096 \\ \text { C } & -1.368354 & -3.182842 & 0.156453 \\ \text { C } & -2.252633 & -3.908552 & 0.929701 \\ \text { H } & -2.027808 & -4.946983 & 1.158738 \\ \text { C } & -3.920906 & 2.801297 & -0.796632 \\ \text { C } & -3.239478 & 0.131786 & -0.211937 \\ \text { C } & -2.370087 & 1.179300 & 0.064578 \\ \text { C } & -2.713632 & 2.545738 & -0.174976 \\ \text { H } & -4.200069 & 3.832117 & -0.998376 \\ \text { O } & -0.813372 & -1.068682 & -0.872327 \\ \text { P } & 0.032863 & 0.073029 & -0.043089 \\ \text { O } & -1.168273 & 0.913817 & 0.702293 \\ \text { C } & 2.143287 & -5.179253 & -1.314621 \\ \text { C } & 1.801821 & -5.257183 & 0.036379 \\ \text { C } & 0.679003 & -4.580341 & 0.513448 \\ \text { C } & -0.121573 & -3.815115 & -0.349148 \\ \text { C } & 0.247262 & -3.725122 & -1.702617 \\ \text { C } & 1.366397 & -4.404684 & -2.179981 \\ \text { H } & 2.411805 & -5.837694 & 0.722967 \\ \text { H } & 1.626762 & -4.336636 & -3.233165 \\ \text { C } & -0.371679 & 5.947055 & 1.039966 \\ \text { C } & 0.231693 & 4.915828 & 0.315805 \\ \text { C } & -0.507717 & 3.794599 & -0.065556 \\ \text { C } & -1.868023 & 3.689812 & 0.266172 \\ \text { C } & -2.461510 & 4.733423 & 0.995935 \\ \text { C } & -1.721283 & 5.851360 & 1.380712 \\ \text { H } & 1.280211 & 4.977052 & 0.039493 \\ \text { H } & -2.199964 & 6.643384 & 1.951202 \\ \text { C } & -4.445994 & 0.408114 & -0.943546\end{array}$




\begin{tabular}{|c|c|c|c|}
\hline C & -4.787553 & 1.768617 & -1.227409 \\
\hline C & -5.979459 & 2.056341 & -1.946189 \\
\hline C & -6.797816 & 1.044979 & -2.392369 \\
\hline C & -6.447687 & -0.302688 & -2.141124 \\
\hline C & -5.305886 & -0.612900 & -1.435482 \\
\hline $\mathrm{H}$ & -6.225904 & 3.096711 & -2.145539 \\
\hline $\mathrm{H}$ & -7.704078 & 1.275796 & -2.945671 \\
\hline $\mathrm{H}$ & -7.082685 & -1.102056 & -2.513663 \\
\hline $\mathrm{H}$ & -5.047125 & -1.650901 & -1.261393 \\
\hline C & -3.792344 & -1.996348 & 1.101293 \\
\hline C & -3.449177 & -3.345928 & 1.438012 \\
\hline C & -4.310752 & -4.095988 & 2.283556 \\
\hline C & -5.452023 & -3.535416 & 2.807860 \\
\hline C & -5.773617 & -2.190764 & 2.509026 \\
\hline C & -4.968367 & -1.442740 & 1.678272 \\
\hline $\mathrm{H}$ & -4.040237 & -5.122748 & 2.518644 \\
\hline $\mathrm{H}$ & -6.099295 & -4.116150 & 3.459357 \\
\hline $\mathrm{H}$ & -6.662291 & -1.740670 & 2.943324 \\
\hline $\mathrm{H}$ & -5.224365 & -0.410823 & 1.469150 \\
\hline 0 & 0.828737 & 0.865286 & -1.023857 \\
\hline 0 & 0.742723 & -0.580157 & 1.154860 \\
\hline $\mathrm{H}$ & 1.865007 & -0.925618 & 1.130440 \\
\hline $\mathrm{H}$ & -0.355637 & -3.132348 & -2.382341 \\
\hline $\mathrm{H}$ & 3.007077 & -5.719884 & -1.692677 \\
\hline $\mathrm{H}$ & 0.426417 & -4.628938 & 1.568620 \\
\hline $\mathrm{H}$ & -3.508240 & 4.655586 & 1.277453 \\
\hline $\mathrm{H}$ & 0.207434 & 6.817649 & 1.337430 \\
\hline $\mathrm{H}$ & -0.031616 & 2.997792 & -0.627704 \\
\hline C & 3.580240 & -1.536295 & 0.046320 \\
\hline $\mathrm{O}$ & 3.008185 & -1.396183 & 1.181888 \\
\hline $\mathrm{H}$ & 3.000077 & -1.365548 & -0.871686 \\
\hline C & 4.562203 & -2.705289 & -0.061712 \\
\hline $\mathrm{O}$ & 5.037546 & -3.300987 & 0.873143 \\
\hline 0 & 4.841496 & -2.966634 & -1.360281 \\
\hline C & 5.772065 & -4.040204 & -1.578784 \\
\hline $\mathrm{H}$ & 6.732852 & -3.817053 & -1.106637 \\
\hline $\mathrm{H}$ & 5.381347 & -4.972522 & -1.164330 \\
\hline C & 4.306918 & 1.077834 & -0.261564 \\
\hline C & 4.971660 & -0.163214 & -0.289375 \\
\hline $\mathrm{H}$ & 3.680678 & 0.816492 & -2.173407 \\
\hline$N$ & 3.728760 & 1.494091 & -1.420480 \\
\hline C & 3.146188 & 2.728329 & -1.756090 \\
\hline 0 & 3.136448 & 3.724425 & -1.073694 \\
\hline 0 & 2.666430 & 2.612318 & -3.002029 \\
\hline
\end{tabular}




$\begin{array}{llll}\mathrm{C} & 1.964667 & 3.767565 & -3.498779 \\ \mathrm{H} & 1.679565 & 3.510636 & -4.518400 \\ \mathrm{H} & 2.616872 & 4.644029 & -3.485970 \\ \mathrm{H} & 1.079013 & 3.956442 & -2.888178 \\ \mathrm{H} & 5.596059 & -0.386359 & 0.568796 \\ \mathrm{H} & 5.357473 & -0.502402 & -1.248057 \\ \mathrm{C} & 4.122013 & 1.779113 & 1.013197 \\ \mathrm{C} & 2.859848 & 2.266796 & 1.400437 \\ \mathrm{C} & 5.202345 & 1.869160 & 1.912733 \\ \mathrm{C} & 2.688630 & 2.829165 & 2.660621 \\ \mathrm{H} & 2.017522 & 2.168287 & 0.728918 \\ \mathrm{C} & 5.029961 & 2.460080 & 3.159543 \\ \mathrm{H} & 6.182788 & 1.508550 & 1.617200 \\ \mathrm{C} & 3.771114 & 2.935392 & 3.536910 \\ \mathrm{H} & 1.705770 & 3.185038 & 2.952962 \\ \mathrm{H} & 5.873646 & 2.544615 & 3.838094 \\ \mathrm{H} & 3.633731 & 3.384806 & 4.516654 \\ \mathrm{H} & 5.883297 & -4.117353 & -2.660659\end{array}$

Catalyst (R)-1 TS Conformation 241

B3LYP/6-31G(d) Energy = -2809.693237

B3LYP-D3(BJ)/def2-TZVPP-IEF-PCM(DCM) Energy $=-2810.983369$

B3LYP-D3(BJ)/def2-TZVPP-IEF-PCM(DCM)//B3LYP/6-31G(d) Free Energy (Quasiharmonic) = 2810.339457

Frequencies (Top 3 out of 270)

1. $-312.2230 \mathrm{~cm}-1$

2. $\quad 14.8721 \mathrm{~cm}-1$

3. $22.6904 \mathrm{~cm}-1$

B3LYP/6-31G(d) Molecular Geometry in Cartesian Coordinates

$\begin{array}{llll}\text { C } & 3.090202 & -0.284114 & -0.330875 \\ \text { C } & 2.136522 & -1.290045 & -0.256946 \\ \text { C } & 2.391045 & -2.627181 & -0.688254 \\ \text { C } & 3.626495 & -2.894160 & -1.244743 \\ \text { H } & 3.842246 & -3.905060 & -1.580402 \\ \text { C } & 2.487976 & 3.744450 & 1.047472 \\ \text { C } & 2.835479 & 1.059998 & 0.265023 \\ \text { C } & 1.722536 & 1.793969 & -0.116375 \\ \text { C } & 1.545800 & 3.169428 & 0.216702\end{array}$




\begin{tabular}{|c|c|c|c|}
\hline $\mathrm{H}$ & 2.377500 & 4.790435 & 1.320986 \\
\hline $\mathrm{O}$ & 0.920430 & -1.021600 & 0.362776 \\
\hline$P$ & -0.161745 & 0.028204 & -0.275002 \\
\hline 0 & 0.775701 & 1.186480 & -0.939358 \\
\hline C & -0.287134 & -5.989727 & -0.489460 \\
\hline C & -0.672442 & -4.831418 & -1.168685 \\
\hline C & 0.169636 & -3.719698 & -1.202325 \\
\hline C & 1.415622 & -3.748574 & -0.559871 \\
\hline C & 1.790597 & -4.914570 & 0.127787 \\
\hline C & 0.947125 & -6.025810 & 0.164356 \\
\hline $\mathrm{H}$ & -1.629636 & -4.778960 & -1.679650 \\
\hline $\mathrm{H}$ & 1.257749 & -6.920734 & 0.697969 \\
\hline C & -1.545434 & 5.747018 & -1.303850 \\
\hline C & -0.198552 & 6.056783 & -1.497846 \\
\hline C & 0.790865 & 5.199873 & -1.016074 \\
\hline C & 0.452054 & 4.015278 & -0.341114 \\
\hline C & -0.905109 & 3.709091 & -0.160383 \\
\hline C & -1.894018 & 4.573273 & -0.632179 \\
\hline $\mathrm{H}$ & 0.084822 & 6.964943 & -2.023937 \\
\hline $\mathrm{H}$ & -2.935938 & 4.324904 & -0.454849 \\
\hline C & 3.745415 & 1.640445 & 1.216172 \\
\hline C & 3.563261 & 3.007087 & 1.600520 \\
\hline C & 4.457284 & 3.595404 & 2.535754 \\
\hline C & 5.478280 & 2.862865 & 3.094973 \\
\hline C & 5.641205 & 1.502475 & 2.742128 \\
\hline C & 4.801099 & 0.908379 & 1.826088 \\
\hline $\mathrm{H}$ & 4.308664 & 4.637218 & 2.809847 \\
\hline $\mathrm{H}$ & 6.151941 & 3.320784 & 3.814118 \\
\hline $\mathrm{H}$ & 6.433760 & 0.918443 & 3.202221 \\
\hline $\mathrm{H}$ & 4.933085 & -0.137477 & 1.573950 \\
\hline C & 4.325988 & -0.552600 & -1.019658 \\
\hline C & 4.597999 & -1.887515 & -1.456895 \\
\hline C & 5.820559 & -2.174549 & -2.122414 \\
\hline C & 6.735418 & -1.180562 & -2.378746 \\
\hline C & 6.453401 & 0.148513 & -1.984773 \\
\hline C & 5.284545 & 0.454294 & -1.323002 \\
\hline $\mathrm{H}$ & 6.010246 & -3.197577 & -2.438667 \\
\hline $\mathrm{H}$ & 7.664170 & -1.408310 & -2.894621 \\
\hline $\mathrm{H}$ & 7.163080 & 0.939251 & -2.212711 \\
\hline $\mathrm{H}$ & 5.082718 & 1.480725 & -1.041531 \\
\hline $\mathrm{O}$ & -1.049565 & 0.506247 & 0.823346 \\
\hline $\mathrm{O}$ & -0.791096 & -0.605365 & -1.543159 \\
\hline $\mathrm{H}$ & -1.736224 & -1.138055 & -1.467202 \\
\hline $\mathrm{H}$ & 2.750926 & -4.945730 & 0.635923 \\
\hline
\end{tabular}




$\begin{array}{llll}\mathrm{H} & -0.940018 & -6.859021 & -0.472576 \\ \mathrm{H} & -0.132497 & -2.835199 & -1.749027 \\ \mathrm{H} & -1.187232 & 2.805401 & 0.367768 \\ \mathrm{H} & -2.318202 & 6.417744 & -1.671255 \\ \mathrm{H} & 1.839131 & 5.439755 & -1.173725 \\ \mathrm{C} & -4.047719 & -1.651493 & -1.408774 \\ \mathrm{O} & -2.813316 & -2.031952 & -1.463223 \\ \mathrm{H} & -4.789633 & -2.365490 & -1.807946 \\ \mathrm{C} & -4.436616 & -0.247233 & -1.924753 \\ \mathrm{O} & -5.587596 & 0.143668 & -2.007635 \\ \mathrm{O} & -3.368663 & 0.459678 & -2.288006 \\ \mathrm{C} & -3.612261 & 1.780972 & -2.810969 \\ \mathrm{H} & -4.233141 & 1.719724 & -3.708302 \\ \mathrm{H} & -4.108127 & 2.394662 & -2.056515 \\ \mathrm{C} & -3.927100 & -0.990689 & 1.167633 \\ \mathrm{C} & -4.825025 & -1.643197 & 0.277121 \\ \mathrm{H} & -2.823944 & 0.693445 & 1.299301 \\ \mathrm{~N} & -3.801474 & 0.366316 & 1.235414 \\ \mathrm{C} & -4.715539 & 1.371213 & 0.877734 \\ \mathrm{O} & -4.351698 & 2.488601 & 0.579219 \\ \mathrm{O} & -5.983464 & 0.962884 & 0.983065 \\ \mathrm{C} & -6.972895 & 1.891591 & 0.491478 \\ \mathrm{H} & -7.932293 & 1.461011 & 0.776899 \\ \mathrm{H} & -6.890343 & 1.960632 & -0.595183 \\ \mathrm{H} & -6.832856 & 2.872159 & 0.949772 \\ \mathrm{H} & -4.973447 & -2.695164 & 0.502445 \\ \mathrm{H} & -5.745550 & -1.122288 & 0.040794 \\ \mathrm{C} & -2.940363 & -1.741144 & 1.937005 \\ \mathrm{C} & -2.445301 & -1.210986 & 3.149059 \\ \mathrm{C} & -2.487244 & -3.003969 & 1.504256 \\ \mathrm{C} & -1.539651 & -1.932707 & 3.912859 \\ \mathrm{H} & -2.799661 & -0.246898 & 3.498075 \\ \mathrm{C} & -1.551599 & -3.704538 & 2.259933 \\ \mathrm{H} & -2.809533 & -3.395676 & 0.547581 \\ \mathrm{H} & -1.086519 & -3.178267 & 3.466176 \\ \mathrm{H} & -1.175064 & -4.654400 & 1.895384 \\ \mathrm{H} & -365878 & -3.735964 & 4.058038 \\ \mathrm{H} & 2.182073 & -3.041491\end{array}$

Catalyst (R)-1 TS Conformation 242

$\mathrm{B} 3 \mathrm{LYP} / 6-31 \mathrm{G}(\mathrm{d})$ Energy $=-2809.691316$ 
B3LYP-D3(BJ)/def2-TZVPP-IEF-PCM(DCM) Energy = -2810.982765

B3LYP-D3(BJ)/def2-TZVPP-IEF-PCM(DCM)//B3LYP/6-31G(d) Free Energy (Quasiharmonic) = 2810.339396

Frequencies (Top 3 out of 270)

1. $-269.4166 \mathrm{~cm}-1$

2. $\quad 12.7024 \mathrm{~cm}-1$

3. $\quad 14.1247 \mathrm{~cm}-1$

B3LYP/6-31G(d) Molecular Geometry in Cartesian Coordinates

$\begin{array}{llll}\text { C } & -2.740319 & -1.454416 & 0.367712 \\ \text { C } & -1.537977 & -1.801957 & -0.224992 \\ \text { C } & -0.887296 & -3.051554 & -0.009727 \\ \text { C } & -1.462526 & -3.907886 & 0.909640 \\ \text { H } & -1.008802 & -4.880653 & 1.079159 \\ \text { C } & -4.749398 & 2.221463 & -0.627754 \\ \text { C } & -3.430310 & -0.197512 & -0.042135 \\ \text { C } & -2.775129 & 1.023610 & 0.032482 \\ \text { C } & -3.424881 & 2.264633 & -0.238218 \\ \text { H } & -5.263674 & 3.154709 & -0.841381 \\ \text { O } & -0.929863 & -0.879686 & -1.081657 \\ \text { P } & -0.234512 & 0.415687 & -0.369973 \\ \text { O } & -1.461886 & 1.065269 & 0.491067 \\ \text { C } & 2.556310 & -4.471135 & -2.148921 \\ \text { C } & 1.524851 & -3.827777 & -2.836784 \\ \text { C } & 0.425364 & -3.323968 & -2.145393 \\ \text { C } & 0.332374 & -3.467179 & -0.751099 \\ \text { C } & 1.387607 & -4.093737 & -0.068794 \\ \text { C } & 2.492016 & -4.588879 & -0.759650 \\ \text { H } & 1.573322 & -3.717376 & -3.916596 \\ \text { H } & 3.305793 & -5.055534 & -0.211870 \\ \text { C } & -1.699622 & 6.197922 & -0.014903 \\ \text { C } & -1.105007 & 5.221137 & -0.818009 \\ \text { C } & -1.622509 & 3.925643 & -0.862379 \\ \text { C } & -2.761709 & 3.593466 & -0.112719 \\ \text { C } & -3.349792 & 4.580895 & 0.694115 \\ \text { C } & -2.821365 & 5.870761 & 0.748130 \\ \text { H } & -0.235316 & 5.468672 & -1.421291 \\ \text { H } & -3.289682 & 6.619318 & 1.382079 \\ \text { C } & -4.774689 & -0.231445 & -0.553519 \\ \text { C } & -5.443654 & 1.004215 & -0.823906 \\ \text { C } & -6.777671 & 0.988018 & -1.314096\end{array}$




\begin{tabular}{|c|c|c|c|}
\hline C & -7.426146 & -0.199821 & -1.557667 \\
\hline C & -6.755548 & -1.424237 & -1.327703 \\
\hline C & -5.467925 & -1.440836 & -0.838652 \\
\hline $\mathrm{H}$ & -7.270712 & 1.938106 & -1.505958 \\
\hline $\mathrm{H}$ & -8.443718 & -0.201893 & -1.938591 \\
\hline $\mathrm{H}$ & -7.258789 & -2.362373 & -1.545595 \\
\hline $\mathrm{H}$ & -4.967231 & -2.388518 & -0.680047 \\
\hline C & -3.283051 & -2.322183 & 1.377829 \\
\hline C & -2.626015 & -3.566853 & 1.641305 \\
\hline C & -3.152837 & -4.437887 & 2.633287 \\
\hline C & -4.263939 & -4.087718 & 3.364372 \\
\hline C & -4.892566 & -2.841666 & 3.133013 \\
\hline C & -4.417871 & -1.983898 & 2.165090 \\
\hline $\mathrm{H}$ & -2.649058 & -5.385037 & 2.811304 \\
\hline $\mathrm{H}$ & -4.653199 & -4.758168 & 4.125708 \\
\hline $\mathrm{H}$ & -5.755926 & -2.555711 & 3.727731 \\
\hline $\mathrm{H}$ & -4.905050 & -1.028726 & 2.007515 \\
\hline $\mathrm{O}$ & 0.332750 & 1.332805 & -1.398453 \\
\hline $\mathrm{O}$ & 0.703022 & -0.068690 & 0.776457 \\
\hline $\mathrm{H}$ & 1.681792 & -0.439399 & 0.517470 \\
\hline $\mathrm{H}$ & 1.346196 & -4.175571 & 1.013651 \\
\hline $\mathrm{H}$ & 3.408923 & -4.872257 & -2.691551 \\
\hline $\mathrm{H}$ & -0.371617 & -2.828787 & -2.689411 \\
\hline $\mathrm{H}$ & -4.224954 & 4.328688 & 1.286998 \\
\hline $\mathrm{H}$ & -1.293864 & 7.206085 & 0.012498 \\
\hline $\mathrm{H}$ & -1.149339 & 3.177034 & -1.489113 \\
\hline C & 3.868660 & -0.513806 & 1.098475 \\
\hline $\mathrm{O}$ & 2.970333 & -0.939820 & 0.291996 \\
\hline $\mathrm{H}$ & 3.568539 & 0.051930 & 1.992365 \\
\hline C & 5.035909 & -1.464287 & 1.364425 \\
\hline $\mathrm{O}$ & 5.371594 & -2.380521 & 0.650492 \\
\hline $\mathrm{O}$ & 5.651753 & -1.133680 & 2.522013 \\
\hline C & 6.769626 & -1.962357 & 2.882362 \\
\hline $\mathrm{H}$ & 7.142177 & -1.559911 & 3.824635 \\
\hline $\mathrm{H}$ & 6.450855 & -3.000499 & 3.007121 \\
\hline C & 3.978491 & 1.678927 & -0.309135 \\
\hline C & 4.991225 & 0.888995 & 0.274688 \\
\hline $\mathrm{H}$ & 2.316315 & 1.630586 & -1.527712 \\
\hline$N$ & 3.250891 & 1.237939 & -1.361246 \\
\hline C & 3.448147 & 0.113113 & -2.212795 \\
\hline $\mathrm{O}$ & 2.568180 & -0.281612 & -2.935373 \\
\hline $\mathrm{O}$ & 4.704658 & -0.342409 & -2.180380 \\
\hline C & 4.915755 & -1.595123 & -2.864503 \\
\hline $\mathrm{H}$ & 4.568895 & -1.525111 & -3.897159 \\
\hline
\end{tabular}




$\begin{array}{lrrr}\mathrm{H} & 4.381457 & -2.384851 & -2.334488 \\ \mathrm{H} & 5.991855 & -1.762565 & -2.823259 \\ \mathrm{H} & 5.528477 & 1.330907 & 1.106003 \\ \mathrm{H} & 5.574715 & 0.252063 & -0.372861 \\ \mathrm{C} & 3.561276 & 2.937788 & 0.352466 \\ \mathrm{C} & 4.550352 & 3.734613 & 0.963684 \\ \mathrm{C} & 2.224073 & 3.372176 & 0.395908 \\ \mathrm{C} & 4.212460 & 4.918964 & 1.610725 \\ \mathrm{H} & 5.592994 & 3.441211 & 0.902848 \\ \mathrm{C} & 1.889820 & 4.549542 & 1.062766 \\ \mathrm{H} & 1.434493 & 2.788803 & -0.065331 \\ \mathrm{C} & 2.878067 & 5.324818 & 1.671099 \\ \mathrm{H} & 4.991802 & 5.524923 & 2.064116 \\ \mathrm{H} & 0.849730 & 4.855957 & 1.102549 \\ \mathrm{H} & 2.610157 & 6.243677 & 2.185540 \\ \mathrm{H} & 7.543789 & -1.919365 & 2.111210\end{array}$

Catalyst (R)-1 TS Conformation 243

B3LYP/6-31G(d) Energy $=-2809.694036$

B3LYP-D3(BJ)/def2-TZVPP-IEF-PCM(DCM) Energy = -2810.98202

B3LYP-D3(BJ)/def2-TZVPP-IEF-PCM(DCM)//B3LYP/6-31G(d) Free Energy (Quasiharmonic) = 2810.339377

Frequencies (Top 3 out of 270)

1. $-417.8350 \mathrm{~cm}-1$

2. $8.3143 \mathrm{~cm}-1$

3. $12.3472 \mathrm{~cm}-1$

B3LYP/6-31G(d) Molecular Geometry in Cartesian Coordinates

$\begin{array}{llll}\text { C } & 3.358959 & -0.705937 & -0.369374 \\ \text { C } & 2.316048 & -1.454412 & 0.161451 \\ \text { C } & 2.225989 & -2.870915 & 0.011178 \\ \text { C } & 3.198903 & -3.497009 & -0.742913 \\ \text { H } & 3.150811 & -4.575062 & -0.872360 \\ \text { C } & 3.638164 & 3.541751 & 0.335155 \\ \text { C } & 3.480944 & 0.750127 & -0.063057 \\ \text { C } & 2.414934 & 1.594034 & -0.322954 \\ \text { C } & 2.464903 & 3.008331 & -0.160514 \\ \text { H } & 3.722818 & 4.619110 & 0.450740 \\ \text { O } & 1.368201 & -0.833568 & 0.968326\end{array}$




\begin{tabular}{|c|c|c|c|}
\hline$P$ & 0.320223 & 0.267362 & 0.371107 \\
\hline $\mathrm{O}$ & 1.219661 & 1.027078 & -0.763487 \\
\hline C & -0.795715 & -5.397153 & 1.748011 \\
\hline C & 0.556389 & -5.626161 & 2.005733 \\
\hline C & 1.524759 & -4.784472 & 1.457338 \\
\hline C & 1.160438 & -3.696066 & 0.648278 \\
\hline C & -0.202312 & -3.469470 & 0.400130 \\
\hline C & -1.168583 & -4.318058 & 0.942685 \\
\hline $\mathrm{H}$ & 0.860238 & -6.458872 & 2.634831 \\
\hline $\mathrm{H}$ & -2.217300 & -4.130150 & 0.726950 \\
\hline C & -0.789751 & 5.641102 & -1.150558 \\
\hline C & -0.409795 & 4.635963 & -2.042808 \\
\hline C & 0.629727 & 3.764656 & -1.721423 \\
\hline C & 1.314741 & 3.887196 & -0.500683 \\
\hline C & 0.919950 & 4.898650 & 0.389349 \\
\hline C & -0.122478 & 5.767366 & 0.068265 \\
\hline $\mathrm{H}$ & -0.920560 & 4.531921 & -2.996778 \\
\hline $\mathrm{H}$ & -0.418872 & 6.536338 & 0.776629 \\
\hline C & 4.667147 & 1.312003 & 0.525653 \\
\hline C & 4.738053 & 2.731161 & 0.710650 \\
\hline C & 5.907067 & 3.302532 & 1.282585 \\
\hline C & 6.955279 & 2.511080 & 1.690581 \\
\hline C & 6.871109 & 1.106423 & 1.546996 \\
\hline C & 5.759823 & 0.523055 & 0.978848 \\
\hline $\mathrm{H}$ & 5.949150 & 4.382315 & 1.404288 \\
\hline $\mathrm{H}$ & 7.840461 & 2.958804 & 2.133916 \\
\hline $\mathrm{H}$ & 7.688880 & 0.480046 & 1.893002 \\
\hline $\mathrm{H}$ & 5.707672 & -0.555356 & 0.886102 \\
\hline C & 4.299509 & -1.359049 & -1.240724 \\
\hline C & 4.222784 & -2.778808 & -1.405598 \\
\hline C & 5.155053 & -3.438153 & -2.251975 \\
\hline C & 6.113416 & -2.728148 & -2.936406 \\
\hline C & 6.169096 & -1.320468 & -2.806099 \\
\hline C & 5.289264 & -0.654676 & -1.981390 \\
\hline $\mathrm{H}$ & 5.085461 & -4.518313 & -2.357049 \\
\hline $\mathrm{H}$ & 6.817552 & -3.241074 & -3.585749 \\
\hline $\mathrm{H}$ & 6.909686 & -0.757049 & -3.367261 \\
\hline $\mathrm{H}$ & 5.340382 & 0.424839 & -1.902861 \\
\hline $\mathrm{O}$ & -0.874910 & -0.319365 & -0.302919 \\
\hline $\mathrm{O}$ & 0.115851 & 1.216737 & 1.571691 \\
\hline $\mathrm{H}$ & -0.881519 & 1.646220 & 1.768205 \\
\hline $\mathrm{H}$ & -0.508841 & -2.637385 & -0.223726 \\
\hline $\mathrm{H}$ & -1.552175 & -6.053770 & 2.170224 \\
\hline $\mathrm{H}$ & 2.576551 & -4.961555 & 1.665859 \\
\hline
\end{tabular}




\begin{tabular}{|c|c|c|c|}
\hline $\mathrm{H}$ & 1.419549 & 4.985080 & 1.349968 \\
\hline $\mathrm{H}$ & -1.602065 & 6.318027 & -1.402217 \\
\hline $\mathrm{H}$ & 0.920184 & 2.989844 & -2.423077 \\
\hline C & -3.128783 & 1.611002 & 1.762917 \\
\hline 0 & -2.064649 & 2.282023 & 1.974580 \\
\hline $\mathrm{H}$ & -4.089233 & 2.101770 & 1.978169 \\
\hline C & -3.207175 & 0.135188 & 2.191149 \\
\hline 0 & -4.160395 & -0.589915 & 1.981434 \\
\hline 0 & -2.136017 & -0.211286 & 2.907799 \\
\hline C & -2.127933 & -1.550826 & 3.435794 \\
\hline $\mathrm{H}$ & -3.012072 & -1.716333 & 4.056858 \\
\hline $\mathrm{H}$ & -2.106448 & -2.278153 & 2.622338 \\
\hline C & -4.235591 & 0.569042 & -0.635608 \\
\hline$C$ & -3.402045 & 1.617417 & -0.204641 \\
\hline $\mathrm{H}$ & -2.618561 & -0.652238 & -0.733896 \\
\hline$N$ & -3.633411 & -0.617545 & -0.911740 \\
\hline C & -4.175003 & -1.755414 & -1.519440 \\
\hline $\mathrm{O}$ & -5.286371 & -1.881653 & -1.977478 \\
\hline 0 & -3.213100 & -2.701842 & -1.538220 \\
\hline C & -3.571360 & -3.921196 & -2.210637 \\
\hline $\mathrm{H}$ & -4.461488 & -4.361923 & -1.755351 \\
\hline $\mathrm{H}$ & -2.709032 & -4.576072 & -2.089652 \\
\hline $\mathrm{H}$ & -3.765743 & -3.728430 & -3.268932 \\
\hline $\mathrm{H}$ & -3.827837 & 2.613651 & -0.241000 \\
\hline $\mathrm{H}$ & -2.356864 & 1.549684 & -0.482135 \\
\hline C & -5.702853 & 0.753595 & -0.686891 \\
\hline C & -6.214932 & 1.891970 & -1.331306 \\
\hline C & -6.589092 & -0.130224 & -0.048366 \\
\hline C & -7.587970 & 2.130306 & -1.360351 \\
\hline $\mathrm{H}$ & -5.536962 & 2.573597 & -1.836299 \\
\hline C & -7.956006 & 0.125810 & -0.059527 \\
\hline $\mathrm{H}$ & -6.196414 & -0.986776 & 0.484185 \\
\hline C & -8.460341 & 1.249518 & -0.720745 \\
\hline $\mathrm{H}$ & -7.972725 & 3.003867 & -1.878794 \\
\hline $\mathrm{H}$ & -8.632212 & -0.554757 & 0.449910 \\
\hline $\mathrm{H}$ & -9.530428 & 1.438203 & -0.733552 \\
\hline $\mathrm{H}$ & -1.216068 & -1.619304 & 4.027760 \\
\hline
\end{tabular}

Catalyst (R)-1 TS Conformation 244

B3LYP/6-31G(d) Energy $=-2809.69301$

B3LYP-D3(BJ)/def2-TZVPP-IEF-PCM(DCM) Energy = -2810.981943 
B3LYP-D3(BJ)/def2-TZVPP-IEF-PCM(DCM)//B3LYP/6-31G(d) Free Energy (Quasiharmonic) = 2810.33931

Frequencies (Top 3 out of 270)

1. $-327.9055 \mathrm{~cm}-1$

2. $\quad 4.5432 \mathrm{~cm}-1$

3. $10.6146 \mathrm{~cm}-1$

B3LYP/6-31G(d) Molecular Geometry in Cartesian Coordinates

\begin{tabular}{|c|c|c|c|}
\hline C & -3.377026 & 0.730542 & -0.208211 \\
\hline C & -2.243441 & 1.528610 & -0.279745 \\
\hline C & -2.268934 & 2.875978 & -0.751650 \\
\hline C & -3.469199 & 3.349627 & -1.245261 \\
\hline $\mathrm{H}$ & -3.517306 & 4.369170 & -1.618473 \\
\hline C & -3.212944 & -3.153826 & 1.669878 \\
\hline C & -3.324079 & -0.589612 & 0.488460 \\
\hline C & -2.394358 & -1.540277 & 0.102521 \\
\hline C & -2.327281 & -2.852343 & 0.654119 \\
\hline $\mathrm{H}$ & -3.207843 & -4.152943 & 2.097634 \\
\hline $\mathrm{O}$ & -1.044080 & 1.041983 & 0.227797 \\
\hline$P$ & -0.263194 & -0.204461 & -0.478231 \\
\hline $\mathrm{O}$ & -1.479640 & -1.204876 & -0.894694 \\
\hline C & 1.041298 & 5.620308 & -0.541695 \\
\hline C & -0.199256 & 5.954696 & 0.003262 \\
\hline C & -1.257438 & 5.048456 & -0.059272 \\
\hline C & -1.096105 & 3.792097 & -0.667008 \\
\hline C & 0.155354 & 3.467928 & -1.212293 \\
\hline C & 1.212314 & 4.374937 & -1.148753 \\
\hline $\mathrm{H}$ & -0.344028 & 6.918820 & 0.484186 \\
\hline $\mathrm{H}$ & 2.171180 & 4.098623 & -1.579454 \\
\hline C & 0.377364 & -5.912083 & -0.700994 \\
\hline C & -0.347498 & -5.160030 & -1.628352 \\
\hline C & -1.204922 & -4.147719 & -1.200134 \\
\hline C & -1.361885 & -3.874488 & 0.168897 \\
\hline C & -0.625908 & -4.635603 & 1.090953 \\
\hline C & 0.236599 & -5.643760 & 0.661099 \\
\hline $\mathrm{H}$ & -0.252354 & -5.368397 & -2.691079 \\
\hline $\mathrm{H}$ & 0.801682 & -6.216442 & 1.391978 \\
\hline C & -4.188896 & -0.894532 & 1.597634 \\
\hline C & -4.130865 & -2.202794 & 2.179197 \\
\hline C & -4.986708 & -2.522146 & 3.268159 \\
\hline C & -5.845332 & -1.584369 & 3.792123 \\
\hline
\end{tabular}




\begin{tabular}{|c|c|c|c|}
\hline$C$ & -5.875532 & -0.279387 & 3.247231 \\
\hline C & -5.072104 & 0.056088 & 2.179604 \\
\hline $\mathrm{H}$ & -4.938142 & -3.524031 & 3.688244 \\
\hline $\mathrm{H}$ & -6.489758 & -1.837621 & 4.629485 \\
\hline $\mathrm{H}$ & -6.535408 & 0.468663 & 3.678230 \\
\hline $\mathrm{H}$ & -5.100921 & 1.063618 & 1.782402 \\
\hline C & -4.590894 & 1.205986 & -0.814899 \\
\hline C & -4.628399 & 2.540852 & -1.330706 \\
\hline C & -5.822656 & 3.025183 & -1.930005 \\
\hline C & -6.933982 & 2.222584 & -2.042061 \\
\hline C & -6.890337 & 0.892550 & -1.561776 \\
\hline C & -5.752197 & 0.398311 & -0.963210 \\
\hline $\mathrm{H}$ & -5.835031 & 4.044016 & -2.310025 \\
\hline $\mathrm{H}$ & -7.839644 & 2.601368 & -2.507812 \\
\hline $\mathrm{H}$ & -7.761134 & 0.251794 & -1.671611 \\
\hline $\mathrm{H}$ & -5.732049 & -0.626546 & -0.610771 \\
\hline 0 & 0.715318 & -0.766517 & 0.499163 \\
\hline 0 & 0.273464 & 0.231704 & -1.868587 \\
\hline $\mathrm{H}$ & 1.359001 & 0.302583 & -1.905514 \\
\hline $\mathrm{H}$ & 0.297664 & 2.513474 & -1.703304 \\
\hline $\mathrm{H}$ & 1.867723 & 6.324910 & -0.492265 \\
\hline $\mathrm{H}$ & -2.216193 & 5.305401 & 0.383337 \\
\hline $\mathrm{H}$ & -0.718607 & -4.418218 & 2.151314 \\
\hline $\mathrm{H}$ & 1.046080 & -6.699902 & -1.037815 \\
\hline $\mathrm{H}$ & -1.767029 & -3.572018 & -1.927930 \\
\hline C & 3.623687 & -0.294609 & -1.940456 \\
\hline 0 & 2.708746 & 0.593538 & -1.801933 \\
\hline $\mathrm{H}$ & 4.659758 & 0.061755 & -2.035890 \\
\hline C & 3.424811 & -1.488835 & -2.885523 \\
\hline 0 & 4.343040 & -2.149281 & -3.325335 \\
\hline 0 & 2.130923 & -1.698511 & -3.154264 \\
\hline C & 1.840371 & -2.795491 & -4.036044 \\
\hline $\mathrm{H}$ & 0.759460 & -2.777344 & -4.170835 \\
\hline $\mathrm{H}$ & 2.354883 & -2.662466 & -4.991040 \\
\hline C & 4.195501 & -0.376322 & 0.624471 \\
\hline C & 3.879168 & -1.349726 & -0.347597 \\
\hline $\mathrm{H}$ & 2.209780 & -0.010104 & 0.929554 \\
\hline$N$ & 3.171471 & 0.262776 & 1.226689 \\
\hline C & 3.150973 & 1.123686 & 2.344870 \\
\hline 0 & 2.167569 & 1.759934 & 2.636587 \\
\hline 0 & 4.295796 & 1.092227 & 3.044449 \\
\hline C & 4.315814 & 1.950285 & 4.200037 \\
\hline $\mathrm{H}$ & 3.543406 & 1.646794 & 4.910600 \\
\hline $\mathrm{H}$ & 4.146999 & 2.989494 & 3.907764 \\
\hline
\end{tabular}




$\begin{array}{llll}\mathrm{H} & 5.309180 & 1.825554 & 4.630605 \\ \mathrm{H} & 4.700066 & -1.982862 & -0.669642 \\ \mathrm{H} & 2.909490 & -1.833620 & -0.253554 \\ \mathrm{C} & 5.595863 & 0.083249 & 0.756426 \\ \mathrm{C} & 5.913942 & 1.443185 & 0.597441 \\ \mathrm{C} & 6.629851 & -0.848477 & 0.930869 \\ \mathrm{C} & 7.242430 & 1.857693 & 0.618986 \\ \mathrm{H} & 5.119738 & 2.162935 & 0.423443 \\ \mathrm{C} & 7.957075 & -0.425089 & 0.976841 \\ \mathrm{H} & 6.389331 & -1.900255 & 1.053995 \\ \mathrm{C} & 8.265823 & 0.926811 & 0.817871 \\ \mathrm{H} & 7.480535 & 2.907971 & 0.476564 \\ \mathrm{H} & 8.749220 & -1.152326 & 1.129709 \\ \mathrm{H} & 9.301446 & 1.254481 & 0.841175 \\ \mathrm{H} & 2.156998 & -3.739188 & -3.583852\end{array}$

Catalyst (R)-1 TS Conformation 245

B3LYP/6-31G(d) Energy $=-2809.689603$

B3LYP-D3(BJ)/def2-TZVPP-IEF-PCM(DCM) Energy $=-2810.981582$

B3LYP-D3(BJ)/def2-TZVPP-IEF-PCM(DCM)//B3LYP/6-31G(d) Free Energy (Quasiharmonic) = 2810.339308

Frequencies (Top 3 out of 270)

1. $-741.0297 \mathrm{~cm}-1$

2. $\quad 11.5235 \mathrm{~cm}-1$

3. $13.4218 \mathrm{~cm}-1$

B3LYP/6-31G(d) Molecular Geometry in Cartesian Coordinates

$\begin{array}{llll}\text { C } & 2.955159 & -1.088145 & -0.393398 \\ \text { C } & 1.767092 & -1.642864 & 0.061986 \\ \text { C } & 1.422282 & -3.016250 & -0.128572 \\ \text { C } & 2.299452 & -3.789943 & -0.865590 \\ \text { H } & 2.092309 & -4.848312 & -0.997577 \\ \text { C } & 3.930577 & 3.021852 & 0.484763 \\ \text { C } & 3.309435 & 0.318614 & -0.035751 \\ \text { C } & 2.428873 & 1.345783 & -0.337282 \\ \text { C } & 2.721150 & 2.723817 & -0.112636 \\ \text { H } & 4.199163 & 4.062566 & 0.646088 \\ \text { O } & 0.892607 & -0.852451 & 0.789421 \\ \text { P } & 0.060627 & 0.370285 & 0.078297\end{array}$




\begin{tabular}{|c|c|c|c|}
\hline 0 & 1.207775 & 1.015550 & -0.908172 \\
\hline C & -2.000461 & -4.996677 & 1.585943 \\
\hline C & -1.333718 & -4.004963 & 2.311012 \\
\hline C & -0.245427 & -3.330423 & 1.753697 \\
\hline C & 0.201497 & -3.635729 & 0.455231 \\
\hline C & -0.497706 & -4.616982 & -0.270087 \\
\hline C & -1.581237 & -5.293420 & 0.287822 \\
\hline $\mathrm{H}$ & -1.644792 & -3.755456 & 3.321849 \\
\hline $\mathrm{H}$ & -2.099981 & -6.049494 & -0.295873 \\
\hline C & 0.101715 & 5.952393 & -1.222687 \\
\hline C & 0.322780 & 4.897384 & -2.110362 \\
\hline C & 1.152132 & 3.835827 & -1.752499 \\
\hline C & 1.782663 & 3.811350 & -0.497030 \\
\hline C & 1.549183 & 4.877012 & 0.387426 \\
\hline C & 0.717513 & 5.937166 & 0.029318 \\
\hline $\mathrm{H}$ & -0.150661 & 4.899822 & -3.088831 \\
\hline $\mathrm{H}$ & 0.543614 & 6.746634 & 0.733584 \\
\hline C & 4.528875 & 0.640246 & 0.654866 \\
\hline C & 4.838366 & 2.017371 & 0.901018 \\
\hline C & 6.046124 & 2.352366 & 1.571471 \\
\hline C & 6.905137 & 1.374051 & 2.014935 \\
\hline C & 6.583032 & 0.012084 & 1.808917 \\
\hline C & 5.429064 & -0.345046 & 1.146428 \\
\hline $\mathrm{H}$ & 6.271009 & 3.403218 & 1.738518 \\
\hline $\mathrm{H}$ & 7.821977 & 1.642334 & 2.532750 \\
\hline $\mathrm{H}$ & 7.249820 & -0.761055 & 2.181226 \\
\hline $\mathrm{H}$ & 5.193002 & -1.393431 & 1.006445 \\
\hline C & 3.808015 & -1.884578 & -1.232945 \\
\hline C & 3.470988 & -3.258268 & -1.455283 \\
\hline C & 4.314430 & -4.062729 & -2.268947 \\
\hline C & 5.430694 & -3.532251 & -2.872185 \\
\hline C & 5.745062 & -2.165316 & -2.686847 \\
\hline C & 4.958389 & -1.364605 & -1.888128 \\
\hline $\mathrm{H}$ & 4.049740 & -5.107340 & -2.415756 \\
\hline $\mathrm{H}$ & 6.063977 & -4.154355 & -3.498750 \\
\hline $\mathrm{H}$ & 6.613603 & -1.740839 & -3.183194 \\
\hline $\mathrm{H}$ & 5.208499 & -0.317412 & -1.764532 \\
\hline $\mathrm{O}$ & -0.435558 & 1.288672 & 1.138303 \\
\hline $\mathrm{O}$ & -0.953050 & -0.251617 & -0.905371 \\
\hline $\mathrm{H}$ & -1.849969 & 0.437265 & -1.252810 \\
\hline $\mathrm{H}$ & -0.195971 & -4.839921 & -1.289304 \\
\hline $\mathrm{H}$ & -2.835755 & -5.533410 & 2.029442 \\
\hline $\mathrm{H}$ & 0.258047 & -2.569147 & 2.336126 \\
\hline $\mathrm{H}$ & 2.006710 & 4.858652 & 1.372642 \\
\hline
\end{tabular}




$\begin{array}{llll}\mathrm{H} & -0.549422 & 6.776458 & -1.502295 \\ \mathrm{H} & 1.317688 & 3.022981 & -2.450977 \\ \mathrm{C} & -3.205011 & 1.815932 & -0.509502 \\ \mathrm{O} & -2.817570 & 1.152022 & -1.543463 \\ \mathrm{H} & -2.495446 & 1.979062 & 0.307055 \\ \mathrm{C} & -4.112478 & 3.015368 & -0.742789 \\ \mathrm{O} & -4.223338 & 3.923300 & 0.053083 \\ \mathrm{O} & -4.770690 & 2.936813 & -1.910657 \\ \mathrm{C} & -5.632699 & 4.050654 & -2.201386 \\ \mathrm{H} & -6.402507 & 4.152608 & -1.431447 \\ \mathrm{H} & -6.081646 & 3.826511 & -3.169037 \\ \mathrm{C} & -4.080564 & -0.453263 & 0.805009 \\ \mathrm{C} & -4.540207 & 0.866286 & 0.651146 \\ \mathrm{H} & -2.785319 & -1.793036 & 1.619056 \\ \mathrm{~N} & -3.183478 & -0.864654 & 1.741195 \\ \mathrm{C} & -2.530856 & -0.201283 & 2.810613 \\ \mathrm{O} & -1.745125 & -0.805293 & 3.503296 \\ \mathrm{O} & -2.904198 & 1.066292 & 2.946802 \\ \mathrm{C} & -2.080455 & 1.849710 & 3.845706 \\ \mathrm{H} & -1.078746 & 1.914424 & 3.419071 \\ \mathrm{H} & -2.059017 & 1.387428 & 4.834206 \\ \mathrm{H} & -2.557953 & 2.828289 & 3.879778 \\ \mathrm{H} & -5.453755 & 0.950653 & 0.072469 \\ \mathrm{H} & -4.457912 & 1.539776 & 1.492332 \\ \mathrm{C} & -4.532622 & -1.502737 & -0.130122 \\ \mathrm{C} & -4.695639 & -2.832987 & 0.301528 \\ \mathrm{C} & -4.827294 & -1.175475 & -1.467787 \\ \mathrm{C} & -5.149635 & -3.808724 & -0.580054 \\ \mathrm{H} & -4.503746 & -3.100981 & 1.335730 \\ \mathrm{H} & -5.257779 & -2.165079 & -2.348437 \\ \mathrm{H} & -4.667979 & -0.165951 & -1.827786 \\ & -5.427508 & -3.478756 & -1.908497 \\ \mathrm{H} & -5.289328 & -4.826641 & -0.228369 \\ \mathrm{H} & -5.05450303 & -1.906090 & -3.383640 \\ \mathrm{H} & 4.976840 & -2.250346\end{array}$

Catalyst (R)-1 TS Conformation 246

$B 3 L Y P / 6-31 G(d)$ Energy $=-2809.69334$

B3LYP-D3(BJ)/def2-TZVPP-IEF-PCM(DCM) Energy $=-2810.98289$

B3LYP-D3(BJ)/def2-TZVPP-IEF-PCM(DCM)//B3LYP/6-31G(d) Free Energy (Quasiharmonic) = 2810.339196 
Frequencies (Top 3 out of 270)

1. $-253.8799 \mathrm{~cm}-1$

2. $\quad 9.4925 \mathrm{~cm}-1$

3. $\quad 11.9155 \mathrm{~cm}-1$

B3LYP/6-31G(d) Molecular Geometry in Cartesian Coordinates

$\begin{array}{lrrr}\text { C } & -3.111047 & -1.117233 & 0.249766 \\ \text { C } & -1.936343 & -1.728397 & -0.157777 \\ \text { C } & -1.644196 & -3.103341 & 0.087327 \\ \text { C } & -2.566799 & -3.817867 & 0.828720 \\ \text { H } & -2.393496 & -4.875570 & 1.006738 \\ \text { C } & -3.939916 & 3.017691 & -0.609177 \\ \text { C } & -3.388719 & 0.297428 & -0.134768 \\ \text { C } & -2.489289 & 1.294460 & 0.208700 \\ \text { C } & -2.760499 & 2.684719 & 0.031323 \\ \text { H } & -4.197638 & 4.066084 & -0.730760 \\ \text { O } & -1.014227 & -0.973555 & -0.878636 \\ \text { P } & -0.152431 & 0.188325 & -0.120448 \\ \text { O } & -1.284744 & 0.926432 & 0.802354 \\ \text { C } & 1.711544 & -5.297338 & -1.464140 \\ \text { C } & 1.051312 & -4.370603 & -2.273137 \\ \text { C } & -0.008832 & -3.619951 & -1.767833 \\ \text { C } & -0.437049 & -3.791888 & -0.441603 \\ \text { C } & 0.250480 & -4.711700 & 0.369317 \\ \text { C } & 1.313675 & -5.457358 & -0.135366 \\ \text { H } & 1.359943 & -4.224859 & -3.304278 \\ \text { H } & 1.831961 & -6.161360 & 0.510572 \\ \text { C } & -0.427205 & 5.937861 & 1.611100 \\ \text { C } & -0.978544 & 6.017292 & 0.330492 \\ \text { C } & -1.690398 & 4.938404 & -0.193812 \\ \text { C } & -1.878757 & 3.762804 & 0.553432 \\ \text { C } & -1.302016 & 3.689997 & 1.833668 \\ \text { C } & -0.585410 & 4.766400 & 2.354410 \\ \text { H } & -0.855398 & 6.919443 & -0.263690 \\ \text { H } & -0.157613 & 4.691714 & 3.350619 \\ \text { C } & -4.570105 & 0.657336 & -0.869240 \\ \text { C } & -4.839942 & 2.043451 & -1.103129 \\ \text { C } & -6.008675 & 2.416206 & -1.821077 \\ \text { C } & -6.866079 & 1.463014 & -2.318841 \\ \text { C } & -6.583916 & 0.091000 & -2.118922 \\ \text { C } & -5.469256 & -0.301813 & -1.411109\end{array}$




\begin{tabular}{|c|c|c|c|}
\hline $\mathrm{H}$ & -6.204789 & 3.474047 & -1.979522 \\
\hline $\mathrm{H}$ & -7.752430 & 1.758676 & -2.873374 \\
\hline $\mathrm{H}$ & -7.250771 & -0.661043 & -2.531808 \\
\hline $\mathrm{H}$ & -5.261952 & -1.356850 & -1.274613 \\
\hline C & -4.022313 & -1.854194 & 1.082434 \\
\hline C & -3.737794 & -3.228950 & 1.362268 \\
\hline C & -4.632950 & -3.977160 & 2.174281 \\
\hline C & -5.751163 & -3.391034 & 2.719525 \\
\hline C & -6.015321 & -2.022658 & 2.476101 \\
\hline C & -5.176513 & -1.275244 & 1.678773 \\
\hline $\mathrm{H}$ & -4.407075 & -5.023510 & 2.365880 \\
\hline $\mathrm{H}$ & -6.424873 & -3.970446 & 3.344814 \\
\hline $\mathrm{H}$ & -6.886373 & -1.554350 & 2.926439 \\
\hline $\mathrm{H}$ & -5.389526 & -0.225966 & 1.511771 \\
\hline O & 0.493548 & 1.057477 & -1.141530 \\
\hline $\mathrm{O}$ & 0.722069 & -0.452063 & 0.996290 \\
\hline $\mathrm{H}$ & 1.731718 & -0.727785 & 0.781378 \\
\hline $\mathrm{H}$ & -0.044913 & -4.829370 & 1.408067 \\
\hline $\mathrm{H}$ & 2.531860 & -5.888578 & -1.864102 \\
\hline $\mathrm{H}$ & -0.510031 & -2.903413 & -2.408058 \\
\hline $\mathrm{H}$ & -1.429742 & 2.792706 & 2.428495 \\
\hline $\mathrm{H}$ & 0.123632 & 6.778717 & 2.024448 \\
\hline $\mathrm{H}$ & -2.101404 & 5.002522 & -1.197288 \\
\hline C & 3.969188 & -0.464289 & 1.267923 \\
\hline $\mathrm{O}$ & 3.081645 & -1.149606 & 0.647590 \\
\hline $\mathrm{H}$ & 3.663352 & 0.394065 & 1.885119 \\
\hline C & 5.113369 & -1.202015 & 1.965825 \\
\hline 0 & 5.708402 & -0.745919 & 2.919356 \\
\hline 0 & 5.374154 & -2.394276 & 1.403958 \\
\hline C & 6.421136 & -3.147852 & 2.038077 \\
\hline $\mathrm{H}$ & 7.366908 & -2.599723 & 2.003436 \\
\hline $\mathrm{H}$ & 6.167693 & -3.351157 & 3.081697 \\
\hline C & 4.174861 & 1.185066 & -0.721745 \\
\hline C & 5.142375 & 0.466817 & 0.009857 \\
\hline $\mathrm{H}$ & 2.389785 & 0.998206 & -1.723509 \\
\hline$N$ & 3.303328 & 0.562259 & -1.552076 \\
\hline C & 3.310773 & -0.751783 & -2.080539 \\
\hline $\mathrm{O}$ & 2.327438 & -1.219258 & -2.602381 \\
\hline $\mathrm{O}$ & 4.519026 & -1.326608 & -2.034518 \\
\hline C & 4.537845 & -2.715693 & -2.414203 \\
\hline $\mathrm{H}$ & 5.582919 & -3.016525 & -2.338442 \\
\hline $\mathrm{H}$ & 4.173727 & -2.835132 & -3.436892 \\
\hline $\mathrm{H}$ & 3.915338 & -3.291385 & -1.726718 \\
\hline $\mathrm{H}$ & 5.808802 & 1.052949 & 0.633168 \\
\hline
\end{tabular}




$\begin{array}{llll}\mathrm{H} & 5.577878 & -0.412164 & -0.442009 \\ \mathrm{C} & 3.971261 & 2.630096 & -0.469067 \\ \mathrm{C} & 5.102612 & 3.430166 & -0.210624 \\ \mathrm{C} & 2.704926 & 3.242671 & -0.514263 \\ \mathrm{C} & 4.972990 & 4.799631 & -0.002115 \\ \mathrm{H} & 6.091432 & 2.983971 & -0.210518 \\ \mathrm{C} & 2.582412 & 4.612669 & -0.292104 \\ \mathrm{H} & 1.806841 & 2.656353 & -0.684798 \\ \mathrm{C} & 3.710490 & 5.394495 & -0.038358 \\ \mathrm{H} & 5.858606 & 5.401165 & 0.182119 \\ \mathrm{H} & 1.595638 & 5.063484 & -0.307694 \\ \mathrm{H} & 3.607050 & 6.463307 & 0.128801 \\ \mathrm{H} & 6.494420 & -4.077785 & 1.473672\end{array}$

Catalyst (R)-1 TS Conformation 247

B3LYP/6-31G(d) Energy $=-2809.685835$

B3LYP-D3(BJ)/def2-TZVPP-IEF-PCM(DCM) Energy $=-2810.980262$

B3LYP-D3(BJ)/def2-TZVPP-IEF-PCM(DCM)//B3LYP/6-31G(d) Free Energy (Quasiharmonic) = 2810.339131

Frequencies (Top 3 out of 270)

1. $-724.2935 \mathrm{~cm}-1$

2. $\quad 10.4979 \mathrm{~cm}-1$

3. $11.0553 \mathrm{~cm}-1$

B3LYP/6-31G(d) Molecular Geometry in Cartesian Coordinates

$\begin{array}{llll}\mathrm{C} & 3.552022 & 0.348712 & 0.294834 \\ \mathrm{C} & 2.816978 & 1.407861 & -0.216786 \\ \mathrm{C} & 2.979958 & 2.758079 & 0.212523 \\ \mathrm{C} & 3.891806 & 2.993771 & 1.222849 \\ \mathrm{H} & 4.060226 & 4.014442 & 1.556058 \\ \mathrm{C} & 2.885643 & -3.663497 & -1.152715 \\ \mathrm{C} & 3.359418 & -1.025666 & -0.258871 \\ \mathrm{C} & 2.088159 & -1.578202 & -0.281857 \\ \mathrm{C} & 1.817645 & -2.915114 & -0.697823 \\ \mathrm{H} & 2.721159 & -4.694521 & -1.454935 \\ \mathrm{O} & 1.892828 & 1.157847 & -1.223759 \\ \mathrm{P} & 0.493581 & 0.383172 & -0.875562 \\ \mathrm{O} & 1.019271 & -0.798673 & 0.140207 \\ \mathrm{C} & 0.841720 & 6.094634 & -1.464623\end{array}$




\begin{tabular}{|c|c|c|c|}
\hline C & 1.406350 & 5.134726 & -2.307161 \\
\hline C & 2.082112 & 4.038108 & -1.774558 \\
\hline C & 2.211000 & 3.883127 & -0.383854 \\
\hline C & 1.635112 & 4.853444 & 0.452430 \\
\hline C & 0.957073 & 5.948597 & -0.081739 \\
\hline $\mathrm{H}$ & 1.322948 & 5.239636 & -3.385794 \\
\hline $\mathrm{H}$ & 0.511478 & 6.682650 & 0.584642 \\
\hline C & -2.099042 & -4.696934 & -0.559516 \\
\hline C & -1.632594 & -3.951684 & 0.526243 \\
\hline C & -0.371936 & -3.357682 & 0.483450 \\
\hline C & 0.449661 & -3.497234 & -0.648703 \\
\hline C & -0.033776 & -4.245475 & -1.734144 \\
\hline C & -1.294036 & -4.841301 & -1.690218 \\
\hline $\mathrm{H}$ & -2.253074 & -3.829682 & 1.410749 \\
\hline $\mathrm{H}$ & -1.649363 & -5.410702 & -2.545159 \\
\hline C & 4.446663 & -1.791387 & -0.804333 \\
\hline C & 4.195810 & -3.132152 & -1.243804 \\
\hline C & 5.264781 & -3.903170 & -1.775905 \\
\hline C & 6.526664 & -3.371160 & -1.903518 \\
\hline C & 6.768588 & -2.035099 & -1.506217 \\
\hline C & 5.758204 & -1.267225 & -0.970212 \\
\hline $\mathrm{H}$ & 5.059755 & -4.922832 & -2.093645 \\
\hline $\mathrm{H}$ & 7.334075 & -3.967940 & -2.318917 \\
\hline $\mathrm{H}$ & 7.760171 & -1.608053 & -1.629715 \\
\hline $\mathrm{H}$ & 5.957427 & -0.242186 & -0.679865 \\
\hline C & 4.441972 & 0.601401 & 1.395804 \\
\hline C & 4.616919 & 1.949825 & 1.847171 \\
\hline C & 5.503633 & 2.216195 & 2.925649 \\
\hline C & 6.171035 & 1.196185 & 3.562465 \\
\hline C & 5.969456 & -0.140634 & 3.146086 \\
\hline C & 5.130153 & -0.430143 & 2.092664 \\
\hline $\mathrm{H}$ & 5.633273 & 3.247231 & 3.246315 \\
\hline $\mathrm{H}$ & 6.840982 & 1.411426 & 4.390416 \\
\hline $\mathrm{H}$ & 6.477637 & -0.948677 & 3.665504 \\
\hline $\mathrm{H}$ & 4.979918 & -1.461049 & 1.794439 \\
\hline $\mathrm{O}$ & -0.135388 & -0.087113 & -2.137331 \\
\hline $\mathrm{O}$ & -0.370403 & 1.229700 & 0.094642 \\
\hline $\mathrm{H}$ & -1.378369 & 1.789735 & -0.352867 \\
\hline $\mathrm{H}$ & 1.701416 & 4.732075 & 1.529983 \\
\hline $\mathrm{H}$ & 0.311906 & 6.946421 & -1.883025 \\
\hline $\mathrm{H}$ & 2.518236 & 3.300014 & -2.438718 \\
\hline $\mathrm{H}$ & 0.576544 & -4.338449 & -2.627868 \\
\hline $\mathrm{H}$ & -3.081269 & -5.161490 & -0.523627 \\
\hline $\mathrm{H}$ & -0.015561 & -2.786888 & 1.334290 \\
\hline
\end{tabular}




$\begin{array}{llll}\mathrm{C} & -2.963489 & 1.451922 & -1.594708 \\ \mathrm{O} & -2.482033 & 2.115728 & -0.610854 \\ \mathrm{H} & -2.306518 & 1.114409 & -2.400396 \\ \mathrm{C} & -4.383088 & 1.739914 & -2.037625 \\ \mathrm{O} & -4.820411 & 1.369847 & -3.107041 \\ \mathrm{O} & -5.069713 & 2.440357 & -1.125269 \\ \mathrm{C} & -6.426149 & 2.752211 & -1.491033 \\ \mathrm{H} & -7.007677 & 1.834543 & -1.610968 \\ \mathrm{H} & -6.447683 & 3.317481 & -2.425888 \\ \mathrm{C} & -3.635084 & -0.561043 & 0.206197 \\ \mathrm{C} & -3.193015 & -0.594707 & -1.112421 \\ \mathrm{H} & -1.836314 & 0.176547 & 0.897165 \\ \mathrm{~N} & -2.740416 & -0.221612 & 1.184871 \\ \mathrm{C} & -2.775198 & -0.483480 & 2.565470 \\ \mathrm{O} & -2.007659 & 0.037925 & 3.339481 \\ \mathrm{O} & -3.699716 & -1.405007 & 2.887031 \\ \mathrm{C} & -3.799317 & -1.688634 & 4.294871 \\ \mathrm{H} & -4.589357 & -2.434447 & 4.380320 \\ \mathrm{H} & -4.060186 & -0.784008 & 4.849583 \\ \mathrm{H} & -2.851941 & -2.080835 & 4.671543 \\ \mathrm{H} & -3.906049 & -0.874842 & -1.879296 \\ \mathrm{H} & -2.147988 & -0.800362 & -1.328381 \\ \mathrm{C} & -5.075393 & -0.675596 & 0.522544 \\ \mathrm{C} & -5.699666 & 0.257971 & 1.368430 \\ \mathrm{C} & -5.849427 & -1.673942 & -0.088188 \\ \mathrm{C} & -7.070740 & 0.187924 & 1.596591 \\ \mathrm{H} & -5.112167 & 1.056596 & 1.810529 \\ \mathrm{C} & -7.219779 & -1.750045 & 0.155825 \\ \mathrm{H} & -5.367616 & -2.403302 & -0.732255 \\ \mathrm{C} & -7.832895 & -0.819293 & 0.996526 \\ \mathrm{H} & -7.547568 & 0.921432 & 2.240806 \\ \mathrm{H} & -7.807468 & -2.535446 & -0.310625 \\ \mathrm{H} & -8.902020 & -0.875507 & 1.182215 \\ & -6.817403 & 3.350737 & -0.668685\end{array}$

Catalyst (R)-1 TS Conformation 248

B3LYP/6-31G(d) Energy $=-2809.679825$

B3LYP-D3(BJ)/def2-TZVPP-IEF-PCM(DCM) Energy = -2810.979582

B3LYP-D3(BJ)/def2-TZVPP-IEF-PCM(DCM)//B3LYP/6-31G(d) Free Energy (Quasiharmonic) = 2810.33912

Frequencies (Top 3 out of 270) 
1. $-719.0872 \mathrm{~cm}-1$

2. $\quad 7.0631 \mathrm{~cm}-1$

3. $\quad 11.1785 \mathrm{~cm}-1$

B3LYP/6-31G(d) Molecular Geometry in Cartesian Coordinates

$\begin{array}{llll}\mathrm{C} & 3.071446 & 0.947278 & 0.241886 \\ \mathrm{C} & 1.948652 & 1.693859 & -0.077065 \\ \mathrm{C} & 1.809097 & 3.073751 & 0.253731 \\ \mathrm{C} & 2.831746 & 3.660062 & 0.973539 \\ \mathrm{H} & 2.766758 & 4.716524 & 1.220431 \\ \mathrm{C} & 3.335284 & -3.208372 & -0.864175 \\ \mathrm{C} & 3.161722 & -0.472025 & -0.210168 \\ \mathrm{C} & 2.161009 & -1.368651 & 0.137209 \\ \mathrm{C} & 2.243469 & -2.767048 & -0.140847 \\ \mathrm{H} & 3.443389 & -4.271081 & -1.064291 \\ \mathrm{O} & 0.917705 & 1.074662 & -0.769550 \\ \mathrm{P} & -0.057500 & 0.030961 & 0.053167 \\ \mathrm{O} & 1.054224 & -0.903728 & 0.831572 \\ \mathrm{C} & -1.499606 & 5.551179 & -0.929887 \\ \mathrm{C} & -1.046096 & 5.559812 & 0.389711 \\ \mathrm{C} & 0.009037 & 4.732547 & 0.771167 \\ \mathrm{C} & 0.628564 & 3.879038 & -0.156072 \\ \mathrm{C} & 0.148430 & 3.862945 & -1.476413 \\ \mathrm{C} & -0.902666 & 4.695456 & -1.859096 \\ \mathrm{H} & -1.519362 & 6.204136 & 1.125340 \\ \mathrm{H} & -1.250545 & 4.679257 & -2.888708 \\ \mathrm{C} & -0.532585 & -5.732935 & 1.286308 \\ \mathrm{C} & -0.113056 & -4.703084 & 2.130578 \\ \mathrm{C} & 0.756819 & -3.716371 & 1.667398 \\ \mathrm{C} & 1.236115 & -3.746162 & 0.346549 \\ \mathrm{C} & 0.807171 & -4.788731 & -0.492177 \\ \mathrm{C} & -0.067606 & -5.771756 & -0.028590 \\ \mathrm{H} & -0.455255 & -4.674108 & 3.162081 \\ \mathrm{H} & -0.385525 & -6.569136 & -0.695719 \\ \mathrm{C} & 4.249969 & -0.933834 & -1.027199 \\ \mathrm{C} & 4.331412 & -2.326833 & -1.348185 \\ \mathrm{C} & 5.408552 & -2.798688 & -2.146574 \\ \mathrm{C} & 6.355878 & -1.932169 & -2.639859 \\ \mathrm{C} & 5.258283 & -0.549664 & -2.355080 \\ \mathrm{C} & 5.461592 & -3.861879 & -2.369451 \\ \mathrm{C} & -2.31242 & -2.302816 & -3.255071\end{array}$




\begin{tabular}{|c|c|c|c|}
\hline $\mathrm{H}$ & 6.994564 & 0.137165 & -2.763826 \\
\hline $\mathrm{H}$ & 5.170650 & 0.998938 & -1.368130 \\
\hline C & 4.096304 & 1.551253 & 1.048930 \\
\hline C & 3.967941 & 2.932887 & 1.404836 \\
\hline C & 4.977090 & 3.547690 & 2.194564 \\
\hline C & 6.058628 & 2.828433 & 2.646893 \\
\hline C & 6.169180 & 1.454317 & 2.329390 \\
\hline C & 5.216448 & 0.833261 & 1.551791 \\
\hline $\mathrm{H}$ & 4.868764 & 4.600392 & 2.445158 \\
\hline $\mathrm{H}$ & 6.820383 & 3.307463 & 3.255933 \\
\hline $\mathrm{H}$ & 7.011604 & 0.880838 & 2.706805 \\
\hline $\mathrm{H}$ & 5.311976 & -0.222616 & 1.327186 \\
\hline $\mathrm{O}$ & -0.909835 & -0.684974 & -0.934226 \\
\hline 0 & -0.718932 & 0.766603 & 1.233447 \\
\hline $\mathrm{H}$ & -1.783655 & 1.242658 & 1.091477 \\
\hline $\mathrm{H}$ & 0.610799 & 3.206366 & -2.205731 \\
\hline $\mathrm{H}$ & -2.313424 & 6.206397 & -1.229501 \\
\hline $\mathrm{H}$ & 0.347225 & 4.728849 & 1.803335 \\
\hline $\mathrm{H}$ & 1.159032 & -4.819802 & -1.519909 \\
\hline $\mathrm{H}$ & -1.214932 & -6.496417 & 1.649299 \\
\hline $\mathrm{H}$ & 1.080605 & -2.925658 & 2.335111 \\
\hline C & -3.288423 & 1.843960 & -0.257694 \\
\hline $\mathrm{O}$ & -2.867071 & 1.833721 & 0.951423 \\
\hline $\mathrm{H}$ & -2.637371 & 1.461124 & -1.054620 \\
\hline C & -4.105902 & 3.069372 & -0.668962 \\
\hline $\mathrm{O}$ & -4.671980 & 3.818342 & 0.088475 \\
\hline $\mathrm{O}$ & -4.128039 & 3.181429 & -2.018539 \\
\hline C & -4.889346 & 4.289698 & -2.526006 \\
\hline $\mathrm{H}$ & -4.469520 & 5.233886 & -2.170739 \\
\hline $\mathrm{H}$ & -4.818522 & 4.222744 & -3.611990 \\
\hline C & -4.305902 & -0.705790 & -0.308738 \\
\hline C & -4.796640 & 0.593301 & -0.541512 \\
\hline $\mathrm{H}$ & -3.514216 & -0.796439 & -2.175416 \\
\hline$N$ & -3.739306 & -1.355746 & -1.360173 \\
\hline C & -3.373963 & -2.705722 & -1.496708 \\
\hline O & -3.578571 & -3.589772 & -0.701833 \\
\hline $\mathrm{O}$ & -2.815914 & -2.840553 & -2.710765 \\
\hline C & -2.342251 & -4.164215 & -3.015539 \\
\hline $\mathrm{H}$ & -3.172501 & -4.875370 & -3.013334 \\
\hline $\mathrm{H}$ & -1.594121 & -4.470311 & -2.281345 \\
\hline $\mathrm{H}$ & -1.902212 & -4.087678 & -4.009593 \\
\hline $\mathrm{H}$ & -5.436321 & 1.006185 & 0.230570 \\
\hline $\mathrm{H}$ & -5.081095 & 0.837419 & -1.562780 \\
\hline C & -4.274815 & -1.244739 & 1.054853 \\
\hline
\end{tabular}




$\begin{array}{llll}\text { C } & -3.113378 & -1.853411 & 1.567364 \\ \text { C } & -5.383058 & -1.049333 & 1.901468 \\ \text { C } & -3.069531 & -2.246486 & 2.900161 \\ \text { H } & -2.245775 & -1.981477 & 0.932521 \\ \text { C } & -5.340959 & -1.473915 & 3.224914 \\ \text { H } & -6.288139 & -0.595995 & 1.509450 \\ \text { C } & -4.180341 & -2.066890 & 3.727643 \\ \text { H } & -2.161271 & -2.693925 & 3.290208 \\ \text { H } & -6.208005 & -1.336661 & 3.864239 \\ \text { H } & -4.140926 & -2.385296 & 4.765888 \\ \text { H } & -5.931382 & 4.220787 & -2.201532\end{array}$

Catalyst (R)-1 TS Conformation 249

B3LYP/6-31G(d) Energy $=-2809.690684$

B3LYP-D3(BJ)/def2-TZVPP-IEF-PCM(DCM) Energy = -2810.980366

B3LYP-D3(BJ)/def2-TZVPP-IEF-PCM(DCM)//B3LYP/6-31G(d) Free Energy (Quasiharmonic) = 2810.33912

Frequencies (Top 3 out of 270)

1. $-516.5642 \mathrm{~cm}-1$

2. $\quad 8.8962 \mathrm{~cm}-1$

3. $\quad 15.4063 \mathrm{~cm}-1$

B3LYP/6-31G(d) Molecular Geometry in Cartesian Coordinates

$\begin{array}{llll}\text { C } & 3.568625 & 0.336398 & 0.297180 \\ \text { C } & 2.690547 & 1.380203 & 0.044963 \\ \text { C } & 2.870275 & 2.696962 & 0.558843 \\ \text { C } & 3.941175 & 2.908920 & 1.404138 \\ \text { H } & 4.116798 & 3.907848 & 1.794801 \\ \text { C } & 2.893248 & -3.571591 & -1.391084 \\ \text { C } & 3.359570 & -0.994629 & -0.348938 \\ \text { C } & 2.146301 & -1.645068 & -0.188551 \\ \text { C } & 1.875304 & -2.954335 & -0.687044 \\ \text { H } & 2.745391 & -4.584061 & -1.756414 \\ \text { O } & 1.580866 & 1.153757 & -0.769331 \\ \text { P } & 0.358371 & 0.241472 & -0.194852 \\ \text { O } & 1.153251 & -0.989469 & 0.529697 \\ \text { C } & 0.418805 & 6.081736 & -0.457107 \\ \text { C } & 0.681369 & 5.775014 & 0.878734 \\ \text { C } & 1.454155 & 4.659902 & 1.202165\end{array}$




\begin{tabular}{|c|c|c|c|}
\hline C & 1.971819 & 3.826609 & 0.198335 \\
\hline C & 1.687085 & 4.134740 & -1.141833 \\
\hline C & 0.925625 & 5.257032 & -1.464707 \\
\hline $\mathrm{H}$ & 0.284051 & 6.403187 & 1.671671 \\
\hline $\mathrm{H}$ & 0.737785 & 5.495102 & -2.508819 \\
\hline C & -1.859295 & -5.034580 & -0.162629 \\
\hline C & -1.161373 & -5.114616 & -1.368927 \\
\hline C & 0.036349 & -4.420825 & -1.531226 \\
\hline C & 0.570089 & -3.640720 & -0.489858 \\
\hline C & -0.146205 & -3.567246 & 0.717956 \\
\hline C & -1.349849 & -4.254423 & 0.877816 \\
\hline $\mathrm{H}$ & -1.554734 & -5.706853 & -2.191412 \\
\hline $\mathrm{H}$ & -1.892726 & -4.158353 & 1.813205 \\
\hline C & 4.370078 & -1.615900 & -1.158954 \\
\hline C & 4.127085 & -2.933398 & -1.665934 \\
\hline C & 5.124638 & -3.571816 & -2.452420 \\
\hline C & 6.302198 & -2.930917 & -2.759277 \\
\hline C & 6.527642 & -1.614303 & -2.292778 \\
\hline C & 5.589126 & -0.975044 & -1.512764 \\
\hline $\mathrm{H}$ & 4.930154 & -4.576946 & -2.819214 \\
\hline $\mathrm{H}$ & 7.053862 & -3.426496 & -3.367595 \\
\hline $\mathrm{H}$ & 7.448358 & -1.100397 & -2.555604 \\
\hline $\mathrm{H}$ & 5.773345 & 0.036465 & -1.169481 \\
\hline C & 4.638561 & 0.556364 & 1.233671 \\
\hline C & 4.823007 & 1.867174 & 1.781161 \\
\hline C & 5.880900 & 2.098691 & 2.701683 \\
\hline C & 6.709830 & 1.075769 & 3.098695 \\
\hline C & 6.505769 & -0.228879 & 2.591381 \\
\hline C & 5.500557 & -0.481785 & 1.684062 \\
\hline $\mathrm{H}$ & 6.012951 & 3.103260 & 3.096659 \\
\hline $\mathrm{H}$ & 7.510806 & 1.262588 & 3.808707 \\
\hline $\mathrm{H}$ & 7.144806 & -1.042046 & 2.924824 \\
\hline $\mathrm{H}$ & 5.352097 & -1.489741 & 1.315430 \\
\hline $\mathrm{O}$ & -0.515532 & -0.195239 & -1.324867 \\
\hline $\mathrm{O}$ & -0.300475 & 1.001827 & 0.983299 \\
\hline $\mathrm{H}$ & -1.038579 & 0.359276 & 1.543711 \\
\hline $\mathrm{H}$ & 2.079421 & 3.501388 & -1.930892 \\
\hline $\mathrm{H}$ & -0.173214 & 6.957167 & -0.711452 \\
\hline $\mathrm{H}$ & 1.647606 & 4.417807 & 2.243352 \\
\hline $\mathrm{H}$ & 0.228972 & -2.965018 & 1.536115 \\
\hline $\mathrm{H}$ & -2.797242 & -5.569717 & -0.036551 \\
\hline $\mathrm{H}$ & 0.553064 & -4.460589 & -2.485913 \\
\hline C & -3.083760 & -0.466831 & 1.963179 \\
\hline $\mathrm{O}$ & -1.808379 & -0.539189 & 2.092704 \\
\hline
\end{tabular}




$\begin{array}{llll}\mathrm{H} & -3.563631 & 0.520591 & 1.926526 \\ \mathrm{C} & -3.851423 & -1.469084 & 2.827212 \\ \mathrm{O} & -3.480232 & -2.581415 & 3.114890 \\ \mathrm{O} & -5.015515 & -0.926233 & 3.258338 \\ \mathrm{C} & -5.809281 & -1.774498 & 4.109521 \\ \mathrm{H} & -6.105184 & -2.681981 & 3.576394 \\ \mathrm{H} & -5.241167 & -2.053333 & 5.000032 \\ \mathrm{C} & -4.049750 & -0.108066 & -0.604474 \\ \mathrm{C} & -3.600545 & -1.183164 & 0.204912 \\ \mathrm{H} & -2.148741 & 0.291638 & -1.314825 \\ \mathrm{~N} & -3.133477 & 0.643413 & -1.254110 \\ \mathrm{C} & -3.297385 & 1.990403 & -1.652561 \\ \mathrm{O} & -4.212935 & 2.718256 & -1.347976 \\ \mathrm{O} & -2.242735 & 2.325301 & -2.406039 \\ \mathrm{C} & -2.197256 & 3.703373 & -2.815945 \\ \mathrm{H} & -1.340697 & 3.771040 & -3.485383 \\ \mathrm{H} & -2.052106 & 4.350258 & -1.947768 \\ \mathrm{H} & -3.120273 & 3.977999 & -3.332003 \\ \mathrm{H} & -4.340764 & -1.957164 & 0.385208 \\ \mathrm{H} & -2.610801 & -1.574855 & -0.011508 \\ \mathrm{C} & -5.492478 & 0.162550 & -0.771924 \\ \mathrm{C} & -6.003153 & 0.456015 & -2.049746 \\ \mathrm{C} & -6.384441 & 0.022935 & 0.303723 \\ \mathrm{C} & -7.371530 & 0.606027 & -2.243835 \\ \mathrm{H} & -5.327158 & 0.535096 & -2.894973 \\ \mathrm{C} & -7.752427 & 0.202407 & 0.107760 \\ \mathrm{H} & -6.008491 & -0.197389 & 1.296698 \\ \mathrm{C} & -8.250529 & 0.489235 & -1.163861 \\ \mathrm{H} & -7.753175 & 0.817468 & -3.238521 \\ \mathrm{H} & -8.430598 & 0.114384 & 0.951861 \\ \mathrm{H} & -9.318771 & 0.617291 & -1.315255 \\ \mathrm{H} & -6.683447 & -1.182105 & 4.379935 \\ & & & \end{array}$

Catalyst (R)-1 TS Conformation 250

B3LYP/6-31G(d) Energy $=-2809.689809$

B3LYP-D3(BJ)/def2-TZVPP-IEF-PCM(DCM) Energy $=-2810.980477$

B3LYP-D3(BJ)/def2-TZVPP-IEF-PCM(DCM)//B3LYP/6-31G(d) Free Energy (Quasiharmonic) = 2810.33908

Frequencies (Top 3 out of 270)

1. $-737.7898 \mathrm{~cm}-1$ 
2. $\quad 8.2321 \mathrm{~cm}-1$

3. $\quad 9.4878 \mathrm{~cm}-1$

B3LYP/6-31G(d) Molecular Geometry in Cartesian Coordinates

\begin{tabular}{|c|c|c|c|}
\hline C & -3.140369 & -0.161301 & 0.338230 \\
\hline C & -2.666725 & -1.117527 & -0.549328 \\
\hline C & -2.961426 & -2.509227 & -0.423662 \\
\hline C & -3.663553 & -2.909526 & 0.696438 \\
\hline $\mathrm{H}$ & -3.900019 & -3.963236 & 0.819546 \\
\hline C & -2.592509 & 4.072965 & -0.253561 \\
\hline C & -2.990307 & 1.294805 & 0.041300 \\
\hline C & -1.737341 & 1.833641 & -0.206930 \\
\hline C & -1.497773 & 3.234755 & -0.324478 \\
\hline $\mathrm{H}$ & -2.440896 & 5.145809 & -0.339441 \\
\hline $\mathrm{O}$ & -1.964939 & -0.705307 & -1.675527 \\
\hline$P$ & -0.482985 & -0.033282 & -1.550248 \\
\hline $\mathrm{O}$ & -0.646467 & 0.971994 & -0.252447 \\
\hline C & -2.046213 & -5.498040 & -3.383298 \\
\hline C & -1.029489 & -4.676977 & -2.892074 \\
\hline C & -1.308773 & -3.691296 & -1.945796 \\
\hline C & -2.617363 & -3.512679 & -1.470905 \\
\hline C & -3.632491 & -4.345832 & -1.970115 \\
\hline C & -3.350892 & -5.329014 & -2.918293 \\
\hline $\mathrm{H}$ & -0.009492 & -4.803165 & -3.245967 \\
\hline $\mathrm{H}$ & -4.153024 & -5.956801 & -3.297815 \\
\hline C & 2.407437 & 5.012824 & -0.678625 \\
\hline C & 1.564543 & 5.350427 & 0.381186 \\
\hline C & 0.306985 & 4.755598 & 0.491002 \\
\hline C & -0.129512 & 3.814084 & -0.455091 \\
\hline C & 0.722140 & 3.486583 & -1.523339 \\
\hline C & 1.980631 & 4.082383 & -1.629802 \\
\hline$H$ & 1.884867 & 6.074273 & 1.126384 \\
\hline $\mathrm{H}$ & 2.633262 & 3.815322 & -2.457035 \\
\hline C & -4.131080 & 2.171339 & 0.003819 \\
\hline C & -3.915180 & 3.580701 & -0.130987 \\
\hline C & -5.031355 & 4.460006 & -0.159193 \\
\hline C & -6.316063 & 3.974747 & -0.085427 \\
\hline C & -6.534494 & 2.580492 & 0.011625 \\
\hline C & -5.473095 & 1.703503 & 0.057308 \\
\hline $\mathrm{H}$ & -4.847376 & 5.527488 & -0.254910 \\
\hline $\mathrm{H}$ & -7.162367 & 4.655489 & -0.115472 \\
\hline $\mathrm{H}$ & -7.550344 & 2.195961 & 0.043191 \\
\hline $\mathrm{H}$ & -5.659732 & 0.637841 & 0.119038 \\
\hline
\end{tabular}




\begin{tabular}{|c|c|c|c|}
\hline C & -3.778140 & -0.607907 & 1.549002 \\
\hline C & -4.046912 & -2.004189 & 1.715553 \\
\hline C & -4.681250 & -2.458271 & 2.903632 \\
\hline C & -5.017103 & -1.579341 & 3.906857 \\
\hline C & -4.721966 & -0.203540 & 3.761056 \\
\hline C & -4.122496 & 0.269519 & 2.614294 \\
\hline $\mathrm{H}$ & -4.886885 & -3.521223 & 3.007055 \\
\hline $\mathrm{H}$ & -5.497079 & -1.938144 & 4.813260 \\
\hline $\mathrm{H}$ & -4.965960 & 0.487276 & 4.563636 \\
\hline $\mathrm{H}$ & -3.894962 & 1.325196 & 2.524210 \\
\hline $\mathrm{O}$ & -0.108324 & 0.638058 & -2.817333 \\
\hline $\mathrm{O}$ & 0.505776 & -1.088586 & -0.967788 \\
\hline $\mathrm{H}$ & 1.607384 & -1.142766 & -1.495364 \\
\hline $\mathrm{H}$ & -4.652970 & -4.204979 & -1.623933 \\
\hline $\mathrm{H}$ & -1.823987 & -6.261230 & -4.124590 \\
\hline $\mathrm{H}$ & -0.509496 & -3.068945 & -1.560293 \\
\hline $\mathrm{H}$ & 0.394094 & 2.772458 & -2.272266 \\
\hline $\mathrm{H}$ & 3.387823 & 5.473741 & -0.767368 \\
\hline $\mathrm{H}$ & -0.342135 & 5.010271 & 1.324772 \\
\hline C & 3.151870 & 0.124873 & -1.741795 \\
\hline 0 & 2.778904 & -1.094930 & -1.721027 \\
\hline $\mathrm{H}$ & 2.462400 & 0.903021 & -2.077501 \\
\hline C & 4.605211 & 0.462851 & -1.988966 \\
\hline 0 & 4.967868 & 1.584636 & -2.278181 \\
\hline O & 5.406105 & -0.600873 & -1.863449 \\
\hline C & 6.805300 & -0.343386 & -2.086519 \\
\hline $\mathrm{H}$ & 7.296359 & -1.311022 & -1.988528 \\
\hline $\mathrm{H}$ & 6.960137 & 0.071622 & -3.085258 \\
\hline C & 3.365830 & -0.057549 & 1.036870 \\
\hline C & 2.973381 & 1.010056 & 0.238766 \\
\hline $\mathrm{H}$ & 1.607123 & -1.035859 & 0.644730 \\
\hline$N$ & 2.470073 & -1.078069 & 1.200510 \\
\hline C & 2.471622 & -2.075531 & 2.188127 \\
\hline O & 3.284724 & -2.219083 & 3.071123 \\
\hline $\mathrm{O}$ & 1.382421 & -2.838722 & 1.992084 \\
\hline C & 1.195329 & -3.894854 & 2.949178 \\
\hline $\mathrm{H}$ & 0.278239 & -4.396989 & 2.642936 \\
\hline $\mathrm{H}$ & 1.093049 & -3.483122 & 3.956337 \\
\hline $\mathrm{H}$ & 2.041903 & -4.585617 & 2.925198 \\
\hline $\mathrm{H}$ & 3.644077 & 1.851390 & 0.117089 \\
\hline $\mathrm{H}$ & 1.914861 & 1.218796 & 0.121937 \\
\hline C & 4.754676 & -0.162977 & 1.531538 \\
\hline C & 5.498693 & -1.345171 & 1.375408 \\
\hline C & 5.374439 & 0.969193 & 2.084475 \\
\hline
\end{tabular}




$\begin{array}{llrl}\mathrm{C} & 6.832691 & -1.388241 & 1.766636 \\ \mathrm{H} & 5.036940 & -2.214831 & 0.922104 \\ \mathrm{C} & 6.706245 & 0.916069 & 2.492194 \\ \mathrm{H} & 4.800915 & 1.881399 & 2.217791 \\ \mathrm{C} & 7.437911 & -0.261510 & 2.331910 \\ \mathrm{H} & 7.401786 & -2.304158 & 1.635248 \\ \mathrm{H} & 7.169812 & 1.792856 & 2.934935 \\ \mathrm{H} & 8.477082 & -0.303351 & 2.646731 \\ \mathrm{H} & 7.183966 & 0.358297 & -1.339159\end{array}$

Catalyst (R)-1 TS Conformation 251

B3LYP/6-31G(d) Energy $=-2809.69032$

B3LYP-D3(BJ)/def2-TZVPP-IEF-PCM(DCM) Energy = -2810.982616

B3LYP-D3(BJ)/def2-TZVPP-IEF-PCM(DCM)//B3LYP/6-31G(d) Free Energy (Quasiharmonic) = 2810.339034

Frequencies (Top 3 out of 270)

1. $-301.8059 \mathrm{~cm}-1$

2. $\quad 4.6052 \mathrm{~cm}-1$

3. $15.7010 \mathrm{~cm}-1$

B3LYP/6-31G(d) Molecular Geometry in Cartesian Coordinates

$\begin{array}{llll}\mathrm{C} & 3.063850 & -0.854616 & -0.386416 \\ \mathrm{C} & 1.908815 & -1.560660 & -0.086091 \\ \mathrm{C} & 1.681263 & -2.899479 & -0.507773 \\ \mathrm{C} & 2.636423 & -3.497397 & -1.300685 \\ \mathrm{H} & 2.489146 & -4.523246 & -1.628770 \\ \mathrm{C} & 3.726325 & 3.188847 & 0.937308 \\ \mathrm{C} & 3.278305 & 0.512411 & 0.174605 \\ \mathrm{C} & 2.329485 & 1.502571 & -0.038540 \\ \mathrm{C} & 2.545835 & 2.874253 & 0.292182 \\ \mathrm{H} & 3.917120 & 4.223847 & 1.208565 \\ \mathrm{O} & 0.935055 & -0.966159 & 0.708985 \\ \mathrm{P} & 0.037083 & 0.259241 & 0.098388 \\ \mathrm{O} & 1.152789 & 1.159855 & -0.694415 \\ \mathrm{C} & -1.740522 & -5.254521 & 0.634977 \\ \mathrm{C} & -0.615560 & -5.199186 & 1.460363 \\ \mathrm{C} & 0.480149 & -4.413757 & 1.097198 \\ \mathrm{C} & 0.466000 & -3.666617 & -0.090529 \\ \mathrm{C} & -0.673546 & -3.715025 & -0.906044\end{array}$




\begin{tabular}{|c|c|c|c|}
\hline C & -1.766677 & -4.511007 & -0.548093 \\
\hline $\mathrm{H}$ & -0.584615 & -5.776258 & 2.380960 \\
\hline $\mathrm{H}$ & -2.627251 & -4.550870 & -1.210222 \\
\hline C & -0.109436 & 6.085947 & -0.786643 \\
\hline C & 1.242321 & 6.131911 & -1.130475 \\
\hline C & 2.087397 & 5.077646 & -0.784428 \\
\hline C & 1.598072 & 3.960142 & -0.087801 \\
\hline C & 0.238083 & 3.926625 & 0.258817 \\
\hline C & -0.604977 & 4.981269 & -0.091234 \\
\hline $\mathrm{H}$ & 1.639685 & 6.983782 & -1.676507 \\
\hline $\mathrm{H}$ & -1.656671 & 4.930507 & 0.180383 \\
\hline C & 4.455147 & 0.840670 & 0.932350 \\
\hline C & 4.676183 & 2.205070 & 1.306284 \\
\hline C & 5.837015 & 2.545144 & 2.052566 \\
\hline C & 6.737533 & 1.580248 & 2.439758 \\
\hline C & 6.505928 & 0.226808 & 2.098887 \\
\hline C & 5.397409 & -0.133049 & 1.364296 \\
\hline $\mathrm{H}$ & 5.992616 & 3.587228 & 2.321802 \\
\hline $\mathrm{H}$ & 7.618475 & 1.851296 & 3.015209 \\
\hline $\mathrm{H}$ & 7.206297 & -0.537651 & 2.424584 \\
\hline $\mathrm{H}$ & 5.229077 & -1.175632 & 1.119944 \\
\hline C & 4.013852 & -1.457529 & -1.284189 \\
\hline C & 3.795127 & -2.802012 & -1.728832 \\
\hline C & 4.731127 & -3.411000 & -2.607601 \\
\hline C & 5.829292 & -2.718907 & -3.061563 \\
\hline C & 6.028367 & -1.378138 & -2.657047 \\
\hline C & 5.148114 & -0.765163 & -1.793050 \\
\hline $\mathrm{H}$ & 4.551994 & -4.435431 & -2.925464 \\
\hline $\mathrm{H}$ & 6.534898 & -3.191860 & -3.739043 \\
\hline $\mathrm{H}$ & 6.881474 & -0.822588 & -3.037083 \\
\hline $\mathrm{H}$ & 5.311075 & 0.266354 & -1.504867 \\
\hline 0 & -0.679562 & 0.954609 & 1.196326 \\
\hline $\mathrm{O}$ & -0.804949 & -0.354976 & -1.059346 \\
\hline $\mathrm{H}$ & -1.775788 & 0.106739 & -1.235346 \\
\hline $\mathrm{H}$ & -0.711223 & -3.125541 & -1.816022 \\
\hline $\mathrm{H}$ & -2.587596 & -5.878586 & 0.908215 \\
\hline $\mathrm{H}$ & 1.362166 & -4.385156 & 1.731677 \\
\hline $\mathrm{H}$ & -0.156451 & 3.081664 & 0.812664 \\
\hline $\mathrm{H}$ & -0.770761 & 6.904088 & -1.060848 \\
\hline $\mathrm{H}$ & 3.134774 & 5.107414 & -1.073216 \\
\hline C & -3.495266 & 1.375925 & -0.520162 \\
\hline $\mathrm{O}$ & -3.011175 & 0.655610 & -1.475320 \\
\hline $\mathrm{H}$ & -2.836214 & 1.656725 & 0.309854 \\
\hline C & -4.421422 & 2.508303 & -0.971104 \\
\hline
\end{tabular}




$\begin{array}{llll}\mathrm{O} & -5.074334 & 2.517160 & -1.989165 \\ \mathrm{O} & -4.416403 & 3.508214 & -0.061868 \\ \mathrm{C} & -5.256652 & 4.632000 & -0.380199 \\ \mathrm{H} & -5.143140 & 5.327563 & 0.451441 \\ \mathrm{H} & -4.934934 & 5.094497 & -1.316704 \\ \mathrm{C} & -4.187758 & -0.800279 & 0.745823 \\ \mathrm{C} & -4.838357 & 0.425006 & 0.483925 \\ \mathrm{H} & -3.296054 & -2.459628 & -0.013786 \\ \mathrm{~N} & -3.931050 & -1.695316 & -0.234526 \\ \mathrm{C} & -4.249091 & -1.695255 & -1.622720 \\ \mathrm{O} & -3.628808 & -2.399460 & -2.385196 \\ \mathrm{O} & -5.327202 & -0.968677 & -1.901941 \\ \mathrm{C} & -5.508660 & -0.642932 & -3.299862 \\ \mathrm{H} & -6.500024 & -0.196304 & -3.361026 \\ \mathrm{H} & -5.442709 & -1.545949 & -3.908362 \\ \mathrm{H} & -4.745377 & 0.083370 & -3.582439 \\ \mathrm{H} & -5.023462 & 1.048459 & 1.352845 \\ \mathrm{H} & -5.620068 & 0.418973 & -0.263644 \\ \mathrm{C} & -3.602716 & -1.093026 & 2.069423 \\ \mathrm{C} & -4.315275 & -0.734169 & 3.228727 \\ \mathrm{C} & -2.354975 & -1.727866 & 2.204220 \\ \mathrm{C} & -3.797280 & -1.013516 & 4.489526 \\ \mathrm{H} & -5.290077 & -0.265420 & 3.138341 \\ \mathrm{C} & -1.835604 & -1.990964 & 3.468315 \\ \mathrm{H} & -1.756237 & -1.970280 & 1.332832 \\ \mathrm{C} & -2.554646 & -1.639874 & 4.611771 \\ \mathrm{H} & -4.363698 & -0.743528 & 5.376091 \\ \mathrm{H} & -0.858854 & -2.456058 & 3.551083 \\ \mathrm{H} & -2.145473 & -1.847223 & 5.596637 \\ \mathrm{H} & -6.298305 & 4.314765 & -0.479822\end{array}$

Catalyst (R)-1 TS Conformation 252

$B 3 L Y P / 6-31 G(d)$ Energy $=-2809.692818$

B3LYP-D3(BJ)/def2-TZVPP-IEF-PCM(DCM) Energy = -2810.982137

B3LYP-D3(BJ)/def2-TZVPP-IEF-PCM(DCM)//B3LYP/6-31G(d) Free Energy (Quasiharmonic) = 2810.338947

Frequencies (Top 3 out of 270)

1. $-306.1391 \mathrm{~cm}-1$

2. $\quad 5.6620 \mathrm{~cm}-1$

3. $\quad 12.1401 \mathrm{~cm}-1$ 
B3LYP/6-31G(d) Molecular Geometry in Cartesian Coordinates

\begin{tabular}{|c|c|c|c|}
\hline C & 3.329237 & -1.087256 & -0.237450 \\
\hline C & 2.049704 & -1.616182 & -0.162057 \\
\hline C & 1.755963 & -2.992017 & -0.404045 \\
\hline C & 2.796334 & -3.792811 & -0.832019 \\
\hline $\mathrm{H}$ & 2.603486 & -4.844330 & -1.027696 \\
\hline C & 4.293162 & 2.942517 & 0.954139 \\
\hline C & 3.613027 & 0.292984 & 0.258610 \\
\hline C & 2.909308 & 1.383983 & -0.227411 \\
\hline C & 3.254478 & 2.736021 & 0.067686 \\
\hline $\mathrm{H}$ & 4.577842 & 3.961541 & 1.202257 \\
\hline $\mathrm{O}$ & 1.011917 & -0.796736 & 0.274627 \\
\hline$P$ & 0.503558 & 0.456439 & -0.630827 \\
\hline 0 & 1.872903 & 1.164954 & -1.134388 \\
\hline C & -2.075224 & -4.810560 & 0.333604 \\
\hline C & -0.919871 & -5.316964 & 0.932129 \\
\hline C & 0.314782 & -4.712324 & 0.695750 \\
\hline C & 0.416281 & -3.592894 & -0.146393 \\
\hline C & -0.750337 & -3.101551 & -0.748270 \\
\hline C & -1.986139 & -3.699951 & -0.507722 \\
\hline $\mathrm{H}$ & -0.978685 & -6.179181 & 1.591685 \\
\hline $\mathrm{H}$ & -2.870165 & -3.282237 & -0.981982 \\
\hline C & 1.448166 & 6.198576 & -1.741378 \\
\hline C & 2.829206 & 6.006067 & -1.791022 \\
\hline C & 3.396912 & 4.870327 & -1.214048 \\
\hline C & 2.596227 & 3.905835 & -0.580181 \\
\hline C & 1.207773 & 4.108112 & -0.536344 \\
\hline C & 0.643936 & 5.246801 & -1.111618 \\
\hline $\mathrm{H}$ & 3.466440 & 6.736103 & -2.283471 \\
\hline $\mathrm{H}$ & -0.432407 & 5.392305 & -1.062851 \\
\hline C & 4.619880 & 0.525349 & 1.261709 \\
\hline C & 4.965641 & 1.874089 & 1.595345 \\
\hline C & 5.963983 & 2.118817 & 2.576951 \\
\hline C & 6.583279 & 1.079138 & 3.230135 \\
\hline C & 6.218050 & -0.254056 & 2.929967 \\
\hline C & 5.265777 & -0.524108 & 1.971791 \\
\hline $\mathrm{H}$ & 6.218778 & 3.149903 & 2.810359 \\
\hline $\mathrm{H}$ & 7.340425 & 1.277612 & 3.983758 \\
\hline $\mathrm{H}$ & 6.688384 & -1.074458 & 3.465239 \\
\hline $\mathrm{H}$ & 4.990419 & -1.551236 & 1.764360 \\
\hline C & 4.374852 & -1.908412 & -0.789158 \\
\hline C & 4.094754 & -3.282599 & -1.077262 \\
\hline
\end{tabular}




\begin{tabular}{|c|c|c|c|}
\hline C & 5.119376 & -4.106956 & -1.616061 \\
\hline C & 6.367347 & -3.597157 & -1.888718 \\
\hline C & 6.637400 & -2.231556 & -1.637424 \\
\hline C & 5.670216 & -1.410732 & -1.099975 \\
\hline $\mathrm{H}$ & 4.890412 & -5.150023 & -1.821308 \\
\hline $\mathrm{H}$ & 7.141017 & -4.234780 & -2.307619 \\
\hline $\mathrm{H}$ & 7.615691 & -1.823457 & -1.876658 \\
\hline $\mathrm{H}$ & 5.890879 & -0.364248 & -0.924825 \\
\hline $\mathrm{O}$ & -0.394397 & 1.301182 & 0.216061 \\
\hline O & -0.083958 & -0.044263 & -1.984421 \\
\hline $\mathrm{H}$ & -1.157398 & -0.173056 & -1.931001 \\
\hline $\mathrm{H}$ & -0.690294 & -2.260839 & -1.425023 \\
\hline $\mathrm{H}$ & -3.037460 & -5.280129 & 0.523159 \\
\hline $\mathrm{H}$ & 1.208134 & -5.096047 & 1.181468 \\
\hline $\mathrm{H}$ & 0.572108 & 3.382229 & -0.040838 \\
\hline $\mathrm{H}$ & 1.002236 & 7.082108 & -2.190758 \\
\hline $\mathrm{H}$ & 4.471271 & 4.715750 & -1.268013 \\
\hline C & -3.308606 & 0.510199 & -2.125901 \\
\hline $\mathrm{O}$ & -2.509834 & -0.414238 & -1.753667 \\
\hline $\mathrm{H}$ & -2.956985 & 1.284974 & -2.825289 \\
\hline C & -4.758094 & 0.152865 & -2.456756 \\
\hline $\mathrm{O}$ & -5.528606 & 0.931634 & -2.980294 \\
\hline $\mathrm{O}$ & -5.059988 & -1.113641 & -2.132942 \\
\hline C & -6.396687 & -1.525357 & -2.470643 \\
\hline $\mathrm{H}$ & -6.453106 & -2.579445 & -2.198319 \\
\hline $\mathrm{H}$ & -7.129080 & -0.941734 & -1.907482 \\
\hline C & -3.938517 & 1.177323 & 0.441819 \\
\hline C & -3.589636 & 1.875935 & -0.729919 \\
\hline $\mathrm{H}$ & -1.969625 & 0.742091 & 0.782392 \\
\hline$N$ & -2.931662 & 0.624999 & 1.158653 \\
\hline C & -2.906585 & 0.108742 & 2.472342 \\
\hline $\mathrm{O}$ & -1.958207 & -0.507864 & 2.893020 \\
\hline $\mathrm{O}$ & -3.998494 & 0.437874 & 3.180441 \\
\hline C & -4.008755 & -0.059730 & 4.531120 \\
\hline $\mathrm{H}$ & -4.960257 & 0.268849 & 4.948796 \\
\hline $\mathrm{H}$ & -3.171848 & 0.358585 & 5.095167 \\
\hline $\mathrm{H}$ & -3.937411 & -1.150048 & 4.537866 \\
\hline $\mathrm{H}$ & -4.371813 & 2.453768 & -1.210179 \\
\hline $\mathrm{H}$ & -2.590565 & 2.302202 & -0.756279 \\
\hline C & -5.357423 & 0.886771 & 0.742007 \\
\hline C & -5.776762 & -0.423112 & 1.034947 \\
\hline C & -6.314246 & 1.909526 & 0.657388 \\
\hline C & -7.124612 & -0.695248 & 1.247667 \\
\hline $\mathrm{H}$ & -5.047921 & -1.226871 & 1.058572 \\
\hline
\end{tabular}




$\begin{array}{llll}\mathrm{C} & -7.661259 & 1.636099 & 0.889916 \\ \mathrm{H} & -5.997295 & 2.923708 & 0.435086 \\ \mathrm{C} & -8.069015 & 0.334483 & 1.184372 \\ \mathrm{H} & -7.440820 & -1.712318 & 1.462054 \\ \mathrm{H} & -8.390494 & 2.439154 & 0.837153 \\ \mathrm{H} & -9.119723 & 0.119902 & 1.359288 \\ \mathrm{H} & -6.576288 & -1.393300 & -3.540442\end{array}$

Catalyst (R)-1 TS Conformation 253

B3LYP/6-31G(d) Energy $=-2809.691112$

B3LYP-D3(BJ)/def2-TZVPP-IEF-PCM(DCM) Energy $=-2810.982596$

B3LYP-D3(BJ)/def2-TZVPP-IEF-PCM(DCM)//B3LYP/6-31G(d) Free Energy (Quasiharmonic) = 2810.33893

Frequencies (Top 3 out of 270)

1. $-283.2610 \mathrm{~cm}-1$

2. $\quad 6.3272 \mathrm{~cm}-1$

3. $12.8371 \mathrm{~cm}-1$

B3LYP/6-31G(d) Molecular Geometry in Cartesian Coordinates

$\begin{array}{llll}\text { C } & 3.275607 & 0.017791 & 0.379553 \\ \text { C } & 2.640140 & 1.164361 & -0.072679 \\ \text { C } & 3.168138 & 2.477597 & 0.119201 \\ \text { C } & 4.295128 & 2.589132 & 0.911484 \\ \text { H } & 4.713379 & 3.575693 & 1.091297 \\ \text { C } & 1.934669 & -3.969204 & -0.551856 \\ \text { C } & 2.808857 & -1.337274 & -0.043241 \\ \text { C } & 1.503555 & -1.735737 & 0.194392 \\ \text { C } & 1.039723 & -3.072525 & 0.002041 \\ \text { H } & 1.637090 & -5.006251 & -0.679056 \\ \text { O } & 1.488569 & 1.033162 & -0.845217 \\ \text { P } & 0.109155 & 0.448125 & -0.217942 \\ \text { O } & 0.615768 & -0.801333 & 0.711379 \\ \text { C } & 1.735427 & 6.037079 & -1.832984 \\ \text { C } & 3.091349 & 5.706054 & -1.848377 \\ \text { C } & 3.531591 & 4.542026 & -1.220890 \\ \text { C } & 2.628601 & 3.688225 & -0.561685 \\ \text { C } & 1.268176 & 4.032222 & -0.554110 \\ \text { C } & 0.829278 & 5.195698 & -1.186194 \\ \text { H } & 3.806938 & 6.346973 & -2.357406\end{array}$




\begin{tabular}{|c|c|c|c|}
\hline $\mathrm{H}$ & -0.230853 & 5.428006 & -1.173440 \\
\hline C & -2.790660 & -4.585321 & 1.269897 \\
\hline C & -2.210943 & -5.023610 & 0.078414 \\
\hline C & -0.992634 & -4.495249 & -0.345875 \\
\hline C & -0.312779 & -3.531926 & 0.418989 \\
\hline C & -0.911739 & -3.095275 & 1.614974 \\
\hline C & -2.138042 & -3.612931 & 2.030835 \\
\hline $\mathrm{H}$ & -2.708453 & -5.776874 & -0.527436 \\
\hline $\mathrm{H}$ & -2.579596 & -3.259627 & 2.959019 \\
\hline C & 3.694492 & -2.258237 & -0.703679 \\
\hline C & 3.239475 & -3.593010 & -0.952069 \\
\hline C & 4.107468 & -4.519384 & -1.591527 \\
\hline C & 5.364550 & -4.142503 & -2.002791 \\
\hline C & 5.803382 & -2.814302 & -1.791417 \\
\hline C & 4.993562 & -1.898604 & -1.156001 \\
\hline $\mathrm{H}$ & 3.750391 & -5.532563 & -1.760827 \\
\hline $\mathrm{H}$ & 6.016620 & -4.856510 & -2.498339 \\
\hline $\mathrm{H}$ & 6.787885 & -2.511442 & -2.137472 \\
\hline $\mathrm{H}$ & 5.341596 & -0.882854 & -1.009728 \\
\hline C & 4.395918 & 0.161106 & 1.271632 \\
\hline C & 4.903960 & 1.473160 & 1.533986 \\
\hline C & 6.006601 & 1.632951 & 2.416392 \\
\hline C & 6.578164 & 0.547529 & 3.038274 \\
\hline C & 6.059766 & -0.747707 & 2.804601 \\
\hline C & 5.000431 & -0.936643 & 1.944107 \\
\hline $\mathrm{H}$ & 6.382869 & 2.636913 & 2.598123 \\
\hline $\mathrm{H}$ & 7.416930 & 0.681958 & 3.715796 \\
\hline $\mathrm{H}$ & 6.496773 & -1.602398 & 3.313958 \\
\hline $\mathrm{H}$ & 4.608677 & -1.934896 & 1.787553 \\
\hline $\mathrm{O}$ & -0.824177 & 0.083787 & -1.318859 \\
\hline $\mathrm{O}$ & -0.380382 & 1.449334 & 0.870704 \\
\hline $\mathrm{H}$ & -1.427071 & 1.499661 & 1.078139 \\
\hline $\mathrm{H}$ & 0.548957 & 3.404166 & -0.044047 \\
\hline $\mathrm{H}$ & 1.387950 & 6.940967 & -2.327201 \\
\hline $\mathrm{H}$ & 4.584361 & 4.275062 & -1.258681 \\
\hline $\mathrm{H}$ & -0.407828 & -2.358278 & 2.228981 \\
\hline $\mathrm{H}$ & -3.739541 & -4.997661 & 1.603634 \\
\hline $\mathrm{H}$ & -0.566409 & -4.823780 & -1.289248 \\
\hline C & -3.565267 & 0.636676 & 1.511560 \\
\hline $\mathrm{O}$ & -2.790242 & 1.657337 & 1.444716 \\
\hline $\mathrm{H}$ & -3.153127 & -0.367226 & 1.325494 \\
\hline C & -4.584533 & 0.625476 & 2.656706 \\
\hline $\mathrm{O}$ & -5.033150 & 1.601110 & 3.207908 \\
\hline $\mathrm{O}$ & -4.922484 & -0.650630 & 2.961705 \\
\hline
\end{tabular}




$\begin{array}{lrrr}\mathrm{C} & -5.878886 & -0.789911 & 4.027252 \\ \mathrm{H} & -6.044576 & -1.862072 & 4.135826 \\ \mathrm{H} & -5.481812 & -0.366307 & 4.953291 \\ \mathrm{C} & -4.074665 & 0.627036 & -1.008881 \\ \mathrm{C} & -4.896686 & 0.771502 & 0.127820 \\ \mathrm{H} & -2.286632 & 1.218989 & -1.739207 \\ \mathrm{~N} & -3.181767 & 1.580699 & -1.375265 \\ \mathrm{C} & -3.081645 & 2.936130 & -0.994424 \\ \mathrm{O} & -2.049011 & 3.547793 & -1.141468 \\ \mathrm{O} & -4.245749 & 3.452178 & -0.583462 \\ \mathrm{C} & -4.152370 & 4.777950 & -0.024740 \\ \mathrm{H} & -3.719674 & 5.468372 & -0.751372 \\ \mathrm{H} & -3.539196 & 4.748720 & 0.878704 \\ \mathrm{H} & -5.177459 & 5.058668 & 0.215741 \\ \mathrm{H} & -5.655364 & 0.006725 & 0.262402 \\ \mathrm{H} & -5.213274 & 1.769587 & 0.397125 \\ \mathrm{C} & -4.017704 & -0.629278 & -1.776644 \\ \mathrm{C} & -3.624190 & -0.605819 & -3.128046 \\ \mathrm{C} & -4.409366 & -1.854531 & -1.206110 \\ \mathrm{C} & -3.633617 & -1.770905 & -3.888567 \\ \mathrm{H} & -3.341859 & 0.333662 & -3.591260 \\ \mathrm{C} & -4.409110 & -3.017033 & -1.969076 \\ \mathrm{H} & -4.679156 & -1.907595 & -0.156561 \\ \mathrm{C} & -4.027573 & -2.979298 & -3.312484 \\ \mathrm{H} & -3.336625 & -1.732834 & -4.932455 \\ \mathrm{H} & -4.696446 & -3.957111 & -1.509467 \\ \mathrm{H} & -4.035371 & -3.888985 & -3.906525 \\ \mathrm{H} & -6.811774 & -0.278442 & 3.774802\end{array}$

Catalyst (R)-1 TS Conformation 254

B3LYP/6-31G(d) Energy $=-2809.690178$

B3LYP-D3(BJ)/def2-TZVPP-IEF-PCM(DCM) Energy $=-2810.981169$

B3LYP-D3(BJ)/def2-TZVPP-IEF-PCM(DCM)//B3LYP/6-31G(d) Free Energy (Quasiharmonic) = 2810.338855

Frequencies (Top 3 out of 270)

1. $-624.4117 \mathrm{~cm}-1$

2. $8.9059 \mathrm{~cm}-1$

3. $12.6388 \mathrm{~cm}-1$

B3LYP/6-31G(d) Molecular Geometry in Cartesian Coordinates 


\begin{tabular}{|c|c|c|c|}
\hline C & -3.496015 & 0.324400 & -0.042588 \\
\hline C & -2.558542 & 1.347392 & -0.036490 \\
\hline C & -2.909666 & 2.719961 & -0.204961 \\
\hline C & -4.236563 & 3.016147 & -0.443049 \\
\hline $\mathrm{H}$ & -4.527814 & 4.055394 & -0.571143 \\
\hline C & -2.555558 & -3.819894 & 0.628383 \\
\hline C & -3.106245 & -1.075601 & 0.297153 \\
\hline C & -2.092366 & -1.707558 & -0.406320 \\
\hline C & -1.826189 & -3.105519 & -0.302186 \\
\hline $\mathrm{H}$ & -2.371942 & -4.885853 & 0.734237 \\
\hline 0 & -1.231079 & 1.048728 & 0.257096 \\
\hline$P$ & -0.308111 & 0.144856 & -0.749438 \\
\hline O & -1.359651 & -0.962985 & -1.327032 \\
\hline C & -0.202277 & 6.054200 & 0.054765 \\
\hline C & -0.002636 & 5.069981 & -0.915398 \\
\hline C & -0.855422 & 3.968544 & -0.991239 \\
\hline C & -1.927602 & 3.837519 & -0.096644 \\
\hline C & -2.121865 & 4.833550 & 0.874612 \\
\hline C & -1.264776 & 5.931866 & 0.952221 \\
\hline $\mathrm{H}$ & 0.820079 & 5.153930 & -1.620383 \\
\hline $\mathrm{H}$ & -1.428541 & 6.690785 & 1.713077 \\
\hline C & 0.889165 & -5.294916 & -2.825249 \\
\hline C & -0.448364 & -5.676540 & -2.715019 \\
\hline C & -1.318464 & -4.947183 & -1.904880 \\
\hline C & -0.869736 & -3.822806 & -1.192469 \\
\hline C & 0.477409 & -3.447650 & -1.310240 \\
\hline C & 1.345694 & -4.180451 & -2.118981 \\
\hline $\mathrm{H}$ & -0.818530 & -6.538597 & -3.263974 \\
\hline $\mathrm{H}$ & 2.387722 & -3.879135 & -2.194933 \\
\hline C & -3.780400 & -1.809806 & 1.334668 \\
\hline C & -3.497517 & -3.204600 & 1.488590 \\
\hline C & -4.158369 & -3.943824 & 2.506763 \\
\hline C & -5.045835 & -3.332570 & 3.361421 \\
\hline C & -5.302912 & -1.947321 & 3.233192 \\
\hline C & -4.690508 & -1.206962 & 2.245922 \\
\hline $\mathrm{H}$ & -3.937001 & -5.004093 & 2.603899 \\
\hline $\mathrm{H}$ & -5.540206 & -3.905796 & 4.140932 \\
\hline $\mathrm{H}$ & -5.985899 & -1.460589 & 3.924180 \\
\hline $\mathrm{H}$ & -4.890338 & -0.144583 & 2.168011 \\
\hline C & -4.853362 & 0.639198 & -0.406830 \\
\hline C & -5.222455 & 2.010416 & -0.586278 \\
\hline C & -6.561977 & 2.338318 & -0.929622 \\
\hline C & -7.503639 & 1.354570 & -1.120420 \\
\hline
\end{tabular}




\begin{tabular}{|c|c|c|c|}
\hline$C$ & -7.134313 & -0.003996 & -0.983152 \\
\hline C & -5.847941 & -0.352394 & -0.634528 \\
\hline $\mathrm{H}$ & -6.823024 & 3.386747 & -1.052874 \\
\hline $\mathrm{H}$ & -8.523432 & 1.615218 & -1.389959 \\
\hline $\mathrm{H}$ & -7.871161 & -0.782535 & -1.161446 \\
\hline $\mathrm{H}$ & -5.582527 & -1.399068 & -0.546856 \\
\hline 0 & 0.806088 & -0.446150 & 0.052894 \\
\hline $\mathrm{O}$ & 0.033286 & 0.947353 & -2.022584 \\
\hline $\mathrm{H}$ & 1.056320 & 1.429373 & -2.148145 \\
\hline $\mathrm{H}$ & -2.947264 & 4.737797 & 1.575260 \\
\hline $\mathrm{H}$ & 0.464011 & 6.911268 & 0.110369 \\
\hline $\mathrm{H}$ & -0.695435 & 3.211431 & -1.750176 \\
\hline $\mathrm{H}$ & 0.841636 & -2.591374 & -0.753743 \\
\hline $\mathrm{H}$ & 1.569245 & -5.860048 & -3.457358 \\
\hline $\mathrm{H}$ & -2.363249 & -5.237728 & -1.834282 \\
\hline C & 3.192444 & 1.840691 & -1.685090 \\
\hline 0 & 2.207130 & 1.908874 & -2.501278 \\
\hline $\mathrm{H}$ & 4.175998 & 2.142549 & -2.066540 \\
\hline C & 3.050980 & 2.303380 & -0.231771 \\
\hline 0 & 4.013539 & 2.571984 & 0.462158 \\
\hline 0 & 1.782488 & 2.379282 & 0.158641 \\
\hline C & 1.548576 & 2.744924 & 1.538215 \\
\hline $\mathrm{H}$ & 2.018847 & 3.706460 & 1.752180 \\
\hline $\mathrm{H}$ & 0.466981 & 2.806148 & 1.631446 \\
\hline C & 4.279643 & -0.342249 & -0.269095 \\
\hline C & 3.619414 & -0.087318 & -1.489431 \\
\hline $\mathrm{H}$ & 2.478581 & -0.393504 & 0.678950 \\
\hline$N$ & 3.500167 & -0.491970 & 0.830209 \\
\hline C & 3.809501 & -0.819506 & 2.164516 \\
\hline 0 & 3.045823 & -0.563873 & 3.067723 \\
\hline 0 & 4.971659 & -1.470884 & 2.285150 \\
\hline C & 5.336588 & -1.813138 & 3.635930 \\
\hline $\mathrm{H}$ & 4.594311 & -2.488140 & 4.067923 \\
\hline $\mathrm{H}$ & 5.408616 & -0.913225 & 4.251356 \\
\hline $\mathrm{H}$ & 6.305780 & -2.304055 & 3.553024 \\
\hline $\mathrm{H}$ & 4.219076 & -0.179855 & -2.388160 \\
\hline $\mathrm{H}$ & 2.598943 & -0.444669 & -1.568183 \\
\hline C & 5.756917 & -0.279009 & -0.197597 \\
\hline C & 6.512308 & -1.018612 & -1.121349 \\
\hline C & 6.416920 & 0.555754 & 0.720423 \\
\hline C & 7.904441 & -0.949108 & -1.110188 \\
\hline $\mathrm{H}$ & 6.007256 & -1.668898 & -1.829495 \\
\hline C & 7.805812 & 0.640023 & 0.709917 \\
\hline $\mathrm{H}$ & 5.836818 & 1.173030 & 1.396285 \\
\hline
\end{tabular}




$\begin{array}{llll}\mathrm{C} & 8.553151 & -0.117372 & -0.196676 \\ \mathrm{H} & 8.479186 & -1.539791 & -1.817670 \\ \mathrm{H} & 8.307411 & 1.304750 & 1.407482 \\ \mathrm{H} & 9.637797 & -0.052636 & -0.195006 \\ \mathrm{H} & 1.953294 & 1.972031 & 2.195973\end{array}$

Catalyst (R)-1 TS Conformation 255

B3LYP/6-31G(d) Energy $=-2809.689399$

B3LYP-D3(BJ)/def2-TZVPP-IEF-PCM(DCM) Energy = -2810.980507

B3LYP-D3(BJ)/def2-TZVPP-IEF-PCM(DCM)//B3LYP/6-31G(d) Free Energy (Quasiharmonic) = 2810.33879

Frequencies (Top 3 out of 270)

1. $-705.6403 \mathrm{~cm}-1$

2. $\quad 10.2543 \mathrm{~cm}-1$

3. $\quad 11.0049 \mathrm{~cm}-1$

B3LYP/6-31G(d) Molecular Geometry in Cartesian Coordinates

$\begin{array}{llll}\mathrm{C} & -3.110202 & -1.315069 & 0.053996 \\ \mathrm{C} & -1.837923 & -1.610686 & -0.407524 \\ \mathrm{C} & -1.192178 & -2.864763 & -0.194737 \\ \mathrm{C} & -1.866431 & -3.797551 & 0.569467 \\ \mathrm{H} & -1.422169 & -4.777033 & 0.725223 \\ \mathrm{C} & -5.038723 & 2.453435 & -0.744821 \\ \mathrm{C} & -3.760633 & -0.022653 & -0.317391 \\ \mathrm{C} & -3.130145 & 1.183070 & -0.042924 \\ \mathrm{C} & -3.766150 & 2.449908 & -0.207379 \\ \mathrm{H} & -5.545810 & 3.404049 & -0.887249 \\ \mathrm{O} & -1.159233 & -0.648879 & -1.148043 \\ \mathrm{P} & -0.579327 & 0.678251 & -0.389858 \\ \mathrm{O} & -1.856015 & 1.158996 & 0.514414 \\ \mathrm{C} & 2.617382 & -3.973777 & -1.870696 \\ \mathrm{C} & 1.691190 & -3.272828 & -2.646792 \\ \mathrm{C} & 0.465566 & -2.885869 & -2.106745 \\ \mathrm{C} & 0.138691 & -3.192618 & -0.773463 \\ \mathrm{C} & 1.085281 & -3.886543 & -0.000750 \\ \mathrm{C} & 2.309681 & -4.276983 & -0.543437 \\ \mathrm{H} & 1.918534 & -3.033286 & -3.682218 \\ \mathrm{H} & 3.023016 & -4.817300 & 0.074032 \\ \mathrm{C} & -2.101113 & 6.225009 & 1.014945\end{array}$




\begin{tabular}{|c|c|c|c|}
\hline C & -3.356200 & 5.818473 & 1.469401 \\
\hline C & -3.874335 & 4.584579 & 1.076855 \\
\hline C & -3.147427 & 3.734311 & 0.227151 \\
\hline C & -1.884899 & 4.151261 & -0.223738 \\
\hline C & -1.371974 & 5.387875 & 0.168215 \\
\hline $\mathrm{H}$ & -3.931839 & 6.458072 & 2.133663 \\
\hline $\mathrm{H}$ & -0.396452 & 5.699715 & -0.196364 \\
\hline C & -5.043173 & 0.005641 & -0.967714 \\
\hline C & -5.687716 & 1.268242 & -1.168278 \\
\hline C & -6.958087 & 1.311584 & -1.804195 \\
\hline C & -7.565386 & 0.161295 & -2.250918 \\
\hline C & -6.916323 & -1.084685 & -2.084431 \\
\hline C & -5.691176 & -1.161310 & -1.459144 \\
\hline $\mathrm{H}$ & -7.435540 & 2.278910 & -1.941549 \\
\hline $\mathrm{H}$ & -8.533763 & 0.206982 & -2.741579 \\
\hline $\mathrm{H}$ & -7.385516 & -1.990282 & -2.459474 \\
\hline $\mathrm{H}$ & -5.203012 & -2.122936 & -1.350858 \\
\hline C & -3.759686 & -2.264760 & 0.918091 \\
\hline C & -3.124100 & -3.525441 & 1.160672 \\
\hline C & -3.761096 & -4.479720 & 1.999744 \\
\hline C & -4.961325 & -4.196986 & 2.608659 \\
\hline C & -5.571402 & -2.937152 & 2.404579 \\
\hline C & -4.989316 & -1.998580 & 1.581022 \\
\hline $\mathrm{H}$ & -3.270714 & -5.436931 & 2.160993 \\
\hline $\mathrm{H}$ & -5.435585 & -4.931121 & 3.254171 \\
\hline $\mathrm{H}$ & -6.506977 & -2.704805 & 2.906035 \\
\hline $\mathrm{H}$ & -5.466050 & -1.035353 & 1.443866 \\
\hline $\mathrm{O}$ & -0.098167 & 1.656700 & -1.400372 \\
\hline $\mathrm{O}$ & 0.449593 & 0.196341 & 0.674560 \\
\hline $\mathrm{H}$ & 1.259630 & 0.983656 & 0.978105 \\
\hline $\mathrm{H}$ & 0.863536 & -4.104040 & 1.039743 \\
\hline $\mathrm{H}$ & 3.568447 & -4.280970 & -2.298018 \\
\hline $\mathrm{H}$ & -0.247996 & -2.351499 & -2.723658 \\
\hline $\mathrm{H}$ & -1.310514 & 3.515783 & -0.889623 \\
\hline $\mathrm{H}$ & -1.694133 & 7.186074 & 1.318691 \\
\hline $\mathrm{H}$ & -4.845751 & 4.264226 & 1.444297 \\
\hline C & 2.765120 & 2.275202 & 0.213902 \\
\hline $\mathrm{O}$ & 2.303711 & 1.626168 & 1.218302 \\
\hline $\mathrm{H}$ & 2.083430 & 2.786796 & -0.473543 \\
\hline C & 4.088115 & 2.998353 & 0.380088 \\
\hline $\mathrm{O}$ & 4.483920 & 3.839514 & -0.403426 \\
\hline $\mathrm{O}$ & 4.749339 & 2.588775 & 1.467931 \\
\hline C & 6.014096 & 3.230139 & 1.710096 \\
\hline $\mathrm{H}$ & 5.889197 & 4.314724 & 1.755208 \\
\hline
\end{tabular}




$\begin{array}{llrr}\mathrm{H} & 6.357300 & 2.837568 & 2.666819 \\ \mathrm{C} & 3.969723 & -0.008682 & -0.634942 \\ \mathrm{C} & 3.199347 & 0.954902 & -1.294719 \\ \mathrm{H} & 2.301749 & -0.763111 & 0.267936 \\ \mathrm{~N} & 3.323591 & -0.789905 & 0.280140 \\ \mathrm{C} & 3.849088 & -1.256482 & 1.502864 \\ \mathrm{O} & 4.997725 & -1.186066 & 1.867602 \\ \mathrm{O} & 2.835376 & -1.795460 & 2.199399 \\ \mathrm{C} & 3.177197 & -2.237836 & 3.523599 \\ \mathrm{H} & 3.940911 & -3.018651 & 3.481268 \\ \mathrm{H} & 2.249367 & -2.625298 & 3.943500 \\ \mathrm{H} & 3.548178 & -1.400120 & 4.118921 \\ \mathrm{H} & 3.656780 & 1.503074 & -2.111012 \\ \mathrm{H} & 2.133187 & 0.787328 & -1.418473 \\ \mathrm{C} & 5.409714 & -0.179512 & -0.902106 \\ \mathrm{C} & 5.988605 & -1.460680 & -0.853521 \\ \mathrm{C} & 6.197008 & 0.904581 & -1.332773 \\ \mathrm{C} & 7.319016 & -1.648674 & -1.213151 \\ \mathrm{H} & 5.384428 & -2.311374 & -0.560156 \\ \mathrm{C} & 7.534258 & 0.713460 & -1.671148 \\ \mathrm{H} & 5.773655 & 1.901764 & -1.388816 \\ \mathrm{C} & 8.099581 & -0.562151 & -1.614011 \\ \mathrm{H} & 7.747951 & -2.646031 & -1.179534 \\ \mathrm{H} & 8.132519 & 1.562932 & -1.988099 \\ \mathrm{H} & 9.140334 & -0.710306 & -1.888482 \\ \mathrm{H} & 6.725206 & 2.979635 & 0.918804\end{array}$

Catalyst (R)-1 TS Conformation 256

B3LYP/6-31G(d) Energy $=-2809.685877$

B3LYP-D3(BJ)/def2-TZVPP-IEF-PCM(DCM) Energy = -2810.980759

B3LYP-D3(BJ)/def2-TZVPP-IEF-PCM(DCM)//B3LYP/6-31G(d) Free Energy (Quasiharmonic) = 2810.338786

Frequencies (Top 3 out of 270)

1. $-716.9616 \mathrm{~cm}-1$

2. $\quad 7.5616 \mathrm{~cm}-1$

3. $\quad 9.9299 \mathrm{~cm}-1$

B3LYP/6-31G(d) Molecular Geometry in Cartesian Coordinates

$\begin{array}{llll}\text { C } & 3.696872 & 0.081307 & 0.223071\end{array}$ 


\begin{tabular}{|c|c|c|c|}
\hline C & 2.999782 & 1.200605 & -0.215254 \\
\hline C & 3.447808 & 2.534468 & 0.033342 \\
\hline C & 4.564292 & 2.692222 & 0.831625 \\
\hline $\mathrm{H}$ & 4.920730 & 3.696870 & 1.043381 \\
\hline C & 2.445617 & -3.853020 & -1.039506 \\
\hline C & 3.297590 & -1.279031 & -0.245459 \\
\hline C & 1.996889 & -1.714398 & -0.054741 \\
\hline C & 1.539959 & -3.012829 & -0.423754 \\
\hline $\mathrm{H}$ & 2.134113 & -4.857062 & -1.316163 \\
\hline $\mathrm{O}$ & 1.884325 & 1.033524 & -1.021346 \\
\hline$P$ & 0.500346 & 0.350311 & -0.463285 \\
\hline $\mathrm{O}$ & 1.089236 & -0.834170 & 0.524490 \\
\hline C & 1.720196 & 6.077060 & -1.697893 \\
\hline C & 0.904955 & 5.171450 & -1.016342 \\
\hline C & 1.442138 & 4.008599 & -0.464804 \\
\hline C & 2.813528 & 3.734050 & -0.583204 \\
\hline C & 3.625061 & 4.652691 & -1.269906 \\
\hline C & 3.084560 & 5.813010 & -1.823510 \\
\hline $\mathrm{H}$ & -0.158366 & 5.370087 & -0.908562 \\
\hline $\mathrm{H}$ & 3.729561 & 6.506034 & -2.357763 \\
\hline C & -2.457587 & -4.432325 & 0.297417 \\
\hline C & -1.894769 & -4.518122 & -0.976968 \\
\hline C & -0.605280 & -4.038419 & -1.208058 \\
\hline C & 0.145753 & -3.465288 & -0.170314 \\
\hline C & -0.432688 & -3.381462 & 1.106404 \\
\hline C & -1.720982 & -3.861410 & 1.338183 \\
\hline $\mathrm{H}$ & -2.460446 & -4.955438 & -1.795743 \\
\hline $\mathrm{H}$ & -2.147568 & -3.795153 & 2.335790 \\
\hline C & 4.211738 & -2.139768 & -0.947891 \\
\hline C & 3.771418 & -3.448212 & -1.332330 \\
\hline C & 4.666108 & -4.313555 & -2.018372 \\
\hline C & 5.936793 & -3.902407 & -2.346489 \\
\hline C & 6.360962 & -2.596871 & -2.005235 \\
\hline C & 5.523654 & -1.740211 & -1.324862 \\
\hline $\mathrm{H}$ & 4.318232 & -5.307144 & -2.291251 \\
\hline $\mathrm{H}$ & 6.609749 & -4.570127 & -2.877451 \\
\hline $\mathrm{H}$ & 7.355896 & -2.263295 & -2.287550 \\
\hline $\mathrm{H}$ & 5.861918 & -0.740048 & -1.081940 \\
\hline C & 4.798270 & 0.265387 & 1.128382 \\
\hline C & 5.235059 & 1.595797 & 1.425483 \\
\hline C & 6.323709 & 1.791541 & 2.317911 \\
\hline C & 6.948842 & 0.722736 & 2.916976 \\
\hline C & 6.500612 & -0.592240 & 2.649147 \\
\hline C & 5.456594 & -0.815282 & 1.778318 \\
\hline
\end{tabular}




\begin{tabular}{|c|c|c|c|}
\hline $\mathrm{H}$ & 6.646104 & 2.809117 & 2.526114 \\
\hline $\mathrm{H}$ & 7.776566 & 0.884561 & 3.602103 \\
\hline $\mathrm{H}$ & 6.980789 & -1.434875 & 3.139522 \\
\hline $\mathrm{H}$ & 5.118818 & -1.828367 & 1.591942 \\
\hline $\mathrm{O}$ & -0.310141 & -0.145551 & -1.605032 \\
\hline 0 & -0.167651 & 1.309314 & 0.550791 \\
\hline $\mathrm{H}$ & -1.311469 & 1.603028 & 0.339542 \\
\hline $\mathrm{H}$ & 4.685040 & 4.442107 & -1.384843 \\
\hline $\mathrm{H}$ & 1.295484 & 6.979895 & -2.129277 \\
\hline $\mathrm{H}$ & 0.801585 & 3.318532 & 0.072152 \\
\hline $\mathrm{H}$ & 0.140130 & -2.953844 & 1.923119 \\
\hline $\mathrm{H}$ & -3.460823 & -4.809134 & 0.479552 \\
\hline $\mathrm{H}$ & -0.178944 & -4.085742 & -2.205850 \\
\hline C & -2.968459 & 1.235285 & -0.845490 \\
\hline $\mathrm{O}$ & -2.478777 & 1.896636 & 0.147912 \\
\hline $\mathrm{H}$ & -2.283403 & 0.776675 & -1.568757 \\
\hline C & -4.227746 & 1.778110 & -1.493688 \\
\hline $\mathrm{O}$ & -4.567267 & 1.479957 & -2.621490 \\
\hline $\mathrm{O}$ & -4.905693 & 2.609505 & -0.689366 \\
\hline C & -6.083326 & 3.202153 & -1.267999 \\
\hline $\mathrm{H}$ & -5.824265 & 3.752990 & -2.175391 \\
\hline $\mathrm{H}$ & -6.471590 & 3.877473 & -0.505605 \\
\hline C & -4.573945 & -0.314775 & 0.641814 \\
\hline C & -3.494181 & -0.573089 & -0.212113 \\
\hline $\mathrm{H}$ & -5.237168 & 0.761879 & 2.231072 \\
\hline$N$ & -4.423057 & 0.291637 & 1.853530 \\
\hline C & -3.316872 & 0.505519 & 2.712502 \\
\hline $\mathrm{O}$ & -3.445295 & 1.222485 & 3.678497 \\
\hline $\mathrm{O}$ & -2.245655 & -0.201952 & 2.376816 \\
\hline C & -1.087669 & -0.004142 & 3.227308 \\
\hline $\mathrm{H}$ & -0.285840 & -0.550575 & 2.737848 \\
\hline $\mathrm{H}$ & -1.299774 & -0.394265 & 4.225556 \\
\hline $\mathrm{H}$ & -0.843219 & 1.056380 & 3.277471 \\
\hline $\mathrm{H}$ & -3.696654 & -1.174084 & -1.091225 \\
\hline $\mathrm{H}$ & -2.517843 & -0.741237 & 0.220564 \\
\hline C & -5.977378 & -0.583600 & 0.251631 \\
\hline C & -6.964831 & -0.770968 & 1.240417 \\
\hline C & -6.352016 & -0.708742 & -1.100769 \\
\hline C & -8.282047 & -1.053976 & 0.889205 \\
\hline $\mathrm{H}$ & -6.698245 & -0.746779 & 2.292789 \\
\hline C & -7.673508 & -0.980742 & -1.445366 \\
\hline $\mathrm{H}$ & -5.624018 & -0.558277 & -1.888391 \\
\hline C & -8.643296 & -1.153189 & -0.455357 \\
\hline $\mathrm{H}$ & -9.023057 & -1.208003 & 1.668149 \\
\hline
\end{tabular}




$\begin{array}{llll}\mathrm{H} & -7.943684 & -1.058315 & -2.494361 \\ \mathrm{H} & -9.671111 & -1.373063 & -0.729625 \\ \mathrm{H} & -6.818772 & 2.431613 & -1.513307\end{array}$

Catalyst (R)-1 TS Conformation 257

B3LYP/6-31G(d) Energy $=-2809.689907$

B3LYP-D3(BJ)/def2-TZVPP-IEF-PCM(DCM) Energy $=-2810.981011$

B3LYP-D3(BJ)/def2-TZVPP-IEF-PCM(DCM)//B3LYP/6-31G(d) Free Energy (Quasiharmonic) = 2810.338776

Frequencies (Top 3 out of 270)

1. $-510.2941 \mathrm{~cm}-1$

2. $\quad 10.2056 \mathrm{~cm}-1$

3. $10.7431 \mathrm{~cm}-1$

B3LYP/6-31G(d) Molecular Geometry in Cartesian Coordinates

$\begin{array}{llll}\text { C } & -3.285541 & -0.611910 & 0.500821 \\ \text { C } & -2.439902 & -1.415463 & -0.248744 \\ \text { C } & -2.346812 & -2.827082 & -0.079295 \\ \text { C } & -3.082541 & -3.393718 & 0.942535 \\ \text { H } & -3.046397 & -4.470518 & 1.085853 \\ \text { C } & -3.477007 & 3.622494 & -0.306852 \\ \text { C } & -3.393288 & 0.843997 & 0.186241 \\ \text { C } & -2.247953 & 1.623609 & 0.176080 \\ \text { C } & -2.257710 & 3.032283 & -0.038736 \\ \text { H } & -3.523206 & 4.698209 & -0.455608 \\ \text { O } & -1.658072 & -0.828040 & -1.239870 \\ \text { P } & -0.375980 & 0.074455 & -0.779511 \\ \text { O } & -1.024078 & 1.006350 & 0.406601 \\ \text { C } & -0.098738 & -5.448309 & -2.642437 \\ \text { C } & -0.968454 & -4.504412 & -3.195312 \\ \text { C } & -1.669248 & -3.625180 & -2.370883 \\ \text { C } & -1.524791 & -3.685155 & -0.974838 \\ \text { C } & -0.643000 & -4.631866 & -0.431129 \\ \text { C } & 0.066681 & -5.504006 & -1.257625 \\ \text { H } & -1.107823 & -4.456372 & -4.272430 \\ \text { H } & 0.749762 & -6.225444 & -0.817102 \\ \text { C } & 1.253201 & 5.508768 & 0.179677 \\ \text { C } & 0.386366 & 5.605269 & -0.909380 \\ \text { C } & -0.739559 & 4.785666 & -0.983551\end{array}$




\begin{tabular}{|c|c|c|c|}
\hline C & -1.018583 & 3.852282 & 0.026888 \\
\hline C & -0.133823 & 3.757569 & 1.114194 \\
\hline C & 0.988163 & 4.581653 & 1.190452 \\
\hline $\mathrm{H}$ & 0.589480 & 6.313594 & -1.708090 \\
\hline $\mathrm{H}$ & 1.652636 & 4.504322 & 2.047604 \\
\hline C & -4.645407 & 1.460534 & -0.156777 \\
\hline C & -4.676147 & 2.873106 & -0.395939 \\
\hline C & -5.908739 & 3.497367 & -0.729191 \\
\hline C & -7.064233 & 2.761793 & -0.853687 \\
\hline C & -7.029917 & 1.361669 & -0.654236 \\
\hline C & -5.854552 & 0.728580 & -0.314273 \\
\hline $\mathrm{H}$ & -5.916391 & 4.571896 & -0.896333 \\
\hline $\mathrm{H}$ & -7.999225 & 3.249331 & -1.115729 \\
\hline $\mathrm{H}$ & -7.938745 & 0.778387 & -0.775397 \\
\hline $\mathrm{H}$ & -5.843636 & -0.346180 & -0.174786 \\
\hline C & -3.998873 & -1.206233 & 1.598371 \\
\hline C & -3.890970 & -2.619086 & 1.810263 \\
\hline C & -4.593580 & -3.218863 & 2.890349 \\
\hline C & -5.351454 & -2.459193 & 3.750650 \\
\hline C & -5.431343 & -1.058889 & 3.565734 \\
\hline C & -4.775207 & -0.449317 & 2.519003 \\
\hline $\mathrm{H}$ & -4.509671 & -4.294159 & 3.029173 \\
\hline $\mathrm{H}$ & -5.879072 & -2.927984 & 4.576755 \\
\hline $\mathrm{H}$ & -6.012259 & -0.456775 & 4.259185 \\
\hline $\mathrm{H}$ & -4.838739 & 0.625786 & 2.397871 \\
\hline 0 & 0.754448 & -0.683802 & -0.171304 \\
\hline $\mathrm{O}$ & -0.127491 & 0.940265 & -2.031926 \\
\hline $\mathrm{H}$ & 0.918308 & 1.246469 & -2.287251 \\
\hline $\mathrm{H}$ & -0.500723 & -4.668786 & 0.645122 \\
\hline $\mathrm{H}$ & 0.446086 & -6.133567 & -3.286682 \\
\hline $\mathrm{H}$ & -2.344831 & -2.896754 & -2.807749 \\
\hline $\mathrm{H}$ & -0.335216 & 3.043975 & 1.906486 \\
\hline $\mathrm{H}$ & 2.129055 & 6.149627 & 0.239917 \\
\hline $\mathrm{H}$ & -1.400338 & 4.849914 & -1.843327 \\
\hline C & 3.127683 & 1.116020 & -2.067734 \\
\hline $\mathrm{O}$ & 2.124100 & 1.753806 & -2.536081 \\
\hline $\mathrm{H}$ & 4.123509 & 1.544627 & -2.249340 \\
\hline C & 3.199435 & -0.413970 & -2.184540 \\
\hline $\mathrm{O}$ & 4.124657 & -1.077233 & -1.754061 \\
\hline $\mathrm{O}$ & 2.171704 & -0.904284 & -2.873184 \\
\hline C & 2.110927 & -2.341116 & -2.971643 \\
\hline $\mathrm{H}$ & 1.979235 & -2.771591 & -1.977059 \\
\hline $\mathrm{H}$ & 1.240620 & -2.551064 & -3.590182 \\
\hline C & 3.931636 & 0.533252 & 0.590833 \\
\hline
\end{tabular}




$\begin{array}{llll}\mathrm{C} & 3.147785 & 1.464030 & -0.118640 \\ \mathrm{H} & 2.361641 & -0.756303 & 0.658140 \\ \mathrm{~N} & 3.326867 & -0.610531 & 1.000340 \\ \mathrm{C} & 3.749666 & -1.648137 & 1.845805 \\ \mathrm{O} & 3.122458 & -2.678029 & 1.945554 \\ \mathrm{O} & 4.852033 & -1.339719 & 2.544502 \\ \mathrm{C} & 5.312754 & -2.375851 & 3.429583 \\ \mathrm{H} & 6.217525 & -1.977251 & 3.888154 \\ \mathrm{H} & 5.531787 & -3.288269 & 2.869741 \\ \mathrm{H} & 4.556359 & -2.591946 & 4.187949 \\ \mathrm{H} & 3.557400 & 2.464376 & -0.203081 \\ \mathrm{H} & 2.079189 & 1.424973 & 0.051299 \\ \mathrm{C} & 5.384368 & 0.777353 & 0.759477 \\ \mathrm{C} & 6.342011 & -0.150939 & 0.317403 \\ \mathrm{C} & 5.810331 & 1.999495 & 1.301519 \\ \mathrm{C} & 7.697776 & 0.143583 & 0.425511 \\ \mathrm{H} & 6.012188 & -1.071156 & -0.149866 \\ \mathrm{C} & 7.170578 & 2.279308 & 1.428423 \\ \mathrm{H} & 5.073597 & 2.718717 & 1.647256 \\ \mathrm{C} & 8.116375 & 1.353177 & 0.988020 \\ \mathrm{H} & 8.431935 & -0.570809 & 0.063419 \\ \mathrm{H} & 7.488566 & 3.221615 & 1.865463 \\ \mathrm{H} & 9.176653 & 1.574729 & 1.075001 \\ \mathrm{H} & 3.024134 & -2.728219 & -3.430289\end{array}$

Catalyst (R)-1 TS Conformation 258

B3LYP/6-31G(d) Energy $=-2809.690328$

B3LYP-D3(BJ)/def2-TZVPP-IEF-PCM(DCM) Energy $=-2810.981806$

B3LYP-D3(BJ)/def2-TZVPP-IEF-PCM(DCM)//B3LYP/6-31G(d) Free Energy (Quasiharmonic) = 2810.33875

Frequencies (Top 3 out of 270)

1. $-376.4444 \mathrm{~cm}-1$

2. $8.5826 \mathrm{~cm}-1$

3. $11.6976 \mathrm{~cm}-1$

B3LYP/6-31G(d) Molecular Geometry in Cartesian Coordinates

$\begin{array}{llll}C & 3.028321 & 0.279015 & 0.307842 \\ C & 2.157996 & 1.304148 & -0.018501 \\ C & 2.354011 & 2.650638 & 0.408457\end{array}$




\begin{tabular}{|c|c|c|c|}
\hline C & 3.386661 & 2.887984 & 1.295659 \\
\hline $\mathrm{H}$ & 3.579696 & 3.907339 & 1.618856 \\
\hline C & 2.657430 & -3.672561 & -1.330362 \\
\hline C & 2.879638 & -1.052677 & -0.343003 \\
\hline C & 1.694152 & -1.764826 & -0.230470 \\
\hline C & 1.575712 & -3.117827 & -0.672530 \\
\hline $\mathrm{H}$ & 2.583708 & -4.697701 & -1.683133 \\
\hline 0 & 1.053862 & 1.002128 & -0.816447 \\
\hline$P$ & -0.154870 & 0.151195 & -0.100909 \\
\hline O & 0.622806 & -1.193924 & 0.445406 \\
\hline C & 0.483464 & 6.179932 & -1.167106 \\
\hline C & 0.613227 & 6.010139 & 0.212577 \\
\hline C & 1.160397 & 4.833753 & 0.724979 \\
\hline C & 1.588032 & 3.805356 & -0.130304 \\
\hline C & 1.414173 & 3.970882 & -1.514450 \\
\hline C & 0.876433 & 5.150626 & -2.026239 \\
\hline $\mathrm{H}$ & 0.298361 & 6.797720 & 0.892645 \\
\hline $\mathrm{H}$ & 0.779920 & 5.271706 & -3.102300 \\
\hline C & -1.719811 & -5.805570 & -0.043543 \\
\hline C & -0.437597 & -6.130339 & 0.401011 \\
\hline C & 0.609822 & -5.229349 & 0.215650 \\
\hline C & 0.395044 & -3.986477 & -0.406650 \\
\hline C & -0.902627 & -3.660828 & -0.827996 \\
\hline C & -1.947635 & -4.571555 & -0.656297 \\
\hline $\mathrm{H}$ & -0.249630 & -7.083457 & 0.889029 \\
\hline $\mathrm{H}$ & -2.940184 & -4.303268 & -0.998948 \\
\hline C & 3.961701 & -1.610011 & -1.108445 \\
\hline C & 3.840482 & -2.946577 & -1.602177 \\
\hline C & 4.901123 & -3.514819 & -2.358392 \\
\hline C & 6.035138 & -2.789344 & -2.639523 \\
\hline C & 6.147543 & -1.456727 & -2.177347 \\
\hline C & 5.141449 & -0.883140 & -1.431316 \\
\hline $\mathrm{H}$ & 4.791887 & -4.534808 & -2.719423 \\
\hline $\mathrm{H}$ & 6.838535 & -3.230453 & -3.223162 \\
\hline $\mathrm{H}$ & 7.034403 & -0.876813 & -2.418485 \\
\hline $\mathrm{H}$ & 5.240511 & 0.142540 & -1.095665 \\
\hline C & 4.058194 & 0.526248 & 1.279884 \\
\hline C & 4.223059 & 1.855354 & 1.783956 \\
\hline C & 5.233065 & 2.117233 & 2.748606 \\
\hline C & 6.034958 & 1.105837 & 3.224012 \\
\hline C & 5.853897 & -0.215076 & 2.750952 \\
\hline C & 4.895110 & -0.497455 & 1.802701 \\
\hline $\mathrm{H}$ & 5.351699 & 3.135226 & 3.112247 \\
\hline $\mathrm{H}$ & 6.799159 & 1.315295 & 3.967485 \\
\hline
\end{tabular}




\begin{tabular}{|c|c|c|c|}
\hline $\mathrm{H}$ & 6.474437 & -1.016514 & 3.142725 \\
\hline $\mathrm{H}$ & 4.762354 & -1.516406 & 1.458222 \\
\hline 0 & -1.212716 & -0.154956 & -1.106556 \\
\hline 0 & -0.500741 & 0.913065 & 1.194693 \\
\hline $\mathrm{H}$ & -1.505703 & 1.107474 & 1.597227 \\
\hline $\mathrm{H}$ & 1.731596 & 3.183712 & -2.190629 \\
\hline $\mathrm{H}$ & 0.079553 & 7.105822 & -1.569293 \\
\hline $\mathrm{H}$ & 1.261348 & 4.706242 & 1.799019 \\
\hline $\mathrm{H}$ & -1.094757 & -2.702312 & -1.299782 \\
\hline $\mathrm{H}$ & -2.538550 & -6.508630 & 0.088329 \\
\hline $\mathrm{H}$ & 1.608625 & -5.481661 & 0.561662 \\
\hline C & -3.704329 & 0.894417 & 2.321123 \\
\hline $\mathrm{O}$ & -2.616250 & 1.578664 & 2.223951 \\
\hline $\mathrm{H}$ & -4.412452 & 1.231013 & 3.098146 \\
\hline C & -3.646919 & -0.648017 & 2.371751 \\
\hline $\mathrm{O}$ & -4.631898 & -1.354791 & 2.489038 \\
\hline O & -2.393761 & -1.094043 & 2.320360 \\
\hline C & -2.214152 & -2.523003 & 2.429246 \\
\hline $\mathrm{H}$ & -2.785154 & -3.035749 & 1.654334 \\
\hline $\mathrm{H}$ & -1.147888 & -2.686263 & 2.287169 \\
\hline C & -4.271691 & 1.000883 & -0.270694 \\
\hline C & -4.958666 & 1.171212 & 0.957646 \\
\hline $\mathrm{H}$ & -3.097068 & -0.353581 & -1.229027 \\
\hline$N$ & -4.039323 & -0.225260 & -0.828655 \\
\hline C & -4.781612 & -1.411055 & -0.732111 \\
\hline $\mathrm{O}$ & -4.319629 & -2.478013 & -1.071181 \\
\hline $\mathrm{O}$ & -6.034652 & -1.203669 & -0.312778 \\
\hline C & -6.794559 & -2.400653 & -0.051372 \\
\hline $\mathrm{H}$ & -6.356721 & -2.929683 & 0.797900 \\
\hline $\mathrm{H}$ & -6.806361 & -3.044474 & -0.932832 \\
\hline $\mathrm{H}$ & -7.798606 & -2.052688 & 0.189963 \\
\hline $\mathrm{H}$ & -5.301101 & 2.184648 & 1.142320 \\
\hline $\mathrm{H}$ & -5.674184 & 0.407460 & 1.234731 \\
\hline C & -3.625091 & 2.126410 & -0.936315 \\
\hline C & -3.270151 & 3.289042 & -0.219826 \\
\hline C & -3.409192 & 2.084748 & -2.331110 \\
\hline C & -2.717497 & 4.375126 & -0.889320 \\
\hline $\mathrm{H}$ & -3.368615 & 3.309897 & 0.858479 \\
\hline C & -2.886413 & 3.186393 & -2.993580 \\
\hline $\mathrm{H}$ & -3.691425 & 1.201159 & -2.893262 \\
\hline C & -2.539617 & 4.333128 & -2.273530 \\
\hline $\mathrm{H}$ & -2.410591 & 5.252425 & -0.329899 \\
\hline $\mathrm{H}$ & -2.746762 & 3.152520 & -4.069991 \\
\hline $\mathrm{H}$ & -2.122954 & 5.192151 & -2.789917 \\
\hline
\end{tabular}


$\mathrm{H}$

Catalyst (R)-1 TS Conformation 259

$B 3 L Y P / 6-31 G(d)$ Energy $=-2809.685226$

B3LYP-D3(BJ)/def2-TZVPP-IEF-PCM(DCM) Energy = -2810.979759

B3LYP-D3(BJ)/def2-TZVPP-IEF-PCM(DCM)//B3LYP/6-31G(d) Free Energy (Quasiharmonic) = 2810.338734

Frequencies (Top 3 out of 270)

1. $-748.5663 \mathrm{~cm}-1$

2. $\quad 9.9225 \mathrm{~cm}-1$

3. $\quad 11.3049 \mathrm{~cm}-1$

B3LYP/6-31G(d) Molecular Geometry in Cartesian Coordinates

$\begin{array}{llll}\mathrm{C} & 3.575496 & 0.162956 & 0.335989 \\ \mathrm{C} & 2.910155 & 1.306754 & -0.086056 \\ \mathrm{C} & 3.288662 & 2.619957 & 0.326918 \\ \mathrm{C} & 4.310182 & 2.729371 & 1.249117 \\ \mathrm{H} & 4.615090 & 3.718328 & 1.581149 \\ \mathrm{C} & 2.572781 & -3.726115 & -1.248506 \\ \mathrm{C} & 3.260098 & -1.166491 & -0.267733 \\ \mathrm{C} & 1.956992 & -1.634678 & -0.258166 \\ \mathrm{C} & 1.577729 & -2.929993 & -0.716557 \\ \mathrm{H} & 2.326793 & -4.729901 & -1.585017 \\ \mathrm{O} & 1.905475 & 1.203648 & -1.039203 \\ \mathrm{P} & 0.494973 & 0.427908 & -0.754637 \\ \mathrm{O} & 0.961276 & -0.796823 & 0.233310 \\ \mathrm{C} & 1.589303 & 6.250495 & -1.238643 \\ \mathrm{C} & 0.757799 & 5.284578 & -0.668123 \\ \mathrm{C} & 1.291476 & 4.095334 & -0.172788 \\ \mathrm{C} & 2.672141 & 3.853503 & -0.238260 \\ \mathrm{C} & 3.500008 & 4.833117 & -0.809602 \\ \mathrm{C} & 2.963941 & 6.020996 & -1.307183 \\ \mathrm{H} & -0.313718 & 5.455954 & -0.603985 \\ \mathrm{H} & 3.621044 & 6.763455 & -1.752854 \\ \mathrm{C} & -2.433802 & -4.472595 & -0.475482 \\ \mathrm{C} & -1.873337 & -3.811752 & 0.620490 \\ \mathrm{C} & -0.581774 & -3.291672 & 0.544949 \\ \mathrm{C} & 0.177559 & -3.424342 & -0.630616 \\ \mathrm{C} & -0.400542 & -4.085560 & -1.726427\end{array}$




\begin{tabular}{|c|c|c|c|}
\hline C & -1.692061 & -4.606488 & -1.650051 \\
\hline $\mathrm{H}$ & -2.444858 & -3.699129 & 1.538446 \\
\hline $\mathrm{H}$ & -2.120197 & -5.110259 & -2.512793 \\
\hline C & 4.269643 & -1.976135 & -0.896699 \\
\hline C & 3.910258 & -3.277125 & -1.378224 \\
\hline C & 4.899523 & -4.092554 & -1.991922 \\
\hline C & 6.186802 & -3.638492 & -2.159740 \\
\hline C & 6.534604 & -2.338997 & -1.722549 \\
\hline C & 5.603839 & -1.531361 & -1.106633 \\
\hline $\mathrm{H}$ & 4.611994 & -5.081840 & -2.340178 \\
\hline $\mathrm{H}$ & 6.932595 & -4.267720 & -2.637706 \\
\hline $\mathrm{H}$ & 7.545113 & -1.971159 & -1.878656 \\
\hline $\mathrm{H}$ & 5.884850 & -0.534848 & -0.787325 \\
\hline C & 4.564135 & 0.288843 & 1.373941 \\
\hline C & 4.939583 & 1.596515 & 1.819523 \\
\hline C & 5.921677 & 1.734537 & 2.837428 \\
\hline C & 6.498568 & 0.629583 & 3.418656 \\
\hline C & 6.105198 & -0.665023 & 3.005842 \\
\hline C & 5.166646 & -0.831281 & 2.011162 \\
\hline $\mathrm{H}$ & 6.198800 & 2.736446 & 3.156813 \\
\hline $\mathrm{H}$ & 7.243773 & 0.746651 & 4.200708 \\
\hline $\mathrm{H}$ & 6.542726 & -1.538125 & 3.482536 \\
\hline $\mathrm{H}$ & 4.869155 & -1.830813 & 1.716226 \\
\hline $\mathrm{O}$ & -0.118225 & 0.018786 & -2.044625 \\
\hline $\mathrm{O}$ & -0.390592 & 1.257597 & 0.219979 \\
\hline $\mathrm{H}$ & -1.362333 & 1.821419 & -0.261644 \\
\hline $\mathrm{H}$ & 4.569222 & 4.650646 & -0.877898 \\
\hline $\mathrm{H}$ & 1.169035 & 7.174627 & -1.627008 \\
\hline $\mathrm{H}$ & 0.641006 & 3.357957 & 0.283589 \\
\hline $\mathrm{H}$ & 0.162160 & -4.169763 & -2.651645 \\
\hline $\mathrm{H}$ & -3.439296 & -4.881236 & -0.412767 \\
\hline $\mathrm{H}$ & -0.152550 & -2.786574 & 1.403835 \\
\hline C & -2.927019 & 1.561067 & -1.567594 \\
\hline $\mathrm{O}$ & -2.452392 & 2.197817 & -0.563492 \\
\hline $\mathrm{H}$ & -2.258472 & 1.206397 & -2.356354 \\
\hline C & -4.323864 & 1.898364 & -2.048720 \\
\hline $\mathrm{O}$ & -4.749981 & 1.531627 & -3.123707 \\
\hline $\mathrm{O}$ & -5.003047 & 2.639119 & -1.162785 \\
\hline C & -6.336108 & 3.001667 & -1.566569 \\
\hline $\mathrm{H}$ & -6.953896 & 2.107548 & -1.682676 \\
\hline $\mathrm{H}$ & -6.311646 & 3.548595 & -2.512165 \\
\hline C & -3.728386 & -0.439991 & 0.189628 \\
\hline C & -3.230761 & -0.483747 & -1.108156 \\
\hline $\mathrm{H}$ & -1.935580 & 0.226675 & 0.958381 \\
\hline
\end{tabular}




$\begin{array}{llll}\mathrm{N} & -2.865622 & -0.132315 & 1.207110 \\ \mathrm{C} & -2.965693 & -0.386468 & 2.586024 \\ \mathrm{O} & -2.201659 & 0.100751 & 3.385543 \\ \mathrm{O} & -3.946444 & -1.257906 & 2.876402 \\ \mathrm{C} & -4.111944 & -1.528400 & 4.280877 \\ \mathrm{H} & -4.347736 & -0.608780 & 4.821927 \\ \mathrm{H} & -3.199776 & -1.964880 & 4.693927 \\ \mathrm{H} & -4.940709 & -2.233627 & 4.339585 \\ \mathrm{H} & -3.916731 & -0.738410 & -1.907698 \\ \mathrm{H} & -2.183387 & -0.716062 & -1.279570 \\ \mathrm{C} & -5.184103 & -0.509951 & 0.441921 \\ \mathrm{C} & -5.958877 & -1.486946 & -0.201440 \\ \mathrm{C} & -5.817707 & 0.444295 & 1.257094 \\ \mathrm{C} & -7.340499 & -1.521809 & -0.019419 \\ \mathrm{H} & -5.469813 & -2.232064 & -0.821569 \\ \mathrm{C} & -7.199191 & 0.415527 & 1.423061 \\ \mathrm{H} & -5.227302 & 1.226354 & 1.724182 \\ \mathrm{C} & -7.963004 & -0.570665 & 0.790951 \\ \mathrm{H} & -7.929636 & -2.290828 & -0.510651 \\ \mathrm{H} & -7.682685 & 1.164663 & 2.043894 \\ \mathrm{H} & -9.040607 & -0.594637 & 0.928223 \\ \mathrm{H} & -6.719706 & 3.632651 & -0.765108\end{array}$

Catalyst (R)-1 TS Conformation 260

B3LYP/6-31G(d) Energy $=-2809.685375$

B3LYP-D3(BJ)/def2-TZVPP-IEF-PCM(DCM) Energy = -2810.979945

B3LYP-D3(BJ)/def2-TZVPP-IEF-PCM(DCM)//B3LYP/6-31G(d) Free Energy (Quasiharmonic) = 2810.338723

Frequencies (Top 3 out of 270)

1. $-612.7270 \mathrm{~cm}-1$

2. $\quad 6.4226 \mathrm{~cm}-1$

3. $10.0340 \mathrm{~cm}-1$

B3LYP/6-31G(d) Molecular Geometry in Cartesian Coordinates

$\begin{array}{llll}\text { C } & -2.970404 & -0.200159 & 0.185757 \\ \text { C } & -2.514540 & -1.200224 & -0.657626 \\ \text { C } & -2.766307 & -2.588328 & -0.446697 \\ \text { C } & -3.461565 & -2.934066 & 0.695781 \\ \text { H } & -3.697970 & -3.979467 & 0.875605\end{array}$




\begin{tabular}{|c|c|c|c|}
\hline C & -2.257394 & 3.964275 & -0.669000 \\
\hline C & -2.752064 & 1.231162 & -0.178895 \\
\hline C & -1.472638 & 1.703533 & -0.444891 \\
\hline C & -1.193042 & 3.084401 & -0.674352 \\
\hline $\mathrm{H}$ & -2.067991 & 5.020305 & -0.842787 \\
\hline $\mathrm{O}$ & -1.782683 & -0.829901 & -1.778488 \\
\hline$P$ & -0.225306 & -0.385885 & -1.548663 \\
\hline 0 & -0.401687 & 0.820307 & -0.398161 \\
\hline C & -1.536063 & -5.696814 & -3.153473 \\
\hline C & -2.110326 & -4.525885 & -3.652209 \\
\hline C & -2.492536 & -3.503080 & -2.786041 \\
\hline C & -2.311640 & -3.635643 & -1.399067 \\
\hline C & -1.729343 & -4.816595 & -0.910619 \\
\hline C & -1.344766 & -5.837630 & -1.778447 \\
\hline $\mathrm{H}$ & -2.262364 & -4.406023 & -4.721598 \\
\hline $\mathrm{H}$ & -0.886244 & -6.738671 & -1.379559 \\
\hline C & 2.705564 & 4.775892 & -1.357327 \\
\hline C & 1.908220 & 5.231269 & -0.306555 \\
\hline C & 0.657352 & 4.656337 & -0.078652 \\
\hline C & 0.183480 & 3.614016 & -0.892102 \\
\hline C & 0.995396 & 3.156936 & -1.943957 \\
\hline C & 2.243561 & 3.739774 & -2.172641 \\
\hline $\mathrm{H}$ & 2.257733 & 6.034253 & 0.337396 \\
\hline $\mathrm{H}$ & 2.854661 & 3.380874 & -2.997162 \\
\hline C & -3.859745 & 2.142759 & -0.287265 \\
\hline C & -3.595891 & 3.531675 & -0.512107 \\
\hline C & -4.680238 & 4.445879 & -0.604851 \\
\hline C & -5.981333 & 4.011327 & -0.508301 \\
\hline C & -6.248306 & 2.634178 & -0.324283 \\
\hline C & -5.218337 & 1.725974 & -0.215634 \\
\hline $\mathrm{H}$ & -4.458327 & 5.497785 & -0.768624 \\
\hline $\mathrm{H}$ & -6.803365 & 4.717368 & -0.587485 \\
\hline $\mathrm{H}$ & -7.276998 & 2.287406 & -0.275707 \\
\hline $\mathrm{H}$ & -5.443113 & 0.673578 & -0.088199 \\
\hline C & -3.620815 & -0.582825 & 1.410062 \\
\hline C & -3.875372 & -1.972403 & 1.650715 \\
\hline C & -4.522692 & -2.365131 & 2.854098 \\
\hline C & -4.876463 & -1.436121 & 3.805293 \\
\hline C & -4.590079 & -0.067241 & 3.589086 \\
\hline C & -3.982583 & 0.348137 & 2.423320 \\
\hline $\mathrm{H}$ & -4.721657 & -3.422355 & 3.013395 \\
\hline $\mathrm{H}$ & -5.364948 & -1.749770 & 4.723763 \\
\hline $\mathrm{H}$ & -4.850562 & 0.664161 & 4.349453 \\
\hline $\mathrm{H}$ & -3.764521 & 1.399464 & 2.276439 \\
\hline
\end{tabular}




\begin{tabular}{|c|c|c|c|}
\hline $\mathrm{O}$ & 0.359150 & 0.122832 & -2.816457 \\
\hline $\mathrm{O}$ & 0.495366 & -1.474312 & -0.742397 \\
\hline $\mathrm{H}$ & 1.705858 & -1.721137 & -0.936937 \\
\hline $\mathrm{H}$ & -1.554542 & -4.921366 & 0.156499 \\
\hline $\mathrm{H}$ & -1.233980 & -6.490117 & -3.832082 \\
\hline $\mathrm{H}$ & -2.937707 & -2.598440 & -3.185315 \\
\hline $\mathrm{H}$ & 0.649439 & 2.351313 & -2.584001 \\
\hline $\mathrm{H}$ & 3.677721 & 5.226153 & -1.540929 \\
\hline $\mathrm{H}$ & 0.040061 & 5.010645 & 0.742840 \\
\hline C & 3.316781 & -0.747361 & -1.566590 \\
\hline 0 & 2.862114 & -1.815244 & -1.037119 \\
\hline $\mathrm{H}$ & 2.645291 & -0.116242 & -2.153259 \\
\hline C & 4.766911 & -0.750906 & -1.997546 \\
\hline $\mathrm{O}$ & 5.603871 & -1.550153 & -1.643445 \\
\hline $\mathrm{O}$ & 4.984148 & 0.259192 & -2.860630 \\
\hline C & 6.325503 & 0.354502 & -3.373819 \\
\hline $\mathrm{H}$ & 7.035500 & 0.511826 & -2.557390 \\
\hline $\mathrm{H}$ & 6.592644 & -0.560175 & -3.908718 \\
\hline C & 3.250999 & 0.334941 & 1.129135 \\
\hline C & 3.531858 & 0.883977 & -0.123545 \\
\hline $\mathrm{H}$ & 1.224923 & 0.574430 & 0.903750 \\
\hline$N$ & 1.952964 & 0.175726 & 1.501557 \\
\hline C & 1.451738 & -0.723665 & 2.472867 \\
\hline $\mathrm{O}$ & 2.089687 & -1.557361 & 3.066785 \\
\hline $\mathrm{O}$ & 0.143145 & -0.474741 & 2.615131 \\
\hline C & -0.554154 & -1.370152 & 3.502505 \\
\hline $\mathrm{H}$ & -0.064261 & -1.392714 & 4.478666 \\
\hline $\mathrm{H}$ & -0.570278 & -2.376556 & 3.077573 \\
\hline $\mathrm{H}$ & -1.563908 & -0.970498 & 3.577323 \\
\hline $\mathrm{H}$ & 4.539095 & 1.250421 & -0.282836 \\
\hline $\mathrm{H}$ & 2.749879 & 1.451548 & -0.619536 \\
\hline C & 4.335073 & -0.037610 & 2.065023 \\
\hline C & 4.311995 & 0.452948 & 3.382034 \\
\hline C & 5.430248 & -0.797574 & 1.629244 \\
\hline C & 5.373962 & 0.197771 & 4.242729 \\
\hline $\mathrm{H}$ & 3.471619 & 1.051844 & 3.720234 \\
\hline C & 6.479255 & -1.070109 & 2.506922 \\
\hline $\mathrm{H}$ & 5.445737 & -1.209855 & 0.626163 \\
\hline C & 6.458781 & -0.569461 & 3.808985 \\
\hline $\mathrm{H}$ & 5.353578 & 0.592885 & 5.254474 \\
\hline $\mathrm{H}$ & 7.313130 & -1.678044 & 2.167764 \\
\hline $\mathrm{H}$ & 7.283157 & -0.776417 & 4.485986 \\
\hline $\mathrm{H}$ & 6.318411 & 1.208739 & -4.050312 \\
\hline
\end{tabular}


Catalyst (R)-1 TS Conformation 261

B3LYP/6-31G(d) Energy $=-2809.686322$

B3LYP-D3(BJ)/def2-TZVPP-IEF-PCM(DCM) Energy = -2810.980157

B3LYP-D3(BJ)/def2-TZVPP-IEF-PCM(DCM)//B3LYP/6-31G(d) Free Energy (Quasiharmonic) = 2810.338709

Frequencies (Top 3 out of 270)

1. $-649.3890 \mathrm{~cm}-1$

2. $\quad 11.1003 \mathrm{~cm}-1$

3. $\quad 13.5647 \mathrm{~cm}-1$

B3LYP/6-31G(d) Molecular Geometry in Cartesian Coordinates

$\begin{array}{llll}\text { C } & 3.040074 & -1.305419 & -0.138791 \\ \text { C } & 1.712811 & -1.672491 & 0.011472 \\ \text { C } & 1.205241 & -2.961578 & -0.330774 \\ \text { C } & 2.099236 & -3.857141 & -0.887072 \\ \text { H } & 1.763473 & -4.862501 & -1.126054 \\ \text { C } & 4.519558 & 2.577811 & 0.990031 \\ \text { C } & 3.507609 & 0.027636 & 0.346663 \\ \text { C } & 2.896469 & 1.190531 & -0.101812 \\ \text { C } & 3.416289 & 2.493785 & 0.162338 \\ \text { H } & 4.931888 & 3.557273 & 1.217303 \\ \text { O } & 0.834260 & -0.746943 & 0.562365 \\ \text { P } & 0.368858 & 0.535051 & -0.330635 \\ \text { O } & 1.785318 & 1.086098 & -0.931637 \\ \text { C } & -2.826875 & -4.311771 & 0.361610 \\ \text { C } & -2.191674 & -3.499754 & 1.303568 \\ \text { C } & -0.897484 & -3.030056 & 1.079226 \\ \text { C } & -0.207092 & -3.367346 & -0.097466 \\ \text { C } & -0.865282 & -4.169884 & -1.046392 \\ \text { C } & -2.157778 & -4.641530 & -0.819591 \\ \text { H } & -2.694827 & -3.232107 & 2.228857 \\ \text { H } & -2.640100 & -5.268433 & -1.565724 \\ \text { C } & 1.963685 & 6.141197 & -1.602603 \\ \text { C } & 1.070683 & 5.276240 & -0.967811 \\ \text { C } & 1.515921 & 4.080889 & -0.403705 \\ \text { C } & 2.874353 & 3.732145 & -0.465005 \\ \text { C } & 3.765241 & 4.609681 & -1.106357 \\ \text { C } & 3.315713 & 5.802950 & -1.670468 \\ \text { H } & 0.015709 & 5.531961 & -0.909441\end{array}$




\begin{tabular}{|c|c|c|c|}
\hline $\mathrm{H}$ & 4.021288 & 6.462856 & -2.168858 \\
\hline C & 4.594175 & 0.139433 & 1.282112 \\
\hline C & 5.104579 & 1.439581 & 1.595507 \\
\hline C & 6.179570 & 1.565353 & 2.516768 \\
\hline C & 6.720196 & 0.458518 & 3.128536 \\
\hline C & 6.197056 & -0.825171 & 2.845551 \\
\hline C & 5.164998 & -0.981229 & 1.946446 \\
\hline $\mathrm{H}$ & 6.559075 & 2.560416 & 2.736982 \\
\hline $\mathrm{H}$ & 7.537825 & 0.566992 & 3.835940 \\
\hline $\mathrm{H}$ & 6.608870 & -1.696782 & 3.347204 \\
\hline $\mathrm{H}$ & 4.768277 & -1.970626 & 1.750324 \\
\hline C & 3.932187 & -2.218505 & -0.801757 \\
\hline C & 3.445660 & -3.516586 & -1.161415 \\
\hline C & 4.319138 & -4.438467 & -1.800049 \\
\hline C & 5.613241 & -4.089797 & -2.108063 \\
\hline C & 6.084242 & -2.793822 & -1.792238 \\
\hline C & 5.268548 & -1.884577 & -1.155132 \\
\hline $\mathrm{H}$ & 3.936218 & -5.424206 & -2.053821 \\
\hline $\mathrm{H}$ & 6.269688 & -4.799667 & -2.603825 \\
\hline $\mathrm{H}$ & 7.098629 & -2.510034 & -2.059255 \\
\hline $\mathrm{H}$ & 5.643137 & -0.893163 & -0.930031 \\
\hline $\mathrm{O}$ & -0.314319 & 1.517073 & 0.574805 \\
\hline $\mathrm{O}$ & -0.412773 & 0.021573 & -1.552994 \\
\hline $\mathrm{H}$ & -1.191272 & 0.769061 & -1.943110 \\
\hline $\mathrm{H}$ & -0.362048 & -4.412686 & -1.977813 \\
\hline $\mathrm{H}$ & -3.830487 & -4.687736 & 0.545658 \\
\hline $\mathrm{H}$ & -0.428504 & -2.397706 & 1.822575 \\
\hline $\mathrm{H}$ & 4.815710 & 4.340597 & -1.178428 \\
\hline $\mathrm{H}$ & 1.608705 & 7.068993 & -2.043943 \\
\hline $\mathrm{H}$ & 0.811662 & 3.424322 & 0.095024 \\
\hline C & -3.144036 & 1.895950 & -2.226179 \\
\hline $\mathrm{O}$ & -1.868618 & 1.777011 & -2.324802 \\
\hline $\mathrm{H}$ & -3.569866 & 2.780745 & -2.717512 \\
\hline C & -4.063563 & 0.704277 & -2.485173 \\
\hline $\mathrm{O}$ & -5.201177 & 0.824906 & -2.888882 \\
\hline $\mathrm{O}$ & -3.451513 & -0.460424 & -2.234489 \\
\hline C & -4.192652 & -1.647623 & -2.571484 \\
\hline $\mathrm{H}$ & -3.563445 & -2.478420 & -2.254310 \\
\hline $\mathrm{H}$ & -5.152045 & -1.660071 & -2.049226 \\
\hline C & -3.917879 & 1.485400 & 0.492744 \\
\hline C & -3.678454 & 2.490665 & -0.481067 \\
\hline $\mathrm{H}$ & -1.904805 & 1.246450 & 0.960716 \\
\hline$N$ & -2.894585 & 1.017489 & 1.240627 \\
\hline C & -2.951635 & 0.316546 & 2.464955 \\
\hline
\end{tabular}




$\begin{array}{lrrr}\text { O } & -2.051646 & -0.388914 & 2.855538 \\ \text { O } & -4.069070 & 0.600796 & 3.153924 \\ \mathrm{C} & -4.194684 & -0.083333 & 4.413366 \\ \mathrm{H} & -3.348575 & 0.155720 & 5.061357 \\ \mathrm{H} & -4.236965 & -1.164688 & 4.258687 \\ \mathrm{H} & -5.128140 & 0.279007 & 4.843469 \\ \mathrm{H} & -4.581079 & 3.012181 & -0.785503 \\ \mathrm{H} & -2.820686 & 3.133140 & -0.299486 \\ \mathrm{C} & -5.249806 & 0.850325 & 0.589746 \\ \mathrm{C} & -5.356955 & -0.550135 & 0.686362 \\ \mathrm{C} & -6.420892 & 1.621877 & 0.527270 \\ \mathrm{C} & -6.608773 & -1.156705 & 0.720058 \\ \mathrm{H} & -4.458151 & -1.160356 & 0.697467 \\ \mathrm{C} & -7.671531 & 1.010850 & 0.579712 \\ \mathrm{H} & -6.352699 & 2.703719 & 0.472144 \\ \mathrm{C} & -7.768760 & -0.378208 & 0.672845 \\ \mathrm{H} & -6.680492 & -2.239098 & 0.779236 \\ \mathrm{H} & -8.569734 & 1.620231 & 0.545037 \\ \mathrm{H} & -8.744824 & -0.854224 & 0.703880 \\ \mathrm{H} & -4.369898 & -1.681827 & -3.649907\end{array}$

Catalyst (R)-1 TS Conformation 262

B3LYP/6-31G(d) Energy = -2809.686727

B3LYP-D3(BJ)/def2-TZVPP-IEF-PCM(DCM) Energy = -2810.980393

B3LYP-D3(BJ)/def2-TZVPP-IEF-PCM(DCM)//B3LYP/6-31G(d) Free Energy (Quasiharmonic) = 2810.338706

Frequencies (Top 3 out of 270)

1. $-675.0342 \mathrm{~cm}-1$

2. $\quad 8.9786 \mathrm{~cm}-1$

3. $\quad 15.5031 \mathrm{~cm}-1$

B3LYP/6-31G(d) Molecular Geometry in Cartesian Coordinates

$\begin{array}{lrrr}\text { C } & 3.171487 & -0.166919 & 0.228001 \\ \text { C } & 2.626809 & 1.014769 & -0.253370 \\ \text { C } & 3.200689 & 2.296704 & 0.011042 \\ \text { C } & 4.258249 & 2.342344 & 0.899929 \\ \text { H } & 4.705493 & 3.304500 & 1.134634 \\ \text { C } & 1.777652 & -4.080631 & -0.905077 \\ \text { C } & 2.688992 & -1.488560 & -0.272556\end{array}$




\begin{tabular}{|c|c|c|c|}
\hline C & 1.351266 & -1.836927 & -0.164966 \\
\hline C & 0.870840 & -3.155260 & -0.427186 \\
\hline $\mathrm{H}$ & 1.437019 & -5.090794 & -1.117207 \\
\hline $\mathrm{O}$ & 1.540503 & 0.947414 & -1.116710 \\
\hline$P$ & 0.084828 & 0.434693 & -0.575640 \\
\hline $\mathrm{O}$ & 0.456564 & -0.896783 & 0.323019 \\
\hline C & 2.113698 & 5.965771 & -1.964404 \\
\hline C & 1.114840 & 5.149552 & -1.431065 \\
\hline C & 1.442975 & 3.950038 & -0.798715 \\
\hline C & 2.781995 & 3.544643 & -0.686737 \\
\hline C & 3.777888 & 4.374005 & -1.233268 \\
\hline C & 3.449029 & 5.572826 & -1.864037 \\
\hline $\mathrm{H}$ & 0.069776 & 5.433273 & -1.504787 \\
\hline $\mathrm{H}$ & 4.236457 & 6.192844 & -2.285374 \\
\hline C & -3.135764 & -4.483083 & 0.414711 \\
\hline C & -2.932124 & -3.369584 & -0.403703 \\
\hline C & -1.641079 & -2.914999 & -0.676099 \\
\hline C & -0.527342 & -3.576829 & -0.134097 \\
\hline C & -0.743361 & -4.701158 & 0.678841 \\
\hline C & -2.035669 & -5.150149 & 0.952967 \\
\hline $\mathrm{H}$ & -3.784478 & -2.853410 & -0.837122 \\
\hline $\mathrm{H}$ & -2.180422 & -6.016022 & 1.594098 \\
\hline C & 3.598712 & -2.431259 & -0.867661 \\
\hline C & 3.126923 & -3.747272 & -1.176973 \\
\hline C & 4.015956 & -4.690639 & -1.759530 \\
\hline C & 5.316192 & -4.350516 & -2.051832 \\
\hline C & 5.777203 & -3.041649 & -1.776927 \\
\hline C & 4.943878 & -2.109198 & -1.198927 \\
\hline $\mathrm{H}$ & 3.641254 & -5.687352 & -1.980827 \\
\hline $\mathrm{H}$ & 5.985575 & -5.077771 & -2.503248 \\
\hline $\mathrm{H}$ & 6.797472 & -2.766203 & -2.030172 \\
\hline $\mathrm{H}$ & 5.310220 & -1.107696 & -1.006015 \\
\hline C & 4.213833 & -0.092004 & 1.217289 \\
\hline C & 4.757240 & 1.189090 & 1.551241 \\
\hline C & 5.783854 & 1.280819 & 2.529824 \\
\hline C & 6.247323 & 0.158719 & 3.176184 \\
\hline C & 5.691862 & -1.105888 & 2.870462 \\
\hline C & 4.705320 & -1.228822 & 1.916546 \\
\hline $\mathrm{H}$ & 6.189455 & 2.262282 & 2.764436 \\
\hline $\mathrm{H}$ & 7.028741 & 0.240931 & 3.926808 \\
\hline $\mathrm{H}$ & 6.042212 & -1.989304 & 3.397589 \\
\hline $\mathrm{H}$ & 4.282883 & -2.203889 & 1.704007 \\
\hline $\mathrm{O}$ & -0.783676 & 0.140755 & -1.749584 \\
\hline $\mathrm{O}$ & -0.423145 & 1.422801 & 0.495370 \\
\hline
\end{tabular}




\begin{tabular}{|c|c|c|c|}
\hline $\mathrm{H}$ & -1.262802 & 1.067161 & 1.323057 \\
\hline $\mathrm{H}$ & 4.817150 & 4.061031 & -1.180611 \\
\hline $\mathrm{H}$ & 1.853436 & 6.897435 & -2.460610 \\
\hline $\mathrm{H}$ & 0.656026 & 3.333721 & -0.382483 \\
\hline $\mathrm{H}$ & 0.111188 & -5.212661 & 1.113870 \\
\hline $\mathrm{H}$ & -4.144255 & -4.823414 & 0.633050 \\
\hline $\mathrm{H}$ & -1.488907 & -2.053146 & -1.317951 \\
\hline$C$ & -3.027682 & 0.053270 & 1.712893 \\
\hline $\mathrm{O}$ & -2.099760 & 0.834145 & 2.119555 \\
\hline $\mathrm{H}$ & -2.856198 & -0.615729 & 0.864878 \\
\hline$C$ & -3.932407 & -0.582274 & 2.759419 \\
\hline $\mathrm{O}$ & -4.557832 & -1.599886 & 2.552145 \\
\hline $\mathrm{O}$ & -3.947524 & 0.114726 & 3.901956 \\
\hline C & -4.755523 & -0.448286 & 4.951477 \\
\hline $\mathrm{H}$ & -4.396362 & -1.446618 & 5.213173 \\
\hline $\mathrm{H}$ & -4.649633 & 0.232691 & 5.795635 \\
\hline C & -4.196993 & 1.291542 & -0.465024 \\
\hline C & -4.570153 & 1.159211 & 0.876884 \\
\hline $\mathrm{H}$ & -3.085941 & 2.154416 & -1.928014 \\
\hline$N$ & -3.346561 & 2.237301 & -0.951524 \\
\hline C & -2.681812 & 3.335322 & -0.367422 \\
\hline $\mathrm{O}$ & -2.004469 & 4.065416 & -1.052977 \\
\hline 0 & -2.923392 & 3.464113 & 0.934448 \\
\hline C & -2.138227 & 4.474457 & 1.605703 \\
\hline $\mathrm{H}$ & -1.078392 & 4.229994 & 1.516243 \\
\hline $\mathrm{H}$ & -2.457604 & 4.433094 & 2.646034 \\
\hline $\mathrm{H}$ & -2.336036 & 5.456751 & 1.171864 \\
\hline $\mathrm{H}$ & -5.398326 & 0.483372 & 1.054095 \\
\hline $\mathrm{H}$ & -4.470542 & 1.999145 & 1.549440 \\
\hline C & -4.680868 & 0.325969 & -1.481960 \\
\hline C & -3.824015 & -0.156130 & -2.490552 \\
\hline C & -6.022232 & -0.097318 & -1.456189 \\
\hline C & -4.312057 & -1.044821 & -3.447655 \\
\hline $\mathrm{H}$ & -2.765037 & 0.095729 & -2.481213 \\
\hline C & -6.501761 & -0.974611 & -2.424903 \\
\hline $\mathrm{H}$ & -6.697838 & 0.288447 & -0.699380 \\
\hline C & -5.647752 & -1.450805 & -3.422738 \\
\hline $\mathrm{H}$ & -3.637885 & -1.429380 & -4.207194 \\
\hline $\mathrm{H}$ & -7.543243 & -1.282038 & -2.403463 \\
\hline $\mathrm{H}$ & -6.022026 & -2.139497 & -4.175052 \\
\hline $\mathrm{H}$ & -5.800369 & -0.515752 & 4.636261 \\
\hline
\end{tabular}

Catalyst (R)-1 TS Conformation 263 
B3LYP/6-31G(d) Energy $=-2809.685012$

B3LYP-D3(BJ)/def2-TZVPP-IEF-PCM(DCM) Energy $=-2810.981323$

B3LYP-D3(BJ)/def2-TZVPP-IEF-PCM(DCM)//B3LYP/6-31G(d) Free Energy (Quasiharmonic) = 2810.338691

Frequencies (Top 3 out of 270)

1. $-339.5649 \mathrm{~cm}-1$

2. $\quad 12.6330 \mathrm{~cm}-1$

3. $\quad 17.9971 \mathrm{~cm}-1$

B3LYP/6-31G(d) Molecular Geometry in Cartesian Coordinates

$\begin{array}{llll}\text { C } & -3.022544 & -0.888803 & 0.141819 \\ \text { C } & -1.923675 & -1.667142 & -0.177668 \\ \text { C } & -1.759312 & -3.016270 & 0.249736 \\ \text { C } & -2.736932 & -3.538189 & 1.073651 \\ \text { H } & -2.656376 & -4.571305 & 1.401378 \\ \text { C } & -3.437517 & 3.156172 & -1.278641 \\ \text { C } & -3.148620 & 0.482333 & -0.434587 \\ \text { C } & -2.138101 & 1.417162 & -0.252227 \\ \text { C } & -2.276679 & 2.787774 & -0.626287 \\ \text { H } & -3.563939 & 4.192083 & -1.581899 \\ \text { O } & -0.924918 & -1.103667 & -0.967345 \\ \text { P } & 0.073753 & -0.016347 & -0.259797 \\ \text { O } & -0.977106 & 1.043607 & 0.417986 \\ \mathrm{C} & 1.541831 & -5.515441 & -0.912234 \\ \mathrm{C} & 1.154946 & -5.430752 & 0.425613 \\ \mathrm{C} & 0.094624 & -4.605567 & 0.796137 \\ \mathrm{C} & -0.594525 & -3.843954 & -0.161368 \\ \mathrm{C} & -0.186593 & -3.925600 & -1.503207 \\ \mathrm{C} & 0.868715 & -4.758106 & -1.873875 \\ \mathrm{H} & 1.687829 & -5.997267 & 1.183942 \\ \mathrm{H} & 1.160976 & -4.817154 & -2.919286 \\ \mathrm{C} & 0.538827 & 5.909793 & 0.294906 \\ \mathrm{C} & 0.979080 & 4.746814 & -0.341821 \\ \mathrm{C} & 0.087867 & 3.711820 & -0.630005 \\ \mathrm{C} & -1.268727 & 3.831284 & -0.288387 \\ \mathrm{C} & -1.700336 & 5.005030 & 0.353444 \\ \mathrm{C} & -0.806648 & 6.035153 & 0.644585 \\ \mathrm{H} & 2.023782 & 4.639176 & -0.618301 \\ \mathrm{H} & -1.161890 & 6.931658 & 1.146369 \\ \mathrm{C} & -4.306185 & 0.861043 & -1.199586\end{array}$




\begin{tabular}{|c|c|c|c|}
\hline C & -4.447623 & 2.223526 & -1.614508 \\
\hline C & -5.589107 & 2.611751 & -2.367164 \\
\hline C & -6.547721 & 1.691881 & -2.722311 \\
\hline C & -6.395466 & 0.337602 & -2.342004 \\
\hline C & -5.307286 & -0.066750 & -1.600414 \\
\hline $\mathrm{H}$ & -5.682485 & 3.652896 & -2.667050 \\
\hline $\mathrm{H}$ & -7.413567 & 1.997906 & -3.303048 \\
\hline $\mathrm{H}$ & -7.141270 & -0.392986 & -2.643413 \\
\hline $\mathrm{H}$ & -5.200862 & -1.110112 & -1.327441 \\
\hline C & -3.995117 & -1.421528 & 1.057953 \\
\hline C & -3.843584 & -2.771245 & 1.514523 \\
\hline C & -4.800580 & -3.315550 & 2.413416 \\
\hline C & -5.850703 & -2.556655 & 2.874836 \\
\hline C & -5.981084 & -1.211725 & 2.456561 \\
\hline C & -5.080400 & -0.659890 & 1.572044 \\
\hline $\mathrm{H}$ & -4.676544 & -4.345273 & 2.740266 \\
\hline $\mathrm{H}$ & -6.571840 & -2.981538 & 3.567677 \\
\hline $\mathrm{H}$ & -6.797143 & -0.605402 & 2.840386 \\
\hline $\mathrm{H}$ & -5.190180 & 0.375030 & 1.270107 \\
\hline 0 & 0.994692 & 0.536350 & -1.284846 \\
\hline $\mathrm{O}$ & 0.679923 & -0.647796 & 1.032420 \\
\hline $\mathrm{H}$ & 1.561224 & -1.264509 & 0.899747 \\
\hline $\mathrm{H}$ & -0.704251 & -3.342419 & -2.257439 \\
\hline $\mathrm{H}$ & 2.368523 & -6.159690 & -1.199062 \\
\hline $\mathrm{H}$ & -0.189088 & -4.526201 & 1.841719 \\
\hline $\mathrm{H}$ & -2.744448 & 5.099041 & 0.639658 \\
\hline $\mathrm{H}$ & 1.238703 & 6.711746 & 0.516438 \\
\hline $\mathrm{H}$ & 0.447434 & 2.815768 & -1.125540 \\
\hline C & 3.339020 & -1.806684 & -0.332927 \\
\hline $\mathrm{O}$ & 2.712421 & -2.028213 & 0.769012 \\
\hline $\mathrm{H}$ & 2.854899 & -1.197956 & -1.107106 \\
\hline C & 4.124773 & -2.985829 & -0.916508 \\
\hline $\mathrm{O}$ & 4.639202 & -3.871942 & -0.275822 \\
\hline $\mathrm{O}$ & 4.179644 & -2.879220 & -2.260970 \\
\hline C & 4.894544 & -3.929934 & -2.932390 \\
\hline $\mathrm{H}$ & 4.875763 & -3.668298 & -3.990573 \\
\hline $\mathrm{H}$ & 5.922900 & -3.990122 & -2.565742 \\
\hline C & 4.385901 & 0.382910 & 0.733695 \\
\hline C & 4.901320 & -0.750761 & 0.067136 \\
\hline $\mathrm{H}$ & 3.944972 & -0.789369 & 2.306702 \\
\hline$N$ & 3.868356 & 0.165269 & 1.964078 \\
\hline C & 2.894023 & 0.865041 & 2.738165 \\
\hline $\mathrm{O}$ & 2.560487 & 0.420090 & 3.809454 \\
\hline $\mathrm{O}$ & 2.454889 & 1.966049 & 2.147452 \\
\hline
\end{tabular}




$\begin{array}{llll}\mathrm{C} & 1.355347 & 2.626680 & 2.822676 \\ \mathrm{H} & 1.206422 & 3.554016 & 2.273314 \\ \mathrm{H} & 1.615682 & 2.813096 & 3.866270 \\ \mathrm{H} & 0.468611 & 1.994131 & 2.757524 \\ \mathrm{H} & 5.465107 & -0.556280 & -0.840443 \\ \mathrm{H} & 5.331206 & -1.525842 & 0.698394 \\ \mathrm{C} & 4.434174 & 1.719752 & 0.110277 \\ \mathrm{C} & 4.994083 & 2.794233 & 0.822124 \\ \mathrm{C} & 4.065904 & 1.895613 & -1.232917 \\ \mathrm{C} & 5.203866 & 4.017600 & 0.191955 \\ \mathrm{H} & 5.292009 & 2.658895 & 1.857376 \\ \mathrm{C} & 4.260704 & 3.129523 & -1.850497 \\ \mathrm{H} & 3.579986 & 1.089868 & -1.771509 \\ \mathrm{C} & 4.840704 & 4.187773 & -1.146527 \\ \mathrm{H} & 5.655067 & 4.836594 & 0.744856 \\ \mathrm{H} & 3.955702 & 3.263023 & -2.884264 \\ \mathrm{H} & 5.005886 & 5.142809 & -1.637770 \\ \mathrm{H} & 4.401394 & -4.891085 & -2.765714\end{array}$

Catalyst (R)-1 TS Conformation 264

B3LYP/6-31G(d) Energy $=-2809.688229$

B3LYP-D3(BJ)/def2-TZVPP-IEF-PCM(DCM) Energy $=-2810.980256$

B3LYP-D3(BJ)/def2-TZVPP-IEF-PCM(DCM)//B3LYP/6-31G(d) Free Energy (Quasiharmonic) = 2810.33868

Frequencies (Top 3 out of 270)

1. $-718.7054 \mathrm{~cm}-1$

2. $\quad 7.1651 \mathrm{~cm}-1$

3. $10.0809 \mathrm{~cm}-1$

B3LYP/6-31G(d) Molecular Geometry in Cartesian Coordinates

$\begin{array}{llll}\text { C } & -3.611333 & 0.161144 & -0.133165 \\ \text { C } & -2.774383 & 1.230971 & 0.137943 \\ \text { C } & -3.142011 & 2.588854 & -0.088580 \\ \text { C } & -4.359302 & 2.823492 & -0.696234 \\ \text { H } & -4.677569 & 3.849176 & -0.863565 \\ \text { C } & -2.512669 & -3.909669 & 0.731618 \\ \text { C } & -3.206961 & -1.220743 & 0.258618 \\ \text { C } & -2.008053 & -1.752045 & -0.195779 \\ \text { C } & -1.652495 & -3.122331 & -0.008828\end{array}$




\begin{tabular}{|c|c|c|c|}
\hline $\mathrm{H}$ & -2.261339 & -4.954729 & 0.892832 \\
\hline $\mathrm{O}$ & -1.514973 & 0.972967 & 0.676178 \\
\hline$P$ & -0.385188 & 0.335616 & -0.322276 \\
\hline $\mathrm{O}$ & -1.168042 & -0.958562 & -0.962378 \\
\hline C & -0.885564 & 6.011726 & 1.207165 \\
\hline C & -1.134391 & 4.960031 & 2.093334 \\
\hline C & -1.825736 & 3.826910 & 1.665246 \\
\hline C & -2.296837 & 3.733102 & 0.345143 \\
\hline C & -2.034575 & 4.792338 & -0.537060 \\
\hline C & -1.332463 & 5.920211 & -0.111527 \\
\hline $\mathrm{H}$ & -0.796682 & 5.024739 & 3.124806 \\
\hline $\mathrm{H}$ & -1.134070 & 6.726630 & -0.812633 \\
\hline C & 1.814932 & -5.044631 & -1.683490 \\
\hline C & 0.536307 & -5.549652 & -1.921566 \\
\hline C & -0.579936 & -4.904117 & -1.389597 \\
\hline C & -0.440205 & -3.740680 & -0.615496 \\
\hline C & 0.849623 & -3.237041 & -0.386982 \\
\hline C & 1.964433 & -3.888713 & -0.914486 \\
\hline $\mathrm{H}$ & 0.404915 & -6.444757 & -2.524101 \\
\hline $\mathrm{H}$ & 2.957867 & -3.493465 & -0.715712 \\
\hline C & -4.040371 & -2.024751 & 1.110888 \\
\hline C & -3.684663 & -3.393034 & 1.334815 \\
\hline C & -4.503087 & -4.201738 & 2.169097 \\
\hline C & -5.618972 & -3.682110 & 2.782601 \\
\hline C & -5.956327 & -2.321748 & 2.589184 \\
\hline C & -5.190787 & -1.516063 & 1.775191 \\
\hline $\mathrm{H}$ & -4.220576 & -5.240783 & 2.321702 \\
\hline $\mathrm{H}$ & -6.234469 & -4.307602 & 3.423351 \\
\hline $\mathrm{H}$ & -6.824944 & -1.905992 & 3.092742 \\
\hline $\mathrm{H}$ & -5.457661 & -0.473488 & 1.646585 \\
\hline C & -4.845917 & 0.415993 & -0.826959 \\
\hline C & -5.215057 & 1.771612 & -1.105282 \\
\hline C & -6.432710 & 2.039128 & -1.787471 \\
\hline C & -7.246319 & 1.014325 & -2.210938 \\
\hline C & -6.866563 & -0.326994 & -1.971314 \\
\hline C & -5.701212 & -0.618595 & -1.296834 \\
\hline $\mathrm{H}$ & -6.702130 & 3.075109 & -1.979175 \\
\hline $\mathrm{H}$ & -8.171383 & 1.230251 & -2.738424 \\
\hline $\mathrm{H}$ & -7.497554 & -1.136776 & -2.327646 \\
\hline $\mathrm{H}$ & -5.420665 & -1.652210 & -1.132692 \\
\hline 0 & 0.802273 & -0.058449 & 0.497002 \\
\hline $\mathrm{O}$ & -0.203387 & 1.266339 & -1.528503 \\
\hline $\mathrm{H}$ & 0.834098 & 1.537074 & -1.968941 \\
\hline $\mathrm{H}$ & -2.371785 & 4.719651 & -1.567112 \\
\hline
\end{tabular}




\begin{tabular}{|c|c|c|c|}
\hline $\mathrm{H}$ & -0.346630 & 6.893938 & 1.542696 \\
\hline $\mathrm{H}$ & -2.019455 & 3.016533 & 2.360854 \\
\hline $\mathrm{H}$ & 0.974040 & -2.342398 & 0.213273 \\
\hline $\mathrm{H}$ & 2.686905 & -5.547646 & -2.093729 \\
\hline $\mathrm{H}$ & -1.575106 & -5.293960 & -1.586025 \\
\hline C & 3.024883 & 1.702840 & -2.028301 \\
\hline 0 & 1.893459 & 1.727700 & -2.630171 \\
\hline $\mathrm{H}$ & 3.917995 & 1.822283 & -2.652944 \\
\hline C & 3.233191 & 2.432036 & -0.699455 \\
\hline 0 & 4.340231 & 2.717970 & -0.283219 \\
\hline 0 & 2.088562 & 2.706883 & -0.082155 \\
\hline C & 2.194352 & 3.330117 & 1.217115 \\
\hline $\mathrm{H}$ & 2.826788 & 4.218351 & 1.155655 \\
\hline $\mathrm{H}$ & 1.174563 & 3.592410 & 1.490016 \\
\hline C & 4.187394 & -0.297418 & -0.407167 \\
\hline C & 3.364121 & -0.195253 & -1.548343 \\
\hline $\mathrm{H}$ & 2.556618 & -0.002360 & 0.782425 \\
\hline$N$ & 3.581161 & -0.174404 & 0.800002 \\
\hline C & 4.076080 & -0.315590 & 2.111412 \\
\hline $\mathrm{O}$ & 3.519199 & 0.198423 & 3.054998 \\
\hline 0 & 5.154036 & -1.105293 & 2.176831 \\
\hline C & 5.709670 & -1.265024 & 3.496149 \\
\hline $\mathrm{H}$ & 4.979873 & -1.736220 & 4.158363 \\
\hline $\mathrm{H}$ & 5.999169 & -0.295352 & 3.908231 \\
\hline $\mathrm{H}$ & 6.581721 & -1.904358 & 3.362166 \\
\hline $\mathrm{H}$ & 3.809434 & -0.497755 & -2.489553 \\
\hline $\mathrm{H}$ & 2.326048 & -0.476080 & -1.416103 \\
\hline C & 5.658073 & -0.368723 & -0.552010 \\
\hline C & 6.207828 & -1.305991 & -1.441381 \\
\hline C & 6.511335 & 0.519293 & 0.125549 \\
\hline C & 7.587087 & -1.374854 & -1.629851 \\
\hline $\mathrm{H}$ & 5.554096 & -1.998361 & -1.963575 \\
\hline C & 7.885307 & 0.462232 & -0.085655 \\
\hline $\mathrm{H}$ & 6.089490 & 1.284283 & 0.766896 \\
\hline C & 8.427673 & -0.488979 & -0.954673 \\
\hline $\mathrm{H}$ & 8.002161 & -2.115961 & -2.306765 \\
\hline $\mathrm{H}$ & 8.535549 & 1.167564 & 0.423934 \\
\hline $\mathrm{H}$ & 9.502167 & -0.533363 & -1.110006 \\
\hline $\mathrm{H}$ & 2.616994 & 2.619194 & 1.931755 \\
\hline
\end{tabular}

Catalyst (R)-1 TS Conformation 265

B3LYP/6-31G(d) Energy $=-2809.695371$ 
B3LYP-D3(BJ)/def2-TZVPP-IEF-PCM(DCM) Energy $=-2810.982732$

B3LYP-D3(BJ)/def2-TZVPP-IEF-PCM(DCM)//B3LYP/6-31G(d) Free Energy (Quasiharmonic) = 2810.338644

Frequencies (Top 3 out of 270)

1. $-271.3418 \mathrm{~cm}-1$

2. $\quad 9.8163 \mathrm{~cm}-1$

3. $\quad 14.8973 \mathrm{~cm}-1$

B3LYP/6-31G(d) Molecular Geometry in Cartesian Coordinates

$\begin{array}{llll}\text { C } & -3.323953 & -0.774313 & 0.217824 \\ \text { C } & -2.132123 & -1.484766 & 0.256859 \\ \text { C } & -2.050826 & -2.845302 & 0.683281 \\ \text { C } & -3.204476 & -3.422480 & 1.177559 \\ \text { H } & -3.171637 & -4.454125 & 1.517728 \\ \text { C } & -3.503102 & 3.140737 & -1.594615 \\ \text { C } & -3.386498 & 0.558187 & -0.455012 \\ \text { C } & -2.530679 & 1.575558 & -0.068870 \\ \text { C } & -2.576381 & 2.897104 & -0.599845 \\ \text { H } & -3.586838 & 4.143238 & -2.005700 \\ \text { O } & -0.976765 & -0.892661 & -0.241855 \\ \text { P } & -0.297941 & 0.400622 & 0.485841 \\ \text { O } & -1.579777 & 1.301861 & 0.914413 \\ \text { C } & 1.457850 & -5.313977 & 0.314537 \\ \text { C } & 1.548198 & -4.071806 & 0.946995 \\ \text { C } & 0.422064 & -3.258171 & 1.064475 \\ \text { C } & -0.815175 & -3.667345 & 0.546499 \\ \text { C } & -0.893287 & -4.917361 & -0.090837 \\ \text { C } & 0.231300 & -5.734090 & -0.204690 \\ \text { H } & 2.491422 & -3.721249 & 1.356337 \\ \text { H } & 0.148989 & -6.696297 & -0.703821 \\ \text { C } & -0.079263 & 6.134912 & 0.739293 \\ \text { C } & -0.257129 & 5.893463 & -0.623486 \\ \text { C } & -1.051151 & 4.828768 & -1.048080 \\ \text { C } & -1.682543 & 3.984756 & -0.120179 \\ \text { C } & -1.489699 & 4.233722 & 1.249093 \\ \text { C } & -0.698309 & 5.300226 & 1.672128 \\ \text { H } & 0.227948 & 6.529711 & -1.359216 \\ \text { H } & -0.569243 & 5.482344 & 2.735999 \\ \text { C } & -4.291317 & 0.808597 & -1.546124 \\ \text { C } & -4.350067 & 2.126696 & -2.104766 \\ \text { C } & -5.248121 & 2.393375 & -3.173797\end{array}$




\begin{tabular}{|c|c|c|c|}
\hline C & -6.036259 & 1.397490 & -3.701129 \\
\hline C & -5.949976 & 0.085327 & -3.180131 \\
\hline C & -5.103579 & -0.201231 & -2.131613 \\
\hline $\mathrm{H}$ & -5.288473 & 3.402765 & -3.576327 \\
\hline $\mathrm{H}$ & -6.713545 & 1.611221 & -4.523419 \\
\hline $\mathrm{H}$ & -6.553391 & -0.707036 & -3.614636 \\
\hline $\mathrm{H}$ & -5.043088 & -1.214587 & -1.753386 \\
\hline C & -4.489044 & -1.357128 & 0.826996 \\
\hline C & -4.418477 & -2.704667 & 1.305045 \\
\hline C & -5.563315 & -3.293460 & 1.907169 \\
\hline C & -6.729364 & -2.579700 & 2.057663 \\
\hline C & -6.793036 & -1.237733 & 1.614273 \\
\hline C & -5.704986 & -0.643444 & 1.013519 \\
\hline $\mathrm{H}$ & -5.493584 & -4.320323 & 2.258243 \\
\hline $\mathrm{H}$ & -7.596506 & -3.037782 & 2.525429 \\
\hline $\mathrm{H}$ & -7.707357 & -0.667445 & 1.754430 \\
\hline $\mathrm{H}$ & -5.767049 & 0.389060 & 0.689416 \\
\hline $\mathrm{O}$ & 0.652035 & 1.028141 & -0.478133 \\
\hline $\mathrm{O}$ & 0.250039 & 0.006189 & 1.890986 \\
\hline $\mathrm{H}$ & 1.296269 & -0.207837 & 1.888165 \\
\hline $\mathrm{H}$ & -1.840315 & -5.239530 & -0.515434 \\
\hline $\mathrm{H}$ & 2.333550 & -5.953498 & 0.232379 \\
\hline $\mathrm{H}$ & 0.504209 & -2.312092 & 1.581303 \\
\hline $\mathrm{H}$ & -1.969107 & 3.594524 & 1.982672 \\
\hline $\mathrm{H}$ & 0.538947 & 6.964537 & 1.072237 \\
\hline $\mathrm{H}$ & -1.168436 & 4.631884 & -2.109992 \\
\hline C & 3.674453 & 0.011501 & 1.824617 \\
\hline $\mathrm{O}$ & 2.621347 & -0.702257 & 1.676369 \\
\hline $\mathrm{H}$ & 4.642018 & -0.498723 & 1.714760 \\
\hline C & 3.793490 & 1.025125 & 2.968558 \\
\hline $\mathrm{O}$ & 4.860836 & 1.422071 & 3.391016 \\
\hline $\mathrm{O}$ & 2.595260 & 1.407976 & 3.424510 \\
\hline C & 2.608385 & 2.357855 & 4.504016 \\
\hline $\mathrm{H}$ & 1.560537 & 2.547599 & 4.734584 \\
\hline $\mathrm{H}$ & 3.126520 & 1.940163 & 5.371051 \\
\hline C & 4.100407 & 0.497174 & -0.688307 \\
\hline C & 3.807118 & 1.324926 & 0.418444 \\
\hline $\mathrm{H}$ & 2.112409 & 0.250851 & -1.081892 \\
\hline$N$ & 3.058374 & -0.131896 & -1.276981 \\
\hline C & 3.002720 & -1.381532 & -1.935924 \\
\hline $\mathrm{O}$ & 2.063339 & -1.694064 & -2.626467 \\
\hline $\mathrm{O}$ & 4.062527 & -2.151944 & -1.655631 \\
\hline C & 4.032350 & -3.456676 & -2.265409 \\
\hline $\mathrm{H}$ & 3.955349 & -3.370263 & -3.351987 \\
\hline
\end{tabular}




$\begin{array}{llll}\mathrm{H} & 3.182364 & -4.026296 & -1.882804 \\ \mathrm{H} & 4.974440 & -3.925206 & -1.980666 \\ \mathrm{H} & 4.572986 & 2.040098 & 0.701794 \\ \mathrm{H} & 2.787196 & 1.696504 & 0.481527 \\ \mathrm{C} & 5.485526 & 0.319543 & -1.160973 \\ \mathrm{C} & 5.749842 & 0.133278 & -2.530418 \\ \mathrm{C} & 6.568156 & 0.434440 & -0.269574 \\ \mathrm{C} & 7.059480 & 0.051982 & -2.992481 \\ \mathrm{H} & 4.926551 & 0.089804 & -3.236584 \\ \mathrm{C} & 7.876721 & 0.333683 & -0.735488 \\ \mathrm{H} & 6.388710 & 0.591266 & 0.789395 \\ \mathrm{C} & 8.127085 & 0.142423 & -2.095804 \\ \mathrm{H} & 7.247613 & -0.076770 & -4.054566 \\ \mathrm{H} & 8.701967 & 0.409310 & -0.033419 \\ \mathrm{H} & 9.149272 & 0.073114 & -2.457368 \\ \mathrm{H} & 3.111010 & 3.278503 & 4.195598\end{array}$

Catalyst (R)-1 TS Conformation 266

B3LYP/6-31G(d) Energy $=-2809.685452$

B3LYP-D3(BJ)/def2-TZVPP-IEF-PCM(DCM) Energy $=-2810.980567$

B3LYP-D3(BJ)/def2-TZVPP-IEF-PCM(DCM)//B3LYP/6-31G(d) Free Energy (Quasiharmonic) = 2810.338644

Frequencies (Top 3 out of 270)

1. $-631.2635 \mathrm{~cm}-1$

2. $\quad 2.9727 \mathrm{~cm}-1$

3. $\quad 9.8367 \mathrm{~cm}-1$

B3LYP/6-31G(d) Molecular Geometry in Cartesian Coordinates

$\begin{array}{lrrr}\text { C } & 3.763826 & 0.436593 & 0.108859 \\ \text { C } & 2.867776 & 1.423374 & -0.276516 \\ \text { C } & 3.030064 & 2.801296 & 0.057549 \\ \text { C } & 4.114234 & 3.138896 & 0.844182 \\ \text { H } & 4.282733 & 4.183213 & 1.093941 \\ \text { C } & 3.067958 & -3.646848 & -1.100498 \\ \text { C } & 3.552175 & -0.967521 & -0.354083 \\ \text { C } & 2.338690 & -1.590906 & -0.102215 \\ \text { C } & 2.071400 & -2.949800 & -0.445653 \\ \text { H } & 2.906058 & -4.691508 & -1.353401 \\ \text { O } & 1.774536 & 1.065317 & -1.048564\end{array}$




\begin{tabular}{|c|c|c|c|}
\hline$P$ & 0.521479 & 0.262760 & -0.342931 \\
\hline $\mathrm{O}$ & 1.341781 & -0.869413 & 0.535168 \\
\hline C & 0.390988 & 5.929141 & -1.274550 \\
\hline C & 0.809097 & 5.872161 & 0.055479 \\
\hline C & 1.647648 & 4.843070 & 0.482212 \\
\hline C & 2.085713 & 3.850886 & -0.410090 \\
\hline C & 1.651642 & 3.915623 & -1.745109 \\
\hline C & 0.815339 & 4.946163 & -2.171141 \\
\hline $\mathrm{H}$ & 0.476047 & 6.624370 & 0.766066 \\
\hline $\mathrm{H}$ & 0.496182 & 4.981422 & -3.209629 \\
\hline C & -1.614400 & -4.974071 & 0.473418 \\
\hline C & -1.046625 & -5.076255 & -0.797058 \\
\hline C & 0.137473 & -4.400968 & -1.091541 \\
\hline C & 0.778953 & -3.611507 & -0.123582 \\
\hline C & 0.193802 & -3.512246 & 1.150164 \\
\hline C & -0.989281 & -4.188352 & 1.444482 \\
\hline $\mathrm{H}$ & -1.529487 & -5.674883 & -1.565165 \\
\hline $\mathrm{H}$ & -1.422559 & -4.102332 & 2.437743 \\
\hline C & 4.550523 & -1.682779 & -1.100709 \\
\hline C & 4.299049 & -3.046534 & -1.461136 \\
\hline C & 5.283049 & -3.769425 & -2.188787 \\
\hline C & 6.458000 & -3.170299 & -2.578911 \\
\hline C & 6.692339 & -1.812159 & -2.259466 \\
\hline C & 5.766175 & -1.089179 & -1.540158 \\
\hline $\mathrm{H}$ & 5.080224 & -4.807208 & -2.443233 \\
\hline $\mathrm{H}$ & 7.199603 & -3.731066 & -3.141350 \\
\hline $\mathrm{H}$ & 7.609860 & -1.332195 & -2.589341 \\
\hline $\mathrm{H}$ & 5.956809 & -0.046797 & -1.312920 \\
\hline C & 4.843366 & 0.793238 & 0.988137 \\
\hline C & 5.019007 & 2.170145 & 1.343014 \\
\hline C & 6.090151 & 2.538766 & 2.201583 \\
\hline C & 6.940219 & 1.590669 & 2.721540 \\
\hline C & 6.745453 & 0.225586 & 2.405218 \\
\hline C & 5.727304 & -0.162191 & 1.561950 \\
\hline $\mathrm{H}$ & 6.216065 & 3.590177 & 2.449750 \\
\hline $\mathrm{H}$ & 7.751499 & 1.884151 & 3.382244 \\
\hline $\mathrm{H}$ & 7.402609 & -0.525746 & 2.835074 \\
\hline $\mathrm{H}$ & 5.586428 & -1.213125 & 1.337602 \\
\hline $\mathrm{O}$ & -0.356717 & -0.287043 & -1.410275 \\
\hline $\mathrm{O}$ & -0.103789 & 1.134748 & 0.759364 \\
\hline $\mathrm{H}$ & -1.281047 & 1.490709 & 0.600927 \\
\hline $\mathrm{H}$ & 1.975266 & 3.158353 & -2.450490 \\
\hline $\mathrm{H}$ & -0.263818 & 6.729609 & -1.609213 \\
\hline $\mathrm{H}$ & 1.950484 & 4.790322 & 1.524206 \\
\hline
\end{tabular}




\begin{tabular}{|c|c|c|c|}
\hline $\mathrm{H}$ & 0.674154 & -2.907788 & 1.911864 \\
\hline $\mathrm{H}$ & -2.537587 & -5.499390 & 0.704654 \\
\hline $\mathrm{H}$ & 0.560910 & -4.463466 & -2.089880 \\
\hline C & -2.977005 & 1.394179 & -0.573220 \\
\hline 0 & -2.423967 & 1.751499 & 0.541037 \\
\hline $\mathrm{H}$ & -2.341514 & 1.278951 & -1.458146 \\
\hline C & -4.325624 & 2.018600 & -0.895858 \\
\hline 0 & -4.818905 & 2.001950 & -2.005012 \\
\hline 0 & -4.906773 & 2.561853 & 0.184713 \\
\hline C & -6.179146 & 3.187896 & -0.055902 \\
\hline $\mathrm{H}$ & -6.912509 & 2.448025 & -0.389743 \\
\hline $\mathrm{H}$ & -6.474949 & 3.620105 & 0.900141 \\
\hline C & -4.404505 & -0.723928 & 0.310715 \\
\hline C & -3.424390 & -0.497636 & -0.670308 \\
\hline $\mathrm{H}$ & -6.374019 & -0.385458 & 0.770119 \\
\hline $\mathrm{N}$ & -5.740338 & -0.599197 & 0.010419 \\
\hline C & -6.362237 & -0.711911 & -1.244973 \\
\hline 0 & -5.862195 & -1.122330 & -2.261643 \\
\hline O & -7.641790 & -0.310351 & -1.098071 \\
\hline C & -8.429936 & -0.368661 & -2.304661 \\
\hline $\mathrm{H}$ & -7.991868 & 0.277569 & -3.068339 \\
\hline $\mathrm{H}$ & -9.419835 & -0.015716 & -2.016783 \\
\hline $\mathrm{H}$ & -8.477612 & -1.394377 & -2.677347 \\
\hline $\mathrm{H}$ & -2.426282 & -0.891878 & -0.509180 \\
\hline $\mathrm{H}$ & -3.752737 & -0.540529 & -1.701986 \\
\hline C & -4.086902 & -0.962077 & 1.721019 \\
\hline C & -2.790819 & -0.704555 & 2.213868 \\
\hline C & -5.061908 & -1.459096 & 2.616526 \\
\hline C & -2.499599 & -0.896505 & 3.562794 \\
\hline $\mathrm{H}$ & -2.010344 & -0.338174 & 1.563916 \\
\hline C & -4.758067 & -1.664476 & 3.955599 \\
\hline $\mathrm{H}$ & -6.049451 & -1.737404 & 2.259804 \\
\hline C & -3.476670 & -1.372299 & 4.436241 \\
\hline $\mathrm{H}$ & -1.499975 & -0.673597 & 3.922566 \\
\hline $\mathrm{H}$ & -5.515675 & -2.061484 & 4.624942 \\
\hline $\mathrm{H}$ & -3.241601 & -1.529691 & 5.485206 \\
\hline $\mathrm{H}$ & -6.085141 & 3.965370 & -0.817897 \\
\hline
\end{tabular}

Catalyst (R)-1 TS Conformation 267

B3LYP/6-31G(d) Energy $=-2809.681461$

B3LYP-D3(BJ)/def2-TZVPP-IEF-PCM(DCM) Energy = -2810.980881 
B3LYP-D3(BJ)/def2-TZVPP-IEF-PCM(DCM)//B3LYP/6-31G(d) Free Energy (Quasiharmonic) = 2810.338605

Frequencies (Top 3 out of 270)

1. $-537.6656 \mathrm{~cm}-1$

2. $\quad 8.9844 \mathrm{~cm}-1$

3. $\quad 13.2560 \mathrm{~cm}-1$

B3LYP/6-31G(d) Molecular Geometry in Cartesian Coordinates

$\begin{array}{lrrr}\text { C } & 3.237789 & -1.139680 & -0.104412 \\ \text { C } & 1.985133 & -1.689636 & 0.110355 \\ \text { C } & 1.649221 & -3.030422 & -0.243007 \\ \text { C } & 2.609667 & -3.769897 & -0.905420 \\ \text { H } & 2.396747 & -4.803463 & -1.165726 \\ \text { C } & 4.224031 & 2.813303 & 1.284312 \\ \text { C } & 3.548784 & 0.213314 & 0.442064 \\ \text { C } & 2.759966 & 1.308353 & 0.110322 \\ \text { C } & 3.105719 & 2.642108 & 0.491170 \\ \text { H } & 4.498789 & 3.818324 & 1.593363 \\ \text { O } & 1.015533 & -0.901731 & 0.713970 \\ \text { P } & 0.332446 & 0.280682 & -0.216466 \\ \text { O } & 1.657897 & 1.131248 & -0.711214 \\ \text { C } & -2.069803 & -4.944966 & 0.763882 \\ \text { C } & -1.528826 & -5.078800 & -0.515319 \\ \text { C } & -0.336218 & -4.435605 & -0.841557 \\ \text { C } & 0.338298 & -3.641481 & 0.100366 \\ \text { C } & -0.224923 & -3.500847 & 1.380144 \\ \text { C } & -1.414014 & -4.151107 & 1.708053 \\ \text { H } & -2.041611 & -5.675693 & -1.264457 \\ \text { H } & -1.822362 & -4.043112 & 2.710049 \\ \text { C } & 1.057127 & 6.234520 & -0.696580 \\ \text { C } & 2.431231 & 6.097665 & -0.895526 \\ \text { C } & 3.073859 & 4.915475 & -0.529104 \\ \text { C } & 2.357820 & 3.848631 & 0.040233 \\ \text { C } & 0.973667 & 3.993082 & 0.228285 \\ \text { C } & 0.333567 & 5.180046 & -0.134953 \\ \text { H } & 3.004742 & 6.907394 & -1.339941 \\ \text { H } & -0.737912 & 5.271016 & 0.012292 \\ \text { C } & 4.651990 & 0.398945 & 1.346471 \\ \text { C } & 4.995307 & 1.725786 & 1.757164 \\ \text { C } & 6.087169 & 1.926108 & 2.644700 \\ \text { C } & 6.805257 & 0.860276 & 3.134224\end{array}$




\begin{tabular}{|c|c|c|c|}
\hline C & 6.448367 & -0.456089 & 2.758047 \\
\hline C & 5.403466 & -0.680946 & 1.888841 \\
\hline $\mathrm{H}$ & 6.335788 & 2.943394 & 2.938321 \\
\hline $\mathrm{H}$ & 7.634905 & 1.023742 & 3.816720 \\
\hline $\mathrm{H}$ & 6.999810 & -1.300029 & 3.164014 \\
\hline $\mathrm{H}$ & 5.137767 & -1.697071 & 1.622240 \\
\hline C & 4.199439 & -1.893107 & -0.862304 \\
\hline C & 3.870468 & -3.229625 & -1.258911 \\
\hline C & 4.813833 & -3.989376 & -2.002449 \\
\hline C & 6.023714 & -3.449658 & -2.372493 \\
\hline C & 6.336602 & -2.117415 & -2.013958 \\
\hline C & 5.451250 & -1.361248 & -1.277367 \\
\hline $\mathrm{H}$ & 4.552315 & -5.006614 & -2.284818 \\
\hline $\mathrm{H}$ & 6.733823 & -4.037599 & -2.947734 \\
\hline $\mathrm{H}$ & 7.282983 & -1.684057 & -2.326404 \\
\hline $\mathrm{H}$ & 5.701884 & -0.339009 & -1.018788 \\
\hline $\mathrm{O}$ & -0.606551 & 1.063399 & 0.637947 \\
\hline O & -0.180192 & -0.335424 & -1.527196 \\
\hline $\mathrm{H}$ & -1.268155 & -1.013213 & -1.496137 \\
\hline $\mathrm{H}$ & 0.277239 & -2.889021 & 2.121506 \\
\hline $\mathrm{H}$ & -2.998174 & -5.449546 & 1.018123 \\
\hline $\mathrm{H}$ & 0.069173 & -4.527329 & -1.845171 \\
\hline $\mathrm{H}$ & 0.398774 & 3.182095 & 0.665521 \\
\hline $\mathrm{H}$ & 0.551583 & 7.154320 & -0.979875 \\
\hline $\mathrm{H}$ & 4.142111 & 4.806754 & -0.696810 \\
\hline C & -3.010706 & -1.019799 & -0.535684 \\
\hline 0 & -2.245132 & -1.602620 & -1.396447 \\
\hline $\mathrm{H}$ & -2.572251 & -0.243056 & 0.098716 \\
\hline C & -4.031075 & -1.921191 & 0.147408 \\
\hline 0 & -4.657527 & -2.808295 & -0.382618 \\
\hline O & -4.138296 & -1.565995 & 1.441053 \\
\hline C & -5.057597 & -2.352455 & 2.220655 \\
\hline $\mathrm{H}$ & -4.744283 & -3.399000 & 2.226538 \\
\hline $\mathrm{H}$ & -5.019753 & -1.932778 & 3.225652 \\
\hline C & -4.753979 & 1.099738 & -0.787076 \\
\hline C & -4.282977 & 0.078368 & -1.619802 \\
\hline $\mathrm{H}$ & -4.579409 & 2.960121 & 0.008494 \\
\hline $\mathrm{N}$ & -4.135281 & 2.301549 & -0.620085 \\
\hline C & -3.000993 & 2.908901 & -1.221546 \\
\hline 0 & -2.736208 & 4.056550 & -0.945341 \\
\hline $\mathrm{O}$ & -2.371356 & 2.105295 & -2.060323 \\
\hline C & -1.165274 & 2.629806 & -2.680132 \\
\hline $\mathrm{H}$ & -0.552358 & 3.131586 & -1.932905 \\
\hline $\mathrm{H}$ & -0.654864 & 1.751690 & -3.068822 \\
\hline
\end{tabular}




$\begin{array}{llll}\mathrm{H} & -1.447130 & 3.325554 & -3.474218 \\ \mathrm{H} & -4.974855 & -0.722692 & -1.852232 \\ \mathrm{H} & -3.577030 & 0.335054 & -2.395004 \\ \mathrm{C} & -5.938722 & 0.898282 & 0.080667 \\ \mathrm{C} & -5.961034 & 1.389208 & 1.400056 \\ \mathrm{C} & -7.063430 & 0.212807 & -0.409872 \\ \mathrm{C} & -7.083753 & 1.203092 & 2.202339 \\ \mathrm{H} & -5.080835 & 1.869533 & 1.818756 \\ \mathrm{C} & -8.187923 & 0.037867 & 0.393906 \\ \mathrm{H} & -7.068437 & -0.156020 & -1.430141 \\ \mathrm{C} & -8.201677 & 0.532585 & 1.699843 \\ \mathrm{H} & -7.081771 & 1.573988 & 3.223036 \\ \mathrm{H} & -9.055695 & -0.480226 & -0.003304 \\ \mathrm{H} & -9.079111 & 0.393837 & 2.325017 \\ \mathrm{H} & -6.066414 & -2.278861 & 1.806842\end{array}$

Catalyst (R)-1 TS Conformation 268

$B 3 L Y P / 6-31 G(d)$ Energy $=-2809.689607$

B3LYP-D3(BJ)/def2-TZVPP-IEF-PCM(DCM) Energy $=-2810.980722$

B3LYP-D3(BJ)/def2-TZVPP-IEF-PCM(DCM)//B3LYP/6-31G(d) Free Energy (Quasiharmonic) = 2810.338602

Frequencies (Top 3 out of 270)

1. $-589.8442 \mathrm{~cm}-1$

2. $\quad 9.1953 \mathrm{~cm}-1$

3. $13.5818 \mathrm{~cm}-1$

B3LYP/6-31G(d) Molecular Geometry in Cartesian Coordinates

$\begin{array}{llll}\text { C } & 3.071139 & -0.777378 & -0.277050 \\ \text { C } & 1.924204 & -1.501052 & 0.005221 \\ \text { C } & 1.790577 & -2.899764 & -0.253871 \\ \text { C } & 2.802088 & -3.490084 & -0.989310 \\ \text { H } & 2.731368 & -4.547131 & -1.231488 \\ \text { C } & 3.578192 & 3.171407 & 1.407217 \\ \text { C } & 3.247677 & 0.580775 & 0.323940 \\ \text { C } & 2.316445 & 1.587765 & 0.118710 \\ \text { C } & 2.479353 & 2.915224 & 0.613051 \\ \text { H } & 3.736902 & 4.179604 & 1.780980 \\ \text { O } & 0.886375 & -0.840694 & 0.650486 \\ \text { P } & 0.047010 & 0.255463 & -0.231203\end{array}$




\begin{tabular}{|c|c|c|c|}
\hline $\mathrm{O}$ & 1.188859 & 1.339770 & -0.654654 \\
\hline C & -1.245625 & -5.311405 & 1.630521 \\
\hline C & 0.075042 & -5.755755 & 1.543355 \\
\hline C & 1.040625 & -4.965634 & 0.921440 \\
\hline C & 0.705623 & -3.723899 & 0.350045 \\
\hline C & -0.632867 & -3.304536 & 0.424043 \\
\hline C & -1.595141 & -4.080553 & 1.071430 \\
\hline $\mathrm{H}$ & 0.362371 & -6.707657 & 1.982897 \\
\hline $\mathrm{H}$ & -2.609791 & -3.700681 & 1.157504 \\
\hline C & -0.062663 & 6.243760 & -0.364300 \\
\hline C & 0.455814 & 5.436205 & -1.379764 \\
\hline C & 1.242822 & 4.328796 & -1.067306 \\
\hline C & 1.542433 & 4.019522 & 0.269584 \\
\hline C & 1.014672 & 4.836502 & 1.280760 \\
\hline C & 0.215251 & 5.936339 & 0.967685 \\
\hline $\mathrm{H}$ & 0.259195 & 5.678202 & -2.421642 \\
\hline $\mathrm{H}$ & -0.189073 & 6.552611 & 1.766451 \\
\hline C & 4.354346 & 0.846747 & 1.208129 \\
\hline C & 4.515196 & 2.165208 & 1.744580 \\
\hline C & 5.606808 & 2.443122 & 2.610938 \\
\hline C & 6.496171 & 1.456850 & 2.967510 \\
\hline C & 6.319150 & 0.144023 & 2.472533 \\
\hline C & 5.280480 & -0.152832 & 1.617447 \\
\hline $\mathrm{H}$ & 5.716783 & 3.453982 & 2.996557 \\
\hline $\mathrm{H}$ & 7.323589 & 1.678475 & 3.635949 \\
\hline $\mathrm{H}$ & 7.006069 & -0.642096 & 2.774189 \\
\hline $\mathrm{H}$ & 5.156974 & -1.168007 & 1.261025 \\
\hline C & 4.078090 & -1.388072 & -1.099195 \\
\hline C & 3.920392 & -2.763168 & -1.468596 \\
\hline C & 4.899078 & -3.375684 & -2.297411 \\
\hline C & 5.981617 & -2.663767 & -2.760215 \\
\hline C & 6.128023 & -1.300184 & -2.412527 \\
\hline C & 5.203261 & -0.679698 & -1.601151 \\
\hline $\mathrm{H}$ & 4.769980 & -4.421695 & -2.565666 \\
\hline $\mathrm{H}$ & 6.720005 & -3.142318 & -3.397753 \\
\hline $\mathrm{H}$ & 6.974768 & -0.735516 & -2.793402 \\
\hline $\mathrm{H}$ & 5.321043 & 0.368656 & -1.349929 \\
\hline $\mathrm{O}$ & -0.557439 & -0.283241 & -1.487279 \\
\hline $\mathrm{O}$ & -0.906015 & 0.888378 & 0.810791 \\
\hline $\mathrm{H}$ & -1.803652 & 0.213775 & 1.046374 \\
\hline $\mathrm{H}$ & -0.929057 & -2.375049 & -0.038306 \\
\hline $\mathrm{H}$ & -1.993542 & -5.912434 & 2.141014 \\
\hline $\mathrm{H}$ & 2.075495 & -5.296386 & 0.908683 \\
\hline $\mathrm{H}$ & 1.224857 & 4.596531 & 2.319340 \\
\hline
\end{tabular}




\begin{tabular}{|c|c|c|c|}
\hline $\mathrm{H}$ & -0.676062 & 7.106674 & -0.610242 \\
\hline $\mathrm{H}$ & 1.647807 & 3.709878 & -1.861797 \\
\hline C & -3.919648 & -0.030019 & 1.488462 \\
\hline 0 & -2.782873 & -0.590609 & 1.284902 \\
\hline $\mathrm{H}$ & -3.959984 & 1.058660 & 1.627089 \\
\hline C & -4.873232 & -0.792996 & 2.406541 \\
\hline $\mathrm{O}$ & -4.779829 & -1.962040 & 2.690881 \\
\hline $\mathrm{O}$ & -5.841783 & 0.034157 & 2.862161 \\
\hline C & -6.799778 & -0.575421 & 3.745165 \\
\hline $\mathrm{H}$ & -7.498891 & 0.217436 & 4.012064 \\
\hline $\mathrm{H}$ & -7.318306 & -1.394875 & 3.240117 \\
\hline C & -4.201948 & 0.265970 & -1.077897 \\
\hline C & -5.130499 & -0.089491 & -0.082952 \\
\hline $\mathrm{H}$ & -2.419101 & -0.389748 & -1.916022 \\
\hline$N$ & -3.350213 & -0.664863 & -1.576303 \\
\hline C & -3.567944 & -2.057812 & -1.626147 \\
\hline O & -4.523722 & -2.657370 & -1.186491 \\
\hline $\mathrm{O}$ & -2.559083 & -2.600820 & -2.316351 \\
\hline C & -2.636155 & -4.026635 & -2.505682 \\
\hline $\mathrm{H}$ & -3.556681 & -4.287292 & -3.033819 \\
\hline $\mathrm{H}$ & -2.600813 & -4.537045 & -1.541767 \\
\hline $\mathrm{H}$ & -1.760527 & -4.277633 & -3.103184 \\
\hline $\mathrm{H}$ & -5.883867 & 0.638498 & 0.192035 \\
\hline $\mathrm{H}$ & -5.436502 & -1.127094 & -0.048983 \\
\hline C & -4.002659 & 1.673635 & -1.483006 \\
\hline C & -2.771864 & 2.152554 & -1.972861 \\
\hline C & -5.089843 & 2.568417 & -1.410030 \\
\hline C & -2.635159 & 3.485170 & -2.350448 \\
\hline $\mathrm{H}$ & -1.903535 & 1.505422 & -2.031549 \\
\hline C & -4.949826 & 3.895447 & -1.802847 \\
\hline $\mathrm{H}$ & -6.061254 & 2.218258 & -1.079413 \\
\hline C & -3.718818 & 4.360699 & -2.268400 \\
\hline $\mathrm{H}$ & -1.669581 & 3.841130 & -2.693412 \\
\hline $\mathrm{H}$ & -5.804502 & 4.563725 & -1.750009 \\
\hline $\mathrm{H}$ & -3.605686 & 5.398952 & -2.567735 \\
\hline $\mathrm{H}$ & -6.301762 & -0.965742 & 4.636380 \\
\hline
\end{tabular}

Catalyst (R)-1 TS Conformation 269

B3LYP/6-31G(d) Energy $=-2809.682939$

B3LYP-D3(BJ)/def2-TZVPP-IEF-PCM(DCM) Energy $=-2810.980258$

B3LYP-D3(BJ)/def2-TZVPP-IEF-PCM(DCM)//B3LYP/6-31G(d) Free Energy (Quasiharmonic) = 2810.338555 
Frequencies (Top 3 out of 270)

1. $-675.6989 \mathrm{~cm}-1$

2. $\quad 12.6107 \mathrm{~cm}-1$

3. $\quad 18.0852 \mathrm{~cm}-1$

B3LYP/6-31G(d) Molecular Geometry in Cartesian Coordinates

\begin{tabular}{|c|c|c|c|}
\hline C & 2.896035 & 0.493069 & -0.072520 \\
\hline C & 2.190285 & 1.428289 & -0.816707 \\
\hline C & 2.313935 & 2.838300 & -0.628814 \\
\hline C & 3.144323 & 3.269675 & 0.387329 \\
\hline $\mathrm{H}$ & 3.286188 & 4.336625 & 0.537683 \\
\hline C & 2.451999 & -3.752363 & -0.683608 \\
\hline C & 2.772961 & -0.962478 & -0.385665 \\
\hline C & 1.519159 & -1.556309 & -0.417255 \\
\hline C & 1.329801 & -2.964780 & -0.532588 \\
\hline $\mathrm{H}$ & 2.335680 & -4.829874 & -0.768479 \\
\hline 0 & 1.354231 & 0.983535 & -1.827044 \\
\hline$P$ & -0.067047 & 0.251043 & -1.469863 \\
\hline $\mathrm{O}$ & 0.398877 & -0.759774 & -0.236884 \\
\hline C & 0.322345 & 5.786817 & -3.048826 \\
\hline C & 0.925706 & 4.682139 & -3.653068 \\
\hline C & 1.553841 & 3.708749 & -2.878260 \\
\hline C & 1.594810 & 3.824886 & -1.478553 \\
\hline C & 0.980823 & 4.939092 & -0.883266 \\
\hline C & 0.350693 & 5.910798 & -1.659343 \\
\hline $\mathrm{H}$ & 0.908269 & 4.575403 & -4.734436 \\
\hline $\mathrm{H}$ & -0.125750 & 6.760043 & -1.176276 \\
\hline C & -2.537732 & -4.838079 & -0.236544 \\
\hline C & -1.543918 & -5.106233 & 0.708971 \\
\hline C & -0.295088 & -4.488707 & 0.606648 \\
\hline C & -0.021226 & -3.591991 & -0.439033 \\
\hline C & -1.024356 & -3.330363 & -1.386368 \\
\hline C & -2.272864 & -3.950326 & -1.284997 \\
\hline $\mathrm{H}$ & -1.738661 & -5.794058 & 1.527935 \\
\hline $\mathrm{H}$ & -3.041330 & -3.726559 & -2.020368 \\
\hline C & 3.924401 & -1.781085 & -0.653181 \\
\hline C & 3.752092 & -3.196903 & -0.787054 \\
\hline C & 4.884267 & -4.017401 & -1.040349 \\
\hline C & 6.137759 & -3.469547 & -1.184282 \\
\hline C & 6.306399 & -2.068348 & -1.087097 \\
\hline C & 5.231226 & -1.247351 & -0.826842 \\
\hline
\end{tabular}




\begin{tabular}{|c|c|c|c|}
\hline $\mathrm{H}$ & 4.735867 & -5.090817 & -1.131922 \\
\hline $\mathrm{H}$ & 6.994994 & -4.106224 & -1.385199 \\
\hline $\mathrm{H}$ & 7.292830 & -1.634096 & -1.225973 \\
\hline $\mathrm{H}$ & 5.375442 & -0.174610 & -0.767222 \\
\hline C & 3.690410 & 0.958654 & 1.034826 \\
\hline C & 3.820982 & 2.370134 & 1.246966 \\
\hline C & 4.614371 & 2.844664 & 2.326844 \\
\hline C & 5.229530 & 1.970434 & 3.192523 \\
\hline C & 5.066497 & 0.576807 & 3.013585 \\
\hline C & 4.320795 & 0.084407 & 1.964422 \\
\hline $\mathrm{H}$ & 4.714969 & 3.919184 & 2.461427 \\
\hline $\mathrm{H}$ & 5.828767 & 2.345436 & 4.017743 \\
\hline $\mathrm{H}$ & 5.531626 & -0.114024 & 3.711660 \\
\hline $\mathrm{H}$ & 4.201103 & -0.986117 & 1.848459 \\
\hline $\mathrm{O}$ & -0.577846 & -0.457561 & -2.667504 \\
\hline 0 & -0.975751 & 1.249247 & -0.718265 \\
\hline $\mathrm{H}$ & -2.113439 & 1.198674 & -0.951888 \\
\hline $\mathrm{H}$ & 0.979133 & 5.029413 & 0.199504 \\
\hline $\mathrm{H}$ & -0.171056 & 6.541187 & -3.656003 \\
\hline $\mathrm{H}$ & 2.018799 & 2.855911 & -3.359798 \\
\hline $\mathrm{H}$ & -0.830272 & -2.631890 & -2.194177 \\
\hline $\mathrm{H}$ & -3.508187 & -5.322651 & -0.162357 \\
\hline $\mathrm{H}$ & 0.467605 & -4.678732 & 1.355793 \\
\hline C & -3.602165 & -0.224389 & -1.252552 \\
\hline $\mathrm{O}$ & -3.349035 & 1.036988 & -1.157235 \\
\hline $\mathrm{H}$ & -2.768183 & -0.904944 & -1.452076 \\
\hline C & -4.831528 & -0.642560 & -2.055699 \\
\hline $\mathrm{O}$ & -4.964856 & -1.754427 & -2.525102 \\
\hline 0 & -5.731454 & 0.343333 & -2.163687 \\
\hline C & -6.902523 & 0.022962 & -2.935980 \\
\hline $\mathrm{H}$ & -7.438869 & -0.818800 & -2.489393 \\
\hline $\mathrm{H}$ & -7.515615 & 0.923953 & -2.920732 \\
\hline C & -3.360460 & -0.692435 & 1.469231 \\
\hline C & -4.183666 & -1.102404 & 0.393432 \\
\hline $\mathrm{H}$ & -2.142675 & -2.317602 & 1.299484 \\
\hline$N$ & -2.238180 & -1.405181 & 1.741901 \\
\hline C & -1.022469 & -1.030277 & 2.384121 \\
\hline $\mathrm{O}$ & -0.217364 & -1.870396 & 2.709429 \\
\hline $\mathrm{O}$ & -0.918373 & 0.282030 & 2.535980 \\
\hline C & 0.326526 & 0.740625 & 3.103348 \\
\hline $\mathrm{H}$ & 0.225100 & 1.823119 & 3.163399 \\
\hline $\mathrm{H}$ & 1.153709 & 0.467139 & 2.447823 \\
\hline $\mathrm{H}$ & 0.474701 & 0.304473 & 4.094093 \\
\hline $\mathrm{H}$ & -5.221091 & -0.794444 & 0.480376 \\
\hline
\end{tabular}




$\begin{array}{llll}\text { H } & -4.047711 & -2.123699 & 0.043894 \\ \mathrm{C} & -3.748527 & 0.458109 & 2.297615 \\ \mathrm{C} & -4.381402 & 1.565345 & 1.704377 \\ \mathrm{C} & -3.582737 & 0.420749 & 3.695946 \\ \mathrm{C} & -4.805046 & 2.628912 & 2.499994 \\ \mathrm{H} & -4.492110 & 1.609804 & 0.625861 \\ \mathrm{C} & -4.041265 & 1.470010 & 4.482517 \\ \mathrm{H} & -3.128043 & -0.446499 & 4.164820 \\ \mathrm{C} & -4.644762 & 2.581925 & 3.885126 \\ \mathrm{H} & -5.269197 & 3.492763 & 2.033228 \\ \mathrm{H} & -3.930232 & 1.422965 & 5.562043 \\ \mathrm{H} & -4.995529 & 3.404677 & 4.502195 \\ \mathrm{H} & -6.622713 & -0.235635 & -3.960212\end{array}$

Catalyst (R)-1 TS Conformation 270

B3LYP/6-31G(d) Energy $=-2809.690739$

B3LYP-D3(BJ)/def2-TZVPP-IEF-PCM(DCM) Energy $=-2810.979645$

B3LYP-D3(BJ)/def2-TZVPP-IEF-PCM(DCM)//B3LYP/6-31G(d) Free Energy (Quasiharmonic) = 2810.338542

Frequencies (Top 3 out of 270)

1. $-737.9385 \mathrm{~cm}-1$

2. $4.4023 \mathrm{~cm}-1$

3. $\quad 9.5448 \mathrm{~cm}-1$

B3LYP/6-31G(d) Molecular Geometry in Cartesian Coordinates

$\begin{array}{llll}\text { C } & -3.383161 & -0.753962 & 0.210215 \\ \text { C } & -2.426937 & -1.591715 & -0.339158 \\ \text { C } & -2.256176 & -2.954776 & 0.041165 \\ \text { C } & -3.070513 & -3.433524 & 1.048543 \\ \text { H } & -2.987301 & -4.475336 & 1.346791 \\ \text { C } & -3.817449 & 3.347024 & -1.040413 \\ \text { C } & -3.541441 & 0.636087 & -0.312506 \\ \text { C } & -2.453708 & 1.498620 & -0.345158 \\ \text { C } & -2.570193 & 2.883484 & -0.670018 \\ \text { H } & -3.933346 & 4.396532 & -1.297939 \\ \text { O } & -1.589819 & -1.081865 & -1.327148 \\ \text { P } & -0.399339 & -0.059275 & -0.866115 \\ \text { O } & -1.207272 & 1.030222 & 0.054121 \\ \text { C } & 0.602666 & -5.607155 & -1.777048\end{array}$




\begin{tabular}{|c|c|c|c|}
\hline C & 0.479406 & -5.541986 & -0.388735 \\
\hline C & -0.437858 & -4.666959 & 0.192165 \\
\hline C & -1.248543 & -3.839534 & -0.602026 \\
\hline C & -1.109715 & -3.909418 & -1.998718 \\
\hline C & -0.195168 & -4.787395 & -2.578100 \\
\hline $\mathrm{H}$ & 1.104490 & -6.165220 & 0.245254 \\
\hline $\mathrm{H}$ & -0.108018 & -4.831854 & -3.660633 \\
\hline C & 0.635380 & 5.744731 & -0.417575 \\
\hline C & -0.563704 & 5.956181 & 0.263869 \\
\hline C & -1.587029 & 5.011478 & 0.185673 \\
\hline C & -1.430239 & 3.838462 & -0.570784 \\
\hline C & -0.219687 & 3.633847 & -1.252192 \\
\hline C & 0.799880 & 4.582794 & -1.174433 \\
\hline $\mathrm{H}$ & -0.703480 & 6.854124 & 0.860387 \\
\hline $\mathrm{H}$ & 1.727281 & 4.413745 & -1.716292 \\
\hline C & -4.808765 & 1.111481 & -0.798449 \\
\hline C & -4.941035 & 2.492592 & -1.151892 \\
\hline C & -6.190299 & 2.976777 & -1.626241 \\
\hline C & -7.266158 & 2.132829 & -1.773747 \\
\hline C & -7.129750 & 0.760528 & -1.457734 \\
\hline C & -5.936197 & 0.263756 & -0.981985 \\
\hline $\mathrm{H}$ & -6.273714 & 4.030215 & -1.883009 \\
\hline $\mathrm{H}$ & -8.214728 & 2.512412 & -2.143532 \\
\hline $\mathrm{H}$ & -7.973000 & 0.089603 & -1.597980 \\
\hline $\mathrm{H}$ & -5.845787 & -0.792358 & -0.755819 \\
\hline C & -4.169583 & -1.245546 & 1.310299 \\
\hline C & -4.011232 & -2.610829 & 1.715682 \\
\hline C & -4.790089 & -3.114438 & 2.792810 \\
\hline C & -5.668123 & -2.302680 & 3.472256 \\
\hline C & -5.796220 & -0.943569 & 3.101765 \\
\hline C & -5.069458 & -0.429731 & 2.050109 \\
\hline $\mathrm{H}$ & -4.666705 & -4.156725 & 3.077592 \\
\hline $\mathrm{H}$ & -6.253312 & -2.697344 & 4.298369 \\
\hline $\mathrm{H}$ & -6.471692 & -0.296263 & 3.654622 \\
\hline $\mathrm{H}$ & -5.173615 & 0.616051 & 1.786484 \\
\hline 0 & 0.270020 & 0.489444 & -2.076650 \\
\hline 0 & 0.496530 & -0.745741 & 0.201511 \\
\hline $\mathrm{H}$ & 1.475211 & -1.347958 & -0.183821 \\
\hline $\mathrm{H}$ & -1.725232 & -3.278423 & -2.630658 \\
\hline $\mathrm{H}$ & 1.318495 & -6.287076 & -2.231409 \\
\hline $\mathrm{H}$ & -0.513909 & -4.603605 & 1.274061 \\
\hline $\mathrm{H}$ & -0.080661 & 2.739649 & -1.850894 \\
\hline $\mathrm{H}$ & 1.434327 & 6.479579 & -0.359844 \\
\hline $\mathrm{H}$ & -2.514710 & 5.172763 & 0.728476 \\
\hline
\end{tabular}




$\begin{array}{llll}\mathrm{C} & 3.123269 & -1.124978 & -1.390695 \\ \mathrm{O} & 2.589563 & -1.737695 & -0.407291 \\ \mathrm{H} & 2.506324 & -0.777731 & -2.223781 \\ \mathrm{C} & 4.560792 & -1.486433 & -1.702649 \\ \mathrm{O} & 5.287456 & -2.115656 & -0.969879 \\ \mathrm{O} & 4.907178 & -1.013325 & -2.916789 \\ \mathrm{C} & 6.261477 & -1.288173 & -3.317503 \\ \mathrm{H} & 6.435282 & -2.366526 & -3.356269 \\ \mathrm{H} & 6.368455 & -0.844985 & -4.307481 \\ \mathrm{C} & 3.847244 & 0.865063 & 0.402193 \\ \mathrm{C} & 3.397312 & 0.946861 & -0.912141 \\ \mathrm{H} & 1.994720 & 0.267950 & 1.056961 \\ \mathrm{~N} & 2.939668 & 0.525650 & 1.363645 \\ \mathrm{C} & 3.076072 & 0.657333 & 2.756242 \\ \mathrm{O} & 4.028589 & 1.105947 & 3.349361 \\ \mathrm{O} & 1.937377 & 0.216957 & 3.316709 \\ \mathrm{C} & 1.881366 & 0.323282 & 4.748799 \\ \mathrm{H} & 2.678569 & -0.267819 & 5.206566 \\ \mathrm{H} & 0.902815 & -0.067966 & 5.025329 \\ \mathrm{H} & 1.982088 & 1.366681 & 5.058044 \\ \mathrm{H} & 4.107984 & 1.244911 & -1.673980 \\ \mathrm{H} & 2.350946 & 1.150455 & -1.121547 \\ \mathrm{C} & 5.291334 & 0.966186 & 0.705575 \\ \mathrm{C} & 6.032262 & 2.030175 & 0.167095 \\ \mathrm{C} & 5.953387 & -0.033848 & 1.437021 \\ \mathrm{C} & 7.407535 & 2.108210 & 0.378427 \\ \mathrm{H} & 5.521292 & 2.808945 & -0.391452 \\ \mathrm{C} & 7.329588 & 0.036925 & 1.626068 \\ \mathrm{H} & 5.394154 & -0.879910 & 1.819564 \\ \mathrm{C} & 8.058053 & 1.110257 & 1.106189 \\ \mathrm{H} & 7.968661 & 2.946791 & -0.024050 \\ \mathrm{H} & 7.835744 & -0.748726 & 2.179229 \\ \mathrm{H} & 9.131428 & 1.166291 & 1.266061 \\ \mathrm{H} & 6.964817 & -0.837464 & -2.612286\end{array}$

Catalyst (R)-1 TS Conformation 271

B3LYP/6-31G(d) Energy $=-2809.694449$

B3LYP-D3(BJ)/def2-TZVPP-IEF-PCM(DCM) Energy = -2810.981886

B3LYP-D3(BJ)/def2-TZVPP-IEF-PCM(DCM)//B3LYP/6-31G(d) Free Energy (Quasiharmonic) = 2810.33853

Frequencies (Top 3 out of 270) 
1. $-374.7858 \mathrm{~cm}-1$

2. $\quad 10.6891 \mathrm{~cm}-1$

3. $\quad 14.9791 \mathrm{~cm}-1$

B3LYP/6-31G(d) Molecular Geometry in Cartesian Coordinates

\begin{tabular}{|c|c|c|c|}
\hline C & -3.153067 & -0.588471 & 0.426315 \\
\hline C & -2.346063 & -1.424048 & -0.327711 \\
\hline C & -2.244067 & -2.829525 & -0.115908 \\
\hline C & -2.941980 & -3.356867 & 0.952777 \\
\hline $\mathrm{H}$ & -2.910380 & -4.428821 & 1.129199 \\
\hline C & -3.512255 & 3.633284 & -0.359918 \\
\hline C & -3.295856 & 0.851787 & 0.056161 \\
\hline C & -2.175624 & 1.663050 & -0.060393 \\
\hline C & -2.254950 & 3.078133 & -0.229179 \\
\hline $\mathrm{H}$ & -3.600894 & 4.708501 & -0.491416 \\
\hline $\mathrm{O}$ & -1.603092 & -0.867771 & -1.368223 \\
\hline$P$ & -0.298562 & 0.011217 & -0.948298 \\
\hline $\mathrm{O}$ & -0.914274 & 1.103190 & 0.105662 \\
\hline C & -0.047200 & -5.518427 & -2.657792 \\
\hline C & -0.871971 & -4.541274 & -3.220856 \\
\hline C & -1.561958 & -3.645224 & -2.405361 \\
\hline C & -1.448517 & -3.716256 & -1.006554 \\
\hline C & -0.611577 & -4.698790 & -0.453463 \\
\hline C & 0.083801 & -5.590770 & -1.270015 \\
\hline $\mathrm{H}$ & -0.985920 & -4.479889 & -4.300110 \\
\hline $\mathrm{H}$ & 0.728997 & -6.341438 & -0.820880 \\
\hline C & 1.142141 & 5.721147 & -0.192301 \\
\hline C & 0.095200 & 5.896907 & 0.714328 \\
\hline C & -0.994104 & 5.025045 & 0.704077 \\
\hline C & -1.054905 & 3.962305 & -0.211753 \\
\hline C & 0.001121 & 3.797838 & -1.120075 \\
\hline C & 1.089978 & 4.669379 & -1.109630 \\
\hline $\mathrm{H}$ & 0.126106 & 6.710907 & 1.434197 \\
\hline $\mathrm{H}$ & 1.891575 & 4.515042 & -1.826640 \\
\hline C & -4.589861 & 1.430847 & -0.188934 \\
\hline C & -4.689081 & 2.845686 & -0.384756 \\
\hline C & -5.962353 & 3.432147 & -0.618357 \\
\hline C & -7.096795 & 2.657328 & -0.683797 \\
\hline C & -6.998458 & 1.255125 & -0.524484 \\
\hline C & -5.780669 & 0.658478 & -0.281844 \\
\hline $\mathrm{H}$ & -6.018671 & 4.509126 & -0.757761 \\
\hline $\mathrm{H}$ & -8.064285 & 3.115433 & -0.869805 \\
\hline
\end{tabular}




\begin{tabular}{|c|c|c|c|}
\hline $\mathrm{H}$ & -7.891612 & 0.640901 & -0.600882 \\
\hline $\mathrm{H}$ & -5.722761 & -0.418421 & -0.173902 \\
\hline$C$ & -3.810658 & -1.140662 & 1.581491 \\
\hline C & -3.703059 & -2.547409 & 1.831478 \\
\hline C & -4.355485 & -3.108014 & 2.963007 \\
\hline C & -5.059948 & -2.315262 & 3.838556 \\
\hline C & -5.133934 & -0.920136 & 3.617289 \\
\hline C & -4.529142 & -0.348903 & 2.519157 \\
\hline $\mathrm{H}$ & -4.274910 & -4.179717 & 3.129022 \\
\hline $\mathrm{H}$ & -5.548707 & -2.753783 & 4.704196 \\
\hline $\mathrm{H}$ & -5.669658 & -0.291025 & 4.322933 \\
\hline $\mathrm{H}$ & -4.588213 & 0.722727 & 2.370930 \\
\hline 0 & 0.783821 & -0.723287 & -0.235289 \\
\hline $\mathrm{O}$ & 0.029274 & 0.709525 & -2.295039 \\
\hline $\mathrm{H}$ & 1.062916 & 1.021168 & -2.457987 \\
\hline $\mathrm{H}$ & -0.495041 & -4.749044 & 0.625528 \\
\hline $\mathrm{H}$ & 0.488314 & -6.216827 & -3.295520 \\
\hline $\mathrm{H}$ & -2.202585 & -2.893255 & -2.853427 \\
\hline $\mathrm{H}$ & -0.038050 & 2.999864 & -1.850660 \\
\hline $\mathrm{H}$ & 1.990262 & 6.401226 & -0.185314 \\
\hline $\mathrm{H}$ & -1.800598 & 5.156442 & 1.420779 \\
\hline C & 3.294941 & 1.043753 & -2.019517 \\
\hline 0 & 2.310595 & 1.617555 & -2.597621 \\
\hline $\mathrm{H}$ & 4.289332 & 1.498814 & -2.133368 \\
\hline C & 3.421014 & -0.487115 & -2.055205 \\
\hline 0 & 4.326546 & -1.102970 & -1.525456 \\
\hline 0 & 2.456578 & -1.041363 & -2.789436 \\
\hline C & 2.436887 & -2.481059 & -2.817534 \\
\hline $\mathrm{H}$ & 3.388358 & -2.866756 & -3.191957 \\
\hline $\mathrm{H}$ & 2.246742 & -2.865330 & -1.813267 \\
\hline C & 3.894383 & 0.604663 & 0.719914 \\
\hline C & 3.146289 & 1.482067 & -0.087723 \\
\hline $\mathrm{H}$ & 2.335265 & -0.701450 & 0.749903 \\
\hline$N$ & 3.280804 & -0.534747 & 1.129268 \\
\hline C & 3.727616 & -1.477223 & 2.063896 \\
\hline 0 & 4.733230 & -1.420922 & 2.732710 \\
\hline $\mathrm{O}$ & 2.810293 & -2.462009 & 2.117813 \\
\hline C & 3.091735 & -3.496231 & 3.073377 \\
\hline $\mathrm{H}$ & 4.037589 & -3.989917 & 2.835984 \\
\hline $\mathrm{H}$ & 2.260521 & -4.196289 & 2.990785 \\
\hline $\mathrm{H}$ & 3.146571 & -3.080968 & 4.082989 \\
\hline $\mathrm{H}$ & 3.535351 & 2.489314 & -0.183997 \\
\hline $\mathrm{H}$ & 2.068694 & 1.420701 & -0.000718 \\
\hline C & 5.316167 & 0.897555 & 1.009385 \\
\hline
\end{tabular}




$\begin{array}{lrrr}\text { C } & 5.656077 & 2.173007 & 1.489418 \\ \text { C } & 6.336457 & -0.030280 & 0.740595 \\ \text { C } & 6.989025 & 2.507097 & 1.723590 \\ \text { H } & 4.871299 & 2.891228 & 1.707859 \\ \text { C } & 7.666235 & 0.317931 & 0.951927 \\ \text { H } & 6.080935 & -0.999534 & 0.331847 \\ \text { C } & 7.996357 & 1.581387 & 1.451036 \\ \text { H } & 7.237913 & 3.489707 & 2.114087 \\ \text { H } & 8.449834 & -0.399912 & 0.726805 \\ \text { H } & 9.036939 & 1.843146 & 1.622999 \\ \text { H } & 1.616492 & -2.746493 & -3.482071\end{array}$

Catalyst (R)-1 TS Conformation 272

B3LYP/6-31G(d) Energy $=-2809.685108$

B3LYP-D3(BJ)/def2-TZVPP-IEF-PCM(DCM) Energy = -2810.981249

B3LYP-D3(BJ)/def2-TZVPP-IEF-PCM(DCM)//B3LYP/6-31G(d) Free Energy (Quasiharmonic) = 2810.338524

Frequencies (Top 3 out of 270)

1. $-333.3758 \mathrm{~cm}-1$

2. $\quad 12.8794 \mathrm{~cm}-1$

3. $\quad 17.5541 \mathrm{~cm}-1$

B3LYP/6-31G(d) Molecular Geometry in Cartesian Coordinates

$\begin{array}{llll}\text { C } & -2.985030 & -0.995259 & 0.138439 \\ \text { C } & -1.863796 & -1.718296 & -0.230617 \\ \text { C } & -1.645271 & -3.078863 & 0.134354 \\ \text { C } & -2.592252 & -3.668567 & 0.949396 \\ \text { H } & -2.475932 & -4.713113 & 1.225594 \\ \text { C } & -3.597658 & 3.072710 & -1.137378 \\ \text { C } & -3.179128 & 0.387975 & -0.387825 \\ \text { C } & -2.204735 & 1.358269 & -0.195766 \\ \text { C } & -2.407677 & 2.732591 & -0.523496 \\ \text { H } & -3.773171 & 4.111457 & -1.404314 \\ \text { O } & -0.903423 & -1.086195 & -1.015011 \\ \text { P } & 0.063545 & 0.020177 & -0.292834 \\ \text { O } & -1.015499 & 1.012952 & 0.439431 \\ \text { C } & 1.673820 & -5.463008 & -1.205837 \\ \text { C } & 1.019599 & -4.615648 & -2.103018 \\ \text { C } & -0.040664 & -3.819256 & -1.672960\end{array}$




\begin{tabular}{|c|c|c|c|}
\hline$C$ & -0.467229 & -3.855906 & -0.334071 \\
\hline C & 0.212189 & -4.699209 & 0.560602 \\
\hline C & 1.270788 & -5.496801 & 0.129557 \\
\hline $\mathrm{H}$ & 1.333768 & -4.575360 & -3.142259 \\
\hline $\mathrm{H}$ & 1.785089 & -6.137636 & 0.840789 \\
\hline C & 0.301877 & 5.942431 & 0.411350 \\
\hline C & -1.034764 & 5.997466 & 0.809828 \\
\hline C & -1.893227 & 4.938961 & 0.514309 \\
\hline C & -1.433982 & 3.806297 & -0.179849 \\
\hline C & -0.086063 & 3.756750 & -0.569423 \\
\hline C & 0.769377 & 4.820454 & -0.277445 \\
\hline $\mathrm{H}$ & -1.410501 & 6.861450 & 1.352117 \\
\hline $\mathrm{H}$ & 1.807402 & 4.767565 & -0.591998 \\
\hline C & -4.368283 & 0.741662 & -1.115904 \\
\hline C & -4.575994 & 2.109737 & -1.481493 \\
\hline C & -5.749496 & 2.473827 & -2.195983 \\
\hline C & -6.676538 & 1.526277 & -2.561902 \\
\hline C & -6.458800 & 0.167847 & -2.231699 \\
\hline C & -5.338233 & -0.214141 & -1.527420 \\
\hline $\mathrm{H}$ & -5.892907 & 3.519388 & -2.458380 \\
\hline $\mathrm{H}$ & -7.567297 & 1.814176 & -3.113487 \\
\hline $\mathrm{H}$ & -7.179543 & -0.583618 & -2.542579 \\
\hline $\mathrm{H}$ & -5.182038 & -1.260642 & -1.293377 \\
\hline C & -3.919501 & -1.598089 & 1.050427 \\
\hline C & -3.713857 & -2.959756 & 1.445043 \\
\hline C & -4.633951 & -3.574612 & 2.337070 \\
\hline C & -5.698807 & -2.872145 & 2.851021 \\
\hline C & -5.882161 & -1.515670 & 2.494151 \\
\hline C & -5.018817 & -0.896353 & 1.617092 \\
\hline $\mathrm{H}$ & -4.469379 & -4.612655 & 2.616281 \\
\hline $\mathrm{H}$ & -6.391210 & -3.350484 & 3.538307 \\
\hline $\mathrm{H}$ & -6.709742 & -0.954394 & 2.919549 \\
\hline $\mathrm{H}$ & -5.169019 & 0.146140 & 1.362175 \\
\hline $\mathrm{O}$ & 0.939478 & 0.641706 & -1.317217 \\
\hline $\mathrm{O}$ & 0.722473 & -0.626025 & 0.966401 \\
\hline $\mathrm{H}$ & 1.627523 & -1.191998 & 0.793800 \\
\hline $\mathrm{H}$ & -0.081468 & -4.711650 & 1.606302 \\
\hline $\mathrm{H}$ & 2.491752 & -6.092262 & -1.547453 \\
\hline $\mathrm{H}$ & -0.547373 & -3.172015 & -2.380166 \\
\hline $\mathrm{H}$ & 0.294331 & 2.892936 & -1.105095 \\
\hline $\mathrm{H}$ & 0.973871 & 6.767268 & 0.635241 \\
\hline $\mathrm{H}$ & -2.930313 & 4.978429 & 0.836578 \\
\hline C & 3.406777 & -1.632170 & -0.498968 \\
\hline $\mathrm{O}$ & 2.817154 & -1.895632 & 0.616002 \\
\hline
\end{tabular}




$\begin{array}{llll}\mathrm{H} & 2.875766 & -1.047321 & -1.261127 \\ \mathrm{C} & 4.216108 & -2.742783 & -1.172146 \\ \mathrm{O} & 4.344000 & -2.831185 & -2.374080 \\ \mathrm{O} & 4.772804 & -3.580878 & -0.280900 \\ \mathrm{C} & 5.543597 & -4.652165 & -0.848897 \\ \mathrm{H} & 5.925405 & -5.219614 & 0.000145 \\ \mathrm{H} & 4.911396 & -5.282327 & -1.479133 \\ \mathrm{C} & 4.361763 & 0.605385 & 0.560911 \\ \mathrm{C} & 4.912582 & -0.493343 & -0.137784 \\ \mathrm{H} & 4.023500 & -0.615312 & 2.120693 \\ \mathrm{~N} & 3.896133 & 0.342720 & 1.803468 \\ \mathrm{C} & 2.918079 & 0.979064 & 2.625836 \\ \mathrm{O} & 2.643546 & 0.494515 & 3.696931 \\ \mathrm{O} & 2.408012 & 2.071449 & 2.078206 \\ \mathrm{C} & 1.305901 & 2.665328 & 2.809374 \\ \mathrm{H} & 1.097670 & 3.599229 & 2.291537 \\ \mathrm{H} & 0.445544 & 1.996153 & 2.757637 \\ \mathrm{H} & 1.595433 & 2.835256 & 3.848062 \\ \mathrm{H} & 5.429938 & -0.261369 & -1.063899 \\ \mathrm{H} & 5.416090 & -1.239115 & 0.473374 \\ \mathrm{C} & 4.325501 & 1.950025 & -0.044112 \\ \mathrm{C} & 4.839005 & 3.045173 & 0.671569 \\ \mathrm{C} & 3.928637 & 2.120672 & -1.380194 \\ \mathrm{C} & 4.975111 & 4.284277 & 0.052085 \\ \mathrm{H} & 5.160259 & 2.915091 & 1.700414 \\ \mathrm{C} & 4.048579 & 3.369401 & -1.986366 \\ \mathrm{H} & 3.480349 & 1.295479 & -1.921811 \\ \mathrm{C} & 4.583138 & 4.449179 & -1.278949 \\ \mathrm{H} & 5.391798 & 5.119818 & 0.607326 \\ \mathrm{H} & 3.721973 & 3.497155 & -3.014172 \\ \mathrm{H} & 4.690988 & 5.416561 & -1.761889 \\ \mathrm{H} & 6.366484 & -4.258343 & -1.452111 \\ & & & \end{array}$

Catalyst (R)-1 TS Conformation 273

B3LYP/6-31G(d) Energy $=-2809.685201$

B3LYP-D3(BJ)/def2-TZVPP-IEF-PCM(DCM) Energy $=-2810.980052$

B3LYP-D3(BJ)/def2-TZVPP-IEF-PCM(DCM)//B3LYP/6-31G(d) Free Energy (Quasiharmonic) = 2810.338519

Frequencies (Top 3 out of 270)

1. $-691.1224 \mathrm{~cm}-1$ 
2. $\quad 7.0625 \mathrm{~cm}-1$

3. $\quad 12.1171 \mathrm{~cm}-1$

B3LYP/6-31G(d) Molecular Geometry in Cartesian Coordinates

\begin{tabular}{|c|c|c|c|}
\hline C & -2.913897 & -1.121691 & 0.121851 \\
\hline C & -1.790654 & -1.807734 & -0.309925 \\
\hline C & -1.499577 & -3.153846 & 0.061009 \\
\hline C & -2.362531 & -3.760500 & 0.953466 \\
\hline $\mathrm{H}$ & -2.191135 & -4.795705 & 1.235982 \\
\hline C & -3.802433 & 2.871313 & -1.223740 \\
\hline C & -3.208504 & 0.235535 & -0.425358 \\
\hline C & -2.266344 & 1.252131 & -0.333088 \\
\hline C & -2.554246 & 2.603337 & -0.696292 \\
\hline $\mathrm{H}$ & -4.042069 & 3.891230 & -1.512708 \\
\hline $\mathrm{O}$ & -0.908246 & -1.151690 & -1.162500 \\
\hline$P$ & 0.064394 & -0.030536 & -0.465964 \\
\hline $\mathrm{O}$ & -1.029827 & 0.982834 & 0.236248 \\
\hline C & 1.736142 & -5.503555 & -1.530430 \\
\hline C & 1.439373 & -5.536234 & -0.166216 \\
\hline C & 0.413421 & -4.742615 & 0.347833 \\
\hline C & -0.345075 & -3.910330 & -0.492050 \\
\hline C & -0.028663 & -3.878503 & -1.861245 \\
\hline C & 1.000731 & -4.667026 & -2.372787 \\
\hline $\mathrm{H}$ & 2.005168 & -6.180659 & 0.502325 \\
\hline $\mathrm{H}$ & 1.222343 & -4.633280 & -3.436294 \\
\hline C & 0.087459 & 5.969943 & -0.244974 \\
\hline C & 0.518675 & 4.837197 & -0.938713 \\
\hline C & -0.313152 & 3.724990 & -1.064122 \\
\hline C & -1.598155 & 3.729970 & -0.499419 \\
\hline C & -2.019800 & 4.871937 & 0.202148 \\
\hline C & -1.184767 & 5.982686 & 0.329421 \\
\hline$H$ & 1.507515 & 4.814403 & -1.388782 \\
\hline $\mathrm{H}$ & -1.531506 & 6.857600 & 0.874009 \\
\hline C & -4.462973 & 0.511752 & -1.072929 \\
\hline C & -4.761267 & 1.857172 & -1.458907 \\
\hline C & -6.001100 & 2.147410 & -2.090172 \\
\hline C & -6.908575 & 1.149478 & -2.358335 \\
\hline C & -6.603101 & -0.187344 & -2.010234 \\
\hline C & -5.415889 & -0.497865 & -1.384235 \\
\hline $\mathrm{H}$ & -6.211561 & 3.177179 & -2.369362 \\
\hline $\mathrm{H}$ & -7.850850 & 1.380968 & -2.847367 \\
\hline $\mathrm{H}$ & -7.309178 & -0.979306 & -2.245175 \\
\hline $\mathrm{H}$ & -5.194462 & -1.529287 & -1.136196 \\
\hline
\end{tabular}




\begin{tabular}{|c|c|c|c|}
\hline$C$ & -3.755588 & -1.738644 & 1.111599 \\
\hline C & -3.469448 & -3.081724 & 1.518700 \\
\hline C & -4.297430 & -3.709069 & 2.488898 \\
\hline C & -5.348258 & -3.034389 & 3.065170 \\
\hline C & -5.609693 & -1.694591 & 2.693927 \\
\hline C & -4.837454 & -1.064985 & 1.742426 \\
\hline $\mathrm{H}$ & -4.073104 & -4.733491 & 2.776775 \\
\hline $\mathrm{H}$ & -5.969743 & -3.521509 & 3.811562 \\
\hline $\mathrm{H}$ & -6.425507 & -1.154544 & 3.166909 \\
\hline $\mathrm{H}$ & -5.046023 & -0.035487 & 1.476119 \\
\hline $\mathrm{O}$ & 0.967264 & -0.546752 & 0.598480 \\
\hline O & 0.691773 & 0.670338 & -1.690111 \\
\hline $\mathrm{H}$ & 1.807348 & 1.008688 & -1.587974 \\
\hline $\mathrm{H}$ & -0.598473 & -3.240691 & -2.527735 \\
\hline $\mathrm{H}$ & 2.532083 & -6.124455 & -1.933765 \\
\hline $\mathrm{H}$ & 0.207267 & -4.753169 & 1.414027 \\
\hline $\mathrm{H}$ & -3.008721 & 4.882963 & 0.653194 \\
\hline $\mathrm{H}$ & 0.737221 & 6.836843 & -0.154714 \\
\hline $\mathrm{H}$ & 0.025010 & 2.856592 & -1.617584 \\
\hline C & 3.785825 & 0.386214 & -1.253740 \\
\hline O & 3.010748 & 1.335153 & -1.620655 \\
\hline $\mathrm{H}$ & 3.358013 & -0.572669 & -0.946733 \\
\hline C & 5.101332 & 0.280706 & -2.022851 \\
\hline 0 & 5.683107 & 1.203448 & -2.539974 \\
\hline $\mathrm{O}$ & 5.522848 & -1.005029 & -2.055817 \\
\hline C & 6.742800 & -1.223532 & -2.787437 \\
\hline $\mathrm{H}$ & 6.625546 & -0.906286 & -3.826590 \\
\hline $\mathrm{H}$ & 7.566028 & -0.663288 & -2.335813 \\
\hline C & 3.785709 & 0.813895 & 1.508064 \\
\hline C & 4.747937 & 0.775583 & 0.490297 \\
\hline $\mathrm{H}$ & 2.620571 & -0.105330 & 2.887208 \\
\hline$N$ & 3.354697 & -0.271903 & 2.209227 \\
\hline C & 3.540060 & -1.655661 & 2.036199 \\
\hline 0 & 3.012774 & -2.450583 & 2.777902 \\
\hline $\mathrm{O}$ & 4.353587 & -1.944265 & 1.015925 \\
\hline C & 4.533919 & -3.351978 & 0.754510 \\
\hline $\mathrm{H}$ & 3.569975 & -3.820316 & 0.548287 \\
\hline $\mathrm{H}$ & 5.008005 & -3.835726 & 1.611975 \\
\hline $\mathrm{H}$ & 5.178036 & -3.389050 & -0.123100 \\
\hline $\mathrm{H}$ & 5.137955 & 1.738333 & 0.180736 \\
\hline $\mathrm{H}$ & 5.444915 & -0.051965 & 0.481363 \\
\hline C & 3.133078 & 2.085736 & 1.881049 \\
\hline C & 1.759107 & 2.132612 & 2.188484 \\
\hline C & 3.893169 & 3.267693 & 1.954467 \\
\hline
\end{tabular}




$\begin{array}{llll}\mathrm{C} & 1.165846 & 3.338719 & 2.550862 \\ \mathrm{H} & 1.147233 & 1.244829 & 2.059992 \\ \mathrm{C} & 3.296482 & 4.464048 & 2.340588 \\ \mathrm{H} & 4.957669 & 3.240602 & 1.745296 \\ \mathrm{C} & 1.931785 & 4.502765 & 2.636033 \\ \mathrm{H} & 0.097477 & 3.372553 & 2.738692 \\ \mathrm{H} & 3.897019 & 5.366529 & 2.409706 \\ \mathrm{H} & 1.462636 & 5.440632 & 2.918252 \\ \mathrm{H} & 6.930627 & -2.296058 & -2.732437\end{array}$

Catalyst (R)-1 TS Conformation 274

B3LYP/6-31G(d) Energy $=-2809.689219$

B3LYP-D3(BJ)/def2-TZVPP-IEF-PCM(DCM) Energy = -2810.98166

B3LYP-D3(BJ)/def2-TZVPP-IEF-PCM(DCM)//B3LYP/6-31G(d) Free Energy (Quasiharmonic) = 2810.338457

Frequencies (Top 3 out of 270)

1. $-331.3191 \mathrm{~cm}-1$

2. $\quad 8.4064 \mathrm{~cm}-1$

3. $12.0863 \mathrm{~cm}-1$

B3LYP/6-31G(d) Molecular Geometry in Cartesian Coordinates

$\begin{array}{llll}\mathrm{C} & 3.155961 & -0.592623 & -0.452915 \\ \mathrm{C} & 2.052773 & -1.407442 & -0.231215 \\ \mathrm{C} & 2.041134 & -2.793249 & -0.565236 \\ \mathrm{C} & 3.155903 & -3.320743 & -1.182670 \\ \mathrm{H} & 3.168417 & -4.377297 & -1.437935 \\ \mathrm{C} & 3.186885 & 3.531108 & 0.808415 \\ \mathrm{C} & 3.175951 & 0.812321 & 0.051209 \\ \mathrm{C} & 2.153731 & 1.678572 & -0.300451 \\ \mathrm{C} & 2.140042 & 3.063527 & 0.037861 \\ \mathrm{H} & 3.226122 & 4.586837 & 1.063344 \\ \mathrm{O} & 0.944878 & -0.910467 & 0.438574 \\ \mathrm{P} & -0.001322 & 0.289136 & -0.171263 \\ \mathrm{O} & 1.086058 & 1.165304 & -1.030729 \\ \mathrm{C} & -1.167225 & -5.538758 & 0.277774 \\ \mathrm{C} & 0.038981 & -5.624027 & 0.973761 \\ \mathrm{C} & 1.063297 & -4.712326 & 0.710144 \\ \mathrm{C} & 0.893663 & -3.692388 & -0.239141 \\ \mathrm{C} & -0.328739 & -3.604641 & -0.923624\end{array}$




\begin{tabular}{|c|c|c|c|}
\hline C & -1.346042 & -4.530492 & -0.674208 \\
\hline $\mathrm{H}$ & 0.189480 & -6.404683 & 1.715046 \\
\hline $\mathrm{H}$ & -2.266100 & -4.466030 & -1.248706 \\
\hline C & -0.885824 & 5.837020 & -1.250288 \\
\hline C & -0.362270 & 4.908261 & -2.152052 \\
\hline C & 0.601277 & 3.989918 & -1.738636 \\
\hline C & 1.064050 & 3.985766 & -0.411927 \\
\hline C & 0.524325 & 4.920466 & 0.486508 \\
\hline C & -0.440278 & 5.837851 & 0.072125 \\
\hline $\mathrm{H}$ & -0.702917 & 4.898487 & -3.184097 \\
\hline $\mathrm{H}$ & -0.849111 & 6.547815 & 0.786576 \\
\hline C & 4.214587 & 1.296608 & 0.920499 \\
\hline C & 4.214227 & 2.681472 & 1.287486 \\
\hline C & 5.239617 & 3.178497 & 2.137157 \\
\hline C & 6.211354 & 2.343809 & 2.637868 \\
\hline C & 6.190863 & 0.967895 & 2.310179 \\
\hline C & 5.221695 & 0.458826 & 1.473650 \\
\hline $\mathrm{H}$ & 5.231443 & 4.235008 & 2.394794 \\
\hline $\mathrm{H}$ & 6.985830 & 2.734060 & 3.292519 \\
\hline $\mathrm{H}$ & 6.944602 & 0.304329 & 2.725552 \\
\hline $\mathrm{H}$ & 5.215712 & -0.599389 & 1.240208 \\
\hline C & 4.264072 & -1.128331 & -1.198839 \\
\hline C & 4.264521 & -2.517480 & -1.545621 \\
\hline C & 5.361667 & -3.060674 & -2.267133 \\
\hline C & 6.411335 & -2.264972 & -2.662482 \\
\hline C & 6.397407 & -0.883969 & -2.355865 \\
\hline C & 5.355918 & -0.331453 & -1.643553 \\
\hline $\mathrm{H}$ & 5.346193 & -4.119840 & -2.513254 \\
\hline $\mathrm{H}$ & 7.241955 & -2.688655 & -3.220266 \\
\hline $\mathrm{H}$ & 7.213684 & -0.250047 & -2.691610 \\
\hline $\mathrm{H}$ & 5.357303 & 0.730578 & -1.428500 \\
\hline $\mathrm{O}$ & -0.681195 & 1.004723 & 0.933185 \\
\hline $\mathrm{O}$ & -0.877001 & -0.361281 & -1.282087 \\
\hline $\mathrm{H}$ & -1.920686 & -0.012234 & -1.314274 \\
\hline $\mathrm{H}$ & -0.481591 & -2.821135 & -1.658518 \\
\hline $\mathrm{H}$ & -1.959059 & -6.259184 & 0.466836 \\
\hline $\mathrm{H}$ & 2.008028 & -4.788201 & 1.242302 \\
\hline $\mathrm{H}$ & 0.848655 & 4.908776 & 1.523181 \\
\hline $\mathrm{H}$ & -1.637970 & 6.551196 & -1.575488 \\
\hline $\mathrm{H}$ & 1.002802 & 3.275381 & -2.448845 \\
\hline C & -3.633480 & 1.111780 & -0.398017 \\
\hline $\mathrm{O}$ & -3.213689 & 0.386210 & -1.382319 \\
\hline $\mathrm{H}$ & -2.897474 & 1.489620 & 0.320972 \\
\hline C & -4.710083 & 2.136032 & -0.765268 \\
\hline
\end{tabular}




$\begin{array}{llll}\mathrm{O} & -5.410528 & 2.095121 & -1.751090 \\ \mathrm{O} & -4.779670 & 3.100605 & 0.176753 \\ \mathrm{C} & -5.749764 & 4.132285 & -0.067501 \\ \mathrm{H} & -5.669528 & 4.816189 & 0.777714 \\ \mathrm{H} & -5.527327 & 4.650564 & -1.003798 \\ \mathrm{C} & -3.978629 & -1.065862 & 1.009215 \\ \mathrm{C} & -4.737290 & 0.109922 & 0.817384 \\ \mathrm{H} & -3.105425 & -2.690991 & 0.163871 \\ \mathrm{~N} & -3.808316 & -1.970059 & 0.018806 \\ \mathrm{C} & -4.310946 & -2.020174 & -1.313095 \\ \mathrm{O} & -3.755468 & -2.701863 & -2.143146 \\ \mathrm{O} & -5.463109 & -1.371805 & -1.452582 \\ \mathrm{C} & -5.857540 & -1.100840 & -2.818534 \\ \mathrm{H} & -5.811567 & -2.015407 & -3.411346 \\ \mathrm{H} & -6.877376 & -0.724888 & -2.750021 \\ \mathrm{H} & -5.194268 & -0.332685 & -3.218108 \\ \mathrm{H} & -4.832962 & 0.750028 & 1.688053 \\ \mathrm{H} & -5.623379 & 0.023202 & 0.202679 \\ \mathrm{C} & -3.197396 & -1.290918 & 2.240969 \\ \mathrm{C} & -3.756367 & -0.938341 & 3.483213 \\ \mathrm{C} & -1.912096 & -1.861223 & 2.208438 \\ \mathrm{C} & -3.052227 & -1.163591 & 4.662091 \\ \mathrm{H} & -4.756229 & -0.518116 & 3.524536 \\ \mathrm{C} & -1.206898 & -2.070468 & 3.389546 \\ \mathrm{H} & -1.427902 & -2.093505 & 1.266100 \\ \mathrm{C} & -1.775337 & -1.728331 & 4.617607 \\ \mathrm{H} & -3.500726 & -0.899587 & 5.615441 \\ \mathrm{H} & -0.205270 & -2.485024 & 3.339982 \\ \mathrm{H} & -1.222356 & -1.893892 & 5.538024 \\ \mathrm{H} & -6.756018 & 3.707977 & -0.127125\end{array}$

Catalyst (R)-1 TS Conformation 275

B3LYP/6-31G(d) Energy $=-2809.69214$

B3LYP-D3(BJ)/def2-TZVPP-IEF-PCM(DCM) Energy = -2810.981997

B3LYP-D3(BJ)/def2-TZVPP-IEF-PCM(DCM)//B3LYP/6-31G(d) Free Energy (Quasiharmonic) = 2810.338404

Frequencies (Top 3 out of 270)

1. $-284.9431 \mathrm{~cm}-1$

2. $\quad 10.0169 \mathrm{~cm}-1$

3. $\quad 11.8140 \mathrm{~cm}-1$ 
B3LYP/6-31G(d) Molecular Geometry in Cartesian Coordinates

\begin{tabular}{|c|c|c|c|}
\hline C & -3.137398 & -1.098559 & 0.015873 \\
\hline C & -1.949365 & -1.725401 & -0.316003 \\
\hline C & -1.674691 & -3.096268 & -0.046004 \\
\hline C & -2.641757 & -3.809441 & 0.634022 \\
\hline $\mathrm{H}$ & -2.475947 & -4.863870 & 0.838815 \\
\hline C & -3.840434 & 3.035007 & -0.967443 \\
\hline C & -3.363262 & 0.317343 & -0.398437 \\
\hline C & -2.458614 & 1.307127 & -0.037707 \\
\hline C & -2.691240 & 2.695080 & -0.279136 \\
\hline $\mathrm{H}$ & -4.037354 & 4.083644 & -1.173367 \\
\hline $\mathrm{O}$ & -0.957729 & -0.971956 & -0.945461 \\
\hline$P$ & -0.129609 & 0.076392 & -0.005571 \\
\hline $\mathrm{O}$ & -1.319227 & 0.955237 & 0.683612 \\
\hline C & 1.924545 & -5.099080 & -1.276378 \\
\hline C & 1.224473 & -4.302047 & -2.185472 \\
\hline C & 0.071202 & -3.629003 & -1.787211 \\
\hline C & -0.408301 & -3.748759 & -0.471637 \\
\hline C & 0.310691 & -4.543164 & 0.435179 \\
\hline C & 1.468484 & -5.212256 & 0.037789 \\
\hline $\mathrm{H}$ & 1.574896 & -4.206518 & -3.209792 \\
\hline $\mathrm{H}$ & 2.019255 & -5.809310 & 0.759109 \\
\hline C & -0.185970 & 5.943762 & 1.024660 \\
\hline C & 0.378653 & 4.867924 & 0.334532 \\
\hline C & -0.414422 & 3.793091 & -0.071565 \\
\hline C & -1.791082 & 3.779778 & 0.204013 \\
\hline C & -2.346073 & 4.865638 & 0.902341 \\
\hline C & -1.552338 & 5.937876 & 1.309279 \\
\hline $\mathrm{H}$ & 1.444037 & 4.855569 & 0.122022 \\
\hline $\mathrm{H}$ & -2.002245 & 6.765301 & 1.852094 \\
\hline C & -4.502152 & 0.681955 & -1.197369 \\
\hline C & -4.743194 & 2.066592 & -1.466761 \\
\hline C & -5.869006 & 2.442845 & -2.248701 \\
\hline C & -6.716007 & 1.493375 & -2.770301 \\
\hline C & -6.461703 & 0.121502 & -2.535262 \\
\hline C & -5.386806 & -0.273824 & -1.769850 \\
\hline $\mathrm{H}$ & -6.039518 & 3.500332 & -2.436249 \\
\hline $\mathrm{H}$ & -7.570513 & 1.791108 & -3.371718 \\
\hline $\mathrm{H}$ & -7.117238 & -0.629088 & -2.968485 \\
\hline $\mathrm{H}$ & -5.201148 & -1.329433 & -1.610034 \\
\hline C & -4.104593 & -1.833844 & 0.785877 \\
\hline C & -3.845194 & -3.211373 & 1.083361 \\
\hline
\end{tabular}




\begin{tabular}{|c|c|c|c|}
\hline$C$ & -4.794730 & -3.953109 & 1.837187 \\
\hline C & -5.941503 & -3.359935 & 2.311148 \\
\hline C & -6.181230 & -1.990011 & 2.052929 \\
\hline C & -5.289439 & -1.247897 & 1.309969 \\
\hline $\mathrm{H}$ & -4.587720 & -5.000516 & 2.043479 \\
\hline $\mathrm{H}$ & -6.656472 & -3.935287 & 2.892797 \\
\hline $\mathrm{H}$ & -7.075441 & -1.516191 & 2.448759 \\
\hline $\mathrm{H}$ & -5.483817 & -0.197054 & 1.130421 \\
\hline 0 & 0.851977 & 0.823778 & -0.827852 \\
\hline O & 0.398645 & -0.698780 & 1.251056 \\
\hline $\mathrm{H}$ & 1.373161 & -1.024315 & 1.185453 \\
\hline $\mathrm{H}$ & -0.029810 & -4.616081 & 1.464013 \\
\hline $\mathrm{H}$ & 2.819954 & -5.627726 & -1.592239 \\
\hline $\mathrm{H}$ & -0.468143 & -3.014204 & -2.500114 \\
\hline $\mathrm{H}$ & -3.406673 & 4.858329 & 1.139168 \\
\hline $\mathrm{H}$ & 0.435882 & 6.777624 & 1.339915 \\
\hline $\mathrm{H}$ & 0.035261 & 2.967812 & -0.612675 \\
\hline C & 3.618075 & -1.702098 & 0.321170 \\
\hline 0 & 2.820239 & -1.527250 & 1.307714 \\
\hline $\mathrm{H}$ & 3.307133 & -1.412072 & -0.693105 \\
\hline C & 4.467711 & -2.978135 & 0.335612 \\
\hline 0 & 4.697237 & -3.652373 & 1.310812 \\
\hline $\mathrm{O}$ & 4.943482 & -3.236850 & -0.903939 \\
\hline C & 5.778926 & -4.400791 & -1.006997 \\
\hline $\mathrm{H}$ & 6.082802 & -4.453308 & -2.052854 \\
\hline $\mathrm{H}$ & 6.652267 & -4.306221 & -0.355569 \\
\hline C & 4.568093 & 0.763393 & 0.533973 \\
\hline C & 5.168622 & -0.513725 & 0.556791 \\
\hline $\mathrm{H}$ & 3.331966 & 0.148953 & 1.992524 \\
\hline $\mathrm{N}$ & 3.690263 & 1.001669 & 1.537634 \\
\hline C & 3.093155 & 2.211951 & 1.932509 \\
\hline 0 & 3.409983 & 3.316385 & 1.558590 \\
\hline 0 & 2.161445 & 1.912018 & 2.847826 \\
\hline C & 1.475035 & 3.034372 & 3.436493 \\
\hline $\mathrm{H}$ & 0.802283 & 2.596930 & 4.173249 \\
\hline $\mathrm{H}$ & 0.913252 & 3.575828 & 2.674119 \\
\hline $\mathrm{H}$ & 2.193272 & 3.704916 & 3.915367 \\
\hline $\mathrm{H}$ & 5.861561 & -0.736783 & -0.247726 \\
\hline $\mathrm{H}$ & 5.429645 & -0.925229 & 1.528480 \\
\hline C & 4.768275 & 1.682623 & -0.599158 \\
\hline C & 6.076710 & 1.905164 & -1.063471 \\
\hline C & 3.683268 & 2.277829 & -1.266545 \\
\hline C & 6.301908 & 2.736188 & -2.157799 \\
\hline $\mathrm{H}$ & 6.914962 & 1.450872 & -0.543216 \\
\hline
\end{tabular}




$\begin{array}{llll}\mathrm{C} & 3.916541 & 3.083883 & -2.377065 \\ \mathrm{H} & 2.668174 & 2.053423 & -0.957670 \\ \mathrm{C} & 5.220899 & 3.325061 & -2.817097 \\ \mathrm{H} & 7.317324 & 2.920695 & -2.496619 \\ \mathrm{H} & 3.073721 & 3.521052 & -2.904530 \\ \mathrm{H} & 5.394163 & 3.965294 & -3.677964 \\ \mathrm{H} & 5.222374 & -5.297559 & -0.722625\end{array}$

Catalyst (R)-1 TS Conformation 276

B3LYP/6-31G(d) Energy $=-2809.69328$

B3LYP-D3(BJ)/def2-TZVPP-IEF-PCM(DCM) Energy = -2810.982139

B3LYP-D3(BJ)/def2-TZVPP-IEF-PCM(DCM)//B3LYP/6-31G(d) Free Energy (Quasiharmonic) = 2810.338362

Frequencies (Top 3 out of 270)

1. $-240.3728 \mathrm{~cm}-1$

2. $\quad 9.7353 \mathrm{~cm}-1$

3. $11.0842 \mathrm{~cm}-1$

B3LYP/6-31G(d) Molecular Geometry in Cartesian Coordinates

$\begin{array}{lrrr}\text { C } & -3.140118 & -1.075412 & 0.280936 \\ \text { C } & -1.985082 & -1.709178 & -0.147331 \\ \text { C } & -1.710521 & -3.087136 & 0.100080 \\ \text { C } & -2.628615 & -3.781049 & 0.866196 \\ \text { H } & -2.468314 & -4.840149 & 1.048082 \\ \text { C } & -3.915816 & 3.068422 & -0.584629 \\ \text { C } & -3.401001 & 0.341674 & -0.106159 \\ \text { C } & -2.477935 & 1.324987 & 0.213335 \\ \text { C } & -2.729934 & 2.718655 & 0.034604 \\ \text { H } & -4.158363 & 4.120429 & -0.706294 \\ \text { O } & -1.065549 & -0.973870 & -0.892145 \\ \text { P } & -0.168593 & 0.176311 & -0.159831 \\ \text { O } & -1.266931 & 0.940100 & 0.783286 \\ \text { C } & 1.579766 & -5.339452 & -1.504758 \\ \text { C } & 0.909886 & -4.416100 & -2.309432 \\ \text { C } & -0.129042 & -3.647321 & -1.788066 \\ \text { C } & -0.525915 & -3.797950 & -0.449550 \\ \text { C } & 0.170129 & -4.715771 & 0.355948 \\ \text { C } & 1.213007 & -5.478963 & -0.164930 \\ \text { H } & 1.195831 & -4.286160 & -3.349191\end{array}$




\begin{tabular}{|c|c|c|c|}
\hline $\mathrm{H}$ & 1.741537 & -6.178606 & 0.477200 \\
\hline C & -0.324655 & 5.943184 & 1.563646 \\
\hline C & -0.892327 & 6.024597 & 0.290320 \\
\hline C & -1.627361 & 4.953910 & -0.218645 \\
\hline C & -1.822537 & 3.784798 & 0.536903 \\
\hline C & -1.228236 & 3.709047 & 1.808905 \\
\hline C & -0.489050 & 4.777334 & 2.314531 \\
\hline $\mathrm{H}$ & -0.763982 & 6.921874 & -0.310054 \\
\hline $\mathrm{H}$ & -0.048639 & 4.701113 & 3.305152 \\
\hline C & -4.590555 & 0.717869 & -0.818977 \\
\hline C & -4.841528 & 2.107022 & -1.055693 \\
\hline C & -6.017700 & 2.495626 & -1.752765 \\
\hline C & -6.900690 & 1.554346 & -2.227950 \\
\hline C & -6.637881 & 0.178865 & -2.025439 \\
\hline C & -5.516309 & -0.228910 & -1.337297 \\
\hline $\mathrm{H}$ & -6.199007 & 3.555745 & -1.913622 \\
\hline $\mathrm{H}$ & -7.792642 & 1.861908 & -2.766811 \\
\hline $\mathrm{H}$ & -7.325323 & -0.564019 & -2.420753 \\
\hline $\mathrm{H}$ & -5.324091 & -1.286521 & -1.198686 \\
\hline C & -4.046118 & -1.791716 & 1.137025 \\
\hline C & -3.778203 & -3.169168 & 1.420262 \\
\hline C & -4.668405 & -3.897039 & 2.255882 \\
\hline C & -5.765443 & -3.289082 & 2.819972 \\
\hline C & -6.012407 & -1.918222 & 2.572537 \\
\hline C & -5.178141 & -1.189974 & 1.752996 \\
\hline $\mathrm{H}$ & -4.455747 & -4.945710 & 2.449888 \\
\hline $\mathrm{H}$ & -6.435447 & -3.853324 & 3.462889 \\
\hline $\mathrm{H}$ & -6.866373 & -1.432777 & 3.037262 \\
\hline $\mathrm{H}$ & -5.377549 & -0.138482 & 1.583002 \\
\hline $\mathrm{O}$ & 0.477725 & 1.025979 & -1.195741 \\
\hline $\mathrm{O}$ & 0.715489 & -0.473037 & 0.948125 \\
\hline $\mathrm{H}$ & 1.699060 & -0.777068 & 0.698646 \\
\hline $\mathrm{H}$ & -0.101252 & -4.817206 & 1.402998 \\
\hline $\mathrm{H}$ & 2.386224 & -5.941833 & -1.915652 \\
\hline $\mathrm{H}$ & -0.638086 & -2.932866 & -2.424623 \\
\hline $\mathrm{H}$ & -1.360670 & 2.816229 & 2.409480 \\
\hline $\mathrm{H}$ & 0.243576 & 6.778095 & 1.965412 \\
\hline $\mathrm{H}$ & -2.051864 & 5.019449 & -1.216383 \\
\hline C & 3.999399 & -0.675017 & 1.119666 \\
\hline $\mathrm{O}$ & 3.046456 & -1.252726 & 0.491212 \\
\hline $\mathrm{H}$ & 3.769930 & 0.133031 & 1.830469 \\
\hline C & 5.129075 & -1.583374 & 1.611681 \\
\hline $\mathrm{O}$ & 5.418215 & -2.658791 & 1.141146 \\
\hline $\mathrm{O}$ & 5.770099 & -1.009048 & 2.654481 \\
\hline
\end{tabular}




$\begin{array}{llll}\mathrm{C} & 6.852371 & -1.776488 & 3.207983 \\ \mathrm{H} & 6.487120 & -2.736437 & 3.582079 \\ \mathrm{H} & 7.619609 & -1.959822 & 2.450626 \\ \mathrm{C} & 4.184653 & 1.075453 & -0.813666 \\ \mathrm{C} & 5.157034 & 0.336561 & -0.107184 \\ \mathrm{H} & 2.403855 & 0.937637 & -1.823514 \\ \mathrm{~N} & 3.301425 & 0.475257 & -1.644785 \\ \mathrm{C} & 3.265089 & -0.853697 & -2.148012 \\ \mathrm{O} & 2.260338 & -1.298436 & -2.647027 \\ \mathrm{O} & 4.457853 & -1.454392 & -2.102805 \\ \mathrm{C} & 4.431932 & -2.878728 & -2.330777 \\ \mathrm{H} & 3.875347 & -3.357711 & -1.523879 \\ \mathrm{H} & 5.476783 & -3.187542 & -2.312880 \\ \mathrm{H} & 3.974275 & -3.099134 & -3.296921 \\ \mathrm{H} & 5.822826 & 0.908748 & 0.529818 \\ \mathrm{H} & 5.600278 & -0.516838 & -0.598709 \\ \mathrm{C} & 4.000877 & 2.519955 & -0.540294 \\ \mathrm{C} & 2.741268 & 3.146859 & -0.558921 \\ \mathrm{C} & 5.145130 & 3.304278 & -0.291398 \\ \mathrm{C} & 2.637587 & 4.515715 & -0.319960 \\ \mathrm{H} & 1.834548 & 2.572030 & -0.723389 \\ \mathrm{C} & 5.034376 & 4.672762 & -0.065461 \\ \mathrm{H} & 6.128541 & 2.846601 & -0.313714 \\ \mathrm{C} & 3.778204 & 5.281984 & -0.075097 \\ \mathrm{H} & 1.656068 & 4.978078 & -0.316415 \\ \mathrm{H} & 5.929555 & 5.262711 & 0.110222 \\ \mathrm{H} & 3.689420 & 6.350027 & 0.105051 \\ \mathrm{H} & 7.252750 & -1.174133 & 4.023821\end{array}$

Catalyst (R)-1 TS Conformation 277

B3LYP/6-31G(d) Energy $=-2809.690393$

B3LYP-D3(BJ)/def2-TZVPP-IEF-PCM(DCM) Energy = -2810.983211

B3LYP-D3(BJ)/def2-TZVPP-IEF-PCM(DCM)//B3LYP/6-31G(d) Free Energy (Quasiharmonic) = 2810.33834

Frequencies (Top 3 out of 270)

1. $-119.2576 \mathrm{~cm}-1$

2. $\quad 9.9056 \mathrm{~cm}-1$

3. $\quad 15.5105 \mathrm{~cm}-1$

B3LYP/6-31G(d) Molecular Geometry in Cartesian Coordinates 


\begin{tabular}{|c|c|c|c|}
\hline C & 3.029356 & -0.870564 & -0.201940 \\
\hline C & 1.916375 & -1.621306 & 0.140954 \\
\hline C & 1.786648 & -3.006936 & -0.171623 \\
\hline C & 2.761657 & -3.567251 & -0.974393 \\
\hline $\mathrm{H}$ & 2.708577 & -4.627014 & -1.208676 \\
\hline C & 3.565032 & 3.153200 & 1.226116 \\
\hline C & 3.203344 & 0.500465 & 0.358160 \\
\hline C & 2.222729 & 1.463865 & 0.174164 \\
\hline C & 2.390393 & 2.822756 & 0.578616 \\
\hline $\mathrm{H}$ & 3.715122 & 4.181182 & 1.545347 \\
\hline 0 & 0.885614 & -1.005524 & 0.851280 \\
\hline$P$ & -0.034779 & 0.090851 & 0.051309 \\
\hline O & 1.079698 & 1.125803 & -0.538014 \\
\hline C & -1.059628 & -5.740746 & 1.534490 \\
\hline C & -0.788676 & -5.769484 & 0.165413 \\
\hline C & 0.092520 & -4.844429 & -0.394849 \\
\hline C & 0.723172 & -3.874447 & 0.401194 \\
\hline C & 0.420377 & -3.837941 & 1.773595 \\
\hline C & -0.457195 & -4.765844 & 2.333780 \\
\hline $\mathrm{H}$ & -1.262208 & -6.513696 & -0.469721 \\
\hline $\mathrm{H}$ & -0.660614 & -4.734338 & 3.401242 \\
\hline C & -0.384448 & 6.050734 & -0.035512 \\
\hline C & -0.793423 & 4.901669 & 0.643602 \\
\hline C & 0.081966 & 3.829852 & 0.816098 \\
\hline C & 1.390878 & 3.897557 & 0.317797 \\
\hline C & 1.793692 & 5.057209 & -0.363501 \\
\hline C & 0.913134 & 6.123718 & -0.543521 \\
\hline $\mathrm{H}$ & -1.801332 & 4.840574 & 1.047591 \\
\hline $\mathrm{H}$ & 1.242438 & 7.010450 & -1.079239 \\
\hline C & 4.373714 & 0.837496 & 1.123759 \\
\hline C & 4.556668 & 2.193857 & 1.541687 \\
\hline C & 5.713758 & 2.548267 & 2.287033 \\
\hline C & 6.648638 & 1.601253 & 2.634001 \\
\hline C & 6.454260 & 0.252582 & 2.253413 \\
\hline C & 5.349982 & -0.119292 & 1.518510 \\
\hline $\mathrm{H}$ & 5.837933 & 3.585775 & 2.588375 \\
\hline $\mathrm{H}$ & 7.527077 & 1.881535 & 3.208829 \\
\hline $\mathrm{H}$ & 7.180489 & -0.499899 & 2.548897 \\
\hline $\mathrm{H}$ & 5.213647 & -1.159066 & 1.245727 \\
\hline C & 3.995485 & -1.446195 & -1.098378 \\
\hline C & 3.844124 & -2.814490 & -1.490686 \\
\hline C & 4.790268 & -3.396392 & -2.377046 \\
\hline C & 5.830812 & -2.654745 & -2.886062 \\
\hline
\end{tabular}




\begin{tabular}{|c|c|c|c|}
\hline C & 5.963671 & -1.292803 & -2.527330 \\
\hline C & 5.073895 & -0.705249 & -1.654880 \\
\hline $\mathrm{H}$ & 4.666698 & -4.440460 & -2.654943 \\
\hline $\mathrm{H}$ & 6.543652 & -3.107170 & -3.569994 \\
\hline $\mathrm{H}$ & 6.772883 & -0.702084 & -2.948072 \\
\hline $\mathrm{H}$ & 5.183043 & 0.342182 & -1.398935 \\
\hline 0 & -0.991677 & 0.709066 & 1.017959 \\
\hline $\mathrm{O}$ & -0.577645 & -0.631230 & -1.208538 \\
\hline $\mathrm{H}$ & -1.569664 & -0.494083 & -1.567843 \\
\hline $\mathrm{H}$ & 0.895284 & -3.095007 & 2.405880 \\
\hline $\mathrm{H}$ & -1.737006 & -6.468079 & 1.974321 \\
\hline $\mathrm{H}$ & 0.293792 & -4.867438 & -1.462095 \\
\hline $\mathrm{H}$ & 2.803020 & 5.114277 & -0.762494 \\
\hline $\mathrm{H}$ & -1.071305 & 6.882996 & -0.167426 \\
\hline $\mathrm{H}$ & -0.245510 & 2.939484 & 1.341485 \\
\hline C & -3.971107 & -0.723697 & -2.157340 \\
\hline $\mathrm{O}$ & -2.772622 & -0.244353 & -2.332396 \\
\hline $\mathrm{H}$ & -4.549552 & -0.933225 & -3.073198 \\
\hline C & -4.189267 & -1.905973 & -1.205715 \\
\hline $\mathrm{O}$ & -5.148617 & -2.647508 & -1.270640 \\
\hline $\mathrm{O}$ & -3.221531 & -1.989513 & -0.282472 \\
\hline C & -3.366926 & -3.049556 & 0.680460 \\
\hline $\mathrm{H}$ & -3.423165 & -4.014199 & 0.173165 \\
\hline $\mathrm{H}$ & -2.477083 & -2.999875 & 1.304410 \\
\hline C & -4.418849 & 1.007873 & -0.349306 \\
\hline C & -5.099620 & 0.516269 & -1.510447 \\
\hline $\mathrm{H}$ & -2.574140 & 1.627630 & 0.280718 \\
\hline$N$ & -3.261326 & 1.674324 & -0.484148 \\
\hline C & -2.641000 & 2.206078 & -1.656083 \\
\hline $\mathrm{O}$ & -1.452929 & 2.402150 & -1.689968 \\
\hline $\mathrm{O}$ & -3.527030 & 2.594579 & -2.581183 \\
\hline C & -2.926121 & 2.998889 & -3.829013 \\
\hline $\mathrm{H}$ & -3.759368 & 3.304777 & -4.461714 \\
\hline $\mathrm{H}$ & -2.394676 & 2.149735 & -4.264700 \\
\hline $\mathrm{H}$ & -2.234520 & 3.827473 & -3.665935 \\
\hline $\mathrm{H}$ & -6.042025 & 0.012479 & -1.316316 \\
\hline $\mathrm{H}$ & -5.136846 & 1.190282 & -2.356547 \\
\hline C & -4.851739 & 0.622309 & 1.009587 \\
\hline C & -6.232139 & 0.506611 & 1.267052 \\
\hline C & -3.942860 & 0.400507 & 2.064031 \\
\hline C & -6.693664 & 0.186457 & 2.540709 \\
\hline $\mathrm{H}$ & -6.948698 & 0.700766 & 0.476229 \\
\hline C & -4.414214 & 0.068044 & 3.331287 \\
\hline $\mathrm{H}$ & -2.871417 & 0.439248 & 1.891742 \\
\hline
\end{tabular}




$\begin{array}{llll}\mathrm{C} & -5.785502 & -0.036452 & 3.576849 \\ \mathrm{H} & -7.761971 & 0.114409 & 2.722548 \\ \mathrm{H} & -3.701659 & -0.115266 & 4.130342 \\ \mathrm{H} & -6.144242 & -0.290846 & 4.570434 \\ \mathrm{H} & -4.272811 & -2.896651 & 1.273352\end{array}$

Catalyst (R)-1 TS Conformation 278

B3LYP/6-31G(d) Energy $=-2809.690957$

B3LYP-D3(BJ)/def2-TZVPP-IEF-PCM(DCM) Energy = -2810.980711

B3LYP-D3(BJ)/def2-TZVPP-IEF-PCM(DCM)//B3LYP/6-31G(d) Free Energy (Quasiharmonic) = 2810.3383

Frequencies (Top 3 out of 270)

1. $-468.3444 \mathrm{~cm}-1$

2. $9.9612 \mathrm{~cm}-1$

3. $12.4908 \mathrm{~cm}-1$

B3LYP/6-31G(d) Molecular Geometry in Cartesian Coordinates

$\begin{array}{llll}\text { C } & 3.499497 & -0.825872 & 0.084804 \\ \text { C } & 2.377580 & -1.615251 & 0.268095 \\ \text { C } & 2.340579 & -3.015039 & 0.007438 \\ \text { C } & 3.487133 & -3.590182 & -0.502809 \\ \text { H } & 3.504046 & -4.660065 & -0.693817 \\ \text { C } & 3.475071 & 3.385099 & 1.005634 \\ \text { C } & 3.460061 & 0.613751 & 0.479378 \\ \text { C } & 2.479598 & 1.459023 & -0.025142 \\ \text { C } & 2.482414 & 2.868456 & 0.196538 \\ \text { H } & 3.497253 & 4.455802 & 1.190707 \\ \text { O } & 1.211784 & -1.005526 & 0.725805 \\ \text { P } & 0.383690 & -0.116301 & -0.371005 \\ \text { O } & 1.506869 & 0.951104 & -0.879324 \\ \text { C } & -1.118563 & -5.466215 & 0.738107 \\ \text { C } & -0.443935 & -5.539142 & -0.481047 \\ \text { C } & 0.667679 & -4.730656 & -0.716148 \\ \text { C } & 1.124783 & -3.832981 & 0.261422 \\ \text { C } & 0.432020 & -3.761803 & 1.481855 \\ \text { C } & -0.676321 & -4.573784 & 1.717704 \\ \text { H } & -0.787582 & -6.218843 & -1.256185 \\ \text { H } & -1.191889 & -4.513046 & 2.672898 \\ \text { C } & -0.280210 & 5.689418 & -1.510897\end{array}$




\begin{tabular}{|c|c|c|c|}
\hline$C$ & -0.763020 & 4.615999 & -0.758881 \\
\hline C & 0.117156 & 3.670269 & -0.230998 \\
\hline C & 1.500203 & 3.796495 & -0.433278 \\
\hline C & 1.974440 & 4.881138 & -1.189085 \\
\hline C & 1.092299 & 5.817187 & -1.728904 \\
\hline $\mathrm{H}$ & -1.825562 & 4.511891 & -0.560018 \\
\hline $\mathrm{H}$ & 1.479237 & 6.645609 & -2.317022 \\
\hline C & 4.420164 & 1.153518 & 1.405164 \\
\hline C & 4.430996 & 2.563770 & 1.650295 \\
\hline C & 5.382757 & 3.110897 & 2.553024 \\
\hline C & 6.276608 & 2.301821 & 3.214612 \\
\hline C & 6.245438 & 0.903291 & 3.003177 \\
\hline C & 5.344784 & 0.344816 & 2.123072 \\
\hline $\mathrm{H}$ & 5.380148 & 4.185572 & 2.719437 \\
\hline $\mathrm{H}$ & 6.996013 & 2.729823 & 3.907379 \\
\hline $\mathrm{H}$ & 6.934737 & 0.261496 & 3.545302 \\
\hline $\mathrm{H}$ & 5.328233 & -0.729584 & 1.982440 \\
\hline C & 4.660949 & -1.423971 & -0.518036 \\
\hline C & 4.645632 & -2.829360 & -0.798620 \\
\hline C & 5.789078 & -3.436109 & -1.385513 \\
\hline C & 6.895265 & -2.689412 & -1.717811 \\
\hline C & 6.897344 & -1.295060 & -1.480335 \\
\hline C & 5.812244 & -0.679721 & -0.895513 \\
\hline $\mathrm{H}$ & 5.764929 & -4.505772 & -1.580052 \\
\hline $\mathrm{H}$ & 7.760434 & -3.163371 & -2.173298 \\
\hline $\mathrm{H}$ & 7.761347 & -0.701507 & -1.766777 \\
\hline $\mathrm{H}$ & 5.826736 & 0.391133 & -0.730547 \\
\hline $\mathrm{O}$ & -0.785662 & 0.486975 & 0.335096 \\
\hline $\mathrm{O}$ & 0.146162 & -0.960302 & -1.640314 \\
\hline $\mathrm{H}$ & -0.850715 & -1.414237 & -1.842221 \\
\hline $\mathrm{H}$ & 0.770134 & -3.073751 & 2.249642 \\
\hline $\mathrm{H}$ & -1.983588 & -6.097847 & 0.923590 \\
\hline $\mathrm{H}$ & 1.174383 & -4.772876 & -1.675959 \\
\hline $\mathrm{H}$ & 3.042875 & 4.980501 & -1.362027 \\
\hline $\mathrm{H}$ & -0.968644 & 6.424175 & -1.921234 \\
\hline $\mathrm{H}$ & -0.275564 & 2.843555 & 0.350753 \\
\hline C & -3.091736 & -1.518362 & -1.772865 \\
\hline $\mathrm{O}$ & -1.982053 & -2.090840 & -2.061678 \\
\hline $\mathrm{H}$ & -4.004869 & -2.092868 & -1.989613 \\
\hline C & -3.331780 & -0.048436 & -2.154448 \\
\hline $\mathrm{O}$ & -4.401334 & 0.511736 & -1.995061 \\
\hline $\mathrm{O}$ & -2.255317 & 0.507983 & -2.702985 \\
\hline C & -2.369982 & 1.897318 & -3.070857 \\
\hline $\mathrm{H}$ & -1.404236 & 2.160848 & -3.499145 \\
\hline
\end{tabular}




$\begin{array}{llll}\mathrm{H} & -3.173265 & 2.028027 & -3.800255 \\ \mathrm{C} & -4.121585 & -0.507255 & 0.640169 \\ \mathrm{C} & -3.261340 & -1.519211 & 0.144792 \\ \mathrm{H} & -2.542572 & 0.761700 & 0.724807 \\ \mathrm{~N} & -3.569832 & 0.719839 & 0.835839 \\ \mathrm{C} & -4.139480 & 2.004359 & 0.724535 \\ \mathrm{O} & -3.435436 & 2.988998 & 0.655190 \\ \mathrm{O} & -5.471690 & 2.001111 & 0.702963 \\ \mathrm{C} & -6.080072 & 3.287374 & 0.483702 \\ \mathrm{H} & -5.798549 & 3.671303 & -0.499510 \\ \mathrm{H} & -5.768807 & 3.994263 & 1.256014 \\ \mathrm{H} & -7.153155 & 3.104875 & 0.531886 \\ \mathrm{H} & -3.580962 & -2.542026 & 0.317050 \\ \mathrm{H} & -2.210314 & -1.344418 & 0.345548 \\ \mathrm{C} & -5.525706 & -0.799974 & 0.979646 \\ \mathrm{C} & -6.046675 & -0.386531 & 2.218519 \\ \mathrm{C} & -6.314399 & -1.600505 & 0.138761 \\ \mathrm{C} & -7.326128 & -0.772760 & 2.606076 \\ \mathrm{H} & -5.435638 & 0.215412 & 2.883390 \\ \mathrm{C} & -7.603689 & -1.963421 & 0.520595 \\ \mathrm{H} & -5.929532 & -1.902665 & -0.828921 \\ \mathrm{C} & -8.110770 & -1.556747 & 1.756485 \\ \mathrm{H} & -7.711691 & -0.461225 & 3.572723 \\ \mathrm{H} & -8.212178 & -2.565594 & -0.147982 \\ \mathrm{H} & -9.112275 & -1.851010 & 2.057854 \\ \mathrm{H} & -2.570317 & 2.503016 & -2.184645\end{array}$

Catalyst (R)-1 TS Conformation 279

B3LYP/6-31G(d) Energy $=-2809.685152$

B3LYP-D3(BJ)/def2-TZVPP-IEF-PCM(DCM) Energy = -2810.981276

B3LYP-D3(BJ)/def2-TZVPP-IEF-PCM(DCM)//B3LYP/6-31G(d) Free Energy (Quasiharmonic) = 2810.338285

Frequencies (Top 3 out of 270)

1. $-430.0347 \mathrm{~cm}-1$

2. $\quad 8.7286 \mathrm{~cm}-1$

3. $8.8455 \mathrm{~cm}-1$

B3LYP/6-31G(d) Molecular Geometry in Cartesian Coordinates

$\begin{array}{llll}\text { C } & 3.794196 & 0.309600 & 0.366304\end{array}$ 


\begin{tabular}{|c|c|c|c|}
\hline C & 3.052215 & 1.335348 & -0.201817 \\
\hline C & 3.371224 & 2.716218 & -0.033445 \\
\hline C & 4.445972 & 3.023850 & 0.777961 \\
\hline $\mathrm{H}$ & 4.732347 & 4.064571 & 0.905502 \\
\hline C & 2.660753 & -3.790288 & -0.355002 \\
\hline C & 3.431280 & -1.108494 & 0.069915 \\
\hline C & 2.136530 & -1.544428 & 0.314601 \\
\hline C & 1.723384 & -2.899136 & 0.131017 \\
\hline $\mathrm{H}$ & 2.387693 & -4.835385 & -0.476318 \\
\hline O & 1.965370 & 1.008294 & -0.995173 \\
\hline$P$ & 0.582344 & 0.473556 & -0.273666 \\
\hline O & 1.207884 & -0.634620 & 0.786017 \\
\hline C & 1.235529 & 5.933603 & -1.932552 \\
\hline C & 1.580183 & 4.796667 & -2.666465 \\
\hline C & 2.250917 & 3.738572 & -2.055539 \\
\hline C & 2.596358 & 3.799691 & -0.694912 \\
\hline C & 2.239542 & 4.946598 & 0.032767 \\
\hline C & 1.566056 & 6.003327 & -0.578732 \\
\hline $\mathrm{H}$ & 1.327724 & 4.732293 & -3.721823 \\
\hline $\mathrm{H}$ & 1.292136 & 6.877364 & 0.006647 \\
\hline C & -2.219967 & -4.370153 & 1.051034 \\
\hline C & -1.583820 & -4.737059 & -0.136102 \\
\hline C & -0.315344 & -4.238182 & -0.433466 \\
\hline C & 0.345233 & -3.362787 & 0.445083 \\
\hline C & -0.309187 & -2.997498 & 1.634301 \\
\hline C & -1.575482 & -3.499302 & 1.933050 \\
\hline $\mathrm{H}$ & -2.074255 & -5.412678 & -0.832502 \\
\hline $\mathrm{H}$ & -2.055566 & -3.216244 & 2.866750 \\
\hline C & 4.371159 & -2.029199 & -0.508169 \\
\hline C & 3.973742 & -3.391567 & -0.704547 \\
\hline C & 4.898482 & -4.316292 & -1.261536 \\
\hline C & 6.157137 & -3.915362 & -1.644390 \\
\hline C & 6.539233 & -2.561940 & -1.489347 \\
\hline C & 5.672369 & -1.645344 & -0.935988 \\
\hline $\mathrm{H}$ & 4.583652 & -5.349275 & -1.391157 \\
\hline $\mathrm{H}$ & 6.853189 & -4.629585 & -2.075825 \\
\hline $\mathrm{H}$ & 7.525127 & -2.240518 & -1.814465 \\
\hline $\mathrm{H}$ & 5.977534 & -0.610589 & -0.833016 \\
\hline C & 4.862033 & 0.648549 & 1.266620 \\
\hline C & 5.192123 & 2.029635 & 1.456731 \\
\hline C & 6.253974 & 2.379416 & 2.334446 \\
\hline C & 6.947758 & 1.414888 & 3.027432 \\
\hline C & 6.598170 & 0.052842 & 2.872721 \\
\hline C & 5.585422 & -0.320012 & 2.016295 \\
\hline
\end{tabular}




\begin{tabular}{|c|c|c|c|}
\hline $\mathrm{H}$ & 6.498765 & 3.432044 & 2.456686 \\
\hline $\mathrm{H}$ & 7.753097 & 1.695298 & 3.700945 \\
\hline $\mathrm{H}$ & 7.130259 & -0.707209 & 3.438710 \\
\hline $\mathrm{H}$ & 5.323881 & -1.367174 & 1.917733 \\
\hline $\mathrm{O}$ & -0.284145 & -0.131754 & -1.325779 \\
\hline 0 & 0.009756 & 1.549088 & 0.645011 \\
\hline $\mathrm{H}$ & -1.202147 & 1.965078 & 0.434327 \\
\hline $\mathrm{H}$ & 2.472817 & 4.995978 & 1.092640 \\
\hline $\mathrm{H}$ & 0.709076 & 6.755481 & -2.410959 \\
\hline $\mathrm{H}$ & 2.513804 & 2.860701 & -2.635260 \\
\hline $\mathrm{H}$ & 0.181790 & -2.324640 & 2.328227 \\
\hline $\mathrm{H}$ & -3.204968 & -4.763773 & 1.289034 \\
\hline $\mathrm{H}$ & 0.167648 & -4.515746 & -1.366239 \\
\hline C & -2.933783 & 1.481882 & -0.461033 \\
\hline $\mathrm{O}$ & -2.280326 & 2.278628 & 0.317116 \\
\hline $\mathrm{H}$ & -2.391985 & 0.922799 & -1.226976 \\
\hline C & -4.313451 & 1.933544 & -0.902654 \\
\hline 0 & -4.925009 & 1.393689 & -1.805570 \\
\hline $\mathrm{O}$ & -4.751650 & 2.986204 & -0.204577 \\
\hline C & -6.021136 & 3.522383 & -0.614950 \\
\hline $\mathrm{H}$ & -6.010149 & 3.755924 & -1.682309 \\
\hline $\mathrm{H}$ & -6.821520 & 2.806629 & -0.409908 \\
\hline C & -4.562565 & -0.704766 & 0.354247 \\
\hline C & -3.279666 & -0.196375 & 0.598660 \\
\hline $\mathrm{H}$ & -5.863202 & -1.834251 & -0.718200 \\
\hline$N$ & -4.904869 & -1.508419 & -0.687252 \\
\hline C & -4.192772 & -1.983082 & -1.818368 \\
\hline 0 & -4.742872 & -2.724499 & -2.601340 \\
\hline 0 & -2.957532 & -1.522925 & -1.863361 \\
\hline C & -2.147997 & -1.951493 & -2.988039 \\
\hline $\mathrm{H}$ & -1.189000 & -1.469605 & -2.814032 \\
\hline $\mathrm{H}$ & -2.615999 & -1.619546 & -3.917380 \\
\hline $\mathrm{H}$ & -2.065545 & -3.039879 & -2.980139 \\
\hline $\mathrm{H}$ & -3.155210 & 0.278946 & 1.564048 \\
\hline $\mathrm{H}$ & -2.418452 & -0.727742 & 0.211797 \\
\hline C & -5.708766 & -0.320214 & 1.214360 \\
\hline C & -6.968725 & -0.045393 & 0.648990 \\
\hline C & -5.554612 & -0.235045 & 2.608449 \\
\hline C & -8.044505 & 0.304448 & 1.462551 \\
\hline $\mathrm{H}$ & -7.089838 & -0.050079 & -0.430573 \\
\hline C & -6.636146 & 0.104686 & 3.417410 \\
\hline $\mathrm{H}$ & -4.594750 & -0.464701 & 3.059477 \\
\hline C & -7.882324 & 0.375005 & 2.847890 \\
\hline $\mathrm{H}$ & -9.007873 & 0.527850 & 1.013263 \\
\hline
\end{tabular}




$\begin{array}{llll}H & -6.506216 & 0.153809 & 4.494440 \\ H & -8.723503 & 0.642005 & 3.481208 \\ H & -6.157595 & 4.426578 & -0.022046\end{array}$

Catalyst (R)-1 TS Conformation 280

B3LYP/6-31G(d) Energy $=-2809.688294$

B3LYP-D3(BJ)/def2-TZVPP-IEF-PCM(DCM) Energy = -2810.981654

B3LYP-D3(BJ)/def2-TZVPP-IEF-PCM(DCM)//B3LYP/6-31G(d) Free Energy (Quasiharmonic) = 2810.338242

Frequencies (Top 3 out of 270)

1. $-291.7421 \mathrm{~cm}-1$

2. $\quad 9.4367 \mathrm{~cm}-1$

3. $\quad 14.0415 \mathrm{~cm}-1$

B3LYP/6-31G(d) Molecular Geometry in Cartesian Coordinates

$\begin{array}{llll}\text { C } & -3.010010 & -0.801009 & 0.409969 \\ \text { C } & -1.970670 & -1.534711 & -0.138417 \\ \text { C } & -1.748824 & -2.912855 & 0.153767 \\ \text { C } & -2.567004 & -3.493788 & 1.104198 \\ \text { H } & -2.446929 & -4.550119 & 1.328823 \\ \text { C } & -3.794286 & 3.241326 & -0.842984 \\ \text { C } & -3.280171 & 0.578468 & -0.085885 \\ \text { C } & -2.280891 & 1.541608 & -0.069548 \\ \text { C } & -2.520501 & 2.901132 & -0.431542 \\ \text { H } & -3.996755 & 4.271402 & -1.124265 \\ \text { O } & -1.102774 & -0.892698 & -1.023520 \\ \text { P } & -0.037707 & 0.152801 & -0.343141 \\ \text { O } & -1.023842 & 1.213095 & 0.419835 \\ \text { C } & 0.978375 & -5.536518 & -1.880515 \\ \text { C } & 0.249281 & -4.590068 & -2.604310 \\ \text { C } & -0.596326 & -3.698392 & -1.947313 \\ \text { C } & -0.738054 & -3.744722 & -0.550767 \\ \text { C } & 0.025109 & -4.679547 & 0.168676 \\ \text { C } & 0.874141 & -5.568058 & -0.488357 \\ \text { H } & 0.332880 & -4.546498 & -3.686799 \\ \text { H } & 1.452473 & -6.285724 & 0.087910 \\ \text { C } & 0.314145 & 6.132908 & -0.488745 \\ \text { C } & 0.568388 & 4.968711 & -1.218635 \\ \text { C } & -0.312705 & 3.887877 & -1.162769\end{array}$




\begin{tabular}{|c|c|c|c|}
\hline C & -1.481217 & 3.968469 & -0.389972 \\
\hline C & -1.725793 & 5.140403 & 0.343576 \\
\hline C & -0.833263 & 6.211561 & 0.301587 \\
\hline $\mathrm{H}$ & 1.454324 & 4.902158 & -1.844992 \\
\hline $\mathrm{H}$ & -1.039121 & 7.108349 & 0.880333 \\
\hline C & -4.569683 & 0.924302 & -0.622232 \\
\hline C & -4.828881 & 2.285674 & -0.977954 \\
\hline C & -6.103757 & 2.647555 & -1.491536 \\
\hline C & -7.084848 & 1.702085 & -1.677112 \\
\hline C & -6.820684 & 0.348021 & -1.363326 \\
\hline C & -5.599833 & -0.030668 & -0.849861 \\
\hline $\mathrm{H}$ & -6.282176 & 3.689189 & -1.748158 \\
\hline $\mathrm{H}$ & -8.054357 & 1.987458 & -2.076196 \\
\hline $\mathrm{H}$ & -7.586660 & -0.403395 & -1.535365 \\
\hline $\mathrm{H}$ & -5.413342 & -1.074400 & -0.626792 \\
\hline C & -3.798307 & -1.396367 & 1.454634 \\
\hline C & -3.564375 & -2.766268 & 1.797096 \\
\hline C & -4.338538 & -3.371890 & 2.823694 \\
\hline C & -5.285240 & -2.651266 & 3.513732 \\
\hline C & -5.492026 & -1.286473 & 3.203838 \\
\hline C & -4.771626 & -0.676389 & 2.200435 \\
\hline $\mathrm{H}$ & -4.156344 & -4.417236 & 3.061872 \\
\hline $\mathrm{H}$ & -5.865546 & -3.122023 & 4.302623 \\
\hline $\mathrm{H}$ & -6.223051 & -0.711705 & 3.766104 \\
\hline $\mathrm{H}$ & -4.934560 & 0.372693 & 1.982741 \\
\hline 0 & 0.792477 & 0.798264 & -1.405114 \\
\hline $\mathrm{O}$ & 0.662548 & -0.546834 & 0.842070 \\
\hline $\mathrm{H}$ & 1.637799 & -1.040943 & 0.737777 \\
\hline $\mathrm{H}$ & -0.043528 & -4.699680 & 1.252445 \\
\hline $\mathrm{H}$ & 1.622953 & -6.244034 & -2.397061 \\
\hline $\mathrm{H}$ & -1.161083 & -2.971856 & -2.520744 \\
\hline $\mathrm{H}$ & -2.622639 & 5.205699 & 0.953835 \\
\hline $\mathrm{H}$ & 1.002208 & 6.973125 & -0.539797 \\
\hline $\mathrm{H}$ & -0.100902 & 2.987572 & -1.729820 \\
\hline C & 3.875480 & -1.587212 & 1.192660 \\
\hline $\mathrm{O}$ & 2.748349 & -1.829862 & 0.595277 \\
\hline $\mathrm{H}$ & 4.475283 & -2.470170 & 1.464308 \\
\hline C & 3.866286 & -0.577859 & 2.345030 \\
\hline $\mathrm{O}$ & 3.045417 & 0.295072 & 2.501052 \\
\hline $\mathrm{O}$ & 4.924148 & -0.781192 & 3.166263 \\
\hline C & 5.023828 & 0.135599 & 4.269646 \\
\hline $\mathrm{H}$ & 5.911706 & -0.168197 & 4.825137 \\
\hline $\mathrm{H}$ & 5.127269 & 1.161758 & 3.906293 \\
\hline C & 4.381483 & 0.137469 & -0.624495 \\
\hline
\end{tabular}




$\begin{array}{llll}\mathrm{C} & 5.129866 & -0.868135 & 0.060694 \\ \mathrm{H} & 2.609240 & 0.426900 & -1.646077 \\ \mathrm{~N} & 3.416332 & -0.202666 & -1.496275 \\ \mathrm{C} & 3.184077 & -1.426442 & -2.187254 \\ \mathrm{O} & 2.152165 & -1.622546 & -2.776555 \\ \mathrm{O} & 4.256565 & -2.229250 & -2.210559 \\ \mathrm{C} & 4.055439 & -3.472655 & -2.912978 \\ \mathrm{H} & 3.794926 & -3.278354 & -3.955932 \\ \mathrm{H} & 3.258547 & -4.045513 & -2.435574 \\ \mathrm{H} & 5.010350 & -3.994185 & -2.844215 \\ \mathrm{H} & 5.937509 & -0.503624 & 0.687844 \\ \mathrm{H} & 5.386628 & -1.750789 & -0.507446 \\ \mathrm{C} & 4.494808 & 1.548660 & -0.205110 \\ \mathrm{C} & 5.770356 & 2.044869 & 0.132211 \\ \mathrm{C} & 3.385458 & 2.410362 & -0.119830 \\ \mathrm{C} & 5.933262 & 3.363330 & 0.545552 \\ \mathrm{H} & 6.641641 & 1.405088 & 0.036979 \\ \mathrm{C} & 3.553595 & 3.720794 & 0.320841 \\ \mathrm{H} & 2.387737 & 2.054821 & -0.355700 \\ \mathrm{C} & 4.821991 & 4.201993 & 0.650762 \\ \mathrm{H} & 6.926157 & 3.734045 & 0.783978 \\ \mathrm{H} & 2.683169 & 4.362151 & 0.410607 \\ \mathrm{H} & 4.944019 & 5.227598 & 0.988522 \\ \mathrm{H} & 4.133913 & 0.071396 & 4.900944\end{array}$

Catalyst (R)-1 TS Conformation 281

B3LYP/6-31G(d) Energy $=-2809.687016$

B3LYP-D3(BJ)/def2-TZVPP-IEF-PCM(DCM) Energy $=-2810.980563$

B3LYP-D3(BJ)/def2-TZVPP-IEF-PCM(DCM)//B3LYP/6-31G(d) Free Energy (Quasiharmonic) = 2810.338186

Frequencies (Top 3 out of 270)

1. $-532.7025 \mathrm{~cm}-1$

2. $\quad 7.7442 \mathrm{~cm}-1$

3. $8.4075 \mathrm{~cm}-1$

B3LYP/6-31G(d) Molecular Geometry in Cartesian Coordinates

$\begin{array}{llll}\text { C } & 3.569493 & -0.381974 & -0.174361 \\ \text { C } & 2.632718 & -1.389428 & -0.000481 \\ \text { C } & 2.869523 & -2.754003 & -0.346975\end{array}$




\begin{tabular}{|c|c|c|c|}
\hline C & 4.099832 & -3.056922 & -0.898527 \\
\hline $\mathrm{H}$ & 4.329685 & -4.090484 & -1.143249 \\
\hline C & 2.738725 & 3.740958 & 0.753716 \\
\hline C & 3.252071 & 1.014092 & 0.252947 \\
\hline C & 2.115781 & 1.644693 & -0.239135 \\
\hline C & 1.857006 & 3.036811 & -0.043357 \\
\hline $\mathrm{H}$ & 2.562329 & 4.799634 & 0.925868 \\
\hline $\mathrm{O}$ & 1.410875 & -1.057914 & 0.567674 \\
\hline$P$ & 0.300264 & -0.241008 & -0.330872 \\
\hline $\mathrm{O}$ & 1.241478 & 0.919837 & -1.031106 \\
\hline C & 0.024145 & -5.941474 & 0.184872 \\
\hline C & 0.769305 & -5.839925 & -0.990756 \\
\hline C & 1.672617 & -4.791808 & -1.158126 \\
\hline C & 1.856077 & -3.825700 & -0.153870 \\
\hline C & 1.095199 & -3.937645 & 1.021247 \\
\hline C & 0.189468 & -4.983933 & 1.186829 \\
\hline $\mathrm{H}$ & 0.639720 & -6.570112 & -1.785587 \\
\hline $\mathrm{H}$ & -0.394445 & -5.043260 & 2.101155 \\
\hline C & -1.339765 & 5.196714 & -1.956055 \\
\hline C & -1.622101 & 4.029581 & -1.242982 \\
\hline C & -0.597156 & 3.313888 & -0.623954 \\
\hline C & 0.733639 & 3.752688 & -0.712838 \\
\hline C & 1.005087 & 4.929718 & -1.430154 \\
\hline C & -0.021597 & 5.646452 & -2.045163 \\
\hline $\mathrm{H}$ & -2.643863 & 3.663908 & -1.171084 \\
\hline $\mathrm{H}$ & 0.211892 & 6.550433 & -2.602233 \\
\hline C & 4.102924 & 1.736937 & 1.158208 \\
\hline C & 3.837605 & 3.123248 & 1.399562 \\
\hline C & 4.672880 & 3.849217 & 2.291426 \\
\hline C & 5.716740 & 3.234519 & 2.943215 \\
\hline C & 5.962790 & 1.857417 & 2.731009 \\
\hline C & 5.179937 & 1.129697 & 1.861700 \\
\hline $\mathrm{H}$ & 4.461567 & 4.903326 & 2.456332 \\
\hline $\mathrm{H}$ & 6.345278 & 3.798731 & 3.626963 \\
\hline $\mathrm{H}$ & 6.774285 & 1.367359 & 3.262503 \\
\hline $\mathrm{H}$ & 5.375316 & 0.073277 & 1.716471 \\
\hline C & 4.809839 & -0.702232 & -0.829260 \\
\hline C & 5.075643 & -2.067900 & -1.170097 \\
\hline C & 6.305422 & -2.405870 & -1.797926 \\
\hline C & 7.228656 & -1.437148 & -2.114757 \\
\hline C & 6.950244 & -0.081786 & -1.820751 \\
\hline C & 5.775854 & 0.275654 & -1.195309 \\
\hline $\mathrm{H}$ & 6.494426 & -3.449898 & -2.036961 \\
\hline $\mathrm{H}$ & 8.161995 & -1.706386 & -2.601799 \\
\hline
\end{tabular}




\begin{tabular}{|c|c|c|c|}
\hline $\mathrm{H}$ & 7.667290 & 0.687078 & -2.095970 \\
\hline $\mathrm{H}$ & 5.575869 & 1.320146 & -0.988617 \\
\hline 0 & -0.712328 & 0.321590 & 0.617161 \\
\hline 0 & -0.152797 & -1.110510 & -1.501142 \\
\hline $\mathrm{H}$ & -1.368263 & -1.136688 & -1.873075 \\
\hline $\mathrm{H}$ & 1.211218 & -3.201072 & 1.807075 \\
\hline $\mathrm{H}$ & -0.685457 & -6.754586 & 0.315305 \\
\hline $\mathrm{H}$ & 2.225789 & -4.701754 & -2.088600 \\
\hline $\mathrm{H}$ & 2.032897 & 5.270923 & -1.522521 \\
\hline $\mathrm{H}$ & -2.140023 & 5.749941 & -2.441396 \\
\hline $\mathrm{H}$ & -0.826625 & 2.417547 & -0.058341 \\
\hline C & -3.129020 & -0.363105 & -1.352384 \\
\hline $\mathrm{O}$ & -2.466049 & -1.064128 & -2.207551 \\
\hline $\mathrm{H}$ & -2.571982 & 0.189581 & -0.590958 \\
\hline C & -4.343472 & 0.388823 & -1.855560 \\
\hline $\mathrm{O}$ & -4.647797 & 1.478853 & -1.413776 \\
\hline $\mathrm{O}$ & -5.008802 & -0.263636 & -2.814810 \\
\hline C & -6.145303 & 0.431941 & -3.360656 \\
\hline $\mathrm{H}$ & -5.835726 & 1.389768 & -3.785481 \\
\hline $\mathrm{H}$ & -6.539870 & -0.223653 & -4.136614 \\
\hline C & -4.454118 & -0.914665 & 0.989510 \\
\hline C & -4.024344 & -1.679266 & -0.101728 \\
\hline $\mathrm{H}$ & -3.969826 & 0.094919 & 2.694495 \\
\hline$N$ & -3.643666 & -0.601235 & 2.035174 \\
\hline C & -2.392970 & -1.176307 & 2.371983 \\
\hline $\mathrm{O}$ & -1.938239 & -2.181293 & 1.884634 \\
\hline $\mathrm{O}$ & -1.880560 & -0.450978 & 3.367704 \\
\hline C & -0.531298 & -0.801761 & 3.747671 \\
\hline $\mathrm{H}$ & 0.125966 & -0.664564 & 2.888202 \\
\hline $\mathrm{H}$ & -0.496615 & -1.836036 & 4.098549 \\
\hline $\mathrm{H}$ & -0.276947 & -0.112833 & 4.552629 \\
\hline $\mathrm{H}$ & -4.786466 & -2.039826 & -0.783211 \\
\hline $\mathrm{H}$ & -3.153158 & -2.307923 & 0.028009 \\
\hline C & -5.792051 & -0.280402 & 1.015427 \\
\hline C & -6.914695 & -1.010086 & 0.588394 \\
\hline C & -5.969659 & 1.038912 & 1.470351 \\
\hline C & -8.185243 & -0.439883 & 0.633875 \\
\hline $\mathrm{H}$ & -6.794409 & -2.036009 & 0.255270 \\
\hline C & -7.239846 & 1.607512 & 1.504886 \\
\hline $\mathrm{H}$ & -5.108923 & 1.646221 & 1.736169 \\
\hline C & -8.350945 & 0.868660 & 1.092817 \\
\hline $\mathrm{H}$ & -9.046689 & -1.021688 & 0.319016 \\
\hline $\mathrm{H}$ & -7.359427 & 2.633550 & 1.839584 \\
\hline $\mathrm{H}$ & -9.341724 & 1.312913 & 1.124679 \\
\hline
\end{tabular}


$\begin{array}{llll}H & -6.893435 & 0.607272 & -2.582918\end{array}$

Catalyst (R)-1 TS Conformation 282

B3LYP/6-31G(d) Energy $=-2809.683381$

B3LYP-D3(BJ)/def2-TZVPP-IEF-PCM(DCM) Energy = -2810.980365

B3LYP-D3(BJ)/def2-TZVPP-IEF-PCM(DCM)//B3LYP/6-31G(d) Free Energy (Quasiharmonic) = 2810.338091

Frequencies (Top 3 out of 270)

1. $-623.7077 \mathrm{~cm}-1$

2. $\quad 5.4228 \mathrm{~cm}-1$

3. $\quad 9.0850 \mathrm{~cm}-1$

B3LYP/6-31G(d) Molecular Geometry in Cartesian Coordinates

$\begin{array}{llll}\text { C } & -3.125028 & 0.082826 & 0.280181 \\ \text { C } & -2.826218 & -0.912327 & -0.637634 \\ \text { C } & -3.200730 & -2.278814 & -0.466342 \\ \text { C } & -3.842453 & -2.613356 & 0.710469 \\ \text { H } & -4.169070 & -3.638822 & 0.862353 \\ \text { C } & -1.995239 & 4.183496 & -0.403659 \\ \text { C } & -2.776853 & 1.501703 & -0.029582 \\ \text { C } & -1.465915 & 1.840341 & -0.341584 \\ \text { C } & -1.036990 & 3.193299 & -0.502743 \\ \text { H } & -1.695644 & 5.220695 & -0.529622 \\ \text { O } & -2.138530 & -0.559994 & -1.789243 \\ \text { P } & -0.527502 & -0.275267 & -1.651445 \\ \text { O } & -0.514388 & 0.836518 & -0.400567 \\ \text { C } & -2.507873 & -5.355180 & -3.393316 \\ \text { C } & -2.245254 & -5.589230 & -2.043009 \\ \text { C } & -2.453004 & -4.579316 & -1.104787 \\ \text { C } & -2.927507 & -3.316521 & -1.495454 \\ \text { C } & -3.181122 & -3.091435 & -2.858947 \\ \text { C } & -2.975035 & -4.102505 & -3.795799 \\ \text { H } & -1.868475 & -6.556027 & -1.719021 \\ \text { H } & -3.180507 & -3.908961 & -4.845286 \\ \text { C } & 3.020566 & 4.466819 & -1.173392 \\ \text { C } & 2.450148 & 3.499350 & -2.005178 \\ \text { C } & 1.145051 & 3.053797 & -1.787155 \\ \text { C } & 0.386331 & 3.576976 & -0.726340 \\ \text { C } & 0.972392 & 4.544458 & 0.107245\end{array}$




\begin{tabular}{|c|c|c|c|}
\hline C & 2.277357 & 4.986352 & -0.112179 \\
\hline $\mathrm{H}$ & 3.018621 & 3.094558 & -2.838740 \\
\hline $\mathrm{H}$ & 2.709569 & 5.737417 & 0.544393 \\
\hline C & -3.776882 & 2.534055 & -0.027905 \\
\hline C & -3.366692 & 3.894556 & -0.203295 \\
\hline C & -4.343554 & 4.926889 & -0.195183 \\
\hline C & -5.679222 & 4.635698 & -0.044495 \\
\hline C & -6.091980 & 3.289635 & 0.095907 \\
\hline C & -5.168055 & 2.267908 & 0.105259 \\
\hline $\mathrm{H}$ & -4.012172 & 5.954676 & -0.324010 \\
\hline $\mathrm{H}$ & -6.418316 & 5.432180 & -0.046385 \\
\hline $\mathrm{H}$ & -7.149622 & 3.058246 & 0.189809 \\
\hline $\mathrm{H}$ & -5.502826 & 1.241487 & 0.200959 \\
\hline C & -3.724339 & -0.295480 & 1.531778 \\
\hline C & -4.092223 & -1.665813 & 1.733986 \\
\hline C & -4.692977 & -2.053191 & 2.963003 \\
\hline C & -4.896971 & -1.140131 & 3.971538 \\
\hline C & -4.499480 & 0.205335 & 3.789930 \\
\hline C & -3.931502 & 0.616470 & 2.603725 \\
\hline $\mathrm{H}$ & -4.980696 & -3.094060 & 3.092813 \\
\hline $\mathrm{H}$ & -5.352593 & -1.449688 & 4.908234 \\
\hline $\mathrm{H}$ & -4.641120 & 0.921896 & 4.594620 \\
\hline $\mathrm{H}$ & -3.626852 & 1.649560 & 2.483922 \\
\hline $\mathrm{O}$ & 0.010111 & 0.280582 & -2.917837 \\
\hline $\mathrm{O}$ & 0.117554 & -1.500313 & -0.989433 \\
\hline $\mathrm{H}$ & 1.318926 & -1.756857 & -1.118931 \\
\hline $\mathrm{H}$ & -3.543479 & -2.122685 & -3.184240 \\
\hline $\mathrm{H}$ & -2.343379 & -6.139736 & -4.127238 \\
\hline $\mathrm{H}$ & -2.222137 & -4.759282 & -0.058533 \\
\hline $\mathrm{H}$ & 0.399063 & 4.945474 & 0.939005 \\
\hline $\mathrm{H}$ & 4.030665 & 4.823868 & -1.361232 \\
\hline $\mathrm{H}$ & 0.711437 & 2.309278 & -2.447738 \\
\hline C & 3.101619 & -0.813618 & -1.232559 \\
\hline $\mathrm{O}$ & 2.479550 & -1.927177 & -1.076888 \\
\hline $\mathrm{H}$ & 2.664728 & -0.037879 & -1.871856 \\
\hline C & 4.616268 & -0.849820 & -1.328528 \\
\hline $\mathrm{O}$ & 5.268942 & 0.059402 & -1.801133 \\
\hline $\mathrm{O}$ & 5.131627 & -1.978167 & -0.821786 \\
\hline C & 6.565791 & -2.103553 & -0.910172 \\
\hline $\mathrm{H}$ & 6.902128 & -1.910424 & -1.931001 \\
\hline $\mathrm{H}$ & 7.051879 & -1.402386 & -0.226166 \\
\hline C & 3.399296 & -0.334871 & 1.427440 \\
\hline C & 2.861716 & 0.395774 & 0.364417 \\
\hline $\mathrm{H}$ & 4.991841 & -0.867634 & 2.579379 \\
\hline
\end{tabular}




$\begin{array}{llll}\mathrm{N} & 4.682272 & -0.192520 & 1.891152 \\ \mathrm{C} & 5.750895 & 0.644325 & 1.513673 \\ \mathrm{O} & 6.884559 & 0.377342 & 1.853119 \\ \mathrm{O} & 5.359092 & 1.700826 & 0.811150 \\ \mathrm{C} & 6.414977 & 2.501275 & 0.235003 \\ \mathrm{H} & 5.910967 & 3.382762 & -0.157982 \\ \mathrm{H} & 6.888182 & 1.938241 & -0.571916 \\ \mathrm{H} & 7.146120 & 2.769195 & 0.999179 \\ \mathrm{H} & 1.782320 & 0.386019 & 0.272931 \\ \mathrm{H} & 3.344382 & 1.307762 & 0.042327 \\ \mathrm{C} & 2.638515 & -1.445579 & 2.029212 \\ \mathrm{C} & 1.240584 & -1.352220 & 2.162916 \\ \mathrm{C} & 3.283555 & -2.626002 & 2.452916 \\ \mathrm{C} & 0.515807 & -2.395692 & 2.732556 \\ \mathrm{H} & 0.716091 & -0.461915 & 1.836663 \\ \mathrm{C} & 2.553332 & -3.668013 & 3.012593 \\ \mathrm{H} & 4.347529 & -2.765127 & 2.281521 \\ \mathrm{C} & 1.168614 & -3.551308 & 3.162427 \\ \mathrm{H} & -0.561607 & -2.304485 & 2.828831 \\ \mathrm{H} & 3.061366 & -4.578882 & 3.315229 \\ \mathrm{H} & 0.599955 & -4.366662 & 3.600629 \\ \mathrm{H} & 6.782912 & -3.131486 & -0.619962\end{array}$

Catalyst (R)-1 TS Conformation 283

B3LYP/6-31G(d) Energy $=-2809.684384$

B3LYP-D3(BJ)/def2-TZVPP-IEF-PCM(DCM) Energy = -2810.979592

B3LYP-D3(BJ)/def2-TZVPP-IEF-PCM(DCM)//B3LYP/6-31G(d) Free Energy (Quasiharmonic) = 2810.338065

Frequencies (Top 3 out of 270)

1. $-604.9106 \mathrm{~cm}-1$

2. $\quad 6.5756 \mathrm{~cm}-1$

3. $9.6398 \mathrm{~cm}-1$

B3LYP/6-31G(d) Molecular Geometry in Cartesian Coordinates

$\begin{array}{llll}\text { C } & 2.958828 & 0.282243 & 0.203765 \\ \text { C } & 2.469081 & 1.284396 & -0.618373 \\ \text { C } & 2.659953 & 2.675910 & -0.367713 \\ \text { C } & 3.329566 & 3.020003 & 0.790554 \\ \text { H } & 3.521391 & 4.069126 & 0.999467\end{array}$




\begin{tabular}{|c|c|c|c|}
\hline C & 2.433656 & -3.885816 & -0.763032 \\
\hline C & 2.807256 & -1.147321 & -0.200139 \\
\hline C & 1.552554 & -1.666683 & -0.494134 \\
\hline C & 1.333068 & -3.051784 & -0.760375 \\
\hline $\mathrm{H}$ & 2.290983 & -4.944383 & -0.963911 \\
\hline $\mathrm{O}$ & 1.771820 & 0.915162 & -1.760104 \\
\hline$P$ & 0.234708 & 0.383620 & -1.582259 \\
\hline $\mathrm{O}$ & 0.446264 & -0.827636 & -0.441062 \\
\hline C & 1.331877 & 5.805309 & -3.003842 \\
\hline C & 1.124647 & 5.902271 & -1.627345 \\
\hline C & 1.541169 & 4.873909 & -0.783262 \\
\hline C & 2.172139 & 3.729177 & -1.297025 \\
\hline C & 2.368836 & 3.640557 & -2.685406 \\
\hline C & 1.954396 & 4.670641 & -3.527810 \\
\hline $\mathrm{H}$ & 0.629370 & 6.774603 & -1.208941 \\
\hline $\mathrm{H}$ & 2.119267 & 4.584867 & -4.598557 \\
\hline C & -2.494323 & -4.874520 & -1.507741 \\
\hline C & -1.689118 & -5.318558 & -0.457992 \\
\hline C & -0.461408 & -4.703169 & -0.209950 \\
\hline C & -0.018881 & -3.632128 & -1.003469 \\
\hline C & -0.837005 & -3.189802 & -2.056957 \\
\hline C & -2.063131 & -3.810960 & -2.304570 \\
\hline $\mathrm{H}$ & -2.015059 & -6.143449 & 0.170544 \\
\hline $\mathrm{H}$ & -2.683891 & -3.457591 & -3.124034 \\
\hline C & 3.953731 & -2.008562 & -0.316588 \\
\hline C & 3.750894 & -3.401199 & -0.579071 \\
\hline C & 4.873823 & -4.266575 & -0.680635 \\
\hline C & 6.154305 & -3.780648 & -0.557002 \\
\hline C & 6.361075 & -2.398673 & -0.335548 \\
\hline C & 5.292598 & -1.537335 & -0.217391 \\
\hline $\mathrm{H}$ & 4.698289 & -5.322332 & -0.873298 \\
\hline $\mathrm{H}$ & 7.006139 & -4.449544 & -0.643427 \\
\hline $\mathrm{H}$ & 7.373661 & -2.010605 & -0.265480 \\
\hline $\mathrm{H}$ & 5.471319 & -0.479979 & -0.061133 \\
\hline C & 3.579198 & 0.659493 & 1.445267 \\
\hline C & 3.774288 & 2.051513 & 1.724356 \\
\hline C & 4.393346 & 2.438834 & 2.944298 \\
\hline C & 4.775001 & 1.500528 & 3.875444 \\
\hline C & 4.546128 & 0.127279 & 3.621415 \\
\hline C & 3.967927 & -0.281885 & 2.438718 \\
\hline $\mathrm{H}$ & 4.547803 & 3.498766 & 3.132518 \\
\hline $\mathrm{H}$ & 5.241478 & 1.809697 & 4.806801 \\
\hline $\mathrm{H}$ & 4.828007 & -0.612469 & 4.365904 \\
\hline $\mathrm{H}$ & 3.793947 & -1.336949 & 2.262839 \\
\hline
\end{tabular}




\begin{tabular}{|c|c|c|c|}
\hline $\mathrm{O}$ & -0.279780 & -0.136500 & -2.874806 \\
\hline $\mathrm{O}$ & -0.572348 & 1.415030 & -0.783100 \\
\hline $\mathrm{H}$ & -1.797900 & 1.579990 & -1.021062 \\
\hline $\mathrm{H}$ & 2.851438 & 2.764605 & -3.104436 \\
\hline $\mathrm{H}$ & 1.005223 & 6.604299 & -3.664175 \\
\hline $\mathrm{H}$ & 1.354528 & 4.944045 & 0.284722 \\
\hline $\mathrm{H}$ & -0.513278 & -2.364006 & -2.682677 \\
\hline $\mathrm{H}$ & -3.449783 & -5.353520 & -1.705115 \\
\hline $\mathrm{H}$ & 0.161160 & -5.047545 & 0.611883 \\
\hline C & -3.315711 & 0.465571 & -1.642490 \\
\hline 0 & -2.949528 & 1.589883 & -1.156125 \\
\hline $\mathrm{H}$ & -2.589391 & -0.139185 & -2.189899 \\
\hline C & -4.726499 & 0.295634 & -2.161939 \\
\hline $\mathrm{O}$ & -5.052933 & -0.647992 & -2.850056 \\
\hline O & -5.537213 & 1.303762 & -1.806205 \\
\hline C & -6.879595 & 1.218603 & -2.321762 \\
\hline $\mathrm{H}$ & -7.375890 & 0.319309 & -1.947370 \\
\hline $\mathrm{H}$ & -7.383293 & 2.116828 & -1.965677 \\
\hline C & -3.186548 & -0.537959 & 1.087934 \\
\hline C & -3.431334 & -1.119140 & -0.157809 \\
\hline $\mathrm{H}$ & -1.150228 & -0.666685 & 0.875594 \\
\hline $\mathrm{N}$ & -1.902830 & -0.308815 & 1.469949 \\
\hline C & -1.460531 & 0.618438 & 2.443054 \\
\hline $\mathrm{O}$ & -2.149627 & 1.418535 & 3.026789 \\
\hline 0 & -0.143198 & 0.438812 & 2.602831 \\
\hline C & 0.493732 & 1.365176 & 3.503972 \\
\hline $\mathrm{H}$ & 1.518696 & 1.011958 & 3.600545 \\
\hline $\mathrm{H}$ & -0.017555 & 1.365211 & 4.469316 \\
\hline $\mathrm{H}$ & 0.472989 & 2.371154 & 3.078259 \\
\hline $\mathrm{H}$ & -4.416236 & -1.539132 & -0.322173 \\
\hline $\mathrm{H}$ & -2.618080 & -1.656693 & -0.636318 \\
\hline C & -4.298757 & -0.208166 & 2.007557 \\
\hline C & -4.279692 & -0.694948 & 3.325466 \\
\hline C & -5.416000 & 0.505724 & 1.552100 \\
\hline C & -5.366551 & -0.481475 & 4.166529 \\
\hline $\mathrm{H}$ & -3.421788 & -1.258552 & 3.679738 \\
\hline C & -6.491508 & 0.737292 & 2.409057 \\
\hline $\mathrm{H}$ & -5.422891 & 0.914779 & 0.547977 \\
\hline C & -6.474019 & 0.239871 & 3.712361 \\
\hline $\mathrm{H}$ & -5.348187 & -0.873809 & 5.179327 \\
\hline $\mathrm{H}$ & -7.343942 & 1.310918 & 2.056020 \\
\hline $\mathrm{H}$ & -7.317926 & 0.414344 & 4.374110 \\
\hline $\mathrm{H}$ & -6.863627 & 1.190495 & -3.413798 \\
\hline
\end{tabular}


Catalyst (R)-1 TS Conformation 284

B3LYP/6-31G(d) Energy $=-2809.683977$

B3LYP-D3(BJ)/def2-TZVPP-IEF-PCM(DCM) Energy = -2810.980199

B3LYP-D3(BJ)/def2-TZVPP-IEF-PCM(DCM)//B3LYP/6-31G(d) Free Energy (Quasiharmonic) = 2810.338019

Frequencies (Top 3 out of 270)

1. $-558.2466 \mathrm{~cm}-1$

2. $\quad 8.4838 \mathrm{~cm}-1$

3. $\quad 10.4112 \mathrm{~cm}-1$

B3LYP/6-31G(d) Molecular Geometry in Cartesian Coordinates

$\begin{array}{lrrr}\text { C } & -3.520738 & 0.373194 & -0.182617 \\ \text { C } & -2.549703 & 1.342418 & 0.025178 \\ \text { C } & -2.773329 & 2.736019 & -0.193447 \\ \text { C } & -4.026849 & 3.106770 & -0.643485 \\ \text { H } & -4.246099 & 4.161397 & -0.786837 \\ \text { C } & -2.583437 & -3.786633 & 0.467113 \\ \text { C } & -3.201673 & -1.056828 & 0.106862 \\ \text { C } & -2.097242 & -1.643183 & -0.497155 \\ \text { C } & -1.774716 & -3.027342 & -0.356982 \\ \text { H } & -2.385066 & -4.850232 & 0.570684 \\ \text { O } & -1.311169 & 0.936800 & 0.497240 \\ \text { P } & -0.254981 & 0.194493 & -0.536388 \\ \text { O } & -1.280473 & -0.857368 & -1.292666 \\ \text { C } & 0.173050 & 5.818050 & 0.412001 \\ \text { C } & 0.062654 & 4.772977 & 1.330665 \\ \text { C } & -0.875076 & 3.758963 & 1.139983 \\ \text { C } & -1.724753 & 3.769299 & 0.021553 \\ \text { C } & -1.595129 & 4.822303 & -0.901067 \\ \text { C } & -0.659427 & 5.836881 & -0.708075 \\ \text { H } & 0.712135 & 4.736411 & 2.200936 \\ \text { H } & -0.572642 & 6.634798 & -1.441148 \\ \text { C } & 1.474492 & -4.979959 & -2.396811 \\ \text { C } & 0.673640 & -4.061850 & -3.079159 \\ \text { C } & -0.365170 & -3.404742 & -2.422071 \\ \text { C } & -0.628026 & -3.656883 & -1.064719 \\ \text { C } & 0.189736 & -4.577606 & -0.388818 \\ \text { C } & 1.229347 & -5.233666 & -1.046732 \\ \text { H } & 0.854778 & -3.857020 & -4.131161\end{array}$




\begin{tabular}{|c|c|c|c|}
\hline $\mathrm{H}$ & 1.850687 & -5.939844 & -0.501315 \\
\hline C & -3.983343 & -1.841805 & 1.022332 \\
\hline C & -3.667583 & -3.229342 & 1.187916 \\
\hline C & -4.440658 & -4.019490 & 2.081701 \\
\hline C & -5.465033 & -3.464757 & 2.813096 \\
\hline C & -5.754166 & -2.085941 & 2.681520 \\
\hline C & -5.035539 & -1.297294 & 1.809900 \\
\hline $\mathrm{H}$ & -4.196240 & -5.074394 & 2.184013 \\
\hline $\mathrm{H}$ & -6.044956 & -4.077676 & 3.497837 \\
\hline $\mathrm{H}$ & -6.549097 & -1.643459 & 3.275976 \\
\hline $\mathrm{H}$ & -5.264623 & -0.241252 & 1.725640 \\
\hline C & -4.788432 & 0.769528 & -0.731143 \\
\hline C & -5.040932 & 2.164039 & -0.938315 \\
\hline C & -6.297501 & 2.576491 & -1.459686 \\
\hline C & -7.260374 & 1.655148 & -1.799525 \\
\hline C & -6.997850 & 0.274475 & -1.636992 \\
\hline C & -5.796959 & -0.156393 & -1.117109 \\
\hline $\mathrm{H}$ & -6.476183 & 3.640284 & -1.598461 \\
\hline $\mathrm{H}$ & -8.214292 & 1.982045 & -2.204464 \\
\hline $\mathrm{H}$ & -7.748691 & -0.454451 & -1.930234 \\
\hline $\mathrm{H}$ & -5.609084 & -1.218270 & -1.009585 \\
\hline 0 & 0.791382 & -0.475005 & 0.290815 \\
\hline 0 & 0.143253 & 1.165980 & -1.645279 \\
\hline $\mathrm{H}$ & 1.349531 & 1.524305 & -1.785506 \\
\hline $\mathrm{H}$ & -2.216275 & 4.827457 & -1.792166 \\
\hline $\mathrm{H}$ & 0.907668 & 6.605249 & 0.561575 \\
\hline $\mathrm{H}$ & -0.936640 & 2.951957 & 1.858776 \\
\hline $\mathrm{H}$ & 0.017914 & -4.763569 & 0.667752 \\
\hline $\mathrm{H}$ & 2.283700 & -5.490634 & -2.912652 \\
\hline $\mathrm{H}$ & -0.980839 & -2.695504 & -2.963501 \\
\hline C & 3.197805 & 0.898626 & -1.343148 \\
\hline 0 & 2.464351 & 1.751504 & -1.972507 \\
\hline $\mathrm{H}$ & 2.710603 & 0.026914 & -0.898283 \\
\hline C & 4.569276 & 0.660148 & -1.960728 \\
\hline $\mathrm{O}$ & 5.317553 & 1.513087 & -2.377542 \\
\hline $\mathrm{O}$ & 4.815444 & -0.663125 & -1.992964 \\
\hline C & 6.065473 & -1.041826 & -2.599943 \\
\hline $\mathrm{H}$ & 6.902073 & -0.629841 & -2.030342 \\
\hline $\mathrm{H}$ & 6.112636 & -0.675237 & -3.628121 \\
\hline C & 4.163411 & 0.808990 & 1.229906 \\
\hline C & 3.783054 & 1.833349 & 0.357274 \\
\hline $\mathrm{H}$ & 3.609022 & -0.623681 & 2.572429 \\
\hline$N$ & 3.307280 & 0.223904 & 2.108471 \\
\hline C & 2.023500 & 0.665520 & 2.505446 \\
\hline
\end{tabular}




$\begin{array}{llll}\mathrm{O} & 1.556076 & 1.752260 & 2.269074 \\ \mathrm{O} & 1.492346 & -0.297378 & 3.262901 \\ \mathrm{C} & 0.118573 & -0.080924 & 3.650621 \\ \mathrm{H} & -0.150006 & -0.956364 & 4.241253 \\ \mathrm{H} & -0.499609 & -0.005397 & 2.755091 \\ \mathrm{H} & 0.034877 & 0.829375 & 4.249461 \\ \mathrm{H} & 4.569739 & 2.408921 & -0.116640 \\ \mathrm{H} & 2.858522 & 2.356589 & 0.561659 \\ \mathrm{C} & 5.511115 & 0.192604 & 1.166935 \\ \mathrm{C} & 5.684886 & -1.198152 & 1.295874 \\ \mathrm{C} & 6.643945 & 1.004272 & 0.987424 \\ \mathrm{C} & 6.959640 & -1.757323 & 1.257444 \\ \mathrm{H} & 4.821466 & -1.854175 & 1.371407 \\ \mathrm{C} & 7.918499 & 0.441343 & 0.959512 \\ \mathrm{H} & 6.527930 & 2.079109 & 0.898676 \\ \mathrm{C} & 8.080326 & -0.938781 & 1.096418 \\ \mathrm{H} & 7.076874 & -2.833546 & 1.344735 \\ \mathrm{H} & 8.785288 & 1.083730 & 0.835677 \\ \mathrm{H} & 9.074709 & -1.375600 & 1.074092 \\ \mathrm{H} & 6.081133 & -2.131259 & -2.577009\end{array}$

Catalyst (R)-1 TS Conformation 285

B3LYP/6-31G(d) Energy = -2809.687323

B3LYP-D3(BJ)/def2-TZVPP-IEF-PCM(DCM) Energy $=-2810.980538$

B3LYP-D3(BJ)/def2-TZVPP-IEF-PCM(DCM)//B3LYP/6-31G(d) Free Energy (Quasiharmonic) = 2810.338002

Frequencies (Top 3 out of 270)

1. $-472.0648 \mathrm{~cm}-1$

2. $\quad 5.5194 \mathrm{~cm}-1$

3. $\quad 11.8776 \mathrm{~cm}-1$

B3LYP/6-31G(d) Molecular Geometry in Cartesian Coordinates

$\begin{array}{llll}\text { C } & 2.771054 & -1.471173 & -0.042009 \\ \text { C } & 1.602863 & -1.842083 & 0.605264 \\ \text { C } & 0.990806 & -3.121742 & 0.445457 \\ \text { C } & 1.584629 & -3.999076 & -0.441395 \\ \text { H } & 1.163978 & -4.993665 & -0.564567 \\ \text { C } & 4.551072 & 2.399673 & 0.591283 \\ \text { C } & 3.388549 & -0.146406 & 0.261176\end{array}$




\begin{tabular}{|c|c|c|c|}
\hline C & 2.643285 & 1.017003 & 0.115858 \\
\hline C & 3.218617 & 2.319653 & 0.235569 \\
\hline $\mathrm{H}$ & 5.009499 & 3.379511 & 0.696821 \\
\hline $\mathrm{O}$ & 1.015345 & -0.933911 & 1.469482 \\
\hline$P$ & 0.193399 & 0.340294 & 0.820023 \\
\hline $\mathrm{O}$ & 1.311382 & 0.919959 & -0.260300 \\
\hline C & -2.519844 & -4.403232 & 2.580529 \\
\hline C & -1.511763 & -3.707635 & 3.250593 \\
\hline C & -0.380381 & -3.268530 & 2.565261 \\
\hline C & -0.232408 & -3.521106 & 1.190625 \\
\hline C & -1.256658 & -4.217897 & 0.527832 \\
\hline C & -2.388221 & -4.655540 & 1.214623 \\
\hline $\mathrm{H}$ & -1.604967 & -3.504211 & 4.314137 \\
\hline $\mathrm{H}$ & -3.171340 & -5.186005 & 0.678704 \\
\hline C & 1.159144 & 5.995427 & -0.650531 \\
\hline C & 0.594766 & 5.083178 & 0.243424 \\
\hline C & 1.238552 & 3.880402 & 0.536493 \\
\hline C & 2.467810 & 3.570763 & -0.069049 \\
\hline C & 3.027585 & 4.495557 & -0.968515 \\
\hline C & 2.380717 & 5.697369 & -1.257382 \\
\hline $\mathrm{H}$ & -0.357527 & 5.303699 & 0.717678 \\
\hline $\mathrm{H}$ & 2.830233 & 6.397014 & -1.957843 \\
\hline C & 4.746064 & -0.044854 & 0.723673 \\
\hline C & 5.330381 & 1.252982 & 0.876846 \\
\hline C & 6.673229 & 1.367636 & 1.328161 \\
\hline C & 7.411825 & 0.250733 & 1.642096 \\
\hline C & 6.827353 & -1.032338 & 1.523763 \\
\hline C & 5.532514 & -1.176755 & 1.076259 \\
\hline $\mathrm{H}$ & 7.101599 & 2.361898 & 1.431999 \\
\hline $\mathrm{H}$ & 8.435633 & 0.350222 & 1.992383 \\
\hline $\mathrm{H}$ & 7.403085 & -1.913082 & 1.795540 \\
\hline $\mathrm{H}$ & 5.096359 & -2.166257 & 1.003698 \\
\hline C & 3.330736 & -2.364466 & -1.019644 \\
\hline C & 2.726822 & -3.650628 & -1.203016 \\
\hline C & 3.276525 & -4.550869 & -2.155835 \\
\hline C & 4.358502 & -4.193861 & -2.926438 \\
\hline C & 4.932572 & -2.909661 & -2.776215 \\
\hline C & 4.434484 & -2.021096 & -1.848455 \\
\hline $\mathrm{H}$ & 2.813546 & -5.528258 & -2.271477 \\
\hline $\mathrm{H}$ & 4.765985 & -4.888529 & -3.656010 \\
\hline $\mathrm{H}$ & 5.773012 & -2.619230 & -3.401093 \\
\hline $\mathrm{H}$ & 4.881416 & -1.038559 & -1.751981 \\
\hline $\mathrm{O}$ & -0.150296 & 1.286683 & 1.914311 \\
\hline $\mathrm{O}$ & -0.922843 & -0.180886 & -0.100946 \\
\hline
\end{tabular}




\begin{tabular}{|c|c|c|c|}
\hline $\mathrm{H}$ & -2.065778 & -0.335904 & 0.513476 \\
\hline $\mathrm{H}$ & -1.171035 & -4.396971 & -0.540426 \\
\hline $\mathrm{H}$ & -3.403312 & -4.738589 & 3.117360 \\
\hline $\mathrm{H}$ & 0.395294 & -2.729341 & 3.097110 \\
\hline $\mathrm{H}$ & 3.971244 & 4.259285 & -1.453528 \\
\hline $\mathrm{H}$ & 0.651317 & 6.930537 & -0.873322 \\
\hline $\mathrm{H}$ & 0.787279 & 3.183208 & 1.235398 \\
\hline$C$ & -3.381784 & 0.909029 & 1.263772 \\
\hline O & -3.070940 & -0.319403 & 1.033189 \\
\hline $\mathrm{H}$ & -2.588886 & 1.658340 & 1.242432 \\
\hline C & -4.485230 & 1.122627 & 2.280464 \\
\hline 0 & -5.335628 & 0.307787 & 2.563484 \\
\hline O & -4.387651 & 2.352044 & 2.810781 \\
\hline C & -5.375071 & 2.679607 & 3.805800 \\
\hline $\mathrm{H}$ & -5.144178 & 3.697029 & 4.119929 \\
\hline $\mathrm{H}$ & -5.304777 & 1.989172 & 4.649767 \\
\hline C & -4.139475 & 1.005592 & -1.367848 \\
\hline C & -4.462586 & 1.817834 & -0.274954 \\
\hline $\mathrm{H}$ & -2.731991 & 0.375884 & -2.695129 \\
\hline$N$ & -3.006906 & 1.151049 & -2.103001 \\
\hline C & -2.038406 & 2.175573 & -2.021732 \\
\hline 0 & -2.076834 & 3.112936 & -1.259368 \\
\hline $\mathrm{O}$ & -1.118511 & 1.926602 & -2.952950 \\
\hline C & 0.035997 & 2.801451 & -2.950181 \\
\hline $\mathrm{H}$ & 0.650531 & 2.579785 & -2.078000 \\
\hline $\mathrm{H}$ & -0.280989 & 3.845188 & -2.932858 \\
\hline $\mathrm{H}$ & 0.566544 & 2.566296 & -3.872252 \\
\hline $\mathrm{H}$ & -5.494832 & 1.757152 & 0.050654 \\
\hline $\mathrm{H}$ & -3.984021 & 2.783945 & -0.192802 \\
\hline C & -4.965400 & -0.159127 & -1.737572 \\
\hline C & -5.651632 & -0.891199 & -0.750514 \\
\hline C & -5.071504 & -0.556220 & -3.085816 \\
\hline C & -6.415111 & -1.998856 & -1.113305 \\
\hline $\mathrm{H}$ & -5.559209 & -0.628104 & 0.297192 \\
\hline C & -5.849840 & -1.653874 & -3.438797 \\
\hline $\mathrm{H}$ & -4.584768 & 0.023958 & -3.865245 \\
\hline C & -6.519125 & -2.381712 & -2.451525 \\
\hline $\mathrm{H}$ & -6.924986 & -2.567651 & -0.341516 \\
\hline $\mathrm{H}$ & -5.939236 & -1.937157 & -4.483453 \\
\hline $\mathrm{H}$ & -7.121719 & -3.242826 & -2.726659 \\
\hline $\mathrm{H}$ & -6.379906 & 2.623059 & 3.378525 \\
\hline
\end{tabular}

Catalyst (R)-1 TS Conformation 286 
B3LYP/6-31G(d) Energy $=-2809.687965$

B3LYP-D3(BJ)/def2-TZVPP-IEF-PCM(DCM) Energy $=-2810.981292$

B3LYP-D3(BJ)/def2-TZVPP-IEF-PCM(DCM)//B3LYP/6-31G(d) Free Energy (Quasiharmonic) = 2810.337931

Frequencies (Top 3 out of 270)

1. $-325.3668 \mathrm{~cm}-1$

2. $\quad 8.9992 \mathrm{~cm}-1$

3. $\quad 12.1006 \mathrm{~cm}-1$

B3LYP/6-31G(d) Molecular Geometry in Cartesian Coordinates

$\begin{array}{llll}\mathrm{C} & 3.145779 & -0.588830 & -0.510232 \\ \mathrm{C} & 2.043445 & -1.401045 & -0.274468 \\ \mathrm{C} & 2.010749 & -2.777731 & -0.642391 \\ \mathrm{C} & 3.098985 & -3.296579 & -1.312107 \\ \mathrm{H} & 3.095245 & -4.346522 & -1.593626 \\ \mathrm{C} & 3.248787 & 3.493282 & 0.878755 \\ \mathrm{C} & 3.195741 & 0.800583 & 0.033388 \\ \mathrm{C} & 2.170342 & 1.684755 & -0.258459 \\ \mathrm{C} & 2.176125 & 3.057351 & 0.125749 \\ \mathrm{H} & 3.300927 & 4.539250 & 1.169277 \\ \mathrm{O} & 0.960324 & -0.915489 & 0.442148 \\ \mathrm{P} & 0.009068 & 0.312695 & -0.098945 \\ \mathrm{O} & 1.075902 & 1.201566 & -0.970137 \\ \mathrm{C} & -1.174466 & -5.529305 & 0.267143 \\ \mathrm{C} & 0.053770 & -5.625714 & 0.921496 \\ \mathrm{C} & 1.070377 & -4.711878 & 0.636188 \\ \mathrm{C} & 0.871419 & -3.678422 & -0.292366 \\ \mathrm{C} & -0.373177 & -3.578458 & -0.933980 \\ \mathrm{C} & -1.382505 & -4.507300 & -0.663952 \\ \mathrm{H} & 0.227515 & -6.416750 & 1.646497 \\ \mathrm{H} & -2.319542 & -4.436189 & -1.209301 \\ \mathrm{C} & -0.889120 & 5.870198 & -0.965714 \\ \mathrm{C} & -0.416243 & 5.811463 & 0.345758 \\ \mathrm{C} & 0.563857 & 4.883692 & 0.695529 \\ \mathrm{C} & 1.089507 & 3.996773 & -0.257611 \\ \mathrm{C} & 0.600049 & 4.060568 & -1.572912 \\ \mathrm{C} & -0.377348 & 4.990823 & -1.922084 \\ \mathrm{H} & -0.818213 & 6.480620 & 1.101938 \\ \mathrm{H} & -0.738991 & 5.028376 & -2.946434 \\ \mathrm{C} & 4.265338 & 1.250345 & 0.883588\end{array}$




\begin{tabular}{|c|c|c|c|}
\hline$C$ & 4.285598 & 2.622427 & 1.295806 \\
\hline C & 5.340655 & 3.085332 & 2.128212 \\
\hline C & 6.322655 & 2.229389 & 2.569551 \\
\hline C & 6.283016 & 0.865294 & 2.197393 \\
\hline C & 5.284244 & 0.389384 & 1.376283 \\
\hline $\mathrm{H}$ & 5.347267 & 4.132667 & 2.420920 \\
\hline $\mathrm{H}$ & 7.120030 & 2.593597 & 3.211602 \\
\hline $\mathrm{H}$ & 7.045414 & 0.184292 & 2.566156 \\
\hline $\mathrm{H}$ & 5.264173 & -0.660541 & 1.108680 \\
\hline C & 4.223406 & -1.112464 & -1.307531 \\
\hline C & 4.200343 & -2.491341 & -1.692517 \\
\hline C & 5.267586 & -3.022186 & -2.466167 \\
\hline C & 6.309907 & -2.223561 & -2.874889 \\
\hline C & 6.318446 & -0.851771 & -2.529136 \\
\hline C & 5.306550 & -0.311735 & -1.766396 \\
\hline $\mathrm{H}$ & 5.234899 & -4.073913 & -2.740894 \\
\hline $\mathrm{H}$ & 7.117434 & -2.637613 & -3.472418 \\
\hline $\mathrm{H}$ & 7.128466 & -0.214934 & -2.874394 \\
\hline $\mathrm{H}$ & 5.324408 & 0.743628 & -1.521269 \\
\hline $\mathrm{O}$ & -0.624313 & 1.001655 & 1.048738 \\
\hline $\mathrm{O}$ & -0.913019 & -0.298744 & -1.195577 \\
\hline $\mathrm{H}$ & -1.937679 & 0.100018 & -1.210925 \\
\hline $\mathrm{H}$ & -0.550134 & -2.784683 & -1.652390 \\
\hline $\mathrm{H}$ & -1.960929 & -6.251292 & 0.471897 \\
\hline $\mathrm{H}$ & 2.032189 & -4.796566 & 1.135298 \\
\hline $\mathrm{H}$ & 0.991470 & 3.382914 & -2.324055 \\
\hline $\mathrm{H}$ & -1.655349 & 6.590949 & -1.238948 \\
\hline $\mathrm{H}$ & 0.909599 & 4.824000 & 1.723585 \\
\hline C & -3.614916 & 1.202150 & -0.200739 \\
\hline $\mathrm{O}$ & -3.219485 & 0.551830 & -1.248591 \\
\hline $\mathrm{H}$ & -2.864083 & 1.505735 & 0.538652 \\
\hline C & -4.643576 & 2.317837 & -0.400693 \\
\hline $\mathrm{O}$ & -4.844798 & 3.189937 & 0.417113 \\
\hline $\mathrm{O}$ & -5.300243 & 2.213099 & -1.571565 \\
\hline C & -6.260859 & 3.253242 & -1.819821 \\
\hline $\mathrm{H}$ & -5.773017 & 4.231259 & -1.823131 \\
\hline $\mathrm{H}$ & -7.040931 & 3.249968 & -1.053242 \\
\hline C & -3.952398 & -1.036265 & 1.087129 \\
\hline C & -4.725082 & 0.135506 & 0.926230 \\
\hline $\mathrm{H}$ & -3.038493 & -2.612872 & 0.191328 \\
\hline$N$ & -3.756082 & -1.902518 & 0.066288 \\
\hline C & -4.244987 & -1.917684 & -1.267931 \\
\hline $\mathrm{O}$ & -3.669139 & -2.554156 & -2.119871 \\
\hline $\mathrm{O}$ & -5.414559 & -1.293973 & -1.399419 \\
\hline
\end{tabular}




$\begin{array}{llll}\mathrm{C} & -5.804547 & -1.018767 & -2.762526 \\ \mathrm{H} & -5.763843 & -1.930823 & -3.359885 \\ \mathrm{H} & -5.134382 & -0.257502 & -3.165806 \\ \mathrm{H} & -6.824031 & -0.640063 & -2.695928 \\ \mathrm{H} & -4.848861 & 0.742664 & 1.816633 \\ \mathrm{H} & -5.597548 & 0.061140 & 0.290694 \\ \mathrm{C} & -3.180156 & -1.291171 & 2.317800 \\ \mathrm{C} & -1.892584 & -1.857445 & 2.281261 \\ \mathrm{C} & -3.749306 & -0.971194 & 3.564601 \\ \mathrm{C} & -1.196446 & -2.094956 & 3.462149 \\ \mathrm{H} & -1.398902 & -2.064569 & 1.337955 \\ \mathrm{C} & -3.053489 & -1.223842 & 4.742713 \\ \mathrm{H} & -4.750079 & -0.553898 & 3.609569 \\ \mathrm{C} & -1.775051 & -1.784570 & 4.694001 \\ \mathrm{H} & -0.193398 & -2.505903 & 3.410460 \\ \mathrm{H} & -3.509658 & -0.983715 & 5.698659 \\ \mathrm{H} & -1.228564 & -1.971548 & 5.614177 \\ \mathrm{H} & -6.683734 & 3.033121 & -2.800508\end{array}$

Catalyst (R)-1 TS Conformation 287

B3LYP/6-31G(d) Energy = -2809.685455

B3LYP-D3(BJ)/def2-TZVPP-IEF-PCM(DCM) Energy $=-2810.980283$

B3LYP-D3(BJ)/def2-TZVPP-IEF-PCM(DCM)//B3LYP/6-31G(d) Free Energy (Quasiharmonic) = 2810.337924

Frequencies (Top 3 out of 270)

1. $-475.7803 \mathrm{~cm}-1$

2. $\quad 7.6956 \mathrm{~cm}-1$

3. $\quad 9.9097 \mathrm{~cm}-1$

B3LYP/6-31G(d) Molecular Geometry in Cartesian Coordinates

$\begin{array}{llll}\text { C } & -3.540880 & 0.523809 & -0.156407 \\ \text { C } & -2.501556 & 1.417123 & 0.062528 \\ \text { C } & -2.628296 & 2.827490 & -0.126132 \\ \text { C } & -3.855391 & 3.295415 & -0.558023 \\ \text { H } & -4.001022 & 4.365692 & -0.677155 \\ \text { C } & -2.898325 & -3.704192 & 0.405890 \\ \text { C } & -3.323387 & -0.930829 & 0.102940 \\ \text { C } & -2.267163 & -1.582057 & -0.520523 \\ \text { C } & -2.042728 & -2.988079 & -0.409298\end{array}$




\begin{tabular}{|c|c|c|c|}
\hline $\mathrm{H}$ & -2.774374 & -4.780872 & 0.488190 \\
\hline 0 & -1.292431 & 0.917000 & 0.516538 \\
\hline$P$ & -0.296594 & 0.118000 & -0.536093 \\
\hline 0 & -1.401724 & -0.840325 & -1.306174 \\
\hline C & 0.526008 & 5.686458 & 0.527877 \\
\hline C & -0.313133 & 5.791221 & -0.582465 \\
\hline C & -1.316375 & 4.846933 & -0.792324 \\
\hline C & -1.508864 & 3.780288 & 0.103340 \\
\hline C & -0.651190 & 3.682299 & 1.211517 \\
\hline C & 0.354058 & 4.625950 & 1.419069 \\
\hline $\mathrm{H}$ & -0.180265 & 6.601752 & -1.294601 \\
\hline $\mathrm{H}$ & 1.007038 & 4.522454 & 2.281358 \\
\hline C & 1.061415 & -5.111988 & -2.502167 \\
\hline C & 0.808323 & -5.371631 & -1.154790 \\
\hline C & -0.184530 & -4.662707 & -0.479850 \\
\hline C & -0.945736 & -3.681293 & -1.135804 \\
\hline C & -0.676302 & -3.425049 & -2.490993 \\
\hline C & 0.315250 & -4.135570 & -3.165181 \\
\hline $\mathrm{H}$ & 1.389247 & -6.121980 & -0.624229 \\
\hline $\mathrm{H}$ & 0.503836 & -3.925351 & -4.214806 \\
\hline C & -4.153622 & -1.676282 & 1.008651 \\
\hline C & -3.936143 & -3.085770 & 1.145037 \\
\hline C & -4.757966 & -3.836540 & 2.029197 \\
\hline C & -5.735910 & -3.225245 & 2.778902 \\
\hline C & -5.927097 & -1.827082 & 2.676276 \\
\hline C & -5.159531 & -1.074321 & 1.814667 \\
\hline $\mathrm{H}$ & -4.588313 & -4.907915 & 2.109369 \\
\hline $\mathrm{H}$ & -6.353635 & -3.809011 & 3.456056 \\
\hline $\mathrm{H}$ & -6.684747 & -1.341120 & 3.285331 \\
\hline $\mathrm{H}$ & -5.313192 & -0.003130 & 1.753103 \\
\hline C & -4.780578 & 1.020240 & -0.687151 \\
\hline C & -4.935412 & 2.433026 & -0.864134 \\
\hline C & -6.162951 & 2.943837 & -1.367218 \\
\hline C & -7.190602 & 2.099974 & -1.718407 \\
\hline C & -7.025119 & 0.701147 & -1.586054 \\
\hline C & -5.854461 & 0.176011 & -1.084187 \\
\hline $\mathrm{H}$ & -6.266920 & 4.020281 & -1.482860 \\
\hline $\mathrm{H}$ & -8.121587 & 2.501660 & -2.109247 \\
\hline $\mathrm{H}$ & -7.827308 & 0.033151 & -1.888351 \\
\hline $\mathrm{H}$ & -5.741324 & -0.898461 & -0.999716 \\
\hline $\mathrm{O}$ & 0.695702 & -0.645269 & 0.277257 \\
\hline $\mathrm{O}$ & 0.172402 & 1.079522 & -1.623693 \\
\hline $\mathrm{H}$ & 1.423897 & 1.293853 & -1.819063 \\
\hline $\mathrm{H}$ & -0.759961 & 2.861144 & 1.908304 \\
\hline
\end{tabular}




\begin{tabular}{|c|c|c|c|}
\hline $\mathrm{H}$ & 1.312137 & 6.419384 & 0.691457 \\
\hline $\mathrm{H}$ & -1.943847 & 4.918216 & -1.676100 \\
\hline $\mathrm{H}$ & -1.249124 & -2.669555 & -3.016811 \\
\hline $\mathrm{H}$ & 1.836647 & -5.661312 & -3.030040 \\
\hline $\mathrm{H}$ & -0.360840 & -4.853387 & 0.575153 \\
\hline C & 3.202743 & 0.546362 & -1.321699 \\
\hline 0 & 2.538044 & 1.394066 & -2.033114 \\
\hline $\mathrm{H}$ & 2.649267 & -0.234768 & -0.792428 \\
\hline C & 4.529108 & 0.068173 & -1.875483 \\
\hline 0 & 4.943097 & -1.054194 & -1.671791 \\
\hline O & 5.163509 & 1.002011 & -2.596336 \\
\hline C & 6.412079 & 0.585449 & -3.178173 \\
\hline $\mathrm{H}$ & 6.255983 & -0.267337 & -3.843367 \\
\hline $\mathrm{H}$ & 6.772815 & 1.448357 & -3.737729 \\
\hline C & 4.275045 & 0.575222 & 1.210037 \\
\hline C & 3.863607 & 1.555161 & 0.296504 \\
\hline $\mathrm{H}$ & 3.746825 & -0.849973 & 2.569944 \\
\hline $\mathrm{N}$ & 3.422215 & -0.024391 & 2.081302 \\
\hline C & 2.130095 & 0.407171 & 2.471207 \\
\hline 0 & 1.665467 & 1.495549 & 2.237755 \\
\hline $\mathrm{O}$ & 1.594135 & -0.563657 & 3.211494 \\
\hline C & 0.215758 & -0.351989 & 3.590454 \\
\hline $\mathrm{H}$ & -0.390275 & -0.253122 & 2.689462 \\
\hline $\mathrm{H}$ & 0.130037 & 0.543657 & 4.210694 \\
\hline $\mathrm{H}$ & -0.060431 & -1.240849 & 4.156888 \\
\hline $\mathrm{H}$ & 4.641858 & 2.126796 & -0.196615 \\
\hline $\mathrm{H}$ & 2.936988 & 2.078356 & 0.493855 \\
\hline C & 5.653414 & 0.033909 & 1.202343 \\
\hline C & 6.742105 & 0.911237 & 1.061898 \\
\hline C & 5.902532 & -1.342625 & 1.349972 \\
\hline C & 8.047713 & 0.424899 & 1.088172 \\
\hline $\mathrm{H}$ & 6.564966 & 1.978024 & 0.969443 \\
\hline C & 7.208121 & -1.824819 & 1.365297 \\
\hline $\mathrm{H}$ & 5.076143 & -2.047123 & 1.386068 \\
\hline C & 8.283771 & -0.942883 & 1.240736 \\
\hline $\mathrm{H}$ & 8.880421 & 1.116504 & 0.998395 \\
\hline $\mathrm{H}$ & 7.384838 & -2.892097 & 1.459100 \\
\hline $\mathrm{H}$ & 9.301969 & -1.321079 & 1.257296 \\
\hline $\mathrm{H}$ & 7.122688 & 0.305152 & -2.395840 \\
\hline
\end{tabular}

Catalyst (R)-1 TS Conformation 288

B3LYP/6-31G(d) Energy $=-2809.679857$ 
B3LYP-D3(BJ)/def2-TZVPP-IEF-PCM(DCM) Energy = -2810.980391

B3LYP-D3(BJ)/def2-TZVPP-IEF-PCM(DCM)//B3LYP/6-31G(d) Free Energy (Quasiharmonic) = 2810.337919

Frequencies (Top 3 out of 270)

1. $-604.1590 \mathrm{~cm}-1$

2. $\quad 3.1324 \mathrm{~cm}-1$

3. $9.8008 \mathrm{~cm}-1$

B3LYP/6-31G(d) Molecular Geometry in Cartesian Coordinates

$\begin{array}{llll}\text { C } & 3.712279 & 0.170347 & 0.298798 \\ \text { C } & 2.917393 & 1.265419 & -0.007363 \\ \text { C } & 3.241993 & 2.594421 & 0.395797 \\ \text { C } & 4.347316 & 2.769110 & 1.203561 \\ \text { H } & 4.626533 & 3.774038 & 1.510080 \\ \text { C } & 2.665283 & -3.764727 & -1.114972 \\ \text { C } & 3.370003 & -1.174472 & -0.253229 \\ \text { C } & 2.114513 & -1.709919 & -0.007958 \\ \text { C } & 1.739580 & -3.030822 & -0.397949 \\ \text { H } & 2.425267 & -4.784956 & -1.402567 \\ \text { O } & 1.774658 & 1.081970 & -0.769078 \\ \text { P } & 0.469109 & 0.319149 & -0.108096 \\ \text { O } & 1.197544 & -0.938755 & 0.682872 \\ \text { C } & 1.138699 & 6.108403 & -0.922170 \\ \text { C } & 1.574332 & 5.161077 & -1.852802 \\ \text { C } & 2.221990 & 4.001934 & -1.426650 \\ \text { C } & 2.459455 & 3.774716 & -0.060473 \\ \text { C } & 2.013651 & 4.731163 & 0.864325 \\ \text { C } & 1.356415 & 5.886397 & 0.438234 \\ \text { H } & 1.416769 & 5.328420 & -2.915469 \\ \text { H } & 1.014423 & 6.612227 & 1.171574 \\ \text { C } & -1.966277 & -4.946108 & 0.658684 \\ \text { C } & -1.452236 & -5.061510 & -0.633683 \\ \text { C } & -0.268823 & -4.409330 & -0.976854 \\ \text { C } & 0.427997 & -3.631834 & -0.036951 \\ \text { C } & -0.110855 & -3.508697 & 1.255554 \\ \text { C } & -1.294076 & -4.161473 & 1.598826 \\ \text { H } & -1.972422 & -5.658559 & -1.378602 \\ \text { H } & -1.684791 & -4.063013 & 2.608507 \\ \text { C } & 4.293424 & -1.921273 & -1.061489 \\ \text { C } & 3.926729 & -3.239117 & -1.486901 \\ \text { C } & 4.833880 & -3.994405 & -2.278607\end{array}$




\begin{tabular}{|c|c|c|c|}
\hline C & 6.044180 & -3.467944 & -2.665908 \\
\hline C & 6.394171 & -2.153427 & -2.277050 \\
\hline C & 5.544276 & -1.401865 & -1.495435 \\
\hline $\mathrm{H}$ & 4.544317 & -4.997587 & -2.583068 \\
\hline $\mathrm{H}$ & 6.726379 & -4.052432 & -3.277266 \\
\hline $\mathrm{H}$ & 7.341024 & -1.730222 & -2.601765 \\
\hline $\mathrm{H}$ & 5.823083 & -0.393032 & -1.213548 \\
\hline C & 4.825522 & 0.356856 & 1.189871 \\
\hline C & 5.140119 & 1.679765 & 1.640877 \\
\hline C & 6.239624 & 1.876611 & 2.519375 \\
\hline C & 6.988850 & 0.812949 & 2.965578 \\
\hline C & 6.659654 & -0.498842 & 2.550959 \\
\hline C & 5.609681 & -0.720937 & 1.687149 \\
\hline $\mathrm{H}$ & 6.469998 & 2.889527 & 2.841560 \\
\hline $\mathrm{H}$ & 7.823252 & 0.974794 & 3.642574 \\
\hline $\mathrm{H}$ & 7.237366 & -1.341372 & 2.921677 \\
\hline $\mathrm{H}$ & 5.364736 & -1.733576 & 1.388941 \\
\hline $\mathrm{O}$ & -0.443502 & -0.101856 & -1.205099 \\
\hline $\mathrm{O}$ & -0.071419 & 1.192220 & 1.035726 \\
\hline $\mathrm{H}$ & -1.104673 & 0.747861 & 1.612312 \\
\hline $\mathrm{H}$ & 2.172349 & 4.556065 & 1.924650 \\
\hline $\mathrm{H}$ & 0.634300 & 7.011572 & -1.255848 \\
\hline $\mathrm{H}$ & 2.560607 & 3.271696 & -2.154798 \\
\hline $\mathrm{H}$ & 0.405847 & -2.909190 & 1.996387 \\
\hline $\mathrm{H}$ & -2.880679 & -5.466823 & 0.932558 \\
\hline $\mathrm{H}$ & 0.115429 & -4.487580 & -1.989866 \\
\hline C & -2.891032 & -0.043538 & 1.135246 \\
\hline $\mathrm{O}$ & -2.066213 & 0.289964 & 2.070867 \\
\hline $\mathrm{H}$ & -2.512724 & -0.116982 & 0.110522 \\
\hline C & -3.915501 & -1.095110 & 1.533843 \\
\hline $\mathrm{O}$ & -4.363420 & -1.247351 & 2.645677 \\
\hline $\mathrm{O}$ & -4.251644 & -1.833452 & 0.458310 \\
\hline C & -5.171721 & -2.909159 & 0.718136 \\
\hline $\mathrm{H}$ & -4.752343 & -3.587179 & 1.464286 \\
\hline $\mathrm{H}$ & -6.126340 & -2.517889 & 1.078164 \\
\hline C & -4.931648 & 1.331612 & -0.180576 \\
\hline C & -4.079103 & 1.525030 & 0.916668 \\
\hline $\mathrm{H}$ & -5.285799 & 1.391282 & -2.180091 \\
\hline$N$ & -4.588410 & 1.588988 & -1.472778 \\
\hline C & -3.429025 & 2.138367 & -2.087858 \\
\hline $\mathrm{O}$ & -3.389217 & 2.230989 & -3.292892 \\
\hline $\mathrm{O}$ & -2.517431 & 2.514409 & -1.210381 \\
\hline C & -1.264297 & 3.003431 & -1.764619 \\
\hline $\mathrm{H}$ & -0.785454 & 2.194704 & -2.315257 \\
\hline
\end{tabular}




$\begin{array}{lrrr}\mathrm{H} & -0.670682 & 3.278229 & -0.897115 \\ \mathrm{H} & -1.461503 & 3.863709 & -2.406212 \\ \mathrm{H} & -4.537774 & 1.464803 & 1.897013 \\ \mathrm{H} & -3.269297 & 2.232658 & 0.813241 \\ \mathrm{C} & -6.274559 & 0.725660 & -0.016044 \\ \mathrm{C} & -7.059058 & 1.047810 & 1.105082 \\ \mathrm{C} & -6.797558 & -0.161302 & -0.977087 \\ \mathrm{C} & -8.335222 & 0.509500 & 1.253287 \\ \mathrm{H} & -6.682074 & 1.744544 & 1.845882 \\ \mathrm{C} & -8.070759 & -0.702277 & -0.821333 \\ \mathrm{H} & -6.188267 & -0.475282 & -1.820145 \\ \mathrm{C} & -8.845112 & -0.364578 & 0.291626 \\ \mathrm{H} & -8.932590 & 0.777661 & 2.119434 \\ \mathrm{H} & -8.454593 & -1.395339 & -1.564196 \\ \mathrm{H} & -9.839945 & -0.784304 & 0.409889 \\ \mathrm{H} & -5.297243 & -3.421206 & -0.235666\end{array}$

Catalyst (R)-1 TS Conformation 289

B3LYP/6-31G(d) Energy $=-2809.686038$

B3LYP-D3(BJ)/def2-TZVPP-IEF-PCM(DCM) Energy $=-2810.979293$

B3LYP-D3(BJ)/def2-TZVPP-IEF-PCM(DCM)//B3LYP/6-31G(d) Free Energy (Quasiharmonic) = 2810.337872

Frequencies (Top 3 out of 270)

1. $-663.9011 \mathrm{~cm}-1$

2. $8.2591 \mathrm{~cm}-1$

3. $11.0235 \mathrm{~cm}-1$

B3LYP/6-31G(d) Molecular Geometry in Cartesian Coordinates

$\begin{array}{llll}\text { C } & 3.668256 & -0.848422 & -0.043891 \\ \text { C } & 2.501531 & -1.537183 & 0.249514 \\ \text { C } & 2.333683 & -2.933221 & 0.011723 \\ \text { C } & 3.384607 & -3.607789 & -0.577248 \\ \text { H } & 3.298677 & -4.677395 & -0.751052 \\ \text { C } & 3.904801 & 3.373674 & 0.815938 \\ \text { C } & 3.765661 & 0.601318 & 0.302496 \\ \text { C } & 2.802927 & 1.483425 & -0.168108 \\ \text { C } & 2.860054 & 2.892338 & 0.050943 \\ \text { H } & 3.992888 & 4.444682 & 0.978672 \\ \text { O } & 1.445365 & -0.840977 & 0.815661\end{array}$




\begin{tabular}{|c|c|c|c|}
\hline$P$ & 0.555946 & 0.148322 & -0.157386 \\
\hline 0 & 1.748225 & 0.985366 & -0.918344 \\
\hline C & -1.261652 & -5.078410 & 1.022833 \\
\hline C & -0.679530 & -4.211885 & 1.952518 \\
\hline C & 0.475933 & -3.500955 & 1.628707 \\
\hline C & 1.077990 & -3.647114 & 0.366781 \\
\hline C & 0.484467 & -4.521943 & -0.557414 \\
\hline C & -0.673376 & -5.230387 & -0.233889 \\
\hline $\mathrm{H}$ & -1.124903 & -4.092220 & 2.936916 \\
\hline $\mathrm{H}$ & -1.119530 & -5.895304 & -0.969002 \\
\hline C & 0.050860 & 5.716326 & -1.580632 \\
\hline C & 0.557604 & 4.691808 & -2.384623 \\
\hline C & 1.446975 & 3.756097 & -1.858688 \\
\hline C & 1.853993 & 3.830241 & -0.515787 \\
\hline C & 1.330760 & 4.859685 & 0.283798 \\
\hline C & 0.438388 & 5.793736 & -0.241483 \\
\hline $\mathrm{H}$ & 0.264955 & 4.623080 & -3.429214 \\
\hline $\mathrm{H}$ & 0.044083 & 6.579877 & 0.397373 \\
\hline C & 4.803193 & 1.109229 & 1.157878 \\
\hline C & 4.871392 & 2.519542 & 1.400196 \\
\hline C & 5.899873 & 3.036377 & 2.234150 \\
\hline C & 6.810332 & 2.199978 & 2.836662 \\
\hline C & 6.721803 & 0.802959 & 2.631648 \\
\hline C & 5.747419 & 0.272478 & 1.814941 \\
\hline $\mathrm{H}$ & 5.943787 & 4.110849 & 2.396532 \\
\hline $\mathrm{H}$ & 7.587982 & 2.605931 & 3.477866 \\
\hline $\mathrm{H}$ & 7.426436 & 0.140537 & 3.127288 \\
\hline $\mathrm{H}$ & 5.687856 & -0.800778 & 1.676875 \\
\hline C & 4.725846 & -1.547788 & -0.720976 \\
\hline C & 4.576259 & -2.950848 & -0.972105 \\
\hline C & 5.619263 & -3.657200 & -1.630368 \\
\hline C & 6.754539 & -3.008674 & -2.057359 \\
\hline C & 6.887794 & -1.616152 & -1.846826 \\
\hline C & 5.902599 & -0.905899 & -1.196510 \\
\hline $\mathrm{H}$ & 5.494167 & -4.723862 & -1.801734 \\
\hline $\mathrm{H}$ & 7.542006 & -3.558225 & -2.565839 \\
\hline $\mathrm{H}$ & 7.773971 & -1.099870 & -2.206146 \\
\hline $\mathrm{H}$ & 6.016262 & 0.162232 & -1.052444 \\
\hline $\mathrm{O}$ & -0.338534 & 0.959171 & 0.712765 \\
\hline 0 & -0.039278 & -0.689195 & -1.303024 \\
\hline $\mathrm{H}$ & -1.205959 & -0.854042 & -1.364943 \\
\hline $\mathrm{H}$ & 0.922872 & -4.624859 & -1.545941 \\
\hline $\mathrm{H}$ & -2.168637 & -5.620940 & 1.274474 \\
\hline $\mathrm{H}$ & 0.918924 & -2.830641 & 2.357318 \\
\hline
\end{tabular}




\begin{tabular}{|c|c|c|c|}
\hline $\mathrm{H}$ & 1.613086 & 4.913035 & 1.331438 \\
\hline $\mathrm{H}$ & -0.637200 & 6.449039 & -1.995040 \\
\hline $\mathrm{H}$ & 1.835007 & 2.966847 & -2.492836 \\
\hline C & -2.772687 & -1.751231 & -0.357665 \\
\hline 0 & -2.409816 & -1.110793 & -1.407966 \\
\hline $\mathrm{H}$ & -2.017414 & -2.282163 & 0.236858 \\
\hline C & -4.087847 & -2.517739 & -0.387711 \\
\hline 0 & -4.514114 & -3.147586 & 0.567329 \\
\hline $\mathrm{O}$ & -4.730111 & -2.393214 & -1.550025 \\
\hline C & -5.995239 & -3.078683 & -1.635492 \\
\hline $\mathrm{H}$ & -6.360819 & -2.881703 & -2.642891 \\
\hline $\mathrm{H}$ & -5.858504 & -4.150826 & -1.475829 \\
\hline C & -4.321661 & 0.152048 & 0.839772 \\
\hline C & -3.144933 & -0.543119 & 1.157664 \\
\hline $\mathrm{H}$ & -5.467538 & -1.396951 & 1.517220 \\
\hline$N$ & -5.511756 & -0.414317 & 1.251790 \\
\hline C & -6.770093 & 0.140429 & 1.516975 \\
\hline $\mathrm{O}$ & -7.738853 & -0.558503 & 1.723619 \\
\hline $\mathrm{O}$ & -6.742007 & 1.477314 & 1.567036 \\
\hline C & -8.011786 & 2.102453 & 1.832249 \\
\hline $\mathrm{H}$ & -7.809151 & 3.172896 & 1.819773 \\
\hline $\mathrm{H}$ & -8.391318 & 1.790304 & 2.807834 \\
\hline $\mathrm{H}$ & -8.737693 & 1.836795 & 1.059937 \\
\hline $\mathrm{H}$ & -2.200423 & -0.010436 & 1.064221 \\
\hline $\mathrm{H}$ & -3.203085 & -1.254563 & 1.977529 \\
\hline C & -4.307014 & 1.286041 & -0.084910 \\
\hline C & -5.345696 & 1.464305 & -1.023699 \\
\hline C & -3.195861 & 2.151687 & -0.121252 \\
\hline C & -5.281133 & 2.489079 & -1.957047 \\
\hline $\mathrm{H}$ & -6.176377 & 0.767074 & -1.050346 \\
\hline C & -3.146348 & 3.187936 & -1.051216 \\
\hline $\mathrm{H}$ & -2.365561 & 2.016092 & 0.562251 \\
\hline C & -4.185998 & 3.360623 & -1.965172 \\
\hline $\mathrm{H}$ & -6.075863 & 2.603651 & -2.688696 \\
\hline $\mathrm{H}$ & -2.283787 & 3.847203 & -1.067286 \\
\hline $\mathrm{H}$ & -4.139395 & 4.163369 & -2.696302 \\
\hline $\mathrm{H}$ & -6.691400 & -2.690989 & -0.886880 \\
\hline
\end{tabular}

Catalyst (R)-1 TS Conformation 290

B3LYP/6-31G(d) Energy $=-2809.684952$

B3LYP-D3(BJ)/def2-TZVPP-IEF-PCM(DCM) Energy = -2810.980261 
B3LYP-D3(BJ)/def2-TZVPP-IEF-PCM(DCM)//B3LYP/6-31G(d) Free Energy (Quasiharmonic) = 2810.337855

Frequencies (Top 3 out of 270)

1. $-550.0823 \mathrm{~cm}-1$

2. $\quad 4.5523 \mathrm{~cm}-1$

3. $\quad 10.5454 \mathrm{~cm}-1$

B3LYP/6-31G(d) Molecular Geometry in Cartesian Coordinates

$\begin{array}{lrrr}\text { C } & 3.500560 & -0.434352 & -0.152888 \\ \text { C } & 2.524073 & -1.408723 & -0.014476 \\ \text { C } & 2.730149 & -2.783387 & -0.340746 \\ \text { C } & 3.977477 & -3.130680 & -0.824778 \\ \text { H } & 4.185330 & -4.173240 & -1.049849 \\ \text { C } & 2.749226 & 3.721549 & 0.688813 \\ \text { C } & 3.203781 & 0.975238 & 0.242251 \\ \text { C } & 2.112772 & 1.632952 & -0.313512 \\ \text { C } & 1.888850 & 3.034787 & -0.146147 \\ \text { H } & 2.596854 & 4.787016 & 0.840687 \\ \text { O } & 1.290956 & -1.026395 & 0.495515 \\ \text { P } & 0.247481 & -0.197755 & -0.473397 \\ \text { O } & 1.254435 & 0.926441 & -1.139526 \\ \text { C } & -0.243573 & -5.875285 & 0.036058 \\ \text { C } & -0.116935 & -4.908962 & 1.035139 \\ \text { C } & 0.829866 & -3.892112 & 0.919842 \\ \text { C } & 1.672317 & -3.820163 & -0.201498 \\ \text { C } & 1.526070 & -4.793829 & -1.205268 \\ \text { C } & 0.581558 & -5.811715 & -1.087871 \\ \text { H } & -0.761715 & -4.935927 & 1.909116 \\ \text { H } & 0.482250 & -6.547193 & -1.882102 \\ \text { C } & -1.125328 & 5.286420 & -2.241749 \\ \text { C } & 0.209370 & 5.693427 & -2.256454 \\ \text { C } & 1.175384 & 4.945680 & -1.583290 \\ \text { C } & 0.827267 & 3.779278 & -0.881480 \\ \text { C } & -0.519098 & 3.380917 & -0.869890 \\ \text { C } & -1.482124 & 4.129642 & -1.545986 \\ \text { H } & 0.502945 & 6.587881 & -2.800099 \\ \text { H } & -2.518224 & 3.798980 & -1.530474 \\ \text { C } & 4.028661 & 1.682964 & 1.182853 \\ \text { C } & 3.793513 & 3.078961 & 1.397415 \\ \text { C } & 4.602912 & 3.789440 & 2.324980 \\ \text { C } & 5.592302 & 3.150786 & 3.035947\end{array}$




\begin{tabular}{|c|c|c|c|}
\hline C & 5.807195 & 1.764718 & 2.849346 \\
\hline C & 5.048960 & 1.051360 & 1.946967 \\
\hline $\mathrm{H}$ & 4.415704 & 4.851174 & 2.468712 \\
\hline $\mathrm{H}$ & 6.201526 & 3.703240 & 3.746230 \\
\hline $\mathrm{H}$ & 6.574992 & 1.256517 & 3.426700 \\
\hline $\mathrm{H}$ & 5.219763 & -0.011787 & 1.821360 \\
\hline C & 4.761416 & -0.800182 & -0.740449 \\
\hline C & 4.998876 & -2.177589 & -1.053241 \\
\hline C & 6.247701 & -2.562649 & -1.612747 \\
\hline C & 7.217504 & -1.628104 & -1.890693 \\
\hline C & 6.969197 & -0.260988 & -1.625343 \\
\hline C & 5.776453 & 0.141742 & -1.065605 \\
\hline $\mathrm{H}$ & 6.414217 & -3.614915 & -1.831395 \\
\hline $\mathrm{H}$ & 8.165353 & -1.933144 & -2.325794 \\
\hline $\mathrm{H}$ & 7.724562 & 0.480826 & -1.870646 \\
\hline $\mathrm{H}$ & 5.600642 & 1.194577 & -0.880150 \\
\hline $\mathrm{O}$ & -0.801146 & 0.400631 & 0.411819 \\
\hline $\mathrm{O}$ & -0.165433 & -1.069368 & -1.656438 \\
\hline $\mathrm{H}$ & -1.387202 & -1.310801 & -1.896717 \\
\hline $\mathrm{H}$ & 2.141531 & -4.732810 & -2.098189 \\
\hline $\mathrm{H}$ & -0.985047 & -6.664996 & 0.127128 \\
\hline $\mathrm{H}$ & 0.906354 & -3.146757 & 1.701307 \\
\hline $\mathrm{H}$ & -0.809470 & 2.491263 & -0.321714 \\
\hline $\mathrm{H}$ & -1.878938 & 5.863786 & -2.771541 \\
\hline $\mathrm{H}$ & 2.216928 & 5.254143 & -1.617158 \\
\hline C & -3.206459 & -0.638311 & -1.415883 \\
\hline 0 & -2.503896 & -1.425161 & -2.154659 \\
\hline $\mathrm{H}$ & -2.684130 & 0.110638 & -0.815582 \\
\hline C & -4.538185 & -0.212681 & -2.015869 \\
\hline 0 & -5.316300 & -0.931302 & -2.597340 \\
\hline O & -4.711764 & 1.108872 & -1.815039 \\
\hline C & -5.919097 & 1.660201 & -2.376809 \\
\hline $\mathrm{H}$ & -5.943065 & 1.492989 & -3.456165 \\
\hline $\mathrm{H}$ & -5.884446 & 2.725921 & -2.151903 \\
\hline C & -4.299459 & -0.899960 & 1.102513 \\
\hline C & -3.903561 & -1.795911 & 0.105548 \\
\hline $\mathrm{H}$ & -3.769663 & 0.314451 & 2.655278 \\
\hline $\mathrm{N}$ & -3.459839 & -0.455986 & 2.076457 \\
\hline C & -2.191035 & -0.966977 & 2.438203 \\
\hline 0 & -1.730113 & -2.017184 & 2.064655 \\
\hline $\mathrm{O}$ & -1.664038 & -0.120287 & 3.326021 \\
\hline C & -0.302322 & -0.408210 & 3.711492 \\
\hline $\mathrm{H}$ & -0.035252 & 0.379635 & 4.415233 \\
\hline $\mathrm{H}$ & 0.334841 & -0.378401 & 2.826641 \\
\hline
\end{tabular}




$\begin{array}{llll}\mathrm{H} & -0.245845 & -1.389027 & 4.190035 \\ \mathrm{H} & -4.680054 & -2.270998 & -0.482553 \\ \mathrm{H} & -2.997879 & -2.365756 & 0.264845 \\ \mathrm{C} & -5.638695 & -0.262872 & 1.092571 \\ \mathrm{C} & -6.770672 & -1.020398 & 0.746592 \\ \mathrm{C} & -5.808059 & 1.091623 & 1.436631 \\ \mathrm{C} & -8.039131 & -0.443759 & 0.763944 \\ \mathrm{H} & -6.660001 & -2.068968 & 0.492255 \\ \mathrm{C} & -7.076401 & 1.666215 & 1.444205 \\ \mathrm{H} & -4.944425 & 1.717044 & 1.647506 \\ \mathrm{C} & -8.196255 & 0.898622 & 1.114381 \\ \mathrm{H} & -8.905182 & -1.046834 & 0.508069 \\ \mathrm{H} & -7.189045 & 2.715793 & 1.699728 \\ \mathrm{H} & -9.185958 & 1.346219 & 1.127388 \\ \mathrm{H} & -6.795286 & 1.195376 & -1.918594\end{array}$

Catalyst (R)-1 TS Conformation 291

B3LYP/6-31G(d) Energy $=-2809.681668$

B3LYP-D3(BJ)/def2-TZVPP-IEF-PCM(DCM) Energy $=-2810.980701$

B3LYP-D3(BJ)/def2-TZVPP-IEF-PCM(DCM)//B3LYP/6-31G(d) Free Energy (Quasiharmonic) = 2810.337775

Frequencies (Top 3 out of 270)

1. $-325.6954 \mathrm{~cm}-1$

2. $\quad 6.1853 \mathrm{~cm}-1$

3. $\quad 10.0662 \mathrm{~cm}-1$

B3LYP/6-31G(d) Molecular Geometry in Cartesian Coordinates

$\begin{array}{llll}\mathrm{C} & 3.437145 & -0.650893 & -0.324594 \\ \mathrm{C} & 2.309517 & -1.463730 & -0.331087 \\ \mathrm{C} & 2.369575 & -2.853436 & -0.658071 \\ \mathrm{C} & 3.585915 & -3.373330 & -1.052402 \\ \mathrm{H} & 3.651785 & -4.427834 & -1.308112 \\ \mathrm{C} & 3.209871 & 3.446103 & 1.005443 \\ \mathrm{C} & 3.356437 & 0.745937 & 0.196793 \\ \mathrm{C} & 2.422205 & 1.621364 & -0.334558 \\ \mathrm{C} & 2.339142 & 2.998462 & 0.031101 \\ \mathrm{H} & 3.195653 & 4.495632 & 1.287631 \\ \mathrm{O} & 1.097920 & -0.962754 & 0.103807 \\ \mathrm{P} & 0.280398 & 0.224523 & -0.716010\end{array}$




\begin{tabular}{|c|c|c|c|}
\hline $\mathrm{O}$ & 1.535433 & 1.135124 & -1.280736 \\
\hline C & -0.951523 & -5.580744 & -0.381085 \\
\hline C & -1.058990 & -4.429103 & -1.165944 \\
\hline C & -0.002318 & -3.520104 & -1.244060 \\
\hline C & 1.190722 & -3.758393 & -0.541543 \\
\hline C & 1.289429 & -4.920254 & 0.241047 \\
\hline C & 0.227570 & -5.822575 & 0.324301 \\
\hline $\mathrm{H}$ & -1.967297 & -4.242565 & -1.734376 \\
\hline $\mathrm{H}$ & 0.324263 & -6.713609 & 0.939544 \\
\hline C & -0.383505 & 5.810678 & -1.757817 \\
\hline C & 0.301781 & 4.896360 & -2.560524 \\
\hline C & 1.168342 & 3.966069 & -1.989182 \\
\hline C & 1.370532 & 3.934304 & -0.598902 \\
\hline C & 0.670306 & 4.855396 & 0.197279 \\
\hline C & -0.197030 & 5.784944 & -0.375107 \\
\hline $\mathrm{H}$ & 0.163456 & 4.906988 & -3.638537 \\
\hline $\mathrm{H}$ & -0.733087 & 6.484077 & 0.261955 \\
\hline C & 4.199259 & 1.207479 & 1.267112 \\
\hline C & 4.124015 & 2.583577 & 1.658922 \\
\hline C & 4.959358 & 3.058338 & 2.706370 \\
\hline C & 5.814117 & 2.210318 & 3.371406 \\
\hline C & 5.861162 & 0.842235 & 3.014927 \\
\hline C & 5.078050 & 0.355144 & 1.991185 \\
\hline $\mathrm{H}$ & 4.898662 & 4.109134 & 2.980450 \\
\hline $\mathrm{H}$ & 6.443133 & 2.583921 & 4.174937 \\
\hline $\mathrm{H}$ & 6.519116 & 0.167180 & 3.555869 \\
\hline $\mathrm{H}$ & 5.120997 & -0.697409 & 1.736963 \\
\hline C & 4.670952 & -1.180124 & -0.841705 \\
\hline C & 4.740945 & -2.566434 & -1.192740 \\
\hline C & 5.957887 & -3.102698 & -1.693751 \\
\hline C & 7.063394 & -2.303827 & -1.870721 \\
\hline C & 6.988722 & -0.925978 & -1.558633 \\
\hline C & 5.827586 & -0.379967 & -1.057143 \\
\hline $\mathrm{H}$ & 5.992189 & -4.159659 & -1.947860 \\
\hline $\mathrm{H}$ & 7.986910 & -2.722671 & -2.261152 \\
\hline $\mathrm{H}$ & 7.854070 & -0.289359 & -1.722803 \\
\hline $\mathrm{H}$ & 5.785005 & 0.679965 & -0.835266 \\
\hline $\mathrm{O}$ & -0.600555 & 0.930486 & 0.255323 \\
\hline $\mathrm{O}$ & -0.336890 & -0.383607 & -1.978765 \\
\hline $\mathrm{H}$ & -1.569639 & 0.040025 & -2.316976 \\
\hline $\mathrm{H}$ & 2.205346 & -5.109504 & 0.794873 \\
\hline $\mathrm{H}$ & -1.777435 & -6.285337 & -0.325309 \\
\hline $\mathrm{H}$ & -0.093108 & -2.629194 & -1.856965 \\
\hline $\mathrm{H}$ & 0.791922 & 4.823519 & 1.276338 \\
\hline
\end{tabular}




\begin{tabular}{llll}
$\mathrm{H}$ & -1.060292 & 6.533320 & -2.206477 \\
$\mathrm{H}$ & 1.695587 & 3.261908 & -2.623068 \\
$\mathrm{C}$ & -3.204790 & 0.644689 & -1.413818 \\
$\mathrm{O}$ & -2.617868 & 0.324304 & -2.514328 \\
$\mathrm{H}$ & -2.590191 & 0.945451 & -0.560499 \\
$\mathrm{C}$ & -4.550931 & 1.319299 & -1.594789 \\
$\mathrm{O}$ & -5.121014 & 1.449208 & -2.648748 \\
$\mathrm{O}$ & -4.989969 & 1.809746 & -0.412797 \\
$\mathrm{C}$ & -6.216591 & 2.556692 & -0.496935 \\
$\mathrm{H}$ & -6.084210 & 3.431041 & -1.139275 \\
$\mathrm{H}$ & -7.012962 & 1.930850 & -0.907922 \\
$\mathrm{C}$ & -4.098975 & -1.012749 & 0.751517 \\
$\mathrm{C}$ & -3.756963 & -1.183821 & -0.588320 \\
$\mathrm{H}$ & -5.518702 & -0.762214 & 2.194325 \\
$\mathrm{~N}$ & -5.389018 & -0.846420 & 1.193803 \\
$\mathrm{C}$ & -6.572358 & -0.880552 & 0.456593 \\
$\mathrm{O}$ & -6.670438 & -1.006225 & -0.742437 \\
$\mathrm{O}$ & -7.600112 & -0.752008 & 1.320132 \\
$\mathrm{C}$ & -8.908985 & -0.802661 & 0.720552 \\
$\mathrm{H}$ & -9.055689 & -1.756513 & 0.208677 \\
$\mathrm{H}$ & -9.032976 & 0.013836 & 0.005259 \\
$\mathrm{H}$ & -9.607600 & -0.697943 & 1.550096 \\
$\mathrm{H}$ & -2.750854 & -1.540774 & -0.770526 \\
$\mathrm{H}$ & -4.519586 & -1.460420 & -1.304564 \\
$\mathrm{C}$ & -3.081686 & -0.925842 & 1.815926 \\
$\mathrm{C}$ & -1.935941 & -1.737908 & 1.768948 \\
$\mathrm{C}$ & -3.238520 & -0.024588 & 2.887788 \\
$\mathrm{C}$ & -0.978199 & -1.658988 & 2.774909 \\
$\mathrm{H}$ & -1.799361 & -2.447884 & 0.960374 \\
$\mathrm{H}$ & -2.272199 & 0.056437 & 3.884519 \\
$\mathrm{H}$ & -4.080469 & 0.662934 & 2.906885 \\
& -1.143204 & -0.764820 & 3.832901 \\
\hline & -0.096081 & -2.287560 & 2.716050 \\
$\mathrm{H}$ & -0.3865841 & 0.774008 & 4.691246 \\
$\mathrm{H}$ & -0.695738 & 4.609200 \\
$\mathrm{H}$ & -2.863462 & 0.524276
\end{tabular}

Catalyst (R)-1 TS Conformation 292

B3LYP/6-31G(d) Energy $=-2809.686788$ B3LYP-D3(BJ)/def2-TZVPP-IEF-PCM(DCM) Energy $=-2810.979447$ B3LYP-D3(BJ)/def2-TZVPP-IEF-PCM(DCM)//B3LYP/6-31G(d) Free Energy (Quasiharmonic) = 2810.337731 
Frequencies (Top 3 out of 270)

1. $-787.3102 \mathrm{~cm}-1$

2. $\quad 8.1132 \mathrm{~cm}-1$

3. $\quad 17.5029 \mathrm{~cm}-1$

B3LYP/6-31G(d) Molecular Geometry in Cartesian Coordinates

$\begin{array}{llll}\text { C } & 3.265326 & -0.222333 & 0.332411 \\ \text { C } & 2.722376 & 1.005894 & -0.012190 \\ \text { C } & 3.327284 & 2.243434 & 0.360433 \\ \text { C } & 4.407625 & 2.199047 & 1.218508 \\ \text { H } & 4.895613 & 3.128309 & 1.500955 \\ \text { C } & 1.635177 & -4.013320 & -0.848078 \\ \text { C } & 2.697236 & -1.493224 & -0.207085 \\ \text { C } & 1.373311 & -1.809423 & 0.049213 \\ \text { C } & 0.830332 & -3.114535 & -0.170063 \\ \text { H } & 1.248257 & -5.005067 & -1.065517 \\ \text { O } & 1.586278 & 1.056840 & -0.808488 \\ \text { P } & 0.142845 & 0.456620 & -0.303799 \\ \text { O } & 0.580368 & -0.828924 & 0.628753 \\ \text { C } & 2.486833 & 6.117865 & -1.298577 \\ \text { C } & 2.705770 & 5.023475 & -2.140155 \\ \text { C } & 2.907206 & 3.752093 & -1.604207 \\ \text { C } & 2.919709 & 3.555351 & -0.213091 \\ \text { C } & 2.686727 & 4.658987 & 0.621862 \\ \text { C } & 2.466216 & 5.928601 & 0.084324 \\ \text { H } & 2.728016 & 5.161186 & -3.218458 \\ \text { H } & 2.287845 & 6.770585 & 0.748197 \\ \text { C } & -2.856156 & -4.509561 & 1.572588 \\ \text { C } & -1.719375 & -5.319570 & 1.548276 \\ \text { C } & -0.537963 & -4.848883 & 0.979088 \\ \text { C } & -0.468297 & -3.565801 & 0.402869 \\ \text { C } & -1.624394 & -2.770084 & 0.426350 \\ \text { C } & -2.802403 & -3.232570 & 1.012720 \\ \text { H } & -1.743115 & -6.311575 & 1.992761 \\ \text { H } & -3.666273 & -2.576475 & 1.052374 \\ \text { C } & 3.500346 & -2.417855 & -0.956031 \\ \text { C } & 2.939412 & -3.690382 & -1.295104 \\ \text { C } & 3.710330 & -4.609775 & -2.056926 \\ \text { C } & 4.978891 & -4.288361 & -2.481419 \\ \text { C } & 5.528718 & -3.024483 & -2.161396 \\ \text { C } & 4.810547 & -2.114599 & -1.416461\end{array}$




\begin{tabular}{|c|c|c|c|}
\hline $\mathrm{H}$ & 3.272564 & -5.574461 & -2.303150 \\
\hline $\mathrm{H}$ & 5.557113 & -4.997901 & -3.067090 \\
\hline $\mathrm{H}$ & 6.524786 & -2.766776 & -2.511328 \\
\hline $\mathrm{H}$ & 5.239372 & -1.145314 & -1.187531 \\
\hline & 4.357733 & -0.254774 & 1.269561 \\
\hline C & 4.923818 & 0.980362 & 1.720532 \\
\hline C & 6.000351 & 0.962927 & 2.647641 \\
\hline C & 6.490703 & -0.224374 & 3.138897 \\
\hline C & 5.913883 & -1.446342 & 2.720946 \\
\hline C & 4.879312 & -1.462489 & 1.811270 \\
\hline $\mathrm{H}$ & 6.423328 & 1.912100 & 2.968436 \\
\hline $\mathrm{H}$ & 7.310048 & -0.226895 & 3.852554 \\
\hline $\mathrm{H}$ & 6.286615 & -2.383417 & 3.125738 \\
\hline $\mathrm{H}$ & 4.442904 & -2.408234 & 1.513449 \\
\hline 0 & -0.646658 & 0.069452 & -1.513489 \\
\hline 0 & -0.496422 & 1.429750 & 0.704773 \\
\hline $\mathrm{H}$ & -1.621042 & 1.047906 & 1.090360 \\
\hline $\mathrm{H}$ & 2.679279 & 4.516022 & 1.698913 \\
\hline $\mathrm{H}$ & 2.334502 & 7.109069 & -1.717753 \\
\hline $\mathrm{H}$ & 3.084573 & 2.907738 & -2.263126 \\
\hline $\mathrm{H}$ & -1.606738 & -1.786815 & -0.019173 \\
\hline $\mathrm{H}$ & -3.772811 & -4.865594 & 2.035946 \\
\hline $\mathrm{H}$ & 0.353798 & -5.468503 & 1.010268 \\
\hline C & -3.671116 & 1.220947 & 1.693791 \\
\hline $\mathrm{O}$ & -2.641780 & 0.526898 & 1.366788 \\
\hline $\mathrm{H}$ & -3.536883 & 2.258247 & 2.006349 \\
\hline C & -4.775417 & 0.464881 & 2.406719 \\
\hline $\mathrm{O}$ & -4.976729 & -0.724864 & 2.334887 \\
\hline 0 & -5.514299 & 1.326058 & 3.138395 \\
\hline C & -6.603558 & 0.734820 & 3.868362 \\
\hline $\mathrm{H}$ & -7.083096 & 1.559102 & 4.396225 \\
\hline $\mathrm{H}$ & -7.306929 & 0.252840 & 3.183699 \\
\hline C & -4.178086 & 1.214144 & -0.948019 \\
\hline C & -4.911389 & 1.771362 & 0.112526 \\
\hline $\mathrm{H}$ & -2.357720 & 1.202553 & -1.922352 \\
\hline$N$ & -3.013086 & 1.762629 & -1.370247 \\
\hline C & -2.496707 & 3.020935 & -0.998474 \\
\hline $\mathrm{O}$ & -2.949088 & 3.749207 & -0.140680 \\
\hline $\mathrm{O}$ & -1.454877 & 3.289140 & -1.781364 \\
\hline C & -0.740144 & 4.498487 & -1.450913 \\
\hline $\mathrm{H}$ & -0.265101 & 4.386238 & -0.475070 \\
\hline $\mathrm{H}$ & -1.424849 & 5.349300 & -1.443468 \\
\hline $\mathrm{H}$ & 0.012762 & 4.603677 & -2.226921 \\
\hline $\mathrm{H}$ & -5.873961 & 1.318059 & 0.314369 \\
\hline
\end{tabular}




$\begin{array}{llll}\text { H } & -4.835940 & 2.833128 & 0.297174 \\ \mathrm{C} & -4.567517 & -0.072305 & -1.560084 \\ \mathrm{C} & -3.613446 & -0.976365 & -2.067178 \\ \mathrm{C} & -5.935040 & -0.394315 & -1.670350 \\ \mathrm{C} & -4.025961 & -2.173336 & -2.648003 \\ \mathrm{H} & -2.549444 & -0.778282 & -1.972568 \\ \mathrm{C} & -6.337729 & -1.583855 & -2.267469 \\ \mathrm{H} & -6.687194 & 0.305226 & -1.321590 \\ \mathrm{C} & -5.383191 & -2.480253 & -2.753774 \\ \mathrm{H} & -3.277375 & -2.871640 & -3.009443 \\ \mathrm{H} & -7.396478 & -1.809456 & -2.356332 \\ \mathrm{H} & -5.697093 & -3.413747 & -3.212606 \\ \mathrm{H} & -6.228425 & -0.009971 & 4.574761\end{array}$

Catalyst (R)-1 TS Conformation 293

B3LYP/6-31G(d) Energy = -2809.687381

B3LYP-D3(BJ)/def2-TZVPP-IEF-PCM(DCM) Energy $=-2810.979724$

B3LYP-D3(BJ)/def2-TZVPP-IEF-PCM(DCM)//B3LYP/6-31G(d) Free Energy (Quasiharmonic) = 2810.337677

Frequencies (Top 3 out of 270)

1. $-560.7219 \mathrm{~cm}-1$

2. $\quad 8.4540 \mathrm{~cm}-1$

3. $10.2862 \mathrm{~cm}-1$

B3LYP/6-31G(d) Molecular Geometry in Cartesian Coordinates

$\begin{array}{llll}\text { C } & 3.534345 & -1.050430 & -0.090999 \\ \mathrm{C} & 2.343901 & -1.689532 & 0.216586 \\ \mathrm{C} & 2.118683 & -3.079647 & -0.007854 \\ \mathrm{C} & 3.132261 & -3.793799 & -0.616329 \\ \mathrm{H} & 3.004078 & -4.860633 & -0.779997 \\ \mathrm{C} & 4.035398 & 3.141607 & 0.782877 \\ \mathrm{C} & 3.709410 & 0.388210 & 0.268942 \\ \mathrm{C} & 2.794581 & 1.329125 & -0.182802 \\ \mathrm{C} & 2.949465 & 2.732494 & 0.032004 \\ \mathrm{H} & 4.202605 & 4.204241 & 0.936803 \\ \mathrm{O} & 1.322808 & -0.945331 & 0.790658 \\ \mathrm{P} & 0.483336 & 0.090443 & -0.172397 \\ \mathrm{O} & 1.701476 & 0.899587 & -0.920565 \\ \mathrm{C} & -1.458824 & -5.159654 & 1.166973\end{array}$




\begin{tabular}{|c|c|c|c|}
\hline$C$ & -0.847801 & -4.268410 & 2.051461 \\
\hline C & 0.296268 & -3.569713 & 1.670136 \\
\hline C & 0.857150 & -3.755996 & 0.395297 \\
\hline C & 0.228963 & -4.649945 & -0.486622 \\
\hline C & -0.918195 & -5.344770 & -0.105693 \\
\hline $\mathrm{H}$ & -1.259353 & -4.118517 & 3.046526 \\
\hline $\mathrm{H}$ & -1.393511 & -6.024045 & -0.808453 \\
\hline C & 0.408513 & 5.792079 & -1.618363 \\
\hline C & 0.847634 & 5.870571 & -0.295166 \\
\hline C & 1.640333 & 4.855331 & 0.240701 \\
\hline C & 2.019194 & 3.745926 & -0.534471 \\
\hline C & 1.559850 & 3.674511 & -1.861058 \\
\hline C & 0.764607 & 4.687350 & -2.394745 \\
\hline $\mathrm{H}$ & 0.574994 & 6.722682 & 0.322868 \\
\hline $\mathrm{H}$ & 0.428094 & 4.615257 & -3.425661 \\
\hline C & 4.786339 & 0.824881 & 1.114931 \\
\hline C & 4.948497 & 2.226483 & 1.359179 \\
\hline C & 6.017611 & 2.674077 & 2.182101 \\
\hline C & 6.878694 & 1.778853 & 2.772410 \\
\hline C & 6.698063 & 0.391029 & 2.564922 \\
\hline C & 5.682640 & -0.073209 & 1.757940 \\
\hline $\mathrm{H}$ & 6.132840 & 3.743057 & 2.345817 \\
\hline $\mathrm{H}$ & 7.688103 & 2.131787 & 3.405629 \\
\hline $\mathrm{H}$ & 7.364223 & -0.316884 & 3.050742 \\
\hline $\mathrm{H}$ & 5.552939 & -1.139897 & 1.617468 \\
\hline C & 4.551083 & -1.789876 & -0.787970 \\
\hline C & 4.339122 & -3.184424 & -1.039297 \\
\hline C & 5.339572 & -3.930894 & -1.719010 \\
\hline C & 6.492497 & -3.328176 & -2.165453 \\
\hline C & 6.687601 & -1.943277 & -1.952879 \\
\hline C & 5.744909 & -1.195396 & -1.282001 \\
\hline $\mathrm{H}$ & 5.167419 & -4.990925 & -1.890646 \\
\hline $\mathrm{H}$ & 7.246868 & -3.907909 & -2.690372 \\
\hline $\mathrm{H}$ & 7.587773 & -1.462835 & -2.326836 \\
\hline $\mathrm{H}$ & 5.905576 & -0.133447 & -1.136784 \\
\hline 0 & -0.394335 & 0.918380 & 0.697306 \\
\hline 0 & -0.129584 & -0.683138 & -1.358952 \\
\hline $\mathrm{H}$ & -1.197363 & -1.091959 & -1.263949 \\
\hline $\mathrm{H}$ & 0.633259 & -4.781030 & -1.486337 \\
\hline $\mathrm{H}$ & -2.351566 & -5.703146 & 1.466305 \\
\hline $\mathrm{H}$ & 0.764457 & -2.881347 & 2.365305 \\
\hline $\mathrm{H}$ & 1.835537 & 2.826806 & -2.477800 \\
\hline $\mathrm{H}$ & -0.204898 & 6.583812 & -2.040925 \\
\hline $\mathrm{H}$ & 1.962255 & 4.914170 & 1.276576 \\
\hline
\end{tabular}




$\begin{array}{lrrr}\mathrm{C} & -3.279476 & -0.621395 & -1.155245 \\ \mathrm{O} & -2.387956 & -1.542133 & -1.205291 \\ \mathrm{H} & -3.041070 & 0.381711 & -1.537224 \\ \mathrm{C} & -4.714084 & -0.995944 & -1.518147 \\ \mathrm{O} & -5.595316 & -0.168751 & -1.664734 \\ \mathrm{O} & -4.880432 & -2.312817 & -1.681319 \\ \mathrm{C} & -6.195609 & -2.717134 & -2.094102 \\ \mathrm{H} & -6.452565 & -2.261048 & -3.053737 \\ \mathrm{H} & -6.151099 & -3.802480 & -2.185177 \\ \mathrm{C} & -4.455859 & 0.896363 & 0.810007 \\ \mathrm{C} & -3.458792 & -0.086314 & 0.702499 \\ \mathrm{H} & -6.360209 & 1.456135 & 1.242576 \\ \mathrm{~N} & -5.745490 & 0.652558 & 1.199000 \\ \mathrm{C} & -6.454728 & -0.503764 & 1.556081 \\ \mathrm{O} & -7.614069 & -0.435049 & 1.900201 \\ \mathrm{O} & -5.726854 & -1.621690 & 1.474042 \\ \mathrm{C} & -6.411733 & -2.828181 & 1.869310 \\ \mathrm{H} & -7.307909 & -2.971272 & 1.262218 \\ \mathrm{H} & -6.692091 & -2.772867 & 2.923588 \\ \mathrm{H} & -5.692600 & -3.628183 & 1.698686 \\ \mathrm{H} & -2.434551 & 0.277191 & 0.752733 \\ \mathrm{H} & -3.628813 & -1.043114 & 1.176550 \\ \mathrm{C} & -4.199661 & 2.294614 & 0.406508 \\ \mathrm{C} & -2.929064 & 2.868998 & 0.601313 \\ \mathrm{C} & -5.214093 & 3.064862 & -0.200289 \\ \mathrm{C} & -2.695991 & 4.190216 & 0.224754 \\ \mathrm{H} & -2.117737 & 2.292540 & 1.031986 \\ \mathrm{C} & -4.970670 & 4.381848 & -0.574607 \\ \mathrm{H} & -6.170243 & 2.613094 & -0.449053 \\ \mathrm{C} & -3.713170 & 4.950456 & -0.354003 \\ \mathrm{H} & -1.709061 & 4.616835 & 0.373007 \\ \mathrm{H} & -5.755503 & 4.957294 & -1.057074 \\ \mathrm{H} & -3.522731 & 5.978477 & -0.650043 \\ \mathrm{H} & -6.942290 & -2.420600 & -1.352077\end{array}$

Catalyst (R)-1 TS Conformation 294

B3LYP/6-31G(d) Energy $=-2809.686637$

B3LYP-D3(BJ)/def2-TZVPP-IEF-PCM(DCM) Energy = -2810.9798

B3LYP-D3(BJ)/def2-TZVPP-IEF-PCM(DCM)//B3LYP/6-31G(d) Free Energy (Quasiharmonic) = 2810.337651

Frequencies (Top 3 out of 270) 
1. $-624.9753 \mathrm{~cm}-1$

2. $\quad 7.5928 \mathrm{~cm}-1$

3. $\quad 11.6822 \mathrm{~cm}-1$

B3LYP/6-31G(d) Molecular Geometry in Cartesian Coordinates

\begin{tabular}{|c|c|c|c|}
\hline C & 3.081793 & -1.013638 & -0.425069 \\
\hline C & 1.878060 & -1.659751 & -0.171973 \\
\hline C & 1.691047 & -3.056006 & -0.404275 \\
\hline C & 2.733744 & -3.760784 & -0.970581 \\
\hline $\mathrm{H}$ & 2.611982 & -4.824715 & -1.157172 \\
\hline C & 3.664281 & 3.131231 & 0.620746 \\
\hline C & 3.286333 & 0.402574 & 0.001913 \\
\hline C & 2.393510 & 1.379800 & -0.408102 \\
\hline C & 2.567844 & 2.769755 & -0.137787 \\
\hline $\mathrm{H}$ & 3.847458 & 4.183784 & 0.820390 \\
\hline 0 & 0.842319 & -0.975503 & 0.437528 \\
\hline$P$ & 0.062602 & 0.283182 & -0.272242 \\
\hline $\mathrm{O}$ & 1.276796 & 0.985144 & -1.132373 \\
\hline C & -1.858915 & -5.263595 & 0.619480 \\
\hline C & -0.618897 & -5.632659 & 1.140405 \\
\hline C & 0.521523 & -4.896516 & 0.816244 \\
\hline C & 0.442334 & -3.774371 & -0.022876 \\
\hline C & -0.811134 & -3.403951 & -0.535303 \\
\hline C & -1.948649 & -4.150303 & -0.221952 \\
\hline $\mathrm{H}$ & -0.535554 & -6.493525 & 1.798764 \\
\hline $\mathrm{H}$ & -2.905149 & -3.875165 & -0.658445 \\
\hline C & -0.047335 & 5.862140 & -1.595497 \\
\hline C & 0.336508 & 4.818119 & -2.439773 \\
\hline C & 1.164311 & 3.799187 & -1.971202 \\
\hline C & 1.629655 & 3.806015 & -0.645058 \\
\hline C & 1.230700 & 4.858846 & 0.194849 \\
\hline C & 0.402003 & 5.877229 & -0.274446 \\
\hline $\mathrm{H}$ & -0.006101 & 4.797094 & -3.471101 \\
\hline $\mathrm{H}$ & 0.102903 & 6.679204 & 0.395829 \\
\hline C & 4.373977 & 0.786592 & 0.861898 \\
\hline C & 4.562816 & 2.175987 & 1.156081 \\
\hline C & 5.641552 & 2.572807 & 1.992338 \\
\hline C & 6.484929 & 1.640786 & 2.550616 \\
\hline C & 6.275308 & 0.265052 & 2.296990 \\
\hline C & 5.250993 & -0.150389 & 1.474567 \\
\hline $\mathrm{H}$ & 5.778056 & 3.632971 & 2.193035 \\
\hline $\mathrm{H}$ & 7.301690 & 1.955579 & 3.194481 \\
\hline
\end{tabular}




\begin{tabular}{|c|c|c|c|}
\hline $\mathrm{H}$ & 6.925690 & -0.472751 & 2.759154 \\
\hline $\mathrm{H}$ & 5.098888 & -1.208822 & 1.299580 \\
\hline C & 4.116608 & -1.735865 & -1.116792 \\
\hline C & 3.937790 & -3.133185 & -1.372504 \\
\hline C & 4.958367 & -3.859620 & -2.043469 \\
\hline C & 6.105121 & -3.234635 & -2.474719 \\
\hline C & 6.270353 & -1.846718 & -2.256674 \\
\hline C & 5.305712 & -1.118543 & -1.595476 \\
\hline $\mathrm{H}$ & 4.806458 & -4.921795 & -2.221013 \\
\hline $\mathrm{H}$ & 6.876220 & -3.798278 & -2.992793 \\
\hline $\mathrm{H}$ & 7.164523 & -1.347483 & -2.620318 \\
\hline $\mathrm{H}$ & 5.444491 & -0.053878 & -1.448163 \\
\hline 0 & -0.506895 & 1.147483 & 0.802273 \\
\hline $\mathrm{O}$ & -0.886285 & -0.257752 & -1.353419 \\
\hline $\mathrm{H}$ & -2.004860 & 0.296177 & -1.472909 \\
\hline $\mathrm{H}$ & -0.890435 & -2.542554 & -1.190018 \\
\hline $\mathrm{H}$ & -2.747365 & -5.843089 & 0.858419 \\
\hline $\mathrm{H}$ & 1.485487 & -5.182945 & 1.228092 \\
\hline $\mathrm{H}$ & 1.558673 & 4.864348 & 1.230550 \\
\hline $\mathrm{H}$ & -0.692659 & 6.655384 & -1.964187 \\
\hline $\mathrm{H}$ & 1.457998 & 2.995819 & -2.637538 \\
\hline C & -3.255243 & 1.664683 & -0.640250 \\
\hline 0 & -3.030553 & 0.836675 & -1.597522 \\
\hline $\mathrm{H}$ & -2.433129 & 1.928552 & 0.029122 \\
\hline C & -4.279229 & 2.740104 & -0.952537 \\
\hline 0 & -5.126840 & 2.660126 & -1.812687 \\
\hline 0 & -4.111890 & 3.792448 & -0.130455 \\
\hline C & -5.023783 & 4.886367 & -0.335484 \\
\hline $\mathrm{H}$ & -6.055352 & 4.557379 & -0.183228 \\
\hline $\mathrm{H}$ & -4.745598 & 5.639658 & 0.401278 \\
\hline C & -4.114665 & -0.442583 & 0.999142 \\
\hline C & -4.408035 & 0.925188 & 0.942876 \\
\hline $\mathrm{H}$ & -2.812362 & -1.943282 & 1.441139 \\
\hline$N$ & -3.079159 & -0.993526 & 1.688631 \\
\hline C & -2.176890 & -0.478938 & 2.657163 \\
\hline 0 & -1.301264 & -1.185926 & 3.091428 \\
\hline 0 & -2.462287 & 0.767100 & 3.026595 \\
\hline C & -1.441637 & 1.400548 & 3.834250 \\
\hline $\mathrm{H}$ & -1.230445 & 0.794729 & 4.717250 \\
\hline $\mathrm{H}$ & -1.863509 & 2.365436 & 4.115037 \\
\hline $\mathrm{H}$ & -0.548223 & 1.523211 & 3.220669 \\
\hline $\mathrm{H}$ & -5.415223 & 1.156302 & 0.615445 \\
\hline $\mathrm{H}$ & -3.989437 & 1.578588 & 1.693835 \\
\hline C & -4.921380 & -1.405480 & 0.220192 \\
\hline
\end{tabular}




$\begin{array}{llll}\text { C } & -5.174076 & -2.694586 & 0.730064 \\ \text { C } & -5.472414 & -1.040173 & -1.022915 \\ \text { C } & -5.961116 & -3.593840 & 0.016483 \\ \text { H } & -4.789681 & -2.978599 & 1.705424 \\ \text { C } & -6.240749 & -1.955762 & -1.739437 \\ \text { H } & -5.274648 & -0.062486 & -1.446261 \\ \text { C } & -6.489809 & -3.229040 & -1.224443 \\ \text { H } & -6.166347 & -4.576465 & 0.431382 \\ \text { H } & -6.644174 & -1.669533 & -2.706162 \\ \text { H } & -7.098108 & -3.933965 & -1.784258 \\ \text { H } & -4.921157 & 5.281254 & -1.349267\end{array}$

Catalyst (R)-1 TS Conformation 295

B3LYP/6-31G(d) Energy $=-2809.682697$

B3LYP-D3(BJ)/def2-TZVPP-IEF-PCM(DCM) Energy = -2810.978635

B3LYP-D3(BJ)/def2-TZVPP-IEF-PCM(DCM)//B3LYP/6-31G(d) Free Energy (Quasiharmonic) = 2810.337582

Frequencies (Top 3 out of 270)

1. $-666.9917 \mathrm{~cm}-1$

2. $\quad 8.6368 \mathrm{~cm}-1$

3. $\quad 12.8258 \mathrm{~cm}-1$

B3LYP/6-31G(d) Molecular Geometry in Cartesian Coordinates

$\begin{array}{llll}\text { C } & -3.563672 & -0.954956 & 0.115874 \\ \text { C } & -2.383746 & -1.595938 & -0.223145 \\ \text { C } & -2.107602 & -2.957309 & 0.098033 \\ \text { C } & -3.063188 & -3.644110 & 0.820223 \\ \text { H } & -2.897874 & -4.691449 & 1.059495 \\ \text { C } & -4.283034 & 3.152174 & -0.970669 \\ \text { C } & -3.794642 & 0.447560 & -0.340330 \\ \text { C } & -2.870288 & 1.442343 & -0.044151 \\ \text { C } & -3.109038 & 2.822475 & -0.322512 \\ \text { H } & -4.484026 & 4.196207 & -1.196385 \\ \text { O } & -1.417179 & -0.875447 & -0.911780 \\ \text { P } & -0.533345 & 0.198750 & -0.029771 \\ \text { O } & -1.713688 & 1.117875 & 0.647232 \\ \text { C } & 1.494808 & -5.005063 & -1.072761 \\ \text { C } & 0.809721 & -4.212777 & -1.998129 \\ \text { C } & -0.346599 & -3.528834 & -1.623182\end{array}$




\begin{tabular}{|c|c|c|c|}
\hline$C$ & -0.845800 & -3.628325 & -0.312712 \\
\hline C & -0.144375 & -4.423376 & 0.608668 \\
\hline C & 1.013261 & -5.105888 & 0.233640 \\
\hline $\mathrm{H}$ & 1.171960 & -4.132037 & -3.019944 \\
\hline $\mathrm{H}$ & 1.540980 & -5.711284 & 0.966120 \\
\hline C & -0.509442 & 6.080823 & 0.748733 \\
\hline C & -0.011733 & 5.009064 & 0.003531 \\
\hline C & -0.830184 & 3.926422 & -0.321543 \\
\hline C & -2.173994 & 3.909601 & 0.084116 \\
\hline C & -2.665283 & 4.992205 & 0.831664 \\
\hline C & -1.840723 & 6.066684 & 1.165855 \\
\hline $\mathrm{H}$ & 1.020059 & 5.019870 & -0.340030 \\
\hline $\mathrm{H}$ & -2.239930 & 6.890900 & 1.751447 \\
\hline C & -4.959757 & 0.795633 & -1.108642 \\
\hline C & -5.208050 & 2.173465 & -1.406894 \\
\hline C & -6.361833 & 2.531958 & -2.155374 \\
\hline C & -7.230302 & 1.572017 & -2.619814 \\
\hline C & -6.969667 & 0.206223 & -2.358480 \\
\hline C & -5.867651 & -0.171526 & -1.623207 \\
\hline $\mathrm{H}$ & -6.536718 & 3.584762 & -2.364628 \\
\hline $\mathrm{H}$ & -8.106180 & 1.856623 & -3.196476 \\
\hline $\mathrm{H}$ & -7.642055 & -0.553930 & -2.747183 \\
\hline $\mathrm{H}$ & -5.677945 & -1.223175 & -1.442809 \\
\hline C & -4.513660 & -1.658069 & 0.935929 \\
\hline C & -4.255422 & -3.026769 & 1.272393 \\
\hline C & -5.191171 & -3.738783 & 2.070803 \\
\hline C & -6.323036 & -3.124006 & 2.552940 \\
\hline C & -6.559747 & -1.760935 & 2.258253 \\
\hline C & -5.681701 & -1.048516 & 1.471124 \\
\hline $\mathrm{H}$ & -4.984847 & -4.780494 & 2.305368 \\
\hline $\mathrm{H}$ & -7.027384 & -3.676197 & 3.169079 \\
\hline $\mathrm{H}$ & -7.440653 & -1.268363 & 2.661109 \\
\hline $\mathrm{H}$ & -5.873493 & -0.002342 & 1.264298 \\
\hline 0 & 0.364118 & 0.935757 & -0.967581 \\
\hline $\mathrm{O}$ & 0.070668 & -0.532841 & 1.177543 \\
\hline $\mathrm{H}$ & 1.246522 & -0.743368 & 1.251840 \\
\hline $\mathrm{H}$ & -0.500242 & -4.485856 & 1.632932 \\
\hline $\mathrm{H}$ & 2.396815 & -5.534595 & -1.367326 \\
\hline $\mathrm{H}$ & -0.871437 & -2.918528 & -2.349976 \\
\hline $\mathrm{H}$ & -3.700357 & 4.981289 & 1.162797 \\
\hline $\mathrm{H}$ & 0.133831 & 6.920685 & 0.998932 \\
\hline $\mathrm{H}$ & -0.430420 & 3.099228 & -0.898788 \\
\hline C & 2.879602 & -1.615075 & 0.316080 \\
\hline $\mathrm{O}$ & 2.424656 & -1.006187 & 1.347059 \\
\hline
\end{tabular}




$\begin{array}{llll}\text { H } & 2.192595 & -2.162739 & -0.340800 \\ \mathrm{C} & 4.239796 & -2.274588 & 0.496113 \\ \mathrm{O} & 4.945006 & -2.151574 & 1.467880 \\ \mathrm{O} & 4.575912 & -3.007530 & -0.597225 \\ \mathrm{C} & 5.828356 & -3.716745 & -0.494549 \\ \mathrm{H} & 5.828470 & -4.360210 & 0.388087 \\ \mathrm{H} & 6.664398 & -3.015024 & -0.425230 \\ \mathrm{C} & 4.405687 & 0.385788 & -0.686603 \\ \mathrm{C} & 3.283827 & -0.314150 & -1.147949 \\ \mathrm{H} & 5.621417 & -0.950859 & -1.617291 \\ \mathrm{~N} & 5.635572 & -0.065232 & -1.122817 \\ \mathrm{C} & 6.901481 & 0.527818 & -1.218635 \\ \mathrm{O} & 7.859296 & -0.114481 & -1.594778 \\ \mathrm{O} & 6.896106 & 1.826760 & -0.911069 \\ \mathrm{C} & 8.178960 & 2.478286 & -0.996612 \\ \mathrm{H} & 8.895452 & 1.997949 & -0.326353 \\ \mathrm{H} & 7.993963 & 3.507835 & -0.692352 \\ \mathrm{H} & 8.556076 & 2.437396 & -2.020935 \\ \mathrm{H} & 2.305944 & 0.158697 & -1.069909 \\ \mathrm{H} & 3.416482 & -0.948248 & -2.022445 \\ \mathrm{C} & 4.286993 & 1.365617 & 0.391859 \\ \mathrm{C} & 5.230963 & 1.399281 & 1.439630 \\ \mathrm{C} & 3.146179 & 2.188683 & 0.467612 \\ \mathrm{C} & 5.047007 & 2.252775 & 2.518742 \\ \mathrm{H} & 6.069834 & 0.712836 & 1.433568 \\ \mathrm{C} & 2.979068 & 3.054378 & 1.545582 \\ \mathrm{H} & 2.389370 & 2.148128 & -0.308220 \\ \mathrm{C} & 3.928043 & 3.090951 & 2.568035 \\ \mathrm{H} & 5.765828 & 2.253348 & 3.332935 \\ \mathrm{H} & 2.095804 & 3.683908 & 1.590946 \\ \mathrm{H} & 3.787856 & 3.757573 & 3.414664 \\ \mathrm{H} & 5.901423 & -4.310734 & -1.405729\end{array}$

Catalyst (R)-1 TS Conformation 296

B3LYP/6-31G(d) Energy $=-2809.68764$

B3LYP-D3(BJ)/def2-TZVPP-IEF-PCM(DCM) Energy $=-2810.97946$

B3LYP-D3(BJ)/def2-TZVPP-IEF-PCM(DCM)//B3LYP/6-31G(d) Free Energy (Quasiharmonic) = 2810.337528

Frequencies (Top 3 out of 270)

1. $-609.0665 \mathrm{~cm}-1$ 
2. $\quad 3.2391 \mathrm{~cm}-1$

3. $\quad 5.5183 \mathrm{~cm}-1$

B3LYP/6-31G(d) Molecular Geometry in Cartesian Coordinates

$\begin{array}{lrrr}\text { C } & -3.859059 & 0.360929 & -0.214519 \\ \text { C } & -2.992510 & 1.326352 & 0.277990 \\ \text { C } & -3.283182 & 2.723136 & 0.255657 \\ \text { C } & -4.469282 & 3.114243 & -0.334279 \\ \text { H } & -4.733261 & 4.168562 & -0.344393 \\ \text { C } & -2.765734 & -3.805695 & 0.036609 \\ \text { C } & -3.504774 & -1.083675 & -0.077642 \\ \text { C } & -2.288639 & -1.534686 & -0.569894 \\ \text { C } & -1.893923 & -2.906116 & -0.546008 \\ \text { H } & -2.510344 & -4.862164 & 0.045325 \\ \text { O } & -1.795506 & 0.920465 & 0.847375 \\ \text { P } & -0.583546 & 0.386136 & -0.129394 \\ \text { O } & -1.422618 & -0.614154 & -1.136213 \\ \text { C } & -0.730807 & 5.744134 & 1.952366 \\ \text { C } & -0.995173 & 4.573299 & 2.666179 \\ \text { C } & -1.801301 & 3.578206 & 2.116068 \\ \text { C } & -2.365225 & 3.737637 & 0.839027 \\ \text { C } & -2.087653 & 4.917499 & 0.129985 \\ \text { C } & -1.278858 & 5.911312 & 0.680104 \\ \text { H } & -0.573926 & 4.433644 & 3.658558 \\ \text { H } & -1.070719 & 6.812631 & 0.109207 \\ \text { C } & 1.811483 & -4.363450 & -2.183843 \\ \text { C } & 1.052406 & -3.432845 & -2.896919 \\ \text { C } & -0.139647 & -2.940004 & -2.368363 \\ \text { C } & -0.599869 & -3.371781 & -1.112471 \\ \text { C } & 0.175247 & -4.305305 & -0.404688 \\ \text { C } & 1.367844 & -4.797448 & -0.933950 \\ \text { H } & 1.387443 & -3.089489 & -3.872256 \\ \text { H } & 1.953509 & -5.514807 & -0.364423 \\ \text { C } & -4.364399 & -2.019597 & 0.593620 \\ \text { C } & -3.986106 & -3.401083 & 0.630711 \\ \text { C } & -4.834230 & -4.340011 & 1.278522 \\ \text { C } & -5.994719 & -3.937530 & 1.897420 \\ \text { C } & -6.350710 & -2.568267 & 1.897779 \\ \text { H } & -5.559366 & -1.636080 & 1.263134 \\ \text { H } & -6.538033 & -5.386526 & 1.285302 \\ \text { H } & -255275 & -2.247351 & 2.407513 \\ & -0.589916 & 1.280370\end{array}$




\begin{tabular}{|c|c|c|c|}
\hline C & -5.052627 & 0.789681 & -0.891209 \\
\hline C & -5.358361 & 2.188714 & -0.933219 \\
\hline C & -6.541770 & 2.625700 & -1.588085 \\
\hline C & -7.380293 & 1.729482 & -2.208891 \\
\hline C & -7.060538 & 0.351422 & -2.204308 \\
\hline C & -5.930113 & -0.105816 & -1.563137 \\
\hline $\mathrm{H}$ & -6.764036 & 3.690281 & -1.599153 \\
\hline $\mathrm{H}$ & -8.278428 & 2.076430 & -2.712655 \\
\hline $\mathrm{H}$ & -7.710014 & -0.353661 & -2.716279 \\
\hline $\mathrm{H}$ & -5.694687 & -1.163582 & -1.578753 \\
\hline 0 & 0.420008 & -0.317172 & 0.719976 \\
\hline O & -0.119957 & 1.518141 & -1.047621 \\
\hline $\mathrm{H}$ & 1.103779 & 1.685893 & -1.175336 \\
\hline $\mathrm{H}$ & -2.491870 & 5.042225 & -0.870594 \\
\hline $\mathrm{H}$ & -0.099094 & 6.516978 & 2.382709 \\
\hline $\mathrm{H}$ & -2.001027 & 2.673348 & 2.679469 \\
\hline $\mathrm{H}$ & -0.151979 & -4.628399 & 0.579597 \\
\hline $\mathrm{H}$ & 2.741435 & -4.744028 & -2.598451 \\
\hline $\mathrm{H}$ & -0.720484 & -2.218675 & -2.931985 \\
\hline C & 2.958152 & 1.515526 & -0.291640 \\
\hline $\mathrm{O}$ & 2.250194 & 1.884021 & -1.304925 \\
\hline $\mathrm{H}$ & 2.459288 & 1.340835 & 0.666772 \\
\hline C & 4.307588 & 2.192378 & -0.110432 \\
\hline $\mathrm{O}$ & 4.914970 & 2.170798 & 0.942620 \\
\hline $\mathrm{O}$ & 4.740599 & 2.792810 & -1.224146 \\
\hline C & 5.993508 & 3.488461 & -1.101754 \\
\hline $\mathrm{H}$ & 6.793631 & 2.792811 & -0.833068 \\
\hline $\mathrm{H}$ & 6.176082 & 3.928855 & -2.081768 \\
\hline C & 4.503946 & -0.697969 & 0.289072 \\
\hline C & 3.468229 & -0.353937 & -0.599070 \\
\hline $\mathrm{H}$ & 6.476258 & -0.355147 & 0.709758 \\
\hline$N$ & 5.820031 & -0.489766 & -0.049178 \\
\hline C & 6.381139 & -0.333052 & -1.321272 \\
\hline $\mathrm{O}$ & 5.828102 & -0.483992 & -2.384014 \\
\hline $\mathrm{O}$ & 7.680446 & -0.003473 & -1.154086 \\
\hline C & 8.433238 & 0.124469 & -2.376034 \\
\hline $\mathrm{H}$ & 7.992321 & 0.891743 & -3.016214 \\
\hline $\mathrm{H}$ & 8.450283 & -0.827456 & -2.912131 \\
\hline $\mathrm{H}$ & 9.437803 & 0.409134 & -2.064391 \\
\hline $\mathrm{H}$ & 2.489990 & -0.783126 & -0.405766 \\
\hline $\mathrm{H}$ & 3.737737 & -0.250382 & -1.642217 \\
\hline C & 4.280040 & -1.181997 & 1.658417 \\
\hline C & 5.330413 & -1.758303 & 2.407890 \\
\hline C & 2.998824 & -1.105130 & 2.243318 \\
\hline
\end{tabular}




$\begin{array}{llll}\mathrm{C} & 5.115120 & -2.211566 & 3.703758 \\ \mathrm{H} & 6.312438 & -1.905606 & 1.968090 \\ \mathrm{C} & 2.795563 & -1.556178 & 3.544721 \\ \mathrm{H} & 2.149350 & -0.710538 & 1.694246 \\ \mathrm{C} & 3.847360 & -2.101803 & 4.281924 \\ \mathrm{H} & 5.933465 & -2.660871 & 4.258845 \\ \mathrm{H} & 1.802179 & -1.481783 & 3.976598 \\ \mathrm{H} & 3.680110 & -2.454286 & 5.296004 \\ \mathrm{H} & 5.925173 & 4.265422 & -0.336243\end{array}$

Catalyst (R)-1 TS Conformation 297

B3LYP/6-31G(d) Energy $=-2809.689419$

B3LYP-D3(BJ)/def2-TZVPP-IEF-PCM(DCM) Energy $=-2810.979135$

B3LYP-D3(BJ)/def2-TZVPP-IEF-PCM(DCM)//B3LYP/6-31G(d) Free Energy (Quasiharmonic) = 2810.337521

Frequencies (Top 3 out of 270)

1. $-651.7415 \mathrm{~cm}-1$

2. $\quad 3.6947 \mathrm{~cm}-1$

3. $\quad 10.0615 \mathrm{~cm}-1$

B3LYP/6-31G(d) Molecular Geometry in Cartesian Coordinates

$\begin{array}{llll}\text { C } & -3.579593 & 0.294722 & -0.200417 \\ \text { C } & -2.637063 & 1.305723 & -0.064988 \\ \text { C } & -2.961445 & 2.691577 & -0.191561 \\ \text { C } & -4.247070 & 3.003256 & -0.592313 \\ \text { H } & -4.519866 & 4.047990 & -0.714387 \\ \text { C } & -2.558532 & -3.798079 & 0.712756 \\ \text { C } & -3.235096 & -1.111627 & 0.167523 \\ \text { C } & -2.147172 & -1.731283 & -0.423713 \\ \text { C } & -1.787468 & -3.091332 & -0.189809 \\ \text { H } & -2.335016 & -4.846021 & 0.894563 \\ \text { O } & -1.340750 & 0.974283 & 0.314021 \\ \text { P } & -0.359695 & 0.127734 & -0.681084 \\ \text { O } & -1.377458 & -0.989591 & -1.310823 \\ \text { C } & -0.345460 & 5.941965 & 0.874541 \\ \text { C } & -1.658823 & 5.894473 & 1.344797 \\ \text { C } & -2.485202 & 4.826687 & 0.998184 \\ \text { C } & -2.020052 & 3.788368 & 0.171178 \\ \text { C } & -0.697556 & 3.847677 & -0.295355\end{array}$




\begin{tabular}{|c|c|c|c|}
\hline C & 0.128434 & 4.914862 & 0.057085 \\
\hline $\mathrm{H}$ & -2.039340 & 6.682609 & 1.989848 \\
\hline $\mathrm{H}$ & 1.150645 & 4.927435 & -0.309565 \\
\hline C & 1.490111 & -5.092068 & -2.135087 \\
\hline C & 0.639326 & -4.267701 & -2.874662 \\
\hline C & -0.413238 & -3.598724 & -2.251786 \\
\hline C & -0.638334 & -3.743856 & -0.872121 \\
\hline C & 0.228383 & -4.571760 & -0.139361 \\
\hline C & 1.281030 & -5.240387 & -0.763222 \\
\hline $\mathrm{H}$ & 0.791416 & -4.146231 & -3.943964 \\
\hline $\mathrm{H}$ & 1.941055 & -5.872524 & -0.174451 \\
\hline C & -3.978228 & -1.837345 & 1.162618 \\
\hline C & -3.634334 & -3.204805 & 1.417756 \\
\hline C & -4.368974 & -3.940578 & 2.387065 \\
\hline C & -5.382143 & -3.350336 & 3.105792 \\
\hline C & -5.696966 & -1.988926 & 2.885498 \\
\hline C & -5.016194 & -1.253565 & 1.940026 \\
\hline $\mathrm{H}$ & -4.103080 & -4.981223 & 2.557805 \\
\hline $\mathrm{H}$ & -5.932370 & -3.921063 & 3.848919 \\
\hline $\mathrm{H}$ & -6.481218 & -1.516330 & 3.470751 \\
\hline $\mathrm{H}$ & -5.264809 & -0.209575 & 1.790824 \\
\hline C & -4.884551 & 0.633721 & -0.699979 \\
\hline C & -5.212521 & 2.013233 & -0.894618 \\
\hline C & -6.497153 & 2.362853 & -1.392207 \\
\hline C & -7.420772 & 1.394257 & -1.709233 \\
\hline C & -7.089466 & 0.028520 & -1.546000 \\
\hline C & -5.857278 & -0.341857 & -1.053475 \\
\hline $\mathrm{H}$ & -6.730921 & 3.416264 & -1.527717 \\
\hline $\mathrm{H}$ & -8.397684 & 1.672850 & -2.094904 \\
\hline $\mathrm{H}$ & -7.811324 & -0.736766 & -1.818444 \\
\hline $\mathrm{H}$ & -5.614934 & -1.392960 & -0.946780 \\
\hline 0 & 0.738909 & -0.473328 & 0.133439 \\
\hline $\mathrm{O}$ & -0.003039 & 0.995329 & -1.902276 \\
\hline $\mathrm{H}$ & 1.055353 & 0.912013 & -2.337067 \\
\hline $\mathrm{H}$ & -0.312755 & 3.070787 & -0.943677 \\
\hline $\mathrm{H}$ & 0.303210 & 6.770774 & 1.147603 \\
\hline $\mathrm{H}$ & -3.498336 & 4.781445 & 1.388769 \\
\hline $\mathrm{H}$ & 0.085025 & -4.672946 & 0.932787 \\
\hline $\mathrm{H}$ & 2.309252 & -5.613079 & -2.624182 \\
\hline $\mathrm{H}$ & -1.068538 & -2.964327 & -2.838032 \\
\hline C & 3.278315 & 0.846477 & -2.322869 \\
\hline $\mathrm{O}$ & 2.164546 & 0.700537 & -2.947144 \\
\hline $\mathrm{H}$ & 4.189461 & 0.759751 & -2.926598 \\
\hline C & 3.381492 & 1.986495 & -1.313226 \\
\hline
\end{tabular}




\begin{tabular}{llll} 
O & 2.451485 & 2.487054 & -0.723071 \\
O & 4.663982 & 2.393827 & -1.190969 \\
C & 4.871505 & 3.525660 & -0.327795 \\
H & 4.390320 & 4.412939 & -0.748179 \\
H & 4.457272 & 3.336624 & 0.665701 \\
$\mathrm{C}$ & 4.169375 & -0.564282 & -0.011551 \\
$\mathrm{C}$ & 3.565500 & -0.778669 & -1.276574 \\
$\mathrm{H}$ & 2.326396 & -0.173962 & 0.759737 \\
$\mathrm{~N}$ & 3.338677 & -0.222603 & 1.004485 \\
$\mathrm{C}$ & 3.600024 & -0.216091 & 2.388102 \\
$\mathrm{O}$ & 4.647291 & -0.480825 & 2.933172 \\
$\mathrm{O}$ & 2.460173 & 0.121372 & 3.007403 \\
$\mathrm{C}$ & 2.519657 & 0.132075 & 4.443227 \\
$\mathrm{H}$ & 1.522074 & 0.427223 & 4.766299 \\
$\mathrm{H}$ & 3.267742 & 0.850000 & 4.789035 \\
$\mathrm{H}$ & 2.770952 & -0.862041 & 4.821544 \\
$\mathrm{H}$ & 4.178698 & -1.303738 & -2.000545 \\
$\mathrm{H}$ & 2.525303 & -1.084553 & -1.245842 \\
$\mathrm{C}$ & 5.639896 & -0.600023 & 0.127762 \\
$\mathrm{C}$ & 6.358055 & -1.617999 & -0.524992 \\
$\mathrm{C}$ & 6.352887 & 0.389601 & 0.827349 \\
$\mathrm{C}$ & 7.749369 & -1.654402 & -0.467365 \\
$\mathrm{H}$ & 5.821935 & -2.403333 & -1.048192 \\
$\mathrm{C}$ & 7.742367 & 0.364929 & 0.861127 \\
$\mathrm{H}$ & 5.818207 & 1.182942 & 1.334074 \\
$\mathrm{C}$ & 8.444857 & -0.658867 & 0.219383 \\
$\mathrm{H}$ & 8.287677 & -2.459037 & -0.959571 \\
$\mathrm{H}$ & 8.280275 & 1.142141 & 1.396197 \\
$\mathrm{H}$ & 9.530445 & -0.680399 & 0.257855 \\
$\mathrm{H}$ & 5.951648 & 3.663861 & -0.280302 \\
& & & \\
\hline
\end{tabular}

Catalyst (R)-1 TS Conformation 298

B3LYP/6-31G(d) Energy $=-2809.684925$

B3LYP-D3(BJ)/def2-TZVPP-IEF-PCM(DCM) Energy = -2810.980039

B3LYP-D3(BJ)/def2-TZVPP-IEF-PCM(DCM)//B3LYP/6-31G(d) Free Energy (Quasiharmonic) = 2810.337416

Frequencies (Top 3 out of 270)

1. $-450.6089 \mathrm{~cm}-1$

2. $\quad 6.4079 \mathrm{~cm}-1$

3. $\quad 8.3283 \mathrm{~cm}-1$ 
B3LYP/6-31G(d) Molecular Geometry in Cartesian Coordinates

\begin{tabular}{|c|c|c|c|}
\hline C & 3.775922 & 0.238298 & 0.357336 \\
\hline C & 3.039553 & 1.285977 & -0.176707 \\
\hline C & 3.386074 & 2.658108 & 0.005416 \\
\hline C & 4.485116 & 2.934410 & 0.795161 \\
\hline $\mathrm{H}$ & 4.791927 & 3.968014 & 0.932656 \\
\hline C & 2.549702 & -3.827733 & -0.402995 \\
\hline C & 3.380185 & -1.168283 & 0.047973 \\
\hline C & 2.083867 & -1.585176 & 0.315978 \\
\hline C & 1.639747 & -2.927871 & 0.118133 \\
\hline $\mathrm{H}$ & 2.254343 & -4.865330 & -0.535627 \\
\hline $\mathrm{O}$ & 1.926303 & 0.990548 & -0.947202 \\
\hline$P$ & 0.555304 & 0.471563 & -0.194374 \\
\hline $\mathrm{O}$ & 1.184068 & -0.666349 & 0.826879 \\
\hline C & 1.252774 & 5.937664 & -1.786801 \\
\hline C & 1.611345 & 5.976901 & -0.438903 \\
\hline C & 2.284643 & 4.900722 & 0.138023 \\
\hline C & 2.612710 & 3.764373 & -0.619049 \\
\hline C & 2.239485 & 3.734041 & -1.973341 \\
\hline C & 1.569358 & 4.811714 & -2.549798 \\
\hline $\mathrm{H}$ & 1.359262 & 6.842145 & 0.168804 \\
\hline $\mathrm{H}$ & 1.295624 & 4.771585 & -3.601084 \\
\hline C & -2.316331 & -4.333425 & 1.082148 \\
\hline C & -1.705321 & -4.698394 & -0.118480 \\
\hline C & -0.432273 & -4.220577 & -0.429504 \\
\hline C & 0.258515 & -3.369537 & 0.449896 \\
\hline C & -0.370838 & -3.006344 & 1.653174 \\
\hline C & -1.642614 & -3.485815 & 1.964596 \\
\hline $\mathrm{H}$ & -2.218454 & -5.357037 & -0.815027 \\
\hline $\mathrm{H}$ & -2.104614 & -3.202045 & 2.906907 \\
\hline C & 4.289149 & -2.096175 & -0.566942 \\
\hline C & 3.861903 & -3.447659 & -0.775367 \\
\hline C & 4.756323 & -4.380023 & -1.368077 \\
\hline C & 6.012974 & -3.995915 & -1.774008 \\
\hline C & 6.423562 & -2.652279 & -1.607061 \\
\hline C & 5.586901 & -1.729092 & -1.019241 \\
\hline $\mathrm{H}$ & 4.419557 & -5.404941 & -1.506256 \\
\hline $\mathrm{H}$ & 6.685582 & -4.715709 & -2.232513 \\
\hline $\mathrm{H}$ & 7.407450 & -2.343680 & -1.950147 \\
\hline $\mathrm{H}$ & 5.913606 & -0.701890 & -0.907171 \\
\hline C & 4.871174 & 0.544536 & 1.236256 \\
\hline C & 5.229984 & 1.916595 & 1.439601 \\
\hline
\end{tabular}




\begin{tabular}{|c|c|c|c|}
\hline$C$ & 6.318700 & 2.234010 & 2.296458 \\
\hline C & 7.011810 & 1.246701 & 2.957246 \\
\hline C & 6.634580 & -0.106474 & 2.790148 \\
\hline C & 5.595068 & -0.448193 & 1.953050 \\
\hline $\mathrm{H}$ & 6.584818 & 3.280155 & 2.429118 \\
\hline $\mathrm{H}$ & 7.837886 & 1.502405 & 3.615267 \\
\hline $\mathrm{H}$ & 7.166524 & -0.884429 & 3.331366 \\
\hline $\mathrm{H}$ & 5.312633 & -1.488958 & 1.844965 \\
\hline 0 & -0.352536 & -0.096967 & -1.234959 \\
\hline $\mathrm{O}$ & 0.034239 & 1.543764 & 0.759753 \\
\hline $\mathrm{H}$ & -1.147254 & 2.052966 & 0.611643 \\
\hline $\mathrm{H}$ & 2.480814 & 2.864857 & -2.575282 \\
\hline $\mathrm{H}$ & 0.726321 & 6.774734 & -2.237995 \\
\hline $\mathrm{H}$ & 2.540125 & 4.926472 & 1.193602 \\
\hline $\mathrm{H}$ & 0.143098 & -2.352079 & 2.348129 \\
\hline $\mathrm{H}$ & -3.305684 & -4.709591 & 1.330287 \\
\hline $\mathrm{H}$ & 0.030871 & -4.495577 & -1.373084 \\
\hline C & -2.812634 & 1.667539 & -0.379132 \\
\hline $\mathrm{O}$ & -2.214617 & 2.412752 & 0.488566 \\
\hline $\mathrm{H}$ & -2.210202 & 1.136509 & -1.119885 \\
\hline C & -4.155640 & 2.178910 & -0.854762 \\
\hline $\mathrm{O}$ & -4.835155 & 3.003169 & -0.288453 \\
\hline $\mathrm{O}$ & -4.483946 & 1.581662 & -2.021549 \\
\hline C & -5.732867 & 2.001259 & -2.603050 \\
\hline $\mathrm{H}$ & -6.547092 & 1.895068 & -1.881892 \\
\hline $\mathrm{H}$ & -5.669350 & 3.046652 & -2.915805 \\
\hline C & -4.572273 & -0.467028 & 0.426845 \\
\hline C & -3.243199 & -0.060736 & 0.601698 \\
\hline $\mathrm{H}$ & -6.046538 & -1.227337 & -0.749935 \\
\hline$N$ & -5.041316 & -1.132792 & -0.668525 \\
\hline C & -4.408379 & -1.598981 & -1.848076 \\
\hline $\mathrm{O}$ & -5.077849 & -2.049096 & -2.751881 \\
\hline $\mathrm{O}$ & -3.096351 & -1.468454 & -1.795253 \\
\hline C & -2.339555 & -1.868879 & -2.962990 \\
\hline $\mathrm{H}$ & -2.762349 & -1.398443 & -3.852877 \\
\hline $\mathrm{H}$ & -2.376069 & -2.955857 & -3.062252 \\
\hline $\mathrm{H}$ & -1.333144 & -1.512372 & -2.753813 \\
\hline $\mathrm{H}$ & -3.000294 & 0.283581 & 1.599498 \\
\hline $\mathrm{H}$ & -2.456263 & -0.603144 & 0.093031 \\
\hline C & -5.607763 & -0.143783 & 1.434802 \\
\hline C & -5.528914 & 1.048027 & 2.179138 \\
\hline C & -6.676291 & -1.029417 & 1.674680 \\
\hline C & -6.505476 & 1.346220 & 3.125741 \\
\hline $\mathrm{H}$ & -4.733936 & 1.759866 & 1.986653 \\
\hline
\end{tabular}




$\begin{array}{llll}\text { C } & -7.639757 & -0.730608 & 2.634566 \\ \text { H } & -6.728239 & -1.980336 & 1.150819 \\ \text { C } & -7.560002 & 0.460732 & 3.358527 \\ \text { H } & -6.443063 & 2.278535 & 3.678834 \\ \text { H } & -8.446866 & -1.432614 & 2.822659 \\ \text { H } & -8.314521 & 0.695741 & 4.103834 \\ \text { H } & -5.886092 & 1.349908 & -3.463209\end{array}$

Catalyst (R)-1 TS Conformation 299

B3LYP/6-31G(d) Energy $=-2809.685641$

B3LYP-D3(BJ)/def2-TZVPP-IEF-PCM(DCM) Energy $=-2810.978994$

B3LYP-D3(BJ)/def2-TZVPP-IEF-PCM(DCM)//B3LYP/6-31G(d) Free Energy (Quasiharmonic) = 2810.337414

Frequencies (Top 3 out of 270)

1. $-666.5438 \mathrm{~cm}-1$

2. $7.9080 \mathrm{~cm}-1$

3. $\quad 10.1683 \mathrm{~cm}-1$

B3LYP/6-31G(d) Molecular Geometry in Cartesian Coordinates

$\begin{array}{llll}\text { C } & 2.745903 & -1.502107 & -0.265248 \\ \text { C } & 1.428496 & -1.812325 & 0.030598 \\ \text { C } & 0.810460 & -3.042048 & -0.346485 \\ \text { C } & 1.569120 & -3.929260 & -1.085882 \\ \text { H } & 1.139038 & -4.887839 & -1.363760 \\ \text { C } & 4.592447 & 2.216559 & 0.851877 \\ \text { C } & 3.344884 & -0.229157 & 0.233834 \\ \text { C } & 2.758135 & 0.987626 & -0.086038 \\ \text { C } & 3.399219 & 2.240865 & 0.154439 \\ \text { H } & 5.095989 & 3.156510 & 1.061303 \\ \text { O } & 0.682874 & -0.892701 & 0.758744 \\ \text { P } & 0.193658 & 0.497579 & 0.026734 \\ \text { O } & 1.543059 & 0.986086 & -0.762165 \\ \text { C } & -3.188883 & -4.219498 & 0.715651 \\ \text { C } & -2.359293 & -3.632501 & 1.672430 \\ \text { C } & -1.071554 & -3.220867 & 1.333229 \\ \text { C } & -0.584796 & -3.395512 & 0.027050 \\ \text { C } & -1.432987 & -3.981789 & -0.927163 \\ \text { C } & -2.721456 & -4.389756 & -0.587298 \\ \text { H } & -2.716557 & -3.490242 & 2.688657\end{array}$




\begin{tabular}{|c|c|c|c|}
\hline $\mathrm{H}$ & -3.362830 & -4.831639 & -1.345424 \\
\hline C & 2.088722 & 6.043654 & -1.374687 \\
\hline C & 1.189727 & 5.237682 & -0.674085 \\
\hline C & 1.585257 & 3.992465 & -0.183408 \\
\hline C & 2.896938 & 3.535826 & -0.384754 \\
\hline C & 3.792641 & 4.355509 & -1.094272 \\
\hline C & 3.394215 & 5.597735 & -1.585310 \\
\hline $\mathrm{H}$ & 0.170160 & 5.567052 & -0.502664 \\
\hline $\mathrm{H}$ & 4.102091 & 6.211611 & -2.136801 \\
\hline C & 4.538908 & -0.231323 & 1.033670 \\
\hline C & 5.164198 & 1.018237 & 1.342919 \\
\hline C & 6.342992 & 1.031974 & 2.136847 \\
\hline C & 6.878541 & -0.135835 & 2.628207 \\
\hline C & 6.247540 & -1.370677 & 2.346950 \\
\hline C & 5.111182 & -1.418058 & 1.569492 \\
\hline $\mathrm{H}$ & 6.808413 & 1.990001 & 2.356636 \\
\hline $\mathrm{H}$ & 7.776969 & -0.112965 & 3.239032 \\
\hline $\mathrm{H}$ & 6.659853 & -2.290556 & 2.753003 \\
\hline $\mathrm{H}$ & 4.633123 & -2.370778 & 1.371933 \\
\hline C & 3.495634 & -2.401772 & -1.100549 \\
\hline C & 2.891357 & -3.637676 & -1.498485 \\
\hline C & 3.623456 & -4.545222 & -2.311425 \\
\hline C & 4.891204 & -4.239618 & -2.747916 \\
\hline C & 5.475969 & -3.002023 & -2.390590 \\
\hline C & 4.799255 & -2.109233 & -1.588783 \\
\hline $\mathrm{H}$ & 3.152418 & -5.484297 & -2.592620 \\
\hline $\mathrm{H}$ & 5.439087 & -4.937649 & -3.375058 \\
\hline $\mathrm{H}$ & 6.467724 & -2.749917 & -2.756362 \\
\hline $\mathrm{H}$ & 5.259337 & -1.162003 & -1.334190 \\
\hline $\mathrm{O}$ & -0.243270 & 1.426142 & 1.117475 \\
\hline 0 & -0.772501 & 0.175403 & -1.120667 \\
\hline $\mathrm{H}$ & -1.880253 & -0.355523 & -0.964237 \\
\hline $\mathrm{H}$ & -1.081827 & -4.097092 & -1.948742 \\
\hline $\mathrm{H}$ & -4.194226 & -4.534476 & 0.982981 \\
\hline $\mathrm{H}$ & -0.432458 & -2.770941 & 2.085300 \\
\hline $\mathrm{H}$ & 4.804148 & 4.002363 & -1.276611 \\
\hline $\mathrm{H}$ & 1.774091 & 7.012092 & -1.756138 \\
\hline $\mathrm{H}$ & 0.876966 & 3.387423 & 0.371421 \\
\hline C & -3.790951 & 0.052094 & -1.471414 \\
\hline $\mathrm{O}$ & -2.970061 & -0.794798 & -0.980243 \\
\hline $\mathrm{H}$ & -3.404840 & 0.959753 & -1.942403 \\
\hline C & -5.063136 & -0.449658 & -2.126856 \\
\hline $\mathrm{O}$ & -5.666947 & 0.207205 & -2.949627 \\
\hline $\mathrm{O}$ & -5.417107 & -1.667065 & -1.699661 \\
\hline
\end{tabular}




$\begin{array}{lrrr}\mathrm{C} & -6.600721 & -2.209815 & -2.312786 \\ \mathrm{H} & -6.457705 & -2.311891 & -3.391475 \\ \mathrm{H} & -6.745069 & -3.185508 & -1.849492 \\ \mathrm{C} & -3.915308 & 1.438809 & 0.887418 \\ \mathrm{C} & -4.895289 & 1.201777 & -0.080232 \\ \mathrm{H} & -2.076963 & 2.253466 & 1.331524 \\ \mathrm{~N} & -2.917385 & 2.362032 & 0.756224 \\ \mathrm{C} & -2.728772 & 3.420707 & -0.147735 \\ \mathrm{O} & -1.844999 & 4.229146 & 0.015354 \\ \mathrm{O} & -3.614860 & 3.440762 & -1.155547 \\ \mathrm{C} & -3.441810 & 4.529523 & -2.088970 \\ \mathrm{H} & -4.213744 & 4.380404 & -2.843124 \\ \mathrm{H} & -2.446168 & 4.485816 & -2.534520 \\ \mathrm{H} & -3.573460 & 5.486541 & -1.579369 \\ \mathrm{H} & -5.684583 & 0.515843 & 0.200274 \\ \mathrm{H} & -5.154957 & 1.963424 & -0.799617 \\ \mathrm{C} & -3.867293 & 0.599243 & 2.109102 \\ \mathrm{C} & -2.659578 & 0.256964 & 2.747405 \\ \mathrm{C} & -5.080272 & 0.170244 & 2.686032 \\ \mathrm{C} & -2.675297 & -0.498195 & 3.918520 \\ \mathrm{H} & -1.701944 & 0.545934 & 2.323465 \\ \mathrm{C} & -5.087100 & -0.574351 & 3.860692 \\ \mathrm{H} & -6.025516 & 0.458415 & 2.238956 \\ \mathrm{C} & -3.882615 & -0.914074 & 4.481101 \\ \mathrm{H} & -1.732773 & -0.759993 & 4.390461 \\ \mathrm{H} & -6.033692 & -0.879085 & 4.297725 \\ \mathrm{H} & -3.887179 & -1.493278 & 5.400513 \\ \mathrm{H} & -7.461061 & -1.561179 & -2.127027\end{array}$

Catalyst (R)-1 TS Conformation 300

B3LYP/6-31G(d) Energy $=-2809.682126$

B3LYP-D3(BJ)/def2-TZVPP-IEF-PCM(DCM) Energy = -2810.980799

B3LYP-D3(BJ)/def2-TZVPP-IEF-PCM(DCM)//B3LYP/6-31G(d) Free Energy (Quasiharmonic) = 2810.337327

Frequencies (Top 3 out of 270)

1. $-328.8012 \mathrm{~cm}-1$

2. $\quad 8.1019 \mathrm{~cm}-1$

3. $\quad 9.0447 \mathrm{~cm}-1$

B3LYP/6-31G(d) Molecular Geometry in Cartesian Coordinates 


\begin{tabular}{|c|c|c|c|}
\hline C & 3.780229 & 0.251181 & 0.350196 \\
\hline C & 3.054321 & 1.303682 & -0.189008 \\
\hline C & 3.408092 & 2.673521 & -0.001511 \\
\hline C & 4.501837 & 2.942015 & 0.798200 \\
\hline $\mathrm{H}$ & 4.813829 & 3.973528 & 0.939808 \\
\hline C & 2.536628 & -3.807838 & -0.419126 \\
\hline C & 3.377975 & -1.152499 & 0.036291 \\
\hline C & 2.076893 & -1.561146 & 0.295146 \\
\hline C & 1.628822 & -2.902756 & 0.096497 \\
\hline $\mathrm{H}$ & 2.237067 & -4.844236 & -0.552057 \\
\hline 0 & 1.948161 & 1.015472 & -0.970141 \\
\hline$P$ & 0.563315 & 0.506687 & -0.231062 \\
\hline O & 1.178488 & -0.638274 & 0.797158 \\
\hline C & 1.313262 & 5.969706 & -1.808582 \\
\hline C & 1.661821 & 6.005746 & -0.457980 \\
\hline C & 2.322429 & 4.924249 & 0.123599 \\
\hline C & 2.647566 & 3.785618 & -0.631303 \\
\hline C & 2.284291 & 3.758544 & -1.988356 \\
\hline C & 1.626926 & 4.841536 & -2.569477 \\
\hline $\mathrm{H}$ & 1.411531 & 6.872595 & 0.148203 \\
\hline $\mathrm{H}$ & 1.360553 & 4.803647 & -3.622744 \\
\hline C & -2.331484 & -4.298952 & 1.060995 \\
\hline C & -1.721845 & -4.664913 & -0.140268 \\
\hline C & -0.447723 & -4.189628 & -0.451874 \\
\hline C & 0.245599 & -3.339534 & 0.426428 \\
\hline C & -0.382386 & -2.975000 & 1.630137 \\
\hline C & -1.654552 & -3.452912 & 1.942828 \\
\hline $\mathrm{H}$ & -2.236966 & -5.322474 & -0.836248 \\
\hline $\mathrm{H}$ & -2.113670 & -3.171337 & 2.887455 \\
\hline C & 4.285792 & -2.085495 & -0.572392 \\
\hline C & 3.852856 & -3.434658 & -0.784132 \\
\hline C & 4.746037 & -4.371650 & -1.371318 \\
\hline C & 6.007472 & -3.994279 & -1.768690 \\
\hline C & 6.424253 & -2.652985 & -1.598184 \\
\hline C & 5.588698 & -1.725489 & -1.015604 \\
\hline $\mathrm{H}$ & 4.404604 & -5.394679 & -1.512184 \\
\hline $\mathrm{H}$ & 6.679172 & -4.717518 & -2.223109 \\
\hline $\mathrm{H}$ & 7.412139 & -2.349612 & -1.934422 \\
\hline $\mathrm{H}$ & 5.920126 & -0.700096 & -0.900797 \\
\hline C & 4.869793 & 0.549290 & 1.238828 \\
\hline C & 5.235110 & 1.918844 & 1.447463 \\
\hline C & 6.318445 & 2.228372 & 2.313945 \\
\hline C & 7.000325 & 1.235963 & 2.978834 \\
\hline
\end{tabular}




\begin{tabular}{|c|c|c|c|}
\hline C & 6.616582 & -0.114678 & 2.806206 \\
\hline C & 5.581992 & -0.448804 & 1.959951 \\
\hline $\mathrm{H}$ & 6.589605 & 3.272740 & 2.450528 \\
\hline $\mathrm{H}$ & 7.822441 & 1.485750 & 3.644080 \\
\hline $\mathrm{H}$ & 7.139565 & -0.896722 & 3.350312 \\
\hline $\mathrm{H}$ & 5.294439 & -1.487737 & 1.847641 \\
\hline 0 & -0.329666 & -0.065883 & -1.282494 \\
\hline 0 & 0.031708 & 1.577915 & 0.711760 \\
\hline $\mathrm{H}$ & -1.194936 & 2.092051 & 0.526215 \\
\hline $\mathrm{H}$ & 2.522950 & 2.887451 & -2.588530 \\
\hline $\mathrm{H}$ & 0.796492 & 6.810846 & -2.263421 \\
\hline $\mathrm{H}$ & 2.569772 & 4.947629 & 1.181169 \\
\hline $\mathrm{H}$ & 0.133881 & -2.321620 & 2.324243 \\
\hline $\mathrm{H}$ & -3.320665 & -4.674723 & 1.310341 \\
\hline $\mathrm{H}$ & 0.014707 & -4.466514 & -1.395222 \\
\hline C & -2.860973 & 1.623638 & -0.400301 \\
\hline 0 & -2.240471 & 2.422510 & 0.405110 \\
\hline $\mathrm{H}$ & -2.279138 & 1.067651 & -1.138234 \\
\hline C & -4.227324 & 2.110797 & -0.838101 \\
\hline 0 & -4.895058 & 2.940575 & -0.270417 \\
\hline 0 & -4.584010 & 1.490570 & -1.987993 \\
\hline C & -5.822218 & 1.939057 & -2.567286 \\
\hline $\mathrm{H}$ & -6.644346 & 1.834821 & -1.854599 \\
\hline $\mathrm{H}$ & -5.742367 & 2.989113 & -2.860502 \\
\hline C & -4.537663 & -0.526212 & 0.500550 \\
\hline C & -3.227097 & -0.061708 & 0.666019 \\
\hline $\mathrm{H}$ & -5.923359 & -1.621390 & -0.509189 \\
\hline$N$ & -4.962734 & -1.302643 & -0.537500 \\
\hline C & -4.316447 & -1.789113 & -1.701669 \\
\hline 0 & -4.934712 & -2.470343 & -2.489787 \\
\hline $\mathrm{O}$ & -3.056890 & -1.404769 & -1.771313 \\
\hline C & -2.299613 & -1.839420 & -2.928021 \\
\hline $\mathrm{H}$ & -1.317106 & -1.399581 & -2.772129 \\
\hline $\mathrm{H}$ & -2.778541 & -1.467667 & -3.836575 \\
\hline $\mathrm{H}$ & -2.260492 & -2.930108 & -2.946220 \\
\hline $\mathrm{H}$ & -3.029116 & 0.412144 & 1.618886 \\
\hline $\mathrm{H}$ & -2.407726 & -0.616101 & 0.225381 \\
\hline C & -5.610765 & -0.133347 & 1.444481 \\
\hline C & -6.918191 & 0.127268 & 0.991861 \\
\hline C & -5.337641 & -0.022890 & 2.819354 \\
\hline C & -7.918985 & 0.492647 & 1.887810 \\
\hline $\mathrm{H}$ & -7.146312 & 0.091993 & -0.069865 \\
\hline C & -6.343844 & 0.332266 & 3.713370 \\
\hline $\mathrm{H}$ & -4.343048 & -0.244734 & 3.191218 \\
\hline
\end{tabular}




$\begin{array}{llll}\mathrm{C} & -7.635445 & 0.592586 & 3.251209 \\ \mathrm{H} & -8.917044 & 0.710806 & 1.519680 \\ \mathrm{H} & -6.118765 & 0.402774 & 4.773313 \\ \mathrm{H} & -8.417160 & 0.875930 & 3.950037 \\ \mathrm{H} & -5.982198 & 1.307671 & -3.441205\end{array}$

Catalyst (R)-1 TS Conformation 301

B3LYP/6-31G(d) Energy = -2809.684202

B3LYP-D3(BJ)/def2-TZVPP-IEF-PCM(DCM) Energy = -2810.978511

B3LYP-D3(BJ)/def2-TZVPP-IEF-PCM(DCM)//B3LYP/6-31G(d) Free Energy (Quasiharmonic) = 2810.337294

Frequencies (Top 3 out of 270)

1. $-684.9027 \mathrm{~cm}-1$

2. $\quad 9.8187 \mathrm{~cm}-1$

3. $\quad 11.9156 \mathrm{~cm}-1$

B3LYP/6-31G(d) Molecular Geometry in Cartesian Coordinates

$\begin{array}{llll}\mathrm{C} & 3.695896 & 0.214170 & -0.057203 \\ \mathrm{C} & 2.878009 & 1.303407 & -0.314767 \\ \mathrm{C} & 3.312741 & 2.656435 & -0.196692 \\ \mathrm{C} & 4.602477 & 2.868599 & 0.250162 \\ \mathrm{H} & 4.974592 & 3.886792 & 0.328637 \\ \mathrm{C} & 2.136786 & -3.773426 & -0.583777 \\ \mathrm{C} & 3.171590 & -1.164527 & -0.289123 \\ \mathrm{C} & 1.998662 & -1.563488 & 0.334594 \\ \mathrm{C} & 1.468872 & -2.883377 & 0.234600 \\ \mathrm{H} & 1.770930 & -4.793722 & -0.664082 \\ \mathrm{O} & 1.575927 & 1.068648 & -0.734634 \\ \mathrm{P} & 0.473110 & 0.540727 & 0.361264 \\ \mathrm{O} & 1.314089 & -0.642861 & 1.119226 \\ \mathrm{C} & 0.888181 & 6.063828 & -1.208231 \\ \mathrm{C} & 0.939528 & 4.964258 & -2.067648 \\ \mathrm{C} & 1.702435 & 3.845577 & -1.737153 \\ \mathrm{C} & 2.436394 & 3.807946 & -0.539675 \\ \mathrm{C} & 2.372620 & 4.917948 & 0.317726 \\ \mathrm{C} & 1.606086 & 6.035072 & -0.012174 \\ \mathrm{H} & 0.386092 & 4.977759 & -3.003332 \\ \mathrm{H} & 1.563534 & 6.879072 & 0.671360 \\ \mathrm{C} & -1.933548 & -4.344073 & 2.418306\end{array}$




\begin{tabular}{|c|c|c|c|}
\hline$C$ & -1.832715 & -4.557218 & 1.042392 \\
\hline C & -0.742717 & -4.051712 & 0.334343 \\
\hline C & 0.263748 & -3.323388 & 0.987517 \\
\hline C & 0.137030 & -3.091002 & 2.366951 \\
\hline C & -0.948711 & -3.601535 & 3.074921 \\
\hline $\mathrm{H}$ & -2.603462 & -5.112084 & 0.514111 \\
\hline $\mathrm{H}$ & -1.022732 & -3.420336 & 4.143904 \\
\hline C & 3.818050 & -2.081771 & -1.187258 \\
\hline C & 3.287645 & -3.405648 & -1.322735 \\
\hline C & 3.920937 & -4.324797 & -2.202723 \\
\hline C & 5.015799 & -3.952829 & -2.947449 \\
\hline C & 5.519235 & -2.634683 & -2.844495 \\
\hline C & 4.938196 & -1.725223 & -1.988262 \\
\hline $\mathrm{H}$ & 3.512209 & -5.329400 & -2.283508 \\
\hline $\mathrm{H}$ & 5.487612 & -4.662474 & -3.621692 \\
\hline $\mathrm{H}$ & 6.370032 & -2.334514 & -3.450357 \\
\hline $\mathrm{H}$ & 5.330107 & -0.716539 & -1.929050 \\
\hline C & 5.010255 & 0.451749 & 0.472863 \\
\hline C & 5.462957 & 1.803765 & 0.613720 \\
\hline C & 6.764361 & 2.053689 & 1.127622 \\
\hline C & 7.582044 & 1.019356 & 1.519225 \\
\hline C & 7.123410 & -0.315053 & 1.416860 \\
\hline C & 5.873773 & -0.591606 & 0.907108 \\
\hline $\mathrm{H}$ & 7.096293 & 3.085485 & 1.216986 \\
\hline $\mathrm{H}$ & 8.572237 & 1.223423 & 1.917493 \\
\hline $\mathrm{H}$ & 7.760893 & -1.130284 & 1.748545 \\
\hline $\mathrm{H}$ & 5.533583 & -1.618798 & 0.844978 \\
\hline O & -0.710642 & 0.064939 & -0.415207 \\
\hline 0 & 0.302070 & 1.619259 & 1.440229 \\
\hline $\mathrm{H}$ & -0.738643 & 2.018990 & 1.718569 \\
\hline $\mathrm{H}$ & 2.910545 & 4.891018 & 1.261103 \\
\hline $\mathrm{H}$ & 0.289810 & 6.933674 & -1.466774 \\
\hline $\mathrm{H}$ & 1.737532 & 2.997681 & -2.412686 \\
\hline $\mathrm{H}$ & 0.895697 & -2.515024 & 2.885549 \\
\hline $\mathrm{H}$ & -2.774165 & -4.751309 & 2.975539 \\
\hline $\mathrm{H}$ & -0.682166 & -4.200096 & -0.739454 \\
\hline C & -2.928820 & 1.954225 & 1.761069 \\
\hline $\mathrm{O}$ & -1.846435 & 2.620014 & 1.959470 \\
\hline $\mathrm{H}$ & -3.867931 & 2.460932 & 2.019683 \\
\hline C & -2.942469 & 0.494468 & 2.226877 \\
\hline $\mathrm{O}$ & -1.965187 & -0.131837 & 2.557573 \\
\hline $\mathrm{O}$ & -4.206248 & 0.015826 & 2.290027 \\
\hline C & -4.316985 & -1.327378 & 2.801087 \\
\hline $\mathrm{H}$ & -3.746797 & -2.024444 & 2.182646 \\
\hline
\end{tabular}




$\begin{array}{llll}\mathrm{H} & -3.936893 & -1.372584 & 3.824832 \\ \mathrm{C} & -4.008156 & 0.868362 & -0.620115 \\ \mathrm{C} & -3.193283 & 1.924755 & -0.145396 \\ \mathrm{H} & -2.384419 & -0.360126 & -0.641646 \\ \mathrm{~N} & -3.399884 & -0.318768 & -0.870753 \\ \mathrm{C} & -3.829664 & -1.435266 & -1.615489 \\ \mathrm{O} & -3.245132 & -2.492599 & -1.575732 \\ \mathrm{O} & -4.890845 & -1.163888 & -2.390168 \\ \mathrm{C} & -5.359139 & -2.271030 & -3.181935 \\ \mathrm{H} & -6.221680 & -1.887387 & -3.726329 \\ \mathrm{H} & -5.646826 & -3.107011 & -2.539627 \\ \mathrm{H} & -4.578843 & -2.599272 & -3.872402 \\ \mathrm{H} & -3.630541 & 2.914985 & -0.214382 \\ \mathrm{H} & -2.149976 & 1.860291 & -0.432349 \\ \mathrm{C} & -5.475971 & 1.028320 & -0.680874 \\ \mathrm{C} & -6.343259 & 0.049131 & -0.164956 \\ \mathrm{C} & -6.021859 & 2.213647 & -1.200855 \\ \mathrm{C} & -7.718304 & 0.256001 & -0.165942 \\ \mathrm{H} & -5.932626 & -0.857441 & 0.264890 \\ \mathrm{C} & -7.401643 & 2.408304 & -1.220684 \\ \mathrm{H} & -5.365017 & 2.969418 & -1.619932 \\ \mathrm{C} & -8.252212 & 1.433112 & -0.698777 \\ \mathrm{H} & -8.376839 & -0.499889 & 0.252450 \\ \mathrm{H} & -7.810123 & 3.322395 & -1.641539 \\ \mathrm{H} & -9.327401 & 1.589079 & -0.703566 \\ \mathrm{H} & -5.382433 & -1.560329 & 2.780156\end{array}$

Catalyst (R)-1 TS Conformation 302

B3LYP/6-31G(d) Energy $=-2809.685432$

B3LYP-D3(BJ)/def2-TZVPP-IEF-PCM(DCM) Energy = -2810.979707

B3LYP-D3(BJ)/def2-TZVPP-IEF-PCM(DCM)//B3LYP/6-31G(d) Free Energy (Quasiharmonic) = 2810.33727

Frequencies (Top 3 out of 270)

1. $-470.7264 \mathrm{~cm}-1$

2. $\quad 5.5589 \mathrm{~cm}-1$

3. $\quad 7.7075 \mathrm{~cm}-1$

B3LYP/6-31G(d) Molecular Geometry in Cartesian Coordinates

$\begin{array}{llll}\text { C } & 3.439177 & -1.220100 & -0.041468\end{array}$ 


\begin{tabular}{|c|c|c|c|}
\hline C & 2.154518 & -1.715320 & 0.126263 \\
\hline C & 1.805063 & -3.078739 & -0.104817 \\
\hline C & 2.801087 & -3.923151 & -0.553739 \\
\hline $\mathrm{H}$ & 2.573521 & -4.973515 & -0.717000 \\
\hline C & 4.193581 & 2.946292 & 0.789563 \\
\hline C & 3.715528 & 0.209956 & 0.289812 \\
\hline C & 2.952355 & 1.206830 & -0.302985 \\
\hline C & 3.180382 & 2.598999 & -0.083322 \\
\hline $\mathrm{H}$ & 4.413779 & 3.997775 & 0.954694 \\
\hline $\mathrm{O}$ & 1.160111 & -0.849035 & 0.549279 \\
\hline$P$ & 0.545604 & 0.213850 & -0.557016 \\
\hline $\mathrm{O}$ & 1.939447 & 0.841545 & -1.173790 \\
\hline C & -2.157675 & -4.641246 & 0.519785 \\
\hline C & -1.565003 & -3.830995 & 1.492069 \\
\hline C & -0.289061 & -3.305456 & 1.290894 \\
\hline C & 0.424052 & -3.586108 & 0.113145 \\
\hline C & -0.183133 & -4.401024 & -0.855826 \\
\hline C & -1.460889 & -4.923205 & -0.656173 \\
\hline $\mathrm{H}$ & -2.094769 & -3.612825 & 2.416157 \\
\hline $\mathrm{H}$ & -1.914088 & -5.543858 & -1.424825 \\
\hline C & 0.925880 & 5.743593 & -1.972367 \\
\hline C & 1.358286 & 4.648368 & -2.723095 \\
\hline C & 2.070426 & 3.613563 & -2.118899 \\
\hline C & 2.370115 & 3.655582 & -0.746651 \\
\hline C & 1.926070 & 4.761624 & -0.002250 \\
\hline C & 1.211737 & 5.795542 & -0.607398 \\
\hline $\mathrm{H}$ & 1.143326 & 4.598949 & -3.787442 \\
\hline $\mathrm{H}$ & 0.876741 & 6.640153 & -0.010268 \\
\hline C & 4.712641 & 0.587068 & 1.253724 \\
\hline C & 4.958981 & 1.979261 & 1.485160 \\
\hline C & 5.953938 & 2.366532 & 2.423614 \\
\hline C & 6.660043 & 1.425721 & 3.136224 \\
\hline C & 6.390259 & 0.050679 & 2.940874 \\
\hline C & 5.444855 & -0.357295 & 2.025645 \\
\hline $\mathrm{H}$ & 6.136627 & 3.427808 & 2.576069 \\
\hline $\mathrm{H}$ & 7.413644 & 1.733912 & 3.855858 \\
\hline $\mathrm{H}$ & 6.930916 & -0.691739 & 3.521872 \\
\hline $\mathrm{H}$ & 5.244274 & -1.414299 & 1.895474 \\
\hline C & 4.447500 & -2.092916 & -0.576998 \\
\hline C & 4.115762 & -3.466088 & -0.818269 \\
\hline C & 5.106983 & -4.342900 & -1.336737 \\
\hline C & 6.368583 & -3.886377 & -1.639688 \\
\hline C & 6.687255 & -2.522486 & -1.440721 \\
\hline C & 5.754236 & -1.650776 & -0.923477 \\
\hline
\end{tabular}




\begin{tabular}{|c|c|c|c|}
\hline $\mathrm{H}$ & 4.841283 & -5.384480 & -1.502215 \\
\hline $\mathrm{H}$ & 7.115679 & -4.564880 & -2.042447 \\
\hline $\mathrm{H}$ & 7.676373 & -2.156946 & -1.703502 \\
\hline $\mathrm{H}$ & 6.011459 & -0.606778 & -0.787201 \\
\hline $\mathrm{O}$ & -0.293896 & 1.199032 & 0.187481 \\
\hline $\mathrm{O}$ & -0.048587 & -0.555706 & -1.734711 \\
\hline $\mathrm{H}$ & -1.319594 & -0.590386 & -1.935864 \\
\hline $\mathrm{H}$ & 0.344243 & -4.602828 & -1.783720 \\
\hline $\mathrm{H}$ & -3.153329 & -5.047671 & 0.678429 \\
\hline $\mathrm{H}$ & 0.162051 & -2.677551 & 2.051497 \\
\hline $\mathrm{H}$ & 2.130714 & 4.799212 & 1.064285 \\
\hline $\mathrm{H}$ & 0.369837 & 6.547993 & -2.446959 \\
\hline $\mathrm{H}$ & 2.401200 & 2.769122 & -2.712851 \\
\hline C & -2.938528 & 0.429788 & -1.426077 \\
\hline $\mathrm{O}$ & -2.444215 & -0.551469 & -2.103740 \\
\hline $\mathrm{H}$ & -2.268246 & 1.225771 & -1.095039 \\
\hline C & -4.324582 & 0.874523 & -1.842882 \\
\hline 0 & -5.118376 & 0.214372 & -2.471477 \\
\hline $\mathrm{O}$ & -4.543473 & 2.136447 & -1.409621 \\
\hline C & -5.822358 & 2.703898 & -1.751804 \\
\hline $\mathrm{H}$ & -5.889263 & 3.631024 & -1.182960 \\
\hline $\mathrm{H}$ & -5.867556 & 2.903885 & -2.825563 \\
\hline C & -4.453060 & 0.023445 & 0.974988 \\
\hline C & -3.181576 & -0.258797 & 0.455978 \\
\hline $\mathrm{H}$ & -5.823630 & 1.366298 & 1.648255 \\
\hline$N$ & -4.832883 & 1.232498 & 1.484267 \\
\hline C & -4.142002 & 2.462256 & 1.629638 \\
\hline 0 & -4.757342 & 3.472572 & 1.890636 \\
\hline 0 & -2.840517 & 2.324110 & 1.458395 \\
\hline C & -2.030523 & 3.523862 & 1.502560 \\
\hline $\mathrm{H}$ & -2.440506 & 4.268209 & 0.817164 \\
\hline $\mathrm{H}$ & -1.045987 & 3.186824 & 1.185011 \\
\hline $\mathrm{H}$ & -2.022252 & 3.920520 & 2.520512 \\
\hline $\mathrm{H}$ & -2.995117 & -1.308817 & 0.261214 \\
\hline $\mathrm{H}$ & -2.323407 & 0.299830 & 0.813711 \\
\hline C & -5.529435 & -0.992174 & 0.949463 \\
\hline C & -6.494222 & -1.041331 & 1.974394 \\
\hline C & -5.594243 & -1.932789 & -0.095611 \\
\hline C & -7.496973 & -2.007256 & 1.954771 \\
\hline $\mathrm{H}$ & -6.431932 & -0.359196 & 2.818297 \\
\hline C & -6.610384 & -2.884439 & -0.115798 \\
\hline $\mathrm{H}$ & -4.881181 & -1.890937 & -0.911314 \\
\hline C & -7.561102 & -2.927459 & 0.906436 \\
\hline $\mathrm{H}$ & -8.222106 & -2.045915 & 2.762415 \\
\hline
\end{tabular}




$\begin{array}{llll}\mathrm{H} & -6.661542 & -3.590742 & -0.938975 \\ \mathrm{H} & -8.346966 & -3.677243 & 0.888480 \\ \mathrm{H} & -6.630544 & 2.019422 & -1.483192\end{array}$

Catalyst (R)-1 TS Conformation 303

B3LYP/6-31G(d) Energy $=-2809.682164$

B3LYP-D3(BJ)/def2-TZVPP-IEF-PCM(DCM) Energy = -2810.978581

B3LYP-D3(BJ)/def2-TZVPP-IEF-PCM(DCM)//B3LYP/6-31G(d) Free Energy (Quasiharmonic) = 2810.337252

Frequencies (Top 3 out of 270)

1. $-642.8181 \mathrm{~cm}-1$

2. $\quad 6.6796 \mathrm{~cm}-1$

3. $\quad 10.5239 \mathrm{~cm}-1$

B3LYP/6-31G(d) Molecular Geometry in Cartesian Coordinates

$\begin{array}{lrrr}\text { C } & 2.952402 & 0.586556 & 0.078971 \\ \text { C } & 2.228170 & 1.546064 & -0.612357 \\ \text { C } & 2.289055 & 2.941230 & -0.318425 \\ \text { C } & 3.076141 & 3.326577 & 0.749464 \\ \text { H } & 3.170097 & 4.383747 & 0.983470 \\ \text { C } & 2.743928 & -3.591911 & -0.957016 \\ \text { C } & 2.905477 & -0.839233 & -0.362602 \\ \text { C } & 1.683551 & -1.488153 & -0.481161 \\ \text { C } & 1.576108 & -2.885953 & -0.748977 \\ \text { H } & 2.687701 & -4.657564 & -1.164042 \\ \text { O } & 1.415425 & 1.133030 & -1.657882 \\ \text { P } & -0.002290 & 0.395444 & -1.283209 \\ \text { O } & 0.520706 & -0.781061 & -0.231944 \\ \text { C } & 0.231613 & 5.972999 & -2.574161 \\ \text { C } & 0.222481 & 5.998319 & -1.179076 \\ \text { C } & 0.875123 & 5.000166 & -0.457014 \\ \text { C } & 1.549607 & 3.957520 & -1.113162 \\ \text { C } & 1.545470 & 3.939705 & -2.518142 \\ \text { C } & 0.894801 & 4.939572 & -3.238835 \\ \text { H } & -0.301454 & 6.790239 & -0.650088 \\ \text { H } & 0.906937 & 4.909884 & -4.325201 \\ \text { C } & -2.124961 & -5.089279 & -0.842585 \\ \text { C } & -1.096599 & -5.459724 & 0.025594 \\ \text { C } & 0.089444 & -4.725317 & 0.059416\end{array}$




\begin{tabular}{|c|c|c|c|}
\hline C & 0.271175 & -3.606112 & -0.769573 \\
\hline C & -0.769989 & -3.234837 & -1.637744 \\
\hline C & -1.954613 & -3.976847 & -1.673051 \\
\hline $\mathrm{H}$ & -1.217522 & -6.317551 & 0.681869 \\
\hline $\mathrm{H}$ & -2.738039 & -3.694480 & -2.373059 \\
\hline C & 4.104932 & -1.563827 & -0.684244 \\
\hline C & 4.013606 & -2.964537 & -0.967557 \\
\hline C & 5.193018 & -3.694879 & -1.276051 \\
\hline C & 6.417570 & -3.071046 & -1.330353 \\
\hline C & 6.507492 & -1.680643 & -1.084834 \\
\hline C & 5.384421 & -0.947922 & -0.769298 \\
\hline $\mathrm{H}$ & 5.104443 & -4.759150 & -1.481542 \\
\hline $\mathrm{H}$ & 7.312091 & -3.637856 & -1.573603 \\
\hline $\mathrm{H}$ & 7.471477 & -1.183569 & -1.152582 \\
\hline $\mathrm{H}$ & 5.469796 & 0.118585 & -0.596034 \\
\hline C & 3.699206 & 0.995918 & 1.238931 \\
\hline C & 3.765347 & 2.391121 & 1.559842 \\
\hline C & 4.510371 & 2.811731 & 2.695038 \\
\hline C & 5.139256 & 1.898024 & 3.508616 \\
\hline C & 5.040641 & 0.516864 & 3.219136 \\
\hline C & 4.342825 & 0.077842 & 2.114941 \\
\hline $\mathrm{H}$ & 4.562424 & 3.875668 & 2.914491 \\
\hline $\mathrm{H}$ & 5.700640 & 2.231669 & 4.377117 \\
\hline $\mathrm{H}$ & 5.517374 & -0.206346 & 3.875391 \\
\hline $\mathrm{H}$ & 4.270937 & -0.984314 & 1.912579 \\
\hline $\mathrm{O}$ & -0.615318 & -0.160544 & -2.520191 \\
\hline $\mathrm{O}$ & -0.825016 & 1.302537 & -0.359744 \\
\hline $\mathrm{H}$ & -2.038311 & 1.457708 & -0.575116 \\
\hline $\mathrm{H}$ & 2.056736 & 3.142295 & -3.045817 \\
\hline $\mathrm{H}$ & -0.279317 & 6.748158 & -3.139214 \\
\hline $\mathrm{H}$ & 0.843512 & 5.011687 & 0.628888 \\
\hline $\mathrm{H}$ & -0.651132 & -2.371916 & -2.286006 \\
\hline $\mathrm{H}$ & -3.046964 & -5.663960 & -0.877313 \\
\hline $\mathrm{H}$ & 0.879312 & -5.004877 & 0.750374 \\
\hline C & -3.581313 & 0.465553 & -1.393542 \\
\hline $\mathrm{O}$ & -3.193040 & 1.518252 & -0.768331 \\
\hline $\mathrm{H}$ & -2.833537 & -0.130644 & -1.923073 \\
\hline C & -4.946732 & 0.568042 & -2.048011 \\
\hline $\mathrm{O}$ & -5.809185 & 1.356569 & -1.735281 \\
\hline $\mathrm{O}$ & -5.061070 & -0.353701 & -3.023056 \\
\hline C & -6.313785 & -0.350410 & -3.731488 \\
\hline $\mathrm{H}$ & -7.141478 & -0.548205 & -3.044883 \\
\hline $\mathrm{H}$ & -6.473879 & 0.616767 & -4.214252 \\
\hline C & -3.492423 & -0.983565 & 1.050645 \\
\hline
\end{tabular}




$\begin{array}{lrrr}\mathrm{C} & -4.158514 & -1.129821 & -0.179429 \\ \mathrm{H} & -2.055478 & -2.351145 & 0.577399 \\ \mathrm{~N} & -2.307873 & -1.620973 & 1.241255 \\ \mathrm{C} & -1.218496 & -1.320136 & 2.109121 \\ \mathrm{O} & -0.388886 & -2.156765 & 2.374119 \\ \mathrm{O} & -1.247243 & -0.059260 & 2.522339 \\ \mathrm{C} & -0.103790 & 0.360104 & 3.294179 \\ \mathrm{H} & -0.315620 & 1.391132 & 3.573679 \\ \mathrm{H} & 0.793897 & 0.304920 & 2.676119 \\ \mathrm{H} & 0.011523 & -0.270760 & 4.178684 \\ \mathrm{H} & -5.234332 & -1.000061 & -0.142506 \\ \mathrm{H} & -3.811571 & -1.916736 & -0.843483 \\ \mathrm{C} & -4.096431 & -0.197294 & 2.138349 \\ \mathrm{C} & -4.855499 & 0.952027 & 1.852257 \\ \mathrm{C} & -3.996845 & -0.643892 & 3.470944 \\ \mathrm{C} & -5.476953 & 1.648960 & 2.887467 \\ \mathrm{H} & -4.932994 & 1.320342 & 0.836101 \\ \mathrm{C} & -4.640796 & 0.043729 & 4.492210 \\ \mathrm{H} & -3.445712 & -1.551691 & 3.697247 \\ \mathrm{C} & -5.375729 & 1.198268 & 4.203905 \\ \mathrm{H} & -6.044889 & 2.545921 & 2.658901 \\ \mathrm{H} & -4.573475 & -0.320882 & 5.513229 \\ \mathrm{H} & -5.872977 & 1.738910 & 5.004645 \\ \mathrm{H} & -6.230326 & -1.142579 & -4.475241\end{array}$

Catalyst (R)-1 TS Conformation 304

B3LYP/6-31G(d) Energy $=-2809.682393$

B3LYP-D3(BJ)/def2-TZVPP-IEF-PCM(DCM) Energy = -2810.980338

B3LYP-D3(BJ)/def2-TZVPP-IEF-PCM(DCM)//B3LYP/6-31G(d) Free Energy (Quasiharmonic) = 2810.337247

Frequencies (Top 3 out of 270)

1. $-442.0075 \mathrm{~cm}-1$

2. $\quad 3.6949 \mathrm{~cm}-1$

3. $8.3073 \mathrm{~cm}-1$

B3LYP/6-31G(d) Molecular Geometry in Cartesian Coordinates

$\begin{array}{llll}\text { C } & 3.221891 & -1.359179 & -0.263450 \\ \text { C } & 1.896846 & -1.647701 & 0.022062 \\ \text { C } & 1.285952 & -2.899892 & -0.283604\end{array}$




\begin{tabular}{|c|c|c|c|}
\hline C & 2.050043 & -3.834406 & -0.954064 \\
\hline $\mathrm{H}$ & 1.622746 & -4.808359 & -1.178702 \\
\hline C & 4.992047 & 2.429532 & 0.764100 \\
\hline C & 3.808414 & -0.059550 & 0.180667 \\
\hline C & 3.214559 & 1.136464 & -0.202443 \\
\hline C & 3.816910 & 2.409822 & 0.037557 \\
\hline $\mathrm{H}$ & 5.466442 & 3.385417 & 0.970217 \\
\hline 0 & 1.129361 & -0.681551 & 0.653040 \\
\hline$P$ & 0.630891 & 0.614287 & -0.243533 \\
\hline O & 2.043505 & 1.095862 & -0.939281 \\
\hline C & -2.705449 & -4.014724 & 0.884633 \\
\hline C & -1.855559 & -3.392637 & 1.803140 \\
\hline C & -0.573355 & -2.997766 & 1.422112 \\
\hline C & -0.109884 & -3.224525 & 0.114585 \\
\hline C & -0.977955 & -3.841614 & -0.800788 \\
\hline C & -2.261872 & -4.233717 & -0.420767 \\
\hline $\mathrm{H}$ & -2.185907 & -3.229091 & 2.826319 \\
\hline $\mathrm{H}$ & -2.913753 & -4.714055 & -1.146431 \\
\hline C & 2.364416 & 6.157695 & -1.503541 \\
\hline C & 1.496564 & 5.309902 & -0.812758 \\
\hline C & 1.940188 & 4.082316 & -0.320710 \\
\hline C & 3.273233 & 3.684005 & -0.511770 \\
\hline C & 4.138661 & 4.544454 & -1.208625 \\
\hline C & 3.690037 & 5.769516 & -1.701061 \\
\hline $\mathrm{H}$ & 0.462582 & 5.604744 & -0.651732 \\
\hline $\mathrm{H}$ & 4.375118 & 6.415509 & -2.244411 \\
\hline C & 4.980107 & -0.014760 & 1.012092 \\
\hline C & 5.578011 & 1.254962 & 1.294987 \\
\hline C & 6.738181 & 1.314607 & 2.113819 \\
\hline C & 7.281835 & 0.173338 & 2.656001 \\
\hline C & 6.675861 & -1.080050 & 2.403924 \\
\hline C & 5.558031 & -1.172146 & 1.603864 \\
\hline $\mathrm{H}$ & 7.182481 & 2.287343 & 2.311903 \\
\hline $\mathrm{H}$ & 8.166045 & 0.231714 & 3.284949 \\
\hline $\mathrm{H}$ & 7.092507 & -1.978943 & 2.850641 \\
\hline $\mathrm{H}$ & 5.099866 & -2.139032 & 1.429964 \\
\hline C & 3.982757 & -2.312954 & -1.025259 \\
\hline C & 3.380733 & -3.569190 & -1.360485 \\
\hline C & 4.124416 & -4.525148 & -2.104108 \\
\hline C & 5.401489 & -4.249716 & -2.533876 \\
\hline C & 5.984680 & -2.995115 & -2.239088 \\
\hline C & 5.296624 & -2.054347 & -1.504573 \\
\hline $\mathrm{H}$ & 3.655231 & -5.477987 & -2.338315 \\
\hline $\mathrm{H}$ & 5.957956 & -4.985226 & -3.108393 \\
\hline
\end{tabular}




\begin{tabular}{|c|c|c|c|}
\hline $\mathrm{H}$ & 6.984183 & -2.768196 & -2.600239 \\
\hline $\mathrm{H}$ & 5.754664 & -1.094515 & -1.297431 \\
\hline 0 & 0.048175 & 1.612439 & 0.703162 \\
\hline 0 & -0.212102 & 0.107840 & -1.413434 \\
\hline $\mathrm{H}$ & -1.287364 & 0.749046 & -1.738165 \\
\hline $\mathrm{H}$ & -0.643394 & -4.000508 & -1.821901 \\
\hline $\mathrm{H}$ & -3.700828 & -4.331212 & 1.186351 \\
\hline $\mathrm{H}$ & 0.083762 & -2.525425 & 2.144454 \\
\hline $\mathrm{H}$ & 5.166931 & 4.237520 & -1.380866 \\
\hline $\mathrm{H}$ & 2.010140 & 7.110994 & -1.887610 \\
\hline $\mathrm{H}$ & 1.254348 & 3.438578 & 0.220084 \\
\hline C & -2.943325 & 1.394310 & -0.861842 \\
\hline $\mathrm{O}$ & -2.293645 & 1.211912 & -1.959779 \\
\hline $\mathrm{H}$ & -2.386359 & 1.561969 & 0.062594 \\
\hline C & -4.237135 & 2.171245 & -1.018862 \\
\hline $\mathrm{O}$ & -4.860675 & 2.287467 & -2.045343 \\
\hline $\mathrm{O}$ & -4.578978 & 2.737476 & 0.161001 \\
\hline C & -5.732004 & 3.598110 & 0.111081 \\
\hline $\mathrm{H}$ & -5.868945 & 3.962128 & 1.129572 \\
\hline $\mathrm{H}$ & -5.549925 & 4.431428 & -0.572303 \\
\hline C & -4.730006 & -0.452200 & 0.444273 \\
\hline C & -3.568690 & -0.449785 & -0.335341 \\
\hline $\mathrm{H}$ & -5.660988 & -0.439152 & 2.249668 \\
\hline$N$ & -4.763810 & -0.302565 & 1.800494 \\
\hline C & -3.772845 & -0.044553 & 2.778563 \\
\hline $\mathrm{O}$ & -4.074687 & -0.074248 & 3.951265 \\
\hline $\mathrm{O}$ & -2.590487 & 0.231351 & 2.255054 \\
\hline C & -1.533220 & 0.547146 & 3.205389 \\
\hline $\mathrm{H}$ & -1.882262 & 1.323825 & 3.888099 \\
\hline $\mathrm{H}$ & -0.709320 & 0.891349 & 2.582516 \\
\hline $\mathrm{H}$ & -1.278747 & -0.353027 & 3.769044 \\
\hline $\mathrm{H}$ & -3.707549 & -0.763164 & -1.362036 \\
\hline $\mathrm{H}$ & -2.628289 & -0.731523 & 0.121153 \\
\hline C & -6.069136 & -0.573516 & -0.179683 \\
\hline C & -6.258432 & -1.402304 & -1.299594 \\
\hline C & -7.176570 & 0.124426 & 0.340367 \\
\hline C & -7.517744 & -1.529789 & -1.879324 \\
\hline $\mathrm{H}$ & -5.424986 & -1.972016 & -1.696130 \\
\hline C & -8.432378 & 0.000817 & -0.248118 \\
\hline $\mathrm{H}$ & -7.048433 & 0.802000 & 1.179970 \\
\hline C & -8.606678 & -0.828575 & -1.358010 \\
\hline $\mathrm{H}$ & -7.648907 & -2.181374 & -2.737945 \\
\hline $\mathrm{H}$ & -9.272832 & 0.558323 & 0.154753 \\
\hline $\mathrm{H}$ & -9.586902 & -0.926280 & -1.815483 \\
\hline
\end{tabular}


$\begin{array}{llll}H & -6.611238 & 3.045591 & -0.228932\end{array}$

Catalyst (R)-1 TS Conformation 305

$B 3 L Y P / 6-31 G(d)$ Energy $=-2809.684491$

B3LYP-D3(BJ)/def2-TZVPP-IEF-PCM(DCM) Energy $=-2810.978706$

B3LYP-D3(BJ)/def2-TZVPP-IEF-PCM(DCM)//B3LYP/6-31G(d) Free Energy (Quasiharmonic) = 2810.33724

Frequencies (Top 3 out of 270)

1. $-483.6476 \mathrm{~cm}-1$

2. $\quad 4.7297 \mathrm{~cm}-1$

3. $\quad 9.8780 \mathrm{~cm}-1$

B3LYP/6-31G(d) Molecular Geometry in Cartesian Coordinates

$\begin{array}{llll}\text { C } & 3.622756 & 0.350742 & 0.215262 \\ \text { C } & 2.782101 & 1.363378 & -0.222266 \\ \text { C } & 3.002787 & 2.745487 & 0.052816 \\ \text { C } & 4.096319 & 3.062972 & 0.835798 \\ \text { H } & 4.314364 & 4.107613 & 1.041227 \\ \text { C } & 2.789827 & -3.748860 & -0.836589 \\ \text { C } & 3.358285 & -1.060464 & -0.198295 \\ \text { C } & 2.116953 & -1.628289 & 0.046322 \\ \text { C } & 1.798406 & -2.988175 & -0.245773 \\ \text { H } & 2.598374 & -4.798256 & -1.043547 \\ \text { O } & 1.675801 & 1.016710 & -0.991133 \\ \text { P } & 0.403856 & 0.323372 & -0.230516 \\ \text { O } & 1.135058 & -0.842825 & 0.640439 \\ \text { C } & 0.521022 & 5.939352 & -1.417525 \\ \text { C } & 0.876839 & 4.887969 & -2.264506 \\ \mathrm{C} & 1.662559 & 3.837226 & -1.794326 \\ \mathrm{C} & 2.112029 & 3.818950 & -0.463291 \\ \mathrm{C} & 1.741286 & 4.879604 & 0.380123 \\ \mathrm{C} & 0.955077 & 5.929953 & -0.091205 \\ \mathrm{H} & 0.542187 & 4.883029 & -3.298427 \\ \mathrm{H} & 0.675743 & 6.736854 & 0.581665 \\ \mathrm{C} & -1.987036 & -4.855292 & 0.601790 \\ \mathrm{C} & -1.420971 & -3.979265 & 1.529434 \\ \mathrm{C} & -0.205913 & -3.350779 & 1.260259 \\ \mathrm{C} & 0.470736 & -3.589712 & 0.052457 \\ \mathrm{C} & -0.116548 & -4.464778 & -0.877810\end{array}$




\begin{tabular}{|c|c|c|c|}
\hline C & -1.330545 & -5.092796 & -0.606833 \\
\hline $\mathrm{H}$ & -1.923276 & -3.774065 & 2.470740 \\
\hline $\mathrm{H}$ & -1.768347 & -5.758499 & -1.346215 \\
\hline C & 4.345018 & -1.843036 & -0.891532 \\
\hline C & 4.050468 & -3.211950 & -1.192886 \\
\hline C & 5.022993 & -4.004360 & -1.861589 \\
\hline C & 6.227024 & -3.467069 & -2.252747 \\
\hline C & 6.504002 & -2.104044 & -1.994074 \\
\hline C & 5.590193 & -1.314598 & -1.331008 \\
\hline $\mathrm{H}$ & 4.787473 & -5.045247 & -2.070913 \\
\hline $\mathrm{H}$ & 6.959398 & -4.080606 & -2.770369 \\
\hline $\mathrm{H}$ & 7.444893 & -1.673425 & -2.326093 \\
\hline $\mathrm{H}$ & 5.814653 & -0.269982 & -1.149859 \\
\hline C & 4.706743 & 0.693246 & 1.095178 \\
\hline C & 4.946018 & 2.074670 & 1.389364 \\
\hline C & 6.023792 & 2.429451 & 2.245709 \\
\hline C & 6.817936 & 1.465302 & 2.821190 \\
\hline C & 6.558380 & 0.098231 & 2.565642 \\
\hline C & 5.533340 & -0.277532 & 1.725455 \\
\hline $\mathrm{H}$ & 6.199151 & 3.483619 & 2.447529 \\
\hline $\mathrm{H}$ & 7.634360 & 1.748390 & 3.480021 \\
\hline $\mathrm{H}$ & 7.170488 & -0.663872 & 3.040469 \\
\hline $\mathrm{H}$ & 5.342152 & -1.329391 & 1.548119 \\
\hline 0 & -0.313660 & 1.253876 & 0.696767 \\
\hline $\mathrm{O}$ & -0.409885 & -0.359866 & -1.349971 \\
\hline $\mathrm{H}$ & -1.198536 & 0.307441 & -1.777481 \\
\hline $\mathrm{H}$ & 2.054659 & 4.865276 & 1.420241 \\
\hline $\mathrm{H}$ & -0.093157 & 6.756556 & -1.787169 \\
\hline $\mathrm{H}$ & 1.931502 & 3.027550 & -2.463091 \\
\hline $\mathrm{H}$ & 0.372605 & -4.631419 & -1.833236 \\
\hline $\mathrm{H}$ & -2.934523 & -5.344438 & 0.814682 \\
\hline $\mathrm{H}$ & 0.211798 & -2.668082 & 1.989965 \\
\hline C & -3.157438 & 1.531294 & -2.136112 \\
\hline 0 & -1.888239 & 1.336829 & -2.227440 \\
\hline $\mathrm{H}$ & -3.530815 & 2.418379 & -2.669154 \\
\hline C & -4.078542 & 0.332352 & -2.369656 \\
\hline 0 & -3.789286 & -0.821152 & -2.147014 \\
\hline $\mathrm{O}$ & -5.265328 & 0.741220 & -2.869617 \\
\hline C & -6.207496 & -0.304637 & -3.166814 \\
\hline $\mathrm{H}$ & -5.769098 & -1.022935 & -3.864239 \\
\hline $\mathrm{H}$ & -6.502936 & -0.825268 & -2.252804 \\
\hline C & -3.898875 & 1.145526 & 0.534258 \\
\hline C & -3.658606 & 2.152753 & -0.449674 \\
\hline $\mathrm{H}$ & -1.882689 & 0.929365 & 0.992915 \\
\hline
\end{tabular}




$\begin{array}{llrl}\mathrm{N} & -2.873398 & 0.664969 & 1.256766 \\ \mathrm{C} & -2.904484 & -0.116351 & 2.436812 \\ \mathrm{O} & -1.981023 & -0.818556 & 2.770387 \\ \mathrm{O} & -4.020909 & 0.093466 & 3.151958 \\ \mathrm{C} & -4.111563 & -0.670880 & 4.367991 \\ \mathrm{H} & -4.114070 & -1.741257 & 4.146750 \\ \mathrm{H} & -5.054430 & -0.370565 & 4.824505 \\ \mathrm{H} & -3.269890 & -0.439768 & 5.024708 \\ \mathrm{H} & -4.560286 & 2.700965 & -0.711802 \\ \mathrm{H} & -2.792343 & 2.785209 & -0.266979 \\ \mathrm{C} & -5.244001 & 0.538069 & 0.652702 \\ \mathrm{C} & -5.387986 & -0.861635 & 0.656521 \\ \mathrm{C} & -6.389737 & 1.346845 & 0.708111 \\ \mathrm{C} & -6.655656 & -1.432738 & 0.724275 \\ \mathrm{H} & -4.510428 & -1.493081 & 0.559097 \\ \mathrm{C} & -7.655158 & 0.769518 & 0.795121 \\ \mathrm{H} & -6.287019 & 2.427660 & 0.718971 \\ \mathrm{C} & -7.790749 & -0.620072 & 0.802147 \\ \mathrm{H} & -6.758285 & -2.514050 & 0.710728 \\ \mathrm{H} & -8.533833 & 1.404914 & 0.857795 \\ \mathrm{H} & -8.778096 & -1.069590 & 0.863324 \\ \mathrm{H} & -7.065554 & 0.194527 & -3.618057\end{array}$

Catalyst (R)-1 TS Conformation 306

B3LYP/6-31G(d) Energy $=-2809.68538$

B3LYP-D3(BJ)/def2-TZVPP-IEF-PCM(DCM) Energy = -2810.978366

B3LYP-D3(BJ)/def2-TZVPP-IEF-PCM(DCM)//B3LYP/6-31G(d) Free Energy (Quasiharmonic) = 2810.337142

Frequencies (Top 3 out of 270)

1. $-743.9608 \mathrm{~cm}-1$

2. $\quad 5.6137 \mathrm{~cm}-1$

3. $9.5718 \mathrm{~cm}-1$

B3LYP/6-31G(d) Molecular Geometry in Cartesian Coordinates

$\begin{array}{llll}\text { C } & 3.364993 & -1.078383 & -0.225941 \\ \text { C } & 2.181969 & -1.597842 & 0.278755 \\ \text { C } & 1.776052 & -2.951986 & 0.087884 \\ \text { C } & 2.573916 & -3.744474 & -0.714225 \\ \text { H } & 2.308211 & -4.788165 & -0.859537\end{array}$




\begin{tabular}{|c|c|c|c|}
\hline C & 4.506552 & 2.985685 & 0.671548 \\
\hline C & 3.783233 & 0.310837 & 0.131334 \\
\hline C & 2.925230 & 1.369922 & -0.118870 \\
\hline C & 3.266889 & 2.733979 & 0.116740 \\
\hline $\mathrm{H}$ & 4.810943 & 4.014983 & 0.842349 \\
\hline O & 1.361286 & -0.784945 & 1.050654 \\
\hline$P$ & 0.543684 & 0.457914 & 0.367805 \\
\hline $\mathrm{O}$ & 1.671597 & 1.087374 & -0.646981 \\
\hline C & -1.632157 & -4.770146 & 1.986143 \\
\hline C & -0.795017 & -3.922888 & 2.716573 \\
\hline C & 0.293184 & -3.305881 & 2.102501 \\
\hline C & 0.568170 & -3.524734 & 0.740676 \\
\hline C & -0.289293 & -4.366443 & 0.014669 \\
\hline C & -1.375620 & -4.986970 & 0.631871 \\
\hline $\mathrm{H}$ & -0.984245 & -3.747170 & 3.772435 \\
\hline $\mathrm{H}$ & -2.022951 & -5.634678 & 0.046552 \\
\hline C & 0.690427 & 6.046353 & -0.833751 \\
\hline C & 0.870245 & 5.015079 & -1.758241 \\
\hline C & 1.686581 & 3.927613 & -1.451644 \\
\hline C & 2.344683 & 3.853218 & -0.212400 \\
\hline C & 2.153191 & 4.895089 & 0.709215 \\
\hline C & 1.334254 & 5.981203 & 0.402497 \\
\hline $\mathrm{H}$ & 0.375823 & 5.057562 & -2.725402 \\
\hline $\mathrm{H}$ & 1.192293 & 6.771665 & 1.134848 \\
\hline C & 5.039681 & 0.584161 & 0.774395 \\
\hline C & 5.400006 & 1.946997 & 1.031687 \\
\hline C & 6.643811 & 2.233593 & 1.657102 \\
\hline C & 7.490939 & 1.222224 & 2.045897 \\
\hline C & 7.120606 & -0.125627 & 1.828280 \\
\hline C & 5.929843 & -0.436339 & 1.208983 \\
\hline $\mathrm{H}$ & 6.906649 & 3.273942 & 1.833923 \\
\hline $\mathrm{H}$ & 8.436003 & 1.453684 & 2.529575 \\
\hline $\mathrm{H}$ & 7.779519 & -0.924729 & 2.157230 \\
\hline $\mathrm{H}$ & 5.657289 & -1.474469 & 1.058955 \\
\hline C & 4.143610 & -1.894158 & -1.118041 \\
\hline C & 3.735519 & -3.246924 & -1.353284 \\
\hline C & 4.501444 & -4.065829 & -2.226709 \\
\hline C & 5.609913 & -3.569438 & -2.872077 \\
\hline C & 5.994467 & -2.222993 & -2.670795 \\
\hline C & 5.283445 & -1.408823 & -1.816673 \\
\hline $\mathrm{H}$ & 4.183566 & -5.093856 & -2.384193 \\
\hline $\mathrm{H}$ & 6.183339 & -4.202668 & -3.543532 \\
\hline $\mathrm{H}$ & 6.856630 & -1.824762 & -3.198991 \\
\hline $\mathrm{H}$ & 5.585745 & -0.376844 & -1.681827 \\
\hline
\end{tabular}




\begin{tabular}{|c|c|c|c|}
\hline $\mathrm{O}$ & 0.058982 & 1.375820 & 1.430458 \\
\hline 0 & -0.507686 & -0.122520 & -0.618639 \\
\hline $\mathrm{H}$ & -1.321299 & 0.707215 & -1.041670 \\
\hline $\mathrm{H}$ & -0.116275 & -4.516436 & -1.046651 \\
\hline $\mathrm{H}$ & -2.476464 & -5.254830 & 2.469950 \\
\hline $\mathrm{H}$ & 0.941007 & -2.657608 & 2.682079 \\
\hline $\mathrm{H}$ & 2.631818 & 4.837035 & 1.682684 \\
\hline $\mathrm{H}$ & 0.050125 & 6.891237 & -1.073521 \\
\hline $\mathrm{H}$ & 1.821910 & 3.133768 & -2.178321 \\
\hline C & -2.622878 & 2.059270 & -0.268374 \\
\hline $\mathrm{O}$ & -2.278994 & 1.360874 & -1.284725 \\
\hline $\mathrm{H}$ & -1.864189 & 2.425838 & 0.427883 \\
\hline C & -3.850693 & 2.941008 & -0.366779 \\
\hline $\mathrm{O}$ & -4.138257 & 3.757661 & 0.482866 \\
\hline $\mathrm{O}$ & -4.547900 & 2.720758 & -1.489707 \\
\hline C & -5.717994 & 3.543011 & -1.650620 \\
\hline $\mathrm{H}$ & -6.123043 & 3.281859 & -2.628136 \\
\hline $\mathrm{H}$ & -5.447536 & 4.600995 & -1.613460 \\
\hline C & -3.954155 & -0.175777 & 0.659304 \\
\hline C & -3.231231 & 0.793907 & 1.344124 \\
\hline $\mathrm{H}$ & -2.253577 & -0.948350 & -0.197420 \\
\hline$N$ & -3.263752 & -1.096694 & -0.077608 \\
\hline C & -3.687389 & -2.315498 & -0.638733 \\
\hline $\mathrm{O}$ & -3.041215 & -2.894569 & -1.480032 \\
\hline $\mathrm{O}$ & -4.833535 & -2.754032 & -0.096064 \\
\hline C & -5.327462 & -3.987725 & -0.645513 \\
\hline $\mathrm{H}$ & -4.622249 & -4.798009 & -0.446701 \\
\hline $\mathrm{H}$ & -5.476700 & -3.895810 & -1.724083 \\
\hline $\mathrm{H}$ & -6.275119 & -4.167489 & -0.138096 \\
\hline $\mathrm{H}$ & -3.776247 & 1.520783 & 1.934615 \\
\hline $\mathrm{H}$ & -2.200405 & 0.608832 & 1.632923 \\
\hline C & -5.427897 & -0.070214 & 0.549632 \\
\hline C & -6.060117 & -0.118009 & -0.704836 \\
\hline C & -6.197956 & 0.165940 & 1.697747 \\
\hline C & -7.436981 & 0.061772 & -0.801326 \\
\hline $\mathrm{H}$ & -5.463651 & -0.257026 & -1.601057 \\
\hline C & -7.579091 & 0.329350 & 1.598420 \\
\hline $\mathrm{H}$ & -5.713533 & 0.198577 & 2.668945 \\
\hline C & -8.200741 & 0.278530 & 0.349871 \\
\hline $\mathrm{H}$ & -7.916096 & 0.035326 & -1.776141 \\
\hline $\mathrm{H}$ & -8.167449 & 0.497654 & 2.495780 \\
\hline $\mathrm{H}$ & -9.276376 & 0.411102 & 0.271742 \\
\hline $\mathrm{H}$ & -6.443762 & 3.327795 & -0.862283 \\
\hline
\end{tabular}


Catalyst (R)-1 TS Conformation 307

B3LYP/6-31G(d) Energy $=-2809.693117$

B3LYP-D3(BJ)/def2-TZVPP-IEF-PCM(DCM) Energy $=-2810.980866$

B3LYP-D3(BJ)/def2-TZVPP-IEF-PCM(DCM)//B3LYP/6-31G(d) Free Energy (Quasiharmonic) = 2810.337117

Frequencies (Top 3 out of 270)

1. $-281.1578 \mathrm{~cm}-1$

2. $8.5859 \mathrm{~cm}-1$

3. $\quad 12.2424 \mathrm{~cm}-1$

B3LYP/6-31G(d) Molecular Geometry in Cartesian Coordinates

$\begin{array}{lrrr}\mathrm{C} & 3.135325 & 1.104787 & -0.004320 \\ \mathrm{C} & 1.947341 & 1.708960 & -0.377340 \\ \mathrm{C} & 1.672532 & 3.095425 & -0.195870 \\ \mathrm{C} & 2.643572 & 3.848820 & 0.434889 \\ \mathrm{H} & 2.483101 & 4.915572 & 0.566269 \\ \mathrm{C} & 3.867496 & -3.073189 & -0.747715 \\ \mathrm{C} & 3.369428 & -0.331124 & -0.336935 \\ \mathrm{C} & 2.467652 & -1.304621 & 0.071824 \\ \mathrm{C} & 2.709903 & -2.702342 & -0.090119 \\ \mathrm{H} & 4.071938 & -4.130524 & -0.892778 \\ \mathrm{O} & 0.963676 & 0.917346 & -0.970588 \\ \mathrm{P} & 0.132494 & -0.096862 & 0.002295 \\ \mathrm{O} & 1.319280 & -0.918202 & 0.762077 \\ \mathrm{C} & -1.945516 & 5.017458 & -1.512927 \\ \mathrm{C} & -1.424606 & 5.277080 & -0.244444 \\ \mathrm{C} & -0.262288 & 4.634876 & 0.181780 \\ \mathrm{C} & 0.405535 & 3.724261 & -0.653079 \\ \mathrm{C} & -0.130116 & 3.468968 & -1.927578 \\ \mathrm{C} & -1.293148 & 4.109693 & -2.350667 \\ \mathrm{H} & -1.927080 & 5.973935 & 0.421654 \\ \mathrm{H} & -1.692279 & 3.899906 & -3.339271 \\ \mathrm{C} & 0.212296 & -5.904310 & 1.336314 \\ \mathrm{C} & -0.349139 & -4.872849 & 0.578927 \\ \mathrm{C} & 0.440348 & -3.810145 & 0.135469 \\ \mathrm{C} & 1.810390 & -3.766339 & 0.438475 \\ \mathrm{C} & 2.362044 & -4.806966 & 1.204892 \\ \mathrm{C} & 1.571599 & -5.866063 & 1.650693 \\ \mathrm{H} & -1.409213 & -4.885680 & 0.340725\end{array}$




\begin{tabular}{|c|c|c|c|}
\hline $\mathrm{H}$ & 2.018658 & -6.658453 & 2.245624 \\
\hline C & 4.516526 & -0.733005 & -1.106177 \\
\hline C & 4.768602 & -2.128990 & -1.293940 \\
\hline C & 5.902746 & -2.541998 & -2.044702 \\
\hline C & 6.747245 & -1.618337 & -2.614383 \\
\hline C & 6.481767 & -0.237052 & -2.461159 \\
\hline C & 5.398808 & 0.194264 & -1.727217 \\
\hline $\mathrm{H}$ & 6.081401 & -3.607342 & -2.169760 \\
\hline $\mathrm{H}$ & 7.608090 & -1.944241 & -3.191668 \\
\hline $\mathrm{H}$ & 7.134998 & 0.491913 & -2.933047 \\
\hline $\mathrm{H}$ & 5.204890 & 1.255995 & -1.630747 \\
\hline C & 4.100182 & 1.885174 & 0.722755 \\
\hline C & 3.843811 & 3.279777 & 0.926840 \\
\hline C & 4.793139 & 4.067738 & 1.632764 \\
\hline C & 5.935977 & 3.504105 & 2.150145 \\
\hline C & 6.172014 & 2.119095 & 1.985510 \\
\hline C & 5.280926 & 1.331804 & 1.289718 \\
\hline $\mathrm{H}$ & 4.588862 & 5.127289 & 1.767460 \\
\hline $\mathrm{H}$ & 6.650717 & 4.114935 & 2.694741 \\
\hline $\mathrm{H}$ & 7.062894 & 1.670044 & 2.416174 \\
\hline $\mathrm{H}$ & 5.472628 & 0.270769 & 1.181318 \\
\hline $\mathrm{O}$ & -0.817271 & -0.899844 & -0.804004 \\
\hline $\mathrm{O}$ & -0.440788 & 0.731347 & 1.205994 \\
\hline $\mathrm{H}$ & -1.415507 & 1.031708 & 1.092417 \\
\hline $\mathrm{H}$ & 0.369895 & 2.770048 & -2.589108 \\
\hline $\mathrm{H}$ & -2.859947 & 5.501592 & -1.842129 \\
\hline $\mathrm{H}$ & 0.121779 & 4.820201 & 1.180870 \\
\hline $\mathrm{H}$ & 3.417354 & -4.774720 & 1.462399 \\
\hline $\mathrm{H}$ & -0.406384 & -6.729503 & 1.679551 \\
\hline $\mathrm{H}$ & -0.006123 & -3.019426 & -0.457432 \\
\hline C & -3.639434 & 1.698124 & 0.106578 \\
\hline $\mathrm{O}$ & -2.892299 & 1.514869 & 1.131210 \\
\hline $\mathrm{H}$ & -3.280773 & 1.422335 & -0.895630 \\
\hline C & -4.490524 & 2.968362 & 0.022937 \\
\hline $\mathrm{O}$ & -4.893007 & 3.430717 & -1.023814 \\
\hline $\mathrm{O}$ & -4.739149 & 3.490865 & 1.234514 \\
\hline C & -5.525334 & 4.693392 & 1.232043 \\
\hline $\mathrm{H}$ & -6.496695 & 4.519608 & 0.760690 \\
\hline $\mathrm{H}$ & -5.648492 & 4.963644 & 2.280989 \\
\hline C & -4.606136 & -0.774722 & 0.270647 \\
\hline C & -5.204047 & 0.503100 & 0.236961 \\
\hline $\mathrm{H}$ & -3.463913 & -0.135039 & 1.794438 \\
\hline$N$ & -3.800642 & -0.996456 & 1.338515 \\
\hline C & -3.246360 & -2.198385 & 1.808750 \\
\hline
\end{tabular}




$\begin{array}{llll}\mathrm{O} & -3.536086 & -3.311401 & 1.437623 \\ \mathrm{O} & -2.393331 & -1.879445 & 2.793431 \\ \mathrm{C} & -1.772841 & -2.989052 & 3.471426 \\ \mathrm{H} & -1.176737 & -2.536895 & 4.263420 \\ \mathrm{H} & -1.137433 & -3.546494 & 2.781816 \\ \mathrm{H} & -2.536916 & -3.649754 & 3.889158 \\ \mathrm{H} & -5.829812 & 0.728873 & -0.620289 \\ \mathrm{H} & -5.537872 & 0.918101 & 1.184295 \\ \mathrm{C} & -4.729949 & -1.710280 & -0.858557 \\ \mathrm{C} & -6.000305 & -1.915203 & -1.426657 \\ \mathrm{C} & -3.607535 & -2.343421 & -1.421335 \\ \mathrm{C} & -6.152695 & -2.762991 & -2.520340 \\ \mathrm{H} & -6.868473 & -1.432774 & -0.987276 \\ \mathrm{C} & -3.766082 & -3.167336 & -2.531696 \\ \mathrm{H} & -2.617060 & -2.133900 & -1.033617 \\ \mathrm{C} & -5.034355 & -3.388754 & -3.075297 \\ \mathrm{H} & -7.140186 & -2.931778 & -2.940104 \\ \mathrm{H} & -2.892722 & -3.633794 & -2.978088 \\ \mathrm{H} & -5.150011 & -4.042422 & -3.935736 \\ \mathrm{H} & -5.005468 & 5.487623 & 0.689800\end{array}$

Catalyst (R)-1 TS Conformation 308

B3LYP/6-31G(d) Energy = -2809.692648

B3LYP-D3(BJ)/def2-TZVPP-IEF-PCM(DCM) Energy = -2810.980479

B3LYP-D3(BJ)/def2-TZVPP-IEF-PCM(DCM)//B3LYP/6-31G(d) Free Energy (Quasiharmonic) = 2810.337066

Frequencies (Top 3 out of 270)

1. $-279.9631 \mathrm{~cm}-1$

2. $\quad 8.3531 \mathrm{~cm}-1$

3. $\quad 11.6593 \mathrm{~cm}-1$

B3LYP/6-31G(d) Molecular Geometry in Cartesian Coordinates

$\begin{array}{lrrr}\text { C } & 3.932429 & 0.141437 & 0.140206 \\ \text { C } & 3.198030 & 1.271872 & -0.185684 \\ \text { C } & 3.580257 & 2.594358 & 0.185689 \\ \text { C } & 4.721716 & 2.728147 & 0.952104 \\ \text { H } & 5.057096 & 3.723414 & 1.231435 \\ \text { C } & 2.562690 & -3.746551 & -1.143908 \\ \text { C } & 3.491260 & -1.197818 & -0.353130\end{array}$




\begin{tabular}{|c|c|c|c|}
\hline C & 2.203225 & -1.630745 & -0.082243 \\
\hline C & 1.708634 & -2.917460 & -0.443752 \\
\hline $\mathrm{H}$ & 2.227402 & -4.743686 & -1.417279 \\
\hline $\mathrm{O}$ & 2.039156 & 1.126164 & -0.943267 \\
\hline$P$ & 0.703671 & 0.460726 & -0.287240 \\
\hline $\mathrm{O}$ & 1.343127 & -0.764528 & 0.588739 \\
\hline C & 1.429637 & 6.140475 & -0.960550 \\
\hline C & 1.848702 & 5.960171 & 0.358095 \\
\hline C & 2.527936 & 4.798679 & 0.724013 \\
\hline C & 2.801286 & 3.795112 & -0.219496 \\
\hline C & 2.368697 & 3.985785 & -1.542636 \\
\hline C & 1.692263 & 5.148480 & -1.907708 \\
\hline $\mathrm{H}$ & 1.639891 & 6.719781 & 1.106911 \\
\hline $\mathrm{H}$ & 1.371614 & 5.280125 & -2.937894 \\
\hline C & -2.261890 & -4.257437 & 0.541577 \\
\hline C & -1.461093 & -3.659942 & 1.517948 \\
\hline C & -0.179709 & -3.210751 & 1.204343 \\
\hline C & 0.331489 & -3.357817 & -0.095717 \\
\hline C & -0.478388 & -3.966951 & -1.067328 \\
\hline C & -1.762813 & -4.410934 & -0.752826 \\
\hline $\mathrm{H}$ & -1.833512 & -3.542363 & 2.532162 \\
\hline $\mathrm{H}$ & -2.377508 & -4.868483 & -1.523714 \\
\hline C & 4.343419 & -2.044622 & -1.142648 \\
\hline C & 3.865125 & -3.340058 & -1.526375 \\
\hline C & 4.701166 & -4.190903 & -2.299330 \\
\hline C & 5.947084 & -3.777276 & -2.709492 \\
\hline C & 6.406049 & -2.484111 & -2.365471 \\
\hline C & 5.627355 & -1.641786 & -1.602637 \\
\hline $\mathrm{H}$ & 4.327840 & -5.175330 & -2.571568 \\
\hline $\mathrm{H}$ & 6.574110 & -4.434138 & -3.306097 \\
\hline $\mathrm{H}$ & 7.380616 & -2.149421 & -2.710434 \\
\hline $\mathrm{H}$ & 5.989876 & -0.650699 & -1.355871 \\
\hline C & 5.074936 & 0.293181 & 1.000009 \\
\hline C & 5.473466 & 1.611936 & 1.392999 \\
\hline C & 6.608679 & 1.777445 & 2.232282 \\
\hline C & 7.309744 & 0.689695 & 2.697738 \\
\hline C & 6.894582 & -0.615765 & 2.344642 \\
\hline C & 5.809136 & -0.809122 & 1.518636 \\
\hline $\mathrm{H}$ & 6.904270 & 2.786409 & 2.510106 \\
\hline $\mathrm{H}$ & 8.171767 & 0.828325 & 3.344474 \\
\hline $\mathrm{H}$ & 7.433958 & -1.475580 & 2.732778 \\
\hline $\mathrm{H}$ & 5.499197 & -1.816545 & 1.266814 \\
\hline $\mathrm{O}$ & -0.256499 & 0.076427 & -1.347829 \\
\hline $\mathrm{O}$ & 0.203471 & 1.425674 & 0.842368 \\
\hline
\end{tabular}




\begin{tabular}{|c|c|c|c|}
\hline $\mathrm{H}$ & -0.824684 & 1.548449 & 0.846935 \\
\hline $\mathrm{H}$ & 2.569492 & 3.223447 & -2.287473 \\
\hline $\mathrm{H}$ & 0.898667 & 7.044354 & -1.247494 \\
\hline $\mathrm{H}$ & 2.831204 & 4.653023 & 1.756993 \\
\hline $\mathrm{H}$ & -0.105122 & -4.065554 & -2.082836 \\
\hline $\mathrm{H}$ & -3.267716 & -4.587291 & 0.786578 \\
\hline $\mathrm{H}$ & 0.431476 & -2.746004 & 1.970669 \\
\hline$C$ & -2.879995 & 1.923266 & -0.282199 \\
\hline 0 & -2.345293 & 1.674140 & 0.858984 \\
\hline $\mathrm{H}$ & -2.238659 & 2.209238 & -1.126543 \\
\hline C & -4.219736 & 2.654567 & -0.259763 \\
\hline 0 & -4.973532 & 2.694939 & 0.686418 \\
\hline $\mathrm{O}$ & -4.458315 & 3.240433 & -1.452515 \\
\hline C & -5.712334 & 3.936570 & -1.555752 \\
\hline $\mathrm{H}$ & -5.743737 & 4.335144 & -2.570011 \\
\hline $\mathrm{H}$ & -6.545308 & 3.249647 & -1.384068 \\
\hline C & -4.291320 & -0.342725 & -0.231019 \\
\hline C & -3.398823 & 0.242876 & -1.148917 \\
\hline $\mathrm{H}$ & -2.987891 & 0.004383 & 1.267803 \\
\hline $\mathrm{N}$ & -3.788778 & -0.597252 & 1.007063 \\
\hline C & -4.320052 & -1.426325 & 1.997002 \\
\hline $\mathrm{O}$ & -5.186170 & -2.257463 & 1.843787 \\
\hline $\mathrm{O}$ & -3.666100 & -1.178474 & 3.147959 \\
\hline C & -4.079337 & -1.980691 & 4.265905 \\
\hline $\mathrm{H}$ & -5.139460 & -1.822111 & 4.478887 \\
\hline $\mathrm{H}$ & -3.464848 & -1.645992 & 5.101341 \\
\hline $\mathrm{H}$ & -3.909181 & -3.041073 & 4.061934 \\
\hline $\mathrm{H}$ & -3.812458 & 0.518548 & -2.114511 \\
\hline $\mathrm{H}$ & -2.363515 & -0.095692 & -1.165516 \\
\hline C & -5.727582 & -0.481973 & -0.530178 \\
\hline C & -6.122918 & -0.960012 & -1.791096 \\
\hline C & -6.709598 & -0.076688 & 0.391208 \\
\hline C & -7.473947 & -1.053824 & -2.116775 \\
\hline $\mathrm{H}$ & -5.366960 & -1.284603 & -2.499778 \\
\hline C & -8.056484 & -0.150877 & 0.052167 \\
\hline $\mathrm{H}$ & -6.410270 & 0.339737 & 1.346158 \\
\hline C & -8.442136 & -0.647187 & -1.196615 \\
\hline $\mathrm{H}$ & -7.769951 & -1.442865 & -3.086750 \\
\hline $\mathrm{H}$ & -8.808295 & 0.179977 & 0.762822 \\
\hline $\mathrm{H}$ & -9.496211 & -0.713282 & -1.452330 \\
\hline $\mathrm{H}$ & -5.760580 & 4.745901 & -0.822546 \\
\hline
\end{tabular}

Catalyst (R)-1 TS Conformation 309 
B3LYP/6-31G(d) Energy $=-2809.68111$

B3LYP-D3(BJ)/def2-TZVPP-IEF-PCM(DCM) Energy = -2810.979399

B3LYP-D3(BJ)/def2-TZVPP-IEF-PCM(DCM)//B3LYP/6-31G(d) Free Energy (Quasiharmonic) = 2810.337054

Frequencies (Top 3 out of 270)

1. $-617.0456 \mathrm{~cm}-1$

2. $\quad 6.2451 \mathrm{~cm}-1$

3. $\quad 7.6304 \mathrm{~cm}-1$

B3LYP/6-31G(d) Molecular Geometry in Cartesian Coordinates

$\begin{array}{llll}\mathrm{C} & 3.638328 & 0.303061 & 0.356255 \\ \mathrm{C} & 2.815090 & 1.350815 & -0.024017 \\ \mathrm{C} & 3.016212 & 2.695258 & 0.404817 \\ \mathrm{C} & 4.025032 & 2.931299 & 1.316537 \\ \mathrm{H} & 4.214521 & 3.949582 & 1.646604 \\ \mathrm{C} & 3.078925 & -3.695390 & -1.140074 \\ \mathrm{C} & 3.446270 & -1.049990 & -0.244826 \\ \mathrm{C} & 2.213609 & -1.682932 & -0.153574 \\ \mathrm{C} & 2.011665 & -3.037792 & -0.559450 \\ \mathrm{H} & 2.948397 & -4.723834 & -1.466565 \\ \mathrm{O} & 1.752953 & 1.092199 & -0.880122 \\ \mathrm{P} & 0.453732 & 0.288832 & -0.266792 \\ \mathrm{O} & 1.164149 & -1.016557 & 0.453860 \\ \mathrm{C} & 0.847592 & 6.079176 & -1.129802 \\ \mathrm{C} & 1.410766 & 5.149600 & -2.008446 \\ \mathrm{C} & 2.081102 & 4.030861 & -1.514725 \\ \mathrm{C} & 2.213299 & 3.827163 & -0.130589 \\ \mathrm{C} & 1.637765 & 4.764108 & 0.741403 \\ \mathrm{C} & 0.958924 & 5.878991 & 0.246933 \\ \mathrm{H} & 1.334985 & 5.299328 & -3.082582 \\ \mathrm{H} & 0.517139 & 6.590679 & 0.939719 \\ \mathrm{C} & -1.614045 & -5.284074 & 0.013727 \\ \mathrm{C} & -1.663507 & -4.030966 & -0.600481 \\ \mathrm{C} & -0.503075 & -3.276357 & -0.774287 \\ \mathrm{C} & 0.735183 & -3.772814 & -0.336642 \\ \mathrm{C} & 0.773891 & -5.033579 & 0.282467 \\ \mathrm{C} & -0.388904 & -5.783247 & 0.457646 \\ \mathrm{H} & -2.611263 & -3.630423 & -0.950019 \\ \mathrm{H} & -0.336441 & -6.753766 & 0.944677 \\ \mathrm{C} & 4.517364 & -1.715009 & -0.935612\end{array}$




\begin{tabular}{|c|c|c|c|}
\hline C & 4.323503 & -3.063275 & -1.376075 \\
\hline C & 5.375075 & -3.735670 & -2.055762 \\
\hline C & 6.568276 & -3.102883 & -2.315828 \\
\hline C & 6.752653 & -1.760224 & -1.909665 \\
\hline C & 5.756962 & -1.085723 & -1.237636 \\
\hline $\mathrm{H}$ & 5.211150 & -4.761758 & -2.376923 \\
\hline $\mathrm{H}$ & 7.363458 & -3.624808 & -2.841248 \\
\hline $\mathrm{H}$ & 7.686940 & -1.253092 & -2.135571 \\
\hline $\mathrm{H}$ & 5.911140 & -0.053886 & -0.943804 \\
\hline C & 4.642682 & 0.550171 & 1.356342 \\
\hline C & 4.831108 & 1.887580 & 1.834304 \\
\hline C & 5.821931 & 2.145113 & 2.819880 \\
\hline C & 6.581927 & 1.125136 & 3.343171 \\
\hline C & 6.373483 & -0.202121 & 2.900742 \\
\hline C & 5.432829 & -0.481871 & 1.933817 \\
\hline $\mathrm{H}$ & 5.958632 & 3.168504 & 3.161658 \\
\hline $\mathrm{H}$ & 7.331647 & 1.332829 & 4.101802 \\
\hline $\mathrm{H}$ & 6.957459 & -1.011006 & 3.331618 \\
\hline $\mathrm{H}$ & 5.278597 & -1.505898 & 1.614875 \\
\hline $\mathrm{O}$ & -0.457217 & -0.078270 & -1.388531 \\
\hline $\mathrm{O}$ & -0.094409 & 1.111697 & 0.909468 \\
\hline $\mathrm{H}$ & -1.088894 & 0.680531 & 1.525751 \\
\hline $\mathrm{H}$ & 1.713196 & 4.605122 & 1.813371 \\
\hline $\mathrm{H}$ & 0.326456 & 6.951355 & -1.516050 \\
\hline $\mathrm{H}$ & 2.518830 & 3.314841 & -2.202977 \\
\hline $\mathrm{H}$ & 1.724055 & -5.418710 & 0.642948 \\
\hline $\mathrm{H}$ & -2.521554 & -5.868616 & 0.145591 \\
\hline $\mathrm{H}$ & -0.556105 & -2.307298 & -1.260092 \\
\hline C & -2.914665 & -0.108722 & 1.172215 \\
\hline $\mathrm{O}$ & -2.042068 & 0.254718 & 2.049876 \\
\hline $\mathrm{H}$ & -2.586165 & -0.240271 & 0.135647 \\
\hline C & -3.931080 & -1.124608 & 1.674293 \\
\hline $\mathrm{O}$ & -4.386047 & -1.159396 & 2.792485 \\
\hline $\mathrm{O}$ & -4.252990 & -1.982579 & 0.684743 \\
\hline C & -5.157120 & -3.038421 & 1.065046 \\
\hline $\mathrm{H}$ & -4.711151 & -3.643988 & 1.857317 \\
\hline $\mathrm{H}$ & -6.104329 & -2.622038 & 1.415316 \\
\hline C & -4.976499 & 1.213202 & -0.133573 \\
\hline C & -4.092616 & 1.454122 & 0.929816 \\
\hline $\mathrm{H}$ & -5.389753 & 1.193860 & -2.122174 \\
\hline$N$ & -4.676410 & 1.431277 & -1.443383 \\
\hline C & -3.555934 & 2.001251 & -2.112058 \\
\hline $\mathrm{O}$ & -3.557635 & 2.054965 & -3.319932 \\
\hline $\mathrm{O}$ & -2.633228 & 2.440120 & -1.276817 \\
\hline
\end{tabular}




$\begin{array}{llll}\mathrm{C} & -1.420793 & 2.965522 & -1.887144 \\ \mathrm{H} & -1.678047 & 3.788031 & -2.556398 \\ \mathrm{H} & -0.918433 & 2.157760 & -2.417659 \\ \mathrm{H} & -0.818473 & 3.305975 & -1.049224 \\ \mathrm{H} & -4.521018 & 1.431204 & 1.925337 \\ \mathrm{H} & -3.290204 & 2.160557 & 0.773782 \\ \mathrm{C} & -6.299556 & 0.584273 & 0.093227 \\ \mathrm{C} & -7.056631 & 0.927548 & 1.226947 \\ \mathrm{C} & -6.828996 & -0.349954 & -0.818431 \\ \mathrm{C} & -8.313761 & 0.364655 & 1.434184 \\ \mathrm{H} & -6.674058 & 1.658401 & 1.931007 \\ \mathrm{C} & -8.082498 & -0.915877 & -0.603006 \\ \mathrm{H} & -6.239051 & -0.679011 & -1.669540 \\ \mathrm{C} & -8.830608 & -0.556139 & 0.520992 \\ \mathrm{H} & -8.890657 & 0.649476 & 2.308809 \\ \mathrm{H} & -8.471279 & -1.644783 & -1.307997 \\ \mathrm{H} & -9.810423 & -0.995118 & 0.685580 \\ \mathrm{H} & -5.305430 & -3.633920 & 0.164385\end{array}$

Catalyst (R)-1 TS Conformation 310

B3LYP/6-31G(d) Energy = -2809.686422

B3LYP-D3(BJ)/def2-TZVPP-IEF-PCM(DCM) Energy $=-2810.979331$

B3LYP-D3(BJ)/def2-TZVPP-IEF-PCM(DCM)//B3LYP/6-31G(d) Free Energy (Quasiharmonic) = 2810.337024

Frequencies (Top 3 out of 270)

1. $-669.8173 \mathrm{~cm}-1$

2. $\quad 4.7822 \mathrm{~cm}-1$

3. $10.2345 \mathrm{~cm}-1$

B3LYP/6-31G(d) Molecular Geometry in Cartesian Coordinates

$\begin{array}{lrrr}\text { C } & 3.703232 & 0.445447 & 0.122333 \\ \text { C } & 2.811189 & 1.436564 & -0.260441 \\ \text { C } & 2.970119 & 2.810772 & 0.089235 \\ \text { C } & 4.047110 & 3.139788 & 0.889242 \\ \text { H } & 4.213185 & 4.181348 & 1.151754 \\ \text { C } & 3.022169 & -3.624833 & -1.137450 \\ \text { C } & 3.495919 & -0.953431 & -0.358121 \\ \text { C } & 2.280702 & -1.580623 & -0.124453 \\ \text { C } & 2.017922 & -2.936026 & -0.485272\end{array}$




\begin{tabular}{|c|c|c|c|}
\hline $\mathrm{H}$ & 2.864692 & -4.667253 & -1.401979 \\
\hline $\mathrm{O}$ & 1.723186 & 1.085732 & -1.044587 \\
\hline$P$ & 0.466564 & 0.279991 & -0.351859 \\
\hline 0 & 1.277706 & -0.867285 & 0.513479 \\
\hline C & 0.342487 & 5.951600 & -1.234224 \\
\hline C & 0.778067 & 4.980052 & -2.137851 \\
\hline C & 1.610726 & 3.945313 & -1.714901 \\
\hline C & 2.029853 & 3.865046 & -0.375999 \\
\hline C & 1.580739 & 4.845837 & 0.523320 \\
\hline C & 0.745683 & 5.879024 & 0.099642 \\
\hline $\mathrm{H}$ & 0.470735 & 5.027781 & -3.179413 \\
\hline $\mathrm{H}$ & 0.403632 & 6.622157 & 0.815425 \\
\hline C & -1.670387 & -4.983351 & 0.373000 \\
\hline C & -1.064758 & -4.196556 & 1.355418 \\
\hline C & 0.118688 & -3.512653 & 1.080963 \\
\hline C & 0.723771 & -3.604299 & -0.184066 \\
\hline C & 0.101141 & -4.394614 & -1.163853 \\
\hline C & -1.082824 & -5.078278 & -0.889067 \\
\hline $\mathrm{H}$ & -1.513218 & -4.115713 & 2.342255 \\
\hline $\mathrm{H}$ & -1.549531 & -5.678911 & -1.665661 \\
\hline C & 4.501905 & -1.659284 & -1.103447 \\
\hline C & 4.255740 & -3.019478 & -1.480246 \\
\hline C & 5.247491 & -3.733674 & -2.206024 \\
\hline C & 6.425076 & -3.128925 & -2.579057 \\
\hline C & 6.654433 & -1.773775 & -2.243593 \\
\hline C & 5.720684 & -1.059468 & -1.525449 \\
\hline $\mathrm{H}$ & 5.048649 & -4.769126 & -2.472777 \\
\hline $\mathrm{H}$ & 7.172774 & -3.682878 & -3.140147 \\
\hline $\mathrm{H}$ & 7.574293 & -1.289256 & -2.559958 \\
\hline $\mathrm{H}$ & 5.907853 & -0.019304 & -1.285593 \\
\hline C & 4.774962 & 0.792529 & 1.014955 \\
\hline C & 4.947229 & 2.165600 & 1.386002 \\
\hline C & 6.010433 & 2.525002 & 2.258243 \\
\hline C & 6.855675 & 1.571321 & 2.775823 \\
\hline C & 6.663905 & 0.209696 & 2.443217 \\
\hline C & 5.653587 & -0.169063 & 1.586543 \\
\hline $\mathrm{H}$ & 6.134043 & 3.573666 & 2.518780 \\
\hline $\mathrm{H}$ & 7.660811 & 1.857672 & 3.447053 \\
\hline $\mathrm{H}$ & 7.317116 & -0.546166 & 2.871099 \\
\hline $\mathrm{H}$ & 5.514843 & -1.217564 & 1.349808 \\
\hline $\mathrm{O}$ & -0.415229 & -0.251069 & -1.425700 \\
\hline $\mathrm{O}$ & -0.153491 & 1.142358 & 0.763070 \\
\hline $\mathrm{H}$ & -1.317904 & 1.505675 & 0.618394 \\
\hline $\mathrm{H}$ & 1.872076 & 4.780877 & 1.567892 \\
\hline
\end{tabular}




\begin{tabular}{lrrr}
$\mathrm{H}$ & -0.309482 & 6.755366 & -1.566440 \\
$\mathrm{H}$ & 1.943494 & 3.197067 & -2.425718 \\
$\mathrm{H}$ & 0.540105 & -4.452252 & -2.155789 \\
$\mathrm{H}$ & -2.593277 & -5.515531 & 0.589225 \\
$\mathrm{H}$ & 0.583668 & -2.908206 & 1.851994 \\
$\mathrm{C}$ & -3.013767 & 1.380313 & -0.548190 \\
$\mathrm{O}$ & -2.470418 & 1.773656 & 0.555812 \\
$\mathrm{H}$ & -2.368363 & 1.217450 & -1.418447 \\
$\mathrm{C}$ & -4.355374 & 1.992812 & -0.922194 \\
$\mathrm{O}$ & -4.831159 & 1.903193 & -2.038455 \\
$\mathrm{O}$ & -4.942472 & 2.612113 & 0.106616 \\
$\mathrm{C}$ & -6.209762 & 3.236241 & -0.185574 \\
$\mathrm{H}$ & -6.493126 & 3.751793 & 0.731886 \\
$\mathrm{H}$ & -6.953894 & 2.481137 & -0.451973 \\
$\mathrm{C}$ & -4.438162 & -0.746257 & 0.426188 \\
$\mathrm{C}$ & -3.486535 & -0.520318 & -0.582185 \\
$\mathrm{H}$ & -6.353470 & -0.398242 & 1.032374 \\
$\mathrm{~N}$ & -5.788249 & -0.596351 & 0.215415 \\
$\mathrm{C}$ & -6.573310 & -0.486777 & -0.950478 \\
$\mathrm{O}$ & -7.701365 & -0.046351 & -0.883298 \\
$\mathrm{O}$ & -5.965751 & -0.950564 & -2.037484 \\
$\mathrm{C}$ & -6.651272 & -0.692232 & -3.283740 \\
$\mathrm{H}$ & -6.063801 & -1.210373 & -4.040449 \\
$\mathrm{H}$ & -6.659455 & 0.383395 & -3.469913 \\
$\mathrm{H}$ & -7.669846 & -1.081565 & -3.241954 \\
$\mathrm{H}$ & -2.490145 & -0.924117 & -0.438325 \\
$\mathrm{H}$ & -3.832552 & -0.559708 & -1.606298 \\
$\mathrm{C}$ & -4.058888 & -1.029765 & 1.816793 \\
$\mathrm{C}$ & -2.760458 & -0.733657 & 2.278414 \\
$\mathrm{C}$ & -4.980924 & -1.608629 & 2.718129 \\
$\mathrm{C}$ & -2.415437 & -0.971662 & 3.607155 \\
$\mathrm{H}$ & -2.021807 & -0.297158 & 1.622315 \\
$\mathrm{H}$ & -4.621987 & -1.861006 & 4.036131 \\
\hline & -5.966709 & -1.913421 & 2.378596 \\
$\mathrm{H}$ & -3.339578 & -1.532509 & 4.488385 \\
$\mathrm{H}$ & -5.338209 & -2.322150 & 4.709889 \\
$\mathrm{H}$ & -0.101531 & 3.945712 & -1.009257
\end{tabular}

Catalyst (R)-1 TS Conformation 311

B3LYP/6-31G(d) Energy $=-2809.691217$ 
B3LYP-D3(BJ)/def2-TZVPP-IEF-PCM(DCM) Energy $=-2810.979378$

B3LYP-D3(BJ)/def2-TZVPP-IEF-PCM(DCM)//B3LYP/6-31G(d) Free Energy (Quasiharmonic) = 2810.336982

Frequencies (Top 3 out of 270)

1. $-473.7347 \mathrm{~cm}-1$

2. $8.6801 \mathrm{~cm}-1$

3. $12.1210 \mathrm{~cm}-1$

B3LYP/6-31G(d) Molecular Geometry in Cartesian Coordinates

$\begin{array}{lrrr}\text { C } & 3.547222 & 0.676686 & -0.074419 \\ \text { C } & 2.499962 & 1.539336 & -0.350062 \\ \text { C } & 2.575790 & 2.953253 & -0.192442 \\ \text { C } & 3.752846 & 3.466614 & 0.315188 \\ \text { H } & 3.857098 & 4.542704 & 0.426652 \\ \text { C } & 3.190841 & -3.564373 & -0.765089 \\ \text { C } & 3.403240 & -0.776901 & -0.381610 \\ \text { C } & 2.335689 & -1.505325 & 0.128130 \\ \text { C } & 2.215312 & -2.917072 & -0.034063 \\ \text { H } & 3.120504 & -4.640846 & -0.897653 \\ \text { O } & 1.298491 & 0.994022 & -0.799990 \\ \text { P } & 0.374751 & 0.262658 & 0.335807 \\ \text { O } & 1.389332 & -0.872573 & 0.926711 \\ \text { C } & -0.608374 & 5.650760 & -1.237577 \\ \text { C } & 0.049168 & 5.771807 & -0.012882 \\ \text { C } & 1.067501 & 4.881628 & 0.326356 \\ \text { C } & 1.448196 & 3.853734 & -0.551017 \\ \text { C } & 0.772649 & 3.736651 & -1.777585 \\ \text { C } & -0.242973 & 4.629064 & -2.117012 \\ \text { H } & -0.235971 & 6.553873 & 0.685796 \\ \text { H } & -0.746332 & 4.528429 & -3.075321 \\ \text { C } & -0.931130 & -5.378695 & 1.559942 \\ \text { C } & 0.391051 & -5.570969 & 1.963911 \\ \text { C } & 1.401301 & -4.749290 & 1.462304 \\ \text { C } & 1.104416 & -3.715157 & 0.560857 \\ \text { C } & -0.229112 & -3.522851 & 0.169518 \\ \text { C } & -1.236968 & -4.355035 & 0.659444 \\ \text { H } & 0.639534 & -6.363214 & 2.665684 \\ \text { H } & -2.256117 & -4.201233 & 0.316829 \\ \text { C } & 4.346673 & -1.448891 & -1.235742 \\ \text { C } & 4.245392 & -2.867061 & -1.402292 \\ \text { C } & 5.182391 & -3.545198 & -2.228239\end{array}$




\begin{tabular}{|c|c|c|c|}
\hline C & 6.168591 & -2.854936 & -2.893095 \\
\hline C & 6.248362 & -1.448435 & -2.763174 \\
\hline C & 5.364680 & -0.764912 & -1.957326 \\
\hline $\mathrm{H}$ & 5.093245 & -4.623803 & -2.334451 \\
\hline $\mathrm{H}$ & 6.875920 & -3.382268 & -3.527318 \\
\hline $\mathrm{H}$ & 7.010744 & -0.899848 & -3.309756 \\
\hline $\mathrm{H}$ & 5.434961 & 0.313563 & -1.879353 \\
\hline C & 4.735542 & 1.218586 & 0.528810 \\
\hline C & 4.831670 & 2.636772 & 0.709041 \\
\hline C & 6.003566 & 3.187884 & 1.294791 \\
\hline C & 7.030141 & 2.377998 & 1.721240 \\
\hline C & 6.920213 & 0.974581 & 1.582892 \\
\hline C & 5.805901 & 0.410549 & 1.001304 \\
\hline $\mathrm{H}$ & 6.065059 & 4.267229 & 1.412359 \\
\hline $\mathrm{H}$ & 7.917624 & 2.810374 & 2.175163 \\
\hline $\mathrm{H}$ & 7.720335 & 0.333815 & 1.943557 \\
\hline $\mathrm{H}$ & 5.733603 & -0.667003 & 0.912439 \\
\hline 0 & -0.840176 & -0.285910 & -0.336003 \\
\hline $\mathrm{O}$ & 0.205085 & 1.224685 & 1.529386 \\
\hline $\mathrm{H}$ & -0.796763 & 1.635090 & 1.792381 \\
\hline $\mathrm{H}$ & 1.051675 & 2.948923 & -2.469333 \\
\hline $\mathrm{H}$ & -1.401684 & 6.344581 & -1.503668 \\
\hline $\mathrm{H}$ & 1.558971 & 4.964549 & 1.291439 \\
\hline $\mathrm{H}$ & -0.482113 & -2.733128 & -0.529149 \\
\hline $\mathrm{H}$ & -1.717485 & -6.026200 & 1.939988 \\
\hline $\mathrm{H}$ & 2.431092 & -4.901882 & 1.774847 \\
\hline C & -3.020010 & 1.563692 & 1.860966 \\
\hline $\mathrm{O}$ & -1.955439 & 2.238292 & 2.076748 \\
\hline $\mathrm{H}$ & -3.975915 & 2.034555 & 2.133211 \\
\hline C & -3.073287 & 0.071281 & 2.232797 \\
\hline O & -4.042856 & -0.639954 & 2.046620 \\
\hline $\mathrm{O}$ & -1.963451 & -0.311578 & 2.861504 \\
\hline C & -1.920076 & -1.682649 & 3.305294 \\
\hline $\mathrm{H}$ & -1.992946 & -2.358632 & 2.451957 \\
\hline $\mathrm{H}$ & -0.953333 & -1.792961 & 3.794491 \\
\hline C & -4.189236 & 0.612681 & -0.523835 \\
\hline C & -3.336424 & 1.641533 & -0.075817 \\
\hline $\mathrm{H}$ & -2.587813 & -0.619712 & -0.681993 \\
\hline$N$ & -3.605419 & -0.567908 & -0.852945 \\
\hline C & -4.102463 & -1.741379 & -1.435911 \\
\hline $\mathrm{O}$ & -3.437444 & -2.754123 & -1.480008 \\
\hline $\mathrm{O}$ & -5.322048 & -1.594856 & -1.966550 \\
\hline C & -5.861736 & -2.779551 & -2.581291 \\
\hline $\mathrm{H}$ & -5.232959 & -3.092268 & -3.418168 \\
\hline
\end{tabular}




$\begin{array}{llll}\mathrm{H} & -6.854015 & -2.492356 & -2.928154 \\ \mathrm{H} & -5.925106 & -3.592330 & -1.853963 \\ \mathrm{H} & -3.758861 & 2.640293 & -0.076667 \\ \mathrm{H} & -2.301454 & 1.576613 & -0.390657 \\ \mathrm{C} & -5.657574 & 0.816787 & -0.516845 \\ \mathrm{C} & -6.522619 & -0.036574 & 0.188643 \\ \mathrm{C} & -6.184336 & 1.940430 & -1.172616 \\ \mathrm{C} & -7.887335 & 0.232979 & 0.226351 \\ \mathrm{H} & -6.110375 & -0.873281 & 0.739376 \\ \mathrm{C} & -7.555767 & 2.191999 & -1.150825 \\ \mathrm{H} & -5.520312 & 2.601768 & -1.721485 \\ \mathrm{C} & -8.409060 & 1.340491 & -0.448822 \\ \mathrm{H} & -8.546972 & -0.420339 & 0.790675 \\ \mathrm{H} & -7.953573 & 3.055208 & -1.676721 \\ \mathrm{H} & -9.476477 & 1.541930 & -0.420248 \\ \mathrm{H} & -2.738033 & -1.875895 & 4.004227\end{array}$

Catalyst (R)-1 TS Conformation 312

B3LYP/6-31G(d) Energy $=-2809.686257$

B3LYP-D3(BJ)/def2-TZVPP-IEF-PCM(DCM) Energy = -2810.979329

B3LYP-D3(BJ)/def2-TZVPP-IEF-PCM(DCM)//B3LYP/6-31G(d) Free Energy (Quasiharmonic) = 2810.336961

Frequencies (Top 3 out of 270)

1. $-666.1329 \mathrm{~cm}-1$

2. $\quad 6.0168 \mathrm{~cm}-1$

3. $\quad 9.7128 \mathrm{~cm}-1$

B3LYP/6-31G(d) Molecular Geometry in Cartesian Coordinates

$\begin{array}{lrrr}\text { C } & 3.715190 & 0.158942 & 0.195489 \\ \text { C } & 2.976200 & 1.287544 & -0.137532 \\ \text { C } & 3.413479 & 2.613023 & 0.168387 \\ \text { C } & 4.571066 & 2.748113 & 0.909567 \\ \text { H } & 4.921004 & 3.745977 & 1.160823 \\ \text { C } & 2.489550 & -3.744481 & -1.178360 \\ \text { C } & 3.316100 & -1.181870 & -0.326835 \\ \text { C } & 2.035071 & -1.655292 & -0.095391 \\ \text { C } & 1.591520 & -2.951750 & -0.491026 \\ \text { H } & 2.195022 & -4.748933 & -1.471139 \\ \text { O } & 1.824046 & 1.147855 & -0.894115\end{array}$




\begin{tabular}{|c|c|c|c|}
\hline$P$ & 0.481992 & 0.401446 & -0.309349 \\
\hline 0 & 1.139398 & -0.827367 & 0.567854 \\
\hline C & 1.503529 & 6.212139 & -1.220253 \\
\hline C & 0.756939 & 5.250700 & -0.536251 \\
\hline C & 1.354028 & 4.069739 & -0.096133 \\
\hline C & 2.717353 & 3.832633 & -0.330820 \\
\hline C & 3.459770 & 4.807205 & -1.018026 \\
\hline C & 2.859289 & 5.985834 & -1.460401 \\
\hline $\mathrm{H}$ & -0.298684 & 5.419846 & -0.338817 \\
\hline $\mathrm{H}$ & 3.450735 & 6.723206 & -1.997287 \\
\hline C & -2.320552 & -4.527000 & 0.371465 \\
\hline C & -1.769680 & -4.653969 & -0.904447 \\
\hline C & -0.510475 & -4.121808 & -1.180260 \\
\hline C & 0.225130 & -3.453915 & -0.187694 \\
\hline C & -0.343693 & -3.326834 & 1.091128 \\
\hline C & -1.602196 & -3.860267 & 1.366928 \\
\hline $\mathrm{H}$ & -2.322550 & -5.162065 & -1.690472 \\
\hline $\mathrm{H}$ & -2.020009 & -3.757717 & 2.365050 \\
\hline C & 4.213041 & -1.988114 & -1.111237 \\
\hline C & 3.786798 & -3.292501 & -1.523520 \\
\hline C & 4.666643 & -4.106634 & -2.287266 \\
\hline C & 5.907281 & -3.648352 & -2.664341 \\
\hline C & 6.314880 & -2.345164 & -2.294943 \\
\hline C & 5.492742 & -1.538593 & -1.538920 \\
\hline $\mathrm{H}$ & 4.330696 & -5.098666 & -2.580204 \\
\hline $\mathrm{H}$ & 6.568434 & -4.276777 & -3.254817 \\
\hline $\mathrm{H}$ & 7.284561 & -1.973514 & -2.615127 \\
\hline $\mathrm{H}$ & 5.817308 & -0.539324 & -1.274363 \\
\hline C & 4.861075 & 0.313249 & 1.050567 \\
\hline C & 5.292990 & 1.632790 & 1.399060 \\
\hline C & 6.427107 & 1.799010 & 2.239279 \\
\hline C & 7.101546 & 0.710585 & 2.741649 \\
\hline C & 6.658464 & -0.595402 & 2.425966 \\
\hline C & 5.570917 & -0.789079 & 1.602686 \\
\hline $\mathrm{H}$ & 6.744523 & 2.809399 & 2.486617 \\
\hline $\mathrm{H}$ & 7.963985 & 0.849500 & 3.387929 \\
\hline $\mathrm{H}$ & 7.177362 & -1.455057 & 2.841708 \\
\hline $\mathrm{H}$ & 5.238406 & -1.796428 & 1.379986 \\
\hline $\mathrm{O}$ & -0.371543 & -0.030217 & -1.448520 \\
\hline $\mathrm{O}$ & -0.159928 & 1.272289 & 0.793511 \\
\hline $\mathrm{H}$ & -1.316397 & 1.651090 & 0.583742 \\
\hline $\mathrm{H}$ & 4.512188 & 4.627217 & -1.220937 \\
\hline $\mathrm{H}$ & 1.032430 & 7.129331 & -1.564449 \\
\hline $\mathrm{H}$ & 0.768722 & 3.334995 & 0.444832 \\
\hline
\end{tabular}




\begin{tabular}{|c|c|c|c|}
\hline $\mathrm{H}$ & 0.208183 & -2.815302 & 1.872195 \\
\hline $\mathrm{H}$ & -3.301066 & -4.942902 & 0.588923 \\
\hline $\mathrm{H}$ & -0.097460 & -4.202027 & -2.181648 \\
\hline$C$ & -2.970698 & 1.486628 & -0.625027 \\
\hline 0 & -2.449412 & 1.956891 & 0.456778 \\
\hline $\mathrm{H}$ & -2.305386 & 1.210750 & -1.450085 \\
\hline C & -4.291030 & 2.081804 & -1.085186 \\
\hline 0 & -4.743159 & 1.892303 & -2.198457 \\
\hline $\mathrm{O}$ & -4.886314 & 2.809878 & -0.135398 \\
\hline C & -6.134811 & 3.425043 & -0.516643 \\
\hline $\mathrm{H}$ & -6.431861 & 4.025608 & 0.342893 \\
\hline $\mathrm{H}$ & -5.992416 & 4.055510 & -1.397429 \\
\hline C & -4.490461 & -0.524969 & 0.486324 \\
\hline C & -3.501029 & -0.434659 & -0.501321 \\
\hline $\mathrm{H}$ & -6.410874 & -0.052364 & 0.985883 \\
\hline$N$ & -5.828007 & -0.351753 & 0.213541 \\
\hline C & -6.571007 & -0.339837 & -0.983428 \\
\hline $\mathrm{O}$ & -7.688039 & 0.132712 & -1.000423 \\
\hline $\mathrm{O}$ & -5.941238 & -0.923965 & -1.997853 \\
\hline C & -6.580463 & -0.775788 & -3.285841 \\
\hline $\mathrm{H}$ & -5.980012 & -1.375418 & -3.968585 \\
\hline $\mathrm{H}$ & -6.560590 & 0.276469 & -3.575775 \\
\hline $\mathrm{H}$ & -7.607907 & -1.140882 & -3.241685 \\
\hline $\mathrm{H}$ & -2.523014 & -0.843623 & -0.276334 \\
\hline $\mathrm{H}$ & -3.806125 & -0.548212 & -1.532366 \\
\hline C & -4.168347 & -0.683060 & 1.912370 \\
\hline C & -2.876545 & -0.387775 & 2.392560 \\
\hline C & -5.140790 & -1.140790 & 2.829480 \\
\hline C & -2.585211 & -0.509804 & 3.749422 \\
\hline $\mathrm{H}$ & -2.099047 & -0.044510 & 1.725702 \\
\hline C & -4.836547 & -1.277085 & 4.178448 \\
\hline $\mathrm{H}$ & -6.125290 & -1.442841 & 2.483966 \\
\hline C & -3.559091 & -0.951220 & 4.645156 \\
\hline $\mathrm{H}$ & -1.588500 & -0.259212 & 4.099179 \\
\hline $\mathrm{H}$ & -5.592371 & -1.646181 & 4.865532 \\
\hline $\mathrm{H}$ & -3.323762 & -1.053790 & 5.700790 \\
\hline $\mathrm{H}$ & -6.884995 & 2.660596 & -0.734769 \\
\hline
\end{tabular}

Catalyst (R)-1 TS Conformation 313

B3LYP/6-31G(d) Energy $=-2809.686108$

B3LYP-D3(BJ)/def2-TZVPP-IEF-PCM(DCM) Energy = -2810.979162 
B3LYP-D3(BJ)/def2-TZVPP-IEF-PCM(DCM)//B3LYP/6-31G(d) Free Energy (Quasiharmonic) = 2810.336935

Frequencies (Top 3 out of 270)

1. $-665.2612 \mathrm{~cm}-1$

2. $\quad 2.9071 \mathrm{~cm}-1$

3. $\quad 9.4625 \mathrm{~cm}-1$

B3LYP/6-31G(d) Molecular Geometry in Cartesian Coordinates

$\begin{array}{llll}\text { C } & 3.465017 & -1.039100 & -0.088869 \\ \text { C } & 2.208744 & -1.582594 & 0.130952 \\ \text { C } & 1.921710 & -2.973429 & 0.000693 \\ \text { C } & 2.954621 & -3.800258 & -0.394454 \\ \text { H } & 2.776177 & -4.869088 & -0.480468 \\ \text { C } & 4.047181 & 3.211561 & 0.367251 \\ \text { C } & 3.673312 & 0.424745 & 0.123363 \\ \text { C } & 2.861447 & 1.334510 & -0.540454 \\ \text { C } & 3.042167 & 2.748119 & -0.459919 \\ \text { H } & 4.230319 & 4.281062 & 0.429258 \\ \text { O } & 1.178190 & -0.735658 & 0.507315 \\ \text { P } & 0.498970 & 0.221264 & -0.653971 \\ \text { O } & 1.844409 & 0.854850 & -1.352034 \\ \text { C } & -1.973712 & -4.652955 & 0.733172 \\ \text { C } & -1.420126 & -3.751740 & 1.646220 \\ \text { C } & -0.164904 & -3.192002 & 1.411392 \\ \text { C } & 0.564794 & -3.525461 & 0.257335 \\ \text { C } & -0.003625 & -4.431965 & -0.651633 \\ \text { C } & -1.259751 & -4.991238 & -0.416861 \\ \text { H } & -1.965862 & -3.486070 & 2.548066 \\ \text { H } & -1.683440 & -5.683471 & -1.139793 \\ \text { C } & 0.711519 & 5.615855 & -2.665687 \\ \text { C } & 0.983353 & 5.813724 & -1.311477 \\ \text { C } & 1.720893 & 4.868024 & -0.600368 \\ \text { C } & 2.201978 & 3.706597 & -1.226713 \\ \text { C } & 1.915166 & 3.515911 & -2.589012 \\ \text { C } & 1.179870 & 4.463081 & -3.299397 \\ \text { H } & 0.614788 & 6.701485 & -0.803753 \\ \text { H } & 0.973919 & 4.299120 & -4.353967 \\ \text { C } & 4.662602 & 0.926092 & 1.037510 \\ \text { C } & 4.852103 & 2.342153 & 1.142780 \\ \text { C } & 5.836043 & 2.850727 & 2.033763 \\ \text { C } & 6.585707 & 2.005873 & 2.818602\end{array}$




\begin{tabular}{|c|c|c|c|}
\hline C & 6.373528 & 0.608936 & 2.746365 \\
\hline C & 5.439993 & 0.083722 & 1.879952 \\
\hline $\mathrm{H}$ & 5.975515 & 3.927844 & 2.090607 \\
\hline $\mathrm{H}$ & 7.330516 & 2.406916 & 3.500671 \\
\hline $\mathrm{H}$ & 6.949615 & -0.056762 & 3.383583 \\
\hline $\mathrm{H}$ & 5.283702 & -0.988152 & 1.843692 \\
\hline C & 4.510977 & -1.900271 & -0.569020 \\
\hline C & 4.244484 & -3.302056 & -0.703098 \\
\hline C & 5.273559 & -4.167317 & -1.164138 \\
\hline C & 6.509542 & -3.675254 & -1.513309 \\
\hline C & 6.762961 & -2.286551 & -1.421061 \\
\hline C & 5.792306 & -1.423666 & -0.961485 \\
\hline $\mathrm{H}$ & 5.057379 & -5.229859 & -1.248311 \\
\hline $\mathrm{H}$ & 7.285966 & -4.345781 & -1.871437 \\
\hline $\mathrm{H}$ & 7.731362 & -1.895053 & -1.720906 \\
\hline $\mathrm{H}$ & 5.999902 & -0.361400 & -0.907012 \\
\hline $\mathrm{O}$ & -0.381698 & 1.203380 & 0.040495 \\
\hline $\mathrm{O}$ & -0.082139 & -0.662136 & -1.764089 \\
\hline $\mathrm{H}$ & -1.289645 & -0.723715 & -1.881677 \\
\hline $\mathrm{H}$ & 0.535175 & -4.676846 & -1.562385 \\
\hline $\mathrm{H}$ & -2.953350 & -5.086139 & 0.917403 \\
\hline $\mathrm{H}$ & 0.258093 & -2.495478 & 2.127157 \\
\hline $\mathrm{H}$ & 2.274299 & 2.625306 & -3.092463 \\
\hline $\mathrm{H}$ & 0.135574 & 6.350914 & -3.221965 \\
\hline $\mathrm{H}$ & 1.909714 & 5.016533 & 0.459205 \\
\hline C & -3.076757 & -0.859445 & -0.855645 \\
\hline $\mathrm{O}$ & -2.470926 & -0.852269 & -1.992401 \\
\hline $\mathrm{H}$ & -2.495431 & -1.044632 & 0.054578 \\
\hline C & -4.441998 & -1.531881 & -0.865466 \\
\hline $\mathrm{O}$ & -5.194055 & -1.571893 & -1.813085 \\
\hline $\mathrm{O}$ & -4.708363 & -2.067352 & 0.342176 \\
\hline C & -5.976224 & -2.748305 & 0.448589 \\
\hline $\mathrm{H}$ & -6.800707 & -2.057463 & 0.254866 \\
\hline $\mathrm{H}$ & -6.021962 & -3.571479 & -0.268419 \\
\hline C & -4.430016 & 1.096175 & 0.608622 \\
\hline C & -3.582646 & 0.999328 & -0.512167 \\
\hline $\mathrm{H}$ & -6.270902 & 0.691363 & 1.378855 \\
\hline$N$ & -5.789725 & 0.930422 & 0.520814 \\
\hline C & -6.693882 & 0.845032 & -0.559672 \\
\hline $\mathrm{O}$ & -7.806981 & 0.399983 & -0.376186 \\
\hline $\mathrm{O}$ & -6.205921 & 1.323851 & -1.697403 \\
\hline C & -7.017611 & 1.077372 & -2.869278 \\
\hline $\mathrm{H}$ & -8.025769 & 1.466368 & -2.717531 \\
\hline $\mathrm{H}$ & -7.044139 & 0.003654 & -3.062975 \\
\hline
\end{tabular}




$\begin{array}{llll}\mathrm{H} & -6.510763 & 1.603160 & -3.677121 \\ \mathrm{H} & -2.574565 & 1.389392 & -0.397612 \\ \mathrm{H} & -4.035499 & 1.157459 & -1.480794 \\ \mathrm{C} & -3.919914 & 1.260959 & 1.982425 \\ \mathrm{C} & -4.773439 & 1.654339 & 3.037726 \\ \mathrm{C} & -2.554665 & 1.050495 & 2.265435 \\ \mathrm{C} & -4.286474 & 1.798565 & 4.331702 \\ \mathrm{H} & -5.812965 & 1.908388 & 2.850545 \\ \mathrm{C} & -2.077886 & 1.191603 & 3.566259 \\ \mathrm{H} & -1.847791 & 0.804337 & 1.478961 \\ \mathrm{C} & -2.937231 & 1.555777 & 4.603481 \\ \mathrm{H} & -4.957123 & 2.114575 & 5.125416 \\ \mathrm{H} & -1.022584 & 1.024510 & 3.759375 \\ \mathrm{H} & -2.557504 & 1.668478 & 5.615187 \\ \mathrm{H} & -6.016923 & -3.126199 & 1.470269\end{array}$

Catalyst (R)-1 TS Conformation 314

B3LYP/6-31G(d) Energy $=-2809.689552$

B3LYP-D3(BJ)/def2-TZVPP-IEF-PCM(DCM) Energy $=-2810.980185$

B3LYP-D3(BJ)/def2-TZVPP-IEF-PCM(DCM)//B3LYP/6-31G(d) Free Energy (Quasiharmonic) = 2810.33688

Frequencies (Top 3 out of 270)

1. $-334.4059 \mathrm{~cm}-1$

2. $\quad 8.5599 \mathrm{~cm}-1$

3. $16.9553 \mathrm{~cm}-1$

B3LYP/6-31G(d) Molecular Geometry in Cartesian Coordinates

$\begin{array}{llll}\text { C } & 3.106824 & -0.608391 & -0.492449 \\ \text { C } & 1.983948 & -1.403452 & -0.297969 \\ \text { C } & 1.954569 & -2.788375 & -0.636923 \\ \text { C } & 3.074516 & -3.332028 & -1.231830 \\ \text { H } & 3.072984 & -4.387042 & -1.493423 \\ \text { C } & 3.207558 & 3.510319 & 0.782334 \\ \text { C } & 3.146539 & 0.793507 & 0.019092 \\ \text { C } & 2.150530 & 1.683814 & -0.346483 \\ \text { C } & 2.162152 & 3.068014 & -0.004989 \\ \text { H } & 3.267442 & 4.564534 & 1.039494 \\ \text { O } & 0.872057 & -0.891100 & 0.352597 \\ \text { P } & -0.028971 & 0.343272 & -0.238325\end{array}$




\begin{tabular}{|c|c|c|c|}
\hline $\mathrm{O}$ & 1.080272 & 1.195601 & -1.091706 \\
\hline C & -1.301472 & -5.518810 & 0.049575 \\
\hline C & -0.090470 & -5.675955 & 0.723618 \\
\hline C & 0.947253 & -4.764834 & 0.516560 \\
\hline C & 0.787185 & -3.673797 & -0.350677 \\
\hline C & -0.442452 & -3.510897 & -1.008430 \\
\hline C & -1.472485 & -4.436577 & -0.820215 \\
\hline $\mathrm{H}$ & 0.055563 & -6.514160 & 1.400355 \\
\hline $\mathrm{H}$ & -2.394864 & -4.318880 & -1.382899 \\
\hline C & -0.787097 & 5.908404 & -1.325979 \\
\hline C & -0.275369 & 4.967412 & -2.221786 \\
\hline C & 0.663477 & 4.028245 & -1.798417 \\
\hline C & 1.112925 & 4.014626 & -0.467148 \\
\hline C & 0.585544 & 4.962466 & 0.425014 \\
\hline C & -0.354202 & 5.900834 & 0.000620 \\
\hline $\mathrm{H}$ & -0.606138 & 4.964169 & -3.257049 \\
\hline $\mathrm{H}$ & -0.753607 & 6.620915 & 0.710288 \\
\hline C & 4.180756 & 1.252216 & 0.907625 \\
\hline C & 4.206743 & 2.636242 & 1.276761 \\
\hline C & 5.228978 & 3.108011 & 2.144499 \\
\hline C & 6.171604 & 2.249833 & 2.660884 \\
\hline C & 6.123690 & 0.875012 & 2.331426 \\
\hline C & 5.157534 & 0.390014 & 1.477303 \\
\hline $\mathrm{H}$ & 5.241712 & 4.164232 & 2.403165 \\
\hline $\mathrm{H}$ & 6.943857 & 2.620899 & 3.329177 \\
\hline $\mathrm{H}$ & 6.853724 & 0.193175 & 2.759313 \\
\hline $\mathrm{H}$ & 5.129958 & -0.667569 & 1.242715 \\
\hline C & 4.220706 & -1.160273 & -1.218092 \\
\hline C & 4.204511 & -2.548076 & -1.568567 \\
\hline C & 5.306286 & -3.108434 & -2.269693 \\
\hline C & 6.377104 & -2.329983 & -2.641921 \\
\hline C & 6.380393 & -0.949652 & -2.332124 \\
\hline C & 5.334446 & -0.381090 & -1.639116 \\
\hline $\mathrm{H}$ & 5.277374 & -4.166548 & -2.519081 \\
\hline $\mathrm{H}$ & 7.211319 & -2.766463 & -3.184257 \\
\hline $\mathrm{H}$ & 7.213644 & -0.328824 & -2.650176 \\
\hline $\mathrm{H}$ & 5.349811 & 0.680369 & -1.421890 \\
\hline $\mathrm{O}$ & -0.677683 & 1.076448 & 0.875610 \\
\hline $\mathrm{O}$ & -0.937617 & -0.250175 & -1.356581 \\
\hline $\mathrm{H}$ & -1.971190 & 0.096385 & -1.341490 \\
\hline $\mathrm{H}$ & -0.586694 & -2.674854 & -1.684997 \\
\hline $\mathrm{H}$ & -2.101741 & -6.242161 & 0.186117 \\
\hline $\mathrm{H}$ & 1.894970 & -4.896319 & 1.032014 \\
\hline $\mathrm{H}$ & 0.900126 & 4.945345 & 1.464666 \\
\hline
\end{tabular}




\begin{tabular}{llll}
$\mathrm{H}$ & -1.520386 & 6.638367 & -1.658921 \\
$\mathrm{H}$ & 1.055824 & 3.304482 & -2.504337 \\
$\mathrm{C}$ & -3.625537 & 1.220946 & -0.312084 \\
$\mathrm{O}$ & -3.289202 & 0.503677 & -1.329353 \\
$\mathrm{H}$ & -2.833471 & 1.622642 & 0.329148 \\
$\mathrm{C}$ & -4.773296 & 2.202501 & -0.551723 \\
$\mathrm{O}$ & -5.581300 & 2.136341 & -1.450278 \\
$\mathrm{O}$ & -4.769918 & 3.163720 & 0.396995 \\
$\mathrm{C}$ & -5.803364 & 4.154769 & 0.274094 \\
$\mathrm{H}$ & -5.652964 & 4.840589 & 1.108129 \\
$\mathrm{H}$ & -5.714019 & 4.682771 & -0.678805 \\
$\mathrm{C}$ & -3.799490 & -1.031716 & 1.091620 \\
$\mathrm{C}$ & -4.553768 & 0.158206 & 1.020598 \\
$\mathrm{H}$ & -2.948188 & -2.542906 & 0.041167 \\
$\mathrm{~N}$ & -3.731698 & -1.891986 & 0.046347 \\
$\mathrm{C}$ & -4.408170 & -1.917108 & -1.203615 \\
$\mathrm{O}$ & -3.956664 & -2.558931 & -2.124060 \\
$\mathrm{O}$ & -5.578250 & -1.284379 & -1.173523 \\
$\mathrm{C}$ & -6.162758 & -1.011081 & -2.468719 \\
$\mathrm{H}$ & -7.161369 & -0.632950 & -2.254718 \\
$\mathrm{H}$ & -5.563469 & -0.243994 & -2.960690 \\
$\mathrm{H}$ & -6.203894 & -1.924923 & -3.063076 \\
$\mathrm{H}$ & -4.604619 & 0.735957 & 1.937558 \\
$\mathrm{H}$ & -5.487895 & 0.086485 & 0.479792 \\
$\mathrm{C}$ & -2.945891 & -1.368391 & 2.245918 \\
$\mathrm{C}$ & -2.722074 & -2.715958 & 2.589035 \\
$\mathrm{H}$ & -2.365886 & -0.358731 & 3.035410 \\
$\mathrm{H}$ & -1.943291 & -3.042916 & 3.695203 \\
$\mathrm{H}$ & -3.183108 & -3.511659 & 2.012003 \\
$\mathrm{H}$ & -1.579009 & -0.693762 & 4.132166 \\
$\mathrm{H}$ & -2.473007 & 0.680939 & 2.753077 \\
\hline & -1.369312 & -2.032965 & 4.468952 \\
$\mathrm{H}$ & -1.786559 & -4.086606 & 3.950544 \\
$\mathrm{H}$ & & 0.095268 & 4.715072 \\
$\mathrm{H}$ & -2.288272 & 5.328212 \\
$\mathrm{H}$ & -3546 & 3.688982 & 0.330474
\end{tabular}

Catalyst (R)-1 TS Conformation 315

B3LYP/6-31G(d) Energy $=-2809.688957$

B3LYP-D3(BJ)/def2-TZVPP-IEF-PCM(DCM) Energy $=-2810.979928$

B3LYP-D3(BJ)/def2-TZVPP-IEF-PCM(DCM)//B3LYP/6-31G(d) Free Energy (Quasiharmonic) = 2810.336821 
Frequencies (Top 3 out of 270)

1. $-303.6533 \mathrm{~cm}-1$

2. $\quad 11.0766 \mathrm{~cm}-1$

3. $\quad 12.5594 \mathrm{~cm}-1$

B3LYP/6-31G(d) Molecular Geometry in Cartesian Coordinates

$\begin{array}{llll}\text { C } & 3.082697 & -1.056360 & -0.405148 \\ \text { C } & 1.854268 & -1.608568 & -0.079249 \\ \text { C } & 1.453564 & -2.918013 & -0.471427 \\ \text { C } & 2.328835 & -3.644811 & -1.252605 \\ \text { H } & 2.058605 & -4.653628 & -1.554129 \\ \text { C } & 4.027947 & 2.951161 & 0.877351 \\ \text { C } & 3.427668 & 0.308717 & 0.092071 \\ \text { C } & 2.573887 & 1.367531 & -0.181375 \\ \text { C } & 2.861026 & 2.718717 & 0.174666 \\ \text { H } & 4.291789 & 3.971916 & 1.141100 \\ \text { O } & 0.960702 & -0.856201 & 0.675141 \\ \text { P } & 0.165734 & 0.372482 & -0.062586 \\ \text { O } & 1.393086 & 1.107704 & -0.866062 \\ \text { C } & -2.303534 & -4.669739 & 0.673338 \\ \text { C } & -1.920767 & -4.633804 & -0.670003 \\ \text { C } & -0.705739 & -4.053238 & -1.034107 \\ \text { C } & 0.142174 & -3.491733 & -0.067353 \\ \text { C } & -0.259688 & -3.518864 & 1.277972 \\ \text { C } & -1.467583 & -4.109370 & 1.645463 \\ \text { H } & -2.573518 & -5.040260 & -1.436155 \\ \text { H } & -1.755872 & -4.131628 & 2.692459 \\ \text { C } & 0.383163 & 6.079119 & -0.865348 \\ \text { C } & 0.654727 & 5.092723 & -1.815709 \\ \text { C } & 1.435462 & 3.987407 & -1.482164 \\ \text { C } & 1.965925 & 3.849693 & -0.188311 \\ \text { C } & 1.680691 & 4.846072 & 0.759402 \\ \text { C } & 0.897501 & 5.950137 & 0.425291 \\ \text { H } & 0.259999 & 5.183989 & -2.824316 \\ \text { H } & 0.683905 & 6.705567 & 1.177166 \\ \text { C } & 4.598780 & 0.557903 & 0.886341 \\ \text { C } & 4.898756 & 1.905341 & 1.269205 \\ \text { C } & 6.060182 & 2.167831 & 2.045600 \\ \text { C } & 6.881435 & 1.145104 & 2.459416 \\ \text { C } & 6.566946 & -0.190698 & 2.115196 \\ \text { C } & 5.458119 & -0.476591 & 1.349298\end{array}$




\begin{tabular}{|c|c|c|c|}
\hline $\mathrm{H}$ & 6.279902 & 3.197850 & 2.316694 \\
\hline $\mathrm{H}$ & 7.762924 & 1.357520 & 3.058185 \\
\hline $\mathrm{H}$ & 7.203782 & -1.000081 & 2.462010 \\
\hline $\mathrm{H}$ & 5.226104 & -1.506048 & 1.101925 \\
\hline C & 3.958551 & -1.799086 & -1.270532 \\
\hline C & 3.570980 & -3.115885 & -1.682727 \\
\hline C & 4.431103 & -3.863358 & -2.532056 \\
\hline C & 5.614007 & -3.330330 & -2.988320 \\
\hline C & 5.980771 & -2.015919 & -2.615693 \\
\hline C & 5.176987 & -1.271449 & -1.780523 \\
\hline $\mathrm{H}$ & 4.126283 & -4.865242 & -2.825225 \\
\hline $\mathrm{H}$ & 6.260134 & -3.908798 & -3.642903 \\
\hline $\mathrm{H}$ & 6.903392 & -1.586214 & -2.996488 \\
\hline $\mathrm{H}$ & 5.468185 & -0.262192 & -1.514271 \\
\hline $\mathrm{O}$ & -0.532966 & 1.203355 & 0.948336 \\
\hline $\mathrm{O}$ & -0.656788 & -0.248949 & -1.227550 \\
\hline $\mathrm{H}$ & -1.679792 & 0.074514 & -1.331529 \\
\hline $\mathrm{H}$ & 0.380316 & -3.081009 & 2.036829 \\
\hline $\mathrm{H}$ & -3.240193 & -5.141581 & 0.961894 \\
\hline $\mathrm{H}$ & -0.421826 & -4.005685 & -2.081121 \\
\hline $\mathrm{H}$ & 2.059933 & 4.739796 & 1.771931 \\
\hline $\mathrm{H}$ & -0.227426 & 6.939130 & -1.128101 \\
\hline $\mathrm{H}$ & 1.642462 & 3.229587 & -2.229727 \\
\hline C & -3.338459 & 1.452170 & -0.697959 \\
\hline $\mathrm{O}$ & -2.985936 & 0.529944 & -1.527343 \\
\hline $\mathrm{H}$ & -2.590185 & 1.834984 & 0.006425 \\
\hline C & -4.224442 & 2.559468 & -1.277300 \\
\hline $\mathrm{O}$ & -4.885931 & 2.477044 & -2.287396 \\
\hline 0 & -4.173861 & 3.655632 & -0.490552 \\
\hline C & -4.960966 & 4.772516 & -0.935796 \\
\hline $\mathrm{H}$ & -4.802092 & 5.556985 & -0.195604 \\
\hline $\mathrm{H}$ & -4.629620 & 5.102994 & -1.923621 \\
\hline C & -4.185296 & -0.485129 & 0.935155 \\
\hline C & -4.630981 & 0.802007 & 0.563102 \\
\hline $\mathrm{H}$ & -3.562730 & -2.317220 & 0.324123 \\
\hline$N$ & -4.143898 & -1.519650 & 0.066680 \\
\hline C & -4.591764 & -1.637154 & -1.282770 \\
\hline $\mathrm{O}$ & -4.156158 & -2.511353 & -1.991568 \\
\hline $\mathrm{O}$ & -5.571445 & -0.783500 & -1.570606 \\
\hline C & -5.854166 & -0.629022 & -2.981157 \\
\hline $\mathrm{H}$ & -6.743758 & -0.002707 & -3.024943 \\
\hline $\mathrm{H}$ & -5.009657 & -0.120175 & -3.447166 \\
\hline $\mathrm{H}$ & -6.031743 & -1.604063 & -3.437508 \\
\hline $\mathrm{H}$ & -4.692535 & 1.516762 & 1.378066 \\
\hline
\end{tabular}




$\begin{array}{lrrr}\text { H } & -5.472772 & 0.816315 & -0.117381 \\ \mathrm{C} & -3.656448 & -0.769228 & 2.286450 \\ \mathrm{C} & -4.089494 & -1.924409 & 2.962313 \\ \mathrm{C} & -2.771075 & 0.115979 & 2.924521 \\ \mathrm{C} & -3.659915 & -2.179291 & 4.263012 \\ \mathrm{H} & -4.794230 & -2.598508 & 2.483376 \\ \mathrm{C} & -2.325751 & -0.163216 & 4.214642 \\ \mathrm{H} & -2.371214 & 0.970234 & 2.390285 \\ \mathrm{C} & -2.774257 & -1.300564 & 4.890212 \\ \mathrm{H} & -4.020344 & -3.060602 & 4.786223 \\ \mathrm{H} & -1.616464 & 0.509151 & 4.687845 \\ \mathrm{H} & -2.432182 & -1.503616 & 5.901304 \\ \mathrm{H} & -6.018878 & 4.500261 & -0.989119\end{array}$

Catalyst (R)-1 TS Conformation 316

B3LYP/6-31G(d) Energy $=-2809.689848$

B3LYP-D3(BJ)/def2-TZVPP-IEF-PCM(DCM) Energy = -2810.980691

B3LYP-D3(BJ)/def2-TZVPP-IEF-PCM(DCM)//B3LYP/6-31G(d) Free Energy (Quasiharmonic) = 2810.336811

Frequencies (Top 3 out of 270)

1. $-292.8796 \mathrm{~cm}-1$

2. $\quad 10.0224 \mathrm{~cm}-1$

3. $\quad 17.8133 \mathrm{~cm}-1$

B3LYP/6-31G(d) Molecular Geometry in Cartesian Coordinates

$\begin{array}{llll}\text { C } & 2.817135 & -1.233580 & -0.365855 \\ \text { C } & 1.552486 & -1.751664 & -0.136242 \\ \text { C } & 1.198301 & -3.093335 & -0.473106 \\ \text { C } & 2.120787 & -3.834114 & -1.186233 \\ \text { H } & 1.871502 & -4.855133 & -1.462597 \\ \text { C } & 4.211566 & 2.567819 & 1.065747 \\ \text { C } & 3.240939 & 0.058635 & 0.246028 \\ \text { C } & 2.532742 & 1.224779 & 0.004034 \\ \text { C } & 3.039152 & 2.518060 & 0.335516 \\ \text { H } & 4.613414 & 3.538360 & 1.343784 \\ \text { O } & 0.626689 & -0.988081 & 0.566501 \\ \text { P } & 0.035919 & 0.426532 & -0.003647 \\ \text { O } & 1.331667 & 1.139295 & -0.696510 \\ \text { C } & -2.368218 & -5.131518 & 0.799759\end{array}$




\begin{tabular}{|c|c|c|c|}
\hline$C$ & -2.472574 & -3.916999 & 0.119568 \\
\hline C & -1.328390 & -3.225729 & -0.280590 \\
\hline C & -0.056326 & -3.750024 & -0.012272 \\
\hline C & 0.038797 & -4.973696 & 0.673705 \\
\hline C & -1.106066 & -5.658731 & 1.078612 \\
\hline $\mathrm{H}$ & -3.443823 & -3.494629 & -0.116209 \\
\hline $\mathrm{H}$ & -1.010126 & -6.601368 & 1.611954 \\
\hline C & 1.435681 & 6.267076 & -1.031107 \\
\hline C & 2.778694 & 5.945885 & -1.233284 \\
\hline C & 3.272634 & 4.718237 & -0.796202 \\
\hline C & 2.436091 & 3.789332 & -0.151496 \\
\hline C & 1.087011 & 4.119180 & 0.040112 \\
\hline C & 0.596596 & 5.351161 & -0.395081 \\
\hline $\mathrm{H}$ & 3.441508 & 6.645970 & -1.735818 \\
\hline $\mathrm{H}$ & -0.449774 & 5.582822 & -0.227957 \\
\hline C & 4.408467 & 0.121938 & 1.085258 \\
\hline C & 4.889956 & 1.403841 & 1.499574 \\
\hline C & 6.038423 & 1.484672 & 2.332730 \\
\hline C & 6.680506 & 0.347142 & 2.763497 \\
\hline C & 6.190816 & -0.923114 & 2.378849 \\
\hline C & 5.088270 & -1.033461 & 1.559968 \\
\hline $\mathrm{H}$ & 6.393485 & 2.468181 & 2.631570 \\
\hline $\mathrm{H}$ & 7.554235 & 0.419865 & 3.405441 \\
\hline $\mathrm{H}$ & 6.685519 & -1.821795 & 2.737499 \\
\hline $\mathrm{H}$ & 4.720009 & -2.014798 & 1.284531 \\
\hline C & 3.726623 & -1.979158 & -1.196170 \\
\hline C & 3.362052 & -3.300049 & -1.607563 \\
\hline C & 4.249216 & -4.048904 & -2.427015 \\
\hline C & 5.443608 & -3.512992 & -2.848882 \\
\hline C & 5.794541 & -2.196361 & -2.468789 \\
\hline C & 4.962208 & -1.451309 & -1.662347 \\
\hline $\mathrm{H}$ & 3.957170 & -5.053628 & -2.723584 \\
\hline $\mathrm{H}$ & 6.111878 & -4.091294 & -3.481124 \\
\hline $\mathrm{H}$ & 6.727371 & -1.764900 & -2.821743 \\
\hline $\mathrm{H}$ & 5.241568 & -0.439949 & -1.391296 \\
\hline 0 & -0.544886 & 1.162211 & 1.161598 \\
\hline 0 & -0.879222 & 0.119128 & -1.214544 \\
\hline $\mathrm{H}$ & -1.842713 & 0.638426 & -1.353219 \\
\hline $\mathrm{H}$ & 1.021068 & -5.379309 & 0.901294 \\
\hline $\mathrm{H}$ & -3.263586 & -5.665515 & 1.109323 \\
\hline $\mathrm{H}$ & -1.433338 & -2.292258 & -0.820233 \\
\hline $\mathrm{H}$ & 0.420553 & 3.429288 & 0.544274 \\
\hline $\mathrm{H}$ & 1.046066 & 7.223987 & -1.370073 \\
\hline $\mathrm{H}$ & 4.314304 & 4.462300 & -0.970605 \\
\hline
\end{tabular}




$\begin{array}{lrrr}\mathrm{C} & -4.161838 & 0.948999 & -1.727680 \\ \mathrm{O} & -2.942749 & 1.405722 & -1.631371 \\ \mathrm{H} & -4.813897 & 1.507495 & -2.415546 \\ \mathrm{C} & -4.335964 & -0.552557 & -1.957635 \\ \mathrm{O} & -3.588173 & -1.413968 & -1.555219 \\ \mathrm{O} & -5.464793 & -0.798197 & -2.658498 \\ \mathrm{C} & -5.735341 & -2.184815 & -2.929898 \\ \mathrm{H} & -4.900352 & -2.637838 & -3.469697 \\ \mathrm{H} & -5.896374 & -2.734194 & -1.997947 \\ \mathrm{C} & -4.213282 & 1.062573 & 0.848614 \\ \mathrm{C} & -5.159830 & 1.175966 & -0.224375 \\ \mathrm{H} & -2.342104 & 1.706655 & 1.415907 \\ \mathrm{~N} & -3.234730 & 1.974133 & 0.970685 \\ \mathrm{C} & -3.085931 & 3.265697 & 0.397035 \\ \mathrm{O} & -2.056051 & 3.877834 & 0.532659 \\ \mathrm{O} & -4.200051 & 3.751564 & -0.161446 \\ \mathrm{C} & -4.042878 & 5.048213 & -0.773648 \\ \mathrm{H} & -3.734922 & 5.784688 & -0.028519 \\ \mathrm{H} & -5.025392 & 5.292688 & -1.176838 \\ \mathrm{H} & -3.298268 & 4.992988 & -1.570378 \\ \mathrm{H} & -5.943005 & 0.423829 & -0.223999 \\ \mathrm{H} & -5.543930 & 2.171150 & -0.400799 \\ \mathrm{C} & -4.166205 & -0.132052 & 1.710928 \\ \mathrm{C} & -5.372657 & -0.802292 & 2.003976 \\ \mathrm{C} & -2.973465 & -0.603715 & 2.297270 \\ \mathrm{C} & -5.386585 & -1.905608 & 2.850750 \\ \mathrm{H} & -6.310609 & -0.434851 & 1.602078 \\ \mathrm{C} & -2.994175 & -1.720057 & 3.127285 \\ \mathrm{H} & -2.018560 & -0.136631 & 2.078125 \\ \mathrm{C} & -4.195570 & -2.372302 & 3.410542 \\ \mathrm{H} & -6.328381 & -2.397339 & 3.076729 \\ \mathrm{H} & -2.061214 & -2.087023 & 3.543114 \\ \mathrm{H} & -4.203435 & -3.240453 & 4.063528 \\ & -6.639014 & -2.193155 & -3.539738\end{array}$

Catalyst (R)-1 TS Conformation 317

B3LYP/6-31G(d) Energy $=-2809.688337$

B3LYP-D3(BJ)/def2-TZVPP-IEF-PCM(DCM) Energy = -2810.980278

B3LYP-D3(BJ)/def2-TZVPP-IEF-PCM(DCM)//B3LYP/6-31G(d) Free Energy (Quasiharmonic) = 2810.336805

Frequencies (Top 3 out of 270) 
1. $-322.8379 \mathrm{~cm}-1$

2. $\quad 7.6944 \mathrm{~cm}-1$

3. $\quad 16.7785 \mathrm{~cm}-1$

B3LYP/6-31G(d) Molecular Geometry in Cartesian Coordinates

$\begin{array}{lrrr}\mathrm{C} & 3.106690 & -0.577572 & -0.550751 \\ \mathrm{C} & 2.002411 & -1.389945 & -0.323995 \\ \mathrm{C} & 1.976851 & -2.769738 & -0.682576 \\ \mathrm{C} & 3.074408 & -3.288637 & -1.337759 \\ \mathrm{H} & 3.075725 & -4.339851 & -1.614307 \\ \mathrm{C} & 3.212356 & 3.509210 & 0.825226 \\ \mathrm{C} & 3.154570 & 0.812915 & -0.009414 \\ \mathrm{C} & 2.134111 & 1.699548 & -0.309986 \\ \mathrm{C} & 2.141762 & 3.073667 & 0.068968 \\ \mathrm{H} & 3.267294 & 4.556380 & 1.110849 \\ \mathrm{O} & 0.910566 & -0.904511 & 0.378773 \\ \mathrm{P} & -0.025609 & 0.330945 & -0.151028 \\ \mathrm{O} & 1.040695 & 1.216845 & -1.024501 \\ \mathrm{C} & -1.195092 & -5.552998 & 0.169689 \\ \mathrm{C} & 0.047745 & -5.681643 & 0.789509 \\ \mathrm{C} & 1.058385 & -4.754675 & 0.526285 \\ \mathrm{C} & 0.839673 & -3.675943 & -0.343368 \\ \mathrm{C} & -0.420703 & -3.542005 & -0.947566 \\ \mathrm{C} & -1.423887 & -4.483799 & -0.702667 \\ \mathrm{H} & 0.239193 & -6.509522 & 1.467600 \\ \mathrm{H} & -2.371844 & -4.388973 & -1.225040 \\ \mathrm{C} & -0.913974 & 5.889370 & -1.043433 \\ \mathrm{C} & -0.439110 & 5.840387 & 0.267737 \\ \mathrm{C} & 0.538046 & 4.911965 & 0.623958 \\ \mathrm{C} & 1.059204 & 4.014616 & -0.322065 \\ \mathrm{C} & 0.568254 & 4.069490 & -1.637295 \\ \mathrm{C} & -0.406498 & 5.000106 & -1.992884 \\ \mathrm{H} & -0.837085 & 6.517985 & 1.018528 \\ \mathrm{H} & -0.769574 & 5.030097 & -3.016934 \\ \mathrm{C} & 4.220102 & 1.262364 & 0.846386 \\ \mathrm{C} & 4.243354 & 2.636290 & 1.252213 \\ \mathrm{C} & 5.295183 & 3.099053 & 2.088826 \\ & 6.270608 & 2.241142 & 2.540759 \\ \mathrm{C} & 6.227227 & 0.875284 & 2.175547 \\ \mathrm{H} & 5.231883 & 0.399504 & 1.350218 \\ \mathrm{C} & 7.065569 & 2.605219 & 3.185874\end{array}$




\begin{tabular}{|c|c|c|c|}
\hline $\mathrm{H}$ & 6.984005 & 0.192804 & 2.553000 \\
\hline $\mathrm{H}$ & 5.208739 & -0.651697 & 1.088126 \\
\hline C & 4.193144 & -1.102364 & -1.335577 \\
\hline C & 4.177161 & -2.483247 & -1.712733 \\
\hline C & 5.252441 & -3.015772 & -2.474027 \\
\hline C & 6.296244 & -2.216781 & -2.878237 \\
\hline C & 6.298054 & -0.843037 & -2.540382 \\
\hline C & 5.278103 & -0.301386 & -1.789494 \\
\hline $\mathrm{H}$ & 5.224737 & -4.069113 & -2.743043 \\
\hline $\mathrm{H}$ & 7.110008 & -2.632068 & -3.466371 \\
\hline $\mathrm{H}$ & 7.109208 & -0.205900 & -2.882408 \\
\hline $\mathrm{H}$ & 5.291136 & 0.755499 & -1.550710 \\
\hline 0 & -0.647506 & 1.028103 & 0.999651 \\
\hline $\mathrm{O}$ & -0.964550 & -0.255680 & -1.249994 \\
\hline $\mathrm{H}$ & -1.975723 & 0.143606 & -1.244065 \\
\hline $\mathrm{H}$ & -0.611332 & -2.717130 & -1.626620 \\
\hline $\mathrm{H}$ & -1.975501 & -6.288303 & 0.350119 \\
\hline $\mathrm{H}$ & 2.030495 & -4.863513 & 0.999788 \\
\hline $\mathrm{H}$ & 0.956181 & 3.384447 & -2.383436 \\
\hline $\mathrm{H}$ & -1.678230 & 6.610206 & -1.321765 \\
\hline $\mathrm{H}$ & 0.885775 & 4.860687 & 1.651861 \\
\hline C & -3.613391 & 1.266087 & -0.166837 \\
\hline 0 & -3.285512 & 0.605523 & -1.228297 \\
\hline $\mathrm{H}$ & -2.815481 & 1.616466 & 0.498097 \\
\hline C & -4.703995 & 2.330880 & -0.287760 \\
\hline 0 & -4.842637 & 3.229630 & 0.514471 \\
\hline 0 & -5.490637 & 2.150936 & -1.365851 \\
\hline C & -6.518626 & 3.141412 & -1.535680 \\
\hline $\mathrm{H}$ & -7.045888 & 2.862662 & -2.448529 \\
\hline $\mathrm{H}$ & -6.077788 & 4.136455 & -1.636096 \\
\hline C & -3.766005 & -1.002237 & 1.167196 \\
\hline C & -4.566871 & 0.156281 & 1.069849 \\
\hline $\mathrm{H}$ & -2.802565 & -2.456199 & 0.129501 \\
\hline$N$ & -3.621727 & -1.850915 & 0.118490 \\
\hline C & -4.255369 & -1.900778 & -1.149590 \\
\hline 0 & -3.741337 & -2.500633 & -2.065556 \\
\hline 0 & -5.466835 & -1.343753 & -1.152218 \\
\hline C & -6.024228 & -1.117387 & -2.464718 \\
\hline $\mathrm{H}$ & -6.013515 & -2.040569 & -3.046137 \\
\hline $\mathrm{H}$ & -5.440468 & -0.339695 & -2.960689 \\
\hline $\mathrm{H}$ & -7.044710 & -0.779753 & -2.286123 \\
\hline $\mathrm{H}$ & -4.691692 & 0.721229 & 1.987627 \\
\hline $\mathrm{H}$ & -5.468437 & 0.054485 & 0.480830 \\
\hline C & -2.936242 & -1.301681 & 2.346812 \\
\hline
\end{tabular}




$\begin{array}{lrrr}\text { C } & -2.621259 & -2.635457 & 2.672830 \\ \text { C } & -2.463772 & -0.268370 & 3.177162 \\ \text { C } & -1.859422 & -2.925659 & 3.800689 \\ \text { H } & -2.996879 & -3.452686 & 2.064834 \\ \text { C } & -1.694551 & -0.565551 & 4.296481 \\ \text { H } & -2.646762 & 0.766590 & 2.915991 \\ \text { C } & -1.393547 & -1.891951 & 4.614658 \\ \text { H } & -1.631270 & -3.959635 & 4.041237 \\ \text { H } & -1.314609 & 0.243660 & 4.912479 \\ \text { H } & -0.793159 & -2.118284 & 5.491349 \\ \text { H } & -7.200443 & 3.141354 & -0.680562\end{array}$

Catalyst (R)-1 TS Conformation 318

B3LYP/6-31G(d) Energy = -2809.681326

B3LYP-D3(BJ)/def2-TZVPP-IEF-PCM(DCM) Energy = -2810.978408

B3LYP-D3(BJ)/def2-TZVPP-IEF-PCM(DCM)//B3LYP/6-31G(d) Free Energy (Quasiharmonic) = 2810.336781

Frequencies (Top 3 out of 270)

1. $-695.2779 \mathrm{~cm}-1$

2. $\quad 12.8814 \mathrm{~cm}-1$

3. $\quad 17.3002 \mathrm{~cm}-1$

B3LYP/6-31G(d) Molecular Geometry in Cartesian Coordinates

$\begin{array}{llll}\text { C } & 2.734600 & 0.499428 & -0.154646 \\ \mathrm{C} & 2.054871 & 1.421720 & -0.936150 \\ \mathrm{C} & 2.150288 & 2.833805 & -0.746960 \\ \mathrm{C} & 2.920135 & 3.277927 & 0.311099 \\ \mathrm{H} & 3.042923 & 4.346800 & 0.464698 \\ \mathrm{C} & 2.414968 & -3.747682 & -0.801404 \\ \mathrm{C} & 2.657698 & -0.956536 & -0.477754 \\ \mathrm{C} & 1.419769 & -1.576863 & -0.556116 \\ \mathrm{C} & 1.267874 & -2.991005 & -0.673365 \\ \mathrm{H} & 2.328915 & -4.827215 & -0.895493 \\ \mathrm{O} & 1.263658 & 0.954971 & -1.974537 \\ \mathrm{P} & -0.170235 & 0.240097 & -1.622605 \\ \mathrm{O} & 0.280660 & -0.804605 & -0.410332 \\ \mathrm{C} & 0.253335 & 5.747969 & -3.283188 \\ \mathrm{C} & 0.882355 & 4.636793 & -3.847961 \\ \mathrm{C} & 1.480733 & 3.674942 & -3.036029\end{array}$




\begin{tabular}{|c|c|c|c|}
\hline C & 1.465482 & 3.808623 & -1.637263 \\
\hline C & 0.825919 & 4.929521 & -1.082357 \\
\hline C & 0.225969 & 5.889970 & -1.895369 \\
\hline $\mathrm{H}$ & 0.908504 & 4.515844 & -4.927656 \\
\hline $\mathrm{H}$ & -0.270453 & 6.744728 & -1.443021 \\
\hline C & -2.529994 & -5.003636 & -0.378327 \\
\hline C & -1.475171 & -5.340102 & 0.472849 \\
\hline C & -0.253990 & -4.672085 & 0.372547 \\
\hline C & -0.061141 & -3.660226 & -0.584318 \\
\hline C & -1.126609 & -3.332864 & -1.441288 \\
\hline C & -2.351396 & -3.999193 & -1.334578 \\
\hline $\mathrm{H}$ & -1.603258 & -6.116952 & 1.222442 \\
\hline $\mathrm{H}$ & -3.167736 & -3.725988 & -1.997800 \\
\hline C & 3.838097 & -1.743981 & -0.705015 \\
\hline C & 3.703743 & -3.161486 & -0.861001 \\
\hline C & 4.863237 & -3.952409 & -1.082676 \\
\hline C & 6.108550 & -3.374558 & -1.170202 \\
\hline C & 6.241407 & -1.971646 & -1.045720 \\
\hline C & 5.138114 & -1.178565 & -0.817934 \\
\hline $\mathrm{H}$ & 4.743420 & -5.027650 & -1.193347 \\
\hline $\mathrm{H}$ & 6.987301 & -3.988928 & -1.346271 \\
\hline $\mathrm{H}$ & 7.222649 & -1.513747 & -1.137893 \\
\hline $\mathrm{H}$ & 5.255168 & -0.103773 & -0.737695 \\
\hline C & 3.454583 & 0.975880 & 0.995680 \\
\hline C & 3.555383 & 2.388561 & 1.212026 \\
\hline C & 4.276496 & 2.872976 & 2.337339 \\
\hline C & 4.845033 & 2.006370 & 3.241845 \\
\hline C & 4.707545 & 0.610288 & 3.056904 \\
\hline C & 4.034710 & 0.108353 & 1.963245 \\
\hline $\mathrm{H}$ & 4.358196 & 3.948673 & 2.475711 \\
\hline $\mathrm{H}$ & 5.388802 & 2.388993 & 4.101366 \\
\hline $\mathrm{H}$ & 5.137620 & -0.074283 & 3.783261 \\
\hline $\mathrm{H}$ & 3.932879 & -0.963347 & 1.839493 \\
\hline $\mathrm{O}$ & -0.704120 & -0.449183 & -2.822670 \\
\hline $\mathrm{O}$ & -1.054987 & 1.240026 & -0.852337 \\
\hline $\mathrm{H}$ & -2.286065 & 1.172254 & -1.009030 \\
\hline $\mathrm{H}$ & 0.781802 & 5.034717 & -0.001720 \\
\hline $\mathrm{H}$ & -0.216618 & 6.493303 & -3.919404 \\
\hline $\mathrm{H}$ & 1.965729 & 2.816983 & -3.487578 \\
\hline $\mathrm{H}$ & -0.993116 & -2.562507 & -2.195125 \\
\hline $\mathrm{H}$ & -3.482455 & -5.522006 & -0.301854 \\
\hline $\mathrm{H}$ & 0.554583 & -4.913503 & 1.056094 \\
\hline C & -3.685133 & -0.257574 & -1.104987 \\
\hline $\mathrm{O}$ & -3.447481 & 1.000527 & -1.072148 \\
\hline
\end{tabular}




$\begin{array}{llll}\text { H } & -2.874731 & -0.949211 & -1.347669 \\ \mathrm{C} & -5.020811 & -0.728640 & -1.653479 \\ \mathrm{O} & -5.190408 & -1.853998 & -2.075861 \\ \mathrm{O} & -5.957322 & 0.224950 & -1.609664 \\ \mathrm{C} & -7.237506 & -0.145853 & -2.154100 \\ \mathrm{H} & -7.866800 & 0.736276 & -2.039116 \\ \mathrm{H} & -7.137370 & -0.414344 & -3.208599 \\ \mathrm{C} & -3.021072 & -0.598692 & 1.596893 \\ \mathrm{C} & -4.025180 & -1.106239 & 0.762367 \\ \mathrm{H} & -1.717067 & -2.060082 & 1.043071 \\ \mathrm{~N} & -1.839391 & -1.272160 & 1.676405 \\ \mathrm{C} & -0.733040 & -1.185234 & 2.547351 \\ \mathrm{O} & 0.167225 & -1.990273 & 2.479593 \\ \mathrm{O} & -0.827132 & -0.189402 & 3.428305 \\ \mathrm{C} & 0.299512 & -0.066666 & 4.322296 \\ \mathrm{H} & 1.219864 & 0.080685 & 3.753086 \\ \mathrm{H} & 0.390142 & -0.963359 & 4.939772 \\ \mathrm{H} & 0.077149 & 0.805782 & 4.935790 \\ \mathrm{H} & -5.011476 & -0.680181 & 0.908342 \\ \mathrm{H} & -3.986675 & -2.151150 & 0.464400 \\ \mathrm{C} & -3.236738 & 0.710605 & 2.246442 \\ \mathrm{C} & -2.354206 & 1.782938 & 2.025554 \\ \mathrm{C} & -4.402986 & 0.916519 & 3.002624 \\ \mathrm{C} & -2.642191 & 3.034475 & 2.563414 \\ \mathrm{H} & -1.481627 & 1.644569 & 1.397068 \\ \mathrm{C} & -4.666214 & 2.164033 & 3.562463 \\ \mathrm{H} & -5.084929 & 0.088833 & 3.175152 \\ \mathrm{C} & -3.787626 & 3.226326 & 3.339365 \\ \mathrm{H} & -1.969474 & 3.864732 & 2.369163 \\ \mathrm{H} & -5.558453 & 2.307855 & 4.165020 \\ \mathrm{H} & -4.000099 & 4.204250 & 3.762867 \\ \mathrm{H} & -7.655142 & -0.995214 & -1.606784 \\ & & & \end{array}$

Catalyst (R)-1 TS Conformation 319

B3LYP/6-31G(d) Energy $=-2809.6882$

B3LYP-D3(BJ)/def2-TZVPP-IEF-PCM(DCM) Energy $=-2810.978493$

B3LYP-D3(BJ)/def2-TZVPP-IEF-PCM(DCM)//B3LYP/6-31G(d) Free Energy (Quasiharmonic) = 2810.336713

Frequencies (Top 3 out of 270)

1. $-562.5004 \mathrm{~cm}-1$ 
2. $\quad 5.2948 \mathrm{~cm}-1$

3. $\quad 10.2860 \mathrm{~cm}-1$

B3LYP/6-31G(d) Molecular Geometry in Cartesian Coordinates

\begin{tabular}{llll} 
C & -3.641210 & 0.513689 & -0.069061 \\
C & -2.584438 & 1.412903 & -0.018345 \\
C & -2.764096 & 2.826740 & -0.087911 \\
C & -4.045799 & 3.297885 & -0.289657 \\
H & -4.209216 & 4.370971 & -0.345690 \\
C & -2.987353 & -3.706065 & 0.565111 \\
C & -3.413252 & -0.936837 & 0.205072 \\
C & -2.467450 & -1.639495 & -0.522842 \\
C & -2.239854 & -3.039808 & -0.386411 \\
H & -2.863205 & -4.779617 & 0.679382 \\
O & -1.299028 & 0.940316 & 0.219925 \\
P & -0.512297 & 0.003239 & -0.866005 \\
O & -1.700924 & -0.940818 & -1.454973 \\
C & 0.391596 & 5.706593 & 0.435595 \\
C & 0.480935 & 4.754712 & -0.582490 \\
C & -0.526645 & 3.805155 & -0.749541 \\
C & -1.643405 & 3.792454 & 0.099505 \\
C & -1.725811 & 4.756393 & 1.116396 \\
C & -0.716037 & 5.704789 & 1.284556 \\
H & 1.331781 & 4.749411 & -1.258976 \\
H & -0.795453 & 6.440034 & 2.081334 \\
C & 0.571574 & -5.274938 & -2.756460 \\
C & -0.268647 & -4.342339 & -3.368259 \\
C & -1.168364 & -3.597333 & -2.607724 \\
C & -1.247964 & -3.774475 & -1.216037 \\
C & -0.393975 & -4.712146 & -0.612376 \\
C & 0.506432 & -5.455859 & -1.374282 \\
H & -0.226922 & -4.194607 & -4.444219 \\
H & 1.161902 & -6.171934 & -0.885123 \\
C & -4.123236 & -1.630692 & 1.247092 \\
C & -3.909265 & -3.038242 & 1.407673 \\
C & -4.613871 & -3.740864 & 2.422737 \\
C & -5.470909 & -3.083679 & 3.274006 \\
C & -5.651381 & -1.686596 & 3.146146 \\
H & -4.998155 & -0.980166 & 2.160163 \\
\hline & -4.448891 & -4.811216 & 2.521102 \\
H & -5.998227 & -3.629922 & 4.051272 \\
H & -140794 & 0.091109 & 2.084245
\end{tabular}




\begin{tabular}{|c|c|c|c|}
\hline$C$ & -4.950914 & 1.015053 & -0.389874 \\
\hline C & -5.148230 & 2.430082 & -0.483618 \\
\hline C & -6.440013 & 2.937805 & -0.788996 \\
\hline C & -7.496905 & 2.088979 & -1.021466 \\
\hline C & -7.298080 & 0.689469 & -0.964376 \\
\hline C & -6.061557 & 0.166836 & -0.655282 \\
\hline $\mathrm{H}$ & -6.572008 & 4.015581 & -0.848526 \\
\hline $\mathrm{H}$ & -8.478692 & 2.487900 & -1.261320 \\
\hline $\mathrm{H}$ & -8.127528 & 0.019113 & -1.172950 \\
\hline $\mathrm{H}$ & -5.924527 & -0.907927 & -0.626860 \\
\hline $\mathrm{O}$ & 0.574756 & -0.714874 & -0.140157 \\
\hline $\mathrm{O}$ & -0.130198 & 0.834824 & -2.113260 \\
\hline $\mathrm{H}$ & 0.920462 & 1.262375 & -2.200116 \\
\hline $\mathrm{H}$ & -2.581763 & 4.750400 & 1.786141 \\
\hline $\mathrm{H}$ & 1.177427 & 6.446587 & 0.564251 \\
\hline $\mathrm{H}$ & -0.459584 & 3.082952 & -1.554178 \\
\hline $\mathrm{H}$ & -0.423803 & -4.839955 & 0.466067 \\
\hline $\mathrm{H}$ & 1.273413 & -5.852751 & -3.352170 \\
\hline $\mathrm{H}$ & -1.818121 & -2.878640 & -3.095016 \\
\hline C & 2.764441 & 1.554490 & -1.204801 \\
\hline O & 2.105285 & 1.784610 & -2.275452 \\
\hline $\mathrm{H}$ & 2.228987 & 1.360038 & -0.267507 \\
\hline C & 4.055458 & 2.335394 & -1.018149 \\
\hline 0 & 4.766274 & 2.752478 & -1.903852 \\
\hline $\mathrm{O}$ & 4.295318 & 2.494381 & 0.300163 \\
\hline C & 5.485289 & 3.229461 & 0.635756 \\
\hline $\mathrm{H}$ & 5.466427 & 3.332938 & 1.720539 \\
\hline $\mathrm{H}$ & 5.475567 & 4.209224 & 0.152307 \\
\hline C & 4.032464 & -0.713910 & -0.136725 \\
\hline C & 3.443832 & -0.332271 & -1.353754 \\
\hline $\mathrm{H}$ & 2.185060 & -1.027631 & 0.666095 \\
\hline$N$ & 3.187124 & -0.960114 & 0.907403 \\
\hline C & 3.382421 & -0.836045 & 2.295676 \\
\hline $\mathrm{O}$ & 2.557663 & -1.223369 & 3.090142 \\
\hline $\mathrm{O}$ & 4.533191 & -0.219657 & 2.607853 \\
\hline C & 4.772975 & -0.080261 & 4.019931 \\
\hline $\mathrm{H}$ & 5.747051 & 0.402511 & 4.097967 \\
\hline $\mathrm{H}$ & 4.786806 & -1.058970 & 4.505784 \\
\hline $\mathrm{H}$ & 3.995950 & 0.536702 & 4.477210 \\
\hline $\mathrm{H}$ & 4.066403 & -0.330204 & -2.241620 \\
\hline $\mathrm{H}$ & 2.419520 & -0.657387 & -1.500490 \\
\hline C & 5.489088 & -0.915585 & -0.012397 \\
\hline C & 5.989507 & -1.963350 & 0.783181 \\
\hline C & 6.392011 & -0.159233 & -0.781488 \\
\hline
\end{tabular}




$\begin{array}{llrr}\text { C } & 7.353344 & -2.235715 & 0.818822 \\ \text { H } & 5.303136 & -2.588990 & 1.344315 \\ \text { C } & 7.758985 & -0.421973 & -0.723906 \\ \text { H } & 6.033049 & 0.643199 & -1.416800 \\ \text { C } & 8.244772 & -1.459362 & 0.074426 \\ \text { H } & 7.720555 & -3.058970 & 1.425020 \\ \text { H } & 8.443795 & 0.180736 & -1.313519 \\ \text { H } & 9.310092 & -1.669968 & 0.107239 \\ \text { H } & 6.375539 & 2.679489 & 0.320406\end{array}$

Catalyst (R)-1 TS Conformation 320

B3LYP/6-31G(d) Energy $=-2809.685662$

B3LYP-D3(BJ)/def2-TZVPP-IEF-PCM(DCM) Energy $=-2810.978308$

B3LYP-D3(BJ)/def2-TZVPP-IEF-PCM(DCM)//B3LYP/6-31G(d) Free Energy (Quasiharmonic) = 2810.336672

Frequencies (Top 3 out of 270)

1. $-572.1314 \mathrm{~cm}-1$

2. $8.6420 \mathrm{~cm}-1$

3. $\quad 11.9666 \mathrm{~cm}-1$

B3LYP/6-31G(d) Molecular Geometry in Cartesian Coordinates

$\begin{array}{lllr}\text { C } & -3.539766 & -0.966453 & 0.086043 \\ \text { C } & -2.350182 & -1.578564 & -0.271800 \\ \text { C } & -2.058874 & -2.949014 & -0.008324 \\ \text { C } & -3.007193 & -3.675369 & 0.684135 \\ \text { H } & -2.830258 & -4.729822 & 0.879765 \\ \text { C } & -4.319421 & 3.165819 & -0.856715 \\ \text { C } & -3.791450 & 0.447988 & -0.320241 \\ \text { C } & -2.885528 & 1.446634 & 0.014861 \\ \text { C } & -3.143158 & 2.831844 & -0.214886 \\ \text { H } & -4.535935 & 4.213903 & -1.046251 \\ \text { O } & -1.387483 & -0.818869 & -0.925199 \\ \text { P } & -0.532239 & 0.243723 & -0.006794 \\ \text { O } & -1.725718 & 1.114849 & 0.700400 \\ \text { C } & 1.559768 & -4.908977 & -1.278756 \\ \text { C } & 0.858808 & -4.089955 & -2.168518 \\ \text { C } & -0.302819 & -3.434685 & -1.760128 \\ \text { C } & -0.791816 & -3.589753 & -0.450921 \\ \text { C } & -0.076028 & -4.412322 & 0.434336\end{array}$




\begin{tabular}{|c|c|c|c|}
\hline C & 1.087027 & -5.066165 & 0.025399 \\
\hline $\mathrm{H}$ & 1.215166 & -3.964214 & -3.187657 \\
\hline $\mathrm{H}$ & 1.626034 & -5.693872 & 0.730400 \\
\hline C & -0.598342 & 6.085492 & 0.993277 \\
\hline C & -1.931096 & 6.035211 & 1.402752 \\
\hline C & -2.737807 & 4.962312 & 1.023026 \\
\hline C & -2.226692 & 3.917230 & 0.236449 \\
\hline C & -0.881617 & 3.970351 & -0.161853 \\
\hline C & -0.081009 & 5.051400 & 0.209395 \\
\hline $\mathrm{H}$ & -2.345367 & 6.829907 & 2.017910 \\
\hline $\mathrm{H}$ & 0.951792 & 5.090976 & -0.128812 \\
\hline C & -4.958912 & 0.804995 & -1.081116 \\
\hline C & -5.227067 & 2.188691 & -1.331517 \\
\hline C & -6.383142 & 2.555763 & -2.072285 \\
\hline C & -7.234641 & 1.599635 & -2.574410 \\
\hline C & -6.954158 & 0.229593 & -2.360236 \\
\hline C & -5.849569 & -0.157165 & -1.633571 \\
\hline $\mathrm{H}$ & -6.573383 & 3.612469 & -2.245137 \\
\hline $\mathrm{H}$ & -8.112316 & 1.891024 & -3.144873 \\
\hline $\mathrm{H}$ & -7.613093 & -0.526449 & -2.778771 \\
\hline $\mathrm{H}$ & -5.644565 & -1.211529 & -1.489583 \\
\hline C & -4.482570 & -1.713465 & 0.875112 \\
\hline C & -4.207080 & -3.090667 & 1.159062 \\
\hline C & -5.135016 & -3.844910 & 1.927238 \\
\hline C & -6.275790 & -3.263810 & 2.429718 \\
\hline C & -6.530030 & -1.893732 & 2.186704 \\
\hline C & -5.659871 & -1.140220 & 1.429668 \\
\hline $\mathrm{H}$ & -4.915736 & -4.892152 & 2.121909 \\
\hline $\mathrm{H}$ & -6.974108 & -3.848391 & 3.022366 \\
\hline $\mathrm{H}$ & -7.418329 & -1.428662 & 2.605642 \\
\hline $\mathrm{H}$ & -5.865150 & -0.089537 & 1.262327 \\
\hline 0 & 0.365469 & 1.018782 & -0.910412 \\
\hline $\mathrm{O}$ & 0.074708 & -0.513028 & 1.191831 \\
\hline $\mathrm{H}$ & 1.200970 & -0.739991 & 1.216851 \\
\hline $\mathrm{H}$ & -0.424883 & -4.519317 & 1.457403 \\
\hline $\mathrm{H}$ & 2.468894 & -5.410811 & -1.598088 \\
\hline $\mathrm{H}$ & -0.839625 & -2.803194 & -2.459749 \\
\hline $\mathrm{H}$ & -0.466433 & 3.173387 & -0.769783 \\
\hline $\mathrm{H}$ & 0.030987 & 6.924391 & 1.279470 \\
\hline $\mathrm{H}$ & -3.774000 & 4.922890 & 1.348443 \\
\hline C & 2.823713 & -1.620796 & 0.178031 \\
\hline $\mathrm{O}$ & 2.429359 & -1.059103 & 1.259549 \\
\hline $\mathrm{H}$ & 2.082696 & -2.073804 & -0.496410 \\
\hline C & 4.099364 & -2.461602 & 0.220515 \\
\hline
\end{tabular}




$\begin{array}{llll}\mathrm{O} & 4.669951 & -2.880414 & -0.774574 \\ \mathrm{O} & 4.510025 & -2.691600 & 1.467965 \\ \mathrm{C} & 5.701092 & -3.491675 & 1.592376 \\ \mathrm{H} & 6.540093 & -3.009594 & 1.084081 \\ \mathrm{H} & 5.887543 & -3.565515 & 2.663396 \\ \mathrm{C} & 4.437042 & 0.362289 & -0.742556 \\ \mathrm{C} & 3.292400 & -0.306587 & -1.200152 \\ \mathrm{H} & 5.644325 & -1.096228 & -1.503443 \\ \mathrm{~N} & 5.659676 & -0.140423 & -1.150514 \\ \mathrm{C} & 6.889318 & 0.486656 & -1.376187 \\ \mathrm{O} & 7.876977 & -0.142609 & -1.688524 \\ \mathrm{O} & 6.815196 & 1.819750 & -1.259080 \\ \mathrm{C} & 8.053120 & 2.517806 & -1.488419 \\ \mathrm{H} & 7.816845 & 3.571219 & -1.340735 \\ \mathrm{H} & 8.815637 & 2.188862 & -0.778230 \\ \mathrm{H} & 8.406873 & 2.338703 & -2.506339 \\ \mathrm{H} & 2.336218 & 0.206517 & -1.128454 \\ \mathrm{H} & 3.414215 & -0.935023 & -2.078207 \\ \mathrm{C} & 4.353565 & 1.374290 & 0.309866 \\ \mathrm{C} & 5.369617 & 1.488356 & 1.283138 \\ \mathrm{C} & 3.192262 & 2.161983 & 0.443268 \\ \mathrm{C} & 5.233832 & 2.373054 & 2.343663 \\ \mathrm{H} & 6.242572 & 0.847079 & 1.230360 \\ \mathrm{C} & 3.067945 & 3.054799 & 1.505236 \\ \mathrm{H} & 2.383877 & 2.078211 & -0.274711 \\ \mathrm{C} & 4.085755 & 3.165554 & 2.452778 \\ \mathrm{H} & 6.014538 & 2.436648 & 3.096245 \\ \mathrm{H} & 2.165201 & 3.651205 & 1.595072 \\ \mathrm{H} & 3.980964 & 3.856101 & 3.285216 \\ \mathrm{H} & 5.541833 & -4.481512 & 1.157503\end{array}$

Catalyst (R)-1 TS Conformation 321

B3LYP/6-31G(d) Energy $=-2809.68898$

B3LYP-D3(BJ)/def2-TZVPP-IEF-PCM(DCM) Energy = -2810.978064

B3LYP-D3(BJ)/def2-TZVPP-IEF-PCM(DCM)//B3LYP/6-31G(d) Free Energy (Quasiharmonic) = 2810.336596

Frequencies (Top 3 out of 270)

1. $-479.3591 \mathrm{~cm}-1$

2. $8.2959 \mathrm{~cm}-1$

3. $\quad 11.6762 \mathrm{~cm}-1$ 
B3LYP/6-31G(d) Molecular Geometry in Cartesian Coordinates

\begin{tabular}{|c|c|c|c|}
\hline C & 3.594897 & 0.360421 & 0.288921 \\
\hline C & 2.655606 & 1.378753 & 0.181676 \\
\hline C & 2.894817 & 2.708695 & 0.640637 \\
\hline C & 4.086444 & 2.951338 & 1.294907 \\
\hline $\mathrm{H}$ & 4.292295 & 3.955068 & 1.657224 \\
\hline C & 2.911603 & -3.510999 & -1.492952 \\
\hline C & 3.376680 & -0.957418 & -0.382098 \\
\hline C & 2.218798 & -1.673830 & -0.131326 \\
\hline C & 1.946400 & -2.967146 & -0.666510 \\
\hline $\mathrm{H}$ & 2.764243 & -4.509804 & -1.894679 \\
\hline 0 & 1.461582 & 1.147375 & -0.496332 \\
\hline$P$ & 0.355322 & 0.091381 & 0.054003 \\
\hline $\mathrm{O}$ & 1.270922 & -1.090296 & 0.705668 \\
\hline C & 0.279547 & 6.068940 & 0.006551 \\
\hline C & -0.208279 & 4.917769 & 0.628427 \\
\hline C & 0.616057 & 3.808410 & 0.817894 \\
\hline C & 1.953390 & 3.838601 & 0.393557 \\
\hline C & 2.434800 & 5.001471 & -0.229968 \\
\hline C & 1.605853 & 6.105984 & -0.425233 \\
\hline $\mathrm{H}$ & -1.236312 & 4.883562 & 0.981699 \\
\hline $\mathrm{H}$ & 1.997013 & 6.993117 & -0.916610 \\
\hline C & -1.706030 & -5.132136 & 0.055929 \\
\hline C & -1.101628 & -4.424752 & 1.097061 \\
\hline C & 0.081697 & -3.720486 & 0.878460 \\
\hline C & 0.680207 & -3.698438 & -0.393210 \\
\hline C & 0.055718 & -4.409117 & -1.433170 \\
\hline C & -1.120364 & -5.123224 & -1.211101 \\
\hline $\mathrm{H}$ & -1.555407 & -4.405670 & 2.083665 \\
\hline $\mathrm{H}$ & -1.586650 & -5.659871 & -2.033445 \\
\hline C & 4.323330 & -1.499523 & -1.319824 \\
\hline C & 4.086021 & -2.807190 & -1.855487 \\
\hline C & 5.022547 & -3.368727 & -2.765814 \\
\hline C & 6.131804 & -2.661610 & -3.166642 \\
\hline C & 6.344803 & -1.352680 & -2.674391 \\
\hline C & 5.467126 & -0.788041 & -1.775020 \\
\hline $\mathrm{H}$ & 4.833768 & -4.367549 & -3.152228 \\
\hline $\mathrm{H}$ & 6.836180 & -3.098029 & -3.869482 \\
\hline $\mathrm{H}$ & 7.206839 & -0.784082 & -3.012592 \\
\hline $\mathrm{H}$ & 5.641076 & 0.219247 & -1.415774 \\
\hline C & 4.779738 & 0.605555 & 1.068336 \\
\hline C & 5.026317 & 1.926693 & 1.561165 \\
\hline
\end{tabular}




\begin{tabular}{|c|c|c|c|}
\hline C & 6.197865 & 2.182667 & 2.324048 \\
\hline C & 7.084476 & 1.173492 & 2.618569 \\
\hline C & 6.826003 & -0.141226 & 2.164609 \\
\hline C & 5.707499 & -0.417535 & 1.409432 \\
\hline $\mathrm{H}$ & 6.371623 & 3.194629 & 2.682260 \\
\hline $\mathrm{H}$ & 7.973576 & 1.378691 & 3.208474 \\
\hline $\mathrm{H}$ & 7.513182 & -0.943498 & 2.419557 \\
\hline $\mathrm{H}$ & 5.519698 & -1.432920 & 1.080603 \\
\hline 0 & -0.504101 & -0.371084 & -1.075845 \\
\hline O & -0.345625 & 0.730826 & 1.283126 \\
\hline $\mathrm{H}$ & -1.148604 & 0.083842 & 1.733789 \\
\hline $\mathrm{H}$ & 3.464412 & 5.029987 & -0.576543 \\
\hline $\mathrm{H}$ & -0.366912 & 6.930799 & -0.138593 \\
\hline $\mathrm{H}$ & 0.227105 & 2.924196 & 1.309785 \\
\hline $\mathrm{H}$ & 0.481841 & -4.374755 & -2.431640 \\
\hline $\mathrm{H}$ & -2.628837 & -5.680368 & 0.228280 \\
\hline $\mathrm{H}$ & 0.537320 & -3.179249 & 1.698802 \\
\hline C & -3.267980 & -0.539540 & 1.937732 \\
\hline $\mathrm{O}$ & -2.033991 & -0.764606 & 2.182844 \\
\hline $\mathrm{H}$ & -3.625581 & 0.493048 & 1.834033 \\
\hline C & -4.292190 & -1.393798 & 2.674160 \\
\hline 0 & -5.413780 & -1.003574 & 2.938405 \\
\hline $\mathrm{O}$ & -3.814682 & -2.598345 & 3.004921 \\
\hline C & -4.725075 & -3.441218 & 3.734336 \\
\hline $\mathrm{H}$ & -5.011558 & -2.966950 & 4.676252 \\
\hline $\mathrm{H}$ & -5.624751 & -3.635399 & 3.144120 \\
\hline C & -4.033957 & -0.067810 & -0.707626 \\
\hline C & -3.704302 & -1.199365 & 0.073067 \\
\hline $\mathrm{H}$ & -2.077669 & 0.226687 & -1.299867 \\
\hline $\mathrm{N}$ & -3.033674 & 0.648957 & -1.270384 \\
\hline C & -3.028490 & 2.001606 & -1.682517 \\
\hline 0 & -2.248751 & 2.419617 & -2.503588 \\
\hline 0 & -3.926307 & 2.738267 & -1.009302 \\
\hline C & -3.961076 & 4.128189 & -1.384086 \\
\hline $\mathrm{H}$ & -4.228451 & 4.232812 & -2.438633 \\
\hline $\mathrm{H}$ & -2.985474 & 4.588540 & -1.211072 \\
\hline $\mathrm{H}$ & -4.723635 & 4.576489 & -0.747409 \\
\hline $\mathrm{H}$ & -4.494336 & -1.935882 & 0.183346 \\
\hline $\mathrm{H}$ & -2.713432 & -1.620490 & -0.067867 \\
\hline C & -5.440830 & 0.303959 & -0.971377 \\
\hline C & -5.814278 & 0.707131 & -2.267508 \\
\hline C & -6.428801 & 0.179116 & 0.018777 \\
\hline C & -7.146087 & 0.979082 & -2.564086 \\
\hline $\mathrm{H}$ & -5.063429 & 0.772285 & -3.049672 \\
\hline
\end{tabular}




$\begin{array}{llll}\mathrm{C} & -7.757697 & 0.474661 & -0.281274 \\ \mathrm{H} & -6.160963 & -0.120342 & 1.027021 \\ \mathrm{C} & -8.121513 & 0.870828 & -1.569404 \\ \mathrm{H} & -7.423331 & 1.272202 & -3.572738 \\ \mathrm{H} & -8.510406 & 0.391872 & 0.497577 \\ \mathrm{H} & -9.160593 & 1.089344 & -1.800132 \\ \mathrm{H} & -4.178886 & -4.365725 & 3.920198\end{array}$

Catalyst (R)-1 TS Conformation 322

B3LYP/6-31G(d) Energy $=-2809.683851$

B3LYP-D3(BJ)/def2-TZVPP-IEF-PCM(DCM) Energy = -2810.979019

B3LYP-D3(BJ)/def2-TZVPP-IEF-PCM(DCM)//B3LYP/6-31G(d) Free Energy (Quasiharmonic) = 2810.33654

Frequencies (Top 3 out of 270)

1. $-493.2241 \mathrm{~cm}-1$

2. $\quad 4.8761 \mathrm{~cm}-1$

3. $\quad 9.9445 \mathrm{~cm}-1$

B3LYP/6-31G(d) Molecular Geometry in Cartesian Coordinates

$\begin{array}{lrrr}\text { C } & 3.722635 & 0.263058 & 0.086013 \\ \text { C } & 2.916035 & 1.309917 & -0.337117 \\ \text { C } & 3.198800 & 2.679473 & -0.052705 \\ \text { C } & 4.308587 & 2.949450 & 0.724067 \\ \text { H } & 4.567329 & 3.983472 & 0.936753 \\ \text { C } & 2.670095 & -3.789864 & -0.958057 \\ \text { C } & 3.387636 & -1.133956 & -0.323050 \\ \text { C } & 2.124469 & -1.637657 & -0.048501 \\ \text { C } & 1.738901 & -2.981380 & -0.335742 \\ \text { H } & 2.418596 & -4.826686 & -1.166039 \\ \text { O } & 1.795197 & 1.021894 & -1.098662 \\ \text { P } & 0.475895 & 0.357967 & -0.369566 \\ \text { O } & 1.196512 & -0.806549 & 0.556308 \\ \text { C } & 0.841693 & 5.974901 & -1.503560 \\ \text { C } & 1.246368 & 5.925610 & -0.169109 \\ \text { C } & 1.992764 & 4.843722 & 0.296451 \\ \text { C } & 2.349473 & 3.789852 & -0.560499 \\ \text { C } & 1.929588 & 3.847897 & -1.900237 \\ \text { C } & 1.186213 & 4.931377 & -2.365284 \\ \text { H } & 0.973880 & 6.725438 & 0.514665\end{array}$




\begin{tabular}{|c|c|c|c|}
\hline $\mathrm{H}$ & 0.877243 & 4.960592 & -3.407107 \\
\hline C & -2.111381 & -4.631449 & 0.660275 \\
\hline C & -1.546081 & -4.855772 & -0.595598 \\
\hline C & -0.307558 & -4.300592 & -0.916191 \\
\hline C & 0.393738 & -3.512705 & 0.010965 \\
\hline C & -0.188663 & -3.291021 & 1.270900 \\
\hline C & -1.427069 & -3.845862 & 1.590889 \\
\hline $\mathrm{H}$ & -2.071867 & -5.458344 & -1.332016 \\
\hline $\mathrm{H}$ & -1.855551 & -3.667464 & 2.573898 \\
\hline C & 4.318219 & -1.964091 & -1.037530 \\
\hline C & 3.948194 & -3.314672 & -1.341078 \\
\hline C & 4.864362 & -4.150514 & -2.035600 \\
\hline C & 6.086535 & -3.673019 & -2.447886 \\
\hline C & 6.438992 & -2.328350 & -2.184888 \\
\hline C & 5.580501 & -1.497863 & -1.498463 \\
\hline $\mathrm{H}$ & 4.571650 & -5.176554 & -2.246497 \\
\hline $\mathrm{H}$ & 6.775699 & -4.319457 & -2.984476 \\
\hline $\mathrm{H}$ & 7.394587 & -1.944622 & -2.532160 \\
\hline $\mathrm{H}$ & 5.861858 & -0.467677 & -1.313825 \\
\hline C & 4.830239 & 0.555772 & 0.954225 \\
\hline C & 5.125761 & 1.924051 & 1.259560 \\
\hline C & 6.225550 & 2.228779 & 2.106850 \\
\hline C & 6.990127 & 1.229705 & 2.662832 \\
\hline C & 6.676757 & -0.123708 & 2.395587 \\
\hline C & 5.627988 & -0.451561 & 1.564478 \\
\hline $\mathrm{H}$ & 6.442721 & 3.273517 & 2.317178 \\
\hline $\mathrm{H}$ & 7.824347 & 1.475099 & 3.314495 \\
\hline $\mathrm{H}$ & 7.266121 & -0.913431 & 2.853965 \\
\hline $\mathrm{H}$ & 5.395937 & -1.493715 & 1.378307 \\
\hline $\mathrm{O}$ & -0.435361 & -0.168754 & -1.423085 \\
\hline 0 & -0.083487 & 1.317794 & 0.689445 \\
\hline $\mathrm{H}$ & -1.283144 & 1.734596 & 0.538570 \\
\hline $\mathrm{H}$ & 2.191827 & 3.043429 & -2.578455 \\
\hline $\mathrm{H}$ & 0.258526 & 6.816571 & -1.868197 \\
\hline $\mathrm{H}$ & 2.284903 & 4.799163 & 1.341878 \\
\hline $\mathrm{H}$ & 0.336788 & -2.687274 & 2.002450 \\
\hline $\mathrm{H}$ & -3.076454 & -5.063674 & 0.912342 \\
\hline $\mathrm{H}$ & 0.115017 & -4.457773 & -1.904458 \\
\hline C & -2.957063 & 1.520808 & -0.572777 \\
\hline $\mathrm{O}$ & -2.388321 & 2.021592 & 0.474105 \\
\hline $\mathrm{H}$ & -2.326969 & 1.243929 & -1.423757 \\
\hline C & -4.316856 & 2.116921 & -0.890761 \\
\hline $\mathrm{O}$ & -5.034724 & 2.666287 & -0.087574 \\
\hline $\mathrm{O}$ & -4.621733 & 1.928264 & -2.190601 \\
\hline
\end{tabular}




$\begin{array}{lrrr}\mathrm{C} & -5.881171 & 2.489124 & -2.617076 \\ \mathrm{H} & -5.915008 & 2.334431 & -3.695603 \\ \mathrm{H} & -6.712445 & 1.977219 & -2.125195 \\ \mathrm{C} & -4.409985 & -0.413679 & 0.656099 \\ \mathrm{C} & -3.443213 & -0.396846 & -0.358120 \\ \mathrm{H} & -6.330945 & 0.209500 & 1.008170 \\ \mathrm{~N} & -5.755364 & -0.315150 & 0.359538 \\ \mathrm{C} & -6.485022 & -0.660878 & -0.785121 \\ \mathrm{O} & -7.614274 & -0.252414 & -0.956955 \\ \mathrm{O} & -5.828802 & -1.503759 & -1.589456 \\ \mathrm{C} & -6.553677 & -1.913535 & -2.767021 \\ \mathrm{H} & -7.476685 & -2.423821 & -2.483666 \\ \mathrm{H} & -5.880299 & -2.590074 & -3.291816 \\ \mathrm{H} & -6.792037 & -1.046553 & -3.387108 \\ \mathrm{H} & -2.446995 & -0.767419 & -0.146795 \\ \mathrm{H} & -3.772297 & -0.593543 & -1.369912 \\ \mathrm{C} & -4.071073 & -0.374241 & 2.079793 \\ \mathrm{C} & -5.056976 & -0.603507 & 3.067344 \\ \mathrm{C} & -2.747523 & -0.118765 & 2.498844 \\ \mathrm{C} & -4.736776 & -0.551260 & 4.417097 \\ \mathrm{H} & -6.070785 & -0.865717 & 2.781444 \\ \mathrm{C} & -2.437730 & -0.056920 & 3.855257 \\ \mathrm{H} & -1.955053 & 0.045511 & 1.783417 \\ \mathrm{C} & -3.426070 & -0.267500 & 4.816166 \\ \mathrm{H} & -5.505895 & -0.739930 & 5.160275 \\ \mathrm{H} & -1.416112 & 0.157180 & 4.153257 \\ \mathrm{H} & -3.177757 & -0.224144 & 5.872958 \\ \mathrm{H} & -5.919679 & 3.554434 & -2.378740\end{array}$

Catalyst (R)-1 TS Conformation 323

B3LYP/6-31G(d) Energy $=-2809.685761$

B3LYP-D3(BJ)/def2-TZVPP-IEF-PCM(DCM) Energy = -2810.979446

B3LYP-D3(BJ)/def2-TZVPP-IEF-PCM(DCM)//B3LYP/6-31G(d) Free Energy (Quasiharmonic) = 2810.336534

Frequencies (Top 3 out of 270)

1. $-423.7951 \mathrm{~cm}-1$

2. $\quad 7.7307 \mathrm{~cm}-1$

3. $\quad 10.6937 \mathrm{~cm}-1$

B3LYP/6-31G(d) Molecular Geometry in Cartesian Coordinates 


\begin{tabular}{|c|c|c|c|}
\hline C & 3.267110 & -1.393940 & -0.037004 \\
\hline C & 1.946132 & -1.775329 & 0.130781 \\
\hline C & 1.469465 & -3.092458 & -0.134697 \\
\hline C & 2.377048 & -4.009607 & -0.625517 \\
\hline $\mathrm{H}$ & 2.051541 & -5.029038 & -0.816627 \\
\hline C & 4.591243 & 2.624519 & 0.762606 \\
\hline C & 3.686827 & -0.008421 & 0.329775 \\
\hline C & 3.042113 & 1.084653 & -0.236692 \\
\hline C & 3.512809 & 2.425068 & -0.078418 \\
\hline $\mathrm{H}$ & 4.961936 & 3.635198 & 0.912023 \\
\hline $\mathrm{O}$ & 1.040932 & -0.831541 & 0.591500 \\
\hline$P$ & 0.530406 & 0.318880 & -0.472718 \\
\hline $\mathrm{O}$ & 1.961210 & 0.868593 & -1.074846 \\
\hline C & -2.594066 & -4.338070 & 0.545843 \\
\hline C & -1.904859 & -3.630445 & 1.534512 \\
\hline C & -0.596152 & -3.203113 & 1.313722 \\
\hline C & 0.053991 & -3.483431 & 0.100146 \\
\hline C & -0.649944 & -4.192387 & -0.886207 \\
\hline C & -1.961193 & -4.615095 & -0.667178 \\
\hline $\mathrm{H}$ & -2.385624 & -3.415476 & 2.485681 \\
\hline $\mathrm{H}$ & -2.488843 & -5.157223 & -1.447725 \\
\hline C & 1.976125 & 5.853174 & -2.184753 \\
\hline C & 3.344725 & 5.582834 & -2.159516 \\
\hline C & 3.821859 & 4.458945 & -1.486059 \\
\hline C & 2.943910 & 3.582808 & -0.824673 \\
\hline C & 1.567974 & 3.861914 & -0.860624 \\
\hline C & 1.094685 & 4.988285 & -1.533596 \\
\hline $\mathrm{H}$ & 4.042699 & 6.241246 & -2.670471 \\
\hline $\mathrm{H}$ & 0.026435 & 5.190885 & -1.547256 \\
\hline C & 4.748521 & 0.226475 & 1.269655 \\
\hline C & 5.204213 & 1.567529 & 1.477482 \\
\hline C & 6.253208 & 1.814093 & 2.404310 \\
\hline C & 6.821608 & 0.786164 & 3.119966 \\
\hline C & 6.353254 & -0.536753 & 2.939648 \\
\hline C & 5.346839 & -0.809573 & 2.039266 \\
\hline $\mathrm{H}$ & 6.591242 & 2.838440 & 2.543414 \\
\hline $\mathrm{H}$ & 7.619516 & 0.987043 & 3.829748 \\
\hline $\mathrm{H}$ & 6.787495 & -1.345417 & 3.521534 \\
\hline $\mathrm{H}$ & 4.992025 & -1.827000 & 1.921203 \\
\hline C & 4.185252 & -2.338575 & -0.614792 \\
\hline C & 3.724912 & -3.666455 & -0.895302 \\
\hline C & 4.623784 & -4.614163 & -1.455499 \\
\hline C & 5.918959 & -4.267152 & -1.761569 \\
\hline
\end{tabular}




\begin{tabular}{|c|c|c|c|}
\hline C & 6.365097 & -2.946063 & -1.523971 \\
\hline C & 5.523546 & -2.008920 & -0.965772 \\
\hline $\mathrm{H}$ & 4.259953 & -5.620425 & -1.650170 \\
\hline $\mathrm{H}$ & 6.595019 & -4.998347 & -2.196324 \\
\hline $\mathrm{H}$ & 7.380715 & -2.665043 & -1.789524 \\
\hline $\mathrm{H}$ & 5.879257 & -0.998805 & -0.801135 \\
\hline 0 & -0.227036 & 1.340259 & 0.319474 \\
\hline $\mathrm{O}$ & -0.139027 & -0.346334 & -1.671689 \\
\hline $\mathrm{H}$ & -1.378046 & -0.118860 & -1.992430 \\
\hline $\mathrm{H}$ & -0.169009 & -4.391443 & -1.839564 \\
\hline $\mathrm{H}$ & -3.614335 & -4.670161 & 0.720099 \\
\hline $\mathrm{H}$ & -0.068922 & -2.654914 & 2.087250 \\
\hline $\mathrm{H}$ & 0.870639 & 3.202044 & -0.356266 \\
\hline $\mathrm{H}$ & 1.599867 & 6.726866 & -2.710827 \\
\hline $\mathrm{H}$ & 4.886659 & 4.241935 & -1.487395 \\
\hline C & -2.900406 & 0.918434 & -1.303117 \\
\hline $\mathrm{O}$ & -2.463258 & 0.106622 & -2.205848 \\
\hline $\mathrm{H}$ & -2.178357 & 1.526462 & -0.752997 \\
\hline C & -4.227750 & 1.578629 & -1.606518 \\
\hline $\mathrm{O}$ & -5.040312 & 1.190903 & -2.412810 \\
\hline $\mathrm{O}$ & -4.366184 & 2.683026 & -0.839781 \\
\hline C & -5.579670 & 3.434393 & -1.036135 \\
\hline $\mathrm{H}$ & -5.557781 & 3.931677 & -2.009360 \\
\hline $\mathrm{H}$ & -6.450180 & 2.775570 & -0.992660 \\
\hline C & -4.545583 & -0.008361 & 0.861636 \\
\hline C & -3.265705 & -0.232858 & 0.340381 \\
\hline $\mathrm{H}$ & -5.867242 & 1.204934 & 1.820151 \\
\hline$N$ & -4.878502 & 1.038407 & 1.675353 \\
\hline C & -4.119198 & 2.111030 & 2.203904 \\
\hline $\mathrm{O}$ & -4.680585 & 3.058164 & 2.708726 \\
\hline $\mathrm{O}$ & -2.818664 & 1.913685 & 2.074782 \\
\hline C & -1.938535 & 2.978107 & 2.510381 \\
\hline $\mathrm{H}$ & -2.276765 & 3.928704 & 2.093889 \\
\hline $\mathrm{H}$ & -0.965819 & 2.691279 & 2.116005 \\
\hline $\mathrm{H}$ & -1.941429 & 3.029198 & 3.601697 \\
\hline $\mathrm{H}$ & -3.121186 & -1.201544 & -0.122453 \\
\hline $\mathrm{H}$ & -2.405393 & 0.161011 & 0.865790 \\
\hline C & -5.680740 & -0.888149 & 0.504875 \\
\hline C & -5.735471 & -1.500350 & -0.761235 \\
\hline C & -6.714053 & -1.136167 & 1.429335 \\
\hline C & -6.807039 & -2.325421 & -1.091928 \\
\hline $\mathrm{H}$ & -4.967804 & -1.296000 & -1.499153 \\
\hline C & -7.773725 & -1.975584 & 1.095774 \\
\hline $\mathrm{H}$ & -6.665372 & -0.716987 & 2.430941 \\
\hline
\end{tabular}




$\begin{array}{llll}\mathrm{C} & -7.825863 & -2.567625 & -0.167845 \\ \mathrm{H} & -6.847435 & -2.774971 & -2.079493 \\ \mathrm{H} & -8.553226 & -2.173388 & 1.825726 \\ \mathrm{H} & -8.655656 & -3.217935 & -0.429733 \\ \mathrm{H} & -5.601300 & 4.165862 & -0.228662\end{array}$

Catalyst (R)-1 TS Conformation 324

B3LYP/6-31G(d) Energy $=-2809.686692$

B3LYP-D3(BJ)/def2-TZVPP-IEF-PCM(DCM) Energy $=-2810.978322$

B3LYP-D3(BJ)/def2-TZVPP-IEF-PCM(DCM)//B3LYP/6-31G(d) Free Energy (Quasiharmonic) = 2810.336523

Frequencies (Top 3 out of 270)

1. $-670.4714 \mathrm{~cm}-1$

2. $\quad 7.7891 \mathrm{~cm}-1$

3. $\quad 11.2256 \mathrm{~cm}-1$

B3LYP/6-31G(d) Molecular Geometry in Cartesian Coordinates

$\begin{array}{llll}\mathrm{C} & -3.806306 & -0.080575 & -0.370466 \\ \mathrm{C} & -3.163956 & 1.113650 & -0.067607 \\ \mathrm{C} & -3.743359 & 2.392011 & -0.334546 \\ \mathrm{C} & -4.947302 & 2.417320 & -1.010966 \\ \mathrm{H} & -5.405232 & 3.377369 & -1.234164 \\ \mathrm{C} & -2.144037 & -3.874262 & 0.842518 \\ \mathrm{C} & -3.250699 & -1.382510 & 0.107954 \\ \mathrm{C} & -1.947855 & -1.730467 & -0.209340 \\ \mathrm{C} & -1.364841 & -2.989414 & 0.122553 \\ \mathrm{H} & -1.746221 & -4.855726 & 1.086980 \\ \mathrm{O} & -1.963067 & 1.087193 & 0.623753 \\ \mathrm{P} & -0.592952 & 0.460725 & -0.025825 \\ \mathrm{O} & -1.177016 & -0.807572 & -0.899611 \\ \mathrm{C} & -2.127277 & 6.153701 & 0.998043 \\ \mathrm{C} & -1.318510 & 5.265038 & 0.286769 \\ \mathrm{C} & -1.816087 & 4.032656 & -0.136836 \\ \mathrm{C} & -3.143696 & 3.670508 & 0.142367 \\ \mathrm{C} & -3.949071 & 4.572168 & 0.858354 \\ \mathrm{C} & -3.446890 & 5.801817 & 1.283824 \\ \mathrm{H} & -0.291143 & 5.533683 & 0.053139 \\ \mathrm{H} & -4.086189 & 6.480852 & 1.842396 \\ \mathrm{C} & 2.582814 & -4.235106 & -1.061951\end{array}$




\begin{tabular}{|c|c|c|c|}
\hline C & 1.764530 & -3.554709 & -1.967967 \\
\hline C & 0.495382 & -3.122673 & -1.585464 \\
\hline C & 0.015069 & -3.365009 & -0.286584 \\
\hline C & 0.854882 & -4.035651 & 0.618352 \\
\hline C & 2.124152 & -4.468732 & 0.236175 \\
\hline $\mathrm{H}$ & 2.109014 & -3.369057 & -2.982017 \\
\hline $\mathrm{H}$ & 2.753199 & -4.989505 & 0.953822 \\
\hline C & -4.019538 & -2.281495 & 0.926155 \\
\hline C & -3.451328 & -3.548462 & 1.279893 \\
\hline C & -4.203945 & -4.453821 & 2.076299 \\
\hline C & -5.454771 & -4.118411 & 2.539394 \\
\hline C & -6.001902 & -2.852086 & 2.226135 \\
\hline C & -5.305793 & -1.959815 & 1.440392 \\
\hline $\mathrm{H}$ & -3.762069 & -5.416229 & 2.324013 \\
\hline $\mathrm{H}$ & -6.017708 & -4.815702 & 3.153868 \\
\hline $\mathrm{H}$ & -6.979722 & -2.577766 & 2.612843 \\
\hline $\mathrm{H}$ & -5.736002 & -0.990537 & 1.217928 \\
\hline C & -5.007911 & -0.033791 & -1.159894 \\
\hline C & -5.583698 & 1.239366 & -1.471139 \\
\hline C & -6.773153 & 1.299255 & -2.246642 \\
\hline C & -7.366309 & 0.153214 & -2.722541 \\
\hline C & -6.782515 & -1.105132 & -2.444874 \\
\hline C & -5.637591 & -1.196755 & -1.684069 \\
\hline $\mathrm{H}$ & -7.199152 & 2.275450 & -2.466490 \\
\hline $\mathrm{H}$ & -8.272158 & 0.211164 & -3.319874 \\
\hline $\mathrm{H}$ & -7.237696 & -2.008893 & -2.841203 \\
\hline $\mathrm{H}$ & -5.197406 & -2.168317 & -1.491686 \\
\hline $\mathrm{O}$ & 0.319708 & 0.063673 & 1.081051 \\
\hline $\mathrm{O}$ & -0.082527 & 1.430784 & -1.108140 \\
\hline $\mathrm{H}$ & 1.066542 & 1.299848 & -1.470188 \\
\hline $\mathrm{H}$ & -4.972542 & 4.295106 & 1.096867 \\
\hline $\mathrm{H}$ & -1.732438 & 7.111552 & 1.327198 \\
\hline $\mathrm{H}$ & -1.179828 & 3.355852 & -0.696217 \\
\hline $\mathrm{H}$ & 0.512406 & -4.202513 & 1.635518 \\
\hline $\mathrm{H}$ & 3.563754 & -4.590381 & -1.369517 \\
\hline $\mathrm{H}$ & -0.132393 & -2.602499 & -2.299958 \\
\hline C & 3.070063 & 1.506150 & -0.947228 \\
\hline $\mathrm{O}$ & 2.200622 & 1.202757 & -1.843524 \\
\hline $\mathrm{H}$ & 2.771549 & 2.105996 & -0.082038 \\
\hline C & 4.465060 & 1.869363 & -1.426330 \\
\hline $\mathrm{O}$ & 5.215378 & 2.571794 & -0.776119 \\
\hline $\mathrm{O}$ & 4.748640 & 1.341471 & -2.620190 \\
\hline C & 6.034944 & 1.687586 & -3.164942 \\
\hline $\mathrm{H}$ & 6.136095 & 2.773102 & -3.240087 \\
\hline
\end{tabular}




$\begin{array}{llrl}\text { H } & 6.835492 & 1.292586 & -2.534616 \\ \mathrm{C} & 4.621009 & -0.027170 & 0.813756 \\ \mathrm{C} & 3.408411 & -0.142967 & 0.120311 \\ \mathrm{H} & 5.732436 & 0.616794 & 2.387222 \\ \mathrm{~N} & 4.799097 & 0.633420 & 1.994242 \\ \mathrm{C} & 3.913597 & 1.299147 & 2.875772 \\ \mathrm{O} & 4.320466 & 1.714672 & 3.937714 \\ \mathrm{O} & 2.685969 & 1.373986 & 2.390975 \\ \mathrm{C} & 1.672703 & 1.937827 & 3.260402 \\ \mathrm{H} & 0.734747 & 1.661600 & 2.784289 \\ \mathrm{H} & 1.803681 & 3.021176 & 3.315133 \\ \mathrm{H} & 1.761109 & 1.503608 & 4.257703 \\ \mathrm{H} & 3.428977 & -0.830698 & -0.718152 \\ \mathrm{H} & 2.464019 & -0.087924 & 0.656948 \\ \mathrm{C} & 5.876367 & -0.576815 & 0.245979 \\ \mathrm{C} & 5.870230 & -1.839683 & -0.372004 \\ \mathrm{C} & 7.086629 & 0.137484 & 0.331982 \\ \mathrm{C} & 7.050299 & -2.379589 & -0.877806 \\ \mathrm{H} & 4.947050 & -2.408425 & -0.425515 \\ \mathrm{C} & 8.261221 & -0.404172 & -0.186674 \\ \mathrm{H} & 7.096599 & 1.140734 & 0.747110 \\ \mathrm{C} & 8.247149 & -1.665249 & -0.786931 \\ \mathrm{H} & 7.036272 & -3.362771 & -1.339141 \\ \mathrm{H} & 9.185803 & 0.162792 & -0.127553 \\ \mathrm{H} & 9.165282 & -2.088692 & -1.184365 \\ \mathrm{H} & 6.062070 & 1.229067 & -4.153244\end{array}$

Catalyst (R)-1 TS Conformation 325

B3LYP/6-31G(d) Energy $=-2809.683422$

B3LYP-D3(BJ)/def2-TZVPP-IEF-PCM(DCM) Energy = -2810.979039

B3LYP-D3(BJ)/def2-TZVPP-IEF-PCM(DCM)//B3LYP/6-31G(d) Free Energy (Quasiharmonic) = 2810.336521

Frequencies (Top 3 out of 270)

1. $-496.1069 \mathrm{~cm}-1$

2. $\quad 6.2193 \mathrm{~cm}-1$

3. $\quad 9.8962 \mathrm{~cm}-1$

B3LYP/6-31G(d) Molecular Geometry in Cartesian Coordinates

$\begin{array}{llll}\text { C } & 3.361288 & -1.196523 & -0.142156\end{array}$ 


\begin{tabular}{|c|c|c|c|}
\hline C & 2.069354 & -1.708563 & -0.155033 \\
\hline C & 1.794206 & -3.092953 & -0.375451 \\
\hline C & 2.858726 & -3.924700 & -0.658222 \\
\hline $\mathrm{H}$ & 2.671743 & -4.981643 & -0.830386 \\
\hline C & 4.074188 & 2.916255 & 0.954191 \\
\hline C & 3.604638 & 0.212841 & 0.287818 \\
\hline C & 2.931017 & 1.251021 & -0.336708 \\
\hline C & 3.156969 & 2.628139 & -0.037821 \\
\hline $\mathrm{H}$ & 4.296910 & 3.954574 & 1.185553 \\
\hline $\mathrm{O}$ & 1.006813 & -0.884998 & 0.166366 \\
\hline$P$ & 0.546800 & 0.366455 & -0.812593 \\
\hline $\mathrm{O}$ & 2.001717 & 0.936850 & -1.317733 \\
\hline C & -2.120569 & -4.866671 & -0.116677 \\
\hline C & -1.889832 & -3.813639 & -1.006967 \\
\hline C & -0.630598 & -3.216642 & -1.081365 \\
\hline C & 0.421735 & -3.666203 & -0.269025 \\
\hline C & 0.179025 & -4.725377 & 0.619868 \\
\hline C & -1.081349 & -5.319831 & 0.697989 \\
\hline$H$ & -2.684477 & -3.458191 & -1.658404 \\
\hline $\mathrm{H}$ & -1.248412 & -6.138184 & 1.393930 \\
\hline C & 1.188718 & 5.894108 & -2.037324 \\
\hline C & 1.666310 & 4.810411 & -2.777085 \\
\hline C & 2.286478 & 3.737059 & -2.139526 \\
\hline C & 2.446089 & 3.727640 & -0.743408 \\
\hline C & 1.957384 & 4.822822 & -0.010600 \\
\hline C & 1.335679 & 5.895468 & -0.649495 \\
\hline $\mathrm{H}$ & 1.558646 & 4.799657 & -3.858578 \\
\hline $\mathrm{H}$ & 0.963619 & 6.730573 & -0.061044 \\
\hline C & 4.490961 & 0.527937 & 1.376792 \\
\hline C & 4.735122 & 1.904043 & 1.691728 \\
\hline C & 5.622063 & 2.232237 & 2.752955 \\
\hline C & 6.221652 & 1.248990 & 3.504672 \\
\hline C & 5.948163 & -0.110501 & 3.225602 \\
\hline C & 5.108845 & -0.461308 & 2.190867 \\
\hline $\mathrm{H}$ & 5.806127 & 3.282449 & 2.967517 \\
\hline $\mathrm{H}$ & 6.892256 & 1.511935 & 4.318247 \\
\hline $\mathrm{H}$ & 6.401046 & -0.887025 & 3.836277 \\
\hline $\mathrm{H}$ & 4.903670 & -1.507568 & 1.998400 \\
\hline C & 4.444416 & -2.051144 & -0.548449 \\
\hline C & 4.181936 & -3.437544 & -0.791808 \\
\hline C & 5.246517 & -4.294049 & -1.182392 \\
\hline C & 6.520697 & -3.805760 & -1.355173 \\
\hline C & 6.777556 & -2.429775 & -1.149802 \\
\hline C & 5.769702 & -1.577247 & -0.755808 \\
\hline
\end{tabular}




\begin{tabular}{|c|c|c|c|}
\hline $\mathrm{H}$ & 5.028397 & -5.345351 & -1.355663 \\
\hline $\mathrm{H}$ & 7.325821 & -4.468267 & -1.661052 \\
\hline $\mathrm{H}$ & 7.778846 & -2.039328 & -1.311033 \\
\hline $\mathrm{H}$ & 5.981710 & -0.523786 & -0.614198 \\
\hline $\mathrm{O}$ & -0.240541 & 1.312490 & 0.029821 \\
\hline 0 & -0.079463 & -0.180162 & -2.099822 \\
\hline $\mathrm{H}$ & -1.361122 & -0.220111 & -2.157583 \\
\hline $\mathrm{H}$ & 0.983883 & -5.075383 & 1.260881 \\
\hline $\mathrm{H}$ & -3.098642 & -5.340092 & -0.069733 \\
\hline $\mathrm{H}$ & -0.452369 & -2.410670 & -1.783527 \\
\hline $\mathrm{H}$ & 2.053143 & 4.821504 & 1.071793 \\
\hline $\mathrm{H}$ & 0.704395 & 6.728420 & -2.538056 \\
\hline $\mathrm{H}$ & 2.653372 & 2.902372 & -2.725957 \\
\hline C & -3.081937 & 0.561582 & -1.447749 \\
\hline $\mathrm{O}$ & -2.498700 & -0.300082 & -2.208127 \\
\hline $\mathrm{H}$ & -2.527116 & 1.442628 & -1.122458 \\
\hline C & -4.553867 & 0.773582 & -1.742677 \\
\hline 0 & -5.275297 & -0.003744 & -2.318286 \\
\hline 0 & -4.937644 & 1.990622 & -1.287659 \\
\hline C & -6.293379 & 2.360168 & -1.597939 \\
\hline $\mathrm{H}$ & -6.448732 & 3.329010 & -1.123183 \\
\hline $\mathrm{H}$ & -6.424239 & 2.437353 & -2.680490 \\
\hline C & -4.269217 & 0.020403 & 1.122924 \\
\hline C & -3.080826 & -0.226227 & 0.425562 \\
\hline $\mathrm{H}$ & -5.436338 & 1.210452 & 2.291861 \\
\hline$N$ & -4.564156 & 1.182299 & 1.778522 \\
\hline C & -3.879625 & 2.414722 & 1.907833 \\
\hline 0 & -4.377098 & 3.316614 & 2.545403 \\
\hline 0 & -2.716759 & 2.408170 & 1.282102 \\
\hline C & -1.909045 & 3.606418 & 1.378591 \\
\hline $\mathrm{H}$ & -2.415571 & 4.429497 & 0.869129 \\
\hline $\mathrm{H}$ & -0.977780 & 3.335024 & 0.886561 \\
\hline $\mathrm{H}$ & -1.755663 & 3.860892 & 2.429371 \\
\hline $\mathrm{H}$ & -2.955985 & -1.247481 & 0.086666 \\
\hline $\mathrm{H}$ & -2.172104 & 0.299635 & 0.701455 \\
\hline C & -5.362065 & -0.981139 & 1.147537 \\
\hline C & -5.060110 & -2.353782 & 1.205203 \\
\hline C & -6.713720 & -0.586242 & 1.128537 \\
\hline C & -6.082032 & -3.298358 & 1.249824 \\
\hline $\mathrm{H}$ & -4.027005 & -2.683028 & 1.240311 \\
\hline C & -7.731492 & -1.535361 & 1.162122 \\
\hline $\mathrm{H}$ & -6.975738 & 0.464644 & 1.040352 \\
\hline C & -7.418283 & -2.894393 & 1.227331 \\
\hline $\mathrm{H}$ & -5.832050 & -4.353626 & 1.306811 \\
\hline
\end{tabular}




$\begin{array}{rrrr}H & -8.768297 & -1.214137 & 1.127142 \\ H & -8.212397 & -3.634901 & 1.256899 \\ H & -6.995584 & 1.617673 & -1.210783\end{array}$

Catalyst (R)-1 TS Conformation 326

B3LYP/6-31G(d) Energy $=-2809.685937$

B3LYP-D3(BJ)/def2-TZVPP-IEF-PCM(DCM) Energy = -2810.978694

B3LYP-D3(BJ)/def2-TZVPP-IEF-PCM(DCM)//B3LYP/6-31G(d) Free Energy (Quasiharmonic) = 2810.336479

Frequencies (Top 3 out of 270)

1. $-679.1125 \mathrm{~cm}-1$

2. $\quad 8.6989 \mathrm{~cm}-1$

3. $\quad 11.5698 \mathrm{~cm}-1$

B3LYP/6-31G(d) Molecular Geometry in Cartesian Coordinates

$\begin{array}{lrrr}\text { C } & 3.687709 & -0.344608 & -0.284441 \\ \text { C } & 2.822100 & -1.308945 & 0.216724 \\ \text { C } & 3.056679 & -2.711019 & 0.068898 \\ \text { C } & 4.144465 & -3.096039 & -0.691538 \\ \text { H } & 4.339969 & -4.155881 & -0.831792 \\ \text { C } & 3.033751 & 3.837124 & 0.563645 \\ \text { C } & 3.488608 & 1.095239 & 0.060035 \\ \text { C } & 2.272392 & 1.700973 & -0.208117 \\ \text { C } & 2.016715 & 3.086776 & 0.007539 \\ \text { H } & 2.883117 & 4.902198 & 0.719798 \\ \text { O } & 1.737881 & -0.910823 & 0.983068 \\ \text { P } & 0.480183 & -0.105460 & 0.302471 \\ \text { O } & 1.248910 & 0.920455 & -0.726880 \\ \text { C } & 0.760262 & -5.818493 & 1.972909 \\ \text { C } & 0.105255 & -4.799756 & 1.278197 \\ \text { C } & 0.828102 & -3.774228 & 0.668432 \\ \text { C } & 2.230559 & -3.752207 & 0.743023 \\ \text { C } & 2.878766 & -4.781091 & 1.447800 \\ \text { C } & 2.152918 & -5.804575 & 2.056407 \\ \text { H } & -0.979903 & -4.798708 & 1.208306 \\ \text { H } & 2.676767 & -6.584860 & 2.602733 \\ \text { C } & -1.678415 & 5.031258 & -1.031588 \\ \text { C } & -1.092390 & 5.245602 & 0.216464 \\ \text { C } & 0.094487 & 4.595691 & 0.553091\end{array}$




\begin{tabular}{|c|c|c|c|}
\hline C & 0.717988 & 3.718226 & -0.348647 \\
\hline C & 0.111057 & 3.501353 & -1.597425 \\
\hline C & -1.073010 & 4.154948 & -1.935375 \\
\hline $\mathrm{H}$ & -1.562123 & 5.913064 & 0.934000 \\
\hline $\mathrm{H}$ & -1.518629 & 3.984394 & -2.912297 \\
\hline C & 4.512101 & 1.872606 & 0.705673 \\
\hline C & 4.272974 & 3.265342 & 0.944310 \\
\hline C & 5.279025 & 4.048968 & 1.571878 \\
\hline C & 6.464358 & 3.484272 & 1.981492 \\
\hline C & 6.687390 & 2.101580 & 1.783478 \\
\hline C & 5.739590 & 1.318202 & 1.162091 \\
\hline $\mathrm{H}$ & 5.085095 & 5.106732 & 1.734039 \\
\hline $\mathrm{H}$ & 7.222923 & 4.092167 & 2.467037 \\
\hline $\mathrm{H}$ & 7.613563 & 1.650735 & 2.129762 \\
\hline $\mathrm{H}$ & 5.922745 & 0.258596 & 1.028331 \\
\hline C & 4.759836 & -0.762068 & -1.146679 \\
\hline C & 4.987909 & -2.162099 & -1.339555 \\
\hline C & 6.045444 & -2.588586 & -2.188071 \\
\hline C & 6.838190 & -1.676049 & -2.844139 \\
\hline C & 6.595758 & -0.291672 & -2.681243 \\
\hline C & 5.586882 & 0.153136 & -1.855289 \\
\hline $\mathrm{H}$ & 6.208085 & -3.656295 & -2.316195 \\
\hline $\mathrm{H}$ & 7.640527 & -2.013369 & -3.494701 \\
\hline $\mathrm{H}$ & 7.207444 & 0.428633 & -3.217920 \\
\hline $\mathrm{H}$ & 5.407600 & 1.216920 & -1.750907 \\
\hline 0 & -0.428433 & -0.957774 & -0.522202 \\
\hline 0 & -0.094874 & 0.668974 & 1.495328 \\
\hline $\mathrm{H}$ & -1.248768 & 1.025962 & 1.499172 \\
\hline $\mathrm{H}$ & 3.961782 & -4.763717 & 1.535065 \\
\hline $\mathrm{H}$ & 0.190957 & -6.612286 & 2.449985 \\
\hline $\mathrm{H}$ & 0.303947 & -2.992302 & 0.130010 \\
\hline $\mathrm{H}$ & 0.575179 & 2.825263 & -2.307291 \\
\hline $\mathrm{H}$ & -2.598147 & 5.546011 & -1.299544 \\
\hline $\mathrm{H}$ & 0.535037 & 4.749085 & 1.534065 \\
\hline C & -3.225615 & 0.428053 & 1.319003 \\
\hline 0 & -2.394362 & 1.381524 & 1.545455 \\
\hline $\mathrm{H}$ & -2.916014 & -0.608474 & 1.494925 \\
\hline C & -4.666763 & 0.726886 & 1.706592 \\
\hline $\mathrm{O}$ & -5.163929 & 1.827842 & 1.765310 \\
\hline $\mathrm{O}$ & -5.326759 & -0.421189 & 1.970703 \\
\hline C & -6.705560 & -0.261117 & 2.361899 \\
\hline $\mathrm{H}$ & -7.285819 & 0.185028 & 1.549443 \\
\hline $\mathrm{H}$ & -7.062257 & -1.266526 & 2.585980 \\
\hline C & -4.418013 & -0.564548 & -0.999498 \\
\hline
\end{tabular}




$\begin{array}{llll}\mathrm{C} & -3.363418 & 0.288358 & -0.643681 \\ \mathrm{H} & -6.388409 & -0.843969 & -1.430856 \\ \mathrm{~N} & -5.692215 & -0.130464 & -1.255463 \\ \mathrm{C} & -6.312721 & 1.138095 & -1.209525 \\ \mathrm{O} & -7.522081 & 1.215359 & -1.172344 \\ \mathrm{O} & -5.449537 & 2.144588 & -1.236406 \\ \mathrm{C} & -6.005707 & 3.454476 & -0.978613 \\ \mathrm{H} & -6.382328 & 3.486832 & 0.044864 \\ \mathrm{H} & -6.802628 & 3.671329 & -1.691967 \\ \mathrm{H} & -5.167915 & 4.139544 & -1.099307 \\ \mathrm{H} & -2.360687 & -0.121825 & -0.736478 \\ \mathrm{H} & -3.463340 & 1.341836 & -0.862491 \\ \mathrm{C} & -4.254536 & -2.035162 & -1.004925 \\ \mathrm{C} & -3.005398 & -2.601891 & -1.325185 \\ \mathrm{C} & -5.327082 & -2.896041 & -0.689580 \\ \mathrm{C} & -2.850324 & -3.986542 & -1.354869 \\ \mathrm{H} & -2.149501 & -1.972423 & -1.538060 \\ \mathrm{C} & -5.162502 & -4.276598 & -0.716487 \\ \mathrm{H} & -6.283448 & -2.496345 & -0.362987 \\ \mathrm{C} & -3.924427 & -4.826900 & -1.058541 \\ \mathrm{H} & -1.880250 & -4.404991 & -1.605272 \\ \mathrm{H} & -5.996087 & -4.922662 & -0.457044 \\ \mathrm{H} & -3.796614 & -5.905493 & -1.082154 \\ \mathrm{H} & -6.775946 & 0.377705 & 3.245250\end{array}$

Catalyst (R)-1 TS Conformation 327

B3LYP/6-31G(d) Energy = -2809.689595

B3LYP-D3(BJ)/def2-TZVPP-IEF-PCM(DCM) Energy = -2810.978622

B3LYP-D3(BJ)/def2-TZVPP-IEF-PCM(DCM)//B3LYP/6-31G(d) Free Energy (Quasiharmonic) = 2810.336405

Frequencies (Top 3 out of 270)

1. $-343.6363 \mathrm{~cm}-1$

2. $\quad 8.6085 \mathrm{~cm}-1$

3. $\quad 10.0903 \mathrm{~cm}-1$

B3LYP/6-31G(d) Molecular Geometry in Cartesian Coordinates

$\begin{array}{llll}\text { C } & 3.591920 & 0.221236 & 0.057035 \\ \text { C } & 2.711273 & 1.229530 & -0.307905 \\ \text { C } & 3.082142 & 2.607883 & -0.355583\end{array}$




\begin{tabular}{|c|c|c|c|}
\hline C & 4.343242 & 2.939029 & 0.101431 \\
\hline $\mathrm{H}$ & 4.650887 & 3.981253 & 0.088628 \\
\hline C & 2.503402 & -3.943869 & -0.254472 \\
\hline C & 3.217830 & -1.214546 & -0.119020 \\
\hline C & 2.065828 & -1.707057 & 0.469805 \\
\hline C & 1.695791 & -3.082665 & 0.461766 \\
\hline $\mathrm{H}$ & 2.264994 & -5.004149 & -0.267097 \\
\hline 0 & 1.439981 & 0.891838 & -0.757283 \\
\hline$P$ & 0.333899 & 0.200219 & 0.219245 \\
\hline O & 1.231305 & -0.809788 & 1.132243 \\
\hline C & 0.683516 & 5.719561 & -2.123124 \\
\hline C & 2.018522 & 5.547088 & -2.489149 \\
\hline C & 2.774205 & 4.527012 & -1.912026 \\
\hline C & 2.215624 & 3.661693 & -0.955550 \\
\hline C & 0.871821 & 3.846793 & -0.591319 \\
\hline C & 0.118055 & 4.865741 & -1.174228 \\
\hline $\mathrm{H}$ & 2.471614 & 6.198723 & -3.231847 \\
\hline $\mathrm{H}$ & -0.922021 & 4.990365 & -0.883806 \\
\hline C & -1.648730 & -4.685005 & 2.636054 \\
\hline C & -0.774834 & -3.790680 & 3.258428 \\
\hline C & 0.294812 & -3.246084 & 2.551188 \\
\hline C & 0.514489 & -3.592727 & 1.207229 \\
\hline C & -0.375343 & -4.484866 & 0.590688 \\
\hline C & -1.448052 & -5.025739 & 1.298475 \\
\hline $\mathrm{H}$ & -0.925275 & -3.515350 & 4.299014 \\
\hline $\mathrm{H}$ & -2.134431 & -5.701918 & 0.796252 \\
\hline C & 4.009811 & -2.111407 & -0.917974 \\
\hline C & 3.638109 & -3.494316 & -0.974405 \\
\hline C & 4.413741 & -4.393400 & -1.755514 \\
\hline C & 5.495688 & -3.950649 & -2.480152 \\
\hline C & 5.842753 & -2.579652 & -2.455815 \\
\hline C & 5.122073 & -1.685454 & -1.694779 \\
\hline $\mathrm{H}$ & 4.124677 & -5.441521 & -1.777473 \\
\hline $\mathrm{H}$ & 6.076569 & -4.646599 & -3.079233 \\
\hline $\mathrm{H}$ & 6.683233 & -2.226474 & -3.047203 \\
\hline $\mathrm{H}$ & 5.395484 & -0.636869 & -1.696175 \\
\hline C & 4.865386 & 0.593241 & 0.613216 \\
\hline C & 5.237144 & 1.975676 & 0.628010 \\
\hline C & 6.492022 & 2.356801 & 1.175682 \\
\hline C & 7.343972 & 1.419346 & 1.711348 \\
\hline C & 6.966984 & 0.055878 & 1.725878 \\
\hline C & 5.763239 & -0.346792 & 1.190289 \\
\hline $\mathrm{H}$ & 6.760355 & 3.410673 & 1.171812 \\
\hline $\mathrm{H}$ & 8.298391 & 1.722565 & 2.132951 \\
\hline
\end{tabular}




\begin{tabular}{|c|c|c|c|}
\hline $\mathrm{H}$ & 7.630564 & -0.681240 & 2.169902 \\
\hline $\mathrm{H}$ & 5.485183 & -1.393867 & 1.220271 \\
\hline $\mathrm{O}$ & -0.704402 & -0.437903 & -0.636319 \\
\hline $\mathrm{O}$ & -0.128333 & 1.267374 & 1.251878 \\
\hline $\mathrm{H}$ & -1.162384 & 1.159126 & 1.564444 \\
\hline $\mathrm{H}$ & 0.420075 & 3.203948 & 0.155305 \\
\hline $\mathrm{H}$ & 0.088588 & 6.508845 & -2.575412 \\
\hline $\mathrm{H}$ & 3.805842 & 4.380943 & -2.220339 \\
\hline $\mathrm{H}$ & -0.242521 & -4.729679 & -0.458801 \\
\hline $\mathrm{H}$ & -2.484676 & -5.105922 & 3.189035 \\
\hline $\mathrm{H}$ & 0.969705 & -2.553964 & 3.043847 \\
\hline C & -3.438623 & 1.582772 & 1.509288 \\
\hline $\mathrm{O}$ & -2.474327 & 0.825532 & 1.871900 \\
\hline $\mathrm{H}$ & -4.457004 & 1.278325 & 1.791673 \\
\hline C & -3.342171 & 3.110446 & 1.665667 \\
\hline 0 & -4.316465 & 3.832492 & 1.702449 \\
\hline $\mathrm{O}$ & -2.075147 & 3.530267 & 1.783042 \\
\hline C & -1.905473 & 4.937403 & 2.035501 \\
\hline $\mathrm{H}$ & -2.322145 & 5.194865 & 3.012901 \\
\hline $\mathrm{H}$ & -0.829984 & 5.108567 & 2.015574 \\
\hline C & -4.239641 & 0.281495 & -0.668666 \\
\hline C & -3.666279 & 1.545333 & -0.412451 \\
\hline $\mathrm{H}$ & -2.412875 & -0.666797 & -0.577036 \\
\hline $\mathrm{N}$ & -3.431169 & -0.798513 & -0.761454 \\
\hline C & -3.707636 & -2.076811 & -1.292795 \\
\hline 0 & -2.975278 & -3.020486 & -1.118757 \\
\hline 0 & -4.818368 & -2.085314 & -2.048987 \\
\hline C & -5.147066 & -3.363727 & -2.620297 \\
\hline $\mathrm{H}$ & -5.302012 & -4.106645 & -1.833890 \\
\hline $\mathrm{H}$ & -4.345373 & -3.701183 & -3.281401 \\
\hline $\mathrm{H}$ & -6.066984 & -3.198098 & -3.180768 \\
\hline $\mathrm{H}$ & -4.335054 & 2.389002 & -0.551508 \\
\hline $\mathrm{H}$ & -2.638877 & 1.698001 & -0.733280 \\
\hline C & -5.709969 & 0.131479 & -0.590586 \\
\hline C & -6.278516 & -0.849841 & 0.240959 \\
\hline C & -6.551742 & 1.027877 & -1.266413 \\
\hline C & -7.660015 & -0.928064 & 0.389408 \\
\hline $\mathrm{H}$ & -5.632670 & -1.526877 & 0.792434 \\
\hline C & -7.935434 & 0.930672 & -1.133092 \\
\hline $\mathrm{H}$ & -6.120914 & 1.783022 & -1.916791 \\
\hline C & -8.491874 & -0.043643 & -0.302744 \\
\hline $\mathrm{H}$ & -8.088612 & -1.676959 & 1.049295 \\
\hline $\mathrm{H}$ & -8.577845 & 1.619761 & -1.673543 \\
\hline $\mathrm{H}$ & -9.570335 & -0.110601 & -0.189688 \\
\hline
\end{tabular}


$\begin{array}{llll}H & -2.408186 & 5.528985 & 1.266409\end{array}$

Catalyst (R)-1 TS Conformation 328

B3LYP/6-31G(d) Energy $=-2809.679873$

B3LYP-D3(BJ)/def2-TZVPP-IEF-PCM(DCM) Energy $=-2810.978047$

B3LYP-D3(BJ)/def2-TZVPP-IEF-PCM(DCM)//B3LYP/6-31G(d) Free Energy (Quasiharmonic) = 2810.336386

Frequencies (Top 3 out of 270)

1. $-613.3904 \mathrm{~cm}-1$

2. $\quad 11.8535 \mathrm{~cm}-1$

3. $16.0483 \mathrm{~cm}-1$

B3LYP/6-31G(d) Molecular Geometry in Cartesian Coordinates

\begin{tabular}{|c|c|c|c|}
\hline C & 2.767769 & 0.368948 & -0.157908 \\
\hline C & 2.134517 & 1.299840 & -0.967453 \\
\hline C & 2.311753 & 2.709850 & -0.831072 \\
\hline C & 3.115406 & 3.146931 & 0.204482 \\
\hline $\mathrm{H}$ & 3.299481 & 4.211949 & 0.318587 \\
\hline C & 2.206303 & -3.871698 & -0.672660 \\
\hline C & 2.605692 & -1.090198 & -0.430600 \\
\hline C & 1.334125 & -1.642020 & -0.482363 \\
\hline C & 1.104113 & -3.048455 & -0.561269 \\
\hline $\mathrm{H}$ & 2.059582 & -4.946820 & -0.738011 \\
\hline $\mathrm{O}$ & 1.303234 & 0.840432 & -1.978514 \\
\hline$P$ & -0.169279 & 0.243950 & -1.568716 \\
\hline O & 0.240125 & -0.806757 & -0.347028 \\
\hline C & 0.555768 & 5.630473 & -3.459156 \\
\hline C & 0.547139 & 5.823410 & -2.077255 \\
\hline C & 1.100852 & 4.861689 & -1.233518 \\
\hline C & 1.674378 & 3.688679 & -1.751488 \\
\hline C & 1.671394 & 3.504237 & -3.144516 \\
\hline C & 1.119462 & 4.467385 & -3.987212 \\
\hline $\mathrm{H}$ & 0.100594 & 6.719172 & -1.653242 \\
\hline $\mathrm{H}$ & 1.130323 & 4.306661 & -5.061980 \\
\hline C & -2.795174 & -4.854004 & -0.244308 \\
\hline C & -1.761116 & -5.232376 & 0.614508 \\
\hline C & -0.507143 & -4.629662 & 0.508815 \\
\hline C & -0.259283 & -3.641602 & -0.459932 \\
\hline C & -1.304641 & -3.269070 & -1.322995 \\
\hline
\end{tabular}




\begin{tabular}{|c|c|c|c|}
\hline C & -2.561130 & -3.871815 & -1.211203 \\
\hline $\mathrm{H}$ & -1.931017 & -5.991378 & 1.373868 \\
\hline $\mathrm{H}$ & -3.355900 & -3.571266 & -1.889185 \\
\hline C & 3.738715 & -1.948770 & -0.641504 \\
\hline C & 3.525280 & -3.360627 & -0.753829 \\
\hline C & 4.637491 & -4.221311 & -0.957359 \\
\hline C & 5.912218 & -3.716537 & -1.069085 \\
\hline C & 6.123263 & -2.319977 & -0.988576 \\
\hline C & 5.067293 & -1.460253 & -0.779193 \\
\hline $\mathrm{H}$ & 4.457436 & -5.291081 & -1.034518 \\
\hline $\mathrm{H}$ & 6.754395 & -4.383797 & -1.230773 \\
\hline $\mathrm{H}$ & 7.127640 & -1.920253 & -1.100062 \\
\hline $\mathrm{H}$ & 5.244351 & -0.391796 & -0.732273 \\
\hline C & 3.524952 & 0.844108 & 0.968704 \\
\hline C & 3.707276 & 2.255635 & 1.132779 \\
\hline C & 4.464581 & 2.738249 & 2.234812 \\
\hline C & 4.991332 & 1.873622 & 3.166116 \\
\hline C & 4.773919 & 0.481892 & 3.032676 \\
\hline C & 4.064086 & -0.019766 & 1.962681 \\
\hline $\mathrm{H}$ & 4.607912 & 3.811834 & 2.333771 \\
\hline $\mathrm{H}$ & 5.563172 & 2.255311 & 4.007644 \\
\hline $\mathrm{H}$ & 5.171047 & -0.199482 & 3.780485 \\
\hline $\mathrm{H}$ & 3.901096 & -1.087795 & 1.878445 \\
\hline $\mathrm{O}$ & -0.786672 & -0.434530 & -2.736659 \\
\hline $\mathrm{O}$ & -0.959134 & 1.319828 & -0.803006 \\
\hline $\mathrm{H}$ & -2.208749 & 1.385820 & -0.976351 \\
\hline $\mathrm{H}$ & 2.105754 & 2.605452 & -3.567447 \\
\hline $\mathrm{H}$ & 0.121215 & 6.376707 & -4.119006 \\
\hline $\mathrm{H}$ & 1.070542 & 5.007385 & -0.157160 \\
\hline $\mathrm{H}$ & -1.131412 & -2.515079 & -2.085127 \\
\hline $\mathrm{H}$ & -3.772375 & -5.323700 & -0.164370 \\
\hline $\mathrm{H}$ & 0.286247 & -4.904475 & 1.197445 \\
\hline C & -3.724666 & 0.112646 & -1.134715 \\
\hline O & -3.363647 & 1.336126 & -1.047716 \\
\hline $\mathrm{H}$ & -2.986775 & -0.642800 & -1.413416 \\
\hline C & -5.138584 & -0.129345 & -1.633628 \\
\hline $\mathrm{O}$ & -6.026139 & 0.688535 & -1.633438 \\
\hline $\mathrm{O}$ & -5.255201 & -1.397453 & -2.081321 \\
\hline C & -6.548437 & -1.742190 & -2.612136 \\
\hline $\mathrm{H}$ & -6.466053 & -2.780896 & -2.931211 \\
\hline $\mathrm{H}$ & -6.794047 & -1.096611 & -3.458774 \\
\hline C & -3.098064 & -0.329487 & 1.589487 \\
\hline C & -4.114650 & -0.785800 & 0.744228 \\
\hline $\mathrm{H}$ & -1.862724 & -1.859024 & 1.059154 \\
\hline
\end{tabular}




$\begin{array}{llll}\text { N } & -1.954136 & -1.065976 & 1.690779 \\ \mathrm{C} & -0.866889 & -1.045167 & 2.587608 \\ \mathrm{O} & -0.015874 & -1.904077 & 2.543619 \\ \mathrm{O} & -0.919076 & -0.042324 & 3.464822 \\ \mathrm{C} & 0.193778 & 0.014827 & 4.381529 \\ \mathrm{H} & 0.011360 & 0.900103 & 4.989856 \\ \mathrm{H} & 1.132645 & 0.106447 & 3.830978 \\ \mathrm{H} & 0.219204 & -0.884457 & 5.001364 \\ \mathrm{H} & -5.081022 & -0.312390 & 0.874402 \\ \mathrm{H} & -4.116834 & -1.827272 & 0.432896 \\ \mathrm{C} & -3.252283 & 0.991130 & 2.232957 \\ \mathrm{C} & -2.300854 & 2.008028 & 2.035243 \\ \mathrm{C} & -4.424037 & 1.269622 & 2.956849 \\ \mathrm{C} & -2.527080 & 3.276112 & 2.563446 \\ \mathrm{H} & -1.420894 & 1.814881 & 1.432005 \\ \mathrm{C} & -4.627025 & 2.532542 & 3.506684 \\ \mathrm{H} & -5.159648 & 0.485691 & 3.111812 \\ \mathrm{C} & -3.680100 & 3.539179 & 3.306544 \\ \mathrm{H} & -1.800402 & 4.063808 & 2.387101 \\ \mathrm{H} & -5.526002 & 2.732198 & 4.082593 \\ \mathrm{H} & -3.845254 & 4.529673 & 3.721784 \\ \mathrm{H} & -7.317899 & -1.631815 & -1.843358\end{array}$

Catalyst (R)-1 TS Conformation 329

B3LYP/6-31G(d) Energy $=-2809.681568$

B3LYP-D3(BJ)/def2-TZVPP-IEF-PCM(DCM) Energy = -2810.977969

B3LYP-D3(BJ)/def2-TZVPP-IEF-PCM(DCM)//B3LYP/6-31G(d) Free Energy (Quasiharmonic) = 2810.336345

Frequencies (Top 3 out of 270)

1. $-688.1049 \mathrm{~cm}-1$

2. $\quad 12.0349 \mathrm{~cm}-1$

3. $\quad 17.7910 \mathrm{~cm}-1$

B3LYP/6-31G(d) Molecular Geometry in Cartesian Coordinates

$\begin{array}{llll}\text { C } & 2.713061 & 0.211972 & -0.058707 \\ \text { C } & 2.193873 & 1.265236 & -0.799566 \\ \text { C } & 2.565556 & 2.627050 & -0.575262 \\ \text { C } & 3.386522 & 2.890931 & 0.504465 \\ \text { H } & 3.679681 & 3.918450 & 0.703209\end{array}$




\begin{tabular}{|c|c|c|c|}
\hline C & 1.910075 & -3.920895 & -0.974799 \\
\hline C & 2.470098 & -1.201721 & -0.473042 \\
\hline C & 1.173515 & -1.665404 & -0.621469 \\
\hline C & 0.857838 & -3.039961 & -0.831813 \\
\hline $\mathrm{H}$ & 1.699794 & -4.975120 & -1.136164 \\
\hline 0 & 1.356742 & 0.986301 & -1.868596 \\
\hline$P$ & -0.145886 & 0.383131 & -1.613547 \\
\hline $\mathrm{O}$ & 0.131166 & -0.768857 & -0.453166 \\
\hline C & 1.537512 & 5.921779 & -3.149217 \\
\hline C & 2.864787 & 5.677891 & -2.794376 \\
\hline C & 3.179986 & 4.597163 & -1.971519 \\
\hline C & 2.177042 & 3.739131 & -1.488703 \\
\hline C & 0.845396 & 3.992743 & -1.853861 \\
\hline C & 0.533165 & 5.076087 & -2.674901 \\
\hline $\mathrm{H}$ & 3.657936 & 6.323117 & -3.163531 \\
\hline $\mathrm{H}$ & -0.504011 & 5.258531 & -2.944194 \\
\hline C & -3.158442 & -4.596116 & -0.779986 \\
\hline C & -2.196280 & -5.074592 & 0.112077 \\
\hline C & -0.901702 & -4.552518 & 0.091800 \\
\hline C & -0.544283 & -3.546537 & -0.823216 \\
\hline C & -1.518513 & -3.073539 & -1.719602 \\
\hline C & -2.815275 & -3.595438 & -1.694461 \\
\hline $\mathrm{H}$ & -2.452313 & -5.850327 & 0.829373 \\
\hline $\mathrm{H}$ & -3.560558 & -3.210871 & -2.384813 \\
\hline C & 3.556802 & -2.110722 & -0.719721 \\
\hline C & 3.260446 & -3.490676 & -0.964638 \\
\hline C & 4.324117 & -4.401939 & -1.203706 \\
\hline C & 5.631391 & -3.974420 & -1.224995 \\
\hline C & 5.925532 & -2.607012 & -1.014047 \\
\hline C & 4.917673 & -1.700862 & -0.766482 \\
\hline $\mathrm{H}$ & 4.080796 & -5.446802 & -1.381937 \\
\hline $\mathrm{H}$ & 6.436149 & -4.679224 & -1.415408 \\
\hline $\mathrm{H}$ & 6.956505 & -2.265861 & -1.054946 \\
\hline $\mathrm{H}$ & 5.159609 & -0.654535 & -0.620006 \\
\hline C & 3.476149 & 0.515095 & 1.122381 \\
\hline C & 3.819855 & 1.877955 & 1.394294 \\
\hline C & 4.574613 & 2.189776 & 2.557707 \\
\hline C & 4.953866 & 1.205615 & 3.441011 \\
\hline C & 4.583328 & -0.137865 & 3.195588 \\
\hline C & 3.868088 & -0.475391 & 2.066222 \\
\hline $\mathrm{H}$ & 4.837267 & 3.229095 & 2.741397 \\
\hline $\mathrm{H}$ & 5.526844 & 1.456710 & 4.329558 \\
\hline $\mathrm{H}$ & 4.865312 & -0.912379 & 3.904025 \\
\hline $\mathrm{H}$ & 3.583862 & -1.507484 & 1.896772 \\
\hline
\end{tabular}




\begin{tabular}{|c|c|c|c|}
\hline $\mathrm{O}$ & -0.701248 & -0.166754 & -2.873415 \\
\hline O & -0.961642 & 1.423451 & -0.810804 \\
\hline $\mathrm{H}$ & -2.190729 & 1.450911 & -0.956101 \\
\hline $\mathrm{H}$ & 0.054703 & 3.351065 & -1.482607 \\
\hline $\mathrm{H}$ & 1.288397 & 6.761309 & -3.793119 \\
\hline $\mathrm{H}$ & 4.217111 & 4.399116 & -1.714195 \\
\hline $\mathrm{H}$ & -1.258344 & -2.300651 & -2.437026 \\
\hline $\mathrm{H}$ & -4.167053 & -5.001368 & -0.767462 \\
\hline $\mathrm{H}$ & -0.161899 & -4.904820 & 0.804321 \\
\hline C & -3.732067 & 0.173256 & -1.131097 \\
\hline 0 & -3.365130 & 1.394593 & -1.025263 \\
\hline $\mathrm{H}$ & -2.997332 & -0.588352 & -1.403777 \\
\hline C & -5.106930 & -0.120689 & -1.705384 \\
\hline $\mathrm{O}$ & -5.386858 & -1.187677 & -2.211486 \\
\hline $\mathrm{O}$ & -5.943122 & 0.915977 & -1.584267 \\
\hline C & -7.252792 & 0.718304 & -2.149223 \\
\hline $\mathrm{H}$ & -7.790953 & 1.647255 & -1.962778 \\
\hline $\mathrm{H}$ & -7.177138 & 0.524101 & -3.221883 \\
\hline C & -3.138477 & -0.386415 & 1.558759 \\
\hline C & -4.181476 & -0.741183 & 0.695364 \\
\hline $\mathrm{H}$ & -1.987138 & -1.947568 & 0.936980 \\
\hline$N$ & -2.035413 & -1.186308 & 1.611431 \\
\hline C & -0.941838 & -1.266008 & 2.498318 \\
\hline $\mathrm{O}$ & -0.117127 & -2.143470 & 2.380449 \\
\hline $\mathrm{O}$ & -0.961548 & -0.334429 & 3.451347 \\
\hline C & 0.155614 & -0.380624 & 4.364572 \\
\hline $\mathrm{H}$ & 1.095912 & -0.279677 & 3.818295 \\
\hline $\mathrm{H}$ & 0.151827 & -1.323362 & 4.916642 \\
\hline $\mathrm{H}$ & 0.003260 & 0.463047 & 5.036848 \\
\hline $\mathrm{H}$ & -5.117373 & -0.216987 & 0.852241 \\
\hline $\mathrm{H}$ & -4.250445 & -1.766525 & 0.340150 \\
\hline C & -3.214169 & 0.906578 & 2.268457 \\
\hline C & -2.204285 & 1.873890 & 2.118519 \\
\hline C & -4.365217 & 1.216245 & 3.012564 \\
\hline C & -2.352552 & 3.124561 & 2.711948 \\
\hline $\mathrm{H}$ & -1.338888 & 1.661335 & 1.501119 \\
\hline C & -4.490794 & 2.459041 & 3.627829 \\
\hline $\mathrm{H}$ & -5.144795 & 0.469487 & 3.132632 \\
\hline C & -3.486034 & 3.416731 & 3.474212 \\
\hline $\mathrm{H}$ & -1.579939 & 3.875112 & 2.572954 \\
\hline $\mathrm{H}$ & -5.373765 & 2.681256 & 4.220115 \\
\hline $\mathrm{H}$ & -3.590049 & 4.392144 & 3.941654 \\
\hline $\mathrm{H}$ & -7.754565 & -0.125061 & -1.667287 \\
\hline
\end{tabular}


Catalyst (R)-1 TS Conformation 330

B3LYP/6-31G(d) Energy $=-2809.687124$

B3LYP-D3(BJ)/def2-TZVPP-IEF-PCM(DCM) Energy = -2810.978799

B3LYP-D3(BJ)/def2-TZVPP-IEF-PCM(DCM)//B3LYP/6-31G(d) Free Energy (Quasiharmonic) = 2810.33627

Frequencies (Top 3 out of 270)

1. $-563.8363 \mathrm{~cm}-1$

2. $\quad 6.4079 \mathrm{~cm}-1$

3. $\quad 10.0653 \mathrm{~cm}-1$

B3LYP/6-31G(d) Molecular Geometry in Cartesian Coordinates

$\begin{array}{llll}\text { C } & 3.346934 & -1.197246 & -0.166931 \\ \text { C } & 2.063639 & -1.677370 & 0.036570 \\ \text { C } & 1.676515 & -3.024313 & -0.225952 \\ \text { C } & 2.634439 & -3.866861 & -0.754267 \\ \text { H } & 2.381493 & -4.907083 & -0.942618 \\ \text { C } & 4.397979 & 2.893107 & 0.681421 \\ \text { C } & 3.677875 & 0.208658 & 0.213297 \\ \text { C } & 2.935540 & 1.263140 & -0.304244 \\ \text { C } & 3.305346 & 2.631292 & -0.122739 \\ \text { H } & 4.695634 & 3.925681 & 0.844055 \\ \text { O } & 1.105498 & -0.806465 & 0.534473 \\ \text { P } & 0.483835 & 0.315114 & -0.498525 \\ \text { O } & 1.849395 & 0.986747 & -1.119111 \\ \text { C } & -2.252077 & -4.588515 & 0.581413 \\ \text { C } & -1.605391 & -3.798551 & 1.535531 \\ \text { C } & -0.342362 & -3.268376 & 1.273871 \\ \text { C } & 0.303496 & -3.523406 & 0.051717 \\ \text { C } & -0.360053 & -4.314348 & -0.899943 \\ \text { C } & -1.624372 & -4.842354 & -0.638752 \\ \text { H } & -2.081613 & -3.600458 & 2.492648 \\ \text { H } & -2.120591 & -5.447120 & -1.393441 \\ \text { C } & 1.403060 & 5.981092 & -2.044783 \\ \text { C } & 0.628701 & 5.048263 & -1.352412 \\ \text { C } & 1.221544 & 3.944780 & -0.738723 \\ \text { C } & 2.611955 & 3.759689 & -0.806125 \\ \text { C } & 3.382189 & 4.704102 & -1.505845 \\ \text { C } & 2.785051 & 5.804241 & -2.120465 \\ \text { H } & -0.448599 & 5.178964 & -1.285549\end{array}$




\begin{tabular}{|c|c|c|c|}
\hline $\mathrm{H}$ & 3.399848 & 6.517714 & -2.663403 \\
\hline C & 4.752482 & 0.502479 & 1.122032 \\
\hline C & 5.116142 & 1.869112 & 1.344806 \\
\hline C & 6.178973 & 2.173506 & 2.238074 \\
\hline C & 6.847684 & 1.176160 & 2.908877 \\
\hline C & 6.469955 & -0.173635 & 2.716059 \\
\hline C & 5.452832 & -0.501670 & 1.846658 \\
\hline $\mathrm{H}$ & 6.446067 & 3.217026 & 2.388396 \\
\hline $\mathrm{H}$ & 7.655344 & 1.420991 & 3.593388 \\
\hline $\mathrm{H}$ & 6.983227 & -0.959709 & 3.263552 \\
\hline $\mathrm{H}$ & 5.168976 & -1.539941 & 1.719017 \\
\hline C & 4.312029 & -2.065028 & -0.787142 \\
\hline C & 3.942346 & -3.421053 & -1.066644 \\
\hline C & 4.889329 & -4.293798 & -1.667988 \\
\hline C & 6.143199 & -3.847696 & -2.014900 \\
\hline C & 6.497494 & -2.498914 & -1.778027 \\
\hline C & 5.608631 & -1.632620 & -1.180092 \\
\hline $\mathrm{H}$ & 4.595111 & -5.322790 & -1.861431 \\
\hline $\mathrm{H}$ & 6.856170 & -4.522165 & -2.481229 \\
\hline $\mathrm{H}$ & 7.479102 & -2.140057 & -2.075702 \\
\hline $\mathrm{H}$ & 5.893207 & -0.600046 & -1.016280 \\
\hline $\mathrm{O}$ & -0.345506 & 1.256677 & 0.316816 \\
\hline 0 & -0.156304 & -0.393047 & -1.693168 \\
\hline $\mathrm{H}$ & -1.350673 & -0.149181 & -2.001350 \\
\hline $\mathrm{H}$ & 0.113416 & -4.495556 & -1.860549 \\
\hline $\mathrm{H}$ & -3.235956 & -5.001856 & 0.788190 \\
\hline $\mathrm{H}$ & 0.153269 & -2.660605 & 2.023099 \\
\hline $\mathrm{H}$ & 4.456667 & 4.560257 & -1.582827 \\
\hline $\mathrm{H}$ & 0.933588 & 6.836490 & -2.524008 \\
\hline $\mathrm{H}$ & 0.605952 & 3.232667 & -0.199411 \\
\hline C & -3.061938 & 0.682550 & -1.316629 \\
\hline $\mathrm{O}$ & -2.459058 & 0.054350 & -2.265885 \\
\hline $\mathrm{H}$ & -2.462435 & 1.256158 & -0.604824 \\
\hline C & -4.401888 & 1.287881 & -1.697642 \\
\hline $\mathrm{O}$ & -5.147949 & 0.857360 & -2.548289 \\
\hline 0 & -4.646932 & 2.372469 & -0.939973 \\
\hline C & -5.883664 & 3.061639 & -1.222761 \\
\hline $\mathrm{H}$ & -5.895524 & 3.919619 & -0.550873 \\
\hline $\mathrm{H}$ & -5.901251 & 3.388057 & -2.265195 \\
\hline C & -4.508483 & -0.250165 & 0.946751 \\
\hline C & -3.674302 & -0.756214 & -0.061894 \\
\hline $\mathrm{H}$ & -6.309082 & 0.566823 & 1.423428 \\
\hline$N$ & -5.860712 & -0.079027 & 0.784438 \\
\hline C & -6.777525 & -0.484633 & -0.208971 \\
\hline
\end{tabular}




$\begin{array}{llll}\text { O } & -7.864833 & 0.047023 & -0.279076 \\ \text { O } & -6.326967 & -1.479313 & -0.964596 \\ \mathrm{C} & -7.143395 & -1.799144 & -2.115788 \\ \mathrm{H} & -8.166771 & -2.012970 & -1.803364 \\ \mathrm{H} & -6.674900 & -2.677911 & -2.556492 \\ \mathrm{H} & -7.120060 & -0.958844 & -2.811631 \\ \mathrm{H} & -2.694202 & -1.094047 & 0.256066 \\ \mathrm{H} & -4.131750 & -1.343771 & -0.844787 \\ \mathrm{C} & -3.989497 & 0.230041 & 2.240461 \\ \mathrm{C} & -2.657865 & 0.671909 & 2.361748 \\ \mathrm{C} & -4.816491 & 0.236176 & 3.385126 \\ \mathrm{C} & -2.182723 & 1.128226 & 3.588887 \\ \mathrm{H} & -1.980323 & 0.695133 & 1.513035 \\ \mathrm{C} & -4.327680 & 0.681014 & 4.608869 \\ \mathrm{H} & -5.827007 & -0.160484 & 3.337088 \\ \mathrm{C} & -3.010495 & 1.137146 & 4.712677 \\ \mathrm{H} & -1.157508 & 1.479634 & 3.652495 \\ \mathrm{H} & -4.971275 & 0.661622 & 5.483594 \\ \mathrm{H} & -2.631546 & 1.489400 & 5.668057 \\ \mathrm{H} & -6.738257 & 2.406672 & -1.035013\end{array}$

Catalyst (R)-1 TS Conformation 331

B3LYP/6-31G(d) Energy = -2809.686207

B3LYP-D3(BJ)/def2-TZVPP-IEF-PCM(DCM) Energy = -2810.978581

B3LYP-D3(BJ)/def2-TZVPP-IEF-PCM(DCM)//B3LYP/6-31G(d) Free Energy (Quasiharmonic) = 2810.336265

Frequencies (Top 3 out of 270)

1. $-630.6544 \mathrm{~cm}-1$

2. $\quad 5.1743 \mathrm{~cm}-1$

3. $\quad 7.4051 \mathrm{~cm}-1$

B3LYP/6-31G(d) Molecular Geometry in Cartesian Coordinates

$\begin{array}{llll}\text { C } & -3.821119 & 0.311055 & -0.186672 \\ \text { C } & -2.995940 & 1.310979 & 0.308168 \\ \text { C } & -3.344015 & 2.694477 & 0.287103 \\ \text { C } & -4.543888 & 3.036868 & -0.305265 \\ \text { H } & -4.850953 & 4.079444 & -0.314963 \\ \text { C } & -2.550062 & -3.805513 & 0.065290 \\ \text { C } & -3.407060 & -1.117663 & -0.051131\end{array}$




\begin{tabular}{|c|c|c|c|}
\hline C & -2.172559 & -1.515885 & -0.542611 \\
\hline C & -1.718628 & -2.868568 & -0.517145 \\
\hline $\mathrm{H}$ & -2.248275 & -4.849718 & 0.075434 \\
\hline $\mathrm{O}$ & -1.784016 & 0.954394 & 0.879844 \\
\hline$P$ & -0.548772 & 0.468466 & -0.091749 \\
\hline 0 & -1.345271 & -0.558908 & -1.106645 \\
\hline C & -0.924051 & 5.815314 & 1.996288 \\
\hline C & -1.144794 & 4.634731 & 2.708852 \\
\hline C & -1.907108 & 3.607956 & 2.154553 \\
\hline C & -2.470355 & 3.745038 & 0.874656 \\
\hline C & -2.237029 & 4.935197 & 0.166954 \\
\hline C & -1.471584 & 5.960570 & 0.721131 \\
\hline $\mathrm{H}$ & -0.723895 & 4.512095 & 3.703642 \\
\hline $\mathrm{H}$ & -1.296505 & 6.869454 & 0.151243 \\
\hline C & 2.048434 & -4.158808 & -2.154916 \\
\hline C & 1.631581 & -4.601114 & -0.898704 \\
\hline C & 0.417852 & -4.163126 & -0.369536 \\
\hline C & -0.404759 & -3.275840 & -1.082945 \\
\hline C & 0.029430 & -2.833570 & -2.344485 \\
\hline C & 1.241900 & -3.273314 & -2.873705 \\
\hline $\mathrm{H}$ & 2.253736 & -5.283304 & -0.324883 \\
\hline $\mathrm{H}$ & 1.554332 & -2.925852 & -3.855205 \\
\hline C & -4.226126 & -2.090294 & 0.618711 \\
\hline C & -3.788105 & -3.454114 & 0.656963 \\
\hline C & -4.595573 & -4.428852 & 1.303809 \\
\hline C & -5.773405 & -4.076932 & 1.920729 \\
\hline C & -6.188582 & -2.724439 & 1.920035 \\
\hline C & -5.437624 & -1.758867 & 1.286277 \\
\hline $\mathrm{H}$ & -4.254351 & -5.461555 & 1.311333 \\
\hline $\mathrm{H}$ & -6.378918 & -4.829981 & 2.417768 \\
\hline $\mathrm{H}$ & -7.107046 & -2.443088 & 2.428229 \\
\hline $\mathrm{H}$ & -5.765344 & -0.725978 & 1.302600 \\
\hline C & -5.030235 & 0.690699 & -0.865008 \\
\hline C & -5.392929 & 2.076066 & -0.906807 \\
\hline C & -6.591907 & 2.464595 & -1.563870 \\
\hline C & -7.391789 & 1.535121 & -2.186765 \\
\hline C & -7.016003 & 0.171278 & -2.182080 \\
\hline C & -5.869052 & -0.239678 & -1.538916 \\
\hline $\mathrm{H}$ & -6.857584 & 3.519157 & -1.574867 \\
\hline $\mathrm{H}$ & -8.302364 & 1.845276 & -2.692145 \\
\hline $\mathrm{H}$ & -7.635196 & -0.559501 & -2.695521 \\
\hline $\mathrm{H}$ & -5.590616 & -1.286972 & -1.554574 \\
\hline $\mathrm{O}$ & 0.476134 & -0.200922 & 0.759318 \\
\hline $\mathrm{O}$ & -0.119549 & 1.616324 & -1.007587 \\
\hline
\end{tabular}




\begin{tabular}{|c|c|c|c|}
\hline $\mathrm{H}$ & 1.095939 & 1.847072 & -1.096243 \\
\hline $\mathrm{H}$ & -2.640970 & 5.043889 & -0.835613 \\
\hline $\mathrm{H}$ & -0.326326 & 6.613037 & 2.429736 \\
\hline $\mathrm{H}$ & -2.073217 & 2.695703 & 2.717006 \\
\hline $\mathrm{H}$ & -0.588657 & -2.147209 & -2.912287 \\
\hline $\mathrm{H}$ & 2.993161 & -4.499920 & -2.570646 \\
\hline $\mathrm{H}$ & 0.109485 & -4.493318 & 0.618449 \\
\hline C & 2.948068 & 1.625310 & -0.221906 \\
\hline 0 & 2.238236 & 2.094770 & -1.190643 \\
\hline $\mathrm{H}$ & 2.447095 & 1.327307 & 0.703006 \\
\hline C & 4.297265 & 2.302096 & -0.045081 \\
\hline $\mathrm{O}$ & 4.935053 & 2.830878 & -0.927850 \\
\hline 0 & 4.695472 & 2.220417 & 1.239232 \\
\hline C & 5.962431 & 2.844767 & 1.533034 \\
\hline $\mathrm{H}$ & 6.758834 & 2.400689 & 0.930274 \\
\hline $\mathrm{H}$ & 5.910696 & 3.915893 & 1.323225 \\
\hline C & 4.555219 & -0.687939 & 0.005223 \\
\hline C & 3.505684 & -0.183190 & -0.785664 \\
\hline $\mathrm{H}$ & 6.514470 & -0.546161 & 0.531091 \\
\hline$N$ & 5.872996 & -0.394720 & -0.237636 \\
\hline C & 6.553717 & 0.250890 & -1.293665 \\
\hline $\mathrm{O}$ & 7.691786 & 0.632682 & -1.126845 \\
\hline 0 & 5.840796 & 0.330861 & -2.410642 \\
\hline C & 6.412075 & 1.161457 & -3.448570 \\
\hline $\mathrm{H}$ & 7.421753 & 0.823721 & -3.687725 \\
\hline $\mathrm{H}$ & 6.422820 & 2.197707 & -3.106666 \\
\hline $\mathrm{H}$ & 5.745364 & 1.043145 & -4.301494 \\
\hline $\mathrm{H}$ & 2.541757 & -0.664987 & -0.662032 \\
\hline $\mathrm{H}$ & 3.754824 & 0.117611 & -1.793008 \\
\hline C & 4.325829 & -1.488773 & 1.222129 \\
\hline C & 3.069768 & -1.474461 & 1.860801 \\
\hline C & 5.350325 & -2.299668 & 1.759787 \\
\hline C & 2.867542 & -2.219582 & 3.020243 \\
\hline $\mathrm{H}$ & 2.239578 & -0.896854 & 1.466014 \\
\hline C & 5.133933 & -3.047997 & 2.911295 \\
\hline $\mathrm{H}$ & 6.305335 & -2.399801 & 1.251324 \\
\hline C & 3.893368 & -3.000980 & 3.553339 \\
\hline $\mathrm{H}$ & 1.894484 & -2.186633 & 3.500825 \\
\hline $\mathrm{H}$ & 5.929278 & -3.677037 & 3.300451 \\
\hline $\mathrm{H}$ & 3.725986 & -3.582952 & 4.455491 \\
\hline $\mathrm{H}$ & 6.131942 & 2.669915 & 2.595413 \\
\hline
\end{tabular}

Catalyst (R)-1 TS Conformation 332 
B3LYP/6-31G(d) Energy $=-2809.686149$

B3LYP-D3(BJ)/def2-TZVPP-IEF-PCM(DCM) Energy $=-2810.978753$

B3LYP-D3(BJ)/def2-TZVPP-IEF-PCM(DCM)//B3LYP/6-31G(d) Free Energy (Quasiharmonic) = 2810.336194

Frequencies (Top 3 out of 270)

1. $-580.9159 \mathrm{~cm}-1$

2. $\quad 9.7501 \mathrm{~cm}-1$

3. $\quad 13.7227 \mathrm{~cm}-1$

B3LYP/6-31G(d) Molecular Geometry in Cartesian Coordinates

$\begin{array}{llll}\mathrm{C} & 3.591784 & -0.087509 & 0.429720 \\ \mathrm{C} & 3.295972 & 1.016030 & -0.356066 \\ \mathrm{C} & 3.768584 & 2.332342 & -0.072952 \\ \mathrm{C} & 4.515753 & 2.500021 & 1.076629 \\ \mathrm{H} & 4.917327 & 3.483001 & 1.308329 \\ \mathrm{C} & 2.146566 & -4.029254 & -0.551991 \\ \mathrm{C} & 3.131326 & -1.443662 & 0.006471 \\ \mathrm{C} & 1.784528 & -1.668778 & -0.250895 \\ \mathrm{C} & 1.259682 & -2.972569 & -0.505856 \\ \mathrm{H} & 1.768205 & -5.030176 & -0.744165 \\ \mathrm{O} & 2.522837 & 0.829981 & -1.492343 \\ \mathrm{P} & 0.909864 & 0.592768 & -1.307876 \\ \mathrm{O} & 0.895889 & -0.614599 & -0.159847 \\ \mathrm{C} & 3.058321 & 5.750349 & -2.588885 \\ \mathrm{C} & 2.905789 & 5.843821 & -1.205020 \\ \mathrm{C} & 3.117773 & 4.725121 & -0.400483 \\ \mathrm{C} & 3.486971 & 3.491366 & -0.961112 \\ \mathrm{C} & 3.630635 & 3.408907 & -2.356401 \\ \mathrm{C} & 3.420246 & 4.528463 & -3.159450 \\ \mathrm{H} & 2.612148 & 6.786300 & -0.749807 \\ \mathrm{H} & 3.540230 & 4.444212 & -4.236385 \\ \mathrm{C} & -2.930264 & -3.841172 & -1.012437 \\ \mathrm{C} & -2.194141 & -4.451457 & 0.007734 \\ \mathrm{C} & -0.841589 & -4.149804 & 0.169969 \\ \mathrm{C} & -0.199111 & -3.232169 & -0.678428 \\ \mathrm{C} & -0.945102 & -2.623646 & -1.702004 \\ \mathrm{C} & -2.299386 & -2.927675 & -1.865357 \\ \mathrm{H} & -2.671745 & -5.163991 & 0.675633 \\ \mathrm{H} & -2.864829 & -2.442433 & -2.656453 \\ \mathrm{C} & 4.055274 & -2.533705 & -0.153689\end{array}$




\begin{tabular}{|c|c|c|c|}
\hline C & 3.544498 & -3.845117 & -0.418968 \\
\hline C & 4.447585 & -4.932495 & -0.566328 \\
\hline C & 5.806757 & -4.739370 & -0.483460 \\
\hline C & 6.317319 & -3.439459 & -0.256805 \\
\hline C & 5.467084 & -2.367861 & -0.094772 \\
\hline $\mathrm{H}$ & 4.039911 & -5.921940 & -0.760436 \\
\hline $\mathrm{H}$ & 6.488696 & -5.576581 & -0.604714 \\
\hline $\mathrm{H}$ & 7.391979 & -3.283010 & -0.216873 \\
\hline $\mathrm{H}$ & 5.875421 & -1.377067 & 0.066896 \\
\hline C & 4.300894 & 0.119750 & 1.664145 \\
\hline C & 4.776874 & 1.435184 & 1.973252 \\
\hline C & 5.491581 & 1.653606 & 3.182311 \\
\hline C & 5.704009 & 0.629268 & 4.075260 \\
\hline C & 5.198886 & -0.661524 & 3.793294 \\
\hline C & 4.518513 & -0.909758 & 2.621163 \\
\hline $\mathrm{H}$ & 5.857141 & 2.655982 & 3.393156 \\
\hline $\mathrm{H}$ & 6.245958 & 0.810210 & 4.999582 \\
\hline $\mathrm{H}$ & 5.344845 & -1.465263 & 4.510130 \\
\hline $\mathrm{H}$ & 4.130238 & -1.902565 & 2.426752 \\
\hline $\mathrm{O}$ & 0.317943 & 0.153881 & -2.600827 \\
\hline $\mathrm{O}$ & 0.300967 & 1.779215 & -0.549615 \\
\hline $\mathrm{H}$ & -0.881991 & 2.146523 & -0.835860 \\
\hline $\mathrm{H}$ & 3.911198 & 2.465673 & -2.811568 \\
\hline $\mathrm{H}$ & 2.890499 & 6.620261 & -3.218527 \\
\hline $\mathrm{H}$ & 2.973257 & 4.797733 & 0.673838 \\
\hline $\mathrm{H}$ & -0.466146 & -1.907667 & -2.363208 \\
\hline $\mathrm{H}$ & -3.981582 & -4.082849 & -1.150053 \\
\hline $\mathrm{H}$ & -0.274213 & -4.618397 & 0.969620 \\
\hline C & -2.527129 & 1.152380 & -1.246837 \\
\hline $\mathrm{O}$ & -2.015428 & 2.310578 & -0.979508 \\
\hline $\mathrm{H}$ & -1.905086 & 0.430411 & -1.784964 \\
\hline C & -3.978571 & 1.076111 & -1.666662 \\
\hline $\mathrm{O}$ & -4.463774 & 0.062023 & -2.135962 \\
\hline $\mathrm{O}$ & -4.638083 & 2.213746 & -1.444611 \\
\hline C & -6.037797 & 2.208724 & -1.794521 \\
\hline $\mathrm{H}$ & -6.165671 & 1.904508 & -2.835980 \\
\hline $\mathrm{H}$ & -6.582069 & 1.526502 & -1.137396 \\
\hline C & -3.754681 & -0.048557 & 0.976038 \\
\hline C & -2.463717 & 0.050646 & 0.426755 \\
\hline $\mathrm{H}$ & -4.005555 & -1.854301 & 0.080369 \\
\hline$N$ & -4.508711 & -1.122497 & 0.582355 \\
\hline C & -5.899223 & -1.168259 & 0.373344 \\
\hline $\mathrm{O}$ & -6.694304 & -0.287600 & 0.603499 \\
\hline $\mathrm{O}$ & -6.193110 & -2.378296 & -0.131917 \\
\hline
\end{tabular}




$\begin{array}{llll}\mathrm{C} & -7.574222 & -2.568963 & -0.492300 \\ \mathrm{H} & -7.854403 & -1.874663 & -1.288040 \\ \mathrm{H} & -8.219355 & -2.411362 & 0.374891 \\ \mathrm{H} & -7.638938 & -3.598943 & -0.841503 \\ \mathrm{H} & -1.734987 & 0.654893 & 0.954070 \\ \mathrm{H} & -2.051073 & -0.852986 & -0.013085 \\ \mathrm{C} & -4.274053 & 0.934434 & 1.933525 \\ \mathrm{C} & -3.820174 & 2.267097 & 1.881130 \\ \mathrm{C} & -5.148268 & 0.545076 & 2.966386 \\ \mathrm{C} & -4.256690 & 3.188902 & 2.828104 \\ \mathrm{H} & -3.157150 & 2.586412 & 1.083227 \\ \mathrm{C} & -5.556155 & 1.466038 & 3.923842 \\ \mathrm{H} & -5.482730 & -0.483998 & 3.034046 \\ \mathrm{C} & -5.118223 & 2.791556 & 3.853043 \\ \mathrm{H} & -3.915823 & 4.218207 & 2.768587 \\ \mathrm{H} & -6.217025 & 1.151152 & 4.726056 \\ \mathrm{H} & -5.443276 & 3.510769 & 4.599792 \\ \mathrm{H} & -6.372144 & 3.235409 & -1.647884\end{array}$

Catalyst (R)-1 TS Conformation 333

B3LYP/6-31G(d) Energy = -2809.682402

B3LYP-D3(BJ)/def2-TZVPP-IEF-PCM(DCM) Energy $=-2810.978472$

B3LYP-D3(BJ)/def2-TZVPP-IEF-PCM(DCM)//B3LYP/6-31G(d) Free Energy (Quasiharmonic) = 2810.336084

Frequencies (Top 3 out of 270)

1. $-579.5824 \mathrm{~cm}-1$

2. $\quad 6.4703 \mathrm{~cm}-1$

3. $\quad 8.9354 \mathrm{~cm}-1$

B3LYP/6-31G(d) Molecular Geometry in Cartesian Coordinates

$\begin{array}{llll}\text { C } & -3.652431 & 0.003248 & -0.290159 \\ \text { C } & -2.883347 & 1.154608 & -0.173831 \\ \text { C } & -3.395305 & 2.455865 & -0.466062 \\ \text { C } & -4.679683 & 2.541838 & -0.965903 \\ \text { H } & -5.089179 & 3.520874 & -1.200868 \\ \text { C } & -2.114657 & -3.821447 & 0.984153 \\ \text { C } & -3.133074 & -1.305445 & 0.208280 \\ \text { C } & -1.916519 & -1.780278 & -0.254343 \\ \text { C } & -1.383528 & -3.055838 & 0.096930\end{array}$




\begin{tabular}{|c|c|c|c|}
\hline $\mathrm{H}$ & -1.754818 & -4.811256 & 1.252643 \\
\hline $\mathrm{O}$ & -1.603391 & 1.071599 & 0.350598 \\
\hline$P$ & -0.382242 & 0.291391 & -0.436664 \\
\hline 0 & -1.186816 & -0.974474 & -1.115882 \\
\hline C & -1.298686 & 6.144198 & 0.272214 \\
\hline C & -0.698176 & 5.146543 & -0.500023 \\
\hline C & -1.352585 & 3.935651 & -0.732054 \\
\hline C & -2.630460 & 3.706619 & -0.196336 \\
\hline C & -3.226116 & 4.717453 & 0.576164 \\
\hline C & -2.567079 & 5.924568 & 0.810830 \\
\hline $\mathrm{H}$ & 0.284231 & 5.313471 & -0.935264 \\
\hline $\mathrm{H}$ & -3.044651 & 6.690449 & 1.416689 \\
\hline C & 2.287758 & -4.656414 & -1.479210 \\
\hline C & 1.387132 & -4.010765 & -2.329145 \\
\hline C & 0.205896 & -3.468781 & -1.825181 \\
\hline C & -0.100662 & -3.564663 & -0.456924 \\
\hline C & 0.817554 & -4.209774 & 0.387709 \\
\hline C & 1.998744 & -4.752000 & -0.117328 \\
\hline $\mathrm{H}$ & 1.600257 & -3.933111 & -3.392231 \\
\hline $\mathrm{H}$ & 2.694955 & -5.245069 & 0.556689 \\
\hline C & -3.842021 & -2.079547 & 1.191702 \\
\hline C & -3.321404 & -3.360990 & 1.565768 \\
\hline C & -4.017025 & -4.144302 & 2.526382 \\
\hline C & -5.163226 & -3.676867 & 3.125805 \\
\hline C & -5.657304 & -2.394887 & 2.789182 \\
\hline C & -5.016638 & -1.619029 & 1.848024 \\
\hline $\mathrm{H}$ & -3.614058 & -5.119866 & 2.788488 \\
\hline $\mathrm{H}$ & -5.682220 & -4.281684 & 3.864427 \\
\hline $\mathrm{H}$ & -6.548902 & -2.015429 & 3.281179 \\
\hline $\mathrm{H}$ & -5.403968 & -0.635553 & 1.609517 \\
\hline C & -4.947806 & 0.101061 & -0.907851 \\
\hline C & -5.464955 & 1.395100 & -1.235671 \\
\hline C & -6.746753 & 1.505059 & -1.839569 \\
\hline C & -7.487562 & 0.384848 & -2.136090 \\
\hline C & -6.965956 & -0.897551 & -1.844737 \\
\hline C & -5.732851 & -1.036071 & -1.246324 \\
\hline $\mathrm{H}$ & -7.125163 & 2.497241 & -2.074425 \\
\hline $\mathrm{H}$ & -8.463684 & 0.480099 & -2.603867 \\
\hline $\mathrm{H}$ & -7.540657 & -1.783379 & -2.101706 \\
\hline $\mathrm{H}$ & -5.343706 & -2.026587 & -1.041287 \\
\hline $\mathrm{O}$ & 0.644484 & -0.104202 & 0.567645 \\
\hline $\mathrm{O}$ & 0.041920 & 1.139202 & -1.645841 \\
\hline $\mathrm{H}$ & 1.250041 & 1.110754 & -1.986970 \\
\hline $\mathrm{H}$ & -4.208671 & 4.545259 & 1.007528 \\
\hline
\end{tabular}




$\begin{array}{llll}\mathrm{H} & -0.783791 & 7.084999 & 0.449532 \\ \mathrm{H} & -0.879478 & 3.170368 & -1.337930 \\ \mathrm{H} & 0.609692 & -4.265475 & 1.452448 \\ \mathrm{H} & 3.205362 & -5.083383 & -1.876581 \\ \mathrm{H} & -0.487752 & -2.973686 & -2.495668 \\ \mathrm{C} & 3.065540 & 0.409996 & -1.436153 \\ \mathrm{O} & 2.363283 & 1.039484 & -2.310761 \\ \mathrm{H} & 2.551935 & -0.151157 & -0.650719 \\ \mathrm{C} & 4.361972 & -0.177991 & -1.969176 \\ \mathrm{O} & 5.098105 & 0.353007 & -2.767566 \\ \mathrm{O} & 4.552487 & -1.396946 & -1.432084 \\ \mathrm{C} & 5.708689 & -2.108404 & -1.912211 \\ \mathrm{H} & 5.662381 & -3.088295 & -1.437588 \\ \mathrm{H} & 5.667999 & -2.202759 & -2.999940 \\ \mathrm{C} & 4.454159 & 1.264373 & 0.855034 \\ \mathrm{C} & 3.836858 & 1.875946 & -0.237805 \\ \mathrm{H} & 4.349284 & 0.412758 & 2.696165 \\ \mathrm{~N} & 3.827484 & 0.965893 & 2.027654 \\ \mathrm{C} & 2.579531 & 1.332479 & 2.599936 \\ \mathrm{O} & 2.248682 & 0.835361 & 3.650976 \\ \mathrm{O} & 1.949985 & 2.276523 & 1.918361 \\ \mathrm{C} & 0.639342 & 2.628184 & 2.435008 \\ \mathrm{H} & 0.732918 & 2.966711 & 3.468804 \\ \mathrm{H} & -0.013685 & 1.759320 & 2.366044 \\ \mathrm{H} & 0.286792 & 3.427297 & 1.785547 \\ \mathrm{H} & 4.480254 & 2.267459 & -1.016796 \\ \mathrm{H} & 2.897899 & 2.386902 & -0.080014 \\ \mathrm{C} & 5.856687 & 0.780885 & 0.774736 \\ \mathrm{C} & 6.244539 & -0.437867 & 1.363094 \\ \mathrm{C} & 6.828881 & 1.554208 & 0.118130 \\ \mathrm{C} & 7.569639 & -0.862168 & 1.303848 \\ \mathrm{H} & 5.502879 & -1.085310 & 1.823480 \\ \mathrm{C} & 8.155002 & 1.129846 & 0.067899 \\ & 6.551917 & 2.502986 & -0.328361 \\ \mathrm{H} & \mathbf{8 . 5 3 0 0 4 1} & -0.076675 & 0.661440 \\ \mathrm{H} & 8.850278 & -1.810421 & 1.753022 \\ \mathrm{H} & & 1.746061 & -0.432796 \\ \mathrm{H} & -0.405668 & 0.621310 \\ \mathrm{H} & & & -1.628791\end{array}$

Catalyst (R)-1 TS Conformation 334

B3LYP/6-31G(d) Energy $=-2809.682943$ 
B3LYP-D3(BJ)/def2-TZVPP-IEF-PCM(DCM) Energy = -2810.979386

B3LYP-D3(BJ)/def2-TZVPP-IEF-PCM(DCM)//B3LYP/6-31G(d) Free Energy (Quasiharmonic) = 2810.336053

Frequencies (Top 3 out of 270)

1. $-323.0736 \mathrm{~cm}-1$

2. $\quad 5.1694 \mathrm{~cm}-1$

3. $10.9353 \mathrm{~cm}-1$

B3LYP/6-31G(d) Molecular Geometry in Cartesian Coordinates

$\begin{array}{llll}\text { C } & 3.432434 & -1.208008 & -0.098928 \\ \text { C } & 2.157623 & -1.702939 & 0.134343 \\ \text { C } & 1.805705 & -3.072219 & -0.057183 \\ \text { C } & 2.779363 & -3.917506 & -0.551712 \\ \text { H } & 2.550523 & -4.971795 & -0.684987 \\ \text { C } & 4.246647 & 2.958015 & 0.670407 \\ \text { C } & 3.728234 & 0.222259 & 0.213919 \\ \text { C } & 2.943505 & 1.219363 & -0.349036 \\ \text { C } & 3.193366 & 2.611706 & -0.154067 \\ \text { H } & 4.483027 & 4.008989 & 0.815207 \\ \text { O } & 1.181219 & -0.836662 & 0.593095 \\ \text { P } & 0.520204 & 0.231106 & -0.484950 \\ \text { O } & 1.890148 & 0.852381 & -1.166730 \\ \text { C } & -2.037164 & -4.743622 & 0.925980 \\ \text { C } & -1.403629 & -3.874341 & 1.818805 \\ \text { C } & -0.173851 & -3.303018 & 1.493991 \\ \text { C } & 0.453133 & -3.596973 & 0.271081 \\ \text { C } & -0.201028 & -4.460914 & -0.622451 \\ \text { C } & -1.433372 & -5.028718 & -0.300424 \\ \text { H } & -1.860682 & -3.651102 & 2.779792 \\ \text { H } & -1.920578 & -5.693845 & -1.008748 \\ \text { C } & 0.906876 & 5.759454 & -1.997773 \\ \text { C } & 1.291427 & 4.645982 & -2.747712 \\ \text { C } & 2.012308 & 3.609951 & -2.156256 \\ \text { C } & 2.368796 & 3.668945 & -0.798191 \\ \text { C } & 1.971740 & 4.792775 & -0.054422 \\ \text { C } & 1.248913 & 5.827928 & -0.646647 \\ \text { H } & 1.032176 & 4.583211 & -3.801468 \\ \text { H } & 0.949468 & 6.685782 & -0.049573 \\ \text { C } & 4.770752 & 0.598637 & 1.128690 \\ \text { C } & 5.035079 & 1.990789 & 1.339775 \\ \text { C } & 6.073420 & 2.377805 & 2.230035\end{array}$




\begin{tabular}{|c|c|c|c|}
\hline C & 6.806238 & 1.437240 & 2.915615 \\
\hline C & 6.521111 & 0.062608 & 2.740446 \\
\hline C & 5.532942 & -0.345331 & 1.871467 \\
\hline $\mathrm{H}$ & 6.268596 & 3.438919 & 2.367522 \\
\hline $\mathrm{H}$ & 7.593241 & 1.745455 & 3.598567 \\
\hline $\mathrm{H}$ & 7.084111 & -0.679486 & 3.300294 \\
\hline $\mathrm{H}$ & 5.321445 & -1.402023 & 1.756494 \\
\hline C & 4.414201 & -2.082494 & -0.679252 \\
\hline C & 4.074895 & -3.458003 & -0.893989 \\
\hline C & 5.040019 & -4.335649 & -1.458137 \\
\hline C & 6.282725 & -3.877702 & -1.829359 \\
\hline C & 6.607520 & -2.511890 & -1.654842 \\
\hline C & 5.700311 & -1.639376 & -1.094809 \\
\hline $\mathrm{H}$ & 4.769221 & -5.379040 & -1.602747 \\
\hline $\mathrm{H}$ & 7.009755 & -4.556668 & -2.266582 \\
\hline $\mathrm{H}$ & 7.580721 & -2.145537 & -1.970584 \\
\hline $\mathrm{H}$ & 5.961253 & -0.593967 & -0.977913 \\
\hline $\mathrm{O}$ & -0.267204 & 1.225863 & 0.303944 \\
\hline 0 & -0.141650 & -0.536229 & -1.621688 \\
\hline $\mathrm{H}$ & -1.412476 & -0.312492 & -1.984368 \\
\hline $\mathrm{H}$ & 0.256204 & -4.672323 & -1.584700 \\
\hline $\mathrm{H}$ & -2.986811 & -5.203738 & 1.189667 \\
\hline $\mathrm{H}$ & 0.312311 & -2.634093 & 2.195569 \\
\hline $\mathrm{H}$ & 2.218537 & 4.843057 & 1.002588 \\
\hline $\mathrm{H}$ & 0.343644 & 6.564848 & -2.462158 \\
\hline $\mathrm{H}$ & 2.306084 & 2.751371 & -2.749404 \\
\hline C & -2.939202 & 0.700787 & -1.314299 \\
\hline $\mathrm{O}$ & -2.476936 & -0.118671 & -2.200298 \\
\hline $\mathrm{H}$ & -2.239410 & 1.359590 & -0.796412 \\
\hline C & -4.301200 & 1.282213 & -1.631284 \\
\hline $\mathrm{O}$ & -5.109128 & 0.818008 & -2.398226 \\
\hline 0 & -4.471425 & 2.429122 & -0.930776 \\
\hline C & -5.696712 & 3.139958 & -1.184821 \\
\hline $\mathrm{H}$ & -5.742670 & 3.921621 & -0.426770 \\
\hline $\mathrm{H}$ & -5.675478 & 3.574911 & -2.187700 \\
\hline C & -4.486750 & -0.193077 & 0.916126 \\
\hline C & -3.209486 & -0.396326 & 0.381595 \\
\hline $\mathrm{H}$ & -5.799270 & 0.903523 & 2.021680 \\
\hline$N$ & -4.840942 & 0.870852 & 1.696607 \\
\hline C & -4.144297 & 2.042715 & 2.084150 \\
\hline $\mathrm{O}$ & -4.738532 & 2.945212 & 2.631954 \\
\hline $\mathrm{O}$ & -2.859897 & 1.977303 & 1.787017 \\
\hline C & -2.051510 & 3.145311 & 2.069887 \\
\hline $\mathrm{H}$ & -1.077060 & 2.892177 & 1.657340 \\
\hline
\end{tabular}




$\begin{array}{lrrr}\mathrm{H} & -2.013488 & 3.310208 & 3.149090 \\ \mathrm{H} & -2.485070 & 4.017422 & 1.576049 \\ \mathrm{H} & -3.062564 & -1.349574 & -0.110010 \\ \mathrm{H} & -2.342459 & 0.024678 & 0.875690 \\ \mathrm{C} & -5.602230 & -1.112558 & 0.591332 \\ \mathrm{C} & -5.363365 & -2.494103 & 0.479846 \\ \mathrm{C} & -6.910923 & -0.632509 & 0.394046 \\ \mathrm{C} & -6.407826 & -3.367476 & 0.188921 \\ \mathrm{H} & -4.365783 & -2.887118 & 0.647837 \\ \mathrm{C} & -7.949286 & -1.509069 & 0.092685 \\ \mathrm{H} & -7.114434 & 0.434419 & 0.423811 \\ \mathrm{C} & -7.701391 & -2.879529 & -0.006081 \\ \mathrm{H} & -6.210253 & -4.432856 & 0.116121 \\ \mathrm{H} & -8.948841 & -1.120459 & -0.077873 \\ \mathrm{H} & -8.512408 & -3.563367 & -0.239496 \\ \mathrm{H} & -6.556206 & 2.469603 & -1.108977\end{array}$

Catalyst (R)-1 TS Conformation 335

B3LYP/6-31G(d) Energy $=-2809.685946$

B3LYP-D3(BJ)/def2-TZVPP-IEF-PCM(DCM) Energy $=-2810.978487$

B3LYP-D3(BJ)/def2-TZVPP-IEF-PCM(DCM)//B3LYP/6-31G(d) Free Energy (Quasiharmonic) = 2810.336028

Frequencies (Top 3 out of 270)

1. $-554.6408 \mathrm{~cm}-1$

2. $\quad 7.1355 \mathrm{~cm}-1$

3. $\quad 9.4644 \mathrm{~cm}-1$

B3LYP/6-31G(d) Molecular Geometry in Cartesian Coordinates

$\begin{array}{llll}\text { C } & 3.439723 & -1.095504 & -0.161074 \\ \text { C } & 2.180449 & -1.632843 & 0.059342 \\ \text { C } & 1.872679 & -3.012034 & -0.135577 \\ \text { C } & 2.881730 & -3.827084 & -0.609588 \\ \text { H } & 2.687981 & -4.888071 & -0.745005 \\ \text { C } & 4.119192 & 3.104722 & 0.552136 \\ \text { C } & 3.682610 & 0.347366 & 0.139678 \\ \text { C } & 2.873394 & 1.312715 & -0.443420 \\ \text { C } & 3.085267 & 2.714635 & -0.277176 \\ \text { H } & 4.326070 & 4.164315 & 0.677679 \\ \text { O } & 1.171995 & -0.797234 & 0.510263\end{array}$




\begin{tabular}{|c|c|c|c|}
\hline$P$ & 0.484590 & 0.253833 & -0.561103 \\
\hline 0 & 1.829000 & 0.902860 & -1.256118 \\
\hline C & -1.979529 & -4.742280 & 0.702204 \\
\hline C & -1.392053 & -3.868500 & 1.620778 \\
\hline C & -0.154548 & -3.286056 & 1.348859 \\
\hline C & 0.524695 & -3.570859 & 0.151668 \\
\hline C & -0.079160 & -4.447318 & -0.764097 \\
\hline C & -1.317993 & -5.027850 & -0.492687 \\
\hline $\mathrm{H}$ & -1.894603 & -3.645070 & 2.558705 \\
\hline $\mathrm{H}$ & -1.768419 & -5.698151 & -1.220263 \\
\hline C & 0.764859 & 5.761417 & -2.240863 \\
\hline C & 1.073671 & 5.868781 & -0.884388 \\
\hline C & 1.807201 & 4.865681 & -0.252129 \\
\hline C & 2.247501 & 3.735911 & -0.960892 \\
\hline C & 1.923691 & 3.636617 & -2.324676 \\
\hline C & 1.192378 & 4.641000 & -2.956274 \\
\hline $\mathrm{H}$ & 0.737308 & 6.730642 & -0.313552 \\
\hline $\mathrm{H}$ & 0.957878 & 4.547570 & -4.013523 \\
\hline C & 4.704312 & 0.769396 & 1.058224 \\
\hline C & 4.924954 & 2.171949 & 1.249422 \\
\hline C & 5.940582 & 2.603324 & 2.145481 \\
\hline C & 6.692299 & 1.695632 & 2.854604 \\
\hline C & 6.450435 & 0.310512 & 2.697925 \\
\hline C & 5.485406 & -0.140034 & 1.823971 \\
\hline $\mathrm{H}$ & 6.103072 & 3.671743 & 2.267938 \\
\hline $\mathrm{H}$ & 7.461588 & 2.037751 & 3.541603 \\
\hline $\mathrm{H}$ & 7.028609 & -0.405689 & 3.275735 \\
\hline $\mathrm{H}$ & 5.306694 & -1.204213 & 1.722801 \\
\hline C & 4.458102 & -1.940078 & -0.722969 \\
\hline C & 4.167419 & -3.327551 & -0.932325 \\
\hline C & 5.169297 & -4.176618 & -1.475925 \\
\hline C & 6.401342 & -3.680291 & -1.832970 \\
\hline C & 6.677944 & -2.303140 & -1.664926 \\
\hline C & 5.734328 & -1.457272 & -1.124490 \\
\hline $\mathrm{H}$ & 4.935198 & -5.229358 & -1.616631 \\
\hline $\mathrm{H}$ & 7.156719 & -4.337862 & -2.254556 \\
\hline $\mathrm{H}$ & 7.642685 & -1.906755 & -1.970142 \\
\hline $\mathrm{H}$ & 5.958968 & -0.402983 & -1.012498 \\
\hline $\mathrm{O}$ & -0.337899 & 1.221074 & 0.223481 \\
\hline $\mathrm{O}$ & -0.165038 & -0.539116 & -1.696345 \\
\hline $\mathrm{H}$ & -1.364087 & -0.305198 & -2.011444 \\
\hline $\mathrm{H}$ & 0.419505 & -4.654313 & -1.706607 \\
\hline $\mathrm{H}$ & -2.943950 & -5.195618 & 0.916766 \\
\hline $\mathrm{H}$ & 0.294858 & -2.612589 & 2.070412 \\
\hline
\end{tabular}




$\begin{array}{llll}\mathrm{H} & 2.251243 & 2.772029 & -2.891084 \\ \mathrm{H} & 0.192230 & 6.541519 & -2.735884 \\ \mathrm{H} & 2.025007 & 4.944129 & 0.809393 \\ \mathrm{C} & -3.063097 & 0.542463 & -1.329742 \\ \mathrm{O} & -2.473408 & -0.115397 & -2.269123 \\ \mathrm{H} & -2.454120 & 1.154853 & -0.659289 \\ \mathrm{C} & -4.419635 & 1.113919 & -1.704502 \\ \mathrm{O} & -5.173228 & 0.645758 & -2.528536 \\ \mathrm{O} & -4.671033 & 2.215939 & -0.974810 \\ \mathrm{C} & -5.923549 & 2.875624 & -1.256097 \\ \mathrm{H} & -6.763844 & 2.213422 & -1.032246 \\ \mathrm{H} & -5.937576 & 3.754189 & -0.611394 \\ \mathrm{C} & -4.441357 & -0.322009 & 0.997805 \\ \mathrm{C} & -3.615506 & -0.848612 & -0.008372 \\ \mathrm{H} & -6.250980 & 0.469155 & 1.481536 \\ \mathrm{~N} & -5.800100 & -0.189424 & 0.857457 \\ \mathrm{C} & -6.725938 & -0.649344 & -0.103545 \\ \mathrm{O} & -7.826354 & -0.144910 & -0.170126 \\ \mathrm{O} & -6.266791 & -1.658592 & -0.834197 \\ \mathrm{C} & -7.095595 & -2.034068 & -1.959431 \\ \mathrm{H} & -8.108841 & -2.257990 & -1.622059 \\ \mathrm{H} & -6.616142 & -2.917541 & -2.378410 \\ \mathrm{H} & -7.101282 & -1.217517 & -2.683357 \\ \mathrm{H} & -2.514350 & 1.648237 & 5.606274 \\ \mathrm{H} & -2.621743 & -1.151681 & 0.302580 \\ \mathrm{H} & -4.075931 & -1.480734 & -0.753923 \\ \mathrm{C} & -3.908518 & 0.221479 & 2.260158 \\ \mathrm{H} & -2.586672 & 0.701444 & 2.335030 \\ \mathrm{H} & -4.712060 & 0.251556 & 3.421217 \\ \mathrm{H} & -2.099070 & 1.217619 & 3.533334 \\ \mathrm{H} & -1.926337 & 0.708731 & 1.472054 \\ \mathrm{H} & -5.712519 & -0.172494 & 3.410313 \\ \mathrm{H} & -4.834798 & 0.754550 & 5.504565 \\ \mathrm{H} & -2.307714\end{array}$

Catalyst (R)-1 TS Conformation 336

B3LYP/6-31G(d) Energy $=-2809.680029$

B3LYP-D3(BJ)/def2-TZVPP-IEF-PCM(DCM) Energy = -2810.977523 
B3LYP-D3(BJ)/def2-TZVPP-IEF-PCM(DCM)//B3LYP/6-31G(d) Free Energy (Quasiharmonic) = 2810.335933

Frequencies (Top 3 out of 270)

1. $-624.0573 \mathrm{~cm}-1$

2. $\quad 11.0450 \mathrm{~cm}-1$

3. $\quad 16.7845 \mathrm{~cm}-1$

B3LYP/6-31G(d) Molecular Geometry in Cartesian Coordinates

$\begin{array}{llll}\text { C } & 2.739947 & 0.091006 & -0.054555 \\ \text { C } & 2.267203 & 1.144898 & -0.824833 \\ \text { C } & 2.718106 & 2.490504 & -0.656466 \\ \text { C } & 3.571302 & 2.745792 & 0.400012 \\ \text { H } & 3.924922 & 3.761542 & 0.556348 \\ \text { C } & 1.706632 & -4.019165 & -0.834871 \\ \text { C } & 2.414986 & -1.320089 & -0.417944 \\ \text { C } & 1.093569 & -1.718000 & -0.537446 \\ \text { C } & 0.704341 & -3.079401 & -0.707982 \\ \text { H } & 1.439143 & -5.064565 & -0.966310 \\ \text { O } & 1.393687 & 0.874887 & -1.867721 \\ \text { P } & -0.137199 & 0.381724 & -1.550923 \\ \text { O } & 0.100934 & -0.766330 & -0.378608 \\ \text { C } & 1.829752 & 5.742608 & -3.334155 \\ \mathrm{C} & 3.148056 & 5.431549 & -2.998899 \\ \mathrm{C} & 3.417266 & 4.365403 & -2.141346 \\ \mathrm{C} & 2.376165 & 3.589244 & -1.604078 \\ \mathrm{C} & 1.053931 & 3.910127 & -1.949589 \\ \mathrm{C} & 0.787713 & 4.978774 & -2.805324 \\ \mathrm{H} & 3.969518 & 6.012923 & -3.409866 \\ \mathrm{H} & -0.242753 & 5.214662 & -3.058252 \\ \mathrm{C} & -3.384564 & -4.433106 & -0.633556 \\ \mathrm{C} & -2.447283 & -4.945422 & 0.266042 \\ \mathrm{C} & -1.129266 & -4.487113 & 0.240525 \\ \mathrm{C} & -0.721942 & -3.511592 & -0.686201 \\ \mathrm{C} & -1.671449 & -3.001624 & -1.588651 \\ \mathrm{C} & -2.991175 & -3.461329 & -1.558490 \\ \mathrm{H} & -2.741405 & -5.698172 & 0.992984 \\ \mathrm{H} & -3.710981 & -3.056265 & -2.264667 \\ \mathrm{C} & 3.448978 & -2.292516 & -0.650043 \\ \mathrm{C} & 3.077759 & -3.661631 & -0.849214 \\ \mathrm{C} & 4.088755 & -4.635017 & -1.071591 \\ & 5.416276 & -4.278264 & -1.120775\end{array}$




\begin{tabular}{|c|c|c|c|}
\hline C & 5.784349 & -2.922410 & -0.956269 \\
\hline C & 4.828866 & -1.957023 & -0.725597 \\
\hline $\mathrm{H}$ & 3.788432 & -5.670432 & -1.214641 \\
\hline $\mathrm{H}$ & 6.180421 & -5.030127 & -1.297989 \\
\hline $\mathrm{H}$ & 6.831149 & -2.637582 & -1.019665 \\
\hline $\mathrm{H}$ & 5.127582 & -0.921129 & -0.614594 \\
\hline C & 3.538816 & 0.392132 & 1.103102 \\
\hline C & 3.962000 & 1.742399 & 1.320065 \\
\hline C & 4.751825 & 2.052577 & 2.460357 \\
\hline C & 5.090299 & 1.080625 & 3.373257 \\
\hline C & 4.642326 & -0.247909 & 3.181983 \\
\hline C & 3.891193 & -0.584657 & 2.076122 \\
\hline $\mathrm{H}$ & 5.074355 & 3.081473 & 2.602576 \\
\hline $\mathrm{H}$ & 5.690356 & 1.330737 & 4.244025 \\
\hline $\mathrm{H}$ & 4.892316 & -1.011233 & 3.914168 \\
\hline $\mathrm{H}$ & 3.548166 & -1.604821 & 1.948052 \\
\hline 0 & -0.769089 & -0.156499 & -2.781432 \\
\hline $\mathrm{O}$ & -0.860433 & 1.486107 & -0.749563 \\
\hline $\mathrm{H}$ & -2.094929 & 1.641582 & -0.918050 \\
\hline $\mathrm{H}$ & 0.235666 & 3.333012 & -1.534771 \\
\hline $\mathrm{H}$ & 1.616321 & 6.571123 & -4.004577 \\
\hline $\mathrm{H}$ & 4.446369 & 4.114429 & -1.898298 \\
\hline $\mathrm{H}$ & -1.374513 & -2.250946 & -2.315139 \\
\hline $\mathrm{H}$ & -4.410777 & -4.791680 & -0.617663 \\
\hline $\mathrm{H}$ & -0.408096 & -4.866585 & 0.958103 \\
\hline C & -3.732186 & 0.528852 & -1.159535 \\
\hline $\mathrm{O}$ & -3.252577 & 1.702297 & -1.002886 \\
\hline $\mathrm{H}$ & -3.070239 & -0.285956 & -1.461457 \\
\hline C & -5.155841 & 0.458287 & -1.684206 \\
\hline $\mathrm{O}$ & -5.955396 & 1.361558 & -1.644551 \\
\hline $\mathrm{O}$ & -5.393207 & -0.763386 & -2.205456 \\
\hline C & -6.707252 & -0.944357 & -2.766248 \\
\hline $\mathrm{H}$ & -6.726482 & -1.967197 & -3.141584 \\
\hline $\mathrm{H}$ & -6.873187 & -0.232020 & -3.577969 \\
\hline C & -3.205765 & -0.110009 & 1.551537 \\
\hline C & -4.248319 & -0.422541 & 0.674718 \\
\hline $\mathrm{H}$ & -2.112579 & -1.722117 & 0.953723 \\
\hline$N$ & -2.139518 & -0.959454 & 1.627127 \\
\hline C & -1.075724 & -1.095160 & 2.541209 \\
\hline $\mathrm{O}$ & -0.300360 & -2.019992 & 2.451189 \\
\hline $\mathrm{O}$ & -1.062529 & -0.154968 & 3.486551 \\
\hline C & 0.030167 & -0.256988 & 4.423671 \\
\hline $\mathrm{H}$ & 0.985825 & -0.212813 & 3.896684 \\
\hline $\mathrm{H}$ & -0.037280 & -1.193899 & 4.981517 \\
\hline
\end{tabular}




$\begin{array}{lrrr}\mathrm{H} & -0.088300 & 0.598896 & 5.087316 \\ \mathrm{H} & -5.163823 & 0.141360 & 0.810941 \\ \mathrm{H} & -4.347888 & -1.441343 & 0.309017 \\ \mathrm{C} & -3.234854 & 1.187685 & 2.255477 \\ \mathrm{C} & -2.173203 & 2.101979 & 2.129654 \\ \mathrm{C} & -4.388580 & 1.559962 & 2.966226 \\ \mathrm{C} & -2.273777 & 3.361819 & 2.713365 \\ \mathrm{H} & -1.302725 & 1.841515 & 1.538238 \\ \mathrm{C} & -4.467893 & 2.811208 & 3.571551 \\ \mathrm{H} & -5.208700 & 0.855166 & 3.067631 \\ \mathrm{C} & -3.411830 & 3.715719 & 3.441838 \\ \mathrm{H} & -1.460561 & 4.071568 & 2.592768 \\ \mathrm{H} & -5.355177 & 3.082018 & 4.136396 \\ \mathrm{H} & -3.479504 & 4.698225 & 3.900976 \\ \mathrm{H} & -7.472302 & -0.797387 & -1.999289\end{array}$

Catalyst (R)-1 TS Conformation 337

B3LYP/6-31G(d) Energy $=-2809.683538$

B3LYP-D3(BJ)/def2-TZVPP-IEF-PCM(DCM) Energy = -2810.979372

B3LYP-D3(BJ)/def2-TZVPP-IEF-PCM(DCM)//B3LYP/6-31G(d) Free Energy (Quasiharmonic) = 2810.335771

Frequencies (Top 3 out of 270)

1. $-315.8284 \mathrm{~cm}-1$

2. $\quad 8.4302 \mathrm{~cm}-1$

3. $\quad 10.6307 \mathrm{~cm}-1$

B3LYP/6-31G(d) Molecular Geometry in Cartesian Coordinates

$\begin{array}{llll}\text { C } & 3.293254 & -1.346931 & -0.091013 \\ \text { C } & 1.986241 & -1.747671 & 0.134324 \\ \text { C } & 1.522739 & -3.075786 & -0.101476 \\ \text { C } & 2.422153 & -3.977257 & -0.635699 \\ \text { H } & 2.109535 & -5.004873 & -0.802528 \\ \text { C } & 4.605881 & 2.677867 & 0.695050 \\ \text { C } & 3.713498 & 0.039860 & 0.270352 \\ \text { C } & 3.033937 & 1.130969 & -0.257343 \\ \text { C } & 3.495696 & 2.475074 & -0.102570 \\ \text { H } & 4.970831 & 3.691165 & 0.840940 \\ \text { O } & 1.087073 & -0.818121 & 0.630651 \\ \text { P } & 0.521789 & 0.332615 & -0.409503\end{array}$




\begin{tabular}{|c|c|c|c|}
\hline $\mathrm{O}$ & 1.925275 & 0.909888 & -1.054518 \\
\hline C & -2.417892 & -4.497976 & 0.885987 \\
\hline C & -1.851483 & -4.786219 & -0.357570 \\
\hline C & -0.587086 & -4.294351 & -0.682065 \\
\hline C & 0.137999 & -3.507265 & 0.227400 \\
\hline C & -0.451883 & -3.207349 & 1.467663 \\
\hline C & -1.714349 & -3.700571 & 1.793514 \\
\hline $\mathrm{H}$ & -2.391079 & -5.397292 & -1.076727 \\
\hline $\mathrm{H}$ & -2.143404 & -3.474145 & 2.766458 \\
\hline C & 1.828145 & 5.908189 & -2.097612 \\
\hline C & 0.986480 & 5.024347 & -1.419774 \\
\hline C & 1.502121 & 3.895966 & -0.782227 \\
\hline C & 2.881669 & 3.634263 & -0.809540 \\
\hline C & 3.719400 & 4.529373 & -1.497092 \\
\hline C & 3.199768 & 5.655108 & -2.135112 \\
\hline $\mathrm{H}$ & -0.083719 & 5.213657 & -1.384329 \\
\hline $\mathrm{H}$ & 3.866761 & 6.328565 & -2.667422 \\
\hline C & 4.811224 & 0.276300 & 1.167618 \\
\hline C & 5.260480 & 1.620238 & 1.371130 \\
\hline C & 6.345048 & 1.868988 & 2.255386 \\
\hline C & 6.955103 & 0.840161 & 2.934570 \\
\hline C & 6.494326 & -0.486036 & 2.759286 \\
\hline C & 5.453476 & -0.760815 & 1.899514 \\
\hline $\mathrm{H}$ & 6.677032 & 2.895702 & 2.391644 \\
\hline $\mathrm{H}$ & 7.780214 & 1.042694 & 3.612052 \\
\hline $\mathrm{H}$ & 6.961998 & -1.295892 & 3.312957 \\
\hline $\mathrm{H}$ & 5.105540 & -1.781066 & 1.785502 \\
\hline C & 4.197998 & -2.275125 & -0.714357 \\
\hline C & 3.747374 & -3.610016 & -0.975305 \\
\hline C & 4.633601 & -4.541450 & -1.581085 \\
\hline C & 5.906126 & -4.171682 & -1.949192 \\
\hline C & 6.341103 & -2.843742 & -1.729378 \\
\hline C & 5.512212 & -1.922208 & -1.127913 \\
\hline $\mathrm{H}$ & 4.277935 & -5.553512 & -1.760256 \\
\hline $\mathrm{H}$ & 6.572400 & -4.890280 & -2.418662 \\
\hline $\mathrm{H}$ & 7.337795 & -2.545107 & -2.043042 \\
\hline $\mathrm{H}$ & 5.858219 & -0.906536 & -0.977216 \\
\hline $\mathrm{O}$ & -0.216427 & 1.339809 & 0.418222 \\
\hline $\mathrm{O}$ & -0.183007 & -0.335697 & -1.582027 \\
\hline $\mathrm{H}$ & -1.414783 & 0.028274 & -1.971389 \\
\hline $\mathrm{H}$ & 0.089723 & -2.596955 & 2.181978 \\
\hline $\mathrm{H}$ & -3.392980 & -4.899856 & 1.151631 \\
\hline $\mathrm{H}$ & -0.158006 & -4.508177 & -1.656628 \\
\hline $\mathrm{H}$ & 4.785754 & 4.326048 & -1.547001 \\
\hline
\end{tabular}




$\begin{array}{llll}\mathrm{H} & 1.418754 & 6.783354 & -2.595801 \\ \mathrm{H} & 0.835729 & 3.221002 & -0.256266 \\ \mathrm{C} & -2.919030 & 0.999288 & -1.202197 \\ \mathrm{O} & -2.456045 & 0.313387 & -2.193496 \\ \mathrm{H} & -2.214018 & 1.528975 & -0.558047 \\ \mathrm{C} & -4.243289 & 1.685466 & -1.463277 \\ \mathrm{O} & -5.035478 & 1.391073 & -2.324610 \\ \mathrm{O} & -4.396578 & 2.709182 & -0.589713 \\ \mathrm{C} & -5.576266 & 3.512234 & -0.776792 \\ \mathrm{H} & -5.600407 & 4.197237 & 0.070487 \\ \mathrm{H} & -5.508458 & 4.064227 & -1.717996 \\ \mathrm{C} & -4.585513 & -0.168578 & 0.812703 \\ \mathrm{C} & -3.305315 & -0.358031 & 0.283082 \\ \mathrm{H} & -5.866483 & 0.785540 & 2.075902 \\ \mathrm{~N} & -4.902141 & 0.755237 & 1.768840 \\ \mathrm{C} & -4.148522 & 1.771951 & 2.403899 \\ \mathrm{O} & -4.700370 & 2.569022 & 3.129899 \\ \mathrm{O} & -2.862491 & 1.699754 & 2.107974 \\ \mathrm{C} & -1.998895 & 2.718976 & 2.668905 \\ \mathrm{H} & -2.372049 & 3.707328 & 2.392754 \\ \mathrm{H} & -1.978372 & 2.621997 & 3.756722 \\ \mathrm{H} & -1.029518 & 2.514005 & 2.219496 \\ \mathrm{H} & -3.193798 & -1.217610 & -0.364825 \\ \mathrm{H} & -2.436708 & -0.083016 & 0.866503 \\ \mathrm{C} & -5.743386 & -0.935018 & 0.296127 \\ \mathrm{C} & -5.588143 & -2.286980 & -0.058958 \\ \mathrm{C} & -7.010775 & -0.338089 & 0.156693 \\ \mathrm{C} & -6.673635 & -3.019003 & -0.532560 \\ \mathrm{H} & -4.625452 & -2.772094 & 0.066258 \\ \mathrm{C} & -8.089982 & -1.071855 & -0.327300 \\ \mathrm{H} & -7.147897 & 0.716759 & 0.378353 \\ \mathrm{H} & -7.925169 & -2.415393 & -0.669588 \\ -6.541482 & -4.065007 & -0.792848 \\ \mathrm{H} & -8.055954 & -0.591021 & -0.449314 \\ \mathrm{H} & -671656 & 2.886253 & -0.799180\end{array}$

Catalyst (R)-1 TS Conformation 338

B3LYP/6-31G(d) Energy $=-2809.681236$ B3LYP-D3(BJ)/def2-TZVPP-IEF-PCM(DCM) Energy $=-2810.977078$ B3LYP-D3(BJ)/def2-TZVPP-IEF-PCM(DCM)//B3LYP/6-31G(d) Free Energy (Quasiharmonic) = 2810.335763 
Frequencies (Top 3 out of 270)

1. $-517.9201 \mathrm{~cm}-1$

2. $\quad 6.1506 \mathrm{~cm}-1$

3. $\quad 13.1794 \mathrm{~cm}-1$

B3LYP/6-31G(d) Molecular Geometry in Cartesian Coordinates

\begin{tabular}{llll}
$\mathrm{C}$ & 3.257107 & 0.437810 & 0.121973 \\
$\mathrm{C}$ & 2.377528 & 1.436461 & -0.265010 \\
$\mathrm{C}$ & 2.517316 & 2.800367 & 0.128433 \\
$\mathrm{C}$ & 3.559739 & 3.107487 & 0.981401 \\
$\mathrm{H}$ & 3.711913 & 4.141254 & 1.280513 \\
$\mathrm{C}$ & 2.708595 & -3.548137 & -1.419124 \\
$\mathrm{C}$ & 3.089010 & -0.935840 & -0.437558 \\
$\mathrm{C}$ & 1.873358 & -1.593693 & -0.303911 \\
$\mathrm{C}$ & 1.652363 & -2.921548 & -0.783494 \\
$\mathrm{H}$ & 2.586419 & -4.572407 & -1.760408 \\
$\mathrm{O}$ & 1.309163 & 1.093641 & -1.084587 \\
$\mathrm{P}$ & 0.052989 & 0.296416 & -0.379616 \\
$\mathrm{O}$ & 0.837114 & -0.948610 & 0.360055 \\
$\mathrm{C}$ & -0.095123 & 5.948595 & -1.205545 \\
$\mathrm{C}$ & 0.384200 & 5.006675 & -2.117971 \\
$\mathrm{C}$ & 1.215172 & 3.971422 & -1.693238 \\
$\mathrm{C}$ & 1.589583 & 3.862286 & -0.343019 \\
$\mathrm{C}$ & 1.100058 & 4.816317 & 0.564459 \\
$\mathrm{C}$ & 0.265382 & 5.848621 & 0.138422 \\
$\mathrm{H}$ & 0.111227 & 5.077081 & -3.167815 \\
$\mathrm{H}$ & -0.113024 & 6.567742 & 0.860050 \\
$\mathrm{C}$ & -1.989622 & -5.182742 & -0.373238 \\
$\mathrm{C}$ & -1.538799 & -4.395174 & 0.689209 \\
$\mathrm{C}$ & -0.376273 & -3.634869 & 0.560245 \\
$\mathrm{C}$ & 0.361586 & -3.646280 & -0.635659 \\
$\mathrm{C}$ & -0.116652 & -4.427565 & -1.701726 \\
$\mathrm{C}$ & -1.275849 & -5.191263 & -1.572255 \\
$\mathrm{H}$ & -2.104312 & -4.364106 & 1.616413 \\
$\mathrm{H}$ & -1.622780 & -5.787703 & -2.412285 \\
$\mathrm{C}$ & 4.144652 & -1.570759 & -1.178580 \\
$\mathrm{C}$ & 3.947807 & -2.907254 & -1.651546 \\
$\mathrm{C}$ & 4.989869 & -3.559129 & -2.365804 \\
$\mathrm{C}$ & 6.171731 & -2.911668 & -2.639160 \\
\hline & 5.353507 & -1.575110 & -2.211896 \\
& 5.369727 & -0.923221 & -1.501359
\end{tabular}




\begin{tabular}{|c|c|c|c|}
\hline $\mathrm{H}$ & 4.825853 & -4.579266 & -2.705185 \\
\hline $\mathrm{H}$ & 6.959060 & -3.416192 & -3.192525 \\
\hline $\mathrm{H}$ & 7.277036 & -1.054722 & -2.451068 \\
\hline $\mathrm{H}$ & 5.523369 & 0.103588 & -1.191642 \\
\hline C & 4.288859 & 0.758727 & 1.068969 \\
\hline C & 4.439582 & 2.120057 & 1.488953 \\
\hline C & 5.462693 & 2.453936 & 2.417507 \\
\hline C & 6.287703 & 1.485829 & 2.941104 \\
\hline C & 6.116344 & 0.134874 & 2.557363 \\
\hline C & 5.145834 & -0.218800 & 1.645726 \\
\hline $\mathrm{H}$ & 5.571730 & 3.494022 & 2.716007 \\
\hline $\mathrm{H}$ & 7.061825 & 1.752566 & 3.655472 \\
\hline $\mathrm{H}$ & 6.753983 & -0.632228 & 2.988662 \\
\hline $\mathrm{H}$ & 5.021610 & -1.259225 & 1.367996 \\
\hline $\mathrm{O}$ & -0.929970 & -0.109291 & -1.417840 \\
\hline $\mathrm{O}$ & -0.451991 & 1.149057 & 0.812579 \\
\hline $\mathrm{H}$ & -1.204564 & 2.145102 & 0.431586 \\
\hline $\mathrm{H}$ & 1.358480 & 4.729614 & 1.616237 \\
\hline $\mathrm{H}$ & -0.751085 & 6.748698 & -1.537666 \\
\hline $\mathrm{H}$ & 1.581154 & 3.245163 & -2.410696 \\
\hline $\mathrm{H}$ & 0.417789 & -4.419464 & -2.647111 \\
\hline $\mathrm{H}$ & -2.892312 & -5.778568 & -0.266011 \\
\hline $\mathrm{H}$ & -0.031857 & -3.026718 & 1.388412 \\
\hline C & -2.960126 & 2.256527 & -0.444995 \\
\hline $\mathrm{O}$ & -2.014331 & 2.882528 & 0.145439 \\
\hline $\mathrm{H}$ & -2.756614 & 1.295058 & -0.922516 \\
\hline C & -4.057532 & 3.115617 & -1.041232 \\
\hline $\mathrm{O}$ & -4.278876 & 4.264084 & -0.741614 \\
\hline 0 & -4.736466 & 2.401327 & -1.957659 \\
\hline C & -5.798899 & 3.106669 & -2.624341 \\
\hline $\mathrm{H}$ & -6.545007 & 3.445677 & -1.900462 \\
\hline $\mathrm{H}$ & -5.401388 & 3.972869 & -3.159190 \\
\hline C & -3.920347 & 0.151905 & 1.269247 \\
\hline C & -4.231186 & 1.501804 & 1.136083 \\
\hline $\mathrm{H}$ & -1.949327 & 0.420097 & 1.868366 \\
\hline$N$ & -2.755438 & -0.215737 & 1.902486 \\
\hline C & -2.583691 & -1.366955 & 2.676942 \\
\hline $\mathrm{O}$ & -3.412754 & -2.225513 & 2.879760 \\
\hline 0 & -1.349487 & -1.325209 & 3.213718 \\
\hline C & -1.050909 & -2.370571 & 4.153555 \\
\hline $\mathrm{H}$ & -1.011735 & -3.340945 & 3.652779 \\
\hline $\mathrm{H}$ & -1.805534 & -2.401265 & 4.943313 \\
\hline $\mathrm{H}$ & -0.073133 & -2.115002 & 4.561234 \\
\hline $\mathrm{H}$ & -5.206023 & 1.734469 & 0.724051 \\
\hline
\end{tabular}




$\begin{array}{llll}\text { H } & -3.811660 & 2.223030 & 1.828350 \\ \mathrm{C} & -4.752625 & -0.878287 & 0.625500 \\ \mathrm{C} & -6.154866 & -0.807463 & 0.692565 \\ \mathrm{C} & -4.144362 & -1.887343 & -0.143056 \\ \mathrm{C} & -6.936312 & -1.740513 & 0.017406 \\ \mathrm{H} & -6.625349 & -0.043975 & 1.305253 \\ \mathrm{C} & -4.932800 & -2.800737 & -0.835672 \\ \mathrm{H} & -3.063586 & -1.920773 & -0.234703 \\ \mathrm{C} & -6.326063 & -2.735192 & -0.751221 \\ \mathrm{H} & -8.019046 & -1.693912 & 0.091690 \\ \mathrm{H} & -4.453038 & -3.564175 & -1.440187 \\ \mathrm{H} & -6.937061 & -3.457880 & -1.285448 \\ \mathrm{H} & -6.232605 & 2.389051 & -3.320147\end{array}$

Catalyst (R)-1 TS Conformation 339

B3LYP/6-31G(d) Energy $=-2809.686059$

B3LYP-D3(BJ)/def2-TZVPP-IEF-PCM(DCM) Energy $=-2810.977401$

B3LYP-D3(BJ)/def2-TZVPP-IEF-PCM(DCM)//B3LYP/6-31G(d) Free Energy (Quasiharmonic) = 2810.335713

Frequencies (Top 3 out of 270)

1. $-706.8825 \mathrm{~cm}-1$

2. $\quad 9.0532 \mathrm{~cm}-1$

3. $11.9979 \mathrm{~cm}-1$

B3LYP/6-31G(d) Molecular Geometry in Cartesian Coordinates

$\begin{array}{llll}\text { C } & -3.169362 & -1.323332 & 0.124168 \\ \text { C } & -1.922517 & -1.646685 & -0.384140 \\ \text { C } & -1.274845 & -2.895568 & -0.156864 \\ \text { C } & -1.914684 & -3.795127 & 0.672674 \\ \text { H } & -1.462533 & -4.767405 & 0.849673 \\ \text { C } & -5.078088 & 2.448740 & -0.707893 \\ \text { C } & -3.818846 & -0.032927 & -0.255575 \\ \text { C } & -3.160587 & 1.170788 & -0.043160 \\ \text { C } & -3.784724 & 2.441619 & -0.222567 \\ \text { H } & -5.576484 & 3.402391 & -0.860452 \\ \text { O } & -1.264675 & -0.711254 & -1.178657 \\ \text { P } & -0.626554 & 0.606534 & -0.455985 \\ \text { O } & -1.867060 & 1.146143 & 0.466428 \\ \text { C } & 2.445816 & -4.067264 & -1.975889\end{array}$




\begin{tabular}{|c|c|c|c|}
\hline C & 2.231902 & -4.262342 & -0.610686 \\
\hline C & 1.034540 & -3.853449 & -0.021526 \\
\hline C & 0.025899 & -3.246971 & -0.787556 \\
\hline C & 0.259108 & -3.042798 & -2.159442 \\
\hline C & 1.456001 & -3.450442 & -2.745789 \\
\hline $\mathrm{H}$ & 2.997120 & -4.727654 & 0.005199 \\
\hline $\mathrm{H}$ & 1.612206 & -3.292431 & -3.809731 \\
\hline C & -2.013824 & 6.228762 & 0.797922 \\
\hline C & -1.331249 & 5.349036 & -0.044478 \\
\hline C & -1.878385 & 4.108043 & -0.370885 \\
\hline C & -3.129225 & 3.729406 & 0.142300 \\
\hline C & -3.808941 & 4.622211 & 0.987422 \\
\hline C & -3.256594 & 5.860380 & 1.314465 \\
\hline $\mathrm{H}$ & -0.365744 & 5.630688 & -0.457282 \\
\hline $\mathrm{H}$ & -3.795956 & 6.533202 & 1.976374 \\
\hline C & -5.126694 & -0.004199 & -0.852864 \\
\hline C & -5.761322 & 1.261347 & -1.066054 \\
\hline C & -7.056574 & 1.304539 & -1.649682 \\
\hline C & -7.698336 & 0.150439 & -2.034046 \\
\hline C & -7.060531 & -1.099705 & -1.855295 \\
\hline C & -5.811258 & -1.175745 & -1.279687 \\
\hline $\mathrm{H}$ & -7.525781 & 2.274396 & -1.797424 \\
\hline $\mathrm{H}$ & -8.685874 & 0.195809 & -2.484991 \\
\hline $\mathrm{H}$ & -7.558042 & -2.009209 & -2.181209 \\
\hline $\mathrm{H}$ & -5.332581 & -2.140863 & -1.160656 \\
\hline C & -3.786570 & -2.239946 & 1.045831 \\
\hline C & -3.144960 & -3.494207 & 1.307016 \\
\hline C & -3.748006 & -4.413419 & 2.207838 \\
\hline C & -4.920533 & -4.103282 & 2.856173 \\
\hline C & -5.535567 & -2.849513 & 2.631313 \\
\hline C & -4.986073 & -1.944223 & 1.750127 \\
\hline $\mathrm{H}$ & -3.253045 & -5.365468 & 2.384477 \\
\hline $\mathrm{H}$ & -5.368335 & -4.810751 & 3.548675 \\
\hline $\mathrm{H}$ & -6.448397 & -2.594777 & 3.162986 \\
\hline $\mathrm{H}$ & -5.465204 & -0.984338 & 1.598455 \\
\hline $\mathrm{O}$ & -0.134350 & 1.558714 & -1.486771 \\
\hline $\mathrm{O}$ & 0.408403 & 0.104832 & 0.594183 \\
\hline $\mathrm{H}$ & 1.197228 & 0.890913 & 0.944821 \\
\hline $\mathrm{H}$ & -0.505140 & -2.571683 & -2.768043 \\
\hline $\mathrm{H}$ & 3.374767 & -4.391497 & -2.438466 \\
\hline $\mathrm{H}$ & 0.892286 & -3.976283 & 1.047336 \\
\hline $\mathrm{H}$ & -4.770260 & 4.332030 & 1.403256 \\
\hline $\mathrm{H}$ & -1.580384 & 7.193129 & 1.050368 \\
\hline $\mathrm{H}$ & -1.339180 & 3.439020 & -1.033290 \\
\hline
\end{tabular}




$\begin{array}{llll}\mathrm{C} & 2.681647 & 2.223181 & 0.228562 \\ \mathrm{O} & 2.226306 & 1.548508 & 1.220985 \\ \mathrm{H} & 1.991510 & 2.740318 & -0.447354 \\ \mathrm{C} & 3.979308 & 2.987258 & 0.419182 \\ \mathrm{O} & 4.373661 & 3.826478 & -0.367168 \\ \mathrm{O} & 4.624964 & 2.621154 & 1.533617 \\ \mathrm{C} & 5.853327 & 3.321597 & 1.795212 \\ \mathrm{H} & 5.686665 & 4.401344 & 1.792298 \\ \mathrm{H} & 6.603715 & 3.070860 & 1.040516 \\ \mathrm{C} & 3.917839 & -0.016528 & -0.642007 \\ \mathrm{C} & 3.145494 & 0.961414 & -1.281384 \\ \mathrm{H} & 2.254261 & -0.870082 & 0.185373 \\ \mathrm{~N} & 3.275522 & -0.838782 & 0.236836 \\ \mathrm{C} & 3.726871 & -1.391243 & 1.455803 \\ \mathrm{O} & 3.036832 & -2.142850 & 2.103661 \\ \mathrm{O} & 4.948377 & -0.964988 & 1.793942 \\ \mathrm{C} & 5.436981 & -1.474005 & 3.048386 \\ \mathrm{H} & 4.790743 & -1.144888 & 3.865176 \\ \mathrm{H} & 6.438032 & -1.056621 & 3.154385 \\ \mathrm{H} & 5.472365 & -2.565976 & 3.031651 \\ \mathrm{H} & 3.610015 & 1.531980 & -2.078633 \\ \mathrm{H} & 2.084834 & 0.778057 & -1.433644 \\ \mathrm{C} & 5.358912 & -0.178057 & -0.914608 \\ \mathrm{C} & 6.159953 & 0.919696 & -1.276062 \\ \mathrm{C} & 5.922680 & -1.467156 & -0.934147 \\ \mathrm{C} & 7.498881 & 0.732155 & -1.611680 \\ \mathrm{H} & 5.744434 & 1.921828 & -1.284604 \\ \mathrm{C} & 7.255506 & -1.649818 & -1.289392 \\ \mathrm{H} & 5.300280 & -2.327076 & -0.708134 \\ \mathrm{C} & 8.051385 & -0.550385 & -1.619601 \\ \mathrm{H} & 8.108899 & 1.590982 & -1.876801 \\ \mathrm{H} & 7.672298 & -2.652704 & -1.314608 \\ \mathrm{H} & 9.092818 & -0.693955 & -1.893730 \\ \mathrm{H} & 6.175933 & 2.982613 & 2.779580\end{array}$

Catalyst (R)-1 TS Conformation 340

B3LYP/6-31G(d) Energy $=-2809.685077$

B3LYP-D3(BJ)/def2-TZVPP-IEF-PCM(DCM) Energy = -2810.977257

B3LYP-D3(BJ)/def2-TZVPP-IEF-PCM(DCM)//B3LYP/6-31G(d) Free Energy (Quasiharmonic) = 2810.33571

Frequencies (Top 3 out of 270) 
1. $-713.6851 \mathrm{~cm}-1$

2. $\quad 9.6675 \mathrm{~cm}-1$

3. $\quad 11.2072 \mathrm{~cm}-1$

B3LYP/6-31G(d) Molecular Geometry in Cartesian Coordinates

\begin{tabular}{|c|c|c|c|}
\hline C & -3.253446 & -1.273436 & 0.145548 \\
\hline C & -2.002597 & -1.616946 & -0.342993 \\
\hline C & -1.404550 & -2.895814 & -0.145916 \\
\hline C & -2.095767 & -3.804267 & 0.631160 \\
\hline $\mathrm{H}$ & -1.679405 & -4.796590 & 0.783319 \\
\hline C & -4.897210 & 2.625875 & -0.698947 \\
\hline C & -3.841469 & 0.057282 & -0.194483 \\
\hline C & -3.131718 & 1.213631 & 0.091727 \\
\hline C & -3.645101 & 2.526391 & -0.123716 \\
\hline $\mathrm{H}$ & -5.330578 & 3.610264 & -0.854891 \\
\hline $\mathrm{O}$ & -1.293342 & -0.681960 & -1.088797 \\
\hline$P$ & -0.634034 & 0.610325 & -0.331837 \\
\hline $\mathrm{O}$ & -1.861580 & 1.089048 & 0.644066 \\
\hline C & 2.323393 & -4.122315 & -1.912607 \\
\hline C & 2.073229 & -4.348475 & -0.558472 \\
\hline C & 0.874324 & -3.922205 & 0.014882 \\
\hline C & -0.098988 & -3.266612 & -0.755743 \\
\hline C & 0.171135 & -3.031055 & -2.115794 \\
\hline C & 1.369097 & -3.456573 & -2.686858 \\
\hline $\mathrm{H}$ & 2.811891 & -4.849700 & 0.061345 \\
\hline $\mathrm{H}$ & 1.553922 & -3.274265 & -3.742329 \\
\hline C & -1.563267 & 6.134851 & 0.951029 \\
\hline C & -2.170331 & 6.012400 & -0.299333 \\
\hline C & -2.825874 & 4.831824 & -0.646663 \\
\hline C & -2.887431 & 3.751058 & 0.247708 \\
\hline C & -2.266894 & 3.884390 & 1.501195 \\
\hline C & -1.614306 & 5.065999 & 1.848282 \\
\hline $\mathrm{H}$ & -2.126673 & 6.832853 & -1.010893 \\
\hline $\mathrm{H}$ & -1.145802 & 5.151796 & 2.825330 \\
\hline C & -5.110841 & 0.178958 & -0.858075 \\
\hline C & -5.640954 & 1.488315 & -1.097510 \\
\hline C & -6.899931 & 1.624060 & -1.743251 \\
\hline C & -7.600720 & 0.519590 & -2.168205 \\
\hline C & -7.061981 & -0.773057 & -1.967738 \\
\hline C & -5.852364 & -0.939332 & -1.329717 \\
\hline $\mathrm{H}$ & -7.292819 & 2.624924 & -1.906175 \\
\hline $\mathrm{H}$ & -8.558894 & 0.636365 & -2.667107 \\
\hline
\end{tabular}




\begin{tabular}{|c|c|c|c|}
\hline $\mathrm{H}$ & -7.605071 & -1.643892 & -2.324976 \\
\hline $\mathrm{H}$ & -5.449658 & -1.936198 & -1.193178 \\
\hline C & -3.927872 & -2.204423 & 1.009152 \\
\hline C & -3.334922 & -3.488171 & 1.240363 \\
\hline C & -3.995657 & -4.420362 & 2.085657 \\
\hline C & -5.178765 & -4.097030 & 2.707982 \\
\hline C & -5.747516 & -2.816679 & 2.511941 \\
\hline C & -5.140786 & -1.896831 & 1.685124 \\
\hline $\mathrm{H}$ & -3.537186 & -5.394245 & 2.240548 \\
\hline $\mathrm{H}$ & -5.671012 & -4.815373 & 3.357818 \\
\hline $\mathrm{H}$ & -6.669909 & -2.553564 & 3.022656 \\
\hline $\mathrm{H}$ & -5.584705 & -0.916920 & 1.554024 \\
\hline $\mathrm{O}$ & -0.167661 & 1.602124 & -1.331715 \\
\hline $\mathrm{O}$ & 0.419616 & 0.065386 & 0.679857 \\
\hline $\mathrm{H}$ & 1.223537 & 0.839850 & 1.022111 \\
\hline $\mathrm{H}$ & -0.565635 & -2.521248 & -2.727136 \\
\hline $\mathrm{H}$ & 3.252914 & -4.461072 & -2.363698 \\
\hline $\mathrm{H}$ & 0.702902 & -4.071839 & 1.076170 \\
\hline $\mathrm{H}$ & -2.303096 & 3.061810 & 2.207254 \\
\hline $\mathrm{H}$ & -1.049961 & 7.053534 & 1.222734 \\
\hline $\mathrm{H}$ & -3.275616 & 4.733009 & -1.630617 \\
\hline C & 2.698625 & 2.178830 & 0.289825 \\
\hline 0 & 2.266158 & 1.485101 & 1.280918 \\
\hline $\mathrm{H}$ & 1.993792 & 2.728162 & -0.344488 \\
\hline C & 4.016603 & 2.913848 & 0.457374 \\
\hline 0 & 4.408497 & 3.758468 & -0.324336 \\
\hline 0 & 4.685452 & 2.514946 & 1.547507 \\
\hline C & 5.936134 & 3.183527 & 1.783632 \\
\hline $\mathrm{H}$ & 6.657988 & 2.930408 & 1.002301 \\
\hline $\mathrm{H}$ & 6.280792 & 2.820040 & 2.751729 \\
\hline C & 3.860702 & -0.056895 & -0.682215 \\
\hline C & 3.087737 & 0.957018 & -1.263620 \\
\hline $\mathrm{H}$ & 2.209492 & -0.896292 & 0.184744 \\
\hline$N$ & 3.233259 & -0.891195 & 0.195866 \\
\hline C & 3.717228 & -1.483277 & 1.383207 \\
\hline 0 & 3.034105 & -2.231936 & 2.041525 \\
\hline 0 & 4.962194 & -1.096016 & 1.682407 \\
\hline C & 5.485299 & -1.646373 & 2.904678 \\
\hline $\mathrm{H}$ & 5.492562 & -2.738213 & 2.861780 \\
\hline $\mathrm{H}$ & 4.879435 & -1.321448 & 3.753515 \\
\hline $\mathrm{H}$ & 6.499939 & -1.256171 & 2.981388 \\
\hline $\mathrm{H}$ & 3.538200 & 1.542048 & -2.058512 \\
\hline $\mathrm{H}$ & 2.019233 & 0.799488 & -1.388924 \\
\hline C & 5.286876 & -0.240879 & -1.012954 \\
\hline
\end{tabular}




$\begin{array}{lrrr}\text { C } & 5.819805 & -1.540807 & -1.092600 \\ \text { C } & 6.099310 & 0.849967 & -1.369875 \\ \text { C } & 7.134280 & -1.741282 & -1.502397 \\ \text { H } & 5.186307 & -2.393474 & -0.869768 \\ \text { C } & 7.420592 & 0.643752 & -1.760144 \\ \text { H } & 5.706863 & 1.860711 & -1.332202 \\ \text { C } & 7.942783 & -0.649661 & -1.827945 \\ \text { H } & 7.526744 & -2.751763 & -1.573683 \\ \text { H } & 8.040255 & 1.496991 & -2.020972 \\ \text { H } & 8.970012 & -0.807284 & -2.144714 \\ \text { H } & 5.794050 & 4.266651 & 1.804372\end{array}$

Catalyst (R)-1 TS Conformation 341

B3LYP/6-31G(d) Energy $=-2809.690314$

B3LYP-D3(BJ)/def2-TZVPP-IEF-PCM(DCM) Energy = -2810.979257

B3LYP-D3(BJ)/def2-TZVPP-IEF-PCM(DCM)//B3LYP/6-31G(d) Free Energy (Quasiharmonic) = 2810.335619

Frequencies (Top 3 out of 270)

1. $-281.3686 \mathrm{~cm}-1$

2. $\quad 8.5573 \mathrm{~cm}-1$

3. $10.3793 \mathrm{~cm}-1$

B3LYP/6-31G(d) Molecular Geometry in Cartesian Coordinates

$\begin{array}{llll}\text { C } & 3.333699 & 0.599832 & 0.069461 \\ \text { C } & 2.289849 & 1.472407 & -0.194322 \\ \text { C } & 2.360538 & 2.877097 & 0.042905 \\ \text { C } & 3.525584 & 3.359198 & 0.609450 \\ \text { H } & 3.628734 & 4.428007 & 0.775875 \\ \text { C } & 2.899400 & -3.592523 & -0.845645 \\ \text { C } & 3.196929 & -0.840426 & -0.296962 \\ \text { C } & 2.125258 & -1.573417 & 0.188298 \\ \text { C } & 1.964163 & -2.970615 & -0.041549 \\ \text { H } & 2.817891 & -4.662031 & -1.020947 \\ \text { O } & 1.122580 & 0.958167 & -0.750904 \\ \text { P } & 0.115565 & 0.057296 & 0.171843 \\ \text { O } & 1.161292 & -0.921359 & 0.957732 \\ \text { C } & -0.745728 & 5.686791 & -0.938452 \\ \text { C } & -0.431039 & 4.660045 & -1.831647 \\ \text { C } & 0.559095 & 3.731150 & -1.515423\end{array}$




\begin{tabular}{|c|c|c|c|}
\hline C & 1.252369 & 3.809286 & -0.294830 \\
\hline C & 0.915023 & 4.839329 & 0.599252 \\
\hline C & -0.070960 & 5.771695 & 0.279881 \\
\hline $\mathrm{H}$ & -0.964240 & 4.578546 & -2.774020 \\
\hline $\mathrm{H}$ & -0.317263 & 6.557638 & 0.989176 \\
\hline C & -1.116578 & -5.409754 & 1.708976 \\
\hline C & -0.387097 & -4.524176 & 2.505691 \\
\hline C & 0.584637 & -3.699672 & 1.939565 \\
\hline C & 0.860152 & -3.761684 & 0.564223 \\
\hline C & 0.120846 & -4.655943 & -0.227207 \\
\hline C & -0.861403 & -5.469251 & 0.338075 \\
\hline $\mathrm{H}$ & -0.564504 & -4.483513 & 3.577516 \\
\hline $\mathrm{H}$ & -1.426181 & -6.151151 & -0.292273 \\
\hline C & 4.123491 & -1.486672 & -1.186330 \\
\hline C & 3.966969 & -2.885710 & -1.450472 \\
\hline C & 4.880029 & -3.538783 & -2.322305 \\
\hline C & 5.891547 & -2.840349 & -2.938954 \\
\hline C & 6.025584 & -1.450600 & -2.710497 \\
\hline C & 5.167517 & -0.792044 & -1.857501 \\
\hline $\mathrm{H}$ & 4.753658 & -4.603886 & -2.501564 \\
\hline $\mathrm{H}$ & 6.579519 & -3.348360 & -3.609127 \\
\hline $\mathrm{H}$ & 6.810305 & -0.895294 & -3.217029 \\
\hline $\mathrm{H}$ & 5.278092 & 0.274669 & -1.702118 \\
\hline C & 4.505153 & 1.106136 & 0.729766 \\
\hline C & 4.595869 & 2.512274 & 0.985906 \\
\hline C & 5.754177 & 3.031796 & 1.625511 \\
\hline C & 6.772617 & 2.200361 & 2.029158 \\
\hline C & 6.668443 & 0.806146 & 1.812308 \\
\hline C & 5.566998 & 0.273549 & 1.179047 \\
\hline $\mathrm{H}$ & 5.812186 & 4.103400 & 1.801163 \\
\hline $\mathrm{H}$ & 7.650032 & 2.607919 & 2.523717 \\
\hline $\mathrm{H}$ & 7.463093 & 0.147742 & 2.152711 \\
\hline $\mathrm{H}$ & 5.499154 & -0.797707 & 1.029060 \\
\hline $\mathrm{O}$ & -0.906121 & -0.583804 & -0.685350 \\
\hline $\mathrm{O}$ & -0.381190 & 0.942257 & 1.372543 \\
\hline $\mathrm{H}$ & -1.314957 & 1.330349 & 1.202115 \\
\hline $\mathrm{H}$ & 1.417181 & 4.894377 & 1.560934 \\
\hline $\mathrm{H}$ & -1.513545 & 6.412535 & -1.193385 \\
\hline $\mathrm{H}$ & 0.801855 & 2.944633 & -2.221086 \\
\hline $\mathrm{H}$ & 0.313516 & -4.700445 & -1.295652 \\
\hline $\mathrm{H}$ & -1.876626 & -6.047455 & 2.151950 \\
\hline $\mathrm{H}$ & 1.147160 & -3.016746 & 2.567655 \\
\hline C & -3.163352 & 2.071235 & -0.250906 \\
\hline $\mathrm{O}$ & -2.735161 & 1.941504 & 0.950039 \\
\hline
\end{tabular}




$\begin{array}{lrrr}\text { H } & -2.626150 & 1.591655 & -1.080527 \\ \mathrm{C} & -3.740385 & 3.417827 & -0.692743 \\ \mathrm{O} & -3.740748 & 3.792680 & -1.846472 \\ \mathrm{O} & -4.243308 & 4.116717 & 0.337757 \\ \mathrm{C} & -4.786414 & 5.402614 & -0.001196 \\ \mathrm{H} & -5.583398 & 5.302875 & -0.743334 \\ \mathrm{H} & -5.176564 & 5.809847 & 0.931833 \\ \mathrm{C} & -4.589528 & -0.192838 & -0.059723 \\ \mathrm{C} & -4.906266 & 1.130161 & -0.424957 \\ \mathrm{H} & -3.714165 & 0.519291 & 1.608825 \\ \mathrm{~N} & -4.135279 & -0.337555 & 1.213961 \\ \mathrm{C} & -4.047106 & -1.501325 & 1.986401 \\ \mathrm{O} & -4.552173 & -2.569070 & 1.731727 \\ \mathrm{O} & -3.355227 & -1.199570 & 3.100417 \\ \mathrm{C} & -3.218004 & -2.279145 & 4.039202 \\ \mathrm{H} & -2.633582 & -1.868849 & 4.862582 \\ \mathrm{H} & -2.696034 & -3.117871 & 3.573977 \\ \mathrm{H} & -4.200355 & -2.607906 & 4.388654 \\ \mathrm{H} & -5.226313 & 1.298638 & -1.447942 \\ \mathrm{H} & -5.388254 & 1.746162 & 0.328870 \\ \mathrm{C} & -4.600687 & -1.295320 & -1.030944 \\ \mathrm{C} & -3.556570 & -2.235557 & -1.094742 \\ \mathrm{C} & -5.660894 & -1.376025 & -1.952700 \\ \mathrm{C} & -3.581823 & -3.231864 & -2.064576 \\ \mathrm{H} & -2.701184 & -2.142221 & -0.437591 \\ \mathrm{C} & -5.689314 & -2.389287 & -2.906341 \\ \mathrm{H} & -6.476636 & -0.661555 & -1.895125 \\ \mathrm{C} & -4.647737 & -3.318047 & -2.964034 \\ \mathrm{H} & -2.759967 & -3.939345 & -2.118731 \\ \mathrm{H} & -6.520841 & -2.453992 & -3.602202 \\ \mathrm{H} & -4.664107 & -4.104721 & -3.713752 \\ \mathrm{H} & -4.003889 & 6.050590 & -0.404196 \\ & & & \end{array}$

Catalyst (R)-1 TS Conformation 342

B3LYP/6-31G(d) Energy $=-2809.68535$

B3LYP-D3(BJ)/def2-TZVPP-IEF-PCM(DCM) Energy = -2810.977267

B3LYP-D3(BJ)/def2-TZVPP-IEF-PCM(DCM)//B3LYP/6-31G(d) Free Energy (Quasiharmonic) = 2810.335464

Frequencies (Top 3 out of 270)

1. $-565.6997 \mathrm{~cm}-1$ 
2. $\quad 8.3106 \mathrm{~cm}-1$

3. $\quad 9.4107 \mathrm{~cm}-1$

B3LYP/6-31G(d) Molecular Geometry in Cartesian Coordinates

\begin{tabular}{lccc} 
C & 3.704096 & -0.991633 & -0.003526 \\
C & 2.498660 & -1.617361 & 0.274599 \\
C & 2.271221 & -3.010642 & 0.074034 \\
C & 3.307833 & -3.753308 & -0.454933 \\
H & 3.176155 & -4.822659 & -0.599352 \\
C & 4.093651 & 3.249534 & 0.696312 \\
C & 3.854592 & 0.465645 & 0.289569 \\
C & 2.943322 & 1.366933 & -0.243276 \\
C & 3.049633 & 2.780175 & -0.077070 \\
H & 4.220411 & 4.321759 & 0.821008 \\
O & 1.457499 & -0.857536 & 0.784570 \\
P & 0.640122 & 0.134417 & -0.243615 \\
O & 1.890764 & 0.880845 & -1.004303 \\
C & -1.479808 & -4.919466 & 0.986057 \\
C & -0.886747 & -4.063026 & 1.918095 \\
C & 0.321576 & -3.430277 & 1.627215 \\
C & 0.966119 & -3.646865 & 0.397333 \\
C & 0.361739 & -4.511800 & -0.529129 \\
C & -0.848972 & -5.141510 & -0.239372 \\
H & -1.362213 & -3.892964 & 2.881096 \\
H & -1.303086 & -5.799442 & -0.975778 \\
C & 0.355045 & 5.623697 & -1.861874 \\
C & 0.731408 & 5.745323 & -0.523153 \\
C & 1.588872 & 4.807591 & 0.050812 \\
C & 2.088638 & 3.730339 & -0.699221 \\
C & 1.696297 & 3.614782 & -2.043582 \\
C & 0.840354 & 4.553481 & -2.617707 \\
H & 0.353198 & 6.567572 & 0.078925 \\
H & 0.557026 & 4.450830 & -3.662073 \\
C & 4.888816 & 0.965983 & 1.153269 \\
C & 5.009054 & 2.381437 & 1.339846 \\
C & 6.035855 & 2.890197 & 2.180854 \\
C & 6.894161 & 2.043428 & 2.842591 \\
C & 6.752620 & 0.643802 & 2.692594 \\
H & 5.778976 & 0.119776 & 1.870824 \\
H & 7.670781 & 2.443991 & 3.488440 \\
H & & -0.025426 & 3.234821 \\
\hline & -0.955042 & 1.775075
\end{tabular}




\begin{tabular}{|c|c|c|c|}
\hline C & 4.749052 & -1.762876 & -0.620015 \\
\hline C & 4.542285 & -3.165973 & -0.827679 \\
\hline C & 5.572174 & -3.942420 & -1.424844 \\
\hline C & 6.749817 & -3.362251 & -1.835041 \\
\hline C & 6.940740 & -1.970457 & -1.669058 \\
\hline C & 5.969078 & -1.192988 & -1.077968 \\
\hline $\mathrm{H}$ & 5.402900 & -5.007752 & -1.563456 \\
\hline $\mathrm{H}$ & 7.526896 & -3.965187 & -2.296875 \\
\hline $\mathrm{H}$ & 7.861014 & -1.508229 & -2.016050 \\
\hline $\mathrm{H}$ & 6.127678 & -0.126608 & -0.967861 \\
\hline $\mathrm{O}$ & -0.251978 & 1.013232 & 0.556627 \\
\hline $\mathrm{O}$ & 0.031224 & -0.722060 & -1.375457 \\
\hline $\mathrm{H}$ & -1.115943 & -0.655740 & -1.487216 \\
\hline $\mathrm{H}$ & 0.834554 & -4.667347 & -1.494620 \\
\hline $\mathrm{H}$ & -2.424827 & -5.406059 & 1.212069 \\
\hline $\mathrm{H}$ & 0.772126 & -2.766315 & 2.356881 \\
\hline $\mathrm{H}$ & 2.067922 & 2.789850 & -2.641016 \\
\hline $\mathrm{H}$ & -0.308195 & 6.357045 & -2.313856 \\
\hline $\mathrm{H}$ & 1.858591 & 4.894259 & 1.099528 \\
\hline C & -2.910864 & -1.372501 & -0.661392 \\
\hline $\mathrm{O}$ & -2.375761 & -0.631742 & -1.570602 \\
\hline $\mathrm{H}$ & -2.288271 & -2.150483 & -0.194806 \\
\hline C & -4.322559 & -1.895321 & -0.911638 \\
\hline 0 & -4.922037 & -2.610773 & -0.126314 \\
\hline $\mathrm{O}$ & -4.810372 & -1.467440 & -2.076942 \\
\hline C & -6.151219 & -1.875586 & -2.400834 \\
\hline $\mathrm{H}$ & -6.864932 & -1.291128 & -1.813834 \\
\hline $\mathrm{H}$ & -6.271375 & -1.657488 & -3.462042 \\
\hline C & -4.289605 & 0.342395 & 1.002710 \\
\hline C & -3.123223 & -0.462176 & 1.017692 \\
\hline $\mathrm{H}$ & -5.278416 & -1.133347 & 1.970091 \\
\hline$N$ & -5.432112 & -0.253700 & 1.488956 \\
\hline C & -6.756250 & -0.152272 & 1.025694 \\
\hline 0 & -7.159884 & 0.534046 & 0.116978 \\
\hline $\mathrm{O}$ & -7.504966 & -0.978435 & 1.779344 \\
\hline C & -8.888782 & -1.070218 & 1.396965 \\
\hline $\mathrm{H}$ & -9.353680 & -0.081847 & 1.405847 \\
\hline $\mathrm{H}$ & -9.348236 & -1.721627 & 2.139805 \\
\hline $\mathrm{H}$ & -8.978591 & -1.505796 & 0.398579 \\
\hline $\mathrm{H}$ & -2.164180 & 0.052388 & 1.053282 \\
\hline $\mathrm{H}$ & -3.183433 & -1.339233 & 1.659454 \\
\hline C & -4.289786 & 1.717319 & 0.521497 \\
\hline C & -3.214682 & 2.167558 & -0.276542 \\
\hline C & -5.285244 & 2.641592 & 0.911222 \\
\hline
\end{tabular}




$\begin{array}{llll}\mathrm{C} & -3.164617 & 3.491702 & -0.702039 \\ \mathrm{H} & -2.421199 & 1.490041 & -0.559566 \\ \mathrm{C} & -5.214935 & 3.963642 & 0.498480 \\ \mathrm{H} & -6.095936 & 2.332185 & 1.558501 \\ \mathrm{C} & -4.160015 & 4.390085 & -0.317319 \\ \mathrm{H} & -2.328324 & 3.822917 & -1.309860 \\ \mathrm{H} & -5.978654 & 4.667482 & 0.816223 \\ \mathrm{H} & -4.108062 & 5.428156 & -0.634891 \\ \mathrm{H} & -6.288544 & -2.940973 & -2.203083\end{array}$

Catalyst (R)-1 TS Conformation 343

B3LYP/6-31G(d) Energy $=-2809.683334$

B3LYP-D3(BJ)/def2-TZVPP-IEF-PCM(DCM) Energy = -2810.977271

B3LYP-D3(BJ)/def2-TZVPP-IEF-PCM(DCM)//B3LYP/6-31G(d) Free Energy (Quasiharmonic) = 2810.335464

Frequencies (Top 3 out of 270)

1. $-659.6558 \mathrm{~cm}-1$

2. $\quad 9.4269 \mathrm{~cm}-1$

3. $\quad 11.1807 \mathrm{~cm}-1$

B3LYP/6-31G(d) Molecular Geometry in Cartesian Coordinates

$\begin{array}{llll}\text { C } & 3.645686 & -0.942264 & -0.114411 \\ \mathrm{C} & 2.468987 & -1.613955 & 0.178625 \\ \mathrm{C} & 2.268620 & -2.999691 & -0.092404 \\ \mathrm{C} & 3.298694 & -3.681276 & -0.709717 \\ \mathrm{H} & 3.188406 & -4.744305 & -0.908169 \\ \mathrm{C} & 3.996566 & 3.261179 & 0.790306 \\ \mathrm{C} & 3.777693 & 0.498448 & 0.256694 \\ \mathrm{C} & 2.829539 & 1.408555 & -0.189435 \\ \mathrm{C} & 2.929303 & 2.814341 & 0.035301 \\ \mathrm{H} & 4.117976 & 4.328303 & 0.956813 \\ \mathrm{O} & 1.436561 & -0.912469 & 0.780952 \\ \mathrm{P} & 0.551107 & 0.129672 & -0.137404 \\ \mathrm{O} & 1.747973 & 0.942024 & -0.921302 \\ \mathrm{C} & -1.353417 & -5.105551 & 0.898002 \\ \mathrm{C} & -0.774983 & -5.242805 & -0.364527 \\ \mathrm{C} & 0.390807 & -4.545175 & -0.680809 \\ \mathrm{C} & 1.002311 & -3.697074 & 0.256452 \\ \mathrm{C} & 0.408670 & -3.564526 & 1.523598\end{array}$




\begin{tabular}{|c|c|c|c|}
\hline C & -0.755337 & -4.264347 & 1.840129 \\
\hline $\mathrm{H}$ & -1.234676 & -5.887160 & -1.109480 \\
\hline $\mathrm{H}$ & -1.192148 & -4.157691 & 2.830025 \\
\hline C & 0.216218 & 5.739076 & -1.581609 \\
\hline C & 0.621701 & 5.808632 & -0.247669 \\
\hline C & 1.479347 & 4.841250 & 0.274569 \\
\hline C & 1.950223 & 3.785265 & -0.523010 \\
\hline C & 1.523961 & 3.718725 & -1.860508 \\
\hline C & 0.668972 & 4.688043 & -2.383626 \\
\hline $\mathrm{H}$ & 0.267694 & 6.614354 & 0.390334 \\
\hline $\mathrm{H}$ & 0.363390 & 4.625877 & -3.424997 \\
\hline C & 4.838945 & 0.971192 & 1.102760 \\
\hline C & 4.945916 & 2.376781 & 1.357673 \\
\hline C & 5.997367 & 2.858757 & 2.183808 \\
\hline C & 6.893562 & 1.993347 & 2.766515 \\
\hline C & 6.767565 & 0.601202 & 2.548260 \\
\hline C & 5.770124 & 0.104020 & 1.738446 \\
\hline $\mathrm{H}$ & 6.070802 & 3.930048 & 2.356241 \\
\hline $\mathrm{H}$ & 7.688987 & 2.372909 & 3.402064 \\
\hline $\mathrm{H}$ & 7.461539 & -0.083785 & 3.028023 \\
\hline $\mathrm{H}$ & 5.681612 & -0.965866 & 1.589595 \\
\hline C & 4.680426 & -1.646727 & -0.821361 \\
\hline C & 4.499329 & -3.040225 & -1.102660 \\
\hline C & 5.519768 & -3.752464 & -1.789381 \\
\hline C & 6.662980 & -3.117544 & -2.215487 \\
\hline C & 6.826916 & -1.733104 & -1.975460 \\
\hline C & 5.864227 & -1.018076 & -1.297257 \\
\hline $\mathrm{H}$ & 5.370598 & -4.812134 & -1.983381 \\
\hline $\mathrm{H}$ & 7.432984 & -3.671117 & -2.745875 \\
\hline $\mathrm{H}$ & 7.718973 & -1.226607 & -2.334150 \\
\hline $\mathrm{H}$ & 6.001618 & 0.043966 & -1.131110 \\
\hline $\mathrm{O}$ & -0.294078 & 0.949630 & 0.771646 \\
\hline $\mathrm{O}$ & -0.121321 & -0.655284 & -1.279169 \\
\hline $\mathrm{H}$ & -1.304150 & -0.655145 & -1.296966 \\
\hline $\mathrm{H}$ & 0.865462 & -2.915038 & 2.262314 \\
\hline $\mathrm{H}$ & -2.262902 & -5.645983 & 1.146175 \\
\hline $\mathrm{H}$ & 0.822087 & -4.635748 & -1.673607 \\
\hline $\mathrm{H}$ & 1.871994 & 2.910425 & -2.493844 \\
\hline $\mathrm{H}$ & -0.444628 & 6.497466 & -1.994117 \\
\hline $\mathrm{H}$ & 1.774843 & 4.889780 & 1.318767 \\
\hline C & -2.925489 & -1.407785 & -0.263103 \\
\hline $\mathrm{O}$ & -2.531202 & -0.719992 & -1.280203 \\
\hline $\mathrm{H}$ & -2.184574 & -2.029074 & 0.259005 \\
\hline C & -4.275592 & -2.100890 & -0.422711 \\
\hline
\end{tabular}




$\begin{array}{llll}\mathrm{O} & -5.108631 & -1.821899 & -1.254085 \\ \mathrm{O} & -4.424899 & -3.068309 & 0.509351 \\ \mathrm{C} & -5.650643 & -3.826671 & 0.427838 \\ \mathrm{H} & -5.749730 & -4.276077 & -0.563072 \\ \mathrm{H} & -6.512955 & -3.183916 & 0.622661 \\ \mathrm{C} & -4.382248 & 0.481246 & 1.068806 \\ \mathrm{C} & -3.247392 & -0.328729 & 1.306366 \\ \mathrm{H} & -5.558478 & -0.821632 & 2.092299 \\ \mathrm{~N} & -5.607016 & -0.056101 & 1.428835 \\ \mathrm{C} & -6.811972 & -0.171741 & 0.698692 \\ \mathrm{O} & -7.667849 & -0.951573 & 1.062436 \\ \mathrm{O} & -6.859322 & 0.614998 & -0.368247 \\ \mathrm{C} & -7.959818 & 0.366210 & -1.267662 \\ \mathrm{H} & -8.910905 & 0.438451 & -0.736537 \\ \mathrm{H} & -7.847063 & -0.626499 & -1.708123 \\ \mathrm{H} & -7.877724 & 1.137436 & -2.032396 \\ \mathrm{H} & -2.279477 & 0.164796 & 1.379483 \\ \mathrm{H} & -3.392548 & -1.141643 & 2.016516 \\ \mathrm{C} & -4.294722 & 1.811410 & 0.490018 \\ \mathrm{C} & -3.127531 & 2.202713 & -0.201520 \\ \mathrm{C} & -5.319662 & 2.763645 & 0.698843 \\ \mathrm{C} & -3.016234 & 3.493974 & -0.709483 \\ \mathrm{H} & -2.306428 & 1.511580 & -0.327490 \\ \mathrm{C} & -5.188938 & 4.053505 & 0.208416 \\ \mathrm{H} & -6.197180 & 2.495242 & 1.275034 \\ \mathrm{C} & -4.041804 & 4.417910 & -0.508419 \\ \mathrm{H} & -2.111892 & 3.782085 & -1.236023 \\ \mathrm{H} & -5.973715 & 4.782094 & 0.390568 \\ \mathrm{H} & -3.941394 & 5.431227 & -0.888257 \\ \mathrm{H} & -5.563606 & -4.598840 & 1.192521\end{array}$

Catalyst (R)-1 TS Conformation 344

B3LYP/6-31G(d) Energy $=-2809.690576$

B3LYP-D3(BJ)/def2-TZVPP-IEF-PCM(DCM) Energy = -2810.979333

B3LYP-D3(BJ)/def2-TZVPP-IEF-PCM(DCM)//B3LYP/6-31G(d) Free Energy (Quasiharmonic) = 2810.335375

Frequencies (Top 3 out of 270)

1. $-238.0134 \mathrm{~cm}-1$

2. $8.1676 \mathrm{~cm}-1$

3. $\quad 13.7915 \mathrm{~cm}-1$ 
B3LYP/6-31G(d) Molecular Geometry in Cartesian Coordinates

\begin{tabular}{|c|c|c|c|}
\hline C & 3.409704 & 0.637787 & 0.063094 \\
\hline C & 2.449431 & 1.470046 & -0.491777 \\
\hline C & 2.524643 & 2.893270 & -0.454916 \\
\hline C & 3.594699 & 3.449958 & 0.218315 \\
\hline $\mathrm{H}$ & 3.698185 & 4.531500 & 0.244434 \\
\hline C & 2.982683 & -3.636493 & -0.315744 \\
\hline C & 3.289289 & -0.840751 & -0.108380 \\
\hline C & 2.120237 & -1.480534 & 0.276468 \\
\hline C & 1.932772 & -2.893146 & 0.190901 \\
\hline $\mathrm{H}$ & 2.893467 & -4.718567 & -0.359520 \\
\hline 0 & 1.358396 & 0.893243 & -1.136624 \\
\hline$P$ & 0.192582 & 0.199976 & -0.224878 \\
\hline $\mathrm{O}$ & 1.090050 & -0.710284 & 0.800499 \\
\hline C & -0.328741 & 5.509425 & -2.332240 \\
\hline C & 0.098042 & 5.746775 & -1.025082 \\
\hline C & 1.007627 & 4.881841 & -0.417801 \\
\hline C & 1.508550 & 3.763804 & -1.104183 \\
\hline C & 1.065352 & 3.531576 & -2.417074 \\
\hline C & 0.157911 & 4.398195 & -3.023892 \\
\hline $\mathrm{H}$ & -0.283193 & 6.601153 & -0.471814 \\
\hline $\mathrm{H}$ & -0.168049 & 4.204517 & -4.042549 \\
\hline C & -1.650807 & -4.980878 & 1.365870 \\
\hline C & -1.172649 & -3.925910 & 2.147680 \\
\hline C & -0.026380 & -3.223394 & 1.769406 \\
\hline C & 0.672635 & -3.570479 & 0.600536 \\
\hline C & 0.173060 & -4.628430 & -0.181298 \\
\hline C & -0.973052 & -5.326941 & 0.195262 \\
\hline $\mathrm{H}$ & -1.683205 & -3.642837 & 3.063850 \\
\hline $\mathrm{H}$ & -1.339431 & -6.137407 & -0.429436 \\
\hline C & 4.333142 & -1.620240 & -0.715388 \\
\hline C & 4.175565 & -3.041711 & -0.791726 \\
\hline C & 5.209001 & -3.829877 & -1.367856 \\
\hline C & 6.340939 & -3.244094 & -1.884144 \\
\hline C & 6.480053 & -1.836471 & -1.850261 \\
\hline C & 5.505338 & -1.046698 & -1.281183 \\
\hline $\mathrm{H}$ & 5.078315 & -4.908901 & -1.404596 \\
\hline $\mathrm{H}$ & 7.121222 & -3.855579 & -2.328915 \\
\hline $\mathrm{H}$ & 7.362966 & -1.372549 & -2.281609 \\
\hline $\mathrm{H}$ & 5.624499 & 0.030265 & -1.271462 \\
\hline C & 4.473373 & 1.232774 & 0.825473 \\
\hline C & 4.563805 & 2.661221 & 0.885150 \\
\hline
\end{tabular}




\begin{tabular}{|c|c|c|c|}
\hline C & 5.617022 & 3.263507 & 1.625677 \\
\hline C & 6.529433 & 2.496078 & 2.311295 \\
\hline C & 6.418579 & 1.085943 & 2.287918 \\
\hline C & 5.420197 & 0.471241 & 1.564577 \\
\hline $\mathrm{H}$ & 5.677871 & 4.349008 & 1.649905 \\
\hline $\mathrm{H}$ & 7.325673 & 2.968034 & 2.880394 \\
\hline $\mathrm{H}$ & 7.124509 & 0.481085 & 2.850663 \\
\hline $\mathrm{H}$ & 5.343272 & -0.609792 & 1.566607 \\
\hline 0 & -0.759849 & -0.550357 & -1.075664 \\
\hline O & -0.361469 & 1.306185 & 0.726075 \\
\hline $\mathrm{H}$ & -1.401261 & 1.347504 & 0.799644 \\
\hline $\mathrm{H}$ & 1.438046 & 2.672732 & -2.964557 \\
\hline $\mathrm{H}$ & -1.038487 & 6.181843 & -2.807159 \\
\hline $\mathrm{H}$ & 1.317513 & 5.057306 & 0.608470 \\
\hline $\mathrm{H}$ & 0.680451 & -4.889947 & -1.105558 \\
\hline $\mathrm{H}$ & -2.541617 & -5.526980 & 1.665396 \\
\hline $\mathrm{H}$ & 0.319227 & -2.403571 & 2.386746 \\
\hline C & -3.713742 & 1.561619 & 0.092430 \\
\hline $\mathrm{O}$ & -2.852046 & 1.487722 & 1.038688 \\
\hline $\mathrm{H}$ & -3.399424 & 1.351358 & -0.940899 \\
\hline C & -4.692763 & 2.742338 & 0.174696 \\
\hline $\mathrm{O}$ & -5.008859 & 3.314533 & 1.191620 \\
\hline $\mathrm{O}$ & -5.159038 & 3.055411 & -1.054371 \\
\hline C & -6.076075 & 4.161581 & -1.099942 \\
\hline $\mathrm{H}$ & -6.959396 & 3.953802 & -0.489602 \\
\hline $\mathrm{H}$ & -5.595286 & 5.070661 & -0.729440 \\
\hline C & -4.313016 & -0.970757 & 0.288893 \\
\hline C & -5.069451 & 0.221206 & 0.317708 \\
\hline $\mathrm{H}$ & -2.785612 & -2.048095 & 1.087894 \\
\hline$N$ & -3.446812 & -1.295972 & 1.273072 \\
\hline C & -3.168562 & -0.662769 & 2.518366 \\
\hline $\mathrm{O}$ & -2.114873 & -0.853532 & 3.077830 \\
\hline $\mathrm{O}$ & -4.227847 & -0.013224 & 3.001256 \\
\hline C & -3.944171 & 0.953567 & 4.038072 \\
\hline $\mathrm{H}$ & -3.506487 & 1.833832 & 3.563464 \\
\hline $\mathrm{H}$ & -3.267332 & 0.525777 & 4.778805 \\
\hline $\mathrm{H}$ & -4.910640 & 1.192301 & 4.481385 \\
\hline $\mathrm{H}$ & -5.756190 & 0.348416 & -0.513715 \\
\hline $\mathrm{H}$ & -5.430867 & 0.564373 & 1.277954 \\
\hline C & -4.333373 & -1.857108 & -0.895390 \\
\hline C & -5.572058 & -2.151772 & -1.495980 \\
\hline C & -3.161064 & -2.432412 & -1.416945 \\
\hline C & -5.639340 & -3.015887 & -2.584897 \\
\hline $\mathrm{H}$ & -6.483818 & -1.728861 & -1.085538 \\
\hline
\end{tabular}




$\begin{array}{llll}\mathrm{C} & -3.237834 & -3.284500 & -2.517140 \\ \mathrm{H} & -2.187584 & -2.147567 & -1.030085 \\ \mathrm{C} & -4.470904 & -3.584175 & -3.098392 \\ \mathrm{H} & -6.602765 & -3.247787 & -3.029938 \\ \mathrm{H} & -2.323049 & -3.702691 & -2.926087 \\ \mathrm{H} & -4.522567 & -4.252662 & -3.953573 \\ \mathrm{H} & -6.350334 & 4.272962 & -2.149291\end{array}$

Catalyst (R)-1 TS Conformation 345

$B 3 L Y P / 6-31 G(d)$ Energy $=-2809.681062$

B3LYP-D3(BJ)/def2-TZVPP-IEF-PCM(DCM) Energy $=-2810.977466$

B3LYP-D3(BJ)/def2-TZVPP-IEF-PCM(DCM)//B3LYP/6-31G(d) Free Energy (Quasiharmonic) = 2810.335368

Frequencies (Top 3 out of 270)

1. $-346.2209 \mathrm{~cm}-1$

2. $\quad 11.2401 \mathrm{~cm}-1$

3. $16.3336 \mathrm{~cm}-1$

B3LYP/6-31G(d) Molecular Geometry in Cartesian Coordinates

$\begin{array}{llll}\text { C } & -3.021084 & -0.889431 & 0.232639 \\ \text { C } & -1.924675 & -1.643719 & -0.151246 \\ \text { C } & -1.729728 & -3.002210 & 0.235661 \\ \text { C } & -2.670774 & -3.554162 & 1.083896 \\ \text { H } & -2.570652 & -4.595314 & 1.378797 \\ \text { C } & -3.438286 & 3.142480 & -1.240377 \\ \text { C } & -3.182676 & 0.490505 & -0.313038 \\ \text { C } & -2.170190 & 1.424175 & -0.145176 \\ \text { C } & -2.286824 & 2.780633 & -0.568939 \\ \text { H } & -3.562580 & 4.175068 & -1.556008 \\ \text { O } & -0.976002 & -1.051397 & -0.976156 \\ \text { P } & 0.042790 & 0.057218 & -0.325127 \\ \text { O } & -0.992617 & 1.035501 & 0.490360 \\ \text { C } & 1.516863 & -5.471833 & -1.126960 \\ \text { C } & 0.854321 & -4.635334 & -2.027925 \\ \text { C } & -0.182737 & -3.812167 & -1.591304 \\ \text { C } & -0.578941 & -3.813171 & -0.242934 \\ \text { C } & 0.105263 & -4.650338 & 0.653881 \\ \text { C } & 1.142144 & -5.472531 & 0.216954 \\ \text { H } & 1.144624 & -4.621044 & -3.074893\end{array}$




\begin{tabular}{|c|c|c|c|}
\hline $\mathrm{H}$ & 1.662724 & -6.106395 & 0.929902 \\
\hline C & 0.562820 & 5.896521 & 0.246581 \\
\hline C & 0.104210 & 5.681561 & -1.053372 \\
\hline C & -0.793626 & 4.646972 & -1.317749 \\
\hline C & -1.247002 & 3.807029 & -0.289101 \\
\hline C & -0.769602 & 4.025788 & 1.013178 \\
\hline C & 0.121527 & 5.064458 & 1.277965 \\
\hline $\mathrm{H}$ & 0.442422 & 6.320725 & -1.865093 \\
\hline $\mathrm{H}$ & 0.462416 & 5.236241 & 2.296205 \\
\hline C & -4.347092 & 0.865521 & -1.068761 \\
\hline C & -4.469116 & 2.216127 & -1.528784 \\
\hline C & -5.617577 & 2.601651 & -2.272082 \\
\hline C & -6.598734 & 1.689025 & -2.581219 \\
\hline C & -6.463848 & 0.344829 & -2.161047 \\
\hline C & -5.370672 & -0.056034 & -1.424983 \\
\hline $\mathrm{H}$ & -5.698178 & 3.634578 & -2.602511 \\
\hline $\mathrm{H}$ & -7.469328 & 1.992743 & -3.156012 \\
\hline $\mathrm{H}$ & -7.227833 & -0.380979 & -2.426251 \\
\hline $\mathrm{H}$ & -5.278664 & -1.092088 & -1.121355 \\
\hline C & -3.951166 & -1.454062 & 1.170550 \\
\hline C & -3.767109 & -2.812142 & 1.587745 \\
\hline C & -4.684239 & -3.388700 & 2.508008 \\
\hline C & -5.725736 & -2.653594 & 3.024530 \\
\hline C & -5.888736 & -1.301358 & 2.641685 \\
\hline C & -5.027077 & -0.717974 & 1.738775 \\
\hline $\mathrm{H}$ & -4.537177 & -4.424273 & 2.805642 \\
\hline $\mathrm{H}$ & -6.416252 & -3.103431 & 3.732667 \\
\hline $\mathrm{H}$ & -6.699192 & -0.715545 & 3.067041 \\
\hline $\mathrm{H}$ & -5.160588 & 0.321511 & 1.461781 \\
\hline 0 & 0.832340 & 0.684304 & -1.411110 \\
\hline O & 0.797209 & -0.605065 & 0.872300 \\
\hline $\mathrm{H}$ & 1.661324 & -1.208916 & 0.593621 \\
\hline $\mathrm{H}$ & -0.166128 & -4.637301 & 1.705678 \\
\hline $\mathrm{H}$ & 2.319938 & -6.119018 & -1.470372 \\
\hline $\mathrm{H}$ & -0.694239 & -3.171164 & -2.300681 \\
\hline $\mathrm{H}$ & -1.119272 & 3.390573 & 1.820904 \\
\hline $\mathrm{H}$ & 1.255952 & 6.706698 & 0.456791 \\
\hline $\mathrm{H}$ & -1.141440 & 4.476343 & -2.332676 \\
\hline C & 3.293382 & -1.557493 & -0.877840 \\
\hline 0 & 2.787930 & -1.934981 & 0.251125 \\
\hline $\mathrm{H}$ & 2.708172 & -0.894734 & -1.526935 \\
\hline C & 3.995716 & -2.621641 & -1.723348 \\
\hline 0 & 3.951330 & -2.642118 & -2.933894 \\
\hline $\mathrm{O}$ & 4.665266 & -3.514094 & -0.970631 \\
\hline
\end{tabular}




$\begin{array}{llll}\mathrm{C} & 5.329255 & -4.555238 & -1.704872 \\ \mathrm{H} & 4.602953 & -5.143126 & -2.271491 \\ \mathrm{H} & 6.062035 & -4.132623 & -2.398062 \\ \mathrm{C} & 4.412610 & 0.462125 & 0.425222 \\ \mathrm{C} & 4.831460 & -0.470885 & -0.552463 \\ \mathrm{H} & 4.295611 & -1.053314 & 1.741806 \\ \mathrm{~N} & 4.139508 & -0.052438 & 1.646584 \\ \mathrm{C} & 3.255285 & 0.375716 & 2.680575 \\ \mathrm{O} & 3.092139 & -0.323135 & 3.651500 \\ \mathrm{O} & 2.684041 & 1.542819 & 2.423591 \\ \mathrm{C} & 1.629764 & 1.918987 & 3.336561 \\ \mathrm{H} & 2.002990 & 1.931614 & 4.362650 \\ \mathrm{H} & 0.804631 & 1.210950 & 3.239600 \\ \mathrm{H} & 1.325875 & 2.912316 & 3.011577 \\ \mathrm{H} & 5.190798 & -0.054197 & -1.489079 \\ \mathrm{H} & 5.437055 & -1.293408 & -0.177145 \\ \mathrm{C} & 4.279510 & 1.899808 & 0.129812 \\ \mathrm{C} & 4.933481 & 2.830469 & 0.956359 \\ \mathrm{C} & 3.606343 & 2.341299 & -1.020217 \\ \mathrm{C} & 4.928448 & 4.181890 & 0.625804 \\ \mathrm{H} & 5.465576 & 2.487919 & 1.839061 \\ \mathrm{C} & 3.582378 & 3.700814 & -1.325084 \\ \mathrm{H} & 3.041009 & 1.641196 & -1.625393 \\ \mathrm{C} & 4.249982 & 4.620154 & -0.514245 \\ \mathrm{H} & 5.452120 & 4.892642 & 1.259022 \\ \mathrm{H} & 3.027466 & 4.040173 & -2.194137 \\ \mathrm{H} & 4.237901 & 5.677065 & -0.765970 \\ \mathrm{H} & 5.821361 & -5.174492 & -0.954441\end{array}$

Catalyst (R)-1 TS Conformation 346

B3LYP/6-31G(d) Energy $=-2809.681212$

B3LYP-D3(BJ)/def2-TZVPP-IEF-PCM(DCM) Energy = -2810.977375

B3LYP-D3(BJ)/def2-TZVPP-IEF-PCM(DCM)//B3LYP/6-31G(d) Free Energy (Quasiharmonic) = 2810.335342

Frequencies (Top 3 out of 270)

1. $-349.7832 \mathrm{~cm}-1$

2. $\quad 10.6151 \mathrm{~cm}-1$

3. $\quad 16.5255 \mathrm{~cm}-1$

B3LYP/6-31G(d) Molecular Geometry in Cartesian Coordinates 


\begin{tabular}{|c|c|c|c|}
\hline C & -3.048324 & -0.769365 & 0.242520 \\
\hline C & -1.982609 & -1.577685 & -0.116122 \\
\hline C & -1.837328 & -2.927826 & 0.316651 \\
\hline C & -2.796705 & -3.418080 & 1.181045 \\
\hline $\mathrm{H}$ & -2.729521 & -4.450191 & 1.515012 \\
\hline C & -3.281217 & 3.239612 & -1.331462 \\
\hline C & -3.147946 & 0.602341 & -0.337989 \\
\hline C & -2.094690 & 1.493641 & -0.189826 \\
\hline C & -2.147811 & 2.842720 & -0.648926 \\
\hline $\mathrm{H}$ & -3.358328 & 4.268474 & -1.673183 \\
\hline 0 & -1.007561 & -1.048182 & -0.954345 \\
\hline$P$ & 0.057485 & 0.023575 & -0.317015 \\
\hline $\mathrm{O}$ & -0.938411 & 1.070072 & 0.461869 \\
\hline C & 1.386912 & -5.485787 & -0.933256 \\
\hline C & 1.037641 & -5.393574 & 0.414143 \\
\hline C & -0.000837 & -4.553649 & 0.812474 \\
\hline C & -0.705604 & -3.784032 & -0.126943 \\
\hline C & -0.340799 & -3.879218 & -1.480192 \\
\hline C & 0.692267 & -4.726703 & -1.877757 \\
\hline $\mathrm{H}$ & 1.583734 & -5.965542 & 1.159154 \\
\hline $\mathrm{H}$ & 0.951939 & -4.794191 & -2.931360 \\
\hline C & 0.855684 & 5.833112 & 0.082070 \\
\hline C & 0.369117 & 5.620998 & -1.208262 \\
\hline C & -0.580307 & 4.626406 & -1.444359 \\
\hline C & -1.059432 & 3.824881 & -0.396683 \\
\hline C & -0.553723 & 4.040343 & 0.895584 \\
\hline C & 0.390070 & 5.038331 & 1.131973 \\
\hline $\mathrm{H}$ & 0.726029 & 6.230894 & -2.034392 \\
\hline $\mathrm{H}$ & 0.755020 & 5.206996 & 2.142304 \\
\hline C & -4.292408 & 1.010832 & -1.106431 \\
\hline C & -4.352711 & 2.354091 & -1.599134 \\
\hline C & -5.481642 & 2.772636 & -2.354471 \\
\hline C & -6.502256 & 1.897697 & -2.644273 \\
\hline C & -6.428536 & 0.559246 & -2.191714 \\
\hline C & -5.355643 & 0.127694 & -1.443261 \\
\hline $\mathrm{H}$ & -5.515392 & 3.799899 & -2.709753 \\
\hline $\mathrm{H}$ & -7.357508 & 2.226279 & -3.228361 \\
\hline $\mathrm{H}$ & -7.224016 & -0.137683 & -2.441349 \\
\hline $\mathrm{H}$ & -5.310657 & -0.903700 & -1.114094 \\
\hline C & -4.001666 & -1.270818 & 1.193337 \\
\hline C & -3.868114 & -2.620920 & 1.654576 \\
\hline C & -4.807852 & -3.133709 & 2.589562 \\
\hline C & -5.823461 & -2.345291 & 3.078329 \\
\hline
\end{tabular}




\begin{tabular}{|c|c|c|c|}
\hline$C$ & -5.936134 & -1.001028 & 2.652042 \\
\hline C & -5.051277 & -0.478420 & 1.734467 \\
\hline $\mathrm{H}$ & -4.699065 & -4.163736 & 2.920928 \\
\hline $\mathrm{H}$ & -6.531657 & -2.746960 & 3.797872 \\
\hline $\mathrm{H}$ & -6.725775 & -0.372810 & 3.055482 \\
\hline $\mathrm{H}$ & -5.146005 & 0.555952 & 1.424428 \\
\hline 0 & 0.890981 & 0.586084 & -1.406152 \\
\hline 0 & 0.763553 & -0.644720 & 0.906302 \\
\hline $\mathrm{H}$ & 1.596229 & -1.303120 & 0.657069 \\
\hline $\mathrm{H}$ & -0.872870 & -3.292573 & -2.221506 \\
\hline $\mathrm{H}$ & 2.202652 & -6.133722 & -1.241447 \\
\hline $\mathrm{H}$ & -0.252846 & -4.467289 & 1.865731 \\
\hline $\mathrm{H}$ & -0.920948 & 3.434471 & 1.717711 \\
\hline $\mathrm{H}$ & 1.589601 & 6.612184 & 0.270374 \\
\hline $\mathrm{H}$ & -0.948734 & 4.456719 & -2.452148 \\
\hline C & 3.244415 & -1.738930 & -0.759229 \\
\hline 0 & 2.685318 & -2.096429 & 0.348147 \\
\hline $\mathrm{H}$ & 2.718359 & -1.032761 & -1.412615 \\
\hline C & 3.937855 & -2.862415 & -1.538463 \\
\hline 0 & 4.552202 & -3.781260 & -1.047376 \\
\hline 0 & 3.772135 & -2.673486 & -2.862806 \\
\hline C & 4.367946 & -3.672942 & -3.707145 \\
\hline $\mathrm{H}$ & 5.443159 & -3.741127 & -3.520749 \\
\hline $\mathrm{H}$ & 4.171986 & -3.348099 & -4.729125 \\
\hline C & 4.439655 & 0.194598 & 0.603606 \\
\hline C & 4.844403 & -0.755411 & -0.360039 \\
\hline $\mathrm{H}$ & 4.186870 & -1.311519 & 1.913959 \\
\hline $\mathrm{N}$ & 4.086485 & -0.304283 & 1.810583 \\
\hline C & 3.192580 & 0.179638 & 2.810476 \\
\hline 0 & 2.945546 & -0.506790 & 3.772342 \\
\hline $\mathrm{O}$ & 2.710162 & 1.382727 & 2.534967 \\
\hline C & 1.647132 & 1.825948 & 3.406356 \\
\hline $\mathrm{H}$ & 1.423710 & 2.839001 & 3.076216 \\
\hline $\mathrm{H}$ & 1.977672 & 1.810702 & 4.446916 \\
\hline $\mathrm{H}$ & 0.780907 & 1.175373 & 3.272072 \\
\hline $\mathrm{H}$ & 5.272548 & -0.356435 & -1.275370 \\
\hline $\mathrm{H}$ & 5.362946 & -1.630367 & 0.028146 \\
\hline C & 4.396467 & 1.640126 & 0.309311 \\
\hline C & 5.110114 & 2.524611 & 1.136286 \\
\hline C & 3.743443 & 2.126225 & -0.833643 \\
\hline C & 5.184819 & 3.875790 & 0.811930 \\
\hline $\mathrm{H}$ & 5.623744 & 2.145938 & 2.015310 \\
\hline C & 3.799988 & 3.486690 & -1.132117 \\
\hline $\mathrm{H}$ & 3.132037 & 1.464973 & -1.438463 \\
\hline
\end{tabular}




$\begin{array}{llll}\mathrm{C} & 4.527313 & 4.359882 & -0.321779 \\ \mathrm{H} & 5.753670 & 4.550560 & 1.445588 \\ \mathrm{H} & 3.259011 & 3.863768 & -1.994394 \\ \mathrm{H} & 4.577190 & 5.416944 & -0.568317 \\ \mathrm{H} & 3.912521 & -4.648830 & -3.519663\end{array}$

Catalyst (R)-1 TS Conformation 347

B3LYP/6-31G(d) Energy $=-2809.687096$

B3LYP-D3(BJ)/def2-TZVPP-IEF-PCM(DCM) Energy = -2810.978821

B3LYP-D3(BJ)/def2-TZVPP-IEF-PCM(DCM)//B3LYP/6-31G(d) Free Energy (Quasiharmonic) = 2810.335312

Frequencies (Top 3 out of 270)

1. $-289.3579 \mathrm{~cm}-1$

2. $\quad 10.5707 \mathrm{~cm}-1$

3. $\quad 11.6490 \mathrm{~cm}-1$

B3LYP/6-31G(d) Molecular Geometry in Cartesian Coordinates

$\begin{array}{llll}\mathrm{C} & -3.410343 & 0.406726 & -0.101100 \\ \mathrm{C} & -2.438202 & 1.362611 & 0.145401 \\ \mathrm{C} & -2.596182 & 2.744578 & -0.165182 \\ \mathrm{C} & -3.775220 & 3.120746 & -0.779077 \\ \mathrm{H} & -3.940987 & 4.170336 & -1.006952 \\ \mathrm{C} & -2.705230 & -3.712756 & 0.954904 \\ \mathrm{C} & -3.176041 & -1.005444 & 0.322085 \\ \mathrm{C} & -2.039761 & -1.672446 & -0.110817 \\ \mathrm{C} & -1.783613 & -3.048245 & 0.167355 \\ \mathrm{H} & -2.562172 & -4.770414 & 1.158687 \\ \mathrm{O} & -1.246421 & 0.957797 & 0.741181 \\ \mathrm{P} & -0.163309 & 0.132354 & -0.166098 \\ \mathrm{O} & -1.115663 & -0.980091 & -0.888928 \\ \mathrm{C} & 0.329366 & 5.774799 & 0.704010 \\ \mathrm{C} & -0.279072 & 5.715692 & -0.550355 \\ \mathrm{C} & -1.210573 & 4.716844 & -0.828471 \\ \mathrm{C} & -1.551210 & 3.757538 & 0.139473 \\ \mathrm{C} & -0.921352 & 3.819371 & 1.393867 \\ \mathrm{C} & 0.007656 & 4.821086 & 1.672472 \\ \mathrm{H} & -0.020819 & 6.440631 & -1.317293 \\ \mathrm{H} & 0.477828 & 4.856577 & 2.651616 \\ \mathrm{C} & 1.533725 & -5.320193 & -1.367697\end{array}$




\begin{tabular}{|c|c|c|c|}
\hline$C$ & 0.881868 & -4.398437 & -2.189958 \\
\hline C & -0.172862 & -3.632412 & -1.694415 \\
\hline C & -0.599887 & -3.775893 & -0.363509 \\
\hline C & 0.079238 & -4.692727 & 0.458707 \\
\hline C & 1.132908 & -5.459134 & -0.037156 \\
\hline $\mathrm{H}$ & 1.188912 & -4.273497 & -3.224591 \\
\hline $\mathrm{H}$ & 1.637985 & -6.167126 & 0.615163 \\
\hline C & -4.079285 & -1.689435 & 1.206379 \\
\hline C & -3.836914 & -3.067919 & 1.508899 \\
\hline C & -4.730263 & -3.761963 & 2.369746 \\
\hline C & -5.803784 & -3.119801 & 2.940998 \\
\hline C & -6.023152 & -1.747377 & 2.675972 \\
\hline C & -5.186371 & -1.051759 & 1.831258 \\
\hline $\mathrm{H}$ & -4.538548 & -4.811963 & 2.577991 \\
\hline $\mathrm{H}$ & -6.476047 & -3.658150 & 3.603406 \\
\hline $\mathrm{H}$ & -6.857686 & -1.235119 & 3.147037 \\
\hline $\mathrm{H}$ & -5.363380 & 0.001217 & 1.646081 \\
\hline C & -4.598641 & 0.801706 & -0.807130 \\
\hline C & -4.778400 & 2.185375 & -1.131773 \\
\hline C & -5.953621 & 2.594241 & -1.818872 \\
\hline C & -6.903503 & 1.677350 & -2.204098 \\
\hline C & -6.709540 & 0.304948 & -1.920919 \\
\hline C & -5.589940 & -0.121321 & -1.240738 \\
\hline $\mathrm{H}$ & -6.079385 & 3.650120 & -2.046523 \\
\hline $\mathrm{H}$ & -7.794283 & 2.000684 & -2.735609 \\
\hline $\mathrm{H}$ & -7.448405 & -0.421692 & -2.247871 \\
\hline $\mathrm{H}$ & -5.452638 & -1.177716 & -1.041701 \\
\hline O & 0.935036 & -0.366560 & 0.692152 \\
\hline 0 & 0.209523 & 1.015503 & -1.409033 \\
\hline $\mathrm{H}$ & 1.131491 & 1.458506 & -1.321289 \\
\hline $\mathrm{H}$ & -1.167719 & 3.086499 & 2.154490 \\
\hline $\mathrm{H}$ & 1.049752 & 6.558675 & 0.922640 \\
\hline $\mathrm{H}$ & -1.664233 & 4.660786 & -1.813831 \\
\hline $\mathrm{H}$ & -0.218399 & -4.795066 & 1.498509 \\
\hline $\mathrm{H}$ & 2.344404 & -5.929204 & -1.760140 \\
\hline $\mathrm{H}$ & -0.674237 & -2.927502 & -2.347260 \\
\hline C & 3.014011 & 2.330104 & -0.037888 \\
\hline $\mathrm{O}$ & 2.520002 & 2.143590 & -1.206291 \\
\hline $\mathrm{H}$ & 2.562137 & 1.827375 & 0.828362 \\
\hline C & 3.527403 & 3.738992 & 0.282591 \\
\hline $\mathrm{O}$ & 3.863095 & 4.564793 & -0.531721 \\
\hline $\mathrm{O}$ & 3.569737 & 3.921642 & 1.622385 \\
\hline C & 4.060991 & 5.202431 & 2.048575 \\
\hline $\mathrm{H}$ & 5.076977 & 5.366928 & 1.678633 \\
\hline
\end{tabular}




$\begin{array}{llll}\mathrm{H} & 4.047809 & 5.175022 & 3.138540 \\ \mathrm{C} & 4.567630 & 0.177716 & -0.269437 \\ \mathrm{C} & 4.815749 & 1.533716 & 0.021048 \\ \mathrm{H} & 3.482604 & 0.733587 & -1.871794 \\ \mathrm{~N} & 4.029834 & -0.062129 & -1.495358 \\ \mathrm{C} & 3.924564 & -1.249783 & -2.232847 \\ \mathrm{O} & 3.128007 & -1.386716 & -3.132501 \\ \mathrm{O} & 4.864496 & -2.135754 & -1.869254 \\ \mathrm{C} & 4.824008 & -3.387283 & -2.577013 \\ \mathrm{H} & 5.675915 & -3.954315 & -2.201640 \\ \mathrm{H} & 4.913405 & -3.219257 & -3.652848 \\ \mathrm{H} & 3.888808 & -3.909614 & -2.363574 \\ \mathrm{H} & 5.205664 & 1.759115 & 1.008318 \\ \mathrm{H} & 5.193236 & 2.151478 & -0.789172 \\ \mathrm{C} & 4.702351 & -0.875160 & 0.749480 \\ \mathrm{C} & 5.827691 & -0.878456 & 1.592173 \\ \mathrm{C} & 3.700819 & -1.846875 & 0.927077 \\ \mathrm{C} & 5.962633 & -1.850618 & 2.579772 \\ \mathrm{H} & 6.608290 & -0.137340 & 1.447275 \\ \mathrm{C} & 3.833731 & -2.802956 & 1.929116 \\ \mathrm{H} & 2.792236 & -1.803398 & 0.337261 \\ \mathrm{C} & 4.965102 & -2.813816 & 2.749487 \\ \mathrm{H} & 6.843503 & -1.856809 & 3.215430 \\ \mathrm{H} & 3.043697 & -3.534219 & 2.071309 \\ \mathrm{H} & 5.066043 & -3.567061 & 3.526406 \\ \mathrm{H} & 3.415679 & 6.001714 & 1.675627\end{array}$

Catalyst (R)-1 TS Conformation 348

B3LYP/6-31G(d) Energy $=-2809.687382$

B3LYP-D3(BJ)/def2-TZVPP-IEF-PCM(DCM) Energy = -2810.979453

B3LYP-D3(BJ)/def2-TZVPP-IEF-PCM(DCM)//B3LYP/6-31G(d) Free Energy (Quasiharmonic) = 2810.335308

Frequencies (Top 3 out of 270)

1. $-298.2616 \mathrm{~cm}-1$

2. $\quad 9.3485 \mathrm{~cm}-1$

3. $\quad 15.5562 \mathrm{~cm}-1$

B3LYP/6-31G(d) Molecular Geometry in Cartesian Coordinates

$\begin{array}{llll}\text { C } & -2.946410 & -1.005363 & 0.317367\end{array}$ 


\begin{tabular}{|c|c|c|c|}
\hline C & -1.791681 & -1.703848 & 0.000993 \\
\hline C & -1.605838 & -3.083116 & 0.322159 \\
\hline C & -2.572901 & -3.684094 & 1.105422 \\
\hline $\mathrm{H}$ & -2.453189 & -4.728601 & 1.380439 \\
\hline C & -3.695036 & 2.993742 & -1.100298 \\
\hline C & -3.192249 & 0.353266 & -0.252226 \\
\hline C & -2.284821 & 1.377677 & -0.037782 \\
\hline C & -2.535014 & 2.735738 & -0.394955 \\
\hline $\mathrm{H}$ & -3.932769 & 4.020071 & -1.366475 \\
\hline $\mathrm{O}$ & -0.813763 & -1.076010 & -0.760503 \\
\hline$P$ & 0.035416 & 0.192826 & -0.183249 \\
\hline $\mathrm{O}$ & -1.089575 & 1.074140 & 0.608939 \\
\hline C & 1.526020 & -5.572213 & -1.277344 \\
\hline C & 1.849280 & -4.341981 & -0.701461 \\
\hline C & 0.853436 & -3.513688 & -0.181110 \\
\hline C & -0.494208 & -3.905923 & -0.231987 \\
\hline C & -0.806859 & -5.145457 & -0.817764 \\
\hline C & 0.190785 & -5.972355 & -1.332522 \\
\hline $\mathrm{H}$ & 2.885719 & -4.018588 & -0.658755 \\
\hline $\mathrm{H}$ & -0.078469 & -6.923245 & -1.785140 \\
\hline C & -0.211921 & 6.131363 & 0.847522 \\
\hline C & -0.473287 & 5.095915 & 1.746969 \\
\hline C & -1.181956 & 3.968192 & 1.337023 \\
\hline C & -1.654935 & 3.860762 & 0.018833 \\
\hline C & -1.371308 & 4.901299 & -0.879874 \\
\hline C & -0.656174 & 6.025319 & -0.470780 \\
\hline $\mathrm{H}$ & -0.135169 & 5.169038 & 2.777820 \\
\hline $\mathrm{H}$ & -0.445026 & 6.817490 & -1.184512 \\
\hline C & -4.358881 & 0.626596 & -1.048131 \\
\hline C & -4.600146 & 1.971668 & -1.476144 \\
\hline C & -5.749719 & 2.259386 & -2.260775 \\
\hline C & -6.617029 & 1.260803 & -2.638015 \\
\hline C & -6.363444 & -0.074226 & -2.245142 \\
\hline C & -5.267421 & -0.382915 & -1.469477 \\
\hline $\mathrm{H}$ & -5.923459 & 3.288281 & -2.567002 \\
\hline $\mathrm{H}$ & -7.488750 & 1.491378 & -3.244289 \\
\hline $\mathrm{H}$ & -7.037148 & -0.865743 & -2.562147 \\
\hline $\mathrm{H}$ & -5.082743 & -1.412567 & -1.186510 \\
\hline C & -3.900535 & -1.619719 & 1.201111 \\
\hline C & -3.698170 & -2.980151 & 1.597766 \\
\hline C & -4.629195 & -3.598771 & 2.475412 \\
\hline C & -5.710154 & -2.902723 & 2.964039 \\
\hline C & -5.898693 & -1.549972 & 2.595310 \\
\hline C & -5.020824 & -0.926101 & 1.736082 \\
\hline
\end{tabular}




\begin{tabular}{|c|c|c|c|}
\hline $\mathrm{H}$ & -4.462764 & -4.634815 & 2.761045 \\
\hline $\mathrm{H}$ & -6.412716 & -3.383583 & 3.639144 \\
\hline $\mathrm{H}$ & -6.741195 & -0.994772 & 2.998750 \\
\hline $\mathrm{H}$ & -5.173761 & 0.114153 & 1.473113 \\
\hline 0 & 0.693121 & 0.863207 & -1.340450 \\
\hline $\mathrm{O}$ & 0.922892 & -0.355578 & 0.967696 \\
\hline $\mathrm{H}$ & 1.789248 & 0.199661 & 1.325231 \\
\hline $\mathrm{H}$ & -1.847235 & -5.450496 & -0.888391 \\
\hline $\mathrm{H}$ & 2.306972 & -6.210951 & -1.682015 \\
\hline $\mathrm{H}$ & 1.123836 & -2.569598 & 0.277664 \\
\hline $\mathrm{H}$ & -1.704010 & 4.818621 & -1.910789 \\
\hline $\mathrm{H}$ & 0.334702 & 7.013725 & 1.171325 \\
\hline $\mathrm{H}$ & -1.387696 & 3.174594 & 2.047373 \\
\hline C & 4.023516 & 0.649059 & 2.013237 \\
\hline O & 2.798727 & 1.007862 & 1.828257 \\
\hline $\mathrm{H}$ & 4.600264 & 1.253113 & 2.729217 \\
\hline C & 4.408637 & -0.817259 & 2.243870 \\
\hline O & 5.512407 & -1.152843 & 2.625048 \\
\hline $\mathrm{O}$ & 3.396395 & -1.664735 & 2.019904 \\
\hline C & 3.676128 & -3.046187 & 2.315163 \\
\hline $\mathrm{H}$ & 3.934695 & -3.159570 & 3.371042 \\
\hline $\mathrm{H}$ & 2.761148 & -3.586236 & 2.077526 \\
\hline C & 4.335281 & 0.940049 & -0.572223 \\
\hline C & 5.181829 & 1.086585 & 0.556197 \\
\hline $\mathrm{H}$ & 2.489583 & 1.474032 & -1.324273 \\
\hline$N$ & 3.300527 & 1.783043 & -0.769017 \\
\hline C & 2.983452 & 3.040059 & -0.188144 \\
\hline $\mathrm{O}$ & 1.925345 & 3.569604 & -0.414604 \\
\hline 0 & 3.984110 & 3.585290 & 0.518143 \\
\hline C & 3.654818 & 4.854085 & 1.118954 \\
\hline $\mathrm{H}$ & 4.549159 & 5.149434 & 1.667658 \\
\hline $\mathrm{H}$ & 2.801763 & 4.738313 & 1.790018 \\
\hline $\mathrm{H}$ & 3.410988 & 5.586861 & 0.346737 \\
\hline $\mathrm{H}$ & 6.015157 & 0.398996 & 0.635000 \\
\hline $\mathrm{H}$ & 5.413921 & 2.097257 & 0.856481 \\
\hline C & 4.439244 & -0.242383 & -1.456939 \\
\hline C & 5.701256 & -0.844560 & -1.639592 \\
\hline C & 3.336429 & -0.769122 & -2.159332 \\
\hline C & 5.855241 & -1.937488 & -2.486960 \\
\hline $\mathrm{H}$ & 6.574741 & -0.436203 & -1.144100 \\
\hline C & 3.496591 & -1.870182 & -2.996981 \\
\hline $\mathrm{H}$ & 2.342150 & -0.350555 & -2.039610 \\
\hline C & 4.752029 & -2.457352 & -3.166471 \\
\hline $\mathrm{H}$ & 6.839389 & -2.377056 & -2.621290 \\
\hline
\end{tabular}




$\begin{array}{llll}\mathrm{H} & 2.629803 & -2.273269 & -3.511609 \\ \mathrm{H} & 4.870631 & -3.311833 & -3.827093 \\ \mathrm{H} & 4.509035 & -3.405020 & 1.704817\end{array}$

Catalyst (R)-1 TS Conformation 349

B3LYP/6-31G(d) Energy $=-2809.686926$

B3LYP-D3(BJ)/def2-TZVPP-IEF-PCM(DCM) Energy $=-2810.977188$

B3LYP-D3(BJ)/def2-TZVPP-IEF-PCM(DCM)//B3LYP/6-31G(d) Free Energy (Quasiharmonic) = 2810.33512

Frequencies (Top 3 out of 270)

1. $-621.7096 \mathrm{~cm}-1$

2. $\quad 3.4499 \mathrm{~cm}-1$

3. $\quad 5.6376 \mathrm{~cm}-1$

B3LYP/6-31G(d) Molecular Geometry in Cartesian Coordinates

$\begin{array}{llll}\text { C } & -3.766823 & 0.533461 & -0.164001 \\ \text { C } & -2.784177 & 1.417940 & 0.255786 \\ \text { C } & -2.933841 & 2.835948 & 0.206519 \\ \text { C } & -4.105643 & 3.330490 & -0.332188 \\ \text { H } & -4.263214 & 4.405543 & -0.360709 \\ \text { C } & -3.083426 & -3.715726 & 0.142070 \\ \text { C } & -3.548160 & -0.935451 & -0.004901 \\ \text { C } & -2.412360 & -1.518523 & -0.548310 \\ \text { C } & -2.160960 & -2.923000 & -0.513182 \\ \text { H } & -2.937450 & -4.792600 & 0.162361 \\ \text { O } & -1.605445 & 0.904285 & 0.773834 \\ \text { P } & -0.506516 & 0.238691 & -0.255871 \\ \text { O } & -1.487093 & -0.705405 & -1.183269 \\ \text { C } & 0.010591 & 5.616334 & 1.663291 \\ \text { C } & -0.592873 & 5.808617 & 0.419968 \\ \text { C } & -1.531228 & 4.891591 & -0.052357 \\ \text { C } & -1.885876 & 3.764981 & 0.707228 \\ \text { C } & -1.266165 & 3.579343 & 1.954638 \\ \text { C } & -0.330014 & 4.497746 & 2.426934 \\ \text { H } & -0.327701 & 6.668909 & -0.189268 \\ \text { H } & 0.133123 & 4.339656 & 3.397624 \\ \text { C } & 1.233228 & -4.815754 & -2.364138 \\ \text { C } & 0.528646 & -3.823228 & -3.048867 \\ \text { C } & -0.557261 & -3.186865 & -2.449949\end{array}$




\begin{tabular}{|c|c|c|c|}
\hline C & -0.964982 & -3.535504 & -1.151031 \\
\hline C & -0.244317 & -4.531490 & -0.471730 \\
\hline C & 0.843236 & -5.166076 & -1.070929 \\
\hline $\mathrm{H}$ & 0.821902 & -3.544191 & -4.057771 \\
\hline $\mathrm{H}$ & 1.389131 & -5.930143 & -0.523161 \\
\hline C & -4.457604 & -1.763902 & 0.738257 \\
\hline C & -4.218744 & -3.175454 & 0.793848 \\
\hline C & -5.117710 & -4.008029 & 1.514401 \\
\hline C & -6.193939 & -3.475195 & 2.184876 \\
\hline C & -6.410116 & -2.077151 & 2.165374 \\
\hline C & -5.567403 & -1.245275 & 1.461273 \\
\hline $\mathrm{H}$ & -4.928307 & -5.078842 & 1.534671 \\
\hline $\mathrm{H}$ & -6.870472 & -4.121059 & 2.738009 \\
\hline $\mathrm{H}$ & -7.246805 & -1.654128 & 2.714945 \\
\hline $\mathrm{H}$ & -5.741905 & -0.175645 & 1.464269 \\
\hline C & -4.947524 & 1.063682 & -0.789250 \\
\hline C & -5.114302 & 2.485136 & -0.855731 \\
\hline C & -6.282796 & 3.023553 & -1.459899 \\
\hline C & -7.239373 & 2.201950 & -2.009145 \\
\hline C & -7.058677 & 0.799144 & -1.981028 \\
\hline C & -5.945567 & 0.245490 & -1.387322 \\
\hline $\mathrm{H}$ & -6.398454 & 4.104538 & -1.490360 \\
\hline $\mathrm{H}$ & -8.125076 & 2.625655 & -2.474731 \\
\hline $\mathrm{H}$ & -7.802652 & 0.151284 & -2.436917 \\
\hline $\mathrm{H}$ & -5.817940 & -0.830735 & -1.383917 \\
\hline $\mathrm{O}$ & 0.481804 & -0.521624 & 0.562196 \\
\hline $\mathrm{O}$ & -0.004123 & 1.299700 & -1.237673 \\
\hline $\mathrm{H}$ & 1.214048 & 1.492865 & -1.310829 \\
\hline $\mathrm{H}$ & -1.524699 & 2.715080 & 2.556550 \\
\hline $\mathrm{H}$ & 0.743399 & 6.328987 & 2.032854 \\
\hline $\mathrm{H}$ & -1.979436 & 5.033149 & -1.031726 \\
\hline $\mathrm{H}$ & -0.529458 & -4.792958 & 0.543470 \\
\hline $\mathrm{H}$ & 2.080017 & -5.309788 & -2.833809 \\
\hline $\mathrm{H}$ & -1.097611 & -2.418976 & -2.992149 \\
\hline C & 3.021861 & 1.401618 & -0.325299 \\
\hline $\mathrm{O}$ & 2.366091 & 1.713242 & -1.392349 \\
\hline $\mathrm{H}$ & 2.475340 & 1.272727 & 0.614346 \\
\hline C & 4.356911 & 2.094356 & -0.102729 \\
\hline $\mathrm{O}$ & 4.864960 & 2.186675 & 0.997216 \\
\hline $\mathrm{O}$ & 4.897228 & 2.561165 & -1.234542 \\
\hline C & 6.131920 & 3.292607 & -1.078799 \\
\hline $\mathrm{H}$ & 6.014191 & 4.078239 & -0.329430 \\
\hline $\mathrm{H}$ & 6.335300 & 3.722200 & -2.059679 \\
\hline C & 4.567912 & -0.759469 & 0.408360 \\
\hline
\end{tabular}




$\begin{array}{llrr}\mathrm{C} & 3.553941 & -0.470750 & -0.524065 \\ \mathrm{H} & 6.485990 & -0.277238 & 0.908320 \\ \mathrm{~N} & 5.893974 & -0.523038 & 0.123422 \\ \mathrm{C} & 6.590790 & -0.342770 & -1.081588 \\ \mathrm{O} & 7.701658 & 0.145240 & -1.087060 \\ \mathrm{O} & 5.934008 & -0.802780 & -2.147984 \\ \mathrm{C} & 6.611036 & -0.620207 & -3.409646 \\ \mathrm{H} & 5.949975 & -1.066307 & -4.151439 \\ \mathrm{H} & 7.579321 & -1.124430 & -3.394477 \\ \mathrm{H} & 6.752748 & 0.444216 & -3.608592 \\ \mathrm{H} & 2.574666 & -0.905646 & -0.347194 \\ \mathrm{H} & 3.846962 & -0.399168 & -1.561997 \\ \mathrm{C} & 4.297975 & -1.185132 & 1.788805 \\ \mathrm{C} & 5.332056 & -1.694999 & 2.605965 \\ \mathrm{C} & 2.991129 & -1.119389 & 2.316988 \\ \mathrm{C} & 5.075259 & -2.094532 & 3.911947 \\ \mathrm{H} & 6.334929 & -1.829610 & 2.212155 \\ \mathrm{C} & 2.746327 & -1.517035 & 3.628375 \\ \mathrm{H} & 2.155316 & -0.775731 & 1.714980 \\ \mathrm{C} & 3.781708 & -1.996851 & 4.432051 \\ \mathrm{H} & 5.881952 & -2.492617 & 4.520504 \\ \mathrm{H} & 1.734342 & -1.453270 & 4.016589 \\ \mathrm{H} & 3.581924 & -2.307669 & 5.453830 \\ \mathrm{H} & 6.937833 & 2.617227 & -0.781389\end{array}$

Catalyst (R)-1 TS Conformation 350

B3LYP/6-31G(d) Energy $=-2809.690726$

B3LYP-D3(BJ)/def2-TZVPP-IEF-PCM(DCM) Energy = -2810.978925

B3LYP-D3(BJ)/def2-TZVPP-IEF-PCM(DCM)//B3LYP/6-31G(d) Free Energy (Quasiharmonic) = 2810.335116

Frequencies (Top 3 out of 270)

1. $-266.6316 \mathrm{~cm}-1$

2. $\quad 9.6421 \mathrm{~cm}-1$

3. $12.7807 \mathrm{~cm}-1$

B3LYP/6-31G(d) Molecular Geometry in Cartesian Coordinates

$\begin{array}{llll}C & 3.004859 & -1.378911 & 0.061166 \\ C & 1.720934 & -1.750549 & 0.424523 \\ C & 1.255500 & -3.097386 & 0.412095\end{array}$




\begin{tabular}{|c|c|c|c|}
\hline C & 2.136790 & -4.064457 & -0.029686 \\
\hline $\mathrm{H}$ & 1.823636 & -5.105248 & -0.030738 \\
\hline C & 4.193442 & 2.760189 & 0.256638 \\
\hline C & 3.419412 & 0.050318 & 0.184420 \\
\hline C & 2.676353 & 1.042112 & -0.439650 \\
\hline C & 3.050283 & 2.419873 & -0.442941 \\
\hline $\mathrm{H}$ & 4.531086 & 3.792813 & 0.246140 \\
\hline 0 & 0.832973 & -0.758033 & 0.832687 \\
\hline$P$ & 0.198662 & 0.223517 & -0.312134 \\
\hline O & 1.529478 & 0.675025 & -1.138979 \\
\hline C & -2.713682 & -4.230526 & 1.630777 \\
\hline C & -1.956510 & -3.372053 & 2.431364 \\
\hline C & -0.674800 & -2.987470 & 2.038535 \\
\hline C & -0.121731 & -3.462242 & 0.837540 \\
\hline C & -0.890348 & -4.330039 & 0.044245 \\
\hline C & -2.174048 & -4.708869 & 0.435430 \\
\hline $\mathrm{H}$ & -2.365132 & -2.997410 & 3.366384 \\
\hline $\mathrm{H}$ & -2.762297 & -5.364274 & -0.200748 \\
\hline C & 0.947165 & 5.557881 & -2.509295 \\
\hline C & 1.100780 & 4.309188 & -3.113749 \\
\hline C & 1.759733 & 3.277201 & -2.448121 \\
\hline C & 2.277276 & 3.472231 & -1.156204 \\
\hline C & 2.103106 & 4.730733 & -0.553304 \\
\hline C & 1.449993 & 5.764680 & -1.223506 \\
\hline $\mathrm{H}$ & 0.705130 & 4.134113 & -4.110107 \\
\hline $\mathrm{H}$ & 1.331340 & 6.730094 & -0.737540 \\
\hline C & 4.553226 & 0.437948 & 0.978531 \\
\hline C & 4.946370 & 1.814622 & 0.992623 \\
\hline C & 6.076949 & 2.210927 & 1.758031 \\
\hline C & 6.776703 & 1.297445 & 2.510993 \\
\hline C & 6.365591 & -0.056225 & 2.532410 \\
\hline C & 5.286063 & -0.475165 & 1.786210 \\
\hline $\mathrm{H}$ & 6.369423 & 3.258274 & 1.745915 \\
\hline $\mathrm{H}$ & 7.634827 & 1.612799 & 3.098155 \\
\hline $\mathrm{H}$ & 6.903975 & -0.772487 & 3.147159 \\
\hline $\mathrm{H}$ & 4.979586 & -1.513988 & 1.821358 \\
\hline C & 3.884924 & -2.386324 & -0.466156 \\
\hline C & 3.437470 & -3.747313 & -0.492991 \\
\hline C & 4.300922 & -4.755712 & -1.000832 \\
\hline C & 5.544673 & -4.439689 & -1.495536 \\
\hline C & 5.973144 & -3.091584 & -1.508001 \\
\hline C & 5.167318 & -2.093090 & -1.006494 \\
\hline $\mathrm{H}$ & 3.950154 & -5.785041 & -1.002246 \\
\hline $\mathrm{H}$ & 6.192960 & -5.218311 & -1.888004 \\
\hline
\end{tabular}




\begin{tabular}{|c|c|c|c|}
\hline $\mathrm{H}$ & 6.945663 & -2.839696 & -1.922205 \\
\hline $\mathrm{H}$ & 5.507179 & -1.064400 & -1.033411 \\
\hline $\mathrm{O}$ & -0.582705 & 1.297160 & 0.344736 \\
\hline $\mathrm{O}$ & -0.490264 & -0.675566 & -1.393353 \\
\hline $\mathrm{H}$ & -1.516507 & -0.725506 & -1.397304 \\
\hline $\mathrm{H}$ & -0.485105 & -4.683781 & -0.899691 \\
\hline $\mathrm{H}$ & -3.721772 & -4.509375 & 1.921740 \\
\hline $\mathrm{H}$ & -0.096511 & -2.317857 & 2.666220 \\
\hline $\mathrm{H}$ & 2.471107 & 4.892542 & 0.456055 \\
\hline $\mathrm{H}$ & 0.435672 & 6.360650 & -3.033939 \\
\hline $\mathrm{H}$ & 1.876726 & 2.315844 & -2.934355 \\
\hline C & -3.831684 & -1.391100 & -0.773920 \\
\hline 0 & -3.028015 & -0.918573 & -1.648989 \\
\hline $\mathrm{H}$ & -3.483820 & -1.594098 & 0.248930 \\
\hline C & -4.846065 & -2.456894 & -1.195989 \\
\hline $\mathrm{O}$ & -5.313652 & -3.271914 & -0.427609 \\
\hline 0 & -5.147040 & -2.381868 & -2.502258 \\
\hline C & -6.074418 & -3.372435 & -2.975788 \\
\hline $\mathrm{H}$ & -6.203854 & -3.166154 & -4.038327 \\
\hline $\mathrm{H}$ & -5.669668 & -4.376780 & -2.826050 \\
\hline C & -4.439699 & 1.072592 & 0.029737 \\
\hline C & -5.222950 & -0.031068 & -0.370285 \\
\hline $\mathrm{H}$ & -3.511972 & 0.949027 & -1.742769 \\
\hline$N$ & -3.655422 & 1.586267 & -0.950322 \\
\hline C & -2.830368 & 2.725227 & -1.060539 \\
\hline 0 & -2.136523 & 2.879850 & -2.037915 \\
\hline 0 & -2.982836 & 3.577972 & -0.048785 \\
\hline C & -2.060099 & 4.687546 & -0.062957 \\
\hline $\mathrm{H}$ & -1.036126 & 4.314008 & -0.007451 \\
\hline $\mathrm{H}$ & -2.313172 & 5.275970 & 0.818926 \\
\hline $\mathrm{H}$ & -2.187169 & 5.275293 & -0.974428 \\
\hline $\mathrm{H}$ & -5.861538 & -0.484822 & 0.380043 \\
\hline $\mathrm{H}$ & -5.624299 & -0.014292 & -1.380025 \\
\hline C & -4.388477 & 1.475320 & 1.448892 \\
\hline C & -5.600730 & 1.567775 & 2.157092 \\
\hline C & -3.173993 & 1.682221 & 2.128264 \\
\hline C & -5.604672 & 1.882691 & 3.513433 \\
\hline $\mathrm{H}$ & -6.540174 & 1.419552 & 1.632825 \\
\hline C & -3.187812 & 1.971012 & 3.490738 \\
\hline $\mathrm{H}$ & -2.230640 & 1.586990 & 1.600469 \\
\hline C & -4.395965 & 2.080011 & 4.184075 \\
\hline $\mathrm{H}$ & -6.547964 & 1.969675 & 4.045084 \\
\hline $\mathrm{H}$ & -2.245438 & 2.109867 & 4.013129 \\
\hline $\mathrm{H}$ & -4.395690 & 2.315140 & 5.245181 \\
\hline
\end{tabular}


$\begin{array}{llll}\mathrm{H} & -7.028501 & -3.292024 & -2.447281\end{array}$

Catalyst (R)-1 TS Conformation 351

B3LYP/6-31G(d) Energy $=-2809.68402$

B3LYP-D3(BJ)/def2-TZVPP-IEF-PCM(DCM) Energy = -2810.977269

B3LYP-D3(BJ)/def2-TZVPP-IEF-PCM(DCM)//B3LYP/6-31G(d) Free Energy (Quasiharmonic) = 2810.334945

Frequencies (Top 3 out of 270)

1. $-523.2182 \mathrm{~cm}-1$

2. $\quad 9.0557 \mathrm{~cm}-1$

3. $12.5488 \mathrm{~cm}-1$

B3LYP/6-31G(d) Molecular Geometry in Cartesian Coordinates

$\begin{array}{llll}\mathrm{C} & 3.538509 & -1.038808 & -0.176457 \\ \mathrm{C} & 2.346085 & -1.643751 & 0.183916 \\ \mathrm{C} & 2.030014 & -3.001526 & -0.113853 \\ \mathrm{C} & 2.954985 & -3.721360 & -0.843467 \\ \mathrm{H} & 2.757609 & -4.766531 & -1.067498 \\ \mathrm{C} & 4.384137 & 3.061194 & 0.841160 \\ \mathrm{C} & 3.814738 & 0.362479 & 0.258809 \\ \mathrm{C} & 2.918626 & 1.379123 & -0.046722 \\ \mathrm{C} & 3.199236 & 2.757465 & 0.199069 \\ \mathrm{H} & 4.618275 & 4.102216 & 1.047572 \\ \mathrm{O} & 1.407605 & -0.891947 & 0.879123 \\ \mathrm{P} & 0.550961 & 0.221877 & 0.025241 \\ \mathrm{O} & 1.742860 & 1.068471 & -0.715578 \\ \mathrm{C} & -1.606305 & -4.923708 & 1.159406 \\ \mathrm{C} & -0.865495 & -4.159250 & 2.065149 \\ \mathrm{C} & 0.303822 & -3.518307 & 1.657023 \\ \mathrm{C} & 0.759716 & -3.633225 & 0.331908 \\ \mathrm{C} & 0.005576 & -4.402518 & -0.568484 \\ \mathrm{C} & -1.165477 & -5.041910 & -0.159598 \\ \mathrm{H} & -1.198400 & -4.064245 & 3.095408 \\ \mathrm{H} & -1.736006 & -5.626711 & -0.876616 \\ \mathrm{C} & 0.730606 & 6.066120 & -1.019375 \\ \mathrm{C} & 0.171237 & 5.016195 & -0.287987 \\ \mathrm{C} & 0.946411 & 3.920123 & 0.092443 \\ \mathrm{C} & 2.307573 & 3.864793 & -0.248008 \\ \mathrm{C} & 2.860129 & 4.925636 & -0.985253\end{array}$




\begin{tabular}{|c|c|c|c|}
\hline C & 2.080104 & 6.015704 & -1.370246 \\
\hline $\mathrm{H}$ & -0.877184 & 5.048225 & -0.002875 \\
\hline $\mathrm{H}$ & 2.527331 & 6.822009 & -1.946111 \\
\hline C & 4.994774 & 0.688266 & 1.013410 \\
\hline C & 5.281071 & 2.062963 & 1.291583 \\
\hline C & 6.447368 & 2.399602 & 2.030883 \\
\hline C & 7.291958 & 1.422537 & 2.503626 \\
\hline C & 6.994608 & 0.060937 & 2.260052 \\
\hline C & 5.879298 & -0.296500 & 1.534717 \\
\hline $\mathrm{H}$ & 6.651657 & 3.449849 & 2.225778 \\
\hline $\mathrm{H}$ & 8.177676 & 1.690892 & 3.073008 \\
\hline $\mathrm{H}$ & 7.648951 & -0.711783 & 2.654687 \\
\hline $\mathrm{H}$ & 5.660736 & -1.344806 & 1.367710 \\
\hline C & 4.458105 & -1.777275 & -1.000066 \\
\hline C & 4.156830 & -3.141379 & -1.319491 \\
\hline C & 5.061684 & -3.886985 & -2.122824 \\
\hline C & 6.204627 & -3.309421 & -2.624518 \\
\hline C & 6.484368 & -1.951272 & -2.345262 \\
\hline C & 5.636804 & -1.206664 & -1.554533 \\
\hline $\mathrm{H}$ & 4.822994 & -4.924585 & -2.344529 \\
\hline $\mathrm{H}$ & 6.885184 & -3.887331 & -3.243817 \\
\hline $\mathrm{H}$ & 7.374378 & -1.488192 & -2.762821 \\
\hline $\mathrm{H}$ & 5.861345 & -0.164723 & -1.359530 \\
\hline $\mathrm{O}$ & -0.290124 & 0.996884 & 0.977754 \\
\hline $\mathrm{O}$ & -0.131820 & -0.478536 & -1.171417 \\
\hline $\mathrm{H}$ & -1.255445 & -0.673864 & -1.106897 \\
\hline $\mathrm{H}$ & 0.330139 & -4.477492 & -1.602378 \\
\hline $\mathrm{H}$ & -2.522128 & -5.412500 & 1.479556 \\
\hline $\mathrm{H}$ & 0.872070 & -2.928432 & 2.368218 \\
\hline $\mathrm{H}$ & 3.907973 & 4.883832 & -1.270527 \\
\hline $\mathrm{H}$ & 0.120681 & 6.916865 & -1.313205 \\
\hline $\mathrm{H}$ & 0.495566 & 3.114809 & 0.663134 \\
\hline C & -2.845756 & -1.383560 & 0.113731 \\
\hline $\mathrm{O}$ & -2.513018 & -0.906915 & -1.039010 \\
\hline $\mathrm{H}$ & -2.048816 & -1.800432 & 0.749111 \\
\hline C & -4.081448 & -2.286496 & 0.193716 \\
\hline $\mathrm{O}$ & -4.489773 & -2.770132 & 1.235931 \\
\hline $\mathrm{O}$ & -4.661109 & -2.475559 & -0.994193 \\
\hline C & -5.811107 & -3.344959 & -0.987952 \\
\hline $\mathrm{H}$ & -6.127955 & -3.408596 & -2.028875 \\
\hline $\mathrm{H}$ & -6.604893 & -2.927172 & -0.362739 \\
\hline C & -4.459198 & 0.617559 & 0.997959 \\
\hline C & -3.295761 & -0.079553 & 1.405312 \\
\hline $\mathrm{H}$ & -5.617746 & -0.737077 & 1.962640 \\
\hline
\end{tabular}




$\begin{array}{llll}\mathrm{N} & -5.669278 & 0.048871 & 1.319441 \\ \mathrm{C} & -6.895850 & -0.013430 & 0.620552 \\ \mathrm{O} & -7.782783 & -0.743349 & 1.006577 \\ \mathrm{O} & -6.932225 & 0.757856 & -0.463996 \\ \mathrm{C} & -8.159626 & 0.696867 & -1.218665 \\ \mathrm{H} & -8.021831 & 1.401947 & -2.037336 \\ \mathrm{H} & -9.005854 & 0.985633 & -0.591474 \\ \mathrm{H} & -8.317632 & -0.314132 & -1.600521 \\ \mathrm{H} & -2.371091 & 0.492721 & 1.449434 \\ \mathrm{H} & -3.437458 & -0.773774 & 2.231395 \\ \mathrm{C} & -4.378755 & 1.884042 & 0.274330 \\ \mathrm{C} & -3.275871 & 2.132396 & -0.565681 \\ \mathrm{C} & -5.334765 & 2.901368 & 0.479837 \\ \mathrm{C} & -3.166008 & 3.354292 & -1.225664 \\ \mathrm{H} & -2.530835 & 1.363358 & -0.720968 \\ \mathrm{C} & -5.194466 & 4.129717 & -0.150809 \\ \mathrm{H} & -6.162706 & 2.735905 & 1.160859 \\ \mathrm{C} & -4.116981 & 4.354167 & -1.016172 \\ \mathrm{H} & -2.320503 & 3.530369 & -1.883129 \\ \mathrm{H} & -5.920906 & 4.916301 & 0.032113 \\ \mathrm{H} & -4.013749 & 5.314827 & -1.513523 \\ \mathrm{H} & -5.538602 & -4.331927 & -0.606498\end{array}$

Catalyst (R)-1 TS Conformation 352

B3LYP/6-31G(d) Energy $=-2809.682278$

B3LYP-D3(BJ)/def2-TZVPP-IEF-PCM(DCM) Energy = -2810.976812

B3LYP-D3(BJ)/def2-TZVPP-IEF-PCM(DCM)//B3LYP/6-31G(d) Free Energy (Quasiharmonic) = 2810.334939

Frequencies (Top 3 out of 270)

1. $-816.3284 \mathrm{~cm}-1$

2. $\quad 13.9132 \mathrm{~cm}-1$

3. $20.0403 \mathrm{~cm}-1$

B3LYP/6-31G(d) Molecular Geometry in Cartesian Coordinates

$\begin{array}{lrrr}\text { C } & 3.179364 & -0.180675 & 0.395973 \\ \text { C } & 2.684269 & 0.973806 & -0.193647 \\ \text { C } & 3.254660 & 2.265782 & 0.033037 \\ \text { C } & 4.234717 & 2.358608 & 1.003797 \\ \text { H } & 4.672551 & 3.329745 & 1.217922\end{array}$




\begin{tabular}{|c|c|c|c|}
\hline C & 1.819259 & -4.132403 & -0.637477 \\
\hline C & 2.723397 & -1.530040 & -0.056715 \\
\hline C & 1.378481 & -1.862400 & -0.021662 \\
\hline C & 0.884963 & -3.181367 & -0.267762 \\
\hline $\mathrm{H}$ & 1.499037 & -5.158977 & -0.790173 \\
\hline 0 & 1.655255 & 0.866260 & -1.122067 \\
\hline$P$ & 0.163983 & 0.391856 & -0.648319 \\
\hline $\mathrm{O}$ & 0.477906 & -0.877075 & 0.345837 \\
\hline C & 2.416496 & 5.773022 & -2.328059 \\
\hline C & 3.726964 & 5.420810 & -2.002817 \\
\hline C & 3.975467 & 4.276739 & -1.246297 \\
\hline C & 2.922383 & 3.464944 & -0.786058 \\
\hline C & 1.609398 & 3.833467 & -1.119188 \\
\hline C & 1.362364 & 4.972081 & -1.886193 \\
\hline $\mathrm{H}$ & 4.559967 & 6.026120 & -2.351433 \\
\hline $\mathrm{H}$ & 0.336946 & 5.214587 & -2.148227 \\
\hline C & -3.196269 & -4.465708 & 0.256863 \\
\hline C & -2.401250 & -5.010184 & -0.753963 \\
\hline C & -1.096467 & -4.556643 & -0.940298 \\
\hline C & -0.544529 & -3.565313 & -0.107061 \\
\hline C & -1.363061 & -3.021724 & 0.899871 \\
\hline C & -2.675149 & -3.461464 & 1.073699 \\
\hline $\mathrm{H}$ & -2.798402 & -5.783960 & -1.406934 \\
\hline $\mathrm{H}$ & -3.287336 & -2.999075 & 1.842456 \\
\hline C & 3.661374 & -2.506888 & -0.538596 \\
\hline C & 3.189603 & -3.828911 & -0.819963 \\
\hline C & 4.105952 & -4.814529 & -1.277957 \\
\hline C & 5.430547 & -4.507588 & -1.484800 \\
\hline C & 5.891935 & -3.192182 & -1.243204 \\
\hline C & 5.033037 & -2.219861 & -0.779451 \\
\hline $\mathrm{H}$ & 3.732946 & -5.816956 & -1.475019 \\
\hline $\mathrm{H}$ & 6.120187 & -5.266869 & -1.843446 \\
\hline $\mathrm{H}$ & 6.933494 & -2.944457 & -1.429536 \\
\hline $\mathrm{H}$ & 5.400824 & -1.214895 & -0.608280 \\
\hline C & 4.143247 & -0.052462 & 1.456659 \\
\hline C & 4.667436 & 1.243973 & 1.760517 \\
\hline C & 5.612179 & 1.388489 & 2.812508 \\
\hline C & 6.014217 & 0.303517 & 3.556032 \\
\hline C & 5.476905 & -0.975145 & 3.277382 \\
\hline C & 4.569372 & -1.149409 & 2.255446 \\
\hline $\mathrm{H}$ & 6.004886 & 2.380539 & 3.023421 \\
\hline $\mathrm{H}$ & 6.733152 & 0.426056 & 4.361579 \\
\hline $\mathrm{H}$ & 5.777880 & -1.828339 & 3.879407 \\
\hline $\mathrm{H}$ & 4.158529 & -2.133859 & 2.064585 \\
\hline
\end{tabular}




\begin{tabular}{|c|c|c|c|}
\hline $\mathrm{O}$ & -0.642277 & 0.054150 & -1.856058 \\
\hline O & -0.405892 & 1.432711 & 0.350198 \\
\hline $\mathrm{H}$ & -1.359644 & 1.000768 & 0.954416 \\
\hline $\mathrm{H}$ & 0.778259 & 3.232134 & -0.777118 \\
\hline $\mathrm{H}$ & 2.219977 & 6.656365 & -2.930412 \\
\hline $\mathrm{H}$ & 5.000821 & 3.990053 & -1.030090 \\
\hline $\mathrm{H}$ & -0.980119 & -2.246262 & 1.550297 \\
\hline $\mathrm{H}$ & -4.217417 & -4.811106 & 0.396724 \\
\hline $\mathrm{H}$ & -0.500409 & -4.966280 & -1.750807 \\
\hline C & -3.288324 & 1.151429 & 1.891236 \\
\hline 0 & -2.310182 & 0.442982 & 1.457266 \\
\hline $\mathrm{H}$ & -3.103002 & 2.190374 & 2.178344 \\
\hline C & -4.271929 & 0.425054 & 2.795020 \\
\hline $\mathrm{O}$ & -4.402908 & -0.773138 & 2.875305 \\
\hline O & -4.984082 & 1.323287 & 3.511792 \\
\hline C & -5.948216 & 0.759445 & 4.418199 \\
\hline $\mathrm{H}$ & -6.422102 & 1.610059 & 4.908263 \\
\hline $\mathrm{H}$ & -6.687533 & 0.167030 & 3.872190 \\
\hline C & -4.098235 & 1.200712 & -0.690591 \\
\hline C & -4.671964 & 1.705779 & 0.493496 \\
\hline $\mathrm{H}$ & -2.554394 & 1.236714 & -2.032044 \\
\hline $\mathrm{N}$ & -3.041242 & 1.773873 & -1.312673 \\
\hline C & -2.406841 & 3.027107 & -1.147874 \\
\hline $\mathrm{O}$ & -1.652857 & 3.447223 & -1.991408 \\
\hline 0 & -2.753750 & 3.659192 & -0.021381 \\
\hline C & -2.089028 & 4.925223 & 0.190696 \\
\hline $\mathrm{H}$ & -2.301684 & 5.605766 & -0.636331 \\
\hline $\mathrm{H}$ & -1.012479 & 4.768556 & 0.276192 \\
\hline $\mathrm{H}$ & -2.501651 & 5.308401 & 1.123580 \\
\hline $\mathrm{H}$ & -5.593171 & 1.222549 & 0.795901 \\
\hline $\mathrm{H}$ & -4.631326 & 2.769046 & 0.681245 \\
\hline C & -4.554139 & -0.084543 & -1.256295 \\
\hline C & -5.930755 & -0.385200 & -1.245981 \\
\hline C & -3.655475 & -0.995820 & -1.844090 \\
\hline C & -6.399917 & -1.560220 & -1.822904 \\
\hline $\mathrm{H}$ & -6.638098 & 0.322617 & -0.826044 \\
\hline C & -4.135136 & -2.177797 & -2.403302 \\
\hline $\mathrm{H}$ & -2.583485 & -0.812203 & -1.830094 \\
\hline C & -5.501765 & -2.460715 & -2.401044 \\
\hline $\mathrm{H}$ & -7.465613 & -1.770321 & -1.826228 \\
\hline $\mathrm{H}$ & -3.429621 & -2.885634 & -2.825287 \\
\hline $\mathrm{H}$ & -5.867857 & -3.381797 & -2.846396 \\
\hline $\mathrm{H}$ & -5.452122 & 0.119065 & 5.151908 \\
\hline
\end{tabular}


Catalyst (R)-1 TS Conformation 353

B3LYP/6-31G(d) Energy $=-2809.682087$

B3LYP-D3(BJ)/def2-TZVPP-IEF-PCM(DCM) Energy = -2810.97839

B3LYP-D3(BJ)/def2-TZVPP-IEF-PCM(DCM)//B3LYP/6-31G(d) Free Energy (Quasiharmonic) = 2810.334823

Frequencies (Top 3 out of 270)

1. $-313.7605 \mathrm{~cm}-1$

2. $\quad 7.4413 \mathrm{~cm}-1$

3. $\quad 9.2394 \mathrm{~cm}-1$

B3LYP/6-31G(d) Molecular Geometry in Cartesian Coordinates

$\begin{array}{lrrr}\text { C } & 3.696379 & 0.570237 & 0.310938 \\ \text { C } & 2.774603 & 1.492495 & -0.157508 \\ \text { C } & 2.861628 & 2.892309 & 0.101795 \\ \text { C } & 3.900073 & 3.323527 & 0.903324 \\ \text { H } & 4.012113 & 4.386653 & 1.100016 \\ \text { C } & 3.357744 & -3.633031 & -0.572329 \\ \text { C } & 3.571675 & -0.864083 & -0.085444 \\ \text { C } & 2.388756 & -1.554270 & 0.152664 \\ \text { C } & 2.269611 & -2.965238 & -0.044938 \\ \text { H } & 3.287952 & -4.704749 & -0.739788 \\ \text { O } & 1.717795 & 1.032466 & -0.928459 \\ \text { P } & 0.488175 & 0.269757 & -0.139761 \\ \text { O } & 1.311496 & -0.886541 & 0.704811 \\ \text { C } & 0.126929 & 5.803230 & -1.500297 \\ \text { C } & 0.644394 & 4.803223 & -2.326527 \\ \text { C } & 1.512766 & 3.841875 & -1.812019 \\ \text { C } & 1.887081 & 3.866119 & -0.457823 \\ \text { C } & 1.355857 & 4.874055 & 0.363115 \\ \text { C } & 0.484351 & 5.833219 & -0.151808 \\ \text { H } & 0.374012 & 4.772043 & -3.379071 \\ \text { H } & 0.077846 & 6.598379 & 0.504466 \\ \text { C } & -1.183584 & -5.322591 & 0.986618 \\ \text { C } & -1.332944 & -4.171037 & 0.210853 \\ \text { C } & -0.229077 & -3.381848 & -0.111364 \\ \text { C } & 1.053708 & -3.738387 & 0.334677 \\ \text { C } & 1.192843 & -4.897670 & 1.115740 \\ \text { C } & 0.085931 & -5.682152 & 1.440580 \\ \text { H } & -2.316018 & -3.883736 & -0.155518\end{array}$




\begin{tabular}{|c|c|c|c|}
\hline $\mathrm{H}$ & 0.216889 & -6.571570 & 2.051797 \\
\hline C & 4.657249 & -1.555154 & -0.727132 \\
\hline C & 4.544044 & -2.963542 & -0.957475 \\
\hline C & 5.613115 & -3.659240 & -1.584464 \\
\hline C & 6.745376 & -2.995098 & -1.995069 \\
\hline C & 6.847360 & -1.597486 & -1.799924 \\
\hline C & 5.833953 & -0.897690 & -1.182526 \\
\hline $\mathrm{H}$ & 5.511193 & -4.730342 & -1.743637 \\
\hline $\mathrm{H}$ & 7.554348 & -3.535952 & -2.478658 \\
\hline $\mathrm{H}$ & 7.731499 & -1.068834 & -2.146217 \\
\hline $\mathrm{H}$ & 5.923890 & 0.174380 & -1.051261 \\
\hline C & 4.726408 & 1.024397 & 1.206525 \\
\hline C & 4.827214 & 2.425818 & 1.487679 \\
\hline C & 5.847306 & 2.891616 & 2.360913 \\
\hline C & 6.717732 & 2.014850 & 2.965399 \\
\hline C & 6.594924 & 0.626760 & 2.722726 \\
\hline C & 5.628478 & 0.145244 & 1.866930 \\
\hline $\mathrm{H}$ & 5.916402 & 3.960000 & 2.552379 \\
\hline $\mathrm{H}$ & 7.488906 & 2.382345 & 3.637012 \\
\hline $\mathrm{H}$ & 7.266271 & -0.068204 & 3.220133 \\
\hline $\mathrm{H}$ & 5.542278 & -0.922082 & 1.701023 \\
\hline $\mathrm{O}$ & -0.423756 & -0.297111 & -1.185092 \\
\hline $\mathrm{O}$ & -0.087248 & 1.163118 & 0.950416 \\
\hline $\mathrm{H}$ & -1.308957 & 1.726612 & 0.861726 \\
\hline $\mathrm{H}$ & 1.612142 & 4.887676 & 1.418675 \\
\hline $\mathrm{H}$ & -0.552799 & 6.549634 & -1.903237 \\
\hline $\mathrm{H}$ & 1.909439 & 3.069940 & -2.462439 \\
\hline $\mathrm{H}$ & 2.177236 & -5.174393 & 1.483723 \\
\hline $\mathrm{H}$ & -2.047445 & -5.933898 & 1.235734 \\
\hline $\mathrm{H}$ & -0.357555 & -2.489752 & -0.714691 \\
\hline C & -2.931988 & 1.410157 & -0.161698 \\
\hline $\mathrm{O}$ & -2.346646 & 2.078685 & 0.778413 \\
\hline $\mathrm{H}$ & -2.315788 & 0.973775 & -0.950272 \\
\hline C & -4.275959 & 1.959367 & -0.594199 \\
\hline $\mathrm{O}$ & -4.986267 & 2.688801 & 0.053201 \\
\hline $\mathrm{O}$ & -4.558116 & 1.513401 & -1.842186 \\
\hline C & -5.778658 & 2.008220 & -2.423368 \\
\hline $\mathrm{H}$ & -5.936046 & 1.412156 & -3.322036 \\
\hline $\mathrm{H}$ & -6.612693 & 1.894884 & -1.726771 \\
\hline C & -4.659416 & -0.790907 & 0.394279 \\
\hline C & -3.327093 & -0.415259 & 0.612354 \\
\hline $\mathrm{H}$ & -6.127886 & -1.526890 & -0.806359 \\
\hline$N$ & -5.138590 & -1.312619 & -0.772392 \\
\hline C & -4.542731 & -1.513723 & -2.043256 \\
\hline
\end{tabular}




$\begin{array}{lrrr}\text { O } & -5.236620 & -1.778559 & -2.999534 \\ \text { O } & -3.227732 & -1.392360 & -2.001763 \\ \text { C } & -2.518550 & -1.478190 & -3.263904 \\ \text { H } & -1.498633 & -1.197736 & -3.009164 \\ \text { H } & -2.962558 & -0.782734 & -3.978775 \\ \text { H } & -2.581913 & -2.498423 & -3.648455 \\ \text { H } & -3.095663 & -0.131145 & 1.631143 \\ \text { H } & -2.531143 & -0.903264 & 0.064189 \\ \text { C } & -5.692726 & -0.558290 & 1.429700 \\ \text { C } & -6.989422 & -0.132191 & 1.084951 \\ \text { C } & -5.387607 & -0.771317 & 2.785853 \\ \text { C } & -7.950127 & 0.078189 & 2.069929 \\ \text { H } & -7.237492 & 0.088034 & 0.050266 \\ \text { C } & -6.355459 & -0.571672 & 3.766292 \\ \text { H } & -4.401017 & -1.123577 & 3.067923 \\ \text { C } & -7.637066 & -0.145278 & 3.412212 \\ \text { H } & -8.939039 & 0.428896 & 1.790344 \\ \text { H } & -6.108193 & -0.752124 & 4.808072 \\ \text { H } & -8.388255 & 0.016881 & 4.179771 \\ \text { H } & -5.669572 & 3.066510 & -2.675178\end{array}$

Catalyst (R)-1 TS Conformation 354

B3LYP/6-31G(d) Energy = -2809.690195

B3LYP-D3(BJ)/def2-TZVPP-IEF-PCM(DCM) Energy = -2810.978283

B3LYP-D3(BJ)/def2-TZVPP-IEF-PCM(DCM)//B3LYP/6-31G(d) Free Energy (Quasiharmonic) = 2810.334818

Frequencies (Top 3 out of 270)

1. $-274.0894 \mathrm{~cm}-1$

2. $\quad 4.9101 \mathrm{~cm}-1$

3. $\quad 11.5749 \mathrm{~cm}-1$

B3LYP/6-31G(d) Molecular Geometry in Cartesian Coordinates

$\begin{array}{llll}\text { C } & 3.936106 & 0.333007 & 0.146347 \\ \text { C } & 3.075326 & 1.361546 & -0.203969 \\ \text { C } & 3.310291 & 2.731088 & 0.114391 \\ \text { C } & 4.442754 & 3.020694 & 0.850257 \\ \text { H } & 4.667973 & 4.056715 & 1.089135 \\ \text { C } & 3.017175 & -3.730585 & -0.973533 \\ \text { C } & 3.640888 & -1.063075 & -0.295541\end{array}$




\begin{tabular}{|c|c|c|c|}
\hline C & 2.412945 & -1.631758 & 0.007057 \\
\hline C & 2.070096 & -2.981653 & -0.300993 \\
\hline $\mathrm{H}$ & 2.805670 & -4.772516 & -1.198283 \\
\hline $\mathrm{O}$ & 1.924069 & 1.054163 & -0.924852 \\
\hline$P$ & 0.687251 & 0.307403 & -0.167808 \\
\hline $\mathrm{O}$ & 1.471620 & -0.853865 & 0.674099 \\
\hline C & 0.727783 & 5.956078 & -1.088946 \\
\hline C & 1.084523 & 4.968716 & -2.009969 \\
\hline C & 1.904258 & 3.908684 & -1.625959 \\
\hline C & 2.387956 & 3.818184 & -0.309799 \\
\hline C & 2.018812 & 4.815489 & 0.607424 \\
\hline C & 1.197190 & 5.874404 & 0.222586 \\
\hline $\mathrm{H}$ & 0.726527 & 5.024529 & -3.034787 \\
\hline $\mathrm{H}$ & 0.917370 & 6.630419 & 0.951634 \\
\hline C & -1.680804 & -4.821718 & 0.729975 \\
\hline C & -1.114675 & -5.020143 & -0.529981 \\
\hline C & 0.090516 & -4.402284 & -0.859557 \\
\hline C & 0.758068 & -3.580162 & 0.063996 \\
\hline C & 0.173999 & -3.386427 & 1.327578 \\
\hline C & -1.034280 & -3.999955 & 1.655906 \\
\hline $\mathrm{H}$ & -1.614952 & -5.648432 & -1.262548 \\
\hline $\mathrm{H}$ & -1.475142 & -3.826642 & 2.633302 \\
\hline C & 4.579206 & -1.831095 & -1.067411 \\
\hline C & 4.257609 & -3.189273 & -1.390061 \\
\hline C & 5.182827 & -3.966366 & -2.139040 \\
\hline C & 6.364948 & -3.423597 & -2.585533 \\
\hline C & 6.666695 & -2.070419 & -2.303616 \\
\hline C & 5.799738 & -1.296202 & -1.564189 \\
\hline $\mathrm{H}$ & 4.928573 & -4.999515 & -2.363964 \\
\hline $\mathrm{H}$ & 7.061001 & -4.025208 & -3.163619 \\
\hline $\mathrm{H}$ & 7.589461 & -1.635459 & -2.677977 \\
\hline $\mathrm{H}$ & 6.041875 & -0.258771 & -1.365133 \\
\hline C & 5.068312 & 0.643336 & 0.976983 \\
\hline C & 5.322738 & 2.012442 & 1.313925 \\
\hline C & 6.445484 & 2.335244 & 2.123658 \\
\hline C & 7.270733 & 1.350796 & 2.614747 \\
\hline C & 6.998346 & -0.005316 & 2.318248 \\
\hline C & 5.928825 & -0.349742 & 1.521158 \\
\hline $\mathrm{H}$ & 6.630501 & 3.380695 & 2.358980 \\
\hline $\mathrm{H}$ & 8.121589 & 1.609100 & 3.239167 \\
\hline $\mathrm{H}$ & 7.635765 & -0.784357 & 2.727666 \\
\hline $\mathrm{H}$ & 5.728995 & -1.394284 & 1.313124 \\
\hline $\mathrm{O}$ & -0.318268 & -0.155155 & -1.152004 \\
\hline $\mathrm{O}$ & 0.208946 & 1.253824 & 0.985706 \\
\hline
\end{tabular}




\begin{tabular}{|c|c|c|c|}
\hline $\mathrm{H}$ & -0.822089 & 1.345946 & 1.050273 \\
\hline $\mathrm{H}$ & 2.360892 & 4.743440 & 1.635956 \\
\hline $\mathrm{H}$ & 0.086127 & 6.779863 & -1.390592 \\
\hline $\mathrm{H}$ & 2.177067 & 3.149326 & -2.350658 \\
\hline $\mathrm{H}$ & 0.669528 & -2.756158 & 2.057244 \\
\hline $\mathrm{H}$ & -2.619851 & -5.305129 & 0.988438 \\
\hline $\mathrm{H}$ & 0.510932 & -4.536974 & -1.852118 \\
\hline$C$ & -2.860995 & 1.948603 & 0.062173 \\
\hline 0 & -2.327835 & 1.462436 & 1.125394 \\
\hline $\mathrm{H}$ & -2.215108 & 2.402820 & -0.702659 \\
\hline C & -4.183006 & 2.691911 & 0.243510 \\
\hline $\mathrm{O}$ & -4.935623 & 2.554385 & 1.180900 \\
\hline $\mathrm{O}$ & -4.406351 & 3.518944 & -0.800615 \\
\hline$C$ & -5.638857 & 4.257628 & -0.746761 \\
\hline $\mathrm{H}$ & -6.492185 & 3.574912 & -0.715343 \\
\hline $\mathrm{H}$ & -5.659881 & 4.859851 & -1.655335 \\
\hline C & -4.290943 & -0.262472 & -0.332341 \\
\hline C & -3.412906 & 0.504494 & -1.123878 \\
\hline $\mathrm{H}$ & -2.935594 & -0.280177 & 1.157258 \\
\hline$N$ & -3.751081 & -0.803224 & 0.793377 \\
\hline C & -4.201472 & -1.824199 & 1.636900 \\
\hline $\mathrm{O}$ & -3.744613 & -1.998053 & 2.744243 \\
\hline 0 & -5.124348 & -2.596995 & 1.041550 \\
\hline C & -5.623471 & -3.673037 & 1.853743 \\
\hline $\mathrm{H}$ & -6.373866 & -4.170494 & 1.239470 \\
\hline $\mathrm{H}$ & -6.070376 & -3.285675 & 2.772636 \\
\hline $\mathrm{H}$ & -4.815196 & -4.362153 & 2.109896 \\
\hline $\mathrm{H}$ & -3.847303 & 0.990057 & -1.992924 \\
\hline $\mathrm{H}$ & -2.389369 & 0.146699 & -1.240099 \\
\hline C & -5.741834 & -0.293331 & -0.593263 \\
\hline C & -6.668582 & -0.076426 & 0.442387 \\
\hline C & -6.206018 & -0.468507 & -1.907292 \\
\hline C & -8.030922 & -0.039333 & 0.162149 \\
\hline $\mathrm{H}$ & -6.311883 & 0.116586 & 1.448410 \\
\hline C & -7.572545 & -0.452153 & -2.178629 \\
\hline $\mathrm{H}$ & -5.492592 & -0.645771 & -2.706549 \\
\hline C & -8.486296 & -0.235664 & -1.145149 \\
\hline $\mathrm{H}$ & -8.739491 & 0.149723 & 0.963471 \\
\hline $\mathrm{H}$ & -7.922998 & -0.606813 & -3.195060 \\
\hline $\mathrm{H}$ & -9.551706 & -0.213977 & -1.357857 \\
\hline $\mathrm{H}$ & -5.661479 & 4.897168 & 0.139438 \\
\hline
\end{tabular}

Catalyst (R)-1 TS Conformation 355 
B3LYP/6-31G(d) Energy $=-2809.683788$

B3LYP-D3(BJ)/def2-TZVPP-IEF-PCM(DCM) Energy $=-2810.977222$

B3LYP-D3(BJ)/def2-TZVPP-IEF-PCM(DCM)//B3LYP/6-31G(d) Free Energy (Quasiharmonic) = 2810.334767

Frequencies (Top 3 out of 270)

1. $-416.8973 \mathrm{~cm}-1$

2. $\quad 8.6684 \mathrm{~cm}-1$

3. $\quad 12.9778 \mathrm{~cm}-1$

B3LYP/6-31G(d) Molecular Geometry in Cartesian Coordinates

\begin{tabular}{|c|c|c|c|}
\hline C & -3.134962 & 0.577765 & -0.546347 \\
\hline C & -2.060242 & 1.438929 & -0.362693 \\
\hline C & -2.081009 & 2.802436 & -0.786549 \\
\hline C & -3.183578 & 3.233331 & -1.497858 \\
\hline $\mathrm{H}$ & -3.221035 & 4.265263 & -1.836924 \\
\hline C & -3.097710 & -3.367741 & 1.204060 \\
\hline C & -3.147323 & -0.767878 & 0.102022 \\
\hline C & -2.096134 & -1.641874 & -0.115866 \\
\hline C & -2.041545 & -2.965326 & 0.410407 \\
\hline $\mathrm{H}$ & -3.105047 & -4.378586 & 1.603311 \\
\hline O & -0.951696 & 1.011802 & 0.359913 \\
\hline$P$ & 0.029968 & -0.186639 & -0.179958 \\
\hline O & -1.037043 & -1.198280 & -0.900701 \\
\hline C & 0.924187 & 5.716835 & 0.221480 \\
\hline C & -0.420513 & 5.944775 & 0.518766 \\
\hline C & -1.378919 & 4.983868 & 0.196137 \\
\hline C & -1.013261 & 3.778407 & -0.426708 \\
\hline C & 0.341949 & 3.559093 & -0.720733 \\
\hline C & 1.298785 & 4.522816 & -0.399671 \\
\hline $\mathrm{H}$ & -0.725338 & 6.867910 & 1.005251 \\
\hline $\mathrm{H}$ & 2.342621 & 4.336025 & -0.637372 \\
\hline C & 1.267548 & -5.625872 & -0.288900 \\
\hline C & 0.740313 & -5.469322 & 0.993220 \\
\hline C & -0.328795 & -4.600556 & 1.210512 \\
\hline C & -0.893452 & -3.873179 & 0.150546 \\
\hline C & -0.360451 & -4.046605 & -1.138108 \\
\hline C & 0.708538 & -4.914674 & -1.352985 \\
\hline $\mathrm{H}$ & 1.170780 & -6.012365 & 1.830757 \\
\hline $\mathrm{H}$ & 1.109874 & -5.033911 & -2.355885 \\
\hline C & -4.200474 & -1.174644 & 0.993808 \\
\hline
\end{tabular}




\begin{tabular}{|c|c|c|c|}
\hline C & -4.171739 & -2.503261 & 1.530542 \\
\hline C & -5.212121 & -2.926674 & 2.401605 \\
\hline C & -6.226444 & -2.070915 & 2.762566 \\
\hline C & -6.234724 & -0.745723 & 2.268163 \\
\hline C & -5.251049 & -0.310051 & 1.407468 \\
\hline $\mathrm{H}$ & -5.180904 & -3.942184 & 2.789384 \\
\hline $\mathrm{H}$ & -7.012240 & -2.404064 & 3.435003 \\
\hline $\mathrm{H}$ & -7.022240 & -0.062071 & 2.573742 \\
\hline $\mathrm{H}$ & -5.268629 & 0.711407 & 1.046400 \\
\hline C & -4.226684 & 1.013193 & -1.375845 \\
\hline C & -4.246014 & 2.365001 & -1.846315 \\
\hline C & -5.322087 & 2.807119 & -2.662680 \\
\hline C & -6.332235 & 1.947974 & -3.027331 \\
\hline C & -6.299797 & 0.602278 & -2.591829 \\
\hline C & -5.278052 & 0.147826 & -1.787314 \\
\hline $\mathrm{H}$ & -5.322999 & 3.839598 & -3.004222 \\
\hline $\mathrm{H}$ & -7.146722 & 2.294516 & -3.657519 \\
\hline $\mathrm{H}$ & -7.085330 & -0.082257 & -2.900390 \\
\hline $\mathrm{H}$ & -5.262589 & -0.889135 & -1.472498 \\
\hline $\mathrm{O}$ & 0.779796 & -0.771180 & 0.960501 \\
\hline $\mathrm{O}$ & 0.834220 & 0.374966 & -1.384948 \\
\hline $\mathrm{H}$ & 1.836923 & -0.083009 & -1.554016 \\
\hline $\mathrm{H}$ & 0.644757 & 2.639431 & -1.208545 \\
\hline $\mathrm{H}$ & 1.673678 & 6.463995 & 0.470324 \\
\hline $\mathrm{H}$ & -2.422862 & 5.157549 & 0.443243 \\
\hline $\mathrm{H}$ & -0.785493 & -3.498416 & -1.971989 \\
\hline $\mathrm{H}$ & 2.114480 & -6.284231 & -0.458191 \\
\hline $\mathrm{H}$ & -0.712804 & -4.456657 & 2.216525 \\
\hline C & 3.329200 & -1.612649 & -1.021146 \\
\hline $\mathrm{O}$ & 3.008321 & -0.653703 & -1.818488 \\
\hline $\mathrm{H}$ & 2.571425 & -2.001332 & -0.329485 \\
\hline C & 4.167932 & -2.754586 & -1.605862 \\
\hline $\mathrm{O}$ & 4.218775 & -3.862399 & -1.112562 \\
\hline $\mathrm{O}$ & 4.835527 & -2.380771 & -2.707233 \\
\hline C & 5.627572 & -3.411110 & -3.322016 \\
\hline $\mathrm{H}$ & 6.380777 & -3.786671 & -2.623775 \\
\hline $\mathrm{H}$ & 4.992569 & -4.242260 & -3.639554 \\
\hline C & 4.188986 & -0.044197 & 1.100263 \\
\hline C & 4.630052 & -1.156865 & 0.340055 \\
\hline $\mathrm{H}$ & 3.379250 & -1.258251 & 2.493784 \\
\hline$N$ & 3.456235 & -0.285453 & 2.214681 \\
\hline C & 2.444509 & 0.459237 & 2.893009 \\
\hline $\mathrm{O}$ & 1.945060 & 0.001673 & 3.891809 \\
\hline $\mathrm{O}$ & 2.184677 & 1.624435 & 2.318787 \\
\hline
\end{tabular}




$\begin{array}{llll}\mathrm{C} & 1.076891 & 2.356545 & 2.894850 \\ \mathrm{H} & 0.154611 & 1.800302 & 2.723137 \\ \mathrm{H} & 1.059258 & 3.303896 & 2.359057 \\ \mathrm{H} & 1.240894 & 2.503513 & 3.964487 \\ \mathrm{H} & 5.528021 & -0.981779 & -0.244850 \\ \mathrm{H} & 4.619587 & -2.117356 & 0.853040 \\ \mathrm{C} & 4.573308 & 1.317874 & 0.707032 \\ \mathrm{C} & 4.907091 & 2.284083 & 1.675971 \\ \mathrm{C} & 4.713192 & 1.629244 & -0.658333 \\ \mathrm{C} & 5.369816 & 3.534546 & 1.285538 \\ \mathrm{H} & 4.833522 & 2.041654 & 2.730650 \\ \mathrm{C} & 5.144118 & 2.899332 & -1.039447 \\ \mathrm{H} & 4.444124 & 0.893224 & -1.410035 \\ \mathrm{C} & 5.481205 & 3.848915 & -0.073259 \\ \mathrm{H} & 5.646072 & 4.265996 & 2.039502 \\ \mathrm{H} & 5.229595 & 3.140121 & -2.095127 \\ \mathrm{H} & 5.841214 & 4.828810 & -0.375148 \\ \mathrm{H} & 6.100678 & -2.939576 & -4.183422\end{array}$

Catalyst (R)-1 TS Conformation 356

B3LYP/6-31G(d) Energy $=-2809.6895$

B3LYP-D3(BJ)/def2-TZVPP-IEF-PCM(DCM) Energy = -2810.978073

B3LYP-D3(BJ)/def2-TZVPP-IEF-PCM(DCM)//B3LYP/6-31G(d) Free Energy (Quasiharmonic) = 2810.33468

Frequencies (Top 3 out of 270)

1. $-272.1380 \mathrm{~cm}-1$

2. $\quad 7.5082 \mathrm{~cm}-1$

3. $\quad 9.0212 \mathrm{~cm}-1$

B3LYP/6-31G(d) Molecular Geometry in Cartesian Coordinates

$\begin{array}{lrrr}\text { C } & 3.958063 & 0.244889 & 0.119643 \\ \text { C } & 3.140677 & 1.330472 & -0.156831 \\ \text { C } & 3.457569 & 2.671137 & 0.210613 \\ \text { C } & 4.625393 & 2.868448 & 0.921666 \\ \text { H } & 4.911888 & 3.880171 & 1.196136 \\ \text { C } & 2.788306 & -3.716370 & -1.132371 \\ \text { C } & 3.578510 & -1.115159 & -0.368207 \\ \text { C } & 2.334457 & -1.632403 & -0.042596 \\ \text { C } & 1.910259 & -2.947934 & -0.392581\end{array}$




\begin{tabular}{|c|c|c|c|}
\hline $\mathrm{H}$ & 2.511284 & -4.734109 & -1.394430 \\
\hline $\mathrm{O}$ & 1.955843 & 1.118052 & -0.858135 \\
\hline$P$ & 0.700911 & 0.376332 & -0.134803 \\
\hline $\mathrm{O}$ & 1.456630 & -0.830550 & 0.679701 \\
\hline C & 1.024669 & 6.079875 & -0.774192 \\
\hline C & 1.300563 & 5.117198 & -1.747215 \\
\hline C & 2.070632 & 3.998487 & -1.434401 \\
\hline C & 2.584908 & 3.823842 & -0.138702 \\
\hline C & 2.298737 & 4.798182 & 0.831264 \\
\hline C & 1.525946 & 5.915435 & 0.517478 \\
\hline $\mathrm{H}$ & 0.914067 & 5.236126 & -2.755997 \\
\hline $\mathrm{H}$ & 1.306861 & 6.651402 & 1.286626 \\
\hline C & -1.905827 & -4.603073 & 0.719739 \\
\hline C & -1.152820 & -3.894984 & 1.660340 \\
\hline C & 0.078281 & -3.343516 & 1.306775 \\
\hline C & 0.581144 & -3.487016 & 0.001687 \\
\hline C & -0.188394 & -4.197267 & -0.934021 \\
\hline C & -1.417697 & -4.752502 & -0.579166 \\
\hline $\mathrm{H}$ & -1.525266 & -3.771035 & 2.673632 \\
\hline $\mathrm{H}$ & -1.996306 & -5.295724 & -1.322010 \\
\hline C & 4.447216 & -1.898561 & -1.203458 \\
\hline C & 4.041442 & -3.222762 & -1.570979 \\
\hline C & 4.896799 & -4.013693 & -2.385477 \\
\hline C & 6.090760 & -3.514827 & -2.851311 \\
\hline C & 6.475261 & -2.193393 & -2.523380 \\
\hline C & 5.677479 & -1.407660 & -1.720969 \\
\hline $\mathrm{H}$ & 4.579380 & -5.021015 & -2.644656 \\
\hline $\mathrm{H}$ & 6.732855 & -4.126129 & -3.479459 \\
\hline $\mathrm{H}$ & 7.407107 & -1.791899 & -2.912267 \\
\hline $\mathrm{H}$ & 5.982073 & -0.394305 & -1.486822 \\
\hline C & 5.129747 & 0.459653 & 0.925338 \\
\hline C & 5.464984 & 1.797374 & 1.313179 \\
\hline C & 6.627352 & 2.026144 & 2.098755 \\
\hline C & 7.415725 & 0.980294 & 2.518292 \\
\hline C & 7.064792 & -0.345522 & 2.171579 \\
\hline C & 5.954500 & -0.599100 & 1.396423 \\
\hline $\mathrm{H}$ & 6.873348 & 3.049254 & 2.373118 \\
\hline $\mathrm{H}$ & 8.297923 & 1.166969 & 3.124483 \\
\hline $\mathrm{H}$ & 7.673917 & -1.173407 & 2.524360 \\
\hline $\mathrm{H}$ & 5.695129 & -1.621895 & 1.149493 \\
\hline 0 & -0.306502 & -0.053779 & -1.131426 \\
\hline $\mathrm{O}$ & 0.231873 & 1.293935 & 1.045960 \\
\hline $\mathrm{H}$ & -0.796470 & 1.303663 & 1.178059 \\
\hline $\mathrm{H}$ & 2.665257 & 4.662281 & 1.844918 \\
\hline
\end{tabular}




$\begin{array}{lrrr}\mathrm{H} & 0.417307 & 6.947015 & -1.019371 \\ \mathrm{H} & 2.279505 & 3.258081 & -2.198901 \\ \mathrm{H} & 0.172269 & -4.292973 & -1.954135 \\ \mathrm{H} & -2.863221 & -5.035362 & 0.999222 \\ \mathrm{H} & 0.658516 & -2.803998 & 2.047328 \\ \mathrm{C} & -2.662370 & -0.035076 & 1.585165 \\ \mathrm{O} & -2.293091 & 1.182992 & 1.418472 \\ \mathrm{H} & -1.901957 & -0.817851 & 1.719581 \\ \mathrm{C} & -3.904712 & -0.260668 & 2.443317 \\ \mathrm{O} & -4.762122 & 0.565348 & 2.658225 \\ \mathrm{O} & -3.923293 & -1.522546 & 2.927880 \\ \mathrm{C} & -5.067027 & -1.850252 & 3.735917 \\ \mathrm{H} & -4.928975 & -2.890252 & 4.032674 \\ \mathrm{H} & -5.988254 & -1.731630 & 3.159358 \\ \mathrm{C} & -4.289828 & 0.068575 & -0.523565 \\ \mathrm{C} & -3.249466 & -0.792078 & -0.125848 \\ \mathrm{H} & -3.111004 & 1.665077 & -0.172576 \\ \mathrm{~N} & -3.939622 & 1.369560 & -0.717129 \\ \mathrm{C} & -4.600456 & 2.415990 & -1.370490 \\ \mathrm{O} & -4.307159 & 3.576684 & -1.197512 \\ \mathrm{O} & -5.517481 & 1.961600 & -2.241457 \\ \mathrm{C} & -6.217222 & 2.988230 & -2.965677 \\ \mathrm{H} & -6.915962 & 2.456623 & -3.611487 \\ \mathrm{H} & -5.515991 & 3.580521 & -3.558292 \\ \mathrm{H} & -6.752164 & 3.647006 & -2.277018 \\ \mathrm{H} & -3.517361 & -1.822081 & 0.089168 \\ \mathrm{H} & -2.270130 & -0.641519 & -0.580545 \\ \mathrm{C} & -5.699663 & -0.364389 & -0.520838 \\ \mathrm{C} & -6.041144 & -1.614492 & -1.062409 \\ \mathrm{C} & -6.698920 & 0.423243 & 0.078682 \\ \mathrm{C} & -7.360999 & -2.059614 & -1.027475 \\ \mathrm{H} & -5.272619 & -2.219367 & -1.534285 \\ \mathrm{H} & -8.011590 & -0.035468 & 0.129427 \\ -6.429874 & 1.363058 & 0.548780 \\ \mathrm{H} & -8.347310 & -1.271947 & -0.430224 \\ \mathrm{H} & -8.773966 & 0.569332 & 0.612092 \\ \mathrm{H} & -9.375348 & -1.622374 & -0.395656 \\ \mathrm{H} & -1.202192 & 4.615068\end{array}$

Catalyst (R)-1 TS Conformation 357

B3LYP/6-31G(d) Energy $=-2809.68691$ 
B3LYP-D3(BJ)/def2-TZVPP-IEF-PCM(DCM) Energy = -2810.977227

B3LYP-D3(BJ)/def2-TZVPP-IEF-PCM(DCM)//B3LYP/6-31G(d) Free Energy (Quasiharmonic) = 2810.334435

Frequencies (Top 3 out of 270)

1. $-619.6548 \mathrm{~cm}-1$

2. $\quad 11.2868 \mathrm{~cm}-1$

3. $\quad 14.2229 \mathrm{~cm}-1$

B3LYP/6-31G(d) Molecular Geometry in Cartesian Coordinates

$\begin{array}{llll}\text { C } & 3.414868 & -1.089651 & -0.143352 \\ \text { C } & 2.173530 & -1.702534 & -0.048172 \\ \text { C } & 1.983433 & -3.104874 & -0.242569 \\ \text { C } & 3.079264 & -3.847190 & -0.634926 \\ \text { H } & 2.961447 & -4.916126 & -0.792650 \\ \text { C } & 4.092862 & 3.044637 & 0.866389 \\ \text { C } & 3.600608 & 0.327030 & 0.293039 \\ \text { C } & 2.823983 & 1.341360 & -0.247177 \\ \text { C } & 3.078480 & 2.727408 & -0.016196 \\ \text { H } & 4.305901 & 4.090829 & 1.069511 \\ \text { O } & 1.083250 & -0.952802 & 0.367962 \\ \text { P } & 0.472641 & 0.263807 & -0.547321 \\ \text { O } & 1.807007 & 1.002228 & -1.131601 \\ \text { C } & -1.720857 & -5.180337 & 0.462129 \\ \text { C } & -0.553132 & -5.568717 & 1.122356 \\ \text { C } & 0.639008 & -4.878410 & 0.901221 \\ \text { C } & 0.684244 & -3.789372 & 0.015348 \\ \text { C } & -0.495132 & -3.411775 & -0.641635 \\ \text { C } & -1.689657 & -4.097461 & -0.419914 \\ \text { H } & -0.568265 & -6.408636 & 1.812537 \\ \text { H } & -2.584965 & -3.773121 & -0.943681 \\ \text { C } & 1.080433 & 5.981556 & -2.008644 \\ \text { C } & 2.473377 & 5.905821 & -1.982947 \\ \text { C } & 3.103352 & 4.835855 & -1.347720 \\ \text { C } & 2.356097 & 3.821398 & -0.725602 \\ \text { C } & 0.954739 & 3.906675 & -0.758925 \\ \text { C } & 0.327895 & 4.978280 & -1.394916 \\ \text { H } & 3.072469 & 6.674513 & -2.464449 \\ \text { H } & -0.758445 & 5.025940 & -1.410722 \\ \text { C } & 4.583741 & 0.673179 & 1.286111 \\ \text { C } & 4.831898 & 2.056285 & 1.560344 \\ \text { C } & 5.803135 & 2.413920 & 2.534493\end{array}$




\begin{tabular}{|c|c|c|c|}
\hline C & 6.489623 & 1.450596 & 3.235987 \\
\hline C & 6.221898 & 0.082928 & 2.993348 \\
\hline C & 5.297662 & -0.295534 & 2.044352 \\
\hline $\mathrm{H}$ & 5.983591 & 3.469815 & 2.722351 \\
\hline $\mathrm{H}$ & 7.225686 & 1.735233 & 3.982928 \\
\hline $\mathrm{H}$ & 6.746017 & -0.677863 & 3.565563 \\
\hline $\mathrm{H}$ & 5.097480 & -1.347689 & 1.880295 \\
\hline C & 4.518354 & -1.855172 & -0.661256 \\
\hline C & 4.340012 & -3.256402 & -0.894760 \\
\hline C & 5.423877 & -4.026200 & -1.396924 \\
\hline C & 6.633965 & -3.439925 & -1.686217 \\
\hline C & 6.803666 & -2.049433 & -1.489560 \\
\hline C & 5.776921 & -1.279275 & -0.988834 \\
\hline $\mathrm{H}$ & 5.270880 & -5.090340 & -1.560898 \\
\hline $\mathrm{H}$ & 7.453702 & -4.036693 & -2.076842 \\
\hline $\mathrm{H}$ & 7.751491 & -1.581825 & -1.742409 \\
\hline $\mathrm{H}$ & 5.921077 & -0.213419 & -0.856129 \\
\hline $\mathrm{O}$ & -0.376929 & 1.100854 & 0.350080 \\
\hline $\mathrm{O}$ & -0.158174 & -0.293503 & -1.842776 \\
\hline $\mathrm{H}$ & -1.275749 & -0.582337 & -1.816381 \\
\hline $\mathrm{H}$ & -0.473591 & -2.593453 & -1.348061 \\
\hline $\mathrm{H}$ & -2.646321 & -5.727963 & 0.627112 \\
\hline $\mathrm{H}$ & 1.542650 & -5.174298 & 1.427779 \\
\hline $\mathrm{H}$ & 0.358115 & 3.138783 & -0.279050 \\
\hline $\mathrm{H}$ & 0.586327 & 6.811710 & -2.507005 \\
\hline $\mathrm{H}$ & 4.188138 & 4.771327 & -1.348256 \\
\hline C & -3.392589 & -0.256050 & -1.382639 \\
\hline $\mathrm{O}$ & -2.453595 & -1.044859 & -1.784870 \\
\hline $\mathrm{H}$ & -3.314054 & 0.817621 & -1.600637 \\
\hline C & -4.801463 & -0.806887 & -1.592740 \\
\hline $\mathrm{O}$ & -5.106494 & -1.978107 & -1.573745 \\
\hline $\mathrm{O}$ & -5.678622 & 0.202630 & -1.783127 \\
\hline C & -7.047589 & -0.197660 & -2.000806 \\
\hline $\mathrm{H}$ & -7.584397 & 0.720821 & -2.238961 \\
\hline $\mathrm{H}$ & -7.107128 & -0.905048 & -2.830809 \\
\hline C & -4.328443 & 0.616683 & 1.025670 \\
\hline C & -3.283445 & -0.177284 & 0.508757 \\
\hline $\mathrm{H}$ & -6.242140 & 0.786704 & 1.692917 \\
\hline$N$ & -5.525519 & 0.114278 & 1.447702 \\
\hline C & -6.055234 & -1.197036 & 1.517354 \\
\hline $\mathrm{O}$ & -7.253028 & -1.355824 & 1.613296 \\
\hline $\mathrm{O}$ & -5.122367 & -2.136812 & 1.496121 \\
\hline C & -5.598863 & -3.497811 & 1.377582 \\
\hline $\mathrm{H}$ & -6.318557 & -3.713703 & 2.168818 \\
\hline
\end{tabular}




$\begin{array}{lrrr}\mathrm{H} & -4.705184 & -4.112205 & 1.475217 \\ \mathrm{H} & -6.052887 & -3.630467 & 0.394051 \\ \mathrm{H} & -2.298802 & 0.285300 & 0.527533 \\ \mathrm{H} & -3.291487 & -1.232110 & 0.747063 \\ \mathrm{C} & -4.243323 & 2.091842 & 1.008527 \\ \mathrm{C} & -2.996002 & 2.723392 & 1.184725 \\ \mathrm{C} & -5.388503 & 2.891860 & 0.809874 \\ \mathrm{C} & -2.911660 & 4.114334 & 1.191658 \\ \mathrm{H} & -2.091696 & 2.138854 & 1.311728 \\ \mathrm{C} & -5.292965 & 4.279068 & 0.809830 \\ \mathrm{H} & -6.351455 & 2.437833 & 0.590977 \\ \mathrm{C} & -4.054459 & 4.894794 & 1.010520 \\ \mathrm{H} & -1.943450 & 4.584890 & 1.334234 \\ \mathrm{H} & -6.181662 & 4.879495 & 0.639098 \\ \mathrm{H} & -3.981136 & 5.978701 & 1.013495 \\ \mathrm{H} & -7.458622 & -0.662028 & -1.100166\end{array}$

Catalyst (R)-1 TS Conformation 358

B3LYP/6-31G(d) Energy $=-2809.687188$

B3LYP-D3(BJ)/def2-TZVPP-IEF-PCM(DCM) Energy = -2810.977302

B3LYP-D3(BJ)/def2-TZVPP-IEF-PCM(DCM)//B3LYP/6-31G(d) Free Energy (Quasiharmonic) = 2810.334431

Frequencies (Top 3 out of 270)

1. $-536.7155 \mathrm{~cm}-1$

2. $\quad 8.9318 \mathrm{~cm}-1$

3. $\quad 14.5879 \mathrm{~cm}-1$

B3LYP/6-31G(d) Molecular Geometry in Cartesian Coordinates

$\begin{array}{llll}\text { C } & 3.525979 & -0.929410 & -0.201245 \\ \text { C } & 2.322269 & -1.609360 & -0.065577 \\ \text { C } & 2.211837 & -3.024760 & -0.229389 \\ \text { C } & 3.338430 & -3.708233 & -0.641946 \\ \text { H } & 3.279441 & -4.784883 & -0.778796 \\ \text { C } & 3.829085 & 3.238193 & 0.883526 \\ \text { C } & 3.634874 & 0.500117 & 0.218822 \\ \text { C } & 2.771021 & 1.447858 & -0.305445 \\ \text { C } & 2.850703 & 2.840653 & -0.007063 \\ \text { H } & 3.942624 & 4.295086 & 1.109724 \\ \text { O } & 1.198044 & -0.919234 & 0.361213\end{array}$




\begin{tabular}{|c|c|c|c|}
\hline$P$ & 0.493472 & 0.248613 & -0.555080 \\
\hline $\mathrm{O}$ & 1.785623 & 1.023420 & -1.188916 \\
\hline C & -1.338826 & -5.289151 & 0.662017 \\
\hline C & -0.121864 & -5.608441 & 1.268200 \\
\hline C & 1.020309 & -4.859312 & 0.983932 \\
\hline C & 0.965638 & -3.779209 & 0.087505 \\
\hline C & -0.261848 & -3.472872 & -0.516125 \\
\hline C & -1.406511 & -4.217390 & -0.231272 \\
\hline $\mathrm{H}$ & -0.059882 & -6.439184 & 1.966880 \\
\hline $\mathrm{H}$ & -2.341262 & -3.945682 & -0.714438 \\
\hline C & 0.292495 & 5.852208 & -1.718081 \\
\hline C & 0.588127 & 5.861320 & -0.353511 \\
\hline C & 1.398021 & 4.866125 & 0.194149 \\
\hline C & 1.934626 & 3.845928 & -0.609418 \\
\hline C & 1.624415 & 3.845985 & -1.980023 \\
\hline C & 0.813074 & 4.839426 & -2.526074 \\
\hline $\mathrm{H}$ & 0.191117 & 6.645001 & 0.287539 \\
\hline $\mathrm{H}$ & 0.591140 & 4.823369 & -3.589879 \\
\hline C & 4.590825 & 0.920754 & 1.209469 \\
\hline C & 4.691895 & 2.315094 & 1.522535 \\
\hline C & 5.643624 & 2.749288 & 2.484966 \\
\hline C & 6.444226 & 1.847317 & 3.145672 \\
\hline C & 6.316200 & 0.465504 & 2.871859 \\
\hline C & 5.417288 & 0.014871 & 1.930072 \\
\hline $\mathrm{H}$ & 5.715226 & 3.813237 & 2.698624 \\
\hline $\mathrm{H}$ & 7.163143 & 2.189864 & 3.884929 \\
\hline $\mathrm{H}$ & 6.929830 & -0.249554 & 3.413188 \\
\hline $\mathrm{H}$ & 5.326867 & -1.048004 & 1.741451 \\
\hline C & 4.658329 & -1.637969 & -0.734364 \\
\hline C & 4.555323 & -3.050137 & -0.945538 \\
\hline C & 5.669442 & -3.762377 & -1.466104 \\
\hline C & 6.836191 & -3.110999 & -1.792430 \\
\hline C & 6.930816 & -1.710632 & -1.615210 \\
\hline C & 5.873414 & -0.994493 & -1.098417 \\
\hline $\mathrm{H}$ & 5.574908 & -4.835723 & -1.613411 \\
\hline $\mathrm{H}$ & 7.679289 & -3.664708 & -2.196527 \\
\hline $\mathrm{H}$ & 7.844323 & -1.193078 & -1.895638 \\
\hline $\mathrm{H}$ & 5.958296 & 0.079679 & -0.979820 \\
\hline $\mathrm{O}$ & -0.370432 & 1.063446 & 0.341586 \\
\hline $\mathrm{O}$ & -0.130018 & -0.369028 & -1.830212 \\
\hline $\mathrm{H}$ & -1.208788 & -0.726322 & -1.771368 \\
\hline $\mathrm{H}$ & -0.318901 & -2.662421 & -1.228962 \\
\hline $\mathrm{H}$ & -2.226300 & -5.879366 & 0.879725 \\
\hline $\mathrm{H}$ & 1.961676 & -5.100228 & 1.470999 \\
\hline
\end{tabular}




$\begin{array}{lrrr}\mathrm{H} & 2.025409 & 3.068041 & -2.619846 \\ \mathrm{H} & -0.336711 & 6.627099 & -2.148367 \\ \mathrm{H} & 1.606794 & 4.866747 & 1.260256 \\ \mathrm{C} & -3.363309 & -0.517814 & -1.347290 \\ \mathrm{O} & -2.374018 & -1.272548 & -1.690756 \\ \mathrm{H} & -3.366109 & 0.532581 & -1.671195 \\ \mathrm{C} & -4.733762 & -1.180326 & -1.485895 \\ \mathrm{O} & -4.959923 & -2.362388 & -1.354872 \\ \mathrm{O} & -5.679505 & -0.253209 & -1.755112 \\ \mathrm{C} & -7.020613 & -0.759832 & -1.912442 \\ \mathrm{H} & -7.616562 & 0.091997 & -2.240850 \\ \mathrm{H} & -7.039549 & -1.555174 & -2.660737 \\ \mathrm{C} & -4.319311 & 0.546022 & 0.963473 \\ \mathrm{C} & -3.246791 & -0.254625 & 0.513932 \\ \mathrm{H} & -6.228407 & 0.694606 & 1.651567 \\ \mathrm{~N} & -5.482490 & 0.035732 & 1.465083 \\ \mathrm{C} & -5.950039 & -1.283368 & 1.675649 \\ \mathrm{O} & -7.137750 & -1.484346 & 1.812797 \\ \mathrm{O} & -4.977345 & -2.181409 & 1.724989 \\ \mathrm{C} & -5.395681 & -3.566136 & 1.744022 \\ \mathrm{H} & -6.089911 & -3.737449 & 2.568242 \\ \mathrm{H} & -4.474519 & -4.131452 & 1.876944 \\ \mathrm{H} & -5.861676 & -3.809559 & 0.787648 \\ \mathrm{H} & -2.279612 & 0.242783 & 0.486377 \\ \mathrm{H} & -2.218610 & 5.872475 & 0.259484 \\ \mathrm{H} & -3.210136 & -1.277799 & 0.861831 \\ \mathrm{C} & -4.304673 & 2.010527 & 0.773107 \\ \mathrm{H} & -3.077823 & 2.705908 & 0.775079 \\ \mathrm{H} & -5.495856 & 2.738005 & 0.561313 \\ \mathrm{H} & -3.055628 & 4.087288 & 0.594376 \\ \mathrm{H} & -2.138137 & 2.181293 & 0.912935 \\ \mathrm{H} & -6.452159 & 2.229383 & 0.471004 \\ \mathrm{H} & -6.388501 & 4.656848 & 0.204110 \\ \mathrm{H} & -1.148536 & -0.962231\end{array}$

Catalyst (R)-1 TS Conformation 359

B3LYP/6-31G(d) Energy $=-2809.683505$

B3LYP-D3(BJ)/def2-TZVPP-IEF-PCM(DCM) Energy = -2810.976574 
B3LYP-D3(BJ)/def2-TZVPP-IEF-PCM(DCM)//B3LYP/6-31G(d) Free Energy (Quasiharmonic) = 2810.334344

Frequencies (Top 3 out of 270)

1. $-497.2559 \mathrm{~cm}-1$

2. $\quad 9.1406 \mathrm{~cm}-1$

3. $11.4379 \mathrm{~cm}-1$

B3LYP/6-31G(d) Molecular Geometry in Cartesian Coordinates

$\begin{array}{llll}\text { C } & 3.643045 & -0.935198 & -0.109021 \\ \text { C } & 2.468124 & -1.589831 & 0.226488 \\ \text { C } & 2.256717 & -2.983684 & 0.012333 \\ \text { C } & 3.272544 & -3.693119 & -0.596746 \\ \text { H } & 3.153280 & -4.762055 & -0.754093 \\ \text { C } & 4.022969 & 3.294570 & 0.655940 \\ \text { C } & 3.788660 & 0.516876 & 0.209903 \\ \text { C } & 2.837399 & 1.416875 & -0.249306 \\ \text { C } & 2.941645 & 2.828159 & -0.066439 \\ \text { H } & 4.148202 & 4.365773 & 0.790301 \\ \text { O } & 1.445703 & -0.860721 & 0.815083 \\ \text { P } & 0.556576 & 0.150893 & -0.130131 \\ \text { O } & 1.744018 & 0.932346 & -0.952933 \\ \text { C } & -1.372527 & -5.007796 & 1.141671 \\ \text { C } & -0.824263 & -5.188767 & -0.128959 \\ \mathrm{C} & 0.346200 & -4.520634 & -0.490262 \\ \mathrm{C} & 0.991939 & -3.658012 & 0.409734 \\ \mathrm{C} & 0.431212 & -3.483958 & 1.686955 \\ \mathrm{C} & -0.737116 & -4.154410 & 2.048054 \\ \mathrm{H} & -1.311835 & -5.844159 & -0.846122 \\ \mathrm{H} & -1.151919 & -4.012476 & 3.042726 \\ \mathrm{C} & 0.174647 & 5.697404 & -1.691984 \\ \mathrm{C} & 0.617143 & 4.631022 & -2.479264 \\ \mathrm{C} & 1.492256 & 3.681282 & -1.953768 \\ \mathrm{C} & 1.948334 & 3.782496 & -0.628369 \\ \mathrm{C} & 1.488785 & 4.854335 & 0.154482 \\ \mathrm{C} & 0.611647 & 5.802653 & -0.370366 \\ \mathrm{H} & 0.287055 & 4.541227 & -3.511070 \\ \mathrm{H} & 0.266805 & 6.621135 & 0.256324 \\ \mathrm{C} & 4.865420 & 1.012286 & 1.023017 \\ \mathrm{C} & 4.980777 & 2.424889 & 1.231836 \\ \mathrm{C} & 6.047912 & 2.928948 & 2.024024 \\ \mathrm{C} & 6.951501 & 2.079179 & 2.618137\end{array}$




\begin{tabular}{|c|c|c|c|}
\hline C & 6.817380 & 0.681300 & 2.446427 \\
\hline C & 5.804576 & 0.162313 & 1.670073 \\
\hline $\mathrm{H}$ & 6.127362 & 4.004850 & 2.161444 \\
\hline $\mathrm{H}$ & 7.758975 & 2.475764 & 3.227542 \\
\hline $\mathrm{H}$ & 7.517282 & 0.009318 & 2.935835 \\
\hline $\mathrm{H}$ & 5.710260 & -0.911415 & 1.557050 \\
\hline C & 4.662477 & -1.671279 & -0.806057 \\
\hline C & 4.469353 & -3.073084 & -1.033382 \\
\hline C & 5.474427 & -3.815397 & -1.710809 \\
\hline C & 6.613549 & -3.202860 & -2.178674 \\
\hline C & 6.788797 & -1.811671 & -1.991690 \\
\hline C & 5.841365 & -1.067094 & -1.323875 \\
\hline $\mathrm{H}$ & 5.316676 & -4.880538 & -1.863608 \\
\hline $\mathrm{H}$ & 7.371630 & -3.779733 & -2.701349 \\
\hline $\mathrm{H}$ & 7.677351 & -1.323661 & -2.383193 \\
\hline $\mathrm{H}$ & 5.987021 & -0.000538 & -1.198526 \\
\hline $\mathrm{O}$ & -0.295217 & 0.992197 & 0.748765 \\
\hline $\mathrm{O}$ & -0.110053 & -0.675515 & -1.254966 \\
\hline $\mathrm{H}$ & -1.243519 & -0.744881 & -1.224736 \\
\hline $\mathrm{H}$ & 0.915728 & -2.823006 & 2.397567 \\
\hline $\mathrm{H}$ & -2.290411 & -5.516515 & 1.422270 \\
\hline $\mathrm{H}$ & 0.753287 & -4.644573 & -1.489737 \\
\hline $\mathrm{H}$ & 1.807830 & 4.929836 & 1.190102 \\
\hline $\mathrm{H}$ & -0.502322 & 6.440261 & -2.106592 \\
\hline $\mathrm{H}$ & 1.831702 & 2.860615 & -2.575759 \\
\hline C & -2.836104 & -1.508689 & -0.064905 \\
\hline $\mathrm{O}$ & -2.523795 & -0.889497 & -1.151057 \\
\hline $\mathrm{H}$ & -2.029593 & -2.009234 & 0.494183 \\
\hline C & -4.078837 & -2.405900 & -0.065896 \\
\hline $\mathrm{O}$ & -4.456092 & -3.026373 & 0.913854 \\
\hline $\mathrm{O}$ & -4.696031 & -2.433153 & -1.249823 \\
\hline C & -5.846847 & -3.298720 & -1.326846 \\
\hline $\mathrm{H}$ & -6.184304 & -3.234777 & -2.361307 \\
\hline $\mathrm{H}$ & -6.627411 & -2.960553 & -0.640109 \\
\hline C & -4.403555 & 0.385228 & 1.114203 \\
\hline C & -3.244916 & -0.374673 & 1.404767 \\
\hline $\mathrm{H}$ & -5.570286 & -1.084653 & 1.887104 \\
\hline$N$ & -5.618105 & -0.220751 & 1.353371 \\
\hline C & -6.833771 & -0.194668 & 0.636592 \\
\hline $\mathrm{O}$ & -7.728477 & -0.963063 & 0.917763 \\
\hline $\mathrm{O}$ & -6.853913 & 0.702140 & -0.347775 \\
\hline C & -8.069941 & 0.737413 & -1.120848 \\
\hline $\mathrm{H}$ & -8.222320 & -0.217673 & -1.628423 \\
\hline $\mathrm{H}$ & -7.920931 & 1.538840 & -1.843326 \\
\hline
\end{tabular}




$\begin{array}{lrrr}\mathrm{H} & -8.925527 & 0.946844 & -0.475012 \\ \mathrm{H} & -2.314550 & 0.178872 & 1.507632 \\ \mathrm{H} & -3.381225 & -1.176588 & 2.127453 \\ \mathrm{C} & -4.320779 & 1.747443 & 0.599475 \\ \mathrm{C} & -3.184537 & 2.144932 & -0.133631 \\ \mathrm{C} & -5.305136 & 2.707874 & 0.921160 \\ \mathrm{C} & -3.061963 & 3.461827 & -0.569944 \\ \mathrm{H} & -2.402596 & 1.432030 & -0.356347 \\ \mathrm{C} & -5.159621 & 4.023675 & 0.506462 \\ \mathrm{H} & -6.158118 & 2.426195 & 1.528841 \\ \mathrm{C} & -4.043299 & 4.400563 & -0.250696 \\ \mathrm{H} & -2.181637 & 3.756326 & -1.132705 \\ \mathrm{H} & -5.909151 & 4.761234 & 0.779111 \\ \mathrm{H} & -3.931693 & 5.432868 & -0.571610 \\ \mathrm{H} & -5.567646 & -4.324534 & -1.074772\end{array}$

Catalyst (R)-1 TS Conformation 360

B3LYP/6-31G(d) Energy $=-2809.69116$

B3LYP-D3(BJ)/def2-TZVPP-IEF-PCM(DCM) Energy $=-2810.977374$

B3LYP-D3(BJ)/def2-TZVPP-IEF-PCM(DCM)//B3LYP/6-31G(d) Free Energy (Quasiharmonic) = 2810.334156

Frequencies (Top 3 out of 270)

1. $-359.7679 \mathrm{~cm}-1$

2. $\quad 10.3501 \mathrm{~cm}-1$

3. $\quad 12.9873 \mathrm{~cm}-1$

B3LYP/6-31G(d) Molecular Geometry in Cartesian Coordinates

$\begin{array}{llll}\text { C } & -3.533396 & 0.607015 & -0.017107 \\ \text { C } & -2.502532 & 1.525566 & 0.115115 \\ \text { C } & -2.690835 & 2.933511 & -0.012492 \\ \text { C } & -3.946253 & 3.375001 & -0.378958 \\ \text { H } & -4.119048 & 4.443085 & -0.482125 \\ \text { C } & -3.026476 & -3.575615 & 0.910984 \\ \text { C } & -3.327629 & -0.819130 & 0.373096 \\ \text { C } & -2.288261 & -1.563521 & -0.165355 \\ \text { C } & -2.122895 & -2.958747 & 0.070639 \\ \text { H } & -2.926086 & -4.641082 & 1.100777 \\ \text { O } & -1.239857 & 1.069078 & 0.485146 \\ \text { P } & -0.366553 & 0.179035 & -0.570815\end{array}$




\begin{tabular}{|c|c|c|c|}
\hline $\mathrm{O}$ & -1.416371 & -0.958125 & -1.066730 \\
\hline C & 0.323290 & 5.877976 & 0.870157 \\
\hline C & 0.550016 & 4.930401 & -0.130130 \\
\hline C & -0.411594 & 3.961425 & -0.414066 \\
\hline C & -1.619185 & 3.923775 & 0.297908 \\
\hline C & -1.840301 & 4.884309 & 1.297581 \\
\hline C & -0.876592 & 5.852413 & 1.582902 \\
\hline $\mathrm{H}$ & 1.472139 & 4.938920 & -0.705118 \\
\hline $\mathrm{H}$ & -1.064087 & 6.584484 & 2.364375 \\
\hline C & 0.953521 & -5.438387 & -1.629169 \\
\hline C & -0.383065 & -5.628974 & -1.983517 \\
\hline C & -1.372911 & -4.803761 & -1.447636 \\
\hline C & -1.039749 & -3.768133 & -0.561650 \\
\hline C & 0.306867 & -3.578533 & -0.218098 \\
\hline C & 1.294381 & -4.413827 & -0.742504 \\
\hline $\mathrm{H}$ & -0.658606 & -6.423138 & -2.672840 \\
\hline $\mathrm{H}$ & 2.325518 & -4.263990 & -0.435066 \\
\hline C & -4.187125 & -1.451470 & 1.341122 \\
\hline C & -4.042689 & -2.855081 & 1.584872 \\
\hline C & -4.897510 & -3.496423 & 2.521800 \\
\hline C & -5.841858 & -2.782724 & 3.221627 \\
\hline C & -5.959609 & -1.388258 & 3.015747 \\
\hline C & -5.157799 & -0.741346 & 2.101309 \\
\hline $\mathrm{H}$ & -4.777509 & -4.564884 & 2.684679 \\
\hline $\mathrm{H}$ & -6.485618 & -3.281516 & 3.940921 \\
\hline $\mathrm{H}$ & -6.685951 & -0.818953 & 3.589497 \\
\hline $\mathrm{H}$ & -5.256022 & 0.329086 & 1.967012 \\
\hline C & -4.801569 & 1.073769 & -0.512665 \\
\hline C & -5.003210 & 2.481192 & -0.681221 \\
\hline C & -6.253607 & 2.955889 & -1.161599 \\
\hline C & -7.262154 & 2.081368 & -1.492932 \\
\hline C & -7.054083 & 0.688334 & -1.361564 \\
\hline C & -5.859381 & 0.197953 & -0.881909 \\
\hline $\mathrm{H}$ & -6.391174 & 4.028546 & -1.275638 \\
\hline $\mathrm{H}$ & -8.211410 & 2.454942 & -1.867032 \\
\hline $\mathrm{H}$ & -7.842148 & -0.002892 & -1.647932 \\
\hline $\mathrm{H}$ & -5.712673 & -0.872601 & -0.798129 \\
\hline $\mathrm{O}$ & 0.833701 & -0.330176 & 0.153577 \\
\hline $\mathrm{O}$ & -0.150601 & 0.986868 & -1.877629 \\
\hline $\mathrm{H}$ & 0.832257 & 1.428404 & -2.041592 \\
\hline $\mathrm{H}$ & -2.768948 & 4.860274 & 1.861835 \\
\hline $\mathrm{H}$ & 1.073340 & 6.633388 & 1.090746 \\
\hline $\mathrm{H}$ & -0.232753 & 3.248323 & -1.207943 \\
\hline $\mathrm{H}$ & 0.585188 & -2.789177 & 0.470969 \\
\hline
\end{tabular}




$\begin{array}{llll}\mathrm{H} & 1.723728 & -6.089093 & -2.035878 \\ \mathrm{H} & -2.414035 & -4.955866 & -1.720254 \\ \mathrm{C} & 3.101972 & 1.561266 & -1.878469 \\ \mathrm{O} & 2.009800 & 2.154963 & -2.188524 \\ \mathrm{H} & 4.042335 & 2.092441 & -2.092015 \\ \mathrm{C} & 3.282390 & 0.074515 & -2.238532 \\ \mathrm{O} & 4.274645 & -0.576258 & -1.968247 \\ \mathrm{O} & 2.253236 & -0.380584 & -2.951325 \\ \mathrm{C} & 2.325789 & -1.755969 & -3.375031 \\ \mathrm{H} & 2.308312 & -2.418216 & -2.507315 \\ \mathrm{H} & 1.439022 & -1.912959 & -3.987713 \\ \mathrm{C} & 4.127152 & 0.674582 & 0.582293 \\ \mathrm{C} & 3.271242 & 1.666378 & 0.052381 \\ \mathrm{H} & 2.562468 & -0.608598 & 0.626415 \\ \mathrm{~N} & 3.562030 & -0.523334 & 0.871880 \\ \mathrm{C} & 4.052617 & -1.687592 & 1.481263 \\ \mathrm{O} & 3.415056 & -2.718521 & 1.469480 \\ \mathrm{O} & 5.226354 & -1.510659 & 2.096811 \\ \mathrm{C} & 5.755309 & -2.684029 & 2.742725 \\ \mathrm{H} & 5.078344 & -3.019303 & 3.531859 \\ \mathrm{H} & 6.712138 & -2.371143 & 3.159703 \\ \mathrm{H} & 5.892394 & -3.489634 & 2.017644 \\ \mathrm{H} & 3.653168 & 2.680922 & 0.091969 \\ \mathrm{H} & 2.220932 & 1.563553 & 0.299192 \\ \mathrm{C} & 5.579790 & 0.942177 & 0.704382 \\ \mathrm{C} & 6.543845 & 0.128395 & 0.085873 \\ \mathrm{C} & 5.992718 & 2.089511 & 1.400121 \\ \mathrm{C} & 7.892526 & 0.460045 & 0.172249 \\ \mathrm{H} & 6.222704 & -0.726650 & -0.496035 \\ \mathrm{H} & 7.347547 & 2.402800 & 1.503757 \\ \mathrm{H} & 5.252094 & 2.720470 & 1.882709 \\ \mathrm{H} & 8.299345 & 1.590555 & 0.887152 \\ \mathrm{H} & 8.630111 & -0.162834 & -0.326117 \\ \mathrm{H} & 3.655674 & 3.283406 & 2.060053 \\ \mathrm{H} & & 1.840298 & 0.955675 \\ \mathrm{H} & -1.924483 & -3.953404\end{array}$

Catalyst (R)-1 TS Conformation 361

B3LYP/6-31G(d) Energy $=-2809.684039$

B3LYP-D3(BJ)/def2-TZVPP-IEF-PCM(DCM) Energy $=-2810.976264$

B3LYP-D3(BJ)/def2-TZVPP-IEF-PCM(DCM)//B3LYP/6-31G(d) Free Energy (Quasiharmonic) = 2810.33412 
Frequencies (Top 3 out of 270)

1. $-653.4965 \mathrm{~cm}-1$

2. $\quad 7.5125 \mathrm{~cm}-1$

3. $\quad 9.9481 \mathrm{~cm}-1$

B3LYP/6-31G(d) Molecular Geometry in Cartesian Coordinates

$\begin{array}{llll}\text { C } & 3.221741 & -1.325901 & 0.078054 \\ \text { C } & 1.879474 & -1.658974 & 0.152153 \\ \text { C } & 1.386147 & -2.985129 & -0.023266 \\ \text { C } & 2.308169 & -3.970696 & -0.313925 \\ \text { H } & 1.969623 & -4.997058 & -0.430652 \\ \text { C } & 4.573607 & 2.732522 & 0.585333 \\ \text { C } & 3.645536 & 0.082757 & 0.335825 \\ \text { C } & 3.087341 & 1.122918 & -0.397532 \\ \text { C } & 3.570563 & 2.465524 & -0.326704 \\ \text { H } & 4.953012 & 3.747685 & 0.667056 \\ \text { O } & 0.965284 & -0.649510 & 0.418283 \\ \text { P } & 0.594838 & 0.385366 & -0.810867 \\ \text { O } & 2.087449 & 0.841833 & -1.316581 \\ \text { C } & -2.794587 & -3.977504 & 0.250818 \\ \text { C } & -2.023792 & -4.437522 & -0.817459 \\ \text { C } & -0.671700 & -4.104045 & -0.902610 \\ \text { C } & -0.062084 & -3.306129 & 0.078434 \\ \text { C } & -0.847539 & -2.853296 & 1.152561 \\ \text { C } & -2.198810 & -3.186626 & 1.236938 \\ \text { H } & -2.476552 & -5.047337 & -1.595074 \\ \text { H } & -2.789732 & -2.826054 & 2.074922 \\ \text { C } & 2.287110 & 5.691267 & -2.872243 \\ \text { C } & 3.641580 & 5.386481 & -2.732865 \\ \text { C } & 4.037751 & 4.327409 & -1.916813 \\ \text { C } & 3.090455 & 3.552410 & -1.226292 \\ \text { C } & 1.729661 & 3.865198 & -1.375703 \\ \text { C } & 1.337948 & 4.927135 & -2.190887 \\ \text { H } & 4.391458 & 5.967305 & -3.264019 \\ \text { H } & 0.280425 & 5.158451 & -2.291391 \\ \text { C } & 4.620975 & 0.396657 & 1.344228 \\ \text { C } & 5.092150 & 1.743843 & 1.455908 \\ \text { C } & 6.058287 & 2.067033 & 2.447059 \\ \text { C } & 6.529605 & 1.109822 & 3.315078 \\ \text { C } & 6.042539 & -0.215775 & 3.228828 \\ \text { C } & 5.116103 & -0.563222 & 2.270185\end{array}$




\begin{tabular}{|c|c|c|c|}
\hline $\mathrm{H}$ & 6.410198 & 3.094085 & 2.511504 \\
\hline $\mathrm{H}$ & 7.264398 & 1.369542 & 4.072334 \\
\hline $\mathrm{H}$ & 6.398372 & -0.966650 & 3.929325 \\
\hline $\mathrm{H}$ & 4.745579 & -1.580851 & 2.224682 \\
\hline C & 4.160794 & -2.348202 & -0.299206 \\
\hline C & 3.687074 & -3.689070 & -0.477429 \\
\hline C & 4.605554 & -4.712584 & -0.836527 \\
\hline C & 5.934838 & -4.429497 & -1.047288 \\
\hline C & 6.397913 & -3.099669 & -0.913451 \\
\hline C & 5.536550 & -2.088162 & -0.548833 \\
\hline $\mathrm{H}$ & 4.230263 & -5.726404 & -0.955403 \\
\hline $\mathrm{H}$ & 6.626175 & -5.219076 & -1.328928 \\
\hline $\mathrm{H}$ & 7.442912 & -2.871715 & -1.105677 \\
\hline $\mathrm{H}$ & 5.906565 & -1.073541 & -0.461681 \\
\hline $\mathrm{O}$ & -0.231792 & 1.480729 & -0.219827 \\
\hline $\mathrm{O}$ & 0.040920 & -0.408127 & -1.999110 \\
\hline $\mathrm{H}$ & -1.149799 & -0.290037 & -2.272149 \\
\hline $\mathrm{H}$ & -0.393332 & -2.240332 & 1.923776 \\
\hline $\mathrm{H}$ & -3.851528 & -4.220306 & 0.310685 \\
\hline $\mathrm{H}$ & -0.084333 & -4.438980 & -1.752716 \\
\hline $\mathrm{H}$ & 0.979378 & 3.286186 & -0.847890 \\
\hline $\mathrm{H}$ & 1.974010 & 6.514845 & -3.508969 \\
\hline $\mathrm{H}$ & 5.092457 & 4.081576 & -1.825725 \\
\hline C & -3.031279 & -0.323571 & -1.454472 \\
\hline $\mathrm{O}$ & -2.305944 & -0.242222 & -2.518531 \\
\hline $\mathrm{H}$ & -2.580501 & -0.708214 & -0.532936 \\
\hline C & -4.453442 & -0.834172 & -1.619777 \\
\hline $\mathrm{O}$ & -5.042068 & -1.419778 & -0.731368 \\
\hline 0 & -4.973164 & -0.539771 & -2.815455 \\
\hline C & -6.309301 & -1.031720 & -3.056537 \\
\hline $\mathrm{H}$ & -7.017292 & -0.576098 & -2.359382 \\
\hline $\mathrm{H}$ & -6.537318 & -0.746865 & -4.083305 \\
\hline C & -4.272515 & 1.533466 & 0.202078 \\
\hline C & -3.379399 & 1.509685 & -0.891530 \\
\hline $\mathrm{H}$ & -5.831593 & 1.856166 & -1.056068 \\
\hline$N$ & -5.619210 & 1.564650 & -0.107668 \\
\hline C & -6.706621 & 0.804865 & 0.381240 \\
\hline $\mathrm{O}$ & -7.748973 & 0.771818 & -0.238363 \\
\hline $\mathrm{O}$ & -6.442400 & 0.172830 & 1.518431 \\
\hline C & -7.457983 & -0.755468 & 1.951271 \\
\hline $\mathrm{H}$ & -7.109227 & -1.126120 & 2.914387 \\
\hline $\mathrm{H}$ & -7.536887 & -1.570759 & 1.229014 \\
\hline $\mathrm{H}$ & -8.420440 & -0.249809 & 2.050994 \\
\hline $\mathrm{H}$ & -2.347898 & 1.807558 & -0.714674 \\
\hline
\end{tabular}




$\begin{array}{llll}\mathrm{H} & -3.786374 & 1.822971 & -1.851272 \\ \mathrm{C} & -3.827849 & 1.554541 & 1.593150 \\ \mathrm{C} & -4.649729 & 2.105626 & 2.600960 \\ \mathrm{C} & -2.523661 & 1.135993 & 1.932334 \\ \mathrm{C} & -4.191466 & 2.207664 & 3.907488 \\ \mathrm{H} & -5.632145 & 2.486117 & 2.347562 \\ \mathrm{C} & -2.079893 & 1.226759 & 3.247773 \\ \mathrm{H} & -1.839010 & 0.774480 & 1.174134 \\ \mathrm{C} & -2.909798 & 1.755453 & 4.238352 \\ \mathrm{H} & -4.828830 & 2.648661 & 4.668422 \\ \mathrm{H} & -1.073234 & 0.900170 & 3.489700 \\ \mathrm{H} & -2.554034 & 1.834503 & 5.262027 \\ \mathrm{H} & -6.335464 & -2.118104 & -2.943979\end{array}$

Catalyst (R)-1 TS Conformation 362

B3LYP/6-31G(d) Energy = -2809.682301

B3LYP-D3(BJ)/def2-TZVPP-IEF-PCM(DCM) Energy $=-2810.975006$

B3LYP-D3(BJ)/def2-TZVPP-IEF-PCM(DCM)//B3LYP/6-31G(d) Free Energy (Quasiharmonic) = 2810.333974

Frequencies (Top 3 out of 270)

1. $-750.7916 \mathrm{~cm}-1$

2. $\quad 9.4163 \mathrm{~cm}-1$

3. $\quad 13.5319 \mathrm{~cm}-1$

B3LYP/6-31G(d) Molecular Geometry in Cartesian Coordinates

$\begin{array}{llll}\text { C } & 3.295021 & 0.626570 & 0.276688 \\ \text { C } & 2.299313 & 1.573267 & 0.083666 \\ \text { C } & 2.469600 & 2.952662 & 0.409449 \\ \text { C } & 3.660078 & 3.330212 & 0.996301 \\ \text { H } & 3.812556 & 4.375681 & 1.251441 \\ \text { C } & 2.984483 & -3.538185 & -0.751070 \\ \text { C } & 3.135356 & -0.773240 & -0.217482 \\ \text { C } & 2.044315 & -1.534276 & 0.173905 \\ \text { C } & 1.977057 & -2.948325 & -0.012468 \\ \text { H } & 2.956493 & -4.611597 & -0.919344 \\ \text { O } & 1.129533 & 1.206296 & -0.563454 \\ \text { P } & 0.055869 & 0.141825 & 0.070640 \\ \text { O } & 1.012261 & -0.918439 & 0.871166 \\ \text { C } & -0.410869 & 6.054723 & -0.356320\end{array}$




\begin{tabular}{|c|c|c|c|}
\hline C & -0.763887 & 4.956262 & 0.431152 \\
\hline C & 0.153244 & 3.930344 & 0.661153 \\
\hline C & 1.442477 & 3.990793 & 0.111930 \\
\hline C & 1.787116 & 5.100045 & -0.676141 \\
\hline C & 0.867601 & 6.122692 & -0.911302 \\
\hline $\mathrm{H}$ & -1.754219 & 4.890377 & 0.873395 \\
\hline $\mathrm{H}$ & 1.151071 & 6.970405 & -1.529801 \\
\hline C & -0.947065 & -5.485831 & 1.874598 \\
\hline C & 0.415817 & -5.766409 & 1.975274 \\
\hline C & 1.348461 & -4.928830 & 1.363959 \\
\hline C & 0.940064 & -3.796590 & 0.638395 \\
\hline C & -0.433562 & -3.525073 & 0.542626 \\
\hline C & -1.365948 & -4.363863 & 1.155492 \\
\hline $\mathrm{H}$ & 0.756495 & -6.631916 & 2.537655 \\
\hline $\mathrm{H}$ & -2.427706 & -4.145958 & 1.065389 \\
\hline C & 4.119986 & -1.382773 & -1.071802 \\
\hline C & 4.032104 & -2.786805 & -1.337611 \\
\hline C & 4.996655 & -3.399905 & -2.182222 \\
\hline C & 5.997997 & -2.659326 & -2.766066 \\
\hline C & 6.069899 & -1.266423 & -2.529594 \\
\hline C & 5.159405 & -0.645778 & -1.702555 \\
\hline $\mathrm{H}$ & 4.919269 & -4.468858 & -2.366924 \\
\hline $\mathrm{H}$ & 6.726012 & -3.137153 & -3.415933 \\
\hline $\mathrm{H}$ & 6.847437 & -0.678529 & -3.009837 \\
\hline $\mathrm{H}$ & 5.221107 & 0.424106 & -1.540246 \\
\hline C & 4.482265 & 1.015183 & 0.994697 \\
\hline C & 4.666710 & 2.393717 & 1.334045 \\
\hline C & 5.840466 & 2.796125 & 2.026758 \\
\hline C & 6.790953 & 1.875911 & 2.402090 \\
\hline C & 6.594658 & 0.507220 & 2.104597 \\
\hline C & 5.474912 & 0.088722 & 1.419650 \\
\hline $\mathrm{H}$ & 5.964009 & 3.849579 & 2.266796 \\
\hline $\mathrm{H}$ & 7.681704 & 2.193061 & 2.937434 \\
\hline $\mathrm{H}$ & 7.331378 & -0.224340 & 2.425560 \\
\hline $\mathrm{H}$ & 5.338562 & -0.965981 & 1.213426 \\
\hline $\mathrm{O}$ & -0.708327 & -0.424821 & -1.084428 \\
\hline $\mathrm{O}$ & -0.738204 & 0.785255 & 1.220348 \\
\hline $\mathrm{H}$ & -1.796379 & 1.336047 & 0.968418 \\
\hline $\mathrm{H}$ & 2.779878 & 5.151424 & -1.115392 \\
\hline $\mathrm{H}$ & -1.125418 & 6.854578 & -0.534412 \\
\hline $\mathrm{H}$ & -0.122895 & 3.087753 & 1.284691 \\
\hline $\mathrm{H}$ & -0.764786 & -2.671068 & -0.035357 \\
\hline $\mathrm{H}$ & -1.677094 & -6.133072 & 2.353572 \\
\hline $\mathrm{H}$ & 2.409712 & -5.138433 & 1.466142 \\
\hline
\end{tabular}




$\begin{array}{llll}\mathrm{C} & -2.894838 & 2.079149 & -0.577725 \\ \mathrm{O} & -2.759201 & 1.989039 & 0.693421 \\ \mathrm{H} & -2.110177 & 1.681092 & -1.227854 \\ \mathrm{C} & -3.537776 & 3.329016 & -1.161760 \\ \mathrm{O} & -3.435333 & 3.627447 & -2.331846 \\ \mathrm{O} & -4.219278 & 4.030041 & -0.244641 \\ \mathrm{C} & -4.831794 & 5.237689 & -0.733749 \\ \mathrm{H} & -5.542760 & 5.010175 & -1.532490 \\ \mathrm{H} & -5.341202 & 5.672600 & 0.125880 \\ \mathrm{C} & -4.277028 & -0.421400 & -0.809058 \\ \mathrm{C} & -4.340116 & 0.858966 & -1.371544 \\ \mathrm{H} & -2.452366 & -0.946796 & -1.633514 \\ \mathrm{~N} & -3.344361 & -1.310253 & -1.273530 \\ \mathrm{C} & -3.524964 & -2.697372 & -1.369624 \\ \mathrm{O} & -4.465942 & -3.327820 & -0.941896 \\ \mathrm{O} & -2.494283 & -3.199409 & -2.068859 \\ \mathrm{C} & -2.543985 & -4.617379 & -2.310834 \\ \mathrm{H} & -1.694556 & -4.822273 & -2.961725 \\ \mathrm{H} & -3.483439 & -4.885821 & -2.799629 \\ \mathrm{H} & -2.444222 & -5.165208 & -1.371715 \\ \mathrm{H} & -5.193964 & 1.452220 & -1.062202 \\ \mathrm{H} & -4.015948 & 0.984586 & -2.400172 \\ \mathrm{C} & -5.097804 & -0.767132 & 0.358669 \\ \mathrm{C} & -4.510421 & -1.430145 & 1.453220 \\ \mathrm{C} & -6.439042 & -0.353111 & 0.445334 \\ \mathrm{C} & -5.248879 & -1.661664 & 2.607989 \\ \mathrm{H} & -3.466085 & -1.720519 & 1.407304 \\ \mathrm{C} & -7.181333 & -0.612059 & 1.593253 \\ \mathrm{H} & -6.906279 & 0.135784 & -0.404114 \\ \mathrm{C} & -6.586121 & -1.261321 & 2.677713 \\ \mathrm{H} & -4.781097 & -2.153153 & 3.455786 \\ \mathrm{H} & -8.222721 & -0.307877 & 1.643289 \\ \mathrm{H} & -7.163418 & -1.453387 & 3.577892 \\ \mathrm{H} & -4.069738 & 5.919828 & -1.118831\end{array}$

Catalyst (R)-1 TS Conformation 363

B3LYP/6-31G(d) Energy $=-2809.682814$

B3LYP-D3(BJ)/def2-TZVPP-IEF-PCM(DCM) Energy = -2810.97595

B3LYP-D3(BJ)/def2-TZVPP-IEF-PCM(DCM)//B3LYP/6-31G(d) Free Energy (Quasiharmonic) = 2810.333971

Frequencies (Top 3 out of 270) 
1. $-656.1281 \mathrm{~cm}-1$

2. $\quad 8.1041 \mathrm{~cm}-1$

3. $\quad 10.1146 \mathrm{~cm}-1$

B3LYP/6-31G(d) Molecular Geometry in Cartesian Coordinates

\begin{tabular}{|c|c|c|c|}
\hline C & 3.596402 & -0.948881 & -0.274649 \\
\hline C & 2.393935 & -1.605354 & -0.058016 \\
\hline C & 2.133085 & -2.935110 & -0.503865 \\
\hline C & 3.130835 & -3.571905 & -1.215573 \\
\hline $\mathrm{H}$ & 2.976560 & -4.595271 & -1.547966 \\
\hline C & 4.112424 & 3.068296 & 1.223162 \\
\hline C & 3.793200 & 0.421306 & 0.288678 \\
\hline C & 2.878716 & 1.421844 & -0.007722 \\
\hline C & 3.024471 & 2.772897 & 0.425609 \\
\hline $\mathrm{H}$ & 4.267282 & 4.093122 & 1.550529 \\
\hline $\mathrm{O}$ & 1.398383 & -0.944681 & 0.642775 \\
\hline$P$ & 0.551289 & 0.231197 & -0.147217 \\
\hline $\mathrm{O}$ & 1.775651 & 1.112536 & -0.789897 \\
\hline C & -1.578872 & -4.990084 & 0.235449 \\
\hline C & -0.955411 & -4.283466 & 1.267947 \\
\hline C & 0.240661 & -3.604720 & 1.035909 \\
\hline C & 0.838769 & -3.617887 & -0.236453 \\
\hline C & 0.199969 & -4.329877 & -1.264395 \\
\hline C & -0.994963 & -5.010996 & -1.031982 \\
\hline $\mathrm{H}$ & -1.399680 & -4.264218 & 2.259763 \\
\hline $\mathrm{H}$ & -1.471991 & -5.552148 & -1.845190 \\
\hline C & 0.306379 & 5.933287 & -0.647764 \\
\hline C & 0.761743 & 5.042931 & -1.623443 \\
\hline C & 1.624448 & 4.002178 & -1.281675 \\
\hline C & 2.055764 & 3.835989 & 0.045189 \\
\hline C & 1.588576 & 4.736193 & 1.016274 \\
\hline C & 0.722088 & 5.774043 & 0.674727 \\
\hline $\mathrm{H}$ & 0.453057 & 5.163686 & -2.659030 \\
\hline $\mathrm{H}$ & 0.366094 & 6.453178 & 1.445031 \\
\hline C & 4.878760 & 0.729386 & 1.179706 \\
\hline C & 5.037833 & 2.078432 & 1.635938 \\
\hline C & 6.113669 & 2.398353 & 2.507963 \\
\hline C & 6.984250 & 1.427491 & 2.945248 \\
\hline C & 6.806208 & 0.087285 & 2.528963 \\
\hline C & 5.783889 & -0.252177 & 1.670097 \\
\hline $\mathrm{H}$ & 6.226320 & 3.429748 & 2.833992 \\
\hline $\mathrm{H}$ & 7.798660 & 1.683147 & 3.617606 \\
\hline
\end{tabular}




\begin{tabular}{|c|c|c|c|}
\hline $\mathrm{H}$ & 7.479315 & -0.683791 & 2.894167 \\
\hline $\mathrm{H}$ & 5.655826 & -1.285554 & 1.369668 \\
\hline C & 4.594895 & -1.596609 & -1.080493 \\
\hline C & 4.354116 & -2.933722 & -1.536931 \\
\hline C & 5.339500 & -3.591223 & -2.322492 \\
\hline C & 6.504729 & -2.952569 & -2.677399 \\
\hline C & 6.727503 & -1.618462 & -2.262758 \\
\hline C & 5.800170 & -0.959450 & -1.485831 \\
\hline $\mathrm{H}$ & 5.145612 & -4.610154 & -2.649601 \\
\hline $\mathrm{H}$ & 7.247451 & -3.463189 & -3.284269 \\
\hline $\mathrm{H}$ & 7.637188 & -1.106009 & -2.564109 \\
\hline $\mathrm{H}$ & 5.982229 & 0.065580 & -1.184707 \\
\hline $\mathrm{O}$ & -0.317147 & -0.269787 & -1.245078 \\
\hline $\mathrm{O}$ & -0.082836 & 1.023789 & 1.010941 \\
\hline $\mathrm{H}$ & -1.239313 & 0.879974 & 1.201806 \\
\hline $\mathrm{H}$ & 0.634145 & -4.326756 & -2.260028 \\
\hline $\mathrm{H}$ & -2.507884 & -5.523643 & 0.420415 \\
\hline $\mathrm{H}$ & 0.719753 & -3.065477 & 1.845670 \\
\hline $\mathrm{H}$ & 1.890402 & 4.603161 & 2.051308 \\
\hline $\mathrm{H}$ & -0.366596 & 6.743592 & -0.916266 \\
\hline $\mathrm{H}$ & 1.972492 & 3.317736 & -2.047467 \\
\hline C & -2.778973 & -0.532647 & 1.336490 \\
\hline 0 & -2.441622 & 0.711338 & 1.407268 \\
\hline $\mathrm{H}$ & -1.989855 & -1.292624 & 1.425315 \\
\hline C & -4.053347 & -0.899161 & 2.090989 \\
\hline $\mathrm{O}$ & -4.914037 & -0.116247 & 2.422463 \\
\hline $\mathrm{O}$ & -4.106375 & -2.229517 & 2.320154 \\
\hline C & -5.273494 & -2.687619 & 3.035670 \\
\hline $\mathrm{H}$ & -5.131831 & -3.760919 & 3.163066 \\
\hline $\mathrm{H}$ & -6.180119 & -2.480093 & 2.461050 \\
\hline C & -4.397549 & -0.430769 & -0.841769 \\
\hline C & -3.227532 & -1.114911 & -0.440996 \\
\hline $\mathrm{H}$ & -5.525432 & -2.064755 & -0.423669 \\
\hline$N$ & -5.600800 & -1.066284 & -0.585284 \\
\hline C & -6.772471 & -0.598500 & 0.053483 \\
\hline $\mathrm{O}$ & -7.579263 & -1.391067 & 0.492995 \\
\hline $\mathrm{O}$ & -6.846680 & 0.724618 & 0.114415 \\
\hline C & -7.898540 & 1.242695 & 0.955283 \\
\hline $\mathrm{H}$ & -7.848368 & 2.324019 & 0.834382 \\
\hline $\mathrm{H}$ & -7.702391 & 0.961334 & 1.991863 \\
\hline $\mathrm{H}$ & -8.868141 & 0.855797 & 0.635703 \\
\hline $\mathrm{H}$ & -2.290277 & -0.866921 & -0.938258 \\
\hline $\mathrm{H}$ & -3.346822 & -2.178109 & -0.234395 \\
\hline C & -4.362641 & 0.868991 & -1.492621 \\
\hline
\end{tabular}




$\begin{array}{llll}\text { C } & -5.437608 & 1.310470 & -2.297986 \\ \text { C } & -3.204378 & 1.671445 & -1.400222 \\ \text { C } & -5.363159 & 2.524147 & -2.964082 \\ \text { H } & -6.312402 & 0.682881 & -2.420710 \\ \text { C } & -3.152788 & 2.903506 & -2.046134 \\ \text { H } & -2.354441 & 1.339096 & -0.823697 \\ \text { C } & -4.226301 & 3.331198 & -2.827481 \\ \text { H } & -6.186887 & 2.844386 & -3.595514 \\ \text { H } & -2.261941 & 3.516628 & -1.948138 \\ \text { H } & -4.174501 & 4.283766 & -3.348052 \\ \text { H } & -5.339590 & -2.190614 & 4.006450\end{array}$

Catalyst (R)-1 TS Conformation 364

B3LYP/6-31G(d) Energy $=-2809.683191$

B3LYP-D3(BJ)/def2-TZVPP-IEF-PCM(DCM) Energy = -2810.976543

B3LYP-D3(BJ)/def2-TZVPP-IEF-PCM(DCM)//B3LYP/6-31G(d) Free Energy (Quasiharmonic) = 2810.333745

Frequencies (Top 3 out of 270)

1. $-524.3641 \mathrm{~cm}-1$

2. $\quad 5.3721 \mathrm{~cm}-1$

3. $\quad 9.1843 \mathrm{~cm}-1$

B3LYP/6-31G(d) Molecular Geometry in Cartesian Coordinates

$\begin{array}{llll}\mathrm{C} & 3.628106 & -0.612580 & -0.335748 \\ \mathrm{C} & 2.552400 & -1.483452 & -0.215930 \\ \mathrm{C} & 2.649431 & -2.875262 & -0.523355 \\ \mathrm{C} & 3.840820 & -3.333030 & -1.050720 \\ \mathrm{H} & 3.937085 & -4.386790 & -1.299169 \\ \mathrm{C} & 3.328768 & 3.470727 & 1.026184 \\ \mathrm{C} & 3.532266 & 0.781893 & 0.190865 \\ \mathrm{C} & 2.507381 & 1.609528 & -0.238643 \\ \mathrm{C} & 2.388911 & 2.979377 & 0.141213 \\ \mathrm{H} & 3.287300 & 4.517313 & 1.316332 \\ \mathrm{O} & 1.362986 & -1.028088 & 0.329104 \\ \mathrm{P} & 0.421284 & 0.088954 & -0.437903 \\ \mathrm{O} & 1.556804 & 1.079039 & -1.098480 \\ \mathrm{C} & -0.432397 & -5.774464 & 0.278570 \\ \mathrm{C} & 0.862657 & -5.956648 & 0.764867 \\ \mathrm{C} & 1.845673 & -5.000114 & 0.509715\end{array}$




\begin{tabular}{|c|c|c|c|}
\hline C & 1.554482 & -3.844158 & -0.233985 \\
\hline C & 0.247397 & -3.669421 & -0.718247 \\
\hline C & -0.732458 & -4.629633 & -0.463117 \\
\hline $\mathrm{H}$ & 1.109507 & -6.840864 & 1.347084 \\
\hline $\mathrm{H}$ & -1.736278 & -4.484771 & -0.855341 \\
\hline C & -0.644835 & 5.644184 & -1.346541 \\
\hline C & 0.012397 & 4.777619 & -2.222509 \\
\hline C & 0.980215 & 3.894239 & -1.747206 \\
\hline C & 1.313682 & 3.863081 & -0.382440 \\
\hline C & 0.640523 & 4.735247 & 0.488541 \\
\hline C & -0.328236 & 5.617755 & 0.012286 \\
\hline $\mathrm{H}$ & -0.226092 & 4.790104 & -3.282890 \\
\hline $\mathrm{H}$ & -0.840419 & 6.279437 & 0.706299 \\
\hline C & 4.455534 & 1.286620 & 1.171779 \\
\hline C & 4.349001 & 2.656860 & 1.576969 \\
\hline C & 5.261228 & 3.174620 & 2.536174 \\
\hline C & 6.222892 & 2.372368 & 3.104734 \\
\hline C & 6.304800 & 1.008888 & 2.737227 \\
\hline C & 5.447354 & 0.481267 & 1.796645 \\
\hline $\mathrm{H}$ & 5.173449 & 4.220285 & 2.821946 \\
\hline $\mathrm{H}$ & 6.910064 & 2.777836 & 3.842388 \\
\hline $\mathrm{H}$ & 7.048676 & 0.369149 & 3.204585 \\
\hline $\mathrm{H}$ & 5.518560 & -0.567698 & 1.534394 \\
\hline C & 4.824943 & -1.083487 & -0.979729 \\
\hline C & 4.926507 & -2.468040 & -1.329596 \\
\hline C & 6.106408 & -2.946064 & -1.961336 \\
\hline C & 7.142502 & -2.093335 & -2.263074 \\
\hline C & 7.032865 & -0.718323 & -1.948664 \\
\hline C & 5.907854 & -0.227333 & -1.323249 \\
\hline $\mathrm{H}$ & 6.167524 & -4.002334 & -2.213049 \\
\hline $\mathrm{H}$ & 8.037402 & -2.468298 & -2.752221 \\
\hline $\mathrm{H}$ & 7.841421 & -0.040573 & -2.209204 \\
\hline $\mathrm{H}$ & 5.835539 & 0.830899 & -1.100521 \\
\hline $\mathrm{O}$ & -0.448641 & 0.737730 & 0.584072 \\
\hline $\mathrm{O}$ & -0.236576 & -0.575313 & -1.657057 \\
\hline $\mathrm{H}$ & -1.376474 & -0.135600 & -2.019722 \\
\hline $\mathrm{H}$ & 0.007031 & -2.789625 & -1.305418 \\
\hline $\mathrm{H}$ & -1.200510 & -6.518342 & 0.474296 \\
\hline $\mathrm{H}$ & 2.849470 & -5.138604 & 0.902541 \\
\hline $\mathrm{H}$ & 0.864827 & 4.701794 & 1.550913 \\
\hline $\mathrm{H}$ & -1.399425 & 6.331636 & -1.720299 \\
\hline $\mathrm{H}$ & 1.485853 & 3.227976 & -2.437399 \\
\hline C & -3.040431 & 0.614850 & -1.211254 \\
\hline $\mathrm{O}$ & -2.427003 & 0.247166 & -2.280440 \\
\hline
\end{tabular}




$\begin{array}{llll}\mathrm{H} & -2.452974 & 0.851502 & -0.318356 \\ \mathrm{C} & -4.281595 & 1.455622 & -1.441336 \\ \mathrm{O} & -4.904358 & 1.511949 & -2.476787 \\ \mathrm{O} & -4.582269 & 2.145151 & -0.323898 \\ \mathrm{C} & -5.713038 & 3.031185 & -0.429656 \\ \mathrm{H} & -5.786417 & 3.524677 & 0.539295 \\ \mathrm{H} & -5.544745 & 3.763282 & -1.223003 \\ \mathrm{C} & -4.711372 & -0.856094 & 0.569229 \\ \mathrm{C} & -3.777310 & -1.129857 & -0.435346 \\ \mathrm{H} & -5.047650 & 0.018326 & 2.376939 \\ \mathrm{~N} & -4.357357 & -0.488676 & 1.836685 \\ \mathrm{C} & -3.158518 & -0.612758 & 2.587176 \\ \mathrm{O} & -3.068629 & -0.052943 & 3.655953 \\ \mathrm{O} & -2.276123 & -1.417022 & 2.017380 \\ \mathrm{C} & -1.004582 & -1.539842 & 2.712761 \\ \mathrm{H} & -1.182258 & -1.874312 & 3.736505 \\ \mathrm{H} & -0.496734 & -0.576875 & 2.687481 \\ \mathrm{H} & -0.446953 & -2.277431 & 2.139917 \\ \mathrm{H} & -4.153515 & -1.590663 & -1.340925 \\ \mathrm{H} & -2.781489 & -1.430776 & -0.139386 \\ \mathrm{C} & -6.170453 & -0.873552 & 0.314852 \\ \mathrm{C} & -6.689884 & -0.731888 & -0.987150 \\ \mathrm{C} & -7.073569 & -1.086881 & 1.376730 \\ \mathrm{C} & -8.063917 & -0.772956 & -1.208493 \\ \mathrm{H} & -6.029544 & -0.555223 & -1.827053 \\ \mathrm{C} & -8.445710 & -1.137642 & 1.147167 \\ \mathrm{H} & -6.704958 & -1.266688 & 2.382088 \\ \mathrm{C} & -8.946922 & -0.973365 & -0.145303 \\ \mathrm{H} & -8.443329 & -0.645978 & -2.217994 \\ \mathrm{H} & -9.121802 & -1.317149 & 1.977938 \\ \mathrm{H} & -10.017682 & -1.010942 & -0.324181 \\ & -6.622358 & 2.465844 & -0.648172\end{array}$

Catalyst (R)-1 TS Conformation 365

B3LYP/6-31G(d) Energy $=-2809.681069$

B3LYP-D3(BJ)/def2-TZVPP-IEF-PCM(DCM) Energy $=-2810.976094$

B3LYP-D3(BJ)/def2-TZVPP-IEF-PCM(DCM)//B3LYP/6-31G(d) Free Energy (Quasiharmonic) = 2810.333742

Frequencies (Top 3 out of 270)

1. $-479.6224 \mathrm{~cm}-1$ 
2. $\quad 8.0319 \mathrm{~cm}-1$

3. $\quad 10.4907 \mathrm{~cm}-1$

B3LYP/6-31G(d) Molecular Geometry in Cartesian Coordinates

\begin{tabular}{lrrr} 
C & -3.807587 & 0.257226 & -0.157461 \\
C & -3.015272 & 1.340557 & 0.199174 \\
C & -3.449930 & 2.695254 & 0.086193 \\
C & -4.701887 & 2.917929 & -0.453275 \\
H & -5.071699 & 3.937173 & -0.529111 \\
C & -2.230062 & -3.732705 & 0.339270 \\
C & -3.297097 & -1.130087 & 0.057933 \\
C & -2.074787 & -1.487656 & -0.489689 \\
C & -1.518553 & -2.796010 & -0.383171 \\
H & -1.841800 & -4.744613 & 0.424484 \\
O & -1.755452 & 1.108089 & 0.727564 \\
P & -0.534584 & 0.566982 & -0.237123 \\
O & -1.350567 & -0.522951 & -1.171155 \\
C & -1.136111 & 6.089018 & 1.370194 \\
C & -1.244106 & 4.966651 & 2.194124 \\
C & -1.970545 & 3.852666 & 1.777370 \\
C & -2.610601 & 3.841653 & 0.526756 \\
C & -2.490884 & 4.974906 & -0.293606 \\
C & -1.760915 & 6.087720 & 0.122676 \\
H & -0.762594 & 4.958460 & 3.168804 \\
H & -1.674221 & 6.950250 & -0.533097 \\
C & 2.239659 & -3.869922 & -2.179945 \\
C & 1.256823 & -3.234304 & -2.943173 \\
C & 0.043318 & -2.868176 & -2.363436 \\
C & -0.214300 & -3.141905 & -1.009686 \\
C & 0.781827 & -3.777895 & -0.253438 \\
C & 1.999960 & -4.136540 & -0.831514 \\
H & 1.433753 & -3.023244 & -3.994831 \\
H & 2.762630 & -4.607157 & -0.217603 \\
C & -3.997591 & -2.096394 & 0.858705 \\
C & -3.452818 & -3.416772 & 0.983267 \\
C & -4.139747 & -4.383126 & 1.767162 \\
C & -5.300842 & -4.062244 & 2.431298 \\
C & -5.820080 & -2.749325 & 2.341988 \\
& -5.187274 & -1.793875 & 1.577311 \\
H & -3.719433 & -5.383587 & 1.840307 \\
H & -5.813449 & -4.808625 & 3.032102 \\
H & -24911 & -2.490117 & 2.885271 \\
\hline & -0.790176 & 1.526226
\end{tabular}




\begin{tabular}{|c|c|c|c|}
\hline$C$ & -5.076813 & 0.509358 & -0.782868 \\
\hline C & -5.526126 & 1.863187 & -0.915217 \\
\hline C & -6.784948 & 2.125589 & -1.520835 \\
\hline C & -7.563374 & 1.102229 & -2.009172 \\
\hline C & -7.105026 & -0.232939 & -1.915946 \\
\hline C & -5.897210 & -0.521566 & -1.319432 \\
\hline $\mathrm{H}$ & -7.114966 & 3.158731 & -1.601733 \\
\hline $\mathrm{H}$ & -8.520812 & 1.315829 & -2.476564 \\
\hline $\mathrm{H}$ & -7.708904 & -1.039138 & -2.323931 \\
\hline $\mathrm{H}$ & -5.556468 & -1.549045 & -1.266494 \\
\hline $\mathrm{O}$ & 0.496613 & -0.070927 & 0.637478 \\
\hline O & -0.103916 & 1.657428 & -1.213029 \\
\hline $\mathrm{H}$ & 1.161272 & 1.737316 & -1.454838 \\
\hline $\mathrm{H}$ & -2.955962 & 4.970235 & -1.275359 \\
\hline $\mathrm{H}$ & -0.565856 & 6.955032 & 1.696281 \\
\hline $\mathrm{H}$ & -2.049578 & 2.986653 & 2.425390 \\
\hline $\mathrm{H}$ & 0.614466 & -3.962590 & 0.803396 \\
\hline $\mathrm{H}$ & 3.185816 & -4.153003 & -2.634834 \\
\hline $\mathrm{H}$ & -0.712731 & -2.369794 & -2.961185 \\
\hline C & 2.895954 & 0.712441 & -1.293090 \\
\hline $\mathrm{O}$ & 2.266555 & 1.756229 & -1.723265 \\
\hline $\mathrm{H}$ & 2.320649 & -0.161164 & -0.974964 \\
\hline C & 4.171544 & 0.399434 & -2.056847 \\
\hline 0 & 4.775857 & 1.180945 & -2.753639 \\
\hline $\mathrm{O}$ & 4.530058 & -0.887285 & -1.862706 \\
\hline C & 5.700056 & -1.313125 & -2.586227 \\
\hline $\mathrm{H}$ & 6.575990 & -0.741323 & -2.269530 \\
\hline $\mathrm{H}$ & 5.819775 & -2.370217 & -2.348640 \\
\hline C & 4.543380 & 0.349186 & 0.932124 \\
\hline C & 3.472992 & 1.174345 & 0.548934 \\
\hline $\mathrm{H}$ & 5.054163 & -1.611366 & 1.193116 \\
\hline$N$ & 4.343551 & -0.920316 & 1.401311 \\
\hline C & 3.255457 & -1.504976 & 2.099420 \\
\hline $\mathrm{O}$ & 3.143511 & -2.709510 & 2.150960 \\
\hline $\mathrm{O}$ & 2.524486 & -0.593382 & 2.720510 \\
\hline C & 1.324933 & -1.077835 & 3.373935 \\
\hline $\mathrm{H}$ & 0.578384 & -1.286203 & 2.608546 \\
\hline $\mathrm{H}$ & 0.999810 & -0.251902 & 4.005303 \\
\hline $\mathrm{H}$ & 1.559052 & -1.961615 & 3.969757 \\
\hline $\mathrm{H}$ & 3.696308 & 2.226755 & 0.415616 \\
\hline $\mathrm{H}$ & 2.486415 & 0.953644 & 0.948238 \\
\hline C & 5.955616 & 0.743873 & 0.763403 \\
\hline C & 6.326592 & 1.801857 & -0.091988 \\
\hline C & 6.966022 & 0.096764 & 1.506377 \\
\hline
\end{tabular}




$\begin{array}{llll}\mathrm{C} & 7.661462 & 2.176538 & -0.214171 \\ \mathrm{H} & 5.582125 & 2.312206 & -0.689944 \\ \mathrm{C} & 8.297722 & 0.480904 & 1.384750 \\ \mathrm{H} & 6.705269 & -0.677456 & 2.221118 \\ \mathrm{C} & 8.651136 & 1.518434 & 0.519157 \\ \mathrm{H} & 7.927272 & 2.984339 & -0.889211 \\ \mathrm{H} & 9.057808 & -0.021507 & 1.975841 \\ \mathrm{H} & 9.690890 & 1.818233 & 0.423799 \\ \mathrm{H} & 5.551561 & -1.174695 & -3.659794\end{array}$

Catalyst (R)-1 TS Conformation 366

B3LYP/6-31G(d) Energy $=-2809.681717$

B3LYP-D3(BJ)/def2-TZVPP-IEF-PCM(DCM) Energy $=-2810.975875$

B3LYP-D3(BJ)/def2-TZVPP-IEF-PCM(DCM)//B3LYP/6-31G(d) Free Energy (Quasiharmonic) = 2810.333718

Frequencies (Top 3 out of 270)

1. $-667.8120 \mathrm{~cm}-1$

2. $9.5923 \mathrm{~cm}-1$

3. $13.9713 \mathrm{~cm}-1$

B3LYP/6-31G(d) Molecular Geometry in Cartesian Coordinates

$\begin{array}{llll}\text { C } & 3.594457 & -0.031999 & 0.455486 \\ \text { C } & 3.280719 & 1.083758 & -0.305585 \\ \text { C } & 3.713008 & 2.404295 & 0.019047 \\ \text { C } & 4.438242 & 2.561295 & 1.184107 \\ \text { H } & 4.809577 & 3.548154 & 1.447557 \\ \text { C } & 2.267296 & -3.984351 & -0.642087 \\ \text { C } & 3.176393 & -1.388453 & -0.008855 \\ \text { C } & 1.839838 & -1.642546 & -0.290739 \\ \text { C } & 1.352191 & -2.952737 & -0.582875 \\ \text { H } & 1.917636 & -4.989995 & -0.861844 \\ \text { O } & 2.530664 & 0.907530 & -1.459177 \\ \text { P } & 0.923800 & 0.616549 & -1.311381 \\ \text { O } & 0.923101 & -0.612542 & -0.188764 \\ \text { C } & 2.948135 & 5.868422 & -2.416518 \\ \text { C } & 3.351533 & 4.672411 & -3.013469 \\ \text { C } & 3.580108 & 3.537672 & -2.237137 \\ \text { C } & 3.413329 & 3.578730 & -0.842589 \\ \text { C } & 3.002436 & 4.786676 & -0.255370\end{array}$




\begin{tabular}{|c|c|c|c|}
\hline C & 2.772358 & 5.920558 & -1.033234 \\
\hline $\mathrm{H}$ & 3.489994 & 4.620393 & -4.090219 \\
\hline $\mathrm{H}$ & 2.446613 & 6.842322 & -0.557875 \\
\hline C & -2.810543 & -3.916821 & -1.149543 \\
\hline C & -2.070988 & -4.519223 & -0.126640 \\
\hline C & -0.727555 & -4.187987 & 0.054078 \\
\hline C & -0.097606 & -3.246574 & -0.777385 \\
\hline C & -0.845783 & -2.646047 & -1.804113 \\
\hline C & -2.190451 & -2.980746 & -1.986436 \\
\hline $\mathrm{H}$ & -2.540275 & -5.248503 & 0.528831 \\
\hline $\mathrm{H}$ & -2.758854 & -2.501162 & -2.778719 \\
\hline C & 4.130876 & -2.449749 & -0.182299 \\
\hline C & 3.658181 & -3.766998 & -0.486301 \\
\hline C & 4.591477 & -4.826505 & -0.647710 \\
\hline C & 5.943902 & -4.600094 & -0.541689 \\
\hline C & 6.417104 & -3.293379 & -0.276408 \\
\hline C & 5.536881 & -2.248616 & -0.099865 \\
\hline $\mathrm{H}$ & 4.212599 & -5.821118 & -0.871376 \\
\hline $\mathrm{H}$ & 6.649173 & -5.416012 & -0.674088 \\
\hline $\mathrm{H}$ & 7.486665 & -3.110087 & -0.218017 \\
\hline $\mathrm{H}$ & 5.916821 & -1.251791 & 0.091448 \\
\hline C & 4.279477 & 0.161385 & 1.705723 \\
\hline C & 4.715058 & 1.480375 & 2.056409 \\
\hline C & 5.405858 & 1.685626 & 3.281584 \\
\hline C & 5.632886 & 0.643953 & 4.150545 \\
\hline C & 5.167111 & -0.651927 & 3.827181 \\
\hline C & 4.510930 & -0.887031 & 2.638676 \\
\hline $\mathrm{H}$ & 5.741099 & 2.691431 & 3.524111 \\
\hline $\mathrm{H}$ & 6.156258 & 0.814634 & 5.087439 \\
\hline $\mathrm{H}$ & 5.324397 & -1.470280 & 4.524820 \\
\hline $\mathrm{H}$ & 4.152827 & -1.884379 & 2.412351 \\
\hline $\mathrm{O}$ & 0.366900 & 0.192524 & -2.623925 \\
\hline $\mathrm{O}$ & 0.267475 & 1.770669 & -0.538000 \\
\hline $\mathrm{H}$ & -0.900927 & 2.100278 & -0.830942 \\
\hline $\mathrm{H}$ & 2.839969 & 4.826496 & 0.818107 \\
\hline $\mathrm{H}$ & 2.766400 & 6.750193 & -3.025465 \\
\hline $\mathrm{H}$ & 3.893107 & 2.614916 & -2.712674 \\
\hline $\mathrm{H}$ & -0.376058 & -1.912119 & -2.452046 \\
\hline $\mathrm{H}$ & -3.856144 & -4.177437 & -1.296335 \\
\hline $\mathrm{H}$ & -0.158163 & -4.651419 & 0.855362 \\
\hline C & -2.524920 & 1.068843 & -1.290523 \\
\hline $\mathrm{O}$ & -2.053588 & 2.238062 & -0.997681 \\
\hline $\mathrm{H}$ & -1.873104 & 0.376481 & -1.833440 \\
\hline C & -3.960085 & 0.961703 & -1.760555 \\
\hline
\end{tabular}




$\begin{array}{llll}\mathrm{O} & -4.419368 & -0.061962 & -2.231151 \\ \mathrm{O} & -4.641722 & 2.100617 & -1.594854 \\ \mathrm{C} & -6.009640 & 2.073357 & -2.039726 \\ \mathrm{H} & -6.383800 & 3.085349 & -1.886378 \\ \mathrm{H} & -6.061272 & 1.796829 & -3.095552 \\ \mathrm{C} & -3.749730 & -0.230894 & 0.881072 \\ \mathrm{C} & -2.457766 & -0.047443 & 0.350620 \\ \mathrm{H} & -3.865997 & -2.054751 & -0.000204 \\ \mathrm{~N} & -4.426521 & -1.346807 & 0.476561 \\ \mathrm{C} & -5.796597 & -1.621470 & 0.295338 \\ \mathrm{O} & -6.165803 & -2.717599 & -0.059324 \\ \mathrm{O} & -6.586140 & -0.568743 & 0.533342 \\ \mathrm{C} & -7.997147 & -0.831335 & 0.384186 \\ \mathrm{H} & -8.307198 & -1.633317 & 1.057773 \\ \mathrm{H} & -8.220558 & -1.116326 & -0.646110 \\ \mathrm{H} & -8.488767 & 0.105179 & 0.645599 \\ \mathrm{H} & -1.774849 & 0.581392 & 0.909766 \\ \mathrm{H} & -1.988112 & -0.924458 & -0.086332 \\ \mathrm{C} & -4.322971 & 0.707882 & 1.856544 \\ \mathrm{C} & -5.118267 & 0.240511 & 2.920007 \\ \mathrm{C} & -3.990214 & 2.074072 & 1.792693 \\ \mathrm{C} & -5.574209 & 1.121486 & 3.894277 \\ \mathrm{H} & -5.345125 & -0.817528 & 3.001521 \\ \mathrm{C} & -4.475090 & 2.953301 & 2.757632 \\ \mathrm{H} & -3.376356 & 2.448836 & 0.979180 \\ \mathrm{C} & -5.262043 & 2.481482 & 3.810432 \\ \mathrm{H} & -6.168948 & 0.747571 & 4.722715 \\ \mathrm{H} & -4.227200 & 4.008492 & 2.691125 \\ \mathrm{H} & -5.622535 & 3.168762 & 4.570822 \\ \mathrm{H} & -6.581479 & 1.354748 & -1.447769\end{array}$

Catalyst (R)-1 TS Conformation 367

B3LYP/6-31G(d) Energy $=-2809.684189$

B3LYP-D3(BJ)/def2-TZVPP-IEF-PCM(DCM) Energy = -2810.977308

B3LYP-D3(BJ)/def2-TZVPP-IEF-PCM(DCM)//B3LYP/6-31G(d) Free Energy (Quasiharmonic) = 2810.333627

Frequencies (Top 3 out of 270)

1. $-278.0273 \mathrm{~cm}-1$

2. $\quad 6.5212 \mathrm{~cm}-1$

3. $\quad 12.7066 \mathrm{~cm}-1$ 
B3LYP/6-31G(d) Molecular Geometry in Cartesian Coordinates

\begin{tabular}{|c|c|c|c|}
\hline C & 2.995233 & -1.221980 & -0.182991 \\
\hline C & 1.798625 & -1.778543 & 0.242400 \\
\hline C & 1.397877 & -3.109447 & -0.076554 \\
\hline C & 2.222021 & -3.836871 & -0.912946 \\
\hline $\mathrm{H}$ & 1.959883 & -4.863860 & -1.152815 \\
\hline C & 4.131152 & 2.784284 & 0.925280 \\
\hline C & 3.397770 & 0.141831 & 0.275213 \\
\hline C & 2.549705 & 1.215209 & 0.052543 \\
\hline C & 2.898890 & 2.568945 & 0.336381 \\
\hline $\mathrm{H}$ & 4.449693 & 3.803187 & 1.127635 \\
\hline 0 & 0.952259 & -1.029392 & 1.054584 \\
\hline$P$ & 0.165513 & 0.265340 & 0.447342 \\
\hline 0 & 1.306346 & 0.953181 & -0.510743 \\
\hline C & -2.036446 & -5.135349 & 1.543710 \\
\hline C & -1.223944 & -4.360829 & 2.375982 \\
\hline C & -0.134615 & -3.665290 & 1.852004 \\
\hline C & 0.171351 & -3.738773 & 0.482159 \\
\hline C & -0.661971 & -4.507678 & -0.346778 \\
\hline C & -1.752060 & -5.202320 & 0.178573 \\
\hline $\mathrm{H}$ & -1.426031 & -4.312164 & 3.443309 \\
\hline $\mathrm{H}$ & -2.372410 & -5.804509 & -0.480882 \\
\hline C & 0.482986 & 5.995193 & -0.632061 \\
\hline C & 1.160058 & 5.925689 & 0.586533 \\
\hline C & 1.913360 & 4.797021 & 0.904032 \\
\hline C & 2.013468 & 3.718224 & 0.008764 \\
\hline C & 1.313256 & 3.795413 & -1.207799 \\
\hline C & 0.555095 & 4.922346 & -1.523543 \\
\hline $\mathrm{H}$ & 1.098006 & 6.747444 & 1.295415 \\
\hline $\mathrm{H}$ & 0.016017 & 4.957333 & -2.465891 \\
\hline C & 4.638185 & 0.376591 & 0.960928 \\
\hline C & 5.002906 & 1.725145 & 1.276965 \\
\hline C & 6.232676 & 1.976264 & 1.944280 \\
\hline C & 7.060076 & 0.942585 & 2.316592 \\
\hline C & 6.684784 & -0.392800 & 2.037923 \\
\hline C & 5.508228 & -0.668581 & 1.376410 \\
\hline $\mathrm{H}$ & 6.500454 & 3.006589 & 2.166405 \\
\hline $\mathrm{H}$ & 7.994039 & 1.146538 & 2.833058 \\
\hline $\mathrm{H}$ & 7.328750 & -1.209630 & 2.352552 \\
\hline $\mathrm{H}$ & 5.230699 & -1.697449 & 1.177987 \\
\hline C & 3.804546 & -1.965842 & -1.111115 \\
\hline C & 3.406167 & -3.294469 & -1.467396 \\
\hline
\end{tabular}




\begin{tabular}{|c|c|c|c|}
\hline C & 4.201620 & -4.044248 & -2.375752 \\
\hline C & 5.331112 & -3.500915 & -2.941568 \\
\hline C & 5.706636 & -2.174981 & -2.622232 \\
\hline C & 4.966520 & -1.428957 & -1.731443 \\
\hline $\mathrm{H}$ & 3.889423 & -5.055754 & -2.624720 \\
\hline $\mathrm{H}$ & 5.927688 & -4.080173 & -3.640917 \\
\hline $\mathrm{H}$ & 6.585279 & -1.737493 & -3.088467 \\
\hline $\mathrm{H}$ & 5.263490 & -0.411284 & -1.507624 \\
\hline $\mathrm{O}$ & -0.373258 & 1.119560 & 1.524843 \\
\hline $\mathrm{O}$ & -0.831684 & -0.327015 & -0.617640 \\
\hline $\mathrm{H}$ & -1.377666 & 0.411383 & -1.111562 \\
\hline $\mathrm{H}$ & -0.457689 & -4.550227 & -1.412568 \\
\hline $\mathrm{H}$ & -2.878613 & -5.684559 & 1.956696 \\
\hline $\mathrm{H}$ & 0.494727 & -3.076066 & 2.509948 \\
\hline $\mathrm{H}$ & 1.367183 & 2.974444 & -1.913315 \\
\hline $\mathrm{H}$ & -0.094652 & 6.880331 & -0.887272 \\
\hline $\mathrm{H}$ & 2.416073 & 4.739329 & 1.865221 \\
\hline C & -2.766851 & 2.243880 & -0.824032 \\
\hline $\mathrm{O}$ & -2.214699 & 1.500816 & -1.726410 \\
\hline $\mathrm{H}$ & -2.444935 & 2.128006 & 0.220434 \\
\hline C & -2.985234 & 3.715299 & -1.201091 \\
\hline $\mathrm{O}$ & -2.916887 & 4.167071 & -2.319262 \\
\hline $\mathrm{O}$ & -3.276022 & 4.436747 & -0.097344 \\
\hline C & -3.476978 & 5.842930 & -0.313010 \\
\hline $\mathrm{H}$ & -4.266963 & 6.010926 & -1.050113 \\
\hline $\mathrm{H}$ & -3.759716 & 6.250805 & 0.657801 \\
\hline C & -4.592477 & 0.400993 & -0.472696 \\
\hline C & -4.621418 & 1.804247 & -0.645987 \\
\hline $\mathrm{H}$ & -3.508520 & 0.261063 & -2.156909 \\
\hline$N$ & -4.138037 & -0.291694 & -1.546842 \\
\hline C & -4.170496 & -1.664781 & -1.848131 \\
\hline $\mathrm{O}$ & -3.449137 & -2.154038 & -2.684544 \\
\hline $\mathrm{O}$ & -5.137184 & -2.296509 & -1.168402 \\
\hline C & -5.218056 & -3.713386 & -1.411510 \\
\hline $\mathrm{H}$ & -6.069897 & -4.054747 & -0.823708 \\
\hline $\mathrm{H}$ & -4.299112 & -4.203124 & -1.080734 \\
\hline $\mathrm{H}$ & -5.375647 & -3.908290 & -2.474697 \\
\hline $\mathrm{H}$ & -4.965215 & 2.394294 & 0.196852 \\
\hline $\mathrm{H}$ & -4.945032 & 2.157352 & -1.622767 \\
\hline C & -4.790882 & -0.217624 & 0.845141 \\
\hline C & -3.883293 & -1.175054 & 1.335185 \\
\hline C & -5.850630 & 0.213594 & 1.661678 \\
\hline C & -4.041515 & -1.686826 & 2.618847 \\
\hline $\mathrm{H}$ & -3.027874 & -1.470794 & 0.735609 \\
\hline
\end{tabular}




$\begin{array}{lrrr}\text { C } & -6.016406 & -0.321118 & 2.936274 \\ \text { H } & -6.556850 & 0.945696 & 1.281314 \\ \text { C } & -5.110426 & -1.269428 & 3.416731 \\ \text { H } & -3.321211 & -2.406397 & 2.994351 \\ \text { H } & -6.847545 & 0.004534 & 3.555037 \\ \text { H } & -5.231987 & -1.676530 & 4.416842 \\ \text { H } & -2.551759 & 6.304629 & -0.665744\end{array}$

Catalyst (R)-1 TS Conformation 368

B3LYP/6-31G(d) Energy $=-2809.683605$

B3LYP-D3(BJ)/def2-TZVPP-IEF-PCM(DCM) Energy $=-2810.975725$

B3LYP-D3(BJ)/def2-TZVPP-IEF-PCM(DCM)//B3LYP/6-31G(d) Free Energy (Quasiharmonic) = 2810.3335

Frequencies (Top 3 out of 270)

1. $-555.8789 \mathrm{~cm}-1$

2. $\quad 6.5277 \mathrm{~cm}-1$

3. $10.1992 \mathrm{~cm}-1$

B3LYP/6-31G(d) Molecular Geometry in Cartesian Coordinates

$\begin{array}{llll}\text { C } & 3.614990 & -0.986420 & 0.024415 \\ \text { C } & 2.397335 & -1.609096 & 0.241796 \\ \text { C } & 2.190514 & -3.011935 & 0.093715 \\ \text { C } & 3.269180 & -3.769702 & -0.316821 \\ \text { H } & 3.155294 & -4.846151 & -0.416198 \\ \text { C } & 4.084024 & 3.273060 & 0.473972 \\ \text { C } & 3.741944 & 0.482292 & 0.264351 \\ \text { C } & 2.885639 & 1.371434 & -0.375019 \\ \text { C } & 3.064992 & 2.788110 & -0.322959 \\ \text { H } & 4.235829 & 4.347364 & 0.538031 \\ \text { O } & 1.319665 & -0.825107 & 0.626348 \\ \text { P } & 0.594456 & 0.073670 & -0.548136 \\ \text { O } & 1.875590 & 0.879289 & -1.186577 \\ \text { C } & -1.598358 & -4.924046 & 0.811622 \\ \text { C } & -1.101088 & -3.996169 & 1.730036 \\ \text { C } & 0.118940 & -3.361445 & 1.500788 \\ \text { C } & 0.868941 & -3.645302 & 0.346479 \\ \text { C } & 0.355569 & -4.577487 & -0.569759 \\ \text { C } & -0.865285 & -5.211401 & -0.340284 \\ \text { H } & -1.663011 & -3.766336 & 2.631625 \\ & & & \end{array}$




\begin{tabular}{|c|c|c|c|}
\hline $\mathrm{H}$ & -1.247713 & -5.921542 & -1.068712 \\
\hline C & 0.791275 & 5.652188 & -2.595099 \\
\hline C & 2.186114 & 5.659016 & -2.629443 \\
\hline C & 2.906617 & 4.712707 & -1.901286 \\
\hline C & 2.249439 & 3.741379 & -1.127294 \\
\hline C & 0.845433 & 3.740388 & -1.102810 \\
\hline C & 0.128559 & 4.690725 & -1.829764 \\
\hline $\mathrm{H}$ & 2.715789 & 6.396167 & -3.227645 \\
\hline $\mathrm{H}$ & -0.958172 & 4.679947 & -1.794068 \\
\hline C & 4.733481 & 1.007115 & 1.163742 \\
\hline C & 4.906611 & 2.425279 & 1.253999 \\
\hline C & 5.886831 & 2.956160 & 2.135782 \\
\hline C & 6.654970 & 2.128592 & 2.921141 \\
\hline C & 6.463992 & 0.728034 & 2.859585 \\
\hline C & 5.531522 & 0.182513 & 2.004729 \\
\hline $\mathrm{H}$ & 6.009069 & 4.035786 & 2.184383 \\
\hline $\mathrm{H}$ & 7.397699 & 2.545737 & 3.595798 \\
\hline $\mathrm{H}$ & 7.054397 & 0.075708 & 3.497535 \\
\hline $\mathrm{H}$ & 5.390333 & -0.891786 & 1.978494 \\
\hline C & 4.707701 & -1.776550 & -0.476244 \\
\hline C & 4.524356 & -3.190038 & -0.627033 \\
\hline C & 5.599372 & -3.986377 & -1.106978 \\
\hline C & 6.800556 & -3.416980 & -1.459931 \\
\hline C & 6.970659 & -2.016861 & -1.352738 \\
\hline C & 5.954381 & -1.219470 & -0.873695 \\
\hline $\mathrm{H}$ & 5.446171 & -5.058810 & -1.203115 \\
\hline $\mathrm{H}$ & 7.612537 & -4.035335 & -1.832851 \\
\hline $\mathrm{H}$ & 7.910685 & -1.564004 & -1.656493 \\
\hline $\mathrm{H}$ & 6.098629 & -0.147545 & -0.808548 \\
\hline 0 & -0.410359 & 0.947680 & 0.134471 \\
\hline O & 0.138958 & -0.827553 & -1.696222 \\
\hline $\mathrm{H}$ & -1.055961 & -1.241926 & -1.735753 \\
\hline $\mathrm{H}$ & 0.908462 & -4.783741 & -1.481664 \\
\hline $\mathrm{H}$ & -2.549966 & -5.417681 & 0.991840 \\
\hline $\mathrm{H}$ & 0.497147 & -2.643914 & 2.220774 \\
\hline $\mathrm{H}$ & 0.316079 & 3.002883 & -0.508971 \\
\hline $\mathrm{H}$ & 0.226020 & 6.387617 & -3.162038 \\
\hline $\mathrm{H}$ & 3.992514 & 4.710622 & -1.944796 \\
\hline C & -2.778885 & -1.161010 & -0.706907 \\
\hline 0 & -2.150705 & -1.604672 & -1.744104 \\
\hline $\mathrm{H}$ & -2.199212 & -0.865908 & 0.170936 \\
\hline C & -4.100549 & -1.840377 & -0.400562 \\
\hline 0 & -4.952813 & -2.121150 & -1.215959 \\
\hline $\mathrm{O}$ & -4.188423 & -2.056115 & 0.920826 \\
\hline
\end{tabular}




$\begin{array}{llll}\mathrm{C} & -5.395153 & -2.691543 & 1.390581 \\ \mathrm{H} & -6.223524 & -1.980435 & 1.354457 \\ \mathrm{H} & -5.623606 & -3.567600 & 0.779690 \\ \mathrm{C} & -4.493503 & 1.077825 & -0.470223 \\ \mathrm{C} & -3.366217 & 0.666986 & -1.207526 \\ \mathrm{H} & -5.672879 & 0.501851 & -2.012678 \\ \mathrm{~N} & -5.716332 & 0.791075 & -1.041117 \\ \mathrm{C} & -6.902720 & 0.350931 & -0.429134 \\ \mathrm{O} & -7.106287 & 0.226313 & 0.756253 \\ \mathrm{O} & -7.780850 & 0.083686 & -1.410203 \\ \mathrm{C} & -9.036327 & -0.471849 & -0.977243 \\ \mathrm{H} & -8.877042 & -1.451135 & -0.519371 \\ \mathrm{H} & -9.633958 & -0.566631 & -1.883202 \\ \mathrm{H} & -9.520462 & 0.194028 & -0.259497 \\ \mathrm{H} & -2.414178 & 1.153286 & -1.016298 \\ \mathrm{H} & -3.548493 & 0.392298 & -2.242997 \\ \mathrm{C} & -4.395991 & 1.778785 & 0.809477 \\ \mathrm{C} & -5.458523 & 2.569745 & 1.296788 \\ \mathrm{C} & -3.181482 & 1.751928 & 1.530715 \\ \mathrm{C} & -5.319848 & 3.287747 & 2.477243 \\ \mathrm{H} & -6.382652 & 2.645579 & 0.738466 \\ \mathrm{C} & -3.059355 & 2.461956 & 2.720718 \\ \mathrm{H} & -2.318870 & 1.208341 & 1.158852 \\ \mathrm{C} & -4.125035 & 3.225877 & 3.200625 \\ \mathrm{H} & -6.143337 & 3.899978 & 2.832816 \\ \mathrm{H} & -2.119952 & 2.426313 & 3.263748 \\ \mathrm{H} & -4.021485 & 3.784991 & 4.126585 \\ \mathrm{H} & -5.186610 & -2.979810 & 2.420766\end{array}$

Catalyst (R)-1 TS Conformation 369

B3LYP/6-31G(d) Energy $=-2809.682651$

B3LYP-D3(BJ)/def2-TZVPP-IEF-PCM(DCM) Energy $=-2810.97533$

B3LYP-D3(BJ)/def2-TZVPP-IEF-PCM(DCM)//B3LYP/6-31G(d) Free Energy (Quasiharmonic) = 2810.333195

Frequencies (Top 3 out of 270)

1. $-543.1499 \mathrm{~cm}-1$

2. $\quad 7.9761 \mathrm{~cm}-1$

3. $\quad 9.0520 \mathrm{~cm}-1$

B3LYP/6-31G(d) Molecular Geometry in Cartesian Coordinates 


\begin{tabular}{|c|c|c|c|}
\hline C & 3.775339 & 0.492269 & 0.284318 \\
\hline C & 2.831109 & 1.456413 & -0.037970 \\
\hline C & 2.928603 & 2.819529 & 0.370217 \\
\hline C & 4.000300 & 3.166071 & 1.169277 \\
\hline $\mathrm{H}$ & 4.119049 & 4.201591 & 1.477484 \\
\hline C & 3.259743 & -3.549408 & -1.145164 \\
\hline C & 3.629218 & -0.894550 & -0.253282 \\
\hline C & 2.448081 & -1.587303 & -0.032654 \\
\hline C & 2.234968 & -2.933360 & -0.453882 \\
\hline $\mathrm{H}$ & 3.141796 & -4.583282 & -1.459347 \\
\hline O & 1.744096 & 1.096740 & -0.822434 \\
\hline$P$ & 0.548120 & 0.183666 & -0.175441 \\
\hline $\mathrm{O}$ & 1.425158 & -0.944664 & 0.647362 \\
\hline C & 0.117009 & 5.869748 & -0.779305 \\
\hline C & 0.604822 & 4.974476 & -1.734632 \\
\hline C & 1.498296 & 3.968617 & -1.368135 \\
\hline C & 1.928286 & 3.842940 & -0.036420 \\
\hline C & 1.428024 & 4.747405 & 0.914148 \\
\hline C & 0.531149 & 5.750398 & 0.547945 \\
\hline $\mathrm{H}$ & 0.297581 & 5.064314 & -2.773758 \\
\hline $\mathrm{H}$ & 0.150737 & 6.433756 & 1.302731 \\
\hline C & -1.427785 & -5.076856 & 0.277518 \\
\hline C & -0.830272 & -4.346200 & 1.308520 \\
\hline C & 0.351705 & -3.641859 & 1.080130 \\
\hline C & 0.959997 & -3.651958 & -0.187404 \\
\hline C & 0.349505 & -4.391322 & -1.213003 \\
\hline C & -0.830883 & -5.098560 & -0.983644 \\
\hline $\mathrm{H}$ & -1.288152 & -4.326624 & 2.293871 \\
\hline $\mathrm{H}$ & -1.288061 & -5.658587 & -1.795485 \\
\hline C & 4.655756 & -1.523616 & -1.038442 \\
\hline C & 4.463588 & -2.876786 & -1.469834 \\
\hline C & 5.476867 & -3.515869 & -2.234853 \\
\hline C & 6.622852 & -2.845369 & -2.593715 \\
\hline C & 6.797416 & -1.496634 & -2.204101 \\
\hline C & 5.842161 & -0.854177 & -1.447386 \\
\hline $\mathrm{H}$ & 5.319911 & -4.546962 & -2.543067 \\
\hline $\mathrm{H}$ & 7.387171 & -3.342511 & -3.184768 \\
\hline $\mathrm{H}$ & 7.691798 & -0.959802 & -2.508822 \\
\hline $\mathrm{H}$ & 5.987291 & 0.182176 & -1.165518 \\
\hline C & 4.842931 & 0.853323 & 1.177260 \\
\hline C & 4.954424 & 2.215458 & 1.607855 \\
\hline C & 6.012468 & 2.587505 & 2.481013 \\
\hline C & 6.910680 & 1.654349 & 2.943674 \\
\hline
\end{tabular}




\begin{tabular}{|c|c|c|c|}
\hline C & 6.779491 & 0.301105 & 2.552903 \\
\hline C & 5.775552 & -0.088387 & 1.693618 \\
\hline $\mathrm{H}$ & 6.088958 & 3.628232 & 2.787280 \\
\hline $\mathrm{H}$ & 7.711107 & 1.949570 & 3.616617 \\
\hline $\mathrm{H}$ & 7.474335 & -0.440287 & 2.938268 \\
\hline $\mathrm{H}$ & 5.683537 & -1.131080 & 1.412932 \\
\hline 0 & -0.302395 & -0.366176 & -1.261023 \\
\hline $\mathrm{O}$ & -0.111033 & 0.991243 & 0.965819 \\
\hline $\mathrm{H}$ & -1.203247 & 0.752268 & 1.216173 \\
\hline $\mathrm{H}$ & 1.728907 & 4.644967 & 1.952921 \\
\hline $\mathrm{H}$ & -0.579181 & 6.653341 & -1.067306 \\
\hline $\mathrm{H}$ & 1.871268 & 3.280279 & -2.118493 \\
\hline $\mathrm{H}$ & 0.792371 & -4.387363 & -2.204878 \\
\hline $\mathrm{H}$ & -2.349415 & -5.623142 & 0.459890 \\
\hline $\mathrm{H}$ & 0.810843 & -3.082848 & 1.888342 \\
\hline C & -2.698651 & -0.768573 & 1.326349 \\
\hline $\mathrm{O}$ & -2.422637 & 0.482937 & 1.485332 \\
\hline $\mathrm{H}$ & -1.864692 & -1.488169 & 1.316719 \\
\hline C & -3.867177 & -1.353808 & 2.125490 \\
\hline $\mathrm{O}$ & -4.165502 & -2.535087 & 2.099113 \\
\hline $\mathrm{O}$ & -4.521319 & -0.432102 & 2.838606 \\
\hline C & -5.607076 & -0.932341 & 3.645402 \\
\hline $\mathrm{H}$ & -5.249039 & -1.709826 & 4.324253 \\
\hline $\mathrm{H}$ & -5.969077 & -0.069617 & 4.204689 \\
\hline C & -4.400202 & -0.579237 & -0.775217 \\
\hline C & -3.210642 & -1.261226 & -0.426299 \\
\hline $\mathrm{H}$ & -5.505159 & -2.127082 & -0.070252 \\
\hline$N$ & -5.586377 & -1.168443 & -0.398000 \\
\hline C & -6.798936 & -0.623359 & 0.076866 \\
\hline $\mathrm{O}$ & -7.648346 & -1.344666 & 0.554494 \\
\hline $\mathrm{O}$ & -6.867718 & 0.701438 & -0.032525 \\
\hline C & -8.078894 & 1.296764 & 0.474842 \\
\hline $\mathrm{H}$ & -7.972717 & 2.362576 & 0.276962 \\
\hline $\mathrm{H}$ & -8.170784 & 1.109334 & 1.546917 \\
\hline $\mathrm{H}$ & -8.949327 & 0.887322 & -0.042466 \\
\hline $\mathrm{H}$ & -2.311009 & -0.998741 & -0.979882 \\
\hline $\mathrm{H}$ & -3.317080 & -2.326503 & -0.228067 \\
\hline C & -4.371758 & 0.685059 & -1.504632 \\
\hline C & -5.384338 & 1.015559 & -2.430860 \\
\hline C & -3.263643 & 1.543876 & -1.360844 \\
\hline C & -5.292274 & 2.179203 & -3.181300 \\
\hline $\mathrm{H}$ & -6.218585 & 0.339594 & -2.584266 \\
\hline C & -3.200361 & 2.729188 & -2.089293 \\
\hline $\mathrm{H}$ & -2.473257 & 1.297503 & -0.665984 \\
\hline
\end{tabular}




$\begin{array}{llll}\mathrm{C} & -4.206813 & 3.045630 & -3.002223 \\ \mathrm{H} & -6.062582 & 2.412929 & -3.910681 \\ \mathrm{H} & -2.350233 & 3.391032 & -1.952955 \\ \mathrm{H} & -4.141654 & 3.958053 & -3.588936 \\ \mathrm{H} & -6.396809 & -1.344369 & 3.011437\end{array}$

Catalyst (R)-1 TS Conformation 370

B3LYP/6-31G(d) Energy $=-2809.683203$

B3LYP-D3(BJ)/def2-TZVPP-IEF-PCM(DCM) Energy = -2810.975153

B3LYP-D3(BJ)/def2-TZVPP-IEF-PCM(DCM)//B3LYP/6-31G(d) Free Energy (Quasiharmonic) = 2810.333005

Frequencies (Top 3 out of 270)

1. $-565.7452 \mathrm{~cm}-1$

2. $\quad 5.8176 \mathrm{~cm}-1$

3. $\quad 7.3662 \mathrm{~cm}-1$

B3LYP/6-31G(d) Molecular Geometry in Cartesian Coordinates

$\begin{array}{llll}\text { C } & -3.928160 & 0.229554 & -0.130820 \\ \text { C } & -3.114924 & 1.281130 & 0.267738 \\ \text { C } & -3.517313 & 2.648662 & 0.203338 \\ \text { C } & -4.762165 & 2.918493 & -0.330962 \\ \text { H } & -5.109663 & 3.947597 & -0.370169 \\ \text { C } & -2.485787 & -3.823107 & 0.222155 \\ \text { C } & -3.451525 & -1.175402 & 0.042783 \\ \text { C } & -2.234129 & -1.551047 & -0.505691 \\ \text { C } & -1.728897 & -2.884373 & -0.451468 \\ \text { H } & -2.143626 & -4.854221 & 0.258715 \\ \text { O } & -1.860785 & 0.996383 & 0.784411 \\ \text { P } & -0.661090 & 0.502390 & -0.228196 \\ \text { O } & -1.477015 & -0.591324 & -1.156449 \\ \text { C } & -1.124362 & 5.935407 & 1.614129 \\ \text { C } & -1.253192 & 4.782561 & 2.391657 \\ \text { C } & -2.006339 & 3.702876 & 1.933722 \\ \text { C } & -2.652380 & 3.757734 & 0.687171 \\ \text { C } & -2.511072 & 4.920964 & -0.086703 \\ \text { C } & -1.754911 & 5.999414 & 0.371064 \\ \text { H } & -0.766997 & 4.722896 & 3.362133 \\ \text { H } & -1.652127 & 6.886154 & -0.249157 \\ \text { C } & 1.967446 & -4.115508 & -2.283617\end{array}$




\begin{tabular}{|c|c|c|c|}
\hline C & 1.657583 & -4.505061 & -0.979824 \\
\hline C & 0.466195 & -4.085724 & -0.388211 \\
\hline C & -0.439688 & -3.269651 & -1.085338 \\
\hline C & -0.112272 & -2.878384 & -2.395050 \\
\hline C & 1.077427 & -3.300198 & -2.986919 \\
\hline $\mathrm{H}$ & 2.345910 & -5.131217 & -0.417870 \\
\hline $\mathrm{H}$ & 1.305642 & -2.995123 & -4.005126 \\
\hline C & -4.190648 & -2.145495 & 0.803168 \\
\hline C & -3.698180 & -3.489351 & 0.874308 \\
\hline C & -4.426485 & -4.461646 & 1.612301 \\
\hline C & -5.578058 & -4.124573 & 2.284633 \\
\hline C & -6.045288 & -2.789643 & 2.249671 \\
\hline C & -5.372071 & -1.827842 & 1.528813 \\
\hline $\mathrm{H}$ & -4.045161 & -5.479743 & 1.644443 \\
\hline $\mathrm{H}$ & -6.122553 & -4.875215 & 2.851067 \\
\hline $\mathrm{H}$ & -6.941930 & -2.518603 & 2.800654 \\
\hline $\mathrm{H}$ & -5.738298 & -0.807870 & 1.519818 \\
\hline C & -5.188664 & 0.532159 & -0.751924 \\
\hline C & -5.607022 & 1.899834 & -0.835207 \\
\hline C & -6.856805 & 2.212665 & -1.435586 \\
\hline C & -7.655168 & 1.226002 & -1.965523 \\
\hline C & -7.226849 & -0.121536 & -1.920988 \\
\hline C & -6.028847 & -0.459253 & -1.330417 \\
\hline $\mathrm{H}$ & -7.163573 & 3.255192 & -1.478776 \\
\hline $\mathrm{H}$ & -8.605340 & 1.478332 & -2.428422 \\
\hline $\mathrm{H}$ & -7.846264 & -0.898165 & -2.361728 \\
\hline $\mathrm{H}$ & -5.711328 & -1.495358 & -1.314666 \\
\hline $\mathrm{O}$ & 0.419485 & -0.107080 & 0.601485 \\
\hline $\mathrm{O}$ & -0.310617 & 1.617124 & -1.213479 \\
\hline $\mathrm{H}$ & 0.906768 & 1.915303 & -1.387277 \\
\hline $\mathrm{H}$ & -2.980012 & 4.966862 & -1.065550 \\
\hline $\mathrm{H}$ & -0.533470 & 6.774470 & 1.972375 \\
\hline $\mathrm{H}$ & -2.100429 & 2.812869 & 2.546160 \\
\hline $\mathrm{H}$ & -0.796217 & -2.246691 & -2.950864 \\
\hline $\mathrm{H}$ & 2.893606 & -4.444351 & -2.748361 \\
\hline $\mathrm{H}$ & 0.240779 & -4.373809 & 0.634677 \\
\hline C & 2.726902 & 1.711144 & -0.544409 \\
\hline $\mathrm{O}$ & 2.021575 & 2.186787 & -1.517461 \\
\hline $\mathrm{H}$ & 2.215417 & 1.431046 & 0.379143 \\
\hline C & 4.096778 & 2.339371 & -0.367700 \\
\hline $\mathrm{O}$ & 4.887838 & 2.570788 & -1.257378 \\
\hline $\mathrm{O}$ & 4.301185 & 2.581722 & 0.935924 \\
\hline C & 5.564478 & 3.181225 & 1.290526 \\
\hline $\mathrm{H}$ & 5.773584 & 4.034311 & 0.641378 \\
\hline
\end{tabular}




$\begin{array}{llll}\mathrm{H} & 6.360386 & 2.437965 & 1.204850 \\ \mathrm{C} & 4.373953 & -0.588953 & -0.454184 \\ \mathrm{C} & 3.203200 & -0.139361 & -1.093477 \\ \mathrm{H} & 5.439497 & -0.053574 & -2.091060 \\ \mathrm{~N} & 5.554417 & -0.345539 & -1.126247 \\ \mathrm{C} & 6.799011 & 0.059945 & -0.614730 \\ \mathrm{O} & 7.101811 & 0.183067 & 0.549447 \\ \mathrm{O} & 7.603563 & 0.295582 & -1.665215 \\ \mathrm{C} & 8.904513 & 0.816816 & -1.337728 \\ \mathrm{H} & 8.810237 & 1.803366 & -0.877391 \\ \mathrm{H} & 9.431161 & 0.888333 & -2.288806 \\ \mathrm{H} & 9.424956 & 0.141977 & -0.654551 \\ \mathrm{H} & 2.259074 & -0.598915 & -0.819792 \\ \mathrm{H} & 3.304529 & 0.130124 & -2.141289 \\ \mathrm{C} & 4.362230 & -1.286213 & 0.831303 \\ \mathrm{C} & 3.218636 & -1.212707 & 1.657188 \\ \mathrm{C} & 5.434523 & -2.114768 & 1.225639 \\ \mathrm{C} & 3.179004 & -1.914767 & 2.857807 \\ \mathrm{H} & 2.347457 & -0.636091 & 1.362769 \\ \mathrm{C} & 5.376380 & -2.824855 & 2.417473 \\ \mathrm{H} & 6.301502 & -2.225238 & 0.586932 \\ \mathrm{C} & 4.254460 & -2.716490 & 3.244857 \\ \mathrm{H} & 2.294914 & -1.841063 & 3.483678 \\ \mathrm{H} & 6.205933 & -3.465638 & 2.701711 \\ \mathrm{H} & 4.214807 & -3.267855 & 4.180479 \\ \mathrm{H} & 5.450841 & 3.500186 & 2.326460\end{array}$

Catalyst (R)-1 TS Conformation 371

B3LYP/6-31G(d) Energy $=-2809.679293$

B3LYP-D3(BJ)/def2-TZVPP-IEF-PCM(DCM) Energy = -2810.975002

B3LYP-D3(BJ)/def2-TZVPP-IEF-PCM(DCM)//B3LYP/6-31G(d) Free Energy (Quasiharmonic) = 2810.333001

Frequencies (Top 3 out of 270)

1. $-563.5712 \mathrm{~cm}-1$

2. $\quad 8.8650 \mathrm{~cm}-1$

3. $\quad 13.4930 \mathrm{~cm}-1$

B3LYP/6-31G(d) Molecular Geometry in Cartesian Coordinates

$\begin{array}{llll}\text { C } & 3.605789 & -0.070622 & 0.447825\end{array}$ 


\begin{tabular}{|c|c|c|c|}
\hline C & 3.298373 & 1.037137 & -0.327274 \\
\hline C & 3.766482 & 2.353629 & -0.038380 \\
\hline C & 4.522518 & 2.516472 & 1.106069 \\
\hline $\mathrm{H}$ & 4.920591 & 3.499864 & 1.342031 \\
\hline C & 2.177003 & -4.010880 & -0.564516 \\
\hline C & 3.149175 & -1.425335 & 0.016462 \\
\hline C & 1.802087 & -1.655709 & -0.235273 \\
\hline C & 1.284706 & -2.959562 & -0.503937 \\
\hline $\mathrm{H}$ & 1.803442 & -5.011629 & -0.766712 \\
\hline $\mathrm{O}$ & 2.513234 & 0.855283 & -1.456684 \\
\hline$P$ & 0.902985 & 0.620208 & -1.246607 \\
\hline $\mathrm{O}$ & 0.905369 & -0.610236 & -0.124487 \\
\hline C & 3.012461 & 5.785991 & -2.521454 \\
\hline C & 2.869073 & 5.867289 & -1.135840 \\
\hline C & 3.095525 & 4.743956 & -0.341766 \\
\hline C & 3.470203 & 3.517699 & -0.914982 \\
\hline C & 3.604494 & 3.447333 & -2.311833 \\
\hline C & 3.379780 & 4.571573 & -3.104406 \\
\hline $\mathrm{H}$ & 2.571037 & 6.803686 & -0.671100 \\
\hline $\mathrm{H}$ & 3.492776 & 4.496940 & -4.182814 \\
\hline C & -2.895878 & -3.860379 & -1.044892 \\
\hline C & -2.163319 & -4.463227 & -0.017362 \\
\hline C & -0.814614 & -4.151103 & 0.156800 \\
\hline C & -0.171948 & -3.226252 & -0.683379 \\
\hline C & -0.913612 & -2.621100 & -1.711780 \\
\hline C & -2.262515 & -2.940257 & -1.889455 \\
\hline $\mathrm{H}$ & -2.642072 & -5.179331 & 0.645606 \\
\hline $\mathrm{H}$ & -2.819066 & -2.466408 & -2.694307 \\
\hline C & 4.078568 & -2.508336 & -0.160123 \\
\hline C & 3.574306 & -3.820232 & -0.435044 \\
\hline C & 4.482813 & -4.900943 & -0.597441 \\
\hline C & 5.841243 & -4.700547 & -0.520392 \\
\hline C & 6.345329 & -3.399681 & -0.284861 \\
\hline C & 5.489770 & -2.334695 & -0.108049 \\
\hline $\mathrm{H}$ & 4.079804 & -5.890900 & -0.798512 \\
\hline $\mathrm{H}$ & 6.527422 & -5.532526 & -0.653124 \\
\hline $\mathrm{H}$ & 7.419247 & -3.237133 & -0.249759 \\
\hline $\mathrm{H}$ & 5.893357 & -1.343116 & 0.060359 \\
\hline C & 4.324296 & 0.130814 & 1.677718 \\
\hline C & 4.796359 & 1.446286 & 1.992548 \\
\hline C & 5.519908 & 1.659276 & 3.197307 \\
\hline C & 5.744579 & 0.629409 & 4.080860 \\
\hline C & 5.243411 & -0.661745 & 3.793542 \\
\hline C & 4.554653 & -0.904675 & 2.625209 \\
\hline
\end{tabular}




\begin{tabular}{|c|c|c|c|}
\hline $\mathrm{H}$ & 5.882254 & 2.661848 & 3.412662 \\
\hline $\mathrm{H}$ & 6.293150 & 0.806203 & 5.002068 \\
\hline $\mathrm{H}$ & 5.399074 & -1.469974 & 4.503247 \\
\hline $\mathrm{H}$ & 4.169507 & -1.897892 & 2.426625 \\
\hline $\mathrm{O}$ & 0.285322 & 0.208774 & -2.537673 \\
\hline $\mathrm{O}$ & 0.312286 & 1.793574 & -0.455836 \\
\hline $\mathrm{H}$ & -0.857328 & 2.215910 & -0.743809 \\
\hline $\mathrm{H}$ & 3.889136 & 2.509867 & -2.776404 \\
\hline $\mathrm{H}$ & 2.833223 & 6.659524 & -3.142860 \\
\hline $\mathrm{H}$ & 2.957867 & 4.806721 & 0.734055 \\
\hline $\mathrm{H}$ & -0.436291 & -1.897028 & -2.365162 \\
\hline $\mathrm{H}$ & -3.945013 & -4.108643 & -1.187624 \\
\hline $\mathrm{H}$ & -0.250150 & -4.617514 & 0.959773 \\
\hline C & -2.515333 & 1.299180 & -1.250769 \\
\hline O & -1.977651 & 2.421108 & -0.900321 \\
\hline $\mathrm{H}$ & -1.903707 & 0.595561 & -1.824015 \\
\hline C & -3.966273 & 1.380063 & -1.680193 \\
\hline O & -4.706918 & 2.309899 & -1.466348 \\
\hline $\mathrm{O}$ & -4.308776 & 0.262176 & -2.358920 \\
\hline C & -5.643425 & 0.261276 & -2.900134 \\
\hline $\mathrm{H}$ & -5.735798 & 1.030562 & -3.671221 \\
\hline $\mathrm{H}$ & -6.373516 & 0.456947 & -2.111601 \\
\hline C & -3.778885 & -0.076674 & 0.893331 \\
\hline C & -2.488706 & 0.103616 & 0.366042 \\
\hline $\mathrm{H}$ & -3.906552 & -1.913580 & 0.024284 \\
\hline$N$ & -4.464777 & -1.189696 & 0.478614 \\
\hline C & -5.836093 & -1.453075 & 0.313520 \\
\hline 0 & -6.220441 & -2.539579 & -0.060942 \\
\hline 0 & -6.609159 & -0.394189 & 0.568626 \\
\hline C & -8.027438 & -0.629787 & 0.454046 \\
\hline $\mathrm{H}$ & -8.492391 & 0.323321 & 0.702530 \\
\hline $\mathrm{H}$ & -8.339758 & -1.409586 & 1.152425 \\
\hline $\mathrm{H}$ & -8.280592 & -0.933077 & -0.564147 \\
\hline $\mathrm{H}$ & -1.798252 & 0.711753 & 0.938111 \\
\hline $\mathrm{H}$ & -2.029784 & -0.762037 & -0.104219 \\
\hline C & -4.343538 & 0.842104 & 1.891405 \\
\hline C & -5.109884 & 0.345780 & 2.963478 \\
\hline C & -4.032925 & 2.213696 & 1.841773 \\
\hline C & -5.556525 & 1.203515 & 3.961986 \\
\hline $\mathrm{H}$ & -5.319672 & -0.716939 & 3.031954 \\
\hline C & -4.509180 & 3.069502 & 2.831588 \\
\hline $\mathrm{H}$ & -3.448422 & 2.612787 & 1.019167 \\
\hline C & -5.265456 & 2.569235 & 3.893393 \\
\hline $\mathrm{H}$ & -6.127941 & 0.807734 & 4.796683 \\
\hline
\end{tabular}




$\begin{array}{rrrr}\mathrm{H} & -4.281558 & 4.129648 & 2.774439 \\ \mathrm{H} & -5.620523 & 3.239206 & 4.671575 \\ \mathrm{H} & -5.785121 & -0.730607 & -3.328911\end{array}$

Catalyst (R)-1 TS Conformation 372

B3LYP/6-31G(d) Energy $=-2809.684267$

B3LYP-D3(BJ)/def2-TZVPP-IEF-PCM(DCM) Energy = -2810.976481

B3LYP-D3(BJ)/def2-TZVPP-IEF-PCM(DCM)//B3LYP/6-31G(d) Free Energy (Quasiharmonic) = 2810.332961

Frequencies (Top 3 out of 270)

1. $-273.6259 \mathrm{~cm}-1$

2. $\quad 7.3462 \mathrm{~cm}-1$

3. $\quad 9.1116 \mathrm{~cm}-1$

B3LYP/6-31G(d) Molecular Geometry in Cartesian Coordinates

$\begin{array}{llll}\text { C } & 3.124641 & -0.945109 & -0.340544 \\ \text { C } & 1.964842 & -1.633999 & -0.020254 \\ \text { C } & 1.698151 & -2.964690 & -0.453744 \\ \text { C } & 2.617090 & -3.554070 & -1.298898 \\ \text { H } & 2.452597 & -4.575944 & -1.630644 \\ \text { C } & 3.753297 & 3.025150 & 1.224839 \\ \text { C } & 3.369728 & 0.407895 & 0.242689 \\ \text { C } & 2.423422 & 1.405283 & 0.068172 \\ \text { C } & 2.591627 & 2.742728 & 0.532284 \\ \text { H } & 3.927067 & 4.039961 & 1.572905 \\ \text { O } & 1.010144 & -1.019161 & 0.786350 \\ \text { P } & 0.121096 & 0.206867 & 0.176648 \\ \text { O } & 1.255661 & 1.084752 & -0.617060 \\ \text { C } & -1.649446 & -5.331977 & 0.843451 \\ \text { C } & -1.350821 & -5.217204 & -0.515108 \\ \text { C } & -0.283804 & -4.420837 & -0.932574 \\ \text { C } & 0.501519 & -3.724194 & -0.001960 \\ \text { C } & 0.176935 & -3.828672 & 1.361834 \\ \text { C } & -0.884918 & -4.629272 & 1.779489 \\ \text { H } & -1.947590 & -5.744200 & -1.254489 \\ \text { H } & -1.104784 & -4.720169 & 2.840464 \\ \text { C } & -0.333931 & 5.837903 & -0.072276 \\ \text { C } & 0.034745 & 5.010538 & -1.135054 \\ \text { C } & 0.974304 & 3.998666 & -0.949019\end{array}$




\begin{tabular}{|c|c|c|c|}
\hline C & 1.566711 & 3.796026 & 0.308920 \\
\hline C & 1.193709 & 4.639177 & 1.367560 \\
\hline C & 0.252816 & 5.651009 & 1.179149 \\
\hline $\mathrm{H}$ & -0.417599 & 5.150851 & -2.112912 \\
\hline $\mathrm{H}$ & -0.033092 & 6.282281 & 2.016516 \\
\hline C & 4.538300 & 0.700035 & 1.026602 \\
\hline C & 4.728111 & 2.036763 & 1.506525 \\
\hline C & 5.885144 & 2.344500 & 2.272820 \\
\hline C & 6.807212 & 1.372931 & 2.585034 \\
\hline C & 6.602734 & 0.043912 & 2.145312 \\
\hline C & 5.500346 & -0.283551 & 1.386739 \\
\hline $\mathrm{H}$ & 6.019810 & 3.366572 & 2.619029 \\
\hline $\mathrm{H}$ & 7.684360 & 1.619210 & 3.177159 \\
\hline $\mathrm{H}$ & 7.319777 & -0.727775 & 2.412296 \\
\hline $\mathrm{H}$ & 5.354201 & -1.308384 & 1.065746 \\
\hline C & 4.039422 & -1.546416 & -1.273109 \\
\hline C & 3.774516 & -2.871984 & -1.747731 \\
\hline C & 4.674024 & -3.478130 & -2.666074 \\
\hline C & 5.777548 & -2.799736 & -3.128169 \\
\hline C & 6.021951 & -1.476875 & -2.690531 \\
\hline C & 5.178450 & -0.867595 & -1.787712 \\
\hline $\mathrm{H}$ & 4.463396 & -4.489238 & -3.006510 \\
\hline $\mathrm{H}$ & 6.454360 & -3.270551 & -3.835860 \\
\hline $\mathrm{H}$ & 6.880954 & -0.933130 & -3.074300 \\
\hline $\mathrm{H}$ & 5.374602 & 0.150156 & -1.471313 \\
\hline 0 & -0.621702 & 0.917238 & 1.238734 \\
\hline 0 & -0.694403 & -0.434590 & -1.004865 \\
\hline $\mathrm{H}$ & -1.443697 & 0.172302 & -1.384351 \\
\hline $\mathrm{H}$ & 0.772935 & -3.294988 & 2.094924 \\
\hline $\mathrm{H}$ & -2.465950 & -5.969469 & 1.173974 \\
\hline $\mathrm{H}$ & -0.064496 & -4.322816 & -1.991662 \\
\hline $\mathrm{H}$ & 1.623412 & 4.477118 & 2.352159 \\
\hline $\mathrm{H}$ & -1.082896 & 6.610792 & -0.218269 \\
\hline $\mathrm{H}$ & 1.252733 & 3.361388 & -1.781529 \\
\hline C & -2.963774 & 1.979675 & -1.111416 \\
\hline 0 & -2.572579 & 1.048530 & -1.919849 \\
\hline $\mathrm{H}$ & -2.376529 & 2.176570 & -0.204783 \\
\hline C & -3.457577 & 3.293175 & -1.724955 \\
\hline $\mathrm{O}$ & -3.415519 & 4.358038 & -1.146812 \\
\hline $\mathrm{O}$ & -3.947993 & 3.118209 & -2.964317 \\
\hline C & -4.415473 & 4.313053 & -3.611456 \\
\hline $\mathrm{H}$ & -3.598494 & 5.030408 & -3.725682 \\
\hline $\mathrm{H}$ & -5.217047 & 4.778819 & -3.031224 \\
\hline C & -4.466066 & 0.172966 & 0.113494 \\
\hline
\end{tabular}




$\begin{array}{lrrr}\mathrm{C} & -4.636319 & 1.521386 & -0.280168 \\ \mathrm{H} & -3.823163 & -0.243457 & -1.746291 \\ \mathrm{~N} & -4.272920 & -0.686566 & -0.921688 \\ \mathrm{C} & -4.390027 & -2.082542 & -1.001089 \\ \mathrm{O} & -3.911859 & -2.719014 & -1.910813 \\ \mathrm{O} & -5.159059 & -2.569121 & -0.015538 \\ \mathrm{C} & -5.333152 & -3.997644 & -0.035587 \\ \mathrm{H} & -4.368480 & -4.495601 & 0.084171 \\ \mathrm{H} & -5.792762 & -4.311192 & -0.975965 \\ \mathrm{H} & -5.988983 & -4.216186 & 0.807091 \\ \mathrm{H} & -4.752176 & 2.257971 & 0.508568 \\ \mathrm{H} & -5.269225 & 1.671840 & -1.151418 \\ \mathrm{C} & -4.276192 & -0.223591 & 1.512064 \\ \mathrm{C} & -5.053975 & 0.376541 & 2.518376 \\ \mathrm{C} & -3.275661 & -1.146272 & 1.870769 \\ \mathrm{C} & -4.850448 & 0.044977 & 3.854472 \\ \mathrm{H} & -5.835291 & 1.079306 & 2.244892 \\ \mathrm{C} & -3.064164 & -1.457790 & 3.208603 \\ \mathrm{H} & -2.633603 & -1.575052 & 1.108743 \\ \mathrm{C} & -3.853623 & -0.870436 & 4.200932 \\ \mathrm{H} & -5.465186 & 0.501869 & 4.624510 \\ \mathrm{H} & -2.270739 & -2.149013 & 3.474863 \\ \mathrm{H} & -3.685776 & -1.118906 & 5.245338 \\ \mathrm{H} & -4.781714 & 3.992343 & -4.586880\end{array}$

Catalyst (R)-1 TS Conformation 373

B3LYP/6-31G(d) Energy $=-2809.678002$

B3LYP-D3(BJ)/def2-TZVPP-IEF-PCM(DCM) Energy $=-2810.974027$

B3LYP-D3(BJ)/def2-TZVPP-IEF-PCM(DCM)//B3LYP/6-31G(d) Free Energy (Quasiharmonic) = 2810.332868

Frequencies (Top 3 out of 270)

1. $-619.3607 \mathrm{~cm}-1$

2. $\quad 6.1377 \mathrm{~cm}-1$

3. $10.3939 \mathrm{~cm}-1$

B3LYP/6-31G(d) Molecular Geometry in Cartesian Coordinates

$\begin{array}{llll}C & -2.624332 & -1.325720 & 0.524080 \\ C & -1.475335 & -1.828914 & -0.061252 \\ C & -0.902600 & -3.085504 & 0.294126\end{array}$




\begin{tabular}{|c|c|c|c|}
\hline C & -1.472569 & -3.760158 & 1.356453 \\
\hline $\mathrm{H}$ & -1.078042 & -4.732704 & 1.638597 \\
\hline C & -4.539199 & 2.205968 & -1.022402 \\
\hline C & -3.277725 & -0.120222 & -0.062300 \\
\hline C & -2.576610 & 1.068151 & -0.222799 \\
\hline C & -3.202281 & 2.268552 & -0.680025 \\
\hline $\mathrm{H}$ & -5.030812 & 3.106850 & -1.379570 \\
\hline $\mathrm{O}$ & -0.852950 & -1.073196 & -1.050638 \\
\hline$P$ & -0.048975 & 0.268665 & -0.531133 \\
\hline $\mathrm{O}$ & -1.249131 & 1.145388 & 0.177073 \\
\hline C & 2.238683 & -5.057512 & -1.877683 \\
\hline C & 2.266616 & -5.014882 & -0.482815 \\
\hline C & 1.266271 & -4.340877 & 0.215727 \\
\hline C & 0.219826 & -3.697313 & -0.464401 \\
\hline C & 0.218391 & -3.724124 & -1.869738 \\
\hline C & 1.216699 & -4.401456 & -2.567988 \\
\hline $\mathrm{H}$ & 3.075286 & -5.493215 & 0.061969 \\
\hline $\mathrm{H}$ & 1.188850 & -4.424214 & -3.654399 \\
\hline C & -1.393266 & 6.143857 & -1.121637 \\
\hline C & -0.793191 & 5.029357 & -1.710396 \\
\hline C & -1.336780 & 3.755104 & -1.538232 \\
\hline C & -2.508057 & 3.582221 & -0.783585 \\
\hline C & -3.098372 & 4.710476 & -0.187227 \\
\hline C & -2.545567 & 5.979952 & -0.351154 \\
\hline $\mathrm{H}$ & 0.112709 & 5.144189 & -2.295520 \\
\hline $\mathrm{H}$ & -3.016412 & 6.838381 & 0.121611 \\
\hline C & -4.640695 & -0.191601 & -0.520533 \\
\hline C & -5.278587 & 1.001110 & -0.985826 \\
\hline C & -6.628068 & 0.951151 & -1.429040 \\
\hline C & -7.324133 & -0.234632 & -1.441332 \\
\hline C & -6.686424 & -1.424274 & -1.017707 \\
\hline C & -5.383860 & -1.404393 & -0.569614 \\
\hline $\mathrm{H}$ & -7.095035 & 1.871765 & -1.771297 \\
\hline $\mathrm{H}$ & -8.353733 & -0.264072 & -1.787383 \\
\hline $\mathrm{H}$ & -7.227086 & -2.366335 & -1.052427 \\
\hline $\mathrm{H}$ & -4.910970 & -2.329163 & -0.261849 \\
\hline C & -3.159539 & -1.999174 & 1.675703 \\
\hline C & -2.563081 & -3.233077 & 2.091234 \\
\hline C & -3.082176 & -3.910520 & 3.227611 \\
\hline C & -4.127750 & -3.383280 & 3.949491 \\
\hline C & -4.696874 & -2.147709 & 3.561090 \\
\hline C & -4.228838 & -1.475957 & 2.452963 \\
\hline $\mathrm{H}$ & -2.625563 & -4.852411 & 3.522725 \\
\hline $\mathrm{H}$ & -4.510982 & -3.906382 & 4.821416 \\
\hline
\end{tabular}




\begin{tabular}{|c|c|c|c|}
\hline $\mathrm{H}$ & -5.508734 & -1.721980 & 4.144723 \\
\hline $\mathrm{H}$ & -4.668973 & -0.525853 & 2.172532 \\
\hline $\mathrm{O}$ & 0.594540 & 0.938484 & -1.694017 \\
\hline 0 & 0.820262 & -0.112108 & 0.689879 \\
\hline $\mathrm{H}$ & 1.818142 & -0.658381 & 0.515679 \\
\hline $\mathrm{H}$ & -0.576122 & -3.225327 & -2.414209 \\
\hline $\mathrm{H}$ & 3.009269 & -5.597497 & -2.422364 \\
\hline $\mathrm{H}$ & 1.304393 & -4.292953 & 1.299957 \\
\hline $\mathrm{H}$ & -3.994946 & 4.583517 & 0.413785 \\
\hline $\mathrm{H}$ & -0.962659 & 7.132492 & -1.259151 \\
\hline $\mathrm{H}$ & -0.852643 & 2.897908 & -1.995772 \\
\hline C & 3.396087 & -1.028024 & -0.850119 \\
\hline 0 & 2.911259 & -1.282762 & 0.319611 \\
\hline $\mathrm{H}$ & 2.724349 & -0.594356 & -1.602219 \\
\hline C & 4.334785 & -2.101138 & -1.405663 \\
\hline 0 & 4.981801 & -2.872035 & -0.737733 \\
\hline $\mathrm{O}$ & 4.367900 & -2.035861 & -2.753781 \\
\hline C & 5.232036 & -2.989047 & -3.395407 \\
\hline $\mathrm{H}$ & 4.896254 & -4.006160 & -3.180483 \\
\hline $\mathrm{H}$ & 5.159827 & -2.778477 & -4.462632 \\
\hline C & 4.238987 & 1.466497 & -0.135636 \\
\hline C & 4.712491 & 0.371190 & -0.902012 \\
\hline $\mathrm{H}$ & 3.458848 & 2.366521 & -1.774792 \\
\hline$N$ & 3.492423 & 2.406004 & -0.761184 \\
\hline C & 2.507571 & 3.320671 & -0.282056 \\
\hline 0 & 2.155891 & 4.237856 & -0.984308 \\
\hline 0 & 2.081960 & 3.007622 & 0.929918 \\
\hline C & 1.017094 & 3.827299 & 1.469902 \\
\hline $\mathrm{H}$ & 1.222195 & 4.883156 & 1.286303 \\
\hline $\mathrm{H}$ & 1.005667 & 3.602630 & 2.535593 \\
\hline $\mathrm{H}$ & 0.074779 & 3.538607 & 1.003299 \\
\hline $\mathrm{H}$ & 5.605879 & -0.102900 & -0.507467 \\
\hline $\mathrm{H}$ & 4.736558 & 0.520512 & -1.980430 \\
\hline C & 4.574912 & 1.581252 & 1.286618 \\
\hline C & 4.725163 & 0.417174 & 2.064193 \\
\hline C & 4.840348 & 2.839941 & 1.863160 \\
\hline C & 5.095423 & 0.523479 & 3.403740 \\
\hline $\mathrm{H}$ & 4.502134 & -0.553391 & 1.634152 \\
\hline C & 5.243390 & 2.930253 & 3.188872 \\
\hline $\mathrm{H}$ & 4.769226 & 3.739700 & 1.260089 \\
\hline C & 5.361241 & 1.772277 & 3.965782 \\
\hline $\mathrm{H}$ & 5.184119 & -0.376245 & 4.005222 \\
\hline $\mathrm{H}$ & 5.468387 & 3.901904 & 3.618976 \\
\hline $\mathrm{H}$ & 5.669361 & 1.846910 & 5.005081 \\
\hline
\end{tabular}


H $\quad 6.261264 \quad-2.870690 \quad-3.045489$

Catalyst (R)-1 TS Conformation 374

B3LYP/6-31G(d) Energy $=-2809.680894$

B3LYP-D3(BJ)/def2-TZVPP-IEF-PCM(DCM) Energy = -2810.974654

B3LYP-D3(BJ)/def2-TZVPP-IEF-PCM(DCM)//B3LYP/6-31G(d) Free Energy (Quasiharmonic) = 2810.332787

Frequencies (Top 3 out of 270)

1. $-697.6140 \mathrm{~cm}-1$

2. $8.0348 \mathrm{~cm}-1$

3. $10.3409 \mathrm{~cm}-1$

B3LYP/6-31G(d) Molecular Geometry in Cartesian Coordinates

$\begin{array}{llll}\mathrm{C} & 3.668776 & 0.476457 & 0.341913 \\ \mathrm{C} & 2.843962 & 1.487237 & -0.130149 \\ \mathrm{C} & 2.944290 & 2.844296 & 0.299330 \\ \mathrm{C} & 3.883470 & 3.132825 & 1.270429 \\ \mathrm{H} & 4.005156 & 4.161250 & 1.600368 \\ \mathrm{C} & 3.205096 & -3.523048 & -1.208492 \\ \mathrm{C} & 3.544160 & -0.897908 & -0.229184 \\ \mathrm{C} & 2.309350 & -1.530249 & -0.218321 \\ \mathrm{C} & 2.108943 & -2.862866 & -0.687733 \\ \mathrm{H} & 3.093193 & -4.549031 & -1.549369 \\ \mathrm{O} & 1.890202 & 1.175452 & -1.087014 \\ \mathrm{P} & 0.545231 & 0.344846 & -0.630990 \\ \mathrm{O} & 1.218582 & -0.844465 & 0.294104 \\ \mathrm{C} & 0.554447 & 6.055620 & -1.280449 \\ \mathrm{C} & 1.123767 & 5.119290 & -2.146006 \\ \mathrm{C} & 1.880230 & 4.061880 & -1.643571 \\ \mathrm{C} & 2.087209 & 3.923105 & -0.260622 \\ \mathrm{C} & 1.505139 & 4.868926 & 0.599037 \\ \mathrm{C} & 0.746447 & 5.924835 & 0.095422 \\ \mathrm{H} & 0.981090 & 5.212256 & -3.219579 \\ \mathrm{H} & 0.298398 & 6.640112 & 0.780441 \\ \mathrm{C} & -1.662490 & -4.934331 & -0.551542 \\ \mathrm{C} & -0.877685 & -4.962427 & -1.705055 \\ \mathrm{C} & 0.332238 & -4.270441 & -1.745886 \\ \mathrm{C} & 0.784626 & -3.538036 & -0.636029 \\ \mathrm{C} & -0.018724 & -3.512002 & 0.516669\end{array}$




\begin{tabular}{|c|c|c|c|}
\hline C & -1.228148 & -4.204954 & 0.557806 \\
\hline $\mathrm{H}$ & -1.209553 & -5.517085 & -2.579037 \\
\hline $\mathrm{H}$ & -1.830280 & -4.176739 & 1.462192 \\
\hline C & 4.656479 & -1.570415 & -0.842596 \\
\hline C & 4.476002 & -2.908709 & -1.321028 \\
\hline C & 5.571029 & -3.591243 & -1.917288 \\
\hline C & 6.790930 & -2.974948 & -2.070585 \\
\hline C & 6.961251 & -1.639325 & -1.636202 \\
\hline C & 5.924686 & -0.956676 & -1.038403 \\
\hline $\mathrm{H}$ & 5.418962 & -4.610960 & -2.263543 \\
\hline $\mathrm{H}$ & 7.618726 & -3.504177 & -2.534690 \\
\hline $\mathrm{H}$ & 7.917973 & -1.144412 & -1.780175 \\
\hline $\mathrm{H}$ & 6.069420 & 0.069279 & -0.720799 \\
\hline C & 4.587981 & 0.779065 & 1.404507 \\
\hline C & 4.697160 & 2.133618 & 1.858180 \\
\hline C & 5.610914 & 2.449302 & 2.900200 \\
\hline C & 6.367686 & 1.469855 & 3.500062 \\
\hline C & 6.233535 & 0.125142 & 3.081444 \\
\hline C & 5.369666 & -0.210798 & 2.062150 \\
\hline $\mathrm{H}$ & 5.690087 & 3.484879 & 3.222968 \\
\hline $\mathrm{H}$ & 7.057996 & 1.722658 & 4.300290 \\
\hline $\mathrm{H}$ & 6.814430 & -0.651747 & 3.571448 \\
\hline $\mathrm{H}$ & 5.272271 & -1.247067 & 1.759890 \\
\hline $\mathrm{O}$ & -0.163537 & -0.138608 & -1.845976 \\
\hline $\mathrm{O}$ & -0.238132 & 1.164332 & 0.412721 \\
\hline $\mathrm{H}$ & -1.381417 & 1.481847 & 0.119117 \\
\hline $\mathrm{H}$ & 1.631470 & 4.758603 & 1.672410 \\
\hline $\mathrm{H}$ & -0.037800 & 6.877114 & -1.675240 \\
\hline $\mathrm{H}$ & 2.318161 & 3.341374 & -2.325416 \\
\hline $\mathrm{H}$ & 0.310655 & -2.951702 & 1.384672 \\
\hline $\mathrm{H}$ & -2.605315 & -5.474446 & -0.517206 \\
\hline $\mathrm{H}$ & 0.926313 & -4.275515 & -2.655219 \\
\hline C & -2.929540 & 1.170839 & -1.205895 \\
\hline $\mathrm{O}$ & -2.534052 & 1.694391 & -0.093411 \\
\hline $\mathrm{H}$ & -2.175396 & 0.966450 & -1.976343 \\
\hline C & -4.252241 & 1.666821 & -1.785952 \\
\hline $\mathrm{O}$ & -4.743253 & 1.215496 & -2.805553 \\
\hline $\mathrm{O}$ & -4.804213 & 2.636417 & -1.052844 \\
\hline C & -6.038944 & 3.174995 & -1.570683 \\
\hline $\mathrm{H}$ & -5.893254 & 3.547477 & -2.587174 \\
\hline $\mathrm{H}$ & -6.300813 & 3.988826 & -0.894797 \\
\hline C & -4.328281 & -0.954936 & -0.180793 \\
\hline C & -3.311218 & -0.744636 & -1.129525 \\
\hline $\mathrm{H}$ & -5.743037 & -0.732347 & -1.619663 \\
\hline
\end{tabular}




$\begin{array}{llll}\mathrm{N} & -5.628595 & -0.803840 & -0.612042 \\ \mathrm{C} & -6.761036 & -0.247132 & 0.020482 \\ \mathrm{O} & -7.761556 & -0.001619 & -0.618422 \\ \mathrm{O} & -6.585476 & -0.017020 & 1.320242 \\ \mathrm{C} & -7.710225 & 0.583622 & 1.993990 \\ \mathrm{H} & -7.920853 & 1.568311 & 1.571046 \\ \mathrm{H} & -7.401890 & 0.668685 & 3.035173 \\ \mathrm{H} & -8.593832 & -0.051056 & 1.897910 \\ \mathrm{H} & -2.324749 & -1.140227 & -0.915018 \\ \mathrm{H} & -3.597259 & -0.808809 & -2.176193 \\ \mathrm{C} & -4.026039 & -1.331939 & 1.201186 \\ \mathrm{C} & -2.832020 & -0.894532 & 1.805967 \\ \mathrm{C} & -4.867632 & -2.220107 & 1.902621 \\ \mathrm{C} & -2.514941 & -1.304297 & 3.099308 \\ \mathrm{H} & -2.163701 & -0.220881 & 1.285713 \\ \mathrm{C} & -4.524616 & -2.652083 & 3.177224 \\ \mathrm{H} & -5.769453 & -2.594927 & 1.430336 \\ \mathrm{C} & -3.353136 & -2.184918 & 3.784665 \\ \mathrm{H} & -1.601639 & -0.941647 & 3.560900 \\ \mathrm{H} & -5.168047 & -3.354211 & 3.699711 \\ \mathrm{H} & -3.091556 & -2.518155 & 4.785292 \\ \mathrm{H} & -6.816596 & 2.406565 & -1.575674\end{array}$

Catalyst (R)-1 TS Conformation 375

B3LYP/6-31G(d) Energy $=-2809.682529$

B3LYP-D3(BJ)/def2-TZVPP-IEF-PCM(DCM) Energy = -2810.97454

B3LYP-D3(BJ)/def2-TZVPP-IEF-PCM(DCM)//B3LYP/6-31G(d) Free Energy (Quasiharmonic) = 2810.332719

Frequencies (Top 3 out of 270)

1. $-646.9966 \mathrm{~cm}-1$

2. $\quad 6.6600 \mathrm{~cm}-1$

3. $8.6420 \mathrm{~cm}-1$

B3LYP/6-31G(d) Molecular Geometry in Cartesian Coordinates

$\begin{array}{llll}\text { C } & -3.892524 & 0.295755 & -0.040051 \\ \text { C } & -3.045106 & 1.307857 & 0.388353 \\ \text { C } & -3.420277 & 2.684389 & 0.412768 \\ \text { C } & -4.675849 & 3.007088 & -0.064134 \\ \text { H } & -5.002872 & 4.043195 & -0.034995\end{array}$




\begin{tabular}{|c|c|c|c|}
\hline C & -2.525830 & -3.797295 & 0.044787 \\
\hline C & -3.440746 & -1.125696 & 0.040975 \\
\hline C & -2.248989 & -1.493927 & -0.565715 \\
\hline C & -1.769496 & -2.837487 & -0.599279 \\
\hline $\mathrm{H}$ & -2.204410 & -4.835257 & 0.014349 \\
\hline 0 & -1.780904 & 0.971160 & 0.847110 \\
\hline$P$ & -0.625170 & 0.509631 & -0.227825 \\
\hline 0 & -1.493190 & -0.514062 & -1.187506 \\
\hline C & -0.914638 & 5.842588 & 1.918360 \\
\hline C & -1.039634 & 4.650415 & 2.634759 \\
\hline C & -1.829769 & 3.612053 & 2.144745 \\
\hline C & -2.517126 & 3.748462 & 0.926904 \\
\hline C & -2.379253 & 4.950579 & 0.214216 \\
\hline C & -1.586362 & 5.987742 & 0.704016 \\
\hline $\mathrm{H}$ & -0.521064 & 4.527371 & 3.582187 \\
\hline $\mathrm{H}$ & -1.487412 & 6.905982 & 0.130749 \\
\hline C & 1.854044 & -4.031398 & -2.594778 \\
\hline C & 1.567575 & -4.490929 & -1.308546 \\
\hline C & 0.399626 & -4.084209 & -0.663862 \\
\hline C & -0.505883 & -3.211352 & -1.289028 \\
\hline C & -0.202265 & -2.750605 & -2.581753 \\
\hline C & 0.964122 & -3.159476 & -3.226817 \\
\hline $\mathrm{H}$ & 2.256455 & -5.161459 & -0.801153 \\
\hline $\mathrm{H}$ & 1.174196 & -2.799293 & -4.230776 \\
\hline C & -4.176619 & -2.121862 & 0.770177 \\
\hline C & -3.710962 & -3.476973 & 0.751454 \\
\hline C & -4.437156 & -4.474536 & 1.457145 \\
\hline C & -5.560260 & -4.152997 & 2.183094 \\
\hline C & -5.999583 & -2.809239 & 2.236887 \\
\hline C & -5.328220 & -1.822067 & 1.549370 \\
\hline $\mathrm{H}$ & -4.076983 & -5.500172 & 1.420801 \\
\hline $\mathrm{H}$ & -6.103301 & -4.923302 & 2.723940 \\
\hline $\mathrm{H}$ & -6.872996 & -2.551839 & 2.830090 \\
\hline $\mathrm{H}$ & -5.672709 & -0.796213 & 1.608329 \\
\hline C & -5.165466 & 0.656645 & -0.601965 \\
\hline C & -5.557482 & 2.034570 & -0.595689 \\
\hline C & -6.818823 & 2.404425 & -1.136531 \\
\hline C & -7.653976 & 1.464481 & -1.693959 \\
\hline C & -7.252732 & 0.108634 & -1.738258 \\
\hline C & -6.044018 & -0.284530 & -1.206763 \\
\hline $\mathrm{H}$ & -7.104875 & 3.453418 & -1.111890 \\
\hline $\mathrm{H}$ & -8.612788 & 1.760488 & -2.110878 \\
\hline $\mathrm{H}$ & -7.901794 & -0.630051 & -2.201001 \\
\hline $\mathrm{H}$ & -5.747920 & -1.325761 & -1.259030 \\
\hline
\end{tabular}




\begin{tabular}{|c|c|c|c|}
\hline $\mathrm{O}$ & 0.473958 & -0.159729 & 0.523657 \\
\hline 0 & -0.283811 & 1.674757 & -1.159817 \\
\hline $\mathrm{H}$ & 0.915975 & 1.861304 & -1.385148 \\
\hline $\mathrm{H}$ & -2.880401 & 5.059870 & -0.743422 \\
\hline $\mathrm{H}$ & -0.294768 & 6.649158 & 2.301363 \\
\hline $\mathrm{H}$ & -1.920370 & 2.690995 & 2.709936 \\
\hline $\mathrm{H}$ & -0.886035 & -2.074474 & -3.082673 \\
\hline $\mathrm{H}$ & 2.762001 & -4.349561 & -3.100966 \\
\hline $\mathrm{H}$ & 0.193395 & -4.427203 & 0.346056 \\
\hline C & 2.862567 & 1.637178 & -0.705733 \\
\hline 0 & 2.051607 & 2.070495 & -1.615004 \\
\hline $\mathrm{H}$ & 2.462030 & 1.383853 & 0.280223 \\
\hline C & 4.212101 & 2.331980 & -0.614552 \\
\hline $\mathrm{O}$ & 4.851574 & 2.384753 & 0.418079 \\
\hline $\mathrm{O}$ & 4.609607 & 2.839893 & -1.786323 \\
\hline C & 5.850608 & 3.577930 & -1.763729 \\
\hline $\mathrm{H}$ & 5.798001 & 4.378300 & -1.022067 \\
\hline $\mathrm{H}$ & 5.955176 & 3.990420 & -2.767000 \\
\hline C & 4.483226 & -0.632181 & -0.483034 \\
\hline C & 3.399813 & -0.142996 & -1.250547 \\
\hline $\mathrm{H}$ & 5.793166 & 0.065627 & -1.868468 \\
\hline$N$ & 5.744981 & -0.278786 & -0.914977 \\
\hline C & 6.867949 & 0.206035 & -0.203646 \\
\hline $\mathrm{O}$ & 7.779675 & 0.736086 & -0.803285 \\
\hline $\mathrm{O}$ & 6.782020 & 0.026363 & 1.107671 \\
\hline C & 7.813365 & 0.670466 & 1.883992 \\
\hline $\mathrm{H}$ & 8.801058 & 0.345839 & 1.550801 \\
\hline $\mathrm{H}$ & 7.625551 & 0.362729 & 2.911796 \\
\hline $\mathrm{H}$ & 7.721001 & 1.753884 & 1.782846 \\
\hline $\mathrm{H}$ & 2.445603 & -0.647358 & -1.135955 \\
\hline $\mathrm{H}$ & 3.635191 & 0.150366 & -2.271780 \\
\hline C & 4.316625 & -1.494472 & 0.683236 \\
\hline C & 3.106265 & -1.496822 & 1.406698 \\
\hline C & 5.325366 & -2.420941 & 1.029701 \\
\hline C & 2.937193 & -2.374955 & 2.473642 \\
\hline $\mathrm{H}$ & 2.288205 & -0.834837 & 1.140665 \\
\hline C & 5.135896 & -3.307410 & 2.080776 \\
\hline $\mathrm{H}$ & 6.238811 & -2.466892 & 0.447692 \\
\hline C & 3.945738 & -3.277350 & 2.816069 \\
\hline $\mathrm{H}$ & 2.003585 & -2.356253 & 3.027488 \\
\hline $\mathrm{H}$ & 5.912325 & -4.026504 & 2.325698 \\
\hline $\mathrm{H}$ & 3.802282 & -3.967472 & 3.643259 \\
\hline $\mathrm{H}$ & 6.686873 & 2.914995 & -1.528049 \\
\hline
\end{tabular}


Catalyst (R)-1 TS Conformation 376

B3LYP/6-31G(d) Energy $=-2809.683619$

B3LYP-D3(BJ)/def2-TZVPP-IEF-PCM(DCM) Energy = -2810.975241

B3LYP-D3(BJ)/def2-TZVPP-IEF-PCM(DCM)//B3LYP/6-31G(d) Free Energy (Quasiharmonic) = 2810.332566

Frequencies (Top 3 out of 270)

1. $-361.6889 \mathrm{~cm}-1$

2. $\quad 9.9301 \mathrm{~cm}-1$

3. $\quad 10.7059 \mathrm{~cm}-1$

B3LYP/6-31G(d) Molecular Geometry in Cartesian Coordinates

$\begin{array}{llll}\text { C } & 3.154202 & -0.518201 & -0.313305 \\ \text { C } & 2.044020 & -1.352939 & -0.343315 \\ \text { C } & 2.146372 & -2.763100 & -0.547817 \\ \text { C } & 3.399783 & -3.285497 & -0.797503 \\ \text { H } & 3.501596 & -4.355544 & -0.959173 \\ \text { C } & 2.760996 & 3.666573 & 0.662146 \\ \text { C } & 3.009983 & 0.913903 & 0.084756 \\ \text { C } & 2.113635 & 1.729214 & -0.587088 \\ \text { C } & 1.980929 & 3.128242 & -0.342946 \\ \text { H } & 2.709528 & 4.734366 & 0.857712 \\ \text { O } & 0.792775 & -0.832748 & -0.055061 \\ \text { P } & 0.048069 & 0.257991 & -1.036806 \\ \text { O } & 1.309445 & 1.154930 & -1.565668 \\ \text { C } & -1.143236 & -5.534424 & -0.324597 \\ \text { C } & -1.200354 & -4.455275 & -1.210602 \\ \text { C } & -0.152485 & -3.536132 & -1.274654 \\ \text { C } & 0.977438 & -3.684312 & -0.456189 \\ \text { C } & 1.027540 & -4.775572 & 0.426511 \\ \text { C } & -0.023542 & -5.691778 & 0.494540 \\ \text { H } & -2.056805 & -4.326534 & -1.867729 \\ \text { H } & 0.035824 & -6.529878 & 1.184570 \\ \text { C } & -0.619718 & 5.736394 & -2.567414 \\ \text { C } & -0.554173 & 5.818469 & -1.175995 \\ \text { C } & 0.275635 & 4.954861 & -0.462371 \\ \text { C } & 1.056761 & 3.992994 & -1.123614 \\ \text { C } & 0.976570 & 3.916157 & -2.524327 \\ \text { C } & 0.148165 & 4.781414 & -3.236747 \\ \text { H } & -1.155797 & 6.549990 & -0.642569\end{array}$




\begin{tabular}{|c|c|c|c|}
\hline $\mathrm{H}$ & 0.104520 & 4.708962 & -4.320307 \\
\hline C & 3.753740 & 1.474478 & 1.181386 \\
\hline C & 3.627542 & 2.875108 & 1.455291 \\
\hline C & 4.365104 & 3.446213 & 2.527932 \\
\hline C & 5.171267 & 2.668935 & 3.326437 \\
\hline C & 5.266276 & 1.278460 & 3.084321 \\
\hline C & 4.579202 & 0.697934 & 2.040633 \\
\hline $\mathrm{H}$ & 4.267927 & 4.513596 & 2.712258 \\
\hline $\mathrm{H}$ & 5.725075 & 3.115824 & 4.147588 \\
\hline $\mathrm{H}$ & 5.884916 & 0.660713 & 3.729839 \\
\hline $\mathrm{H}$ & 4.657430 & -0.369998 & 1.874649 \\
\hline C & 4.434495 & -1.060840 & -0.681691 \\
\hline C & 4.551378 & -2.469308 & -0.909516 \\
\hline C & 5.812811 & -3.019774 & -1.263699 \\
\hline C & 6.917951 & -2.215350 & -1.415741 \\
\hline C & 6.799309 & -0.818446 & -1.225900 \\
\hline C & 5.593491 & -0.256974 & -0.867370 \\
\hline $\mathrm{H}$ & 5.882571 & -4.092893 & -1.425749 \\
\hline $\mathrm{H}$ & 7.876180 & -2.645602 & -1.693744 \\
\hline $\mathrm{H}$ & 7.666661 & -0.180082 & -1.371204 \\
\hline $\mathrm{H}$ & 5.518605 & 0.816450 & -0.738059 \\
\hline $\mathrm{O}$ & -0.994703 & 0.969129 & -0.257938 \\
\hline 0 & -0.370572 & -0.459916 & -2.354132 \\
\hline $\mathrm{H}$ & -1.433472 & -0.718795 & -2.407917 \\
\hline $\mathrm{H}$ & 1.895519 & -4.898435 & 1.069184 \\
\hline $\mathrm{H}$ & -1.958679 & -6.252024 & -0.280223 \\
\hline $\mathrm{H}$ & -0.200157 & -2.712158 & -1.976200 \\
\hline $\mathrm{H}$ & 1.569232 & 3.179921 & -3.055892 \\
\hline $\mathrm{H}$ & -1.267446 & 6.407250 & -3.125725 \\
\hline $\mathrm{H}$ & 0.304306 & 5.007676 & 0.622390 \\
\hline C & -3.497835 & -0.458284 & -1.644175 \\
\hline $\mathrm{O}$ & -2.751075 & -1.074088 & -2.483824 \\
\hline $\mathrm{H}$ & -3.073289 & 0.380464 & -1.075723 \\
\hline C & -4.940427 & -0.148638 & -2.065827 \\
\hline $\mathrm{O}$ & -5.775058 & 0.361481 & -1.327580 \\
\hline 0 & -5.182452 & -0.461356 & -3.334881 \\
\hline C & -6.506345 & -0.160158 & -3.815078 \\
\hline $\mathrm{H}$ & -7.255973 & -0.701739 & -3.232439 \\
\hline $\mathrm{H}$ & -6.702016 & 0.912459 & -3.742144 \\
\hline C & -3.770004 & -0.921405 & 1.070556 \\
\hline C & -3.895846 & -1.650454 & -0.138823 \\
\hline $\mathrm{H}$ & -5.299216 & 0.286756 & 0.496041 \\
\hline$N$ & -4.711838 & 0.040227 & 1.304488 \\
\hline C & -5.095756 & 0.605816 & 2.528432 \\
\hline
\end{tabular}




$\begin{array}{lrrr}\text { O } & -4.680419 & 0.320031 & 3.626182 \\ \text { O } & -6.054970 & 1.516830 & 2.267664 \\ \mathrm{C} & -6.598427 & 2.171151 & 3.426384 \\ \mathrm{H} & -7.344517 & 2.865096 & 3.039800 \\ \mathrm{H} & -5.813641 & 2.708265 & 3.964729 \\ \mathrm{H} & -7.060016 & 1.441562 & 4.096640 \\ \mathrm{H} & -3.137985 & -2.405574 & -0.311168 \\ \mathrm{H} & -4.903160 & -1.954725 & -0.410283 \\ \mathrm{C} & -2.611792 & -1.086091 & 1.949999 \\ \mathrm{C} & -2.081024 & -2.373960 & 2.157240 \\ \mathrm{C} & -1.975433 & 0.021333 & 2.543413 \\ \mathrm{C} & -0.962010 & -2.552629 & 2.963257 \\ \mathrm{H} & -2.560217 & -3.236035 & 1.705425 \\ \mathrm{C} & -0.846008 & -0.161192 & 3.329225 \\ \mathrm{H} & -2.333488 & 1.021985 & 2.337211 \\ \mathrm{C} & -0.343144 & -1.446620 & 3.548885 \\ \mathrm{H} & -0.566892 & -3.551399 & 3.118780 \\ \mathrm{H} & -0.346028 & 0.700909 & 3.759861 \\ \mathrm{H} & 0.540128 & -1.583379 & 4.166948 \\ \mathrm{H} & -6.515384 & -0.485026 & -4.855064\end{array}$

Catalyst (R)-1 TS Conformation 377

B3LYP/6-31G(d) Energy = -2809.683201

B3LYP-D3(BJ)/def2-TZVPP-IEF-PCM(DCM) Energy = -2810.974703

B3LYP-D3(BJ)/def2-TZVPP-IEF-PCM(DCM)//B3LYP/6-31G(d) Free Energy (Quasiharmonic) = 2810.332551

Frequencies (Top 3 out of 270)

1. $-570.7122 \mathrm{~cm}-1$

2. $\quad 3.6824 \mathrm{~cm}-1$

3. $\quad 9.0161 \mathrm{~cm}-1$

B3LYP/6-31G(d) Molecular Geometry in Cartesian Coordinates

$\begin{array}{llll}\text { C } & -3.923486 & 0.270951 & -0.121801 \\ \text { C } & -3.082408 & 1.303391 & 0.268480 \\ \text { C } & -3.451855 & 2.680113 & 0.203801 \\ \text { C } & -4.693868 & 2.978863 & -0.321607 \\ \text { H } & -5.016649 & 4.015992 & -0.360724 \\ \text { C } & -2.580540 & -3.815683 & 0.227115 \\ \text { C } & -3.479410 & -1.144647 & 0.051618\end{array}$




\begin{tabular}{|c|c|c|c|}
\hline C & -2.275571 & -1.551488 & -0.504778 \\
\hline C & -1.804413 & -2.897496 & -0.453124 \\
\hline $\mathrm{H}$ & -2.265414 & -4.855423 & 0.261416 \\
\hline $\mathrm{O}$ & -1.831418 & 0.988938 & 0.775612 \\
\hline$P$ & -0.653181 & 0.469108 & -0.249389 \\
\hline 0 & -1.499667 & -0.612508 & -1.163668 \\
\hline C & -0.967856 & 5.910640 & 1.586854 \\
\hline C & -1.118841 & 4.763306 & 2.368551 \\
\hline C & -1.901892 & 3.701289 & 1.919494 \\
\hline C & -2.556251 & 3.768830 & 0.677907 \\
\hline C & -2.392402 & 4.926202 & -0.100301 \\
\hline C & -1.606379 & 5.986902 & 0.348554 \\
\hline $\mathrm{H}$ & -0.626718 & 4.694236 & 3.335413 \\
\hline $\mathrm{H}$ & -1.486703 & 6.869224 & -0.274927 \\
\hline C & 1.840109 & -4.233767 & -2.315445 \\
\hline C & 0.972142 & -3.386662 & -3.008499 \\
\hline C & -0.199965 & -2.930725 & -2.406971 \\
\hline C & -0.531405 & -3.318239 & -1.097134 \\
\hline C & 0.352742 & -4.166278 & -0.410184 \\
\hline C & 1.526119 & -4.620445 & -1.011823 \\
\hline $\mathrm{H}$ & 1.203652 & -3.083218 & -4.026442 \\
\hline $\mathrm{H}$ & 2.197260 & -5.271989 & -0.457955 \\
\hline C & -4.237047 & -2.094474 & 0.819317 \\
\hline C & -3.778649 & -3.450346 & 0.888466 \\
\hline C & -4.525934 & -4.402902 & 1.633215 \\
\hline C & -5.663322 & -4.035718 & 2.313859 \\
\hline C & -6.096459 & -2.689283 & 2.280747 \\
\hline C & -5.404383 & -1.745851 & 1.553507 \\
\hline $\mathrm{H}$ & -4.170548 & -5.430389 & 1.663733 \\
\hline $\mathrm{H}$ & -6.222517 & -4.771545 & 2.885389 \\
\hline $\mathrm{H}$ & -6.981606 & -2.394744 & 2.838221 \\
\hline $\mathrm{H}$ & -5.744439 & -0.716846 & 1.545981 \\
\hline C & -5.181038 & 0.602588 & -0.734076 \\
\hline C & -5.566895 & 1.979821 & -0.817097 \\
\hline C & -6.813294 & 2.321566 & -1.408676 \\
\hline C & -7.639201 & 1.353445 & -1.930535 \\
\hline C & -7.243159 & -0.003940 & -1.886448 \\
\hline C & -6.049219 & -0.369352 & -1.304191 \\
\hline $\mathrm{H}$ & -7.095146 & 3.371108 & -1.451758 \\
\hline $\mathrm{H}$ & -8.586492 & 1.627745 & -2.386796 \\
\hline $\mathrm{H}$ & -7.884418 & -0.766232 & -2.320930 \\
\hline $\mathrm{H}$ & -5.756676 & -1.412780 & -1.288675 \\
\hline 0 & 0.426656 & -0.154490 & 0.570618 \\
\hline 0 & -0.295672 & 1.573585 & -1.243942 \\
\hline
\end{tabular}




\begin{tabular}{|c|c|c|c|}
\hline $\mathrm{H}$ & 0.920292 & 1.868896 & -1.415709 \\
\hline $\mathrm{H}$ & -2.867689 & 4.981049 & -1.075612 \\
\hline $\mathrm{H}$ & -0.353787 & 6.735878 & 1.938176 \\
\hline $\mathrm{H}$ & -2.013057 & 2.815466 & 2.535139 \\
\hline $\mathrm{H}$ & 0.125093 & -4.452520 & 0.612744 \\
\hline $\mathrm{H}$ & 2.752523 & -4.589091 & -2.787788 \\
\hline $\mathrm{H}$ & -0.867053 & -2.275133 & -2.955433 \\
\hline C & 2.739648 & 1.675321 & -0.565440 \\
\hline $\mathrm{O}$ & 2.036585 & 2.140849 & -1.545044 \\
\hline $\mathrm{H}$ & 2.225886 & 1.403696 & 0.359468 \\
\hline C & 4.106849 & 2.309830 & -0.388784 \\
\hline $\mathrm{O}$ & 4.900980 & 2.535256 & -1.277251 \\
\hline O & 4.305038 & 2.565523 & 0.913281 \\
\hline C & 5.564875 & 3.172706 & 1.267066 \\
\hline $\mathrm{H}$ & 5.773233 & 4.020795 & 0.611160 \\
\hline $\mathrm{H}$ & 5.446374 & 3.500395 & 2.299729 \\
\hline C & 4.390174 & -0.617685 & -0.445887 \\
\hline C & 3.221444 & -0.176306 & -1.095276 \\
\hline $\mathrm{H}$ & 5.461575 & -0.097548 & -2.083631 \\
\hline$N$ & 5.573094 & -0.378833 & -1.115247 \\
\hline C & 6.814607 & 0.035569 & -0.603211 \\
\hline 0 & 7.112578 & 0.171990 & 0.560719 \\
\hline 0 & 7.622498 & 0.262273 & -1.653059 \\
\hline C & 8.920657 & 0.790864 & -1.326236 \\
\hline $\mathrm{H}$ & 8.821684 & 1.782147 & -0.877196 \\
\hline $\mathrm{H}$ & 9.450847 & 0.853426 & -2.275973 \\
\hline $\mathrm{H}$ & 9.440311 & 0.125102 & -0.633620 \\
\hline $\mathrm{H}$ & 2.276467 & -0.634925 & -0.822338 \\
\hline $\mathrm{H}$ & 3.327940 & 0.082746 & -2.145252 \\
\hline C & 4.373805 & -1.300777 & 0.846992 \\
\hline C & 3.224579 & -1.223528 & 1.664839 \\
\hline C & 5.447509 & -2.119637 & 1.257630 \\
\hline C & 3.180732 & -1.911787 & 2.873229 \\
\hline $\mathrm{H}$ & 2.352071 & -0.655547 & 1.357835 \\
\hline C & 5.385317 & -2.815929 & 2.457332 \\
\hline $\mathrm{H}$ & 6.318979 & -2.233488 & 0.625741 \\
\hline C & 4.257719 & -2.703438 & 3.276399 \\
\hline $\mathrm{H}$ & 2.292146 & -1.835628 & 3.492389 \\
\hline $\mathrm{H}$ & 6.216085 & -3.449390 & 2.754128 \\
\hline $\mathrm{H}$ & 4.214816 & -3.244145 & 4.218074 \\
\hline $\mathrm{H}$ & 6.363791 & 2.431656 & 1.190782 \\
\hline
\end{tabular}

Catalyst (R)-1 TS Conformation 378 
B3LYP/6-31G(d) Energy $=-2809.683042$

B3LYP-D3(BJ)/def2-TZVPP-IEF-PCM(DCM) Energy $=-2810.974327$

B3LYP-D3(BJ)/def2-TZVPP-IEF-PCM(DCM)//B3LYP/6-31G(d) Free Energy (Quasiharmonic) = 2810.332521

Frequencies (Top 3 out of 270)

1. $-672.1537 \mathrm{~cm}-1$

2. $\quad 6.1046 \mathrm{~cm}-1$

3. $\quad 9.1812 \mathrm{~cm}-1$

B3LYP/6-31G(d) Molecular Geometry in Cartesian Coordinates

\begin{tabular}{|c|c|c|c|}
\hline C & -3.869119 & 0.138422 & -0.155600 \\
\hline C & -3.137669 & 1.258004 & 0.221990 \\
\hline C & -3.707259 & 2.566837 & 0.285690 \\
\hline C & -5.012101 & 2.715262 & -0.142415 \\
\hline $\mathrm{H}$ & -5.466101 & 3.702264 & -0.112229 \\
\hline C & -2.133454 & -3.807141 & 0.081015 \\
\hline C & -3.282377 & -1.228084 & -0.016922 \\
\hline C & -2.069544 & -1.516394 & -0.620416 \\
\hline C & -1.472437 & -2.811534 & -0.611114 \\
\hline $\mathrm{H}$ & -1.722762 & -4.813557 & 0.085794 \\
\hline 0 & -1.833799 & 1.103373 & 0.666052 \\
\hline$P$ & -0.625111 & 0.601491 & -0.323735 \\
\hline $\mathrm{O}$ & -1.404573 & -0.490919 & -1.276494 \\
\hline C & -1.736521 & 6.036566 & 1.900871 \\
\hline C & -1.105648 & 5.278763 & 0.912349 \\
\hline C & -1.718040 & 4.139677 & 0.389985 \\
\hline C & -2.983618 & 3.741576 & 0.849193 \\
\hline C & -3.610100 & 4.511525 & 1.843583 \\
\hline C & -2.993179 & 5.647861 & 2.366270 \\
\hline $\mathrm{H}$ & -0.128945 & 5.576938 & 0.539386 \\
\hline $\mathrm{H}$ & -3.493097 & 6.224574 & 3.140427 \\
\hline C & 2.200558 & -3.771434 & -2.641249 \\
\hline C & 1.983253 & -4.196383 & -1.329593 \\
\hline C & 0.798466 & -3.863654 & -0.672815 \\
\hline C & -0.192937 & -3.100871 & -1.311784 \\
\hline C & 0.042431 & -2.671350 & -2.629355 \\
\hline C & 1.225502 & -3.006679 & -3.286348 \\
\hline $\mathrm{H}$ & 2.738084 & -4.783100 & -0.812263 \\
\hline $\mathrm{H}$ & 1.382184 & -2.673368 & -4.309081 \\
\hline C & -3.918673 & -2.254777 & 0.764406 \\
\hline
\end{tabular}




\begin{tabular}{|c|c|c|c|}
\hline C & -3.333456 & -3.562645 & 0.793422 \\
\hline C & -3.958234 & -4.590861 & 1.550225 \\
\hline C & -5.096275 & -4.340749 & 2.280943 \\
\hline C & -5.653011 & -3.040384 & 2.287959 \\
\hline C & -5.082197 & -2.026825 & 1.549729 \\
\hline $\mathrm{H}$ & -3.507854 & -5.580845 & 1.549330 \\
\hline $\mathrm{H}$ & -5.561130 & -5.133142 & 2.861260 \\
\hline $\mathrm{H}$ & -6.537732 & -2.836896 & 2.885274 \\
\hline $\mathrm{H}$ & -5.516468 & -1.034445 & 1.574140 \\
\hline C & -5.191134 & 0.327520 & -0.689552 \\
\hline C & -5.765631 & 1.638468 & -0.668726 \\
\hline C & -7.072916 & 1.838340 & -1.189172 \\
\hline C & -7.784950 & 0.795351 & -1.734112 \\
\hline C & -7.207902 & -0.495265 & -1.786609 \\
\hline C & -5.948177 & -0.723562 & -1.277664 \\
\hline $\mathrm{H}$ & -7.494910 & 2.840192 & -1.157956 \\
\hline $\mathrm{H}$ & -8.781281 & 0.960911 & -2.134925 \\
\hline $\mathrm{H}$ & -7.760800 & -1.314088 & -2.239268 \\
\hline $\mathrm{H}$ & -5.516770 & -1.716072 & -1.337748 \\
\hline $\mathrm{O}$ & 0.459576 & 0.010446 & 0.508924 \\
\hline $\mathrm{O}$ & -0.256556 & 1.727852 & -1.301779 \\
\hline $\mathrm{H}$ & 0.946064 & 1.854947 & -1.529579 \\
\hline $\mathrm{H}$ & -4.581658 & 4.202694 & 2.220276 \\
\hline $\mathrm{H}$ & -1.252323 & 6.921489 & 2.306045 \\
\hline $\mathrm{H}$ & -1.221303 & 3.565585 & -0.384266 \\
\hline $\mathrm{H}$ & -0.708020 & -2.078624 & -3.140637 \\
\hline $\mathrm{H}$ & 3.120678 & -4.034109 & -3.157247 \\
\hline $\mathrm{H}$ & 0.644955 & -4.177777 & 0.355614 \\
\hline C & 2.886091 & 1.683577 & -0.800271 \\
\hline $\mathrm{O}$ & 2.093887 & 2.024310 & -1.759650 \\
\hline $\mathrm{H}$ & 2.472418 & 1.523507 & 0.199364 \\
\hline C & 4.246593 & 2.359417 & -0.765269 \\
\hline $\mathrm{O}$ & 4.868005 & 2.521120 & 0.266797 \\
\hline 0 & 4.671312 & 2.723337 & -1.980119 \\
\hline C & 5.925523 & 3.438780 & -2.020526 \\
\hline $\mathrm{H}$ & 6.051518 & 3.733921 & -3.061962 \\
\hline $\mathrm{H}$ & 5.876985 & 4.318206 & -1.374277 \\
\hline C & 4.483236 & -0.584150 & -0.319885 \\
\hline C & 3.423068 & -0.176026 & -1.156717 \\
\hline $\mathrm{H}$ & 5.832892 & -0.055253 & -1.743461 \\
\hline$N$ & 5.759355 & -0.290068 & -0.758967 \\
\hline C & 6.869457 & 0.261085 & -0.078465 \\
\hline $\mathrm{O}$ & 7.800526 & 0.716695 & -0.709334 \\
\hline 0 & 6.751839 & 0.224831 & 1.242481 \\
\hline
\end{tabular}




$\begin{array}{llll}\mathrm{C} & 7.772219 & 0.940010 & 1.969328 \\ \mathrm{H} & 7.694732 & 2.006959 & 1.749791 \\ \mathrm{H} & 8.763612 & 0.572601 & 1.697118 \\ \mathrm{H} & 7.557351 & 0.746964 & 3.019537 \\ \mathrm{H} & 2.458031 & -0.648739 & -1.007262 \\ \mathrm{H} & 3.677636 & 0.022627 & -2.195568 \\ \mathrm{C} & 4.284442 & -1.316564 & 0.928955 \\ \mathrm{C} & 5.274544 & -2.211840 & 1.390398 \\ \mathrm{C} & 3.062272 & -1.228623 & 1.626155 \\ \mathrm{C} & 5.055038 & -2.980240 & 2.525640 \\ \mathrm{H} & 6.198021 & -2.328066 & 0.834502 \\ \mathrm{C} & 2.862370 & -1.987211 & 2.776348 \\ \mathrm{H} & 2.258368 & -0.589684 & 1.275397 \\ \mathrm{C} & 3.852759 & -2.859817 & 3.230983 \\ \mathrm{H} & 5.818048 & -3.677354 & 2.860018 \\ \mathrm{H} & 1.919798 & -1.899213 & 3.307949 \\ \mathrm{H} & 3.685726 & -3.456764 & 4.123608 \\ \mathrm{H} & 6.745920 & 2.792606 & -1.698471\end{array}$

Catalyst (R)-1 TS Conformation 379

B3LYP/6-31G(d) Energy $=-2809.676556$

B3LYP-D3(BJ)/def2-TZVPP-IEF-PCM(DCM) Energy = -2810.973261

B3LYP-D3(BJ)/def2-TZVPP-IEF-PCM(DCM)//B3LYP/6-31G(d) Free Energy (Quasiharmonic) = 2810.332369

Frequencies (Top 3 out of 270)

1. $-744.2466 \mathrm{~cm}-1$

2. $\quad 4.7807 \mathrm{~cm}-1$

3. $10.5392 \mathrm{~cm}-1$

B3LYP/6-31G(d) Molecular Geometry in Cartesian Coordinates

$\begin{array}{llll}\text { C } & 3.138762 & -0.417954 & -0.304774 \\ \text { C } & 2.065563 & -1.293261 & -0.421424 \\ \text { C } & 2.235776 & -2.682809 & -0.709557 \\ \text { C } & 3.517822 & -3.136245 & -0.949768 \\ \text { H } & 3.670619 & -4.188304 & -1.176402 \\ \text { C } & 2.531276 & 3.682667 & 0.891774 \\ \text { C } & 2.919644 & 0.981216 & 0.168971 \\ \text { C } & 2.011676 & 1.795349 & -0.489425 \\ \text { C } & 1.810654 & 3.171502 & -0.170265\end{array}$




\begin{tabular}{|c|c|c|c|}
\hline $\mathrm{H}$ & 2.426946 & 4.734336 & 1.145329 \\
\hline $\mathrm{O}$ & 0.787614 & -0.842284 & -0.142830 \\
\hline$P$ & 0.022586 & 0.269293 & -1.095339 \\
\hline $\mathrm{O}$ & 1.269203 & 1.245924 & -1.525747 \\
\hline C & -0.926532 & -5.607178 & -0.780858 \\
\hline C & 0.185813 & -5.781283 & 0.044698 \\
\hline C & 1.193384 & -4.815346 & 0.073746 \\
\hline C & 1.107247 & -3.657292 & -0.716471 \\
\hline C & -0.015510 & -3.492308 & -1.542522 \\
\hline C & -1.019386 & -4.461109 & -1.575161 \\
\hline $\mathrm{H}$ & 0.274393 & -6.671455 & 0.662796 \\
\hline $\mathrm{H}$ & -1.868680 & -4.323006 & -2.240183 \\
\hline C & -0.822825 & 5.794666 & -2.338286 \\
\hline C & 0.005201 & 4.909465 & -3.031502 \\
\hline C & 0.845274 & 4.039302 & -2.338925 \\
\hline C & 0.877098 & 4.041116 & -0.934116 \\
\hline C & 0.035620 & 4.933027 & -0.249215 \\
\hline C & -0.805803 & 5.801588 & -0.943000 \\
\hline $\mathrm{H}$ & -0.000344 & 4.895703 & -4.118261 \\
\hline $\mathrm{H}$ & -1.454057 & 6.477948 & -0.391653 \\
\hline C & 3.600485 & 1.507435 & 1.321752 \\
\hline C & 3.403860 & 2.883210 & 1.670270 \\
\hline C & 4.078775 & 3.420811 & 2.799952 \\
\hline C & 4.890943 & 2.632748 & 3.581781 \\
\hline C & 5.055470 & 1.264097 & 3.264146 \\
\hline C & 4.430140 & 0.717447 & 2.164757 \\
\hline $\mathrm{H}$ & 3.929041 & 4.470765 & 3.040827 \\
\hline $\mathrm{H}$ & 5.396853 & 3.053884 & 4.446356 \\
\hline $\mathrm{H}$ & 5.679411 & 0.636325 & 3.894814 \\
\hline $\mathrm{H}$ & 4.561681 & -0.334471 & 1.940057 \\
\hline C & 4.452104 & -0.883445 & -0.661314 \\
\hline C & 4.636480 & -2.268757 & -0.971434 \\
\hline C & 5.930813 & -2.744053 & -1.315713 \\
\hline C & 7.004942 & -1.887494 & -1.379691 \\
\hline C & 6.820661 & -0.511324 & -1.108122 \\
\hline C & 5.581129 & -0.023060 & -0.757445 \\
\hline $\mathrm{H}$ & 6.051336 & -3.801061 & -1.541527 \\
\hline $\mathrm{H}$ & 7.988986 & -2.260006 & -1.650857 \\
\hline $\mathrm{H}$ & 7.664078 & 0.169741 & -1.184055 \\
\hline $\mathrm{H}$ & 5.456285 & 1.036227 & -0.565407 \\
\hline 0 & -1.047263 & 0.915082 & -0.287708 \\
\hline $\mathrm{O}$ & -0.357040 & -0.394344 & -2.434492 \\
\hline $\mathrm{H}$ & -1.518351 & -0.621366 & -2.596109 \\
\hline $\mathrm{H}$ & -0.089153 & -2.614146 & -2.173419 \\
\hline
\end{tabular}




$\begin{array}{llll}\mathrm{H} & -1.707203 & -6.363069 & -0.814223 \\ \mathrm{H} & 2.055590 & -4.952250 & 0.721382 \\ \mathrm{H} & 0.026954 & 4.926589 & 0.837179 \\ \mathrm{H} & -1.479126 & 6.469642 & -2.881459 \\ \mathrm{H} & 1.484225 & 3.357284 & -2.888737 \\ \mathrm{C} & -3.453493 & -0.263940 & -1.923117 \\ \mathrm{O} & -2.700905 & -0.857220 & -2.778343 \\ \mathrm{H} & -3.010743 & 0.502147 & -1.277926 \\ \mathrm{C} & -4.865082 & 0.041697 & -2.415381 \\ \mathrm{O} & -5.362111 & -0.356903 & -3.435903 \\ \mathrm{O} & -5.507829 & 0.866774 & -1.534221 \\ \mathrm{C} & -6.837232 & 1.274494 & -1.920496 \\ \mathrm{H} & -7.191274 & 1.912377 & -1.110825 \\ \mathrm{H} & -6.797717 & 1.827694 & -2.861242 \\ \mathrm{C} & -3.782736 & -0.997452 & 0.773656 \\ \mathrm{C} & -3.955233 & -1.590788 & -0.496881 \\ \mathrm{H} & -5.180570 & 0.408103 & 0.326963 \\ \mathrm{~N} & -4.670241 & -0.007111 & 1.108587 \\ \mathrm{C} & -5.119631 & 0.495145 & 2.338157 \\ \mathrm{O} & -5.877319 & 1.440373 & 2.383415 \\ \mathrm{O} & -4.680860 & -0.208010 & 3.386636 \\ \mathrm{C} & -5.125539 & 0.273823 & 4.669368 \\ \mathrm{H} & -6.214883 & 0.225160 & 4.735992 \\ \mathrm{H} & -4.798888 & 1.304865 & 4.822997 \\ \mathrm{H} & -4.662476 & -0.391019 & 5.397777 \\ \mathrm{H} & -3.242748 & -2.362176 & -0.764476 \\ \mathrm{H} & -4.976816 & -1.793479 & -0.808623 \\ \mathrm{C} & -2.643388 & -1.313922 & 1.634582 \\ \mathrm{C} & -2.192836 & -2.644042 & 1.728790 \\ \mathrm{C} & -1.955132 & -0.302378 & 2.333454 \\ \mathrm{C} & -1.100237 & -2.960387 & 2.529288 \\ \mathrm{H} & -2.713777 & -3.431216 & 1.194024 \\ \mathrm{H} & -0.853622 & -0.622107 & 3.115263 \\ -2.244208 & 0.733020 & 2.200411 \\ \mathrm{H} & -0.430574 & -1.950271 & 3.222576 \\ \mathrm{H} & -0.307379 & 0.166695 & 3.623470 \\ \mathrm{H} & -33406 & -2.194456 & 3.834699 \\ \mathrm{H} & -2.402267 & -2.043160\end{array}$

Catalyst (R)-1 TS Conformation 380

B3LYP/6-31G(d) Energy $=-2809.678523$ 
B3LYP-D3(BJ)/def2-TZVPP-IEF-PCM(DCM) Energy $=-2810.974306$

B3LYP-D3(BJ)/def2-TZVPP-IEF-PCM(DCM)//B3LYP/6-31G(d) Free Energy (Quasiharmonic) = 2810.332343

Frequencies (Top 3 out of 270)

1. $-555.4793 \mathrm{~cm}-1$

2. $\quad 6.9998 \mathrm{~cm}-1$

3. $\quad 9.2428 \mathrm{~cm}-1$

B3LYP/6-31G(d) Molecular Geometry in Cartesian Coordinates

$\begin{array}{llll}\text { C } & 3.877688 & -0.025303 & 0.389388 \\ \text { C } & 3.315304 & 1.139866 & -0.117667 \\ \text { C } & 3.874207 & 2.432641 & 0.125410 \\ \text { C } & 4.955667 & 2.509143 & 0.981582 \\ \text { H } & 5.393009 & 3.482092 & 1.189890 \\ \text { C } & 2.320314 & -3.862397 & -0.829155 \\ \text { C } & 3.373332 & -1.355408 & -0.063664 \\ \text { C } & 2.027999 & -1.657120 & 0.069961 \\ \text { C } & 1.471518 & -2.920815 & -0.283132 \\ \text { H } & 1.929335 & -4.842711 & -1.089816 \\ \text { O } & 2.240801 & 1.052949 & -0.986190 \\ \text { P } & 0.764205 & 0.510511 & -0.504935 \\ \text { O } & 1.179191 & -0.677538 & 0.566213 \\ \text { C } & 2.569822 & 6.070577 & -1.770216 \\ \text { C } & 1.640166 & 5.254520 & -1.122694 \\ \text { C } & 2.040442 & 4.062751 & -0.519004 \\ \text { C } & 3.387109 & 3.668201 & -0.550259 \\ \text { C } & 4.314471 & 4.497101 & -1.203584 \\ \text { C } & 3.910822 & 5.686872 & -1.809064 \\ \text { H } & 0.593658 & 5.546449 & -1.083691 \\ \text { H } & 4.643979 & 6.309113 & -2.316133 \\ \text { C } & -2.629396 & -4.060034 & 0.358628 \\ \text { C } & -2.045774 & -4.199065 & -0.903256 \\ \text { C } & -0.724585 & -3.796983 & -1.112328 \\ \text { C } & 0.036154 & -3.248915 & -0.067592 \\ \text { C } & -0.569664 & -3.092218 & 1.190547 \\ \text { C } & -1.886373 & -3.499112 & 1.402273 \\ \text { H } & -2.612627 & -4.632303 & -1.723759 \\ \text { H } & -2.329673 & -3.389066 & 2.388786 \\ \text { C } & 4.234466 & -2.320990 & -0.692554 \\ \text { C } & 3.690974 & -3.593305 & -1.065717 \\ \text { C } & 4.531326 & -4.560056 & -1.681281\end{array}$




\begin{tabular}{|c|c|c|c|}
\hline C & 5.850465 & -4.281193 & -1.952389 \\
\hline C & 6.380378 & -3.011905 & -1.622254 \\
\hline C & 5.596209 & -2.059424 & -1.009315 \\
\hline $\mathrm{H}$ & 4.103772 & -5.524287 & -1.946329 \\
\hline $\mathrm{H}$ & 6.481950 & -5.025409 & -2.429921 \\
\hline $\mathrm{H}$ & 7.415808 & -2.782876 & -1.859642 \\
\hline $\mathrm{H}$ & 6.016132 & -1.088831 & -0.774035 \\
\hline C & 4.941025 & 0.081305 & 1.350549 \\
\hline C & 5.486888 & 1.372900 & 1.638294 \\
\hline C & 6.540617 & 1.492002 & 2.584464 \\
\hline C & 7.028495 & 0.387619 & 3.243527 \\
\hline C & 6.471106 & -0.886682 & 2.984212 \\
\hline C & 5.457666 & -1.036358 & 2.063022 \\
\hline $\mathrm{H}$ & 6.947237 & 2.480603 & 2.784885 \\
\hline $\mathrm{H}$ & 7.830693 & 0.491319 & 3.969142 \\
\hline $\mathrm{H}$ & 6.841679 & -1.755699 & 3.521451 \\
\hline $\mathrm{H}$ & 5.034158 & -2.018132 & 1.884356 \\
\hline $\mathrm{O}$ & 0.022565 & 0.005759 & -1.694267 \\
\hline $\mathrm{O}$ & 0.090598 & 1.561617 & 0.394887 \\
\hline $\mathrm{H}$ & -1.037284 & 2.030131 & 0.009351 \\
\hline $\mathrm{H}$ & 5.356745 & 4.192913 & -1.251392 \\
\hline $\mathrm{H}$ & 2.251544 & 6.996433 & -2.242636 \\
\hline $\mathrm{H}$ & 1.312604 & 3.441498 & -0.009642 \\
\hline $\mathrm{H}$ & 0.002406 & -2.663247 & 2.007016 \\
\hline $\mathrm{H}$ & -3.649801 & -4.394421 & 0.529763 \\
\hline $\mathrm{H}$ & -0.276495 & -3.896517 & -2.096540 \\
\hline C & -2.596115 & 1.384239 & -1.027506 \\
\hline $\mathrm{O}$ & -2.109568 & 2.323248 & -0.282658 \\
\hline $\mathrm{H}$ & -1.903996 & 0.817072 & -1.659417 \\
\hline C & -3.961746 & 1.586553 & -1.644650 \\
\hline $\mathrm{O}$ & -4.430489 & 0.814477 & -2.457998 \\
\hline $\mathrm{O}$ & -4.567728 & 2.693642 & -1.197398 \\
\hline C & -5.866105 & 2.954562 & -1.759357 \\
\hline $\mathrm{H}$ & -6.558832 & 2.154867 & -1.486696 \\
\hline $\mathrm{H}$ & -5.803149 & 3.024077 & -2.848081 \\
\hline C & -4.165667 & -0.470850 & 0.425777 \\
\hline C & -2.810799 & -0.263100 & 0.135845 \\
\hline $\mathrm{H}$ & -4.270342 & -1.945492 & -0.961226 \\
\hline$N$ & -4.847564 & -1.335822 & -0.389429 \\
\hline C & -6.186085 & -1.384426 & -0.824153 \\
\hline $\mathrm{O}$ & -6.571680 & -2.278819 & -1.540839 \\
\hline $\mathrm{O}$ & -6.924358 & -0.363818 & -0.374374 \\
\hline C & -8.308010 & -0.402537 & -0.780997 \\
\hline $\mathrm{H}$ & -8.777660 & -1.329137 & -0.443573 \\
\hline
\end{tabular}




$\begin{array}{llcl}\mathrm{H} & -8.382782 & -0.332892 & -1.868318 \\ \mathrm{H} & -8.768753 & 0.460978 & -0.302158 \\ \mathrm{H} & -2.170554 & 0.088989 & 0.935811 \\ \mathrm{H} & -2.328055 & -0.957639 & -0.546080 \\ \mathrm{C} & -4.821140 & 0.154379 & 1.585415 \\ \mathrm{C} & -5.787255 & -0.553601 & 2.325255 \\ \mathrm{C} & -4.412520 & 1.426204 & 2.027547 \\ \mathrm{C} & -6.333269 & -0.000350 & 3.478249 \\ \mathrm{H} & -6.081073 & -1.551244 & 2.015379 \\ \mathrm{C} & -4.983088 & 1.982945 & 3.169562 \\ \mathrm{H} & -3.670281 & 1.986344 & 1.467733 \\ \mathrm{C} & -5.939060 & 1.272951 & 3.898983 \\ \mathrm{H} & -7.063057 & -0.563854 & 4.052530 \\ \mathrm{H} & -4.671538 & 2.971314 & 3.494262 \\ \mathrm{H} & -6.369013 & 1.704968 & 4.798409 \\ \mathrm{H} & -6.182412 & 3.904470 & -1.328883\end{array}$

Catalyst (R)-1 TS Conformation 381

B3LYP/6-31G(d) Energy $=-2809.680731$

B3LYP-D3(BJ)/def2-TZVPP-IEF-PCM(DCM) Energy = -2810.974211

B3LYP-D3(BJ)/def2-TZVPP-IEF-PCM(DCM)//B3LYP/6-31G(d) Free Energy (Quasiharmonic) = 2810.332318

Frequencies (Top 3 out of 270)

1. $-704.1701 \mathrm{~cm}-1$

2. $\quad 8.5337 \mathrm{~cm}-1$

3. $\quad 9.9301 \mathrm{~cm}-1$

B3LYP/6-31G(d) Molecular Geometry in Cartesian Coordinates

$\begin{array}{lrrr}\text { C } & 3.685259 & 0.265609 & 0.388015 \\ \text { C } & 2.945212 & 1.376888 & 0.003588 \\ \text { C } & 3.272246 & 2.703301 & 0.422235 \\ \text { C } & 4.307979 & 2.850161 & 1.324215 \\ \text { H } & 4.571839 & 3.848440 & 1.663527 \\ \text { C } & 2.857528 & -3.604329 & -1.332228 \\ \text { C } & 3.429572 & -1.061941 & -0.245938 \\ \text { C } & 2.153971 & -1.601484 & -0.219934 \\ \text { C } & 1.834078 & -2.890350 & -0.740228 \\ \text { H } & 2.656311 & -4.601679 & -1.714503 \\ \text { O } & 1.913964 & 1.223659 & -0.909485\end{array}$




\begin{tabular}{|c|c|c|c|}
\hline$P$ & 0.543228 & 0.398350 & -0.536566 \\
\hline 0 & 1.136571 & -0.851442 & 0.355372 \\
\hline C & 1.413391 & 6.283740 & -1.079912 \\
\hline C & 2.798600 & 6.123633 & -1.130627 \\
\hline C & 3.384036 & 4.950750 & -0.654214 \\
\hline C & 2.597452 & 3.916043 & -0.121204 \\
\hline C & 1.205110 & 4.087091 & -0.076402 \\
\hline C & 0.622501 & 5.262219 & -0.550265 \\
\hline $\mathrm{H}$ & 3.425605 & 6.908356 & -1.546375 \\
\hline $\mathrm{H}$ & -0.457239 & 5.378978 & -0.500892 \\
\hline C & -2.071226 & -4.688815 & -0.535127 \\
\hline C & -1.339944 & -4.712585 & -1.723574 \\
\hline C & -0.085257 & -4.107231 & -1.786081 \\
\hline C & 0.465775 & -3.467715 & -0.663465 \\
\hline C & -0.284585 & -3.443110 & 0.524483 \\
\hline C & -1.538602 & -4.050163 & 0.587395 \\
\hline $\mathrm{H}$ & -1.747701 & -5.197020 & -2.607141 \\
\hline $\mathrm{H}$ & -2.098601 & -4.026405 & 1.518489 \\
\hline C & 4.465838 & -1.784107 & -0.934668 \\
\hline C & 4.166365 & -3.080244 & -1.466761 \\
\hline C & 5.183016 & -3.812926 & -2.137502 \\
\hline C & 6.439751 & -3.282495 & -2.312309 \\
\hline C & 6.726843 & -1.985766 & -1.825489 \\
\hline C & 5.768658 & -1.257797 & -1.154698 \\
\hline $\mathrm{H}$ & 4.940486 & -4.800295 & -2.523574 \\
\hline $\mathrm{H}$ & 7.206890 & -3.848617 & -2.833550 \\
\hline $\mathrm{H}$ & 7.711942 & -1.556253 & -1.986794 \\
\hline $\mathrm{H}$ & 6.003568 & -0.261940 & -0.798449 \\
\hline C & 4.693029 & 0.425661 & 1.401086 \\
\hline C & 5.007484 & 1.743441 & 1.863350 \\
\hline C & 6.004353 & 1.915465 & 2.861591 \\
\hline C & 6.654629 & 0.832808 & 3.406543 \\
\hline C & 6.324261 & -0.473505 & 2.975165 \\
\hline C & 5.372420 & -0.671841 & 1.999099 \\
\hline $\mathrm{H}$ & 6.234852 & 2.924812 & 3.194613 \\
\hline $\mathrm{H}$ & 7.411081 & 0.975771 & 4.173436 \\
\hline $\mathrm{H}$ & 6.821986 & -1.329968 & 3.422201 \\
\hline $\mathrm{H}$ & 5.123555 & -1.679909 & 1.687876 \\
\hline $\mathrm{O}$ & -0.145473 & -0.002468 & -1.792372 \\
\hline 0 & -0.265147 & 1.189767 & 0.517663 \\
\hline $\mathrm{H}$ & -1.392602 & 1.521984 & 0.182988 \\
\hline $\mathrm{H}$ & 0.583643 & 3.305340 & 0.344916 \\
\hline $\mathrm{H}$ & 0.954046 & 7.196236 & -1.451428 \\
\hline $\mathrm{H}$ & 4.461811 & 4.822813 & -0.710533 \\
\hline
\end{tabular}




\begin{tabular}{|c|c|c|c|}
\hline $\mathrm{H}$ & 0.121523 & -2.953372 & 1.402818 \\
\hline $\mathrm{H}$ & -3.048138 & -5.162898 & -0.483366 \\
\hline $\mathrm{H}$ & 0.468692 & -4.107684 & -2.720353 \\
\hline C & -2.905978 & 1.252526 & -1.189327 \\
\hline 0 & -2.527872 & 1.779366 & -0.074545 \\
\hline $\mathrm{H}$ & -2.135729 & 0.993198 & -1.926223 \\
\hline C & -4.195147 & 1.773245 & -1.817696 \\
\hline 0 & -4.669505 & 1.313064 & -2.840804 \\
\hline $\mathrm{O}$ & -4.735502 & 2.778099 & -1.124254 \\
\hline C & -5.936309 & 3.343927 & -1.691769 \\
\hline $\mathrm{H}$ & -6.191634 & 4.180963 & -1.042276 \\
\hline $\mathrm{H}$ & -6.737737 & 2.600534 & -1.703791 \\
\hline$C$ & -4.416820 & -0.817868 & -0.171311 \\
\hline C & -3.362321 & -0.674138 & -1.086605 \\
\hline $\mathrm{H}$ & -5.776421 & -0.585235 & -1.662768 \\
\hline$N$ & -5.696792 & -0.630598 & -0.650473 \\
\hline C & -6.824026 & -0.010946 & -0.070891 \\
\hline $\mathrm{O}$ & -7.794764 & 0.254266 & -0.747023 \\
\hline 0 & -6.678565 & 0.250979 & 1.226892 \\
\hline C & -7.799584 & 0.911584 & 1.848589 \\
\hline $\mathrm{H}$ & -7.960395 & 1.890920 & 1.392593 \\
\hline $\mathrm{H}$ & -7.519781 & 1.014976 & 2.896162 \\
\hline $\mathrm{H}$ & -8.703221 & 0.307429 & 1.742573 \\
\hline $\mathrm{H}$ & -2.398593 & -1.095564 & -0.824459 \\
\hline $\mathrm{H}$ & -3.609501 & -0.739334 & -2.142604 \\
\hline C & -4.177966 & -1.172246 & 1.230101 \\
\hline C & -2.991340 & -0.765638 & 1.869161 \\
\hline C & -5.076785 & -2.012407 & 1.919002 \\
\hline C & -2.735517 & -1.158352 & 3.181213 \\
\hline $\mathrm{H}$ & -2.279708 & -0.129743 & 1.359068 \\
\hline C & -4.796193 & -2.427992 & 3.214366 \\
\hline $\mathrm{H}$ & -5.975001 & -2.363671 & 1.422308 \\
\hline C & -3.630260 & -1.991685 & 3.854118 \\
\hline $\mathrm{H}$ & -1.826109 & -0.819892 & 3.668207 \\
\hline $\mathrm{H}$ & -5.484375 & -3.093438 & 3.727760 \\
\hline $\mathrm{H}$ & -3.417290 & -2.311765 & 4.870418 \\
\hline $\mathrm{H}$ & -5.747574 & 3.688018 & -2.711166 \\
\hline
\end{tabular}

Catalyst (R)-1 TS Conformation 382

B3LYP/6-31G(d) Energy $=-2809.689661$

B3LYP-D3(BJ)/def2-TZVPP-IEF-PCM(DCM) Energy = -2810.97664 
B3LYP-D3(BJ)/def2-TZVPP-IEF-PCM(DCM)//B3LYP/6-31G(d) Free Energy (Quasiharmonic) = 2810.332297

Frequencies (Top 3 out of 270)

1. $-236.1417 \mathrm{~cm}-1$

2. $\quad 8.6590 \mathrm{~cm}-1$

3. $12.0062 \mathrm{~cm}-1$

B3LYP/6-31G(d) Molecular Geometry in Cartesian Coordinates

$\begin{array}{llll}\text { C } & 3.361371 & 0.215615 & 0.324987 \\ \text { C } & 2.611838 & 1.274875 & -0.162700 \\ \text { C } & 3.001014 & 2.641067 & -0.017208 \\ \text { C } & 4.106197 & 2.894775 & 0.773205 \\ \text { H } & 4.420911 & 3.924533 & 0.918498 \\ \text { C } & 2.483361 & -3.923445 & -0.473127 \\ \text { C } & 3.044375 & -1.190920 & -0.064590 \\ \text { C } & 1.787099 & -1.722677 & 0.173694 \\ \text { C } & 1.487921 & -3.111430 & 0.035583 \\ \text { H } & 2.283946 & -4.984316 & -0.599321 \\ \text { O } & 1.477640 & 0.997035 & -0.924991 \\ \text { P } & 0.172670 & 0.299774 & -0.257077 \\ \text { O } & 0.798034 & -0.885925 & 0.678004 \\ \text { C } & 1.242883 & 5.959152 & -2.123369 \\ \text { C } & 2.624714 & 5.762706 & -2.117098 \\ \text { C } & 3.170598 & 4.674783 & -1.438275 \\ \text { C } & 2.349614 & 3.764572 & -0.747842 \\ \text { C } & 0.962165 & 3.973857 & -0.761889 \\ \text { C } & 0.417541 & 5.060855 & -1.445768 \\ \text { H } & 3.279038 & 6.448755 & -2.649184 \\ \text { H } & -0.660268 & 5.187778 & -1.449504 \\ \text { C } & -2.174522 & -4.973987 & 1.321702 \\ \text { C } & -2.222940 & -3.853053 & 0.490464 \\ \text { C } & -1.047697 & -3.225275 & 0.077274 \\ \text { C } & 0.202680 & -3.715157 & 0.485957 \\ \text { C } & 0.238889 & -4.844524 & 1.321267 \\ \text { C } & -0.937405 & -5.468174 & 1.736461 \\ \text { H } & -3.180938 & -3.466953 & 0.152031 \\ \text { H } & -0.885257 & -6.335757 & 2.389273 \\ \text { C } & 4.035767 & -2.029725 & -0.684423 \\ \text { C } & 3.740934 & -3.416823 & -0.881892 \\ \text { C } & 4.711134 & -4.258250 & -1.490748 \\ \text { C } & 5.918981 & -3.754072 & -1.913212\end{array}$




\begin{tabular}{|c|c|c|c|}
\hline C & 6.201348 & -2.377768 & -1.747764 \\
\hline C & 5.287557 & -1.539322 & -1.147791 \\
\hline $\mathrm{H}$ & 4.472732 & -5.310678 & -1.625805 \\
\hline $\mathrm{H}$ & 6.651106 & -4.405063 & -2.383129 \\
\hline $\mathrm{H}$ & 7.146336 & -1.975869 & -2.103080 \\
\hline $\mathrm{H}$ & 5.515521 & -0.485498 & -1.038983 \\
\hline C & 4.455159 & 0.503496 & 1.215120 \\
\hline C & 4.822248 & 1.869101 & 1.435764 \\
\hline C & 5.896516 & 2.171269 & 2.315902 \\
\hline C & 6.573287 & 1.171755 & 2.975051 \\
\hline C & 6.193538 & -0.177241 & 2.782711 \\
\hline C & 5.165541 & -0.503164 & 1.925237 \\
\hline $\mathrm{H}$ & 6.165460 & 3.214231 & 2.465679 \\
\hline $\mathrm{H}$ & 7.388992 & 1.414485 & 3.650592 \\
\hline $\mathrm{H}$ & 6.713079 & -0.964784 & 3.321914 \\
\hline $\mathrm{H}$ & 4.879837 & -1.541049 & 1.800621 \\
\hline $\mathrm{O}$ & -0.755889 & -0.156377 & -1.324141 \\
\hline $\mathrm{O}$ & -0.382284 & 1.276996 & 0.829819 \\
\hline $\mathrm{H}$ & -1.416956 & 1.294992 & 0.952470 \\
\hline $\mathrm{H}$ & 0.303228 & 3.301308 & -0.227631 \\
\hline $\mathrm{H}$ & 0.813033 & 6.802554 & -2.658021 \\
\hline $\mathrm{H}$ & 4.244650 & 4.510793 & -1.459441 \\
\hline $\mathrm{H}$ & 1.199217 & -5.221818 & 1.662168 \\
\hline $\mathrm{H}$ & -3.093080 & -5.457398 & 1.644360 \\
\hline $\mathrm{H}$ & -1.097190 & -2.360905 & -0.574785 \\
\hline C & -3.706095 & 0.552913 & 1.519850 \\
\hline 0 & -2.861990 & 1.475351 & 1.239289 \\
\hline $\mathrm{H}$ & -3.390919 & -0.501705 & 1.484594 \\
\hline C & -4.628808 & 0.837964 & 2.714326 \\
\hline $\mathrm{O}$ & -4.940012 & 1.939098 & 3.104002 \\
\hline 0 & -5.050419 & -0.318372 & 3.269559 \\
\hline C & -5.909230 & -0.173924 & 4.414505 \\
\hline $\mathrm{H}$ & -6.151604 & -1.189075 & 4.729477 \\
\hline $\mathrm{H}$ & -5.391211 & 0.363318 & 5.212985 \\
\hline C & -4.414082 & 0.351963 & -0.983221 \\
\hline C & -5.126491 & 0.532641 & 0.223888 \\
\hline $\mathrm{H}$ & -2.845039 & 1.007653 & -2.098002 \\
\hline$N$ & -3.574749 & 1.301934 & -1.452988 \\
\hline C & -3.345546 & 2.636458 & -1.017556 \\
\hline $\mathrm{O}$ & -2.315253 & 3.199672 & -1.300715 \\
\hline 0 & -4.420401 & 3.173119 & -0.438125 \\
\hline C & -4.172577 & 4.368190 & 0.335433 \\
\hline $\mathrm{H}$ & -3.607671 & 5.091645 & -0.254176 \\
\hline $\mathrm{H}$ & -3.628688 & 4.083645 & 1.238164 \\
\hline
\end{tabular}




$\begin{array}{lrrr}\mathrm{H} & -5.159423 & 4.755509 & 0.587018 \\ \mathrm{H} & -5.786649 & -0.281611 & 0.505450 \\ \mathrm{H} & -5.499654 & 1.524549 & 0.439785 \\ \mathrm{C} & -4.455589 & -0.934749 & -1.714733 \\ \mathrm{C} & -3.345167 & -1.448645 & -2.411774 \\ \mathrm{C} & -5.673268 & -1.642027 & -1.761760 \\ \mathrm{C} & -3.457625 & -2.640598 & -3.124376 \\ \mathrm{H} & -2.375884 & -0.965197 & -2.342046 \\ \mathrm{C} & -5.779222 & -2.826467 & -2.485534 \\ \mathrm{H} & -6.549713 & -1.242262 & -1.262665 \\ \mathrm{C} & -4.670666 & -3.330427 & -3.168603 \\ \mathrm{H} & -2.585798 & -3.035734 & -3.637161 \\ \mathrm{H} & -6.729956 & -3.350493 & -2.521860 \\ \mathrm{H} & -4.751368 & -4.256828 & -3.730347 \\ \mathrm{H} & -6.816067 & 0.375335 & 4.146777\end{array}$

Catalyst (R)-1 TS Conformation 383

B3LYP/6-31G(d) Energy $=-2809.688944$

B3LYP-D3(BJ)/def2-TZVPP-IEF-PCM(DCM) Energy $=-2810.977254$

B3LYP-D3(BJ)/def2-TZVPP-IEF-PCM(DCM)//B3LYP/6-31G(d) Free Energy (Quasiharmonic) = 2810.33228

Frequencies (Top 3 out of 270)

1. $-265.4610 \mathrm{~cm}-1$

2. $\quad 11.5424 \mathrm{~cm}-1$

3. $\quad 16.5452 \mathrm{~cm}-1$

B3LYP/6-31G(d) Molecular Geometry in Cartesian Coordinates

$\begin{array}{llll}\text { C } & 2.817807 & -1.050190 & -0.269577 \\ \text { C } & 1.588372 & -1.662591 & -0.081751 \\ \text { C } & 1.347214 & -3.030379 & -0.414626 \\ \text { C } & 2.359586 & -3.711430 & -1.063933 \\ \text { H } & 2.198664 & -4.749695 & -1.341022 \\ \text { C } & 3.808558 & 2.935896 & 0.986379 \\ \text { C } & 3.101550 & 0.302851 & 0.291634 \\ \text { C } & 2.310153 & 1.385822 & -0.053826 \\ \text { C } & 2.678608 & 2.737324 & 0.215405 \\ \text { H } & 4.110577 & 3.953546 & 1.218590 \\ \text { O } & 0.573868 & -0.962988 & 0.566965 \\ \text { P } & -0.088583 & 0.396031 & -0.035767\end{array}$




\begin{tabular}{|c|c|c|c|}
\hline $\mathrm{O}$ & 1.148084 & 1.142284 & -0.789282 \\
\hline C & -2.144086 & -5.347982 & 0.569319 \\
\hline C & -2.293749 & -4.104532 & -0.048426 \\
\hline C & -1.177933 & -3.320066 & -0.345864 \\
\hline C & 0.113229 & -3.774973 & -0.037754 \\
\hline C & 0.249188 & -5.022944 & 0.595176 \\
\hline C & -0.866682 & -5.802564 & 0.896958 \\
\hline $\mathrm{H}$ & -3.284209 & -3.740950 & -0.306910 \\
\hline $\mathrm{H}$ & -0.735493 & -6.763093 & 1.388678 \\
\hline C & 0.794761 & 6.211750 & -1.480124 \\
\hline C & 0.018217 & 5.275508 & -0.795862 \\
\hline C & 0.602800 & 4.132241 & -0.249321 \\
\hline C & 1.981905 & 3.912531 & -0.377994 \\
\hline C & 2.754775 & 4.862807 & -1.068968 \\
\hline C & 2.167883 & 6.002327 & -1.616209 \\
\hline $\mathrm{H}$ & -1.049836 & 5.421033 & -0.675785 \\
\hline $\mathrm{H}$ & 2.782644 & 6.720456 & -2.153156 \\
\hline C & 4.219638 & 0.521253 & 1.169822 \\
\hline C & 4.566231 & 1.864980 & 1.519464 \\
\hline C & 5.664729 & 2.098682 & 2.390386 \\
\hline C & 6.384276 & 1.051506 & 2.917279 \\
\hline C & 6.027105 & -0.278918 & 2.594925 \\
\hline C & 4.976483 & -0.537665 & 1.742045 \\
\hline $\mathrm{H}$ & 5.918318 & 3.126153 & 2.640369 \\
\hline $\mathrm{H}$ & 7.218285 & 1.241442 & 3.587357 \\
\hline $\mathrm{H}$ & 6.583106 & -1.105571 & 3.028944 \\
\hline $\mathrm{H}$ & 4.708533 & -1.562920 & 1.514022 \\
\hline C & 3.823705 & -1.743294 & -1.031829 \\
\hline C & 3.581468 & -3.097069 & -1.425517 \\
\hline C & 4.564257 & -3.796766 & -2.176823 \\
\hline C & 5.736150 & -3.182423 & -2.551250 \\
\hline C & 5.965972 & -1.833570 & -2.192076 \\
\hline C & 5.038640 & -1.134029 & -1.451353 \\
\hline $\mathrm{H}$ & 4.363881 & -4.827568 & -2.459492 \\
\hline $\mathrm{H}$ & 6.478910 & -3.723490 & -3.130997 \\
\hline $\mathrm{H}$ & 6.880962 & -1.340807 & -2.509447 \\
\hline $\mathrm{H}$ & 5.227611 & -0.097992 & -1.197115 \\
\hline $\mathrm{O}$ & -0.716352 & 1.163785 & 1.074519 \\
\hline $\mathrm{O}$ & -0.993773 & -0.048010 & -1.232937 \\
\hline $\mathrm{H}$ & -1.891452 & 0.459481 & -1.415916 \\
\hline $\mathrm{H}$ & 1.241442 & -5.375798 & 0.862450 \\
\hline $\mathrm{H}$ & -3.016689 & -5.955768 & 0.795038 \\
\hline $\mathrm{H}$ & -1.304463 & -2.361505 & -0.836587 \\
\hline $\mathrm{H}$ & 3.820890 & 4.691607 & -1.192410 \\
\hline
\end{tabular}




$\begin{array}{llll}\mathrm{H} & 0.333156 & 7.098925 & -1.906778 \\ \mathrm{H} & -0.016705 & 3.428743 & 0.294754 \\ \mathrm{C} & -4.279458 & 0.447724 & -1.734969 \\ \mathrm{O} & -3.202670 & 1.127376 & -1.729696 \\ \mathrm{H} & -5.142753 & 0.877869 & -2.270488 \\ \mathrm{C} & -4.247762 & -1.071879 & -1.994232 \\ \mathrm{O} & -5.010475 & -1.903097 & -1.540317 \\ \mathrm{O} & -3.311168 & -1.331173 & -2.916788 \\ \mathrm{C} & -3.265970 & -2.676806 & -3.432334 \\ \mathrm{H} & -4.265263 & -2.999981 & -3.733903 \\ \mathrm{H} & -2.595001 & -2.631010 & -4.289899 \\ \mathrm{C} & -4.251422 & 0.752808 & 0.943057 \\ \mathrm{C} & -5.292055 & 0.616924 & 0.013203 \\ \mathrm{H} & -2.445361 & 1.680916 & 1.219792 \\ \mathrm{~N} & -3.425323 & 1.836228 & 0.930238 \\ \mathrm{C} & -3.561310 & 3.103726 & 0.343469 \\ \mathrm{O} & -2.638258 & 3.886244 & 0.324974 \\ \mathrm{O} & -4.800706 & 3.380921 & -0.091411 \\ \mathrm{C} & -4.946822 & 4.683493 & -0.688320 \\ \mathrm{H} & -5.997861 & 4.752064 & -0.969076 \\ \mathrm{H} & -4.304555 & 4.767422 & -1.567786 \\ \mathrm{H} & -4.686613 & 5.463610 & 0.030413 \\ \mathrm{H} & -5.945095 & -0.240171 & 0.112370 \\ \mathrm{H} & -5.777711 & 1.524988 & -0.307904 \\ \mathrm{C} & -3.889936 & -0.309947 & 1.903657 \\ \mathrm{C} & -4.369382 & -1.625605 & 1.748211 \\ \mathrm{C} & -3.118235 & -0.006002 & 3.043439 \\ \mathrm{C} & -4.078839 & -2.598955 & 2.698399 \\ \mathrm{H} & -4.940090 & -1.895832 & 0.867126 \\ \mathrm{H} & -2.835822 & -0.984092 & 3.991949 \\ \mathrm{H} & -2.756315 & 1.002490 & 3.206345 \\ \mathrm{H} & -3.314611 & -2.283693 & 3.823955 \\ -4.443267 & -3.611517 & 2.554374 \\ \mathrm{H} & -2.242105 & -0.726977 & 4.864087 \\ \mathrm{H} & -370992 & -3.360323 & -2.678668\end{array}$

Catalyst (R)-1 TS Conformation 384

B3LYP/6-31G(d) Energy $=-2809.690086$ B3LYP-D3(BJ)/def2-TZVPP-IEF-PCM(DCM) Energy $=-2810.976084$ B3LYP-D3(BJ)/def2-TZVPP-IEF-PCM(DCM)//B3LYP/6-31G(d) Free Energy (Quasiharmonic) = 2810.332079 
Frequencies (Top 3 out of 270)

1. $-265.6907 \mathrm{~cm}-1$

2. $\quad 7.5977 \mathrm{~cm}-1$

3. $\quad 12.5642 \mathrm{~cm}-1$

B3LYP/6-31G(d) Molecular Geometry in Cartesian Coordinates

$\begin{array}{llll}\text { C } & 3.228009 & -0.926014 & -0.073443 \\ \text { C } & 2.079295 & -1.598874 & 0.309187 \\ \text { C } & 1.932854 & -3.016757 & 0.251133 \\ \text { C } & 3.011365 & -3.732487 & -0.234648 \\ \text { H } & 2.956527 & -4.817266 & -0.259989 \\ \text { C } & 3.564049 & 3.365347 & 0.034994 \\ \text { C } & 3.310280 & 0.558071 & 0.073499 \\ \text { C } & 2.352843 & 1.371311 & -0.516874 \\ \text { C } & 2.480226 & 2.790748 & -0.601792 \\ \text { H } & 3.683633 & 4.444835 & -0.002187 \\ \text { O } & 1.017853 & -0.848191 & 0.809612 \\ \text { P } & 0.128523 & 0.058617 & -0.208368 \\ \text { O } & 1.257604 & 0.775423 & -1.140036 \\ \text { C } & -1.591907 & -5.184479 & 1.439329 \\ \text { C } & -0.893359 & -5.536737 & 0.283428 \\ \text { C } & 0.233482 & -4.812758 & -0.099811 \\ \text { C } & 0.692195 & -3.725444 & 0.665593 \\ \text { C } & -0.026067 & -3.375897 & 1.821399 \\ \text { C } & -1.155981 & -4.099791 & 2.201357 \\ \text { H } & -1.232537 & -6.367780 & -0.329621 \\ \text { H } & -1.696192 & -3.801084 & 3.094733 \\ \text { C } & -0.107720 & 5.371449 & -2.880070 \\ \text { C } & -0.659929 & 4.456257 & -1.981815 \\ \text { C } & 0.159764 & 3.601926 & -1.244385 \\ \text { C } & 1.554962 & 3.649050 & -1.394578 \\ \text { C } & 2.099323 & 4.573267 & -2.302565 \\ \text { C } & 1.277481 & 5.426812 & -3.038006 \\ \text { H } & -1.738014 & 4.402611 & -1.851971 \\ \text { H } & 1.720847 & 6.127815 & -3.740544 \\ \text { C } & 4.376153 & 1.180125 & 0.811170 \\ \text { C } & 4.498873 & 2.605973 & 0.779214 \\ \text { C } & 5.548825 & 3.233229 & 1.503538 \\ \text { C } & 6.432297 & 2.491558 & 2.252501 \\ \text { C } & 6.294366 & 1.084609 & 2.311861 \\ \text { C } & 5.296298 & 0.445958 & 1.609270\end{array}$




\begin{tabular}{|c|c|c|c|}
\hline $\mathrm{H}$ & 5.632090 & 4.316719 & 1.461584 \\
\hline $\mathrm{H}$ & 7.227604 & 2.981959 & 2.807148 \\
\hline $\mathrm{H}$ & 6.978848 & 0.502086 & 2.922556 \\
\hline $\mathrm{H}$ & 5.197137 & -0.631466 & 1.673614 \\
\hline C & 4.302052 & -1.681394 & -0.661018 \\
\hline C & 4.187634 & -3.108026 & -0.714231 \\
\hline C & 5.248480 & -3.874122 & -1.269905 \\
\hline C & 6.366044 & -3.263617 & -1.788779 \\
\hline C & 6.462231 & -1.852335 & -1.778643 \\
\hline C & 5.460243 & -1.082788 & -1.229270 \\
\hline $\mathrm{H}$ & 5.149766 & -4.956917 & -1.289524 \\
\hline $\mathrm{H}$ & 7.167153 & -3.858890 & -2.218291 \\
\hline $\mathrm{H}$ & 7.333018 & -1.369035 & -2.213368 \\
\hline $\mathrm{H}$ & 5.547597 & -0.002976 & -1.240134 \\
\hline $\mathrm{O}$ & -0.744081 & 0.960741 & 0.584180 \\
\hline 0 & -0.538195 & -0.871258 & -1.280497 \\
\hline $\mathrm{H}$ & -1.496199 & -1.176953 & -1.061863 \\
\hline $\mathrm{H}$ & 0.290069 & -2.534176 & 2.424927 \\
\hline $\mathrm{H}$ & -2.474557 & -5.744743 & 1.737188 \\
\hline $\mathrm{H}$ & 0.752307 & -5.073770 & -1.017799 \\
\hline $\mathrm{H}$ & 3.175996 & 4.605411 & -2.446072 \\
\hline $\mathrm{H}$ & -0.751316 & 6.031566 & -3.455790 \\
\hline $\mathrm{H}$ & -0.281367 & 2.902719 & -0.543323 \\
\hline C & -3.864651 & -1.059310 & -1.472137 \\
\hline $\mathrm{O}$ & -2.934312 & -1.692632 & -0.864965 \\
\hline $\mathrm{H}$ & -3.660907 & -0.074942 & -1.921462 \\
\hline C & -4.840158 & -1.832174 & -2.365495 \\
\hline $\mathrm{O}$ & -5.403682 & -1.327457 & -3.313229 \\
\hline 0 & -4.983462 & -3.108784 & -1.978643 \\
\hline C & -5.857568 & -3.902163 & -2.799837 \\
\hline $\mathrm{H}$ & -5.483910 & -3.941618 & -3.826183 \\
\hline $\mathrm{H}$ & -6.867500 & -3.482633 & -2.805033 \\
\hline C & -4.515119 & 0.239097 & 0.757094 \\
\hline C & -5.250429 & -0.526146 & -0.170231 \\
\hline $\mathrm{H}$ & -3.306830 & -1.347878 & 1.027995 \\
\hline$N$ & -3.589807 & -0.461834 & 1.465762 \\
\hline C & -2.838775 & -0.170818 & 2.617900 \\
\hline $\mathrm{O}$ & -1.998560 & -0.938004 & 3.028105 \\
\hline $\mathrm{O}$ & -3.224160 & 0.961035 & 3.212996 \\
\hline C & -2.446842 & 1.324084 & 4.370675 \\
\hline $\mathrm{H}$ & -1.397701 & 1.444351 & 4.092178 \\
\hline $\mathrm{H}$ & -2.535484 & 0.557178 & 5.143677 \\
\hline $\mathrm{H}$ & -2.869836 & 2.268720 & 4.711566 \\
\hline $\mathrm{H}$ & -5.995032 & -0.005053 & -0.762713 \\
\hline
\end{tabular}




$\begin{array}{llll}\text { H } & -5.503753 & -1.543289 & 0.115948 \\ \mathrm{C} & -4.634975 & 1.707657 & 0.783900 \\ \mathrm{C} & -3.501159 & 2.541338 & 0.800371 \\ \mathrm{C} & -5.915721 & 2.284247 & 0.705617 \\ \mathrm{C} & -3.659463 & 3.923276 & 0.734419 \\ \mathrm{H} & -2.509130 & 2.102937 & 0.827401 \\ \mathrm{C} & -6.064905 & 3.668047 & 0.663436 \\ \mathrm{H} & -6.793351 & 1.644695 & 0.707339 \\ \mathrm{C} & -4.935955 & 4.489823 & 0.672892 \\ \mathrm{H} & -2.779188 & 4.559983 & 0.727115 \\ \mathrm{H} & -7.059270 & 4.102993 & 0.620337 \\ \mathrm{H} & -5.050204 & 5.569688 & 0.630044 \\ \mathrm{H} & -5.855200 & -4.895954 & -2.351985\end{array}$

Catalyst (R)-1 TS Conformation 385

B3LYP/6-31G(d) Energy = -2809.679102

B3LYP-D3(BJ)/def2-TZVPP-IEF-PCM(DCM) Energy $=-2810.97443$

B3LYP-D3(BJ)/def2-TZVPP-IEF-PCM(DCM)//B3LYP/6-31G(d) Free Energy (Quasiharmonic) = 2810.332066

Frequencies (Top 3 out of 270)

1. $-389.9478 \mathrm{~cm}-1$

2. $\quad 5.5828 \mathrm{~cm}-1$

3. $\quad 8.5162 \mathrm{~cm}-1$

B3LYP/6-31G(d) Molecular Geometry in Cartesian Coordinates

$\begin{array}{llll}\mathrm{C} & 2.933428 & -0.249951 & -0.223026 \\ \mathrm{C} & 2.530020 & -1.116685 & 0.780298 \\ \mathrm{C} & 2.712095 & -2.530443 & 0.722785 \\ \mathrm{C} & 3.267357 & -3.046257 & -0.431935 \\ \mathrm{H} & 3.446442 & -4.115984 & -0.500851 \\ \mathrm{C} & 2.367642 & 4.011399 & 0.076478 \\ \mathrm{C} & 2.785246 & 1.224309 & -0.036771 \\ \mathrm{C} & 1.542078 & 1.763312 & 0.268881 \\ \mathrm{C} & 1.295963 & 3.169168 & 0.298008 \\ \mathrm{H} & 2.206433 & 5.086156 & 0.096698 \\ \mathrm{O} & 1.931931 & -0.581786 & 1.913873 \\ \mathrm{P} & 0.388950 & -0.055254 & 1.800703 \\ \mathrm{O} & 0.467037 & 0.908165 & 0.450711 \\ \mathrm{C} & 1.689541 & -5.227390 & 3.914127\end{array}$




\begin{tabular}{|c|c|c|c|}
\hline C & 1.348287 & -5.528181 & 2.594989 \\
\hline C & 1.666035 & -4.638292 & 1.570067 \\
\hline C & 2.330505 & -3.431436 & 1.842246 \\
\hline C & 2.662365 & -3.136967 & 3.175237 \\
\hline C & 2.346305 & -4.028598 & 4.198685 \\
\hline $\mathrm{H}$ & 0.824847 & -6.452101 & 2.362933 \\
\hline $\mathrm{H}$ & 2.614617 & -3.784017 & 5.222997 \\
\hline C & -2.570856 & 4.968677 & 0.889463 \\
\hline C & -1.824759 & 5.246674 & -0.256739 \\
\hline C & -0.580877 & 4.642251 & -0.443992 \\
\hline C & -0.063081 & 3.746384 & 0.506218 \\
\hline C & -0.822439 & 3.469283 & 1.655528 \\
\hline C & -2.063452 & 4.080954 & 1.841906 \\
\hline $\mathrm{H}$ & -2.208316 & 5.934416 & -1.006142 \\
\hline $\mathrm{H}$ & -2.629941 & 3.868517 & 2.745421 \\
\hline C & 3.909203 & 2.112028 & -0.161537 \\
\hline C & 3.683648 & 3.525509 & -0.118369 \\
\hline C & 4.784901 & 4.414078 & -0.250947 \\
\hline C & 6.066246 & 3.935806 & -0.396054 \\
\hline C & 6.297158 & 2.539964 & -0.405689 \\
\hline C & 5.249178 & 1.652966 & -0.293382 \\
\hline $\mathrm{H}$ & 4.593547 & 5.484207 & -0.221829 \\
\hline $\mathrm{H}$ & 6.901652 & 4.624209 & -0.489524 \\
\hline $\mathrm{H}$ & 7.312524 & 2.163235 & -0.494993 \\
\hline $\mathrm{H}$ & 5.445163 & 0.586884 & -0.289828 \\
\hline C & 3.436612 & -0.810579 & -1.448604 \\
\hline C & 3.609151 & -2.230205 & -1.538398 \\
\hline C & 4.106573 & -2.798467 & -2.743077 \\
\hline C & 4.391605 & -2.011024 & -3.834738 \\
\hline C & 4.186304 & -0.613183 & -3.762843 \\
\hline C & 3.726001 & -0.029006 & -2.602061 \\
\hline $\mathrm{H}$ & 4.247773 & -3.876002 & -2.786912 \\
\hline $\mathrm{H}$ & 4.765376 & -2.458263 & -4.751754 \\
\hline $\mathrm{H}$ & 4.394106 & 0.007047 & -4.630679 \\
\hline $\mathrm{H}$ & 3.573702 & 1.043354 & -2.565413 \\
\hline $\mathrm{O}$ & -0.013798 & 0.676429 & 3.023295 \\
\hline $\mathrm{O}$ & -0.446591 & -1.260392 & 1.294051 \\
\hline $\mathrm{H}$ & -1.539247 & -1.227237 & 1.399510 \\
\hline $\mathrm{H}$ & 3.172582 & -2.209108 & 3.409004 \\
\hline $\mathrm{H}$ & 1.439667 & -5.917926 & 4.715284 \\
\hline $\mathrm{H}$ & 1.374784 & -4.865184 & 0.548327 \\
\hline $\mathrm{H}$ & -0.440768 & 2.781353 & 2.403425 \\
\hline $\mathrm{H}$ & -3.536341 & 5.444423 & 1.042183 \\
\hline $\mathrm{H}$ & -0.003973 & 4.857439 & -1.339830 \\
\hline
\end{tabular}




$\begin{array}{llll}\mathrm{C} & -3.248735 & 0.103605 & 1.490119 \\ \mathrm{O} & -2.891881 & -1.130501 & 1.422281 \\ \mathrm{H} & -2.569913 & 0.819549 & 1.976777 \\ \mathrm{C} & -4.705977 & 0.299532 & 1.935273 \\ \mathrm{O} & -5.703889 & 0.284074 & 1.232732 \\ \mathrm{O} & -4.745328 & 0.453699 & 3.259409 \\ \mathrm{C} & -6.057286 & 0.544258 & 3.852734 \\ \mathrm{H} & -5.881537 & 0.659377 & 4.921671 \\ \mathrm{H} & -6.626445 & -0.365408 & 3.647968 \\ \mathrm{C} & -3.542207 & 0.101111 & -1.218762 \\ \mathrm{C} & -3.216401 & 1.042207 & -0.222359 \\ \mathrm{H} & -5.474493 & 0.020919 & -0.612764 \\ \mathrm{~N} & -4.857057 & -0.221568 & -1.396848 \\ \mathrm{C} & -5.526595 & -0.802696 & -2.481509 \\ \mathrm{O} & -6.682851 & -1.153410 & -2.400866 \\ \mathrm{O} & -4.769701 & -0.854974 & -3.587032 \\ \mathrm{C} & -5.413187 & -1.443323 & -4.731955 \\ \mathrm{H} & -4.663685 & -1.420678 & -5.522673 \\ \mathrm{H} & -6.293244 & -0.860805 & -5.014581 \\ \mathrm{H} & -5.715376 & -2.470710 & -4.514992 \\ \mathrm{H} & -2.178463 & 1.357755 & -0.207472 \\ \mathrm{H} & -3.934975 & 1.834903 & -0.030885 \\ \mathrm{C} & -2.484312 & -0.694551 & -1.848019 \\ \mathrm{C} & -1.294194 & -0.085005 & -2.282538 \\ \mathrm{C} & -2.604968 & -2.096509 & -1.911935 \\ \mathrm{C} & -0.258446 & -0.857332 & -2.797704 \\ \mathrm{H} & -1.193360 & 0.994046 & -2.230300 \\ \mathrm{C} & -1.555585 & -2.864823 & -2.402695 \\ \mathrm{H} & -3.498000 & -2.576301 & -1.525443 \\ \mathrm{C} & -0.385468 & -2.247284 & -2.853149 \\ \mathrm{H} & 0.656595 & -0.381867 & -3.136505 \\ \mathrm{H} & -1.644384 & -3.947167 & -2.422993 \\ \mathrm{H} & 0.436430 & -2.847566 & -3.232907 \\ & -6.595796 & 1.406174 & 3.451313\end{array}$

Catalyst (R)-1 TS Conformation 386

B3LYP/6-31G(d) Energy $=-2809.67724$

B3LYP-D3(BJ)/def2-TZVPP-IEF-PCM(DCM) Energy = -2810.973019

B3LYP-D3(BJ)/def2-TZVPP-IEF-PCM(DCM)//B3LYP/6-31G(d) Free Energy (Quasiharmonic) = 2810.331905

Frequencies (Top 3 out of 270) 
1. $-731.5125 \mathrm{~cm}-1$

2. $\quad 10.0364 \mathrm{~cm}-1$

3. $\quad 11.3690 \mathrm{~cm}-1$

B3LYP/6-31G(d) Molecular Geometry in Cartesian Coordinates

$\begin{array}{llll}\mathrm{C} & 3.034641 & -0.688519 & -0.299295 \\ \mathrm{C} & 1.876198 & -1.440933 & -0.436581 \\ \mathrm{C} & 1.893246 & -2.830151 & -0.768318 \\ \mathrm{C} & 3.118174 & -3.412413 & -1.026048 \\ \mathrm{H} & 3.156248 & -4.468061 & -1.282412 \\ \mathrm{C} & 3.036205 & 3.430162 & 0.958412 \\ \mathrm{C} & 2.973238 & 0.709111 & 0.222454 \\ \mathrm{C} & 2.167110 & 1.652868 & -0.397849 \\ \mathrm{C} & 2.214087 & 3.044793 & -0.082768 \\ \mathrm{H} & 3.088211 & 4.482466 & 1.225223 \\ \mathrm{O} & 0.655820 & -0.858754 & -0.134767 \\ \mathrm{P} & 0.022637 & 0.344157 & -1.064707 \\ \mathrm{O} & 1.341190 & 1.241869 & -1.435734 \\ \mathrm{C} & -1.571471 & -5.384230 & -0.932132 \\ \mathrm{C} & -0.508184 & -5.682455 & -0.077637 \\ \mathrm{C} & 0.600429 & -4.835717 & -0.017971 \\ \mathrm{C} & 0.664652 & -3.674583 & -0.805339 \\ \mathrm{C} & -0.408724 & -3.385373 & -1.661537 \\ \mathrm{C} & -1.514123 & -4.234954 & -1.725487 \\ \mathrm{H} & -0.536525 & -6.577826 & 0.538584 \\ \mathrm{H} & -2.323564 & -3.999775 & -2.412281 \\ \mathrm{C} & 0.177653 & 6.144376 & -2.267406 \\ \mathrm{C} & 1.556072 & 6.204319 & -2.059395 \\ \mathrm{C} & 2.201469 & 5.183069 & -1.362776 \\ \mathrm{C} & 1.483489 & 4.083226 & -0.863747 \\ \mathrm{C} & 0.097114 & 4.031296 & -1.079324 \\ \mathrm{C} & -0.544882 & 5.056422 & -1.774064 \\ \mathrm{H} & 2.132296 & 7.041850 & -2.444344 \\ \mathrm{H} & -1.619773 & 5.003627 & -1.928183 \\ \mathrm{C} & 3.744697 & 1.112556 & 1.368097 \\ \mathrm{C} & 3.775512 & 2.498242 & 1.727031 \\ \mathrm{C} & 4.535303 & 2.911996 & 2.854779 \\ \mathrm{C} & 5.220988 & 1.998071 & 3.620658 \\ & 5.166169 & 0.623923 & 3.288719 \\ \mathrm{C} & 4.450867 & 0.193432 & 2.192628 \\ \mathrm{H} & 4.554165 & 3.969891 & 3.106352 \\ \mathrm{H} & & & \\ \mathrm{C} & 5.794641 & 2.325393 & 4.483541\end{array}$




\begin{tabular}{|c|c|c|c|}
\hline $\mathrm{H}$ & 5.690378 & -0.100365 & 3.906600 \\
\hline $\mathrm{H}$ & 4.412496 & -0.863885 & 1.957583 \\
\hline C & 4.289776 & -1.280960 & -0.680621 \\
\hline C & 4.323275 & -2.668984 & -1.029662 \\
\hline C & 5.557477 & -3.271056 & -1.395573 \\
\hline C & 6.716900 & -2.533080 & -1.445192 \\
\hline C & 6.682080 & -1.152862 & -1.137134 \\
\hline C & 5.503959 & -0.544302 & -0.763610 \\
\hline $\mathrm{H}$ & 5.562543 & -4.328271 & -1.650506 \\
\hline $\mathrm{H}$ & 7.654023 & -3.001287 & -1.733623 \\
\hline $\mathrm{H}$ & 7.592873 & -0.563778 & -1.203036 \\
\hline $\mathrm{H}$ & 5.494910 & 0.516749 & -0.544203 \\
\hline $\mathrm{O}$ & -1.017180 & 1.044240 & -0.257569 \\
\hline $\mathrm{O}$ & -0.383379 & -0.232547 & -2.437308 \\
\hline $\mathrm{H}$ & -1.536082 & -0.437243 & -2.581517 \\
\hline $\mathrm{H}$ & -0.364265 & -2.505754 & -2.292594 \\
\hline $\mathrm{H}$ & -2.430320 & -6.048297 & -0.989408 \\
\hline $\mathrm{H}$ & 1.425775 & -5.069959 & 0.649564 \\
\hline $\mathrm{H}$ & -0.477812 & 3.196953 & -0.691591 \\
\hline $\mathrm{H}$ & -0.328649 & 6.937445 & -2.811727 \\
\hline $\mathrm{H}$ & 3.277776 & 5.224390 & -1.217719 \\
\hline C & -3.489727 & -0.048167 & -1.914772 \\
\hline 0 & -2.739419 & -0.665651 & -2.755150 \\
\hline $\mathrm{H}$ & -3.038760 & 0.718219 & -1.275284 \\
\hline C & -4.884930 & 0.295004 & -2.432220 \\
\hline 0 & -5.381569 & -0.104255 & -3.452399 \\
\hline $\mathrm{O}$ & -5.513568 & 1.154193 & -1.572321 \\
\hline C & -6.825976 & 1.593941 & -1.981899 \\
\hline $\mathrm{H}$ & -7.496048 & 0.738770 & -2.100873 \\
\hline $\mathrm{H}$ & -7.172158 & 2.253205 & -1.186043 \\
\hline C & -3.878301 & -0.737324 & 0.776835 \\
\hline C & -4.045116 & -1.335499 & -0.494003 \\
\hline $\mathrm{H}$ & -5.234787 & 0.695996 & 0.295147 \\
\hline$N$ & -4.745993 & 0.277305 & 1.088800 \\
\hline C & -5.206426 & 0.800190 & 2.306407 \\
\hline $\mathrm{O}$ & -5.940859 & 1.764244 & 2.329125 \\
\hline $\mathrm{O}$ & -4.805656 & 0.094654 & 3.367967 \\
\hline C & -5.263269 & 0.596889 & 4.638685 \\
\hline $\mathrm{H}$ & -6.354535 & 0.575209 & 4.683996 \\
\hline $\mathrm{H}$ & -4.914342 & 1.620724 & 4.791300 \\
\hline $\mathrm{H}$ & -4.830917 & -0.073707 & 5.380521 \\
\hline $\mathrm{H}$ & -3.352136 & -2.131557 & -0.739973 \\
\hline $\mathrm{H}$ & -5.068217 & -1.518342 & -0.813881 \\
\hline C & -2.761239 & -1.074362 & 1.658125 \\
\hline
\end{tabular}




$\begin{array}{lrrr}\text { C } & -2.336053 & -2.412385 & 1.760603 \\ \text { C } & -2.067489 & -0.075328 & 2.369862 \\ \text { C } & -1.264824 & -2.747297 & 2.582119 \\ \text { H } & -2.858719 & -3.190909 & 1.214988 \\ \text { C } & -0.986440 & -0.413685 & 3.171779 \\ \text { H } & -2.336824 & 0.965183 & 2.234172 \\ \text { C } & -0.589684 & -1.749338 & 3.287531 \\ \text { H } & -0.949189 & -3.782876 & 2.655212 \\ \text { H } & -0.436091 & 0.365482 & 3.690277 \\ \text { H } & 0.257936 & -2.008636 & 3.916049 \\ \text { H } & -6.758727 & 2.131984 & -2.929843\end{array}$

Catalyst (R)-1 TS Conformation 387

B3LYP/6-31G(d) Energy $=-2809.681141$

B3LYP-D3(BJ)/def2-TZVPP-IEF-PCM(DCM) Energy = -2810.973925

B3LYP-D3(BJ)/def2-TZVPP-IEF-PCM(DCM)//B3LYP/6-31G(d) Free Energy (Quasiharmonic) = 2810.331607

Frequencies (Top 3 out of 270)

1. $-425.8589 \mathrm{~cm}-1$

2. $\quad 9.5729 \mathrm{~cm}-1$

3. $\quad 10.7878 \mathrm{~cm}-1$

B3LYP/6-31G(d) Molecular Geometry in Cartesian Coordinates

$\begin{array}{llll}\mathrm{C} & 3.116071 & -0.588050 & -0.343963 \\ \mathrm{C} & 1.975425 & -1.376596 & -0.430739 \\ \mathrm{C} & 2.026995 & -2.775202 & -0.717442 \\ \mathrm{C} & 3.262085 & -3.329787 & -0.988132 \\ \mathrm{H} & 3.325150 & -4.391605 & -1.211981 \\ \mathrm{C} & 2.866792 & 3.544412 & 0.872029 \\ \mathrm{C} & 3.021576 & 0.822947 & 0.135865 \\ \mathrm{C} & 2.162037 & 1.708450 & -0.494120 \\ \mathrm{C} & 2.077768 & 3.094765 & -0.168989 \\ \mathrm{H} & 2.851698 & 4.600078 & 1.129798 \\ \mathrm{O} & 0.742374 & -0.827638 & -0.120713 \\ \mathrm{P} & 0.046150 & 0.346052 & -1.043109 \\ \mathrm{O} & 1.347290 & 1.221981 & -1.510228 \\ \mathrm{C} & -1.365769 & -5.428765 & -0.683579 \\ \mathrm{C} & -1.373816 & -4.297986 & -1.504763 \\ \mathrm{C} & -0.292482 & -3.415981 & -1.506150\end{array}$




\begin{tabular}{|c|c|c|c|}
\hline C & 0.823187 & -3.654727 & -0.689150 \\
\hline C & 0.823912 & -4.797139 & 0.127836 \\
\hline C & -0.261114 & -5.675640 & 0.133832 \\
\hline $\mathrm{H}$ & -2.217970 & -4.101209 & -2.161083 \\
\hline $\mathrm{H}$ & -0.239392 & -6.554812 & 0.773132 \\
\hline C & -0.407793 & 5.920016 & -2.255002 \\
\hline C & -0.355186 & 5.916048 & -0.860626 \\
\hline C & 0.437211 & 4.983230 & -0.193099 \\
\hline C & 1.192581 & 4.036595 & -0.904226 \\
\hline C & 1.125552 & 4.046707 & -2.307663 \\
\hline C & 0.334923 & 4.981298 & -2.973929 \\
\hline $\mathrm{H}$ & -0.938412 & 6.633775 & -0.289486 \\
\hline $\mathrm{H}$ & 0.300833 & 4.975678 & -4.060238 \\
\hline C & 3.774702 & 1.290735 & 1.268968 \\
\hline C & 3.696492 & 2.676665 & 1.623798 \\
\hline C & 4.443850 & 3.156618 & 2.733671 \\
\hline C & 5.213901 & 2.305088 & 3.491093 \\
\hline C & 5.261064 & 0.928608 & 3.168355 \\
\hline C & 4.563376 & 0.435649 & 2.087310 \\
\hline $\mathrm{H}$ & 4.383697 & 4.214301 & 2.979499 \\
\hline $\mathrm{H}$ & 5.775884 & 2.682786 & 4.340947 \\
\hline $\mathrm{H}$ & 5.851230 & 0.252013 & 3.780725 \\
\hline $\mathrm{H}$ & 4.604860 & -0.622856 & 1.859141 \\
\hline C & 4.378415 & -1.156696 & -0.734229 \\
\hline C & 4.444609 & -2.552937 & -1.043352 \\
\hline C & 5.687854 & -3.129440 & -1.419721 \\
\hline C & 6.823838 & -2.360143 & -1.516037 \\
\hline C & 6.755837 & -0.973156 & -1.245604 \\
\hline C & 5.568526 & -0.388052 & -0.863874 \\
\hline $\mathrm{H}$ & 5.718832 & -4.193148 & -1.643980 \\
\hline $\mathrm{H}$ & 7.767886 & -2.809573 & -1.811648 \\
\hline $\mathrm{H}$ & 7.647881 & -0.360850 & -1.346868 \\
\hline $\mathrm{H}$ & 5.532655 & 0.678088 & -0.672532 \\
\hline $\mathrm{O}$ & -0.969395 & 1.054012 & -0.225211 \\
\hline $\mathrm{O}$ & -0.395295 & -0.280141 & -2.395797 \\
\hline $\mathrm{H}$ & -1.487176 & -0.459516 & -2.489335 \\
\hline $\mathrm{H}$ & 1.680839 & -4.990524 & 0.768021 \\
\hline $\mathrm{H}$ & -2.207234 & -6.117082 & -0.688936 \\
\hline $\mathrm{H}$ & -0.302909 & -2.549773 & -2.156935 \\
\hline $\mathrm{H}$ & 1.698806 & 3.323610 & -2.877257 \\
\hline $\mathrm{H}$ & -1.026634 & 6.644788 & -2.777496 \\
\hline $\mathrm{H}$ & 0.455354 & 4.969576 & 0.893091 \\
\hline C & -3.518140 & -0.119520 & -1.734824 \\
\hline $\mathrm{O}$ & -2.795728 & -0.704859 & -2.618712 \\
\hline
\end{tabular}




$\begin{array}{llll}\text { H } & -3.050529 & 0.637126 & -1.090556 \\ \mathrm{C} & -4.931209 & 0.312365 & -2.146934 \\ \mathrm{O} & -5.755821 & 0.783531 & -1.373358 \\ \mathrm{O} & -5.155243 & 0.156205 & -3.447457 \\ \mathrm{C} & -6.447534 & 0.585541 & -3.917974 \\ \mathrm{H} & -6.586101 & 1.652222 & -3.725893 \\ \mathrm{H} & -7.240934 & 0.024949 & -3.417171 \\ \mathrm{C} & -3.889378 & -0.804270 & 0.925344 \\ \mathrm{C} & -4.003170 & -1.416675 & -0.347680 \\ \mathrm{H} & -5.347434 & 0.523853 & 0.437559 \\ \mathrm{~N} & -4.811055 & 0.155065 & 1.235693 \\ \mathrm{C} & -5.251403 & 0.665155 & 2.467536 \\ \mathrm{O} & -5.984581 & 1.626504 & 2.526623 \\ \mathrm{O} & -4.829206 & -0.059859 & 3.512052 \\ \mathrm{C} & -5.252942 & 0.429623 & 4.797664 \\ \mathrm{H} & -4.892544 & 1.448835 & 4.956193 \\ \mathrm{H} & -4.809960 & -0.253357 & 5.522042 \\ \mathrm{H} & -6.343130 & 0.417411 & 4.868299 \\ \mathrm{H} & -3.262286 & -2.176554 & -0.566935 \\ \mathrm{H} & -5.010721 & -1.662509 & -0.671920 \\ \mathrm{C} & -2.739970 & -1.062065 & 1.797817 \\ \mathrm{C} & -2.238188 & -2.370405 & 1.922223 \\ \mathrm{C} & -2.086063 & -0.008639 & 2.465760 \\ \mathrm{C} & -1.129215 & -2.624363 & 2.723066 \\ \mathrm{H} & -2.729493 & -3.190056 & 1.408471 \\ \mathrm{C} & -0.967307 & -0.265281 & 3.247028 \\ \mathrm{H} & -2.418366 & 1.011905 & 2.314125 \\ \mathrm{C} & -0.492911 & -1.572885 & 3.385303 \\ \mathrm{H} & -0.754067 & -3.638799 & 2.812647 \\ \mathrm{H} & -0.449175 & 0.556863 & 3.731387 \\ \mathrm{H} & 0.384069 & -1.768205 & 3.996477 \\ \mathrm{H} & -6.445163 & 0.381752 & -4.988285 \\ & & & \end{array}$

Catalyst (R)-1 TS Conformation 388

B3LYP/6-31G(d) Energy $=-2809.679758$

B3LYP-D3(BJ)/def2-TZVPP-IEF-PCM(DCM) Energy = -2810.973056

B3LYP-D3(BJ)/def2-TZVPP-IEF-PCM(DCM)//B3LYP/6-31G(d) Free Energy (Quasiharmonic) = 2810.331513

Frequencies (Top 3 out of 270)

1. $-662.8371 \mathrm{~cm}-1$ 
2. $\quad 8.6717 \mathrm{~cm}-1$

3. $\quad 11.3275 \mathrm{~cm}-1$

B3LYP/6-31G(d) Molecular Geometry in Cartesian Coordinates

\begin{tabular}{|c|c|c|c|}
\hline C & 3.658402 & -0.743354 & 0.002095 \\
\hline C & 2.522438 & -1.513562 & 0.194208 \\
\hline C & 2.476666 & -2.919208 & -0.040704 \\
\hline C & 3.624564 & -3.517534 & -0.521666 \\
\hline $\mathrm{H}$ & 3.632432 & -4.591442 & -0.689451 \\
\hline C & 3.538003 & 3.486438 & 0.838375 \\
\hline C & 3.620791 & 0.710128 & 0.343697 \\
\hline C & 2.648701 & 1.525069 & -0.220891 \\
\hline C & 2.596458 & 2.936579 & -0.010781 \\
\hline $\mathrm{H}$ & 3.547517 & 4.561996 & 0.993669 \\
\hline O & 1.369752 & -0.888398 & 0.646846 \\
\hline$P$ & 0.517684 & 0.013248 & -0.435640 \\
\hline $\mathrm{O}$ & 1.705884 & 0.958786 & -1.065232 \\
\hline C & -1.013233 & -5.334233 & 0.667541 \\
\hline C & -0.300140 & -5.452272 & -0.525896 \\
\hline C & 0.820502 & -4.654448 & -0.753201 \\
\hline C & 1.249263 & -3.722249 & 0.205439 \\
\hline C & 0.516808 & -3.605794 & 1.398936 \\
\hline C & -0.601081 & -4.406623 & 1.626979 \\
\hline $\mathrm{H}$ & -0.621041 & -6.158692 & -1.286759 \\
\hline $\mathrm{H}$ & -1.148788 & -4.306346 & 2.560529 \\
\hline C & -0.209035 & 5.598363 & -1.905724 \\
\hline C & 0.384942 & 4.571827 & -2.642509 \\
\hline C & 1.274219 & 3.687179 & -2.034229 \\
\hline C & 1.591457 & 3.812584 & -0.670808 \\
\hline C & 0.979824 & 4.844794 & 0.061379 \\
\hline C & 0.091733 & 5.730788 & -0.548933 \\
\hline $\mathrm{H}$ & 0.159845 & 4.460311 & -3.699990 \\
\hline $\mathrm{H}$ & -0.364718 & 6.524334 & 0.037941 \\
\hline C & 4.539663 & 1.286632 & 1.286774 \\
\hline C & 4.498199 & 2.699355 & 1.518093 \\
\hline C & 5.412320 & 3.285094 & 2.435650 \\
\hline C & 6.313561 & 2.511017 & 3.128388 \\
\hline C & 6.330158 & 1.109849 & 2.932892 \\
\hline C & 5.469489 & 0.514495 & 2.037028 \\
\hline $\mathrm{H}$ & 5.374889 & 4.361275 & 2.588269 \\
\hline $\mathrm{H}$ & 7.002948 & 2.968693 & 3.832658 \\
\hline $\mathrm{H}$ & 7.025770 & 0.495752 & 3.498557 \\
\hline $\mathrm{H}$ & 5.489301 & -0.561125 & 1.906636 \\
\hline
\end{tabular}




\begin{tabular}{|c|c|c|c|}
\hline C & 4.822210 & -1.366536 & -0.566489 \\
\hline C & 4.797115 & -2.777855 & -0.813928 \\
\hline C & 5.944509 & -3.409895 & -1.365449 \\
\hline C & 7.064993 & -2.682968 & -1.693969 \\
\hline C & 7.078221 & -1.283453 & -1.488215 \\
\hline C & 5.988749 & -0.643355 & -0.939216 \\
\hline $\mathrm{H}$ & 5.912420 & -4.483606 & -1.535419 \\
\hline $\mathrm{H}$ & 7.933326 & -3.176587 & -2.121820 \\
\hline $\mathrm{H}$ & 7.954454 & -0.706056 & -1.770775 \\
\hline $\mathrm{H}$ & 6.011747 & 0.430953 & -0.797923 \\
\hline $\mathrm{O}$ & -0.550874 & 0.733583 & 0.308367 \\
\hline $\mathrm{O}$ & 0.139672 & -0.854969 & -1.651237 \\
\hline $\mathrm{H}$ & -0.874687 & -1.441077 & -1.611892 \\
\hline $\mathrm{H}$ & 0.828919 & -2.888872 & 2.150518 \\
\hline $\mathrm{H}$ & -1.884312 & -5.959603 & 0.847229 \\
\hline $\mathrm{H}$ & 1.357697 & -4.732759 & -1.694074 \\
\hline $\mathrm{H}$ & 1.194244 & 4.941873 & 1.122010 \\
\hline $\mathrm{H}$ & -0.900177 & 6.287310 & -2.384274 \\
\hline $\mathrm{H}$ & 1.732125 & 2.898032 & -2.619526 \\
\hline C & -2.784440 & -1.551183 & -0.729290 \\
\hline $\mathrm{O}$ & -1.949966 & -2.061095 & -1.578574 \\
\hline $\mathrm{H}$ & -2.385178 & -0.916335 & 0.069962 \\
\hline C & -3.868192 & -2.529287 & -0.268836 \\
\hline 0 & -4.648907 & -3.103820 & -1.000644 \\
\hline $\mathrm{O}$ & -3.853019 & -2.655670 & 1.065889 \\
\hline C & -4.805937 & -3.593304 & 1.612296 \\
\hline $\mathrm{H}$ & -4.638531 & -4.587251 & 1.191637 \\
\hline $\mathrm{H}$ & -4.626232 & -3.592782 & 2.687194 \\
\hline C & -4.795543 & 0.338348 & -0.933324 \\
\hline C & -3.833537 & -0.330124 & -1.727484 \\
\hline $\mathrm{H}$ & -6.071630 & -1.224251 & -1.156037 \\
\hline$N$ & -5.943147 & -0.357098 & -0.638481 \\
\hline C & -6.746676 & -0.386101 & 0.522887 \\
\hline $\mathrm{O}$ & -7.617203 & -1.220228 & 0.644670 \\
\hline $\mathrm{O}$ & -6.416845 & 0.540885 & 1.419791 \\
\hline C & -7.199154 & 0.527277 & 2.631504 \\
\hline $\mathrm{H}$ & -7.066887 & -0.421996 & 3.155268 \\
\hline $\mathrm{H}$ & -8.257000 & 0.672110 & 2.401681 \\
\hline $\mathrm{H}$ & -6.812231 & 1.354226 & 3.225423 \\
\hline $\mathrm{H}$ & -3.069803 & 0.298836 & -2.172009 \\
\hline $\mathrm{H}$ & -4.211552 & -1.107912 & -2.387320 \\
\hline C & -4.599768 & 1.713095 & -0.470036 \\
\hline C & -3.308523 & 2.188126 & -0.169654 \\
\hline C & -5.690785 & 2.607681 & -0.444237 \\
\hline
\end{tabular}




$\begin{array}{llll}\mathrm{C} & -3.124294 & 3.526435 & 0.170299 \\ \mathrm{H} & -2.445504 & 1.526961 & -0.160784 \\ \mathrm{C} & -5.490725 & 3.945365 & -0.129131 \\ \mathrm{H} & -6.682605 & 2.258157 & -0.712261 \\ \mathrm{C} & -4.207818 & 4.406309 & 0.186788 \\ \mathrm{H} & -2.124053 & 3.874500 & 0.407778 \\ \mathrm{H} & -6.332826 & 4.631689 & -0.135218 \\ \mathrm{H} & -4.055372 & 5.452866 & 0.436805 \\ \mathrm{H} & -5.826152 & -3.271741 & 1.386841\end{array}$

Catalyst (R)-1 TS Conformation 389

B3LYP/6-31G(d) Energy $=-2809.679939$

B3LYP-D3(BJ)/def2-TZVPP-IEF-PCM(DCM) Energy $=-2810.973145$

B3LYP-D3(BJ)/def2-TZVPP-IEF-PCM(DCM)//B3LYP/6-31G(d) Free Energy (Quasiharmonic) = 2810.331496

Frequencies (Top 3 out of 270)

1. $-686.5137 \mathrm{~cm}-1$

2. $\quad 7.6971 \mathrm{~cm}-1$

3. $\quad 10.6779 \mathrm{~cm}-1$

B3LYP/6-31G(d) Molecular Geometry in Cartesian Coordinates

$\begin{array}{llll}\text { C } & 3.598967 & -0.906917 & 0.069213 \\ \text { C } & 2.414451 & -1.605387 & 0.231845 \\ \text { C } & 2.287776 & -3.007261 & 0.006411 \\ \text { C } & 3.411055 & -3.679924 & -0.432254 \\ \text { H } & 3.358267 & -4.753992 & -0.590491 \\ \text { C } & 3.843233 & 3.337176 & 0.763262 \\ \text { C } & 3.645679 & 0.549843 & 0.394712 \\ \text { C } & 2.755577 & 1.429196 & -0.210009 \\ \text { C } & 2.863877 & 2.848357 & -0.080266 \\ \text { H } & 3.940028 & 4.412257 & 0.889757 \\ \text { O } & 1.289354 & -0.903183 & 0.642381 \\ \text { P } & 0.536885 & 0.031055 & -0.481837 \\ \text { O } & 1.781665 & 0.930050 & -1.061547 \\ \text { C } & -1.359592 & -5.205215 & 0.622170 \\ \text { C } & -0.925565 & -4.291551 & 1.585498 \\ \text { C } & 0.243951 & -3.559591 & 1.386666 \\ \text { C } & 1.006694 & -3.731966 & 0.219061 \\ \text { C } & 0.554592 & -4.647678 & -0.744788\end{array}$




\begin{tabular}{|c|c|c|c|}
\hline C & -0.616840 & -5.377598 & -0.546368 \\
\hline $\mathrm{H}$ & -1.496444 & -4.149364 & 2.499504 \\
\hline $\mathrm{H}$ & -0.952723 & -6.073810 & -1.310236 \\
\hline C & 0.496837 & 5.721848 & -2.245091 \\
\hline C & -0.131124 & 4.668901 & -1.576877 \\
\hline C & 0.618606 & 3.716236 & -0.886917 \\
\hline C & 2.019655 & 3.804775 & -0.850165 \\
\hline C & 2.640963 & 4.867005 & -1.528814 \\
\hline C & 1.888677 & 5.816463 & -2.219843 \\
\hline $\mathrm{H}$ & -1.215191 & 4.585916 & -1.588362 \\
\hline $\mathrm{H}$ & 2.392237 & 6.624644 & -2.744260 \\
\hline C & 4.595259 & 1.071606 & 1.339764 \\
\hline C & 4.693944 & 2.489186 & 1.511994 \\
\hline C & 5.630934 & 3.017917 & 2.440846 \\
\hline C & 6.427562 & 2.186656 & 3.193169 \\
\hline C & 6.310142 & 0.783989 & 3.049486 \\
\hline C & 5.421046 & 0.241546 & 2.147764 \\
\hline $\mathrm{H}$ & 5.696942 & 4.097798 & 2.552090 \\
\hline $\mathrm{H}$ & 7.136713 & 2.601581 & 3.904307 \\
\hline $\mathrm{H}$ & 6.923056 & 0.127152 & 3.660980 \\
\hline $\mathrm{H}$ & 5.335806 & -0.835251 & 2.058384 \\
\hline C & 4.739292 & -1.606354 & -0.459402 \\
\hline C & 4.635144 & -3.016274 & -0.693880 \\
\hline C & 5.757209 & -3.724238 & -1.203674 \\
\hline C & 6.929375 & -3.071285 & -1.505788 \\
\hline C & 7.021810 & -1.672786 & -1.314964 \\
\hline C & 5.958253 & -0.960622 & -0.805279 \\
\hline $\mathrm{H}$ & 5.663857 & -4.795890 & -1.363702 \\
\hline $\mathrm{H}$ & 7.777982 & -3.622115 & -1.902229 \\
\hline $\mathrm{H}$ & 7.939212 & -1.153086 & -1.578129 \\
\hline $\mathrm{H}$ & 6.043308 & 0.111796 & -0.675908 \\
\hline 0 & -0.527331 & 0.806685 & 0.219759 \\
\hline 0 & 0.153631 & -0.821663 & -1.701646 \\
\hline $\mathrm{H}$ & -0.944096 & -1.276802 & -1.743835 \\
\hline $\mathrm{H}$ & 1.115992 & -4.767182 & -1.666924 \\
\hline $\mathrm{H}$ & -2.269519 & -5.778878 & 0.780820 \\
\hline $\mathrm{H}$ & 0.573660 & -2.854270 & 2.141745 \\
\hline $\mathrm{H}$ & 3.725553 & 4.934526 & -1.529114 \\
\hline $\mathrm{H}$ & -0.092456 & 6.458818 & -2.784848 \\
\hline $\mathrm{H}$ & 0.117652 & 2.904059 & -0.371614 \\
\hline C & -2.864864 & -1.338846 & -0.887118 \\
\hline $\mathrm{O}$ & -2.058090 & -1.773313 & -1.802402 \\
\hline $\mathrm{H}$ & -2.434227 & -0.859586 & -0.001169 \\
\hline C & -4.021361 & -2.294086 & -0.590925 \\
\hline
\end{tabular}




$\begin{array}{llll}\mathrm{O} & -4.793121 & -2.730251 & -1.420286 \\ \mathrm{O} & -4.082772 & -2.572477 & 0.719642 \\ \mathrm{C} & -5.105078 & -3.516540 & 1.106545 \\ \mathrm{H} & -4.950476 & -4.467534 & 0.592083 \\ \mathrm{H} & -6.096325 & -3.128669 & 0.857923 \\ \mathrm{C} & -4.795658 & 0.663891 & -0.841945 \\ \mathrm{C} & -3.812084 & 0.097264 & -1.688889 \\ \mathrm{H} & -6.118238 & -0.766583 & -1.411728 \\ \mathrm{~N} & -5.987607 & -0.010084 & -0.743164 \\ \mathrm{C} & -6.875849 & -0.190411 & 0.341362 \\ \mathrm{O} & -7.798442 & -0.970398 & 0.253386 \\ \mathrm{O} & -6.559927 & 0.534758 & 1.412424 \\ \mathrm{C} & -7.434691 & 0.364896 & 2.547096 \\ \mathrm{H} & -8.460714 & 0.623800 & 2.276961 \\ \mathrm{H} & -7.047542 & 1.044522 & 3.305045 \\ \mathrm{H} & -7.400492 & -0.668724 & 2.898300 \\ \mathrm{H} & -2.997585 & 0.754878 & -1.973248 \\ \mathrm{H} & -4.183693 & -0.530402 & -2.495925 \\ \mathrm{C} & -4.579620 & 1.925138 & -0.129345 \\ \mathrm{C} & -5.636759 & 2.851023 & -0.003357 \\ \mathrm{C} & -3.294881 & 2.277268 & 0.326701 \\ \mathrm{C} & -5.412111 & 4.097873 & 0.565976 \\ \mathrm{H} & -6.620035 & 2.604324 & -0.390500 \\ \mathrm{C} & -3.088811 & 3.519951 & 0.922801 \\ \mathrm{H} & -2.455409 & 1.592145 & 0.242796 \\ \mathrm{C} & -4.139200 & 4.432261 & 1.040378 \\ \mathrm{H} & -6.227225 & 4.812429 & 0.636283 \\ \mathrm{H} & -2.096909 & 3.772114 & 1.285053 \\ \mathrm{H} & -3.967240 & 5.405507 & 1.491897 \\ \mathrm{H} & -4.992353 & -3.637445 & 2.183745\end{array}$

Catalyst (R)-1 TS Conformation 390

B3LYP/6-31G(d) Energy $=-2809.679243$

B3LYP-D3(BJ)/def2-TZVPP-IEF-PCM(DCM) Energy $=-2810.973791$

B3LYP-D3(BJ)/def2-TZVPP-IEF-PCM(DCM)//B3LYP/6-31G(d) Free Energy (Quasiharmonic) = 2810.331327

Frequencies (Top 3 out of 270 )

1. $-551.2881 \mathrm{~cm}-1$

2. $\quad 8.9371 \mathrm{~cm}-1$

3. $\quad 9.7741 \mathrm{~cm}-1$ 
B3LYP/6-31G(d) Molecular Geometry in Cartesian Coordinates

\begin{tabular}{|c|c|c|c|}
\hline C & 3.629783 & -0.916005 & -0.135784 \\
\hline C & 2.470591 & -1.628302 & 0.121365 \\
\hline C & 2.306366 & -3.009077 & -0.195084 \\
\hline C & 3.356490 & -3.638726 & -0.833960 \\
\hline $\mathrm{H}$ & 3.279190 & -4.697729 & -1.066392 \\
\hline C & 4.042129 & 3.243263 & 0.907398 \\
\hline C & 3.737460 & 0.503937 & 0.316045 \\
\hline C & 2.792751 & 1.443277 & -0.079907 \\
\hline C & 2.956002 & 2.844423 & 0.152429 \\
\hline $\mathrm{H}$ & 4.182051 & 4.301723 & 1.110449 \\
\hline 0 & 1.420200 & -0.960994 & 0.730931 \\
\hline$P$ & 0.536890 & 0.053318 & -0.224497 \\
\hline 0 & 1.699355 & 1.041531 & -0.830495 \\
\hline C & -1.222805 & -5.278298 & 0.768431 \\
\hline C & -0.672699 & -4.409115 & 1.713688 \\
\hline C & 0.458315 & -3.654569 & 1.403982 \\
\hline C & 1.065908 & -3.757339 & 0.140476 \\
\hline C & 0.498554 & -4.630710 & -0.801831 \\
\hline C & -0.632839 & -5.384795 & -0.491786 \\
\hline $\mathrm{H}$ & -1.119253 & -4.322942 & 2.701133 \\
\hline $\mathrm{H}$ & -1.055809 & -6.051177 & -1.239336 \\
\hline C & 0.475765 & 5.911090 & -1.577518 \\
\hline C & 1.865981 & 5.975721 & -1.672981 \\
\hline C & 2.650794 & 4.966353 & -1.116633 \\
\hline C & 2.065666 & 3.875381 & -0.450929 \\
\hline C & 0.665451 & 3.821399 & -0.359634 \\
\hline C & -0.116778 & 4.831214 & -0.920178 \\
\hline $\mathrm{H}$ & 2.341986 & 6.805484 & -2.189345 \\
\hline $\mathrm{H}$ & -1.199638 & 4.770557 & -0.846111 \\
\hline C & 4.810335 & 0.926809 & 1.175625 \\
\hline C & 4.958053 & 2.320455 & 1.466651 \\
\hline C & 6.013666 & 2.750776 & 2.315392 \\
\hline C & 6.882214 & 1.845476 & 2.879106 \\
\hline C & 6.721079 & 0.464244 & 2.618866 \\
\hline C & 5.715650 & 0.017392 & 1.789708 \\
\hline $\mathrm{H}$ & 6.113689 & 3.814490 & 2.518784 \\
\hline $\mathrm{H}$ & 7.682306 & 2.184994 & 3.531287 \\
\hline $\mathrm{H}$ & 7.392993 & -0.252870 & 3.082899 \\
\hline $\mathrm{H}$ & 5.599265 & -1.045293 & 1.611302 \\
\hline C & 4.683547 & -1.564190 & -0.869074 \\
\hline C & 4.537924 & -2.949941 & -1.204489 \\
\hline
\end{tabular}




\begin{tabular}{|c|c|c|c|}
\hline C & 5.576298 & -3.608473 & -1.917437 \\
\hline C & 6.702835 & -2.928338 & -2.317468 \\
\hline C & 6.831523 & -1.550796 & -2.023001 \\
\hline C & 5.851261 & -0.887774 & -1.317566 \\
\hline $\mathrm{H}$ & 5.454405 & -4.663320 & -2.152574 \\
\hline $\mathrm{H}$ & 7.486638 & -3.440917 & -2.868513 \\
\hline $\mathrm{H}$ & 7.710320 & -1.008032 & -2.360791 \\
\hline $\mathrm{H}$ & 5.961552 & 0.169874 & -1.109218 \\
\hline 0 & -0.161734 & -0.629441 & -1.348275 \\
\hline O & -0.313032 & 0.831856 & 0.799743 \\
\hline $\mathrm{H}$ & -1.411201 & 0.254952 & 1.121050 \\
\hline $\mathrm{H}$ & 0.938205 & -4.699130 & -1.792744 \\
\hline $\mathrm{H}$ & -2.101313 & -5.869696 & 1.014196 \\
\hline $\mathrm{H}$ & 0.879589 & -2.986873 & 2.147353 \\
\hline $\mathrm{H}$ & 0.194051 & 2.994510 & 0.159605 \\
\hline $\mathrm{H}$ & -0.140540 & 6.691962 & -2.015874 \\
\hline $\mathrm{H}$ & 3.732000 & 5.008255 & -1.216403 \\
\hline C & -2.753652 & -1.063506 & 0.403547 \\
\hline $\mathrm{O}$ & -2.442838 & -0.209600 & 1.319532 \\
\hline $\mathrm{H}$ & -1.949655 & -1.531684 & -0.172393 \\
\hline C & -3.953441 & -1.940630 & 0.720342 \\
\hline $\mathrm{O}$ & -4.751572 & -1.730269 & 1.605117 \\
\hline $\mathrm{O}$ & -4.010619 & -2.978865 & -0.135280 \\
\hline C & -5.081592 & -3.919671 & 0.093373 \\
\hline $\mathrm{H}$ & -6.051072 & -3.441101 & -0.067698 \\
\hline $\mathrm{H}$ & -5.030984 & -4.304455 & 1.114516 \\
\hline C & -4.588749 & 0.444617 & -1.012210 \\
\hline C & -3.371547 & -0.190204 & -1.298066 \\
\hline $\mathrm{H}$ & -5.632130 & -1.099240 & -1.828511 \\
\hline$N$ & -5.741029 & -0.297527 & -1.216866 \\
\hline C & -6.845494 & -0.522489 & -0.363825 \\
\hline $\mathrm{O}$ & -7.596785 & -1.451231 & -0.575727 \\
\hline $\mathrm{O}$ & -6.923234 & 0.349210 & 0.633640 \\
\hline C & -7.898654 & 0.035416 & 1.650491 \\
\hline $\mathrm{H}$ & -7.872145 & 0.881393 & 2.335981 \\
\hline $\mathrm{H}$ & -7.603843 & -0.883582 & 2.161028 \\
\hline $\mathrm{H}$ & -8.889058 & -0.079959 & 1.206076 \\
\hline $\mathrm{H}$ & -2.482850 & 0.403347 & -1.481465 \\
\hline $\mathrm{H}$ & -3.413163 & -1.106475 & -1.882071 \\
\hline C & -4.675775 & 1.822247 & -0.535884 \\
\hline C & -5.831092 & 2.594562 & -0.785117 \\
\hline C & -3.575773 & 2.427317 & 0.105887 \\
\hline C & -5.889437 & 3.922921 & -0.387120 \\
\hline $\mathrm{H}$ & -6.667059 & 2.155082 & -1.317198 \\
\hline
\end{tabular}




$\begin{array}{llll}\mathrm{C} & -3.657024 & 3.750442 & 0.532861 \\ \mathrm{H} & -2.669302 & 1.867262 & 0.290095 \\ \mathrm{C} & -4.807783 & 4.501023 & 0.286417 \\ \mathrm{H} & -6.776715 & 4.511354 & -0.601806 \\ \mathrm{H} & -2.812403 & 4.195408 & 1.049831 \\ \mathrm{H} & -4.858873 & 5.538430 & 0.605307 \\ \mathrm{H} & -4.918846 & -4.720099 & -0.628008\end{array}$

Catalyst (R)-1 TS Conformation 391

B3LYP/6-31G(d) Energy $=-2809.675295$

B3LYP-D3(BJ)/def2-TZVPP-IEF-PCM(DCM) Energy $=-2810.97252$

B3LYP-D3(BJ)/def2-TZVPP-IEF-PCM(DCM)//B3LYP/6-31G(d) Free Energy (Quasiharmonic) = 2810.330568

Frequencies (Top 3 out of 270)

1. $-443.6915 \mathrm{~cm}-1$

2. $\quad 10.6366 \mathrm{~cm}-1$

3. $13.8096 \mathrm{~cm}-1$

B3LYP/6-31G(d) Molecular Geometry in Cartesian Coordinates

$\begin{array}{llll}\text { C } & -3.346146 & -0.177539 & -0.182889 \\ \text { C } & -2.657752 & 1.030210 & -0.198793 \\ \text { C } & -3.285640 & 2.264664 & -0.549749 \\ \text { C } & -4.609105 & 2.226579 & -0.941202 \\ \text { H } & -5.103593 & 3.154935 & -1.215054 \\ \text { C } & -1.477843 & -3.855630 & 1.066912 \\ \text { C } & -2.695524 & -1.420644 & 0.327946 \\ \text { C } & -1.494551 & -1.836785 & -0.223810 \\ \text { C } & -0.865014 & -3.074867 & 0.105184 \\ \text { H } & -1.050063 & -4.822547 & 1.318291 \\ \text { O } & -1.347580 & 1.085463 & 0.246405 \\ \text { P } & -0.109501 & 0.311145 & -0.513192 \\ \text { O } & -0.881994 & -1.003895 & -1.148241 \\ \text { C } & -1.442313 & 6.153156 & -0.466056 \\ \text { C } & -2.603358 & 5.900889 & 0.265794 \\ \text { C } & -3.174546 & 4.627946 & 0.252248 \\ \text { C } & -2.593249 & 3.583040 & -0.484210 \\ \text { C } & -1.418260 & 3.842364 & -1.207837 \\ \text { C } & -0.855769 & 5.119909 & -1.201741 \\ \text { H } & -3.067656 & 6.694051 & 0.846376\end{array}$




\begin{tabular}{|c|c|c|c|}
\hline $\mathrm{H}$ & 0.043430 & 5.309925 & -1.782907 \\
\hline C & 2.708143 & -4.575189 & -1.772501 \\
\hline C & 1.742744 & -3.916248 & -2.537532 \\
\hline C & 0.593993 & -3.404045 & -1.935657 \\
\hline C & 0.386026 & -3.538927 & -0.551569 \\
\hline C & 1.374491 & -4.189539 & 0.206989 \\
\hline C & 2.521383 & -4.705507 & -0.395089 \\
\hline $\mathrm{H}$ & 1.878604 & -3.807613 & -3.610196 \\
\hline $\mathrm{H}$ & 3.268439 & -5.208943 & 0.213540 \\
\hline C & -3.270549 & -2.200915 & 1.389930 \\
\hline C & -2.649833 & -3.441803 & 1.746173 \\
\hline C & -3.214659 & -4.232565 & 2.783607 \\
\hline C & -4.326758 & -3.807433 & 3.472283 \\
\hline C & -4.917724 & -2.562997 & 3.150500 \\
\hline C & -4.406433 & -1.783059 & 2.136381 \\
\hline $\mathrm{H}$ & -2.738939 & -5.178746 & 3.031262 \\
\hline $\mathrm{H}$ & -4.745220 & -4.416867 & 4.268644 \\
\hline $\mathrm{H}$ & -5.781710 & -2.216542 & 3.711250 \\
\hline $\mathrm{H}$ & -4.865954 & -0.828555 & 1.907859 \\
\hline C & -4.689599 & -0.214231 & -0.698151 \\
\hline C & -5.328952 & 1.014010 & -1.059910 \\
\hline C & -6.660357 & 0.993842 & -1.556611 \\
\hline C & -7.336052 & -0.192618 & -1.720641 \\
\hline C & -6.695233 & -1.412550 & -1.400677 \\
\hline C & -5.410756 & -1.423820 & -0.902862 \\
\hline $\mathrm{H}$ & -7.129762 & 1.939421 & -1.817975 \\
\hline $\mathrm{H}$ & -8.351445 & -0.197817 & -2.107431 \\
\hline $\mathrm{H}$ & -7.218683 & -2.352203 & -1.555797 \\
\hline $\mathrm{H}$ & -4.933193 & -2.369645 & -0.676176 \\
\hline $\mathrm{O}$ & 0.934347 & -0.048940 & 0.487983 \\
\hline $\mathrm{O}$ & 0.293376 & 1.136341 & -1.744219 \\
\hline $\mathrm{H}$ & 1.462393 & 0.918594 & -2.283817 \\
\hline $\mathrm{H}$ & -0.952984 & 3.047475 & -1.780907 \\
\hline $\mathrm{H}$ & -0.999613 & 7.145989 & -0.466210 \\
\hline $\mathrm{H}$ & -4.077027 & 4.433588 & 0.825738 \\
\hline $\mathrm{H}$ & 1.244797 & -4.279543 & 1.281881 \\
\hline $\mathrm{H}$ & 3.592655 & -4.991091 & -2.248778 \\
\hline $\mathrm{H}$ & -0.151835 & -2.904385 & -2.542956 \\
\hline C & 3.234524 & 0.205630 & -1.763052 \\
\hline $\mathrm{O}$ & 2.483832 & 0.679692 & -2.695677 \\
\hline $\mathrm{H}$ & 2.779377 & -0.019136 & -0.794274 \\
\hline C & 4.327357 & -0.751791 & -2.213018 \\
\hline $\mathrm{O}$ & 4.652628 & -0.959103 & -3.355358 \\
\hline $\mathrm{O}$ & 4.873604 & -1.343590 & -1.128215 \\
\hline
\end{tabular}




$\begin{array}{llll}\mathrm{C} & 5.881129 & -2.340978 & -1.386586 \\ \mathrm{H} & 6.276078 & -2.603701 & -0.405489 \\ \mathrm{H} & 5.424606 & -3.209192 & -1.866821 \\ \mathrm{C} & 4.493820 & 1.683663 & 0.213681 \\ \mathrm{C} & 4.518683 & 1.737280 & -1.184958 \\ \mathrm{H} & 6.124702 & 0.464725 & 0.303845 \\ \mathrm{~N} & 5.344012 & 0.802883 & 0.854622 \\ \mathrm{C} & 4.940601 & -0.221388 & 1.757707 \\ \mathrm{O} & 5.697404 & -1.118968 & 2.052985 \\ \mathrm{O} & 3.682506 & -0.058040 & 2.133927 \\ \mathrm{C} & 3.047917 & -1.127984 & 2.866069 \\ \mathrm{H} & 3.253892 & -1.011905 & 3.933302 \\ \mathrm{H} & 3.421667 & -2.091266 & 2.515398 \\ \mathrm{H} & 1.988343 & -1.011860 & 2.643672 \\ \mathrm{H} & 4.032956 & 2.574695 & -1.672602 \\ \mathrm{H} & 5.405157 & 1.375580 & -1.698708 \\ \mathrm{C} & 3.623476 & 2.531625 & 1.029389 \\ \mathrm{C} & 4.070643 & 2.947994 & 2.300256 \\ \mathrm{C} & 2.390261 & 3.006422 & 0.546405 \\ \mathrm{C} & 3.306812 & 3.824653 & 3.060927 \\ \mathrm{H} & 5.032651 & 2.605458 & 2.667126 \\ \mathrm{C} & 1.619746 & 3.865299 & 1.323476 \\ \mathrm{H} & 2.003654 & 2.665184 & -0.407418 \\ \mathrm{C} & 2.077428 & 4.280005 & 2.576772 \\ \mathrm{H} & 3.669062 & 4.152587 & 4.031070 \\ \mathrm{H} & 0.657606 & 4.200681 & 0.951208 \\ \mathrm{H} & 1.474599 & 4.956794 & 3.175970 \\ \mathrm{H} & 6.663254 & -1.937931 & -2.035273\end{array}$

Catalyst (R)-1 TS Conformation 392

B3LYP/6-31G(d) Energy $=-2809.68219$

B3LYP-D3(BJ)/def2-TZVPP-IEF-PCM(DCM) Energy = -2810.972915

B3LYP-D3(BJ)/def2-TZVPP-IEF-PCM(DCM)//B3LYP/6-31G(d) Free Energy (Quasiharmonic) = 2810.330332

Frequencies (Top 3 out of 270)

1. $-321.2825 \mathrm{~cm}-1$

2. $\quad 6.8211 \mathrm{~cm}-1$

3. $\quad 13.0681 \mathrm{~cm}-1$

B3LYP/6-31G(d) Molecular Geometry in Cartesian Coordinates 


\begin{tabular}{|c|c|c|c|}
\hline C & 3.109259 & -0.917848 & -0.259466 \\
\hline C & 1.885755 & -1.562952 & -0.159238 \\
\hline C & 1.734428 & -2.973116 & -0.306937 \\
\hline C & 2.853477 & -3.706325 & -0.641224 \\
\hline $\mathrm{H}$ & 2.766525 & -4.784002 & -0.754324 \\
\hline C & 3.612980 & 3.279409 & 0.587442 \\
\hline C & 3.238060 & 0.522020 & 0.116870 \\
\hline C & 2.426151 & 1.483371 & -0.469019 \\
\hline C & 2.619124 & 2.886315 & -0.287601 \\
\hline $\mathrm{H}$ & 3.781090 & 4.340812 & 0.749652 \\
\hline $\mathrm{O}$ & 0.766788 & -0.836111 & 0.210659 \\
\hline$P$ & 0.119240 & 0.306501 & -0.768939 \\
\hline O & 1.434416 & 1.075116 & -1.353768 \\
\hline C & -1.986406 & -5.026560 & 0.394276 \\
\hline C & -1.885655 & -4.098270 & -0.647418 \\
\hline C & -0.686263 & -3.417988 & -0.871320 \\
\hline C & 0.432252 & -3.658696 & -0.060923 \\
\hline C & 0.322770 & -4.597982 & 0.975440 \\
\hline C & -0.876419 & -5.273836 & 1.204260 \\
\hline $\mathrm{H}$ & -2.725508 & -3.912774 & -1.312294 \\
\hline $\mathrm{H}$ & -0.942968 & -5.992191 & 2.017132 \\
\hline C & 0.496072 & 5.967906 & -2.414804 \\
\hline C & 1.891048 & 5.936125 & -2.407195 \\
\hline C & 2.562063 & 4.921008 & -1.726068 \\
\hline C & 1.853294 & 3.918808 & -1.042317 \\
\hline C & 0.449757 & 3.959023 & -1.056901 \\
\hline C & -0.217578 & 4.977472 & -1.737479 \\
\hline $\mathrm{H}$ & 2.459309 & 6.696675 & -2.936658 \\
\hline $\mathrm{H}$ & -1.304451 & 4.995342 & -1.735091 \\
\hline C & 4.196337 & 0.947698 & 1.104018 \\
\hline C & 4.386684 & 2.349743 & 1.323816 \\
\hline C & 5.334134 & 2.784987 & 2.289865 \\
\hline C & 6.051059 & 1.879182 & 3.036168 \\
\hline C & 5.838556 & 0.493258 & 2.848979 \\
\hline C & 4.939142 & 0.040033 & 1.908867 \\
\hline $\mathrm{H}$ & 5.471407 & 3.854007 & 2.434991 \\
\hline $\mathrm{H}$ & 6.768647 & 2.223144 & 3.776080 \\
\hline $\mathrm{H}$ & 6.385741 & -0.222213 & 3.456937 \\
\hline $\mathrm{H}$ & 4.781239 & -1.025078 & 1.788276 \\
\hline C & 4.241438 & -1.676342 & -0.723541 \\
\hline C & 4.104832 & -3.091702 & -0.897400 \\
\hline C & 5.219463 & -3.852960 & -1.341427 \\
\hline C & 6.419345 & -3.247185 & -1.633291 \\
\hline
\end{tabular}




\begin{tabular}{|c|c|c|c|}
\hline C & 6.547544 & -1.845065 & -1.498139 \\
\hline C & 5.490551 & -1.081599 & -1.053383 \\
\hline $\mathrm{H}$ & 5.098634 & -4.927234 & -1.459753 \\
\hline $\mathrm{H}$ & 7.262718 & -3.838263 & -1.979616 \\
\hline $\mathrm{H}$ & 7.487429 & -1.363419 & -1.754096 \\
\hline $\mathrm{H}$ & 5.603131 & -0.007228 & -0.966907 \\
\hline 0 & -0.821982 & 1.109448 & 0.056598 \\
\hline 0 & -0.419782 & -0.358099 & -2.067637 \\
\hline $\mathrm{H}$ & -1.482772 & -0.606009 & -2.041224 \\
\hline $\mathrm{H}$ & 1.180594 & -4.784003 & 1.615797 \\
\hline $\mathrm{H}$ & -2.917292 & -5.562007 & 0.564525 \\
\hline $\mathrm{H}$ & -0.613794 & -2.711899 & -1.689242 \\
\hline $\mathrm{H}$ & -0.120533 & 3.202991 & -0.527495 \\
\hline $\mathrm{H}$ & -0.030468 & 6.756286 & -2.946570 \\
\hline $\mathrm{H}$ & 3.648359 & 4.889298 & -1.737356 \\
\hline C & -3.690915 & -0.248256 & -1.620014 \\
\hline 0 & -2.774767 & -1.033085 & -2.072984 \\
\hline $\mathrm{H}$ & -3.382811 & 0.684610 & -1.125427 \\
\hline C & -4.904241 & 0.041830 & -2.514220 \\
\hline 0 & -5.597690 & 1.033231 & -2.388340 \\
\hline 0 & -5.106096 & -0.912972 & -3.428289 \\
\hline C & -6.214821 & -0.691239 & -4.317756 \\
\hline $\mathrm{H}$ & -6.068769 & 0.230911 & -4.885839 \\
\hline $\mathrm{H}$ & -7.150284 & -0.619309 & -3.755937 \\
\hline C & -4.114497 & -0.692261 & 0.981709 \\
\hline C & -4.639329 & -1.152679 & -0.258214 \\
\hline $\mathrm{H}$ & -2.663867 & -2.112077 & 0.965205 \\
\hline$N$ & -2.980757 & -1.267384 & 1.441494 \\
\hline C & -1.953079 & -0.790985 & 2.314172 \\
\hline 0 & -1.048829 & -1.526674 & 2.624215 \\
\hline $\mathrm{O}$ & -2.136527 & 0.467793 & 2.682727 \\
\hline C & -1.011069 & 1.083146 & 3.346967 \\
\hline $\mathrm{H}$ & -0.208607 & 1.212147 & 2.619791 \\
\hline $\mathrm{H}$ & -0.680007 & 0.466864 & 4.185071 \\
\hline $\mathrm{H}$ & -1.381120 & 2.048429 & 3.690897 \\
\hline $\mathrm{H}$ & -5.699898 & -0.957720 & -0.386549 \\
\hline $\mathrm{H}$ & -4.346505 & -2.152429 & -0.565845 \\
\hline C & -4.821313 & 0.353721 & 1.740457 \\
\hline C & -4.945607 & 0.250920 & 3.138823 \\
\hline C & -5.484427 & 1.396118 & 1.067118 \\
\hline C & -5.708230 & 1.173434 & 3.846371 \\
\hline $\mathrm{H}$ & -4.470157 & -0.570385 & 3.664767 \\
\hline C & -6.224443 & 2.330966 & 1.787408 \\
\hline $\mathrm{H}$ & -5.413616 & 1.487457 & -0.012602 \\
\hline
\end{tabular}




$\begin{array}{lrrr}\mathrm{C} & -6.340744 & 2.222860 & 3.174409 \\ \mathrm{H} & -5.809560 & 1.073569 & 4.923226 \\ \mathrm{H} & -6.715037 & 3.143087 & 1.259058 \\ \mathrm{H} & -6.927907 & 2.948620 & 3.730305 \\ \mathrm{H} & -6.229665 & -1.554062 & -4.983519\end{array}$

Catalyst (R)-1 TS Conformation 393

B3LYP/6-31G(d) Energy $=-2809.683144$

B3LYP-D3(BJ)/def2-TZVPP-IEF-PCM(DCM) Energy = -2810.973315

B3LYP-D3(BJ)/def2-TZVPP-IEF-PCM(DCM)//B3LYP/6-31G(d) Free Energy (Quasiharmonic) = 2810.330312

Frequencies (Top 3 out of 270)

1. $-322.1419 \mathrm{~cm}-1$

2. $\quad 7.4015 \mathrm{~cm}-1$

3. $\quad 9.6247 \mathrm{~cm}-1$

B3LYP/6-31G(d) Molecular Geometry in Cartesian Coordinates

$\begin{array}{llll}\mathrm{C} & 3.789332 & 0.372373 & 0.285858 \\ \mathrm{C} & 2.983160 & 1.421677 & -0.129670 \\ \mathrm{C} & 3.156322 & 2.767250 & 0.310542 \\ \mathrm{C} & 4.152412 & 3.004634 & 1.237752 \\ \mathrm{H} & 4.329470 & 4.022529 & 1.575017 \\ \mathrm{C} & 3.100603 & -3.584635 & -1.288650 \\ \mathrm{C} & 3.585166 & -0.987487 & -0.296825 \\ \mathrm{C} & 2.329953 & -1.574108 & -0.236220 \\ \mathrm{C} & 2.054356 & -2.890818 & -0.711351 \\ \mathrm{H} & 2.934337 & -4.601206 & -1.635168 \\ \mathrm{O} & 1.966569 & 1.161765 & -1.040731 \\ \mathrm{P} & 0.624466 & 0.370418 & -0.531628 \\ \mathrm{O} & 1.290747 & -0.853347 & 0.338506 \\ \mathrm{C} & 0.819147 & 6.089423 & -1.108383 \\ \mathrm{C} & 1.316630 & 5.150075 & -2.013951 \\ \mathrm{C} & 2.055070 & 4.057418 & -1.562889 \\ \mathrm{C} & 2.315636 & 3.886074 & -0.192830 \\ \mathrm{C} & 1.805741 & 4.835376 & 0.707695 \\ \mathrm{C} & 1.064714 & 5.926437 & 0.255439 \\ \mathrm{H} & 1.131436 & 5.268017 & -3.078517 \\ \mathrm{H} & 0.671725 & 6.643700 & 0.971352 \\ \mathrm{C} & -1.791298 & -4.806462 & -0.446681\end{array}$




\begin{tabular}{|c|c|c|c|}
\hline$C$ & -1.289409 & -4.100270 & 0.648884 \\
\hline C & -0.053846 & -3.459008 & 0.568314 \\
\hline C & 0.707243 & -3.513619 & -0.611762 \\
\hline C & 0.187027 & -4.222445 & -1.707340 \\
\hline C & -1.048347 & -4.863747 & -1.626461 \\
\hline $\mathrm{H}$ & -1.860137 & -4.048195 & 1.572090 \\
\hline $\mathrm{H}$ & -1.432942 & -5.400595 & -2.489906 \\
\hline C & 4.641290 & -1.692784 & -0.969983 \\
\hline C & 4.387478 & -3.017240 & -1.453428 \\
\hline C & 5.426857 & -3.733048 & -2.107609 \\
\hline C & 6.660738 & -3.160949 & -2.311634 \\
\hline C & 6.901890 & -1.838018 & -1.871990 \\
\hline C & 5.921156 & -1.124372 & -1.218802 \\
\hline $\mathrm{H}$ & 5.220230 & -4.742023 & -2.456916 \\
\hline $\mathrm{H}$ & 7.445302 & -3.715157 & -2.819560 \\
\hline $\mathrm{H}$ & 7.868955 & -1.377657 & -2.055746 \\
\hline $\mathrm{H}$ & 6.119660 & -0.108654 & -0.897401 \\
\hline C & 4.770478 & 0.623700 & 1.305910 \\
\hline C & 4.953966 & 1.966090 & 1.771451 \\
\hline C & 5.928650 & 2.230943 & 2.771595 \\
\hline C & 6.674579 & 1.214219 & 3.320714 \\
\hline C & 6.467873 & -0.117949 & 2.891748 \\
\hline C & 5.543446 & -0.405317 & 1.911524 \\
\hline $\mathrm{H}$ & 6.063415 & 3.257648 & 3.103933 \\
\hline $\mathrm{H}$ & 7.411847 & 1.428204 & 4.089717 \\
\hline $\mathrm{H}$ & 7.040486 & -0.923820 & 3.343059 \\
\hline $\mathrm{H}$ & 5.390892 & -1.432581 & 1.601575 \\
\hline $\mathrm{O}$ & -0.194748 & -0.038745 & -1.698170 \\
\hline $\mathrm{O}$ & -0.047793 & 1.210123 & 0.593140 \\
\hline $\mathrm{H}$ & -1.089541 & 1.487874 & 0.407076 \\
\hline $\mathrm{H}$ & 1.973492 & 4.700376 & 1.772507 \\
\hline $\mathrm{H}$ & 0.240275 & 6.938339 & -1.462859 \\
\hline $\mathrm{H}$ & 2.437630 & 3.334944 & -2.275473 \\
\hline $\mathrm{H}$ & 0.748122 & -4.248347 & -2.637092 \\
\hline $\mathrm{H}$ & -2.755073 & -5.305032 & -0.381316 \\
\hline $\mathrm{H}$ & 0.327452 & -2.916767 & 1.426402 \\
\hline C & -2.914914 & 1.366680 & -0.868424 \\
\hline $\mathrm{O}$ & -2.424357 & 1.749731 & 0.260606 \\
\hline $\mathrm{H}$ & -2.216716 & 1.240179 & -1.711998 \\
\hline C & -4.204767 & 2.055262 & -1.342618 \\
\hline $\mathrm{O}$ & -4.951364 & 1.618512 & -2.206803 \\
\hline $\mathrm{O}$ & -4.397064 & 3.223616 & -0.727880 \\
\hline C & -5.553172 & 3.967255 & -1.150843 \\
\hline $\mathrm{H}$ & -5.559154 & 4.866403 & -0.535197 \\
\hline
\end{tabular}




$\begin{array}{llll}\mathrm{H} & -5.475436 & 4.223852 & -2.210551 \\ \mathrm{C} & -4.445098 & -0.787433 & -0.075505 \\ \mathrm{C} & -3.381143 & -0.452288 & -0.952111 \\ \mathrm{H} & -5.745745 & -0.259703 & -1.519187 \\ \mathrm{~N} & -5.711571 & -0.608679 & -0.562329 \\ \mathrm{C} & -6.917501 & -0.389729 & 0.132005 \\ \mathrm{O} & -7.104534 & -0.465135 & 1.321459 \\ \mathrm{O} & -7.849062 & -0.075083 & -0.789337 \\ \mathrm{C} & -9.160172 & 0.191963 & -0.259534 \\ \mathrm{H} & -9.126798 & 1.035608 & 0.434033 \\ \mathrm{H} & -9.546534 & -0.687821 & 0.260815 \\ \mathrm{H} & -9.775820 & 0.428870 & -1.126742 \\ \mathrm{H} & -2.420564 & -0.908708 & -0.739638 \\ \mathrm{H} & -3.637809 & -0.473588 & -2.008471 \\ \mathrm{C} & -4.185875 & -1.291634 & 1.275428 \\ \mathrm{C} & -3.045569 & -0.826928 & 1.959399 \\ \mathrm{C} & -4.985865 & -2.290340 & 1.865182 \\ \mathrm{C} & -2.743440 & -1.320378 & 3.226398 \\ \mathrm{H} & -2.427912 & -0.053575 & 1.517287 \\ \mathrm{C} & -4.650352 & -2.807720 & 3.110004 \\ \mathrm{H} & -5.852418 & -2.674901 & 1.341133 \\ \mathrm{C} & -3.536365 & -2.315890 & 3.799599 \\ \mathrm{H} & -1.877230 & -0.934911 & 3.755665 \\ \mathrm{H} & -5.262110 & -3.590484 & 3.548985 \\ \mathrm{H} & -3.285191 & -2.715963 & 4.778275 \\ \mathrm{H} & -6.463436 & 3.382753 & -0.992448\end{array}$

Catalyst (R)-1 TS Conformation 394

B3LYP/6-31G(d) Energy = -2809.679116

B3LYP-D3(BJ)/def2-TZVPP-IEF-PCM(DCM) Energy $=-2810.973768$

B3LYP-D3(BJ)/def2-TZVPP-IEF-PCM(DCM)//B3LYP/6-31G(d) Free Energy (Quasiharmonic) = 2810.330288

Frequencies (Top 3 out of 270)

1. $-294.5577 \mathrm{~cm}-1$

2. $\quad 9.4281 \mathrm{~cm}-1$

3. $\quad 10.2927 \mathrm{~cm}-1$

B3LYP/6-31G(d) Molecular Geometry in Cartesian Coordinates

$\begin{array}{llll}\text { C } & -3.080480 & 1.016889 & -0.177923\end{array}$ 


\begin{tabular}{|c|c|c|c|}
\hline C & -1.932363 & 1.744651 & 0.084168 \\
\hline C & -1.805411 & 3.139379 & -0.180373 \\
\hline C & -2.882285 & 3.768058 & -0.774404 \\
\hline $\mathrm{H}$ & -2.831352 & 4.836471 & -0.966824 \\
\hline C & -3.359249 & -3.200831 & 0.629022 \\
\hline C & -3.146365 & -0.426028 & 0.199752 \\
\hline C & -2.191905 & -1.312770 & -0.280156 \\
\hline C & -2.307805 & -2.729679 & -0.136048 \\
\hline $\mathrm{H}$ & -3.465523 & -4.272625 & 0.773486 \\
\hline $\mathrm{O}$ & -0.851084 & 1.085581 & 0.658395 \\
\hline$P$ & 0.033564 & 0.067552 & -0.269964 \\
\hline $\mathrm{O}$ & -1.125370 & -0.814531 & -1.018695 \\
\hline C & 1.651761 & 5.496292 & 0.816963 \\
\hline C & 1.057950 & 5.606957 & -0.440768 \\
\hline C & -0.047408 & 4.820274 & -0.763902 \\
\hline C & -0.581226 & 3.910309 & 0.162710 \\
\hline C & 0.033800 & 3.799114 & 1.421777 \\
\hline C & 1.137467 & 4.587019 & 1.744493 \\
\hline $\mathrm{H}$ & 1.457608 & 6.300336 & -1.176028 \\
\hline $\mathrm{H}$ & 1.592747 & 4.494844 & 2.727128 \\
\hline C & 0.174757 & -5.654295 & -2.097493 \\
\hline C & 0.768489 & -4.568628 & -1.451197 \\
\hline C & -0.014388 & -3.598241 & -0.824419 \\
\hline C & -1.415468 & -3.701772 & -0.828711 \\
\hline C & -2.000567 & -4.796448 & -1.490182 \\
\hline C & -1.216044 & -5.763402 & -2.116992 \\
\hline $\mathrm{H}$ & 1.850207 & -4.468850 & -1.433396 \\
\hline $\mathrm{H}$ & -1.693770 & -6.595481 & -2.627933 \\
\hline C & -4.184388 & -0.927809 & 1.057721 \\
\hline C & -4.282766 & -2.340028 & 1.268860 \\
\hline C & -5.300609 & -2.850390 & 2.119727 \\
\hline C & -6.177856 & -2.005188 & 2.758179 \\
\hline C & -6.065416 & -0.606732 & 2.574176 \\
\hline C & -5.097662 & -0.082158 & 1.745915 \\
\hline $\mathrm{H}$ & -5.365429 & -3.926527 & 2.262854 \\
\hline $\mathrm{H}$ & -6.948952 & -2.405664 & 3.410594 \\
\hline $\mathrm{H}$ & -6.745342 & 0.060981 & 3.096362 \\
\hline $\mathrm{H}$ & -5.017403 & 0.991923 & 1.624390 \\
\hline C & -4.164705 & 1.668856 & -0.862228 \\
\hline C & -4.056386 & 3.068869 & -1.146724 \\
\hline C & -5.123745 & 3.731511 & -1.811436 \\
\hline C & -6.244132 & 3.042428 & -2.212975 \\
\hline C & -6.336891 & 1.652145 & -1.969345 \\
\hline C & -5.327302 & 0.984132 & -1.311674 \\
\hline
\end{tabular}




\begin{tabular}{|c|c|c|c|}
\hline $\mathrm{H}$ & -5.029110 & 4.796800 & -2.008384 \\
\hline $\mathrm{H}$ & -7.050627 & 3.558069 & -2.727026 \\
\hline $\mathrm{H}$ & -7.211097 & 1.103413 & -2.309217 \\
\hline $\mathrm{H}$ & -5.411166 & -0.083003 & -1.143752 \\
\hline $\mathrm{O}$ & 0.963338 & -0.687286 & 0.610379 \\
\hline 0 & 0.622006 & 0.860981 & -1.469002 \\
\hline $\mathrm{H}$ & 1.689612 & 1.012328 & -1.457143 \\
\hline $\mathrm{H}$ & -0.362342 & 3.101426 & 2.151661 \\
\hline $\mathrm{H}$ & 2.508117 & 6.113972 & 1.074179 \\
\hline $\mathrm{H}$ & -0.492208 & 4.893978 & -1.752094 \\
\hline $\mathrm{H}$ & -3.083440 & -4.875002 & -1.530624 \\
\hline $\mathrm{H}$ & 0.789678 & -6.404537 & -2.588186 \\
\hline $\mathrm{H}$ & 0.468153 & -2.766165 & -0.324893 \\
\hline C & 3.539680 & 1.731287 & -0.382154 \\
\hline $\mathrm{O}$ & 3.049535 & 1.311633 & -1.491159 \\
\hline $\mathrm{H}$ & 2.880701 & 1.801824 & 0.498541 \\
\hline C & 4.466580 & 2.955957 & -0.503570 \\
\hline $\mathrm{O}$ & 5.002034 & 3.324357 & -1.519460 \\
\hline $\mathrm{O}$ & 4.607396 & 3.569272 & 0.697632 \\
\hline C & 5.447489 & 4.735535 & 0.690623 \\
\hline $\mathrm{H}$ & 5.464898 & 5.092739 & 1.720825 \\
\hline $\mathrm{H}$ & 5.033628 & 5.498118 & 0.026065 \\
\hline C & 4.333609 & -0.677334 & 0.751088 \\
\hline C & 4.861969 & 0.586011 & 0.365564 \\
\hline $\mathrm{H}$ & 3.982617 & 0.058423 & 2.587523 \\
\hline$N$ & 3.848831 & -0.771307 & 2.017922 \\
\hline C & 2.844931 & -1.562879 & 2.647158 \\
\hline $\mathrm{O}$ & 2.399293 & -1.191913 & 3.708278 \\
\hline $\mathrm{O}$ & 2.546358 & -2.674036 & 1.996737 \\
\hline C & 1.400881 & -3.385453 & 2.519486 \\
\hline $\mathrm{H}$ & 0.522830 & -2.741890 & 2.454071 \\
\hline $\mathrm{H}$ & 1.583420 & -3.680291 & 3.555062 \\
\hline $\mathrm{H}$ & 1.289971 & -4.253993 & 1.872574 \\
\hline $\mathrm{H}$ & 5.594661 & 0.548863 & -0.434972 \\
\hline $\mathrm{H}$ & 5.162190 & 1.221016 & 1.197976 \\
\hline C & 4.385553 & -1.809494 & -0.179496 \\
\hline C & 4.227096 & -1.557434 & -1.556029 \\
\hline C & 4.725365 & -3.104736 & 0.255729 \\
\hline C & 4.362144 & -2.598894 & -2.470993 \\
\hline $\mathrm{H}$ & 3.966573 & -0.557620 & -1.894423 \\
\hline C & 4.901449 & -4.126227 & -0.670830 \\
\hline $\mathrm{H}$ & 4.877690 & -3.300492 & 1.310378 \\
\hline C & 4.711086 & -3.878738 & -2.034559 \\
\hline $\mathrm{H}$ & 4.211495 & -2.404082 & -3.528594 \\
\hline
\end{tabular}




$\begin{array}{llll}\mathrm{H} & 5.189173 & -5.116884 & -0.330573 \\ \mathrm{H} & 4.846875 & -4.680979 & -2.754971 \\ \mathrm{H} & 6.456170 & 4.481465 & 0.353346\end{array}$

Catalyst (R)-1 TS Conformation 395

B3LYP/6-31G(d) Energy $=-2809.683582$

B3LYP-D3(BJ)/def2-TZVPP-IEF-PCM(DCM) Energy = -2810.972867

B3LYP-D3(BJ)/def2-TZVPP-IEF-PCM(DCM)//B3LYP/6-31G(d) Free Energy (Quasiharmonic) = 2810.330241

Frequencies (Top 3 out of 270)

1. $-397.7972 \mathrm{~cm}-1$

2. $\quad 4.0482 \mathrm{~cm}-1$

3. $\quad 11.4887 \mathrm{~cm}-1$

B3LYP/6-31G(d) Molecular Geometry in Cartesian Coordinates

$\begin{array}{llll}\text { C } & 3.427183 & -0.279793 & -0.051574 \\ \text { C } & 2.554076 & -1.351361 & 0.042517 \\ \text { C } & 2.865449 & -2.664741 & -0.416319 \\ \text { C } & 4.088371 & -2.843536 & -1.032617 \\ \text { H } & 4.370071 & -3.837239 & -1.370801 \\ \text { C } & 2.419062 & 3.663132 & 1.356372 \\ \text { C } & 3.053478 & 1.043807 & 0.530690 \\ \text { C } & 1.873857 & 1.665027 & 0.141997 \\ \text { C } & 1.548651 & 3.006222 & 0.508343 \\ \text { H } & 2.192725 & 4.683317 & 1.655385 \\ \text { O } & 1.312068 & -1.146242 & 0.636562 \\ \text { P } & 0.178388 & -0.314797 & -0.192054 \\ \text { O } & 1.020773 & 0.995954 & -0.723052 \\ \text { C } & 0.305335 & -6.087335 & 0.070550 \\ \text { C } & 0.906158 & -5.821037 & -1.160276 \\ \text { C } & 1.714949 & -4.695922 & -1.315395 \\ \text { C } & 1.938838 & -3.815093 & -0.245038 \\ \text { C } & 1.320282 & -4.088474 & 0.986068 \\ \text { C } & 0.515340 & -5.215593 & 1.140923 \\ \text { H } & 0.740669 & -6.485206 & -2.004657 \\ \text { H } & 0.053586 & -5.415147 & 2.104498 \\ \text { C } & -1.843306 & 5.217067 & -0.953976 \\ \text { C } & -0.549243 & 5.719012 & -1.098822 \\ \text { C } & 0.541124 & 4.982045 & -0.636400\end{array}$




\begin{tabular}{|c|c|c|c|}
\hline C & 0.359640 & 3.730414 & -0.025115 \\
\hline C & -0.945900 & 3.232603 & 0.112490 \\
\hline C & -2.035876 & 3.973748 & -0.346556 \\
\hline $\mathrm{H}$ & -0.385328 & 6.683061 & -1.573784 \\
\hline $\mathrm{H}$ & -3.040948 & 3.577428 & -0.228543 \\
\hline C & 3.894842 & 1.703281 & 1.491810 \\
\hline C & 3.569565 & 3.037820 & 1.895536 \\
\hline C & 4.396669 & 3.703728 & 2.840269 \\
\hline C & 5.490606 & 3.076284 & 3.389248 \\
\hline C & 5.796766 & 1.746089 & 3.016734 \\
\hline C & 5.022743 & 1.078875 & 2.092917 \\
\hline $\mathrm{H}$ & 4.138325 & 4.719771 & 3.129575 \\
\hline $\mathrm{H}$ & 6.112528 & 3.592847 & 4.115254 \\
\hline $\mathrm{H}$ & 6.647714 & 1.243107 & 3.468249 \\
\hline $\mathrm{H}$ & 5.264769 & 0.056545 & 1.826077 \\
\hline C & 4.663372 & -0.465912 & -0.764505 \\
\hline C & 4.992624 & -1.774611 & -1.245192 \\
\hline C & 6.215665 & -1.977208 & -1.940425 \\
\hline C & 7.071751 & -0.929608 & -2.187276 \\
\hline C & 6.730370 & 0.371820 & -1.750860 \\
\hline C & 5.561080 & 0.597491 & -1.058108 \\
\hline $\mathrm{H}$ & 6.454188 & -2.980225 & -2.286467 \\
\hline $\mathrm{H}$ & 8.000488 & -1.095013 & -2.726507 \\
\hline $\mathrm{H}$ & 7.394333 & 1.204064 & -1.968702 \\
\hline $\mathrm{H}$ & 5.311337 & 1.603130 & -0.741709 \\
\hline $\mathrm{O}$ & -0.955434 & 0.028109 & 0.709302 \\
\hline $\mathrm{O}$ & -0.100104 & -1.110061 & -1.492440 \\
\hline $\mathrm{H}$ & -1.017608 & -0.875081 & -2.063806 \\
\hline $\mathrm{H}$ & 1.479088 & -3.419339 & 1.824858 \\
\hline $\mathrm{H}$ & -0.324489 & -6.964641 & 0.193790 \\
\hline $\mathrm{H}$ & 2.162803 & -4.481001 & -2.281437 \\
\hline $\mathrm{H}$ & -1.105355 & 2.271266 & 0.589723 \\
\hline $\mathrm{H}$ & -2.696132 & 5.792343 & -1.306409 \\
\hline $\mathrm{H}$ & 1.548520 & 5.369943 & -0.762166 \\
\hline C & -2.932859 & 0.112947 & -1.961581 \\
\hline $\mathrm{O}$ & -2.117742 & -0.497243 & -2.740089 \\
\hline $\mathrm{H}$ & -2.600732 & 0.341771 & -0.938786 \\
\hline C & -3.705616 & 1.320543 & -2.512770 \\
\hline $\mathrm{O}$ & -4.565821 & 1.920882 & -1.876110 \\
\hline $\mathrm{O}$ & -3.306642 & 1.675722 & -3.725382 \\
\hline C & -3.908412 & 2.869003 & -4.265486 \\
\hline $\mathrm{H}$ & -4.995562 & 2.765989 & -4.302985 \\
\hline $\mathrm{H}$ & -3.644630 & 3.730384 & -3.647024 \\
\hline C & -4.580941 & -0.971514 & -0.131150 \\
\hline
\end{tabular}




$\begin{array}{llll}\mathrm{C} & -4.444119 & -1.030788 & -1.540642 \\ \mathrm{H} & -5.026183 & 1.001189 & -0.268163 \\ \mathrm{~N} & -4.991537 & 0.213646 & 0.394191 \\ \mathrm{C} & -5.462413 & 0.483988 & 1.690425 \\ \mathrm{O} & -5.668467 & -0.317806 & 2.568648 \\ \mathrm{O} & -5.677842 & 1.810622 & 1.767409 \\ \mathrm{C} & -6.191436 & 2.269624 & 3.030715 \\ \mathrm{H} & -7.155110 & 1.800261 & 3.243549 \\ \mathrm{H} & -6.302944 & 3.347721 & 2.919160 \\ \mathrm{H} & -5.488947 & 2.034807 & 3.833889 \\ \mathrm{H} & -4.101120 & -1.978845 & -1.938928 \\ \mathrm{H} & -5.224707 & -0.551792 & -2.124993 \\ \mathrm{C} & -4.131619 & -2.081889 & 0.718451 \\ \mathrm{C} & -4.520507 & -3.392152 & 0.384376 \\ \mathrm{C} & -3.270434 & -1.870858 & 1.810603 \\ \mathrm{C} & -4.091056 & -4.468929 & 1.153667 \\ \mathrm{H} & -5.186241 & -3.556178 & -0.457692 \\ \mathrm{C} & -2.819382 & -2.955783 & 2.553771 \\ \mathrm{H} & -2.899970 & -0.876060 & 2.024061 \\ \mathrm{C} & -3.238789 & -4.250881 & 2.238384 \\ \mathrm{H} & -4.414542 & -5.475078 & 0.903849 \\ \mathrm{H} & -2.132518 & -2.789263 & 3.377878 \\ \mathrm{H} & -2.893210 & -5.092397 & 2.832709 \\ \mathrm{H} & -3.491877 & 2.971198 & -5.266917\end{array}$

Catalyst (R)-1 TS Conformation 396

B3LYP/6-31G(d) Energy $=-2809.680189$

B3LYP-D3(BJ)/def2-TZVPP-IEF-PCM(DCM) Energy = -2810.97206

B3LYP-D3(BJ)/def2-TZVPP-IEF-PCM(DCM)//B3LYP/6-31G(d) Free Energy (Quasiharmonic) = 2810.329986

Frequencies (Top 3 out of 270)

1. $-707.0410 \mathrm{~cm}-1$

2. $\quad 5.8143 \mathrm{~cm}-1$

3. $\quad 7.5372 \mathrm{~cm}-1$

B3LYP/6-31G(d) Molecular Geometry in Cartesian Coordinates

$\begin{array}{llll}C & -3.307232 & -0.377280 & 0.314167 \\ C & -2.795736 & -1.321779 & -0.562005 \\ C & -2.931591 & -2.729252 & -0.371337\end{array}$




\begin{tabular}{|c|c|c|c|}
\hline C & -3.564950 & -3.149569 & 0.782201 \\
\hline $\mathrm{H}$ & -3.714470 & -4.213488 & 0.946396 \\
\hline C & -2.907880 & 3.849906 & -0.424657 \\
\hline C & -3.206636 & 1.075038 & -0.019089 \\
\hline C & -1.969028 & 1.641483 & -0.297895 \\
\hline C & -1.786258 & 3.046129 & -0.477737 \\
\hline $\mathrm{H}$ & -2.794370 & 4.922301 & -0.561018 \\
\hline 0 & -2.132805 & -0.877552 & -1.698650 \\
\hline$P$ & -0.619414 & -0.277542 & -1.521503 \\
\hline $\mathrm{O}$ & -0.846170 & 0.829759 & -0.305893 \\
\hline C & -1.552862 & -5.693032 & -3.170035 \\
\hline C & -2.213519 & -4.552877 & -3.631596 \\
\hline C & -2.644742 & -3.575537 & -2.736383 \\
\hline C & -2.426609 & -3.722530 & -1.356104 \\
\hline C & -1.756870 & -4.872063 & -0.905713 \\
\hline C & -1.324277 & -5.848068 & -1.802275 \\
\hline $\mathrm{H}$ & -2.395547 & -4.421547 & -4.694979 \\
\hline $\mathrm{H}$ & -0.800200 & -6.725306 & -1.431543 \\
\hline C & 2.002906 & 5.000282 & -1.081554 \\
\hline C & 1.178172 & 5.361548 & -0.015067 \\
\hline C & -0.037018 & 4.704556 & 0.181940 \\
\hline C & -0.448081 & 3.673184 & -0.678474 \\
\hline C & 0.389661 & 3.313425 & -1.747071 \\
\hline C & 1.602636 & 3.976627 & -1.944827 \\
\hline $\mathrm{H}$ & 1.478090 & 6.155321 & 0.664575 \\
\hline $\mathrm{H}$ & 2.235535 & 3.693336 & -2.782442 \\
\hline C & -4.375528 & 1.910835 & -0.073434 \\
\hline C & -4.211037 & 3.320754 & -0.261007 \\
\hline C & -5.357185 & 4.160035 & -0.304729 \\
\hline C & -6.623396 & 3.634558 & -0.195072 \\
\hline C & -6.792053 & 2.237815 & -0.045355 \\
\hline C & -5.700358 & 1.399882 & 0.015314 \\
\hline $\mathrm{H}$ & -5.211313 & 5.229094 & -0.441059 \\
\hline $\mathrm{H}$ & -7.493101 & 4.284585 & -0.236855 \\
\hline $\mathrm{H}$ & -7.793498 & 1.820196 & 0.015258 \\
\hline $\mathrm{H}$ & -5.848711 & 0.331236 & 0.118149 \\
\hline C & -3.889485 & -0.833092 & 1.548139 \\
\hline C & -4.026878 & -2.242297 & 1.766999 \\
\hline C & -4.612888 & -2.707563 & 2.975647 \\
\hline C & -5.018579 & -1.827140 & 3.951431 \\
\hline C & -4.846040 & -0.436700 & 3.756430 \\
\hline C & -4.299271 & 0.046779 & 2.587813 \\
\hline $\mathrm{H}$ & -4.723127 & -3.780204 & 3.117818 \\
\hline $\mathrm{H}$ & -5.459773 & -2.195178 & 4.873792 \\
\hline
\end{tabular}




\begin{tabular}{|c|c|c|c|}
\hline $\mathrm{H}$ & -5.144589 & 0.257677 & 4.537309 \\
\hline $\mathrm{H}$ & -4.166739 & 1.114489 & 2.458787 \\
\hline $\mathrm{O}$ & -0.154152 & 0.329834 & -2.794462 \\
\hline $\mathrm{O}$ & 0.252383 & -1.343836 & -0.825080 \\
\hline $\mathrm{H}$ & 1.425673 & -1.399024 & -1.114283 \\
\hline $\mathrm{H}$ & -1.554696 & -4.986967 & 0.155577 \\
\hline $\mathrm{H}$ & -1.213745 & -6.450876 & -3.871412 \\
\hline $\mathrm{H}$ & -3.156825 & -2.694897 & -3.107603 \\
\hline $\mathrm{H}$ & 0.089595 & 2.520542 & -2.424921 \\
\hline $\mathrm{H}$ & 2.946267 & 5.515865 & -1.243553 \\
\hline $\mathrm{H}$ & -0.674117 & 4.983605 & 1.017199 \\
\hline C & 2.955163 & -0.131387 & -1.524306 \\
\hline 0 & 2.619789 & -1.338655 & -1.231109 \\
\hline $\mathrm{H}$ & 2.225789 & 0.495149 & -2.054270 \\
\hline C & 4.379928 & 0.129257 & -2.001729 \\
\hline 0 & 4.786763 & 1.240277 & -2.290770 \\
\hline $\mathrm{O}$ & 5.114229 & -0.983115 & -2.063457 \\
\hline C & 6.457170 & -0.810777 & -2.565360 \\
\hline $\mathrm{H}$ & 6.434676 & -0.340141 & -3.550764 \\
\hline $\mathrm{H}$ & 7.042044 & -0.191292 & -1.880581 \\
\hline C & 3.809443 & 0.668021 & 0.982098 \\
\hline C & 2.900909 & 1.124973 & 0.013571 \\
\hline $\mathrm{H}$ & 5.297365 & 1.763040 & 0.135407 \\
\hline$N$ & 5.130536 & 1.035098 & 0.824663 \\
\hline C & 6.325330 & 0.316226 & 1.036265 \\
\hline 0 & 7.382519 & 0.747045 & 0.627490 \\
\hline 0 & 6.145470 & -0.836969 & 1.677752 \\
\hline C & 7.340731 & -1.615716 & 1.887217 \\
\hline $\mathrm{H}$ & 7.772061 & -1.909729 & 0.927834 \\
\hline $\mathrm{H}$ & 7.012134 & -2.490614 & 2.446666 \\
\hline $\mathrm{H}$ & 8.074587 & -1.040412 & 2.455819 \\
\hline $\mathrm{H}$ & 1.847625 & 1.099659 & 0.271915 \\
\hline $\mathrm{H}$ & 3.193551 & 1.985732 & -0.581395 \\
\hline C & 3.377191 & -0.137690 & 2.124830 \\
\hline C & 4.011657 & -0.004288 & 3.377806 \\
\hline C & 2.247011 & -0.971515 & 2.013151 \\
\hline C & 3.533067 & -0.693966 & 4.483737 \\
\hline $\mathrm{H}$ & 4.854811 & 0.669300 & 3.486375 \\
\hline C & 1.793331 & -1.682257 & 3.121610 \\
\hline $\mathrm{H}$ & 1.729161 & -1.079356 & 1.068451 \\
\hline C & 2.429359 & -1.544624 & 4.356023 \\
\hline $\mathrm{H}$ & 4.015128 & -0.565824 & 5.448681 \\
\hline $\mathrm{H}$ & 0.929551 & -2.331539 & 3.017569 \\
\hline $\mathrm{H}$ & 2.059038 & -2.085765 & 5.222441 \\
\hline
\end{tabular}


$\begin{array}{llll}H & 6.869321 & -1.817708 & -2.627476\end{array}$

Catalyst (R)-1 TS Conformation 397

$B 3 L Y P / 6-31 G(d)$ Energy $=-2809.681418$

B3LYP-D3(BJ)/def2-TZVPP-IEF-PCM(DCM) Energy = -2810.973817

B3LYP-D3(BJ)/def2-TZVPP-IEF-PCM(DCM)//B3LYP/6-31G(d) Free Energy (Quasiharmonic) = 2810.329962

Frequencies (Top 3 out of 270)

1. $-271.7956 \mathrm{~cm}-1$

2. $\quad 10.1310 \mathrm{~cm}-1$

3. $11.2365 \mathrm{~cm}-1$

B3LYP/6-31G(d) Molecular Geometry in Cartesian Coordinates

$\begin{array}{llll}\text { C } & -3.071434 & 1.044592 & -0.161471 \\ \text { C } & -1.920654 & 1.752743 & 0.140490 \\ \text { C } & -1.782387 & 3.157689 & -0.058386 \\ \text { C } & -2.855354 & 3.820616 & -0.621745 \\ \text { H } & -2.797576 & 4.896644 & -0.762835 \\ \text { C } & -3.379229 & -3.206424 & 0.440795 \\ \text { C } & -3.147789 & -0.414590 & 0.146289 \\ \text { C } & -2.193792 & -1.283679 & -0.365907 \\ \text { C } & -2.316507 & -2.704996 & -0.288406 \\ \text { H } & -3.492281 & -4.283328 & 0.532782 \\ \text { O } & -0.848676 & 1.061250 & 0.693618 \\ \text { P } & 0.038319 & 0.072045 & -0.260471 \\ \text { O } & -1.116348 & -0.757742 & -1.070169 \\ \text { C } & 1.744877 & 5.392250 & 0.985204 \\ \text { C } & 1.228751 & 4.448607 & 1.876866 \\ \text { C } & 0.095339 & 3.708668 & 1.544067 \\ \text { C } & -0.545995 & 3.898081 & 0.307323 \\ \text { C } & -0.015965 & 4.848052 & -0.580625 \\ \text { C } & 1.116653 & 5.589662 & -0.244835 \\ \text { H } & 1.712943 & 4.288742 & 2.836320 \\ \text { H } & 1.512713 & 6.314191 & -0.951877 \\ \text { C } & 0.183770 & -5.546640 & -2.346805 \\ \text { C } & 0.772276 & -4.501944 & -1.631818 \\ \text { C } & -0.016103 & -3.558175 & -0.972170 \\ \text { C } & -1.417590 & -3.647966 & -1.012614 \\ \text { C } & -1.997320 & -4.701361 & -1.742051\end{array}$




\begin{tabular}{|c|c|c|c|}
\hline C & -1.207147 & -5.641663 & -2.401619 \\
\hline $\mathrm{H}$ & 1.854268 & -4.413714 & -1.585021 \\
\hline $\mathrm{H}$ & -1.680331 & -6.441841 & -2.965057 \\
\hline C & -4.196398 & -0.951400 & 0.969870 \\
\hline C & -4.305104 & -2.371618 & 1.111120 \\
\hline C & -5.334340 & -2.916345 & 1.926244 \\
\hline C & -6.212316 & -2.097672 & 2.597380 \\
\hline C & -6.089155 & -0.692668 & 2.483698 \\
\hline C & -5.110562 & -0.134535 & 1.690891 \\
\hline $\mathrm{H}$ & -5.406960 & -3.997744 & 2.015960 \\
\hline $\mathrm{H}$ & -6.991979 & -2.524527 & 3.222305 \\
\hline $\mathrm{H}$ & -6.769325 & -0.046832 & 3.032385 \\
\hline $\mathrm{H}$ & -5.022262 & 0.943639 & 1.623548 \\
\hline C & -4.148923 & 1.735350 & -0.817924 \\
\hline C & -4.032578 & 3.147492 & -1.030341 \\
\hline C & -5.094406 & 3.848491 & -1.663978 \\
\hline C & -6.216424 & 3.186455 & -2.104549 \\
\hline C & -6.316443 & 1.785904 & -1.933393 \\
\hline C & -5.312643 & 1.080236 & -1.306903 \\
\hline $\mathrm{H}$ & -4.993980 & 4.922017 & -1.805621 \\
\hline $\mathrm{H}$ & -7.018560 & 3.731800 & -2.594212 \\
\hline $\mathrm{H}$ & -7.191642 & 1.259480 & -2.304568 \\
\hline $\mathrm{H}$ & -5.402250 & 0.006298 & -1.194480 \\
\hline $\mathrm{O}$ & 0.941815 & -0.730824 & 0.604142 \\
\hline $\mathrm{O}$ & 0.664249 & 0.904757 & -1.415998 \\
\hline $\mathrm{H}$ & 1.721044 & 1.061233 & -1.345724 \\
\hline $\mathrm{H}$ & -0.482982 & 4.985580 & -1.551731 \\
\hline $\mathrm{H}$ & 2.636229 & 5.955240 & 1.245951 \\
\hline $\mathrm{H}$ & -0.299532 & 2.982920 & 2.246648 \\
\hline $\mathrm{H}$ & -3.079748 & -4.767875 & -1.808615 \\
\hline $\mathrm{H}$ & 0.802992 & -6.276233 & -2.862589 \\
\hline $\mathrm{H}$ & 0.462341 & -2.758206 & -0.418876 \\
\hline C & 3.523183 & 1.728615 & -0.129641 \\
\hline $\mathrm{O}$ & 3.099621 & 1.367964 & -1.285543 \\
\hline $\mathrm{H}$ & 2.820030 & 1.739028 & 0.719536 \\
\hline C & 4.411582 & 2.986503 & -0.055343 \\
\hline $\mathrm{O}$ & 4.638697 & 3.581260 & 0.979620 \\
\hline $\mathrm{O}$ & 4.894699 & 3.335586 & -1.253414 \\
\hline C & 5.709020 & 4.519797 & -1.264941 \\
\hline $\mathrm{H}$ & 6.032728 & 4.640265 & -2.298830 \\
\hline $\mathrm{H}$ & 6.569450 & 4.402912 & -0.600258 \\
\hline C & 4.275645 & -0.710435 & 0.956623 \\
\hline C & 4.816492 & 0.564862 & 0.637348 \\
\hline $\mathrm{H}$ & 3.819895 & -0.031477 & 2.792614 \\
\hline
\end{tabular}




$\begin{array}{llll}\text { N } & 3.721636 & -0.843794 & 2.191157 \\ \mathrm{C} & 2.688938 & -1.659993 & 2.735711 \\ \mathrm{O} & 2.178076 & -1.326928 & 3.779723 \\ \mathrm{O} & 2.437609 & -2.751686 & 2.033223 \\ \mathrm{C} & 1.268556 & -3.485737 & 2.462553 \\ \mathrm{H} & 0.391245 & -2.844372 & 2.370615 \\ \mathrm{H} & 1.392517 & -3.818175 & 3.495460 \\ \mathrm{H} & 1.200143 & -4.330557 & 1.779176 \\ \mathrm{H} & 5.590389 & 0.552854 & -0.124486 \\ \mathrm{H} & 5.062608 & 1.184438 & 1.498740 \\ \mathrm{C} & 4.379653 & -1.814526 & -0.004009 \\ \mathrm{C} & 4.273066 & -1.522357 & -1.377102 \\ \mathrm{C} & 4.711473 & -3.119576 & 0.405833 \\ \mathrm{C} & 4.452030 & -2.535069 & -2.316720 \\ \mathrm{H} & 4.016484 & -0.514597 & -1.694626 \\ \mathrm{C} & 4.930661 & -4.112237 & -0.542775 \\ \mathrm{H} & 4.822129 & -3.345621 & 1.459748 \\ \mathrm{C} & 4.792345 & -3.825480 & -1.904968 \\ \mathrm{H} & 4.340883 & -2.310174 & -3.373338 \\ \mathrm{H} & 5.210764 & -5.111157 & -0.220796 \\ \mathrm{H} & 4.961526 & -4.605230 & -2.642834 \\ \mathrm{H} & 5.125416 & 5.385712 & -0.941655\end{array}$

Catalyst (R)-1 TS Conformation 398

B3LYP/6-31G(d) Energy $=-2809.681011$

B3LYP-D3(BJ)/def2-TZVPP-IEF-PCM(DCM) Energy = -2810.972268

B3LYP-D3(BJ)/def2-TZVPP-IEF-PCM(DCM)//B3LYP/6-31G(d) Free Energy (Quasiharmonic) = 2810.329532

Frequencies (Top 3 out of 270)

1. $-282.2618 \mathrm{~cm}-1$

2. $\quad 6.1254 \mathrm{~cm}-1$

3. $\quad 12.0578 \mathrm{~cm}-1$

B3LYP/6-31G(d) Molecular Geometry in Cartesian Coordinates

$\begin{array}{llll}\text { C } & 3.193657 & -0.839028 & -0.243374 \\ \text { C } & 1.991334 & -1.514514 & -0.085424 \\ \text { C } & 1.892188 & -2.937638 & -0.119884 \\ \text { C } & 3.035113 & -3.654442 & -0.406986 \\ \text { H } & 2.985696 & -4.740006 & -0.436162\end{array}$




\begin{tabular}{|c|c|c|c|}
\hline C & 3.436703 & 3.428135 & 0.368723 \\
\hline C & 3.272293 & 0.628964 & 0.022301 \\
\hline C & 2.416695 & 1.504026 & -0.629132 \\
\hline C & 2.489572 & 2.923295 & -0.501007 \\
\hline $\mathrm{H}$ & 3.543019 & 4.505078 & 0.468474 \\
\hline 0 & 0.848204 & -0.805783 & 0.236581 \\
\hline$P$ & 0.150874 & 0.258186 & -0.800415 \\
\hline $\mathrm{O}$ & 1.450842 & 0.978048 & -1.479427 \\
\hline C & -1.738770 & -5.070369 & 0.785094 \\
\hline C & -1.700533 & -4.182793 & -0.295291 \\
\hline C & -0.531386 & -3.476176 & -0.585590 \\
\hline C & 0.620155 & -3.649554 & 0.195521 \\
\hline C & 0.573038 & -4.548609 & 1.271813 \\
\hline C & -0.596390 & -5.250660 & 1.566930 \\
\hline $\mathrm{H}$ & -2.565562 & -4.049525 & -0.940045 \\
\hline $\mathrm{H}$ & -0.614182 & -5.936754 & 2.409725 \\
\hline C & 0.015020 & 5.684535 & -2.685397 \\
\hline C & 0.577676 & 4.586226 & -3.338601 \\
\hline C & 1.361845 & 3.672702 & -2.636540 \\
\hline C & 1.603314 & 3.843434 & -1.262829 \\
\hline C & 1.028215 & 4.950408 & -0.617303 \\
\hline C & 0.242164 & 5.862327 & -1.320257 \\
\hline $\mathrm{H}$ & 0.406992 & 4.438492 & -4.401732 \\
\hline $\mathrm{H}$ & -0.199627 & 6.707054 & -0.797946 \\
\hline C & 4.193285 & 1.169211 & 0.988237 \\
\hline C & 4.277265 & 2.591147 & 1.142374 \\
\hline C & 5.192872 & 3.140181 & 2.080977 \\
\hline C & 5.973454 & 2.326377 & 2.868200 \\
\hline C & 5.861043 & 0.921309 & 2.750595 \\
\hline C & 4.997934 & 0.358633 & 1.835906 \\
\hline $\mathrm{H}$ & 5.253237 & 4.222165 & 2.172750 \\
\hline $\mathrm{H}$ & 6.664754 & 2.757326 & 3.587290 \\
\hline $\mathrm{H}$ & 6.458035 & 0.277915 & 3.391322 \\
\hline $\mathrm{H}$ & 4.918054 & -0.719601 & 1.768079 \\
\hline C & 4.349549 & -1.590610 & -0.654565 \\
\hline C & 4.262538 & -3.018787 & -0.720019 \\
\hline C & 5.401660 & -3.771510 & -1.113609 \\
\hline C & 6.578274 & -3.147574 & -1.457691 \\
\hline C & 6.657801 & -1.735575 & -1.427618 \\
\hline C & 5.575870 & -0.978540 & -1.034810 \\
\hline $\mathrm{H}$ & 5.318775 & -4.855252 & -1.150201 \\
\hline $\mathrm{H}$ & 7.440693 & -3.733071 & -1.764349 \\
\hline $\mathrm{H}$ & 7.579592 & -1.241982 & -1.723582 \\
\hline $\mathrm{H}$ & 5.650483 & 0.102806 & -1.028215 \\
\hline
\end{tabular}




\begin{tabular}{|c|c|c|c|}
\hline $\mathrm{O}$ & -0.777726 & 1.107699 & -0.015265 \\
\hline $\mathrm{O}$ & -0.403784 & -0.508709 & -2.038338 \\
\hline $\mathrm{H}$ & -1.444490 & -0.789576 & -1.959865 \\
\hline $\mathrm{H}$ & 1.456064 & -4.682151 & 1.890806 \\
\hline $\mathrm{H}$ & -2.646593 & -5.625740 & 1.007906 \\
\hline $\mathrm{H}$ & -0.508078 & -2.804108 & -1.434091 \\
\hline $\mathrm{H}$ & 1.182728 & 5.082093 & 0.450071 \\
\hline $\mathrm{H}$ & -0.599777 & 6.392391 & -3.235089 \\
\hline $\mathrm{H}$ & 1.794544 & 2.824933 & -3.155922 \\
\hline C & -3.696806 & -0.516612 & -1.555660 \\
\hline $\mathrm{O}$ & -2.731176 & -1.293514 & -1.909276 \\
\hline $\mathrm{H}$ & -3.448418 & 0.484131 & -1.170283 \\
\hline C & -4.911156 & -0.390442 & -2.488463 \\
\hline $\mathrm{O}$ & -5.670297 & 0.559638 & -2.463861 \\
\hline O & -5.034599 & -1.437086 & -3.312083 \\
\hline C & -6.140856 & -1.372638 & -4.229085 \\
\hline $\mathrm{H}$ & -6.047812 & -0.497895 & -4.877676 \\
\hline $\mathrm{H}$ & -7.088169 & -1.313734 & -3.685846 \\
\hline C & -4.091880 & -0.704381 & 1.060967 \\
\hline C & -4.605685 & -1.311637 & -0.120330 \\
\hline $\mathrm{H}$ & -2.564759 & -2.036391 & 1.149604 \\
\hline $\mathrm{N}$ & -2.923082 & -1.170577 & 1.552373 \\
\hline C & -1.910383 & -0.558061 & 2.357522 \\
\hline $\mathrm{O}$ & -0.962830 & -1.212228 & 2.715863 \\
\hline 0 & -2.163137 & 0.715837 & 2.614441 \\
\hline C & -1.065253 & 1.457287 & 3.191376 \\
\hline $\mathrm{H}$ & -0.301326 & 1.587219 & 2.423992 \\
\hline $\mathrm{H}$ & -0.663621 & 0.929122 & 4.058226 \\
\hline $\mathrm{H}$ & -1.494838 & 2.416297 & 3.479638 \\
\hline $\mathrm{H}$ & -5.674397 & -1.173569 & -0.255381 \\
\hline $\mathrm{H}$ & -4.277042 & -2.327067 & -0.323117 \\
\hline C & -4.843835 & 0.376660 & 1.720508 \\
\hline C & -5.565691 & 1.310029 & 0.953861 \\
\hline C & -4.950570 & 0.410981 & 3.123581 \\
\hline C & -6.346549 & 2.275128 & 1.585602 \\
\hline $\mathrm{H}$ & -5.508746 & 1.293798 & -0.130474 \\
\hline C & -5.753903 & 1.361212 & 3.744153 \\
\hline $\mathrm{H}$ & -4.428331 & -0.326905 & 3.723510 \\
\hline C & -6.445383 & 2.303297 & 2.977889 \\
\hline $\mathrm{H}$ & -6.882546 & 3.003484 & 0.984301 \\
\hline $\mathrm{H}$ & -5.840804 & 1.366757 & 4.826883 \\
\hline $\mathrm{H}$ & -7.064502 & 3.051428 & 3.465262 \\
\hline $\mathrm{H}$ & -6.087537 & -2.291256 & -4.813324 \\
\hline
\end{tabular}


Catalyst (R)-1 TS Conformation 399

B3LYP/6-31G(d) Energy $=-2809.679908$

B3LYP-D3(BJ)/def2-TZVPP-IEF-PCM(DCM) Energy = -2810.970984

B3LYP-D3(BJ)/def2-TZVPP-IEF-PCM(DCM)//B3LYP/6-31G(d) Free Energy (Quasiharmonic) = 2810.329426

Frequencies (Top 3 out of 270)

1. $-650.3128 \mathrm{~cm}-1$

2. $\quad 4.7906 \mathrm{~cm}-1$

3. $\quad 7.9835 \mathrm{~cm}-1$

B3LYP/6-31G(d) Molecular Geometry in Cartesian Coordinates

$\begin{array}{llll}\text { C } & -3.305605 & -0.270860 & 0.391150 \\ \text { C } & -2.798141 & -1.282529 & -0.408579 \\ \text { C } & -2.945764 & -2.670403 & -0.113874 \\ \text { C } & -3.586720 & -2.998073 & 1.065084 \\ \text { H } & -3.743949 & -4.045541 & 1.308578 \\ \text { C } & -2.868031 & 3.883825 & -0.666467 \\ \text { C } & -3.191008 & 1.150871 & -0.050813 \\ \text { C } & -1.947794 & 1.684920 & -0.365876 \\ \text { C } & -1.752489 & 3.069833 & -0.652117 \\ \text { H } & -2.745137 & 4.941556 & -0.884508 \\ \text { O } & -2.122685 & -0.929312 & -1.570426 \\ \text { P } & -0.603403 & -0.338698 & -1.419855 \\ \text { O } & -0.829746 & 0.867070 & -0.304339 \\ \text { C } & -1.575574 & -5.842360 & -2.677768 \\ \text { C } & -1.345974 & -5.892843 & -1.302350 \\ \text { C } & -1.775817 & -4.850392 & -0.482516 \\ \text { C } & -2.443640 & -3.737607 & -1.019412 \\ \text { C } & -2.662608 & -3.695732 & -2.406676 \\ \text { C } & -2.234231 & -4.739510 & -3.224937 \\ \text { H } & -0.822742 & -6.739952 & -0.866232 \\ \text { H } & -2.416803 & -4.689575 & -4.295142 \\ \text { C } & 2.047544 & 4.951899 & -1.395433 \\ \text { C } & 1.644720 & 3.864738 & -2.175280 \\ \text { C } & 0.430344 & 3.221805 & -1.927687 \\ \text { C } & -0.409092 & 3.669823 & -0.894737 \\ \text { C } & 0.003859 & 4.764828 & -0.118081 \\ \text { C } & 1.222521 & 5.398832 & -0.362413 \\ \text { H } & 2.273462 & 3.519492 & -2.992762\end{array}$




\begin{tabular}{|c|c|c|c|}
\hline $\mathrm{H}$ & 1.524667 & 6.242056 & 0.253618 \\
\hline C & -4.352892 & 1.989078 & -0.174855 \\
\hline C & -4.176092 & 3.379095 & -0.468899 \\
\hline C & -5.315198 & 4.221493 & -0.582274 \\
\hline C & -6.586033 & 3.715692 & -0.438970 \\
\hline C & -6.766700 & 2.335817 & -0.183841 \\
\hline C & -5.682129 & 1.496524 & -0.053927 \\
\hline $\mathrm{H}$ & -5.160099 & 5.275826 & -0.799163 \\
\hline $\mathrm{H}$ & -7.450261 & 4.367327 & -0.534502 \\
\hline $\mathrm{H}$ & -7.771752 & 1.931859 & -0.096481 \\
\hline $\mathrm{H}$ & -5.839565 & 0.440057 & 0.129509 \\
\hline C & -3.897101 & -0.627981 & 1.652923 \\
\hline C & -4.045469 & -2.015740 & 1.976780 \\
\hline C & -4.638936 & -2.384259 & 3.214790 \\
\hline C & -5.041641 & -1.429876 & 4.119751 \\
\hline C & -4.858891 & -0.059323 & 3.820926 \\
\hline C & -4.304656 & 0.330761 & 2.621283 \\
\hline $\mathrm{H}$ & -4.757258 & -3.442280 & 3.437196 \\
\hline $\mathrm{H}$ & -5.488495 & -1.724193 & 5.065536 \\
\hline $\mathrm{H}$ & -5.155727 & 0.694053 & 4.545752 \\
\hline $\mathrm{H}$ & -4.164935 & 1.384822 & 2.412160 \\
\hline $\mathrm{O}$ & -0.104439 & 0.143356 & -2.733103 \\
\hline $\mathrm{O}$ & 0.238673 & -1.348973 & -0.609608 \\
\hline $\mathrm{H}$ & 1.328571 & -1.565504 & -0.951307 \\
\hline $\mathrm{H}$ & -3.173408 & -2.844868 & -2.843593 \\
\hline $\mathrm{H}$ & -1.238430 & -6.652258 & -3.319357 \\
\hline $\mathrm{H}$ & -1.572135 & -4.883338 & 0.584122 \\
\hline $\mathrm{H}$ & -0.634818 & 5.112599 & 0.689767 \\
\hline $\mathrm{H}$ & 2.993282 & 5.449364 & -1.595106 \\
\hline $\mathrm{H}$ & 0.130367 & 2.377694 & -2.540460 \\
\hline C & 2.994368 & -0.561319 & -1.671395 \\
\hline 0 & 2.556298 & -1.668723 & -1.192968 \\
\hline $\mathrm{H}$ & 2.321202 & 0.042200 & -2.299588 \\
\hline C & 4.432334 & -0.530532 & -2.190941 \\
\hline $\mathrm{O}$ & 5.109355 & 0.481432 & -2.290614 \\
\hline 0 & 4.844702 & -1.739963 & -2.566106 \\
\hline C & 6.172880 & -1.802770 & -3.122263 \\
\hline $\mathrm{H}$ & 6.907732 & -1.452442 & -2.393155 \\
\hline $\mathrm{H}$ & 6.333927 & -2.853333 & -3.361693 \\
\hline C & 3.887260 & 0.485212 & 0.688386 \\
\hline C & 2.989448 & 0.866604 & -0.317751 \\
\hline $\mathrm{H}$ & 5.466523 & 1.177006 & -0.390039 \\
\hline $\mathrm{N}$ & 5.200079 & 0.875111 & 0.547589 \\
\hline C & 6.211566 & 1.092190 & 1.490874 \\
\hline
\end{tabular}




$\begin{array}{llll}\mathrm{O} & 7.342752 & 1.367450 & 1.155664 \\ \mathrm{O} & 5.765847 & 1.012075 & 2.751802 \\ \mathrm{C} & 6.765901 & 1.237850 & 3.762838 \\ \mathrm{H} & 7.179292 & 2.244675 & 3.669182 \\ \mathrm{H} & 7.572638 & 0.506444 & 3.673080 \\ \mathrm{H} & 6.242353 & 1.121120 & 4.711279 \\ \mathrm{H} & 1.935548 & 0.750083 & -0.095408 \\ \mathrm{H} & 3.237985 & 1.737666 & -0.915539 \\ \mathrm{C} & 3.487711 & -0.483562 & 1.713139 \\ \mathrm{C} & 2.177711 & -0.469682 & 2.227864 \\ \mathrm{C} & 4.366428 & -1.511622 & 2.110514 \\ \mathrm{C} & 1.768264 & -1.442431 & 3.135351 \\ \mathrm{H} & 1.483873 & 0.310030 & 1.933645 \\ \mathrm{C} & 3.946597 & -2.489865 & 3.002406 \\ \mathrm{H} & 5.362356 & -1.563768 & 1.683235 \\ \mathrm{C} & 2.649278 & -2.452594 & 3.523626 \\ \mathrm{H} & 0.756672 & -1.415893 & 3.528160 \\ \mathrm{H} & 4.625337 & -3.289477 & 3.284603 \\ \mathrm{H} & 2.323919 & -3.217778 & 4.223028 \\ \mathrm{H} & 6.237184 & -1.185262 & -4.021439\end{array}$

Catalyst (R)-1 TS Conformation 400

B3LYP/6-31G(d) Energy = -2809.679586

B3LYP-D3(BJ)/def2-TZVPP-IEF-PCM(DCM) Energy = -2810.970354

B3LYP-D3(BJ)/def2-TZVPP-IEF-PCM(DCM)//B3LYP/6-31G(d) Free Energy (Quasiharmonic) = 2810.328207

Frequencies (Top 3 out of 270)

1. $-495.8212 \mathrm{~cm}-1$

2. $\quad 5.6697 \mathrm{~cm}-1$

3. $8.8261 \mathrm{~cm}-1$

B3LYP/6-31G(d) Molecular Geometry in Cartesian Coordinates

$\begin{array}{llll}\text { C } & -3.868687 & 0.337632 & 0.002723 \\ \text { C } & -2.992250 & 1.341964 & 0.386995 \\ \text { C } & -3.333380 & 2.726991 & 0.377753 \\ \text { C } & -4.588631 & 3.065492 & -0.088823 \\ \text { H } & -4.890609 & 4.109526 & -0.084991 \\ \text { C } & -2.618106 & -3.789185 & 0.165579 \\ \text { C } & -3.451253 & -1.092046 & 0.117335\end{array}$




\begin{tabular}{|c|c|c|c|}
\hline C & -2.280712 & -1.510122 & -0.497908 \\
\hline C & -1.842722 & -2.868060 & -0.512028 \\
\hline $\mathrm{H}$ & -2.331084 & -4.837428 & 0.150686 \\
\hline 0 & -1.725543 & 0.989936 & 0.834424 \\
\hline$P$ & -0.605270 & 0.462918 & -0.238921 \\
\hline O & -1.506406 & -0.565555 & -1.154551 \\
\hline C & -0.734305 & 5.867507 & 1.754895 \\
\hline C & -1.416721 & 5.991412 & 0.544176 \\
\hline C & -2.239979 & 4.959192 & 0.095874 \\
\hline C & -2.397657 & 3.783482 & 0.847356 \\
\hline C & -1.698990 & 3.667685 & 2.060784 \\
\hline C & -0.878694 & 4.701341 & 2.509368 \\
\hline $\mathrm{H}$ & -1.302834 & 6.888828 & -0.058456 \\
\hline $\mathrm{H}$ & -0.352106 & 4.595103 & 3.454402 \\
\hline C & 1.708035 & -4.216097 & -2.540030 \\
\hline C & 0.844792 & -3.315908 & -3.169337 \\
\hline C & -0.298249 & -2.858473 & -2.515140 \\
\hline C & -0.604309 & -3.296975 & -1.215252 \\
\hline C & 0.273793 & -4.200124 & -0.593819 \\
\hline C & 1.418103 & -4.655727 & -1.247747 \\
\hline $\mathrm{H}$ & 1.057928 & -2.970383 & -4.177634 \\
\hline $\mathrm{H}$ & 2.087401 & -5.346985 & -0.742169 \\
\hline C & -4.203217 & -2.048226 & 0.882805 \\
\hline C & -3.778999 & -3.416854 & 0.886635 \\
\hline C & -4.521993 & -4.375749 & 1.627643 \\
\hline C & -5.621231 & -4.003632 & 2.365797 \\
\hline C & -6.018820 & -2.646204 & 2.396584 \\
\hline C & -5.330866 & -1.695688 & 1.674704 \\
\hline $\mathrm{H}$ & -4.193896 & -5.412507 & 1.608323 \\
\hline $\mathrm{H}$ & -6.177279 & -4.744608 & 2.933675 \\
\hline $\mathrm{H}$ & -6.872983 & -2.349073 & 2.999119 \\
\hline $\mathrm{H}$ & -5.643199 & -0.658717 & 1.715980 \\
\hline C & -5.141987 & 0.712722 & -0.549947 \\
\hline C & -5.501107 & 2.099279 & -0.578046 \\
\hline C & -6.761789 & 2.483790 & -1.110156 \\
\hline C & -7.627550 & 1.548519 & -1.627128 \\
\hline C & -7.259150 & 0.182751 & -1.638075 \\
\hline C & -6.051873 & -0.224074 & -1.113688 \\
\hline $\mathrm{H}$ & -7.022442 & 3.539619 & -1.111937 \\
\hline $\mathrm{H}$ & -8.585523 & 1.855345 & -2.038020 \\
\hline $\mathrm{H}$ & -7.932566 & -0.553039 & -2.069474 \\
\hline $\mathrm{H}$ & -5.781551 & -1.273179 & -1.140503 \\
\hline $\mathrm{O}$ & 0.512703 & -0.182570 & 0.496686 \\
\hline $\mathrm{O}$ & -0.285682 & 1.609714 & -1.220606 \\
\hline
\end{tabular}




\begin{tabular}{|c|c|c|c|}
\hline $\mathrm{H}$ & 0.797132 & 1.680381 & -1.551668 \\
\hline $\mathrm{H}$ & -1.804901 & 2.767119 & 2.655689 \\
\hline $\mathrm{H}$ & -0.091340 & 6.670621 & 2.105763 \\
\hline $\mathrm{H}$ & -2.750069 & 5.051026 & -0.858843 \\
\hline $\mathrm{H}$ & 0.065777 & -4.528631 & 0.420644 \\
\hline $\mathrm{H}$ & 2.598753 & -4.570242 & -3.052608 \\
\hline $\mathrm{H}$ & -0.961093 & -2.161271 & -3.015063 \\
\hline C & 2.919042 & 1.528658 & -1.055754 \\
\hline 0 & 2.019674 & 1.801891 & -1.948721 \\
\hline $\mathrm{H}$ & 2.595705 & 1.420201 & -0.012675 \\
\hline C & 4.185828 & 2.377391 & -1.222812 \\
\hline 0 & 4.910774 & 2.370112 & -2.198514 \\
\hline $\mathrm{O}$ & 4.385656 & 3.150797 & -0.145649 \\
\hline C & 5.513766 & 4.049183 & -0.225527 \\
\hline $\mathrm{H}$ & 6.441679 & 3.483041 & -0.342935 \\
\hline $\mathrm{H}$ & 5.395954 & 4.726786 & -1.074076 \\
\hline C & 4.606715 & -0.601479 & -0.597069 \\
\hline C & 3.563445 & -0.172577 & -1.461376 \\
\hline $\mathrm{H}$ & 5.947415 & 0.442637 & -1.703553 \\
\hline$N$ & 5.853195 & -0.073891 & -0.830541 \\
\hline C & 6.883226 & 0.319840 & 0.052688 \\
\hline $\mathrm{O}$ & 7.859647 & 0.903889 & -0.362640 \\
\hline 0 & 6.632042 & 0.021874 & 1.327547 \\
\hline C & 7.654294 & 0.423519 & 2.261786 \\
\hline $\mathrm{H}$ & 7.767087 & 1.509938 & 2.254219 \\
\hline $\mathrm{H}$ & 8.608166 & -0.042451 & 2.004968 \\
\hline $\mathrm{H}$ & 7.300754 & 0.077782 & 3.232340 \\
\hline $\mathrm{H}$ & 2.660328 & -0.773772 & -1.439862 \\
\hline $\mathrm{H}$ & 3.881403 & 0.115952 & -2.461623 \\
\hline C & 4.396364 & -1.577187 & 0.472575 \\
\hline C & 3.147757 & -1.674559 & 1.116259 \\
\hline C & 5.410813 & -2.506826 & 0.789224 \\
\hline C & 2.942329 & -2.656202 & 2.083185 \\
\hline $\mathrm{H}$ & 2.335680 & -0.993418 & 0.879642 \\
\hline C & 5.183701 & -3.499187 & 1.733205 \\
\hline $\mathrm{H}$ & 6.358858 & -2.472353 & 0.262590 \\
\hline C & 3.951995 & -3.568087 & 2.394163 \\
\hline $\mathrm{H}$ & 1.979595 & -2.707368 & 2.582452 \\
\hline $\mathrm{H}$ & 5.963857 & -4.222466 & 1.953083 \\
\hline $\mathrm{H}$ & 3.779913 & -4.339659 & 3.139947 \\
\hline $\mathrm{H}$ & 5.509227 & 4.601797 & 0.713768 \\
\hline
\end{tabular}




\section{c) Conformations of Catalyst (R)-1 TS with ethyl group}

Catalyst (R)-1 TS Ethyl Conformation 1

B3LYP/6-31G(d) Energy $=-2849.020879$

B3LYP-D3(BJ)/def2-TZVPP-IEF-PCM(DCM) Energy $=-2850.32922$

B3LYP-D3(BJ)/def2-TZVPP-IEF-PCM(DCM)//B3LYP/6-31G(d) Free Energy (Quasiharmonic) = 2849.657723

Frequencies (Top 3 out of 279)

1. $-289.2319 \mathrm{~cm}-1$

2. $\quad 12.6719 \mathrm{~cm}-1$

3. $16.4800 \mathrm{~cm}-1$

B3LYP/6-31G(d) Molecular Geometry in Cartesian Coordinates

$\begin{array}{llll}\text { C } & 2.996792 & -1.277049 & -0.337172 \\ \text { C } & 1.745612 & -1.785306 & -0.018503 \\ \text { C } & 1.396467 & -3.157681 & -0.206256 \\ \text { C } & 2.332864 & -3.974175 & -0.809835 \\ \text { H } & 2.089860 & -5.021435 & -0.968505 \\ \text { C } & 4.239932 & 2.771538 & 0.425014 \\ \text { C } & 3.384191 & 0.112409 & 0.048236 \\ \text { C } & 2.620111 & 1.192877 & -0.362348 \\ \text { C } & 3.051505 & 2.547142 & -0.242968 \\ \text { H } & 4.593636 & 3.792747 & 0.539256 \\ \text { O } & 0.825016 & -0.959894 & 0.621643 \\ \text { P } & 0.189454 & 0.362620 & -0.098527 \\ \text { O } & 1.408401 & 0.941124 & -1.006055 \\ \text { C } & -2.280877 & -5.019871 & 1.033946 \\ \text { C } & -2.319152 & -3.882257 & 0.223590 \\ \text { C } & -1.132735 & -3.259359 & -0.164830 \\ \text { C } & 0.110333 & -3.754509 & 0.253719 \\ \text { C } & 0.135365 & -4.895501 & 1.073875 \\ \text { C } & -1.049242 & -5.524319 & 1.458716 \\ \text { H } & -3.263443 & -3.460763 & -0.107844 \\ \text { H } & -1.008676 & -6.406495 & 2.092889 \\ \text { C } & 1.096329 & 5.912361 & -2.080202 \\ \text { C } & 0.365590 & 5.056383 & -1.254202 \\ \text { C } & 0.974989 & 3.953289 & -0.656138 \\ \text { C } & 2.335449 & 3.688987 & -0.878438 \\ \text { C } & 3.062278 & 4.558569 & -1.709430\end{array}$




\begin{tabular}{|c|c|c|c|}
\hline C & 2.450046 & 5.660480 & -2.305304 \\
\hline $\mathrm{H}$ & -0.688325 & 5.245376 & -1.069621 \\
\hline $\mathrm{H}$ & 3.029564 & 6.315212 & -2.951100 \\
\hline C & 4.565877 & 0.368850 & 0.828159 \\
\hline C & 4.991781 & 1.723476 & 1.009919 \\
\hline C & 6.157110 & 1.992457 & 1.777801 \\
\hline C & 6.866213 & 0.972241 & 2.367733 \\
\hline C & 6.430232 & -0.365023 & 2.215993 \\
\hline C & 5.313606 & -0.659512 & 1.464719 \\
\hline $\mathrm{H}$ & 6.470516 & 3.026698 & 1.898927 \\
\hline $\mathrm{H}$ & 7.751999 & 1.189870 & 2.958169 \\
\hline $\mathrm{H}$ & 6.978270 & -1.168011 & 2.701460 \\
\hline $\mathrm{H}$ & 4.987033 & -1.688310 & 1.366930 \\
\hline C & 3.915787 & -2.114779 & -1.063101 \\
\hline C & 3.574420 & -3.486929 & -1.282987 \\
\hline C & 4.475200 & -4.330410 & -1.987983 \\
\hline C & 5.659732 & -3.840043 & -2.485365 \\
\hline C & 5.984799 & -2.475558 & -2.302162 \\
\hline C & 5.139373 & -1.637062 & -1.609321 \\
\hline $\mathrm{H}$ & 4.200095 & -5.371776 & -2.137630 \\
\hline $\mathrm{H}$ & 6.338560 & -4.491253 & -3.029102 \\
\hline $\mathrm{H}$ & 6.908155 & -2.081890 & -2.718391 \\
\hline $\mathrm{H}$ & 5.400726 & -0.592327 & -1.490870 \\
\hline $\mathrm{O}$ & -0.294094 & 1.288555 & 0.968518 \\
\hline $\mathrm{O}$ & -0.812573 & -0.066449 & -1.209811 \\
\hline $\mathrm{H}$ & -1.835431 & -0.284103 & -0.928131 \\
\hline $\mathrm{H}$ & 1.091119 & -5.283666 & 1.416399 \\
\hline $\mathrm{H}$ & -3.203987 & -5.508960 & 1.334880 \\
\hline $\mathrm{H}$ & -1.175433 & -2.398588 & -0.818254 \\
\hline $\mathrm{H}$ & 4.111510 & 4.352974 & -1.903785 \\
\hline $\mathrm{H}$ & 0.614256 & 6.767502 & -2.547185 \\
\hline $\mathrm{H}$ & 0.399966 & 3.306760 & -0.002105 \\
\hline C & -4.119385 & 0.020974 & -0.956077 \\
\hline $\mathrm{O}$ & -3.122868 & -0.728962 & -0.659961 \\
\hline $\mathrm{H}$ & -3.941449 & 0.965191 & -1.491733 \\
\hline C & -5.406363 & -0.616596 & -1.485242 \\
\hline $\mathrm{O}$ & -6.222550 & 0.016598 & -2.124764 \\
\hline $\mathrm{O}$ & -5.511984 & -1.909472 & -1.153117 \\
\hline C & -6.697960 & -2.604893 & -1.618186 \\
\hline $\mathrm{H}$ & -6.831903 & -3.413240 & -0.895852 \\
\hline C & -3.853814 & 1.421568 & 1.182943 \\
\hline C & -4.964485 & 0.738233 & 0.656215 \\
\hline $\mathrm{H}$ & -1.893418 & 1.086880 & 1.719020 \\
\hline$N$ & -2.867710 & 0.747163 & 1.819496 \\
\hline
\end{tabular}




$\begin{array}{llll}\mathrm{C} & -2.981962 & -0.504933 & 2.462624 \\ \mathrm{O} & -4.008162 & -1.101589 & 2.697537 \\ \mathrm{O} & -1.752555 & -0.877433 & 2.831085 \\ \mathrm{C} & -1.663052 & -2.130877 & 3.533835 \\ \mathrm{H} & -2.180380 & -2.059353 & 4.494499 \\ \mathrm{H} & -0.596346 & -2.295243 & 3.678384 \\ \mathrm{H} & -2.097208 & -2.931931 & 2.934451 \\ \mathrm{H} & -5.803210 & 1.337713 & 0.319713 \\ \mathrm{H} & -5.223275 & -0.202830 & 1.124545 \\ \mathrm{C} & -3.610483 & 2.851762 & 0.915584 \\ \mathrm{C} & -4.285871 & 3.519866 & -0.125135 \\ \mathrm{C} & -2.730999 & 3.589641 & 1.730974 \\ \mathrm{C} & -4.085199 & 4.879517 & -0.340257 \\ \mathrm{H} & -4.956866 & 2.975066 & -0.780610 \\ \mathrm{C} & -2.539636 & 4.951714 & 1.516615 \\ \mathrm{H} & -2.215842 & 3.103560 & 2.552134 \\ \mathrm{C} & -3.216053 & 5.601545 & 0.482114 \\ \mathrm{H} & -4.608170 & 5.376326 & -1.152145 \\ \mathrm{H} & -1.864198 & 5.506007 & 2.161286 \\ \mathrm{H} & -3.068626 & 6.665480 & 0.318603 \\ \mathrm{H} & -7.548869 & -1.921392 & -1.563806 \\ \mathrm{C} & -6.503380 & -3.138471 & -3.028646 \\ \mathrm{H} & -7.379569 & -3.726226 & -3.325777 \\ \mathrm{H} & -6.384883 & -2.315957 & -3.739593 \\ \mathrm{H} & -5.620645 & -3.783513 & -3.082095\end{array}$

Catalyst (R)-1 TS Ethyl Conformation 2

B3LYP/6-31G(d) Energy $=-2849.02081$

B3LYP-D3(BJ)/def2-TZVPP-IEF-PCM(DCM) Energy = -2850.329454

B3LYP-D3(BJ)/def2-TZVPP-IEF-PCM(DCM)//B3LYP/6-31G(d) Free Energy (Quasiharmonic) = 2849.657956

Frequencies (Top 3 out of 279)

1. $-290.4312 \mathrm{~cm}-1$

2. $\quad 12.8414 \mathrm{~cm}-1$

3. $\quad 16.5736 \mathrm{~cm}-1$

B3LYP/6-31G(d) Molecular Geometry in Cartesian Coordinates
C $\quad 3.036268 \quad-1.276013 \quad-0.343761$
$\begin{array}{llll}\text { C } & 1.778233 & -1.793875 & -0.070818\end{array}$ 


\begin{tabular}{|c|c|c|c|}
\hline C & 1.436569 & -3.161280 & -0.303366 \\
\hline C & 2.389637 & -3.960493 & -0.903994 \\
\hline $\mathrm{H}$ & 2.152649 & -5.003464 & -1.096398 \\
\hline C & 4.252330 & 2.752796 & 0.554722 \\
\hline C & 3.411101 & 0.103374 & 0.087552 \\
\hline C & 2.655952 & 1.193283 & -0.314465 \\
\hline C & 3.081911 & 2.544457 & -0.149276 \\
\hline $\mathrm{H}$ & 4.601326 & 3.771077 & 0.704183 \\
\hline $\mathrm{O}$ & 0.840012 & -0.986404 & 0.566742 \\
\hline$P$ & 0.220747 & 0.353605 & -0.135155 \\
\hline 0 & 1.461648 & 0.957046 & -0.995433 \\
\hline C & -2.267087 & -5.061240 & 0.792751 \\
\hline C & -2.287287 & -3.902175 & 0.012701 \\
\hline C & -1.092757 & -3.267340 & -0.328700 \\
\hline C & 0.140362 & -3.771842 & 0.107723 \\
\hline C & 0.147051 & -4.934454 & 0.897350 \\
\hline C & -1.045539 & -5.575204 & 1.234894 \\
\hline $\mathrm{H}$ & -3.223771 & -3.472943 & -0.330718 \\
\hline $\mathrm{H}$ & -1.019138 & -6.474157 & 1.845835 \\
\hline C & 1.169185 & 5.952622 & -1.951695 \\
\hline C & 0.418709 & 5.075237 & -1.166883 \\
\hline C & 1.014374 & 3.958284 & -0.580841 \\
\hline C & 2.380691 & 3.701362 & -0.773933 \\
\hline C & 3.127385 & 4.592514 & -1.563430 \\
\hline C & 2.528843 & 5.708259 & -2.147344 \\
\hline $\mathrm{H}$ & -0.640078 & 5.258077 & -1.005470 \\
\hline $\mathrm{H}$ & 3.123816 & 6.379746 & -2.761088 \\
\hline C & 4.571887 & 0.340830 & 0.904015 \\
\hline C & 4.990621 & 1.690759 & 1.131650 \\
\hline C & 6.135350 & 1.941011 & 1.935980 \\
\hline C & 6.830858 & 0.906618 & 2.517351 \\
\hline C & 6.401306 & -0.426742 & 2.319831 \\
\hline C & 5.304876 & -0.702872 & 1.532694 \\
\hline $\mathrm{H}$ & 6.443740 & 2.972105 & 2.091839 \\
\hline $\mathrm{H}$ & 7.700805 & 1.109836 & 3.135807 \\
\hline $\mathrm{H}$ & 6.938153 & -1.241455 & 2.798218 \\
\hline $\mathrm{H}$ & 4.982810 & -1.729154 & 1.399820 \\
\hline C & 3.975169 & -2.093325 & -1.067510 \\
\hline C & 3.642031 & -3.459579 & -1.332123 \\
\hline C & 4.562101 & -4.283192 & -2.035699 \\
\hline C & 5.758132 & -3.778577 & -2.489395 \\
\hline C & 6.075949 & -2.419042 & -2.262030 \\
\hline C & 5.211516 & -1.600034 & -1.569329 \\
\hline $\mathrm{H}$ & 4.292753 & -5.320541 & -2.219754 \\
\hline
\end{tabular}




\begin{tabular}{|c|c|c|c|}
\hline $\mathrm{H}$ & 6.451835 & -4.414472 & -3.032484 \\
\hline $\mathrm{H}$ & 7.008969 & -2.013501 & -2.643892 \\
\hline $\mathrm{H}$ & 5.467889 & -0.558491 & -1.416801 \\
\hline 0 & -0.291628 & 1.250750 & 0.943128 \\
\hline 0 & -0.751560 & -0.047178 & -1.282624 \\
\hline $\mathrm{H}$ & -1.781484 & -0.273063 & -1.034019 \\
\hline $\mathrm{H}$ & 1.094658 & -5.330261 & 1.253495 \\
\hline $\mathrm{H}$ & -3.196444 & -5.559766 & 1.056753 \\
\hline $\mathrm{H}$ & -1.120856 & -2.389419 & -0.959708 \\
\hline $\mathrm{H}$ & 4.181731 & 4.393171 & -1.735305 \\
\hline $\mathrm{H}$ & 0.697846 & 6.818544 & -2.409682 \\
\hline $\mathrm{H}$ & 0.423646 & 3.294767 & 0.041409 \\
\hline C & -4.066074 & 0.025218 & -1.113077 \\
\hline $\mathrm{O}$ & -3.073453 & -0.726990 & -0.809973 \\
\hline $\mathrm{H}$ & -3.880347 & 0.982159 & -1.623087 \\
\hline C & -5.338761 & -0.604165 & -1.685329 \\
\hline $\mathrm{O}$ & -6.154648 & 0.045819 & -2.308332 \\
\hline $\mathrm{O}$ & -5.427523 & -1.913215 & -1.418263 \\
\hline C & -6.602940 & -2.600408 & -1.920628 \\
\hline $\mathrm{H}$ & -6.855120 & -2.190440 & -2.901389 \\
\hline C & -3.854596 & 1.373783 & 1.066161 \\
\hline C & -4.951018 & 0.704198 & 0.493546 \\
\hline $\mathrm{H}$ & -1.908568 & 1.026095 & 1.644363 \\
\hline$N$ & -2.884890 & 0.683222 & 1.710116 \\
\hline C & -3.014163 & -0.586130 & 2.315611 \\
\hline $\mathrm{O}$ & -4.045413 & -1.189656 & 2.507374 \\
\hline $\mathrm{O}$ & -1.794398 & -0.967552 & 2.705768 \\
\hline C & -1.720976 & -2.239197 & 3.377067 \\
\hline $\mathrm{H}$ & -2.261914 & -2.193191 & 4.326226 \\
\hline $\mathrm{H}$ & -0.657989 & -2.406843 & 3.543501 \\
\hline $\mathrm{H}$ & -2.139237 & -3.024299 & 2.746125 \\
\hline $\mathrm{H}$ & -5.780462 & 1.312264 & 0.149869 \\
\hline $\mathrm{H}$ & -5.222393 & -0.247208 & 0.933106 \\
\hline C & -3.605619 & 2.810362 & 0.842014 \\
\hline C & -4.254318 & 3.504807 & -0.198439 \\
\hline C & -2.748418 & 3.527223 & 1.698852 \\
\hline C & -4.049375 & 4.869594 & -0.373200 \\
\hline $\mathrm{H}$ & -4.907518 & 2.976852 & -0.884962 \\
\hline C & -2.552914 & 4.894424 & 1.524736 \\
\hline $\mathrm{H}$ & -2.254292 & 3.020263 & 2.520302 \\
\hline C & -3.202746 & 5.570447 & 0.489977 \\
\hline $\mathrm{H}$ & -4.551387 & 5.387007 & -1.185446 \\
\hline $\mathrm{H}$ & -1.895054 & 5.432151 & 2.200841 \\
\hline $\mathrm{H}$ & -3.052147 & 6.638287 & 0.357821 \\
\hline
\end{tabular}




$\begin{array}{llll}\text { H } & -6.277524 & -3.637105 & -2.031332 \\ \mathrm{C} & -7.767637 & -2.478333 & -0.950573 \\ \mathrm{H} & -8.614353 & -3.072947 & -1.312443 \\ \mathrm{H} & -7.487968 & -2.845554 & 0.042128 \\ \mathrm{H} & -8.092897 & -1.437402 & -0.866286\end{array}$

Catalyst (R)-1 TS Ethyl Conformation 3

B3LYP/6-31G(d) Energy $=-2849.021138$

B3LYP-D3(BJ)/def2-TZVPP-IEF-PCM(DCM) Energy = -2850.329973

B3LYP-D3(BJ)/def2-TZVPP-IEF-PCM(DCM)//B3LYP/6-31G(d) Free Energy (Quasiharmonic) = 2849.658849

Frequencies (Top 3 out of 279)

1. $-295.1023 \mathrm{~cm}-1$

2. $\quad 12.8101 \mathrm{~cm}-1$

3. $\quad 15.9426 \mathrm{~cm}-1$

B3LYP/6-31G(d) Molecular Geometry in Cartesian Coordinates

$\begin{array}{llll}\mathrm{C} & 2.978665 & -1.328032 & -0.332732 \\ \mathrm{C} & 1.709835 & -1.811794 & -0.047545 \\ \mathrm{C} & 1.333469 & -3.172828 & -0.263396 \\ \mathrm{C} & 2.263384 & -4.001967 & -0.859676 \\ \mathrm{H} & 1.999797 & -5.040816 & -1.039400 \\ \mathrm{C} & 4.296941 & 2.679929 & 0.513054 \\ \mathrm{C} & 3.389244 & 0.046591 & 0.080788 \\ \mathrm{C} & 2.658365 & 1.149872 & -0.329614 \\ \mathrm{C} & 3.117887 & 2.492077 & -0.182242 \\ \mathrm{H} & 4.671343 & 3.691070 & 0.648902 \\ \mathrm{O} & 0.795173 & -0.974995 & 0.586165 \\ \mathrm{P} & 0.204678 & 0.372604 & -0.126153 \\ \mathrm{O} & 1.454704 & 0.935000 & -1.001131 \\ \mathrm{C} & -2.413135 & -4.962838 & 0.871210 \\ \mathrm{C} & -2.406513 & -3.811553 & 0.079448 \\ \mathrm{C} & -1.197353 & -3.212757 & -0.275037 \\ \mathrm{C} & 0.024202 & -3.745619 & 0.160112 \\ \mathrm{C} & 0.004151 & -4.900042 & 0.961375 \\ \mathrm{C} & -1.203302 & -5.505140 & 1.311716 \\ \mathrm{H} & -3.332960 & -3.360120 & -0.262707 \\ \mathrm{H} & -1.197585 & -6.398312 & 1.931606 \\ \mathrm{C} & 1.278910 & 5.924930 & -2.014263\end{array}$




\begin{tabular}{|c|c|c|c|}
\hline C & 0.511783 & 5.075812 & -1.214596 \\
\hline C & 1.083215 & 3.951455 & -0.618655 \\
\hline C & 2.441557 & 3.658487 & -0.816611 \\
\hline C & 3.205228 & 4.521430 & -1.621061 \\
\hline C & 2.630892 & 5.644649 & -2.214871 \\
\hline $\mathrm{H}$ & -0.541119 & 5.286836 & -1.049200 \\
\hline $\mathrm{H}$ & 3.238520 & 6.293866 & -2.840069 \\
\hline C & 4.560001 & 0.265042 & 0.888258 \\
\hline C & 5.012520 & 1.606904 & 1.098214 \\
\hline C & 6.167425 & 1.838400 & 1.893568 \\
\hline C & 6.840914 & 0.794093 & 2.483084 \\
\hline C & 6.378116 & -0.530601 & 2.303146 \\
\hline C & 5.270970 & -0.788943 & 1.525022 \\
\hline $\mathrm{H}$ & 6.501539 & 2.863408 & 2.035975 \\
\hline $\mathrm{H}$ & 7.718938 & 0.983141 & 3.094582 \\
\hline $\mathrm{H}$ & 6.897705 & -1.352623 & 2.788044 \\
\hline $\mathrm{H}$ & 4.923373 & -1.808542 & 1.405710 \\
\hline C & 3.893361 & -2.176211 & -1.051973 \\
\hline C & 3.525493 & -3.536773 & -1.299448 \\
\hline C & 4.421418 & -4.390538 & -1.998219 \\
\hline C & 5.627032 & -3.920527 & -2.463567 \\
\hline C & 5.979188 & -2.566717 & -2.253274 \\
\hline C & 5.138707 & -1.719032 & -1.565613 \\
\hline $\mathrm{H}$ & 4.125823 & -5.422974 & -2.169150 \\
\hline $\mathrm{H}$ & 6.302113 & -4.579297 & -3.002842 \\
\hline $\mathrm{H}$ & 6.919809 & -2.188485 & -2.644399 \\
\hline $\mathrm{H}$ & 5.421243 & -0.682434 & -1.426208 \\
\hline $\mathrm{O}$ & -0.277038 & 1.294170 & 0.945599 \\
\hline $\mathrm{O}$ & -0.785476 & -0.016353 & -1.262140 \\
\hline $\mathrm{H}$ & -1.820681 & -0.213778 & -1.005973 \\
\hline $\mathrm{H}$ & 0.942758 & -5.317445 & 1.316682 \\
\hline $\mathrm{H}$ & -3.354056 & -5.433256 & 1.145593 \\
\hline $\mathrm{H}$ & -1.205088 & -2.341039 & -0.915151 \\
\hline $\mathrm{H}$ & 4.253272 & 4.294002 & -1.796590 \\
\hline $\mathrm{H}$ & 0.826319 & 6.796776 & -2.479858 \\
\hline $\mathrm{H}$ & 0.480097 & 3.310252 & 0.015011 \\
\hline C & -4.087466 & 0.159924 & -1.083277 \\
\hline $\mathrm{O}$ & -3.122957 & -0.627447 & -0.777521 \\
\hline $\mathrm{H}$ & -3.865685 & 1.108286 & -1.594599 \\
\hline C & -5.380533 & -0.423786 & -1.656617 \\
\hline $\mathrm{O}$ & -6.162189 & 0.246050 & -2.301415 \\
\hline $\mathrm{O}$ & -5.538246 & -1.719465 & -1.362254 \\
\hline C & -6.743354 & -2.340825 & -1.875398 \\
\hline $\mathrm{H}$ & -7.609134 & -1.783453 & -1.503637 \\
\hline
\end{tabular}




$\begin{array}{lrrr}\mathrm{C} & -3.834129 & 1.515542 & 1.086254 \\ \mathrm{C} & -4.949941 & 0.870742 & 0.523462 \\ \mathrm{H} & -1.895517 & 1.120938 & 1.659468 \\ \mathrm{~N} & -2.880286 & 0.805133 & 1.732969 \\ \mathrm{C} & -3.041245 & -0.453705 & 2.352132 \\ \mathrm{O} & -4.087349 & -1.028042 & 2.552870 \\ \mathrm{O} & -1.830673 & -0.863245 & 2.743077 \\ \mathrm{C} & -1.789133 & -2.129198 & 3.427575 \\ \mathrm{H} & -2.325896 & -2.058970 & 4.377623 \\ \mathrm{H} & -0.730503 & -2.323388 & 3.593025 \\ \mathrm{H} & -2.229962 & -2.909519 & 2.806128 \\ \mathrm{H} & -5.765224 & 1.497751 & 0.179704 \\ \mathrm{H} & -5.242825 & -0.071710 & 0.968320 \\ \mathrm{C} & -3.548637 & 2.943335 & 0.849504 \\ \mathrm{C} & -4.182600 & 3.646034 & -0.194507 \\ \mathrm{C} & -2.670132 & 3.644416 & 1.697754 \\ \mathrm{C} & -3.942952 & 5.003648 & -0.380740 \\ \mathrm{H} & -4.851473 & 3.129784 & -0.874852 \\ \mathrm{C} & -2.439719 & 5.004634 & 1.512009 \\ \mathrm{H} & -2.186633 & 3.131246 & 2.521679 \\ \mathrm{C} & -3.075386 & 5.689088 & 0.474014 \\ \mathrm{H} & -4.434187 & 5.527464 & -1.195468 \\ \mathrm{H} & -1.765740 & 5.530423 & 2.181599 \\ \mathrm{H} & -2.897501 & 6.751550 & 0.332752 \\ \mathrm{H} & -6.738637 & -2.258682 & -2.966810 \\ \mathrm{C} & -6.746034 & -3.783372 & -1.408732 \\ \mathrm{H} & -7.644015 & -4.289998 & -1.779087 \\ \mathrm{H} & -5.868210 & -4.317679 & -1.785551 \\ \mathrm{H} & -6.743610 & -3.840069 & -0.315583\end{array}$

Catalyst (R)-1 TS Ethyl Conformation 4

$B 3 L Y P / 6-31 G(d)$ Energy $=-2849.009058$

B3LYP-D3(BJ)/def2-TZVPP-IEF-PCM(DCM) Energy $=-2850.326492$

B3LYP-D3(BJ)/def2-TZVPP-IEF-PCM(DCM)//B3LYP/6-31G(d) Free Energy (Quasiharmonic) = 2849.656562

Frequencies (Top 3 out of 279)

1. $-590.9821 \mathrm{~cm}-1$

2. $8.5692 \mathrm{~cm}-1$

3. $\quad 14.4623 \mathrm{~cm}-1$ 
B3LYP/6-31G(d) Molecular Geometry in Cartesian Coordinates

\begin{tabular}{|c|c|c|c|}
\hline C & -3.007736 & -0.653562 & 0.180826 \\
\hline C & -1.943892 & -1.515235 & -0.050009 \\
\hline C & -1.998482 & -2.902476 & 0.269332 \\
\hline C & -3.128699 & -3.372985 & 0.905432 \\
\hline $\mathrm{H}$ & -3.192422 & -4.430313 & 1.149234 \\
\hline C & -2.969888 & 3.434251 & -1.165254 \\
\hline C & -2.978600 & 0.735053 & -0.358696 \\
\hline C & -1.921939 & 1.580656 & -0.052751 \\
\hline C & -1.902221 & 2.953728 & -0.434295 \\
\hline $\mathrm{H}$ & -2.977057 & 4.480590 & -1.459631 \\
\hline $\mathrm{O}$ & -0.808198 & -1.028854 & -0.695308 \\
\hline$P$ & 0.175123 & 0.021204 & 0.100596 \\
\hline $\mathrm{O}$ & -0.885492 & 1.096849 & 0.737374 \\
\hline C & 0.979785 & -5.859621 & -0.678681 \\
\hline C & -0.173583 & -5.743171 & -1.457223 \\
\hline C & -1.119220 & -4.760108 & -1.161912 \\
\hline C & -0.920992 & -3.874292 & -0.091400 \\
\hline C & 0.242903 & -3.992943 & 0.679042 \\
\hline C & 1.183152 & -4.982396 & 0.388231 \\
\hline $\mathrm{H}$ & -0.342126 & -6.421287 & -2.289945 \\
\hline $\mathrm{H}$ & 2.076098 & -5.064711 & 1.001994 \\
\hline C & 1.173256 & 5.848807 & 0.385127 \\
\hline C & -0.063185 & 5.932029 & 1.028452 \\
\hline C & -1.043020 & 4.966643 & 0.787506 \\
\hline C & -0.797925 & 3.897801 & -0.086962 \\
\hline C & 0.451785 & 3.813331 & -0.718692 \\
\hline C & 1.424491 & 4.787917 & -0.489338 \\
\hline $\mathrm{H}$ & -0.271431 & 6.754237 & 1.708393 \\
\hline $\mathrm{H}$ & 2.378868 & 4.723658 & -1.007081 \\
\hline C & -4.026205 & 1.218731 & -1.218326 \\
\hline C & -4.026323 & 2.597999 & -1.600106 \\
\hline C & -5.064789 & 3.096701 & -2.432447 \\
\hline C & -6.054814 & 2.265382 & -2.901071 \\
\hline C & -6.036707 & 0.892509 & -2.559431 \\
\hline C & -5.053055 & 0.383463 & -1.740612 \\
\hline $\mathrm{H}$ & -5.051183 & 4.149830 & -2.703282 \\
\hline $\mathrm{H}$ & -6.840721 & 2.654458 & -3.542578 \\
\hline $\mathrm{H}$ & -6.803808 & 0.230478 & -2.952035 \\
\hline $\mathrm{H}$ & -5.050476 & -0.672617 & -1.498736 \\
\hline C & -4.130466 & -1.132402 & 0.942039 \\
\hline C & -4.188983 & -2.518195 & 1.293665 \\
\hline C & -5.297732 & -3.007794 & 2.035558 \\
\hline
\end{tabular}




\begin{tabular}{|c|c|c|c|}
\hline$C$ & -6.301882 & -2.162349 & 2.445634 \\
\hline C & -6.229832 & -0.784435 & 2.132452 \\
\hline C & -5.176795 & -0.283503 & 1.399451 \\
\hline $\mathrm{H}$ & -5.327940 & -4.065893 & 2.284639 \\
\hline $\mathrm{H}$ & -7.141738 & -2.544953 & 3.019088 \\
\hline $\mathrm{H}$ & -7.010537 & -0.112580 & 2.478925 \\
\hline $\mathrm{H}$ & -5.132571 & 0.776565 & 1.178771 \\
\hline 0 & 1.110138 & 0.645043 & -0.882950 \\
\hline 0 & 0.724600 & -0.661916 & 1.370462 \\
\hline $\mathrm{H}$ & 1.679419 & -1.261460 & 1.426617 \\
\hline $\mathrm{H}$ & 0.412374 & -3.314374 & 1.507159 \\
\hline $\mathrm{H}$ & 1.713815 & -6.629849 & -0.900849 \\
\hline $\mathrm{H}$ & -2.022536 & -4.676694 & -1.760609 \\
\hline $\mathrm{H}$ & 0.653930 & 2.985667 & -1.390170 \\
\hline $\mathrm{H}$ & 1.931661 & 6.608323 & 0.556920 \\
\hline $\mathrm{H}$ & -2.010116 & 5.040081 & 1.277793 \\
\hline C & 3.787470 & -2.110722 & 1.100968 \\
\hline O & 2.725619 & -1.963972 & 1.823272 \\
\hline $\mathrm{H}$ & 4.554918 & -2.780061 & 1.517059 \\
\hline C & 3.669366 & -2.412613 & -0.400847 \\
\hline $\mathrm{O}$ & 4.566580 & -2.941500 & -1.025545 \\
\hline 0 & 2.470633 & -2.084459 & -0.882530 \\
\hline C & 2.150358 & -2.496905 & -2.241686 \\
\hline $\mathrm{H}$ & 1.061184 & -2.538186 & -2.242922 \\
\hline C & 4.140636 & 0.505629 & 0.909863 \\
\hline C & 4.982907 & -0.613304 & 1.103756 \\
\hline $\mathrm{H}$ & 2.860822 & 1.201028 & -0.545443 \\
\hline$N$ & 3.848149 & 0.973493 & -0.344084 \\
\hline C & 4.713680 & 0.972805 & -1.442359 \\
\hline 0 & 5.862284 & 0.589935 & -1.457782 \\
\hline $\mathrm{O}$ & 4.067214 & 1.533174 & -2.482113 \\
\hline C & 4.834701 & 1.624293 & -3.694641 \\
\hline $\mathrm{H}$ & 5.135306 & 0.629530 & -4.031684 \\
\hline $\mathrm{H}$ & 5.725654 & 2.237171 & -3.536904 \\
\hline $\mathrm{H}$ & 4.168375 & 2.090714 & -4.419912 \\
\hline $\mathrm{H}$ & 5.425703 & -0.700503 & 2.090737 \\
\hline $\mathrm{H}$ & 5.654137 & -0.873855 & 0.293577 \\
\hline C & 3.407058 & 1.112297 & 2.015377 \\
\hline C & 3.314333 & 0.471606 & 3.271778 \\
\hline C & 2.788540 & 2.372466 & 1.855026 \\
\hline C & 2.608421 & 1.064836 & 4.312891 \\
\hline $\mathrm{H}$ & 3.753430 & -0.503997 & 3.422726 \\
\hline C & 2.089783 & 2.960158 & 2.899864 \\
\hline $\mathrm{H}$ & 2.872259 & 2.902957 & 0.914732 \\
\hline
\end{tabular}




$\begin{array}{llll}\mathrm{C} & 1.993561 & 2.304338 & 4.131173 \\ \mathrm{H} & 2.531291 & 0.551818 & 5.266819 \\ \mathrm{H} & 1.619378 & 3.926684 & 2.749836 \\ \mathrm{H} & 1.442835 & 2.762323 & 4.948291 \\ \mathrm{H} & 2.556202 & -3.499645 & -2.392270 \\ \mathrm{C} & 2.676184 & -1.512991 & -3.272003 \\ \mathrm{H} & 2.334746 & -1.818022 & -4.268539 \\ \mathrm{H} & 2.298354 & -0.508815 & -3.063965 \\ \mathrm{H} & 3.770561 & -1.503779 & -3.274354\end{array}$

Catalyst (R)-1 TS Ethyl Conformation 5

B3LYP/6-31G(d) Energy $=-2849.00963$

B3LYP-D3(BJ)/def2-TZVPP-IEF-PCM(DCM) Energy $=-2850.323705$

B3LYP-D3(BJ)/def2-TZVPP-IEF-PCM(DCM)//B3LYP/6-31G(d) Free Energy (Quasiharmonic) = 2849.652549

Frequencies (Top 3 out of 279)

1. $-359.1948 \mathrm{~cm}-1$

2. $9.5095 \mathrm{~cm}-1$

3. $\quad 16.7878 \mathrm{~cm}-1$

B3LYP/6-31G(d) Molecular Geometry in Cartesian Coordinates

$\begin{array}{rrrr}\text { C } & 3.060668 & 0.291678 & 0.176512 \\ \text { C } & 2.156843 & 1.319605 & -0.058246 \\ \text { C } & 2.445501 & 2.681595 & 0.253383 \\ \text { C } & 3.634177 & 2.948832 & 0.904155 \\ \text { H } & 3.875183 & 3.979659 & 1.149918 \\ \text { C } & 2.375437 & -3.697032 & -1.297982 \\ \text { C } & 2.820169 & -1.064622 & -0.393005 \\ \text { C } & 1.635334 & -1.734939 & -0.129327 \\ \text { C } & 1.387069 & -3.067107 & -0.569535 \\ \text { H } & 2.210453 & -4.716711 & -1.636440 \\ \text { O } & 0.959002 & 1.027215 & -0.712362 \\ \text { P } & -0.180767 & 0.132098 & 0.056858 \\ \text { O } & 0.682676 & -1.112231 & 0.672926 \\ \text { C } & 0.072639 & 6.118399 & -0.780051 \\ \text { C } & 1.354719 & 5.952638 & -1.308340 \\ \text { C } & 2.100269 & 4.818673 & -0.987145 \\ \text { C } & 1.575335 & 3.828445 & -0.139773 \\ \text { C } & 0.284767 & 4.000104 & 0.377599\end{array}$




\begin{tabular}{|c|c|c|c|}
\hline C & -0.457095 & 5.138457 & 0.061483 \\
\hline $\mathrm{H}$ & 1.776640 & 6.706527 & -1.968112 \\
\hline $\mathrm{H}$ & -1.452373 & 5.252060 & 0.481314 \\
\hline C & -2.201128 & -5.367125 & 0.027160 \\
\hline C & -1.033644 & -5.692264 & 0.720938 \\
\hline C & 0.118788 & -4.920940 & 0.553042 \\
\hline C & 0.117795 & -3.807819 & -0.299978 \\
\hline C & -1.061547 & -3.483564 & -0.987349 \\
\hline C & -2.209610 & -4.261697 & -0.827914 \\
\hline $\mathrm{H}$ & -1.014515 & -6.553423 & 1.384125 \\
\hline $\mathrm{H}$ & -3.109698 & -4.001216 & -1.379340 \\
\hline C & 3.791319 & -1.690497 & -1.251550 \\
\hline C & 3.569990 & -3.038793 & -1.678234 \\
\hline C & 4.530058 & -3.680653 & -2.506631 \\
\hline C & 5.655444 & -3.013936 & -2.930407 \\
\hline C & 5.857478 & -1.667185 & -2.546999 \\
\hline C & 4.953753 & -1.023910 & -1.730531 \\
\hline $\mathrm{H}$ & 4.347015 & -4.708372 & -2.811313 \\
\hline $\mathrm{H}$ & 6.380408 & -3.510826 & -3.569183 \\
\hline $\mathrm{H}$ & 6.732304 & -1.131463 & -2.905442 \\
\hline $\mathrm{H}$ & 5.121603 & 0.010804 & -1.457313 \\
\hline C & 4.237270 & 0.571270 & 0.955100 \\
\hline C & 4.524589 & 1.926507 & 1.311324 \\
\hline C & 5.687649 & 2.219387 & 2.073770 \\
\hline C & 6.526185 & 1.214690 & 2.496679 \\
\hline C & 6.227083 & -0.130552 & 2.175914 \\
\hline C & 5.116472 & -0.444048 & 1.423760 \\
\hline $\mathrm{H}$ & 5.893405 & 3.256536 & 2.327675 \\
\hline $\mathrm{H}$ & 7.408921 & 1.448134 & 3.085631 \\
\hline $\mathrm{H}$ & 6.876869 & -0.925616 & 2.531642 \\
\hline $\mathrm{H}$ & 4.896184 & -1.480687 & 1.196623 \\
\hline 0 & -1.223812 & -0.293989 & -0.918702 \\
\hline $\mathrm{O}$ & -0.614079 & 0.877184 & 1.348560 \\
\hline $\mathrm{H}$ & -1.514970 & 1.492722 & 1.370122 \\
\hline $\mathrm{H}$ & -0.135013 & 3.257081 & 1.043187 \\
\hline $\mathrm{H}$ & -0.507041 & 7.006031 & -1.020730 \\
\hline $\mathrm{H}$ & 3.097921 & 4.690314 & -1.398855 \\
\hline $\mathrm{H}$ & -1.075909 & -2.621944 & -1.645900 \\
\hline $\mathrm{H}$ & -3.094887 & -5.973975 & 0.146907 \\
\hline $\mathrm{H}$ & 1.030466 & -5.183034 & 1.083516 \\
\hline C & -3.669853 & 2.323063 & 0.969192 \\
\hline $\mathrm{O}$ & -2.596108 & 2.316573 & 1.681432 \\
\hline $\mathrm{H}$ & -4.429657 & 3.070773 & 1.255724 \\
\hline C & -3.576653 & 2.278431 & -0.572980 \\
\hline
\end{tabular}




\begin{tabular}{llll}
$\mathrm{O}$ & -4.536006 & 2.125063 & -1.306036 \\
$\mathrm{O}$ & -2.326357 & 2.489079 & -0.980171 \\
$\mathrm{C}$ & -2.071152 & 2.421591 & -2.412629 \\
$\mathrm{H}$ & -2.634135 & 1.577554 & -2.815579 \\
$\mathrm{C}$ & -4.088725 & -0.267728 & 1.162005 \\
$\mathrm{C}$ & -4.883224 & 0.888854 & 1.319432 \\
$\mathrm{H}$ & -2.959114 & -1.067062 & -0.357353 \\
$\mathrm{~N}$ & -3.920964 & -0.842247 & -0.072347 \\
$\mathrm{C}$ & -4.885395 & -0.875593 & -1.088840 \\
$\mathrm{O}$ & -6.067512 & -0.662506 & -0.955232 \\
$\mathrm{O}$ & -4.282614 & -1.264473 & -2.228719 \\
$\mathrm{C}$ & -5.150797 & -1.322289 & -3.374231 \\
$\mathrm{H}$ & -5.571376 & -0.334082 & -3.574566 \\
$\mathrm{H}$ & -5.961984 & -2.035012 & -3.205835 \\
$\mathrm{H}$ & -4.516021 & -1.647186 & -4.198488 \\
$\mathrm{H}$ & -5.208228 & 1.108341 & 2.331186 \\
$\mathrm{H}$ & -5.623184 & 1.085157 & 0.553207 \\
$\mathrm{C}$ & -3.269955 & -0.793713 & 2.248830 \\
$\mathrm{C}$ & -3.023209 & -0.028784 & 3.411061 \\
$\mathrm{C}$ & -2.730724 & -2.096582 & 2.167339 \\
$\mathrm{C}$ & -2.246207 & -0.548923 & 4.440440 \\
$\mathrm{H}$ & -3.391414 & 0.985132 & 3.485456 \\
$\mathrm{C}$ & -1.964769 & -2.610827 & 3.205006 \\
$\mathrm{H}$ & -2.934256 & -2.714863 & 1.301223 \\
$\mathrm{C}$ & -1.716430 & -1.836578 & 4.342171 \\
$\mathrm{H}$ & -2.047665 & 0.057062 & 5.319399 \\
$\mathrm{H}$ & -1.561202 & -3.614902 & 3.122030 \\
$\mathrm{H}$ & -1.113102 & -2.238699 & 5.151561 \\
$\mathrm{H}$ & -1.005255 & 2.202035 & -2.470033 \\
$\mathrm{H}$ & -2.422601 & 3.728464 & -3.104804 \\
& -2.149258 & 3.661745 & -4.164614 \\
\hline & -1.869680 & 4.561813 & -2.660932
\end{tabular}

Catalyst (R)-1 TS Ethyl Conformation 6 (TS-5Re)

B3LYP/6-31G(d) Energy $=-2849.010015$

B3LYP-D3(BJ)/def2-TZVPP-IEF-PCM(DCM) Energy = -2850.328983

B3LYP-D3(BJ)/def2-TZVPP-IEF-PCM(DCM)//B3LYP/6-31G(d) Free Energy (Quasiharmonic) = 2849.659709

Frequencies (Top 3 out of 279) 
1. $-743.8915 \mathrm{~cm}-1$

2. $\quad 12.1128 \mathrm{~cm}-1$

3. $\quad 18.2059 \mathrm{~cm}-1$

B3LYP/6-31G(d) Molecular Geometry in Cartesian Coordinates

\begin{tabular}{|c|c|c|c|}
\hline C & -2.841874 & -1.093732 & 0.125410 \\
\hline C & -1.648577 & -1.727142 & -0.184723 \\
\hline C & -1.357480 & -3.065283 & 0.201327 \\
\hline C & -2.281283 & -3.721399 & 0.987604 \\
\hline $\mathrm{H}$ & -2.084410 & -4.747095 & 1.289021 \\
\hline C & -3.663536 & 2.908696 & -1.226768 \\
\hline C & -3.114449 & 0.268476 & -0.415096 \\
\hline C & -2.218152 & 1.301424 & -0.174673 \\
\hline C & -2.483023 & 2.650095 & -0.558367 \\
\hline $\mathrm{H}$ & -3.884454 & 3.929841 & -1.526653 \\
\hline 0 & -0.682805 & -1.019589 & -0.902109 \\
\hline$P$ & 0.143129 & 0.116931 & -0.046217 \\
\hline O & -1.069890 & 1.043926 & 0.560025 \\
\hline C & 2.101233 & -5.306622 & -1.024884 \\
\hline C & 1.138177 & -4.930999 & -1.965306 \\
\hline C & 0.037738 & -4.167609 & -1.574929 \\
\hline C & -0.122249 & -3.778308 & -0.236508 \\
\hline C & 0.852882 & -4.152276 & 0.698288 \\
\hline C & 1.958716 & -4.908489 & 0.305466 \\
\hline $\mathrm{H}$ & 1.239075 & -5.239621 & -3.002798 \\
\hline $\mathrm{H}$ & 2.708505 & -5.187553 & 1.040886 \\
\hline C & 0.045778 & 6.065884 & 0.115855 \\
\hline C & -1.230797 & 6.007542 & 0.678159 \\
\hline C & -2.029848 & 4.879995 & 0.481241 \\
\hline C & -1.563534 & 3.788185 & -0.267553 \\
\hline C & -0.273038 & 3.848290 & -0.815753 \\
\hline C & 0.517675 & 4.983593 & -0.631801 \\
\hline $\mathrm{H}$ & -1.609726 & 6.841905 & 1.262914 \\
\hline $\mathrm{H}$ & 1.504575 & 5.027322 & -1.086932 \\
\hline C & -4.285344 & 0.534377 & -1.205563 \\
\hline C & -4.567824 & 1.882932 & -1.592543 \\
\hline C & -5.730815 & 2.163669 & -2.359765 \\
\hline C & -6.575598 & 1.153997 & -2.757394 \\
\hline C & -6.281209 & -0.185081 & -2.407520 \\
\hline C & -5.169427 & -0.487034 & -1.652485 \\
\hline $\mathrm{H}$ & -5.931898 & 3.195729 & -2.637443 \\
\hline $\mathrm{H}$ & -7.458994 & 1.378258 & -3.348923 \\
\hline $\mathrm{H}$ & -6.935767 & -0.984975 & -2.743137 \\
\hline
\end{tabular}




\begin{tabular}{|c|c|c|c|}
\hline $\mathrm{H}$ & -4.954159 & -1.519306 & -1.402367 \\
\hline C & -3.769057 & -1.763321 & 0.997502 \\
\hline C & -3.476075 & -3.098209 & 1.425677 \\
\hline C & -4.382434 & -3.771658 & 2.288390 \\
\hline C & -5.522170 & -3.149582 & 2.741688 \\
\hline C & -5.796144 & -1.817574 & 2.351797 \\
\hline C & -4.945672 & -1.143697 & 1.503287 \\
\hline $\mathrm{H}$ & -4.148376 & -4.788974 & 2.593115 \\
\hline $\mathrm{H}$ & -6.205071 & -3.671593 & 3.406347 \\
\hline $\mathrm{H}$ & -6.684196 & -1.318194 & 2.729866 \\
\hline $\mathrm{H}$ & -5.165528 & -0.119827 & 1.224920 \\
\hline $\mathrm{O}$ & 1.034128 & 0.881807 & -0.970809 \\
\hline 0 & 0.716655 & -0.537169 & 1.219613 \\
\hline $\mathrm{H}$ & 1.749202 & -1.028118 & 1.381743 \\
\hline $\mathrm{H}$ & 0.751098 & -3.832340 & 1.730622 \\
\hline $\mathrm{H}$ & 2.957254 & -5.904174 & -1.327044 \\
\hline $\mathrm{H}$ & -0.716229 & -3.887108 & -2.305473 \\
\hline $\mathrm{H}$ & 0.105929 & 3.008405 & -1.388304 \\
\hline $\mathrm{H}$ & 0.664717 & 6.948891 & 0.253080 \\
\hline $\mathrm{H}$ & -3.026058 & 4.839165 & 0.913719 \\
\hline C & 3.956672 & -1.566350 & 1.412350 \\
\hline 0 & 2.772470 & -1.553098 & 1.918767 \\
\hline $\mathrm{H}$ & 4.726738 & -2.046969 & 2.029654 \\
\hline C & 4.211783 & -1.957696 & -0.044533 \\
\hline $\mathrm{O}$ & 5.201887 & -2.585914 & -0.356869 \\
\hline 0 & 3.255324 & -1.555608 & -0.886951 \\
\hline C & 3.452070 & -1.941478 & -2.279242 \\
\hline $\mathrm{H}$ & 3.492903 & -3.032861 & -2.318733 \\
\hline C & 3.907172 & 1.106278 & 1.087803 \\
\hline C & 4.893967 & 0.169073 & 1.456926 \\
\hline $\mathrm{H}$ & 2.680404 & 1.555880 & -0.500686 \\
\hline$N$ & 3.669819 & 1.451252 & -0.214400 \\
\hline C & 4.582997 & 1.373058 & -1.268935 \\
\hline 0 & 5.747109 & 1.042015 & -1.201226 \\
\hline $\mathrm{O}$ & 3.961367 & 1.778723 & -2.391904 \\
\hline C & 4.783587 & 1.793919 & -3.571097 \\
\hline $\mathrm{H}$ & 5.172017 & 0.794588 & -3.781764 \\
\hline $\mathrm{H}$ & 5.620403 & 2.485217 & -3.443415 \\
\hline $\mathrm{H}$ & 4.125882 & 2.127918 & -4.373103 \\
\hline $\mathrm{H}$ & 5.201921 & 0.199968 & 2.496570 \\
\hline $\mathrm{H}$ & 5.698482 & -0.014854 & 0.755524 \\
\hline C & 2.979207 & 1.663417 & 2.074205 \\
\hline C & 2.811606 & 1.060852 & 3.339883 \\
\hline C & 2.245755 & 2.833572 & 1.782848 \\
\hline
\end{tabular}




$\begin{array}{llll}\mathrm{C} & 1.928788 & 1.604711 & 4.266422 \\ \mathrm{H} & 3.330169 & 0.143416 & 3.581431 \\ \mathrm{C} & 1.369658 & 3.374513 & 2.714793 \\ \mathrm{H} & 2.376990 & 3.334326 & 0.831182 \\ \mathrm{C} & 1.206555 & 2.758854 & 3.958706 \\ \mathrm{H} & 1.796465 & 1.118095 & 5.228168 \\ \mathrm{H} & 0.813140 & 4.272321 & 2.465352 \\ \mathrm{H} & 0.517224 & 3.178786 & 4.686082 \\ \mathrm{H} & 4.426702 & -1.556283 & -2.596889 \\ \mathrm{C} & 2.307378 & -1.380893 & -3.097764 \\ \mathrm{H} & 2.453096 & -1.658172 & -4.148850 \\ \mathrm{H} & 1.351755 & -1.788324 & -2.759411 \\ \mathrm{H} & 2.255881 & -0.292969 & -3.017058\end{array}$

Catalyst (R)-1 TS Ethyl Conformation 7

B3LYP/6-31G(d) Energy = -2849.019794

B3LYP-D3(BJ)/def2-TZVPP-IEF-PCM(DCM) Energy = -2850.331997

B3LYP-D3(BJ)/def2-TZVPP-IEF-PCM(DCM)//B3LYP/6-31G(d) Free Energy (Quasiharmonic) = 2849.662357

Frequencies (Top 3 out of 279)

1. $-456.6953 \mathrm{~cm}-1$

2. $\quad 10.5379 \mathrm{~cm}-1$

3. $\quad 15.4099 \mathrm{~cm}-1$

B3LYP/6-31G(d) Molecular Geometry in Cartesian Coordinates

$\begin{array}{llll}\text { C } & 2.835742 & -1.589368 & -0.264559 \\ \text { C } & 1.526526 & -1.844914 & 0.110677 \\ \text { C } & 0.881449 & -3.098897 & -0.097645 \\ \text { C } & 1.607226 & -4.085493 & -0.735965 \\ \text { H } & 1.152771 & -5.060850 & -0.889312 \\ \text { C } & 4.555230 & 2.310472 & 0.388036 \\ \text { C } & 3.435795 & -0.254091 & 0.028196 \\ \text { C } & 2.804940 & 0.892347 & -0.431851 \\ \text { C } & 3.364527 & 2.197618 & -0.303624 \\ \text { H } & 5.021549 & 3.287662 & 0.482056 \\ \text { O } & 0.807694 & -0.833742 & 0.737974 \\ \text { P } & 0.264673 & 0.424401 & -0.161962 \\ \text { O } & 1.578625 & 0.767322 & -1.077875 \\ \text { C } & -3.156582 & -3.952208 & 1.125004\end{array}$




\begin{tabular}{|c|c|c|c|}
\hline C & -2.726135 & -4.255207 & -0.167807 \\
\hline C & -1.419848 & -3.962474 & -0.558605 \\
\hline C & -0.518761 & -3.355910 & 0.331928 \\
\hline C & -0.963601 & -3.050232 & 1.628549 \\
\hline C & -2.267521 & -3.352553 & 2.020555 \\
\hline $\mathrm{H}$ & -3.411504 & -4.711753 & -0.876966 \\
\hline $\mathrm{H}$ & -2.588426 & -3.116190 & 3.031478 \\
\hline C & 1.731960 & 5.757437 & -2.083720 \\
\hline C & 1.810835 & 4.576489 & -2.826397 \\
\hline C & 2.300707 & 3.408007 & -2.244343 \\
\hline C & 2.736951 & 3.402496 & -0.909110 \\
\hline C & 2.645192 & 4.593726 & -0.171287 \\
\hline C & 2.145567 & 5.759432 & -0.750814 \\
\hline $\mathrm{H}$ & 1.501730 & 4.565979 & -3.868811 \\
\hline $\mathrm{H}$ & 2.078924 & 6.669000 & -0.159516 \\
\hline C & 4.636735 & -0.112268 & 0.804284 \\
\hline C & 5.198254 & 1.194166 & 0.976274 \\
\hline C & 6.389271 & 1.347284 & 1.736765 \\
\hline C & 6.991988 & 0.264491 & 2.333414 \\
\hline C & 6.419568 & -1.022059 & 2.195733 \\
\hline C & 5.275490 & -1.206243 & 1.450826 \\
\hline $\mathrm{H}$ & 6.809174 & 2.344398 & 1.846789 \\
\hline $\mathrm{H}$ & 7.898497 & 0.394653 & 2.918146 \\
\hline $\mathrm{H}$ & 6.884341 & -1.873111 & 2.686193 \\
\hline $\mathrm{H}$ & 4.843924 & -2.196617 & 1.362846 \\
\hline C & 3.554821 & -2.602439 & -0.987888 \\
\hline C & 2.925805 & -3.871051 & -1.206346 \\
\hline C & 3.628356 & -4.887402 & -1.909017 \\
\hline C & 4.889461 & -4.660450 & -2.408531 \\
\hline C & 5.497524 & -3.395727 & -2.229601 \\
\hline C & 4.849732 & -2.395236 & -1.538778 \\
\hline $\mathrm{H}$ & 3.140101 & -5.848112 & -2.054854 \\
\hline $\mathrm{H}$ & 5.414246 & -5.442826 & -2.949885 \\
\hline $\mathrm{H}$ & 6.483868 & -3.209128 & -2.645757 \\
\hline $\mathrm{H}$ & 5.326721 & -1.429453 & -1.420344 \\
\hline $\mathrm{O}$ & -0.147127 & 1.508853 & 0.775587 \\
\hline $\mathrm{O}$ & -0.726817 & -0.106876 & -1.216542 \\
\hline $\mathrm{H}$ & -1.839873 & 0.045266 & -1.175307 \\
\hline $\mathrm{H}$ & -0.283951 & -2.579974 & 2.331200 \\
\hline $\mathrm{H}$ & -4.178597 & -4.164968 & 1.423771 \\
\hline $\mathrm{H}$ & -1.096401 & -4.180359 & -1.572566 \\
\hline $\mathrm{H}$ & 2.954694 & 4.597436 & 0.870131 \\
\hline $\mathrm{H}$ & 1.352897 & 6.667977 & -2.540645 \\
\hline $\mathrm{H}$ & 2.361298 & 2.497844 & -2.831287 \\
\hline
\end{tabular}




$\begin{array}{llll}\mathrm{C} & -3.857565 & -0.388977 & -0.378156 \\ \mathrm{O} & -3.137479 & 0.138049 & -1.295785 \\ \mathrm{H} & -3.379414 & -0.952985 & 0.432646 \\ \mathrm{C} & -5.192861 & -1.032514 & -0.742581 \\ \mathrm{O} & -5.738465 & -1.841748 & -0.016762 \\ \mathrm{O} & -5.664557 & -0.597150 & -1.915508 \\ \mathrm{C} & -6.929051 & -1.153512 & -2.355585 \\ \mathrm{H} & -7.344308 & -0.383683 & -3.009869 \\ \mathrm{C} & -3.568342 & 1.588393 & 1.252752 \\ \mathrm{C} & -4.743088 & 1.060496 & 0.700571 \\ \mathrm{H} & -1.715629 & 2.265199 & 0.677600 \\ \mathrm{~N} & -2.736716 & 2.361358 & 0.508236 \\ \mathrm{C} & -3.087171 & 3.075064 & -0.652761 \\ \mathrm{O} & -4.208426 & 3.336271 & -1.027236 \\ \mathrm{O} & -1.953926 & 3.482671 & -1.240837 \\ \mathrm{C} & -2.129643 & 4.235110 & -2.452670 \\ \mathrm{H} & -2.623741 & 3.619800 & -3.208810 \\ \mathrm{H} & -1.121170 & 4.502226 & -2.765087 \\ \mathrm{H} & -2.729856 & 5.128756 & -2.263398 \\ \mathrm{H} & -5.441346 & 0.578225 & 1.374768 \\ \mathrm{H} & -5.181113 & 1.581813 & -0.139923 \\ \mathrm{C} & -3.085326 & 1.197103 & 2.592150 \\ \mathrm{C} & -2.149438 & 1.996095 & 3.274734 \\ \mathrm{C} & -3.582164 & 0.044545 & 3.231905 \\ \mathrm{H} & -1.729352 & 1.656932 & 4.557665 \\ \mathrm{H} & -1.762848 & 2.894977 & 2.808272 \\ \mathrm{H} & -3.156130 & -0.291504 & 4.512922 \\ \mathrm{H} & -4.282496 & -0.606072 & 2.718891 \\ \mathrm{H} & -2.230384 & 0.513715 & 5.181480 \\ \mathrm{H} & -1.009277 & 2.288345 & 5.069567 \\ \mathrm{H} & -3.546431 & -1.185892 & 4.990373 \\ \mathrm{H} & -1.901331 & 0.249878 & 6.182746 \\ \mathrm{H} & -6.323461 & -2.465968 & -3.095818 \\ \mathrm{H} & -1.283693 & -1.486195 \\ \mathrm{H} & -3.228999 & -2.423255 \\ \mathrm{H} & -2.824090 & -3.488562 \\ \mathrm{H} & -2.333731 & -3.935241\end{array}$

Catalyst (R)-1 TS Ethyl Conformation 8

B3LYP/6-31G(d) Energy = -2849.019784

B3LYP-D3(BJ)/def2-TZVPP-IEF-PCM(DCM) Energy = -2850.332148 
B3LYP-D3(BJ)/def2-TZVPP-IEF-PCM(DCM)//B3LYP/6-31G(d) Free Energy (Quasiharmonic) = 2849.662526

Frequencies (Top 3 out of 279)

1. $-457.5731 \mathrm{~cm}-1$

2. $\quad 10.6598 \mathrm{~cm}-1$

3. $16.3036 \mathrm{~cm}-1$

B3LYP/6-31G(d) Molecular Geometry in Cartesian Coordinates

$\begin{array}{llll}\text { C } & 2.934759 & -1.499710 & -0.317976 \\ \text { C } & 1.633459 & -1.823485 & 0.031275 \\ \text { C } & 1.042927 & -3.093378 & -0.234237 \\ \text { C } & 1.815130 & -4.023061 & -0.902675 \\ \text { H } & 1.402694 & -5.009054 & -1.100386 \\ \text { C } & 4.483700 & 2.438502 & 0.508470 \\ \text { C } & 3.475932 & -0.153641 & 0.034198 \\ \text { C } & 2.802620 & 0.983288 & -0.387665 \\ \text { C } & 3.305796 & 2.304428 & -0.201122 \\ \text { H } & 4.907948 & 3.429524 & 0.646595 \\ \text { O } & 0.866657 & -0.868233 & 0.688917 \\ \text { P } & 0.280948 & 0.399975 & -0.169097 \\ \text { O } & 1.589732 & 0.833617 & -1.053324 \\ \text { C } & -2.969114 & -4.157389 & 0.905734 \\ \text { C } & -2.515613 & -4.385254 & -0.394635 \\ \text { C } & -1.218220 & -4.025081 & -0.757921 \\ \text { C } & -0.349886 & -3.424131 & 0.168224 \\ \text { C } & -0.818043 & -3.193983 & 1.472161 \\ \text { C } & -2.112438 & -3.564262 & 1.836514 \\ \text { H } & -3.176564 & -4.835101 & -1.130648 \\ \text { H } & -2.451341 & -3.386049 & 2.853475 \\ \text { C } & 1.542602 & 5.861917 & -1.857163 \\ \text { C } & 1.676641 & 4.715468 & -2.644625 \\ \text { C } & 2.209593 & 3.546006 & -2.103845 \\ \text { C } & 2.634352 & 3.505610 & -0.765490 \\ \text { C } & 2.487030 & 4.662012 & 0.017394 \\ \text { C } & 1.944513 & 5.828223 & -0.521107 \\ \text { H } & 1.377174 & 4.733462 & -3.689751 \\ \text { H } & 1.835243 & 6.710203 & 0.104645 \\ \text { C } & 4.661975 & 0.006434 & 0.829364 \\ \text { C } & 5.166758 & 1.327005 & 1.059514 \\ \text { C } & 6.342685 & 1.498511 & 1.839324 \\ \text { C } & 6.984029 & 0.418463 & 2.399568\end{array}$




\begin{tabular}{|c|c|c|c|}
\hline C & 6.467191 & -0.884070 & 2.204315 \\
\hline C & 5.339286 & -1.085291 & 1.439421 \\
\hline $\mathrm{H}$ & 6.719558 & 2.506883 & 1.993651 \\
\hline $\mathrm{H}$ & 7.878440 & 0.562380 & 2.999511 \\
\hline $\mathrm{H}$ & 6.962163 & -1.734197 & 2.665989 \\
\hline $\mathrm{H}$ & 4.950278 & -2.088289 & 1.307143 \\
\hline C & 3.702377 & -2.452748 & -1.072380 \\
\hline C & 3.128489 & -3.736185 & -1.348504 \\
\hline C & 3.879316 & -4.693820 & -2.082998 \\
\hline C & 5.134760 & -4.395508 & -2.558666 \\
\hline C & 5.688227 & -3.115196 & -2.322518 \\
\hline C & 4.992956 & -2.170730 & -1.599706 \\
\hline $\mathrm{H}$ & 3.432570 & -5.666997 & -2.272665 \\
\hline $\mathrm{H}$ & 5.696685 & -5.133269 & -3.124816 \\
\hline $\mathrm{H}$ & 6.670006 & -2.871742 & -2.719662 \\
\hline $\mathrm{H}$ & 5.428450 & -1.191798 & -1.437436 \\
\hline $\mathrm{O}$ & -0.188083 & 1.428953 & 0.803596 \\
\hline $\mathrm{O}$ & -0.674225 & -0.131167 & -1.256643 \\
\hline$H$ & -1.793412 & -0.028349 & -1.225129 \\
\hline $\mathrm{H}$ & -0.163807 & -2.729146 & 2.202070 \\
\hline $\mathrm{H}$ & -3.984675 & -4.422932 & 1.183577 \\
\hline $\mathrm{H}$ & -0.877252 & -4.184780 & -1.776961 \\
\hline $\mathrm{H}$ & 2.787177 & 4.637284 & 1.061262 \\
\hline $\mathrm{H}$ & 1.129963 & 6.773449 & -2.281885 \\
\hline $\mathrm{H}$ & 2.312763 & 2.663028 & -2.725324 \\
\hline C & -3.800324 & -0.581475 & -0.476829 \\
\hline $\mathrm{O}$ & -3.091617 & 0.014842 & -1.360071 \\
\hline $\mathrm{H}$ & -3.309562 & -1.159845 & 0.316135 \\
\hline C & -5.103286 & -1.263002 & -0.886619 \\
\hline $\mathrm{O}$ & -5.629205 & -2.116689 & -0.198065 \\
\hline $\mathrm{O}$ & -5.565293 & -0.814964 & -2.058566 \\
\hline C & -6.799983 & -1.403253 & -2.539654 \\
\hline $\mathrm{H}$ & -6.803676 & -2.466730 & -2.288525 \\
\hline C & -3.613983 & 1.338715 & 1.237635 \\
\hline C & -4.758459 & 0.782283 & 0.650858 \\
\hline $\mathrm{H}$ & -1.786760 & 2.117533 & 0.712742 \\
\hline$N$ & -2.809296 & 2.175700 & 0.534073 \\
\hline C & -3.178088 & 2.917989 & -0.603076 \\
\hline $\mathrm{O}$ & -4.305649 & 3.143931 & -0.981771 \\
\hline $\mathrm{O}$ & -2.057641 & 3.397961 & -1.160019 \\
\hline C & -2.252447 & 4.187969 & -2.344693 \\
\hline $\mathrm{H}$ & -2.709658 & 3.580993 & -3.130199 \\
\hline $\mathrm{H}$ & -1.253227 & 4.511017 & -2.633127 \\
\hline $\mathrm{H}$ & -2.893974 & 5.046425 & -2.129787 \\
\hline
\end{tabular}




$\begin{array}{llll}\mathrm{H} & -5.441021 & 0.242648 & 1.296983 \\ \mathrm{H} & -5.210959 & 1.318215 & -0.172668 \\ \mathrm{C} & -3.128778 & 0.916995 & 2.566925 \\ \mathrm{C} & -2.237587 & 1.729611 & 3.291933 \\ \mathrm{C} & -3.580660 & -0.280511 & 3.155361 \\ \mathrm{C} & -1.817578 & 1.359856 & 4.566397 \\ \mathrm{H} & -1.886336 & 2.662202 & 2.865414 \\ \mathrm{C} & -3.154852 & -0.646795 & 4.428128 \\ \mathrm{H} & -4.244800 & -0.941351 & 2.608396 \\ \mathrm{C} & -2.274059 & 0.172200 & 5.139313 \\ \mathrm{H} & -1.132488 & 2.002228 & 5.111594 \\ \mathrm{H} & -3.509967 & -1.575584 & 4.865692 \\ \mathrm{H} & -1.945148 & -0.115429 & 6.134052 \\ \mathrm{H} & -6.745418 & -1.284704 & -3.624088 \\ \mathrm{C} & -8.012397 & -0.691733 & -1.959191 \\ \mathrm{H} & -7.973608 & 0.380923 & -2.174438 \\ \mathrm{H} & -8.928375 & -1.099433 & -2.402211 \\ \mathrm{H} & -8.063480 & -0.835895 & -0.876095\end{array}$

Catalyst (R)-1 TS Ethyl Conformation 9

B3LYP/6-31G(d) Energy $=-2849.020177$

B3LYP-D3(BJ)/def2-TZVPP-IEF-PCM(DCM) Energy $=-2850.332342$

B3LYP-D3(BJ)/def2-TZVPP-IEF-PCM(DCM)//B3LYP/6-31G(d) Free Energy (Quasiharmonic) = 2849.66312

Frequencies (Top 3 out of 279)

1. $-465.1938 \mathrm{~cm}-1$

2. $\quad 10.4648 \mathrm{~cm}-1$

3. $\quad 15.8505 \mathrm{~cm}-1$

B3LYP/6-31G(d) Molecular Geometry in Cartesian Coordinates

$\begin{array}{llll}\text { C } & 2.908969 & -1.501302 & -0.338001 \\ \text { C } & 1.616727 & -1.821966 & 0.046031 \\ \text { C } & 1.019948 & -3.094002 & -0.194225 \\ \text { C } & 1.775377 & -4.029177 & -0.874097 \\ \text { H } & 1.358308 & -5.016761 & -1.053282 \\ \text { C } & 4.477819 & 2.442908 & 0.419440 \\ \text { C } & 3.458739 & -0.152620 & -0.009957 \\ \text { C } & 2.775238 & 0.981125 & -0.423978 \\ \text { C } & 3.282879 & 2.303541 & -0.259993\end{array}$




\begin{tabular}{|c|c|c|c|}
\hline $\mathrm{H}$ & 4.905264 & 3.434909 & 0.539513 \\
\hline $\mathrm{O}$ & 0.866504 & -0.861258 & 0.714628 \\
\hline$P$ & 0.259586 & 0.400203 & -0.138742 \\
\hline $\mathrm{O}$ & 1.546347 & 0.826582 & -1.058373 \\
\hline C & -2.962300 & -4.147927 & 1.054455 \\
\hline C & -2.540865 & -4.388169 & -0.254445 \\
\hline C & -1.252944 & -4.031339 & -0.652992 \\
\hline C & -0.362280 & -3.421390 & 0.245682 \\
\hline C & -0.798212 & -3.179034 & 1.558554 \\
\hline C & -2.083114 & -3.545969 & 1.958172 \\
\hline $\mathrm{H}$ & -3.219700 & -4.845036 & -0.969563 \\
\hline $\mathrm{H}$ & -2.396958 & -3.358069 & 2.981406 \\
\hline C & 1.481295 & 5.849233 & -1.899822 \\
\hline C & 1.596579 & 4.697026 & -2.681846 \\
\hline C & 2.141839 & 3.531326 & -2.145215 \\
\hline C & 2.598001 & 3.500577 & -0.816992 \\
\hline C & 2.469237 & 4.662658 & -0.039273 \\
\hline C & 1.914377 & 5.825093 & -0.573330 \\
\hline $\mathrm{H}$ & 1.272653 & 4.707534 & -3.719756 \\
\hline $\mathrm{H}$ & 1.819949 & 6.711628 & 0.048387 \\
\hline C & 4.663976 & 0.013378 & 0.754571 \\
\hline C & 5.174239 & 1.335586 & 0.962080 \\
\hline C & 6.368946 & 1.512931 & 1.711447 \\
\hline C & 7.023906 & 0.437141 & 2.264073 \\
\hline C & 6.502468 & -0.866772 & 2.091605 \\
\hline C & 5.356116 & -1.073707 & 1.356228 \\
\hline $\mathrm{H}$ & 6.749437 & 2.522411 & 1.848709 \\
\hline $\mathrm{H}$ & 7.932769 & 0.585540 & 2.840751 \\
\hline $\mathrm{H}$ & 7.008650 & -1.713398 & 2.547524 \\
\hline $\mathrm{H}$ & 4.964044 & -2.077645 & 1.241314 \\
\hline C & 3.657684 & -2.460558 & -1.103429 \\
\hline C & 3.077182 & -3.746092 & -1.354858 \\
\hline C & 3.809631 & -4.709743 & -2.099966 \\
\hline C & 5.052960 & -4.415539 & -2.608870 \\
\hline C & 5.612131 & -3.133509 & -2.396722 \\
\hline C & 4.934890 & -2.183104 & -1.664635 \\
\hline $\mathrm{H}$ & 3.358362 & -5.684347 & -2.270655 \\
\hline $\mathrm{H}$ & 5.600729 & -5.157965 & -3.182744 \\
\hline $\mathrm{H}$ & 6.583859 & -2.893495 & -2.819832 \\
\hline $\mathrm{H}$ & 5.374323 & -1.203031 & -1.520944 \\
\hline $\mathrm{O}$ & -0.184828 & 1.436945 & 0.837309 \\
\hline $\mathrm{O}$ & -0.722309 & -0.139130 & -1.197805 \\
\hline $\mathrm{H}$ & -1.841952 & -0.036606 & -1.140900 \\
\hline $\mathrm{H}$ & -0.126353 & -2.707227 & 2.267673 \\
\hline
\end{tabular}




\begin{tabular}{|c|c|c|c|}
\hline $\mathrm{H}$ & -3.970713 & -4.410644 & 1.359613 \\
\hline $\mathrm{H}$ & -0.937077 & -4.200726 & -1.678547 \\
\hline $\mathrm{H}$ & 2.793868 & 4.645391 & 0.997389 \\
\hline $\mathrm{H}$ & 1.059066 & 6.757834 & -2.321395 \\
\hline $\mathrm{H}$ & 2.230245 & 2.643794 & -2.762482 \\
\hline C & -3.826282 & -0.583885 & -0.338021 \\
\hline O & -3.140788 & 0.003250 & -1.245735 \\
\hline $\mathrm{H}$ & -3.314705 & -1.152537 & 0.448666 \\
\hline C & -5.137889 & -1.270107 & -0.708426 \\
\hline O & -5.645019 & -2.123203 & -0.005863 \\
\hline $\mathrm{O}$ & -5.641016 & -0.825218 & -1.863480 \\
\hline C & -6.888264 & -1.428343 & -2.285972 \\
\hline $\mathrm{H}$ & -7.636367 & -1.272630 & -1.501680 \\
\hline C & -3.600435 & 1.352202 & 1.353499 \\
\hline C & -4.758733 & 0.792730 & 0.798077 \\
\hline $\mathrm{H}$ & -1.785065 & 2.125270 & 0.779931 \\
\hline$N$ & -2.811479 & 2.183181 & 0.624974 \\
\hline C & -3.206182 & 2.918235 & -0.507935 \\
\hline $\mathrm{O}$ & -4.342025 & 3.141183 & -0.863047 \\
\hline 0 & -2.098770 & 3.395326 & -1.092979 \\
\hline C & -2.320835 & 4.178673 & -2.277222 \\
\hline $\mathrm{H}$ & -2.796152 & 3.567488 & -3.048606 \\
\hline $\mathrm{H}$ & -1.328547 & 4.499918 & -2.590511 \\
\hline $\mathrm{H}$ & -2.957196 & 5.038444 & -2.052397 \\
\hline $\mathrm{H}$ & -5.427519 & 0.259801 & 1.463915 \\
\hline $\mathrm{H}$ & -5.228382 & 1.321042 & -0.020699 \\
\hline C & -3.084885 & 0.940130 & 2.674431 \\
\hline C & -2.175332 & 1.756557 & 3.371826 \\
\hline C & -3.525190 & -0.251699 & 3.282864 \\
\hline C & -1.726387 & 1.396079 & 4.639073 \\
\hline $\mathrm{H}$ & -1.832237 & 2.684913 & 2.929734 \\
\hline C & -3.070571 & -0.608661 & 4.548291 \\
\hline $\mathrm{H}$ & -4.203271 & -0.915466 & 2.756947 \\
\hline C & -2.171767 & 0.214084 & 5.232083 \\
\hline $\mathrm{H}$ & -1.027430 & 2.041280 & 5.162914 \\
\hline $\mathrm{H}$ & -3.417312 & -1.533097 & 5.001504 \\
\hline $\mathrm{H}$ & -1.820290 & -0.066265 & 6.221168 \\
\hline $\mathrm{H}$ & -6.736355 & -2.507446 & -2.389980 \\
\hline C & -7.285099 & -0.775812 & -3.595944 \\
\hline $\mathrm{H}$ & -6.518470 & -0.938016 & -4.359897 \\
\hline $\mathrm{H}$ & -8.227553 & -1.205245 & -3.953141 \\
\hline $\mathrm{H}$ & -7.421648 & 0.302618 & -3.468865 \\
\hline
\end{tabular}


Catalyst (R)-1 TS Ethyl Conformation 10

B3LYP/6-31G(d) Energy $=-2849.011152$

B3LYP-D3(BJ)/def2-TZVPP-IEF-PCM(DCM) Energy = -2850.323778

B3LYP-D3(BJ)/def2-TZVPP-IEF-PCM(DCM)//B3LYP/6-31G(d) Free Energy (Quasiharmonic) = 2849.654641

Frequencies (Top 3 out of 279)

1. $-557.9753 \mathrm{~cm}-1$

2. $10.9529 \mathrm{~cm}-1$

3. $\quad 14.6487 \mathrm{~cm}-1$

B3LYP/6-31G(d) Molecular Geometry in Cartesian Coordinates

$\begin{array}{llll}\text { C } & 3.828866 & -0.076274 & 0.268573 \\ \text { C } & 3.325832 & 1.052994 & -0.359231 \\ \text { C } & 3.988640 & 2.315166 & -0.363277 \\ \text { C } & 5.170686 & 2.406967 & 0.345403 \\ \text { H } & 5.716407 & 3.346772 & 0.343303 \\ \text { C } & 1.681987 & -3.815976 & 0.132905 \\ \text { C } & 3.103872 & -1.378069 & 0.155513 \\ \text { C } & 1.769673 & -1.453958 & 0.526611 \\ \text { C } & 1.027323 & -2.672765 & 0.551157 \\ \text { H } & 1.162116 & -4.769536 & 0.171336 \\ \text { O } & 2.120844 & 0.952821 & -1.049490 \\ \text { P } & 0.730959 & 0.824673 & -0.208862 \\ \text { O } & 1.130395 & -0.289736 & 0.930087 \\ \text { C } & 2.556092 & 5.787799 & -2.459927 \\ \text { C } & 2.563729 & 4.544438 & -3.095464 \\ \text { C } & 3.004560 & 3.408884 & -2.418211 \\ \text { C } & 3.452696 & 3.497229 & -1.089644 \\ \text { C } & 3.436848 & 4.752609 & -0.460762 \\ \text { C } & 2.992708 & 5.887305 & -1.138436 \\ \text { H } & 2.226387 & 4.456775 & -4.124992 \\ \text { H } & 2.979341 & 6.847332 & -0.629098 \\ \text { C } & -3.059370 & -2.996492 & 1.877034 \\ \text { C } & -2.619348 & -3.692014 & 0.749541 \\ \text { C } & -1.300328 & -3.559218 & 0.315339 \\ \text { C } & -0.388478 & -2.741275 & 1.003343 \\ \text { C } & -0.846083 & -2.046694 & 2.137780 \\ \text { C } & -2.167438 & -2.170404 & 2.565389 \\ \text { H } & -3.303359 & -4.337278 & 0.203649 \\ \text { H } & -2.499838 & -1.619576 & 3.440739\end{array}$




\begin{tabular}{|c|c|c|c|}
\hline C & 3.740229 & -2.560057 & -0.357954 \\
\hline C & 3.013312 & -3.794465 & -0.348910 \\
\hline C & 3.636565 & -4.975217 & -0.837035 \\
\hline C & 4.913135 & -4.942322 & -1.347619 \\
\hline C & 5.618712 & -3.716877 & -1.395154 \\
\hline C & 5.049981 & -2.558879 & -0.912106 \\
\hline $\mathrm{H}$ & 3.075583 & -5.906533 & -0.809718 \\
\hline $\mathrm{H}$ & 5.376759 & -5.849775 & -1.724638 \\
\hline $\mathrm{H}$ & 6.618071 & -3.687574 & -1.820801 \\
\hline $\mathrm{H}$ & 5.600767 & -1.626921 & -0.963278 \\
\hline C & 5.020215 & 0.057495 & 1.063431 \\
\hline C & 5.698817 & 1.319124 & 1.082528 \\
\hline C & 6.884108 & 1.463132 & 1.853747 \\
\hline C & 7.370416 & 0.419993 & 2.606549 \\
\hline C & 6.680140 & -0.814606 & 2.622440 \\
\hline C & 5.538663 & -0.991789 & 1.871683 \\
\hline $\mathrm{H}$ & 7.392754 & 2.424259 & 1.846190 \\
\hline $\mathrm{H}$ & 8.273382 & 0.544286 & 3.197961 \\
\hline $\mathrm{H}$ & 7.050518 & -1.630550 & 3.237204 \\
\hline $\mathrm{H}$ & 5.017302 & -1.941180 & 1.905056 \\
\hline $\mathrm{O}$ & -0.349296 & 0.384694 & -1.135448 \\
\hline $\mathrm{O}$ & 0.524825 & 2.106633 & 0.619474 \\
\hline $\mathrm{H}$ & -0.541719 & 2.435798 & 0.852452 \\
\hline $\mathrm{H}$ & 3.752751 & 4.831312 & 0.575675 \\
\hline $\mathrm{H}$ & 2.207153 & 6.670668 & -2.989041 \\
\hline $\mathrm{H}$ & 3.008352 & 2.448650 & -2.922575 \\
\hline $\mathrm{H}$ & -0.161505 & -1.413167 & 2.689830 \\
\hline $\mathrm{H}$ & -4.086113 & -3.098670 & 2.218978 \\
\hline $\mathrm{H}$ & -0.973764 & -4.080841 & -0.579180 \\
\hline C & -2.583810 & 1.830821 & 1.076356 \\
\hline $\mathrm{O}$ & -1.738746 & 2.786962 & 1.162245 \\
\hline $\mathrm{H}$ & -2.230914 & 0.791769 & 1.081373 \\
\hline C & -3.881935 & 2.073997 & 1.846425 \\
\hline $\mathrm{O}$ & -4.592907 & 3.044768 & 1.727312 \\
\hline $\mathrm{O}$ & -4.065578 & 1.079210 & 2.737075 \\
\hline C & -5.151572 & 1.256196 & 3.687882 \\
\hline $\mathrm{H}$ & -4.836917 & 0.676466 & 4.558911 \\
\hline C & -3.832314 & 0.656153 & -1.192585 \\
\hline C & -3.255707 & 1.879870 & -0.832383 \\
\hline $\mathrm{H}$ & -1.979432 & -0.149560 & -1.519964 \\
\hline$N$ & -2.992403 & -0.337352 & -1.617450 \\
\hline C & -3.316940 & -1.434455 & -2.423759 \\
\hline $\mathrm{O}$ & -4.415254 & -1.746847 & -2.825879 \\
\hline $\mathrm{O}$ & -2.173007 & -2.083459 & -2.715132 \\
\hline
\end{tabular}




$\begin{array}{lrrr}\mathrm{C} & -2.322308 & -3.203230 & -3.600305 \\ \mathrm{H} & -1.314266 & -3.593236 & -3.740700 \\ \mathrm{H} & -2.747283 & -2.883802 & -4.555364 \\ \mathrm{H} & -2.972546 & -3.961395 & -3.155696 \\ \mathrm{H} & -3.915865 & 2.722551 & -0.663414 \\ \mathrm{H} & -2.279030 & 2.102051 & -1.247399 \\ \mathrm{C} & -5.270955 & 0.398593 & -0.983714 \\ \mathrm{C} & -6.207833 & 1.402287 & -1.283211 \\ \mathrm{C} & -5.722223 & -0.813267 & -0.429871 \\ \mathrm{C} & -7.566253 & 1.191737 & -1.055804 \\ \mathrm{H} & -5.872415 & 2.335491 & -1.723723 \\ \mathrm{C} & -7.077122 & -1.013491 & -0.190567 \\ \mathrm{H} & -5.004982 & -1.584053 & -0.170214 \\ \mathrm{C} & -8.003464 & -0.015834 & -0.509376 \\ \mathrm{H} & -8.281119 & 1.969384 & -1.308240 \\ \mathrm{H} & -7.414538 & -1.951629 & 0.241018 \\ \mathrm{H} & -9.062690 & -0.180651 & -0.331528 \\ \mathrm{H} & -5.204539 & 2.314144 & 3.955580 \\ \mathrm{C} & -6.475414 & 0.759715 & 3.131662 \\ \mathrm{H} & -7.250252 & 0.844156 & 3.902760 \\ \mathrm{H} & -6.781587 & 1.354601 & 2.267521 \\ \mathrm{H} & -6.404193 & -0.288804 & 2.827238\end{array}$

Catalyst (R)-1 TS Ethyl Conformation 11

B3LYP/6-31G(d) Energy $=-2849.013267$

B3LYP-D3(BJ)/def2-TZVPP-IEF-PCM(DCM) Energy = -2850.326863

B3LYP-D3(BJ)/def2-TZVPP-IEF-PCM(DCM)//B3LYP/6-31G(d) Free Energy (Quasiharmonic) = 2849.658099

Frequencies (Top 3 out of 279)

1. $-697.0880 \mathrm{~cm}-1$

2. $\quad 9.9291 \mathrm{~cm}-1$

3. $12.7651 \mathrm{~cm}-1$

B3LYP/6-31G(d) Molecular Geometry in Cartesian Coordinates

$\begin{array}{lrrr}\text { C } & 3.821800 & -0.058284 & 0.257178 \\ \text { C } & 3.302652 & 1.067524 & -0.364100 \\ \text { C } & 3.953741 & 2.335975 & -0.368957 \\ \text { C } & 5.139978 & 2.437433 & 0.331342 \\ \text { H } & 5.676573 & 3.382500 & 0.328003\end{array}$




\begin{tabular}{|c|c|c|c|}
\hline C & 1.704817 & -3.815239 & 0.117933 \\
\hline C & 3.107817 & -1.366206 & 0.145290 \\
\hline C & 1.776899 & -1.454275 & 0.525895 \\
\hline C & 1.044919 & -2.679441 & 0.547558 \\
\hline $\mathrm{H}$ & 1.191902 & -4.772739 & 0.153363 \\
\hline 0 & 2.094824 & 0.956615 & -1.045615 \\
\hline$P$ & 0.710937 & 0.818633 & -0.191978 \\
\hline $\mathrm{O}$ & 1.131125 & -0.298665 & 0.940246 \\
\hline C & 2.474417 & 5.800540 & -2.446728 \\
\hline C & 2.488495 & 4.558683 & -3.085134 \\
\hline C & 2.944341 & 3.425566 & -2.413742 \\
\hline C & 3.401476 & 3.514817 & -1.088289 \\
\hline C & 3.378870 & 4.768605 & -0.456448 \\
\hline C & 2.919688 & 5.900862 & -1.128186 \\
\hline $\mathrm{H}$ & 2.144647 & 4.470365 & -4.112483 \\
\hline $\mathrm{H}$ & 2.901564 & 6.859581 & -0.616499 \\
\hline C & -3.030723 & -3.041212 & 1.896761 \\
\hline C & -2.596299 & -3.716320 & 0.754990 \\
\hline C & -1.280599 & -3.572043 & 0.314224 \\
\hline C & -0.367392 & -2.761019 & 1.008241 \\
\hline C & -0.819301 & -2.086497 & 2.156970 \\
\hline C & -2.136678 & -2.223575 & 2.592422 \\
\hline $\mathrm{H}$ & -3.281915 & -4.355259 & 0.203669 \\
\hline $\mathrm{H}$ & -2.464384 & -1.692358 & 3.481756 \\
\hline C & 3.750046 & -2.540462 & -0.378457 \\
\hline C & 3.033016 & -3.780721 & -0.371810 \\
\hline C & 3.662396 & -4.953766 & -0.870474 \\
\hline C & 4.935445 & -4.908096 & -1.388841 \\
\hline C & 5.631006 & -3.676854 & -1.433974 \\
\hline C & 5.056190 & -2.526059 & -0.941012 \\
\hline $\mathrm{H}$ & 3.108883 & -5.889611 & -0.844801 \\
\hline $\mathrm{H}$ & 5.403797 & -5.809801 & -1.773762 \\
\hline $\mathrm{H}$ & 6.627425 & -3.637278 & -1.865678 \\
\hline $\mathrm{H}$ & 5.599263 & -1.589501 & -0.990575 \\
\hline C & 5.017666 & 0.084605 & 1.043371 \\
\hline C & 5.684202 & 1.352672 & 1.061296 \\
\hline C & 6.873809 & 1.505779 & 1.824052 \\
\hline C & 7.375951 & 0.465086 & 2.569854 \\
\hline C & 6.697873 & -0.776253 & 2.586937 \\
\hline C & 5.552469 & -0.962118 & 1.844291 \\
\hline $\mathrm{H}$ & 7.373061 & 2.471833 & 1.815716 \\
\hline $\mathrm{H}$ & 8.282131 & 0.596337 & 3.154834 \\
\hline $\mathrm{H}$ & 7.080891 & -1.590527 & 3.196173 \\
\hline $\mathrm{H}$ & 5.040560 & -1.916641 & 1.878368 \\
\hline
\end{tabular}




\begin{tabular}{|c|c|c|c|}
\hline $\mathrm{O}$ & -0.366170 & 0.357697 & -1.115023 \\
\hline O & 0.490790 & 2.092298 & 0.635020 \\
\hline $\mathrm{H}$ & -0.609770 & 2.435325 & 0.899525 \\
\hline $\mathrm{H}$ & 3.701634 & 4.847764 & 0.577834 \\
\hline $\mathrm{H}$ & 2.114011 & 6.681533 & -2.971310 \\
\hline $\mathrm{H}$ & 2.952855 & 2.466453 & -2.920140 \\
\hline $\mathrm{H}$ & -0.132580 & -1.459251 & 2.713721 \\
\hline $\mathrm{H}$ & -4.054359 & -3.153683 & 2.244709 \\
\hline $\mathrm{H}$ & -0.957550 & -4.078638 & -0.590123 \\
\hline C & -2.576563 & 1.790925 & 1.088979 \\
\hline 0 & -1.754900 & 2.760619 & 1.210966 \\
\hline $\mathrm{H}$ & -2.203638 & 0.761540 & 1.048426 \\
\hline C & -3.922434 & 1.968086 & 1.775312 \\
\hline $\mathrm{O}$ & -4.513189 & 3.017619 & 1.879134 \\
\hline O & -4.344568 & 0.780813 & 2.254390 \\
\hline C & -5.617096 & 0.786768 & 2.955259 \\
\hline $\mathrm{H}$ & -6.292946 & 1.473010 & 2.440195 \\
\hline C & -3.825155 & 0.656325 & -1.223309 \\
\hline C & -3.230250 & 1.870847 & -0.865380 \\
\hline $\mathrm{H}$ & -1.984445 & -0.186069 & -1.521039 \\
\hline$N$ & -3.000431 & -0.357899 & -1.624709 \\
\hline C & -3.342812 & -1.464302 & -2.410818 \\
\hline $\mathrm{O}$ & -4.447834 & -1.769155 & -2.800231 \\
\hline $\mathrm{O}$ & -2.209208 & -2.131819 & -2.698229 \\
\hline C & -2.378025 & -3.266511 & -3.560978 \\
\hline $\mathrm{H}$ & -1.375527 & -3.670304 & -3.701807 \\
\hline $\mathrm{H}$ & -2.807066 & -2.960119 & -4.518441 \\
\hline $\mathrm{H}$ & -3.032999 & -4.008672 & -3.096806 \\
\hline $\mathrm{H}$ & -3.874491 & 2.727832 & -0.708549 \\
\hline $\mathrm{H}$ & -2.235433 & 2.069954 & -1.247676 \\
\hline C & -5.273128 & 0.437196 & -1.032183 \\
\hline C & -6.181364 & 1.454250 & -1.370205 \\
\hline C & -5.757625 & -0.742116 & -0.437590 \\
\hline C & -7.545610 & 1.289797 & -1.137826 \\
\hline $\mathrm{H}$ & -5.819543 & 2.361714 & -1.843042 \\
\hline C & -7.117507 & -0.894659 & -0.191080 \\
\hline $\mathrm{H}$ & -5.061286 & -1.521337 & -0.148401 \\
\hline C & -8.015823 & 0.116906 & -0.545996 \\
\hline $\mathrm{H}$ & -8.238553 & 2.077091 & -1.419671 \\
\hline $\mathrm{H}$ & -7.481202 & -1.807183 & 0.272991 \\
\hline $\mathrm{H}$ & -9.079041 & -0.011106 & -0.361785 \\
\hline $\mathrm{H}$ & -5.986790 & -0.234659 & 2.845090 \\
\hline C & -5.437584 & 1.170360 & 4.415610 \\
\hline $\mathrm{H}$ & -6.398569 & 1.096886 & 4.937658 \\
\hline
\end{tabular}


$\begin{array}{llll}H & -4.725713 & 0.502097 & 4.911228 \\ H & -5.077451 & 2.199051 & 4.503230\end{array}$

Catalyst (R)-1 TS Ethyl Conformation 12

B3LYP/6-31G(d) Energy $=-2849.013345$

B3LYP-D3(BJ)/def2-TZVPP-IEF-PCM(DCM) Energy = -2850.327645

B3LYP-D3(BJ)/def2-TZVPP-IEF-PCM(DCM)//B3LYP/6-31G(d) Free Energy (Quasiharmonic) = 2849.659163

Frequencies (Top 3 out of 279)

1. $-698.3908 \mathrm{~cm}-1$

2. $\quad 8.7196 \mathrm{~cm}-1$

3. $\quad 11.0828 \mathrm{~cm}-1$

B3LYP/6-31G(d) Molecular Geometry in Cartesian Coordinates

$\begin{array}{llll}\text { C } & 3.841481 & -0.070088 & 0.248545 \\ \text { C } & 3.312923 & 1.078626 & -0.320795 \\ \text { C } & 3.964335 & 2.346500 & -0.286625 \\ \text { C } & 5.161172 & 2.421327 & 0.398842 \\ \text { H } & 5.697839 & 3.366038 & 0.423827 \\ \text { C } & 1.716903 & -3.816936 & -0.006709 \\ \text { C } & 3.124858 & -1.372523 & 0.097293 \\ \text { C } & 1.799894 & -1.474371 & 0.494592 \\ \text { C } & 1.066189 & -2.698401 & 0.478354 \\ \text { H } & 1.202365 & -4.774239 & -0.002244 \\ \text { O } & 2.094969 & 0.993520 & -0.987342 \\ \text { P } & 0.723185 & 0.822269 & -0.118930 \\ \text { O } & 1.161670 & -0.335583 & 0.963862 \\ \text { C } & 2.453661 & 5.887663 & -2.206838 \\ \text { C } & 2.458655 & 4.671397 & -2.892885 \\ \text { C } & 2.924683 & 3.513579 & -2.272571 \\ \text { C } & 3.401365 & 3.551934 & -0.951548 \\ \text { C } & 3.387847 & 4.780378 & -0.271526 \\ \text { C } & 2.918420 & 5.937352 & -0.892153 \\ \text { H } & 2.099729 & 4.622564 & -3.917718 \\ \text { H } & 2.907599 & 6.875571 & -0.343595 \\ \text { C } & -2.986421 & -3.108562 & 1.880480 \\ \text { C } & -2.575615 & -3.730092 & 0.700220 \\ \text { C } & -1.267158 & -3.570393 & 0.243586 \\ \text { C } & -0.338594 & -2.795810 & 0.958352\end{array}$




\begin{tabular}{|c|c|c|c|}
\hline C & -0.767008 & -2.173633 & 2.144837 \\
\hline C & -2.076636 & -2.327538 & 2.597508 \\
\hline $\mathrm{H}$ & -3.273723 & -4.339984 & 0.131922 \\
\hline $\mathrm{H}$ & -2.385165 & -1.840223 & 3.518405 \\
\hline C & 3.757074 & -2.525885 & -0.482164 \\
\hline C & 3.037823 & -3.764520 & -0.514441 \\
\hline C & 3.657505 & -4.917426 & -1.069056 \\
\hline C & 4.922763 & -4.852697 & -1.604216 \\
\hline C & 5.619880 & -3.621535 & -1.610517 \\
\hline C & 5.054642 & -2.490667 & -1.063327 \\
\hline $\mathrm{H}$ & 3.102686 & -5.852847 & -1.072536 \\
\hline $\mathrm{H}$ & 5.383606 & -5.738886 & -2.031871 \\
\hline $\mathrm{H}$ & 6.609804 & -3.565968 & -2.055211 \\
\hline $\mathrm{H}$ & 5.598625 & -1.553544 & -1.083669 \\
\hline C & 5.049369 & 0.042643 & 1.020981 \\
\hline C & 5.716397 & 1.309314 & 1.077752 \\
\hline C & 6.917718 & 1.433118 & 1.827353 \\
\hline C & 7.431142 & 0.364408 & 2.524263 \\
\hline C & 6.753134 & -0.876925 & 2.503634 \\
\hline C & 5.596265 & -1.034210 & 1.772242 \\
\hline $\mathrm{H}$ & 7.417020 & 2.398947 & 1.848803 \\
\hline $\mathrm{H}$ & 8.346337 & 0.473166 & 3.099748 \\
\hline $\mathrm{H}$ & 7.145411 & -1.714113 & 3.074731 \\
\hline $\mathrm{H}$ & 5.084647 & -1.989497 & 1.777136 \\
\hline $\mathrm{O}$ & -0.365388 & 0.394689 & -1.044729 \\
\hline 0 & 0.512169 & 2.062553 & 0.758793 \\
\hline $\mathrm{H}$ & -0.587032 & 2.429269 & 1.007889 \\
\hline $\mathrm{H}$ & 3.725954 & 4.819818 & 0.760126 \\
\hline $\mathrm{H}$ & 2.085255 & 6.787952 & -2.691586 \\
\hline $\mathrm{H}$ & 2.925942 & 2.574713 & -2.815669 \\
\hline $\mathrm{H}$ & -0.067971 & -1.574788 & 2.717368 \\
\hline $\mathrm{H}$ & -4.003473 & -3.235219 & 2.242576 \\
\hline $\mathrm{H}$ & -0.961686 & -4.035665 & -0.688637 \\
\hline C & -2.570057 & 1.832034 & 1.159723 \\
\hline $\mathrm{O}$ & -1.725355 & 2.779134 & 1.304384 \\
\hline $\mathrm{H}$ & -2.221815 & 0.794099 & 1.115153 \\
\hline C & -3.920410 & 2.038843 & 1.830084 \\
\hline $\mathrm{O}$ & -4.505376 & 3.093974 & 1.902851 \\
\hline $\mathrm{O}$ & -4.355335 & 0.873331 & 2.345593 \\
\hline C & -5.628323 & 0.932173 & 3.040480 \\
\hline $\mathrm{H}$ & -5.585018 & 1.741857 & 3.774519 \\
\hline C & -3.809118 & 0.758913 & -1.181683 \\
\hline C & -3.190385 & 1.954119 & -0.801935 \\
\hline $\mathrm{H}$ & -1.986050 & -0.119240 & -1.482271 \\
\hline
\end{tabular}




$\begin{array}{llll}\mathrm{N} & -3.004682 & -0.267391 & -1.594815 \\ \mathrm{C} & -3.367655 & -1.349612 & -2.404633 \\ \mathrm{O} & -4.477701 & -1.622213 & -2.803791 \\ \mathrm{O} & -2.247909 & -2.035878 & -2.702111 \\ \mathrm{C} & -2.438618 & -3.148585 & -3.588702 \\ \mathrm{H} & -1.444655 & -3.570945 & -3.735455 \\ \mathrm{H} & -2.858092 & -2.813178 & -4.540648 \\ \mathrm{H} & -3.110786 & -3.885888 & -3.141706 \\ \mathrm{H} & -3.815790 & 2.823323 & -0.636835 \\ \mathrm{H} & -2.187239 & 2.134705 & -1.171271 \\ \mathrm{C} & -5.261998 & 0.567244 & -0.997717 \\ \mathrm{C} & -6.148145 & 1.609062 & -1.318307 \\ \mathrm{C} & -5.771885 & -0.611614 & -0.423835 \\ \mathrm{C} & -7.515635 & 1.470042 & -1.088685 \\ \mathrm{H} & -5.766761 & 2.516868 & -1.774679 \\ \mathrm{C} & -7.134904 & -0.739364 & -0.179833 \\ \mathrm{H} & -5.092816 & -1.411511 & -0.150394 \\ \mathrm{C} & -8.011268 & 0.297566 & -0.516808 \\ \mathrm{H} & -8.191323 & 2.276931 & -1.356535 \\ \mathrm{H} & -7.518313 & -1.652023 & 0.267721 \\ \mathrm{H} & -9.077072 & 0.189117 & -0.335042 \\ \mathrm{H} & -6.406134 & 1.178146 & 2.311252 \\ \mathrm{C} & -5.860434 & -0.418580 & 3.688329 \\ \mathrm{H} & -6.817204 & -0.412900 & 4.221883 \\ \mathrm{H} & -5.890596 & -1.212152 & 2.935171 \\ \mathrm{H} & -5.068052 & -0.650406 & 4.407265\end{array}$

Catalyst (R)-1 TS Ethyl Conformation 13

B3LYP/6-31G(d) Energy $=-2849.01561$

B3LYP-D3(BJ)/def2-TZVPP-IEF-PCM(DCM) Energy = -2850.326469

B3LYP-D3(BJ)/def2-TZVPP-IEF-PCM(DCM)//B3LYP/6-31G(d) Free Energy (Quasiharmonic) = 2849.657692

Frequencies (Top 3 out of 279)

1. $-667.7562 \mathrm{~cm}-1$

2. $\quad 9.1966 \mathrm{~cm}-1$

3. $12.4102 \mathrm{~cm}-1$

B3LYP/6-31G(d) Molecular Geometry in Cartesian Coordinates

$\begin{array}{llll}\text { C } & 3.195528 & -1.285458 & 0.220152\end{array}$ 


\begin{tabular}{|c|c|c|c|}
\hline C & 1.869085 & -1.427929 & 0.599957 \\
\hline C & 1.207067 & -2.689300 & 0.690136 \\
\hline C & 1.937282 & -3.808604 & 0.337446 \\
\hline $\mathrm{H}$ & 1.479365 & -4.790129 & 0.426734 \\
\hline C & 5.006348 & 2.632835 & 0.161440 \\
\hline C & 3.830934 & 0.066797 & 0.250034 \\
\hline C & 3.252449 & 1.118553 & -0.444359 \\
\hline C & 3.831328 & 2.418548 & -0.532322 \\
\hline $\mathrm{H}$ & 5.489464 & 3.604122 & 0.095823 \\
\hline $\mathrm{O}$ & 1.157298 & -0.286933 & 0.943285 \\
\hline$P$ & 0.681065 & 0.736246 & -0.252064 \\
\hline $\mathrm{O}$ & 2.054128 & 0.896764 & -1.117170 \\
\hline C & -2.878742 & -3.182307 & 1.964599 \\
\hline C & -2.377366 & -3.907279 & 0.882698 \\
\hline C & -1.058299 & -3.723759 & 0.467322 \\
\hline C & -0.207806 & -2.823345 & 1.130172 \\
\hline C & -0.724925 & -2.104725 & 2.223423 \\
\hline C & -2.046742 & -2.279350 & 2.630991 \\
\hline $\mathrm{H}$ & -3.014805 & -4.612900 & 0.355271 \\
\hline $\mathrm{H}$ & -2.432524 & -1.705319 & 3.468150 \\
\hline C & 2.174966 & 5.648834 & -2.841539 \\
\hline C & 2.258463 & 4.368964 & -3.393741 \\
\hline C & 2.772124 & 3.310477 & -2.646545 \\
\hline C & 3.218435 & 3.514074 & -1.330039 \\
\hline C & 3.125519 & 4.804899 & -0.785145 \\
\hline C & 2.608859 & 5.862436 & -1.532701 \\
\hline $\mathrm{H}$ & 1.924266 & 4.192437 & -4.412877 \\
\hline $\mathrm{H}$ & 2.537685 & 6.851515 & -1.087681 \\
\hline C & 5.012058 & 0.329225 & 1.027729 \\
\hline C & 5.606204 & 1.631262 & 0.963099 \\
\hline C & 6.780718 & 1.901324 & 1.716769 \\
\hline C & 7.335700 & 0.942204 & 2.531301 \\
\hline C & 6.728108 & -0.331497 & 2.629286 \\
\hline C & 5.599647 & -0.630421 & 1.897735 \\
\hline $\mathrm{H}$ & 7.225109 & 2.891288 & 1.645435 \\
\hline $\mathrm{H}$ & 8.229495 & 1.162697 & 3.108469 \\
\hline $\mathrm{H}$ & 7.152273 & -1.080693 & 3.292371 \\
\hline $\mathrm{H}$ & 5.141642 & -1.607815 & 1.993801 \\
\hline C & 3.910002 & -2.450037 & -0.225876 \\
\hline C & 3.266447 & -3.727283 & -0.143900 \\
\hline C & 3.967784 & -4.890539 & -0.563292 \\
\hline C & 5.240528 & -4.803102 & -1.076999 \\
\hline C & 5.863205 & -3.538388 & -1.197628 \\
\hline C & 5.217759 & -2.394471 & -0.782158 \\
\hline
\end{tabular}




\begin{tabular}{|c|c|c|c|}
\hline $\mathrm{H}$ & 3.469483 & -5.853723 & -0.480908 \\
\hline $\mathrm{H}$ & 5.764109 & -5.698345 & -1.401070 \\
\hline $\mathrm{H}$ & 6.859244 & -3.467645 & -1.626255 \\
\hline $\mathrm{H}$ & 5.705616 & -1.432679 & -0.889267 \\
\hline $\mathrm{O}$ & -0.376686 & 0.169260 & -1.137297 \\
\hline 0 & 0.405232 & 2.051359 & 0.494728 \\
\hline $\mathrm{H}$ & -0.679691 & 2.300242 & 0.850917 \\
\hline $\mathrm{H}$ & -0.086203 & -1.409937 & 2.756856 \\
\hline $\mathrm{H}$ & -3.907373 & -3.316188 & 2.288318 \\
\hline $\mathrm{H}$ & -0.684862 & -4.267854 & -0.395103 \\
\hline $\mathrm{H}$ & 3.439611 & 4.971533 & 0.241381 \\
\hline $\mathrm{H}$ & 1.770316 & 6.471483 & -3.425324 \\
\hline $\mathrm{H}$ & 2.834492 & 2.321119 & -3.086586 \\
\hline C & -2.589435 & 1.502641 & 1.077383 \\
\hline $\mathrm{O}$ & -1.844651 & 2.527932 & 1.241074 \\
\hline $\mathrm{H}$ & -2.138211 & 0.509255 & 0.974427 \\
\hline C & -3.913777 & 1.441380 & 1.814250 \\
\hline 0 & -4.358737 & 0.392601 & 2.237760 \\
\hline $\mathrm{O}$ & -4.496617 & 2.639562 & 1.931494 \\
\hline C & -5.764641 & 2.678720 & 2.637123 \\
\hline $\mathrm{H}$ & -6.342469 & 1.791193 & 2.367783 \\
\hline C & -3.856819 & 0.374709 & -1.189555 \\
\hline C & -3.276678 & 1.603091 & -0.850637 \\
\hline $\mathrm{H}$ & -2.006147 & -0.443825 & -1.482861 \\
\hline$N$ & -3.019824 & -0.638119 & -1.560030 \\
\hline C & -3.355562 & -1.802017 & -2.262913 \\
\hline 0 & -4.463957 & -2.163799 & -2.587342 \\
\hline $\mathrm{O}$ & -2.212092 & -2.450039 & -2.553315 \\
\hline C & -2.376346 & -3.651484 & -3.321063 \\
\hline $\mathrm{H}$ & -2.859462 & -3.433208 & -4.276901 \\
\hline $\mathrm{H}$ & -2.980934 & -4.378237 & -2.771989 \\
\hline $\mathrm{H}$ & -1.366694 & -4.030273 & -3.479036 \\
\hline $\mathrm{H}$ & -3.938120 & 2.448946 & -0.705499 \\
\hline $\mathrm{H}$ & -2.288587 & 1.817362 & -1.242869 \\
\hline C & -5.306912 & 0.159292 & -1.006990 \\
\hline C & -6.210316 & 1.137078 & -1.456359 \\
\hline C & -5.796591 & -0.957140 & -0.306968 \\
\hline C & -7.577896 & 0.989716 & -1.234104 \\
\hline $\mathrm{H}$ & -5.839633 & 1.995580 & -2.008255 \\
\hline C & -7.160212 & -1.087982 & -0.067297 \\
\hline $\mathrm{H}$ & -5.102763 & -1.697948 & 0.073164 \\
\hline C & -8.054369 & -0.121445 & -0.536077 \\
\hline $\mathrm{H}$ & -8.268960 & 1.740670 & -1.606222 \\
\hline $\mathrm{H}$ & -7.527767 & -1.947111 & 0.486266 \\
\hline
\end{tabular}




$\begin{array}{llll}\text { H } & -9.120108 & -0.234552 & -0.356297 \\ \text { H } & -6.259058 & 3.568841 & 2.241708 \\ \text { C } & -5.555477 & 2.776634 & 4.140027 \\ \text { H } & -6.523914 & 2.888358 & 4.641165 \\ \text { H } & -5.073111 & 1.873163 & 4.523279 \\ \text { H } & -4.935139 & 3.643062 & 4.389924\end{array}$

Catalyst (R)-1 TS Ethyl Conformation 14

$B 3 L Y P / 6-31 G(d)$ Energy $=-2849.015196$

B3LYP-D3(BJ)/def2-TZVPP-IEF-PCM(DCM) Energy $=-2850.32715$

B3LYP-D3(BJ)/def2-TZVPP-IEF-PCM(DCM)//B3LYP/6-31G(d) Free Energy (Quasiharmonic) = 2849.658506

Frequencies (Top 3 out of 279)

1. $-666.2279 \mathrm{~cm}-1$

2. $\quad 8.8387 \mathrm{~cm}-1$

3. $\quad 12.3769 \mathrm{~cm}-1$

B3LYP/6-31G(d) Molecular Geometry in Cartesian Coordinates

$\begin{array}{llll}\text { C } & -3.220309 & -1.279209 & -0.181511 \\ \text { C } & -1.900729 & -1.430272 & -0.581349 \\ \text { C } & -1.239147 & -2.693139 & -0.652461 \\ \text { C } & -1.961478 & -3.803635 & -0.258137 \\ \text { H } & -1.504519 & -4.786910 & -0.331698 \\ \text { C } & -5.037608 & 2.636617 & -0.197209 \\ \text { C } & -3.858709 & 0.070876 & -0.236428 \\ \text { C } & -3.270193 & 1.142219 & 0.418419 \\ \text { C } & -3.850069 & 2.443219 & 0.481159 \\ \text { H } & -5.521418 & 3.608605 & -0.149615 \\ \text { O } & -1.196521 & -0.297912 & -0.966154 \\ \text { P } & -0.701566 & 0.757370 & 0.192921 \\ \text { O } & -2.059778 & 0.941044 & 1.076016 \\ \text { C } & 2.822523 & -3.214610 & -1.991913 \\ \text { C } & 2.341962 & -3.914588 & -0.884410 \\ \text { C } & 1.030638 & -3.722146 & -0.449062 \\ \text { C } & 0.167159 & -2.837340 & -1.116196 \\ \text { C } & 0.663153 & -2.144281 & -2.235437 \\ \text { C } & 1.977214 & -2.328113 & -2.663588 \\ \text { H } & 2.989816 & -4.607263 & -0.352564 \\ \text { H } & 2.346453 & -1.774553 & -3.521805\end{array}$




\begin{tabular}{|c|c|c|c|}
\hline C & -2.160180 & 5.738080 & 2.671709 \\
\hline C & -2.232055 & 4.473858 & 3.260393 \\
\hline C & -2.756514 & 3.394494 & 2.551557 \\
\hline C & -3.225472 & 3.561108 & 1.237734 \\
\hline C & -3.144085 & 4.836484 & 0.655883 \\
\hline C & -2.616607 & 5.914909 & 1.365057 \\
\hline $\mathrm{H}$ & -1.880281 & 4.325994 & 4.278175 \\
\hline $\mathrm{H}$ & -2.554680 & 6.891397 & 0.891756 \\
\hline C & -5.054046 & 0.310117 & -0.999899 \\
\hline C & -5.649557 & 1.612535 & -0.960354 \\
\hline C & -6.837803 & 1.860131 & -1.700074 \\
\hline C & -7.405287 & 0.878256 & -2.478051 \\
\hline C & -6.797021 & -0.396736 & -2.551944 \\
\hline C & -5.655155 & -0.673855 & -1.832708 \\
\hline $\mathrm{H}$ & -7.282778 & 2.851025 & -1.647934 \\
\hline $\mathrm{H}$ & -8.309621 & 1.081536 & -3.045027 \\
\hline $\mathrm{H}$ & -7.231414 & -1.164445 & -3.186620 \\
\hline $\mathrm{H}$ & -5.197090 & -1.652855 & -1.910182 \\
\hline C & -3.924839 & -2.432530 & 0.307556 \\
\hline C & -3.281368 & -3.710975 & 0.246189 \\
\hline C & -3.973276 & -4.863597 & 0.708422 \\
\hline C & -5.236191 & -4.763921 & 1.243719 \\
\hline C & -5.858060 & -3.496999 & 1.343549 \\
\hline C & -5.221992 & -2.363664 & 0.886664 \\
\hline $\mathrm{H}$ & -3.475486 & -5.828233 & 0.641319 \\
\hline $\mathrm{H}$ & -5.752463 & -5.650935 & 1.600491 \\
\hline $\mathrm{H}$ & -6.845930 & -3.416020 & 1.788937 \\
\hline $\mathrm{H}$ & -5.708941 & -1.399788 & 0.978109 \\
\hline $\mathrm{O}$ & 0.371143 & 0.215705 & 1.076021 \\
\hline $\mathrm{O}$ & -0.435637 & 2.050904 & -0.593795 \\
\hline $\mathrm{H}$ & 0.647520 & 2.275072 & -0.969997 \\
\hline $\mathrm{H}$ & 0.014070 & -1.462378 & -2.772940 \\
\hline $\mathrm{H}$ & 3.845145 & -3.355082 & -2.331388 \\
\hline $\mathrm{H}$ & 0.673635 & -4.246905 & 0.432093 \\
\hline $\mathrm{H}$ & -3.475868 & 4.974292 & -0.369351 \\
\hline $\mathrm{H}$ & -1.747091 & 6.577056 & 3.225582 \\
\hline $\mathrm{H}$ & -2.809716 & 2.417579 & 3.019721 \\
\hline C & 2.562499 & 1.467969 & -1.211872 \\
\hline $\mathrm{O}$ & 1.806689 & 2.482498 & -1.387791 \\
\hline $\mathrm{H}$ & 2.122651 & 0.476292 & -1.056827 \\
\hline C & 3.856609 & 1.387976 & -2.001728 \\
\hline $\mathrm{O}$ & 4.331141 & 0.322666 & -2.344669 \\
\hline $\mathrm{O}$ & 4.357962 & 2.594287 & -2.286843 \\
\hline C & 5.536413 & 2.631533 & -3.133200 \\
\hline
\end{tabular}




$\begin{array}{llll}\text { H } & 5.464724 & 3.595359 & -3.642313 \\ \mathrm{C} & 3.861779 & 0.403416 & 1.077836 \\ \mathrm{C} & 3.304604 & 1.629791 & 0.692900 \\ \mathrm{H} & 1.997450 & -0.376029 & 1.399381 \\ \mathrm{~N} & 3.009385 & -0.582612 & 1.478347 \\ \mathrm{C} & 3.327890 & -1.736486 & 2.207673 \\ \mathrm{O} & 4.430885 & -2.111955 & 2.534127 \\ \mathrm{O} & 2.174014 & -2.354330 & 2.519843 \\ \mathrm{C} & 2.318923 & -3.540416 & 3.314917 \\ \mathrm{H} & 2.811673 & -3.309164 & 4.262755 \\ \mathrm{H} & 2.906003 & -4.291667 & 2.780010 \\ \mathrm{H} & 1.302883 & -3.895134 & 3.487027 \\ \mathrm{H} & 3.984875 & 2.455620 & 0.518041 \\ \mathrm{H} & 2.325935 & 1.880943 & 1.087126 \\ \mathrm{C} & 5.312705 & 0.160226 & 0.932570 \\ \mathrm{C} & 6.219988 & 1.108276 & 1.432612 \\ \mathrm{C} & 5.800638 & -0.962345 & 0.242293 \\ \mathrm{C} & 7.592164 & 0.922502 & 1.274159 \\ \mathrm{H} & 5.847083 & 1.972195 & 1.974712 \\ \mathrm{C} & 7.169783 & -1.128907 & 0.062501 \\ \mathrm{H} & 5.103106 & -1.680413 & -0.173595 \\ \mathrm{C} & 8.068545 & -0.194597 & 0.586002 \\ \mathrm{H} & 8.286369 & 1.649149 & 1.686443 \\ \mathrm{H} & 7.538436 & -1.992457 & -0.483463 \\ \mathrm{H} & 9.137848 & -0.337393 & 0.455339 \\ \mathrm{H} & 5.463468 & 1.825844 & -3.867650 \\ \mathrm{C} & 6.813658 & 2.522716 & -2.316404 \\ \mathrm{H} & 7.681417 & 2.640434 & -2.976037 \\ \mathrm{H} & 6.855712 & 3.306084 & -1.552764 \\ \mathrm{H} & 6.883034 & 1.547937 & -1.826765\end{array}$

Catalyst (R)-1 TS Ethyl Conformation 15

B3LYP/6-31G(d) Energy $=-2849.016013$

B3LYP-D3(BJ)/def2-TZVPP-IEF-PCM(DCM) Energy $=-2850.327157$

B3LYP-D3(BJ)/def2-TZVPP-IEF-PCM(DCM)//B3LYP/6-31G(d) Free Energy (Quasiharmonic) = 2849.658696

Frequencies (Top 3 out of 279)

1. $-673.0387 \mathrm{~cm}-1$

2. $9.2195 \mathrm{~cm}-1$

3. $\quad 12.7925 \mathrm{~cm}-1$ 
B3LYP/6-31G(d) Molecular Geometry in Cartesian Coordinates

\begin{tabular}{|c|c|c|c|}
\hline C & -3.239595 & -1.245302 & -0.220434 \\
\hline C & -1.919321 & -1.417108 & -0.609509 \\
\hline C & -1.285178 & -2.692626 & -0.701159 \\
\hline C & -2.036686 & -3.795119 & -0.340340 \\
\hline $\mathrm{H}$ & -1.600613 & -4.786466 & -0.430443 \\
\hline C & -4.965812 & 2.710925 & -0.158669 \\
\hline C & -3.846085 & 0.120189 & -0.249224 \\
\hline C & -3.240206 & 1.160984 & 0.438301 \\
\hline C & -3.790642 & 2.473226 & 0.527178 \\
\hline $\mathrm{H}$ & -5.427647 & 3.692439 & -0.091989 \\
\hline $\mathrm{O}$ & -1.185894 & -0.292462 & -0.961026 \\
\hline$P$ & -0.679052 & 0.723259 & 0.228205 \\
\hline $\mathrm{O}$ & -2.042054 & 0.915220 & 1.102935 \\
\hline C & 2.779490 & -3.276999 & -2.004126 \\
\hline C & 2.270486 & -3.988483 & -0.916833 \\
\hline C & 0.958825 & -3.775372 & -0.492200 \\
\hline C & 0.123241 & -2.858222 & -1.151053 \\
\hline C & 0.647802 & -2.153446 & -2.249777 \\
\hline C & 1.962501 & -2.357565 & -2.666597 \\
\hline $\mathrm{H}$ & 2.896270 & -4.706722 & -0.392470 \\
\hline $\mathrm{H}$ & 2.354716 & -1.793683 & -3.507617 \\
\hline C & -2.049910 & 5.672914 & 2.816915 \\
\hline C & -2.156238 & 4.396258 & 3.372623 \\
\hline C & -2.697437 & 3.347199 & 2.631595 \\
\hline C & -3.148937 & 3.557289 & 1.317875 \\
\hline C & -3.032864 & 4.844711 & 0.769374 \\
\hline C & -2.488716 & 5.892770 & 1.510753 \\
\hline $\mathrm{H}$ & -1.818441 & 4.214928 & 4.389729 \\
\hline $\mathrm{H}$ & -2.400077 & 6.879190 & 1.062966 \\
\hline C & -5.026933 & 0.405931 & -1.019057 \\
\hline C & -5.592676 & 1.720510 & -0.953494 \\
\hline C & -6.766581 & 2.013790 & -1.699396 \\
\hline C & -7.347800 & 1.064774 & -2.507440 \\
\hline C & -6.768276 & -0.221861 & -2.606488 \\
\hline C & -5.641182 & -0.543056 & -1.882310 \\
\hline $\mathrm{H}$ & -7.189205 & 3.013197 & -1.627424 \\
\hline $\mathrm{H}$ & -8.240832 & 1.302918 & -3.078747 \\
\hline $\mathrm{H}$ & -7.213142 & -0.963433 & -3.264558 \\
\hline $\mathrm{H}$ & -5.204861 & -1.530249 & -1.979124 \\
\hline C & -3.975599 & -2.393147 & 0.233875 \\
\hline C & -3.360237 & -3.684124 & 0.150460 \\
\hline
\end{tabular}




\begin{tabular}{|c|c|c|c|}
\hline$C$ & -4.083279 & -4.831016 & 0.577986 \\
\hline C & -5.349985 & -4.715002 & 1.100875 \\
\hline C & -5.944422 & -3.436900 & 1.222885 \\
\hline C & -5.277670 & -2.308134 & 0.799691 \\
\hline $\mathrm{H}$ & -3.606410 & -5.804887 & 0.494391 \\
\hline $\mathrm{H}$ & -5.890251 & -5.598001 & 1.431099 \\
\hline $\mathrm{H}$ & -6.935477 & -3.343720 & 1.658717 \\
\hline $\mathrm{H}$ & -5.743909 & -1.335808 & 0.907997 \\
\hline 0 & 0.372320 & 0.135058 & 1.107327 \\
\hline O & -0.380391 & 2.030310 & -0.523485 \\
\hline $\mathrm{H}$ & 0.706658 & 2.254392 & -0.895744 \\
\hline $\mathrm{H}$ & 0.020376 & -1.446191 & -2.780228 \\
\hline $\mathrm{H}$ & 3.802509 & -3.433962 & -2.335186 \\
\hline $\mathrm{H}$ & 0.580005 & -4.309316 & 0.374219 \\
\hline $\mathrm{H}$ & -3.350847 & 5.015716 & -0.255232 \\
\hline $\mathrm{H}$ & -1.623895 & 6.488139 & 3.395902 \\
\hline $\mathrm{H}$ & -2.777347 & 2.360315 & 3.074344 \\
\hline C & 2.592440 & 1.413376 & -1.138440 \\
\hline $\mathrm{O}$ & 1.869565 & 2.454907 & -1.298895 \\
\hline $\mathrm{H}$ & 2.119794 & 0.430749 & -1.028954 \\
\hline C & 3.910272 & 1.320410 & -1.882906 \\
\hline $\mathrm{O}$ & 4.328736 & 0.263966 & -2.313385 \\
\hline $\mathrm{O}$ & 4.524552 & 2.501178 & -2.005542 \\
\hline C & 5.789870 & 2.486079 & -2.713940 \\
\hline $\mathrm{H}$ & 5.624106 & 2.071363 & -3.712972 \\
\hline C & 3.854759 & 0.267805 & 1.122982 \\
\hline C & 3.296029 & 1.506231 & 0.785445 \\
\hline $\mathrm{H}$ & 1.991337 & -0.511631 & 1.440669 \\
\hline $\mathrm{N}$ & 3.001703 & -0.726103 & 1.507899 \\
\hline C & 3.322162 & -1.893379 & 2.212093 \\
\hline O & 4.426854 & -2.274892 & 2.526590 \\
\hline 0 & 2.169659 & -2.518273 & 2.516851 \\
\hline C & 2.318846 & -3.719901 & 3.287421 \\
\hline $\mathrm{H}$ & 2.816307 & -3.507585 & 4.237220 \\
\hline $\mathrm{H}$ & 2.903310 & -4.460202 & 2.734672 \\
\hline $\mathrm{H}$ & 1.303804 & -4.078472 & 3.457539 \\
\hline $\mathrm{H}$ & 3.972485 & 2.338035 & 0.629042 \\
\hline $\mathrm{H}$ & 2.316084 & 1.741746 & 1.185782 \\
\hline C & 5.297476 & 0.022056 & 0.921097 \\
\hline C & 6.226686 & 0.986493 & 1.346291 \\
\hline C & 5.754177 & -1.108831 & 0.222036 \\
\hline C & 7.587098 & 0.812793 & 1.099800 \\
\hline $\mathrm{H}$ & 5.881986 & 1.855595 & 1.898435 \\
\hline C & 7.110566 & -1.266765 & -0.041016 \\
\hline
\end{tabular}




$\begin{array}{llll}\text { H } & 5.040333 & -1.839553 & -0.139983 \\ \mathrm{C} & 8.030529 & -0.312626 & 0.402350 \\ \mathrm{H} & 8.298496 & 1.553540 & 1.453675 \\ \mathrm{H} & 7.452149 & -2.136788 & -0.594133 \\ \mathrm{H} & 9.090541 & -0.446558 & 0.204019 \\ \mathrm{H} & 6.476920 & 1.819298 & -2.183126 \\ \mathrm{C} & 6.297422 & 3.913956 & -2.763291 \\ \mathrm{H} & 7.254091 & 3.948080 & -3.295956 \\ \mathrm{H} & 5.587197 & 4.563013 & -3.284714 \\ \mathrm{H} & 6.450065 & 4.310198 & -1.754356\end{array}$

Catalyst (R)-1 TS Ethyl Conformation 16

B3LYP/6-31G(d) Energy $=-2849.01847$

B3LYP-D3(BJ)/def2-TZVPP-IEF-PCM(DCM) Energy $=-2850.327768$

B3LYP-D3(BJ)/def2-TZVPP-IEF-PCM(DCM)//B3LYP/6-31G(d) Free Energy (Quasiharmonic) = 2849.658619

Frequencies (Top 3 out of 279)

1. $-542.4471 \mathrm{~cm}-1$

2. $\quad 7.9622 \mathrm{~cm}-1$

3. $\quad 11.9765 \mathrm{~cm}-1$

B3LYP/6-31G(d) Molecular Geometry in Cartesian Coordinates

$\begin{array}{llll}\text { C } & 3.779087 & 0.261210 & 0.391664 \\ \text { C } & 2.874658 & 1.298475 & 0.204137 \\ \text { C } & 3.160405 & 2.652136 & 0.556102 \\ \text { C } & 4.354815 & 2.901868 & 1.202886 \\ \text { H } & 4.595376 & 3.922534 & 1.488383 \\ \text { C } & 2.944110 & -3.691316 & -1.136684 \\ \text { C } & 3.513113 & -1.091105 & -0.185535 \\ \text { C } & 2.330820 & -1.745842 & 0.113262 \\ \text { C } & 2.015619 & -3.062733 & -0.330624 \\ \text { H } & 2.753008 & -4.706540 & -1.474417 \\ \text { O } & 1.675935 & 1.052573 & -0.456110 \\ \text { P } & 0.520130 & 0.089059 & 0.172545 \\ \text { O } & 1.396412 & -1.080692 & 0.901738 \\ \text { C } & 0.677920 & 6.015393 & -0.476067 \\ \text { C } & 2.028515 & 5.989734 & -0.827341 \\ \text { C } & 2.815114 & 4.886621 & -0.496125 \\ \text { C } & 2.268333 & 3.788502 & 0.188936\end{array}$




\begin{tabular}{|c|c|c|c|}
\hline$C$ & 0.908756 & 3.823800 & 0.536443 \\
\hline C & 0.124719 & 4.929760 & 0.207139 \\
\hline $\mathrm{H}$ & 2.471180 & 6.826034 & -1.362386 \\
\hline $\mathrm{H}$ & -0.923420 & 4.943484 & 0.495073 \\
\hline C & -1.647418 & -5.083915 & 0.686284 \\
\hline C & -1.177470 & -5.083473 & -0.627776 \\
\hline C & 0.004441 & -4.415712 & -0.949707 \\
\hline C & 0.741383 & -3.737277 & 0.034572 \\
\hline C & 0.258498 & -3.746373 & 1.354872 \\
\hline C & -0.923306 & -4.413562 & 1.675769 \\
\hline $\mathrm{H}$ & -1.734405 & -5.596583 & -1.407567 \\
\hline $\mathrm{H}$ & -1.277715 & -4.414820 & 2.703159 \\
\hline C & 4.433057 & -1.728356 & -1.090248 \\
\hline C & 4.139975 & -3.053803 & -1.550470 \\
\hline C & 5.045736 & -3.702556 & -2.433138 \\
\hline C & 6.180334 & -3.065184 & -2.877852 \\
\hline C & 6.450526 & -1.741405 & -2.459267 \\
\hline C & 5.602610 & -1.091752 & -1.589152 \\
\hline $\mathrm{H}$ & 4.814091 & -4.712988 & -2.761656 \\
\hline $\mathrm{H}$ & 6.861467 & -3.568664 & -3.558357 \\
\hline $\mathrm{H}$ & 7.333551 & -1.228947 & -2.831343 \\
\hline $\mathrm{H}$ & 5.820694 & -0.074349 & -1.287132 \\
\hline C & 4.969707 & 0.523202 & 1.155661 \\
\hline C & 5.256422 & 1.868096 & 1.554122 \\
\hline C & 6.431938 & 2.139860 & 2.305263 \\
\hline C & 7.284822 & 1.126430 & 2.675513 \\
\hline C & 6.987720 & -0.208143 & 2.312200 \\
\hline C & 5.863760 & -0.501846 & 1.571714 \\
\hline $\mathrm{H}$ & 6.636762 & 3.168504 & 2.592479 \\
\hline $\mathrm{H}$ & 8.177315 & 1.344675 & 3.255477 \\
\hline $\mathrm{H}$ & 7.649059 & -1.011263 & 2.625975 \\
\hline $\mathrm{H}$ & 5.645350 & -1.531292 & 1.312417 \\
\hline 0 & -0.358784 & -0.395878 & -0.933795 \\
\hline 0 & -0.165582 & 0.795369 & 1.364369 \\
\hline $\mathrm{H}$ & -1.311145 & 0.685594 & 1.398193 \\
\hline $\mathrm{H}$ & 0.468697 & 2.993587 & 1.077036 \\
\hline $\mathrm{H}$ & 0.063120 & 6.875769 & -0.728270 \\
\hline $\mathrm{H}$ & 3.862318 & 4.863357 & -0.785647 \\
\hline $\mathrm{H}$ & 0.815282 & -3.234261 & 2.132146 \\
\hline $\mathrm{H}$ & -2.569787 & -5.599375 & 0.939744 \\
\hline $\mathrm{H}$ & 0.350731 & -4.396169 & -1.979186 \\
\hline C & -3.001304 & -0.634426 & 1.509032 \\
\hline 0 & -2.573979 & 0.567098 & 1.452586 \\
\hline $\mathrm{H}$ & -2.305348 & -1.458814 & 1.705400 \\
\hline
\end{tabular}




$\begin{array}{llll}\mathrm{C} & -4.370988 & -0.914006 & 2.104161 \\ \mathrm{O} & -4.708277 & -2.026933 & 2.456709 \\ \mathrm{O} & -5.118855 & 0.192268 & 2.200934 \\ \mathrm{C} & -6.442642 & 0.029200 & 2.771595 \\ \mathrm{H} & -7.024527 & 0.839375 & 2.327349 \\ \mathrm{C} & -3.845876 & -0.318408 & -1.069992 \\ \mathrm{C} & -3.371886 & -1.445959 & -0.390776 \\ \mathrm{H} & -1.928982 & 0.346549 & -1.227262 \\ \mathrm{~N} & -2.914632 & 0.597555 & -1.434777 \\ \mathrm{C} & -3.062638 & 1.740659 & -2.237233 \\ \mathrm{O} & -4.055439 & 2.091563 & -2.832323 \\ \mathrm{O} & -1.879952 & 2.378215 & -2.240002 \\ \mathrm{C} & -1.813250 & 3.562495 & -3.051234 \\ \mathrm{H} & -2.638226 & 4.236958 & -2.810249 \\ \mathrm{H} & -1.861248 & 3.297590 & -4.111166 \\ \mathrm{H} & -0.854649 & 4.019615 & -2.808851 \\ \mathrm{H} & -4.073656 & -2.235495 & -0.150684 \\ \mathrm{H} & -2.340834 & -1.742375 & -0.556604 \\ \mathrm{C} & -5.299926 & -0.073719 & -1.201499 \\ \mathrm{C} & -5.884304 & 1.142605 & -0.810730 \\ \mathrm{C} & -6.125380 & -1.115865 & -1.652137 \\ \mathrm{C} & -7.263943 & 1.308788 & -0.878571 \\ \mathrm{H} & -5.259524 & 1.941751 & -0.430251 \\ \mathrm{C} & -7.505740 & -0.938867 & -1.736693 \\ \mathrm{H} & -5.678694 & -2.056227 & -1.960825 \\ \mathrm{C} & -8.077321 & 0.273096 & -1.348591 \\ \mathrm{H} & -7.706430 & 2.251925 & -0.570316 \\ \mathrm{H} & -8.131339 & -1.747015 & -2.104640 \\ \mathrm{H} & -9.153264 & 0.412242 & -1.410698 \\ \mathrm{H} & -6.849637 & -0.930543 & 2.444877 \\ \mathrm{C} & -6.399702 & 0.128851 & 4.288361 \\ \mathrm{H} & -5.945739 & 1.073689 & 4.603822 \\ \mathrm{H} & -7.418100 & 0.083233 & 4.691286 \\ & -5.825586 & -0.699212 & 4.713647\end{array}$

Catalyst (R)-1 TS Ethyl Conformation 17

B3LYP/6-31G(d) Energy $=-2849.017558$

B3LYP-D3(BJ)/def2-TZVPP-IEF-PCM(DCM) Energy = -2850.328402

B3LYP-D3(BJ)/def2-TZVPP-IEF-PCM(DCM)//B3LYP/6-31G(d) Free Energy (Quasiharmonic) = 2849.659417

Frequencies (Top 3 out of 279) 
1. $-620.1288 \mathrm{~cm}-1$

2. $\quad 9.6980 \mathrm{~cm}-1$

3. $\quad 14.3615 \mathrm{~cm}-1$

B3LYP/6-31G(d) Molecular Geometry in Cartesian Coordinates

$\begin{array}{llll}\mathrm{C} & 3.775233 & 0.164636 & 0.386474 \\ \mathrm{C} & 2.931929 & 1.254398 & 0.212782 \\ \mathrm{C} & 3.278934 & 2.578158 & 0.618939 \\ \mathrm{C} & 4.468102 & 2.741911 & 1.301975 \\ \mathrm{H} & 4.754161 & 3.738081 & 1.628969 \\ \mathrm{C} & 2.788945 & -3.691084 & -1.287594 \\ \mathrm{C} & 3.455108 & -1.152112 & -0.243055 \\ \mathrm{C} & 2.233700 & -1.755242 & 0.004456 \\ \mathrm{C} & 1.867740 & -3.041653 & -0.489116 \\ \mathrm{H} & 2.559800 & -4.685968 & -1.660195 \\ \mathrm{O} & 1.738661 & 1.093179 & -0.483681 \\ \mathrm{P} & 0.520393 & 0.178951 & 0.097469 \\ \mathrm{O} & 1.315664 & -1.069175 & 0.793388 \\ \mathrm{C} & 1.006926 & 6.112402 & -0.322348 \\ \mathrm{C} & 2.359711 & 6.023348 & -0.654059 \\ \mathrm{C} & 3.076821 & 4.865067 & -0.355228 \\ \mathrm{C} & 2.457037 & 3.773721 & 0.276485 \\ \mathrm{C} & 1.095332 & 3.871819 & 0.602654 \\ \mathrm{C} & 0.381410 & 5.033552 & 0.307153 \\ \mathrm{H} & 2.858203 & 6.853425 & -1.148078 \\ \mathrm{H} & -0.668904 & 5.096305 & 0.580589 \\ \mathrm{C} & -1.924227 & -4.909551 & 0.332764 \\ \mathrm{C} & -1.393525 & -4.914378 & -0.957846 \\ \mathrm{C} & -0.170226 & -4.294952 & -1.215333 \\ \mathrm{C} & 0.551372 & -3.665137 & -0.187847 \\ \mathrm{C} & 0.008652 & -3.673503 & 1.109513 \\ \mathrm{C} & -1.217853 & -4.286772 & 1.365213 \\ \mathrm{H} & -1.935949 & -5.390650 & -1.770626 \\ \mathrm{H} & -1.629810 & -4.272243 & 2.370213 \\ \mathrm{C} & 4.367401 & -1.805436 & -1.143799 \\ \mathrm{C} & 4.024791 & -3.101393 & -1.650614 \\ \mathrm{C} & 4.922716 & -3.767863 & -2.528154 \\ \mathrm{C} & 6.097804 & -3.173290 & -2.924251 \\ \mathrm{H} & 5.418509 & -1.876236 & -2.459964 \\ \mathrm{H} & 4.652613 & -4.756291 & -2.892331 \\ \mathrm{H} & -1.211645 & -1.593163 \\ \mathrm{C} & -3.689363 & -3.601444\end{array}$




\begin{tabular}{|c|c|c|c|}
\hline $\mathrm{H}$ & 7.334446 & -1.396298 & -2.793894 \\
\hline $\mathrm{H}$ & 5.836345 & -0.214846 & -1.255553 \\
\hline C & 4.957649 & 0.336870 & 1.187968 \\
\hline C & 5.304791 & 1.650518 & 1.638802 \\
\hline C & 6.473040 & 1.834135 & 2.427097 \\
\hline C & 7.260864 & 0.764721 & 2.783684 \\
\hline C & 6.902766 & -0.539411 & 2.368474 \\
\hline C & 5.784731 & -0.747889 & 1.591058 \\
\hline $\mathrm{H}$ & 6.724458 & 2.840399 & 2.753867 \\
\hline $\mathrm{H}$ & 8.148168 & 0.915548 & 3.392359 \\
\hline $\mathrm{H}$ & 7.511876 & -1.386838 & 2.671261 \\
\hline $\mathrm{H}$ & 5.518838 & -1.755147 & 1.292138 \\
\hline 0 & -0.371281 & -0.222683 & -1.032964 \\
\hline $\mathrm{O}$ & -0.136419 & 0.887166 & 1.301680 \\
\hline $\mathrm{H}$ & -1.293058 & 0.748963 & 1.397971 \\
\hline $\mathrm{H}$ & 0.599556 & 3.046769 & 1.101342 \\
\hline $\mathrm{H}$ & 0.446484 & 7.016195 & -0.547994 \\
\hline $\mathrm{H}$ & 4.126347 & 4.793990 & -0.628063 \\
\hline$H$ & 0.552402 & -3.200354 & 1.920002 \\
\hline $\mathrm{H}$ & -2.881464 & -5.381673 & 0.536144 \\
\hline $\mathrm{H}$ & 0.221509 & -4.274536 & -2.228336 \\
\hline C & -2.834239 & -0.679520 & 1.478734 \\
\hline 0 & -2.518688 & 0.557381 & 1.537864 \\
\hline $\mathrm{H}$ & -2.048318 & -1.441919 & 1.472844 \\
\hline C & -4.069650 & -1.178220 & 2.203444 \\
\hline 0 & -4.177078 & -2.338938 & 2.549257 \\
\hline 0 & -4.958769 & -0.209563 & 2.447214 \\
\hline C & -6.110491 & -0.580224 & 3.251349 \\
\hline $\mathrm{H}$ & -5.767293 & -1.218850 & 4.069452 \\
\hline C & -3.863317 & -0.076895 & -0.996320 \\
\hline C & -3.405661 & -1.288727 & -0.471930 \\
\hline $\mathrm{H}$ & -1.932328 & 0.544316 & -1.205619 \\
\hline$N$ & -2.921615 & 0.840455 & -1.325617 \\
\hline C & -3.085050 & 2.058027 & -2.008843 \\
\hline $\mathrm{O}$ & -4.101424 & 2.483199 & -2.507137 \\
\hline 0 & -1.887640 & 2.666831 & -2.027240 \\
\hline C & -1.836318 & 3.914004 & -2.739982 \\
\hline $\mathrm{H}$ & -2.621923 & 4.586866 & -2.388260 \\
\hline $\mathrm{H}$ & -1.962529 & 3.741302 & -3.812416 \\
\hline $\mathrm{H}$ & -0.849750 & 4.323212 & -2.526200 \\
\hline $\mathrm{H}$ & -4.133838 & -2.066163 & -0.273002 \\
\hline $\mathrm{H}$ & -2.405504 & -1.616598 & -0.736876 \\
\hline C & -5.308261 & 0.247940 & -1.010053 \\
\hline C & -5.801445 & 1.411981 & -0.399382 \\
\hline
\end{tabular}




$\begin{array}{llrr}\text { C } & -6.207278 & -0.658497 & -1.590906 \\ \text { C } & -7.169013 & 1.666743 & -0.386309 \\ \text { H } & -5.113541 & 2.096735 & 0.083659 \\ \text { C } & -7.575690 & -0.389508 & -1.594059 \\ \text { H } & -5.827756 & -1.558604 & -2.065657 \\ \text { C } & -8.058251 & 0.773881 & -0.992932 \\ \text { H } & -7.543089 & 2.567077 & 0.092847 \\ \text { H } & -8.261574 & -1.087080 & -2.066235 \\ \text { H } & -9.124287 & 0.984881 & -0.993901 \\ \text { H } & -6.459660 & 0.371719 & 3.657395 \\ \text { C } & -7.190027 & -1.267816 & 2.430618 \\ \text { H } & -6.834230 & -2.229554 & 2.052277 \\ \text { H } & -8.065492 & -1.451492 & 3.064701 \\ \text { H } & -7.498528 & -0.643211 & 1.587569\end{array}$

Catalyst (R)-1 TS Ethyl Conformation 18

B3LYP/6-31G(d) Energy $=-2849.01867$

B3LYP-D3(BJ)/def2-TZVPP-IEF-PCM(DCM) Energy = -2850.328444

B3LYP-D3(BJ)/def2-TZVPP-IEF-PCM(DCM)//B3LYP/6-31G(d) Free Energy (Quasiharmonic) = 2849.659527

Frequencies (Top 3 out of 279)

1. $-520.8613 \mathrm{~cm}-1$

2. $\quad 8.7573 \mathrm{~cm}-1$

3. $\quad 11.7737 \mathrm{~cm}-1$

B3LYP/6-31G(d) Molecular Geometry in Cartesian Coordinates

$\begin{array}{llll}\mathrm{C} & 3.792027 & 0.317390 & 0.381196 \\ \mathrm{C} & 2.863694 & 1.329708 & 0.175194 \\ \mathrm{C} & 3.123072 & 2.698040 & 0.488662 \\ \mathrm{C} & 4.317355 & 2.990391 & 1.117529 \\ \mathrm{H} & 4.538276 & 4.023200 & 1.373729 \\ \mathrm{C} & 3.028590 & -3.690343 & -1.037206 \\ \mathrm{C} & 3.550352 & -1.054954 & -0.158222 \\ \mathrm{C} & 2.385120 & -1.726747 & 0.168284 \\ \mathrm{C} & 2.094176 & -3.060989 & -0.238657 \\ \mathrm{H} & 2.856199 & -4.717728 & -1.347083 \\ \mathrm{O} & 1.664693 & 1.040921 & -0.466994 \\ \mathrm{P} & 0.535731 & 0.069203 & 0.196465 \\ \mathrm{O} & 1.443401 & -1.061397 & 0.948031\end{array}$




\begin{tabular}{|c|c|c|c|}
\hline C & 0.558629 & 5.976301 & -0.614105 \\
\hline C & 1.906367 & 5.970047 & -0.977020 \\
\hline C & 2.719939 & 4.894226 & -0.622005 \\
\hline C & 2.203408 & 3.804536 & 0.099011 \\
\hline C & 0.846562 & 3.820385 & 0.458384 \\
\hline C & 0.035452 & 4.899028 & 0.105000 \\
\hline $\mathrm{H}$ & 2.325833 & 6.800133 & -1.539722 \\
\hline $\mathrm{H}$ & -1.010181 & 4.898141 & 0.402188 \\
\hline C & -1.514231 & -5.133217 & 0.866695 \\
\hline C & -1.057782 & -5.155578 & -0.451935 \\
\hline C & 0.106208 & -4.471213 & -0.802888 \\
\hline C & 0.838171 & -3.752709 & 0.156341 \\
\hline C & 0.368821 & -3.738668 & 1.481421 \\
\hline C & -0.794813 & -4.422915 & 1.831395 \\
\hline $\mathrm{H}$ & -1.611429 & -5.699804 & -1.212726 \\
\hline $\mathrm{H}$ & -1.137966 & -4.406699 & 2.862512 \\
\hline C & 4.475730 & -1.695824 & -1.054832 \\
\hline C & 4.206849 & -3.038538 & -1.478372 \\
\hline C & 5.118364 & -3.690519 & -2.352698 \\
\hline C & 6.235225 & -3.041070 & -2.824045 \\
\hline C & 6.480944 & -1.701630 & -2.441782 \\
\hline C & 5.627083 & -1.047819 & -1.580640 \\
\hline $\mathrm{H}$ & 4.905350 & -4.713683 & -2.653219 \\
\hline $\mathrm{H}$ & 6.920885 & -3.547413 & -3.497845 \\
\hline $\mathrm{H}$ & 7.349610 & -1.180463 & -2.834957 \\
\hline $\mathrm{H}$ & 5.826175 & -0.018656 & -1.306656 \\
\hline C & 4.983364 & 0.625005 & 1.126858 \\
\hline C & 5.244196 & 1.985796 & 1.487369 \\
\hline C & 6.420044 & 2.302419 & 2.220192 \\
\hline C & 7.297991 & 1.317662 & 2.608795 \\
\hline C & 7.026902 & -0.032076 & 2.283137 \\
\hline C & 5.903175 & -0.369252 & 1.561046 \\
\hline $\mathrm{H}$ & 6.604948 & 3.342420 & 2.478574 \\
\hline $\mathrm{H}$ & 8.190536 & 1.570241 & 3.174566 \\
\hline $\mathrm{H}$ & 7.708325 & -0.812240 & 2.611512 \\
\hline $\mathrm{H}$ & 5.705017 & -1.409588 & 1.330552 \\
\hline $\mathrm{O}$ & -0.342290 & -0.461721 & -0.888936 \\
\hline $\mathrm{O}$ & -0.154602 & 0.790997 & 1.377129 \\
\hline $\mathrm{H}$ & -1.293597 & 0.666697 & 1.417194 \\
\hline $\mathrm{H}$ & 0.429694 & 2.996720 & 1.026665 \\
\hline $\mathrm{H}$ & -0.077177 & 6.815436 & -0.885089 \\
\hline $\mathrm{H}$ & 3.764794 & 4.885381 & -0.920674 \\
\hline $\mathrm{H}$ & 0.922118 & -3.195262 & 2.239704 \\
\hline $\mathrm{H}$ & -2.422487 & -5.662056 & 1.142610 \\
\hline
\end{tabular}




$\begin{array}{llrl}\mathrm{H} & 0.441739 & -4.470311 & -1.836110 \\ \mathrm{C} & -2.987397 & -0.660461 & 1.577915 \\ \mathrm{O} & -2.561773 & 0.538233 & 1.475688 \\ \mathrm{H} & -2.292093 & -1.475759 & 1.813190 \\ \mathrm{C} & -4.362304 & -0.917494 & 2.175283 \\ \mathrm{O} & -4.737791 & -2.027430 & 2.496243 \\ \mathrm{O} & -5.070421 & 0.207845 & 2.327857 \\ \mathrm{C} & -6.384947 & 0.048576 & 2.917151 \\ \mathrm{H} & -7.011628 & -0.511373 & 2.215501 \\ \mathrm{C} & -3.830368 & -0.465516 & -1.005155 \\ \mathrm{C} & -3.324836 & -1.553106 & -0.285488 \\ \mathrm{H} & -1.931760 & 0.239045 & -1.199758 \\ \mathrm{~N} & -2.923972 & 0.458781 & -1.410110 \\ \mathrm{C} & -3.104281 & 1.570835 & -2.248120 \\ \mathrm{O} & -4.110038 & 1.880585 & -2.844502 \\ \mathrm{O} & -1.936009 & 2.233662 & -2.283248 \\ \mathrm{C} & -1.903559 & 3.393457 & -3.130930 \\ \mathrm{H} & -2.740866 & 4.056886 & -2.902125 \\ \mathrm{H} & -1.955858 & 3.095243 & -4.181773 \\ \mathrm{H} & -0.952994 & 3.878712 & -2.912633 \\ \mathrm{H} & -4.004140 & -2.349927 & -0.008700 \\ \mathrm{H} & -2.286216 & -1.826690 & -0.442987 \\ \mathrm{C} & -5.291440 & -0.264379 & -1.134965 \\ \mathrm{C} & -5.906348 & 0.950149 & -0.788127 \\ \mathrm{C} & -6.091353 & -1.346183 & -1.535910 \\ \mathrm{C} & -7.290768 & 1.075273 & -0.850168 \\ \mathrm{H} & -5.301068 & 1.781721 & -0.447901 \\ \mathrm{C} & -7.476729 & -1.211223 & -1.614112 \\ \mathrm{H} & -5.621216 & -2.285729 & -1.810037 \\ \mathrm{C} & -8.078931 & -0.000827 & -1.269505 \\ \mathrm{H} & -7.757057 & 2.017851 & -0.577324 \\ \mathrm{H} & -8.082446 & -2.050805 & -1.942755 \\ \mathrm{H} & -9.158799 & 0.106005 & -1.326940 \\ & -6.288628 & -0.545785 & 3.830360 \\ \mathrm{H} & -6.933027 & 1.435782 & 3.189877 \\ \mathrm{H} & -7.927129 & 1.357726 & 3.643759 \\ \mathrm{H} & -281278 & 1.985009 & 3.876491\end{array}$

Catalyst (R)-1 TS Ethyl Conformation 19

B3LYP/6-31G(d) Energy $=-2849.013563$

B3LYP-D3(BJ)/def2-TZVPP-IEF-PCM(DCM) Energy $=-2850.327895$ 
B3LYP-D3(BJ)/def2-TZVPP-IEF-PCM(DCM)//B3LYP/6-31G(d) Free Energy (Quasiharmonic) = 2849.65855

Frequencies (Top 3 out of 279)

1. $-611.5926 \mathrm{~cm}-1$

2. $\quad 10.2364 \mathrm{~cm}-1$

3. $\quad 17.2321 \mathrm{~cm}-1$

B3LYP/6-31G(d) Molecular Geometry in Cartesian Coordinates

$\begin{array}{llll}\text { C } & 3.283242 & -0.171704 & 0.433917 \\ \text { C } & 2.733314 & 0.993055 & -0.077609 \\ \text { C } & 3.187533 & 2.297653 & 0.277260 \\ \text { C } & 4.175425 & 2.381190 & 1.239231 \\ \text { H } & 4.565575 & 3.357658 & 1.513560 \\ \text { C } & 1.930028 & -4.070394 & -0.807408 \\ \text { C } & 2.833833 & -1.502352 & -0.076044 \\ \text { C } & 1.491224 & -1.847364 & -0.024221 \\ \text { C } & 1.005698 & -3.151395 & -0.346627 \\ \text { H } & 1.605968 & -5.083812 & -1.027713 \\ \text { O } & 1.709719 & 0.892634 & -1.013008 \\ \text { P } & 0.229888 & 0.407817 & -0.522344 \\ \text { O } & 0.582157 & -0.898587 & 0.418314 \\ \text { C } & 1.886832 & 5.962202 & -1.563413 \\ \text { C } & 2.002165 & 5.868962 & -0.175509 \\ \mathrm{C} & 2.389363 & 4.666858 & 0.415641 \\ \mathrm{C} & 2.670210 & 3.534758 & -0.366534 \\ \mathrm{C} & 2.532149 & 3.636264 & -1.761271 \\ \mathrm{C} & 2.148318 & 4.839110 & -2.351742 \\ \mathrm{H} & 1.790705 & 6.732283 & 0.450309 \\ \mathrm{H} & 2.064677 & 4.901159 & -3.433870 \\ \mathrm{C} & -3.068751 & -4.453594 & 0.176001 \\ \mathrm{C} & -2.327877 & -4.859543 & -0.935014 \\ \mathrm{C} & -1.022242 & -4.402799 & -1.114003 \\ \mathrm{C} & -0.417548 & -3.548688 & -0.176447 \\ \mathrm{C} & -1.174290 & -3.152502 & 0.941394 \\ \mathrm{C} & -2.485996 & -3.594633 & 1.110843 \\ \mathrm{H} & -2.766841 & -5.530589 & -1.669291 \\ \mathrm{H} & -3.053927 & -3.263757 & 1.975963 \\ \mathrm{C} & 3.764000 & -2.441715 & -0.640129 \\ \mathrm{C} & 3.294442 & -3.745946 & -0.999272 \\ \mathrm{C} & 4.205583 & -4.691111 & -1.544292 \\ \mathrm{C} & 5.522964 & -4.360444 & -1.760216\end{array}$




\begin{tabular}{|c|c|c|c|}
\hline C & 5.981723 & -3.060775 & -1.440600 \\
\hline C & 5.127951 & -2.128439 & -0.893118 \\
\hline $\mathrm{H}$ & 3.834535 & -5.680946 & -1.799778 \\
\hline $\mathrm{H}$ & 6.208856 & -5.088336 & -2.184829 \\
\hline $\mathrm{H}$ & 7.017277 & -2.793355 & -1.632810 \\
\hline $\mathrm{H}$ & 5.493383 & -1.134562 & -0.662143 \\
\hline C & 4.257301 & -0.064758 & 1.487113 \\
\hline C & 4.706912 & 1.236656 & 1.881617 \\
\hline C & 5.675784 & 1.358415 & 2.914362 \\
\hline C & 6.164418 & 0.247366 & 3.561086 \\
\hline C & 5.694346 & -1.037076 & 3.200294 \\
\hline C & 4.769063 & -1.189693 & 2.191002 \\
\hline $\mathrm{H}$ & 6.014308 & 2.353881 & 3.191961 \\
\hline $\mathrm{H}$ & 6.899340 & 0.353009 & 4.354373 \\
\hline $\mathrm{H}$ & 6.062826 & -1.912799 & 3.727748 \\
\hline $\mathrm{H}$ & 4.412755 & -2.180651 & 1.935539 \\
\hline $\mathrm{O}$ & -0.576611 & 0.081158 & -1.732180 \\
\hline $\mathrm{O}$ & -0.285282 & 1.435069 & 0.500546 \\
\hline $\mathrm{H}$ & -1.253395 & 1.335373 & 1.114193 \\
\hline $\mathrm{H}$ & 2.740663 & 2.773288 & -2.384124 \\
\hline $\mathrm{H}$ & 1.598007 & 6.902118 & -2.027402 \\
\hline $\mathrm{H}$ & 2.462104 & 4.596008 & 1.497182 \\
\hline $\mathrm{H}$ & -0.727922 & -2.503402 & 1.685838 \\
\hline $\mathrm{H}$ & -4.089154 & -4.801359 & 0.312954 \\
\hline $\mathrm{H}$ & -0.466367 & -4.700188 & -1.998534 \\
\hline C & -3.176799 & 0.446621 & 1.613499 \\
\hline $\mathrm{O}$ & -2.298580 & 1.352046 & 1.836966 \\
\hline $\mathrm{H}$ & -2.883998 & -0.487180 & 1.116364 \\
\hline C & -4.220661 & 0.277478 & 2.714031 \\
\hline $\mathrm{O}$ & -4.614687 & 1.170534 & 3.426781 \\
\hline $\mathrm{O}$ & -4.630165 & -1.007742 & 2.771649 \\
\hline C & -5.643026 & -1.319881 & 3.764855 \\
\hline $\mathrm{H}$ & -5.496407 & -2.382361 & 3.971628 \\
\hline C & -3.711774 & 1.220106 & -0.862036 \\
\hline C & -4.558617 & 0.959030 & 0.224742 \\
\hline $\mathrm{H}$ & -2.350689 & 0.235671 & -2.050945 \\
\hline$N$ & -3.334598 & 0.230639 & -1.733331 \\
\hline C & -4.075437 & -0.905180 & -2.068821 \\
\hline $\mathrm{O}$ & -5.171651 & -1.209242 & -1.646889 \\
\hline $\mathrm{O}$ & -3.384814 & -1.592583 & -2.994004 \\
\hline C & -4.034194 & -2.777276 & -3.481057 \\
\hline $\mathrm{H}$ & -3.337226 & -3.209152 & -4.199103 \\
\hline $\mathrm{H}$ & -4.979407 & -2.521266 & -3.967161 \\
\hline $\mathrm{H}$ & -4.220803 & -3.472522 & -2.660475 \\
\hline
\end{tabular}




$\begin{array}{llll}\mathrm{H} & -5.036960 & 1.807244 & 0.700555 \\ \mathrm{H} & -5.141733 & 0.047256 & 0.191954 \\ \mathrm{C} & -3.065377 & 2.521460 & -1.040344 \\ \mathrm{C} & -2.445478 & 2.855261 & -2.264658 \\ \mathrm{C} & -3.057737 & 3.472123 & 0.003531 \\ \mathrm{C} & -1.831458 & 4.088367 & -2.432253 \\ \mathrm{H} & -2.462004 & 2.152422 & -3.089735 \\ \mathrm{C} & -2.432095 & 4.702635 & -0.171841 \\ \mathrm{H} & -3.500150 & 3.238871 & 0.962746 \\ \mathrm{C} & -1.816965 & 5.013767 & -1.384055 \\ \mathrm{H} & -1.357786 & 4.329392 & -3.378998 \\ \mathrm{H} & -2.417554 & 5.415442 & 0.647133 \\ \mathrm{H} & -1.320592 & 5.970696 & -1.513292 \\ \mathrm{H} & -5.434048 & -0.740825 & 4.667362 \\ \mathrm{C} & -7.040211 & -1.038902 & 3.234491 \\ \mathrm{H} & -7.785685 & -1.354502 & 3.973476 \\ \mathrm{H} & -7.175651 & 0.030422 & 3.049174 \\ \mathrm{H} & -7.223222 & -1.587700 & 2.305012\end{array}$

Catalyst (R)-1 TS Ethyl Conformation 20

B3LYP/6-31G(d) Energy = -2849.013689

B3LYP-D3(BJ)/def2-TZVPP-IEF-PCM(DCM) Energy = -2850.327564

B3LYP-D3(BJ)/def2-TZVPP-IEF-PCM(DCM)//B3LYP/6-31G(d) Free Energy (Quasiharmonic) = 2849.658246

Frequencies (Top 3 out of 279)

1. $-602.1218 \mathrm{~cm}-1$

2. $\quad 10.1389 \mathrm{~cm}-1$

3. $\quad 16.7480 \mathrm{~cm}-1$

B3LYP/6-31G(d) Molecular Geometry in Cartesian Coordinates

$\begin{array}{lrrr}\text { C } & 3.236674 & -0.178963 & 0.413389 \\ \text { C } & 2.694431 & 0.998345 & -0.077190 \\ \text { C } & 3.149729 & 2.293579 & 0.309203 \\ \text { C } & 4.130315 & 2.353238 & 1.280371 \\ \text { H } & 4.521241 & 3.322322 & 1.578728 \\ \text { C } & 1.880812 & -4.045245 & -0.923052 \\ \text { C } & 2.787116 & -1.496857 & -0.128642 \\ \text { C } & 1.443005 & -1.838340 & -0.095174 \\ \text { C } & 0.955673 & -3.133202 & -0.450198\end{array}$




\begin{tabular}{|c|c|c|c|}
\hline $\mathrm{H}$ & 1.555230 & -5.052435 & -1.168247 \\
\hline $\mathrm{O}$ & 1.677797 & 0.921445 & -1.022406 \\
\hline$P$ & 0.192776 & 0.431446 & -0.553500 \\
\hline 0 & 0.533563 & -0.896359 & 0.360954 \\
\hline C & 1.871108 & 6.000152 & -1.461602 \\
\hline C & 1.976617 & 5.876967 & -0.075260 \\
\hline C & 2.356956 & 4.661553 & 0.492681 \\
\hline C & 2.640625 & 3.545758 & -0.311595 \\
\hline C & 2.512736 & 3.677501 & -1.704776 \\
\hline C & 2.135707 & 4.893615 & -2.271986 \\
\hline $\mathrm{H}$ & 1.762687 & 6.727182 & 0.567430 \\
\hline $\mathrm{H}$ & 2.059742 & 4.979003 & -3.353086 \\
\hline C & -3.129129 & -4.428784 & 0.004752 \\
\hline C & -2.378659 & -4.814765 & -1.106930 \\
\hline C & -1.069379 & -4.360147 & -1.263154 \\
\hline C & -0.470573 & -3.528545 & -0.301866 \\
\hline C & -1.236930 & -3.152725 & 0.816466 \\
\hline C & -2.552243 & -3.592264 & 0.963282 \\
\hline $\mathrm{H}$ & -2.813018 & -5.468185 & -1.859601 \\
\hline $\mathrm{H}$ & -3.127914 & -3.276465 & 1.828937 \\
\hline C & 3.718778 & -2.426991 & -0.705415 \\
\hline C & 3.247867 & -3.721535 & -1.096438 \\
\hline C & 4.160319 & -4.657897 & -1.654323 \\
\hline C & 5.480490 & -4.327219 & -1.852415 \\
\hline C & 5.940888 & -3.036315 & -1.501174 \\
\hline C & 5.085753 & -2.113045 & -0.940615 \\
\hline $\mathrm{H}$ & 3.788099 & -5.640689 & -1.934137 \\
\hline $\mathrm{H}$ & 6.167423 & -5.048154 & -2.287091 \\
\hline $\mathrm{H}$ & 6.978831 & -2.768380 & -1.679258 \\
\hline $\mathrm{H}$ & 5.452541 & -1.125628 & -0.685369 \\
\hline C & 4.202787 & -0.097779 & 1.476175 \\
\hline C & 4.653252 & 1.193423 & 1.902063 \\
\hline C & 5.614338 & 1.289841 & 2.944716 \\
\hline C & 6.094494 & 0.163590 & 3.571185 \\
\hline C & 5.623392 & -1.111290 & 3.179175 \\
\hline C & 4.705608 & -1.239209 & 2.159652 \\
\hline $\mathrm{H}$ & 5.953724 & 2.278018 & 3.246271 \\
\hline $\mathrm{H}$ & 6.823501 & 0.249809 & 4.372241 \\
\hline $\mathrm{H}$ & 5.985111 & -1.999329 & 3.690473 \\
\hline $\mathrm{H}$ & 4.348393 & -2.223312 & 1.880093 \\
\hline $\mathrm{O}$ & -0.606452 & 0.134848 & -1.775676 \\
\hline $\mathrm{O}$ & -0.325794 & 1.438090 & 0.488392 \\
\hline $\mathrm{H}$ & -1.298225 & 1.327063 & 1.089662 \\
\hline $\mathrm{H}$ & 2.723621 & 2.827574 & -2.344537 \\
\hline
\end{tabular}




\begin{tabular}{|c|c|c|c|}
\hline $\mathrm{H}$ & 1.587484 & 6.950427 & -1.907332 \\
\hline $\mathrm{H}$ & 2.421841 & 4.567392 & 1.572944 \\
\hline $\mathrm{H}$ & -0.795401 & -2.521294 & 1.578759 \\
\hline $\mathrm{H}$ & -4.152485 & -4.774395 & 0.123885 \\
\hline $\mathrm{H}$ & -0.505977 & -4.641185 & -2.148263 \\
\hline C & -3.231788 & 0.433570 & 1.558448 \\
\hline $\mathrm{O}$ & -2.351178 & 1.330575 & 1.805949 \\
\hline $\mathrm{H}$ & -2.939113 & -0.491975 & 1.045921 \\
\hline C & -4.283089 & 0.247470 & 2.649079 \\
\hline $\mathrm{O}$ & -4.680781 & 1.129538 & 3.373596 \\
\hline 0 & -4.703710 & -1.035145 & 2.676122 \\
\hline C & -5.724193 & -1.360241 & 3.657027 \\
\hline $\mathrm{H}$ & -6.416100 & -0.517642 & 3.729317 \\
\hline C & -3.746664 & 1.261487 & -0.902662 \\
\hline C & -4.601642 & 0.976884 & 0.172033 \\
\hline $\mathrm{H}$ & -2.379040 & 0.301933 & -2.104451 \\
\hline$N$ & -3.364994 & 0.291725 & -1.793872 \\
\hline C & -4.106234 & -0.833710 & -2.162215 \\
\hline $\mathrm{O}$ & -5.206564 & -1.144418 & -1.756499 \\
\hline O & -3.409907 & -1.500857 & -3.098018 \\
\hline C & -4.059097 & -2.671110 & -3.619020 \\
\hline $\mathrm{H}$ & -3.357047 & -3.088652 & -4.340593 \\
\hline $\mathrm{H}$ & -4.998739 & -2.399905 & -4.107689 \\
\hline $\mathrm{H}$ & -4.256163 & -3.384820 & -2.816951 \\
\hline $\mathrm{H}$ & -5.083337 & 1.814652 & 0.662749 \\
\hline $\mathrm{H}$ & -5.185477 & 0.066758 & 0.114389 \\
\hline C & -3.096599 & 2.565255 & -1.045965 \\
\hline C & -2.466022 & 2.925660 & -2.257272 \\
\hline C & -3.095768 & 3.491895 & 0.019377 \\
\hline C & -1.848112 & 4.160863 & -2.391617 \\
\hline $\mathrm{H}$ & -2.477283 & 2.241963 & -3.098366 \\
\hline C & -2.466307 & 4.724771 & -0.122810 \\
\hline $\mathrm{H}$ & -3.546868 & 3.237982 & 0.969238 \\
\hline C & -1.840423 & 5.062060 & -1.322440 \\
\hline $\mathrm{H}$ & -1.366187 & 4.422410 & -3.328699 \\
\hline $\mathrm{H}$ & -2.457365 & 5.418797 & 0.712220 \\
\hline $\mathrm{H}$ & -1.341116 & 6.020627 & -1.425734 \\
\hline $\mathrm{H}$ & -6.241427 & -2.221914 & 3.228778 \\
\hline C & -5.107302 & -1.686978 & 5.007819 \\
\hline $\mathrm{H}$ & -5.892592 & -1.995118 & 5.707595 \\
\hline $\mathrm{H}$ & -4.385012 & -2.505251 & 4.920602 \\
\hline $\mathrm{H}$ & -4.601944 & -0.810647 & 5.422949 \\
\hline
\end{tabular}


Catalyst (R)-1 TS Ethyl Conformation 21

B3LYP/6-31G(d) Energy $=-2849.013747$

B3LYP-D3(BJ)/def2-TZVPP-IEF-PCM(DCM) Energy = -2850.328288

B3LYP-D3(BJ)/def2-TZVPP-IEF-PCM(DCM)//B3LYP/6-31G(d) Free Energy (Quasiharmonic) = 2849.659331

Frequencies (Top 3 out of 279)

1. $-626.1848 \mathrm{~cm}-1$

2. $\quad 9.9007 \mathrm{~cm}-1$

3. $15.9561 \mathrm{~cm}-1$

B3LYP/6-31G(d) Molecular Geometry in Cartesian Coordinates

$\begin{array}{llll}\text { C } & 3.257117 & -0.286108 & 0.421163 \\ \text { C } & 2.754337 & 0.912062 & -0.061003 \\ \text { C } & 3.260955 & 2.188167 & 0.325310 \\ \text { C } & 4.250586 & 2.208288 & 1.288895 \\ \text { H } & 4.679724 & 3.161217 & 1.586786 \\ \text { C } & 1.749490 & -4.095099 & -0.917661 \\ \text { C } & 2.755386 & -1.584681 & -0.121652 \\ \text { C } & 1.400035 & -1.876743 & -0.078116 \\ \text { C } & 0.862674 & -3.151545 & -0.433475 \\ \text { H } & 1.385057 & -5.088692 & -1.163719 \\ \text { O } & 1.727749 & 0.876254 & -0.997641 \\ \text { P } & 0.229216 & 0.438615 & -0.518544 \\ \text { O } & 0.529596 & -0.904027 & 0.388790 \\ \text { C } & 2.116299 & 5.945682 & -1.429530 \\ \text { C } & 2.225965 & 5.815473 & -0.044147 \\ \text { C } & 2.561614 & 4.584749 & 0.519006 \\ \text { C } & 2.795675 & 3.460335 & -0.289203 \\ \text { C } & 2.663497 & 3.599890 & -1.681228 \\ \text { C } & 2.331222 & 4.831165 & -2.243681 \\ \text { H } & 2.050273 & 6.672166 & 0.601529 \\ \text { H } & 2.251518 & 4.921740 & -3.324095 \\ \text { C } & -3.263567 & -4.294281 & 0.055391 \\ \text { C } & -2.538552 & -4.704557 & -1.064437 \\ \text { C } & -1.214448 & -4.299263 & -1.231459 \\ \text { C } & -0.575792 & -3.494216 & -0.273274 \\ \text { C } & -1.316865 & -3.093768 & 0.853531 \\ \text { C } & -2.646396 & -3.483675 & 1.011091 \\ \text { H } & -3.004264 & -5.338508 & -1.815010 \\ \text { H } & -3.201438 & -3.150424 & 1.883724\end{array}$




\begin{tabular}{|c|c|c|c|}
\hline C & 3.647458 & -2.546265 & -0.709353 \\
\hline C & 3.126069 & -3.821063 & -1.101328 \\
\hline C & 3.998911 & -4.788050 & -1.670217 \\
\hline C & 5.328758 & -4.505399 & -1.877783 \\
\hline C & 5.839222 & -3.233807 & -1.525320 \\
\hline C & 5.023170 & -2.281959 & -0.954387 \\
\hline $\mathrm{H}$ & 3.588528 & -5.755339 & -1.950693 \\
\hline $\mathrm{H}$ & 5.985157 & -5.249359 & -2.320765 \\
\hline $\mathrm{H}$ & 6.884909 & -3.003585 & -1.710703 \\
\hline $\mathrm{H}$ & 5.428136 & -1.309816 & -0.698264 \\
\hline C & 4.233934 & -0.244317 & 1.476406 \\
\hline C & 4.734915 & 1.027876 & 1.903029 \\
\hline C & 5.706773 & 1.085138 & 2.938547 \\
\hline C & 6.149850 & -0.060253 & 3.557598 \\
\hline C & 5.629226 & -1.315527 & 3.164965 \\
\hline C & 4.699669 & -1.405933 & 2.152107 \\
\hline $\mathrm{H}$ & 6.084581 & 2.059074 & 3.240742 \\
\hline $\mathrm{H}$ & 6.887539 & -0.003784 & 4.353338 \\
\hline $\mathrm{H}$ & 5.961876 & -2.218100 & 3.670520 \\
\hline $\mathrm{H}$ & 4.304335 & -2.375217 & 1.872062 \\
\hline $\mathrm{O}$ & -0.588212 & 0.174209 & -1.736348 \\
\hline $\mathrm{O}$ & -0.246816 & 1.458291 & 0.529708 \\
\hline $\mathrm{H}$ & -1.221801 & 1.383762 & 1.141998 \\
\hline $\mathrm{H}$ & 2.836216 & 2.743589 & -2.323918 \\
\hline $\mathrm{H}$ & 1.867834 & 6.907437 & -1.871619 \\
\hline $\mathrm{H}$ & 2.630095 & 4.485856 & 1.598623 \\
\hline $\mathrm{H}$ & -0.844638 & -2.482334 & 1.613691 \\
\hline $\mathrm{H}$ & -4.298094 & -4.601386 & 0.183205 \\
\hline $\mathrm{H}$ & -0.670213 & -4.598408 & -2.122612 \\
\hline C & -3.184680 & 0.576851 & 1.623073 \\
\hline $\mathrm{O}$ & -2.261188 & 1.431095 & 1.863847 \\
\hline $\mathrm{H}$ & -2.940873 & -0.360597 & 1.106767 \\
\hline C & -4.239642 & 0.444928 & 2.717386 \\
\hline $\mathrm{O}$ & -4.575552 & 1.338685 & 3.458182 \\
\hline $\mathrm{O}$ & -4.746500 & -0.805096 & 2.733952 \\
\hline C & -5.785682 & -1.048059 & 3.716198 \\
\hline $\mathrm{H}$ & -5.369659 & -0.869972 & 4.712720 \\
\hline C & -3.675291 & 1.433307 & -0.836538 \\
\hline C & -4.539048 & 1.184230 & 0.239433 \\
\hline $\mathrm{H}$ & -2.351937 & 0.420567 & -2.045235 \\
\hline$N$ & -3.336339 & 0.449594 & -1.729699 \\
\hline C & -4.122648 & -0.646111 & -2.094122 \\
\hline $\mathrm{O}$ & -5.230856 & -0.915985 & -1.680303 \\
\hline $\mathrm{O}$ & -3.459370 & -1.337562 & -3.036108 \\
\hline
\end{tabular}




$\begin{array}{llll}\mathrm{C} & -4.155156 & -2.482891 & -3.552217 \\ \mathrm{H} & -3.475396 & -2.924376 & -4.280835 \\ \mathrm{H} & -5.089019 & -2.177393 & -4.031627 \\ \mathrm{H} & -4.369979 & -3.190248 & -2.749061 \\ \mathrm{H} & -4.982321 & 2.041436 & 0.732825 \\ \mathrm{H} & -5.159954 & 0.298985 & 0.184216 \\ \mathrm{C} & -2.972763 & 2.709727 & -0.981175 \\ \mathrm{C} & -2.336420 & 3.046808 & -2.196052 \\ \mathrm{C} & -2.926649 & 3.632799 & 0.086144 \\ \mathrm{C} & -1.669820 & 4.256315 & -2.332235 \\ \mathrm{H} & -2.381239 & 2.365921 & -3.038332 \\ \mathrm{C} & -2.248736 & 4.839432 & -0.057928 \\ \mathrm{H} & -3.380470 & 3.394828 & 1.038897 \\ \mathrm{C} & -1.618210 & 5.153947 & -1.261362 \\ \mathrm{H} & -1.184094 & 4.500233 & -3.272098 \\ \mathrm{H} & -2.205497 & 5.530404 & 0.778561 \\ \mathrm{H} & -1.081123 & 6.091668 & -1.366177 \\ \mathrm{H} & -6.589128 & -0.321990 & 3.557116 \\ \mathrm{C} & -6.261905 & -2.476654 & 3.539594 \\ \mathrm{H} & -7.059813 & -2.690881 & 4.258942 \\ \mathrm{H} & -6.655557 & -2.635802 & 2.530696 \\ \mathrm{H} & -5.447160 & -3.187628 & 3.711305\end{array}$

Catalyst (R)-1 TS Ethyl Conformation 22

B3LYP/6-31G(d) Energy $=-2849.016078$

B3LYP-D3(BJ)/def2-TZVPP-IEF-PCM(DCM) Energy = -2850.327166

B3LYP-D3(BJ)/def2-TZVPP-IEF-PCM(DCM)//B3LYP/6-31G(d) Free Energy (Quasiharmonic) = 2849.657973

Frequencies (Top 3 out of 279)

1. $-734.3232 \mathrm{~cm}-1$

2. $\quad 9.8754 \mathrm{~cm}-1$

3. $15.0026 \mathrm{~cm}-1$

B3LYP/6-31G(d) Molecular Geometry in Cartesian Coordinates

$\begin{array}{llll}\text { C } & 3.402790 & -0.499930 & 0.040344 \\ \text { C } & 2.895717 & 0.773324 & -0.183700 \\ \text { C } & 3.686646 & 1.952979 & -0.031234 \\ \text { C } & 4.984049 & 1.798964 & 0.418277 \\ \text { H } & 5.602118 & 2.683228 & 0.549125\end{array}$




\begin{tabular}{|c|c|c|c|}
\hline C & 1.050719 & -4.051521 & -0.605796 \\
\hline C & 2.583421 & -1.708159 & -0.267887 \\
\hline C & 1.335928 & -1.858149 & 0.314668 \\
\hline C & 0.556531 & -3.047334 & 0.204015 \\
\hline $\mathrm{H}$ & 0.494812 & -4.981351 & -0.692826 \\
\hline $\mathrm{O}$ & 1.606711 & 0.912293 & -0.680689 \\
\hline$P$ & 0.291990 & 0.506151 & 0.213856 \\
\hline 0 & 0.820381 & -0.798418 & 1.057756 \\
\hline C & 2.468579 & 5.996779 & -0.854638 \\
\hline C & 1.688281 & 5.191801 & -0.021289 \\
\hline C & 2.043485 & 3.864527 & 0.223491 \\
\hline C & 3.202368 & 3.324540 & -0.355131 \\
\hline C & 3.976714 & 4.139991 & -1.198100 \\
\hline C & 3.613314 & 5.462712 & -1.449384 \\
\hline $\mathrm{H}$ & 0.792976 & 5.596409 & 0.443407 \\
\hline $\mathrm{H}$ & 4.225308 & 6.074692 & -2.107147 \\
\hline C & -3.096518 & -3.775305 & 2.351242 \\
\hline C & -1.999233 & -3.214575 & 3.008600 \\
\hline C & -0.823790 & -2.942267 & 2.311624 \\
\hline C & -0.719028 & -3.241565 & 0.942902 \\
\hline C & -1.831264 & -3.799996 & 0.293075 \\
\hline C & -3.011272 & -4.059611 & 0.988220 \\
\hline $\mathrm{H}$ & -2.055802 & -2.987864 & 4.070081 \\
\hline $\mathrm{H}$ & -3.868061 & -4.470369 & 0.461609 \\
\hline C & 3.047911 & -2.729809 & -1.166947 \\
\hline C & 2.261715 & -3.916130 & -1.327828 \\
\hline C & 2.710672 & -4.936841 & -2.209148 \\
\hline C & 3.871508 & -4.787990 & -2.931736 \\
\hline C & 4.631028 & -3.601466 & -2.803035 \\
\hline C & 4.232613 & -2.601661 & -1.942971 \\
\hline $\mathrm{H}$ & 2.107901 & -5.836447 & -2.309545 \\
\hline $\mathrm{H}$ & 4.200891 & -5.571940 & -3.608226 \\
\hline $\mathrm{H}$ & 5.535625 & -3.474938 & -3.391776 \\
\hline $\mathrm{H}$ & 4.820596 & -1.694707 & -1.863463 \\
\hline C & 4.719645 & -0.633360 & 0.603992 \\
\hline C & 5.521361 & 0.539493 & 0.774152 \\
\hline C & 6.828730 & 0.423523 & 1.319585 \\
\hline C & 7.325843 & -0.797864 & 1.709595 \\
\hline C & 6.523592 & -1.955595 & 1.576153 \\
\hline C & 5.257969 & -1.876962 & 1.037920 \\
\hline $\mathrm{H}$ & 7.424354 & 1.326252 & 1.433678 \\
\hline $\mathrm{H}$ & 8.324374 & -0.875300 & 2.131013 \\
\hline $\mathrm{H}$ & 6.906834 & -2.916866 & 1.907848 \\
\hline $\mathrm{H}$ & 4.654558 & -2.773089 & 0.954777 \\
\hline
\end{tabular}




\begin{tabular}{|c|c|c|c|}
\hline $\mathrm{O}$ & -0.113540 & 1.562845 & 1.193802 \\
\hline 0 & -0.716857 & 0.068803 & -0.861976 \\
\hline $\mathrm{H}$ & -1.826263 & -0.346328 & -0.598873 \\
\hline $\mathrm{H}$ & 4.865823 & 3.725542 & -1.665809 \\
\hline $\mathrm{H}$ & 2.187676 & 7.030827 & -1.038594 \\
\hline $\mathrm{H}$ & 1.425913 & 3.250940 & 0.870529 \\
\hline $\mathrm{H}$ & -1.774884 & -4.006988 & -0.771932 \\
\hline $\mathrm{H}$ & -4.014241 & -3.983547 & 2.895471 \\
\hline $\mathrm{H}$ & 0.022723 & -2.505923 & 2.831046 \\
\hline C & -3.794270 & -0.089842 & -1.158204 \\
\hline 0 & -2.950985 & -0.735915 & -0.450886 \\
\hline $\mathrm{H}$ & -3.446424 & 0.528673 & -1.989349 \\
\hline C & -5.161481 & -0.725117 & -1.319727 \\
\hline $\mathrm{O}$ & -5.635838 & -1.536678 & -0.555876 \\
\hline $\mathrm{O}$ & -5.757709 & -0.250726 & -2.429150 \\
\hline C & -7.085754 & -0.757195 & -2.723681 \\
\hline $\mathrm{H}$ & -7.551217 & 0.039431 & -3.308357 \\
\hline C & -3.556901 & 1.983092 & 0.576459 \\
\hline C & -4.648901 & 1.640921 & -0.223018 \\
\hline $\mathrm{H}$ & -1.568459 & 2.485697 & 0.627115 \\
\hline$N$ & -2.458055 & 2.649706 & 0.117844 \\
\hline C & -2.305574 & 3.207389 & -1.158514 \\
\hline 0 & -3.145874 & 3.241774 & -2.034922 \\
\hline 0 & -1.066712 & 3.703195 & -1.257351 \\
\hline C & -0.708339 & 4.213885 & -2.556023 \\
\hline $\mathrm{H}$ & 0.309464 & 4.581796 & -2.442010 \\
\hline $\mathrm{H}$ & -1.388172 & 5.018308 & -2.846878 \\
\hline $\mathrm{H}$ & -0.752811 & 3.412019 & -3.296798 \\
\hline $\mathrm{H}$ & -5.527341 & 1.282135 & 0.300454 \\
\hline $\mathrm{H}$ & -4.813385 & 2.170732 & -1.149641 \\
\hline C & -3.473762 & 1.525910 & 1.974944 \\
\hline C & -4.091385 & 0.324232 & 2.371441 \\
\hline C & -2.794099 & 2.297061 & 2.937517 \\
\hline C & -4.033832 & -0.082622 & 3.701739 \\
\hline $\mathrm{H}$ & -4.573846 & -0.313661 & 1.639434 \\
\hline C & -2.756868 & 1.891360 & 4.266721 \\
\hline $\mathrm{H}$ & -2.319893 & 3.228951 & 2.648232 \\
\hline C & -3.376334 & 0.700155 & 4.652370 \\
\hline $\mathrm{H}$ & -4.497288 & -1.020685 & 3.991397 \\
\hline $\mathrm{H}$ & -2.241380 & 2.503064 & 5.001187 \\
\hline $\mathrm{H}$ & -3.341353 & 0.381395 & 5.690665 \\
\hline $\mathrm{H}$ & -7.626434 & -0.884466 & -1.782543 \\
\hline C & -7.016396 & -2.060240 & -3.504373 \\
\hline $\mathrm{H}$ & -6.558991 & -2.848749 & -2.900219 \\
\hline
\end{tabular}


$\begin{array}{llll}\mathrm{H} & -8.027982 & -2.380437 & -3.778729 \\ \mathrm{H} & -6.434554 & -1.933234 & -4.422853\end{array}$

Catalyst (R)-1 TS Ethyl Conformation 23

B3LYP/6-31G(d) Energy $=-2849.015963$

B3LYP-D3(BJ)/def2-TZVPP-IEF-PCM(DCM) Energy = -2850.327484

B3LYP-D3(BJ)/def2-TZVPP-IEF-PCM(DCM)//B3LYP/6-31G(d) Free Energy (Quasiharmonic) = 2849.658293

Frequencies (Top 3 out of 279)

1. $-733.7361 \mathrm{~cm}-1$

2. $\quad 9.8188 \mathrm{~cm}-1$

3. $\quad 15.6361 \mathrm{~cm}-1$

B3LYP/6-31G(d) Molecular Geometry in Cartesian Coordinates

$\begin{array}{llll}\text { C } & 3.447572 & -0.391359 & 0.045920 \\ \text { C } & 2.888037 & 0.866007 & -0.139428 \\ \text { C } & 3.623187 & 2.072572 & 0.070748 \\ \text { C } & 4.918731 & 1.958609 & 0.537245 \\ \text { H } & 5.494737 & 2.863496 & 0.711753 \\ \text { C } & 1.266405 & -4.014776 & -0.777210 \\ \text { C } & 2.687968 & -1.621648 & -0.322315 \\ \text { C } & 1.439160 & -1.848764 & 0.231746 \\ \text { C } & 0.715418 & -3.065776 & 0.061940 \\ \text { H } & 0.753620 & -4.963797 & -0.909908 \\ \text { O } & 1.602221 & 0.967010 & -0.653532 \\ \text { P } & 0.292899 & 0.469583 & 0.201885 \\ \text { O } & 0.864860 & -0.842208 & 1.005210 \\ \text { C } & 2.239237 & 6.086651 & -0.626572 \\ \text { C } & 1.482117 & 5.217616 & 0.162649 \\ \text { C } & 1.892373 & 3.899174 & 0.365522 \\ \text { C } & 3.083706 & 3.432745 & -0.211171 \\ \text { C } & 3.834659 & 4.312399 & -1.009588 \\ \text { C } & 3.416558 & 5.626182 & -1.219227 \\ \text { H } & 0.562023 & 5.564739 & 0.625426 \\ \text { H } & 4.011360 & 6.288610 & -1.843011 \\ \text { C } & -2.933654 & -4.038855 & 2.116461 \\ \text { C } & -1.871149 & -3.460745 & 2.814726 \\ \text { C } & -0.698689 & -3.108989 & 2.149003 \\ \text { C } & -0.561443 & -3.344916 & 0.770818\end{array}$




\begin{tabular}{|c|c|c|c|}
\hline C & -1.638978 & -3.921708 & 0.079972 \\
\hline C & -2.816792 & -4.260393 & 0.744162 \\
\hline $\mathrm{H}$ & -1.952679 & -3.282646 & 3.883842 \\
\hline $\mathrm{H}$ & -3.647598 & -4.683451 & 0.186631 \\
\hline C & 3.211846 & -2.586113 & -1.251399 \\
\hline C & 2.481613 & -3.798332 & -1.471910 \\
\hline C & 2.989418 & -4.763040 & -2.383833 \\
\hline C & 4.154060 & -4.535430 & -3.079267 \\
\hline C & 4.858239 & -3.322959 & -2.891256 \\
\hline C & 4.402147 & -2.376066 & -2.000522 \\
\hline $\mathrm{H}$ & 2.428683 & -5.683371 & -2.529672 \\
\hline $\mathrm{H}$ & 4.528655 & -5.277028 & -3.779566 \\
\hline $\mathrm{H}$ & 5.765785 & -3.134119 & -3.458373 \\
\hline $\mathrm{H}$ & 4.947995 & -1.448178 & -1.875475 \\
\hline C & 4.759720 & -0.488269 & 0.627655 \\
\hline C & 5.505645 & 0.711278 & 0.855633 \\
\hline C & 6.807821 & 0.632018 & 1.419727 \\
\hline C & 7.352249 & -0.580365 & 1.772933 \\
\hline C & 6.604509 & -1.766221 & 1.582163 \\
\hline C & 5.345589 & -1.722697 & 1.024570 \\
\hline $\mathrm{H}$ & 7.360838 & 1.554963 & 1.578002 \\
\hline $\mathrm{H}$ & 8.346233 & -0.629950 & 2.209043 \\
\hline $\mathrm{H}$ & 7.024623 & -2.721683 & 1.884715 \\
\hline $\mathrm{H}$ & 4.783939 & -2.640542 & 0.897329 \\
\hline $\mathrm{O}$ & -0.174330 & 1.469394 & 1.213691 \\
\hline $\mathrm{O}$ & -0.678792 & 0.030790 & -0.906920 \\
\hline $\mathrm{H}$ & -1.771794 & -0.445826 & -0.678629 \\
\hline $\mathrm{H}$ & 4.749058 & 3.955271 & -1.475812 \\
\hline $\mathrm{H}$ & 1.915365 & 7.113398 & -0.777929 \\
\hline $\mathrm{H}$ & 1.292358 & 3.235460 & 0.978720 \\
\hline $\mathrm{H}$ & -1.558327 & -4.080313 & -0.991743 \\
\hline $\mathrm{H}$ & -3.849232 & -4.309204 & 2.636496 \\
\hline $\mathrm{H}$ & 0.120801 & -2.659797 & 2.699940 \\
\hline C & -3.740984 & -0.257335 & -1.258187 \\
\hline $\mathrm{O}$ & -2.878479 & -0.891949 & -0.563758 \\
\hline $\mathrm{H}$ & -3.410693 & 0.409556 & -2.058467 \\
\hline C & -5.073887 & -0.949626 & -1.467260 \\
\hline $\mathrm{O}$ & -5.517141 & -1.816935 & -0.747458 \\
\hline $\mathrm{O}$ & -5.672701 & -0.464324 & -2.570734 \\
\hline C & -6.965698 & -1.028128 & -2.912785 \\
\hline $\mathrm{H}$ & -6.947064 & -2.098618 & -2.694850 \\
\hline C & -3.622028 & 1.753944 & 0.559616 \\
\hline C & -4.686323 & 1.393135 & -0.268657 \\
\hline $\mathrm{H}$ & -1.660150 & 2.345169 & 0.659652 \\
\hline
\end{tabular}




$\begin{array}{llll}\mathrm{N} & -2.549994 & 2.488647 & 0.144137 \\ \mathrm{C} & -2.408331 & 3.105049 & -1.106244 \\ \mathrm{O} & -3.238218 & 3.135330 & -1.992697 \\ \mathrm{O} & -1.193900 & 3.663350 & -1.166663 \\ \mathrm{C} & -0.844028 & 4.243343 & -2.438304 \\ \mathrm{H} & 0.153864 & 4.653167 & -2.294908 \\ \mathrm{H} & -1.557370 & 5.026571 & -2.705840 \\ \mathrm{H} & -0.841558 & 3.471559 & -3.211635 \\ \mathrm{H} & -5.553815 & 0.974758 & 0.228072 \\ \mathrm{H} & -4.863632 & 1.951441 & -1.176015 \\ \mathrm{C} & -3.536139 & 1.246483 & 1.940461 \\ \mathrm{C} & -4.099191 & 0.001472 & 2.280270 \\ \mathrm{C} & -2.909262 & 2.011628 & 2.942809 \\ \mathrm{C} & -4.040624 & -0.453956 & 3.594691 \\ \mathrm{H} & -4.538531 & -0.630113 & 1.516337 \\ \mathrm{C} & -2.871320 & 1.556563 & 4.255905 \\ \mathrm{H} & -2.477528 & 2.976103 & 2.697113 \\ \mathrm{C} & -3.436556 & 0.322271 & 4.585289 \\ \mathrm{H} & -4.460881 & -1.424319 & 3.840422 \\ \mathrm{H} & -2.397374 & 2.163464 & 5.021671 \\ \mathrm{H} & -3.400819 & -0.034834 & 5.610999 \\ \mathrm{H} & -7.044266 & -0.876962 & -3.991545 \\ \mathrm{C} & -8.089876 & -0.328557 & -2.164804 \\ \mathrm{H} & -8.072918 & 0.749613 & -2.353774 \\ \mathrm{H} & -9.056206 & -0.721280 & -2.501228 \\ \mathrm{H} & -8.007409 & -0.503939 & -1.088313\end{array}$

Catalyst (R)-1 TS Ethyl Conformation 24

B3LYP/6-31G(d) Energy = -2849.016316

B3LYP-D3(BJ)/def2-TZVPP-IEF-PCM(DCM) Energy = -2850.327541

B3LYP-D3(BJ)/def2-TZVPP-IEF-PCM(DCM)//B3LYP/6-31G(d) Free Energy (Quasiharmonic) = 2849.658686

Frequencies (Top 3 out of 279)

1. $-728.4294 \mathrm{~cm}-1$

2. $\quad 9.8156 \mathrm{~cm}-1$

3. $15.3690 \mathrm{~cm}-1$

B3LYP/6-31G(d) Molecular Geometry in Cartesian Coordinates

$\begin{array}{llll}\text { C } & 3.435974 & -0.390919 & -0.003136\end{array}$ 


\begin{tabular}{|c|c|c|c|}
\hline C & 2.871840 & 0.865912 & -0.177967 \\
\hline C & 3.612489 & 2.073006 & 0.008619 \\
\hline C & 4.919850 & 1.960374 & 0.441257 \\
\hline $\mathrm{H}$ & 5.500370 & 2.865733 & 0.597408 \\
\hline C & 1.234009 & -4.017030 & -0.755619 \\
\hline C & 2.666853 & -1.622344 & -0.346989 \\
\hline C & 1.433075 & -1.847339 & 0.240625 \\
\hline C & 0.705146 & -3.064958 & 0.094245 \\
\hline $\mathrm{H}$ & 0.718049 & -4.966560 & -0.871272 \\
\hline $\mathrm{O}$ & 1.572919 & 0.965379 & -0.658201 \\
\hline$P$ & 0.286627 & 0.471425 & 0.233733 \\
\hline $\mathrm{O}$ & 0.879645 & -0.838137 & 1.025599 \\
\hline C & 2.211479 & 6.085064 & -0.665775 \\
\hline C & 1.475193 & 5.218936 & 0.146042 \\
\hline C & 1.890327 & 3.901050 & 0.342523 \\
\hline C & 3.066007 & 3.432336 & -0.263694 \\
\hline C & 3.795870 & 4.309037 & -1.084603 \\
\hline C & 3.372683 & 5.622223 & -1.287656 \\
\hline $\mathrm{H}$ & 0.567659 & 5.567901 & 0.631674 \\
\hline $\mathrm{H}$ & 3.951001 & 6.282341 & -1.929141 \\
\hline C & -2.889802 & -4.028997 & 2.246314 \\
\hline C & -1.810060 & -3.447063 & 2.914268 \\
\hline C & -0.655036 & -3.098492 & 2.217131 \\
\hline C & -0.552846 & -3.341356 & 0.837099 \\
\hline C & -1.647383 & -3.922181 & 0.176984 \\
\hline C & -2.807761 & -4.257757 & 0.872681 \\
\hline $\mathrm{H}$ & -1.864445 & -3.263342 & 3.984151 \\
\hline $\mathrm{H}$ & -3.652328 & -4.684028 & 0.338767 \\
\hline C & 3.166152 & -2.590154 & -1.286063 \\
\hline C & 2.430499 & -3.803178 & -1.482835 \\
\hline C & 2.914293 & -4.771284 & -2.404163 \\
\hline C & 4.060277 & -4.546299 & -3.130754 \\
\hline C & 4.769032 & -3.333141 & -2.965795 \\
\hline C & 4.336371 & -2.382928 & -2.066941 \\
\hline $\mathrm{H}$ & 2.350029 & -5.692171 & -2.531764 \\
\hline $\mathrm{H}$ & 4.416467 & -5.290536 & -3.837827 \\
\hline $\mathrm{H}$ & 5.661406 & -3.146440 & -3.557181 \\
\hline $\mathrm{H}$ & 4.885294 & -1.454617 & -1.959684 \\
\hline C & 4.762938 & -0.486124 & 0.544234 \\
\hline C & 5.514760 & 0.714022 & 0.748446 \\
\hline C & 6.831276 & 0.636399 & 1.278458 \\
\hline C & 7.384596 & -0.574887 & 1.621471 \\
\hline C & 6.631929 & -1.761212 & 1.454465 \\
\hline C & 5.358836 & -1.719313 & 0.929914 \\
\hline
\end{tabular}




\begin{tabular}{|c|c|c|c|}
\hline $\mathrm{H}$ & 7.388387 & 1.559757 & 1.418983 \\
\hline $\mathrm{H}$ & 8.389659 & -0.623206 & 2.031557 \\
\hline $\mathrm{H}$ & 7.059672 & -2.715723 & 1.749233 \\
\hline $\mathrm{H}$ & 4.793884 & -2.637446 & 0.820644 \\
\hline $\mathrm{O}$ & -0.152044 & 1.474726 & 1.254904 \\
\hline $\mathrm{O}$ & -0.715139 & 0.029647 & -0.846442 \\
\hline $\mathrm{H}$ & -1.803118 & -0.448759 & -0.586021 \\
\hline $\mathrm{H}$ & 4.697610 & 3.950038 & -1.573499 \\
\hline $\mathrm{H}$ & 1.883961 & 7.111393 & -0.812040 \\
\hline $\mathrm{H}$ & 1.306470 & 3.239525 & 0.973437 \\
\hline $\mathrm{H}$ & -1.593983 & -4.086409 & -0.895602 \\
\hline $\mathrm{H}$ & -3.791848 & -4.296630 & 2.790798 \\
\hline $\mathrm{H}$ & 0.177995 & -2.646232 & 2.744725 \\
\hline C & -3.784580 & -0.262501 & -1.112988 \\
\hline $\mathrm{O}$ & -2.903475 & -0.894265 & -0.439694 \\
\hline $\mathrm{H}$ & -3.475935 & 0.402125 & -1.923703 \\
\hline C & -5.123869 & -0.952480 & -1.280427 \\
\hline 0 & -5.552521 & -1.814199 & -0.545520 \\
\hline 0 & -5.759055 & -0.468994 & -2.362649 \\
\hline C & -7.065258 & -1.034136 & -2.638790 \\
\hline $\mathrm{H}$ & -7.706946 & -0.866775 & -1.767557 \\
\hline C & -3.618474 & 1.756186 & 0.694645 \\
\hline C & -4.704952 & 1.394233 & -0.103355 \\
\hline $\mathrm{H}$ & -1.654002 & 2.346619 & 0.739963 \\
\hline$N$ & -2.557278 & 2.488748 & 0.247935 \\
\hline C & -2.448351 & 3.099430 & -1.008331 \\
\hline 0 & -3.300500 & 3.124474 & -1.873712 \\
\hline 0 & -1.236632 & 3.659004 & -1.102543 \\
\hline C & -0.919968 & 4.232492 & -2.385733 \\
\hline $\mathrm{H}$ & 0.080931 & 4.643752 & -2.270134 \\
\hline $\mathrm{H}$ & -1.640576 & 5.013802 & -2.639046 \\
\hline $\mathrm{H}$ & -0.936604 & 3.456640 & -3.154814 \\
\hline $\mathrm{H}$ & -5.559023 & 0.976935 & 0.417075 \\
\hline $\mathrm{H}$ & -4.905188 & 1.948430 & -1.008403 \\
\hline C & -3.495858 & 1.253249 & 2.074449 \\
\hline C & -4.052533 & 0.010933 & 2.434139 \\
\hline C & -2.839626 & 2.020184 & 3.056441 \\
\hline C & -3.959077 & -0.439945 & 3.748109 \\
\hline $\mathrm{H}$ & -4.514725 & -0.622177 & 1.685061 \\
\hline C & -2.766564 & 1.569575 & 4.369598 \\
\hline $\mathrm{H}$ & -2.412343 & 2.982657 & 2.795617 \\
\hline C & -3.325812 & 0.338052 & 4.718900 \\
\hline $\mathrm{H}$ & -4.375264 & -1.408147 & 4.008862 \\
\hline $\mathrm{H}$ & -2.270032 & 2.177870 & 5.119787 \\
\hline
\end{tabular}




$\begin{array}{llll}\text { H } & -3.262790 & -0.015535 & 5.744516 \\ \text { H } & -6.955321 & -2.115404 & -2.767538 \\ \mathrm{C} & -7.600120 & -0.358037 & -3.885826 \\ \mathrm{H} & -6.938890 & -0.533447 & -4.739788 \\ \mathrm{H} & -8.589829 & -0.759509 & -4.127469 \\ \mathrm{H} & -7.692641 & 0.722070 & -3.736944\end{array}$

Catalyst (R)-1 TS Ethyl Conformation 25

B3LYP/6-31G(d) Energy $=-2849.012063$

B3LYP-D3(BJ)/def2-TZVPP-IEF-PCM(DCM) Energy $=-2850.328115$

B3LYP-D3(BJ)/def2-TZVPP-IEF-PCM(DCM)//B3LYP/6-31G(d) Free Energy (Quasiharmonic) = 2849.658983

Frequencies (Top 3 out of 279)

1. $-743.0399 \mathrm{~cm}-1$

2. $\quad 11.6188 \mathrm{~cm}-1$

3. $\quad 17.4187 \mathrm{~cm}-1$

B3LYP/6-31G(d) Molecular Geometry in Cartesian Coordinates

$\begin{array}{llll}\text { C } & -2.693375 & -1.514409 & 0.133864 \\ \text { C } & -1.390567 & -1.889000 & -0.154272 \\ \text { C } & -0.832260 & -3.138549 & 0.244974 \\ \text { C } & -1.616439 & -3.960901 & 1.030285 \\ \text { H } & -1.228773 & -4.930856 & 1.330498 \\ \text { C } & -4.332004 & 2.178117 & -1.355432 \\ \text { C } & -3.243084 & -0.255664 & -0.446967 \\ \text { C } & -2.591075 & 0.952521 & -0.237191 \\ \text { C } & -3.131962 & 2.199945 & -0.672504 \\ \text { H } & -4.760675 & 3.117631 & -1.694642 \\ \text { O } & -0.587105 & -1.003263 & -0.869116 \\ \text { P } & -0.032443 & 0.295677 & -0.028967 \\ \text { O } & -1.428702 & 0.974303 & 0.515235 \\ \text { C } & 2.960948 & -4.715220 & -1.016771 \\ \text { C } & 2.108446 & -4.115458 & -1.946618 \\ \text { C } & 0.900706 & -3.554572 & -1.536053 \\ \text { C } & 0.514628 & -3.597878 & -0.186817 \\ \text { C } & 1.390201 & -4.182077 & 0.742679 \\ \text { C } & 2.603183 & -4.734944 & 0.332591 \\ \text { H } & 2.379788 & -4.090401 & -2.998978 \\ \text { H } & 3.265654 & -5.184863 & 1.067692\end{array}$




\begin{tabular}{|c|c|c|c|}
\hline C & -1.394256 & 6.100336 & -0.142590 \\
\hline C & -2.644517 & 5.801804 & 0.402057 \\
\hline C & -3.182610 & 4.522501 & 0.255080 \\
\hline C & -2.477223 & 3.517076 & -0.424687 \\
\hline C & -1.212053 & 3.819787 & -0.951864 \\
\hline C & -0.683944 & 5.104753 & -0.818983 \\
\hline $\mathrm{H}$ & -3.206154 & 6.565489 & 0.934118 \\
\hline $\mathrm{H}$ & 0.284336 & 5.332940 & -1.258801 \\
\hline C & -4.433278 & -0.272141 & -1.253903 \\
\hline C & -4.992656 & 0.971445 & -1.688482 \\
\hline C & -6.178768 & 0.972370 & -2.471458 \\
\hline C & -6.783204 & -0.206565 & -2.840221 \\
\hline C & -6.213255 & -1.439612 & -2.444395 \\
\hline C & -5.072576 & -1.472461 & -1.672854 \\
\hline $\mathrm{H}$ & -6.591837 & 1.928370 & -2.784878 \\
\hline $\mathrm{H}$ & -7.686414 & -0.195312 & -3.444186 \\
\hline $\mathrm{H}$ & -6.676420 & -2.371506 & -2.757537 \\
\hline $\mathrm{H}$ & -4.644774 & -2.426594 & -1.388471 \\
\hline C & -3.471108 & -2.347120 & 1.011227 \\
\hline C & -2.914020 & -3.588297 & 1.457870 \\
\hline C & -3.671721 & -4.423774 & 2.322578 \\
\hline C & -4.918301 & -4.042727 & 2.761403 \\
\hline C & -5.455816 & -2.799517 & 2.353087 \\
\hline C & -4.753875 & -1.975884 & 1.500493 \\
\hline $\mathrm{H}$ & -3.237712 & -5.368669 & 2.641213 \\
\hline $\mathrm{H}$ & -5.485547 & -4.686069 & 3.428546 \\
\hline $\mathrm{H}$ & -6.430434 & -2.488202 & 2.719407 \\
\hline $\mathrm{H}$ & -5.175739 & -1.021980 & 1.206436 \\
\hline $\mathrm{O}$ & 0.701597 & 1.202739 & -0.962130 \\
\hline $\mathrm{O}$ & 0.610406 & -0.179670 & 1.280797 \\
\hline $\mathrm{H}$ & 1.693379 & -0.501072 & 1.517859 \\
\hline $\mathrm{H}$ & 1.118446 & -4.191257 & 1.794330 \\
\hline $\mathrm{H}$ & 3.896905 & -5.163856 & -1.340825 \\
\hline $\mathrm{H}$ & 0.242880 & -3.094619 & -2.265941 \\
\hline $\mathrm{H}$ & -0.647922 & 3.051123 & -1.469278 \\
\hline $\mathrm{H}$ & -0.979788 & 7.100791 & -0.046597 \\
\hline $\mathrm{H}$ & -4.159296 & 4.293975 & 0.673445 \\
\hline C & 3.925401 & -0.740068 & 1.565621 \\
\hline $\mathrm{O}$ & 2.769107 & -0.809042 & 2.125476 \\
\hline $\mathrm{H}$ & 4.770516 & -1.092980 & 2.170200 \\
\hline C & 4.064067 & -1.123256 & 0.098350 \\
\hline $\mathrm{O}$ & 3.188512 & -0.994029 & -0.729611 \\
\hline 0 & 5.298596 & -1.598036 & -0.140094 \\
\hline C & 5.615771 & -1.915151 & -1.518509 \\
\hline
\end{tabular}




$\begin{array}{llll}\mathrm{H} & 4.815948 & -2.540397 & -1.923375 \\ \mathrm{H} & 5.644362 & -0.975170 & -2.077827 \\ \mathrm{C} & 3.553893 & 1.849322 & 0.962296 \\ \mathrm{C} & 4.653194 & 1.086381 & 1.418590 \\ \mathrm{H} & 2.248020 & 1.979585 & -0.617673 \\ \mathrm{~N} & 3.255662 & 2.002064 & -0.358523 \\ \mathrm{C} & 4.117591 & 1.804483 & -1.442770 \\ \mathrm{O} & 5.298857 & 1.524302 & -1.394080 \\ \mathrm{O} & 3.422886 & 2.031159 & -2.565898 \\ \mathrm{C} & 4.137221 & 1.812801 & -3.791265 \\ \mathrm{H} & 4.394500 & 0.755265 & -3.894299 \\ \mathrm{H} & 5.048170 & 2.415585 & -3.819763 \\ \mathrm{H} & 3.448498 & 2.112639 & -4.580694 \\ \mathrm{H} & 4.955415 & 1.271416 & 2.443762 \\ \mathrm{H} & 5.472800 & 0.934398 & 0.727729 \\ \mathrm{C} & 2.577220 & 2.404209 & 1.904889 \\ \mathrm{C} & 1.699903 & 3.435088 & 1.505582 \\ \mathrm{C} & 2.501750 & 1.932263 & 3.232993 \\ \mathrm{C} & 0.777990 & 3.968380 & 2.397130 \\ \mathrm{H} & 1.751758 & 3.833016 & 0.498957 \\ \mathrm{C} & 1.571472 & 2.465934 & 4.118390 \\ \mathrm{H} & 3.129903 & 1.115113 & 3.559202 \\ \mathrm{C} & 0.709816 & 3.483033 & 3.705789 \\ \mathrm{H} & 0.108491 & 4.755343 & 2.065472 \\ \mathrm{H} & 1.512634 & 2.076855 & 5.130530 \\ \mathrm{H} & -0.015894 & 3.896696 & 4.400641 \\ \mathrm{C} & 6.958951 & -2.619594 & -1.524741 \\ \mathrm{H} & 7.243442 & -2.866007 & -2.553701 \\ \mathrm{H} & 7.738273 & -1.981160 & -1.096637 \\ \mathrm{H} & 6.916627 & -3.548822 & -0.947232\end{array}$

Catalyst (R)-1 TS Ethyl Conformation 26

B3LYP/6-31G(d) Energy $=-2849.017569$

B3LYP-D3(BJ)/def2-TZVPP-IEF-PCM(DCM) Energy = -2850.331836

B3LYP-D3(BJ)/def2-TZVPP-IEF-PCM(DCM)//B3LYP/6-31G(d) Free Energy (Quasiharmonic) = 2849.662236

Frequencies (Top 3 out of 279)

1. $-429.5375 \mathrm{~cm}-1$

2. $\quad 10.7331 \mathrm{~cm}-1$

3. $\quad 15.5222 \mathrm{~cm}-1$ 
B3LYP/6-31G(d) Molecular Geometry in Cartesian Coordinates

\begin{tabular}{|c|c|c|c|}
\hline C & 3.431981 & -0.375433 & 0.108482 \\
\hline C & 2.872052 & 0.809454 & -0.345783 \\
\hline C & 3.483772 & 2.084194 & -0.160923 \\
\hline C & 4.647844 & 2.125257 & 0.582264 \\
\hline $\mathrm{H}$ & 5.153267 & 3.077398 & 0.720552 \\
\hline C & 1.475026 & -4.100777 & -0.837093 \\
\hline C & 2.787671 & -1.674427 & -0.246178 \\
\hline C & 1.454039 & -1.881467 & 0.067616 \\
\hline C & 0.765451 & -3.100129 & -0.202112 \\
\hline $\mathrm{H}$ & 0.987123 & -5.051624 & -1.034917 \\
\hline 0 & 1.669122 & 0.755620 & -1.043974 \\
\hline$P$ & 0.304260 & 0.448002 & -0.192507 \\
\hline $\mathrm{O}$ & 0.753941 & -0.856271 & 0.693299 \\
\hline C & 2.102620 & 5.757807 & -1.921501 \\
\hline C & 2.456786 & 5.710054 & -0.572426 \\
\hline C & 2.873478 & 4.508651 & -0.000351 \\
\hline C & 2.939591 & 3.330925 & -0.762212 \\
\hline C & 2.562578 & 3.387138 & -2.114189 \\
\hline C & 2.156240 & 4.590996 & -2.688353 \\
\hline $\mathrm{H}$ & 2.408454 & 6.608614 & 0.037185 \\
\hline $\mathrm{H}$ & 1.892627 & 4.618618 & -3.742839 \\
\hline C & -3.340078 & -3.846624 & 0.849224 \\
\hline C & -2.870042 & -4.141973 & -0.431468 \\
\hline C & -1.542845 & -3.877876 & -0.768171 \\
\hline C & -0.659632 & -3.311581 & 0.165822 \\
\hline C & -1.146527 & -3.008815 & 1.448047 \\
\hline C & -2.472116 & -3.279841 & 1.785765 \\
\hline $\mathrm{H}$ & -3.537366 & -4.573106 & -1.173198 \\
\hline $\mathrm{H}$ & -2.824545 & -3.048883 & 2.787264 \\
\hline C & 3.492686 & -2.698562 & -0.967711 \\
\hline C & 2.819973 & -3.932207 & -1.247112 \\
\hline C & 3.507305 & -4.959810 & -1.948473 \\
\hline C & 4.796745 & -4.775192 & -2.389548 \\
\hline C & 5.450117 & -3.543387 & -2.150598 \\
\hline C & 4.817299 & -2.533872 & -1.459044 \\
\hline $\mathrm{H}$ & 2.985024 & -5.894006 & -2.141095 \\
\hline $\mathrm{H}$ & 5.309937 & -5.565224 & -2.930855 \\
\hline $\mathrm{H}$ & 6.460073 & -3.389336 & -2.520860 \\
\hline $\mathrm{H}$ & 5.329727 & -1.593395 & -1.294242 \\
\hline C & 4.603983 & -0.308061 & 0.936964 \\
\hline C & 5.214829 & 0.966822 & 1.167194 \\
\hline
\end{tabular}




\begin{tabular}{|c|c|c|c|}
\hline C & 6.377985 & 1.046676 & 1.980204 \\
\hline C & 6.906357 & -0.077007 & 2.571712 \\
\hline C & 6.284152 & -1.332492 & 2.375586 \\
\hline C & 5.165758 & -1.445858 & 1.579293 \\
\hline $\mathrm{H}$ & 6.836528 & 2.020639 & 2.134378 \\
\hline $\mathrm{H}$ & 7.792060 & -0.002800 & 3.196707 \\
\hline $\mathrm{H}$ & 6.689738 & -2.215819 & 2.861475 \\
\hline $\mathrm{H}$ & 4.695080 & -2.413191 & 1.446632 \\
\hline 0 & -0.100990 & 1.525839 & 0.754971 \\
\hline O & -0.665949 & -0.018276 & -1.297239 \\
\hline $\mathrm{H}$ & -1.755213 & 0.237499 & -1.323567 \\
\hline $\mathrm{H}$ & 2.604503 & 2.488234 & -2.719834 \\
\hline $\mathrm{H}$ & 1.788571 & 6.695780 & -2.372148 \\
\hline $\mathrm{H}$ & 3.137261 & 4.474248 & 1.053031 \\
\hline $\mathrm{H}$ & -0.482237 & -2.567707 & 2.183249 \\
\hline $\mathrm{H}$ & -4.374137 & -4.050505 & 1.113602 \\
\hline $\mathrm{H}$ & -1.187500 & -4.090223 & -1.772423 \\
\hline C & -3.871605 & -0.084084 & -0.725113 \\
\hline $\mathrm{O}$ & -3.034453 & 0.456789 & -1.524866 \\
\hline $\mathrm{H}$ & -3.513718 & -0.760152 & 0.062548 \\
\hline C & -5.213192 & -0.514843 & -1.315671 \\
\hline 0 & -5.649668 & -0.157108 & -2.382388 \\
\hline $\mathrm{O}$ & -5.839842 & -1.361887 & -0.462267 \\
\hline C & -7.134440 & -1.856070 & -0.887949 \\
\hline $\mathrm{H}$ & -7.648383 & -2.104428 & 0.044099 \\
\hline $\mathrm{H}$ & -7.668297 & -1.047441 & -1.393553 \\
\hline C & -3.538603 & 1.769426 & 1.057679 \\
\hline C & -4.716923 & 1.344216 & 0.429671 \\
\hline $\mathrm{H}$ & -1.626117 & 2.363451 & 0.600829 \\
\hline $\mathrm{N}$ & -2.630683 & 2.524301 & 0.389449 \\
\hline C & -2.887024 & 3.308165 & -0.752489 \\
\hline 0 & -3.973243 & 3.665561 & -1.148361 \\
\hline 0 & -1.708231 & 3.654552 & -1.286401 \\
\hline C & -1.790450 & 4.459675 & -2.474948 \\
\hline $\mathrm{H}$ & -2.300047 & 3.906399 & -3.267701 \\
\hline $\mathrm{H}$ & -0.756014 & 4.666580 & -2.745013 \\
\hline $\mathrm{H}$ & -2.334052 & 5.385732 & -2.271304 \\
\hline $\mathrm{H}$ & -5.469562 & 0.867682 & 1.046631 \\
\hline $\mathrm{H}$ & -5.089358 & 1.940845 & -0.392541 \\
\hline C & -3.140957 & 1.289027 & 2.396976 \\
\hline C & -2.195109 & 2.000235 & 3.158259 \\
\hline C & -3.732427 & 0.141678 & 2.959965 \\
\hline C & -1.857096 & 1.580917 & 4.441860 \\
\hline $\mathrm{H}$ & -1.735434 & 2.893991 & 2.752381 \\
\hline
\end{tabular}




$\begin{array}{llll}\mathrm{C} & -3.389316 & -0.274853 & 4.242308 \\ \mathrm{H} & -4.444115 & -0.441981 & 2.385951 \\ \mathrm{C} & -2.452270 & 0.443755 & 4.989134 \\ \mathrm{H} & -1.127429 & 2.145685 & 5.014431 \\ \mathrm{H} & -3.853596 & -1.163835 & 4.660134 \\ \mathrm{H} & -2.188095 & 0.117940 & 5.991357 \\ \mathrm{C} & -6.996125 & -3.071874 & -1.791411 \\ \mathrm{H} & -6.425403 & -3.863653 & -1.294896 \\ \mathrm{H} & -7.988823 & -3.465977 & -2.037699 \\ \mathrm{H} & -6.492399 & -2.802470 & -2.723665\end{array}$

Catalyst (R)-1 TS Ethyl Conformation 27

B3LYP/6-31G(d) Energy $=-2849.01756$

B3LYP-D3(BJ)/def2-TZVPP-IEF-PCM(DCM) Energy $=-2850.331921$

B3LYP-D3(BJ)/def2-TZVPP-IEF-PCM(DCM)//B3LYP/6-31G(d) Free Energy (Quasiharmonic) = 2849.662285

Frequencies (Top 3 out of 279)

1. $-437.2714 \mathrm{~cm}-1$

2. $\quad 10.7040 \mathrm{~cm}-1$

3. $15.3168 \mathrm{~cm}-1$

B3LYP/6-31G(d) Molecular Geometry in Cartesian Coordinates

$\begin{array}{llll}\text { C } & 3.469391 & -0.284759 & 0.132853 \\ \text { C } & 2.872972 & 0.888737 & -0.304221 \\ \text { C } & 3.430585 & 2.181131 & -0.075992 \\ \text { C } & 4.577878 & 2.248404 & 0.690979 \\ \text { H } & 5.042952 & 3.215560 & 0.862632 \\ \text { C } & 1.672971 & -4.055997 & -0.941631 \\ \text { C } & 2.881962 & -1.598123 & -0.265216 \\ \text { C } & 1.551305 & -1.862586 & 0.016680 \\ \text { C } & 0.914291 & -3.098627 & -0.296872 \\ \text { H } & 1.224817 & -5.018758 & -1.173055 \\ \text { O } & 1.687223 & 0.806150 & -1.028301 \\ \text { P } & 0.318615 & 0.426563 & -0.212811 \\ \text { O } & 0.800875 & -0.880074 & 0.652471 \\ \text { C } & 1.933324 & 5.840934 & -1.769494 \\ \text { C } & 2.266024 & 5.772717 & -0.415853 \\ \text { C } & 2.721259 & 4.574664 & 0.133448 \\ \text { C } & 2.848187 & 3.420521 & -0.656295\end{array}$




\begin{tabular}{|c|c|c|c|}
\hline C & 2.492715 & 3.496466 & -2.013157 \\
\hline C & 2.047658 & 4.697409 & -2.564247 \\
\hline $\mathrm{H}$ & 2.170749 & 6.652592 & 0.215118 \\
\hline $\mathrm{H}$ & 1.801491 & 4.741618 & -3.622389 \\
\hline C & -3.181285 & -4.020197 & 0.649441 \\
\hline C & -2.676787 & -4.260386 & -0.629663 \\
\hline C & -1.353508 & -3.940194 & -0.931599 \\
\hline C & -0.509094 & -3.371256 & 0.036038 \\
\hline C & -1.030867 & -3.123919 & 1.316425 \\
\hline C & -2.352122 & -3.451534 & 1.619464 \\
\hline $\mathrm{H}$ & -3.314182 & -4.691963 & -1.396909 \\
\hline $\mathrm{H}$ & -2.731688 & -3.263087 & 2.620012 \\
\hline C & 3.638778 & -2.577039 & -0.996959 \\
\hline C & 3.018435 & -3.827442 & -1.319792 \\
\hline C & 3.757287 & -4.810910 & -2.031954 \\
\hline C & 5.047071 & -4.567538 & -2.442446 \\
\hline C & 5.648863 & -3.318617 & -2.160674 \\
\hline C & 4.965362 & -2.350944 & -1.457634 \\
\hline$H$ & 3.274291 & -5.758728 & -2.257701 \\
\hline $\mathrm{H}$ & 5.599915 & -5.324151 & -2.992382 \\
\hline $\mathrm{H}$ & 6.659156 & -3.117856 & -2.506860 \\
\hline $\mathrm{H}$ & 5.438662 & -1.396385 & -1.259991 \\
\hline C & 4.621977 & -0.193000 & 0.985835 \\
\hline C & 5.178435 & 1.098317 & 1.258660 \\
\hline C & 6.322152 & 1.202507 & 2.096133 \\
\hline C & 6.882561 & 0.085601 & 2.670751 \\
\hline C & 6.313345 & -1.187573 & 2.432281 \\
\hline C & 5.215319 & -1.323968 & 1.611626 \\
\hline $\mathrm{H}$ & 6.739590 & 2.189212 & 2.282684 \\
\hline $\mathrm{H}$ & 7.752848 & 0.178210 & 3.314662 \\
\hline $\mathrm{H}$ & 6.743744 & -2.066470 & 2.904673 \\
\hline $\mathrm{H}$ & 4.785116 & -2.305045 & 1.446444 \\
\hline $\mathrm{O}$ & -0.146433 & 1.465448 & 0.750771 \\
\hline $\mathrm{O}$ & -0.609909 & -0.049104 & -1.348494 \\
\hline $\mathrm{H}$ & -1.712428 & 0.148749 & -1.384302 \\
\hline $\mathrm{H}$ & 2.581521 & 2.615910 & -2.640291 \\
\hline $\mathrm{H}$ & 1.589027 & 6.776783 & -2.202101 \\
\hline $\mathrm{H}$ & 2.967929 & 4.523746 & 1.190309 \\
\hline $\mathrm{H}$ & -0.396871 & -2.681541 & 2.077229 \\
\hline $\mathrm{H}$ & -4.212309 & -4.267943 & 0.886587 \\
\hline $\mathrm{H}$ & -0.971682 & -4.109862 & -1.934242 \\
\hline C & -3.811362 & -0.283736 & -0.807956 \\
\hline $\mathrm{O}$ & -2.996436 & 0.303747 & -1.597443 \\
\hline $\mathrm{H}$ & -3.425880 & -0.942308 & -0.018724 \\
\hline
\end{tabular}




$\begin{array}{llll}\mathrm{C} & -5.121758 & -0.784266 & -1.413652 \\ \mathrm{O} & -5.553098 & -0.466413 & -2.494862 \\ \mathrm{O} & -5.719334 & -1.653872 & -0.561602 \\ \mathrm{C} & -6.973579 & -2.227090 & -1.007796 \\ \mathrm{H} & -6.903324 & -2.427208 & -2.079693 \\ \mathrm{H} & -7.045801 & -3.173294 & -0.465781 \\ \mathrm{C} & -3.592270 & 1.562757 & 0.996970 \\ \mathrm{C} & -4.740405 & 1.096016 & 0.343523 \\ \mathrm{H} & -1.699742 & 2.244587 & 0.582200 \\ \mathrm{~N} & -2.706675 & 2.366144 & 0.355694 \\ \mathrm{C} & -2.977184 & 3.156225 & -0.778420 \\ \mathrm{O} & -4.070921 & 3.469857 & -1.190590 \\ \mathrm{O} & -1.805464 & 3.565011 & -1.283087 \\ \mathrm{C} & -1.900883 & 4.385390 & -2.460076 \\ \mathrm{H} & -2.368500 & 3.822990 & -3.272051 \\ \mathrm{H} & -0.871804 & 4.643684 & -2.705317 \\ \mathrm{H} & -2.490297 & 5.282206 & -2.253033 \\ \mathrm{H} & -5.482364 & 0.581048 & 0.941980 \\ \mathrm{H} & -5.122930 & 1.684943 & -0.479583 \\ \mathrm{C} & -3.196448 & 1.079407 & 2.335760 \\ \mathrm{C} & -2.297188 & 1.820344 & 3.124539 \\ \mathrm{C} & -3.743757 & -0.103267 & 2.869697 \\ \mathrm{C} & -1.961627 & 1.395457 & 4.406946 \\ \mathrm{H} & -1.872489 & 2.740826 & 2.740825 \\ \mathrm{C} & -3.402754 & -0.525301 & 4.150812 \\ \mathrm{H} & -4.417926 & -0.709290 & 2.273904 \\ \mathrm{C} & -2.512443 & 0.222927 & 4.925247 \\ \mathrm{H} & -1.268413 & 1.983323 & 5.001155 \\ \mathrm{H} & -3.831781 & -1.441922 & 4.545986 \\ \mathrm{H} & -2.249869 & -0.107509 & 5.926376 \\ \mathrm{C} & -8.147971 & -1.312136 & -0.695173 \\ \mathrm{H} & -8.066184 & -0.375413 & -1.253463 \\ \mathrm{H} & -9.085614 & -1.801425 & -0.983049 \\ & -8.195144 & -1.086435 & 0.375529\end{array}$

Catalyst (R)-1 TS Ethyl Conformation 28

B3LYP/6-31G(d) Energy $=-2849.01766$

B3LYP-D3(BJ)/def2-TZVPP-IEF-PCM(DCM) Energy $=-2850.33217$

B3LYP-D3(BJ)/def2-TZVPP-IEF-PCM(DCM)//B3LYP/6-31G(d) Free Energy (Quasiharmonic) = 2849.662927

Frequencies (Top 3 out of 279) 
1. $-441.7717 \mathrm{~cm}-1$

2. $\quad 10.8425 \mathrm{~cm}-1$

3. $\quad 14.5721 \mathrm{~cm}-1$

B3LYP/6-31G(d) Molecular Geometry in Cartesian Coordinates

\begin{tabular}{|c|c|c|c|}
\hline C & 3.445294 & -0.385482 & 0.153214 \\
\hline C & 2.897536 & 0.812746 & -0.280558 \\
\hline C & 3.503021 & 2.081119 & -0.039778 \\
\hline C & 4.645341 & 2.099423 & 0.737294 \\
\hline $\mathrm{H}$ & 5.146019 & 3.046825 & 0.918677 \\
\hline C & 1.517885 & -4.079311 & -0.961571 \\
\hline C & 2.812242 & -1.672956 & -0.259010 \\
\hline C & 1.470360 & -1.889007 & 0.010370 \\
\hline C & 0.790191 & -3.098328 & -0.316523 \\
\hline $\mathrm{H}$ & 1.036098 & -5.023260 & -1.202693 \\
\hline $\mathrm{O}$ & 1.715172 & 0.780489 & -1.014103 \\
\hline$P$ & 0.326233 & 0.446499 & -0.212534 \\
\hline $\mathrm{O}$ & 0.752455 & -0.883150 & 0.647070 \\
\hline C & 2.173724 & 5.807133 & -1.728568 \\
\hline C & 2.488109 & 5.718493 & -0.371724 \\
\hline C & 2.887677 & 4.500012 & 0.175922 \\
\hline C & 2.975961 & 3.345646 & -0.618730 \\
\hline C & 2.638559 & 3.442779 & -1.978840 \\
\hline C & 2.249520 & 4.663795 & -2.528222 \\
\hline $\mathrm{H}$ & 2.422102 & 6.598393 & 0.262937 \\
\hline $\mathrm{H}$ & 2.017023 & 4.723378 & -3.588695 \\
\hline C & -3.342976 & -3.875724 & 0.593560 \\
\hline C & -2.837131 & -4.129807 & -0.682316 \\
\hline C & -1.501030 & -3.855544 & -0.972644 \\
\hline C & -0.644785 & -3.320194 & 0.003737 \\
\hline C & -1.167846 & -3.058290 & 1.280706 \\
\hline C & -2.502287 & -3.339476 & 1.572048 \\
\hline $\mathrm{H}$ & -3.483001 & -4.536586 & -1.456024 \\
\hline$H$ & -2.883077 & -3.140476 & 2.570040 \\
\hline C & 3.537949 & -2.674740 & -0.991300 \\
\hline C & 2.873973 & -3.898918 & -1.327504 \\
\hline C & 3.581419 & -4.904845 & -2.040188 \\
\hline C & 4.882809 & -4.707378 & -2.438514 \\
\hline C & 5.528573 & -3.483746 & -2.143448 \\
\hline C & 4.875911 & -2.495628 & -1.439539 \\
\hline $\mathrm{H}$ & 3.065200 & -5.832437 & -2.276188 \\
\hline $\mathrm{H}$ & 5.411532 & -5.480668 & -2.988974 \\
\hline
\end{tabular}




\begin{tabular}{|c|c|c|c|}
\hline $\mathrm{H}$ & 6.548575 & -3.318845 & -2.479966 \\
\hline $\mathrm{H}$ & 5.383023 & -1.560843 & -1.231522 \\
\hline C & 4.593190 & -0.343524 & 1.016393 \\
\hline C & 5.196230 & 0.923685 & 1.302735 \\
\hline C & 6.335685 & 0.978619 & 2.150621 \\
\hline C & 6.847946 & -0.162629 & 2.722341 \\
\hline C & 6.232643 & -1.411509 & 2.470268 \\
\hline C & 5.137445 & -1.500439 & 1.639375 \\
\hline $\mathrm{H}$ & 6.788865 & 1.947397 & 2.347443 \\
\hline $\mathrm{H}$ & 7.715443 & -0.107588 & 3.374276 \\
\hline $\mathrm{H}$ & 6.625002 & -2.309304 & 2.940244 \\
\hline $\mathrm{H}$ & 4.671591 & -2.463257 & 1.463819 \\
\hline $\mathrm{O}$ & -0.107530 & 1.495443 & 0.754795 \\
\hline $\mathrm{O}$ & -0.610723 & 0.012806 & -1.357802 \\
\hline $\mathrm{H}$ & -1.702581 & 0.264647 & -1.409519 \\
\hline $\mathrm{H}$ & 2.698048 & 2.562420 & -2.609734 \\
\hline $\mathrm{H}$ & 1.873270 & 6.758564 & -2.159859 \\
\hline $\mathrm{H}$ & 3.120647 & 4.433720 & 1.235033 \\
\hline $\mathrm{H}$ & -0.524749 & -2.641186 & 2.048067 \\
\hline $\mathrm{H}$ & -4.383550 & -4.089285 & 0.822643 \\
\hline $\mathrm{H}$ & -1.117374 & -4.035568 & -1.972769 \\
\hline C & -3.830216 & -0.076905 & -0.879291 \\
\hline $\mathrm{O}$ & -2.972069 & 0.482785 & -1.642715 \\
\hline $\mathrm{H}$ & -3.493038 & -0.767507 & -0.095112 \\
\hline C & -5.152567 & -0.498450 & -1.517630 \\
\hline $\mathrm{O}$ & -5.548052 & -0.144722 & -2.601120 \\
\hline $\mathrm{O}$ & -5.819289 & -1.340298 & -0.691332 \\
\hline C & -7.094956 & -1.814716 & -1.184112 \\
\hline $\mathrm{H}$ & -7.727302 & -0.950364 & -1.411283 \\
\hline $\mathrm{H}$ & -6.928245 & -2.356101 & -2.120806 \\
\hline C & -3.552569 & 1.732807 & 0.957433 \\
\hline C & -4.711721 & 1.326847 & 0.283420 \\
\hline $\mathrm{H}$ & -1.626544 & 2.336998 & 0.575410 \\
\hline$N$ & -2.624330 & 2.504807 & 0.338184 \\
\hline C & -2.845944 & 3.320614 & -0.788361 \\
\hline O & -3.919810 & 3.687837 & -1.208441 \\
\hline $\mathrm{O}$ & -1.651603 & 3.683096 & -1.274878 \\
\hline C & -1.697787 & 4.521696 & -2.442071 \\
\hline $\mathrm{H}$ & -2.181131 & 3.990821 & -3.265969 \\
\hline $\mathrm{H}$ & -0.655734 & 4.737146 & -2.673322 \\
\hline $\mathrm{H}$ & -2.249211 & 5.441064 & -2.229369 \\
\hline $\mathrm{H}$ & -5.482983 & 0.835319 & 0.864341 \\
\hline $\mathrm{H}$ & -5.057780 & 1.944176 & -0.534990 \\
\hline C & -3.195806 & 1.214218 & 2.294149 \\
\hline
\end{tabular}




$\begin{array}{llll}\mathrm{C} & -2.272554 & 1.901882 & 3.103220 \\ \mathrm{C} & -3.804830 & 0.052247 & 2.806241 \\ \mathrm{C} & -1.973449 & 1.445664 & 4.383902 \\ \mathrm{H} & -1.799946 & 2.805821 & 2.736692 \\ \mathrm{C} & -3.500544 & -0.401108 & 4.085905 \\ \mathrm{H} & -4.499419 & -0.513778 & 2.194780 \\ \mathrm{C} & -2.585663 & 0.294428 & 4.880553 \\ \mathrm{H} & -1.260656 & 1.992617 & 4.993803 \\ \mathrm{H} & -3.977650 & -1.300955 & 4.464161 \\ \mathrm{H} & -2.351750 & -0.060259 & 5.880491 \\ \mathrm{C} & -7.701948 & -2.700944 & -0.113364 \\ \mathrm{H} & -7.857095 & -2.143971 & 0.816483 \\ \mathrm{H} & -8.672172 & -3.080354 & -0.451905 \\ \mathrm{H} & -7.054563 & -3.557654 & 0.100709\end{array}$

Catalyst (R)-1 TS Ethyl Conformation 29

B3LYP/6-31G(d) Energy $=-2849.0185$

B3LYP-D3(BJ)/def2-TZVPP-IEF-PCM(DCM) Energy = -2850.332412

B3LYP-D3(BJ)/def2-TZVPP-IEF-PCM(DCM)//B3LYP/6-31G(d) Free Energy (Quasiharmonic) = 2849.662679

Frequencies (Top 3 out of 279)

1. $-463.0881 \mathrm{~cm}-1$

2. $\quad 12.1067 \mathrm{~cm}-1$

3. $\quad 15.3504 \mathrm{~cm}-1$

B3LYP/6-31G(d) Molecular Geometry in Cartesian Coordinates

$\begin{array}{lrrr}\text { C } & 3.473815 & -0.377934 & 0.196654 \\ \text { C } & 2.926911 & 0.844419 & -0.171617 \\ \text { C } & 3.606309 & 2.085436 & 0.020985 \\ \text { C } & 4.815407 & 2.049831 & 0.689165 \\ \text { H } & 5.349479 & 2.981149 & 0.857770 \\ \text { C } & 1.474737 & -4.049385 & -0.871505 \\ \text { C } & 2.808709 & -1.650007 & -0.212985 \\ \text { C } & 1.482476 & -1.868701 & 0.118268 \\ \text { C } & 0.782543 & -3.073068 & -0.182331 \\ \text { H } & 0.980882 & -4.991495 & -1.094587 \\ \text { O } & 1.714301 & 0.864672 & -0.852853 \\ \text { P } & 0.329543 & 0.440370 & -0.093848 \\ \text { O } & 0.795247 & -0.858063 & 0.785970\end{array}$




\begin{tabular}{|c|c|c|c|}
\hline$C$ & 2.293103 & 5.913831 & -1.445556 \\
\hline C & 1.420618 & 5.121932 & -0.695856 \\
\hline C & 1.817522 & 3.866335 & -0.234472 \\
\hline C & 3.106657 & 3.385097 & -0.509997 \\
\hline C & 3.976038 & 4.188786 & -1.267259 \\
\hline C & 3.574120 & 5.440266 & -1.732826 \\
\hline $\mathrm{H}$ & 0.421998 & 5.481017 & -0.461173 \\
\hline $\mathrm{H}$ & 4.261094 & 6.042093 & -2.322230 \\
\hline C & -3.301843 & -3.838478 & 0.936558 \\
\hline C & -2.412618 & -3.299066 & 1.869246 \\
\hline C & -1.093214 & -3.024231 & 1.510699 \\
\hline C & -0.634408 & -3.293312 & 0.210583 \\
\hline C & -1.539704 & -3.830860 & -0.719704 \\
\hline C & -2.860223 & -4.100637 & -0.361620 \\
\hline $\mathrm{H}$ & -2.743689 & -3.091742 & 2.883247 \\
\hline $\mathrm{H}$ & -3.544907 & -4.509654 & -1.099905 \\
\hline C & 3.492205 & -2.644635 & -0.996227 \\
\hline C & 2.809146 & -3.864687 & -1.308680 \\
\hline C & 3.474701 & -4.863537 & -2.069977 \\
\hline C & 4.751699 & -4.662163 & -2.538875 \\
\hline C & 5.413361 & -3.441545 & -2.268445 \\
\hline C & 4.802509 & -2.461134 & -1.517717 \\
\hline $\mathrm{H}$ & 2.945005 & -5.788230 & -2.286606 \\
\hline $\mathrm{H}$ & 5.247946 & -5.429634 & -3.126455 \\
\hline $\mathrm{H}$ & 6.412248 & -3.272428 & -2.661396 \\
\hline $\mathrm{H}$ & 5.321047 & -1.528578 & -1.329984 \\
\hline C & 4.682516 & -0.385547 & 0.974950 \\
\hline C & 5.361029 & 0.852375 & 1.210690 \\
\hline C & 6.559213 & 0.859010 & 1.975253 \\
\hline C & 7.062463 & -0.303442 & 2.510916 \\
\hline C & 6.377166 & -1.524435 & 2.307009 \\
\hline C & 5.221236 & -1.565502 & 1.558797 \\
\hline $\mathrm{H}$ & 7.064967 & 1.807927 & 2.137689 \\
\hline $\mathrm{H}$ & 7.976073 & -0.286212 & 3.098813 \\
\hline $\mathrm{H}$ & 6.763050 & -2.438540 & 2.750170 \\
\hline $\mathrm{H}$ & 4.702751 & -2.507392 & 1.421472 \\
\hline 0 & -0.196864 & 1.468310 & 0.855962 \\
\hline $\mathrm{O}$ & -0.550037 & -0.039805 & -1.264059 \\
\hline $\mathrm{H}$ & -1.658007 & 0.135934 & -1.360173 \\
\hline $\mathrm{H}$ & 4.969633 & 3.818118 & -1.504624 \\
\hline $\mathrm{H}$ & 1.978180 & 6.891231 & -1.802277 \\
\hline $\mathrm{H}$ & 1.130948 & 3.265630 & 0.351173 \\
\hline $\mathrm{H}$ & -1.207029 & -4.015965 & -1.736994 \\
\hline $\mathrm{H}$ & -4.330720 & -4.047582 & 1.216766 \\
\hline
\end{tabular}




$\begin{array}{llll}\mathrm{H} & -0.411819 & -2.605723 & 2.243422 \\ \mathrm{C} & -3.788535 & -0.256011 & -0.888213 \\ \mathrm{O} & -2.916031 & 0.268468 & -1.659980 \\ \mathrm{H} & -3.465429 & -0.862528 & -0.032598 \\ \mathrm{C} & -5.066135 & -0.778084 & -1.543361 \\ \mathrm{O} & -5.422730 & -0.524029 & -2.667687 \\ \mathrm{O} & -5.729447 & -1.583991 & -0.678092 \\ \mathrm{C} & -6.963765 & -2.168177 & -1.165341 \\ \mathrm{H} & -6.829949 & -2.438679 & -2.215503 \\ \mathrm{H} & -7.085955 & -3.075782 & -0.569142 \\ \mathrm{C} & -3.660721 & 1.688615 & 0.816690 \\ \mathrm{C} & -4.768906 & 1.217009 & 0.102277 \\ \mathrm{H} & -1.719795 & 2.280997 & 0.523220 \\ \mathrm{~N} & -2.697494 & 2.424651 & 0.204856 \\ \mathrm{C} & -2.839712 & 3.131848 & -1.005147 \\ \mathrm{O} & -3.880715 & 3.445166 & -1.535196 \\ \mathrm{O} & -1.612629 & 3.461241 & -1.436153 \\ \mathrm{C} & -1.570654 & 4.132861 & -2.709214 \\ \mathrm{H} & -1.966062 & 3.476608 & -3.488080 \\ \mathrm{H} & -0.516802 & 4.348521 & -2.878922 \\ \mathrm{H} & -2.158649 & 5.053210 & -2.674078 \\ \mathrm{H} & -5.570482 & 0.759181 & 0.669518 \\ \mathrm{H} & -5.065844 & 1.760477 & -0.784864 \\ \mathrm{C} & -3.388209 & 1.275782 & 2.208684 \\ \mathrm{C} & -2.544952 & 2.047714 & 3.028753 \\ \mathrm{C} & -3.997985 & 0.130841 & 2.756810 \\ \mathrm{C} & -2.324284 & 1.690032 & 4.355769 \\ \mathrm{H} & -2.076319 & 2.941675 & 2.633142 \\ \mathrm{C} & -3.770826 & -0.224722 & 4.082569 \\ \mathrm{H} & -4.630014 & -0.498730 & 2.139495 \\ \mathrm{C} & -2.935664 & 0.554104 & 4.887673 \\ \mathrm{H} & -1.673687 & 2.301339 & 4.973993 \\ \mathrm{H} & -4.245337 & -1.113769 & 4.488420 \\ \mathrm{H} & -2.762391 & 0.275662 & 5.923428 \\ \mathrm{H} & -9.065125 & -1.713606 & -1.302205 \\ \mathrm{H} & -0.96375 & -0.322016 & -1.598702\end{array}$

Catalyst (R)-1 TS Ethyl Conformation 30

B3LYP/6-31G(d) Energy $=-2849.01849$

B3LYP-D3(BJ)/def2-TZVPP-IEF-PCM(DCM) Energy $=-2850.332266$ 
B3LYP-D3(BJ)/def2-TZVPP-IEF-PCM(DCM)//B3LYP/6-31G(d) Free Energy (Quasiharmonic) = 2849.662561

Frequencies (Top 3 out of 279)

1. $-455.5698 \mathrm{~cm}-1$

2. $\quad 11.6935 \mathrm{~cm}-1$

3. $14.8924 \mathrm{~cm}-1$

B3LYP/6-31G(d) Molecular Geometry in Cartesian Coordinates

$\begin{array}{llll}\text { C } & 3.435500 & -0.460016 & 0.181863 \\ \text { C } & 2.926412 & 0.772317 & -0.206845 \\ \text { C } & 3.653505 & 1.991878 & -0.055908 \\ \text { C } & 4.872356 & 1.928011 & 0.592149 \\ \text { H } & 5.442558 & 2.842996 & 0.728830 \\ \text { C } & 1.289000 & -4.082423 & -0.759054 \\ \text { C } & 2.718177 & -1.716585 & -0.185042 \\ \text { C } & 1.391106 & -1.879190 & 0.173855 \\ \text { C } & 0.643881 & -3.064985 & -0.083737 \\ \text { H } & 0.758602 & -5.011831 & -0.949027 \\ \text { O } & 1.703345 & 0.820560 & -0.867932 \\ \text { P } & 0.317654 & 0.464572 & -0.076047 \\ \text { O } & 0.752204 & -0.828295 & 0.827264 \\ \text { C } & 2.455073 & 5.832470 & -1.586868 \\ \text { C } & 1.568653 & 5.091222 & -0.802515 \\ \text { C } & 1.927281 & 3.832046 & -0.320013 \\ \text { C } & 3.191835 & 3.296469 & -0.608663 \\ \text { C } & 4.075452 & 4.049366 & -1.400840 \\ \text { C } & 3.711425 & 5.304344 & -1.887647 \\ \text { H } & 0.589103 & 5.493106 & -0.557195 \\ \text { H } & 4.408525 & 5.866338 & -2.503877 \\ \text { C } & -3.444951 & -3.654796 & 1.121922 \\ \text { C } & -2.522269 & -3.119439 & 2.023938 \\ \text { C } & -1.200354 & -2.901685 & 1.636852 \\ \text { C } & -0.772733 & -3.224556 & 0.338331 \\ \text { C } & -1.711264 & -3.757534 & -0.561077 \\ \text { C } & -3.033960 & -3.970685 & -0.174350 \\ \text { H } & -2.829100 & -2.870604 & 3.036172 \\ \text { H } & -3.744105 & -4.377948 & -0.889234 \\ \text { C } & 3.352015 & -2.754114 & -0.954246 \\ \text { C } & 2.620938 & -3.956426 & -1.223671 \\ \text { C } & 3.237132 & -4.997050 & -1.970449 \\ \text { C } & 4.511788 & -4.853017 & -2.466082\end{array}$




\begin{tabular}{|c|c|c|c|}
\hline C & 5.220786 & -3.650412 & -2.238224 \\
\hline C & 4.658416 & -2.630467 & -1.502440 \\
\hline $\mathrm{H}$ & 2.671441 & -5.907418 & -2.154291 \\
\hline $\mathrm{H}$ & 4.970096 & -5.652080 & -3.042255 \\
\hline $\mathrm{H}$ & 6.217796 & -3.526880 & -2.652345 \\
\hline $\mathrm{H}$ & 5.212680 & -1.712607 & -1.347289 \\
\hline C & 4.656689 & -0.493230 & 0.939783 \\
\hline C & 5.383667 & 0.724257 & 1.133470 \\
\hline C & 6.594755 & 0.705390 & 1.877217 \\
\hline C & 7.064980 & -0.461484 & 2.432877 \\
\hline C & 6.332284 & -1.661048 & 2.270916 \\
\hline C & 5.162529 & -1.677727 & 1.543543 \\
\hline $\mathrm{H}$ & 7.137351 & 1.638772 & 2.007581 \\
\hline $\mathrm{H}$ & 7.988928 & -0.463618 & 3.004643 \\
\hline $\mathrm{H}$ & 6.692520 & -2.577720 & 2.730073 \\
\hline $\mathrm{H}$ & 4.607861 & -2.603007 & 1.438519 \\
\hline $\mathrm{O}$ & -0.155538 & 1.533425 & 0.856288 \\
\hline $\mathrm{O}$ & -0.599506 & -0.013039 & -1.218511 \\
\hline $\mathrm{H}$ & -1.696507 & 0.216399 & -1.308950 \\
\hline $\mathrm{H}$ & 5.049642 & 3.636149 & -1.648174 \\
\hline $\mathrm{H}$ & 2.169952 & 6.812920 & -1.959904 \\
\hline $\mathrm{H}$ & 1.230453 & 3.270836 & 0.292126 \\
\hline $\mathrm{H}$ & -1.402166 & -3.984019 & -1.577434 \\
\hline $\mathrm{H}$ & -4.475607 & -3.819652 & 1.424433 \\
\hline $\mathrm{H}$ & -0.493036 & -2.485722 & 2.346017 \\
\hline C & -3.848019 & -0.067470 & -0.828219 \\
\hline $\mathrm{O}$ & -2.950979 & 0.408800 & -1.603564 \\
\hline $\mathrm{H}$ & -3.555098 & -0.690430 & 0.026685 \\
\hline C & -5.154566 & -0.518950 & -1.478647 \\
\hline $\mathrm{O}$ & -5.510314 & -0.228872 & -2.594617 \\
\hline $\mathrm{O}$ & -5.853692 & -1.294613 & -0.614327 \\
\hline C & -7.130757 & -1.790469 & -1.089801 \\
\hline $\mathrm{H}$ & -7.709531 & -1.962016 & -0.178753 \\
\hline $\mathrm{H}$ & -7.609885 & -1.007939 & -1.683552 \\
\hline C & -3.610345 & 1.888243 & 0.856334 \\
\hline C & -4.747333 & 1.452863 & 0.163947 \\
\hline $\mathrm{H}$ & -1.651316 & 2.395924 & 0.527013 \\
\hline$N$ & -2.626769 & 2.573863 & 0.219327 \\
\hline C & -2.757523 & 3.265275 & -1.001379 \\
\hline $\mathrm{O}$ & -3.792386 & 3.616371 & -1.519457 \\
\hline $\mathrm{O}$ & -1.524640 & 3.530890 & -1.458795 \\
\hline C & -1.475433 & 4.175611 & -2.745509 \\
\hline $\mathrm{H}$ & -1.913252 & 3.522707 & -3.504237 \\
\hline $\mathrm{H}$ & -0.416281 & 4.340991 & -2.937105 \\
\hline
\end{tabular}




$\begin{array}{llll}\mathrm{H} & -2.021555 & 5.121672 & -2.718821 \\ \mathrm{H} & -5.558093 & 1.034087 & 0.748297 \\ \mathrm{H} & -5.036579 & 1.999904 & -0.723577 \\ \mathrm{C} & -3.335063 & 1.486059 & 2.250846 \\ \mathrm{C} & -2.448132 & 2.234306 & 3.046518 \\ \mathrm{C} & -3.985129 & 0.377399 & 2.826402 \\ \mathrm{C} & -2.224120 & 1.889011 & 4.376249 \\ \mathrm{H} & -1.947487 & 3.100892 & 2.629837 \\ \mathrm{C} & -3.754754 & 0.033941 & 4.154787 \\ \mathrm{H} & -4.652483 & -0.234153 & 2.228517 \\ \mathrm{C} & -2.875869 & 0.789179 & 4.935423 \\ \mathrm{H} & -1.539402 & 2.481872 & 4.975290 \\ \mathrm{H} & -4.261370 & -0.826970 & 4.581929 \\ \mathrm{H} & -2.700216 & 0.520576 & 5.973374 \\ \mathrm{C} & -6.966461 & -3.068972 & -1.897044 \\ \mathrm{H} & -7.951275 & -3.455027 & -2.184250 \\ \mathrm{H} & -6.393808 & -2.877185 & -2.808488 \\ \mathrm{H} & -6.454331 & -3.838310 & -1.309681\end{array}$

Catalyst (R)-1 TS Ethyl Conformation 31 (TS-5Si)

B3LYP/6-31G(d) Energy $=-2849.018605$

B3LYP-D3(BJ)/def2-TZVPP-IEF-PCM(DCM) Energy $=-2850.332767$

B3LYP-D3(BJ)/def2-TZVPP-IEF-PCM(DCM)//B3LYP/6-31G(d) Free Energy (Quasiharmonic) = 2849.663424

Frequencies (Top 3 out of 279)

1. $-467.6635 \mathrm{~cm}-1$

2. $\quad 11.9962 \mathrm{~cm}-1$

3. $\quad 14.4045 \mathrm{~cm}-1$

B3LYP/6-31G(d) Molecular Geometry in Cartesian Coordinates

$\begin{array}{lrrr}\text { C } & 3.447979 & -0.472632 & 0.219517 \\ \text { C } & 2.949794 & 0.770874 & -0.147206 \\ \text { C } & 3.672508 & 1.984988 & 0.058839 \\ \text { C } & 4.872997 & 1.901409 & 0.738197 \\ \text { H } & 5.439205 & 2.811574 & 0.917127 \\ \text { C } & 1.325537 & -4.062731 & -0.886414 \\ \text { C } & 2.740587 & -1.717305 & -0.203109 \\ \text { C } & 1.404174 & -1.888588 & 0.114714 \\ \text { C } & 0.663401 & -3.064959 & -0.198473\end{array}$




\begin{tabular}{|c|c|c|c|}
\hline $\mathrm{H}$ & 0.799525 & -4.984972 & -1.118831 \\
\hline $\mathrm{O}$ & 1.745572 & 0.839298 & -0.840018 \\
\hline$P$ & 0.338068 & 0.461285 & -0.098177 \\
\hline $\mathrm{O}$ & 0.748157 & -0.856427 & 0.780813 \\
\hline C & 2.516217 & 5.868187 & -1.395414 \\
\hline C & 1.607786 & 5.104635 & -0.659118 \\
\hline C & 1.953246 & 3.832215 & -0.202445 \\
\hline C & 3.226263 & 3.305195 & -0.468941 \\
\hline C & 4.132098 & 4.080653 & -1.212818 \\
\hline C & 3.781410 & 5.349050 & -1.673949 \\
\hline $\mathrm{H}$ & 0.621009 & 5.499168 & -0.431425 \\
\hline $\mathrm{H}$ & 4.495847 & 5.928537 & -2.253001 \\
\hline C & -3.455214 & -3.686336 & 0.882500 \\
\hline C & -2.554937 & -3.184134 & 1.825287 \\
\hline C & -1.223568 & -2.955749 & 1.478893 \\
\hline C & -0.764011 & -3.234930 & 0.181171 \\
\hline C & -1.680413 & -3.734211 & -0.759447 \\
\hline C & -3.012770 & -3.957745 & -0.413493 \\
\hline $\mathrm{H}$ & -2.886784 & -2.969769 & 2.837541 \\
\hline $\mathrm{H}$ & -3.705510 & -4.338257 & -1.159510 \\
\hline C & 3.394413 & -2.732668 & -0.985074 \\
\hline C & 2.669881 & -3.925139 & -1.310337 \\
\hline C & 3.305369 & -4.944046 & -2.070741 \\
\hline C & 4.593322 & -4.787570 & -2.526636 \\
\hline C & 5.296944 & -3.593597 & -2.243464 \\
\hline C & 4.715518 & -2.595067 & -1.493251 \\
\hline $\mathrm{H}$ & 2.744051 & -5.847477 & -2.297239 \\
\hline $\mathrm{H}$ & 5.066521 & -5.569871 & -3.113670 \\
\hline $\mathrm{H}$ & 6.305104 & -3.459534 & -2.626122 \\
\hline $\mathrm{H}$ & 5.266249 & -1.683254 & -1.295600 \\
\hline C & 4.647943 & -0.528775 & 1.009266 \\
\hline C & 5.369236 & 0.682044 & 1.258214 \\
\hline C & 6.559373 & 0.640644 & 2.034174 \\
\hline C & 7.014255 & -0.542260 & 2.568306 \\
\hline C & 6.286463 & -1.736098 & 2.351270 \\
\hline C & 5.137142 & -1.730731 & 1.591850 \\
\hline $\mathrm{H}$ & 7.098095 & 1.569443 & 2.206587 \\
\hline $\mathrm{H}$ & 7.922107 & -0.561700 & 3.164989 \\
\hline $\mathrm{H}$ & 6.634073 & -2.666036 & 2.793165 \\
\hline $\mathrm{H}$ & 4.585687 & -2.652165 & 1.444547 \\
\hline 0 & -0.161753 & 1.503679 & 0.850292 \\
\hline $\mathrm{O}$ & -0.545588 & 0.016429 & -1.279010 \\
\hline $\mathrm{H}$ & -1.644083 & 0.240486 & -1.393559 \\
\hline $\mathrm{H}$ & 5.113487 & 3.674768 & -1.443256 \\
\hline
\end{tabular}




\begin{tabular}{|c|c|c|c|}
\hline $\mathrm{H}$ & 2.241258 & 6.858868 & -1.748522 \\
\hline $\mathrm{H}$ & 1.239108 & 3.253723 & 0.372523 \\
\hline $\mathrm{H}$ & -1.346164 & -3.926214 & -1.774933 \\
\hline $\mathrm{H}$ & -4.492947 & -3.860676 & 1.154091 \\
\hline $\mathrm{H}$ & -0.533582 & -2.565762 & 2.219257 \\
\hline C & -3.798050 & -0.066027 & -0.968539 \\
\hline $\mathrm{O}$ & -2.887573 & 0.428424 & -1.715854 \\
\hline $\mathrm{H}$ & -3.519473 & -0.696825 & -0.114677 \\
\hline C & -5.084768 & -0.519934 & -1.655231 \\
\hline $\mathrm{O}$ & -5.409356 & -0.239012 & -2.782577 \\
\hline 0 & -5.809810 & -1.295994 & -0.814400 \\
\hline C & -7.061100 & -1.791813 & -1.348291 \\
\hline $\mathrm{H}$ & -7.668751 & -0.939026 & -1.667767 \\
\hline $\mathrm{H}$ & -6.847150 & -2.394980 & -2.236306 \\
\hline C & -3.616440 & 1.856446 & 0.759466 \\
\hline C & -4.732214 & 1.437034 & 0.024821 \\
\hline $\mathrm{H}$ & -1.648907 & 2.373171 & 0.499783 \\
\hline$N$ & -2.615288 & 2.558041 & 0.168288 \\
\hline C & -2.711515 & 3.280073 & -1.037552 \\
\hline O & -3.731442 & 3.639734 & -1.579007 \\
\hline $\mathrm{O}$ & -1.466293 & 3.562368 & -1.449364 \\
\hline C & -1.379907 & 4.240803 & -2.716630 \\
\hline $\mathrm{H}$ & -1.790759 & 3.606496 & -3.505615 \\
\hline $\mathrm{H}$ & -0.316040 & 4.415086 & -2.870531 \\
\hline $\mathrm{H}$ & -1.930905 & 5.183787 & -2.682328 \\
\hline $\mathrm{H}$ & -5.559530 & 1.005427 & 0.575511 \\
\hline $\mathrm{H}$ & -4.994335 & 2.000613 & -0.860734 \\
\hline C & -3.381435 & 1.420710 & 2.151407 \\
\hline C & -2.518935 & 2.149926 & 2.990351 \\
\hline C & -4.046064 & 0.297596 & 2.680547 \\
\hline C & -2.332785 & 1.772344 & 4.317152 \\
\hline $\mathrm{H}$ & -2.007687 & 3.026755 & 2.609511 \\
\hline C & -3.853411 & -0.078102 & 4.006226 \\
\hline $\mathrm{H}$ & -4.694763 & -0.299926 & 2.048824 \\
\hline C & -2.998598 & 0.658554 & 4.830168 \\
\hline $\mathrm{H}$ & -1.666452 & 2.350860 & 4.949994 \\
\hline $\mathrm{H}$ & -4.370428 & -0.949901 & 4.397314 \\
\hline $\mathrm{H}$ & -2.852351 & 0.364612 & 5.865809 \\
\hline C & -7.738757 & -2.600384 & -0.258740 \\
\hline $\mathrm{H}$ & -8.692235 & -2.993650 & -0.627595 \\
\hline $\mathrm{H}$ & -7.114829 & -3.446139 & 0.048258 \\
\hline $\mathrm{H}$ & -7.940761 & -1.981892 & 0.621911 \\
\hline
\end{tabular}


Catalyst (R)-1 TS Ethyl Conformation 32

$B 3 L Y P / 6-31 G(d)$ Energy $=-2849.013768$

B3LYP-D3(BJ)/def2-TZVPP-IEF-PCM(DCM) Energy $=-2850.327541$

B3LYP-D3(BJ)/def2-TZVPP-IEF-PCM(DCM)//B3LYP/6-31G(d) Free Energy (Quasiharmonic) = 2849.658336

Frequencies (Top 3 out of 279)

1. $-709.9003 \mathrm{~cm}-1$

2. $\quad 9.5108 \mathrm{~cm}-1$

3. $\quad 13.7713 \mathrm{~cm}-1$

B3LYP/6-31G(d) Molecular Geometry in Cartesian Coordinates

\begin{tabular}{|c|c|c|c|}
\hline C & 2.891184 & -1.393375 & -0.176010 \\
\hline C & 1.571676 & -1.810763 & -0.075588 \\
\hline C & 1.156940 & -3.142932 & -0.381105 \\
\hline C & 2.101920 & -3.994148 & -0.920779 \\
\hline $\mathrm{H}$ & 1.812604 & -5.011037 & -1.172961 \\
\hline C & 4.130605 & 2.455144 & 1.328783 \\
\hline C & 3.306806 & -0.077721 & 0.396718 \\
\hline C & 2.685499 & 1.091665 & -0.010577 \\
\hline C & 3.105468 & 2.389717 & 0.405292 \\
\hline $\mathrm{H}$ & 4.494981 & 3.428340 & 1.646753 \\
\hline $\mathrm{O}$ & 0.633060 & -0.934389 & 0.446351 \\
\hline$P$ & 0.192487 & 0.404033 & -0.406915 \\
\hline $\mathrm{O}$ & 1.626615 & 1.005631 & -0.906067 \\
\hline C & -2.715643 & -4.743307 & 0.613098 \\
\hline C & -2.627012 & -3.550886 & -0.109728 \\
\hline C & -1.381737 & -3.012969 & -0.442304 \\
\hline C & -0.199588 & -3.660732 & -0.047414 \\
\hline C & -0.303564 & -4.860152 & 0.676922 \\
\hline C & -1.548257 & -5.399192 & 1.002303 \\
\hline $\mathrm{H}$ & -3.537019 & -3.038561 & -0.411893 \\
\hline $\mathrm{H}$ & -1.602536 & -6.324966 & 1.569356 \\
\hline C & 1.634604 & 6.111103 & -1.173094 \\
\hline C & 1.903896 & 5.044432 & -2.033950 \\
\hline C & 2.338841 & 3.821022 & -1.527123 \\
\hline C & 2.523234 & 3.642754 & -0.145518 \\
\hline C & 2.232977 & 4.717635 & 0.710363 \\
\hline C & 1.793171 & 5.939850 & 0.203030 \\
\hline $\mathrm{H}$ & 1.787583 & 5.167801 & -3.107842 \\
\hline $\mathrm{H}$ & 1.575936 & 6.758169 & 0.884821 \\
\hline
\end{tabular}




\begin{tabular}{|c|c|c|c|}
\hline C & 4.322860 & 0.004375 & 1.412612 \\
\hline C & 4.735453 & 1.296353 & 1.873119 \\
\hline C & 5.743595 & 1.395063 & 2.870034 \\
\hline C & 6.306839 & 0.267889 & 3.421023 \\
\hline C & 5.875037 & -1.010257 & 2.996135 \\
\hline C & 4.912666 & -1.139134 & 2.018675 \\
\hline $\mathrm{H}$ & 6.052215 & 2.384927 & 3.198007 \\
\hline $\mathrm{H}$ & 7.071467 & 0.355130 & 4.188049 \\
\hline $\mathrm{H}$ & 6.302767 & -1.900757 & 3.448849 \\
\hline $\mathrm{H}$ & 4.587029 & -2.126668 & 1.714391 \\
\hline C & 3.839172 & -2.259457 & -0.822403 \\
\hline C & 3.427104 & -3.578387 & -1.197487 \\
\hline C & 4.353621 & -4.443803 & -1.839613 \\
\hline C & 5.632714 & -4.025239 & -2.123733 \\
\hline C & 6.034897 & -2.713347 & -1.778868 \\
\hline C & 5.164259 & -1.855188 & -1.143604 \\
\hline $\mathrm{H}$ & 4.025559 & -5.444411 & -2.111518 \\
\hline $\mathrm{H}$ & 6.331016 & -4.693365 & -2.620340 \\
\hline $\mathrm{H}$ & 7.038979 & -2.376825 & -2.022731 \\
\hline $\mathrm{H}$ & 5.484141 & -0.849555 & -0.895653 \\
\hline $\mathrm{O}$ & -0.608616 & 0.084003 & -1.627416 \\
\hline $\mathrm{O}$ & -0.380910 & 1.336019 & 0.666745 \\
\hline $\mathrm{H}$ & -1.424000 & 1.214207 & 1.222639 \\
\hline $\mathrm{H}$ & 0.603185 & -5.360355 & 1.005965 \\
\hline $\mathrm{H}$ & -3.688049 & -5.154314 & 0.871527 \\
\hline $\mathrm{H}$ & -1.317470 & -2.100010 & -1.024578 \\
\hline $\mathrm{H}$ & 2.342236 & 4.586101 & 1.783138 \\
\hline $\mathrm{H}$ & 1.306931 & 7.068015 & -1.572050 \\
\hline $\mathrm{H}$ & 2.553771 & 3.002583 & -2.205585 \\
\hline C & -3.302401 & 0.269081 & 1.533274 \\
\hline $\mathrm{O}$ & -2.473202 & 1.190223 & 1.851263 \\
\hline $\mathrm{H}$ & -2.954705 & -0.612662 & 0.983023 \\
\hline C & -4.400437 & -0.001243 & 2.554845 \\
\hline $\mathrm{O}$ & -4.818194 & 0.816889 & 3.340671 \\
\hline $\mathrm{O}$ & -4.819486 & -1.276094 & 2.445689 \\
\hline C & -5.866588 & -1.697180 & 3.358677 \\
\hline $\mathrm{H}$ & -5.725858 & -2.776846 & 3.444448 \\
\hline $\mathrm{H}$ & -5.689812 & -1.228270 & 4.329530 \\
\hline C & -3.786246 & 1.204850 & -0.925638 \\
\hline C & -4.671559 & 0.841733 & 0.094110 \\
\hline $\mathrm{H}$ & -2.334105 & 0.360329 & -2.108066 \\
\hline$N$ & -3.333042 & 0.297721 & -1.852091 \\
\hline C & -3.972911 & -0.873071 & -2.258471 \\
\hline $\mathrm{O}$ & -5.049852 & -1.287179 & -1.877997 \\
\hline
\end{tabular}




$\begin{array}{llll}\mathrm{O} & -3.198402 & -1.468776 & -3.181701 \\ \mathrm{C} & -3.700204 & -2.710189 & -3.706624 \\ \mathrm{H} & -3.007486 & -2.981622 & -4.502820 \\ \mathrm{H} & -4.711495 & -2.579279 & -4.098244 \\ \mathrm{H} & -3.702405 & -3.476463 & -2.927733 \\ \mathrm{H} & -5.190305 & 1.637355 & 0.615662 \\ \mathrm{H} & -5.213985 & -0.088043 & -0.015953 \\ \mathrm{C} & -3.179330 & 2.537238 & -0.985570 \\ \mathrm{C} & -2.528965 & 2.978960 & -2.158553 \\ \mathrm{C} & -3.242541 & 3.409677 & 0.122310 \\ \mathrm{C} & -1.954948 & 4.241358 & -2.215342 \\ \mathrm{H} & -2.493733 & 2.338488 & -3.032681 \\ \mathrm{C} & -2.657297 & 4.670505 & 0.058111 \\ \mathrm{H} & -3.710700 & 3.093872 & 1.045096 \\ \mathrm{C} & -2.011967 & 5.089180 & -1.105076 \\ \mathrm{H} & -1.457579 & 4.565870 & -3.124153 \\ \mathrm{H} & -2.697961 & 5.322428 & 0.925461 \\ \mathrm{H} & -1.547173 & 6.069344 & -1.147632 \\ \mathrm{C} & -7.244492 & -1.350705 & 2.816432 \\ \mathrm{H} & -8.015096 & -1.747867 & 3.487114 \\ \mathrm{H} & -7.374144 & -0.266524 & 2.752945 \\ \mathrm{H} & -7.394997 & -1.786930 & 1.823589\end{array}$

Catalyst (R)-1 TS Ethyl Conformation 33

B3LYP/6-31G(d) Energy $=-2849.013891$

B3LYP-D3(BJ)/def2-TZVPP-IEF-PCM(DCM) Energy = -2850.327242

B3LYP-D3(BJ)/def2-TZVPP-IEF-PCM(DCM)//B3LYP/6-31G(d) Free Energy (Quasiharmonic) = 2849.658097

Frequencies (Top 3 out of 279)

1. $-710.0650 \mathrm{~cm}-1$

2. $\quad 8.8647 \mathrm{~cm}-1$

3. $13.2679 \mathrm{~cm}-1$

B3LYP/6-31G(d) Molecular Geometry in Cartesian Coordinates

$\begin{array}{llll}\text { C } & 2.842093 & -1.391712 & -0.222473 \\ \text { C } & 1.518560 & -1.801456 & -0.146437 \\ \text { C } & 1.097231 & -3.122156 & -0.490207 \\ \text { C } & 2.041499 & -3.966615 & -1.041587 \\ \text { H } & 1.747353 & -4.974527 & -1.322590\end{array}$




\begin{tabular}{|c|c|c|c|}
\hline C & 4.093003 & 2.407271 & 1.394727 \\
\hline C & 3.261322 & -0.094418 & 0.388270 \\
\hline C & 2.652641 & 1.089723 & 0.005243 \\
\hline C & 3.077107 & 2.373384 & 0.459416 \\
\hline $\mathrm{H}$ & 4.460633 & 3.369190 & 1.741923 \\
\hline $\mathrm{O}$ & 0.580896 & -0.931610 & 0.387990 \\
\hline$P$ & 0.159136 & 0.431180 & -0.435746 \\
\hline 0 & 1.602880 & 1.034894 & -0.903324 \\
\hline C & -2.797781 & -4.717183 & 0.421854 \\
\hline C & -2.692405 & -3.508441 & -0.271047 \\
\hline C & -1.439600 & -2.971829 & -0.576343 \\
\hline C & -0.266665 & -3.637684 & -0.184028 \\
\hline C & -0.387416 & -4.853393 & 0.509886 \\
\hline C & -1.639587 & -5.390825 & 0.808254 \\
\hline $\mathrm{H}$ & -3.595170 & -2.982595 & -0.571719 \\
\hline $\mathrm{H}$ & -1.706908 & -6.329719 & 1.351881 \\
\hline C & 1.645565 & 6.144891 & -1.033857 \\
\hline C & 1.917730 & 5.100054 & -1.920207 \\
\hline C & 2.340064 & 3.860842 & -1.441904 \\
\hline C & 2.508681 & 3.644489 & -0.063736 \\
\hline C & 2.215849 & 4.697846 & 0.817634 \\
\hline C & 1.788642 & 5.935901 & 0.338743 \\
\hline $\mathrm{H}$ & 1.813488 & 5.252857 & -2.991549 \\
\hline $\mathrm{H}$ & 1.569018 & 6.736989 & 1.039953 \\
\hline C & 4.267276 & -0.046202 & 1.416333 \\
\hline C & 4.684143 & 1.230309 & 1.914598 \\
\hline C & 5.682550 & 1.295664 & 2.923983 \\
\hline C & 6.232090 & 0.150454 & 3.451104 \\
\hline C & 5.795715 & -1.113011 & 2.988643 \\
\hline C & 4.842668 & -1.209366 & 1.998384 \\
\hline $\mathrm{H}$ & 5.994723 & 2.274378 & 3.280787 \\
\hline $\mathrm{H}$ & 6.989335 & 0.212120 & 4.227875 \\
\hline $\mathrm{H}$ & 6.212465 & -2.018098 & 3.422274 \\
\hline $\mathrm{H}$ & 4.513327 & -2.186247 & 1.665090 \\
\hline C & 3.790367 & -2.248251 & -0.881056 \\
\hline C & 3.372543 & -3.554017 & -1.293941 \\
\hline C & 4.299338 & -4.409803 & -1.948454 \\
\hline C & 5.584340 & -3.993829 & -2.208724 \\
\hline C & 5.992520 & -2.694235 & -1.826372 \\
\hline C & 5.121643 & -1.845974 & -1.178278 \\
\hline $\mathrm{H}$ & 3.966808 & -5.400636 & -2.249201 \\
\hline $\mathrm{H}$ & 6.282847 & -4.654350 & -2.715116 \\
\hline $\mathrm{H}$ & 7.001508 & -2.359230 & -2.051338 \\
\hline $\mathrm{H}$ & 5.446245 & -0.849432 & -0.901446 \\
\hline
\end{tabular}




\begin{tabular}{|c|c|c|c|}
\hline $\mathrm{O}$ & -0.630669 & 0.148285 & -1.672559 \\
\hline O & -0.419691 & 1.339640 & 0.655202 \\
\hline $\mathrm{H}$ & -1.469986 & 1.210734 & 1.193014 \\
\hline $\mathrm{H}$ & 0.511965 & -5.368222 & 0.836604 \\
\hline $\mathrm{H}$ & -3.776014 & -5.127211 & 0.658954 \\
\hline $\mathrm{H}$ & -1.362287 & -2.045537 & -1.135532 \\
\hline $\mathrm{H}$ & 2.312965 & 4.536908 & 1.887565 \\
\hline $\mathrm{H}$ & 1.327669 & 7.114115 & -1.410362 \\
\hline $\mathrm{H}$ & 2.557307 & 3.059538 & -2.139807 \\
\hline C & -3.361643 & 0.272476 & 1.461596 \\
\hline 0 & -2.527729 & 1.178548 & 1.809437 \\
\hline $\mathrm{H}$ & -3.015790 & -0.599932 & 0.895441 \\
\hline C & -4.472088 & -0.011178 & 2.465873 \\
\hline 0 & -4.890472 & 0.793246 & 3.265561 \\
\hline O & -4.909804 & -1.275548 & 2.316519 \\
\hline C & -5.969582 & -1.706867 & 3.210131 \\
\hline $\mathrm{H}$ & -6.654523 & -0.869946 & 3.367230 \\
\hline $\mathrm{H}$ & -6.479966 & -2.497964 & 2.656127 \\
\hline C & -3.811433 & 1.273673 & -0.976748 \\
\hline C & -4.710927 & 0.887707 & 0.022145 \\
\hline $\mathrm{H}$ & -2.349204 & 0.453395 & -2.164223 \\
\hline$N$ & -3.351369 & 0.389586 & -1.921896 \\
\hline C & -3.992070 & -0.766279 & -2.368022 \\
\hline $\mathrm{O}$ & -5.075713 & -1.184761 & -2.012515 \\
\hline $\mathrm{O}$ & -3.208842 & -1.340900 & -3.297360 \\
\hline C & -3.710402 & -2.564921 & -3.861835 \\
\hline $\mathrm{H}$ & -3.008460 & -2.819260 & -4.655597 \\
\hline $\mathrm{H}$ & -4.715544 & -2.417674 & -4.263367 \\
\hline $\mathrm{H}$ & -3.727591 & -3.351586 & -3.103720 \\
\hline $\mathrm{H}$ & -5.233086 & 1.671501 & 0.558059 \\
\hline $\mathrm{H}$ & -5.255837 & -0.036422 & -0.118909 \\
\hline C & -3.196607 & 2.603651 & -0.992532 \\
\hline C & -2.527485 & 3.072964 & -2.144102 \\
\hline C & -3.270135 & 3.446283 & 0.137605 \\
\hline C & -1.945168 & 4.332734 & -2.158714 \\
\hline $\mathrm{H}$ & -2.484021 & 2.456289 & -3.034815 \\
\hline C & -2.676747 & 4.704773 & 0.115568 \\
\hline $\mathrm{H}$ & -3.753143 & 3.108820 & 1.044919 \\
\hline C & -2.012633 & 5.150584 & -1.026749 \\
\hline $\mathrm{H}$ & -1.433229 & 4.678531 & -3.051437 \\
\hline $\mathrm{H}$ & -2.725894 & 5.333357 & 0.999551 \\
\hline $\mathrm{H}$ & -1.541512 & 6.128616 & -1.036345 \\
\hline C & -5.403054 & -2.216279 & 4.526015 \\
\hline $\mathrm{H}$ & -6.214457 & -2.606037 & 5.151319 \\
\hline
\end{tabular}


$\begin{array}{llll}H & -4.682567 & -3.021997 & 4.353058 \\ \mathrm{H} & -4.907294 & -1.408355 & 5.071366\end{array}$

Catalyst (R)-1 TS Ethyl Conformation 34

B3LYP/6-31G(d) Energy $=-2849.014158$

B3LYP-D3(BJ)/def2-TZVPP-IEF-PCM(DCM) Energy = -2850.328303

B3LYP-D3(BJ)/def2-TZVPP-IEF-PCM(DCM)//B3LYP/6-31G(d) Free Energy (Quasiharmonic) = 2849.659526

Frequencies (Top 3 out of 279)

1. $-709.4385 \mathrm{~cm}-1$

2. $\quad 9.2159 \mathrm{~cm}-1$

3. $\quad 18.1501 \mathrm{~cm}-1$

B3LYP/6-31G(d) Molecular Geometry in Cartesian Coordinates

$\begin{array}{llll}\text { C } & 2.780266 & -1.507699 & -0.229247 \\ \text { C } & 1.438840 & -1.848897 & -0.130761 \\ \text { C } & 0.945165 & -3.147004 & -0.464264 \\ \text { C } & 1.836045 & -4.039969 & -1.027936 \\ \text { H } & 1.486171 & -5.032042 & -1.301351 \\ \text { C } & 4.251221 & 2.226130 & 1.353851 \\ \text { C } & 3.275315 & -0.232139 & 0.370413 \\ \text { C } & 2.722066 & 0.980689 & -0.006883 \\ \text { C } & 3.219306 & 2.242093 & 0.435717 \\ \text { H } & 4.673632 & 3.168773 & 1.691447 \\ \text { O } & 0.555645 & -0.931368 & 0.416365 \\ \text { P } & 0.191184 & 0.450731 & -0.403220 \\ \text { O } & 1.656061 & 0.977109 & -0.897970 \\ \text { C } & -3.012077 & -4.541771 & 0.506337 \\ \text { C } & -2.855727 & -3.341545 & -0.191843 \\ \text { C } & -1.581892 & -2.869088 & -0.515599 \\ \text { C } & -0.438549 & -3.591716 & -0.136468 \\ \text { C } & -0.610590 & -4.797670 & 0.563649 \\ \text { C } & -1.883903 & -5.271171 & 0.880292 \\ \text { H } & -3.735040 & -2.771797 & -0.481586 \\ \text { H } & -1.990677 & -6.204061 & 1.427916 \\ \text { C } & 1.957692 & 6.078594 & -1.045570 \\ \text { C } & 2.157873 & 5.018242 & -1.932668 \\ \text { C } & 2.524369 & 3.760170 & -1.457533 \\ \text { C } & 2.708000 & 3.539443 & -0.081956\end{array}$




\begin{tabular}{|c|c|c|c|}
\hline C & 2.487367 & 4.609374 & 0.800530 \\
\hline C & 2.116199 & 5.866592 & 0.324888 \\
\hline $\mathrm{H}$ & 2.041043 & 5.172968 & -3.002435 \\
\hline $\mathrm{H}$ & 1.952299 & 6.680195 & 1.026937 \\
\hline C & 4.299354 & -0.232980 & 1.381579 \\
\hline C & 4.789674 & 1.021756 & 1.868129 \\
\hline C & 5.806948 & 1.038425 & 2.860512 \\
\hline C & 6.305574 & -0.132093 & 3.382635 \\
\hline C & 5.797029 & -1.372699 & 2.932159 \\
\hline C & 4.823803 & -1.422609 & 1.958232 \\
\hline $\mathrm{H}$ & 6.175047 & 2.000747 & 3.208476 \\
\hline $\mathrm{H}$ & 7.077918 & -0.107341 & 4.146484 \\
\hline $\mathrm{H}$ & 6.173849 & -2.296823 & 3.362158 \\
\hline $\mathrm{H}$ & 4.439074 & -2.382160 & 1.634036 \\
\hline C & 3.672767 & -2.413054 & -0.900381 \\
\hline C & 3.182259 & -3.696700 & -1.302541 \\
\hline C & 4.053520 & -4.600294 & -1.968973 \\
\hline C & 5.353769 & -4.251191 & -2.250880 \\
\hline C & 5.833818 & -2.973238 & -1.879230 \\
\hline C & 5.017890 & -2.080035 & -1.220119 \\
\hline $\mathrm{H}$ & 3.666032 & -5.573518 & -2.261300 \\
\hline $\mathrm{H}$ & 6.009435 & -4.947755 & -2.766180 \\
\hline $\mathrm{H}$ & 6.854836 & -2.690730 & -2.121312 \\
\hline $\mathrm{H}$ & 5.397382 & -1.100694 & -0.951850 \\
\hline $\mathrm{O}$ & -0.634212 & 0.206720 & -1.624978 \\
\hline 0 & -0.320463 & 1.389924 & 0.694868 \\
\hline $\mathrm{H}$ & -1.363077 & 1.306884 & 1.262754 \\
\hline $\mathrm{H}$ & 0.266279 & -5.355821 & 0.880223 \\
\hline $\mathrm{H}$ & -4.006581 & -4.902611 & 0.755794 \\
\hline $\mathrm{H}$ & -1.465896 & -1.949411 & -1.079164 \\
\hline $\mathrm{H}$ & 2.596519 & 4.446919 & 1.869072 \\
\hline $\mathrm{H}$ & 1.683459 & 7.061906 & -1.419870 \\
\hline $\mathrm{H}$ & 2.686031 & 2.946555 & -2.156251 \\
\hline C & -3.277618 & 0.444968 & 1.553790 \\
\hline $\mathrm{O}$ & -2.404423 & 1.313234 & 1.900646 \\
\hline $\mathrm{H}$ & -2.975371 & -0.426655 & 0.962284 \\
\hline C & -4.378909 & 0.179893 & 2.572480 \\
\hline $\mathrm{O}$ & -4.749528 & 0.972769 & 3.405855 \\
\hline $\mathrm{O}$ & -4.870623 & -1.060475 & 2.401010 \\
\hline C & -5.926510 & -1.457614 & 3.311402 \\
\hline $\mathrm{H}$ & -5.540440 & -1.401440 & 4.333962 \\
\hline $\mathrm{H}$ & -6.748922 & -0.740146 & 3.225649 \\
\hline C & -3.737997 & 1.489922 & -0.865089 \\
\hline C & -4.632827 & 1.141980 & 0.151079 \\
\hline
\end{tabular}




$\begin{array}{llll}\mathrm{H} & -2.345344 & 0.603872 & -2.088417 \\ \mathrm{~N} & -3.344228 & 0.590127 & -1.825981 \\ \mathrm{C} & -4.051241 & -0.529900 & -2.262336 \\ \mathrm{O} & -5.147134 & -0.895033 & -1.885724 \\ \mathrm{O} & -3.317333 & -1.139479 & -3.209590 \\ \mathrm{C} & -3.891314 & -2.334428 & -3.767118 \\ \mathrm{H} & -3.220034 & -2.620099 & -4.576593 \\ \mathrm{H} & -4.896179 & -2.135594 & -4.146503 \\ \mathrm{H} & -3.931621 & -3.122584 & -3.011393 \\ \mathrm{H} & -5.100849 & 1.945431 & 0.707445 \\ \mathrm{H} & -5.225605 & 0.246763 & 0.017200 \\ \mathrm{C} & -3.057589 & 2.787677 & -0.887721 \\ \mathrm{C} & -2.390149 & 3.229328 & -2.051060 \\ \mathrm{C} & -3.063691 & 3.626095 & 0.247830 \\ \mathrm{C} & -1.744025 & 4.457554 & -2.071733 \\ \mathrm{H} & -2.397343 & 2.616783 & -2.945644 \\ \mathrm{C} & -2.406868 & 4.852512 & 0.219578 \\ \mathrm{H} & -3.544016 & 3.308411 & 1.163702 \\ \mathrm{C} & -1.744894 & 5.270657 & -0.934405 \\ \mathrm{H} & -1.233946 & 4.782038 & -2.973469 \\ \mathrm{H} & -2.404796 & 5.477228 & 1.107660 \\ \mathrm{H} & -1.224014 & 6.223042 & -0.949080 \\ \mathrm{C} & -6.346795 & -2.864319 & 2.932616 \\ \mathrm{H} & -7.135144 & -3.210203 & 3.609928 \\ \mathrm{H} & -6.733374 & -2.894735 & 1.908906 \\ \mathrm{H} & -5.500641 & -3.555001 & 3.004360\end{array}$

Catalyst (R)-1 TS Ethyl Conformation 35

B3LYP/6-31G(d) Energy $=-2849.016688$

B3LYP-D3(BJ)/def2-TZVPP-IEF-PCM(DCM) Energy $=-2850.330984$

B3LYP-D3(BJ)/def2-TZVPP-IEF-PCM(DCM)//B3LYP/6-31G(d) Free Energy (Quasiharmonic) = 2849.662014

Frequencies (Top 3 out of 279)

1. $-670.2122 \mathrm{~cm}-1$

2. $\quad 9.8348 \mathrm{~cm}-1$

3. $\quad 18.5082 \mathrm{~cm}-1$

B3LYP/6-31G(d) Molecular Geometry in Cartesian Coordinates

$\begin{array}{llll}\text { C } & 2.907107 & -1.533480 & -0.343397\end{array}$ 


\begin{tabular}{|c|c|c|c|}
\hline C & 1.594077 & -1.830479 & -0.008929 \\
\hline C & 0.982543 & -3.091278 & -0.279088 \\
\hline C & 1.752536 & -4.042135 & -0.921498 \\
\hline $\mathrm{H}$ & 1.330508 & -5.024971 & -1.114010 \\
\hline C & 4.517865 & 2.364900 & 0.559380 \\
\hline C & 3.474696 & -0.201501 & 0.024187 \\
\hline C & 2.824614 & 0.954578 & -0.383914 \\
\hline C & 3.336986 & 2.265813 & -0.151448 \\
\hline $\mathrm{H}$ & 4.953152 & 3.346258 & 0.728311 \\
\hline $\mathrm{O}$ & 0.843948 & -0.863493 & 0.642301 \\
\hline$P$ & 0.288987 & 0.427506 & -0.217566 \\
\hline $\mathrm{O}$ & 1.626140 & 0.832935 & -1.075832 \\
\hline C & -3.093658 & -4.065664 & 0.720743 \\
\hline C & -2.560201 & -4.413433 & -0.521014 \\
\hline C & -1.244472 & -4.076915 & -0.837201 \\
\hline C & -0.429545 & -3.391209 & 0.079885 \\
\hline C & -0.980556 & -3.043895 & 1.326090 \\
\hline C & -2.298150 & -3.378433 & 1.641272 \\
\hline $\mathrm{H}$ & -3.171225 & -4.937266 & -1.251512 \\
\hline $\mathrm{H}$ & -2.712516 & -3.093030 & 2.604527 \\
\hline C & 1.507290 & 5.892111 & -1.575550 \\
\hline C & 1.990558 & 5.806328 & -0.268841 \\
\hline C & 2.557687 & 4.618116 & 0.190769 \\
\hline C & 2.657059 & 3.493384 & -0.644880 \\
\hline C & 2.157810 & 3.590247 & -1.954836 \\
\hline C & 1.591265 & 4.778133 & -2.413615 \\
\hline $\mathrm{H}$ & 1.925766 & 6.664055 & 0.396171 \\
\hline $\mathrm{H}$ & 1.218495 & 4.833687 & -3.433039 \\
\hline C & 4.658491 & -0.076190 & 0.829486 \\
\hline C & 5.186062 & 1.231319 & 1.082325 \\
\hline C & 6.364083 & 1.369569 & 1.865807 \\
\hline C & 6.985037 & 0.270136 & 2.410971 \\
\hline C & 6.443491 & -1.019308 & 2.197034 \\
\hline C & 5.313569 & -1.188312 & 1.427231 \\
\hline $\mathrm{H}$ & 6.758219 & 2.368739 & 2.036280 \\
\hline $\mathrm{H}$ & 7.881156 & 0.388828 & 3.013936 \\
\hline $\mathrm{H}$ & 6.920949 & -1.885183 & 2.647894 \\
\hline $\mathrm{H}$ & 4.906580 & -2.182088 & 1.280995 \\
\hline C & 3.665102 & -2.503292 & -1.085397 \\
\hline C & 3.075750 & -3.781435 & -1.352431 \\
\hline C & 3.820096 & -4.758775 & -2.067627 \\
\hline C & 5.083456 & -4.483393 & -2.535923 \\
\hline C & 5.651767 & -3.207364 & -2.311352 \\
\hline C & 4.963559 & -2.245080 & -1.605542 \\
\hline
\end{tabular}




\begin{tabular}{|c|c|c|c|}
\hline $\mathrm{H}$ & 3.361490 & -5.727888 & -2.249982 \\
\hline $\mathrm{H}$ & 5.640136 & -5.235521 & -3.088199 \\
\hline $\mathrm{H}$ & 6.639550 & -2.981607 & -2.704055 \\
\hline $\mathrm{H}$ & 5.410262 & -1.269865 & -1.451440 \\
\hline $\mathrm{O}$ & -0.123560 & 1.471178 & 0.767992 \\
\hline $\mathrm{O}$ & -0.675481 & -0.076387 & -1.291442 \\
\hline $\mathrm{H}$ & -1.875741 & 0.055686 & -1.407548 \\
\hline $\mathrm{H}$ & -0.372067 & -2.510257 & 2.047645 \\
\hline $\mathrm{H}$ & -4.121975 & -4.314702 & 0.966220 \\
\hline $\mathrm{H}$ & -0.847070 & -4.323877 & -1.817363 \\
\hline $\mathrm{H}$ & 2.220790 & 2.733859 & -2.616788 \\
\hline $\mathrm{H}$ & 1.069988 & 6.818901 & -1.938449 \\
\hline $\mathrm{H}$ & 2.912563 & 4.550930 & 1.215338 \\
\hline C & -3.775591 & -0.556308 & -0.810783 \\
\hline $\mathrm{O}$ & -3.043660 & 0.067688 & -1.650133 \\
\hline $\mathrm{H}$ & -3.319911 & -1.217343 & -0.068649 \\
\hline C & -5.158135 & -0.939423 & -1.307055 \\
\hline 0 & -5.733824 & -0.381353 & -2.214139 \\
\hline 0 & -5.637087 & -1.979409 & -0.598264 \\
\hline C & -6.960646 & -2.454472 & -0.958969 \\
\hline $\mathrm{H}$ & -6.963278 & -3.500016 & -0.642847 \\
\hline C & -3.536034 & 1.474846 & 0.970006 \\
\hline C & -4.650576 & 0.676166 & 0.715438 \\
\hline $\mathrm{H}$ & -1.599523 & 1.414248 & 1.668027 \\
\hline$N$ & -2.576633 & 1.133699 & 1.887541 \\
\hline C & -2.715542 & 0.243989 & 2.952433 \\
\hline 0 & -3.710471 & -0.379475 & 3.263719 \\
\hline 0 & -1.545184 & 0.205181 & 3.615568 \\
\hline C & -1.517671 & -0.646072 & 4.770956 \\
\hline $\mathrm{H}$ & -0.528056 & -0.505183 & 5.205038 \\
\hline $\mathrm{H}$ & -1.661904 & -1.691097 & 4.484020 \\
\hline $\mathrm{H}$ & -2.297095 & -0.356774 & 5.480270 \\
\hline $\mathrm{H}$ & -5.474905 & 1.135267 & 0.183638 \\
\hline $\mathrm{H}$ & -4.902114 & -0.106516 & 1.417393 \\
\hline C & -3.255253 & 2.674942 & 0.167933 \\
\hline C & -3.867724 & 2.858842 & -1.090274 \\
\hline C & -2.374516 & 3.669529 & 0.642472 \\
\hline C & -3.602722 & 4.000603 & -1.840944 \\
\hline $\mathrm{H}$ & -4.518879 & 2.099294 & -1.504181 \\
\hline C & -2.118376 & 4.807644 & -0.111418 \\
\hline $\mathrm{H}$ & -1.899942 & 3.557638 & 1.610143 \\
\hline C & -2.729980 & 4.975711 & -1.356453 \\
\hline $\mathrm{H}$ & -4.071325 & 4.119665 & -2.813360 \\
\hline $\mathrm{H}$ & -1.428869 & 5.556641 & 0.264981 \\
\hline
\end{tabular}




$\begin{array}{llll}\text { H } & -2.522187 & 5.863129 & -1.948072 \\ \text { H } & -7.065073 & -2.402001 & -2.045221 \\ \text { C } & -8.046779 & -1.654144 & -0.257278 \\ \text { H } & -8.044495 & -0.615229 & -0.599059 \\ \text { H } & -9.027958 & -2.086000 & -0.485440 \\ \text { H } & -7.907025 & -1.673326 & 0.828362\end{array}$

Catalyst (R)-1 TS Ethyl Conformation 36

$B 3 L Y P / 6-31 G(d)$ Energy $=-2849.0168$

B3LYP-D3(BJ)/def2-TZVPP-IEF-PCM(DCM) Energy $=-2850.330714$

B3LYP-D3(BJ)/def2-TZVPP-IEF-PCM(DCM)//B3LYP/6-31G(d) Free Energy (Quasiharmonic) = 2849.661796

Frequencies (Top 3 out of 279)

1. $-671.0152 \mathrm{~cm}-1$

2. $\quad 9.8049 \mathrm{~cm}-1$

3. $\quad 18.3242 \mathrm{~cm}-1$

B3LYP/6-31G(d) Molecular Geometry in Cartesian Coordinates

$\begin{array}{llll}\text { C } & 2.816367 & -1.613714 & -0.335396 \\ \text { C } & 1.501814 & -1.851641 & 0.038136 \\ \text { C } & 0.837261 & -3.095201 & -0.182602 \\ \text { C } & 1.555513 & -4.091507 & -0.816092 \\ \text { H } & 1.092759 & -5.062588 & -0.970992 \\ \text { C } & 4.593256 & 2.243846 & 0.419241 \\ \text { C } & 3.442063 & -0.294755 & -0.018606 \\ \text { C } & 2.825649 & 0.873709 & -0.443313 \\ \text { C } & 3.392242 & 2.170348 & -0.260214 \\ \text { H } & 5.068848 & 3.212223 & 0.550176 \\ \text { O } & 0.804873 & -0.840053 & 0.680449 \\ \text { P } & 0.277483 & 0.448900 & -0.199685 \\ \text { O } & 1.606193 & 0.779081 & -1.102119 \\ \text { C } & -3.247301 & -3.887736 & 0.937411 \\ \text { C } & -2.756024 & -4.291127 & -0.304932 \\ \text { C } & -1.436792 & -4.013020 & -0.660629 \\ \text { C } & -0.575937 & -3.331885 & 0.217084 \\ \text { C } & -1.084524 & -2.928460 & 1.464443 \\ \text { C } & -2.405759 & -3.204215 & 1.818926 \\ \text { H } & -3.402544 & -4.813375 & -1.005564 \\ \text { H } & -2.786832 & -2.875189 & 2.781980\end{array}$




\begin{tabular}{|c|c|c|c|}
\hline C & 1.661695 & 5.822110 & -1.741867 \\
\hline C & 2.173447 & 5.753983 & -0.445018 \\
\hline C & 2.708292 & 4.558559 & 0.034182 \\
\hline C & 2.746242 & 3.408747 & -0.771812 \\
\hline C & 2.219209 & 3.488533 & -2.071988 \\
\hline C & 1.684962 & 4.683639 & -2.550345 \\
\hline $\mathrm{H}$ & 2.156014 & 6.631198 & 0.197108 \\
\hline $\mathrm{H}$ & 1.289648 & 4.725355 & -3.561904 \\
\hline C & 4.649346 & -0.192617 & 0.754504 \\
\hline C & 5.231411 & 1.100328 & 0.957896 \\
\hline C & 6.432708 & 1.215055 & 1.709157 \\
\hline C & 7.025468 & 0.108112 & 2.270283 \\
\hline C & 6.431096 & -1.165187 & 2.105588 \\
\hline C & 5.277048 & -1.312099 & 1.367701 \\
\hline $\mathrm{H}$ & 6.867887 & 2.202826 & 1.842098 \\
\hline $\mathrm{H}$ & 7.939958 & 0.209092 & 2.848377 \\
\hline $\mathrm{H}$ & 6.886863 & -2.035949 & 2.569300 \\
\hline $\mathrm{H}$ & 4.829829 & -2.293347 & 1.259212 \\
\hline C & 3.519340 & -2.631181 & -1.067679 \\
\hline C & 2.876564 & -3.892873 & -1.284976 \\
\hline C & 3.566490 & -4.916773 & -1.989526 \\
\hline C & 4.827564 & -4.702276 & -2.494410 \\
\hline C & 5.448248 & -3.443064 & -2.318959 \\
\hline C & 4.813548 & -2.436551 & -1.624802 \\
\hline $\mathrm{H}$ & 3.067909 & -5.872456 & -2.133891 \\
\hline $\mathrm{H}$ & 5.342375 & -5.489719 & -3.038013 \\
\hline $\mathrm{H}$ & 6.434005 & -3.265682 & -2.740516 \\
\hline $\mathrm{H}$ & 5.299830 & -1.475156 & -1.508419 \\
\hline $\mathrm{O}$ & -0.069200 & 1.532969 & 0.767384 \\
\hline $\mathrm{O}$ & -0.733900 & -0.045209 & -1.234454 \\
\hline $\mathrm{H}$ & -1.929303 & 0.139532 & -1.323303 \\
\hline $\mathrm{H}$ & -0.440135 & -2.397117 & 2.155855 \\
\hline $\mathrm{H}$ & -4.278117 & -4.090571 & 1.212969 \\
\hline $\mathrm{H}$ & -1.071929 & -4.302847 & -1.641698 \\
\hline $\mathrm{H}$ & 2.235064 & 2.612828 & -2.711094 \\
\hline $\mathrm{H}$ & 1.249168 & 6.754129 & -2.120033 \\
\hline $\mathrm{H}$ & 3.085503 & 4.506054 & 1.051611 \\
\hline C & -3.836079 & -0.382956 & -0.667265 \\
\hline $\mathrm{O}$ & -3.102057 & 0.198369 & -1.535229 \\
\hline $\mathrm{H}$ & -3.387777 & -1.052620 & 0.071624 \\
\hline C & -5.246172 & -0.714848 & -1.120194 \\
\hline $\mathrm{O}$ & -5.826255 & -0.140339 & -2.014401 \\
\hline $\mathrm{O}$ & -5.749771 & -1.721208 & -0.381043 \\
\hline C & -7.105727 & -2.136800 & -0.691449 \\
\hline
\end{tabular}




$\begin{array}{llll}\mathrm{H} & -7.694594 & -1.249206 & -0.935579 \\ \mathrm{C} & -3.471627 & 1.667624 & 1.070372 \\ \mathrm{C} & -4.620112 & 0.903896 & 0.862853 \\ \mathrm{H} & -1.518828 & 1.549791 & 1.713373 \\ \mathrm{~N} & -2.498359 & 1.309513 & 1.966642 \\ \mathrm{C} & -2.638008 & 0.448283 & 3.054579 \\ \mathrm{O} & -3.645531 & -0.130452 & 3.408618 \\ \mathrm{O} & -1.450446 & 0.379599 & 3.684010 \\ \mathrm{C} & -1.420207 & -0.445702 & 4.858043 \\ \mathrm{H} & -0.414174 & -0.330966 & 5.260976 \\ \mathrm{H} & -1.609586 & -1.491087 & 4.600122 \\ \mathrm{H} & -2.168236 & -0.112335 & 5.581656 \\ \mathrm{H} & -5.443983 & 1.382273 & 0.347495 \\ \mathrm{H} & -4.877374 & 0.142836 & 1.586234 \\ \mathrm{C} & -3.172565 & 2.842225 & 0.237903 \\ \mathrm{C} & -3.815525 & 3.025801 & -1.005080 \\ \mathrm{C} & -2.243332 & 3.812737 & 0.667788 \\ \mathrm{C} & -3.532872 & 4.143994 & -1.784246 \\ \mathrm{H} & -4.505579 & 2.283208 & -1.385425 \\ \mathrm{C} & -1.969703 & 4.927443 & -0.114364 \\ \mathrm{H} & -1.744554 & 3.701064 & 1.623244 \\ \mathrm{C} & -2.612054 & 5.095503 & -1.343827 \\ \mathrm{H} & -4.026035 & 4.262820 & -2.744469 \\ \mathrm{H} & -1.243567 & 5.657980 & 0.227926 \\ \mathrm{H} & -2.390909 & 5.964410 & -1.957674 \\ \mathrm{H} & -7.471033 & -2.572048 & 0.241509 \\ \mathrm{C} & -7.127176 & -3.145105 & -1.829504 \\ \mathrm{H} & -6.498889 & -4.010556 & -1.595156 \\ \mathrm{H} & -8.152205 & -3.497652 & -1.991252 \\ \mathrm{H} & -6.770554 & -2.688396 & -2.756779\end{array}$

Catalyst (R)-1 TS Ethyl Conformation 37

B3LYP/6-31G(d) Energy = -2849.016944

B3LYP-D3(BJ)/def2-TZVPP-IEF-PCM(DCM) Energy = -2850.331286

B3LYP-D3(BJ)/def2-TZVPP-IEF-PCM(DCM)//B3LYP/6-31G(d) Free Energy (Quasiharmonic) = 2849.662651

Frequencies (Top 3 out of 279)

1. $-662.9003 \mathrm{~cm}-1$

2. $\quad 9.7246 \mathrm{~cm}-1$

3. $\quad 17.1658 \mathrm{~cm}-1$ 
B3LYP/6-31G(d) Molecular Geometry in Cartesian Coordinates

\begin{tabular}{|c|c|c|c|}
\hline C & 2.832418 & -1.621773 & -0.339213 \\
\hline C & 1.507988 & -1.863790 & -0.005657 \\
\hline C & 0.843369 & -3.096472 & -0.280047 \\
\hline C & 1.572821 & -4.077933 & -0.923724 \\
\hline $\mathrm{H}$ & 1.109320 & -5.041281 & -1.119406 \\
\hline C & 4.604367 & 2.205253 & 0.566211 \\
\hline C & 3.454589 & -0.314874 & 0.029948 \\
\hline C & 2.852975 & 0.867620 & -0.377138 \\
\hline C & 3.420266 & 2.156055 & -0.144461 \\
\hline $\mathrm{H}$ & 5.080574 & 3.167407 & 0.735224 \\
\hline $\mathrm{O}$ & 0.799754 & -0.867463 & 0.648018 \\
\hline$P$ & 0.296918 & 0.445379 & -0.210896 \\
\hline $\mathrm{O}$ & 1.650156 & 0.796958 & -1.068458 \\
\hline C & -3.275329 & -3.890491 & 0.704324 \\
\hline C & -2.753684 & -4.258984 & -0.536509 \\
\hline C & -1.423108 & -3.981095 & -0.847356 \\
\hline C & -0.581426 & -3.335209 & 0.074412 \\
\hline C & -1.120407 & -2.966994 & 1.319849 \\
\hline C & -2.452837 & -3.242448 & 1.629553 \\
\hline $\mathrm{H}$ & -3.384965 & -4.753057 & -1.270571 \\
\hline $\mathrm{H}$ & -2.857451 & -2.941373 & 2.592177 \\
\hline C & 1.747487 & 5.856633 & -1.570422 \\
\hline C & 2.226366 & 5.750875 & -0.263560 \\
\hline C & 2.741922 & 4.539667 & 0.196796 \\
\hline C & 2.793175 & 3.411288 & -0.638270 \\
\hline C & 2.298831 & 3.528815 & -1.948398 \\
\hline C & 1.783756 & 4.739641 & -2.407893 \\
\hline $\mathrm{H}$ & 2.198357 & 6.610958 & 0.400979 \\
\hline $\mathrm{H}$ & 1.413898 & 4.810587 & -3.427422 \\
\hline C & 4.642624 & -0.239620 & 0.835216 \\
\hline C & 5.224453 & 1.044497 & 1.088782 \\
\hline C & 6.407163 & 1.132909 & 1.872397 \\
\hline C & 6.981508 & 0.008151 & 2.417012 \\
\hline C & 6.386496 & -1.257387 & 2.202324 \\
\hline C & 5.250566 & -1.378527 & 1.432343 \\
\hline $\mathrm{H}$ & 6.842747 & 2.114619 & 2.043447 \\
\hline $\mathrm{H}$ & 7.881745 & 0.088906 & 3.020119 \\
\hline $\mathrm{H}$ & 6.827238 & -2.142732 & 2.652760 \\
\hline $\mathrm{H}$ & 4.802326 & -2.354314 & 1.285546 \\
\hline C & 3.549322 & -2.621448 & -1.082429 \\
\hline C & 2.906577 & -3.873014 & -1.352316 \\
\hline
\end{tabular}




\begin{tabular}{|c|c|c|c|}
\hline C & 3.609621 & -4.879849 & -2.068384 \\
\hline C & 4.884073 & -4.657548 & -2.534827 \\
\hline C & 5.505702 & -3.407125 & -2.307543 \\
\hline C & 4.858096 & -2.417654 & -1.600906 \\
\hline $\mathrm{H}$ & 3.110545 & -5.828341 & -2.252884 \\
\hline $\mathrm{H}$ & 5.408993 & -5.431728 & -3.087733 \\
\hline $\mathrm{H}$ & 6.502618 & -3.222824 & -2.698806 \\
\hline $\mathrm{H}$ & 5.345609 & -1.462537 & -1.444691 \\
\hline $\mathrm{O}$ & -0.072844 & 1.504385 & 0.775378 \\
\hline $\mathrm{O}$ & -0.687507 & -0.019525 & -1.283765 \\
\hline $\mathrm{H}$ & -1.881817 & 0.172974 & -1.410121 \\
\hline $\mathrm{H}$ & -0.490953 & -2.463199 & 2.044830 \\
\hline $\mathrm{H}$ & -4.314469 & -4.093991 & 0.946177 \\
\hline $\mathrm{H}$ & -1.033809 & -4.242892 & -1.826905 \\
\hline $\mathrm{H}$ & 2.325283 & 2.670190 & -2.609918 \\
\hline $\mathrm{H}$ & 1.350437 & 6.801147 & -1.933897 \\
\hline $\mathrm{H}$ & 3.093486 & 4.457912 & 1.221454 \\
\hline C & -3.813684 & -0.346106 & -0.834180 \\
\hline $\mathrm{O}$ & -3.042230 & 0.244698 & -1.662062 \\
\hline $\mathrm{H}$ & -3.400599 & -1.036250 & -0.093702 \\
\hline C & -5.211970 & -0.644501 & -1.342450 \\
\hline $\mathrm{O}$ & -5.749603 & -0.050044 & -2.249629 \\
\hline $\mathrm{O}$ & -5.765987 & -1.649653 & -0.640200 \\
\hline C & -7.119745 & -2.007849 & -1.016606 \\
\hline $\mathrm{H}$ & -7.119747 & -2.308614 & -2.068863 \\
\hline C & -3.485517 & 1.663881 & 0.960644 \\
\hline C & -4.635588 & 0.919582 & 0.699891 \\
\hline $\mathrm{H}$ & -1.555880 & 1.511361 & 1.664858 \\
\hline$N$ & -2.545698 & 1.274614 & 1.879330 \\
\hline C & -2.729206 & 0.388708 & 2.940545 \\
\hline $\mathrm{O}$ & -3.752326 & -0.191002 & 3.245056 \\
\hline $\mathrm{O}$ & -1.564953 & 0.295955 & 3.609142 \\
\hline C & -1.580956 & -0.558246 & 4.762499 \\
\hline $\mathrm{H}$ & -0.588942 & -0.460689 & 5.202971 \\
\hline $\mathrm{H}$ & -1.767710 & -1.595570 & 4.472146 \\
\hline $\mathrm{H}$ & -2.351734 & -0.237599 & 5.467765 \\
\hline $\mathrm{H}$ & -5.436325 & 1.419113 & 0.168401 \\
\hline $\mathrm{H}$ & -4.924645 & 0.144986 & 1.396299 \\
\hline C & -3.146797 & 2.853213 & 0.164755 \\
\hline C & -3.745735 & 3.070774 & -1.094595 \\
\hline C & -2.222782 & 3.803932 & 0.646796 \\
\hline C & -3.425914 & 4.202573 & -1.838935 \\
\hline $\mathrm{H}$ & -4.429854 & 2.344057 & -1.514360 \\
\hline C & -1.911888 & 4.932453 & -0.100908 \\
\hline
\end{tabular}




$\begin{array}{llll}\mathrm{H} & -1.757174 & 3.665924 & 1.615446 \\ \mathrm{C} & -2.510877 & 5.134254 & -1.347036 \\ \mathrm{H} & -3.885241 & 4.347496 & -2.812264 \\ \mathrm{H} & -1.189989 & 5.647199 & 0.281271 \\ \mathrm{H} & -2.260368 & 6.013835 & -1.933793 \\ \mathrm{H} & -7.752060 & -1.118829 & -0.925617 \\ \mathrm{C} & -7.570293 & -3.127583 & -0.099062 \\ \mathrm{H} & -7.548938 & -2.809174 & 0.947980 \\ \mathrm{H} & -8.595736 & -3.419941 & -0.349696 \\ \mathrm{H} & -6.927071 & -4.006729 & -0.207738\end{array}$

Catalyst (R)-1 TS Ethyl Conformation 38

B3LYP/6-31G(d) Energy $=-2849.016629$

B3LYP-D3(BJ)/def2-TZVPP-IEF-PCM(DCM) Energy $=-2850.32803$

B3LYP-D3(BJ)/def2-TZVPP-IEF-PCM(DCM)//B3LYP/6-31G(d) Free Energy (Quasiharmonic) = 2849.659035

Frequencies (Top 3 out of 279)

1. $-603.1410 \mathrm{~cm}-1$

2. $\quad 9.8335 \mathrm{~cm}-1$

3. $\quad 15.8690 \mathrm{~cm}-1$

B3LYP/6-31G(d) Molecular Geometry in Cartesian Coordinates

$\begin{array}{llll}\text { C } & 3.771967 & 0.239660 & 0.344882 \\ \text { C } & 2.941248 & 1.312091 & 0.058309 \\ \text { C } & 3.186662 & 2.639761 & 0.514314 \\ \text { C } & 4.272625 & 2.833152 & 1.344998 \\ \text { H } & 4.500336 & 3.837362 & 1.692848 \\ \text { C } & 2.896832 & -3.674055 & -1.245372 \\ \text { C } & 3.494681 & -1.098797 & -0.257872 \\ \text { C } & 2.253127 & -1.686738 & -0.073115 \\ \text { C } & 1.925027 & -2.995837 & -0.534900 \\ \text { H } & 2.692925 & -4.684577 & -1.589437 \\ \text { O } & 1.818696 & 1.100951 & -0.738584 \\ \text { P } & 0.547104 & 0.288368 & -0.118163 \\ \text { O } & 1.285925 & -0.975004 & 0.625431 \\ \text { C } & 0.882315 & 6.079617 & -0.651862 \\ \text { C } & 1.321993 & 5.171328 & -1.618042 \\ \text { C } & 2.036617 & 4.034190 & -1.244193 \\ \text { C } & 2.340107 & 3.792789 & 0.105811\end{array}$




\begin{tabular}{|c|c|c|c|}
\hline C & 1.889913 & 4.710504 & 1.067666 \\
\hline C & 1.164913 & 5.841808 & 0.693632 \\
\hline $\mathrm{H}$ & 1.121673 & 5.355745 & -2.670938 \\
\hline $\mathrm{H}$ & 0.818971 & 6.535450 & 1.455464 \\
\hline C & -1.866379 & -4.910004 & 0.171614 \\
\hline C & -1.232233 & -4.220269 & 1.208453 \\
\hline C & -0.009440 & -3.586676 & 0.985946 \\
\hline C & 0.601083 & -3.624327 & -0.280359 \\
\hline C & -0.051578 & -4.317241 & -1.313387 \\
\hline C & -1.270609 & -4.957341 & -1.089485 \\
\hline $\mathrm{H}$ & -1.698815 & -4.162913 & 2.187583 \\
\hline $\mathrm{H}$ & -1.758425 & -5.484216 & -1.905641 \\
\hline C & 4.466209 & -1.786611 & -1.063292 \\
\hline C & 4.155574 & -3.098977 & -1.546961 \\
\hline C & 5.111657 & -3.796996 & -2.333846 \\
\hline C & 6.315564 & -3.219003 & -2.662569 \\
\hline C & 6.609353 & -1.908232 & -2.218632 \\
\hline C & 5.711429 & -1.211929 & -1.439689 \\
\hline $\mathrm{H}$ & 4.864664 & -4.797033 & -2.682463 \\
\hline $\mathrm{H}$ & 7.035659 & -3.759582 & -3.270669 \\
\hline $\mathrm{H}$ & 7.550988 & -1.443691 & -2.498555 \\
\hline $\mathrm{H}$ & 5.948366 & -0.205274 & -1.115444 \\
\hline C & 4.858627 & 0.444492 & 1.264472 \\
\hline C & 5.106493 & 1.765873 & 1.759523 \\
\hline C & 6.180919 & 1.982782 & 2.664287 \\
\hline C & 6.965935 & 0.938654 & 3.094443 \\
\hline C & 6.700195 & -0.373406 & 2.637277 \\
\hline C & 5.677125 & -0.614088 & 1.746634 \\
\hline $\mathrm{H}$ & 6.361948 & 2.994307 & 3.020129 \\
\hline $\mathrm{H}$ & 7.780093 & 1.115436 & 3.791899 \\
\hline $\mathrm{H}$ & 7.305675 & -1.201334 & 2.996096 \\
\hline $\mathrm{H}$ & 5.480959 & -1.627062 & 1.415347 \\
\hline $\mathrm{O}$ & -0.364961 & -0.122719 & -1.228822 \\
\hline $\mathrm{O}$ & -0.053917 & 1.084614 & 1.055043 \\
\hline $\mathrm{H}$ & -1.193450 & 0.941906 & 1.228032 \\
\hline $\mathrm{H}$ & 2.096213 & 4.522159 & 2.117499 \\
\hline $\mathrm{H}$ & 0.324867 & 6.965206 & -0.945764 \\
\hline $\mathrm{H}$ & 2.375853 & 3.335952 & -2.002184 \\
\hline $\mathrm{H}$ & 0.392098 & -4.333266 & -2.304861 \\
\hline $\mathrm{H}$ & -2.818914 & -5.402766 & 0.347711 \\
\hline $\mathrm{H}$ & 0.480680 & -3.063797 & 1.800158 \\
\hline C & -2.660382 & -0.541642 & 1.501420 \\
\hline $\mathrm{O}$ & -2.410670 & 0.713151 & 1.448397 \\
\hline $\mathrm{H}$ & -1.829538 & -1.255637 & 1.526817 \\
\hline
\end{tabular}




$\begin{array}{llll}\mathrm{C} & -3.815533 & -1.042956 & 2.349826 \\ \mathrm{O} & -3.839844 & -2.177922 & 2.786433 \\ \mathrm{O} & -4.736710 & -0.102971 & 2.587311 \\ \mathrm{C} & -5.805300 & -0.465053 & 3.502055 \\ \mathrm{H} & -5.369568 & -1.019322 & 4.337452 \\ \mathrm{H} & -6.175966 & 0.497724 & 3.860911 \\ \mathrm{C} & -3.856892 & -0.193934 & -0.921693 \\ \mathrm{C} & -3.279385 & -1.322203 & -0.326051 \\ \mathrm{H} & -1.990447 & 0.530845 & -1.311331 \\ \mathrm{~N} & -3.004784 & 0.750595 & -1.383127 \\ \mathrm{C} & -3.298109 & 1.906126 & -2.128931 \\ \mathrm{O} & -4.375124 & 2.236766 & -2.567831 \\ \mathrm{O} & -2.147672 & 2.579798 & -2.287631 \\ \mathrm{C} & -2.244310 & 3.792239 & -3.051393 \\ \mathrm{H} & -1.261739 & 4.255299 & -2.969799 \\ \mathrm{H} & -3.016210 & 4.444621 & -2.636329 \\ \mathrm{H} & -2.484043 & 3.566736 & -4.094244 \\ \mathrm{H} & -3.936283 & -2.133214 & -0.034090 \\ \mathrm{H} & -2.280249 & -1.605355 & -0.642414 \\ \mathrm{C} & -5.320297 & 0.026515 & -0.867851 \\ \mathrm{C} & -6.179194 & -0.985401 & -1.321573 \\ \mathrm{C} & -5.864824 & 1.196475 & -0.314780 \\ \mathrm{C} & -7.562040 & -0.816013 & -1.259385 \\ \mathrm{H} & -5.759883 & -1.891121 & -1.749931 \\ \mathrm{C} & -7.244889 & 1.352743 & -0.235425 \\ \mathrm{H} & -5.204683 & 1.964144 & 0.072599 \\ \mathrm{C} & -8.096622 & 0.353758 & -0.717730 \\ \mathrm{H} & -8.218558 & -1.596124 & -1.634060 \\ \mathrm{H} & -7.658543 & 2.258772 & 0.198302 \\ \mathrm{H} & -9.173957 & 0.487286 & -0.667752 \\ \mathrm{C} & -6.902616 & -1.267865 & 2.821234 \\ \mathrm{H} & -7.717956 & -1.443398 & 3.533082 \\ \mathrm{H} & -7.305936 & -0.728204 & 1.959754 \\ & -6.523036 & -2.237831 & 2.490109\end{array}$

Catalyst (R)-1 TS Ethyl Conformation 39

B3LYP/6-31G(d) Energy $=-2849.017532$

B3LYP-D3(BJ)/def2-TZVPP-IEF-PCM(DCM) Energy = -2850.327459

B3LYP-D3(BJ)/def2-TZVPP-IEF-PCM(DCM)//B3LYP/6-31G(d) Free Energy (Quasiharmonic) = 2849.658165

Frequencies (Top 3 out of 279) 
1. $-483.3275 \mathrm{~cm}-1$

2. $\quad 5.1576 \mathrm{~cm}-1$

3. $\quad 9.6190 \mathrm{~cm}-1$

B3LYP/6-31G(d) Molecular Geometry in Cartesian Coordinates

\begin{tabular}{|c|c|c|c|}
\hline C & -3.833046 & 0.380881 & -0.276872 \\
\hline C & -2.923759 & 1.368891 & 0.070441 \\
\hline C & -3.121039 & 2.752991 & -0.208904 \\
\hline C & -4.259281 & 3.099099 & -0.910690 \\
\hline $\mathrm{H}$ & -4.453352 & 4.147963 & -1.118930 \\
\hline C & -3.025876 & -3.740309 & 0.720150 \\
\hline C & -3.579344 & -1.035886 & 0.123301 \\
\hline C & -2.385510 & -1.640456 & -0.236640 \\
\hline C & -2.082413 & -3.008549 & 0.025442 \\
\hline $\mathrm{H}$ & -2.841380 & -4.793353 & 0.915923 \\
\hline $\mathrm{O}$ & -1.767214 & 1.006811 & 0.755272 \\
\hline$P$ & -0.578594 & 0.207462 & -0.027508 \\
\hline $\mathrm{O}$ & -1.435185 & -0.877450 & -0.906366 \\
\hline C & -0.447552 & 5.880422 & 1.048632 \\
\hline C & -0.827915 & 4.883650 & 1.949598 \\
\hline C & -1.672822 & 3.851623 & 1.545445 \\
\hline C & -2.161314 & 3.801524 & 0.229216 \\
\hline C & -1.769214 & 4.807760 & -0.668058 \\
\hline C & -0.919910 & 5.837040 & -0.263476 \\
\hline $\mathrm{H}$ & -0.468860 & 4.911894 & 2.975438 \\
\hline $\mathrm{H}$ & -0.621724 & 6.600521 & -0.977227 \\
\hline C & 1.554718 & -4.930663 & -1.243948 \\
\hline C & 0.854627 & -4.107927 & -2.130227 \\
\hline C & -0.314779 & -3.466832 & -1.722758 \\
\hline C & -0.810011 & -3.638384 & -0.418153 \\
\hline C & -0.094675 & -4.465532 & 0.462994 \\
\hline C & 1.075317 & -5.106251 & 0.054898 \\
\hline $\mathrm{H}$ & 1.216708 & -3.969665 & -3.145635 \\
\hline $\mathrm{H}$ & 1.614842 & -5.737769 & 0.756065 \\
\hline C & -4.517416 & -1.789986 & 0.908990 \\
\hline C & -4.230860 & -3.164945 & 1.193559 \\
\hline C & -5.155159 & -3.925664 & 1.960009 \\
\hline C & -6.302539 & -3.353326 & 2.457558 \\
\hline C & -6.568852 & -1.985913 & 2.211172 \\
\hline C & -5.702109 & -1.225707 & 1.457061 \\
\hline $\mathrm{H}$ & -4.928543 & -4.971010 & 2.156237 \\
\hline $\mathrm{H}$ & -6.998082 & -3.943229 & 3.048137 \\
\hline
\end{tabular}




\begin{tabular}{|c|c|c|c|}
\hline $\mathrm{H}$ & -7.463840 & -1.528944 & 2.624684 \\
\hline $\mathrm{H}$ & -5.916145 & -0.177241 & 1.285165 \\
\hline C & -4.974725 & 0.750027 & -1.069466 \\
\hline C & -5.186523 & 2.133916 & -1.373421 \\
\hline C & -6.316881 & 2.514315 & -2.146688 \\
\hline C & -7.191550 & 1.571246 & -2.633436 \\
\hline C & -6.963287 & 0.200391 & -2.369106 \\
\hline C & -5.886785 & -0.199328 & -1.608030 \\
\hline $\mathrm{H}$ & -6.468503 & 3.570419 & -2.356997 \\
\hline $\mathrm{H}$ & -8.048254 & 1.873312 & -3.229566 \\
\hline $\mathrm{H}$ & -7.640820 & -0.546071 & -2.774797 \\
\hline $\mathrm{H}$ & -5.721702 & -1.254539 & -1.424707 \\
\hline 0 & 0.335639 & -0.408733 & 0.979266 \\
\hline $\mathrm{O}$ & 0.038662 & 1.115396 & -1.112007 \\
\hline $\mathrm{H}$ & 1.174187 & 1.113342 & -1.148323 \\
\hline $\mathrm{H}$ & -2.117172 & 4.766772 & -1.696379 \\
\hline $\mathrm{H}$ & 0.214694 & 6.681710 & 1.365810 \\
\hline $\mathrm{H}$ & -1.963972 & 3.083582 & 2.253893 \\
\hline $\mathrm{H}$ & -0.449592 & -4.587085 & 1.482508 \\
\hline $\mathrm{H}$ & 2.465461 & -5.429352 & -1.564906 \\
\hline $\mathrm{H}$ & -0.854203 & -2.836382 & -2.421238 \\
\hline C & 2.882590 & -0.064850 & -1.672965 \\
\hline 0 & 2.460483 & 1.054253 & -1.225017 \\
\hline $\mathrm{H}$ & 2.179058 & -0.766919 & -2.139926 \\
\hline C & 4.242817 & -0.136687 & -2.352738 \\
\hline 0 & 4.583188 & -1.091557 & -3.023017 \\
\hline 0 & 4.977460 & 0.962056 & -2.138500 \\
\hline C & 6.281214 & 0.999474 & -2.773229 \\
\hline $\mathrm{H}$ & 6.869052 & 1.661694 & -2.134233 \\
\hline $\mathrm{H}$ & 6.712811 & -0.003795 & -2.749297 \\
\hline C & 3.832775 & -0.651238 & 0.812466 \\
\hline C & 3.224883 & -1.432495 & -0.178993 \\
\hline $\mathrm{H}$ & 1.996901 & 0.069505 & 1.331208 \\
\hline$N$ & 3.010852 & 0.144619 & 1.542529 \\
\hline C & 3.306987 & 0.861577 & 2.712510 \\
\hline 0 & 4.362479 & 0.892717 & 3.302941 \\
\hline 0 & 2.186937 & 1.503196 & 3.087460 \\
\hline C & 2.296775 & 2.259439 & 4.302691 \\
\hline $\mathrm{H}$ & 1.316849 & 2.714524 & 4.444434 \\
\hline $\mathrm{H}$ & 3.069546 & 3.026597 & 4.207920 \\
\hline $\mathrm{H}$ & 2.542051 & 1.603027 & 5.141705 \\
\hline $\mathrm{H}$ & 3.837216 & -2.152715 & -0.708341 \\
\hline $\mathrm{H}$ & 2.181342 & -1.696155 & -0.037147 \\
\hline C & 5.307032 & -0.579348 & 0.914284 \\
\hline
\end{tabular}




$\begin{array}{lrrl}\mathrm{C} & 6.049504 & -1.770801 & 0.892693 \\ \mathrm{C} & 5.986885 & 0.650162 & 0.947122 \\ \mathrm{C} & 7.442705 & -1.737038 & 0.930174 \\ \mathrm{H} & 5.530301 & -2.724160 & 0.873761 \\ \mathrm{C} & 7.377432 & 0.679968 & 0.964585 \\ \mathrm{H} & 5.424321 & 1.575973 & 0.932053 \\ \mathrm{C} & 8.108860 & -0.511827 & 0.964282 \\ \mathrm{H} & 8.004545 & -2.666620 & 0.931511 \\ \mathrm{H} & 7.893424 & 1.635791 & 0.985325 \\ \mathrm{H} & 9.194859 & -0.483168 & 0.989658 \\ \mathrm{C} & 6.181565 & 1.530037 & -4.194950 \\ \mathrm{H} & 7.185049 & 1.625769 & -4.625635 \\ \mathrm{H} & 5.603163 & 0.846182 & -4.822541 \\ \mathrm{H} & 5.703894 & 2.514872 & -4.210087\end{array}$

Catalyst (R)-1 TS Ethyl Conformation 40

B3LYP/6-31G(d) Energy $=-2849.017838$

B3LYP-D3(BJ)/def2-TZVPP-IEF-PCM(DCM) Energy = -2850.328274

B3LYP-D3(BJ)/def2-TZVPP-IEF-PCM(DCM)//B3LYP/6-31G(d) Free Energy (Quasiharmonic) = 2849.65918

Frequencies (Top 3 out of 279)

1. $-467.7919 \mathrm{~cm}-1$

2. $\quad 6.3421 \mathrm{~cm}-1$

3. $\quad 9.0876 \mathrm{~cm}-1$

B3LYP/6-31G(d) Molecular Geometry in Cartesian Coordinates

$\begin{array}{llll}\text { C } & -3.850546 & 0.425917 & -0.258079 \\ \text { C } & -2.920207 & 1.393964 & 0.089707 \\ \text { C } & -3.099896 & 2.785338 & -0.164577 \\ \text { C } & -4.244698 & 3.160244 & -0.840539 \\ \text { H } & -4.425823 & 4.215197 & -1.028647 \\ \text { C } & -3.090910 & -3.723132 & 0.657573 \\ \text { C } & -3.612163 & -1.000970 & 0.114552 \\ \text { C } & -2.433987 & -1.617636 & -0.275243 \\ \text { C } & -2.147940 & -2.994386 & -0.040947 \\ \text { H } & -2.919582 & -4.782001 & 0.832803 \\ \text { O } & -1.758886 & 1.002530 & 0.749855 \\ \text { P } & -0.595402 & 0.197360 & -0.064125 \\ \text { O } & -1.482563 & -0.858178 & -0.947801\end{array}$




\begin{tabular}{|c|c|c|c|}
\hline$C$ & -0.351896 & 5.849512 & 1.088325 \\
\hline C & -0.727386 & 4.842561 & 1.979907 \\
\hline C & -1.597175 & 3.830968 & 1.576876 \\
\hline C & -2.115431 & 3.811636 & 0.271244 \\
\hline C & -1.727676 & 4.827795 & -0.616816 \\
\hline C & -0.853978 & 5.836844 & -0.213370 \\
\hline $\mathrm{H}$ & -0.344213 & 4.846138 & 2.997290 \\
\hline $\mathrm{H}$ & -0.559895 & 6.608350 & -0.920166 \\
\hline C & 1.434549 & -4.952859 & -1.406199 \\
\hline C & 0.732087 & -4.104864 & -2.266341 \\
\hline C & -0.419013 & -3.451584 & -1.827472 \\
\hline C & -0.893500 & -3.636423 & -0.517035 \\
\hline C & -0.175942 & -4.488913 & 0.337759 \\
\hline C & 0.975970 & -5.141477 & -0.101663 \\
\hline $\mathrm{H}$ & 1.077504 & -3.956508 & -3.286151 \\
\hline $\mathrm{H}$ & 1.517773 & -5.792664 & 0.579464 \\
\hline C & -4.548658 & -1.753718 & 0.903451 \\
\hline C & -4.278738 & -3.137399 & 1.160672 \\
\hline C & -5.201846 & -3.896595 & 1.930060 \\
\hline C & -6.331800 & -3.315207 & 2.456163 \\
\hline C & -6.580952 & -1.939996 & 2.236695 \\
\hline C & -5.715188 & -1.180646 & 1.480601 \\
\hline $\mathrm{H}$ & -4.988224 & -4.948384 & 2.105306 \\
\hline $\mathrm{H}$ & -7.026503 & -3.904189 & 3.048648 \\
\hline $\mathrm{H}$ & -7.461761 & -1.476394 & 2.672655 \\
\hline $\mathrm{H}$ & -5.915808 & -0.126346 & 1.329484 \\
\hline C & -4.999519 & 0.825441 & -1.024926 \\
\hline C & -5.194888 & 2.217267 & -1.302404 \\
\hline C & -6.332315 & 2.627744 & -2.049504 \\
\hline C & -7.229744 & 1.706392 & -2.536404 \\
\hline C & -7.018276 & 0.327974 & -2.298745 \\
\hline C & -5.935239 & -0.100782 & -1.563170 \\
\hline $\mathrm{H}$ & -6.471081 & 3.689403 & -2.239759 \\
\hline $\mathrm{H}$ & -8.091759 & 2.031417 & -3.112465 \\
\hline $\mathrm{H}$ & -7.714150 & -0.401180 & -2.704866 \\
\hline $\mathrm{H}$ & -5.783443 & -1.161308 & -1.400146 \\
\hline 0 & 0.323772 & -0.449039 & 0.918420 \\
\hline $\mathrm{O}$ & 0.019353 & 1.112994 & -1.144448 \\
\hline $\mathrm{H}$ & 1.151389 & 1.116535 & -1.177607 \\
\hline $\mathrm{H}$ & -2.098495 & 4.810307 & -1.637789 \\
\hline $\mathrm{H}$ & 0.329839 & 6.634690 & 1.404494 \\
\hline $\mathrm{H}$ & -1.884138 & 3.054866 & 2.278149 \\
\hline $\mathrm{H}$ & -0.514491 & -4.621294 & 1.361483 \\
\hline $\mathrm{H}$ & 2.330978 & -5.461092 & -1.751596 \\
\hline
\end{tabular}




\begin{tabular}{|c|c|c|c|}
\hline $\mathrm{H}$ & -0.960437 & -2.801210 & -2.505848 \\
\hline C & 2.870993 & -0.030504 & -1.751142 \\
\hline 0 & 2.443377 & 1.063322 & -1.250648 \\
\hline $\mathrm{H}$ & 2.173911 & -0.706158 & -2.265312 \\
\hline C & 4.242890 & -0.068816 & -2.412611 \\
\hline 0 & 4.624747 & -1.014763 & -3.072571 \\
\hline $\mathrm{O}$ & 4.939759 & 1.054989 & -2.207131 \\
\hline C & 6.243684 & 1.109559 & -2.836991 \\
\hline $\mathrm{H}$ & 6.883609 & 0.352456 & -2.372774 \\
\hline $\mathrm{H}$ & 6.131601 & 0.853094 & -3.894539 \\
\hline C & 3.812970 & -0.766364 & 0.694506 \\
\hline C & 3.175583 & -1.477384 & -0.330008 \\
\hline $\mathrm{H}$ & 2.002298 & -0.028535 & 1.274726 \\
\hline$N$ & 3.019709 & 0.008500 & 1.478120 \\
\hline C & 3.347040 & 0.645608 & 2.684952 \\
\hline 0 & 4.410600 & 0.616687 & 3.261177 \\
\hline $\mathrm{O}$ & 2.247511 & 1.288557 & 3.114742 \\
\hline C & 2.391188 & 1.963939 & 4.373348 \\
\hline $\mathrm{H}$ & 1.421943 & 2.424960 & 4.561761 \\
\hline $\mathrm{H}$ & 3.175486 & 2.722936 & 4.313471 \\
\hline $\mathrm{H}$ & 2.639431 & 1.251601 & 5.164460 \\
\hline $\mathrm{H}$ & 3.763863 & -2.182050 & -0.905222 \\
\hline $\mathrm{H}$ & 2.126342 & -1.719319 & -0.191920 \\
\hline C & 5.289886 & -0.736390 & 0.779126 \\
\hline C & 6.002067 & -1.941862 & 0.673261 \\
\hline C & 6.001053 & 0.471921 & 0.875432 \\
\hline C & 7.395940 & -1.944290 & 0.688756 \\
\hline $\mathrm{H}$ & 5.459008 & -2.879426 & 0.604978 \\
\hline C & 7.392216 & 0.466955 & 0.870940 \\
\hline $\mathrm{H}$ & 5.461978 & 1.410212 & 0.928508 \\
\hline C & 8.093438 & -0.739928 & 0.785212 \\
\hline $\mathrm{H}$ & 7.934021 & -2.885529 & 0.623666 \\
\hline $\mathrm{H}$ & 7.932541 & 1.406804 & 0.941537 \\
\hline $\mathrm{H}$ & 9.180061 & -0.739107 & 0.793666 \\
\hline C & 6.784596 & 2.512565 & -2.641099 \\
\hline $\mathrm{H}$ & 7.770390 & 2.598097 & -3.111522 \\
\hline $\mathrm{H}$ & 6.119218 & 3.254231 & -3.093866 \\
\hline $\mathrm{H}$ & 6.888463 & 2.746567 & -1.577058 \\
\hline
\end{tabular}

\section{d) Conformations of Catalyst (R)-2 TS}

Catalyst (R)-2 TS Conformation 1 (TS-4Si)

B3LYP/6-31G(d) Energy = -3045.604367 
B3LYP-D3(BJ)/def2-TZVPP-IEF-PCM(DCM) Energy = -3047.024141

B3LYP-D3(BJ)/def2-TZVPP-IEF-PCM(DCM)//B3LYP/6-31G(d) Free Energy (Quasiharmonic) = 3046.224341

Frequencies (Top 3 out of 324)

1. $-379.4982 \mathrm{~cm}-1$

2. $\quad 10.2427 \mathrm{~cm}-1$

3. $\quad 18.6477 \mathrm{~cm}-1$

B3LYP/6-31G(d) Molecular Geometry in Cartesian Coordinates

$\begin{array}{llll}\text { C } & 2.556464 & -1.902003 & -0.392781 \\ \text { C } & 1.206584 & -2.090474 & -0.135704 \\ \text { C } & 0.484837 & -3.254349 & -0.523895 \\ \text { C } & 1.175935 & -4.223404 & -1.221138 \\ \text { H } & 0.659223 & -5.134260 & -1.513554 \\ \text { C } & 4.599403 & 1.668758 & 0.906628 \\ \text { C } & 3.252589 & -0.690807 & 0.132790 \\ \text { C } & 2.751637 & 0.572510 & -0.148610 \\ \text { C } & 3.421235 & 1.779227 & 0.197089 \\ \text { H } & 5.144601 & 2.572044 & 1.169574 \\ \text { O } & 0.522180 & -1.124170 & 0.595952 \\ \text { P } & 0.167538 & 0.313979 & -0.093995 \\ \text { O } & 1.560356 & 0.680890 & -0.863449 \\ \text { C } & -3.692075 & -3.855367 & 0.420945 \\ \text { C } & -3.282086 & -3.552569 & -0.882410 \\ \text { C } & -1.938754 & -3.345169 & -1.210357 \\ \text { C } & -0.963881 & -3.437217 & -0.190927 \\ \text { C } & -1.353923 & -3.738025 & 1.129545 \\ \text { C } & -2.710231 & -3.944011 & 1.409248 \\ \text { H } & -4.032966 & -3.468832 & -1.665614 \\ \text { H } & -3.002885 & -4.183892 & 2.429913 \\ \text { C } & 2.104183 & 5.727811 & -0.963769 \\ \text { C } & 2.659459 & 4.849092 & -1.897878 \\ \text { C } & 3.063502 & 3.556029 & -1.547954 \\ \text { C } & 2.908873 & 3.126229 & -0.213629 \\ \text { C } & 2.329002 & 3.987891 & 0.741984 \\ \text { C } & 1.936951 & 5.270880 & 0.346449 \\ \text { H } & 2.794484 & 5.179802 & -2.926215 \\ \text { H } & 1.490185 & 5.932199 & 1.086687 \\ \text { C } & 4.429773 & -0.785961 & 0.953392 \\ \text { C } & 5.113080 & 0.416442 & 1.327497 \\ \text { C } & 6.285057 & 0.334282 & 2.127435\end{array}$




\begin{tabular}{|c|c|c|c|}
\hline C & 6.754257 & -0.879194 & 2.573131 \\
\hline C & 6.059465 & -2.065588 & 2.239112 \\
\hline C & 4.931180 & -2.021237 & 1.450434 \\
\hline $\mathrm{H}$ & 6.797333 & 1.256511 & 2.391495 \\
\hline $\mathrm{H}$ & 7.647274 & -0.929207 & 3.190080 \\
\hline $\mathrm{H}$ & 6.416435 & -3.021547 & 2.612726 \\
\hline $\mathrm{H}$ & 4.405566 & -2.938565 & 1.212363 \\
\hline C & 3.236375 & -2.876316 & -1.203827 \\
\hline C & 2.532588 & -4.060455 & -1.598266 \\
\hline C & 3.198157 & -5.040692 & -2.383281 \\
\hline C & 4.496426 & -4.854712 & -2.796945 \\
\hline C & 5.180740 & -3.667465 & -2.445467 \\
\hline C & 4.569722 & -2.706577 & -1.670486 \\
\hline $\mathrm{H}$ & 2.651472 & -5.938230 & -2.662934 \\
\hline $\mathrm{H}$ & 4.992678 & -5.607740 & -3.402960 \\
\hline $\mathrm{H}$ & 6.197374 & -3.508737 & -2.794967 \\
\hline $\mathrm{H}$ & 5.106230 & -1.799107 & -1.419770 \\
\hline $\mathrm{O}$ & -0.223891 & 1.256971 & 0.994210 \\
\hline $\mathrm{O}$ & -0.792016 & 0.076192 & -1.282882 \\
\hline $\mathrm{H}$ & -1.852683 & 0.395711 & -1.300588 \\
\hline C & -4.024651 & 0.113804 & -0.838403 \\
\hline $\mathrm{O}$ & -3.127235 & 0.715562 & -1.521126 \\
\hline $\mathrm{H}$ & -3.740577 & -0.695571 & -0.154191 \\
\hline C & -5.374266 & -0.189814 & -1.479479 \\
\hline $\mathrm{O}$ & -6.112476 & -1.065468 & -1.069985 \\
\hline $\mathrm{O}$ & -5.638594 & 0.603832 & -2.522274 \\
\hline C & -6.896569 & 0.364678 & -3.177013 \\
\hline $\mathrm{H}$ & -7.725462 & 0.505744 & -2.478120 \\
\hline $\mathrm{H}$ & -6.945503 & 1.094199 & -3.985115 \\
\hline C & -3.663342 & 1.643825 & 1.223309 \\
\hline C & -4.838619 & 1.392007 & 0.504018 \\
\hline $\mathrm{H}$ & -1.707784 & 2.191143 & 0.939026 \\
\hline$N$ & -2.689741 & 2.439892 & 0.713430 \\
\hline C & -2.840583 & 3.381764 & -0.323205 \\
\hline $\mathrm{O}$ & -3.881817 & 3.855962 & -0.718023 \\
\hline $\mathrm{O}$ & -1.615704 & 3.714982 & -0.751422 \\
\hline C & -1.576835 & 4.656328 & -1.837332 \\
\hline $\mathrm{H}$ & -2.095194 & 4.245740 & -2.707358 \\
\hline $\mathrm{H}$ & -0.517596 & 4.800771 & -2.045380 \\
\hline $\mathrm{H}$ & -2.049800 & 5.596992 & -1.543365 \\
\hline $\mathrm{H}$ & -5.633368 & 0.859176 & 1.013907 \\
\hline $\mathrm{H}$ & -5.150712 & 2.133113 & -0.219721 \\
\hline C & -3.335665 & 0.928821 & 2.473098 \\
\hline C & -2.421242 & 1.481301 & 3.388907 \\
\hline
\end{tabular}




$\begin{array}{lrrr}\mathrm{C} & -3.953642 & -0.295605 & 2.790797 \\ \mathrm{C} & -2.139553 & 0.832367 & 4.587358 \\ \mathrm{H} & -1.946419 & 2.431624 & 3.171507 \\ \mathrm{C} & -3.660644 & -0.945269 & 3.985584 \\ \mathrm{H} & -4.643680 & -0.757178 & 2.092606 \\ \mathrm{C} & -2.756096 & -0.382833 & 4.889252 \\ \mathrm{H} & -1.436257 & 1.277064 & 5.285201 \\ \mathrm{H} & -4.135960 & -1.895990 & 4.208196 \\ \mathrm{H} & -2.531911 & -0.890611 & 5.823233 \\ \mathrm{H} & -6.933058 & -0.653499 & -3.573052 \\ \mathrm{C} & 2.094173 & 3.543664 & 2.168797 \\ \mathrm{H} & 1.428982 & 2.673306 & 2.196244 \\ \mathrm{H} & 3.024946 & 3.260365 & 2.672747 \\ \mathrm{H} & 1.631625 & 4.348108 & 2.750057 \\ \mathrm{C} & 3.658942 & 2.649639 & -2.601401 \\ \mathrm{H} & 4.626607 & 2.242238 & -2.286453 \\ \mathrm{H} & 3.001155 & 1.796864 & -2.806933 \\ \mathrm{H} & 3.809778 & 3.190366 & -3.540921 \\ \mathrm{C} & 1.727534 & 7.140652 & -1.348305 \\ \mathrm{H} & 0.845302 & 7.486527 & -0.798024 \\ \mathrm{H} & 2.541366 & 7.843862 & -1.125400 \\ \mathrm{H} & 1.514000 & 7.223607 & -2.419513 \\ \mathrm{C} & -1.568810 & -3.003292 & -2.637629 \\ \mathrm{H} & -1.024924 & -2.054419 & -2.687959 \\ \mathrm{H} & -0.930272 & -3.768889 & -3.092823 \\ \mathrm{H} & -2.468100 & -2.911958 & -3.254930 \\ \mathrm{C} & -0.339295 & -3.841459 & 2.245597 \\ \mathrm{H} & 0.495998 & -4.497521 & 1.975238 \\ \mathrm{H} & 0.084861 & -2.859392 & 2.485563 \\ \mathrm{H} & -0.800373 & -4.239167 & 3.155198 \\ \mathrm{C} & -5.153864 & -4.079215 & 0.732201 \\ \mathrm{H} & -5.766092 & -3.257246 & 0.344188 \\ \mathrm{H} & -5.522856 & -5.004282 & 0.270003 \\ \mathrm{H} & -5.325347 & -4.161699 & 1.811011\end{array}$

Catalyst (R)-2 TS Conformation 2

B3LYP/6-31G(d) Energy $=-3045.59812$

B3LYP-D3(BJ)/def2-TZVPP-IEF-PCM(DCM) Energy = -3047.012755

B3LYP-D3(BJ)/def2-TZVPP-IEF-PCM(DCM)//B3LYP/6-31G(d) Free Energy (Quasiharmonic) = 3046.214471

Frequencies (Top 3 out of 324) 
1. $-736.9079 \mathrm{~cm}-1$

2. $\quad 8.9772 \mathrm{~cm}-1$

3. $\quad 11.1087 \mathrm{~cm}-1$

B3LYP/6-31G(d) Molecular Geometry in Cartesian Coordinates

\begin{tabular}{|c|c|c|c|}
\hline C & -3.218189 & -1.332335 & 0.240195 \\
\hline C & -1.989304 & -1.776465 & -0.223718 \\
\hline C & -1.484549 & -3.089085 & -0.003837 \\
\hline C & -2.254901 & -3.942921 & 0.756655 \\
\hline $\mathrm{H}$ & -1.910104 & -4.959833 & 0.927941 \\
\hline C & -4.650952 & 2.624443 & -0.737274 \\
\hline C & -3.719667 & 0.017078 & -0.158721 \\
\hline C & -2.937351 & 1.145979 & 0.043669 \\
\hline C & -3.385644 & 2.472683 & -0.210440 \\
\hline $\mathrm{H}$ & -5.029755 & 3.626348 & -0.924163 \\
\hline $\mathrm{O}$ & -1.222547 & -0.920359 & -1.005458 \\
\hline$P$ & -0.462851 & 0.334822 & -0.279319 \\
\hline $\mathrm{O}$ & -1.665575 & 1.004990 & 0.593180 \\
\hline C & 2.327872 & -4.238493 & -1.684518 \\
\hline C & 2.182827 & -4.011450 & -0.312583 \\
\hline C & 0.958118 & -3.649842 & 0.255963 \\
\hline C & -0.169214 & -3.509207 & -0.582594 \\
\hline C & -0.051899 & -3.754427 & -1.965830 \\
\hline C & 1.193584 & -4.118402 & -2.489593 \\
\hline $\mathrm{H}$ & 3.052279 & -4.108119 & 0.335397 \\
\hline $\mathrm{H}$ & 1.277853 & -4.305150 & -3.558588 \\
\hline C & -1.013925 & 5.969005 & 0.697998 \\
\hline C & -1.617528 & 5.223503 & 1.713957 \\
\hline C & -2.374659 & 4.080455 & 1.441683 \\
\hline C & -2.536810 & 3.666794 & 0.102413 \\
\hline C & -1.931313 & 4.399653 & -0.940005 \\
\hline C & -1.180337 & 5.536021 & -0.619223 \\
\hline $\mathrm{H}$ & -1.498434 & 5.538996 & 2.749075 \\
\hline $\mathrm{H}$ & -0.708954 & 6.094753 & -1.425707 \\
\hline C & -4.997319 & 0.187863 & -0.799687 \\
\hline C & -5.467125 & 1.514286 & -1.070197 \\
\hline C & -6.734389 & 1.695485 & -1.687557 \\
\hline C & -7.502120 & 0.616775 & -2.059314 \\
\hline C & -7.023001 & -0.694861 & -1.833378 \\
\hline C & -5.807378 & -0.903786 & -1.220222 \\
\hline $\mathrm{H}$ & -7.078716 & 2.710147 & -1.873498 \\
\hline $\mathrm{H}$ & -8.466056 & 0.767614 & -2.537546 \\
\hline
\end{tabular}




\begin{tabular}{|c|c|c|c|}
\hline $\mathrm{H}$ & -7.616948 & -1.547283 & -2.152014 \\
\hline $\mathrm{H}$ & -5.452234 & -1.915756 & -1.066012 \\
\hline C & -3.960993 & -2.200158 & 1.114909 \\
\hline C & -3.473648 & -3.527339 & 1.352301 \\
\hline C & -4.209125 & -4.398829 & 2.200537 \\
\hline C & -5.362041 & -3.978057 & 2.821542 \\
\hline C & -5.823401 & -2.655742 & 2.622219 \\
\hline C & -5.143998 & -1.792254 & 1.791373 \\
\hline $\mathrm{H}$ & -3.831492 & -5.406246 & 2.359604 \\
\hline $\mathrm{H}$ & -5.911479 & -4.651813 & 3.473353 \\
\hline $\mathrm{H}$ & -6.720135 & -2.315603 & 3.133198 \\
\hline $\mathrm{H}$ & -5.506078 & -0.779680 & 1.656522 \\
\hline 0 & 0.626112 & -0.074867 & 0.658646 \\
\hline $\mathrm{O}$ & -0.102967 & 1.263231 & -1.452965 \\
\hline $\mathrm{H}$ & 0.937933 & 1.112471 & -2.019830 \\
\hline C & 2.825266 & 0.353729 & -1.749428 \\
\hline $\mathrm{O}$ & 2.046914 & 1.008168 & -2.522167 \\
\hline $\mathrm{H}$ & 2.416839 & -0.388263 & -1.056936 \\
\hline C & 4.212587 & -0.005190 & -2.236435 \\
\hline $\mathrm{O}$ & 4.785442 & -1.009678 & -1.863434 \\
\hline 0 & 4.712152 & 0.892308 & -3.092446 \\
\hline C & 6.034638 & 0.604117 & -3.583670 \\
\hline $\mathrm{H}$ & 6.045891 & -0.356237 & -4.104959 \\
\hline $\mathrm{H}$ & 6.271379 & 1.417137 & -4.269653 \\
\hline C & 4.004047 & 1.000754 & 0.765725 \\
\hline C & 3.330735 & 1.696491 & -0.240027 \\
\hline $\mathrm{H}$ & 2.252801 & 0.147615 & 1.406003 \\
\hline$N$ & 3.257322 & 0.250510 & 1.631642 \\
\hline C & 3.642466 & -0.187744 & 2.904982 \\
\hline $\mathrm{O}$ & 4.711846 & -0.005796 & 3.441361 \\
\hline $\mathrm{O}$ & 2.597062 & -0.833436 & 3.454095 \\
\hline C & 2.808963 & -1.301075 & 4.796133 \\
\hline $\mathrm{H}$ & 3.015862 & -0.461552 & 5.464762 \\
\hline $\mathrm{H}$ & 3.646445 & -2.002442 & 4.829873 \\
\hline $\mathrm{H}$ & 1.879431 & -1.796004 & 5.075763 \\
\hline $\mathrm{H}$ & 3.904817 & 2.371767 & -0.863073 \\
\hline $\mathrm{H}$ & 2.287567 & 1.947603 & -0.084081 \\
\hline C & 5.480388 & 0.962657 & 0.785760 \\
\hline C & 6.204377 & 2.148919 & 0.577789 \\
\hline C & 6.177396 & -0.251810 & 0.911276 \\
\hline C & 7.596096 & 2.125246 & 0.517940 \\
\hline $\mathrm{H}$ & 5.673732 & 3.092604 & 0.495632 \\
\hline C & 7.565493 & -0.273786 & 0.830251 \\
\hline $\mathrm{H}$ & 5.626424 & -1.176520 & 1.036336 \\
\hline
\end{tabular}




$\begin{array}{lrrr}\mathrm{C} & 8.278604 & 0.913240 & 0.640541 \\ \mathrm{H} & 8.145827 & 3.051637 & 0.378318 \\ \mathrm{H} & 8.093089 & -1.219281 & 0.914793 \\ \mathrm{H} & 9.363823 & 0.892726 & 0.588629 \\ \mathrm{H} & 6.748362 & 0.574124 & -2.756179 \\ \mathrm{C} & -3.000837 & 3.311099 & 2.582961 \\ \mathrm{H} & -4.072387 & 3.145605 & 2.421684 \\ \mathrm{H} & -2.535800 & 2.324867 & 2.698101 \\ \mathrm{H} & -2.881005 & 3.850429 & 3.527875 \\ \mathrm{C} & -0.227750 & 7.220598 & 1.013761 \\ \mathrm{H} & 0.533999 & 7.418359 & 0.251822 \\ \mathrm{H} & -0.880705 & 8.103074 & 1.056270 \\ \mathrm{H} & 0.275168 & 7.144917 & 1.984263 \\ \mathrm{C} & -2.048354 & 3.969930 & -2.385847 \\ \mathrm{H} & -1.643693 & 2.961972 & -2.526344 \\ \mathrm{H} & -3.088585 & 3.956040 & -2.730294 \\ \mathrm{H} & -1.491286 & 4.652526 & -3.035478 \\ \mathrm{C} & -1.239913 & -3.623092 & -2.891991 \\ \mathrm{H} & -2.113309 & -4.165858 & -2.512853 \\ \mathrm{H} & -1.536700 & -2.573915 & -3.008317 \\ \mathrm{H} & -1.003292 & -4.015047 & -3.886165 \\ \mathrm{C} & 0.878546 & -3.383580 & 1.742798 \\ \mathrm{H} & 0.561141 & -2.354216 & 1.938990 \\ \mathrm{H} & 0.167736 & -4.049951 & 2.244451 \\ \mathrm{H} & 1.858203 & -3.526720 & 2.209535 \\ \mathrm{C} & 3.679576 & -4.566772 & -2.273828 \\ \mathrm{H} & 4.308454 & -3.668335 & -2.319603 \\ \mathrm{H} & 4.214186 & -5.307739 & -1.667595 \\ \mathrm{H} & 3.588247 & -4.964765 & -3.289997\end{array}$

Catalyst (R)-2 TS Conformation 3

B3LYP/6-31G(d) Energy $=-3045.594275$

B3LYP-D3(BJ)/def2-TZVPP-IEF-PCM(DCM) Energy = -3047.018071

B3LYP-D3(BJ)/def2-TZVPP-IEF-PCM(DCM)//B3LYP/6-31G(d) Free Energy (Quasiharmonic) = 3046.219715

Frequencies (Top 3 out of 324)

1. $-719.9848 \mathrm{~cm}-1$

2. $\quad 10.3814 \mathrm{~cm}-1$

3. $\quad 18.0105 \mathrm{~cm}-1$ 
B3LYP/6-31G(d) Molecular Geometry in Cartesian Coordinates

\begin{tabular}{|c|c|c|c|}
\hline C & 2.987769 & -1.161462 & 0.382934 \\
\hline C & 2.759898 & 0.150963 & -0.008741 \\
\hline C & 3.605672 & 1.234825 & 0.360458 \\
\hline C & 4.653830 & 0.960978 & 1.214679 \\
\hline $\mathrm{H}$ & 5.328451 & 1.765511 & 1.497186 \\
\hline C & 0.510271 & -4.435904 & -0.944441 \\
\hline C & 2.156211 & -2.273163 & -0.165492 \\
\hline C & 0.774287 & -2.224866 & -0.061152 \\
\hline C & -0.078782 & -3.307484 & -0.414117 \\
\hline $\mathrm{H}$ & -0.112913 & -5.288309 & -1.204262 \\
\hline 0 & 1.705069 & 0.431261 & -0.871203 \\
\hline$P$ & 0.162496 & 0.313591 & -0.348009 \\
\hline 0 & 0.181449 & -1.099843 & 0.492679 \\
\hline C & 3.309606 & 5.273977 & -1.142399 \\
\hline C & 2.933164 & 4.965215 & 0.166117 \\
\hline C & 2.979149 & 3.658050 & 0.665792 \\
\hline C & 3.427692 & 2.621536 & -0.178213 \\
\hline C & 3.792753 & 2.906968 & -1.512128 \\
\hline C & 3.724535 & 4.225930 & -1.969012 \\
\hline $\mathrm{H}$ & 2.595832 & 5.763402 & 0.825003 \\
\hline $\mathrm{H}$ & 4.015446 & 4.440078 & -2.996067 \\
\hline C & -4.351122 & -3.082880 & 0.196956 \\
\hline C & -3.800675 & -3.036762 & -1.087271 \\
\hline C & -2.421979 & -3.090126 & -1.310676 \\
\hline C & -1.557659 & -3.225174 & -0.202659 \\
\hline C & -2.089997 & -3.295955 & 1.101229 \\
\hline C & -3.476682 & -3.216024 & 1.277133 \\
\hline $\mathrm{H}$ & -4.465179 & -2.954106 & -1.944455 \\
\hline $\mathrm{H}$ & -3.880775 & -3.260997 & 2.286317 \\
\hline C & 2.746008 & -3.412113 & -0.817438 \\
\hline C & 1.904752 & -4.510774 & -1.190574 \\
\hline C & 2.479580 & -5.649362 & -1.817572 \\
\hline C & 3.824725 & -5.699133 & -2.099877 \\
\hline C & 4.651616 & -4.599894 & -1.769277 \\
\hline C & 4.128537 & -3.489725 & -1.143804 \\
\hline $\mathrm{H}$ & 1.827638 & -6.478398 & -2.083032 \\
\hline $\mathrm{H}$ & 4.251468 & -6.571934 & -2.586447 \\
\hline $\mathrm{H}$ & 5.709630 & -4.629059 & -2.015587 \\
\hline $\mathrm{H}$ & 4.774633 & -2.652814 & -0.905772 \\
\hline C & 4.023382 & -1.411665 & 1.350852 \\
\hline C & 4.871311 & -0.330533 & 1.755034 \\
\hline C & 5.906752 & -0.567123 & 2.699387 \\
\hline
\end{tabular}




\begin{tabular}{|c|c|c|c|}
\hline C & 6.086590 & -1.811892 & 3.255545 \\
\hline C & 5.225406 & -2.873129 & 2.890241 \\
\hline C & 4.224765 & -2.680129 & 1.963542 \\
\hline $\mathrm{H}$ & 6.547322 & 0.264308 & 2.984136 \\
\hline $\mathrm{H}$ & 6.876480 & -1.979689 & 3.982557 \\
\hline $\mathrm{H}$ & 5.350432 & -3.850057 & 3.349510 \\
\hline $\mathrm{H}$ & 3.568268 & -3.502479 & 1.705143 \\
\hline 0 & -0.732077 & 0.297217 & -1.543525 \\
\hline $\mathrm{O}$ & -0.061911 & 1.358283 & 0.758407 \\
\hline $\mathrm{H}$ & -1.032410 & 1.409210 & 1.434341 \\
\hline C & -3.070199 & 0.945578 & 1.880348 \\
\hline O & -1.995673 & 1.573460 & 2.181881 \\
\hline $\mathrm{H}$ & -3.025975 & 0.050881 & 1.248656 \\
\hline C & -4.123947 & 0.909841 & 2.980441 \\
\hline O & -4.228073 & 1.732367 & 3.859161 \\
\hline 0 & -4.924458 & -0.164061 & 2.827404 \\
\hline C & -5.971792 & -0.291483 & 3.806511 \\
\hline $\mathrm{H}$ & -6.526492 & -1.186358 & 3.525218 \\
\hline $\mathrm{H}$ & -5.545482 & -0.398587 & 4.807180 \\
\hline C & -3.424126 & 2.173962 & -0.456325 \\
\hline C & -4.307686 & 1.992014 & 0.612807 \\
\hline $\mathrm{H}$ & -2.408961 & 1.020933 & -1.833046 \\
\hline$N$ & -3.349635 & 1.260805 & -1.482319 \\
\hline C & -4.423071 & 0.548501 & -2.014923 \\
\hline $\mathrm{O}$ & -5.565573 & 0.542383 & -1.605049 \\
\hline $\mathrm{O}$ & -3.998004 & -0.092630 & -3.120322 \\
\hline C & -5.028367 & -0.751758 & -3.873047 \\
\hline $\mathrm{H}$ & -4.507364 & -1.281780 & -4.670088 \\
\hline $\mathrm{H}$ & -5.719989 & -0.015195 & -4.291562 \\
\hline $\mathrm{H}$ & -5.585029 & -1.447890 & -3.242824 \\
\hline $\mathrm{H}$ & -4.544255 & 2.852778 & 1.227357 \\
\hline $\mathrm{H}$ & -5.101758 & 1.267132 & 0.488669 \\
\hline C & -2.455942 & 3.270544 & -0.485933 \\
\hline C & -1.764650 & 3.586376 & -1.676484 \\
\hline C & -2.216028 & 4.054976 & 0.663553 \\
\hline C & -0.864965 & 4.642111 & -1.712900 \\
\hline $\mathrm{H}$ & -1.949853 & 3.014853 & -2.578570 \\
\hline C & -1.310271 & 5.109761 & 0.618125 \\
\hline $\mathrm{H}$ & -2.708095 & 3.824492 & 1.599117 \\
\hline C & -0.633218 & 5.405890 & -0.564999 \\
\hline $\mathrm{H}$ & -0.339462 & 4.870549 & -2.634966 \\
\hline $\mathrm{H}$ & -1.128831 & 5.696563 & 1.513621 \\
\hline $\mathrm{H}$ & 0.074588 & 6.228377 & -0.596619 \\
\hline $\mathrm{H}$ & -6.620716 & 0.588016 & 3.787181 \\
\hline
\end{tabular}




$\begin{array}{llll}\mathrm{C} & 2.521962 & 3.385729 & 2.081887 \\ \mathrm{H} & 1.710358 & 2.650351 & 2.091729 \\ \mathrm{H} & 3.328202 & 2.989805 & 2.709646 \\ \mathrm{H} & 2.155525 & 4.304204 & 2.551502 \\ \mathrm{C} & 4.263090 & 1.817391 & -2.448867 \\ \mathrm{H} & 5.084386 & 1.235914 & -2.013964 \\ \mathrm{H} & 3.453685 & 1.113769 & -2.675370 \\ \mathrm{H} & 4.614172 & 2.241913 & -3.394645 \\ \mathrm{C} & 3.298211 & 6.699478 & -1.645816 \\ \mathrm{H} & 2.668319 & 7.342534 & -1.021248 \\ \mathrm{H} & 4.307384 & 7.132955 & -1.640928 \\ \mathrm{H} & 2.929692 & 6.761279 & -2.676449 \\ \mathrm{C} & -1.194504 & -3.454899 & 2.309360 \\ \mathrm{H} & -0.491390 & -4.286315 & 2.184680 \\ \mathrm{H} & -0.597809 & -2.551983 & 2.483914 \\ \mathrm{H} & -1.786358 & -3.645198 & 3.210190 \\ \mathrm{C} & -1.888838 & -2.943701 & -2.718828 \\ \mathrm{H} & -1.340198 & -1.999876 & -2.820874 \\ \mathrm{H} & -1.203542 & -3.751445 & -2.993612 \\ \mathrm{H} & -2.709308 & -2.938531 & -3.443119 \\ \mathrm{C} & -5.844107 & -2.966413 & 0.398286 \\ \mathrm{H} & -6.200976 & -1.968242 & 0.114097 \\ \mathrm{H} & -6.391381 & -3.692337 & -0.215775 \\ \mathrm{H} & -6.120894 & -3.137650 & 1.443731\end{array}$

Catalyst (R)-2 TS Conformation 4

B3LYP/6-31G(d) Energy $=-3045.599989$

B3LYP-D3(BJ)/def2-TZVPP-IEF-PCM(DCM) Energy = -3047.020626

B3LYP-D3(BJ)/def2-TZVPP-IEF-PCM(DCM)//B3LYP/6-31G(d) Free Energy (Quasiharmonic) = 3046.221867

Frequencies (Top 3 out of 324)

1. $-681.4085 \mathrm{~cm}-1$

2. $\quad 9.1488 \mathrm{~cm}-1$

3. $14.1826 \mathrm{~cm}-1$

B3LYP/6-31G(d) Molecular Geometry in Cartesian Coordinates

$\begin{array}{llll}\text { C } & 2.524845 & -1.919723 & -0.454373 \\ C & 1.195095 & -2.104072 & -0.107314 \\ C & 0.451876 & -3.271792 & -0.442861\end{array}$




\begin{tabular}{|c|c|c|c|}
\hline C & 1.083991 & -4.232286 & -1.203822 \\
\hline $\mathrm{H}$ & 0.549190 & -5.143922 & -1.459421 \\
\hline C & 4.678188 & 1.585108 & 0.842295 \\
\hline C & 3.265188 & -0.730014 & 0.058635 \\
\hline C & 2.762046 & 0.546676 & -0.152537 \\
\hline C & 3.465488 & 1.732216 & 0.200957 \\
\hline $\mathrm{H}$ & 5.246061 & 2.473656 & 1.107643 \\
\hline 0 & 0.563088 & -1.135722 & 0.663950 \\
\hline$P$ & 0.158998 & 0.294821 & -0.034893 \\
\hline O & 1.546040 & 0.693031 & -0.809524 \\
\hline C & -3.595924 & -3.826124 & 0.974739 \\
\hline C & -3.339247 & -3.525396 & -0.365089 \\
\hline C & -2.037290 & -3.349895 & -0.853688 \\
\hline C & -0.952145 & -3.464659 & 0.039652 \\
\hline C & -1.186610 & -3.791628 & 1.392678 \\
\hline C & -2.500906 & -3.978198 & 1.830741 \\
\hline $\mathrm{H}$ & -4.175998 & -3.414992 & -1.051971 \\
\hline $\mathrm{H}$ & -2.673607 & -4.254424 & 2.869920 \\
\hline C & 2.173002 & 5.744576 & -0.739750 \\
\hline C & 2.068913 & 5.243051 & 0.558422 \\
\hline C & 2.442371 & 3.932909 & 0.883126 \\
\hline C & 2.953770 & 3.100227 & -0.132117 \\
\hline C & 3.056167 & 3.581947 & -1.455522 \\
\hline C & 2.665121 & 4.893624 & -1.733898 \\
\hline $\mathrm{H}$ & 1.690381 & 5.889034 & 1.349014 \\
\hline $\mathrm{H}$ & 2.754819 & 5.261753 & -2.754519 \\
\hline C & 4.484102 & -0.866722 & 0.809914 \\
\hline C & 5.200772 & 0.314299 & 1.189032 \\
\hline C & 6.413856 & 0.192698 & 1.919578 \\
\hline C & 6.894105 & -1.040212 & 2.294513 \\
\hline C & 6.168804 & -2.207060 & 1.956725 \\
\hline C & 4.999104 & -2.123645 & 1.234211 \\
\hline $\mathrm{H}$ & 6.949573 & 1.100326 & 2.187831 \\
\hline $\mathrm{H}$ & 7.819231 & -1.120732 & 2.858719 \\
\hline $\mathrm{H}$ & 6.535302 & -3.179430 & 2.274820 \\
\hline $\mathrm{H}$ & 4.451923 & -3.027467 & 0.993410 \\
\hline C & 3.140472 & -2.884393 & -1.325775 \\
\hline C & 2.406164 & -4.060674 & -1.686880 \\
\hline C & 3.009153 & -5.027642 & -2.535929 \\
\hline C & 4.274403 & -4.836644 & -3.040316 \\
\hline C & 4.987340 & -3.658113 & -2.717739 \\
\hline C & 4.437689 & -2.710090 & -1.883156 \\
\hline $\mathrm{H}$ & 2.441050 & -5.919433 & -2.790370 \\
\hline $\mathrm{H}$ & 4.722261 & -5.579555 & -3.694634 \\
\hline
\end{tabular}




\begin{tabular}{|c|c|c|c|}
\hline $\mathrm{H}$ & 5.976727 & -3.495933 & -3.136915 \\
\hline $\mathrm{H}$ & 4.993555 & -1.808303 & -1.654488 \\
\hline $\mathrm{O}$ & -0.223517 & 1.244387 & 1.053511 \\
\hline $\mathrm{O}$ & -0.807935 & 0.006333 & -1.190628 \\
\hline $\mathrm{H}$ & -1.894376 & 0.422275 & -1.436415 \\
\hline C & -3.943776 & 0.091773 & -1.192767 \\
\hline $\mathrm{O}$ & -3.013663 & 0.686151 & -1.832245 \\
\hline $\mathrm{H}$ & -3.700688 & -0.724539 & -0.506296 \\
\hline C & -5.279256 & -0.002996 & -1.906172 \\
\hline $\mathrm{O}$ & -5.663031 & 0.764055 & -2.759186 \\
\hline $\mathrm{O}$ & -5.976159 & -1.064160 & -1.452718 \\
\hline C & -7.274332 & -1.247132 & -2.048251 \\
\hline $\mathrm{H}$ & -7.179754 & -1.403490 & -3.125718 \\
\hline $\mathrm{H}$ & -7.694810 & -2.128891 & -1.565305 \\
\hline C & -3.662102 & 1.805994 & 0.866892 \\
\hline C & -4.839309 & 1.237645 & 0.381520 \\
\hline $\mathrm{H}$ & -1.852878 & 1.356163 & 1.747259 \\
\hline$N$ & -2.875606 & 1.194038 & 1.806021 \\
\hline C & -3.267108 & 0.190815 & 2.696829 \\
\hline $\mathrm{O}$ & -4.363952 & -0.324659 & 2.777488 \\
\hline $\mathrm{O}$ & -2.219153 & -0.093419 & 3.485879 \\
\hline C & -2.445712 & -1.124299 & 4.460704 \\
\hline $\mathrm{H}$ & -1.508115 & -1.206772 & 5.009984 \\
\hline $\mathrm{H}$ & -2.685053 & -2.066373 & 3.962997 \\
\hline $\mathrm{H}$ & -3.263037 & -0.844246 & 5.130213 \\
\hline $\mathrm{H}$ & -5.513987 & 1.890584 & -0.158635 \\
\hline $\mathrm{H}$ & -5.286243 & 0.417393 & 0.925576 \\
\hline C & -3.128943 & 3.053323 & 0.299212 \\
\hline C & -3.530840 & 3.492251 & -0.980111 \\
\hline C & -2.226282 & 3.847591 & 1.035791 \\
\hline C & -3.042741 & 4.689054 & -1.496632 \\
\hline $\mathrm{H}$ & -4.192498 & 2.888140 & -1.588131 \\
\hline C & -1.752970 & 5.046175 & 0.516879 \\
\hline $\mathrm{H}$ & -1.915001 & 3.537152 & 2.026758 \\
\hline C & -2.158066 & 5.469626 & -0.751478 \\
\hline $\mathrm{H}$ & -3.350049 & 5.006159 & -2.488761 \\
\hline $\mathrm{H}$ & -1.060410 & 5.646461 & 1.097770 \\
\hline $\mathrm{H}$ & -1.782216 & 6.405008 & -1.157036 \\
\hline $\mathrm{H}$ & -7.902074 & -0.370598 & -1.867966 \\
\hline C & 2.255503 & 3.433250 & 2.298682 \\
\hline $\mathrm{H}$ & 1.540457 & 2.602497 & 2.318667 \\
\hline $\mathrm{H}$ & 3.190226 & 3.070467 & 2.739737 \\
\hline $\mathrm{H}$ & 1.870536 & 4.231666 & 2.941808 \\
\hline C & 1.755721 & 7.158973 & -1.070968 \\
\hline
\end{tabular}




$\begin{array}{llll}\mathrm{H} & 1.566192 & 7.743916 & -0.164785 \\ \mathrm{H} & 2.526133 & 7.680672 & -1.651362 \\ \mathrm{H} & 0.838203 & 7.174683 & -1.674645 \\ \mathrm{C} & 3.585391 & 2.707033 & -2.569098 \\ \mathrm{H} & 4.562397 & 2.277309 & -2.318872 \\ \mathrm{H} & 2.906204 & 1.870078 & -2.769583 \\ \mathrm{H} & 3.694949 & 3.279242 & -3.495599 \\ \mathrm{C} & -0.044025 & -3.941271 & 2.371442 \\ \mathrm{H} & 0.733640 & -4.611578 & 1.988499 \\ \mathrm{H} & 0.433587 & -2.974282 & 2.569716 \\ \mathrm{H} & -0.397885 & -4.345007 & 3.325594 \\ \mathrm{C} & -5.008609 & -3.947237 & 1.495541 \\ \mathrm{H} & -5.313139 & -3.021174 & 2.000601 \\ \mathrm{H} & -5.720892 & -4.133027 & 0.684926 \\ \mathrm{H} & -5.101807 & -4.762063 & 2.222838 \\ \mathrm{C} & -1.830093 & -3.026888 & -2.317481 \\ \mathrm{H} & -1.260110 & -2.100815 & -2.441605 \\ \mathrm{H} & -1.279029 & -3.819783 & -2.836150 \\ \mathrm{H} & -2.792522 & -2.908517 & -2.826018\end{array}$

Catalyst (R)-2 TS Conformation 5

B3LYP/6-31G(d) Energy $=-3045.601777$

B3LYP-D3(BJ)/def2-TZVPP-IEF-PCM(DCM) Energy $=-3047.018692$

B3LYP-D3(BJ)/def2-TZVPP-IEF-PCM(DCM)//B3LYP/6-31G(d) Free Energy (Quasiharmonic) = 3046.219723

Frequencies (Top 3 out of 324)

1. $-550.8827 \mathrm{~cm}-1$

2. $\quad 10.3361 \mathrm{~cm}-1$

3. $\quad 16.1104 \mathrm{~cm}-1$

B3LYP/6-31G(d) Molecular Geometry in Cartesian Coordinates

$\begin{array}{lrrr}\text { C } & 3.649465 & 0.128593 & 0.277447 \\ \text { C } & 2.762850 & 1.188632 & 0.143135 \\ \text { C } & 3.034615 & 2.504984 & 0.610677 \\ \text { C } & 4.216729 & 2.705985 & 1.291934 \\ \text { H } & 4.460147 & 3.705072 & 1.645292 \\ \text { C } & 2.758273 & -3.788397 & -1.309324 \\ \text { C } & 3.352083 & -1.192578 & -0.351907 \\ \text { C } & 2.148283 & -1.825304 & -0.086603\end{array}$




\begin{tabular}{|c|c|c|c|}
\hline C & 1.826474 & -3.139643 & -0.527159 \\
\hline $\mathrm{H}$ & 2.555886 & -4.801825 & -1.647262 \\
\hline $\mathrm{O}$ & 1.570053 & 1.001338 & -0.551299 \\
\hline$P$ & 0.379953 & 0.075507 & 0.067030 \\
\hline 0 & 1.214722 & -1.172803 & 0.712062 \\
\hline C & 0.473278 & 5.905135 & -0.134012 \\
\hline C & 1.270596 & 5.366221 & -1.146848 \\
\hline C & 2.084457 & 4.247812 & -0.931833 \\
\hline C & 2.107134 & 3.651778 & 0.345542 \\
\hline C & 1.302234 & 4.172410 & 1.381778 \\
\hline C & 0.499286 & 5.286814 & 1.118982 \\
\hline $\mathrm{H}$ & 1.273589 & 5.835520 & -2.129529 \\
\hline $\mathrm{H}$ & -0.123410 & 5.681831 & 1.919601 \\
\hline C & -1.931956 & -4.935333 & 0.632110 \\
\hline C & -0.890706 & -4.779524 & 1.552326 \\
\hline C & 0.335105 & -4.211610 & 1.194148 \\
\hline C & 0.531367 & -3.780608 & -0.136157 \\
\hline C & -0.495194 & -3.948096 & -1.088880 \\
\hline C & -1.704462 & -4.528335 & -0.685018 \\
\hline $\mathrm{H}$ & -1.036745 & -5.106542 & 2.580191 \\
\hline $\mathrm{H}$ & -2.494910 & -4.654183 & -1.422853 \\
\hline C & 4.270260 & -1.841995 & -1.249147 \\
\hline C & 3.966835 & -3.164208 & -1.712842 \\
\hline C & 4.874494 & -3.821887 & -2.586557 \\
\hline C & 6.021662 & -3.197583 & -3.017951 \\
\hline C & 6.303895 & -1.877826 & -2.594190 \\
\hline C & 5.454123 & -1.219434 & -1.732837 \\
\hline $\mathrm{H}$ & 4.634607 & -4.829051 & -2.919311 \\
\hline $\mathrm{H}$ & 6.703925 & -3.708381 & -3.691871 \\
\hline $\mathrm{H}$ & 7.197478 & -1.375975 & -2.955458 \\
\hline $\mathrm{H}$ & 5.680598 & -0.205262 & -1.424944 \\
\hline C & 4.831859 & 0.333383 & 1.072621 \\
\hline C & 5.117321 & 1.646983 & 1.568226 \\
\hline C & 6.289113 & 1.863996 & 2.342576 \\
\hline C & 7.136628 & 0.825724 & 2.650508 \\
\hline C & 6.836692 & -0.480787 & 2.198661 \\
\hline C & 5.718516 & -0.720361 & 1.430837 \\
\hline $\mathrm{H}$ & 6.494376 & 2.870545 & 2.699421 \\
\hline $\mathrm{H}$ & 8.025794 & 1.001948 & 3.249577 \\
\hline $\mathrm{H}$ & 7.491798 & -1.305934 & 2.464790 \\
\hline $\mathrm{H}$ & 5.499592 & -1.729942 & 1.104054 \\
\hline $\mathrm{O}$ & -0.553555 & -0.310053 & -1.036416 \\
\hline $\mathrm{O}$ & -0.234031 & 0.756099 & 1.308773 \\
\hline $\mathrm{H}$ & -1.369745 & 0.619834 & 1.431765 \\
\hline
\end{tabular}




\begin{tabular}{|c|c|c|c|}
\hline C & -3.052137 & -0.731019 & 1.544820 \\
\hline 0 & -2.623426 & 0.472181 & 1.582068 \\
\hline $\mathrm{H}$ & -2.348866 & -1.570087 & 1.613769 \\
\hline C & -4.377406 & -1.067436 & 2.209071 \\
\hline $\mathrm{O}$ & -4.737488 & -2.207651 & 2.428001 \\
\hline 0 & -5.076893 & 0.026514 & 2.534502 \\
\hline C & -6.347398 & -0.222718 & 3.161568 \\
\hline $\mathrm{H}$ & -7.004954 & -0.771317 & 2.482418 \\
\hline $\mathrm{H}$ & -6.212497 & -0.800849 & 4.079021 \\
\hline C & -4.056862 & -0.140135 & -0.911941 \\
\hline C & -3.569723 & -1.337481 & -0.374455 \\
\hline $\mathrm{H}$ & -2.136761 & 0.484502 & -1.169157 \\
\hline$N$ & -3.127448 & 0.777473 & -1.271309 \\
\hline C & -3.305843 & 1.992923 & -1.954280 \\
\hline $\mathrm{O}$ & -4.340568 & 2.433395 & -2.399098 \\
\hline O & -2.101164 & 2.577784 & -2.042827 \\
\hline C & -2.072052 & 3.835849 & -2.736765 \\
\hline $\mathrm{H}$ & -1.061429 & 4.215112 & -2.590877 \\
\hline $\mathrm{H}$ & -2.809220 & 4.521642 & -2.312669 \\
\hline $\mathrm{H}$ & -2.285854 & 3.686990 & -3.798901 \\
\hline $\mathrm{H}$ & -4.278651 & -2.129022 & -0.164758 \\
\hline $\mathrm{H}$ & -2.566028 & -1.646275 & -0.647861 \\
\hline C & -5.506908 & 0.155940 & -0.889091 \\
\hline C & -6.405938 & -0.809810 & -1.368297 \\
\hline C & -6.008673 & 1.335269 & -0.313719 \\
\hline C & -7.781029 & -0.589879 & -1.301235 \\
\hline $\mathrm{H}$ & -6.022950 & -1.721726 & -1.816533 \\
\hline C & -7.381985 & 1.541149 & -0.229586 \\
\hline $\mathrm{H}$ & -5.322828 & 2.070290 & 0.090347 \\
\hline C & -8.271035 & 0.585141 & -0.730015 \\
\hline $\mathrm{H}$ & -8.466175 & -1.336030 & -1.693251 \\
\hline $\mathrm{H}$ & -7.760758 & 2.453018 & 0.223354 \\
\hline $\mathrm{H}$ & -9.342580 & 0.756679 & -0.672876 \\
\hline $\mathrm{H}$ & -6.759431 & 0.761758 & 3.382107 \\
\hline C & 2.922860 & 3.704902 & -2.067054 \\
\hline $\mathrm{H}$ & 3.977859 & 3.612222 & -1.784484 \\
\hline $\mathrm{H}$ & 2.581606 & 2.707709 & -2.369416 \\
\hline $\mathrm{H}$ & 2.864580 & 4.359124 & -2.942728 \\
\hline C & 1.270419 & 3.538208 & 2.754602 \\
\hline $\mathrm{H}$ & 0.920366 & 2.501824 & 2.696448 \\
\hline $\mathrm{H}$ & 2.260259 & 3.522949 & 3.224344 \\
\hline $\mathrm{H}$ & 0.593904 & 4.087800 & 3.416671 \\
\hline C & -0.371289 & 7.135758 & -0.373028 \\
\hline $\mathrm{H}$ & -1.359336 & 7.041914 & 0.092318 \\
\hline
\end{tabular}




$\begin{array}{llll}\text { H } & 0.099541 & 8.031875 & 0.052883 \\ \text { H } & -0.516824 & 7.322444 & -1.442383 \\ \mathrm{C} & 1.420497 & -4.065978 & 2.236957 \\ \mathrm{H} & 2.380551 & -4.456346 & 1.880619 \\ \mathrm{H} & 1.577506 & -3.013810 & 2.502154 \\ \mathrm{H} & 1.154726 & -4.604697 & 3.151802 \\ \mathrm{C} & -0.339415 & -3.475144 & -2.518000 \\ \mathrm{H} & -0.171521 & -2.392758 & -2.550785 \\ \mathrm{H} & 0.505833 & -3.952882 & -3.025020 \\ \mathrm{H} & -1.242302 & -3.696570 & -3.096319 \\ \mathrm{C} & -3.270654 & -5.486458 & 1.064631 \\ \mathrm{H} & -3.843046 & -5.866599 & 0.211549 \\ \mathrm{H} & -3.154990 & -6.303921 & 1.785430 \\ \mathrm{H} & -3.871499 & -4.706109 & 1.550379\end{array}$

Catalyst (R)-2 TS Conformation 6

B3LYP/6-31G(d) Energy $=-3045.596119$

B3LYP-D3(BJ)/def2-TZVPP-IEF-PCM(DCM) Energy = -3047.015178

B3LYP-D3(BJ)/def2-TZVPP-IEF-PCM(DCM)//B3LYP/6-31G(d) Free Energy (Quasiharmonic) = 3046.216969

Frequencies (Top 3 out of 324)

1. $-698.9877 \mathrm{~cm}-1$

2. $\quad 6.2371 \mathrm{~cm}-1$

3. $\quad 8.3896 \mathrm{~cm}-1$

B3LYP/6-31G(d) Molecular Geometry in Cartesian Coordinates

$\begin{array}{llll}\text { C } & 3.199849 & -1.323085 & 0.048533 \\ \text { C } & 1.915020 & -1.841763 & -0.012513 \\ \text { C } & 1.627348 & -3.207865 & -0.289247 \\ \text { C } & 2.694890 & -4.038121 & -0.558729 \\ \text { H } & 2.511183 & -5.091484 & -0.756027 \\ \text { C } & 3.888065 & 2.822508 & 1.040372 \\ \text { C } & 3.411240 & 0.096267 & 0.462190 \\ \text { C } & 2.749919 & 1.120841 & -0.200385 \\ \text { C } & 2.991257 & 2.502103 & 0.042601 \\ \text { H } & 4.109239 & 3.868846 & 1.237009 \\ \text { O } & 0.840652 & -1.005917 & 0.270744 \\ \text { P } & 0.411400 & 0.143572 & -0.820642 \\ \text { O } & 1.851239 & 0.801698 & -1.213684\end{array}$




\begin{tabular}{|c|c|c|c|}
\hline C & -2.397170 & -4.783421 & -0.211978 \\
\hline C & -1.730381 & -4.451365 & 0.969936 \\
\hline C & -0.432614 & -3.928548 & 0.965044 \\
\hline C & 0.224455 & -3.732643 & -0.268029 \\
\hline C & -0.430406 & -4.059365 & -1.475810 \\
\hline C & -1.730640 & -4.573219 & -1.422275 \\
\hline $\mathrm{H}$ & -2.229064 & -4.606777 & 1.925086 \\
\hline $\mathrm{H}$ & -2.236009 & -4.811929 & -2.355958 \\
\hline C & 1.173290 & 5.653223 & -2.289726 \\
\hline C & 0.741366 & 5.382519 & -0.990002 \\
\hline C & 1.297608 & 4.355099 & -0.219578 \\
\hline C & 2.332012 & 3.572348 & -0.772479 \\
\hline C & 2.783329 & 3.826480 & -2.085510 \\
\hline C & 2.198657 & 4.863734 & -2.817002 \\
\hline $\mathrm{H}$ & -0.056200 & 5.985187 & -0.559193 \\
\hline $\mathrm{H}$ & 2.557144 & 5.060165 & -3.825899 \\
\hline C & 4.270160 & 0.446698 & 1.561811 \\
\hline C & 4.516711 & 1.831493 & 1.836049 \\
\hline C & 5.375039 & 2.188667 & 2.911131 \\
\hline C & 5.947060 & 1.226955 & 3.710824 \\
\hline C & 5.674128 & -0.139827 & 3.468136 \\
\hline C & 4.861198 & -0.519488 & 2.422992 \\
\hline $\mathrm{H}$ & 5.560776 & 3.244159 & 3.096129 \\
\hline $\mathrm{H}$ & 6.596524 & 1.512616 & 4.533796 \\
\hline $\mathrm{H}$ & 6.106334 & -0.898243 & 4.115395 \\
\hline $\mathrm{H}$ & 4.655472 & -1.570501 & 2.257210 \\
\hline C & 4.293837 & -2.178861 & -0.326296 \\
\hline C & 4.027897 & -3.557455 & -0.614217 \\
\hline C & 5.102434 & -4.416518 & -0.970807 \\
\hline C & 6.387757 & -3.938151 & -1.073899 \\
\hline C & 6.647913 & -2.569208 & -0.830076 \\
\hline C & 5.631324 & -1.714333 & -0.465270 \\
\hline $\mathrm{H}$ & 4.883266 & -5.461963 & -1.174972 \\
\hline $\mathrm{H}$ & 7.199945 & -4.603065 & -1.354663 \\
\hline $\mathrm{H}$ & 7.659181 & -2.186143 & -0.937271 \\
\hline $\mathrm{H}$ & 5.847160 & -0.666467 & -0.292837 \\
\hline $\mathrm{O}$ & -0.539748 & 1.061840 & -0.116113 \\
\hline $\mathrm{O}$ & -0.038428 & -0.509063 & -2.133384 \\
\hline $\mathrm{H}$ & -1.222797 & -0.573277 & -2.416352 \\
\hline C & -3.070055 & 0.124089 & -1.920762 \\
\hline $\mathrm{O}$ & -2.385918 & -0.654364 & -2.664406 \\
\hline $\mathrm{H}$ & -2.588760 & 0.985285 & -1.450105 \\
\hline C & -4.538810 & 0.264230 & -2.271276 \\
\hline $\mathrm{O}$ & -5.215383 & -0.588829 & -2.794306 \\
\hline
\end{tabular}




\begin{tabular}{|c|c|c|c|}
\hline 0 & -4.969436 & 1.493506 & -1.925472 \\
\hline C & -6.349190 & 1.767448 & -2.237174 \\
\hline $\mathrm{H}$ & -6.514211 & 2.803168 & -1.941126 \\
\hline $\mathrm{H}$ & -6.525985 & 1.637514 & -3.307548 \\
\hline C & -3.749832 & -0.050651 & 0.882185 \\
\hline C & -3.304770 & -0.932289 & -0.101714 \\
\hline $\mathrm{H}$ & -1.900792 & 0.845453 & 1.000245 \\
\hline$N$ & -2.829325 & 0.784314 & 1.459842 \\
\hline C & -2.919096 & 1.377451 & 2.723692 \\
\hline $\mathrm{O}$ & -3.826433 & 1.261672 & 3.516950 \\
\hline 0 & -1.795700 & 2.091320 & 2.928441 \\
\hline C & -1.700990 & 2.718566 & 4.217295 \\
\hline $\mathrm{H}$ & -0.744670 & 3.240669 & 4.210810 \\
\hline $\mathrm{H}$ & -1.725525 & 1.967517 & 5.011014 \\
\hline $\mathrm{H}$ & -2.524969 & 3.421858 & 4.362786 \\
\hline $\mathrm{H}$ & -4.003503 & -1.656976 & -0.501225 \\
\hline $\mathrm{H}$ & -2.263084 & -1.230828 & -0.093495 \\
\hline C & -5.189837 & 0.082756 & 1.182980 \\
\hline C & -5.998994 & -1.064860 & 1.231602 \\
\hline C & -5.787869 & 1.345332 & 1.346637 \\
\hline C & -7.370691 & -0.954998 & 1.450680 \\
\hline $\mathrm{H}$ & -5.544770 & -2.045016 & 1.127133 \\
\hline C & -7.159188 & 1.452574 & 1.549199 \\
\hline $\mathrm{H}$ & -5.177443 & 2.239562 & 1.289485 \\
\hline C & -7.953973 & 0.303159 & 1.606870 \\
\hline $\mathrm{H}$ & -7.981672 & -1.851473 & 1.500817 \\
\hline $\mathrm{H}$ & -7.610694 & 2.433514 & 1.667450 \\
\hline $\mathrm{H}$ & -9.023921 & 0.390019 & 1.775119 \\
\hline $\mathrm{H}$ & -7.004749 & 1.097379 & -1.676402 \\
\hline C & 0.239128 & -3.587912 & 2.276450 \\
\hline $\mathrm{H}$ & 1.224809 & -4.059909 & 2.360889 \\
\hline $\mathrm{H}$ & 0.391171 & -2.506779 & 2.376829 \\
\hline $\mathrm{H}$ & -0.368586 & -3.921666 & 3.123432 \\
\hline C & 0.230687 & -3.849110 & -2.820373 \\
\hline $\mathrm{H}$ & 0.555196 & -2.810762 & -2.941837 \\
\hline $\mathrm{H}$ & 1.114963 & -4.484822 & -2.945736 \\
\hline $\mathrm{H}$ & -0.466059 & -4.084240 & -3.630861 \\
\hline C & -3.786730 & -5.378017 & -0.185476 \\
\hline $\mathrm{H}$ & -4.400180 & -5.003473 & -1.012821 \\
\hline $\mathrm{H}$ & -3.754755 & -6.471889 & -0.279622 \\
\hline $\mathrm{H}$ & -4.303269 & -5.150105 & 0.753531 \\
\hline C & 3.885288 & 3.001501 & -2.711094 \\
\hline $\mathrm{H}$ & 4.771469 & 2.950379 & -2.067900 \\
\hline $\mathrm{H}$ & 3.554930 & 1.971201 & -2.888948 \\
\hline
\end{tabular}




$\begin{array}{llll}\mathrm{H} & 4.189897 & 3.425094 & -3.673180 \\ \mathrm{C} & 0.753547 & 4.089907 & 1.166848 \\ \mathrm{H} & 0.278759 & 3.103504 & 1.215450 \\ \mathrm{H} & 1.538179 & 4.115419 & 1.931254 \\ \mathrm{H} & 0.001250 & 4.840203 & 1.432035 \\ \mathrm{C} & 0.535668 & 6.749041 & -3.112188 \\ \mathrm{H} & -0.258464 & 6.351457 & -3.758672 \\ \mathrm{H} & 0.082779 & 7.516774 & -2.475631 \\ \mathrm{H} & 1.266905 & 7.238668 & -3.765083\end{array}$

Catalyst (R)-2 TS Conformation 7

B3LYP/6-31G(d) Energy $=-3045.600257$

B3LYP-D3(BJ)/def2-TZVPP-IEF-PCM(DCM) Energy = -3047.019755

B3LYP-D3(BJ)/def2-TZVPP-IEF-PCM(DCM)//B3LYP/6-31G(d) Free Energy (Quasiharmonic) = 3046.219876

Frequencies (Top 3 out of 324)

1. $-396.2702 \mathrm{~cm}-1$

2. $\quad 8.7711 \mathrm{~cm}-1$

3. $\quad 15.1165 \mathrm{~cm}-1$

B3LYP/6-31G(d) Molecular Geometry in Cartesian Coordinates

$\begin{array}{llll}\mathrm{C} & 2.456434 & -1.979872 & -0.463983 \\ \mathrm{C} & 1.143621 & -2.167727 & -0.059771 \\ \mathrm{C} & 0.386746 & -3.331989 & -0.375412 \\ \mathrm{C} & 0.980757 & -4.272242 & -1.191394 \\ \mathrm{H} & 0.433117 & -5.178705 & -1.437331 \\ \mathrm{C} & 4.717281 & 1.457797 & 0.816871 \\ \mathrm{C} & 3.231889 & -0.812352 & 0.045656 \\ \mathrm{C} & 2.743837 & 0.475986 & -0.119182 \\ \mathrm{C} & 3.483144 & 1.641138 & 0.226542 \\ \mathrm{H} & 5.312363 & 2.330612 & 1.074427 \\ \mathrm{O} & 0.547899 & -1.204349 & 0.753401 \\ \mathrm{P} & 0.153489 & 0.248369 & 0.107254 \\ \mathrm{O} & 1.499924 & 0.653734 & -0.721292 \\ \mathrm{C} & -3.560107 & -4.071188 & 1.217165 \\ \mathrm{C} & -3.383150 & -3.695452 & -0.115436 \\ \mathrm{C} & -2.116937 & -3.451715 & -0.656452 \\ \mathrm{C} & -0.985160 & -3.562345 & 0.177755 \\ \mathrm{C} & -1.138054 & -3.943971 & 1.527366\end{array}$




\begin{tabular}{|c|c|c|c|}
\hline C & -2.421439 & -4.206357 & 2.017211 \\
\hline $\mathrm{H}$ & -4.254915 & -3.563568 & -0.751576 \\
\hline $\mathrm{H}$ & -2.532383 & -4.524552 & 3.052834 \\
\hline C & 2.349579 & 5.727802 & -0.580326 \\
\hline C & 2.267391 & 5.201856 & 0.709861 \\
\hline C & 2.577539 & 3.865194 & 0.990642 \\
\hline C & 3.003108 & 3.030502 & -0.061982 \\
\hline C & 3.070818 & 3.534350 & -1.379490 \\
\hline C & 2.740766 & 4.871220 & -1.613765 \\
\hline $\mathrm{H}$ & 1.959764 & 5.849420 & 1.529456 \\
\hline $\mathrm{H}$ & 2.802741 & 5.255656 & -2.630419 \\
\hline C & 4.476396 & -0.987377 & 0.744965 \\
\hline C & 5.229005 & 0.171992 & 1.119448 \\
\hline C & 6.467260 & 0.013770 & 1.799120 \\
\hline C & 6.938321 & -1.235338 & 2.128951 \\
\hline C & 6.179091 & -2.381766 & 1.795281 \\
\hline C & 4.984002 & -2.262452 & 1.121162 \\
\hline $\mathrm{H}$ & 7.029798 & 0.905727 & 2.064849 \\
\hline $\mathrm{H}$ & 7.882886 & -1.344619 & 2.654749 \\
\hline $\mathrm{H}$ & 6.539830 & -3.366982 & 2.078298 \\
\hline $\mathrm{H}$ & 4.411311 & -3.150945 & 0.882922 \\
\hline C & 3.028927 & -2.923987 & -1.385435 \\
\hline C & 2.275054 & -4.089147 & -1.739619 \\
\hline C & 2.833054 & -5.035032 & -2.641594 \\
\hline C & 4.073156 & -4.833289 & -3.201134 \\
\hline C & 4.805136 & -3.665339 & -2.882291 \\
\hline C & 4.299322 & -2.738069 & -1.998195 \\
\hline $\mathrm{H}$ & 2.250637 & -5.918976 & -2.890724 \\
\hline $\mathrm{H}$ & 4.486740 & -5.559775 & -3.895240 \\
\hline $\mathrm{H}$ & 5.774165 & -3.494887 & -3.343618 \\
\hline $\mathrm{H}$ & 4.868830 & -1.843850 & -1.773150 \\
\hline $\mathrm{O}$ & -0.204587 & 1.179864 & 1.217033 \\
\hline $\mathrm{O}$ & -0.853632 & 0.045913 & -1.054747 \\
\hline $\mathrm{H}$ & -1.933167 & -0.123714 & -0.857755 \\
\hline C & -3.961231 & 0.543010 & -1.349418 \\
\hline $\mathrm{O}$ & -3.244586 & -0.352793 & -0.786672 \\
\hline $\mathrm{H}$ & -3.475640 & 1.331696 & -1.940313 \\
\hline C & -5.289901 & 0.161061 & -1.994461 \\
\hline $\mathrm{O}$ & -5.851134 & 0.878668 & -2.797706 \\
\hline $\mathrm{O}$ & -5.746041 & -1.028268 & -1.580310 \\
\hline C & -7.002621 & -1.432900 & -2.153294 \\
\hline $\mathrm{H}$ & -7.782363 & -0.703408 & -1.918956 \\
\hline $\mathrm{H}$ & -7.230094 & -2.398262 & -1.701588 \\
\hline C & -3.647009 & 2.203514 & 0.603258 \\
\hline
\end{tabular}




\begin{tabular}{|c|c|c|c|}
\hline C & -4.829638 & 1.727129 & 0.021799 \\
\hline $\mathrm{H}$ & -1.931670 & 1.535060 & 1.551623 \\
\hline $\mathrm{N}$ & -2.964371 & 1.453366 & 1.507052 \\
\hline C & -3.498392 & 0.444682 & 2.332261 \\
\hline $\mathrm{O}$ & -4.660433 & 0.113461 & 2.414890 \\
\hline 0 & -2.494612 & -0.044619 & 3.071332 \\
\hline C & -2.860802 & -1.077193 & 4.002224 \\
\hline $\mathrm{H}$ & -3.649045 & -0.724121 & 4.671833 \\
\hline $\mathrm{H}$ & -1.948267 & -1.293131 & 4.557330 \\
\hline $\mathrm{H}$ & -3.198059 & -1.964516 & 3.463343 \\
\hline $\mathrm{H}$ & -5.431978 & 2.428864 & -0.542803 \\
\hline $\mathrm{H}$ & -5.371170 & 0.957413 & 0.555365 \\
\hline C & -2.996234 & 3.445053 & 0.143041 \\
\hline C & -3.361212 & 4.038450 & -1.082817 \\
\hline C & -2.024627 & 4.083516 & 0.936305 \\
\hline C & -2.771905 & 5.227893 & -1.496644 \\
\hline $\mathrm{H}$ & -4.093223 & 3.562290 & -1.726210 \\
\hline C & -1.443553 & 5.277474 & 0.520045 \\
\hline $\mathrm{H}$ & -1.735404 & 3.658785 & 1.890879 \\
\hline C & -1.813289 & 5.853188 & -0.695847 \\
\hline $\mathrm{H}$ & -3.058542 & 5.664586 & -2.448882 \\
\hline $\mathrm{H}$ & -0.693893 & 5.752408 & 1.143715 \\
\hline $\mathrm{H}$ & -1.355038 & 6.783433 & -1.019250 \\
\hline $\mathrm{H}$ & -6.915173 & -1.524923 & -3.238938 \\
\hline C & 2.415877 & 3.341807 & 2.400987 \\
\hline $\mathrm{H}$ & 1.669761 & 2.538864 & 2.429159 \\
\hline $\mathrm{H}$ & 3.348834 & 2.932736 & 2.803550 \\
\hline $\mathrm{H}$ & 2.084159 & 4.140081 & 3.073152 \\
\hline C & 2.040385 & 7.181059 & -0.858134 \\
\hline $\mathrm{H}$ & 1.319993 & 7.289264 & -1.678520 \\
\hline $\mathrm{H}$ & 1.625222 & 7.679298 & 0.024411 \\
\hline $\mathrm{H}$ & 2.942089 & 7.733608 & -1.152726 \\
\hline C & 3.501794 & 2.657159 & -2.532917 \\
\hline $\mathrm{H}$ & 4.470145 & 2.180681 & -2.340133 \\
\hline $\mathrm{H}$ & 2.776957 & 1.854359 & -2.711573 \\
\hline $\mathrm{H}$ & 3.590164 & 3.240837 & -3.454473 \\
\hline C & -1.997151 & -3.074317 & -2.116669 \\
\hline $\mathrm{H}$ & -2.976086 & -2.797086 & -2.517414 \\
\hline $\mathrm{H}$ & -1.320882 & -2.227459 & -2.262147 \\
\hline $\mathrm{H}$ & -1.610007 & -3.906541 & -2.718653 \\
\hline C & 0.055473 & -4.079761 & 2.445938 \\
\hline $\mathrm{H}$ & 0.829692 & -4.725417 & 2.015437 \\
\hline $\mathrm{H}$ & 0.520393 & -3.105356 & 2.638741 \\
\hline $\mathrm{H}$ & -0.241054 & -4.506644 & 3.409493 \\
\hline
\end{tabular}




$\begin{array}{llll}\mathrm{C} & -4.944632 & -4.281851 & 1.785047 \\ \mathrm{H} & -4.920380 & -4.903191 & 2.687008 \\ \mathrm{H} & -5.406080 & -3.322436 & 2.055420 \\ \mathrm{H} & -5.607935 & -4.766026 & 1.059366\end{array}$

Catalyst (R)-2 TS Conformation 8 (TS-4Re)

B3LYP/6-31G(d) Energy = -3045.596693

B3LYP-D3(BJ)/def2-TZVPP-IEF-PCM(DCM) Energy = -3047.022424

B3LYP-D3(BJ)/def2-TZVPP-IEF-PCM(DCM)//B3LYP/6-31G(d) Free Energy (Quasiharmonic) = 3046.22305

Frequencies (Top 3 out of 324)

1. $-812.8962 \mathrm{~cm}-1$

2. $\quad 11.7555 \mathrm{~cm}-1$

3. $17.8706 \mathrm{~cm}-1$

B3LYP/6-31G(d) Molecular Geometry in Cartesian Coordinates

$\begin{array}{lrrr}\text { C } & 2.616440 & -1.591357 & -0.196311 \\ \text { C } & 1.312431 & -2.038265 & -0.040186 \\ \text { C } & 0.873357 & -3.319619 & -0.481651 \\ \text { C } & 1.785546 & -4.109194 & -1.151272 \\ \text { H } & 1.480975 & -5.098396 & -1.484330 \\ \text { C } & 3.845983 & 2.225268 & 1.369970 \\ \text { C } & 3.031418 & -0.294668 & 0.410840 \\ \text { C } & 2.336962 & 0.865443 & 0.097190 \\ \text { C } & 2.745584 & 2.155770 & 0.538974 \\ \text { H } & 4.189374 & 3.200309 & 1.707402 \\ \text { O } & 0.404618 & -1.225437 & 0.636336 \\ \text { P } & -0.149970 & 0.134591 & -0.106629 \\ \text { O } & 1.226826 & 0.771133 & -0.737737 \\ \text { C } & -3.063030 & -4.924970 & 0.297781 \\ \text { C } & -2.095216 & -4.859428 & 1.305374 \\ \text { C } & -0.826019 & -4.318111 & 1.077724 \\ \text { C } & -0.504626 & -3.838096 & -0.209512 \\ \text { C } & -1.452811 & -3.921286 & -1.250120 \\ \text { C } & -2.715837 & -4.456964 & -0.971991 \\ \text { H } & -2.333976 & -5.240984 & 2.296900 \\ \text { H } & -3.448381 & -4.508453 & -1.775202 \\ \text { C } & 1.069101 & 5.965771 & -0.617399 \\ \text { C } & 1.860004 & 5.225922 & -1.501107\end{array}$




\begin{tabular}{|c|c|c|c|}
\hline C & 2.365157 & 3.964930 & -1.163929 \\
\hline C & 2.080895 & 3.428768 & 0.108946 \\
\hline C & 1.266828 & 4.147551 & 1.010983 \\
\hline C & 0.770775 & 5.398390 & 0.625368 \\
\hline $\mathrm{H}$ & 2.101221 & 5.643291 & -2.477360 \\
\hline $\mathrm{H}$ & 0.147360 & 5.951715 & 1.325719 \\
\hline C & 4.121130 & -0.215806 & 1.344327 \\
\hline C & 4.534606 & 1.070918 & 1.816767 \\
\hline C & 5.617834 & 1.166126 & 2.732059 \\
\hline C & 6.255563 & 0.038018 & 3.192239 \\
\hline C & 5.826070 & -1.237953 & 2.756337 \\
\hline C & 4.790318 & -1.362301 & 1.857152 \\
\hline $\mathrm{H}$ & 5.924736 & 2.152890 & 3.070963 \\
\hline $\mathrm{H}$ & 7.078462 & 0.121548 & 3.896870 \\
\hline $\mathrm{H}$ & 6.315310 & -2.129738 & 3.138808 \\
\hline $\mathrm{H}$ & 4.468101 & -2.347635 & 1.541390 \\
\hline C & 3.529742 & -2.387306 & -0.969902 \\
\hline C & 3.101303 & -3.670057 & -1.440201 \\
\hline C & 3.997050 & -4.472925 & -2.197027 \\
\hline C & 5.259044 & -4.023592 & -2.508309 \\
\hline C & 5.673332 & -2.741264 & -2.076968 \\
\hline C & 4.834340 & -1.946189 & -1.327941 \\
\hline $\mathrm{H}$ & 3.657422 & -5.448680 & -2.536495 \\
\hline $\mathrm{H}$ & 5.933418 & -4.642964 & -3.093325 \\
\hline $\mathrm{H}$ & 6.661924 & -2.377318 & -2.343800 \\
\hline $\mathrm{H}$ & 5.164237 & -0.962508 & -1.014710 \\
\hline $\mathrm{O}$ & -0.768807 & 1.014373 & 0.931927 \\
\hline $\mathrm{O}$ & -0.937527 & -0.254843 & -1.367780 \\
\hline $\mathrm{H}$ & -2.055151 & -0.596005 & -1.410611 \\
\hline C & -4.238399 & -0.925012 & -0.997952 \\
\hline $\mathrm{O}$ & -3.212352 & -0.935903 & -1.776144 \\
\hline $\mathrm{H}$ & -5.168050 & -1.315901 & -1.429202 \\
\hline C & -4.139336 & -1.358314 & 0.462456 \\
\hline $\mathrm{O}$ & -5.063137 & -1.881846 & 1.049945 \\
\hline $\mathrm{O}$ & -2.946728 & -1.070183 & 0.986574 \\
\hline C & -2.747364 & -1.392941 & 2.378411 \\
\hline $\mathrm{H}$ & -3.599348 & -1.044980 & 2.967224 \\
\hline $\mathrm{H}$ & -2.640684 & -2.473135 & 2.487470 \\
\hline C & -3.906726 & 1.695817 & -0.501920 \\
\hline C & -5.033184 & 0.877240 & -0.721177 \\
\hline $\mathrm{H}$ & -2.369615 & 1.862113 & 0.856096 \\
\hline$N$ & -3.399750 & 1.914645 & 0.751226 \\
\hline C & -4.124759 & 1.879974 & 1.944389 \\
\hline $\mathrm{O}$ & -5.327779 & 1.786312 & 2.059781 \\
\hline
\end{tabular}




\begin{tabular}{|c|c|c|c|}
\hline $\mathrm{O}$ & -3.259205 & 2.015181 & 2.966645 \\
\hline C & -3.861925 & 2.053746 & 4.270648 \\
\hline $\mathrm{H}$ & -4.427089 & 1.137808 & 4.460590 \\
\hline $\mathrm{H}$ & -4.532699 & 2.912468 & 4.356605 \\
\hline $\mathrm{H}$ & -3.029086 & 2.144667 & 4.967612 \\
\hline $\mathrm{H}$ & -5.541673 & 1.006911 & -1.670212 \\
\hline $\mathrm{H}$ & -5.692431 & 0.691777 & 0.117803 \\
\hline C & -3.119892 & 2.224987 & -1.615614 \\
\hline C & -3.313196 & 1.749603 & -2.931606 \\
\hline C & -2.160037 & 3.238778 & -1.401196 \\
\hline C & -2.565233 & 2.262212 & -3.985679 \\
\hline $\mathrm{H}$ & -4.019426 & 0.955753 & -3.129008 \\
\hline C & -1.420074 & 3.748817 & -2.459321 \\
\hline $\mathrm{H}$ & -2.003693 & 3.641777 & -0.407126 \\
\hline C & -1.617922 & 3.259590 & -3.753742 \\
\hline $\mathrm{H}$ & -2.717369 & 1.873937 & -4.988352 \\
\hline $\mathrm{H}$ & -0.681372 & 4.519504 & -2.269597 \\
\hline $\mathrm{H}$ & -1.033767 & 3.657597 & -4.579081 \\
\hline $\mathrm{H}$ & -1.831928 & -0.873640 & 2.654560 \\
\hline C & 3.211042 & 3.206231 & -2.161059 \\
\hline $\mathrm{H}$ & 4.183367 & 2.927635 & -1.738492 \\
\hline $\mathrm{H}$ & 2.717174 & 2.277698 & -2.470988 \\
\hline $\mathrm{H}$ & 3.392110 & 3.807434 & -3.057596 \\
\hline C & 0.911780 & 3.590829 & 2.371896 \\
\hline $\mathrm{H}$ & 0.390005 & 2.632536 & 2.274830 \\
\hline $\mathrm{H}$ & 1.801709 & 3.418586 & 2.987839 \\
\hline $\mathrm{H}$ & 0.260502 & 4.284922 & 2.913260 \\
\hline C & 0.578087 & 7.349469 & -0.978112 \\
\hline $\mathrm{H}$ & 0.526472 & 7.488997 & -2.063280 \\
\hline $\mathrm{H}$ & -0.417208 & 7.544808 & -0.563570 \\
\hline $\mathrm{H}$ & 1.248952 & 8.124348 & -0.583284 \\
\hline C & 0.178533 & -4.263298 & 2.206980 \\
\hline $\mathrm{H}$ & 1.122342 & -4.749445 & 1.933783 \\
\hline $\mathrm{H}$ & 0.419234 & -3.227997 & 2.476908 \\
\hline $\mathrm{H}$ & -0.211092 & -4.761972 & 3.100217 \\
\hline C & -1.136814 & -3.451479 & -2.653035 \\
\hline $\mathrm{H}$ & -0.420964 & -4.117998 & -3.150230 \\
\hline $\mathrm{H}$ & -2.045716 & -3.422233 & -3.260742 \\
\hline $\mathrm{H}$ & -0.701821 & -2.448110 & -2.651994 \\
\hline C & -4.452051 & -5.444209 & 0.583950 \\
\hline $\mathrm{H}$ & -4.889907 & -5.927785 & -0.296261 \\
\hline $\mathrm{H}$ & -4.449170 & -6.170231 & 1.404319 \\
\hline $\mathrm{H}$ & -5.117133 & -4.619954 & 0.873019 \\
\hline
\end{tabular}


Catalyst (R)-2 TS Conformation 9

B3LYP/6-31G(d) Energy $=-3045.598475$

B3LYP-D3(BJ)/def2-TZVPP-IEF-PCM(DCM) Energy = -3047.017111

B3LYP-D3(BJ)/def2-TZVPP-IEF-PCM(DCM)//B3LYP/6-31G(d) Free Energy (Quasiharmonic) = 3046.218397

Frequencies (Top 3 out of 324)

1. $-752.1732 \mathrm{~cm}-1$

2. $\quad 10.5540 \mathrm{~cm}-1$

3. $16.1043 \mathrm{~cm}-1$

B3LYP/6-31G(d) Molecular Geometry in Cartesian Coordinates

$\begin{array}{lrrr}\text { C } & 3.084320 & -1.048503 & 0.134143 \\ \text { C } & 2.748114 & 0.275522 & -0.111517 \\ \text { C } & 3.582555 & 1.368747 & 0.254639 \\ \text { C } & 4.736263 & 1.080964 & 0.956256 \\ \text { H } & 5.400840 & 1.896099 & 1.232386 \\ \text { C } & 0.620105 & -4.298640 & -1.246791 \\ \text { C } & 2.242406 & -2.148396 & -0.417715 \\ \text { C } & 0.885881 & -2.195304 & -0.131402 \\ \text { C } & 0.047471 & -3.283615 & -0.507449 \\ \text { H } & 0.008086 & -5.151000 & -1.531513 \\ \text { O } & 1.571121 & 0.549476 & -0.806236 \\ \text { P } & 0.154185 & 0.329502 & -0.011671 \\ \text { O } & 0.325249 & -1.171158 & 0.625983 \\ \text { C } & 3.103021 & 5.527752 & -0.798809 \\ \text { C } & 2.797183 & 5.074356 & 0.487647 \\ \text { C } & 2.892807 & 3.724393 & 0.842366 \\ \text { C } & 3.306837 & 2.790540 & -0.131341 \\ \text { C } & 3.578471 & 3.218460 & -1.447595 \\ \text { C } & 3.473643 & 4.579291 & -1.756633 \\ \text { H } & 2.482338 & 5.792009 & 1.243139 \\ \text { H } & 3.703963 & 4.906017 & -2.769267 \\ \text { C } & -4.113708 & -3.666782 & 0.583363 \\ \text { C } & -3.104429 & -3.831855 & 1.533806 \\ \text { C } & -1.750799 & -3.683121 & 1.210967 \\ \text { C } & -1.395133 & -3.369380 & -0.116317 \\ \text { C } & -2.399298 & -3.202050 & -1.094751 \\ \text { C } & -3.737334 & -3.350309 & -0.724243 \\ \text { H } & -3.373080 & -4.084517 & 2.558292\end{array}$




\begin{tabular}{|c|c|c|c|}
\hline $\mathrm{H}$ & -4.510064 & -3.186758 & -1.471775 \\
\hline C & 2.800560 & -3.164859 & -1.267750 \\
\hline C & 1.971523 & -4.260834 & -1.670059 \\
\hline C & 2.513455 & -5.281343 & -2.497699 \\
\hline C & 3.813316 & -5.216213 & -2.942034 \\
\hline C & 4.624398 & -4.115440 & -2.578128 \\
\hline C & 4.133791 & -3.119481 & -1.762942 \\
\hline $\mathrm{H}$ & 1.871518 & -6.111323 & -2.783660 \\
\hline $\mathrm{H}$ & 4.215170 & -5.998415 & -3.580289 \\
\hline $\mathrm{H}$ & 5.643669 & -4.052027 & -2.949701 \\
\hline $\mathrm{H}$ & 4.766218 & -2.278823 & -1.502504 \\
\hline C & 4.240291 & -1.324817 & 0.943163 \\
\hline C & 5.078360 & -0.236704 & 1.347014 \\
\hline C & 6.230592 & -0.495894 & 2.137826 \\
\hline C & 6.535199 & -1.773420 & 2.545455 \\
\hline C & 5.688721 & -2.846971 & 2.180273 \\
\hline C & 4.574831 & -2.630420 & 1.399783 \\
\hline $\mathrm{H}$ & 6.861248 & 0.342287 & 2.424972 \\
\hline $\mathrm{H}$ & 7.414638 & -1.959817 & 3.155803 \\
\hline $\mathrm{H}$ & 5.916778 & -3.852530 & 2.523419 \\
\hline $\mathrm{H}$ & 3.931979 & -3.462591 & 1.138061 \\
\hline 0 & -0.060273 & 1.282520 & 1.120920 \\
\hline 0 & -0.869917 & 0.302507 & -1.165032 \\
\hline $\mathrm{H}$ & -2.022807 & 0.122351 & -0.954194 \\
\hline C & -3.993217 & 0.852700 & -1.247124 \\
\hline 0 & -3.230287 & -0.079980 & -0.823500 \\
\hline $\mathrm{H}$ & -3.592448 & 1.624980 & -1.910884 \\
\hline C & -5.441211 & 0.467947 & -1.491800 \\
\hline 0 & -6.011013 & -0.465849 & -0.972126 \\
\hline $\mathrm{O}$ & -6.004640 & 1.317503 & -2.371734 \\
\hline C & -7.387757 & 1.064944 & -2.677474 \\
\hline $\mathrm{H}$ & -7.996211 & 1.128500 & -1.771378 \\
\hline $\mathrm{H}$ & -7.674753 & 1.838108 & -3.389881 \\
\hline C & -3.366177 & 2.285215 & 0.940471 \\
\hline C & -4.539190 & 2.298604 & 0.176984 \\
\hline $\mathrm{H}$ & -1.328665 & 2.508113 & 0.917855 \\
\hline$N$ & -2.218491 & 2.921454 & 0.573283 \\
\hline C & -2.078583 & 3.820401 & -0.492914 \\
\hline $\mathrm{O}$ & -2.973377 & 4.257529 & -1.188488 \\
\hline $\mathrm{O}$ & -0.782165 & 4.121093 & -0.623098 \\
\hline C & -0.461462 & 4.976463 & -1.736474 \\
\hline $\mathrm{H}$ & 0.624784 & 5.035568 & -1.740953 \\
\hline $\mathrm{H}$ & -0.910155 & 5.963284 & -1.594916 \\
\hline $\mathrm{H}$ & -0.834684 & 4.539736 & -2.665791 \\
\hline
\end{tabular}




$\begin{array}{llll}\mathrm{H} & -5.424173 & 1.910908 & 0.668751 \\ \mathrm{H} & -4.691301 & 3.098501 & -0.533173 \\ \mathrm{C} & -3.259815 & 1.445155 & 2.144213 \\ \mathrm{C} & -3.992200 & 0.246801 & 2.246297 \\ \mathrm{C} & -2.434727 & 1.839207 & 3.215674 \\ \mathrm{C} & -3.896371 & -0.531620 & 3.396731 \\ \mathrm{H} & -4.592251 & -0.102000 & 1.413840 \\ \mathrm{C} & -2.364241 & 1.067603 & 4.369406 \\ \mathrm{H} & -1.871141 & 2.764061 & 3.152043 \\ \mathrm{C} & -3.092288 & -0.121472 & 4.461384 \\ \mathrm{H} & -4.443648 & -1.467255 & 3.453027 \\ \mathrm{H} & -1.736117 & 1.389928 & 5.194607 \\ \mathrm{H} & -3.027455 & -0.729235 & 5.359841 \\ \mathrm{H} & -7.505013 & 0.071296 & -3.117299 \\ \mathrm{C} & 3.993865 & 2.237838 & -2.520758 \\ \mathrm{H} & 4.873986 & 1.657455 & -2.219998 \\ \mathrm{H} & 3.192649 & 1.520237 & -2.732856 \\ \mathrm{H} & 4.235236 & 2.758303 & -3.452834 \\ \mathrm{C} & 2.534439 & 3.293232 & 2.247154 \\ \mathrm{H} & 1.730545 & 2.548892 & 2.229803 \\ \mathrm{H} & 3.385838 & 2.841317 & 2.768715 \\ \mathrm{H} & 2.198641 & 4.151437 & 2.838512 \\ \mathrm{C} & 3.061359 & 7.001502 & -1.134524 \\ \mathrm{H} & 4.008072 & 7.494568 & -0.875570 \\ \mathrm{H} & 2.893938 & 7.167326 & -2.204385 \\ \mathrm{H} & 2.268957 & 7.518934 & -0.582112 \\ \mathrm{C} & -0.702208 & -3.862724 & 2.285319 \\ \mathrm{H} & 0.078368 & -4.568706 & 1.978444 \\ \mathrm{H} & -0.206152 & -2.912571 & 2.516185 \\ \mathrm{H} & -1.152302 & -4.239384 & 3.209443 \\ \mathrm{C} & -2.061426 & -2.830475 & -2.522584 \\ \mathrm{H} & -1.427561 & -1.938214 & -2.562231 \\ \mathrm{H} & -1.522337 & -3.630888 & -3.043032 \\ -2.974700 & -2.622883 & -3.088846 \\ \mathrm{H} & -5.574131 & -3.812007 & 0.943536 \\ \mathrm{H} & -6.021867 & -4.691320 & 0.461788 \\ \mathrm{H} & & -3.924942 & 2.024410\end{array}$

Catalyst (R)-2 TS Conformation 10

B3LYP/6-31G(d) Energy $=-3045.59689$

B3LYP-D3(BJ)/def2-TZVPP-IEF-PCM(DCM) Energy $=-3047.021079$ 
B3LYP-D3(BJ)/def2-TZVPP-IEF-PCM(DCM)//B3LYP/6-31G(d) Free Energy (Quasiharmonic) = 3046.22149

Frequencies (Top 3 out of 324)

1. $-726.9493 \mathrm{~cm}-1$

2. $\quad 12.3608 \mathrm{~cm}-1$

3. $\quad 18.0875 \mathrm{~cm}-1$

B3LYP/6-31G(d) Molecular Geometry in Cartesian Coordinates

$\begin{array}{llll}\text { C } & 1.952457 & -2.348244 & -0.186342 \\ \text { C } & 0.569417 & -2.290129 & -0.081906 \\ \text { C } & -0.287306 & -3.321146 & -0.563074 \\ \text { C } & 0.304079 & -4.392645 & -1.201959 \\ \text { H } & -0.326053 & -5.202358 & -1.561898 \\ \text { C } & 4.436800 & 0.790277 & 1.393552 \\ \text { C } & 2.787068 & -1.280435 & 0.434061 \\ \text { C } & 2.565188 & 0.046962 & 0.093532 \\ \text { C } & 3.403061 & 1.109817 & 0.535556 \\ \text { H } & 5.103636 & 1.580247 & 1.730793 \\ \text { O } & -0.004747 & -1.209687 & 0.580072 \\ \text { P } & -0.008687 & 0.263625 & -0.144069 \\ \text { O } & 1.512285 & 0.345120 & -0.765403 \\ \text { C } & -4.574831 & -3.564434 & -0.106122 \\ \text { C } & -3.722609 & -3.761413 & 0.982906 \\ \text { C } & -2.333846 & -3.630748 & 0.870266 \\ \text { C } & -1.774857 & -3.313928 & -0.384191 \\ \text { C } & -2.616164 & -3.101577 & -1.498062 \\ \text { C } & -3.999515 & -3.224983 & -1.334190 \\ \text { H } & -4.145859 & -4.036472 & 1.947819 \\ \text { H } & -4.643485 & -3.060313 & -2.196274 \\ \text { C } & 3.274752 & 5.253931 & -0.673990 \\ \text { C } & 3.698125 & 4.257501 & -1.558088 \\ \text { C } & 3.692985 & 2.903677 & -1.204878 \\ \text { C } & 3.253260 & 2.530859 & 0.082634 \\ \text { C } & 2.786206 & 3.515630 & 0.979810 \\ \text { C } & 2.803558 & 4.857550 & 0.581381 \\ \text { H } & 4.056829 & 4.539546 & -2.546543 \\ \text { H } & 2.451447 & 5.614682 & 1.280098 \\ \text { C } & 3.808766 & -1.584519 & 1.397183 \\ \text { C } & 4.649999 & -0.526664 & 1.869300 \\ \text { C } & 5.673074 & -0.814073 & 2.813250 \\ \text { C } & 5.846933 & -2.087929 & 3.301365\end{array}$




\begin{tabular}{|c|c|c|c|}
\hline C & 4.993268 & -3.129136 & 2.865526 \\
\hline C & 4.004007 & -2.885918 & 1.938739 \\
\hline $\mathrm{H}$ & 6.309592 & 0.000268 & 3.151667 \\
\hline $\mathrm{H}$ & 6.627749 & -2.295445 & 4.028007 \\
\hline $\mathrm{H}$ & 5.116168 & -4.130259 & 3.270045 \\
\hline $\mathrm{H}$ & 3.352497 & -3.692345 & 1.622858 \\
\hline C & 2.545332 & -3.424939 & -0.931213 \\
\hline C & 1.699938 & -4.467784 & -1.428440 \\
\hline C & 2.272032 & -5.547749 & -2.154115 \\
\hline C & 3.622219 & -5.590356 & -2.411416 \\
\hline C & 4.456051 & -4.541780 & -1.955798 \\
\hline C & 3.934104 & -3.490224 & -1.235567 \\
\hline $\mathrm{H}$ & 1.614544 & -6.335843 & -2.513834 \\
\hline $\mathrm{H}$ & 4.048433 & -6.417231 & -2.972977 \\
\hline $\mathrm{H}$ & 5.519001 & -4.563249 & -2.181031 \\
\hline $\mathrm{H}$ & 4.586405 & -2.691023 & -0.903789 \\
\hline $\mathrm{O}$ & -0.248559 & 1.313331 & 0.890704 \\
\hline $\mathrm{O}$ & -0.865765 & 0.209458 & -1.421407 \\
\hline $\mathrm{H}$ & -2.015308 & 0.266166 & -1.478081 \\
\hline C & -4.211948 & 0.600138 & -1.072473 \\
\hline $\mathrm{O}$ & -3.231438 & 0.363090 & -1.873696 \\
\hline $\mathrm{H}$ & -5.214862 & 0.539730 & -1.513992 \\
\hline C & -4.169214 & 0.034958 & 0.340253 \\
\hline 0 & -3.153440 & -0.166187 & 0.969147 \\
\hline O & -5.418116 & -0.169413 & 0.800226 \\
\hline C & -5.520149 & -0.583134 & 2.176211 \\
\hline $\mathrm{H}$ & -4.863999 & -1.434809 & 2.364133 \\
\hline $\mathrm{H}$ & -5.252007 & 0.254104 & 2.825199 \\
\hline C & -3.091367 & 2.894555 & -0.281035 \\
\hline C & -4.413352 & 2.486785 & -0.580201 \\
\hline $\mathrm{H}$ & -1.551608 & 2.472870 & 1.004510 \\
\hline$N$ & -2.545795 & 2.777394 & 0.961351 \\
\hline C & -3.229944 & 2.637012 & 2.172958 \\
\hline 0 & -4.433540 & 2.655606 & 2.338366 \\
\hline $\mathrm{O}$ & -2.317611 & 2.526011 & 3.148450 \\
\hline C & -2.842359 & 2.318490 & 4.468063 \\
\hline $\mathrm{H}$ & -3.344473 & 1.349116 & 4.526749 \\
\hline $\mathrm{H}$ & -3.545845 & 3.111553 & 4.732717 \\
\hline $\mathrm{H}$ & -1.974140 & 2.334021 & 5.126355 \\
\hline $\mathrm{H}$ & -4.832186 & 2.894386 & -1.493941 \\
\hline $\mathrm{H}$ & -5.111726 & 2.430913 & 0.245413 \\
\hline C & -2.174380 & 3.320361 & -1.341235 \\
\hline C & -0.973131 & 3.993660 & -1.028348 \\
\hline C & -2.474231 & 3.074950 & -2.698950 \\
\hline
\end{tabular}




\begin{tabular}{llll}
$\mathrm{C}$ & -0.104394 & 4.396577 & -2.033236 \\
$\mathrm{H}$ & -0.724888 & 4.216901 & 0.002790 \\
$\mathrm{C}$ & -1.596277 & 3.476827 & -3.699982 \\
$\mathrm{H}$ & -3.366799 & 2.530716 & -2.972776 \\
$\mathrm{C}$ & -0.411745 & 4.136160 & -3.371677 \\
$\mathrm{H}$ & 0.819402 & 4.899004 & -1.769484 \\
$\mathrm{H}$ & -1.834755 & 3.263398 & -4.737704 \\
$\mathrm{H}$ & 0.273805 & 4.446892 & -4.155405 \\
$\mathrm{H}$ & -6.565483 & -0.857091 & 2.321102 \\
$\mathrm{C}$ & 3.353733 & 6.716500 & -1.050095 \\
$\mathrm{H}$ & 3.278773 & 6.859295 & -2.133699 \\
$\mathrm{H}$ & 2.556638 & 7.299205 & -0.575102 \\
$\mathrm{H}$ & 4.308201 & 7.157305 & -0.731877 \\
$\mathrm{C}$ & 2.254936 & 3.150402 & 2.348554 \\
$\mathrm{H}$ & 1.427946 & 2.436810 & 2.265030 \\
$\mathrm{H}$ & 3.023552 & 2.687567 & 2.977872 \\
$\mathrm{H}$ & 1.891349 & 4.042143 & 2.869988 \\
$\mathrm{C}$ & 4.169788 & 1.869709 & -2.199228 \\
$\mathrm{H}$ & 4.969802 & 1.246582 & -1.782679 \\
$\mathrm{H}$ & 3.354653 & 1.196416 & -2.488835 \\
$\mathrm{H}$ & 4.551788 & 2.347659 & -3.106780 \\
$\mathrm{C}$ & -1.461411 & -3.842764 & 2.085793 \\
$\mathrm{H}$ & -0.670027 & -4.577200 & 1.896026 \\
$\mathrm{H}$ & -0.971877 & -2.907384 & 2.381027 \\
$\mathrm{H}$ & -2.054080 & -4.196598 & 2.935519 \\
$\mathrm{C}$ & -2.059286 & -2.744162 & -2.858756 \\
$\mathrm{H}$ & -1.526497 & -3.586757 & -3.316124 \\
$\mathrm{H}$ & -2.866169 & -2.450116 & -3.536520 \\
$\mathrm{H}$ & -1.354831 & -1.909805 & -2.793563 \\
$\mathrm{H}$ & -6.074447 & -3.690735 & 0.035001 \\
\hline & -6.555250 & -2.703690 & 0.032776 \\
$\mathrm{H}$ & -6.348601 & -4.192031 & 0.969417
\end{tabular}

Catalyst (R)-2 TS Conformation 11

B3LYP/6-31G(d) Energy $=-3045.601554$

B3LYP-D3(BJ)/def2-TZVPP-IEF-PCM(DCM) Energy = -3047.023741

B3LYP-D3(BJ)/def2-TZVPP-IEF-PCM(DCM)//B3LYP/6-31G(d) Free Energy (Quasiharmonic) = 3046.22428

Frequencies (Top 3 out of 324) 
1. $-378.3472 \mathrm{~cm}-1$

2. $\quad 9.9487 \mathrm{~cm}-1$

3. $\quad 16.8391 \mathrm{~cm}-1$

B3LYP/6-31G(d) Molecular Geometry in Cartesian Coordinates

$\begin{array}{lrrr}\text { C } & 3.223725 & -0.828994 & 0.177696 \\ \text { C } & 2.789432 & 0.455246 & -0.119605 \\ \text { C } & 3.512605 & 1.629867 & 0.228834 \\ \text { C } & 4.671354 & 1.466360 & 0.959896 \\ \text { H } & 5.256214 & 2.343587 & 1.225780 \\ \text { C } & 1.000944 & -4.262985 & -1.197451 \\ \text { C } & 2.478803 & -2.007963 & -0.353799 \\ \text { C } & 1.117443 & -2.129185 & -0.118432 \\ \text { C } & 0.347006 & -3.258288 & -0.515054 \\ \text { H } & 0.445348 & -5.148774 & -1.495608 \\ \text { O } & 1.616084 & 0.615899 & -0.854099 \\ \text { P } & 0.194685 & 0.321984 & -0.105342 \\ \text { O } & 0.468814 & -1.127870 & 0.598151 \\ \text { C } & 2.431999 & 5.632909 & -0.987259 \\ \text { C } & 2.215186 & 5.197044 & 0.322887 \\ \text { C } & 2.528821 & 3.898013 & 0.735499 \\ \text { C } & 3.078584 & 2.997853 & -0.202200 \\ \text { C } & 3.281234 & 3.406827 & -1.536628 \\ \text { C } & 2.955486 & 4.717084 & -1.903894 \\ \text { H } & 1.791253 & 5.888009 & 1.049335 \\ \text { H } & 3.127260 & 5.030956 & -2.931998 \\ \text { C } & -3.865012 & -3.667549 & 0.366526 \\ \text { C } & -2.904384 & -3.797522 & 1.370392 \\ \text { C } & -1.536370 & -3.651558 & 1.110886 \\ \text { C } & -1.113675 & -3.370833 & -0.203878 \\ \text { C } & -2.067447 & -3.235884 & -1.238320 \\ \text { C } & -3.423408 & -3.383697 & -0.930383 \\ \text { H } & -3.222805 & -4.023454 & 2.386413 \\ \text { H } & -4.155994 & -3.272695 & -1.727848 \\ \text { C } & 3.123868 & -3.017821 & -1.149632 \\ \text { C } & 2.370079 & -4.168034 & -1.551960 \\ \text { C } & 3.000175 & -5.182829 & -2.322179 \\ \text { C } & 4.312742 & -5.061873 & -2.714223 \\ \text { C } & 5.048008 & -3.907810 & -2.355155 \\ \text { C } & 4.471572 & -2.915045 & -1.594024 \\ \text { H } & 2.415252 & -6.053852 & -2.608229 \\ \text { H } & 4.781896 & -5.840587 & -3.309234 \\ \text { H } & 6.076852 & -3.800156 & -2.687930\end{array}$




\begin{tabular}{|c|c|c|c|}
\hline $\mathrm{H}$ & 5.047143 & -2.033543 & -1.337456 \\
\hline C & 4.380686 & -0.976476 & 1.018879 \\
\hline C & 5.115314 & 0.193548 & 1.398092 \\
\hline C & 6.267684 & 0.059602 & 2.219221 \\
\hline C & 6.669222 & -1.172390 & 2.679973 \\
\hline C & 5.923449 & -2.325724 & 2.340107 \\
\hline C & 4.812586 & -2.231550 & 1.531319 \\
\hline $\mathrm{H}$ & 6.819712 & 0.957460 & 2.487099 \\
\hline $\mathrm{H}$ & 7.547795 & -1.261847 & 3.312984 \\
\hline $\mathrm{H}$ & 6.226940 & -3.295525 & 2.725154 \\
\hline $\mathrm{H}$ & 4.247154 & -3.123755 & 1.288927 \\
\hline $\mathrm{O}$ & -0.167563 & 1.290731 & 0.970022 \\
\hline 0 & -0.759241 & 0.116997 & -1.304546 \\
\hline $\mathrm{H}$ & -1.787873 & 0.525839 & -1.359837 \\
\hline C & -3.998190 & 0.404720 & -1.013552 \\
\hline 0 & -3.020890 & 0.950246 & -1.625638 \\
\hline $\mathrm{H}$ & -3.817250 & -0.445386 & -0.343413 \\
\hline C & -5.316939 & 0.303252 & -1.774770 \\
\hline 0 & -5.594009 & 0.906881 & -2.781212 \\
\hline $\mathrm{O}$ & -6.144126 & -0.580908 & -1.160639 \\
\hline C & -7.424370 & -0.752418 & -1.794486 \\
\hline $\mathrm{H}$ & -7.964668 & 0.197424 & -1.827769 \\
\hline $\mathrm{H}$ & -7.298468 & -1.124439 & -2.814471 \\
\hline C & -3.590660 & 1.877562 & 1.097220 \\
\hline C & -4.765349 & 1.712422 & 0.353637 \\
\hline $\mathrm{H}$ & -1.598174 & 2.303826 & 0.865184 \\
\hline$N$ & -2.557002 & 2.612879 & 0.616741 \\
\hline C & -2.626121 & 3.568707 & -0.417375 \\
\hline 0 & -3.626393 & 4.117964 & -0.819210 \\
\hline $\mathrm{O}$ & -1.376208 & 3.813646 & -0.831014 \\
\hline C & -1.260766 & 4.748304 & -1.918227 \\
\hline $\mathrm{H}$ & -1.799062 & 4.372849 & -2.791884 \\
\hline $\mathrm{H}$ & -0.192083 & 4.817613 & -2.115981 \\
\hline $\mathrm{H}$ & -1.669254 & 5.720271 & -1.629685 \\
\hline $\mathrm{H}$ & -5.601434 & 1.224358 & 0.841035 \\
\hline $\mathrm{H}$ & -5.015333 & 2.480814 & -0.366034 \\
\hline C & -3.336793 & 1.132517 & 2.347724 \\
\hline C & -2.414621 & 1.621287 & 3.291208 \\
\hline C & -4.034418 & -0.054772 & 2.638590 \\
\hline C & -2.202921 & 0.946912 & 4.490195 \\
\hline $\mathrm{H}$ & -1.877755 & 2.542567 & 3.094381 \\
\hline C & -3.811902 & -0.730759 & 3.834045 \\
\hline $\mathrm{H}$ & -4.733231 & -0.466949 & 1.918575 \\
\hline C & -2.898697 & -0.231140 & 4.765464 \\
\hline
\end{tabular}




$\begin{array}{llll}\mathrm{H} & -1.492009 & 1.342909 & 5.209330 \\ \mathrm{H} & -4.348823 & -1.652968 & 4.035875 \\ \mathrm{H} & -2.729436 & -0.758720 & 5.700038 \\ \mathrm{H} & -7.960180 & -1.479458 & -1.183873 \\ \mathrm{C} & -0.544315 & -3.797173 & 2.242170 \\ \mathrm{H} & 0.265102 & -4.489897 & 1.985219 \\ \mathrm{H} & -0.081120 & -2.833903 & 2.485840 \\ \mathrm{H} & -1.035835 & -4.171620 & 3.145654 \\ \mathrm{C} & -1.660839 & -2.914677 & -2.660151 \\ \mathrm{H} & -1.072148 & -1.992711 & -2.702939 \\ \mathrm{H} & -1.052277 & -3.710665 & -3.104016 \\ \mathrm{H} & -2.544910 & -2.781655 & -3.291625 \\ \mathrm{C} & -5.339114 & -3.831110 & 0.658014 \\ \mathrm{H} & -5.908363 & -2.963747 & 0.302516 \\ \mathrm{H} & -5.751643 & -4.715778 & 0.155749 \\ \mathrm{H} & -5.525727 & -3.945672 & 1.731059 \\ \mathrm{C} & 2.243465 & 3.479408 & 2.160860 \\ \mathrm{H} & 1.533438 & 2.645067 & 2.182135 \\ \mathrm{H} & 3.148245 & 3.152633 & 2.685495 \\ \mathrm{H} & 1.812302 & 4.311956 & 2.726432 \\ \mathrm{C} & 3.845532 & 2.460310 & -2.571788 \\ \mathrm{H} & 4.784457 & 2.004735 & -2.236402 \\ \mathrm{H} & 3.146665 & 1.642107 & -2.782227 \\ \mathrm{H} & 4.041305 & 2.983636 & -3.512842 \\ \mathrm{C} & 2.139896 & 7.060621 & -1.389789 \\ \mathrm{H} & 1.956356 & 7.146374 & -2.466269 \\ \mathrm{H} & 1.264345 & 7.456663 & -0.863183 \\ \mathrm{H} & 2.984286 & 7.721576 & -1.151770\end{array}$

\section{e) Reoptimization of TS-1Si and TS-2Si with M06-2X}

Reoptimization of TS-1Si

M06-2X/6-31G(d)-IEF-PCM(DCM) Energy = -2808.725249

M06-2X/def2-TZVPP-IEF-PCM(DCM) Energy $=-2809.753442$

M06-2X/def2-TZVPP-IEF-PCM(DCM)//M06-2X/6-31G(d)-IEF-PCM(DCM) Free Energy

(Quasiharmonic) $=-2809.101953$

Frequencies (Top 3)

1. $-496.6117 \mathrm{~cm}-1$

2. $\quad 12.8539 \mathrm{~cm}-1$

3. $\quad 14.5569 \mathrm{~cm}-1$ 
M06-2X/6-31G(d)-IEF-PCM(DCM) Molecular Geometry in Cartesian Coordinates

\begin{tabular}{|c|c|c|c|}
\hline$C$ & 3.315673 & -0.240976 & 0.489665 \\
\hline C & 2.714196 & 0.911846 & 0.021213 \\
\hline C & 3.318084 & 2.198114 & 0.129381 \\
\hline C & 4.509291 & 2.287363 & 0.810467 \\
\hline $\mathrm{H}$ & 4.993379 & 3.255878 & 0.908391 \\
\hline C & 1.469733 & -4.010119 & -0.481142 \\
\hline C & 2.730023 & -1.571044 & 0.159812 \\
\hline C & 1.407554 & -1.814757 & 0.449260 \\
\hline C & 0.731062 & -3.023366 & 0.127052 \\
\hline $\mathrm{H}$ & 0.998098 & -4.959267 & -0.723249 \\
\hline $\mathrm{O}$ & 1.526852 & 0.823889 & -0.687685 \\
\hline$P$ & 0.157626 & 0.363122 & 0.055889 \\
\hline $\mathrm{O}$ & 0.680311 & -0.801216 & 1.054504 \\
\hline C & 1.742207 & 5.694990 & -1.795760 \\
\hline C & 0.911607 & 4.913570 & -0.995184 \\
\hline C & 1.404108 & 3.771622 & -0.368639 \\
\hline C & 2.741938 & 3.397253 & -0.535890 \\
\hline C & 3.571509 & 4.189452 & -1.340267 \\
\hline C & 3.076228 & 5.329924 & -1.965947 \\
\hline $\mathrm{H}$ & -0.130826 & 5.186855 & -0.860435 \\
\hline $\mathrm{H}$ & 3.730981 & 5.928159 & -2.592086 \\
\hline C & -3.444181 & -3.676114 & 0.874793 \\
\hline C & -2.647131 & -3.090588 & 1.859778 \\
\hline C & -1.296770 & -2.853478 & 1.621552 \\
\hline C & -0.720104 & -3.202819 & 0.392162 \\
\hline C & -1.533808 & -3.767497 & -0.597004 \\
\hline C & -2.885258 & -4.005692 & -0.358288 \\
\hline $\mathrm{H}$ & -3.076735 & -2.826800 & 2.821440 \\
\hline $\mathrm{H}$ & -3.502524 & -4.438453 & -1.139684 \\
\hline C & 3.474140 & -2.584786 & -0.532234 \\
\hline C & 2.833021 & -3.822361 & -0.824320 \\
\hline C & 3.558033 & -4.844502 & -1.493694 \\
\hline C & 4.854734 & -4.642003 & -1.888450 \\
\hline C & 5.479016 & -3.396692 & -1.639678 \\
\hline C & 4.809396 & -2.395430 & -0.981411 \\
\hline $\mathrm{H}$ & 3.055967 & -5.786471 & -1.696849 \\
\hline $\mathrm{H}$ & 5.399767 & -5.426045 & -2.404080 \\
\hline $\mathrm{H}$ & 6.496435 & -3.229682 & -1.978874 \\
\hline $\mathrm{H}$ & 5.298008 & -1.442849 & -0.810450 \\
\hline C & 4.507824 & -0.119307 & 1.276641 \\
\hline C & 5.109170 & 1.160805 & 1.425660 \\
\hline C & 6.296127 & 1.290315 & 2.195853 \\
\hline
\end{tabular}




\begin{tabular}{|c|c|c|c|}
\hline C & 6.854035 & 0.200618 & 2.811892 \\
\hline C & 6.240787 & -1.069676 & 2.689049 \\
\hline C & 5.100851 & -1.227264 & 1.941519 \\
\hline $\mathrm{H}$ & 6.746070 & 2.274635 & 2.292669 \\
\hline $\mathrm{H}$ & 7.758140 & 0.308063 & 3.402446 \\
\hline $\mathrm{H}$ & 6.674131 & -1.925648 & 3.196604 \\
\hline $\mathrm{H}$ & 4.633752 & -2.203394 & 1.863083 \\
\hline $\mathrm{O}$ & -0.494452 & 1.403114 & 0.893765 \\
\hline 0 & -0.591154 & -0.284543 & -1.114653 \\
\hline $\mathrm{H}$ & -1.697374 & -0.523463 & -1.176623 \\
\hline $\mathrm{H}$ & 4.606860 & 3.894838 & -1.488268 \\
\hline $\mathrm{H}$ & 1.352450 & 6.581586 & -2.286386 \\
\hline $\mathrm{H}$ & 0.746818 & 3.170617 & 0.251238 \\
\hline $\mathrm{H}$ & -1.104342 & -4.007595 & -1.565360 \\
\hline $\mathrm{H}$ & -4.494920 & -3.869102 & 1.069733 \\
\hline $\mathrm{H}$ & -0.679978 & -2.411858 & 2.396936 \\
\hline C & -3.799235 & -0.803669 & -0.652956 \\
\hline $\mathrm{O}$ & -2.874414 & -0.826894 & -1.507946 \\
\hline $\mathrm{H}$ & -3.578534 & -0.710575 & 0.417525 \\
\hline C & -5.051671 & -1.605447 & -0.978449 \\
\hline $\mathrm{O}$ & -5.271414 & -2.107631 & -2.049173 \\
\hline 0 & -5.853388 & -1.683732 & 0.087069 \\
\hline C & -7.056285 & -2.438973 & -0.109182 \\
\hline $\mathrm{H}$ & -7.656132 & -1.988166 & -0.901607 \\
\hline $\mathrm{H}$ & -6.808672 & -3.467486 & -0.379478 \\
\hline C & -3.911697 & 1.677935 & -0.182496 \\
\hline C & -4.844850 & 1.002084 & -0.948171 \\
\hline $\mathrm{H}$ & -1.929667 & 2.137119 & 0.040116 \\
\hline$N$ & -2.690057 & 2.044862 & -0.646933 \\
\hline C & -2.259002 & 2.126270 & -1.973051 \\
\hline 0 & -2.924408 & 1.944412 & -2.962230 \\
\hline $\mathrm{O}$ & -0.971492 & 2.472912 & -1.946209 \\
\hline C & -0.283368 & 2.422823 & -3.199041 \\
\hline $\mathrm{H}$ & -0.329139 & 1.408126 & -3.599423 \\
\hline $\mathrm{H}$ & 0.743854 & 2.701000 & -2.968478 \\
\hline $\mathrm{H}$ & -0.729888 & 3.126438 & -3.903617 \\
\hline $\mathrm{H}$ & -5.842179 & 0.891615 & -0.538382 \\
\hline $\mathrm{H}$ & -4.733685 & 0.965110 & -2.023481 \\
\hline C & -4.114661 & 1.914717 & 1.265963 \\
\hline C & -3.466853 & 2.981777 & 1.902623 \\
\hline C & -4.954790 & 1.077216 & 2.013174 \\
\hline C & -3.662128 & 3.210423 & 3.260048 \\
\hline $\mathrm{H}$ & -2.832956 & 3.653993 & 1.332487 \\
\hline C & -5.138872 & 1.305801 & 3.371512 \\
\hline
\end{tabular}




$\begin{array}{lrrr}H & -5.446916 & 0.231749 & 1.540535 \\ \mathrm{C} & -4.495310 & 2.372321 & 3.997340 \\ \mathrm{H} & -3.164022 & 4.045942 & 3.740241 \\ \mathrm{H} & -5.781785 & 0.645340 & 3.943863 \\ \mathrm{H} & -4.642534 & 2.548815 & 5.057924 \\ \mathrm{H} & -7.583658 & -2.406425 & 0.841311\end{array}$

Reoptimization of TS-2Si

M06-2X/6-31G(d)-IEF-PCM(DCM) Energy = -2808.720655

M06-2X/def2-TZVPP-IEF-PCM(DCM) Energy $=-2809.747475$

M06-2X/def2-TZVPP-IEF-PCM(DCM)//M06-2X/6-31G(d)-IEF-PCM(DCM) Free Energy (Quasiharmonic) $=-2809.096383$

Frequencies (Top 3)

1. $-730.8310 \mathrm{~cm}-1$

2. $\quad 9.8079 \mathrm{~cm}-1$

3. $\quad 15.8464 \mathrm{~cm}-1$

M06-2X/6-31G(d)-IEF-PCM(DCM) Molecular Geometry in Cartesian Coordinates

$\begin{array}{lrrr}\text { C } & -3.249488 & -0.627721 & -0.137135 \\ \text { C } & -2.150178 & -1.366605 & -0.522443 \\ \text { C } & -2.063368 & -2.782854 & -0.416933 \\ \text { C } & -3.165035 & -3.441063 & 0.076803 \\ \text { H } & -3.152580 & -4.525462 & 0.155021 \\ \text { C } & -2.846737 & 3.628384 & -0.674696 \\ \text { C } & -3.191264 & 0.855039 & -0.296190 \\ \text { C } & -2.110449 & 1.539742 & 0.223922 \\ \text { C } & -1.883282 & 2.929809 & 0.014889 \\ \text { H } & -2.722840 & 4.697008 & -0.832090 \\ \text { O } & -1.041866 & -0.692076 & -1.002428 \\ \text { P } & -0.084004 & -0.036386 & 0.139323 \\ \text { O } & -1.177194 & 0.835296 & 0.967553 \\ \text { C } & 1.567630 & -4.882535 & -1.352184 \\ \text { C } & 1.112001 & -3.875101 & -2.201163 \\ \text { C } & -0.065833 & -3.190491 & -1.912450 \\ \text { C } & -0.806441 & -3.499239 & -0.762692 \\ \text { C } & -0.336881 & -4.511731 & 0.083225 \\ \text { C } & 0.836757 & -5.200212 & -0.210544 \\ \text { H } & 1.671509 & -3.622838 & -3.097747 \\ \text { H } & 1.188999 & -5.973952 & 0.464368 \\ \text { C } & 1.839408 & 4.782253 & 1.097345\end{array}$




\begin{tabular}{|c|c|c|c|}
\hline C & 1.249076 & 5.036020 & -0.139289 \\
\hline C & 0.039479 & 4.433137 & -0.472463 \\
\hline C & -0.609456 & 3.576492 & 0.427046 \\
\hline C & -0.016319 & 3.340897 & 1.672687 \\
\hline C & 1.199576 & 3.935985 & 2.002707 \\
\hline $\mathrm{H}$ & 1.737743 & 5.693006 & -0.852452 \\
\hline $\mathrm{H}$ & 1.643259 & 3.735485 & 2.974070 \\
\hline C & -4.150655 & 1.583703 & -1.073464 \\
\hline C & -3.988464 & 2.991037 & -1.220927 \\
\hline C & -4.945727 & 3.731058 & -1.966436 \\
\hline C & -6.001956 & 3.102637 & -2.572230 \\
\hline C & -6.137489 & 1.697228 & -2.469209 \\
\hline C & -5.237733 & 0.957737 & -1.743378 \\
\hline $\mathrm{H}$ & -4.812566 & 4.805726 & -2.056750 \\
\hline $\mathrm{H}$ & -6.725807 & 3.674358 & -3.143941 \\
\hline $\mathrm{H}$ & -6.958487 & 1.199139 & -2.975139 \\
\hline $\mathrm{H}$ & -5.348110 & -0.119358 & -1.684030 \\
\hline C & -4.363917 & -1.321071 & 0.436777 \\
\hline C & -4.320077 & -2.742864 & 0.514872 \\
\hline C & -5.426131 & -3.442793 & 1.068089 \\
\hline C & -6.515443 & -2.766233 & 1.552273 \\
\hline C & -6.541619 & -1.351316 & 1.513271 \\
\hline C & -5.495389 & -0.647463 & 0.971547 \\
\hline $\mathrm{H}$ & -5.383287 & -4.527811 & 1.109502 \\
\hline $\mathrm{H}$ & -7.352969 & -3.309679 & 1.977620 \\
\hline $\mathrm{H}$ & -7.395425 & -0.819065 & 1.920500 \\
\hline $\mathrm{H}$ & -5.520870 & 0.437206 & 0.954504 \\
\hline $\mathrm{O}$ & 0.969814 & 0.749473 & -0.542593 \\
\hline $\mathrm{O}$ & 0.306383 & -1.114490 & 1.156332 \\
\hline $\mathrm{H}$ & 1.279236 & -1.791040 & 0.938892 \\
\hline $\mathrm{H}$ & -0.886227 & -4.741996 & 0.991884 \\
\hline $\mathrm{H}$ & 2.493012 & -5.405609 & -1.571393 \\
\hline $\mathrm{H}$ & -0.417034 & -2.416549 & -2.585638 \\
\hline $\mathrm{H}$ & -0.503004 & 2.684978 & 2.384223 \\
\hline $\mathrm{H}$ & 2.791053 & 5.238149 & 1.352652 \\
\hline $\mathrm{H}$ & -0.397355 & 4.605015 & -1.452145 \\
\hline C & 3.008023 & -1.816269 & -0.114011 \\
\hline $\mathrm{O}$ & 2.262355 & -2.416132 & 0.706135 \\
\hline $\mathrm{H}$ & 2.642333 & -0.942901 & -0.664880 \\
\hline C & 4.098784 & -2.633875 & -0.777226 \\
\hline $\mathrm{O}$ & 4.477758 & -3.706822 & -0.384135 \\
\hline $\mathrm{O}$ & 4.559789 & -1.990233 & -1.847486 \\
\hline C & 5.610275 & -2.660295 & -2.555982 \\
\hline $\mathrm{H}$ & 5.253823 & -3.622962 & -2.927115 \\
\hline
\end{tabular}




$\begin{array}{lrrr}\mathrm{H} & 5.875877 & -2.003227 & -3.380693 \\ \mathrm{C} & 3.958558 & 0.456960 & 0.967124 \\ \mathrm{C} & 4.523186 & -0.799112 & 1.071498 \\ \mathrm{H} & 2.426700 & 1.740139 & 1.423315 \\ \mathrm{~N} & 2.890100 & 0.878401 & 1.704740 \\ \mathrm{C} & 2.257355 & 0.192292 & 2.738945 \\ \mathrm{O} & 2.627245 & -0.844042 & 3.233642 \\ \mathrm{O} & 1.184563 & 0.891289 & 3.107074 \\ \mathrm{C} & 0.326105 & 0.229655 & 4.043479 \\ \mathrm{H} & -0.495089 & 0.921419 & 4.221644 \\ \mathrm{H} & 0.865299 & 0.025208 & 4.969651 \\ \mathrm{H} & -0.039029 & -0.697158 & 3.599227 \\ \mathrm{H} & 5.436438 & -0.971800 & 0.514938 \\ \mathrm{H} & 4.320967 & -1.431887 & 1.922997 \\ \mathrm{C} & 4.449493 & 1.430320 & -0.039150 \\ \mathrm{C} & 5.822163 & 1.489192 & -0.320677 \\ \mathrm{C} & 3.576495 & 2.313050 & -0.691071 \\ \mathrm{C} & 6.312491 & 2.409291 & -1.238886 \\ \mathrm{H} & 6.512934 & 0.840231 & 0.207440 \\ \mathrm{C} & 4.075317 & 3.227551 & -1.613517 \\ \mathrm{H} & 2.504107 & 2.252930 & -0.527926 \\ \mathrm{C} & 5.439283 & 3.279762 & -1.889568 \\ \mathrm{H} & 7.378104 & 2.453444 & -1.438162 \\ \mathrm{H} & 3.387998 & 3.896640 & -2.121388 \\ \mathrm{H} & 5.822716 & 3.997735 & -2.607614 \\ \mathrm{H} & 6.464417 & -2.817975 & -1.894633\end{array}$

\section{f) Distortion energy calculations}

Isolated catalyst from TS-1Si

B3LYP-D3(BJ)/def2-TZVPP-IEF-PCM(DCM) Energy = -1875.212259

B3LYP/6-31G(d) Molecular Geometry in Cartesian Coordinates

$\begin{array}{lrrr}C & -0.780687 & 0.961599 & 0.277844 \\ C & -1.520691 & -0.160670 & -0.071002 \\ C & -2.933672 & -0.244855 & 0.116329 \\ C & -3.552139 & 0.809995 & 0.760136 \\ \text { H } & -4.625565 & 0.767886 & 0.924429 \\ C & 3.396258 & 1.208174 & -0.775551 \\ \text { C } & 0.652056 & 1.069674 & -0.127033 \\ \text { C } & 1.543144 & 0.071990 & 0.229302\end{array}$




\begin{tabular}{|c|c|c|c|}
\hline C & 2.936579 & 0.116317 & -0.065742 \\
\hline $\mathrm{H}$ & 4.457575 & 1.288579 & -0.995492 \\
\hline 0 & -0.886982 & -1.210833 & -0.727483 \\
\hline$P$ & 0.206242 & -2.139131 & 0.057220 \\
\hline $\mathrm{O}$ & 1.051909 & -1.034538 & 0.917882 \\
\hline C & -5.462273 & -3.428028 & -1.299990 \\
\hline C & -4.330607 & -3.727940 & -0.538575 \\
\hline C & -3.483311 & -2.712914 & -0.092774 \\
\hline C & -3.763306 & -1.371682 & -0.396234 \\
\hline C & -4.903265 & -1.080860 & -1.165061 \\
\hline C & -5.744471 & -2.097987 & -1.614857 \\
\hline $\mathrm{H}$ & -4.102072 & -4.759184 & -0.282488 \\
\hline $\mathrm{H}$ & -6.617192 & -1.850234 & -2.213598 \\
\hline C & 5.755869 & -2.908274 & 1.127754 \\
\hline C & 4.821430 & -2.424342 & 2.046592 \\
\hline C & 3.887571 & -1.461733 & 1.664207 \\
\hline C & 3.876659 & -0.956574 & 0.353517 \\
\hline C & 4.818217 & -1.454798 & -0.562540 \\
\hline C & 5.748386 & -2.421041 & -0.180521 \\
\hline $\mathrm{H}$ & 4.817789 & -2.794229 & 3.068335 \\
\hline $\mathrm{H}$ & 6.462989 & -2.796995 & -0.907976 \\
\hline C & 1.132305 & 2.161967 & -0.930884 \\
\hline C & 2.530127 & 2.228864 & -1.238075 \\
\hline C & 3.023427 & 3.308622 & -2.019752 \\
\hline C & 2.173976 & 4.271019 & -2.513054 \\
\hline C & 0.787293 & 4.184807 & -2.247482 \\
\hline C & 0.280445 & 3.160972 & -1.477540 \\
\hline $\mathrm{H}$ & 4.089151 & 3.349619 & -2.232145 \\
\hline $\mathrm{H}$ & 2.561072 & 5.087774 & -3.116031 \\
\hline $\mathrm{H}$ & 0.113158 & 4.930865 & -2.659455 \\
\hline $\mathrm{H}$ & -0.785851 & 3.105714 & -1.293805 \\
\hline C & -1.423202 & 2.003532 & 1.031665 \\
\hline C & -2.833304 & 1.921117 & 1.262446 \\
\hline C & -3.482165 & 2.946229 & 2.002971 \\
\hline C & -2.770408 & 4.003261 & 2.520252 \\
\hline C & -1.371173 & 4.071581 & 2.321463 \\
\hline C & -0.715806 & 3.100879 & 1.596270 \\
\hline $\mathrm{H}$ & -4.555299 & 2.870590 & 2.161931 \\
\hline $\mathrm{H}$ & -3.275480 & 4.778521 & 3.089876 \\
\hline $\mathrm{H}$ & -0.806358 & 4.894952 & 2.750326 \\
\hline $\mathrm{H}$ & 0.358059 & 3.162551 & 1.462651 \\
\hline $\mathrm{O}$ & -0.386538 & -3.113150 & 1.024402 \\
\hline $\mathrm{O}$ & 1.087664 & -2.651283 & -1.098733 \\
\hline $\mathrm{H}$ & 1.527191 & -3.681919 & -1.166982 \\
\hline
\end{tabular}




$\begin{array}{lrrr}\mathrm{H} & -5.119198 & -0.047761 & -1.423987 \\ \mathrm{H} & -6.118672 & -4.223131 & -1.644483 \\ \mathrm{H} & -2.611838 & -2.961051 & 0.502320 \\ \mathrm{H} & 4.802290 & -1.095287 & -1.587385 \\ \mathrm{H} & 6.479491 & -3.661954 & 1.426231 \\ \mathrm{H} & 3.167134 & -1.093312 & 2.386401\end{array}$

Isolated catalyst from TS-1Re

B3LYP-D3(BJ)/def2-TZVPP-IEF-PCM(DCM) Energy = -1875.204934

B3LYP/6-31G(d) Molecular Geometry in Cartesian Coordinates

$\begin{array}{lrrr}\text { C } & 0.683440 & 1.017149 & -0.178316 \\ \mathrm{C} & 1.520605 & -0.030186 & 0.173021 \\ \mathrm{C} & 2.922179 & -0.020687 & -0.075416 \\ \mathrm{C} & 3.440459 & 1.049090 & -0.775529 \\ \mathrm{H} & 4.509368 & 1.083758 & -0.970104 \\ \mathrm{C} & -3.514307 & 0.944360 & 0.770971 \\ \mathrm{C} & -0.751385 & 0.981364 & 0.225033 \\ \mathrm{C} & -1.547660 & -0.096191 & -0.138588 \\ \mathrm{C} & -2.952604 & -0.128924 & 0.107999 \\ \mathrm{H} & -4.583364 & 0.939475 & 0.967377 \\ \mathrm{O} & 0.963263 & -1.151446 & 0.791051 \\ \mathrm{P} & 0.108941 & -2.155834 & -0.194099 \\ \mathrm{O} & -0.987688 & -1.136537 & -0.866305 \\ \mathrm{C} & 5.711742 & -2.969120 & 1.341216 \\ \mathrm{C} & 4.982092 & -2.199463 & 2.250845 \\ \mathrm{C} & 4.046714 & -1.272013 & 1.792717 \\ \mathrm{C} & 3.835502 & -1.090896 & 0.417418 \\ \mathrm{C} & 4.569707 & -1.869884 & -0.487340 \\ \mathrm{C} & 5.498682 & -2.804676 & -0.028078 \\ \mathrm{H} & 5.146862 & -2.316150 & 3.319113 \\ \mathrm{H} & 6.055770 & -3.404118 & -0.743296 \\ \mathrm{C} & -5.679209 & -3.271456 & -0.990551 \\ \mathrm{C} & -5.828441 & -1.987559 & -1.518208 \\ \mathrm{C} & -4.919275 & -0.983596 & -1.180401 \\ \mathrm{C} & -3.840028 & -1.247895 & -0.322839 \\ \mathrm{C} & -3.688579 & -2.544936 & 0.191051 \\ \mathrm{C} & -4.608514 & -3.542789 & -0.134450 \\ \mathrm{H} & -6.656287 & -1.763381 & -2.186085 \\ \mathrm{H} & -4.494622 & -4.536041 & 0.293845 \\ \mathrm{C} & -1.330026 & 2.039169 & 1.007943 \\ \mathrm{C} & -2.738773 & 2.022974 & 1.259970\end{array}$




$\begin{array}{lrrr}\mathrm{C} & -3.327724 & 3.070665 & 2.018531 \\ \mathrm{C} & -2.558889 & 4.087001 & 2.535441 \\ \mathrm{C} & -1.160615 & 4.088316 & 2.318641 \\ \mathrm{C} & -0.562757 & 3.094572 & 1.575424 \\ \mathrm{H} & -4.400845 & 3.044317 & 2.192827 \\ \mathrm{H} & -3.017846 & 4.880159 & 3.119250 \\ \mathrm{H} & -0.550540 & 4.878454 & 2.748052 \\ \mathrm{H} & 0.510829 & 3.106347 & 1.427844 \\ \mathrm{C} & 1.223496 & 2.096613 & -0.960440 \\ \mathrm{C} & 2.624792 & 2.103245 & -1.255834 \\ \mathrm{C} & 3.172102 & 3.162079 & -2.029585 \\ \mathrm{C} & 2.370677 & 4.164720 & -2.523470 \\ \mathrm{C} & 0.979904 & 4.141830 & -2.265583 \\ \mathrm{C} & 0.421812 & 3.138170 & -1.504863 \\ \mathrm{H} & 4.240261 & 3.155978 & -2.233456 \\ \mathrm{H} & 2.798657 & 4.966000 & -3.119627 \\ \mathrm{H} & 0.343681 & 4.921254 & -2.676263 \\ \mathrm{H} & -0.647130 & 3.130507 & -1.327506 \\ \mathrm{O} & -0.531730 & -3.222042 & 0.634011 \\ \mathrm{O} & 0.981035 & -2.524961 & -1.408122 \\ \mathrm{H} & 1.704943 & -3.401244 & -1.475787 \\ \mathrm{H} & 4.394993 & -1.754182 & -1.552613 \\ \mathrm{H} & 6.441414 & -3.691074 & 1.698521 \\ \mathrm{H} & 3.488395 & -0.666845 & 2.501918 \\ \mathrm{H} & -2.853749 & -2.767329 & 0.847163 \\ \mathrm{H} & -6.394012 & -4.051890 & -1.238570 \\ \mathrm{H} & -5.040651 & 0.017111 & -1.586583 \\ & & & \\ & & & \\ & & & \end{array}$

Isolated substrate pair from TS-1Si

B3LYP-D3(BJ)/def2-TZVPP-IEF-PCM(DCM) Energy = -935.708664

B3LYP/6-31G(d) Molecular Geometry in Cartesian Coordinates

$\begin{array}{lrrr}\mathrm{C} & -1.180841 & -0.894468 & -0.886075 \\ \mathrm{O} & -1.715076 & 0.160544 & -1.370209 \\ \mathrm{H} & -0.305960 & -1.337810 & -1.378785 \\ \mathrm{C} & -2.126484 & -1.939492 & -0.298546 \\ \mathrm{O} & -3.287159 & -1.760478 & -0.025146 \\ \mathrm{O} & -1.471264 & -3.115507 & -0.133677 \\ \mathrm{C} & -2.266779 & -4.180666 & 0.414433 \\ \mathrm{H} & -2.649421 & -3.905357 & 1.400998 \\ \mathrm{H} & -3.111267 & -4.403855 & -0.242745 \\ \mathrm{C} & 0.595925 & 0.442261 & 0.437696\end{array}$




$\begin{array}{lrrr}\text { C } & -0.364910 & -0.460302 & 0.912245 \\ \text { H } & 0.760399 & 2.091613 & -0.768438 \\ \text { N } & 0.241777 & 1.689660 & 0.036057 \\ \text { C } & -0.939810 & 2.369940 & 0.391863 \\ \text { O } & -1.670069 & 2.102828 & 1.318085 \\ \text { O } & -1.078152 & 3.415495 & -0.437218 \\ \text { C } & -2.282253 & 4.184541 & -0.257122 \\ \text { H } & -3.155202 & 3.559343 & -0.458881 \\ \text { H } & -2.208393 & 4.996112 & -0.979491 \\ \text { H } & -2.338189 & 4.571483 & 0.763241 \\ \text { H } & -0.007186 & -1.385586 & 1.348425 \\ \text { H } & -1.269046 & -0.052031 & 1.344210 \\ \text { C } & 1.994977 & 0.042127 & 0.183988 \\ \text { C } & 3.011419 & 1.012300 & 0.111170 \\ \text { C } & 2.347989 & -1.314953 & 0.054141 \\ \text { C } & 4.338253 & 0.636939 & -0.078891 \\ \text { H } & 2.765985 & 2.062225 & 0.223849 \\ \text { C } & 3.675083 & -1.684699 & -0.140029 \\ \text { H } & 1.581708 & -2.082430 & 0.078215 \\ \text { C } & 4.675294 & -0.711240 & -0.204912 \\ \text { H } & 5.108938 & 1.400366 & -0.127699 \\ \text { H } & 3.929590 & -2.735836 & -0.242982 \\ \text { H } & 5.711192 & -1.003042 & -0.353563 \\ \text { H } & -1.599016 & -5.039603 & 0.486786\end{array}$

Isolated substrate pair from TS-1Re

B3LYP-D3(BJ)/def2-TZVPP-IEF-PCM(DCM) Energy = -935.701887

B3LYP/6-31G(d) Molecular Geometry in Cartesian Coordinates

$\begin{array}{lrrr}\mathrm{C} & 0.160685 & 2.210692 & -0.653866 \\ \mathrm{O} & -0.825797 & 2.588262 & 0.084103 \\ \mathrm{H} & 0.318562 & 2.788939 & -1.575900 \\ \mathrm{C} & 1.523503 & 1.864683 & -0.035904 \\ \mathrm{O} & 2.517514 & 1.651566 & -0.701986 \\ \mathrm{O} & 1.472612 & 1.830658 & 1.294691 \\ \mathrm{C} & 2.685636 & 1.432470 & 1.967988 \\ \mathrm{H} & 2.936538 & 0.406920 & 1.691795 \\ \mathrm{H} & 3.498154 & 2.108831 & 1.697061 \\ \mathrm{C} & -0.551115 & -0.334218 & -0.667225 \\ \mathrm{C} & -0.156442 & 0.585847 & -1.661572 \\ \mathrm{H} & 0.263236 & -1.079100 & 1.071317 \\ \mathrm{~N} & 0.383400 & -1.045462 & 0.044079\end{array}$




$\begin{array}{lrrr}\mathrm{C} & 1.598196 & -1.512819 & -0.471602 \\ \mathrm{O} & 1.898346 & -1.577561 & -1.641665 \\ \mathrm{O} & 2.361194 & -1.940267 & 0.553151 \\ \mathrm{C} & 3.635155 & -2.485444 & 0.165249 \\ \mathrm{H} & 4.227135 & -1.729040 & -0.355380 \\ \mathrm{H} & 3.497223 & -3.350385 & -0.488264 \\ \mathrm{H} & 4.115646 & -2.779961 & 1.098070 \\ \mathrm{H} & -0.926626 & 0.899104 & -2.358404 \\ \mathrm{H} & 0.823193 & 0.453623 & -2.104467 \\ \mathrm{C} & -1.935349 & -0.437506 & -0.219559 \\ \mathrm{C} & -2.890096 & 0.544055 & -0.567852 \\ \mathrm{C} & -2.351777 & -1.539388 & 0.559128 \\ \mathrm{C} & -4.205849 & 0.427733 & -0.134317 \\ \mathrm{H} & -2.594109 & 1.418849 & -1.130473 \\ \mathrm{C} & -3.668512 & -1.651343 & 0.983806 \\ \mathrm{H} & -1.644280 & -2.317966 & 0.817156 \\ \mathrm{C} & -4.598304 & -0.665512 & 0.639963 \\ \mathrm{H} & -4.924803 & 1.199298 & -0.393061 \\ \mathrm{H} & -3.965087 & -2.504140 & 1.586108 \\ \mathrm{H} & -5.628017 & -0.750830 & 0.976208 \\ \mathrm{H} & 2.454103 & 1.497326 & 3.027903\end{array}$

\section{g) Diastereoselectivity calculations}

\section{TS-S1(anti)}

B3LYP/6-31G(d) Energy $=-3163.517751$

B3LYP-D3(BJ)/def2-TZVPP-IEF-PCM(DCM) Energy = -3165.003757

B3LYP-D3(BJ)/def2-TZVPP-IEF-PCM(DCM)//B3LYP/6-31G(d) Free Energy (Quasiharmonic) = 3164.117959

Frequencies (Top 3)

1. $-535.5801 \mathrm{~cm}-1$

2. $\quad 9.7060 \mathrm{~cm}-1$

3. $\quad 16.9708 \mathrm{~cm}-1$

B3LYP/6-31G(d) Molecular Geometry in Cartesian Coordinates

$\begin{array}{llll}\text { C } & -2.397663 & 2.770110 & 0.226024 \\ \text { C } & -2.754904 & 1.439858 & 0.052908 \\ \text { C } & -4.014008 & 0.917253 & 0.479268 \\ \text { C } & -4.849761 & 1.770112 & 1.176265 \\ \text { H } & -5.808749 & 1.395202 & 1.523586\end{array}$




\begin{tabular}{|c|c|c|c|}
\hline C & 1.237686 & 4.337098 & -1.470454 \\
\hline C & -1.162662 & 3.305854 & -0.417460 \\
\hline C & 0.062144 & 2.711251 & -0.163238 \\
\hline C & 1.300085 & 3.221521 & -0.655876 \\
\hline $\mathrm{H}$ & 2.161476 & 4.777692 & -1.835093 \\
\hline 0 & -1.898924 & 0.603238 & -0.655957 \\
\hline$P$ & -0.454402 & 0.168404 & -0.018561 \\
\hline 0 & 0.084041 & 1.570202 & 0.634682 \\
\hline C & -5.574926 & -3.060617 & -0.290168 \\
\hline C & -4.287192 & -2.879871 & 0.233201 \\
\hline C & -3.748635 & -1.610044 & 0.455465 \\
\hline C & -4.491121 & -0.458641 & 0.168786 \\
\hline C & -5.778158 & -0.629849 & -0.369533 \\
\hline C & -6.302995 & -1.898082 & -0.594300 \\
\hline $\mathrm{H}$ & -3.675083 & -3.738536 & 0.486191 \\
\hline $\mathrm{H}$ & -7.301507 & -1.977418 & -1.016010 \\
\hline C & 5.268191 & 1.760396 & 0.332349 \\
\hline C & 4.250112 & 1.804097 & 1.295484 \\
\hline C & 2.956770 & 2.228993 & 0.984962 \\
\hline C & 2.623113 & 2.637213 & -0.313933 \\
\hline C & 3.630961 & 2.564810 & -1.291077 \\
\hline C & 4.917047 & 2.141425 & -0.973803 \\
\hline $\mathrm{H}$ & 4.456686 & 1.520652 & 2.321684 \\
\hline $\mathrm{H}$ & 5.660461 & 2.113040 & -1.765601 \\
\hline C & -1.215453 & 4.412845 & -1.333777 \\
\hline C & 0.012881 & 4.934924 & -1.851631 \\
\hline C & -0.018314 & 6.038623 & -2.746930 \\
\hline C & -1.212537 & 6.589912 & -3.148182 \\
\hline C & -2.429865 & 6.050323 & -2.670246 \\
\hline C & -2.432152 & 4.993538 & -1.786435 \\
\hline $\mathrm{H}$ & 0.925224 & 6.430054 & -3.120010 \\
\hline $\mathrm{H}$ & -1.225241 & 7.428210 & -3.839349 \\
\hline $\mathrm{H}$ & -3.373668 & 6.470291 & -3.007421 \\
\hline $\mathrm{H}$ & -3.374230 & 4.586666 & -1.438704 \\
\hline C & -3.236266 & 3.613780 & 1.033161 \\
\hline C & -4.485053 & 3.097538 & 1.503448 \\
\hline C & -5.327181 & 3.919934 & 2.300256 \\
\hline C & -4.948175 & 5.196485 & 2.643999 \\
\hline C & -3.699943 & 5.699549 & 2.206955 \\
\hline C & -2.868004 & 4.931569 & 1.422209 \\
\hline $\mathrm{H}$ & -6.275729 & 3.512700 & 2.642453 \\
\hline $\mathrm{H}$ & -5.596888 & 5.814935 & 3.258308 \\
\hline $\mathrm{H}$ & -3.391202 & 6.699928 & 2.498267 \\
\hline $\mathrm{H}$ & -1.910442 & 5.328514 & 1.105569 \\
\hline
\end{tabular}




\begin{tabular}{|c|c|c|c|}
\hline $\mathrm{O}$ & -0.555490 & -0.841943 & 1.079849 \\
\hline $\mathrm{O}$ & 0.396346 & -0.145657 & -1.262017 \\
\hline $\mathrm{H}$ & 1.024866 & -1.091557 & -1.396515 \\
\hline $\mathrm{H}$ & -6.368682 & 0.245805 & -0.626095 \\
\hline $\mathrm{H}$ & -2.752703 & -1.519756 & 0.874318 \\
\hline $\mathrm{H}$ & 3.398225 & 2.835747 & -2.317012 \\
\hline $\mathrm{H}$ & 2.207477 & 2.259530 & 1.768155 \\
\hline C & 2.905157 & -2.223029 & -1.223900 \\
\hline $\mathrm{O}$ & 1.724596 & -2.103912 & -1.721900 \\
\hline $\mathrm{H}$ & 3.310223 & -1.409986 & -0.606918 \\
\hline C & 3.937527 & -2.845602 & -2.160827 \\
\hline $\mathrm{O}$ & 3.708416 & -3.685907 & -2.995769 \\
\hline $\mathrm{O}$ & 5.157524 & -2.302966 & -1.936570 \\
\hline C & 6.208347 & -2.795339 & -2.788912 \\
\hline $\mathrm{H}$ & 6.333825 & -3.873139 & -2.656174 \\
\hline $\mathrm{H}$ & 5.972785 & -2.590984 & -3.836187 \\
\hline C & 1.889054 & -3.251701 & 0.924041 \\
\hline C & 2.935668 & -3.732741 & 0.104957 \\
\hline $\mathrm{H}$ & 0.005458 & -2.477002 & 0.796600 \\
\hline$N$ & 0.610035 & -3.260161 & 0.475403 \\
\hline C & 0.091885 & -4.033439 & -0.586222 \\
\hline $\mathrm{O}$ & 0.569905 & -5.051768 & -1.029604 \\
\hline $\mathrm{O}$ & -1.070340 & -3.484349 & -0.965522 \\
\hline C & -1.688304 & -4.095082 & -2.113292 \\
\hline $\mathrm{H}$ & -1.034763 & -3.990106 & -2.982542 \\
\hline $\mathrm{H}$ & -2.619319 & -3.548606 & -2.255497 \\
\hline $\mathrm{H}$ & -1.879780 & -5.154496 & -1.925778 \\
\hline $\mathrm{H}$ & 2.592006 & -4.437966 & -0.643118 \\
\hline C & 2.077038 & -2.591737 & 2.232896 \\
\hline C & 1.106733 & -2.775113 & 3.236434 \\
\hline C & 3.202004 & -1.798585 & 2.520006 \\
\hline C & 1.264517 & -2.195770 & 4.491378 \\
\hline $\mathrm{H}$ & 0.237671 & -3.391996 & 3.033224 \\
\hline C & 3.349160 & -1.210068 & 3.773413 \\
\hline $\mathrm{H}$ & 3.945574 & -1.610235 & 1.754812 \\
\hline C & 2.386061 & -1.410734 & 4.764049 \\
\hline $\mathrm{H}$ & 0.509175 & -2.354912 & 5.255236 \\
\hline $\mathrm{H}$ & 4.218595 & -0.591140 & 3.975540 \\
\hline $\mathrm{H}$ & 2.507772 & -0.954828 & 5.742647 \\
\hline $\mathrm{H}$ & 7.107311 & -2.260160 & -2.483602 \\
\hline C & 4.329509 & -4.018632 & 0.645037 \\
\hline $\mathrm{H}$ & 5.027103 & -3.188681 & 0.491506 \\
\hline $\mathrm{H}$ & 4.314595 & -4.240005 & 1.716914 \\
\hline $\mathrm{H}$ & 4.749722 & -4.886926 & 0.128595 \\
\hline
\end{tabular}




$\begin{array}{lrrr}\mathrm{C} & -6.200839 & -4.446175 & -0.531874 \\ \mathrm{C} & -6.530825 & -4.610250 & -2.034603 \\ \mathrm{H} & -5.623945 & -4.537256 & -2.646077 \\ \mathrm{H} & -6.988285 & -5.589696 & -2.221663 \\ \mathrm{H} & -7.229792 & -3.843334 & -2.384241 \\ \mathrm{C} & -7.504479 & -4.572610 & 0.292434 \\ \mathrm{H} & -7.967591 & -5.553317 & 0.127147 \\ \mathrm{H} & -7.301234 & -4.468582 & 1.364365 \\ \mathrm{H} & -8.237319 & -3.807439 & 0.016178 \\ \mathrm{C} & -5.262644 & -5.595419 & -0.117362 \\ \mathrm{H} & -4.328698 & -5.588332 & -0.690737 \\ \mathrm{H} & -5.008896 & -5.550392 & 0.947738 \\ \mathrm{H} & -5.753715 & -6.557938 & -0.300365 \\ \mathrm{C} & 6.718831 & 1.361227 & 0.657723 \\ \mathrm{C} & 7.198132 & 0.252459 & -0.308466 \\ \mathrm{H} & 7.202772 & 0.592673 & -1.349173 \\ \mathrm{H} & 8.221489 & -0.051964 & -0.056235 \\ \mathrm{H} & 6.550860 & -0.629584 & -0.253583 \\ \mathrm{C} & 6.875251 & 0.838925 & 2.098620 \\ \mathrm{H} & 6.609200 & 1.598868 & 2.841647 \\ \mathrm{H} & 6.256489 & -0.048531 & 2.278780 \\ \mathrm{H} & 7.918416 & 0.555742 & 2.278762 \\ \mathrm{C} & 7.627962 & 2.603455 & 0.493159 \\ \mathrm{H} & 7.326461 & 3.403275 & 1.179000 \\ \mathrm{H} & 8.673092 & 2.346561 & 0.706876 \\ \mathrm{H} & 7.581056 & 3.002596 & -0.525639\end{array}$

\section{TS-S2(syn)}

B3LYP/6-31G(d) Energy $=-3163.514529$

B3LYP-D3(BJ)/def2-TZVPP-IEF-PCM(DCM) Energy = -3165.001877

B3LYP-D3(BJ)/def2-TZVPP-IEF-PCM(DCM)//B3LYP/6-31G(d) Free Energy (Quasiharmonic) = 3164.114984

Frequencies (Top 3)

1. $-322.0412 \mathrm{~cm}-1$

2. $\quad 9.7858 \mathrm{~cm}-1$

3. $\quad 14.6209 \mathrm{~cm}-1$

B3LYP/6-31G(d) Molecular Geometry in Cartesian Coordinates

C $\quad-0.974977 \quad 3.369296 \quad-0.523213$ 


\begin{tabular}{|c|c|c|c|}
\hline C & 0.217573 & 2.734864 & -0.216282 \\
\hline C & 1.484428 & 3.170004 & -0.708973 \\
\hline C & 1.487169 & 4.239309 & -1.584563 \\
\hline $\mathrm{H}$ & 2.435645 & 4.618608 & -1.955622 \\
\hline C & -4.674256 & 2.009281 & 1.211212 \\
\hline C & -2.236146 & 2.912087 & 0.131786 \\
\hline C & -2.635937 & 1.587349 & 0.017060 \\
\hline C & -3.887352 & 1.110217 & 0.514776 \\
\hline $\mathrm{H}$ & -5.647698 & 1.689208 & 1.572435 \\
\hline 0 & 0.176005 & 1.639468 & 0.632340 \\
\hline$P$ & -0.392316 & 0.216632 & 0.023558 \\
\hline 0 & -1.813387 & 0.697684 & -0.656981 \\
\hline C & 5.315147 & 1.516991 & 0.505123 \\
\hline C & 5.038217 & 1.845463 & -0.832604 \\
\hline C & 3.797382 & 2.342388 & -1.223120 \\
\hline C & 2.765356 & 2.543721 & -0.291839 \\
\hline C & 3.029875 & 2.206300 & 1.043358 \\
\hline C & 4.275404 & 1.709277 & 1.426213 \\
\hline $\mathrm{H}$ & 5.803059 & 1.715115 & -1.593072 \\
\hline $\mathrm{H}$ & 4.434124 & 1.487708 & 2.475526 \\
\hline C & -5.709309 & -2.755398 & -0.238182 \\
\hline C & -5.746869 & -2.149927 & 1.029405 \\
\hline C & -5.110021 & -0.938917 & 1.280068 \\
\hline C & -4.401786 & -0.263660 & 0.271426 \\
\hline C & -4.319530 & -0.885403 & -0.982256 \\
\hline C & -4.962123 & -2.100187 & -1.227194 \\
\hline $\mathrm{H}$ & -6.295452 & -2.621998 & 1.840363 \\
\hline $\mathrm{H}$ & -4.885403 & -2.522782 & -2.223154 \\
\hline C & -3.030676 & 3.810902 & 0.922985 \\
\hline C & -4.270599 & 3.341843 & 1.462581 \\
\hline C & -5.073566 & 4.221297 & 2.238651 \\
\hline C & -4.661970 & 5.506522 & 2.503812 \\
\hline C & -3.419680 & 5.962281 & 2.002926 \\
\hline C & -2.627299 & 5.139462 & 1.232780 \\
\hline $\mathrm{H}$ & -6.018543 & 3.850942 & 2.629467 \\
\hline $\mathrm{H}$ & -5.280491 & 6.168202 & 3.104139 \\
\hline $\mathrm{H}$ & -3.084533 & 6.970506 & 2.231432 \\
\hline $\mathrm{H}$ & -1.674267 & 5.501798 & 0.865452 \\
\hline C & -0.963476 & 4.431608 & -1.490541 \\
\hline C & 0.294810 & 4.869547 & -2.016617 \\
\hline C & 0.324032 & 5.926240 & -2.966797 \\
\hline C & -0.838712 & 6.512529 & -3.409724 \\
\hline C & -2.085262 & 6.057513 & -2.919145 \\
\hline C & -2.146433 & 5.047168 & -1.984499 \\
\hline
\end{tabular}




\begin{tabular}{|c|c|c|c|}
\hline $\mathrm{H}$ & 1.288652 & 6.254426 & -3.347156 \\
\hline $\mathrm{H}$ & -0.804276 & 7.314563 & -4.142048 \\
\hline $\mathrm{H}$ & -3.004371 & 6.506111 & -3.286543 \\
\hline $\mathrm{H}$ & -3.109680 & 4.703541 & -1.625550 \\
\hline 0 & -0.586922 & -0.710847 & 1.182531 \\
\hline 0 & 0.473023 & -0.181418 & -1.161974 \\
\hline $\mathrm{H}$ & 1.131340 & -1.235060 & -1.531905 \\
\hline $\mathrm{H}$ & 2.259524 & 2.343847 & 1.793833 \\
\hline $\mathrm{H}$ & 3.619404 & 2.566213 & -2.271396 \\
\hline $\mathrm{H}$ & -3.769629 & -0.405787 & -1.784440 \\
\hline $\mathrm{H}$ & -5.161004 & -0.506750 & 2.275660 \\
\hline C & 2.890516 & -2.186840 & -1.320111 \\
\hline 0 & 1.787016 & -2.037616 & -1.959403 \\
\hline $\mathrm{H}$ & 3.190575 & -1.436159 & -0.585547 \\
\hline C & 3.986649 & -2.876085 & -2.093054 \\
\hline 0 & 3.802015 & -3.566389 & -3.070186 \\
\hline $\mathrm{O}$ & 5.189373 & -2.630555 & -1.540290 \\
\hline C & 6.309934 & -3.247249 & -2.202049 \\
\hline $\mathrm{H}$ & 6.358598 & -2.924967 & -3.244911 \\
\hline $\mathrm{H}$ & 7.189802 & -2.914987 & -1.652466 \\
\hline C & 1.671308 & -3.332334 & 0.736556 \\
\hline C & 2.918387 & -3.749992 & 0.238116 \\
\hline $\mathrm{H}$ & 0.677881 & -1.751887 & 1.636541 \\
\hline $\mathrm{N}$ & 1.557463 & -2.318585 & 1.651317 \\
\hline C & 2.523525 & -1.903641 & 2.571784 \\
\hline 0 & 3.669322 & -2.298494 & 2.662251 \\
\hline 0 & 1.957236 & -0.995960 & 3.384404 \\
\hline C & 2.795113 & -0.507600 & 4.442689 \\
\hline $\mathrm{H}$ & 2.191983 & 0.235792 & 4.963425 \\
\hline $\mathrm{H}$ & 3.703082 & -0.055319 & 4.038424 \\
\hline $\mathrm{H}$ & 3.069789 & -1.322249 & 5.118328 \\
\hline $\mathrm{H}$ & 3.768926 & -3.295131 & 0.729636 \\
\hline C & 0.393870 & -3.871548 & 0.246478 \\
\hline C & 0.276884 & -4.398474 & -1.057565 \\
\hline C & -0.746116 & -3.862037 & 1.077602 \\
\hline C & -0.940165 & -4.904577 & -1.504782 \\
\hline $\mathrm{H}$ & 1.119065 & -4.374384 & -1.735676 \\
\hline C & -1.954691 & -4.376178 & 0.626486 \\
\hline $\mathrm{H}$ & -0.678375 & -3.461884 & 2.082533 \\
\hline C & -2.054394 & -4.898623 & -0.665658 \\
\hline $\mathrm{H}$ & -1.017721 & -5.293138 & -2.515912 \\
\hline $\mathrm{H}$ & -2.824056 & -4.354356 & 1.275932 \\
\hline $\mathrm{H}$ & -3.001835 & -5.295609 & -1.018638 \\
\hline $\mathrm{H}$ & 6.219288 & -4.335992 & -2.167064 \\
\hline
\end{tabular}




$\begin{array}{lrrr}\mathrm{C} & 3.167258 & -5.158833 & -0.273672 \\ \mathrm{H} & 2.293670 & -5.801866 & -0.144191 \\ \mathrm{H} & 3.445572 & -5.199952 & -1.332325 \\ \mathrm{H} & 3.994740 & -5.597416 & 0.296029 \\ \mathrm{C} & -6.502761 & -4.049127 & -0.499629 \\ \mathrm{C} & -8.012557 & -3.753616 & -0.324111 \\ \mathrm{H} & -8.604961 & -4.659142 & -0.505839 \\ \mathrm{H} & -8.239972 & -3.401113 & 0.687487 \\ \mathrm{H} & -8.343982 & -2.982387 & -1.028480 \\ \mathrm{C} & -6.285181 & -4.593517 & -1.924203 \\ \mathrm{H} & -6.623808 & -3.884700 & -2.687849 \\ \mathrm{H} & -5.230606 & -4.821451 & -2.118630 \\ \mathrm{H} & -6.855305 & -5.519854 & -2.058278 \\ \mathrm{C} & -6.087265 & -5.148667 & 0.505573 \\ \mathrm{H} & -6.252118 & -4.840005 & 1.542945 \\ \mathrm{H} & -6.671286 & -6.061412 & 0.335145 \\ \mathrm{H} & -5.026718 & -5.404099 & 0.398209 \\ \mathrm{C} & 6.711549 & 1.019590 & 0.920960 \\ \mathrm{C} & 6.727967 & 0.467203 & 2.360397 \\ \mathrm{H} & 6.498961 & 1.242653 & 3.100219 \\ \mathrm{H} & 6.013537 & -0.354831 & 2.486427 \\ \mathrm{H} & 7.726745 & 0.082159 & 2.595915 \\ \mathrm{C} & 7.185449 & -0.111080 & -0.020880 \\ \mathrm{H} & 7.282822 & 0.229230 & -1.057146 \\ \mathrm{H} & 8.169907 & -0.475330 & 0.298108 \\ \mathrm{H} & 6.484333 & -0.951812 & -0.008086 \\ \mathrm{C} & 7.706211 & 2.202166 & 0.833185 \\ \mathrm{H} & 7.715744 & 1.878716 & 1.116816 \\ \mathrm{H} & & 2.608704 & -0.183092 \\ \mathrm{H} & 3.015962 \\ & & & 1.504103\end{array}$




\section{References}

(1) MacroModel, Version 11.3. Schrödinger, LLC: New York, NY 2016.

(2) Frisch, M. J., et al. Gaussian 16; Gaussian, Inc., Wallingford, CT, 2016.

(3) Simón, L.; Goodman, J. M. How Reliable Are DFT Transition Structures? Comparison of GGA, Hybrid-Meta-GGA and Meta-GGA Functionals. Org. Biomol. Chem. 2011, 9, 689700.

(4) Ribeiro, R. F.; Marenich, A. V; Cramer, C. J.; Truhlar, D. G. Use of Solution-Phase Vibrational Frequencies in Continuum Models for the Free Energy of Solvation. J. Phys. Chem. B 2011, 115, 14556-14562.

(5) Lam, Y.-H.; Grayson, M. N.; Holland, M. C.; Simon, A.; Houk, K. N. Theory and Modeling of Asymmetric Catalytic Reactions. Acc. Chem. Res. 2016, 49, 750-762.

(6) CYLview, 1.0b; Legault, C. Y., Université de Sherbrooke, 2009 (http://www.cylview.org).

(7) Pedregal, J. R.-G.; Gómez-Orellana, P.; Maréchal, J.-D. ESIgen: Electronic Supporting Information Generator for Computational Chemistry Publications. J. Chem. Inf. Model. 2018, 58, 561-564. 